


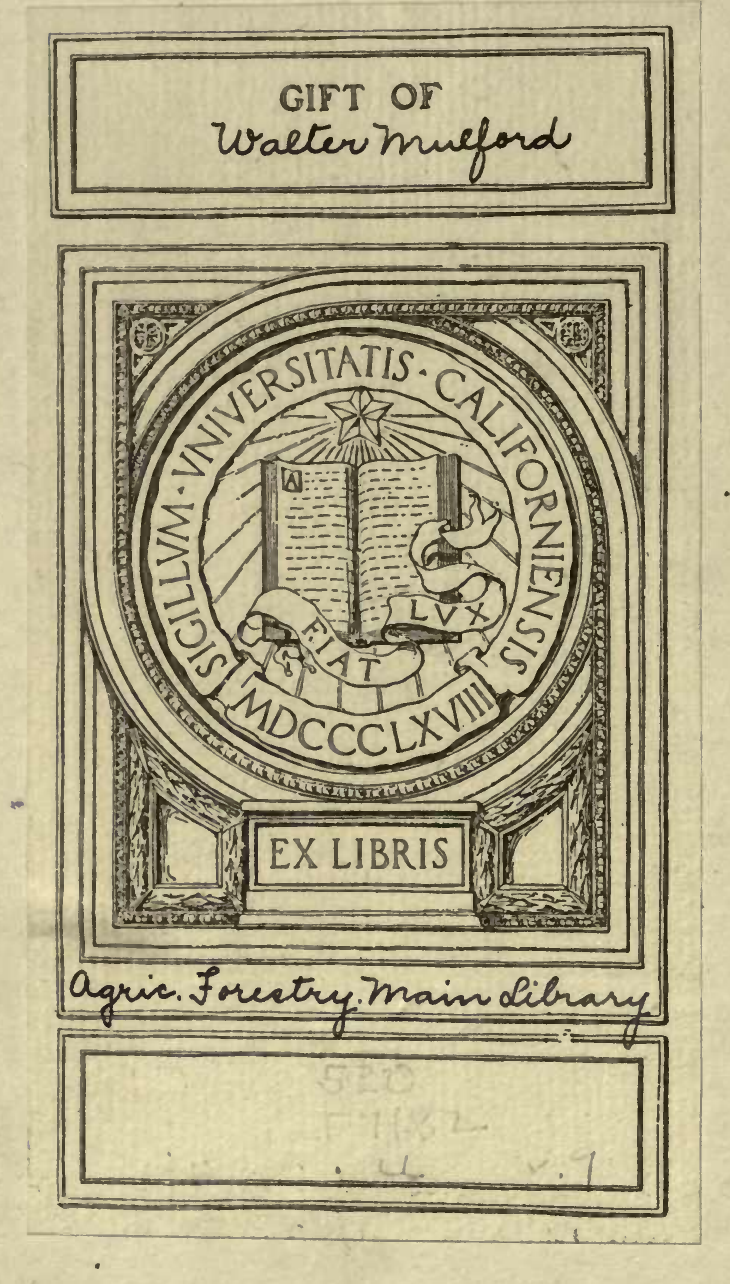




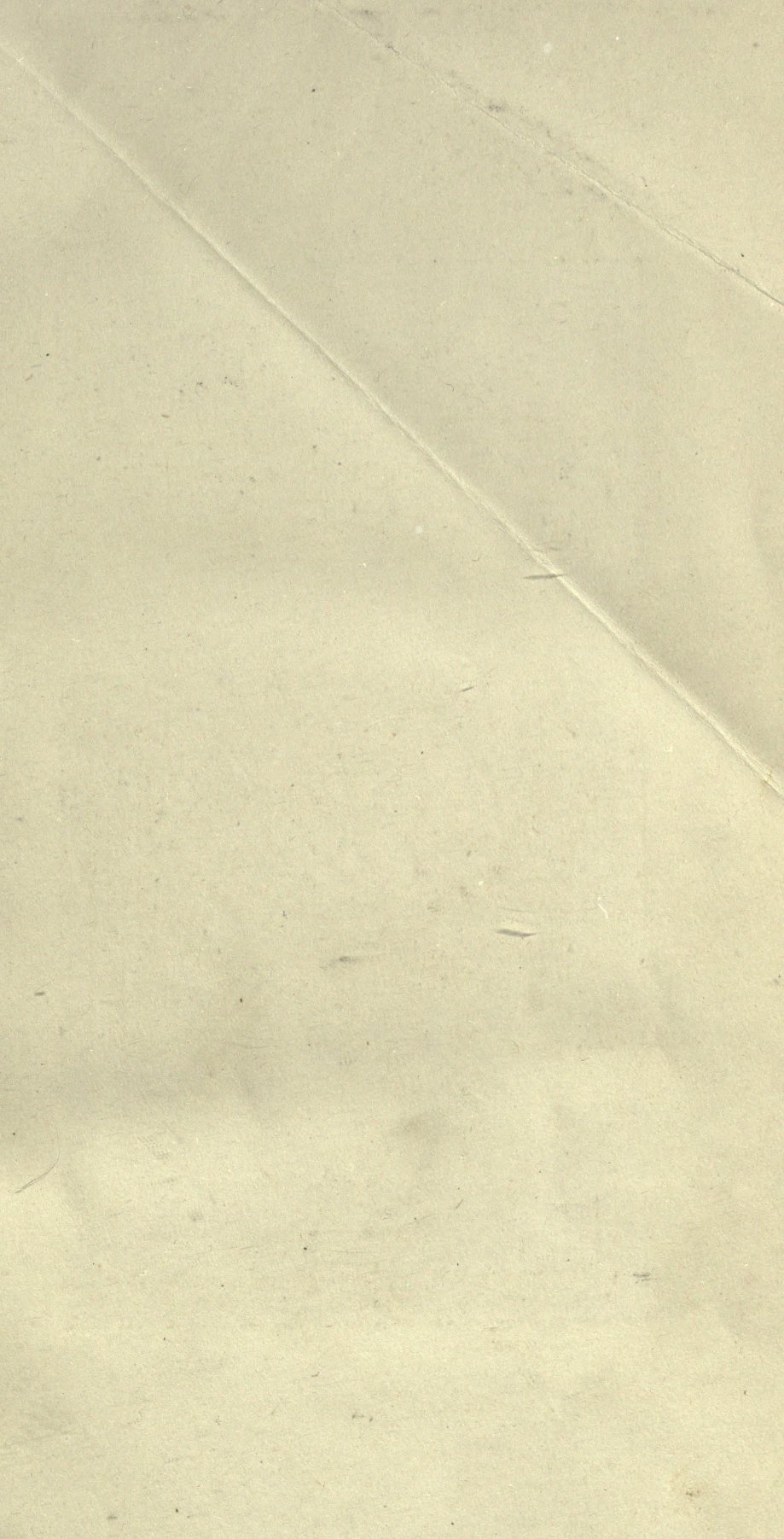





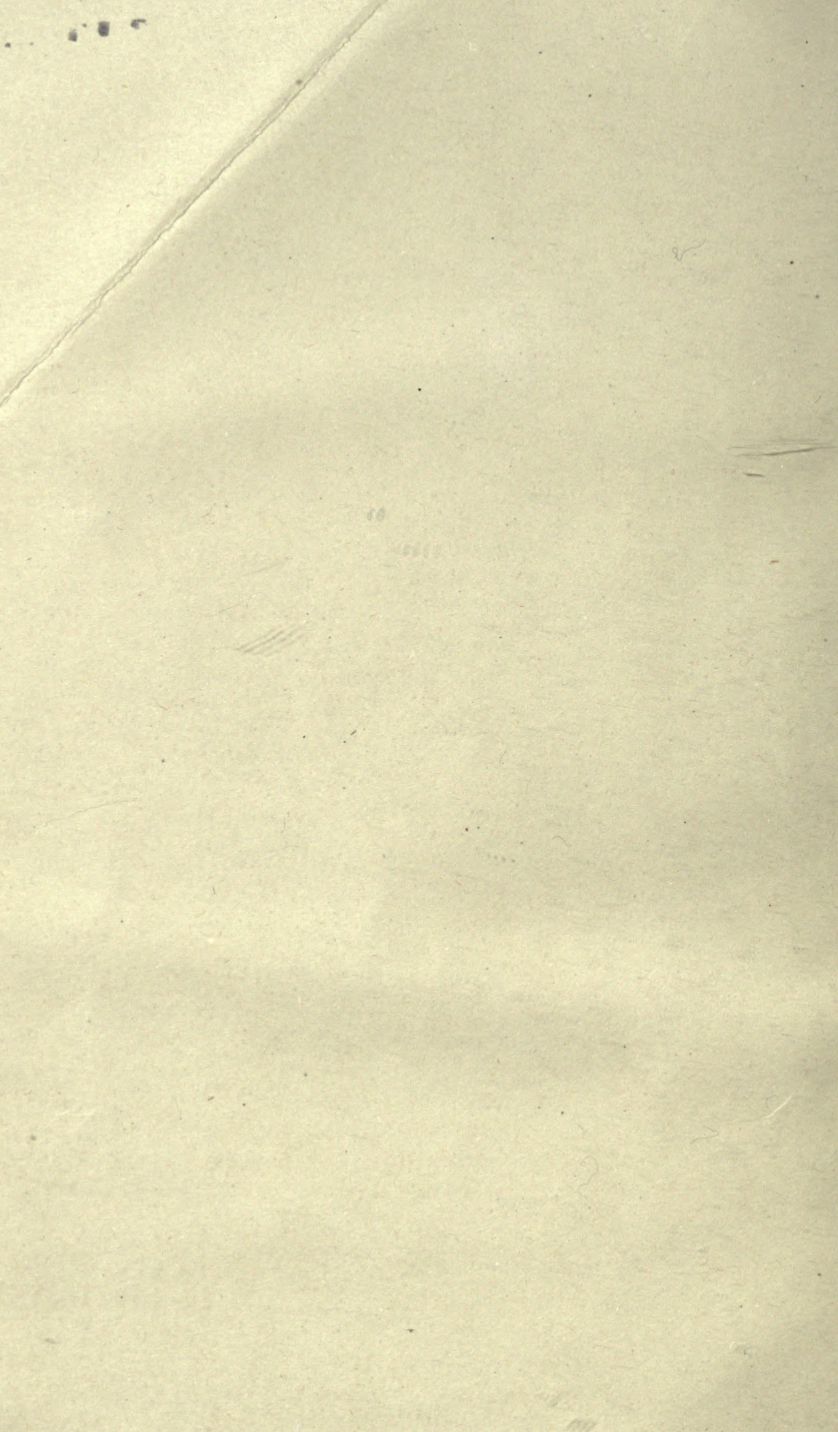


\section{Utilization}

$$
\text { Vo1. IX - Fish o Game. }
$$

The Fishes of North and Niddle America: A Descriptive catalogue of the species of fish-like vertebrates found in the waters of North America, north of the Isthmus of Panama. Bulletin of the United States National Museum. No. 47 . Part III. 


\section{3 \\ the}

motudailitit]

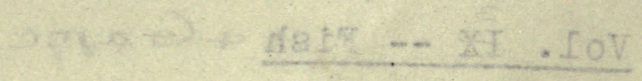

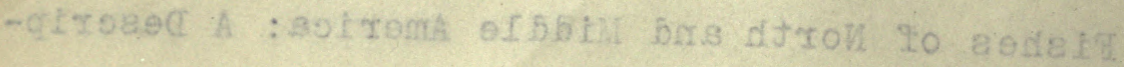

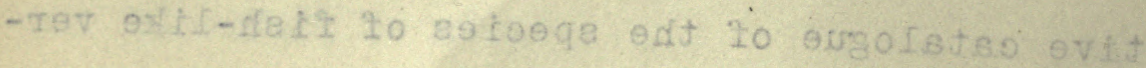

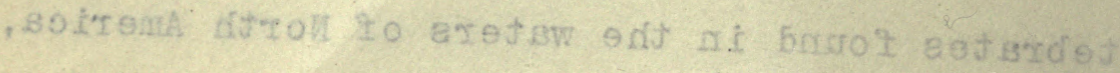

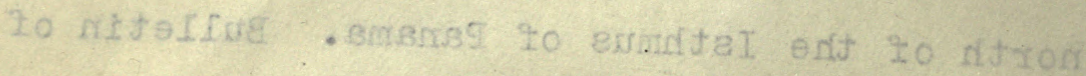

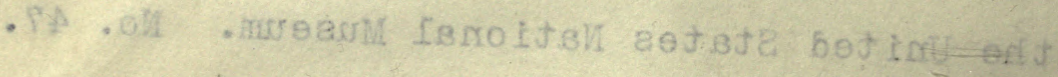
. III Jrac

Main Lib.

Forestry 


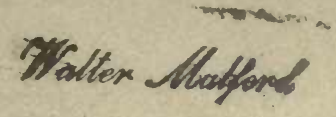

\title{
SMITISONIAN INSTITUTION.
}

UNITED STATES NATIONAL MUSEUM.

\section{BULLETIN}

OF THE

\section{UNITED STATES NATIONAL MUSEUM.}

\author{
No. 47.
}

\section{THE FISHES}

OF

\section{NORTH AND MIDDLE AMERICA:}

A DESCRIPTIVE CATALOGUE OF THE SPECIES OF FISH-LIKE VERTEBRATES FOUND IN the Waters of NORTh america, North of the isthmus of PaNama.

BY

DAVID STARR JORDAN, Ph. D., PRESIDENT OF THE LELAND STANFORD JUNIOR UNIVERSITY AND OF THE CALIFORNIA ACADEMY OF SOIENCES,

$$
\text { AND }
$$

BARTON WARREN EVERMANN, Ph. D., ICBTHYOLOGIST OF THE UNITED STATES FIBH COMMISSION.

PART III.

WASHINGTON:

GOVERNMENT PRINTING OFFICE.

1898. 


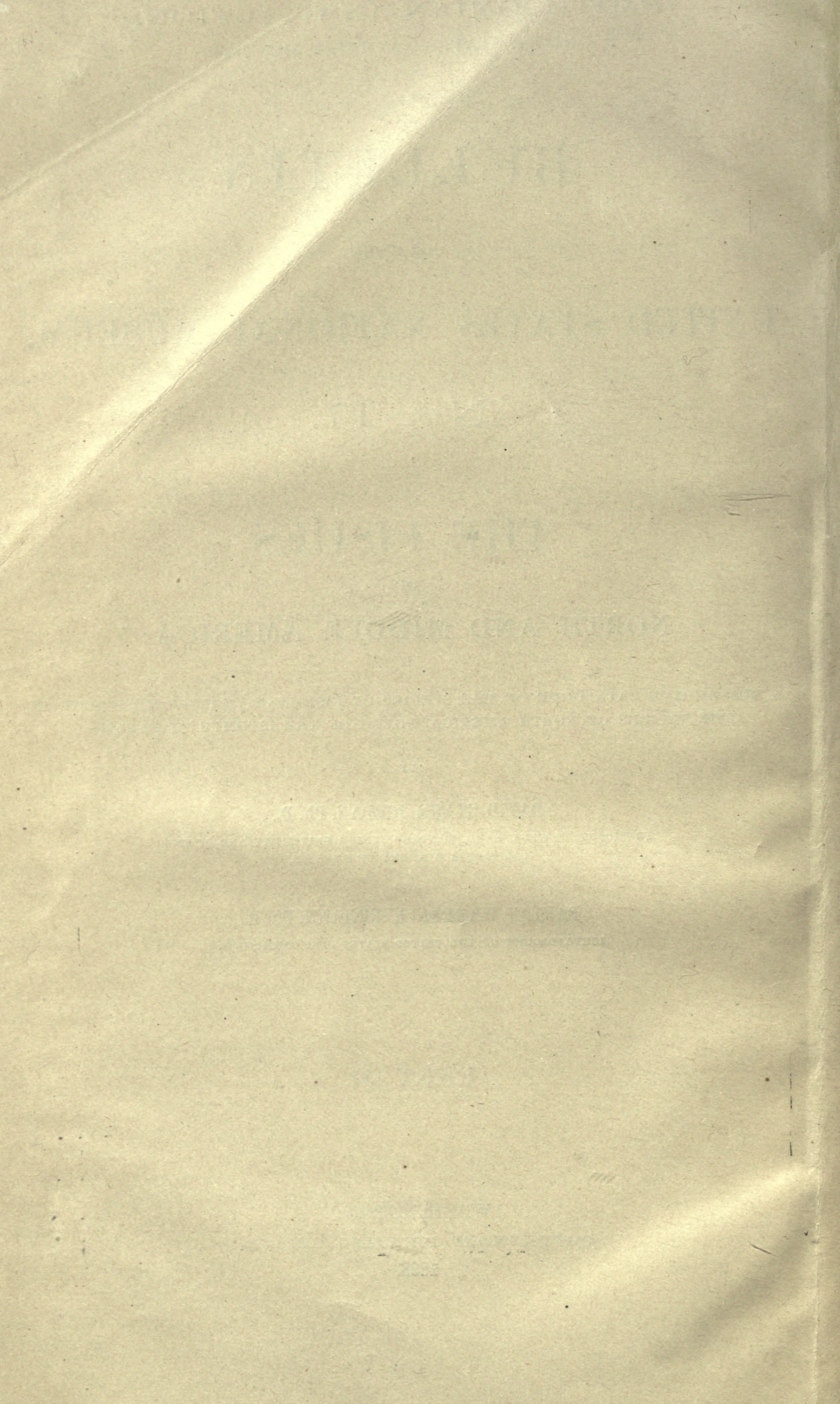




\title{
SMITHSONIAN INSTITUTION.
}

UNITED STATES NATIONAL MUSEUM.

\section{THE FISHES}

OF

\section{NORTH AND MIDDLE AMERICA:}

\section{A DESCRIPTIVE CATALOGUE}

\author{
OF THE \\ SPECIES OF FISH-LIKE VERTEBRATES FOUND IN THE. \\ WATERS OF NORTH AMERICA, NORTH OF \\ THE ISTHMUS OF PANAMA. \\ BY \\ DAVID STARR JORDAN, PH. D., \\ PRESIDENT OF. THE LELAND STANFORD JUNIOR UNIVERSITY AND OF THB \\ CALIFORNIA ACADEMY OF SCIENCES, \\ AND \\ BARTON WARREN EVERMANN, PH. D., \\ ICHTHYOLOGIST OF THE UNITED STATES FISH COMMISSION.
}

PART III.

WASHINGTON :

GOVER'NMENT PRINTING OFFICE.

1898 .

\section{9}




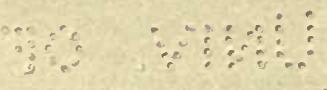

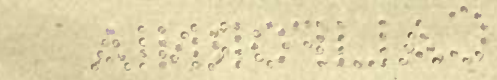




\section{TABLE OF CONTENTS, PART III.}

CLASS III. PISCES-Continued.

ORDER BB. ACANTHOPTERI-Continued.

Family $O L X X X I V$. Triglida-Continued. Page.

Group Gobioidea............................................ 2184

Family $O L X X X V I I$, Callionymida ................................. 2184

Genus 799. Callionymus, Linnæus ............................ 2185

2511. bairdi, Jordan ...................................... 2185

2512. himantophorus, Goode \& Bean......................... 2186

2513. calliurus, Eigenmann \& Eigenmann..................... 2187

2514. pauciraliatus, Gill ................................. 2188

Family $C L X X X V I I I$. Gobiidae.................................. 2188

Genus 800. Ioglossus, Bean ................................... 2192

2515. calliurus, Bean ......................................... 2193

Genus 801. Philypnus, Cuvier \& Valenciennes..................... 2194

2516. dormitor (Lacépède) .................................. 2194

2517. lateralis, Gill....................................... 2195

Genus 802. Dormitator, Gill.................................. 2195

2518. maculatus (Bloch) .................................. 2196

Genus 803. Guavina, Bleeker .................................. 2198

2519. guavina, Cuvier \& Valenciennes ........................... 2198

Genus 804. Eleotris (Gronow) Bloch \& Schneider .................... 2199

2520. amblyopsis (Cope) ...................................... 2199

2521. abacurus, Jordan \& Gilbert ........................... 2200

2522. pisonis (Gmelin) ........................................ 2200

2523. perniger (Cope) .......................................... 2201

2524. pictus (Kner \& Steindachner) ........................... 2201

Genus 805. Alexurus, Jordan ................................ 2202 2525. armiger, Jordan \& Richardson ............................ 2203

Genus 806. Erotelis, Poey..................................... 2203

2526. smaragdus (Cuvier \& Valenciennes)...................... 2204

Genus 807. Gymneleotris, Bleeker ............................. 2204

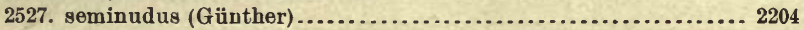

Genus 808. Chriolepis, Gilbert ............................... 2205

2528. minutillus, Gilbert .................................. 2205

Genus 809. Sicydium, Cuvier \& Valenciennes..................... 2205 2529. plumieri (Bloch) .................................... 2206 2530. antillarum, Ogilvie-Grant ........................... 2206 2531. vincente, Jordan \& Evermann ......................... 2207 2531 (a). punctatum, Perugia ............................... 2867

Genus 810. Cotylopus, Guichenot................................ 2207

Subgenus Sicya, Jordan \& Evermann ........................ 2207

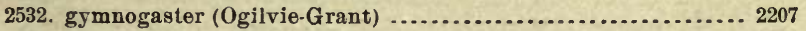

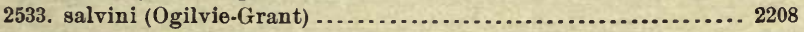

Genus 811. Evorthodus, Gill .................................. 2208 2534. breviceps, Gill....................................... 2208

Genus 812. Lophogobius, Gill................................. 2209

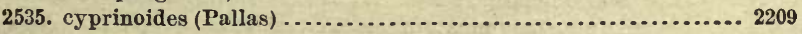


CLASS III. PISCES-Continned.

ORDER BB. ACANTHOPTERI-Continued.

Family CLXXXVIII. Gobiida-Continued. Page,

Genns 813. Gobius (Artedi) Linnæue ........................... 2210

Subgenns Gobius .......................................... 2216

2536. soporator, Cuvier \& Valenciennes........................ 2216

Subgenus Ctenogobius, Gill................................ 2218

2537. nicholsii, Bean...................................... 2218

2538. eigenmanni, Garman................................. 2218

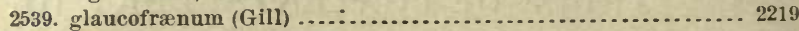

2540. manglicola, Jordan \& Starks............................ 2220

2541. stigmaturus, Goode \& Bean............................. 2220

2542. quadriporus, Cuvier \& V alenciennes ..................... 2221

2543. shufeldti, Jordan \& Eigenmann......................... 2221

2544. boleosoma, Jordan \& Gilbert........................... 2221

2545. fasciatus (Gill) ....................................... 2222

2546. encæomus, Jordan \& Gilbert........................... 2223

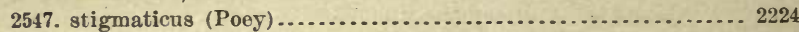

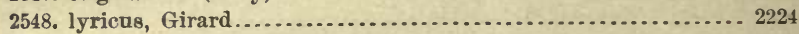

2549. garmani, Eigeumann \& Eigenmànn...................... 2225

2550. zebra, Gilbert................................ 2226; 2867

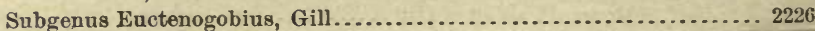

2551. poeyi, Steindachner................................... 2226

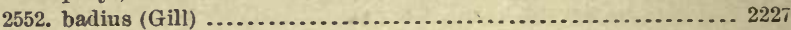

Subgenus Gobionellus, Girard .............................. 2227

2553. microdon, Gilbert ...................................... 2227

2554. smaragdus, Cuvier \& Valenciennes ........................ 2227

2555. strigatus, O'Shaughnessy.............................. 2228

2556. sagittula (Günther).................................. 2228

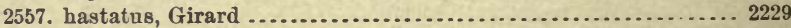

2558. oceanicus, Pallas....................................... 2230

Subgenus Lythrÿ pnus, Jordan \& Evermann ................... 2230

2559. dalli, Gilbert............................................ 2230

Genus 814. Garmannia, Jordan \& Evermann ....................... 2231

Subgenus Garmannia..................................... 2232

2560. paradoxa (Günther) ..................................... 2232

2561. hemigymna (Eigenmann \& Eigenmann) ................. 2233

Subgenus Enypnias, Jordan \& Evermann ....................... 2233

2562. seminuda (Günther) ................................... 2233

Genus 815. Awaous, Steindachner.............................. 2234

2563. flavns (Cuvier \& Valenciennes) ........................... 2235

2564. nelsuni, Evermann...................................... 2235

2565. taiasica (Lichtenstein) ................................. 2236

2566. mexicanus (Günther) .................................. 2237

Genus 816. Bollmannia, Jordan.............................. 2237

2567. ocellata, Gilbert.......................................... 2238

2568. chlamydes, Jordan................................. 2238

2569. Inacropoma, Gilbert ................................... 2239

2570. stigmatura, Gilbert .................................. 2239

Genus 817. Aboma, Jordan \& Starks ............................. 2240

2571. etheostoma, Jordan \& Starks............................. 2240

2572. lucretiæ (Eigenmann \& Eigenmann) ... . . . . . . . . . . . . 2241

2573. chiquita (Jenkins \& Evermann) ........................... 2241

Genus 818. Microgobius, Poey ................................. 2242

2574. gulosus (Girard) ....................................... 2243

2575. eulepis, Eigenmann \& Eigenmann ...................... 2244

2576. thalassinus, Jordan \& Gilbert............................. 2245

2577. signatus, Poey ......................................... 2246

Genus 819. Zalypnus, Jordan \& Evermann...................... 2246 
CLASS III. PISCES-Continued.

Order BB. Acanthopteri-Continued.

Family CLXXXVIII. Gobiidoe-Continued. Page.

2578. cyclolepis (Gilbert) ................................. 2246

2579. emblematicus (Jordan \& Gilbert) ....................... 2247

Genus 820. Encyclogobius, Gill ............................... 2248

2580. newberryi (Girard) .................................... 2248

Genus 821. Lepidogobius, Gill ............................... 2249

2581. lepidus (Girard) ....................................... 2249

Genus 822. Gillichthys, Cooper ............................... 2249

2582. mirabilis, Cooper................................... 2250

2583. detrusus, Gilbert \& Scofield ............................... 2251

Genus 823. Quietula, Jordan \& Evermann ......................... 2251

2584. y-cauda (Jenkins \& Evermann) ........................ 2251

Genus 824. Ilypnus, Jordan \& Evermann .......................... 2253 2585. gilberti (Eigenmann \& Eigenmann) ........................ 2253

Genus 825. Clevelandia, Eigenmann \& Eigenmann ................... 2254 2586. ios (Jordan \& Gilbert) ................................... 2254

2587. rosæ, Jordan \& Evermann ................................ 2255

Genns 826. Evermannia, Jordan .................................. 2256

2588. longipinnis (Steindachner) ............................... 2256

2589. zosterura (Jordan \& Gilbert) .............................. 2256

Genus 827. Gobiosoma, Girard ................................ 2257

2590. histrio, Jordan .......................................... 2258

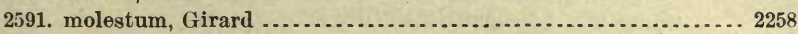

2592. bosci (Lacépède) ............................................. 2259

2593. crescentale, Gilbert ....................................... 2259

2594. multifasciatum, Steindachner ............................ 2260

Genus 828. Barbulifer, Eigenmann \& Eigenmann................... 2260

2595. couthœcus (Jordan \& Gilbert) ............................. 2260

Genus 829. Typhlogobius, Steindachner......................... 2261 2596. californiensis, Steindachner............................ 2262

Genus 830. Tyntlastes, Günther .............................. 2262

2597. brevis (Günther) ....................................... 2262

2598. sagitta (Günther) ........................................ 2263

Genus 831. Gobioides, Lacépède ........................... 2263; 2868 2599. broussonnetii, Lacépède ............................... 2263 2600. peruanus (Steindachner) ................................ 2264

Genus 832. Cayennia, Sauvage................................... 2265 2601. guichenoti, Sauvage.................................... 2265

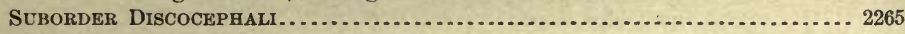

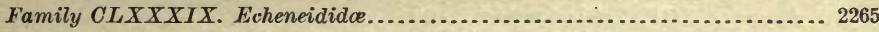

Genus 833. Phtheirichthys, Gill................................ 2268 2602. lineatus (Menzies) ...................................... 2268

Genus 834. Echeneis (Artedi) Linnæus.......................... 2268 2603. naucrates, Linnæus...................................... 2269 2604. naucrateoides, Zuíeuw ................................. 2270

Genus 835. Remilegia, Gill...................................... 2270 2605. australis (Bennett) ..................................... 2270

Genus 836. Remora, Gill....................................... 2271

Subgenus Remora............................................ 2271 2606. remora (Linnæus) ...................................... 2271

Subgenus Remorina, Jordan \& Evermann ......................... 2272 2607. albescens (Temminck \& Schlegel) ....................... 2272

Subgenus Remoropsis, Gill................................... 2272 2608. brachyptera (Lowe) .................................. 2272

Genus 837. Rhombochirus, Gill.............................. 2273 2609. osteochir (Cuvier) ...................................... 2273

Group Trachinoidea............................................ 2273 
CLASS III. PISCES-Continued.

Order BB. AcANTHOPTERI-Continued. Page.

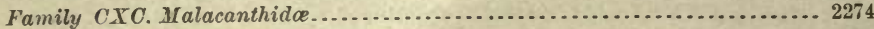

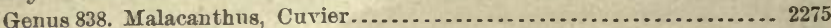

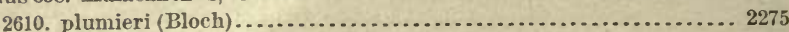

Genus 839. Caulolatilus, Gill .................................. 2276

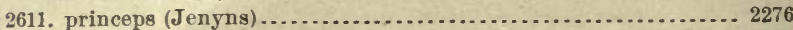

2612. microps, Goode \& Bean............................... 2277

2613. cyanops, Рoey.......................................... 2278

Genus 840. Lopholatilus, Goorle \& Bean .......................... 2278

2614. chamæleonticeps, Goode \& Bean ......................... 2278

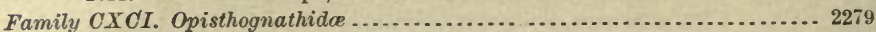

Genus 841. Opisthognathus Cuvier ............................... 2280

2615. lonchurum, Jordan \& Gilbert ............................ 2281

2616 punctatum, Peters....................................... 2281

2617. macrognathum, Poey..................................... 2281

2618. ommatum, Jenkins \& Evermann.......................... 2282

Genus 842. Gnathypops, Gill................................. 2283

2619. scops, Jenkins \& Evermann............................. 2283

2620. maxillosa (Роey) .......................................... 2284

2621. macrops (Рoey) .......................................... 2284

2622. rhomalea (Jordan \& Gilbert) ........................... 2285

2623. snyderi, Jordan \& Evermann .............................. 2285

2624. mystacina, Jordan ....................................... 2286

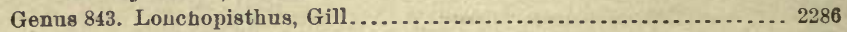

2625. micrognathus (Poey).................................. 2287

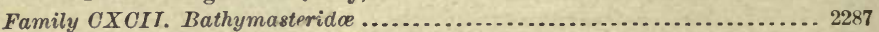

Genus 844. Bathymaster ......................................... 2288

2626. signatus, Cope........................................... 2288

Genus 845. Ronquilus, Jordan \& Starks ............................. 2289 2627. jordani (Gilbert) ............................................ 2289

Genus 846. Rathbunella, Jordan \& Evermann ...................... 2289 2628. hr poplecta (Gilbert) .......................................... 2290

Family CXOIII. Ohrasmodontida................................... 2291

Genus 847. Chiasmodon, Johnson.................................. 2291 2629. niger, Johnson ......................................... 2291

Genus 848. Pseudoscopelus, Lütken .............................. 2292 2630. scriptus, Lütken........................................ 2292

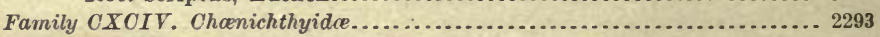

Genus 849. Hypsicometes, Goode ................................ 2293

2631. gobioides, Goode...................................... 2294

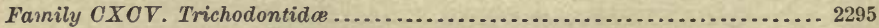

Genus 850. Trichodon (Steller) Cuvier............................ 2295

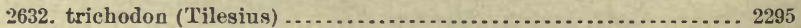

Genus 851. Arctoscopus, Jordan \& Evermann...................... 2297 2633. japonicus (Steindachner) .................................. 2297

Family CXOVI. Daclyloscopidae .................................... 2297

Genus 852. Gillellus, Gilbert.................................... 2298

2634. semicinctus, Gilbert..................................... 2298

2635. arenicola, Gilbert...................................... 2299

2636. ornatus, Gilbert.................................... . . 2299

Genus 853. Dactyloscopus, Gill ................................ 2300

Subgenus Dactyloscopus..................................... 2301

2637. pectoralis, Gill ........................................ 2301

2638. tridigitatus, Gill .................................... 2301

2639. poeyi, Gill.......................................... 2302

2640. lunaticus, Gilbert.................................... 2302

Subgenus Esloscopus, Jordan \& Evermann ...................... 2303 2641. zelotes, Jordan \& Evermaun ........................... 2303 
CLASS III. PISCES-Continued.

ORDER BB. ACANTHOPTERI-Continued.

Family CXCVI. Dactyloscopido-Continued. Page.

Genus 854. Dactylagnus, Gill .................................. 2304

2642. mundus, Gill ......................................... 2304

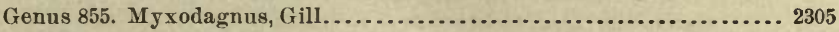

2643. opercularis, Gill ...................................... 2305

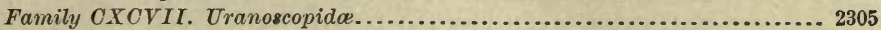

Genus 856. Astroscopus, Brevoort ............................... 2306

2644. y-gracum (Cuvier \& Valenciennes)..................... 2307

2645. zephyreus, Gilbert \& Starks............................. 2309

2646. guttatus (Abbott) .................................... 2310

Genus 857. Kathetostoma, Güntber ............................. 2311

2647. averruncus, Jordan \& Bollman.......................... 2311

2648. albiguttum, Bean................................... 2312

SUBORDER HAPLODOCI .............................................. 2313

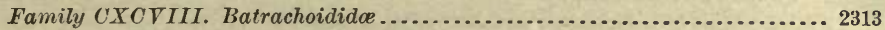

Genus 858. Batrachoides, Lacépède ......................... 2314; 2868 2649. surinamensis (Bloch \& Schneider) ....................... 2314

2650. pacifici (Günther)....................................... 2314

Genus 859. Opsanus, Rafinesque ................................. 2315

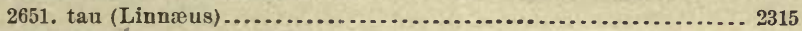

2652. pardús (Goorde \& Bean) ............................... 2316

Genus 860. Porichthys, Girard .................................. 2317

2653. porosissimus (Cuvier \& Valenciennes) .................... 2319

2654. notatus, Girard .................................... 2321

2655. margaritatus (Richardson) ............................. 2322

Genus 861. Thalassophryne, Günther......................... 2323

2656. maculosa, Günther ................................. 2324

2657. reticulata, Günther.................................. 2325

Genus 862. Dretor, Jordan \& Evermann......................... 2325 2658. dowi (Jordan \& Gilbert) ............................... 2325

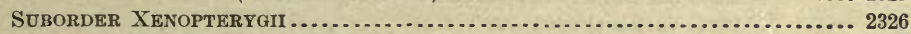

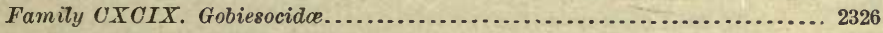

Genus 863. Caularchus, Gill .................................. 2327 2659. mæandricus (Girard) . . . . . . . . . . . . . . . . . . . . . . . 2328

Genus 864. Bryssetæres, Jordan \& Evermann..................... 2328 2660. pinniger (Gilbert) ................................... 2328

Genus 865. Gobiesox, Lacépède.................................. 2329

Subgenus Bryssophilus, Jordan \& Evermann.................... 2330

2661. papillifer, Gilbert ................................... 2330

Subgenus Gobiesox......................................... 2331

2662. gyrinus, Jordan \& Erermann.......................... 2331

2663. nigripinnis (Peters) ..................................... 2331

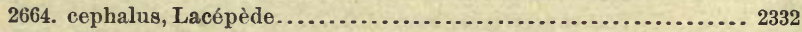

2665. tudes, Richardson . . . . . . . . . . . . . . . . . . . . . . . . . . . . 2333

2666. strumosus, Cope......................................... 2335

2667. virgatulus, J ordan \& Gilbert........................... 2333

2668. adustus, Jordan \& Gilbert ............................. 2334

2669. funebris, Gilbert....................................... 2334

2670. pœecilophthalmus, Jenyns ............................... 2335

2671. rhodospilus, Günther ................................ 2335

2672. macrophthalmus, Günther ........................... 2335

2673. cerasinus, Cope ........................................ 2336

Subgenus Sicyases, Müller \& Troschel............................ 2336

2674. erythrops, Jordan \& Gilbert.......................... 2336

2675. rubiginosus (Рoey).................................... 2337

2676. carneus (Роeу) . . .......................................... 2337

2677. hæres, Jordan \& Bollman................................ 2337 
CLASS III. PISCES-Continued.

Order BB. Acanthopteri-Continued.

Family CXCIX. Gobiesocida-Continued. Page.

2678. punctulatus (Рoey) .................................. 2338

2679. fasciatus (Peters) ..................................... 2338

Genus 866. Rimicola, Jordan \& Evermann........................ 2338

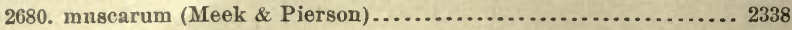

2681. eigenmanni (Gilbert) ..................................... 2339

Genus 867. Arbaciosa, Jordan \& Evermann ........................ 2340

2682. rhessodon (Rosa Smith) .............................. 2340

2683. humeralis (Gilbert) ................................. 2341

2684. rupestris (Рoey) ...................................... 2341

2685. zebra (Jordan \& Gilbert) ............................. 2341

2686. eos (Jordan \& Gilbert) ................................... 2343

Group Blennioidea........................................... 2343

Family CO. Blenniida.......................................... 2344

Genus 868. Enneanectes, Jordan \& Evermann ...................... 2349

2687. carminalis (Jordan \& Gilbert) ........................... 2350

Genus 868(a). Dialommus, Gilbert ................................ 2868

2687 (a). fuscus, Gilbert .................................... 2868

Genus 869. Heterostichus, Girard.............................. 2350

2688. rostratus, Girard ................................... 2351

Genus 870. Gibbonsia, Cooper................................... 2351

2689. evides (Jordan \& Gilbert) .......................... 2352; 2869

2690. elegans (Cooper) ..................................... 2353

Genus 871. Neoclinus, Girard ................................... 2354

Subgenus Neoclinus ........................................ 2354

2691. blanchardi, Girard .................................... 2354

Subgenus Pterognathus, Girard............................... 2355

2692. satirìcus, Girard..................................... 2355

Genus 872. Malacoctenus, Gill ................................... 2356 2693. ocellatus (Steindachner) ......................... 2356; 2869

2694. varius (Poey) ....................................... 2357

2695. macropus (Рoey) …................................ 2357

2696. lngubris (Poey) ........................................ 2357

2697. gillii (Steindachner) .................................... 2358

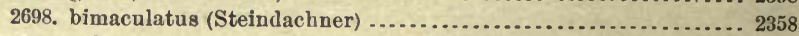

2699. delalandi (Cuvier \& Valenciennes) ......................... 2358

2700. versicolor (Рoey) ........................................ 2359

2701. biguttatus (Cope) ..................................... 2360

Genus 873. Labrisomus, Swainson ................................ 2360

2702. herminier (Le Sueur) ................................. 2361

2703. nuchipinnis (Quoy \& Gaimard) ........................... 2362

2704. xanti, Gill ............................................. 2362

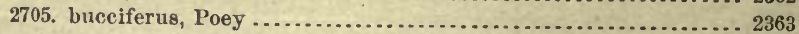

2706. microlepidotus, Poey...................................... 2363

Genus 874. Mnierpes, Jordan \& Evermann ........................... 2364

2707. wacrocephalus (Günther) .................................. 2364

Genus 875. Gobioclinus, Gill...................................... 2364

2708. gobio (Cuvier \& Valenciennes) ......................... 2365

Genus 876. Starksia, Jordan \& Evermann ............................. 2365

2709. cremnobates (Gilbert) ................................... 2365

Genus 877. Cryptotrema, Gilbert ..................................... 2366

2710. corallinum, Gilbert....................................... 2366

Genus 878. Exerpes, Jordan \& Evermann............................ 2367

2711. asper (Jenkins \& Evermann) .............................. 2367

Genus 879. A uchenopterus, Günther .............................. 2369

Snbgenus Corallicola, Jordan \& Evermann .......................... 2369

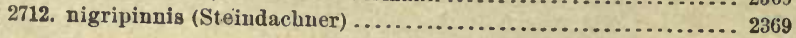


CLASS III. PISCES-Continued.

Order BB. ACANTHOPTERI-Continued.

Family CO. Blenniida-Continued.

Page.

2713. altivelis (Lockington) ............................... 2370

2714. marmoratus (Steindachner) ............................ 2371

Sulgenus Auchenopterus .................................. 2371

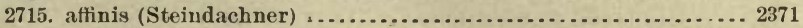

2716. monophthalmus, Günther ............................ 2372

2717. integripinnis (Rosa Smith) . . . . . . . . . . . . . . . . . . . 2372

2718. fasciatus (Steindachner) ............................. 2373

2719. nox (Jordan \& Gilbert) ................................... 2373

Genus 880. Paraclinus, Mocquard............................. 2374

2720. ehaperi, Moequard .................................. 2374

Genus 881. Emmnion, Jordan.................................. 2375

2721. bristolæ, Jordan .................................. 2375

Genus 882. A topoclinus, Vaillant... .......................... 2376

2722. ringens, Vaillant....................................... 2376

Genus 883. Runula, Jordan \& Bollman ......................... 2377

2723. azalea, Jordan \& Bollman .............................. 2377

Genus 884. Blennius (Artedi) Linnæus ......................... . 2377

Subgenus Lipophrys, Gill.................................... 2378

2724. carolinus (Cuvier \& Valenciennes) ....................... 2378

2725. fucorum, Cuvier \& Valenciennes ......................... 2379

2726. stearnsi, Jordan \& Gilbert ................................ 2379

2727. favosus, Goode \& Bean................................ 2380

2728. pilicornis, Cuvier \& Valenciennes........................ 2380

2729. marmoreus, Poey ..................................... 2381

2730. truncatus (Poey) ........................................ 2381

2731. vinctus, Poey ........................................ 2382

2732. cristatus, Linnæus ..................................... 2382

Genus 885. Scartella, Jordan ..................................... 2384

2733. microstoma (Poey) ..................................... 2384

Genus 886. Hypleurochilus, Gill ............................... 2385

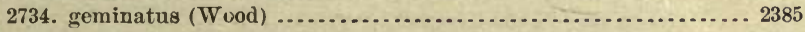

Genus 887. Hypsoblennius, Gill................................ 2386

Subgenus Hypsoblennius .................................. 2386

2735. gilberti (Jordan) .................................... 2386

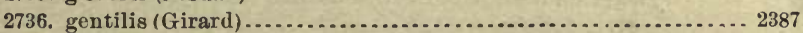

2737. striatus (Steindachner) ................................ 2388

2738. ionthas (Jordan \& Gilbert) ............................ 2388

2739. hentz (Le Suenr) .................................... 2390

Subgenus Blenniolus, Jordan \& Evermann ..................... 2390

2740. brevipinnis (Günther) ................................... 2390

Genus 888. Chasmodes, Cuvier \& Valenciennes ...................... 2391

2741. jenkinsi (Jordan \& Evermann) ........................... 2391

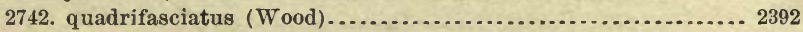

2743. saburræ, Jordan \& Gilbert ............................. 2392

2744. novemlineatus (Wood) ................................. 2393

2745. bosquianus (Lacépède) ................................. 2394

Genus 889. Homesthes, Gilbert ................................. 2394

2746. caulopus, Gilbert...................................... 2394

Genus 890. Scartichthys, Jordan \& Evermann ...................... 2395

2747. rul ropunctatus (Cuvier \& Valenciennes) ................... 2396

Genus 891. Rupiscartes, Swainson ............................. 2396

2748. atlanticus (Cuvier \& Valenciennes) ....................... 2397

Genus 892. Entomacrodus, Gill ................................ 2397

2749. chiostictus (Jordan \& Gilbert) ......................... 2398

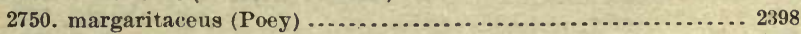

2751. decoratus, Poey ...................................... 2399 
CLASS III. PISCES-Continned.

ORder BB. ACANTHOPTERI-Continued.

Family CC. Blenniidae-Continued.

2752. nigricans, Gill........................................ 2399

Genus 893. Salariichthys, Guichenot ............................ 2400

2753. textilis (Quoy \& Gaimard)............................ 2400

Genus 894. Ophioblennius, Gill ................................ 2400

2754. webbii (Valenciennes) ............................... 2401

2755. steindachneri, Jordan \& Evermann......................... 2401

Genus 895. Emblemaria, Jordan \& Gilbert......................... 2401

2756. atlantica, Jordan \& Evermann............................. 2402

2757. nivipes, Jordan \& Gilbert................................ 2402

2758. oculocirris, Jordan..................................... 2403

Genus 896. Chænopsis, Gill.................................... 2403

2759. ocellatus, Poey........................................ 2403

Genus 897. Iucioblennius, Gilbert............................ 2404

2760. alepidotus, Gilbert .................................. 2404

Genus 898. Pholidichthys, Bleeker ............................. 2405

2761. anguilliformis, Lockington.............................. 2405

Genus 899. Psednoblennius, Jenkins \& Evermann.................... 2406 2762. hypacanthus, Jenkins \& Evermann....................... 2406

Genus 900. Stathmonotus, Bean................................. 2407

2763. hemphillii, Bean..................................... 2407

Genus 901. Bryostemma, Jordan \& Starks........................ 2408

2764. polyactocephalum (Pallas) ............................. 2408

2765. nugator, Jordan \& Williams ............................... 2410

Genus 902. Apodichthys, Girard .................................. 2411

2766. flavidus, Girard ....................................... 2411

2767. nnivittatus, Lockington ................................. 2412

Genus 903. Xererpes, Jordan \& Gilbert............................ 2413

2768. fucorum (Jordan \& Gilbert) ............................. 2413

Genns 904. Ulvicola, Gilbert ..................................... 2413

2769. sanctæ-rosa, Gilbert \& Starks ............................ 2413

Genus 905. Pholis (Gronow) Scopoli ............................... 2414

Subgenus Urocentrıs, Kner................................... 2415

2770. pietus (Kner) ........................................... 2415

Subgenus Rhodymenichthys, Jordan \& Evermann. ............... 2416

2771. dolichogaster (Pallas) .................................. 2416

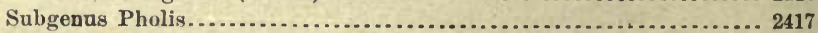

2772. fasciatus (Bloch \& Schneider) ............................ 2417

2773. gunnellus (Linnæus) .................................... 2419

2774. ornatns (Girard) ...................................... 2419

Genus 906. Gunnellops, Bleeker .................................. 2420

2775. rosens (Pallas) ........................................ 2420

Genus 907. Asternopteryx, Rüppell ............................. 2420 2776. gunnelliformis, Rüppell............................... 2420

Genus 908. Anoplarchus, Gill................................... 2421 2777. atropurpureus (Kittlitz) ........................... 2422; 2869

Genus 908(a). Alectrias, Jordan \& Evermann...................... 2869 2778. alectrolophus (Pallas) ............................. 2421; 2869

Genus 909. Xiphistes, Jordan \& Starks ............................. 2423 2779. ulvæe, Jordan \& Starks................................. 2423 2780. chirus (Jordan \& Gilbert) . . . . . . . . . . . . . . . . . . . . . . . . . . 2424

Genus 910. Xiphidion, Girard.................................... 2424 2781. mucosum, Girard..................................... 2425

2782. rupestre (Jordan \& Gilbert) .............................. 2426

Genus 911. Cebedichthys, Ayres.................................. 2426

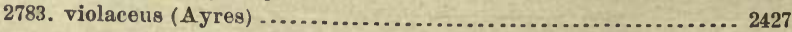

Genus 912. Plagiogrammus, Bean............................. 2427 
CLASS III. PISCES-Continued.

ORDER BB. ACANTHOPTERI-Continued.

Family OC. Blenniidoe-Contiuued.

Page.

2784. hopkinsi, Bean ....................................2428

Genus 913. Opisthocentrus, Kner.............................. 2428

2785. ocellatus (Tilesius) ................................... 2429

Genus 914. Pholidapus, Bean \& Bean........................... 2430

2786. dybowskii (Steindachner) ............................. 2430

Genus 915. Plectobranchus, Gilbert........................... 2431

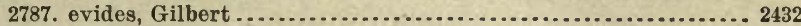

Genus 916. Leptoclinus, Gill................................. 2432

2788. maculatus (Fries) .................................... 2433

Genus 917. Poroclinus, Bean................................ 2433

2789. rothrocki, Bean .................................... 2434

Genus 918. Lumpenus, Reinhardt ............................ 2435

Subgenus Anisarchus, Gill ................................. 2435

2790. medius (Reinhardt) ............................... 2435

Subgenus Lumpenus ......................................... 2136

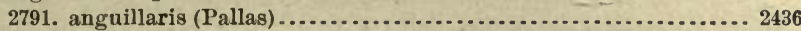

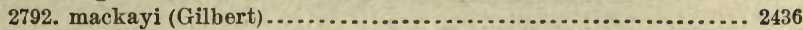

2793. fabricii (Cuvier \& Valenciennes) ........................ 2437

2794. lampetræformis (Walbaum) ........................... 2438

Genus 919. Stichæus, Reinhardt .............................. 2439

2795. punctatus (Fabricius) ............................... 2439

Genus 920. Ulvaria, Jordau \& Evermann ....................... 2440

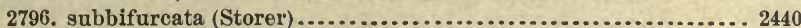

Genus 921. Eumesogrammns, Gill ............................ 2441

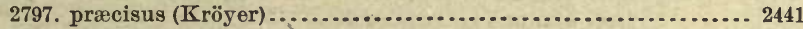

Family COI. Oryptacanthodida ................................. 2442

Genus 922. Delolepis, Bean ................................... 2442

2798. virgatus, Bean .................................. 2442

Genus 923. Cryptacanthodes, Storer ........................... 2443

2799. maculatus, Storer ................................... 2443

Genus 924. Lyconectes, Gilbert ............................... 2444

2800. aleutensis, Gilbert ................................. 2444

Family CCII. Anarhichadidue .................................. 2445

Genus 925. Anarhichas (Artedi) Linnæus....................... 2445

2801. latifrons, Steenstrup \& Hallgrimsson .................... 2446

2802. minor, Olafsen...................................... 2446

2803. lupus, Linnæus ...................................... 2446

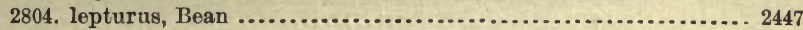

2805. orientalis, Pallas .................................. 2447

Genus 926. Anarrhichthys, Ayres ........................... 2447

2806. ocellatus, Ayres.................................... 2448

Family COIII. Cerdalidoe ........................................ 2448

Genus 927. Cerdale, Jordan \& Gilbert .............................. 2448

2807. ionthas, Jordan \& Gilbert............................... 2449

Genus 928. Microdesmus, Günther............................ 2450

2808. dipus, Günther.................................... 2450

2809. retropinnis, Jordan \& Gilbert......................... 2450

Family $C C I V$. Ptilichthyidoe ..................................... 2451

Fenus 929. Ptilichthys, Bean ................................... 2452

2810. goodei, Bean ........................................... 2452

Group Ophidioidea ........................................... 2453

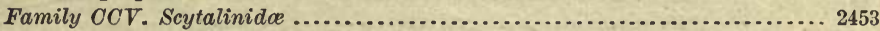

Genus 930. Scytalina, Jordan \& Gilbert......................... 2454

2811. cerdale, Jordan \& Gilbert .............................. 2454

Family COVI. Zoarcidae....................................... 2455

Genus 931. Zoarces, Gill ................................. 2456 
CLASS III. PISCES-Continued.

ORDER BB. ACANTHOPTERI-Coutinued.

Family COVI. Zoarcida-Contiuued. Page.

Subgenus Macrozoarces, Gill................................. 2457

2812. anguillaris (Peck) ................................... 2457

Genus 932. Embryx, Jordan \& Evermann ....................... 2458

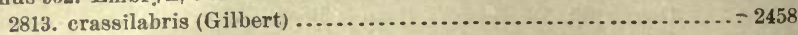

2814. crotalinus (Gilbert) ................................... 2458

Genus 933 . Lycodopsis, Collett................................ 2460

2815. pacificus (Collett) ..................................... 2460

Genus 934. A prodon, Gilbert................................... 2460

2816. cortezianus, Gilbert .................................. 2461

Genus 935. Lycodes, Reinhardt ............................... 2461

Subgenus Lycodes . . ...................................... 2463

2817. esmarkii, Collett..................................... 2463

2818. vahlii, Reinhardt ................................... 2463

2819. concolor, Gill \& Townsend ............................. 2463

2820. zoarchus, Goode \& Bean ................................ 2464

2821. reticulatns, Reinhardt............................... 2465

2822. perspicillım, Kröyer ................................. 2465

2823. frigidns, Collett ..................................... 2465

2824. terræ-nove, Collett .................................. 2466

2825. digitatus, Gill \& Townsend ........................... 2466

- 2826. palearis, Gilbert....................................... 2466

2827. brevipes, Bean ...................................... 2467

Subgenus Lycias, Jorlan \& Evermann....................... 2468

2828. nebulosus, Kröyer.................................. 2468

2829. seminudus, Reinhardt................................. 2468

Genus 936. Lycodalepis, Bleeker................................ 2468

2830. polaris (Sabine) ...................................... 2468

2831. mucosus (Richardson) ................................ 2470

Genus 937. Lycenchelys, Gill ................................ 2470

2832. verrillii (Goode \& Bean) ................................ 2470

2833. paxillus (Goode \& Bean) ................................. 2471

2834. porifer (Gilbert) ............................... 2171; 2869

Genus 938. Furcella, Jordan \& Evermann .......................... 2472

2835. diaptera (Gilbert) .................................. 2472

Genus 939. Lycodonus, Goode \& Bean.......................... 2473

2836. mirabilis, Goode \& Bean................................ 2474

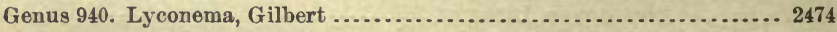

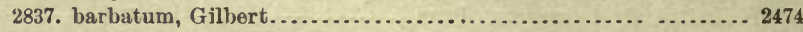

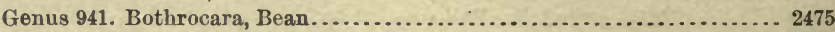

2838. pusilla (Bean) ........................................... 2476

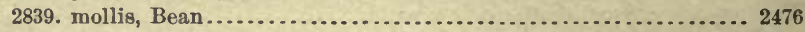

Genus 942. Gymnelis, Reinhardt........................... 2477

2840. viridis (Fabricius) ................................... 2477

2841. stigma (Lay \& Bennett) ............................. 2477

Genus 943. Ly cocara, Gill....................................... 2478

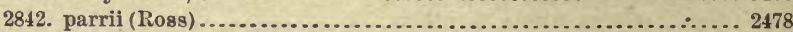

Genus 944. Melanostigma, Günther............................. 2478

2843. gelatinosum, Günther............................ 2479

2844. pammelas, Gilbert.................................... 2479

Family CCVII. Derepodichthyida................................. 2480

Genus 945. Derepodichthys, Gilbert ............................. 2480 .

2815. alepidotus, Gilbert ................................... 2480

Family COVIII. Ophidiidoe....................................... 2481

Genus 946. Lepophidium, Gill.................................. 2482

2846. marmoratum (Goode \& Bean) ............................... 2482

2847. emmelas (Gilbert) .................................. 2483 
CLASS III. PISCES-Continued.

ORDER BB. ACANTHOPTERI-Continued.

Family CCVIII. Ophidiido-Continued. Page.

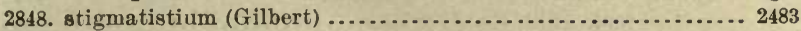

2849. profundorum (Gill) .................................. 2484

2850. cervinum (Goode \& Bean) . . . . . . . . . . . . . . . . . . . . . . . . 2484

2851. prorates (Jordan \& Bollman) . . . . . . . . . . . . . . . . . . 2485

2852. brevibarbe (Cuvier) .................................... 2485

2853. pardale (Gilbert) . .................................... 2486

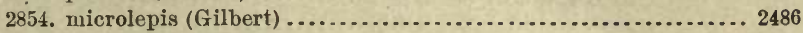

Genus 947. Ophidion (Artedi) Linnæus......................... 2487

2855. beani, Jordan \& Gilbert.................................. 2487

2856. holbrooki (Putnam) .................................. 2487

2857. graellsi, Poey ........................................ 2488

Genus 948. Chilara, Jordan \& Evermann......................... 2488 2858. tavlori (Girard) ......................................... 2489

Genus 949. Rissola, Jordan \& Evermann.......................... 2489

2859. marginata (De Kay) .................................... 2489

Genus 950. Otophidium, Gill ................................... 2490

2860. omostigma (Jordan \& Gilbert) ......................... 2490

2861. indefatigabile, Jordan \& Bollman ..................... 2490

2862. galeoides (Gilbert) .................................... 2491

Family $C O I X$. Lycodapodidoe ....................................... 2491

Genus 951. Lycodapus, Gilbert................................. 2492

2863. dermatinus, Gilbert ................................. 2492

2864. fierasfer, Gilbert...................................... 2493

2865. parviceps, Gilbert .................................... 2493

2866. extensus (Gilbert) ..................................... 2494

Family $C O X$. Fierasferidae. ...................................... 2494

Genus 952. Fierasfer, Cuvier . . . . . . . . . . . . . . . . . . . . . . . . . . . 2495

2867. affinis (Günther) ....................................... 2495

2868. arenicola, Jordan \& Gilbert............................. 2496

2869. bermudensis (Jones) ................................... 2497

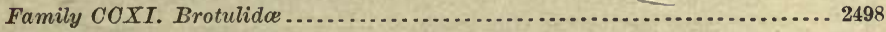

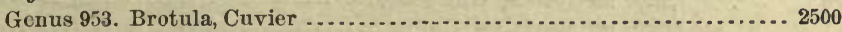

2870. barbata (Bloch \& Schneider) ......................... 2500

Genus 954. Stygicola, Gill........................................ 2500

2871. dentatus (Рoey) .................................... 2500

Genus 955. Lucifuga, Poey ....................................... 2501

2872. subterraneus, Poey .................................... 2501

Genus 956. Brosmophycis, Gill.................................. 2502

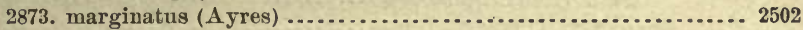

Genus 957. Ogilbia, Jordan \& Evermann......................... 2502

2874. ventralis (Gill) ........................................ 2503

2875. cayorum, Evermann \& Kendall........................... 2503

Genus 958. Bythites, Reinhardt . ............................... 2504

2876. fuscus, Reinhardt ...................................... 2504

Genus 959. Catætyx, Günther..................................... 2504

2877. rubirostris, Gilbert . . . . . . . . . . . . . . . . . . . . . . . . . . 2505

Genus 960. Dicromita, Goode \& Bean.............................. 2506 2878. agassizii, Goode \& Bean .............................. 2506

Genus 961. Bassozetus, Gill................................... 2507

2879. normalis, Gill ........................................ 2507

2880. compressus (Günther) .................................. 2508

2881. catena, Goode \& Bean.................................. 2509

2882. tænia (Günther) .......................................... 2510

Genus 962. Mobia, Goode \& Bean............................... 2510

2883. promelas (Gilbert) ................................... 2511

Genus 963. Neobythites, Goode \& Bean........................ 2512 
CLASS III. PISCES-Continued.

ÓrDER 13B. ACANTHOPTERI-Continued.

Family COXI. Brotulida-Continued. Page.

2884. gillii, Goode \& Bean.................................. 2512

2885. marginatus, Goode \& Bean............................. 2513

Genus 964. Benthocometes, Goode \& Bean......................... 2513

2886. robustus, Goode \& Bean ................................ 2514

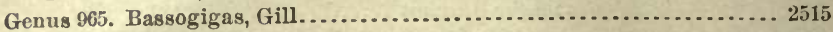

2887. gillii, Goode \& Bean .................................... 2515

2888. stelliferoides (Gilbert) .................................. 2516

Genus 966. Barathrodemus, Goode \& Bean ........................ 2517

2889. manatinus, Goode \& Bcall............................ 2517

Genus 967. Nematonus, Günther .............................. 2518

2890. pectoralis, Goode \& Bean .............................. 2518

Genus 968. Porogadus, Goode \& Bean ............................. 2519

2891. miles, Goode \& Bean .................................. 2520

Genus 969. Penopus, Goode \& Bean................................ 2520

2892. macdonaldi, Goode \& Bean............................. 2521

Genus 970. Dicrolene, Goode \& Bean............................. 2522

2893. intronigra, Goode \& Bean............................. 2522

Genus 971. Mixonus, Giinther .................................. 2523

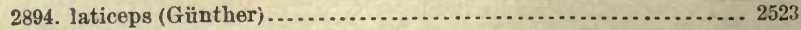

Genus 972. Barathronus, Goode \& Bean........................... 2524

2895. bicolor, Goode \& Bean.................................. 2524

Genus 973. Aphyonus, Günther .................................. 2525

2896. mollis, Goode \& Bean .................................... 2525

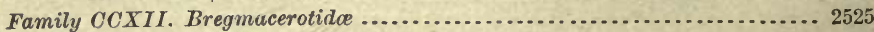

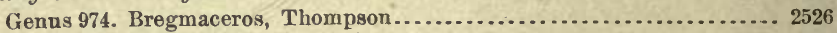

2897. macclellandii, Thompson............................. 2526

2898. atlanticus, Goode \& Bean............................ 2527

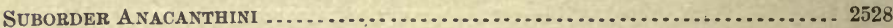

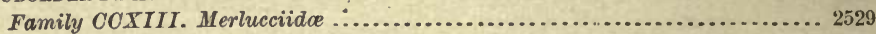

Genus 975. Merluccius, Rafinesque.............................. 2529

2899. merluccius (Linnæus) ................................. 2530

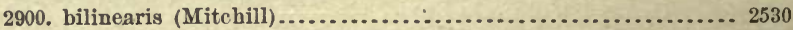

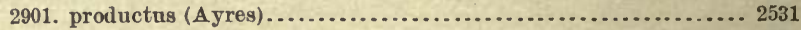

Family $C C X I V$. Gadidae........................................ 2531

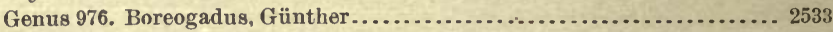

2902. saida (Lepechin) ... . . . . . . . . . . . . . . . . . . . . . . . . . . 2533

Genus 977. Pollachius, Nilsson................................... 2534

2903. virens (Linnæus) ...................................... 2534

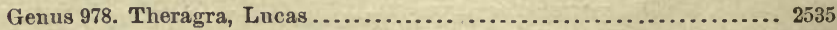

2904. chalcogramma (Pallas) ............................... 2535

2905. fucensis (Jordan \& Gilbert) .......................... 2536

Genus 979. Eleginus, Fischer ...................................... 2537 2906. navaga (Kölreuter) ...................................... 2537

Genus 980. Microgadus, Gill..................................... 2538

2907. proximus (Girard)...................................... 2539

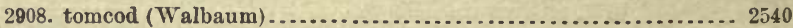

Genus 981. Gadus (Artedi) Linnæus......................... 2540

2909. callarias, Linnæus ................................... 2541

2910. macrocephalus, Tilesius................................ 2541

2911. ogac, Richardson ...................................... 2542

Genus 882. Melanogrammus, Gill ............................... 2542

2912. xglefinus, Linnæus .................................... 2542

Genus 983. Lepedion, Swainson............................... 2543

2913. verecundum, Jordan \& Cramer.......................... 2543

Genus 984. Antimora, Günther .................................... 2544

2914. viola (Goode \& Bean) .................................... 2544 
CLASS III. PISCES-Continued.

ORDER BB. ACANTHOPTERI-Continued.

Family CCXIV. Gadide-Continued. Page.

2915. microlepis, Bean.................................. 2545

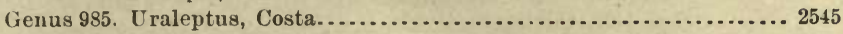

2916. maraldi (Risso) . . . . . . . . . . . . . . . . . . . . . . . . . . . . . . 2545

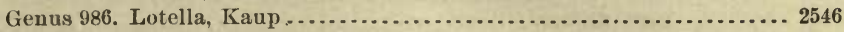

2917. maxillaris, Bean....................................... 2546

Genus 987. Physiculus, Kaup................................. 2547

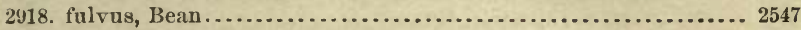

2919. nematopus, Gilbert. . . . . . . . . . . . . . . . . . . . . . . . . 2548

2920. kaupi, Рoey ......................................... 2548

2921. rastrelliger, Gilbert.................................. 2549

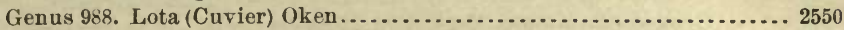

2922. maculosa (Le Sueur) . . . . . . . . . . . . . . . . . . . . . . . . . 2550

Genus 989. Molva, Fleming................................. 2551

2923. molva (Linnæus) ................................... 2551

Genus 990. Urophycis, Gill.................................... 2552

Subgenus Urophyeis ........................................ 2553

2924. regius (Walbaum) .................................. 2553

2925. cirratus (Goode \& Bean) .................................. 2553

2926. tloridanus (Bean \& Dresel) ................................ 2554

Subgenus Emphycus, Jordan \& Evermann ....................... 2554

2927. earlli (Bean) ........................................ 2554

2928. tenuis (Mitchill) . . . . . . . . . . . . . . . . . . . . . . . . . . . . . 2555

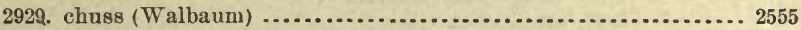

2930. chesteri (Goode \& Bean) .................................. 2556

Genus 991. Læmonema, Günther............................... 2556

2931. barbatulum, Goode \& Bean............................... 2556

2932. melanurum, Goode \& Bean ............................. 2557

Genus 992. Gaidropsarus, Rafinesque............................ 2557

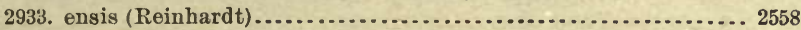

2934. argentatus (Reinhardt) . . . . . . . . . . . . . . . . . . . . . . 2559

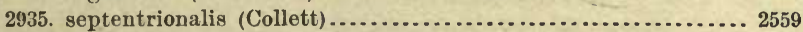

Genus 993. Enchelyopus, Bloch \& Schneider ..................... 2560

2936. cimbrius (Linnæus) ................................... 2560

Genus 994. Brosme (Cuvier) Oken ............................... 2561

2937. brosme (Müller) ...................................... 2561

Family $C C X V$. Macrourida ......................................... 2561

Genus 995. Bathygadus, Günther............................. 2563 2938. arcuatus, Goode \& Bean.................................. 2564

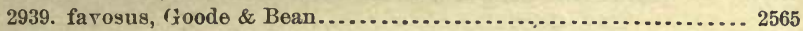

2940. macrops, Goode \& Bean................................. 2566

2941. longifilis, Goode \& Bean ............................... 2566

Genus 996. Steindachneria, Goode \& Bean ........................ 2567 2942. argentea, Goode \& Bean ................................. 2568

Genus 997. Trachyrinchus, Giorna................................. 2568 2943. helolepis, Gilbert..................................... 2569

Genus 998. Malacocephalus, Günther........................... 2569 2944. occidentalis, Goode \& Bean ............................. 2570

Genus 999. Moseleya, Goode \& Bean ............................. 2570 2945. cyclolepis (Gilbert) ................................. 2570

Genus 1000. Nematonurus, Günther ............................ 2571 2946. goodei (Günther) ...................................... 2571 2947. suborbitalis (Gill \& Townsend) ......................... 2572

Genus 1001. Albatrossia, Jordan \& Evermann .................... 2573 2948. pectoralis (Gilbert) ..................................... 2573

Genus 1002. Bogoslovius, Jordan \& Evermann ....................... 2574 2949. clarki, Jordan \& Gilbert................................ 2575 
CLASS II1. PISCES-Continued.

Order 13B. ACANTHOpteri-Continued.

Family CCXV. Macrourido-Continued. Page.

2950. firmisquamis (Gill \& Townsend) ......................... 2575

Genus 1003. Chalinura, Goode \& Bean............................ 2576

2951. serrula, Bean......................................... 2576

2952. filifera, Gilbert........................................ 2577

2953. simula, Goode \& Bean..................................... 2578

Genus 1004. Coryhænoides, Gunner............................... 2578

2954. rupestris, Gunner......................................... 2579

2955. carapinus, Goode \& Bean ................................ 2579

Genus 1005. Hymenocephalus, Giglioli............................ 2580

2956. cavernosus (Goode \& Bean) .... ........................... 2580

Genus 1006. Macrourus, Bloch.................................. 2581

2957. berglax, Lacépède...................................... 2582

2958. holotrachys, Günther................................. 2582

2959. bairdii, Goode \& Bean................................. 2583

2960. lepturus, Gill \& Townsend................................ 2584

2961. acrolepis, Bean......................................... 2585

2962. stelgidolepis, Gilbert................................... 2585

2963. cinereus, Gilbert.................................... 2586

Genus 1007. Colorbynchns, Giorna ............................... 2587

2964. occa (Goode \& Bean) ...................................... 2588

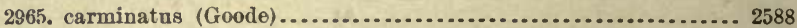

2966. caribbæus (Goode \& Bean) ............................... 2589

2967. scaphopsis (Gilbert) . . ..................................... 2590

Genus 1008. Trachonurus, Günther............................ 2591

2968. sulcatus (Goode \& Bean) ................................. 2591

Genus 1009. Lionurus, Günther.................................. 2592

2969. filicauda (Günther) ..................................... 2592

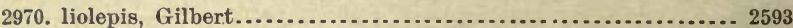

SUBORDER TENIOSOMI ............................................... 2594

Family COXVI. Regalecida .............................. 2595

Genus 1010. Regalecus, Brünnich................................. 2595

2971. glesue (Ascanius) ........................................ 2596

Family CCXVII. Trachypterida . ................................... 2597

Genus 1011. Trachypterus, Gouan................................ 2599

2972. rex-salmonorum, Jordan \& Gilbert........................ 2599

2973. trachyurus, Poey ..................................... 2600

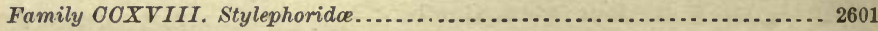

Genus 1012. Stylephorus, Shaw ................................. 2601

2974. chordatus, Shaw ......................................... 2601

Suborder Heterosomata . . . . . . . . . . . . . . . . . . . . . . . . . . . . . . . . . . 2602

Family $C O X I X$. Pleuronectidae.................................... 2602

Geuus 1013. Atheresthes, Jordan \& Gilbert......................... 2609

2975. stomias (Jordan \& Gilbert) ............................... 2609

Genus 1014. Reinhardtins, Gill.................................... 2610

2976. hippoglossoides (W albaum) .............................. 2611

Genus 1015. Hippoglossus, Cuvier ................................ 2611

2977. hippoglossus (Linuæus) .................................. 2611

Genus 1016. Lyopsetta, Jordan \& Goss .............................. 2612

2978. exilis (Jordan \& Gilbert) .................................. 2612

Genus 1017. Eopsetta, Jordan \& Goss . . . . . . . . . . . . . . . . . . . . . . . . 2613

2979. jordani (Lockington) . . . . . . . . . . . . . . . . . . . . . . . . . . . . . 2613

Genus 1018. Hippoglossoides, Gottsche ............................ 2614

2980. platessoides (Fabricius) ................................... 2614

2981. elassodon, Jordan \& Gilbert.................................. 2615

2982. robustus, Gill \& Townsend ................................ 2616

2983. hamilton1, Jordan \& Gilbert ............................. 2616 
CLASS III. PISCES-Continued.

ORDER BB. ACANTHOPTERI-Cuntinued.

Family COXIX. Pleuronectida-Continued. Page.

Genus 1019. Psettichthys, Girard .............................. 2617

2984. melanostictus, Girard ................................... 2618

Genus 1020. Verasper, Jordan \& Gilbert........................... 2618

2985. moseri. Jordan \& Gilbert ................................... 2619

Genus 1021. Hippoglossina, Steindachner..................... 2620

2986. stomata, Eigenmann \& Eigenmanu ...................... 2620

2987. macrops, Steindachner ............................... 2621

2988. bolimani, Gilbert.......................................... 2621

Genus 1022. Lioglossina, Gilbert................................. 2622

2989. tetrophthalma, Gilbert.............................. 2622

Genus 1023. Xystreurys, Jordan \& Gilbert . . . . . . . . . . . . . . . . . . . . 2623

2990. liolepis, Jordan \& Gilbert ............................. 2623

Genus 1024. Paralichthys, Girard.............................. 2624

29̄91. californicus (Ayres) . . . . . . . . . . . . . . . . . . . . . . . . 2625

2991(a). Paralichthys magdalenæ, Abbott...................... 2872

2992. restuarius, Gilbert \& Scofield . . . . . . . . . . . . . . . . . . . . . 2626

2993. brasiliensis (Ranzani) .................................... 2626

2994. sinaloæ, Jordan \& Abbott......................... 2627, 2872

2995. woolmani, Jordan \& Williams........................... 2628

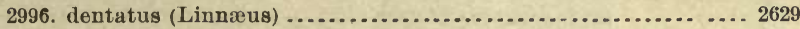

2997. lethostigmus, Jordan \& Gilbert......................... 2630

2998. squamilentus, Jordan \& Gilbert......................... 2631

2999. albiguttus, Jordan \& Gilbert............................... 2631

3000. oblongns (Mitchill) ..................................... 2632

Genus 1025. Ranularia, Jordan \& Evermann ...................... 2633

3001. dendritica (Gilbert) .................................... 2633

Genus 1026. Ancylopsetta, Gill ................................ 2634

3002. quadrocellata, Gill .................................... 2634

Genus 1027. Notosema, Goode \& Bean ............................. 2635 3003. dilectum, Goode \& Bean.................................. 2635

Genus 1028. Gastropsetta, B. A. Bean ............................. 2636 3004. frontalis, B. A. Bean .................................... 2636

Genus 1029. Pleuronichthys, Girard ........................... 2637 3005. decurrens, Jordan \& Gilbert............................. 2637 3006. verticalis, Jordan \& Gilbert . . . . . . . . . . . . . . . . . . . . . . . 2638 3007. cœnosus, Girard ........................................ 2638

Genus 1030. Hypsopsetta, Gill ................................... 2639 3008. guttulata (Girard) ........................................ 2639

Genus 1031. Parophrys, Girard ................................. 2640

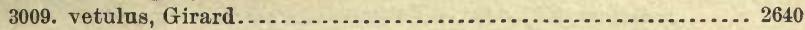

Genus 1032. Inopsetta, Jordan \& Goss ........................... 2641 3010. ischyra (Jordan \& Gilbert) . . . . . . . . . . . . . . . . . . . . . . . 2641

Genus 1033. Isopsetta, Lockington ............................... 2642 3011. isolepis (Lockington) ................................. 2642

Genus 1034. Lepidopsetta, Gill................................. 264z 3012. bilineata (Ayres) ...................................... 2643

Genus 1035. Limanda, Gottsche ................................ 2644 3013. ferruginea (Storer) ................................... 2644 3014. aspera (Pallas) ........................................ 2645 3015. proboscidea, Gilbert . . ................................. 2645

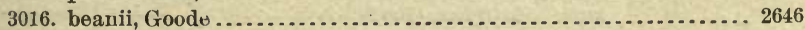

Genus 1036. Pseudopleuronectes, Bleeker ........................ 2646

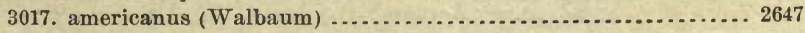

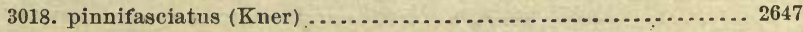

Genus 1037. Pleuronectes (A rtedi) Linnæus ... . . . . . . . . . . . . . . . 2648 3019. quadrituberculatus, Pallas ........................... 2648 
CLASS III. PISCES-Continued.

ORDER BB. ACANTHOPTERI-Continued.

Family COXIX. Pleuronectida - Continued.

Page.

2649

2649

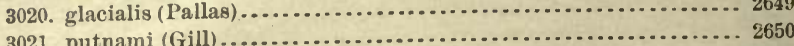

3022. obscura (Herzenstein) ............................... 2651

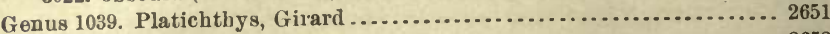

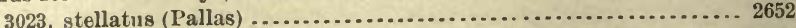

Genus 1040. Microstomus, Gottsche............................. 2653

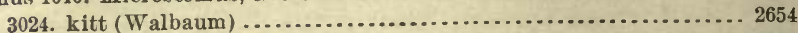

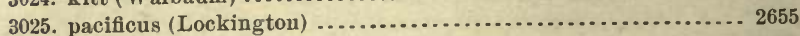

Genus 1041. Embassichthys, Jordan \& Evermann ................... 2655

3026. bathybius (Gilbert) ................................... 2655

Genus 1042. Glyptocephalus, Gottsche.......................... 2656

3027. cynoglossus (Linnæus) .................................. 2657

3028. zachirus, Lockington............................... 2658

Genus 1043. Lophopsetta, Gill .................................. 2659

3029. maculata (Mitchill) ..................................... 2660

Genus 1044. Platophrys, Swainson............................. 2660

3030. spinosus (Poey) ....................................... 2662

3031. constellatus, Jordan .................................. 2663

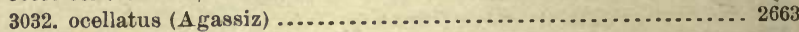

3033. maculifer (Роeу) ...................................... 2664

3034. ellipticus (Poey) ....................................... 2665

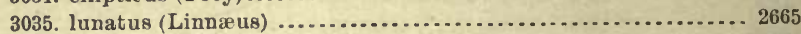

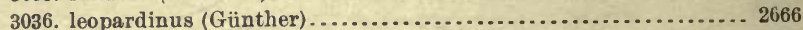

Genus 1045. Perissias, Jordan \& Evermann........................ 2667

3037. tæniopterus (Gilbert) ............................... 2667

Genus 1046. Engyophrys, Jordan \& Bollman ....................... 2608 3038. sancti-laurentii, Jorlan \& Bollman ..................... 2668

Genus 1047. Trichopsetta, Gill................................... 2669 3039. ventralis (Goode \& Bean) .................................. 2669

Genus 1048. Syacium, Ranzani.................................... 2670

3040. papillosum (Linnæus) ................................. 2671

3041. micrurum, Ranzani..................................... 2672

3042. latifrons (Jordan \& Gilbert) ............................. 2673

3043. ovale (Günther) ........................................ 2674

Genus 1049. C5clopsetta, Gill ................................... 2675

3044. querna (Jordan \& Bollman) ............................... 2675

3045. chittendeni, B. A. Bean ................................ 2676

3046. fimbriata (Goode \& Bean) ............................... 2676

Genus 1050. Azevia, Jordan .................................... 2677

3047. panamensis (Steindachner)............................... 2677

Genus 1051. Citharichthys, Bleeker.............................. 2678

Subgenus Orthopsetta, Gill .................................. 2679

3048. sordidus (Girard) .................................... 2679

3049. fragilis, Gilbert .................................... 2680

3050. xanthostigmus, Gilbert .............................. 2680

3051. stigmæus, Jordan \& Gilbert.............................. 2681

Subgenus Citharichthys .......................................... 2682

3052. dinoceros, Goode \& Bean ................................ 2682

3053. platophrys, Gilbert..................................... 2683

3054. arctifrons, Goode..... ................................ 2683

3055. unicornis, Goode ..................................... 2683

3056. uhleri, Jordan. .................................... 2684

3057. macrops, Dressel ......................................... 2684

3058. spilopterus, Günther .................................. 2685

3059. gilberti, Jenkins \& Evermann .......................... 2686 
(ITASS III. PISCES-Continued.

ORDER BB. ACANTHOPTERI-Continued.

Family $6 C X I X$. I'lenronectida-Continned.

Page.

Genus 1052. Etropus, Jordan \& Gilbert......................... 2687 3060. míerostomus (Gill) ................................... 2687

3061. rimosus, Goode \& Bean .................................. 2688

3062. erossotus, Jordan \& Gilbert............................... 2689

Genus 1053. Monolene, Goode................................... 2690

3063. sessilicauda, Goode ................................... 2691

3064. atrimana, Goode \& Bean ................................. 2692

Family $C C X X$. Soleidoe.......................................... 269:2

Genus 1054. Achirus, Lacépède....................................2 2693

Subgenus Baiostoma, Bean ................................... 2695

3065. achirus (Linnæus) ..................................... 2695

3066. inscriptus, Gosse ...................................... 2696

3067. klunzingeri (Steindachner) ............................ 2697

3068. lineatus (Linnæus) ................................... 2697

3069. mazatlanus (Steindachner) .............................. 2698

3070. fonsecensis (Günther) ................................. 2699

3071. fischeri (Steindachner) ................................... 2699

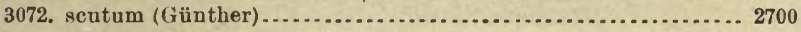

Subgenus Achirus ............................................ 2700

3073. fimbriatus (Günther) ................................... 2700

3074. fasciatus, Lacépède ................................... 2700

3075. panamensis (Steindachner) ............................. 2702

Genus 1055. Apionichtliys, Kaup ............................... 2702

3076. unicolor (Gïnther) .................................. 2702

Genus 1056. Gymnachirus, Kaup ................................. 2703

3077. fasciatns, Giinther .................................. 2703

Genus 1057. Symphurus, Rafiuesque ............................ 2704

Subgenus Symphurus ....................................... 2705

3078. piger (Goode \& Bean) .................................. 2705

3079. marginatus (Goode \& Bean) ............................. 2706

3080. atramentatus, Jorlan \& Bollman ........................ 2706

3081. fasciolaris, Gilbert ................................. 2707

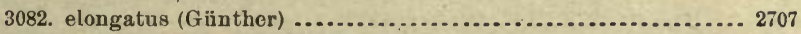

3083. atricaudus (Jorlan \& Gilbert) ......................... 2707

3084. leei, Jordan \& Bollman ................................... 2708

3085. plagusia (Bloch \& Schneider) .......................... 2709

3086. plaginsa (Linnæus) .................................. 2710

3087. jusillus (Goode \& Bean) .............................. 2710

3088. diomedeanus (Goode \& Bean) .......................... 2711

3089. williamsi, Jordan \& Culver............................ 2711

Subgenus Acedia, Jordan ..................................... 2712

3090. nebulosus (Goode \& Bean) ............................... 2712

Order CC. Pediculati ............................................... 2712

Family COXXI. Lophiidae ...................................... 2713

Genus 1058. Lophius (Artedi) Linnæus ........................... 2713

3091. piscatorius, Linnæus................................ 2713

Genus 1059. Lophiomus, Gill ................................... 2714

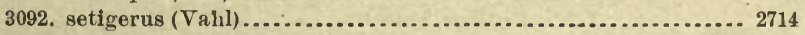

Family COXXII. Antennariida ................................ 2715

Genus 1060. Pterophryne, Gill............................... 2715

3093. histrio (Linnæus) .................................... 2716

3094. gibba (Mitchill) ...................................... 2717

Genus 1061. Antennarius, Lacépède............................ 2717

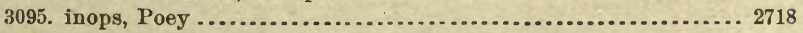

3096. principis (Cuvier \& Valenciennes) ........................ 2719

3097. tenebrosus (Poey) ...................................... 2719 
CLASS III. PISCES-Continued.

Order CC. Pediculati-Continued.

Family OOXXII. Antennariida-Continued. Page.

3098. reticularis, Gilbert .................................. 2719

3099. strigatus, Gill...................................... 2720

3100. sanguineus, Gill..................................... 2721

3101. ocellatus (Bloch \& Schneider) ............................ 2721

3102. scaber (Cuvier) ....................................... 2722

3103. tigris, Poey ............................................ 27:23

3104. nuttingii, Garman .................................... 2723

3105. multiocellatus (Cuvier \& Valenciennes) ..................... 2724

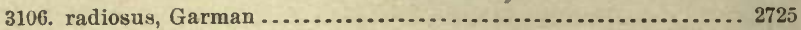

Genus 1062. Chaunax, Lowe................................... 2726

3107. pictus, Lowe...................................... 2726

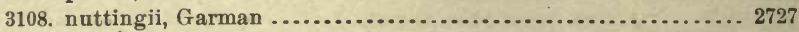

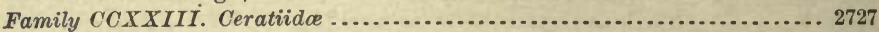

Genus 1063. Ceratias, Kröyer...................................... 2729

3109. holbolli, Kröyer....................................... 2729

Genus 1064. Mancalias, Gill...................................... 2729

3110. uranoscopus (Murray) ............................... 2729

3111. shufeldti (Gill) ........................................ 2730

Genus 1065. Cryptopsaras, Gill .............................. 2731

3112. couesii, Gill ......................................... 2731

Genus 1066. Oneirodes, Lütken ................................. 2732

3113. escrichtii, Lütken................................... 2732

Genus 1067. Himantolophus, Reinhardt....................... 2732

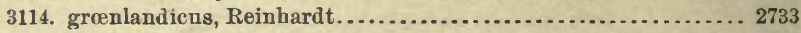

Genus 1068. Corynolophus, Gill .............................. 2733

3115. reinhardti (Lütken) ................................. 2733

Genus 1069. Liocetus, Günther................................... 2733

3116. murrayi (Günther) .................................... 2733

Genus 1070. Linophryne, Collett ............................... 2734

3117. lucifer, Collett............................................ 2734

Genus 1071. Caulophryne, Goode \& Bean........................ 2734

3118. jordani, Groode \& Bean ................................ 2735

Family $C C X X I V$. Ogcocephalidoe................................... 2735

Genus 1072. Ogcocephalus, Fischer ............................. 2736

3119. vespertilio (Linnæus) . . . . . . . . . . . . . . . . . . . . . . . . 2737

3120. nasutus (Cuvier \& Valenciennes) ......................... 2737

3121. radiatus (Mitchill) ........................................ 2738

Genus 1073. Zalieutes, Jordan \& Evermann...................... 2738

3122. elater (Jordan \& Gilbert) ............................... 2738

Genus 1074. Halieutichthys, Poey.................................. 2739 3123. aculeatus (Mitchill) .................................... 2739

3124. caribbæus, Garman....................................... 2741

Genns 1075. Halieutæa, Cuvier \& Valenciennes.................... 2741

3125. spongiosa, Gilbert..................................... 2741

Genus 1076. Halieutella, Goode \& Bean ........................... 2742

3126. lappa, Groode \& Bean ................................. 2742

Genus 1077. Dibranchns, Peters................................... 2743

3127. atlanticus, Peters ....................................... 2743 


\section{LIST OF NEW NAMES.}

The following is a list of the new generic, subgeneric, specific, and subspecific names which appear as new in Part III of the present work:

Page.

Sicydinm vincente, Jordan \& Evermann.................................. 2207

Enypuias, Jordan \& Evermann......................................... 2231

Gnathypops snyderi, Jordan \& Evermann............................... 2285

Dactyloscopus zelotes, Jordan \& Gilbert.................................. 2303

Dæetor, Jordan \& Evermann ........................................... 2325

Bryssophilus, Jordan \& Evermann....................................... 2329

Gobiesox gyrinus, Jordan \& Evermann.................................. 2331

Corallicola, Jordan \& Evermann......................................... 2369

Blenniolus, Jordan \& Evermann............................................ 2386

Homesthes, Gilbert .................................................. 2394

Homesthes caulopus, Gilbert............................................. 2394

Scartichthys, Jordan \& Evermann....................................... 2395

Ophioblennius steindachneri, Jordan \& Evermann.......................... 2401

Emblemaria atlantica, Jordan \& Evermann................................. 2402

Enedrias, Jordan \& Gilbert.............................................. 2414

Embryx, Jordan \& Evermann ................................................ 2458

Lycias, Jordan \& Evermann............................................ 2461

Emphyeus, Jordan \& Evermann .......................................... 2552

Albatrossia, Jordan \& Evermann ........................................ 2573

Bogoslovius, Jordan \& Evermann........................................ 2574

Hippoglossoides hamiltoni, Jordan \& Gilbert.............................. 2616

Verasper, Jordan \& Gilbert............................................ 2618

Verasper moseri, Jordan \& Gilbert......................................... 2619

Ramularia, Jordan \& Evermann ......................................... 2633

Perissias, Jordan \& Evermann .......................................... 2667

Carcharhinus cerdale, Gilbert........................................ 2746

Carcharhinus velox, Gilbert......................................... 2747

Myliobatis asperrimus, Gilbert ........................................ 2754

Aspistor, Jordan \& Evermann........................................... 2763

Galeichthys xenauchen, Gilbert ..................................... 2777

Tachysurus enmelane, Gilbert........................................... 2785

Aztecula, Jordan \& Evermann............................................ 2799

Notropis chamberlaini, Evermann..................................... 2800

Notropis louisianæ, Evermann........................................... 2801

Pisoodonophis daspilotus, Gilbert....................................... 2803

Muræna clepsydra, Gilbert............................................ 2805

Stolephorus rastralis, Gilbert \& Pierson................................... 2811

Stolephorus mundeolus, Gilbert \& Pierson................................. 2812

Stolephorus naso, Filbert \& Pierson ........................................ 2813

Stolephorus starksi, Gilbert \& Pierson....................................... 2813

Cetengraulis engymen, Gilbert \& Pierson................................. 2815

Argyrosomus alascan us, Scofield .......................................... 2817

Osmerus albatrossis, Jordan \& Gilbert ....................................... 2823

Bathylagus milleri, Jordan \& Gilbert ................................... 2825 
Zaphotias, Goode \& Bean............................................... 2826

Characodon garmani, Jordan \& Evermann ................................. 2831

Siphostoma sinaloæ, Jordan \& Starks.................................... 2838

Rhynchias, Gill ...................................................... 2841

Oligoplites mundus, Jordan \& Starks ..................................... 2844

Hemicaranx zelotes, Gilbert. ............................................ 2845

Ulocentra meadiæ, Jordan \& Evermann ... . . . . . . . . . . . . . . . . . . . . . . . . . . ... 2852

Lobotes pacificus, Gilbert............................................... 2857

Porocottus bradfordi, Rutter........................................... 2862

Sigmistes Rutter..................................................... 2863

Sigmistes caulias, Rutter .............................................. 2863

Crystallichthys, Jordan \& Gilbert........................................ 2864

Crystallichthys mirabilis, Jordan \& Gilbert............................... 2865

Allinectes, Jordan \& Evermann.......................................... 2866

Prognurus, Jordan \& Evermann .......................................... 2866

Prognurus cypselurus, Jordan \& Gilbert ................................. 2866

Sicyosus, Jordan \& Evermann ........................................... 2867

Alectrias; Jordan \& Evermanu ........................................... 2869

Furcimanus, Jordan \& Evermann............................................. 2869

Salmo clarkii tahoensis, Jordan \& Evermann............................. 2870

Oligocottus snyderi, Greeley .......................................... 2871

Flammeo, Jordan \& Evermann ......................................... 2871

Paralichthys magdalenæ, Abbott..................................... 2872

Paralichthys sinaloæ, Jordan \& Abbott .................................... 2872 


\section{THE FISHES \\ OF \\ NORTH AND MIDDLE AMERICA.}

BY DAVID STARR JORDAN AND BARTON WARREN EVERMANN.

PART III.

\section{PREFATORY NOTE.}

This volume is the third of a descriptive catalogue of the fishes and fish-like vertebrates of North and Middle America. For the sake of greater completeness the marine fishes of the Galapagos Islands and the South American coast north of the equator have been included, as all of these are sure, sooner or later, to be found within our limits. For the same reason the few species known from Kamchatka and the Kuril Islands are included as a part of the fainin of the Alaskan Sea.

The pagination and the numbering of the species, genera, and higher groups are continuous throughout the three parts.

Part I, Branchiostomatidae to Priacanthida inclusive (pages 1 to 1240), was published October 3, 1896; Part II, Lutianida to Cephalacanthida inclusive (pages 1241 to 2183), was published October 3, 1898; and Part III, Callionymida to Ogcocephalida appears on November 26, 1898. Parts I, II, and III have each their own table of contents, while in Part IV (the Atlas) is given a table of contents complete for the entire work and corrected to include the Addenda.

The present part includes also an artificial key to the fanilies of true fishes, an addendum containing species overlooked or described subsequently to the publication or casting of the part to which they belong, a glossary of scientific terms, and a general index complete for the entire work.

A fourth volume, or Atlas of plates, containing illustrations of one or more species of each of the more important genera, will follow within the year.

The preparation of the manuscript for this work was begun by the senior author in 1891. In 1893 the junior author became associated with him, and since then both have given to it such of their time and energy as could be spared from engrossing official duties to which systematic ichthyology bears no relation.

The insertion of the comma between generic and specific names and the authorities for them, as practiced in this publication, is in accordance with the views held by the authorities of the United States National Museum, and does not express the views of the authors of this work. 


\title{
Class PISCES-Concluded.
}

\section{Subclass TELEOSTOMI-Concluded.}

\author{
Order BB. ACANTHOPTERI-Concluded.
}

Group GOBIOIDEA.

\section{(THe GobIEs.)}

Body elongate, variously scaled or naked; head usually large, armed or not, the suborbital ring withont a bony stay for the preopercle; gill openings reduced, the membranes attached to the isthmus. Gills 4, a slit behind the last; pseudobranchire present. Ventral rays I, 4 or I, 5, inserted below pectoral, the fins close together or united or widely separated or otherwise peculiar; dorsal fins separate or uuited, the first of a few weak spines, sometimes wanting; anal rather long, usually with a single weak spine, similar to soft dorsal; caudal rounded. Usually no air bladder nor pyloric cieca. Vertebræ 24 to 35 . Carnivorous bottom fishes, mostly of small size in warm regions, some marine, others of the fresh waters. Two families.

a. Ventral fins widely separated; preopercle strongly armed; lateral line present.

Callionymide, CLXXXVil.

aa. Ventral fins close together, usually united; preopercle with a weak spine or none; no lateral line.

GOBIDE, CLXXXvir.

\section{Family CLXXXVII. CALLIONYMIDA.}

\section{(The Dragonets.)}

Body elongate, nakerl; head usually broad and depressed; the mouth narrow, the upper jaw very protractile; teeth very small, in jaws only; preopercle armed with a strong spine, which is usually branched. Eyes moderate, usually directed upward. Lateral line present, often duplieated. Dorsal fins 2, the anterior with 3 or 4 flexible spines; soft dorsal and anal short, the latter without distinct spine; ventrals I, 5, widely separated from each other; pectoral fins large. Gill openings small, the membranes broadly attached to the isthmus; gills 4, a slit behind the fourth; pseudobranchiæ present; no air bladder. Vertebra usually $8+13=21$. Small fishes of the shores of warm seas, chiefly of the old world. Allied to the Gobies, but often resembling the Cottida in form. Genera 4, species about 30. (Gobiida Callionymina, Giinther, Cat. Fishes, III, 138-152.)

a. Ventrals entire, the outer ray not detached; head depressed; gill opening reduced to a very small foramen on upper surface of head; lateral line single.

Callionymes, 799. 
799. CALLIONYMUS, Linnæus.

Callionymus, LinNæus, Syst. Nat., Ed. x, 249, 1758 (lyra).

This genus includes Dragonets with the ventral fins entire, without detached ray, the gill opening redueed to a small foramen opening upward, and the lateral line single; head triangular, depressed; eyes directed upward; preopereular spine very large; sexual differences strongly marked. Speeies numerous, living on sea bottoms at some depth. ( $\varkappa \alpha ́ \lambda \lambda \imath \varsigma$, beauty; óvo $\mu \alpha$, name.)

a. Dorsal rays IV, 8 or 9 ; anal rays 8; some of the dorsal spines filamentous.

$b$. Preopercular spine very long, armed with about 9 hooks or spinules; caudal not filamentous.

BAIRDI, 2511.

$b b$. Preopercular spine strong, bifurcate; caudal fin more or less produced or filamentous.

HIMANTOPHORUS, 2512.

aa. Dorsal rays III, 6 or IV, 6 ; anal rays 4.

c. Preopercular spine with 2 barbs, the anterior turned forward; body with white spots.

CALLIURCS, 2513.

cc. Preopercular spine with 3 teeth above, ending in an acute point.

PAUCIRADIATUS, 2514.

2511. CALLIONYMUS BAIRDI, Jordan.

Head $3 \frac{1}{5}$; depth $9 \frac{1}{8}$. D.IV, $9 ;$ A. 8 . Body long and low, very slender, the head much depressed, the least depth of the caudal peduncle about equal to the diameter of the eye. Head triangular as viewed from above, its breadth $\frac{2}{3}$ its length, exelusive of the preopercular spine. Snout bluntish as seen from above, sharp in profile, its outline straight and moderately steep until above the eyes; profile behind the eyes considerably depressed. Snout $2 \frac{2}{3}$ in head to gill opening; eye 4 ; mouth small, inferior, the maxillary reaching front of eye, as long as snout; lower lip conspicuous. Teeth slender, in villiform bands in both jaws, none on vomer. Interorbital area a simple narrow ridge. Bones of head behind eyes rugose; a low rough tuberele of bare bone above the temporal region on each side, somewhat behind each eye. Preopereular spine very long, as long as eye, its exterior ridge with a single antrorse spinule at its base, its posterior edge with 8 conspieuous hooks turned forward and inward, these growing progressively smaller from the second. Gill opening reduced to a pore at upper posterior angle of operele, its width rather less than that of pupil. Dorsal spines strong, the first ending in a slender filament, the whole as long as head; second and third spines broken (probably each with a short filament in life, as a short filament is still present on the fourth spine); fourth spine well behind third (leaving room for another spine, although no trace of such spine is present); soft dorsal high, most of its rays slightly filamentous at tip, the longest about $\frac{3}{5}$ head; eaudal subtruncate, not filamentous, about as long as head to base of preopercular spine; anal fin rather high, the length of its base 3 in body; pectorals about as long as ventrals, each as long as head without preopereular spine. Lateral line single. Color light grayish, mottled or spotted with yellowish and dark brown; cheeks with steel-bluish spots; first dorsal with dusky reticulations around pale gray spots; second dorsal and eaudal with nar$3030-60$ 
row dusky cross streaks; anal with its posterior half chiefly black, the anterior pale; ventrals black; pectorals pale. Type, a specimen $4 \frac{1}{2}$ inches long, in good condition, from the "spewings" of a Suapper or a Grouper (Neomanis aya or Epinephelus morio), taken on the Snapper Banks, between Pensacola and Tampa; 1 other specimen known. ("I have named this species for Prof. Spencer F. Baird, to whom I have been indebted for aids of many kinds in connection with my studies of American fishes." Jordan.)

Callionymus bairdi, JoRJAN, Proc. U. S. Nat. Mus. 1887, 501, Snapper Banks off Pensacola. (Type, No. 39300. Coll. Silas Stearns.)

2512. CALLIONYMUS himaNTOPHORLS, Goode \& Bean.

Head $3 \frac{1}{2}$; depth of head equal to length of its postorbital portion or to greatest depth of body. Greatest depth of body at the head and the anterior portion of the trunk. D. IV , 8; A. 8; P. 19; V. I, 5. Body slender, moderately elongate, fins all well developed, the tail tapering and with some of its rays produced into a filament. Caudal peduncle very slender, the least height of tail scarcely more than $\frac{1}{4}$ greatest height of body. Profile descending very rapidly at snout. Mouth small and the intermaxillary very protractile, but may be almost entirely concealed under the preorbitals. Intermaxillary reaching to front of orbit. Maxillary a roundish, slender bone, extending backward to end of intermaxillary. Mandible about as long as eye, extending to vertical through front of pupil. Teeth in villiform bands on intermaxillary and mandible. Interorbital space very narrow, less than $\frac{1}{4}$ length of eye, which is $1 \frac{1}{2}$ times as long as snout and nearly $\frac{1}{8}$ of total without caudal. A strong bifurcated spine at angle of the preoperculum extending backward slightly beyond the gill opening; length of this spine at its upper articulation $\frac{2}{8}$ length of eye. Gill opening reduced to a small slit, placed at a distance behind eye about equaling length of eye and above median line of body. Skin naked. Lateral line abruptly arched over gill opening and connected across nape with its fellow of the opposite side. Spinous dorsal somewhat elevated in front, the first spine nearly twice as long as last, its length about $\frac{1}{6}$ total length of caudal; sixth and seventh rays longest, their length nearly equaling that of base of fin; caudal consisting of 4 simple and 8 divided rays; of the divided rays the fifth and sixth are the longest, the lower portion of the fifth and the upper portion of the sixth being produced into a filament, making these rays as long as the distance from the tip of the intermaxillary to the fourth anal ray. It is worthy of remark that in another example of the same species and of about the same size as the type, the sixth of the divided rays alone contributes to form the filament; and in a young example, about $\frac{1}{8}$ as large as the type, the first dorsal spine when laid back reaches to the end of soft dorsal. Some of the numerous examples of this species have none of the caudal rays much produced, even in large individuals. Anal fin beginning directly under third ray of soft dorsal, its rays increasing in length to the sixth, which is the longest and twice as long as the first, its length $5 \frac{2}{3}$ 
in total without caudal. All the rays simple except the last, which is divided. The pectoral beginning under middle of spinous dorșal and extending to below the fifth ray of the soft dorsal, its rays all simple. The ventral base overlapping lower extremity of pectoral base, its origin under the gill opening. The fourth and longest ray equaling $\frac{1}{6}$ of total length without caudal. A small but distinct anal papilla. Color generally light brown, the back with numerous narrow streaks and blotches of slightly darker brown; a dark blotch on membraue between the third and fourth dorsal spines, in some cases occupying nearly all the membrane, in other cases more limited and nearly elliptical in shape; anal with a broad subvertical dark band, the tips of rays and a small area of the membrane behind each ray pale; the lower caudal lobe with a narrow submarginal dark band; ventral with 2 indistinct narrow dark bands on its outer half. From Blake Station XXX, off Barbados, in 209 fathoms; Station CLXXX, at 137 fathoms; Station XXXIII, off Santa Cruz, at 115 fathoms; Station 2 CCXVI, at 119 fathoms; Station CCXXX, at 84 fathoms. (i $\mu \alpha 5$, whip; $\phi о \rho \varepsilon \dot{c} \omega$, bear.)

Callionymus himantophorus, * GoodE \& BEAN, Ocean. Ichth., 296, pl. Lxxvi, figs. 268, $268 \mathbf{a}, \mathbf{b}, 1896$, off Barbados.

2513. CaLlionyus CalliURUS, Eigenmann \& Eigenmann.

Head $3 \frac{1}{2}$ to tip of opercular spine (5 in total); depth 7 (9). D. IV, 6 ; A. 4. Body flat below, the ventral surface bordered on each side with a fold of skin which is wider than the pupil; a single lateral line; diameter of eye equaling length of snout, $3 \frac{1}{2}$ in head; maxillary not extending to eye; preopercular spine with 2 barbs above, the anterior one larger and turned forward; gill opening a minute foramen opening upward. The last dorsal ray equaling length of head, and the first dorsal spine reaching its tip when the fin is depressed; ventral fins connected by a broad membrane to the middle of the outer pectoral region; pectoral fins as long as the head. Cheeks, opercles, connecting membrane of ventral fins and antepectoral region with milk-white spots; lower jaw black near the rictus; a series of black dots on branchiostegal membranes, 1 or 2 similar dots in front of pectorals, 2 on the cheek forming a series with the second branchiostegal spot; 4 black spots on the marginal membrane of the belly, other black spots above it; lower half of body with numerous dirty white spots; pectorals transparent, ventrals dusky; membrane of anal sprinkled with minute black points aggregated into black spots in places, and with opaque white spots; caudal transparent, having minute points, its upper half with opaque milk-white bars running obliquely downward and backward from ray to ray; lower half with interrupted longitudinal lines of opaque white, alternating with black spots; dorsal transparent, with white and dark dots most conspicuous between last rays; body marbled with light and darker. Key West, Florida; 1 speci-

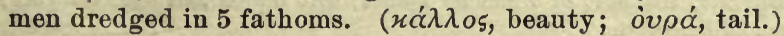

Callionymus calliurus, Eigenmann \& Eigenmann, Proc. Cal. Ac. Sci. 1888, 76, South Beach, Key West. (Type, No. 26265. M. C. Z.)

* The species was listed by Eigenmann, Proc. Cal. Ac. Sci., 2d ser. 1, 78, as " Callionymus agassizii, Goode \& Bean," a name only, accompanied by no description. 
2514. CALLIONYMUS PACCIRAditus, Gill.

"D. III, 6; A. 4. The preopercular spine is armed with three teeth above and terminates in an acute point." (Gill.) Matanzas, Cuba; an imperfectly described species, known only from the above note. (pauci, few ; radiatus, rayed.)

Callionymus pauciradiatus, GLL, Ann. Lyc. Nat. Hist. N. X., viII, 1865, 143, Matanzas, Cuba.

\section{Family CLXXXVIII. GOBIIDA.}

\section{(The Gories.)}

Body oblong or elongate, naked or covered with ctenoid or cycloid scales. Dentition various, the teeth generally small; premaxillaries protractile; suborbital without bony stay. Skin of head continuous with covering of eves. Opercle unarmed; preopercle unarmed or with a short spine; pseudobranchixe present. Gills 4, a slit behind the fourth; gill membranes united to the isthmus, the gill openings thus restricted to the sides. No lateral line. Dorsal fins separate or connected, the spinous dorsal least developed, of 2 to 8 flexible spines, rarely wanting; anal usually with a single weak spine, similar to the soft dorsal; ventral fins close together, separate or fully united, each composed of a short spine and 5 (rarely 4 ) soft rays, the inner rays longest; the ventral fins, when united, form a sucking disk, a cross fold of skin at their base completing the cup; caudal fin convex; anal papilla prominent. No pyloric cæca; usually no air bladder. Carnivorous fishes, mostly of small size, living ou the bottoms near the shores in warm regions. Some inhabit fresh waters, and others live indiscriminately in either fresh or salt water. Many of them bury in the mud of estuaries. Few of them are large enough to be of much value as food. Genera about 80 ; species nearly 600 . The species are for the most part easily recognized, but their arrangement in genera is a matter of extreme difficulty. Until the multitude of Asiatic forms are critically studied, any definition of the American genera must be tentative only. (Gobiida, part; groups Gobiina, Amblyopina, and Trypauchenina, Günther, Cat. Fishes, III, 1-138.)

\section{ANalysis of Genera of North american Gobitde.}

a. Ventral fins separate; body scaly.

OXYMETOPONTINA:

b. Ventral rays $I, 4$.

c. Forehead bluntly rounded, without sharp keel; tongue very slender, sharp; body elongate, compressed, covered with very small scales; head short, compressed, rather broad above; mouth oblique, the lower jaw projecting; teeth in few series, some of them canine.like; isthmus narrow. Dorsals separate, the first of 6 slender spines; soft dorsal and anal elongate; caudal lanceolate.

Eleotridinas:

IoGLOSSCS, 800 .

bb. Ventral rays $\mathbf{I}, \mathbf{5}$.

d. Vomer with a broad patch of villiform teeth; gill openings extending forward to below posterior angle of mouth, the isthmus thus very narrow; 
teeth villiform, the outer scarcely enlarged; vertebræ $12+13$ (dormitor); skull above with conspicuous elevated ridges, one of these bounding the orbit above, the orbital ridges connected posteriorly above by a strong cross ridge; a sharp longitudinal ridge on each side of the occipital, the two nearly parallel, the post-temporals being attached to the posterior ends. Insertions of post-temporals widely separated, the distance between them greater than the rather narrow interorbital width; the post-temporal bones little divergent; top of head depressed, both before and behind the eross ridge between eyes; a flattish triangular area between this and the little elevated supraoceipital region; preopercle without spines; lower pharyngeals with slender, depressible teeth, and withont lamelliform appendages; scales of moderate size, ctenoid.

Philypnus, 801.

$d d$. Vomer without teeth; isthmus broad; gill openings scarcely extending forward below to posterior angle of preopercle; skull without crests.

e. Body scaly, both anteriorly and posteriorly.

$f$. Lower pharyngeal teeth stıff and blunt; the bones with an outer series of broad flexible lamelliform appendages, which are rudimentary gill filaments; body short and elevated; teeth slender, those in the outer row scarcely larger, and movable; top of head without raised crests, flattish, its surface uneven; post-temporal bones rather strongly diverging, the distance between their insertions about $\frac{1}{2}$ the broad flattish interorbital space; no spine on preopercle or branchiostegals; scales large, ctenoid. Species herbivorous. Dormitator, 802.

ff. Lower pharyngeals normal, subtriangular, the teeth stiff, villiform, no lamelliform appendages; scales of moderate or small size; body oblong or elongate.

$g$. Body moderately robust, the depth 4 to $5 \frac{1}{2}$ times in the length to base of caudal; scales ctenoid; cranium without distinct median keel; a small supraoccipital crest.

$h$. Post-temporal bones little divergent, not inserted close together, the distance between their insertions greater than the moderate interorbital space, or 34 in length of head; top of skull little gibbous; lower pharyngeals narrower than in Eleotris; preopercle withont spine; scales very small, about 110 in a longitudinal series. Vertebræ $11+13$; teeth moderate, the outer series on lower jaw enlarged.

Guavina, 803.

hh. Post-temporal bones very strongly divergent, their insertions close together, the distance between them about $\frac{2}{3}$ the narrow interorbital space, and less than $\frac{1}{7}$ length of head; top of skull somewhat elevated and declivous; interorbital area somewhat convex transversely; lower pharyngeals rather broad, the teeth bluntish; preopercle with partly concealed spine directed downwards and forward at its angle; scales moderate, 45 to 60 in a longitudinal series; vertebræ (pisonis) $11+15$; teetl small.

Eleotris, 804 .

gg. Body very slender, elongate, the depth 8 to 9 times in length to base of caudal; scales very small, cycloid.

$i$. Preopercle with a partly concealed antrorse hook at its angle; candal with numerous accessory rays at base.

ALEXURUS, 805. 
aa. Ventral fins nnited.

ii. Preopercle without spine; caudal without many accessory rays at base; post-temporal bones short. strongly dirergent, the distance between their insertions about equal to the narrow interorbital space, or abont $\frac{1}{6}$ length of head; top of head with a strong median keel, which is highest on the occipital region; no supraoccipital crest; mouth very oblique; the teeth small.

Erotelis, 806. ee. Body naked on the anterior part; head naked; lower jaw with 4 larger recnrved teeth.

GYMNELEOTRIS, 807. eee. Body entirely naked.

Chriolepis, 808.

$j$. Dorsal fins separate, free from caudal.

SICYDIINAE:

k. Ventral disk short, adnate to belly; body subcylindrical, covered with ctenoid scales; lips very thick; npper teeth mostly small and morable, lower fixed; dorsal spines 6.

l. Teeth simple; no canines in front of lower jaw.

ll. Teeth trifid (or bifid); no canines in front of lower jaw.

GOBIINAE:

SICYDIOM, 809.

COTYLOPUS, 810

$k k$. Tentral disk free from the belly.

$m$. Dorsal spines 4 to 8 ; eyes well developed.

$n$. Teeth emarginate, nniserial, those of the lower jaw nearly horizontal; dorsal spines 6; scales large, ctenoid; gill openings moderate.

EvorTHODUs, 811.

nn. Teeth simple.

o. Body scaly, more or less.

p. Maxillary normal, not prolonged behind the rictus; skull of the usual gobioid form, comparatively short and abruptly broadened behind the orbits; occipnt depressed; supraoccipital and temporal ridges continuous.

$q$. Dorsal spines 6; scales evidently ctenoid; head naked (the nape scaly as nsual.)

$\boldsymbol{r}$. Interorbital area anteriorly elevated, with a large foramen-like depression in front of eye; body short, compressed, formed mnch as in Dormitator; nape with a fleshy crest; scales large. Vertebræ $11+15$. LOPHOGOBIUS, 812 .

rr. Interorbital area not elevated in front; body more elongate; no fleshy nuchal crest; isthmus broad.

8. Inner edge of shoulder girdle without fleshy cirri or papillæ; cranium anteriorly short; interorbital space narrower, grooved, with a low median ridge or none; median crest on cranium low.

$t$. Body scaly anteriorly and poste. riorly (sometimes a naked strip on back or belly). Vertebræ $12+16$ to $10+15$. GoBIus, 813 .

it. Body entirely naked anteriorly, the posterior half scaled; scales moderate or small.

GarmanNL, 814. 
s. Inner edge of shoulder girdle with 2 or 3 conspicuous dermal flaps; pre: orbital region very long; premaxillary and maxillary strong; interorbital groove with a conspicuous median crest; scales rather small (45 to 70. )

AWAOUS, 815.

$q q$. Dorsal spines 7 or 8 (very rarely 6 , especially in Eucyclogobius.)

$u$. Scales large, ctenoid; shoulder girdle without dermal fiaps.

$v$. Sides of head scaled; soft dorsal and anal ratber short, of 11 to 14 rays each; deep-water species.

BOLLMANNIA, 816. vv. Sides of head naked; soft dorsal and anal short, of 10 to 12 rays each; shore species. Aвома, 817. uu. Scales very small, cycloid or nearly so.

v. Inner edge of shoulder girdie without fleshy processes; head naked; body more or less compressed; mouth very oblique; teeth strong; interorbital groove with or without a median ridge. Vertebræ $11+15$ or 16 ; soft dorsal and anal. long, of 15 to 17 rays each.

$x$. Body chiefly scaly, anteriorly as well as posteriorly.

Microgobius, 818.

$x x$. Body naked anteriorly, scaled posteriorly. ZALYPNUS, 819.

wow. Inner edge of shoulder girdle with

2 or 3 dermal flaps, or processes, as in Awaous.

$y$. Head naked, the interorbital groove with the median ridge high, not extending forward to orbit; bndy rather robust; soft dorsal and ana1 short; fresh-water species.

Eucyclogobius, 820.

$y y$. Head scaled like the body; the interorbital groove with the median ridge little developed; soft dorsal and anal long; body elongate; marine species.

LEPIDOGOBICS, 821.

pp. Maxillary much produced backward, extending beyond the gill opening in the adult; skull comparatively long, gradually (not abruptly) broadened behind orbits; median crest of craninm well doveloped; scales small, cycloid; head naked, occipital region narrowed forward; supraorbital and temporal crests not continuous. 


\section{GobIoIDIN}

z. Occiput depressed, with a blunt median kcel. $a^{\prime}$. Shoulder girdle without dermal flaps; dorsal spines 6; soft dorsal and anal short; mouth very large; isthmus broad; vertebræ $14+16$ (mirabilis).

GILLICHTHYS, 822.

$a a^{\prime}$. Shoulder girdle with 1 to 3 small dermal flaps on the inner edge; dorsal spines 5; soft dorsal and anal long.

QUIETULA, 823.

$z z$. Occiput transversely rounded without median keel.

$b^{\prime}$. Shoulder girdle with 1 to 3 small dermal flaps on its inner edge; dorsal spines 5; soft dorsal and anal long. ILYPNUs, 824.

$b b^{\prime}$. Shoulder girdle without dernal flaps; dorsal spines 4 or 5 ; soft dorsal and anal long.

Clevelandia, 825.

oo. Body and head entirely naked.

$c^{\prime}$. Dorsal spines 4; body long and slender; month large, the lower jaw projecting; no barbels; soft dorsal and anal long; male with ornate colors.

cc'. Dorsal spines 7 (rarely 6).

EvermanNia, 826.

$d^{\prime}$. Chin without barbels; mouth small, little oblique; body robust, soft dorsal and anal short.

GoBIosoma, 827.

$d d^{\prime}$. Chin with a fringe of short barbels; mouth terminal, oblique; soft dorsal and anal

Crystallogobinae: very short.

BARBULIFER, 828.

$m m$. Dorsal spines 2 (or 1); body wholly naked.

$e^{\prime}$. Eyes reduced to small rudiments; interorbital area forming a sharp median range; skull rather abruptly widened behind orbits; anterior portion of skull unusally long; no flaps on shoulder girdle; skull highest at nape, depressed above the eyes; soft dorsal and anal short.

$j j$. Dorsal fin continuous, the soft part and the anal joined to base of candal; eyes minute; body elongate; scales minute or wanting; mouth very oblique, the lower jaw projecting; gill openings moderate.

$f^{\prime}$. Dorsal rays VI, 16 to 23 ; anal rays 17 to 23.

$g^{\prime}$. Teeth small, in a single series; scales present. TrNTLASTES, 830.

$g g^{\prime}$. Teeth in a band, those of the outer series being very strong; scales present.

$h^{\prime}$. Body entirely scaled.

$h h^{\prime}$. Anterior part of body naked.

GoBIOIDES, 831.

CAYENnIA, 832.

\section{8oo. IOGLOSSUS, Bean.}

Ioglossus, BEAN, in Jordan \& Gilbert, Proc. U. S. Nat. Mus. 1882, 297 (calliurus).

Body elongate, strongly compressed, of equal depth throughout, covered with very small, mostly cycloid, scales. Head short, compressed, not keeled above; mouth large, oblique, the lower jaw projecting; teeth in narrow bands or single series, some of them canine; no teeth on vomer or palatines; tongue very slender, sharp; opercles unarmed. Gill openings 
very wide, the membranes narrowly joined to isthmus on median line. No lateral line. Branchiostegals 5. Dorsals separate, the first of 6 very slender, flexible spines; the second elongate, similar to the anal; caudal long and pointed, free from dorsal and anal; ventrals close together, separate, each of 1 spine and 4 rays, their insertion below or behind pectorals; anal papilla present. A remarkable type, belonging to the Oxymetopontina, differing widely from our other Gobioid fishes. Gulf of Mexico, in rather deep water. (

\section{IOGLOSSUS CALLIURUS, Bean.}

Head 5; depth 7 to $7 \frac{1}{2}$. D. VI-22 to 24 ; A. I, 21 to 23 . Body very elongate, slender, much compressed, of equal depth throughout; head compressed, without osseous crest; mouth very oblique, the lower jaw strongly projecting; premaxillaries in front on the level with pupil; maxillary extending to opposite front of pupil, its length $2 \frac{8}{4}$ in head; upper jaw with a narrow band of about 2 series of conical cardiform teeth, those of the outer row much larger than the others, behind these 2 small conical curved canines; lower jaw with a single row of smaller teetl, behind which are about 4 short canines directed somewhat backward; the posterior pair strongly curved; no teeth on vomer or palatines. Tongue narrow, pointed. Eye large, nearly twice length of snout, $3 \frac{1}{2}$ in head, its diameter considerably more than depth of cheek, about $\frac{1}{2}$ more than interorbital width; opercles unarmed. Pseudobranchiæ present. Gill openings wide, extending forward below, the membranes attached mesially to the very narrow isthmus, across which they do not form a fold. Gill rakers long and slender. Dorsal fins separated by a short interval, the first of very slender somewhat filamentous spines, the longest about as long as head; second dorsal little more than $\frac{1}{2}$ as high as first, apparently nearly uniform, separated from the caudal by an interval nearly $\frac{1}{2}$ leugth of head; candal lanceolate, its middle rays filamentous, about $\frac{1}{2}$ the length of rest of body; anal rather high, similar to soft dorsal; ventrals I, 4, inserted very slightly in advance of base of pectorals, the 2 fins very close together, but apparently quite separate and without basal fold of skin, the fin little longer than head, the inner rays filamentous; pectoral with broad base, about $1 \frac{1}{4}$ in head. Anal papilla very short, midway between tip of snout and base of caudal. Body with very small, nonimbricate, embedded scales, these a little larger and imbricate on the tail; cheeks with embedded cycloid scales; scales very weakly ctenoid, most of them appearing cycloid; no lateral line. Color light olive, every where densely punctate; dorsals edged with black; middle of candal reddish, with paler bluish edgings. Length $4 \frac{1}{2}$ inches. Here described from specimens from off Pensacola. Gulf of Mexico; known ouly from the Snapper Banks off Pensacola, in rather deep water. ( $\varkappa \dot{\alpha} \lambda \lambda \lambda_{\circ}$, beauty; ov̀ $\rho \alpha ́$, tail.)

Ioglossus caliiurus (BeAN MS.), in Jordan \& GILBERT, Proc. U. S. Nat. Mus. 1882, 297, Pensacola, Florida; Bean, Proc. U. S. Nat. Mus. 1882, 419; Jordan \& Grlbert, Synopsis, 949, 1883; Jordan, Proc. U. S. Nat. Mus. 1884, 437; Jordan \& Eigenmann, Proc. U.S. Nat. Mus. $1886,481$. 
80r. PHILYPNUS, * Cuvier \& Valencieunes.

(Guavinas.)

Gobiomorus, † LACÉPÈDE, Hist. Nat. Poiss., II, 699, 1798, in part (dormitor, etc.); restricted to dormitor by Jordan \& GrLBerT, Proc. U. S. Nat. Mus. 1882, 571; restricted to Gobiomorus taiboa, Lacépède (Valenciennes' strigata), by GiLL, Proc. U. S. Nat. Mus. 1888, 79, in accordance with the law of exclusion.

Philypnus, Cuvier \& VAlenciennes, Hist. Nat. Poiss., xII, 255, 1837 (dormitator).

Lembus, GüNTHER, Cat. Fishes, I, 505, 1859 (maculatus).

Body elongate, terete anteriorly, compressed behind. Head elongate, depressed above. Mouth large; lower jaw considerably projecting; teeth in jaw rather small, slender, recurved, the outer scarcely enlarged; teeth on vomer villiform, in a broad, crescent-shaped patch; gill openings extending forward to below posterior angle of mouth, the isthmus very narrow. Scales moderate, ctenoid, covering most of the bead, 55 to 66 in a longitudinal series. Dorsal with 6 spines and 9 or 10 rays; anal rays I, 9 or 10 ; ventrals separate. No preopercular spine; insertiou of post-temporals almost midway between occipital crest and edge of skull; parietals with a crest running from insertion of post-temporal forward to just behind eye, where they are connected by a thin, high, transverse crest; supraocular with a short, high crest, extending from above front of eye back to posterior edge of orbit, thence extending outward parallel with the transverse crest, leaving a deep groove between them; bony projections before and behind eye prominent. Vertebræ $12+13=25$; lower pharyngeals triangular, with slender teeth. Largest of the Gobies, some of the species reaching a length of 2 or 3 feet and valued as food. Tropical rivers. ( $\phi i \lambda v \pi \nu o$,

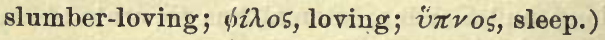

a. Coloration rather obscure, the dark lateral band indistinct or wanting; scales 55 to 57 .

DORMITOR, 2516.

aa. Coloration bright, the black lateral band distinct; scales 52 to 55 . LATERALIS, 2517 .

2516. PHILYPNUS DORMitOR (Lacépède).

(Sleeper; Guatina.)

Head $2 \frac{3}{5}$ to $2 \frac{9}{10}$; depth 5 to $5 \frac{8}{4}$. D. VI-10; A. I, 9 ; scales 55 to 57 ; eye $6 \frac{1}{8}$ to $7 \frac{1}{2}$ in head; snout $3 \frac{2}{5}$; maxillary $2 \frac{3}{5}$. Body elongate, terete anteriorly, compressed behind. Head elongate, depressed above. Mouth large; maxillary reaching to middle of pupil. Lower jaw considerably projecting. Teeth on jaws slender, depressible. Interspace between dorsals slightly greater than interorbital width; dorsal spines slender, the second the longest, $2 \frac{1}{4}$ in head; length of base of anal about $2 \frac{1}{2}$ in head; ventrals reaching $\frac{2}{8}$ of the distance to vent; tips of pectorals reaching ventral.

* The Eleotrina have been made the subject of a special paper (A Review of the American Eleotridinæ, in Proc. Ac. Nat. Sci. Phila. 1885, 66-80) by Eigenmann \& Fordice. The Gobiidoe of America have been discussed in detail by Jordan \& Eigenmann (Proc. U.S. Nat. Mus. 1886, 477-518) and later by Eigenmann \& Eigenmann (Proc. Cal. Ac. Sci., $2 d$ ser., vol. 1. 1888, 51-78). In this paper are valuable notes on the specimens in the Museum of Comparative Zoology.

+ For the reasons in favor of the ase of the name Gobiomorus for Valenciennea, Bleeker, instead of using it for the present genus, see GiLL, Proc. U. S. Nat. Mus. 1888, 69. 
Dark brownish or olive, lighter below; an interrupted dark lateral band extending from base of pectoral to base of caudal (not always present); fins dusky, and with the exception of the anal and ventrals, all distinctly mottled; spinous dorsal margined with blackish; head often with dark spots. Streams of the West Indies and Atlantic shores of Central America, Mexico, and Surinam; everywhere common, reaching a length of 2 feet or more. Here described from Cuban specimens. (dormitor, sleeper.)

Guavina, PArra, Descr. Dif. Piezas Hist. Nat. Cuba, tab. 39, fig.1, 1787, Havana.

Gobiomorus dormitor, LACÉPÈDE, Hist. Nat. Poiss., II, 599, 1798, Martinique ; from a draw-

ing by Plumier; Eigenmann \& Eigenmann, Proc. Cal. Ac. Sci. 1888, 52.

Platycephalus dormitator, BLOCH, Ichth., 1801, Martinique ; after LACGPÈDE.

Batrachus guavina, BLOCH \& SCHNEIDER, Syst. Ichth., 44, 1801; based on Guavina of PARRA. Eleotris longiceps, GÜNTHER, Proc. Zool. Soc. Lond.1864, 151, Nicaragua; GÜNTHER, Fish. Centr. Amer., 440, 1869.

Electris dormitatrix, CUvier, Règne Animal, Ed. II, vol. 2, 246, 1829, Antilles; GÜNTHER, Cat. Fish., III, 119, 1861.

Gobiomorus dormitator, JoRDaN \& GILBERT, Proc. U. S. Nat. Mus. 1882, 572.

Philypnus dormitator, Cuvier \& Valenciennes, Hist. Nat. Poiss., XII, 255, 1837; Poey, Mem. de Cuba, 1I, 381, 1860; Girard, U. S. and Mexican Boundary Survey, Zool., 27, pl. 12, fig. 13, 1859; JoRDAN \& Gilbert, Synopsis, 631, 1883.

2517. PHILYPNUS LATERALIS, Gill.

(ABOMA DE MAR.)

Head $2 \frac{9}{10}$; depth $5 \frac{1}{3}$. D. VI-10; A. I, 10 ; scales 52 to 55 ; eye 6 to $6 \frac{1}{2}$ in head; suout $3 \frac{1}{5}$ to $3 \frac{8}{4}$; maxiliary $2 \frac{1}{2}$ to $2 \frac{8}{4}$. Brownish, lighter or white below; a distinct dark brown or blackish band extending from base of pectoral to base of caudal; dorsals, pectoral and caudal dusky; ventrals and anal lighter; dorsals, caudal, and in some specimens the anal, - distinctly blotched. The only constant difference between this species and Philypnus dormitor seems to be the brighter coloration of lateralis. Streams of Pacific Coast of Mexico and Central America, from Sonora to Panama, entering the sea; common, reaching a much larger size than any other of our Gobies. Here described from specimens from Rio Presidio, Mazatlan. (lateralis, pertaining to the side.)

Philypnus lateralis, GILI, Proc. Ac. Nat. Sci. Phila. 1860, 123, Cape San Lucas (Coll.

Xantus); Jordan \& GilberT, Proc. U. S. Nat. Mus. $1882,377$.

Eleotris lateralis, GuNTHER, Cat., III, 122, 1861.

802. DORMITATOR, Gill.

(PuñeCAs.)

Prochilus, Cuvier, Règne Animal, Ed.1, vol. II, 294, 1817 (macrolepidota=maculatus); name preoccupied.

Dormitator, GmL, Proc. Ac. Nat. Sci. Phila. 1862, 240 (gundlachi).

Body short, robust; head broad and flat above; mouth little oblique; maxillary reaching to anterior margin of orbit; lower jaw little projecting; no teeth on vomer; lower pharyngeal teeth stiff and blunt, the bones with an external series broad, flexible, lamelliform, these being rudimentary gill filaments; scales large, ctenoid, 30 to 33 in a longitudinal 
series; skull much as in Eleotris; D. VII-I, 8; A. I, 9 or 10; no spine on preopercle; post-temporals inserted midway between occipital crest and edge of skull; supraoccipital crest low. (dormitator, one who sleeps.)

\section{DORMITATOR MACULATUS (Bloch).}

\section{(GUavina Mapo; Pañeca.)}

Head $3 \frac{1}{6}$; depth about 3 in adult. D. VII-I, 8 or 9 ; A. I, 9 or 10 ; lateral line 33. Body short, robust; head broad and flat above; eye small, less than snout; caudal a little shorter than head; mouth little oblique; maxillary reaching to anterior margin of orbit; lower jaw little projecting; no teeth on vomer; interspace between dorsals equaling orbit; highest anal ray $1 \frac{8}{4}$ in head; highest dorsal ray $1 \frac{1}{3}$ in head; skull much as in Eleotris, but everywhere broader; no spine on preopercle; post-temporal inserted midway between occipital crest and edge of skull; supraoccipital crest low; scales large, becoming much smaller on belly, 25 series on median line from base of ventrals to vent; 18 series across breast from pectoral to pectoral; 18 on a median line from posterior border of orbit to dorsal. Dark brown, with lighter bluish spots; a faint dark stripe along sides; a conspicuous large dark blue spot edged with black above base of pectorals; a dark streak from eye to angle of mouth; 2 dark streaks on side of head; branchiostegal membrane blackish; dorsals barred with spots; anal dusky, barred with bluish, and with white margin; a dark bar on base of pectoral. Length 1 to 2 feet. Both coasts of America, ranging from South Carolina through the West Indies to Para, Cape San Lucas, and Panama, in fresh or brackish water; everywhere abundant and used as food. Dr. Eigenmann observes:

There seem to be 2 forms of the adult-one with the profile gibbous, the dorsal outline forming a regular curve; the other having the profile depressed over the eyes, the anterior portion being subhorizontal. The specimens from Gurupa and the Rio Grande have the profile depressed; all the other specimens have a gibbous profile. A comparison in detail of the two forms is appended. Only extreme differences are given.

West Indian specimens 5 to $7 \frac{1}{2}$ inches.

Profile regularly curved from first dorsal spine to snout.

Head $3 \frac{1}{2}$ to 4 ; depth 3 to $3 \frac{1}{4}$; depth always greater than length of head.

Highest anal ray $1 \frac{1}{5}$ to $1 \frac{3}{5}$ in head.

Distance from first dorsal spine to snout greater than distance from first dorsal spine to first anal ray.

Scales in median series 29 to 32.

Color usually dark brown, a black spot above base of pectoral, a short bar on base of pectoral.

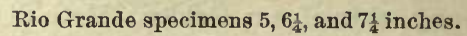
Profile depressed over eye, becoming horizontal anteriorly.

Head 3; depth 3 to $3 \frac{1}{2}$; depth usually less than length of head.

Highest anal ray $1 \frac{2}{3}$ to 2 in head.

Distance from first dorsal spine to snout equals distance from first dorsal spine to base of last anal ray.

Scales in median series 30 to 34 .

Color gray, a jet-black spot above base of pectoral; a black bar at base of pectoral; a black line from eye to mouth; longitudinal black lines on cheeks and opercles; dark spots on back; some silvery scales on sides.

Among our specimens from Mazatlan are 3 markedly different forms which seem like distinct species. In view of the great variations to which this species is subject we do not, however, regard them as such, especially as none of the three corresponds exactly to the account above given of the 2 Atlantic forms. 


\section{DEEP-BODIED SPECIMENS (Dormitator latifrons, Richardson).}

Head 3 ; depth 3 . D. VII-I, 8 ; A. I, 8 or 9 ; scales 30 to 33 ; eye $4 \frac{8}{4}$ to $5 \frac{1}{4}$ in head; snout $3 \frac{1}{4}$ to $3 \frac{1}{2}$ in head; interorbital width $2 \frac{4}{5}$ in head; ventrals reaching $\frac{2}{8}$ the distance to vent, $1 \frac{1}{2}$ to $1 \frac{2}{5}$ in head; highest anal ray $1 \frac{8}{4}$ to 2 in head. Body short, robust, the back elevated; head broad and flat above, the anterior profile from first dorsal spine to tip of snout oblique, descending abruptly; mouth oblique, maxillary reaching anterior margin of orbit; lower jaw little projecting. Color greenish, lighter below; body with cross bars of dark brown; fins dusky, the dorsals distinctly blotched with darker; a dark cross bar at base of pectorals; a dark-blue humeral blotch, becoming blackish in spirits; 3 or 4 dark eross bands extending from eye and below eye to posterior margin of preopercle; a dark band extending from below eye to below tip of maxillary. Two specimens from Rio Presidio, Mazatlan.

\section{Common Form, at Mazatlan.}

Head $3 \frac{1}{6}$; depth $3 \frac{2}{5}$ to $3 \frac{8}{4}$. D. VII-I, 7 ; A. I, 8 ; scales 33 or 34 ; eye $4 \frac{1}{4}$ to $4 \frac{3}{5}$ in head; snout $3 \frac{1}{2}$ to 4 in head; interorbital width 3 to $3 \frac{1}{6}$ in head; ventrals reaching about $\frac{2}{3}$ the distance to vent, $1 \frac{1}{2}$ in head; highest anal ray $1 \frac{5}{6}$ to 2 in head. Borly short, compressed, the back little elevated; head rather broad and slightly convex above, the anterior profile from first dorsal spine to tip of snout slightly convex; mouth oblique, maxillary reaching anterior margin of orbit; lower jaw little projecting. Color olive brown, with cross bars of darker brown, lighter below; fins dusky, the dorsals with about 3 darker cross bars; pectorals with a darker cross bar at base; a distinct dark-brown humeral spot slightly larger than eye; 3 or 4 dark cross bands extending from eye and below eye to posterior margin of preopercle; a distinct dark-brown bar extending from below eye to below tip of maxillary; a dark lateral band extending from base of pectoral to base of caudal. Many specimens from Mazatlan.

\section{LARGE-HEAded Form.}

Head $3 \frac{1}{6}$; depth $3 \frac{1}{2}$. D. VI-I, 8 ; A. I, 9 ; scales 32 or 33 ; eye $4 \frac{1}{3}$ in head; snout $3 \frac{1}{2}$ in head; interorbital width $2 \frac{1}{2}$ in head; ventrals reaching 4 the distance to vent, $1 \frac{1}{2}$ in head; highest anal ray 2 in head. Body moderately compressed, the back little elevated; head very broad above, convex; the anterior profile from first dorsal spine to tip of snout oblique, gently descending; mouth oblique, maxillary reaching anterior margin of orbit; lower jaw little projecting. Color brownish, middle of back darker, lighter below; body with darker cross bands; ventrals yellowish; other fins dusky; dorsals with darker blotches; a dark crossbar at base of pectoral; a dark humeral spot; four cross bands extending from eye and below eye to posterior margin of preopercle; a dark band extending from below eye to below top of maxillary; a dark lateral band extending from base of pectoral to base of caudal. One specimen, from near Mazatlan. (maculatus, spotted.) 
Sciana maculata, BLOCH, Ichth., pl. 299, fig. 2, 1790, West Indies.

Eleotris mugiloides, Cuvier \& Valenciennes, Hist. Nat. Poiss., XII, 226, 1837, Martinique; Surinam.

Eleotris sima, * Cuvier \& Valenciennes, Hist. Nat. Poiss., XII, 232, 1837, Vera Cruz.

Eleotris latifrons, Richardson, Voy. Sulphur, Fishes, 57, pl. 35, figs. 4 and 5, 1837, locality unknown, supposed to be from Pacific coast, Central America.

? Eleotris grandisquama, $\uparrow$ Cuvier \& Valenciennes, Hist. Nat. Poiss., xil, 229, 1837, America; locality unknown.

Eleotris somnolentus, Girard, Proc. Ac. Nat. Sci. Phila. 1858, 169, near mouth of Rio Grande.

Eleotris omocyaneus, PokY, Memorias, II, 269, 1860, Havana.

Dormitator microphthalmus, Grul, Proc. Ac. Nat. Sci. Phila. 1863, 170, Panama. (Coll. Capt. John M. Dow.)

Dormitator gundlachi, PoEx, Synopsis, 396, 1868, Cuba.

Dormitator lineatus, GiLL, Proc. Ac. Nat. Sci. Phila. 1863, 271, Savannah.

Dormitator maculatu\&, JoRdan \& GILBERT, Synopsis, 632, 1883; JoRdAN \& LigenManN, $l$. c., 482; Eigenmann \& Eighnmann, Proc. Cal. Ac. Sci., $2 d$ series, vol. 1, 1888, 52.

\section{GUAVINA, Bleeker.}

Guavina, BLEkKER, Esquisse d'un Syst. Nat. Gobioid., 302, 1874 (guavina).

This genus is allied to Eleotris, differing in having the post-temporal bones little divergent, not inserted close together, the distance between their insertions greater than the moderate interorbital space, or $3 \frac{4}{5}$ in length of head; top of skull little gibbous; lower pharyngeals narrower than in Eleotris; preopercle without spine; scales very small, ctenoid, about 110 in a longitudinal series. Vertebra $11+13$; teeth moderate, the outer series on lower jaw enlarged. Fresh waters of the West Indies and Brazil. Two species known; Guavina brasiliensis (Sauvage) from Bahia, and the following. (Guavina, the Spanish name.)

2519. GUAVIYA GUAVINA (Cuvier \& Valenciennes).

(GUARUBACo; GUavina.)

Head $3 \frac{1}{2}$; depth $4 \frac{1}{2}$ to $5 \frac{1}{4}$. D. VI, or VII-I. 10 ; A. I, 9 or 10 . Body stontish, oblong; mouth oblique; maxillary reaching opposite middle of eye, its length $2 \frac{1}{2}$ to $3 \frac{1}{2}$ in head. Lower jaw little projecting; teeth in broad bands, the outer ones on lower jaw enlarged. Scales on head embedded; those on body very small, ctenoid on sides, cycloid on back and belly, 100 to 110 in a longitudinal series. Isthmus very broad. Pectorals reaching to middle of spinous dorsal. Highest anal ray $1 \frac{4}{5}$ in head. Post-temporals inserted twice as far from occipital crest as in Eleotris pisonis. Parietals ending

* Types, 2 specimens in poor order, from Vera Cruz, $0.09 \mathrm{~mm}$. long. Snont a little more steep and convex than usual in Dormitator maculatus. Head $3 \frac{1}{3}$ in length; depth $3 \frac{1}{4}$. Eye $4 \frac{1}{2}$ in head. D VII, 9; A.11; scales 31-11. Soft dorsal very high, with round black spots. Caudal and anal plain. This seems to be inseparable from Dormitator maculatus.

+ We have the following note on the type of Eleotris grandisquama: Type specimen in fair condition, $0.14 \mathrm{~mm}$. long, from "Amérique Méridionale?" Head slenderer than iv $D$. maculatus, and much depressed, its depth at the eyes less than its width, which is less than that of body. Anterior profile almost concavo. Caudal fin large; other fins moderate. Dorsal VI,9; anal I, 9 ; scales abont 29-11. A fow dusky spots on dorsal and anal. According to Dr. Figenmann, specimens of Dormitator maculatus from the Rio Grande agree fairly with this type, and it is not likely that it is different. 
in a sharp point behind. Preopercular spine none, a broad, thin extension on the lower limb of preopercle taking its place. Lower pharyngeals triangular, normal, rather narrow; the teeth small. Vomer without teeth. Length 1 foot. East coast of tropical America, Cuba to Rio Janeiro, in fresh and brackish waters; very common. (guavina, Spanish name.)

Eleotris guavina, Cuvier \& Valenciennes, Hist. Nat. Poiss., xII, 223, 1837, Martinique. Guavina guavina, JoRdan \& EIGKNMANN, l.c., 483.

\section{ELEOTRIS (Gronow) Bloch \& Schneider.}

Eleotris, Gronow, Zooph., 83, 1763 (nonbinomial).

Eleotris, BLOCH \& SCHNEIDER, Syst. Ichth., 65, 1801 (pisonis).

Oulius, BleEker, Esquisse d'un Syst. Nat. des Gobioid., 303, 1874 (fuscus).

Body long and low, compressed behind. Head long, low, flattened above, without spines or crests, almost everywhere scaly. Mouth large, oblique, lower jaw projecting. Lower pharyngeals rather broad, the teeth small, * bluntish. Preopercle with a small concealed spine below, its tip hooked forward. Branchiostegals unarmed. Eyes small, high, anterior; isthmus broad. Post-temporal bones very strongly divergent, their insertions close together, the distance between them about $\frac{2}{8}$ the narrow interorbital space, and less than + length of head; top of skull somewhat elevated and declivous; interorbital area slightly convex transversely; dorsal fins well apart, the first of 6 or 7 flexible spines; ventrals separate. Scales moderate, ctenoid, 45 to 62 in a longitudinal series; vertebra (pisonis) $11+15$. Tropical seas, entering fresh waters. (í $\lambda \varepsilon \dot{s}$, bewildered.)

a. Toeth subequal, those of inner or outer series enlarged.

b. Cheek entirely scaled.

c. Teeth of inner series of each jaw enlarged.

d. Scales in a median series 40 to 51 , in a cross series 12 to 20 . e. Eye large, 5 to 6 in head; scales 40 to $44-12$ to 14 .

ee. Eye small, 8 in head; scales 51-20.

AMBLYOPSIS, 2520. ABACURUS, 2521.

dd. Scales in a median series 57 to 66 ; in a cruss series 18 to 24 .

PISONIS, 2522.

bb. Lower half of cheek naked; scales 61 .

PERNIGER, 25'3.

aa. Teeth all equal; $\cdot$ scales 60 .

PICTUS, 2524.

\section{ELEOTRIS AHBLYOPSIS (Cope).}

Head $3 \frac{2}{5}$; depth $4 \frac{1}{4}$. D. VI-9; A. I, 8; scales 46 (40 to 44-12 to 14 according to Eigenmann); eye $5 \frac{1}{2}$ in head, 2 in interorbital width; preopercular spine strong, decurved; width of head $\frac{3}{5}$ in its length; chin prominent; premaxillary spines forming a projection in profile. Brown, a black spot above at base of pectoral ; first dorsal and anal dusky; second dorsal and candal delicately cross-barred with blackish; 3 black lines from orbit behind and below. Surinam. Described from 3 specimens each 3 inches long. (Cope.) Dr. Eigenmann mentions 15 other examples,

* The characters of the skeleton are taken from Eleotris pisonis and have not been ver. ified on other species. The hooked preopercular spine supposed to characterize Culius is found on the typical species of Eleotris, as well as in Alexurus. 
the longest $2 \frac{1}{2}$ inches long, from Surinam, in the Muscum of Comparative

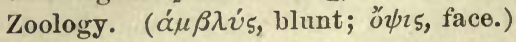

Eleotris amblyopsis, Cope, Trans. Amer. Philos. Soc. 1870, 473, Surinam (Coll. Dr. Charles Hering); Jordan \& Elgenmann, l.c., 483, 1886; Eigenmann \& Eigenmann, l.c., 55.

2521. ELEOTRIS ABACURUS, Jordan \& Gilbert.

Head 3 ; depth $4 \frac{1}{8}$. D. VI-9; A. I, 8; scales $51-20$; eye 8 in head, $2 \frac{1}{8}$ in interorbital width; pectoral $1 \frac{1}{8}$; ventral $1 \frac{1}{2}$; highest dorsal ray 2 ; highest anal ray 2 ; caudal $1 \frac{1}{4}$. Body slender, compressed, the head depressed, becoming very narrow anteriorly, its width $\frac{3}{5}$ its length; a notable depression above orbits, the premaxillary processes protruding before it; lower jaw the longer; maxillary reaching vertical behind pupil, 23 in head. Teeth in jaws in narrow villiform bands, becoming a single series on sides of lower jaw, those of the outer and inner series in each jaw somewhat enlarged, the largest being a single series in sides of lower jaw. Preopercular spine as usual in the genus. Scales smooth above and below, ctenoid on sides. Color in spirits, brown, lighter above and below; each scale on middle of sides with a dusky streak, these forming obscure lengthwise lines; back anteriorly with a few small black spots; under parts, including sides of head, very thickly punctulate with black; no dark stripes from orbit; lips black; a dark streak from snout through eye to upper angle of preopercle; 2 dusky streaks from eye downward and backward across cheek; a very conspicuous black blotch as large as eye in front of upper pectoral rays; pectorals and ventrals transparent, dusky; vertical fins all barred with light and dark in fine pattern. Coast of South Carolina. Known from a single specimen, 4 inches long, taken in the harbor of Charleston. This species agrees very well with Cope's account of Culius amblyopsis, but the scales are larger, the eye is smaller, and there is some difference in color, besides the remote habitat.

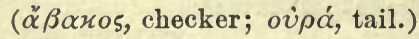

Culius amblyopsis, Jordan \& GILBerT, Proc. U. S. Nat. Mus. 1882, 610; not of Cope.

Eleotris abacurus, Jondan \& Gilbert, Proc. Cal. Ac. Sci. 1896, 228, Charleston. (Coll. Dr. C. H. Gilbert. Type, No. 2009, L. S. Jr. Univ. Mus.)

\section{ELEOTRIS PISONIS (Gmelin).}

(GUAVina Tétard; Sleeper.)

Head 3 to $3 \frac{1}{8}$ in body; depth $4 \frac{1}{8}$ to 5 . D. VI-9; A. I, 8 ; scales 62 ; eye $5 \frac{8}{4}$ to 8 in head; maxillary $2 \frac{2}{5}$; pectoral $1 \frac{1}{2}$; ventral 2; caudal $1 \frac{1}{2}$. Body not mach compressed; head somewhat depressed; mouth rather large, the maxillary reaching to below posterior margin of pupil; lower jaw much projecting, a knob at symphysis; wide bands of villiform teeth in jaws, none on vomer or palatines; interorbital region nearly twice as wide as the horizontal diameter of eye; top of head, cheeks, and opercles covered with small scales; a stout, concealed spine projecting downward on edge of preopercle. Origin of dorsal about midway between tip of snout and end of last dorsal rays; tips of first dorsal spines not reaching front of 
second dorsal when fin is depressed; origin of anal a little behind that of soft dorsal; pectorals reaching to posterior spine of first dorsal; ventrals inserted very slightly behind base of pectorals; caudal peduncle as wide as length of maxillary. Color brownish; fins with dark spots and wavy lines; ventrals dusky; 2 dark stripes behind the orbit. Here described from specimens, 6 or 7 inches long, collected in the Rio Almendares, Cuba, by. Dr. Jordan. Streams of the West Indies, generally common from southern Florida to Rio Janeiro. Dr. Eigenmann enumerates many specimens from various localities in Brazil. (Named for Dr. William Piso, of the University of Leyden, associate of George Marcgraf and Prince Maurice of Nassau, in 1648, in the study of the natural Listory of Brazil.)

Amore pixuma, MARCGRAVE \& Piso, Hist. Brasil., IV, 166, 1648, Brazil.

Eleotris capite plagioplateo, Gronow, Mus. Ichth., II, 168, 1757; after MARCGRAVE.

Gobius pisonis, GMELIN, Syst. Nat., 1206, 1788; based on Eleotris of Gronow.

Gobius amorea, WALbaUM, Artedi Piscium, III, 205, 1792; based on Eleotris of Gronow.

Eleotris gyrinus, Cuvier \& Valenciennes, Hist. Nat. Poiss., XII, 220, pl. 356, 1837, Martinique; San Domingo; Surinam.

Eleotris (Oulius) belizianus, ${ }^{*}$ SAuvage, Bull. Soc. Philom. Paris 1879 (1880), 55, Belize (Coll. Morelet), Cayenne (Coll. Mélinon); Eigrnmann \& Fordice, Proc. Ac. Nat. Sci. Phila. 1885, 75; Eigenmann \& Eigmmanan, Proc. Cal. Ac. Sci. 1888, 55.

Eleotris pisonis, Jordan \& Ergenmann, l. c., 483; Eigenmann \& Eigminann, l. c., 55.

\section{ELEOTRIS PERNIGER (Cope).}

Head $4 \frac{1}{4}$; depth $4 \frac{8}{4}$. D. VI-I, 9; A. I, 9; scales 61 ; eye 3 in interorbital width; no vomerine teeth. A strong spine at posterior angle of preoperculum, directed downward. Premaxillary spines not prominent in profile; scaling of vertex extending to their extremities. Longitudinal diameter of orbit $\frac{1}{6}$ length of head. Color black, abdomen brown, fins dusky; first dorsal with white extremity and 2 longitudinal black bars, 1 along the base; other fins with small black bars; [no] maxillary or caudal spot or ocellus. Length 5 inches. West Indies, south to Rio Janeiro. (Cope.) A specimen in our collection from Jamaica. It is close to E. pisonis, but the cheeks are not fully scaled. (perniger, very black.)

Oulius perniger, COPE, Trans. Am. Philos. Soc. 1870, 473, St. Martins. (Coll. Dr. R. E. van Rijgersma.)

Eleotris perniger, EIGENMANN \& EIGENMANN, l.c., 55.

2524. ELEOTRIS PICTUS, Kner \& Steindachner.

(GUAVINA.)

Head 3 to $3 \frac{1}{8}$; depth 6 . D. VI-I, 7 or 8 ; A. I, 7 or 8 ; lateral line $60 ; 24$ scales in an oblique series from front of soft dorsal downward and back-

*Eleotris belizianus is described as follows: Head 4 in total ; depth 5. D. VI-I, 9; A. I, 8; scales 60 ; eye 5 in head. Preopercle with a spine turned downward; 16 rows of scales between soft dorsal and anal; scales of top of head a little smaller than those of body, extending forward nearly to front of eyes; cheeks scaly; scales ciliate. Interocular space flattened, $\frac{1}{2}$ broader than eje; snout depressed a little longer than eje; lower jaw prominent; outer teeth enlarged; maxillary reaching front of eje. Dorsals contiguous. Color brownish, faint dark streaks on the fins. Belize; Cayenne. (Sauvage.) Length $100 \mathrm{~mm}$. Evidently not different from $E$, pisonis. $3030-61$ 
ward to anal; about 20 in a vertical series. Body elongate, depressed anteriorly; head especially very broad and flat; mouth large, broad, very oblique, the maxillary reaching nearly or quite to opposite posterior margin of eye, its length $2 \frac{1}{8}$ to $2 \frac{2}{8}$ in head; lower jaw considerably projecting. Teeth in jaws all equal, in broad bands, the outer not at all enlarged. Eye small, anterior, its length in adult 2 in interorbital width, which width is about 3 in head; a conspicuous knob at upper anterior and posterior angles of orbit; preopercular spine well developer, strong, compressed, directed downward and forward. Scales on head very small, mostly cycloid, covering cheeks and opercles and upper part of head to the eyes; scales on body smaller and smoother than in most other species, those on belly much smaller than those on sides; scales on back and belly cycloid, only those on sides distinctly ctenoid. Pectoral fins moderate, reaching to near end of base of first dorsal, $1 \frac{2}{3}$ in head; rentrals inserted just behind axil, reaching halfway to vent, about 2 in head. Interspace between dorsals about equal to diameter of eye. Soft dorsal and anal short and high, very similar, coterminous; last ray of anal a little longer than $\frac{1}{2}$ length of head; caudal peduncle long, a little shorter than hearl. Caudal fin rounded, $1 \frac{1}{8}$ in head. Color* dark, dull olivaceous brown, paler below; younger individuals mottled below with bluish and speckled with dark brown; sides without longitudinal stripes; fins dusky, all of them finely mottled and speckled with darker, the dark markings on dorsal and anal forming undulated longitudinal stripes; on pectorals and ventrals forming dark bars. Distinguished from related species by the larger mouth with small, equal teeth, and the small, smoothish scales. Length about 18 inches. Streams of the Pacific Coast, from Sonora, south to Panama; abundant in Rio Presidio, at Mazatlan, where the types of $E$. aquidens were taken; not rare about Panama. (pictus, painted.)

Eleotris pictu\&, Kner \& Steindachner, Abh. Ah. Wiss. Wien 1864, 18, pl. 3, f. 1, Rio Bayano, near Panama; depth 6 to 7 in total length; scales 60.

Culius aequidens, Jordan \& Gilbert, Proc. U. S. Nat. Mus. 1881, 461, Rio Presidio, near Mazatlan. (Types, Nos. 28268 and 29240. Coll. Gilbert.)

Eleotris oequidens JORJAN \& EIGENMANN, l.c., 483.

\section{ALEXURUS, Jordan.}

Alexurus, JoRdan, Proc. Cal. Ac. Sci. 1895, 512 (armiger).

Body elongate, covered with small cycloid scales; preopercle with a small, concealed, hooked spine at its angle, as in Eleotris; caudal fin broad, its base with many procurrent rays. In other respects similar to

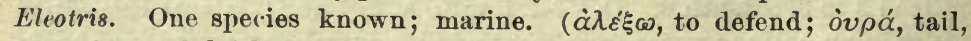
from the caudal fulcra.)

* A young example shows the following details of coloration in life: Blackish every. where, sides with faint whitish streaks, along rows of scales a broad, blackish lateral band occulying whole of side, back and belly paler, traces of faint dark cross bands; caudal black, with a pale margin and some dark cross shades; pectorals, dorsals. and ventrals more or less barred with black; preopercular spine well developed; a whitish 
2525. ALEXURUS ARMIGER, Jordan \& Richardson.

Head $4 \frac{2}{8}$; depth 8 . D. VI-13; A. 11; V. I, 5; scales about $102-30$; eye 8 in head; maxillary $2 \frac{2}{3}$; mandible $2 \frac{1}{2}$; snout $5 \frac{2}{3}$; interorbital $4 \frac{1}{3}$; pectoral $1 \frac{4}{5}$; caudal equals head; ventral 2 ; last dorsal ray $1 \frac{3}{5}$. Body long and low, compressed posteriorly, depressed in front. Head flattish and broad above, the cheeks moderately tumid. Eyes small, high up, separated by a broad, flattish, interorbital space; snout short; mouth moderate, very oblique, the maxillary ceasing below the center of pupil; lower jaw very heavy, oblique, projecting beyond upper, its outline horseshoe-shaped, obtuse in front. Teeth in rather broad bands, the onter enlarged below, but scarcely so above; none of them canine-like. Top of head with very small scales; cheeks and opercles with rudimentary scales above; preopercle with a concealed antrorse hook below, as in Eleotris; scales on body very small, perfectly smooth, partially embedded; scales on nape and throat minute. Gill membranes extending a little forward below, so that the branchiostegals are free from the isthmus. Insertion of dorsal twice as far from middle of base of caudal as from tip of snout; the fin low, its slender rays slightly filamentous; soft dorsal low, its last ray highest; anal similar, beginning under second dorsal ray; caudal long, bluntly pointed behind, with strongly procurrent base above and below, the base above $\frac{2}{5}$ length of head, forned of 14 short rays, that below a little shorter, of 12 rays, this procurrent portion forming an angle with the caudal proper where it joins it; pectorals and ventrals short, the ventrals inserted under pectorals. Color olive green, dusky above, paler below, but everywhere covered with fine black dots; both dorsals with the membranes pale, the rays each barred with black; caudal mesially blackish, all the rays barred or checkered in fine pattern; pectoral and anal pale, similarly speckled, base of pectoral dusky; ventral finely speckled. La Paz, Lower California; 1 specimen, $6 \frac{1}{2}$ inches long, taken by Mr. James A. Richardson. (armiger, bearing arms, from the concealed spine.)

Alexurus armiger, Jordan \& Richardson, Proc. Cal. Ac. Sci. 1895. 511, pl. 48, La Paz. (Type in L. S. Jr. Univ. Mus. Coll. James A. Richardson.)

806. EROTELIS, Poey.

(Esmeraldas DE Mar.)

Erotelis, PoEY, Memorias, 11, 273, 1861 (valenciennesi=smaragdus).

Body very slender, elongate, covered with minute cycloid scales. Ventrals separate, the rays $I, 5$. No teeth on vomer. Lower pharyngeals subtriangular, the teeth stiff, villiform, none of them lamelliform. Posttemporal bones short, strongly divergent, the distance between their insertions about equal to the narrow interorbital space; top of head with a strong median keel, highest on the occipital region; no supraoccipital crest; no preopercular spine. Mouth very oblique. One species known; strictly marine. (Name an anagram of Eleotris.) 
2526. EROTELIS SMARAGDUS (Cuvier \& Valenciennes).

(Esmeralda Negra; Esmeralda de Mar.)

Head $4 \frac{1}{3}$ to $5 \frac{1}{2}$; depth 8 to 12 . D. VI-I, 10; A. I, 9; V. I, 5; scales 100. Body very long and slender, compressed behind, the form much as in Gobius oceanicus. Head depressed, flattish above, the eyes mostly superior, not $\frac{1}{2}$ the width of the interorbital area, which has a knob near its middle. Mouth very oblique, the lower jaw much projecting, the maxillary about reaching front of eyes; teeth rather small, in bands. Fins rather high; dorsal spines slender, lower than the highest soft rays, which are $1 \frac{1}{5}$ in head; caudal lanceolate, $\frac{1}{5}$ longer than head; ventrals moderate, 2 in head. Scales very small, cycloid. Color very dark green, almost black; the fins mostly bluish, the dorsal with brown lines; some dark markings about eye and on base of pectoral above. Length 8 inches. Coral shores among green algæ; known from Key West and Cuba; not common; not entering rivers. Here described from Key West specimens. (б $\mu \alpha \rho \alpha \gamma \delta o ́ s$, emerald.)

Eleotris smaragdus, Cuvier \& VAlencinnnes, Hist. Nat. Poiss., xII, 231, 1837, Cuba; JoRDAN \& GILBERT, Proc. U.S. Nat. Mus. 1884, 143.

Erotelis valeneiennesi, POEY, Memorias, II, 273, 1861, Cuba.

Erotelis smaragdus, JoRDAN \& EIGENMANN, l. c., 484.

\section{GYMNELEOTRIS, Bleeker.}

Gymneleotris, BLeEkER, Esquisse d'un Syst. Nat. des Gobioid., 304, 1874 (seminuda).

Body scaled only posteriorly, the anterior half and the head naked. Ventrals separate, I, 5. Vomer without teeth. Isthmus broad; skull without crests. Lower jaw with 4 large recurved teeth. Otherwise essentially as in Eleotris, the preopercle probably without spine. ( $\gamma v \mu \nu o$ s, naked; Eleotris.)

\section{GYMNELEOTRIS SEMINUDUS (Günther).}

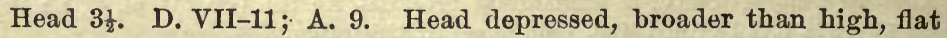
above. Snout rather obtuse, longer than eye, lower jaw somewhat prominent; cleft of mouth extending to below anterior margin of orbit. Teeth in upper jaw in a narrow band, the lower having 4 somewhat larger and recurved teeth in front, appearing to form a single series; palate toothless. None of the fin rays prolonged; pectoral not quite extending to origin of second dorsal; ventral much shorter than pectoral, its inner ray the longest, the others gradually decreasing in length outward; caudal fin rounded. Head and trunk naked; tail covered with small scales. Brown, with numerous well-defined white cross stripes on head as well as on body; vertical fins black. Panama. (Günther); known from the type only, a young example, $1 \frac{8}{4}$ inches long; not seen by us. (seminudus, halfnaked.)

Eleotris seminuda, GÚnTHeR, Proc. Zool. Soc. London 1864, 24, pl. 4, figs. 2, 2a, Panama; Günther, Fish. Centr. Amer., 441, 1869.

Gymneleotris seminuda, JoRdan \& EIGENMAN, $l$. c., 484. 


\section{CHRIOLEPIS, Gilbert.}

Chriolepis, GilBert, Proc. U. S. Nat. Mus. 1891, 557 (minutillus).

This genus differs from Gymneleotris, Bleeker, in the total absence of scales, and the absence of enlarged canines in the front of the mandible. Head and body compressed, the former as deep as wide. Ventrals separate, near together, the inner rays longest, each with 1 spine and 5 soft rays. Teeth in a rather wide band in upper jaw, the outer series somewhat enlarged. Teeth in mandible in a single series, similar to outer row in upper jaw, none of them canine-like. Gill slits narrow; no dermal flaps on inner edge of shoulder girdle. Size small. ( $\chi \rho \varepsilon i \alpha$, want; $\lambda \varepsilon \pi i \zeta$, scale.)

2528. CHRIOLEPIS MINUTILLUS, Gilbert.

Head $3 \frac{1}{3}$; depth $4 \frac{1}{8}$ in length. D. VII-12; A. 11. Mouth oblique, the maxillary reaching to below middle of orbit, $2 \frac{1}{2}$ in head; eyes high up, but with lateral range, separated by a narrow interorbital space less than diameter of pupil; diameter of orbit nearly twice length of snout, $3 \frac{1}{8}$ in head; dorsal spines high and slender, but not filamentous, the longest $\frac{1}{2}$ length of head; soft dorsal rays higher, nearly $\frac{2}{3}$ length of head; the anal lower; caudal short, broadly rounded, the depth of peduncle $\frac{1}{2}$ length of head; length of pectoral equaling that of head without snout. Color uniform light brown on head and body, above and below; fins dusky, the anal blackish. A single specimen, 1 inch long, from Albatross Station 2825, off the east coast of Lower California. (minutillus, very small.)

Chriolepis minutillus, GllBert, Proc. U. S. Nat. Mus. 1891, 558, Albatross Station 2825, Gulf of California, in 79 fathoms.

\section{8og. SICYDIUM, Cuvier \& Valenciennes.}

Sicydium, Cuvier \& Valenciennes, Hist. Nat. Poiss., XII, 168, 1837 (plumieri).

Body subcylindrical, covered with rather small ctenoid scales; head oblong and broad, with cleft of mouth nearly horizontal; upper jaw prominent; snout obtusely rounded; lips very thick, the lower with a series of numerous slender horizontal teeth, of which sometimes only the extremities are visible; upper jaw with a single uniform series of numerous movable small teeth attached by ligament to edge of maxillary; behind this outer visible series lie nnmerons other parallel series of young teeth hidden in the gum, which succeed the former as they become worn out or broken; lower jaw with a series of widely set conical teeth; teeth all simple, slender, the distal half bent inward nearly at a right angle; eyes of moderate size; 2 dorsal fins, the anterior with 6 (5 or 7 ) flexible spines; caudal quite free; ventrals united into a short cup-shaped disk; gill openings of moderate width; 4 branchiostegals. Species few in the

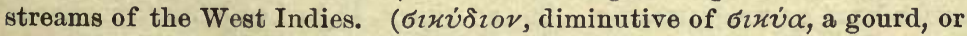
gourd-shaped cupping glass, from the ventral disk.)

a. Body covered with small scales.

b. Scales very small, about, 84 .

bb. Scales moderate, about 68 .

PLUMTERI, 2529.

aa. Body nearly naked. 
2529. SICYDIUM PLUMIERI (Bloch).

\section{(SIRAJo.)}

Head 4 to $4 \frac{3}{5}$; depth $4 \frac{1}{2}$; eye 6 to 7 in head, 2 to 3 in interorbital width. D. VI-I, 10; A.I, 10; scales 84 . T'eeth in upper jaw long, slender, bent inward at right angles, only the lips protruding from the gums. Front teeth of lower jaw not larger than those behind; a single row of inconspicuous papillæ on the gum beneath the upper lip, a large median papilla above the maxillary suture; a median cleft in the upper lip. Pectorals longer than head; third, fourth, and fifth dorsal spines produced into long ribbons, the fourth, which is the longest, being 2 to 3 times hoight of body. Body usually covered with small scales, reduced in size on neck and belly; frequently almost naked, the scales present only on posterior part of body. Caudal deeply emarginate. Color olive or violet brown, with about 7 more or less distinct dark vertical bars; a dark bar at base of pectoral; dorsal with irregular dark markings; aual fin with a dark marginal band, sometimes edged with white; an $\mathrm{H}$-shaped figure on base of caudal fin, and a black bar on its posterior half. Fresh waters of the West Indies. (Named for Père Charles Plumier, who discovered the species at Martinique.)

Gobins plumieri, BLOCH, Ichth., 125, pl. 178, fig. 3, 1786, Martinique; on a drawing by Plumier.

Sicydium siragus, PoEx, Memorias, II, 278, 1861, Santiago de Cuba.

Sicydium plumierii, Cuvier \& V Alenciennnes, Hist. Nat. Poiss., xir, 168, 1837; Grli, Proc. Ac. Nat. Sci. Phila. 1860, 101; Günther, Cat., III, 92, 1861; OGILvie-Grant, Proc. Zool. Soc. Lond. 1884, 156, pl. 11, fig. 1; Jordan \& Eigenmann, l.c., 484; Eigenmann \& EigenMANN, l.c., 56.

\section{SICYDIUM ANTILLARUM, Ogilvie-Grant.}

Head $4 \frac{3}{5}$; depth 6 ; width of head $\frac{2}{3}$ length. D. VI-I, 10; A. I, 10; scales 68. Teeth in upper jaw long, slender, and bent inward over the gam at right angles. A row of small lamelliform transverse papillæ on the gum beneath upper lip, with a larger median lamelliform papilla above maxillary suture; a slight median cleft in upper lip; maxillæ at right angles to one another; horizontal teeth conspicuous. Scales on body and tail subequal and larger than those on neck and belly. Maxilla not extending to vertical from posterior margin of eye, the diameter of which is contained $6 \frac{1}{2}$ times in length of head and twice in interorbital space. Length of pectoral greater than that of head. The third, fourth, and fifth dorsal spines produced into long narrow ribands; the fourth, which is longest, nearly 3 times height of body; second dorsal considerably higher than body. Color uniform violet brown; dorsal fins with irregular wavy dark markings; anal with a black and white marginal band; caudal with a dark band on upper margin. One specimen, $4 \frac{8}{4}$ inches long, from Barbados (Ogilvie-Grant); not seen by us. (antillarum of the Antilles.)

Sicydium antillarum, OGILVEE-Gravt, Proc. Zool. Soc. Lond. 1884, 157, Barbados. 
2531. SICYDIUM VINCENTE, Jordan \& Evermann, new species.

Another species of Sicydium or of some related genus is thus mentioned by Dr. Eigenmann: "Mr. Samuel Garman collected several hundred specimens of this species at Kingston, St. Vincent. Most of these specimens are less than an inch in length, the longest $1 \frac{1}{4}$ inches; they differ considerably in coloration from the adnlt; most are entirely naked, a few of those examined having scales only on the posterior part of the body. Caudal deeply emarginate. There are traces of about 7 dark vertical bars; a black bar at base of pectoral; dorsals with several series of black spots; an $\mathrm{H}$-shaped figure on base of caudal, a black bar on the posterior half of caudal fin; belly and lower part of body plain; everywhere else with black points. The specimens collected by Mr. Garman may be the types of a new species. No large specimens were collected at the Island of St. Vincent. Specimens $1 \frac{1}{2}$ inches in length from Hayti have the fins plain and a series of blotches along the middle of the posterior part of the body; the body, except the belly, is entirely covered with scales which are plainly ctenoid." (Eigenmann.) (Named for St. Vincent.)

Sicydium vincente, JoRDAN \& EvermanN, Chock-List Fishes, 456, 1896, St. Vincent Island; name only.

8ro. COTYLOPUS, Guichenot.

Cotylopus, Guichenot, in Maillard, Notes sur l' Isle de la Réunion, II, Addendum 9, 1864 (acutipinnis).

Sicya, Jordan \& Evermann, Check-List Fishes, 456, 1896 (gymnogaster).

This genus is closely allied to Sicydium, agreeing closely with the latter in external characters and in the absence of larger teeth in front of lower jaw; it differs chiefly in the form of the upper teeth which are curved, tricuspid, and trident-shaped, the middle cusp either permanent (Cotylopus) or else worn away leaving the tooth apparently bicuspid (Sicya).

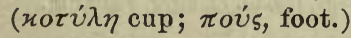

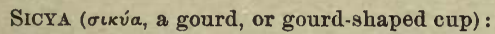

a. Teeth in upper jaw curred, tricuspid, trident-shaped, the lateral lobes long, the middle short and suspended between the outer lobes, and soon wearing away leaving the tooth apparently bicuspid.

$b$. Neck and belly naked; a double or triple row of small papillæo on the gum beneath the upper lip.

GXMNOGASTER, 2532.

$b b$. Neck and belly covered with small scales; gum beneath the upper lip smooth.

SALVINI, 2533.

Subgenus SICYA, Jordan \& Evermann.

2532. COTYLOPUS GMMNOGASTER (Ogilvie-Grant).

Head $4 \frac{1}{2}$ to 5 ; depth $5 \frac{1}{2}$ to 6 . D. VI-I, 10; A. I, 10 ; scales 60 to 64 ; eye 6 in head, twice in interorbital space. Teeth in the upper jaw tricuspid, the middle cusp, which is situated at the anterior end of tooth, is very soft and soon becomes worn away. A double or treble row of small papillæ on the gum beneath the upper lip, without a larger median papilla; upper lip with a very slight median notch; maxillæ containing an angle of about $75^{\circ}$; horizontal teeth more or less inconspicuous. Scales strongly ctenoid; neck and belly naked. Length of pectoral greater than 
that of head. Second, third, and fourth dorsal spines produced into filaments; the third, which is the longest, twice height of body ; second dorsal higher than body. Color violet brown, yellowish in young specimens, shaded with indistinct transverse bands of darker; irregular brown spots on axis of pectoral, and a broad dark band from base of pectoral to root of caudal, both more or less indistinct in adult specimens; fins violet, clouded with darker. Length 48 inches. Streams about Mazatlan (Ogilvie-Grant); not seen by us. ( $\gamma v \mu \nu o ́ s$, naked; $\gamma \alpha \sigma \tau \dot{\rho} \rho$, belly.)

Sicydium gymnogaster, OGILvie-GraNT, Proc. Zool. Soc. Lond. 1884, 158, pl.11; fig. 2, and pl. 12, fig. 6, Mazatlan.

Sicyopterus gymnogaster, JORDAN \& EIGENMANN, l. c., 485.

2533. COTYLOPUS SAIVINI (Ogilvie-Grant).

Head $4 \frac{8}{4}$; depth $6 \frac{1}{4}$. D. VI-9 or 10 ; A.I, 10 ; scales 78 ; eje $5 \frac{1}{2}$ in head, twice in interorbital space. Teeth in upper jaw tricuspid; the middle cusp, which is situated at anterior end of tooth, very soft and soon becomes worn away. Gum beneath upper lip smooth; a median papillose tubercle above maxillary suture; upper lip with a small median notch; maxilla containing an angle of about $75^{\circ}$; horizontal teeth conspicuous. Scales ctenoid, those on neck and belly smaller than those on body and tail. Length of pectoral rather greater than that of head. Second and third dorsal spines subequal and produced into short filaments, $1 \frac{1}{2}$ times height of body; second dorsal not so high as body. Color olive brown; anal yellow, with a black and white band along margin; membrane of second dorsal clear, spotted with brown; caudal with a dark and yellow band round the extremity. Length $4 \frac{2}{8}$ inches. Streams near Panama; 1 specimen known. (Ogilvie-Grant.) (Named for Osbert Salvin, who collected largely in Central America for the British Museum.)

Sicydium salvini, OGILVIE-Grant, Proc. Zool. Soc. Lond. 1884, 159, pl.12, fig. 2, Panama. Sicyopterus salvini, JORDAN \& EIGENMANN, l.c., 485.

\section{8ri. EVORTHODUS, Gill.}

Evorthodus, Gul, Proc. Ac. Nat. Sci. Phila. 1859, 195 (breviceps).

Body elongate, covered with ctenoid scales of moderate size. Head thick, short, naked. Isthmus moderate. Teeth in a single series, with the crown emarginate, those of the lower jaw horizontal; no canines. First dorsal of 6 spines; ventral fins united, not adherent to the belly,

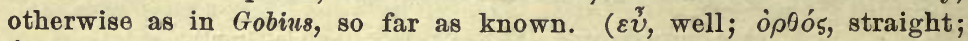
ódovis, tooth.)

\section{EVORTHODUS BREVICEPS, Gill.}

Head $4 \frac{1}{2}$, about as deep as wide; depth $4 \frac{1}{2}$. D. VI-I, 10; A. I, 11; eje 3. Teeth emarginate, uniserial, those of lower jaw nearly horizontal. Snout blunt, profile evenly decurved; caudal rounded, 3 in length of body; some of the dorsal rays filamentous. Color light brown, with irregular blackish blotches along sides; 2 black spots at base of caudal fin, 1 above the other, alternating with 1 more anterior on the peduncle; first dorsal 
with 2 bands parallel with its upper margin; second dorsal with 3 narrow longitudinal bands. (Gill.) Fresh waters of Trinidad and Surinam; not seen by us. (brevis, short; -ceps, head.)

Evorthodus breviceps, GILL, Proc.Ac. Nat. Sci.Phila. 1859, 195, Trinidad; JoRdAN \& EIGENMANN, l.c., 486.

\section{LOPHOGOBIUS, Gill.}

\section{(Crested Gobies.)}

Lophogobius, GiLL, Proc. Ac. Nat. Sci. Phila. 1862, 240 (cristagalli=cyprinoides).

Dorsal spines 6; scales evidently ctenoid. Body short, compressed, form much as in Dormitator; nape with fleshy crest; scales large. Vertebræ $11+15$. Interorbital area of cranium anteriorlv elevated, with a large foramen-like depression in front of eje. One species, differing considerably in form from the other Gobies. The study of its skeletou shows no distinction of much importance unless the peculiar form of its interorbital area be regarded as such. ( $\lambda$ ó $\phi o s$, crest; Gobius.)

\section{LOPIOGOBIUS CYPRINOIDES (Pallas).}

Head $3 \frac{2}{5}$; depth $3 \frac{3}{5}$; greatest width $5 \frac{1}{2}$ to $6 \frac{1}{2}$. D. VI or VII-10 or 11 ; A. 9 or 10 ; scales 26 to 30 ; vertebræ $11+15$; eye $3 \frac{1}{2}$ to 4 . Body short and deep, little compressed, formed much as in Cyprinodon; head naked, a prominent naked dermal crest extending from above middle of eye to near front of spinous dorsal; interorbital width slightly less than diameter of eye; profile convex; snout short, bluntish, about as long as eye; mouth very oblique, the gape slightly curved; front of upper lip on level of lower border of eye; lower jaw somewhat projecting; teeth in both jaws in bands, the outer series erect and somewhat enlarged, those of the inner series small; scales large, reducer on breast and nape; a fow scales on upper part of opercle; median line before dorsal naked; dorsal spines produced in short filaments; last rays of soft dorsal reaching caudal; caudal rounded; pectorals lanceolate, reaching beyond insertion of anal, the upper rays not silk-like; skull very broad and short, with low, median crest, highest behind; double crests of temporal region joining at the upper posterior angles of the eyes and forming a bridge over the interorbital area, the crests ending abruptly above the anterior part of the orbit, forming a decided angle, the bridged interorbital leaving a large foramen in front of this angle. Color blackish green in life; spinous dorsal black; soft dorsal, ventrals, and anal dark, plain ; pectorals lightish, plain; caudal finely mottled. Length 2 inches. West Indies, north to southern Florida; generally common in the streams and brackish waters of Cuba and other islands. Recently taken by Dr. Evermann in brackish

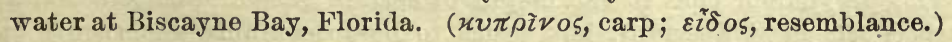

Gobius cyprinoides, PaLLAS, Spicilegia, Zool., vIII, 17, pl. 1, fig. 5, 1770, Ämboina ; Cuvier \& Valenciennes, Hist. Nat. Poiss., XII, 129, 1837; GÜnther, Cat. Fish., III, 8, 1861.

Gobius cristagalli, Valenciennes, in Cuvier \& Valenciennes, Hist. Nat. Poiss., XII, 130, 1837, Havana; Guichenot, in Ramon de la Sagra, Hist. Cuba, 128, pl. 3, fig. 3, 1850.

Lophogobius cyprinoides, PoEx, Repertorio, I, 335, 1867; POEx, Synopsis, 393, 1868; PoEx, Euumeratio, 125, 1876; Jordan \& Eighnmann, Proc. U. S. Nat. Mus. 1886, 487; Evkrmann \& Kendall, Bull. U. S. Fish Comm. 1897, 131, plate 9, fig. 13. 


\section{8r3. GOBIUS (Artedi) Linnæus.}

\section{(GobIes.)}

Gobius, ARTEDI, Genera, 28, 1738 (Gobius ex nigricante varius, etc., =niger).

Gobius, LiNnæus, Syst. Nat., Ed. x, 262, 1758 (niger, etc.), and of authors generally.

Gobionellus, GIRARD, Proc. Ac. Nat. Sci.Phila. 1858, 168 (hastatus=oceanicus).

Ctenogobius, GrLL, Fish. Trinidad, 374, 1858 (fasciatus).

Euctenogobius, GiLl, Annals Lyc. Nat. Hist. Now York 1859, 45 (badius).

Smaragdus, PoEy, Memorias, II, 279, 1861 (smaragdus).

?Pomatoschistus, Gill, Proc. Ac. Nat. Sci. Phila. 1863, 263, footnote (minutus).

Coryphopterus, Gill, Proc. Ac. Nat. Sci. Phila. 1863, 263 (glaucofroenum).

? Deltentosteus, GrLl, Proc. Ac. Nat. Sci. Phila.1863, 263, footnote (quadrimaculatus).

? Gobiichthys, KLunzinger, Fisch. Rothen Meeres, 479, 1871 (petersii).

? Mesogobius, BLEEKER, Esquisse d'un Syst. Nat. Gobioid., 317, 1874 (guavina).

? Stenogobius, BLEEKER, l.c., 317 (gymnopomus).

?Oligolepis, BLEEKER, l.c., 318 (melanostigma).

?Gnatholepis, BLEEKER, l.c., 318 (anjerensis).

? Callogobius, BLEEKER, l. c., 318 (hasselti).

?Hypogymnogobius, BLEEKER, l.c., 318 (xanthozona).

? Hemigobius, BLEEKER, l.c., 318 (melanurus).

?Cephalogobius, BLEEKER, l. c., 320 (sublitus).

?A centrogobius, BLEEKER, l.c., 321 (chlorostigma).

? Porogobius, BLEEKER, l.c., 321 (schlegeli).

?A mblygobius, BLEEKER, l.c., 322 (sphinx).

Zonogobius, BLEEKER, l.c., 323 (semifasciatus).

?Odontogobius, BLEEKER, l.c., 323 (bynoënsis).

? Stigmatogobius, BLEEKER, l.c., 323 (pleurostigma).

?Oxyurichthys, BLEEKER, l.c., 324 (belosso).

Lythrypnu\&, JoRDAN \& EverManN, Check-List Fishes, 458, 1896 (dallii).

Body oblong or elongate, compressed behind. Head oblong, more or less depressed. Eyes high, anterior, close together; opercles unarmed. Mouth moderate. Teeth on jaws only, conical, in several series, those in the outer row enlarged; no canines. Isthmus broad. Shoulder girdle without fleshy flaps or papillæ. Skull depressed, abruptly widened behind the eyes and without distinct median keel. Scales moderate, ctenoid, permanently covering the body; ckeeks usually naked; belly generally scaly. Dorsal with 6 rather weak spines; pectorals well developed, the npper rays sometimes very slender and silky; ventrals completely united, not adnate to the belly; caudal fin usually obtuse. Species very numerous. The genus Gobius, as here understood, comprises a very large number of species more or less closely related to the European type of the genus, Gobius niger, and its American relative, Gobius soporator. An examination of skulls or skeletons of numerous European and American species shows a remarkable uniformity in most respects. The general form and structure of the cranium is the same in all, the only differences being very minor ones in the height of certain crests. Gobius oceanicus seems. the most aberrant, but seems to be inseparable generically on account of intermediate forms. Probably"several of the many genera indicated by Bleeker will prove valid, but only a thorough study of skeletons can establish them. It is not unlikely that Ctenogobius, to which group most of our species belong, may be separable from Gobius. ( $\omega_{0} \beta_{1}$ s $_{5}$; Latin, Gobius or Gobio, a name applied to the gudgeon (Gobio gobio) and 
to other small fishes; allied to Cobitis, chub, etc. According to Apostolides $x \omega \beta \imath o ́ s$ and $\gamma \omega \beta \imath o ́ s$ are common names in modern Greek for all species of the genus Gobius. Aristotle $\varkappa \omega \beta \beta_{\imath o} \sigma_{5}, 610 b, 4,598 a 1116,508 b$ $16,569 b 23,621 b 1319,567 b 11,591 b 13,601 b 22,835 b 14$. The $\varkappa \omega \beta$ ßós has many pyloric appendages above the stomach, spawns near the land on the rocks, the bunches of eggs are flat and crumbling; it feeds on mud, seaweed, sea moss, ete.; lives near the land, gets fat in the rivers, and is found in schools. The white $x \omega \beta$ ßós, found in the Euripus of Lesbos, never leaves that lagoon for the open sea as the other fishes found there do. Latin Gobio and Cobio, Plin. Gobiur, Ovid., Hal. 12, 8. Martial 13, 88. Horace A. Hoffman.)

\section{GoBIUs:}

a. Upper rays of pectoral fin silk-like; i. e., short and very slender and flexible, free for nearly their whole length.

b. Body robust, compressed posteriorly; depth $4 \frac{2}{5}$ to $5 \frac{1}{2}$ in length; head broad, low, rounded in profile, its length $3 \frac{1}{50}$ to $3 \frac{2}{3}$ in body; eye 4 to 5 in head; mouth large, little oblique; lips thick; teeth in both jaws in bands, the outer series enlarged; those on lower jaw subequal; scales large, strongly ctenoid, smaller on nape and belly; dorsal spines short, none filamentous. Color olivaceous, light or dark, varying from sand color to greenish black, every. where mottled and marbled with dark and paler; a faint dusky spot behind eye. D. VI-9 or 10; A. I, 7 to 9 . Scales 36 to 41 .

SOPORATOR, 2536.

Ctenogobids ( $\kappa \tau \epsilon \iota s$, comb; Gobius):

$a a$. Upper rays of pectoral normal, not silk-like, similar to the others.

c. Scales large, 25 to 33.

$d$. Color in life olivaceous, more or less spotted, never red.

e. Dorsal soft rays 12 to 14 ; vertex and nape with a slight median fold of skin.

$f$. Body compressed, its depth 5 in length; head $3 \frac{2}{3}$ to $3 \frac{3}{5}$; eye 3 to $3 \frac{1}{4}$ in head; vertex and nape with a slight median fold of skin; maxillary reaching about to front of pupil; lower jaw very slightly produced; teeth in bands, the outer slightly enlarged. Olivaceons; spinous dorsal black at tip; second dorsal finely checkered in adult. D. VI-14; A.I, 11. Scales 25 or $26-10$.

NICHOLSII, 2537.

ff. Body long, not much compressed; head $3 \frac{1}{2}$; eye 3 in head; no median fold on vertex and nape; a dark spot on first dorsal.

EIGENMANNI, 2538.

ee. Dorsal soft rays 10 to 12 ; no median fold of skin on vertex and nape.

$g$. Caudal with 2 spots at its base; jaws unequal, the lower slightly produced; body robust, compressed behind, the

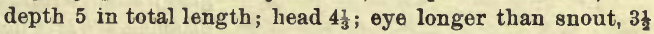
in head; maxillary reaching pupil; teeth in a band, the outer enlarged and distant, the inner enlarged and bent back. ward. Brownish; a faint blue spot on each scale; six spots along middle of back; similar spots on scapular region and middle of sides; 2 spots on base of caudal; a dark spot above opercle; blue dots on head; a straight blue line crossing cheek above and continued on opercle; dorsals faintly spotted. D. VI-10; A.10. Scales 25-7. (Gill.)

GLADCOFRAANUM, 2539.

gg. Caudal plain or with but a single spot at its base.

$h$. Dorsal spines low, the highest little longer than head.

i. Region from nape to dorsal entirely scaled.

$j$. Pores on preopercle not very conspicuous; no canine teeth. 
k. Body very slender, compressed, the depth $5 \frac{2}{3}$ in length; caudal much longer than head; mouth rather large, the lower jaw projecting; teeth unequal, rather strong; yellowish, much spotted with darker. D. VI-12; A. 12 . Seales 35 .

MANGLICOLA, 2540.

$k k$. Body subfusiform, little compressed; depth $4 \frac{1}{2}$ in length; head blunt, 4 in length, rounded in profile; eye equal to snout, 4 in head. Mouth small, horizontal, the lower jaw included; maxillary 3 in head, reaching to below eye. Teeth small, in bands in both jaws, the outer enlarged, those of the upper jaw very slender. Scales large, ctenoid, those of nape and belly little reduced. Longest dorsal spine shorter than head. Caudal scarce. ly pointed, about as long as head. Color whitish gray, middle of sides with 4 or 5 dark blotches, from each of which a narrow dark bar extends downward and forward; a large black blotch above pectorals, obsolete in female; a small black spot at base of caudal; a dark mark below eye; vertical fins barred. D. VI-12; A. 11 or 12 . Scales 33 .

STIGMATURUS, 2541.

jj. Pores on preopercle very conspicuous; lower jaw with small canies.

D. VI-I, 9; A. I, 9.

QUADRIPORUS, 2542.

ii. Region between nape and dorsal with a narrow naked median strip. Body moderately elongate, subfusiform, the depth $5 \frac{1}{3}$ in length. Head large, not so blunt as in $G$. boleosoma, its length $3 \frac{2}{6}$ to $3 \frac{2}{3}$ in length; anterior profile gently decurved; snout $3 \frac{1}{3}$ to $3 \frac{1}{2}$ in head; eye 4; mouth large, slightly oblique; naxillary entending to front of pupil, $2 \frac{1}{3}$ in head. Teeth small, slender and curved, in moderate banils. Scales moderate, ctenoid, those in front much reduced in size; breast naked. Long. est dorsal spine $1 \frac{1}{2}$ in head. Caudal as long as head, somewhat pointed. Olivaceous, mottled with gray; about 5 rounded dark blotches along middle of sides, the last forming a spot at base of candal; no dark spot on side of nape; some dark marks on head; vertical fins barred. D. VI-12; A. 13. Scales 33 to 35.

SHUFELDTI, 2543.

iii. Region between nape and dorsal entirely naked.

l. Highest rays of second dorsal little more than $\frac{1}{2}$ head, none of them reaching base of caudal.

$m$. Profile much decurved, skull rounded behind, without distinct median ridge; mouth horizontal. Body elongate, deepest below front of dorsal, tapering regularly backward, the greatest depth 51 in length. Head short, blunt, pro. 
file auteriorly abruptly decurved, cheek somewhat swollen. Length of bead $3 \frac{1}{2}$ in body. Snout about equal eye, $3 \frac{3}{3}$ in head. Mouth horizontal, maxillary reaching to below pupil (in male); lower jaw included. Teeth in each jaw in a band, the outer row of the upper jaw large, recurved. Scales large, ctenoid, somewhat reduced anteriorly. Nape, breast, and belly naked. Dorsal spines about $\frac{2}{3}$ of head. Caudal pointed, $2 \frac{3}{3}$ to $3 \frac{1}{2}$ in body. Color olivaceous, with numerous dark reticulations on the back; 5 black spots along the sides, the last forming a spot on base of caudal, sometimes with $V$-shaped dark bars extending from them to dorsal; breast and sides of belly with numerous dark specks in male; a dark line between eyes; a dark line from eye to middle of premaxillary, some dark spots below eye, sometimes forming bars, sometimes a stripe; a large oblique spot above pectorals, continued on opercle; a black spot at base of pectoral; dorsals and caudal barred, anal uniform dusky, ventrals and pectorals black in male, white in female. $D$. VI-11; A. 10 to 12 . Scales 25 to 30.

BOLEOSOMA, 2544.

$\boldsymbol{m}$. Profile moderately decurved; eye longer than snout, 3 s in head. Color yellow. ish, oblong dark blotches on middle of sides; dorsal and caudal barred. Head 4; depth 6. D. VI-12; A. 10. FASCIATUS, 2545.

il. Highest rays of second dorsal as long as head, the last reaching base of candal. Body elongate, the back not arched; depth 6 in length; head 4, not compressed, the cheeks tumid. Profile abruptly decurved, the snout $3 \frac{1}{3}$ in head. Mouth large, nearly horizontal, the maxillary reaching posterior edge of eye in males, middle of eye in females. Teeth in narrow bands in each jaw, the outer somewhat enlarged, the outer in some (males?) much enlarged above and recurved, the enlarged teeth fixed, the others movable. Scales large, ctenoid, reduced anteriorly; belly naked. Dorsal spines little filamentous, the longest about equal to head; caudal $2 \frac{1}{4}$ to 3 in body. Males dark olive, with 4 oblong dark blotches along middle of sides; a dark caudal spot; a black blotch larger than eye on each side of shoulder; dorsal spotted; 
caudal reddish above, dusky below; females with 5 oblong dark blotches on sides, the last on base of caudal; from each of the middle blotches a $V$-shaped bar runs to the back; a black shoulder blotch; a dark bar from eye to mouth; ventrals pale, with 2 dark streaks. D. VI-11; A. 12. Scales 30 (27 to 33 ) at least in males.

ENC EOMUS, 2546.

$h$. Dorsal spines high, the highest reaching past middle of second dorsal. Nape scaly. Body elongate, moderately compressed.

$n$. Depth 5 to 6 in length. Profile little decurved, skull flattish behind, much broader than in Gobius boleosoma, with an evident median ridge; mouth very oblique, much larger than in $G$. boleosoma; lower jaw thin and flat. Back slightly arched. Body a little deeper and rather less compressed than in $G$. encoeomus, the depth 5 to 6 in length. Head 4. Anterior profile moderately decurved. Eye $3 \frac{1}{3}$ in head. Mouth large, oblique; maxillary reaching to below pupil in both sexes. Teeth above uniserial, some of them enlarged and recurved; lower teeth in a narrow band; males sometimes with the hindermost of the outer series a strong, exserted, recurved canine; belly naked. Long. est dorsal spine $\frac{8}{3}$ head in females, elevated in males; soft dorsal elevated in males; caudal $3 \frac{1}{2}$ in body. Color light greenish; sides of male with 5 or 6 narrow, straight, rather sharply defined whitish or yellowish cross bars, regularly placed; 4 dark bars, 3 below eye and 1 on opercle; a small dark spot behind and above opercle; vertical fins barred; female with a row of irregular dark spots connected by a dusky streak, and with the pale cross bars obsolete. D. VI-12; A. 13. Scales 27.

stigmatices, 2547.

nn. Depth $4 \frac{2}{3}$ in length; the profile very obtuse anteriorly; mouth nearly horizontal, the maxillary extending beyond pupil, $2 \frac{3}{5}$ in head. Teeth strong, uniserial, 4 shortish canines in lower jaw behind the other teeth; upper teeth largest. Some of the dorsal spines filamentous, reaching (in male) past middle of second dorsal; caudal $\frac{1}{4}$ longer than head; scales large, ctenoid, those on nape and belly much reduced in size. Dark olive, with 4 or 5 irregular, confluent, blackish cross bands, besides irregular, dark blotches; head marked with darker; fins mostly dusky; caudal dark blue with 2 red longitudinal stripes.

D. VI-11; A.10. Scales 27. LYRICUs, 2518.

nnn. Depth 4 in length; mouth nearly horizontal; teeth short and thick, uniserial; yellowish, much mottled and blotched. D. VI-11; A.11. Scales 30.

GARMANI, 2549. 
$d d$. Color in life, cherry red, with many bluish cross bars; body stout; depth $4 \frac{1}{3}$ in length. D. VI-11; A.9. Scales large. ZEBRA, 2550.

ec. Scales moderate or small, 40 to 90 .

$o$. Soft dorsal and anal short, each of 10 to 14 rays; body more or less elongate. EUCTENoGobius (ev̌, well; ктеis, comb; Gobius):

p. Caudal rounded, not much longer than head.

$q$. Scales 40; dorsal with 9 soft rays only; anal with 9; depth $6 \frac{1}{2}$ in total length; head broad, flattish; snout short, decurved; eye $4 \frac{1}{4}$ in head, $1 \frac{1}{3}$ in interorbital area, longer than snout; maxillary extencling to below middle of eye. Some of the dorsal spines produced in filaments, the third $1 \frac{1}{2}$ times depth of body; caudal short, rounded. Two rows of ill-defined blotches on upper half of body; 2 rows of brownish spots on second dorsal, the upper strongly marked

POEYI, 2551.

$q q$. Scales 50; dorsal and anal with 10 soft rays each; profile very oblique. Color dark brown. BADIOS, 2552.

Gobionelues * (diminntive of Gobius):

$p p$. Caudal lanceolate, much longer than head; lower jaw thin; usually a green spot on roof of mouth in life.

$r$. Body rather deep, the depth about 5 in length.

s. Teeth minute, seen with a lens only. Dorsal spines filamentous; scales much reduced below. D. VI-13; A.14. Scales 62 .

MICRODON, 2553.

ss. Teeth well developed.

$t$. Seales rather large, 39 to 42 ; body moderately elon-

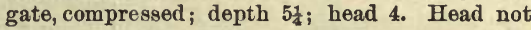
compressed, the cheeks tumid, the snout short, abruptly decurved; mouth large, little oblique, the jaws equal, the maxillary $2 \frac{1}{3}$ in head, reaching to below pupil; eye 5 in head; teeth above large, unequal, uniserial, some of them fixed, those below small, in a band. Scales anteriorly cycloid, becoming larger posteriorly, and ctenoid; dorsal spines scarcely filamentous, none of them as high as body; caudal $2 \frac{1}{4}$ in body. Light olive, with dark olive blotches; body and head with many conspicuous round spots of cream color, each surrounded by a dusky ring, these rnost distinct on the head, all smaller than pupil; snout with dusky streaks; dorsals and caudal sharply barred; anal and ventrals dusky (in male) ; a small round spot at base of caudal. D. VI-11; A.11.

SMARAGDUS, 2554.

tt. Scales comparatively small (53). Body elongate, compressed behind; head a little compressed, 33 in length; depth 5 ; eye $3 \frac{1}{2}$ in head, shorter than the rounded snout; maxillary reaching to below middle of eye; teeth small, the outer a little enlarged; dorsal spines all shorter than head, not filamentous. Nape scaly, its scales much reduced in size; scales ctenoid. Two violet stripes from eye to mouth; 8 or 9 violet bars on sides; 3 or 4 bars on caudal; second dorsal spotted. D. VI-12; A.11 or 12.

STRIGATUS, 2555.

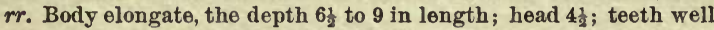
developed; caudal very long.

* Gobionellus is probably generically distinct from Gobius and Otenogobius, but at present we do not know how to limit it, and therefore we are unable to define it. 
u. Scales 55 to 60 ; eye longer than snout, 4 in head; mouth slightly oblique, the jaws equal, the maxillary not reaching center of eye; teeth in a narrow band, the onter much enlarged and separated from the others by a narrow interspace. Second dorsal spine not equal to depth of body. Candal $3 \frac{1}{2}$ in body. Scales on nape and axil very small, those on posterior part of body much larger. Light olive green; a series of brown spots along middle of tail; siles of head with dusky blotches, vertical fins dotted with black. D. VI-13;
A.14. Scales 58-20.
SAGITTULA, 2556.

uu. Scales very small ( 60 to 90 ); caudal more than twice as long as head in adult. Body compressed, extremely elongate, the depth 6 to 9 in length; head higher than wide, short, compressed, $4 \frac{1}{2}$ to 5 in length; mouth wide, oblique; maxillary in adult reaching to below posterior border of eye. Lower jaw very thin and flat; teeth in both jaws small, subequal, those in the upper jaw in a single series, those of the lower in a narrow band; outer teeth somewhat movable. Scales anteriorly small, cycloid, embedded, those behind larger and ctenoid; a few scales on upper anterior corner of opercle; dorsal fins high, some of the spines filamentous, longer than head. Caudal very long filamentous, 2 to $2 \frac{2}{3}$ in body. Light olive; fins dusky in male; a round, black spot on side, a little larger than eye, below spinous dorsal; first dorsal spine with 2 or 3 black spots; a small dusky spot at base of caudal; emerald spot on tongue conspicuous, fading in spirits. D. VI-14; A. 14 or 15.

v. Head $5 \frac{1}{2}$ to 6 in length; scales 60 to 70 ; patch of Bcales on opercle obsolete. HASTATUS, 2557.

vv. Head 7 to 8 in length; scales about 90 ; patch of scales on opercle well developed.

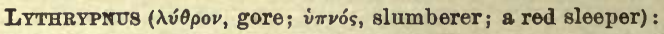

OCEANICCS, 2558.

oo. Soft dorsal and anal very long; D. VI-17; A. 14. Body short, compressed; mouth very oblique; jaws with distant canine-like teeth. Coral red, with bluish crossbands and markings. Scales $40 . \quad$ DALrII, 2559.

\section{Subgenus GOBIUS.}

2536. GOBIUS SOPORATOR, * Cuvier \& Valenciennes.

(Slfeper; Meapo; Catman.)

Head $3 \frac{1}{10}$ to $3 \frac{2}{3}$; depth $4 \frac{2}{5}$ to $5 \frac{1}{2}$; eye 4 to 5 . D. VI-I, 9 or 10 ; A. I, 7 to 9 ; scales 35 to $41-13$ to 15 . Vert. $11+16$. Body robust, compressed pos-

* The specimens examined are from Panama, Barbados, Pará, Itapuana, Cuba, Galapagos, Sambara, Bahia, Urange Key, Bahamas, Pernambuco, St. Thomas, Tortugas. Florida Keys, Martinique, Sao Matheas, Curuca, Rio de Janeiro, Rio Doce. "The color variations among examples of this species are very great, specimens from one locility varying from plain sand color, or gray, to greenish black; some dark brown specimens have light bars across the back; in others the scales have light centers forming horizontal series of light lines; sometimes there are light spots on sides of head and cheek; some specimens are conspicuously marbled with light and dark brown, and white spots occur in the centers of some of the scales on specimens of any ground color, these white spots being brighter on some of the scales than on the others, forming interrupted longitudinal lines. If any value could be placed upon the coloration, almost every specimen would be a distinct species. The color variation is irrespective of locality, some localities havlng all the above-described variations. The types of Poey's mapo, lacertus, and brunneus prove to be color varioties of Gobius soporator." (Eigenmann.) 
teriorly; head broad, low, rounded in profile; mouth large, little oblique; lips thick; tecth on upper jaw in a broad band, those of outer series enlarged, the inner ones minute; teeth on lower jaw in a broad band, the outer row enlarged, but not quite as large as the outer series on upper jaw. Anterior half of trunk scaled, head naked; scales large, strongly ctenoid, smaller on nape and belly. Dorsal spines short, not filamentous; upper rays of pectoral fin silk-like, short, and very slender and flexible, free for nearly their whole length; caudal short. Skull posteriorly much as in Lophogobius cyprinoides, but the median crest reduced to a slight ridge. Lateral crests very high and closely approximated, rising obliquely outward; the inner crests meeting behind eye, the outer ones forming a very high border about the orbit. Interorbital very narrow and deep, with a median ridge. Coloration that of the rocks, usually granite gray or olivaceous, light or dark, varying from sand color to greenish black, everywhere mottled and marbled with darker and paler, often with brassy or greenish; a faint dusky spot behind eye; coloration varying indefinitely with the surroundings; pectorals, dorsals, and caudal generally mottled; anal and ventrals usually plain. Length 3 to 6 inches. Specimens from Pensacola show the following characters: Head $3 \frac{1}{3}$ (4 in total); depth 4 (5). D. VI-10; A. I, 9 ; scales 30 to 38 ; 12 rows of scales from first dorsal downward and backward to anal. Scales on nape extremely small, those on sides firm, ctenoid; first dorsal with an oblique median shade of blackish, the base in front and the distal part light orange; second dorsal dusky at the base, with some spots, its margin light orange; caudal reddish, with dusky cross lines or spots; anal and ventral dusky, yellowish at base in the female; pectoral olivaceous, yellowish at base, reddish at tip, 2 dark spots on base of pectorals. Form robust. Head rather blunt and heavy, the snout less abruptly decurved than in G. lyricus. Mouth moderate, the jaws equal, the maxillary reaching about to front of pupil, $2 \frac{2}{8}$ in head. Teeth in moderate bands, the outer series somewhat enlarged. Cheeks full, tumid. Eyes moderate, placer rather high, much broader than the interorbital space. Dorsal spines slender, the first longer than the other, but not filamentous, $1 \frac{3}{5}$ in head; caudal rounded, $1 \frac{1}{3}$ in head; upper rays of pectorals silk-like, the fin somewhat longer than the ventral, $1 \frac{1}{4}$ in head. Color in life, very deep olive green, the back and sides obscurely barred and much marbled with different shades of olive green; cheeks with dark markings, forming reticulations around pale spots; whole under part of head blackish in the males, yellowish in the females. Tropical seas; universally distributed and almost everywhere common, lurking among stones or on sand in shallow water, or in rock pools, moving very quickly when disturbed; north on our coast to Carolina and Gulf of California. The commonest of all shore fishes in tropical America. Among our species it seems to be the one most nearly related to the European Gobius niger, and it may, therefore, be held to represent the subgenus Gobius, if our other species be placed in different subgenera. Perhaps all the others will ultimately be removed from Gobius.

Gobius soporator, Cuvier \& VALenciennes, Hist. Nat. Poiss., xIr, 56, 1837, Martinique; GüNTHer, Cat. Fish., III, 26, 549, 1861; PoeY, Enumeratio, 124, 1876; JordaN \& GILBERT, Synopsis, 634, 1883.

$3030-62$ 
Gobius lineatus, JENYNS, Zool. Voy. Beagle, 95, pl.19. fig. 2, 1842, Galapagos Archipelago. (Coll. Charles Darwin.)

Gobius catulus, Grrard, Proc. Ac. Nat. Sci. Phila. 1858, 169, St. Joseph Island, Texas; GIRARD, U.S. and Mex. Bound. Survey, Zool., 26, pl.12, figs. 9 and 10,1859; Jordan \& EIGENMANN, l.c., 493.

Gobius mapo, Poex, Memorias, II, 277, 1861, Cuba; PoEY, Synopsis, 392, 1868.

Gobius lacertus, Poex, Memorias, II, 278, 1861, Cuba ; PoEY, Synopsis, 392, 1868; Poex, Enumeratio, $125,1876$.

Gobius andrei, SAdvage, Bull. Soc. Philom., Ser.7, rv, 44, 1880, Rio Guayas, Ecuador. (Coll. André.)

Gobius carolinensis, GrL, Proc. Ac. Nat. Sci. Phila. 1863, 268, Charleston, South Carolina ; J ORDAN \& GILBERT, Synopsis, 634, 1883.

Gobius brunneus, POEx, Synopsis, 393, 1868, Havana ; name preoccupied.

Evorthodus catulus, JoRdAN \& GILBERT, Synopsis, 632, 1883.

According to Dr. Eigenmann, Gobius albopunctatus of the Western Pacific can not be separated from Gobius soporator. In this case several other synonyms should be added.

\section{Subgenus CTENOGOBIUS, Gill.}

\section{GOBIUS NICHOLSII, Bean.}

Head $3 \frac{1}{3}$ to $3 \frac{3}{5}$; depth 5 to $5 \frac{1}{4}$. D. VI-I, 12 to 14 ; A. I, 11 ; scales 25 or 26-10. Body compressed; width of head about twice in its length. Mouth oblique, the maxillary reaching to front of pupil, $2 \frac{1}{2}$ to 3 in head; lower jaw very slightly produced. Teeth present on both jaws; the outer series of long, conical teeth, placed at a considerable distance apart; the enlarged teeth on lower jaw not extending on the sides; the inner series of a band of small teeth. Interorbital space very narrow, equaling pupil. Snout 4 to $4 \frac{1}{3}$ in head. Eyes large, placed high, 3 to $3 \frac{1}{4}$ in head. Caudal peduncle $2 \frac{8}{4}$ to $3 \frac{1}{6}$ in head. Scales large, caducous, ctenoid; lacking on head, nape, and fins. Dorsal spines slender, flexible; base of first dorsal $1 \frac{3}{5}$ to 2 in head; soft dorsal and anal similar; base of anal $1 \frac{1}{5}$ to $1 \frac{1}{3}$ in base of soft dorsal, and $1 \frac{1}{4}$ to $1 \frac{1}{8}$ in head; ventrals $1 \frac{1}{4}$ to $1 \frac{2}{5}$ in head, inserted below or slightly behind origin of pectorals; pectorals reaching a considerable distance beyond ventrals, $1 \frac{1}{12}$ to $1 \frac{1}{4}$ in head; caudal rounded, not equaling head. Color in spirits, light yellowish brown, with traces of darker, lighter below; ventrals usually dusky; spinous dorsal narrowly margined with black; second dorsal finely checkered in adult; other fins yellowish, not distinctly marked. Length 2 to $3 \frac{1}{2}$ inches. Coast of British Columbia; not rare. Here described from 5 specimens from Albatross Station 2944, numbered 66 in the L. S. Jr. Univ. Museum. (Named for Capt. Henry E. Nichols, U.S. N., its discoverer.)

Gobius nicholsii, BeAN, Proc. U. S. Nat. Mus. 1881, 469, Departure Bay, British Columbia; JORDAN \& GILBERT, Synopsis, 946, 1883; JoRDAN \& EigenManN, l.c., 494.

2538. GOBIUS EIfENMANNI, Garman.

D. VII-12; A. 13; P. 19; scales 27-7. Body rather stout, body cavity more than $\frac{1}{2}$ the length from snout to base of caudal. Head $\frac{2}{9}$ of the total length or $\frac{2}{7}$ of the distance to the caudal base, blunt and rounded anteriorly, very narrow between the eyes, slightly compressed. Eyes large, $\frac{1}{8}$ of the 
head, very close together. Snout short, little more than $\frac{1}{2}$ as long as the eye. Mouth wide; maxillary reaching a vertical from the middle of the eye, moderately oblique. First dorsal higher, anterior 3 rays prolonged in the filaments, third ray longest and reaching to the eighth ray of the second dorsal; origin of anal fin midway from edge of preopercle to base of cauclal; pectorals nearly as long as the head; candal as long as head, pointed. Scales large, thin, deciduous, 27 in a longitudinal series, 2 rows above the lateral line. Yellowish, with a few punctulations of black near the bases of the caudal rays, with a light-edged black spot on the outer halves of the fourth to the sixth rays of the first dorsal and with a black streak around the mouth immediately above the maxillary. The long body, the large eye, the dorsal spot, and the streak above the mouth serve to distinguish this species from its nearest allies of the same locality. Off Key West, in 60 fathoms. ("The specific name is given in honor of the distinguished ichthyologists who have added so much to our knowledge of the American Gobiidx, C. H. and R. S. Eigenmann.")

Gobius eigenmanni, Garman, Bull. Lab. Nat. Sci. State Univ. Iowa, vol. IV, No. 1, 88, 1896; off Key West in 60 fathoms. (Coll. Iowa Univ. Bahama Expedition.)

\section{GOBIUS GLAUCOFRENUM (Gill).}

Head $3 \frac{1}{8}$; depth $4 \frac{1}{3}$. D. VI-10; A. I, 9; P. 18; lateral transverse 7. Body robust, compressed; head naked; mouth oblique, the lower jaw slightly projecting, the maxillaries extending to below pupil; teeth loug, in many series, the outer curved; scales ctenoid, large. Pectoral fin with the upper rays little branched, not silk-like; cheeks scarcely tumid; caudal and pectoral longer than ventrals, about as long as head. Tawny, with a faint blue spot in the center of each scale, and with 6 spots, each formed by aggregation of dark dots, on the ridge of the back between the second dorsal spine and the axil of the soft dorsal fin; another row of similar but fainter spots runs from the scapular region, and a third row along the middle of the sides; head tawny, with dark spots and blue dots; a straight blue line across the cheek; dorsal fins with fint blue spots. Length $1 \frac{1}{2}$ inches. Florida Keys; said to have come from the coast of Washington, but this is probably an error, as the species has not since been taken there, while 1 apparently iclentical has been taken at Tortugas.* (glaucus, glaucons; franum, bridle.)

\footnotetext{
* Dr. Eigenmanu thus describes the specimens from the Tortugas examined by him:

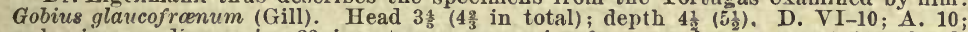
scales in a median series, 23 , in a transverse series, 8 ; eye as long as snout, 31 in head, jaws equal, maxillary barely reaching pupil. Teeth in bands in both jaws, those of the outer row of lower jaw enlarged. Dorsal spines scarcely filamentous, the third highest and equaling depth of body. Posterior dorsal rars highest, as high as spines; anal similar to soft dorsal; pectoral long and narrow, longer than head, $3 \frac{1}{2}$ in body; ventral reaching past vent: scales large, thin, finely toothed, reduced on breast; nape naked. Color in spirits, light yellowish brown; a light spot on each scale, the spots especially conspicuous near shoulder; 6 dark spots on middle of b.1ck; fainter but similar spots along middle of sides; a conspicuous dark spot above opercle; a wavy light line extending forward from it through lower rim of eye to snout; a straight pale-blue bar extending par. allel to it across preopercle and cheek to corner of mouth; a narrow faint bar below it; a triangular dark spot at corner of mouth; cheeks and preopercle purplish chocolate; opercle and snout plain yellowish; 2 brown spots at base of caudal; the smaller specimens differing from this in having the markings more distinct. Length of 4 specimens examined, $1 \frac{7}{8}, 1_{1 \frac{7}{2}}, 1 \frac{1}{3}, 1 \frac{1}{6}$ inches. (Eigenmaun.)
} 
Ooryphopterus glaucofranum, Gill, Proc. Ac. Nat. Sci. Phila. 1863, 263, Coast of Washing. ton (evidently an error).

Gobius glaucofraenum, JoRdan \& Gilbert, Synopsis, 635, 1883; Jordan \& EigenaAn, l. c., 494; Eigenmann \& Eigenmann, Proc. Cal. Ac. Sci. 1888, 59.

2540. GOBICS MAYGLICOLA, Jordan \& Starks.

Head $4 \frac{1}{4}$; depth $5 \frac{2}{3}$. D. VI-12; A. 12 ; scales abont 35 , not to be exactly counted; candal lanceolate, $2 \frac{2}{8}$ in body; pectoral about equal to head; dorsal spine slender, not filamentous, $1 \frac{2}{8}$ in head; eyes large, close together, the range partly vertical, the narrow interorbital deeply furrowed; no flaps on shoulder girdle; scales moderate, ctenoid anteriorly, becoming smooth behind; median keel on head slight; head naked. Body long, compressed, the head depressed, the cheeks tumid; snout bluntly truncate; mouth large, the maxillary reaching the middle of eye, not produced backward, trumcated behind, somewhat oblique, the lower jaw a little the longer; lower jaw flat; teeth strong, the outer in both jaws enlarged; cranium without median crest, abruptly widened behind eyes. Color light olive, mottled with darker; 6 oblong blotches of blackish on sides as in Gobius boleosoma, the last at base of caudal; dorsals and caudal finely checkered and barred with dark brownish orange and blackish; anal mottled; a dark shoulder spot; a dark bar before eye and 1 below eye; ventrals dusky, the edge pale. One specimen, $1 \frac{1}{2}$ inches long. Mazatlan; found in the mud of the Astillero among the roots of mangrove bushes (Rhizophora mangle), (whence the name mangle; colo, I inhabit).

Golius manglicola, Jordan \& Starks, Proc. Cal. Ac. Sci.1895, 496, Mazatlan. (Coll. Hopkins Expedition to Mazatlan. Type, 3095, L. S. Jr. Univ. Mus.)

2541. G0BIUS STIGMaturts, Goode \& Bean.

Head 4; depth $4 \frac{1}{2}$; eye 4, about equal to suout. D. VI-12;A. 11 or 12 ; scales 33. Body subfusiform, little compressed; head blunt, the profile rounded. Mouth small, horizontal, the lower jaw included; maxillary 3 in head, reaching eye. Teeth small, in bauds in both jaws, the outer enlarged, those of the upper jaw very slender. Region from nape to dorsal entirely scaled, the scales large, ctenoid, those on nape and belly little reduced. Dorsal spines short, the longest shorter than the head; caudal fin scarcely pointed, about as long as head. Grayish white, middle of sides with 4 or 5 dark blotches, from each of which a dark bar extends downward and forward; a large black blotch above pectoral, obsolete in the female; a small black spot at base of caudal, and a dark mark below the eje; vertical fins barred. Two specimens taken in a shallow bay at Key West are thus described: Very pale olive, everywhere freckled and spotted; lower part of sides silvery, crossed by faint and narrow cross streaks of light brown; sides with about 5 faint dark blotches; a dark blotch below eye and 1 on opercle; a round black spot at base of caudal; bars on verticle fins light olive. Numerous other specimens are less freckled in coloration, and have a more diffuse caudal spot as well as a vague dark spot at the shoulder. The dusky marks on the sides are larger. 
We find no other differences, and refer all of them to G.stigmaturus. The relations of $G$. boleosoma, G. stigmaturus, and G. enccomus are certainly very intimate. Florida Keys, not very common, our specimens from Key

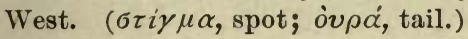

Gobius stigmaturus, Goode \& BEAN, Proc. U. S. Nat. Mus. 1882, 418, no type locality given, but specimens probably from Florida Keys; JORDAN \& GILBERT, Synopsis, 946, 1883; Jordan \& Gilbert, Proc. U.S. Nat. Mus. 1884, 140; Jordan \& Eigenmann, l.c., 495.

2542. GOBIUS QUADRIPORUS, Cuvier \& Valenciennes.

D. VI-I, 9; A. I, 9; scales as in Gobius caninus. The 2 pores on the vertical arm of preopercle very open; 2 snaller ones above them; teeth of outer series small; 2 small canines on each side of lower jaw; dorsal spines not prolonged as filaments. Color yellowish, with lighter lines which follow the rows of scales; brown spots on dorsal; 2 lines on cheek. Surinam. (Cuvier \& Valenciennes.) Not seen by us. (quatuor, four; porus, pore.)

Gobius quadriporus, Cuvier \& VAlenciennes, Hist. Nat. Poiss., xiI, 87, 1837, Surinam; Eigenmann \& Eigenmann, Proc. Cal. Ac. Sci. 1888, 61.

2543. GOBIUS SHUFELDTI, Jordan \& Eigenmann.

Head $3 \frac{2}{5}$ to $3 \frac{2}{3}$; depth $5 \frac{1}{8}$; eye 4 ; snout $3 \frac{1}{3}$ to $3 \frac{1}{2}$. D. VI-12; A. 13 ; scales 33 to 35 . Body moderately elongate, subfusiform; head less blunt than in Gobius boleosoma, the anterior profile gently decurved; mouth large, slightly oblique; maxillary extending to front of pupil, $2 \frac{1}{8}$ in head. Teeth small, slender, and curved, in moderate bands; scales covering anterior half of trunk; head and breast naked; scales moderate, ctenoid, those in front much reduced. Longest dorsal spine $1 \frac{1}{2}$ in head; caudal fin as long as head, somewhat pointed. Olivaceous, mottled with gray; about 5 round dark blotches along middle of side, the last at base of caudal; no dark spot on side of nape; some dark marks on head; vertical fins barred. Gulf coast of the United States, known as yet only from fresh waters about New Orleans. (Named for Dr. Robert Wilson Shufeldt, U. S. A., who collected the types.)

Gobius shufeldti, Jordan \& Eigenmann, Proc. J. S. Nat. Mus. 1886, 495, New Orleans. (Type, No. 35202.)

2544. GOBIUS BOLEOSOMA, Jordan \& Gilbert.

Head 4 ( 5 in total); depth $4 \frac{1}{2}$ to $5 \frac{1}{2}$. D. VI-12; A. I, 10 to 12 ; scales 25 to 30. Body slender, subfusiform, little compressed; head moderate, not very blunt, the anterior profile somewhat evenly decurved, the snout not very short, scarcely shorter than the large eye; mouth not very large, horizontal, the lower jaw included, the maxillary extending slightly beyond front of pupil, its length about 3 in head; teeth small, slender, in narrow bands, those of the onter series longer than the others; eyes placed high, about 4 in head; interorbital space not wider than pupil; scales moderate, ctenoid, those on nape and belly not much rednced in size; gill opening not continued forward above opercle; first dorsal with 
the spines slender but rather firm, none of them filamentous, the longest about $\frac{3}{5}$ head; second dorsal and anal rather large; caudal long, pointed, slightly longer than head; pectorals large, slightly longer than head, none of the upper rays silk-like; ventrals slightly shorter than head, inserted below axil of pectorals; skull rounded behind, no ridges nor crests; crests at side minute; interorbital very narrow. Color in life: Male, deep olive green, mottled with darker; middle of side with 4 or 5 vague darker blotches; a jet-black spot above gill opening, on side of back; head mottled, dusky below; usually a dark bar below eje; dorsals tipped with bright yellowish, each crossed by numerous narrow, somewhat oblique, interrupted bars or series of spots, these being of a rich reddish brown color; caudal barred with black, its upper edge tinged with orange; anal nearly plain, with a slight orange tinge; ventrals bluish black, their edges whitish. Female, paler and duller in color, more mottled, the black spot above gill opening obsolete or nearly so; a dark spot at base of caudal; upper fins barred, as in the male; lower fins mostly pale, tinged with orange. Many specimens of this species, the largest about 2 inches in length, were obtained in the Laguna Grande at Pensacola. It lurks in sea wrack on muddy bottoms in very shallow water ( 6 to 12 inches). In form, size, coloration, and movements this little fish bears a remarkable resemblance to the percoid, Boleosoma olmstedi. Gulf of Mexico, Pensacola to Key West; common in shallow sandy bays, lurking in sea wrack at the depth of a foot (whence the name

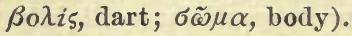

Gobius boleosoma, Jordan \& Gilbert, Proc. U. S. Nat. Mus. 1882, 295, Laguna Grande, Pensacola; ibid, Synopsis, 946, 1883; Jordan \& Eigknmans, l.c., 495.

\section{GOBICS FASCLATUS (Gill).}

Head 4 in length ( $4 \frac{2}{3}$ in total); depth $6(7)$. D. VI-12; A. 10; scales 30-7. Body slender, elongate; head somewhat pointed; profile rounded, not as much as in Gobius garmani and Gobius boleosoma; eye large, slightly longer than snout, $3 \frac{8}{4}$ in head; interorbital area scarcely wider than pupil; mouth slightly oblique, maxillary extending to below anterior margin of pupil, $3 \frac{1}{2}$ in head; lower jaw thin and flat; teeth strong, recurved, in a band in each jaw, the teeth of the outer series of the upper jaw enlarged, several times as large as those of the inner series. Scales finely ctenoid (fallen off anteriorly in specimen examined); antedorsal region and breast naked. Dorsal spines slender, filamentous near tip, not reaching second dorsal, $1 \frac{1}{2}$ in length of head; second dorsal of moderate height; caudal (tips broken) about 5 in length, $1 \frac{2}{5}$ in length of head; ventral not reaching vent, $1 \frac{1}{5}$ in head; pectorals pointed, equaling the head in length. Color yellowish, marbled with darker above; 4 oblong dark blotches along middle of sides; a darker spot at base of caudal; narrow dark stripes across nape; a faint dark stripe along upper margin of opercle, through lower margin of eye to snout; another extending from angle of mouth to edge of preopercle, then extending lown along the margin of the preopercle and ending in a dark blotch on the lower part of the cheek; a dark spot on opercle; first dorsal with 2 curved bars; candal with 3 rather broad dark bars; anal 
dusky; counecting membrane of ventral white, its first rays blackish, outer rays yellowish; lower parts yellowish. West Indies; not seen by us. This description by Eigenmann, from a specimen 18 inches long, No. 13231, M. C. Z., collected in Hayti by Dr. Weinlaud. (fasciatus, branded.)

Ctenogobius fasciatus, GiLL, Fishes Trinidad, 378, 1858, Trinidad.

Gobius fasciatus, GÜnther, Cat., III, 34, 1861; Jordan \& Eigenmann, Proc. U. S. Nat. Mus. 1886, 495; Eigenmann \& Eigenmann, Proc. Cal. Ac. Sci. 1888, 62.

2546. GOBIUS EXCEOHUS, Jordan \& Gilbert.

Head 4; depth 6 ; snout $3 \frac{1}{8}$. D. VI-11; A. 12 ; scales 27 to 33 . Body very elongate, much tapering backward; head compressed, the cheeks high and vertical; snout very short, compressed, obtusely rounded vertically. Mouth nearly horizontal, low, large, the maxillary 2 in head, nearly reaching vertical from posterior margin of orbit. Teeth in very narrow bands in both jaws, those of the outer series in the upper jaw much enlarged and recurved in some specimens; eyes iuserted high, the interorbital space very narrow, about as wide as pupil; diameter of orbit much greater than snout, nearly $\frac{1}{8}$ of head. Gill opening $2 \frac{1}{3}$ in head, the isthmus wide. Dorsals contiguous, the membrane of spinous dorsal reaching nearly to base of soft dorsal; dorsal spines high, of nearly uniform length, the last reaching well beyond origin of soft dorsal when depressed; the longest spine about $\frac{1}{2}$ length of head; soft dorsal and anal long and high, the posterior rays of both fins reaching at least to base of caudal when depressed; caudal lanceolate, the middle rays produced, $2 \frac{2}{3}$ in bod 5 ; ventrals reaching vent, somewhat longer than pectorals, which about equal length of head; ventral sheath well developed, its length $\frac{2}{7}$ that of fin. Body wholly covered with large, strongly ctenoid scales, which are much reduced in size anteriorly; head, antedorsal region, and breast naked. In female specimens the mouth is evidently smaller, and the caudal less elongate. Colors in life: Male, light olivaceous, mottled above with darker olive brown; a series of about 4 obscure oblong dark blotches along middle of sides; a dark spot at base of caudal; each side of nape with an intense blue-black spot larger than eye; an obscure dusky streak from eye forward to mouth; a small dusky spot sometimes present on upper portion of base of pectorals; both dorsals translucent, with a series of bright reddish-brown spots as large as pupil; upper lobe of caudal light reddish, the lower lobe blue black; anal and ventrals dusky bluish, pectorals slightly dusky, with a narrow, bright pink border behind. Female, without bright markings; body light olive, with 5 oblong dark blotches on sides, the last on base of caudal; from each of the 3 middle blotches a $V$-shaped bar runs to the back (these visible also in males); back somewhat mottled with dusky; a black blotch on scapula; a small one on opercle; a dark bar from eye for ward to mouth. Vertical fius with dusky streaks, these appearing on caudal in the form of cross bars; ventrals light, with 2 lengthwise dark streaks; pectorals plain. South Carolina to Key West, in sandy bays; scarce. Length 2

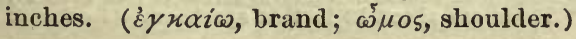


Gobius encoeomus, * Jordan \& GILBERT, Proc. U.S. Nat. Mus. 1882, 611, Charleston, South Carolina (Type, No. 29673, 3 specimens. Coll. C. H. Gilbert); Jordan \& GilberT, Synopsis, 945, 1883; Jordan \& Gilbert, Proc. U. S. Nat. Mus. 1884, 142; Jordan \& EigenManN, l. c., 496.

\section{GOBIUS STIGMATICES (Poey).}

Head 4 ; depth 5 to 6 ; eye $3 \frac{1}{8}$. D. VI-12;A. 12 or 13 ; scales 27 . Body a little deeper and less compressed than in Gobius encocomus. Anterior profile moderately decurved; back slightly arched; skull flattish behind, much broader than in $G$. boleosoma, with an evident median ridge; mouth oblique, large, lower jaw thin and flat, maxillary reaching to below pupil. Teeth above uniserial, some of them enlarged and recurved; lower teeth in a narrow band, males sometimes with the hindmost of the outer series a strong, exserted, recurved canine (present in Poey's type). Anterior half of body scaled except region between nape and dorsal, which is naked; breast naked. Longest dorsal spine $\frac{2}{8}$ head, sometimes elongate; caudal $3 \frac{1}{2}$ in body. Light greenish, sides of male with 5 or 6 narrow, straight, whitish or yellowish cross bars, regularly placed; 4 dark bars on head, 3 below the eye and 1 on opercle; a sinall dark spot behind and above opercle; ventral fins barred; female with a row of irregular dark spots connected by a dusky streak, the pale cross bars obsolete. Coast of North Carolina, Florida Keys, the West Indies, southward to Rio .Janeiro; common at Havana. Subject to considerable variation. Brazilian specimens said by Eigenmann to be darker, the bars on cheek conspicuous; third dorsal spine often much elongate, reaching fifth dorsal ray, last soft ray sometimes reaching caudal. (stigmaticus, spotty.)

Smaragdus stigmaticus, PoEx, Memorias, II, 281, 1861, Cuba.

Gobionellus stigmaticus, PoEx, Synopsis, 394, 1868; PoEY, Enumeratio, 126, 1876; JORDAN \& Gilbert, Synopsis, 947, 1883.

Gobius stigmaticus, JoRdan, Proc. U. S. Nat. Mus. 1886, 49; Jordan \& Eigenmann, l. c., 496.

\section{GOBIUS LYRICUS, Girard.}

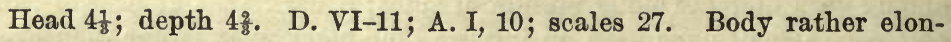
gate, moderately compressed; head rather short, the profile very obtuse, descending abruptly from before the front of the eye to the snout; eyes small, placed high, about as long as snout, and about $4 \frac{1}{2}$ in head; mouth nearly horizontal, much below level of eye, the maxillary extending to beyond pupil, $2 \frac{3}{5}$ in head; jaws subequal; teeth strong, in 1 series in each jaw; in the lower jaw about 4 shortish, canine-like teeth behind the other teeth; anterior teeth of lower jaw small, of upper jaw rather large; gill * One small specimen, taken with the seine in a shallow bay, at Key West, is described
as follow 3 :

Light green, with 5 diffuse spots of darker green on sides, the posterior one most conspicuous; pectorals, both dorsals, and caudal edged above with pale orange; ventrals mostly black, edged with paler; anal dark; a conspicuous dusky shoulder spot; maxillary reaching to below middle of eye; caudal about $\frac{1}{2}$ longer than head. Lateral line about 30 . This little specimen appears to be identical with that described by us from Charleston nnder the name Gobius encoeomus. The species is allied to G. stigmaturus, but has a much slenderer body. The number of scales in a lateral series is less than 37 , the number originally stated by us. There are about 33 in this specimen. (Jordan \& 
opening not continued forward above opercle; first dorsal with 2 or 3 spines filamentous, the longest reaching. past the middle of the second dorsal, which is of moderate height and similar to the anal; caudal long and pointed, $\frac{1}{4}$ longer than the head; pectoral as long as head, abont reaching front of anal; upper rays of pectorals not silk-like; ventrals somewhat shorter than head, their insertion below front of pectorals; scales large, rough, those on nape, pectoral region, and belly reduced in size; head naked: Color in life, dark olive, with 4 or 5 irregular confluent blackish cross bands, besides dark blotches and irregular markings; head marbled with darker, the jaws, opercles, and brauchiostegals blackish; first dorsal mostly dusky translucent, semewhat barred; second dorsal and anal plain dusky; caudal dark blue, with 2 longitudinal stripes of bright red; pectoral finely barred or reticulated with blackish and pale; head and belly yellowish. Female specimens duller and paler. Gulf of Mexico, from Galveston to Cuba and the Lesser* Antilles; rather common. (lyricus, pertaining to a lyre, apparently an allusion to the dorsal spiness.)

Gobius lyricus, GIRARD, Proc. Ac. Nat. Sci. Phila. 1858, 169, Brazos Santiago, Texas ; Grrard, U.S. and Mex. Bound. Surv., 25, pl. 12, figs. 4 and 5, 1859; GUNTHER, Cat., III, 550, 1861; JoRdan \& EigenmanN, l. c., 496; Eigenmann \& EigenManN, l. c., 63.

Smaragdus costalesi, Poex, Memorias, II, 280, 1861, Havana. (Type, No. 13109, M. C. Z. Coll. Felipe Poey.)

Gobius wurdemanni, GIRARD, Proc. Ac. Nat. Sci. Phila. 1858, 169, Brazos Santiago; probably the female; JoRDAN \& GILBERT, Synopsis, 634. ${ }^{\dagger}$

Euctengobius lyricus, JoRDAN \& GILBERT, Synopsis, 633, 1883.

2549. GOBIUS GARMANI, Eigenmann \& Eigenmann.

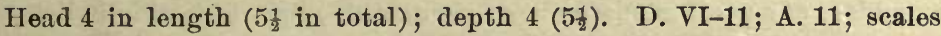
30-7. Body robust, head short and blunt; profile in front of eye abruptly decurved, rounded much as in Gobius boleosoma; mouth inferior, horizontal; lower jaw included; maxillary extending to below pupil, $2 \frac{1}{2}$ in head; lips thin; teeth short and thick, in a single series in each jaw. Dorsals contiguous; dorsal spines filamentous, the second and third longer than the rest, reaching past first third of second dorsal; last dorsal rays reaching base of candal; pectorals equaling heal in length; ventral short and broad, 5 in body; caudal rather long and pointed, 3 in body. Scales large, slightly reduced and cycloid on nape. Color yellowish, marbled with brown; a series of irregular blotches along the sides; a light spot at base

* A specimen from St. Kitts is thus described by Eigenmann: "Depth 5 in length; head 4. The second and third dorsal spines extend to base of caudal; dorsal scarcely less than length of head, the last rays reaching past base of caudal; the caudal fin is $\frac{2}{3}$ longer than the head, $2 \frac{1}{4}$ in body. Color light brown, faintly marked with darker; the first dorsal with minute dark points, the lower fourth of the spines with simple dark spots, above which are jet-black spots ocellated with white; the second dorsal fin dusky, darker posteriorly, the basal portion of the last half of the fin evenly black, the anterior 4 rays marked with dark points similar to the spots on the lower parts of the spines of the first dorsal; caudal dusky, with 2 light bars; anal plain, darker than body; ventral fins blackish, edged with white; pectorals blackish, with many series of white spots on the membrane, and short, white bars at base; branchiostegal membrane black, with a light margin.

† Gobius wurdemanni, Girard. Appearance of Gobius lyricus. Reddish brown, obscurely barred with dusky. Head larger; caudal shorter; ventrals shorter; anal lower; scales smaller than in $G$. lyricus; teeth very slender, much smaller than in $G$. lyricus; third dorsal spine filamentous. D. V.I-11; A. 12. Brazos Santiago, Texas. (Girard.) (Named for Dr. Gustav Würdemann, its collector.) 
of caudal, partly or wholly surrounded by a broad ring of dark brown; head slate color, white below; 3 dark bars extending forward and downward from eye to mouth; a triangular spot on opercle; dorsals, caudal, and pectorals finely barred with black; a chocolate bar on base of ventral; anal margined with white; an irregular black bar on shoulder and upper half of pectoral; everywhere more or less blotched with darker, the blotches at times forming numerous bars across the back. Dominica, Fort de France, Martinique, St. Kitts. (Eigenmann \& Eigenmann.) Not seen by us. Apparently very close to Gobius lyricus, if not the same. (Named for its discoverer, Prof. Samuel Garman.)

Gobius garmani, Eigenmann \& Eigemann, Bull. Cal. Ac. Sci.1888, 61, Dominica, Fort de France, Martinique, St. Kitts. (Coll. Samuel Garman.)

2550. GOBIUS ZEBRA, Gilbert.

Head 3 ; •depth $4 \frac{1}{3}$; eye $3 \frac{1}{4}$ in head. D. VI-11 or 12 ; A. 9 . Body not elongate, the snout short, the mouth oblique, with maxillary reaching below middle of orbit. Mouth small, the maxillary $2 \frac{1}{2}$ in head. Interorbital space very narrow. Teeth in upper jaw in a narrow band or double series, the outer row enlarged and spaced; lower jaw apparently with a single series, similar to the outer row in the upper jaw. Scales cycloid, large, wanting on nape and a narow strip along base of spinous dorsal. Color cherry red, head and sides with 15 blue cross bars, a little narrower than interspaces, encircling the body posteriorly, lacking for a short distance on belly and under side of head; on upper side of head and nape these bars run obliquely forward and downward, but elsewhere vertical; on middle of each interspace a very narrow blue line, becoming indistinct on lower part of sides; on cheeks the blue bars are connected by narrow cross lines, forming blue reticulations surrounding round spots of the ground color. Length of types $\frac{1}{2}$ inch. Two specimens from Albatross Station 2989, west coast of Mexico, in 36 fathoms. (zebra, zebra, from the stripes.)

Gobius zebra, Gilbert, Proc. U.S. Nat. Mus. 1890, 73, Albatross Station 2989, west Coast of Mexico.

\section{Subgenus EUCTENOGOBIUS, Gill.}

2551. GOBIUS POEXI, Steindachner.

Head broad and flattish; depth $6 \frac{1}{2}$ in total length; eye $4 \frac{1}{4}, 1 \frac{1}{3}$ in interorbital width, longer than snout; snont short and decurved. D. VI-9; A.9; scales 40. Maxillary extending to below middle of eye. Some of the dorsal spines produced and filamentous, the third $1 \frac{1}{2}$ times depth of body; caudal short, rounded. Two rows of ill-defined blotches on upper half of body; dorsals and caudal sharply barred, anal and ventrals dusky (male). A small round dark spot at base of eaudal. (Steindachner.) Barbados; not seen by us. (Named for Prof. Felipe Poey.)

Gobius poeyi, SteINDACHNER, Ichthyol. Notizen, vi, 44, 1867, Barbados; JORDAN \& EIGENMANN, l.c., 497. 
2552. GOBIUS BADIUS (Gill).

Head 6 in total; depth 7. D. VI-I, 10; A. I, 10; scales 50-18. Anterior profile very oblique; a line of pores above each eye; 2 on upper ascending margin of preopercle; eye 4 in head; interorbital space $3 \frac{1}{8}$ in eye; caudal 5 in total length; pectoral 6 . Color dark bay with a posteriorly straight heavy dot in the center of each scale on back and sides above; head plumbeous, with 2 livid blue bands from eye to upper jaw. (Gill). About mouth of Amazon; not seen by us. (badius, bay color, dark red.)

Euctenogobius badius, Gill, Ann. Lyc. Nat. Hist. N. Y., vir, 1857, 47, Amazon. Gobius bosci, Sauvage, Bull. Soc. Philom. Paris, IV, 44, 1880.

Gobius badius, Eigenmann \& Eigenmann, l. c., 65.

\section{Subgenus GOBIONELLUS, Girard.}

\section{GOBIUS MICRODON, Gilbert.}

Head $4 \frac{1}{6}$; depth 5. D. VI-13; A. 14; scales 62 . Head and body compressed, everywhere deeper than wide. Mouth at lower profile of snout, nearly horizontal, the lower jaw extremely weak, broadly rounded anteriorly; maxillary reaching vertical from hinder margin of pupil, nearly $\frac{1}{2}$ length of head. Teeth minute scarcely perceptible without the use of a lens, those in upper jaw in a single series. Mandible with a close set outer series of teeth, separated by an interval from an inner narrow band of still smaller teeth. Interorbital space narrow, less than diameter of pupil. Isthmus wide, the gill slits extending little below base of pectorals. Scales minute and cycloid anteriorly and on belly, becoming larger posteriorly; on sides they are everywhere ctenoid behind the middle of spinous dorsal; belly wholly scaled; nape scaled forward nearly to orbits, but with a narrow median naked streak running laack to front of dorsal; breast and sides of head naked. Dorsal fins not connected. First 4 spines filamentous, the longest longer than head, reaching when depressed to base of third ray of soft dorsal. Soft dorsal and anal similar, not high, the last rays not extending beyond the base of caudal; caudal lanceolate, much longer than head; pectorals and ventrals about equal, reaching vent. Color nearly uniform light olive, with minute darker punctulations which sometimes form darker margins to the scales; an oblique dusky streak on opercle; 3 or 4 oblique obscure dark cross bars on spinous dorsal, and 4 or 5 on tail; ventrals with white pigment. Length 2 inches. San Juan Lagoon, west coast of Mexico. (Gilbert.) ( small; ódov́s, tooth.)

Gobius microdon, Gilbert, Proc. U. S. Nat. Mus. 1891, 554, San Juan Lagoon, north of Rio Ahomè, Mexico. (Coll. Gilbert.)

2554. GOBIUS SMARAGDUS, Cuvier \& Valenciennes.

(ESMERALDA.)

Head 4 ; depth $5 \frac{1}{4}$ to $5 \frac{7}{8}$; eye 4 to 5 . D. VI-11 or 12 ; A. 11 or 12 ; scales 39 to 42. Body moderately elongate, compressed; head not compressed; the cheeks tumid; the snout short and abruptly decurved; month large, little oblique; lower jaw slightly inferior; maxillary reaching to below 
pupil or to posterior margin of orbit, $2 \frac{1}{8}$ to $2 \frac{1}{8}$ in head; outer row of teeth on upper jaw enlarged; the narrow band of teeth back of this row separated from it by a space; teeth on lower jaw in a band, subequal. Scales cycloid anteriorly, becoming larger and ctenoid posteriorly. Caudal $2 \frac{1}{4}$ to $2 \frac{1}{2}$ in body. Male, light olive, with dark-olive blotches; body and head with many conspicuous round cream-colored spots, each surrounded by a dusky ring, these smaller than pupil and most distinct on head; snout with dusky streaks; dorsal and caudal plainly barred ; pectoral crossed with dark wavy lines, dusky at base; anal and ventrals dusky; a small dark spot at base of caudal; a shining deep-green spot inside the mouth in life. Female, plain olivaceous, nearly or quite immaculate. West Indies, south to Rio Janeiro, north to St. Augustine, Florida (Dr. Oliver P. Hay), and to Charleston (C. H. Gilbert); specimens before us from Marco Island, Florida (J. A. Hen-

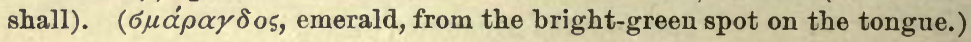

Gobius smaragdus, Cuvier \& Valeancinnnes, Hist. Nat. Poiss., XII, 120, 1837, Cuba; JordaN \& EigRNMANN, l.c., 497.

Smaragdus valenciennei, PoEx, Memorias, II, 280, 1861, Cuba.

Gobionellus smaragdus, PoEY, Synopsis, 394, 1868; POEY, Enumeratio, 126, 1876.

2555. GOBIUS STRIGATUS, O'Shaughnessy.

Head 38 ; depth 5 ; eye $3 \frac{1}{2}$, shorter than the rounded snout. D. VI-12; A. 11 or 12 ; scales 53-13. Body elongate, compressed posteriorly; head little compressed; maxillary reaching to below middle of eye; teeth small, the outer a little enlarged; dorsal spines all shorter than head, not filamentous. Head naked; anterior half of body covered with ctenoid scales, those on nape much reduced in size. Two violet stripes from mouth to eye, 8 or 9 violet bars on side, 3 or 4 on caudal; second dorsal spotted. (Steinđachner.) Coast of Surinam. (strigatus, striped.)

Gobius strigatus, O'SHAUGHNessy, Ann. Mag. Nat. Hist, , series 4, xv, 1875, 145, Surinam.

Gobius kraussi, SteINDAChNer, Ichth. Beiträge, vili, 16, 1879, Surinam; JoRdAN \& EIGENMANN, l. c., 497.

25อ6. GOBIUS SAGITTULA (Günther).

Head $4 \frac{1}{2}$ to 5 in length to base of caudal; depth 6 to 8 ; eye $4 \frac{8}{4}$ to $5 \frac{1}{4}$. D. VI-13 or 14;A. 13; scales about 66 in longitudinal, 15 in transverse series, counted just below space between the two dorsals. Body slender, tapering pretiy regularly from middle of first dorsal to caudal, most compressed posteriorly, depth about uniform from head to origin of second dorsal. Head short, depressed, and broad; mouth large, nearly horizontal, the maxillary in adults $2 \frac{3}{5}$ in head, reaching beyond middle of eye; distance between maxillaries at their posterior ends greater than their length; eye about $\frac{2}{7}$ the bony interorbital space. Teeth in a narrow band in each jaw, those in lower jaw uniform, the outer series in upper jaw considerably enlarged and separated by an interspace from the inner band. Pseudobranchix well developed. Gill rakers short and flexible. Longest dorsal spine about $\frac{3}{5}$ head; distance between dorsals less than diameter of eye; pectorals $1 \frac{1}{8}$ in head, their tips reaching past middle of spinous dorsal; ventrals about equaling pectorals, reaching more than halfway to origin of anal; anal equal and opposite to the second dorsal, but slightly lower; caudal fin greatly elongate, more than $\frac{1}{2}$ head and 
body in largest specimens, $2 \frac{1}{2}$ in smaller ones, its relative length increasing with age. Head scaleless, predorsal region with small scales; body covcred with close-set etenoid scales, small and greatly crowded anteriorly, toward the caudal fin growing gradually larger and more strongly ctenoid. General color light yellowish, palest below, upper parts darker; middle of sides with 5 elongate black blotches, most distinct in the young; the first under first dorsal, second under origin of second dorsal, the third, which is sometimes almost double, at about middle of second dorsal, the fourth near its posterior end, and the last at base of caudal; a large black spot upon each shoulder just above origin of pectoral fin; head plain; lips and maxillary dark; opercle with a dark blotch; basal portion of dorsal fins with dark lines formed of spots; anal unmarked; pectorals with cross lines formed of dots; ventrals plain; candal crossed by numerous narrow dark bars. Reaching a length of 8 inches. Gulf of California and neighboring waters south to Panama; very common in lagoons and mouths of rivers. The types of sagittula are evidently the young, those of longicauda the adults of the same species. (diminutive of sagitta, arrow.)

Euctenogobius sagittula, GüNTHer, Proc. Zool. Soc. London 1861,3, West coast Central America, young individuals; GÜNTHER, Cat. Fishes, III, 555, 1861; Günther, Fishes of Centr. Amer., 389, 1869.

Gobius longicauda, Jenkins \& Evermann, Proc. U. S. Nat. Mus. 1888, 146, adult examples,

Guaymas. (Coll. Evermann \& Jenkins. Type, No.39636.)

Gobius sagittula, JoRDAN \& EIGENMANN, l.c., 497.

\section{GOBIUS HASTATUS, Girard.}

(Emerald Fish; Sharp-tailed Goby.)

Head $4 \frac{1}{3}$ to 5 ; depth 6 to $7 \frac{2}{3}$. D. VI-14; A. 14 or 15 ; scales 60 ; vertebræ $11+15$. Body compressed, extremely elongate; depth nearly equal throughout; head short, compressed, deeper than wide; mouth wide, oblique, the jaws equal; maxillary in adult reaching to below posterior border of eye; lower jaw very thin and flat; teeth in each jaw small, subequal, those in the upper jaw in a single series, those in the lower jaw in a narrow band; onter teeth somewhat movable; scales anteriorly small, cycloid, and embedded, those behind larger and ctenoid; the scales larger than in Gobius oceanicus; a few scales on upper anterior corner of opercle, but without the large patch seen in $G$. occanicus; dorsal fins high, some of the spines filamentous and longer than the head; caudal very long and filamentous, 2 to $2 \frac{2}{3}$ in body; pectoral slightly longer than head or than ventrals, none of its rays silk-like. A singlo specimen from-Ceylou belongs to this species, which appears to be characterized by a longer head ( 5 in length, 7 in total), by the much larger scales ( 60 in a lateral line), by the obsolescence of the patch of scales on opercles, and by slightly different coloration. This may be really only the extreme of variation of $G$. oceanicus, with which species most authors have hitherto confounded it. The two need detailed comparison. Coast of Texas. (hastatus, spear-like.)

Gobionellus hastatus, Girard, Proc. Ac. Nat. Sci. Phila. 1858, 168, St. Josephs Island,

Texas; Girard, U.S. and Mex. Bound. Surv., 25, pl. 12, figs. 7 and 8, 1859.

Gobius lanceolatus, GîntHer, Cat., III, 50, 1861, and of authors; not of BLOCH. 
2558. GOBIUS OCEANICUS, Pallas.

(Esmeralda; Endormi Emeraude; Bacalhao Sabara.)

Head $4 \frac{1}{8}$ to 6 ; depth $6 \frac{1}{6}$ to $8 \frac{1}{2}$; eye 4 to 5 in head; ventral 6 to $6 \frac{1}{2}$; pectorals $5 \frac{7}{8}$ to $6 \frac{1}{2}$. D. VI-14. A. I, 14 or 15 ; scales about 65 . Body extremely elongate; head very short; upper part of opercle scaled, head otherwise naked. Scales on body very small, becoming much larger behind. All the dorsal spines more or less filamentous; caudal fin nearly half length of rest of body. Skull behind eye broad and short, its length $1 \frac{1}{2}$ in width, no decided ridges nor crests; lateral crests large and stout behind, minute forward; interorbital area narrow, deeply grooved, with a median ridge. Color in spirits, reddish olive; a distinct, round, blackish blotch below spinous dorsal, twice as large as orbit; an indistinct dusky shade along middle of sides, terminating in a dusky blotch on base of caudal; middle of sides with a series of marks, formed by very veiny lines widely diverging backward; a similar narrow line from eye to maxillary, and 1 from eye backward to upper angle of preopercle; evident traces of the emerald spot at base of tongue; 2 small dark spots on first dorsal spine; spinous dorsal dusky, with a light and dusky streak at base; soft dorsal dusky, a light (bluish-in life) area behind each ray; anterior rays barred with light and dark; anal and ventrals whitish (probably blue in life), the ventrals without dark markings; pectorals dusky, the base lighter, and with some indistinct dusky bars; a dusky half bar on the upper part of the axil; base of tongue tuberculate, and shining with bright blue and green reflections like a precious stone (hence the names smaragdus, esmeralda, etc.), this color fading in spirits. Vertebrie elongate, $11+15=26$. Length a foot. Sonth Atlantic and Gulf coasts of the United States and southward through the West Indies; not rare, perhaps intergrading with the preceding. Here described from a specimen 11 inches long, taken by Dr. Gilbert in Charleston Harbor. (oceanicus, ocean.)

Gobius cauda longissima acuminata, GRoNow, Zooph., 82, No. 277, pl.4, fig. 4, 1763, locality unkuown.

Gobius oceanicus, Pallas, Spicilegia, viII, 4, 1769, locality unknown; after GRoNow ; JoRDan \& EigenmanN, l.c, 497.

Gobius lanceolatus, BLOCH, Fische Deutschlands, II, 8, pl. 38, fig. 1, 1783, Martinique, figure probably from Plumer; Covier \& Valenciennes, Hist. Nat. Poiss., XII, 114, 1837; PoEx, Synopsis, 393, 1868.

Gobius bacalaus, Cuvier \& VAlenciennes, Hist. Nat. Poiss., xir, 119, 1837, Surinam (Coll. Le Valliant); Cayenne (Coll. Richard); Cuba (Coll. Poey).

Gobionellus oceanicus, Jordan \& GLberT, Proc. U.S. Nat. Mus.1882, 613; Jordan \& GILBERT, Synopsis, 636, 1883.

Subgenus LYTHRYPNUS, Jordan \& Evermann.

2559. GOBIUS DALLI, Gilbert.

Head $3 \frac{2}{6}$; depth $4 \frac{1}{8}$. D. VI-17; A. 14; scales 40 . Body short, compressed, resembling Microgobius. Head high, mouth moderate, very oblique; upper pectoral rays normal; scales ctenoid, of moderate size; anterior dorsal spines much produced. Mouth very oblique, the maxillary 
reaching vertical from front of pupil, $2 \frac{1}{2}$ in length of head. Snout short, $\frac{2}{8}$ diameter of orbit, which is 3 in head. Jaws with an outer series of long. distant, canine-like teeth, and an inner series or a narrow band of minute teeth. Dorsal spines 6, the 2 anterior greatly elongate, not free, in our largest specimen extending beyond middle of soft dorsal; membrane from last dorsal spine reaching to, or nearly to, base of first soft ray; soft dorsal rather high, the fin long; caudal rounded, less than length of head; ventrals free from belly, fully united; pectorals short, the upper rays not free nor silk-like. Scales of moderate size, ctenoid, covering entire trunk, with possible exception of the nape; the scales are readily caducous, and are lacking on nape and frequently on anterior third of body in our specimens. Color light coral red, anteriorly with 4 to 6 narrow blue bands not reaching ventral outline, the posterior ones growing narrower and fainter; a blue streak upward and backward from each orbit, the 2 uniting on occiput; a transverse interorbital bar, a continuation of which encircles the orbit anteriorly; below orbit, a blue bar consisting of 2 portions, 1 running downward and obliquely backward, the other upward and backward; in the largest specimen a blue streak runs from occipnt along profile to front of dorsal; the first blue bar runs from nape obliquely downward and forward, ending on opercle; the second vertically downward from front of spinous dorsal, the third under middle of spinous dorsal, the remaining bars under soft dorsal; fins unmarked. Several small specimens, the largest 1 inch long, from Albatross Station 3001, in 33 fathoms. A single slightly larger example dredged by Dr. W. H. Dall, in about 35 fathoms, off Catalina Harbor, California. Probably the type of a distinct genus distinguished by the many-rayed fins and the form of the body and head. (Named for its discoverer, William Healey Dall.)

Gobius dalli, Gilbert, Proc. U. S. Nat. Mus. 1890,73, Albatross Station 3001, Lower California (Coll. Albatross); Catalina Harbor (Coll. W.H. Dall).

8r4. GARMANNIA, Jordan \& Evermann.

\section{(HALF-NAKED GOBIES.)}

Garmannia, Jordan \& Evermann, Proc. Cal. Ac. Sci. 1895, 495, pl. 49 (paradoxus). Enypnias, JoRdan \& EvermanN, new subgenus (seminudus).

Anterior half of body naked; posterior half covered with moderate or sinall scales; teeth rather strong, unequal, usually 2 small curved canines in front. Very small gobies. Otherwise essentially as in Gobius. ("Named for Mr. Samuel Garman, the accomplished ichthyologist of the Museum of Comparative Zoology at Cambridge, Mass., in recognition of his important contributions to ichthyology.")

Garmannia :

a. Scales moderate.

b. Scales ctenoid, 13 or 14 series developed; first dorsal spine filamentous; D. VI11 ; A. 9. Body rather robust, the depth about $4 \frac{2}{3}$ in length; the head $3 \frac{1}{3}$; lower jaw with 2 curved canines.

PARADOXA, 2560.

bb. Scales smaller, 17 series developed; depth $4 \frac{8}{3}$ in length. D. VI-10; A. 8; first dorsal spine not filamentous; lower jaw with small canines.

HEMIG̈YMNA, 2561. 


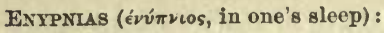

aa. Scales excessively minute; body slender, the depth 6 in length. D. VI-15; A.10; dorsal spines not filamentous; lower jaw with 2 small curved canines in front. SEMINUDA, 2562.

\section{Subgenus GARMANNIA.}

2560. Garmaxnia Paladoxa (Günther).

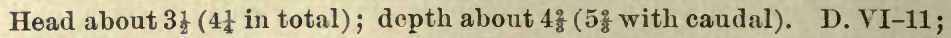
A. 9 ; scales 14 . Head nearly as broad as high, its width being rather more than $\frac{1}{2}$ of its length. Eyes rather close together, of moderate size. Snout obtuse, rounded, as long as the eye; cleft of the mouth slightly oblique, with the jaws equal in length, and with maxillary extending to below middle of the eye. Teeth in villiform bands; 2 curved canine teeth on each side of the lower jaw. Head and trunk entirely naked to between second dorsal and anal, the remainder covered with ctenoid scales of moderate size, 9 or 10 of them in 1 of the anterior transverse series. First dorsal spine elongate, filiform, sometimes extending to the base of the caudal; caudal rounded, shorter than head; none of pectoral rays silk-like; ventral terminating at a great distance from vent. Blackish in spirits; caudal and ventral fins black, dorsal filament whitish. (Giinther.) Panama to Mazatlan; scarce. Our single specimen from the estuary at Mazatlan differs somewhat from Dr. Günther's account. It is thus described: Head $3 \frac{1}{2}$; depth $4 \frac{1}{8}$. D. VI-11; A. 9; scales 12 ; өye 4 in head; snout $4 \frac{1}{4}$; pectoral $1 \frac{1}{6}$ in head; dorsal spine $1 \frac{1}{5}$. Form of Gobiosoma bosci. Body compressed; head broad and depressed, with tumid cheeks; snout not very blunt, short, oblique-truncate; eyes rather large, high, the maxillary not produced, extending to their posterior margin; mouth large, oblique; lower jaw heavy, slightly projecting; teeth strong; gill openings narrow, not wider than base of pectoral. First dorsal rather high, the first spine filamentous, reaching past soft dorsal; other fins low. Head and anterior half of body to front of soft dorsal naked; scattering scales coming in above, 12 rows of imbricated slightly etcnoirl scales along median line of caudal peduncle and forward to middle of soft dorsal, the scaled area about as long as head, the upper parts better scaled than lower. No flaps on shoulder girdle. Olivaceous, with 7 or 8 dark cross shades, 2 on head, 1 across gill openings, 1 behind pectoral, and a broad 1 below soft dorsal; dorsals dusky, the filamentous ray pink; lower half of soft dorsal yellowish, upper dusky; lower fins black; caudal dusky; a dark speck at angle of opercle; skin everywhere punctate with black; a pale olive bar at base of caudal. Skull without median crest; interorbital space not concave; head not very abruptly widened behind eyes. Pacific coast of Mexico and Central America. One specimen, $1 \frac{1}{2}$ inches long, recently obtained on muddy bottoms among the mangroves lining the estuary at Mazatlan. (paradoxus, paradox.)

Gobius paradoxus, GÜNTHER, Proc. Zool. Soc. Lond. 1861, 3, west coast Central America;

GUnther, Cat., III, 549, 1861; Jordan \& Eigenmann, Proc. U. S. Nat. Mus. 1886, 498. Garmannia paradoxa, JoRDAN, Proc. Cal. Ac. Sci. 1895,497, pl. 59. 
2561. GARMANNIA IIEMIGYMNA (Eigenmann \& Eigenmann).

Head $3 \frac{2}{3}\left(4 \frac{1}{2}\right.$ in total); depth $4 \frac{2}{3}$. D. VI-10; A. 8; scales smaller than in Garmannia paradoxa, 17-7. Body compressed, depressed auteriorly, the greatest depth in this specimen being at origin of anal and second dorsal fins. Head wider than deep, rounded; profile much decurved from eye to mouth as in paradoxa; eye perfectly round, smaller than in paradoxa, $1 \frac{1}{8}$ in rounded snout, 5 in head; interorbital space scarcely wider than orbit; mouth somewhat oblique, larger than in paradoxa; maxillary reaching bejond posterior rim of orbit; lower jaw slightly shorter thau upper; teeth in upper jaw in a band, the outer series remote, and the teeth several times as large as in the inuer row, all more or less movable; teeth in lower jaw similar, a recurved canine on each side near the front. Scales very weakly ctenoid, covering only the sides of the posterior half of body, not extending quite to base of dorsal or anal fins even at their posterior insertion; the upper and lower edges of the caudal peduncle likewise free from scales, the scaly regiou, however, widest on peduncle and tapering forward to the central point opposite beginning of anal, where the scales are smallest. First spine of the dorsal not elongate as in G.paradoxa, $1 \frac{1}{2}$ in head, the third, fourth, and fifth spines slightly excceding the first in height, equaling the posterior rays of soft dorsal, which are little higher than the anterior rays of the soft dorsal; caudal rounded, about $t$ in length of body, $1 \frac{1}{4}$ in head; ventral not reaching vent, $1 \frac{1}{2}$ in head; pectorals rounded, rather short and broad, $1 \frac{1}{4}$ in head. Color light olivaceous, without distinct markings, everywhere with minute dark punctulations; 8 faint cross bars from dorsal to middle of sides, which, close under dorsal fins, are formed of 2 blackish dots; 8 black dots along lateral line, the last at base of caudal; fins all smutty, the pectoral lightest, white on its anterior half, 2 dusky spots at its base; opercle ashy; a light bar at base of caudal; iris blackish blue, a short straight streak of eame color from eye to upper lip; an irregular bluish mark on cheeks formed of punctulations closely crowded. West Indies, exact locality unknown; taken with the dredge. ( $\ddot{\mu} \mu \tau$, half; $\gamma v \mu \nu o ́ s$, naked.)

Gobius hemigymnus, Eigenmann \& Eigenmann, Proc. Cal. Ac. Sci. 1888, 66, dredged in the West Indies.

Subgenus ENYPNIAS, Jordan \& Evermann.

2562. GARMANNIA SEMINUDA (Günther).

Head 4; depth 6. D. VI-15; A. 10. Head and anterior portion of trunk naked; sides with exceedingly small scales, becoming somewhat larger posteriorly. Head with the cheeks swollen, depressed, broader than high, its width $\frac{2}{8}$ length. Eyes close together, directed upward, of moderate size; snout obtuse, as long as the cye; cleft of the mouth slightly oblique, with the jaws equal anteriorly, and with the maxillary extending to below the middle of the eye. Teeth in villiform bands, the anterior of the lower jaw slightly enlarged; 2 small curved canine teeth on each side of lower jaw. Dorsal fins rather low, the hind part of the spinous dorsal scarcely lower than anterior; caudal rounded, as long as pectoral; none of pectoral $3030-63$ 
rays silk-like; ventral rather short, terminating at a great distance from vent. Blackish; fins aud sides of head dotted with black; ventrals black. (Giinther.) Panama; not seen by us; probably the type of a distinct genus. (seminudus, half-naked.)

Gobius seminudus, GünTHER, Proc. Zool. Soc. London 1861, 3, west coast Central America; Günther, Cat., III, 554, 1861; Jordan \& Eigenmann, Proc. U. S. Nat. Mus. 1886, 498.

\section{AWAOUS, Steindachner.}

Awaous, * Steindachner, Verk. Mat. Phys. Naturw. 1860, 289; after les A waous of Cuvier \& VALENCIENNES (ocullaris, etc).

Chonophorus, PоEт, Memorias, II, 274, 1861 (buccelentus=taiasica).

Awaous, Bleeker, Esquisse d'un Syst. Nat. Gobioides, 320, 1874 (ocellaris); after les A waous of CuVIER \& VALENCIENNES.

Inner edge of shoulder girdle with 2 or more conspicuous dermal flaps; preorbital region very long; premaxillary and maxillary strong; lips thick; scales rather small, ctenoid, 40 to 80 in a longitudinal series; interorbital groove witl a conspicuous median crest; otherwise essentially as in Gobius. The species reach a large size and are confined to the fresh waters of the tropics of America and the Hawaiian Islands: The Asiatic species of similar habit have much larger scales and seem to form a distinct genus, Rhinogobius, Gill. The physiognomy in each is peculiar, the snout being long and convex. (Awaou, a Hawaiian name.)

a. Scales about 53 , little crowded anteriorly, 21 before dorsal on nape; depth $5 \frac{2}{3}$ in length; head 4; eyes placed high, interorbital area equal to diameter of eye; mouth horizontal; maxillary extending to middle of eje, $2 \frac{1}{3}$ in head, lower jaw more flat than in A.taiasica; teeth small, in narrow bands, those of the outer row above enlarged, some large teeth in band of lower jaw. D. VI-I, 12; A.I, 10. Uniform yellowish in spirits.

FLAVUS, 2563.

aa. Scales 60 to 70 , crowded anteriorly, about 30 scales before the dorsal on nape; body compressed posteriorly, rather depressed anteriorly; greatest depth $5 \frac{1}{4}$ in length; head $3 \frac{1}{4}$ in lengtl. Olivaceous, a series of irregular, roundish blotches along middle of sides; narrow dark streaks radiating from eye; a blackish streak running across upper margin of opercle and extending obliquely across base of upper pectoral rays; belly white; dorsal and caudal more or less distinctly barred with wavy blackish lines.

b. About 15 scales between second dorsal and base of anal.

$b b$. About 21 scales between second dorsal and base of anal.

NELSONI, 2564. TAIASICA, 2565.

aaa. Scales 76 to $82 ; 24$ scales between second dorsal and anal; head as broad as high; depth of body $6 \frac{3}{5}$ iu length; head 4 ; head flat above, snout elongate, upper profile oblique; eye $\frac{1}{8}$ of head, equals interorbital area (in adult); mouth horizontal; lower jaw included; maxillary reaching to below anterior margin of eye; teeth of the outer series enlarged; canine teeth none; scales ctenoid, those on nape and anterior part of body very small; head naked; dorsal fins lower than body, none of the spines produced; caudal rounded, 7 in length of body. Yellowish olive; back and sides reticulated with blackish; head, dorsal, caul. dal, and pectoral fins dotted with blackish, the spots forming streaks on second dorsal; 6 cross series of dots ou the caudal; an irregular small blackish spot on the upper part of the root of pectoral. D. VI-11; A. 11; scales abont 80 .

MEXICANUS, 2566.

*The name "Les Awaous," given to this group by Valenciennes, was a French plural, not a generic appellation, and if used as the name of a genus must be dated from its use in that sense by Steindachner or Bleeker. The Hawaiian ty pe of "A waous" agrees with the American species (Chonophorus) in the character of the flaps on the shoulder girdle, as well as in general appearance. The Asiatic genus, Rhinogobius, Gill (similis), seems to be very close to Chonophorus, but the scales are larger, 28 in the lateral series. 
2563. AWAOUS FLAVUS (Cuvier \& Valenciennes).

Head 4; depth $5 \frac{2}{3}$ to $6 \frac{1}{2}$; eye equal to the interorbital width, placed high. D. VI-I, 12 ; A.I, 10; scales about 53 to 55 , little crowded anteriorly, 21 before the dorsal. Mouth horizontal, maxillary extending to middle of eye, $2 \frac{1}{8}$ in head; lower jaw flatter than in Awaous taiasica; teeth small, in narrow bauds, those of the outer row enlarged; some large teeth in band of lower jaw. Yellowish, with a row of faint ocellated spots along middle of sides; dorsal and caudal faintly barred; lines radiating from өye, a line along opercle halfway to pectoral, sometimes uniform blue-black. Rivers of Surinam and Brazil, south to Bahia. (flavus, yellow.)

Gobius flavus, Cuvier \& VALenciennes, Hist. Nat. Poiss., xil, 60, 1837, Surinam; GÜnTHerR, Cat. Fish., III, 13, 1861.

Chonophorus flavus, JoRdan \& EigenManN, l. c., 500; ErgenManN \& EigenmanN, l.c., 67.

2564. AWAOUS NELSONI, Evermann.

Head $3 \frac{1}{2}$; depth 6 ; өye $5 \frac{8}{4}$ in head; snout 3 ; maxillary $2 \frac{7}{8}$. D. VI-11; A. 11; scales about 63 . Body long, compressed and tapering posteriorly; head large, quadrate, mouth nearly horizontal, lower jaw included; snout abruptly lecurved; top of head flat, the interorbital with a slight median groove with a thin, raised edge on each side; maxillary reaching about to vertical of anterior edge of pupil; teeth in bands on jaws very small, the outer somewhat enlarged; pectoral rays normal, the longest $1 \frac{1}{2}$ in head; ventrals completely united, the disk free from belly, 1: in head. Dorsal fins separated by a space about $\frac{2}{8}$ diameter of eye; dorsal spines slender, weak, about $1 \frac{3}{5}$ in head; soft dorsal and anal similar, each free from caudal; caudal fin rather short and rounded, its middle rays about $1 \frac{1}{4}$ in head. Gill membranes broadly united to the isthmus; eyes moderate, high up, the interorbital width equal to the eye's diameter. Scales ctenoid, very small and irregularly crowded anteriorly, much larger posteriorly, about 15 rows counting from origin of soft dorsal downward and backward to the anal fin; head naked, but with slight indication of a few minute embedded scales on opercles. Color grayish; head mottled and blotched with dark; side with 7 or 8 black blotches, the largest under middle of pectoral fin; dorsals pale, crossed by several lines of black spots; caudal pale, with about 6 or 7 dark cross bars; ventrals and anal pale; pectorals pale, dusted with dark specks and with a small dark blotch at base of upper rays. Close to A. taiasica, but with broader interorbital, longer snout and larger scales on posterior part of body. Length 4 inches. Known only from fresh water at Rosario, Sinaloa, where 8 specimens were obtained July 27, 1897, by Mr. E. W. Nelson. (Named for Mr. Edward William Nelson, the well-known ornithologist, in recognition of his work upon the fishes of Illinois in 1876.)

A waous nelsoni, Evermann, Proc. Biol. Soc. Washington, vol. xII, 1898, 3, fresh-water pools at Rosario, Sinaloa, Mexico. (Type, No. 48836, U.S. Nat. Mus.; cotypes, No. 533 U. S. Fish Comm., 5793 L. S.Jr. Univ. Mus., and 48837 U. S. Nat. Mus.) 
2565. AWAOUS TAIASICA (Lichtenstein).

(Guavina Hoyera; Aboma de Rio.)

Head $3 \frac{1}{4}$; depth $5 \frac{1}{4}$; eye small, less than interorbital width (in adult), 3 in snout (twice in young), and about 7 in head. D. VI-11; A. 11; scales 60 to 70 , crowded anteriorly, about 30 before dorsal fin, 21 between second dorsal and anal. Body compressed posteriorly, rather depressed anteriorly; head broader than deep. Distance from eye to mouth $3 \frac{1}{2}$ in head, the preorbital being much enlarged; month large, horizontal, maxillary extending to below anterior part of orbit in adult male, shorter in young; lower jaw included. Teeth of the upper jaw in 2 series, those in anterior series much enlarged and recurved; teeth of lower jaw in a narrow band, the outer series scarcely enlarged. Inner edge of the shoulder girdle with 2 or 3 rather long papillæ. Body covered with ctenoid scales, much reduced in size anteriorly; nape closely scaled, breast scaly, head naked. Dorsal fins less than depth of body, the spines scarcely filamentous, not as long as the soft rays; caudal rounded, shorter than the head; ventrals very broad and short, $1 \frac{1}{2}$ to $1 \frac{4}{5}$ in head, the rays very much branched. Skull rounded behind, with a very short crest in its middle; lateral crests high and thin, converging into 1 opposite the insertion of suprascapula, inner crests not meeting behind eye, the outer ones extending around orbit. A low, blunt ridge between the posterior corners of orbit, becoming much higher forward, continied as the ethmoid and ending abruptly some distance in advance of orbit. Teeth in upper jaw in a few series, those of outer series many times larger than the others, which are minute; those of lower jaw all alike small, in a band. Olivaceous, with a series of jrregular, roundish blotches along middle of side, and narrow dark streaks radiating from eye; a blackish streak running across upper margin of opercle and extending obliquely across base of upper pectoral ray; belly white; dorsal and caudal more or less distinctly barred with wavy blackish lines. Length a foot or more. Extremely variable in form and coloration, as is the case with most widely distributed fresh-water fishes. Fresh waters of the West Indies and both coasts of Mexico, south to Brazil; common in Cuba, in Sinaloa, and about La Paz in Lower California, thence southward to Panama. (taiasica, Brazilian name of some other goby.)

A more guacu, MARCGrave, Hist. Brasil., 166, 1648, Brazil.

Gobius taiasica, Lichtensten, Berl. Abhandl., 273, 1822, Brazil; not Tajasica MARCGRAve. Gobiu banana, Cuvier \& Valenciennes, Hist. Nat. Poiss., xII, 103, 1837, San Domingo ; GÜTher, Cat, III, 59, 1861.

Gobius martinicus, Cuvier \& VAlenciennes, Hist. Nat. Poiss., XII, 105, 1837, Martinique. Chonophorus bucculentus, PoEY, Memorias, II, 275, 1861, Cuba.

Rhinogobius contractus, * PoEY, Memorias, I, 424, 1861, Cuba ; Pokx, Ennmeratio, 125, 1875

* The following are the characters assigned to Awaous contractus (Poey): Head 4; depth 51; D. VI-11; A. 11; eye 7 in head; maxillary ceasing $\frac{1}{3}$ an eye's diameter before eye. Head smaller than in A. taiasica. Greenish brown; the cheeks with brown lines; body with brown points; dorsals brownish, with brown longitudinal bands more numerous on the second; caudal with 7 brown bands, made of lanceolate spots on tbe rays; pectorals speckled; ventrals and anal rose color. Cuba (Poey); probably not different from 4 taiasica; said to differ in the small mouth, which probably varies with age and sex. 
Gobius dolichocephalus, Cope, Trans. Amer. Philos. Soc. Phila. 1869, 403, near Orizaba, Mexico.

Euctenogobius latus, O'Shaughnessy, Ann. Mag. Nat. Hist., Series 4, XV, 1875, 146, Bahia. (Coll. Dr. Wucherer.)

Chonophorus taiasica, JoRDAN \& EIGENMANN, l. c., 500.

2566. A WAOUS MEXICANUS (Günther).

Head 4 ; depth $6 \frac{3}{5}$; eye 8. D. VI-11; A. 11 ; scales 76 to 82,24 between second dorsal and anal. Head as broad as deep, flat above, suout elongate, upper profile oblique; mouth horizontal, lower jaw included, maxillary reaching to below anterior margin of eye. Teeth of the outer series enlarged; no canine teeth. Scales ctenoid, those on nape and anterior part of body very small; head naked. Dorsal fins lower than depth of body, none of the spines produced; caudal rounded, 7 in length of body. Yellowish olive; back and sides reticulated with blackish; head, dorsal, caudal, and pectoral fins dotted with blackish, the spots forming streaks on second dorsal; 6 cross series of dots on caudal; an irregular, small blackish spot on the upper part of the base of the pectoral. (Günther.) Fresh-water streams of the eastern slope of Mexico; known to us only from Dr. Giinther's description.

Gobius mexicanus, GüNTHER, Cat., III, 61, 1861, Mexico.

Chronophorus mexicanus, JoRDAN \& Eigenmann, l.c., 501.

8×6. BOLLMANNIA, Jordan.

Bollmannia, JordaN, Proc. U.S. Nat. Mus. 1889, 164 (chlamydes).

This genius differs from Lepidogobius by having no fleshy processes on inner edge of shoulder girdle, the interorbital area of skull narrower and without trace of median keel, and by very large ctenoid scales. From Gobius proper it is distinguished by the presence of 7 dorsal spines and by the presence of large scales on the cheeks. Species inhabiting the depths of the Pacific; not found in shoal waters as is the case with most other gobies. ("I have named this species in honor of my late colleague, Mr. Charles Harvey Bollman, whose untimely death, while engaged in the exploration of the rivers of Georgia, took place while this paper was passing through the press."-Jordan.)

a. * A conspicuons black spot on posterlor portion of spinous dorsal. Body deep, the least depth of caudal peduncle greater than diameter of orbit.

b. Filamentons dorsal spines very long, reaching beyond middle of soft dorsal when depressed. Lower caudal rays black; dorsal spot conspicuously ocellated. Eye large, 3 to $3 \frac{1}{5}$ in head. OCELlata, 2567.

$b b$. Filamentous dorsal spines shorter. Lower caudal rays not black, and dorsal spot not ocellated. Eye smaller, $3 \frac{3}{4}$ to 4 in head. CHLAMYDEs, 2568.

aa. No black spot on spinous dorsal. Body slender, the depth \& the length. Least depth of caudal peduncle not greater than diameter of orbit.

c. Head large, 3 to $3 \frac{1}{4}$ in length. No black spot at base of caudal. Fins low.

MACROPOMA, 2569.

cc. Head smaller, $3 \frac{4}{6}$ in length. A black spot at base of caudal. Fins higher.

STIGMATURA, 2570.

* This analysis of species is taken from Gilbert, Proc. U. S. Nat. Mus. 1891, 555. 
2567. BOLLMANNiA OCELLATA, Gilbert.

Head $3 \frac{1}{2}$ to $3 \frac{2}{3}$ in length; depth $4 \frac{1}{2}$. D. VII-14 or 15 ; A. 14; scales 27. Very close to Bollmannia chlamydes, differing from the latter constantly in the following respects: The eye is larger, 3 to $3 \frac{1}{5}$ in head ( $3 \frac{8}{4}$ to 4 in chlamydes); the filamentous rays of spinous dorsal are much longer, reaching in adults, when laid back, to or nearly to end of base of soft dorsal, $1 \frac{1}{2}$ to $1 \frac{2}{8}$ times length of head; rarely the filamentous dorsal rays are little more elongate than in chlamydes. Teeth in a narrow band in each jaw, the outer series in upper jaw, and both outer and inner series in lower jaw enlarged, but not canine-like; maxillary not reaching vertical from middle of pupil, $\frac{1}{2}$ length of head; interorbital width less than $\frac{1}{2}$ diameter of pupil; opercle short, its length being less than the diameter of the eye; pectorals nearly as long as head, a trifle more than length of ventrals, which scarcely reach vent; caudal much longer than head in adults, 7 or 8 scales before dorsal. Black spot on posterior part of spinous dorsal jet black, conspicuously ocellated with white; a black streak along lower margin of caudal, including several of the lower rays, and running from base to tip of fin; no dusky bars visible on sides in any of the types; fins dusky; membranes uniting outer rays of ventrals white instead of black, as in chlamydes; no black spot at base of caudal; branchiostegal membrane with a medial black streak; anal blackish. Numerous specimens from the northern part of the Gulf of California, at Albatross Stations 3031 and 3035 , in 30 and 33 fathoms. This species may vary into the typical chlamydes, but the material before us does not justify us in so identifying it. (Gilbert.) (ocellatus, ocellated.)

Bollmannia ocellata, GiberT, Proc. U. S. Nat. Mus. 1891, 555, Gulf of California.

\section{BOLLMANNIA CHCAMYDES, Jordan.}

Head $3 \frac{1}{2}$ ( 5 to $5 \frac{1}{2}$ in total); depth $4 \frac{1}{2}$ ( $6 \frac{2}{8}$ to 7$)$. D. VII-15; A. 15 ; scales in a longitudinal series about 28,8 or 9 in a cross series at vent. Body rather robust, compressed; head large and heavy, its profile evenly curved; mouth very large, oblique, the lower jaw projecting; maxillary reaching to opposite pupil, $2 \frac{1}{5}$ to $2 \frac{2}{7}$ in head; teeth sinall, sharp, in several series, the outer, especially in lower jaw, somewhat enlarged; eye longer than snout, $3 \frac{8}{4}$ to 4 in head; interorbital area very narrow, concave, its least width about $\frac{1}{8}$ of eye or almost equal to pupil; scales very large, ctenoid; little reduced on breast and nape; about 8 before dorsal, where they are little smaller than on body; top and sides of head with large scales; scales on cheek in 4 rows; 2 rows on upper part of opercle; the scales on head lost in some of the specimens; dorsal spines slender, filamentous, fifth longest, $1 \frac{1}{5}$ in head; first 2 in head, last $3 \frac{7}{2}$ to 4 ; first soft dorsal ray $2 \%$ in head, the antepenultimate longest and about equal to head; first anal ray equal to snout, the antepenultimate $1 \frac{1}{4}$ in head; middle candal rays very long, somewhat more than $\frac{1}{2}$ length of body; pectorals $1 \frac{1}{5}$ in head; ventrals $1 \frac{1}{8}$. Color olivaceous, darkest above; scales with a few black dots, some of the posterior occasionally dark edged; sides with 8 or 10 obscure dusky vertical bars, which are narrower than the inter- 
spaces, and in some specimens wholly obsolete; snout bluish; opercles with a dark shade; lips, gular region, and anterior branchiostegals very dark in males; upper part of spinous dorsal darkest, with a fow lighter dark-edged oval spots, a well-marked black blotch between last 2 spines; soft dorsal dusky, usually with about 3 well-developed rows of lighter, dark-edged oval spots; anal dusky, crossed by 2 narrow bluish streaks; some of the last rays occasionally with a few spots similar to those on dorsal; caudal, pectorals, and ventrals dusky, tinged with blue; ventrals edged with pale. Length $4 \frac{8}{4}$ inches. West coast of Colombia. Many specimens of this abundant species were dredged at Albatross Stations 2800 in 7 fathoms and 2805 in $51 \frac{1}{2}$ fathoms. ( $\chi \lambda \alpha \mu v \dot{\delta} \eta 5$, cloaked.)

Bollmannia chlamydes, Jordan, Proc. U. S. Nat. Mus. 1889, 164, Pacific Ocean, off coast of Colombia, Station $2800,8^{\circ} 5^{I^{\prime}}$ N., $79^{\circ} 4 x^{\prime} 30^{\prime \prime}$ W., and Station $2805,7^{\circ} 5^{6^{\prime}}$ N., $79^{\circ}$ $4 I^{\prime} 30^{\prime \prime}$ W. (Type, No. 41158, U. S. Nat. Mus. Coll. Albatross.)

\section{BOLLMANNIA MACROPOMA, Gilbert.}

Head 3 to $3 \frac{1}{2}$; depth 5. D. VII-14; A. 14; scales 28 . Characterized by its sleuder form, low fins, large opercle, and comparatively plain coloration. Caudal peduncle correspondingly slender, its least height equaling diameter of eye. Head very large and heavy; opercle conspicuously larger than in $B$. ocellata, agreeing in this respect more nearly with B. chlamydes; dentition as in other species of the genus; eye large, $3 \frac{1}{4}$ to $3 \frac{1}{3}$ in the head. Dorsal spines slender, comparatively little produced, the longest usually not reaching the base of the first ray of second dorsal, and never beyond the base of the second or third ray; soft dorsal and anal low, the posterior rays usually not reaching the rudimentary caudal rays when depressed, about $\frac{1}{2}$ length of head; pectoral long, extending beyond front of anal; the ventrals to or nearly to vent; middle caudal rays produced as usual, varying in length; scales 8 to 10 in front of dorsal. Color in spirits, light brownish, the sides with 3 vertical dusky bars; spinous dorsal dusky, but without distinct black spot; caudal slightly dusky, with rather large elliptical light spots, as in $B$. chlamydes, the lower rays not black and no black spot at its base; ventrals blackish, including anterior membrane; second dorsal and anal dusky, without evident light spots; branchiostegal membranes sometimes slightly dusky, but not black. Many specimens from the Gulf of California just north of La Paz Bay, at Albatross Station 2996, in 112 fathoms. (Gilbert.) ( $\mu \alpha \varkappa \rho o ́ s, ~ l a r g e ; ~ \pi \tilde{\omega} \mu \alpha$, opercle.)

Bollmannia macropoma, Gilbert, Proc. U. S. Nat. Mus. 1891, 556, Albatross Station 2996, near La Paz, Lower California.

2570. BOLLMANNIA STIGMATURi, Gilbert.

Head short, $3 \frac{2}{3}$ in length; depth 5 ; least depth of caudal peduncle slightly less than diameter of eye; өye large, 24 in head. D. VII-15; A. 14 ; lateral line 28. Dorsal spines filamentous, longer than in B. macropoma, the longest reaching base of fifth to seventh ray of second dorsal; posterior rays of second dorsal and anal often reaching base of median rays when depressed; pectorals not reaching beyond front of anal. Color 
almost uniform light brownish; lips black, the fins only slightly dusky, the caudal with elliptical light spots; a roundish dusky spot at base of caudal; branchiostegal membranes not black. Many specimens from the northern part of the Gulf of California, at Albatross Stations 3016 and 3017, in 76 and 58 fathoms. This species agrees with Bollmannia macropoma in its elongate form, comparatively low fins, and in the absence of a black spot ou the spinous dorsal. It differs conspicuously in the very short head and narrow opercle, and in the presence of a black spot at base of tail. The eye is also larger and the fins higher. None of the specimens shows dusky bars on the sides, a conspicuous feature in B. macropoma. (Gilbert.)

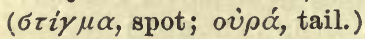

Bollmannia stigmatura, Gilbert, Proc. U. S. Nat. Mus. 1891, 556, Gulf of California, Albatross Stations 3016, 3017.

\section{ABOMA, Jordan \& Starks.}

Aboma, Jordan \& Starks, Proc. Cal. Ac. Sci. 1895, 497 (etheostoma).

This genus, allied to Microgobius, is distinguished by the large, ctenoid scales, which cover the body; head naked, rather long, pointed in profile; the mouth moderate, not very oblique; teeth rather strong. Dorsal spines more than 6, none of them filamentous; soft dorsal and anal short; no flaps on shoulder girdle. Cranium with a slight median crest. (The name Aboma is used by the Mexicans in Sinaloa as synonymous with goby.)

a. Scales very large, 26 or 27 ; profile not very steep, the snout rather pointed.

b. Sides with a jet-black lateral band; caudal with dark cross bars; maxillary 3 in head.

ETHEOSTOMA, 2571.

bb. Sides with 4 oblique dark eross bars; a large dark spot at base of candal; mouth larger, the maxillary 2 in head.

LUCRETIAE, 2572.

aa. Scales smaller, about 37 ; profile very steep, the snout rounded; sides with numerous pale cross bands with darker spots.

CHIQUITA, 2573.

2571. ABOMA ETHEOSTOMA, Jordan \& Starks.

Head $3 \frac{1}{8}$; depth 5. D. VIII-11; A. 10; scales 26 ; longest dorsal spine $1 \frac{8}{4}$ in head; eye 3 ; snout 4 ; maxillary 3 . Body long and low, moderately depressed and pointed forward. Scales large, ctenoid behind, none on head, those on nape and belly much reduced. Mouth moderate, terminal, moderately oblique; the maxillary reaching middle of pupil; jaws subequal, or the lower a little the longer; teeth rather strong. No flaps on shoulder girdle. Cranium with a slight median crest. Interorbital ridge not hollowed out; skull not abruptly widened behind. Color olivaceous, side with a very broad jet-black lateral band, 3 times interrupted by silvery; caudal white, with $4<$ shaped bands, growing progressively fainter behind; pectoral mottled gray, with a jet-black oblique crescent toward its base surrounding a large yellow spot; side of head with 4 round gray spots separated by black, the largest below eye, with a black streak before it; first dorsal jet-black, second mottler, the produced spine with yellowish; ventral and anal pale. A single small specimen, $1 \frac{1}{8}$ inches long, 
found in the mud on a shallow bottom in the Astillero at Mazatlan. (Etheostoma, a darter, which this species strongly resembles.)

Aboma etheostoma, Jordan \& Starks, Proc. Cal. Ac. Sci. 1895, 498, pl.50, Mazatlan. (Coll. Hopkins Expedition to Mazatlan.)

2572. ABOMA LUCRETIE (Figenmann \& Eigenmann).

Head $3 \frac{1}{2}$ in length; depth $5 \frac{1}{8}$. D. VII-10; A. 12 ; scales 28-8. Body slightly compressed posteriorly; head little wider than high; eye placed high, its diameter equaling length of snout, $4 \frac{1}{2}$ in head; profile little decurved; mouth large, oblique; maxillary extending below posterior margin of orbit, 2 in head; intermaxillary anteriorly on a level with center of pupil; teeth all recurved, large, those of upper jaw in a narrow band; teeth of outer and inner series enlarged, those of lower jaw similar, largest in front. No dermal flaps on shoulder girdle. Scales large, very weakly ctenoid, becoming cycloid and very much crowded above and below pectoral; head, breast, and anterior part of nape naked. As seen through a lens, these regions seem to be covered with minute embedded scales; this effect is, no doubt, due to light reticulations on a darker ground. Dorsal spines slender, not filamentous; caudal pointed, 3 in length of hody; ventrals $1 \frac{1}{4}$ in head; pectorals longer than head. Color light brownish, with 4 oblique dark cross bars as wide as interspaces; 4 narrower transverse bars on nape and back; a large dusky spot at base of caudal; upper half of base of pectoral black; a black spot on opercle, margined below and behind with silvery; fins dusky. Pearl Island, Gulf of Panama; only 1 specimen known. (Named for Mrs. Lucretia M. Smith of San Diego, mother of Mrs. Eigenmann.)

\section{ABOMA CHIQUITA (Jenkins \& Evermann).}

Head $3 \frac{1}{3}$ to $3 \frac{1}{2}$; depth $4 \frac{1}{8}$ to $4 \frac{8}{4}$. D. VII-11; A. 10; eye $4 \frac{8}{4}$ in head in adult, 4 in young; scales 37-17. Body rather stout, compressed; head short, somewhat depressed, widened behind orbits; snout short and narrowly rounded; profile in front of eye very steep, less so to occiput, and nearly straight from there to caudal fin; eyes moderate, well up; interorbital space very narrow, less than eje; greatest width of head equaling greatest depth of body. Top of head, opercles, and space in front of dorsal naked, rest of body covered with small, strongly ctenoid scales, which increase in size upon the caudal peduncle. Spinous dorsal with its first spine filamentous in adult, much longer than head and reaching middle of soft dorsal, this filament wanting in young; distance from snout to origin of spinous dorsal a little more than $\frac{1}{8}$ distance to base of eaudal; second dorsal but slightly separated from spinous, its origin about midway of total length of fish; anal of about the same shape and size as soft dorsal, but beginning a little behind it; pectorals tapering, about equaling head in length, their tips not reaching origin of anal, but to origin of soft dorsal; ventrals united, free from belly, inserted behind pectorals, but their tips not reaching tips of pectorals. Teeth apparently in a single series, small and weak. Ground color pale yellowish, thickly mottled with fine punc- 
tulations of dark; about 7 pretty well-defined larger spots of dark brown along middle of side; 8 or 9 faint cross bars of lighter, a number of small light spots scattered irregularly over the sides; head dark; dorsal, anal, and ventral fins covered with fine black points; in some specimens the dorsals and aual quite dark; pectorals plainer; caudal similar to ventrals; "the cranium is depressed and flattish behind the orbits, without distinct median keel on occipnt or on interorbital area. The form of the head is as in typical Gobius, the occiput abruptly widened behind the eyes; the ridges also similar, the orbital ridge bounding the orbit behind as well as above the eye and joining the temporal ridge laterally." (Gilbert MS.) Length 1 to 2 inches. Gulf of California; abundant. The original description from young examples, here corrected in accordance with Dr. Gilbert's notes on many adults taken by him at La Paz. (Spanish, chiquito; a diminutive of chico, a little one.)

Gobius chiquita, Jenkins \& Evermann, Proc. U. S. Nat. Mus. 1888, 146, Guaymas, Sonora. (Type, No. 39634. Coll. Jenkins \& Evermann.)

\section{MICROGOBIUS, Poey.}

Microgobius, PoEx, Enumeratio, 127, 1875 (signatus).

Dorsal spines 7 or 8 ; scales very small, cycloid or weakly ctenoid, the body scaled anteriorly as well as posteriorls, the head naked, the nape, belly, and breast usually so. Inner edge of shoulder girdle withoutfleshy processes; body more or less compressed; mouth large, very oblique; the lower jaw conspicuous, teeth strong; interorbital groove with or without a median ridge. Vertebræ $11+15$ or 16 . (

a. Scales about 42. Body elongate, moderately compressed, the depth 4 to 5 in length; head long and large, rather sharp in profile, 3 to $3 \frac{1}{2}$ in body; eye longer than snout, 4 in head; month large, very oblique, the lower jaw strongly projecting; maxillary $1 \frac{1}{2}$ to $2 \frac{1}{2}$ in head, extending to opposite middle of eye, or much beyond front of orbit; teeth in few series, the outer very long and slender, curved, the lower longest, none canine-like; scales small, some of them with short, thick teeth, those of anterior part of body not well developed; dorsal spines more or less filamentous, the third and fourth or fourth and fifth sometimes with long filaments; candal pointed, about as long as head. Grayish olive, with rather sharply-defined markings of darker brown overlaid with orange in life; head with a pale bluish or gilt stripe from maxillary backward across suborbital region to upper edge of gill opening; another pale gilt streak from snout along lower part of eje, another from angle of mouth upward and backward; rest of head dark; opercle with an obliqne blackish bar; top of head and nape with dark marbling surrounded by paler reticulations; back with a series of black cross blotches mostly separated on the median line; 2 narrower dark vertical bars behind pectoral; middle line of side posteriorly with longitudinally oblong black blotches; besides these, numerous other blotches not regularly arranged; first dorsal with 2 or 3 oblique black bands; second dorsal pale, with about 4 series of black dots; caudal spotted with black; pectoral yellowish; ventral black, its center yellowish (male); anal pale. D. VII-15; A. 16 or 17.

GULOSUS, 2574.

aa. Scales about 50 ; snout not pointed; depth $5 \frac{1}{2}$ in length; moutl large, the maxillary $2 \frac{1}{4}$ in head; teeth strong. Color yellowish, much dotted, but without bars. 
aaa. Scales 65 or more.

$b$. Caudal fin more than $\frac{1}{3}\left(\frac{2}{5}\right)$ length of body. Scales very small, cycloid, deciduous. Body elongate, much compressed, highest in front of ventrals, tapering regularly to the very narrow, short candal peduncle; greatest depth $4 \frac{3}{4}$ in length; head $3 \frac{1}{2}$. Head compressed, much higher than wide; snout very short, acute, preorbital not as wide as pupil; mouth terminal, very wide and oblique; jaws equal; maxillary reaching vertical from middle of orbit, 2 in head. Outer series of teeth enlarged. Eye 3 in head. Dorsals closely contiguous; spines very slender, the fifth slightly produced and filamentous; pectorals as long as head. Head and body translucent, overlaid by brilliant green luster, formed by minute, close-set greeu points; 3 conspicuous translucent bars wider than the interspaces, crossing body close behind head; head with 2 brilliant narrow blue and green lines running obliquely across cheek below eye; dorsal whitish, with 2 or 3 lengthwise series of large reddish-brown spots; spinous dorsal blackish at base, upper caudal rays marked with red, the lower portion of caudal and most of the anal fin blackish, anal whitish at base, the auterior rays tipped with white. In spirits, body dusted with dark points; 2 light cross bars toward head; lower part of caudal and anal black. D. VII-16; A. 15.

THALASSINUS, 2576.

$b b$. Caudal fin less than $\frac{1}{3}$ length of body. 'Scales small, cycloid, embedded. Body very much compressed, more or less elongate, greatest depth at ventrals 4 (female) to $6 \frac{1}{2}$ (male) in length; head $3 \frac{1}{2}$ to 4 . Head much compressed, much deeper than wide. Snout very short, acute, the anterior profile not decurved, not steep; preorbital not as wide as pupil; mouth very large, very oblique or almost vertical; maxillary extending to below pupil, 2 in head (in male, $2 \frac{1}{4}$ in female). Lower jaw projecting, the teeth of the outer series enlarged, recurved. Eye $3 \frac{1}{4}$ to 4 in head. Dorsals contiguous, spines very fine, produced in filaments, the third highest, a little longer than head; second dorsal and anal high. Head and nape naked. In the female the depth is greater, mouth less oblique, smaller; profile from spinous dorsal oblique. First dorsal spine highest, $3 \frac{1}{3}$ in length. Ventrals much shorter than in males. Dark gray; female with a short bright blue bar bordered by blackish above pectorals; a blotch of sky blue and orange below eye; fins dusky, the ventrals pale in female, dusky in males. Males with the body plain bluish gray. D. VII-17 to 20 ; A. 18 to 21 ; scales 68 to 70 .

SIGNATUS, 2577.

\section{MICROGOBIUS GULOSUS (Girard).}

Head 3 to $3 \frac{1}{2}$; depth 4 to 5 ; eye 4 in head, longer than snout. D. VII15 ; A. 16 or 17 ; scales about 42 ; vertebræ $11+15$. Body elongate, moderately compressed; head long and large, rather sharp in profile; mouth large, very oblique, the lower jaw strongly projecting; maxillary $1 \frac{1}{2}$ to $2 \frac{1}{2}$ in head, extending to opposite middle of eye. Teeth in few series, the outer very long and slender, curved, the lower longest, none canine-like. Body entirely scaled, except the nape, bell $J$, breast, and head, which are naked; scales small, some of them with short thick teeth, those on anterior part of body not well developed. Dorsal spines more or less filamentous, the third to fifth sometimes with long filaments; caudal pointed, as long as head. Ventrals as long as pectorals, which are $1 \frac{1}{4}$ in head. Skull flattened behind, with a median ridge extending from eyes back to end of skull. Double crests bordering skull in front and on sides, the inner ones meeting in front of median crest. Interorbital very narrow and deeply grooved, with a median ridge. Froutal bones very thin and fragile. 
Teeth on each jaw in narrow bands, all alike. Coloration in life, light grayish olive, with rather sharply defined markings of darker brown; head with a pale bluish stripe from behind the angle of the mouth upward and forward parallel with the gape to below front of eye, then turning abruptly backward across suborbital region to upper edge of gill opening; another pale streak from snout along lower part of eye; between this and the first streak a dusky area; below the first-mentioned streak a dusky region on cheek; opercle with an oblique blackish bar; top of head with dark marblings surrounded by paler reticulations; back. with a series of black cross blotches, mostly separated on the median line; 2 narrow vertical dark bars behind pectoral; middle line of side posteriorly with longitudinally oblong black blotches; besides these numerous other blotches not regularly arranged; first dorsal with 2 or 3 oblique black bands; second dorsal pale, with about 4 series of black dots; caudal spotted with black, pectoral yellowish, ventral black, its center yellowish; anal pale; lower side of head pale; jaws dusky. Coast of Florida to Texas, in sandy or weedy bays, common north to Indian River. A strongly marked species with no near relative among our other gobies. The specimens here described from Pensacola. (gulosus, largemouthed.)

Gobius gulosus, GrRard, Proc. Ac. Nat. Sci. Phila. 1858, 169, Indianola, Texas; GIRARD, U. S. and Mex. Bound. Surv., Zool., 26, 1859; Jordax \& Grlbert, Synopsis, 634, 1883.

Lepidogobius gulosus, JoRdAN \& GLBERT, Proc. U. S. Nat. Mus. 1882, 294; JORDAN \& GILBERT, Synopsis, 945, 1883.

Microgobius gulosus, JORDAN \& EIGENMANN, l.c., 505.

2575. MICROGOBIUS EULEPIS, Eigenmann \& Eigenmann.

Head 4 in length ( $5 \frac{1}{8}$ in total); depth $5 \frac{1}{2}$ (7). D. VII-15; A. 16 ; scales 50-14. Body elongate, scarcely compressed; head slightly higher than wide, the depth $1 \frac{1}{8}$ in its length; eye large, longer than snout, $3 \frac{1}{8}$ in head; snout 5 in head, rather broad, not pointed as in $M$. thalassinus; preorbital narrower than pupil; month very oblique, maxillary not extending beyond anterior margin of pupil, $2 \frac{1}{4}$ in head; teeth in upper jaw in a very narrow baud, slightly enlarged in outer series, largest toward angle of mouth; teeth of lower jaw in a similar band, some of outer ones in front long and slender. Scales cycloid, rather large, crowded anteriorly, regularly. arranged, not embedded as in $M$. signatus, not decidnous as in $M$. thalassinus; breast, nape, and region along spinous dorsal naked. First dorsal spine equidistant from tip of snout and first anal rav; longest dorsal spine $1 \frac{1}{2}$ in head; caudal fin about 4 in body; ventral not reaching vent, equaling length of head, the basal membrane $\frac{1}{1}$ of its actual length; pectoral equaling length of head. Color yellow or very light brown, dotted with minute dark points above; scales along back with a dark margin; head and nape with minute points; spinous dorsal transparent, a marked black spot on upper part of membrane between fourth and fifth dorsal spines; other fins plain; a light vertical bar on posterior margin of preopercle; 
no other bars or stripes anywhere. Fortress Monroe, Virginia; known from a specimen $1 \frac{7}{8}$ inches long. ( $\varepsilon v^{5}$, well; $\lambda \varepsilon \pi i 5$, scaled.)

Mficrogobius eulepis, Eigenmann \& Eigenmann, Proc. Cal. Ac. Sci. 1888, 69, Fortress Monroe, Virginia. (Type, No. 27123, M. C. Z. Coll. Mrs. C.N. Willard.)

2576. MICROGOBIUS THALASSINUS, Jordan \& Gilbert.

Head $3 \frac{1}{2}$ in length; depth 48. D. VII-16; A. 15; eye 3 in head. Body elongate, much compressed, highest in front of ventrals, thence tapering regularly to a very narrow, short caudal peduncle; the body with a peculiar, translucent, fragile appearance, common also to $Z$. emblematicus. Head compressed, much higher than wide; snout very short, acute, the preorbital not as wide as pupil; mouth terminal, very wide and oblique, the jaws equal; maxillary reaching vertical from middlo of orbit, $\frac{1}{2}$ length of head; teeth in a narrow band in each jaw, the outer series enlarged, canine-like (under a microscope the band of small teeth behind the outer series seems evident, but the size of our specimens does not enable us to verify it with certainty); eyes placed high, separated by a narrow ridge, the diameter about $\frac{1}{3}$ length of head. Dorsals very closely contiguous; spines very slender, the fifth slightly produced and filamentous, reaching (in our specimens) to base of third soft ray when depressed; caudal lanceolate, very long and pointed, the middle rays produced, $2 \frac{2}{5}$ in body; pectorals as long as head; the upper rays not silk-like; ventrals with basal membranes well developed; the fin long, reaching to or slightly beyond front of anal, somewhat longer than head. Body covered with rather small cycloid scales; head naked; the scales very readily deciduous; as they have in our specimens mostly fallen off, the count can not be given. Head and body translucent, overlaid by brilliant green luster, which is formed by exceedingly minute close-set green points; the luster is intense toward the head, where it assumes a blue tint, and becomes hardly noticeable on caudal peduncle; 3 conspicuous translucent bars, wider than the interspaces, crossing body immediately behind head; head with 2 brilliant narrow blue or green lines running obliquely across cheek below eye; opercle with greenish luster; branchiostegal membrane white; dorsals whitish, with 2 or 3 length wise series of large reddish-brown spots; spinous dorsal blackish at base; upper caudal rays marked with red, the lower portion of caudal and the most of the anal fin blackish, anal whitish at base, the anterior rays tipped with brilliant white; ventrals light buff; pectorals translucent. In spirits, the body appears dusted with dark points; 2 light cross bars toward head; lower part of caudal and anal black. Coast of South Carolina; two specimens, the largest $1 \frac{1}{2}$ inches long (No. 29674, U. S. Nat. Mus.), were taken in muddy tide pools in Charleston Harbor. ( $\theta \alpha \lambda \alpha \sigma \sigma \imath \nu o ́ s$, thalassinus, sea-green; $\theta \alpha \dot{\alpha} \alpha \alpha \sigma \sigma \alpha$, the sea.)

Gobins thalassinus, JoRdan \& GILBERT, Proc. U. S. Nat. Mus. 1882, 612, Charleston Harbor, South Carolina. (Coll. C. H. Gilbert.)

Lepidogooius thalassinus, JORDAN \& GILBERT, Synopsis, 947, 1883.

Microgobius thalassinus, JoRdan \& EIGENMANN, l. c., 505. 
2577. Microgobids signates, Poey.

Head $3 \frac{1}{2}$ to 4 ; depth 4 (female) to $6 \frac{1}{2}$ (male); eye $3 \frac{1}{4}$ to 4 . D. VII-17 to 20 ; A. 18 to 21 ; scales 68 to 70 ; vertebræ $14+15$. Body very much compressed, more or less elongate; head much compressed, deeper than wide; snout very short, acute, the anterior profile not decurved, not steep; preorbital not as wide as pupil; mouth very large, almost vertical; maxillary extending to below pupil, 2 in head in male, $2 \frac{1}{4}$ in female; lower jaw projecting; teeth of the outer series enlarged and recurved. Dorsals contiguous, spines very fine, produced in filaments, the third longest, a little longer than head; second dorsal and anal high. Scales as in M. gulosus. Skull rounded, very fragile; a median crest which is highest between eyes; lateral crests developed, the inner ones meeting above posterior part of eje; interorbital comparatively broad, the median crest ending above anterior part of the orbit. Teeth in each jaw in 2 or 3 series; outer series of the upper jaw enlarged and recurved, the inner ones minute; outer series of lower jaw smaller than those of upper jaw, the one nearest angle of mouth an enlarged canine. Dark gray; female with a short bright blue bar, bordered by blackish above pectoral; a blotch of sky blue and orange below eye; fins dusky, the ventrals pale in female; males with the body plain bluish gray. The sexual differences in this species are very strongly marked. West Indies, in salt water; common in Cuba; one of the smallest gobies, barely 2 inches long. Here described from Havana examples collected by Dr. Jordan. (signatus, marked.)

Microgobius signatus, PoEx, Enumeratio, 127, pl. 5, fig. 3, 1875, Cuba (Type in M. C. Z. Coll. Poey); Jordan, Proc. U. S. Nat. Mus. 1886, 49; Jordan \& Eigenann, l. c., 505.

\section{I9. ZALYPNUS, Jordan \& Evermann.}

Zalypnus, Jordan \& Evermann, Check-List Fishes, 459, 1896 (emblematicus).

This genus differs from Microgobius in having the anterior half of the body naked. Soft dorsal and anal long, of 16 or 17 rays. Two species

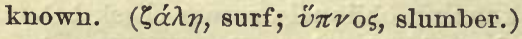

a. Scales 48; shoulder with a round black spot; none of the dorsal spines elongate.

CYCLOLEPIS, 2578.

aa. Scales 65 ; a silvery cross bar behind pectorals; some of the dorsal spines usually elongate.

EMBLEMATICUS, 2579.

\section{ZALYPNUS CYCLOLEPIS (Gilbert).}

D. VII-16; A.17; scales 48. Body somewhat elongate, compressed, the mouth very large, narrow, and oblique; maxillary produced beyond the rictus for a distance equaling $\frac{2}{8}$ diameter of orbit, reaching vertical from posterior margin of pupil, $1 \frac{3}{5}$ in head; snout short, 5 in head; eye larger, $3 \frac{8}{4}$ in head; interorbital width $\frac{1}{2}$ orbit; teeth in upper jaw in 2 series, the outer enlarged and distant; in lower jaw apparently in a single series, similar to outer series of upper jaw, with 2 stronger canines anteriorly. Inner edge of shoulder girdle without fleshy prominences. Dorsal spines 
7, none of them elongate, the membrane of last spine reaching base of first soft ray; soft anal rays of moderate height, $1 \frac{1}{2}$ in head, the tips of last rays reaching base of caudal, the fin similar to soft dorsal but lower; candal long, apparently rounded posteriorly, longer than head (mutilated in our specimen); ventrals and pectorals reaching vent. Scales cycloid, small, absent on belly, nape, and on sides in front of fourth dorsal spine. Color in spirits, light olive, the fins dusky; a conspicuous round black spot on shoulder, $\frac{1}{2}$ size of eye, its posterior margin denser black. Resembling Zalypnus emblematicus, differing in its larger scales and different coloration. A single specimen, about 2 inches long, from Lower California, in 7 fathoms. (Gilbert.) ( $\dot{u} \varkappa \lambda \circ 5$, circle, cycloid; $\lambda \varepsilon \pi i 5$, scale.)

Microgobius cyclolepis, GILBERT, Proc. U. S. Nat. Mus. 1891, 74, Albatross Station 3020, Lower California.

2579. ZALYPNUS EMBLEMATICUS (Jordan \& Gilbert).

Head $3 \frac{2}{3}$; depth 5. D. VII-16; A. 17; scales about 65. Anterior part of body naked; teeth of upper jaw in one series; body elongate, compressed, heaviest forward; depth 5 in length; head $3 \%$; snout short, rather broad, acute in profile; mouth terminal, very oblique; gape wide, its length nearly $\frac{1}{2}$ head; maxillary reaching to opposite middle of pupil; lower jaw projecting. Teeth in lower jaw partly in 2 series in front, forming a single row laterally; anterior teeth in both jaws strong, incurved. Eyes very large, about $\frac{1}{8}$ of head; snout less than orbit. Scales extremely small, cycloid, scarcely increasing in size toward caudal peduncle; head and anterior part of body to front of dorsal fin naked; a narrow naked strip alcng base of anterior $\frac{1}{2}$ of spinous dorsal. Dorsal spines very slender and weak, some of the middle ones usually prolonged, sometimes reaching nearly to the base of caudal, sometimes little elevated; second dorsal and anal similar to each other, the rajs high, the last when depressed nearly reaching to the base of caudal; candal pointed, a little longer than head. Light olivaceous; above thickly punctate with pale dots; sides very thickly covered with golden-green specks; back with 6 pairs of golden-green spots on each side of the dorsal fin, each nearly as large as pupil; sides of head and anterior half of body with wide streaks and bars alternately of purplish blue and golden bronze; those on cheek longitudinal; those on opercle extending obliquely upward and backward, those on body vertical; first dorsal dusky, second dorsal with about 3 series of light-blue spots; anal pale; caudal yellowish green below, dusky above, a very conspicuous narrow bright-red streak from the lower end of the base to the tip of the fifth or sixth ray from the bottom, thus erossing the rays obliquely; ventrals bluish. In spirits, plain light olive, with a silvery cross bar behind pectorals. Length $3 \frac{1}{2}$ inches. Panama; known only from the original types. ( $\varepsilon^{\prime} \mu \beta \lambda \eta \mu \alpha$, a banner, from the high dorsal.)

Gobius emblematicus, JoRdaN \& GilberT, Bull.U.S.Fish Comm.1881, 330, Bay of Panama. Lepidogobius emblematicus, JoRDAN \& EIGENMANN, l. c., 505. 
820. EUCYCLOGOBIUS, Gill.

\section{Eucyclogobius, GrL, Proc. Ac. Nat. Sci. Phila. 1862, 279 (newberryi).}

This genus is allied to Lepidogobius, differing chiefly in the naked head and short, chubby body; shoulder girdle with a few dermal flaps; opercle adnate to shoulder girdle from the angle upward; dorsal spines 6 or 7 ; soft dorsal short; scales all cycloid; cranium depressed behind the parietal region, somewhat excavated, the supraoccipital crest rather high, not extending so far forward as the orbit. Species small, in fresh or brackish waters of California. ( $\varepsilon v^{\zeta}$, well; $\varkappa v_{\varkappa \lambda} \circ 5$, circle (cycloid); Gobius.)

2580. EUCYCLOGOBIUS NEWBERRYI (Girard).

Head $3 \frac{2}{8}$ to $3 \frac{8}{4}$; depth $4 \frac{4}{7}$ to 5 1. D. VI or VII*-11; A. 10 or 11 (8 in one specimen, perhaps abnormal); scales about 60 to 70 , too irregular for exact counting. Body moderately elongate, somewhat compressed, tapering posteriorly; head rounded above, its width $2 \frac{1}{5}$ in its length; mouth large, oblique, the maxillary reaching to or beyond posterior margin of orbit, 2 to $2 \frac{1}{6}$ in head; interorbital space wide, 4 to $4 \frac{1}{2}$ in head; snout bluntish, broad, a little longer than interorbital width; eye small, 5 in head; teeth present on both jaws, slender, canine-like, arranged in series, the outer row enlarged; caudal pednncle 3 to $3 \frac{1}{8}$ in head; gill slit about $2 \frac{1}{2}$ in head, its upper edge opposite or slightly above uppermost ray of pectoral; scales minute, cycloid, inconspicuous, wanting on head, nape, and fins; shoulder girdle with 2 or 3 small dermal flaps; dorsals separated by a narrow space; dorsal spines very slender; base of spinous dorsal $2 \frac{1}{3}$ to $2 \frac{3}{5}$ in head; anal similar to soft dorsal, its base about $1 \frac{1}{8}$ in head; caudal subtruncate, $1 \frac{1}{4}$ to $1 \frac{1}{2}$ in head; ventrals inserted under or slightly behind lower edge of base of pectorals, $1 \frac{3}{5}$ to 2 in head; pectorals $1 \frac{1}{2}$ to $1 \frac{7}{8}$ in head. Dark olivaceous, mottled with darker; head with some dusky markings; the sides and back with irregular dark markings as in species of Etheostomina; dorsals distinctly mottled; the first 3 or 4 dorsal spines margined with paler; caudal with faint, broad, wavy cross bars, a faint spot at its base; anal dusky; ventrals yellowish, dusky in males; pectorals plain. Length about 2 inches. Streams of California, in small clear brooks near the sea; locally common in San Luis Obispo Creek, where the specimens here described were taken; probably confined to fresh waters. (Named for Dr. John Strong Newberry of Columbia College, then also on the U. S. Geological Survey.)

Gobius newberryi, GrRARd, Proc. Ac. Nat. Sci. Phila. 1856, 136, Tomales Bay (Coll. E. Samuels); Girard, Jour. Bost. Soc. Nat. Hist. 1857, 530, pl. 25, figs. 5 to 8; Girard, Pac. R. R. Surv., X, 128, 1858.

Lepidogobius newberryi, JORDAN \& GLLBERT, Synopsis, 637, 1883; JORDAN \& EIGENMANN, l. c., 503.

* Of the nine specimens examined from San Luis Obispo Creek, five have 7 dorsal spines and the other four 6. Girard gives the fin rays as D. VIII-13; A. 12; but we have seen no specimens either with 8 spines or 13 rays. Six specimens from Wadell Creek, Santa Cruz County, California, show the following fin variation: D. VI in 4; D. VII in 1 ; D. $V(?)$ in 1 ; D. rays 10 in 4 ; D. rays 9 in $2 ; A .10$ in $2 ; A .8$ in $1 ; A .9$ in 3. 


\section{2r. LEPIDOGOBIUS, Gill.}

Lepidogobius, GiLL, Ann. Lyc. Nat. Hist. N. Y.1859, 14 (lepidus).

Cyclogobius, SteindachNer, S. B. K. Ak. Wiss. Wien, XlII, 1860, 284 (lepidus).

This genus contains small gobies with the head and body covered with small cycloid scales; dorsal spines 7 ; inner edge of shoulder girdle with 2 or 3 dermal flaps; interorbital groove with the median ridge of skull little developed; body elongate, subterete; otherwise essentially as in Gobius, the skull nearly as in Gillichthys, with a median keel and not abruptly widened behind the eye. Pacific Ocean; not entering rivers. ( $\lambda \varepsilon \pi i$, scale; Gobius.)

\section{LEPIDOGOBIUS LEPIDUS (Girard).}

Head $4 \frac{1}{6}$, regularly conical; depth 7; eye 4, equal to snout, twice as long as deep. D. VII-16 to 18 ; A. 15; scales about 86 . Body elongate, subfusiform, little compressed. Snout not obtuse in profile; interorbital space narrow, about equal to diameter of pupil. Month rather large, maxillary reaching to below posterior edge of pupil, $2 \frac{1}{2}$ in head; teeth small, all similar, those of upper jaw in 2 or 3 series, those of lower jaw close set, in a broad band. Body covered with small cycloid scales which are very much reduced anteriorly, especially on the nape; cheeks, sides of head, and upper posterior part of opercles covered with small scales; top of head scaly to eye; breast scaled. Dorsal spines weak, the longest 2 in head; soft dorsal low, none of the rays reaching caudal; caudal long, somewhat pointed. Color very pale olive, with roundish blotches of rusty red on back and sides; vertical fins mottled with reddish; distal half of all fins and under side of head blackish, especially in the males. "This species is remarkable for numerous lines of papilla on mandible, snout, and sides of head. The occipital region of the skull is somewhat more depressed than in Gobius soporator, and has much lower ridges. A low median carina is present and the low supraorbital ridges are continuous behind the eyes with the temporal crests." (Gilbert MS.) Pacific coast of North America, from Vancouver Island to Lower California; in rather deep water off San Francisco Bay; often seined in great numbers and sold in restaurants as "whitebait." (lepidus, pretty.)

Gobius gracilis, Grrard, Proc. Ac. Nat. Sci. Phila. 1854, 134, San Francisco; preoccupied by Gobius gracilis, JENYNS.

Gobius lepidus, Girard, Pac. R. R. Surv., x, 127, pl. 25a, figs. 5 and 6, 1858; substitute for gracilis; GüNTHER, Cat., III, 78, 1861.

Lepidogobius gracilis, Gru, Ann. Lyc. Nat. Hist. N. Y. 1859, 14; JoRdan \& Gilbert, Synopsis, 637, 1883; JordaN \& EigenMaNn, l. c., 502.

\section{GILLICHTHYS, Cooper.}

Gillichthys, Cooper, Proc. Cal. Ac. Sci. 1863, 109 (mirabilis).

Gillia, GÜNTHER, Zool. Record 1864, 157 (mirabilis); name preoccupied.

Saccostoma (Gichenot MS.) Suavage, Bull. Soc. Philom. Paris 1882, 171 (gulosum); name preoccupied.

Body moderately elongate, compressed, covered with small, cycloid, embedded scales; belly and head naked. Scales of the young more or $3030-64$ 
less ciliated. Eyes small, almost superior. Gape wide, the maxillary in the adult inordinately developed, prolonged backward to the base of the pectorals, its posterior part a cartilaginous expansion, connected to an expansion of the skin of the lower jaw, thus forming a channel backward from the mouth, almost exactly as in Neoclinus and Opisthognathus, genera otherwise very different. Teeth small, even, in broad bands. Skull in adult with a strong median keel, not abruptly widened behind the eye, triangular behind; young with the keel obsolete. Dorsal fins 2, the second high, the first of 6 very weak spines, none of which is exserted; soft dorsal and anal short; caudal less rounded; pectorals large; isthmus broad. Singular little fishes, in brackish waters, burrowing in the mud; confined to the Pacific. (Named for Theodore Gill.)

a. Head moderately depressed; dorsal fins close together.

MIRABILIS, 2582.

aa. Head very broad and depressed; distance between dorsals $\frac{1}{2}$ length of first dorsal. DETRUSUS, 2583.

2582. GILLICHTHYS MIRABILIS, Cooper.

\section{(LONG-JAWED GOBY.)}

Head $3 \frac{1}{5}$; depth 5 ; eye 6 to 7 ; snout longer than eye, low, little decurved. D. VI-12; A. 10; vertebræ 15+17. Body stout, somewhat compressed behind, broad and depressed anteriorly; head broader than deep, its width $1 \frac{1}{2}$, its depth 2 or more in its length; interorbital space greater than eye. Mouth very large; maxillary variable, extending to base of pectoral in adult, broadened behind; fold of lower lip extending its full length. Teeth all alike, small, fixed, and in bands, the band of the lower jaw broaler than that of the upper. Scales small, cycloid, irregularly placed, largest from front of dorsal backward, decreasing in size anteriorly; head, breast, belly, and $\frac{1}{2}$ of nape naked. Dorsal spines not filamentous, not as long as the soft rays which are little more than $\frac{1}{2}$ depth of body; caudal broad, short, rounded; pectorals broad and rounded, longer than ventrals, 2 in head. Skull not abruptly widened behind eye, as in Gobius, being triangular posteriorly. No lateral ridges; a strong median keel; a short transverse crest behind orbit. Interorbital not deeply grooved, with a blunt median ridge. Orbit not bordered by any prominent ridges. Teeth in both jaws, close set, in bands, all alike. Dull olive, very finely marbled with darker; sides of head and maxillary finely punctuate; fins olive; belly yellowish. Length 8 inches. Pacific coast of North America, from San Francisco to Cerros Island; a most remarkable little fish; very abundant in the mud flats in shallow water along the California coast, burrowing in holes in the unud like a crawfish, and readily taking the hook baited with flesh or worm when dropped into the mouth of the burrow. (mirabilis, wonderful.)

Gillichthys mirabilis, Cooper, Proc. Cal. Ac. Sci. 1863, 109, San Diego Bay; Lockington, Amer. Nit. 1879; Jordan \& Gilbert, Synopsis, 636, 1883; JoRdan \& Eigenmann, l.c., 510; Evermann \& Jenkins, Proc. U. S. Nat. Mus. 1891, 162.

Gobius townsendi, Eigenmann \& Elgenmann, Proc. U. S. Nat. Mus. 1888, 463, San Diego; young. 
2583. GHLLCHTHYS DETRUSUS, Gilbert \& Scofield.

Allied to Gillichthys mirabilis, Cooper, differing in the broader and more depressed head, the larger anal fin, and greater distance between the 2 dorsals. Head $3 \frac{1}{2}$; depth 5 ; eye 7 in head; snout 4 ; interorbital $5 \frac{1}{2}$. D. VI-13; A. 11 developed rays (10 in $G$. mirabilis); scales very fine anteriorly but becoming much larger posteriorly; about 75 scales from base of pectoral to caudal, and about 25 longitudinal rows between front of anal and front of second dorsal. The head is depressed, the frontals broad, the shortest distance across being contained in the head 8 times (11 times in G. mirabilis.) The postfrontals are small and project but very little, differing from $G$. mirabilis, where the postfrontals project into an elevated wing-like process. The width of the isthmus contained 3 times in the head; maxillary $1 \frac{1}{3}$ and mandible $1 \frac{2}{3}$ in head. Least depth of caudal peduncle $2 \frac{2}{3}$ in head. Distance between dorsals equal to $\frac{1}{2}$ length of first

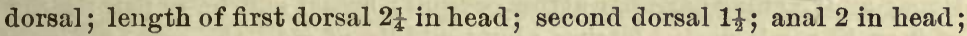
length of longest pectoral ray $1 \frac{8}{4}$ in head. Color a very pale olive, some with dark punctulations about the head and fins. The pale coloration is probably due to their life in shallow water on bottom of pale sand. Gulf of California. The types and numerous other specimens, the longest about 5 inches long, were taken by Dr. C. H. Gilbert at Horseshoe Bend, near the mouth of the Colorado River, in Mexico, where they are quite abundant. These are numbered 3836 in L. S. Jr. Univ. Mus. (detrusus, depressed.)

Gillichthys detrusus, GilBerT \& Scorield, Proc. U. S. Nat. Mus., xx, 1897, 498, pl. 38, Horseshoe Bend, mouth of Colorado River. (Type, No.48127. Coll. Gilbert \& Alexander.)

\section{QUIETULA, Jordan \& Evermann.}

Quietula, Jordan \& Evermann, Proc. Cal. Ac. Sci. 1895, 839 (y-cauda).

This genus is closely related to Gillichthys, from which it differs in the presence of 2 or 3 cutaneous flaps on the inner edge of the shoulder girdle. Maxillary elongate, as in Gillichthys; scales rather small, cycloid; cranium essentially as in Gillichthys. Small gobies living in the mud of lagoons and river mouths. (A diminutive, from quies, quiet.)

2584. QUIETULA Y-(AUDA (Jenkins \& Evermann).

Head $3 \frac{1}{2}(4)$; depth $7(8)$; eye $3 \frac{1}{2}$. D. V-14 or 15 ; A. 15; scales about 50-18; B.5. Body moderately elongate, compressed, narrowing regularly from shoulder girdle to caudal fin; head not greatly depressed, broader than body, its length 4 in body; snont rounded, short, about equal to diameter of eye; interorbital spaee narrow, not greater than $\frac{1}{2}$ diameter of eye; mouth rather large, its gape extending nearly to vertical of posterior margin of orbit; maxillary somewhat variable in length, but usually prolonged behind eye for a distance nearly equal to diameter of eye. Scales small, cycloid, about 50 in longitudinal series, 18 in transverse. Teeth in a narrow band on premaxillaries and mandible, short, blunt, and curved slightly backward, most closely set and most numerous 
on premaxillaries. Shoulder girdle with 2 or 3 small cutaneous flaps on its inner edge. Fins moderate; dorsal of 5 spines and 16 soft rays, the spines uncounected with the rayed portion, the space between them abont equal to $\frac{1}{2}$ diameter of eye; the spines weak and flexible, their length $\frac{1}{2}$ that of head; soft dorsal beginning at a point a little nearer end of snout than tip of caudal and extending nearly to caudal, its height about equal to that of spinous portion, the first fer rays slightly graduated; anal having 15 rays and beginning a little behind origin of soft dorsal, the rays about equaling those of dorsal in length; pectorals moderate, inserted a little below axis of the body, their length greater than depth of body, their tips reaching.a vertical from posterior part of spinous dorsal; ventrals united, but not adnate to belly, inserted slightly in front of pectorals and their tips not quite reaching those of pectorals. Ground color light; head and body pretty uniformly covered with dark punctulations; an irregular dark bar across occiput; breast and belly pale; a row of 9 or 10 small dark blotches along middle of side, the one at base of caudal plainest and having a shape something like the Greek letter $\Upsilon$; about 6 dark blotches along median line of back; peritoneum dark. Length about $1 \frac{3}{5}$ inches. Pacific coast of North America, from Guaymas to Vancouver Island; excessively abundant from San Diego southward in mud flats; specimens recorded from Saanich Arm, Vancouver Island, San Diego, mouth of Colorado River, San Luis Gonzales Bay, St. Georges Bay, Concepcion Bay, Guaymas, and La Paz. It was at first confounded with the young of Gillichthys mirabilis, from which genus it differs in the pres. ence of dermal flaps on the shoulder girdle.* (cauda, tail, which has a Y-like mark.)

Gillichthys y-cauda, Jenkins \& Evermann, Proc. U. S. Nat. Mus. 1888, 147, Guaymas,

Sonora. ('Type, No. 39637. Coll. Jenkins \& Fvermann.)

Quietula y-cauda, Jordan \& Starks, Proc. Cal. Ac. Sci.1895, 839.

Gillichthys guaymasice, $\uparrow$ Jenkins \& Evermann, Proc. U. S. Nat. Mus. 1888, 148, Guaymas, Sonora; young specimens $2 \frac{4}{6}$ inches long. (Type, No. 39637. Coll. Jenkins \& Evermann.)

* "The cranium is similar to that of Gullichthy; mirabilis, the occiput being depressed, wedge-shaped, narrowed anteriorly with a blunt median carina, the supraorbital and temporal ridges not continuous behind the eye. As in Gillichthys mirabilis, the supraorbital ridges end in wing-like expansions immediately behind the interorbital space." (Gilbert MS.)

+ Gillichthys guaymasioe is thas described: Head 3 (33 in total); depth 6 (7). D. V-14; A. 13 ; eye 5. Body quite slender, elongate, but little compressed; head long, narrow, not much widened behind the eyes, not depressed, forming $\frac{1}{3}$ the length to base of caudal. Profile gently arched from snout to $\frac{1}{2}$ the distance to dorsal fin, from there nearly straight to dorsal, and then gently curved to caudal peduncle; ventral outline nearly straight; a considerable prominence on the snout made bj the enlarged end of the turbinal bone. Eye somewhat above the median line, not quite equaling the snout in length; interorbital

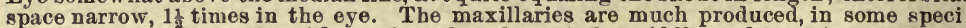
mens nearly reaching the gill openings, broadest at the middle, and tapering to a blunt point posteriorly; premaxillaries not protractile, but little movable at the symphysis, more than as long as the maxillaries. Gill rakers 2 above the angle, 10 below, short and blunt, the first 4 the largest, those on the second arch but little developed. Teeth well developed, in a aingle series, on mandible and premaxillaries, all slightly curved backward. Tongue not so broad as in Gillichthys mirabilis, Cooper; it is gently rounded at the tip, which is free for a much greater length than in Gillichthys mirabilis. Peritoneum black or blackish, and the intestine short, but little longer than the head, and not at all convoluted. Scales small, embedded, and scarcely perceptible except on sides; no pores appear to be developed. First dorsal of fine flexible spines, distance of origin from snout 2 ? than length of snout; second dorsal of 14 rays of nearly equal length, which equals the 
824. ILYPNUS, Jordan \& Evermann.

Ilypnus, JoRdan \& EverManN, Check-List Fishes, 460, 1896 (gilberti).

This genus is allied to Clevelandia, from which it differs chiefly in the presence of dermal flaps on the inner edge of the shoulder girdle; scales minute, embedded, cycloid; dorsal with 5 spines; occiput transversely rounded, without median keel; maxillary moderate. Small gobies, inhabiting mud flats. ( $i \lambda v_{\zeta}$, mud; $\ddot{\pi} \pi v o s$, slumber.)

\section{ILYPNUS GILBERTI (Eigenmann \& Eigenmann.)}

Head 3 to $3 \frac{1}{3}$ ( $3 \frac{2}{3}$ to 4 in total); depth 5 to $5 \frac{1}{2}$ ( 6 to 7 ). D. V-15 to $17 ; \mathrm{A}$. 14 to 16 ; B. 5 ; vertebræ $15+19$. Form elongate, compressed. Head long, subconical, about as high as wide, its width $2 \frac{1}{4}$ in its length. Profile nearly straight from eyes to spinous dorsal, decidedly decurved in front of eyes. Eye entirely above the premaxillary level, 1 in snout, $4 \frac{1}{2}$ in head, $\frac{1}{2}$ in interorbital. Mouth slightly oblique; maxillary extending to below middle of eye, lower jaw slightly included. Teeth villiform, in a broad band in each jaw, the outer series of lower jaw somewhat enlarged. One, rarely 2, dermal flaps on inner edge of shoulder girdle. Scales cycloid, embedded, very small; head, nape, and breast naked. Distance from tip of snout to insertion of spinous dorsal $2 \frac{2}{5}$ in length; highest dorsal spine about $\frac{2}{5}$ length of head; soft dorsal rays lower; interdorsal area about $\frac{1}{2}$ orbital diameter; tip of last dorsal ray not reaching base of caudal; caudal broad and rounded when expanded; anal similar to soft dorsal fiu; ventral fins large, nearly reaching vent in specimens $1 \frac{8}{4}$ inches long. Pectorals usually shorter than ventrals. Color in life, sand color; head and body with small rust-colored spots, which are dotted with black, the punctulations forming a more or less regular network; dorsal fins hyaline at base, bright rust-colored above, and rather broadly margined with white, everywhere black punctate except on margins; about 3 groups of black dots on each ray, giving a barred appearance to these fins; caudal margined with white, upper and lower parts of fin rust colored, median portion dark gray; about 5 wavy, rustlike, vertical bars; entire fin dotted with black except its margin; anal fin hyaline at base, sparsely dotted, its middle third jet-black, margined with white; pectorals and ventrals milky white, yellowish, sparingly black dotted and white edged; a large, conspicuous, metallic blue-black spot on opercie; top of head blackish; belly white or yellowish; chin and throat white, sometimes

distance from end of snout to middle of pupil; length of base of soft dorsal not quite equaling length of head; distance of posterior end from caudal fin equaling distance between the 2 dorsal fins. Origin of anal behind that of soft dorsal and a little posterior to middle of total length of fish; its base $1 \frac{1}{4}$ times in base of soft dorsal, or about 4 in length of fish to base of caudal fin; pectorals moderate, a little more than $\frac{1}{2}$ length of head; ventrals inserted slightly behind the pectorals and about equaling them in length. Color in life whitish beneath, grayish or mottled above; 6 double white spots along the back, alternating with fine blackish areas; a white spot behind each eye on top of head; cheek with 2 dark bands extending obliquely backward and downward from eye; a number of dark splotches on opercles; about 7 dusky areas along the side, the last and most marked being upon the base of the candal fin; dorsal fins finely marked lengthwise by about 4 series of small dark spots: caudal crossed by 5 or 6 wavy vertical bars of very fine dark spots or points; anal, pectorals, and ventrals plain. In alcohol these markings are Jess plain, especially the white and black areas upon the back. Length $2 \frac{4}{6}$ inches. 
punctate. Young lighter, showing the reticulations, but the other markings faint or undeveloped. Length about $2 \frac{1}{4}$ inches. (Eigenmann.) "This species agrees with Lepidogobius in the presence of papillæ on the inner edge of shoulder girdle. It differs decidedly in the shape of the occipital region of the cranium, which is transversely evenly convex as in Clevelandia; not abruptly widened behind the orbits, not continuous laterally with the temporal ridge as in Gobius, Lepidogobius, etc. From Clevelandia and Gillichthys, Lepidogobius gilberti differs in the presence of papillx on the shoulder girdle, and from Gillichthys $y$-cauda in the shape of the cranium." (Gilbert MS.) San Diego Bay and southward; found by Dr. Gilbert abundant at Magdalena Bay, at Concepcion Bay, and St. Georges Bay, in the Gulf of California. (Named for Charles Henry Gilbert, professor of Zoology in the Leland Stanford Junior University.)

Lepidogobius gilberti, Eigenmann \& Eigenmann, Proc. U. S. Nat. Mus. 1888, 464, San Diego Bay. (Type, No. 40128, U. S. Nat. Mus. Coll.C. H. Eigenmann.)

\section{CLEVELANDIA, Eigenmann \& Eigenmann.}

Clevelandia, Ergenmann \& Eigenmann, Proc. Cal. Ac. Sci. 1888, 73 (longipinnis, EigenMANN \& EIGLNMANN, = rosce).

This genus is closely allied to Gillichthys, differing chiefly in the form of the skull, which is rounded above, strongly convex in transverse profile, perfectly smooth, without ridges or crests. Body long and slender; maxillary much produced, but not extending to the gill opening; mouth horizontal; dorsal spines 4 or 5 , very weak; body covered with minute cycluid embedded scales; soft dorsal and anal long, each of 14 to 17 rays. (Named for Daniel Cleveland, esq., president of the San Diego Society of Natural History, a gentleman deeply interested in scientific matters.)

a. Caudal short, rounded; dorsal spines 5 .

aa. Caudal pointed, scarcely shorter than head; dorsal spines 4.

$105,2586$. ROSE, 2587.

2586. CLEVELANDIA IOS (Jordan \& Gilbert).

Head $3 \frac{1}{2}$ in length of body; depth 6 . D. V-16; A. 14; eye $6 \frac{1}{2}$ in head; maxillary $1 \frac{4}{6}$; pectoral $1 \frac{3}{5}$; ventrals $1 \frac{7}{8}$; candal $1 \frac{1}{8}$; base of soft dorsal 3 in length of body; base of anal $3 \frac{1}{2}$. Body long and slender, compressed, the back not elevated; caudal perluncle moderately wide; head long, profile steep to within a short distance of the front of the eye, thence horizontal; mouth very large, not very oblique, the maxillary projecting to opposite the middle of the cheek; jaws subequal; teeth in narrow villiform bands; eye small, longer than wide, set high in head; interorbital space narrow, about as wide as eye. Body covered with very small cycloid scales, too small to count; spinous dorsal well separated from soft dorsal, the spines slender; soft dorsal the higher, its origin a little nearer base of caudal fin than tip of snout; anal about equal to soft dorsal in height, its origin a little behind first dorsal ray, ending at about the same comparative place as soft dorsal; ventrals inserted slightly behind pectorals, reaching midway between their base and front of anal; caudal short, its end rounded. 
Color light olivaceous, the cheeks and sides with many dark points which form mottlings ; snout dark; a dark spot on upper part of opercle; top of head black; dorsals light, with 3 or 4 dark lines running across the rays; some dark spots on base of anal; pectorals crossed with dark wavy lines; caudal with about 5 irregular cross bars. Puget Sound and neighboring waters. Here described from 2 specimens, each 2 inches in length, dredged off Port Orchard by Mr. Edwin C. Starks. The original description is imperfect and partly incorrect, the single type, from the stomach of Hexagrammos asper, being in bad condition. (iós, arrow.)

Gobiosoma ios, Jordan \& Gilbert, Proc. U. S. Nat. Mus. 1882, 437, Saanich Arm, Vancouver Island (Coll. Jordan \& Gilbert); JordaN \& GILBERT, Synopsis, 948, 1883; JoRDAN \& EIGENMANN, $l . c ., 509$.

Clevelandia ios, Jordan \& StARKs, Proc. Cal. Ac. Sci. 1895, 839, pl. 100.

2587. CLEVELANDIA ROSE, Jordan \& Evermann.

Head 4 (48 in total); depth 6\% (7). D. IV-16; A. 17; scales 70-18. Body very much elongate, slender; head long and slender, depressed anteriorly much as in Lucius; profile straight; eye moderate, slightly shorter than snout, $4 \frac{1}{8}$ in length of head; interorbital area about as wide as pupil; anteorbital area scarcely $\frac{1}{2}$ diameter of eye; mouth large, maxillary extending much beyond orbit; lower jaw flat, slightly curved upward anteriorly; mouth very much as in Lucius; teeth all small, in narrow bands in each jaw; the outer ones of the upper jaw slightly larger than the others. Scales minute, slightly enlarged posteriorly; the margins plain, anterior part of the exposed area lengthwise striated; breast and antedorsal area naked. Distance from snout to insertion of first dorsal spine $2 \frac{2}{8}$ in body; the spines slender and short, 3 in head; interdorsal area equals snout and eye; dorsal rays slightly longer than spines, the last ray not extending halfway to caudal; caudal pointed, scarcely shorter than head; ventrals not reaching halfway to vent, $1 \frac{2}{5}$ in head; pectoral $1 \frac{1}{2}$ in head; vent slightly behind middle of body. Color light brownish; numerous darker spots of aggregated points along nape and upper half of body; belly white; head slightly darker than body; posterior edge of opercle white; an oblique silvery bar on the lower half of opercle, and a light blotch at the upper corner of opercle; cheek with black points; some light areas below eye; lower surface of head and posterior part of maxillaries plain; 2 dark bars on spinous dorsal; second dorsal with 3 or 4 dark bars; a curved black bar at base of caudal; remainder of caudal irregularly barred with dark; other fins plain. Length $1 \frac{7}{8}$ inches. San Diego Bay (Eigenmann \& Eigenmann); at first incorrectly identified by Mr. and Mrs. Eigenmann with Evermannia longipinne (Steindachner), a species similar in habit but wholly scaleless. (Named for Mrs. Rosa Smith Eigenmann.)

Clevelandia longipinnis, Eigenmann \& Eigenmann, Proc. Cal. Ac. Sc1. 1888, 73; not Gobiosoma longipinne, STEINDACHNER.

Clevelandia rosae, Jordan \& Evermann, Proc. Cal. Ac. Sci. 1896, 229, San Diego. (Coll. R. S. Eigenmann.) 
826. EVERMANNIA, Jordan.

Evermannia, JoRDaN, Proc. Cal. Ac. Sci., Iv, 1895, series 2, 592 (zosterura).

Body slender, compressed behind, entirely naked. Head long, slender. Snout rather pointed; mouth moderate, terminal, the maxillary more or less produced backward; teeth small and slender, the outer above slightly enlarged. Skull with a small median crest, not much widened behind. Interorbital space very narrow, channeled; no dermal flaps on shoulder girdle; first dorsal of 4 to 6 spines; second dorsal and anal long, of 14 or 15 rays. Caudal lanceolate. Ventrals formed as in Gobius and Gobio8oma. Size small, the sexes not colored alike. Species living in holes in sand and mud between tide marks. (Named for "my former student and later scientific associate, Dr. Barton Warren Evermann, now ichthyologist of the United States Fish Commission, in recognition of his work on the fishes of the Gulf of California."-Jordan.)

a. Head 3as; depth $5 \frac{1}{4}$; body and fins dotted.

I.ONGIPINNIS, 2588.

aa. Head $3 \frac{1}{3}$; depth $6 \frac{2}{3}$; vertical fins in males banded with black and with white edgings. ZOSTERURA, 2589.

2589. EVERMANIA LONGIPIXNIS (Steindachner).

Head $3 \frac{4}{5}$; depth 5 to $5 \frac{1}{8}$. D. IV to VI-16 or 17 ; A. 16 or 17 ; snout slightly decurved in profile, $3 \frac{1}{2}$ in head; eye 6 , greater than interorbital width. Body very slender. Mouth somewhat oblique, the jaws equal; maxillary extending beyond middle of head to a distance behind eje equal to diameter of eye. Teeth in each jaw in 2 series laterally and 3 in front, those of the outer series somewhat enlarged. Fins low, the longest dorsal spine 2 in head; pectoral a little shorter than caudal, scarcely longer than ventrals. Caudal rounded, shorter than head, probably $4 \frac{2}{8}$ in body. Body and head completely naked.* Brownish yellow; upper parts of head and body with small, irregularly placed brown spots and streaks; dorsals and candal finely barred with dark specks. (Steindachner). Gulf of California; not seen by us; known from 3 specimens $37 \frac{1}{2}$ $\mathrm{mm}$. long. We refer this species provisionally to Evermannia, with which genus it agrees in external respects, although the mouth is much larger. It may be the type of a distinct genus. It differs from Clevelandia in the entire absence of scales. (longus, long; pinna, fin.)

Gobiosoma longipinne, STEINDACHNER, Ich. Beitr., vir, 27, 1879, Las Animas Bay, Gulf of California; JoRdan \& EigenManN, l.c., 509.

Evermannia longipinnis, JoRdan, Proc. Cal. Ac. Sci. 1896, 229.

2589. EVERMANIA ZOSTERURA (Jordan \& Gilbert).

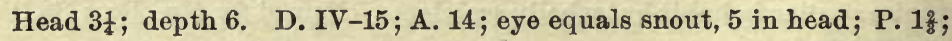
C. $1 \frac{1}{8}$. Body compressed, profile convex; snout short, not very blunt; eyes high, the maxillary reaching to their posterior margin; mouth oblique, jaws equal ; first spine of dorsal filamentous, reaching to middle

* At our request Dr. Steindachner has reexamined the types of this species. He still finds them "vollkommen schuppenlos." 
of soft dorsal (male); body entirely naked. Body everywhere speckled with dots of dark brown. Maie sometimes with traces of 8 olive cross bands; fins very ornate, the dorsal and anal yellowish at base, then a broad median band of jet black, then a broad white margin; middle of caudal yellow to the tip, with a black band above and below, and a white edge above and below this as in dorsal and anal; no bands on tail. Female with dorsal. filament short, reaching about to first soft ray; dorsals and anal checkered with blackish; caudal faintly barred; all vertical fins with pale edgings, but without the black stripe of the males. Length 2 inches. Very common on sandy bottoms, everywhere about the estuary of Mazatlan, the numerous specimens here described being dug out of the sand. It is seldom found much, if any, below the mark of low tide. It is a very handsomely colored species, the male being more strikingly marked

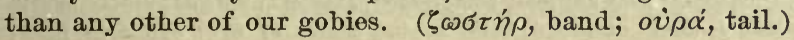

Gobiosoma zosterurum, Jordan \& Gilbert, Proc. U. S. Nat. Mus. 1881, 361, Mazatlan (fin rays incorrect), (Type, No. 29245, U. S. Nat. Mus. Coll. C. H. Gilbert); JordAN \& Eraminann, $l . c ., 509$.

Evermannia zosterura, JoRdan, Proc. Cal. Ac. Sci., 2d ser., vol. 1v, 1895, 498, pl. 51.

827. GOBIOSOMA, Girard.

\section{(NAKED GoBIES.)}

Gobiosoma, Grrard, Proc. Ac. Nat. Sci. Phila. 1858, 169 (alepidotus).

Body entirely naked; mouth moderate, horizontal; snout blunt; teeth in several series, the outer row enlarged; no canines; dorsal spines normally 7 , rarely 5 or 6 ; second dorsal and anal short; no barbels about head; shoulder girdle without flaps. Species chiefly American. (Gobius: $\sigma \tilde{\omega} \mu \alpha$, body.)

a. Coloration olivaceous, mottled with darker; no red nor blue.

b. Maxillary extending to beyond pupil, $\frac{1}{4}$ in head; color blackish, with sharply defined cross bars of whitish. Body rather short, the depth $5 \frac{4}{5}$ in length; head $3 \frac{1}{4}$; snout low, little obtuse; month large, rather oblique, the maxillary $2 \frac{2}{3}$ in head; teeth small, in fow series above, in a band below, the outer enlarged; fins low; caudal $1 \frac{1}{4}$ in head. Cross bands on body as wide as eye, not quite meeting below; a dark blotch on base of pectoral, a fainter one on base of caudal; fins nearly plain. D. VII-13; A.12. HISTRIO, 2590.

$b b$. Maxillary extending to below posterior part of orbit; coloration not sharply defined, the body usually with dark cross streaks.

c. Body rather short, chubby, the depth about 4 in length; head abont $3 \frac{2}{3}$; head rounded above; teeth in several series, slender, the outer ones somewhat elongate, none of the inner ones specially enlarged. Color olivaceons, with dark points; sides with narrow, alternating light and. dark bars; a row of small linear dark spots along middle of sides; first dorsal with 3 oblique dark bars; second dorsal, caudal, and pectorals finely barred, base and edge of anal light, middle dark; breast with many well-defined spots; a dark line running forward and downward from eye to angle of mouth, another extending straight down; a black bar on edge of preopercle, a black spot on upper edge of opercle. D. VII-13; A. 10.

MOLESTUM, 2591. 
cc. Body more elongate, depth 5 to 6 in body; head very broad, flattish above, with tumid cheeks, its length $3 \frac{1}{3}$ in body; eye small, longer than snout, 5 in bead; mouth large, little oblique, the jaws subequal.

d. Soft dorsal with 14 rays; no crescent at base of caudal; maxillary extending to below posterior part of orbit (at least in male), $2 \frac{1}{2}$ in head; teeth in fow series, the outer considerably enlarged; 2 teeth ou each side of inner series of lower jaw especially large canines; dorsal spines slender, none filamentous; caudal rounded. Olivaceous, with darker cross shades of rounded spots; vertical fins dusky, faintly barred. Teeth of the female similar to those of the male but smaller; head narrower; more slender. D. VII14 ; A. 10.

BOSCI, 2592.

$d d$. Soft dorsal with 12 rays; a brown crescent at base of caudal.

CRESCENTALE, 2593.

aa. Coloration not plain olivaceous; head with a red bar; anterior dorsal rays not produced in filaments; head and body compressed; greatest depth $5 \frac{2}{3}$ in total length, head about 4; angle of mouth little behind center of eye; eye 4 in head; teeth pointed, in several series, those of the outer series a little enlarged; caudal rounded. Head light yellow; a carmine-red bar extending along upper edge of head, from upper corner of gill opening to snout, where it joins its fellow, ending behind over the pectoral in a small indigo-blue spot; body with 16 or 17 light green, well-defined cross bars, separated by narrow white stripes; fins chiefly gre 3nish. D. VII (VI)-11 or $12 ;$ A. 10.

MULTIFASCIATUM, 2594.

2590. GOBIOSOMA HISTRIO, Jordan.

Head $3 \frac{1}{4}$; depth $5 \frac{4}{5}$. D. VII-12 or 13 ; A. 11 or 12 ; maxillary $2 \frac{1}{4}$ in head; caudal $1 \frac{1}{4}$. Body rather short; snout depressed, little obtuse; mouth large, rather oblique, maxillary reaching to below posterior part of orbit; chin without barbels; many series of minute papillæ along mucous pores of head. Teeth small, in fow series above, in a band below, the outer enlarged. Fins low. Cross bands on body whitish, as wide as eye, not quite meeting below; a dark blotch on base of pectoral, a fainter one on base of candal; fins nearly plain. Length 2 inches. Gulf of California; known only from the Gulf of California at Guaymas (Emeric; Evermann \& Jenkins) and La Paz (Gilbert). (histrio, a harlequin.)

Gobiosoma histrio, Jordan, Proc. U.S. Nat. Mus. 1884, 260, Guaymas, Mexico (Coll. H. F. Emeric); Jordan \& Eigenmann, l.c., 508; Evermann \& Jenkins, Proc. U. S. Nat. Mus. $1891,162$.

\section{GOBIOSOMA MOLESTUM, Girard.}

Head abont 3 ; ; depth 4. D. VII-13; A. 10; vertebræ $12+15$. Body rather short, maxillary extending to below posterior part of orbit. Teeth in several series, slender, the outer ones somewhat elongate, none of the inner ones specially enlarged. Skull flattish, with a slight median keel; lateral crests developed, lower and stronger than in Gobius; interorbital very narrow, bounded by 2 minute crests; bones of the skull very weak and fragile. Teeth in both jaws recurved, in 2 or 3 series. Olivaceous, with dark points; sides with narrow, alternating light and dark bars; a row of small dark spots along middle of side; first dorsal with 3 oblique dark bars; second dorsal, caudal, and pectorals finely barred; base and 
edge of anal light, middle dark; breast with many well-defined spots; a dark line running forward and downward from eye to angle of mouth, another extending straight downward from eye; a black bar on edge of preopercle, and a black spot on upper edge of opercle. A specimen taken at Key IVest is thus described: Pale olive, with darker cross bands formed of dark dots; a row of dark dots along middle of side; vertical fins all mottled and faintly barred with dark olive; pectorals and ventrals nearly plain. Length $2 \frac{1}{2}$ inches. Gulf coast of the United States; common in shallow waters along the coast from Key West to 'Texas and south to Bahia. (molestus, disturbed.)

Gobiosoma molestum, Girard, Proc. Ac. Nat. Sci. Phila. 1858, 169, Indianola, Texas; Girard, U.S. and Mex. Bound. Surv., 27, pl.12, fig. 14. 1859; GÜnther, Cat., III, 556, 1861; Jordan \& Gilbert, Synopsis, 638, 1883; JoRdaN \& EigenManN, l.c., 508.

Gobiosoma alepidotum, Jordan \& GilBert, Proc. U. S. Nat. Mus. 1882, 297, Laguna Grande, Pensacola. (Coll. Dr. Jordan.)

2592. GobIOSOMA BoscI (Lacépède).

(NAKED GOBY.)

Head $3 \frac{1}{3}$; depth 5 to 6 . D. VII-14; A. 10 ; eye 5, longer than snout. Body more elongate; head very broad, flattish above, with tumid cheeks. Eye small. Mouth large, little oblique, jaws subequal, the maxillary extending to below posterior part of orbit (at least in male), $2 \frac{1}{8}$ in head. Teeth in few series, the outer considerably enlarged; 2 teeth on each side of inner series of lower jaw especially large canines. Dorsal spines slender, not filamentous; caudal rounded. Olivaceous, with darker cross shades of rouncled spots; vertical fins dusky, faintly barred. Atlantic coast of the United States, Cape Cod to Florida; genorally common, especially southward in shallow grassy bays. (Named for M. Bosc, French consul at Charleston in the last century; an ardent naturalist.)

Gobius bosci, LACéPł̀DE, Hist. Nat. Poiss., II, 555, pl. 16, fig. 1, 1798, Charleston, South Carolina. (Coll. M. Bosc.)

Gobius alepidotus, BLoch \& SchNeIDER, Syst. Ichthyol., 547, 1801, after LACÉPk̀DH; DH KAY, N. Y. Fauna: Fishes, 160, pl. 23, fig. 70, 1842.

Gobius viridipallidus, MrchiLL, Trans. Lit. and Philos. Soc. N. Y., I, 1814, 379, pl.1, fig. 8, New York.

Gobiosoma bosci, Jordan \& Gilbert, Proc. U. S. Nat. Mus. 1882, 613; Jordan \& Eigenmann, l. c., 508.

Gobiosoma alepidotum, GüNthel, Cat., III, 85, 1861; JoRdAN \& GILBERT, Synopsis, 638, 1883.

2593. GOBIOSOMA CRESCENTALE, Gilbert.

Head $3 \frac{8}{4}$ in length; depth $6 \frac{1}{4}$; eye $5 \frac{1}{8}$ in head; snout $5 \frac{1}{8}$. D. VII-12; A. 11. Body very slender, the head depressed, broad and flattened above, the head and body of nearly equal depth throughout. Mouth small, oblique, the maxillary not extending beyond the vertical from posterior border of orbit, $2 \frac{1}{2}$ in head; eyes small, $1 \frac{2}{5}$ in the rather broad interorbital space. Teeth in bands in both jaws, the outer series enlarged, caninelike, and distant. Fins all small, the caudal short and rounded from a broad base, pectoral as long as head without snout; ventrals short, not 
reaching $\frac{2}{8}$ the distance from their base to vent; dorsal spines not filamentous; skin wholly naked. Color in spirits, lower half of head and body uniform warm brown, the back much lighter, the two areas separated by a well-defined line along middle of sides; this line passing through orbit and through the middle of the base of the pectoral fin; back light grayish, with brownish reticulations, which tend to form 5 or 6 indistinct darker bars uniting with the darker area below the lateral line; a conspicuous brown crescent at base of caudal and pectorals, broad below, narrowing above, margined in front with whitish; anal brown at base; dorsal and caudal with small brown spots forming faint cross series. A single specimen known. Off coast of Lower California. (Gilbert.) (crescentalis, pertaining to a crescent.)

Gobiosoma crescentalis, GruberT, Proc. U. S. Nat. Mus. 1891, 557, off coast of Lower California, at Albatross Station $2825,24^{\circ} 22^{\prime}$ N., $110^{\circ} 19^{\prime} 15^{\prime \prime}$ W., in 79 fathoms.

2594. GOBIOSOMA MULTIFASCIATUM, Steindachner.

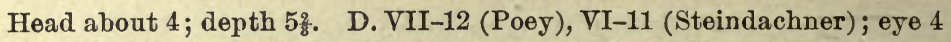
in head. Body and head compressed. Angle of mouth little behind center of eye. Teeth pointed, in several series, those of outer series somewhat enlarged. Dorsal rays not filamentous; caudal fin rounded. Head light yellow; a carmine-red bar extending along upper edge of head, from upper corner of gill opening to snout, where it joins its fellow, ending behind over the pectoral in a small indigo-blue spot; body with 16 or 17 light-green, well-defined cross bars, separated by narrow white stripes. (Steindachner.) West Indies; known from Cuba, St. Thomas, and the Lesser Antilles; not seen by us. Its coloration is very different from that of Gobiosoma, and it may belong to a distinct genus. (multus, many; fasciatus, banded.)

Gobius lineatus,* PoEx, Memorias, II, 424, 1861, Cụba; name preoccupied by Gobius lineaius, JENYNS.

Gobiosoma multifasciatum, StEINDACHNER, Ichth. Beiträge, v, 183, 1870, Lesser Antilles; Jordan \& Eighimann, $l . c ., 509$; Eigmanann \& Eigenmann, $l . c ., 73$.

\section{BARBULIFER, Eigenmann \& Eigenmann.}

Barbulifer, Ergenmann \& Ergenmann, Proc. Cal. Ac. Sci. 1888, 70 (papillosus).

A series of numerous minute barbels around the mouth and chin; otherwise as in Gobiosoma; body naked, the dorsal spines 7 ; second dorsal and anal very short. (barbula, a small barbel; fero, I bear.)

2595. BARBULIFER CEUTHECUS (Jordan \& Gilbert).

Head $3 \frac{2}{8}$; depth 7. D. VII-10; eye 4; A. 10. Body slender; head narrow and slender, depressed; snout not blunt; mouth terminal, oblique, the maxillary reaching to below eye, 3 in head; eyes close together; chin

* Gobius lineatus is thus described: Head $3 \frac{1}{2}$; depth of body 6 in length. D. VII-12; eye 6 in head. Body elongate, subcylindrical, maxillary extending almost to below middle of eye; pectorals rounded; dorsals high. Yellowish green; the body with 20 vertical yellow bands; a red band extending from snout to point of opercle; fins yellowish. Cuba. (Poey.) Type.43 mm. in length. 
with a fringe of short barbles; vertical fins high, rays not filamentous. Upper half of head and body brown, finely speckled; 4 oblong, colorless areas along base of dorsals and a smaller one on back of caudal peduncle; lower parts abruptly pale; back with 5 or 6 blackish cross bars reaching to middle of sides, below which they extend as 5 or 6 short V-shaped projections; a brownish streak below eye; a small brown bar on base of pectoral, and a jet black bar at base of caudal. About Key West; scarce.

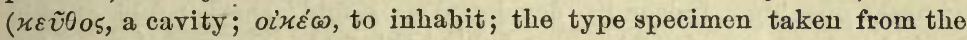
eavity of a sponge.)

Gobiosoma ceuthocum, Jordan \& Gilbert, Proc. U.S.Nat.Mus. 1884, 29, Key West; young (Type in U.S. N. M.); Jordan \& Eigenmann, l. c., 508.

Barbulifer papillosus, * Eigenmann \& Eigenmann, Proc. Cal. Ac. Sci.1888, 70, Key West, Florida; adult.

\section{TYPHLOGOBIUS, Steindachner.}

\section{(BLIND Gobies.)}

Typhlogobius, STEINDACHrER, Ichth. Beiträge, vIII, 24, 1879 (californiensis).

Othonops, RosA Smith, Proc. U.S. Nat. Mus. 1881, 19 (eos=californiensis).

Body moderately elongate, compressed, covered with loose, smooth, naked skin. Head large, depressed, with tumid cheeks. Mouth large, the maxillary reaching to beyond the orbit; jaws equal, each with a narrow band of villiform teeth, the outer teeth slightly enlarged; lower jaw capable of little motion; snout rounded; no cirri. Eyes very small, reduced to mere vestages, covered by skin, and functional only in the young. Skull greatly modified, the brain case quadrate. Fins low; first dorsal of 2 flexible spines; second dorsal moderate; anal very short; caudal rounded; ventral disk as in Gobius. Gill openings rather narrow. Qne species known; singular blind gobies, living like slugs under rocks between tide

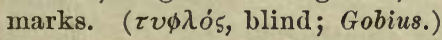

* This species, which we snppose to be the adult of Barbulifer ceuthoecus, is thus described by Dr. Eigenmann: Head $3 \frac{1}{2}\left(4 \frac{2}{5}\right.$ in total); depth $4 \frac{1}{3}\left(5 \frac{2}{3}\right)$. D. VII-9; A.9. Body short and robust, deepest below first dorsal spine; head blunt, protile straight from first dorsal spine to eye, much curved in front of eye; eye longer than snout, $3 \frac{1}{3}$ in head; interorbital area $\frac{2}{3}$ diameter of eve; snout blunt; mouth small, oblique; maxillary 3 in head, reaching to below anterior margin of pnpil; lips thick. About 21 barbels, in Jength $\frac{1}{2}$ orbital diameter or longer, arranged as follows: A series of 7 cross the snout from one angle of the mouth to the opposite angle, the anterior 3 on the snout rather thick and colored ( 2 of them nasal), all the others yellowish, the barbel nearest each angle of the mouth longer than any of the others; on the lower jaw a barbel near each rictus, 2 on the chin, behind which are 2 pairs of barbels; posterior to these and below the rictus are 2 barbels on each side; 1 slender barbel on each side of preopercle below the posterior margin of the eye. Numerous rows of pores or papilla on the head; 1 series extending straight downward on the anterior part of the opercle, from the upper end of which another series extends perpendicularly backward; other pores irregularly scattered on the opercle; a double series extending along edge of preopercle, the pores becoming larger and especially conspicuous below, meeting on the chin; 6 or 7 series radiating from eye, extending to snout, maxillary, and opercular series below; a row of pores nearly surrounding mouth, curving backward, encircling the nasal opening; 1 series about the eye posteriorly, otherwise none on top of head or nape; fins high and rounded; second dorsal higher than first, $1 \frac{1}{b}$ in head, caudal very broad and rounded, equal to the head in length; anal lower than soft dorsal; ventral reaching $\frac{2}{3}$ to vent, $1 \frac{1}{3}$ in head; pectoral $1 \frac{1}{4}$ in head. Color yellow; upper half of body with a broad band of purplish spots; 6 diamond-shaped spots of darker cross the band, extending abore and below it; nape, top of head, and upper part of cheok covered with dark points; opercle light yellow, cheeks darker; an oblique bar of black points on upper half of pectoral base, a curved bar of fainter spots on base of caudal; fins otherwise colorless and transparent. Length $1 \frac{1}{8}$ inches. (Eigenmann.) 
2596. TYPHLOGOBIUS CALIFORIENSIS, Steindachner.

(Blind Goby of Polnt Loma; Penk-Fish.)

Head $3 \frac{1}{2}$; depth 5 ; eye 6 ; eye concealed, very small; D. II-12; A. 12 . Vertebra $17+13$. Body subcylindrical, the males more compressed behind; head very broad behind, its greatest width $\frac{2}{8}$ its length. Interorbital space a mere ridge; skin about mouth and eye very loose; a small papilla in front of nasal opening. Lower lip developed as a fold; another fold of skin behind it, bordered with fine cilia ; behind this fold is a row of short, thick papillæ; edge of jaw rounded. Spinous dorsal remote from the soft dorsal in the male, but connected with it by a low membrane, this membrane absent in the female; soft dorsal much higher than the spinous; caudal broad, rounded; anal very short, inserted under sixth dorsal ray, and coterminous with dorsal; pectorals little longer than ventrals, 2 in head. Body naked; males with small tubercular plates irregularly placed. Skull highest at its posterior part, depressed forward; the bones all thick and strong. No lateral crests; a median keel which is lowest behind. Orbit not bounded by any ridges. Two keels diverge from the posterior end of the median keel to the insertion of the snprascapula. Premaxillaries and mandible very long. Teeth of the upper jaw all alike, long, close-set, in a broad band, those of the lower jaw in a narrow band, the inner ones apparently larger. Color uniform light pink. Length 2 inches. Coast of Lower California, from San Diego southward to Cerros Island; an extraordinary fish, found attached to the lower side of rocks in shallow water or surf; especially common at Point Loma.

Typhlogobius californiensis, STEINDACHNER, Ichth. Beiträge, virr, 24, 1879, False Bay, San Diego, California (Coll. Prof. Essmark); Jordan \& GILBERT, Synopsis, 639, 1883; Jordan \& EigenManN, $l$. c., 511.

Othonops eos, RosA Smrt, Proc. U. S. Nat. Mns. 1881, 53, Point Loma, California.

\section{TYNTLASTES, Günther.}

Tyntlastes, GÜNTHER, Proc. Zool. Soc. London 1862, 193 (sagitta).

Body elongate, compressed, covered with small, imbricate, cycloid scales. Head elongate, quadrangular. Mouth wide, oblique, the lower jaw projecting; teeth small, in single series, none on vomer or palatines. Eyes very small, or rudimentary. Dorsal fin single, continuous, about 6 of its anterior rays simple; caudal fin pointed, more or less joined to the dorsal and anal; ventral fins united. Air bladder very small or absent. No pseudobranchiæ. Vertebræ $11+20$. Pacific Ocean. ( $\tau v \nu \tau \lambda \alpha \dot{\sigma} \tau \eta \zeta, \mathbf{a}$ mud-dabbler.)

a. Dorsal and anal each with 15 soft rays; head $4 \frac{1}{2}$ in length. $a a$. Soft dorsal and anal each with 21 unbranched or soft rays; head $5 \frac{1}{2}$ in length.

BREVIS, 2597. SAGITTA, 2598.

2597. TYNTLASTES BREVIS (Günther).

Head $4 \frac{1}{2}$; depth 8 . D. VI, 15 ; $^{*}$ A. 15. Eyes minute. Jaws each with a

* The dorsal formula is apparently VIII, 14 in 2 half-digested specimens taken from the stomach of a Centropomus at Panama. (Gilbert.) 
series of wide-set teeth. Caudal fin black. (Giinther.) Panama; not seen by us. (brevis, short.)

Amblyopus brevis, GÜnther, Proc. Zool. Soc. London 1864, 151, Panama; GUnther, Fishes Centr. Amer., 441, 1869.

Tyntlastes brevis JORDAN \& EigenManN, l. c., 512.

2598. TYNTIASTES SAGITTA (Günther).

Head $5 \frac{3}{5}$; depth 93. D. VI, 21; A. 21. Body and head elongate, compressed. Maxillary reaching to behind eye; teeth subhorizontal, very small. Scales becoming larger posteriorly. Caudal arrow-shaped, about 4 in body; pectorals as long as ventrals, 2 in head. Grayish, sides and under parts silvery; an ovate gray spot before each dorsal ray; caudal grayish. (Giinther.) Length $9 \frac{1}{2}$ inches. Coast of Lower California; exact locality unknown. (sagitta, arrow.)

Amblyopus sagitta, Günther, Proc. Zool. Soc. London 1862, 193, "California," probably from Lower California.

Tyntlastes sagitta, JoRdAN \& GILBERT, Synopsis, 639, 1883; JoRdan \& Eigenmann, l. c., 512.

831. GOBIOIDES, Lacépède.

(BARRETOS.)

Gobioides, LACÉPÈDE, Hist. Nat. Poiss., 11, 580, 1798 (broussonnetii).

Plecopodus, RAFINESQUE, Analyse de la Nature, 87, 1815 (broussonnetii); substitute for Gobioides, regarded as objectionable.

Ognichodes, Sw AINSON, Nat. Hist. Class'n Animals, II, 183 and 278, 1839 (broussonnetii).

Body greatly elongate, compressed behind, the scales very minute; head small; eyes very small; mouth large, oblique, the lower jaw projecting; gill openings moderate. Teeth in a band, those in the outer series being very strong. Dorsal rays V to VII, 15 to 23 ; anal rays 16 to 23. Dorsal fin low, continuous, the spines similar to the soft rays, but more widely separated; the soft dorsal and the anal are joined to base of caudal; ventrals 45 , united in a disk which is formed much as in Gobius. No air bladder; no pseudobranchiæ. From Tanioides (=Amblyopus) the genus Gobioides is distinguished by the absence of barbels, the presence of scales, and by the much smaller number of rays in its vertical fins. Brackish waters of the Tropics, reaching a considerable size. (Gobius;

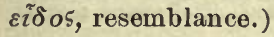

a. Eye small, but evident; scales evident, larger behind.

aa. Eye minute, not evident; scales minute.

BROUSSONNETII, 2599. PERUANUS, 2600.

2599. GOBIOIDES BROUSSONNETII, Lacépède.

Head $5 \frac{1}{4}$ (young) to 7 (adult); caudal $3 \frac{1}{2}$ to 5 ; eye small but evident, 7 to 10 in head; interorbital space 1 to $1 \frac{2}{8}$ diameter of eye. D. VII, 16; A. I, 16. Body elongate, mouth oblique, maxillary extending beyond eye; teeth in bands, the outer series enlarged, shorter, and closer set than in Gobioides peruanus; scales twice as large as in peruanus, those on anterior part of body not imbricated, much smaller than those on posterior part, 
which are elongate oval in form. Violet bars extending downward and forward on the upper part of body; sometimes a violet spot with a lighter or darker dot at end of the bars; head marbled or spotted with dark violet or brown. (Steindachner.) Length 20 inches or more. West Indies to Brazil; common southward, ascending rivers; onee taken near New Orleans (Bean \& Bean). (Named for Dr. Augustin Broussonnet, professor in the University of Montpelier.)

Gobioides broussonnetii, LACÉPh̀DE, Hist. Nat. Poiss., II, 580, 1798, probably from Surinam, "given by Holland to France."

Amblyopus brasiliensis, BLOCH \& SCHNEIDER, Syst. Ichth., 69, 1801, Brazil; on drawing made by Prince Maurice; Covier \& Valenciennes, Hist. Nat. Poiss., XII, 121, 1837.

Gobious oblongus, BLOCH \& SCHNEIDER, Syst. Ichth., 548, 1801; based on LACÉPÈDE.

Gobioides barreto, Poey, Memorias, II, 282, 1861, Cuba ; Poty, Synopsis, 394, 1868; Poex, Enumeratio, 125, 1876.

Amblyopus mexicanus, O'Shadghnessy, Ann. Mag. Nat. Hist., series IV, vol. xv, 1875, 147, Mexico.*

Gobioides broussoneti, Jordan \& Eigenmann, l. c., 512; Bean \& Bean, $\dagger$ Proc. U. S. Nat. Mus. 1895, 631.

2600. GOBIOIDES PERUANÚ (Steindachner).

Head 5; depth 11. D. VII, 17; A. I, 16. Eye scarcely visible, much smaller than in $G$. broussoneti; scales very minute; snout $2 \frac{1}{2}$ in postorbital part of head; interorbital 5 in head; lower jaw slightly projecting; maxillary 23 in head; a series of large slender teeth in each jaw, behind which, in each jaw, is a narrow band of fine teeth; caudal $4 \frac{1}{8}$ in

* The following is Mr. O'Shaughnessy's description of Amblyopus mexicanus: D. VII, 15; A. I, 15. Depth 13 in total length. Body covered all over with scale-shaped crypts. Head naked. Dorsal $\frac{3}{4}$ height of body. Eye small, but distinct. Snout obtuse; lower jaw extending a little beyond upper. Teeth small, close set, the onter series much smaller and more closely set than in G.broussonnetii. Dorsal and anal connected with the caudal. Upper parts dark brown, with a series of white spots along the whole length of the side; lower parts of sides and belly white. One specimen in the British Museum, from Mexico, purchased. Length $20 \frac{1}{4}$ inches. (O'Shaughnessy.)

This seems to differ from $G$. broussonnetii in color only.

t'The following description is given by Bean \& Bean of Gobioides broussonnetii (Lacépède) : Head 7; depth 14. D. VI, 17; A. I, 16. The greatest depth of the head equals the length of the upper jaw, or about $\frac{1}{2}$ the length of head without snout. The body is compressed. Its greatest thickuess is contained $1 \frac{2}{3}$ times in its greatest depth. The teeth are in narrow bands in each jaw, some of those in the outer row enlarged, canine-like, and curved inward. All of the teeth are more or less curved in ward and depressible. The vomer and palate are toothless. Themouth is oblique, the lower jaw projecting slightly beyond the upper. The maxilla extends well behind the eye, its length is slightly more than $\frac{1}{2}$ that of head without the snout. It is not much expanded posteriorly. Eyes very small, their diameter equaling length of snout, alout equal to width of interorbital space. The snout scarcely equals more than $\frac{1}{5}$ of the head's length. Gill openings wide, the membranes wholly joined to the isthmus. Branchiostegals much curved, 4 in number. The dorsal begins at a distance from the nape equal to the postorbital part of the head, the origin being about over the end of the extended pectoral. The ventral reaches farther back than the pectoral, and is longer than that fin, its length equaling postorbital part of head. The distance of the vent from the tip of the snout equals somewhat more than 3 times the length of the head; it is under the interspace between the last spine and first ray of the dorsal, with a small genital papilla behind it. The caudal is very long and tapering, $1 \frac{2}{3}$ times as long as the head. The dorsal spines are long and slender, the fifth nearly as long as the postorbital part of the head. The second dorsal ray is slightly longer. The anal rays are about as long as those of the dorsal. The scales are thin, not imbricated, except on the posterior part of the head, where they are long and elliptical in shape. The head and breast are naked. The colors have fader out in alcohol; the ground color appears to have been light brown, with darker bletches on the median line of the body under the spinous portion of the dorsal and the anterior part of the soft dorsal. (Bean \& Bean.) Here described from a specimen obtained in the Gulf of Mexico by Mr. Robert S. Day, of Now Orleans, Lonisiana, and is No. 38220, U. S. Nat. Mas. 
body, connected by membrane to dorsal and anal; sides with regular cross series of pores. Body with narrow angular cross bars; dorsal rays violet, the membrane yellowish. (Steindachner.) Shores of Ecuador and Peru, aşcending rivers.

Amblyopus peruanus, Steindachner, Fisch-Fauna des Cauca und Flüsse bei Guayaquil, 42,1880 , Guayaquil.

Gobioides peruanus, Ergenuann \& Eigenmann, Proc. Cal. Ac. Sci., 2d ser., I, 1888, 75.

832. CAYENNIA, Sauvage.

Cayennia, Sauvage, Bull. Sci. Philom., ser. 7, IV, 1880, 57 (guichenoti).

Body much elongate; dorsals united, caudal free from dorsal and anal; ventrals united, not adhering to belly; teeth small, the outer enlarged; anterior part of body naked, posterior part covered with cycloid scales. Otherwise as in Gobioides, from which the genus may not be separable. (Name from Cayenne.)

\section{CAYENNiA GUICHExoti, Sauvage.}

Head 9 ; depth 17. D. VI, 17; A. I, 16 ; vertebræ about 36 . Head deeper than wide; eye small, placed well forward; maxillary reaching to below posterior margin of eye; a low membrane connecting dorsal and caudal; caudal 7 in length; ventrals $1 \frac{1}{2}$ in head. Color brownish, marbled with black anteriorly. Cayenne (Sauvage); not seen by us. (Named for A. Guichenot, formerly ichthyologist of the Muséum d'Histoire Naturelle at Paris.)

Cayennia guichenoti, SAUVAGE, Bull. Soc. Philom., ser. 7, Iv, 1880, 57 Cayenne; Ergen. mann \& Eigenmann, Proc. Cal. Ac. Sci. $1888,76$.

\section{Suborder DISCOCEPHALI.}

Bony fishes "with a suctorial transversely laminated oval disk on the upper surface of the head (homologous with a flat dorsal fin), thoracic ventral fius with external spines, a simple basis cranii, intermaxillary bones flattened, with the ascending processes deflected sideways, and with the supramaxillary bones attenuated backward, flattened, and appressed to the dorsal surface of the intermaxillaries; hypercoracoid (or scapula) perforated nearly in the center, and with 4 short actinosts (carpals)." (Gill.)

This remarkable group consists of a single family, Echeneidida. ( $\delta i \sigma \varkappa o 5$, disk; $\varkappa \varepsilon \varphi \alpha \lambda \eta$, head).

\section{Family CLXXXIX. ECHENEIDIDA.}

\section{(THE REMORAs.)}

Body fusiform, elongate, covered with minute, cycloid scales. Mouth wide, with villiform teeth on jaws, vomer, palatines, and usually on tongue. Premaxillaries not protractile. Lower jaw projecting beyond upper. Spinous dorsal modified into a sucking disk, which is placed on 3030 $-65$ 
the top of the head and neck, and is composed of a double series of transverse, movable, cartilaginous plates, serrated on their posterior or free edges. By means of this disk these fishes attach themselves to other fishes or to floating objects, and are carried for great distances in the sea. Opercles unarmed. Pectoral fins placed high; ventral fins present, thoracic and close together, I, 5; dorsal and anal fins long, withont spines, opposite each other; caudal fin emarginate or rounded. Branchiostegals 7. Gills 4, a slit behind the fourth; yill rakers short; gill membranes not united, free from the isthmus. Pseudobranchiæ obsolete. Several pyloric appendages. No air bladder. No finlets. No caudal keel. Vertebræ more than $10+14$. Genera 4 ; species about 10 , found in all seas, all having a very wide range. The species of this group are apparently descended from a fossil genus, Opisthomyzon, ${ }^{*}$ Cope (glaronensis), characterized by the small posterior disk and slender body.

The following description of this family is given by Dr. Gill: Body elongated, subcylindrical, diminishing backward gradually firom the head and into the slender caudal peduncle. Anus subcentral. Scales eycloid, very small, and not, or scarcely, imbricated. Lateral line nearly straight and very faint. Head above oblong and with a flattened straight upper surface, furnished with an adhesive oblong or elongated, laminated disk. The eyes are rather small, submedian, and overhung by the disk. Suborbital bones forming a slender infraorbital chain; the first or preorbital triangular and thick. Opercular apparatus normally developed and unarmed. Nostrils double, close together. Mouth terminal or, rather, superior, the lower jaw projecting, but with the cleft nearly horizontal and not extending laterally to the eyes. Teeth present on the jaws and palate. Branchial apertures ample and fissured forward. Branchiostegal rays 7 (or 8 ) on each side. The adhesive disk on the upper surface of the head is a modified first dorsal fin, and from the snout generally extends more or less posteriorly on the nape and back; it is oblong or elongated and of an oval or elliptical form, divided into equal halves by a longitudinal septum, and with more or less numerous transverse lamina in each division, the laminæ being slightly erectile and depressible. Dorsal fin oblong or elongated on the posterior half of the body (including head), ending some distance from the caudal. Anal fin opposite and similar to the dorsal. Caudal fin rather small, variable in outline, but never deeply forked. Pectoral fins moderate, inserted high on the sides. Ventral fins thoracic, each with a spine and 5 branched rays. The vertebral columu has vertebræ in slightly increased numbers, the abdominal vertebrx being about 12 to 14 and the caudal 15 or 16 . The stomach is creal and the pyloric caca are present in moderate numbers. The air bladder is obsolete.

* "A careful comparison of the proportions of all the parts of the skeleton of the fossil Echeneis with those of the living forms, such as Echeneis naucrates or Echeneis remora, shows that the fossil differs nearly equally from both, and that it was a more normally shaped fish than either of these forms. The head was narrower and less flattened, the preoperculum wider, but its two jaws had nearly the same length. The ribs, as also the neural and hæmal spines, were longer, the tail more forked, and the soft dorsal fin much longer. In fact, it was a more compressed type, probably a far better swimmer than its living congeners, as might be expected, if the smallness of the adhesive disk is taken into account." (Storms.) This form (Echeneis glaronensis, Wellstein) is made the type of the genus Opisthomyzon, Cope, the name referring to the posterior portion of the small disk. The vertebræ in Opisthomyzon are $10+13=23$. 
Concerning the relations of this family, Dr. Gill has the following pertinent remarks :

"The family of Scombéroïdes was constituted by Cuvier for certain forms of knowul organization, among which were fishes evidently related to Caranx, but which had free dorsal spines. In the absence of knowledge of its structure, the genus Elacate was approximated to such because it also had free dorsal spines. Dr. Giinther conceived the idea of disintegrating this family, because, inter alias, the typical Scomberoides (family Scombrida) had more than 24 vertebre and others (family Carangida) had just 24. The assumption of Cuvier as to the relationship of Elacate was repeated, but inasmuch as it has 'more than 24 vertebro' (it has $25=12+13$ ) it was severed from the free-spined Carangida and associated with the Scombrida. Elacate has an elongated body, flattish head, and a colored longitudinal lateral band; Echeneis has also an elongated body, flattened head, and a longitudinal lateral band; therefore Echeneis was considered to be next allied to Elacate and to belong to the same family. The very numerous differences in structure between the two were entirely ignored, and the reference of the Echencis to the Scombrida is simply due to assumption piled on assumption. The collocation need not, therefore, longer detain us. The possession by Echeneis of the anterior oval cephalic disk in place of a spinous dorsal fin would alone necessitate the isolation of the genus as a peculiar family. But that difference is associated with almost innumerable other peculiarities of the skeleton and other parts, and in a Iogical system it must be removed far from the Scombrida, and probably be endowed with subordinal distinction. In all essential respects it departs greatly from the type of structure manifested in the Scombrida and rather approximates-but very distantly-the Gobioidea and Blennioidea. In those types we have in some a tendency to flattening of the head, of anterior development of the dorsal fin, a simple basis cranii, etc. Nevertheless, there is no close affinity nor even any tendency to the extreme modification of the spinous dorsal exhibited by Echeneis. In view of all these facts Echeneis, with its subdivisions, may be regarded as constituting not only a family but a suborder. * * * Who can consistently object to the proposition to segregate the Echeneidida as a suborder of teleocephaleous fishes? Not those who consider that the development of 3 or 4 inarticulate rays (or even less) in the front of the dorsal fin is sufficient to ordinarily differentiate a given form from another with only 1 or 2 such. Certainly the difference between the constituents of a disk and any rays or spines is much greater than the mere development or atrophy of articulations. Not those who consider that the manner of depression of spines, whether directly over the following, or to the right or left alternately, are of ordinal importance; for such differences again are manifestly of less morphological significance than the factors of a suctorial disk. Nevertheless, there are doubtless many who will passively resist the proposition because of a conservative spirit, and who will vaguely recur to the development of the disk as being a 'teleological modification,' and as if it were not an actual fact and a development correlated with radical modifications of all parts of the skeleton at least. But whatever may be the closest relations of Echeneis, or the systematic 
value of its peculiarities, it is certain that it is not allied to Elacate any more than to others of the hosts of Scombroid, Percoid, and kindred fishes, and that it differs in toto from it, notwithstanding the claims that have been made otherwise. It is true that there is a striking resemblance, especially between the young-almost as great, for example, as that between the placental mouse and the marsupial Antechinomys-but the like is entirely superficial, and the scientific ichthyologist should be no more misled in the case than would the scientific therologist by the likeness of the marsupial and placental mammals."

a. Body very slender, the vertebræ $14+16=30$; ventrals narrowly adnate to abdomen; lower jaw produced in a flap; pectorals acute, with flexible rays.

b. Laminæ 10 only.

bb. Laminæ 20 to 28.

Phtheirichthys, 833. ECHENEIS, 834.

$a a$. Body rather robust, the vertebræ $12+15=27$; ventrals broadly adnate to abdomen; lower jaw not produced; pectorals rounded.

c. Laminæ 24 to 27.

cc. Laminæ 16 to 20.

d. Pectoral rays soft and flexible.

dd. Pectoral rays stiff and ossified.

REMILEGIA, 835.

REMORA, 836. RHомвоснIRUS, 837.

\section{PHTHEIRICHTHYS, Gill.}

Phtheirichthys, GILL, Proc. Ac. Nat. Sci. Phila. 1862, 239 (lineata).

Disk with 10 laminx; palatines with sharp teeth; teeth in pairs, uniform in all ages; otherwise as in Echeneis. A single species, found attached to spearfishes and Barracudas. ( $\psi \theta \varepsilon i \rho$, a louse; $i \chi \theta v_{5}$, fish.)

\section{PHTHEIRICHTHYS LINEATCS (Menzies).}

Head 5; disk twice as long as broad, its length $4 \frac{1}{2}$ in body. D. X-33; A. 33. Lower jaw very narrow, much projecting. Body blackish, with 2 whitish lateral bands; all the fins white-margined. Tropical seas, ranging north to South Carolina and Pensacola ; rather rare. (lineatus, striped.)

Echeneis lineata, MEnzies, Trans. Linn. Soc. London, I, 1791, 187, pl. 17, fig. 1, Pacific Ocean between the tropics; GÜNTHER, Cat., II, 382, 1860.

Echeneis tropica, EupHrASEN, Nya Handl., XII, 317, 1791, Atlantic between the Tropics.

Echeneis apicalis, Posy, Memorias, II, 254, 1861, Cuba. (Coll. Poey.)

Echeneis sphyrcenarum, POEY, Memorias, II, 255, 1861, Cuba, on Barracudas. (Coll. Poey.) Phtheirichthys lineatus, JORDAN \& GLBERT, Synopsis, 969, 1883.

\section{ECHENEIS (Artedi) Linnæus.}

Echeneis (ARTED:) LINNAUs, Syst. Nat., Ed. X, 260, 1758 (naucrates).

Leptecheneis, Grul, Proc. Ac. Nat. Sci. Phila. 1864, 60 (naucrates); the name Echeneis being transferred to $E$. remora, the only species known to Artedi.

Body comparatively elongate, the vertebræ $14+16=30$; disk long, of 20 to 28 laminæ; pectoral pointed, its rays soft and flexible; soft dorsal and anal long, of 30 to 41 rays each; caudal lunate in the adult, convex in the young. Species of wide distribution, attaching themselves mainly to sea turtles and large fishes. ( $\dot{x} \chi v \nu \eta i \bar{s}$, an ancient name, from $\varepsilon^{\prime} \chi \omega$, to hold back; $v \alpha v \dot{s}$, a ship.) 
a. Disk of 22 to 26 laminæ (rarely 21 or 28 ), its length less than $\frac{1}{4}$ body.

NAUCRATES, 2603.

aa. Disk of 20 or 21 lamina, its length more than $\frac{1}{4}$ body. NAUCRATEOIDES, 2604.

2603. ECIENFIS NAUCRATES, Linnæus.

(Shark-sucker; Pega; Pegador; Sucking-fish.)

Head $5 \frac{1}{4}$; depth 11 to 12 . D. XXII to XXVIII (rarely XXI)-32 to 41 ; A. 31 to 38 . Breadth between pectorals $7 \frac{1}{2}$; disk 4 to 5 in body; eye 5 in head; snont $2 \frac{1}{3}$; maxillary 3 ; from angle of mouth to tip of lower jaw $2 \frac{2}{3}$; pectoral $1 \frac{2}{5}$; ventrals $1 \frac{1}{2}$; niddle caudal rays $1 \frac{2}{5}$; highest anal ray 2 ; highest dorsal ray $2 \frac{1}{3}$; width of disk $2 \frac{1}{2}$ in its length; base of dorsal $2 \frac{1}{2}$, anal $2 \frac{1}{2}$, in body. Body elongate, subterete, slender. Lower jaw strongly projecting, the tip flexible; maxillary reaching nostril; teeth uniform in the adult, the young with series of small slender teeth iu advance of the others; gill rakers short and slender, abont equal to pupil; vertical fins low. Anal rays higher than dorsal anteriorly; pectorals reaching very slightly past tips of ventrals; origin of ventral spine nnder middle of pectoral base; inner rays of ventral fins narrowly adnate to the abdomen; dorsal and anal commencing and ending opposite each other; caudal with the middle rays produced in the young, the fin becoming emarginate or Innate with age. Color brownish; belly dark, like the back, as usual in this family; sides with a broad stripe of darker edged with whitish extending through eye to snout; candal black, its onter angles whitish; pectorals and ventrals black, sometimes bordered with pale; dorsal and anal broadly edged with white anteriorly; adult nearly uniform dark brown, not paler below. Warm seas, universally distributed; common north to Cape Cod and occasionally to San Francisco, attaching itself to turtles and to large fishes. This species is very common in the tropics, being found attached to sharks, groupers, or any otler large fish, without regard to species. Few large sharks at Key West are without them. They are often caught with hook and line from the wharf, where they frequently forsake their host to take the bait. Liitken's remark that only Remora remora has been recorded from sharks is no longer true. Several writers have recognized 2 species of Echeneis proper-naucrates, with 22 to 26 lamina, the disk 4 to 5 in body, and naucrateoides (=albicauda=holbrooki $=$ lineatus $)$, in which the disk is longer, $3 \frac{3}{5}$ to 4 in body, but composed of fewer, 20 or 21, lamina. The latter form is rather common on our coast, the specimens from Key West above mentioned having 21 . We doubt the existence of any permanent difference between the two, but provisionally retain Echeneis naucrateoides as a species distinct from Echeneis naucrates until more complete comparison can be made. (naucrates, a pilot; $\nu \alpha \tilde{v} \varsigma$, ship; $\varkappa \rho \alpha \tau \varepsilon \dot{\varepsilon} \omega$, to govern, guide.)

Echeneis neucrates (misprint for naucrates), LiNNAus, Syst. Nat., Ed. X, 261, 1758, "in

Pelago Indico ;" Günther, Cat., II, 384, 1860; Jordan \& GILBERT, Synopsis, 416, 1883.

Echeneis albicauda, Mrrchul, Amer. Monthly Mag., If, 1817, 244, New York.

Echeneis lunata, BAncroft, Proc. Comm. Zool. Soc., I, 1830, 134, Kingston, Jamaica.

$?$ Echeneis vittata, Lowe, Proc. Zool. Soc. Lond. 1839, 89, Madeira.

Echeneis fasciata, Gronow, Ed. Gray, 92, 1854, Mediterranean Sea.

Leptecheneis naucrates, GiLL, Proc. Ac. Nat. Sci. Phila. 1864, 60. 
Echeneis vittata, RïPPELL, Neue Wirb. Fische, 82, 1835, Red Sea.

Echeneis guaiacan, PoEx, Memorias, II, 248, 1861, Cuba; young. (Coll. Poey.)

Echeneis verticalis, PoEY, Memorias, II, 253, 1861, Cuba; young.

Echeneis metallica, PoEx, Memorias, II, 252, 1861, Cuba; D. XxIII, 40; A.37; large specimen, metallic green, the bands faint. (Coll. Poey.)

Echeneis fusca, Grovow, Cat. Fish., 92, 1854; after E. naucrates, L.

2604. ECHENEIS NAUCRATEOIDES, Zuiew.

Head 5; depth 11. D. XX or XXI-32 to 35 ; A. 33 to 35 . Disk $3 \frac{2}{3}$ to $3 \frac{8}{4}$ in total, twice width of body between pectorals. In all other respects essentially as in Echeneis naucrates, the disk longer, but composed of fower laminæ, the lamina being farther apart. Color of Echeneis naucrates. Cape Cod to West Indies, common on our south Atlantic coast; speci-

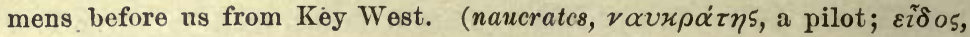
resemblance.)

Echeneis neucratoides, ZUIEw, Nova Acta Acad. Sci. Imp. Petropol., IV, 1789, 279, no locality. Echeneis lineata, HoLвrook, Ichth. S. C., 102, 1860, Charleston, South Carolina; not of Menzies.

Echeneis holbrooki, GüNTHER, Cat., II, 382, 1860, Jamaica; D. XIII, 35; A. 33.

Leptecheneis naucrateoides, Gwh, l. c., 61.

\section{REMILEGIA, Gill.}

Remilegia, Grl., Proc. Ac. Nat. Sci. Phila. 1864, 61 (australis).

This genus differs from Remora chiefly in the length of the sucking disk, which has 24 to 27 laminæ; the soft dorsal and anal are proportionately short. (A metathesis for remeligo, the delayer or hinderer.)

\section{REMILEGIA AUSTRAIIS (Bennett).}

D. XXVII-22; A.21 to 23 . The length of the disk is $2 \frac{1}{8}$ in the total, the width of the body between the pectorals $5 \frac{3}{5}$. Caudal truncated; dorsal and anal fins not continued to the caudal. Color brown. This species has the general babit of E. remora, but may be readily distinguished from all the others by the extraordinary size of the disk, which is elongate, subelliptical, obtusely rounded anteriorly and posteriorly, and formed by 27 pairs of lamine; it extends backward beyond the vertical from the tip of the ventrals, and its length is $2 \frac{1}{8}$ in the total. The spines with which the single lamina are armed are less conspicuous than in the other species, and do not offer the same resistance to the touch. There is a large posterior portion of the disk which is not provided with laminæ, but quite smooth. The width of the disk, taken between the extremities of the bony laminx, is $\frac{1}{8}$ of its length; the membranaceous margin is bent upward. The head and the body below the disk are depressed, and their height is $9 \frac{1}{2}$ in the total length, whilst the width between the pectorals is $5 \frac{3}{5}$ in it. The body between the disk and the vertical fins is quadrangular, tapering posteriorly. The upper jaw is subtruneated, and overreached by the lower, which is mueh narrower; both are armed with a broad band of villiform teeth, and with an onter series of larger ones on 
the sides; the vomerine and palatine bones have a continuous band of teeth, narrowest on the vomer; the tongue is hard, cartilaginous, and destitute of teeth. The cleft of the mouth reaches only to the vertical from the nostril; the eye is small. The pectoral is rounded and small, its length being $\frac{1}{9}$ of the total; the ventrals are slightly pointed, and, as in all the species of the genus, composed of 1 spine, hidden in the skin, and 4 soft rays; they are inserted immediately behind the vertical from the pectoral, which they equal in length; they ean be received in a shallow groove on the abdomen. The distance between the dorsal and the disk is $3 \frac{1}{2}$ in the length of the latter; the dorsal is low, and enveloped in a thick membrane. The caudal is truncated when stretched out. The anal is very similar to the dorsal, and its origin and termination fall vertically below those of the latter. The scales are minute, and can be perceived only by the aid of a magnifier; they are embedded in pore-like cavities. (Guinther: description of type of Echeneis scutata.) Tropical seas; rare; recorded by Dr. Lütken from $10^{\circ}$ N., $39^{\circ}$ W. (Coll. Capt. V. Hygom) from a dolphin; not seen by us. (australis, southern.)

Echeneis australis, BENNETT, Narr. Whaling Voyage, II, 273, pls. 24-26, 1840.

Echeneis scutata, GÜNTHer, Ann. Mag. Nat. Hist. 1860, 401, pl. 10, f. B, Ceylon (Coll. Dr. Sibbald); GÜnther, Cat. Fish., II, 381, 1860; Lëtken, Vid. Medd. Kjöbenh. 1875, 42.

\section{REMORA, Gill.}

\section{(REMORAS.)}

Remora, Grul, Proc. Ac. Nat. Sci. Phila. 1862, 239 (remora).

Echeneis, GIL, Proc. Ac. Nat. Sci. Phila. 1864, 60 (remora); not Echeneis, GILL, 1862, restricted to naucrates.

Remoropsis, GILL, Proc. Ac. Nat. Sci. Phila. 1864, 60 (brachypterus).

Remorina, Jordan \& Evermann, Check-List Fishes, 490, 1896 (albesens).

Body rather robust, the vertebræ $12+15=27$; disk shortish, of 13 to 18 laminæ; pectoral rounded, its rays soft and flexible; soft dorsal and anal moderate, of 20 to 30 rays; caudal subtruncate. Species attaching themselves to large fishes, especially to sharks. (Remora, an ancient name, "holding back.")

REMORA :

a. Laminæ about 18 ; soft dorsal with 23 rays.

REMORA, 2606.

aa. Laminæ 13 to 16.

REMORINA :

b. Dorsal rays XIII, 22.

ALBESCENS, 2607.

REMOROPSIS (Remora; ö $\psi$ is, appearance) :

bb. Dorsal rays XIV, XVI, 29 to 32.

BRACHYPTERA, 2608.

Subgenus REMORA.

2606. REMORA REMORA (Linnaus).

(REMORA.)

Head 4; disk $2 \frac{8}{4}$; width between pectorals $5 \frac{1}{4}$. D. XVIII-23; A. 25; vertebræ $12+15$. Body comparatively robust, compressed behind. Pectoral fins rounded, short, and broad, their rays short and flexible; ventral fins 
adnate to the abdomen for more than $\frac{1}{2}$ the length of their inner edge. Tip of lower jaw not produced into a flap; head broad, depressed; disk longer than the dorsal or the anal fin; maxillary scarcely reaching front of orbit. Caudal lunate; vertical fins rather high; pectoral $\frac{3}{5}$ length of head. Color blackish, nearly uniform above and below. Length 15 inches. Warm seas, north to New York and San Francisco, where it is not rare; usually found attached to large sharks; very common in the West Indies; more robust than Echeneis naucrates, and reaching a smaller size.

Echeneis remora, Linweus, Syst. Nat., Ed. x, 260, 1758, "in Pelago Indico;" Günther, Cat., II, 378, 1860; Lütken, Vid. Medd. Kjöbenh.1875, 38; JoRdaN \& Gilbert, Synopsis, 417, 1883.

Echeneis squalipeta, DALDorF, Skrivt. Naturh. Selsk., II, 1797, 157, Atlantic Ocean between the tropics ; GÜNTHER, Cat., II, 377, 1860.

Echeneis jacobaea, Lowe, Proc. Zool. Soc. London 1839, 89, Madeira.

Echeneis remoroides, BLEEKER, Batoë, II, 70, Batoe.

Echeneis parva, Growow, Cat. Fish., Ed. Gray, 92, 1854, no locality ; after E. remora, L. Echeneis postica, PokY, Memorias, II, 255, 1861, Havana. (Coll. Poey.)

Remora jacoboea, GiLl, Proc. Ac. Nat. Sci. Phila. 1862, 239.

Subgenus REMORINA, Jordan \& Evermann.

2607. REYORA ALBESCENS (Temminck \& Schlegel).

Length of disk $3 \frac{1}{5}$ to $3 \frac{1}{4}$ in total length; width between pectorals 5 to $5 \frac{1}{3}$; number of laminæe on disk 13 or 14. D. XIII-22; A. 22. Angle of mouth in the vertical from the third lamina of the disk. Length of ventral fius equal to the distance between root of pectoral and posterior margin of eye. Color uniform grayish brown. (Günther.) Tropical Pacific, straying to America; a specimen taken at La Paz, Gulf of California (Streets), and 1 in the Gulf of Mexico (Bean). (albescens, whitish.)

Echeneis albescens, Temminck \& Schlegel, Fauna Japonica, Poiss., 272, pl. 120, fig. 3, 1842,

Japan; GÜNTher, Cat., II, 377, 1860; STreets, Bull. U. S. Nat. Mus., viI, 54, 1877.

Remora albescens, JoRDAN, Cat. Fishes, 66, 1885.

Subgenus REMOROPSIS, Gill.

2608. REMORA BRACIYPTERA (Lowe).

Head nearly 4; width between pectorals $6 \frac{1}{2}$. D. XIV to XVI-29 to 32 ; A. 25 to 30 . Body robust, the greatest depth nearly twice the length of the short pectoral fins; disk shorter than base of dorsal, rather broad; npper jaw angular. Caudal nearly truncate. Light brown, darker below, fins paler. Warm seas, occasionally north to Cape Cod. ( $\beta \rho \alpha \chi v \dot{v}$, short; $\pi \tau \varepsilon \rho o \dot{v}$, fin.)

Echeneis brachyptera, Lowe, Proc. Zool. Soc. London 1839, 89, Madeira; GüNTHER, Cat., II, 378, 1860; JoRDAN \& GILBERT, Synopsis, 417, 1883.

Echeneis sexdecimlamellata, ExDoux \& GervaIs, Voy. Favorite, v, 77, pl.31, 1839, Indian Ocean?

Echeneis quatuordecimlaminatus, STORER, Rept. Fishes Mass., 155, 1839, Holmes Hole.

Echeneis pallida, Temminck \& Schleg EL, Fauna Japonica, Poiss., 271, pl. 120, tig. 2, 3, 1842, Japan.

Echeneis nieuhofi, BLEEKER, Sumatra, II, 279, Sumatra.

Kemoropsis brachypterus, GiLl, Proc. Ac. Nat. Sci. Phila. 1864, 60. 


\section{RHOMBOCHIRUS, Gill.}

Rhombochirus, GiLL, Proc. Ac. Nat. Sci. Phila. 1863, 88 (osteochir).

This genus agrees with Remora in every respect excepting the structure of the pectoral fins. These are short and broad, rhombic in outline, the rays all flat, broad and stiff, being partially ossified, although showing the usual articulation; upper rays of pectoral broader than the others. One species known. (

\section{RHOMBOCHIRUS OSTEOCHIR (Cuvier).}

Head $4 \frac{2}{3}$ in length; disk $2 \frac{1}{4}$; width between pectorals 5. D. XVIII-21 to 23 ; A. 20 or 21 ; P. 20 . Mouth very small, maxillary not nearly reaching to the line of the orbit; outer series of teeth longer than the others. Disk very large, broader and rongher than in Remora remora, extending forward beyond the tip of the snout. Caudal fin emarginate, with rounded angles. Light brown; underside of head, ventral line, part of ventrals and a spot on pectorals pale. West Indies north to Cape Cod; parasitic

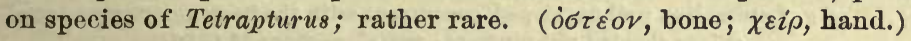

Echeneis osteochir, Cuvier, Règne Animal, Ed. 2, vol. II, 348, 1829, no locality given; GÜNTHER, Cat., II, 381,1860; Jordan \& Gilbert, Synopsis, 418, 1883.

Echeneis tetrapturorum, PoEx, Memorias, II, 256, 1858, Cuba. (Coll. Poey.)

\section{Group TRACHINOIDEA.}

\section{(The Trachinoid Fishes.)}

A large group of transitional forms, some of them of doubtful relationships, showing affinities with the Percoidea on the one hand and with the Batrachoidide and Blennoidea on the other. In general, the spinous dorsal is short or weak, the soft dorsal long and similar to the anal, and the squamation is less complete and less ctenoid than in the Percoidea. The skull is, in general, depressed, with the supracular crest low, and the suborbital stay is wanting, although in some genera the suborbital bones are enlarged. The bones of the skull are not strongly armed, and the ventral fins are often inserted well forward, and they are sometimes reduced in size. The group is divided by Dr. Gill into Percophidoidea, Trachinoidea, and Uranoscopoidea. The two latter groups are natural and related, but, as Dr. Gill observes, "the Percophidoidea are undoubtedly a heterogeneons group and need a thorough revision." The relations of Bathymaster, Trichodon, and Latilus especially are uncertain. Several of the leading families of this group are confined to the South Temperate Zone, and none of the Trachinidee oceurs within our limits.

a. Mouth horizontal or moderately oblique, the lips not fringed; eyes lateral; ventral rays $I, 5$, their insertion more or less before the pectorals; suborbitals moderate; gills 4, a slit behind the fourth.

b. Snout subconic, not prolonged and spatulate; ventrals not widely separated.

c. Body covered with scales; dorsal spines flexible.

d. Lateral line complete; caudal fin forked; vertebræ 24 to 27. 
$d d$. Lateral line incomplete, running close to the back; caudal rounded or lanceolate; dorsal fin continuous.

e. Vertebræ about 27; scales cycloid; maxillary more or less dilated behind, with a supplemental bone; middle rays of ventrals longest.

OPISTHOGNATHIDE, CXCI.

ee. Vertebræ about 50; scales ctenoid; maxillary not dilated, without supplement bone; inner rays of ventrals longest.

BATHYMASTERIDA, CXCII.

cc. Body naked; snout short; mouth very large, the maxillary much produced

behind; jaws with sharp canines; lateral line well developed; dorsals 2; caudal forked.

CHIASMODONTID , CXCIII.

$b b$. Snout much prolonged and spatulate; ventrals widely separated; body scaly or naked; lateral line near the back; dorsal usually divided.

Chenichthyide, CXCIV.

aa. Mouth vertical, the lips fringed.

$f$. Eyes lateral; gills 4, a slit behind the last; preopercle armed; body naked, compressed; caudal lunate, on a slender peduncle; vertebræ about 48.

TRICHODONTIDE, CXCV.

ff. Eyes superior; gills more or less reduced, usually $3 \frac{1}{2}$, the last slit small or wanting; suborbitals more or less dilated; body scaly or naked.

g. Lateral line well developed, concurrent with the back anteriorly; dorsal spines slender, not pungent; vertebræ about 25 to 30 .

$h$. Ventral rays I, 3.

DACTYLOSCOPIDE, CXCVI. gg. Lateral line obscure; dorsal spines few, more or less pungent, some. times obsolete.

URANOSCOPIDE, CXCVII-

\section{Family CXC. MALACANTHIDA.}

\section{(The Blanguillos.)}

Body more or less elongate, fusiform or compressed. Head subconical, the anterior profile usually convex; suborbital without bony stay; the bones not greatly developed; cranial bones not caveruous; opercular bones mostly uuarmed. Mouth rather terminal, little oblique; teeth rather strong; no teeth on vomer or palatines; the premaxillary usually with a blunt posterior canine, somewhat as in the Labrida; premaxillaries protractile; maxillary without supplomental bone, not slipping under the edge of the preorbital. Gills 4, a long slit behind the fourth; pseudobranchire well developed; gill membranes separate, or more or less united, often adherent to the isthmus; lower pharyngeals separate. Scales small, ctenoid; lateral line present, complete, more or less concurrent with the back; dorsal fin long and low, usually continuous, the spinous portion always much less developed than the soft portion, but never obsolete; anal fin very long, its spines feeble and few; caudal fin forked; tail diphycercal; ventrals thoracic or subjugular, I, 5 , close together; pectoral fins not very broad, the rays all branched; vertebre in normal or slightly increased number (24 to 30). Pyloric cœea few or none. Fishes of the temperate and tropical seas, some of them reaching a large size. Genera about 6; species about 8 to 10, mostly American. The relationships of the family are obscure, and it may be that the genera here associated are not really closely allied. (Malacanthida, Giinther, Cat., III, 359, 1861; Trachinida, part, Giinther, Cat., II, 225-264, 1860.) 
MaLACANTHINA:

a. Vertebræ 24; preopercle entire.

b. Soft dorsal and anal extremely long, each with more than 40 rays; preopercle entire; form slender; scales very small.

Malacanthus, 838.

aa. Vertebræ more than 24; preopercle more or less serrate.

CaUlOLathina:

c. Soft dorsal and anal moderate, each with 22 to 27 soft rays; preopercle serrate; scales rather small; form robust.

d. Upper jaw with posterior canines; dorsal spines graduated.

LATILIN A:

Caulolatilus, 839.

cc. Soft dorsal and anal short, each of 13 to 15 soft rays; preopercle denticulate; scales small; form robust.

e. Nape with a large adipose appendage; a fleshy prolongation on each side of the labial fold, extending forward behind angle of mouth.

LophoLATiLUs, 840.

838. MALACANTHUS, Cuvier.

\section{(Matajúlelo Blanco.)}

Malacanthus, Cuvier, Règne Animal, Ed. 2, vol. II, 205, 1829 (plumieri).

Body elongate, slightly compressed; cleft of mouth horizontal, with the jaws equal; eyes lateral; scales very small, minutely ciliated; one continuous dorsal, with the first 4 to 6 rays not articulated; dorsal and anal very long; pectoral rays all branched; jaws with villiform teeth; an outer series of stronger teeth, some of them canine-like, and with a canine at the posterior extremity of the intermaxillary; no teeth on the palate; preopercle entire; opercle with a spine; gill rakers little developed; vertebræ in small number, $10+14=24$. One species, a shore fish of tropical America. ( $(\mu \alpha \lambda \alpha \varkappa o ́ s$, soft; $\ddot{\alpha} \varkappa \alpha \nu \theta \alpha$, spine.)

\section{Malacanthos PLUMieri (Bloch).}

(Matajuelo Blanco.)

Head $3 \frac{2}{8}$; depth $6 \frac{1}{2}$. D. VI, 49 ; A. 48; scales $14-130-30$; eye $5 \frac{1}{2}$ in head; maxillary $2 \frac{7}{5}$; snout $2 \frac{1}{2} ;$ P. 2 ; 1ongest dorsal rays 3 , equal to anal ray; upper caudal lobe 12. Body elongate, little compressed. Head moderately long and pointed; eje placed high; interorbital flat, as wide as eye; profile of head obliquely straight from. tip of snout to above nostril, where there is a slight angle formed, thence nearly horizontally straight to dorsal. Mouth large, maxillary reaching slightly past the vertical from posterior nostril; jaws equal; a band of villiform teeth in upper jaw growing broader anteriorly, and another row of small, even, conical teeth at the sides, and 6 well-developed canines in front, the 2 outer ones the largest; a canine on premaxillary at angle of mouth; villiform teeth in lower jaw not extending very far back; large recurved canines on side of jaw anteriorly, small conical teeth in front and on sides posteriorly, with a single large canine at angle of mouth; gill rakers rudimentary, about $5+7$. Top of head forward from above middle of eye, preorbital, and lower jaw, naked; fins withou scales. Dorsal and anal similar, long and low, continuous; pectoral reaching past tips of ventrals to front of 
anal; ventrals not reaching to vent, origin of ventral spine slightly behind base of pectoral; caudal forked, the lobes elongate, sometimes produced into a filament. Color in spirits, uniform, pale olive brown above, white below; fins light brownish; no distinct markings. Length 15 inches. West Indies, rather common; used as food. Here described from specimens from Havana. (Named for Père Plumier, of Martinique.)

Matejuelo blanco, PARra, Dif. Piezas Hist. Nat. Cuba, 22, tab. 13, f. r. 1787, Cuba.

Coryphana plumieri, BLOCH, Ichthyol., v, 119, pl. 175, 1787, Martinique; from a drawing by Plumier.

Malacanthus trachinus, VALENCIENNES, in CUVIER, Règne Animal, pl.90, fig. 3.

Sparus oblongus, BLOCH \& SCHNEIDER, Syst. Ichth., 283, 1801; after PARRA.

Malacanthus plumieri, Cuvier \& VAlenciennes, Hist. Nat. Poiss., XIII, 319, 380, 1839, specimens from San Domingo; GÜNTHER, Cat., III, 359, 1861.

\section{CAULOLATILUS, Gill.}

\section{(BlaNquillos:)}

Caulotatilus, Gill, Proc. Ac. Nat. Sci. Phila. 1862, 240 (no diagnosis), and Gill, Proc. Ac Nat. Sci. Phila. 1865, 66 (chrysops).

Dekaya, CoOPER, Proc. Cal. Ac. Sci. 1864, 70 (princeps), not Dekayia, Milne-Edwards \& HAIME, 1851, a genus of corals.

Body elongate, subfusiform, not strongly compressed, heavy forward, tapering to a rather slender caudal peduncle; profile of head strongly arched; mouth moderate, little oblique, the jaws nearly equal; lips thick ; maxillary narrow, not slipping under the preorbital; teeth in villiform bands, preceded by a row of stronger acute teeth; posterior teeth in each jaw canine-like, directed forward; posterior canines of upper jaw largest; no teeth on vomer or palatines; preopercle pectinate, the teeth nearly even; opercle with a blunt, flat spine; eyes large, lateral; gill membranes slightly connected, forming a fold across the isthmus, with which they are narrowly joined; branchiostegals 6 ; gill rakers short and stout; nostrils double, round, close together; scales small, firm, ctenoid; lateral line continuous, concurrent with the back; dorsal with 7 to 9 slender, pointed, graduated spines and 22 to 27 soft rays; anal similar to soft dorsal, with 1 or 2 small spines and more than 20 soft rays; caudal fin forked; ventral fins thoracic; no adipose appendage at the nape; vertebræ $12+15=27$. Large fishes of the warm seas of America; valued as food. ( $\varkappa \alpha v \lambda o$, stem; Latilus; being distinguished from Latilus by the many rays.)

$a$. Scales small, about 125 in the lateral line, about 50 in a transverse series.

b. Eye large, $4 \frac{1}{2}$ in the head; depth 4 in length; scales 16-125-40.

$b b$. Eye small, 6 in head; depth $3 \frac{1}{2}$ in body; scales 13-120-35.

PRINCEPS, 2611. MICROPS, 2612. aa. Scales larger, about 108 in the lateral line, about 25 in a transverse series; scales 12-108-25. CYANOPS, 2613.

2611. CaUlolatildS PRixceps (Jenyng).

(BLANQUILLO; WHITE-FISH.)

Head $3 \frac{2}{3}$; depth 4. D. IX, 24; A. II, 23; scales 16-125-40. Flesh of the occiput becoming thick with age, as in Harpe. Eye large, about $\frac{7}{2}$ the convex iuterorbital space, $4 \frac{1}{2}$ in head; maxillaries reaching front of eje; 
teeth rather strong; preopercle finely, evenly, and acutely serrate behind, nearly entire below; preopercle, interopercle, and preorbital naked; cheeks and opercles scaly; top of head scaled on the median line to between the eyes; dorsal spines flexible; ventrals slightly behind the pectorals, the outer rays longest; caudal moderately forked, the upper lobe the longer; caudal perincle short and slender, abruptly contracted; pectorals falcate, longer than caudal, $\frac{5}{6}$ length of the head. Olivaceous, with bluish reflections; brownish above, greenish below; fins light greenish olive, tinged with bluish and orange, the colors always pale; dorsal and anal greenish, with a bluish band near the tip; axil dusky. Rocky islands of the Pacific coast from Monterey southward to the Galapagos; abundant about the Santa Barbara Islands; a food fish of considerable importance. Length 40 inches. We are unable to detect any differences by which the Californian form, Caulolatilus anomalus, can be separated from Caulolatilus princeps. (princeps, a leader.)

Latilus princeps, JenYNs, Zool. Beagle, Fishes, 52, pl. 11, 1840, Chatham Island, Galapagos Archipelago (Coll. Charles Darwin); Günther, Cat., Ir, 253, 1860.

Dekaya anomala, Cooper, Proc. Cal. Ac. Sci. 1864, 70, coast of Southern California.

Caulolatilus affinis, GiLl, Proc. Ac. Nat. Sci. Phila. 1865, 68, Cape St. Lucas. (Coll. John Xantus.)

Caulolatilus princeps, GILL, l. c. 68.

Caulolatilus anomalus, GiLl, l. c. 68; STreets, Bull. U. S. Nat. Mus., vir, 48, 1877; JoRdAN \& GILbert, Synopsis, 625, 1883.

\section{CAULOLATILUS MICROPS, Goodo \& Bean.}

Head $3 \frac{1}{2}$; depth $3 \frac{1}{2}$. D. VII, 25; A. I, 23 ; scales 105 counting the oblique series, 120 counting the row above lateral line; transverse rows $12+30$; eye $5 \frac{8}{4}$ in head; snout 2 ; maxillary $2 \frac{1}{2}$; pectoral $1 \frac{1}{3}$; ventral $2 \frac{1}{10}$; highest dorsal spine $3 \frac{1}{3}$; highest anal rays $3 \frac{1}{5}$; upper caudal lobe $1 \frac{1}{2}$. Body rather robust; upper profile of head rather steep, evenly rounded from tip of snout to dorsal; nostrils small, midway between eye and tip of snout, separated by a distance equal to $\frac{1}{2}$ diameter of pupil; mouth large, maxillary scarcely reaching to anterior margin of eye; lips thick; lower jaw included; jaws with small conical teeth, the outer row enlarged, caninelike, a large tooth on posterior end of maxillary at angle of mouth; preopercle finely and evenly serrate on its vertical limb; a broad flat spine on opercle; snout, preorbital and lower jaw naked; fins scaleless; dorsal and anal similar, long and low; pectorals reaching far past tips of ventrals to vent; origin of ventral spine about the length of 2 scales behind the vertical from pectoral base; caudal fin lunate when spread, its upper lobe slightly the longer. Color reddish, marked with yellow; a yellow band below the eye; a dark blotch in and above axil of pectoral; dorsal light at base, darker above, with many indistinct brownish spots. Gulf of Mexico, in rather deep water; not rare. Here described from a specimen from the Pensacola Snapper Banks, 26 inches in length. A rather doubt-

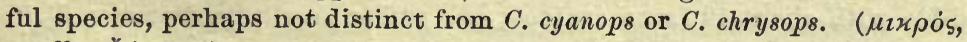
small;

Caulolatilus microps, Goode \& Bean, Proc. U. S. Nat. Mus. 1878, 43, off Pensacola, Florida. (Coll. Silas Stearns.)

Caulolatilus chrysops, JoRDAN \& GILBERT, Synopsis, 626, 1883; not Latilus chrysops, CUVier \& VALENCIENNES. 


\section{CAUlOLATILUS CYAYOPS,* Poey.}

(BLANQUillo.)

Head 4 in total length. D. VII, 24; A. I, 22 (scales 10-108-25. Bean). Profile convex before the eye, not ascending to the nape; no scales on the fins; soft rays little divided; caudal slightly lunate; first caudal vertebra spoon-like, its cavity receiving the air bladder; vertebræ $12+15$; no pyloric cæca, stomach short, air bladder large. Color greenish above, a faint, broad, interrupted brown band above the lateral line; some small brown spots above and below it; region below the eye clear blue, not very different from the color of the belly; soft dorsal brown, paler at its base, edged with orange; spinous dorsal orange. (Poey.) Coast of Cuba; not seen by us. Both this and the preceding species may be identical with Caulolatilus chrysops, a species described from the coast of Brazil.

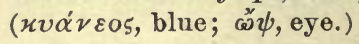

? Latilus chrysops, Cuvier \& Valenciennes, Hist. Nat. Poiss., 1X,496, 1833, Brazil (Coll. M. Gay); GÜNTHER, Cat., II, 253, 1860.

Caulolatilus cyanops, PoEy, Repertorio, I, 312, 1867, Cuba. (Coll. Poey.)

\section{LOPHOLATILUS, Goode \& Bean.}

\section{('TILE-FISHES.)}

Lopholatilus, Goode \& BEAv, Proc. U.S. Nat. Mus. 1879, 205 (chamoeleonticeps).

Body stout; somewhat compressed; mouth moderate, maxillary reaching anterior margin of the orbit; opercle and preopercle scaly, the latter finely denticulate; upper jaw with outer series of stronger teeth, behind which is a band of villiform teeth; lower jaw with a few large canines, and an inner series of small conical teeth; vomer and palatines toothless; nape with a large adipose appendage; a fleshy prolongation npon each side of the labial fold, extending backward beyond the angle of the mouth; stomach small, siphonal, barely more than a loop in the very large intestine; alimentary canal short, less than total length of the body; air bladder simple, with thick muscular walls, strongly attached to the roof of the abdominal cavity by numerous root-like appendages, resembling somewhat that of Pogonias. Deep-sea fishes. ( $\lambda$ óøos, crest; Latilus.)

\section{LOPHOLATILUS CHAMELEONTICEPS, Goode \& Bean.}

\section{(TILE-FISA.)}

Head 3 ; depth $3 \frac{1}{2}$. D. VII, 15; A. II, 13 ; scales $8-93-30$. Body stout, somewhat compressed, its greatest width equaling length of caudal peduncle; intermaxillaries supplied with a series of from 19 to 23 canine teeth, behind which is a band of villiform teeth, widest at the symphysis; mandible with about 12 large canines; eye rather small, its diameter $6 \frac{1}{2}$ in

* The characters distinguishing Caulolatilus chrysops are thus given by Poey: Head $4 \frac{1}{2}$ in total length. D. VIII, 24; A. II, 22. Profile most gibbous behind the eye; a very bright gilded band below the eye, broader anteriorly; dorsal fin brown with irregular blue spots; axillary spot green. Coast of Brazil. 
head, and about twice length of labial appendages; distance between posterior nostril and eye equal first anal spine, and $\frac{1}{2}$ distance from tip of snont to anterior nostril. Caudal fin emarginate, middle rays $1 \frac{1}{2}$ in outer rays; vent under interval between fourth and fifth dorsal rays. Back bluish, with a green tinge, iridescent, changing through purplish blue and bluish gray to rosy white below, and milky white toward median line of belly; head rosy, iridescent, with red tints most abundant on forehead, blue under the eyes, cheeks fawn-colored; throat and under side of head pearly white, with an occasional tint of lemon yellow, most pronounced in front of ventrals and on anterior portion of ventral fins; back with numerous maculations of bright yellow or golden; anal purplish, with blue and rose tints, iridescent; margin of anal rich purplish blue, iridescent, like the most beautiful mother-of-pearl, this color pervading more or less the whole fin, which has large yellow maculations, the lower border rose-colored, like the belly, base of the fin also partaking of this general hue; dashes of milk white on base of anal between the rays; dorsal gray; in front of the seventh dorsal the upper third posterior to the upper two-thirds dark brown; spots of yellow, large, elongate, on or near the rays; adipose fin whitish brown or yellow, a large group of bright yellow confluent spots at the base; pectorals sepia-colored, with rosy and purplish iridescence. (Goode \& Bean.) Deep waters of the western Atlantic, at times very abundant; now rare or almost extinct. "The tilefish was first observed in 1879 by fishermen fishing for cod on Nantucket Shoals. From its abundance it was thought to become of some economic importance. In March and April, 1882, vessels arriving at New York, Philadelphia, and Boston reported having passed large numbers of dead and dying fish, the majority of which were tilefish. Captain Collins estimated the area covered by dead and dying fish to be from 5,000 to 7,500 square statute miles, the number of fish to be $1,000,000,000$. Several visits were made by the Fish Commission vessels to the grounds where these fishes were formerly abundant, but no specimen was obtained, and it was thought to have become extinct. In 1892 several specimens were taken by the Grampus in latitude $38^{\circ}$ to $40^{\circ} \mathrm{N}$, and longitude $71^{\circ}$ to $73^{\circ} \mathrm{W}$. The wholesale destruction of the tilefish in 1882 is thought by Colonel McDonald to be due to climatic causes." (Goode \& Bean.) (chamaleon, $\chi \alpha \mu \alpha \imath \lambda \varepsilon \dot{\varepsilon} \omega$; - ceps, head.)

Lopholatilus chamaleonticeps, Goode \& BEAN, Proc. U. S. Nat. Mus. 1879, 205, Nantucket Shoals; Jordan \& GilberT, Synopsis, 624, 1883; Collins, Rept. U. S. Fish Comm. (1882) 1884, 237; LUCAS, Rept. U. S. Nat. Mus. (Smithsonian Report) 1889, 647, with plate; Goode \& BeAN, Oceanic Ichthyology, 284, 1896.

\section{Family CXCI. OPISTHOGNATHID正.}

\section{('The JaW-Fishes.)}

Body oblong or elongate, low, moderately compressed, covered with small cycloid scales; lateral line present, straight, running close to the dorsal fin, not extending much behind middle of body. Head large, naked, the anterior profile decurved, no ridges, spines, or crests above. Mouth 
terminal, horizontal, its cleft usually very wide, the maxillary sometimes greatly dilated; supplemental maxillary present; premaxillaries protractile; jaws subequal, with conical or cardiform teeth; vomer usually with a few teeth; palatines toothless; opercles unarmed; no suborbital stay. Pseudobranchiæ present. Gill rakers rather long; gills 4, a slit behind the fourth; gill membranes somewhat united, free from the isthmus. Branchiostegals 6. Air bladder present. No pyloric caca. Vertebræ large, about 27 in number. Dorsal fin long, continuous, its anterior half composed of slender, flexible spines, which pass gradually into soft rays; caudal distinct, rounded or lanceolate; tail not isocercal, the last vertebra expanded (27 to 34 ); anal long and low, without distinct spines; ventrals separate, jugular, I, 5, the middle rays longest; pectorals fanshaped. Three genera, of about 15 species; small fishes inhabiting rocky bottoms in tropical seas, many of them with bright markings. The American species are all rarities, living about rocks in deep or shallow water; nowhere abundant and none of the species well represented in collections. (Trachinida, genus Opisthognathus, Gïnther, Cat., II, 254-256.)

a. Maxillary of great length, nearly as long as head, produced behind in a flexible lamina.

OPISTHOGNATHUS, 841.

aa. Maxillary normal, truncate behind, much shorter than head.

b. Caudal moderate, rounded behind; body oblong, moderately compressed.

GNATHYPOP8, 842 .

$b b$. Caudal lanceolate, long and pointed; body elongate.

LONCHOPISTHUS, 843.

\section{I. OPISTHOGNATHUS, Cuvier.}

Opisthognathus, Cưvier, Règne Auim., Ed.2, vol. II, 240, 1829 (8onnerati).

Maxillary prolonged backward in a long flexible lamina, which reaches about to base of pectoral. Characters of the genus otherwise included above. It has been suggested that the species of Gnathypops are females of analogous species of Opisthognathus, the long maxillary being a character of the male. This seems impossible, but deserves an investigation. The fact that Gnathypops maxillosa has but 27 vertebræ, while its longjawed cognate, Opisthognathus macrognathum, is said by Poey to have 34 vertebræ, is opposed to this view, as is also the fact that the analogous species do not in other respects exactly correspond, as in Gnathypops mystacina, the scales are smaller than in Opisthognathus lonchurum; Gnathypops rhomalea has fewer fin rays than Opisthognathus punctatum, etc. But the parallelism of species in the two genera living in the same waters is remarkable. (ö $\pi \imath \sigma \theta \varepsilon$, behind; $\gamma v \alpha \dot{\theta} 0$ os, jaw.)

a. Scales moderate, about 67 ; D. X, 15; A. II, 13; body nearly plain olivaceous, the maxillary not distinctly striped within.

LONCHURUM, 2615.

aa. Scales very small, 100 to 150 in longitudinal series; dorsal rays about XI, 17 ; A. II, 16; body and fins much variegated, the maxillary within with 2 ink-black stripes on a milk-white ground.

$b$. Dorsal without large black spot in front; seales 120.

$b b$. Dorsal with a large black spot more or less ocellated.

PUNCTATUM, 2616.

c. Scales about 100 .

cc. Scales about 140 .

MACROGNATHUM, 2617. OMMATUM, 2618. 
2615. OPISTHOGNATHUS LONCHURUM, Jordan \& Gilbert.

Head $3 \frac{1}{8}$; depth $4 \frac{3}{5}$. D. 25 ; A. 15 ; scales 67 . Head moderate; snout very short, shorter than pupil; eye $3 \frac{1}{8}$ in head; maxillary $1 \frac{1}{8}$ in head, rather narrow; lower jaw included; vomer with 5 rather large teeth. Longest dorsal spine about as long as head, slightly higher than soft rays; candal long, the middle rays scarcely shorter than head; longest anal rays $1 \frac{1}{5}$ in head; pectoral little more than $\frac{1}{2}$ head. Scales moderate. Olivaceous; margin of upper lip with a narrow black stripe; caudal with 3 dusky bars; color of rest of body uniform. Gulf of Mexico, in deep water. Two specimens known, taken from the stomach of a Red Snapper at Pensacola, Florida. The species resembles Gnathypops mystacinus, found in the same waters, but the latter species has smaller scales. ( $\lambda$ ó $\chi \eta$, lance; ovं $\rho \alpha$, tail.)

Opisthognathus lonchurus, JoRdAN \& GilberT, Proc. U.S. Nat. Mus. 1882, 290, Snapper Banks, off Pensacola, Florida (Type, No. 29671. Coll. Jordan \& Stearus); JordAN \& GILbERT, Synopsis, 943, 1883.

\section{OPISThognathus PUnCtatum, Peters.}

D. 28 ; A. 18. Body moderately elongate; scales very small, about 125 in lateral line. Dorsal spines continuous with the soft rays. No vomerine teoth. Maxillary very long, extending slightly beyond head. Head everywhere finely speckled with black, the body more coarsely and irregularly spotted; pectoral finely and closely speckled, its edge plain; ventral fin dusky, similarly marked; dorsal without large black blotch, finely spotted, the spots behind gradually forming the boundaries of white ocelli, the base of the fins having rings of white around black spots, the upper part with dark rings around pale spots; caudal with pale spots, its edge, like that of the dorsal, somewhat dusky, not black; anal with a broad, blackish edge, and with dark spots, those near the base of the fin largest; lining membrane of maxillary with the nsual bands of white and inky black. Mazatlan. Only the type of this species is yet known, this description having been taken by us from the original specimen. It bears considerable resemblance to Gnathypops rhomalea, which is found in the same waters, differing in the generic character of the dilated maxillary. (punctatus, spotted.)

Opisthognathus punctatus, PETERS, Berliner Monatsberichte 1869, 708, Mazatlan; JoRDAN, Proc. Ac. Nat. Sci. Phila. 1883, 290; Jordan, Cat. Fish. N. A.. 118, 1885.

2617. OPISTHOGNATHUS MACROGNATHUM, Poey.

Head $3 \frac{2}{3}$; depth 5. D. XI, 16; A. II, 16 or $17 ;$ P. 17; scales 100 . Body moderately elongate, somewhat compressed. Head blunt anteriorly; snout very short, about as long as pupil; eye large, 4 in head; maxillary reaching slightly past edge of preopercle, but not to end of head, its length contained $3 \frac{8}{4}$ times in length of body. Teeth rather strong, wide set, forming 2 distinct series, directed backward, especially in the upper jaw; lateral teeth of lower jaw largest; a single vomerine tooth. Gill rakers long and slender, nearly 20 below angle. Scales very small. $3030-66$ 
Dorsal fin low, continuous, the soft rays but little higher than the spines, which are slender and flexible, the longest $3 \frac{1}{3}$ in head; caudal short, rounded, its length $5 \frac{3}{5}$ in body; anal similar to soft dorsal; pectoral $\frac{1}{2}$ as long as head. Grayish olive, much variegated with Jellowish and dark olive; about 6 irregular dusky bands on the body, which extend on the dorsal fin; whitish markings on body forming roundish spots, surrounded by reticulations of grayish olive; head marbled, its posterior part, as well as the sides of the back and pectoral base, with small blackish dots; membrane lining inside of maxillary with 2 curved inky-black bands on a white ground; angle of mouth with a black spot; lining of opercle black; fins all variegated like the body. Florida Keys to Cuba. Here described from the type of 0 . scaphiurum, from Garden Key, but $O$. macrognathum seems to be the same. ( $\mu \alpha \varkappa \rho \dot{s}$, long; $\gamma v \alpha \alpha^{\prime} 0$ os, jaw.)

Opisthognathus macrognathus, * PoEx, Memorias, 11, 284, July, 1860, Cuba. (Coll. Poey.)

Opisthognathus megastoma, GëNTHER, Cat., II, 255, September, 1860, Gulf of Mexico. (Haslar Collection.)

Opisthognathus scaphiurvs, Goode \& BEAN, Proc. U. S. Nat. Mus. 1882, 417, Garden Key, Florida (Type, No. 5936, U.S. Nat. Mus. Coll. Dr. Whitehurst); Jordan \& GILBERT, Synopsis, 943, 1883.

2618. OPISTHOGNATHUS OMMATUM, Jenkins \& Evermann.

Head 3 ; width of head 5 ; depth 5 ; eye 3 in head. D. 28; A. 18; scales about 140 . Body moderate, compressed, depth $4 \frac{1}{7}$; width behind the head $8_{10}^{3}$ in length of body. Head large, its breadth equaling its depth, being 5 in length of body. Scales small, embedded; head naked, lateral line extending past middle of dorsal fin. Mouth large. Maxillary long, $1 \frac{1}{2}$ in head; postorbital portion $2{ }_{10}^{3}$ in head, not extending beyond head; snout short, its length less than $\frac{1}{2}$ diameter of eye; distance from tip of snout to end of maxillary $33_{10}^{3}$ in length of body and $1 \frac{1}{5}$ in head. Teeth in frout part of each jaw in several series, on sides of jaws reduced to a single series, the outer series strong; a tooth on the vomer; gill membranes connected; the interorbital space very narrow, $11 \frac{3}{5}$ in head. Distance from snout to origin of dorsal but little greater than length of head; space between dorsal and caudal fins $\frac{1}{2}$ greater than length of snout; no depression between spinous and soft rays of dorsal fin, the dorsal equaling the anal in lieight, its longest ray $1 \frac{2}{3}$ times the eye; pectorals slightly longer than ventrals, being 2 in head; breadth of pectorals 3 in head; ventrals inserted slightly in front of pectorals; candal rounded and narrow. Coloration: Body irregularly mottled with dark, head evenly blackish; dorsal fin blackish on the posterior portion, with 2 row $\$$ of 4 or 5 pale spots well separated; a large ocellated spot from the third to the sixth spines, including them, greater than diameter of eye; anal fin black, with a series of pale spots on the rays, the base pale; caudal black, with 2 pale

* Poey thus describes his specimens of Opisthognathus macrognathum: "Head $3 \frac{1}{4}$ in total; depth 5t; eye nearly 4, twice length of snout, 3 times interorbital width. D. XI, 16; A. II, 16. Vomer with 2 teeth; spines not pungent. Body covered with large yellowish points on a brown grouud; 7 bruad brown bands on sides, not reaching belly, but extending to middle of dorsal, which, like the anal, has yellow points; a Iarge black ocellus between sixth and ninth spines of dorsal; maxillary with 2 ink-black bands on a milkwhite ground; pectorals, ventrals, and caudal yellowish with black points. No pjloric caca; vertebrx $10+24=34$, the first 5 strong." (Poey.) 
spots at the base and a row of spots across the middle; lining of maxillary with bands of black and white. Bay of Guaymas; 3 specimens known.

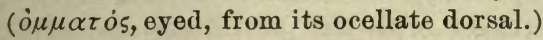

Opisthognathus ommata, Jenkins \& Evermann, Proc. U. S. Nat. Mus. 1888, 153, Guaymas.

(Type, No. 39640. Coll. Jenkins \& Evermann.)

\section{GNATHYPOPS, Gill.}

Gnathypops, GLLl, Proc. Ac. Nat. Sci. Phila. 1862, 241 (maxillosus).

This genus differs from Opisthognathus in having the maxillary of medium length and truncate behind, not extending to edge of opercle; caudal moderate, rounded behind. Species in form and habit agreeing closely with

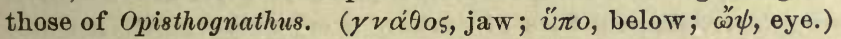

a. Body and fins spotted with black and often with pale.

b. Dorsal fin with a conspicuous dusky blotch in front. c. Scales very small, about 120 ; dorsal rays 26 .

SCOPS, 2619. cc. Scales moderate, about 65 ; dorsal rays 15. MAXILLOSA, 2620.

$b b$. Dorsal tin without distinct blotch in front; scales small, about 100 .

d. Dorsal rays about XI, 16; dark spots on hcad and body few.

MACROPS, 2621.

dd. Dorsal rays about XI, 13; dark spots on head and body numerous.

e. Dorsal fin distinctly notched; lateral line not reaching middle of dorsal. RHOMALEA, 2622.

ee. Dorsal fin not notched; lateral line reaching middle of dorsal.

SNYDERI, 2623.

aa. Body and fins nearly uniform olive; the spots few and spare; dorsal rays 24 ; scales 100 ; no black on membrane of maxillary. MYSTACINA, 2624.

\section{GNATHYPOPS SCOPS, Jenkins \& Evermann.}

Head $3 \frac{1}{2}$; width of head $5 \frac{8}{4}$, its depth $4 \frac{1}{2}$. D. 26 (X, 16); A. 19 (II, 17); scales 3-122-40. Scales small, none on head; lateral line extending to about middle of dorsal fin; mouth large; maxillary extending beyond eye a distance $4 \gamma_{10}^{\frac{1}{0}}$ in head; snout $6 \frac{1}{2}$ in head; teeth in bands, outer series on upper jaw rather strong; a single tooth on vomer; gill membranes connected. Opercle ending in a long flap, which extends upward and backward, nearly meeting over the back in front of the dorsal fin. Eye large, $2 \frac{1}{2}$ in head; interorbital space narrow, 11 in head. No depression between the dorsal spines and the soft rays, which are scarcely distinguishable; height of dorsal equal to that of anal; ventrals inserted in front of pectorals; peetorals equal to ventrals in length, 7 in body; caudal rounded. Coloration, in alcohol: Body pale, covered with many dark spots about the size of 3 to 6 scales; top of head with smaller dark spots; sides of head with whitish spots; dorsal fin with a black ocellated spot equal to eye on the space between second and fifth spines; remainder of fin dark, with many white spots running into each other on some portions, so as to form irregular lines; base of anal pale, the outer edge black; caudal dark with 2 whitish spots at the base, and a row of 6 white spots across the middle on alternate rays; pectorals lighter, with small whitish specks; ventrals dusky; belly pale. Guaymas; 3 specimens known, respectively $115 \mathrm{~cm} ., 10 \mathrm{~cm}$, and $7 \mathrm{~cm}$. in length to base of caudal. This species is the 
analogue of Opisthognathus ommatum, also from Guaymas. (8cops, the

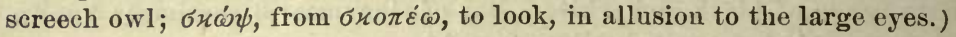
Gnathypops scops, Jenkins \& Evermann, Proc. U.S. Nat. Mus. 1888, 152, Guaymas. (Type, No. 39641, U. S. Nat. Mus. Coll. Jenkins \& Evermann.)

\section{GNATHYPOPS MAXILLOSA (Poey).}

Head $3 \frac{5}{6}$; depth $4 \frac{1}{8}$. D. VIII, 17; A. II, 13; scales 65 . Body moderately compressed; head not very large; maxillary truncate behind, extending behind eye for a distance for about $\frac{2}{3}$ diameter of eje, its length $1 \frac{2}{8}$ in head; eye $3 \frac{2}{8}$ in head. Teeth conical, curved, well separated, inostly in a single series; no teeth on vomer. Fins moderate; dorsal continuous, its spines slender; eaudal short, its length $\frac{2}{8}$ head. Color grayish olive, with 7 irregular ᄉ-shaped bars of darker, everywhere much marbled and variegated; fins all similarly marked, the ventrals dusky, the dorsal with a dusky blotch in front. Cuba, north to Florida, from which locality the specimen here deseribed was taken. Evidently very close to the Brazilian species $G$. curieri, the eye perhaps smaller. According to Poey, Gnathypops maxillosa has the eye 4 in head; D. VIII, 18; A. II, 15; 2 teeth on vomer; spinous dorsal lower than soft dorsal; body covered with large yellow spots on a ground color of clear brown; 6 brown cross bands reaching middle of dorsal, which is variegated with yellow and reddish, as is the anal; maxillary yellowish on its posterior border, the middle blackish; other spots on the jaws; ventrals, pectoral, and caudal yellowish, the ventrals finely spotted with brown, the caudal with 5 brown bands; base of pectorals with dark spots. Vertebræ $10+17=27$. (maxillosus, pertaining to the jaw.)

Opisthognathus maxillosus, PoEY, Míemorias, II, 286, 1860, Cuba. (Coll. Poey.)

Gnathypops maxillosus, GiLl, Proc. Ac. Nat. Sci. Phila. 1862, 241; Poey, Synopsis, 400; JORDAN \& GILBERT, Synopsis, 942, 1883.

\section{GNATHYPOPS MACROPS (Poey).}

Head $3 \frac{1}{3}$ in total (with caudal ?) ; depth about $4 \frac{1}{2}$. D. XI, 16; A. II, 15 or 16 ; scales 100 . Eye $3 \frac{1}{2}$ in head; maxillary extending beyond eye $\frac{2}{3}$ of a diameter, $5 \frac{1}{5}$ in head; vomer with 6 conical teeth. Color (faded in the type) redilish olive, with round, yellowish spots and vestiges of vertical bands; dorsal and anal plain, pectorals with brown bands; jaws not spotted with brown and white. Coast of Cuba (Pocy); known from 1 specimen $132 \mathrm{~mm}$. long; not seen by us. According to Poey, it may not be distinct from G. maxillosa, which in turn may possibly be the female of Opisthognathus macrognathum. This species may also be identical with the Brazilian species Gnathypops cuvieri, * but the latter has a dorsal ocellus and apparently larger scales. (

Opisthognathus macrops, PoEy, Memorias, II, 287, 1860, Cuba. (Coll. Poej.)

* Gnathypops cuvieri (Valenciennes). Head $3 \frac{1}{6}$; depth $4 \frac{1}{2}$; eye $3 \frac{1}{6}$ in head. D. X, 18; A. II, 16; scales 70. Maxillary reaching beyond the vertical from posterior margin of orbit, $1 \frac{1}{2}$ in head; eye $3 \frac{1}{2}$ in head, dorsal fin not notched. Olivaceous; a large dark-blue ovate ocellate spot between the fourth and eighth dorsal spines; dorsal and anal mottled, the edge dusky posteriorly; caudal with 3 dark-bluish bands. Bahia (Valenciennes). (Named for Georges Dagobert Cuvier.)

Opisthognathus cuvieri, Cuvier \& VAlenciennes, Hist. Nat. Poiss., XI, 504, 1836, Bahia (Coll. Blanchet); GUNTHER, Cat., II, 256, 1860. 
2622. GNATHYPOPS RHOHALEA (Jordan \& Gilbert).

Head 27 ; depth 4. D. XI, 13; A. II, 13 ; scales 103 (pores fewer). Body rather robust, compressed; head very large, ovoid, thicker and deeper than body, with swollen cheeks, the occipital region high, the snout somewhat truncate, the intermediate profile forming a nearly even curve; greatest depth of head equal to its thickness and $\frac{2}{8}$ its length. Eye not very large, 6 in head, longer than snout, about equal to the width of the flattish interorbital space. Mouth large, the maxillary extending well beyond the eye, but not to the margin of the preopercle nor to the mandibulary joint, its posterior margin truncate; supplemental bone small, but distinct; length of maxillary from end of snout 18 in head. Teeth moderate, in both jaws, in broad bands which become narrow on the sides; outer series of teeth somewhat enlarged, especially in upper jaw; 1 rather small, blunt tooth on middle of vomer. Gill membranes scarcely connected; gill rakers long and slender, abont $\frac{8}{4}$ diameter of eye, $9+19$; pseudobranchiæ situated in a cavity above the gill arches. Head naked; scales on body small, smooth, somewhat embedded; breast naked; lateral line ceasing opposite anterior third of second dorsal; 103 scales in a longitudinal series from head to caudal. Dorsal fin high; a rather deep notch separating the spines from the soft rays; the longest spines 3 in length of head, more than $\frac{1}{2}$ longer than the last spine, and scarcely lower than the soft rays. Insertion of dorsal opposite tip of the bony opercle, the opercular flap extending to opposite the third spine, last rays of dorsal and anal reaching past the base of caudal rays; caudal fin rounded, about $\frac{1}{2}$ length of head; anal higher than soft dorsal, its longest rays $2 \frac{1}{4}$ in head; ventrals large, close together, inserted in front of pectoral, $1 \frac{4}{5}$ in head; pectorals short and broad, 14 in head. Color in spirits, olivaceous, slightly brownish above, scarcely paler below, everywhere more or less tinged and mottled with greenish; head everywhere thickly and closely covered with small rounded dark-brown spots, largest above and on cheeks, where they are about as large as pin heads; smaller on lips and opercles, most thickly set on the anterior part of the head; eye thickly spotted; spots similar to those on the head extending along upper part of back, forming a vague band, which grows narrower backward and disappears opposite front of second dorsal; front side of pectoral and first 3 or 4 dorsal spines with dark spots; dorsal dusky olive, with darker clouds, and with some dark spots, especially on the spinous part; caudal and anal plain dusky or faintly marbled with paler; ventrals blackish, greenish at base; pectorals dusky green. Gulf of California, in shallow water; 1 specimen known, the type (above described) 16 inches long. This is perhaps the largest species of the genus. (jo $\mu \alpha \lambda \varepsilon \varepsilon^{\circ}$, robust.)

Opisthognathus rhomaleus, Jordan \& GiLbert, Proc. U. S. Nat. Mus. 1881, 276, Santa Maria Cove, Lower California. (Type, No. 29382. Coll. Lieut. Henry L. Nichols.)

2623. GNATHYPOPS SNYDERI, Jordan \& Evermann, new species.

Head $3 \frac{1}{5}$; depth $4 \frac{1}{8}$. D. X, 14; A. II, 13 ; scales $93 ; 60$ pores; 3 or 4 teeth on vomer; lateral line very distinct, extending to fourteenth ray of dorsal; no notch separating the dorsals, the spines and soft rays not sepa- 
rable, the last spine not much shorter than the longest, which is $2 \frac{1}{2}$ head; longest anal ray 2 , pectoral $2 \frac{1}{2}$. Vertebra $10+17=27$. Body olivaceous, with 5 broad faint dusky cross shades; head with many round black spots of varying sizes, some as large as pin heads, the largest below and between eyes, covering both jaws and the membrane of the maxillary, few on cheeks, most numerons on forehead; similar spots extending along side of back to end of lateral line; dorsal dusky, with 6 round dusky blotches at its base, corresponding to the dark shades on body; caudal, anal, and pectorals plain dusky olive; ventrals blackish. Gulf of California; known from 1 specimen collected by Dr. Gilbert in San Luis Gonzales Bay. The species is close to G. rhomalea, but has a different dorsal fin and lateral line. Type, No. 2014 L. S. Jr. Univ. Mus., about 8 inches long. (Named for John O. Snyder, curator of fishes in Leland Stanford Junior University.)

\section{GNATHYPOPS MYSTACINA, Jordan.}

Head $3 \frac{1}{12}$ in length ( $3 \frac{5}{6}$ to tip of caudal); depth $4 \frac{4}{5}\left(5_{6}^{5}\right)$. D. 23 or 24 (X, 14); A. II, 11; lateral line with about 54 tubes; 100 scales between gill opening and caudal. Head rather elongate, very blunt in profile; snout very short, not longer than pupil; eye large, about $3 \frac{1}{3}$ in length; maxillary $1 \frac{2}{8}$ in length of head, 5 in length to base of caudal, $6 \frac{1}{8}$ in total length to tip of caudal; end of maxillary abruptly truncate, not ending in a flexible lamina, the supplemental bone well developed; lower jaw slightly included. Teeth in each jaw in a narrow band, the outer slender, enlarged; vomer with about 4 slender teeth; palatines toothless. Gill rakers long and slender. Gill membranes nearly separate, free from the isthmus. Scales very small; lateral line extending to below anterior part of soft dorsal, its length $\frac{5}{4}$ that of head. Dorsal spines not distinguishable from the soft rays, the rays apparently fewer than usual, none of them very high, the last ray $2 \frac{1}{4}$ in head; caudal short, apparently truncate, $1 \frac{1}{4}$ in head; anal rather low; pectorals 2 in head; ventrals $1 \frac{8}{4}$. Color nearly plain olive green, without bands or spots on body or fins; vertical fins tipped with blackish; maxillary with a faint median blackish stripe; pectoral with 2 dusky cross shades; no black or white on lining membrane of jaws. Length $3 \frac{1}{2}$ inches. Deep waters of Gulf of Mexico; the few specimens known from the stomachs of Red Snappers (Neomanis aya) from the Pensacola Snapper Banks. It resembles Opisthognathus lonchurum, but the scales, are smaller. ( $\mu v \dot{\sigma} \tau \alpha \xi$, mustache, from the maxillary stripe).

Gnathypops mystacinus, Jordan, Proc. U. S. Nat. Mus. 1884, 37, Snapper Banks off Pensacola. (Coll. Jordan \& Stearns. Type, 34976, U. S. Nat. Mus.)

\section{LONCHOPISTHUS, Gill.}

Lonchopisthus, Gru, Proc. Ac. Nat. Sci. Phila. 1862, 241 (micrognathus).

This genus differs from Gnathypops in the slender, compressed body, the still smaller maxillary and the lanceolate caudal fin. The single species is very rare. ( $\lambda o ́ \gamma \chi \eta$, lance; o้ $\pi \imath \sigma \theta \varepsilon$, behind, from the form of the caudal.) 


\section{LONCHOPISTIUS MIGROGNATHUS (Poev).}

Head 5 in total; depth 6 . D. X, 17; A. II, 16 ; scales 80 ; eye 3 in head. Body elongate, compressed, snout short; maxillary reaching $\frac{1}{2}$ an eye's diameter behind the eye; no teeth on vomer; no second row of teeth in jaws; no scales on head except on cheok; lateral line almost touching profile of back. Caudal long and pointed as in Gobius oceanicus. Dark brown, paler below; 20 narrow vertical whitish bands from back to belly, the first 2 on cheek, the third on opercle; fins colored like body, except the pectorals, which are yellow, the edge orange. Vertebræ $10+18=28$. Length 4 inches. Cuba; rare (Poey); only the types known, examined by us in the National Musenm. (

Opisthognathus micrognathus, PoEY, Mernorias, II, 287, 1860, Cuba. (Coll.Poey.) Lonchopisthu\& micrognathus, GiLl, Proc. Ac. Nat. Sci. Phila. 1862, 241.

\section{Family CXCII. BATHYMASTERIDA.}

\section{(The RONQUILS.)}

Body rather elongate, moderately compressed, covered with small, ctenoid scales. Head rather large, subconic. Eyes large. Mouth moderate, nearly horizontal, the lower jaw slightly projecting; lips full; premaxillaries protractile, not extending to angle of the mouth; maxillary without supplemental bone, not slipping under the narrow preorbital. Teeth moderate, in a cardiform band in each jaw, the outer somewhat enlarged; bands of teeth on vomer and palatines. No barbels; no crests or spines on head. Branchiostegals 6. Gill membranes scarcely or broadly connected, free from the isthmus; gill rakers few, very short. Psendobranchiæ large. Opercular bones unarmed. Mucous pores numerous on top and sides of head, sometimes provided with fringed flaps. Lateral line conspicuous, placed high, not quite reaching the caudal fin, its scales sometimes enlarged. Dorsal fin long, continuous, moderately high, a few of the foremost rays inarticulate, none of them pungent or spine-like; the posterior rays branched; anal fin long, similar to the dorsal; caudal convex; pectorals rather broad, their bases extending obliquely downward and backward, their rays all branched; ventrals slightly in front of pectorals, I, 5, close together, the inner rays longest. Skeleton well ossified. Pyloric cæca fow (2 or 3 ). No anal papilla. Vertebræ in large numbers, about $14+35$. Three species known, from the Northern Pacific; here referred to 3 genera. The relations of the group are uncertain; externally they resemble the Opisthognathido, but the relation can not be close, and the number of vertebræ is greatly increased.

a. Gill membranes not connected below.

b. Head naked; scales in lateral line not enlarged; only first 3 or 4 rays in dorsal fin unbranched; pores of head with small fiaps.

BATHYMASTER, 844 .

bb. Head scaly on cheeks; scales in lateral line enlarged; anterior 20 to 30 rays of dorsal fin unbranched; pores of head mostly without flaps.

RONQUILUS, 845 .

aa. Gill membranes broadly connected; cheeks scaly; scales in lateral line enlarged; about 15 of anterior rays of dorsal simple.

RATHBUNELLA, 846. 
844. BATHYMASTER, Cope.

Bathymaster, Cope, Proc. Amer. Phil. Soc. 1873, 31 (signatus).

Head naked; pores of head large, many of them with dermal flaps; gill membranes scarcely connected; scales of lateral line similar to the others; dorsal fin with but 3 or 4 of its anterior rays unbranched; characters otherwise included above. ( $\beta \alpha \theta \dot{v}$, deep; $\mu \alpha \sigma \tau \dot{\eta} \rho$, searcher.)

\section{BATHYMASTER SIGNATUS, Cope.}

Head $3 \frac{1}{2}$; depth 5. D. 47 ; A. 34 ; scales $6-95-19$; eye $4 \frac{1}{8}$ in head ; maxillary $2 \frac{1}{8}$; snout $4 \frac{1}{8}$; pectoral $1 \frac{4}{5}$; ventral $2 \frac{1}{2}$; highest dorsal ray $2 \frac{3}{5}$; highest anal ray $3 \frac{1}{2}$; caudal $2 \frac{2}{5}$. Body compressed, elongate, anterior profile convex from tip of snout to dorsal; mouth not very oblique, the maxillary reaching the vertical from posterior edge of orbit; snout about equal to eye; jaws equal, with bands of small conical teeth, outer row enlarged; lower jaw with a single row at the sides; well developed conical teeth on vomer and palatines. Branchiostegal membranes not united; margin of preopercle free, furnished with 5 or 6 conspicuous mucous pores; large pores on top and sides of head, each with small flap; opercle ending in a flap behind; gill rakers moderately long and slender, $\frac{2}{8}$ eye, about $7+18$; many mucous pores on top of head and under eye; head entirely naked; dorsal and pectoral with fine scales running about halfway up the fin; anal naked; a naked strip from nape to dorsal; pectoral broad and fanshaped, its lower rays smaller, reaching to front of anal; origin of ventral spine abovit the diameter in front of the lower end of pectoral base; dorsal about uniform in height for nearly its entire length, higher than anal; dorsal and anal rays about reaching to base of caudal rays; first 3 or 4 rays of dorsal simple, the others branched; caudal truncate or slightly rounded. Color almost uniform warm brown with darker shades, the fins somewhat mottled with yellowish, the anal and ventrals blackish, other fins dusky; a conspicuous black ocellated blotch on front of dorsal, covering tips of 4 or 5 spines. * Shores of southern Alaska, from Unimak

\footnotetext{
* Concerning this species, Dr. Gilbert has the following note: "Bathymaster signatus is taken very abundantly in our series of shallow-water dredgings along the southern shore of the Alaskan Peninsula, and northward through Unimak Pass. The stations at which it was obtained are numbered $3211,3212,3213,3214,3215,3217,3220,3222$, and 3223 , and the depth range from 34 to 56 fathoms. In addition, a very few sinall specimens were secured at Stations 3262, 3309, 3221 and 3333, north of the Aleutian Islands, in depths of 19 to 71 fathoms, but the species is evidently not abundant in Bering Sea. No examples were taken in any of the very numerous dredgings made in Bristol Bay. In life the sides are olive brown, and the upper parts show faint traces of 6 or 7 broad dusky cross bars, which correspond to or alternate with an equal number below the lateral line; the anal and ventral fins, the branchiostegal and gular membranes, the lower pectoral rays, and the snout blue black; anterior edge of orbit and front edge of preorbital light yellow; the pores on edge of preopercle, 2 pores above and behind maxillary, and 3 at upper edge of opercle, bright scarlet; a large black blotch on anterior dorsal rays; distal half of anterior portion of dorsal fin and the upper pectoral rays yellow. Outer ventral ray simple and inarticulate, followed by 5 brauched rays. Only the first 2 dorsal rays spinous, being soft and flexible, but unjointed. The third and all following rays jointed and forked. All of the anal rays jointed. A specimen from Albatross Station 3211, 35 $\mathrm{mm}$. in length to base of caudal, shows that the ventrals occupy very different positions in adults and in young. In the latter they are truly tboracic in position, and are inserted as much behind base of pectorals as they are located in advance of this point in adults. A specimen $65 \mathrm{~mm}$. long is entirely similar to adults in this respect."
} 
Pass to Sitka; not uncommon in water of moderate depths. Here described from a specimen collected by the Albatross (No.2143, L. S. Jr. Univ. Mus.), Station 3214, 11 inches in length. Other specimens taken in rock pools at Sitka are dark green, almost black. (signatus, marked.)

Bathymaster signatus, Cope, Proc. Amer. Philos. Soc. 1873, 31, Sitka (Coll. Prof. George Davidson); Gilbert, Proc. U. S. Nat. Mus. 1888, 554.

\section{RONQUILUS, Jordan \& Starks.}

Ronquilus, Jordan \& Starks, Proc. Cal. Ac. Sci.1895, 838 (jordani).

Cheeks scaly; scales of lateral line enlarged; anterior half of dorsal fin more or less composed of unbranched rays; mucous pores on head without conspicuous flaps; gill membranes separate. One species. (Ronquil, a Spanish name of the typical species, possibly from $\rho \dot{\gamma} \chi 05$, one who grunts.)

\section{RONQUILUS JORDANI (Gilbert).}

\section{(RONQUIL.)}

Head $4 \frac{1}{6}$; depth $6 \frac{2}{8}$. D. 41 ; A. 33 ; V. I, 5 ; P. 18 ; scales $92+6$ (tubes), about 200 transverse. Body rather elongate, moderately compressed. Eye large, about as long as snout, 4 in head, its diameter much more than the interocular space; maxillary extending to below front of pupil; cheeks closely scaly; rest of head entirely naked; a narrow, naked area in frout of dorsal, bounded by rows of mucous pores; skull with large mucous cavities behind the eyes, which are translucent in life; scales of lateral line enlarged, twice as far apart as the others. Dorsal fin inserted at a distance behind the occiput, less than the diameter of the eye; pectorals $\frac{5}{6}$ the length of the head; fourth ray of ventrals longest; vent much nearer snout than root of caudal; vertebræ $14+35=49$; olivaceous, tinged with brown; about 8 round, faint-bluish blotches along the sides, each surrounded by rings of yellow spots; a yellow ring around the eye and yellow band along the cheek; fins translucent, the anal with a yellowish strip and a deep-bluish or black edging; dorsal reddish or yellow, with a dusky blotch in front; ventrals dusky; pectorals with the lower rays blackish or dark blue, larger specimens nearly uniformly dark, the color varying with the surroundings. Bristol Bay to Puget Sound, about rocks, in water of moderate depth. Length 6 to 10 inches. Known from Seattle and from Wrangel and Bristol Bay, the latter specimen in 32 fathoms. (Named for its discoverer, David Starr Jordan.)

Bathymaster signatus, JordAN \& GILBERT, Synopsis, 623,1883 ; not B. signatus, Cope. Bathymaster jordani, GLBerT, Proc. U. S. Nat. Mus. 1888, 554, Elliott Bay at Seattle (Coll. Jordan) and Fort Wrangel, Alaska. (Coll. Albatross.)

Ronquilus jordani, Jordan \& StARKs, Proc. Cal. Ac. Sci. 1895, 838, pl. 99.

\section{RATHBUNELLA, Jordan \& Evermann.}

Rathbunella, Jordan \& Evermann, Check-List Fishes, 463, 1896 (hypoplectus).

This genus differs from Ronquilus in having the gill membranes broadly united across the isthmus. The unbranched anterior rays form about $\frac{1}{8}$ 
of the dorsal fin. (Named for Mr. Richard Rathbun, then chief of the Division of Scientific Inquiry in the U.S. Fish Commission, in recognition of his many services to science.)

\section{RATHBUNELLA HYPOPLECTA (Gilbert).}

Head $4 \frac{2}{8}$ in length; depth 7. D.46; A.33. Head and body compressed, elongate, the anterior profile of head compressed, declivous; mouth somewhat oblique, at lower side of snout, small, the maxillary reaching vertical from middle of pupil, $3 \frac{1}{6}$ in head; snout very slightly shorter than orbit, $4 \frac{1}{8}$ in head; diameter of orbit 4 in head; teeth well developed, in broad bands on jaws, vomer and palatines, the vomer and palatine patches nearly continuous; branchiostegal membranes broadly united, free from isthmus, forming a fold whose depth exceeds $\frac{1}{2}$ diameter of orbit. Margin of preopercle adnate behind, slightly free below, furnished with a series of 6 conspicuous mucous pores; head without spines, ridges or filaments ; inner margin of shoulder girdle conspicnously notched above and below, but without hook; gill rakers tubercular, few in number; a well-marked slit behind last gill. Distance from nape to front of dorsal fin equals its distance from posterior border of eye; anterior 10 or 12 dorsal rays simple and apparently not articulate, but flexible and not spine-like; distance from front of anal to base of ventrals $2 \frac{1}{8}$ in its distance from base of caudal, all but first $\frac{1}{8}$ of dorsal rays, and all of anal rays forked at tip; dorsal not high, the longest rays $\frac{1}{2}$ head; highest anal ray equals snout and $\frac{1}{2}$ eye; last dorsal and anal rays entirely disconnected from caudal, leaving a free space on caudal peduncle $\frac{1}{2}$ diameter of orbit; ventrals I, 5, in advance of base of pectorals, narrowly triangular, the inner rays longest; pectorals with curved base running backward and downward, the rays all branched, 18 in number, the width of base of fin $3 \frac{1}{4}$ in head, the longest ray $1 \frac{1}{8}$ in head; caudal rounded, $\frac{2}{8}$ length of head. Body covered with small, partially embedded, cycloid scales, including antedorsal region, belly, breast, and area in front of base of pectorals; cheeks covered with similar but smaller scales, the opercles and rest of head naked. Lateral line running high, parallel with back, on a series of enlarged scales, which are also partly embedded in the thick skin; the lateral line fails to reach base of caudal by a distance equaling $\frac{1}{2}$ of head, and is present on 82 scales. Color, dark olive-brown above, lighter below; a series of about 12 quadrate dark blotches below lateral line, connected more or less by dusky streaks with an alternating series along base of dorsal; no bright colors; dorsal, pectorals, ventrals and branchiostegal membranes dusky straw color; anal black, the rays white tipped; caudal blackish; peritoneum white. A single specimen, 8 inches long, from Albatross Station 2944, off Santa Barbara Islands, in 30 fathoms:

Bathymaster hypoplectu\&, GruBerT, Proc. U.S. Nat. Mus. 1890, 97, off Santa Barbara Islands, California, at Albatross Station 2944. (Coll. Albatross.) 


\section{Family CXCIII. CHIASMODONTIDA.}

\section{(The Black Swaliowers.)}

Body elongate, subcylindrical, or slightly tapering; head subconic. Skin naked; lateral line continuous, placed low; 2 dorsal fins, the first rather short, of slender spines, the second dorsal and anal long; ventrals normal, thoracic, inserted before pectorals, the rays I, 5; pectorals long and narrow; mouth very deeply cleft, reaching beyond the eyes, with numerous long, sharp, movable teeth, the anterior canines movable; teeth on palatines; upper jaw not protractile, the maxillary produced backward. Opercular apparatus very oblique and reduced; no spines or cirri on head; candal fin forked. Genera 2; species 2; deep-sea fishes, notable for the sharp teeth and for the extensible stomach. (Chiasmodontida, Gill, in Jordan \& Gilbert, Synopsis, 964, 1883.)

a. Jaws with some of the anterior canines extremely long and movable, the 2 anterior crossing each other; lower jaw projecting.

Chiasmodon, 847.

aa. Jaws with slender, close-set teeth, none of them greatly produced; lower jaw not prominent.

PseUdosCOPELUS, 848.

\section{CHIASMODON, Johnson.}

\section{(Black SWallowers.)}

Chiasmodon, Johnson, Proc. Zool. Soc. Loudon 1863, 408 (niger).

Chiasmodus, GÜNTHER, change of spelling.

Body elongate, compressed, and tapering posteriorly, naked; belly pendent, its walls membranaceous, capable of great dilation. Mouth very large; lower jaw longer than upper; each jaw with 2 series of large, pointed teeth, some of the anterior being very large and movable; vomerine teeth none; palatines with teeth similar to those in the jaws. Gills 4. No pseudobranchiæ. Gill openings very wide, the membranes joined to the isthmus for a short distance. Dorsal fins 2; anal single; ventrals inserted below pectorals, each of 5 soft rays. Tail truncate at base of caudal. Caudal forked, free from dorsal and anal. Singular fishes of the deep sea, remarkable for their ability to swallow fishes of many times their own size by means of the great distensibility of the walls of the body. ( $\chi i \alpha \sigma \mu \alpha$, a mark of the form of the letter $\chi$; ó ov́s, tooth; the 2 anterior canines crossing each other when depressed.)

\section{CHIASMODON NIGER, Johnson.}

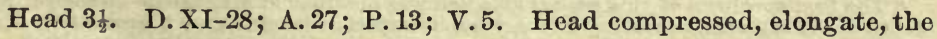
crown flat, its depth less than $\frac{1}{2}$ its length; maxillary reaching angle of preopercle; both jaws armed with long, pointed, wide-set teeth, nearly all of which are movable; 2 anterior teeth of upper jaw very long, crossing each other when depressed; 3 anterior pairs of teeth in lower jaw 
likewise prolonged, the third pair the longest; palatines with a longer, fixed tooth in front. Eye moderate, above the anterior part of maxillary, $4 \frac{1}{2}$ in head, shorter than snout, as wide as interorbital space. Lateral line in a longitudinal groove. First dorsal of slender rays, its base $2 \frac{1}{8}$ in in that of second dorsal; anal commencing behind second dorsal, its anterior rays without connection with vertebral column; posteriur rays of anal and dorsal very feeble; pectoral as long as head without snout; ventral $\frac{1}{2}$ as long as pectoral. Color entirely black. Length 12 inches. (Giinther.) Deep waters of the Atlantic; a remarkable fish, the walls of the body inordinately extensible; taken at Madeira, in the inid-Atlantic, near the island of Dominica, and off the coast of Massachusetts. * (niger, black.)

Chiasmodon niger, Johnson, Proc. Zool. Soc. London 1863, 408, Madeira; Jordan \& GrLBERT, Synopsis, 964; GOODE \& BEAN, Oceanic Ichthyology, 292, 1896.

Chiasmodus niger, Günther, Cat., v, 435, 1864; CARTER, Proc. Zool. Soc. 1866, 38; Günther, Challenger Report, Deep Sea Fishes, xxI, 99, 1887.

\section{PSEUDOSCOPELUS, Lütken.}

Pseudoscopelus, LÜtken, Spolia Atlantica, Scopelini, 64, 1892 (8criptus).

Body perciform, scaleless, naked; mouth very large; eyes moderate; the slender maxillary reaching far beyond eye; jaws and palate with slender, close-set teeth; ventral fins short, subthoracic, of 1 spine and 5 rays; first dorsal short, of about 8 slender spines; posterior dorsal long, similar to the anal. Each jaw with a distinct line of pores, a median line of pores before ventrals, a cross line connecting ventrals, a series of pores from the vent passing around anal on each side. Lateral line well developed, running high. Head without spines. Gill openings very broad. Pectorals long; caudal short, forked. One species known, in deep water.

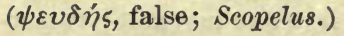

2630. PSEUDOSCOPEIUS SCIRIPTUS, Lütken.

Head $3 \frac{1}{2}$; depth $4 \frac{1}{2}$. D. VIII-22; A. $22 ;$ V. I, 5. Body subfusiform, somewhat compressed. Head large, the snout short and pointed, $4 \frac{1}{2}$ in head, the small eye, about 5. Jaws subequal, maxillary $1 \frac{1}{2}$ in head; cheek V-shaped, very oblique; bones of head not serrate. Form of head and mouth much as in Engraulis or Scopelus. Pectoral nearly as long as head, reaching past front of anal; soft dorsal higher than spinous, the anterior rays of soft dorsal and anal elevated. Pores as above described.

* The first specimen of this remarkable fish was obtained at Magdalena (Madeira), at a depth of 312 fathoms, in 1850 , by Lowe, who, however, omitted to give a description of it. The species was rediscovered at the same locality by Jobnson twelve years later. A third specimen was picked up from the surface, near the island of Dominica. A fourth example was obtained by the Challenger in mid-Atlantic, at Station 107, in 1,500 fathoms, on August 26, 1873. A fifth was obtained by the U. S. National Museum from Capt. Thomas F. Hodgdon of the Gloucester schooner Bessre W. Somers. It was found on Le Have Bank, floating on the surface, in June, 1880. (Goode \& Bean.) 
One specimen from Old Bahama Straits. (Luitken.) A singular fish of uncertain relationships, remarkable for the development of mucous pores. (scriptus, written.)

Pseudoscopelus scriptus, LÜTKEN, Spolia Atlantica, Scopelini, 64, 1892, Old Bahama Straits.

\section{Family CXCIV. CHENICHTHYIDA.}

Body rather clongated, gradually and regularly declining from the nape to the caudal fin; anteriorly subcylindrical or scarcely compressed. Skin naked or covered with small scales. Lateral line high on the sides and near the dorsal fin. Head moderate or large, with the snout prolonged, depressed, and spatuliform. Crown depressed, not relieved by crests or ridges. Preorbital bones large; suborbital chain very narrow, not articulated with the preopercle. Opercular bones all present, the interopercle and subopercle moderately developed. Mouth terminal, with the cleft lateral and large, extending to the vertical of the eye; upper jaw with its border formed almost entirely by the premaxillaries, whose posterior processes are very short; maxillaries with their articulations entirely posterior to the premaxillaries, slender and gradually enlarged toward their extremities. Teeth on the jaws; palate unarmed. Gill openings wide; gill membranes inferiorly deeply emarginated behind. Branchiostegals 6. Psendobranchiæ developed. Dorsal fin with its spinous portion short, and usually distinct from the soft, the rays of the latter often simply articulated and not branched; anal fin a little shorter than the dorsal, its rays divided, the membrane notched behind each; caudal fin not forked; pectoral fins well developed, with their inferior rays divided; ventral fins jugular or subjugular, separated by a rhomboid area, each with a spine and 5 rays, the first of which is frequently thickened and entire. Cranium flattened behind, the crests little developed or obsolete. The spatnliform snout is principally formed by the elongated frontal bones. Stomach of moderate size and cacal. Pyloric cuca in very small number. The chief distinctive characteristic of this family is doubtless the spatuliform extensions of the snout. This, combined with the extent of the fins, structure of the head, and general form, distinguish the group from all others. It appears to be most closely allied to the Harpagiferida and Notothenida. From the former it is separated by the form of the head, as well as by that of the body. From the latter, by the same features, and also by the naked skin. (Gill.) Genera 3 or 4 , with about 6 species; inhabiting rather deep waters, mostly in the Tropics. (Chanichthyoida, Gill, Proc. Ac. Nat. Sci. Phila. 1861, 507.)

a. Body covered with cycloid, deciduous scales; maxillary with a flap; opercle with a dermal flap.

HYPSICOMETES, 849.

849. HYPSICOMETES, Goode.

Hypsicometes, Goode, Proc. U.S. Nat. Mus. 1880, 347 (goboides).

Body elongate, subcylindrical, tapering posteriorly. Head very large, much depressed, with snout elongate, spatulate; cleft of mouth very wide, 
horizontal, with lower jaw much the longer; the posterior margin of the maxillary wide, free, and with a long cutaneous flap. Eyes very large, close together, subvertical. Scales large, cycloid, deciduous; lateral line conspicuous and continuous, descending abruptly behind pectorals, its scales smaller than those of the body adjoining. Teeth acicular, in bands on the jaws, vomer, and palatines, the largest being upon the palatines, the vomer, and upon 2 pads on either side of the symphysis of the maxillaries. A sharp, short, strong scapular spine. Operele with 3 feeble, sharp spines, each at the cnd of a strong feeble ridge; a long, skinny opercular flap extending far beyond the bony portion, and covered with scales. Branchiostegals 6. Gill membranes free from the isthmus, except far in front, where they are united to it, the left-hand flap overlapping the right at the point of junction. Pseudobranchir present. Gill rakers short.

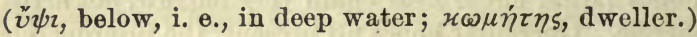

2631. HYPSICOMETES GOBOIDES, Goodo.

Head about $2 \frac{1}{2}$; depth $7 \frac{1}{2}$; orbit $4 \frac{1}{2}$ in head, or $1 \frac{1}{2}$ in snout. D. VI-15 to 17 ; A. 16 to 18 ; V. I, 5; P. 26 ; scales 65 . Mouth very wide, horizontal, the maxillary, which is expanded spoon-like posteriorly, reaching considerably beyond vertical from anterior margin of orbit; eye considerably nearer tip of snout than end of flap, and equidistant between tip of snout and tip of uppermost spine of operculum; entire upper surface of head, cheeks, and opercula covered with scales, except upon bony portion of snout; first dorsal fin placed far forward, not far behind vertical from axil of pectoral; interspace between termination of first dorsal and beginning of second equal to diameter of the orbit, this fin composed of 6 spines, the first and second of which are longest, equal to distance from anterior margin of orbit to tip of lower jaw, and triangular in form; origin of second dorsal almost vertical from that of anal, and terminativg a little in advance of the latter; second dorsal fin highest in front and low behind; length of caudal peduncle a little less than length of snout; caudal rounded; pectoral very broad at base, rounded, extending beyond vent and nearly to vertical from origin of anal; lower rays branched; ventrals far apart, horizontal, Trigla-like, composed of 1 flexible spine and 5 branched rays, their insertion far forward and far in advance of base of pectorals. Color grayish brown; lighter and yellowish below. Known only from a very small specimen, in which many of the important characters were not discernible. This specimen (No. 26007, U. S. Nat. Mus.) was taken by the Fish Hawk from Station 871 , in $40^{\circ} 02^{\prime} 54^{\prime \prime}$ N. lat., $70^{\circ} 23^{\prime} 40^{\prime \prime}$ W. lon., at a depth of 115 fathoms, and is much contracted and distorted from immersion in strong alcohol. (Goode.) (Gobius; $\varepsilon i \tilde{\delta} \circ 5$, resemblance.)

Hypsicometes goboides, GooDE, Proc. U. S. Nat. Mus. $1880,348,1$ at. $40^{\circ}, \mathrm{o2}^{\prime}, 54^{\prime \prime}$ N., lon. $70^{\circ}$ $23^{\prime} 40^{\prime \prime}$ W., in 115 fathoms (Coll. Fish Hawk); JordaN \& GILBERT, Synopsis, 808, 1883; Goode \& BeAN, Oceanic Ichthyology, 290, fig. 263, 1896. 


\section{Family CXCV. TRICHODONTIDA.}

\section{(The SAND-Fishes.)}

Body rather elongate, compressed, naked. Head short, flat on top, the sides vertical. Eyes large, high up, but not superior. Mouth large, almost vertical; lower jaw projecting, its tip entering the protile; lips fringed; premaxillaries protractile; maxillary very broad, without supplemental bone, not slipping under the very narrow preorbital. Teeth moderate, slender and sharp, but not setiform, in bands on jaws and vomer; palatines toothless; inner teeth of jaws depressible. Gill rakers short, slender; gill membranes narrowly united, free from the isthmus. Branchiostegals 5. Gills 4, a slit behind the fourth. Pseudobranchia large. Preopercle with 5 prominent spines, the 2 upper directed strongly upward, the 2 lower downward, the middle 1 downward and backward; no barbels; opercle small, strongly striate, unarmed; preorbital with spines; no suborbital stay. Lateral line obsolete. Dorsal fins separate, the first the larger, of numerous slender spines; anal fin elongate, without distinct spines, the rays of anterior third of the fin much shorter than the others, the beginning of the fin below middle of spinous dorsal; pectorals with a very broad, curved, procurrent base; a broad lunate area between pectoral and gill opening, nearly covered by the opercle; soft rays of dorsal, anal, and pectoral fins all simple; ventrals $I, 5$, close together, thoracic, but behind the pectorals, the middle rays longest; caudal lunate, with many accessory rays, on a slender peduncle. Vertebræ numerous, 48 in typical species. Two genera and 2 species known; from the North Pacific; living in sand near the shore. The fringed lips and other characters indicate the relationship of these fishes with the Uranoscopida. (Trachinida, genus Trichodon, Günther, Cat., II, 250.)

a. First dorsal long and rather low, of 14 or $\mathbf{1 5}$ spines.

aa. First dorsal short and high, of 10 spines.
Trichodon, 850. ARCTOSCOPUS, 851 .

\section{TRICHODON (Steller) Cuvier.}

\section{(SAND-FISHES.)}

Trichodon, Steller, in Tilesius, Mem. Acad. St. Petersburg, IV, 1811, 468 (trichodon). Trichodon, Cuvier, Règne A nimal, Ed. II, vol. 2, 149, 1829 (trichodon).

Characters of the genus included above, the first dorsal long and rather low, of 15 spines. One species. ( $\theta \rho i \xi$, hair; ö $\delta \circ v$ s, tooth.)

\section{TRICHODON TRICHODON (Tilesius).}

(SAND-FISH.)

Head from tip of upper jaw, $3 \frac{4}{5}$; depth $3 \frac{1}{2}$. D. XIII-I, 18; A. 28; P. 22 ; eye $4 \frac{1}{8}$ in head, snout $4 \frac{1}{2}$; maxillary 2 ; interorbital 3 ; pectoral $1 \frac{1}{8}$; ventral 1量; height of spinous dorsal $3 \frac{1}{6}$. Body moderately elongate, compressed; dorsal outline slightly concave and sloping gently upward from snout to dorsal, thence turning at a very slight angle nearly straight to caudal; 
ventral outline well rounded from chin to caudal peduncle, the curve much more gradual posteriorly; head and body everywhere covered with thin naked skin. Mouth large, superior, nearly vertical, the lower jaw projecting, its tips entering the profile; lips fringed; maxillary reaching to middle of pupil; teeth in 2 or 3 rows, small, sharp and recurved; teeth on vomer; palatines toothless. Eyes placed high, their diameter equal to length of snout; interorbital wide and flat, a third wider than eye; top of head smooth, sometimes rugose in younger individuals, covered with thin smooth skin; anterior nostril ending in a tube; preopercle with 5 spines, the 1 at angle largest, the 2 upper ones pointing upward and backward, the middle one pointing downward and backward, the 2 lower ones pointing downward and forward; opercle with radiating ridges; gill rakers short and slender, numerous. Origin of spinous dorsal behind base of pectoral, its distance from snout 3 in body, the spines not varying greatly in length, the last one connected by a membrane to the back; soft dorsal well separated from spinous, its rays about equal to spines in length, highest in front; anal long, its origin nearer to tho snout than base of caudal by a distance equal to the length of the eye. Pectoral, when spread, broadly rounded behind, its lower rays rapidly decreasing in size below, roaching well past front of anal; ventrals inserted behind base of pectorals a distance equal to $\frac{2}{8}$ eye, their tips reaching to rent. Lateral line running high. Vertebræ $17+30=47$. Color silvery, light brown above; a dark brown streak following the lateral line, broken up into spots anteriorly; quadrangular, dark brown marks along the back at base of dorsals, chain-like markings in front of dorsal on nape; snout and tip of lower jaw dark; a dark line at lower part of eye ; dorsals light, a dark streak along upper part of spinous dorsal; pectorals dusky; ventrals and anal colorless. Length 8 to 10 inches. North Pacific, on sandy shores, from Bering Sea to Monterey; very abundant northward; burying in the sand. Here described from a specimen, $8 \frac{1}{2}$ inches in length, from Herendeen Bay, Alaska (Albatross collection). Possibly detailed comparison may show a difference between California specimens and those from Bering Sea.

Trachinus trichodon, 'TILesius, * Mem. Acad. St. Petersburg, IV, 1811, pl. 15, fig. 8, 473, Kamchatka; Pallas, Zoographia Rosso-Asiatica, III, ‘35, 1811.†

* The specific name trichodon should apparently date from Tilesins, 1811 . Although Vol. Iv, of the Mem. Acad. St. Petersburg bears the date 1813 it was for the year 1811 , and it is evident that the plate containing the figure of this species was accessible to Pallas as early as 1811, for, in his "Zoographia," printed in 1811, though not published until 1831, Pallas refers to the plate of Tilesins in very detinite terms. The fact that Pallas was, in 1811, thus able to refer definitely to Tilesius's plate of Trachinus trichodon, fixes the date of publication of that plate at least as early as 1811 . That this plate appeared in the volume of Memoirs for 1811 (though the volume was not published until 1813), fixes 1811 as the date for the name. Though the "Zoographia" of Pallas was not formally published until 1831, it was printed in 1811, and Cuvier \& Valenciennes evidently had a copy in 1829 , as they refer to it.

$\uparrow$ Tilesius confused matters greatly by using, in one and the same article, three different names or combinations of names for this fish. At the beginning of this article (p. 406) in a bald list of the species discussed in the paper, he has "Drachinus trichodon." On page 466 he has "Trachinus gasteropelecus," accompanied by a full description of the species. In a footnote on page 473 , he has "Trachinus trichodon " together with a description which he says applies to the young, and finally his pl. 15, fig. 8, is marked "Trachinus tricho- 
Drachinus trichodon, Truesius, Mem. Acad. St. Petersburg, Iv, 1811, 406; name only.

Trachinus gasteropelecus, TiLesius, l.c., 466, 1811, Kamchatka.

Trichodon stelleri, Cuvier \& VAlenciennes, Hist. Nat. Poiss., III, 154, pl. 57, 1829; based on Trachinus trichodon Pallas; Günther, Cat., II, 251, 1860; JoRdan \& GILBERT, Synop. sis, $627,1883$.

Trichodon lineatus, AYers, Proc. Ac. Nat. Sci. Phila. 1860, 60, San Francisco; D. XV-18; A. $28 ;$ P. 23 .

\section{ARCTOSCOPUS, Jordan \& Evermann.}

Arctoscopus, Jordan \& EvermanN, Check-List Fishes, 464, 1896 (japonicus).

This genus differs from Trichodon in the short, high, triangular spinous

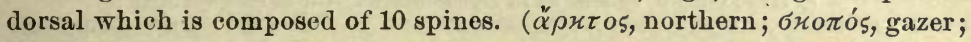
for Uranoscopus:)

2633. ARCTOSCOPUS JAPONICUS (Steindachner).

Head $3 \frac{8}{4}$; depth $3 \frac{8}{4}$. D. X or XI-13; A. 30 or 31 ; P. 25 . Form of body and coloration of Trichodon trichodon. First dorsal high, triangular, the spines slender, separated by a long interval from the second dorsal. Preopercle with 5 sharp spines; the 2 spines on the preorbital very small. Pectoral well developed, all its rays simple, the lower a little thickened, the fin considerably longer than the head and reaching past the last spine of the dorsal; anal fin with its rays gradually longer posteriorly. Dentition as in Trichodon trichodon, but the mouth rather more oblique. Length $4 \frac{1}{2}$ inches. North Pacific; scarce. Recorded from Strietok, in the Sea of Japan, and Sitka, Alaska, by Steindachner, and by Jordan \& Gilbert from Iturup Island (Kurils). (japonicus, from Japan.)

Trichodon japonicus, STEINDACHNER, Iehth. Beitr., x, 4, 1881, Strietok; Sitka ; JoRDAN, Cat.

Fishes N. A., 117, 1885.

Arctoscopus japonicus, JoRdAN \& GILBERT, Rept. Fur Seal Investig., 1898.

\section{Family CXCVI. DACTYLOSCOPIDA.}

\section{(The SAND StaR-Gazers.)}

Body oblong, low, compressed posteriorly, covered with moderate, cycloid, imbricated scales; lateral line complete, anteriorly running along side of back, posteriorly median; head oblong, nearly plane above; eyes small, superior, well forward; suborbital bones enlarged, but without bony stay connecting with the preopercle; nostrils double; opercles fringed; mouth nearly vertical; premaxillaries protractile, not forming the entire edge of the upper jaw; lips fringed as in Uranoscopida; gill openings very broad, the membranes separated and free from the isthmus, pseudobranchiæ present or obsolete. Dorsal fin very long, continuous or divided, several of the anterior rays spinous; anal very long, commencing close behind the vent, which is near the breast; caudal diphycercal, free from dorsal and anal; pectorals variable, the base broad and procurrent; ventrals jugular, I, 3 ; vertebræ more than $10+14$; pyloric cæca none. Genera 4; species about 10; small fishes living on sandy shores of tropical $3030-67$ 
America. This family is nearly related to Uranoscopida, of which group it seems to be a reduced or degenerate branch. Its relations with the Asiatic family Leptoscopida are most intimate, the incomplete ventrals and simple pectoral rays of Dactyloscopida being the chief distinctive features. (Dactyloscopida, Gill, Arrangm. Families Fishes, 1872.)

a. Dorsal fin divided, the first dorsal composed of 3 spines inserted on the nape; head not cuboid; chin without flap; fringes of lips small.

GILLELLUS, 852.

aa. Dorsal fin continuous.

b. Dorsal fin commencing at the nape; pseudobranchiæ very small or obsolete; head cuboid.

DACTYLOSCOPUS, 853.

$b b$. Dorsal fin commencing far behind the nape; pseudobranchire well developed. c. Head cuboid, formed as in Dactyloscopus; the mouth vertical.

DACTYLAGNUS, 854 . cc. Head elongate-conoid, the lower jaw projecting, with a fleshy flap at tip. MYXOdaGNus, 855

\section{GILLELLUS, Gilbert.}

Gillellus, Gilbert, Proc. U.S. Nat. Mus. 1890, 98 (semicinctus).

A separate dorsal fin on the nape composed of 3 spines. Lateral line descending posteriorly, its dorsal and median portions about equal. Fringes of upper lip obsolete, those of lower lip little evident. Head not cuboid, the mouth moderately oblique, the lower jaw rounded in front and without symphyseal flap. The physiognomy is intermodiate between Dactyloscopus and Myxodagnus, from each of which the genus is well separated by the characters of the dorsal fin and the lateral line. ("Named in honor of Dr. Theodore Gill, to whom we owe our knowledge of the previously described members of this most interesting group." Gilbert.)

a. Tip of lower jaw projecting.

b. Anterior portion of lateral line longer than posterior portion; the scales 25 to $28+3+15$ to $18=43$ to 49 . D. III-IX, $28 ; A$. II, 30 or 31 .

SEMICINCTUS, 2634.

$b b$. Anterior portion of lateral line much shorter than posterior portion, $2 \frac{1}{3}$ times in the latter; scales $18+3+27=48$. D. II-IX, 31; A. II, 35.

ARENICOLA, 2635.

aa. Tip of lower jaw scarcely projecting; anterior portion of lateral line $1 \frac{1}{4}$ times in -posterior. D. I-IX, 31; A. II, 34.

ORNATUS, 2636.

\section{G1LLELLUS SEMICINCTUS, Gilbert.}

Head $3 \frac{2}{8}$; depth $5 \frac{1}{3}$. D. III-IX or X, 28; A. II, 30 or 31 ; scales 25 to $28-$ $3-15$ to 18 (43 to 49 scales in all). Body deep, tapering rapidly either way from front of dorsal. Mouth moderately oblique, the maxillary extending beyond orbit, 3 in head; tip of lower jaw projecting; teeth in a narrow band in front of jaws, becoming a single series laterally; none of the teeth enlarged. Opercular fringes well developed, 8 or 9 in number; fold of membrane between rami of lower jaw well developed; pseudobranchiæ apparently not developed; gill rakers obsolete. Dorsal fin beginning at a distance from occiput less than diameter of eye, the first 3 rays entirely detached from the rest of the fin, the first ray the highest, the second and third shortened; of the remaining part of the fin the first 9 or 
10 rays are unarticulated and spinous; first 2 anal rays not articulated; caudal about $1 \frac{8}{4}$ in head; pectorals $1 \frac{1}{8}$. Lateral line running anteriorly along the very base of spinous dorsal, no scales intervening between it and base of fin; it descends to middle of sides posteriorly, the median portion of its length shorter than the dorsal portion. Color light oliva. ceous, the back with 6 broad eross bars of pink, narrowly margined behind and in front.with blackish, terminating below on middle of sides; the lower of these bars frequently black; a black bar across caudal peduncle, and sometimes a black line at base of caudal; along median line of sides frequently a series of small black spots alternating with the cross bars; a similar series along median dorsal line; a large pink bloteh covering occiput; a dusky bar across interorbital space, running downward and backward across cheek; silvery spots and blotches on cheeks and anterior portions of opercles; fins unmarked. Specimens have been obtained in the Gulf of California by the Albatross, at Stations 2827 and 2829, and by the Grampus in the Atlantic, at Stations 5108 and 5112, off the coast of Florila; no specific difference among them noticed, but the Atlantic form needs further study. (Gilbert.) (semi, half; cinctus, belted.)

Gillellus semicinctus, Gilbert, Proc. U. S. Nat. Mus. 1890, 98, Albatross Stations 2827, 2829, Gulf of California (Coll. Albatross); Jokdan, Proc. Cal. Ac. Sci. 1896, 229, pl. 32.

2635. GILLELLUS A RENICOLA, Gilbert.

Head $4 \frac{3}{5}$ in length; depth 8: D. II-IX, 31; A. II, 35; scales 18-3-27. Body very slender and elongate, much as in Myxodagnus, the snout sharp, the mandible produced at symphysis and conspicuously projecting; labial fringes apparently obsolete; maxillary reaching vertical from middle of orbit; eye small, about equaling length of snout, 6 in head; opercular fringes nearly obsolete, 3 or 4 small ones at upper edge of opercle. Anterior dorsal inserted close behind occiput, composed of 3 rays, and separated by a short interspace from rest of fin; pectorals longer than head. Lateral line anteriorly running along base of dorsal, from which it is not separated by intervening scales, the anterior portion contained $2 \frac{1}{3}$ times in the posterior median portion. Color light olivaceous, the head with grayish blotches and small pearly spots; 11 dark bars downward from back, the alternate ones narrower and fainter and not extending to middle of sides, as do the others; the margins of the larger bars darker than the median portion, the bars not continued onto dorsal fin; all the fins translucent. A single specimen $1 \frac{1}{2}$ inches long, from Cape San Lucas. (Gilbert.) (arena, sand; colo, I inhabit.)

Gillellus arenicola, Gilbert, Proc.U.S.Yat.Mus.1890, 99, Cape San Lucas. (Coll.Gilbert.

\section{GILLEILUS ORNATUS, Gilbert.}

Head $4 \frac{1}{8}$ in length; depth 8. D. III-IX, 31; A. II, 34; scales not counted. With the elongate form and general appearance of Gillellus arenicola, bnt differing in the subequal jaws and in the long anterior portion of the lateral line. Head conical, acute, very small; jaws neariy equal, the lower slightly longer than the upper, but not noticeably protruding. In this 
respect the species resembles most strongly $G$. semicinctus, from which it varies widely in the general form and proportions. Snout extremely short, scarcely equaling diameter of the minute eye; diameter of orbit about 7 in head. Mouth oblique, the maxillary 4 in head, reaching nearly to rertical from posterior margin of orbit. Lips without fringes. Eyes separated by a narrow septum, the interorbital width being less than the diameter of the pupil. Opercular fringes few and small, flat, and not terminating evident ridges as in Dactyloscopus. Dorsal beginning well forward, its origin less than diameter of orbit behind the posterior line of occiput; anterior detached part of fin consisting apparently of 3 rays, the first of which is the longest, the second and third equal and short; fourth spine again longer; spines as usual slenderer than the rays, and showing no articulations, but with some difficulty discriminated from them; pectoral as long as head. Anterior part of lateral line running immediately along base of dorsal, without intervening scales, as in other members of this genus. It is much longer than in G.arenicola and is contained $1 \frac{1}{4}$ times in the posterior median portiou. There are 3 scales between the posterior part of the lateral line and the base of the dorsal. Color similar to that of G.arenicola and G. semicinctus, light olivaceous, unmarked below the middle of the sides, the back and upper half of sides with 8 brown bars which extend downward to lateral line; the upper part of each bar with a lighter central area, the light areas between the bars marked more or less with brown, which sometimes forms indistinct secondary bars ; a blackish bar at base of caudal, and a faint streak below eje; a large pearly blotch on opercle. A single specimen, about 2 iuckes long, from Albatross Station 2828 in the Gulf of California. (Gilbert.) (ornatus, adorned.)

Gillellus ornatus, Gilbert, Proc. U. S. Nat. Mus. 1891, 558, Gulf of California. (Coll. Gilbert.)

\section{DACTYLOSCOPUS, * Gill.}

Dactyloscopus, Gill, Proc. Ac. Nat. Sci. Phila. 1859, 132 (tridigitatus).

Esloscopus, Jordan \& Evermann, Check-List Fishes, 465, 1896 (zelotes).

Body moderately elongate, covered with rather large, cycloid scales; head cuboid, oblong, and nearly flat above; eyes small; interorbital space broad; mouth nearly vertical; lower jaw not dilated beneath nor emarginate in front, without barbels; no intralabial filament; teeth villiform, on jaws only; pseudobranchiæ very small or obsolete. Dorsal commencing at the nape, with 6 or 12 slender spines, the soft rays numerous; anal

* This genus is thus defined by Dr. Gill: "Body elongate with the dorsal and abdominal outlines slowly converging to the caudal fin. Scales large, regularly imbricated. Lateral line straight, and running along the middle of the side. Head oblong, subcubical, and smooth. Preopercle entire, opercle radiately fringed behind. Mouth nearly vertical. Tongue thick, narrowed anteriorly, attached to the floor of the mouth. Labial velum without a barbel. Anus a short distance behind the base of the pectoral fins. Dorsal fin subequal, single, and very long, commeneing above or before the anus and continued almost to the base of the caudal. Anal fin commencing behind the anus, and with the same form and termination as the dorsal. Caudal fin small and narrow, posteriorly subtruncated. Pectoral fins subangular. Ventral fins jugular, closely approximated, and each witl 3 stout simple and articulated rays." 


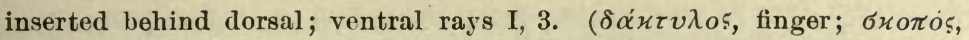
gazer, short for Uranoscopus.)

\section{DaCtyloscopus :}

a. Dorsal rays $\mathrm{X}$ to $\mathrm{XII}, 22$ to 31 ; anal rays less than 35 .

b. Soft dorsal with 22 soft rays; anal with 26.

$b b$. Soft dorsal with 28 to 31 rays; anal with 32 or 33 ; scales about 45 .

c. Body rather slender, the depth about 6 in length (7 with eaudal); opercular fringe of 15 filaments.

TRIDIGITATUS, 2638.

cc. Body rather stout, the depth $5 \frac{1}{4}$ in length ( 6 in total with caudal); opercular fringe of 18 filaments.

d. Back not barred; head blotched and dotted.

POEXI, 2639.

$d d$. Back with about 10 pale cross bars; head marked with whitish; a dark bar at base of caudal.

LUNATICUS, 2640.

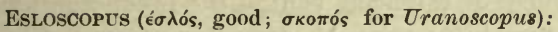

aa. Dorsal rays VI, 38 ; anal rays II, 37 ; scales 6-51-5.

ZELOTES, 2641.

\section{Subgenus DACTYLOSCOPUS.}

\section{DACTyLoscopus PECTORALIS, Gill.}

Head about 5 in total length with caudal; depth about 7 (in total). D. XII, 22; A. II, 26; P. 12; V. I, 3. Width of head behind operculum 7 in total length with caudal; өye small, 10 in head; interorbital space ecjuals diameter of eye; preoperculum broader at the angle than in Dactyloscopus tridigitatus; pores well developed; opercular fringe of 11 or 12 free filaments; origin of dorsal between $\frac{1}{6}$ and $\frac{1}{6}$ length of fish from tip of snout; origin of anal under sixth or seventh dorsal ray, the first 12 dorsal and 2 anal rays simple. Pseudobranchire obsolete. Color light brownish yellow, with dark spots on the baek, arranged in lines forming the outlines of about 6 quadrangular areas, from the angles of which irregular lines proceed downward, converging toward those departing from the angles of adjoining areas; more scattered and irregular spots and dots often present below the lateral line; head lighter, diffused with pink above. Each orbit with 4 diverging bands, 1 in front, a bifurcated one from the antero-inferior angle, and 2 from posterior border, a transverse sinuated nuchal line; upper angle of operculum whitish, bounded in front by a dark line or spot. (Gill.) Cape San Lucas; not seen by us. (pectoralis, pertaining to the breast.)

Dactyloscopus pectoralis, GiLl, Proc. Ac. Nat. Sci. Phila.1861, 267, Cape San Lucas. (Coll. John Xantus.)

2638. DACTYLOSCOPUS TRIDIGITATUS, Gill

Head 5 (in total) with caudal; depth 7. D. XII, 28; A. II, 32; P. 13; V. I, 3; scales $11+4+30=45$. Body slender, much eompressed posteriorly; opercular fringe of 15 separate filaments. Origin of dorsal fin over the lower angle of the base of the pectorals, or immediately before the margin of the opereulum, its distance from snout to dorsal 5 in total length of body. Pseudobranchiæ very small (overlooked by Dr. Gill, but evident in living specimens). In life, pale sand color above, the lower part whitish; above 12 narrow cross bands of whitish on the back, not 
extending down far on the sides; head mottled above; fins all pale. West Indies, north to Key West; rather common in coral sand in shallow water about Key West. (tres, tbree; digitus, finger, from the 3 ventral rays.)

Dactyloscopus tridigitatus, Gru, Proc. Ac. Nat. Sci. Phila. 1859, 132, Barbados (Coll. Dr. Gill); Gill, l. c., 1861, 261; GiLl, l. c., 1862, 505; GÜNTher, Cat., III, 279, 1861; JoRdAN \& Grlbert, Synopsis, 753, 1883; Jordan, Proc. U. S. Nat. Mus. 1884, 140.

2639. DACTYLOSCOPIS POEYI, Gill.

Head 5 in total length; depth $6 \frac{1}{4}$ in total. D. XI, 31; A. II, 32. Body more robust than in $D$. tridigitatus; head plane above and obtusely angulated at the sides of the plane; thickness of the head behind the preoperculum exceeding $\frac{1}{2}$ of its length; interorbital space $\frac{2}{8}$ diameter of eye. Eye about 7 in head; preoperele as in $D$. tridigitatus, pores indistinct or obsolete; opercular fringe of about 18 filaments, the lowest of which are scarcaly extended beyond the margin; origin of dorsal fin $\frac{1}{6}$ distance from tip of snout; origin of anal fin under sixth dorsal ray; scales of moderate size and regularly imbricated. Color reddish brown, dotted with darker above the lateral line; head blotched and dotted with darker; opercles variegated; opercular bones nearly immaculate. (Gill.) Cuba; not seen by us. (Named for Prof. Felipe Poey.)

Dactyloscopus poeyi, Gill, Proc. Ac. Nat. Sci. Phila. 1861, 266, Cuba. (Coll. Felipe Poey.)

\section{DACTYLOSCOPUS LUNATICES, Gilbert.}

Head (to end of opercular fringes) $3 \frac{2}{3}$, from tip of lower jaw to base of fringes 4 ; depth greater than in related species, $5 \frac{1}{4}$ in length. D.X or XI, 29 or 30 ; A. II, 32 or 33 ; scales about $11+4+30=$ about 45 . Head cuboid, narrowed forward, the vertex gently convex; width at occiput $\frac{1}{2}$ length of head (to base of fringes on opercle). Mouth nearly vertical, maxillary $2 \frac{2}{3}$ in head. Labial fringes short but evident. A short nasal filament. Teeth in a rather broad cardiform band on front of upper jaw, becoming narrow laterally; in lower jaw a single series, or an irregular double series anteriorly; vomer and palatines toothless. Eyes small, very close together, the interorbital width about $\frac{1}{2}$ their diameter, which equals length of snout, or about $\frac{1}{8}$ head. Gill laminæ much reduced in size; a small round pore behind inner arch. Gill rakers obsolete; pseudobranchiæ small but evident. Opercular fringes composed of 18 filaments. Dorsal beginning at a distance behind occiput equaling diameter of orbit, its anterior rays but partly joined by membrane, the first 10 or 11 slender and not articulated, the last ray distant from base of caudal about a diameter of orbit; origin of anal nnder sixth dorsal spine, the 2 anterior rays not articulated; pectorals short, $1 \frac{2}{8}$ in head, containing 14 or 15 rays; candal very small, with 10 developed rays, its length $2 \frac{8}{4}$ in head. Lateral line running high in its anterior portion, declining on 3 or 4 scales, the posterior portion on middle of sides with 29 or 30 tubes; 4 scales between median portions of lateral line and base of dorsal. Color light olivaceous, a dark streak along back, 1 
along middle of sides, and a fainter one along base of anal, formed by darker margins to the scales; median dorsal line with 10 or 11 more or iess evident narrow pearly white cross bars; top of head and front of mandible colored like the back, the pearly blotches varying in size and shape, but symmetrically arranged, many of them narrowly edged with black; nasal tentacle white; white streaks on preopercle; caudal with a narrow black bar at base. Gulf of California. 'Three specimens, the longest 3 inches, from Albatross Stations 2797 and 3012, the latter in 22 fathoms. (Gilbert.) (Iunaticus, moon-struck.)

Dactyloscopus lunatieus, Gubert, Proc. U. S. Nat. Mus. 1890, 99, Gulf of California. (Coll. Albatross.)

Subgenus ESLOSCOPUS, Jordan \& Evermann.

2641. DACTYLOSCOPUS ZELOTES, Jordan \& Gilbert, new species.

Head $4 \frac{1}{2}$ in length; depth $6 \frac{2}{3}$. D. VI, 38; A. II, 37; V. 3; scales 6-51-5; B. 6. Head and body slender, compressed, the greatest width at occiput, $\frac{4}{9}$ length of head; the greatest depth immediately behind insertion of anal fin, thence tapering to a very narrow tail. Head narrow, cuboid, compressed, the upper surface nearly plane, the cheeks vertical. Eyes very small, superior, with little lateral range; diameter of orbit about $\frac{1}{15}$ length of head; snont very short, about equaling orbit; anterior nostril in a short tube; gape subvertical, the lower jaw very heavy, projecting, as in Uranoscopus; premaxillaries protractile, the processes reaching far - behind orbits; lips fringed; both jaws with bauds of villiform teeth; no teeth on tongue, vomer, or palatines. Subopercle and interopercle very wide, flexible, striate, the latter overlapping throat and baso of ventral fins, the former wholly covering base of pectoral fins; the striations of opercle terminate posteriorly in a wide, coarse, membranaceous fringe; branchiostegal membranes not united, free from the isthmus; pubic bones forming a sharp projection at throat; no pseudobranchia; gills small, a round pore behind the fourth. Dorsal beginning on the nape, its dist: nce from snout about equaling depth of body, the first 6 rays shorter than those following and not connected by membrane; as no traces of articulation can be found, they are probably flexible spines, but are not clearly differentiated from those immediately following; origin of anal under fourth dorsal spine; caudal distinct, narrow, short; ventrals inserted under anterior margin of preopercle; ventrals 2 in head; pectorals $1 \frac{1}{4}$. Scales large, with entire edges, wanting on head, breast, and region behind pectoral fins. Lateral line beginning at upper posterior angle of operele, running parallel with the back on about 12 scales, then obliquely downward to middle of body. Color in spirits, light olivaceous, the edgings of the scales, some vermiculations on top of head, and the labial fringes clear brown; fins translucent, the eaudal with a brown bar at base; eyes dark. Length $3 \frac{1}{4}$ inches. Panama; 1 specimen known. The present description copied from the original in Proc. Nat. Mus. 1882, 628.

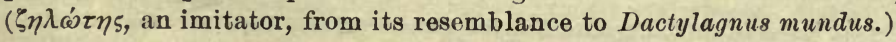

Dactyloscopus, sp. nov., Jordan \& GilberT, Proc. U.S. Nat. Mus. 1882, 628, Panama. Dactyloscopus zelotes, Jordan \& Gilbert, new species (MS. 1882), Panama (Coll. Capt. Dow). 
854. DACTYLAGNUS, Gill.

Dactylagnus, GiLl, Proc. Ac. Nat. Sci. Phila. 1862, 505 (mundus).

Body moderately elongated, covered with rather large and uniform scales. Head cuboid, oblong, scarcely convex transversely above. Eyes small, directed obliquely upward, and sitnated near the snout on the upper surface of the head. Interorbital area moderate and channeled. Mouth very oblique or subvertical, the snout truncated in front; lower jaw transversely convex in front and with no barbel; teeth acute, in a narrow band along each jaw; palate smooth. Dorsal fin perfectly entire, commencing rather farther behind than the anal, and with its anterior portion armed with about 10 slender spines; anal fin longer than the dorsal. This genus closely resembles Dactyloscopus externally. It differs from the latter genns chiefly in the structure of the dorsal fin and the well-developed pseudobranchiæ. ( $\delta \alpha \dot{\varkappa} \tau v \lambda o$ s, finger; $\alpha$ $\gamma v o \varsigma$, Agnus, an old name of Uranoscopus scaber.)

2642. DACTYLAGNES MUNDUS, Gill.

Head $4 \frac{4}{5}$; depth $6 \frac{1}{3}$. D. X, 31; A. II, 38; scales 2-48-10; eje 6 in head; maxillary $2 \frac{5}{6}$; snout equals eye; highest dorsal spine 3 ; highest anal ray $2 \frac{1}{2}$; pectoral equals head; caudal 15. Body elongate, compressed, tapering posteriorly; upper profile of head nearly horizontal, slightly convex; eyes superior, looking upward; interorbital narrow, concave; lower jaw strongly projecting, mouth nearly vertical ; teeth small and conical, in narrow bands, widest in front; vomer and palatines toothless; lips furnished with labial fringes about as long as diameter of eye; nostril ending in a tube; preopercle entire; opercle fringed on its upper edge, a flap of skin downward from opercle covers the branchiostegals; pseudobranchiæ present; gill rakers not developed; head and belly naked; fins naked. Lateral line running near the back throngh 14 scales, deflected on 4, and thence continued along the middle through 36 . Dorsal low, long, and continuous, distance from its origin to tip of snout $3 \frac{8}{4}$ in body; anal similar, slightly higher and longer; posterior rays of dorsal and anal reaching to base of caudal rays; upper rays of pectoral the longest, reaching to the vertical from tenth anal ray, the lower rays short, graduated, tip of fin slightly curved up; origin of ventrals in front of pectorals, the inner rays the longest, reaching about to vent; caudal truncate, or very slightly rounded. Color in spirits, light brown above, white below, each scale ou back with a dark brown spot; top of head with a few lorown spots; fins colorless. Length $4 \frac{1}{2}$ inches. Gulf of California. Here described from specimens collected by the Albatross at Carmen Island, Gulf of California; the type from Cape San Lucas. (mundus, neat.)

Dactylagnus mundus, GiLl, Proc. Ac. Nat. Sci. Phila. 1862, 505, Cape San Lucas. (Coll. Xantus.) 


\section{MYXODAGNUS, ${ }^{*}$ Gill.}

Myxodagnus, GILL, Proc. Ac. Nat. Sci. Phila. 1861, 269 (opercularis).

This genus differs from Dactyloscopus in the form of the head, which is elongate-conoid, the lower jaw obtusely pointed and provided with a short flap in front. The pseudobranchise are well developed and the dorsal fin commences far behind the nape. One species known. (Myxodes,

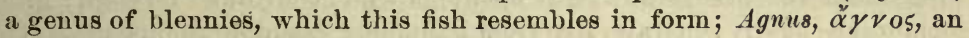
old name of Uranoscopus scabcr.)

2643. MYXODAGNUS OPERCULARIS, Gill.

Head 5 without lower jaw; depth 7. D. 36 ; A. II, 36; scales 2-44-9; pectorals equal head; ventrals $1 \frac{8}{4}$; caudal $1 \frac{1}{2}$. The body is deepest at front of dorsal fin, tapering regularly to the caudal fin. Head elongated, acutely conical; profile nearly straight, but slightly concave in front of the eyes; the crown is transversely arched and smooth; the frontal bones between the eyes are exceedingly narrow, so that the orbits appear separated by little more than a mere septum; eyes large, longitudinally elliptical; opercular pores obsolete; the postorbital or temporal ridge is nearly as long as the diameter of the orbit; the opercular fringe is composed of 6 or 7 short filaments; origin of dorsal above vent, the fin very low and continuous, its last rays not reaching to base of candal rays; anal commencing slightly in front of dorsal, similar to it but higher, its last ray reaching to base of caudal rays; pectoral large and pointed, reaching to curve in lateral line; rays of ventral subequal, reaching about to vent; caudal truncate; scales moderate, finely striated concentrically and arranged in 11 rows on each side; the lateral line runs through 12 scales on the sides of the back, is then deflected through 3 , and thence runs along the fifth row from the back through 36 . Color light yellowish brown, rendered darker on the back by congregations of dark spots on the scales; there is a pearly patch behind and beneath the eye, and the operculum is also colored in the same manner. (Gill.) Cape San Lucas. Described from a specimen $2 \frac{1}{2}$ inches in length. Not obtained by recent collectors. (opercularis, pertaining to the gill cover.)

Myxodagnus opercularis, Gill, Proc. Ac. Nat. Sci. Phila. 1861, 270, Cape San Lucas. (Coll. Xantus.)

\section{Family CXCVII. URANOSCOPIDA.}

(The StAR-Gazers.)

Head large, broad, partly covered with bony plates. Body elongate, conic, subcompressed, widest and usually deepest at the occiput. Body either naked or covered with very small, smooth, adherent scales, which

* This genus is thus defined by Dr. Gill: Body quite slender, the greatest height contained about 10 times in length. Head rather elongated and acutely conical, about, twice as long as high; eyes large and elliptical, and very closely approximated; frontal bones extrenely narrow. Mouth oblique; lower jaw projecting much beyond the upper and furnished with a short, compressed, and wide flap or barbel in front of the symphysis; villiform teeth present only on the jaws. Dorsal fin inserted behind the vertical of the anus, and furnished with simple and articulated rays; anal fin as long as or longer than the dorsal. 
are arranged in very oblique series running downward and backward; the scales on the belly inconspicuous or obsolete. Lateral line little developed, running high. Eyes small, on anterior and upper portion of head, with vertical rings. Mouth vertical, with strong and prominent mandible; teeth moderate, on jaws, vomer, and palatines. Premaxillaries freely protractile; maxillary broad, without supplemental bones, not slipping under the preorbital. Gill openings wide, continued forward; gill membranes nearly separate, free from istbmus. Pseudobranchiæ present; 6 branchiostegals; $3 \frac{1}{2}$ gills, a slit behind the last; no anal papilla. Spinous dorsal very short or wanting; second dorsal long. Anal and pectorals large, the latter with broad oblique bases, the lower rays rapidly shortened, most of them branched; ventrals jugular, close together, I, 5 , the spine very short, innermost ray longest; caudal not forked. Air bladder generally absent; pyloric ceca in moderate number. Vertebræ 24 to 26. Carnivorons fishes, living on the bottom of the shores of most warm regions. Genera 8 ; species 25.

URANOSCOPIN

a. Spinous dorsal of 4 or 5 well developed spines; scales present.

b. Head above notentireiy covered with bone, the occipital plate ceasing much behind the orbits; from the middle line anteriorly a $Y$-shaped bony process extends forward, the tips of the fork between the eyes; a trapezoidal space on either side of the $Y$, covered by naked skin, bounded by the $Y$, the eyes, the suborbitals, and the occipital plate. A covered furrow behind and on the inner side of each eye terminating near front of orbits, its edges fringed. Head without spines; humeral spine obsolete; lips and nostrils fringed; no retractile tentacle in mouth.

Astroscopus, 856.

\section{KATHETOSTOMATINAE:}

aa. Spinous dorsal obsolete; no scales; head abore corered with bone except the groove of the premaxillary spine; the bony occipital plate coaleseing with the orbital rims; humeral spine well dereloped; no distinct protuberances on top of head; no spine in front of humeral spine; 2 small forward-directed spines in front of eye; 3 small spines on lower margin of preopercle; upper lip scarcely fringed; no retractile tentacle in mouth; ventral fin not largely adnate to abdomen.

KatheTOSTOMA, 857.

\section{ASTROSCOPUS, Brevoort.}

(Electric Star-gazers.)

Astroscopus (Brevoort) GIL, Proc. Ac. Nat. Sci. Phila. 1860, 20 (anoplos; young).

Agnus, GÜnther, Cat. Fishes, 11, 229, 1860 (anoplos).

Upselonphorus, Gill, Proc. Ac. Nat. Sei. Phila. 1861, 113 (misprint for Upsilonphorus)

(y-graecum; adult).

Borly robust. Head above not entirely covered with bone, the occipital plate ceasing much bchind the orbits; from the middle line anteriorly a $\mathrm{Y}$-shaped bony process extends forward, the tips of the fork between the eyes; a trapezoidal space on either side of the $Y$, covered by naked skin, bounded by the $Y$, the eyes, the suborbitals, and the occipital plate. A covered furrow behind and on the inner side of each eye terminating near front of orbits, its edges fringed. Head without spines; humeral spine obsolete; lips and nostrils fringed; no retractile tentacle in mouth. Young individuals with top of head largely covered by bone. Head scaleless; back and sides covered with close-set scales; belly mostly naked. Humeral 
spine obsolete; no spine before the ventrals. First dorsal small, of 4 or 5 low, stout, pungent spines, connected by membrane to the second dorsal, which is rather high and long; pectorals and ventrals large. Species American, distinguished from the Old World genus, Uranoscopus, ${ }^{*}$ chiefly

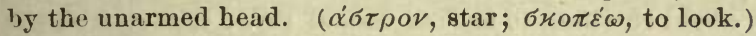

$a$. Naked space between forks of the $Y$ on top of head long and narrow, but shorter than the vertical limb of the $Y$; no distinct spines before eye; sides with round pale spots, each with a dark ring.

b. Dorsal spines 4, rather high; scales normal.

Y-QRACCM, 2644.

$b b$. Dorsal spines 5 , lower than in y-groecum; scales of sides cohering in oblique series.

ZEPHYREUS, 2645.

aa. Naked space between the forks of the $Y$ short and broad, but longer than the very short vertical limb of the $Y ; 2$ distinct spines directed forward before the eye; sides with small pale spots, not dark-edged.

QUTTATUS, 2646.

\section{ASTROSCOPUS Y-GRECUM (Cuvier \& Valenciennes).}

Head, without lower jaw, $2 \frac{5}{6}$; depth $3 \frac{1}{2}$. D. IV-I, 12; A.13; scales 80 ; eye $12 \frac{1}{2}$ in head; maxillary 2 ; pectoral $1 \frac{1}{10}$; second dorsal spine 4 ; highest dorsal ray 2 ; highest anal ray 3 ; caudal $1 \frac{1}{3}$. Body moderately elongate, very robust forward, greatest depth at occiput; anteriorly subcylindrical, posteriorly somewhat compressed. Head large and broad; mouth large, vertical, a fringe of barbels on each jaw, slightly longer than the diameter of the eye; tongue extremely large and fleshy, forming a pad under membrane of lower jaw which projects forward somewhat. Teeth conical, small and movable, in many bands in upper jaw, in lower jaw the teeth are larger and in fower bands; teeth on vomer and palatines. Eyes very small but prominent, set on top of head; interorbital very wide, $3 \frac{1}{2}$ times wider than the eye; bones on top of head coarsely granular; Y-shaped ridge on top of head conspicuous, on each side of which is a broad naked area; naked space between forks of $Y$ on top of head long and narrow, but shorter than vertical limb of the $Y$ which is very long; edges of nostrils fringed, anterior nostril round, separated from the eye by a high granular ridge; posterior nostril ending in a long curved furrow, which runs obliquely across the naked area behind eye, its posterior end not curved forward, its length $2 \frac{1}{2}$ times the diameter of the eye; 2 or 3 small blunt spines in front of the eye; surface of the bones of opercle, preopercle, and humeral process coarsely granular; gill rakers not developed; pseudobranchire small. Head entirely scaleless; belly naked below a line drawn from fifth anal ray to upper end of pectoral base; fins without scales; scales very small and somewhat embedded. Width of pectoral at base less than $\frac{1}{2}$ length of the head, the upper rays longest, the lower rays very short, graduated from the lower side to the upper; fin somewhat pointed behind and curved up, its tip reaching to the vertical from base of sixth dorsal ray; the rays of ventrals very thick and swollen, theinner

* The following are the characters of Cranoscopus: Head with spines; humeral spine rell developed; 1 strong spine on subopercle, 4 smaller ones on preopercle, all directed downward; 1 small spine directly above and in front of lumeral spine; 4 low, stout protuberances on top of head pointing backward; naked space between eyes extending back to posterior part of orbits; upper lip and nostrils not fringed; retractile tentacle in month more or less developed. First dorsal with about 4 pungent spines; scales well developed. 
rays the longest, reaching midway from their base to end of pectorals; origin of fin a distance of the width of pectoral in front of the lower edge of pectoral base; soft dorsal much higher than anal; posterior rays reaching slightly past the vertical from base of the last anal ray; end of the last anal ray about reaching to base of caudal rays; caudal truncate or slightly rounded; a ridge of skin along middle of belly from the ventrals to vent. Dark brown above, paler below; upper parts densely covered with small rounded white spots, each surrounded by a black ring; lower jaw and labial fringes similarly spotted; spinous dorsal black, white posteriorly; soft dorsal brown anteriorly with a horizontal white and black band, then tipped with white; posteriorly with 2 vertical black stripes and a white one between them; caudal black, tipped with white, with 2 to 4 white longitudinal stripes, its upper and lower edges narrowly white; the anal white at base and tip, with a black median band, $\frac{1}{2}$ depth of fin, darkest posteriorly; pectorals brown, with a black band below, the lower edge white, the upper ray spotted; ventrals white with a black lengthwise streak. Old examples lose the black ring around the spots, and the edges of the spots are blended into the dark brown of the back; a dark stripe running from the upper angle of gill opening to caudal. South Atlantic coast from Cape Hatteras to the Caribbean Sea, in sandy bays, rather common in shallow water, varying much with age. Here described from a specimen, 15 inches in length, from Charleston, South Carolina. It is recorded from Charleston, Beaufort, Matanzas River, St. Johns River, Pensacola, Key West, and "the Caribbean Sea." According to Dr. James A. Henshall, the naked area on top of the head in Astroscopus is the seat of electric power. This interesting statement needs verification. (Named from the armature of the head, in the form of the Greek $\Upsilon$.)

Uranoscopus y.groecum, Cuvier \& VAlenciennes, Hist. Nat. Poiss., III, 308, 1829, origin unknown; GÜNTHER, Cat., II, 229, 1860.

Tranoscopus anoplos, * Cuvier \& Valexciennes, Hist. Nat. Poiss., vili, 493, 1831 (young examples), Charleston, South Carolina.

Upsilonphorus y-groecum, GrLL, Proc. Ac. Nat. Sci. Phila. 1861, 113; KIRsch, l.c., 263, 1889. Astroscopus y.groecum, Bean, Proc. U. S. Nat. Mns. 1879, 58; Jordan \& Gilbert, Synopsis, $628,1883$.

Agnus anoplus, GUnNHer, Cat., II, 229, 1860.

Astroscopus anoplus, JORDAN \& GILBERT, Synopsis, 629, 1883.

Astroscopus anoplos, KIRSCH, Proc. Ac. Nat. Sci. Phila. 1889, 262.

* The genus Astroscopus was based on small specimens which, in our present opinion are simply immature examples of the species y-grocum. The supposed genus is thus described in distinction from Upsilonphorus, which seems to us the adult of the same type: Head covered above with bone except a small region between and in front of the eyes, the bony occipital plate coalescing with the orbital rims; no spines on head; humeral spines obsolete; occipital region with bluntish projections; naked space between eyes extending back to near middle of orbits; lips and nostrils fringed; no retractile tentacle in mouth.

The following characters are assigned by Dr. Kirsch to Astroscopus anoplos: Head $2 \frac{1}{2}$; depth $3 \frac{1}{4}$. D. IV -I, 13; A. 13. Pectorals rather large, their longest ray equaling in length base of second dorsal and extending to front of that fin; ventrals equaling pectorals in length, and extending to front of that fin; the second dorsal equaling anal but its anterior insertion slightly posterior to that; anal rays reaching base of caudal; vent much nearer base of caudal than to tip of snout. Color dark brown above, yellowish below; lighter portions of body covered with small white specks; chin jet-black; all the fins whitish. Length 2 inches. (Specimen from Key West). Small individuals are found along the coast from Cape Hatteras to Florida wherever A.y-grocum is found. The adult differs mainly in the armature of 1 .be top of the head, a characteristic which is developed at different ages in different individuals. 
2645. ASTROSCOPUS ZEPHYREUS, Gilbert \& Starks.

Head, without lower jaw, $2 \frac{2}{3}$; depth $3 \frac{2}{5}$. D. V, 13 ; A. 14 ; scales 84 ; eye 12 in head; maxillary $2 \frac{1}{3}$; pectoral $1 \frac{1}{4}$; second dorsal spine 7 ; highest dorsal ray $2 \frac{1}{8}$; highest anal ray $3 \frac{1}{6}$; caudal $1 \frac{8}{4}$. Body robust, widest at occiput, slightly compressed posteriorly; anteriorly subcylindrical. Head very large and broad, wider than the body; mouth large, vertical, a fringe of barbels curving over mouth on each jaw; length a little greater than the diameter of the eye; tongue very large and fleshy, forming a pad under the membrane of lower jaw, which projects forward somewhat; teeth conical, small and movable, in many bands in upper jaw; in lower jaw the teeth are larger and in 2 or 3 rows; vomer and palatines with teeth; eyes very small but prominent, set on top of head; interorbital very wide, 4 times as wide as the eve; bones on top of head coarsely granular; Y-shaped rilge on top of head conspicuous, on each side of which is a broad naked area, the form of these and other bones of the head exactly as in $A . y$-grcecum; edges of nostrils closely fringed, anterior nostril round, the ridge between it and eye not very high or conspicuous; posterior nostril ending in a long curved furrow which runs obliquely across the naked area behind eyes; at its posterior end it turns sharply forward, its length $2 \frac{2}{3}$ times the diameter of the eye; 2 very short blunt spiues in front of the eye; surface of the opercle, preopercle, and humeral process granular, not so rough as in Astroscopus y-grocum; gill rakers not developed; pseudobranchiæ very small. Head entirely scaleless; belly naked below a line drawn from first anal ray to the middle of the pectoral base; fins without scales; scales small and nearly square, grown together side by side, forming series of oblique plates. Width of pectoral at base slightly less than $\frac{1}{2}$ length of head, the lower rays very short and graduated to the long upper rays, the fin pointed and slightly turned up, its tip reaching to the vertical from base of the third dorsal ray; the ventral rays thick and swollen, the imner rays the longest, its tip reaching about midway between its base and tips of pectorals; origin of fin in front of pectorals a distance equal to the width of pectoral base; soft dorsal somewhat higher than anal, its posterior rays reaching to the vertical from base of last anal ray; tip of last anal ray nearly reaching to the base of caudal rays; caudal truncate or slightly rounded; a fold of skin along middle line of belly from ventrals to vent. Color dark brown above, paler below; upper parts with many round white spots of various sizes, edged with rings of clark brown; spinous dorsal black, light posteriorly; soft dorsal light at base, the ends of the rays with black and white stripes; pectoral and anal dusky with light edge; caudal with longitudinal black and white stripes. Pacific coast of Mexico. One specimen, numbered 333, in the Leland Stanford Junior University Museum, collected by the Albatross at Magdalena Bay, Lower California. It is 12 inches in length. A distinct electric shock was given by this fish when alive, the electric organs being in the fleshy areas on top of head behind 
eyes. (Gilbert.) A second large specimen was sent from Mazatlan by Dr. George W. Rogers, having been taken by Ygnacio Moreno in January,

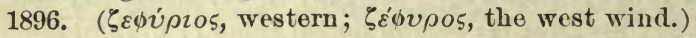

Astroscopus zephyreus, Gilbert \& Starks, Proc. U.S. Nat. Mus. 1896, 453, pl. 53, fig. 2, and pl.54, Magdalena Bay, Lower California (Type No. 47743. Coll. Albatross).

2646. ASTROSCOPLS GLTTATLS (Abbott).

Depth 4 in length in young and $3 \frac{1}{4}$ in adult. D. IV or V-13 or 14; A.13; V.I, 5. Eye $5 \frac{1}{2}$ in interorbital space. Naked space between forks of $Y$ on top of head short and broad, but longer than the vertical limb of the $Y$, which is very short; 2 distinct spinules directed forward before eye; white spots on body very small and irregular without dark rings; base of dorsals equaling in length the distance from front of first dorsal to tip of snout; base of first dorsal twice length of its longest spine; first spine equaling second in length, and 3 times length of last; length of middle caudal rays a little less than that of ventrals; pectorals slightly Ionger than ventrals, $3_{\frac{1}{2}}$ in total length, and extending to fifth anal ray. Color of upper parts of body and lower jaw bright chocolate; belly and throat white; darker portions covered with numerous circular spots much lighter than ground color; membrane of first dorsal black ; sccond dorsal white with 3 irregular bands of dull black obliquely across it; the caudal with 3 parallel bands of blackish brown, the middle of which appears to be the coutinuation of a variable longitudinal band on the center of each side; the anal having a variable band of dull brown, darker upon the posterior termination. Length 12 inches. Atlantic coast of the United States, from Long Island to Virginia; apparently scarce. Recorded from Cape May; Tompkinsville, New York; Norfolk, Virginia; Somers Point, New Jersey, etc.; not known south of Cape Hatteras. In Astroscopus guttatus the pale spots are much smaller, less sharply defined, and occupy a smaller area than in A.y-gracum; the lower part of the head has 2 black blotches in each species; the second dorsal, anal, and ventrals are nearly or quite plain. The naked area behind each eye is (in A. guttatus) lunate, its length barely twice that of the snout; the bony $Y$-shaped plate is short and broad, concave on the median line, and forked for about $\frac{1}{2}$ its length, the posterior undivided portion broader than long; the bony bridge across the occiput but little shorter than the part of the head which precedes it. In A. y-gracum the naked area is trapezoidal, longer than broad, and about 4 times the length of the snout; the $Y$ is forked for more than $\frac{1}{2}$ its length, its undivided part more than twice as long as broad, and not concave; the occipital plate is not $\frac{1}{2}$ as iong as the part of the head which precedes it. (guttatus, spotted, as with rain drops.)

Astroscopus guttatus, Аввотт, Proc. Ac. Nat. Sci. Phila. 1860, 365, Cape May, New Jersey. Opsilonphorus guttatus, BeAN, Proc. U. S. Nat. Mus. 1879, 60; KIrsCH, l. c., 264, 1889. 
857. KATHETOSTOMA, Günther.

Tathetostoma, GÜNTHER, Cat. Fish., II, 231, 1860 (loeve).

Body robust, formed as in Astroscopus and Uranoscopus. Scales none. One continuous dorsal without spines; ventrals jugular not adnate to the abdomen; pectoral rays branched; some bones of the head armed. Cavity of the gills without superior opening; 6 branchiostegals; pseudobranchia present. Air bladiler none. Three species known, the type, Kathe-

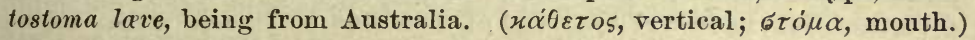

a. Dorsal rays 13; anal 13; body shaded and dotted with blackish. AVERruNCUs, 2647. $a a$. Dorsal rays 10 ; anal 12 ; body spotted with white.

ALBIGUTTA, 2648.

2647. KATHETOSTOMA AVERRUNCUS, Jordan \& Bollman.

Head $2 \frac{2}{3}, 3 \frac{1}{2}$ with caudal ; depth $3 \frac{8}{4}$. D. $13 ;$ A. 13 . Body short and robust, its width behind base of pectorals equal to length of top of head. Head very large, its width at peropercle less than its length by $\frac{1}{2}$ length of eye. Mouth large, vertical; maxillary 2 in head. Snout $1 \frac{2}{5}$ in eye. Eye rather small, 5 in hear. Teeth of lower jaw largest, inner row of each jaw enlarged and movable; vomer and palatines with a few large, conical teeth. Lower jaw without tentacle. Interorbital space lightly concave, $1 \frac{1}{2}$ times length of eye. Premaxillary groove as broad as long, $1 \frac{1}{2}$ in eye, obtuse behind, extending backward just past middle of pupil. Distance between bases of humeral spines $1 \frac{1}{4}$ in top of head. Preorbital with 3 spines in front directed forward and downward. Preopercle with 3 spines below angle directed downward and forward. Two antrorse spines on mandible, and 2 on breast before ventrals. Bones of top of head coarsely granular, striate, no naked area above except premaxillary groove; 2 points on occipital region whence granular ridges radiate; opercles and orbital bones coarsely granular, but not striate. No trace of scales or of spinous dorsal. Base of dorsal equal to base of anal, $1 \frac{2}{5}$ in head, longest ray equal to depth of cheek; pectorals $\frac{1}{2}$ eje, length greater than that of top of head; ventrals reaching more than halfway to vent, their length equal to that of top of head. A few small depressions resembling embedded scales on region beforedorsal and above head. Color blackish brown, mottled with paler; lower parts pale, dusted with brown; lips and gular region black; dorsal dusty, with 5 indistinct, partly confluent, whitish spots along its base; anterior part of anal pale, posterior thickly dusted with blackish, tips of rays pale; pectorals blackish, faintly barred; axil disted outside, inuer part very pale; ventrals pale; caudal with 3 irregular oblique lark bars; floor of mouth pinkish; tongue dusted with dark specks. Length $4 \frac{1}{2}$ inches. Pacific Ocean, off coast of Colombia; a single specimen dredged at a depth of 7 fathoms; a most singular fish. (averruncus, a deity which wards off; from the mailed head.)

Kathetostoma averruncus, JoRdan \& Bollman, Proc. U.S. Nat. Mus. 1889, 163, off coast of Colombia, at Albatross Station $2800,8^{\circ} 57^{\prime}$ N. $79^{\circ} 3^{\prime \prime} 30^{\prime \prime}$ W.; KrRSCH, l. c., 259, $1889_{i}$ Jordan, Proc. Cal. Ac. Sci. 1896, 229, pl. 31. 
2649. KathetOStONA ALBigCtTA, Bean.

Head 3; greatest width 3 ; depth $3 \frac{1}{2}$. D. 10 ; A. 12 ; interorbital space 4 in head, containing a deep groove, the length of which is slightly greater than its width and nearly equaling length of eye. Mouth nearly vertical when closed; intermaxillary slightly protractile, the length of its tooth-bearing surface $\frac{2}{7}$ length of head; maxillary very broadly expanded behind, its greatest width about 3 in length, extending almost to vertical from middle of eye; end of mandible not much farther back; length of mandible $4 \frac{2}{3}$ in length; mandible having 2 blunt prominences at its posterior end; the exposed portion of the maxillary traversed by radiating strix. The lower limb of preoperculum with 3 stout spines along its lower border; length of humeral spine 3 in head; humerus very strongly rugose on its npper border; 3 short spines on the anterior edge of preorbital. Teeth in villiform bands in the intermaxillary and mandidible, and on vomer; palatines in a very short band; a cavity between head of vomer and the processes of the intermaxillary ending in a semicircular canal behind, which is separated from the anterior cavity by a flap of skin. Gill openings very wide and only narrowly attached to the isthmus, leaving a free posterior border. Pseudobranchice present, small; a small, narrow slit behind the last gill, its length about $\frac{2}{3}$ that of eye; gill rakers tubercular, none on auterior arch. A pair of short but stout spines in front of ventrals. The origin of dorsal a little nearer to root of caudal than to tip of snout, midway between base of caudal and middle of eye; length of dorsal base about 3 in length, the third ray the longest, its length nearly $\frac{1}{2}$ length of base of fin, the last ray about as long as eje, and the first scarcely longer than this. The anal origin directly under that of dorsal, the base of fin slightly longer than that of dorsal; the seventh, eighth, and ninth anal rays about the longest, their length equaling about $\frac{1}{2}$ that of middle caudal rays; the first ray not much more than $\frac{1}{2}$ as long as the longest and the rays gradually increasing in size to the ninth; length of pectoral $3 \frac{1}{2}$ in body; length of lowermost ray less than $\frac{1}{4}$ length of head; only the first ray simple, the rest divided. Ventral origin under eye; the longest ray of ventral slightly shorter than mandible. Caudal slightly rounded when expanded, the middle rays as long as head without snout. The lateral line beginning near the root of humeral spine, curving upward slightly and running along back to end of dorsal, then curving downward to near the middle of the caudal base; skin naked. Color, upper parts light brown, the upper surface of the head minutely dotted with white; the back with numerous roundish spots and oblong blotches of whitish; lower parts pale; the dorsal with 2 or three dark blotches near the margin, in some cases not much larger than eye, in others fully twice as long; caudal with 9 black blotches, those on outer rays largest, differing in size in different specimens, these blotches distributed over the greater portion of the fin; anal pale, with the exception of a brownish blotch on the membrane of the last 3 rays; pectoral with a brownish submarginal band on its outer half, this band sometimes broken up on the mem. 
brane; ventrals pale. Length about $6 \frac{1}{2}$ inches. Gulf of Mexico, in 27 to 88 fathoms; 1 specimen known. (albus, white; gutta, spot.)

Cathetostoma albigutta, BEAN, Proc. U. S. Nat. Mus. 1892, 121, Gulf of Mexico, at Albatross Station 2403 , Lat. $28^{\circ} 42^{\prime} 30^{\prime \prime}$ N., Lon. $85^{\circ} 29^{\prime} 0^{\prime \prime}$ W. (Type, No. 39304, U. S. Nat. Mus.)

\section{Suborder HAPLODOCI.}

This group is distinguished mainly by the undivided post-temporal, the reduction in the number of gill arches to 3, and by the absence of pecn-

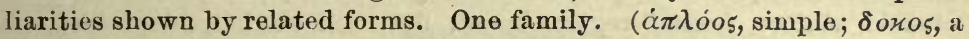
shaft or beam, from the form of the post-temporal.)

\section{Family CXCVIII. BATRACHOIDIDA.}

\section{(The TOAD-FIshes.)}

Body more or less robust, depressed anteriorly, compressed behind; head large, depressed, its muciferous channels well developed; mouth very large, the teeth generally strong; premaxillaries protractile; gllls 3, a slit behind the last; pseudobranchis none; gill openings restricted to the sides, the membranes broadly united to the isthmus; branchiostegals mostly 6; gill rakers present, moderate; suborbital without bony stay; post-temporal bone simple, undivided; scales small, cycloid, or wanting; dorsal fins 2, the first of 2 or 3 low, stout spines; soft dorsal very long; anal fin similar, but shorter; ventrals rather large, jugular, I, 2 or I, 3; pectorals very broad, the rays branched; pyloric caca none; tail diphycercal, the caudal fin distinct, rounded; vertebræ in large number, 32 to 15. Carnivorous coast fishes, mostly of the warm seas, some of them ascending rivers; the young of some or all the species fasten themselves to rocks by means of an adhesive ventral disk, which soon disappears. In some species the spines of the head and dorsal fin are provided with poison glands. Genera 7; species about 15. (Batrachida, Günther, Cat., III, 166-177.).

a. Dorsal spines 3 ; opercle developed as 2 strong diverging spines; subopercle rather strong, with 2 spines similar to those of opercle; no venom glands.

b. Body scaly; branches of subopercular spine subequal and diverging; frontal region bread, flat, and slightly depressed, its median ridge rather prominent.

BATRACHOIDES, 858.

bu. Body scaleless; branches of subopercular spine parallel, the lower branch much the shorter; vertebræ $10+22$; frontal region not depressed, its median ridge prominent; axil with a large foramen. OPsanus, 859.

aa. Dorsal spines 2; opercle very small, its posterior part developed as a single strong spine; subopercle feebly developed, narrowed, and not ending in a spine; body scaleless.

c. Spines selid, without venom glands; several lateral lines on sides of head and body, composed of pores and shining spots, some of these accompanied by cirri; canine teeth present; vertebra $12+31$; frontal region depressed, forming a triangular area below level of temporal region, its median ridge very low.

PoRichthys, 860 .

cc. Spines of dorsal fin and operculum hollow and connected with venom glands; lateral line on sides of body single; no canine teeth.

$d$. Dorsal and anal free from caudal.

ThaLASSOPHRYNE, 861.

$d d$. Dorsal and anal fully joined to caudal.

DECTOR, 862. 
858. BATRACHOIDES, Lacépède.

Batrachoides, LACÉPÈve, Hist. Nat. Poiss., III, 306, 1798 ("tau," Lacépède*= surinamensis). Batrachus (KLEIN), Bloch \& SChNEIDER Syst. Ichth., 42, 1801 ("tau," didactylus, suri. namensis, etc.; substitute for Batrachoides).

Batrictius, RAFINESQUE, Anal. Nat. 1815, 82 (substitute for Batrachoides).

Body robust, formed as in Opsanus. Dorsal spines 3 ; opercle developed as 2 strong diverging spines; subopercle strongly developed; branches of subopercular spine subequal aud diverging; body covered with small ctenoid scales; frontal region broad, flat, and slightly depressed, its median ridge rather prominent. Mucous pores of sides not greatly developed. No poison glands. Shore fishes of warm regions. ( $\beta \alpha \dot{\tau} \rho \alpha \chi o 5$, frog; $\varepsilon \tilde{\delta} \delta \circ$, resemblance.)

$a$. Teeth small, about 14 on the vomer; anterior teeth of lower jaw in a band; lateral teeth of palatine enlarged and canine-like; irregularly arranged.

SURINAMENSIS, 2649.

aa. Teeth larger, about 8 on vomer; anterior teeth of lower jaw in 2 rows; 3 teeth on middle of palatines enlarged and canine-like, the middle one the smallest.

PACIFICI, 2650.

2649. BATRACHOIDES SURINAMENSIS (Bloch \& Schneidor).

(SAPO.)

Head $3 \frac{1}{4}$ in length of body; depth 6. D. III-29; A. 26. Teeth small, about 14 on vomer; anterior teeth on lower jaw in a band; lateral teeth on palatines enlarged and canine-like, irregularly arranged; pectoral without pores on its inner surface. Color grayish, darker on sides and head; base of soft dorsal pale, with a dark, irregular line above; upper part of fin lighter; caudal nearly black; anal fin light with some dark markings. Coasts of Guiana and Brazil; not rare on sandy shores; our specimen from Curaçao.

Batrachoides tau, LACÉPł̀DE, Hist. Nat. Poiss., 306, pl. 12, fig. 1, 1798; not Gadus tau, Linvexs.

Batrachus surinamensis, BLOCH \& SCHNEIDER, Syst. Ichth., 43, 1801, Surinam; from a specimen in the Musenm of Vaillant in Paris; GÜNTHER, Cat., III, 173, 1861; MEEK \& Hall, Proc. Ac. Nat. Sci. Phila.1885, 61.

\section{BATRACHOIDES PACIFICI (Günther).}

Head 3 in length; depth about 6. D. III-26; A. 22. Teeth rather large, about 8 on vomer; anterior teeth on lower jaw in 2 rows; lateral teeth on lower jaw gradually increasing to middle of jaw, behind which they become abruptly smaller and then gradually increase to end of jaw; 3 teeth on middle of palatines enlarged and canine-like, the middle one the smallest; pectoral with a row of pores on inner surface. Color olivaceous brown; some indistinct dark cross bands on body; dorsal with about 7 very irregular oblique dark bars, anal with about 5 ; pectorals and caudal

* "Il est revêtu d'écailles molles, petites, minces, rondes, brunes, bordées de blanc, et arrosées par une mucosité très abondante, comme celles de la lote et de la mustelle." (Lacépèle.) Lacépède's specimen was therefore one of the scaly species, not an Opsanus. No species of the latter group seems to have been known to Lacépede or to Schneider. 
dark, with few light cross bands. Panama; locally common, close to the preceding but with smaller teeth and fower fin rays. 'The specimen examined by us collected by Dr. Gilbert.

Batrachus pacifici, Günther, Cat., III, 173, 1861, Panama ; Günther, Fishes Centr. Amer., $435,1869$.

Batrachoides pacifici, GILL, Proc. Ac. Nat. Sci. Phila. 1863, 170; MEeK \& Hald, Proc. Ac. Nat. Sci. Phila. 1885, 62.

\section{OPSANUS, * Rafinesque.}

\section{(TOAD-FISHES.)}

Opsanus, Rafinesque, Amer. Monthly Mag. 1817, 203 (cerapalus).

Batrachus, JoRDAN \& GILBERT, Synopsis, 751, 1883, and of authors; not of BLOCH \& SCHNEIDER.

Body comparatively short and robust, scaleless; head large, depressed; jaws, vomer, and palatines each with a single series of strong blunt teeth; mandible with an additional external series at symphysis; teeth of upper jaw small; dentary bones forming an acute angle at symphysis; lips fleshy ; upper angle of opercle with 2 diverging spines, more or less concealed in the skin; no poison glands; spinous dorsal of 3 stout, short spines, the second the longest; axil of pectoral with a large foramen; $\dagger$ lateral line obscure, its pores not conspicuous; young with a series of small, tufted cirri on back and sides; branchiostegals 6 ; vertebræ $12+22$. Shore fishes, mostly of temperate regions; voracions creatures, living on the bottoms, feeding on mollusks and crustacea, and having great strength of jaw. ( $\psi$, eye; $\alpha 2 \nu \omega$, upward ; "the name means looking up." Rafinesque.)

a. Nostrils with fleshy tentacle between them. Color brownish or dusky greenish, mottled with darker and lighter, the dark on sides of body in large irregular blotches extending from base of dorsal to about $\frac{2}{3}$ distance to base of anal, and more or less covered with small pale spots; belly and chin plain white or yellowish.

TAU, 2651.

aa. Nostrils without fleshy tentacle. Color whitish or gray, everywhere blotched or spotted with brownish yellow and black, the black spots on top of head smaller and more numerous thau on rest of body; a large black blotch at base of spinous dorsal, running up on fin; 3 black blotches along base of soft dorsal, which do not extend $\frac{1}{2}$ the distance to base of anal; pectoral with black spots which do not form eross bands; ventrals with more dark markings than in tau; dorsal, anal, and candal marked nearly as in tau.

PARDUS, 2652.

2651. OPSANUS TAU (Linnæus).

(TOAdFISH; SAPO; Slimer; OYSTER-Fish.)

Head $2 \frac{2}{8}$; depth $4 \frac{1}{8}$. D. III-26 to 28 ; A. 24 . Body robust, naked, the head broad; mouth large, the very strong jaws closing with great force; teeth blunt, those on mandible small anteriorly, regularly increasing in

* The name Batrachus should not be used for this genus, as it was originally given merely as a substitute for Batrachoides, having properly the same type, surinamensis, wrongly supposed to be tau of Linnæus, a species unknown to Lacépede and Bloch \& Schneider. No congener of tau was placed in Batrachus by Bloch \& Schneider. Prior to any use of Batrachus as the generic name of the naked toadfishes, allied to tau, Rafinesque had given to one of the latter the generic name Opsanus, which can not be set aside for Batrachus, the latter being an unnecessary synonym of Batrachoides.

$\dagger$ The Brazilian genus, Marcgravia (cryptocentra), in which this foramen is wanting, has not been recorded from north of the equator. 
size backward, tbose on vomer prominent; a broad flap above orbit; tip of maxillary and lower side of mandible with conspicnous cirri; a series of smaller cirri along margin of preopercle; subopercle ending in a long, sharp spine; orbit about equaling interorbital width or length of snout; pectoral with a large foramen in the axil. Dusky olive, with black markings confluent on the sides and forming irregular, indistinet bars; belly and under side of head lighter; sides often with many pale yellow or whitish spots; soft dorsal with 6 to 9 oblique light bands; anal with 5 to 9; caudal and pectoral fins with 5 to 7 light cross bands, these formed chiefly from light spots; ventrals with some dark markings. In specimens from shallow water or algæ, the brown becomes nearly black and more extended, the belly and chin spotted with darker, and top of the head has no distinct markings. The deeper-water specimens are lighter in coloration than those from near the surface, and those from the coral reefs (var. beta, Goode \& Bean) are paler than those from the green alga and sea wrack; otherwise no differences seem to exist. In young individuals the head is more narrow and rounded, and the lower branch of the subopercular spine proportionally larger than in the adult. Cape Cod to Cuba; very abundant among rocks and weeds close to the shore northward, in deeper water southward; the young clinging to rocks by a ventral sucking disk, which is soon lost. Length 15 inches. Not valued as food. (tau, T, the bones on the head when dried showing a T-shaped figure.)

Gadus tau, Linnaeus, Syst. Nat., Ed. XII, 440, 1766, Carolina. (Coll. Dr. Garden.)

Cottus glaber, SchöpF, Schrift. Naturf. Freunde, vil, 1788, 146, Long Island; D. 25; V. 3;

A. 21; short cirri below mouth.

Cottus choetodon, BLOCH \& SCHNEIDER, Syst. Ichth., 62, 1801, New York; after SCHÖPF.

Lophius bufo, MiтchIL, Trans. Lit. and Phil. Soc. 1815, 463, New York.

Opsanus cerapalus, RAFINESQde, Amer. Monthly Mag., Jan., 1817, 204, south coast of

Long Island. (Coll. C. S. Rafinesque.)

Batrachoides vernullas, LE SUEdR, Mém. Mus., v, 1819, 157, pl. 17, coast of Rhode Island.

Batrachoides variegatus, LE SUEUR, Jour. Ac. Nat. Sci. Phila., IIr, 1823, 399 and 401, Egg Harbor, New Jersey.

Batrachus celatus, DE KAY, New York Fauna: Fishes, 170, pl.50, f. 161, 1842, New York.

Batrachus tau beta, Goode \& BeAn, Proc. U. S. Nat. Mus. 1882, 236, Gulf of Mexico.

Oottus glaber, WaLBaUM, Artedi Piscum, III, 392, 1792; after SCH ÖPF.

Batrachus tau, Cuvier \& Valenciennes, Hist. Nat. Poiss., XII, 478, 1837; De KaY, N. Y. Fauna: Fishes, 168, pl. 28, fig. 26, 1842; Günther, Cat., III, 167, 1861; Jordan \& GILBERT, Synopsis, 751, 1883; Meek \& Hall, Proc. Ac. Nat. Sci. Phila. 1885, 59.

Batrachus variegatus, Cuvier \& VALEnciennes, Hist. Nat. Poiss., XII, 484, 1837.

2652. OPSANUS PARdUS (Goode \& Bean).

(SAPO.)

Head to end of opercular spine 3 ; depth 4. D. III-26; A. 22; maxillary $1 \frac{1}{5}$ in head; pectoral $2 \frac{1}{6}$; ventral 2; highest dorsal ray $2 \frac{5}{6}$; highest anal ray $3 \frac{1}{8}$; caudal 2. Body short and robust, compressed posteriorly; head large, somewhat depressed, wider than the body; eyes placed high, not so wide as the slightly concave interorbital space; mouth large, the maxillary reaching far beyond the eye, the lower jaw slightly projecting; a double row of small blunt teeth in upper jaw, not running very far back at the sides; lower jaw with a single row of much larger pebble-like teeth running well back and biting against a single row of similar teeth on pala- 
tines; a fow teeth in front of jaw which bite against the premaxillary teeth; vomer with 1 or 2 irregnlar rows of large blunt teeth; bead with many fleshy tentacles, 1 over each eye, a row around lower jaw, 1 on end of maxillary, and a row around preopercle; opercle ending in 2 diverging spines, the lower shorter; subopercle ending in a spine, its tip equal with the lower opercular spine, these spines not piercing the skin; gill rakers very short, scarcely developed. Body and fins covered with a soft smooth skin, which is exceedingly loose nearly to the ends of fin rays, and entirely covering the dorsal spines. Dorsal spines very short but stout; soft dorsal longer and higher than anal, but in other ways similar, reaching past base of caudal rays; pectoral short, as wide as long, round and fan-shaped behind, reaching to vertical from base of fourth dorsal ray; origin of ventral far in front of pectorals, the fins reaching to the vertical from the posterior edge of spinous dorsal; caudal well rounded, fan-shaped when spread. Color very pale yellowish brown, thickly covered with round spots of dark brown, those on head smaller; belly with numerous spots, the largest as large as eye; back with many oblong blotches, besides small round spots; fins blotched and banded. Gulf of Mexico, in deep water. This form has a very different coloration from 0 . tau and the texture of its skin and flesh is also less firm, but the technical differences are slight and, it is rather a deep-water variety than a species. (pardus, leopard.)

Batrachus tau pardus, Goode \& Bean, Proc. U. S. Nat. Mus. 1879, 336, Pensacola Snapper Banks; Jordan \& Gilbert, Synopsis, 751, 1883; Meek \& Hall, Proc. Ac. Nat. Sci. Phila. 1885, 60 .

86o. PORICHTHYS, Girard.

\section{(MIDSHIPMEN.)}

Porichthys, Girard, Proc. Ac. Nat. Sci. Phila.1854, 141 (notatus).

Body rather elongate; head not very broad, depressed, the lower jaw projecting. Dorsal spines 2; pectoral broad, without foramen in axil; opercle very small, its posterior part developed as a strong, single spine; suboperculum feebly devcloped, narrowed and not ending in a spine; no scales on body; spines solid, without venom glands; several lateral lines on sides of head and body, composed of pores and shining spots, some of these accompanied by cirri; canine teeth present; vertebræ $12+31$; froutal region depressed, forming a triangular area below level of temporal region, its median ridge very low. Branchiostegals 6; interorbital area short, wide, and with shallow grooves. Air bladder more or less deeply divided into 2 lateral parts. Pyloric appendages none. Species American; remarkable for the very great development of mucous pores, some of which simulate the photophores of Myctophum, but are different in origin and not at all luminous. ( $\pi$ ó $\rho \circ 5$, pore; $i \chi \theta \dot{v} 5$, fish; in allusion to the extraordinary development of the mucous system.)

Note.-The following account of the distribution, structure, and development of the phosphorescent organs of Porichthys is furnished us by Prof. Charles Wilson Greeue, who has made a careful study of these organs:

"Porichthys has numerous lines of conspicuous bright silvery spots distributed in rows over the surface of the body. These spots have been called phosphorescent organs, although no such function has yet been observed, the name arising out of a superficial 
resemblance. These so-called phosphorescent organs are arranged in rows over the body, and are definite and characteristic and quite constant in location in different individuals. They are accompanied by rows of epidermal sense organs, the two having an intimate relation in distribution over the surface of the fish. In surface view the shining organs have a bright silvery appearance, are more or less round in outline, size from a mere dot to $0.8 \mathrm{~mm}$. in diameter, and surrounded or bordered on one side by an increased amount of pigment. The end buds present a round, transparent, or pellucid, and usually slightly raised, point. Each end bud is bordered by a pair of papillæ. There are about 20 well-defined lines as follows: The lateral row, from posterior upper border of pectoral straight alongside to upper third of base of caudal, 35 pairs with an end bud between each pair, upper series small or rudimentary, segmentally arranged and between myomeres. The pleural row, from middle of base of pectoral, curves backward and downward to a point above first anal ray then straight nearly to base of caudal, 43 to 62 organs. End buds below each organ to above niddle of caudal, 31 organs. The caudal rows, end buds only, 2 longitudinal rows on upper and lower thirds of fin. The anal row, on either side base of anal fin from third anal ray to base of caudal. Phosphorescent organs in pairs, a pair for each anal ray, 1 end bud for each pair. The gastric row, from front around lower edge of pectoral and along side of belly to opposite anal papilla, 30 phospinorescent organs. The gular row, from isthmus along ventral side of ventral fin then outward to join gastric row, spur runs forward along external side of rentral fin, 27 organs. A parallel line of 50 end buds follows the gular row and posterior end of gastric. The ventral row with its fellow forms a parenthesis on the stomach from the side of the anus $\frac{3}{4}$ the distance to the ventral fin, 34 organs; no end buds. The branchiostegal row, from the - isthmus outward over branchiostegal membrane and between first and second rays, no end buds. The mandibular row of phosphorescent organs extends around inner edge of ridge formed by the dentary bones; the row of end buds along the outer rim of the same ridge. The opercular rows, upper and lower, extend backward and upward across opercle. The scapular row, from above opercular spine straight back above pectoral fin, the curves in toward the base of the dorsal fin opposite the third dorsal ray. The dorsal row, along base of dorsal fin to base of caudal. This row and the scapular row consist of well developed end buds and rudimentary phosphorescent organs. The occipital and frontal rows, along the occipital and frontal regions, short rows of small and poorly developed organs. The nasal, from the posterior nasal tube to base of anterior tube. The suborbital and postorbital, from posterior nasal opening around under eye backward and downward to opercle. A malar row, from the suborbital down across the cheek. A maxillary across the posterior end of maxillary bone. The rows on the head consist of well-developed end buds with rudimentary and irregularly placed phosphorescent organs. The phosphorescent organs are embedded in the connective tissue dermis of the skin, and in section show a uniform general structure throughont the body. A typical organ from the anal or ventral rows consists of an outer spherical group of cells called a lens, resting in a deeper cup-like structure, the capsule, and this in turn in a cup of fibrillar connective tissue called the reflector. The lens consists of cells, polygonal in the center of the group and flattened or fusiform around the periphery. They have a large conspicnous nucleus and a dense, homogeneous, highly refracting cell body. The outlines of the cells are very distinct. In the cells of the capsule the nuclei stain readily, but the granular protoplasm with difficulty, and the cell boundaries are indistinct and usually obliterated. In some specimens connective tissue septa penetrate the capsule. Blood capillaries are always present. The reflector extends well ap around the sides of the lens; it consists of fibrillar connective tissue which strongly reflects light. Much pigment is embcdded in its meshes. No nerves have yet been traced to the organ. The developing phosphorescent organs do not appear in the embryo fish until it is 15 to $16 \mathrm{~mm}$. long. Then a bud appears in the lower layer of the epidermis, which soon becomes constricted off as a spherical mass of shells lying in the subepidermal connective tissue. This mass later slightly elongates and gives rise by constriction to the lens and the capsule. The reflector is developed from the surrounding connective tissue, so also the pigment cells. Mature organs are not found until the fish reaches a length of over $20 \mathrm{~mm}$. The end buds appear much earlier, 9 to $10 \mathrm{~mm}$." (Charles Wilson Greene.) 
a. Abdomen with 4 longitudinal series of pores, each of which is accompanied by a shining silvery body; 4 rows of shining spots on sides of body; a white bloteh below eye, with a black crescent below it.

$b$. Tecth on palatines few ( 4 or 5 ), 1 to 3 of them developed as very strong canines, as large as canines on vomer; dorsal fin with distinct black blotches; back with dark saddles; third lateral line extending nearly to base of caudal.

POROSISSIMUs, 2653.

$b b$. Teeth on palatines numerous, none of them canine, and all much smaller than canines on vomer.

c. Third lateral line ceasing at second third of anal; cross bands on back and dorsal fin very faint or wanting; dorsal fin with a faint dark edge; sides of head and shoulder without distinct spots; body rather elongate.

NOTATUS, 2654.

cc. Third lateral line extending nearly to end of anal; cross bands on back and dorsal fin very distinct, appearing as roundish blotches, those on the dorsal fin along the margin; sides of head and humeral region much spotted with brown; body robust. MARGARITATUS, 2655.

2653. PORIChTHYS Porosissimus (Cuvier \& Valenciennes).

(BAGRE SAPO.)

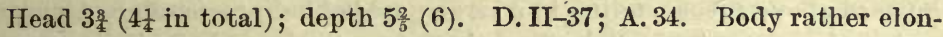
gate, tapering and compressed behind. Head depressed, $\frac{2}{8}$ as broad as long and $\frac{1}{2}$ wider than deep; lower jaw considerably projecting, maxillary reaching to well behind eye, its length $1 \frac{8}{4}$ in head. Teeth in single series on jaws, vomer, and palatines, those of upper jaw very small, a few of the anterior and 2 or 3 of the lateral teeth somewhat enlarged, the latter strongly hooked forward; teeth in lower jaw strong, rather weaker than in P. margaritatus, those in the front of the jaw hooked strongly inward; the lateral teeth, which are larger, hooked backward and inward; 1 or 2 strong canines on each side of vomer, these curved backward and outward; teeth on palatines distant, few in number (usually 4 or 5); among these are 1 to 3 very strong canines (usually, but not always, much larger than canines on vomer), strongly curved forward and inward. In $P$. margaritatus and $P$. notatus, the palatine teeth are not especially enlarged, subequal and more numerons, the canines on the vomer being much larger than any of the other teeth. Gill openings extending from the upper edge of pectoral to just below lower edge. Pectoral without axilliary foramen; height of soft dorsal about 3 in head; length of caudal nearly 2; height of anal $3 \frac{1}{3}$; length of pectorals $1 \frac{3}{5}$; of ventrals, 2: Color in life, light brown above, the top of head much darker and clouded with dark brown; a row of about 10 bar-like dark blotches along middle of side, each larger than eye, those anteriorly deeper than long, the others longer than deep; each of these blotches usually more or less confluent with a saddle-like dark blotch across the back; a crescent-shaped pale trauslucent area below the eye; below this a larger blue-black area, irregularly crescent-shaped, covering the preorbital and suborbital region, bounded below and behind by a row of shining mucous pores; on it are about 4 large pores, and above and behind it, close behind and below eye, is a large shining pore bordered with black; cheek steel bluish; sides of body silvery, becoming golden below; lower 
part of head and belly bright golden; a dark stripe along base of dlorsal; soft dorsal with 2 or 3 rows of small round dark olive spots, the upper row posteriorly becoming a dark edging to the fin; caudal, dull red, edged with dusky; anal very pale, edged with blackish; pectorals light orange, usually with some small dark spots above; ventrals orange, slightly darker anteriorly. Numerous series of pores on the body, those of the lateral line accompanied by shining golden bodies, as in other species of the genus. According to fishermen, these bodies are phosphorescent, shining at night; a statement which is probably true, although we have been unable to verify it; pores on sides of back not shining. Most of the pores, as in other species, accompanied by numerous small cirri or cilia; the arrangement of the lines of pores and shining bodies not very different from that found in $P$. notatus. It may be thus described in detail: A series of pores beginning at tip of snout, extending down around preorbital region, bounding the dark subocular blotch and joining almost at a right angle with a series of pores which extends downward from lower posterior corner of eye to angle of mouth. Another series diverges from the first in front of eye, passing close below eye, then upward above cheek, ending in a large pore behind preopercle. A curved series of pores extending backward along opercle, and another parallel with it along subopercle. Two obscure series from front of eye along top of head, becoming wide apart at the vertex, converging at the nape, then slightly diverging, converging in front of spinous dorsal, then again diverging to pass around the fin, each at last becoming straight at front of soft dorsal, extending close to its base to its last ray, there being about 2 pores to each ray. Just below this series, at front of soft dorsal on each side, begins a second series, with the pores wider apart and somewhat irregular, ceasing near the middle of the soft dorsal fin. The lateral line proper next begins above upper posterior angle of preopercle, whence a short branch passes directly upward. Opposite front of soft dorsal, the lateral line is interrupted for a distance a little more than diameter of eye. A short branch arises at this interruption and passes upward and backward at an angle from the end of the anterior part; thence the lateral line passes straight to base of caudal. The next series arises just behind axil of pectoral, then cnrves abruptly downward and backward, becoming straight opposite third ray of anal, thence proceeding to base of caudal, the pores small and close-set, anteriorly bead-like and shining, becoming dull toward the tail. Next comes a double series on each side of base of anal, the 2 series converging behind and finally coalescing. Another series begins at the middle of the base of the pectoral in front, curves downward, around the base of the fin, and, proceeding directly backward, ceases opposite vent. A series begins midway between gill opening and ventral and, extending straight backward, ceases opposite base of pectoral. Another begins, on each side, on lower side of head, directly below angle of mouth, the two diverging slightly between ventrals, then converging a little behind ventrals, then abruptly diverging, joining the series last mentioned, on each side, just in front of base of pectoral. A cross series of pores extends straight across belly, between 
vent and anal fin. At each end of this cross series a series of pores turns abruptly forward, the two meeting in an acute angle on the belly just in front of a vertical from base of pectorals. Finally, 3 parallel series on each side of lower parts of head meet in front, the two anterior in obtuse curves, the posterior in an acute angle. The anterior series along the mandible ends at the corner of the mouth. The next just behind the mandible ends just below the corner of the mouth. The next passes along the branchiostegal region, ending at the gill opening. Mandible with 2 large foramina. A series of dark-colored pores along each side of tongue. Length 8 inches. South Carolina to Texas, and southward to Argentina, on sandy shores; not very common, and found in rather deep water. Not rare about Galveston, but unknown to fishermen at Pensacola. Here described from the types of $P$. plectrodon, the North American form. The types of $P$. porosissimus examined by us in Paris agree in dentition and other respects. Except for the remote locality there is no suggestion of differences. We are informed by Dr. Vaillant that the type specimen of $P$. porosissimus from St. Catherine, has 33 anal rays, that from Rio Janeiro 32, and that the number 27, given by Valenciennes for this species, represents an error in counting. According to Valenciennes, $P$. porosissimus has D. II-36; A. 27; each palatine bone with a row of small, pointed, unequal teeth; row of pores above anal reaching base of caudal. Color grayish brown above, silvery white below; dorsal and anal whitish, edged with brown; pectoral with longitudinal lines; ventrals brownish on the outer edge; caudal whitish at base, the rest brownish; some specimens with dark cross bands. (porosissimus, most porous.)

Batrachus porosissimus, Cuvier \& VAlenciennes, Hist. Nat. Poiss., xiI, 501, 1837, Surinam (Coll. Leschenault \& Doumerc), Cayenne (Coll. Poiteau), Rio Janeiro (Coll. Delalande), St. Catherine (Coll. Lesson \& Garnot).

Porichthys plectrodon, Jordan \& GILBERT, Proc. U. S. Nat. Mus. 1882, 291, Galveston, Texas (Type, No. 30894. Coll. D. S. Jordan); Jordan \& GILBERT, Synopsis, 958, 1883.

Porichthys porosissimus, GǗNTHER, Cat., III, 176, 1861; Jordan, Proc. Ac. Nat. Sci. Phila. 1883, 291; Berg, An. Mus. Nac. Buenos Aires, 1895, 70.

Porichthys porosissimus, Jordan \& Gllbert, Synopsis, 751, 1883; Meek \& Hall, Proc. Ac. Nat. Sci. Phila. $1885,57$.

2654. PoRichthYs nota'tus, Girard.

(Singing Fish; Midshipman; Cabezon; SAPo.)

Head $3 \frac{2}{3}$; depth $6 \frac{1}{2}$. D. II-37; A. 33; V. I, 2; P. 18; eye 8 in head; maxillary 2 ; pectoral $1 \frac{3}{5}$; ventral $2 \frac{4}{5}$; caudal $2 \frac{3}{5}$. Head narrowed forward; opercle developed as a strong spine; maxillary reaching beyond orbit; lower jaw with a single row of about 10 large, recurved teeth, behind which is a patch of small teeth; sides of jaw with a single series of canines similar to those in front, but larger; upper jaw with an irregular series of small teeth; palatines with a single series of conical teeth; 2 large curved canines on vomer; head with several rows of fringed pores; 1 row along lower line of opercle and subopercle; another along upper edge of cheek, this branching behind and below the orbit, 1 branch running forward 
below the orbit and around the snout, the other vertically downward behind the maxillary; a series of fringes behind the lower lip; behind this a series of pores without fringes; a short straight series of pores on each side of vertex; a row of pores along the base of the dorsal fin, curving at front of dorsal, and terminating at upper angle of opercle; a row below this, not reaching base of pectoral; the third row not reaching base of caudal, but ceasing at second third of anal to about its $t w e n-$ tieth ray, and is anteriorly strongly curved upward to base of pectoral; 2 concentric series on the abdomen, the outer extending forward between bases of ventrals. The so-called "shining pores" on the sides are not pores, but bright round pieces of shiny membrane, showing through a translucent skin; each of the spots has above it a pair of fringed flaps with a small pore between them; the rows of flaps along dorsal and anal similar, long and low, their last rays reaching base of caudal rays; pectoral broad, somewhat pointed behind, reaching to the vertical from the fifth anal ray; origin of ventrals in advance of pectorals, in distance equal to length of maxillary, their tips not reaching to pectoral base; caudal well rounded. Olive brown above, with coppery reflections, the belly brassy-yellow; sides with irregular broad vertical cross blotches, most distinct in the young; dorsal grayish, with oblique dark bars; vertical fins sometines margined with black; pores of lateral line bead-like, shining silvery; a white space below eye, with a black crescent below it; head yellowish brown, with no dark spots on opercle and shoulder; peritoneum black. Length 15 inches. Pacific coast; very abundant from Lower California to Puget Sound; living under stones, near the shore northward, in deeper water southward. It makes a peculiar humming noise with its air bladder, hence the name singing fish. (notatus, spotted; noted.)

Porichthys notatus, Girard, Proc. Ac. Nat. Sel. Phila.1854, 141, San Francisco; Grrard, Pac. R. R. Surv., X, Fishes, 134, 1858.

Porichthys margaritatus, Meek \& HAll, Proc. Ac. Nat. Sci. Phila. 1885, 56; not of RICHARDSON.

Porichthys porosissimus, JoRdAN \& GILBERT, Synopsis, 751, 1883 (not of CUVIER \& VALENCIENNES); GÜNTHER, Cat., 1II, 176, 1861 (in part).

\section{PORICHTHYS MARGARITATUS (Richardson).}

Head $3 \frac{1}{8}$ to $3 \frac{2}{8}$; depth $4 \frac{4}{3}$ to $5 \frac{1}{2}$. D. II-37; A. 33. Similar to Porichthys notatus, differing chiefly in color. Top and sides of head and space above pectorals with numerous round dark brown spots and freckles, behind pectorals 6 to 8 vertical $\frac{1}{2}$ eross bars; dorsal not margined with black, but with 8 to 10 black submarginal spots; anal, with the exception of a few posterior rays, pale; caudal black at base and tip; pectorals with a few dots at base and on upper rays; a roundish white blotch below eye, below this a jet-black crescent. Palatine teeth small, 1 or 2 slightly enlarged. Series of shining spots arranged as in $P$. notatus, except that the third series extends almost to end of anal, to about its thirtieth ray. Pacific coast of tropical America. This species was obtained by the Albatross in large numbers off the west coast of Colombia, at Station 2795 at 
a depth of 33 fathoms, and at Station 2802 at a depth of 16 fathoms. The largest specimens are about $4 \frac{1}{2}$ inches long. In dentition it agrees with Porichthys notatus, but in color and arrangement of spots it resembles $P$. porosissimus. (margaritatus, bearing pearls; $\mu \alpha \dot{\rho} \rho \alpha \rho \circ \rho_{.}$)

Batrachus margaritatus, Richardson, Voyage Sulphur, Fishes, 67, 1845, Pacific coast of Central America; coloration and arrangement of lines identical with porosissimus.

Porichthys nautopodium,* Jordan \& Bollman, Proc. U.S. Nat. Mus. 1889, 171, Pacific Ocean, off coast of Colombia, Albatross Station, No. $2802,8^{\circ} 3^{8^{\prime}} \mathrm{N} ., 7^{\circ} 3^{1^{\prime}} 30^{\prime \prime}$ W., in 16 fathoms. (Type, No.41145, U.S. Nat. Mus. Coll. Albatross.)

86r. THALASSOPHRYNE, Günther.

\section{(Poison Toad-Fishes.)}

Thalassophryne, GüNTHER, Cat. Fishes, III,174, 1861 (maculosa.).

Body rather elongate, compressed; head moderate. Dorsal spines $2 ; \dagger$ soft dorsal and anal rather short, free from caudal; opercle very small, its posterior part developed as a single strong spine; subopercle feebly developed, narrowed and not ending in a spine; no scales on body. Spines hollow, and connected with venom glands. Lateral line on sides of body single; jaws without canine teeth. Species all South American, some of them ascending rivers; all of them noted for their venomous spines. $\ddagger$ ( $(\theta \alpha \dot{\alpha} \lambda \alpha \sigma \sigma \alpha$, the sea; $\phi \rho \dot{v} \nu \eta$, toad. $)$

* vavtoraííov, sailor-boy, from the common name "midshipman," a name given in allusion to the "buttons" on the belly of the fish.

† In Thalassothia, Berg, a South American genus, likewise with poison glands, 4 dorsal spines are present.

+ The poison organs of Thalassophryne reticulata are thus described by Dr. Günther: "In this species I first observed and closely examined the poison organ with which the fishes of this genus are provided. Its structure is as follows: (1) The opercular part: The operculum is very narrow, vertically styliform, and very mobile; it is armed behind with a spine, 8 lines long in a specimen of $10 \frac{1}{2}$ inches, and of the same form as the venom fang of a snake; it is, however, somewhat less curved, being only slightly bent upward; it has a longish slit at the outer side of its extremity, which leads in to a canal perfectly closed, and running along the whole length of its interior; a bristle introduced into the canal reappears through another opening at the base of the spine, entering into a sac situated on the opercle and along the basal half of the spine; the sac is of an oblongovate shape, and abont double the size of an oat grain. Though the specimen had been preserved in spirits for about 9 months, it still contained a whitish substance of the consistency of thick cream, which on the slightest pressure freely flowed from the opening in the extremity of the spine. On the other hand, the sac could be easily filled with air or fluid from the foramen of the spine. No gland could be discovered in the immediate neighborhood of the sac; but on a more careful inspection I found a minute tube floating free in the sac, whilst on the left-hand side there is only a small opening instead of the tube. The at tempts to introduce a bristle into this opening for any distance failed, as it appears to lead into the interior of the basal portion of the operulum, to which the sac firmly adheres at this spot. (2) The dorsal part is composed of the 2 dorsal spines, each of which is 10 lines long. The whole arrangement is the same as in the opercular spines; their slit is at the front side of the point; each has a separate sac, which occupies the front of the basal portion; the contents were the same as in the opercular sacs, but in somewhat greater quantity: A strong branch of the lateral line ascends to the immediate neighborhood of their base. Thns we have 4 poison spines, each with a sac at its base; the walls of the sacs are thin, composed of a fibrous membrane, the interior of which is coated over with mucons. There are no secretory glands embedded between these membranes, and these sacs are probably merely the reservoirs in which the fluid secreted accumulates. The absence of a secretory organ in the immediate neighborhood of the reservoirs (an organ the size of which would be in accordance with the quantity of fluid secreted), the diversity of the osseous spines which have been modified into poison organs, and the actual communication indicated by the foramen in the sac, lead me to the opinion that the organ of secretion is either that system of muciferous channels which is found in nearly the whole class of fishes, and the secretion of which has poisonous qualities in a few of them, or at least an independent portion of it. This description was 
a. Dorsal and anal fins not joined to the candal.

b. Dorsal and anal fins rather short; D. II-19; A. 18; pectoral fins short, their tips reaching to origin of anal. Color brown, marbled with darker; pectoral fins and sides of body with some round black spots; chiu and rentrals brownish; belly white.

MACULOSA, 2656.

$b b$. Dorsal and anal fins longer; D. II-24; A. 24; pectoral fins longer, their tips reaching to sixth anal ray. Color of head, body, and fins brown, with a network of yellowish lines; dorsal, anal, caudal, and pectoral fins with white margins.

RETICULATA, 2657.

2656. THALASSOPHRYNE MACCLOSA, Günther.

D.II-19; A.18; V.I, 2. The head is somewhat longer than broad, its length being contained $3 \frac{1}{8}$ in the total; it is moderately depressed. The snout is short, obtuse, with the cleft of the mouth ascending obliquely upward, and with the chin prominent. The maxillary extends to the vertical from the posterior margin of the orbit. The teeth are obtusely conical, standing in single series, except anteriorly in the lower jaw, where they form 2 series, and in the upper, where they are cardiform, in a narrow band. The eyes are directed upward and very small, their width being $\frac{1}{2}$ of that of the bony bridge between the orbits. Gill covers with a single spine; it is long, slender, cylindrical, like one of the dorsal spines, and has the operculum for its base. Gill opening notvery narrow; it extends from the upper

made from the first example; through the kindness of Captain Dow I received 2 other specimens, and in the hope of proving the connection of the poison bags with the lateralline system, I asked Dr. Pettigrew, of the Royal College of Surgeons, a gentleman whose great skill has enriched that collection with a series of the most admirable anatomical preparations, to lend $m \theta$ his assistance in injecting the canals. The injection of the bags through the opening of the spine was easily accomplished; but we failed to drive the fluid beyond the bag, or to fill with it any other part of the system of muciferous channels. This, however, does not disprove the connection of the poison bags with that system, inasmuch as it became apparent that, if there be minute openings they are so contracted by the action of the spirit in which the specimeus were preserved, as to be impassable to the fluid of injection. A great part of the lateral-line system consists of open canals; however, on some parts of the body, these canals are entirely covered by the skin; thus, for instance, the open lateral line ceases apparently in the suprascapular region, being continued in the parietal region. We could not discover any trace of an opening by which the open canal leads to below the skin; yet we could distinctly trace the existence of the continuation of the canal by a depressed line, so that it is quite evident that such openings do exist, althongh they may be passable only in fresh specimens. Thus, likewise, the existence of openings in the bags, as I believed to have found in the first specimen dissected, may be proved by examination of fresh examples. The sacs are without an external muscnlar layer, and situated immediately below the loose, thick skin which envelops their spines to their extremity; the ejection of the poison into a living animal, therefore, can only be effected by the pressure to which the sac is subjected the moment the spine enters another body. Nobody will suppose that a complicated apparatus like the one described can be intended for conveying an innocuous substance; and therefore I have not hesitated to designate it as poisonous; and, Captain Dow iuforms me in a letter lately received, "the natives of Panama seemed quite familiar with the existence of the spines and of the emission from them of a poison which, when introduced into a wound, caused fever, an effect somewhat similar to that produced by the sting of a scorpion; but in no case was a wound caused by one of them known to result seriously. The slightest pressure of the finger at the base of the spine caused the poison to jet a foot or more from the opening of the spine.' The greatest importance must be attached to this fact, inasmuch as it assists us in onr inquiries into the nature of the functions of the muciferous sy stem, the idea of its being a secretory orgau having lately been superseded by the notion that it serves merely as a stratum for the distribution of peripheric nerves. Also the objection that the Stingrays and many Siluroid fishes are not poisonous, because they have no poison organ, can not be maintained, although the organs conveying their poison are neither so well adapted for this purpose nor in such a perfect connection with the secretory mucous system as in Thalassophryne. The poison organ serves merely as a weapon of defense. All the Batrachoids with obtuse tcoth on the palate and in the lower jaw feed on Mollusca and Crustaceans." (Günther.) 
base of the pectoral obliquely downward and forward to the level of the inferior base of the pectoral. The 2 dorsal spines are slender, pungent, about $\frac{1}{8}$ the length of the head. Dorsal and anal fins terminate immediately before the root of the caudal, the length of which is $\frac{1}{4}$ the total; pectoral obliquely rouuded, extending to the origin of the anal; ventral rather short, not quite $\frac{1}{2}$ the length of the head, extending to the base of the pectoral. Skin perfectly smooth, with some very short tentacles at the lower jaw. Two short horizontal muciferous channels on the cheek and the lateral line are very distinct; they are not, as usually, composed of a series of distant pores, but the pores are confluent, forming 1 continuous groove of a white color. Other nuciferous channels, as for instance along the base of the anal, are composed of separate indistinct pores. Color brown, marbled with darker; pectoral fins and sides of the body with some round black spots; chin and ventrals brownish; belly white. The general habit is that of a Batrachus [Opsanus]. One specimen, from Puerto Cabello, Caribbean Sea. (Giinther.) (maculosus, spotted.)

Thalassophryne maculosa, GÜnther, Cat., III, 175, 1861, Puerto Cabello; GUnther, Fishes of Centr. Amer., 436, pl. 68, fig. 1, 1869; MEex \& HALL, Proc. Ac. Nat. Sci. Phila. 1885, 54.

\section{THALASSOPHRYNE RETICULATA, Günther.}

D. II-24; A. $24 ;$ V. I, 2; P. 16. The length of the head is $\frac{2}{7}$ of the total length (without caudal). The teeth on the palate are in a single scries, very short, obtuse, incisor-like. Pectoral very large, extending back to the sixth anal ray. Head, body, and fins brown, with a network of jellowish lines; vertical and pectoral fins with a white margin. In other respects this species agrees with $T$. maculosa. Length 13 inches. Panama; not rare. (reticulatus, netted.)

Thalassophryne reticulata, GUnther, Proc. Zool. Son. London 1864, 150, 155, Panama; GÜNTher, Fish. Centr. Amer., 437, pl. 68, fig. 2, 1869; Jordan \& Grubert, Proc. U. S. Nat. Mus.1882, 62; Merk \& Hall, Proc. Ac. Nat. Sci. Phila. 1885 ?

862. D $\mathrm{E} C T O R$, Jordan \& Evermann, new genus.

\section{(Poison Toad-Fishes.)}

Dactor, Jordan \& Evermann, new genus (dowi).

This genus differs from Thalassophryne in the more elongate body and the many-rayed soft dorsal and anal fins, the last rays of which are fully joined to the caudal. ( $\delta \alpha i \kappa \tau \omega \rho$, slayer; from $\delta \alpha i \zeta \omega$, to slay.)

2658. DECTOR DOWI (Jordan \& Gilbert).

Head 4 in length ( $4 \frac{2}{8}$ with caudal); depth $5 \frac{2}{8}\left(6 \frac{2}{5}\right)$. D. II-33; A. 30 . Body comparatively elongate, compressed behind. Head low and rather narrow, its width $1 \frac{1}{8}$ in its length. Eye very small, the diameter not $\frac{1}{2}$ the interorbital space, and about as long as snout, 8 in head. Interorbital width about $5 \frac{1}{2}$ in head. Opercular spine short, nearly 4 in head. Mouth oblique, the lower jaw much projecting. Maxillary 2 in head, extending 
to beyond eye. Teeth small, those on the palatine largest; teeth of upper jaw smaller than those of the lower; anterior teeth of the lower jaw in about 2 series. Pectoral fins long, $1 \frac{1}{6}$ in head, reaching about to fifth anal ray; last rays of dorsal and anal fully joined to the candal. Color olivaceous, with darker blotches; first dorsal black; under parts pale; posterior portion of anal edged with dark. Pacific coast of North America, from Punta Arenas to Panama; rare. (Named for Capt. John M. Dow, who obtained a fine specimen (now destroyed) from Panama.)

Thalassophryne dowi, Jordan \& Gilbert, Proc. U. S. Nat. Mus. 1887, 388, Punta Arenas (Type, No. 39085, U.S. Nat. Mus. Coll. Cornell University); Jordav, Proc. Cal. Ac. Sci. 1896,231, pl. 38.

\section{Suborder XENOPTERYGII.}

\section{(The Cling-Fishes.)}

Breast with a broad sucking disk, between the wide-set ventral fins, this formed from the skin of the breast, not from the ventral fins themselves. Ventral rays I, 4 or I, 5; no scales; no spinous dorsal; no suborbital ring; palatine arcade materially modified; no air bladder; vertebræ in increased numbers; gill arches reduced. A well-marked group of small fishes, constituting a single family. ( $\xi \varepsilon \dot{v} 05$, strange; $\pi \tau \varepsilon \dot{\rho} \rho \xi$, fin.)

\section{Family CXCIX. GOBIESOCIDA.}

\section{(CLING-FISHES.)}

Body rather elongate, tadpole-shaped, broad and depressed in front, covered by smooth, naked skin; mouth moderate; upper jaw protractile; teeth usually rather strong, the anterior conical or incisor-like; posterior canines sometimes present; suborbital ring wanting; no bony stay from suborbital across cheek; opercle reduced to a spine-like projection concealed in the skin, behind the angle of the large preopercle, this spine sometimes obsolete; pseudobranchiæ small or wanting, gills 3 or $2 \frac{1}{2}$; gill membranes broadly united, free or united to the isthmus; dorsal fin on the posterior part of the body, opposite to the anal and similar to it, both fins without spines; ventral fins wide apart, each with 1 concealed spine and 4 or 5 soft rays. Between and behind the ventrals is a large sucking disk, the ventrals usually forming part of it. This sucking disk, which is wholly different in structure from that of Cyclopterus and Liparis, is thus described by Dr. Giinther: "The whole disk is exceedingly large, subcircular, longer than broad, its length being (often) $\frac{1}{8}$ of the whole length of the fish. The central portion is formed merely by skin, which is separated from the pelvic or pubic bones by several layers of muscles. The peripheric portion is divided into an anterior and posterior part by a deep notch behind the ventrals. The anterior peripheric portion is formed by the ventral rays, the membrane between them and a broad fringe, which extends anteriorly from one ventral to the other. This fringe is a fold of the skin containing on one side the rudimentary ventral spine, but 
no cartilage. The posterior peripheric portion is suspended on each side on the coracoid, the upper bone of which is exceedingly broad, becoming a free, movable plate behind the pectoral. The lower bone of the coracoid is of a triangular form, and supports a very broad fold of the skin, exteuding from one side to the other, and containing a cartilage which runs through the whole of that fold. Fine processes of the cartilage are continued into the soft striated margin, in which the disk terminates posteriorly. The face of the disk is coated with a thick epidermis, like the sole of the foot in higher animals. The epidermis is divided into many polygonal plates. There are no such plates between the roots of the ventral fins." (Günther, Cat., III, 495.) No air bladder; intestines short; pyloric cxea few or none; skeleton firm; vertebræ 13 or $14+13$ to $22=26$ to 36 . Carnivorous fishes of small size, chiefly of the warm seas, usually living among loose stones between the tide marks and elinging to them firmly by means of the adhesive disk. 'Their relations are obscure, but they are probably descended from allies or ancestors of the Cottida or Batrachoidida. Genera about 15 ; species 50 . The principal genus is Gobiesox. (Gobesocida, Günther, Cat., III, 489-515.)

GOBIESOCIN ג :

a. Gill membranes free from the isthmus; gills 3 ; posterior part of sucking disk with no free anterior margin.

$b$. Incisors of lower jaw with entire edges.

c. Vertebræ about 32; anal fin long, nearly as long as dorsal.

cc. Vertebræ about 26; anal fin short.

Caularchus, 863.

d. Dorsal fin very long, of about 17 rays, twice as long as the moderate anal, which has 8 or 9 rays; disk broad; upper teeth in several rows.

BRYSSET ARES, 864.

dd. Dorsal fin moderate or short, of 4 to 13 rays.

e. Disk more or less broad, its length $2 \frac{1}{2}$ to 3 in body; dorsal and anal not very short, their rays 6 or more; body tapering rapidly backward; opercular spine strong. GOBIEsox, 865 .

ee. Disk very narrow, its width 4 to 5 in body; head short, $3 \frac{1}{4}$ to 4 in body; dorsal and anal very short and small; a patch of teeth in each jaw behind the large teeth; sucking disk small.

RIMICOLA, 866.

$b b$. Incisors of lower jaw tricuspid or serrate; dorsal and anal fins short; verte. bræ about 28 .

ARBACIOSA, 867 .

863. CAULARCHUS, Gill.

Caularchus, GILL, Proc. Ac. Nat. Sci. Phila. 1862, 330 (moeandricus).

This genus differs from Gobiesox chiefly in the numerous vertebræ, 32 in the only species known. The incisors are entire, the anal fin similar to the dorsal, each having 12 or 13 rays. The single species reaches a large size and is found farther north than any other of the group, a fact in accord with the increased number of vertebræ. ( $\varkappa \alpha v \lambda o ́ s$, stem; $\dot{\alpha} \rho \chi o ́ s$, anus; from the many-rayed anal.) 
2659. CAULARCHUS MEANDRICUS (Girard).

(SUCK-FISH.)

Head $2 \frac{8}{4}$; depth $6 \frac{1}{2}$. D. 13 ; A. 12 ; V.I, 4 ; vertebræ $13+19=32$; eye $7 \frac{1}{2}$ in head; distance from vent to caudal $2 \frac{8}{4}$ in length of body; sucking disk as broad as long, $3 \frac{1}{2}$ in length. Head broad, nearly circular when viewed from above; interorbital width 3 in head; mouth wide, its width more than $\frac{1}{2}$ length of head; maxillary extending to below eye; outer teeth of upper jaw rather strong, close set, vertical, conical, or slightly compressed, a narrow band of small, conical teeth behind them; lower jaw with larger teeth, 6 or 8 of the anterior broad, incisor-like, with entire edges, placed nearly horizontally; lateral and posterior teeth small, as in upper jaw; nostrils ending in tubes; spine on opercle sharp, but not projecting through the skin; origin of dorsal fin a little in advance of vent, the fin much higher than the anal; vent midway between anal and posterior edge of disk; pectorals short and broad, not extending back past the margin of the ventral disk, the 3 lower rays forming part of disk; caudal rounded. Color light olive, everywhere reticulated with brownish orange; middle of upper lip black; a light bar between eyes and 1 across cheek; vertical fins dusky; caudal with 2 faint brownish bars near its base. Specimens from red algw are light pink, mottled with darker, the pale band between eyes very distinct. Length 6 inches. Pacific coast of United States, from Vancouver Island to Point Concepcion; everywhere very abundant in rock pools; the largest species of Gobiesocido. (maandricus, meandering, in allusion to the reticulated streaks.)

Lepadogaster reticulatus, GIRARD, Proc. Ac. Nat. Sci. Phila. 1854, 155, San Luis Obispo, California ; name preoccupied.

Lepidogaster maeandricus, GrRard, Pacific R. R. Surv., X, Fishes, 130, 1858, San Luis

Obispo, California; substitute for reticulatus, preoccupied in Lepadogaster; GUNTHER, Cat., III, 505, 1861.

Gobiesox reticulatus, JORDAN \& GILBERT, Synopsis, 749, 1883.

\section{BRYSSET FERS, Jordan \& Evermann.}

Bryssetoeres, Jordan \& Evermann, Proc. Cal. Ac. Sci. 1896, 230 (pinniger).

This genus differs from Gobiesox solely in the great development of the dorsal fin, which has 17 rays, the moderate anal having but 8 or 9 ; the vertebra $10+16$, as usual in Gobiesox. One species known. ( $\beta \rho v ́ \sigma \sigma o 5$, sea-urchin; $\check{\varepsilon} \tau \alpha \imath \rho \circ$, comrade, the species living in rock pools with the sea-urchins.)

2660. BRYSSETERES PINYIGER (Gilbert).

Head $2 \frac{3}{5}$ to $2 \frac{2}{5}$; width of body $4 \frac{1}{6}$; of head 3 in length. D. 16 or 17 ; A. 8 or 9 . Interorbital width $3 \frac{1}{4}$ in head; eye $\frac{1}{2}$ interorbital width; width of mouth $1 \frac{3}{5}$ to $1 \frac{8}{4}$ in head. Teeth in upper jaw conic, acute, in several series, the anterior row in front enlarged, unequal; in lower jaw the teeth mesially in 2 distinct series, those in middle of anterior row narrow, entire incisors, those laterally conic, canine-like. No evident oper- 
cular spine. Disk about as broad as long, its length about that of head. Front of dorsal varying in position, about midway between snout and base of caudal, its length about $\frac{1}{2}$ that of body. Vent nearly equidistant between disk and front of anal, the base of the latter $3 \frac{1}{2}$ to $3 \frac{8}{4}$ in body. Caudal $1 \frac{1}{2}$ to $1 \frac{8}{4}$ in head. Pectorals about $\frac{1}{8}$ of head, with a distinct fold at base. Color variable; anteriorly usually with reticulating dark lines surrounding yellowish spots; a narrow dark streak forward, 1 downward, and 1 backward from orbit; below dorsal fin about 6 dark bars running obliquely downward and backward, these sometimes in greater number, frequently more or less irregular and interconnected, often divided by vertical streaks or series of dots; body sometimes light in spirits, with out distinctive markings; vertical fins usually dusky, narrowly margined with white, sometimes lighter with dark margins. Length $2 \frac{1}{4}$ inches. (Gilbert.) Gulf of California, abundant; specimens known from Puerto Refugio (Angel Island), San Luis Gonzales Bay, and La Paz. Well distinguished by its long dorsal. (pinniger, fin-bearing.)

Gobiesox pinniger, GiLbert, Proc. U. S. Nat. Mus. 1890, 94, Puerto Refugio, Gulf of California. (Coll. Albatross.)

Bryssetceres pinniger, JoRdAN, Proc. Cal. Ac. Sci. 1896, 230, pl. 34.

865. GOBIESOX, Lacépède.

\section{(CLING-Fishes.)}

Gobiesox, LACEPèDE, Hist. Nat. Poiss., II, 595, 1799 (cephalus).

Megaphalus, Rafinesque, Analyse de la Nature 1815, 86 (cephalus, substitnte for Gobie$80 x$, regarded as an objectionable compound).

Sicyases, MÜller \& Troschel, Archiv fur Naturgesch. 1843, 298 (sanguineus; small spo. cies, with upper teeth uniserial).

Tomicodon, BRISOUT DE BARNeville, Rov. Zool., 144, 1846 (chilensis = Sicyases).

Sicyogaster, BRISOUT DE BARNEVILLE, Rev. Zool., 144, 1846 (marmoratus= Gobiesox).

Brys8ophilus, JoRdaN \& EvERMaNn, now subgenus (papillifer).

Body anteriorly very broad and depressed, posteriorly slender, covered with tough, smooth skin; opercle with a strong spine; head large, rounded in front; mouth terminal, crescent-shaped; lower jaw with a series of strong incisors in front, their edges rounded or truncate; upper jaw with a series of strong teeth, behind which are sometimes smaller teeth; no teeth on vomer or palatines; gills 3 ; gill membranes broadly united under the throat, not attached to the isthmus; sucking disk large, the posterior portion without anterior free margin. Dorsal and anal moderate, the dorsal rays 6 to 12, the anal rays 6 to 10 . Vertebræ about 26, as far as known. Species numerous, all American; mostly tropical, clinging to rocks near the shore. (Gobius; Esox; the resemblances either to the goby or the pike being few or remote.)

BRyssophiLus ( $\beta \rho v ́ \sigma \sigma o s$, sea urchin; $\phi \iota \lambda \dot{\omega} \omega$, to love) :

a. Dorsal fin comparatively long, of abont 13 rays; anal rays 9; disk broad; upper teoth in several rows; lower incisors narrow; papillø below chin; color olivaceous.

aa. Dorsal fin moderate or short, its rays 6 to 11 .

PAPILLIFER, 2661.

$3030-69$ 
GobIesox :

c. Upper teeth in more than 1 series (character not verified in a few species); head broad.

d. Coloration in life chiefl, olivaceous, without red, sometimes banded with darker or paler.

e. Dorsal rays 12; anal rays 7 .

ee. Dorsal rays 11 ; anal rays 6 ; fins black.

eee. Dorsal rays 9 or 10 ; anal rays 6.

eeee. Dorsal rays 8 ; anal rays 6.

eeeee. Dorsal rays 11 ; anal rays 10.

eеeeee. Dorsal rays 10 ; anal rays 8.

eeeeeee. Dorsal rays 9; anal rays 7.

GYRINUS, 2662.

NIGRIPINNIS, 2663.

CEPHALUS, 2664.

TUDES, 2665 .

STRUMOSUS, 2666.

VIRGATULUS, 2667.

$f$. Width of head $3 \frac{2}{3}$ in length; color plain brown.

ADUSTUS, 2668.

ff. Width of head 5 in length; color blackish, with yellow vermiculations.

FUNEBRIS, 2669.

eeeeeeee. Dorsal rays 7; anal rayṣ 7; өyes variegated.

PCEILOPHTHALMUS, 2670.

$d d$. Coloration in life chiefly bright red, or else with red spots or bands, the color not fading in spirits.

g. Color red, with deep red spots. D. 6; A. 5. RHodospiLus, 2671.

gg. Color uniform red, unspotted, the color not fading in spirits; dorsal rays 6 to 8 ; anal rays 6 .

$h$. Lower jaw with short incisors on each side, followed by ca. nines.

MACROPHTHALMUS, 2672.

$h$. Lower jaw with 2 horizontal incisors on each side, the third horizontal tooth not incisor-like; no distinct canines.

SICYASES ( $\sigma \iota x v ́ \alpha$, a sucking cup made of a gourd):

CERASINUS, 2673.

cc. Upper teeth in a single series (character not verified on some species); dorsal and anal short.

2. Color chiefly red.

$j$. Body with cross bands of deep red; iris red; dorsal rays 6; anal rays 5 ; head broad, the eyes very large.

ERYTHROPS, 2674.

$j j$. Body with dark cross bands and with spots of clear blue; body rather slender. D. 6 or 7 ; A. 6 .

RUBIGINOSUS, 2675.

jjj. Body plain, light red; form rather slender. CARNEUs, 2676.

ii. Color olivaceous or brownish, not red.

$k$. Dorkal rays 9 ; anal rays 6 .

l. Color olivaceous, without bands.

HAERES, 2677.

ll. Color greenish, with 3 dark cross bands and many dots.

PCNCTULATUS, 2678.

$k k$. Dorsal rays 7; anal rays 7; body with dark cross bands.

FASCLATUS, 2679.

Subgenus BRYSSOPHILUS, Jordan \& Evermann.

2661. GOBIESOX PAPILLIFER, Gilbert.

Head $2 \frac{3}{5}$; width of boly $3 \frac{2}{3}$; width of head $2 \frac{4}{5}$. D.13; A.9. Width of mouth $1 \frac{4}{5}$ in head; interorbital width 3 ; өye $\frac{1}{2}$ interorbital width; teeth in upper jaw conic, acute, very small, in 2 or more series, 2 of them slightly enlarged, canine-like; teeth in lower jaw in 2 series, the outer anteriorly, narrow entire incisors, with rounded tips, becoming conical laterally; opercular spine sharp, evident, though not projecting through the integument; lips and lower side of head anteriorly with fleshy papillæ; disk about as broad as long, its length $1 \frac{1}{5}$ in head; distance from 
front of dorsal to base of caudal $1 \frac{1}{2}$ in its distance from tip of snout; vent exceptional in position, immediately in front of anal fin; base of anal 18 in head; caudal rather acute, $1 \frac{2}{3}$ in head; pectorals $2 \frac{2}{3}$ in head, a distinct fleshy fold at base. In spirits, uniform dark olivaceous, lower side of head and disk light; pectorals dusky; vertical fins with a black bar at base, then a white bar; followed by a wide, dusky area, and narrowly margined with white; caudal with all these marks except the black bar, having the posterior outlines curved, following margin of fin. Length $1 \frac{1}{2}$ inches. Magdalena Bay, Lower California. (Gilbert.) Possibly related to the genus Caularchus. (papilla; fero, I bear.)

Gobiesox papillifer, GrLbert, Proc. U.S. Nat. Mus.1890, 96, Magdalena Bay, Lower California. (Coll. Albatross.)

\section{Subgenus GOBIESOX.}

2662. GOBIESOX GYRINUS, Jordan \& Evermann, new species.

B. 6 ; D. 12 ; A. 7 ; V. I, 4 ; P. 20. A vertical fold of skin at base of pectoral; coracoid distinctly below level of upper margin of pectoral; teeth of upper jaw cardiform, lower jaw with very narrow but compressed incisors, which are as short as the other teeth. Lateral profile of head nearly semicircular; head much depressed, as long as broad, its length being $\frac{2}{T}$ of the total; width of interorbital space somewhat less than $\frac{1}{2}$ greatest width of head, or 3 times diameter of eye; cleft of mouth extending bevond anterior margin of eye; distance of origin of dorsal from caudal more than $\frac{1}{2}$ of its distance from snout. Brownish, with scattered dark spots; a black blotch anteriorly on the dorsal fin. Length 3 inches. (Guinther.) West Indies; not seen by us. A valid species, according to Dr. Günther, but apparantly as yet without tenable specific name, as the original Cyclopterus nudus, Linnæus, must have been some other fish. (gyrinus; yvpĩvo5, a tadpole.)

Lepadogaster nudus, BLOCH \& SCHNEIDER, Syst. Ichth., 2, 1801; in part, description taken from Cycbopterus nudus, Linnæus, except the count of fin rays. D.12; A.6.

Cotylis nuda, MÜller \& Troschel. Hor. Ichth., III, 18, pl. 3, f. 2,

Gobiesox nudus, GÜnther, Cat. Fish., III, 502, 1861, Island of Cordova. (Coll. G. U. Skinner.)

Gobiesox gyrinus, Jordan \& EvermanN, Check-List Fishes, 491, 1896, Cordova; after GÜNTHER; name only.

\section{GOBIESOX NIGRIPINNIS (Peters).}

D. 11 ; A. 6 ; P. 22 . "Nostrils, mouth, teeth, opercular spine, and fin rays as in Cotylis stannii (Gobiesox cephalus), but the dorsal fin longer. Light brown above (minutely dotted with black, if viewed by a magnifier); vertical fins black." Puerto Cabello (Peters); not seen by us; a doubtful species, perhaps identical with G. cephalus or G. nudus. (niger, black; pinna, fin.)

Cotylis nigripinnis, Peters, Berl. Monatsber. 1859, 412, Puerto Cabello.

Gobiesox nigripinnis, Günther, Cat., II, 502, 1861; after PeTERS; GÜnther, Fish. Centr.

Amer., 390, 1869. 
2664. GOBIESOX CEPHALUS, Lacépède.

(Tétard; Testar.)

D. 9 or 10 ; A. 6 ; C. 12 ; P. 19 or 20 . Head and anterior part of body very broad, much depressed; skin tough, naked, and smooth; head nearly as broad as long, with its profile semielliptical, the snout being very obtuse and rounded. The upper surface of the head is quite flat, gently sloping downward in a straight line from the nape to the snout. The greatest width of the interorbital space is $\frac{1}{2}$ of that of the head, or 4 times the diameter of the eye. The cleft of the mouth is horizontal, curved, wide, extending to below the center of the eye; the lips are thick, the lower being divided into 5 portions by 4 vertical grooves, the central portion being the smallest, the lateral ones the largest and hanging downward. The upper jaw is slightly protractile, and there is a broad velum behind the teeth in each jaw. A band of short conical teeth in the upper jaw; a single series in the lower, the anterior ones being slightly compressed incisors, and small like the lateral teeth, which are conical. The eye is small, situated immediately below the upper profile of the head. Two nostrils, close together, opposite the upper angle of the orbit, their margins being slightly raised. The lower angle of the opercular apparatus terminates posteriorly in an obtuse movable point enveloped in skin and directed backward. The gill openings are somewhat narrow in consequence of the small degree of expansibility of the gill covers, but the gill membranes have the margin quite free, being united together under the throat, and not attached to the isthmus. There are only 3 gills; the pseudobranchiæ are quite rudimentary, indicated by 2 or 3 short lamellæ. The distance of the origin of the dorsal fin from the caudal is nearly $\frac{1}{3}$ of its distance from the snout, its first ray is much shorter than the others, and apparently without articulations. The caudal rounded and of moderate length; the anal is only $\frac{1}{2}$ as long as the dorsal, commencing below its middle and terminating in the same vertical. The pectoral is broad and short, its lower $\frac{1}{2}$ being longer than the upper; it is slightly connected with the ventral. A vertical fold of the skin at the base of the pectoral; the coracoid is so high as to reach to the upper margin of the pectoral. The adhesive apparatus as broad as long, its length being contained $3 \frac{1}{2}$ times in the total. The vent and the porus urogenitalis are close together, situated midway between the margin of the ventral disk and the anal. The anal papilla is small. The color is brown (in spirits), whitish inferiorly. Length of adult, 7 inches. (Guinther.) Caribbean Sea, said to be common; not seen by us. The original $G$. cephalus seems nearer the next species, if the 2 are really different. If that be the case the present species may stand as Gobiesox stannii. But we have no material adequate to settle this question. (cephalus, big-headed; $\varkappa \varepsilon \phi \alpha \lambda \dot{\eta}$, head.)

Gobiesox cephalus, LACÉPÈDE, Hist. Nat. Poiss., 1I, 595, 1798, Martinique; on a drawing by Plumier; D.8; A. 4 or 5 ; color plain reddish; anal inserted behind dorsal; head broad; ejes blue; Gưtrer, Cat., III, 499, 1861.

Lepadogaster testar, BLOCH \& SCHNEIDER, Syst. Ichth., 445, 1801, Martinique; after Plumier.

Cotylis stannii, Mïllen \& TroscheL, Hor. Ichthyol., III, 18, taf. 3, fig. 3, 1845. 
2665. GOBIESOX TUDES, Richardson.

Head $2 \frac{1}{2}$; depth $4 \frac{2}{8}$; width of head $2 \frac{1}{2}$. D. 8 ; A. 6 in plate ( 5 in the description, the first short ray apparently not counted by Richardson). Head very broad, as broad as long, abruptly truneated anteriorly; mouth large, the maxillary reaching front of eje; lower jaw included; teeth entire; eye large, $4 \frac{8}{4}$ in head, a little more than $\frac{1}{2}$ interorbital width, $1 \frac{1}{2}$ in suout. Distance from front of dorsal to caudal about equal to length of head; insertion of dorsal before vent; the anal behind dorsal and much shorter than it; pectorals short. Color uniform, probably greenish, without spots or stripes. Length 5 inches. Locality "unknown, but supposed to be from China." (Richardson.) The species is, however, certainly not Chinese and is more likely to be from the West Indies. This species differs from Gobiesox cephalus, as described by Günther, in the larger eye and shorter dorsal. It is probably the same species. (tudes, hammer.)

Gobiesox tudes, Richardson, Voy. Sulphur, Fish., 103, pl. 46, figs. 1-3, 1845, habitat unknown, erroneously supposed to be China.

2666. GOBIESOX STRUMOSUS, Cope.

D. 11 ; A. 10 ; C. 16 ; P. 21 . Head extremely wide, its width $2 \frac{5}{6}$ in total length; this width partly produced by a large fleshy mass extending from end of maxillary to end of interopercle; eye small; profile of head descending abruptly from posterior line of orbits. Superior dental series 12 on each side, externally, but the 3 median teeth conceal some series of which the second 3 external teeth are a continuation; inferior teeth 11 on each side; 4 median incisors horizontal and subequal; no marked canine. Bluish plumbeous, fins blackish. (Cope.) Hilton Head, South Carolina, and Indian River, Florida; 4 specimens recently taken at Titusville by Evermann \& Bean; apparently distinguished from G. virgatulus by its longer anal. (strumosus, from struma, a scrofulous tumor, alluding to the swollen cheek.)

Gobiesox strumosus, Cope, Proc. Ac. Nat. Sci. Phila. 1870, 121, Hilton Head, South Carolina; Jordan \& Gilbert, Synopsis, 749, 1883; Evermans \& BEAN, Fishes of Indian River, Florida, in Rept. U. S. Fish Comm. 1896, 248.

2667. GOBIESOX VIRGATULUS, Jordan \& Gilbert.

Head $2 \frac{8}{4}\left(3 \frac{2}{5}\right.$ with caudal); width of head $3 \frac{1}{4}$; depth 6 ( 7 in total). D. 10 ; A. 8 or 9 ; vertebræ $10+16=26$. Body rather slender, the head low and rather broad, broadly rounded anteriorly; eyes very small, about 4 to 6 in head, about $2 \frac{1}{2}$ in interorbital width; interorbital space broad, slightly eonvex. Cheeks prominent; opercle ending in a sharp spine. Cleft of mouth extending to below front of orbit; lower jaw somewhat shorter than upper. Teeth of upper jaw in a narrow band of about 2 series; 4 teeth of outer series a little larger than the rest, somewhat canine-like; middle teeth of lower jaw incisor-like and partly horizontal, their edges entire or some what concave. Ventral disk considerably shorter than head. Distance from root of caudal to front of dorsal $2 \frac{4}{6}$ in length. Pectoral 
short, about $2 \frac{2}{5}$ in head. Color in life olivaceous, with numerous paler spots and broad diffuse dark bars; the whole body covered with rather faint, wavy, longitudinal stripes or lines of a light orange-brown color, about as wide as the interspace, much as in some species of Liparis, these entirely disappearing in alcohol; skin everywhere with dark punctulations; caudal dusky, slightly barred with paler, its tip abruptly yellowish; dorsal and anal dusky, the darker parts corresponding to dark bars on the body, barred. A rather large species. Length 2 to 4 inches. Common among ballast rocks, from Pensacola Bay north to Charleston. Our specimens from Pensacola and Charleston. (virgatulus, narrowly striped.)

Gobiesox virgatulus, Jordan \& Gilbert, Proc. U. S. Nat. Mus. 1882, 293, Pensacola, Florida (Coll. Jordan \& Stearns); Jordan \& Gilbert, Synopsis, 958, 1883; Goode \& BEAN, Proc. U. S. Nat. Mus. 1882, 236; JoRDAN, Proc. U. S. Nat. Mus. 1884, 149.

2668. GOBIESOX ADUSTUS, Jordan \& Gilbert.

Head 3 ; depth $5 \frac{1}{2}$. D. 9 ; A. 7. Head and body broad and flat, mnch depressed; width of head nearly equal to its length, $3 \frac{2}{3}$ in body. Incisors in middle of lower jaw entire, broad; those in upper jaw narrow, blunt, littlo compressed, entire, shorter than the lateral teeth; behind these 2 or 3 series of smaller teeth. Eyes rather large, separated by a broad interorbital space, which is $\frac{1}{8}$ length of head and about $\frac{1}{2}$ greater thau diameter of eye. Opercular spine sharp. Pectoral short, about $\frac{1}{2}$ length of head; ventral disk as long as head; distance from base of caudal to front of dorsal equaling $\frac{3}{10}$ of the length; caudal rounded behind. Brown, banded with blackish on body, head marbled with darker brown; front of dorsal black, the fins dusky with darker points. Pacific Coast of Mexico. Three specimens, the largest about 2 inches long, were obtained in a tide pool at Mazatlan. (adustus, scorched; brown.)

Gobiesox adustus, Jordan \& GiLbert, Proc. U.S. Nat. Mus. 1881, 360, Mazatlan, Mexico; Jordan \& Gilbert, Proc. U. S. Nat. Mus. 1882, 627; JoRdAN \& GiLbert, Bull. U. S. Fish Comm. 1882, 108.

2669. GOBIESOX FUNEBRIS, Gilbert.

Body rather slender, its width 5 in length; width of head $3 \frac{1}{2}$ to nearly 4 ; head $2 \frac{8}{4}$ to 3 in length; depth $\frac{1}{2}$ head. D.9;A.6 or 7. Teeth in upper jaw conical, in several series, unequal but without canines; in lower jaw mesially in 2 series, the outer of narrow, entire incisors, truncate or rounded, without lateral canines. Interorbital space wide, 3 in head, the eye small, $\frac{2}{5}$ interorbital width. Mouth very wide, $\frac{1}{2}$ or more than $\frac{1}{2}$ length of head. Ventral disk wider than long, its length $1 \frac{1}{2}$ to $1 \frac{2}{8}$ in head. No evident opercular spine. Distance from front of dorsal to base of caudal $2 \frac{2}{8}$ to 3 in length anterior to dorsal; distance from vent to front of anal fin $1 \frac{1}{2}$ to $1 \frac{2}{8}$ in distance from vent to disk; base of dorsal from $1 \frac{1}{2}$ to $1 \frac{1}{4}$ in head; base of anal about $\frac{1}{2}$ head; candal rounded, $1 \frac{3}{5}$ to $1 \frac{4}{4}$ in head; pectorals $3 \frac{1}{4}$ in head. Color varying from dark olive brown to black, everywhere covered with fine, yellowish vermiculations, usually arranged to 
form narrow lighter bars on the sides; 3 or 4 obscure dark streaks radiating from the eye; blackish below, the fins varying from blackish to straw color. Length $2 \frac{1}{2}$ inches. (Gilbert.) Gulf of California; abundant at Puerto Refugio (Angel Island) and La Paz. (funebris, funereal, from the dark color.)

Gobiesox funebris, GilberT, Proc. U.S. Nat. Mus. 1890, 95, Puerto Refugio, Gulf of California. (Coll. Albatross.)

2670. GOBIESOX PECILOPHTHALMU, Jenyns.

Head 3, as wide as long. D. 7; A. 7. Opercular spine long and slender; teeth strong, somewhat crowded in front, the anterior in both jaws incisorlike; upper teeth conical, with smaller ones behind; 6 middlo teeth of lower jaw incisor-like, projecting forward, their form not described (probably entire). Eyes large, close together, less than a diameter apart. General color olivaceous or brownish white, unmarked; iris golden, with pink and blue. Length $1 \frac{5}{6}$ inches. (Jenyns.) Chatham Island, Galapagos; only the single type known. ( $\pi \circ \varkappa \varkappa i \lambda \circ \varsigma$, variegated; ó $\phi \alpha \alpha \lambda \mu \delta$ s, eye.)

Gobiesox pocilophthalmus, Jenrns, Voy. Beagle, Fishes, 141, pl. 27, figs. 2, 2a, 2b, 1842, Chat. ham Island (Coll. Darwin); Günther, Cat., III, 503, 1861.

\section{GOBIESOX RHODOSPILUS, Günther.}

D. 6 ; A. 5 ; C. 8 or 9 ; P. 16 . A vertical fold of skin along lower half of base of pectoral. Distance from front of dorsal to caudal $2 \frac{2}{8}$ in its distance from snout; anal before third dorsal ray. A very narrow band of short conical teeth in upper jaw, 1 lateral tooth larger than the others, recurved, canine-like; lower jaw with 1 series of teeth, the anterior narrow incisors, the outer distinctly canine, like the outer above. Rosecolored with rose-red transverse spots, each with an edge of deep-red dots. Panama. (Giinther.) Not seen by us; known from 2 specimens, each $1 \frac{1}{2}$ inches long. ( $\dot{0} \delta \circ \nu$, rose; $\sigma \pi i \lambda o s$, spot.)

Gobiesox rhodospilus, Günther, Proc. Zool. Soc. Lond. 1864, 25, Panama (Coll. Captain

Dow); GÛnther, Fish. Centr. Amer., 445, 1869.

\section{GOBIESOX MACROPHTHALMUS, Günther.}

Eje $4 \frac{1}{2}$ in head. D. 8 ; A. 6 ; C. 12 ; P. 22. Head and anterior part of body very broad and much depressed, the head as broad as long, its profile semielliptical, the snout obtuse and rounded; top of head quite flat; interorbital width equal to eye. Mouth horizontal, curved, moderate, the cleft reaching beyond anterior margin of eye; an acute spine at lower angle of opercle; 4 short incisors on each side in lower jaw, separated from the conical lateral teeth by a larger canine-like tooth. Insertion of dorsal nearer caudal than snout; caudal rounded. Color, uniform reddish. (Günther.) Locality unknown; probably West Indies. ( $\mu \alpha \varkappa \rho o ́ s, ~ l a r g e ;$ $\dot{\phi} \phi \theta \alpha \lambda \mu \dot{\delta} 5$, eye.)

Dr. Eigenmann gives the following notes on a small specimen from St. 
Thomas, which seems referable to Gobiesox macrophthalmus, differing in the slightly shorter dorsal and larger eye:

"Dorsal 6 or 7 ; anal about 7 ; head about 3 ; width of body $3 \frac{1}{2}$; width of mouth 2 in head; interorbital width $4 \frac{1}{2}$, equal to snout. Eye large, $2 \frac{4}{5}$ in head. Teeth in the upper jaw conic, in more than 1 series in front, some in the outer row enlarged; teeth on the lower jaw in a single series, about 4 blunt incisors on each side followed by the canines, behind which the teeth are much smaller and conic. Width of disk $1 \frac{8}{4}$ in its length, $2 \frac{1}{2}$ in head; opercular spine strong; distance of origin of dorsal from caudal $2 \frac{1}{2}$ in its distance from tip of snout. Sides and back uniform bright red; eye black, iris bright red; lower surface jellow, dotted with bright red. One specimen $23 \mathrm{~mm}$. long in the Museum of the University of Indiana from St. Thomas (Coll. Edward W. Brigham), much shrunken and fins hardened by strong alcohol." (Eigenmann, in lit.)

Gobiesox macrophthalmus, GU'NTHER, Cat., III, 502, 1861, locality unknown.

\section{GOBIESOX CERASINUS, Copo.}

Head 3 in total with caudal. D. 6 ; A. 6 ; C. 12 ; P. $24 ;$ V.4. Head very wide, ovate, as broad as long to upper base of pectoral. Eye large, $3 \frac{1}{2}$ in head, equal to frontal width. Ten teeth on each side of each jaw, none of the upper being incisors, the 2 median on each side larger than the others; 3 teeth on each side in lower jaw horizontal, the others vertical, 2 of the horizontal teeth incisors, the median one on each side of these much the larger; each horizontal tooth with a small one behind it; no canines. Profile regularly descending from supraoccipital; a long subopercular spine. Dorsal beginning with last fourth of distance between tip of snout and base of caudal. Body and fins light crimson lake above, whitish below; no spots. One specimen, $2 \frac{1}{2}$ inches long, from St. Martins. (Cope.)

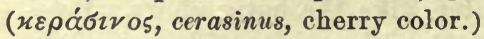

?Oyclopterusnudus, Linn aus, Syst. Nat., Ed. X, 260, 1758, "India;" from a specimen in Mns. Adolph Fred. (tab. 27), said to be 2 inches in length; the head broad with a sharp spine behind; dorsal rays 6; not Lepadogaster nudus, BLOCH \& SCHNEIDER, Syst. Ichth., 2, 1801, who give "D.12, A. 6," * the description otherwise that of Linnæus: not Gobiesox nudus of recent authors, which is a species (G. gyrinus) allied to G. virgatulus.

Gobierox cerasinus, Cope, Trans. Am. Phil. Soc., xIv, 1871, 473, St. Martins, West Indies. (Coll. Dr. R. E. Van Rijgersma. Type in Ac. Sci. Phila.)

S’bgenus SICYASES, $\nmid$ Müller \& Troschel.

2674. GOBIESOX ERYTHROPS, Jordan \& Gilbert.

Head $2 \frac{1}{2}$; depth 6. D. 6 ; A.5. Head scarcely longer than broad, proportionately very broad and depressed, its breadth 3 times in total.

\footnotetext{
* We do not know by what anthority the number of fin rays given by Linnæus (D. 6) was altered to "D. 12, A. 6" by Schneider (Syst. Ichth.). The last-named figures agree with nudus, as described by Ir. Günther, that is, with onr G. gyrinus. If the Linnæan type of nudus really had D. 6, it must have been cerasinus or macrophthalmus or some very similar species. The scanty Linnæan description agrees best with cerasinus. The name nudus, if used at all, must be taken for a species to which the Linnæan description may be applied. In our judgment the uncertainty is too great to justify the substitution of nudus for either cerasinus or macrophthalmus. It could be no other known species, however.

t'This subgenus is composed of small species with the upper teeth in 1 series. This character should be verified on all our species, as perhaps none of them helongs to it.
} 
Incisors in both jaws, entire and rather broad, the lateral teeth, as usual, pointed; no canines. Eyes very large, considerably wider than the narrow interorbital area, $3 \frac{1}{3}$ in head; interorbital area nearly 5 in head. Ventral disk a little longer than head, $2 \frac{2}{8}$ in body. Pectoral about $\frac{1}{3}$ length of head. Distance from front of dorsal to caudal, $3 \%$ in body. Caudal truncate, with rounded edges. Light olivaceous; body with 3 or 4 bars of cherry red; head marbled with red; eyes intensely cherry red, their upper border blackish; fins pale, the upper mottled with reddish; caudal barred with red. Two specimens, $1 \frac{1}{2}$ inches long, taken in a rock pool at Mazatlan; also recorded from the Tres Marias Islands. ( $k \rho v \theta \rho o ́ s$, red;

Gobiesox erythrops, Jordan \& Gribert, Proc. U. S. Nat. Mus. 1881, 320, Mazatlan, Mexico (Type, No. 29248. Coll. Gilbert); Jordan \& Gilbert, Bull. U. S. Fish Comm. 1882, 108; Jordan, Fishes of Sinaloa, in Proc. Cal. Ac. Sci. 1895, 499.

\section{GOBIESOX RUBIGINOSUS (Poey).}

D. 6 or 7 ; A. 6 ; V. 4 ; P. 25. Head 3 , including caudal, its greatest width twice its height; eye 2 in interorbital width. Body slender; head semioval, obtuse; distance from front of dorsal to caudal $1 \frac{1}{3}$ in length, including candal; dorsal opposite anal, beginning at fourth seventh of total length; mouth terminal; teeth not examined by Poey. Color red, with 12 dark bands and with many scattered spots of clear blue on the body; eyes with a red circle. Length $22 \mathrm{~mm}$. Cuba (Poey); not seen by us; locally common at Matanzas; perhaps a species of Arbaciosa. (rubiginosus, reddish.)

Sicyases rubiginosus, PoEY, Synopsis, 391, 1868, wharves of Palmasola, Matanzas, Cuba (Coll. Poey); PoEy, Enumeratio, 124, 1875.

\section{GOBIESOX CARNEUS (Poey).}

Head rounded; body very slender; eyes large, as wide as interorbital space; mouth inferior; teeth not examined by Poey. Color pale red, with some white specks and bands. Length $22 \mathrm{~mm}$. Otherwise essentially as in Crobiesox rubiginosus. (Poey.) Matanzas; a doubtful species. (carneus, flesh-colored.)

Sicyases carneus, Pokx, Synopsis, 392, 1868, wharves of Palmasola, Matanzas, Cuba (Coll. Poey); Poey, Enumeratio, 124, 1875.

2677. GOBIESOX HERES, Jordan \& Bollman.

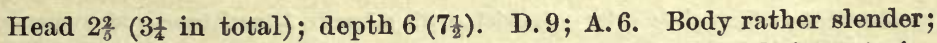
head low and broad, greatest bread th not quite equal to length, its anterior margin not so broadly rounded as in G. virgatulus. Eyes very small, 1? in interorbital space, 5 in head; interorbital bone appearing convex, least width $3 \frac{1}{2}$ in head and about equal to length of snout; cleft of mouth extending to beyond middle of eye; lower jaw included; teeth uniserial, those of upper jaw all canines, the first 3 on each side small, but becoming larger outward, next 3 or 4 much larger, rest smaller than those in front; anterior teeth of lower jaw entire incisors, which have on each side 
about 6 large graduated canines and behind these a few smaller ones; teeth of lower jaw slightly oblique. Distance from front of dorsal to root of caudal about $2 \frac{5}{6}$ in body ( $3 \frac{1}{2}$ in total). Pectorals moderate, 2 in head; ventral disk $1 \frac{1}{4}$ in head. Color olivaceous, without any distinct bands; the occipital region and the caudal peduncle darker; body irregularly mottled with groups of darker spots; nape, preopercle, cheeks, and snout with numerous dark points; indistinct dark lines radiating from eye; lips dark; fins dusky; dorsal and anal with the first rays black; a pale spot near base of caudal; axil of pectoral dusky. Green Turtle Cay, Bahamas; a single specimen known, $2 \frac{1}{4}$ inches in length. (hares, one who clings.)

Gobiesox hoeres, Jordan \& Bollman, Proc. U. S. Nat. Mus. 1888, 552, Green Turtle Cay, Bahamas. (Coll. Dr. Charles L. Edwards.)

\section{GOBIESOX PUNCTULATUS (Poey).}

Hend very broad, 3 in total length with caudal. D. 9; A. 6. Color brown, covered with black points; 3 dark transverse bauds; none on the head. Teeth not described, the incisors probably entire. Length $38 \mathrm{~mm}$. Cuba (Poey); not seen by us. (punctulatus, speckled.)

Sicyases punctulatus, POEY, Enumeratio, 124, 1875, Havana.

2679. GOBIESOX FASCIATUS (Peters).

D. 7; A. 7; head and body with alternate dark green and yellowish cross bands. Commencement of dorsal before that of anal, its distance from caudal equal to length of its base. Type, $50 \mathrm{~mm}$. long. (Peters); not seen by us; teeth not described. Puerto Cabello. (fasciatus, banded.)

Sicyaxes fasciatus, Peters, Monatsber. Berl. Acad. 1859,412, Puerto Cabello; GÜnther, Cat., III, 497, 1861; GünTHER, Fishes Centr. Amer., 390, 1869.

\section{RIMICOLA, Jordan \& Evermann.}

Rimicola, Jordan \& Evermann, Proc. Cal. Ac. Sci. 1896, 231 (muscarum).

This genus differs from Gobiesox mainly in the very slender body and head. Head $3 \frac{1}{4}$ to 4 in length, its width less than its length; dorsal and anal very short, of 4 to 6 rays each; incisors entire; a crescent-shaped patch of teeth in each jaw behind the large teeth; opercular spine weak or obsolete; sucking disk small. Species of small size; living below tide marks. (rima, a crevice; colo, I inhabit.)

$a$. Dorsal rays 6; anal 5; color yellowish, with a brown lateral band and numerous brownish spots.

aa. Dorsal rays 4; anal 5; color uniform light green. MUSCARUM, 2680. EIGENMANNI, 2681.

2650. RIMICOLA MUSCARUM (Meek \& Pierson).

Head $3 \frac{4}{6}$ in length; depth $8 \frac{8}{4} ;$ D. 6 ; A.5. Body elongate, slender, depressed anteriorly, but very narrow, slightly compressed posteriorly, the greatest width of body immediately behind head, 7 in length. Head narrow, much depressed, wider posteriorly. Eye small, its diameter $2 \frac{1}{2}$ in interorbital width, 5 in head. Maxillary reaching to the front of the eye, 
its length less than 3 in head. Teeth in upper jaw conical, acute, curred, forming a crescent-shaped patch, those of the anterior row enlarged; in the lower jaw an anterior row of about 5 broad, entire incisors placed nearly horizontally; behind these a crescent-shaped patch of teeth, similar to those in the upper jaw, becoming canine-like laterally. No evident opercular spine. Ventral disk longer than broad, its length $1 \frac{1}{2}$ in head $6 \frac{1}{4}$ in leugth; distance from vent to front of anal $2 \frac{1}{2}$ in the distance from vent to disk; pectoral fin broad, short, $2 \frac{1}{8}$ in head; dorsal and anal fins small, the anal slightly in advance; caudal fin rounded. Ground color, in alcohol, light yellowish, paler below; above everywhere sparsely covered with distinct brownish-red spots about as large as pupil; a lateral band of the same color begins on the front of the snout, where it joins the one on the opposite side, extends through the eye across the opercle to the caudal, becoming very indistinct posteriorly; this lateral stripe is in strong contrast with the uniform pale ventral surface. Coast of California. Two specimens were dredged in Monterey Bay at a depth of about 10 fathoms. One of these, the type, is $1 \frac{1}{2}$ inches long. The second specimen ( $1 \frac{1}{10}$ inches long) has the dorsal spots confined to the top of the head and nuchal region and the lateral stripe disappearing slightly behind middle of body, and having the ventral surface marked posteriorly with brownish-red spots like the spots on the dorsal surface. (muscarum, of the flies, from the fly-speck markings.)

Gobiesox muscarum, Meex \& Pierson, Proc. Cal. Ac. Sci. 1895, 571, with colored plate,

Monterey Bay. (Coll. S. E. Meek and Charles J. Pierson. Typein L. S.Jr. Univ. Mus.)

\section{RIMICOLA EIGENMANNI (Gilbert).}

D. 4 ; A. 5. Head $3 \frac{2}{3}$ in length; depth about $\frac{1}{2}$ head. Body very slender and narrow, the width of head $4 \frac{4}{5}$ in length; width of body 6 . Mouth wide, the distance between its angles $\frac{1}{2}$ length of head, the maxillary scarcely reaching vertical from front of orbit. Interorbital space wide, about $\frac{1}{2}$ head. Eye very small, about 3 in interorbital width. Teeth in upper jaw conic, acute, in several series, the anterior in upper jaw enlarged; teeth in lower jaw also in several series, those of front row narrow incisors, entire, with rounded or truncate edges; disk very small and narrow, its width about $\frac{2}{8}$ its length, the latter.12 in length of head. Fins all small, the base of dorsal $\frac{2}{5}$ length of head, less than free portion of caudal peduncle; distance from origin of dorsal to base of candal $3 \frac{1}{3}$ in length before dorsal; distance from vent to front of anal fin $1 \frac{3}{5}$ in its distance from disk; caudal broadly rounded, its length $1 \frac{4}{5}$ in head ; pectoral somewhat pointed, about $\frac{1}{2}$ head; coracoid plate small, about $\frac{1}{2}$ height of pectoral and less than $\frac{1}{2}$ its length. Color uniform light olive green, without distinctive markings. Type, a single specimen, about 1 inch long, taken at Point Loma, near San Diego, California. Other specimens were taken some years since at San Cristobal Bay by Mr. Charles H. Townsend, and were referred to as Gobiesox rhessodon by Mrs. Eigenmann, Proc. U. S. Nat. Mus. 1884, page 553. (Named for Dr. Carl H. Eigenmann.)

Gobiesox eigenmanni, GrLbert, Proc. U. S. Nat. Mus. 1890, 96, Point Loma, near San Diego,

California. (Coll. Gilbert.) 
867. ARBACIOSA, Jordan \& Evermann.

Arbaciosa, Jordan \& Everuan, Proc. Cal. Ac. Sci.1896, 290 (humeralis.)

This genus differs from Gobiesox chiefly in the character of the incisor teeth of the lower jaw; these are strongly serrate, or tricuspid, making a ragged cutting edge. Size small; dorsal and anal comparatively short; head not very broad, the jaws contracted; vertebra (in Arbaciosa zebra) 28. Some species provisionally referred to the section Sicyases of Gobiesox may prove to belong to Arbaciosa; small species, living in rock pools, among the sea urchins, by whose spines they are protected. This relation of Arbaciosa zebra with the Echinoid Arbacia stellata is especially constant. (Arbacia, a sea urchin.)

a. Anal fin long, about 10 rays; dorsal rays 11; teeth above in 1 series; color olivaceous. RHESSODON, 2682.

aa. Anal fin of 5 to 7 rays.

b. Dorsal fin of 8 or 9 rays; teeth in single series; color brownish, with red bars and a large black humeral spot.

HUMERALIS, 2683.

$b b$. Dorsal fin of 7 rays; color greenish, with pale spots and numerous pale cross bands; no red; body slender.

RUPESTRIS, 2684.

$b b b$. Dorsal fin of 6 rays; color chiefly red.

c. General color pinkish olivaceous, with some bright red; back with 5 reddish-brown or blackish bars. Upper teeth in more than 1 series. Body comparatively slender, the depth nearly 8 in lengtl.

ZEBRA, 2685.

cc. General color bright rosy red, black, with 1 to 3 faint dark bars. Upper teeth nearly uniserial. Body comparatively stout, the depth $5 \frac{1}{2}$ in length.

EOS, 2686.

\section{ARBACIOSA RHESSODON (Rosa Smith).}

Head $3 \frac{1}{4}$; depth $6 \frac{1}{2}$. D. 11 ; A. 10 ; eye $4 \frac{1}{2}$ in head, $\frac{3}{5}$ in interorbital space; ventral disk $1 \frac{1}{8}$ in head; pectoral 2; caudal $2 \frac{1}{8}$. Form much as in Gobiesox mocandricus; snout bluntly and evenly decurved; the greatest height of the body across the pectoral fins; head broader than body but less deep; maxillary extending to below the eye; incisors of lower jaw not mnch declined, each of them tricuspid, the central cusp longest; teeth of upper jaw conical, in an irregular series of 7 to 9 ; teeth in each jaw in single series; opercular spine sharp; distance from vent to caudal $2 \frac{2}{5}$ in leugth of body; dorsal a little longer than the anal, having its origin in advance of the anal and terminating opposite it; caudal rounded. Color dark olivaceous, usually with 3 broad yellowish cross bands above, the first across interorbital space and cheek, the second very wide, across back and front of dorsal fin, the third below middle of dorsal, some or all of these sometimes wanting; a dark bar at base of caudal; belly yellowish. Length $2 \frac{1}{2}$ inches. San Diego to the northern part of the Gulf of California; locally abundant in rock pools. ( $\dot{\eta} \sigma \sigma \omega$, to make ragged; ósov́s, tooth.)

Gobiesox rhessodon, Rosa SмIтH, Proc. U. S. Nat. Mus. 1881, 140, San Diego, California ; Jordan \& Gilbert, Synopsis, 749, 1883; Rosa Smith, Proc. U. S. Nat. Mus. 1883, 235. 


\section{ARBACIOSA IUMERALIS (Gilbert).}

Head 3 to $3 \frac{1}{2}$; width of body $4 \frac{1}{4}$; width of head $3 \frac{8}{4}$; eye very small, 3 in interorbital width. D. 8 or 9 ; A. 7 . Body of moderate width, the head not evenly rounded anteriurly, becoming contracted opposite eyes, the snout forming a quadrate projection beyond the profile; as seen from above. Teeth in a single series in each jaw, the anterior narrow incisors, trilobate at tip, the 2 posterior teeth on each side strong, conical canines, somewhat recurved; about 12 incisors in the upper jaw. Interorbitalspace very wide, about equaling width of mouth, $2 \frac{1}{3}$ to $2 \frac{1}{2}$ in length of head. Ventral disk about as wide as long, its length $1 \frac{1}{4}$ in head. Opercular spine large and strong, but not exposed. Distance from front of dorsal to base of caudal 3 in length anterior to dorsal; base of dorsal $1 \frac{2}{8}$ in head; base of anal about equals base of dorsal; distance from vent to front of anal half its distance from disk; caudal broadly rounded, $1 \frac{8}{4}$ in head; pectoral $\frac{1}{8}$ head, without distinct fold of skin across it. Groundcolor dark olive brownish, crossed by many carmine-red bars, these somewhat broken anteriorly and above, to form reticulating lines, posteriorly and on lower part of sides more regular and running obliquely downward and backward; a couspicuous round humeral spot, larger than eye, in life black with golden-green reflections; numerous streaks from eye backward across cheek and opcrcles. (Gilbert.) Gulf of California; abundant at Puerto Refugio (Angel Island); also known from La Paz. (humeralis, pertaining to the shoulder, humerus.)

Gobiesox humeralis, Gilbert, Proc. U. S. Nat. Mus. 1890, 95, Puerto Refugio, Gulf of California. (Coll. Albatross.)

Arbaciosa humeralis, JoRdan, Proc. Cal. Ac. Sci. 1896, 230, pl. 35.

\section{ARBACIOSA RUPESTRIS (Poey).}

Head 4 in total length with caudal; depth 6 ; eye 4 in head; snout less than eye. D. 7; A. 7. Forehead little decurved; eyes well separated; mouth small, with 1 row of compressed, close-set incisors with denticulated edges, 6 on each side in each jaw; snout truncate, as seen from above. Pectorals short, rounded. Dorsal and anal alike, opposed, highest in front. Caudal rounded. Color greenish ash, each side with 6 large oval spots, those behind touching; sides with about a dozen vertical bands of straw yellow or whitish, these bands sometimes interrupted, forming 2 series of points; 2 small similar bands from the eye, another toward tip of snout; a brown pale-edged band between eyes; some white spots on sides of head. Length $1 \frac{1}{2}$ inches. Coral reefs of Cuba; not rare. (Poey): not seen by us; said to be distinguished from other Cuban species by the slender body and narrow head. (rupestris, living among rocks.)

Gobiesox rupestris, POEY, Memorias, II, 283, 1861, Cuba.

Sicyases rupestris, PoEY, Synopsis, 391, 1868; PokY, Enumeratio, 124, 1875.

2685. ARBACIOSA ZEBRA (Jordan \& Gilbert).

Head $3 \frac{2}{8}$ in length; depth nearly 8. D. 6 or 7 ; A. 5 or 6 ; vertebra $11+$ $17=28$. Body comparatively very long and narrow, the greatest width about $\frac{1}{5}$ the total length. Head narrow, depressed, its width about $4 \frac{1}{2}$ 
times in length of body; eye small, its diameter about $\frac{1}{2}$ interorbital width; opercular spine well developed; ventral disk nearly as long as head; mouth rather small, anterior, maxillary reaching front of eye; incisors of lower jaw nearly horizontal, rather broad, 3-lobed at tip, the middle cusp the longest; upper teeth much smaller, the median ones compressed, blunt, close set, a little shorter than the lateral teeth and with dentate edges, 1 or 2 series of small teeth close behind them; anal beginning under middle of dorsal; the distance from insertion of dorsal to base of caudal contained $3 \frac{2}{3}$ in length; pectoral $\frac{1}{2}$ as long as head; caudal truncate, with rounded angles. Back with 5 dark cross bars abont as wide as the interspaces, 3 of them in front of dorsal fin, the 2 anterior much broader and more distinct than the others; these bars all distinct on back, fading on sides, which are often vaguely clouded with dark; the color of these dark bars varies from reddish brown to black, and that of the interspaces from olivaceous to light pink and bright rose red; top of head bright red, marbled with light slaty bluish; a black blotch on opercle, and 2 very distinct black cross spots, 1 on each side of median line, forming the front of first dorsal bar; cheek sometimes with 2 or 3 pale bluish streaks; dorsal, pectoral, and caudal more or less shaded with dusky; lower fins pale; usually a dark bar at base of caudal and 1 across middle of fin; shade of ground color extremely variable. * Very abundant in the rocky tide pools around Mazatlan, hiding everywhere under the numerous sea-urchins, especially Arbacia stellata, the protective coloration of both being that of the Corallina, which lines the rock pools. Length 2 to 3 inches. (zebra, from the banded coloration.)

Gobiesox zebra, Jordan \& Gilbert, Proc. U. S. Nat. Mus. 1881, 359, Mazatlan, Mexico (Type, No. 29250. Coll. Gilbert); JordaN \& GilberT, Bull. U. S. Fish Comm. 1882, 108; Jordan, Proc. Cal. Ac. Sci. 1895, 499.

* The following note on the variations is furnished by Miss Susan B. Bristol:

"I find 4 specimens of this species which differ considerably from the typical form. These may represent a divtinct species, but at present we are inclined to think that all these forms are modifications of one species, Arbaciosa zebra. The following is a description of a specimen $1 \frac{1}{4}$ inches long, taken at Mazatlan (No.4166 in the L. S. Jr. Univ. Museum): Head $3 \frac{4}{7}$; depth 9 . D. 5 or 6 ; A. 6 . Bolly slender, much depressed, compressed posteriorly, the greatest width 43 in length. Head depressed, its width $1 \frac{1}{2}$ in its length. Eye very small. about $1 \frac{1}{3}$ in interorbital width. Snout rather rounded, $3 \frac{1}{7}$ in head. ('per. cular spine present. Interorbital width $2 \frac{3}{5}$ in head. Ventral disk $1 \frac{1}{7}$ in bead. Mouth small, the lower jaw inferior; outer teeth in both jaws serrate. Anal beginuing at end of the first $\frac{2}{5}$ of dorsal. Distance from trunt of dorsal to base of caudal $1 \frac{1}{6}$ in head. Caudal terminate. Pectoral $2 \frac{2}{3}$ in head. Color bright red, with very irregular yellow mottlings on back and sides, light yellow below; back with 4 irregular dark-red cross bars, the posterior 3 of which are wider than the interspaces; 3 of the cross bars in front of the dorsal fin, and the fourth on either side of the dorsal; 2 conspicuous black spots ahout $\frac{1}{3}$ as large as eye, 1 on either side of median line on back above the pectorals a short distance benind their origin; snout plain, dark red; pupil white; 2 yellow parallel stripes extending from eye backward and downward, the second ending at a point about 4. the distance from tip of snout to end of opercle; dorsal, caudal, and anal rlusky; ven. trals and pectorals paler; a large red blotch at base of pectorals extending for a cousiderable distance on the fin. Another specimen from Mazatlan, bright red in color, about $\frac{3}{4}$ of an inch long (also in bottle No. 4166. L. S. Jr. Univ. Museum), differs from the preceding form in the following respects: In the greater depth, which is 63 in length, in the smaller ventral disk, which is $1 \frac{1}{3}$ in head; in the more pointed snout; in the absence of the 2 black spots above pectorals; and in having the 4 dark red bands on the back more distinctly marked. Two specimens from Guaymas, Mexico, 1 and 11 inches long, No. 92 in the L.S. Jr. Univ. Museum, are chocolate brown in color, the shorter having on its back, including the bar at base of caudal, 7 dark brown cross bars and no dark spots above the pectoral, while in the longer there are no cross bars but a dark brown spot about $\frac{1}{2}$ as large as the eye is present above the pectoral; also, in the longer one, the dorsal begins at the end of first third of anal. The eye in the larger specimens of zebra is larger than in these 4 specimens, but some of the smaller specimens seem to be intermediate in this regard between the typical form and these forms." 
2686. ARBACIOSA EOS (Jordan \& Gilbert).

Head 3 ; depth $5 \frac{1}{2}$; eye moderate, $1 \frac{1}{2}$ in interorbital width, which is about $3 \frac{1}{2}$ in head. D. 6 ; A. 6. Body comparatively short, stout, and narrow; the head rather broad, but, like the body, much less depressed than in G. erythrops; width of head less than its length, or $3 \frac{2}{8}$ in body. Incisors serrate or tricuspid. Pectorals about 4 in head; ventral disk shorter than head. Distance from base of caudal to front of dorsal $3 \frac{4}{5}$ in total length; caudal truncate. Bright rosy red, sometimes dusky above with black points; back with 1 to 3 faint dark bars; 3 dark lines downward and backward from orbit, and usually 1 or 2 more on opercle; caudal usually with a reddish bar at base and a dusky one toward tip; fins otherwise nearly plain. Pacific coast of Mexico; abundant in rock pools about Mazatlan in company with Arbaciosa zebra, hiding under sea-urchins, especially with Arbacia stellata. Length $1 \frac{1}{2}$ inches. ( $\dot{\eta} \omega$ s, sunrise; from the red colors.)

Gobiesox eos, Jordan \& Gilbert, Proc. U. S. Nat. Mus. 1891, 360, Mazatlan, Mexico (Coll. Gilbert. Type, No. 29247); Jordan \& GILBERT, Bull. U.S. Fish Com. 1882, 108; Jordan, Proc. Cal. Ac. Sci. 1895, 499.

\section{Group BLENNIODEA.}

\section{(Blennioid Fishes.)}

Body more or less elongate, naked or with scales, large or small; ventral fins small, more or less advanced in position, often wanting, the number of soft rays always less than 5 ; hypercoracoid perforate, the shoulder girlle normally formed; skull not armed with spines; suborbital not developed as a bouy stay articulating with the preopercle; pseudobranchiæ present; dorsal fin long, its anterior half, and sometimes the whole fin, composed of spines; anal long; tail homocercal, the caudal usually rounded, rarely forked; vertebræ numerous, especially in the arctic species. A large group, with ill-defined boundaries, the more primitive forms showing affinities with the Trachinoidea, Cirrhitida, and other more typical fishes, the extremes very aberrant and passing directly into the Ophidoidea, and other forms lacking spines in the fins. We begin the series with the least moditied of the type, the Clinino, from ancestors of which group the others have doubtless descended.

a. Caudal fin present, sometimes united to dorsal and anal; dorsal spines connected by membrane.

b. Gill openings not reduced to horizontal slits below the pectoral fins.

c. Teeth not developed as coarse molars.

$d$. Mouth not vertical.

BLENNIDA, CC.

$d d$. Mouth nearly vertical; scales small or wanting; no lateral line; no ventral fins; dorsal composed entirely of slender spines; gill membranes attached to the isthmus; teeth strong.

CRyPtaCANTHOdIDE, CCI.

cc. Teeth dereloped as coarse molars on vomer, palatines, and sides of lower jaw; dorsal of tlexible spines only; scales minute; gill membranes joined to the isthmus; no ventral fins; air bladder present; no lateral line. 
$b b$. Gill openings reduced to separate, narrow, nearly horizontal slits below and in front of the pectoral fin; ventrals small; dorsal fin long and low, anteriorly of slender spines; vertical fins connected. CERDALIDE, CCIIr. aa. Caudal fin none, the tail tapering to a point; no rentral fins; no lateral line; scales rulimentary; anterior part of dorsal of low free-hooked spines, the posterior part of many slender soft rays; teeth in jaws only, close set in 1 row.

Ptilichthyide, cCiv.

Family CC. BLENNIIDA.

\section{(The Blennies.)}

Body oblong or elongate, naked or covered with moderate or small scales which are ctenoid or cycloid; lateral line variously developed, often wanting, often duplicated; mouth large or small, the teeth various; gill membranes free from isthmus or more or less attached to it; pseudobranchiæ present; ventrals jugular or subthoracic, of 1 spine and 1 to 3 soft rays, often wanting; dorsal fin of spines anteriorly, with or without soft rays; anal fin long, similar to soft dorsal; caudal well developed. Vertebræ in moderate or large number, 30 to 80 . Carnivorous fishes of moderate or small size, mostly living near the shore in the tropical and temperate or arctic seas; most of them are carnivorous, the Clinina, so far as known, ovoviriparous, the rest mostly oviparous. Genera, about 80 ; species, about 400 ; chiefly of the rock pools and algr; some species in the lakes of Italy. Dr. Gill divides the tropical Blennies into 3 families, Clinida, Blenniida, and Chanopsida. The first and second of these are fairly well defined. The third is now heterogeneous, and some of its members are intermediate between the other two. The arctic Blennies he again divides into Xiphidiida, Cebedichthyida, and Stichaida, but the first and last of these groups intergrade, the Xiphidiince are modified Clinina, and there are other forms as well entitled to separate rank as Cebedichthys. It seems to us better to treat the group as a single family with many subfamilies. (Blenniida, Günther, Cat., III, 206-297.)

I. Tropical Blernies, with the vertebræ mostly in moderate number, usually fewer than 45; lateral line usually arched high above the pectoral, if present; dorsal fin with soft rays, at least 1 being present; anal spines little developed; ventrals well developed, usually $I, 3$.

a. Body scaly.

CuIninæ:

b. Lateral line present, arched anteriorly orer the pectoral, becoming posteriorly median in position, or else obsolete; species ovoviriparous.

c. Scales ctenoid, very rough, 35 to 40 in lateral line; dorsal divided into 3 fins; no cirri above eye.

ENNEANECTES, 868.

cc. Scales cycloid; dorsal fin not divided into 3 fins.

$d$. Dorsal with 6 to 20 soft rays.

e. Shoulder girdle with a small upturned hook on its inner edge.

$f$. Scales along lateral line anteriorly not enlarged; snout sharp; first 5 spines of dorsal more or less modified.

g. Caudal fin forked; air bladder present; scales minute; teeth in jaws in more than 1 series, on vomer and palatines; first 5 dorsal spines lengthened, and partly separated.

HETEROSTICHUS, 869. 
gg. Caudal fin truncate; air bladder wanting; scales minute; teeth in jaws in more than 1 series; teeth on vomer, none on palatines; first 5 dorsal spines lengthened and partly separated. GibBonsia, 870. $e e$. Shoulder girdle without upturned hook on its inner edge above.

$h$. Maxillary greatly developed, reaching much beyond eye; teeth on vomer and palatines; scales minute; soft dorsal long.

Neoclinus, 871.

$h h$. Maxillary normal, not greatly expanded.

$i$. Anterior part of lateral line normally formed; usually a comb of filaments at the nape.

$j$. Palatines without teeth; scales moderate or small, 38 to 110 in lateral line.

$k$. Teeth in jaws in 1 row only; teeth usually on vomer, none on palatines; usually a comb of filaments at the nape.

Malacoctenus, 872.

$k k$. Teeth in jaws in more than 1 row, a band of villiform teeth behind the others; teeth on vomer, none on palatines.

l. Body oblong, the depth $3 \frac{1}{2}$ to $4 \frac{1}{2}$ in length; a filament above the eye.

LABRISOMUS, 873.

li. Body elongate, the depth about 6 in length; no filaments above the eye. MNIERPES, 874.

$j j$. Palatines with teeth, those in jaws in more than 1 series; scales large, 30 to 37 in lateral line; no nuchal filaments.

$m$. Head very broad, depressed; soft dorsal of about 20 rays.

GobIocLINUs, 875.

$m m$. Head moderate, not depressed; soft dorsal of about 8 rays. STARKSIA, 876 .

ii. Anterior part of lateral line running on a series of enlarged scales without visible pores; teeth in more than 1 series in jaws; teeth on vomer and front of palatines.

CRYptotrema, 877.

$d d$. Dorsal with 1 short soft ray only; scales large; teeth in jaws in more than 1 series; teeth on vomer, none on palatines.

$n$. Dorsal fin more or less deeply notched behind the third spine.

o. First 3 spines of dorsal very slender, close set, forming a separate ribbon-shaped fin, which is much higher than any of the spines in the second dorsal; anal spines rather high; body strongly compressed, the snout very sharp.

EXERPES, 878.

oo. First 3 dorsal spines stiff, wide set, not remote from rest of fin behind dorsal notch; anal spines short; body more elongate, the snout less acute.

EMMNIINA:

AUChenopterus, 879.

Pabaclinus, 880.

nn. Dorsal fin continuous, not notched.

bb. Lateral line straight, close to the dorsal fin; scales small, cycloid; dorsal notched, its anterior half of slender spines; nocirri on head; ventrals thickish, inserted slightly before pectorals; teeth in bands, the outer enlarged.

Emmion, 881. 
aa. Body scaleless; species oviparous, so far as known.

$p$. Teetl comb-shaped, in a single row in each jaw, behind which are sometimes long canines; romer and palatines usually toothless; lateral line usually single, with a strong arch anteriorly; dorsal fin long, continuous, or divided into 2 fins, the anterior portion composed of spines, which are stiff or flexible; anal fin long, usually with 1 or 2 small spines; ventrals welldeveloped, jugular, of 2 or 3 rays.

$q$. Teeth all fixed, attached to the bone of the jaws and not movable. RUNCLINAE:

$r$. Caudal fin lunate or forked; teeth compressed; spines and soft rays of dorsal indistinguishable.

8. Ventral fins very long, each of a spine and a soft ray.

ATopochinus, 882.

88. Ventral fins not $\frac{1}{2}$ length of head, each with about 2 soft rays; gill opening reduced to a small slit above pectoral.

\section{BLENMIINA:}

RUNULA, 883.

$r r$. Caudal fin ronnded; teeth slender; gill membranes not reduced to a small slit.

$t$. Teeth all fixed, attached to the bone of the jaws.

- v. Gill membraues free from the isthmus, or at least form. ing a distinct fold across it.

w. Jaws one or both with a posterior fang-like canine, much longer than the anterior teeth.

BLENius, 884.

w2w. Jaws without canines, the teeth all equal.

SCARTELIA, 885.

$v v$. Gill membranes broadly united to the isthmus, the gill openings restricted to the sides.

$x$. Jaws one or both with posterior fang-like canines.

HYPLEUROCHILUS, 886.

$x x$. Jaws without posterior canines; the teeth equal.

$y$. Three articulated ventral rays.

$z$. Mouth small, the maxillary extending scarcely beyond front of eye; the head decurved in profile.

HYPSOBLENNIUS, 887.

$z z$. Month large, the maxillary extending beyond vertical from middle of eye; the head rather pointed in profile. Chasmones, 888.

$y y$. Four articulated rentral rays.

\section{SALARIINE:}

HoMesthes, 889.

$q q$. Teeth of front of jaws all movable, implanted on the skin of the lips.

$a^{\prime}$. Vomer toothless.

$b^{\prime}$. Jaws without posterior canines; dorsal fin deeply notched.

$b b^{\prime}$. Jaws one or both with posterior fang-like canines.

SCARTICHTHYS, 890.

$x$. Dorsal fin continnous.

RUPISCARTES, 891.

$x x$. Dorsal fin divided.

ENTOMACRODUS, 892.

$a a^{\prime}$. Vomer with a few teeth; posterior canines small.

SALARIICHTHYS, 893.

$p p$. Teeth unequal, not comb-like; body oblong or elongate, more or less eelshaped, naked, or rarely with rudimentary scales; supraocular flap sometimes present. Gill membranes united, free from the isthmus; dorsal fin very long, sometimes divicled into 2 fins; formed of flexible spines, which often pass gradually into soft rays; anal fin long; ventral 
fins thoracic or subjugular, usually, not much, if any, before the pectorals, composed of 2 soft rays each, the spine rudimentary; caudal well developed, the dorsal and anal usually more or less joined to it at base.

OPHIOBLENNIINA:

$c^{\prime}$. Jaws each with 4 strong hooked canines in front; a hooked posterior canine below; a cirrus above eye and 1 above nostril; body scaleless; caudal fin forked; dorsal fin notched; body not eel-shaped; dorsal and anal free from caudal; ventrals small.

OPHIOBLENNIUS, 894.

$c c^{\prime}$. Jaws with numerous teeth, not as above; candal fin not forked.

Emblemarinas:

$d^{\prime}$. Body not eel-shaped; dorsal and anal not joined to caudal; no scales; no cirri; no lateral line; ventrals before pectorals; teeth on palatines; caudal fin rounded.

$e^{\prime}$. Dorsal fin vory high, not notched, the spines passing gradually into the soft rays; jaws long, sharp at tip.

EMblemaria, 895.

$d d^{\prime}$. Body elongate or eel-shaped; the dorsal and anal low, joined to base of caudal.

CHAENOPSIN a:

$f^{\prime}$. Ventrals subjugular, more or less before pectorals; pala tines with teeth; jaws long and sharp.

$g^{\prime}$. Jaws with strong teeth, not as above described; dorsal fin with its anterior half of flexible spines, the posterior half of soft rays, the former gradually passing into the latter; jaws long, pike-like; ventrals inserted slightly before pectorals; anal with 2 spines; a villiform band of teeth in each jaw behind anterior teeth.

$h^{\prime}$. Vomer toothless. Dorsal rays about XVIII, 38; anal II, 38.

CHANOPSIS, 896.

$h h^{\prime}$. Vomer with a few teeth. Dorsal rays XVIII,

\section{Pholidichthyinas:} 32 ; anal II, 30.

LUCIOBLENNIUS, 897.

$f^{\prime}$. Ventrals subthoracic, inserted below pectorals; teeth in jaws uniserial; anal fin without spines.

$i^{\prime}$. Dorsal fin continuous, its spines indistinguishable from the soft rays.

Pholidichthys, 898.

$i^{\prime}$. Dorsal divided into 2 fins, the anterior portion of 3 fioxible spines behind the nape.

Psednoblennius, 899.

II. Blennies arctic or subartic; the vertebræ in large number, usually 50 or more; lateral line rarious, usually median; dorsal fin usually without soft rays; scales small, cycloid, rarely wanting.

$j^{\prime}$. Gill openings not continued forward below, the membranes broadly united, sometimes joined to the isthmus; ventral fins small or obsolete; scales small. cycloid.

$k^{\prime}$. Pectoral fins short or wanting, never pointed, and never more than $\frac{1}{2}$ head; pyloric erca asually, but not always, obsolete.

7. Body not covered with crosswise tubes at right angles to the lateral line.

$m^{\prime}$. Dorsal fin composed of spines only.

\section{STATHMONOTIN E:}

$n^{\prime}$. Body scaleless; ventrals moderately developed; anal spines 2; no lateral line; no pseudobranchiæ. Statнmonotus, 900.

$n n^{\prime}$. Body covered with small smooth scales.

Chirolophine:

$o^{\prime}$. Ventral fins well developed, of 1 spine and 3 rays; no anal spines; top of head with many cirri; a row of large pores above base of pectorals; gill membranes free from isthmus; no pyloric cæca. 
$p^{\prime}$. Lateral line obsolete, only the row of pores being present.

BRyostemia, 901.

$00^{\prime}$. Ventral fins rudimentary or wanting, not more than 1 soft ray present; dorsal spines all short and rigid.

\section{Pholidina:}

$q^{\prime}$. Lateral line obsolete.

$r^{\prime}$. Gill membranes broadly united, free from the isthmus; no pyloric cæca; carnivorous.

$s^{\prime}$. Anal fin with a large sheathed spine; ventrals wanting.

$t^{\prime}$. Anal spine very long, penshaped, its anterior surface channelled; pectoral fins moderate.

APODICHTHYS, 902.

$t t^{\prime}$. Anal spine moderate or small, not pen-shaped, its anterior edge convex, not chaunelled.

$u^{\prime}$. Pectoral fins very small; anal spine moderate.

XERERPES, 903. $u u^{\prime}$. Pectoral fins wholly wanting ; anal spine small.

Ulvicola, 904.

88. Anal fin with 2 small spines or with none.

$v^{\prime}$. Ventral fins reduced to a short spine, followed by a rudimentary ray.

$w^{\prime}$. Caudal fin well developed.

Pнolis, 905.

ww'. Caudal fin very nar-

row, the dorsal and anal united around the tapering tail.

GUNNELLOPS, 906.

$v v^{\prime}$. Ventral fins entirely wanting; caudal as in Pholis. ASTERNOPTERXX, 907.

$r^{\prime}$. Gill membranes joined to the isthmus, sometimes forming a fold across it; no ventral fins; no anal spines; top of head with fleshy crests; pyloric ceca present; body naked anteriorly, with small scales pos. teriorly. ANOPLARCHUS, 908.

\section{XIPHIDINA :}

$q q^{\prime}$. Lateral lines several, each with many short cross branches; pyloric cæca present; gill membranes free from isthmus; ventrals none; anal spines 2 or 3 , small; herbivorous. 
Cebedichthrin e:

$w^{\prime}$. Pectorals small but well developed, much longer than eye.

XIPHistes, 909.

$w w^{\prime}$. Pectorals minute, not longer than eye.

XipHidion, 910.

$m m^{\prime}$. Dorsal fin with its posterior half composed of soft rays; gill membranes broadly united, free from isthmus; ventrals wanting; lateral line single, high; pyloric cæca present; herbivorous.

Dictrosomatines:

Cebedichthys, 911.

$l l^{\prime}$. Body covered with crosswise tubes at right angles with the lateral line and forming a network with it.

$x^{\prime}$. Dorsal fin of spines only; teeth strong; ventral fins present, well developed; gill membranes broadly united, free from the isthmus.

Plagiogrammus, 912.

$k k^{\prime}$. Pectoral fins long and rounded or pointed, nearly as long as head; dorsal fin high; gill membranes broadly united, free from the isthmus; no lateral

line; species probably all herbivorous.

OPISTIOCENTRINAE:

$y^{\prime}$. Ventral fins wanting.

$z^{\prime}$. Dorsal with its posterior splnes rigld and sharp; head scaly.

OPISTHOCENTRUS, 913.

$z z^{\prime}$. Dorsal with its spines all flexible; hoad naked. Pholidapus, 914.

PLectobranchin

$y y^{\prime}$. Ventral fins well developed; dorsal spines all pungent; body greatly elongate.

Plectobranchus, 915.

$j j^{\prime}$. Gill openings continued forward below, the membranes separate or nearly so, scarcely joined to the isthmus; pectorals and ventrals well developed; dorsal spines slender, pungent, the fin without soft rays; herbivorous species.

LUMPENIN 2 :

$a^{\prime \prime}$. Lateral line obsolete or obscure; body greatly elongate.

$b^{\prime \prime}$. Pectorals with the upper and middle rays shortened, shorter than lower; teeth on vomer and palatines.

LEPTOCLINUS, 916.

$b b^{\prime \prime}$. Pectorals with the middle rays longest.

$c^{\prime \prime}$. Lateral line not wholly obsolete, a series of distant pores along sides; teeth on vomer and palatines. Poroclinus, 917. $c c^{\prime \prime}$. Lateral line obsolete, ouly a few small pores being traceable; no teeth on vomer; palatine teeth small or wanting.

STICHAINA :

LUMPENUS, 918.

$a a^{\prime \prime}$. Lateral line present, single, double, or triple; body moderately elongate; teeth on jaws, vomer, and palatines.

$d^{\prime \prime}$. Lateral line simple, one on each side of back.

$d d^{\prime \prime}$. Lateral lines 2 , or dividing into 2 on each side.

StTichages, 919.

$d d d^{\prime \prime}$. Lateral line forking, forming 3 on each gide. EUMresogramus, 921.

\section{ENNEANECTES, Jordan \& Evermann.}

Enneanecte8, Jordan \& Evermann, Proc. Cal. Ac. Sci. 1895, 501 (carminalis).

Body rather robust, covered with large, rough ctenoid scales; lateral line almost obsolete; mouth moderate, the jaws equal; no tentacle above the eye or on nape; no hook on shoulder girdle; eye large; dorsal fin divided into 3 fins, the first of 3 or 4 slender spines, the second of about 10 , the soft dorsal of about 7 rays; caudal rounded; anal fin long; pectoral long, the lower rays simple and thickened. Small fish of the rock 
pools, closely allied to the Old World genus, Tripterygion, Risso, but distinguished by the chubby body, short fins, and large, rough scales. ( $\varepsilon \nu \nu \varepsilon \alpha$, nine; $\nu \eta \varkappa \tau \eta \rho$, swimmer, there being 9 fins.)

2657. ENNEANECTES CARMINALIS (Jordan \& Gilbert).

Head $3 \frac{2}{8}$; depth $4 \frac{1}{2}$ to $5 \frac{1}{2}$. D. III-XII, 9 (IV-X, 8 in the specimen before us); A. II, 11 (misprinted II, 17) scales 33 to 40 . Boly rather stont, heavy forward, rapidly tapering behind. Head short, the snout low and rather pointed, the profile straight and steep from the snout to opposite the front of the eyes, there forming an angle and extending backward nearly in a straight line; eyes very large, longer than snout, 3 in head, high up, and close together; mouth wide, the jaws subequal, the maxillary extending hackward to front of pupil; teeth moderate, essentially as in species of Labrisomus, those of the outer series enlarged; no evident cirri on the head; scales on body of moderate size, ctenoid, the edges strongly pectinate; belly naked; lateral line extending to opposite last ray of soft dorsal, ascending anteriorly, but without convex curve; dorsals 3 , the first and second contiguous, the second and third well separated; first dursal of 3 spines, the first of which is the highest and about as long as diameter of eye; the second dorsal of higher and slenderer spines, the anterior the highest, the longest about equaling greatest depth of body; soft dorsal shorter and a little lower than second spinous dorsal; candal small; anal long, beginning nearly under middle of spinous dorsal; pectoral long, longer than head, reaching much past front of anal; ventrals 8 length of head. Color light brownish, with 4 dark-brown cross bars on sides, about as wide as the interspaces, which are marked with more or less reddish and with some lighter spots; belly pale; space behind pectoral dark; a dark bar downward and 1 forward from eye; first dorsal mottled with darker, second and third dorsals nearly plain; a narrow, dark bar at base of caudal and a broader one toward the tip, the fin sometimes entirely black; pectorals somewhat barred; lower fins plain. Mazatlan, in tide pools; the types, 4 specimens, each about $1 \frac{1}{2}$ inches long. Another from the same locality, since figured by Dr. Jordan, differs somewhat in the count of the fin rays; but the very small size of the specimen prevents us from being entirely sure of its correctness. (carmen, a hetchel, from the rough scales.)

Tripterygium carminale, JORDAN \& GHBERT, Proc. U. S. Nat. Mus. 1881, 362, Mazatlan. (Type, No. 28118. Coll. Gilbert.)

Enneanectes carminalis, JoRdan, Proc. Cal. Ac. Sci. 1895, 510, with plate of young example.

869. HETEROSTICHUS, Girard.

Heterostichus, Girard, Proc. Ac. Nat. Sci.Phila.1854, 143 (rostratus).

Body rather elongate, compressed, covered with very small, smooth scales, those along lateral line not enlarged; head long and low, the snout conic, produced, ver acute; premaxillaries protractile; mouth moderate, terminal; each jaw with a row of conical teeth, behind which anteriorly is a broad patch of villiform teeth; vomer and palatines with villiform, teeth; gill rakers feeble; gill membranes broadly united, free from the 
isthmus; orbital cirri minute or wanting; cheeks scaly. Dorsal fin very long, the posterior rays soft, the 5 anterior spines wider apart than the rest and separated from them by a notch, the first and second spines longest, rather flexible, the other spines stiff; caudal fin forked; ventrals I, 3 ; pectorals moderate; lateral line simple, complete, abruptly curved behind pectorals; air bladder present, large. Size large. Close to Gibbonsia, from which the presence of the air bladder and the form of the caudal

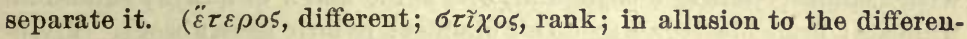
tiation of the anterior dorsal spines.)

2688. HETEROSTICHUS ROSTRATUS, Girard.

(KELPFISH.)

Head $3 \frac{4}{5}$ in body; depth $4 \frac{1}{8}$. D. V-XXXIII, 13; A. II, 34; eye 7 in head; maxillary $2 \frac{1}{2}$; pectoral $1 \frac{4}{5}$; ventral $2 \frac{1}{2}$; first dorsal spine $4 \frac{1}{5}$; highest ray of soft dorsal $2 \frac{1}{2}$; third anal ray $2 \frac{5}{6}$; caudal $2 \frac{1}{6}$. Body much compressed, deepest anteriorly; head slender, compressed and pointed; lower jaw strongly projecting, with thick lip; maxillary reaching pupil; width of interorbital a little greater than eye; orbital cirrus minute, usually entirely wanting; cheek and upper edge of opercle with small scales, rest of head naked. Origin of dorsal a little in front of the vertical from gill opening; pectoral under third dorsal spine, reaching to below the eleventh or twelfth; ventrals inserted in front of pectorals in distance equal to length of snout, their tips reaching about $\frac{1}{4}$ of their length beyond base of the pectoral; soft dorsal higher than spinous, ending slightly anterior to the anal; caudal furcate, the middle rays $\frac{2}{8}$ length of outer. Color translucent, roddish brown, varying to blackish or olive, a series of large irregular light spots along sides below lateral line, continuous with a distinct light bar from eye to edge of opercle, bordered with black above, a similar spot on base of pectoral; an irregular line of large spots following outline of body under dorsal and above anal; a clear cut white streak from dorsal to tip of snout and continued on lower lip, the hue and pattern of color varying greatly; young examples most variegated; a translucent spot behind third dorsal spine, generally followed by similar spots for the whole length of the fin. San Francisco to San Diego. The largest of the Clinoid blennies, very abundant in the kelp, with which it agrees in coloration. Here described from a specimen, 16 inches in length, from San Francisco market. (rostratus, long-nosed.)

Heterostichus rostratus, GIRARD, Proc. Ac. Nat. Sci. Phila. 1854, 143, San Diego, California (Type, No. 284. Coll. A. Cassidy); Girard, Pac. R. R. Surv., X, Fishes, 26, pl. 13, 1858; GÜNTHER, Cat., 261, 1861; JoRDAN \& GILBERT, Synopsis, 764, 1883.

\section{GIBBONSIA, Cooper.}

Gibbonsia, COOPER, Proc. Cal. Ac. Nat. Sci., III, 1864, 109 (elegans). Blakea, STEINDACHNER, Ichth. Beiträge, v, 148, 1876 (elegans).

Body less elongate and compressed, covered with minute cycloid scales, those along lateral line not enlarged; lateral line complete, abruptly decurved behind the pectoral; head somewhat pointed; snout unequal; conical teeth on jaws and vomer, the teeth mostly in single series, except 
in front, where there is a narrow villiform band; no conspicnous posterior canines; maxillary not produced backward from angle of mouth; a tentacle above eye, none at nape; gill membranes united, free from the isthmus. Shoulder girdle with an upturned hook on its inner edge as in Clinus. Dorsal fin long and low, chiefly composed of spines, 5 of the anterior spines different from the others, longer and set farther apart; anal fin low, with 2 spines; ventral fins jugular, of 1 spine and 2 or 3 rays; caudal fin truncate; branchiostegals 6; no air bladder; pyloric cæca absent. Viviparous. Pacific coast; bright-colored fishes, inhabiting rock pools among algæ. This genus is very close to Clinus (type C. acuminatus, Cnvier \& Valenciennes), differing chiefly in the form of the dorsal fin and in the pointed snout. In Clinus the first 3 dorsal spines are shorter than the others. (Named for Dr. William Peters Gibbons, of Alameda, California, who was one of the early naturalists in the California Academy of Sciences.)

a. Dorsal rays about $\nabla-\mathrm{XXXI}, 10$; anal rays about II, 26 ; soft dorsal low; coloration comparatively plain, the soft dorsal without pellucid area.

EVIDES, 2689.

aa. Dorsal rays about $\mathrm{V}$-XXVIII, 7 ; anal rays II, 24; soft dorsal high; coloration more or less highly variegated; soft dorsal with a large pellucid blotch posteriorly.

ELEGANS, 2690.

2689. GIBBONSIA EVIDES (Jordan \& Gilbert).

(KELPFISH; SEÑORITA.)

Head $4 \frac{2}{3}$; depth $4 \frac{1}{2}$. D. V-XXX or XXXI, 10 or 11; A. II, 26 or 27 . Body elongate, compressed; head small, rather pointed; mouth quite small, terminal, the maxillary about reaching pupil, $3 \frac{1}{4}$ in head; lower jaw projecting, vomer with teeth; no teeth on palatines; posterior teeth not recurved; eye moderate, shorter than snout, 5 to 6 in head; a small supraocular flap, not higher than pupil; nasal cirrus very small; first spine of dorsal inserted over preopercle, its length more than $\frac{1}{8}$ that of head, the second nearly equal; the third, fourth, and fifth progressively shorter; the sixth about as long as the fourth; the seventh longer; the rest nearly equal to the last, which is lower than the soft rays; the soft dorsal lower and more rounded than in $G$. elegans, the longest ray 23 in head; pectorals moderate, not reaching vent; ventrals moderate; scales very small, smooth; head naked; no air bladder. Usual color of adult, translucent, reddish or orange, nearly plain or with oblong dark clouds below middle of sides anteriorly; often scattered blackish spots on sides, irregularly placed, forming a broken lateral band, most distinct in the young; a large pellucid spot on the membrane behind third dorsal spine, sometimes some small ones behind it; pectorals nearly plain; dorsal and anal plain, reddish, with a broad dusky shade distally; soft dorsal without pellucid area; caudal plain; a dark streak backward from eye; young examples often variegated, with light and dark shades of red, brown, and white, sometimes with 6 to 8 dark cross bars, sometimes with 4 or 5 lengthwise stripes alternating with paler ones, the hue varying exceedingly and dependent on the surrroundings, but never so extravagantly spotted as in Fibbonsia clegans. Length 9 inches. Coast of California south to Point Concepcion; abundant in the kelp, rarely in rock pools. Here described from specimens from Monterey. ( $\varepsilon \dot{v} \varepsilon \imath \delta \dot{\eta} 5$, comely; $\varepsilon v^{\Im}$, well; $\varepsilon i^{\tau} \delta o 5$, appearance.) 
Blakea elegans, Steindachner, Ichth. Beiträge, v, 148, 1876, specimens from San Francisco; not Myxodes elegans, Cooper.

Clinus evides, ${ }^{*}$ JoRdAN \& GILBERT, Synopsis, 763, 1883; specimens from Monterey, exclusive of part of synonymy; name a substitute for elegans, preoccupied in Olinus.

2690. GIBBONSIA ELEGANS (Cooper).

(SPOTTED KeLPFISH.)

Head $4 \frac{1}{3}$; depth $4 \frac{1}{3}$. D. V-XXVIII, 7; A. II, 24. Body rather strongly compressed; head short, rather pointed, mouth small, terminal, rather oblique, the maxillary barely reaching pupil, $3 \frac{1}{5}$ in head; lower jaw projecting; teeth as in Gibbonsia evides; eye rather large, $4 \frac{1}{2}$ in head, as long as snout; a small fringed supraocular flap, as long as pupil; a slender nasal cirrus; first dorsal spine $2 \frac{2}{3}$ in head; fins as in $G$. evides, the soft dorsal shorter, higher, and less rounded, its longest ray $2 \frac{1}{4}$ in head; pectorals and ventrals moderate, about as in G. evides; caudal fan-shaped on a slender peduncle; scales small and smooth; head naked. Color brown or red, agreeing with rocks or with Corallina, usually with eight irregular darker cross bars extending on the dorsal and anal, sometimes nearly plain brown; a dark spot probably always present behind head, and some, 1 or more, along lateral line posteriorly; spinous dorsal with a pellucid spot; usually many pale and dark spots and freckles on head and fins; pectoral and caudal usually barred, but plain in specimens taken in the kelp (Macrocystis), these latter much less variegated than tide-pool specimens; soft dorsal always with a large pellucid blotch posteriorly, this wanting or obscure in G. evides. Coast of southern California; abundant in rock pools lined with Corallina from Point Concepcion to Todos Santos; the specimens here described from Point Loma. Close to the preceding, but smaller and more brightly colored, the fin rays fewer. These differences, though small, seem to be constant; whether the 2 species overlap each other in geographical range is not known. (elegans, elegant.)

Myxodes elegans, CoOPer, Proc. Cal. Ac. Sci., III, 186 $\$$, 109, San Diego and Santa Barbara. Clinus ocellifer, $\dagger$ MocQUARD, Bnll. Soc. Philom. Paris 1886, 44, California.

Olinus evides, RosA SмIтн, Proc. U. S. Nat. Mus. 1883, 235, specimens from Todos Santos; not of JORDAN \& GILBERT.

* The name evides may apparently be retained for this species, as the description of Jordan \& Gilbert (Synopsis, 763) is based entirely on Monterey specimens, typical of this species. It was intended, however, as a substitute for the name elegans, already used in the genus Clinus, to which these species were then referred.

t The following is a translation of the description of Olinus ocellifer (Mocquard):

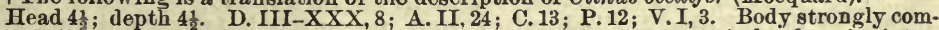
pressed, tapering rapidly behind. Eye a little longer than snout, 3 in head, $t$ wice interorbital space; lower jaw a little longer than maxillary, reaching front of eye; a little tentacle on anterior nostril, elongate, with 4 or 5 unequal branches; a tentacle over eye. Three first dorsal spines nearly duuble length of those which follow, and separated by an interval equal to that which separates the first spine from the third; last dorsal spines longer than those that precede and stronger than any of the others; dorsal and caudal well separated. Scales very small. Opposite fifth and sixth dorsal spines immediately below lateral line is a lens-shaped spot of brownish black with a dnll border; a second ocellus a little before the posterior extremity of the spinous dorsal; this surrounded by a pale brown circle in 1 specimen; the sides also with 5 irregular bands of a paler brown than that of the spots; the anterior is a little behind the corresponding spot; the posterior opposite the third or fourth soft ray of the dorsal; the posterior spot at the upper extremity of the fourth band; other spots of the same color at the base of the dorsal on the right of the caudal; sides with a longitudinal series of small white spots, not surrounded by black circle; other spots on the anal in 6 transverse lines; larger spots on sibopercle and about the ventrals. T'eeth on the vomer, none on the palatines. Coast of California. Two specimens, $93 \mathrm{~mm}$. long. (Mocquard.) 


\section{7x. NEOCLINUS, Girard.}

Neoclinus, Grrard, U. S. Pac. R. R. Surv., x, Fish., 114, 1858 (blanchardi). Pterognathus, ${ }^{\star}$ Grrard, Proc. Ac. Nat. Sci.Phila. 1859, 57 (satiricus).

Body compressed, rather elongate, corered with minute cycloid scales; lateral line present, incomplete, high anteriorly; head naked, the cheeks tumid; upper jaw protractile; maxillary greatly produced backward, more than $\frac{2}{8}$ length of head, reaching far bejond the eye; both jaws, vomer, and palatines with stout, nnequal, conical teeth in a single series, besides which, in the front of the jaws, are smaller teeth; nasal and supraocular region with fringed tentacles; gill membranes broadly united, free from the isthmus; gill rakers weak. Dorsal fin long, scarcely emarginate, its anterior $\frac{2}{8}$ composed of slender, flexible spines, which are similar to the soft rays, all of which are simple; anal long, its rays all simple; ventrals moderate, I, 3; caudal fin distinct; pectorals rather broad, rounded; no air bladder; no pyloric cæca. Pacific coast, in shallow water; remarkable for the great development of the maxillary, as in

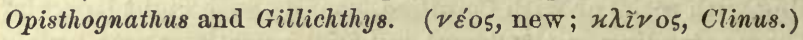

Neochines:

a. Maxillary long, but not reaching beyond head; membrane of jaws white, BLANCHARDI, 2691.

Pterognathus ( $\pi \tau \in \rho o ́ v$, wing; $\gamma \nu \dot{\alpha} \theta 0$ s, jaw) :

$a a$. Maxillary inordinately developed, reaching gill opening in the adult; maxillary flap blackish, edged with bright yellow.

SATIRICUS, 2692.

\section{Subgenus NEOCLINUS.}

\section{NEOCLINUS BLANCHARDI, Girard.}

Head 4; depth 5:. D. XXIV, 17 ; A. II, 30; eye 5 in head ; maxillary variable, about $1 \frac{1}{2}$; pectoral 2 ; caudal $1 \frac{8}{4}$ to 2 . Upper profile of head convex, snout rather steep; jaws subequal; teeth on jaws, vomer, and palatines, subequal, canine-like; eye set high in head, equal to length of snout. Males with a long thick cirrus over front of middle of eye, twice as long as eye, its end multifid, 3 or 4 short, slender ones behind it over posterior half of eye; females with a much smaller cirrus in front, seldom as long as eye, the posterior ones similar to those of male; both with a multifid flap at anterior nostril ; maxillary never reaching past preopercle (in specimens from 6 to 8 inches in length), not longer in males than in females. Head naked; scales on body very small, somewhat embedded; no scales on fins; origin of dorsal directly behind occiput, no notch between spinous and soft dorsals; the tips of last dorsal and anal rays reaching to base of candal fin; pectorals broad, scarcely reaching to vent; about $\frac{1}{2}$ the length of ventrals in front of base of pectoral. Color varying from dark red or

* "It is more than probable that had we been acquainted with this second species of Neoclinus first, we would have been misled as to its real generical characters, and framed a name in allusion to the condition of the upper jaw, such as Pterognathus, for example, which would have been most characteristic, for that upper jaw is as truly winged as the upper members of the flying squirrels. We can not help thinking that Cuvier himself would not have coined the name of Opisthognathus had he had before him the species which bears his name instead of that which hededicated to Sonnerat. These two genera (Opisthognathus and Neeoclinus) will furnish one of the best themes to ichthyological studies, as they exemplify the fact that specific characters may be developed to exaggeration, and become more conspicuous than the generic characters themselves." (Girard.) 
plum color to olive green; sides mottled and spotted with darker; a dark spot, ocellated with yellow, generally present between first and second dorsal spines; dorsal blackish toward ends of rays; pectorals and anal white in female, slightly dusky in male; unexposed portion of lower lip entirely white; a yellow spot on base of caudal rays below and above. Coast of California, from Monterey to Santa Barbara; not rare; a remarkable fish. Here described from specimens from 6 to 8 inches in length, from Pacific Grove, California. We do not know what variation there may be in maxillary and barbels in larger or smaller specimens. This species differs from N. satiricus in having no second spot behind seventh spine of dorsal; in having that part of lower lip which is covered by the maxillary entirely white; barbels in male much longer; maxillary shorter; head slightly shorter; and in having the pectorals and anal lighter. (Named for its discoverer, Dr. S. B. Blanchard.)

Neoclinus blanchardi, Girard, U. S. Pac. R. R. Surv., x, Fish., 114, 1858, San Diego (Type, No.691. Coll. Dr. S. B. Blanchard); GüntHer, Cat., III, 259, 1861; JORDAN \& GILBERT, Synopsis, 761, 1883.

Subgenus PTEROGNATHUS, Girard.

2692. NEOCLINUS SATIRICUS, Girard.

Head $3 \frac{1}{2}$ in body; depth 6 . D.XVI, 17 ; A. 30 ; eye 5 in head; pectoral 2 ; caudal $2 \frac{1}{2}$. Head bluntish, convex in profile; snout steep; jaws subequal; unequal, small canines on jaws, vomer, and palatines; eye about equal to length of snout, interorbital flattish, about $\frac{1}{2}$ eye in width; 3 or 4 small barbels above eye, seldom as long as eye, the anterior one sometimes absent on one or both sides; cirri not differentiated in the female; a multifid flap on anterior nostril; maxillary always reaching past edge of preopercle (in examples 6 to 9 inches in length), just past in females, longer than head in males. Head naked, scales on body small, partly embedded; no scales on fins. Origin of dorsal directly behind occiput; no notch between spinous and soft dorsals; pectorals in the larger examples reaching to vent; last rays of dorsal and anal reaching base of caudal fin; anterior half of ventrals in front of base of pectorals. Color in spirits, reddish brown or olive green, mottled and spotted with darker; a dark spot ocellated with yellow between first and second dorsal spines, a similar one betweeu seventh and ninth; dorsal blackish, pectoral, anal and ventrals varying from dusky to black, in no case light in our specimens; a vellow spot sometimes present, below and above, on base of candal rays; the membrane connecting maxillary with lower jaw blackish, broadly and abruptly edged with white (probably yellow in life). Coast of California, from Monterey to Santa Barbara; a rare and most interesting species. Here described from specimens, 6 to 9 inches in length, from Pacific Grove, California. Differing from $N$. blanchardi in length of maxillary; slightly larger head; males without long cirri; a second spot on dorsal; fins darker, and especially in having the membrane of lower lip blackish, edged with white. (satiricus, satirical.)

Neociinus satiricus, GIrard, Proc. Ac. Nat. Sci. Phila. 1859, 57, Monterey, California, in 30 fathoms (Coll. A. S. Taylor); GUNTher, Cat., III., 260, 1861; JoRdaN \& Glllbert, Synopsis, 761, 1883. 
872. MALACOCTENUS, Gill.

Malacoctenus, GiLL, Proc. Ac. Nat. Sci. Phila. 1860, 103 (delalandi).

This genus is very close to Labrisomus, differing in the dentition, the teeth in the jaws being in single series; vomer with a few teeth or with none, none on palatines. The form of the dorsal fin in some species is different, there being usually a notch behind the fourth dorsal spine as well as at front of soft dorsal. Most of the species are not well known, and perhaps more than 1 genus is here included. ( $\mu \alpha \lambda \alpha \varkappa o ́ s$, soft; $\varkappa \tau \varepsilon i \varsigma$, comb, in reference to the comb of filaments at the nape in the typical species.)

a. Nape without filaments.

b. Orbital tentacle present.

c. D. XXI, 8; spinous dorsal not notched, the first rays shortest; body elon. gate; snout pointed; scales large, about 38 . OCELLATUS, 2693.

cc. D. XX, 12; spinous dorsal weakly notched; body rather robust.

VARICS, 2694.

bb. Orbital tentacle wanting; dorsal rays XXI, 11; spinous dorsal weakly notched; ventrals long.

MACROPUS, 2695.

aa. Nape with a single tentacle. D. XVIII, 9; a tentacle above eye. LUGUBRIS, 2696. aaa. Nape with a comb of slender tentacles; spinous dorsal more or less notched behind fourth or fifth spine.

d. Orbital tentacle present. D. XVIII to XX, 11 or 12 vomer with teeth.

e. Scales 43 or 44 .

f. Highest soft ray of dorsal $1 \frac{1}{2}$ in head; dorsal without ocelli.

GILLII, 2697.

ff. Soft rays of dorsal $1 \frac{1}{5}$ in head; dorsal fin with 2 large black ocelli; ventral fins long, as long as head.

BIMACULATUS, 2698.

ee. Scales 55; ventrals moderate, shorter than head.

$d d$. Orbital tentacle wanting; (no vomerine teeth?).

DELALANDI, 2699.

VERSICOLOR, 2700.

aaaa. Nuchal and other filaments undescribed; a black ocellus on front of dorsal.

D. XX, 11; scales 46 .

BIGUTTATUS, 2701.

\section{MALACOCTENUS OCELLATUS (Steindachner).}

Head 4 to $4 \frac{1}{4}$; depth 5 to $5 \frac{2}{8}$. D.XXI, 8; A.II, 8; scales 38 ; eye $4 \frac{1}{2}$ to 5 in head; snout 5\%; interorbital width 10 . Body elongate; the snont short; profile not steep; tentacle above eye very slender, none on nape. Maxillary $\frac{1}{2}$ long as head, reaching posterior margin of eye. Teeth on jaws and vomer in 1 row, none on palatines. Dorsal with a notch between the spines and soft rays; spines all short, the longest not $\frac{1}{2}$ head, the anterior shortest; the longest soft rays $1 \frac{1}{2}$ in head; dorsal slightly joined to base of caudal; ventral and caudal each $1 \frac{1}{8}$ in head; pectoral almost as long as head. Lateral line complete, strongly arched anteriorly. Color brownish; 8 pairs of narrow dark-brown cross bands on the body, most distinct above, sometimes broken up into cross spots; first membrane of the dorsal fin with black spot behind, sometimes a similar one, oval and indigo, behind eye; numerous sky-blue spots bordered with darker on sides of head and part of body; anal pale violet, edged with white, sometimes spotted; caudal gray, with darker spots in cross rows. Bahama Islands. Length 2 inches. (Steindachner.) Not seen by 
us. Perhaps not a member of this genus; the large scales, entire spinous dorsal, and short soft dorsal, indicating affinities with Starksia, which has, however, a different dentition. It may prove to be the type of a distinct genus. (ocellatus, with eye-like spots.)

Clinus ocellatus, STEINDACHNER, Ichth. Beitr., v, 182, 1876, Bahama Islands.

\section{MALACOCTENUS VARIUS (Poey).}

Head $3 \frac{3}{5}$ in total length; depth $4 \frac{1}{5}$. D. XX, 12; A. 18; C. 14; pectoral $1 \frac{1}{5}$ in head; eye $3 \frac{2}{8}$ in head, equal to snout. Mouth small; maxillary reaching opposite front of eye; profile prolonged; nostrils small, not tubular. Teeth firm, in 1 row, the points sharp and incurved; no teeth on vomer; a tentacle over eye, none at the nape; head naked; body scaly; lateral line short; dorsal beginning over middle of opercle, the spinous part forming a sinuous curve; the spines firm; the first higher than the 4 which follow; the last low; the next to the last lower than the last; soft dorsal higher than the spines; ventral rays apparently 2 , the last one deeply divided. Color clear yellowish; the body spotted with black; an isolated spot at the end of the dorsal fin; vertical fins with all the rays dotted with black; pectoral pale, without specks. Length $52 \mathrm{~mm}$. Cuba. (Poey.) Not seen by us. (varius, variegated.)

Myxodes varius, PoEx, Enumeratio, 132, pl.5, f. 2, 1875, Havana. (Coll. Rafael Arango.)

\section{MALACOCTENUS MACROPUS (Poey).}

Head $4 \frac{1}{4}$ in total length with caudal; depth $5 \frac{1}{5}$. D. XXI, 11; A. I, 20; P. 17; eye $\frac{1}{2}$ longer than snout, $3 \frac{1}{4}$ in head. Maxillary reaching front of eye. Teeth in 1 series, acute, not close-set; none on the vomer or palatines; no cilia over the eye nor on the nape; lateral line almost complete; ventrals as long as the depth of the trunk; first dorsal spine longest, the others forming a weak curve. Color uniform metallic coppery brown. Cuba (Poey); one specimen $35 \mathrm{~mm}$. long. The type of this species examined by us in the Mus. Comp. Zool. It has scales 35; no hook on the shoulder girdle, and apparently no teeth on vomer or palatines.

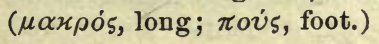

Myxodes macropus, Poex, Synopsis, III, 99, 1868, Havana. (Coll. Poey.)

\section{MaLacoctends LUGUBRIS (Poey).}

D. XVIII, 9; A. 20. Tentacle over eye; a filiform appendage on the side of the neck. Ventral very long, extending much beyond the vent. Dorsal fin with 2 depressions, the soft part short and very high, the first spine moderate. Color dark brown, with oblique vertical bands and brown points scattered over the head and trunk; a black spot at the base of the first 3 dorsal membranes; ventral entirely white. Cuba. Onespecimen $55 \mathrm{~mm}$. long. (Poey.) Not seen by us. (lugubris, dismal, from the dark color.)

Myxodes lugubris, Pokr, Enumeratio, 131, 1875, Cuba. (Coll. Poey.) 
2697. MALACOCTEXUS GILLII (Steindachner).

Head $4 \frac{1}{2}$; depth $4 \frac{1}{2}$; eye 4 in head; snout $3 \frac{1}{4}$; interorbital 6 in head. D. XIX, 11; A. II, 17; P. 14; scales 43. Head pointed, conic anteriorly; snout longer than eye; a rather high tentacle above the eye, slender and split to the base, numerous others on the side of the nape; teeth not described. First three dorsal spines wider apart than others, first longest; eighth to tenth spines highest, $\frac{1}{2}$ head; highest soft ray $1 \frac{1}{2}$ in head; dorsal deeply notched. Body greenish gray, with brown spots or faint cross bands; head and dorsal marbled with darker; ventrals white, the longest ray a little longer than head, reaching anal; anal edged with dark; pectoral as long as head. Barbados. Two specimens, the larger 2 inches long. (Steindachner.) This species may be a Labrisomus. (Named for Dr. Theodore Gill.)

Clinus gillii, SteINdACHNER, Ichth. Notizen, vi, 46, 1867, Barbados.

2698. MALACOCTENUS BIMACULATUS (Steindachner).

Head $4 \frac{2}{5}$; depth $4 \frac{1}{2}$. D. XX, 10; A. II, 19; ventral 3 ; scales 44 . Near to M. delalandi, but the body deeper (said to be $5 \frac{1}{2}$ in the latter species, which is not the case). Profile to snout steep; eye a little shorter than snout, $3 \frac{1}{2}$ in head; jaws equal, each like the vomer with : row of teeth; maxillary reaching about to front of pupil. Interorbital space narrow, more than $\frac{1}{2}$ width of eye; a very slender, rather long, bifid tentacle above eye; tentacles on the nape, npper 1 almost as long as tentacle above eye. Upper margin of dorsal weakly notched between first and fifth spines, more deeply between spines and soft rays, the former as in $M$. delalandi; longest soft rays $1 \frac{1}{b}$ in head; longest spines 2 in head; first 4 spines more widely separated than the others; pectoral and ventral as long as head; caudal a little shorter. Body brown, with dark-brown bands and numerous blackish spots, only the cross bands on the head strongly marked; tips of the anal rays whitish; above these a bluish violet streak; pectoral with 2 milk-white spots at base; a large black isolated spot at the base of the first 4 dorsal spines, a second on the last 4 spines, extending on the body; anal and candal thickly spotted with brown. Small rocky islands to the north of Cuba. (Steindachner.) Not seen by us; evidently elose to Malacoctenus delalandi, but the scales larger. (bis, two; maculatus, spotted.)

Clinus bimaculatus, STEINDACHNER, Ichth. Beitr., v, 180, 1876, small, rocky islands north of Cuba.

2699. MALACOCTENUS DELALANDI (Cuvier \& Valenciennes).

Head $3 \frac{1}{2}$; depth $3 \frac{1}{2}$ to $4 \frac{1}{2}$. D. IV-XVI, 11; A. II, 18; scales 55. Form rather stout, compressed; snout not very short, rather pointed, the profile gibbous above the eyes, thence declining straight to the tip of the snout; mouth rather small, the maxillary reaching front of eye; teeth in a single series in each jaw; vomer with a few teeth, none on palatines; eye large, $3 \frac{1}{2}$ in head, as long as snout; small sleuder cirri above the eyes, and a fringe of moderately long filaments at the nape rather longer than the orbital cirri. Ontline of spinous dorsal emarginate; first spine a little longer. than eye, the second, third, and fourth progressively shortened, the 
fifth again longer; the eighth to eleventh spines longest, thence gradually decreasing to the next to the last, which is much shorter than the last; soft dorsal rays considerably higher than the spines, the longest about $\frac{1}{2}$ length of head; anal long, not very high, the membrane deeply notched between all but the last 6 rays, which are the highest. Pectorals $\frac{5}{6}$ length of head; ventrals as long as from snout to edge of preopercle. Belly naked anteriorly; the scales small, cycloid; lateral line complete. Color olivaceous, darker above, much mottled and speckled with clear dark brown; sides with 5 distinct irregular dark-brown bars, extending from base of dorsal to level of lower margin of pectoral, their lower edges connected by a vague undulating longitudinal band; a blackish blotch on occipital region, and black blotches on cheeks, opercles, and before base of pectoral; opercle with several narrow pinkish streaks; head below with narrow streaks formed by series of dark-brown spots; an interrupted brown bar across lower jaw; belly unspotted; ventrals pale; other fins all barred with narrow series of dark-brown dots; anal somewhat dusky. Coast of Brazil and the west coast of Mexico; common. Here described from the types of Clinus zonifer. This is the most abundant denizen of the rock pools around-Mazatlan, with the single exception of Gobius soporator, reaching a length of 3 to 5 inches. We are unable to separate M. zonifer from Mazatlan from Bahia examples of $M$. delalandi, and take our account from specimens of the former. (Named for Delalande, who collected for Cuvier in Brazil.)

Olinus delalandii, Cuvier \& V Alenciennes, Hist. Nat. Poiss., XI, 378, 1836, Brazil (Coll. Delalande); Günther, Cat., III, 261, 1861.

Clinus zonifer, JordaN \& Gilbert, Proc. U. S. Nat. Mas. 1881, 361, Mazatlan. (Coll. C. H. Gilbert.)

Clinus philipii, Lockington, Proc. Ac. Nat. Sci. Phila. 1881, 114; not of Steindachner. Labrisomus delalandi, JordaN, Proc. U. S. Nat. Mus. 1888, 333.

\section{MALACOCTENUS VERSICOLOR (Poey).}

Head $3 \frac{1}{2}$; depth $3 \frac{3}{4}$. D. XVIII, 12; A. 20. Body compressed; head moderate; snout prolonged; pectoral $1 \frac{1}{5}$ in head; ventral 12$\frac{2}{5}$; eye large, as long as snout, $3 \frac{1}{2}$ in head; nostrils not tubular; mouth small; maxillary not reaching so far as eye; teeth firm, in 1 row, those above much larger and slightly curved backward; 12 teeth above and 9 below on each side [no teeth on vomer]; no tentacle over eye; no anal papilla; a comb of filiform tentacles on each side of the neck; head naked; body scaly; lateral line short; dorsal with 2 depressions, the first spine higher than the 4 which follow, the depressions much more marked than in $M$. varius; pectoral reaching beyond front of anal. Color yellowish brown; head, trunk, and fins varied with vertical brown bands and large brown spots; ventrals yellowish. On the figure the 5 bands behind the anal cross the body and extend on the vertical fins. Cuba. One specimen known, $53 \mathrm{~mm}$. in length. (Poey.) Apparently very close to $M$. delalandi, but lacking the orbital tentacle, and, according to Poey, vomerine teeth also. (versicolor, variegated.)

Myxodes versicolor, * PoEx, Enumeratio, 131, pl. 5, f. 1, 1875, Cuba. (Coll. Poey.)

* This species and its affines were referred by Poey to Myxodes, a South American genus allied to Clinus and Gibbonsia, but differing from the latter in its uniserial teeth. 


\section{MALACOCTENCS BIGUTTATUS (Cope).}

Dorsal XIX-I, 11; anal II, 16; The first dorsal spines the longest, last spine longer than penultimate; length of head without opercular flap, $3 \frac{2}{8}$ times in length (exclusive of caudal fin); eye a little less than $\frac{1}{4}$ length of head, $\frac{2}{5}$ greater than interorbital width; pectoral fin reaching to fifth anal; scales large, 4-46-10 [cirri and teoth not described]. Pale reddish brown, humeral red-veined; rufous specks on anterior part of sides; 7 subquadrate brown blotches from nape to caudal fin, continued with interruptions as lateral bands, the fourth near end of spinous dorsal black; a black spot at base of membrane between first to third dorsal spines; 2 small brown spots behind orbit, the posterior on operculum. Length 2.25 inches. This species is well distinguished from Labrisomus nuchipinnis by the large scales, form of dorsal fin, coloration, etc. From Now Providence, Bahamas; Dr. H. C. Wood's collection. Also a very small specimen from Dr. Rijgersma, St. Martins. (Cope.) Not seen by us. (bis, two; guttatus, spotted.)

Labrisomus biguttatus, CoPr, Trans. Am. Philos. Soc. Phila. 1873, 473, New Providence, Bahama Islands. (Coll. Dr. H. C. Wood.)

\section{LABRISOMUS, * Swainson.}

Labrisomus, Swansson, Nat. Hist. Class'n Fishes, II, 277, 1839 (pectinifer).

Lepiroma, De KAY, New York Fauna: Fishes, 41, 1842 (cirrhosum).

Labrosomus, GiLl, amended spelling.

? Blennioclinus, GiLl, Proc. Ac. Nat. Sci. Phila. 1860, 103 (brachycephalus).

?Auchenionchus (misprinted Anchenionchus), GiL, Proc. Ac. Nat. Sci. Phila. 1860, 103 (variolosus).

?Calliclinus, Gill, Proc. Ac. Nat. Sci. Phila. 1860, 103 (geniguttatus).

? Ophthalmolophus, Grul, Proc. Ac. Nat. Sci.Phila.1860, 104 (latipinnis).

* Concerning this genus and its affines, Dr. Gill remarks :

"The name Labrosomus (or Labrisomus) was first published in 1839, in the second volume of the 'Natural History of Fishes, Amphibians, and Reptiles.' At the seventy-fifth page of that volume, Swainson has divided the Cuvieran genus Clinus into 5 genera: Clinus, of which the Clinus acuminatus, Cuvier, is taken as the type; Labrisornus with Otinus pectinifer, Valenciennes, as type; Tripterygion, Risso, Clinitrachus, Reese, which is typified by Blennius variabilis of Rafinesque, and Blennophis, of which the Clinus anguillaris, Valenciennes is the only true species. Of these genera, Clinus Swainson, and Clinitrachus Swainson, are distinguished by false or illusive characters, and cannot be regarded as distinct. The others are valid, but their characters require revision. 'The only claim to distinction of the genus Labrosomus given by Swainson, is founded on the strong, conic, and pointed row of front teeth, behind which are villiform ones; a thicker body than in Clinus, and the 'dorsal fin distinctly emarginate toward the caudal.' The genus resting on these characters alone is composed of very incongruous elements. To it are referred, at page 277 of the second volume, the following species, all of which are described as species of Clinus by Valenciennes: Labrosomus gobio, $L$. pectinifer, $L$. capillatus, $L$. delalandii, $L$. linearis, L. variolosus, I. peruvianus, L. microcirrhis, L. ? geniguttatus, L. elegans, L. ? littoreus and $L$. latipinnis. Of these species, not more than 3 can, with propriety, be regarded as congeners, if the Labrosomus pectinifer is taken as the type. These are Labrosomus pectinifer, L. capillatus, and perhaps $L$. delalandii. The latter is more probably the representative of a distinct genus. That genus is distinguished from Labrosomus by the smaller mouth, the presence of only 2 rays to the ventral fins, and perhaps by the undulating margin of the spinous portion of the dorsal fin. It may be named Malacoctenus, in allusion to the pectiniform row of filaments. This genus is the nearest ally of Labrosomus. All the others are very distinct. Labrisomus gobio Swainson, is the type of quite a distinct genus, whose characters consist of a broad, depressed head, with a very short muzzle, large approximated eyes, superciliary and nasal tentacles, 2 ventral rays, and a comparatively short spinous dorsal. The genus may becalled Gobioclinus. The only species, Gobioclinus gobio, is found in the West Indies, and has but 18 dorsal spines. Labrisomus linearis Swainson is synonymous with Clinus brachycephalus, Valeuciennes. This, also, is the type of a 
Body oblong, robust; head naked, short, compressed above; mouth rather large, with a row of stout, bluntish teeth in front of each jaw, behind which is a band of smaller teeth, broadest in lower jaw; teeth on vomer, no teeth on palatines; a tentacle above the eje; sides of neck with a tuft or series of fine filaments; dorsal fin continuous, with numerous slender spines and many soft rays, the spines not very unequal; pectorals long; lateral line continuous; scales moderate or small, cycloid; shoulder girdle without upturned hook-like process on its inner edge. Intestinal canal short, shorter than body. The limits of this genus are not well defined, and most of the nominal genera above named will probably be found worthy of recognition. This genus differs from Clinus chiefly in the absence of the upturned spine-like processes on the inner edge of the shoulder girdle. This process is found on Clinus acuminatus, the type of the genus Clinus. (Labrus; бю̃ $\mu \alpha$, body.)

a. Scales moderate, about 70 in lateral line (so far as known); soft dorsal with 11 to 13 rays.

b. Dorsal spines 16; anal rays 20 ; tentacles on nape.

HERMINIER, 2702.

$b b$. Dorsal spines 18; no teeth on palatines; first ray of dorsal not longest; orbital tentacle well developed; nape with a conspicuous comb of fringes.

d. Vomer with a cluster of small teeth.

$d d$. Vomer with 3 to 5 large blunt teeth arranged in the form of a $\wedge$.

NUCHIPINNIS, 2703.

XANTI, 2704.

$b b b$. Dorsal spines 20; teeth on palatines ( $?$ ); first dorsal spine longest.

BUCCIFERUS, 2705.

aa. Scales very small, about 110 ; a comb of fringes at nape; first dorsal spines low; head with yellow spots.

MICROLEPIDOTUS, 2706.

\section{LABRISOMUS HERMINIER (Le Sueur).}

D.XVI, 11; A. 20; C. 14; P.16; V.3. Body slender, compressed. Cilia on nostrils, above the eye, and on the nape; lips thick, concealing conical teeth, behind each band of smaller teeth; teeth also on the palate and on the base of the gill arches. Scales rather large. Lateral line curved from the pectoral, becoming straight thence to the tail. Color reddish brown with numerous spots; a black spot at front of spinous dorsal.

distinct genus distinguished by its abbreviated and blenniform head, the profile being very convex; by the villiform teeth, the absence of superciliary tentacles, the spinous portion of the dorsal long, and the presence of only 2 rays to the ventral fins. The name Blennioclinus is conferred on it; for the species, the specitic name of $\nabla$ alenciennes must be retained. Labrisomus variolosus is distinguished by a large thick head, with lateral eyes, short superciliary tentacles, and a small nuchal one. The mouth is large; the teeth of the jaws in an outer row strong and conical, behind which are villi. form ones; those of the vomer and palate are villiform, in 3 patches, 1 on the vomer and 1 on each palatine bone. The spinous portion of the dorsal is long, and the ventrals have each 3 rars. The species thus characterized is the type of a new genus which may be named Anchenionchus (misprint for Auchenionchus). Labrisomus microcirrhis, $L$. elegans and $L$. peruvianus are nearly related to Anchenionchus, and are from the same zoological province. Labrosomus? geniguttatus is distinguished from Anchenionchus by the more approximated eyes and by the disposition of the vomero-palatine teeth, as well as the small size of the anterior row of maxillary teeth. The dorsal is moderately long, and each of the ventrals has 3 rays. The mouth is comparatively small, and there are superciliary, nasal, and nuchal tentacles. For this specles the generio name Oalliclinus is proposed. Labrisomus latipinnis is related to Blennioclinus, but is distinguisbed from the species of that genus by the presence of superciliary tentacles. The generic name of Ophthalmolophus may be retained for it." (Proc. Ac. Nat. Sci. Phila.1860, 102, 103.) $3030-71$ 
St. Bartholomew, West Indies; known from one specimen taken among madreporic rocks. (Le Suenr.) Not recognized by any recent author; perhaps not distinct from L. nuchipinnis.

Blennius herminier, Le Sueur, Jour. Ac. Nat. Sci. Phila., IV, 1824, 361, St. Bartholomew: Clinus hermineri, Cuvier \& Valenciennes, Hist. Nat. Poiss., XI, 380, 1836.

\section{LABRISOMUS NUCHIPINNIS (Quoy \& Gaimard).}

Head $3 \frac{1}{2}$; depth $3 \frac{1}{2}$. D. XVIII, 12; A. II, 17; scales 70. Body oblong, rather robust; head naked, thick, short, not very obtuse anteriorly, compressed above; mouth rather large, the maxillaries not prolonged backward, extending to opposite the posterior part of eye, $2 \frac{1}{2}$ in head; teeth on vomer and palatines; front teeth of jaws conic, strong, behind them a band of villiform teeth, broadest in lower jaw; vomer with a patch of smallish teeth; eyes large; interorbital space very narrow; each side of neck with a long series of hair-like filaments, nearly as long as eye; orbital tentacle short and broad, multifid; nostril with a tufted barbel; lower jaw slightly projecting, its posterior teeth sometimes recurved; pectorals a little shorter than head, reaching vent. Dorsal spines rather slender, the 3 anterior spines scarcely shorter than the others, all the spines lower than the soft rays; dorsal fin commencing near the nape, the spinous portion long; soft rays higher than the spines; caudal small; pectorals rather large; ventrals moderate; gill-membranes broadly united, free from the isthmus; lateral line complete, high anteriorly, then abruptly decurved; membranes of vertical fins scaly; scales not very small, cycloid. Reddish brown, sometimes with vertical bands; a black spot on opercle, which is often edged with white; cheeks and fins reticulate or dotted. Length 6 to 8 inches. West Indies, north to Florida Keys, south to Brazil; generally-common in rock pools; also recorded from the Canary Islands. (nucha, nape; pinna, fin.)

Clinus nuchipinnis, QUoy \& GAIMARD, Voy. Uranie et Physicienne, Zool., 255, 1824, Brazil (Coll. M.Freycinet \& M. Gay); GÜnther, Cat., III, 262, 1861; Jordan \& GIlbert, Synopsis, $762,1883$.

Olinus pectinifer, Cuvier \& VAlenciennes, Hist. Nat. Poiss., XI, 374, 1836, Bahia.

Lepisoma eirrhosum, DE KAY, N. Y. Fauna: Fishes, 41, 1842, Florida.

Olinus canariensis, Valenciennes, in WebB \& Berthelot, Poiss. Iles Canaries, 60, 17, f. 3 , Canary Islands.

Clinus capillatus, Cuvier \& VAlenciennes, Hist. Nat. Poiss., xI, 377, 1836, Martinique.

Labrosomus pectinifer, Gill, Proc. Ac. Nat. Sci. Phila. 1860, 105.

Labrisomus capillatus, GILl, Proc. Ac. Nat. Sci. Phila. 1860, 107.

\section{LABRISOMUS XANTI, Gill.}

Head $3 \frac{1}{2}$ in body; depth $3 \frac{1}{2}$. D. XVIII, 12; A. II, 18; scales 10-64 (pores)-12 (from front of straight portion of lateral line to anal); eye $4 \frac{1}{2}$ in head, maxillary 2; highest dorsal spine $2 \frac{5}{6}$; pectoral $1 \frac{1}{2}$; caudal $1 \frac{3}{5}$. Body not greatly elongate, compressed, anterior profile well rounded from snout to nape; mouth rather large, the maxillary reaching to below middle of eye; teeth small, canine-like, growing gradually larger toward 
front of upper jaw; side teeth on lower jaw very small, abruptly enlarged on front half of jaw; teeth on vomer $A$-shaped, in a single row, the ones at the angles enlarged, 1 or 2 small ones between them at the sides; small multifid dermal flaps at nape, over eye, and above nostril; interorbital concave at the middle, $\frac{3}{5}$ the diameter of eye; gill rakers small and short, $3+6$ in number. First dorsal spine inserted behind eye a distance equal to diameter of eye, about $\frac{1}{6}$ shorter than longest spine; soft dorsal the higher; origin of anal midway between snout and base of caudal, not running as far back as dorsal; pectoral reaching a little past front of anal; ventrals long and slender, inserted a little in front of pectorals, their ends not reaching vent; caudal rounded. Color in spirits, brownish gray, with about 6 wide irregular cross bars which are darker toward their edges, 2 black streaks running downward and backward from eye; cheeks and opercles with many small light blue spots; spinous dorsal mottled and spotted with darker, other fins with small irregular dark lines running across the rays; ventrals dusky; tentacles on head black. Described from a specimen 5 inches in length from La Paz, Lower California. Pacific coast of Tropical America from Gulf of California to Panama; common in rock pools; representing on the Pacific coast the scarcely different $L$. nuchipinnis. (Named for John Xantus.)

Labrosomus xanti, Gili, Proc. Ac. Nat. Sci. Phila. 1860, 107, Cerro Blanco (Type, Nos. 2331, 2335, 2478. Coll. J. Xantus); Jordan \& Gilbert, Proc. U. S. Nat. Mus. 1882. 368.

2705. LABRISOMUS BUCCIFERUS, Poey.

Head $3 \frac{8}{4}$ in total length with caudal; depth 5. D. XX, 11; A. II, 19; eye 4 in head, a little longer than snout; anterior nostril with a little tube; lower jaw longer; forehead convex, the snout short; month large, reaching beyond mildle of eye; a few filaments on nape and 1 above preopercle. Teeth cardiform, the outer ones large; teeth on vomer (and palatines). Borly scaly. Lateral line complete. First ray of dorsal longest, the others forming a convex curve up to the 19 , which is shortest; pectoral moderate, of 12 rays, the lower thickened. Color brownish jellow, with vertical brown points extending on fins; a series of pale points along sides; the head gray, cheek dark brown. One specimen $55 \mathrm{~mm}$.long. Cuba. (Poey.) Not seen by us. (bucca, cheek; fero, I bear).

Labrisomus bucciferus, Poex, Synopsis, 399, 1868, Cuba. (Coll. Poey.)

2706. LABRISOMUS miCROLEPIdotus, Poey.

Length of head equal to depth; pectoral $1 \frac{2}{8}$ in head; eye $1 \frac{2}{5}$ in snout, $4 \frac{1}{2}$ in head. Maxillary reaching to base of middle of eye, $2 \frac{1}{3}$ in head. Mouth oblique, with strong teeth; the lower jaw the longer; small fringe of tentacles at anterior nostril above eye, and a comb of fringes at the nape. First 3 dorsal spines subequal, considerably lower than the second 3 , which become progressively longer. Scales in lateral line about 110. Head brown, with small yellow spots scattered over its lower part and on the gill membranes. Pectoral and caudal with some black points. Cuba. 
(Poey.) Known from an imperfect description, with a drawing of the head of a specimen $180 \mathrm{~mm}$. long. ( $(\mu \imath \varkappa \rho o ́ s$, small; $\lambda \varepsilon \pi \imath \delta \omega \tau o ́ s$, scaly.)

Labrosomus microlepidotus, PoEx, Anal. Soc. Esp. Hist. Nat., XIX, 1880, 246, 1, 8, f. 2, Cuba. (Coll. Poey.)

874. MNIERPES, Jordan \& Evermann.

Mnierpes, Jordan \& EvERMAN, Check-List Fishes, 468, 1896 (macrocephulus).

This genus is close to Labrisomus, from which it differs chiefly in the very elongate body and in the absence of an orbital tentacle. The dorsal spines are more numerous, and probably the vertebræ also. The lips are thick and there is no trace of hook on the shoulder girdle. A band of fillitorm teeth in the jaws behiud the anterior series; teeth on vomer, none on palatines. ( $\mu \nu$ iov, moss; $\ddot{\varepsilon} \rho \pi \eta s$, creepẹr.)

\section{MNIERPES MACROCEPHALUS (Günther).}

Head $4 \frac{1}{4}$; depth 6 to $6 \frac{1}{4}$ ( $7 \frac{1}{2}$ in total). D. XXII, 12; A. II, 24; C. 13; P. 13; V. I, 3; scales about 70.' The head is depressed, rather short, nearly as broad as long; crown of the head broad and flat; interorbital space concave, narrower than the orbit. Snout very short, obtuse, rounded; the maxillary not extending to behind the posterior margin of the orbit; lips thick. Teeth in jaws forming a band with an outer series of stronger ones; vomerine teeth in a narrow band; palatine teeth none. No orbital tentacles, those at the nostril and on the neck very small. Gill openings wide, the gill membranes being united at the throat. Head naked; scales on the body not very small, eycloid. Dorsal fin commencing at occiput, and terminating near base of caudal, the spines flexible, and much lower than the soft rays; the 3 anterior ones rather more remote from one another than the following; none of the rays of this or of the other fins branched; caudal rounded; anal higher posteriorly than ante_ riorly, about as high as the spinous dorsal; pectorals rounded, with the middle rays longest, shorter than the head; ventrals jugular, $\frac{1}{2}$ as long as the pectoral, with the spine and the outer ray enveloped in a common thick membrane. Dark grayish olive; head and fins blackish; head, base of the pectoral, anterior part of the body, and dorsal dotted with white. Pacific coast of Central America. (Günther.) Known from a fow specimens from Panama. Those examined by us (Mus. Comp. Zool.) have the sides much freckled and mottled with pale. ( $\mu \alpha \varkappa \rho \sigma_{5}$, long; $\varkappa \varepsilon \phi \alpha \lambda \dot{\eta}$, head.)

Olinus macrocephalus, GUNTHER, Cat., III, 267, 1861, Pacific coast of Central America

(Coll. Capt. John M. Dow); Güntuer, Fish. Centr. Amer., 442, pl. 69, fig. 2, 1869. Labrosomus macrocephalus, JoRDAN, Proc. U. S. Nat. Mus. 1885, 389.

\section{GOBIOCLINUS, Gill.}

Gobioclinus, Gill, Proc. Ac. Nat. Sci. Phila. 1860, 102 (gobio).

Body robust; head broad, depressed, with a very short muzzle. Eyes large, approximated, close together; palatine teeth present; a tentacle above eye; no nuchal filaments. Scales very large, about 30 in the lateral 
line. Spinous dorsal of 18 spines. This genus seems to differ from $L a b$ risomus in the large scales, differently formed head, and in the absence of nuchal filaments. (Gobio, the gudgeon; Clinus.)

\section{GOBIOCLINUS GOBIO (Cuvier \& Valenciennes).}

Head $3 \frac{1}{2}$ in total length; depth $4 \frac{1}{2}$. D. XVIII, 19; A. II, 17; C. 15; P. 14 ; V. 2 ; scales $30-10$. Head nearly as broad as long, its height a third less. Eye large, $2 \frac{1}{2}$ in head, twice interorbital space; a very small tentacle over the eye, another on the nostril. Profile rounded between the eyes, descending vertically to the snout, which is very short. Cheeks inflated; the skull a little rough. Mouth reaching to opposite middle of eye, somewhat black; teeth small, conic, and pointed; upper jaw with 26 equal teeth, the lower with 16, the last 2 larger and more curved; teeth on vomer and palatines, simple, in 2 irregular rows; gill membranes united, free from isthmus. Body posteriorly compressed. Dorsal slightly notched between spines and soft rays of anal; pectorals equal to ventrals, 5 in total length; caudal obtuso, 6 in total length. Lateral line disappearing opposite tip of ventral. Color greenish, with traces of cloudy brownish; the cross bands a deep brown, pointed at base of caudal. Lesser Antilles. Known from several specimens, one 2 inches in length. (Cuvier \& Valenciennes.) Not seen by us; apparently a strongly marked species. (Gobio, the gudgeon, from its resemblance to Cottus gobio, the miller's thumb.)

Clinus gobio, Cuvier \& Valenciennes, Hist. Nat. Poiss., XI, 395, 1836, Lesser Antilles. (Coll. Plée.)

Gobioclinus gobio, GILL, Proc. Ac. Nat. Sci. Phila. 1860, 102.

\section{STARKSIA, Jordan \& Evermann.}

Starksia, Jordan \& Evermann, Proc. Cal. Ac. Sci.1896, 231 (cremnobates).

This gen us is related to Labrisomus, differing in the large scales, the presence of palatine teeth, the short soft dorsal fin, and the absence of the comb of nuchal filaments. (Named for Mr. Edwin Chapin Starks, in recognition of his work on the fishes of Western America.)

\section{STARKSIA CREMNOBATES (Gilbert).}

Head $3 \frac{1}{3}$ in length; depth $4 \frac{8}{4}$. D. XXI or XXII, 8; A. II, 19 ; scales 37. In appearance resembling very strongly the species of the genus Auchenopterus. Body sleuder, snout sharp, the jaws equal; mouth wide, oblique, the maxillary reaching vertical from posterior margin of orbit, $2 \frac{1}{4}$ in head. Teeth small, villiform, forming a band in front of upper jaw, the onter series enlarged; in lower jaw a single series laterally, becoming double in front; similar teeth on vomer and palatines. Eye longer than snout, 4 in head; interorbital width less than diameter of pupil; opercle terminating in an evenly convex process behind, without spinous points; gill membranes broadly united, free from isthmus; no hook on inner edge of shoulder girdle; nostrils with a flap; a single slender filament above eye and 1 or more on each side of the nape. A slight notch between first 
and third dorsal spines and another between the eighteenth and twentyfirst spines; the spines are low and strong, the highest equaling the snout and $\frac{1}{2}$ eye; soft rays higher, the longest equaling $\frac{1}{2}$ head; caudal short, rounded, entirely free from dorsal and anal; anal similar to soft dorsal, the first 2 rays spinous; ventrals inserted well in advance of pectorals, each consisting of 1 spine and 2 soft rays, which are joined only at base; pectorals pointed, the lower rays the longest, $1 \frac{1}{4}$ in head. Scales large, cycloid, the lateral line running high in front, descending to middle of sides immediately behind pectorals, thence running straight to tail. In the types, which are probably immature, the pores are not developed on posterior part of body. Color in spirits, uniform light olivaceous, a small dusky spot behind orbit and 1 below and behind it; opercle dusky. In 1 specimen the rays of soft dorsal, anal, and caudal are finely barred with dusky. (Gilbert.) Length $1 \frac{1}{2}$ inches. Gulf of California. Two specimens known, from Albatross Station 3001, in 71 fathoms. (Cremnobates;

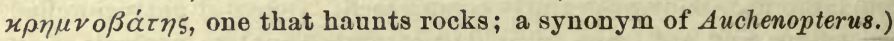

Labrosomus cremnobates, Grbert, Proc. U. S. Nat. Mus. 1890, 100, Gulf of California. (Coll. Albatross).

Starksia cremnobates, Jordan, Proc. Cal. Ac. Sci. 1896, 231.

\section{CRYPTOTREMA, Gilbert.}

Oryptotrema, GrLBert, Proc. U. S. Nat. Mus. 1890, 101 (corallinum).

'This genus differs from Labrisomus chiefly in the absence of nuchal filaments and in the modified anterior portion of the lateral line, which runs on a series of enlarged scales having no externally visible pores. ( $\rho \rho \pi \tau o$, concealed; $\tau \rho \tilde{\eta} \mu \alpha$, pore.)

2710. CRYPTOTREMA CORALLINUM, Gilbert.

Head $3 \frac{4}{5}$ to 4 in length; depth $5 \frac{1}{2}$. D. XXVII, 12; A. II, 27. Bod. elongate, regularly tapering backward to caudal peduncle, whose depth equals length of snout, which is sharp; mouth nearly horizontal; maxillary reaching middle of eye or beyond, $2 \frac{1}{8}$ to $2 \frac{1}{2}$ in head; teeth strong, but none of them enlarged, in a single series in jaws laterally, becoming double anteriorly; teeth on vomer and in a small distinct patch on front of palatines; eyes large, the interorbital space flat, nearly $\frac{1}{2}$ diameter of orbit; orbit slightly exceeding length of snout, $3 \frac{1}{2}$ in head; branchiostegal membranes broadly united, free from isthmus, the posterior edge on vertical from preopercular margin; anterior nostril iu a short tube, a slender flap arising from its posterior margin; a pair of simple slencler filaments arising from the upper edge of each orbit, 1 on each side of nape, none others on head; gill rakers very short and weak; shoulder girdle without hook on its inuer edge. Scales rather large, cycloid, the head alone naked; lateral line in its npper anterior portion withont externally visible tubes, its position shown by a series of enlarged scales twice the size of the others; on these the tubes are wholly on the under side, each opening anteriorly by a single pore under the edge of the pre- 
ceding scale; anteriorly the lateral line runs near the back and parallel with it, becoming suddenly declined behind middle of trunk, thence running on middle of side; the oblique portion of lateral line rests on about 7 scales, and the externally visible tubes of lateral line begin at this point; posterior portion of lateral line contained $1 \frac{1}{2}$ to $1 \frac{8}{4}$ in dorsal portion; scales of lateral line, 45 in dorsal portion, 7 in oblique portion, and 18 in posterior portion. A slight notch behind fourth dorsal spine, the second and third spines slightly longer than those following, the first little longer than the fourth, the longest spine about $2 \frac{1}{4}$ in head; first 2 anal rays spinous, but weak and flexible; last dorsal and anal rays not joined by membrane to caudal peduncle, the depth of the latter equaling the length of its free portion; ventrals long and narrow, nearly reaching vent in males, consisting of 1 spine and 3 simple rays; pectorals with some of the lower rays longest, $1 \frac{1}{5}$ in head; all of pectoral rays simple, 14 in number; caulal fin truncate, $1 \frac{2}{5}$ to $1 \frac{1}{2}$ in head. Lenerth 5 inches. Color dusky olive above, with irregular narrow longitudinal streaks of bright coral red, and 7 round black blotches above middle of sides; reticulating red lines and spots on top and sides of head and suout; branchiostegal membranes dusky in males; 2 red streaks on base of pectorals; dorsal somewhat dusky, marked with lines of red spots; caudal with 3 rather faint cross bars; pectorals, ventrals, and anal largely black in males, pale in females; the red shades persistent in alcohol. Santa Barbara Islands. Three specimens from Albatross Station 2945, in 30 fathoms. (Gilbert.) (Corallina, a calcareous alga, among which it lives.)

Cryptotrema corallinum, GilbFrT, Proc. U. S. Nat. Mus. 1890, 101, off Santa Barbara Islands. , (Coll. C. H. Gilbert.)

878. EXERPES, Jordan \& Evermann.

Exerpes, Jordan \& Evermann, Proc. Cal. Ac. Sci. 1896, 232 (asper).

Body slender, much compressed; the snout long, sharp in profile; first dorsal ribbon-shaped, the 3 slender spines close tugether, inserted at the nape, much in advance of the rest of the fin; ventrals very long and slender. Otherwise as in Auchenopterus, the scales large, and but 1 soft ray in the dorsal fin. ( $\varepsilon^{\prime} \xi \omega$, without; $\ddot{\varepsilon} \rho \pi \eta \xi$, creeper.)

2711. EXERPES ASPER (Jenkins \& Evermann).

Head 3 ( $3 \frac{2}{3}$ in total); depth $5 \frac{1}{2}\left(6 \frac{1}{8}\right)$; eye $4 \frac{1}{5}$ in head; scales 6-43-7, about 40 pores. D. III-XXV, 1 ; A. II, 20. Body compressed; head narrow, pointed; snout long, lower jaw slightly the longer; mouth a little oblique, cleft moderate, maxillary not reaching nearly to vertical at front of orbit. Teeth in 1 well-defined outer series and a broken inner one, those in the outer series strongest and of pretty uniform size, short and broad; vomerine teeth in a single patch; no palatine teetl. No tentacles of any kind about the head. Profile nearly straight from snout to origin of first dorsal, but very slightly arched from there to base of caudal fin. Scales rather large, cycloid, about 6 rows between origin of second dorsal and lateral line just behind its angle, and about 7 from there to mid- 
dle of ventral surface; 9 rows from origin of second dorsal to upper limb of opercle; entire head, opercles, and fins naked. Lateral line beginning at upper limb of opercle on a level with the pupil, almost exactly under the middle of the first dorsal fin, and a little more than $\frac{1}{4}$ the distance from top of nape to the under side of the throat, arching gently for 7 or 8 scales, leaving but 1 row of scales between it and the first spines of the second dorsal; on the ninth, tenth, and eleventh scales it bears slightly downward until 2 rows are left between it and the dorsal, then a sharp turn is made which puts it 4 scales further down, and from there it pursues a nearly direct line to middle of base of caudal fin. Dorsal fins separate, the first of 3 slender, very close-set, flexible spines, their length about twice in that of head, the fin ribbon-shaped; second dorsal separated from first by a distance somewhat greater than diameter of eye, and composed of 25 rather stout, sharp spines and 1 terminal soft ray; the first 3 are graduated, the first being contained $1 \frac{1}{2}$ times in distance between the 2 fins, the second is about $\frac{1}{2}$ longer, and the third still a little longer; the remaining 22 are of approximately equal length, about equaling distance from origin of first dorsal to that of second; the 1 soft ray somewhat shorter than spines, well separated from caudal by a space equal to that between dorsals; pectorals inserted under middle of space separating dorsals, composed of 14 rays, equaling eye and snout in length, and reaching slightly past origin of anal; ventral of 2 rays inserted directly under origin of first dorsal and considerably in front of pectorals, which they somewhat exceed in length, in some specimens reaching vent; anal fin beginning slightly in front of posterior end of pectorals, a little lower than second dorsal and reaching a trifle nearer to caudal fin; first spine longer and more slender than the first regular dorsal spine, while the second equals the third dorsal in length. Caudal rounded, equaling in length the greatest depth of fish. Coloration in alcohol, pale, pretty regularly covered with very fine dark punctulations, thickest on back, palest below; a large dark opercular blotch, 2 similar postocular blotches, and usually a darkish bar extends downward from eye; upper half of preorbital region dark, outer margin of jaws dark; breast and under parts of head pale, top of head and nape dark; first dorsal quite dark, almost black; second dorsal pale, obscurely mottled with brown, which is disposed in about 5 indistinct areas; a large black ocellus upon the twelfth and thirteenth spines of second dorsal, and a similar one upon the twenty-third and twenty-fourth spines; each ocellus is surrounded by a narrow circle of white or pale orange. In the 6 specimens before us there is a slight variation as to the exact position of the 2 ocelli; in 1 example the second ocellus extends back upon the twenty-fifth spine also, but in every case the $t$ welfth and thirteenth and the twenty-third and twenty-fourth are the spines which most evidently locate the spots; pectorals and ventrals plain; anal paler than dorsal, sparsely covered with fine dark points, so gronped as to form 3 or 4 darker areas. Length $2 \frac{1}{4}$ inches. Gulf of California. Known from 6 specimens taken from masses of kelp hauled out by the seine from the bay of Guaymas. (Jenkins \& Evermann.) (asper, rough.)

Auchenopterus asper, Jenkins \& Evermann, Proc. U. S. Nat. Mus. 1888, 154, Guaymas, Mexico. (Type, No. 39643. Coll.Jenkins \& Evermann.) 


\section{AUCHENOPTERUS, Günther.}

A uchenopterus, GÜNTHER, Cat., III, 275, 1861 (monophthalmus).

Cremnobates, GÜnTHER, Proc. Zool. Soc. Lond.1861, 374 (monophthalmus). Substitute for A uchenopterus, regarded as preoccupied on account of its similarity to Auchenipterus, a genus of Siluridoe.

Corallicola, Jordan \& Evermann, new subgenus (marmoratus).

Body moderately elongate, compressed, covered with rather large, cycloid scales; head shortish, naked, the snout rather pointed; cheeks full; mouth moderate, with a band of conical teeth in the jaws and about 1 series on the vomer, none on the palatines; lower jaw prominent; gill membranes united, free from the isthmus; upper surface of head with tentacles. Dorsal fin composed of stiff spines, with but a single soft ray, which is lower than the spines; first 3 spines more or less separated from the others, stiff and rather wider set, sometimes higher than the others; anal fiu low, with 2 short spines; ventrals jugular, well developed; pectorals broad; lateral line complete, strongly curved anteriorly. Warm seas. This genus differs from Cristiceps in having but 1 soft ray in the dorsal fin, and in the large scales. ( $\alpha \dot{v} \chi \dot{\eta} \nu$, nape; $\pi \tau \varepsilon \rho o ́ \nu$, fin.)

Corallicola (Corallus, coral; colo, I inhabit):

a. First 3 or 4 spines of dorsal forming a separate fin, being much higher than any of the spines in the posterior part of the fin; snout rather acute.

b. Scales 33; dorsal with 1 ocellus, anal with none; a black cross bar at base of caudal; a yellow spot behind eye; snout pointed. NIGRIPINNIs, 2712.

$b b$. Scales 37 or 38 .

c. First dorsal spine longer than second; dorsal with 2 ocelli; anal blackish; D. IV-XXIV, 1

ALTIVELIS, 2713.

cc. First dorsal spine shorter than second; snout slender, very acute; caudal pale; dorsal with 2 ocelli, anal with 1; D. III-XXII, 1.

AUChenopterus:

MARMORATUS, 2714.

$a a$. First 3 spines of dorsal scarcely forming a separate fin, none of them higher than the posterior spines; snout not very acute; anal without ocellus.

d. Caudal fin pale, usually with a dark bar at its base; a notch between third and fourth dorsal spines.

e. Dorsal spines about 31 .

$f$. Scales 34 to 36 ; membrane of third spine joining fourth at its base; dorsal and anal plain dusky.

AFFINIS, 2715 .

\section{ff. Scales 38 .}

g. Membrane of third spine joining fourth slightly above its base.

MONOPHTHALMUS, 2716.

gg. Membrane of third spine joining fourth spine much above its base.

INTEGRIPLNNIS, 2717.

ee. Dorsal spines abont 28 ; membrane of third spine joining fourth above its base; scales 38; body with distinct cross bars; dorsal with 1 ocellus.

FASCIATUS, 2718.

dd. Caudal fin black; body chiefly black; head mottled with whitish; membrane of third dorsal fln joining fourth near its summit, the fin not notched; dorsal spines 30 ; dorsal with 2 ocelli.

NoX, 2719 .

Subgenus CORALLICOLA, Jordan \& Evermann.

2712. AUCHENOPTERUS NIGRIPINNIS (Steindachner).

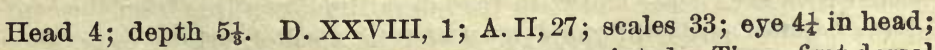
snout $4 \frac{1}{2}$, equal to interorbital space; snout pointed. Three first dorsal spines higher than the others and further apart. A tentacle over eye. 
Scales of body much largest anteriorly; lateral line arched. A deep black spot with a white ring between the twenty-second and twenty-fourth spines; anal edged with white; black cross band at base of caudal with silvery point at upper base of pectoral; a diffuse yellowish spot below and behind eye. Barbados. One specimen 1 inch and 7 lines long. (Steindachner); not seen by us. (niger, black; pinnis, fin.)

Clinus nigripinnis, STEINDACHNER, Ich. Notizen, vI, 46, 1867, Barbados.

\section{AUCHENOPTERUS ALTIVELIS (Lockington).}

D.IV-XXIV, 1; A. 21; P.13; C. 13; V.2; scales 37. Body compressed, greatest depth a little behind pectoral axil; greatest thickness at gill covers; dorsal and abdominal profiles of similar curvature, decreasing regularly to the caudal fin; profile of occiput and superorbital regions convex; snout somewhat produced, its upper outline slightly concave. Head 4 in total length; greatest depth a little less than Jength of head; caudal peduncle about $\frac{1}{4}$ of the greatest depth. Eye round, lateral, with a slight direction upward, its diameter less than the length of the snout; interorbital area nearly equal in width to the liameter of the eye, concave transversely, upper orbital borders slightly raised. A short nasal tentacle slightly anterior to the front margin of the eye; a large fimbriated tentacle on each side of the first dorsal ray. Cleft of mouth oblique, the lower jaw the longer; the posterior convex extremity of the club-shaped maxillary about vertical with the center of the pupil. Teeth of the outer row regular, sharp, incurved, the largest in front, gradually decreasing along the lateral portious of the jaws, and not extending much past the middle of their length; a narrow band of small teeth in the rear of the outer row ; vomerine teeth present. Branchiostegals 6; gill openings continuous, membranes not attached to the isthmus. Distance from first ray of dorsal to posterior margin of eye equal to length of snout; first 2 rays of dorsal much developed, the first slightly the longer, and nearly equal in height to the distance of its base from the tip of the upper jaw; third ray about $\frac{1}{2}$ the length of the first; fourth very short; succeeding rays to the twenty-sixth longer than the third, the last 3 somewhat decreasing. Anal commencing under eleventh dorsal ray, coterminous with, and equal in height to, the dorsal. Caurlal with 13 simple jointed rays, the longest in the center, posterior margin convex. Pectorals narrow, lanceolate, the fifth and sixth rays longest and $\frac{4}{5}$ the length of the head. Ventrals inserted in advance of the pectorals. Lateral line with 37 simple pores, parallel with dorsal ontline to opposite the origin of the anal, where it is deflected almost perpendicularly downward to the middle of the side of the body, along which it continues to its termination. Scales rather large, about 10 in a transverse row in the central part of the body, their posterior margin membranaceous; no scales on fins; a line of pores around the margin of the orbit, another along the posterior margin of the preoperculum, connected with each other and with the lateral line by a line from the center of the hinder border of the eye. Color in alcohol, bright pink above, becoming dusky below; underside of head light olivaceous, lower lip 
blackish; dorsal pink, dusky on its margin, a black spot on the fourth ray, and another on its hinder part upon the twenty-fourth and twentyfifth rays, the latter spot extending on to the body; membrane of anal black; occipital tentacles black. La Paz, Lower California. A single specimen, $\mathbf{1}_{1} \frac{9}{0}$ inches long, dredged at a depth of 22 fathoms. (Lockington.) (altus, high; velum, sail.)

Cremnobates altivelis, Lockington, Proc. Ac. Nat. Sci. Phila. 1881, 116, La Paz, Lower California. (Coll. W.J. Fisher.)

2714. AUCHENOPTERUS MARMORATUS (Steindachner).

Head $3 \frac{3}{5}$ to $3 \frac{4}{5}$ in body; depth $3 \frac{1}{2}$ to $3 \frac{5}{6}$. D. III-XXII, 1 ; A. II, 19 ; scales 2-36-9 (28 or 29 anteriorly); eye 4 to 5 in head; first dorsal $1 \frac{1}{4}$; pectoral

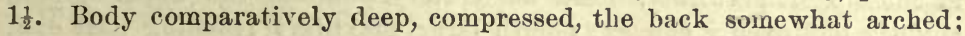
head pointed; mouth large, the maxillary extending to behind the eye, 2 in head; opercle with a sharp spine; jaws equal; teeth pointed, in narrow bands, the outer larger; vomerine teeth in 1 row; supraocular tentacle small, about as large as nuchal tentacle; no nasal tentacle. Pectoral a little shorter than head; dorsals separate, the first dorsal higher than second dorsal, the spines of which are about $\frac{1}{2}$ head. Color in life of varying shades of olive gray or sand color, with a series of whitish blotches on head and along sides; markings on dorsal and anal whitish; 2 dark-blue ocelli on dorsal and 1 on anal, these edged with orange and interiorly with black; ventrals, pectorals, and caudal whitish, barred with clear orange red; first dorsal black at tip; a curved blackish line at base of caudal; lower side of head yellowish brown, with whitish bands; specimens from coral reefs more spotted. Florida Keys to Cuba; common in the eelgrass at Key West. Our specimens, 2 to $2 \frac{1}{2}$ inches long, taken at Key West and Havana. (marmoratus, marbled.)

Cremnobates marmoratus, STEiNDACHNER, Ichth. Beiträge, v, 174, pl. 12, f. 6, 1876, a small rocky island north of Cuba; JORDAN \& GILBERT, Synopsis, 962, 1883; JORDAN \& GIL. BERT, Proc. U. S. Nat. Mus. 1884, 142.

\section{Subgenus AUCHENOPTERUS.}

2715. AUCHENOPTERUS AFFINIS (Steindachner).

Head 4; depth 4\%. D. III-XXVII, 1; A. II, 19; V. I, 2; scales 33 to 35. Form of $A$. integripinnis; maxillary reaching to below posterior margin of eye; a fringed tentacle above eje and 1 on each side of occiput. First dorsal low; its longest (second) ray shorter than the highest of second dorsal; membrane of third spine joining the fourth spine just above its base; last ray of second dorsal joined by membrane to base of caudal. Dark brown, paler than in $A$. nox, but darker and more uniform than in Auchenopterus fasciatus; lower sile of head pearly gray, thickly speckled with darker; sides with 5 very faint darker cross bands; dorsal and anal dusky, the latter with a pale edge; between the eighteenth and twenty-second dorsal spines a large dark spot ocellated with yellowish; caudal jellowish white, with darker cross streaks, a blackish band at its base; pectoral 
dusky at base, its posterior half yellowish, with darker cross streaks; ventral similar; a wedge-shaped, whitish band extending backward from eye to opercle. West Indies; recorded from Key West and St. Thomas. Here described from specimens from Key West. (affinis, related,-to $A$. monophthalmus.)

Cremnobates affinis, Steindachner, Ichth. Beiträge, v, 178, 1876, St. Thomas; JoRdan, Proc. U. S. Nat. Mus. 1884, 142; JoRDAN, Cat. Fishes N. A., 121, 1885.

2716. AUCHENOPTERUS MONOPHTHALYUS, Günther.

Head 34 ; depth 4. D. III-XXVI, 1; A. II, 18; scales 2-32-9; eye 5 in head; maxillary $1 \frac{1}{5}$; pectoral $1 \frac{1}{5}$; caudal $1 \frac{1}{4}$. Body compressed, deepest at middle of pectorals; head moderately pointed, the upper profile slightly and ovenly convex; mouth large, maxillary reaching past eye; jaws subequal; teeth villiform, in bands on jaws, vomer, and palatines; interorbital space flat, as wide as eye; a multifid dermal flap over posterior edge of eye, and a smaller one on each side of nape; head naked; body with rather large, regular scales; fins naked. Origin of dorsal over edge of preopercle, the first 3 spines separated from rest of fin by a rather deep notch, the membrane from third spine joining fourth spine at about its middle; spines of posterior part of dorsal the highest; front of anal midway between tip of snout and base of candal, tips of last rays reaching slightly beyond base of caudal and tips of last dorsal rays; pectorals reaching front of anal; rentrals long and slender, inserted in front of base of pectorals a distance equal to $1 \frac{1}{4}$ eje; candal rounded. Color light grayish red or brown, with about 6 cross bars of darker brown, running up on dorsal; between the bars are scattered milky white irregular spots; a black spot, ocellated with white, on front of dorsal, a similar spot near posterior end, sometimes duplicated; narrow cross bars on anal; a dark bar on base of caudal, and a dark blotch on base of pectoral. Here described from specimens, a couple of inches in length, from La Paz, Lower California. Gulf of California to Panama, abundant in rock pools, creeping about among Corallina; close to $A$.integripinnis, but the first dorsal higher and more separate from rest of fin. ( $\mu \dot{\delta} \nu o 5$, one; $\dot{\phi} \phi \alpha \lambda \mu \dot{o}^{5}$, eye, from the dorsal ocellus.)

A uchenopterus monophthalmu\&, Günther, Cat. Fish., III, 275, 1861, Panama; Jordan, Proc. Cal. Ac. Sci. 1895, 501.

Cremnobates monophthalmus, GüNTher, Proc. Zool. Soc. Lond. 1861, 374; GÜNTher, Fish. C'entr. A mer., 442, pl. 69, fig. 1, 1869.

\section{AUCHENOPTERUS INTEGRIPINNIS (Rosa Smith).}

Head $3 \frac{1}{2}$; depth $4 \frac{1}{2}$; eye 4 in head. D. III-XXVII, 1; A. II, 20; scales

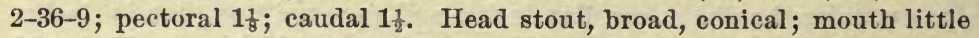
oblique, maxillary reaching posterior margin of eye; eyes large; nasal, supraocular and nuchal regions with fringed cirri, those at the nape flaplike. First and second dorsal spines low, a little higher than the third, which, in turn, is higher than the fourth and separated from it by an interspace, the membrane between the third aud fourth spines not deeply 
emarginate, membrane from third spine attached to the lower $\frac{2}{8}$ of fourth ; anterior spines not forming a separate fin; highest anterior spine not higher than the highest of the posterior part of fin. Color dark brown, variegated with different shades of brown and reddish; about 5 indistinct dark cross bars; a distinct ocellated black spot on posterior part of dorsal fin; caudal fin abruptly translucent, speckled, a black bar at its base; base of pectorals violet, bordered with black, the rest of the fin checkered; ventrals barred. Length $2 \frac{1}{2}$ inches. Coast of California and sonthward to Todos Santos; abundant in rock pools among Corallina. Here described from a specimen, $1 \frac{1}{2}$ inches in length, from San Cristobal, Lower California. (integer, entire; pinna, fin.)

Cremnobates integripinnis, RosA Sмiт,, Proc. U. S. Nat. Mus. 1880, 147, La Jolla, near San Diego (Coll. Rosa Smith); Jordan \& Gilbert, Synopsis, 764, 1883.

\section{AUCHENOPTERUS FASCIATUS (Steindachner).}

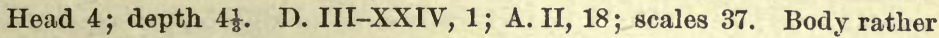
slender, a little deeper than in A. integripinnis, the snout less acute than in A. marmoratus. First dorsal spiue rather higher than second and lower than the spines of posterior part of fin; membrane of third spino joining second dorsal at a point above its base, the two parts of the fin therefore separated only by an emargination. Tentacle above eye slender, small; cirri on side of occiput bluish. In life, light pinkish brown, much mottled, and with traces of 6 to 8 faint darker bars; head and its cirri above whitish; 3 blackish spots behind eye, radiating from it, the lower one largest; preopercle with 3 dark dots; dorsal pale, with 9 blackish blotches, in the next to the last of which is a large blue-black ocellus, edged with orange; anal with 5 dark blotches and no ocellus; a blackish bar across base of caudal; rest of caudal and pale part of anal with dark dots; ventrals whitish, barred with black; pectoral similar, its base with a whitish area, which has a brown center, below which is a small black spot. Length 2 inches. Florida Straits; north to Key West. Here described from specimens from Key West. (fasciatus, banded.)

Oremnobates fasciatus, STEINDACHNER, Ichth. Beiträge, v, 176, 1876, Florida Straits; JoRDAN, Proc. U. S. Nat. Mus. 1884, 142; JoRDAN, Cat. Fishes N. A., 121, 1885.

2719. AUCHENOPTERUS NOX (Jordan \& Gilbert).

Head $3 \frac{3}{5}$; depth $3 \frac{5}{6}$. D. III-XXVII; A. II, 18; lateral line with 34 tubes. Snout not very acute, the upper and lower profiles of head nearly evenly convex; mouth large, maxillary reaching slightly beyond eye, $\frac{1}{2}$ length of head; eye large, equaling length of snout, greater than interorbital width, 4 in head (to end of opercular spine); interorbital width 48 in head; nasal, supraorbital, and occipital tentacles present, those on snout and above the orbits simple, slender filaments, the latter about as long as diameter of orbit, 1 of them divided to the base, the other simple; the tentacle on each side of nape a compressed slip of skin higher than wide, the margin uneven, but not fringed. Anterior dorsal spines not much elevated, 
not higher than some of the posterior spines; the first and second spines about equal, $2 \frac{1}{2}$ in head; the third spine shorter, about equal in leugth to the fourth, from which it is separated by a wide membrane, which is, however, not at all notched; the spines thence increase in length toward the last; caudal $1 \frac{1}{3}$ in head; pectorals reaching anal, nearly equaling length of head; ventrals not reaching vent, $1 \frac{1}{5}$ in head. Scales large, 4 series above lateral line and 4 below. Color, body and fins uniform blackish brown; a few small silvery-white specks on dorsal region, mostly along base of dorsal fin; head and base of pectoral fin with light pink areas and mottlings; snout pink above; nape with a pink cross bar; a dark streak upward and backward from eye to nape; a light streak from eye backward to opercle and 1 backward and downward; lower jaw mottled with light and dark; a small round, black spot near base of dorsal between twenty-third and twenty-fifth spines, and 1 . between twenty-eighth and thirtieth, both very faintly ocellated with lighter; slight whitish tips on ventrals and lower edge of caudal. Key West; known from a single specimen, $1 \frac{8}{4}$ inches long, taken with the seine in algæe on a rocky bottom at Key West. Its congeners, A. marmoratus, A. fasciatus, and A. affinis, were found in the same waters, $A$. marmoratus being much the most abundant of the 4, and reaching the largest size. (nox, night.)

Cremnobates nox, JoRdan \& GILBERT, Proc. U. S. Nat. Mus. 1884, 30, Key West. (Coll. Jordan.)

\section{PARACLINUS, Mocquard.}

Acanthoclinus, MOcQUARD, Bull. Soc. Philom. Paris 1885, 18 (chaperi); name preoccupied. Paraclinus, MocQUARD, Bull. Soc. Philom. Paris 1886, 11 (chaperi).

Body elongate, compressed, covered with cycloid scales; month large, each jaw armed with an external row of conical teeth, with some teeth behind; teeth on the palate; dorsal very long, continuous, composed entirely of spines, anal with 2 spines; ventrals jugular, with few rays; tentacles on head; gill opening very broad; 6 branchiostegals; lateral line interrupted. Evidently very close to Auchenopterus, from which it may be distinguished by the continuous dorsal fin, a character which needs verification. ( $\pi \alpha \rho \dot{\alpha}$, near; Clinus.)

2720. Parachindes chaperi, Mocquard.

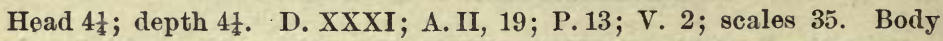
elongate, very strongly compressed; eye large, equal to snout or interorbital width; lower jaw slightly the longer; mouth oblique, reaching front of eye; outer row of teeth strong, canine-like, slenderer and more close set above, below diminishing rapidly in length, the bands of small teeth limited to front of each jaw, a curved group of teeth on palate; dorsal beginning over preopercle, not notched, composed entirely of stout spines; anal equally long; ventrals very narrow, of 2 soft rays, well separated, the inner slightly longer than outer; head with 3 pairs of tentacles, 1 at the nape, filiform, small, $\frac{1}{2}$ as long as eye; the second below the orbit, broadened at base, separated into 3 or 4 branches, progressively 
longer from the inner ontward, longer than eye; nuchal filament a little in front of dorsal, in form, oblong, entire, laminated, a little broader at its free edge, $\frac{8}{4}$ as long as eye; scales large, cycloid; lateral line interrupted before front of anal, anterior part rounding over eye with only 2 rows of scales between it and the dorsal, posterior part median; gill membranes broadly united, free from isthmus. Body brownish yellow, fins brown, the base and the caudal darker. Bay of Guanta, near Barcelona, in Venezuela; 1 specimen, $33 \mathrm{~mm}$. long to base of caudal. (Mocquard.) Not seen by us. (Named for its collector, M. Chaper.)

Acanthoclinus chaperi, MOCQUARD, Bull. Soc. Philom. Paris 1885, 19, Bay of Guanta, Venezuela.

Paraclinus chaperi, MocqUARD, Bull. Soc. Philom. Paris 1886, 41.

88r. EMMNION, Jordan.

Emmnion, Jordan, in Gilbert. Proc. U. S. Nat. Mus. 1896, 454 (bristoloe).

Body elongate, covered with caducous, cycloid scales of small size; lateral line straiglit, ending near base of last dorsal ray. Head moderate, decurved anteriorly, without cirri; mouth moderate; teeth in jaws in bands, the outer enlarged; no teeth on vomer or palatines; dorsal notched, its anterior $\frac{2}{8}$ of flexible spines of moderate height; ventrals $\mathrm{I}, 3$, the rays thickish, the fin inserted slightly before pectorals; caudal free. Galapagos Islands. ( $\dot{\varepsilon} \nu$, in; $\mu \nu i o \nu$, sea moss, or alga.)

\section{EMMNION BRISTOLE, Jordan.}

Head $5 \frac{2}{7}$; depth $7 \frac{1}{2}$. D. XXV, 13; A. I, 27; P. 13; V. I, 3; Br. 5; scales 3-5u-11, the count not certain. Body slender, moderately compressed, the dorsal profile forming a nearly straight line from occiput to first dorsal ray, from thence descending very gently to base of caudal; ventral profile about straight. Head broad, slightly convex above, its width $1 \frac{1}{2}$ in its length; anterior profile from first dorsal spine to a point above eye straight, thence abruptly descending to tip of suout; mouth horizontal, the lower jaw included; maxillary reaching nearly to posterior margin of eye, abont $2 \frac{1}{2}$ in head. Teeth present on both jaws, canine-like; upper jaw with 8 enlarged teeth in front, about 2 or 3 series of much smaller teeth behind these, only 1 series of which extends into posterior region of mouth; lower jaw with a series of teeth in front and on sides which is greatly enlarged in front; a patch of very small teeth behind the enlarged front teeth; no teeth on vomer or palatines. Premaxillary very protractile; snout blunt, $4 \frac{1}{6}$ in head; eyes large, round, placed close together, $3 \frac{1}{4}$ in head; interorbital region very narrow, less than pupil; nostrils equal. Caudal peduncle $2 \frac{4}{5}$ in head; branchiostegal membranes deeply united, free from isthmus; gills 4, a small slit behind the fourth; no cirri above eyes, nor flaments on nape; head naked, body covered with eycloid scales, those on nape miuch smaller; belly naked. The scales on the body are apparently caducous as all have fallen, but the points are very distinct and they seem to have been embedded on their anterior edge, 
as the sac-like fold of skin is prominent. Lateral line simple, straight, running from upper edge of gill opening to last ray of clorsal when it is lost, not reaching the caudal; it is placed very high, and gradually approaches the dorsal fin, from which it is separated only by a very small distance. Dorsal extending from a point a short distance behind occiput nearly to base of caudal, emarginate; last spine shortest, about $2 \frac{1}{4}$ in first soft ray, which is 27 in head; the longest spines about 3 in head, all the spines slender and flexible. Anal extending from behind vent nearly to base of caudal; similar to soft dorsal, its rays lower. Ventrals well developed with broad base, the rays thickish, inserted very slightly in front of base of pectorals, $1 \frac{1}{8}$ in head, reaching $\frac{3}{6}$ the distance to vent. Caudal subtruncate. Pectorals reaching past vent, abont as long as head. Dorsal and anal free from caudal. Color in spirits, dark dull reddishbrown, lighter below; head very dark; dorsals, pectorals, and caudal blackish, pectorals and caudal with lighter blotches; anal and ventrals dusky, anal margined with darker. Length about 3 inches. Galapagos Islands; one specimen known, evidently a rock-pool species. (Named for Miss Susan Brown Bristol, of the department of zoology in Leland Stanford Junior University.)

Emmnion bristoloe, Jordan, in GILBert, Proc. U. S. Nat. Mus. 1896, 454, pl. 55, fig. 1, Galapagos Islands. (Coll. Albatross.)

\section{ATOPOCLINUS, Vaillant.}

Atopoclinus, VAtulant, Bull. Sci. Philom. Paris, serie 8, tome vi, 1894, 73 (ringens).

- Body elongate, subcylindrical, without visible scales. Head obtuse, the snout short, rounded; mouth inferior, transverse, with compressed trenchant teeth in each jaw, those above at least in a single row, solidly fastened to theskeleton; teeth on vomer and palatines uncertain. Dorsal continuous, extending the whole length of the back, from the nape to the caudal peduncle, its rays mostly simple, only the posterior articulate; anal occnpying nearly $\frac{1}{2}$ the length, touching the caudal, which is, nevertheless, distinct; caudal deeply forked; ventrals distinctly jugular, very long, of a spine and a ray; no tentacles; gill membranes apparently rounded at the isthmus. Gulf of California; a singular genus evidently closely allied to Runula.

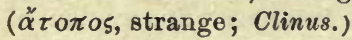

2722. ATOPOCLINUS RINGENS, Vaillant.

Head 5; depth 7. D. 24; A. 18; P. 15; V.I, 1. Eye large, 7 in head; interorbital space broad, 3 in head. Caudal a little longer than head. Color clear chamois brown, the belly pale; a brown band before the snout, across the eye to the caudal, on which it extends; a silvery stripe bordering this band above, and below for part of its length. Gulf of California. (Vaillant); known from 1 specimen badly shriveled, $39 \mathrm{~mm}$. in length. (ringens, gaping.)

A topoclinus ringens, Vailuant, Bull. Sei. Philom. Paris, serie 8, tome vi, No. 2, February 25, 1894, 74, Gulf of California. (Coll. Léon Diguet.) 
883. RUNULA, Jordan \& Bollman.

Runula, JoRdan \& Bollman, Proc. U. S. Nat. Mus. 1889, 171 (azalea).

Body slender, its back not elevated; mouth small, inferior, destitute of canines; teeth fixed, upper largest; dorsal fin continuous, its spines and soft rays indistinguishable, most of them articulate; caudal fin lunate; gill openings reduced to a vertical slit in front of pectoral; scales none. This genus is remotely allied to the East Indian genus Petroskirtes, but has the mouth and dentition different, and the caudal fin, unlike that of most blennioid fishes, is forked. (Diminutive of runa, a dart or javelin.)

\section{RUNULA AZALEA, Jordan \& Bollman.}

Head $4 \frac{4}{5}$; depth $6 \frac{1}{5}$. D. 42 ; A. 26 or 27 ; V. I, 2. Body moderately elongate, not much compressed; head rather long, its upper outlines convex; snout short and very blunt; mouth entirely inferior, transverse, each jaw provided with long, slender, close-set curved teeth; no evident posterior canines; eye moderate, equal to snout and nearly equal to interorbital width, 4 in head; no tentacles on head; gill membranes fully united to the isthmus, the gill opening reduced to a vertical slit, its lower edge opposite middle of base of pectoral; no scales; lateral line very high, concurrent with the back; dorsal fin very low, continuous; the feeble spines and soft rays indistinguishable, the fin beginning at occiput; anal similar to soft dorsal; caudal lunate behind, well separated from dorsal and anal; pectorals small, rounded, about $1 \frac{4}{5}$ in head; ventrals short, before pectorals, about 2 in head. Color reddish brown, silvery below, about 5 dusky cross shades; a dusky lateral streak; a black spot surrounded by paler at base of caudal; dorsal with about 6 black crossbars; anal with 4 ; other fins pale; lower half of head abruptly pale. Galapagos Archipelago. The type, 2 inches long, taken at Indefatigable Island; 3 more specimens have since been obtained from the same island. ( $\dot{\alpha} \zeta \alpha \lambda \varepsilon$ \&́ 5 , parched, from the brown color.)

Runula azalea, Jordan \& Boll.Man, Proc. U. S. Nat. Mus. 1889, 171, Indefatigable Island, Galapagos Archipelago (Coll. Albatross); JoRdan, Proc. Cal. Ac. Sci. 1896, 233, pl. 37.

\section{BLENNIUS (Artedi) Linnæus.}

\section{(BlenNies.)}

Blenniu8, Artedi, Genera Piscium, 27,1738.

Blenniu\&, Linnaus, Syst. Nat., Ed. x, 256, 1758 (galerita).

Salaria, Fonsk ̊̊L, Descr. Anim., 22, 1777 (basiliscus).

Pholis, Fleming, Brit. Anim., 207, 1828 (loevis=pholis); not Pholis Scopour, 1777.

Adonis, Gronow, Cat. Fish., Ed. Gray, 93, 1754 (pavoninus=ocellaris).

Lipophrys, GILL, American Naturalist, June, 1896, 498 (pholis).

Body oblong, compressed, naked; head short, the profile usually bluntly rounded; mouth small, horizontal, with a single series of long, slender, curved, close-set teeth in each jaw, besides which, in the lower jaw at least, is a rather short and stout fang-like canine tooth on each side; $3030-72$ 
premaxillaries not protractile; gill openings wide, extending forward below, the membranes free from the isthmus, or at least forming a broad fold across it. Dorsal fin entire, or more or less emarginate, the spines slender; pectorals moderate; ventrals well developed, I, 3; no pyloric cæca; lateral line developed anteriorly. Species numerous, lurking under rocks and algæ in most warm seas; some species in the lakes of northern Italy. The European species in general are larger in size than ours, with higher fins. (Blennius, the ancient name, from $\beta \lambda \varepsilon \dot{\varepsilon} v \alpha$, slime.)

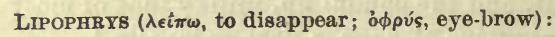

a. Supraorbital cirrus wanting; snout not very blunt in profile.

b. Posterior canine present in each jaw ; dorsal slightly emarginate; D. XII, 18.

CAROLLNCE, 2724.

\section{BLennius :}

aa. Supraorbital cirrus present; profile of snout more or less blunt.

c. Canines strong, present in both jaws; no nuchal cirri.

d. Dorsal rays XI or XII, 17 or 18.

e. Snpraorbital cirrus bifid; dorsal free from caudal.

$f$. Supraorbital cirrus as long as head; dorsal emarginate; sides spotted; D. XI, 17.

1. $\mathrm{CCOHCM,} 2725$.

ff. Supraorbital cirrus as long as eye and snout; dorsal continuous; color olivaceous, with dark bars; D. XI, 18.

STEARNSI, 2726.

ee. Supraorbital cirrus bifid, nearly as long as head; last ray of dorsal joined to caudal; sides with a network of blue lines; D. XII, 18.

FAYOSUS, 2727.

$d d$. Dorsal rays XII, 21 or 22; supraorbital cirrus long, fringed; dorsal free from caudal; cheeks with network of lines; body nearly plain.

PILICORNIS, 2728.

cc. Canines short and stoutish, present in lower jaw only (undescribed in truncatus and in marmoreus.)

g. Nape without cirrus; snout abruptly decurved; body robust, marbled; D. XII, 20. MARMOREUS, 2729.

gg. Nape with a cirrus on each side:

$h$. Dorsal and anal free from caudal. Nape with a filiform bifid tentacle on each side; teeth undescribed; supraorbital tentacle simple; color olive, with bright spots.

TRUNCATUS, 2730.

$h h$. Dorsal and anal with the last ray largely joined by membrane to caudal; nape with a small cirrus; posterior canines strong, in lower jaw only; dorsal not notched; color uniform brown; D. XII, 13.

VINCTCS, 2731.

ggg. Nape with a comb of many close-set cirri on a fleshy crest; lower jaw only with short posterior canines; dorsal fin continuous, free from caudal; D. XII, 16 or 17. CRISTATUS, 2732.

\section{Subgenus LIPOPHRYS, Gill.}

2724. BLENNIUS CAROLIYUS (Cuvier \& Valenciennes).

D. XII, 18; A.17. Body rather long and slender, more elongato than in the European species, Blennius pholis, more compressed, the head longer; maxillary extending to opposite middle of eye; teeth $\frac{16}{14}$, with strong canines on both jaws; gill membranes free from isthmus; no trace of tentacles above eye; dorsal spines slender, a little lower than the soft 
rays, the fin little emarginate; dorsal and anal not joined to the caudal. Greenish, with 4 or 5 irregular dark spots or shades along the back; dorsal with a large black spot in front; anal brown-edged. South Carolina. Only the original type in the musenm at Paris known; from this the present description was taken. No later collector has recognized the species and it may not be American.

Pholis carolinus, Cuvier \& VAlenciennes, Hist. Nat. Poiss, XI, 276, 1836, Carolina. (Coll. M. Bosc.)

Blennius carolinus, JoRDAN \& GILBERT, Synopsis, 760, 1883.

2725. BLENNIUS FUCORUM, Cuvier \& Valenciennes.

Head 5 in total length. D. XI, 17; A. 18. Orbitial cirri nearly as long as head, bifid at tip, and fringed at the base. Dorsal fin slightly emarginate, free from the caudal, the spines rather stiff. Head very short and steep, its profile nearly vertical; 24 teeth in each jaw; each jaw with very strong canines; gill membranes free from the isthmus posteriorly. Olive green, becoming darker above, with numerous brown spots on the cheeks and sides of the body; below reddish; dorsal with a large black spot in front, behind which are smaller spots; spinous dorsal edged with paler. (Cuvier \& Valenciennes.) Open ocean in floating Fucus; the type from near the Azores; recorded by De Kay from the open sea, off New York, in floating seaweed. (fucorum, of the seaweed, Fucus.)

Blennius fucorum, CUvier \& VAlenciennes, Hist. Nat. Poiss., XI, 263, 1836, 240 miles south of the Azores (Coll. Claude Gay); Günther, Cat., III, 217, 1861; DE KAY, N. Y. Fauna: Fishes, 149, pl.22, fig. 66, 1842; JordaN \& Gilbert, Synopsis, 710, 1883.

Blennius oceanicus, * Cuvier \& VAlenciennes, Hist. Nat. Poiss., XI, 265, 1836, open sea, $29^{\circ}$ N., $50^{\circ}$ W.; on a drawing by ClaUde GaY.

2726. BLENNIUS STEARNSI, Jordan \& Gilbert.

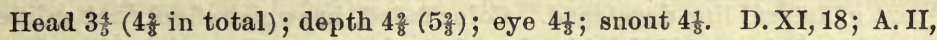
21. Body much elongate, compressed, tapering regularly behind; anterior profile moderately decurved; snout short and blunt; mouth large, oblique, the jaws eyen; maxillary reaching slightly beyond middle of orbit, $2 \frac{1}{4}$ times in head; teeth in the front of the jaws only, occupying on each side a space equal to $\frac{1}{2}$ length of maxillary; teeth $\frac{26}{2}$, the lateral one on each side much enlarged and canine-like, rather short but strongly curved; canine in upper jaw equaling about $\frac{1}{2}$ diameter of pupil; interorbital space very narrow, not as wide as pupil; upper posterior rim of orbit with a long slender filament, forked at base, its length equaling distance from tip of snout to posterior rim of orbit; no filaments at the nape; gill membranes somewhat united to the isthmus in front, but forming a broad fold across it posteriorly, the gill openings of the two sides therefore continuous below. Dorsals rather high; no notch between the spines and soft portion, the membrane of last ray not reaching base of caudal; spines of

* Very near Blennius fucorum, the profile more oblique, the cirri shorter, the spinous dorsal lower, the eauilal more truncate; anal shorter. Color brown with brown spots on body and fins; sides clear green; belly silvery. Length 2 inches. (Cuvier \& Valenciennes.) 
nearly uniform height, all very slender and flexible, the tips almost filamentous; highest spine $\frac{1}{2}$ length of head; highest soft ray $1 \frac{3}{5}$ in head; anal lower than dorsal, its longest ray very slightly less than $\frac{1}{2}$ length of head; length of eaudal peduncle more than $\frac{1}{2}$ its height, about equaling the diameter of orbit; caudal about equaling pectoral, $1 \frac{1}{8}$ in head; ventrals long, the inner ray much the longest, $1 \frac{1}{8}$ in head, not quite reaching vent. Color light greenish olire, somewhat mottled; sides with irregular dark bars formed of spots, these extending on the fin; skin everywhere finely punctate; dorsal dark olive, the spinous part darker at tip; anal blaekish, with paler edge; ventrals dusky; pectorals and caudal olive. Gulf of Mexico, in deep water. Three specimens known, the largest 3 inches long, taken from the stomach of a Red Snapper, at Pensacola. (Named for Silas Stearns.)

Blennius stearnsi, JoRdan \& GilBerT, Proc. U. S. Nat. Mus. 1882, 300, Pensacola Snapper Banks. (Type, No. 29669, U. S. Nat. Mus. Coll. Jordan \& Stearns.)

\section{BLENIIUS FAVOSUS, ${ }^{\circ}$ Goode \& Bean.}

Head $3 \frac{2}{8}$; depth $4 \frac{8}{4}$. D. XII, 18; A. II, 20. Body comparatively elongate and compressed; anterior profile moderately decurved; head nearly $\frac{1}{2}$ longer than deep; snout very short and blunt; mouth large, horizontal; jaws even; maxillary reaching posterior margin of orbit, its length $2 \frac{1}{2}$ in head. Each jaw with a long, curved, posterior canine; the canines of lower jaw largest. Preorbital $\frac{2}{8}$ diameter of eye, which is $3 \frac{8}{4}$ in head, and equals more than twice interorbital width. An extremely long and slender supraocular cirmus, trifid to the base, the longest branch nearly as long as the head; no nuchal cirri. Gill membranes forming a rather narrow fold across the isthmus. Dorsal low, continuous, the spines very slender and flexible, the longest $\frac{1}{2}$ as long as the head; the longest soft ray $\frac{8}{4}$ as long as head; the last ray slightly joined to base of candal; caudal $\frac{8}{4}$ as long as head; anal rather high; pectorals $\frac{4}{5}$ as long as head; only the straight part of lateral line developed. Color faded, brownish, finely reticulated, a series of obscure bluish blotches along the sides; front and sides of head marked with very distinct blue, reticulating lines surrounding honeycomb-like hexagonal interspaces; top of head with many small blue spots; dorsal with black dots and streaks; a black spot bordered with whitish between the first and second dorsal spines; anal with oblique blue streaks, the fin margined with dusky, tips of rays whitish; base of pectorals with blue reticulations. The whole body was probably reticulated with blue in life. Gulf of Mexico. Known from 2 specimens collected at Garden Key, Florida, by Gustar Würdemann; they are $3 \frac{2}{6}$ inches and 3 inches long, respectively. (favosus, honeycombed.)

Blennius favosus, Goode \& Bean, Proc. U. S. Nat. Mus. 1882, 416, Garden Key, Florida (Type, No. 2629, U. S. Nat. Mus. Coll. Gustav Würdemann); JordaN \& GILBERT, Synopsis, 961, 1883.

2728. BLEXNIUS PILICORNIS, Cuvier \& Valenciennes.

Head $4 \frac{8}{4}$ with caudal; depth $5 \frac{1}{5}$. D. XII, 21 or $22 ;$ A. 23 or 24 . Snout obtuse, the upper profile very oblique. A strong curved canine in each jaw. Orbital tentacle filiform, with several smaller ones at base. Inter- 
orbital space flat, its width $\frac{1}{2}$ vertical diameter of eye; no groove or crest on the neck. Dorsal slightly notched, the spines flexible; candal separate. Brown, dorsal and caudal spotted with darker. Length 5 to 6 inches. (Günther.) Coast of Brazil north to the West Indies, recorded from Rio Janeiro, Bahia, and the Tortugas, and off the coast of Florida. Mr. Garman gives the following color note on Tortugas specimens, collected by Prof. C. C. Nutting: Small, hexagonal reticulations on cheeks, resembling scales; anal darker toward ends of rays, the tips white; dorsal darker in outer half; basal part of dorsal and anal pale, sides with a few scattered black dlots; median rays of caudal longer, the outer margin dark; caudal, pectorals, and ventrals paler than dorsal. (pilicornis, with downy horns.)

Blennius pilicornis, Cuvier \& VALenciennes, Hist. Nat. Poiss., XI, 254, 1836, Rio Janeiro (Coll. Delalande and Gay); Castelnad, Anim. Nouv., etc., Amer. Sud, 25, 1855; GarMAN, Bull. Iowa Lab. Nat. Sci. 1896, 89.

Blennius filicornis, GÜnther, Cat., III, 216, 1861. (Coll. M. Parzudaki.)

\section{BLENNIUS MARMoreds, Poey.}

Hearl $4 \frac{1}{2}$ in total length with caudal; depth 5. D. XII, 20; A. 16; P. 13. Eye very high, near the profile, twice length of snont. Snout round, falling off abruptly, but less so than in Blennius truncatus; posterior nostrils with a distinct tube; superciliary tentacle divided into 3 branches; no cilia at the nape. Teeth undescribed. Gill membranes not described. Pectoral and caudal round; dorsal low, the median spines highest, the soft rays a little higher, the difference slight. Color yellowish brown, darker medially, paler below; under the lens covered with small dots; fins below yellowish. This species differs from Scartella microstoma in the stont trunk, the more blunt head, the cilia on the head and in the tube of the nostril. Cuba; 1 specimen 2 inches long. (Poey); not seen by us; perhaps not a Blennius as here understood. (marmoreus, marbled.)

Blennius marmoreus, PoEx, Enumeratio, 130, 1875, Cuba. (Coll. Rafael Arango.)

\section{BLENNIUS TRUNCATUS (Poey).}

Head $5 \frac{1}{4}$ in total length with caudal; depth $5 \frac{1}{4}$. D. XII, 19; A. I, 20. Eyes placed very high, profile before them vertical, suggesting the forehead of a bull without horns; mouth small, maxillary reaching below posterior border of eye; anterior nostril divided into 5 at tip; 2 filiform tentacles with a common base on each side of nape; a simple tentacle behind eye; some pores on the head, which is compressed; teeth undescribed; gill membranes undescribed; gill membranes united and free from isthmus; dorsal notched medially; caudal truncate, with 2 faint angles; lateral line long, reaching beyond the point of the pectorals. Color olive, with some bright spots on trunk; the vertical fins darker. Cuba; 1 specimen $3 \frac{1}{4}$ inches long. (Poey); not seen by us; perhaps not a species of Blennius. (truncatus, cut off short.)

Blennius truncatus, Pokx, Memorias, II, 424, 1861, Cuba. (Coll. Poey.) 


\section{BLenvits vinctus, Poey.}

Head $3 \frac{1}{2}$ to base of caudal; depth 4. D. XII, 13; A. I, 8; V. 3. Eye high, 4 in head, as long as snout. Anterior nostril in a short tube. Jaws equal; 4 pores on the side of the lower jaw; 1 on the opercle; 4 on the suborbital; 4 below eye. A long tentacle above eye; another very small one on the nape. Maxillary reaching to below front of pupil. Teeth large, not pointed, compressed, in 1 series of 10 to 12 on each side of each jaw, feeble, somewhat moveable; gill membranes united, free from isthmus. Dorsal elevated backward, connected by a membrane to the first third of the caudal, as is also the anal, twenty second ray highest, its height $\frac{1}{2}$ depth of body and double length of the dorsal ray above tip of pectoral; anal similar, $\frac{1}{8}$ also of the rays of the dorsal and anal simple; the spines flexible, differing from the others in not being articulate; pectoral pointed, its middle rays longest, and also more robust, all simple; ventral not very short; caudal rounded. Lateral line forming a curve anteriorly. Color uniform brown. Cuba. (vinctus, bound.)

Blennius vinctus, Poex, Repertorio, 243, 1867, Havana. (Coll. Felipe Poey. Type, ${ }^{*}$ No. 12647, Mus. Comp. Zool.)

2732. BLENIUS CRISTATUS, Linnæus.

Head 4; depth 4. D. XI, 16; A. 19; maxillary 3. Body moderately elongate, compressed; the head very blunt and deep, almost as deep as long, its anterior profile straight or slightly concave, and nearly vertical. Mouth moderate, the maxillary reaching to past front of eye; lower jaw with 2 short stoutish posterior canines, scarcely longer than the front teeth; upper jaw without canines. Teeth about $\frac{32}{2} \frac{2}{8}$. Preorbital deep, its depth equal to diameter of eye and contained $4 \frac{1}{4}$.times in length of head. Interorbital space flat, narrow, $\frac{2}{3}$ width of eye. Supraocular cirri small, fringed, their length about equal to that of pupil. Nape with a longitudinal dermal crest reaching to front of dorsal, provided with a series of about 20 filaments, the longest about as long as the eye. Gill membranes forming a broad fold across the isthmus, as in all species of Blennius. Dorsal nearly continuous, the last spine a little lower than the first soft ray, not very high, beginning on the nape in front of the vertical of the preopercle, the spines all slender and flexible, the longest $\frac{8}{8}$ as long as the head, the longest soft ray $\frac{4}{7}$ as long as the head; caudal free from dorsal and anal, $\frac{f}{5}$ as long as head; anal moderate, $\frac{f}{9}$ length of head; pectoral somewhat shorter than head; ventral a little more than $\frac{1}{2}$ length of head. Lateral line forming the usual arch above pectoral, and continued backward on median line to base of caudal, becoming indistinct posteriorly.

*On the type of Blennius vinctus we have the following notes: "No. 12647, M. C. Z. Cuba. (Poey.) One and a half inches long, in poor condition. Head ca 31; depth ca 4 . D. XII, 13; A. II, 13. Dorsal joined to candal as far as tips of the rays, which are high. Dorsal spines high and stiff, the fin not notched, the soft rays higher. A thick scale-like fringed cirrus above each eye, nearly as long as eye, which is small. Gill membrane free. Head blunt. Maxillary to front of pupil. Lower jaw with very strong canines; upper jaw with none. No nuchal cirri," 
Color faded, apparently olivaceous, with about 6 dark cross bars, which extend on the dorsal fin; anal and posterior $\frac{1}{2}$ of borly with numerous round, whitish, stellate spots, probably bluish in life; bluish streaks from eye across the cheeks; anal edged with dusky; the other fins vaguely marked. Length $2 \frac{1}{2}$ to 4 inches. Tropical parts of the Atlantic, among rocks, widely diffused and variable. The above description from the type of Blennius asterias, from Garden Key, Florida. We have the following notes on numerous specinens from Abrolhos Islands, off the Coast of Brazil (Coll. Albatross): D. XII, 15. Nape with a fringed crest of 10 to 18 filaments. A small trifid tentacle above eye; posterior canines in lower jaw only, short and small; gill membranes broadly united, nearly free from the isthmus. Dorsal slightly notched; nasal tentacle present. Color excessively variable, mostly grayish, with 5 or 6 cross blotches on the back, extending to form quadrate blotches on the side; body mottled; fins also mottled; the anal dark, with a pale edge. Some specimens highly variegated, the caudal banded and with black and white spots; pale streaks from the eye across the cheek; dark bars on sides, extending on dorsal. Most specimens have the region above anal with numerous round whitish spots and some dark ones. These spots sometimes nearly obsolete, most evident on the paler specinens.

The following notes are taken from a specimen, No.4635, M. C. Z., from

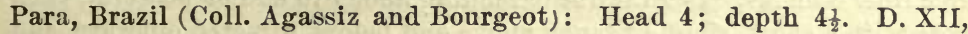
14; A. I, 16. Maxillary to front of eye, about equal to eye. Gill membranes free. Lower jaw with a very small canine, not twice the length of the upper teeth. Orbital cirrus quite small; a row of cirri along the nape, louger than the orbital cirrus. Head not very blunt, the anterior profile forming an angle above eye, thence straight and steep. Dorsal spines rather low and flexible, the fin scarcely notched. Color nearly lost; dark marblings on sides and on dorsal fin. This species is evidently the Blennius crinitus of Günther and the B. asterias of Goode \& Bean, probably the nuchifilis of Cuvier and Valenciennes, and in all probability the cristatus of Linnæus, also. These nominal species are from various localities in the Atlantic. If our specimens are all alike, all these forms most likely belong to 1 species. For this cristatus is the oldest name. The very small canines show considerable divergence from the type of Blennius, appreaching Scartella. (Eu.) (cristatus, crested.)

Blennius crista setacea longitudinale inter oculos, GroNow, Museum, I, No. 75; D. 26 ; A. 16 ; locality unknown. (Coll. Vosmaer.)

Blennius cristatus, Linvaus, Syst. Nat., Ed. X, I, 256, 1758, Indies, after Grovow; GUNTHER, Cat. Fish., III, 223, 1861; JordAN, Proc. U. S. Nat. Mus. 1890, 329.

Blennius crinitus, CUvier \& VAlenciennes, Hist. Nat. Poiss., XI, 237, 1836, La Rochelle, France (Coll. D'Orbigny); Gënther, Cat., III, 224, 1861.

Blennius nuchifilis, Cuvier \& Valenciennes, Hist. Nat. Poiss., XI, 253, 1836, Isle of Ascension. (Coll. Quoy \& Gaimard.)

Blennius asterias, GOODE \& BEAN, Proc. U. S. Nat. Mus. 1882, 416, Garden Key, Florida (Type, No. 2620. Coll. G. Würdemann); Garden Key, Florida (Type, No. 2625. Coll. Dr. Whitehurst); Tortugas (Type, No. 6596. Coll. Dr.J. B. Holder); J ORDAN \& GIr BERT, Synopsis, 961, 1883.

Adonis cristatus, Growow, Cat. Fish., Ed. Gray, 95, 1854. 
885. SCARTELLA, Jordan.

Scartella, Jordan, Proc. U. S. Nat. Mus. 1886, 50 (microstoma).

This genus differs from Blennius only in the entire absence of the posterior canine. The relations of this genus with such species of Blennius as Blennius cristatus are very close. It may be that the groups should be reunited, or that several species here referred to Blennius should be placed

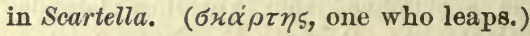

\section{SCARTELLA MICROSTOMA (Poey).}

Head 4 in length (5 with caudal); depth $3 \frac{5}{6}\left(4 \frac{2}{3}\right)$; eye $3 \frac{1}{4}$. D. XI, $14 ; \mathrm{A}$. 15 or 16 . Body rather stout, compressed posteriorly; head short, the anterior profile straight and very steep, almost vertical from tip of snout to above eye, where a sharp angle is formed with the straight line of the back. Eye large, longer than snout. Mouth moderate, the maxillary reaching to below front of pupil, its length $3 \frac{1}{5}$ in head. Teeth uniform; no posterior canines in either jaw. A small tufted or multifid cirrus over each eye, its length less than diameter of pupil; a row of about 3 short, slender cirri along each side of nape. Gill membranes broadly united, free from isthmus. Lateral line extending about to end of pectoral, each pore with a short, simple branch above and below, directed outward and backward; some conspicuous pores radiating from the eye. Dorsal fin low, subcontinuous, the spines rather slender, lower than the soft rays, the middle spines not much higher than the last; longest rays of dorsal about $\frac{1}{2}$ as long as head; caudal free from dorsal and anal, a little shorter than head; anal low; pectorals slightly longer than head; ventrals $1 \frac{1}{8}$ in head. The fins are somewhat shriveled, so that the count of the rays is made with difficulty and may not be perfectly exact. Color very dark olive brown, paler below; head and anterior half of body plain, posterior half sprinkled with sharply defined dots of a vivid sky-blue color, becoming white in alcohol; about 6 obscure round darker blotches in a longitudinal series along sides posteriorly; fins dusky olive, mottled with darker, the caudal obscurely barred, the anal with a pale edge; spinous dorsal nearly black. Length $3 \frac{1}{4}$ inches. Cuba. Here described from a specimen taken by Dr. Jordan in Havana. We have also the following notes on Poey's type in the museum at Cambridge: D. XI, 15; A. 17. Dorsal and anal free from caudal. Body rather robust, the head blunt. Last tooth in each jaw a shade longer than its neighbor, but not canine-like. Gill membrane free from isthmus. Dorsal spines low, rather stiff, the fin deeply notched. Color much mottled, with some white spots on posterior half of body; a black ocellus behind first dorsal spine; 5 dark bars along back.

The following is Poey's description: Head $4 \frac{1}{8}$ in total length with caudal; depth 5\%. D. XII, 15; A. I, 17; P. 14. Snout short; profile falling abruptly; mouth small; eye 3 in head, twice interorbital space. Teeth 15 on each side in each jaw. - Gill membrane broadly united, free from isthmus. Lat- 
eral line disappearing on middle of back; a row of 6 filaments arranged in pairs on each side of the nape. Membranaceous tentacles over the eye; dorsal somewhat notched, pectoral strongly developed at base. Color brown, with 5 or 6 darker points which form on the back and reach base of the dorsal; pearly spots along sides and some below of the same color; caudal

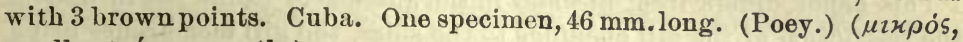

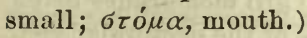

Blennius microstomus, PoEy, Memorias, II, 288, 1861, Cuba. (Coll. Poey.)

Scartella microstoma, JoRdan, Proc. U. S. Nat. Mus. 1886, 50.

886. HYPLEUROCHILUS, Gill.

Hypleurochilus, GILL, Proc. Ac. Nat. Sci. Phila. 1861, 168 (geminatus).

This genus differs from Blennius in the restriction of the gill-openings to the sides, the gill-membranes being broadly and fully joined to the isthmus; canines well developed. ( $v$, upsilon; $\pi \lambda \varepsilon \tilde{v} \rho \circ \nu$, side; $\chi \varepsilon \tilde{\imath} \lambda \circ 5$, lip; in allusion to the V-shaped lateral lips.)

\section{HYPLEUROCHILUS GEMINATUS (Wood).}

Head $3 \frac{1}{2}$ to $3 \frac{8}{4}$; depth $3 \frac{1}{2}$ to 4 . D. XI, 15 to XIII, 14; A. II, 18. Head not very blunt, the anterior profile straight, oblique; male (multifilis) with the supraocular cirrus very large, each with 4 smaller ones at base; supraocular cirrus in female (geminatus) low, shorter than eje, branched at tip; interorbital space concave, not $\frac{1}{2}$ diameter of eye; a slight transverse groove behind eye; canines in both jaws, very strong, hooked backward, the lower considerably stronger than upper; gill openings extending downward to opposite or slightly below lower edge of pectoral. Dorsal fin not emarginate, the spines slender, but rather stiff, lower than the soft rays; pectorals shortish, ventrals rather long. Olive brown, faintly barred with darker; sides plain, or with several pairs of spots of a reddish-brown color, arranged pretty regularly in a double row; vertical fins edged with darker, especially the anal; dorsal black in front. Length $2 \frac{1}{2}$ inches. South Atlantic and Gulf coast of the United States, in shallow water; abundant in empty shells and clusters of tunicates. The sexes quite unlike, the male (multifilis) distinguished by the high suborbital crest. (geminatus, twin.)

Blennius geminatus, Wood, Journ. Ac. Nat. Sci. Phila., IV, 1824, 278, Charleston, South Carolina, female (Coll. Prof. Bache); Cuvier \& Valenciennes, Hist. Nat. Poiss., xI, $265,1836$.

Blennius multifilis, GIRARd, Proc. Ac. Nat. Sci. Phila. 1858, 169, St. Josephs Island, Texas, male (Coll. Gustar Würdemann); Girard, U. S. and Mex. Bound. Surv., Zool., pl. 12, fig. 6, 27, 1859; GÜNTHER, Cat., III, 562, 1861

Hypleurochilus multifilis, GrLL, Proc. Ac. Nat. Sci. Phila. 1861, 168; JoRDAN \& GInBERT, Synopsis, 758, 1883.

Hypleurochilus geminatus, JoRDAN \& GILBERT, Synopsis, 759, 1883.

iBlennius geminatus, GƯNHrer, Cat., III, 288, 1861. 


\section{HYPSOBLENNIUS, ${ }^{*}$ Gill.}

Hypsoblennius, GiL, Cat. Fish. East Coast U. S., 20, 1861 (hentz; no diagnosis).

Isesthe8, JORDAN \& GILBERT, Synopsis, 757, 1883 (gentilis).

Blenniolus, JoRDAN \& EvERMANN, new subgenus (brevipinnis).

This genus differs from Blennius in the absence of eanine teeth and in the restriction of the gill openings to the sides, the gill membranes being fully united to the isthmus as far upward as the base of the pectorals; ventral with 1 short, strong spine and 3 simple, articulated rays. The known species are American. ( $\ddot{\psi} \psi$, high; Blennius.)

\section{HYPSOBLENNIUS:}

$a$. Dorsal fin continuous, its margin entire or slightly notched.

b. Dorsal rays XI to XIII, 17 to 19 . Pacific species.

c. Orbital cirrus multifid; spines of dorsal stiff; sides blotched or freckled.

cc. Orbital cirrus simple or fringed.

GILBERTI, 2735.

$d$. Spines of dorsal slender and flexible; sides with round dark spots; anal rays 21 .

GENTILIS, 2736.

$d d$. Spines of dorsal rather stiff; sides with irregular dark cross bands rather than spots; anal rays 19.

STRIATUS, 2737.

$b b$. Dorsal rays XII, 14 or XII, 15. Atlantic species.

e. Orbital cirrus simple, large or small; body everywhere with dark spots; dorsal spines rather low, stiffish.

IONTHAS, 2738.

$e e$. Orbital tentacle forked at tip, long in males; dorsal spines stiff; body spotted.

HENTZ, 2739.

Blenniolus, (diminutive form, from Blennius):

aa. Dorsal fin deeply notched, very short, its rays XI, 12 or XII, 12; orbital tentacle slender, fringed; a dark lateral shade.

BREVIPINNIS, 2740.

Subgenus HYPSOBLENNIUS, Gill.

\section{HYPSOBLENNIUS GILBERTI (Jordan).}

Head 4 in length ( $4 \frac{2}{8}$ with caudal); depth 4 (42). D. XII, 19; A. II, 21. Body comparatively robust, deep, and compressed. Head large, rounded, the anterior profile less blunt than in $H$. gentilis and less rounded, nearly straight from tip of snout to above eye, thence again nearly straight to front of dorsal. Length of snout about equal to diameter of eye, $4 \frac{1}{4}$ in head. Mouth rather small, terminal, the maxillary reaching to opposite middle of eye, $2 \frac{2}{3}$ in head. Teeth subequal, with no trace of posterior canines. Superciliary tentacle large, multifid, much branched from near the base, the principal division $3 \frac{2}{3}$ in head. Gill openings larger than in $H$, gentilis, extending downward to the level of lower edge of pectoral, the length of the slit 18 in head. Lateral line developed beyond the straight part, its posterior portion curved downward. Dorsal fin continuous, with a slight but distinct depression between the spinous and soft parts, the spines somewhat curved, but stiff and strong, the longest spine about $2 \frac{1}{3}$ in head; longest soft rays 2 in head. Caudal fin free from dorsal and anal, $1 \frac{1}{2}$ in head; ventrals $1 \frac{1}{8}$ in head; pectorals about as long as head. Males,

* The recent identification of Blennius hentz with Tsesthes punctatus enables us to understand the undefined genus Hypsoblennius, and to substitute it for the later Isesthes. Our judgment is opposed to the recognition of such unexplained "typonyms, "but we defer to the custom of the American Ornithologists' Union. 
as usual in this genus, with the anal spines partly detached, and provided with fleshy tips. Coloration olivaceous, the body and fins everywhere profusely mottled and reticulated with darker; obscure dark shades extending downward from eye across, or partly across, lower side of head; head without distinct spots or other sharply defined markings, except faint streaks radiating from eye; no pale bars on side of head in either sex; some yellowish markings on anterior part of dorsal. Length 5 inches. California, from Point Concepcion southward to Todos Santos or beyond; common among rocks in the kelp; our specimens from Santa Barbara and Point Loma. (Named for Charles Henry Gilbert.)

Isesthes gilberti, JoRdan, Proc. U. S. Nat. Mus. 1882, 349, Santa Barbara, California (Type, Nos. 26916 and 26917. Coll. Jordan \& Gilbert); RosA Surth, Proc. U. S. Nat. Mus. 1883, 235, specimens from Todos Santos Bay; D. XI or XII, 16 to 21; A. 19 to 21; head $4 \frac{1}{8}$; depth $4 \frac{1}{8}$.

\section{HYPSOBLENNIUS GENTILIS (Girard).}

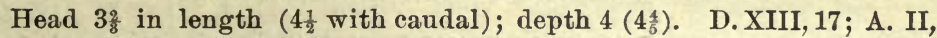
19. Body rather robust, deep and compressed, the head large, very bluntly and evenly rounded in profile, more obtuse and more evenly curved than in $H$. gilberti, the snout shorter, about equal to eye, $4 \frac{1}{2}$ in head. Mouth rather small, terminal, the maxillary reaching to opposite middle of eye, its length 3 in head. Teeth subequal, the hindmost on each side of upper jaw shorter than the others, and a little apart from them but not forming "a small canine," as stated by Girard. Superciliary tentacle long and simple in the male, its edge fringed with short branchlets, its length about 3 in head; tentacles much smaller in the female, where they are scarcely visible. Gill opening extending downward not quite to lower edge of pectoral, its length (vertical) $2 \frac{1}{6}$ in head. Lateral line with only the straight anterior portion developed, not curved down ward posteriorly. Dorsal fins continuous, with scarcely a trace of emargination between the spinous and soft parts. Dorsal spines comparatively low and flexible, much less strong than in $H$. gilberti, the longest spines 3 in head; longest

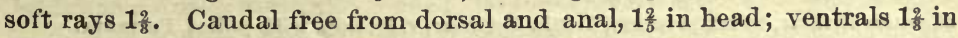
head; pectorals $1 \frac{1}{8}$. Coloration in spirits, brown, the whole body closely mottled and blotched with darker brown, so that the light ground color forms, especially anteriorly, light reticulations around darker spots; on the head the dark spots are small and close together, smallest anteriorly, the lower parts of the head being immaculate, extending from the curve of the preopercle downward, across the interopercle and branchiostegals, in a sharply defined white bar (said to be golden yellow in life), edged with black; behind this and parallel with it across subopercle and isthmus is a similar bar, these bars present only in the males; a few pale spots or bars in front of these; back with abont 6 dusky cross shades, below each of these is an oblong dark blotch, the anterior placed along the lateral line, altogether forming an interrupted dark stripe; a similar dark stripe near the median line of the body, interrapted by some pale blotches. Fins all blotched and spotted by light and dark colors, but without distinct markings (a bluish spot in front of dorsal in life); 
ventrals and anal nearly blackish in males, the base of the anal with a pale streak. Females more distinctly blotched, with a black spot in front of dorsal and white spots on middle of sides; head lacking the pale bars and black spots, but much mottled with brown and whitish; a very distinct blackish blotch on front of spinal dorsal; pectoral and caudal pale, a dark blotch on base of pectoral. Length about 4 inches. Monterey to Cape San Lucas; common southward in rock pools. Here described from specimens from Angel Island, Gulf of California, from Cape San Lucas, and from Monterey and San Diego. (gentilis, related.)

Blenniusgentilis, Grrard, Proc. Ac. Nat. Sci. Phil. 1854, 149, Monterey, California. Types, Nos. 690 and 785 (Coll. A. Cassidy; No.489, Lieut. Trowbridge); Girard, Pac. R. R. Surv., x, Fishes, 113, pl. 25a, fig. 4, 1858; GüNTHER, Cat., III, 217, 1861.

Isesthes gentilis, SteIndachneR, Ichth. Beiträge, v, 150, 1876; JoRdAN, Proc. U. S. Nat. Mus. 1882, 350; Jordan \& Gilbert, Synopsis, 956, 1883; Jordan,Proc. U. S. Nat. Mus. 1882, 349 .

2737. HYPSOBLENNIUS STRIATUS (Steindachner).

Head 4 to $4 \frac{1}{2}$; depth $4 \frac{3}{5}$ to 5 . D. XI or XII, 17; A. 19; P. 15; V. I, 3. Snout steep, and slightly concave in older examples; interorbital narrow, equal to $\frac{1}{2}$ eye; origin of dorsal a little before the edge of preopercle; second and third dorsal spines equal to the distance from tip of snout to edge of preopercle; dorsal and anal free from caudal; pectoral reaching nearly to front of anal. Color yellowish below, sides brownish, irregular dark-brown cross bars on back and sides; toward the caudal are rows of spots, 4 or 5 wider cross bars of dark brown or violet; a dark blotch from the third to the fifth dorsal spine, behind which are irregular longitudinal dark stripes; anal edged with white, behind which runs a violet line; pectoral and caudal spotted; a dark oval spot behind eye; a brown line from first dorsal spine to eje. Panama (Steindachner), where specimens were also taken by Dr. Gilbert, none of these showing posterior eanines, although Steindachner notes the presence of a small canine in 1 specimen. (striatus, striped.)

Blennius striatus, SteINDACHNER, Ichth. Beiträge, $\nabla, 15$, 1876, with plates, Panama. Isesthes striatus, JORDAN \& GILBERT, Bull. U. S. Fish Comm. 1882, 111.

2738. HYPSOBLENNIUS IONTHAS (Jordan \& Gilbert).

Head $3 \frac{3}{5}$ to 4 ( $4 \frac{1}{8}$ to $4 \frac{2}{8}$ in total); depth $3 \frac{1}{6}$ to $3 \frac{1}{2}\left(3 \frac{4}{5}\right.$ to $\left.4 \frac{2}{7}\right)$. D. XII, 13 , or XII, 14; A. II, 13, or II, 14. Body rather deep, moderately compressed, the back little elevated. Head short, blunt, but less so than in $H$. punctatus; the profile prominent above the eye, thence descending abruptly but not vertically to the tip of the snout; length of snout $3 \frac{1}{5}$ in head. Mouth small, low, its cleft largely anterior, the short maxillary scarcely reaching past the front of the eye, 4 in head. Eyes large, placed high, 5 in head, the interorbital space about $\frac{1}{2}$ their diameter. Female (ionthas) with the orbital cirrus low, scarcely larger than nasal cirrus, which is about equal to diameter of pupil. Teeth moderate, equal; no posterior canines. Gill opening extending 
downward to a point varying from a little above to a little below middle of base of pectoral, the height of the slit 3 in head. Lateral line not reaching tip of pectoral. Dorsal fin continuous, the spines low and rather stiff, slenderer than in $H$. punctatus, the longest spines a little lower than the soft rays, which are about $1 \frac{1}{8}$ in head. Caudal free from anal, slightly connected with dorsal; a little shorter than head; pectoral about as long as head; ventrals shorter than head. Color of female clear olive green, with only traces of darker bars; body everywhere densely freckled with small round blackish spots, smaller than the pupil; on the sides and lower part of head these spots are reduced to close-set dots; 2 dark lines, separated by a golden area, downward from eye; a rertical curved blackish patch behind eye, in front of which is a golden area; vertical fins olive green, dorsal and caudal usually mottled with dusky; paired fins dusky olive; lower parts of head tinged with golden, sometimes with dusky cross bars; cirri green.

The male (8crutator) is thus described: Head 4 ( $4 \frac{3}{6}$ in total); depth $3 \frac{8}{4}\left(4 \frac{1}{2}\right)$. D. XII, 14 or 15; A. II, 15 or 16. Body rather deep, compressed, the back not elevated. Head short, very blunt, almost as deep as long, the profile abruptly descending before eye, the snout about $\frac{1}{8}$ length of head. Mouth very small, anterior, the maxillary extending to opposite front of eye, $3 \frac{1}{8}$ in head; teeth subequal, without canines: Orbital cirri very long, reaching when depressed about to the front of dorsal, their length more than $\frac{1}{2}$ head in adult, somewhat shorter in young; a short branch near its middle. Nasal barbel minute. Eye large, much broader than the concave interorbital space, about $4 \frac{1}{2}$ in head. Lower edge of gill opening a little below middle of base of pectoral, the depth of the slit $2 \frac{1}{2}$ to 3 in head. Dorsal fin scarcely emarginate, the spines rather stiff, lower than the soft rays, the longest spine 2 in head. Caudal slightly connected at base with dorsal, $1 \frac{1}{8}$ in head; pectoral about as long as head, reaching past frout of anal; ventrals $1 \frac{2}{5}$ in head. Lateral line extending to base of eighth spine, not to tip of pectoral. Color in life, deep olive green, almost immaculate, or with faint traces of darker vertical bars; a golden blotch behind eye, behind which is a dusky crescent; 2 dark bars downward from eye, separated by a yellowish area; fins all dusky greenish, nearly or quite immaculate; front of spinous dorsal blackish. South Carolina to Texas, in rock pools; numerous specimens, the largest about $2 \frac{1}{2}$ inches long, were obtained with hook and line from the wharves at Pensacola. (iov $\theta \alpha$, freckled.)

Isesthes ionthas, Jordan \& Gilbert, Proc. U. S. Nat. Mus. 1882, 299, Pensacola, Florida (Type, No. 30856, U. S. Nat. Mus. Coll. Jordan \& Stearns), female; JoRdAN \& GiLBERT, Synopsis, 960, 1883.

Isesthes scrutator, * Jordan \& GILbERT, Proc. U.S. Nat. Mus. 1882, 300, Pensacola (Type, No.30850. (Coll. Jordan \& Stearns); Galveston (Coll. Dr. August Galny); JoRdAN \& Gilbert, Synopsis, 960, 1883.

* The form called scrutator agrees very closely with Hypsoblennius ionthas in all respects except the great length of the orbital cirrus and the different coloration of the body. In both the golden blotch and dark crescent behind the eye are distinct, as also the 2 dark bars separated by a yellow one below the eyo. Renewed comparison strengthens our impres. sion that Hypsoblennius scrutator is the male of Hypsoblennius ionthas. 


\section{HYPSOBLENNIUS HENTZ (Le Sueur).}

Head $3 \frac{2}{5}$; depth 3 . D. XII, 15; A. 18 ; pectoral $1 \frac{1}{4}$ in head; ventral 18; gill slit $2 \frac{1}{4}$; eye $4 \frac{1}{2}$; maxillary $2 \frac{2}{3}$. Orbital tentacle very slender, once forked, 3 in head. Body rather deep; head large, obtuse; interorbital space concave, $\frac{1}{2}$ the diameter of orbit; orbital cirrus as long as dorsal spines, bifid at tip, branched below; a minute nasal cirrus; no canines; gill openings extending to about lower fourth of base of pectoral, thus narrower than in most related species. Dorsal fin high, little notched, the soft part highest, the spines stiff, $2 \frac{2}{3}$ in head. Tip of each dorsal spine with a filiform, articnlated, ray-like appendage. Color in spirits, olivaceous, back and sides of head and body everywhere covered with brown spots, very irregular in size and shape; on posterior part of body the spots are larger, and show a tendency to form vertical bars; cheeks dark; lower side of head with traces of 3 cross bars; spinous dorsal with an elliptical black spot on membrane of first 3 spines; soft dorsal and caudal obscurely barred; anal, ventrals, and lower rays of pectorals dusky ; pectorals olivaceous, spotted with brown. Coasts of North and Sonth Carolina, south to Indian River, Florida; locally common. (Named for its collector, Dr. Nicholas Marcellus Hentz, "the father of American Araneology.")

Blennius punctatus, Wood, Journ. Ac. Nat. Sci. Phila., IV, 1825, 278, Charleston, South Carolina (Coll. Prof. Bache); Cuvier \& Valenciennes, Hist. Nat. Poiss., XI, 267, 1836; GÜNTHER, Cat., III, 228, 1861; not Blennius punctatus, Fabricius, 1780, which is a Stichoeus.

Blennius hentz, ${ }^{*}$ Le Sugur, Journ. Ac. Nat. Sci. Phila., Iv, 1825, 363, Charleston, South Carolina. (Coll. Dr. Hentz.)

Hypsoblennius hentzi, GiLl, Cat. Fish. East Coast N. A., 1861 (nomen nudum).

Hypleurochilus punctatus, GiLl, Cat. Fish. East Coast N. A., 20, 1873.

Isesthes punctatus, JoRDAN \& GILBERT, Synopsis, 758, 1883; JoRDAN \& GILBERT, Proc. U. S. Nat. Mus. 1883, 616.

Isesthes hentzi, JORDAN \& GILBERT, Synopsis, 960, 1883.

Subgenus BLENNIOLUS, Jordan \& Evermann.

2740. HYPSOBLENYICS BREVIPINNIS (Günther).

Head $3 \frac{1}{5}$; depth 4. D. XII, 12; A. II, 14; pectoral $1 \frac{2}{5}$ in head; ventral

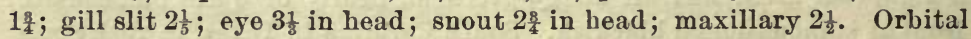
tentacle slender, less than eye. Body rather deep, compressed, back not elevated ; anterior profile from first dorsal spine to above eye almost horizontal or slightly decurved, from thence to tip of snout abruptly decurved; head large, its width not quite 2 in its length; interorbital space narrow, grooved, about equaling pupil; ejes large, placed high and close together. Month small, low, the maxillary reaching to pupil; teeth subequal, pectinate; no canines; dorsal fin continuous, deeply emarginate, the spines lower than the soft rays, the longest spine about $2 \frac{1}{2}$ in head; caudal free

* The following is the substance of the account of " Blennius hentz:" Depth $3 \frac{1}{3}$ (in total). D. XI, 14; A.16. Body little elougate; smout very short, but not vertically truncate; eyes above angle of mouth, placed high; gill slit extending from level of base of pectoral fin to height of eye; teeth equal; dorsal slightly depressed in the middle; pectorals large; a short cirrus above each eje and a smaller one over each nostril. Light bluish ash. mixed with rufons, with numerous irregular black and rufons spots; dorsal black, with whitish spots: soft dorsal with 5 dark bands; ventrals blackish, with pale bands; caudal with 3 or 4 dark bands. Charleston Harbor, South Carolina. (Le Sueur.) 
from anal and dorsal; lateral line not reaching soft dorsal. Olive brown, lighter below; back and upper half of sides irregularly marked with about 6 distinct dark-brown cross bars, these uniting at their lower edges and forming a continuous line from head to base of caudal; the bars nearly confluent on the back at base of dorsal fin; a därk lateral band nearly as wide as eye from opercle to basê of caudal, containing 5 or 6 light-yellowish spots corresponding to the pale interspaces along the back; fins dusky, anal margined with black; head with a dark spot behind each eye, and 2 smaller blotches in the median line, 1 immediately behind the eyes, the other a short distance in front of dorsal. Pacific coast of Mexico, from Mazatlan to Panama; rather common. The specimens here described from Mazatlan. (brevis, short; pinna, a tin.)

Blennius brevipinnis, GüNTHER, Cat. Fish., III, 226, 1861, Pacific coast Central America (Coll. Capt. John M. Dow); one specimen wrongly attributed to Hawaiian Islands.

888. CHASMODES, Cnvier \& Valenciennes.

Chasmodes, Cuvier \& VAlenciennes, Hist. Nat. Poiss., XI, 295, 1836 (bosquianus). Blenitrachus, Swainson, Class'n Fishes, etc., II, 78, 274, 1839 (quadrifasciatus).

Body oblong, compressed, naked; head triangular in profile, the snout somewhat pointed; mouth large, with lateral cleft, the maxillary usually, but not always, extending to beyond eye; premaxillaries not protractile; teeth in a single series, long and slender, comb-like, confined to the front of each jaw ; no canines; cirri very small or wanting; gill openings very small, their lower edge above the middle of the base of the pectorals; lateral line incomplete. Fins as in Blennius. American. The species with smaller mouth approach Hypsoblennius, which genus is not far separated from Chasmodes. ( $\chi \alpha б \mu \dot{c}^{\prime} \delta \eta$.s, yawning.)

$a$. Dorsal and anal free from caudal.

b. Anal rays 18 or 19 ; body not banded.

JENKINSI, 2741.

bb. Anal rays 15; body with 4 dark cross bands.

QUADRIFASCLATUS, 2742.

aa. Dorsal joined to base of caudal.

c. Mouth moderate, the maxillary not extending to posterior border of eye, $2 \frac{1}{3}$ in head.

SABURRE, 2743.

cc. Mouth large, maxillary reaching posterior border of eye.

NOVEMLINEATUS, 2744.

ccc. Mouth very large, the maxillary extending to beyond eye.

BOSQUIANUS, 2745.

2741. CHASMODES JENKINSI (Jordan \& Evermann).

Head $3 \frac{1}{8}$ ( 4 in total); depth 4 (5). D. XII, 17; A. 18 or 19; eye 4 to 5 in head. Body more robust than in related species, resembling Hypsoblennius; head large, gently rounded in profile, the snout steep, 4 in head; interorbital space narrow, grooved; orbital tentacle (male) much as in Hypsoblennius gilberti, about 3 in head, branched, the branches usually 4; mouth much larger than in Hypsoblennius, the maxillary $2 \frac{8}{4}$ to 3 in head, reaching to below posterior margin of eye; teeth even, comb-like; gill opening 2 in head, extending downward nearly to lower edge of pectoral, much larger than in Chasmodes saburra. Dorsal little notched, the spines 
slender, $2 \frac{1}{2}$ in head, the rays a little higher; anal lower, the rays $3 \frac{1}{2}$ to 4 in head; pectorals reaching anal, $1 \frac{1}{3}$ in head; ventrals $2 \frac{1}{4}$; dorsal and anal free from caudal. Color in life, accorling to Evermann \& Jenkins, yellowish; 5 quadrate spots of darker extending from dorsal to a line drawn from middle of eye to lower base of caudal, the anterior one above tip of pectoral; median line of side with a more or less distinct series of small spots; a shurt dark vertical line behind the eye; a dark blotch in front of origin of dorsal fin and another on humeral region; underside of head with 2 ill-defined dark bands; dorsal fin more or less speckled with black, the anal with a narrow white border above which is a broader band of deep brown. Six specimens, the largest about 3 inches long, were obtained at Guaymas, Sonora, by Drs. Evermann \& Jenkins, in 1887. One of these, (No. 412, L. S. Jr. Univ. Mus.), examined by us, is the type of the present description. The large mouth distinguishes this species at once from Hypsoblennius striatus, with which it has been identified. The species is intermediate between typical Chasmodes and Hypsoblennius, and its discovery may make it necessary to merge the latter in Chasmodes. (Named for Dr. Oliver Peebles Jenkins.)

Hypsoblennius striatus, Evernann \& Jenkins, Proc. U. S. Nat. Mus. 1891, 163; not of STEINDACHNER.

Chasmodes jenkinsi, Jordan \& EYermann, Proc. Cal. Ac. Sci.1896, 232, pl. 39, Guaymas. (Coll. Evermann \& Jenkins.)

\section{CHASMODES QUADRIFASCIATUS (Wood).}

D. 27 ; A. 15 . Form of Chasmodes bosquianus: Lower jaw slightly longer than the upper. Dorsal and anal free from caudal; anal fin highest anteriorly. Body with 4 distinct brownish bands, a fifth broader and less marked on the neck; 4 round yellowish spots along base of anal; head spotted with blackish. (Wood.) Habitat uncertain; probably South Atlantic coast of the United States; not recognized by recent collectors; very likely based on the female of $C$. bosquianus, with the candal torn from the other vertical fins. (quadri-, four; fasciatus, banded).

Pholis quadrifasciatus, WooD, Journ. Ac. Nat. Sci. Phila., IV, 1825, 282; locality unknown, probably South Carolina. (Coll. Rubens Peale.)

Chasmodes quadrifasciatus, Cuvier \& VAlenciennes, Hist. Nat. Poiss., XI, 298, 1836; GÜNTHER, Cat. Fish., III, 229, 1861; JoRdAN \& GILBERT, Synopsis, 757, 1883.

\section{CHASMODES SABURRE, Jordan \& Gilbert.}

Head $3 \frac{1}{2}$ to $3 \frac{8}{4}$; depth $3 \frac{1}{4}$ to $3 \frac{8}{4}$. D. XI or XII, 17 to $19 ;$ A. II, 18 or 19. Body rather deep and compressed, less elongate than in C. bosquianus; the back somewhat arched. Head comparatively short, much shorter than in C. bosquianus, not $\frac{1}{4}$ longer than deep; profile forming a nearly even curve from the base of the dorsal to the tip of the snout; mouth notably smaller than in C. bosquianus; maxillary not reaching posterior margin of eje, its length $2 \frac{1}{3}$ in head; teeth occupying about $\frac{1}{2}$ of lower jaw; height of gill slit $3 \frac{2}{8}$ in head, its lower ray opposite third ray of pectoral. A minute cirrus, shorter than pupil, above each eje and each nostril. Dorsal con- 
tinuous, with slender rays, the last one joined to the caudal. First two rays of anal short, thick, and fleshy in the males. Male deep olive, with dark cross shades; numerous pale spots on the sides which form undulating lines converging backwards; dark stripes downward and forward from eye; top of head and upper part of dorsal fin usually with fine black spots; spinous dorsal with a median orange longitudinal band; other fins mostly dusky olive. Some specimens with the outer part of both dorsals and the top of head dusted with black spots, others with these spots obsolete; soft dorsal and caudal light orange, barred with light greenish; anal dull orange, with an obscure blackish median band, the exserted tips of the rays abruptly whitish; pectorals dusky olive, strongly tinged with orange; ventrals blackish, orange at tip. Female with about 8 blackish cross bands extending on the dorsal fin; the body everywhere with pale spots; fins all sharply barred with blackish and olive. Pensacola Bay, Florida; common about the wharves and ballast rocks in shallow water; taken with seines and pinhooks. Allied to Chasmodes bosquianus, but with the mouth smaller, the form less elongate. (saburra, ballast.)

Chasmodes saburroe, Jordan \& Gilbert, Proc. U. S. Nat. Mus. 1882, 298, Pensacola, Florida (Type, No. 30824. Coll. Jordan \& Stearns) ; JoRdAN \& GilberT, Synopsis, 958, 1883.

\section{CHASMODES NOVEMLINEATUS (Wood).}

Head $3 \frac{3}{5}$; depth $3 \frac{3}{5}$; eye $4 \frac{8}{4}$; snout $3 \frac{8}{4}$; maxillary reaching posterior border of eye. D. XI, 18; A, III, 17. Head and shoulders heavy, the body lance-shaped, tapering gradually to tail; snout short, blant, profile nearly vertical to eye, thence gently rounded; mouth rather large, somewhat oblique, the maxillary reaching posterior border of eye; dorsal and anal high, longest dorsal rays 2 in head; anal considerably lower; pectoral nearly as long as head; ventrals $1 \frac{8}{4}$ in head. Color, side with 6 broad, dark, vertical bars, the anterior 4 extending ou the dorsal fin, these bars separated by irregular narrow pale spaces; entire side profusely covered with small white spots; a small black spot at base of caudal; head mottled with light and dark; 2 small dark spots on under side of lower jaw; just behind these and extending down ward from the angles of the mouth are 2 other larger, blacker spots, while behind these, extending downward and backward from middle of cheek, is an irregular black line; whole head with numerous fine dark punctulations; dorsal and anal variously spotted or barred with light and dark; spinous dorsal with a large dark area at top of anterior spines; caudal faintly barred; pectorals and ventrals more plainly barred. Length 2 inches. South Atlantic coast of the United States, South Carolina to Florida; abundant in Indian River, Florida, where numerous specimens were taken in January, 1896, by Evermann \& Bean. (novem, nine; lineatus, lined.)

Pholis novemlineatus, Wood, * Journ. Ac. Nat. Sci. Phila., IV, 1825, 280, Charleston Harbor, South Carolina.

* The following is the substance of Wood's original description of this species: "Body with 9 whitish longitudinal bands; dorsal fin with an irregular blackish spot between the first and second rays; remainder of the fin clouded with dusky brown. Head descending somewhat abruptly, tuberculated anteriorly; nostrils with a small appendage; head, lips, $3030-73$ 
Chasmodes saburra, KVERMANN \& BEAN, Fishes of Indian River, Florida, in Rept. U. S. Fisl Comm. 1896, 247; not of Jordan \& Gilbert.

Chasmodes novemlineatus, GüNTHER, Cat., 11I, 229, 1861.

\section{CHASMODES BOSQUIANUS (Lacépède).}

Head $3 \frac{1}{2}$; depth $3 \frac{1}{2}$. D.XI, 19; A.II, 19. Orbital tentacle very minute or wanting; maxillary extendiug to rather beyond eye; interocular space very narrow, not concave. Dorsal fin not emarginate, the spines slender. Dorsal joined to base of caudal; anal free. Color (in male) olive green, with about 9 horizontal narrow blue lines, these somewhat irregular and interrupted, converging backward; opercular membrane and a broad stripe through middle of spinous dorsal deep onange yellow; anal fin dark, the rays with white membranaceous tips; female dark olive green, reticulated with narrow, pale green lines, and with several broad dark bars, which are more distinct posteriorly; vertical fins similarly marked; head finely dotted with black; a dusky spot at hase of caudal in both sexes. New York to Florida; common southward in shallow water. (Named for M. Bosc, who collected at Charleston for Lacépède.)

Blennius bosquianus, IıACÉPÈDE, Nat. Hist. Poiss., 11, 493, 1800 (female), South Carolina. (Coll. Bosc.)

?1'holis quadrifasciatus, Wood, Journ. Ac. Nat. Sci. Phila., IV, 1824, 282, locality unknown, probably South Carolina. (Coll. Rubens Peale.)

Chasinodes boscianus, GÜNTHER, Cat., III, 229, 1861.

Chasmodes bosquianus, JoRDAN \& GILBERT, Synopsis, 756, 1883.

889. HOMESTHES, Gilbert, new genus.

Homesthes, Gilbert, new genus (caulopus).

Differing from Hypsoblennius chiefly in the presence of 4 articulated ventral rays instead of 3 , as usual in Blenniina. We have examined the ventrals of Hypsoblennius striatus, punctatus, ionthas, gentilis, and gilberti, and have found them to consist constantly of 1 short, strong spine and 3 simple articulated rays. In Homesthes caulopus there is 1 strong, short spine and

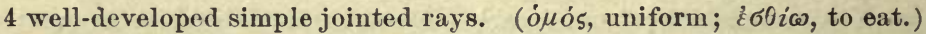

2746. HOMESTHES CAULOPUS, Gilbert, new species.

Head $3 \frac{2}{3}$ in length; depth at base of ventrals 4 , at middle of abdomen $3 \frac{3}{5}$; least depth of eaudal peduncle $\frac{1}{8}$ length of head; snout 4 ; eye 4 to $4 \frac{1}{5}$. D. XII, 15 or 16 ; A. II, 17; P. 14. Longest dorsal spine $2 \frac{2}{3}$; last dorsal

opercnia, etc., and base of the pectoral fins, finely spotted with bluish black, the spots being larger on the front and opercula; branchial opening extremely small, extending $\frac{1}{3}$ of the length of the external curve of the operculum; mouth descending little; gape moderate; sides of the head fleshy; body compressed; rib spaces evident; sides with 9 longitudinal whitish lines, some of which are interrupted; behind the eyo and under the dorsal fin are 2 irregnlar whitish patches; dorsal fin commencing before the pectoral fins; between the first and second rays is an irregular blackish spot, several of the following rays are also spotted, the color of the spots becoming lighter as they recede toward the tail, where they mingle with the dusky color of the fin and are lost; fin rising posteriorly, and joining the caudal fin at about the distance from its extremity; anal fin commencing under the termination of the pectoral fin, and extending nearly to the tail; caudal fin rounded; rentral fins 2-rayed; pectoral fins rather large, the base thick and fleshy, finely spotted with bluish black; anus small, tuborcle small; color brownish, fins dusky. D. $30 ;$ C. 123 ; A. 20 ; V.2; P. 13 . Length $3 \frac{1}{4}$ inches; depth, exclusive of the dorsal fin, hardly 1 inch." 
spine $3 \frac{4}{5}$; longest (tenth) dorsal ray 2 ; longest (fifteenth) anal ray $2 \frac{1}{2}$; ventrals $1 \frac{5}{6}$; longest pectoral ray $1 \frac{3}{5}$ to $1 \frac{2}{8}$; caudal $1 \frac{1}{2}$. Robust, moderately compressed, with wide heavy head and short, bluntly rounded suout, the anterior profile of which is nearly vertical. In shape and general appearance much resembling Hypsoblennius gilberti. Mouth very wide, horizontal, short, the maxillaries reaching vertical from hinder edge of pupil, 3 to $3 \frac{1}{5}$ in head. Tecth, as usual in this group, the posterior not enlarged or canine-like. Nostrils with slightly elevated margins, scarcely tubular, the hinder edge of anterior nostril produced into a conspicuous laciniate flap, about $\frac{2}{8}$ as long as the diameter of orbit. A similar but larger orbital cirrus, divided nearly to the base into 6 or 8 slender filaments. Interorbital space deeply grooved, without median ridge, opening posteriorly into the deep transverse groove which separates the orbital region from the somewhat swollen oeciput, its width

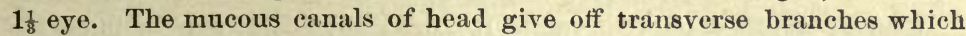
open by numerous pores. These thickly beset the snont, subocular region, top of head, preopercle, and upper portion of opercle. Width of gill slit equaling or slightly exceeding $\frac{1}{2}$ length of head, confined to area above lower base of pectorals. First dorsal spine over margin of preopercle; spinous dorsal low, of nearly uniform height, much lower than second dorsal, the spines rather strong at base, with weak reflexed tips; membrane of last dorsal ray joined to extreme base of rudimentary caudal rays; anal low, rising slightly posteriorly, leaving a short free interval between its last ray and caudal. Lateral line strongly developed anteriorly for a distance equaling length of head; from that point it is only faintly visible, declining abruptly to middle of sides, along which it may be traced to base of caudal; the anterior portion gives off numerous pairs of short transverse lines, each of which ends in a pore; no pores or lines are visible posteriorly. Blackish, without sharp markings, the sides with irregular light blotches, some of which are subcircular in outline and contain 1 or more black central specks; the light markings near the back elongate and vertically placed, faintly outlining dark bars of the ground color; a vertical black blotch on cheek behind eye; lower parts lighter; no distinct bars on head; fins all blackish, the anal, the ventrals, the lower caudal and pectoral rays deeper black; anal and caudal margined with white, some of the dorsal rays narrowly tipped with white; tentacles whitish. Two specimens, 4 and $4 \frac{1}{2}$ inches long, from Panama Bay. (Gilbert.) ( $\alpha \alpha v \lambda o ́ s$, stem; $\pi$ ov́s, foot.)

Homesthes caulopus, Gilbert MS., Fishes of Panama, Panama. (Coll. Gilbert. Type, No. 5623, L. S. Jr. Univ. Mus.)

89o. SCARTICHTHYS, Jordan \& Evermann, new genus.

Scartes, JoRDAN \& EverManN, Chock-List Fishes, 47!, 1896 (rubropunctatus); preoccupied by Scartes, Swainson, a genus of mammals.

Scartichthys, JoRDAN \& EvERMANN, now genus (rubripunctatus).

Body elongate, slowly declining to the caudal. Head obliquely compressed, oblong, the profile more or less vertical. Eyes lateral, closely approximated, situated at the angle of the profile with the postocular 
region. Gill apertures continuous under the throat, gill membrane free from isthmus. Branchiostegals 6. Mouth moderate, the contour of the upper jaw semicircular; upper jaw protruding beyond the lower; lips moderate, uniform and free, concealing the teeth. Teeth labial and movable, very slender and recurved, contiguous and uniserial; no posterior canines. Dorsal fin divided; anal similar to soft dorsal; caudal obtusely rounded; pectorals moderate, angularly rounded; ventrals approximated, each with 3 simple rays, the internal of which is smallest. This genus is very close to the Old World genus, Salarias, ${ }^{*}$ Cuvier, which differs in

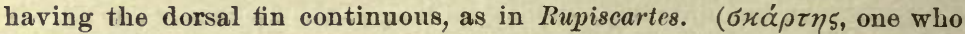
leaps; $i \chi \theta \dot{v} 5$, fish.)

\section{SCARTICHTHYS RUBROPUNCTATUS (Cuvier \& Valenciennes).}

Head 4; depth 4 .(5 with caudal); D. XI-16; A. 20; eye $4 \frac{1}{8}$ in head; teeth less flexible than in Rupiscartes atlanticus; no canine teeth; the forehead not projecting beyond the mouth; a very small tentacle on the neck, a longer fringed one above the orbit; dorsal fin deeply notched, not extending on to the candal. Color brown, marbled with black, and dotted with reddish; a black spot on the anterior part of the dorsal; throat with 2 or 3 brownish cross bands; a jet-black spot behind eye, with a narrow edge posteriorly. (Günther.) Coast of Peru and Chile, north to Panama. Specimens examined by us collected by Prof. Frank H. Bradley at Pearl Islands, near Pauama, and at Callao. Length 3 inches. (ruber, red; punctatus, spotted.)

Salarias rubropunctatus, Cuvier \& VAlenciennes, Hist. Nat. Poiss., XI, 348, 1836, Juan Fernandez (Coll. Claude Gay); GÜNTHER, Cat., III, 249, 1861; JoRdAN \& Gilbert, Proc. U. S. Nat. Mus. 1882, 628; not of KNER, Novara-Fische, 198.

\section{8gr. RUPISCARTES, Swainson.}

Alticus, † Commerson, in LACÉp̀̀De, Hist. Nat. Poiss., II, 458, 1800 (saliens). Alticus, $\ddagger$ Cuvier \& Valenciennes, Hist. Nat. Poiss., XI, 337, 1836 (alticus). Rupiscartes, Swainson, Nat. Hist. Class'n Anim., II, 275, 1839 (alticus).

This genus, as here understood, differs from Salarias only in the presence in 1 or both jaws of posterior canines. Dorsal fin continuous, without deep

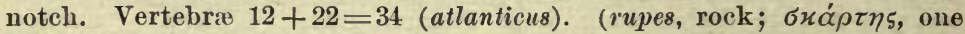
who leaps; Rupiscartes tridactylus (alticus), "said to jump on the sea rocks lit:e a lizard." Swainson.)

\footnotetext{
* Salarias, Cưvier, Règne Anim., Ed. 2, II, 175, 1829 (quadripinnis). Erpichthys, SWAIN-

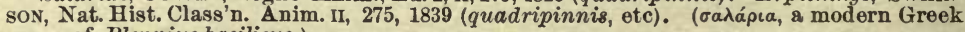
name of Blennius basilicus.)

t We do not think that the name Alticus can be substituted for Rupiscartes, because Lacépède does not arlopt this genus of Commerson, but merges it in Blennius, quoting Commerson's account as a footnote. This is as follows: "Alticus saltatorius, pinna spuria in capitis vertice; seu pinnula longitudinali pone oculos cartilaginea; seu alticus desultor, occipite cristato, ore circulare deorsum patnlo." A pparently this quotation of a generic description not approved, does not give priority to the latter.

+ This genus Alticus is not adopted by Cuvier \& Valenciennes. Valenciennes speaks of "un petit Salarias que nous paraît être celuj.là même sur lequel Commerson avait établi son geure Alticus." But a genns is not established until it is accepted by some anthority as well as defined.
} 
2748. RUPISCARTES ATLANTICUS (Cuvier \& Valenciennes).

Head 4 to $4 \frac{1}{2}$; depth $3 \frac{1}{2}$ to $3 \frac{2}{8}$. D. XII, 21 or XIII, 20 ; A. 24 or 25 ; vertebræ $12+22=34$; eye 4 to $4 \frac{1}{2}$ in head. Body rather high, compressed. Head short, very blunt, its width about 2 in the length; anterior profile from first dorsal spine to above eye straight or slightly convex; from thence to tip of snout abruptly decurved, in some specimens nearly vertical. Month inferior, lower jaw included; maxillary about reaching posterior border of eye. Teeth small, pectinate, the lower canines exceedingly large and entering the cavity in the palate. Supraorbital tentaele well developed, slender; a group of 5 or 6 short tentacles on either side of head in front of nostrils and on either side of neck, these shorter than pupil. Dorsal fin not emarginate, extending from a point above middle of operculum to base of caudal; anal lower than soft dorsal, $1 \frac{1}{2}$ to 2 in dorsal; pectorals reaching past vent, about equaling head; ventrals abont 2 in head. "The intestinal traet is more than 3 times as long as the entire body. The structure of the skeleton is very similar to that of the Blennies; the jaw bones, however, are still shorter, and the intermaxillary and mandibulary are deeply concave anteriorly. There are 12 abdominal and 22 caudal vertebrie, the former portion being only $\frac{1}{2}$ as long as the caudal." (Giinther.) Some specimens, apparently males, with the anterior profile vertical and very high; fins high; caudal lanceolate, the black median rays much exceeding the outer pale ones. Females with the anterior profile a nearly even curve, the caudal lunate, its median black rays shorter than the outer pale ones. Body liver brown, paler below, with usually 5 or 6 darker cross bars extending on the dorsal; a black spot behind eye in all; fins mostly blackish, an orange area on upper edge of caudal; a yellow one tinged reddish below; eye red posteriorly. Length 6 to 8 inches. Tropical America, on both coasts, very abundant in rock pools, north to West Indies and to Todos Santos. Here described from specimens from Mazatlan.

Punaru, Marcarave, Hist. Brazil, 165, 1648, Brazil.

Salarias atlanticus, Cuvier \& Valenciennes, Hist. Nat. Poiss, xI, 321, 1836, Madeira (Coll. Richardson), Antilles (Coll. Plée); Günther, Cat. Fish., III, 242, 1861.

Rupiscartes atlanticus, JoRdAn, Proc. U. S. Nat. Mus. 1888, 333.

\section{ENTOMACRODUS, * Gill.}

Salarias, SwaInson, Nat. Hist. Class'n Fishes, II, 274, 1839 (vermicularis; not of CuviER). Entomacrodus, GiLl, Proc. Ac. Nat. Sci. Phila. 1859, 168 (nigricans).

This genus has large posterior canines as in Rupiscartes, but the dorsal fin is divided into 2 fins as in Scartichthys. ( $\dot{\varepsilon} \nu$, in; $\tau o ́ \mu \circ$, cutting; $\dot{\alpha} \varkappa \rho o ́ s$, sharp; ódov́s, tooth.)

a. Orbital cirrus present; dorsal rays XII or XIII-15; canines small.

b. Cirrus above eye divided; anal rays 15.

chIostictus, 2749.

$b b$. Cirrus above eye simple or nearly so; anal rays 18 ; borly with pearly spots.

MARGARITACEUS, 2750 .

* This genus is equivalent to Salarias of Swainson, but the generic name Salarias was based on Salarias quadripinnis, before either of the species referred to it by Swainson was made known. 
aa. Orbital cirrus wanting; no cirri at nape.

c. Dorsal rays XII-19; anal 15; body rather slender, the depth about 5 in length; body with bands and spots. DECORATUS, 2751.

cc. Dorsal rays XI-15; anal 17; body very slender, the depth about 6 in length; color blackish, nearly plain. NIGRICANS, 2752.

2749. ENTOMACRODUS CHIOSTICTUS (Jordan \& Gilbert).

Head $4 \frac{1}{2}$ in length; depth $5 \frac{1}{4}$. D. XII-15; A. 15 ; eye $3 \frac{1}{3}$ to $4 \frac{8}{4}$ in head; varying with age. Body moderately elongate, compressed, the head short, blunt, almost globular, about as broad as deep, and a little longer than broad. Mouth inferior, with little lateral cleft, the lower jaw included; width of cleft of mouth $\frac{2}{8}$ length of head. Teeth small, weak, finely pectinate; canine teeth small, not so long as diameter of pupil. Supraorbital cirrus divided into 4, its height $\frac{8}{4}$ that of eye; a few minute slips at the nape. Interorbital space channeled, narrower than eje. Maxillary extending to behind middle of eye. No crest on top of head. First dorsal low and even, its spines rather slender, the last spines short, scarcely connected by membrane with the soft rays; soft dorsal well separated from candal; caudal subtruncate, with rounded angles; anal lower than soft dorsal, with a little longer base; pectorals a little longer than head; ventrals about $\frac{1}{2}$ as long. Color in life, olive brown above, lighter below; 5 broad, dark bars from dorsal fin to middle of sides, each terminating above on the fin, and below on sides in a pair of black spots; sometimes only the dark spots are distinguishable, the bars being obscure; sides below spinous dorsal with numerous black specks, and with numerous oblong spots of bright silvery; sometimes a silvery streak from upper portion of base of pectorals to base of caudal; a broad salmoncolored streak on each side of ventral line; sometimes the space between the silvery lateral band and the base of the anal is darker, the vertieal bars again appearing as pairs of black, vertical blotches; head yellowish olive, darker above, and reticulating with narrow brown lines, these appearing as parallel bars on the upper lip, and radiating from the median line on the upper side of the head; vertical fins light grayish, with black spots, which appear as wavy bars on the caudal fin; pectorals and ventrals pale, the former with a jellowish shade at base; orbital tentacles bright red. Pacific coast of Mexico. Known from 4 specimens (the largest $2 \frac{1}{4}$ inches in length), taken in a deep rock pool at Mazatlan. Two

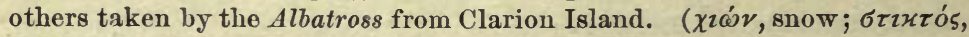
spotted.)

Salarias chiostictu8, JORDAN \& GILBERT, Synopsis, 363, 1883, Mazatlan, Mexico. (Coll. Jordan \& Gilbert.)

\section{ENTOMACRODUS MARGARITACEUS (Poey).}

Head 5 in total length with candal; depth $6 \frac{1}{2}$. I. XII-14; A.I, 14 ; eye $4 \frac{1}{2}$ in head, well forward. Body large, snout abruptly decurved; mouth very low, maxillary reaching anterior nostril, which has a little tentacle; (canines small); small tentacle over eye; gill membranes broadly connected, free from isthmus ; dorsal deeply emarginate, almost divided; anal beginning under middle of body without caudal, and anal papills and caudal 
rounded; ventrals short; lateral line present anteriorly, no tentacles on nape. Color brown, with 2 vertical bands of a dusky silvery; a central point in each band shining bright. One specimen, $2 \frac{1}{2}$ inches long. Cuba. (Poey.) Perhaps a Salarias.

We have the following notes on a specimen, possibly the type of this

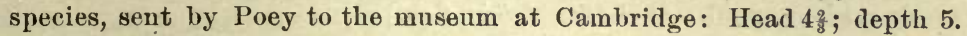
D. XII-15; A. 18. Body slender. Interorbital concave. Head short, blunt, almost round; a small cirrus over the eye, none on nape. Canines present, small. Body with about 6 dark cross bars besides pearly spots and various markings. Dorsal divided nearly to base. Closely resembles Salariichthys textilis. (margarita, $\mu \alpha \rho \gamma \alpha \rho i \tau \eta 5$, pearl.).

Salarias margaritaceus, PoEx, Memorias, 1I, 289, 1861, Cuba. (Coll. Poey.)

\section{1. entomacrodus decoratus, Poey.}

Head 5 in total length with caudal; depth 5. -D. XII-19; A. 15; P. 14. Eye very high; anterior nostril prolonged in a tube; nape following a straight line to the posterior nostril, profile thin, following a straight and oblique line to mouth, which is very low and short, the maxillary reaching posterior nostril. Lower jaw shorter. Teeth movable, numerous, incurved, close set, in 1 row. (Canines not described.) No cilia on head. Dorsals of equal length, the soft rays more elovated; anal similar to second dorsal; pectoral broad, its lower rays thickened; caudal rounded. Color brownish yellow; the body with darker cross bands, which begin below the middle of the first dorsal, alteruating with narrower spaces of the ground color; along the middle and edges of the bands vertical rows of sky-blue spots; in the pale interspaces below the lateral line, which is much curved, a white spot; 3 pale spots placed obliquely below the eye; rays of dorsal and caudal dotted with black. One specimen, 2 inches long. Cuba. (Poey.) Not seen by us; perhaps a Salarias. (decoratus, decorated.)

Entomacrodus decoratus, Poky, Synopsis, 398, 1868, Cuba. (Coll. Poey.)

\section{ENTOMACRODUS NIGRICANS, Gill.}

The elongated body, from the snout to the end of the caudal fin, is between 7 and 8 times longer than it is high at the pectorals. Its height at the caudal is about $\frac{1}{3}$ of the same leugth. The head is subquadrate, and forms $\frac{2}{y}$ of the total length. Its greatest height equals $\frac{2}{3}$ of its length. Its sides decline obliquely outward and downward. The first dorsal commences near the nape, and 2 of its rays are in advance of the pectorals. The second dorsal commences immediately behind the first, and nearly over the fourth ray of the anal, it ceases some distance from the base of the caudal. The anal is more uniform in height than the dorsal, and ceases before it does. The caudal forms less than $\frac{1}{5}$ of the total length. D. XI-15; A. $17 ;$ P. $15 ;$ V. 3. The general color of the body and fins is blackish. West Indies. A single specimen was caught in shallow water, at the island of Barbados, near Bridgetown. (Gill.) Not seen by us. (nigricans, blackish.)

Entomacrodus nigricans, Gill, Proc. Ac. Nat. Sci. Phila. 1859, 168, Barbados. (Coll. Dr. Gill.) 
893. SALARIICHTHYS, Guichenot.

Salariichthys, Guichenot, Mém. Soc. Sci. Nat. Cherbourg, XIII, 1867, 96 (textilis).

This genus differs from Entomacrodus in the presence of teeth on the vomer; dorsal deeply notched; cirri present over eye and on nape; posterior canines small. (Salarias; $i \chi \theta \dot{v} 5$, fish.)

2753. SALARIICHTHYS TEXTILIS (Quoy \& Gaimard).

D. XII, 16; A. 18. A few bluntish teeth on vomer; tentacles very small, fringed over nostril and eye, simple on neck; canines quite short; depth $4 \frac{3}{5}$; head $4 \frac{3}{5}$; pectoral short, little longer than head; gill membranes broadly united, free from isthmus; dorsal notched almost to base, free from caudal; orbital filament $\frac{1}{4}$ eye. Olive, with 13 silvery cross streaks, not $\frac{1}{2}$ as wide as the dark interspaces, some of the cross streaks Y-shaped; both dorsals with cross markings, the second with 12 or 13 streaks of dark obliquely upward and backward, alternately with similar pale streaks; cross bars on sides bent in middle, extending up and back and down and back from middle line parallel with muscular impressions; sides with some obscure pale dots; caudal barred with 7 dark bars; anal darkest mesially; lower side of head with dark streaks radiating from the isthmus; bars at chin $\mathrm{Y}$-shaped, upper part of head with darker markings; pectoral nearly plain; a dusky area at base below which is a dusky spot; marblings at base of dorsal. West Indies, from Bermudas to Brazil. Here described from a specimen from Abrolhos Islands (Coll. Albatros8). This specimen agrees fairly with the account given by Jenyns, but Jenyns describes 5 bars on the tail. It also agrees fairly with the account of the Bermuda specimens given by Goode. It is evidently the Salarias vomerinus of Cuvier \& Valenciennes, and probably their textilis also; but their description of the latter does not apply very well to the coloration of our specimen. (textilis, woven.)

Salarias textilis, Quox \& GaImard MS., Cuvier \& Valenciennes, Hist. Nat. Poiss., XI, 307, 1836, Ascension 1sland (Coll. Quoy \& Gaimard); GÜnTHER, Cat., III, 248, 1861; Goode, Bull. U. S. Nat. Mus., v, 29, 1876.

Salarius vomerinus, Cuvier \& Valenciennes, Hist. Nat. Poiss., XI, 349, 1836, Bahia. (Coll. Blanchet.)

Salariichthys textilis, JORDAN, Proc. U. S. Nat. Mus. 1890, 329.

\section{OPHIOBLENNIUS, Gill.}

Blennophis, Valenciennes, in WebB \& Berthelot, Poiss. Îles Canar., 60, 1844 (webbii; not Blennophis, Cuvier \& VAlencienves, a genus of (linina).

Ophioblennius, GrLl, Proc. Ac. Nat. Sci. Phila. 1860, 103 (webbii; substitute for Blennophis).

Body oblong, strongly compressed, scaleless; snout short, high, abruptly decurved anteriorly; symphysis of lower jaw of 4 hooked canines, the outer strongest and bent backward, almost forming a right angle; sides of lower jaw with 2 or 3 still larger canines, the hindermost very large and bent backward; upper jaw with 4 slender canines in front, followed by a long row of shorter, slender, movable teeth, which are set close together; nasal tentacle digitate; a low, simple tentacle above eye; gill openings wide. Dorsal fin long, the spines slender, separated by a slight notch from 
the soft rays; caudal lunate or forked, free from dorsal and anal; ventrals small, I, 2; lateral line incomplete; pectorals large. A strongly marked genus, perhaps more nearly allied to Blennius than to Emblemaria or Chanopsis. (ǒøıs, snake; Blennius, in allusion to the fang-like teeth.)

a. D. X, 20; A. 20 ; depth $5 \frac{1}{2}$ in length.

aa. D. XI, 22; A. II, 23 ; depth $4 \frac{1}{4}$ in length.
WEBBII, 2754.

STEINDACHNERI, 2755.

\section{OPHIOBLENNIUS WEBBII (Valenciennes).}

Head 5 ; depth $5 \frac{1}{2}$. D. X, 20; A. 20; P. 16. A slender tentacle above eye in front, and a much broader one, divided into 4 to the base, above the nostril. Snout obtuse, nearly vertical at tip; eye large; 4 teeth at end of upper jaw, strongly pointed, curved backward like hooks; lower jaw with 4 teeth at tip, the two middle ones like upper teeth, the two outer hidden and turned backward; a little recurved tooth on side of lower jaw ; caudal fin forked; dorsal somewhat notched at the last spine; lateral line ending near middle of body. Olive green, light or dark; dorsal and anal dusky violet, the base pale; back and sides often with fine points; a dark spot behind eye; the silvery swim bladder showing through sides of belly. (Steindachner). Tropical Atlantic; known only from the Canaries and Barbados; not seen by us. (Named for P. B. Webb, one of the explorers of the Canary Islands.)

Blennophis webbii, VAlenciennes, in WebB \& Berthelot, Îles Canar., Poiss., 60, pl. 20, f. 1, 1844, Fortaventura, Canary Islands (Coll. Webb); " caught in myriads at Puerto de Cabras in August, eaten as Anchovias" (Webb); GÜNTher, Cat., III, 259, 1861; STEINDACHNER, Ichth. Notizen, vi, 48, 1867.

Ophioblennius webbi, JoRdan \& GILBERT, Synopsis, 756, 1883.

275. OPHIOBLENNIUS STEINDACHNERI, Jordan \& Evermann, new species.

Head 4 to $4 \frac{1}{5}$; depth 4 to $4 \frac{1}{3}$. D. XI, 22 ; A. II, 23 ; V. I, 2; P. 15 . Head much compressed; eye $3 \frac{1}{4}$ in head; snout $4 \frac{1}{2}$. Dorsal beginning above gill opening, ending just before caudal, its soft rays somewhat higher than the spines, the highest spine $1 \frac{3}{5}$ in head; caudal and pectorals each about as long as head; ventrals $1 \frac{1}{2}$ in head. Dark golden brown, sometimes with a broad cross band of dusky violet on back and dorsal fin; caudal with 2 dark longitudinal stripes; dorsal and anal purplish or orange; an intense, round, dark, ocellated spot behind eye. (Steindachner.) West coast of Mexico; not seen by us; recorded from near Mazatlan and the Tres Marias Islands. (Named for Dr. Franz Steindachner.)

Blennophis (Ophioblennius) webbi, STEINDACHNER, Ich. Beitr., viu, 41, 1879, 5 specimens $70 \mathrm{~mm}$. long, from Navidad near Mazatlan and the Tres Marias Islands.

Ophioblennius steindachneri, JoRdan \& Everuan, Check-List Fishes N. and M. A., 472, 1896, name only, Tres Marias Islands; after SteindaChNer.

\section{EMBLEMARIA, Jordan \& Gilbert.}

Emblemaria, JoRdan \& GIlberT, Proc. U.S. Nat. Mus. 1883, 627 (nivipes).

Body slender, not eel-shaped, compressed, scaleless. Ventrals present, jugular, each of 1 spine and 2 soft rays. A single high dorsal fin beginning on the nape and extending to the caudal, with which it is not conflu- 
ent; no notch between spinous and soft parts. Head cuboid, compressed, narrowed anteriorly. Symphysis of lower jaw forming a very acute angle. A single series of strong, blunt, conical teeth on each jaw, and on vomer and palatines. Vomer and palatine teeth larger, their series continuons, parallel to the series in upper jaw. No cirri at the nape; sometimes a cirrus on upper part of eyeball. Gill openings very wide, the membranes broadly united below, free from the isthmus. Lateral line obsolete. This genus bears some resemblance to Blennius, but the dentition is entirely different, approaching that of Chanopsis. Tropical America, in rather deep water. (Emblema; $\check{\varepsilon} \mu \beta \lambda \eta \mu \alpha$, a banner.)

a. Eye without cirrus.

b. Depth 5 in length; dorsal rays 33; ventrals not pure white.

$b b$. Depth 7 in length; dorsal rays 37 ; ventrals pure white.

ATLANTICA, 2756. NIVIPES, 2757.

aa. Eye with a long cirrus on eyeball above pupil; ventrals dusky; maxillary not extending beyond eye. OCULOCIRRIS, 2758.

2756. EMBLEMARIA ATLANTICA, Jordan \& Evermann, new species.

Head $3 \frac{3}{5}$; depth 5. D. 35 ; A. 24 ; P. 15 ; V. 3. Body slender, compressed; head heavy; snont evenly decurved; mouth large, horizontal, reaching back of eye. Jaws with short, strong, incurved conical teeth. Fin rays long and filamentous, the longest dorsal rays as long as head; anal rays shorter. Coloration faded in the type, but traces of about 7 broad brown vertical bars as broad as eye and twice as broad as the pale interspaces, the dark bars extending upon dorsal fin; ventrals pale. Gulf of Mexico. Known from 1 specimen, $3 \frac{1}{8}$ inches long, taken from the stomach of Neomonis aya, on the Snapper Banks off Pensacola, Florida; very close to $E$. nivipes, but more robust, with fewer dorsal rays.

Emblemaria atlantica, Jordan \& Evermann, Check-List Fishes, 472, 1896, name only, Snapper Banks off Pensacola, Florida. (Type, No. 33915. Coll. Silas Stearns.)

\section{EMBLEMARIA NIVIPES, Jordan \& Gilbert.}

Héad $3 \frac{8}{4}$ in length; depth 7. D. XXIII, 14; A. 25. Body everywhere equally compressed, posteriorly tapering; head wider than body, of about equal depth, with very short, subvertical, sharply compressed snout; eyes very large, approximated above, with some vertical range; orbital ridges sharply raised above, the interorbital region very narrow, channeled, about equaling diameter of pupil; eye $3 \frac{2}{3}$ in head. Gape very wide, horizontal, low, reaching much beyond eye, the maxillary about $\frac{4}{7}$ head, not produced beyond angle of mouth; intermaxillaries separated by a groove from the snout, this groove continuous for the entire length of the upper jaw, maxillary not evident, apparently adnate to the skin of the preorbital. First dorsal spine inserted over margin of preopercle; spines all very slender and flexible, the posterior but weakly differentiated from the soft rays, the anterior portion of fin very high, the spines filiform, not exserted beyond the membrane; the longest dorsal spine about $\frac{1}{8}$ length of body, the last spine about $\frac{1}{2}$ head; membranes of last rays of both dorsal and anal slightly joined to base of caudal. Front of anal nearer snout than 
base of caudal by a distance equaling $\frac{1}{8}$ length of head. Caudal $\frac{3}{5}$ length of head; ventrals and pectorals slightly less. Color in spirits, sides dark brown, with 8 to 10 lighter vertical bars of variable width; body lighter below; obscure cross bands on lower side of head; dorsal blackish anteriorly, whitish behind, with membrane at intervals of every second, third, or fourth ray dusky; caudal light at base, its tip blackish; anal dusky translucent; ventrals bright white, the basal portion dusky. Pearl Islands, near Panama. A specimen 2 inches long is the type of the species. Numerous smaller specimens were obtained at the same time. (nix, nivis, snow; pes, foot.)

Emblemaria nivipes, Jordan \& GIlbert, Proc. U. S. Nat. Mus. 1883,627, Pearl Islands, near Panama. (Type, No. 29676. Coll. Prof. Frank H. Bradley.)

2758. FMBLEMARIA OCULOCIRRIS, Jordan.-

Head $3 \frac{3}{4}$; depth $6 \frac{2}{3}$. D. about $35 ;$ A. 25 . Upper part of eyeball above pupil (sclerotica) with a slender cirrus tipped with black, this nearly as long as eye; eye longer than snout, about $3 \frac{8}{4}$ in head, the maxillary extending to below posterior part of pupil; snout sharper than in Emblemaria nivipes, $\frac{2}{x_{1}}$ eye; teeth small, rather sharp, directed backward; longest dorsal spines as long as head; pectorals $1 \frac{1}{8}$ in head; ventrals $1 \frac{2}{5}$, inserted before pectorals. Color in spirits, brown, with traces of about 9 blackish cross bars, which are separated on the back by whitish, quadrate interspaces; a white spot at nape; some dusky below eye; dorsal dusky, the pale bars of back extending on its base; anal dusky; ventrals blackish; caudal pale, its tip black; pectorals pale. Gulf of California. Known from 1 specimen, $1 \frac{1}{2}$ inches long, from La Paz. It is shriveled and in poor condition. It seems to be very close to Emblemaria nivipes, but differs in the presence of an ocular cirrus, in the sharper snout, smaller mouth, and dusky ventrals. The teeth seem rather more slender, but can not be well examined. (oculus, eye ; cirrus, filament.)

Emblemaria oculocirris, Jordan, in Gilbert, Proc. U. S. Nat. Mus. 1896, 456, La Paz. (Type, No. 47749. Coll. Albatros8.)

\section{CH $Æ$ NOPSIS, Gill.}

Ohoenopsis, Gill, Ann. Lyc. Nat. Hist. N. Y., viri, 1865, 141 (ocellatus).

Body naked, eel-like. Head much elongate, quadrate behind, conic in front, profile straight; snout acute, jaws produced; no teeth on vomer, teeth in front of jaws strong, with villiform teeth behind them. Dorsal and anal long, continuous, confluent with the caudal. Dorsal rays about XVIII, 38; anal II, 38. Ventrals inserted slightly before pectorals. West

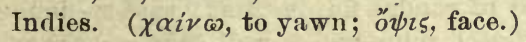

\section{CHENOPSIS OCELLATUS, Poey.}

D. XVIII, 38; A. II, 38; C. 15. Body naked, eel-like; anus submedian. Head much elongate, quadrate behind at the opercular region, conic in front, with the profile rectilinear and the snout acute; eyes moderate; 
mouth large, with the cleft wide and nearly horizontal. Teeth subcylindrical, in a uniform row, behind which, in front, there is a broad band of villiform teeth; on the palatine bones, uniserial and obtusely subcylindrical like those of the jaws; the palatine rows are parallel; vomer edentulons. Gill membranes confluent below, free from the isthmus. Dorsal and anal long, confluent with caudal; ventrals slightly in advance of pectorals, with 2 or 3 rays. (Gill.) Matanzas, Cuba; 1 specimen, examined by us in the National Museum. (ocellatus, having eye-like spots.)

Choenopsis ocellatus, PoEY, in_Giti, Ann. Lyc. Nat. Hist. N. Y., VII, 1867, 143, Matanzas, Cuba. (Coll. Poey.)

897. LUCIOBLENNIUS, Gilbert.

Lucioblennius, Gilbert, Proc. U. S. Nat. Mas. 1890, 103 (alepidotus).

Body் very elongate, wholly naked; gill membranes broadly united, free from isthmus; dorsal fin single, extending along the entire back, its anterior half spinous. Ventrals in front of pectorals, I, 2. First two anal rays spinous. Last rays of dorsal and anal joined to caudal. Teeth conic, not movable, in jaws and on vomer and palatines. Lateral line not described. A strange genus, evidently very close to Chanopsis. (Lucius, pike; Blennius, blenny.)

2760. LUCIOBLENNIUS ALEPIDOTUS, Gilbert.

Head 3 in length; depth $3 \frac{1}{4}$ in head. D. XVIII, 32; A. II, 30. Body much compressed, slender throughout, the head rather deeper and wider than body. Snout long, depressed, and rather wide, the anterior profile descending very gradually. Mouth nearly horizontal, the lower jaw protruding, the gape extenaing to much behind orbit, the entire physiognomy remarkably pike-like. Snout 4 in head; maxillary $1 \frac{8}{4}$; eye $4 \frac{2}{8}$ to 5 . Teeth in a villiform band in upper jaw, the outer series slightly larger; in lower jaw in a single series laterally, widening into a patch anteriorly, the outer enlarged; a few teeth only on vomer; palatines with a long and rather broad patch similar to those in jaws. Dorsal fin beginning on the nape in advance of middle of opercle, the fin uniformly low, extending the whole length of back, the posterior ray joined by membrane with the candal; the spines and rays are similar in appearance, flexible and simple, none of the soft rays branched; the spines are more slender, and show no joints, the articulations being present in small number on all the soft rays; the highest ray is less than diameter of orbit; anal and caudal rays similar to those of soft dorsal; caudal short, rounded; origin of anal midway between tip of snout and end of caudal fin, its first 2 rays spinous; ventrals under opercular margin, of 1 spine and 2 well-developed rays, nearly $\frac{1}{2}$ as long as head; pectorals narrow, of apparently unbranched rays, about $\frac{1}{2}$ as long as head. Color light olivaceous, with 11 vertical dark blotches on sides, most of which divide to form on middle of sides donble vertical bars; top and sides of head with dark cloudings, and with numerous black specks of varying size; middle of sides and base 
of dorsal with numerous pearly dots nearly as large as pupil; branchiostegal membrane black posteriorly; the lateral bars extended to base of dorsal, the anterior ones usually forming conspicuous black blotches which extend well up on the fin; other fins unmarked. Length $1 \frac{1}{2}$ inches. Gulf of California; two specimens from Albatross Station 3005, in 21 fathoms. ( $\dot{\alpha} \lambda \varepsilon \pi \tau \delta \omega \tau o ́ s$, scaleless.)

Lucioblennius alepidotus, GilberT, Proc. U. S. Nat. Mus. 1890, 103, Lower California (Coll. Albatross); Jordan, Proc. Cal. Ac. Sci. 1896, 233, pl. 37.

898. PHOLIDICHTHYS, Blecker.

Pholidichthys, BLEEKER, Boeroe, 406, 1856 (leucotonia).

Body elongate, tapering, naked; snout obtuse; no cirri; teeth unequal, on jaws only; dorsal, anal, and caudal fins distinct, but connected by a membrane; the dorsal formed of flexible spines; the soft rays, if present, not distinguishable from them; ventrals inserted scarcely before the pectorals, of 2 rays. Lateral line and vertebræ undescribed. Tropical parts of the Pacific. (Pholis; $i \chi \theta \dot{v} 5$, tish.)

\section{PHOLIDICHTHYS ANGUILLIFORMIS, Lockington.}

Head 62 in total length with caudal; depth 16 . Body exceedingly elongate, much compressed, naked; upper profile of head forming a continuous convex curve to the tip of the snout, which is abont equal in length to the eye. Eye lateral, round; interorbital space about $\frac{2}{8}$ of the diameter of the eye, convex transversely. Posterior extremity of maxillary vertical with the hinder margin of the eye. Tip of snout a little below the level from the center of the eye; mouth moderately oblique, lower jaw slightly the longer. Teeth of lower jaw in a close-set row, the largest in front, diminishing along the sides; teeth of upper jaw similar, but smaller; palate smooth. Vertical fins continuous, but distinct; dorsal entirely spinous; anal commencing a little behind the middle of the entire length of the fish; ventrals 2-rayed, very slightly in advance of the pectorals, which are about equal in length to the distance of their base from the eye. Color in spirits, dark blackish brown mingled with white upon top, sides, and lower parts of head; interorbital area and top of snout white. Gulf of California; a single specimen dredged off San Jose Island, Amortiguado Bay. 'T'otal length $1_{12}^{\frac{5}{2}}$ inches. Head $\frac{1}{4}$ inch. The example is broken across, the branchiostegals are defective, the caudal fin broken and some fin rays missing, so that the fin formula can not be exactly given. The dorsal fin has above 60 rays. The body is much more slender than that of P. leucotonia, Bleeker, and there is no trace of the longitudinal bluish-white band of that species. (Lockington.) (Anguilla, eel; forma, shape.)

Pholidichthys anguilliformis, Lockington, Proc. Ac. Nat. Sci. Phila. 1881, 118, San Jose Island, Lower California. (Coll. W. J. Fisher.) 
899. PSEDNOBLENNIUS, Jenkins \& Evermann.

Prednoblennius, Jenkins \& Evermans, Proc. U. S. Nat. Mus. 1888, 156 (hypacanthus).

Body compressed, elongate, naked; head short, blunt; no cirri; mouth large, the jaws subequal; teeth in a single series in each jaw, none on vomer or palatines; lateral line not developed. Dorsal fins 2 , the first at the nape, of three flexible spines; second dorsal with a few slender spines which pass into the soft rays; anal much shorter than second dorsal, both fins joined to base of candal; dorsal rays III-34; anal 27; ventral rays 2, the fin directly below pectorals. Appareutly close to Pholidichthys, but with the dorsal divided and changing gradually from spines to soft rays. ( $\psi \varepsilon \delta v o ́ s$, naked; Blennius.)

2762. PSEDNOBLEXNIUS HTPACANTHUS, Jenkins \& Evermann.

Head $4 \frac{8}{8}$ (5 in total); depth 7 (8); eye 4, equal to snout; B. 6. D. III-31; A. 27. Body greatly compressed, elongate; head short, snout blunt, about equal to eye; anteorbital profile very steep, gently rounded from front of eye to first dorsal, from there nearly straight to candal; ventral line nearly straight. Body naked, no membranaceous appendages. Mouth large. horizontal, jaws subequal, extending to beyond middle of eye. Teeth in a single series in each jaw, well developed, pretty uniform in size, slightly projecting backward; vomer and palatines apparently smooth. Eye large, equal to twice interorbital space, high up. Dorsal fins 2, the first of 3 very slender, flexible spines, hard to distinguish from soft rays, but they do not appear to be at all jointed. This fin is inserted upon the nape immediately above the posterior edge of the preopercle, and a distance in front of secoud dorsal nearly equal to length of suout, its very soft spines equal distance from end of snont to posterior rim of orbit; second dorsal begins directly over origin of pectorals and extends to caudal, with which it is slightly comnected; first fow rays of second dorsal very weak, flexible spines, the last few pretty evidently soft, jointed rays, while the intermediate ones are not distinguishable as definite spines or soft rays-in short, there seoms to be a gradual change from spines to soft rays from the anterior to the posterior part of the fin. This character, if we mistake not, is entirely unique. The fin is of nearly uniform height, the rays about equaling those of the first dorsal in length; anal similar to second dorsal in shape and height, but much shorter, its origin being much behind that of the second dorsal or nearly halfway from the snout to base of caudal; posteriorly it extends coterminously with the dorsal, and, like it, is slightly joined to the caudal fin; caudal fin apparently rounded, fan-shaped, but its shape can not be exactly made out, as some of its rays are broken off; pectorals inserted below axis of body, directly over ventrals, their length about $\frac{8}{4}$ that of head; ventrals of 2 rays, inserted under pectorals, about equal to pectorals in length; body entirely scaleless. Coloration in alcohol, pale, mottled with fine dark points so arranged as to inclose circular areas with fewer spots; a long dark blotch behind the axil, inclining downward and backward; head covered with similar punctulations; opercles dusky; chin with 2 
dark cross lines, separated by 1 of white, extending onto upper jaw on each side; top of head with a purple spot; sides with a series of about 6 short black lines, the last broadest and plainest; base of caudal with a distinct black blotch; first dorsal quite dark, almost black; second dorsal with about 8 pretty well-defined dark blotches at its base; rest of fin with numerous dark spots of different sizes; anal with about 12 dark blotehes extending somewhat regularly from the base sligbtly forward, these separated by plain unmarked spaces of a little greater width; caudal sparingly marked with dark points arranged in wavy cross bars; pectorals and ventrals unmarked. Gulf of California at Guaymas. A single specimen, 18 inches loug, obtained from a shallow arm of the bay. (Jenkins \& Evermann.) ( $\dot{\pi} \dot{o}$, below (imperfect); $\alpha \varkappa \alpha \nu \theta \alpha$, spine.)

Psednoblennius hypacanthus, Jenkins \& Evermann, Proc. U. S. Nat. Mus. 1888, 156, Guaymas, Mexico. ('Type, No. 39638. Coll. Jenkins \& Evermann.)

9oo. STATHMONOTUS, Bean.

Stathmonotus, BeAN, Proc. U. S. Nat. Mus. 1885, 191 (hemphillii).

Body moderately long and low, much compressed; head small, compressed, naked; mouth small, oblique; conical teeth in both jaws, in 2 series, the outer slightly enlarged and, in the upper jaw, somewhat recurved; a few teeth on the vomer. Gill membranes, as in Pholis, broadly united, free from the isthmus. Scales none. No lateral line. Dorsal fin long and low, beginning near the head, and consisting entirely of stiff, sharp spines, which are very short anteriorly and gradually increase in size posteriorly. Anal similar to dorsal, with 2 spines aud many soft rays. Caudal short, rounded, scarcely separated from the dorsal and anal; pectorals small, much smaller than in Pholis, containing only a few rays; ventrals better developed than in Pholis, their position more anterior, consisting of a spine and 2 rays. Pseudobranchiæ absent. Branchios-

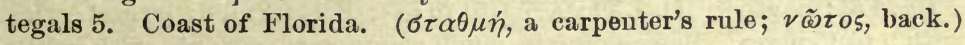

2763. STATHMONOTUS IIEMPHILLI, Bean.

Head 7 ; depth 8 to $8 \frac{1}{2}$; D. LI; A. II, 27 ; V. I, 2 ; P. 5 or 6 ; eye 6 in head. Maxillary extending about to vertical through hind margin of eye; jaws subequal, or the lower projecting very slightly beyond upper; eyes small, separated by an interspace about equal to their own length, and very slightly greater than length of snout; pectoral very little more than $\frac{1}{6}$ as long as head, and scarcely as long as ventral; dorsal beginning over posterior end of pectoral, its anterior spines very much shorter than the posterior ones; length of caudal about equal to length of postorbital part of head; vent slightly in advance of middle of total length to base of caudal, and about under the twentieth dorsal spine. Colors from the alcoholic specimen: A white line extending from tip of snout to caudal, divided into small segments by short cross bars, the first 2 on the head, and the last at origin of caudal; posteriorly, these short bars extend downward, terminating slightly below the base of the dorsal fin; several white blotches, simulating bars, on posterior half of anal fin; edge of 
caudal white; sides and under surface of head with several whitish oblique bands forming $V$-shaped markings; a few roundish white blotches on sides of head, the most conspicuous behind eye; general color darkish brown, nearly black. Length about 2 inches. Key West; 2 specimens known. (Bean.) (Named for the collector, Henry Hemphill.)

Stathmonotus hemphillii, Bean, Proc. U. S. Nat. Mus. 1885, 191, pl. 13, Key West, Florida. (Coll. Henry Hemphill. Type, No.37193, U.S. Nat. Mus.)

901. BRYOSTEMMA, Jordan \& Starks.

Bryostemma, JoRDAN \& STARKs, Proc. Cal. Ac. Sci.1895, 841 (polyactocephalum).

Body moderately elongate, covered with small scales; suout short; no teeth on vomer or palatines; teeth in jaws small; gill membranes united, free from the isthmus; nostrils, orbital regions, and neck with dermal flaps, the supraorbital flaps high. Dorsal fin long, of spines only; pectorals well developed, more than half length of head; ventrals well developed, jugular; caudal fin distinct. No air bladder or pyloric cæea. No true lateral line; a short series of large pores above pectoral. North $\mathrm{Pa}$ cific, representing Chirolophis of the Atlantic. This genus differs from the European genus, Chirolophis, Swainson (Blenniops, Nilsson), in the absence of a true lateral line. Dr. Boulenger informs us that a true median lateral line is developed in Chirolophis ascanii. ( $\beta \rho v v^{\prime} \nu, \operatorname{moss} ; \sigma \tau \varepsilon \dot{ } \mu \mu \alpha$, crown.)

a. Dorsal with about 60 spines; anal with about 55 soft rays; a black spot on anterior part of dorsal, but no ocelli posteriorily. POLYACTOCEPHALUM, 2764.

$a a$. Dorsal with about 54 spines; anal with 40 soft rays; dorsal with several black ocelli, most distinct posteriorly.

NUQATOR, 2765.

\section{BRYOSTEMMA POLYATOCEPHALUM (Pallas).}

Head $6 \frac{1}{2}$; depth 6. D. LXI; A. 55 (51 to 57); P. 14; V. I, 3; lateral series with 9 to 15 pores. Body elongate, much compressed, covered with sinall, smooth, embedded scales. Head very short, blunt in profile; mouth short, terminal, the maxillary 3 in head; lower jaw heavy, projecting, its tip with 2 small slender cirri, which are pale in color; teeth subequal, small, bluntish, close set, in 1 row in each jaw; eyes 4 in head, near together; the snont 4 ; supraorbital cirri $2 \frac{1}{3}$ in head; interorbital space flat; a flat fringed cirrus over front of eye, these 2 joined at base, about 3 in head; a small cirrus about $\frac{1}{2}$ length of this over posterior part of each eye, these 5 to 6 in head; top of head and nape covered with series of erect cirri, the longest nearly as long as eye; about 15 minute cirri along dorsal edge of lateral line, 1 on each pore. Rows of pores running around eye, under preopercle, and along entire length of the short lateral line; lateral series of pores $\frac{1}{2}$ length of head; gill rakers not developed. Dorsal fin beginning over pectoral and running to caudal; anterior rays fringed with fleshy cirri; first ray, including cirri, 2 in length of head; anal beginning close behind vent and rumning to caudal, to which it is joined at base; distance from tip of snout to vent nearly 3 in body; peetoral fin but little shorter than head, its breadth at base not $\frac{1}{2}$ its length. Color in spirits, pale 
brownish, plain or mottled with darker, with about 13 dark blotches along dorsal and anal fins, more distinct on dorsal; a black spot on fourth to sixth dorsal spines very distinct; a faint one on anterior part of anal; a fow dark markings about head and nape; cirri mostly pale. Bering Sea, soutl to Puget Sound and Yezo. Here described from a fine specimen, $6 \frac{1}{2}$ inches long, from Port Orchard, near Seattle, collected by Prof. O. B. Johnson. Other specimens before us from St. Paul (Pribilof Islands), from Albatross Stations 3213 and 3274, south and north of the Peninsula of Alaska, and from Petropaulski Harbor, Kamchatka. These specimens show a great deal of variation, and possibly represent 3 different species. It is more likely, however, that they represent extremes of variation. Young examples, collected by the Albatross in eastern Bering Sea, are more elongate and less compressed; body much mottled and vaguely barred; ventral fins checkered in fine pattern; head sand color; a black blotch on fourth to sixth dorsal spine; anterior dorsal spino little elevated and with few fringes; sides of head without cirri; anterior cirri joined almost to the tip, a little shorter than the posterior cirri, wlich are long and very slender. In 1 specimen of these, however, the cheeks are covered with densely matted cirri extending from the angle of the mouth to the dorsal. In these examples the anterior cirri are short and separate, about as long as the posterior cirri. The larger example, $75 \mathrm{~cm}$. long, from Petropaulski, is evidently the typical polyactocephalum, and corresponds perfectly to Herzenstein's account of B. japonicum. It shows the following characters: Head $6 \frac{1}{8}$; depth $5 \frac{1}{5}$. D. LXI; A. 45; P. 14; V. I, 3; lateral series with 6 pores. Body a little deeper than in Puget Sound examples; head short, blunt in profile; mouth short, terminal, oblique, the maxillary $2 \frac{2}{3}$ in head; lower jaw heavy, projecting, its tip with 2 broad fringed flaps of a dark color; eyes 4 in head, close together, the interorbital space concave; a fringed cirrus above each eye in front, the 2 connected with each other only in the thickened skin at base; a similar cirrus over each eye behind; the posterior cirri $\frac{1}{5}$ longer than the anterior ones, $2 \frac{1}{8}$ in head; top of head and nape with similar cirri, none of them longer than pupil; a few small cirri on cheeks and opercles; some along lateral series of pores, which is $2 \frac{1}{2}$ in head; anterior rays of dorsal fringed with fleshy cirri, the first 2 in head; distanco from snout to vent $2 \frac{8}{4}$ in body; pectorals nearly as long as head, the rays thickened in the adult, the base of the fin about $\frac{1}{2}$ its length. Color very dark brown, with vaguo cross bands and many spots; dorsal and anal each with a broad black edge; other fins all blâck, the caudal barred. Perhaps the dark coloration and long cirri are characters of the adult male. ( $\pi \circ \lambda$ is, many; $\dot{\alpha} \varkappa \tau i \varsigma, \operatorname{ray} ; \varkappa \varepsilon \phi \alpha \lambda \dot{\eta}$, head.)

Blennius polyactocephalus, PALLAs, Zool. Rosso-Asiat., III, 179, 1811, Kamchatka.

Chirolophus japonicus, Herzenstein, Mélanges Biologiques Soc. Sci. Petersb., Xıri, 1890, 123, Yezo.

Chirolophis polyactocephalus, JornAN \& GILBERT, Synopsis, 765, 1883; BeAN in Nelson, Rept. Nat. Hist. Coll. Alaska, 305, pl. 15, f. 2, 1887.

Bryostemma polyactocephalum, JordaN \& Starks, Proc. Cal. Ac. Sci.1895, 841; JordaN \& Gilbert, Rept. Fur Seal Invest., 1898.

$3030-74$ 
2765. BRYOSTEMMA NUGATOR, Jordan \& Williams.

Head $5 \frac{1}{2}$; depth $5 \frac{1}{2}$; D. LIV; A. 41; V. I, 3; pores of lateral line 25. Body elongate, less compressed than in Bryostemma polyactocephalum, covered with small, smooth, ombedded scales. Head short, very obtuse, almost truncate; top of head from nostrils to near front of clorsal covered with fleshy cirri, much smaller than in B. polyactocephalum; only 2 or 3 small ones extending on first dorsal spine; supraorbital cirrus short, 4 to 5 in head; 2 small cirri placed at the sides of snout with a larger median one behind them, forming a triangle; jaws equal; mouth horizontal, the angle extending to below pupil; eyes small, 4 in head; snout very short, almost vertically truncate, $\frac{2}{8}$ in eye; teeth of both jaws subequal, short, bluntish, and close set. Lateral line short, $7 \frac{1}{2}$ in length of body, concurrent with the dorsal outline of body. A line of pores begins in front of eye on a level with pupil, runs under eye and to a level with pupil again, then back to and along the entire length of the short lateral line. Gill rakers not developed; gill membranes free from isthmus. Vent $\frac{1}{8}$ distance from tip of snout to tip of caudal; distance from origin of ventral to anus $4 \frac{1}{2}$ in length of body Pectoral fin $5 \frac{1}{2}$ in body, as long as head. Dorsal fin beginning in front of the pectoral, highest along the posterior half, the longest spine $2 \frac{2}{3}$ in head, the fin higher than anal; dorsal slightly joined to caudal; anal separated from caudal; caudal rounded, $1_{5}^{2}$ in head; first dorsal spine $4 \frac{1}{2}$ in head, its surface with 2 or 3 small cirri. Color in spir. its of 1 specimen, probably male, dark brown, with 13 pale cross bars along back, extending on dorsal fin; along sides these become obsolete; on belly they become increased in number and broadened below; dorsal fin with 13 large, very distinct black ocelli with yellowish rings, 1 between each pair of the pale blotches; anal with about 7 small blackish spots at base on posterior part, the fin otherwise nearly plain; caudal faintly barred with light and dark; pectorals pale, with 2 dark paleedged oblique bars before it; sides of head with irregular dark vertical bars, 1 of them forming an inverted $\wedge$ below eye, this and others extending across lower jaw; cirri mostly black. The other specimen, probably the female, has the body nearly plain brown, the dorsal with but 4 ocelli, the anterior 9 being replaced by dark bars on the fin; anal with dark oblique cross bars; pectorals barred with black; markings on head more sharply defined, coloration otherwise similar. This second specimen is $4 \frac{8}{4}$ inches in length, the other 4. Puget Sound; the above account from the 2 original types from near Seattle. Three otbers since obtained near Channel Rocks, Port Orchard, show the following life coloration: Dark red above, orange brown below, belly cream color; sides below with cream-colored cross bars, wider than eye, ruming from the axis of body downward and fading into the general color below; a $\Lambda$-shaped mark downward from eye across branchiostegals to isthmus, a similar mark behind eye across edge of preopercle, this last sometimes broken up and chain-like; top of head dark; snout light; 2 oblique dark bars at base of pectoral; dorsal with 12 or 13 sharp dark brown spots as large as eye, edged with bright red, these airanged regularly along the whole length of fin; pectorals and caudal bright red with wavy, irregular, brown 
lines running across the rays; anal red, with dark brown bars as wide as the interspaces running obliquely down ward and forward; ventrals light brown. (nugator, a fop.)

Bryostemma nugator, JoRdan \& Williams, Proc. Cal. Ac. Sci. 1895, 843, pl. 101, Seattle, Washington. (Coll. Young Nat. Soc. Type, No. 3134, L. S. Jr. Univ.)

\section{APODICHTHYS, Girard.}

Apodichthys, Girard, Proc. Ac. Nat. Sci. Phila.1854, 150 (flavidus).

Body elongate, compressed, covered with very small scales; no lateral line; suout short; mouth moderate, oblique; teeth in the jaws moderate, stouter anteriorly; vomer with teeth; gill membranes united, free from the isthmus. Dorsal fin long, low, even, of spines only; anal fin similar, preceded by a very large pen-shaped spine ehanueled along its anterior surface and hidden in a pouch of skin; caudal fin slort, connected with dorsal and anal; no ventral fins; pectoral fins moderate; intestinal canal short, without pyloric caca. Small, bright-colored fishes of the Pacific, living among rocks near shore. ( $\alpha{ }^{\prime} \pi \circ v 5$, without feet; $i \chi \theta \dot{v} \zeta$, fish; in allusion to the want of ventral fins.)

a. Color various, green, olive, or scarlet; sides of head without silvery baud; depth 7 to 8 in length; head 9.

b. General color olivaceous.

bb. General color scarlet.

$b b b$. General color grass green.

FLAVIDUS, 2766.

var. flavidus, 2766a.

var. sanguincus, $2766 \mathrm{~b}$.

var. virescens, $2766 \mathrm{c}$.

$a a$. Color reddish; a bluish silvery stripe on side of head; depth 9 to 10 in length; head 7. UNIVITTATUS, 2767.

\section{APODICHTH YS FLAVIDUS, Girard.}

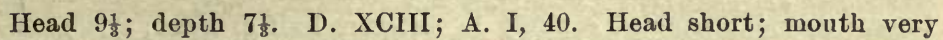
oblique; maxillary reaehing pupil; upper jaw with a series of conical teeth, behind which is a patch of smaller teeth; sides of mandible with conical teeth in a single series, forming a patch in front; vomer with 3 conical teeth; palatines toothless; nape equidistant between front of clor-

- sal and pupil. Anal spine very large, $\frac{2}{5}$ length of head, shaped like a pen, deeply excavated on its anterior side, and very convex behind, very thin, flexible, and with sharp edges, entirely included in a ponch of skin; pectoral fius alout $\%$ length of head. Color orange, varying with the surroundings to intense grass-green (var. virescens), yellowish brown (var. flavidus), crimson and dark purple (var. sanguineus); a fow light round spots along axis of body posteriorly; a narrow black bar downward and backward from eye; a shorter, less distinct bar from upper margin of orbit backward to occiput; anal fin obliquely barred with brownish. Length 18 inches. Pacific coast, Vancouver Island to the Santa Barbara Islands; abundant; usually found below low tide mark. The following color notes are from specimens taken in Puget Sound belonging to the green form (var. virescens), the larger 10 inches in length, the smaller 3 iuches. The large one is a bright grass-green, mottled with light gray; a series of blended white spots, as large as eye, along the axis of body 
from the pectoral fin to the middle of caudal peduncle; belly with many similar spots smaller in size and somewhat sharper in outline; a row of conspicuous black spots, irregular in size, shape, and position, along back at the base of dorsal spines; a black line as wide as pupil from nape to eye, a similar line from eye to posterior end of maxillary; a faint light streak across cheek posteriorly; cheek and base of pectoral dusted with fine dark points. The small one is bright green without distinct markings on body; a silvery bar, running posteriorly from tip of snout through eye, across cheek, to the middle of opercle; no bar downward from eye to maxillary, or from eye to nape as in the large one. (flavidus, yellowish.)

Apodichthys flavidus, Grand, Proc. Ac. Nat. Sci. 1854, 150, Presidio, San Francisco Bay

(Coll. Dr. Kennerly. Type, No. 494, U. S. Nat. Mus.); Girard, Pac. R. R. Surv., x,

Fishes, 117,1858; Günther, Cat., 290, 1861; Jordan \& GILbert, Synopsis, 769, 1883.

Apodichthys virescens, Arres, Proc. Cal. Ac. Nat. Sci: 1855,55, San Francisco; Girard,

Pac. R. R. Surv., X, Fishes, 118, 1858.

Apodichthys inornatus, GiLl, Proc. Ac. Nat. Sci. Phila. 1862, 279, Puget Sound, probably

(Coll. Northwestern Boundary Commission); D. XC; A. 38.

Apodichthys sanguineus, GiLl, Proc. Ac. Nat. Sci. Phila. 1862, 279, California. (Coll. Dr. Samuel Hubbard.)

2767. APODICHTHYS UNIVITTATUS, Lockington.

D. about XCV; A. about I, 40. Body elongate, much compressed, bandlike, preserving almost same depth to about posterior fifth of body, thence tapering more rapidly to caudal fin. Head 7; depth nearly 10 times in total length; depth of caudal peduncle about $\frac{1}{2}$ of that of body; snout obtuse, about $\frac{2}{8}$ as long as diameter of eye, upper profile of head a continuous curve from snout to occiput. Interorbital area highly convex transversely, about equal in width to $\frac{1}{2}$ diameter of eye. Eye entirely lateral, round, contained entirely in anterior half of head; iris golden. Mouth small, posterior extremity of the maxillary reaching to anterior margin of eye. Teeth small. Branchiostegals5. Dorsal continuous with, but distinct from, anal, arising vertically from tip of operculum, and composed of spines only. Anal preceded by a long, sharp, slender spine of V-shaped transverse section, hollow side anterior, length of spine equal to about $\frac{1}{2}$ depth of fish. Distance from anal spine to tip of operculum a little more than to tip of caudal. Caudal with numerous accessory rays, so that its sides are almost straight, posterior margin broken in the type, all rays simple. General color in spirits, light reddish, vertical fins rather bright, and top of head reddish brown; tip of snout brown; a silvery band (possibly bluish in life) from tip of snout, across lower part of eye, cheek, and.opercles, terminating at about middle of length of opercnlum, this band bordered above by a narrower brown band. Lower California, probably from the guff. A single specimen. Length 1.88 inches. The peculiar vitta upon each side of the head at once distinguishes this species from the other described forms. (Lockington.) Not seen by us. (uni-vittatus, having one band.)

A podichthys univittatus, Lockington, Proc. Ac. Nat. Sci. Phila. 1881, 118, Gulf of California. 
903. XERERPES, Jordan \& Gilbert.

Xererpes, Jordan \& Gilbert, Proc. Cal. Ac. Sci. 1895, 846 (fucorum).

This genus differs from Apodichthys in the moderate size of the anal spine, which is rounded and not chauneled on its anterior edge, and in the small size of its pectoral fins. The single known species lives in Fucus chiefly above low-tide mark and may often be shaken out of half-dry mats of seaweed on rocks well above the water. ( $\xi \varepsilon \rho o ́ 5$, drj; $; " \rho \pi \eta 5$, creeper.)

\section{XERERPES FUCORUM (Jordan \& Gilbert).}

Head 10 ; depth $9 \frac{1}{2}$. D. LXXXIII; A. 35. Form and dentition as in Apodichthys flavidus. Mouth very oblique, the maxillary reaching center of pupil; nape nearer front of dorsal than end of snout. Anal spine comparatively small, abont $f$ length of head, transversely very convex in front, and slightly concave or grooved behind, the pouch of skin at its base little developed; pectorals very small, shorter than eye; anal fin beginning nearer tip of caudal than tip of snout by about 3 times length of head. Bright olive green or deep red, the color varying with the surroundings; a row of dark spots along axis of body, these sometimes with light-bluish conter, and connected by a very narrow dark streak; generally a dark streak downward from eye, but no other markings about head. Length 6 inches. Monterey to Puget Sound; abundant in rock pools and bunches of Fucus; remarkable for its active movements. It is found mostly in masses of Fucus attached to rocks between tide marks, and it is often found at low tide at a considerable distance from any water, kept damp by the masses of alga. Sometimes a dozen of them can be shaken from a bunch of algæ attached to a dry rock. It is, like the species of Xiphidion, very active, moving over stones or sand, and showing less anxiety about the presence of its native element than any other fish known to us. (fucorum; of the Fucus or seaweed.)

Apodichthys fucorum, Jordan \& GILBerT, Proc. U. S. Nat. Mus. 1880, 139, Monterey (Coll. Jordan \& Gillert); JoRdaN \& GILBERT, Synopsis, 770, 1883.

Xererpes fucorum, JoRdan \& StakKs, Proc. Cal. Ac. Sci. $1895,846$.

904. ULVICOLA, Gilbert \& Starks.

Ulvicola, Gilbert \& Starks, Proc. U. S. Nat. Mus. 1896, 455 (8anctoe-rosae).

This genus is allied to Xererpes, but differs in having the opercle above angle adnate to shoulder girdle, in the smaller size of the anal spine, and especially in the entire absence of pectoral fins. (Ulva, sea lettuce; colo, I inhabit.)

2769. ULVICOIA SANCTE-ROSE, Gilbert \& Starks.

Head 10 in body; depth 13. D. XCVII; A. I, 40; eye $4 \frac{1}{2}$ in head; caudal 1 $\frac{1}{2}$. Body elongate, as in Apodichthys, strongly compressed, upper profile of head slightly convex, no construction at nape; mouth very small, oblique, the maxillary reaching about to front of eye; teeth very small in 
a single row on jaws; vomer with teeth; interorbital a narrow, sharp ridge; snout about equal to length of eye; gill opening short, limited to the part below angle of opercle, above adnate to shoulder girdle. Origin of dorsal above upper end of gill opening, much nearer occiput than tip of snout; anal spine small, not channeled as in Apodichthys flavidus; origin of anal nearer base of caudal than tip of snout by a distance equal to twice length of head; pectorals and ventrals obsolete; caudal rather long, confluent with dorsal and anal. Color in spirits, light brown, slightly lighter under head and on belly; no markings. The type is a specimen $4 \frac{1}{2}$ inches in length, collected by the Albatross at Santa Rosa Island, off Santa Barbara, January 6, 1889. (Type, No. 47579. Coll. Albatross.)

Clvicola sanctoe-rosa, Gribert \& Starks, Proc. U. S. Nat. Mus. 1896, 455, pl. 55, fig. 2, Santa Rosa Island, California.

\section{PHOLIS (Gronow) Scopoli.}

(GUNxELs.)

Pholis, Growow, Zoophylaceum, 78, 1765 (not binomial).

Pholis, Scopoli, Introd. Hist. Nat., 456, 1777 (gunnellus).

Murcenoides, L ACÉPÈDE, Hist. Nat. Poiss., II, 324, 1800 (sujef).

Centronotus, BLoch \& Schneider, Syst. Ichth., 165, 1801 (fasciatus).

Dactyleptus, Rafinesque Anal. de la Nature 1815,82; substitute for Muronoides.

Centronotus, Cuvier, Règne Animal, Ed.2, II, 239, 1829 (gunnellus).

Ophisomus, * Swainson, Nat. Hist. Class'n. Anim., II, 277, 1839 (gunnellus).

Urocentrus, K.ver, Sitzber. K. Akad. Wiss. Wien, LvII, 1868, 51 (pictus).

Rhodymenichthy8, JoRDAN \& EVERMAN, Check.List Fishes, 474, 1896 (ruberrimus =doli. chogaster).

Body long and low, considerably compressed, somewhat band-shaped, the tail slowly tapering; head small, compressed, naked; $\dagger$ mouth rather small, oblique; jaws with rather small teeth in narrow bands or single series; vomer and palatines usually toothless; gill membranes broadly united, free from the isthmus; scales very small, smooth; no lateral line. Dorsal fin long and low, beginning near the head, composed entirely of stiff, sharp, subequal spines; anal similar in form, of 2 spines and many

*Substitute for Gunnellus, the latter being a barbarous word derived from " gunwale." "Nomina generica quæ ex Græca vel Latina lingua radicem non habent, regicienda sunt." This rule has never been generally adopted.

In Pholis nebulosus, a Japanese species, the head is scaly. This species is the type of a distinct genus; which may be called

ENEDRIAS, Jordan \& Gilbert, new genus.

Enedrias, JORDAN \& GILBERT, new genus (nebulosus).

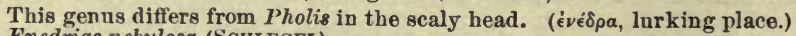

Enedrias nebulosa (SCHLEGEL).

Head $7 \frac{1}{2}$ to $8 ;$ depth $8 \frac{1}{2}$ to $9 \frac{1}{2}$. D. LXXX; A. II, 39. Dorsal and anal somewhat connected to caudal; pectoral $2 \frac{1}{3}$ to $2 \frac{2}{3}$ in head. Head small. Body everywherc freckled with dark blotches; 12 dark triangular blotches ilong base of dorsal; a rov of dusky blotches on middle of side posteriorly; 10 or 12 dark blotches on base of anal; caudal dusky, edged with pale, 2 pale cross streaks on top of head; pectoral pale. Northern Japan to Okhotsk Sea, Gulf of Strietok; our specimens from Hakodate. (nebulosus, clouded.)

Gunnellus nebulosus, Schlenel, Fauna Japonica, Poiss., 138, 1850, Bay of Magi, Japan. Centronotus nebulosus, STEINDACHNER, Iclith. Beitr., IX, 24, 1880.

Enedrias nebulosus, JoRdAN \& GiLBERT, Rept. Fur Seal Invest., 1898, with plate. 
soft rays; caudal fin short and small, more or less joined to dorsal and anal; pectorals short, rather shorter than head; ventrals very small, of 1 spine and a rudimentary ray; intestinal canal short, without creca. Shore fishes of the Northern seas. ( $\phi \omega \lambda i 5$, name of some fish said to shelter itself when lying in wait by producing a clond of mucus; $\phi \omega \lambda \alpha_{5}$, one who lies in wait.)

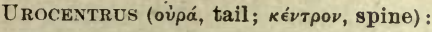

a. Pectoral fin small, $3 \frac{1}{2}$ to 4 times in length of head; dorsal spines about 93 ; anal rays 48; borly with 2 rows of dark blotches; fins nearly plain.

aa. Pectoral fin moderate, 2 to $2 \frac{1}{2}$ times in length of head.

PICTUS, 2770.

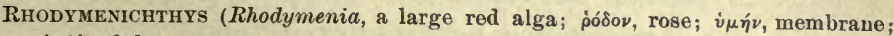
¿ $\chi \theta \dot{v} s$, fish).

b. Dorsal and anal joined to the caudal to the full height of the spines, withont constriction at base of caudal; body greatly compressed, ribbon-like. Dorsal spines about 93 ; anal abont 47 ; pectorals short, $2 \frac{2}{3}$ in head; no ocelli along base of dorsal.

Phоlis :

DOLICHOGASTER, 2771.

$b b$. Dorsal and anal slightly connected with caudal, leaving a constriction of ont-

line at base of caudal; body less compressed; dorsal fin with dark

blotches or ocelli.

c. Pectoral fins well developed, about $\frac{1}{2}$ length of head. Dorsal spines about 88 ; anal rays about 42 ; pectoral $2 \frac{1}{3}$ in head; dorsal fin with dark quadrate blotches rather than ocelli; sides scarlet in adult, bounded with black.

FASCIATUS, 2772.

cc. Dorsal spines about 80 (76 to 85$)$; anal rays about 40 ; pectoral 2 in head; dorsal fin with small rounded black blotches. GuNNELLUs, 2773.

ccc. Dorsal spines about 77 ; anal rays about 35 ; pectoral 2 in heal ; dorsal fin with ocelli, or lunate, dark blotches.

ORNATUS, 2774.

Subgenus UROCENTRUS, Kner.

2770. PHOLIS PICTUS (Kner).

Head $9 \frac{1}{2}$ to $10 \frac{1}{2}$; depth 8 to 10 . D. XCIII or XCIV; A. II, 46 to 48 (misprinted 40 in Kner's account). Eye as long as snont; mouth oblique, the upper jaw the longer, reaching to front of eye; pectorals very short, scarcely longer than eye, 3 to 4 in head; anal said to have an isolated channeled spine hidden in the skin, but our specimens show no peculiar structure. Color yellowish, with 2 lengthwise series of large oblong blackish blotches, the one along base of dorsal, but not on the fin, of 21 or 22 blotches, the other on lower part of sides, of about 25; a series of fainter blotches along base of anal; in other specimens the lower row becomes obscure, the upper more distinct, and the series above anal disappears; a black bar downward from eye, a whitish band behind it; opercles dusky. West side of Bering Sea; our specimens from Shana Bay, Iturup Island, Kuril Group.

As already shown by Steindachner, this is a typical Pholis, Kner having been in error in ascribing to it an isolated and channeled first anal spine. The ventral spines are bound down by the integument more closely than usual, but thoy are in other respects not peculiar. Each is accompanied by 2 short spinous rays concealed in the membrane, and difficult to detect. 
The latter are stiff and pungent, and seem to be not articnlated. The ventrals of $P$. ornatus show the same structure. Kner gives the anal formula as II, 40. This must be a misprint for II, 49, as the artist figures 51 rays in the fin, not differentiating the 2 anterior ones. (pictus, painted.)

Urocentrus pictus, KNER, Sitzungsb.d. k. Akad. D. Wissench., LvIII, 1868, 51, taf. 7, fig. 21, Singapore; an error.

Centronotus pictu\&, STeINDACHNer, Ichth. Beiträge, IX, 25, 1880.

Pholis pictus, Jordan \& GILBERT, Rept. Fur. Seal Invest., 1898.

Subgenus RHODYMENICHTHYS, Jordan \& Evermann.

2771. PHOLIS DOLICHOGASTER * (Pallas).

(BUTTER-FISH.)

Head $9 \frac{4}{5}$ in length; depth 8. D. XCII; A.II, 44 ; pectoral 14 ; eye 5 in hear ; maxillary $2 \frac{8}{4}$; pectoral $2 \frac{1}{2}$; caudal 2 ; ventral spines $1 \frac{3}{5}$ in eye. Body elongate, much compressed; head small, its upper profile convex; mouth moderate, very oblique, the maxillary reaching to below middle of eye; teeth rather large and blunt, arranged in a single row, the anterior one not enlarged; interorbital space narrow, without a sharp ridge, its width less than eye; snout equal in length to eye; distance from tip of snout to occiput $1 \frac{5}{6}$ in head. Head entirely naked; body covered with small, cycloid, inconspicuous scales. Origin of dorsal over upper end of gill slit, its distance from nape equal to distance from nape to front of eye, the spines toward the anterior end of the fin the highest; origin of anal a little nearer tip of caudal than snout; dorsal and anal confluent with caudal, the anal more broadly connected than dorsal; pectorals small, rounded behind; ventral spines inserted directly under base of pectorals, their length little greater than their distance apart; caudal short and broad, well rounded in outline. Bering Sea ; recorded from the Kurils, and from Robben, Bering, and Medni islands, and from Kigiktowik Bay. The specimen above described was taken at Robben Island by Capt. J. G. Blair, then in command of the guardship Leon. It is 9 inches long and is uniform red in color, with a few pale dots. Another specimen, $18 \mathrm{~cm}$. long, taken by Mr. Gerald E. H. Barrett-Hamilton at Bering Island, shows the following characters: The color is cherry red on the body and fins, lighter on belly, lower half of cheek and under side of head; lips blackish anteriorly, a narrow black streak running from them along snout to eye and from eye across cheek and opercles toward upper edge of pectoral base; this line separates the deep-red upper part of the head from the lighter area below;

* The following spec1es is allied to Pholis dolichogaster:

Pholis taczanowskii (Steindachner).

Head 9: depth 10; D. LXXXII; A. II, 45; teeth bluntly conical; dorsal rery low, joined to the caudal without constriction. Snout scarcely longer than eye, which is $5 \frac{1}{3}$ in head. Pectoral 3 in head. Scales very small, the head naked. Clear, yellowish gray, finely dotted, fins grayisl, the pectoral yellowish; a yellowish streak edged with darker from eye to axil. Gulf of 'strietok. (Steindachner.) (A personal name.)

Dentronotus taczanowskii, Steindachner, Ichth. Beitr., IX, 24, pl. 3, fig. 1, 1880, Gulf of Strietok, Okhotsk Sea. (Coll. Prof. Dybowsky.) 
sides of body with a number of minute scattered black spots; along middle of sides is a distant series of light spots as large as pupil, the margin of each with 2 to 4 black specks like those scattered over sides. The dorsal and anal are more widely joined to the caudal than in other species, the fins being higher posteriorly and without perceptible notch. The dorsal contains 93 spines, the anal 2 spines and 47 rays, the pectorals 15 rays. Head $9 \frac{1}{2}$ in length; depth $7 \frac{5}{6}$. Eye 5 in head; maxillary $3 \frac{8}{4}$; pectorals $2 \frac{1}{2}$; caudal $2 \frac{1}{3}$; ventral spine $2 \frac{1}{5}$ in eye. Blennius dolichogaster, Pallas, is undoubtedly identical with Gunnellus ruberrimus, Cuvier \& Valenciennes. They agree in the very long dorsal and anal fins (D. XCIII, A. II, 50 in dolichogaster), and in the color. $P$. dolichogaster is described as having the color brownish olive, shaded with greenish and yellowish, spotted with green above the lateral line; belly yellow; anal, caudal, and pectorals yellowish; dorsal and anal dusky, with transverse pale bars. Compare with this, details of coloration recently published concerning P. ruberrimus by Bean \& Bean (Proc. U. S. Nat. Mus. 1896, 248): "Color olive brown, with minute black spots; belly ycllowish." In another specimen, "Across the spinous dorsal there are 20 narrow, nearly vertical pale streaks. . Similar streaks to the number of 12 cross the anal." The species

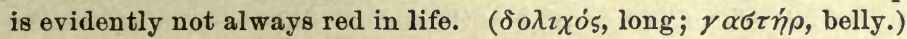

Blennius dolichogaster, PaLlus, Zoogr. Rosso-Asiat., III, 175, 1811, Kamchatka. (Type in Mus. Berlin.)

Gunnellus ruberrimus, Cuvier \& VAlenciennes, Hist. Nat. Poiss., XIV, 440, 1839, Kuril Islands; after notes of PALLAS, * Zoogr. Rosso-Asiat., III, 178, 1811.

Gunellus dolichogaster, Cuvier \& Valenciennes, Hist. Nat. Poiss., XI, 436, 1836.

Centronotus dolichogaster, Günther, Cat., 288, 1861.

Murcenoides dolichogaster, JoRDAN \& GILBERT, Synopsis, 768, 1883.

Pholis dolichogaster, JoRdan \&. Gilbert, Rept. Fur Seal Invest., 1898.

Rhodymenichthys ruberrimus, JoRDAN \& EvERMAN, Check-List Fishes North and Middle America, 474, 1896.

Pholis ruberrimus, BEAN \& BEAN, Proc. U. S. Nat. Mus. 1896, 248.

\section{Subgenus PHOLIS.}

\section{PHOLIS FASCIATUS (Bloch \& Schneider).}

Head 8 to $9 \frac{1}{2}$; depth 7 to 9. D. LXXXVI to LXXXIX; A. II, 42 to 44 ; V. I, 1. Head scaleless; month decidedly oblique, the tip of lower jaw on level of middle of the eye; width of mouth nearly $\frac{1}{2}$ head. Eye equal to snout, a little more than interorbital width; ventral spive $\frac{2}{8}$ eye, $\frac{1}{2}$ length of mandible; candal $\frac{1}{2}$ head; pectoral $2 \frac{1}{4}$ in head; vertical fins slightly joined at base. Ground color yellowish gray in life, the sides of a brilliant scarlet; base of dorsal occupied by 10 or 11 oblong blotches of dark brown, which extend to the tips of the fins; these blotches each divided upon the fin by a median spot of the ground color; the areas of the ground color alternating with these blotches are finely speckled with brown, a large spot of brown usually occupying a median

* Bright red. Form of toenia; scales inconspicuous; ventrals each a single scarcely projecting spine; caudal broad, rounded, distinct. D. CXV. Kuril Islands. (Pallas.) Murcenoides ruberrimus, BEAN, in Nelson, Rept. Nat. Hist. Collections made in Alaska, 305, pl. xiv, fig. 1, 1887. 
position upon the fin; middle and lower part of sides occupied by vermiculating brown lines on the ground color, these vermiculations arranged in more or less distinct cross bars, about 20 in number, reaching to or nearly to the midventral line, the posterior ones often continued faintly onto the anal fin; pectoral and caudal fins yellow, unmarked; a brown blotch across snout and tip of mandible, followed by a narrow yellowish bar descending to front of eye; interorbital space crossed by a broad brown bar with blackish margins, which become much narrower below and traverse the eye and the cheek; behind this a broader yellow bar, margined behind with a narrow brown line. In life the coloration is extremely brilliant, the pale markings being bright orange or scarlet. Bering Sea and Arctic Ocean, from Greenland to the Kurils; locally abundant; numerous fine large specimens taken from the stomachs of cormorants on St. Paul Island, Pribilof Group; others dredged in shallow waters. Our specimens from St. Paul, Bristol Bay, and Upernavik, Greenland. Threo large specimens from St. Paul Island, the type locality of $P$. maxillaris, have been compared with a number of individuals of $P$. fasciatus from Upernavik, Greenland. We can appreciate no differences between the two. The size of the mouth and the length of the head are the same in specimens of equal length, and no difference exists in the development of the ventrals. The agreement seems to be perfect in the fin rays, relative proportion and coloration. Pallas's short account of Blennius tania contains nothing distinctive except the number of fin rays and the statement that the body is banded. As both of these items agree with the present species, we may safely follow Bean \& Bean in making the identification. In a specimen from St. Paul, $29 \mathrm{~cm}$. long, the length of the maxillary is contained $2 \frac{2}{5}$ times in distance from tip of snout to origin of dorsal: the mandible equals the length of the pectoral. In a younger example, $15 \mathrm{~cm}$. long, from Bristol Bay, the maxillary is contained $3 \frac{1}{5}$ in predorsal length; the mandible approximately equals length of pectoral. (fasciatus, banded.)

Centronotus fasciatus, BLOCH \& SCHNEIDER, Syst. Ichth., 165, pl. 37. fig. 1, 1801, Tranquebar; an error? GÜNTHER, Cat., III, 287, 1861.

Gunnellus gronlandicus, Cuvier \& VALenciennes, Hist. Nat. Poiss., XI, 442, 1836, Greenland, after BLOCH \& SCHNEIDER; REINHARDT, Dansk. Vidensk. Selsk. Nat. og Mathem. Afh., viI, 122, 1838.

(iunnellus murcenoides, VAlfinciennes, in Cuvier, Règne Animal, Poiss., pl. 78, fig. 2, 916; after BLOCH \& SCHNEIDER.

Blennius toenia, * Pallas, Zoogr. Rosso-Asiat., III, 1811, 178, Kuril Islands.

Muranoides maxillaris, BeAN, Proc. U. S. Nat. Mus. 1881, 147, St. Paul Island, Alaska (Type, No. 23999. Coll. Henry W. Elliott); Jordan \& Gilbert, Synopsis, 768, 1883.

Gunnellus fasciatus, Cuvier \& VAlenciennes, Hist. Nat. Poiss., XI, 441, 1836.

Murcenoides fasciatus, JORDAN \& GILBHRT, Synopsis, 767, 1883.

Muraenoides taenia, JoRDAN \& GrLBER', Synopsis, 766, 1883.

Pholis fasciatus, GiLberT, Rept. U. S. Fish Comm. 1893, 449; Jordan \& GILBerT, Rept. Fur Seal Invest., 1898.

*Pholis tania is thus described: Body banded; teeth obtase, subdistinct; head subtriangular, compressed; body ensiform, covered with minute embedded scales; vent median. Dorsal fin extending from near the head to the tail, the spines subequal; caudal subdistinct; pectorals small; rentrals represented by 2 recurved spines. Body banded. D. LXXXVIf; A. 47. Kuril Islands. (Pallas.) 
2773. PHOLIS (AUNELLUS (Linnæus).

(GUNNEL; BUTTER Fish.)

Head from 7 to 8 in body; depth 7 to 8 ; D. LXXVI to LXXXV; A. II, 38 to 44 ; V.I, 1 ; eye 5 in head; maxillary 3 ; P. 2; C. 14. Head compressed, naked; mouth oblique, the maxillary reaching to front of pupil; teeth blunt, in a single row, somewhat enlarged anteriorly; interorbital a narrow ridge about $\frac{1}{2}$ eye. Distance from origin of dorsal to nape equal to distance from nape to middle of eye; pectoral rather large, about 2 in head, inserted directly under front of dorsal. Color olive brown, sides with numerous obscure darker bars; base of dorsal with blackish spots, generally bordered with a narrow yellow line, a dark bar rumning downward and backward from eye; anal with dusky bars across the rays. This species differs from Pholis ornatus in the more numernus fin rays and in coloration; the spots on dorsal are black, edged with yellow; in $P$. ornatus they are yellow with a black bar before and behind, each partly encircling it; no black bordered light streak from eye to occiput. Length 12 inches. North Atlantic, from Labrador south to Woods Hole and Norway to France; abundant on rocky shores among algæ, both in America and Europe. Here described from specimens from Salem, Massachusetts. (Eu.) (grunnellus, English gunnel, said to be corrupted from gunwale.)

Blennius pinna dorsalis ocellis $X$ nigris, LinN Eus, Mus. Adolph-Fred., I, 69.

Blennius gunnellus, LINNæשUs. Syst. Nat., Ed.X, 257, 1758, Atlantic Ocean; after Blennius pinna dorsalis, etc.

Ophidion imberbe, LINNæus, Syst. Nat., Ed. x, 259, 1758, Europe; after Oph. cirris careus, ARTEDi.

Centronotus yunnellus, BLOCH \& SCHNEIDER, Syst. Ichth., 167, 1801; GüNTHER, Cat., III, 285, after RÜPPELL's type.

Murcenoides gunnellus, JoRDAN \& GILBERT, Synopsis, 767, 1883.

Blennius europceus, OLAFSEN, Reisei Island, I, 81, 1772, Iceland.

Blennius murcenoides, SuJEF, Act. Petrop. Il, 1779, 195, no locality, probably the Baltic; GMelin, Syst. Nat., 1184, 1788.

Ifurcenoides sujef, LACÉPÈDE, Hist. Nat. Poiss., II, 324, 1800; after SuJEF.

Ophidium mucronatum, MitchinL, Trans. Lit. \& Phil. Soc. N. Y., II, 1815, 361, pl. 1, f. 1, New York; earliest American name.

Gunellus vulgaris, FLeming, British Anim., 207, 1828, England.

Murcenoides guttatus, LACÉPÈDE, Hist. Nat. Poiss., II, 324, 1800; YARRELL, Brit. Fish., I, 269.

Gunellus ingens, H. R. STORER, Bost. Journ. Nat. Fist., vi, 1850, 261, pl. 8, f. 1, Labrador. (Coll. H. R. Storer.)

Gunellus macrocephalus, GIRARD, in H. R. STORER, Bost. Journ. Nat. Hist., vi, 1850, 263, Chelsea Beach, Massachusetts (Coll. Chas. Girard); D. H. Storer, Rept. Fish. Mass., 261, pl. 17, f. 3 .

2774. PIIOLIS ORNATUS (Girard).

Head 8; depth 8. D. LXXVII to LXXIX; A. II, 35 to 37. Head naked, very narrow above; nape nearly equidistant between origin of dorsal and front of orbit; origin of anal equidistant between base of caudal and base of pectoral; pectoral 2 in head. Coloration, usually olive green above, yellow or orange below, * but varying with the surroundings to brown

* A specimen from near Seattle varies much in color from all the others before us. It is purplish red, paler below; 2 conspicuons white spots bordered with white on front of dorsal; a pale streak bordered with black from eye to nape. 
and cherry red; traces of about 20 darker bars along sides; a dark bar downward from eye; fins reddish; a V-shaped mark from eye to occiput, grayish, bordered by jet-black; the common form with about 14 red spots along base of dorsal, each with a curved black bar in front and behind, partly encircling it; others with about as many broad -shaped darker blotches, which extend on the fin, the first one or two blotches often shaped as in the former case; anal white, unmarked. Length 12 inches. San Francisco to Bering Sea; very common northward, its range extending to Kamchatka; * very common at Unalaska; always in shallow water. (ornatus, ornamented.)

Gunnellus ornatus, Girard, Proc. Ac. Nat. Sci. Phila. 1854, 149; Girard, Pac. R. R. Surv., $\mathrm{x}$, Fishes, 116, pl. 25b, figs. 6 and 7, 1858 (Type, No. 490, Presidio, California, Coll. Lieut. Trowbridge; No. 491, Shoalwater Bay, Washington, Coll. Dr. J. G. Cooper; No. 492, Fort Steilacoom, Washington, Coll. Dr. Geo. Suckley).

Centronotus laetus, Core, Proc. Amer. Phil. Soc. Phila. 1873,27 , Sitka or Unalaska (Coll. George Davidson); A. II, 33.

Muraenoides ornatus, JoRDAN \& GILBERT, Synopsis, 767, 1883.

Pholis ornatus, Gilbert, Rept. U. S. Fish Comm. 1893, 450.

906. GUNNELLOPS, Bleeker.

Gunnellops, BLEEKkR, Versl. Ak. Amst., 2, viI, 1874, 368 (roseus).

This genus is apparently distinguished from Pholis by the tapering tail, around which the vertical fins are confluent; palatine teeth present.

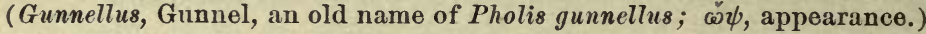

\section{GUNNELLOPS ROSEUS (Pallas).}

D. ca. C ; A. ca. 90 ; P. 9; V. I. Head obtuse, the lower jaw projecting; eyes large; body very long, compressed, tapering into a slender tail; pectorals small, ovate, hyaline; 2 spines in place of ventrals ; dorsal extending from the nape to the end of the tail; anal joined to caudal. Color intensely red. Kuril Islands. (Pallas.) Not seen by any recent collector. (roseus, rosy.)

Blennius roseus, PALLAS, Zoogr. Rosso-Asiat., IIr, 177, 1811, Kuril Islands.

Centronotus roseus, GünTHцв, Cat., III, 290, 1861.

Gunnellop roseus, JoRdan \& EvermanN, Check-List Fishes N. and M. A., 474, 1896.

907. ASTERNOPTERYX, Rüppell.

Asternopteryx (RÜPPELl MS.) GüNTHER, Cat. Fishes Brit. Mus., II, 288, 1861, name only ; JORDAN \& GIIBERT, Synopsis, 769, 1883 (gunelliformis).

This genus is closely allied to Pholis, differing chiefly in the entire absence of ventral fins. From Pholidapus it is distinguished by the shorter pectorals and by the more broadly united gill membranes. Greenland. A sin-

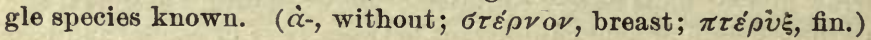

2776. ASTERNOPTERYX GUNELLIFORMIS, Rüppell.

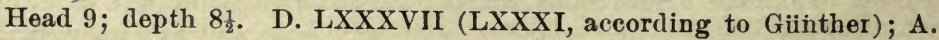
II, 40. Head and body strongly compressed; head bluntish, snout short,

* We have specimens collected at Tareinsky Bay by Mr. Barrett-Hamilton. 
jaws equal; maxillary reaching pupil, 3 in head; eye $5 \frac{1}{2}$; gill membranes broadly united, their outline not notched; wo trace of ventral fins; pectoral large, 2 in head ( 3 according to Giinther). Dorsal and anal joined to the caudal, the anal with a slight notch behind the last ray; dorsal spines short and all pungent. Color dark brown, elouded with darker; about 11 quadrate pale areas along dorsal fin extending on the sides, these areas each with a black central spot at tip and faintly marked with dark blotches; dorsal with dark spots; a dark band from eye downward, a pale band behind it; lips dark; anal fin bright orange; pectorals and gill membranes pale orange; caudal orange. Greenland. Here described from a fine specimen, $9 \frac{1}{2}$ inches long, in the U. S. National Museum, from Omanak Fjord, Karsak, Noursoak Peninsula, taken in 1897 by Schuchert and White; only the original type in the Senckenburg Museum hitherto known. (Gunellus; forma, shape.)

Asternopteryx gunelliformis, RüPPELL MS.; type (in Senckenburg Museum) from Greenland.

Centronotus gunelliformis, GüNTHER, Cat., III, 288, 1861.

Ifurcenoides gunelliformis, JoldDAN \& GILBERT, Synupsis, 769, 1883.

\section{ANOPLARCHUS, Gill.}

Anoplarchus, Gill, Proc. Ac. Nat. Sci. Phila. 1861, 261 (atropurpureus).

Body elongated, compressed, covered with very small, embedded scales which are obsolete or concealed anteriorly; lateral line obsolete. Head small, compressed; eyes small; mouth oblique; teeth in each jaw in a narrow band, the outer somewhat enlarged; narrow bands of teeth on vomer and palatines; gill membranes attached to the isthmus; sometimes with a free fold behind; branchiostegals 5. Dorsal fin not very low; no anal spines; ventrals wanting; caudal fin small, entire; pectoral fins moderate or small; pyloric cæca present, few. Pacific. ( $\alpha 2 \% \pi \lambda \circ 5$, unarmed; $\alpha$ ผ $\chi 05$, anus; the anal tin being without spines.)

a. Gill membranes narrowly joined to the isthmus, with a free fold behind; dorsal with about 63 spines.

ALECTROLOPHUS, 2777.

aa. Gill membranes broadly joined to the isthmus, without free fold behind; dorsal with 54 to 57 spines. ATROPURPUREUS, 2778.

\section{ANOPLARCHUS ALECTROLOPIIUS (Pallas).}

Head $6 \frac{2}{8}$ in length; depth 73. D. LXII or LXIII; A. 43. Mouth oblique, maxillary reaching vertical behind pupil, $2 \frac{1}{4}$ in head. Teeth in narrow bands on the jaws, the outer series in upper jaw somewhat enlarged; vomer and palatines with narrow bands of teeth; dentition similar to that in $A$. atropurpureus, which has been erroneously described as having the teeth in the jaws in single series and the vomer and palate toothless; gill membranes-rather narrowly joined to the isthmus and with a free posterior edge slightly wider than pupil. A. atropurpureus has the gill opening somewhat more restricted and the gill membranes without free fold. Large pores on head arranged similarly in the two species. Spinous dorsal beginning slightly in advance of base of pectoral, its distance 
from snout less than length of head; distance from origin of anal to tip of snout $2 \frac{2}{5}$ in length to base of caudal; pectoral short and broad, rounded, $2 \frac{1}{6}$ in head. Scales small, embedded, those on the anterior part of the body concealed by the thickened integument, as in $A$. atropurpureus. Coloration in our specimens nearly uniform dark olive, with obscure dusky mottlings on the side. In 1 specimen there is a light bar extending obliquely downward and backward from eye, with a dark bar above and below it, the 3 separated by narrow light gray lines; caudal narrowly cross-banded with light and dark as in $A$. atropurpureus, and the anal obliquely barred with the same. In the smallest specimen is a series of roundish spots about as large as eye along back just below dorsal fin; each spot seems to have a narrow dark margin, a light ring, a dusky ring, and a light center; a series of similar but smaller spots along middle of sides posteriorly; the colors were probably brighter and more varied in life. Western part of Bering Sea and Sea of Okhotsk. Here described from 3 small specimens, $3 \frac{1}{3}$ to 9 inches long, taken at Tarciusky Bay, Kamchatka, by Mr. Barrett-Hanilton; 2 other fine specimens since taken lyy Arthur W. Greeley in Monterey Bay; the only ones recorded since Pallas. They differ from specimens of $A$. atropurpureus in the higher crest, the more numerous fin rays, and in having the gill membranes with a distinct free margin. ( $\dot{\alpha} \lambda \dot{\varepsilon} \varkappa \tau \omega \rho$, cock; $\lambda o_{\phi \circ}$, crest.)

Blennius alectrolophus, PALLAS, Zoogr. Rosso-A siat., III, 174, 1811, Island of Talek, Gulf of Penshin, Okhotsk Sea.

Gunnellus alectrolophus, Cuvier \& VALencienves, Hist. Nat. Poiss., XI, 447, 1836.

Centronotus alectrolophus, GÜNTHER, Cat., III, 289, 1861.

Anoplarchus alectrolophus, JORDAN \& GILBERT, Rept. Fur Seal Invest., 1898.

2778. ANOPLARCIUS ATROPURPUREUS (Kittlitz).

Head $6 \frac{1}{2}$ in body; depth 7. D. LV; A. 40 ; eje $5 \frac{1}{3}$ in head; maxillary $2 \frac{1}{2}$; pectoral $2 \frac{1}{2}$; caudal $1 \frac{8}{4}$. Head with a fleshy crest, which rests on a ridge of bone, its height in older examples about equal to eye; mouth rather large, the maxillary reaching beyond the orbit. Dorsal and anal comparatively high, barely connected with the base of caudal; nape midway between origin of dorsal and pupil. Body naked anteriorly, scaled behind. Color grayish olive, varying to brown; everywhere above finely marked with blackish reticulations; along each side of back a series of small, irregular, starply defined grayish spots; a series of small pale spots along lateral line; belly pale; crest and middle line of back rather pale; under parts of head yellowish; an oblique, wedge-shaped, pale streak extending downward and backward from the eye, bounded on each side by a sharp light-red line, and then by a dusky area; lower jaw mottled; dorsal olivaceons, speckled, a blackish spot on front; anal olive, tinged with red; pectorals dull orange, barred at base; caudal reddish, with narrow pale streaks, and a light bar at base ; color sometimes nearly plain purplish, but more often grayish and mottled. Alaska to San Francisco; abundant northward; common in Bering Sea. Here described from specimens from Neah Bay, Straits of Fuca, Washington. We have also specimens from the Pribilof Islands. (ater, black; purpureus, purple.) 
Ophidium atropurpureum, KITtLitz, Denkwürd einer Reise Russ.-Amer., I, 225, 1858, Alaska.

Centronotus cristagalli, GünTHER, Cat., III, 289, 1861, Vancouver Island.

Anoplarchus purpurescens, GiLL, Proc. Ac. Nat. Sci. Phila. 1861, 261, Washington Territory. (Coll. Dr. Kennerly.)

Anoplarchus cristagalli, GÜNTHER, Cat., III, 564, 1861.

Anoplarchus atropurpureu\&, JORDAN \& GILBERT, Synopsis, 771, 1883; JoRDAN \& STARKs, Proc. Cal. Ac. Sci. 1895, 846.

909. XIPHISTES, Jordan \& Starks.

Xiphistes, Jordan \& Starks, Proc. Cal. Ac. Sci. 1895, 846 (chirus).

This genus is very close to Xiphidion, differing in the well-developed pectoral fins, which are longer than eje; lower lateral line not connected

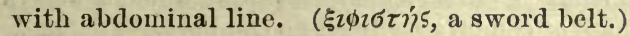

a. Anal spines 3; branches of upper lateral line extending on dorsal fin; color grassgreen.

ULVAE, 2779.

aa. Anal spines 2; branches of upper lateral line shorter; color brownish, marbled, and with red blotches.

CHIRUS, 2780.

2779. XIPHISTES ULVE, Jordan \& Stark8.

Head 8; depth 10. D. LXXIV; A. III, 48; eye 5 in head; maxillary $2 \frac{4}{4}$; pectoral $3 \frac{1}{2}$. Body eel-shaped, as in the related species; head short; mouth small, oblique, maxillary extending to below posterior margin of eye; jaws subequal, with canine teeth; 4 enlarged canines in front of lower jaw; teeth in upper jaw gradually enlarged from behind forward; eye moderate, equal to length of snout; interorbital space prominent, sharply convex, narrower than width of eye; nape not constricted. Five mucous canals radiating downward and backward from eye, not reaching to edge of preopercle, the branches running upward from upper lateral line ending on the membrane of dorsal, the lower lateral line not connected with the abdominal line. Lateral line otherwise as in Xiphistes chirus. Origin of dorsal at a distance behind nape equal to distance from nape to middle of eye, the fin posteriorly barely connecting with caudal; anal with 3 spines, its origin about a head's length vearer snont than base of caudal, connected with caudal posteriorly; pectorals equal in length to snout and $\frac{1}{2}$ eye, slightly shorter than caudal; caudal rounded, fan-shaped. Color olive-green above, very bright green below; middle and lateral line posteriorly, with conspicuous white spots, $\frac{1}{2}$ as large as pupil, each with a black spot before and behind it; a black streak from tip of snout, through eye, to nape, a streak starting from eye behind quickly fading out; dorsal larker than body, unmarked; the anterior third of anal green, without markings, behind this, faint cross bars of brown appear, growing broader and darker posteriorly; caudal olive green, with a light bar across base; pectorals green, without markings. One specimen obtained at Waadda Island, Neah Bay. It was found high on the rocks, among algæ, just below high water mark. Length 5 inches. This species is very closely related to Xiphistes chirus; it differs from it chiefly in having 3 anal 
spines, in the branches of the upper lateral line running higher, and in coloration. (Ulva, the green sea lettuce.)

Tiphiaion ulvoe, Jordan \& Starks, Fishes of Puget Sound, 847, 1895, Waadda Island, Neah Bay. (Type, No. 3132, L. S. Jr. Univ. Mus. Coll. E. C. Starks.)

2780. XIPHISTES CHIRUS (Jordan \& Gilbert).

Head 7; depth 9. D. LXX; A. II, 50. Head short; nape not constricted; month small; maxillary extending to middle of pupil; teeth strong, the anterior canine-like, bluntish; abont 4 canines in lower jaw, 5 or 6 in the upper, similar to the teeth behind them, but somewhat larger. Abdominal lines meeting on the breast, but not connected with the lower lateral line. Dorsal fin beginning close behind pectoral; nape midway between middle of eye and front of dorsal; anal beginning abont a head's length nearer snout than base of caudal; pectoral in comparatively large, longer than the eye, its length about equal to distance between middle and lower lateral lines. Color olive brown, yellowish below; sides with marblings of different shades of brown, sometimes with short blackish vertical bars; some round black spots along the back and sides; a black spot behind opercles; numerous black spots on sides of head, forming in older individuals light and dark streaks, which radiate from eye across cheek and opercles, the pale streaks forming reticulations; dorsal with black spots and a series of bright reddish brown cross blotches; pectorals and caudal plain. Monterey to Alaska; smaller than the other species, and living in deeper water; abundant about Cape Flattery. (Jordan \& Gilbert.) ( $\chi \varepsilon i \rho$, hand.)

Xiphister chirus, JoRdan \& GILBERT, Proc. U.S. Nat.Mns. 1880, 135, Point of Los Pinos, near Monterey, California (Coll. Jordan \& Gilbert); JoRdAN \& GILBERT, Synopsis, 772, 1883; Jordan \& StaRks, Fishes of Puget Sound, 846, 1895.

9ro. XIPHIDION, Girard.

Xiphidion, Girard, Pac. R. R. Surv., X, Fishes, 119, 1858 (mucosum); not Xiphidium, Serv., a genus of Grasshoppers.

Xiphister, JoRdan, Proc. U. S. Nat. Mus. 1879, 241 (mucosum); substitute for Xiphidion, regarded as preoccupied by Xiphidium.

Body elongate, eel-shaped, covered with small scales; lateral lines several: 1 along the median line of the side, 1 above this, and 1 below it; 1 on each side of the abdomen, the 2 meeting in front, and 1 from the occiput toward the base of the dorsal fin. Each of these has on each side series of short branches, placed at right angles to the main line, those on opposite sides alternating. Each of these branches has about 2 open mucous pores. Lower lateral line connected with the abdominal line. Head short, bluntish, scaleless; mouth moderate, oblique; jaws with rather strong teeth, the anterior canine-like; no teeth on vomer or palatines. Branchiostegals 6; gill membranes separate, free from the isthmus. A single long, low, uniform dorsal fin, consisting of spines only; anal fin similar in form, with small spines, indistinct or obsolete; candal short, joined to dorsal and anal; no ventral fins; pectoral fins very small, shorter 
than eye. Intestinal canal moderately elongate, with 4 to 6 well-developed pyloric cæca. Herbivorous, feeding on algæ. Active fishes, inhabiting ticle pools and crevices among rocks in the North Pacific. ( $₹ \downarrow \imath \delta \imath \_\nu$, a small sword.)

a. Distance from origin of dorsal to occiput less than that from occiput to tip of snout; streaks radiating from eye paler in the center, edged above and bolow with blackish.

MUCosum, 2781.

aa. Distance from origin of dorsal to occiput greater than that from occiput to snout; streaks radiating from eye black, abruptly margined with pale olive.

RUPESTRE, 2782.

2781. XIPIIDION MUCOSUM, Girard.

Head 7 in body; depth $8 \frac{1}{2}$. D. LXXIV; A. 46; eye $7 \frac{1}{2}$ in head; maxillary 24 ; caudal $2 \frac{3}{5}$; pectoral a little longer than eye. Lower jaw with a series of short, stout conical teeth; upper jaw with a narrow band of similar teeth ; 2 strong canines in upper jaw, 4 in the lower. Lower lateral line sending a branch to the abdominal line; nape not constricted. Dorsal beginning anteriorly, distance from its origin to occiput less than that from occiput to tip of snout; origin of anal nearer snout than tip of caudal by about $\frac{1}{2}$ length of head. Blackish green, pale on belly and sides of head, marked posteriorly with olive green in various pattern; a transverse light-greenish bar at base of caudal; 3 olive-brown streaks radiating backward from eye, paler in the center and edged above and below with blackish, outside of which is sometimes a streak of pale olive; these streaks all merge backward into the color of the head; mildle streak broadly wedge-shaped, the third streak terminating before reaching margin of preopercle; old individuals often coarsely blotched with yellow. Length 18 inches. Monterey to Alaska; very abundant among rocks and alga. Here described from specimens, 9 or 10 inches in length, from Neah Bay, Straits of Fuca, Washington. (mucosus, slimy.)

Xiphidion mucosum, GIRARD, Pac. R. R. Surv., X, Fishes, 119, 1858, South Farallones, California (Coll. Lieut. Trowbridge. Type, No. 493, U. S. Nat. Mus.); GüNTHER, Cat., III, 291, 1861; JoRdan \& Starks, Fishes Puget Souud, 848, 1895.

Xiphidion cruoreum, ${ }^{*}$ Cope, Proc. Amer. Phil. Soc. Phila. 1873, 27, Sitka (Coll. Prof. George

Davidson); JordaN \& GILBERT, Proc. U. S. Nat. Mus. 1880, 137.

Xiphister mucosum, JoRDAN \& GILBERT, Synopsis, 772, 1883.

\footnotetext{
* The following is the original description of Xiphidion cruoreum: Head 81 in total length; depth $9 \frac{1}{2}$; eye 7 in head, equal to length of pectoral fin. D. about $70 ; A .48 ;$ Br. 5 . Teeth, 2 canines above, 4 below, subequal. Dorsal spines not commencing near the head, the anterior buried in a soft fold of skin; caudal fin not distinct. Three lateral mucous canals extending entire length of caudal fin, which have numerous alternating transverse branches, those of the superior reaching base of dorsal, those of inferior reaching base of anal; each of the cross branches with several excretory pores, none on the main stem; a similar but short tube extending from near base of dorsal fin to supra-occipital region, and not branching anteriorly; the superior lateral canal descending to near themedian, but not joining it, nor does the latter extend into the inferior; another tubular line on each side of abdomen, these uniting on jugular region by a continuation of the inferior lateral tube. Vent nearer end of muzzle than end of candal fin, by length of head. Color maroon, more reddish below; a vertical, broad, reddish bar at base of tail, beyond which is a dark spot; 2 brown radii, black edged, extending backward and downward from eye. Body covered with small scales, except on the jugular and abdominal regions, which are naked. Length 8 inches. This fish is not very different from $X$. mucosum, Girard. It differs in the smaller eye, the more remote origin of the dorsal fin from the bead, the lack of anterior union of the mucous canals, and the coloration. (Cope.)
} 
2782. XIPHIDION RUPESTRE (Jordan \& Gilbert).

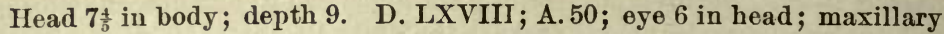
24 ; caudal $2 \frac{4}{5}$. Teeth essentially as in $X$. mucosum. The lower lateral line sends a branch to the abdominal line; a constriction at the nape. Distance from origin of dorsal to the occiput greater than the distance from the occiput to the snout. Anal fin beginning much in advance of middle of body, the distance from the first ray to tip of caudal exceerling the distance to snout by nearly twice length of head; pectoral very short, its length less than diameter of eye. Reddish brown, uniform or variously shaded with lighter; a light olivaceous bar at base of caudal, extending on dorsal and anal, behind this a blackish area; tip of caudal usually pale; 3 long, welldefined stripes radiating backward from eye, these stripes uniform black, abruptly margined with very light olive; the central stripe proceeding straight backward from the eje, $\frac{1}{2}$ breadth of cheek, at which point it is broadest; it is then narrowed and bent abruptly downward; both the middle and lower stripes reach the margin of preopercle. Length 12 inches. Smaller than the preceding, and equally abundant; among rocks and algre, from Vancouver Island to Monterey. Here described from specimens, 6 or 7 inches in length, from Neah Bay, Straits of Fuca, Washington. (rupestris, living among rocks.)

Xiphister rupestris, Jordan \& GILBert, Proc. U.S. Nat. Mus. 1880, 137, Monterey Bay, California (Coll. Jordan \& Gilbert); JoRdAN \& GilberT, Synopsis, 773, 1883. Xiphidion rupestre, JoRdan \& StaRKs, Fishes Puget Sound, 848, 1895.

\section{I I. CEBEDICHTHYS, * Ayres.}

Debedichthys, A yres, Proc. Cal. Ac. Nat. Sci., I, 1855, 59 (violaceus).

Body comparatively short, compressed, covered with minute scales; lateral line distinct, running very high, with very short branches, each ending in a pore, as in Xiphistes, but the branches more oblique and less regular. Head short; crown with a conspicuous fleshy longitudinal crest in the adult; jaws subequal, with conical teeth; villiform teeth on vomer and palatines; gill membranes united, free from the isthmus. Dorsal fin continuous, long and low, the anterior part composed of sharp spines, which are rather lower than the soft rays; caudal fin rounded, connected with dorsal and anal; anal fin similar to soft dorsal, with 1 or 2 small spines; pectorals small; ventrals wanting. Intestinal canal elongate, with several pyloric caca. Pacific Ocean. Herbivorous; similar in habits

* The following remarkable genus may be allied to Cebedichthys:

NEOZOARCES, Steindachner.

Neozoarces, SteindaChNer, Iehth. Beitr., IX, 26, 1880 (pulcher).

NeOzoARCES PULCher, Steindachner.

Body elongate, taperiug backward, thedorsal and anal united at the tail withont distinct candal. Scales small, embedded, no lateral line. Mouth very large, the maxillary extending far beyond eye; lower jaw slightly longer than upper; blunt, conical teeth in many rows on jaws, vomer, and palatines. A thick tentacle above nostril; gill membranes united, free from isthmus. Dorsal low, the anterior portion of short, stiffish spines; no anal spine; ventrals wanting; pectorals moderate; pseudobranchiæ present. Head 6 ; depth 9. D. XLI, 50; A. I, 75. Color highly variegated. Gulf of Strietok, Okhotsk Sea. (véos, new; Zoarces; but it has littlo affinity with the latter genus.)

Neozoarces pulcher, Steind ACHNER, Ichth. Beitr., IX, 27, taf. 6, f. 2, 1880, Gulf of Strietok. (Coll. Professor Dybowski.) 


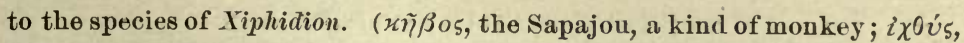
fish; in allusion to the "peculiar monkey-like" physiognomy as seen from the front.)

\section{CEBEDICITHYS VIOLACEUS (Ayres).}

Head $6 \frac{1}{2}$; depth 6. D. XXIII, 41; A. I, 41. Maxillary extending to or beyond orbit. Dorsal scaly at base; vent nearer snout than base of caudal; pectoral $z$ length of head; nape midway between dorsal and eye. Dull olive grayish, mottled with lighter, sometimes reddish tinged; vertical fins all edged with reddish; cheek with 3 darker stripes, edged with paler, 1 downward and backward from the eye, close behind angle of mouth; another above it to root of pectoral; another running upward and backward from the eye, and meeting its fellow over the crest. Length 30 inches. San Francisco to Point Concepcion; abundant; often brought into the markets. (violaceus, violet.)

Apodichthys violaceus, Girard, Proc. Ac. Nat. Sci. Phila. 1854, 150, San Luis Obispo, California. (Coll. Dr. Kennerly.)

Cebedichthy s cristagalli, Ayres, Proc. Cal. Ac. Nat. Sci., I, 1855, 58, San Francisco.

Cebedichthys violaceus, Girand, Pac. R. R. Surv., x, Fishes, 121, pl. 26, figs. 4 and 5, 1858; JokDAN \& GiLbERT, Synopsis, 774, 1883.

\section{PLAGIOGRAMMUS, Bean.}

Plagiogrammus, BeAN, Proc. U.S. Nat. Mus. 1893, 699 (hopkinsi).

Body moderately elongate, compressed, covered with very small scales; lateral lines 2, viz, 1 beginning above and slightly in advance of the upper angle of the gill opening and extending along the upper part of the body, but not reaching the tail, and 1 beginning in advance of the end of this and reaching to the caudal; numerous lateral ridges on the sides, similar to those on Dictyosoma of Ternminck \& Schlegel; a series of subpentagonal plate-like bodies along the abdominal edge on each side between the ventral and the anal. Head moderately long, naked, with pointed snout; mouth oblique and rather large; jaws subequal, or the lower slightly projecting; jaws with strong teeth in broad bands, the intermaxillaries with an outer series of eularged canine-like teeth; teeth on vomer and palate; a pair of large canines near the symphysis in each jaw, the canines of the upper jaw fitting into an interspace behind the mandibulary canines. A series of pores on the ramus of the mandibula continuing around the preopercular edge; a series of similar pores along the lower margin of the preorbital continued backward and upward toward the nape. Anterior nostril tubular; posterior without tube. Maxillary broadly expanded posteriorly; lips well developed. Branchiostegals 5; gill membranes partly united, but free from the isthmus behind. Gill rakers minute, tubercular, in moderate number. A single long dorsal fin consisting of spines only, the spines longest in the posterior portion; anal fin lower than the dorsal, but similar in shape. Pectoral large, entirely below median line. Ventrals well developed, in advance of pectorals; caudal rounded, distinct. Intestinal canal short, with 5 small pyloric cæca. ( $(\pi \lambda \dot{\alpha} \gamma \imath o 5$, oblique; $\gamma \rho \alpha \mu \mu \eta \dot{\eta}$, line.) 


\section{PIAGIOGRAMMUS HOPKINSI, Bean.}

Head 4 ; depth $5 \frac{1}{3}$; eye 5. D. XLI ; A. II, 29; V.I, 5; 13. 5; scales about 95 ; ridges on side 32 . Snout acute; anterior nostril tubular and nearer eye than tip of snout; posterior nostril close to upper anterior margin of eye; maxillary extending almost to vertical through hind margin of eje; intermaxillary long, slender, and reaching nearly as far back as maxillary; intermaxillary teeth in broad bands, with an outer series of 5 or 6 large canines, those near the symphysis largest; teeth in mandible in broad bands in front, followed by several enlarged canine-like teeth; a large canine on each side of symphysis, the interspace between the 2 mandibulary canines receiving the canines of the iutermaxillary when the jaws are closed. A row of 8 pores along ramus of mandible and edge of preopercle; another series around lower margin of preorbital bone as described for the genus; about 8 gill rakers on first arch below angle. Distance of dorsal origin from snout nearly equal to length of head; spines lowest in front, the longest spine $\frac{2}{7}$ length of head; longest rays of anal near end of fin and scarcely exceed length of eye; length of pectoral equaling that of postorbital part of head; ventrals close together; inner rays longest. $\frac{2}{7}$ as long as head; caudal rounded, its length nearly $\frac{1}{2}$ that of head; vent under eleventh spine of dorsal. Upper lateral line beginning above and slightly in advance of upper angle of gill opening, curving very slightly over pectoral and extending to below twenty-fifth spine of dorsal, its distance from dorsal edge equal to diameter of eje and also equal to its distance from lower lateral line; lower lateral line beginning under sixteenth spine of dorsal and extending to caudal. On each side of the abdominal ridge, between the ventrals and the vent, are about $10 \mathrm{sub}$ pentagonal plate-like bodies, the largest about $\frac{1}{2}$ as long as eye. Color dusky brown, the fins black. Monterey, California; a few specimens dredged among rocks. Little is known about the habits of the species, beyond the fact that in the aquarium it hides in rock crevices and seldom ventures from its hiding place. (I take pleasure in associating with this blenny the name of Mr. Timothy Hopkins, of Menlo Park, California, the founder of the Seaside Laboratory at Pacific Grove, Monterey Bay, in commemoration of his services in behalf of science. Bean.)

Plagiogrammus hopkinsi, Bean, Proc. U. S. Nat. Mus. 1893, 699, Monterey Bay, Callfornia. ('Type, No. 44721, U. S. Nat. Mus.)

\section{OPISTHOCENTRUS, Kner.}

Opisthocentrus, KNER, Sitzber. Akad. Wiss. Wien 1868, 49 (quinquemaculatus). Blenniophidium, Boulenger, Proc. Zool. Soc. Lond. 1892, 583 (petropauli).

Body moderately elongate, compressed, covered with very small cycloid scales. Mouth small, horizontal, protractile, with fleshy lips; small conical teeth in jaws and on vomer and palatines. No cirri. Gill membranes broadly counected, but free from isthmus; branchiostegals 4 . Dorsal fin very long, extending from the nape to the caudal, with which it is subcontinuous; a fow of the posterior rays are stiff spines, the rest being 
simple and not articulate, but flexible; anal fin extending from the anus, which is a little nearer the anterior than the posterior extremity, to the caudal, formed exclusively of soft rays; no ventrals. No lateral line. No prominent anal papillæ. Pyloric appendages present. A remarkable genus, allied to Lumpenus, or rather to Plectobranchus, distinguished by having only the posterior spines rigid. North Pacific. (ö $\pi \tau \theta \varepsilon \varepsilon$, behind; $\varkappa \dot{\varepsilon} v \tau \rho \circ \nu$, spine.)

\section{OPISTHOCENTRUS OCELLATUS (TIlesius).}

Head $6 \frac{1}{4}$; depth $6 \frac{1}{4}$ (without caudal). D. LV to LXI, usually LIX; A. 36 to $39 ; 5$ to 7 of the posterior dorsal spines rigid; Eye as long as snout, 4 in head, and a little more than interorbital width; maxillary extending to below anterior fourth of eye; some wide pores on the head; cheeks, opercles, and occiput closely scaled; strips of small scales on the branchiostegal membrane between the rays. Dorsal rays continuous and subequal in depth, the longest spine $2 \frac{1}{5}$ in head in females, $1 \frac{1}{6}$ in males; pectoral $1 \frac{1}{8}$ in head, about as long as caudal. Anus twice as far from caudal as from base of pectoral. Yellowish brown, with ill-defined darker marblings; a crescentic black line on the top of the head from eye to eye; a black line, obliquely directed forward, below the eye, and another, in opposite direction, from the eye to the opercle; 2 dark-brown streaks across the nape, the second crossing the origin of the dorsal fin and extending to the base of the pectoral; dorsal and caudal fins grayish olive, lighter at the base, the dorsal with 5 to 9 (usually 6 ) large black spots at regular intervals, these wanting in the males; pectorals and anal colorless. Numerous specimens are from Tareinsky Bay, Kamchatka; Petropaulski Harbor, and Shana Bay, Iturup Island. The number of dorsal ocelli varies from 5 to 9 in our specimens, 6 being the prevailing number. Of 24 specimens whose fins we have enumerated, 4 have 58 dorsal spines, 10 have 59,5 have 60 , and 5 have 61. In addition, 1 specimen has but 55 spines. The latter is the only male in the collection and is conspicuous by the absence of distinct dorsal ocelli and the great height of the vertical fins, the longest dorsal spine exceeding the length of the pectoral and contained $1 \frac{1}{6}$ times in head. In females the longest spine is $2 \frac{1}{5}$ in head. The anal contains 36 to 39 rays in all our specimens. The dorsal fin is composed exclusively of spines, the anterior flexible ones passing into the strong pungent ones near the posterior end. The stronger spines vary from 7 to 12 in number in our specimens. Our material answers the description of the type of 0 .quinquemaculatus which had 57 dorsal spines and 36 anal rays. It also agrees with specimens from Petropaulski, reported on by Bean \& Bean (Proc. U. S. Nat. Mus. 1896, 391), with dorsal spines 58 in number. Blenniophidium petropauli, Boulenger, has but 52 dorsal spines, but it is otherwise not to be distinguished from 0 . ocellatus. Still more aberrant are 4 specimens from Gulf of Strietok, northern Japan, mentioned by Steindachner (Ichth. Beitrïge, Ix, 25), with but 50 to 53 spines and 32 to 31 anal rays. These may represent a distinct species. Ophidium ocellatum of Tilesius must be this species, but the count of fin rays is incorrect and may be taken from 
the rough figure. Opisthocentrus tenuis is probably also identical with $O$. ocellatus, though the writers did not think so until after examination of the present large material. Coast of Kamchatka, southwestward to Okhotsk Sea, generally common from Komandorski Islands to Yezo. (ocellatur, with eye-like spots.)

Ophidium ocellatum, TiLesius, Mém. Ac. St. Petersb., II, 1811, 237, Kamchatka. D. 80; A. 50; evidently an error. The rude figure shows D. 73 ; A. 50, the spines low; the dorsal with 5 ocelli.

Centronotus (Opisthocentrus) quinquemaculatus, KNer, Sitzber. A kad. Wiss. Wein 1868. 48, taf. 7, f. 20, "Pinang." Described from a young specimen 2 inches long, No. 6353 , Mus. Wien.

Gunnellus apos, Cuvier \& Valenciennes, Hist. Nat. Poiss., xiv, 426, 1839; after Tilesius. Centronotus apus, GÜNTHER, Cat., III, 288, 1861.

Blenniophidium petropauli, Bodlenger, Proc. Zool. Soc. London 1892, 584, with plate, Petropaulski (Coll. George Baden-Powell); D. 52; A. 37; 5 ocelli.

Opisthocentrus tenuis, ${ }^{*}$ BEAN \& BEAN, Proc. U. S. Nat. Mus. 1897, Volcano Bay, Port Morusan, Japan. (Coll. Col. Nicolai A. Grebnitski. Type, No. 47565, U. S. Nat. Mus.) Opisthocentru\& quinquemaculatus, SteINDACHNER, Ichth. Beitr., IX, 25, 1880; BEAN \& BEAN, Proc. U. S. Nat. Mus. 1896, 381, 392.

Opisthocentrus ocellatus, JoRDAN \& GILBERT, Rept. Fur Seal Invest., 1898.

\section{9r4. PHOLIDAPUS, Bean \& Bean.}

Pholidapus, BeAn \& BeAn, Proc. U.S. Nat. Mus. 1896, 389 (grebnitskii).

Body moderately elongate, compressed, covered with very small, smooth scales. Mouth small, horizontal; bands of small teeth on jaws and vomer, none ou palatines. Head naked; gill membranes broadly connected, free from the isthmus; dorsal very long, composed entirely of flexible spines; anal of soft rays; caudal short, rounded, separate; no ventral fins; no lateral line; pyloric cæca present. This genus is close to Opisthocentrus, but has no pungent spines, and the head is naked. Okhotsk

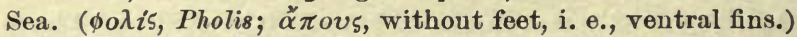

2786. PHOLIDAPUS DYBOWSKII (Steindachner).

Head $5 \frac{1}{2}$ to $6 \frac{2}{5}$; depth 6 to $6 \frac{1}{2}$. D. LXII or LXIII; A. II, 39. Eye $3 \frac{3}{5}$ to to $4 \frac{2}{3}$ in head; snout a little longer than eye; lower jaw scarcely included; 1 or 2 strong conical teeth on each side behind the narrow premaxillary band of teeth; teeth on vomer, none on palatines; no cirri; large pores

* Opisthocentrus tenuis is thus described:

D. $39, \mathrm{XV} ; \mathrm{A} .38$. Length of fish to caudal base 51 inches; length of head 1 ; depth of body 7 the greatest width of the body is contained $2 \frac{1}{2}$ times in the length of the hearl. The diameter of the eye is nearly equal to the length of the snout and is contained $4 \frac{1}{2}$ times in the length of the head; the width of the interorbital space is almost equal to the long diameter of eye. The maxilla reaches to the vertical past front of eye. 'Teeth bluntly rounded, embedded in flesh; vomerine teeth present; palatines none. The origin of the dorsal fin is over the end of the gill cover, its first 39 rays are simple and flexible, the last 15 are strong spines and end slightly abore the membrane in stiff points, the longest spine is almost $\frac{2}{3}$ as long as the head. The anal originates under the twentieth ray of the dorsal; its rays are divided and articulated; the longest ray is $\frac{1}{3}$ as long as the head. The general color is brown with cross reticulations of black. Sides of head and body along base of anal, orange; anal, caudal, and pectorals light with dusky shadings; dorsal finely mottled with black and bearing 6 black spots on areas of white, the first of these spots being on the sixth ray and the last on the next to last spine; a black bar from front of eye downward, and another from posterior margin obliquely down and backward. This species differs from the typical form in its greater compression of the body and its increased number of dorsal spines. (Bean \& Bean.) 
about eye and on opercles; longest dorsal spines $2 \frac{1}{2}$ to 3 in depth of body, last spines shorter and stiffer than others; dorsal and anal slightly joined to caudal; pectoral as long as caudal, about $1 \frac{1}{4}$ in head. Head naked. Brown or grayish, with faint spots or marblings; 1 or 2 , rarely 3 , clark ocelli on the dorsal; 3 or 4 dark streaks radiating from eje, the uppermost joining its fellow. Length 10 to 15 inches. Coast of northern Japan and sea of Okhotsk, north to the Kuril Islands. Our specinens, 5 in number, the largest $25 \mathrm{~cm}$. long, from Shana Bay, Iturup Island. Steindachner's excellent and detailed description leaves nothing to be desired, and corresponds perfectly with our material except in the character of the scales. A careful examination of these under high magnification fails to show that they are "am hinteren Rande mit kurzen Zähnchen bewaffnet." The posterior border is entire and the scales strongly marked with concentric striæ. Dorsal spines number $62,63,63,64,64$. Dorsal ocelli present in all our specimens, 2 of them being faintly visible even in the youngest, $55 \mathrm{~mm}$. long. Pholidapus grebnitskii seems to differ only in the shorter dorsal fin (57 spines). (Named for Professor Dybowski, its first collector.)

Centronotus dybowskii, Steindachner, Ichth. Beiträge, Ix, 22, 1880, Gulf of Strietok, northern Japan (Coll. Prof. Dybowski) ; Jondan \& Gilbert, Rept. Fur Seal Invest., 1898.

?Pholidapus grebnitskii, * BEAN \& BEAN. Proc. U. S. Nat. Mus. 1896, pl. 34, 390, Yezo, Japan. (Coll. Col. Nicolai A. Grebnitski.)

9r5. PLECTOBRANCHUS, Gilbert.

Plectobranchus, Gilbert, Proc. U.S. Nat. Mus.1890, 102 (evides).

Teeth conic, on jaws, vomer, and palatines, some of them canine-like. Body scaly; lateral line obsolete, its course indicated by a lighter streak on middle of sides. Gill slits not continued far forward, the membranes

\footnotetext{
*Pholidapus grebnitskii, Bean \& Bean, is thus described: The specimens are $141 \mathrm{~mm}$. long, including caudal; $126 \mathrm{~mm}$. to base of caudal. The head $(22 \mathrm{~mm}$.) is equal to the greatest depth of body. The eye is slightly longer than the snout and 1 as long as the head. The interorbital space is narrow, $\frac{2}{3}$ of the length of the eye. The naked head resembles that of Pholis, its length is contained about $5 \frac{1}{2}$ times in total length without the caudal. The mouth is small and very oblique; the mandible is slightly included and has a well developed lip. The maxilla is partly concealed under the preorbital bone; it does not quite reach to below the anterior margin of the pupil. The anterior nostril is midway between the eye and the tip of the intermaxilla. Seven mucous pores around the orbit; 3 on the preorbital bone. The pore in the origin of the semicircular dark band around the nape is continned backward by a series of 6 similar ones ending near the upper angle of tho gill opening. A series of 10 or 11 pores beginning near the front of the chin on each side, extending backward and curving upward to the upper anterior edge of the operculum. The gill membranes are broadly united, but they are not joined to the isthmus. The dorsal origin is over the end of the head; the fin is low, and consists of spines, the longest and strongest in the posterior third being slightly longer than the eye. The distance of the vent from the tip of the snout contains the head length $2 \frac{2}{3}$ times. The anal is slightly lower than the dorsal, the rays longest posteriorly. The caulal is rounded, and is barely separated from the dorsal and anal. The pectoral base is broad, and the fin is as long as the head. The intestine is slender, and is more than twice as long as the head. Stomach short, pear-shaped, with 6 slender pylorle crea of unequal length, the longest about twice as long as the eye. The body is completely scaled, the scales very small, cycloid, closely imbricated, with numerous concentrio strix, and they extend halfway up the membrane connecting the dorsal spines. The general body color is brown, the sides sparsely and vaguely mottled. The pectorals are pale. A narrow, dark band extends from the middle of the eye downward and forward, a similar band running backward from the eye on the preopercle; an interrupted semicircular band from running backward from the eye on the preopercle; an interrupted semicircular band from Grebnitski, to whose industry and zeal the Museum is indebted for many valuable collections. Bean \& Bean.)
} 
broadly united, wholly free from isthmus. Dorsal of spines only. Anal with 2 spines. Ventral with 1 spine and 3 well-developed rays. Lower pectoral rays longest, as in Leptoclinus. North Pacific. ( $\pi \lambda \varepsilon \varkappa \tau$ ós, enfolded; $\beta \rho \dot{\alpha} \gamma \chi 05$, gill.)

2787. PIECTOBRANCHUS EVIDES, Gilbert.

Head rather long, $4 \frac{8}{4}$ in length, extending well beyond origin of dorsal fin; depth about 11. D. LVI; A. II, 34. Body very slender, the depth nearly constant throughout. Caudal peduncle without free portion, its depth $2 \frac{1}{2}$ in that of body. Upper jaw with a broad inner band of minute teeth in front and on the sides, the outer series enlarged, 2 in the front of the jaw distinctly canine-like; teeth in the lower jaw similar to the outer series above, in a single series laterally, forming a patch in front of jaw, where 2 of them are much enlarged canines, the largest teeth in the jaws; vomer and palatines with bands of small but very evident teeth. Eyes large, elose together, the interorbital space $\frac{1}{2}$ pupil. Orbit $3 \frac{4}{5}$ in head, longer than snout. Posterior nostril with a short flap, the tube obsolete. Mouth large, somewhat oblique, maxillary reaching middle of orbit, 24 in head. 'Top of head with very large pores, a series running backward from each eye, the two joined by a cross series on occiput. Body covered with very small eycloid scales, including belly, nape, breast, and cheeks, those on breast and cheeks not imbricated; lateral line without visible pores. Spinous dorsal beginning well forward, the distance from its origin to nape less than from latter to posterior margin of orbit. Anterior spines short, but fully united by membrane, the longest spine $3 \frac{1}{2}$ in head; membrane of last spine reaching base of upper caudal rays; origin of anal very slightly in advance of middle of body; anal with 2 short, sharp spines, the rays longer, their terminal $\frac{1}{8}$ free from membrane; last anal ray connected with base of lower caudal ray; ventrals well developed, nearly $\frac{1}{2}$ head; pectorals with lowermost rays abruptly lengthened, $\frac{2}{8}$ head; caudal short, rounded, little more than $\frac{1}{2}$ head. Color dusky olive above, lighter below; sides crossed by about 25 narrow white bars, narrower than interspaces; 3 equidistant dark blotches near back, each double, the two halves occupying contiguous interspaces between white bars; branchiostegal membrane black; head without markings; pectorals white at base, the distal half black, margined with white; ventrals white; dorsal with alternating oblique bars of white and blackish, 2 jet-black roundish spots on its posterior portion; caudal whitish at base, then dusky, margined with white, its upper ray jet-black; anal light at base, becoming black at edge of membrane, the free tips of rays white. Coast of Oregon. A single specimen, 4 inches long, from Albatross Station 3064, in 46 fathoms. ( $\varepsilon \dot{v} \varepsilon \imath \delta \dot{\eta} 5$, comely.)

Plectobranchus evides, GiLBerT, Proc. U. S. Nat. Mus. 1890, 102, coast of Oregon, at Albatross Station 3064. (Coll. Albatross.)

9r6. LEPTOCLINUS, Gill.

Ctenodon, NilssoN, Skandinav. Faun., IV, 190, 1853 (maculatus) (name three times* preoccupied).

Leptoclinus, Gils, Proc. Ac. Nat. Sci. Phila. 1864, 209 (aculeatus).

*Ctenodon, Wagler, 1830, a lizard; Ehrenberg, 1838, a rotifer, and Swainson, 1839, a fish. 
Body much elougated; lateral line obsolete; teeth on jaws, vomer, and palatines; pectoral fins with the upper rays shortened; caudal fin subtruncate. Arctic seas. This genus is close to Lumpenus, differing mainly in the form of the pectoral. ( $\lambda \varepsilon \pi \tau o$ s, slender; Clinus.)

\section{LEPTOCLINUS MACULATUS (Fries).}

(LANGBARN.)

Head 5; depth 8. D. LX (LVIII to LX); A. 36 (35 to 38 ). Eye large, $3 \frac{1}{2}$ in head; snout short and blunt, $4 \frac{8}{4}$ in head, maxillary reaching past middle of eye, $2 \frac{1}{3}$ in head. Teeth in jaws, vomer, and palatines; jaws each having 2 strong canines in front. Scales small, cycloid. First 3 or 4 dorsal spines short and free; longest dorsal spines as long as eye; caudal fin free from dorsal and anal; ventrals 3 in head; pectorals rather large, $1 \frac{1}{2}$ in head. Color yellowish, irregularly marked with dark spots, a series of about 6 of these spots extending along sides close to base of dorsal fin; a series of smaller spots extending along center of sides from upper base of pectoral to caudal; dorsal irregularly covered with dark spots; caudal with 4 dark cross bands; anal, ventral, and pectorals plain yellowish. Bering Sea to Spitzbergen, south to Aleutian Islands and the coasts of Sweden and Norway. This description is taken from a specimen, $5 \frac{1}{4}$ inches long, from Alaska, near Unimak Pass (Albatross Station 3309). A few young individuals of this species, hitherto known only from the North Atlantic, were taken in Unimak Pass and in Bristol Bay, in $29 \frac{1}{2}$ to 70 fathoms. Three small specimens were also taken off Robben Reef, near the Kamchatka coast, in 28 fathoms, and one off Karluk, Kadiak Island. Having no Atlantic specimens of this species, we are unable to satisfy ourselves of the identity of the two, but no difference is evident from descriptions. The lateral line is much more distinct than in our specimens of Lumpenus medius, in which it can be made out with difficulty on scattered scales along middle of sides. (Eu.) (maculatus, spotted.)

Clinus maculatus, Fries, Kgl. Vet. Ak. Handl. 49, 1837, Bohüslän, Sweden.

Lumpenus aculeatus, ReINHARDT, Kong. Dansk. Vid. Selsk., vi, 1837, 190, no description.

Clinus aculeatus, REINHARDT, Dansk. Vidensk. Selsk. Natur. Af h., vII, 1838, 114, 122, 194, Spitzbergen.

Ctenodon maculatus, NiLsson, Skand. Fauna, IV, 190, 1853.

Stichoeus maculatus, GUtNTHER, Cat., III, 281, 1861.

Lumpenus aculeatus, KRöYER, Naturhist. Tidsskr., I, 377, 1862.

Stichceus aculeatus, GÜNTHER, Cat., III, 282, 1861; COLLETT, Norske Nord-Hars Exp.,67, 1880. Lumpenus maculatus, JoRdAN \& GILBERT, Synopsis, 777, 1883; Lilljeborg, Sveriges Och Norges Fish., 500, 1891.

Leptoclinus maculatus, GILBERT, Rept. U. S. Fish Comm. 1893, 450.

\section{POROCLINUS, Bean.}

Poroclinus, Bean, Proc. U.S. Nat. Mus. 1890, 40 (rothrocki).

Body elongate, moderately compressed, covered with small scales; lateral line obsolete. Head moderately long; snout short; eyes large; interorbital space narrow. Mouth small, lower jaw slightly included; teeth on vomer and palate; narrow bands of teeth in jaws, the outer series 
enlarged. Gill openings slightly prolonged forward below, narrowly attached to the isthmus anteriorly. Dorsal composed of many sharp, flexible spines, diminished in length anteriorly. Caudal long, pointed; anal with 3 spines and many rays; pectorals large, the middle rays longest; ventrals jugular, with 1 spine and 3 rays. Intestine short; pyloric eæca 1 or 2 ; no air bladder. Northern Seas. ( $\pi$ ó os, pore; Clinus.)

2789. POROCLINUS ROTHROCKI, Bean.

Head $6 \frac{1}{4}$ in length; depth at nape 12. D. LVII to LX; A. III, 40 to 42. Body tapering uniformly backward. Vent placed anteriorly, its distance from snout $1 \frac{2}{3}$ to $1 \frac{8}{4}$ in its distance from base of eaudal. Snout compressed, slightly projecting, the lower jaw included; maxillary reaching vertical from front of pupil, $3 \frac{1}{3}$ to $3 \frac{1}{2}$ in head. Teeth acute, in narrow bands in the jaws, a single well-marked series on vomer, and a pateh on front of palatines, those on vomer and palatines fully as large as those on jaws, and equally developed in young and adults. Eyes large, close together, the interorbital space convex, its width about $\frac{1}{2}$ pupil. Diameter of orbit equaling length of maxillary, about $3 \frac{1}{2}$ in head. Nostril tubes well developed, $\frac{1}{2}$ diameter of pupil. Gill openings narrower than in other described members of this group, extending forward below the vertical from posterior part of cheek, where they are firmly joined to isthmus, across which they do not form a fold. Gill rakers obsolete. Dorsal beginning over end of opercular flap, its distance from nape equaling distance of latter from posterior margin of pupil; membrane of last spine slightly joined to base of caudal; anterior dorsal spines short, but well connected by membrane; anal with 3 distinct spines, shorter than the rays that follow, the second the longest, all as strong as dorsal spines, and fully connected by membrane, rays all branched at tip, membrane of last ray joined only slightly to base of candal; caudal sharply pointed in all our specimens, the mecian rays longest, about as long as head; pectorals evenly rounded, the median rajs longest, 14 or 15 in number, all branched; ventrals well developed, about $\frac{2}{5}$ as long as head, consisting of 1 short, sharp spine and 3 rays, the spine not closely joined to rays. Lateral line indistinct, usually appearing obsolete, more evident toward head, consisting of a series of distant pores along median line; scales very small, cycloid, imbricated, covering body, inclosing abdomen, breast, and nape; cheoks scaled, the head otherwise naked, or sometimes with a small patch of scales on upper part of opercles. Color, sides with a series of 10 to 12 narrow white cross bars, the first in front of dorsal fin, the last under last dorsal spine, the bars about $\frac{1}{5}$ interspaces; above lateral line scales conspicuonsly margined with darker, below lateral line they broaden out and become forked; upper caudal rays at base with an oval white ring inelosing a darker area, this mark more conspicuous in the young; belly and ventrals white, other fins dusky, but without definite markings. (Gilbert.) Bering Sea. Known from 2 specimens; the type, 7 inches long, was taken August 4, 1888, at Albatross Station 2852 , north latitude $55^{\circ} 15^{\prime}$, west longitude $159^{\circ} 37^{\prime}$, at a depth of 58 fathoms, between Nagai and Big Koniushi Islands. The spec- 
imen here described from Unalaska. (Named for Dr. J. T. Rothrock, professor of botany, University of Pennsylvania.)

Poroclinus rothrocki, BEAN, Proc. U. S. Nat. Mus. $1890,40,55^{\circ}$ I $5^{\prime}$ N., $159^{\circ} 37^{\prime}$ W., between Nagai Island and Koniushi Islands. (Coll. Albatross.)

\section{LUMPENUS, Reinhardt.}

\section{(SNAKe Blennies.)}

Lumpenus, ReINHARDT, Dansk. Vidensk. Selsk. Natur., vI, 1837, 110](lumpenus=fabricii). Leptogunnellus, A yres, Proc. Cal. Ac. Nat. Sci., I, 1854, 26 (gracilis).

Centroblennius, GrLl, Proc. Ac. Nat. Sci. Phila. 1864, 209 (nubilus).

Leptoblennius, GiLl, Proc. Ac. Nat. Sci.Phila. 1864, 209 (serpentinus).

Anisarchus, Gill, Proc. Ac. Nat. Sci. Phila. 1864, 209 (medius).

Body greatly elongate, moderately compressed, covered with small scales; lateral line indistinct or obsolete. Head long; snout short; no cirri; eyes large, placed high; mouth moderate, with a single row of rather small conical teeth on each jaw; palatine teeth present or absent; gill openings prolonged forward below, very narrowly united anteriorly to the isthmus, not forming a free fold across it. Dorsal composed of numerous, sharp, flexible, rather high, spines; caudal fin long; anal manyrayed; pectorals large, more than $\frac{1}{2}$ length of head, the middle rays longest; ventrals well developed, jugular, I, 3 or I, 4 ; intestinal canal long; pyloric cxca present; no air bladder. Chiefly herbivorous. Northern seas. (Lumpen, a Danish name of Zoarces viviparus, with which these fishes were at first confounded.)

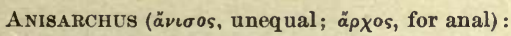

$a$. Anal fin very low in front, the rays gradually lengthened; dorsal spines 61 ; anal rays 42 .

MEDIUS, 2790.

aa. Anal fin not much lower in front than behind.

LUMPENUS:

b. Teeth on palatines more or less developed, at least in the adult; anal rays 40 to 46 ; dorsal spines 63 to 71 .

c. Dorsal spines 69 to 71 .

d. Anal rays 46; dorsal separate from caudal.

dd. Anal rays 41; dorsal slightly joined to caudal.

cc. Dorsal spines about 63 ; anal rays 43.

ANGUILLARIS, 2791. MACKAYI, 2792. FABRICII, 2793.

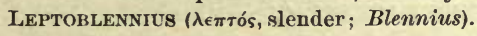

$b b$. Teeth on palatines wanting; dorsal spines 72 to 75 ; anal rays about 50 .

LAMPETRAFORMIS, 2794.

Subgenus ANISARCHUS, Gill.

2790. LUMPENUS MEDIUS (Reinhardt).

Head 6; depth 10. D. LXI ; A.42; V. I, 3. Lower jaw scarcely included, the maxillary reaching front of eye; teeth on palatines, none on vomer; ventrals slender, $\frac{1}{3}$ length of head; lower rays of pectoral shorter than middle ones, the fin shorter than head. Dorsal and anal slightly joined to the truncate caudal; anterior half of anal with the rays shortened. (Collett.) Yellowish, nearly plain. Greenland to Norway and Spitzbergen and westward to Bering Sea and Kamchatka. Specimens from the 
coast of Kamchatka are not evidently different from the current figures and descriptions of Atlantic specimens. (Eu.) (medius, middle.)

Clinus medius, ReInhardt, Dansk. Vidensk. Afh., vIr, 1838, 194, Greenland.

Lumpenus medius, KRörER, Naturh. Tidsskr., I, 377, 1837; JORDAN \&: GiLBERT, Synopsis, $777,1883$.

Stichoeus medius, GÜNTHER, Cat., III, 281, 1861.

A nisarchus medius, GiLL, Proc. Ac. Nat. Sci. Phila. 1864, 210.

Lumpenus medius, ColletT, Norske Nord-Havs Exp., 62, 1880; JORDAN \& GrLBERT, Rept. Fur Seal Invest., 1898.

\section{Subgenus LUMPENUS.}

\section{LUMPENUS ANGUILLARIS (Pallas).}

Head 8; depth 14. D. LXXI; A. 46 (45 to 50); V. I, 4; B. 7 . Cheeks scaly; mouth somewhat oblique, the lower jaw included; maxillary reaching frout of pupil; teeth on palatines, none on the vomer; a single series of rather long, conical, and not very closely-set teeth in each jaw. Gill openings prolonged forward a distance greater thau length of snout; pyloric crea 4, unequal. Fins all comparatively high, pectorals $\frac{2}{3}$ length of head, the middle rays longest; ventrals $\frac{1}{3}$ length of head; dorsal and anal distinct from the pointed caudal, which is nearly as long as head. Olive green above, pale below; sides marked above with dark olive brown; a series of more or less distinct oblong blotches of olive brown along middle of sides; dorsal barred or spotted; anal pale; opercle with a dark blotch; head dusky above. Length 18 inches. San Francisco to Alaska; very abundant northward to Sitka and Unalaska; originally recorded from Kamchatka. (anguillaris, eel-like.)

Blennius anguillaris, PALLAS, Zoogr. Rosso-Asiat., Ir, 176, 1811, Kamchatha and Aleutian Islands. (Coll. Billings and Merk.)

Septogunnellus gracilis, AYres, Proc. Cal. Ac. Nat. Sci., I, 1855, 26, San Francisco.

Gunnellus anguillaris, Cuvier \& VAlenciennes, Hist. Nat. Poiss., XI, 434, 1836.

Lumpenus anguillaris, Girard, Pac. R. R. Surv., X, Fishes, 123, pl. 25b, figs. 1 to 3, 1858;

Storer, Synopsis, 121, 1846; Jordan \& Gilbert, Synopsis, 777, 1883; Jordan \&

STARKS, Fishes Puget Sound, 848, 1895.

Stichoeus anguillaris, GUNTHER, Cat., III, 282, 1861.

\section{LUMPENUS MACKAYI (Gilbert).}

Head $6 \frac{2}{3}$; depth 13 or 14 ; eye 8 in head; snout 4 . D. LXIX; A. II, 41. Very elongate. Head compressed and high, especially anteriorly, the upper profile of snont very convex, the npper jaw decidedly longer than the lower. Mouth nearly horizontal. Maxillary reaching vertical from front or middle of pupil, its length $3 \frac{3}{5}$ to $3 \frac{8}{4}$ in head. Teeth small, in a narrow band in jaws; a single series of weak teeth on palatines; vomer toothless. Gill openings continued forward to below middle of cheeks, the membranes then narrowly joined to isthmus; gill rakers short and weak, about 10 on horizontal limb of arch. Eye small, its horizontal diameter $\frac{1}{2}$ longer than its vertical, slightly longer than interorbital width. Distance from snont to nape equaling length of postorbital part of head. Opercles large, continued to beyond base of pectorals. Dorsal 
beginning immediately above upper end of gill slit, the spines short, strong, and pungent, not flexible; some of the anterior spines short, but not free, the fin increasing in height to opposite front of anal, the longest spine equaling length of snout, the membrane of last spine joining base of upper rays of caudal; anal with 2 strong spines similar to those of the dorsal fin, the second twice length of first and $\frac{8}{4}$ that of highest dorsal spines; anal rays all forked, the posterior longest, equaling length of snout and eye, free from the caudal; caudal fin rounded in younger specimens, lanceolate in adults, becoming in the latter $\frac{8}{4}$ as long as head; ventrals short, of 1 short spine and 3 simple rays, the fin $\frac{1}{4}$ length of head; pectorals large, the middle rays longest, $\frac{2}{8}$ length of head. Scales small, smooth, elongate, imperfectly imbricated, partially embedded or altogether wanting on anterior part of back; cheeks scaled, head otherwise naked; faint traces of a lateral line sometimes visible on middle of sides anteriorly. Color in spirits, light olivaceous (light yellowish in life); a continuous jet-black streak from occiput along each side of dorsal to base of caudal, with 2 interrupted black streaks below it, the lowermost running on middle of side; top and sides of head darker, variously marked with anastomosing black lines and spots; opercles blackish; dorsal and caudal fins dusky translucent, without distinctive markings; anal and ventrals white; pectorals white or dusky; roof of mouth black; peritoneum black dorsally, white ventrally. Bering Sea. Several specimens were seined near the mouth of the Nushagak River, Alaska. (Gilbert.) (Named for Charles Lesley McKay, of Appleton, Wisconsin, a very able young ichthyologist, who was drowned at Nushagak, in Bristol Bay, in 1883.)

Lumpenus maickayi, GILBERT, Rept. U. S. Fish Comm. $1893(1896), 450$, pl. 32, mouth of Nushagak River, Bristol Bay. (Coll. Gilbert.)

2793. LUMPENUS FABRICII (Cuvier \& Valenciennes).

Head 8 or 9 ; depth 11 to 15 . D. LXIII to LXV; A. 41 to 43 ; V. I, 3 ; P. 15. Upper jaw scarcely longer than lower; teeth on palatines few and small, often really or apparently wantiug, especially in the young; maxillary not reaching eye; vertical fins distinct; pectorals large, ovate. Color light brown, with large pale rounded blotches separated by brown shades; head yellowish; pectorals yellowish mottled, with a dusky spot at base. Arctic seas; recorded from Spitzbergen, Greenland, the Gulf of St. Lawrence, Wellington Sound, Bristol Bay, and other localities in Bering Sea (Petropaulski and Plover Bay, as L. anguillaris). We have specimens from Bristol Bay, Disco, Upernavik, and the Gulf of St. Lawrence. These are apparently identical, and they show clearly the identity of $L$. nubilus with $L$. fabricii.

The following notes are from specimens taken in Bristol Bay, in $4 \frac{1}{2}$ to 14 fathoms: These specimens seem to agree in structural details with specimens of Lumpenus fabricii from the North Atlantic. The Pacific specimens are lighter in color, with the dusky mottlings confined to the dorsal region, and with a very distinct series of oblong brown blotches along lateral line, alternating with a lower series of small, faint, round spots. 
Under parts immaculate; the mottlings along base of dorsal frequently uniting to form a series of oblong blotches alternating with those of lateral line; other specimens show no traces of dorsal blotches; dorsal fin translucent, faintly mottled with darker; caudal with brownish eross bars; pectoral with a round dusky sharle at base; fins otherwise unmarked. Mandible with a single series of conical teeth, which widens at symphysis into an irregular double series or narrow patch; a similar series of conical teeth in premaxillaries, within which is a band of fine villiform teeth. A number of small specimens from Disco, Greenland, are entirely similar except for the darker coloration. This species is near $L$. anguillaris, but the latter has a larger mouth, larger teeth, and more numerous fin rays. (Named for Otho Fabricius, the first student of the fishes of Greenland.)

Blennius lumpenus, FABRICIUs, Fauna Grönlandica, 151, 1780, Greènland; not Blennius lumpenus, LINNAUS, which is a species of Gaidropsarus, with 2 barbels at the chin.

Gunnellus fabricii, Cuvier \& Valenciennes, Hist. Nat. Poiss., xi, 431, 1836, Greenland, after FABrIClUs; KRöYER, Naturhist. Tidsskr., I, 377, 1837; GAIMARD, Voy. Scand.,

Zool., Poiss., pl. 14, fig. 1.

Lumpenus nubilus, Richardson, Last Aretic Voyage, Fishes, 13, pl. 28, 1855, Wellington

Sound. (Coll. Edward Belcher.)

Blennius (Clinus) lumpenus, Richardson, Fauna Bor.-Amer., 90, 1836.

Clinus lumpenus, ReINHARdt, Dans. Vidensk. Selsk. Nat. Afh., viI, 194, 1838.

Stichaus lumpenus, GüNTHER, Cat., III, 280, 1861.

Stichoeus nubilus, GÜNTHER, Cat., III, 564, 1861.

Centroblennius nubilus, GiLL, Proc. Ac. Nat. Sci. Phila. 1864, 209.

Lumpenus fabricii, JoRdAN \& GILBERT, Synopsis, 778, 1883.

Leptoblennius nubilus, Jordan \& GllberT, Synopsis, 778, 1883; GILBERT, Rept. U. S. Fish Comm. 1893 (1896), 451.

\section{LUMPENUS LAMPETREFORYIS (Walbaum).}

(SNake Blenny; TANgbrosme.)

Head 9; depth about 15. D. LXXIII (LXVIII to LXXIV); A. 50 (49 to 52); V.I, 3. Body elongate, head slender; lower jaw little shorter than upper; maxillary reaching front of eye. Vent well forward, near end of first third of body; pectoral convex, somewhat shorter than head; first 3 or 4 rays of dorsal short, little connected; caudal acuminate, free from dorsal and anal. Yellowish or greenish, with numerous (about 20) faint brown blotches of different sizes, some of them confluent and extending obliquely upward on dorsal; caudal with transverse dark shades. (Collett.) North Atlantic and Arctic on both shores, south to Sweden and Norway, east to Spitzbergen; rare south to Cape Cod, if L. serpentinus is the same. We can find no difference on a comparison of our notes with published figures and descriptions, except that Storer describes serpentinus as having the caudal plain yellowish. (Eu.) (Lampetra, lamprey.; forma, form.)

Blennius capiti lavi, otc., MOHR, Hist. Nat. Islandiæ, 85, taf. 4, 1786, Iceland; D. 72 ; A. 54. Blennius lampetraformis, W ALBAUM, Artedi Piscium, III, 184, 1792, Iceland; after MoHR. Centronotus islandicus, Bloch \& SCHNEIDER, Syst. Ichth., 157, 1801, Iceland; after MoHR.

Clinus nebulosus, Fries, Vet. Akad. Handl., 55, 1837, Bohuslän, Sweden.

Clinus mohri, KRöYER, Naturh. Tjdsskr., 1 R, 1837, 32, Iceland.

Blennius gracilis, Stuvitz, Nye Mag., Naturvid., I, 406, 1838, west coast of Norway. 
Blennius serpentinus, Storer, Proc. Bost. Soc. Nat. Hist., III, 1848, 30, Massachusetts Bay, from the stomach of a colfish (Coll. Capt. Nathaniel E. Atwood); STorer, Hist. Fish. Mass. 169, pl. 18, f. 1, 1867.

Gunnellus islandicus, Cuvier \& VAlenciennes, Hist. Nat. Poiss., XI, 433, 1836.

Stichous islandicus, GÜNTHER, Cat., III, 281, 1861.

Lumpenus lampetraformis, COLLET1, Norske Nord-Havs Exp., 71, 1880; Jordan \& GILBERT, Synopsis, 778, 1883.

Leptoblenninus serpentinus, JORDAN \& GLBERT, Synopsis, 778, 1883.

\section{9r9. STICHÆUS, Reinhardt.}

Stichous, Reinhardt, Dansk. Vidensk. Natur. og Math. Af handl. 1837, 109 (punctatus). Notogrammus, BEAN, Proc. U.S. Nat. Mus., IV, 1881, 147 (rothrocki); young.

Body moderately elongate, covered with small scales; teeth on jaws, vomer, and palatines. Lateral line present, single, running along side of back; pectorals and ventrals well developed. Dorsal moderately high, of spines only; gill openings continued forward below, the membranes scarcely united to the isthmus; pyloric crea present. Aretic seas.

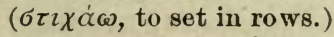

\section{STICHEUS PUNCTATUS (Fabricius).}

Head $4 \frac{1}{2}$; depth about 7: D. XLVIII or XLVIX; A. 32 to 35; eye twice interorbital width, $4 \frac{1}{2}$ in head; snout subconical, 4 in head. Maxillary about equal to snont, $3 \frac{2}{3}$ in head, reaching slightly beyond front of eye. Narrow bands of teeth in the jaws and present on vomer and palatines, the outer series in the upper jaw and the inner series in lower jaw enlarged. Scales small; cycloid; head and cheeks scaleless; longest dorsal spines slightly longer than snout. The membrane from last dorsal spine joining extreme base of upper caudal ray; anal wholly distinct; pectorals rather long, reaching vent, $1 \frac{1}{5}$ in head; ventrals $2 \frac{1}{2}$ in head. Numerous large pores scattered over top and sides of head. Lateral line rather close to back, running along the upper fourth of height of body and ending abruptly at about $\frac{2}{8}$ the length of body. Color bright scarlet, the head marked below with 5 or 6 brown reticulations; a brown streak from snout through eye; fins irregularly marked by dark bars or spots; a narrow row of 5 large round black spots, each with a white band near its posterior margin, occurring at regular instances along dorsal fin; a row of about 8 large dark spots on anal. Arctic seas, from Greenland to northern Siberia, south to Bristol Bay and Newfonndland. Our description (from Dr. Gilbert) taken from a specimen, about 5 inches in length, from Karta Bay, Alaska. It agrees very closely with the account by Ensign H. G. Dresel, of 2 examples from Godhavn, Disco Island, Greenland. The Alaska species must be the same as the other. Dresel finds the depth $7 \frac{8}{4}$ in length. Dr.Gilbertfurther observes: A single specimen, $86 \mathrm{~mm}$. long, was dredged in Bristol Bay, Alaska, Station 3239 , depth $11 \frac{1}{2}$ fathoms. Several larger individuals were seined in Karta Bay, Prince of Wales Island, Alaska, July 12, 1889. The position of the lateral line in this species is incorrectly given as "median" by Jordan \& Gilbert in the Synopsis, pp. 755 and 775. Cuvier and Valenciennes, in their description, drawn from the writings of Fabrieius, state 
that the lateral line runs along the upper fifth of the height of the body and terminates at about the middle of the length. This correctly describes its position in all our specimens, where it originates immediately above the opercle, exhibiting at first rather a strong upward convex curve, then running nearly parallel to the back, separated from base of dorsal fin by $\frac{1}{5}$ height of body. It is very distinct throughout its course, and terminates at about the middle of the length. The narrow brown streak bounding the lateral line above, in Notogrammus rothrocki, is conspicuous in our smallest specimen $(86 \mathrm{~mm}$.). Branchiostegal membranes very narrowly joined anteriorly, forming a narrow free fold across tlie isthmus, from which they are entirely distinct. Narrow bands of tceth in the jaws, and distinctly present on vomer and palatines; the outer series in upper jaw and the inner series in the lower jaw enlarged. D. XLVII or XLVIII; A. I, 32 to 35 . The membranes from last dorsal spine join extreme base of upper caudal ray ; anal wholly distinct. We have not the material for a comparison of Pacific with Atlantic representatives of this species, and the published descriptions of the latter lack detail. (punctatus, spotted.)

Blennius punctatus, Fabricius, Fauna Grönlandica, 153, 1780, Greenland; ReinhardT, Naturhist. Selsk. Skrift., II, pt. 2, pl. 10, fig. 3.

Notogrammus rothrocki, BEan, Proc. U.S. Nat. Mus., Iv, 1881, 146, Plover Bay and Cape Lisburne, Siberia; young. (Types, Nos. 27565, 27580, and 27573. Coll. Dr. Bean.)

Clinus punctatus, RichaRdson, Fauna Bor.-Amer., III, 88, 1836.

Gunnellus punctatus, Covier \& VALEnCIEnnes, Hist. Nat. Poiss., XI, 428, 1836.

Stichaeus punctatus, KRöYER, Naturhist. Tidsskr., I, 377, 1837; GAIMARD, Voy. en Seand. et Lapon., Zool., Poiss., pl. 20, fig. 2; GǗnther, Cat., III, 283, 1861; Jordan \& GILBERT, Syuopsis, 775, 1883; Dresel, Proc. U. S. Nat. Mus. 1884, 249; Gilbert, Rept. U. S. Fish Comm. 1893 (1896), 450.

\section{ULVARIA, Jordan \& Evermann.}

Ulvaria, Jordan \& Evermann, Check-List Fishes N. and M. A., 475, 1896 (8ubbifurcatus).

This genus is very close to Eumesogrammus, from which it differs in the absence of the lowermost or third lateral line, the median line being bifurcate. (Ulva, the sea lettuce, in which many Blennioid fishes live.)

2796. ULVARIA SUBBIFURCATA (Storer).

Head $4 \frac{1}{8}$; depth nearly 5. D. XLIV; A. 30. Mouth rather large; maxillary reaching to below orbit; back somewhat arched; ventral outline nearly straight; eyes large; lateral lines 2 (the lowermost lateral line wanting); median lateral line forked; upper branch of median lateral line about $\frac{2}{8}$ length of the head. Brownish, with several round paler blotches above at the base of the dorsal fin; spaces between these blotches darker, appearing like bars; a broad black bar crossing the opercle obliquely from below the orbit, and 2 parallel dark bars running backwards from orbit; belly yellowish white; dorsal fin with numerous black dots. North Atlantic, south to Cape Cod; very rare. (subbifurcatus, somewhat forked.)

Pholis subbifurcatus, STorer, Rep. Fish. Mass., 63, 1839, Nahant, Mass. (Coll. Dr. Thos.

M. Brewer); DE KAY, N. Y. Fauna: Fishes, 150, 1842; Storer, Hist. Fish. Mass., 258, 1867.

Eumesogrammus subbifurcatus, JoRDAN \& GILBERT, Synopsis, 775, 1883. 


\section{2x. EUMESOGRAMMUS, * Gill.}

Eumesogrammus, GiLl, Proc. Ac. Nat. Sci. Phila. 1864, 210 (procisus).

Body comparatively short, the back somewhat arched; month rather large, the jaws with villiform teeth; teeth on vomer and palatines. Scales small; lateral lines 3 , without accessory branches; pectorals and ventrals well developed. Dorsal moderately high, of spines only, free or slightly connected with the rounded caudal; gill openings continued forward below, the membranes narrowly joined to the isthmus; pyloric cace present. Northern scas. ( $\varepsilon v^{3}$, well; $\mu \varepsilon^{\prime} \sigma o s$, middle; $\gamma \rho \alpha \mu \mu \eta \dot{~}$, line; the longest lateral line being the middle one.)

\section{LUMESOGRAMUS PRECISUS (Kröyer).}

Head 4 ; depth nearly 6. D. XLIX; A. 34; V. 3. Snout subconical; cleft of mouth slightly oblique; vomerine and palatine teeth present; 3 lateral lines on each side, the median one contirued to the base of the caudal; ventral fin $\frac{1}{2}$ as long as the pectoral, which is much shorter than liead; dorsal fin terminating just at root of caudal. An ovate, black, whiteedged spot between the sixth and tenth dorsal spines. Coasts of Greenland. (Giinther.) (procisus, exact.)

Olinus proecisus, KRörer, Naturh. Tidsskr., I, 25, A ugust, 1836, † Greenland.

Clinus unimaculatus, Reinhardt, Dansk. Vidensk. Selsk., vir, 114, Feb., 1837, Greenland. Stichoeus unimaculatus, ReINHARDT, Dansk. Vidensk., 109, 1837; GÜNTHER, Cat., 283, 1861. Eumesogrammus procisus, JORDAN \& GILBERT, Synopsis, 774, 1883.

* The 2 following species from the Okhotsk Sea seem to represent 2 new genera (Erno. grammus and Ozorthe) closely related to Eumesogrammus:

\section{ERnogrammus enNeagrammus (Kner).}

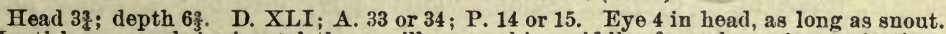
Mouth large, nearly horizontal, the maxillary reaching middle of eye; lower jaw projecting; profile of snout nearly horizontal; fine pointed teeth in bands on jaws aud across the vomer. Head naked; dorsal of high, slender spines; caudal separate, rounded; anal high; pectoral long, $1 \frac{1}{2}$ in head; ventrals $\frac{1}{2}$ as long as pectorals; scales very small, smooth; lateral lines each with short oblique branches, each ending in a wide pore; 1 lateral line along base of dorsal from head to caudal, 1 along middle of side, 1 aloug base of anal to caudal, this fork. ing at the vent and sending 2 parallel branches forward to the breast; brownish, 2 rows of small dark spots along middle lateral line; dorsal and anal with dark spots and a broad dark inargin; pectorals with 3 black cross bands; a dark bar at base of caudal; 3 black bars from eye. Okhotsk Sea. Known from a specimen, 13 inches long, from Decastris

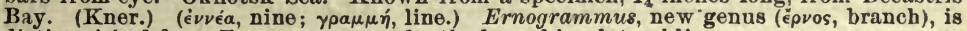
distinguislied from Eumesogrammus by the branching lateral line.

Stichous enneagrammus, KNER, Sitzber. Akad. Wiss. Wien 1868, 16, taf. vi, f. 19 Decastris Bay. (No.1401c Mus. Wien.)

OZORTHE HEXAGRAMMA (Schlogel).

Head $5 \frac{1}{4}$; depth $5 \frac{1}{4}$. D. XLIII; A. 24. Snout pointed; mouth little oblique; the maxillary reaching front of eye; bands of fine teeth on vomer and palatines; a few large caninelike teeth in front; eye 5 in head; dorsal spines all stiff, the middle ones longest; dorsal joined to caudal by membrane; lateral lines 3 , the upper partly interrupted, sending at riglt angles upward and downward lines which join the middle line; third lateral line along base of anal only: Scales small. Dorsal with large dark brown spots obliquely placed; 3 brown stripes across cheek; anal colored like dorsal; caudal pectoral and ven. trals each with 3 dark cross bands. Northern coast of Japan to Okhotsk Sea. This description (after Kner) from a specimen from Decastris Bay (No. 5575, Mus. Wien.). This

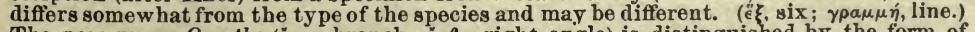
The new genus Ozorthe (öyos, branch; $0 \theta \eta \eta$, right angle) is distinguished by the form of its lateral lines as above described.

Stichous hexagrammus, Schleged, Fauna Japonica, Pisces, 136, pl. 3, f. 1., 1850. Bay of Simabara, Japan. Head $4 \frac{1}{2}$; depth $6 \frac{1}{2}$. D. XL; A. 29. GÜNTHER, Cat., III, 284, 1861; KNER, Sitzber. Akad. Wiss. Wien 1868, 45.

† These dates are thus given by Kröyer, as quoted by Dr. Gill, Proc. Ac. Nat. Sci. Phila. 1864,210 . We have been unable to verify them.

$3030-76$ 


\section{Family CCI. CRYPTACANTHODIDA.}

\section{(The WRY-Mouths.)}

Body very long and slender, compressed, naked or covered with small, cycloid scales; lateral line obsolete or composed of open pores without tubes; head oblong, cuboid, with vertical cheeks; conspicuous muciferous channels in mandible and preopercle; head flattish above, with deep rounded pits between and behind eyes; month large, very oblique; lower jaw very heavy, its tip projecting; premaxillary not protractile; jaws with rather sharp, conical teeth; larger teeth on the vomer and sometimes on palatines. Gill membranes joined to the isthmus, the gill openings prolonged forward below. Pyioric cæca 5. Pseudobrauchiæ small. Dorsal fin long, composed entirely of spines, which are rather strong, but enveloped in the skin; dorsal and anal joined to the caudal; no ventral fins; pectorals short. Blennies of large size, of the Northern shores of America. Three species known, forming 3 genera. (Blenniida, genus Cryptacanthodes, Guinther, Cat., III, 291, 1861.)

a. Body scaly; lateral line present, composed of open pores; isthmus narrow; teeth on palatines.

DELOLEPIS, 922.

aa. Body naker; lateral line obsolete.

c. Palatines with teeth; isthmus narrow.

cc. Palatines toothless; isthmus rather broad.

Cryptacanthodes, 923. LYCONECTES, 924.

\section{DELOLEPIS, Bean.}

Delolepis, Bean, Proc. U. S. Nat. Mus. 1882, 465 (virgatus).

Body anguilliform, moderately compressed posteriorly, covered with small, imbricated, cycloid scales; vent nearly median; a small anal papilla; lateral line continuous, straight, nearly median, composed of open pores, without prominent tubes. Head oblong, subquadrangular, naked, the muciferous channels well developed, the vertex shallow conoave; snout short, obtuse; nostril tubular, close behind premaxillary; eyes small, high, separated by an interspace of moderate width, surrounded by a series of shallow pits; mouth wide, oblique, terminal, the lower jaw projecting beyond the upper; lips fleshy; premaxillaries slightly protractile, with 2 rows of small conical teeth; a few larger teeth at the symphysis; vomer and palatines with a few rather large teeth; tongue smooth, adherent; mandible with a few shallow pits, the series continued on the posterior border of preopercle; opercles unarmed. Gill membranes attached to a narrow isthmus; gill rakers very short; pseudobranchiæ present. Branchiostegals 6. Pectorals short, placed low, their bases vertical; ventrals none; dorsal beginning above gill opening, composed entirely of spines; anal with 2 spines and many split rays; dorsal and anal continuous with the caudal, which is rather long and pointed. Intestine short, with a few pyloric cæca. ( $\delta \tilde{\eta} \lambda \circ 5$, visible; $\lambda \varepsilon \pi i$, scale.)

2798. DELOPLEPIS VIRGATUS, Bean.

Head 6; depth 10. D. LXXVI; A. II, 46; P.13; cæca 6. Width of head equal to greatest depth of body; interorbital area equal to snout, or $\frac{1}{8}$ length of maudible; maxillary reaching a little behind eye, its length 3 in 
distance from snout to front of dorsal; eye 2 in snout, 11 in head. Beginning at a short distance behind origin of dorsal, small, oblong, cycloid scales, closely imbricated, cover a strip of the body along the lateral line; the scaled area gradually widens backward until, behind the vent, only a very narrow strip along bases of dorsal and anal is naked. Dorsal beginning over upper angle of gill opening; first spine $\frac{1}{2}$ as long as the seventyfirst or longest; caudal 11 in length; pectoral 3 in head. Brownish yellow; a brown stripe along lateral line, another along back, a third along base of anal. Length 30 inches. Coast of southern Alaska to Puget Sound; not rare about Seattle. (virgatus, striped.)

Delolepis virgatus, BeAN, Proc. U. S. Nat. Mus. 1881, 466, Kingcombe Inlet, British Columbia; Port Wrangel, Alaska (Coll. Capt. H. E. Nichols. Types, Nos. 29149 and 29150, U. S. Nat. Mus.); Jordan \& Starks, Fishes Puget Sound, in Proc. Cal.Ac. Sci. 1895,848 .

\section{CRYPTACANTHODES, Storer.}

Cryptacanthodes, Storer, Rept. Fish. Mass., 28, 1839 (maculatus).

Body long and slender, compressed, naked, without lateral line; head cuboid, with vertical cheoks and conspicuous muciferous cavities; eyes small, placed high; mouth large, very oblique, the very heavy lower jaw prominent in front; jaws, vomer, and palatines with stoutish conical teeth, in few series. Gill openings prolonged forward below, narrowly attached to the isthmus. Dorsal fin of stoutish spines, hidden in the skin; dorsal and anal joined to caudal; pectorals short; ventrals wanting. ( $\rho \rho \pi \tau o$, hidden; $\dot{\alpha} \varkappa \alpha \nu \theta \hat{\jmath} \delta \eta \zeta$, spined.)

\section{CRYPTACANTHODES MACULATUS, Storer.}

(WRY-MOUTH; GHOST-FISH.)

Head $6 \frac{1}{2}$; depth 13. D. LXXIII; A. 50. Eyes small, placed high, not so wide as the interorbital space, which has 2 ridges and 3 pits; orbital rim raised; 2 deep pits behind each eye at the temples; a deeper pit on the top of head between them; a raised ridge continued backward on each side of head behind orbital rim; maxillary extending to beyond eye; pseudobranchiæ small; pectorals short, 3 in head, their tips reaching beyond front of dorsal; vent a little in front of middle of body. Light brownish, with several series of smallish dark spots, arranged in more or less regular rows, from head to base of caudal; vertical fins closely spotted with darker; head above thickly speckled; body sometimes ("inornatus") entirely immaculate. Length 24 inches. Labrador to Long Island Sound; not very common; a fow specimens have been taken at Woods Hole. The ghost-fish form (inornatus) occasionally seen, is doubtless an albino. (maculatus, spotted.)

Cryptacanthodes maculatus, STORER, Rept. Fish. Mass., 28, 1839, coast of Massachusetts; De KAY, N. Y. Fauna: Fishes, 63, pl. 18, fig. 50, 1842; GÜNTHER, Cat., 1Ir, 291, 1861; JoRDAN \& GILBERT, Synopsis, 780, 1883.

Ophidium imberbe, PECK, Amer. Acad., 2d part, II, 1804, 46, pl.4, New Hampshire; A.49; P. 14; C. 22; not of LinNaUs.

Fierasfer borealis, DeKAY, New York Fauna: Fishes, 316, 1842, New York; after PeCK. Cryptacanthodes inornatus, GiLL, Proc. Ac. Nat. Sci. Phila.1863, 332, Coast of Massachusetts; albino form. 


\section{LYCONECTES, Gilbert.}

Lyconectes, GLbBrT, Rept. U. S. Fish Comm. 1893 (1896), 452 (aleutensis).

Mouth subvertical; lower jaw projecting; premaxillary protractile. Teeth strong, conie, wide set, in more than 1 series. Mucous pits prominent on head. Gill opening narrow, ceasing opposite middle of base of pectorals, the membranes widely joined to isthmus. Dorsal and anal wholly joined to caudal, the latter extending well beyond them; dorsal fin composed of spines only; no ventral fins. Body naked; no lateral line. This genus differs from Cryptacanthodes principally in the absence of palatine teeth, agreeing with it in general appearance and in most details of structure. Alaska. ( $\lambda \dot{v} \varkappa \circ 5$, wolf; $\nu \eta \varkappa \tau \dot{\rho} \rho$, swimmer.)

\section{LYCONECTES ALEUTENSIS, Gilbert.}

Head $7 \frac{1}{8}$; depth $14 \frac{1}{8}$. D. LXIX; A. 49; P. 13; caudal 18. Head square in cross section, the upper and lower surfaces plain, the cheeks vertical, the depth and width equal. Mouth still more oblique than in Cryptacanthodes maculatus, with much heavier mandible and less expanded maxillary, the exposed portion of the latter lying vertically, and not extending beyond vertical from middle of eye. Teeth all similar, few in number, those in premaxillary arranged in 2 series, the inuer of which are smaller than the outer, from which they are separated by a wide interspace; teeth in mandible in a single series laterally, becoming a sparsely filled patch toward symphysis; 4 or 5 similar conical teeth on head of vomer; palatines toothless. A long nostril tube overhangs the upper lip. Upper lip separated by a fold from forchead, the upper jaw protractile. Eye extremely small, sunken in the socket, which it does not nearly fill, its diameter slightly less than $\frac{1}{2}$ in terorbital width; supraorbital rim not elevated, and containing no conspicuous projections; suborbital rim swollen, with an enlarged mucous channel; a conspicuous series of mucous pits along each mandible and the margin of preopercle; 2 series on top of head diverging backward from above the eyes; otherwise no pits or projections on head; a shallow triangular depression on occiput. Gill slit much less oblique than margin of preopercle, its length $1 \frac{1}{2}$ times the distance between lower ends of gill slits, the latter reaching the vertical from middle of opercles. Dorsal fin of rather flexible spines, not concealed in heavy fin membranes; origin of dorsal immediately behind axil of pectorals. Hinder margin of occiput midway between front of dorsal and middle of eye. Origin of anal well in advance of middle of length, its distance from tip of snout contained $1 \frac{2}{5}$ times in its distance from base of caudal. Pectoral short, rounded, its base separated by a wide prepectoral area from gill slit, the width of area $\frac{8}{4}$ length of fin, the latter equaling distance from tip of snout to middle of eye. No ventrals. Body covered with lax naked skin, which also covers but does not obscure rays of anal fin; no pores to lateral line. Color in life, reddish on head, body, and fins, due to the blood vessels in the skin. Aleutian Islands. A single specimen, $180 \mathrm{~mm}$. long, known. (Gilbert.)

Lyconectes aleutensis, GrLbert, Rept. U. S. Fish Comm. 1893 (1896), 452, pl. 34, fig. 3, Albatross Station 3312, north of Unalaska Island, in 45 fathoms. (Coll. Albatross.) 


\section{Family CCII. ANARHICHADIDA.}

\section{(The Wolf-Fishes.)}

Body oblong or elongate, covered with rudimentary scales; no lateral line. Head scaleless, without cirri, its bones very thick and strong, the profile strongly decurved. Mouth very large, oblique, the jaws anteriorly with very strong conical canines; sides of lower jaw with very strong molar teeth, which shut against a series of very coarse molars on the palatines; vomer solid, armed with strong molar teeth, the dentition adapted for crushing sea-urchins and mollusks. Gill membranes broadly united to the isthmus; no pyloric cæca. Dorsal fin high, composed entirely of flexible spines; no ventral fins; pectoral fins broad, placed low. Large carnivorous fishes of the northern seas. Two genera and about 6 species known. (Blenniida, pt., Guinther, Cat., III, 208-211, 1861.)

\section{ANARHICHADINE:}

a. Body moderately elongate, the tail not tapering to a point; dorsal and anal separate from the caudal.

ANARHICHAS, 925.

\section{ANARRHICHTHYINAE:}

$a a$. Body eel-shaped, excessively elongate; the dorsal and anal joined with the caudal at the end of the long and tapering tail.

ANARRHICHTHYS, 926.

\section{ANARHICHAS (Artedi) Linnæus.}

\section{(WoLF-Fishes.)}

Anarhichas (ARTEDI) Linnfeus, Syst. Nat., Ed. x, 247, 1758 (lupus).

Body moderately elongate, covered with rudimentary scales; head scaleless, without cirri, compressed, narrowed above, the profile strongly decurved; mouth wide, oblique; premaxillary not protractile; jaws with very strong conical canines anteriorly; lateral teeth of lower jaw either molar or with pointed tubercles; upper jaw without lateral teeth; vomer extremely thick and solid, with 2 series of coarse molar teeth; palatines with 1 or 2 similar series. Gill membranes broadly joined to the isthmus; no lateral line. Dorsal fin rather high, composed entirely of flexible spines, which are enveloped in the skin; anal fin lower; candal fin developed, free from dorsal and anal; no ventral fins; pectoral fins broad, placed low; air-bladder present; nopyloric cæca. Northern seas. (Anarhichas (or Scansor), the climber; an ancient name of Anarhichas lupus; from $\dot{\alpha} v \alpha \rho \rho \imath \chi \alpha \dot{\alpha} \mu \alpha \imath$, to climb or scramble up; the allusion not evident, the word spelled with a single $r$ by Artedi and Linnaus.)

a. Dorsal spines 60 to 70 .

b. Vomerine teeth not extending farther backward than the palatine teeth.

c. Back and sides vaguely mottled, without spots or bands; vomerine teeth not extending nearly as far backward as palatine teeth.

LATIFRONS, 2801.

cc. Back and sides profusely covered with roundish black spots; vomerine teeth extending nearly as far backward as palatine teeth.

MINOR, 2802.

bb. Vomerine teeth extending much farther backward than the short band of palatine teeth : sides of body with 9 to 12 darker cross bars; nape and shoulder with dark spots.

LUPUS, 2803. 
aa. Dorsal spines 80 to 85 ; body without bands or spots; vomerine teeth extending farther backward than palatine band.

d. Head moderate, $4 \frac{1}{2}$ in length; caudal rays 20 ; upper canines 4 .

$d d$. Head very large; caudal rays 17 ; upper canines 6.

LEPTURUS, 2804.

ORIENT ALIS, 2805.

2501. ANARHICHAS LATIFRONS, Steenstrup \& Hallgrimossn.

Head 5; depth 4. D. LXVII; A.45. Body more robust than A. lupus, the dorsal fin lower. Head broad, the profile not strongly decurved; teeth much smaller than in $A$. lирuв; vomerine teeth not extending nearly as far back as the palatine series. Pectorals $\frac{3}{5}$ length of head; dorsal fin not very high, beginning above the gill opening, the lougest spine less than $\frac{1}{2}$ head; caudal $2 \frac{1}{2}$ in head. Brown, obscurely spotted with darker; the sides without dark bars or black spots. (Collett.) North Atlantic on both coasts, chiefly north of the Arctic Circle, south to Banquereau on our coast. (Eu.) (latus, broad; frons, forehead.)

Anarrhichas latifrons, SteenstruP \& Hallgrimsson, Förh. Skand. Naturf. 3 die Möte 1842, 647; Bean, Proc. U. S. Nat. Mus., II, 1879, 218; ColletT, Meddelsk. Norges Fiske 1879, 46; Jordan \& GILBERT, Synopsis, 782, 1883; Goode \& BEAN, Oceanic Ichthyology, 301, fig. 271, 1896.

Anarrhichas denticulatus, KRöYER, Overs. Vidensk. Selsk. Kjöb. 1844, 140.

2802. ANARHICHAS MINOR, Olafsen.

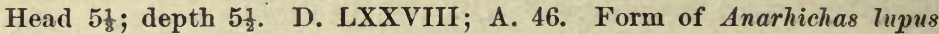
or a little more slender; fins similarly formed, the dorsal a little lower. Vomerine teeth extending nearly or quite as far back as the palatines. Body pale olivaceous or yellowish; sides without vertical bars; round, black spots covering dorsal and caudal fins as well as back and sides down to the level of the pectoral; head spotted; belly immaculate. North Atlantic, on both coasts, chiefly north of the Arctic Circle, south to Eastport, Maine; Gloncester; and Norway. (Eu.) (minor, smaller.)

Anarrhichas minor, OLAFSEN, Reise i Island, 592, 1772, Iceland.

Anarrhichas pantherinus, ZuInw, Nov. Act. Petrop. 1781, 271; Bean, Proc. U. S. Nat.

Mus., II, 1879, 217; Jordan \& Gilbert, Synopsis, 781, 1883; Goode \& BeAN, Oceanic Ichthyology, 301, fig. 270, 1896.

Anarrhichas karrak, BONNATERRE, Encycl. Ichth., 38, 1788, Iceland; after OLAFSEN.

Anarrhichas maculatus, BLOCH \& SCHNEIDER, Syst. Ichth., 496, 1801, Iceland; after OLAFsén.

Anarrhichas leopardus, AGASsIz in SPIX, Pisc. Brasil., tab. 51, 1829, "Atlantic Ocean."

2503. ANA RHICHAS LUPUS, Linnæus.

(WOLF-FISH.)

Head 6 ; depth $5 \frac{1}{2}$. D. LXII ; A. 42. Maxillary reaching beyond orbit; band of vomerine teeth extending much farther back than the short palatine band. Pectorals large, rounded, $\frac{2}{8}$ length of head. Dorsal high, beginning over the gill opening, its longest rays about $\frac{1}{2}$ length of head. Browuish or bluish gray; sides with numerous (9 to 12 ) very dark transverse bars, which are continued on the dorsal fin; besides these 
numerous dark spots and reticulations, the spots most distinct below front of dorsal; fins dark; caudal tipped with reddish. Length 3 to 4 feet. North Atlantic, south to Cape Cod and France; rather conmon both in America and Europe. A large voracious fish, not valued as food. The American form, vomerinus, seems to be fully identical with the European. (Eu.) (Lupus, a wolf.)

Anarhichaslupus, LINNAes, Syst. Nat., Ed. x, 247, 1758, no definite locality ; after ARTEDI; GUNTHer, Cat., III, 208, 1861; JoRdan \& Gilbert, Synopsis, 781, 1883; Goode \& BeAN, Oceanic Ichthyology, 299, 1896.

Anarhichas strigosus, Gmelin, Syst. Nat., I, 1144, 1788, British Sea.

Anarrhichas vomerinus, AdAssiz in STORER, Hist. Fish. Mass., 265, p]. 18, fig. 1, 1867, Cusk Rocks, between Boston and Cape Ann.

2804. ANARHICHAS LEPTURUS, Bean.

(ALASKA WOLF-FISH.)

Head $4 \frac{1}{2}$; depth 5. D. LXXXI; A. 52 ; C. 20 or 21 . Head moderate; maxillary $\frac{1}{2}$ as long as head; nostril nearer eye than mouth. Four large canines in the upper jaw and 5 in the lower, all of them strongly recurved; behind the canines in each jaw are a few sharp, conical teeth, also recurved; palatine teeth in 2 series, 4 in the outer and 5 in the inner series, those in the outer series the longer; vomerine teeth in 2 series, the vormerine patch beginning in advance of the palatine, and extending farther back than the latter; head and fins scaleless; median line of body and all of tail with small, widely separated scales. Dark brown, without bands or spots; belly pale, clouded with very dark brown. (Bean.) Coasts of Alaska, sonth to Vaucouver Island; common about the Aleutian Islands, and perhaps identical with Anarhichas orientalis. ( $\lambda \varepsilon \pi \tau o$ s, slender; ovं $\rho \dot{\alpha}$, tail.)

Anarrhichas lepturus, BeAN, Proc. U. S. Nat. Mus., In, 1879, 212, St. Michaels, Alaska; Jor. DAN \& Gilbert, Synopsis, 782, 1883; GOODE \& BeAN, Ocean. Ichth., 299, 1896.

i A narrhichas orientalis, PALlAS, Zoogr. Rosso-Asiat., III, 77, 1811, Kamchatka.

\section{ANARHCHAS ORIENTALIS, Pallas.}

This species, if correctly described, would differ from Anarhichas lepturus in the very large head, $2 \frac{1}{8}$ times in total length of body; in the absence of scales; in having the nostril midway between eye and mouth, and in having 6 canines in the upper jaw. Color plain brown. D. LXXXIV; C. 17. Coast of Kamchatka. (Pallas.) As the first of these characters is certainly erroneous, it is likely that the others are also, and that this species is not distinct from Anarhichas lepturus. (orientalis, eastern.)

Anarrhichas orientalis, PALLAs, Zoogr. Rosso-A siat., III, 77, 1811, Kamchatka. ? Anarrhichas lepturus, BEAN, Proc. U. S. Nat. Mus., II, 1879, 212, St. Michaels.

\section{ANARRHICHTHYS, Ayres.}

Anarrhichthys, Arres, Proc. Cal. Ac. Nat. Sci., I, 1855, 32 (ocellatus).

Body elongate, tapering backward into a very long and compressed tail, around which the dorsal and.anal are confluent with the caudal. Scales rudimentary; no lateral line. Dorsal high, composed entirely of 
flexible spines; pectoral fins broad, placed low; no ventral fins. Head very large, compressed, the snout rather short; mouth large; jaws with verystrong, conical canines anteriorly; vomer and palatines each with about 2 rows of coarse molars, the palatine band shutting against similar teeth on the sides of the lower jaw. Gill membranes broadly united to the isthmus. No pyloric exca. Large, eel-shaped fishes of the North Pacific, remarkable for the tremendous dentition, the head essentially as in Anarhichas, the body strikingly different. (Anarhichas; $i \chi \theta \dot{v} 5$, fish.)

\section{ANARRHICHTHYS OCELLATUS, Ayres.}

\section{(WoLF-EEL.)}

Head 11; depth 15. D. CCL; A. 233; P. 19. Body elongate, formed as in an eel; the head and jaws very strong. Pectorals broad, more than $\frac{1}{2}$ head; longest dorsal spine $\frac{1}{2}$ head. Color dark greenish, the body and dorsal fin everywhere covered with round, ocellated black spots of various sizes, the light markings forming reticulations around the spots; head paler, with the reticulations in much finer pattern; anal pale-edged. Length 5 to 8 feet. Pacific coast, from Monterey north to Puget Sound; generally common. One of our most remarkable fishes; rarely used as food. It feeds chiefly on sea-urchins and sand dollars. (ocellatus, with eye-like spots.)

Anarrhichthys ocellatus, A Yres, Proc. Cal. Ac. Nat. Sci., I, 1855, 31, San Francisco; JordaN \& Gilbert, Synopsis, 782, 1893; Jordan \& Starks, Fishes Pugat Sound, 848, 1895.

Anarrhichthys felis, Girard, Proc. Ac. Nat. Sci. Phila. 1854, 150, San Francisco (Type, No. 511. Coll. W. O. Ayres'), name only, no description; Girard, U.S. Pac. R. R. Surv., X, Fish., 125, pl. 25a, figs. 1 to 3, 1858; GÜnTHER, Cat., III, 211, 1861.

\section{Family CCIII. CERDALIDA.}

Body elongate, compressed, covered with small scales; no lateral line; head small; gill openings reduced to small slit-like openings more or less horizontal in position; dorsal fin very long and low, anteriorly of slender spines, which pass gradually into the soft rays; no free spines; no cirri; tail not isocereal; pseudobranchiæ well developed. Three species known, from the west coast of tropical America in rock pools near the shore. The presence of some spines in the dorsal separates them from the Scytalinida, while the small gill openings distinguish them from the Blenniida, to which they are more nearly allied.

a. Ventral fins each with 2 rays; dorsal rays 41 ; body moderately elongate; greatest depth 103 in length; distance from insertion of dorsal to occiput equal to length of head.

Cerdale, 927.

$a a$. Ventral fins each with 1 ray; dorsal rays 48 to 55 ; body very elongate, eel-like, its depth 15 to 18 in length.

Microdrsmus, 928.

\section{CERDALE, Jordan \& Gilbert.}

Cerdale, Jordan \& GiLberT, Bull. U. S. Fish Comm. 1881, 332 (ionthas).

This genus differs from Microdesmus in the presence of 2 rays in the ventral fin. Its body is much less elongate than in Microdesmus. The gill openings are reduced to small, nearly horizontal slits below and in front of the pectoral fins. ( $\varkappa \varepsilon \rho \delta \alpha \lambda \hat{\eta}$, the wary one, the fox-like.) 
2807. CERDALE IONTHAS, Jordan \& Gilbert.

Head $7 \frac{8}{4}$ in length; depth $10 \frac{8}{4}$. D. $41 ;$ A. 36 to 38 ; C.4-17-4; P. 12 ; V. 2. Body considerably elongate, compressed, of nearly equal depth throughout, the head tapering rapidly from occiput to snout; snout short, not obtuse, but the lower jaw heavy and blunt, much projecting beyond the premaxillaries; gape very short and oblique, the tip of the premaxillary not reaching ventral from orbit. Margin of npper jaw formed en. tirely by the premaxillaries, which are free laterally, but scarcely movable mesially. Maxillary not distinguishable, probably enveloped in the integument of the snout. Teeth rather strong, short, blunt, in a double series in each jaw, apparently wanting on the vomer and palatines. Lips developed laterally, where they form a fold around the angle of the mouth; lower lip adnate mesially, the upper reduced to an obsolete fold. Length of gape $\frac{1}{5}$ length of head. Nostrils 2, distant, the anterior at the end of the snout, almost labial, the posterior above front of orbit, both circular. Eye very small, somewhat less than interorbital width or than length of snout. Distance from snout to past margin of orbit contained $2 \frac{2}{8}$ times in length of head. Pseudobranchix well developed. Gill openings very narrow, reduced to a short, nearly horizontal slit, extending forward from a point just below the lower base of the pectoral fin. Branchiostegals evident, apparently 4 in number. Vertical fins well developed; dorsal and anal both long, the membrane of the last ray of each joining the base of the rudimentary rays of the caudal. Distance from occiput to the origin of dorsal fin equal to the length of the head; rays of dorsal fin very slender, distinct, the membrane thin and transparent, the rays all, or nearly all, articulate, the anterior simple, the posterior bifid at tip. Vent slightly in advance of middle of length of body, the anal fin beginning immediately behind it; anal rays bifid at tip, excepting the first 2 , which appear simple; tail not isocercal, truncate at base of caudal, most of the rays of the caudal springing from the expanding last vertebra; caudal fin rounded, $\frac{4}{6}$ length of head, its rays much branched, more closely set than the rays of the dorsal and anal; rudimentary rays very numerous; ventral fins small, close together, inserted slightly in advance of the lower end of the pectoral, each fin composed of 2 rays, the inner prolonged beyond the outer, and bifid at tip, about as long as pectoral fin and $\frac{3}{5}$ length of head; pectorals well developed, broad, the rays branched at tip. Head and body entirely covered with small scales, which are close set but hardly imbricate, not arranged in series; mandible, snout, and gill membrane scaly; scales on belly and breast smaller than the others and more thickly set; base of caudal and pectoral fins scaled. Coloration in life, body translucent light olive, immaculate below; back and sides very finely marked with clusters of fine dots, the ground color appearing as reticulations between the clusters, which are of irregular size and form; on the sides of the head these dots form bars, which radiate from the eye to the snout and lower side of the head. This species is known from 3 specimens, $2 \frac{1}{2}$ to 3 inches in length, taken in a rock pool at Panama. (iov $\theta \dot{\alpha} 5$, freckled.)

Cerdale ionthas, Jordan \& GiLBerT, Bull. U. S. Fish Comm. 1881, 332, Panama. (Coll. Chas. H. Gillbert.) 


\section{MICRODESMUS, Giinther.}

Microdesmus, GÜNTher, Proc. Zool. Soc. London 1864, 26 (dipus).

Body anguilliform, covered with rudimentary scales; head small, with short, obtuse snout and small mouth; lower jaw projecting; teeth minnte, in jaws only; eyes very small; gill opening reduced to a very narrow, somewhat oblique slit, in front of lower part of pectorals; vertical fins well developed, the dorsal and anal joined to the caudal by a thin membrane; rays of dorsal mostly articulate, all but a few of the last simple; ventral fins very small, reduced to a single ray; pectorals moderate; vent normal, in middle of body. Pacific coast of tropical America. ( small; $\delta \varepsilon \sigma \mu \dot{s}$, a band.)

$a$. Dorsal rays 55 , the fin beginning less than a head's length behind occiput.

DIPUS, 2808.

$a a$. Dorsal rays 48 , the fin beginning more than a head's length behind the occiput. RETROPINNIS, 2809.

2508. MICRODESKUS DIPUS, Günther.

Head about 11 in total length; depth about 18. D. 55; A. 34; C. 16; P. 12 ; V.1. Head rather compressed, snout short, mouth very narrow, lower jaw very prominent. Eye minute, lateral, and in anterior third of head. Dorsal fin commencing at a distance from occiput which is somewhat less than length of head, nearly even, the rays very distinct, the interradial membrane being thin and transparent; anal fin commencing immediately behind vent. Caudal rays much more slender and more closely set than those of dorsal and anal; caudal fin rounded, $\frac{2}{8}$ length of head; pectorals as long as ventrals, and $\frac{1}{2}$ as long as head; ventrals close together, and inserted a little behind root of pectoral. Upper parts uniformly brownish olive. Panama. Known from a single specimen, $4 \frac{1}{2}$ inches long. (Günther.) ( $\delta i s$, two; $\pi$ ov́s, foot.)

Microdesmus dipus, Günther, Proc. Zool. Soc. London, January 26, 1864, 4, pl. 3, fig. 2, Central America (Coll. Capt. Dow); Jordan, Cat., 126, 1885.

2809. MICRODESMCS RETROPINNIS, Jordan \& Gilbert.

Head $14 \frac{1}{2}$ in length; greatest depth $15 \frac{2}{3}$. D.48; A. 29; C. 3-17-3; P. 13; V.1. Body very elongate, compressed, tapering somewhat from front of dorsal to caudal peduncle. Head very small, rapidly tapering forward from occiput; upper profile with a noticable depression behind the orbits, the outline thence to snout strongly convex. Mouth very small, somewhat oblique, the fleshy tip at symphysis of lower jaw projecting much beyond the premaxillaries; gape scarcely reaching vertical from orbit. Teeth small, apparently in a single series in each jaw only. Nostrils double, distant, the anterior near the end of snout, the posterior above anterior margin of orbit. Gill openings a very narrow, somewhat oblique slit, from front of lower third of pectoral fin downward and forward. Branchiostegals evident, 4 or 5 in number. Eye very small, lateral, sitnated near the upper profile of the head, its diameter nearly $\frac{1}{2}$ the leugth of the short snout. Vertical fins well dereloped; dorsal and anal 
connected with the caudal by a very delicate membrane. Distance from origin of dorsal fin to occiput 3 times the length of the head, its rays distinct, connected by thin transparent membrane, as are the rays of the anal; most of the rays simple and undivided (but mostly articulate), a few of the posterior only forked at tip; origin of anal fin nearly equidistant between gill rakers and tip of candal, its rays mostly forked at tip; caudal rays much divided and more closely set than those of dorsal and anal, the fin somewhat pointed in outline, as long as the head; tail not isocercal, truncate at base of caudal fin; ventral fins very small, close together, inserted slightly behind base of pectorals; each fin reduced to a single undivided filament; pectoral fin small, pointed, the middle rays longest, much shorter than the ventrals, and $\frac{1}{2}$ the length of the head. Vent considerably behind middle of total length of the fish (with eaudal). Head and body covered with scattered rudimentary scales. Color in life, translucent light olive, with a series of irregular quadrate dark blotches along the back and a series along each side, these blotches formed of clusters of dark points. One specimen, nearly 4 inches in length, was taken in a rock pool at Panama; others since taken by Dr. Gilbert. This species differs from the description of the previously known Microdesmus dipus, Giinther, in the posterior insertion of the dorsal and the posterior position of the vent, the smaller number of fin rays, the shorter head, longer ventrals, and mottled coloration. (retro, backward ; pinna, fin.)

Microdesmus retropinnis, JORDAN \& GuBERT, Bull. U. S. Fish Comm. 1881, 331, Panama. (Coll. C. H. Gilbert.)

\section{Family CCIV. PTILICHTHYIDA.}

\section{(THE QUILL-Fishes.)}

Body extremely elongate, serpentiform, little compressed, the tail tapering to a point. Skin with a few thin, loose, scattered scales; no lateral line. Head unarmed, rather small; upper jaw not protractile; snout short; mouth oblique; lower jaw projecting considerably beyond the upper, with a protruding fleshy appendage at tip. Maxillary reaching front of eye. Mandible little movable. Both jaws with fine, close-set, sharp teeth, in $1 \mathrm{row}$, the posterior teeth a little the largest; no evident teeth on vomer or palatines. Gill openings restricted to below the most convex part of the opercle, the membranes broadly united below, free from the isthnus. Gills 4, a slit behind the fonrth. Pseudobranchix very small, almost obsolete. Gill rakers short and stout. Pectorals short; ventrals wanting; dorsal beginning close behind the nape, the anterior portion for about $\frac{1}{2}$ the length of the body composed of very low, stiff, free spines, hooked backward, the posterior portion higher, of slender soft rays connected by thin membrane. No caudal fin, the tip of the tail free. Anal similar to the soft dorsal, without spines. Vent at considerable distance from the head. North Pacific. A single species known.

Concerning the relationships of this interesting group, Dr. Gilbert observes:

"The genus Ptilichthys, of which this species [P.goodei] is the sole representative, has been doubtfully referred by Dr. Bean to the Mastacembelida, a 
family of fresh-water fishes inhabiting the East Indies, characterized by having the shoulder girdle posteriorly placed aud not articulating with the cranium (Order Opisthomi, Gill). The necessity for preserving intact the unique type of the species prevented Dr. Bean from making any anatomical examination of Ptilichthys, and it was reserved for Dr. Theodore Gill, in the Standard Natural History, III, 259, 1885, to express his disbelief in the relationships which have been suggested, and to make the fish the type of a peculiar family, the Ptilichthyida, to be placed provisionally among the Blennioid series. His adherence to this view is again expressed in his list of 'Families and Subfamilies of Fishes,' appearing as the Sixth Memoir of Volume VI, of the National Academy of Sciences. He has doubtless indicated the proper position of this peculiar fish as nearly as we are now able to determine it. An examination of its shoulder girdle shows it to be entirely normal. The post-temporal is not furcate, but is a very slender bony rod attaching to the epiotic region of the skull, and giving loose attachment posteriorly to the almost equally slender posterotemporal. The latter overlaps the npper end of the clavicle in the usual manner. A postclavicle was not detected. The coracoid portion consists of a roundish, oblong, perforated hypercoracoid meeting the hypocoracoid directly, without intervening cartilage. The curved line separating the two bones corresponds distally with the interspace between the first (upper) and second actinosts. The hypocoracoid is broad and short; its mesially directed (i. e., inferior) process joins at its tip the clavicle, but is elsewhere separated from the latter by the usual elongate membranaceous interspace. The actinosts are 4 in number, of large size, hourglass-shaped. The jaws are normal, the premaxillary alone occupying the front and sides of upper jaw and bearing the teeth, while the maxillary is a broad bone lying behind it, overlapped proximally by the maxillary process of the palatines. Both vomer and palatines seem to be toothless. The alimentary canal is almost perfectly straight, with the anterior portion entirely enveloped in the long, narrow liver. At the pylorus occurs a short and abrupt U-shaped flexure, scarcely noticeable on account of the closeness with which the sides are joined, and the fact that the width of the flexure is no greater than the cross diameter of the tube. Pyloric caca are not evidezt. Air bladder is entirely wanting. The ovary is single, apparently without viaduct, and contains in our specimen eggs which are comparatively very large." (Gilbert.) (Ptilichthyida, Gill, Standard Nat. Hist., III, 259, 1885.)

929. PTILICHTHYS, Bean.

Ptilichthys, BeAN, Proc. U. S. Nat. Mus., Iv, 1881, 157 (goodei).

Characters of the genus included above. ( $\pi \tau i \lambda \circ v$, quill; $i \chi \theta \dot{v} 5$, fish.)

2510. PTILIChthys GoOdei, Bean.

D. XC, 145; A. about 185; P. 12. Eye rather large, as long as snont, 5 in head; cheeks and opercles long; pectoral fin $\frac{1}{2}$ as long as head; soft dorsal and anal deeper than body posteriorly, anal a little lower than dorsal. Vent near end of anterior third of body; distance from vent to 
begiuning of soft dorsal $3 \frac{1}{4}$ times length of head; length of head twice its greatest depth, $5 \frac{1}{2}$ in distance to vent; appendage of mandible $\frac{1}{2}$ as long as eje; free tip of caudal $\frac{2}{8}$ eye. Orange or yellowish, body with a blackish longitudinal stripe; anal darker in color than dorsal. Length about 12 inches. Aleutian Islands ; rare; in water of moderate depth. Here described from the original type from Unalaska; 2 other specimens known, the one studied by Dr. Gilbert taken in the entrance to the harbor of Unalaska. (Named for Dr. George Brown Goode.)

Ptilichthys goodei, Bean, Proc. U. S. Nat. Mus., IV, 1881, 157, Port Levachef, Unalaska (Col. Sylvanus Bailey. Type, No.26619, U. S. Nat. Mus.); Jordan \& Gubert, Synopsis, 369, 1883; GilberT, Rept. U. S. Fish Comm. 1893 (1896), 453.

\section{Group OPHIDIOIDEA.}

\section{(The Eel-Pouts.)}

This group, as a whole, agrees with the Blennioidea in all respects, except that no spines are developed in any of the fins, save sometimes in the posterior part of the dorsal. From the Anacanthini, with which the Ophidioidea agree in the jugular ventrals and in the absence of spines, they are separated by the form of the hypercoracoid, which is perforate, as in ordinary fishes. The group is a very large and varied one, widely distributed in all seas.

a. Pseudobranchixe well developed, very rarely small or obsolete.

b. Ventral fins jugular, inserted much behind the eye, often wanting, never filamentous.

c.- Gill membranes broadly united, free from the isthmus; ventrals wanting; no scales. SCYTALINIDA, CCV. cc. Gill membranes united to the isthmus, the gill openings lateral.

ZOARCIDA, CCVI.

bb. Ventral fins developed as slender filaments attached at the throat not far behind eye.

e. Gill membranès broadly attached to the isthmus; no scales.

DEREPODICHTHYID $\boldsymbol{A}$, CCVII. ee. Gill membranes nearly separate, free from the isthmus; body scaly.

OPHIDIDE, CCVIII.

aa. Pseudobranohiso absent (or rudimentary in some Brotulidoe).

f. Ventral fins wanting; no scales.

g. Vent normal, well behind pectorals.

LYCODAPODIDA, CCIX. gg. Vent at the throat.

Fierasferid A, CCX.

ff. Ventral fins well developed; vent posterior, normal.

$h$. Dorsal fin single, low; ventral fins short.

BRoTULIDÆ, CCXI.

$h h$. Dorsal fins 2 , the anterior, at the nape, of a single long ray; ventral fins elongate.

BREGMACEROTIDE, CCXII.

\section{Family CCV. SCYTALINIDAE.}

Body elongate, compressed, eel-shaped, naked. Head depressed, with tumid cheeks, like the head of a snake. Mouth moderate, horizontal, the lower jaw the longer; teeth in a single series in the jaws, vomer, and palatines; no barbels. Gills 4, a slit behind the fourth; pseudobranchiæ present. Gill membranes broadly connected, free from the isthmus. Dor- 
sal fin long and low, beginuing near middle of body, of slender rays embedded in the skin; anal similar to dorsal, both connected to the caudal fin; tail diphycercal; pectoral fins small, ventral fins wanting. Vent remote from the head, without papilla. Air bladder none; ceca none. Vertebræ numerous, small. The skeleton does not differ essentially from that of Lycodopsis pacificus, with which it has been compared. The skull is not at all depressed, the wide depressed form of the head of the fish is due to the fleshy cheeks. The frontal takes up the greater part of the top of the skull, the parietals are separated by the supraoccipital, which extends forward to the frontals. Opereles all present. Lower jaw large and strong. Post-temporal scarcely so firmly attached as in Lycodes; the clavicle long and slender. As here understood, this family consists of a single species, a shore fish of the Northern Pacific, living in the gravel between tide marks, and diving with great activity into the wet gravel when disturbed. Its relations are apparently with the Zoarcida. It is not certain that Scytalina has any special affinity with the Congrogadida, in which group it was at first placed by Jordan \& Gilbert.

\section{SCYTALINA, Jordan \& Gilbert.}

Scytalina, Jordan \& Gilbert, Proc. U. S. Nat. Mus. 1880, 266 (cerdale). Scytaliscus, JordaN \& GilberT, Proc. U.S. Nat. Mus. 1883, 111 (cerdale); substitute for Scytalina on account of the earlier Scytalinus, Erichson, a genus of Coleoptera.

Body very long and slender, covered with small scales. Head depressed, shaped like the head of a snake, with tumid cheeks and a distinct neck. Eyes small, superior. Mouth rather large, the lower jaw slightly projecting. Teeth conic, in single series on jaws, vomer, and palatines. Each jaw with 2 eanines in front. No lateral line; pseudobranchiæ small. Gill rakers almost obsolete. Dorsal fin very low, its first ray near the middle of the body. Anal fin similar to dorsal, nearly as long. Tail diphycercal, the caudal well developed. (Diminutive of Scytale, from

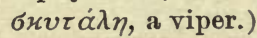

\section{SCYTALINA CERDALE, Jordan \& Gilbert.}

Head 8 ; depth 14. D. 41; A. 36. Head broader than body; body much deeper behind vent than anteriorly; snout depressed, rounded at tip; cheeks very long; opercle short; interorbital space rather broad, concave posteriorly; eyes very small, anterior and superior, 10 to 12 in head, 2 in snout, 3 to 4 in interorbital width; upper lip separated by a crease from the skin of the forehead; lower jaw scarcely projecting; edge of lower lip with pores, and small dermal flaps and fringes; maxillary extending somewhat beyond eye; anterior nostrils with small flaps. Lower jaw with a series of close-set, even, conical teeth, besides 2 divergent canines in front; upper jaw with similar teeth in several series in front, the canines smaller and closer together. Pectorals inserted high, little longer than eye; insertion of dorsal slightly in front of anal, a little in front of middle of body; rays of vertical fins low and weak, those of caudal most developed; dorsal and anal joined to caudal; vent close in front of anal, 
which is similar to dorsal. Flesh colored, with much mottling of purplish in fine pattern; belly nearly plain; caudal reddish-edged. Length 6 inches. Straits of Juan de Fuca; burrowing among rocks near tide mark. The 2 original types came from the shore of Waadda Island, near Cape Flattery, where the species lives in wet shingle and shows extraordinary activity in hiding among rocks when disturbed. In the same locality 25 additional specimens have been dug out of the gravel by Mr. E. C. Starks in 1895. The species is still unknown from any other locality. ( $\varkappa \varepsilon \rho \delta \alpha \lambda \tilde{\eta}$, the wary one, the fox.)

Scytalina cerdale, Jordan \& Gilbert, Proc. U. S. Nat. Mus., III, 1880, 266, Waadda Island (Type No. 27400. Coll. Jordan \& Gilbert); Jordan \& Gilbert, Synopsis, 791, 1883; Jordan \& Starks, Fishes of Puget Sound, in Proc. Cal. Ac. Sci. 1895, 849, pl. 104.

\section{Family CCVI. ZOARCIDA.}

\section{(The Eel-Pouts.)}

Body elongate, more or less eel-shaped, naked or covered with very small, embedded, cycloid scales; head large; mouth large, with conical teeth in jaws, and sometimes on vomer and palatines; bones of head unarmed. Gill membranes broadly united to the isthmus, the gill opening reduced to a vertical slit; pseudobranchiæ present; gills 4, a slit behind the fourth. Dorsal and anal fins very long, of soft rays only, or the clorsal with a few spines in its posterior portion; vertical fins sometimes confluent around the tail; pectorals small; ventrals jugular, very small or wanting, if present, inserted behind the eye. Lateral line obsolete or little developed, sometimes bent downward behind pectorals, sometimes sending a branch on median line backward. Gill rakers small; pyloric creca rudimentary; vent not near head. Pseudobranchix present. Genera about 15; species 50. Bottom fishes, chiefly of the Arctic and Antaretic seas; some of them, at least, are viviparous, and some descend to considerable depths. Dr. Gill thus enumerates the skeletal characters of the Zoarcida:

Orbito-rostral portion of the cranium contracted and shorter than the posterior, the cranial cavity open in front, but bounded laterally by the expansion of the annectant parasphenoid and frontals, with the supraoccipital declivous and tectiform behind, the occipitals above inclined forward along the sides of the supraoccipital, and the exoccipital condyles distant, with the hypercoracoid foraminate about its center and the hypocoracoid with an inferior process convergent to the proscapula. These characters are formulated from the skeleton of Zoarces anguillaris. (Gill, Proc. Ac. Nat. Sci. Phila. 1884, 179.) Zoarchida, ${ }^{*}$ Swalnson, Nat. Hist. Class. Fishes, II, 82, 184, and 283, 1839. Lycodida, GÜTHER, Cat., IV, 319326, 1862; genus Zoarces, Günthur, Cat., III, 295. 1861.

\section{ZOARCINA:}

I. Dorsal fin low behind, some of its posterior rays short and spine-like; rentrals small; scales present; teeth strong, conic, in jaws only; lateral line present, along middle of side.

ZOARCES, 931.

II. Dorsal fin continuous, of soft rays only. 


\section{LYCODINA:}

a. Ventral fins present.

b. Vomer without teeth; body scaly.

c. Palatines without teeth.

d. Body very slender, the depth 12 to 16 times in length; lateral line short and faint, ventral in position.

EмBRyx, 932.

$d d$. Body rather robust, the depth 8 to 9 in length; lateral line rather faint, lateral in position.

LYCODOPSIS, 933. cc. Palatines with teeth; lateral line distinct, running along middle of side.

$b b$. Vomer and palatines with teeth.

APRODON, 934.

e. Lower jaw without barbels.

$f$. Dorsal fin without sculptured scutes at base.

$g$. Body rather deep, the depth 6 to 8 times in the length.

$h$. Body more or less scaly.

LTCODES, 935.

hh. Body entirely naked, or with a fow scales on tail only; none on body or fins. LYCODALEPIS, 936.

$g g$. Body more slender, the depth 12 to 20 in the length; lateral line lateral in position.

$i$. Pectoral fin with rounded outlines, the lower rays not greatly produced.

LYCENCHELSS, 937.

ii. Pectoral fin deeply notched, the lower rays much produced; lateral line ventral in position.

Furcimanes, 938.

ff. Dorsal fin with the rays each provided with a sculptured scute or appendage at base; no lateral line; body elongate.

LYCODONUs, 939.

ee. Lower jaw with many barbels: boly slender, scaly. Lyconema, 940.

aa. Ventral fins entirely wanting.

GYMNELINA:

$j$. Teeth moderate, nearly uniform, on jaws, vomer, and palatines.

$k$. Body scaly; vomer and palatines with teeth; body compressed, not very slender; skull cavernous.

Bothrocara, 941.

$k k$. Body scaleless.

l. Lower jaw not very prominent; body very slender; gill openings very narrow.

GYMNELIS, 942.

ll. Lower jaw very prominent; body slender, tapering behind; scales undescribed.

LyCOCARA, 943.

\section{Melanostigmatina:}

$j j$. Teeth long, unequal, on jaws, vomer, and palatines; skin lax; gill openings reduced to a small foramen; boily very slender; scales obsolete.

Melanostigma, 944.

\section{ZOARCES, Gill.}

\section{(EkL-Pouts.)}

Enchelyopus, KLEIN, Ichthyologia Missus, IV, 52, 1747; not as restricted by BLOCH \& SCHNEIDER.

Zoarces, Cuvikr, Règne Animal, Ed. 2, II, 240, 1829 (viviparus).

Zoarchus, SwAINson, Nat. Hist. Class'n Fishes, II, 283, 1839 (viviparus).

Enchelyopus, GiLl, Proc. Ac. Nat. Sci. Phila. 1863, 258 (viviparus); not of BLOCH \& SCHNEIDER.

Macrozoarces, GLL, Proc. Ac. Nat. Sci. Phila. 1863, 258 (anguillaris).

Body elongate, compressed, tapering posteriorly; head oblong, heavy, narrowed above, the profile decurved; mouth large; teeth strong, conic, bluntish, in 2 series in the front of each jaw and 1 series on the sides; 
teeth in outer series larger; no teeth on vomer or palatines; dorsal fin very long, low, some of its posterior rays much lower than the others, developed as sharp spines; pectoral fins broad; ventrals jugular, of 3 or 4 soft rays; scales small, not imbricated, embedded in the skin; lateral line slender, lateral in position; size large; species viviparous. The American and Asiatic species (subgenus Macrozoarces) differ from the European type of Zoarces, Cuvier, in the increased number of fin rays and vertebra. In Zoarces viviparus (Linnæus), the European eslpout, the dorsal rays are about 100 , the anal about 85 , and the number of vertebre is proportionally diminished. ( $๘ \alpha \rho น \eta \dot{5}$, viviparous.)

\section{Subgenus MACROZOARCES, Gill.}

2812. ZOARCES ANGUILLARIS * (Peck).

\section{(Eel-Pout; Mutton-Fish; Mother of Eels.)}

Head 6 ; depth 7. D. 95, XVIII, 17; A. 105. Mouth moderate, lower jaw included; maxillary reaching beyond orbit; pectoral long, about $\frac{2}{8}$ lengtl of head; ventrals $\frac{1}{6}$ head; highest ray of dorsal about equal to suout, the posterior spines about $\frac{1}{8}$ length of eye ; first ray of dorsal above preopercle. Reddish brown, mottled with olive, the scales paler than the skin about them; dorsal fin marked with darker; a dark streak from eye across cheek and opercles. Length 20 inches. Delaware to Labrador; rather common north of Cape Cod. Two forms occur, distinguished by the size of the jaws. These have been regarded as distinct species, but the largemouthed form (ciliatus; labrosus) is doubtless the male, as a similar variation occurs in Lycodopsis pacificus, and exists in some degree in species of Lycodes. (anguillaris, eel-like.)

? Encheliopus, Gronow, Zoophyl., 77, No. 266, 1763, America (unicolor); dorsal and anal united with the candal.

? Blennius americanus, BLOCH \& SCHNEIDER, Syst. Ichth., 171, 1801, America; after Gronow.

Blennius anguillaris, PECK, Mem. Amer. Ac. Sci., II, 1804, 46, New Hampshire.

Blennius fimbriatus, Mrtchill, Trans. Lit. and Phil. Soc. N. Y. 1815, 374, pl. 1, fig. 6, New York.

Blennius ciliatus, MrтchiLl, Trans. Lit. and Phil. Soc. N.Y. 1815, 374, pl. 1, fig. 7, New York.

Zources labrosus, Cuvier, Règne Anim., Ed. II, vol. 2, 240, 1829, America; Cuvier \& VAlenciennes, Hist. Nat. Poiss., XI, 466, 1836.

Zoarces gronovii, Cuvier \& VAlenciennes, Hist. Nat. Poiss., XI, 469, 1836; after Gronow.

? Enchelyopus americanus, Grovow, Cat. Fishes, Ed. Gray, 101, 1854, American Ocean.

Zoarces fimbriatus, Cuvier \& VAlenciennes, Hist. Nat. Poiss., XI, 468, 1836.

Blennius labrosus, MrtchILL, Trans. Lit. and Phil. Soc. N. Y.1815, 375.

Zoarces anguillaris, StORER, Fishes Mass., 66, 1839; StORER, Synopsis Fishes N. A., 375, 1845; Gunther, Cat., III, 296, 1861; Jordan \& GILbert, Synopsis, 784, 1883.

* Allied to Zoarces anguillaris is the following species from the Ochotsk Sea:

\section{ZOARCES ELONGATUS, Kner.}

Head $5 \frac{2}{3}$; depth $11 \frac{1}{2}$. D. 80 , XII, 22. A. 90 or more. Lateral line extending somewhat beyond pectorals. Color brownish, no brown streak behind eye; dorsal with 12 to 14 large dark spots which extend on the back as faint bands, between which are smaller ones. Known from 1 specimen, $10 \frac{1}{2}$ inches long, from Decastris Bay, near the mouth of the Amur. (Kner). (elongatus, elongate.)

Zoarces elongatus, KNER, Sitzber. k. k. Akad. Wien 1868, 52, taf. 7, f. 2, Ochotsk Sea. (No. 1502, Wion Mus.) 


\section{EMBRYX, Jordan \& Evermann.}

Embryx, Jordan \& EvermanN, new genus (crotalinus).

This genus differs from Lycodopsis in the very slender borly, the depth being 12 to 16 times in the length, and especially in the ventral position of the lateral line which is faint and incomplete, only the anterior descendiug portion developed. Deep seas. ( $\varepsilon$, in; $\beta \rho \dot{v} \xi$, abyss.)

$a$. Ventrals nearly as long as eye; head $6 \frac{3}{4}$ in length; no scales on head.

$a a$. Ventrals shorter than pupil; head $5 \frac{1}{3}$ in length; heal with some seales.

CRASSILABRIS, 2813.

CROTALINUS, 2814.

2813. EMBRYX CRASSILABRIS (Gilbert).

Head 6: depth 16 ; maxillary reaching vertical from front of pupil, 3 in head; exposed portion of eye 6 ; snout 4 ; width of snout 3 . Body exceedingly slender. Occiput flat, forming a right angle with the descending cheeks, the snout short and wide, the upper lip conspicuously thickened and fleshy on the sides. Upper jaw with a single series of rather large, distant teeth ; mandible with a broad patch of cardiform teeth anteriorly, which becomes abruptly constricted on middle of lateral portion of jaw, the inner series alone continued backward toward angle. Palate smooth. Head not conspicuously excavated with mucous canals; series of pores present on mandible and sides of head. Gill openings continued furward to below pectorals, and about to vertical from middle of opercle; the width of the isthmus $\frac{1}{4}$ the length of slit. Opercular flap with a wide membranaceous border, produced backward and largely covering base of pectorals. Gill rakers very little developed, about 12 movable rudiments on horizontal limb of arch. Origin of dorsal in front of middle of pectorals, slightly farther from occiput than is the latter from front of eye; distance from origin of anal to tip of snout $3 \frac{1}{8}$ in total length; ventrals nearly as long as eye, inserted under middle of opercle; pectorals with 14 or 15 rays, the upper portion of fin longest, the lower rays rapidly shortened, the longest rays $\frac{1}{2}$ as long as head. Scales small, circular, covering nape, breast, and under side of pectorals, but absent on head. Lateral line single, inconspicuous, running below middle of sides, ventral in position, the pores not developed on the scales. Color light brownish above, dark below; lower side of head, margins of snout, gill membranes, part of opercles, and margins of vertical fins jet black; ventrals and posterior face of pectorals black; anterior face of pectorals light glaucous blue, margined with black; lining of mouth and gill cavity and peritoneum black. Pacific coast of southern California. A single specimen, 12 inches long, from Albatross Station 2839. (Gilbert.) (crassus, thick; labrum, lip.)

Lycodopsis crassilabris, GilberT, Proc. U.S. Nat. Mus. 1890, 106, off southern California.

(Type, No.44280. Coll. Albatross.)

\section{EMBRYX CROTALINUS (Gilbert).}

Head $5 \frac{1}{8}$; depth 12 ; maxillary reaching to behind middle of pupil, $2 \frac{2}{5}$ in head; eye 6 ; interorbital width 14 ; snout 4 . Body very slender, with 
much the appearance of Lycenchelys paxillus, the cheeks tumid, much projecting laterally, the greatest width of head more than $\frac{1}{2}$ its length. Snout short and broad, much depressed, the head scarcely constricted opposite orbits. Eyes with little lateral range. In the single type specimen the upper jaw greatly overlaps the lower, the mandibular band of teeth shutting entirely within those on premaxillaries. Teeth in upper jaw in a single series, 2 or 3 small teeth sometimes present anteriorly, giving traces of an inner series. In lower jaw the teeth are sparsely set in a broad band anteriorly, becoming suddenly contracted to a single series on middle of sides. None of the anterior mandibular tceth enlarged, 2 or 3 of posterior teeth on sides larger and hooked backward. No teeth on vomer or palatiues. Nostril in a short tube. Gill slits wide, reaching to below pectorals, but not extending fartber forward below than above. Width of isthmus $\frac{1}{8}$ length of slit. A series of 7 pores along mandible and preopercle; a second series of 7 or 8 extending from snout along sides of head above premaxillaries. Lateral line faint, descending, its position ventral. Dorsal inserted over middle of pectorals, its origin as far from occiput as is the latter from front of pupil; distance of front of anal from snout equals $\frac{1}{8}$ length of body; ventrals short, less than length of pupil; pectorals with posterior margin obliquely truncate, the upper rays longest, the lower growing regularly shorter, thickened at tips, the rays 15 or 16 , the longest $2 \frac{2}{5}$ in head. Scales small, embedded, covering body and most of vertical fins. A few very small, scattered scales on nape, posterior part of occiput, and contiguous parts of cheeks and opercles. Lateral line single, indistinct, running obliquely downward to near base of anal, thence backward, not reaching base of candal fin. Color dark brown, black on opercles, sides of snout, fins, and lower parts generally; a broad light bar across head behind eyes, extending down on cheeks; some light mottling on mandible and gular membrane; lower rays of pectorals margined with whitish; lining of mouth, gill cavity, and peritoneum jet black. North Pacific. Two specimens knowu; the type above described from Santa Barbara Islands, the second from Albatross Station 3210, south of Saanak Islands, Alaska, depth 483 fathoms.

On this Dr. Gilbert has the following notes:

"The stomach contained remains of Crustacea. Colors in life, head and body light brown, the lower parts darker; snout, suborbital region, and a band across pectorals greenish gilt; no light bar on head. Depth $12 \frac{8}{4}$ in

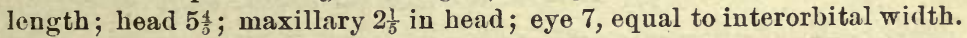
Width of bone between orbits 17 in head. Snout $3 \frac{1}{5}$ in head. Teeth above in a narrow band, reaching only about halfway of gape. In the mandible, teeth are absent on posterior $\frac{2}{5}$ of gape. The gill slit extends a little farther forward below than above. Ventrals as long as pupil. Longest pectoral ray $2 \frac{8}{4}$ in head. Head wholly scaled behind eyes. Lateral line not evident."

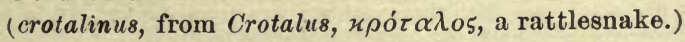

Lycodopsis crotalinus, Gilbert, Proc. U. S. Nat. Mus. 1890, 105, Albatross Station, 2980, off Santa Barbara Islands. (Coll. Albatross.) 


\section{LYCODOPSIS, Collett.}

Lycodopsis, Collett, Proc. Zool. Soc. London 1879, 381 (pacificus).

Leurynnis, Lockington, Proc. U.S. Nat. Mus. 1879, 326 (paucidens).

Body moderately elongate, the depth 8 to 9 times in length, covered with small, smooth, embedded scales. Lateral line rather faint, extending along middle of side. Head large; snout broad and long; interorbital space very narrow; mouth large, horizontal; teeth conical, those of the upper jaw in a single row; those of the lower in a band in front, the inner series enlarged, larger than the upper teeth; no tecth on vomer or palatines. Ventral fins very small; vertical fins continuous, without spines. Sexes more or less unlike, the mouth larger in the male. Pacific Ocean. (Lycodes; o้ $\psi \imath$, appearance.)

\section{LYCODOPSIS PACIFICUN (Collett).}

Head $4 \frac{1}{2}$ (male) to $5 \frac{1}{2}$ (female); depth 8 (imale) to $8 \frac{1}{2}$ (female). D. 100; A. 85. Female (pacificus), head comparativeły short; orbital region not restricted, nor cheeks tumid; mouth comparatively small, the maxillary reaching center of pupil. Male (paucidens), with the head and mouth large, the snout very broad, the interorbital region constricted; maxillary reaching posterior edge of orbit. Head, nape, and axil of pectoral naked. Dorsal and anal fins enveloped in thick skin, which is covered with embedded scales like those on the body; pectoral $\frac{1}{2}$ the length of head in female, $\frac{2}{5}$ in male; ventrals $\frac{1}{2}$ length of orbit; maudible $\frac{1}{2}$ length of head in female, $\frac{3}{5}$ in male; distance from snout to base of dorsal $4 \frac{1}{2}$ in length in female, $3 \frac{8}{4}$ in male. Lateral line lateral in portion. Light reddish olive, becoming lighter below; vertical fins margined with black; the scales paler than skin, forming light spots; pectorals dusky. Length 12 to 18 inches. Sau Francisco to Puget Sound; rather common in water of moderate depth offshore. Sexes markedly different.

Lycodes pacificus, ${ }^{*}$ CoLleTt, Proc. Zool. Soc. London 1879, 381, female, Japan. (Coll. Peters) the locality giren probably an error.

Leurynnir paucidens, † Lockington, Proc. U. S. Nat. Mus. 1879, 326, off San Francisco, California, male (Type, No. 23502, U.S. Nat. Mus. Coll. W. N. Lockington); JordaN \& GiLberT, Synopsis, 785, 1883.

Lycodopsis paucidens, GILL, Proc. U.S. Nat. Mus. 1880, 248.

Iycodopsis pacificus, JoRdan \& GILBERT, Synopsis, 785, 1883.

\section{APRODON, Gilbert.}

Aprodon, GllberT, Proc. U.S. Nat. Mus.1890, 106 (cortezianus).

This genus differs from Lycodes only in the dentition, the teeth being present in a single strong series on the palatines, but none on the vomer.

* In regard to the type specimen of Lycodes pacificus, Professor Collett writes us as follows (December 2, 1895):

"I got the specimen for describing from the Museum of Berlin from the hands of Professor Peters himself, and he told me that the specimen was from Japan. It] is not impossible that he was mistaken ; but I can not have any opinion about that."

In view of the fact that the species is abundant off the California coast, whence Pro. fessor Peters had obtained collections, that it has not been found in Japan nor in Alaska, we have no doubt that the locality given by Professor Peters is erroneous, and that the fish really camo from Californis.

$t$ The examination of many specimens leares no room for doubt that L.pacificus is the female and $L$. paucidens the male of the same species. 
The genus is thus intermediate between Iycodes and Lycodopsis. ( $\dot{\alpha}$, without; $\pi \rho o ́$, before; ó ovंs, tooth.)

2816. A PRODON CORTEZIANUS, Gilbert.

Head $4 \frac{1}{3}$ to $4 \frac{1}{2}$; depth $7 \frac{1}{2}$ to 9 in length; head high and narrow, snout broader, but long and very convex. Mouth large, maxillary reaching vertical from middle of orbit, $2 \frac{1}{3}$ in head; eye $4 \frac{4}{5}$; snout 3 ; depth of head 2. Teeth in premaxillaries strong, conical, in a single series; lower jaw with the teeth mainly in 2 series, an outer row of slightly enlarged teeth, and an inner row directed backward, a wide interspace between the two series with occasional scattered teeth only posteriorly; on sides of mandible a single series of teeth similar to those in upper jaw; vomer toothless; palatines with a single series of strong conical teeth. Head without conspicuous mucous pores; a strong ridge on middle of occiput anteriorly; gill slit wide, continued forward to vertical from preopercle, the width of isthmus 5 times in length of slit; gill rakers short, better developed than usual, 15 on horizontal limb of outer arch. The vertical limb of arehes joined to gill cover by a fold of the lining membrane of the latter, as in Macrourus. Pseudobranchiæ well developed. Origin of dorsal but little behind base of pectorals; the hinder margin of occiput midway between dorsal and front or middle of eye; distance from snout to origin of anal 2 2 in total length; ventrals inserted under front of opercles, their length abont $\frac{3}{5}$ of orbit; pectorals very large, broadly rounded, the upper portion of fin longest, the lower rays rapidly shortened, the lowermost with broad, fleshy tips; rays 20 or 21 in number; scales of the usual type, those on abdomen so deeply embedded as to be almost invisible; head, anterior half of nape, breast, and base of pectorals naked; pectorals and ventrals not scaled, other fins partly eovered; lateral line little developed, running along middle of sides and tail. Color light brownish, lighter below; vertical fins broadly margined with black, becoming almost wholly black behind; pectorals light at base, black distally, with a conspicuous white edge; ventrals white; lining of mouth white, of gill cavity dusky; peritoneum black. Cortez Banks, near San Diego, California. The types, 6 specimens, the longest 15 inches, from Albatross Stations 2925 and 2948, in 339 and 266 fathoms. Dr. Gilbert also records 1 specimen from Albatross Station 3349, off the coast of northern California, depth 239 fathoms. (cortezianus, from Cortez Banks.)

A prodon corteziana, GilBert, Proc. U. S. Nat. Mus. 1890, 107, Cortez Banks, off San Diego.

(Type, No. 46457. Coll. Albatross.)

935. LYCODES, Reinhardt.

Lycodes, REINHARDT, Kongl. Dansk. Vidensk. Selsk. Naturv., vII, 1838, 153 (vahli).

Lycia8, JoRDAN \& EvERMANN, new subgenus (seminudus).

Body moderately elongate, more or less eel-shaped, tapering behind, the depth from 6 to 10 times in the length; head oblong; mouth nearly horizontal; lower jaw included; conical teeth on jaws, vomer, and palatines, those on jaws and palatines mostly in a single series. Dorsal fin beginning behind base of pectoral, without any spines; the rays all soft and articu- 
late; pectorals moderate, inserted rather high, its outline rounded; ventral fins small, of 3 or 4 rays. Scales small and embedded, present on part or all of the body, the scaly area more extensive in the adult than in the young. Lateral line faint, sometimes obsolete, normally bent downward behind pectorals and following rentral outline, sometimes with an accessory branch following middle of side; the median branch usually wanting. No air bladder; no anal papilla; pyloric cæea 2 or none. Species numerons, chiefly of the northern seas, inhabiting considerable depths. In general, the male has the head and mouth larger than the female, and

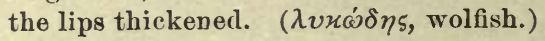

\section{LYCODES: *}

I. Trunk more or less completely scaled.

a. Dorsal rays about 115 ; anal rays 90 to 105 .

b. Head $4 \frac{1}{3}$ to 5 in length; depth 7 to 8 .

c. Nape wholly scaly.

d. Lateral line double, with a median and a ventral branch; pectoral rays 22 ; body blackish with yellowish cross bands or series of spots.

ESMARKII, 2817.

$d d$. Lateral line simple, ventral; body blackish, the young with 6 darker cross bands.

VAHLII, 2818.

cc. Nape naked; lateral line obsolete; color plain brown, the fins edged with darker, pectoral rays 21 ; ventrals short. CONCOLOR, 2819.

$b b$. Head $5 \frac{2}{3}$ in length; depth 9; a naked area aronnd dorsal; pectoral rays 19; lateral line ventral; color brownish mottled, the young barred; a black blotch at front of dorsal.

ZOARCH US, 2820.

aa. Dorsal rays 85 to 105 ; anal rays 68 to 93 .

e. Head large, $3 \frac{2}{3}$ to $\frac{1}{2}$ in length; ventrala ahout as long as eye; depth 8 to $9 \frac{1}{2}$ in length; body chiefly scaly, the fins naked.

$f$. Body brownish, with a fine network of black lines on head and body, those on body in 5 groups; dorsal edged with black; lateral line probably developed anteriorly only, figured as median; pectorals broad, of about 23 rays.

RETICULATUS, 2821.

$f f$. Body not corered with a network of black lines.

g. Color pale, with dark bands and 2 ocellated spots on the forehead; pectoral rays about 17 ; lateral line figured as lateral.

PERSPICILLUM, 2822.

gg. Color grayish, without bands or spots; pectoral rays about 20 ; lateral line single, ventral. $\quad$ FRIGIDUs, 2823.

ee. Hearl short, 5 to $5 \frac{1}{2}$ in length.

h. Pectoral broad, of 23 or 24 rays; lateral line single, ventral; color plain.

TERRA-NOV E, 2824.

$h h$. Pectorals narrow, of about 18 rays; ventral fins shorter than eye; lateral line obsolete, or nearly so.

$i$. Dorsal rays 101 to 105 ; anal rays 81 to 90 ; dorsal and anal without dark markings; ventrals more than $\frac{1}{2}$ length of eye; jaws with enlarged flaps of skin.

j. Body in adult not barred, but with 4 dark longitudinal stripes. DigitATUS, 2825.

$j j$. Body with 14 to 16 pale crossbars above, which disappeal in the adult.

PALEARIS, 2826.

ii. Dorsal rays 85 ; anal 74 ; ventrals minute, not $\frac{1}{2}$ length of eye; flaps of jaws narrow or obsolete. BREVIPES, 2827.

* The analytical key to the species here given is far from satisfactory. The species should be divided into groups distinguished by the development of the lateral line and the breadth of the pectoral; unfortunately the last-named character has been neglected in most of the current deseriptions; we have examined all the species accessible to us. 
LyCiAs ( $\lambda$ úkos, wolf) :

II. Trunk naked anteriorly, scaled only on the tail or posterior half.

$k$. Dorsal fin scaled posteriorly; color brown, with faint yellow transverse bands on back. NEBULOSUS, 2828.

$k k$. Dorsal fin naked; color uniform pale grayish brown without spots or bands;

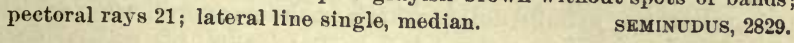

\section{Subgenus LYCODES.}

\section{LYCODES ESMARKII, Collett.}

Head $4 \frac{1}{2}$; depth 8. D. 110 to $116 ;$ P. 22 ; A.95; V.4. Body behind front of dorsal scaled; vertical fins scaly; nape scaly; snout obtuse; maxillary not more than $\frac{1}{2}$ head; lateral line indistinct, divided, having a median branch besides the ventral series of pores, the median series faint, soon obsolete; pectorals 8 in length; vertebræ $25+87$. Brownish black, with a whitish-yellow patch on the nape, and 5 to 8 transverse bands of the same color across the dorsal and posteriorly across the anal, these bands becoming broken into annular spots with age. North Atlantic; recorded from Finmark and Spitzbergen. American specimens from the Gulf Stream in about lat. $40^{\circ}$. (Collett.) (Named for Professor Lauritz Esmark, of Copenhagen.)

Lycodes esmarkii, CoLLETT, Norges Fiske, 95, 1874, Varanger Fjord, Finmark (Coll. Lensmand Klerk and Prof. Esmark); ColleTt, Norske Nord-Havs Exp., Fiske, 84, pl. 3, fig. $22,1880$.

Lycodes vahti, Goode \& Bean, Proc. U. S. Nat. Mus. 1879, 209, not of Reinhardt; Jordan \& GiLberT, Synopsis, 786, 1883; Goode \& BeAN, Oceanic Ichthyology, 303, 1896.

2818. LYCODES VAHLII, Reinhardt.

Head $4 \frac{1}{3}$; depth 8 . D. 116; A.93; V.4. Head nearly twice as long as high; snout long, maxillary reaching to opposite middle of eye; distance of vent from ventrals nearly equal to length of head; ventral fins less than $\frac{1}{4}$ as long as pectorals; vertical fins scaly; body wholly scaly; lateral line distinct, ventral in position; vertebrse $25+87$. Brownish yellow, with 6 blackish cross bands extending on the dorsal fin and confluent on the belly, the first cross band on and below the anterior dorsal rays, the second above the vent; adults nearly uniform blackish. Coast of Greenland. (Günther.) (Named for Martiu Vahl, an early Danish naturalist.)

Lycodes vahlii, Reinhardt, Kon. Dan. Vidensk. Selsk. Nat. Math. Afh., vir, 1838, 153, tab. V, Greenland; GiLL, Cat. Fishes East Coast N. A., 46, 1861; Günther, Cat., Iv, 319, 1862 ; JoRdAN \& GILBERT, Synopsis, 786, 1883; GOODE \& BEAN, Oceanic Ichthyology, 303, 1896.

2819. LYCODES CONCOLOR, Gill \& Townsend.

Head 5 in total; depth about $7 \frac{1}{2}$; eye $7 \frac{8}{4}$ in head; snout 3 ; ventral fin 2 in eye; pectoral 2 in head. D. $118 ;$ A. 98; P. 21. Body rather elongate, covered with very small, entirely separated embedded scales which becomo more listinct anteriorly and extend in advance of the dorsal fin and scapular region, as well as on the vertical fins; lateral line obsolete; pectorals with scattered scales on external and internal surfaces near base; a special. ized area of smaller scales behind base of pectoral and a naked area around 
upper axilla of pectoral; head moderate, entirely naked; nape naked. Upper teeth in a cardiform band in front, thinning out behind. Lips rather thin. Color nearly uniform, only relieved by the apparently lighter hue of the scales and the somewhat darker margins of the fins; the scales paler than the ground color, which is thas covered with whitish or silvery specks. Bering Sea. Only the type known, its length 22 inches, from which we have taken the above description. (concolor, uniformly colored.)

Lycodes concolor, Gill \& Townsend, Proc. Biol. Soc. Wash., XI, 1897 (Sept. 17, 1897), 233, Bering Sea, lat. $55^{\circ} \mathrm{Ig}^{\prime}$ N., long. $168^{\circ} \mathrm{II} \mathrm{I}^{\prime}$ W., Albatross Station 3608, (Aug. 12, 1895), in 276 fathoms. (Type, No.48764, U.S. Nat. Mus. ('oll. Albatross.)

\section{LYCODES ZOARCHUS, Goode \& Bean.}

Head nearly $5 \frac{2}{3}$ in total length; depth 9 ; eye 4 in head $=$ snont. D. 116; A. 102 ; P. 19. Body covered with conspicuous embedded scales which extend behind the dorsal and anal, leaving only a narrow naked margin around these fins; head and pectorals naked. A lateral line begins slightly above the upper angle of the gill opening, rapidly curving downward and extending along the lower part of the body not far from base of anal fin; it can be traced above the anterior $\frac{2}{8}$ of the anal. Interorbital distance, measured on the bone, 4 in eye; nostrils placed close to npper lip and as far from each other as from the eye; maxillary reaching to vertical through middle of eye; upper jaw $2 \frac{1}{8}$ in head; mandible nearly $\frac{1}{2}$ head; maudible with a conspicuous flap on each side, about as long as eje, beginning at a distance from the symphysis equal to $\frac{1}{2}$ length of eye; inner edge of mandible also with a slightly elevated ridge of skin. Length of intermaxillary series of teeth equal to $\frac{1}{5}$ length of head; length of palatine series nearly equal to that of intermaxillary; vomerines in a round patch; mandibular teeth in 3 series; width of gill opening 2 length of head; ventrals in front of base of pectorals, their length 8 in head. Distance between lower angles of gill opening nearly $\frac{1}{5}$ length of head; origin of dorsal distant from the head a space equal to $\frac{1}{8}$ length of head, slightly behind middle of pectoral; pectoral, when extended, reaching to about vertical from sixth dorsal ray; longest ray of dorsal about $\frac{1}{4}$ length of head; anal origin under seventeenth ray of dorsal; vent under fifteenth ray of dorsal; longest pectoral ray contained about $9 \frac{1}{8}$ times in total length. Lateral line distinct, ventral in position, the median pores absent. Color grayish browu, lighter on the belly and under surface of the head; sides irregularly mottled with darker, a narrow dark edge at tip of first 4 dorsal rays. In a young example (No. 39299, U. S. Nat. Mus.) the mottlings on. the sides are band-like, the bands not extending below the middle of the body entirely. This example is from lat. $44^{\circ} 26^{\prime} \mathrm{N}$., long. $57^{\circ} 11^{\prime} 15^{\prime \prime} \mathrm{W}$., 190 fathoms. The type of the description is a specimen $366 \mathrm{~mm}$. long, obtained by the Albatross in lat. $44^{\circ} 46^{\prime} 30^{\prime \prime}$ N., 130 fathoms, off Nova Scotia. (Zoarchus, a synonym of

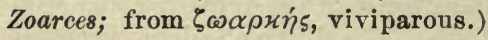

Lycodes zoarchus, GOODE \& BEAN, Oceanic Ichthyology, 308, 1896, off Nova Scotia, in I30 fathoms. (Type, No. 39298. Coll. Albatross.) 


\section{IYCODES RETICULATUS, Reinhardt.}

Head 4 ; depth about 8. D. 94 ; A. $75 ;$ V.4. Body entirely scaly; lateral line faint, developed anteriorly (fide Giintber's plate), probably becoming ventral; vertical fins naked. Head twice as long as high; snout long; maxillary extending to behind middle of eye; distance from vent to ventrals more than length of head; cæca 2. Brownish, with reticulated black lines on the head and body, those on the body disposed in 5 groups or cross bands, the 3 anterior of which emit 1 or 2 vertical streaks on the dorsal fin; dorsal dark edged. Isength 14 inches. North Atlantic, from Greenland south to Narragansett Bay, in 17 to 140 fathoms; abundant also in northern Europe. (Eu.) (reticulatus, netted.)

Lycodes reticulatus, REINHARDT, Kong. Dansk. Vid. Afh., vil, 1838, 167, Greenland ; GUNTHER, Cat., IV, 320; Gill, l. c., 260; ColletT, Nord-Havs Exp., 84; JordaN \& GilbERT, Synopsis, 787, 1883; GoodE \& BEAN, Oceanic Ichthyology, 305, 1896.

Lycodes rossi, MALMGREN, Om Spetsbergen Fiskfauna, 516, 1864, Spitzbergen.

Lycodes gracilis, SARS, Christ. Vid. Selsk. Forh. 1866, Dröbak.

\section{LYCODES PERSPICILLUM, Kröyer.}

This species is distinguished by a light body color and dark bands, also 2 ocellated spots on the forehead, which have suggested the specific name. Still further separated from the previously known species of Lycodes by the smaller number of fin rays, larger eje, etc. (Kröyer.) Greenland and southward in deep water. Specimens were obtained by the Albatross from Station 2491, in $45^{\circ} 24^{\prime} 30^{\prime \prime}$ N. lat., $58^{\circ} 35^{\prime} 15^{\prime \prime}$ W. long., at a depth of 59 fathoms, and from Station 2456, in $47^{\circ} 29^{\prime} \mathrm{N}$. lat., $52^{\circ} 18^{\prime} \mathrm{W}$. long., at a depth of 86 fathoms.

The following is the substance of Dr. Günther's description:

Head 4 in total length; depth nearly 8 . Head not quite twice as long as high; snout long; upper maxillary extending to below middle of eye. Distance of vent from ventrals nearly equal to length of head. Yellowish, with 9 or 10 brownish cross bands, edged with dark brown, and broader than the interspaces, the first occupying the upper parts of the head and inclosing a pair of roundish, yellowish spots situated behind the level of the eyes; the second cross band is on and before the anterior dorsal rays.

(In the figure of Goode \& Bean the lateral line is represented as median, which is probably not correct.) (perspicillum, eyebrow, from the spot above the eye.)

Lycodes perspicillum, KRöYER, Dansk. Vidensk. Selsk. Afhandl., xI, 1845, 233, Greenland; Günther, Cat., IV, 320, 1862; GILL, Proc. Ac. Nat. Sci. Phila. 1863, 260.

\section{LYCODES FRIGIDUS, Collett.}

Head 4 to $4 \frac{1}{2}$ in total length; depth $6 \frac{1}{2}$ (to $9 \frac{1}{2}$, young). D. 93 to 98 (including $\frac{1}{2}$ of the caudal, 99 to 104 ); A. 80 to 85 (including $\frac{1}{2}$ of the caudal 86 to $90)$; P. 20 to 21 ; V.3. Head wide and flat. Scales with very conspicuous mucous cavities below, small, covering the entire body, but not the head, nor the base of the dorsal and anal fins. In the young the middle of the belly, the base of the fins, and the fins themselves are usually naked. 
Teeth present on intermaxillary, mandible, palatines, and vomer; lateral line low, extending from upper end of gill opening in a curved direction down toward vent from which it runs close along anal to end of tail. (Goode \& Bean.) Pectoral fin obliquely truncate at tip, appearing furcate when not spread open. North Atlantic and Arctic Ocean, from Spitzbergen south to the New England coast, where many specimens were taken in 516 to 1,423 fathoms. (Eu.) One of Collett's specimens from Hammerfest, examined by us.) (frigidus, frozen.)

Lycodes frigidus, ColLETT, Forh. Selsk. Christ. 1878, Nos. 14 and 15, Beeren Island and Spitzbergen; Collett, Norske Nord-Havs Exp., 96, pl. 3, f. 23, 24, 1880; GOODE \& BEAN, Oceanic Ichthyology, 305, 1896.

\section{LYCODES TERRE-YOVE, Collett.}

Head 5 to $5 \frac{1}{2}$; depth 8 to 11 . D. 106 to 108 ; A. 89 to 93 ; P. 23 or 24 . Body slender, head small; pectorals broad; maxillary reaching to middle of eye; band of palatine teeth very short, scarcely $\frac{1}{2}$ length of maxillary band; body entircly scaly, head naked; lateral line ventral, extending along edge of belly, the median branch wasting; vent before middle of body. Color lost in type, the only specimen known. Banks of Newfoundland, in 155 fathoms. (Collett.) (terra, land; novus, new, from Newfoundland.)

Lycodes terra-nova, Colletr, Campagnes Scientifiques, L'Hirondelle, X, 1896, 54, Bank of Newfoundland, Hirondelle Station $\mathbf{1 6 2}$, in $\mathbf{1 5 5}$ fathoms. (Coll. Albert, Prince of Monaco.)

\section{LYCODES DIGITATUS, Gill \& Townsend.}

Head 5 in total; depth about $8 \frac{1}{2}$; eye $6 \frac{1}{2}$ in head; snout 3 ; ventral fin $1 \frac{8}{4}$ in eye; pectoral $1 \frac{9}{10}$ in head. D. $101 ;$ A. $81 ;$ P. 18 . Body moderately elongate; covered with small, entirely separated embedded scales, which become nearer anteriorly and extend in advance of the dorsal fin as well as on the vertical fins; no specialized area of smaller scales behind base of pectorals; pectorals scaleless; head moderate, entirely naked; nape naked; upper jaw with outer row of close-set teeth, broader in front; teeth on vomer and palatimes; lips rather thick. Color in alcohol, brownish yellow, suffused with reddish in front, variegated, darker anteriorly, with 4 dark longitudinal stripes most distinct about middle of lody, fading out backward; fins light and without dark margins; head dark above and laterally light below. Bering Sea. Only the type known, from which we have taken this description, its length 18 inches; possibly the adult of L. palearis, but the pectoral fins are shorter than in the latter. (digitatus, fingered.)

Lycodes digitatus, GiLl \& Townsend, Proc. Biol. Soc. Wash., XI, 1897 (Sept. 17, 1897), 232, Bering Sea, lat. $5^{\circ} 14^{\prime}$ N., long. $164^{\circ} 8^{\prime}$ W., at Albatross Station $354^{1}$, in 49 fathoms. (Type, No. 48765, U.S. Nat. Mus. Coll. Albatross.)

\section{LYCODES PAIEARIS, Gilbert.}

Head $5 \frac{1}{4}$ in length; depth $9 \frac{1}{2}$ to 11 in length, $2 \frac{1}{6}$ in head; eye 5 to 6 in head, $1 \frac{1}{3}$ to 2 in snout. Dorsal with about 105 rays, counted to middle of caudal; anal about 90 ; pectoral 18 ; ventrals $1 \frac{1}{2}$ to $1 \frac{1}{3}$ in eye, twice as long 
as in $L$. brevipes; pectorals $1 \frac{1}{3}$ in head. Head naked; nape more or less naked, the scaleless area variable in extent, sometimes confined to its anterior third, sometimes reaching nearly to front of dorsal; body sparsely covered with embedded scales; axil naked; lateral line short, decurved, extending scarcely beyond middle of pectorals. Anal origin under eight. eenth dorsal ray. Teeth present in jaws, vomer and palatines, those in premaxillaries laterally in a single series which widens anteriorly into a rather broad patch, the outer teeth somewhat enlarged, especially in front; all the premaxillary teeth shut outside on the mandibular series which are opposed to those on vomer and palatines; mandibular teeth arranged similarly to those in upper jaw, the lateral series somewhat enlarged, continuous with the inner edge of the symphyseal patch; vomerine teeth bluntly conic, 3 or 4 in number; palatines in a single series. Snout long, prominent, the upper jaw projecting beyoud the lower for a distance equaling $\frac{2}{8}$ of orbit; upper lip thin, much expanded laterally, continuous posteriorly with the lower lip which forms a wide free membranaceous lobe opposite middle of each mandible; anteriorly the lower lip becomes abruptly contracted and adnate to the jaw, leaving the symphyseal portion without free margin; inner edge of mandible with wide membranaceous borders, which increase in width anteriorly where they terminate in a pair of acutely pointed free flaps; these and the membranaceous margins very conspicuous in both young and old individuals. In L. brevipes they are very inconspicuous, becoming evident in adults only. General color brownish olive, growing lighter on the lower parts; dorsal with 14 to 16 white vertical bars, extending in young examples across back and sides and onto anal fin, in adults confined to the fins, and frequently indistinct or wanting; anterior dorsal angle frequently black, separated from remainder of fin by a curved white bar; dorsal and anal not black margined as in $L$. brevipes; in the latter, the white lateral bars are 9 to 12 in number, and are usually confined to upper half of body; there is also no black spot on anterior dorsal rays. This species is very close to $L$. brevipes Bean, differing constantly in the longer ventrals, the greater development of mandibular and labial folis, the more numerous white bars, and the smaller eye. Bering Sea. Three specimens, 113 to $166 \mathrm{~mm}$. long, from Albatross Stations 3253 and 3254, in Bristol Bay, in 36 and 46 fathoms. (Gilbert.) (palea, the wattles of a cock.)

Lycodes palearis, Gilbert, Rept. U. S. Fish Comm. 1893 (1896), 454, Bristol Bay, Alaska. (Coll. Albatross.)

\section{LYCODES BREVIPES, Bean.}

Head 5 in total length; depth 10. D. 85 to middle of caudal; A. 74; P. 21. Body covered with scales except immediately behind pectoral fins; head naked; dorsal and anal fins minutely scaled; diameter of eye equals the length of the snout, 4 in head; dorsal origin nearly over middle of pectoral; anal origin under eighteenth ray of dorsal; ventrals minute, scarcely more than $\frac{1}{3}$ diameter of eye; pectorals 9 in length of the body; lateral line single, very faint, ventral in position, abruptly decurved and becoming obsolete over about the tenth anal ray. A narrow light band 
across the nape and from 9 to 11 across the back extending downward about to median line and becoming obscure in adults; dorsal and anal each with a narrow dark margin. (Bean.) Alentian Islands to Kadiak; abundant; taken by us in large numbers off Karluk in 1897. (brevis, short; pes, foot.)

Iycodes brevipes, BeAN, Proc. U.S. Nat. Mus. 1890, 38, between Unga and Nagai islands, at Albatross Station 2848, in rro fathoms. (Type, No. 45362. Coll. Albatross.)

Subgenus LYCIAS, Jordan \& Erermann.

2828. LYCODES NEBULOSUS, Kröyer.

D. 87 ; A. 68 ; P. 19 ; V. 3 . Borly naked anteriorly, the posterior part of dorsal fin scaly; the anal naked or nearly so. Brown, with small, faint, yellow, transverse bands across the back. Greenland. (Kröyer.) An imperfectly described species, not recogniżed by any recent writer. This species and the next should perhaps be placed in Lycodalepis. (nebulosus, clouded.)

Lycodes nebulosus, KröYer, Kong. Dan. Vidensk. Sel. 1844, 140, Greenland; GiLL, Proc. Ac. Nat. Sci. Phila. 1863, 261; Jordan \& Grlbert, Synopsis, 787, 1883.

\section{LYCODES SEMIXUDUS, Reinhardt.}

Head $3 \frac{1}{2}$; depth 7. D. 91 ; A. 74; P. 21. Body naked in front of vent, scaly behind; fins naked. Head large. Distance of ventrals from vent somewhat more than length of head; cæca 2 . Color uniform pale grayish brown, without spots or bands. North Atlantic, from Greenland to Spitzbergen; rare. (Collett.) (8cmi-, half; nudus, naked.)

Lycodes seminudus, Rernhandт, Kong. Dansk. Selsk., etc., 1838, 221, Omenak, Greenland; Günther, Cat.. Iv, 320, 1862; JoRdan \& Gilbert, Synopsis, 787, 1883; Goode \& BKaN, Oceanic Ichthyology, 307, 1896.

936. LYCODALEPIS, Bleeker.

Lycodalepis, BleEkER, Verl. Akad. Amst., Ed. 2, vin, 1874, 369 (mucosus).

This genus differs from Lycodes in the absence of scales on trunk and fins; scattered scales sometimes present on the tail only. ( $\lambda v \varkappa œ$ Lycodes; $\dot{\alpha} \lambda \varepsilon \pi i s$, without scales.)

a. Color brownish, with many cross bands and streaks of cream color; head $4 \frac{1}{5}$ in length; depth 8; lateral line obsolete; tail sometimes with a few scales. POLARIs, 2830.

aa. Color blackish, with about 5 narrow pale cross bars on back; head 34 in length; depth 8; lateral line double, a median and a ventral series of pores being faintly developed.

Mucosus, 2831.

2830. LYCODALEPIS POLARIS (Sabine).

Head $4 \frac{1}{5}$; depth 8 . D. 85 ; A. 67 ; P. 18 ; V. 3 ; Br. 6 . Head depressed, its greatest width $\frac{8}{4}$ of its length; distance from tip of snout to nape nearly equaling greatest width of head, 6 in length; upper jaw 18 to 2 in head, extending to vertical of hiud margin of orbit, larger in male than in the female; a full series of teeth on premaxilliaries, and in front of these a few smaller teeth form an outer imperfect series; a toothless space at sy mphysis, 
first tooth on each side of this larger than any of the rest; 1 complete series of teeth on mandible, and in front of it, about the symphysis, 2 irregular short series; a few teeth in a cluster on head of vomer; palatines with a short single series; teeth all slender and slightly recurved; long diameter of eye 9 in head. Pectoral $1 \frac{4}{5}$ in head; ventral about as long as eye; longest dorsal ray $3 \frac{2}{7}$ in head; vent in middle of total length, immediately behind third cross band; longest anal ray $4 \frac{1}{5}$ in head; scattered scales present on posterior two-thirds of tail in 1 specimen (type of $L$. coccineus), wholly wanting in the others, typical of L. turneri; no scales on the fins; no trace of lateral line. Color light brown; abdomen grayish brown; lower parts of head cream; a band of eream on the anal from origin of rays to about their middle; a crescentic $V$-shaped band of same color, mottled with umber, crossing nape and continuing behind pectorals, extending backward to the first cross bar; a streak of cream, more or less interrupted by umber, extending backward from eye across cheek almost to end of operculum; 10 bands of cream color, bordered with dark umber, from tips of dorsal rays extending on lower half of body, becoming wider and somewhat broken below middle of body; a very indistinct caudal tip of cream color. In young examples these markings are very distinct; in older ones they grow progressively more obscure, the oldest having scattering blotches of cream color instead of bands, the V-shaped nuchal band persisting longest. The type of Lycodes coccineus is described as brown, red below; pectorals reddish brown above, carmine below; 9 bluish-white bands on the dorsal; a few whitish blotches on sides and on head; anal brownish red; head white below; a whitish blotch as large as eye at upper angle of gill opening. Length 18 to 20 inches. Arctic Ocean, Bering Straits, and adjacent waters south to St. Michaels. Here described from the type of Lycodes coccineus and from a number of specimens from Point Barrow referred to Lycodes turneri. Evidently all belong to the same species, but 1 has a scaly tail while the others are wholly naked. In 2 large examples, supposed to be males, the head is very much depressed, broad and flat, and the maxillary is more than $\frac{1}{2}$ head. In the others the head is smaller, less flattened, with smaller mouth, the maxillary 2 in head. These are doubtless females and young. The species should probably stand as Lycodalepis polaris. (polaris, polar.)

?Blennius oolaris, ${ }^{*}$ SABINE, Parry's Journal, Voyage 1819-20, Supplement, 212, North Georgia.

Lycodes turneri, Bean, Proc. U. S. Nat. Mus. 1878, 464, St. Michaels, Alaska (Type, Ño. 21529. Coll. Dr. Lucien M. Turner); Turner, Contr. Nat. Hist. Alaska, 93, pl. 4, 1886.

Lycodes coccineus, BEAN, Proc. U.S. Nat. Mns., Iv, 1881, 144, Big Diomede Island, Bering Strait (Coll. Dr. Bean. Type, No. 27748, 20 inches long, with scales on the tail); JoRDAN \& GILBER'T, Synopsis, 787, 1883.

Blennius (Zoarches?) polaris, Richardson, Fauna Bor.-Amer., 1II, 94, 1836.

Lycodes polaris, GüN'HER, Cat., IV, 321, 1862.

Lycodalepis turneri, JoRdan \& GILBERT, Synopsis, 788, 1883; SCOFIELd, in JORDAN \& GILBERT, Fur Seal Invest., 1898.

Lycodalepis polaris, JORDAN \& GILBERT, Synopsis, 788, 1883.

* Blennius polaris is thus described: Without any scales; length of the pectoral exceeding twice its breadth, having 15 rays. Yellowish, lighter on the belly, with 11 large saddle-like markings across the back, the middle of these markings being much lighter than their edges; the whole back and the sides marbled. (Sabine.) Coast of North Georgia. 
2831. LYCODALEPIS MUCOSUS (Richardson).

Head $3 *$; depth 8 . D. (including $\frac{1}{2}$ of caudal) 90 ; A. (including $\frac{1}{2}$ of caudal) 71 ; P. 18; V. 3 . Body robust, head very large; snout 3 in head; interorbital area 6 in head; nostrils much farther from eyes than from each other, their distance from eyes $4 \frac{1}{8}$ in head; upper jaw $6 \frac{1}{4}$ in total length; lower jaw $6 \frac{2}{3}$; eyes small, close together, their long diameter 11 in the head; distance from tip of snout to base of pectoral fin $3 \frac{1}{2}$ in total length; pectoral fin $6 \frac{2}{3}$; length of ventrals equaling long diameter of eye. (Goode \&. Bean.) Lateral line (in specimens from Cumberland Gulf) very faint, but with both median and ventral branch. Blackish, with irregular white markings in the form of 5 faint and narrow bars across the back. Arctic America. (mucosus, slimy.)

Lycodes mucosus, Richardson, Last Arctic Voyage, 362, pl. 26, 1855, Northumberland

Sound; BeAn, Bull. U. S. Nat. Mus., No. 15, 112, 1879; Goode \& BEAN, Oceanic Ichthy. ology, 306, 1896.

Lycodalepis mucosus, JORDAN \& GILBERT, Synopsis, 788, 1883.

\section{LYCENCHELYS, Gill.}

Lycenchelys, GiLl, Proc. Ac. Nat. Sci. Phila. 1884, 110 (murana).

This genus contains small and very slender species differing from Lycodes in the elongation of the body, the depth being from 10 to 20 times in the length. The lateral line is single and median in all known species. The genus is very elose to Lycodes, but the position of the lateral line sufficiently defines it, especially in conuection with the slender eel-like form. ( $\lambda \dot{v} \varkappa o 5$, wolf; $\check{\varepsilon} \gamma \chi \varepsilon \lambda v 5$, eel.)

a. Lower half of pectoral not notably longer than upper; depth 12 to 16 in length.

b. Dorsal rays 92; anal 88; color grayish, with irregular brown patches.

$b b$. Dorsal rays 118; anal 110; color brown, the head darker. VERRILLII, 2832. PAXILLUS, 2833. aa. Lower half of pectoral considerably longer than upper; head with large pores; depth 14 times in length; color dusky brown. PORIFER, 2834.

2S32. LYCENCHELYS VERRILLII (Goode \& Bean).

Head $5 \frac{2}{3}$; depth about 13 ; eye 2 in snont. D. $92 ;$ A. $88 ;$ P. $15 ;$ V. 5. Body elongate; head much depressed. Distance of vent from ventrals slightly greater than head, its distance from snout about 3 in body; distance of dorsal fin from snout $\frac{1}{2}$ greater than head; distance of anal from snout twice head; dorsal and anal fins about equal in height, with even margins, not differentiated from caudal, the rays increasing somewhat in length posteriorly; distance of pectoral from suout about equal to head, twice length of pectoral; pectoral reaching vertical from base of second dorsal ray; distance of ventrals from snout less than head, their length less than $\frac{1}{4}$ that of pectorals. Head, body, and fins enveloped in tough, lax skin. Scales eycloid, eircular, and ovate, with numerous concentric striæ, and about 18 lobes on margin, the whole porimeter being lobed; scales deeply embedded in the skin at distances from each other equal to their own diameters, most numerous on upper part of body and 
extending upon base of dorsal; very few scales upon lower half of body, none on anal fin. Upper jaw far overlapping the lower; gape reaching orbit. A series of 6 large pores on each side, extending backward from nostril toward angle of opercle, the fourth of the series under center of orbit; a similar series, 7 on each side, along line of lower jaw from its symphysis to angle of opercle, all slit-like, the others eircular. Nostrils at extremities of fleshy tubes. Teeth in lower jaw in 2 rows, nearly uniform in size; teeth of upper jaw in a single series, somewhat enlarged near the symphysis; patches of smaller teeth behind; about 7 teeth on vomer; a single row on palatines; all the teeth curved. Gill opening narrow, the membranes attached to the isthmus. Color, body above lateral line light grayish brown with numerous minute circular dots marking the position of the scales; pearly white below lateral line; brown irregular patches upon sides, bisected by lateral line, the lower half color of dorsal, that above darker and with the white dots, these brown patches 7 to 10 in number; a brown spot on tip of tail; abdominal region livid blue. Coast of Massachusetts, in deep water; a dwarf species very small in size. (Named for Prof. Addison E. Verrill of Yale University.)

Lycodes verrillii, Goode \& BeAx, Amer. Journ. Sci. Arts, xiv, 1877, 474, off coast of New England in the Gulf Stream; JorDAN \& GILBERT, Synopsis, 786, 1883.

Lycenchelys verrilli, JoRDAN, Cat., 124, 1885; GOODE \& BEAN, Oceanic Ichthyology, 309, figs. 277 and $277 \mathrm{~A}, 1896$.

\section{LYCENChELYS PAXILLUS (Goode \& Bean).}

Head 8; depth 16 ; eye $3 \frac{1}{2}$ to 4 in head, equal to snout, which is 4 times interorbital width. D. (with $\frac{1}{2}$ of caudal) 118 ; A.110; P.16; V.3. Body attenuate, head broad, flat above, with declivous profile; cheeks full and protuberant; teeth stout, recurved, and sharply pointed, in a single series in each jaw, except at the symphysis; a few teeth elustered at the head of the vomer; palatines with a single series; the tubular nostril much nearer tip of snout than eye. Lateral line median, faint and short (in specimens examined by us). Dorsal beginning over tip of pectoral; veutral little longer than pupil. Scales very small, present everywhere except on head and pectorals, nearly covering vertical fins. Light brown, the head somewhat darker. Gulf stream, lat. $35^{\circ}$ to $41^{\circ}$ N., in deep water, 263 to 904 fathoms. (Goode \& Bean.) (paxillus, a peg.)

Lycodes paxillus, Goode \& BEAN, Proc. U. S. Nat. Mus. 1879,44, between LaHave and

Sable Island Banks (Type, No. 22177. Coll. Capt.J. W. Collins), a male in breeding form; JoRDAN \& GILBERT, Synopsis, 785, 1883.

Lycodes paxilloides, Goode \& BEAN, Bull. Mus. Comp. Zool., $x$, No.5, 207, 1883, off Newfoundland (Type in M. C. Z. Coll. The Blake); a normal, not sexually distortod individual.

Lycenchelys paxillus, JoRDAN, Cat., 124, 1885; GOODE \& BEAN, Oceanic Ichthyology, 311, figs. 279 and $282,1896$.

\section{LYCENCHELYS PORIFER (G;lbert).}

Head $5 \%$; depth 14 . Body very slender. Head much contracted opposite orbits, the snout expanded, as in Lycodopsis paucidens. Mouth moderate, the maxillary reaching vertical from front of pupil, $3 \frac{1}{5}$ in head; eye $5 \frac{2}{3}$; snout $3 \frac{2}{5}$; interorbital width $\frac{1}{8}$ eye. Teeth in front of premaxillaries 
in 2 series, merging into 1 laterally, the outer series anteriorly somewhat enlarged; teeth in front of mandible in a broad band, narrowing laterally to a single series, none of them enlarged; vomer and palatines with single series. Head with 2 series of large and very conspicuous elongate pores, 1 series on mandible and suboperele, the second parallel with it on level of snout. Gill openings wide, extending forward beyond preopercular margin, the width of isthmus less than $\frac{1}{4}$ length of slit. Distance from origin of dorsal to tip of snout $4 \frac{1}{3}$ in length. Median dorsal rays simply forked near base, those posteriorly in both dorsal and anal repeatedly subdividing. Distance of anal from snout $2 \frac{7}{8}$ in length; pectorals rounded, the lower half of fin longer than the upper, the rays thickened, the fin containing. 15 or 16 rays, its length less than $\frac{1}{2}$ head; ventrals longer and slenderer than usual, each apparently composed of 2 rays closely joined, their length $\frac{8}{4}$ orbit, inserted unusually far forward, being in advance of preopercular margin. 'Scales very small, circular, partially embedded, covering body and vertical fins; head, antedorsal region, breast, and a strip connecting the two latter embracing base and axil of pectorals, naked; lateral line median. Color dusky brown, the fins, sides of head, and belly blackish; lining of mouth and gill cavity and peritoneum black. Off Lower California. A single specimen, 12 inches long, from Albatros station 3009, in 857 fathoms. A transitional species approaching Furcella. (porus, pore; fero, I bear.)

Lycodes porifer, GiLBert, Proc. U. S. Nat. Mus. 1890, 104, off Lower California, in 857 fathoms. (Type, No. 44384. Coll. Dr. Gilbert.)

\section{FURCIMANUS, Jordan \& Evermann.}

Furcimanus, new genus (diapterus); JoRDAN \& Evermann, Check-List Fishes, 480, 1896 (diapterus); preoccupied by Furcella, Lamarck, 1801, a genus of mollusca.

This genus differs from Lycenchelys in the forked pectorals, the upper and lower rays being much longer than the middle ones. The lateral line is single and ventral in position (not lateral as in Lycenchelys). (furca, a fork; manus, hand.)

\section{FURCIMANUS DIAPTERA (Gilbert).}

Head $5 \frac{2}{8}$ to 6 ; depth 12 ; eye large, usually longer than snont, 3 to $3 \frac{2}{3}$ in head; snout $3 \frac{1}{2}$ to $3 \frac{2}{8}$; interorbital width about 10 . Body slender. Mouth small, somewhat variable in length, the maxillary reaching vertical from between front and middle of pupil, $2 \frac{1}{2}$ to $3 \mathrm{in}$ head. Teeth in premaxillaries in a double row throughout, the 2 series well separated, rarely with 1 or 2 teeth intercalated, showing traces of a third row; the teeth of inner series small and directed obliquely inward; those of outer series anteriorly enlarged, becoming smaller on sides of jaw ; on front of mandible the teeth are in a broad band, in which traces of 3 or 4 irregular series can be made out; none of these enlarged; laterally the teeth are arranged in a single series, those opposite middle of cleft considerably enlarged; a small patch of from 2 to 5 teeth on vomer; palatines with a single row much shorter than premaxillary patch. Nostril with a short inconspicuous tube. Mandible and preopercular border with deep pit-like excavations, which are not evident in fresh specimens; no evident mucous pores on the head. 
Gill openings wide, extending below the base of the pectorals; the gill membranes joined to isthmus for a distance equaling $\frac{2}{5}$ length of slit; gill rakers very short, almost tubercular, but compressed and slightly movable, about 15 present on anterior limb of outer arch; a wide slit behind fourth gill. Ventrals short, inserted under middle of opercle. Pectorals deeply notched in both young and adults, the median rays much shorter than either upper or lower, the lobe produced by the elongate lower rays varying in length, being sometimes shorter than upper lobe, sometimes longer; the rays of lower lobe are thickened, and undoubtedly serve as a support to the fish when resting on the bottom, as has been observed in so many other forms; the pectorals contain 20 or 21 rays; in the structure of this fin the present species seems to differ from all previously described forms, with the exception of $L$. esmarkii, in which the notched condition of the fin does not persist in the adults. Scales small, embedded, covering entire body and vertical fins; the scales on nape are much reduced in size, and in 2 specimens ( $11 \frac{1}{2}$ and $7 \frac{1}{2}$ inches long) are continued onto occiput, which they entirely cover; in another specimen, 9 inches long, the occiput is naked, and in another, 5 inches long, the anterior part of nape is likewise naked; in the latter, as in other specimens, the dorsal and anal are well scaled. Lateral line single, wavj, ventral in position, extending from above gill slit obliquely downward to near base of anal, along which it is continued for a variable distance, not reaching base of caudal. Color dusky brownish, blue-black on belly and along anterior portion of base of anal; 8 or 9 narrow white bars on sides, most conspicuous in the young, in which they are continued up on dorsal fin and become forked below on middle of sides, forming $\wedge$-shaped marks; in adults these bars become faint or wholly disappear; when present, they are not continued on dorsal, and are nsually vertically divided by a streak of the ground color; in the small specimen there is a distinct black blotch on margin of anterior dorsal rays; in adults, the vertical fins are brownish on basal portion, their distal half black; pectorals and ventrals deep blue-black; month, gill cavity, and peritoneum dusky or black. Several specimens, from Albatross Stations 2892, 2896, 3067, and 3077, in depths from 82 to 376 fathoms, off the coasts of California and Oregon. (Gilbert.) A remarkable species. ( $\delta \imath \dot{\alpha}$, divided; $\pi \tau \varepsilon \rho o ́ v$, fin.)

Lycodes diapterus, GiLBERT, Proc. U. S. Nat. Mus. 1891, 564, off the coast of Oregon, in 685 to 877 fathoms. (Type, No. 44385. Coll. Dr. Gilbert.)

939. LYCODONUS, Goode \& Bean.

Lycodonus, Goode \& BEAN, Ball.Mus. Comp. Zool., X, No. 5, 208, 1883 (mirabilis).

Body elongate, formed as in Lycenchelys and Lyciscus; scales small, circular, embedded in the skin; lateral line very short or obsolete; jaws without fringes, lower jaw included; fin rays all articulated, each ray of dorsal and anal supported laterally by a pair of sculptured scutes; caudal distinct, not fully connate with dorsal and anal; ventrals present; gill opening narrow ; teeth as in Lycodes. Deep water. (Lycodes, with a meaningless change of termination.)

$3030-78$ 
2836. LYCODONUS MIRABILIS, Goode \& Bean.

Head 7 in total length; depth about 18. D. about 80 ; A. about 70 ; C.9; P. 18; V. 3; scales as in Lycodes, the scales not extending out upon the fins; no scales on head and nape. Lateral line apparently obsolete posteriorly; not extending back of the extremity of the pectoral, its position median; eye high up, $2 \frac{1}{2}$ in head, equal to postorbital portion of the head; the width of interorbital space less than diameter of pupil, $3 \frac{1}{2}$ times in long diameter of eye; nostrils immediately in front of eye ; maxillary extending to vertical through anterior margin of pupil; mandible, to a little behind vertical through posterior margin of the pupil; dorsal fin inserted slightly behind vertical through base of pectoral (the portion of the fin present in the mutilated specimen before us contains 80 articulated rays; the first 10 or 11 scutes do not support rays, but whether rays were originally present or not can not be ascertained); longest dorsal ray about equal to longest anal ray, its length about 3 in head; distance of vent from snout twice length of head; anal beginning immediately behind vent, of about 70 articulated rays; caudal rays extending beyond tips of ultimate dorsal and anal rays, about 9 in number; distance of ventral from snout equal to twice length of upper jaw; middle ventral ray longest, it being $\frac{1}{2}$ as long as postorbital part of head; length of pectoral equaling 3 times that of snout. Off the Now England coast, in depths of 721 to 1,309 fathoms; a most remarkable little fish. (mirabilis, wonderful.)

Iycodonus mirabilis, Goode \& BEAN, Bull. Mus. Comp. Zool., x, No. 5, 208, 1883, New England Coast, lat. $3^{\circ} 20^{\prime} 8^{\prime \prime}$ N., long. $73^{\circ} 23^{\prime} 20^{\prime \prime}$ W., in 740 fathoms (Type in M. C. Z.) ; Jordan, Cat. Fishes, 124, 1885; Goode \& BEAN, Oceanic Ichthyology, 312, 1896.

\section{LYCONEMA, Gilbert.}

Iyconema, GILBert, Rept. U.S. Fish Comm. 1893 (1896), 471 (barbatum).

Generic characters as in Lycodes, but the lower jaw covered with a dense mass of slender filaments or barbels, between which can be seen the mucous pores of the mandible. In Iluocotes, a related genus from the Antarctic, the mandible is provided with a series of hollow tubes, which are doubtless the produced margins of the pores. Alaska. ( $\lambda \dot{v}$ os, wolf; $v \tilde{\eta} \mu \alpha$, thread.)

2837. LYCONEMA BARBATUM, Gilbert.

Head $6 \frac{1}{3}$; depth $11 \frac{1}{2}$; maxillary 3 in head; eye $3 \frac{1}{3}$; snout $4 \frac{1}{2}$. D. 103; A. 90 (each counted to middle of candal); P. 15, its length $11_{10}^{9}$ in head; ventrals very short, $\frac{1}{2}$ to $\frac{2}{5}$ diameter of orbit. A dense fringe of filaments covers the entire under surface of lower jaw, extending to behind angle of mouth; another series laterally on the throat, and a few scattering ones sometimes present ou the branchiostegal membranes; upper jaw without barbels. Body slender; upper jaw orerlapping the lower; mouth small, maxillary reaching vertical from front of pupil; teeth all conical, none of them much enlarged, those in lower jaw in a patch or irregular double series, narrowing to a single series laterally; in upper jaw, a single series, the teeth of which increase in size toward the middle line, the mid- 
dle teeth being almost canine-like; behind the latter, a short inner series of small teeth directed backward; teeth on vomer and palatines in a single series. Gill slits continued forward to slightly beyond bases of ventrals, and to level of lower edge of base of pectorals; width between gill slits $\frac{1}{2}$ diameter of eye; pseudobranchiæ well developed; posterior line of occiput midway between origin of dorsal and front of pupil or front of eye; origin of anal fin at end of tirst third of length of body; pectorals broad, with the posterior edge emarginate, some of the upper and the lower rays longer than the intermediate ones. Scales showing traces of definite arrangement in series, willely separated anteriorly, becoming crowded toward end of tail, continued up on the vertical fins, but not on head, on anterior half of nape, nor on the pectoral fins; lateral line very faintly shown, and for only a short distance behind head, where its course is obliquely downward; the usual series of mucous pores present, but not conspicuous. In spirits this species has an olive-brown ground color, becoming white on underside of head and on abdomen; a series of 8 or 9 brown spots $\frac{1}{2}$ as large as eye, along middle of sides, those posteriorly continued downward onto base of anal, the last 2 or 3 reaching edge of fin and there developing into intense black blotches; a similar series of smaller spots corresponding in position to those just described occurs along the base of dorsal, these continued as faint bars on the fin, at the margin of which they develop into a black blotch, those posteriorly wider and more intense; an intermediate series of spots alteruating with the 2 just described; an elliptical jet-black spot occupies the greater part of caudal fin, and is narrowly margined all around with white; peritonenm jet-black; the mouth and gill cavities white. Coast of Alaska, in rather deep water; known from 12 specimens, the longest $6 \frac{1}{2}$ inches; depth 204 fathoms. (barbatus, bearded.)

Lyconema barbatum, Gilbert, Rept. U. S. Fish Comm. 1893 (1896), 471, coast of Alaska, at Albatross Station 3129 , lat. $3^{\circ} 39^{\prime} 40^{\prime \prime}$ N., long. $122^{\circ}$ or $I^{\prime}$ W., in 204 fathoms.

\section{BOTHROCARA, Bean.}

Bothrocara, Bean, Proc. U.S. Nat. Mus. 1890, 38 (mollis).

Body elongate, compressed, semitranslucent, covered with small scales; small teeth in jaws and on vomer and palatines; mucous pores about head largely developed. No ventral fins; dorsal and anal joined to caudal. Deep-sea fishes, allied to Lycodes, but lacking ventrals. The species have been referred to the Antarctic genus Maynea, Cunningham. From the latter, however, Bothrocara mollis seems to be distinct, differing in the larger mouth, more cavernous head, and lower dorsal. In some regards B. pusilla is intermediate, and it may belong to Maynea. ( $\beta o ́ \theta \rho o s$, cavity; « ́́p $\alpha$, head.)

a. Body elongate, with the head short, 6 in length; depth 9 ; mouth small; mucous cavities small; color light brown, the dorsal dark-edged.

PUSILLA, 2838.

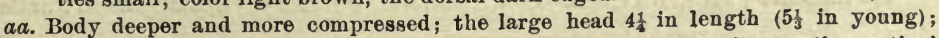
depth 62 ; month large; mucous cavities large; color uniform brown, the vertical fins dark-edged. Size large.

MOLLIS, 2839. 
2839. Bothirocara PUSILLA (Bean).

Head 6 in the total length; depth 9. D. 95, including $\frac{1}{2}$ caudal; A. 81, including $\frac{1}{2}$ of caudal; P. 17; eye 3 in head; snout 4. Body elongate, little compressed; head short; mouth small; maxillary extending to below front of pupil; gill clefts narrow, the anterior end below margin of preopercle; width of isthmus rather less than $\frac{1}{2}$ of orbit; the low dorsal beginning nearly over axil of pectoral; pectoral nearly $\frac{2}{3}$ as long as head; vent as far from end of head as dorsal origin from tip of snout. Color light brown; dorsal and anal with a narrow dark margin. Size small; length $6 \frac{1}{5}$ inches. Eastern parts of Bering Sea, and about the Alaskan Peninsula, in rather deep water. Besides the original types Dr. Gilbert records a few specimens from north of Unalaska, at depths of 121 to 351 fathoms. (pusillus, weak.)

Maynea pusilla, Bean, Proc. U. S. Nat. Mus. 1890, 39, off Nagai Island, lat. $55^{\circ} 10^{\prime}$ N., lon. $160^{\circ} 18^{\prime}$ W., in 1 Io fathoms (Type, No. 45360. Coll. Albatross); Gilbert, Rept. U. S. Fish Comm. 1893 (1895), 455.

\section{S39. BOTHROCARA MOLIIS, Bean.}

Head $4 \frac{1}{4}$ in total length in adult, $5 \frac{1}{3}$ to $5 \frac{1}{2}$ in young; depth $6 \frac{2}{3}$ in adult, 10 in young. D. 100 to 105 to middle of caudal; A. 89 to 95 to middle of caudal; eye 4 in head in adult, $3 \frac{1}{2}$ in young. Body covered with emberlded scales, which extend on dorsal and anal fins. Head naked, breast and nape scaly; snout blunt, the lower jaw included; maxillary reaching niddle of pupil, $2 \frac{1}{2}$ in head; large mucous cavities conspicuous along mandible, suborbital ring, and top of head; vomerine and palatine teeth present, the latter in a narrow band, obscure in the young. Pectoral 2 in head; origin of dorsal slightly behind base of pectoral, its distance from tip of snout 4 in total length; origin of anal under seventeenth dorsal ray; longest dorsal ray 5 in head; longest anal ray $8 \frac{1}{2}$ in head. Gill openings wider than in Bothrocara pusilla, the anterior end of the cleft under posterior margin of eye, the width of the isthmus less than $\frac{1}{2}$ diameter of pupil. Color uniform brown, fins lighter; dorsal and anal margined with black, more prominent posteriorly where it covers the entire fins. North Pacific. Adult examples from southern California, 18 inches long, were described as Maynea brunnea, while a young individual, $5 \frac{1}{2}$ inches long, from Queen Charlotte Islands, with the vomerine and palatine teeth not evident, was made the type of a distinct genus, as Bothrocara mollis. The two are identical and apparently belong to the same genus as B. pusilla. Similar specimens, 1 adult and 2 young, were dredged by us (Albatross) off Bogoslof Island in 664 fathoms. Dr. Gilbert records also specimens from near Unalaska, depth 316 fathoms. The teeth on the palatines are in a single series instead of a wide band, as stated in the original description. (mollis, soft.)

Bothrocara mollis, BeAN, Proc. U.S. Nat. Mus. 1890, 38, off Queen Charlotte Islands, in 876 fathoms (Type, No. 45359. Coll. Albatross); Jordan \& Gilbert, Rept. Fur Seal Invest., 1898.

Maynea brunnea, Benn, Proc. U. S. Nat. Mus. 1890 , 39, lat. $33^{\circ} 8^{\prime}$ N., lon. $118^{\circ} 40^{\prime}$ W., off San Clemente Island, southern California, in 414 fathoms. (Coll. Albatross.) 
942. GYMNELIS, Reinhardt.

Gymnelis, ReINHARDT, Dansk. Vidensk. Selsk. Af handl., vir, 131, 1838 (viride). Cepolophis, KAUP, in Archiv fur Naturgesch. 1856, 96 (viridis).

Body elongate, naked. Vertical fins without spines; ventral fins none. Small conical teeth on the jaws, vomer, and palatines. Gill openings very narrow. No air bladder; pyloric cæca none; no anal papilla. Size small. Cold seas. Two or 3 species known: G. pictus, from the Antaretic, and G. viridis, which ranges widely in Arctic waters, and with which the very dubious G. stigma is probably identical. ( $\gamma v \mu v o ́ s$, naked; $\varepsilon^{\prime} \gamma \chi \varepsilon \lambda v \varsigma$, eel.)

$a$. Dorsal fin inserted close behind pectoral, its distance from it much less than diameter of eye; no ocellus on dorsal fin. VIRIDIs, 2840.

$a a$. Dorsal fin inserted an eye's diameter behind pectoral; a large black spot, ocellated with white, on dorsal fin above vent; other ocelli sometimes present.

STIGMA, 2841.

2840. GYMNELIS VIRIDIS (Fabricius).

Head about $6 \frac{1}{2}$; depth about 13 ; eye 7 in head. 1. 100 ; A. 80 . Snout subconical, longer than the eye; jaws equal; mouth oblique; maxillary reaching beyond eye; teeth rather small, conical, in a single series on each side, forming a patch anteriorly; distance from snout to vent $2 \frac{1}{8}$ times length of head. Pectoral rounded, inserted low, its length less than $\frac{1}{2}$ that of head. Dorsal fin inserted close behind pectoral, its distance from it much less than diameter of eye. Body pale, with faint dark cross shades; dorsal clonded but withont black spot; anal dusky. Arctic seas, Alaska to Greenland and Nova Scotia; abundant in the Arctic waters south to Unalaska and Bristol Bay, where specimens were taken in shallow water; our specimens from Bristol Bay.

Ensign H. G. Dresel records 1 small specimen (No. 28636, U. S. Nat. Mus.), badly preserved, obtained by Mr. Newton Pratt Scudder in Davis Straits, July, 1879. Length $100 \mathrm{~mm}$. D. ca. 97 ; A. ca. 80 . In this specimen the maxillary does not extend to the posterior margin of the eye, which is comparatively very large. Its diameter is longer than distance from tip of snont to orbit, and is contained 4 times in head. Head 7 in total length; depth 12. Pectoral 2 in head. (viridis, green.)

Ophidium viride, Fabriclus, Faun. Gron., 141, 1780, Greenland.

Ophidium unernak, LACÉPÈUE, Hist. Nat. Poiss., II, 280, 1800, Greenland; after FABriciUs. Gymnelis viridis, Richa Ruson, Last Arctic Voyage, 321, pl. 29, 1854.

Aymnelis viridis, ReInHARDT, Dansk. Vidensk. Selsk. Afh., vir, 1838, 131; Gïnther, Cat.,

IV, 323, 1862 ; Kröyer, Poissons du Nord, Voy. en Scand. et Lap., pl. 15, a-f; ColleTt,

Norske Nordh. Exped., Fiske, 123, pl. 4, fig. 32, 1880; JORDAN \& GILbERT, Synopsis, 789; GILBERT, Rept. U. S. Fish Comm. 1893 (1896), 455.

i Gymnelis pictus, GÜNTHER, Cat., Iv, 324, 1862, no locality.

2841. GYMNELIS STIGMA (Lay \& Bennett).

Head 6 ; depth 11. D. 90; A. 70. Form, size, and general appearance of $G$. viridis, the dorsal inserted farther back, an eye's diameter behind pectoral. A large, ronnd black ocellus, ringed with white, on dorsal fin above vent; 2 or 3 other ocelli sometimes present; head and nape with small white spots; body with faint dark shades and bands. Otherwise 
as in G. viridis, from which it may not be distinct; but the above characters appear in our specimens (from near the Pribilof Islands) and in Richardson's figure of G. unimaculatus. The white spots on the head were mistaken for "very small scales" in the original description of G. stigma from Dr. Collie's notes. This description is, in substance, as follows: No trace of ventral fins; dorsal, caudal, and anal fins united into a transparent ridge; rays of branchial covering distinct; scales very small. Color dilute brown, with void swathes and spots; a purplish spot near beginning of dorsal fin. Snout obtuse; chin with a large gibbosity; teeth small. Length about 5 inches. (Lay \& Bennett.) Arctic regions, Greenland to Bering Sea, with the preceding, and apparently equally

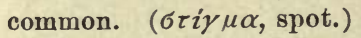

Ophidium stigma, LAY \& BenneTr, Zool. Beechey's Voy.. 6i, pl. 20, fig. 1, 1839, Kotzebue Sound. (Coll. Dr. Collie.)

Gymnelis viridis var. unimaculatus, RICHARDson, Last.Arctic Voyage, 367, 1854, Northumberland Sound. (Coll. Edward Belcher.)

Gymnelis stigma, GÛNTHER, Cat., IV, 325, 1862; JORDAN \& GILBERT, Synopsis, 789, 1883.

\section{LYCOCARA, Gill.}

Uronectes, GÜNTHER, Cat., IV, 325, 1862 (parrii); name preoccupied in Crustacea. Lycocara, GILl, Proc. Ac. Nat. Sci. Phila. 1884, 180 (parrii).

Body ensiform, compressed; tail long and tapering; ventrals none; vent not far distant from the head; numerous minute teeth in jaws and on palate; lower jaw the longer; no barbel ; scales and gill openings unknown. One species, very imperfectly known, no specimens having been obtained by any recent collector. ( $\lambda \dot{v} \varkappa o 5$, wolf; $\varkappa \alpha ́ \rho \alpha$, head.)

2842. LYCOCARA PARRII (Ross).

Head 4. D. 50 ; A.45; P. 37. Head very obtuse, its length, depth, and breadth equal; head broader than the body, flattened and grooved between the eyes, which are lateral and rather large; lower jaw the longer; jaws and palate with minute teeth; greatest depth of body somewhat more than length of head; neck much arched. Dorsal inserted just behind head; pectoral extending beyond ver.t. Vent not far distant from head. Color uniform. Baffins Bay. (Günther.) (Named for Capt. William Edward Parry, the Arctic explorer.)

Ophidium parrii, Ross, Parry's Third Voyage, App., 109, 1826, Baffins Bay.

Uronectes parrii, Günther, Cat., IV, 326, 1862; JoRDAN \& GILBERT, Synopsis, 789, 1883.

\section{MELANOSTIGMA, Günther.}

Melanostigma, GÜNTHER, Proc. Zool. Soc. Lond.1881, 21 (gelatinosum).

This genns is distinguished from Bothrocara by the much more elongate teeth, which in the jaws, as well as on the vomer and palatines, stand in single series. Gill openings much smaller than in related forms, reduced to a small foramen above the base of the pectoral. Skin loose and movable, as in Liparis, enveloping the vertical fins; pectorals very small; 
ventrals none. Body tapering very rapidly backward; the tail very slender. Deep-sea fishes, of soft substance, allied to Bothrocara, but with stronger teeth. ( $\mu \dot{\varepsilon} \lambda \alpha 5$, black; $\sigma \tau i \gamma \mu \alpha$, spot.)

a. Maxillary reaching beyond front of pupil; color purplish gray, becoming black on the tail. GELATINOSUM, 2843.

aa. Maxillary not reaching beyond vertical from front of pupil; color uniform deep black. PAMMELAS, 2844.

2843. MELANOSTIGMA GELATINOSUM, Günther.

Body enveloped in a loose, delicate skin, as in Liparis. Head large, deep, compressed, with obtuse snout. Eye large, $3 \frac{1}{2}$ in head, and longer than snout. Cleft of mouth rather oblique, but lower jaw not projecting beyond upper; lips not fleshy; gill opening reduced to a very narrow foramen above base of pectoral fin; origin of dorsal fin and root of pectoral enveloped in loose skin of body; dorsal fin probably commencing above middle of pectoral, low at first, but becoming considerably higher posteriorly; pectorals very narrow, consisting of a few rays only. Upper parts tinged with a purplish-gray; sides marbled with same color, which toward end of tail becomes more intense, almost black; inside of mouth, gill openings, and vent black. Total length of the type specimen $5 \frac{1}{2}$ inches; distance of the snout from the gill opening $\frac{7}{8}$ inches, from the vent $1 \frac{7}{8}$ inches. (Günther.) Deep waters of the western Atlantic; originally known from the Straits of Magellan, but since obtained at various localities from Cape Cod to West Indies, in 500 to 1,000 fathoms. The identity of these specimens with the original types from South America may be questionable. (gelatinosus, jelly-like.)

Melanostigma gelatinosum, GÜnther, Proc. Zool. Soc. London 1881, 21, Tilly Bay, Straits of Magellan, in 24 fathoms (Coll. H. M. S. Alert, Dr. Coppinger); Günther, Challenger Report, xxir, 82, 1887; Goove \& BEAN, Bull. Mus. Comp. Zool., x, No. 5, 209, 1883 ; Jordan, Cat. Fish. N. A., 125, 1885; Goode \& BEAN, Oceanic Ichthyology, 314, 1896.

2844. melanostigma Pammelas, Gilbert.

Head 8 in total length; depth $12 \frac{1}{2}$; pectoral narrow, its length $2 \frac{2}{5}$ in head ; eye large, $3 \frac{1}{2}$ in head ; snout short and broad, 7 in head. Well distinguished from $M$. gelatinosum by the wider, blunter head, the smaller, less oblique mouth, the uniform black coloration, and the arrangement of the teeth in the jaws in 2 series. As in $M$. gelatinosum, the head and body are enveloped in a loose, thin skin, which is thrown into folds in alcoholic specimens, and entirely conceals anterior portion of dorsal and anal fins. On dissection the dorsal is seen to have its origin close behind the head, at a point over middle of pectoral fin; anal beginning immediately behind vent, the rays of both fins enveloped in a gelatinous, subcutaneous tissue. Head broad, with its greatest width equaling its greatest depth; mouth broad, somewhat oblique, with equal jaws, the maxillary reaching vertical from front of pupil; each jaw with teeth in two distinct series in front, in a single series laterally in lower jaw, the outer teeth in front enlarged, almost canine-like. Gill opening a small pore above base of pectoral, its diameter about $\frac{1}{2}$ that of eye. Color intense black on head and abdomen, brownish black elsewhere. Length 
of type $4 \frac{1}{2}$ inches. Coast of southern Alaska. Three other specimens are at hand from Albatross Station 3126 (lat. $36^{\circ} 49^{\prime} 20^{\prime \prime}$ N., long. $122^{\circ} 12^{\prime} 30^{\prime \prime}$ W.; depth 456 fathoms). In the smallest, $2 \frac{1}{2}$ inches long, the head and abdomen are jet-black, but the rest of the body is only slightly dusky. (Gilbert.) ( $\pi \tilde{\alpha} \varsigma$, all; $\mu \varepsilon \dot{\lambda} \alpha \varsigma$, black. )

Melanostigma pammelas, GiLBerT, Rept. U. S. Fish Comm. 1893 (1896), 472, pl. 35, coast of southern Alaska, at Albatross Station 3202, lat. $3^{6} 4^{\prime} 6^{\prime} 1^{\prime \prime}$ N., long. $121^{\circ} 5^{\prime} 45^{\prime \prime}$ W., in 382 fathoms.

\section{Family CCVII. DEREPODICHTHYIDA.}

Deep-sea fishes of slender body, scaleless, and without lateral line, somewhat resembling the Zoarcida, but with each ventral fin reduced to a slender, unbranched filament, the two very closely approximate, and springing from a common projecting base located far forward, below the eye. Gill opening a narrow, vertical slit. Character otherwise given below. A single species known; apparently intermediate between the Zoarcida and the Ophidiida.

\section{DEREPODICHTHYS, Gilbert.}

Derepodichthys, GILBERT, Rept. U.S. Fish Comm. 1893 (1886), 456 (alepidotus).

Body slender; no scales; no lateral line; ventral fins reduced each to a slender, unbranched filament, the two very closely approximate, and springing from a common projecting base, which is located far forward below the eye, as Ophidion. Gill opening a narrow, vertical slit, little wider than base of pectorals. Teeth cardiform, curved, few in number, in narrow bands or irregular single series on jaws, vomer, and palatines. ( $\delta \dot{\varepsilon} \rho \eta$, throat; $\pi$ ov́s, foot; $\imath \chi \theta \dot{v} 5$, fish.)

2845. DEREPODICHTHYS ALEPIDOTLS, Gilbert.

Head $8 \frac{1}{2}$ in total length; depth of head and body $2 \frac{1}{6}$ in head; width of head $2 \frac{3}{5}$ in head; distance from tip of snout to base of ventrals $2 \frac{1}{3}$ in length of head. Distance from tip of snout to front of dorsal5 $\frac{1}{2}$ in total length, from tip of snout to vent $3 \frac{2}{3}$ in total. Head and body very long and slender, the former resembling a Lycodes in appearance, being moderately compressed, with a flattish occiput and a gentle rounded decurved rostral profile. Mouth slightly oblique, quite at lower side of snout; the lower jaw shorter, fitting within the upper; maxillary and premaxillary entirely concealed within the thick skin of the upper lip, which is directly continuous with that of the forehead, the upper jaw being therefore nonprotractile; angle of mouth under front of pupil, its distance from tip of snout $2_{5}^{3}$ in head. Teeth cardiform, curved, few in number, in narrow bands or irregular single series on jaws, vomer, and palatines. Eye small, not filling the elongate orbit, the diameter of exposed portion of eyeball slightly less than $\frac{8}{4}$ length of snout, the latter $3 \frac{1}{4}$ in head. A series of large mncous pores on snout and lower part of cheeks; a second series on mandible; no pores on boay. Gill slit vertical, not continued forward, its lower end slightly above base of lower pectoral rays; length of slit $\frac{1}{6}$ length of 
head, slightly less than distance between slits. Pectorals long and sleilder, reaching halfway to vent, $1 \frac{1}{8}$ in head; dorsal and anal confluent with the caudal, concealed in the thick integument, so that the rays can not be counted. Color in spirits, light brownish, the dorsal and pectorals whitish, the anal with a dark margin which becomes black posteriorly; lips dusky; abdominal region blue black. Coast of British Columbia. A single specimén, $4 \frac{1}{2}$ inches long, dredged off Queen Charlotte Island. (Gilbert.) ( $\dot{\alpha} \lambda \varepsilon \pi \imath \delta \omega \tau \dot{s} 5$, scaleless.)

Derepodichthys alepidotus, GHberT, Rept. U.S. Fish Comm. 1893 (1896), 456, Queen Charlotte Island, at Albatross Station 3342, in 1,588 fathoms.

\section{Family CCVIII. OPHIDIIDAE.}

\section{(The Cusk Eels.)}

-Body elongate, compressed, more or less eel-shaped, usually covered with very small scales, which are not imbricated, but placed in oblique series at right angles with each other; head large, lower jaw included; both jaws, and usually vomer and palatines also, with villiform or cardiform teeth; premaxillaries protractile; gill openings very wide, the gill membranes separate, anteriorly narrowly joined to the isthmus behind the ventrals; pseudobranchir small. Gills 4, a slit behind the fourth; vent more or less posterior. Vertical fins low, without spines, confluent around the tail; tail isocercal; ventral fins at the throat, each developed as a long, forked barbel. Air bladder and pyloric cæca present. To this Dr. Gill adds the following characters, shared more or less by related families: "Orbito-rostral portion of cranium contracted and shorter than the posterior, the cranial cavity closed in part by the expansion and junction of the parasphenoid and frontals, the supraoccipital horizontal and cariuiform posteriorly, the exoccipitals expanded backward and upward behind the supraoccipital, the exoccipital condyles contiguous, and with the hypercoracoid (scapula, Parker) fenestrate (or foraminate) about its center, and the hypercoracoid with its inferior process divergent from the proscapula." Genera 7, species about 25. Carnivorous fishes; found in most warm seas, some of them descending to considerable depths, the group especially well represented in tropical America. (Ophidiidar, group Ophidiina, Günther, Cat., IV, 376-380, 1862.)

a. Head scaly, at least above; body covered with scales imbricated in quincnnx; snout nsually with a spine at tip; opercle with or without spinous tip; air bladder, so far as known, ovate, without posterior foramen.

LEPOPHIDIUM, 946.

aa. Head scaleless; scales of body rudimentary, scarcely embedded.

b. Air bladder oblong-ovate, not contracted behind, and without posterior foramen.

c. Opercle ending in a flat point behind, without spine. OPHIDION, 947.

cc. Opercle ending behind in a strong spine concealed in the skin.

Chibara, 948.

bb. Air bladder short, thick, reniform or orbicular, with a large foramen behind.

$d$. Operclo ending in a flat point, without spine.

RissoLA, 949.

dd. Opercle ending behind in a spine concealed in the skin.

OTOPHIDTUM, 950. 


\section{LEPOPHIDIUM, Gill.}

Leptophidium, GrLL, Proc. Ac. Nat. Sci. Phila.1863, 210 (profundorum); name preoccupied in Serpents by Leptophidium, HALLOWELL, 1860.

Lepophidium, GILL, Amer. Nat., Feb., 1895, 16 (profundorum).

Body much elongate, moderately compresserl, with back and abdominal regions arched, more compressed and slowly decreasing in height backward to an abruptly rounded point; scales regularly imbricated in quincunx oval, and with striæ radiating backwarl; head with imbricated scales, extending to forehead; snout high, projecting forward, and obtusely roundecl, armed above with a short, nearly concealed spine directed forward and somewhat downward, obsolete in 1 species; mouth moderate, oblique; teeth of jaws villiform, immersed in a mucous membrane, separated by an interval from the longer ones in the outer row, which are pointed and usually movable; vomer and palatines with teeth. Deep waters of America on both coasts. Perhaps a fuller knowledge of the species of this genus will lead to its subdivision. ( $\lambda \varepsilon^{\prime} \pi o 5$, scale; Ophidium, from the squamation.)

a. Snout without decurred hook or spine; gill rakers 8; head 5 in length; depth 7; pectorals 10 ; body marbled, the vertical fins $\epsilon$ dged with black.

MARMORATUM, 2846.

aa. Snout with a decurved hook or spine at tip, sometimes more or less concealed in the skin.

b. Gill rakers 7 to 9 in number.

c. Head large, 3 to $4 \frac{1}{2}$ in length.

$d$. Body stoutish, the depth 6 in length; scales 125 ; no black blotch on front of dorsal. EMMELAS, 2847.

$d d$. Borly slender, the depth $9 \frac{1}{4}$ in length; dorsal with a black blotch in front; scales 180. STIGMATISTIUM, 2848.

cc. Head moderate, 6 in length; depth 10 ; vertical fins black-edged.

$e$. Anterior teeth in jaws movable; pectoral 11 in body; body without white spots. PROFUNDORUM, 2849.

ee. Anterior teeth in jaws not movable; pectoral 13 to 14 in body; body with whitish spots.

CERVINUM, 2850.

bb. Gill rakers 4 in number.

$f$. Scales moderate, 175 to 200 in lateral line.

g. Body without dark cross bars; dorsal and anal margined with black; air bladder oblong.

$h$. Head $4 \frac{1}{2}$ in length; depth 8; pectoral $10 \frac{1}{2}$. Pacific species.

PRORATES, 2851.

hh. Atlantic species imperfectly described. BREVIBARBE, 2852.

gg. Body with dark cross bars; dorsal spotted with black; anal wholly black; head $5 \frac{1}{2}$ in length; depth $8 \frac{1}{2}$.

PARDALE, 2853.

ff. Scales minute, about 250 in lateral line; head 42; depth $7 \frac{1}{2}$ to 8 ; color nearly plain, the fins dark edged.

MICROLAPIS, 2854.

2846. LEPOPHIDIUM MARMORATUM (Goode \& Bean).

Head 5; depth $7 \frac{1}{8}$; eye 4 in head; snout about 5 . Body somewhat elongate, stoutish anteriorly, gradually tapering; head thickish; interorbital area broad, convex, its width nearly equal to length of snout, which is blunt, spineless; eye circular, somewhat exceeding length of snout. Maxillary extending to vertical through posterior margin of orbit, 
the mandible far beyond, its length equal to that of postorbital portion of head. Teeth on vomer and in jaws in villiform bands, the outer series in the latter slightly enlarged. Psendobranchiæ present; gill rakers short, 8 below angle of first arch, the longest less than $\frac{1}{2}$ diameter of eye. Branchiostegals 7.' Ventrals as long as postorbital part of head. Dorsal origin at distance from snout contained $4 \frac{1}{2}$ in total length, with 28 rays in a space equal to length of head, counting from the origin of the fin; anal origin separated from snont by distance $2 \frac{2}{3}$ in total length ; length of pectoral 2 in head, or 10 in total. Scales closely imbricated, ornamented with delicate concentric strix; lateral line apparently complete, located about $\frac{1}{4}$ distance from dorsal to ventral outline. Color yellowish gray, marbled along the upper half of head and body with olive brown; dorsal and anal fins with black margins. Gulf Stream, in 213 fathoms. (Goode \& Bean.) (marmoratus, marbled.)

Leptophidium marmoratum, Goode \& BEAN, Proc. U. S. Nat. Mus. 1885, 423, 1at. $23^{\circ}$ Io $^{\prime} 39^{\prime \prime}$ N., long. $82^{\circ} 20^{\prime} 2 \mathrm{I}^{\prime \prime}$ W., in $2 \mathrm{r}_{3}$ fathoms (Type, No. 37237, U. S. Nat. Mus. Coll. Albatross); GOODE \& BEAN, Oceanic Ichthyology, 348, 1896.

\section{LEPOPHIDIUM EMMELAS (Gilbert).}

Head 3 年 to 4 ; depth $5 \frac{2}{8}$ to 6 ; eye 48 in head; snout 48 ; interorbital width 7 ; vertebræ $13+44=57$; maxillary $2 \frac{1}{8}$ to $2 \frac{1}{4}$ in head; ventral filament $2 \frac{8}{4}$; pectoral 2 in head; seales $8-125-18$ or 20 before dorsal. Body deep, compressed. Maxillary reaching slightly beyond orbit. Jaws slender and weak, the teeth in very narrow bands, the outer not enlarged. Rostral ridge very sharp, bearing a flat spine at its base directed upward and backward, terminating in a very slender sharp spine anteriorly. Opercle ending in a weak spinons point behind. Gill rakers short and slender, the longest $\frac{1}{2}$ pupil, 8 or 9 movable ones developed. Skull and all bones of head very thin and papery. Dorsal beginning over base of pectorals, the nape midway between its origin and middle of orbit. Distance from snout to origin of anal $1 \frac{1}{3}$ in distance from latter to end of tail. Scales large, covering cheeks, opercles and top of head forward to middle of interorbital space. Color brownish, much dusted with minute specks; fins blackish, the vertical fins with an indistinct narrow whitish margin; inside of mouth dusky; the roof of mouth, lining of gill eavity, and peritoneum jet-black. Coast of Lower California. Many specimens, the longest 9 inches, from Albatross Stations 3007 and 3008, in 362 and 306 fathoms. (Gilbert.) ('่v, within; $\mu \dot{\lambda} \lambda \alpha 5$, black.)

Leptophidium emmelas, GiLBert, Proc. U. S. Nat. Mus. 1890, 110, coast of Lower California. (Coll. Albatross.)

\section{LEPOPHIDIUM STIGMATISTIUM (Gilbert).}

Head $4 \frac{1}{2}$ in length; depth $9 \frac{1}{4}$; eye $4 \frac{1}{8}$ in head; snout 6 ; interorbital width $6 \frac{1}{2}$; naxillary reaching slightly beyond posterior border of eyes, $2 \frac{1}{8}$ in head. A strong rostral spine. Outer teeth scarcely enlarged, evidently so only in front of upper jaw. Gill rakers long and slender, strongly curved forward at tip, the longest equaling $\frac{1}{2}$ eye; 7 well-developed gillrakers present. Opercle ending in a rounded process, a broad soft flap 
projecting beyond it. Dorsal inserted behind middle of pectorals, the nape equidistant from front of dorsal and base of rostral spine; pectorals $2 \frac{2}{5}$ in head; longest ventral filament $2 \frac{8}{4}$ in head; scales small, about as in L. prorates, 180 transverse series, 28 in front of dorsal, continued forward on top of head to front of pupil; cheeks and opercles scaly. Color dusky olivaceous, lighter below; dorsal with a large black blotch on anterior rays, the margin obscurely dusky; anal broadly margined with jet-black; caudal with median rays black at base, the outer rays and the margin light; lining of gill cavity jet-black; inside of mouth white; peritoneum bright silvery. A single specimen 10 inches long. Coast of Lower California. (Gilbert.) Much resembling L. prorates, differing in

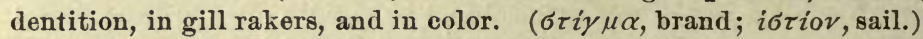

Leptophidium stigmatistium, Gilbert, Proc. U. S. Nat. Mus. 1890, 109, off Lower California, at Albatross Station 29g6, in 112 fathoms.

\section{LEPOPHIDIUM PROFUNDORUM (Gill).}

Head 6 ; depth 10. Body very slender; scales regularly arranged in quincunx order, those on head extending to forehead, opercles, and cheeks; snout high, projecting, armed with a concealed spinous hook; teeth villiform, separated by an interval from an outer row of longer, slender, movable teeth; eye longer than snout, $3 \frac{1}{2}$ in head; lateral line obsolete behind; vent toward end of first third of length; ventral fins short; gill rakers 8 . Light rufous; vertical fins margined with black. Gulf Stream, off the coast of Florida. (Gill.) One specimen known. (profundorum, of the depths.)

Leptophidium profundorum, Gri, Proc. Ac. Nat. Sci. Phila. 1863, 211, Gulf Stream, off the Coast of Florida (Coll. Commodore Rodgers); Goode \& BEAN, Oceanic Ichthyology, $347,1896$.

Ophidium prefundorum, JoRdAN \& GILBERT, Synopsis, 793, 1883.

2850. LEPOPHIDIUM CERVINUM (Goode \& Bean).

Head about $6 \frac{1}{4}$; depth about $10 \frac{1}{2}$; eye 4 in head; ventrals 3 in head. Body elongate, slender; head slender, somewhat compressed; interorbital area broad, convex, its width equal to length of snout, and $5 \frac{2}{3}$ in head; snout sharp, conical, armed with a short but sharp spine, and somewhat overhanging mouth; eye much exceeding length of snout; maxillary extending nearly to vertical through posterior margin of orbit, $2 \frac{2}{8}$ in head; mandible extending behind same vertical, its length equal to that of head without postorbital portion. Jaws, vomer, and palatines with narrow bands of villiform teeth, some of which are noticeably enlarged (not movable). Pseudobranchiæe present. Gill rakers short, 8 below angle of first arch, 4 of which are rudimentary, the longest 5 in diameter of eje. (In $L$. profundorum the gill rakers are slenderer and longer, though about equally numerous on the first arch.) Scales in about 11 rows from the origin of the dorsal to the median line of the body. Dorsal origin far back, at a distance from the snout $4 \frac{8}{4}$ in total length; at a distance from the eye equal to the head's length. (In L. profundorum this distance is $\frac{2}{3}$ of the head's length and the first ray of the dorsal is nearly over the 
middle of the extended pectoral; in $L$. cervinum, over its tip, or nearly so.) Distance of anal origin with snout 3 in total length. Length of pectoral 2 in head's length and 13 to 14 in that of body (10 in L. marmoratum, 11 in $L$. profundorum). Scales ornamented with radiating striæ, densely covering all parts of the fish except snout, under surface of head, and the fins; lateral line continued almost to end of tail. Color brownish yellow, with numerous subcircular spots of white, with diameter $\frac{1}{2}$ that of eye, along the upper half of body; vertical fins with narrow black margin. Gulf Stream. (Goode \& Bean.) A specimen from off Sand Key Light, Florida, recorded by Mr. Garman. (cervinus, deer-like, from the fauncolor.)

Leptophidum cervinum, Goode \& Bean, Proc. U. S. Nat. Mus. 1885,422 , lat. $40^{\circ} \mathbf{I}^{\prime}$ N., long. $69^{\circ} 5^{\prime}$ W., depth 76 fathoms (Type, No. 28764. Coll. Fish Hawk); Goode \& BEA. , Oceanic Ichthyology, 346, 1896.

Lepophidium cervinum, GARMAN, Bull. Iowa Lab. Nat. Hist. 1896, 91.

\section{LEPOPHIDIUM PRORATES (Jordan \& Bollman).}

Head $4 \frac{1}{8}$ to $4 \frac{2}{3}$ ( $4 \frac{2}{3}$ to $4 \frac{8}{4}$ in total); depth $7 \frac{1}{3}$ to $8 \frac{1}{6}$ ( $7 \frac{3}{3}$ to $\left.8 \frac{1}{2}\right)$; eye $4 \frac{1}{2}$ in head; snout 5 ; maxillary $2 \frac{1}{4}$; interorbital $1 \frac{1}{3}$ in eje; pectoral $2 \frac{1}{8}$ in hearl ; inner ventral filament shortest, the longer $2 \%$ in head. Body moderately elongate, compressed, considerably stonter than in L. profundorum. Month large, maxillary reaching about $\frac{1}{2}$ pupil's length beyond posterior border of eye. Outer tecth slightly enlarged, a little movable, those of npper jaw largest. Gill rakers rather long and slender, $\frac{1}{4}$ length of eye, 4 developed. Tip of snont with a strong spine directed forward and slightly downward; opercle without spine, ending in a flat projection covered by skin. Dorsal beginning over middle of pectorals, longest ray 4 in head. Scales regularly imbricated, but very small, about 225 in a longitudinal series; scales on top of head extending forward to base of ethmoid spine; sides of head covered with small scales; lateral line not reaching end of tail. Air bladder oblong-lanceolate. Color olivaceous, paler below; scales rather profusely dotted with black; a pale shade across opercles; lower jaw, gular region, and anterior brauchiostegals dusted; dorsal and anal margined with black, the band on anal the broader; pectorals pale. Specimens of this species were obtained at Panama and at Albatross Station 2801, south of Panama. Length of type 10 inches. ( $\pi \rho \omega \rho \alpha \dot{\tau} \eta 5$, prow-bearing, from the rostral spine.)

Leptophidium prorates, Jordan \& Bollman, Proc. U. S. Nat. Mus. 1889, 172, Panama. (Type, No 41149, U.S. Nat. Mus. Coll. Albatross.)

\section{LEPOPHIDIUM BREVIBARBE (Cuvier).}

A short decurved spine at tip of snout; teeth strong; occiput and opercles scaly. Vertical fins edged with black. (Kaup.) Air bladder oblong ovate, without contracted portion and without posterior foramen; no single anterior bone replaced by cartilage. (Müller.) West Indies and Brazil; a scarcely known species; apparently close to $L$. prorates, but very insufficiently described. (brevis, short; barba, beard.)

Ophidion brevibarbe, Cuvier, Règne Animal, Ed. 2, vol. II, 358, 1829, Brazil; MULLER, Abhandl. Berl. Acad. 1843, 153, pl. 4, f.4; KAUP, Apodes, 154, pl.16, f.1; GUnTHer, Cat. Fish., IV, 379, 1862. 
2853. LEPOPHIDIUM PARDALE (Gilbert).

Head $5 \frac{1}{2}$ in length; depth $8 \frac{1}{2}$; eye $3 \frac{2}{3}$ in head; snout $4 \frac{2}{8}$; interorbital $1 \frac{1}{2}$ in eye. Body very slender, with a short head and small mouth; maxillary scarcely reaching vertical from posterior border of orbit, its length $2 \frac{1}{6}$ in head; outer teeth very little enlarged, not movable; teeth present on jaws, vomer, and palatines. Gill rakers slender, the longest $\frac{1}{4}$ eye, 4 developed. Tip of snout with a strong, concealed spine, as in $L$. prorates. Opercle ending in a short spine. Nape midway between front of dorsal and front of pupil; dorsal beginning over middle of pectorals, which are $2 \frac{1}{4}$ in head; ventral filaments very short; the inner the longer, $4 \frac{2}{3}$ in head. Scales very small, about 200 in a longitudinal series, extending forward on top of head to middle of interorbital space; cheeks and opercles scaly. Light olive, a series of 8 black bars downward from back, scarcely reaching lateral line, sometimes continuous with their fellows of the other side, and alternating with smaller black spots on dorsal outline; below the smaller spots a series of round spots nearly as large as eye along middle line of sides; sides and lower parts of head and body dusted with rather coarse black specks; dorsal light, the margin with 10 elongate black blotches, usually longer than the interspaces; caudal dusky at base, its distal half white; anal wholly black; peritoneum and lining of gill cavity white. Lower California. A single specimen, leugth $7 \frac{1}{8}$ inches, from Albatross Station 3014, in 29 fathoms. (Gilbert.) ( $\pi \alpha \dot{\alpha} \rho \delta \alpha \lambda \iota s$, leopard.)

Leptophidium pardale, GiLbert, Proc. U. S. Nat. Mus. 1890, 108, off Lower California. ('Type, No. 44382. Coll. Dr. Gilbert.)

2854. LEPOPHIDIUM MICROLEPIS (Gilbert).

Head 4\% in length; depth $7 \frac{1}{2}$ to 8 ; өye $4 \frac{1}{4}$ to 5 in head; snout 5 ; interorbital width $6 \frac{1}{2}$; maxillary extending beyond orbit, $2 \frac{1}{4}$ to $2 \frac{1}{2}$. Rostral spine very strong, as in $L$. prorates. Outer teeth enlarged, not at all movable, those in upper jaw largest. Four gill rakers developed, the longest $3 \frac{1}{2}$ in eye. Opercle ending in a short concealed spinous point. Dorsal inserted in front of middle of pectorals, the distance from nape to front of dorsal usually less than from nape to middle of eye; longest ventral filament $3 \frac{1}{3}$ to $3 \frac{1}{2}$ in length of head; pectorals $2 \frac{1}{4}$ to $2 \frac{1}{2}$ in head. Scales exceedingly small, regularly imbricated, in about 250 transverse series, 35 transverse series between nape and dorsal (about 175 transverse rows in L. prorates, 25 series between nape and dorsal). Top of head scaly as far as front of eyes. Cheeks and opercles scaly. Color as in L. prorates, the lining of peritoneum and gill cavity silvery white, the former with little or no black specking. Closely related to $L$. prorates, differing principally in the much smaller scales. Gulf of California. Many specimens, the longest 14 inches, from Albatross Statious 3015 and 3016 , in 145 and 76 fathoms. (Gilbert.) ( $\mu \imath \varkappa \rho o ́ s$, small; $\lambda \varepsilon \pi i 5$, scale.)

Leptophidium microlepis, GiLbert, Proc. U. S. Nat. Mus. 1890, 109, Gulf of California. (Coll. Dr. Gilbert.) 


\section{OPHIDION (Artedi) Linnæus.}

\section{(CUsK Eels.)}

Ophidion (ARTEDI) Linv Axus, Syst. Nat., Ed. x, 259, 1758 (barbatum).

Ophidium, LINNAUs, Syst. Nat., Ed. XII, 431, 1766, and of most recent authors; changed spelling.

Body moderately elongate, compressed; scales small, usually not imbricated, but arranged in short, oblique series, often placed at right angles with each other, much as in Anguilla. Head naked; teeth villiform, those of the outer series more or less enlarged, none of them movable; teeth on vomer and palatines bluntish, some of them enlarged. Vent well behind pectorals. Opercle without distinct spine; sometimes $(O$. barbatum $)$ a distinct spine at tip of snout. Air bladder oblong-ovate, tapering behind, without foramen. Shore species mostly European. (Ophidium, an ancient name, from ó $\phi i \delta \imath o v$, a small snake.)

a. Gill rakers 4.

b. Head $4 \frac{2}{3}$ in length; depth 7 ; fins not dark edged.

BEANI, 2855.

bb. Head 6 in length; inner ray of ventral $1 \frac{1}{2}$ in length of outer, which is shorter than head; fins dark-edged.

HOLBROOKI, 2856.

aa. Gill rakers 6 or 7 ; head $5 \frac{1}{2}$ to 6 in length; depth 8 to 10 ; color silvery, unspotted; fins not dark-edged; ventrals nearly as long as head.

GRAELLSI, 2857.

\section{OPHIDION BEANI, Jordan \& Gilbert.}

Head $4 \frac{2}{8}$ in length; depth about 7 . Head small, the profile not very obtuse; snout $4 \frac{2}{8}$ in head; eye $3 \frac{1}{4}$, more than twice the narrow interorbital space; mouth oblique, the maxillary reaching to posterior border of pupil, 2 in head; lower jaw slightly included; teeth small, in narrow bands in the jaws, the outer series in upper jaw somewhat enlarged; vomerine and palatine teeth small, subequal; head naked; snout spineless; opercle without spine; no evident pseudobranchiæ; gill rakers rather long and strong, 4 below angle of arch; occiput nearly midway between origin of dorsal and front of eye. Air bladder long and slender, occupying nearly the whole length of abdominal cavity, tapering backward. Very light olive, somewhat punctate above, slightly silvery below; fins without trace of dark edging (but being mutilated they may have been dark-edged in life). Gulf of Mexico. Two specimens, 1 of which is in good condition and about 4 inches long, were taken from the stomach of a red snapper, at Pensacola. (Named for Dr. Tarleton Hoffman Bean.)

Ophidium groellsi, Jordan \& GilberT, Proc. U.S. Nat. Mus. 1882, 301; JoRdan \& GLbert, Synopsis, 963, 1883; not of POEY.

Ophidion beani, Jordan \& GiLbert, Proc. U. S. Nat. Mus. 1883, 43, Snapper Banks off Pensacola (Coll. Jordan \& Stearns. Type, No. 30868, U. S. Nat. Mus.); Jordan, Cat. Fishes N. A., 126, 1885.

\section{OPHIDION HOLBROOKI (Putnam).}

Head 6 in total length. Inner barbel nearly $\frac{2}{8}$ length of the outer; outer barbel equal to distance from center of eye to point of operculum; maxillary reaching to posterior border of eye. Length of eye equal to distance from its posterior margin to ridge of preoperculum. Dorsal and anal 
with a black margin. Gill rakers 4; air bladder long, pointed, with a foramen. (Putnam.) Length 6 inches. Gulf of Mexico; recorded from Key West, Florida; not seen by us. (Named for Dr. John Edwards Holbrook, the distinguished ichthyologist of Charleston.)

?Ophidion josephi, GIRARD, U. S. and Mex. Bound. Surv., Ichth., 29, 1859, St. Joseph Island, Texas; JoRdan \& GILBERT, Synopsis 793, 1883; quite as likely to be Rissola marginata.

Ophidium holbrooki, Putnam, Proc. Bost. Soc. Nat. Hist. 1874, 342, Key West, Florida; JoRDAN \& GILBERT, Synopsis, 793, 1883.

\section{S57. OPHIDION GRAELLSI, Poey.}

Head $5 \frac{8}{4}$ in body; depth 10 ; eye 3 in head; pectoral $2 \frac{4}{5}$; ventral scarcely as long as head. Body elongate, compressed; mouth large, the maxillary reaching to posterior margin of pupil; small teeth on jaws, vomer, and palatines; eye very large, greater than length of snout; interorbital space $\frac{2}{8}$ of eye, a sharp ridge along its middle to tip of snout, where it ends in a sharp spine; opercles unarmed; about 6 gill rakers developed on lower part of gill arch, apparently none above; pseudobranchiæ small, if present. Air bladder, injured in specimen examined, apparently lanceolate; dorsal and anal low, confluent with caudal, which ends in a point; pectorals small, their ends scarcely reaching midway from their base to front of anal; ventrals with 2 filamentous rays, the outer scarcely as long as head, the inner $\frac{1}{2}$ as long. Color in spirits, reddish brown, with silvery reflections on sides; head silvery, upper part of eye black; fins the color of the body, with no dark edgings. Coasts of Cuba; rare. Here described from a specimen from Havana, Cuba, $2 \frac{1}{2}$ inches in length, sent by Professor Poey. Poey has also sent a drawing of his original type, a much larger specimen, which he describes as follows:

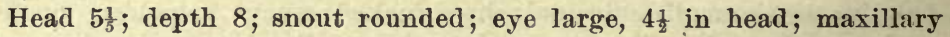
reaching posterior border of eye; teeth small, slender, with a villiform band behind them; teeth on vomer and palatines; scales small; head scaly, except on snout; lateral line high; branchiostegals 7 ; dorsal beginning over second third of pectoral, joining anal behind; about 100 rays in each fin; vent a little behind first third of length. Yellowish brown, silvery on side of head; no black on fins. Air bladder distinct; no pyloric caca. Intestine with 2 short turns. Cuba. (Poey.) Air bladder, gill rakers, and ventral not described. Length $230 \mathrm{~mm}$. Rare; not reaching a foot in length. (Named for Mariano de la P. Graëlls, director of the Botanic Garden at Madrid, "comme témoignage de mon estime pour ses travaux scientifiques, et pour la zèle qu'il déploit... pour l'acquisition des objets ot l'acclimatation des espèces.")

Ophidion graellsi, PokY, Memorias, 11, 425, 1860, Havana (Coll. Poey); PoEY, Synopsis, 402, 1867.

\section{CHILARA, Jordan \& Evermann.}

Chilara, Jordan \& Evermann, Check-List Fish. N. and M. A., 482, 1896 (taylori).

This genus contains a single robust species which differs from Ophidion only in the presence of a stont concealed spine at tip of opercle; the air bladder 
is oblong-ovale, the head naked and the snout without spine. ( $\chi_{\imath} \lambda \dot{\alpha} \rho \rho$, the modern Greek name of the species of Ophidion and Rissola.)

\section{CHILARA TAYLORI (Girard).}

Head 6; depth 8; head large, little compressed, naked; top of head with conspicuous mucous pores; dorsal fin beginning over the pectorals; outer ray of ventral little more than $\frac{1}{2}$ length of head, inner about $\frac{1}{3}$; air bladder ovate, not contracted; 7 gill rakers below the angle of the arch; pseudobranchix developed; no spine on the end of the snout; opercle with a flat spine concealed in its membranes; outer teeth in both jaws considerably enlarged, the upper largest. Color light olive; head and upper parts covered with conspicuous round dark, olive-brown spots; chin dusky; vertical fins edged with black. Length 12 inches. Coast of California, from Monterey to San Diego; not rare in waters of moderate depth. (Named for A. S. Taylor, its discoverer.)

Ophidium taylori, GIRARD, Pac. R. R. Surv., x, Fishes, 138, 1858, Monterey, California

(Type, No. 867. Coll. A. S. Taylor); Jordan \& Gilbert, Synopsis, 793, 1883.

949. RISSOLA, Jordan \& Evermann.

Rissola, Jordan \& Evermann, Check-List Fish. N. and M. A., 483, 1896 (marginatum).

This genus contains species agreeing with Ophidion in general characters, but with the air bladder short, broad, spherical or kidney-shaped, with a posterior foramen. Species chiefly of the Mediterranean. (Named for Anastase Risso, apothecary at Nice, author of the Ichthyologie de Nice, 1810, and Histoire Naturelle de l'Europe Méridionale, 1826, two of the very best of local faunal works, the foundation of our knowledge of the fishes of the Mediterranean.)

\section{RISSOLA MARGINATA (DeKay).}

Head $6 \frac{1}{2}$; depth $7 \frac{1}{2}$; eye 4 in head; maxillary reaching posterior margin of orbit; air bladder sliort and broad, with a foramen on the under side; upper ray of ventral abont equaling length of head; inner ray $\frac{1}{2}$ length of outer; gill rakers 4; color nearly plain brownish; dorsal and anal fius margined with black. Coast of the United States, from New York south to Pensacola and the coast of Texas; not very common; very similar to the Mediterranean species Rissola rochii (Muiller), but probably distinct. (marginatus, margined.)

Ophidium marginatum, DE KAX, N.Y. Fauna: Fish., 315, 1842, New York Harbor; PUTNAM, Proc. Bost. Soc. Nat. Hist. 1874, 342; Jordan \& GILBERT, Synopsis, 792, 1883.

POphidium josephi, * GrRard, U. S. and Mex. Bound. Surv., Zool., 29, 1859, Saint Joseph Island, Texas; JoRDAN \& GILBERT, Synopsis, 793, 1893.

* The scanty description of Ophidion josephi agrees fairly with either Rissola marginata or Ophidion holbrooki, and may be either. The following is the substance of Girard's account:

"Head 6 in length; eye moderate, 4 in head; maxillary extending to opposite its posterior margin; origin of dorsal at some distance behind base of pectorals. Body shorter and pectorals more elongate than in $O$. taylori. Pale olive, sprinkled all over with . brownish specks; belly and sides of head plain; vertical fins edged with black." $3030-79$ 
950. OTOPHIDIUM, Gill.

Otophidium, Gill, in Jordan, Cat. Fish. N. A., 126, 1885 (omostigma).

This genus differs from Ophidion, in the form of the air bladder, which is short, thick, and with a large foramen (not examined in 0 . galeoides). The opercle ends in a concealed spine as in Chilara. Species American, so

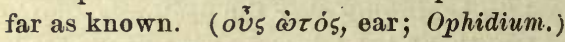

a. Gill rakers 4.

b. Head long, $4 \frac{1}{3}$ to $4 \frac{1}{2}$ in length; depth $5 \frac{1}{2}$ to 6 .

c. Scapular region with a jet:black spot; pseudobranchia little developed; ventrals $\frac{1}{2}$ length of head; maxillary $1 \frac{7}{8}$ in head. OMOSTIGNUM, 2860. cc. Scapular region without jet-black spot; pseudobranchia well developed; ventrals with the inner ray longest, $\frac{1}{2}$ head; body with dark cross bands.

INDEFATIGABILE, 2861.

$b b$. Head moderate, $5 \frac{1}{2}$ in body; depth 6 ; a pale spot before dorsal; pale spots along lateral line; ventral $\frac{1}{2}$ head.

GALEOIDES, 2862.

2860. OTOPHIDIUM OMOSTIGMUM (Jordan \& Gilbert).

Head $4 \frac{1}{8}$ in length; depth about 6. Body comparatively short, highest at occiput, thence tapering rapidly to tip of tail; upper profile of head very convex; snout blunt; mouth horizontal, the lower jaw included; maxillary not quite reaching posterior border of orbit; teeth in jaws uniform, strongly incurved, in rather broad bands; a single series of small teeth on vomer, those on palatines minute; maxillary $1 \frac{7}{8}$ in head; eye large, 3 in head, much larger than snout, equaling twice interorbital width; opercle terminating in a strong; compressed spine, the length of which is about $\frac{2}{8}$ diameter of pupil; gill rakers very small, 4 below on anterior arch. Longest ventral filament $\frac{1}{2}$ length of head; the shorter $\frac{8}{4}$ length of longer. Distance from origin of dorsal to tip of snout $3 \frac{1}{8}$ in total length; distance from origin of anal to snout $2 \frac{1}{6}$ in total length. Scales minute, embedded. Pseudobranchiæ probably present (type reexamined by us). Air bladder short, thick, with a large posterior foramen. Color light olive green, silvery on belly, cheeks, and lower side of head; sides above with a few irregular, large, scattered, dark blotches, about 9 of these along base of dorsal fin; an intensely black, round blotch on scapular region, rather larger than pupil; dorsal with black blotches; anal largely black; upper half of eye black, lower half bright silvery. Gulf of Mexico. A single specimen, $3 \frac{1}{2}$ inches long, taken from the stomach of a red snapper, at the Snapper Banks off Pensacola. ( $\omega^{5} \mu \circ 5$, shoulder; $\sigma \tau i \gamma \mu \alpha$, spot.)

Genypterus omostigma, Jordan \& Gilbert, Proc. U. S. Nat. Mus. 1882, 301, Pensacola

Snapper Banks (Coll. Jordan \& Stearns. Type, 29670, U. S. Nat. Mus.); JoRdAN \&

GILBERT, Synopsis, 963, 1883.

Otophidium omostigma, GOodE \& BEAN, Oceanic Ichthyology, 345, fig. 305, 1896.

2861. OTOPHIDIUM INDEFATIGABILE, Jordan \& Bollman.

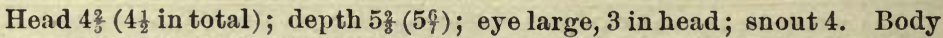
rather short, compressed, width of nape $2 \frac{1}{2}$ in head. Mouth large; maxillary reaching to opposite posterior margin of pupil, $1 \frac{4}{5}$ in head; outer row of teeth of each jaw very slightly enlarged. Interorbital space 2 in eye; interorbital area with a thin crest under the skin, this ending in 2 com- 
pressed spines, 1 turning forward, the other backward over front of eye, these spines concealed by the skin. Gill rakers short and thick, less than $\frac{1}{2}$ pupil, 4 developed. Dorsal beginning at end of anterior third of pectorals, longest ray $3 \frac{1}{2}$ in head; pectorals 2 in head; inner ventral filament longest, 2 in head. Air bladder short and thick, with a foramen. Scales very small, more or less imbricated on body; head naked. Opercle with a sharp, partly concealed spine. Pseudobranchise present. Color pale yellowish brown, silvery on belly and sides of head; back with about 12 irregular dark cross bands, the alternate ones being narrower and broken up into spots, 2 before dorsal; a few scattered spots about as large as pupil on sides, these most distinct about the shoulder; dorsal pale, first rays black, and with 3 or 4 other black blotches on upper part; anal black, margined with white; pectorals pale, axil dusky; caudal and posterior part of anal pale; chin pale. A single specimen obtained at Indefatigable Island, Galapagos Archipelago. Length 4 inches. (indefatigabilis, tireless.)

Otophidium indefatigabile, JondaN \& Bollman, Proc. U. S. Nat. Mus. 1889, 172, Indefatigable Island, in the Galapagos Archipelago. (Type, No.44393. Coll. Albatross.)

\section{OTOPHIDIUM GALEOIDES (Gilbert).}

Head $5 \frac{1}{8}$ in length; depth 6. D. 125. Maxillary reaching beyond pupil, $2 \frac{1}{3}$ in head; snout $4 \frac{2}{8}$; eye $3 \frac{3}{5}$. Gill rakers short and broad, 4 of them developed. Opercle ending in a sharp concealed spine. Outer teeth little enlarged. Dorsal beginning over middle of pectorals, the nape equidistant between front of dorsal and tip of snout. Caudal very short and bluntly rounded, as in Chilara taylori, the rays not projecting beyond dorsal and anal; pectorals $1 \frac{2}{3}$ in head; ventral filament $\frac{1}{2}$ head. Scales as in $C$. taylori, not at all imbricated, arranged with their long axes frequently at right angles to each other; head naked. Color light olive, without bars, a narrow dusky streak along base of dorsal, and a round light spot at origin of dorsal; a series of small olive-brown spots along lateral line, with a few scattering spots below it but none above; nape and head without spots; vertical fins translucent; dorsal with a large black blotch on tip of anterior rays, the fin behind this narrowly edged with black, which does not surround the caudal; anal with much silverywhite pigment anteriorly on distal portion, becoming dusky behind; pec. torals translucent, edged with white below; peritoneum, buccal, and gill cavities white. Closely related to Otophidium indefatigabile, differing in color, and in the much shorter head, smaller mouth, less imbricated scales, the more posterioi insertion of dorsal, and the absence of spines on head. Air bladder not examined. Pseudobranchiæ present. Gulf of California. One specimen, $5 \frac{1}{2}$ inches long, from Albatross Station 3025, in $9 \frac{1}{2}$ fathoms. (Gilbert.) ( $\gamma \alpha \lambda \tilde{\eta}$, shark; $\varepsilon \tilde{\imath}^{\tilde{\delta}} \delta \varsigma$, appearance.)

Otophidion galeoides, GiLbert, Proc. U. S. Nat. Mus. 1890, 110, Gulf of California, lat. $3^{\mathrm{I}^{\circ}} 2 \mathrm{I}^{\prime} \mathrm{I}^{\prime \prime} \mathrm{N}$., long. $\mathrm{II}^{\circ} 59^{\prime} \mathrm{W}$. (Type, No.44381. Coll. Albatross.)

\section{Family CCIX. LYCODAPODIDA.}

Deep-sea fishes allied to the Fierasferida, differing chiefly in the normal position of the vent, which is remote from the head, and just before the 
anal fin; gill openings large, the membranes united anteriorly only, free from the isthmus, as in Fierasfer. Psendobranchia wanting; no scales; no lateral line; no ventral fins. One genus with 4 known species, from the North Pacific.

\section{LYCODAPUS, Gilbert.}

Lycodapus, GiLbert, Proc. U.S. Nat. Mus. 1890, 107 (fierasfer).

Body naked. Ventrals wanting. Vertical fins united around the tail. Gill openings wide, continued forward under the throat; the gill membranes anteriorly narrowly united, loosely joined to the isthmus by a fold of lax skin. Branchiostegals 6. No pseudobranchiæ. Gills 4, a wide slit behind inner arch. Gill rakers developed. Teeth present in jaws and on vomer and palatines, none of them enlarged. Vent remote from the throat. (Lycodes; $\alpha$ $\pi$ ov 5 , footless.)

a. Body slender, the depth 8 to 11 in length.

$b$. Head rather large, $4 \frac{3}{4}$ to $5 \frac{1}{2}$ in length.

c. Head, body, and fins with very many mucous pores; dorsal rays 70 ; anal 60 . DERMATLUS, 2863.

cc. Heal, body, and fins with very fow mucous pores; dorsal rays 82 ; anal 70. FIERASFER, 2864.

$b b$. Head small, $7 \frac{2}{3}$ in Jength; gill openings not extending above base of pectorals. PARVICEPS, 2865.

aa. Body very slender, the depth about 15 in length; dorsal rays about 100.

EXTENSUS, 2866.

\section{LYCODAPUS DERMATINUS, Gilbert.}

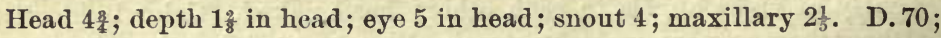
A. 60. Very similar to L. fierasfer, but the head, body and fins covered with a thick loose skin which contains numerons pores, or openings for the mucous canals. One series of these runs along middle of sides and forms the lateral line; it rises anteriorly above the gill opening, and is continued forward on top of head, the two meeting between eyes; a second series runs between eye and upper lip, and curves around on middle of cheek, running upward to behind eje; one series runs along a fold bordering mandible, 1 along preopercular margin, and 1 on opercle. In $L$. fierasfer a fow pores are visible on mandible, and 1 or 2 can frequently be made out on preopercular margins. The skin is very thin and delicate, and the fin rays are very evident through the membrane. The general proportions and the dentition of the type are essentially as in $L$. fierasfer, but the vomerine teeth are long and hooked backward. Mandible heavier than in L. fierasfer. Origin of dorsal vertically above axil of pectorals. Length of head and trunk $\frac{1}{8}$ total length. Teeth in narrow bands in the jaws, a single series on vomer and palatines. Gill membranes very narrowly joined below and free from the isthmus, as in $L$. fierasfer. Pectorals much longer than in $L$. fierasfer. General color in spirits light brownish yellow, made somewhat dusky by the pigment spots in the skin; body, and especially the fins, darker posteriorly. Aleutian 
Islands, in deep water. Only the type known, an example $4 \frac{8}{4}$ inches long. ( $\delta \varepsilon \rho \mu \alpha$, skin; dermatinus, skinny.)

Lycodapus dermatinus, GILBERT, Rept. U.S. Fish Comm. 1893 (1896), 471, pl. 35, Aleutian Islands, lat. $37^{\circ} 54^{\prime} x 0^{\prime \prime}$ N., long. $123^{\circ} 30^{\prime}$ W., at Albatross Station 3162 , in $55^{2}$ fathoms.

2864. LYCODAPUS FIERASFER, Gilbert.

Hear $5 \frac{1}{2}$; depth 10 ; eye $4 \frac{1}{2}$ in head; snout $3 \frac{1}{3}$; maxillary 2 to $2 \frac{1}{2}$. D. 82 ; A. 70. Body compressed, elongate, tapering rather rapidly backward, the tail not produced to a filament; head flat above, the cheeks deep, vertical, the mouth very oblique, with the lower jaw slightly the longer and nearly entering the upper profile; skull rery thin and papery, translucent; jaws weak; gape of mouth wide, the maxillary reaching vertical from behind front of pupil; teeth all small, in a very narrow band in jaws, in a single series on vomer and palatines; interorbital width $\frac{2}{8}$ of eye; snout broad, depressed, spatulate, its tip prominent, turned upward, the upper profile thus longitudinally concave; an evident median ridge on snout and interorbital space; gill slits continued forward below to vertical from middle of eye, the membranes united for a distance equaling diameter of pupil; gill rakers short, less than diameter of pupil, strongly toothed, about 10 on horizontal limb of arch; head without conspicuous mucous pores or cavities. Dorsal beginning well forward, its distance from occiput slightly less than that from occiput to nostril. Dorsal and anal rays slender, all articulated, branched only at tips; caudal not distinct, the rays springing from end of tail not projecting beyond the others; origin of anal immediately behind vent, its distance from snout nearly equaling $\frac{1}{8}$ total length; pectorals narrow, varying in length, about $2 \frac{1}{2}$ in hear. Body and fins invested in a rather lax transparent skin, without traces of scales. Color, body translucent, dusted with black specks; abdomen blackish; lips, inside of mouth, lining of gill cavity, and peritoneum jetblack; iris silvery. (Gilbert.) North Pacific. The types, several specimens, the longest $5 \frac{1}{4}$ inches, from Albatross Stations 2980, 3010, 3072, off Lower California, in 610 to 1,005 fathoms. Also taken near Unalaska in 109 fathoms. (Fierasfer, the pearlfish.)

Lycodapus fierasfer, GiLbert, Proc. U. S. Nat. Mus. 1890, 108, off Lower California, in 6ro to $\mathrm{x}, 005$ fathoms (Coll. Dr. Gilbert); JoRdaN, Proc. Cal. Ac. Scl. 1896, 234, pl. 23.

\section{S65. LYCODAPUS PARVICEPS, Gilbert.}

Head $7 \frac{2}{5}$; depth 11 ; eye $4 \frac{1}{2}$ in head; snout $3 \frac{1}{4}$; least interorbital width 5 ; maxillary $2 \frac{1}{6}$; pectoral $2 \frac{8}{4}$. D. 100 ; A. about 85 (both counted to middle of caudal); P.9; no ventrals. Upper profile of hear nearly straight, not longitudinally concave as in L. fierasfer; head deeper and narrower, the snout less spatulate; skin thicker. A conspicuous series of pores on mandible and along preopercular margin; gill slit very oblique, extending anteriorly as far as vertical from eye, the membranes then narrowly united, free from the isthmus except at extreme front; gill slit superiorly much more restricted than in $L$. fierasfer, not extending abovo base of pectorals, while in the latter it extends above them for $\frac{2}{8}$ diameter of eye. Mouth 
oblique, maxillary reaching vertical from middle of eye; jaws even at tip, the mandible slightly included laterally; mandibular teeth in a moderate band anteriorly, the inner series enlarged, narrowing posteriorly to a single row; premaxillary teeth of uniform size, in a narrow band throughout; vomer with 4 canine-like teeth; palatine teeth small, in a single close-set series. Distance from origin of dorsal to occiput slightly less than that from occiput to posterior nostril; head and trunk contained $3 \frac{1}{5}$ in tail. Body brownish in spirits, fins whitish, translucent; everywhere dusted with black specks; tail and fins distinctly blackish posteriorly; orbit blackish above; gill cavity silvery, blackish anteriorly; mouth blackish, except anteriorly; peritoneum black, the color not showing through the abdominal wall. Similar to L. fierasfer, differing in the much smaller head, longer, slenderer body, the thicker skin with more evident mucous pores, and in the more restricted gill openings. Aleutian Islands, in moderately deep water. Only the type known, a specimen about 5 inches long. (Gilbert.) (parvus, small; -ceps, head.)

,Lycodapus parviceps, GILBERT, Rept. U. S. Fish Comm. 1893 (1896), 455, north of Unalaska Island at Albatross Station 3324, in Iog fathoms. (Coll. Dr. Gilbert.)

\section{LYCODAPUS EXTENSUS (Gilbert).}

Head $6 \frac{8}{4}$; depth $15 \frac{1}{8}$; eye $4 \frac{1}{4}$ in head; snont $3 \frac{3}{5}$; interorbital width $1 \frac{1}{8}$ in eye; pectoral $2 \frac{2}{5}$ in head. D. 96 (the extreme end of the tail wanting). Gill openings as in $L$. fierasfer, extending well above base of ventrais. Skin thin, the mucous pores inconspicuous, evident on mandible and along margin of preopercle. Upper profile of head longitudinally concave, shaped as in $L$. fierasfer, but slenderer, its depth greater than that of body. Mouth oblique, the maxillary reaching vertical from middle of eye, $2 \frac{1}{5}$ in head. Teeth in narrow bands in each jaw, tapering laterally to single series; vomerine teeth more numerous than in $L$. parviceps or $L$. fievasfer, small, not canine-like, in a single series; palatine teeth wanting, as in some individuals of $L$. fierasfer. Occiput midway between front of dorsal and anterior nostril; pectorals slenderer and longer than in L. fierasfer. Head and trunk contained 23 times in tail. Color light brownish, the black peritoneum visible through the skin of the abdomen; mouth and gill cavity largely dusky; a narrow dark-brown streak along base of dorsal and anal, occupying, toward tip of tail, the entire height of both fins. An extremely slender elongate form, with hear smaller than $L$. fierasfer, but otherwise resembling that species more than L. parviceps. Aleutian Islands, in rather decp water. Only the type, a specimen 4 inches long, known. (Gilbert.) (extensus, stretched ont.)

Iycodalepis extensus, GiLbert, Rept. U.S. Fish Comm. 1893 (1896), 455, north of Unalaska, at Albatross Station 3324 , in 109 fathoms. (Coll. Dr. Gilbert.)

\section{Family CCX. FIERASFERID AE.}

\section{(The Pearl-Fishes.)}

Body elongate, compressed, tapering into a long and slender tail; no scales; tceth cardiform, on jaws, vomer, and palatines; canine teeth often present; no barbels; lower jaw iucluded; vent at the throat; gill mem- 
branes somewhat united, free from the isthmus; no pseudobranchiæ; no pyloric crea; vertical fins very low, confluent, without spines; no ventral fins; pectoral fins present or absent. Small shore fishes of tropical seas, often living in shells of mollusks, echinoderms, etc., being especially often commensal with the pearl oyster and with the larger Holothuria. Genera 3; species 12. (Ophidiido, group Fierasferina, Giinther, Cat., Iv, 381-384, 1862.)

a. Pectoral fins present; no distinct caudal fin; gill membranes connected anteriorly only.

Fimrasfer, 952.

952. FIERASFER, Cuvier.

Fierasfer, Cuvier, Règne Anim., Ed. 1, II, 239, 1817 (imberbe=acus).

Echiodon, Thompson, Proc. Zool. Soc. London 1837, 55 (drummondi).

Diaphasia, Lowe, Proc. Zool. Soc. London 1843, 92 (acus).

Oxybeles, Richardson, Voy. Erebus and Terror, Fishes, 74, 1844-48 (homei).

Porobronchus, KAUP, Ann. Mag. Nat. Hist. 1860, 272 (larva of Fierasfer acus).

Carapus, * Gill, Proc. Ac. Nat. Sci. Phila. 1864,152 (after RAFINESQUE, 1810; not type).

Vexillifer, Gasco, Bull. Assoc. Nat. Med. Napoli 1870, 59 (larva of Fierasfer acus).

Lefroyia, JoNes, Zoologist, IX, 1874, 3838 (bermudensis).

Gill membranes little connected, leaving the isthmus bare. No distinct caudal fin; pectoral fins developed. The species of this genus are not well known, and their characters and nomenclatures are uncertain. It is not unlikely that the American species are all reducible to one, Fierasfer affinis or dubius, but our scanty material will not justify us in taking this view. (Fierasfer, the ancient name, from $\phi \imath \varepsilon \rho o ́ s$, sleek and shining.)

a. Vomer with canine teeth; pectoral about $\frac{1}{2}$ length of head.

b. Front teeth of upper jaw enlarged; head 7 to 8 in length; depth $11 \frac{1}{2}$ to 15 times in length of body.

AFFINIS, 2867.

$b b$. Front teeth of upper jaw not enlarged; head $6 \frac{1}{2}$ in length; depth about $10 \frac{1}{2}$ times in length of body.

ARENICOLA, 2868.

aa. Vomer with small teeth, scarcely canine-like; pectoral about $2 \frac{1}{2}$ in head; head 7 to $8 \frac{1}{2}$ in body. BERMUDENSIS, 2869.

2867. FIERASFER AFFINIS † (Günther).

(Pearl-Fish.)

Head $7 \frac{1}{2}$; depth of head 15. Maxillary extending slightly beyond orbit; lower teeth larger than the upper, except 2 to 4 front teeth of upper jaw, which are about equal to lower teeth; vomer with 3 to 6 teeth, 2 or 3 of

* The name Carapus, Rafinesque, has been substitnted for Fierasfer by Gill and Poey. This change seems to us not justifiable, as it is certainly not desirable. The name Carapus first appears in Rafinesque's Indice d'Iltiologia Siciliana, 57, 1810. No type is mentioned by Rafinesque, but the diagnosis is taken from that of Lacépède's second subgenus under Gymnotus, which contains the three species, carapo, fierasfer, and longirostratus. Of these species, carapo is the original Linnzan type (Ed. $\mathrm{x}$ ) of the genus Gymnotus. Carapus should therefore be regarded as a synonym of Gymnotus. The Brazilian name carapo evidently suggested the word Carapus, although Dr. Gill derives the name from кá $\alpha$, head; ärovs, footless, an ex post facto distinction from Ophedion. In a list of Sicilian fishes, on page 37 of Rafinesque's Indice, published somewbat later, the name Carapus acus appears for Fierasfer acus. This reference of a species of Fierasfer to Gymnotus or Carapus was dne to Rafinesque's ignorance of its relations.

$f$ In the Museum of Conparative Zoology is "one valve of a pearl oyster, in which a specimen of Fierasfer dubius is beautifully inclosed in a pearly covering, deposited on it by the oyster." (Putnam.) 
these canine-like. Pectoral $\frac{1}{2}$ head; vent under base of pectoral. Dorsal fin low, but distinct; anal much more developed than dorsal, its longest rays about in the middle of the fish. Air bladder long, slightly constricted behind. Gill membranes not covering isthmus. Color in spirits, uniform light brown, with a short silvery band along the sides of the abdomen made by confluent spots. (Putnam, description of $F$.dubius.) Panama; especially common among the Pearl Islands, chiefly in shells of pearl oysters. This species should probably stand as Fierasfer affinis.

The following notes are from numerous specimens, 3 to. 4 inches long, from Pearl Islands, collected by Prof. Bradley, these also being types of Fierasfer dubius: Head $6 \frac{8}{4}$ to $7 \frac{1}{3}$; eye $4 \frac{1}{2}$ to 5 in head. Teeth in upper jaw small, acute, in a rather narrow band; sometimes a few in the front of the jaw inconspicuously enlarged; those in lower jaw and on palatines conic, blunt, in somewhat wider bands, the outer series of lower jaw enlarged, canine-like; vomer with a narrowly oblong. patch of small, blunt teeth, surrounding a median series of 3 to 6 conspicuously enlarged, retrorsely curved canines, which are usually much the largest teeth in the mouth. Two specimens from Albatross Station 3021, Lower California, agree in

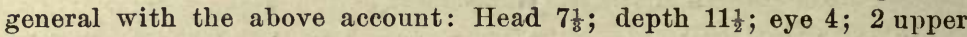
teeth on each side somewhat enlarged, about as large as lateral teeth on mandibles; vomerine canines larger. Professor Putnam refers also to Fierasfer dubius specimens from Key Biscayne, Florida (Coll. Theodore Lyman); Tortugas (Coll. Gustav Würdemann); Cape Florida (Coll. Wuirdemann), and New Providence, Bahama (Coll. F. G. Shaw). 'These specimens apparently belong rather to Fierasfer bermudensis, if that species be different. (affinis, related, to Fierasfer acus.)

? Fierasfer affinis, ${ }^{*}$ GU'NTHER, Cat., IV, 381,1862 , no locality given.

Fierasfer dubius, Putnam, Proc. Bost. Soc. Nat. Hist. 1874, 344, Pearl Islands (Coll. Prof. Frank H. Bradley); Jordan \& GILbert, Proc. U. S. Nat. Mus. 1882, 629; Jordan \& GriBerT, Synopsis, 791, 1883.

\section{FIERASFER ARENICOLA, Jordan \& Gilbert.}

Head $6 \frac{1}{2}$ in length; depth $10 \frac{1}{2}$; eye 5 in head; snout 5 . Body with nape slightly elevated, thence tapering regularly to the tail. Snout blunt, rounded, protruding; mouth subinferior, nearly horizontal, large, the lower jaw included; gape wide, the maxillary $\frac{1}{2}$ length of head, extending beyond vertical from orbit; teeth in upper jaw very small, acute, in a narrow band, none of them enlarged; those in lower jaw and on vomer blunt, conic, in a wirle band; those in outer series acute; a few on each side of mandible and 2 or 3 anteriorly on vomer, enlarged, canine-like. Gill openings very wide, the branchiostegal membranes little united, leaving nearly all of isthmus uncovered; the membranes

* Fierasfer affinis, Günther, is thus described:

"The length of the head is 18 of the total; its greatest width is rather less than $\frac{1}{3}$ of its length. Gill openings rather wide, the united gill membranes leaving the greater portion of the isthmus uncovered. Teeth cardiform; a pair in frent of the upper jaw, a series on the side of the lower, and sereral others on the vomer larger than the rest. Dorsal fin low but very distinct. The length of the pectoral nearly $\frac{1}{3}$ that of the head. (This species is) similar to $F$. acus, but with a very different dentition." (Günther.) Deseribed from a specimen 8 inches long, from unknown locality. This description, so far as it goes, agrees with Fierasfer dubius, but the specimen may not be American. 
united as far back only as vertical from end of maxillary; opercle adherent above the upper angle, which is produced in a point extending above the base of pectorals; below the angle the opercular margin runs very obliquely forward. Eye large, grester than interorbital width. Origin of dorsal fin distant from nape by the length of the head, the fin a very iuconspicuous fold anteriorly, becoming higher posteriorly, where the rays are ovident; anal well developed along entire length, beginning immediately behind vent and running to tail, its rays visible; caudal exceedingly short; pectorals very well developed, more than $\frac{1}{2}$ length of head; vent just in front of base of pectorals. Head and body perfectly translucent; a faint silvery luster on middle of sides anteriorly; a fow inconspicuous small light yellowish spots along middle of sides (disappearing in alcohol); tip of tail dusky; upper margin of orbit black. Pacific coast of Mexico. A single specimen, $3 \frac{1}{4}$ inches long, was found buried in the sand at low tide on the beach at Mazatlan. This specimen may be identical with Fierasfer dubius, but it is more robust than Putnam's types, with longer head and without enlarged teeth in upper jaw. It may be regarded as distinct, pending investigation. (arena, sand; colo, I inhabit.)

Fierasfer arenicola, JoRdan \& GILBERT, Proc. U. S. Nat. Mus. 1881, 363, Mazatlan. (Type, No. 29244. Coll. C. H. Gilbert.)

\section{FIERASFER BERMUDENSIS (Jones).}

Head $8 \frac{1}{2}$ in length; eye 4, longer than snout; mouth large, the maxillary reaching beyond orbit; pectoral $2 \frac{1}{2}$ in head. Teeth small, acute, uniserial, 3 in a line on the vomer; palatine teeth small.* Color pale brownish, a bluish streak crossing the nape between the opercles, 4 pale points on the back. Vertebræ 100. Length $140 \mathrm{~mm}$. West Indies. This description (by Poey) from a specimen taken in the stomach of a holothurian at Havana. Others are recorded from Key West and St. Thomas, the latter from an oyster; not seen by us; doubtfully distinct from Fierasfer dubius or affinis, but the vomerine teeth said to be smaller.

?Carapus afinis, PoEx, Synopsis, 402, 1867; not Fierasfer affinis, GUNTHER.

Lefroyia bermudensis, JonES, Zoologist, IX, 1874, 3838, Bermuda.t (Coll. General Lefroy.)

* In another specimen, according to Poey, the teeth are villiform, with an enlarged series outside, the lower teeth largest, the ninth, tenth, and eleventh largest; teeth on vomer small, acute, in a row; palatine teeth bluntish.

+ Fierasfer bermudensis (Jones) was thus originally described:

"Total length rather more than $4 \frac{1}{3}$ inches. Greatest depth at the vertical of the pectorals $3 \frac{1}{2}$ lines. The length of the head is slightly more than $\frac{1}{7}$ of the total length. The greatest width of the head rather less than $\frac{1}{3}$ of its length. Body naked, attenuate, compressed. Facial ontline rugose. Eye moderate; horizontal diameter of eyecup 13 lines; vertical diameter $1 \frac{1}{4}$ lines. Gape of the mouth ovoid. Lower jaw shorter and received within the upper. Cardiform teetl of irregular size in both jaws, vomer, and palatines, those of the latter largest. Branchiostegals 7, inflated, united below. Vent thoraclc. Pectorals originating at the upper angle of the operculum, 3 lines in extent, and composed of very delicate soft rays. Dorsal indistinct, commencing in a groove about the vertical of the twentieth anal ray, continuous to caudal extreme, where, in conjunction with the anal, it forms a small filamentous tip. Anal prominent, commencing immediately behind the vent in advance of the vertical of the upper angle of the operculum, and extending to the caudal extreme. About its center it is equal in depth to that of the body at same position. Owing to the delicate texture of the fius it is impossible to ascertain certainly the number of rays, but those of the anal exceed 140. Color, when dried out of spirits, golden yellow; the body transparent, showing the vertebræ within; a condition, according to Lefroy, equally observable in life.

"I propose to publish it as Lefroyia bermudensis, in compliment to the gallant officer to whom I am indebted for the specimen." (J. Matthew Jones.)

This species is probably idcntical with the one called affinis by Poey. 
Family CCXI. BROTULIDAE.

\section{(The Brotuloid Fishes.)}

Body elongated, compressed, regularly tapering behind, the tail generally subtruncate at base of caudal fin, not isocercal; vent submedian; scales cycloid and minute, embedded in the lax skin, which more or less envelops the fins, sometimes wanting; gill openings very large, the membranes mostly free from the isthmus; vertical fins united or contiguous at base of caudal; dorsal fin commencing not far from nape; candal narrow or pointed; ventral fins small, few-rayed, attached to the humeral arch and more or less in advance of pectoral. Pyloric caca few (1 or 2), rarely obsolete or in increased number (12); maxillaries generally enlarged behind and produced toward their upper angle. (Gill.) Pseudobranchize small or wanting, hypercoracoid with the usual foramen, as in Blennioid fishes. These fishes are closely related to the Zoarcida. In spite of various external resemblances to the Gadida, their affinities are rather with the Blennioid forms than with the latter. Genera about 45 , species about 100 ; largely of the depths of the sea; 2 species degenerated into blind cave fishes. We have not had material for any elaborate study of these fishes and follow closely the arrangemment given by Goode \& Bean. (Brotuloida, Gill, Proc. Ac. Nat. Sci. Phila. 1863, 252, and 1884, 175.)

\section{BROTULINE:}

$a$. Snout and lower jaw each with well-developed barbels; vertical fins united; teeth on vomer and palatines.

b. Ventrals each reduced to a bifid filament. BRotula, 953.

aa. Snout and lower jaw without barbels.

LUCIFUGINA:

c. Species blind, dwelling in fresh-water streams in caves; barbels replaced by cilia.

d. Palatines with strong teoth; teeth in lower jaw strong. STYGicolA, 954. $d d$. Palatines toothless; teeth in jaws villiform.

cc. Species marine, the eyes usually well developed.

BROSMOPHYCINE:

e. Caudal fin differentiated, on a distinct caudal peduncle.

$f$. Snout and lower jaw with small cilia; head naked, or nearly so.

Brosmophycis, 956.

ff. Snout and lower jaw without cilia; head more or less scaly.

OGILBIA, 957.

ee. Caudal fin not differentiated, without distinct peduncle.

BYTHITIN E:

g. Ventrals inserted on the isthmus, not far from the humeral symphysis.

$h$. Pectorals normal, simple; eyes present.

i. Lateral line present posteriorly, but broken in the middle; palatines with teeth; ventrals a pair of filaments each of 2 closely united rays.

BYThITES, 958.

ii. Lateral line obsolete posteriorly.

$j$. Ventrals each of a single ray.

$k$. Lateral line distinct on frent of body.

l. Preopercle without spines; hear scaly (except snout); opercle with a single spine; vent median.

CAT ETYX, 959. 
ll. Preopercle with 3 or 4 spines, opercle with a single one; head partially naked.

DicromitA, 960.

$k k$. Lateral line obsolescent, almost, or quite invisible; opercle with a feeble spine; head smooth; eyes sunall.

$m$. Ventral consisting of a single ray.

$m m$. Ventral bifid.

Bassozetus, 961. M⿻上丨L, 962.

$j j$. Ventrals each of a pair of rays.

n. Caudal fin exserted, but confluent with anal and dorsal.

o. Head scaly.

$p$. Preopercle with small spines at its angle, opercle with 1 spine.

NeobYThites, 963.

$p p$. Preopercle unarmed.

$q$. Operele with 2 spines; ventrals close together.

BEXTHOCOMETES, 964.

$q q$. Opercle with 1 strong spine; ventrals far apart.

BASSOGIGAS, 965.

nn. Caudal not confluent with vertical fins, but without distinct peduncle; teeth on jaws, vomer, and palatines in villiform bands; preopercle unarmed; head scaly.

r. Opercle with a flat spine; snout much produced and dilated; lateral line very indistinct (or absent?).

BARATHRodemus, 966.

rr. Opercle a triangular flap, unarmed; lower pectoral rays prolonged, the lowest filamentous. Nematonus, 967.

iii. Lateral line represented by 3 rows of pores-dorsal, lateral, and ventral; head with spines.

$s$. Ventrals of 2 distinct rays; opercular spine moderate, straight.

Porogadus, 968.

8s. Ventrals each of 2 united rays, opercular spines strong, curved.

PenopUs, 969.

hh. Pectorals with the lower rays differentiated.

$t$. Preopercle armed with 3 spines; opercle armed with 1 spine; lateral line obsolete posteriorly; ventrals bifid.

DICROLENE, 970.

$t t$. Preopercle nnarmed; a single spine on opercle; lateral line absent (?); ventrals each a pair of filaments, closely united throughout.

Mixonus, 971.

APHYONINAE:

gg. Ventrals inserted on humeral symphysis; lateral line obsolete (in almost every case); ventrals each of a single filament; body naked; notochord persistent.

$u$. Eye visible through the skin; a few fang-like teeth on vomer and mandible.

BARATHRONUS, 972.

uu. Eye not visible; no teeth on maxillary or palatines; teeth on vomer rudimentary, those on mandible small.

APHYONUS, 973. 
953. BROTULA, Cuvier.

(BRótulas.)

Brotula, Covier, Règne, Anim., Ed. 2, II, 296, 1829 (barbata).

Body elongate, compressed, covered with minute smooth scales; eye moderate; mouth medium, with villiform teeth on jaws, vomer, and palatines; lower jaw included; each jaw with 3 barbels on each side. Dorsal fin long and low, the dorsal and anal joined to the caudal. Ventral fins each reduced to a single filament of 1 ray. Eight branchiostegals. Air bladder large, with 2 horns posteriorly. One pyloric cæca. Vertebræ $16+39=55$. Tropical seas, in water of moderate depth. (Brótula, Spanish name of Brotula barbata.)

2870. BROTULA BARBATA (Bloch \& Schneider).

(BRótula.)

Head $4 \frac{1}{2}$; depth about 5. D. 123 ; A. 93; V. 1. Upper jaw the longer. Ventral fin $\frac{1}{2}$ as long as head. Dorsal commencing behind vertical from root of pectoral; vertical fins covered with thick skin. Color nearly uniform brown. Length 12 to 18 inches. West Indies; rare; in water of moderate depth. One specimen obtained by us in the market of Havana. (barbatus, bearded.)

Brótula, PARra, Dif. Piezas Hist. Nat., 70, lam. 31, fig. 2, 1780, Havana.

Enchelyopus barbalus, BLOCH \& SCHNEIDER, Syst. Ichth., 52, 1801; after PARRA.

Brotula barbata, Covier, Règne Anim., Ed. 2, II, 296, 1829; PoEx, Memorias, II, 102, lam. 9, fig. 2, 1860; Günther, Cat., IV, 371, 1862.

954. STYGICOLA, Gill.

Stygicola, GruL, Proc. Ac. Nat. Sci. Phila. 1863, 252 (dentatus).

This genus differs from Lucifuga in the presence of palatine teeth. The teeth in the jaws are larger. As in Lucifuga, the single known species inhabits cave streams in Cuba. ( $\sigma \tau v^{\prime} \xi$, Styx, the river of the lower regions; colo, I inhabit.)

\section{STYGICOLA DeNTATUS (Poey).}

Head $2 \frac{2}{5}$; depth $3 \frac{2}{2}$. D. 90 ; A. 70 ; P. 17 ; V. 1 . Vertebræ $11+37=48$. Eyes usually wanting, occasionally represented by a rudiment; head elevated at the nape, the general form less slender than in Lucifuga, the belly more prominent; no scales on the nape; strong tecth, well separated, on the palatines as well as the vomer; teeth in the jaws larger than in Luci fuga; posterior with a large apophysis. Color translucent violet, with darker areas on nape and throat. Caves of the province of San Antonio, in southern Cuba. Largest specimen 5 inches long. (Рoey.) (dentatus, toothed.)

Lucifuga dentatus, PoEy, Memorias, II, 102, 1860, Cave of Cajío (Coll. Noda), Cave of Castle La Industria (Coll. Dubrocá), Cave of Ashton (Coll. Fabre); GUNTHER, Cat., IV, 373, 1862.

Stygicola dentata, Gru, Proc. Ac. Nat. Sci. Phila. 1863, 252. 


\section{LUCIFUGA, Poey.}

\section{(Cuban Blindfish.)}

Lucifuga, PoEY, Memorias, II, 95, 1860 (subterraneus).

Body moderately elongate, translucent pinkish, covered with minute scales. Eye rudimentary, covered by the skin; bands of villiform teeth in the jaws and vomer, none on the palatines; nostrils 2 on each side; no barbels; head with small tactile cirri; no spines on head; gills 4 ; no psendobranchia ; gill opening large, extending forward nearly to the symphysis, the gill membranes not united; branchiostegals 7 or 8 ; vertical fins low, united around the tail; ventrals each reduced to a short thin filament; male with an anal papilla, no pyloric cæca; air bladder large, rounded behind, joined to the base of the skull. Cave streams of Cuba; the eyes having undergone a degeneration similar to that seen in Amblyopsis. These fishes have no relation to the blind cave fishes of North America, but are derived from marine types, their ancestors being evidently allies of Ogilbia and Brotula. It is known that blindfishes are found also in caves of the islands of Jamaica, but no specimens have been seen by naturalists. (lux, light; fugo, I flee.)

\section{LUCIFUGA SUBTERRANEUS, Poey.}

(Pez Crego.)

Head $2 \frac{2}{5}$; depth $3 \frac{2}{3}$. Branchiostegals 7. D.70; A. 70; P.51; V.1; C.9. Vertebræ $11+36=47$. Body elongate, compressed, tapering, pointed; head low at nape, much depressed anteriorly, broad, covered with soft, white, wrinkled skin, with microscopic cirri, having firm and conical tubes; no barbels on lips or chin; skin of head with many pores; scales not ciliate, present on body and top of head and on opercles; lateral line median, marked by a series of microscopic cirri like those on head, these wanting posteriorly; eyes wanting; nasal openings double; mouth large; lower jaw shorter; lips fleshy; maxillary broad at tip, 2 length of head; teeth in jaws very short and sharp, in a band; vomerine teeth larger; no palatine teeth; pharyugeal teeth slender; tongue smooth; gill openings large; males with an anal papilla; fin rays simple, flexible, jounted but not branched; dorsal beginning at a point about $\frac{1}{2}$ nearer tip of snout than tip of caudal; anal smaller, beginning farther back, the 2 fins fully joined to the pointed caudal; pectoral fin short, falcate, nearly $\frac{1}{2}$ head; ventral in front of pectoral, a slender ray not $\frac{1}{2}$ length of maxillary. Color transparent rosy, head reddish, becoming darker in alcohol. No pyloric crea ; intestines short; air bladder large. Described from 12 specimens, the longest about $4 \frac{1}{2}$ inches; found in caves of the jurisdiction of San Antonio, in the southern part of Cuba. (Poey.) (sub, under; terra, earth.)

Lucifuga subterraneus, PoEx, Memorias, II, 96, 1860, San Antonio, Cuba (Coll. D. Tranquilino); Sandalio de Noda (Coll. D. Juan Antonio Fabre); first coll. from Cajío Cave, 1831 (Noda); second, Cave at La Industria (Coll. Dubrocá); third, Ashton Cave, San Andreas (Coll. Fabre); fourth, Cave of the Dragon (Coll. Fabre); fifth, Cave at the Castle of Concord (Coll. Layunta). 
956. BROSMOPHYCIS, Gill.

Brosmophycis, Giu, Proc. Ac. Nat. Sci. Phila. 1861, 168 (marginatus).

Halias, A YREs, Proc. Cal. Ac.Sci. 1861, 52 (marginatus); preoceupied.

Body elongate, moderately compressed; head unarmed; suout not long; teeth sharp, curved, in bands on jaws, vomer, and palatines; snall cilia above suout and on anterior part of lower jaw. Body covered with thin cycloid scales; scales on head rudimentary or wanting. Caudal fin differentiated, entirely separated from the dorsal and anal; caudal peduncle slender. California. This genus is very close to Ogilbia, differing in the ciliated lips. Its species reaches a larger size. (Brosmius; Phycis.)

\section{BROSMOPHYCIS MARGINATUS (Ayres).}

Head $4 \frac{1}{2}$ in body; depth $6 \frac{1}{2}$. D.92; A. 70 ; eye $7 \frac{1}{4}$ in head; snout $4 \frac{1}{2}$; maxillary 2 ; pectoral $1 \frac{2}{8}$; caudal 3 ; body elongate, moderately compressed ; snout blunt; profile of head straight from snout; snout scarcely overhanging mouth; jaws subequal, the teeth conical, sharp, and slightly curved back, in bands on jaws, vomer, and palatines; maxillary reaching $\frac{1}{2}$ the eve's diameter beyond eye; snout and lower jaw thickly covered with small cilia; head naked with the exception of small scales above; 2 large pores at tip of chin, a few large ones around preopercle and preorbital, 1 around gill opening, behind which is a pocket in the skin; about 3 short gill rakers developed below the angle of first arch, with many rough plates, not differentiated from those on the other arches. Dorsal and anal long and low, the rays embedded in the skin; tips of last rays each beyond the base of the caudal about $\frac{1}{8}$ the length of caudal rays; distance of front of dorsal from snout $3 \frac{1}{6}$ in length of body; origin of anal a little nearer base of caudal than tip of snout; pectoral reaching about half way from its base to front of anal; ventrals developed as long filaments; candal slender and rounded behind. Color bright reddish brown; fins edged with bright rose-red. Coast of California, in water of moderate depth; rare. Here described from a specimen, 12 inches in length, collected off San Francisco by Mr. W. G. W. Harford. (marginatus, edged.)

Brosmius marginatus, A Yres, Proc. Cal. Ac. Nat. Sci., I, 1854, 13, San Francisco(Coll. W. O. Ayres); Girard, Pac. R. R. Surv., x, Fishes, 141, 1858.

Brosmophycis marginatus, Glll, Proc. Ac. Nat. Sci. Phila. 1851, 168; Gill, Proc. Ac. Nat. Sci. Phila. 1862, 280.

Halias marginatus, AYres, Proc. Cal. Ac. Nat. Sci., pt. 2, 1861, 52.

Dinematichthys marginatus, GüNTHER, Cat. Fishes Brit. Mus., IV, 375; JORDAN \& GILBERT, Synopsis, 796, 1883.

957. OGILBIA, Jordan \& Evermann.

Ogilbia, Jordan \& Evermann, in Evermann \& Kendall, Bull. U. S. Fish Comm. 1897 (February 9, 1898), 132 (cayorum).

Body moderately elongate, covered with minute, smooth, embedded scales; sides of head with similar scales; lateral line inconspicuous; opercle with a very small spine, preopercle unarmed; no strong hook on maxillary; no barbels nor cilia; tecth in jaws in bands, similar teeth on 
vomer and palatines; caudal free from the dorsal and anal; lower lip without cirri; dorsal and anal rays covered by the skin, ventrals each reduced to a filament of 2 rays; anal papilla of the male without horny claspers. Small fishes of the tropical shores of America, living in rock pools and shallows among algw. This genus is closely allied to the East Indian genus Dinematichthys, differing in the absence of anal papilla and claspers and in the shorter vertical fins. (Named for J. Douglas Ogilby, the accomplished naturalist of the museum of Sydney, in recognition of his excellent work on the fishes of Australia.)

a. Snout very short, about 7 in head; eye small, 10 or 11 in head; scales small, obscure, snout very short, $6 \frac{1}{2}$ in head.

aa. Snout longer, about 4 in head; eye about $8 \frac{1}{2}$ in head; scales larger, distinct. VENTRALIS, 2874.

CAYORUM, 2875.

\section{OGILBIA VENTRALIS (Gill).}

Head $4 \frac{1}{2}$ in body; depth $5 \frac{1}{2}$. D. 64 ; A. 50 ; scales about 100 ; eye 10 or 11 in head; maxillary 2 ; pectoral $1 \frac{2}{8}$; candal $1 \frac{5}{6}$. Body elongate, moderately compressed; snout blunt, the profile behind snout nearly straight to occiput; mouth large, the maxillary extending 2 or 3 times the eye's diameter behind eye; teeth small, in bands on jaws, vomer, and palatines; eye very small, nearer snout than posterior end of maxillary; no cilia on snout and chin; body apparently naked to the unaided eye; but body and top of the head covered with small scales, which can be seen by the aid of a lens. Origin of dorsal distant from tip of snout by a space contained $3 \frac{1}{4}$ times in body; front of anal about midway between tip of snout and base of caudal; tips of last dorsal and anal rays reaching about to the middle of caudal rays, but not connected; pectorals scarcely reaching midway between their base and the front of anal; veutrals filamentous; caudal slender and rounded behind. Color in spirits, light brown above, lighter below; fins all colorless; without distinct marking anywhere. Gulf of Califoruia; not rare in rock pools; several specimens, 2 to 4 inches in length taken by us at Mazatlan. Here described from a specimen, 2 inches in length, from La Paz Harbor, Lower California. (ventralis, pertaining to the belly.)

Brosmophycis ventralis, GIL, Proc. Ac. Sci. Phila. 1863, 253, Cape San Lucas. (Coll. Xantus.)

Dinematichthys ventralis, JoRdAN, Proc. Cal. Ac. Sci. 1895, 502, pl. 54.

2875. OGILBIA CAYORUM, Evermann \& Kendall.

Head 4; depth $4 \frac{1}{2}$; eye $8 \frac{1}{2}$; snout 4. D. about 68 ; A. about 50 ; scales about 14-87-13; maxillary $1 \frac{4}{5}$; pectoral $1 \frac{4}{5}$; ventral $1 \frac{1}{2}$; caudal $2 \frac{1}{8}$. Body moderately elongate, compressed; head moderate, snout blunt; mouth large, jaws subequal, maxillary extending beyond vertical of eye a distance nearly equal to length of snout; eye very small, high up, situated in anterior third of head; nostril small, close to eje; teeth small, in bands on jaws, vomer, and palatines; back elevated, strongly arched from snout to origin of dorsal fin, thence descending in a nearly straight line to base of caudal; ventral outline comparatively straight, slightly concave at front of anal. Dorsal and anal long and low, distinct from caudal, the 
posterior rays longest, about $3 \frac{1}{2}$ in head, base of each scaled; distance from tip of snout to origin of dorsal about 3 in length of body; origin of anal under about twenty-second dorsal ray, equidistant between tip of snout and base of caudal; scales very small, embedded, but showing distinctly under a lens; cheek and opercles partially covered with minnte, embedded scales; top of head naked; opercle with a large, flat, flexible spine on level with eye. No barbels, cilia, nor tubercles; 2 large mucous pores at symphysis of lower jaw and 2 on preorbitals near anterior edge on each side; a row of 5 or 6 pores on lower jaw and edge of preopercle. Color uniform pale olivaceous or light brown, finely punctate with minute brown specks. Key West. Only the type known, an example, $2 \frac{1}{3}$ inches long, seined on a shoal covered with algæ at Key West. (Cayo Hueso, or Bone Key, the original Spanish name for the Island of Key West, whence the name cayorum, of the keys.)

Ogilbra cayorum, Evermann \& Kendald, Bull. U. S. Fish Comm. 1897 (Feb. 9, 1898), 132, pl. 9, fig. 14, Key West, Florida. (Type, No. 48792. Coll. Evermann \& Kendall.)

\section{BYTHITES, Reinhardt.}

Bythites, Reinhardt, Dansk. Vidensk. Selsk. Afhandl., vir, 1838, 178 (fuscus).

Body elongate, covered with minute scales. Head large, thick; mouth large; jaws equal; no barbel; bands of teeth in the jaws and on vomer and palatines. Branchiostegals 8; gill membranes united, free from the isthmus; eyes moderate. Lateral line interrupted. Vertical fins united; ventral fins reduced to simple filaments, each composed of 2 rays closely united. Air bladder large; 2 pyloric cæca. A thick, conical, anal papilla (in the male). Greenland. ( $\beta v \theta i \tau \eta s$, an animal of the depths, from

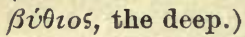

\section{BYTHITES FUSCUS, Reinhardt.}

Head about 4; depth $4 \frac{1}{2}$. Body somewhat compressed, lipariform; snout obtuse, naked, with minute cirri. Mandible long, curved, extending far behind vertical from posterior margin of orbit; eye small; scales moderate on body; lateral line complete, but interrupted over vent, the two parts slightly overlapping the same vertical; vertical fins coufluent, enveloped in thick skin; pectorals broad, lanceolate, with broad base; ventrals filiform, reaching behind origin of pectoral, as long as pectoral and $\frac{2}{8}$ as long as head; a conspicuous anal papilla in the male. The only known specimen, now in the museum at Copenhagen, was obtained in Greenland half a century ago. (Goode \& Bean.) (fuscus, dusky.)

Bythites fuscus, Reinhardt, Dansk. Vidensk. Selsk. Afh., viI, 1838, 178, Greenland; GüNTHER, Cat., IV, 375, 1863; Jordan \& Gilbert, Synopsis, 795, 1883; GoOde \& Bean, Oceanic Ichthyology, 316, 1896.

959. CAT ATYX, Günther.

Oatcetyx, GUNTHER, Challenger Report, XxII, 104, 1887 (messieri).

Body compressed, elongate, covered with very small and thin scales; lateral line indistinct, interrupted. Head oblong, with somewhat pointed snout, covered with very small scales, only the anterior part of the suout 
naked; bones of the head rather firm, but with the muciferous system well developed, the canals having wide openings along the infraorbital, and on the lower limb of the preoperculum; eye rather small; nostrils far apart, the posterior in front of the eye and the anterior at the extremity of the snout; operculum with a spine behind; no other armature on the head; suout not swollen, but the upper jaw slightly overlapping the lower; barbels none; mouth wide; bands of villiform teeth in the jaws, on the vomer, and the palatine bones; a series of larger teeth along the sides of the lower jaw; tail not much attenuated; vertical fins confluent; ventrals close together, reduced to a pair of fine, simple filaments, and inserted somewhat behind the isthmus, below the middle of the operculum. Gills 4, with short, broad gill rakers and well developed laminæ; pseudobranchia none; branchiostegals 8; pyloric appendages. Deep seas. Two species known. ( $\alpha \alpha \tau \alpha i$, at the bottom; $\tau \dot{v} \xi \imath 5, \tau v \gamma \chi \alpha \dot{v} \omega$, find.)

\section{CATETYX RUBRIROSTRIS, Gilbert.}

Depth of body below origin of dorsal equals $\frac{1}{8}$ distance from end of snont to vent, 7 in length; head 4; distance from snout to origin of dorsal $3 \frac{1}{5}$; from snout to vent $2 \frac{2}{7}$; maxillary extending beyond eye, $2 \frac{2}{5}$ in head; eye equaling snout, $5 \frac{1}{2}$; interorbital width 7 ; width of snout $3 \frac{1}{5}$. Teeth in upper jaw in a narrow band, minute, compressed, narrowly triangular, none of them enlarged; in the lower jaw a still narrower band of similar teeth, the posterior row slightly enlarged and increasing a little in size on sicles of jaw, where it is accompanied by a single series only of the smaller teeth; this lateral series is continued backward far beyond premaxillary band; teeth on vomer and palatines similar to those in sides of lower jaw, the former in a V-shaped patch, the latter in a long and very narrow band. Anterior nostril in a short tube at tip of snout, the posterior large, without tube, immediately in front of eye; system of mucons pores well developed but not conspicuous, the pores collapsing on account of the thinness of the skin covering head; large mucous tube below eye, extending around front of snout and opening by slit-like pores along edge of snout and lower margin of infraorbital flap, opening posteriorly by a vertical slit $\frac{1}{2}$ as long as pupil, immediately above end of maxillary; another series of pores along mandible and at edge of expanded limb of preopercle; no other evident pores. Angle of preopercle much expanded, its width equaling diameter of pupil; a sharp, strong spine arising from anterior portion of opercle, the structure of the gill flap apparently like that of Bassogigas stelliferoides; a short, sharp spine directed backward immediately behind posterior nostril; no other spines on head; gill openings wide, continuing forward to below posterior margin of orbit, the membranes wholly free from the isthmus; gill rakers short but not very broad, about $\frac{1}{2}$ length of pupil, only 2 or 3 developed immediately in front of angle of arch. Dorsal beginning over or slightly behind middle of pectorals, the distance from its origin to occiput equaling or somewhat exceeding distance of latter from tip of snout; dorsal and anal fully united to caudal. The caudal has a base of appreciable width, bearing about 12 close-set rays, which extend much beyond tips of last dorsal and $3030-80$ 
anal rays; origin of anal nearer snont than base of caudal; ventrals slender, each consisting of a single ray, inserted very near together, under anterior portion of opercle, their length about equaling that of maxillary; pectorals with about 23 rays, evenly romuled behind, their length 12 in head. Scales very small, cycloid, regularly imbricated, in about 135 transverse series; nape and belly scaled, as is also the head, excepting snout, mandible, suborbital, and sometimes interorbital areas. Color dusky olive, the ventrals white, the other fins black, at least on distal portions; opercles, gill membranes, sides and top of snout, and posterior portion of abdorien blue black; snout flushed with dark ruby red in life; lining membrane of mouth and gill cavity, and peritoneum jet-black. Closely related to $C$. messieri, differing in the shorter, broader snout, the wider preopercle, the more anterior origin of anal, and apparently in the gill rakers and pores on head. Off coast of California. Four specimens known, the longest $4 \frac{1}{2}$ inches in length. (Gilbert.) (ruber, red; rostrum, snout.)

Catcetyx rubrirostris, GILBERT, Proc. U.S. Nat. Mus. 1890, 111, off coast of California, at Albatross Stations 2909, 2925, and 2936, in 205 to 359 fathoms. (Type, No. 44379.)

\section{DICROMITA, Goode \& Bean.}

Dicromila, Goode \& BeAN, Oceanic Ichthyology, 319, 1896 (agassizii).

Brotulids resembling in form and general appearance Catatyx and Diap. lacanthopoma, having the lateral line obsolete, or interrupted posteriorly ; ventrals a pair of simple, fine filaments, and with teeth upon the palatines. It has, however, 3 or 4 small spines upon the preoperculum, as well as a sharp spine upon the upper angle of the operculum; and the lateral line, though indistinct, is traceable for $\frac{1}{2}$ or $\frac{8}{4}$ the length of the body, which, like the upper part of the head, is covered with small, deciduous scales, the opercular region being apparently scaleless, and the bones of the suborbital region almost uncovered, with conspicuous sinuses, which show through the transparent texture of the surface. Head oblong; snout somewhat produced, depressed, and turgid, resembling, though in a less degree, that of Barathrodemus. Eye moderate, conspicuous. Mouth wide; teeth villiform, in bands on the jaws and palatines, and very minute upon the vomer, which has a roughened, knob-like enlargement at its angle. Vent premedian. Ventral fins confluent; ventrals rooted very close together, each reduced to a fine, flexible, simple filament, planted somewhat behind the isthmus and below the middle of the operculum. Gills 4, with well-developed laminæ and rather long, slender gill rakers. Branchiostegals 8.

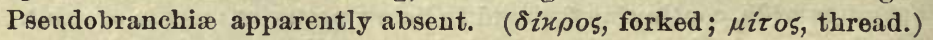

\section{DICROMItA AgASSIZII, Goode \& Bean.}

Body elongate, much compressed, its height about $\frac{1}{5}$ of its total length, its width about $\frac{1}{2}$ its greatest height; head slightly greater than height of body, about twice its own width; mouth very large, the maxillary curved and much dilated at its extremity, reaching far behind the vertical from the posterior margin of orbit; jaws nearly equal, the snout considerably 
produced and dilated, its length equal to diameter of eye and $\frac{1}{4}$ length of head. Teeth very fine, villiform, in bands on jaws and palatines, and also present on vomer, though very small, especially upon the rounded, globular process of the angle. Lateral line very indistinct, interrupted, but extending behind the vent at least $\frac{1}{8}$ of the way to tip of tail. Dorsal origin nearly in vertical from the axil of the pectoral; ventrals very slender, villiform, closely approximate at their roots, and less than $\frac{1}{2}$ as long as the head. Color brownish. A specimen was obtained by the Blake off Granada, Station XCIII, at a depth of 291 fathoms. The collateral type was obtained by the Albatross at Station 2374, in lat. $29^{\circ} 11^{\prime} 30^{\prime \prime} \mathrm{N}$., long. $85^{\circ} 29^{\prime} \mathrm{W}$, at a depth of 26 fathoms. (Goode \& Bean.) (Named for Prof. Alexander Agassiz.)

Dicromita agassizii, GOODE \& BEAN, Oceanic Ichthyology, 319, fig. 285, 1896, off Granada, in $29 \mathrm{r}$ fathoms (Coll. the Blake); Lat. $29^{\circ} \mathrm{II}^{\prime} 30^{\prime \prime} \mathrm{N}$., LLong. $85^{\circ} 29^{\prime} \mathrm{W}$., in 26 fathoms. (Coll. Albatross.) (Type in M. C.Z.)

\section{6r. BASSOZETUS, Gill.}

Bathynectes, GÜNTHER, Ann. and Mag. Nat. Hist., II, 1878, 20 (compressus) ; name preoccupied in Crustacea.

Bassozetus, GiLL, Proc. U.S. Nat. Mus., VI, 1883, 59 (normalis).

Bathyonus, Goode \& BeAN, Proc. U.S. Nat. Mus., virr, 1886, 603 (catena).

Body compressed, with long tapering tail, covered with deciduous thin scales of moderate size. Bones of the head very soft and cavernous, the upper opercular spine very feeble, ridge-like; no other armature of the head. Head scaly, except the snout, which is obtusely rounded off, with the jaws equal or nearly equal in front. Mouth very wide; bauds of villiform teeth in the jaws, on the vomer, and palatine bones. Barbels none. Eye small; anterior nostril about midway between the posterior and the extremity of the snout. Vertical fins confluent; ventrals close together, reduced to a pair of simple filaments, and inserted below the rounded angle of the preoperculum. Gills 4, with short gill lamina, but with long stiff gill rakers on the first branchial arch. Pseudobranchiæ none. Branchi-

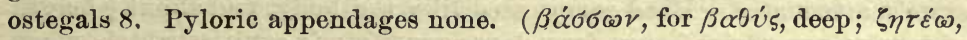
seek.)

a. Body moderately elongate, the depth 9 to 10 in length; dorsal rays 116; anal 92 to 96.

b. Head 6 in length.

bb. Head about $7 \frac{1}{2}$ in length.

aa. Body more elongate, the depth 121 in length; head $8{ }^{\circ}$, heal with like rows of pores.

NORMALIS, 2879. COMPRESSUS, 2880. CATENA, 2881.

aaa. Body excessively attenuate, the depth more than 16 times in length; dorsal rays 138; anal 115; distance from snout to vent nearly 4 times in body.

TAEIA, 2882.

\section{BASSOZETUS NORMALIS, Gill.}

Head 6 in total length; eye 4 in snout. D. 116 ; A. 96. Body much compressed, its width in the region of vent not more than $\frac{1}{8}$ of its height, which at the same point is about $\frac{1}{9}$ of the total length; greatest height of body, over the origin of the pectorals, about $\frac{2}{8}$ the distance from base of pectorals to vent, the vent being about twice as distant from base of 
caudal rays as from snout. Head moderately compressed, flat above; snout obtuse rounded, turgid; lower jaw considerably included. Bones of head not completely ossified, very cavernous in the alcoholic specimen, the head showing many deep sinuosities and depressions. Eye very small, situated about midway between the tip of the snout and the vertical from the posterior end of maxillary. Teeth all small and short, densely set, forming narrow, villiform bands; vomerine band open V-shaped. Dorsal fin beginning far in advance of origin of pectoral and above upper angle of gill opening, rays longest in region of vent; anal beginuing immediately behind vent, its rays not quite so long as those of dorsal; pectoral with broad base, short, not exceeding much more than halfway to vertical from vent, its length considerably less than that of postorbital portion of head. Ventral rays very slender, villiform, reaching almost to vent, far beyond pectoral, their length almost equal to that of head. Scales moderate, very deciduous, extending upon cheeks and on top of head almost to tip of snout; no evidence of a lateral line. Color light, the head and abdomen blackish; inside of mouth purplish brown. The Blake secured specimens from Station CCIV, in lat. $24^{\circ} 33^{\prime} \mathrm{N}$., at a depth of 1,920 fathoms, and from Station LXXXIV, off Dominica, in 1,131 fathoms. The Albatross also obtained examples (No.49416, U. S. Nat. Mus.) from Station 2380, in Lat. $28^{\circ} 02^{\prime} 30^{\prime \prime}$. N., Long. $87^{\circ} 43^{\prime} 45^{\prime \prime}$ W., at a depth of 1,430 fathoms; (No. 33306, U. S. Nat. Mus.) from Station 2042 , in lat. $39^{\circ} 33^{\prime} \mathrm{N}$., Long. $68^{\circ} 26^{\prime} 45^{\prime \prime} \mathrm{W}$., at a depth of 1,555 fathoms. (Goode \& Bean.) West Indies, Gulf of Mexico, and to lat. $40^{\circ} \mathrm{N}$., in region of the Gulf Stream. (normalis, normal.)

Bassozetus normalis, GiLl, Proc. U. S. Nat. Mus. 1883 , 259, Lat. $39^{\circ} 33^{\prime}$ N., Long. $68^{\circ} 26^{\prime} 45^{\prime \prime}$ W., in I,555 fathoms (Type, No. 33306. Coll. Albatross); GoodE \& BeAN, Oceanic Ichthyology, 322, fig. 287, 1896.

\section{BASSOZETUS COMPRESSUS (Günther).}

D. 116 ; A. $92 ;$ P. $23 ;$ V.1. The greatest depth of the body is above the end of the gill cover and about $\frac{1}{2}$ length of trunk; vent twice as distant from extremity of tail as from snout, consequently the tail is more moderately attenuated. Head compressed like the body, and about $\frac{2}{8}$ length of trunk; superficial bones form large muciferous cavities which, when full, must give to the head a much more evenly rounded appearance than in the preserved state, when the supporting bony ridges project more or less from under the skin. Snout slightly swollen, but the jaws nearly even in front, the wide month slightly ascending forward; maxillary with the form usual in these Gadoid fishes, dilated behind, and extending far behind the eye. Eye very small, $\frac{1}{2}$ length of snout, and $\frac{1}{11}$ that of head, placed high up on the side, and not possessing an orbital fold of integument; interorbital space rather convex and equal in width to 3 diameters of eye. Teeth all very small, short, densely set, and forming villiform bands, the broadest on maxillary bone and quite uncovered on the sides, no labial folds being developed; palatine band broader than the mandibulary, and the vomerine band $V$-shaped, each arm being bent with the convexity inward. Gill opening and cavity very wide and of an intense black; gill rakers much longer than the laminæ, 15 in number on 
the anterior arch, besides some rudimentary ones above. Dorsal fin commencing above upper end of gill opening, with short rays partly hidden in the skin, becoming longer in middle of fin, but remaining of moderate length; anal shorter; pectoral with a rather narrow base, quite free, and composed of feeble rays, its length only $\frac{1}{2}$ that of head; ventral rays very feeble, reaching somewhat beyond the root of pectoral. In the specimens examined only very few of the thin, cycloid scales have been preserved; they are of moderate size, there being about 16 in a transverse series running from the vent to the dorsal fin; the lateral line, if it was developed, can no longer be traced. Blackish, with the fins, head, and abdomen black. Specimens of this very fine and truly bathybial fish were obtained at great depths on the southeast of New Guinea, off the Philippine Islands, and in the mid-Atlantic; the exact localities being 75 miles east-southeast of Raine Island, Station 184, depth 1,400 fathoms; two specimens, 17 and $4 \frac{1}{2}$ inches long. Philippine Islands, Station 205, depth 1,050 fathoms; one specimen, $5 \frac{1}{2}$ inches long. Mid-Atlantic, Station 107, depth 1,500 fathoms; one specimen, $5 \frac{1}{2}$ inches long. The young are extremely similar to the old, but have a larger eje, which is $\frac{1}{8}$ of length of head. 'The specimen from Station 205 (Philippine Islands) has longer veutral filaments, extending nearly to the vent. (Günther.) (compressus, compressed.)

Bathynectes compressus, GÜNTHER, Ann. Mag. Nat. Hist., 1I, 1878, 20, Challenger Station 107 , mid-Atlantic, in 1,500 fathoms. (Coll. Challenger.)

Bathyonus compressus, G(inTHER, Challenger Report, XXII, 109, 1887.

Bassozetus compressus, GOODE \& BEAN, Oceanic Ichthyology, 322, 1896.

2881. BASSOZETUS CATENA, Goodo \& Bean.

Head $8 \frac{2}{3}$; depth $1 \frac{1}{2}$ in head or $12 \frac{1}{2}$ in body; eye 5 ; snout 5 ; interorbital width 5. Body very elongate, much compressed, and tapering into a slender, whip-like tail. Head without spines, very cavernous, not much compressed, higher than body. Interorbital area somewhat convex. The muciferous channel upon the infraorbital ring shows in its course several wide subcircular sinuses; closely approximated; a similar row upon the posterior edge of the preoperculum and continued forward upon the under surface of the mandible; the vertex also has a semicircle of similar sinuses. Maxillary extending beyond vertical through posterior margin of orbit, its length equal to that of postorbital part of head; mandible $\frac{2}{8}$ as long as head and equal in length to height of body; jaws, vomer, and palate with bands of villiform teeth, the vomerine band V-shaped. Nostrils in front of middle of eye, separated by a slight interspace, the anterior nearer to its mate than to tip of snout. Branchiostegals 8 ; pseudobranchia absent. Gill rakers long and numerous, the longest slightly exceeding diameter of eye, 15 developed below angle of first arch, besides several rudiments; dorsal origin slightly behind that of pectoral, its distance from tip of snout about $7 \frac{1}{8}$ in total, rays well developed; in the anterior $\frac{1}{8}$ of the fin, in a space equal to length of head, were counted 20 rays, the longest of which is $\frac{2}{5}$ as long as head; anal origin under twenty-first dorsal ray, its rays shorter than those of dorsal; pectoral extending to vertical from eighteenth ray of dorsal, $\frac{4}{5}$ as long as head; ventrals composed each 
of a simple filament, the origin slightly in advance of vertical through pectoral origin, the length $\frac{2}{8}$ that of head, not reaching nearly to vent, the distance of which from origin of ventrals is slightly greater than length of head. Color brownish yellow; head and abdomen blackish. Gulf of Mexico, in great depths. Only the type known, $237 \mathrm{~mm}$. long. (catena, chain, from the arrangement of the mucous cavities on the head.)

Bassozetus catena, Goode \& Bean, Proc. U. S. Nat. Mus. 1885, 603, Lat. $28^{\circ} \mathrm{co}^{\prime} 15^{\prime \prime}$ N., Long. $87^{\circ} 42^{\prime} \mathrm{W}$., in 1,467 fathoms ('Type, No. 37341. Coll. Albatross); GÜNTHER, Challenger Report, xXII, 111, 1887; GOODE \& BEAN, Oceanic Ichthyology, 323, fig. 286, 1896.

2882. BASSOZETUS TENIA (Günther).

D. 138 ; A. 115; P. 30 ; V.1. The greatest depth of the body is below the origin of the dorsal fin and about $\frac{1}{8}$ of the length of the trunk, the vent being not quite thrice as distant from the extremity of the tail as from the snout; therefore, the whole of the fish, and especially the tail, is much attenuated. Head not compressed, low and long, forming $\frac{t}{7}$ length of trunk. Structure of the bones of the head as in B. compressus. Snout rather swollen and broad, the upper jaw but slightly overlapping the lower; maxillary extending far behind the eye, which is very small, $\frac{1}{3}$ length of snout, about $\frac{1}{3_{4}}$ that of head, and $\frac{1}{4}$ width of interorbital space. Teeth very small and short, densely set, forming narrow, villiform bands; vomerine bands open $\wedge$-shaped. Gill cavity deer black; gill rakers long and slender, 16 in number, with some rudimentary ones in front and behind. Dorsal fin commencing above upper end of gill opening, with short rays partly hidden in the skin, the rays becoming longer on the anterior third of tail, but remaining of moderate length, the anal rays still shorter; pectoral with a broad base, quite free, and composed of rather feeble rays, its length equal to that of postorbital portion of head; ventral rays very feeble, reaching nearly to the middle of the pectoral. The scales must have been extremely thin and rather small; there were probably about 20 in a transverse series running from the vent to the dorsal fin. The lateral line can not be made out. Light colored (possibly pink in life), with the head and abdomen black. Only 1 specimen known of this eminently bathybial fish, obtained in mid-Atlantic (Challenger Station 104) at a depth of 2,500 fathoms. Its total length is 10 inches.

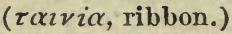

Bathyonus toenia, GüNTHER, Challenger Report, $\mathrm{XxII}, 110,1887$, pl. 23, fig. A, mid-Atlantic, Station 104, at a depth of 2,500 fathoms; GoODE \& BEAN, Oceanic Ichth., 323, 1896.

962. MCEBIA, Goode \& Bean.

Mobia, GOODE \& BEAN, Oceanic Ichthyology, 331, 1896 (gracilis).

Brotulids resembling Bassozetus in general form, excepting that the tail is prolonged in a very slender filament, the dorsal and anal rays being extremely short posteriorly, but positively confluent with the candal rays, which are much longer and much exserted; ventrals each bifid, instead of a single ray, as in Bassozetus. Head very cavernous, the sinuses large and conspicuous on the infraorbital ring, on the mandible, and the pre- 
operculum. A single, short, feeble spine on the shoulder, but none upon the operculum or preoperculum, though certain projections seem to show above the eye, doubtless due to the shrinkage of the integument upon the underlying projections of the bone. Month very wide, the extremity of the maxillary much dilated; posterior nostrils very wide and separated from the eye by a small, spinous projection of bone; teeth in narrow bands, that on the vomer $V$-shaped, with the 2 arms straight. A few large scales in a row starting from the upper angle of the gill opening and terminating over the axle of the pectoral. Gill rakers on outer arch rather numerous, long and slender. Pseudobranchiæ represented by 2 minute globules. Deep sea; 2 species known. ("Named in honor of Prof. Karl Möbius, director of the Royal Zoological Museum in Berlin, who has added much to our knowledge of marine life by his noble work, Die Fauna der Kielerbucht, and by numerous other writings.")

\section{MOEBIA PROMELAS (Gilbert).}

Head 2 in trunk; depth 3. Body $3 \frac{1}{8}$ to $3 \frac{1}{4}$ in tail. Tail produced into a filament, the eaudal basis extremely narrow, supporting 5 long slender rays which are firmly bound together. Mouth terminal, large, the maxillary much dilated at tip, reaching well behind the eye, 1.2 in head; lower jaw included, the tip slightly produced. Teeth in villiform bands on mandible, premaxillary, vomer, and palatines, the band on mandible very narrow, that on vomer with the diverging arms much incurved, the anterior angle rounded. Tongue toothless, some of the basibranchials forming a sharply elevated dentigerous crest. Gill laminæ extremely narrow, the gill rakers of outer arch very long and slender, 1 (with 4 rudiments) above angle, 15 below. Infraorbital chain with 6 mucous sinuses, the mandible with 5, preopercle with 5, and a number on top of head; these are all bridged over with very delicate membrane which is easily ruptured. A row of low, strong spinous points directed posteriorly on the ridge running backward from the cye; no other spines on head, though a number of short spinous points are made evident when the skin is removed; opercular spine rather weak. A distinct membranaceous flap runs along the projecting edge of shoulder girdle, connecting pectorals with upper end of gill flap; pectorals slender, equaling postorbital part of head; ventrals each of a bifid filament, the two branches joined at the base for a very short distance, variable in length, reaching to or nearly to tips of pectorals, usually contained about $1 \frac{1}{8}$ times in head; dorsal beginning a trifle behind base of pectorals, its distance from occiput equaling distance of latter from front of eje. Scales very small, apparently covering a part of top of head; 3 series of large pores on sides; 1 from upper end of gill slit backward parallel with dorsal outline; a second along middle of sides; the third beginning halfway between base of pectorals and ventral outline, extending backward on belly and along base of anal fin, these lines all somewhat indistinct, and it can not be determined how far they extend backward. Color light brown; head (except occiput), mouth, gill cavity, and abdomen jet-black; fins dusky. This species closely resembles Mobia gracilis (Guinther), from New Guinea, dif- 
fering in the following respects: Depth 3 in trunk (in gracilis $3 \frac{1}{2}$ ); eye 6

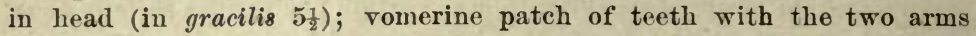
incurved (U-shaped in gracilis); dorsal fin beginning behind the pectoral (over root of pectoral in gracilis); an additional series of large scaies (lateral line) along middle of sides, and another along ventral outline; trunk $2 \frac{1}{8}$ in tail ( $2 \frac{2}{8}$ in gracilis); ventrals shorter, not reaching past tips of pectorals. Five specimens, the largest $9 \frac{1}{2}$ inches long, from dlbatross Station 3010, at a depth of 1,005 fathoms, in the Gulf of California. (Gilbert.) ( $\pi \rho o$, before; $\mu \varepsilon \dot{\lambda} \alpha \varsigma$, black.)

Porogadus promelas, GiLBert, Proc. U. S. Nat. Mus. 1891, 547, Gulf of California, in 1,005 fathoms. (Coll. Albatros8.)

963. NEOBYTHITES, Goode \& Bean.

Neobythites, Goode \& Bean, Proc. U. S. Nat. Mus. 1885, 600 (gilli).

Brotulids having the body elongate, compressed, covered with small scales, and the head also scaled; lateral line incomplete, obsolete posteriorly. Eye moderate; snout moderate, rounded, slightly produced, the lower jaw slightly included; no barbel. Teeth villiform, in narrow bands in jaws and palatines; vomerine teeth in a V-shaped patch; 2 weak spines at angle of preoperculum, and a stronger one at angle of operculum. Gill openings wide, the membranes deeply cleft and not attached to the isthmus; vertical fins united; ventrals reduced each to a bifid ray. Branchiostegals 8. Pseudobranchiø present, but small. Air bladder present. ( $v$ \& 05, new; Bythites.)

a. Scules about 88 in longitudinal series; depth $4 \frac{2}{3}$ in length.

aa. Scales about 123 in longitudinal series; depth $5 \frac{3}{4}$ in length; dorsal rajs 101.

MARGINATUS, 2885.

2884. NEOBYTHITES GILLI, Goode \& Bean.

Body compressed, its height contained $4 \frac{2}{8}$ times in total length, and less than length of head; interorbital area convex, its width equal to diameter of circular eye, $3 \frac{2}{3}$ in length of head, and $1 \frac{1}{2}$ in length of snout in young. Head compressed, deeper than broad, with wide sinuses, its length contained $4 \frac{1}{2}$ times in that of the body; snout obtusely rounded, slightly produced; mouth large, the maxillary extending considerably behind the vertical through posterior margin of eye, expanded posteriorly; mandible still longer, its length about $2 \frac{1}{3}$ times in height of body; interorbital space convex. Teeth in villiform bands in jaws and on palatines; vomerine patch subcircular, with angles extended posteriorly. Gill rakers moderately long and slender, somewhat numerous, the longest about $\frac{2}{8}$ diameter of eye, 11 developed and 3 rndiments below the angle. Pseudobranchiæ absent; gill opening wide, the membrane deeply cleft, free from the isthmus behind. A single long, flat spine attached to posterior portion of operculum, high up, extending back to its edge; a small hidden spine at lower angle of preoperculum. Nostrils small, the anterior one in a very short tube, almost upon tip of snout; posterior nostril slightly larger, not tubular, immediately in front of middle of eye. Scales mod- 
erate, upon head and body, in 88 vertical rows, 7 rows between dorsal origin and lateral line, which becomes obsolete in its posterior half, 16 or 17 from vent forward to lateral line; dorsal origin behind that of ventral and pectoral, its distance from snout contained 4 times in total length, its rays moderately long; anal origin under eighteenth dorsal ray, its distance from snout contained $2 \frac{1}{8}$ times in body length, rays rather slenclerer than those in the dorsal; caudal rays 6 or 7 in number, their length contained 9 times in total length, not differentiated from those of the adjacent fins; pectoral origin well forward, its base somewhat concealed by the flap of 'the operculum, its length about equal to $\frac{2}{8}$ that of head; ventrals each a bifid ray, the inner filament the longer, inserted slightly in advance of the base of the pectoral, not far from humeral symphysis, and reaching nearly to vent, its length nearly equal to height of body; distance from origin of ventral to vent slightly greater than height of body; color light yellow, with silvery reflections, with cloudings of brown above lateral line and numerous black chromatophores; a series of irregular brown blotches above the lateral line, with 1 or 2 much darker, extending upon the dorsal fin. In many specimens the color is uniform yellow, with simply the dark ocelli showing. (Goode \& Bean.) Atlantic, in rather deep water, from Gulf Stream to the coast of Brazil. (Named for Dr. Theodore Gill.)

Neobythites gillii, Goode \& Bean, Proc. U. S. Nat. Mus. 1885 , 601, Lat. $28^{\circ}{ }_{3} 6^{\prime}$ N., Long. $85^{\circ}$ $33^{\prime} \mathrm{W}$., in XxY fathoms (Type, No. 37340. Coll. Albatross); GÜNTHER, Challenger Report, XxII, 103, 1887; GOODE \& BEAN, Oceanic Ichth., 325, fig. 289, 1896.

Neobythites ocellatus, GÜNTHER, Challenger Report, XxII, 103, pl. 21, fig. B, 1887, off Per nambuco, in 350 fathoms.

2885. NEOBYTHites Marginatus, Goode \& Bean.

Head $4 \frac{2}{3}$ in total length; depth 53. D. 101; scales 7-123-29. Body compressed, somewhat elongate; interorbital area convex, its width greater than the diameter of the circular eye. Mouth large, the maxillary extending considerably behind vertical through posterior margin of orbit, its length 2 in head; mandible slightly more than $\frac{2}{8}$ height of body. Teeth as in $N$. gillii. Gill rakers slightly longer than $\frac{1}{2}$ the diameter of eye, 7 and 3 rudiments below the angle of the anterior arch. Pseudobranchix absent. A long flat spine upon the upper edge of the operculum, extending back nearly to its margin; 2 short, flat spines npon the angle of the preoperculum. Nostrils as in $N$. gillii. Scales small, very closely imbricated, the lateral line obsolete in its posterior half. Distance of dorsal origin from snout 4 times in total length; anal origin under fourteenth dorsal ray, at a distance from the snout 2 ? times in total length. Caudal of about 8 or 9 rays, very closely placed, abont $10 \frac{1}{2}$ times in total length; pectoral placed much as in Benthocometes, its length about $2 \frac{1}{8}$ times that of the head, extending to vertical through the vent; ventral a bifid ray inserted in advance of base of pectoral, not reaching to the vent, its length considerably less than height of body; distance of ventral origin from vent slightly more than height of body. Color light yellowish brown, an obscure narrow band of darker brown commencing on the snout, inter- 
rupted by the eye, and extending backward $\frac{2}{3}$ distance to tail; another beginning on the snont, extending over eye and back as far as first described, interrupted posteriorly; dorsal fin milky white at base in its anterior third; above this a blackish band extending whole length of fin; a narrow white margin above. The type is from Blake Station LXXIX, off Barbados, in 209 fathoms. (marginatus, edged.)

Neobythites marginatus, Goode \& BEAN, Bull. Mus. Comp. Zool., x, No. 5,162, 1883 off Barbados, in 209 fathoms (Coll. Blake); Goode \& BrAN, Oceanic Ichthyology, 326, fig. $290,1896$.

964. BENTHOCOMETES, Goode \& Bean.

Benthocometes, Goode \& BEAN, Oceanic Ichthyology, 327, 1896 (robustus).

Brotulids, similar in appearance and structure to Neobythites and Bas8ogigas, distinguished by 2 short flat spines upon the anterior portion of the operculum, placed at some distance from each other, and by the absence of spines on the preoperculum. The lateral line is complete, and extends without interruption to the posterior fourth of the body, where it becomes obsolete. The vomerine teeth are bunched in a circular patch instead of being arranged in triangular form. The head is comparatively short, with the jaws in front nearly equal; the snout not produced, but obtuse, rounded, and almost declivous in its outline. Deep sea. Two species known. ( $\beta \varepsilon \dot{v} \theta 05$, the depths; $\varkappa \omega_{\mu} \dot{n}_{\tau \eta}$, inhabitant.)

2586. BENTHосOMETES ROBUSTUS, Goode \& Bean.

Body rather short and deep, its greatest height nearly $4 \frac{2}{8}$ in total length and about equal to length of head; interorbital area convex, its width greater than diameter of the circular eje, and $1 \frac{1}{2}$ times length of snout; head about 4 times diameter of eye; mouth moderate, the maxillary extending to vertical through posterior margin of eye, the mandible a little beyond, its length equal to that of postorbital part of head. Teeth in villiform bands in jaws and on palatines; vomerine teeth bunched in a circular patch. Gill rakers moderate, the longest a little more than twice in diameter of eye, 4 above angle of first arch, 11 below. Pseudobranchia rudimentary. Gill opening wide, the membrane deeply cleft behind, free from the isthmus. A pair of short flat spines npon the anterior portion of the operculum. Nostrils small, the anterior as close to the snout as the posterior ones are to the eyes; no apparent cirri. Scales minute; lateral line obsolete on the last fourth of body. Dorsal origin behind that of ventral and pectoral, its distance from snout $3 \%$ times in body; height of dorsal fin moderate, the longest ray about 3 times in head; anal origin under eighteenth ray of dorsal, the height of fin about equaling that of dorsal; vertical fins not connate with the caudal, which consists of 12 or 13 very slender rays, its length nearly equal to $\frac{1}{2}$ head; pectoral with a broad base, close to gill opening, its length nearly $\frac{2}{8}$ that of head; ventral a single bifid ray, inserted in advance of vertical through base of pectorals, and not far from humeral symphysis, reaching nearly halfway to vent, the distance of which from the origin of the ven- 
tral is equal to length of head. Color yellowish brown. The type of this species, a specimen $88 \mathrm{~mm}$. long, was taken by the Blake from Station XCIV, off Moro Castle, Cuba, at a depth of from 250 to 400 fathoms. A collateral type specimen (No. 29057) was obtained by the Fish Hawk from Station 1043 in Lat. $38^{\circ} 39^{\prime}$ N., Long. $73^{\circ} 11^{\prime}$ W., at a depth of 130 fathoms. (Goode \& Bean.) West Indies, to lat. $39^{\circ}$ N., in Gulf stream. (robustus, stout.)

Neobythites robustus, Goode \& BEAN, Bull. Mns. Comp. Zool., X, No. 5, 161, 1883, off Moro

Castle, Cuba, in from 250 to 400 fathoms. (Type in M. C.Z. Coll. Blake.)

Benthocometes robustus, GOODE \& BEAN, Oceanic Ichthyology, 327, fig. 288, 1896.

\section{BASSOGIGAS, Gill.}

Bassogigas, GILL MS. in GOODE \& BEAN, Oceanic Ichthyology, 328, 1896 (gillii).

Brotulids having the body elongate, compressed, covered with a thick, heavy skin, which upon the head covers and obscures all the angles of the skull; scales small, covering body and head completely; lateral line indistinct for the greater part of the course, but apparently extending at least $\frac{2}{8}$ of the way from the operculum to the tail; eye moderate; vertical fins completely united; ventrals a pair of bifid filaments inserted behind the humeral symphysis and remote at their bases, short, rather stout; snout without barbels, slightly produced, the lower jaw being barely included; villiform teeth in the jaws, on the vomer and palatines; vomerine patch V-shaped, but with its arms broadly expanded and thicker at the angle, so that it is almost triangular; operculum with a long, sharp spine; preoperenlum unarmed; branchiostegals 8 ; air bladder present; pseudo. branchiæ small. Deep sea. ( $\beta \alpha \dot{\alpha} \sigma \omega v$, for $\beta \alpha \theta \dot{v} 5$, deep; $\gamma$ iy $\alpha$ s, giant.)

a. Dorsal fin with 83 rays; anal 67.

GILLII, 2887.

aa. Dorsal fin with 95 rays; anal 82.

STELLIFEROIDES, 2888 .

\section{BASSOGIGAS GILLII, Goode \& Bean.}

D. 83 ; C. 6 ; A. 67 . Head rather short and broad, with snout slightly overlapping the lower jaw; diameter of the eye scarcely $\frac{1}{8}$ of the length of the snout and about $\frac{1}{12}$ that of head; maxillary extending far behind eye, the vertical from the anterior margin of orbit nearly bisecting it, its length $\frac{1}{2}$ that of head, and its posterior margin ending in a broad triangu. lar dilation; teeth normal; anterior and posterior nostrils separated by : space greater than diameter of eye; preoperculum with a square, rounded. angle; no armature; operculum with a strong, sharp spine above, the tiy of which projects slightly beyond the opercular flap; distares of vent fron root of pectoral slightly more than length of head, as far removed frow this point as is the anterior nostril; scales moderale, cuvering the entir head; lateral line somewhat conspicuous, obsolete iu its posterior third. Dorsal and anal fins enveloped in thick scaly skin; origin of dorsal is advance of middle of pectoral; pectorals rounded, hroad, and very shori: less than $\frac{1}{2}$ as long as head and extending about $\frac{1}{2}$ distance from origic to vertical from vent; ventrals inserted somewhat behind angle of pre. operculum, extending to vertical from axil of pectoral, and abou's $\frac{1}{4}$ of distance from origin to vent; each ventiral filament bifid, the if 1 if $\mathrm{f}$ 
part being the longer. Color uniform grayish brown; fins darker. The type of this species was obtained by the Albatross from Station 2684, off Cape Henlopen, Delaware, in Lat. $39^{\circ} 35^{\prime}$ N., Long. $70^{\circ} 5 t^{\prime}$ W., at a depth of 1,106 fathoms. (Goode \& Bean.) (Named for Dr. Theodore Gill.)

Bassogigas gillii, GOODE \& BEAN, Oceanic Ichthyology, 328, fig. 291, 1896, off Cape Henlopen, Delaware, in $\mathrm{x}, \mathrm{ro6}$ fathoms. (Type, No.39117. Coll. Albatross.)

2888. BASSOGIGAS STELLIFEROIDES (Gilbert).

Head 4 to $4 \frac{1}{5}$ in length; depth 5 to $5 \frac{1}{4}$. D. 95 ; A. 82 ; seales 110 . Physiognomy strikingly like that of the Scirnoid genus Stellifer. Mouth large, oblique, the lower jaw included, maxillary reaching well beyond orbit, $\frac{1}{2}$ length of head. Teeth uniform, small, in narrow bands, those on vomer in a $\Omega$-shaped patch; a well-developed banil on palatines; tongue smooth, a well-developed dentigerous crest on median line behind it; no barbel at symphysis. Snout short, bluntly rounded, about equaling diameter of orbit, slightly overhanging mouth, 5 in head; interorbital width 4; upper limb of preopercle extending obliquely downward and backward, largely adnate, the angle produced into a free membrauaceous flap which entirely conceals the narrow interopercle, and bears no spines. The structure of the gill flap does not appear to have been correctly interpreted. The opercle is strong, but of small extent, forking at its base, 1 branch continued straight backward as a strong spine, the second a narrow flat process downward and somewhat backward, parallel with and little distant from margin of preopercle. Filling the deep notch between these 2 processes, and forming the greater portion of the gill flap, is the thin membranaceous subopercle. Branchiostegal rays 7. Gill rakers long and slender, the longest $\frac{8}{4}$ diameter of orbit, 7 above angle, 13 and about 5 rudiments below. Nape midway between front of dorsal and front of eye; dorsal and anal similar, uniform, low, joined to base of caudal, the latter truncate, projecting well beyond them; ventrals inserted uncler angle of preopercle, each of a single ray forked to the very base, the 2 branches united by membrane for a distance equaliug $\frac{2}{8}$ orbit, the inner filaments being longest, $\frac{1}{3}$ longer than head, and extending well beyond front of anal; pectorals long and narrow, $1 \frac{1}{2}$ in head; a narrow membranaceous flap connecting base of pectorals with upper angle of opercular flap. Scales small, well imbricated, entirely investiug body and head, including gular membrane and part of gill membranes; lateral line nearly complete, lacking for about $\frac{1}{7}$ lengtl of body, running high, parallel with dorsal outline. Color silvery gray, dusted with coarse black specks, darker along dorsal outline; dorsal and anal with a narrow light streak at base, otherwise dusky, becoming black posteriorly, and with a uarrow white margin; caudal black, with a broad white terminal bar; pectorals and ventrals white, with few black specks; peritoneum silvery white; mouth white anteriorly, its posterior portion and gill cavity jet-black. Pacific Ocean, off coast of Lower California. Many specimens from Albatross Station 2996, in 112 fathoms. Length 7 inches. (Stellifer, a genus of Scianida; $\varepsilon i \tilde{\delta} \circ 5$, resemblance.)

Neobythites stelliferoides, Gilbert, Proc, U. S. Nat. Mus. 1891, 112, off Lower California. (Type, No.44383. Coll. Dr. Gilbert.) 
966. BARATHRODEMUS, Goode \& Bean.

Barathrodemus, Goode \& BEAN, Bull. Mus. Comp. Zool., x, No. 5, 200, 1883 (manatinus).

Body brotuliform, much compressed; head compressed; mouth moderate. Head unarmed, except for a short flattened spine at upper angle of opercle. Snout long, projecting far beyond premaxillaries, its tip much swollen; jaws subequal in front. Teeth uninute, in villiform bands on jaws, vomer, and palatines. No barbels. Anterior nostrils on the outer angles of the dilated snout, circular, each surrounded by a cluster of mucous tubes. Posterior nostrils above front of eye. Gill openings wide, the membranes not united. Gill rakers rather few. Body and head covered with small, thin, scarcely imbricated scales. Uorsal and anal loug. Caudal fin separate, long, and slender. Ventrals close together, far in front of pectorals, each reduced to a single bifid ray. Deep-sea fishes. ( $\beta \alpha \dot{\rho} \alpha 0 \rho o v$, a gulf or deep abyss; $\delta \tilde{\eta} \mu о 5$, people.)

\section{BARATHRODEMUS 'MANATINUS, Goode \& Bean.}

Head about 6 in total length; depth $7 \frac{1}{2}$. D. $106 ;$ A. $86 ;$ C. $2+5+2 ;$ P. 18 to 20 ; V. $1 / 1$; scales about 175 . . Body much compressed. Dorsal and anal outline approaching at an equal angle the horizontal axis. Scales small, about 175 rows between the branchial opening and the tail, and about 34 rows, counting upward and forward obliquely from the origin of the anal to the dorsal line; lateral line apparently absent. Head considerably compressed, with rounded upper surface, its width contained $2 \frac{1}{2}$ times in its length, its greatest height equaling $\frac{2}{8}$ its length. Snout slightly longer than the horizontal diameter of the eye, and projecting beyond tip of upper jaw a distance equal to vertical-diameter of eye, much dilated and swollen, the anterior pair of nostrils being situated at the most salient angles; snout in general form resembling that of a manatee, whence the specific name. Mouth moderate, its cleft extending to the vertical from the center of the orbit; length of upper jaw equal to twice horizontal diameter of eye, and contained $2 \frac{1}{2}$ times in length of head; posterior portion of maxillary considerably expanded; maxillary largely included within a skinny sheath; when the mouth is closed the lower jaw is entirely included within the upper. Vomer and palatino with bands of teeth more than twice as broad as the bands of the intermaxillaries and on the mandible. Eye elliptical in form, its vertical dianneter $\frac{2}{8}$ of its horizontal, the latter being equal to distance from tip of snout to posterior nostril; and contained $5 \frac{1}{4}$ times in length of head; distance of eye from dorsal outline equal to $\frac{1}{2}$ its horizontal diameter, and to $\frac{1}{5}$ height of head in a perpendicular through center of eye; interorbital space rounded, its width equal to horizontal diameter of eye. Dorsal fin inserted in the vertical above insertion of pectoral, at a distance from end of snout equal to that of insertion of pectoral; anal inserted under twenty-first to twenty-third dorsal ras, and at a distance from snout about equal to $\frac{1}{3}$ body length; height of dorsal and anal fins about equal to $\frac{1}{2}$ height of body at insertion of anal, their bases extending almost to insertion of caudal; caudal composed of 9 rays, the 5 medial ones almost 
equal in length, though the tip of the tail is slightly rounderl, about equal to height of body midway between branchial opening and base of tail; ventrals inserted almost under middle of opereulum, in length about equal to $\frac{1}{2}$ length of head; pectorals inserted under origin of dorsal, and at a distance behind branchial opening equal to $\frac{2}{3}$ vertical dianeter of eye, its length equal to greatest height of the body. Color grayish brown; abdominal region black. (Goode \& Bean.) Gulf stream, north of the Bermudas, in 647 to 1,395 fathoms. (Manati, like the manatee or. sea cow.)

Barthrodemus manatinus, Goode \& BeaN, Bull. Mus. Comp. Zool., x, No. 5, 200, 1883, Lat. $33^{\circ} 35^{\prime} 20^{\prime \prime}$ N., Long. $76^{\circ}$ W., in 647 fathoms (Type in M. C. Z. Coll. Blake); JORDAN, Cat., 127, 1885; GüNTHER, Challenger Report, XXIı, 100, 1887; GOODE \& BEAN, Oceanic Ichthyology, 332, fig. 294, 1896.

967. NEMATONUS, Giinther.

Nematonus, GÜNTHER, Challenger Report, Xxir, 114, 1887 (pectoralis).

Body compressed, with long tapering tail. Bones of head soft, mucilerous channels moderately developed, and with the integument very thin or absent on the upper portion and snout. Operculum cartilaginous and flat; a broad process near its upper angle corresponding to the opercular spine in some of the related genera, the head otherwise unarmed, though irregular by reason of the cranial bones. Snout much depressed, broad, rounded; jaws equal in front; mouth very wide; bands of villiform teeth in jaws, on vomer and palatines. Barbel none. Eyes small. Vertical fins confluent; ventrals a pair of bifid filaments close together, on the isthmus, close to the humeral symphysis. Gills 4, with very short lamina and rather short, incurved, acicular gill rakers on the first arch, and much shorter, less numerous, spatulate ones on the 3 other arches. Pseudobranchiæ rudimentary. No traces of a lateral line, though the body is covered with scales of considerable size, almost as large as the eye, and the cheek with others still larger. Nematonus differs from Porogadus not only in the absence of spines upon the head, as Giinther has indicated, but in the much less ossified opercular apparatus, in the shorter and thicker head, in the absence of the 3 series of pores simulating lateral lines, and in the tendency to prolongation in the lower rays of the pectoral, which increase from the uppermost to the lowermost in Nematonus, while Porogadus has a lanceolate fin, and also in the extreme exsertion of the caudal rays. ( $\nu \tilde{\eta} \mu \alpha$, thread; Onus, the rockling.)

2890. NeMATONUS PECTORALIS, Goode \& Bean.

D. 93 ; A. 73; P. 17; V.2. Body moderately elongate, much compressed, the tail much shorter and more robust than in Bassozetus catena, its height equaling $1 \frac{1}{8}$ times length of head and $\frac{1}{7}$ that of body. Head stoutish, not much compressed, lower than body, its length contained $5 \frac{1}{8}$ times in the body; snout compressed, broad at its tip, its length exceeding diameter of the circular eye; interorbital area slightly convex, its width slightly exceeding twice diameter of eye, 3 times in head. Maxillary 
extending far behind eye, its length less than that of preorbital portion of head; mandible as long as postorbital portion of head; jaws, vomer, and palatines with narrow bands of villiform teeth, normally arranged. Branchiostegals 8. Gill lamellø very short; gill rakers long and numerous, 18 on first arch below the angle, 5 above, 4 of which are rudimentary. Pseuciobranchire present, but very rudimentary. Anterior nostrils on the top of the snout and near the median line of the head, near its tip, separated by a space about equal to diameter of eye; posterior nostrils in front of eye. Muciferous pores large, arranged much as in B. catena. Dorsal origin in the same vertical with that of pectorals, its distance from tip of snout contained 5 times in total and equaling twice length of maxillary. Rays well developed in anterior third, the longest $\frac{2}{8}$ of head; anal origin under twentieth dorsal ray, its rays nearly as long as those of dorsal; pectoral with its penultimate ray produced, extending to thirteenth ray of anal, nearly twice as long as head; ventrals originating in advance of vertical through pectorals, and each a bifid filament; distance of ventral origin from tip of snout equaling length of ventral anil about 8 as long as head; distance of ventral origin from vent considerably greater than length of head; distance from tip of ventral to vent equal to $\frac{1}{2}$ the length of the head. Number of scales in transverse series from vent to dorsal about 23; from the upper angle of the gill opening to the vertical through origin of anal 32. Color brownish vellow; head and abdomen blackish. The type (No. 37342, U. S. Nat. Mus.) was taken at Albatross Station 2380, Lat. $28^{\circ} 02^{\prime} 30^{\prime \prime}$ N., Long. $87^{\circ} 43^{\prime} 45^{\prime \prime}$ W. in 1,430 fathoms. It is $183 \mathrm{~mm}$. long to the caudal base, 215 with caudal. Another young specimen, $70 \mathrm{~mm}$. long, was taken at Blake Station XCV, off Dominica, in 330 fathoms. (Goode \& Bean.) (pectoralis, pertaining to the breast.)

Nematonus pectoralis, Goone \& Bean, Proc. U.S. Nat. Mus. 1885,604 , Lat. $28^{\circ} 02^{\prime} 30^{\prime \prime}$ N., Long. $87^{\circ} 43^{\prime} 45^{\prime \prime}$ W., in $x, 43^{\circ}$ fathoms (Type, No. 37342 . Coll. Albatross); GUnTher, Challenger Report, XXII, 114, 1887; GOODE \& BEAN, Oceanic Ichth., 333, fig. 295, 1896.

\section{POROGADUS, Goode \& Bean.}

Porogadus, Goode \& Bean, Proc. U. S. Nat. Mus. 1885, 682 (miles).

Body brotuliform, much compressed; head with numerous spines on interorbital space, 2 pairs on the shoulders, 1 at angle of operculum and a double series on angle of preoperculum; head with numerous mucous pores, as in Bassozetus; mouth large; snout moderate, not projecting much beyond the upper jaw; jaws nearly equal in front; teeth in villiform bands in jaws and on vomer and palatines; barbel none; gill openings wide, membranes narrowly united, not attached to the isthmus; gills 4; gill laminæ short; gill rakers moderate, numerous; pseudobranchixe absent; caudal fin of few rays, on a very narrow base, not prolonged, scarcely differentiated from the vertical fins; dorsal and anal fins well developed; pectorals simple, moderate; each ventral a single bifid ray close to the humeral symphysis; branchiostegals 8 ; scales small; lateral line apparently triple, or replaced by 3 series of pores-1 close to ventral outline, 1 median, and another along base of dorsal. ( $\pi$ ó $\rho \circ$, pore; Gadus, the codfish.) 
2891. POROGADUS MILES, Goode \& Bean.

Head $6 \frac{1}{2}$; depth 10 ; eye $5 \frac{8}{4}$ in 1 sad; body much compressed, elongate, tapering to a very slender tail; head long, moderately compressed, subconical, the profile gradually ascending in nearly a straight line from tip of snout to origin of dorsal; interorbital space slightly convex, spiny, its width $4 \frac{3}{5}$ times in length of head, and slightly greater than diameter of eye; opereles and head generally covered with numerous and strong spines, as described in the generic diagnosis; mouth very large and wide; maxillary extending far behind eye and much expanded at its tip, its length more than $\frac{1}{2}$ that of head; length of mandible equal to greatest height of body; jaws, vomer, and palatines with narrow bands of villiform teeth, none of which is enlarged; gill rakers 15 on anterior areh below the angle, 3 rudimentary ones above. Anterior pair of nostrils nearly on top of snout and somewhat nearer its tip than to eye, separated by a narrow space and placed immediately in front of middle of eye; behind each posterior nostril a strong spine projecting outward and upward; pores of the head arranged much as in Bassozetus; scales minute; lateral line not to be clearly made out; 3 rows of minute pores on each side of dorsal, median, and ventral, beginning near head and extending well toward extremity of tail. Dorsal origin slightly behind vertieal through pectoral base, its distance from snout nearly 6 times in length of body, its rays moderately long, the longest about as long as snout, and very numerous; anal origin in vertical from twenty-second or twentythird dorsal ray, its distance from snout $3 \frac{1}{8}$ times in length of body, its rays about as long as those of dorsal; pectoral imperfect, its length in the type equaling $\frac{1}{2}$ that of head; ventrals a bifid filament, placed close to the humeral symphysis, well in advance of pectoral, its length equal to height of body; distance from origin of ventrals to vent nearly equal to length of head; ventral not reaching vent by a distance equal to length of snout. Color blackish brown. The type (No. 35625, U:S. Nat. Mus.) is 153 mm. in length, from Albatross Station 2230 , lat. $38^{\circ} 27^{\prime} \mathrm{N}$., long. $73^{\circ} 02^{\prime} \mathrm{W}$., at a depth of 1,168 fathoms. (Goode \& Bean.) (miles, a soldier.)

Porogadus miles, Goode \& Bean, Proc. U. S. Nat. Mus. 1885, 602, Lat. $3^{8 \circ} 27^{\prime}$ N., Long. $73^{\circ} \mathrm{Oz}^{\prime}$ W., in $\mathrm{x}, \mathrm{1} 68$ fathoms; GOODE \& BEAN, Oceanic Iehthyology, 334, fig. 292, 1896.

969. PENOPUS, Goode \& Bean.

Penopus, GOODE \& BEAN, Oceanic Ichthyology, 335, 1896 (macdonaldi).

Body stont in front, tapering behind; tail not greatly exceeding the length of the rest of the fish; head scaly, thick, its top surface flat, with depressed and moderately projecting snout; a pair of minute postnasal spines; a strong and much curved spine on the operculum; several weak spines on the angle of the preoperculum, and several at the posterior angle of the suboperculum; mouth moderately large, the lower jaw ineluded; several narrow slit-like pores along the margin of the preorbital and suborbital; 2 minute pores on under surface of mandible near its symphysis, and not far behind them 2 long slit-like pores; the 
anterior nostril in a long slit, the posterior larger, oblong in shape, and $\frac{1}{2}$ concealed by a fold of skin; eye small; the teeth appear only in minute asperities, the intermaxillary band much wider in front than behind; mandibulary band narrow throughout; romerine band very narrow, V-shaped; palatines in a long, broad band; gill openings wide, deeply cleft in front, narrowly joined to the isthmus; branchiostegals 8 ; no pseudobranchia ; gill rakers long and slender, not numerous; gill laminie moderately long, a long slit behind the fourth gill; scales very small; lateral lines 3 ; caudal fin consisting of few rays, well differentiated from the dorsal and anal; clorsal beginning not far behind head; ventrals slightly in advance of the pectorals and composed of 2 rays, united by membrane, which forms a margin around them; pectoral normal, several of its upper rays simple; vent not much in advance of middle of total length. This genus agrees with Porogadus in nearly every respect except in the scarcity of spines on the head and in the structure of the ventrals. Porogadus has the ventrals composed of 2 distinct rays which are separated throughout their entire length, but in Penopus the 2 rays are inclosed in a membrane which connects them and forms a margin around them. In Porogadus, also, the suboperculum has a smooth margin and the opercular spine is weaker than in . Penopus, and is not curved. Deep seas. ( $\pi \dot{\eta} v \eta$, thread; $\pi$ ov́s, foot.)

2892. PENOPUS MACDONALDI, Goode \& Bean.

D. 137; A. 102. Greatest height of body equaling length of postorbital part of head and about $\frac{1}{9}$ of total without caudal; greatest width of body anteriorly about $\frac{2}{8}$ of its greatest height; head stout, its greatest width equaling $\frac{8}{4}$ of its greatest depth and more than $\frac{1}{3}$ of its length; width of interorbital space about $\frac{1}{5}$ length of head; eye very small, its length less than $\frac{1}{2}$ width of interorbital space; distance from eye to tip of snout equaling length of intermaxillary; distance of anterior nostril from tip of snout equaling length of eye; distance of posterior nostril from eye slightly less than its distance from tip of snout; maxillary expanded behind and reaching somewhat behind eye, its length equaling that of snout; mandible extendiug much behind eye, its length equal to postorbital part of head. Dorsal beginning over middlle of pectoral, its rays well developed, those in middle of fin longer than anterior ones; anal beginning under twenty-seventh ray of dorsal, middle rays longest; pectoral nearly $\frac{1}{2}$ length of head and about equal to distance of its tip from vent; ventral about $\frac{1}{3}$ distance of its origin from origin of anal. Lateral lines 3 , the uppermost beginning at the upper angle of the gill opening, quickly approaching top of body near base of dorsal and merging into dorsal base about middle of tail; median lateral line beginning a little behind head and extending almost to root of caudal, becoming very faint posteriorly; lowermost lateral line with its origin under and not far from base of pectoral, extending along lower side of tail and merging into base of anal fin somewhat beyond middle of length of tail. Color yellowish brown; operculum, opercular flap and branchiostegal membrane, pectoral, and ventral dusky. Only a single specimen, $315 \mathrm{~mm}$. long, known; obtained by the Albatross September 18, 1886, at Station 2716, Lat. $38^{\circ}$ $3030-81$ 
$29^{\prime} 30^{\prime \prime}$ N., Long. $70^{\circ} 57^{\prime} \mathrm{W}$., in 1,631 fathoms. (Goode \& Bean.) (Named for Hon. Marshall McDonald.)

Penopus macdonaldi, Goode \& BEAN, Oceanic Ichthology, 336, fig. 293, 1896, Lat. $3^{8^{\circ}} 29^{\prime} 30^{\prime \prime}$ N., Long. $70^{\circ} 57^{\prime}$ W., in 1,631 fathoms. (Type, No. 39433.)

970. DICROLENE, Goode \& Bean.

Dicrolene, Goode \& BeAN, Bull. Mus. Comp. Zool., x, No. 5, 202, 1883 (intronigra).

Brotulids with body moderately compressed; head somewhat compressed; mouth large; tip of maxillary much dilated; eye large, placed close to dorsal profile. Head with supraorbital spines; several strong spines on preopercle and 1 long spine at upper angle of opercle. Spont short, not projecting beyond the upper jaw; jaws subequal. Teeth in narrow villiform bands in each jaw, on head of vomer, and on palatines. No barbel. Gill openings wide, membranes not united; gills 4 ; gill laminæ of moderate length; gill rakers rather long, not numerous; pseudobranchix absent. Caudal not confluent with dorsal and anal, but without a distinct peduncle. Dorsal and anal fins long; pectoral rays in 2 groups, several of the lower ones being separated and much produced; ventrals a pair of bifid rays, close together on the isthmus. Branchiostegals 8 . Body and head covered with small scales; lateral line close to base of dorsal fln, apparently becoming obsolete on posterior third of body. Stomach siphonal; pyloric crea few and rudimentary; intestine shorter than body. Deep sea; a single species known. (

2893. DICROLENE INTRONIGRA, Goodo \& Bean.

Head 5; eye large, 4 in head; interorbital width 4. D. 100 ; A. about 85 ; C. 6 or 7 ; V. 1 ; P. $19+7$ or 8 ; scales 110 to 120 . Body moderately compressed, its dorsal and ventral outlines approaching at an equal angle the horizontal axis, and tapering to a narrow point. Head somewhat compressed, with flattish upper surface, which is encroached upon by the upper margin of orbit; a strong spine at posterior upper margin of orbit, pointing backward and upward; a long, sharp spine at upper angle of opercle, its exposed portion 2 in eye; 3 equidistant spines on lower posterior border of preopercle, much weaker than that on opercle. Large muciferous cavities in bones of head; a row of large cavities extending backward from upper angle of orbit, and continuous with those on lateral line. Mouth large, its cleft considerably more than $\frac{1}{2}$ head, the maxillary extending beyond eye and with scales upon its expanded tip. Distance from snout to origin of dorsal fin $\frac{2}{9}$ total length; anal inserted under twenty-fifth or twenty-sixth dorsal ray; height of dorsal and anal fins each about equal to eye; length of caudal fin 2 in distance from snout to dorsal; ventrals about equal to upper jaw; pectorals inserted close to branchial aperture, the 8 lower rays free and much prolonged, the longest and most anterior being about 3 in body, and more than 3 times as long as the contiguous posterior ray of the normally constructed portion of the fin, which is, however, about equal to the last free rays. West Indies, Gulf of 
Mexico, and Gulf Stream in various localities, and off coast of Soudan and on the bank d'Árguin, in deep water. (intro, within ; niger, black.)

Dicrolene intronigra, Goode \& Bean, Bull. Mus. Comp. Zool., x, No. 5, 202, 1883, Gulf Stream, Lat. $39^{\circ} 59^{\prime} 45^{\prime \prime}$ N., Long. $68^{\circ} 54^{\prime}$ W. (Coll. Blake); GÜNTHER, Challenger Report, XxII, 107, 1887; VAILIANT, Exp. Sci. Travailleur et Talisman, 258, pl. 23, fig. 2, 1888; GOODE \& BEAN, Oceanic Ichthyology, 338, fig. 297 A and B, 1896.

\section{MIXONUS, Günther.}

Mixonus, Günther, Challenger Report, XxII, 108, 1887 (laticeps).

Lower pectoral rays free, not united by membrane with, but inserted on the same base as, the upper part of the fin; they are but slightly stronger than the other rays and prolonged. Body elongate, compressed, covered with small, very thin and deciduous scales. Head slightly compressed, broad and flat above, depressed in front, naked (with the exception of the parts between the mandibles, and, perhaps, of the cheeks). Bones thin, with muciferous system moderately developed; only 1 small spine above on the operculum; preoperculum withont spine. Eye snall. Vertical fins united, but the narrow caudal projecting beyond the short dorsal and anal rays. Ventrals each reduced to a filament, which consists of 2 rays firmly bound together in their whole length; they are inserted behind the humeral symphysis and close together. Snout broad, rounder, scarcely overlapping the lower jaw. Mouth very wide; villiform teeth in the jaws, on the vomer, and palatine bones. Gill laminæ short; gill rakers long, not very closely set. Pseudobranchiæ none. ( $\mu i \xi 25$, mixture, half; Onus, a synonym of Gaidropsarus, the rockling.)

\section{MIXONUS LATICEPS (Günther).}

Head 2; depth 3 ; eye 8 in head; snout 4. P. 17. Greatest depth of body below origin of dorsal fin; distance of vent from snout $\frac{2}{8}$ its distance from extremity of spinal column. Crown of head remarkably convex, covered with an extremely thin and transparent skin, which, perhaps, in older examples is scaly; interorbital space less convex, and equaling in width the length of snout including the eye; eye small, above middle of length of the maxillary; posterior nostrils wide, open, in front of the eye. Distance of vent from ventrals exceeds length of head; origin of dorsal fin above root of pectorals, its rays of moderate length, but longer than those of anal; pectoral with a rather narrow base, as long as head without snout, its rays feeble, 3 or 4 lower ones a little stouter, detached, and prolonged; ventral filaments not reaching as far backward as pectoral. Gill rakers 10, much longer than the laminx. Whitish, with the abdomen and gill apparatus black. Mid-Atlantic, in profound depths. One specimen, $5 \frac{1}{2}$ inches long, was obtained in mid-Atlantic (Challenger Station 104), at the enormous depth of 2,500 fathoms. The second (type of Sirembo guntheri) was taken off Cape Verde, in 3,200 meters. (latus, broad; -ceps, head.)

Bathynectes laticeps, Günther, Ann. Mag. Nat. Hist. 1878, 20, mid-Atlantic, in 2,500 fathoms. (Coll. Challenger.)

Sirembo guntheri, VAII.LANT, Exp. Sci. Trav. et Talisman, 268, pl. xxiv, fig. 5, 1889, off the Cape Verde Islands, at a depth of 3,200 meters.

Mixonus laticeps, GÜNTHER, Challenger Report, XxII, 108, pl. 25, fig. 8, 1887; GOODE \& BEAN, Oceanic Ichthyology, 339, fig. 296 A, 1896. 
972. BARATHRONUS, Goode \& Bean.

Barathronus, Goode \& BEAN, Bull. Mus. Comp. Zool., x, No. 5, 164, 1883 (bicolor).

Brotulids having the head stout, body and tail compressed, covered closely by skin; scaleless; vent far behind pectoral, included in a cleft; mouth wide, oblique, the lower jaw projecting; intermaxillary teeth rudimentary; several fang-like teeth on the head of the vomer, none on palatines, a few rather large, recurved, separated teeth in the mandible; nostrils close together and small; eye visible through the skin, partly upon the top of the head, with or without dark pigment in the iris; barbel none; gill rakers very numerous and slender, and rather long; gill lamina well developed on all the arches; no pseudobranchix; head full of muciferous channels; gill membranes not united, but covered by a fold of skin; ventrals reduced to single simple rays, placed in advance of the pectorals and close to the humeral symphysis; dorsal and anal placed far back; caudal scarcely differentiated, composed of rather numerous, very slender rays upon a somewhat narrow base. ( $\beta \alpha \alpha \rho \theta \rho o v$, the abyss; óvos, Onus, the rockling.)

2995. BARATHRONUS BICOLOR, Goode \& Bean.

Head $5 \frac{1}{5}$ in total, its width $\frac{2}{8}$ its length; depth $6 \frac{1}{3}$; orbit $4 \frac{8}{4}$ in head; interorbital width $4 \frac{8}{4}$. D. abont $70 ;$ A.57. Body much compressed; eye concealed by the skin; maxillary extending slightly beyond the perpendicular through posterior margin of orbit, almost entirely concealed under the preorbital, and much expanded at tip, where its width is rather greater than that of eye. Intermaxillary very thin, broad, and slightly protractile; vomer very close to intermaxillary symphysis, its head somewhat raised and bearing 3 fang-like teeth ( 2 of which are off one side and 1 on the other in the type), separated by a moderately wide interspace; mandible with 5 enlarged, separate, recurved teeth upon each side, which increase in size posteriorly, its upper edge, posteriorly, produced above the level of the tooth-bearing surface, and received under the expanded maxillary; longest gill raker about as long as eye. Dorsal origin distant from the snout about $\frac{1}{2}$ total length; dorsal rags well developed, numerous, long, and slender, the longest about 3 times in length of head; anal originating in vertical from fourteenth dorsal ray, equidistant from eye and base of candal, longest rays about as long as those in the dorsal; pectoral with a fleshy base, its length a little less than height of body. Ventral well in advance of pectoral, close to humeral symphysis, the rays being placed very close together at their origin, the length of the fin contained about 9 times in the total length, about 3 times in the distance from its origin to the vent. Caudal with about 10 rays, its length about 8 times in total length. Color yellowish white, with a broad vertical band of black from origin of ventral nearly to vent; another similar and narrower band above it upon each side. The type, $120 \mathrm{~mm}$. long, from Blake Station LXXI, off Gnadaloupe, at a depth of 769 fathoms. (Goode \& Bean.) (bicolor, two-colored.)

Barathronus bicolor, Goode \& BeAN, Bull. Mus. Comp. Zool., x, No. 5, 164, 1883, off Guadaloupe, in 769 fathoms (Coll. Blake); GOODE \& BkAN, Oceanic Ichthyology, 341, fig. 298, 1896. 


\section{APHYONUS, Günther.}

Aphyonus, Günther, Ann. Mag. Nat. Hist. 1878, 22 (gelatinosus).

Head, body, and tapering tail strongly compressed, enreloped in a thin, scaleless, loose skin. Vent far behind the pectoral, at nearly the middle of the total length. Snout swollen, projecting beyond the mouth, which is wide. No teeth in the npper jaw; small conical teeth in the lower, pluriserial in front and uniserial on the side. Vomer with a few rudimentary teeth; palatine teeth none. Nostrils close together, small. No externally visible eye. Barbel none. Ventrals reduced to simple filaments, placed close together and near to the humeral symphysis. Gill membraues not united. Four branchial arches, the posterior without gill laminæ, the anterior with very short gill rakers and with rather short gill lamin:e. Head covered with a system of wide muciferous channels and sinuses, the dermal bones being almost membranaceous, while the others are in a semicartilaginous condition. Notochord persistent, but with a superficial indication of the vertebral segments, as in some Leptocephaline forms. (Günther.) ( $\dot{\alpha} \phi \dot{v} \eta$, anchovy, a small translucent fish; Onus, the rockling.)

\section{APIIYNUS MOLLIS, Goode \& Bean.}

Body much compressed, its greatest height 6 in its total length. Head thicker than body, its height slightly greater. Length of head about $4 \frac{1}{4}$ in total, width over $\frac{1}{2}$ its length. Snout $3 \frac{1}{3}$ in length of head. Eye not externally visible. Diameter of orbit, as seen through the skin, about $\frac{1}{4}$ length of head. Maxillary extending to vertical through posterior margin of orbit, the mandible somewhat farther back, its length nearly equal to height of body. A few weak teeth on vomer, palatines, and mandible, and very rudimentary ones in maxillary, not visible to the eye, but appreciable to the touch. Gill laminæ on the fourth and rudimentary gill rakers, 8 ruliments and 4 developed below the angle. Dorsal origin almost over posterior edge of operculum, its distance from the snout $\frac{1}{4}$ of total length, dorsal rays more than 110, well developed, the longest 3 in head; anal origin slightly nearer base of caudal than to the tip of snout, its rays shorter than those in the dorsal; pectoral with a fleshy base, its origin somewhat behind that of the dorsal, its length equal to width of head; ventral origin in advance of that of pectoral, close to humeral symphysis, the fin a single simple ray, whose length equals that of the pectoral, its tip not reaching vent by a space equal to height of head. Skin not loose. Texture of body rather firm, not transparent; whitish. Gulf of Mexico, in deep water. This species is closely allied to Aphyonus gelatinosus. (Goode \& Bean.) (mollis, soft.)

Aphyonus mollis, Goode \& BeAN, Bull. Mus. Comp. Zool., x, No. 5, 163, 1883, Lat. $24^{\circ} 3^{\prime}$ N., Long. $84^{\circ} 5^{\prime}$ W., in 955 fathoms (Coll. Blake); GOODE \& BEAN, Oceanic Ichthyology, 342, fig. 299, 1896.

\section{Family CCXII. BREGMACEROTIDA.}

Body stout, with robust caudal portion, truncate or convex behind, almost without procurrent caudal rays above or below; vent before mid- 
dle of body; suborbitals moderate; no barbels, spines, nor cirri on head; mouth terminal, with minnte tecth on jaws and vomer, none on palatines; ventrals jugular, extremely long, few-rayed, the rays dilated and separate nearly to base. Dorsal fins 2 , the first an elongate, slender occipital ray; second dorsal on posterior half of body, of soft rays, depressed medially, so that it forms 2 lobes; no spines in fins. Anal nearly similar to the soft dorsal and similarly depressed in the middle; dorsal and anal depressible in a groove of scales. Hypercoracoid perforate; no pseudobranchix; gill openings wide, the membranes free from the isthmus. A single genus with 2 or 3 species found in the open sea, probably near the surface; widely distributed. Tho presence of the hypercoracoid foramen shows that this family is allied to the Brotulida rather than to the Gadida. From the Brotulide it is mainly distinguished by the development of its dorsal and ventral fins.

974. BREGMACEROS, Thompson.

Bregmaceros, Thомpson, in Charlesworth's Mag. Nat. Hist., IV, 1840, 184 (macclellandii). Calloptilum, Richardson, Voy. Sulph., Fish., 94, pl. 46, figs.4-7, 1843 (mirum).

Asthenurus, TickelL, Journ. Asiat. Soc. Bengal 1865, 32 (atripinnis).

Characters of the genus included above. ( $\beta \rho \varepsilon \gamma \mu \alpha$, the upper part of the head, the nape; $\varkappa \varepsilon \rho \alpha 5$, horn.)

$a$. Scales in transverse series 14; scales in lateral series 58 to 64 .

aa. Scales in transverse series 10 ; in lateral series 65 ; anterior lobes of dorsal and anal lower than in B. macclellandii.

ATLANTICUS, 2898.

2897. BREGMACEROS MACCLELLANDII, Thompson.

Head $5 \frac{2}{5}$; depth $6 \frac{2}{8}$. D. about I, 18-X-22 (16+X-15); A. about 18, X, 22 $(22, \mathrm{X}, 20)$; V. 4 or 5 ; scales 58-14 (64-14). Body moderately elongate, compressed, the form somewhat as in Ophidion, the back not elevated. Head short and small, moderately compressed; bones of head thin, without serrature or spine; eye moderate, 3 in head; interorbital space ridged, about as broad as eye; snout blunt, rather shorter than eye; month very oblique, the jaws subequal; maxillary reaching to beyond middle of eye, $2 \frac{1}{5}$ in head; lower jaw flattish, cruved upward; teeth in both jaws moderate, slender, close set, recurved, apparently in a single series. Tongue conspicnous; no teeth evident on vomer or palatines; branchiostegals 7 or 8 ; gill membranes separate, free from the isthmus; no evident pseudobranchix; gill rakers obsolete; no barbels about jaws. Body with rather large, thin, caducous scales (nearly all of them fallen in the typical specimens so that they can not be counted). Dorsal fin beginning with a siugle long and very slender spiue on occiput, this nearly $\frac{1}{3}$ longer than head. Behind this, for a distance about equal to its length, the rudimentary rays, if present, do not rise above the sheath on each side. Nearly opposite the vent begins the dorsal proper, the distance of its first ray from snout being about $\frac{2}{5}$ length of body; about 12 rays are moderately elevated, about $\frac{8}{4}$ length of head. The others are gradually shorter aud more slender, becoming too 
small to count, until just before caudal, where the fin becomes conspicuous again, this posterior lobe not $\frac{1}{2}$ so high as the anterior. Anal opposite lorsal and similar to it, the first ray close behind vent; candal free from dorsal and anal, the caudal peduncle truncate at its base. Ventrals of 3 long rays, with a fourth at the inner base of the third; this fourth is probably a rudiment of 2 . The ventrals are jugular in position, the rays very long and filamentous, the longest about $\frac{1}{2}$ the body, reaching to the middle of anal fin. Pectorals inserted high, somewhat shorter than head. Vent slightly behind eud of anterior $\frac{1}{8}$ of total length. Color brown above, sides and below silvery; back and base of anal closely dotted with dusky; dorsal mostly dusky; caudal pale, dusky at base, with a narrow white cross bar; lower fins pale; the dark marking on front of back assume something of the form of lengthwise streaks. Tropical Pacific; Bay of Bengal; Philippine Islands; coast of China, etc., east to the coast of Central America, living near the surface in the open sea. Here described from the types of Bregmaceros bathymaster, two specimens, 18 and 2 inches in length, dredged at Albatross Station 2804, south of Panama, in 47 fathoms depth. Two others, 4 inches long, found later off the coast of Panama. A recomparison of these latter specimens with Günther's * detailed account of $B$. macclellandii shows no difference whatever, and we regard $B$. bathymaster as identical with the latter. Guinther counts the scales 64-14; we find 58-14. In our largest specimens the ventrals reach middle of anal. (Naned for Dr. John McClelland, of the Bengal Medical Service, who first studied the fishes of the Ganges.)

Bregmaceros macclellandii, Thомpson, in Charlesworth's Mag. Nat. Hist., IV, 1840, 184, mouth of the Ganges; GÜNTHER, Cat., Iv, 368.1862.

Calloptilum mirum, Richardson, Voyage Sulphur, Fish., 95, pl. 46, figs. 4-7, 1843.

Asthenurus atripinnis, Tickell, Journ. Asiat. Soc. Bengal 1865, 32, with plate, Bay of Bengal.

Bregmaceros bathymaster, Jordan \& Bollman, Proc. U. S. Nat. Mus. 1889, Lat. $8^{\circ} 13^{\prime} 30^{\prime \prime}$ N., Long. $79^{\circ} 37^{\prime} 45^{\prime \prime}$ W., southwest of Panama. (Type, No.41137. Coll. Albatross.) Bregmaceros atripinnis, DAY, Proc. Zool. Soc. Lond. 1869, 522, Bay of Bengal; types, same specimens described by TICKELL.

2599. BREGMACEROS ATLANTICUS, Goode \& Bean.

Head $5 \frac{8}{4}$; depth $7 \frac{2}{8}$ in total length. D. I-15, X, 16; A. 15 or $16+\mathrm{X}(7$ or $8)+21$ or 22 ; scales $65-10$. Length $46 \mathrm{~mm}$. Body compressed, moderately elongate. Interorbital area convex, its width greater than eye, which is 4 in head; jaws even in front; maxillary reaching to vertical through middle of eye; mandible to vertical through posterior margin of eye; teeth in intermaxillary minute, apparently in a single series; mandibu-

* The following is Dr. Günther's account of Bregmaceros macclellandii, taken from speci. mens from the China Sea:

"B. 7 ; D. I, $16+\mathrm{X}+15 ; A .22+\mathrm{X}+20 ; \mathrm{V} .5$ or 6 ; scales $64-14$. Occipital ray very slender, longer than head; dorsal and anal fins depressible in a groove formed by the scales along the bases of these fins; anterior portions of dorsal and anal elerated, connected with the posterior lower portion by a series of very short extremely feeble rays. Vent at end of anterior third of total length. Three outer rays of ventral fins dilated, compressed, sim. ple, much elongate, reaching to or nearly to middle of anal; the second and third rays sometimes united at base. Silvery, minutely dotted with brown." 
lary teeth biserial, the inner teeth enlarged. Cephalic appendage reaching nearly to base of first dorsal, its length $4 \frac{1}{2}$ in total. Distance of dorsal from snout $2 \frac{1}{2}$ in total, that of the anal the same; the dorsal and anal fins received in a groove formed by the scales along their bases; anterior portion of second dorsal and second anal less elevated than in $B$. macclellandii. The differentiations between the developed and undeveloped rays of the anal are so slight that the limits of the so-called anterior and posterior sections of the fin can not be determined. Length of the longest anal ray about 2 in body length. Specimens were obtained by the Blake at the following stations: XCIX, off Granada, 90 fathoms; CXIII, off Neris, 305 fathoms; CLXXXV, Lat. $25^{\circ} 33^{\prime}$ N., Long. $84^{\circ} 21^{\prime}$ W., 101 fathoms. (Goode \& Bean.) This species seems doubtfully distinct from B. macclellandii. (atlanticus, of the Atlantic.)

Bregnaceros atlanticus, Goode \& BEAN, Bull. Mns. Comp. Zool., XII, No. 5, 165, 1886, West Indies, off Granada and Neris (Coll. Blake); Goode \& BEAN, Oceanic Ichthyology, 388, fig. 331, 1896.

\section{Suborder ANACANTHINI.}

\section{(The Jugular Fishes.)}

Vertical fins very long, destitute of true spines; tail isocercal, the posterior vertebræ progressively smaller; ventrals jugular, without spines; hypercoracoid without perforation or foramen; no pseudobranchiæ. The osteological characters of this group, called by him Gadoidea, are thus given by Dr. Gill:

"Jugulares with the orbito-rostral portion of the cranium longer than the posterior portion, the cranial cavity widely open in front; the supraoccipital well developed, horizontal and cariniform behind, with the exoccipitals contracted forward and overhung by the supraoccipital, the exoccipital condyles distant and feebly developed, with the hypercoracoid entire, the hypocoracoid with its inferior process convergent toward the proscapula, and the fenestra between the hypercoracoid and hypocoracoid." (Gill, Proc. Ac. Nat. Sci. Phila. 1884, 170.)

A large and important group, chiefly confined to the cold depths of the ocean and the northern seas. From all other typical fishes they are separated by the entire hypercoracoid. ( $\dot{\alpha} v$ - privative, without; $\alpha \varkappa \alpha \nu \theta \alpha$, spine.)

a. Caudal fin present; tail not greatly elongate; body tapering or coniform behind, with many procurrent caudal rays above and below; suborbitals moderate.

b. Frontal bones paired, with a triangular excavated area above, the divergent frontal crests continuous from the forked occipital crest; ribs wide, approximated, channeled below or with inflected sides; no barbels.

MerLucCirde, cCxir.

bb. Frontal bones normal, not forming a triangular excavated area above; ribs normal; chin with a barbel (rarely obsolete).

GADIDA, CCXIV.

aa. Caudal fin wanting; tail very long, tapering behind; suborbitals very broad.

Macrouride, cCXV. 


\section{Family CCXIII. MERLUCCIID A.}

\section{('The HaKes.)}

Body moderately elongate, covered with small, smooth, deciduous scales; posterior part of body coniform and with the caudal rays procurrent forward ; vent submedian. Head elongate, depressed, pike-like; suborbital bones moderate; mouth terminal, with strong teeth; no barbels; ventrals subjugular; dorsal fins 2, a short anterior and long posterior one, a long anal corresponding to the second dorsal; ribs wide, approximated, and channeled below or with inflected sides; frontal bones paired, excavated, with divergent crests continuous from the forked occipital crest. A single genus, with about 4 species; large cod-like fishes, of voracious habit, inhabiting moderate depths, and distinguished from the Gadida mainly by the structure of the frontal bones and the ribs. (Merlucciida, Gill, Proc. Ac. Nat. Sci. Phila. 1884, 772.)

\section{MERLUCCIUS, Rafinesque.}

\section{(HAKES.)}

Merluccius, RAFINESQUE, Caratteri di Alcuni Nuovi Generi, etc., 26, 1810 (merluccius).

Onu., RAFINESQUE, Indice d'Ittiol. Sicil., 12, 1810 (riali=merluccius); substitute for Merluccius.

Merlangus, RAFINESQUE, Indice d'Ittiol. Sicil., 30, 1810 (riali); substitute for Onus.

Merlus, Guichenot, in Gay, Hist. Nat. Chili, Zool., II, 328, 1847 (gayi).

Stomodon, MrtchiLL, Rept. Fish. N. Y.1814, 7 (bilinearis).

Homalopomus, Girard, Proc. Ac. Nat. Sci. Phila. 1856, 132 (trowbridgei).

Epicopus, Günther, Cat. Fish. Brit. Mus., II, 248, 1860 (gayi).

Body elongate, covered with small, deciduous scales. Head slender, conical, the snout long, depressed; a well-defined, oblong, triangular excavation at the forehead, bounded by the ridges on the separated frontal bones, these ridges converging backward into the low occipital crest; eye rather large; edge of preopercle free; preopercle with a channel behind its crest, crossed by short radiating ridges; mouth large, oblique; maxillary extending to opposite the eye; lower jaw longer; no barbels; jaws with slender teeth, of various sizes, in alout 2 series, those of the inner row longer and movable; vomer with similar teeth; palatines toothless. Branchiostegals 7. Gill rakers long; gill membranes not united. Dorsal fins 2, well separated, the first short, the second long, with a deep emargination; anal emarginate, similar to second dorsal; ventral fins well developed, with about 7 rays; vertebre peculiarly modified, the neural spines well developed and wedged into one another; frontal bone double and the skull otherwise peculiar in several respecte. Species severai, very similar in appearance; ill-favored fishes of soft flesh and fragile fins, inhabiting water of some depth. Large voracions fishes, little valued as food. (Merluccius, the ancient name, meaning sea pike.)

a. Scales moderate, abont 110 in lateral line; teeth very strong. D. 10-36; A. 36.

MERLUCCIUS, 2899.

aa. Scales small, 135 to 150 in lateral line; teeth moderate. D. 11 to $13-41$; A. 41 .

b. Ventrals long, about $1 \frac{2}{3}$ in head.

BILINEARIS, 2900.

bb. Ventrals short, about $2 \frac{1}{2}$ in head.

PRODUCTUS, 2901. 
2899. MERLUCCIUS MERLCCCIUS (Linnæus).

(EUROPEAN HAKE.)

Head large, $3 \frac{1}{8}$; derth $6 \frac{1}{2}$. D. $10-36 ;$ A. 36 ; vertebræ $25+26$; scales 150 . Ventrals a little more than $\frac{1}{2}$ head; teeth very long. Dusky above, silvery below; dorsal, caudal, and distal part of pectoral blackish; inside of opercle black; inside of mouth black posteriorly, pale in front; peritoneum black. Coasts of Europe, generally abundant, south to Madeira and Italy, straying to Greenland.* Here described from specimens taken at Genoa. The identity of the Greenland Hake with $M$. merlucciust is perhaps uncertain. (En.) (merluccius, ancient name; mare, sea; Lucius, pike.)

Gadus merluccius, LivNAus, Syst. Nat., Ed. x, 254, 1758, Europe; after authors.

Merluccius smiridus, RAFINESQUE, Caratteri, etc., 26, 1810; JORDAN \& GILBERT, Synopsis, 809, 1883; LiLljeborg, Sveriges Fiske, II, 121, 1891.

Gadus ruber, LACÉPÈDE, Hist. Nat. Poiss., v, 673, 1803, Scotland; Dieppe; on notes by M.

NöEL; joung.

Gadus merlus, Risso, Ichth. Nice, 122, 1810, Nice.

Onus riali, RAFINESQUE, Indice d'Ittiol. Sicil., 26, 1810; substitute for merluccius.

Merlucius vulgaris, Fleming, Brit. Anim., 195, 1828; Günther, Cat., 1v, 344, 1862.

Merluccius esculentus, Risso, Eur. Mérid., III, 1826, 220, Nice.

? Merluccius ambiguus, Lowe, Proc. Zool. Soc. Lond. 1840, 37, Madeira.

Merluccius sinuatus, Swainson, in Lowe, Proc. Zool. Soc. 1840, 38.

Merlucius lanatus, Gronow, Cat. Fish., Ed. Gray, 130, 1854, Mediterranean.

Epicopus gayi, GÜNTher, Cat., II, 248, 1860, no locality; not $M$. gayi, GUicheNot, which is the Chilian Hake.

Merluccius linnœei, MALM, Götheborgs och Bohusläns Fauna, 489, 1877.

\section{MERLUCCIUS BILINEARIS (Mitchill).}

(Silver Hake; New England Hake; Whiting.)

Head $3 \frac{8}{4}$; depth $6 \frac{1}{2}$. D. $13-41$; A. 40 ; scales 100 to 110 . Top of head with W-shaped ridges very conspicuous; eye shorter than snout and less than interorbital width; maxillary reaching posterior border of pupil; teeth not very large, smaller than in the European species, Mcrluccius merluccius. Scales larger than in other species; pectorals and ventrals long, the latter reaching $\frac{8}{4}$ distance to vent, their length about $\frac{3}{5}$ that of head. Grayish, darker above, dull silvery below; axil and edge of pectoral somewhat blackish; inside of opercle dusky silvery; inside of mouth dusky bluish; peritoneum nearly black. Coasts of Now England and north ward to Straits of Belle Isle; south, in deep water, to the Bahamas; rather common; used as food; breeding in deep water, though often taken near shore, northward. This species resembles the European Hake, Merluccius merluccius, but the latter has smaller scales, about 150, and larger teeth. (bilinearis, two-lined.)

* The Iceland Hake has been described as Merluccius argentatus (Faber). According to Faber, it has large teeth, the mouth white within, and the rays D. $15-43$; $\mathrm{A} .51$; the fins deeply notehed. It is perhaps a valid species, and, if so, it doubtless occurs in Greenland. (argentatus, silvered.)

Gadus merluccius (argentatus), FABER, Fische Islands, 90, 1829, Iceland.

Merluccius argentatus. GÜNTHER, Cat., IV, 346, 1862.

† "Dans l'A mérique du Nord, on cite re poisson de Grœenland, mais l'exactitude de cette indication parait douteuge." (Collett, Comp. Sci. Hirondelle, 1896, 58.) 
Stomodon bilinearis, MrTchiLL, Rept. Fish. N. Y., 7, 1814, New York.

Gadus allidus, MrtchiLL, Journ. Ac. Nat. Sci. Phila., I, 1817, 409, New York.

Merlucius albidus, STORER, Hist. Fish. Mass., 363.

Merlucius bilinearis, GOODE \& BEAN, Bull. Essex Inst., xI, 9, 1879, JORdAN \& GILBERT, Synopsis, 809, 1883; GoodE \& BEAN, Oceanic Ichthyology, 386, fig. 330, 1896.

2901. MERLUCCIUS PRODUCTUS (Ayres).

Head $3 \frac{8}{4}$; depth 7. D. 11-41; A. $43 ;$ V. 7 ; scales 136 . Head with the W-shaped ridges less strongly marked; maxillary reaching center of pupil; eye large; pectorals. long and narrow, reaching vent; ventrals much smaller than in M. bilinearis, reaching halfway to vent, their length about $\frac{2}{5}$ that of head; caudal somew hat forked. Scales quite small, deciduous. Teeth moderate. Silver gray; head dusted with coarse black dots; iuside of mouth and opercle jet-black; peritoneum silvery, with black specks. Length 3 feet. Pacific coast of America, from Santa Catalina Island northward to Puget Sound; everywhere abundant at moderate depths; used as food. (productus, drawn out.)

Merlangus productus, A Yres, Proc. Cal. Ac. Nat. Sci. 1855, 64, San Francisco.

Homalopomus trowbridgii, Girard, Proc. Ac. Nat. Sci. Phila. 1856, 132, Astoria, Oregon. (Coll. Lieut. W. P. Trowbridge.)

Gadus productu\&, Günther, Cat., IV, 338, 1862.

Merluccius productus, Gill, Proc. Ac. Nat. Sci. Phila.1863, 247; Jordan \& GILbert, Synopsis, 809, 1883.

\section{Family CCXIV. GADIDA.}

\section{(THe Codfishes.)}

Body more or less elougate, the caudal region moderate, coniform behind, and with the eaudal rays procurrent above and below; vent submedian; suborbital bones moderate; scales small, cycloid; mouth large, terminal; chin with a barbel, more or less developed. Gill openings very wide; gill membranes separated or somewhat united, commonly free from the isthmus; no spines, the fin rays all articnlated. Dorsal fin extending almost the length of the back, forming 1, 2, or 3 fins; anal fin long, single or divided; caudal fin distinct, or confluent with the dorsal and anal; ventral fins jugular, but attached to the pubic bone, each of 1 to 8 branched rays. Gills 4, a slit behind the fourtl. No psendobranchix. Edge of preopercle usually covered by skin of head. Pyloric creca usually numerous, but sometimes few or none. Air bladder generally well developed. Genera abont 25, species about 140; an important family, many of its members being highly valued as food. They inhabit chiefly the northern seas, sometimes venturing into the oceanic abysses. One genus (Lota) is confued to the fresh waters. (Gadida, Günther, Cat., Iv, 326-369.)

GADINE:

a. Anal divided into 2 separate fins; dorsal fin divided into 3.

$b$. Lower jaw distinctly projecting; barbel small or obsolete; caudal concave behind.

c. Teeth in upper jaw slender, wide, set in 1 or 2 series; caudal forked:

BOREOGADUS, 976.

cc. Teeth in upper jaw in a villiform band, the outer somewhat larger; caudal lunate. 
d. Subopercle and postclavicle normal, both thin and flat, not enlarged and ivory-like.

Pollachios, 977.

$d d$. Subopercle and postclavicle enlarged, the bone dense and smooth, like ivory.

Theragra, 978 .

$b b$. Lower jaw included; barbel well developed; candal not concave behind.

e. Hypocoracoid not swollen and ivory-like; lateral line pale; supraoccipital crest moderate.

$f$. Transverse processes of vertebræ thickened, swollen, and ivory-like at tip; small codfishes of the Arctic.

Eleginds, 979.

ff. Transverse processes of vertebræ not swollen at tip.

g. Vent in front of second dorsal; size very small.

MiCROGADUS, 980 .

gg. Vent below second dorsal; typical codfishes of large size.

GADUS, 981 .

ee. Hypocoracoid much swollen and ivory-like; lateral line black; mouth small, the maxillary not reaching to opposite eye; supraoccipital crest very high.

MELANOGRAMMUS, 982.

aa. Anal fin forming a continuous fin or sometimes deeply notched; dorsal not divided into 3 fins.

$h$. Dorsal fin divided into 2 fins.

$i$. Anterior dorsal composed of distinct rays, similar to those in second dorsal.

j. Ventral fins rather broad, each of about 6 rays.

MORINA:

$k$. Anal fin with a deep notch.

l. Snout not much depressed, its edge without keel; tail slender.

LEPIDION, 983.

ll. Snout flat, depressed, keeled on the edge; tail attenuate.

LOTIN E:

ANTIMORA, 984.

$k k$. Anal fin not notched; mouth terminal.

$m$. Vomer toothless.

$n$. Teeth in jaws unequal, outer series enlarged.

o. Barbel obsolete.

URALEPTUS, 985.

oo. Barbel well developed.

LOTELLA, 986.

$n n$. Teeth in jaws all villiform; barbel developed.

Physiculus, 987.

$m m$. Vomer with teeth; head not compressed.

$p$. Vomer and mandible without canincs. Fresh-water species.

LoTA, 988.

$p p$. Vomer and mandible armed with canines. Deepwater species.

MOLVA, 989.

Phychiar:

$j j$. Ventral rays very slender, each of 1 or 2 rays.

$q$. Ventrals each of 2 or 3 slender rays.

UROPHYCIS, 990. $q q$. Ventrals each of a single bifid ray.

LEMONEMA, 991.

\section{GAIDROPSARINAE:}

ii. Anterior dorsal formed of a single slender ray, followerl by a band of fringes; ventrals each of 5 to 7 rays.

$r$. Barbels 3; snout with 2 barbels, 1 at each nostril, none at tip; chin with 1 barbel.

GAIDROPSARUS, 992.

$r r$. Barbels 4; snout with 3 barbels, 1 at tip of snout and 1 on each nostril ; chin with 1 barbel, head high and compressed; no canines.

BROSMINA:

ENCHELTOPUS, 993.

hh. Dorsal fin continuous, undivided; ventrals several-rayed; teeth on jaws, vomer, and palatines; mouth large; frontal bone.

BrosME, 994. 
976. BOREOGADUS, Giinther.

Boreogadus, Günther, Cat. Fish. Brit. Mus., Iv, 336, 1862 (fabricii).

This genus is closely allied to Pollachius, the body more slender, the caudal fin more deeply forked, and the teeth in both jaws slender, sharp,

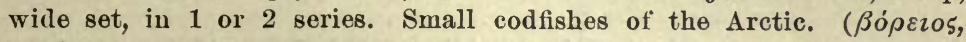
northern; Gadus.)

\section{BOREOGADUS SAIDA (Lepechin).}

Head $3 \frac{1}{2}$; depth $5 \frac{1}{2}$; eye 4 in head; snout $3 \frac{1}{3}$; interorbital space $4 \frac{2}{3}$; gill rakers 9 to $13+30$ to 32 . D. 13-14-20; A. 16-21. Body slender, little compressed; head long, rather pointed, the lower jaw projecting; barbel minute; maxillary reaching middle of pupil; mandible 2 in head; teeth in upper jaw in 1 series, except in front, when the row is double; teeth in lower jaw uniserial; tecth nearly uniform in size, sharp, and wide set; teeth on vomer few, similar to those in jaws. Gill rakers numerous, long and slender, the longest $\frac{1}{2}$ eye; vent slightly before second dorsal; caudal peduncle slencler, rounded, its depth scarcely more than $\frac{1}{2}$ eye. Pectorals reaching vent, $1 \frac{1}{2}$ in head; ventrals $1 \frac{1}{3}$, the second ray exserted for $\frac{2}{5}$ its length; first dorsal highest; front of second dorsal midway between tip of snout and base of cauclal. Caudal forked for a distance equal to $\frac{1}{2}$ eye, the tips rounded. Color plain brownish, silvery below, the body with fine black points, most numerous above; clorsals and caudals dusky, the rays blackish distally, their edge narrowly white; anal similarly colored, pale at base; pectorals uniform dusky, pale-edged; ventrals somewhat dusky; peritoneum biackish. Length 6 to 8 inches. Arctic seas of Asia and America, from Greenland to Siberia; generally common in the far North, but rare in Bering Sea and south of Greenland. Here described (by Mr. Norman B. Scofield) from specimens from Davis Straits and Melville Bay, Greenland, the largest $6 \frac{8}{4}$ inches long, and from specimens taken by Mr. Scofield at Point Barrow, Port Clarence, and Herschel Island. There is no difference between Greenland and Alaskan specimens. The range of fin rays is D. 12 to $15-12$ to $15-18$ to 22 ; A. 15 to $18-20$ to 22 . Concerning its habits Mr. Scofield observes:

"This fish appears to be quite abundant north of Bering Straits. It was especially brought to our notice by its habit of hiding in small holes in the floating ice, from which it was dislodged by our steamer striking and turning over the blocks of ice. This floating ice was usually in 7 fathoms of water and 1 or 2 miles from the coast. At Herschel Island we took it with the seine in shallow water along the beach. Lucien H. Turner reports it from St Michaels, where he took it through the ice in February, and was told by the natives that it appeared there only in winter. According to Richardson it spawns in Greenland in February, laying its eggs in the seaweeds along the shore under the ice." According to Richardson, in Northumberland Sound, "when hotly pursued by the Beluga or white whale, it has been observed, in its endeavors to escape, to leap by hundreds on the ice." (Eu.) (saida, Russian name.) 
Gadus saida, Lepechin, Nov. Comm. Ac. Sci. Petrop. 1774, 512, White Sea; Pallas, Zoogr. Rosso-A siat., III, 199, 1811; GÜnther, Cat., IV, 337, 1862; ColletT, Norske NordHavs Exped , 126, 1880; JoRDAN \& GILBERT, Synopsis, 307, 1883.

Merlangus polaris, SABIne, Supp. Parry's Voyage, CCXI, 1824, Baffins Bay; Richardson, Last Arctic Voyage, 27, 1824.

Gadus fabricii, Richardson, Fauna Bor.-Amer., III, 245, 1836, northern bays of Greenland; after Gadus aglifinus of Fabricius.

Gadus agilis, ReINHARDT, Danske Vid. Selsk. Afh., viI, 126, 1838, Greenland.

Gadus glacialis, Peters, Nord Pol.Expd., II, 172, 1874.

Pollachius polaris, GiLL, Cat. Fish. East Coast N. A., 218, 1861.

Boreogadus polaris, GiLl, Proc. Ac. Nat. Sci. Phila. 1863, 233.

Boreogadus saida, BEAN, Bull. U. S. Nat. Mus., IV, 108, 1879; ScofIELD, in Jordan \& Gilbert, Rept. Fur Seal Invest., 1898.

977. POLLACHIUS, Nilsson.

\section{(Pollacks.)}

Pollachius, NiLsson, in Bonaparte, Catalogo Metodico Pesci Europ., 45, 1846 (pollachius).

Body rather elongate, covered with minute scales; mouth moderate or large, the lower jaw projecting; barbel very small or obsolete; villiform teeth on vomer, none on palatines; teeth in jaws equal or the outer slightly enlarged; gill membranes more or less united; subopercle and postclavicle not enlarged and not ivory-like; dorsal fins 3 ; anal 2 ; caudal lunate; vent under first dorsal. Large fishes of the northern seas. (Polog or Pollack, the English vernacular name, latinized as Pollachius, as though derived from $\pi \circ \lambda \lambda \alpha \chi \tilde{\eta}$, many fashioned.)

2903. POLLACHIUS VIRENS (Linnæus).

(Pollack; Coal-Fish; Green Cod.)

Head 4 ; depth $4 \frac{1}{4}$. D. 13-22-20; A. 25-20; scales about 150 ; vertebræ 54. Body rather elongate, compressed; snont sharp and conic; mouth rather small, oblique; maxillary reaching beyond front of orbit; lower jaw slightly the longer; teeth in the npper jaw nearly equal, the outer series not being especially enlarged; barbel rudimentary or obsolete; gill membranes considerably united, free from isthmus; vent under first dorsal; caudal fin lunate; pectorals short, scarcely reaching anal; ventrals short, their origin in front of base of pectoral a distance about equal to diameter of eye. Greenish brown above; sides and below somewhat silvery; lateral line pale; fins mostly pale; sometimes a black spot in the axil. North Atlantic; common northward on both coasts, south to Cape Cod and France. (Eu.) (virens, green.)

Gadus virens, LnNesus, Syst. Nat., Ed. $x, 253,1758$, Seas of Europe; after Gadus triptery. gius imberbis of the Fauna Suecica; Günther, Cat., IV, 339; JoRdan \& Gilbert, Synopsis, 807, 1888.

Gadus carbonarius, LinNaus, Syst. Nat., Ed. x, 254, 1758, seas of Europe; after Gadus dorso tripterygius imberbi of ARTEDI. 
Gadus colinus, LAcéPìDE, Hist. Nat. Poiss., II, 416, 1800, England, etc.; after LE Colin of Danberton.

Gadus virens, LACÉPÈnE, Hist. Nat. Poiss., 1I, 417, 1800.

Merlangus purpureus, MI'TChILL, Trans. Lit. and Phil. Soc., I, 18i5, 370, New York.

Merlangus leptocephalus, DE KAY, New York Fauna: Fishes, 288, pl.45, fig. 146, 1842, Long Island.

Merlangus purpureus, STORER, Rept. Fish. Mass., 130, 1839.

Pollachius carbonarius, GiLL, Proc. Ac. Nat. Sci. Phila. 1863, 233.

978. THERAGRA, Lucas, a new genus.

\section{(Alaskan Pollacks.)}

Theragra, LucAs, in Jordan \& Gilbert, Rept. Fur Seal Invest. 1896 (1898) (chalcogrammus).

This genus is closely allied to Pollachius, differing in the following respects: Suboperculum thick, smooth and dense instead of being thin and squamous as in Pollachius; the postclavicle is also similar in structure while its proximal portion is subcircular in Theragra and rhomboidal in Pollachius; this ivory-like character of the suboperculum and postclavicle is so marked that it serves to distinguish these bones at a glance, being entirely different from what is found in the corresponding bones of other gadoids. The Alaskan Pollack farther differs from the Atlantic Pollack in having 19 precaudal vertebræ and 33 caudal, instead of 23 precaudals and 32 caudals; the bodies of the vertebræ are also slightly longer and more deeply seulptured in the Alaskan fish and the spinous process of the anterior dorsals less elevated. The vertebral differences between the 2 genera are merely differences of degree and of specific value only, but the differences between the subopercula and postclavicula are different in kind, distinguishing the Alaskan Pollack not only from the Atlantic

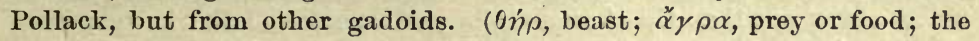
Alaskan Pollack being a chief food of the fur seal, Callorhinus.)

a. Dorsal rays about 13 or $14-17-18$ or 19 ; anal rays $20-20$; side with 2 interrupted dark longitudinal bands.

CHALCOGRAMMA, 2904.

aa. Dorsal rays 10 or 11-13 to 15-16; anal rays 16 to 19-16 to 19; sides plain dusky; body less elongate, the snout blunter, the fins lower. FUCENSIS, 2905.

2904. THERAGRA CHALCOGRAMMA (Pallas).

(Alaska Pollack.)

Head 4; depth 6. D. 12-14-18; A. 20-20. Eye 5 in head; snout $3 \frac{1}{6}$; maxillary $2 \frac{1}{2}$; snout conic, sharp, rounded in profile; mouth oblique; maxillary reaching middle of pupil; chin with a minute barbel; teeth small, those. of the outer row above slightly enlarged; eye large, wider than the flat interorbital space, 4 in head. Gill membranes somewhat united, the posterior outline deeply emarginate; vent under interspace between first and second dorsal; first dorsal higher than the others, the second lowest; ventrals filamentous, reaching nearly to vent; pectorals long, reaching past front of anal, $1 \frac{1}{2}$ in head; caudal somewhat concave. Olivaceous above, sides silvery, with 2 interrupted stripes of lark, brassy, 
olive along sides, these irregular on their edges, about $\frac{1}{2}$ width of eye, with uneveu edges; a trace of a third similar stripe below anteriorly, the stripes very irregular; back mottled. Dorsal plain dark olive; pectoral quite dark; lower fins ashy; caudal ashy olive. Bering S6a and neighboring waters, probably south to Sitka and the Kurils. Our specimens from Unalaska, Robben Reef, Komandorski and Pribilof islands and Bristol Bay. Excessively common throughout Bering Sea, swimming near the surface, and furnishing the greater part of the food of the fur seal. This animal rarely eatches the true codfish, which swims nearer the bottom. Length 3 feet. ( $\chi \alpha \lambda \varkappa o \dot{s}$, brass; $\gamma \rho \alpha \mu \mu \eta \dot{\eta}$, line.)

Gadus chalcogrammus, PALLAS, Zoogr. Rosso-Asiat., III, 198, 1811, Kamchatka; Günther, Cat., IV, 340, 1862; JoRdAN \& GiLbERT, Synopsis, 807, 1883.

Gadus periscopus, CoPE, Proc. Am. Philos. Soc. Phila. 1873, 30, Unalaska (Coll. George Davidson).

Pollachius chalcogrammus, JoRdAN, Cat. Fish. N. A. (130) 918, 1885.

Theragra chalcogramma, JORDAN \& GILBERT, Rept. Fur Seal Invest., 1898.

2905. THERAGRA FUCEXSIS (Jordan \& Gilbert).

(Wall-eyed Pollack; Puget Sound Pollack.)

Head $3 \frac{4}{5}$ in body; depth $5 \frac{1}{2}$. D. 10-13-16 to 11-15-16; A. 16-19 to 19-19; eye $4 \frac{1}{2}$ in head; maxillary $2 \frac{2}{5}$; pectoral $1_{5}^{3}$; longest caudal ray 2 . Body elongate, not greatly compressed; mouth large, the maxillary reaching to below middle of eye; jaws with minute, sharp, curved teeth, the outer series enlarged; teeth on vomer, palatines toothless; lower jaw projecting, a very small barbel under its tip; interorbital space wide, very slightly and evenly convex, wider than the diameter of eye; nostrils much nearer eye than tip of snout, the posterior much the larger; head almost entirely covered with small scales; gill rakers numerous, the longest as long as pupil, about $5+27$ in number. Distance of origin of first dorsal from snout $3 \frac{1}{6}$ in body; first rays of first dorsal reaching far past the ends of last rays where fin is depressed; first rays of other dorsals and anals scarcely reaching the base of last rays; caudal slightly forked or subtruncate when spread, the lobes subequal; end of pectoral reaching to front of anal; ventrals inserted in front of base of pectoral in distance a little more than diameter of eye, ending in a filamentous point. Color nearly plain sooty, with no distinct lateral bands, and with generally only a trace of a pale lateral streak along the side; on the head some diffuse dark spots; fins all dusky. The band of teeth in the premaxillary is wider than in Theragra chalcogramma, and the band is widened at the anterior end; the body is shorter; eje smaller; color darker; fins not so high; caudal not so deeply forked. Pacific coast, from Vancouver Island to Monterey, abundant in Puget Sound; probably northward to Kadiak, replacing $T$. chalcogramma to the southward. This form may intergrade with Theragra chalcogramma, though the original types seem well separated. Little is known of its range to the northward. Scofield and Seale took a specimen in Chignik Bay in northern Alaska, which 
seems as near $T$. fucensis as $T$. chalcogramma. Its rays * are D. 11-16-17; A. 18-17; ventrals reaching $\frac{3}{5}$ distance to vent; interorbital space wider than eye; coloration dark. But its body is as slender as in T.chalcogramma. (fucencis, from the straits of Juan de Fuca.)

Pollachius chalcogrammus fucencis, Jordan \& GiLbert, Proc. U.S. Nat. Mus.1893, 315, Puget Sound at Tacoma. (Type, No.44455. Coll. David H. Hume.)

\section{ELEGINUS, Fischer.}

Eleginus, Fischer, Mem. Soc. Nat. Moscow, v, 4, 2d Ed., 252-257, 1813 (navaga); not Eleginus of later authors.

Tilesia, SwaInson, Nat. Hist. Class'n Fishes, II, 300,1939 (gracilis); name preoccupied.

Pleurogadus, BEAN, in JoRDAN, Cat. Fish. N. A., 130, 1885 (gracilis); substitute for Tilesia preoccupied.

This genus differs from the other codfishes in the structure of the transverse processes of the vertebræ, which are club-shaped, narrow at base, but expanding distally into a rounded hollow bulb at their tips. Skeleton otherwise essentially as in Microgadus, the skull similar. Small codfishes of the Arctic seas. ( $\varepsilon \lambda \varepsilon \gamma$ iv 05 , a social fish mentioned by Aristotle.)

\section{ELEGINUS NAYAGA (Kölreuter).}

(WACHNA COD.)

Head $3 \frac{4}{5}$ in length of body; depth 6 ; eye $5 \frac{8}{4}$ in head; snout 3 ; interorbital space $4 \frac{1}{2}$; gill rakers 20 or 21 ; barbel small, equal to pupil; dorsal 13-18-18; anal 22-20; scales small, 157 transverse rows above lateral line from gill opening to first rudimentary caudal rays. Body slender and rounded with a rather long head; snout viewed from above rounded, but running to a rather sharp point when viewed from the side; lower jaw included, the fleshy snout projecting beyond the maxillary, its length slightly greater than that of the snout; tip of maxillary on a vertical with the front of the pupil; articulation of mandible with quadrate bone on a vertical running midway between pupil and posterior edge of eye; teeth

* The following is the count of fin rays in 13 specimens of Theragra of the two species:

\begin{tabular}{|c|c|c|}
\hline Dorsal. & Anal. & Locality. \\
\hline 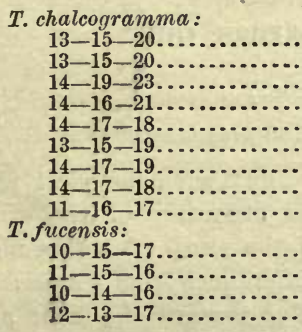 & $\begin{array}{l}19-20 \\
19-21 \\
24-22 \\
21-23 \\
23-21 \\
21-22 \\
21-20 \\
22-20 \\
19-17 \\
18-16 \\
19-18 \\
16-19 \\
19-19\end{array}$ & $\begin{array}{l}\text { Kamchatka. } \\
\text { Unalaska. } \\
\text { Pribilof Islands. } \\
\text { Do. } \\
\text { St. Paul Island. } \\
\text { Do. } \\
\text { Do. } \\
\text { Kamchatka. } \\
\text { Chignik Bay. } \\
\text { Puget Sound. } \\
\text { Do. } \\
\text { Do. } \\
\text { Do. }\end{array}$ \\
\hline
\end{tabular}


all slender and curved backward, those in upper jaw in several irregular rows, the outer row regular and with slightly larger teeth; teeth in lower jaw in a single row except in front where they are in a double row; teeth on vomer fow and about the size of the smaller teeth in the upper jaw ; gill rakers moderate, the longest not quite equal to diameter of pupil; caudal peduncle compressed, its depth equal to diameter of eye; vent under front of second dorsal; pectoral fin not reaching vent, its length $1 \frac{8}{4}$ times in head; ventrals reaching halfway to vent, the second ray moderately produced; first dorsal highest; distance between second and third dorsals twice distance between first and second; caudal fin very slightly concave; third ray of second dorsal midway between tip of snont and base of middle caudal rays. Color somewhat mottled, grayish brown above, light silvery below; the 3 dorsals and caudal dusky and edged with white; pectorals uniform dusky; ventrals but slightly dusted with black; anal with a few punctulations at their anterior ends; peritoneum pale. Arctic shores of Asia and North America, south to Bering Sea, locally abundant. It reaches the length of about a foot. Here described (by Norman B. Scofield) from numerous specimens, the largest 11 inches long, taken at Port Clarence by Scofield and Seale, and at Petropaulski by the Albatross (Fur Seal Invest. of 1896). The range of the fin rays is $\mathrm{D} .12$ to 15-18 to $21-18$ to 21 ; A. 20 to $23-20$ to 23 . Mr. Scofield has prepared a skeleton of this species for comparison with that of Microgradus proximus from San Francisco. There is very little difference in the skulls. There is no difference in the neural spines of the vertebra. The transverse processes of the vertebro in Microgadus proximus are flattened and platelike, while in Eleginus navaga they are clnb-shaped, narrow at base where they leave the centrum, but expanding into a rounded hollow bulb at the distal end. This character defines the genus Eleginus. (navaga, a Russian name.)

Gadus navaga, Kölreuter, Nov. Comm. Ac. Petrop., xiv, 1770, 484, pl.12, coast of northern Russia ; PALLAS, Zoogr. Rosso-A siat., III, 196, 1811.

Gadus gracilis, Trlesios, Mém. Ac. Imp. Petersb., II, 1810, 354, Kamchatka; JoRdAN \& Gilbert, Synopsis, 804, 1883.

Gadus wachna, PALlAS, Zoogr. Rosso-Asiat., III, 182, 1811, Kamchatka.

Tilesia gracilis, Swainson, Nat. Hist. Fish., II, 300,1839; Bean, Proc. U.S. Nat. Mus. 1881, 243.

Pleurogadus gracilis, BEAN, in JORDAN, Cat. Fish. N. A., 130, 1885.

Eleginus navaga, GiLL, Proc. U. S. Nat. Mus. 1890, 303.

980. MICROGADUS, Gill.

\section{(ToMcoDs.)}

Microgadus, GILL, Proc. Ac. Nat. Sci. Phila. 1865, 69 (proximus).

Very small codfishes allied to Gadus, but with the vent placed before the second dorsal and with a different structure of the cranium. The following is Professor Gill's account of the skull of Microgadus proximus, the italicised portions indicating the differences from Gadus:

The cranium is proportionally broader toward the front and less flattened, while the brain case is flattened below, decidedly swollen on each 
side of a depressed sphenoidal groove, and has an ovate cardiform shape; the paraoccipital or epiotic is not produced into an angle behind, but is obtusely rounded, and its posterior or outwardly descending ridge blunt; the opisthotic is well developed, oblong, and with its reentering angle high up, and, on a line with it, the surface is divided into 2 parts-a narrow and a flattened one, and a lower expanded one, much swollen; the alisphenoid or prootic is oblong, acutely emarginate in front, swollen from the region of the high anterior sinus, and above a little produced forward; the great frontal is a little longer than broad, with supraoccipital crest continued forward on the bone, and near the front expanded upward, and with the expanded portion behind dividing into uarrow lateral wings; the lateral testiform ridges of the frontal are continued forward and curved outward toward the antero-lateral angles; the anterior frontals are mostly covered in front by the great frontal, and are much developed in the direction of the antero-lateral angles, the inferior expanded axillary portion being very narrow; the nasal has a rounded ridge in front, continued well below, and its posterior crest is laminar and trenchant.

Species American; valued as food. (

a. Second anal with 21 or 22 rays; snout rather long; body semitranslucent; first anal and ventrals pale; body scarcely blotched with blackish.

PROXIMUs, 2907.

aa. Second anal with 16 to 20 rays; snout shorter; body opaque; first anal and ventrals dusky; body blotched above with blackish.

TOMCOD, 2908.

2907. MICROGADUS PROXIMUS (Girard).

(CAlifornia T'omcod.)

Head $3 \frac{1}{2}$ in body; depth 5. D. $14-18-18$ to 21 ; A. 21 or $22-21$ or 22 ; V. 6-7; eye 5 in head ; maxillary $2 \frac{1}{2}$; pectoral 2 ; highest dorsal spine 2 ; middle caudal rays equal to snout. Head long, convex above, somewhat compressed, with vertical sides; eye moderate; mouth rather large; maxillary reaching to below pupil; barbel small; teeth in each jaw in a band, the onter row a little enlarged. Gill membranes a little connected, free from the isthmus. First dorsal highest, somewhat falcate; first anal longer and higher than second; pectorals moderate, reaching anal; ventrals filamentous, scarcely reaching anal; caudal slightly emarginate or subtruncate when fin is spread. Lateral line very distinct, wavy, high anteriorly, slightly interrupted posteriorly. Vent below first dorsal. Color olivaceous above, pale, or slightly translucent white below ; dorsal fins dusky, paler at base; first anal and ventrals uncolored; second anal dusted with dark points. Monterey to Unalaska; abundant; a food-fish of considerable importance, the flesh delicate but without much flavor. Here described from a specimen, 8 inches in length, from Alaska, Albatross Station 3213 . It reaches the length of about a foot. (proximus, near, to Microgadus tomcod.)

Gadus proximus, Girard, Proc. Ac. Nat. Sci. Phila. 1854, 141, San Francisco; GIRARd, U. S.

Pac. R. R. Surv., X, Fishes, 142, 1858; Jordan \& Gilbert, Synopsis, 805, 1883.

Morrhua californica, Axres, Proc. Cal. Ac. Nat. Sci. 1854, 9, San Francisco.

Gadus californicus, GÜNTHER, Cat., Iv, 332, 1862.

Microgadus proximus, GiLL, Proc. Ac. Nat. Sci. Phila. 1865, 69. 
2908. MICROGADUS TOMCOD (Walbaum).

(Tomcod; Frostrish.)

Head 4 in body; depth 5 . D. 13 to $15-15$ to $19-16$ to 18 ; A. 17 to $21-16$ to 20 ; eye 5 in head; maxillary $2 \frac{2}{5}$; pectoral $1 \frac{3}{5}$; middle caudal rays $2 \frac{1}{2}$; first dorsal rays $1 \frac{2}{8}$. Snout rounded, less produced than in Microgadus proximus; mouth short; maxillary $2 \frac{1}{2}$ in head, reaching pupil; eye large, $3 \frac{2}{5}$ in head; barbel small; pectorals reaching vent; ventrals filamentous, not reaching vent; vent under interval between first and second dorsals. Color olive brown, distinctly blotched and spotted with darker, lighter on the belly; more opaque than in $M$. proximus; back and sides profusely punctulate; dorsals and caudal blotched with darker; anals coarsely punctulate anteriorly, colorless posteriorly; ventrals and pectorals dusky. Virginia to Labrador; very common northward, and valued as a food-fish. Here described from a specimen, 9 inches in length, from Boston, Massachusetts. Length 1 foot. (tomcod, a vernacular name.)

Tomcod, SchöPF, Schrift. Naturf. Freunde, viII, 140, 1780, New York.

Gadus tomcod, W AlbaUm, Artedi Piscium, IU, 133, 1792, after SchöPF; Jordan \& Gilbert, Synopsis, 806, 1883.

Gadus frost, WALBAUM, Artedi Piscium, III, 134, 1792, North America; after Frost-fish of Pennant.

Gadus tomcodus, Mrtchlll, Trans. Lit. and Phil. Soc., I, 1815, 368, New York; Günther, Cat., IV, 331, 1862.

Gadus pruinosus, MitchiLl, Trans. Lit. and Phil. Soc., I, 1815, 368, New York.

Gadus tomcodus fuscus, MitchILL, Trans. Lit. and Philos. Soc., I, 1815, 369, New York.

Gadus tomcodus luteus, MitchiLl, Trans. Lit. and Philos. Soc., I, 1815, 369, New York.

Gadus tomcodus mixtus, MrtchiL,, Trans. Lit. and Philos. Soc., I, 1815, 369, New York.

Gadus polymorphus, MiтchiLL, Trans. Lit. and Philos. Soc., I, 1815, 369, New York.

Morrhua americana, STORER, Rept. Fish. Mass., 120, 1839, coast of Massachusetts.

981. GADUS (Artedi) Linnæus.

\section{(Codfishes.)}

Gadus, LinNedos, Syst. Nat., Ed. x, 251, 1758 (morhua); after A RTEDI.

Morrhua, OKEN, Isis 1817, 1182 (morrhua; on les Morrhues of CUVIER).

Cepphus, Swainson, Nat. Hist. Class'n Fishes, II, 300, 1839 (macrocephalus).

Body moderately elongate, compressed and tapering behind. Scales very small; lateral line present, pale. Head narrowed anteriorly; mouth moderate, the naxillary reaching past front of eye; chin with a barbel; teeth in jaws cardiform, subequal; vomer with teeth; none on the palatiues; cranium without the expanded crests seen in Melanogrammus; no part of the skeleton expanded and ivory-like. Dorsal fins 3 , well separated; anal fins 2; ventral fins well developed, of about 7 rays. Species of the Northern Seas; highly valued as food. (Gadus, the Latin name, akin to the English word cod.)

a. Eye moderate, about $\frac{1}{2}$ snout in adult; axil without dusky spot.

b. Air bladder large. Atlantic codfish.

bb. Air bladder small. Pacific codfish.

CALLARIAS, 2909.

aa. Eye large, more than $\frac{1}{2}$ length of snout; axil with a dusky spot; caudal peduncle slender.

OGAC, 2911. 
2909. GADUS CALLARIAS,* Linnæus.

(Common Confish.)

Head $3 \frac{1}{2}$ to $4 \frac{1}{2}$; depth about 4 . D. 14-21-19; A. 20-18. Head large, but varying much in size; maxillary about reaching middle of orbit; occipital keel not greatly developed; teeth strong, cardiform, in narrow bands, those of the outer row in the upper jaw and of the inner row in the lower jaw somewhat enlarged. Eye moderate, about $\frac{1}{2}$ length of snout. First dorsal little elevated, its height about $\frac{1}{2}$ length of head; vent under front of second dorsal; caudal slightly emarginate; pectorals $\frac{1}{2}$ length of head. Greenish or brownish, subject to many variations, sometimes yellowish or reddish; back and sides with numerous rounded brownish spots; lateral line pale; fins dark. North Atlantic, south to Virginia, and France; one of the most important of food-fishes. (Eu.) (Callarias, an old name of the codfish.)

Gadus callarias, Linneus, Syst. Nat., Ed. $x, 252,1758$, young examples, Baltic Sea and oceans of Europe, after Gadus, etc., cauda integra of the Fauna Suecica; Cuvier, Règne Animal, Ed.2, vol. II, 332, 1829; JordAN \& ǴlLBERT, Synopsis, 804, 1883.

Gadus morhua, Linseus, Syst. Nat., Ed. x, 252, 1758, seas of Europe, after Gadus, etc., cauda subcequali of the Fauna Suecica; Rich ARdson, Fanna Bor.-Amer., 242, 1836.

Gadus barbatus, LinN æus, Syst. Nat., Ed. X, I, 252, 1758.

Gadus vertagus, Walba UM, Artedi Pisc., III, 143, 1792; after Jägershen, KLeIN, Hist. Nat. Pisc., v, 7, pl. 2, fig. 1, 1749.

? Gadus heteroglossus, WALBAOM, l. c., 144; after Hornbogen of KLEIN.

Gadus arenosus, Mitchil, Trans. Lit. and Philos. Soc., I, 1815, 368, New York.

Gadus rupestris, MrтchiL, Trans. Lit. and Philos. Soc., I, 1815, 368, New York.

? Gadus nanus, FABER, Fische Islands, 113, Iceland.

Morrhua americana, Stoner, Hist. Fish Mass., 343, 1867.

Gadus morrhua, GünTHER, Cat., IV, 328, 1862; GoodE \& BEAN, Oceanie-Ichthyology, 354.

2910. GADUS MACROCEPHALUS, Tilesius.

\section{(Alaska Codfish.)}

Head 3 in body; depth 48. D. 13-18-16. A. 21-17; eye 6 in head; maxillary $2 \frac{1}{2}$; highest dorsal ray 3 ; pectoral $2 \frac{1}{2}$; middle caudal rays 4 . Head large, the snout blunt; mouth large, the maxillary reaching to below front of pupil, snout projecting beyond mouth, lower jaw included; teeth strong, eardiform, in narrow bands on jaws and vomer; interorbital wide, $1 \frac{1}{2}$ times wider than diameter of eye, very slightly convex. Gill rakers moderate, about equal to pupil in length, $3+17$ in number. Pectoral reaching to below end of first dorsal; ends of first dorsal rays reaching second dorşal when fin is depressed; ventrals inserted in front of base of pectorals in distance equal to diameter of eye; vcins under front of second dorsal; caudal subtruncate. Color brownish, lighter below, back and sides with numerous brownish spots; fins, with the exception of first anal and ventrals, dusky. This species is very abundant in Bering Sea,

* We retain the name Gadus callarias, Linnæus for the codfish, instead of the com. monly nsed name Gadus morhua, applied by Linnæus to the same species, becanse the name Gadus callarias stands first on the page on which it occurs. To accord priority to the name standing first is essential to fixity, and not the less so if the competing names are of the same actual date, pnblished by the same author. It is not justice nor elegance, but fixity, which the rules of nomenclature aim to secure. 
on both shores, in 15 to 130 fathoms, forming an important article of commerce. Its range southward extends to the off'shore banks of Oregon. In external respects we recognize no distinction between this species and the common eastern codfish, except that the head seems larger. Here described from a specimen 20 inehes long, taken in the Straits of Fuca by the Albatross. Concerning this species Dr. Gilbert observes:

It has been frequently pointed out, and is well known to fishermen that the Pacific codfish has a smaller air bladder or sound than the Atlantic cod. Pending an examination of this question, which we are not now in a position to make, we propose to recognize the Pacific fish as a distinct species. ( $\mu \alpha \varkappa \rho o ́ s$, long; $\varkappa \varepsilon \phi \alpha \lambda \dot{\eta}$, head.)

Gadus macrocephalus, Tinesıus, Mém. Acad. Sci. St. Petersb., II, 1810, 360, Kamchatka;

GÜNTHER, Cat., IV, 330, 1862.

Gadus pygmaeus, Pallas, Zoogr. Rosso-Asiat., III, 1811, Kamchatka.

Gadus auratus, CoPE, Proc. Am. Philos. Soc., 1873, 30, Unalaska.

2911. GADUS OGAC, Richardson.

(GReEnLand Codfish.)

Head $3 \frac{1}{2}$. D. 14 or $15-18$ to $20-17$ to 20 ; A. 20 to $22-18$ to $19 ; \mathrm{V}-6$. This species resembles the common cod (Gadus callarias), but differs from it as follows: It has a more slender caudal peduncle, larger eye, greater interorbital width, longer barbel, more advanced position of ventral fins, and a longer pectoral fin. Color dark, blackish brown above, lighter below, with yellowish marblings; the tip of the dorsal, anal, and caudal fins black; ventral and pectorals dark brown or black, a dusky spot on the axil; barbel black. Coast of Greenland; not seen by us. 'The above notes from specimens collected at Godhavn, Greenland, examined by Ensign Dresel. (ogac, a native name.)

Gadus ogar, Richardson, Fauna Bor.-Amer., 246, 1836, Greenland; ReInHardt, Vid.

Selsk. Naturvid. Math. Afh. 1838; Dresel, Proc. U. S. Nat. Mus. 1884, 246. Gadus ogat, KRöYER, Voy. Scand. et Lap., pl. 19.

\section{MELANOGRAMMUS, Gill.}

\section{(HADDOCKS.)}

Melanogrammus, GiLl, Proc. Ac. Nat. Sci. Phila. 1862, 280 (oeglefinus).

EEglefinus, MALM, Götheborgs och Bohusläns Fauna, 481, 1877 (oeglefinus).

This genus is distinguished from Gadus by its smaller mouth, the produced first dorsal fin, black lateral line, and especially by the great enlargement of the hypocoracoid, which is dense and ivory-like. The lateral line is always black, and the supraoccipital and other crests on the head are largely developed. Food fishes of large size. ( $\mu \varepsilon^{\prime} \lambda \alpha \varsigma$, blaek;

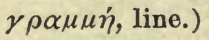

2912. MELANOGRAMUUS EGLEFINUS, LinnæUS.

(HADDOCK.)

Head $3 \frac{8}{4}$; depth $4 \frac{1}{2}$. D. 15-24-21; A. 23-21. Snout long and narrow, overlapping the small mouth; maxillary barely reaching front of orbit; 
teeth subequal, large, in a cardiform band in upper jaw; in a single series on lower jaw and on vomer; occiput carinated; a ridge extending backward from each orbit; eye very large, $\frac{2}{8}$ length of snout, 4 in head. Anterior rays of first dorsal elevated, $\frac{8}{4}$ length of head, the fin pointed, higher than second and third dorsals; caudal lunate; vent below front of second dorsal. The skull in this species is more depressed than in Gadus callarias, broader, and thinner in texture; occipital crest exceedingly high, much higher than in Gadus, the wing-like projections at its base anteriorly spreading widely, raised above the surface of the skull. Dark gray above, whitish below; lateral line black; a large dark blotch above the pectorals; dorsals and caudal dusky. North Atlantic, on both coasts, south to France and North Carolina; in deeper water to Cape Hatteras; an important food-fish, reaching a considerable size. (Eu.) (aglefinus, an old name of the haddock, from the French Aiglefin or Aigrefin, according to Bellon; perhaps from aigre faim, extremely hungry, voracious.)

Gadus oeglefinus, Linn EUS, Syst. Nat., Ed. x, 251, 1758, seas of Europe, after Gadus, etc., cauda biloba, of the Fauna Suecica; JoRdAN \& GILBERT, Synopsis, 803 1883.

Morrhua oeglefinus, Fleming, British Animals, 191, 1828.

Morrhua punctatu\&, Flemive, British Animals, 192, 1828.

Melanogrammus aeglefinus, GiLL, Proc. Ac. Nat. Sci. Phila.1862, 280; ibid. 1863, 237; GoovE \& BEAN, Oceanic Ichthyology, 354, 1896.

AEglefinus linnoci, MALM, Götheborgs och Bohusläns Fauna, 181, 1877.

\section{LEPIDION, Swainson}

Lepidion, * Swansson, Nat. Hist. Class'n Anim., I, 318, 1838, and II, 300, 1839 (lepidion). Haloporphyrus, Günther, Cat. Fish. Brit. Mus., IV, 358, 1862 (lepidion).

Body elongate, covered with small scales; head not greatly depressed, higher than broad; the snout subconical, obtusely rounded; tail tapering behind; jaws with bands of villiform teeth; a roundish patch of teeth on vomer; no teeth on palatines; chin with a barbel; branchiostegals 7 . Caudal fin separate; 2 dorsal fins and 1 anal; the first dorsal short; ventrals narrow, of 6 rays. Deep waters. The American species distinguished from the Lepidion lepidion (Risso), of the Mediterranean, by its non-filamentous first dorsal. ( $\lambda \varepsilon \pi i \delta \imath o v$, diminutive of $\lambda \varepsilon \pi i 5$, scale:-small-scaled.)

2913. LEPIDION VERECUNDUM, Jordan \& Cramer.

Head $3 \frac{1}{3}$; depth $4 \frac{1}{4}$. D.VIII-40; A. 37; V. apparently 4 (some rays broken on each side); scales about 75, not to be exactly counted. Body robust, compressed, tapering from the large head to the very slender, attenuate tail, which is not so broad as pupil; head large, not greatly compressed, not keeled above, its sides scaly; lower jaw with some scales; interorbital space depressed, $5 \frac{8}{4}$ in head; eye very large (in young), $2 \frac{2}{3}$ in head; snout short, depressed, not pointed, and with lateral keel, $5 \frac{8}{4}$ in head; preorbital very narrow; mouth rather large, oblique, the maxillary reaching to below front of pupil, $2 \frac{2}{3}$ in head; lower jaw slightly longer, its tip with a stiffish pointed projection representing the barbel; teeth small, in bands, a fow

* Lepidion is sufficiently distinct from Lepidia, Savigny, 1817. 
on vomer. No spines on snout or opercles. Gill membranes somewhat united, free from isthmus. Gill rakers slender, rather long, 10 to 12 on lower part of arch. Scales very small, mostly lost posteriorly (in our specimen) and not to be exactly counted; lateral line not evident. First dorsal rather low and long, none of its rays produced, the longest about $\frac{1}{2}$ head ; ventrals filamentous, $\frac{1}{2}$ head; pectorals about $\frac{1}{2}$ head ; caudal $2 \frac{1}{2}$ head; anal deeply notched behind the middle, its posterior lobe highest. Color uniform purplish black, the fins paler. One young individual, $2 \frac{1}{4}$ inches long, from Albatross Station 2993, off the Revillagigedo Islands. (verecundus, modest.)

Lepidion verecundum, Jordan \& Cramer, Proc. U. S. Nat. Mus. 1896, 456, Revillagigedo Islands, at Albatross Station 2993. (Coll. Albatross.)

\section{ANTIMORA, Giinther.}

Antimora, Güstrier, Ann. Mag. Nat. Hist. 1876, 2 (rostrata).

This group differs from Lepidion in the form of the snout, the backward position of the vent, the imperfect division of the anal, in which latter respect it approaches Mora. In Lepidion the suout is subconical, obtusely rounded; in Antimora it forms a flat, triangular lamina, sharply keeled at the sides, resembling the snout of Macrourus. Body elongate, compressed, tapering into a slender tail. Scales very small. Head entirely scaly, even to the gill membranes. Snout depressed, thin and flat, projecting beyond the mouth; mouth rather large; chin with a barbel; jaws with bands of villiform teeth; a small roundish patch of teeth on vomer, none on palatines. Dorsal fins 2 , the first short, its anterior ray produced into a long filament; anal fin deeply notched, almost separated into 2 fins; ventral fins with 6 rays, 1 of them filamentous; caudal truncate. Branchi ostegals 7. Deep-water fishes. ( $\dot{\alpha} \nu \tau i$, opposite; Mora, a related genus.)

a. Head rather small, $4 \frac{1}{2}$ in length; scales 115 .

VIOLA, 2914.

aa. Head rather large, about $3 \frac{1}{2}$ in length; scales 130.

MICROLEPIS, 2915.

2914. ANTIMORA VIOLA (Goode \& Bean).

Head $4 \frac{1}{2}$ in body; depth 5. D. 4-53; A. 40; V. 6; scales 11-115-27. Snout broad, pointed at tip, much depressed, forming a roof-like projection above mouth; a conspicuous keel extending backward from tip of snout along the suborbital to the posterior margin of the eye. Mouth $U$-shaped, wholly inferior; maxillary nearly reaching posterior margin of orbit; interorbital space flat, as wide as the large eye, the orbital ridges somewhat elevated; barbel about $\frac{1}{2}$ diameter of orbit. First dorsal with its first ray much produced, longer than head; anal fin deeply notched near its middle. Caudal peduncle as long as eje, its depth more than $\frac{1}{2}$ its length; longest ray of ventrals reaching about halfway to vent; pectoral $1 \frac{1}{2}$ in head. Color deep violet or blue black; inside of mouth and opercles blue black. Banks of Newfoundland and southward, in deep water. (Goode \& Bean.) (viola, violet.)

Haloporphyrus viola, Goode \& BEAN, Proc. U.S. Nat. Mus., I, 1878, 256, La Have Bank, 400 to 500 fathoms ; JORDAN \& GILBERT, Synopsis, 800, 1883.

Antimora viola, GoodE \& BEAN, Oceanic Ichthyology, 372, fig. 324, 1896. 
2915. ANTIMORA MICROLEPIS, Bean.

Head about 4 in total length with eaudal; depth $5 \frac{2}{8}$ without caudal; eye 4 in head, nearly equal to snout. D. 4 or $5-51$; A. 41 ; barbel very slender, 2 in eye; gill rakers short, slender, $4+11$. Maxillary reaching to nearly below posterior edge of eye; longest ray of first dorsal about $\frac{1}{2}$ as long as head; anal deeply emarginate, beginning under twentieth ray of second dorsal; second ventral ray $1_{6}^{1}$ in head. Scales very small, about 9 rows between origin of second dorsal and lateral line, and about 130 in lateral line. Color olivaceous, deeper on opercles and branehiostegal membranes and on inside of mouth. Off Queen Charlotte Islands. Several specimens taken by the Albatross at different stations in Bering Sea, at depths of 350 and 351 fathoms, and off the coasts of the Queen Charlotte Islands and California, at depths of 1,588 and 455 fathoms. One large specimen, from off Bogoslof Island, has the filamentous ray of first dorsal $\frac{7}{8}$ length of head, and the eye is shorter than the snout. ( $\mu$ «นós, small; $\lambda \varepsilon \pi i$, scale.)

Antimora microlepis, BeAN, Proc. U. S. Nat. Mus. 1890, 38, off Cape St. James, Queen Charlotte Island, at Albatross Station 286o, in 876 fathoms (Type, No. 45361); GIL. BErT, Rept. U.S. Fish Comm. 1893 (1896), 456 and 473; Jordan \& Gilbert, Rept. Fur Seal Invest., 1898.

985. URALEPTUS, Costa.

Uraleptus, Costa, Archiv fur Naturgesh. 1858, 87 (maraldi).

Gadella, Lowe, Proc. Zool. Soc. Lond. 1843, 91 (gracilis).

Body elongate, compressed, and tapering posteriorly, covered with small scales. A separate candal; 2 dorsal fins and 1 anal; ventral fins narrow, with flat base, composed of 6 rays. Upper and lower jaw with an outer series of strong curved teeth; vomerine and palatine teeth none; chin without barbel. Branchiostegals 7. Deep waters of the Atlantic. (ov่ $\dot{\alpha}$, tail ; $\lambda \varepsilon \pi \tau o ́ s$, slender.)

\section{URALEPTUS MARALDI (Risso).}

Head 4 ; depth 6 . Head rather thick, its greatest width equal to its height, which is somewhat more than $\frac{1}{2}$ its length; cleft of mouth oblique, wide, the maxillary extending to below posterior margin of orbit; lower jaw received within the upper, but both nearly equal in length anteriorly, each armed with a series of rather large, curved, widely set teeth; another series of small teeth within the outer in the upper jaw. Snout rather broad, obtusely rounder, scarcely longer than eye, which is $4 \frac{1}{2}$ in head; interorbital space emarginate on each side of upper part of orbit, its width somewhat more than diameter of eye. Nape broad, scarcely elevated, with a spine on each side pointing outwards and covered by skin. Operculum small, with a slender horizontal spine posteriorly, the part below the spine being emarginate; gill membranes united below the throat by a rather narrow cutaneous bridge, not attached to the isthmus; gill openings wide; gills 4, a slit behind the fourth; psendobranchir glandular. Trunk rather low; tail tapering into a very narrow band; 
first dorsal fin commencing behind vertical from base of pectoral, somewhat higher than long, and not higher than second; second dorsal commencing immediately behind the first, its rays increasing somewhat in length posteriorly, one of the longest being $\frac{1}{2}$ as long as head, the whole fin naked; caudal fin slender, slightly rounded, entirely free from dorsal and anal, and nearly $\frac{1}{2}$ as long as head; anal fin commencing at some distance behind the vent, which is situated below the origin of the first dorsal, very similar to the second dorsal; pectoral inserted somewhat below middle of body, its length equaling distance between front margin of eye and end of operculum; ventrals narrow, slender, the outer ray produced into a filament shorter than the pectoral. Scales extending over the whole head, the chin and the thin lips being naked. (Günther.) Tropical Atlantic. This form, originally described from Nice, has since been found at Madeira by Johnson, and at Naples and Catania by Giglioli. The Blake obtained a poor specimen, apparently of this form, at station LXXXI, off the Island of Nevis, in the West Indies. (Goode \& Bean.) (Eu.) (A personal name for one of "quelques hommes que les talens, le mérite, la gloire ou l'amitié m'ont désignés.")

Gadus maraldi, Kisso, Ichth. Nice, 123, pl. 6, fig. 13, 1810, Nice.

Merlucius attenuatus, Cocco.

Gadella gracilis, Lowe, Proc. Zool. Soc. Lond.1843,91, Madeira. (Type in University of Cambridge.)

Merlucius maraldi, Risso, Eur. Mérid., III, 220, 1826.

Uraleptus maraldi, GÜnther, Cat., IV, 349, 1862; GỦNThER, Challenger Report, xxII, 87, 1887; GOODE \& BEAN, Oceanic Ichthyology, 367, fig. 320, 1896.

\section{LOTELLA, Kaup.}

Lotella, KAUP, Archiv fur Natnrgesch. 1858, 88 (8chlegeli).

This genus differs from Physiculus chiefly in the presence in both jaws of an outer row of large teeth. Deep sea: (Name, a diminutive of Lota.)

\section{LOTELLA MAXILLARIS, Bean.}

Head about $4 \frac{1}{8}$; depth 5 . D. $5-55$; A. 44 ; V. 10 ; scales about 7 or $8-$ 115-14 or 15. Snout short; eye 3 in head; maxillary reaching vertical through anterior margin of pupil, its length equaling that of postorbital part of head. Teeth in narrow bands in jaws, the outer series enlarged; vomer and palate apparently without teeth. Vent situated about under eighth ray of second dorsal; distance of first dorsal from tip of snout 4 times in total length including caudal; ventrals extending to about vertical from origin of second dorsal, not reaching nearly to vent; longest ray of first dorsal a little more than $\frac{1}{2}$ as long as head; none of the rays of second dorsal or of anal as long as first ray of first dorsal; longest ray of second dorsal not much exceeding $\frac{1}{2}$ of height of body; longest ray of anal about $\frac{1}{2}$ length of ventral; origin of anal about under tenth ray of second dorsal; ventrals situated about under beginning of posterior third of head, their length $\frac{1}{4}$ that of second dorsal base; origin of pectoral somewhat in advance of that of first dorsal, the fin imperfect, but its length probably slightly exceeding that of ventral; caudal 
rounded. Color very light brown; the margins of the dorsal and anal, in their posterior portions, blackish. (Goode \& Bean.) Gulf stream, Lat. $40^{\circ} \mathrm{N}$., in 396 fathoms. (maxillaris, pertaining to the upper jaw.)

Lotella maxillaris, BEAx, Proc. U.S. Nat. Mus. 1884,241 , Lat. $39^{\circ} 55^{\prime}$ N., Long. $70^{\circ} 28^{\prime}$ W. in 396 fathoms (Type, No.29832. Coll. Fish Hawk); Goode \& BeaN, Oceanic Ichthy. ology, 368, 1896.

\section{PHYSICULUS, Kaup.}

Physiculus, KAUP, Archiv fur Naturgesch. 1858, 88 (dalwigkii).

Body elongate, covered with small scales; head entirely scaly; snout broad, obtusely rounded, projecting beyond the mouth; mouth of moderate size; chin with a barbel; jaws with bands of villiform teeth; vomer and palatines toothless. Dorsals 2; anal fin single, not notched; ventral fin with 5 rays, the outer ray filamentous; caudal rounded, slender, free; branchiostegals 7 . ( $\phi v \varkappa i 5$, an ancient name of some fish living in the

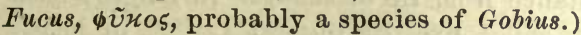

a. Scales moderate, about 62 in a longitudinal series; gill rakers few; dorsal rays 10-49; anal 54; ventral reaching fourth anal ray.

$a a$. Scales very small, about 100 in a longitudinal series.

FULVUS, 2918.

b. Gill rakers few, about 11 below arch; head 4 in length; depth 5; ventrals fila. mentous at tip, as long as head, reaching tenth ray of anal.

NEMATOPUS, 2919.

bb. Gill rakers undescribed, probably few; head 4 in length; depth 5 ; ventrals shorter than head, reaching front of anal.

KAUPI, 2920.

$b b b$. Gill rakers very numerous, $7+18$; head $3 \frac{1}{2}$ in length; depth $4 \frac{3}{4}$; ventrals reaching seventh anal ray. RASTRELLIGER, 2921.

2918. PHYSICULUS FULVUS, Bean.

Head about 4 ; depth $4 \frac{2}{8}$. D. $10-49$; A. 54 ; V. 7 ; scales $6-61$ to $62-16$. Head broad and depressed; snout short; eye $3 \frac{1}{2}$ in head; the length of the upper jaw $2 \frac{1}{3}$ in head, about equal to space between ventrals and anal origin; maxillary not quite reaching vertical through hind margin of eye; barbel 6 in head. Teeth in narrow bands in jaw; no outer series of enlarged teeth, but a few in the middle of the bands in each jaw are slightly larger than the others; all of the teeth, however, inconspicuous; vomer and palate smooth. Vent situated about under third ray of first dorsal ; distance of first dorsal from tip of snout equaling 3 times length of its base, its longest ray twice length of snout, and slightly exceeding length of longest of second dorsal; length of second dorsal base 3 times length of pectoral, which is nearly $5 \frac{1}{2}$ times in total without caudal. Origin of anal about in a vertical let fall from base of fifth ray of first dorsal; distance of ventral from tip of snout about $5 \frac{8}{4}$ times in body. Tip of ventral when extended backward reaching base of fourth anal ray; length of middle caudal ray 3 in head. Lateral line very indistinct, situated rather high, following pretty closely the contour of back. Gill rakers moderately short and not numerous. (xeneral color a light yellowish brown; under surface of head, the abdomen, margins of dorsal and anal fins, lips, and axil of pectoral very dark brown; a dark brown blotch on the suboperculum; inside of mouth and gill membranes white. (Bean.) 
Caribbean Sea, north to $40^{\circ}$ in region of Gulf Stream, reaching a depth of 955 fathoms. (fulvus, brownish yellow.)

Physiculus fulvus, Bean, Proc. D.S. Nat. Mns. 1884,240 , Lat. $40^{\circ} \mathrm{I}^{\prime}$ N., Long. $69^{\circ} 5^{6^{\prime}} \mathrm{W}$. in 79 fathoms (Type, No. 28766. Coll. Fish Hawk); GOODE \& BEAN, Oceanic Ichthyology, 366, 1896.

2919. PHYSICULUS Nematopus, Gilbert.

Head 4 in length; depth 5. D. 7 to $9-56$ to 61 ; A. 59 to 64 ; scales 90 to 105. Length of candal peduncle to base of median caudal rays $5 \frac{1}{4}$ in head. Snout very broadly rounded, its width twice its length, which is $4 \frac{3}{5}$ in head; eye $3 \frac{8}{4}$; interorbital 4 ; maxillary 2, reaching slightly beyond vertical from posterior margin of orbit. None of the teeth enlarged; palate smooth. Branchiostegal membranes moro narrowly joined than in the P.rastrelliger, but wholly free from isthmus. Gill rakers short and slender, 11 movable ones on horizontal limb of arch. Origin of first dorsal over base of pectorals, its distance from tip of snout 3 ? in length; base of first dorsal equaling snout and $\frac{1}{2}$ eye, its highest ray $2 \frac{1}{4}$ in head; free portion of caudal peduncle $\frac{1}{8}$ diameter of orbit; notch of dorsal and anal fins not conspicuous, the posterior dorsal rays little longer than those which precede, $2 \frac{1}{2}$ in head; caudal $2 \frac{1}{3}$; pectorals $1 \frac{1}{2}$; ventrals with broad base and 7 rays, the outer 2 filamentous, the second the longest, reaching base of tenth to twelfth anal rays, and as long as head; distance between bases of ventrals equals interoroital width; scales small, regularly imbricated, becoming minute on snout, which they completely invest, as well as mandible and gular membranes; lateral line present on anterior half of body only, 8 scales above it anteriorly. Color light olive brown, sprinkled with dark specks, the sides of head and trunk with silvery luster; snout, mandible, and gular membrane dusky; abdominal area, branchiostegal membranes, base of ventrals, axillary blotch, and front of anal, purplish black; posterior edge of gill membranes and opercular flap white; dorsals dusky, with an inconspicuous darker margin, which becomes more marked posteriorly; anal darker, margined with black; caudal blackish; pectorals and filamentous portion of ventral white. Inside of month and gill cavity white; peritoneum silvery, rendered black on sides by clusters of spots. Coast of southern California. Many specimens, the largest 7 inches long, from Albatross Stations 2997, 3011, 3015, and 3016, in 71 to 221 fathoms. (Gilbert.) ( $\nu \bar{\eta} \mu \alpha$, thread; $\pi$ ov́s, foot.)

Physiculus nematopus, GrLBert, Proc. U. S. Nat. Mus. 1890, 114, coast of southern California. (Types, No.46486 and 46555. Coll. Dr. Gilbert.)

2920. PHYSICULUS KAUPI, Poey.

Head $3 \frac{1}{2}$; depth 4. D. $10-60$; A. 60 ; P. 30 ; V. 8; C. 17 ; scales 12 to 15 -over 100. Body and head short, swollen; tail regularly narrowed; vent below base of pectoral; eye high, equal to snout, $4 \frac{1}{2}$ in head; nostrils with valves; snout blunt; lower jaw the shorter; maxillary reaching slightly beyond eye; each jaw with a band of cardiform teeth, none on palate and tongue; maxillary sloping under skin of cheek; barbel a little longer than eje; opercular bones covered with skin, without spines; no spines at 
nape; gill membranes somewhat united, free from isthmus; gills 4, a slit behind fourth; no pseudobranchix; lateral line parallel with the back to beyond middle of body, then turning down suddenly, continuing to base of caudal. Scales small, cycloid, not easily counted; head scaly, even to the lips; vertical fins with small scales; ventral filamentous, equaling $\frac{2}{8}$ length of head, all the rays except the first short; ventral with 2 filamentous rays, which reach to front of anal and are about $1 \frac{1}{2}$ in head; first dorsal as high as long, beginning behiud base of pectoral, its longest rays about $2 \frac{1}{2}$ in hearl soft dorsal and anal low, free from the small rounded candal; pectoral falcate, $1 \frac{1}{2}$ in head. Color yellowish brown, bluish on belly; second dorsal and anal edged with darker brown. Type, 1 specimen, $250 \mathrm{~mm}$. long. (Poey.) Deep waters of the Atlantic.

This species has constantly (as far as is shown in our specimens) a broader base to the ventral fins than Physiculus dalwigkii, and they are formed of 7 rays, of which the largest may or may not reach the anal fin; the fin rays vary within proportionate limits; they are, D. 9 or $10-60$ to 66 ; A. 60 to 70 ; there are 13 scales between the anterior dorsal and lateral line; the caudal peduncle is shorter and less slender than in the Madieran form, but otherwise the species are so similar as to scarcely deserve specific separation. Poey obtained a specimen at Cuba, and Melliss 2 at St. Helena. These differ in no respect from 5 examples, 11 to 16 inches in length, found by the Challenger off Inosima in 345 fathoms. (Günther, Challenger Report, XxiI, 88, pl. xvir, fig. A, 1887.) (Named for Dr. J. J. Kaup, author of a work on the Apodal fishes.)

Physiculus kaupi, PoEx, Repertorio, I, 186, 1865, Matanzas. (Coll. Don Cirilo Dalzaides.) ? Physiculus japonicus, HrLaEndorF, Sitz. Naturf. Freunde, Berlin, 1879, 80, Japan.

\section{PHYSICULUS RASTRELLIGER, Gilbert.}

Head $3 \frac{1}{2}$ in length; depth $4 \frac{8}{4}$. D. 8 or $9-53$ to 61 ; A. 57 ; scales 100 to 110. Length of caudal peduncle to base of median caudal rays, $2 \frac{1}{3}$ in head. Snout short and broadly rounded, $4 \frac{1}{4}$ in head; eye $3 \frac{3}{5}$; interorbital width $4 \frac{1}{8}$ to $4 \frac{3}{6}$; maxillary $2 \frac{1}{6}$, extending to vertical from posterior margin of pupil. Teeth in rather broad bands, none of them enlarged; width of patch on premaxillaries $\frac{1}{2}$ pupil; vomer and palatines toothless. Branchiostegal membranes broadly united, joined to the isthmus anteriorly, the width of the free fold more than $\frac{1}{2}$ pupil. Gill rakers numerous, slender, moderately long, the longest $\frac{1}{3}$ diameter of orbit, about 7 above angle, 17 to 19 below, the anterior ones short but movable. Origin of first dorsal slightly in advance of base of pectorals, its distance from tip of snout $3 \frac{2}{7}$ in length; base of first dorsal equaling length of suout, its longest ray $2_{5}^{2}$ in head; free portion of caudal peduncle equaling dianeter of eye; second dorsal notched, the median rays $\frac{8}{4}$ the height of the highest anterior rays, the posterior highest, equaling first dorsal and longest caudal rays; anal similar to soft dorsal, but lower; ventrals under middle of opercle, the distance between their bases little less than interorbital width, equaling distance from vent to anal fin; ventrals with 7 rays, the outer 2 produced, the second the longest, reaching base of seventh or eighth anal ray; pectorals with broad base, covered with lax membrane, 
containing 26 to 28 rays, their length $1 \frac{1}{2}$ to $1 \frac{2}{3}$ in head. Scales small, comparatively little reduced on top of head, a broad ring encircling snout in front of eyes naked, a very narrow patch of scales between this laterally and premaxillaries; scales in 100 to 110 transverse rows, 8 or 9 between lateral line and front of dorsal; lateral line wanting on posterior part of body, in the latter part of its course present on occasional scales only. Color uniform grayish olive on sides, each scale, or at least its marginal $\frac{1}{2}$, closely covered with minute dark specks; gular and branchiostegal membranes, ventral region, and axil of pectorals blue black; basal portion of vertical fins light bluish, margined with blackish; pectorals dusky; ventrals blue black at base, the distal portion white; lining membrane of mouth and gill cavity white; peritonenm silvery, but in places so filled with black specks as to appear black. Coast of southern California. Many specimens, the longest 8 inches, from Albatross Stations 3045 and 2987, in 184 and 171 fathoms. (Gilbert.) (rastrelliger, bearing small gill rakers; rastrum, rake; gero, I bear.)

Physisulus rastrelliger, GrLBert, Proc. U. S. Nat. Mus. 1890, 113, coast of southern California. (Type No.48266. Coll. Albatross.)

988. LOTA (Cuvier) Oken.

(BURBOTs.)

Les Lottes, Cuvier, Règne Anim., Ed. I, vol. 2, 215, 1817 (lota).

Lota, OKeN, Isis 1817, 1182 (lota).

Body long and low, compressed behind. Head small, depressed, rather broad; anterior nostrils each with a small barbel; chin with a long barbel ; snout and lower parts of head naked; mouth moderate, the lower jaw included; each jaw with broad bands of equal, villiform teeth; vomer with a broad, crescent-shaped band of similar teeth; no teeth on palatines. Gill openings wide, the membrane somewhat connected, free from the isthmus. Scales very small, embedded; vertical fins scaly. Dorsal fins 2, the first short, the second long, similar to the anal; caudal rounded, its onter rays procurrent; ventrals of several rays. One or 2 species, living in fresh waters of northern regions. (Lota, the ancient name used by Roudelet, in French, la Lotte.)

\section{LOTA MACULOSA (Le Sueur).}

(BURBOT; LAKE LAWYER; LING.)

Head $4 \frac{1}{2}$ in body; depth $5 \frac{1}{2}$. D. $13-76$; A. 68 ; ventral 7 ; eye 7 in head; pectoral $1 \frac{4}{5}$ in head; maxillary $2 \frac{2}{5}$; middle caudal rays 23. Body elongate, not much compressed anteriorly; head slightly depressed; mouth large, the maxillary reaching to posterior margin of eye; teeth villiform, in bands on jaws and vomer; barbel longer than the small eye; interorbital broad, nearly twice diameter of eye; gill rakers very short, about $3+6$ in number; anterior nostrils with barbels; body covered with small embedded scales; pectorals scarcely reaching to below front of dorsal; ending of ventrals filamentous; caudal rounded; vertebræ $21+38=59$; cæca 30. Dark olive, thickly marbled and reticulated with blackish; 
jellowish or dusky beneath; young often sharply marked, the adult becoming dull grayish; vertical fins with dusky margins. Length 2 feet. Lakes and sluggish streams. New England and Great Lake region, north to the Arctic seas and west to the headwaters of the Missouri, the Frazer River basin, and Bering Straits; abundant northward; rare in the ()hio River and the Upper Mississippi; a rather coarse and tasteless fish, seldom used as food. Here described from a specimen, 18 inches long, from Lake Michigan at Michigan City, Indiana. The American Burbot is very close to the common species of northeru Europe and Asia, Lota lota (Linnæus) = Lota vulgaris, Cuvier = Lota communis, Rapp, and may prove wholly identical with the latter. In Lota lota the pectorals reach beyond front of dorsal, being $1 \frac{1}{8}$ in head. (maculosus, spotted.)

Gadus maculosus, Le SUeUr, Jour. Ac. Nat. Sci. Phila., I, 1817, 83, Lake Erie.

Molva maculosa, Le SeEur, Mém. Mus., v, 1819, pl. 16.

Lota maculosa, De KAY, New York Fauna: Fishes, 284, pl. 52, fig. 168, 1842.

Gadus compressus, Le SUEUR, Jour. Ac. Nat. Sci. Phila., I, 1817, 84, Connecticut River.

Lota compressa, Dr KAY, New York, Fauna: Fishes, 285, pl. 78, figs. 244, 245, 1842.

Gadus lacustris, Mrtchill, Amer. Monthly Mag., II, 1818, 244, Sebago Pond, Maine (Coll. Henry A. S. Dearborn).

Molva huntia, Le Sueur, Mém. Mus., v, 1819, 161, Connecticut River.

Lota inornata, De KAY, New York Fauna: Fishes, 283, pl.45, fig. 145, 1842, Hudson River, Lansingburgh, N. Y.

Lota brosmiana, StoRER, Boston Journ. Nat. Hist., Iv, 1839, pl. 5, fig. 1, New Hampshire.

989. MOLVA, Fleming.

(Lings.)

Molva, Fleming, British Animals, 192, 1828 (vulgaris).

Molva, Nilsson, Skandinav. Fauna, IV, 573, 1832 (molva).

Body elongate, covered with very small scales. Chin with a barbel; lower jaw included; bands of teeth on jaws and vomer; lower jaw with large canines which are arrow-shaped and movable; vomer with a curved series of canines mixed with small teeth, these mostly fixed; no teeth on palatines. Gill membranes broadly united. Two dorsal fins, both well developed; 1 anal fin; ventrals with several rays. Northern seas. (An old name of the salt-water ling.)

2923. MOLYA MOLVA (Linnæus).

Head 5 ; depth 7 or 8 . D. 13 to $16-63$ to $70 ;$ A. 57 to 66 (vertebræ $27+37=64)$. Upper jaw the longer, the maxillary reaching to below middle of orbit. Teeth cardiform in the jaws, with an inner row of rather widely separated and larger ones on mandible; a semicircular band on vomer, among which a few larger ones are interspersed. First dorsal inserted over the latter half of pectoral, its greatest height $\frac{2}{5}$ that of body below it; pectoral about $\frac{1}{2}$ as long as head; anal insertion in vertical over seventh or eighth ray of second dorsal. Barbel longer than eye, which is about equal to width of interorbital space. Scales small, covering head and fins. Color black gray, lighter on the sides and beneath; vertical fins edged with white; a dark blotch at the posterior end of the first dorsal, and a more distinct one on the end of the second dorsal. Arctic parts of the 
Atlantic, south in deep water. This fish, the "ling" of Europe, is found from Spitzbergen to the Gulf of Gascony, where specimens have been taken very exceptionally at Arcachon and San Juan de Luz. It is very rare, however, south of the British Channel, and most abundant along the coast of northern Europe, especially in the German Ocean and off Norway. It is rare about Iceland, Greenland, and the Faroe Islands, and has never been found in the Baltic. It is said to have been found in the deep water off Newfoundland, but we have been unable to find the specific record. Collett states that on the Norwegian coast young examples rarely occur in less depth than 100 fathoms, and according to Lilljeborg the largest are caught in from 80 to 150 fathoms. (Goode \& Bean.) (molva, an ancient name.)

Gadus molva, Linveus, Syst. Nat., Ed. $\mathbf{x}, 254,1858$, seas of Europe; after Gadus dorso dipterygia, ARTEDI.

Molva vulgaris, Fleming, British Animals, 192, 1828; GüNTHER, Cat., IV, 361, 1862; GoOdE \& BEAN, Oceanic Ichthyology, 364, fig. 317, 1896.

Gadus raptor, Ninsson, Prodromus, 46, Sweden.

Molva linnoei, MALM, Götheborgs och Bohusläns Fauna, 491, 1877.

\section{UROPHYCIS, Gill.}

\section{(Codlings.)}

Phycis, BLOCH \& SCHNEIDER, Syst. Ichth., 56, 1801 (tinca=blennioides); not Phycis, Fabricius, 1798, a genus of Lepidoptera.

Phycis, RAFINESQUE, Amer. Monthly Mag. 1818, 243 (marginata).

Urophycis, Grul, Proc. Ac. Nat. Sci. Phila. 1863, 240 (regius).

Emphycus, JORDAN \& EVERMANN, new'subgenus (tenuis).

Body rather elongate; head subconic; mouth rather large, the maxillary reaching to below eye; lower jaw included; chin with a small barbel; jaws and vomer with broad bands of subequal, pointed teeth; palatines toothless. Dorsal fins 2, the first sometimes produced at tip; second dorsal long, similar to the anal; ventrals wide apart, filamentous, each of 3 slender rays, closely jointed, appearing like one befid filament. Gill membranes somewhat connected, narrowly joined to the isthmus. (oúṕ, tail; Phycis.)

UROPHYCIS:

a. First dorsal fin not elevated, none of its rays filamentous.

b. Scales noderate, 90 to 95 in a longitudinal series.

c. Dorsal rays 8-43; anal 45; sides with some pale spots.

REGIUS, 2924.

cc. Dorsal rays 10-66; anal rays 57; barbel minute.

CIRRATCS, 2925.

$b b$. Scales small, 120 to 155 in a longitudinal series.

$d$. Dorsal rays $13-57$; anal about 50 ; scales 120 ; sides with some pale spots.

FLURIDANUS, 2926.

dd. Dorsal rays 10-62; anal about 53; scales 155.

EARLLI, 2927.

EMPHYCUg (ě $\nu$ - $\phi$ v́кos, in the seaweed) :

$a a$. First dorsal fin elevated, 1 or more of its rays filamentous.

e. Scales about 140 ; dorsal rays $9-57$; anal 48 ; ventrals reaching vent.

TENIUS, 2928.

ee. Scales about 110 ; dorsal rays $9-57$; anal 50 ; ventrals reaching beyond rent, not longer than head.

CHUSS, 2929.

eee. Scales about 90; dorsal rays 9-56; anal 56; second dorsal filamentous; ventrals very long, nearly 3 times length of head.

CHESTERI, 2930. 


\section{Subgenus UROPHYCIS.}

\section{UROPHYCIS REGIUS (Walbaum).}

Head $4 \frac{1}{5}$ in body; depth 5. D. $8-43$; A. 40 ; scales about 90 ; eye $4 \frac{1}{8}$ in head; maxillary 2 ; pectoral $1 \frac{2}{5}$; caudal $1 \frac{3}{5}$. Body rather elongate, compressed; month large, the maxillary reaching slightly past posterior margin of eye; lower jaw included; carảiform teeth on jaws and vomer; interorbital flattish, about oqual in width to the diameter of eye; gill rakers short, $3+12$ in number; origin of dorsal over base of pectorals; pectorals slender, barely reaching to front of anal; ventrals filamentous, composed of 2 rays each with the inner ray the larger, inserted in front of base of pectoral in distance equal to $1 \frac{1}{2}$ diameter of eye, their ends reaching beyond front of anal; frout of anal nearer snont than base of caudal, by nearly a head's length; caudal subtruncate. Pale brownisht inged with yellowish, the lateral line dark brown, interrupted by white spots; inside of mouth white; first dorsal largely black, this color surrounded by white; secoud dorsal olivaceous, with irregular round dark spots; caudal, anal, and pectorals dusky; ventrals and lower edge of pectorals white; 2 vertical series of round dark spots on the sides of the head. North Atlantic, south to Cape Fear; ranging from shallow water to a depth of 167 fathoms. Here described from a specimen, 8 inches in length, from Charleston, Sonth Carolina. The species is said to exhibit electric powers in life. (regius, royal.)

Blennius, sp., SchöpF, Schrift. Naturf. Freunde, Berlin, virı, 1780, 142, New York.

Blennius regius, WALBAUM, Artedi, Pisc, III, 186, 1792; after SchöPF.

Enchelyopus regalis, BLOCH \& SCHNEIDER, Syst. Ichth., 53, 1801, after ScHÖPF.

Gadus punctatus, MiтchILL, Trans. Lit. and Phil. Soc. N. Y., I, 1815,.372, New York.

Urophycis regius, GiLl, Proc. Ac. Nat. Sci. Phila. 1863, 240.

Phycis regius, GOODE \& BEAN, Oceanic Ichthyology, 357, 1896.

Phycis regalis, Günther, Cat., IV, 355, 1862.

Phycis punctatus; DE KAX, N.Y. Fauna: Fishes, 292, 1842.

2925. UROPhyCIS CIRRATUS, Goodo \& Bean.

Head 4; depth 5. D. 10-66; A. 57; scales 6-93-20. Body moderately stout; eye large, about 4 in head; interorbital space 2 in eye. Maxillary. not reaching posterior margin of orbit in large specimens, but in smaller ones it extends fully to that vertical; mandible extending far beyond posterior margin of eye, its length about equal to postorbital part of head; barbel minute in all examples examined, its length usually about $\frac{1}{6}$ that of eye. Teeth in villiform bands in both jaws, the intermaxillary bauds being wider than those of mandible; vomerines in a narrow villiform band. Gill rakers $2+12$, the largest club-shaped at end, the longest 4 in eye. Gill membranes attached to isthmus, but with a narrow, free posterior border. Length of pectorals about $\frac{1}{2}$ distance from ventral to anal origin, reaching to about the twenty-sixth row of scales; ventral reaching in some specimens slightly beyond origin of anal; in 1 individual almost to middle of anal fin; none of the dorsal rays filamentous, the longest from $2 \frac{1}{2}$ to 3 times in head; base of first dorsal about equal to length of eye in most specimens; in smaller examples somewhat greater, about 3 in head; 
vent under sixteenth ray of second dorsal. Color light brown; lower parts minutely dotted; dorsals with narrow dark margins; caudal with a broad dark margin; anal with a narrow dark margin in its posterior third; roof of month and interior of gill cavity dark brown. Deep water of the Gulf of Mexico. (Goode \& Bean.) (cirratus, bearing cirri.)

Phycis cirratus, Goode \& BEAN, Oceanic Ichthyology, 358, 1896, Gulf of Mexico at Lat. $29^{\circ} \mathrm{o}^{\prime} 15^{\prime \prime}$ N., Long. $88^{\circ} 16^{\prime} \mathrm{W}$. (Type, No.39059. Coll. Albatro88.)

2926. UROPHYCIS FLORIDANUS, Bean \& Dresel.

Head 4 in body; depth 6 . D. 13-57; A. 49 ; scales about 120 ; eye 6 in head; maxillary 2; height of first dorsal $2 \frac{1}{2}$; middle caudal rays 2 . Body rather elongate, compressed, head subconic; month large, the maxillary reaching to below posterior margin of orbit; upper jaw and snout somewhat projecting beyond lower; small cardiform teeth, in narrow bands on jaws and vomer; barbel very slender, small; interorbital space wide, slightly convex, nearly twice as wide as eye; gill rakers small, slender, $2+11$ in number. Origin of dorsal a little behind the vertical from base of pectoral; first dorsal high, slightly falcate; second dorsal a little higher in its anterior end, higher than anal; origin of anal about midway between tip of snout and base of caudal; pectoral slender, reaching an eye's diameter beyond front of second dorsal; ventrals inserted twice diameter of eye in front of pectorals, 2-rayed, the inner ray the longer, not reaching to vent in larger examples, reaching to front of anal in small ones; caudal long and rounded. Color in spirits, reddish brown, light below, a small black spot above eye, a vertical series of 3 or 4 behind eye, and 2 on opercle, these spots less than $\frac{1}{2}$ pupil, distinct and clear cut; a dark streak from preorbital across cheek to edge of opercle, lateral line black, interrupted at short intervals by white spots; fins dusky, with the exception of pectorals and ventrals, dark toward the ends of the rays. Gulf of Mexico, in rather shallow water, coming to shore in abundance about Pensacola in cold weather. Here described from a specimen, $7 \frac{1}{2}$ inches in length, from Pensacola, Florida. (floridanus, from Florida.)

Phycis foridanus, Bean \& Dresel, Proc. Biol. Soc. Wash. 1884, 100, Pensacola, Florida (Coll. Silas Stearns); JORDAN, Cat. Fish. N. A., 129, 1885.

\section{UROPHYCLS EARLLI, Bean.}

Head $3 \frac{1}{5}$ in body; depth 5. D.10-60; A. 53; scales 155 ; eye 6 in head; maxillary 2. Body moderately elongate, not much compressed anteriorly; mouth large, the maxillary reaching to below or very slightly past posterior margin of eye; suout and upper jaw projecting beyond lower jaw; teeth strong, cardiform in a narrow band on vomer and lower jaw, in a rather wide band in upper; interorbital wide, convex, about $1 \frac{1}{2}$ times eye; gill rakers short and blunt, about $2+9$. Origin of dorsal slightly behind the vertical from base of pectoral; origin of anal about midway between snout and base of caudal; ventrals 2-rayed, the inner a little the longer, not reaching to vent. Color brown, with some light spots on the second dorsal fin and on the sides; anal and both dorsals margined with brown. 
Atlautic coast of United States, southward in water of moderate depth; not common. Here described from a specimen, 17 inches in length, from Charleston, South Carolina. (Named for R. Edward Earll, then assistant to the United States Fish Commission.)

Phycis earlli, Bean, Proc. U. S. Nat. Mus., III, 1880, 69, Charleston, S. C. (Coll. R. E. Earll. Type, Nos. 25207, 25208, and 25209); JoRdAN \& GiLbERT, Synopsis, 798, 1883.

Subgenus EMPHYCUS, Jordan \& Evermann.

2928. UROPHYCIS TENUIS (Mitchill).

(CODling; White HaKe; SqUiRrel-haKe.)

Head $4 \frac{1}{4}$; depth $5 \frac{1}{2}$. D. 9-57; A. 48; scales 138 . Snout longer than eye, narrower and more pointed than in $P$. chuss. Eye large, usually wider than interorbital space; maxillary reaching beyond pupil. Filamentous

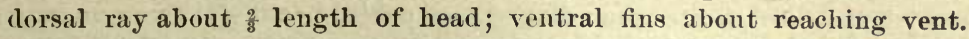
Scales very small. Brownish, lighter and yellowish below; fins very dark. Banks of Newfoumdland to Cape Hatteras; abundant northward in rather deep water, reaching a depth of 304 fathoms. The species resombles Phycis chuss, differing chiefly in the smaller scales. (tenuis, slender.)

Gadus tenuis, MrTchiLl, Trans. Lit. and Phil. Soc. N. Y. 1815, 372, New York.

Phycis dekayi, KAUP, Archiv Natur. 1858, 89, North America.

?Phycis rostratus, GüNTher, Cat. Fish. Brit. Mus., Iv, 353, 1862, no locality; D. 9-59 to 62; A. 49 to 50 ; scales ca. 150 ; ventrals immaculate, reaching front of anal.

Phycis tenuis, De KAY, N. Y. Fauna: Fishes, 293, 1842; Grll, Proc. Ac. Nat. Sci. Phila, 1863, 238; Jordan \& Gilbert, Synopsis, 799, 1883; Goode \& Bean, Oceanic Ichthyology, 359, fig. 312, 1896.

2929. UROPIYCIS CHUSS (Walbaum).

(CODLING; SQUIRREL-HAKE.)

Head $4 \frac{1}{2}$; depth 5. D. 9-57; A.50; scales 110. Body rather slender; head depressed; eye large, about equal to interorbital width; maxillary reaching posterior margin of pupil; filamentous dorsal ray about $\frac{2}{7}$ length of body, when perfect; pectorals $\frac{4}{5}$ length of head; ventral fins extending beyond the vent; scales comparatively large. Brownish above, sides lighter and tinged with yellowish; thickly punctulate with darker; below pale; inside of mouth white; vertical fins somewhat dusky; anal fin margined with pale; lateral line not dark. Atlantic coast, from Gulf of St. Lawrence to Virginia; common northward; reaching a depth of 300 fathoms. (chuss, a vernacular name now obsolete, apparently derived from cusk.)

Chuss, SchöpF, Schrift. Naturf. Frennde, Berlin, vinI, 1780, 143, New York.

Blennius chuss, WALBaUM, Artedi Pisc., 186, 1792; after SchöPF.

Enchelyopus americanu\&, BLOCH \& SCHNEIDER, Syst. Ichth., 53, 1801; after SCHöPF.

Gadus longipes, Mitchili, Trans. Lit. and Phil. Soc. N. Y., 1, 372, pl. 1, fig. 4, 1815, New York. Phycis marginatus, RAFinesque, Amer. Month. Mag., Jan., 1818, 205, Point Judith, Rhode Island. D. 10-60; A.40; ventral reaching anal; tail black-edged.

Phycis americanus, STORER, Rept. Fish. Mass., 138, 1839; GüNTHER, Cat., IV, 353, 1862.

Phycis chuss, Gill, Proc. Ac. Nat. Sci. Phila.1863, 237; Jordan \& GilberT, Synopsis, 799, 1883; GOODE \& BEAN, Oceanic Ichthyology, 359, fig. 311, 1896. 
2930. UROPHYCIS CHESTERI, Goode \& Bean.

Head $4 \frac{1}{3}$; depth 5 ; orbit $3 \frac{1}{3}$ in head; maxillary 2 ; barbel about 3 in orbit. D. 9 or $10-55$ to 57 ; A. 56 ; C. 5,18 to 21,5 ; P. 17 or 18 ; V: 3 ; scales 7-90 or 91-28. Vent situated under the twelfth ray of second dorsal, and equidistant from tip of snout and end of second dorsal; distance of dorsal fin from snout equal to twice length of mandible; thiri ray of first dorsal extremely elongate, extending to a point (thirty-third ray of second dorsal) $\frac{2}{8}$ of distance from snout to tip of candal, its length more than twice that of head, and more than 4 times as long as the rays immediately preceding and following it; anal fin inserted immediately behind vent, its distance from root of ventrals equal to that of dorsal from snout; as in other species of the genus, ventral of 3 rays, the first 2 much prolonged, the first contained 3 times in length of body, the secoud almost 3 times as long as head, reaching to fortieth anal ray or $\frac{8}{4}$ of distance from snout to tip of caudal, the third shorter than diameter of orbit; pectoral 4 times as long as operculum. Seales large and thin, easily wrinkling with the folding of the thick, loose skin, particularly in the median line of sides of body. Lateral line much broken on posterior half of body. (Goode \& Bean.) Atlantic coast of United States, in 100 to 500 fathoms, with Macrourus bairdi, the most abundant fish on the continental slope, swarming everywhere below the 100-fathom line. (Named for Capt. Hubbard C. Chester.)

Phycis chesteri, GOODE \& Bean, Proc. U. S. Nat. Mus. 1878, 256, off Cape Ann, in 140 fathoms (Coll. Captain Chester); Jordan \& GilBert, Synopsis, 800, 1883; Goode \& Bean, Oceanic Ichthyology, 360, fig. 313, 1896.

\section{LAEONEMA, Giinther.}

Lamonema, GÜNTHER, Cat. Fish. Brit. Mus., IV, 356, 1862 (yarrellii).

Bodyof moderate length, covered with small scales; fins naked. A separate caudal; 2 dorsal fins and 1 anal, the anterior dorsal composed of 5 rays; ventrals reduced to a single long ray, bifid at its end. Bands of villiform teeth in the jaws; a small group of vomerine teeth; none on the palatine bones. Chin with a barbel. Branchiostegals 7. Deep sea. ( $\lambda \alpha \imath \mu o ́ s$, throat; $v \tilde{\eta} \mu \alpha$, thread.)

a. Scales 13-140-31; barbel $\frac{1}{2}$ eye; dorsal and anal with narrow black edgings.

BARBATULUM, 2931.

aa. Scales 16-160-38; barbel $\frac{3}{4}$ eye; a large, triangular, black blotch on tail and adjacent parts of vertical fins.

MELANURUM, 2932.

2931. LEMONEMA BARBATULUM, Goode \& Bean.

Head $4 \frac{2}{8}$; depth $4 \frac{1}{2}$; orbit 3 in head ; upper jaw more than 2 ; barbel about 2 in eye. D. $5-63 ;$ A. $59 ;$ P. $19 ;$ V. 2 ; scales $13-140-31$. Vent situated under sixth or seventh ray of second dorsal. Distance of first dorsal from snout 4 in body; base of first dorsal $\frac{1}{2}$ as long as middle caudal rays, that of second slightly more than 3 times length of heal; first dorsal composed of 5 rays, the first of which is elongate, 3 times as long as middle caudal rays, extending to base of twenty-fourth ray of second dorsal; anal fin inserted at a distance from tip of snout equal to twice length of head, 
its distance from insertion of ventrals being equal to length of head; length of ventrals equal to that of pectorals, their tip not extending to vent. Scales small, very thin, deciduous, crowded anteriorly; lateral line not well defined on posterior part of body. Color similar to that of the various species of Phycis; the dorsal and anal fins with narrow black margins. The length of the first dorsal ray is very variable, being shorter in jounger individuals. This species differs from $L$. yarrellii by its much smaller scales, and from $L$. robustum by the greater number of rays in the dorsal and anal fins, and its much shorter ventrals. (Goode \& Bean.) Gulf Stream, reaching a depth of 312 fathoms. (barbatulus, having small barbels.)

Lamonema barbatula, Goode \& BeAN, Bull. Mus. Com. Zool., x, 204, 1883, Gulf Stream, Lat. $3^{\circ} 43^{\prime}$ N., Long. $77^{\circ} 20^{\prime}$ W., in $23^{\circ}$ fathoms, and Lat. $28^{\circ} 35^{\prime}$ N., Long. $73^{\circ} 13^{\prime}$ W.; GOODE \& BEAN, Oceanic Ichthyology, 362, figs. 315 and 315A, 1896.

2932. LEMONEMA MELANURUM, Goode \& Bean.

Head about $4 \frac{2}{8}$; depth $4 \frac{2}{8}$; eye 3 in head; snout 4 ; interorbital width 6 . D. $6-57$; A. 55; P. 25; V. 2 ; Br. 7 ; scales 16-160-38. Maxillary extending tó below middle of eye; intermaxillary nearly $\frac{1}{2}$ length of head; mandible slightly more than twice length of snout. Teeth in intermaxillary and mandible in villiform bands; vomerine teeth in a small circular patch on middle of head of bone. Barbel about as long.as snout. Distance of first dorsal from tip of snout about 4 in snout; length of first ray of dorsal equaling that of head without snout; last ray of dorsal scarcely more than $\frac{1}{4}$ as long as first; ventral consisting of a single bifid ray, its distance from tip of snout equal to length of head, its length nearly equal to that of dorsal or the pectoral when extended, not reaching vent by a distance equal to length of snout; pectoral equaling that of longest dorsal ray, and also equaling head without snout; second dorsal higher anteriorly, and posteriorly much higher than in middle; longest anterior ray $\frac{1}{2}$ length of ventral; longest posterior ray $\frac{1}{2}$ length of head. Vent under eighth ray of second dorsal. Gill rakers $5+15$, the longest $\frac{1}{4}$ as long as snout. Color very light brown, the dorsals and anal with a narrow dark margin; a conspicnous, large, triangular, dark blotch on last rays of dorsal and anal, and a dark blotch occupying almost the whole of caudal, leaving a margin of whitish around it. (Goode \& Bean.) Caribbean Sea, north to New York; reaching a depth of 1,467 fathoms. ( $\mu \varepsilon \dot{\varepsilon} \lambda \alpha^{\prime}$, black; ovipá, tail.)

Lomonema melanurum, Goode \& BeAN, Oceanic Ichthyology, 363, fig. 316, 1896, Gulf Stream, Lat. $30^{\circ} 44^{\prime}$ N., Long. $79^{\circ} 26^{\prime}$ W., in 440 fathoms. ('Type, No. 38270 . Coll. Albatross.)

992. GAIDROPSARUS, Rafinesque.

\section{(THREE-BEARDED ROCKLINGS.)}

Gaidropsarus, RAFINESQUE, Indice d'Ittiol. Siciliana, 1810 (mustellaris=mediterraneus); description from a rough figure of RONDELET.

Les Musteles, Cuvier, Règne Anim., Ed. I, vol. 2, 215, 1817 (tricirrhatus= mediterraneus). ?Mustela, OKEN, Isis. 1817 (for les Musteles; not Mustela, a genus of mammals). 
Onos, Risso, Hist. Eur. Mérid., III, 214, 1826 (mustella=mediterraneus). MIustela, StARK, Elem. Nat. Hist., I, 425, 1828 (after les Mustèles).

Motella, Cuvier, Règne Anim. Ed.2, vol. II, 334, 1829 (vulgaris=tricirratus).

Onus, GÜNTHER, corrected spelling.

Body rather elongate, covered with minute scales; head not compressed, the upper jaw the longer; snout with 2 conspicuous barbels, the chin with 1 ; teeth on jaws and vomer in bands, palatines toothless; dorsals 2 , the anterior of a single long ray followed by a series of short fringe-like rays concealed in a groove; second dorsal and anal long, similar to each other; caudal rounded or lanceolate; ventral rays 5 to 7 . Small fishes of the northern seas, descending to deep water. We here regard the 5-bearded Rocklings (Ciliata, Couch, 1832) $=$ Couchia, Thompson, 1856 = Molvella, Kaup, 1858, as a distinct genus, distinguished by the 5 barbels at the tip of the snout. ( $\gamma \alpha \ddot{i} \delta \rho \alpha \psi \alpha \dot{\alpha} \rho \alpha$, a modern Greek name used by Rondelet for a species of this group.)

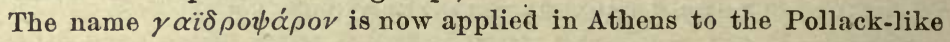
fish, Micromesistius poutassou (Risso).

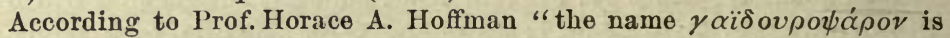

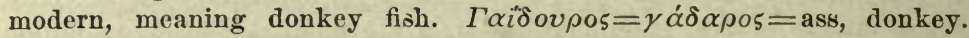
The ancients called a certain fish ǒvos, ass. Dorio, in Athenæus, vir, 99, says some persons call the o้vos (i. e., the tish ǒvos) yádos. Epicharmus, in his Marriage of Hebe, says: 'Wide-gaping $\chi \alpha \dot{v} v \alpha \imath$ and monstrousbellied ǒvor.' (See Aristotle 599b 33, 601a 1, 620b 29, frag. 307, 1530a.) According to Aristotle the oै $v o 5$ has a mouth opening wide (literally, breaking back), like the $\gamma \alpha \lambda \varepsilon o i$. It leads a solitary life, is the ouly fish which bas its heart in its belly, has stones in its brain like millstones in form, and is the only fish which lies torpid in the warmest days under the reign of the dog star, Sirius, the other fishes going into this torpid state

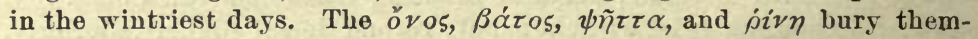
selves in the sand, and after they make themselves invisible they wave the things in their mouths which fishermen call little rods or little wands $(\dot{\rho} \alpha \beta \delta i \alpha)$. (Hoffinan \& Jordan, Fishes of Athens, Proc. Ac. Nat. Sci. Phila. 1887, 146.)

a. First ray of first dorsal long, as long as head; head small, $5 \frac{3}{4}$ in length; teeth rather feeble, uniform. D.59; A.45; P. 25. Color uniform brick red.

aa. First ray of first dorsal short, about as long as snout.

ENSIS, 2933.

b. Pectoral rays 22 to 24 ; upper jaw without cirri or rudimentary barbels along the premaxillary; maxillary reaching posterior border of eye; head $5 \frac{1}{2}$ in length. D. 56; A.45. Color reddish.

ARGENTATUS, 2934.

$b b$. Pectoral rays 16 ; upper jaw with short cirri or barbels along the premaxillary; maxillary reaching far beyond eye. D. 50; A.42. Head 4 in length. Color brownish.

SEPTENTRIONALIS, 2935.

2933. GAIDROPSARUS ENSIS (Reinhardt).

Head $5 \frac{8}{9}$; depth $4 \frac{1}{2}$. D. 59 ; A. 44 to 46 ; P. 22 to 27 ; V. 8. Body unusually deep, being greatest at the vent; head small; eye rather large, nearly as long as snout, equaling interorbital area, and in anterior half of head; posterior margin of orbit nearly equidistant between tip of snout and posterior margin of operculum. Mouth normal; supramaxillary end- 
ing under posterior margin of pupil. Teeth in a narrow band in each jaw, some of those at least in outer row of upper jaw slightly enlarged and brownish colored; teeth of vomer forming a short curved band in 2 rows. Nasal barbel about equaling diameter of eye. Chin barbel small and not much exceeding $\frac{1}{2}$ diameter of eye. Foremost ray of first dorsal springing from back above opercular margin; second dorsal fin low in frout, but risiug rapirly to seventh or eighth ray, behind which it is nearly uniform for a long distance, and the highest at posterior portion; anal fin much lower than second dorsal; eaudal slightly emarginate, almost truneate behind, its median rays about $\frac{2}{8}$ as long as head; pectorals nearly $\frac{8}{4}$ as long as head, produced toward the upper angles, the third ray being longest; ventral fins with their bases mostly in advance of pectorals, the longest ray filamentous and nearly equaling pectoral. Lateral line obsolescent. (Goode \& Bean.) Atlantic coast of North America, from Greenland to Cape Hatteras; in deep waters, reaching a depth in the Gulf Stream of 1,081 fathoms. (ensis, sword.)

Motella ensis, Reinhardt, Dansk. Vidensk. Selsk. Afhandl., viI, 15, 1838, Greenland.

Onos rufus, Gill, Proc. U. S. Nat. Mus. 1883, 259, Gulf Stream; GiLl, Proc. Ac. Nat. Sci. Phila. 1884, 172; Jordan, Cat. Fish. N. A., 128, 1885.

Onos ensis, Gill, Proc. Ac. Nat. Sci. Phila. 1863, 241; Gill, Cat. Fish, E. Coast U. S., 18, 1873; Jordan \& Gilbert, Synopsis, 797, 1883; Jordan, Cat. Fish. N. A., 128, 1885; GOODE \& BEAN, Oceanic Ichthyology, 381, fig. 327, 1896.

2934. GAIDROPSARUS ARGENTATUS (Reinhardt).

Head 5 ; depth $5 \frac{8}{4}$. D. 54 to 59 ; A. 45 or 46 . Body elongate; head smałl; teeth in several rows, 1 row more enlarged than the others; maxillary reaching posterior border of eye; eye large, $5 \frac{1}{2}$ in head; interorbital space scarcely exceeding the eye. Lateral line with about 27 enlarged pores along its entire length. First ray of first dorsal short, little longer than snout; vent near middle of length. Reddish gray, changing to bluish on the head and abdomen; tips of dorsal, anal, and caudal red, also the barbels and first ray of first dorsal; cavity of mouth pale. Coasts of Greenland (Collett), south to Faroë and Bear Islands; not seen by us. There can be no doubt that Motella argentata is the young of the species later ealled Motella reinhardti. (Eu.) (argentatus, silvered.)

Motella argentata, REINHARDT, Dansk. Vidensk. Selsk. Afh., viI, 128, 1838; Greenland; young.

Motella reinhardti, Kröyer MS., 1852; ColletT, Forh. Vid. Selsk. Chr., No. 14, 83, 1878, Greenland.

Oouchia argentata, GÜNTHER, Cat., IV, 365, 1862.

Ciliata argentata, GiLL, Proc. Ac. Nat. Sci.Phila. 1863, 241 ; Gill, Cat. Fish. E. Coast U. S., $18,1873$.

Onos reinhardti, GiLl, Proc. Ae. Nat. Sci. Phila. 1863, 241; GiLl, Cat. Fish. E. Coast U. S., 18, 1873; Collete, Norske Nord-Havs Exp., 131, 1880; Jordan \& Gilbert, Synopsis, 797, 1883 ; Jordan, Cat. Fish. N. A., 128, 1885; Goode \& BEAN, Oceanic Ichthyology, 383,1896.

2935. GAIDROPSARUS SEPTENTRIONALIS (Collett).

Head 4; depth $5 \frac{2}{3}$. D. 50 ; A. 42; P. 16. Three barbels, 2 at the nostrils, 1 at the chin, besides a row of about 8 shorter rudimentary barbels along the edge of the upper lip; eye small, $\frac{1}{2}$ length of snout; eleft of mouth 
extending far beyond eye, its length nearly equal to that of postorbital part of head; teeth rather small, unequal; outer teeth of upper jaw and some of the inner teeth of lower enlarged; first ray of first dorsal short, about as long as snout; vent midway between tip of snout and last anal ray; lateral line with about 20 large pores. Grayish brown, paler below ; cavity of mouth white. Coast of Norway; 1 specimen known from Greenland. (Collett.) (Eu.) (septentrionalis, northern.)

Motella septentrionalis, Colletr, Ann. Mag. Nat. Hist.1874, 15, 82, Lofoten, Norway.

Onos septentrionalis, Collett, Norske Nord-Havs Exped., 139, 1880; Jondan, Cat. Fish. N. A., 128, 1885.

\section{ENCHELYOPUS, Bloch \& Schneider.}

\section{(FOUR-BEARDED ROCKLINGS )}

Enchelyopus, BLOCH \& SCHNEIDER, Syst. Ichth., 50, 1801 (cimbrius; the first species mentioned and the one left as type after elimination of the genera, defined prior to Rhinonemus).

Rhinonemus, GrLl, Proc. Ac. Nat. Sci. Phila. 1883, 241 (cimbrius).

Barbels 4, 1 at each nostril, 1 at tip of snout, and 1 at the chin; head high and compressed anteriorly; teeth in narrow bands, some of them enlarged; otherwise essentially as in Gaidropsarus. North Atlantic. ('ย $\chi \varepsilon \varepsilon \lambda v \omega \pi o ́ s$, resembling an eel; "facie anguillaris.")

\section{ENCHELYOPUS CIMBRIUS (Linnæus).}

(FOUR-BEARDED ROCKLING.)

Head $5 \frac{1}{2}$; depth 9 . D. 45 to 50 ; A. 41 or 42 ; V. 5 . Body slender, tapering from the shoulders back; caudal peduncle narrow, 4 in head; snout moderate, blunt, rounded, not depressed, a little shorter than the eye; eye large, subcircular, 4 in head; interorbital space narrow, equal to vertical diameter of eye, 6 in head; teeth villiform, those in the upper jaw nnequal, small, with about 8 enlarged in front, those of the lower jaw long and slender, of equal length, a few somewhat enlarged in front; maxillary reaching beyond posterior border of eye, a barbel at each nostril, 1 on tip of snout and 1 on chin, stitch-like; lateral line with about 35 enlarged pores along its entire length; first ( free) ray of dorsal nearly as long ashead; ventral $\frac{1}{2}$ head; caudal acute. Light olivaceous (salmon-red); first dorsal ray and posterior end of dorsal and anal abruptly black, as is lower half of caudal; pectorals and ventrals pale; sides of head somewhat silvery ; cavity of mouth dark bluish. North Atlantic, on both coasts, south in deep water to the Gulf Stream; common in Massachusetts Bay ; our specimens from Woods Hole; the young ("mackerel midges") silvery, unlike the adult in appearance. (Eu.) (cimbrius, welsh.)

Gadus cimbrius, Linnæes, Syst. Nat., Ed.12, 1, 440,1766, Atlantic Ocean; Scania (Coll. Dr. Strussenfelt).

Motella caudacuta, Storer, Proc. Bost. Soc. Nat. Hist., III, 1848, 5, Cape Cod, Provincetown, Mass. (Coll. Herman M. Smith); Storer, Amer. Ac. Sci., 411, 1867; Storer, Hist. Fish. Mass., 183, 1867.

Rhinonemus caudacuta, GILl, Proc. Ac. Nat. Scí. Phila.1863, 241; Goone \& Bean, Amer. Journ. Sci. and Arts 1877, 476; JoRDAN, Cat. Fish. N. A., 128, 1885.

Motella cimbria, Nirsson, Prod. Ich. Scand., 48, 1832; BeLL, Can. Nat. and Geol., IV, 209, 1859. 
Onos cimbrius, Goode \& Bean, Proc. U. S. Nat. Mus. 1878, 349; Goode \& Bean, Bull. Essex Inst., XI, 1879; JondaN \& Gilbert, Synopsis, 797, 1883; GOOde \& BEAN, Bull. Mus. Comp. Zool., x, No. 5, 217, 1883.

Rhinonemus cimbrius, Jordan, Cat. Fish N. A., 128, 1885; GoodE \& BEAN, Oceanic Ichthy. ology, 384, fig. 328, 1896.

Enchelyopus cimbricus (misprint for cimbrius), BLOCH \& SCHNEIDER, Syst. Ich., 50, pl.9, 1801.

\section{BROSME (Cuvier) Oken.}

\section{(Cusks.)}

Les Brosmes, (Uuvier, Règne Animal, Ed. I, vol. 2, 216, 1817 (brosme).

Brosme, OKEN, Isis, 1817, 1182; after Cuvier.

Brosmius, Cuvier, Règne Animal Ed. 2, vol. II, 334, 1829 (brosme).

Body moderately elongate, covered with very small scales. Mouth rather large, with teeth in the jaws, vomer, and palatines, some of those on the voiner and palatines enlarged; chin with a barbel; branchiostegals 7 . Dorsal fin single, continuous, not elevated, not notched; anal fin similar, but shorter; caudal fin rounded; ventral fin several-rayed. Northern seas. (From the Danish vernacular name, brosme.)

\section{BROSME BROSME (Mïller)。}

\section{(Cusk.)}

D. 98 ; A. 71 ; P. 24 ; V. 5. Body cylindrical, posteriorly compressed; head flattened above. Mouth large, oblique, maxillary reaching beyond orbit; lower jaw included; several rows of sharp teeth on jaws, vomer, and palatines; barbel about 5 in head; interorbital greater than the diameter of eye. Origin of dorsal above anterior half of pectoral; pectoral round, $2 \frac{1}{2}$ in head; caudal rounded behind. Brownish above, the sides yellowish, sometimes mottled with brown; young uniform dark slate color, or with transverse yellow bands; vertical fins bordered with blackish, and with a white edge. (Storer.) North Atlantic, south to Cape Cod and Denmark; rare southward on our coasts. (brosme, a Danish name.)

Gadus brosme, Müllek, Prodr. Zool. Dan., 41, 1776, Denmark; Fabricius Fauna Gron. landica, 140, 1780.

Gadus lubb, EUPHRASEN, Vet. Akad. Handl. 1794, 223, tab. 8.

Gadus torsk, Bonna TERRe, Encycl. Meth., 51, 1788, Söndmöre, Norway; after Strom.

Brosmius vulgaris, Fleming, British Anim., 194, 1828.

Brosmius flavesny, LE SUEUr, Mém. Mus., v, 1819, 158, Banks of Newfoundland; chin with 2 barbels; lower jaw longest.

Brosmius flavescens, Günther, Cat., Iv, 369, 1862; Storer, Hist. Fish. Mass., 368, 1867.

Enchelyopus brosme, BLOCH \& SCHNEIDER, Syst. Ichth., 51, 1801.

Brosmius brosme, GÜNTHer Cat., IV, 369, 1862; JoRdAN \& GILBert, Synopsis, 802, 1883; GOoDE \& BeAN, Oceanic Ichthyology, 385, fig. 329, 1896.

Blennius torsk, LACÉṖ̀DE, Hist. Nat. Poiss., 11, 508, 1800.

\section{Family CCXV. MACROURIDAE.}

\section{(THE Grenadiers.)}

Body elongate, tapering into a very long compressed tail, which ends in a point; scales moderate, usually keeled or spinous, sometimes smooth. Suborbital bones enlarged, sometimes cavernous. Teetli villiform or cardi- 
form, in bands, on the jaws only ; tip of lower jaw with a barbel; premaxillary protractile. Dorsal fins 2, the first short and high, of stiff, spine-like branched rays; the second dorsal very long, usually of very low feeble rays, continued to the end of the tail; anal fin similar to the second dorsal, but usually much higher; no caudal fin; ventrals small, subjugular, each of about 8 rays. Branchiostegals 6 or 7 . Lateral line present. Gills $3 \frac{1}{2}$ or 4, a slit behind the fourth. Gill rakers small; gill membranes free or narrowly united to the isthmus, usually more or less connecterl; pseuclobranchiæ wanting or rudimentary; pyloric cæca numerous; air bladder present. Genera 18; species about 50, chiefly of the northern seas, all in deep water. They differ from the codfishes chiefly in the elongate and degenerate condition of the posterior part of the body. Dr. Gill succinctly defines the group as "Gadoidea with an elongated tail tapering backward and destitute of a candal fin, postpectoral anus, enlarged suborbital bones, inferior month, subbrachial ventrals, a distinct anterior dorsal, and a long second dorsal and anal converging on end of tail." We here follow Goode \& Bean in the general arrangement of the genera of Macrourida. Some of these can, however, be only provisionally adopted, as the characters of dentition, form of mouth, and character of the second dorsal spine or ray, are subject to much intergradation. These characters seem much more distinct on paper than they are in fact. Still, most of the genera here adopted will ultimately prove valid. (Macrurida, Giinther, Cat., IV, 390-398, 1862.)

a. First branchial arch free, without fold of membrane across it; mouth large; second dorsal well developed, higher than the anal.

BATHYGADINA:

b. Gills $3 \frac{1}{2}$; snout short and blunt, the jaws even in front; teeth in villiform bands, sometimes obsolete; bones of head soft and cavernous; scales smooth; first dorsal low, its spine not produced.

TRACHYRINCHINA:

Bathygadus, 995.

bb. Gills 4; snont rather long.

c. Teeth in upper jaw in 2 series, the outer enlarged, those in lower jaw in 1 series; mouth subterminal; barbel obsolete; nape withont scaleless fossæ; vomer with teeth; bones of head soft and cavernous; tail very long, flagelliform; anal fin with an elevated anterior lobe.

STEINDACHNERIA, 996.

cc. Teeth in both jaws in villiform bands; barbel developed; mouth inferior; a naked fossa on each side of nape; a row of arned scales along base of dorsal anteriorly; opercle very small; anal not elevated in front.

MACROURINE:

TRACHYRINCUS, 997.

aa. First branchial arch with a fold of membrane across its terminal portion; gills 4, a slit behind the fourtb; barbel well developed.

$d$. Teeth not all in villiform bands, those of lower jaw in 1 series; mouth rather large, with more or less of lateral cleft.

e. Upper jaw without villiform band behind the enlarged anterior teeth, the inner teeth, if present chiefly uniserial, not in villiform bands.

$f$. Dorsal fins widely separated, the interspace greater than base of first. $g$. First dorsal with the spine not serrate, its insertion over pectoral or nearly so; pectoral placed high, opposite npper angle of gill cleft; scales small, bristly; bones of head carernons; ventrals short and weak.

Malacocephalus, 998:

gg. First dorsal with its spine more or less strongly serrate; pectoral inserted below upper angie of gill cleft. 
h. Scales nearly smooth, with weak ridges which are not spinigerous.

Moseleya, 999.

hh. Seales rough, with strong ridges. Nematonurus, 1000.

ff. Dorsal fins near together, the interspace less than base of first; scales rough.

i. Dorsal spine weak, unarmed or very nearly so; pectorals moderate.

Albatrossia, 1001.

ii. Dorsal spine very strongly serrate; pectorals very long.

BogosLovius, 1002.

ee. Upper jaw with a distinct villiform band behind the outer series of enlarged tecth; dorsal spino serrate; dorsal fins not widely separated.

Chalinura, 1003.

dd. Tecth in villiform bands above and below, the outer scarcely enlarged and not separated from the rest; the lower band sometimes becoming a single series laterally; scales rough.

j. Mouth wide, with considerable lateral cleft.

$k$. Dorsal spine finely barbed; skull rather firm; dorsals moderately separated.

CORYPHANOIDES, 1004.

$k k$. Dorsal spine entirely smooth; bones of skull very thin and papery; dorsals well separated.

HYMENOCEPHALUS, 1005.

jj. Mouth inferior, small, with little lateral cleft; a more or less distinct ridge across the suborbital region.

$l$. Scales spinous, very rough.

$m$. Scales distinct, regularly imbricated.

$n$. Long dorsal spine serrate in front; mouth subinferior, below the short snout.

Macrourus, 1006.

nn. Long dorsal spine smooth; mouth wholly inferior, below the long sturgeon-like suout. Carorhynchus, 1007.

$\mathrm{mm}$. Scales indistinct, scarcely imbricated; the whole body roughvillous; dorsal spine smooth. T'RACHONURUS, 1008.

ll. Scales all thin and smooth, dorsal fin slightly serrulate.

LIONURUS, 1009.

995. BATHYGADUS, Günther.

Bathygadus, GÜnther, Ann. Mag. Nat. Hist. 1878, 23 (cottoides).

Head large, fleshy, without prominent ridges, spiny armature or external depressions; nape elevated, hump-like. Snout broad, obtuse, not produced; mouth terminal very large, with small villiform teeth or none; suborbital ridge very low, not joined to the angle of the preoperculum. Maxillary entirely received within a groove under the prefrontal and suborbital bones, its tips narrowed and l)lade-like; premaxillaries protractile downward, separated anteriorly, rib-shaped, compressed vertically, very broad and withont true teeth; provided posteriorly with a short flange, which is received under the maxillary; mandible received within the intermaxillary bones, without true teeth, but with minute asperities, similar to those in the upper jaw; vomer and palatines toothless. Barbel sometimes present. No pseudobranchiæ. Gill rakers numerons, moderate, lanceolate, with minute denticulations along their inner edge. Branchiostegal membrane free from the isthmus, deeply cleft. Branchiostegals 7, very stiff. Gill opening very wide; gills $3 \frac{1}{2}$; anterior gill arch free. Operculum with a blunt, spine-like prominence at its angle. Ventrals below the pectorals, many-rayed, the anterior rays produced; dorsal consisting for the nost part of branched rays, higher than the anal, the 
first dorsal low, without differentiated spine. Scales cycloid, unarmed; lateral line strongly arched over the pectoral. Deep seas. This genus differs from Macrourus and its allies in the structure of both the first and last gill arches. It is perhaps the most primitive of the family and as such is nearest allied to the Gadida. ( $\beta \alpha \theta v_{\zeta}$, deep; Gadus, codfish.)

$a$. Pectoral and ventral fins moderate, not much, if any, longer than head.

$b$. Jaws without teeth; pectoral fin broad, of 25 rays; depth $5 \frac{2}{3}$ in length.

ARCUATUS, 2938.

$b b$. Jaws with small teeth; pectoral fin narrow; depth 6 to $6 \frac{1}{2}$ in length.

c. Eye moderate, 5 in head; pectoral rays 14 , the fin $\frac{1}{2}$ as long as head.

FAvosus, 2939.

cc. Eye very large, 23 in head; pectoral as long as head without snout.

MACROPS, 2940.

aa. Pectoral and ventral fins much produced, much longer than head, each reaching about halfway to tip of caudal; depth $7 \frac{1}{2}$ in length; pectoral rays 13.

LONGIFILIS, 2941.

2938. BATHYGADUS ARCUATUS, Goode \& Bean.

Head 5 in total length; depth $5 \frac{2}{8}$; eye $4 \frac{1}{2}$ in head; snout $4 \frac{1}{2}$. D. II, 9 or 10-135; A. 120 ; P. 25 ; V. 8 ; scales $8-140-13$ or 14 (counting backward from vent to lateral line), 22 counting forward. Borly shaped much as in Chalinura simula, but the nape still more convex; back gibbous, the dorsal outline rising rapidly from interorbital region to origin of first dorsal, whence it descends gradually to end of tail. Scales moderate, cycloid, subovate, without armature, those of abdominal region and those above pectorals the largest; lateral line strongly arched over the pectorals, length of the arched portion contained about $3 \frac{1}{4}$ times in straight portion, greatest height of arch about $\frac{1}{4}$ its chord; scales covering all parts of head except jaws and chin. Interorbital area flat, its width 6 in head; postorbital portion of head about $2 \frac{1}{2}$ times diameter of eye; operculum terminating in a flat obtuse spine, its length, including the flap, about equal to diameter of eye; preoperculum entire, with a prominent ridge in advance of its posterior edge; snout very broad, obtuse, the intermaxillaries extending beyond it, its width at nostrils equal to about twice length of eye; posterior extremities of intermaxillary processes elevated, producing a decided hump upon top of snout; ridge formed by prefrontal and suborbital bones terminating very slightly behind posterior margin of orbit, and not connected with angle of preoperculum. Nostrils immediately in front of lower part of eye, not tubular, the anterior one very small, porelike, only about $\frac{1}{4}$ as large as posterior one; distance of anterior nostril from tip of snout about $\frac{8}{4}$ length of eje. Length of barbel $6 \frac{2}{5}$ in length of body, and equal to length of head without snout, more than 3 times as long as eye. No true teeth, the intermaxillaries and mandible being broad plates, covered with minute asperities; a naked space at the symphysis of intermaxillaries; distance of first dorsal from snout nearly $3 \frac{1}{3}$ times length of its base, the first spine minute, the second (in the type) somewhat mutilated, its length nearly 3 in length of head, not stouter than the branched rays, and entirely smooth; second dorsal fin separated from first by a very short interspace, equal to about $\frac{1}{8}$ of length of eye, its rays long, subequal, the first slightly the longest, its length equal to that of base of 
first dorsal; anal much lower than dorsal, the longest rays being in front, its third ray about $\frac{1}{2}$ as long as first ray of second dorsal; this fin inserted under the seventh ray of second dorsal; about 3 of the terminal anal rays might be considered caudal rays; pectoral inserted slightly in advance of ventral, which is in about the same vertical with the origin of the first dorsal, second ray of pectoral slightly produced; length of pectoral equal to that of head without snout; ventral insertion distant from tip of snout a distance equal to that of first dorsal from snout, the first and second rays filamentous, the latter slightly the longer, and extending to the fifteenth or eighteenth ray of anal tin. Color brown; vertical fins bluish or black; peritoneum black; inside of gill covers and roof of mouth bluish. (Goode \& Bean.) West Indies and Gulf of Mexico. Three specimens known; the type from near Martinique. (arcuatus, arched.)

Bathygadus arcuatus, GooDE \& BEAN, Bull. Mus. Comp. Zool., XII, No. 5, 158, 1883, off Martinique, in 334 fathoms (Coll. Blake); GOODE \& BEAN, Oceanic Ichthyology, 421, 1896.

2939. BATHYGADUS FAVOSUS, Goole \& Bean.

Head $5 \frac{1}{2}$ in total length; depth about 6 ; eye 5 in head; snout about 4. D. II, $9-125$; A. 110 ; V. 9 ; P. 14 ; B. 7 ; scales 10-135-16. Body heavy, stont, the profile descending gradually and in a slight curve from first dorsal to snout. Scales small, decidnous, cycloid, without armature; interorbital area slightly convex, its greatest width about 3 in head; the postorbital part of head $2 \frac{2}{8}$ times as long as eye; snout broad, oblique, its width at the nostrils a little more than that of interorbital area; nostrils close to and in front of middle of eye, the posterior somewhat the larger; no barbel. Teeth in both jaws in villiform bands, a naked space at symphysis of intermaxillaries; intermaxillary bands more than twice as wide as those of mandible; vomer and palatines toothless. Gill rakers $20+25$, the longest on anterior arch slightly more than $\frac{1}{2}$ eye; pseudobranchice present, very rudimentary in some individuals, in others wanting or present only on one side; first dorsal distant from snout a distance slightly more than length of head, length of its base about equal to width of snout at nostrils, the fin consisting of 2 spines, the first minute, and 9 brauched rays; length of longest dorsal spine, which is armed, 2 in head; second dorsal beginning immediately behind first, the membrane being continuous; anterior rays longest, apparently about $\frac{1}{4}$ length of head; anal lower than second dorsal, its distance from snout about equal to $\frac{1}{8}$ of total length; pectoral inserted under anterior rays of first dorsal and very slightly in advance of origin of ventral, its length more than $\frac{1}{2}$ that of head; distance of ventral from snout 5 times in total length; this fin inserted nearly under base of pectoral; the first ray somewhat produced, its tip reaching to fourth ray of anal fin. Color bluish brown, darkest upon head and abdomen. West Indies. The type specimen, $350 \mathrm{~mm}$. in length, was obtained by the Blake from Station LXXX, off Martinique, at a depth of 472 fathoms. (Goode \& Bean.) (favosus, like honeycomb.)

Bathygadus favosus, Goode \& BeAN, Bull. Mus. Comp. Zool., xIr, No. 5, 160, 1883, off Martinique in 472 fathoms (Coll. Blake); Goode \& BEAv, Oceanic Ichthyology, 420, fig. $352,1896$. 
2940. BATHYGADCS MACROPS, Goode \& Bean.

Head $5 \frac{1}{4}$ in total length; depth $6 \frac{1}{2}$; eye $2 \frac{8}{4}$ in head; snout 5 . D. II, 8 -about 125 ; V. 8 . Body somewhat compressed; scales small, decidnous, about 25 rows in an oblique line from the vent to the dorsal fin, 24 from the upper angle of operculum to the vertical through origin of the anal; interorbital area nearly flat, its width 4 in head; postorbital part of head somewhat longer than diameter of eye; snout broad, obtuse; nostrils close to eje, the posterior nearly twice as large as anterior one; maxillary extending to vertical through posterior margin of orbit, its length equal to that of head without its postorbital portion; length of mandible 3 times that of snout; intermaxillaries and mandible provided with narrow bands of villiform teeth, those of the mandible much shorter. A minute barbel, about $\frac{1}{8}$ as long as snout. Vomer and palate toothless. Gill rakers lanceolate, elongate, $7+26$, the longest 7 in head; pseudobranchix absent; distance of first dorsal from snout nearly 5 times in total length, second or longest ray in the typical specimen twice length of snout; second dorsal almost continuous with the first, its anterior rays the longest, about.4 times in length of head; anal inserted under fourteenth ray of second dorsal, its rays all very short; in a distance equal to length of head, counting back from insertion, there are 33 rays; pectoral inserted under first branched ray of first dorsal, its length in the most nearly perfect specimens equaling length of head without snout; ventral origin very slightly behind origin of pectoral under third branched ray of dorsal, reaching nearly to vent when laid back, its length equaling 3 times that of the snout. Branchiostegals 7. Color yellowish gray, lighter below. (Goode \& Bean.) In deep waters of the Gulf of Mexico off the United States coast, in 321 to 347 fathoms. ( $\mu \alpha \varkappa \rho o ́ s$, large; œ้ $\psi$, өуе.)

Bathygadus macrops, Goode \& BeAN, Proc. U. S. Nat. Mus. 1885, 598, Gulf of Mexico, Lat. $28^{\circ} 34^{\prime}$ N., Long. $86^{\circ} 4^{\prime}$ W., in 335 fathoms (Tyje, No. 37339. Coll. Albatross); GüNther, Challenger Report, XxII, 156, 1887; Goove \& BeAv, Oceanic Ichthyology, $423,1896$.

2941. BATHYGADUS LONGIFLLIS, Goode \& Bean.

Head about $5 \frac{8}{4}$ in total length; depth $7 \frac{1}{2}$; eye 4 in head; snout 4 . D. II, 8 or 9 -about $140 ;$ P. 13 ; V. 8 ; scales about 142 . Body more compressed than in B. macrops; scales small, cycloid, deciduous, about 25 rows from the vent upward and forward to the dorsal fin, interorbital area flattened,

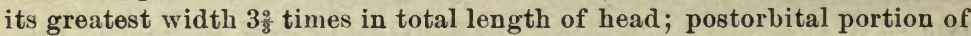
head twice as long as eye; snout and nostrils normal; maxillary reaching somewhat beyond posterior margin of orbit, its length twice in distance from snout to origin of first dorsal; length of mandible $2 \frac{1}{2}$ times in snout; barbel slender, long, its length equal to $1 \frac{1}{2}$ times orbital diameter. Teeth in narrow villiform bands in each jaw, none on vomer or palatine bones; gill rakers very long and slender, numerous, $17+35$, the longest nearly 6 in head; pseudobranchiæ absent; first dorsal of 2 stout spines, the first minute, the second elongate, and 8 or 9 branched rays, its distance from snout $5 \frac{1}{2}$ in total; second or longest simple ray nearly 8 times length of 
snout, and reaching to or beyond the thirtieth ray of the second dorsal; second dorsal almost continuous with the first, its anterior rays longest and not diminishing rapidly in size toward tail; anal inserted under ninth ray of second dorsal, its rays much shorter than those of dorsal, and situated about same distance apart; pectorals inserted under anterior portion of first dorsal, first ray much produced, extending more than halfway from its insertion to tip of tail; ventral origin slightly behind origin of pectoral, under third branched ray of dorsal, its first ray much enlarged, extending more than halfway from its insertion to tip of caudal, its length $2 \frac{1}{8}$ times in total length; branchiostegals 7 . Color yellowish gray, abdomen bluish. This form is closely allied to $B$. multifilis, described by Günther from off the Philippines (Challenger Report, xxII, 155, pl. 42, fig. 13, 1887), which, however, appears to have a smaller eye, less elongate filaments, and ventrals inserted in advance of the first dorsal, while the anal appears to be further back, under the twelfth or thirteenth ray of second dorsal. Both species are proviled with long, slender barbels; in other respects they are closer to $B$. cottoides, the typical species, than to $B$. macrop8. (Goode \& Bean.) Deep waters of the Gulf of Mexico, in 525 to 739 fathoms. (longus, long; filum, thread.)

Bathygadus longifilis, Goode \& Bean, Proc. U.S. Nat. Mus. 1885, 599, Gulf of Mexico. Lat. $28^{\circ} 47^{\prime} 3 \mathrm{o}^{\prime \prime} \mathrm{N}$., Long. $87^{\circ} 27^{\prime} \mathrm{W}$., in 724 fathoms (Type, No. 37338. Coll. Albatross); GÜNTHer, Challenger Report, xxII, 157, 1887; AlCOCK, Ann. Mag. Nat. Hist. 1890, 302; ALCOCK, l. c. 1891, 123; GOODE \& BEAN, Oceanic Ichthyology, 422, 1896.

Hymenocephalus longifilis, VAILLANT, Exp. Sei. Trav. et Tails, 218, pl. 23, fig. 1, 1888.

996. STEINDACHNERIA, GOODE \& BEAN.

Steindachneria, GoODE \& BEAN, in AGAssiz, Three Cruises of the Blake, II, 26, 1888 (no type; short diagnosis *); not Steindachneria, EiGENMANn, Nematognathi, Occasional Papers, I, Cal. Ac. Sci. 1890, 100 and 202, a genus of Siluroid fishes. Steindachneria, GoodE \& BEAN, Cceanic Ichthyology, 419, 1896 (argentea). Steindachnerella, $\nmid$ EigenmanN, American Naturalist, Fobruary, 1897, 159 (argentea).

Body compressed, with tapering tail. Mouth large, terminal. Dorsal fins continuous, both elevated anteriorly; anal divided, the anterior portion elevated, the posterior low. Teeth in each jaw biserial, the outer much enlarged, vomerine teeth present. Bones of head soft and cavernous. Eye large. Gill membranes connected anteriorly, free from the isthmus. Gill rakers slender, rather numerous; vent in anterior third of length. No pseudobranchiæ. Branchiostegals 7. No barbel. Pectorals and ventrals both below first dorsal. Scales thin, cycloid, deciduous. Deep seas. ("This rernarkable genus is named in honor of Dr. Franz Steindachner, Custos of the Imperial Zoological Museum of Vienna," one of the ablest naturalists of the century.)

* "Steindachneria, a Macruroid with a high differentiated first anal spine." (Goode \& Bean.)

$\dagger$ As the original diagnosis of the Macrourid genus Steindachneria, although very short, is correct and sufficient for identification, the name in question should be retained for it rather than Steindachnerella, and the Silurid genus Steindachneria, Eigenmann should receive a new name. 
2942. STEINDACHYERIA ARGENTEA, Goode \& Bean.

Head $5 \frac{1}{8}$ in total; depth $7 \frac{1}{2}$, at anal origin 8 ; eye $3 \frac{1}{3}$ in head; snout about $5 \frac{1}{2}$; interorbital width $5 \frac{1}{2}$; maxillary 2 ; premaxillary 2 ; mandible $1 \frac{8}{4}$; gill rakers 4 or $5+19$; D. VIII, $123+;$ A. $10+113 ;$ P. $15 ;$ V. 8 . Head and body compressed; tail tapering to a very fine point. Scales small, deciduous, eycloid, 6 rows between lateral line and origin of soft dorsal. Nostrils nearer eye than end of snout, the anterior nostril nearly circular, the posterior much longer and slightly concave; no barbel. Maxillary dilated at the extremity and somewhat produced downward into an obtuse point, reaching nearly to a vertical at posterior inargin of orbit, and concealed by the preorbital; premaxillaries slightly protractile, much attenuated posteriorly; mandible reaching slightly behind eye. Premaxillary and mandibular teeth biserial, those of the outer series enlarged and rather widely set, some of the enlarged teeth slightly sagittate at tip; vomerine teeth well developed; upper pharyngeal teeth in 2 broad, well-developed patches. Gill rakers slender, the lougest about 2 in eye. Distance from snout to first dorsal about $\frac{1}{5}$ total length, the first spine elongate, filiform, and reaching fourteenth ray of second dorsal; base of first dorsal about 1 in head; longest ray of second dorsal about $2 \frac{1}{2}$ in head, the rays diminishing in size rapidly, the last minute; origin of anal under sixth ray of second dorsal, not far behind the vent, the anterior elevated portion consisting of 10 rays, all of which except the first are divided, the second ray longest, twice length of eye, the tenth ray only about $\frac{1}{7}$ length of second, and separated by a suall membrane from rest of fin which consists of very minute rays. Kent under fourth ray of second dorsal. Origin of ventrals under base of pectorals and about under third spine of first dorsal; first ventral ray filamentous, reaching origin of anal; pectoral reaching to below fifteenth ray of second dorsal. Gulf of Mexico. Only the type known. Length $233 \mathrm{~mm}$. (argenteus, silvery.)

Steindachneria argentea, GOoDE \& BEAN, Oceanic Ichthyology, 419, fig. 351, 1896, off delta of Mississispi River, Lat. $39^{\circ} 14^{\prime} 30^{\prime \prime} \mathrm{N}$., Long. $88^{\circ} \mathrm{o9^{ \prime }} 3 \mathrm{0}^{\prime \prime} \mathrm{W}$., in 68 fathoms. (Type, No. 37350. Coll. Albatros8.)

\section{TRACHYRINCUS, Gioma.}

Trachyrincus, GionNA, Mem. Accad. Imp. Turin, xvI, 1803, 178 (no type mentioned).

Lepidoleprus, RIsso, Ichth. Nice, 197, 1810 (trachyrincus).

Oxycephas, RAFLNESQUE, Caratteri, 31, 1810 (scabrus =trachyrincus).

Lepidosoma, SwaInson, Nat. Hist. Class'n Fish., II, 261, 1839 (trachyrhynchus).

Trachyrhynchus, GưNTHER, Challenger Report, XxII, 152, 1887; corrected spelling.

Snout produced in a long depressed process which is sharply pointed in front, with a sharp lateral edge, which is continued in a straight line icross the suborbital region. Mouth inferior, horseshoe-shaped, placed like the mouth of a sturgeon. Teeth in both jaws in villiform bands; chin with a barbel; a scaleless fossa on each side of nape. Second dorsal well developed. Scales moderate, spinigerous; a series of larger scales, each armed with a projecting ridge, along each side of base of dorsal and inal anteriorly. Opercle small. Gill membranes scarcely united; gills 4; first gill arch free, with short, styliform gill rakcrs. Deep seas. This 
genus and its allies differ from Macrourus in the important eharacter of the structure of the first gill arch. ( $\tau \rho \alpha \chi v \dot{v}$, rough; $\dot{v} \gamma \chi \circ \varsigma$, snout; hence properly, but not originally, spelled Trachyrrhynchus.)

2943. TRACHYRINCUS HELOLEPIS, Gilbert.

Head $3 \frac{1}{2}$ in total; depth 7 ; eye large, 4 in head, = interorbital width; snout $2 \frac{1}{2}$, its greatest width $1 \frac{2}{7}$ in its length. D. 11. Snout depressed, flat, narrowly triangular, tapering to a sharp point, its lateral ridges continuous backward over suborbital chain and across cheek. Interorbital space wide and flat. Ethmoidal ridge not prominent. Mouth wholly inferior, U-shaped, overpassed by the snout by a distance contained $3 \frac{1}{4}$ head. Barbel slender, short, less than $\frac{1}{5}$ diameter of orbit. Teeth finely villiform, in very broad bands in each jaw, none of them enlarged. Maxillary reaching to or almost to vertical from hinder margin of orbit, $3 \frac{1}{5}$ in head. Opercle very small, triangular, its length behind preopercular margin scarcely more than $\frac{1}{2}$ diameter of orbit; outer gill arch not adnate to the opercle, its lower limb with 17 short gill rakers, which are not tubercular. Distance of dorsal fin from nape $3 \frac{1}{5}$ in head, this 2 dorsal fins closely approximated; second dorsal ray not spine-like, soft and flexible, and not longer than the succeeding rays, its length $\frac{2}{8}$ the diameter of orbit. Vent located immediately in front of origin of anal fin, its distance from ventrals $1 \frac{1}{2}$ in head. Ventrals short, inserted well in arlvance of base of pectorals, the outer ray little produced, its length $1 \frac{1}{8}$ in diameter of orbit. Scales all with their margins embedded, and therefore appearing nonimbricated, the central portion of each projecting, tubercle-like, and bearing a single strong central spine, with sometimes 2 or 3 smaller ones; belly and breast sometimes covered with much smaller scales similarly armed; no naked area betwecn bases of ventrals; enlarged plates along bases of dorsals and anal bearing each a strong compressed backwardlycurved spine, usually without distinct serrations; from the base of the central spine radiate lines of short spinous points; dorsal series of plates continued forward to the nape, the predorsal portion of the included groove covered with scales; ventral series scarcely extending beyond vent, but extending farther posteriorly than do the dorsal plates; scales on top of head with a median serrated ridge; temporal fosss small but evident, naked. Color apparently dark brown; gill cavity and peritoneum black. Pacific Ocean, off the coast of Central America, in decp water. Only the type known, a specimen 18 inches long. ( $\grave{\eta} \lambda$ os, tubercle; $\lambda \varepsilon \pi i 5$, scale.)

Trachyrhynchus helolepis, GiLBert, Proc. U. S. Nat. Mus. 1891, 562, Pacific Coast of Central America in deep water. (Type, No. 48205.)

998. MALACOCEPHALUS, Günther.

Malacocephalus, GÜnther, Cat. Fish. Brit. Mus., IV, 396, 1862 (laevis).

Intermaxillary teoth biserial, mandibulary teeth uniserial. Mouth lateral; snouth short, obtuse. Head without prominent ridges, with wide muciferous cavities. Dorsal fin over origin of pectorals, its longest spine $3030-84$ 
smooth; dorsal fins widely separated. Pectorals short, placed high, opposite upper angle of gill cleft. Scales small, bristly. Origin of lateral line at upper angle of gill cleft. ( $\mu \alpha \lambda \alpha \varkappa o$ s, soft; $\varkappa \varepsilon \phi \alpha \lambda \dot{\eta}$, head.)

2944. MALACOCEPHALUS OCCIDENTALIS, Goode \& Bean.

Eye $2 \frac{1}{4}$ in head; barbel slightly longer than eye; snout 4 in head; interorbital space 4. Agreeing with Giinther's description of M. lavis, but differing in the position of the vent, the ventrals, and the anal fin, the last commencing at a distance behind the vent equal to length of suont; distance of vent from origin of ventrals less than its distance from origin of anal; ventrals originate under middle of first dorsal; origin of pectorals under that of first dorsal, the pectorals as long as head without postorbital flap; ventrals reaching to or slightly beyond origin of anal. Gill rakers rudimentary, $x+11$. Second dorsal spine nearly equal to length of head; first branched dorsal ray about as long as head. Atlantic Ocean, off Cape Hatteras, and Caribbean Sea. Length $8 \frac{1}{2}$ inches; a doubtful species, perhaps identical with $M$. lavis. (occidentalis, western.)

Malacocephalus occidentalis, Goode \& BeAN, Proc. U. S. Nat. Mus. 1885, 597, off Cape Hatteras, at Albatross Station 23ro, Lat. $35^{\circ} 44^{\prime}$ N., Long. $79^{\circ} 51^{\prime}$ W., in 132 fathoms. (Type, No. 37336.)

999. MOSElEYA, Goode \& Bean.

Moseleya, Goode \& Bran, Oceanic Ichthyology, 417, 1896 (longifilis).

This genus is near Nematonurus, having the mouth small, the upper teeth in 1 or 2 series, the dorsal spine weakly serrate, and the dorsal fins well separated. The chief difference lies in the scales, which are feebly ridged and nearly or quite smooth. The typical species, M. longifilis (Giinther), is from off the coast of Japan. ("Named in honor of Prof. Henry N. Moseley, F. R. S., of Oxford University, whose coutributions to natural history while naturalist of H. M. S. Challenger we desire to commemorate:")

2945. MOSELETA CYCLOLEPIS (Gilbert).

Dorsal II-8 or 9 ; ventral 12 ; eye $4 \frac{1}{8}$ in head; snout $3 \frac{8}{4}$; maxillary $2 \frac{2}{2}$. Head smooth, compressed, without conspicuous ridges; median and lateral rostral ridges terminating in slightly projecting points, the median process, a short portion of the median ridge, and the edge of the membrane counecting median with lateral processes, with spinons scales and points. Snout projecting beyond the premaxillaries for $\frac{2}{8}$ its length. Eye small, less than snout, very slightly exceeding interorbital space; mouth small, wholly inferior, maxillary reaching vertical from posterior margin of pupil. Premaxillary teeth in 2 series, the outer similar to those in mandible, not enlarged or canine-like, the inner series smaller, directed obliquely backward; a single series of teeth in mandible, not widening into a patch at symphysis. Barbel thick at base, $\frac{2}{8}$ length of snout. Preopercle incurved above the angle, the lower limb expanded, the marginal region striate. First dorsal inserted behind axil of pectoral (second spine broken in both specimens examined), the basal portion smooth, a single sharp 
barb showing that the spine is serrate; base of first dorsal equals length of snout; interspace between dorsals exceeding length of first dorsal base by $\frac{1}{8}$ to $\frac{2}{5}$ length of latter. Vent immediately in advance of origin of anal, under middle of interspace between dorsals; dorsal low and inconspicuous and the anal higher, as usual in this group; pectorals very slender, $1_{1}$ \% in length of head; outer ventral ray filamentous, reaching third or fourth anal ray. Scales mostly lost, the few remaining on head either entirely smooth or bearing a single median keel with 1 or 2 low spinous points; those on body without spines, either entirely smooth or showing traces of a low median keel; 6 scales in an oblique series between lateral line and middle of base of dorsal. Color dark brown, the anterior portion of back and sides with small scattered black spots; opercles, lower side of head including gill membranes and ventral area black, as are also the mouth and gill cavity and the peritoneum. A species with the general appearance, including the protruding snout, the inferior mouth and comparatively weak dentition of Nematonurus armatus and N. affinis, but with the dorsals less widely separated, the vent anterior in position, and the scales unarmed, as in Moseleya longifilis. (Gilbert.) Coast of British Columbia. 'Two specimens, the longest $150 \mathrm{~mm}$., from Station 3342, off Queen Charlotte Islands, depth 1,588 fathoms. (

Nematonurus cyclolepis, Grubert, Rept. U. S. Fish Comm. 1893 (1896), 458, off Queen Charlotte Islands, at Albatross Station 3342, in I,588 fathoms.

I000. NEMATONURUS, Giinther.

Nematonurus, GüNther, Challenger Report, Deep-Sea Fishes, xxII, 124, 150, 1887 (armatus).

Body rather robust, covered with rough, strongly-ridged scales. Head short; mouth small or moderate, more or less inferior; teeth in upper jaw rather strong, in 1 series or nearly so; lower teeth uniserial; mucous cavities small; pectoral fin inserted low, below upper angle of gill cleft; ventrals well developed, the outer ray filamentous; long ray of dorsal serrated; space between dorsals long, much greater than length of first dorsal. Deep seas. A well-marked genus, distinguished by its rough, firm scales and the wide space between dorsals. ( $\nu \tilde{\eta} \mu \alpha$, thread; ovं $\rho \dot{\alpha}$, tail.)

a. Depth $6 \frac{1}{2}$ in length; scales without distinct median keel.

GOODEI, 2346.

$a a$. Depth $5 \frac{4}{5}$ in length; scales with the merlian keel prominent; suborbital narrow, with well-marked mucous partitions. SUBORBITALIS, 2947.

2946. NEMATONURUS GOODEI* (Günther).

Head $5 \frac{2}{8}$; depth $6 \frac{1}{2}$; eye 5 in head; snout $4 \frac{1}{4}$; interorbital width $4 \frac{1}{4}$; postorbital part of head $8 \frac{1}{2}$; first dorsal II, 8 or 9 ; second dorsal 105 ; A. 110 ; P. 20; V. 10 ; scales 7-150-18, small, strong, free portions covered by series of small vitreous spines arranged in about 6 rows; no specialization of the central row, thongh the median spine at margin of scale projects

\footnotetext{
* By some inadvertence this species is recorded by Goode \& Bean as a Hymenocephalus (Oceanic Ichth., 407). On p. 408 it is said to be a Nematonurus. It has obviously ne affinity with Hymenocephalus, and is, in fact, an ally of Nematonurus armatus.
} 
most strongly and is longest. Width of interorbital area a little greater than horizontal diameter of orbit and length of operculum; snout triangular, depressed, its tip in axis of body nearly on a level with lower margin of eye, its lower surface forming an angle with the body axis, about equal to that formed with same by its upper profile; superior ridge pronounced anteriorly, but ending in advance of concavity in interorbital space; lateral ridges prominent, continuing posteriorly to eye, with strong angular projections in front of nostrils; no ridges continued from supraorbital region; nostrils rather close to eye; barbel shorter than eye; tip of lower jaw under anterior nostril; eleft of mouth under posterior margin of orbit; under surface of head naked, with the exception of a few minute, spiny tubercles on under surface of mandible; suborbital ridge very slightly developed; the intermaxillary a long bone, nearly as long as the maxillary; mouth large; teeth on intermaxillary in a double series, those of the outer series much larger than the inner; teeth in mandible uniserial. Dorsal spine strongly serrated; distance of first dorsal from snout equal to nearly 4 times length of its base, its distance from anterior margin of orbit equal to length of head; first spine minute, second strongly serrated, nearly $\frac{2}{8}$ length of head, when laid down is far from reaching origin of second dorsal; when the fin is erect its superior margin is nearly at right angles to plane of back and slightly convex; distance between dorsals twice length of base of first, the second beginning in the perpendicular from fifth ray of anal; anal about 3 times as high as second dorsal; vent under thirtieth scale of lateral line directly in advance of the anal and at a distance from ventral considerably greater than length of that fin; distance of pectoral from snout slightly more than length of head, its length less than that of dorsal spine, slightly more than $\frac{1}{2}$ its distance from the snout, its insertion (upper axil) in middle line of body; insertion of ventral under that of pectoral, slightly in advance of that of corsal, its first ray not greatly prolonged, about $\frac{1}{2}$ length of distance of fin from snout; branchiostegal membrane narrowly attached to the isthmus, leaving no free margin behind; gill rakers very small tubercles, only 10 below angle on first arch. Color dark reddish brown, spines upon the scales with a metallic luster; young with 3 stellate bosses upon snout, 1 at tip, 1 at some distance upon each side. Length of specimen described 322 millimeters. - (Goode \& Bean.) Gulf Stream, from Cape Cod to Havana; generally abundant. (Named for George Brown Goode.)

Macrurus asper, Goode \& BeAN, Bull. Mus. Comp. Zool., X, No. 5, 196, 1883, Gulf Stream south of New England, Lat. $41^{\circ} 24^{\prime} 25^{\prime \prime}$ N., Long. $65^{\circ} 35^{\prime} 30^{\prime \prime}$ W., in 1,242 fathoms; name preoceupied by Macrurus asper, GÜNTHER; JORDAN, Cat., 131, 1885.

Macrurus goodei, GÜNTHER, Challenger Report, XXI, 136, 1887; substitute for Macrurus asper.

Hymenocephalus goodei, GOODE \& BEAN, Oceanic Ichthyology, 407, fig. 340, 1896.

2947. NEMATONURUS SUBORBITALIS (Gill \& Townsend).

Head $5 \frac{1}{5}$; depth $5 \frac{4}{5}$; eje 5 in head; snout $4 \frac{8}{4}$; maxillary $2 \frac{8}{4}$. D. 12-85; A. 102 ; P. 19 ; V. 11. Mouth wholly inferior; scales closely adherent and rather large, mostly short and roundish, with considerable exposed sur- 
faces, having radiating ridges beset with weak spines; head a little more than $\frac{1}{6}$ of the entire length; snout projecting but little; median and lateral tubercles faintly developed; infraorbital narrow, divided into 2 well marked areas, an upper wider, distinguised by the glassy tubercular scales, and the narrow lower, almost skinny and scaleless; the ridge independently, is little marked; teeth biserial in the upper jaw, robust in the outer row, very weak in the inner; uniserial in lower jaw and scarcely incurved; dorsal spine strongly serrate, $1 \frac{1}{2}$ in head; pectoral $1 \frac{7}{8}$ in head; ventrals 18 in head, with short filaments, reaching vent; interspace between dorsals $\frac{1}{2}$ greater than base of first. Bering Sea. Only the type, 20 inches long, known, the above description taken from it by us. (suborbitalis, pertaining to the region below the eye.)

Macrurus (Nematonurus) suborbitalis, GILL \& Townsend, Proc. Biol. Soc. Wash., XI, 1897 (Sept. 17, 1897), 234, Bering Sea, southwest of Pribilof Islands, Albatross Station $3^{603}$, in I,771 fathoms. (Type, No. 48773, U. S. Nat. Mus. Coll. Albatross.)

roor. ALBATROSSIA, Jordan \& Evermann, new genus.

Albatrossia, JoRdan \& EvermanN, new genus (pectoralis).

This genus has the form and appearance of Chalinura, with the dentition of Nematonurus, and the dorsal spines of Malacocephalus and Optonurus; teeth in the upper jaw strong, in an irregular double series, the onter enlarged; the inner series growing double with age; lower teeth uniserial or nearly so ; scales small, rather firm, rough; dorsal spine weak, smooth or very slightly serrate; dorsal fins close together; ventrals well developed; pectorals moderate. Size large. (Named for the good ship Albatross, in remembrance of her splendid contributions to our knowledge of the life of the deep seas.)

\section{ALBATRosSia PECTORALIS (Gilbert).}

Head 6 in total; depth $1 \frac{2}{5}$ in head; eye $4 \frac{1}{2}$ to 5 in head, $1 \frac{1}{4}$ in snout. D. X-128; A. 121 ; V. 7 ; P. 17 ; mouth wide, lateral, the short snout projecting beyond premaxillaries for a distance about equaling $\frac{1}{2}$ diameter of orbit; suborbital ridge and lateral ridge on snout inconspicuous; a strong median ridge on snout and a pair of parallel ridges forward from above nostrils; maxillary reaching well behind vertical from posterior margin of orbit, $2 \frac{1}{3}$ in head; teeth in 2 somewhat irregular series in front of premaxillaries, the outer series enlarged, the inner directed obliquely inward, the two series merging into one laterally; mandible with a single row, similar to inner series of upper jaw; barbel short, $\frac{3}{5}$ to $\frac{2}{7}$ diameter of orbit; angle of preoperele bluntly rounded, not produced; outer gill arch adnate, as usual in Macrourus, 7 short tuberenlar gill rakers present on its free portion; first dorsal spine slender and weak, with 1 or 2 small retrorse prickles near its middle; distance between dorsals equal to $\frac{2}{5}$ base of first; vent immediately in front of anal origin, its distance from base of ventrals slightly more than $\frac{1}{2}$ head; pectorals long and narrow, reaching vertical from ninth or tenth ray of second dorsal, more than $\frac{1}{2}$ length of head; outer ventral ray produced into a long slender filament, reaching $\frac{5}{6}$ the 
distance from its base to front of anal; scales rather small, 10 or 11 in a series between lateral line and origin of second dorsal or middle of first dorsal; scales on sides very thin and flexible, readily deciduous, each furnished with low diverging ridges, usually 3 in number, bearing fow minute spinules, and projecting but little beyond the margins of the scales; entire head, including snout and mandibles, invested with much smaller scales irregularly imbricated, those on the opercles marked similarly to those on sides, the others usually each with a single median ridge terminating in a spinous point; no naked spots or pits on head or between ventral fins; a small narrow area behind and below axil of pectorals. Color light grayish, darker on belly and head; mouth, gill cavity, and peritoneum black; lateral line black; dorsals and ventrals dusky; anal lighter, edged with blackish; pectorals black. Bering Sea to Oreyon. Specimens have been taken at Albatross Stations 3071, 3074, and 3075, in depths of 685 to 877 fathoms, off the coast of Oregon, and from near Bogoslof Island in Bering Sea in 664 fathoms. It is a large, firm-fleshed species, easily recognized. (pectoralis, pertaining to the pectoral.)

Macrurus (Malacocephalus) pectoralis, GilberT, Proc. U. S. Nat. Mus. 1891, 563, off the coast of Oregon. (Coll. Dr. Gilbert.)

Macrurus (Nematonurus) magnus, ${ }^{*}$ GILl \& Townsexd, Proc. Biol. Soc. Wash., XI, 1897

(Sept. 17, 1897), 234, Bering Sea, southwest of Pribilof Islands. (Types, No. 48770 and 48771, U. S. Nat. Mus. Coll. Albatross.)

Albatrossia pectoralis, JORDAN \& GILBERT, Report Fur Seal Invest., 1898.

I002. BOGOSLOVIUS, Jordan \& Evermann, new genus.

(1)

Bogoslovius, JGRDAN \& EVERMANN, new genus (clarki).

This genus is close to Chalinura, from which it is distinguished by its dentition, having the teeth in the upper jaw in 2 series, the outer slender and sharp, slightly arrow-shaped; those of the inner small, close set, replacing the villiform band of Chalinura. Scales excessively rough; ventral filament produced; dorsal spine filamentous, sharply serrate; dorsal fins close together; pectorals inserted below upper angle of gill opening. Deep seas. (Named for the volcanic island, St. John Bogoslof, in Bering Sea, near which the typical species was dredged.)

a. Ventrals much longer than head, reaching far beyond front of anal. CLARkr, 2949. aa. Ventrals shorter than head, scarcely reaching front of anal. FIRMISQUAMIS, 2950.

\footnotetext{
* We have examined the type and cotypes of Macrurus (Nematonurus) magnus, Gill \& Townsend, and find them to agree fully with Albatrossia pectoralis (Gilbert). The type may be redescribed as follows: Head $5 \frac{1}{4}$; depth $7 \frac{1}{2}$; eye $4 \frac{4}{5}$ in head; snout 42 to $4 \frac{3}{4}$; maxillary $2 \frac{1}{2}$; pectoral 2 in head; ventral with short filament, $2 \frac{1}{4}$ in head. Mouth large, with lateral cleft. Dorsals well separated, the interspace not $\frac{1}{2}$ base of first dorsal; long dorsal spinc smooth, or with 1 or 2 roughnesses near its tip, its length $3 \frac{3}{5}$ in head; second dorsal low; pectoral inserted low, below angle of opercle. Scales moderately large, readily deciduous, decidedly oblong or long, with a small exposed surface which is beset with about 5 radiating ridges with conspicnous spinigerous ridges on dorsal surface, but not arined at tip; head regnlarly conical; snout rather long, projecting $\frac{1}{2}$ its length beyond mandible; tubercles feebly developed, plain, and continuous from 3 parallel ridges; infraorbital flat, with the crest rather nearer the orbit than its lower margin; its entire surface scaly; teeth in the upper jaw biserial or triserial in front, the outer series strongly hooked, the inner series considerably smaller and well separated from the outer series; an irregular series between in the type specimen; teeth in lower jaw uniserial or irregularly biserial. Three specimens, the largest (type of $\mathbb{M r}$. magnus) 43 inches long.
} 
2949. BOGOSLOVIUS CLARKI, Jordan \& Gilbert.

Eye $4 \frac{8}{4}$ in head; maxillary $2 \frac{1}{2}$. D. II, 12- ; P. 19; V.10. Snout short, slightly exceeding diameter of eye, $3 \frac{2}{10}$ in head; median and nasal ridges very little projecting anteriorly, without radiating spines; tip of snout very little projecting beyond the mouth, for a distance not exceeding $\frac{1}{8}$ the interspace between ends of median and nasal ridges. Suborbital ridge inconspicuous; scarcely extending beyond the eye; mucous pores on head prominent. Mouth large, oblique, the lower jaw included, the maxillary nearly reaching vertical from posterior edge of orbit. Outer premaxillary teeth slender, sharp, unequal, rather distant, not very strong, slightly widened and arrow-shaped near tip, becoming very small toward angle of mouth; within this, and well separated from it, a close-set series of short teeth. directed inward. Mandibular teeth slender, unequal, in a single series corresponding to outer series in upper jaw, slightly widening at symphysis, which is not prominent. Barbel very short, less than $\frac{1}{2}$ diameter of pupil. Eye of moderate size, equaling distance from tip of snout to middle of anterior nostril, $1 \frac{1}{10}$ in interorbital width. Preopercle broadly rounded, the angle little produced backward, leaving a strip of interopercle exposed along its entire length. Gill membranes joined to the isthmus, with a narrow free edge. Gill rakers very short and thick, $3+12$ in number, including rudiments. Dorsal beginning above base of pectorals, the second spine long, filamentous at tip, $1 \frac{2}{5}$ in head, its anterior margin sharply serrate, except in basal third; base of first dorsal $2 \frac{4}{5}$ in head; interspace between dorsals very short, usually less than diameter of pupil. Pectorals very long and slender, equaling or exceeding length of head behind snout; insertion of pectorals below upper angle of gill opening. Outer ventral ray excessively produced, twice or more than twice length of head in uninjured adults, reaching base of fiftieth anal ray or beyond. Vent immediately before anal origin. Scales in a strip along the back firm and very rough, none others preserved in our specimens; scales with 3 to 5 sharp, radiating ridges, each ridge with several sharply projecting spines, the posterior of which project beyond the margin of the scale. Color very light gray, the vertical fins blackish posteriorly; mouth and gill cavity and peritoneum jet-black. Bering Sea. Known from 4 specimens, 24 to $41 \mathrm{~cm}$. long, from Albatross Station 3634, off Bogoslof Island, in 664 fathoms. (Named for George Archibald Clark, secretary of the Fur Seal Commission for 1896 and 1897, in recognition of his researches on the mammalia of Bering Sea.)

Bogoslovius clarki, Jordan \& Gilbert, Report Fur Seal Invest., 1898, Bering Sea off Bogoslof Island, in $66_{4}$ fathoms.

\section{BOGOSLOVIUS FIRMISQUAMIS (Gill \& Townsend).}

Head 5 in total; depth $6 \frac{1}{2}$; eye $4 \frac{2}{5}$ in head; snout $3 \frac{2}{5}$; second dorsal spine $1 \frac{3}{5}$ in head; pectoral 2; ventral $1 \frac{1}{2} ; \operatorname{maxillary~} 2 \frac{1}{5}$. D. II, 10-126; A. 105; P. 20 ; V. 8 . Scales firmly affixed, oblong or rather short, and with considerable exposed surfaces, which have subequal radiating ridges beset with numerous acute spinelets, the ridges varying from 3 to 8 in number; head regularly convex in profile: rostral tubercles obsolete and infraor- 
bital ridge rounded; barbel greater than pupil; teeth biserial or partly triserial above; second dorsal spine with short retrorse serra, the lower fifth smooth; base of first dorsal $3 \frac{4}{5}$ in head; interspace between dorsal fins $\frac{1}{2}$ base of first dorsal, greater than diameter of pupil. This species is distinguishable from most American Macrouvi by the very firm scales, and from $B$. clarki by the much shorter ventral. Bering Sea. Only the type, 31 inches long, known. (firmus, firm; squama, scale.)

Macrurıs firmisquamis, Gil. \& Townsend, Proc. Biol. Soc. Wash., xI, 1897 (Sept. 17, 1897), 234, Bering Sea, southwest of Pribilof Islands. (Type, No.48772, U. S. Nat. Mus. Coll. Albatross.)

1003. CHALINURA, Goode \& Bean.

Chalinura, Goode \& BEAN, Bull. Mus. Comp. Zool., x, No. 5, 198, 1883 (8imula).

Chalinurus,* GUnther, Challenger Report, XxII, 124, 144, 1887; change in spelling.

Scales cycloid, fluted longitudinally, with slightly radiating striæ. Snout long, broad, truncate, not much produced. Mouth lateral, subterminal, very large. Head without prominent ridges, except the subocular ones and those upon the snout. Suborbital ridge not reaching angle of preopercle. Teeth in the upper jaw in a villiform band, with an outer series much enlarged, those of the lower jaw uniserial, large. No teeth on vomer or palatines; small pseudobranchix present. Gill rakers spiny, strong, depressible, in double series on anterior arch. Ventrals below the pectorals; chin with a barbel. Dorsal spine serrate; soft dorsal much lower than anal. Deep sea fishes. Species numerous. This genus is allied to Macrourus, differing in the dentition; the genus Optonurus, with dorsal spine

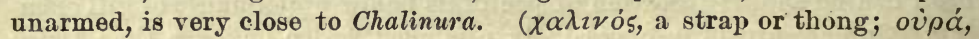
tail.)

a. Snout long, longer than eye, which is 5 in head; pectoral $1 \frac{3}{6}$ in head; dorsal spine $1 \frac{1}{4}$ in head; scales 130.

SERRULA, 2951.

aa. Snout moderate, about as long as eye, which is 4 in head; dorsal, pectoral, and ventral produced, the pectoral $1 \frac{1}{3}$ in head, the dorsal spine and ventral filament each about as long as head.

FILIFERA, 2952.

aaa. Snout very short, as long as eye, which is 5 in head; ventrals very long.

SIMULA, 2953.

2951. ChaLINURA SERRULA, Bean.

Head $5 \frac{1}{2}$ in total length. D. II, 9-76 (q); scales 7 or 8-130-17; Br. 6 . Cheeks and opercles scaly; snout with a median serrated keel on the nose; diameter of eye less than length of snout, 5 in head; maxillary reaching vertical from posterior margin of eye, its length $2 \frac{1}{2}$ in head; mandible about 2 in head, a row of 5 pores on its under surface and 6 pores on the edge of the suborbitals; branchiostegal membrane narrowly free from the isthmus, the first gill opening restricted as in Macrourus; gill rakers small tubercles, 11 below the angle of the first areh, and only 1 or 2 above the angle; length of pectoral equals postorbital part of head; ventrals

* Goode \& Bean rightly protest against the wanton "action of the English ichthyologists in changing the form of the generic name" Chalinura. Chalinura is perfectly correct, and should be used even if it were not so, as it is the original form, the only reason for changing it being that other generic names in the group end in urus. 
about as long as head; longest dorsal spine strongly serrated and nearly equaling length of head without snout; dorsals separated by an interspace $\frac{2}{5}$ as long as head. Color brown; head, abdomen, and inside of mouth purple, the purple areas less marked in the type specimen, which is $12 \frac{1}{2}$ inches long. Coast of British Columbia, east of Prince of Wales Island, in 1,569 fathoms. (serrula, a fine saw.)

Chalinura serrula, Bean, Proc. U. S. Nat. Mus.1890, 37, east of Prince of Wales Iskand, in $\mathrm{x}, 56 \mathrm{~g}$ fathoms. (Coll. Albatross.)

\section{CHALINURA FILIFERA, Gilbert.}

D. II, 12 to 14 ; P. 20 to 22 ; V. 9 or 10 ; eye 4 in head. Snout short, slightly exceeding diameter of eye, $33_{10}^{9}$ in head, median ridge and nasal ridges terminating each in a much projecting point, furnishing each with a short rosette of radiating spines and ridges, outline between these points concave; tip of snout projecting beyond premaxillaries for a distance equaling that which separates the central rosette from 1 of the lateral ones; infraorbital ridges inconspicuous, not reaching angle of preopercle behind or bony portion in front. Mouth large, slightly oblique, with extensive lateral cleft, the maxillary reaching vertical from posterior margin of pupil, $2 \%$ in head, equaling distance from tip of snont to middle of eye. Outer series of tecth in premaxillary strong, succeeding from a narrow band of smaller cardiform teeth; mandibular teeth similar to inner band of upper jaw, the band becoming slightly wider at the prominent symphysis. Barbel short, $\frac{1}{2}$ to $\frac{2}{5}$ length of snout. Eye large, the diameter of orbit slightly less than interorbital width on snout. Angle of preopercle produced backward, concealing all but the extreme posterior angle of interopercle, the margin appearing serrulate when divested of skin; gill membranes joined to isthmus, with a posterior free margin; gill rakers very short and heavy, $1+11$. Dorsal beginning vertically above base of pectorals, the second spine extremely long and slender, smooth basally, the terminal half rather strongly toothed, becoming very slender toward tip and terminating in a long membranaceous filament. (In 1 specimen it exceeds length of head, in the others it equals $\frac{5}{6}$ that length.) Length of base of first dorsal equaling $\frac{1}{8}$ length of head; interspace between dorsals short, $\frac{2}{5}$ to $\frac{8}{4}$ length of snont. Pectorals very long and slender, equaling the head without the snout; outer ventral rays very long and filamentous, equaling length of head; vent immediately in advance of anal origin. Scales rather thin, those on back and sides with above 5 diverging ridges, each of which bears a number of short rigid spinules directed very obliquely backward, the posterior projecting but little beyond the margin of the seale; 8 or 9 scales in an oblique series between the middle of first dorsal and the lateral line. Dark brown; the fins, gill membranes, lips, nostrils, and underside of snout black; anterior part of month and lining of gill cavity purple; peritoneum blackish brown. Related to $C$. serrula, Bean, from the same region and depth, differing in the larger eye, shorter mental barbel, longer snout, longer pectoral fins, shorter interspace between dorsals and the longer dorsal fin. Coast of British Colum- 
bia; known from 3 specimens, 520 to $550 \mathrm{~mm}$. long. (Gilbert.) (filum, thread; fero, I bear.)

Chalinura filifera, Gilbert, Rept. U.S. Fish Comm. 1893 (1896), 458, off Queen Charlotte Islands, at Albatross Station 3342, in I,588 fathoms.

\section{ChaLINURA SIMULA, Goode \& Bean.}

Head 5 ; depth 6 ; orbit 6 in head; snout 3 ; interorbital width greater than eye; postorbital part of head 3 times as long as eye; opercle 2 in upper jaw. I. II, 9-113; A. 118; P. 20; V.9; Br.6; scales 8-150-17 to 19. Body shaped much as in Coryphanoides, but rather stout; back more gibbous in profile, the dorsal outline rising quite rapidly from the interorbital region to origin of first dorsal, thence descending almost in a straight line to end of tail. Preopercle emarginate on its posterior limb. Snout broad, obtuse, scarcely projecting beyond the mouth, its width nearly as great at tip as its own length; median ridge very prominent, gibbous in outline when viewed laterally; lateral ridges starting almost at right angles with the median, aud continued upon sides of head; no supraorbital ridges. Nostrils in front of middle of eye, and nearer its anterior margin than to tip of snout; barbel longer than eye; teeth in upper jaw in a broad villiform band, the outer series very much enlarged; lower jaw with teeth in a single series. Scales rather small, but with indications, particularly on the head, of radiating striæ. Origin of first dorsal from snout $4 \frac{1}{2}$ in its base, or from anterior margin of orbit 1 in head; first dorsal spine very short, second rather stout, $1 \frac{1}{2}$ in head, and with a simple serration anteriorly, the serræ closely appressed to the spine; second dorsal separated from the first by a distance equal to length of upper jaw; anal high, its average rays about 3 times as long as those of dorsal, inserted slightly behind perpendicular from last ray of first dorsal; pectoral inserted over base of ventral; origin of ventral from snout less than its longest ray, which is produced in a filament extending to base of eight. eenth anal ray. (Goode \& Bean.) West Indies and Gulf Stream, in deep water. (simulus, pug-nosed.)

Chalinura simula, GOODE \& BEAN, Bull. Mas. Comp. Zool., x, No. 5, 199, 1883, Gulf Stream, at Blake Station 308 , Lat. $41^{\circ} 25^{\prime} 45^{\prime \prime}$ N., Long. $65^{\circ} 35^{\prime} 30^{\prime \prime} \mathrm{W}$., in $\mathrm{I}, 242$ fathoms ; JoRDAN, Cat., 132, 1885; GOODE \& BEAN, Oceanic Ichthyology, 412, fig. 345, 1896.

Macrurus simulus, GưNTHER, Challenger Report, XXII, 148, 1887.

\section{CORYPHÆNOIDES, Gunner.}

Coryphoenoides, GuNNER, Trondhj. Selsk. Skrift., III, 50, 1765 (rupestris).

Branchiostegus, RAFINESQUE, Analyse de la Nature 1810, 86 (substitute for Coryphanoides).

Snont short, obtuse, high, obliquely truncated, soft to the touch, except its bony center; mouth broad, terminal, its cleft lateral; head without prominent ridges, the membrane bones of the side of the head soft and papery; teeth villiform in both jaws, those in the outer series of upper jaws somewhat enlarged. Scales spinous, second or elongate dorsal ray finely serrated in front. Lower jaw with a barbel at tip. Deep Sea. 
Close to Macrourus, differing in the larger terminal mouth. ( Coryphona; $\varepsilon i \delta o 5$, resemblance.)

a. Head 4 in length; gill rakers $4+15=19$.

aa. Head 6 in length; gill rakers $3+11=14$.

RUPES'TRIS, 2954.

CARAPINUS, 2955.

2954. CORYPHENOIDES RUPESTRIS, Gunner.

D. 10 ; P. 19 ; V. 7 ; gill rakers $4+15=19$. Head short, rather compressed; snout short, obliquely truncated in front; cleft of mouth wide, lateral, extending to beyond the center of eye; intermaxillary not much shorter than maxillary. Teeth in villiform bands in each jaw; barbel very small. Interorbital space convex, its width being considerably more than diameter of eye, which, in a specimen 3 feet long, is equal to the length of the snont and $\frac{1}{4}$ of that of the head. Scales equally rough over the whole of their surface, all the spinelets being directed backward; 7 or 8 scales in a transverse series between the dorsal fin and the lateral line; head entirely covered with small scales. Anterior dorsal spine armed with numerous small closely set barbs; outer ventral ray produced into a long filament. Distance between the vent and isthmus $\frac{2}{8}$ the length of the head. The gill membrane entirely free from the isthmus behind. Intermaxillary continues beyond its vertical process and extending almost as far back as the maxillary, these 2 bones being about equal in length; last third of intermaxillary toothless; intermaxillary teeth in a very narrow band, which is uniform in width, the outer teeth only slightly enlarged; mandible with villiform teeth in a broad bunch-like band at the symphysis and becoming uniserial behind. Eye nearly circular. Snout projecting slightly. Gill rakers longer and less tubercular in character than in Macrourus berglax and $M$. acrolepis. 'The suborbital ridge feebly developed and very abruptly curved upward and narrowed in front of the eye where it joins the nasal ridge. In $M$. berglax and $M$. acrolepis the suborbital ridge is very strong and is continued almost in a straight line toward the nasal ridge. (Goode \& Bean.) Arctic seas and the north Atlantic, on both coasts south to the banks of Newfoundland and Norway, in deep water. (Eu.) (rupestris, living about rocks.)

Coryphoenoides rupestris, GuNNER, Trondhjem Selsk. Skrift., III, 50, pl. 3, fig. 1, 1765, Norway; ColletT, Norges Fiske, 131; Jordan \& Gilbert, Synopsis, 812, 1883; GOODE \& BEAN, Oceanic Ichthyology, 402, 1896.

Lepidoleprus norvegicus,.Nilsson, Prodr. Ichth. Scand., 51, 1832, Norway.

Coryphcenoides noxvegicus, GÜNTHER, Cat., IV, 396, 1862.

Macrourus stromii, ReINHARDT, Dansk. Vidensk. Afhandl., viI, 129, 1828: GaIMARs), Voy. Skand., Poiss., pl. 11.

Macrurus rupestris, GUNTHER, Challenger Report, XxI, 138, 1887.

\section{CORYPHENOIDES CARAPINUS, Goode \& Bean.}

Head 6. D. II, $8-100$; A. 117; V. 10 ; eye 4 in head. Snout acute, projecting beyond the mouth, its tip at a distance from the mouth equal to or greater than diameter of eye. Bones of head very soft and flexible, its surface very irregular, there being a very prominent subocular ridge, a prominent ridge extending from tip of snout to middle of interorbital space, and a curved ridge extending from upper anterior margin of orbit 
over cavity containing nostrils to a prominent point at side of and slightly posterior to tip of snout; barbel $\frac{2}{3}$ as long as eye. Interorbital space almost twice diameter of eye, equal to length of upper jaw ; preopereulum crenulate; upper jaw extending to vertical through posterior margin of pupil, its length equaling $\frac{1}{2}$ that of head without snout; niandible extending behind vertical through posterior margin of orbit, its length 3 times in distance from tip of snout to origin of first dorsal. Teeth in villiform bands on intermaxillary and mandible, the mandibulary series uniserial in about the second half of its length. First ray of dorsal very short, second compressed anteriorly and serrated, with slender teeth closely appressed and bent upward, its length equaling length of head and greater than height of body; this fin seated upon a hump-like elevation of the back, its base as long as snout; second dorsal beginning over tenth or twelfth anal ray, and at a distance from end of first dorsal equal to length of head without snout; vent located not far behind rertical from end of first dorsal. Scales 22 to 24 in a transverse series (the position of the lateral line can not be determined, but there appear to be 4 above it); scales oval, membranaceous, showing several parallel ridges composed of small spines. Gill membrane very deeply cleft and attached to the isthmus; gill rakers short and stout, about 11 below the angle on the first arch. (Goode \& Bean.) Gulf Stream, in deep water. (carapinus, formed as in Carapus.)

Ooryphoenoides carapinus, Goode \& BEAN, Bull. Mus. Comp. Zool., x, No. 5, 195, 1883, Gulf Stream, Lat. $41^{\circ} 24^{\prime} 45^{\prime \prime}$ N., Long. $65^{\circ} 35^{\prime} 30^{\prime \prime} \mathrm{W}$., in $\mathrm{r}, 242$ fathoms (Type in M. C. Z. Coll. Blake); Günthur, Challenger Report, Deep-Sea Fishes, xxII, 139, 1887; GOODE \& BEAN, Oceanic Ichthyology, 404, fig. 339, 1896.

ro05. HYMENOCEPHALUS, Giglioli.

Hymenocephalus, Giglioli, Pelagos, Genoa, 228, 1884 (italicus).

Mystaconurus, GÜNTHER, Challenger Roport, Deep-Sea Fishes, XXIr, 124, 1887 (italicus).

This genus is closely allied to Coryphanoides, differing in the smooth dorsal spine, and the membranaceous skull. First dorsal broad, placed far forward over base of pectoral; second dorsal and anal origins nearly opposite, and separated by a considerable space from the vertical from the ond of first dorsal; vent far from ventrals. Head large, naked, soft, and cavernous; snout abrupt, perpendicular, or parabolic ; month lateral, wide. Eye very large, orbital margin forming part of profile of head. Barbel long. Pectoral rather narrow (10 to 16 rays). Seales thin, deciduous, with fine short spines. Under parts in advance of ventral wholly or partly naked. Deep seas. Remarkable for the papery structure of the bones of the head. ( $\dot{v} \mu \dot{\eta} \nu$, membrane; $\varkappa \varepsilon \phi \alpha \lambda \dot{\eta}$, head.)

2956. HYMENOCEPHALUS CAVERNOSUS (Goode \& Bean).

Head about 6 in total length; depth 7. D. II, 10-133; A. 27 rays, in a space equal to length of head. Body stoutish, the bones of head very soft and cavernous, spongy, in many places withont muscular covering; interorbital area doubly coneave, with a spinous medial ridge, its greatest 
width about $2 \frac{4}{5}$ in length of head; postorbital portion of head about $\frac{1}{2}$ its length, $1 \frac{1}{8}$ as long as eye, which is circular, its diameter contained $2 \frac{4}{5}$ times in length of head. Snout broad, very obtuse, its width at nostril nearly equal to interorbital width, its length 4 2 times in that of the head; nostrils normal. Teeth in each jaw in villiform bands, very small; a naked space at the symphysis of intermaxillaries; vomer and palatine toothless. Gillrakers very short, minute, and rather numerous, about 18 below angle of anterior arch. Pseudobranchice absent. Barbel $\frac{2}{5}$ as long as eye. First dorsal composed of 2 spines, the first minute, inserted at a distance from the snout equal to length of head, the second as long as head without snout, and 10 branched rays, its base equal to diameter of eye; second dorsal almost rudimentary, its rays remarkably short, about 133 in number, its distance from first dorsal $\frac{1}{2}$ length of head; anal much higher than second dorsal, its distance from snont contained about $3 \frac{1}{2}$ times in total length; anterior anal rays longest, in length about $\frac{8}{4}$ diameter of eye; pectoral inserted under first branched ray of first dorsal, its length equal to twice that of eye and about $\frac{2}{8}$ that of head. Scales (on type) mostly wanting, except a few on breast and nape, these being rough with small points, dentate behind. Ventral slightly behind the pectoral, its first ray filamentous, reaching to the base of the tenth anal ray, consisting of 11 rays. Color gray, with silvery tints on sídes; abdomen and lips dark. (Goode \& Bean.) Gulf of Mexico, in deep water. One young individual known. Length $162 \mathrm{~mm}$. (cavernosus, cavernous.)

Bathygadus cavernosus, Goode \& BeAn, Proc. U. S. Nat. Mus. 1885, 598, Gulf of Mexico, at Albatross Station 2398 , Lat. $28^{\circ} 45^{\prime} \mathrm{N}$., Long. $86^{\circ} 26^{\prime} \mathrm{W}$., in 227 fathoms (Type, No. 37337. Coll. Albatross); GÜNTHER, Challenger Report, XXII, 156, 1887.

Hymenocephalus cavernosus, GOODE \& BEAN, Oceanio Ichthyology, 408, fig. 341, 1896.

I006. MACROURUS, Bloch.

Macrourus, BLOCH, Ichth., v, 152, 1787 (rupestris=berglax).

Macruroplus, BleEker, Versl. Med. Akad. Welenth. Amsterd., vIII, 1874, 369 (serratus),

Macrurus, GüNTHER, Cat., IV, 392, 1862; corrected spelling.

Snout broadly conical, high, projecting beyond mouth; mouth moderate, its cleft horizontal, $U$-shaped, entirely inferior; teeth in both jaws in villiform bands, those of the outer series not enlarged; head with roughened bony ridges, one of which, on the suborbital and preorbital, simulates the suborbital stay of the Cottoids; eyes very large; scales imbricate, very rough, keeled. Dorsal spine long, serrated on the anterior edge. Deep

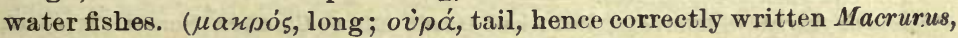
but Macrourus is the original name as given by Bloch.)

a. Top of head with 4 to 6 distinct ridges; depth 6 to 7 in length; 5 scales between lateral line and dorsal.

b. Anal rays 148; scales each with a strong ridge.

BERGLAX, 2957.

bb. Anal rays 121; scales each with 3 to 5 spinules, otherwise almost unarmer; ridges on top of head very rough.

HOLOTRACHYS, 2958.

$a a$. Top of snont with indistinct ridges or with none.

c. Pectoral fin moderate, $1 \frac{1}{2}$ to 2 in head.

d. Body rather elongate, the depth 7 to 8 in length; bones of head rather firm; dorsal spine strongly serrated. 
e. Head short, $6 \frac{1}{2}$ in head; pectoral more than $\frac{1}{2}$ head; snout with bony ridges abore.

ee. Head $5 \frac{1}{2}$ in length; ventrals 5 in body; pectoral $1 \frac{1}{2}$ in head. BAIRDII, 2959. LEPTURCS, 2960.

eee. Head longer, $4 \frac{3}{4}$ in length; pectoral $\frac{1}{2}$ as long as head; eye as long as snout, 4 in head; ventral 8 in body. $\quad$ ACROLEPIS, 2961. $d d$. Body rather robust, the depth $5 \frac{1}{2}$ in length; head without ridges abore; scales spinous, not ridged; dorsal spine $1 \frac{2}{5}$ in head.

STELGIDOLEPIS, 2962. cc. Pectoral tin elongate, about as long as head; head elevated, not ridged above, the bones soft; eye large; second dorsal spine rough, nearly as long as head; scales each with 7 to 9 ridges.

CINEREUS, 2963.

\section{MACROURUS BERGLAX, Lacépède.}

D. $12-124$; A. 148 ; P. 18 or 19 ; V. 8. Short snout, subtrihedral, pointed in front, much shorter than the large eye, which is $\frac{1}{8}$ or $\frac{2}{5}$ length of head in the adult. Intermaxillary very short, $\frac{1}{2}$.length of maxillary, and not continued beyond its expanded vertical process. Eye oblong. Whole under surface of head below suborbital and nasal ridge naked; axil of pectoral naked; space between ventrals scaled; body scales each with a single strong median keel, made up of 5 to 8 spines directed backward; some scales, particularly of head, have also 2 lateral keels; 6 longitudinal series of scales between first dorsal fin and lateral line; first dorsal spine indistinctly denticulated toward the point; length of pectoral nearly or quite $\frac{1}{2}$ length of head; longest spine of dorsal very finely serrated along its anterior margin, the serrations becoming obsolete near its base. Vent situated behind origin of second dorsal fin. Gill rakers very small, tubercular, 9 to 11 on the first arch; gill membranes broadly joined, free from the isthmus behind. This form, originally discovered on the coast of Norway, has been found abundantly as far south as Georges Bank, where the halibut fishermen catch it, or some closely allied form, on their trawls. The first specimen seen by American naturalists was picked up floating at the surface off the month of New York Harbor. The Albatross obtained it from Station 2528 , in Lat. $41^{\circ} 47^{\prime} \mathrm{N}$., Long. $65^{\circ} 37^{\prime} 30^{\prime \prime} \mathrm{W}$, at a depth of 677 fathoms. Günther knew it from Finmark and Greenland, as well as from New England. He calls attention to remarkable individual variations in the specimens examined by him. (berglax, Norwegian name, from berg, cliff; lax, salmon.)

Macrourus berglax, LACÉPÈDE, Hist. Nat. Poiss., III, 170, 1800, Greenland, Söndmöre; JoRDAN, Cat. Fish. N. A., 131, 1885.

Macrourus fabricii, Sundevald, Vet. Akad. Handl. 1840,6; Collett, Norges Fiske, 128, 1875; Luluebong, Sverig. og. Norges Fiske, 242; Goode \& Bean, Cat. Fish. Essex Co. and Mass. Bay, 7, 1879; GüNTHER, Challenger Report, XxII, 130, 1887.

Macrourus rupestris, GÜNThER, Cat. Fish. Brit. Mus., IV, 390, 1862 (not of Gunner).

Macrurus berglax, GoodE \& BEAN, Oceanic Ichthyology, 391, fig. 334, 1896.

2958. MACROURCS HOLOTRACHYS, Günther.

Head $4 \frac{8}{4}$ in length; depth $6 \frac{8}{4}$. D. $12-115$ to 125 ; A. $121 ;$ P. 20 or 21 ; V. 5 ; eye large, round, as long as snout, $2 \frac{4}{5}$ in head, much wider than interorbital space. Snout triangular, each point with a tubercle, covered with 
strong spines, this border continued as a strong ridge below eye, extending across opercle, this crest covered with coanse, spinous tubercles; mouth rather small, the maxillary reaching middle of eye; teeth very small, close set. Head with salient ridges above, covered with spinous scales; 1 ridge above eye, toward upper angle of gill opening, another ridge along the vertex, nearly parallel with this above it, besides a short temporal ridge; vent far back, under seventh ray of second dorsal. First dorsal not far behind eye, the long ray slightly serrulate; ventrals with a short filament. Scales each with a median crest of 3 to 5 spinules, otherwise almost unarmed. Five scales between lateral line and dorsal. (Collett.) Depths of the Atlantic. Known from 2 specimens, the type 9 inches long, from the mouth of Rio de la Plata, in 600 fathoms; the second, above described, about a foot long, from the banks of Newfoundland, in

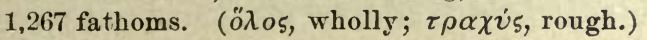

Macrurus holotrachys, GÜNTHER, Ann. Mag. Nat. Hist. II, 1878, 24 mouth of Rio de la Plata in 600 fathoms; Günther, Challenger Report, xxII, pl. 28, fig. B, 1887; Collett, Compagnes Scient. de l'Hirondelle, 1896, 83, pl. 2, fig. 6; Goode \& BEAN, Oceanic Ichthyology, 396, 1896.

2959. MACROURUS BAIRDII, Goode \& Bean.

(COMmon RAT-TAIL.)

Head $6 \frac{1}{2}$ in total length; depth 8 ; greatest width 13 . D. II, 11-137; A. 120 ; P. 15 ; V. 7 ; scales $6-152-19$ or 20 . Body much compressed posteriorly, tapering from first dorsal to tip of tail ; scales irregularly polygonal, the free portions covered with transparent vitreous spines, arranged in from 10 to 12 irregular longitudinal rows. On head and upper part of body, in advance of the first dorsal, the median row of spines most prominent, and presenting the appearance of a low median keel. Lateral line nearly straight, formed by a smooth groove, which replaces 2 or 3 median rows of spines of each scale; greatest height at posterior margin of orbit greater than width at same point, $1 \frac{4}{2}$ times in length of head; width of interorbital area equal to length of snout and length of maxillary; length of postorbital region about equal to horizontal diameter of orbit; length of operculum about $\frac{1}{2}$ length of mandible. Snout sharp, a front view presenting 4 ridges radiating from tip at right angles to each other, the lower one being merely a fold in the skin of the under surface of the head, horizontal ridges continued into the ridges upon the suborbitals; ridge extending backward from tip of snout upon top of head lost in the interorbital space; branches of the horizontal ridges continued upon upper margins of orbits, and there disappearing. Nostrils immediately in front of orbit, the posterior pair much the longer. Mouth situated entirely on lower side of head; symphysis of lower jaw in vertical from anterior margin of orbit, and articulations of mandibles in vertical from posterior margin of orbit; width of cleft of mouth equal to distance between symphysis of maxillaries and line connecting their articulations; upper jaw protractile vertically. Teeth conical, somewhat recurved, of nearly uniform size, arranged in villiform bands; palate smooth. Distance of first dorsal from sucut about 4 times the length of its base, and from anterior margin of 
orbit equal to length of head; first spine very short, not much longer than the teeth of the second spine; second spine in length twice horizontal diameter of orbit, stout, its anterior margin armed from base to tip with 15 teeth pointing upward, the uppermost slender; its length to tip of filament almost equal to distanee from origin of second dorsal, this tip when laid back reaching almost to secoud dorsal; rays decreasing regularly in length so that, when the fin is upright, its shape approximates that of a right-angled triangle, the hypothenuse of which is the second dorsal spine, and its perpendicular side a line touching the tips of the rays; length of base of second dorsal less than that of the anal, its origin over the thirteenth scale of lateral line. Length of longest ray less than length of barbel; all rays very feeble; membrane searcely perceptible; distance of anal from snout 34 times in its length at base, its origin under eighteenth scale of lateral line; length of first ray $\frac{1}{2}$ the length of tenth, and 3 times the length of last ray, the length of rays increasing to a point beneath anterior part of first dorsal, and thence gradually decreasing to tip of tail; distance of pectoral from snout 4 times width of interorbital area, its length twice length of mandible; insertion above the niddle of depth of body, on a level with center of orbit, its third ray longest, its tip reaching to vertical from base of fourth ray; insertion of ventral behind pectoral and almost under that of first dorsal, its distance from snout slightly exceeding twice its length; tip of ventral filament reaching base of third anal ray. Ground color, light brownish gray; under parts silvery; belly darker, bluish; under surface of snout pink, as is also the first dorsal, except spines; spines of dorsal, ventral, and anterior anal rays blackish; throat, branchiostegal membrane, and isthmus rich deep violet; sclerotic coat green; eyes very dark blue. This species was the first deep-sea fish obtained by the Fish Commission or described by an American ichthyologist. It ranges in depths from 9 to 1,255 fathoms. This species is distinguished by Giinther from his Macrourus aqualis, which it closely resembles, (1) by its longer snout, which is nearly equal to the diameter of the eye, and (2) by the smaller number of ventral rays (7). (Goode \& Bean.) West Indies to Massachusetts Bay, usually in great depths; excessively abundant on the continental slope, with Phycis chesteri, far outunmbering all other deop-sea fishes in the region. (Named for Spencer Fullerton Baird.)

Macrourus baïrdii, Goode \& BeAN, Amer. Journ. Sei. and Arts 1877, 471, Massachusetts Bay; Goode, Proc. U.S. Nat. Mus. 1880, 337, 475; GÜnther, Challenger Repurt, xxIr, 135, pl. 22, fig. B, 1887; Goode \& BEAN, Oceanic Ichthyology, 393, fig. 335, 1896.

2960. MACROURUS LEPTURUS, Gilł \& Townsend.

Head $5 \frac{1}{2}$; depth 8 ; eye $4 \frac{2}{5}$ in head; snout 4 ; maxillary $2 \frac{3}{5}$. D. XIV-122; A. $116 ;$ P. $20 ;$ V. 8 . Scales deciduous and moderate, oblong or oval with reduced exposed surfaces, those on the back or above the lateral line with a few, 3 to 5 , ridges beset with spines, but those below mostly unarmed; head regularly conical; snout moderately extended; median tubercle very projecting, the lateral well developed, connected with the nedian by a well-defined ridge; infraorbital vertical, with the ridge linear and near 
the orbit; teeth cardiform in both jaws; the lower teeth beset the outer slope of the jaw. Ventral as long as head; pectoral $1 \frac{3}{5}$ in head; dorsal spine serrate, $1_{\frac{1}{3}}$ in head. Apparently elose to $M$. acrolepis, but probably with shorter head, longer ventrals, and longer dorsal spine, the eye also larger. Length 22 to 26 inches. Bering Sea. Only 2 specimens known. ( $\lambda \varepsilon \pi \tau o ́ s$, slender; ov่ $\rho \alpha$, tail.)

Macrurus lepturiis, GiLL \& Townsend, Proc. Biol. Soc. Wash., xI, 1897 (Sept. 17, 1897), 233, Bering Sea, southwest of Pribilof Islands, Albatross Station 3604 , in 1,401 fathoms. (Type, No.48767, U.S. Nat. Mus. Coll. Albatross.)

Macrurus dorsalis, * GiL.L \& Townsend, Proc. Biol. Soc. Wash., XI, 1897 (Sept. 17, 1897), 233, Bering Sea, southwest of Pribilof Islands, Albatross Station 3604 , in 1,401 fathoms. (Type, No.48768, U.S. Nat. Mus. Coll. Albatross.)

2961. MACROURUS ACROLEPIS, Bean.

Head about $4 \frac{1}{2}$; depth at ventrals 7 ; eye $3 \frac{1}{2}$ in head; snout 4 ; maxillary $2 \frac{4}{5}$; mandible $2 \frac{1}{8}$; pectoral about 2 ; ventral about $1 \frac{2}{3}$. D. XI-111 +; A. $94+;$ P. 20. Form of $M$. berglax, width of head $\frac{8}{4}$ its height; interorbital width $\frac{8}{4}$ eye; snout moderate, pointed. Origin of first dorsal from snout a distance 3 times length of upper jaw; base of first dorsal $3 \frac{1}{2}$ in head, or about 3 times distance between dorsals; first dorsal spine very short, the second about $1 \frac{8}{4}$ in head, serrate in front. Distance of anal from snout $2 \frac{1}{2}$ timcs its length; distance of pectoral from snout slightly greater than head; distance of ventral origin from snout $\frac{1}{6}$ its length. Length 2 feet or more. Coasts of Vancouver Island, Washington and Oregon, in deep water, in 345 to 786 fathoms; common. A small specimen taken by us off Bogoslof Island. Our specimens have 11 rays in the first dorsal, not II, 11 or 13 , as given by Bean. ( $\alpha \varkappa \varkappa \rho \circ$, sharp; $\lambda \varepsilon \pi i \varsigma$, scale.)

Macrurus acrolepis, BeAn, Proc. U.S. Nat, Mus. 1883, 362, Straits of Juan de Fuca, near Neah Bay, Washington (Coll. James G. Swan, from the stomach of a fur seal); JoRDAN, Cat. Fish. N. A., 131, 1885; GILBERT, Rept. U. S. Fish Comm. 1893 (1896), 457.

Macrourus acrolepis, JoRDAN \& GilBERT, Rept. Fur Seal Invest., 1898.

2962. MACROURUS STELGIDOLEPIS, Gilbert.

Head $4 \frac{3}{5}$; depth $5 \frac{1}{2}$; eye small, $3 \frac{1}{2}$ to 4 in head; snout $4 \frac{1}{2}$. D. II, 10 or 11 ; A. 130 ; seales 155 ; 5 or 6 scales between lateral line and base of first dorsal. Body deep, the lower profile rapidly rising along anterior portion of base of anal, the tail thus abruptly becoming slender. Head short and deep; snout heavy, little produced, acute at extreme tip; infraorbital ridge not prominent on sides of head or snout, not eontinued backward on preoperele. A pair of narrow, transverse naked strips on upper surface of snout near tip, separated on each side by a single scale from the naked

*The following is Gill \& Townsend's description of Macrourus dor salis :

"Dorsal 15-120; anal 122; pectoral 21; ventral 9. Scales deciduous and rather small, diversiform, with small exposed surfaces; near the dorsal they have about 5 radiating spinigerous ridges, but below the lateral line these ridges are fewer and unarmed; snout short, projecting a considerable length beyond the eye and a little beyond the supramaxillary; median tubercle very prominent; connecting ridge well defined; infraorbital nearly vertical, with the ridge linear and near the orbit; teeth cardiform."

To this we add the following, from our examination of their type: Head $5 \frac{3}{5}$; depth 7 ; eye $4 \frac{3}{5}$; snout 4 ; interorbital width slightly greater than eye; maxillary $2 \frac{3}{5}$; ventral fin longer than head, $4 \frac{1}{2}$ in body; pectoral $1 \frac{1}{2}$ in head. Dorsal spino strongly serrate, its length equal to that of head. 
nostril fossa; a double series of seales intervenes between the nostrils and the orbit; lower side of snout wholly naked anteriorly, partly sealed laterally. Mouth large, overhung by premaxillaries for a distance about $\frac{1}{2}$ diameter of orbit; premaxillaries in advance of nostrils; maxillaries reaching vertioal from posterior margin of pupil, $2 \frac{2}{3}$ in head; snout about equaling interorbital width; barbel long, $\frac{5}{6}$ orbit. Teeth in eardiforn bands of equal width in both jaws, narrowed laterally, but not to a single series; anterior series in upper jaw enlarged, in lower jaw all the teeth of equal size. Preopercle broadly rounded, the angle but moderately produced, a narrow strip of the interopercle visible for its entire length; outer gill arch partially joined to cover, as usual; gill rakers obsolete; gill membranes united, forming a wide free fold across isthmus posteriorly. Scales without ridges, their exposed surfaces thickly beset with spines which are usually without definite arrangement; the marginal spine longest, thence decreasing in length to the base, about 40 present on each scale on middle of sides; scales on head crowded, the spines shorter and not directed backward as on the body; a rosette of short spines on tip of snout; no naked area between ventrals; maudible and gill membranes partly scaled; no considerable naked area in axil of peetorals. Dorsal inserted over base of pectorals, the length of its base slightly less than $\frac{1}{2}$ the interspace between base of dorsals; second dorsal spine rather short and fragile, furnished anteriorly with a series of retrorse spinules, its length slightly exceeding $\frac{1}{2}$ that of head, its tip not reaching origin of second dorsal; origin of anal fin well in advance of second dorsal; the vent unusually far forward, its distance from base of ventrals 2 to $2 \frac{1}{2}$ in its distance from anal fin; ventrals less widely separated than in $M$. scaphopsis, the outer ray produced, extending beyond front of anal; ventrals with 10 rays; peetorals with 22 to 24 rays; longest pectoral ray equals $\frac{1}{2}$ head. Color very dark brownish, lighter on tail; lower side of head, breast, and abdominal region, including front of anal and base of pectorals, blue black; roof of mouth, valvular flap of membrane behind bands of teeth, gill membranes, and upper posterior portion of opercular lining, black; mouth and gill cavity otherwise white; peritoneum bright silvery, with little black specking; fins dusky. (Gilbert.) Coast of southern California. 'Two specimens, the longest 12 inches in length, from Albatross Station 2960 , in 267 fathoms. ( $\sigma \tau \varepsilon \lambda \gamma i 5$, a scraper; $\lambda \varepsilon \pi i \varsigma$, scale.)

Macrurus stelgidolepis, GiLBerT, Proc. U.S. Nat. Mus.1890, 116, coast of southern California, at Albatross Station 2960 , in 267 fathoms.

2963. MACROURUS CINEREUS, Gilbert.

(POP-EYE.)

D. II, 10 or 11 ; ventral $9 ; 7$ scales between lateral line and first dorsal. Eye $3 \frac{8}{4}$ to 4 in head; snout about 4, high and blunt, but little overlapping the mouth, terminating in a pointed prolongation of the median ridge, which bears at its tip a bony tubercle furnished with radiating ridges; nasal ridges terminating in shorter and smaller, but similar, tubercles, the outline between them concave; tip of snout overpassing the premaxillaries for $\frac{2}{8}$ its length; eye very large and protuberant; mouth of 
moderate size, the maxillary reaching vertical from hinder margin of orbit, equaling length of snout and $\frac{1}{2}$ of eye. Teeth finely villiform, in each jaw, the outer series not at all enlarged, the mandibular band narrow. Barbel short and slender, its length less than $\frac{1}{2}$ diameter of pupil; interorbital width $\frac{6}{7}$ diameter of orbit, equaling length of snout; preopercle greatly expanded, much overlapping the interorbital below, leaving exposed only the extreme posterior angle. Gill membranes narrowly joined, with a posterior fold, free from the istlımus; gill rakers short, compressed, almost tubercular, $2+12$. Origin of dorsal well behind base of pectorals; second dorsal spine long and filamentous, strongly spinous except on extreme base and tip; length of spine $\frac{5}{6}$ to $\frac{6}{7}$ head; base of first. dorsal equaling diameter of orbit; interspace between dorsals $\frac{2}{8}$ to $\frac{2}{5}$ base of first dorsal; pectoral long and slender, equaling length of head behind anterior nostril opening, about as long as the filamentous outer ventral ray; vent immediately in front of anal origin. Scales on sides well imbricated, each with 7 to 9 parallel ridges which bear short sharp spines directed very obliquely backward; 7 scales between lateral line and base of first dorsal. Color uniform light grayish on body and fins, with the exception of the blackish pectorals and ventrals; sides of head silvery; mouth, gill cavity, and peritonoum brownish or purplish black; gill membranes and gnlar membrane dusky. (Gilbert.) Bering Sea; excessively abundant in the depths, where it outnumbers all other fishes. Numerous specimens from north of Unalaska Island, at Albatross Stations 3307 and 3329, in 1,033 and 399 fathoms; and the North Pacific, south of Unimak Island, Albatross Station 3340, in 695 fathoms. Our many specimens from near Bogoslof Island, in 664 fathoms. (cinereus, ashy gray.)

Macrourus ciñereus, Gilbert, Rept. U. S. Fish Comm. 1893 (1896), 457, near Unalaska and Unimak Islands, in 399 to 1,033 fathoms; JORDAN \& GILBERT, Report Fur Seal Invest., 1898.

\section{CELLORHYNCHUS, Giorna.}

Coelorhynchus, Gionna, Mém. Ac. Sci. Turin, Xvi, 178, 1803 ("Coelorhynche la ville").

Krohnius, Cocco, Lettera al Sig. Augusto Krohn, Pesci del Mare de Messina, 1, 1844 (filamentosus; larva).

Paramacrurus, BleEker, Versl. Med. Ak. Wetensk. Amsterd. 1874, 103 (australis).

Oxymacrurus, BleEker, Versl. Med. Ak. Wetensk. Amsterd. 1874, 103 (japonicus).

This genus agrees with Macrourus in all essential respects, except that the, small mouth is wholly below the long-pointed, sturgeon-like snout. Dorsal spine smooth in typical species, those with serrate spine having been lately separated under the generic name Colocephalus. (Gilbert \& Cramer, Proc. U. S. Nat. Mus. 1896, 422) (acipenserinus). Species uumerous.

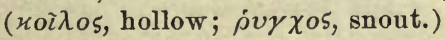

a. Head large, $3 \frac{1}{2}$ in length; depth 7 ; eye $\frac{1}{2}$ length of the long snout, 4 in head; dorsal spine moderate.

OCCA, 2964.

aa. Head short, $4 \frac{1}{3}$ to 5 in lengtl.

b. Body rather elongate, the depth 8 in length; eye as long as suout, 3 in head.

bb. Body less elongate, the depth $6 \frac{1}{2}$ to $6 \frac{3}{4}$ in length.

c. Dorsal spine long; anal rays about 110 ; scales 124.

cc. Dorsal spine very short; anal rays 95 ; scales 98.

CARMINATUS, 2965 . 
2964. COELORHYNCHCS OCCA (Goode \& Bean).

Head $3 \frac{1}{2}$ in total length; depth 7 in total length; snout exceedingly elongate, nearly twice as long as diameter of eye; a black flap between nostrils; angle of mouth nearly reaching vertical from posterior margin of the orbit; ridge of head very strong and continuous from snout to angle of preopercle, having, also, strong supraocular and occipital ridges; eye nearly round, its horizontal diameter 4 in head and equal to interorbital space; rentral originating under middle of first dorsal, and extending to fourth ray of anal ; distance from ventral origin to vent $3 \frac{1}{2}$ in length of head; second spine of dorsal weak and smooth, its length equal to postorbital part of head, its base slightly less than distance between first and second dorsals; squamation excessively rough, each scale bearing about 5 large spines besides many smaller ones, the median spine of the large series being much the largest; 5 rows of scales between origin of dorsal and lateral line, 19 from vent forward to lateral Iine and 12 backward; barbel $\frac{1}{4}$ as long as snout. This species has scales similar to those of Macrourus berglax, there being a strong median keel formed by series of spines, of which the last is the largest; surface of each scale also with about 4 or more lateral ridges formed by series of short spines. In a much larger example (U. S. Nat. Mus. No. 37334), measuring 18 inches in length, the lateral series of keels have greatly increased in number, the individual spines having become more prominent, so that the modian keel has become less conspicuous than in the type. In the larger specimen referred to, the nakedness of the under surface of the head is even more pronounced than in the smaller, in which the under surface of the head beneath the suborbital and nasal ridge is almost entirely naked. The intermaxillary has a very short bone similar in structure and dentition to that of Macrourus berglax, that is to say, the intermaxillary teeth are in a rather broad villiform band, and the outer teeth are not enlarged; mandibulary teeth in a similar broad villiform band; mouth entirely inferior and small. Gill membranes attached across the isthmus, very little emarginate, and not deeply cleft; in the large example the gill membrane is attached to the isthmus and not deeply cleft, but there is a very narrow free margin behind. The gill rakers are very short, tubercular, and few in number, certainly not more numerous than in $\boldsymbol{M}$. berglax; in the large example only 8 little tubercles can be seen on the first gill arch. Second spine of the dorsal in the type specimen is smooth, with the exception of 2 weak spines near its tip, but in the large example there is no trace of serrations on the dorsal spine. (Goode \& Bean.) Length $450 \mathrm{~mm}$. Gulf of Mexico and West Indies, in deep water. (occa, a harrow, from the rough scales.)

Macrurus occa, Groode \& Bean, Proc. U. S. Nat. Mus. 1885, 595, Gulf of Mexico, Lat. $28^{\circ}$ $34^{\prime}$ N., Long. $86^{\circ} 4^{\prime}$ W., in 335 fathoms. (Type, No. 37334. Coll. Albatross.)

Coelorhynchus occa, GoodE \& BEAN, Oceanio Ichthyology, 400, figs. 332, 333, and 337, 1896.

\section{CELORHYYCHUS CARMINATUS (Goode).}

Head about 5 in total length; depth 8 ; eye about 5 in head, equaling interorbital width; snout equaling eye or postorbital part of head; length of opercle about 2 in snout. Body less elongate than in M. bairdii. Snout 
long, sharp, depressed, triangular, the lower surface more nearly parallel with the axis of body than in $M$. bairdii; lateral ridges more prononnced, continued in a straight line nuder eye and upon preopercle; strong liorizontal ridges running from supraorbital margins to gill openings, parallel with subocular ridges; nostrils immediately in front of orbit; barbcl very short. Teeth small, conical, somewhat recurved, arranged in villiform bands. Origin of first dorsal to snout $4 \frac{1}{2}$ times its basc, its distance from anterior margin of orbit much less than length of head; first spine very short, hardly perceptible above the skin; second spine about 2 in head, slender and unarmed, when laid back its tip reaching to or beyond origin of second dorsal, the spines decreasing in length very gradually, the sixth being nearly as long as second, so that the fin is not so triangular as in $M$. bairdii; second dorsal beginning in a perpendicular from seventh anal ray; anal much higher than in $M$. bairdii, nearly equal to $\frac{1}{2}$ interorbital width, its origin under eighteenth scale of lateral line, its longest rays as long as interorbital width; distance of pectoral from snout equaling twice its own length, which about equals longest dorsal spine; origin of pectoral below middle of depth of body and below level of middle of orbit, its tip not reaching origin of anal; insertion of ventrals behind pectoral, slightly in advance of first dorsal, its distance from suout greater than twice its length, the long filament not reaching anal. Color silvery gray. Length $250 \mathrm{~mm}$. This species is extremely close to the common Mediterranean species, C. colorhynchus (Risso), but the spines on the scales are a little larger. West Indies, Gulf of Mexico, and in the Gulf Stream in deep water; abundant; taken at many stations by the Albatross, the Blake, the Fish Hawk, and the Challenger, in 115 to 464 fathoms. (carminatus, from carmen, a wool card.)

Macrurus carminatus, Goode, Proc. U. S. Nat. Mns., III, 1880, 346 and 475, Gulf Stream off Rhode Island, Lat. $40^{\circ} \mathrm{Oz}^{\prime} 54^{\prime \prime} \mathrm{N}$., Long. $70^{\circ} 23^{\prime} 40^{\prime \prime}$, at Fish Hawk Station $87 \mathrm{x}$, in 115 fathoms (Type, No. 26007); Goode \& BeAN, Bull. Mus. Comp. Zool., x, No. 5, 196, 1883 , Macrurus (Ooelorhynchus) carminatus, GüNTHER, Challenger Report, Deep-Sea Fishes, XxII, 129, pl. 5, fig. 13, 1887.

Colorhynchus carminatus, GOODE \& BEAN, Oceanic Ichthyology, 398, fig. 336, 1896.

2966. CELORHYNCHUS CARIBBEUS (Goode \& Bean).

Head $4 \frac{1}{2}$ in total length; depth $6 \frac{1}{2}$ in total length. 1 D. II, $8 ; 2$ D. at least 110 ; A. $110+$; scales $6-124-15$ or 16 . Body normal in shape; scales moderate, strong, densely covered with minute spines, without enlarged median keel; interorbital area flat, its greatest width about 5 times in length of head; postorbital portion of head about 3 in head, and just as long as eye, which is oval, and $1_{5}^{2}$ as long as its vertical diameter. Snout long, thin, diaphanous, with acuminate point, its general form resembling that of $C$. carminatus. The nostrils close to the orbit, the posterior one much the larger. Teeth in each jaw in villiform bands, minute. Barbel slender and short, its length $\frac{1}{8}$ that of eye. Maxillary extending to vertical through middle of pupil; upper jaw about 3 in head; mandible $2 \frac{1}{2}$; intermaxillary short. Onter series of teeth on intermaxillary and mandible not enlarged, the teeth not becoming uniserial. Gill membranes narrowly attached to the isthmus; gill rakers minute, tubercular, about 10 on 
first arch. Suborbital ridge very strong, continued almost in a straight line by the lateral ridge of the snout; under surface of head, except chin and branchiostegal region, densely covered with small, spiny tubercles; a naked space on underside of snout, occupying almost entire distance from front of mouth to tip of snout, widest anteriorly, the greatest width 5 in snout; intermaxillary protractile in a vertical direction; mouth distinctly inferior. Origin of second dorsal over seventh anal ray, about an eye's diameter lehind first dorsal; length of anal rays about 4 in head; origin of pectoral in front of first dorsal, its length 2 in head, its tip reaching fifth anal ray. Color silvery gray, with yellowish and lavender tints. Length $290 \mathrm{~mm}$. Caribbean Sea north to the Gulf of Mexico, in deep water. (caribbaus, of the Caribbean Sea.)

Macrurus caribbous, Goode \& BEAN, Proc. U. S. Nat. Mus. 1885, 594, Gulf of Mexico, at Albatross Station 2377 , Lat. $29^{\circ} \mathrm{O}^{\prime} 3 \mathrm{O}^{\prime \prime} \mathrm{N}$., Long. $88^{\circ} \mathrm{o} 8^{\prime}$ W., in 210 fathoms (Type, No. 37333); GÜNTHER, Challenger Report, Deep-Sea Fishes, XxII, 124, note 3, 1887. Coelorhynchus caribboeus, GOODE \& BEAN, Oceanic Ichthyology, 401, fig. 338, 1896.

\section{CELORH XNCHUS SCAPHOPSIS (Gilbert).}

Depth $6 \frac{8}{4}$ in total length; head $4 \frac{1}{6}$; scales 98 . D. II, 8 ; A. ca. 95. Snout fattened, acute, the conspicuous infraorbital ridge forming a strong ridge along its sides, the two meeting at tip in a salient point; an evident keel extending from tip of snout to middle of interorbital area; supraorbital ridge dividing anteriorly, 1 branch running down in front of nostril, the other separating nostril fossa from orbit; between the ridges the head is covered with a soft, yielding integument, which is semitranslucent. Lower side of snout wholly naked below, and with a large naked area above on each side of tip; snout projecting beyond month for a distance equaling length of maxillary. Mouth of moderate size, the maxillary reaching vertical from posterior margin of pupil, $3 \frac{1}{8}$ in head. Teeth villiform, in a broad band in upper jaw, in a narrower band below, not reduced to a single series laterally in either jaw, and none of the teeth enlarged. Eye large, elliptical, equaling length of snout, $3 \frac{1}{4}$ in head; interorbital width $4 \frac{1}{8}$. Barbel short, about $\frac{1}{2}$ pupil; preopercular angle greatly produced backward, wholly concealing the interopercle, the strong infraorbital ridge failing to reach preopercular margin by only $\frac{1}{8}$ diameter of pupil. Structure of gills as usual in this genus, the gill rakers obsolete; gill membranes broadly united, joined to isthmus, across which they form posteriorly a very narrow free fold. Besides the ridges already described on head, there are a pair on occiput, a pair from upper posterior margin of orbit to upper angle of gill opening, and a median ridge on nape reaching about halfway from occiput to dorsal. These ridges, as well as the interorbital space and the area between the occipital ridges, covered with scales compressed to a knife-like edge, which is provided with a single series of backward-directed spines; scales on infraorbital and rostral ridges bearing stellate spines or are similar to those on temporal region, sides of head, and body generally; scales on body large; 3 longitudinal series between lateral line and middle of first dorsal; each scale provided with a ridge bearing about 6 backward-directed spines, and from 2 to 4 
pairs of lateral ridges also bearing spines, the lateral ridges sometimes extending the whole width of scales, sometimes confined to their basal portion; marginal spines longest; axil of pectoral naked, its base anteriorly with small eycloid scales; a naked, much depressed, elliptical area between bases of ventrals in all specimens; second dorsal spine smooth, weak, little exceeding length of soft rays, equaling length of snout and orbit; base of first dorsal $1 \frac{1}{2}$. in interspace between dorsals, which is $2 \frac{2}{3}$ in head; distance from front of anal to snout equaling $\frac{1}{8}$ total length; ventrals with the outer ray produced, about reaching front of anal; pectorals reaching beyond anal $\frac{1}{2}$ length of head; ventrals with 7 rays; pectorals with 15 to 17 rays. Color light olive brown, dusted with coarse black specks; axil of pectorals, belly, ventrals, and branchiostegal membranes blue black; lower side of head dusky; mouth anteriorly, including tongue and $\frac{1}{2}$ of palate, white, its posterior part and most of lining of gill cavity jet-black; inner lining of cheeks abruptly white; lower part of iris silvery; peritoneum silvery, with coarse dusky specks; vertical fins dusky, the anterior portion of anal black. Coast of southern California. Many specimens, the longest 12 inches long, from Albatross Station 3015, in 145 fathoms. (Gilbert.) (бนá $\emptyset$, spade; ơ $\psi 15$, face.)

Macrurus (Coelorhynchus) scaphopsis, GiLBerT, Proc. U. S. Nat. Mus. 1890, 115, Albatross Station 3015 , coast of southern California, in $\mathrm{x}_{45}$ fathoms.

I008. TRACHONURUS, Günther.

Trachonurus, GÜnther, Challenger Report, Deop-Sea Fishes, XXII, 124, 1887 (villosus).

Scales not imbricated, separated by furrows, and densely covered with sharp spinuies, so that the animal seems villous to the touch; dorsal spine smooth; dorsal much lower than anal; teeth in both jaws in villiform bands; snout obtuse, the mouth subinferior; suborbital ridge little developed. This genus is distinguished from Colorhynchus by the indis-

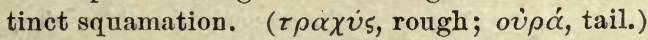

\section{TRACHONURUS SULCATUS (Goode \& Bean).}

Head $7 \frac{1}{2}$ in total length; depth about $9 \frac{1}{2}$; eye $3 \frac{2}{3}$ in head; snout 4 to $4 \frac{1}{2}$. D. II, 8 or 9 , the second of numerous low rays; A. 120 ; V. 7 ; P. 13; scales 7-175 or more-33. Barbel $2 \frac{1}{2}$ to 2 in eye. Body elongate, rapidly contracted behind the abdomen; the tail long and whip-like. Scales moderate, strongly armed, each with 8 to 10 spinelets, irregularly placed, less numerous in the young, which feel bristly to the touch, separated by wide deep furrows; armature of head similar to that of body, but the scales npon snout, cheeks, and chin have very feeble spines. Interorbital area nearly flat, its length equaling diameter of eye or about 3 in head; postorbital part of head as long as eye; snout short, obtuse, scarcely overhanging the mouth; nostrils somewhat above level of middle of eye, the anterior one nearly upon the dorsal outline. Upper jaw with 2 series of teeth in villiform bands, the outer series slightly enlarged; teeth of lower jaw in a single series; maxillary reaching to vertical through hind margin of pupil in adult, shorter in younger individuals; length of upper jaw, 
inclnding maxillary, 3 in head; mandible 2 in depth of body; barbel 2 to $2 \frac{1}{2}$ in eje. Gill rakers very small, tubular, almost rudimentary, about 10 below angle of first arch; attachment of membrane to first arch very extensive, but free from isthmus; no pseudobranchiæ. First dorsal comparatively low, the first spine rudimentary, the second elongate and smooth; insertion of first dorsal immediately over or somewhat behind base of pectoral, its distance from snont $1 \frac{1}{8}$ in head, its base equal to snout, its longest spine, when laid down, reaching behind origin of second dorsal, or $1 \frac{1}{2}$ to 2 in head; second dorsal very low, its distance from first 3 to 4 in head, 32 rays in a distance equal to length of head; 22 in same distance of anal; anal much higher than second dorsal, yet very low, its longest ray equal to eje; distance of anal origin from snout $4 \frac{2}{8}$ in total length, or nearly under origin of second dorsal; pectoral inserted under or somewhat in front of origin of first dorsal, its length about 2 in head; ventral inserted behind vertical from end of base of first dorsal, extending to origin of anal, its length about equaling eye; vent about midway between origin of ventrals and anal. Color brown; abdomen and lower parts of head blackish in the young. West Indies and Gulf of Mexico, in deep water; taken both by the Albatross and the Blake. (sulcatus, furrowed.)

Coryphonoides sulcatus, Goode \& BEAN, Proc. U.S. Nat. Mns. 1885, 596, Gulf of Mexico, at Albatross Station 2394, Lat. $28^{\circ} 3^{\prime} 30^{\prime \prime}$ N., Long. $87^{\circ} 02^{\prime}$ W., in 420 fathoms (Type, No. 37335); Goode \& BEAN, Oceauic Ichthyology, 403, 1896.

Macrurus (Malacocephalus) sulcatus, GüNTHER, Challenger Report, Deep-Sea Fishes, XXII, $169,1887$.

Trachonurus sulcatus, GOODE \& BEAN, Oceanic Ichthyology, 410, fig. 343, 1896.

roog. LIONURUS, Giinther.

Lionurus, GÜNTHER, Challenger Report, xxII, Deep-Sea Fisbes, 124,1887 (filicauda).

This genus is close to Macrourus, differing in the smooth, flaccid scales, and soft, cavernous skull, characters associated with its extreme bathybial degradation. ( $\lambda \varepsilon \check{o} \circ 5$, smooth; ov่ $\dot{\alpha}$, tail.)

a. Barbel minnte, not pupil; eye small, 5 in head; tail very slender.

aa. Barbel moderate, $1 \frac{9}{3}$ in eje; eye $3 \frac{3}{4}$ in head.

FTLICAUDA, 2969. LIOLEPIS, 2970.

\section{LIONURUS FILICACDA (Günther).}

D. 11 ; P. 20; V.9; cæca 7. Snout considerably projecting beyond the mouth, pointed in the middle, twice as long as eye, which is nnusually small, only $\frac{1}{2}$ as wide as interorbital space. Mouth rather wide, extending beyond the center of the eye. Upper teeth villiform, in a very narrow band, those of mandible very small, biserial. Barbel minute. Preoperculum with the angle produced backward, broadly rounded and crenulated on the margin. Terminal portion of the tail prolonged into a long filament, more slender than in any of the other species. Bones of head soft. Scales of moderate size, thin, cycloid, and deciduous, 6 or 7 in a transverse series between the first dorsal spine and the lateral line; snout 
and inferior half of the infraorbital region naked. Second dorsal spine slender, with the barbs in front very inconspicuous and sometimes entirely absent; distance between dorsal fins less than length of head; outer ventral ray produced into a small filament. Distance between vent and isthmus less than length of head. Head and trunk whitish, tail brownish, lower part of head and gill openings black. (Giinther.) This species is clearly one of those in this family which extends to the greatest depths. The decrease in the size of the eye, the very soft bones, the comcomitant want of firmuess in the structure of the scales, and the tail, which tapers into a very fine filament, indicate its abyssal abode. The scales are nearly all gone in all the specimens obtained. The species appears to be abundant in individuals, and has, like a true deep-sea fish, a wide distribution. (Günther.) Antarctic Ocean and deep seas off both coasts of South America. (filum, thread; cauda, tail.)

Coryphonoides (Lionurus) filicauda, GüNTHER, Ann. and Mag. Nat. Hist., xx, 1878, 27, Deep seas on both sides of South America, in 1,375 to 2,650 fathoms.

Macrurus filicauda, GüNTHER, Challenger Report, Deep-Sea Fishes, 141, pl. 34, fig. B, 1887. Lionurus filicauda, Goode \& BEAN, Oceanic Ichthyology, 409, fig. 342, 1896.

\section{LIOXURUS LIOLEPIS, Gilbert.}

Head $4 \frac{2}{8}$ in length; depth $6 \frac{1}{5}$; maxillary nearly reaching vertical from posterior margin of orbit, $2 \frac{4}{5}$ in head; eye $3 \frac{8}{4}$; interorbital space concave, equaling snout, $4 \frac{1}{8}$; barbel $\frac{3}{5}$ eje. D. II, 10. A. 120. Snout short and high, with well-marked lateral ridge, the extreme tip flattened; the median ethmoidal ridge is prominent, and the supraocular ridge is continued forward on the snout, meeting the lateral ridge in a projecting point. Top of snout wholly naked mesially, a narrow band of scales around each margin and in front. Lower side of head, including under side of snout, mandibles, gill membranes, and most of interopercles, naked; a very small patch of scales on posterior part of interopercle. Mouth moderate, the snout overhanging the premaxillaries for a distance equaling $\frac{1}{2}$ maxillary. Teeth in rather narrow cardiform bands in each jaw, not, however, forming single series laterally; the outer series in upper jaw only is enlarged; angle of preopercle little produced, not concealing the interopercle; infraorbital ridge not continued on to it. Gill membranes forming posteriorly a rather wide free fold across isthmus; outer gill arch joined to gill cover as usual in this genus. Scales small, everywhere cycloid, rery deciduous, lost in most specimens; no spines developed, but occasionally can be seen traces of a median ridge and a pair of lateral ridges; about 6 or 7 series of scales between lateral line and base of first dorsal. Origin of first dorsal over or in advance of base of pectorals; base of first dorsal $1 \frac{1}{3}$ to $1 \frac{2}{8}$ in interval between dorsals; second dorsal spine usually smooth, occasionally with from 1 to 3 weak prickles near the middle; length of spine $1 \frac{2}{5}$ in head. Origin of anal slightly behind first dorsal, the vent midway between base of ventrals and anal; ventrals short, the outer ray slightly produced, with from 10 to 12 rays; pectorals with 20 or 21 rays. Color very dark brown; snout, opereles, lower side of head, and abdominal region black or blue black; month and gill cavity 
black; peritoneum dusky silvery. Coast of southern California. Many specimens taken at Albatross Station 2980, in 603 fathoms. ( $\lambda \varepsilon \check{\circ} \circ$ s, smooth; $\lambda \varepsilon \pi i s$, seale.) (Gilbert.)

Macrurus (Lionurus) liolepis, GILBERT, Proc. U. S. Nat. Mus. 1890, 117, coast of southern

California, at Albatross Station 2980, in 603 fathoms.

Remotely related to the Scombriform fishes, and perhaps derived from the same ancestral stock as the Trichiurida, is the singular

\section{Suborder TANIOSOMI.}

\section{(The Ribion-Fishes.)}

This group is thus defined by Dr. Gill:

"Scapular arch subnormal, post-temporal undivided and closely applied to the back of the cranium, between the epiotic and pterotic, or upon the parietal; hypercoracoid perforate at or near the margin; cranium with the epiotics enlarged, encroaching backward and juxtaposed behind, intervening between the exoccipitals and supraoccipital; prootic and opisthotic represented chiefly by the enlarged prootic; suborbital chain imperfect; the copular bones separated by intervening cartilaginous elements; the hypopharyngeals styliform and parallel with the branchial arches; epipharyngeals in full number (4 pairs), and mostly compressed; the dorsal fin composed of inarticulate rays or spines, separable into lateral halves, and the ventrals (when present) subbrachial. A myodome may be present or absent, none being developed in the Regalecida, but 1 being distinct and supplemented by a dichost in the Trachyterida." (Gill.)

"The ribbon-fishes," says Günther, "are true deep-sea fishes, met with in all parts of the oceans, generally found when floating dead on the surface or thrown ashore by the waves. Their body is like a band, specimens of from 15 to 20 feet long being from 10 to 12 inches deep and about an inch or two broad at their thickest part. The eye is large and lateral; the mouth small, armed with very feeble teeth; the head deep and short. A high dorsal fin runs along the whole length of the back, and is supported by extremely numerous rays, its foremost portion, on the head, is detached from the rest of the fin, and composed of very elongate flexible spines. The anal fin is absent. The caudal fin (if preserved, which is rarely the case in adults) has an extra-axial position, being directed upward like a fan. Theventrals are thoracic, either compressed of several rays or reduced to a single long filament. The coloration is generally silvery, with rosy fins. When these fishes reach the surface of the water the expansion of the gases within their bodies has so loosened all the parts of their muscular and bony system that they can be lifted out of the water with difficulty only, and nearly always portions of the body and fins are broken and lost. The bones contain very little bony matter, and are very porous, thin, and light. At what depth ribbon fishes live is not known; probably the depths vary for different species; but although none has yet been obtained by means of the deep-sea dredge, they must be abundant at the bottom of all oceaus, as dead fishes or fragments of them are frequently obtained. 
Some writers have supposed from the great length and narrow shape of these fishes that they have been mistaken for 'sea serpents,' but as these monsters of the sea are always represented by those who have had the good fortune of meeting with them as remarkably active, it is not likely that harmless ribbon-fishes, which are either dying or dead, have been the

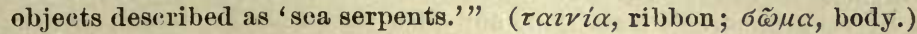

\section{Families of Taniosomi.}

a. Ventral fins rerluced each to a single long filament, thickened at the tip; anterior rays of dorsal produced; mouth small; eaudal fin short or wanting.

REGALECIDA, CCXVI.

$a a$. Ventral fins normally developed or else wanting.

b. Caudal fin short, fan-shaped, inserted at an angle with axis of body; the tail not much produced beyond it.

TRACHYPTERIDA, CCXVII.

bb. Caudal fin short, the tail beyond it ending in a long filament, longer than rest of body. STYLEPHORIDE, CCXVIII.

Family CCXVI. REGALECIDA.

\section{(OAR-Fishres.)}

Body very elongated and compressed, the head oblong, the opercular apparatus well developed (the operculum extended backward, the suboperculum obliquely behind it, and the interoperculum extended upward kelow the 2), the preorbital chain oblique and widest at the second bone; ventrals represented by single elongate rays, the cranium with the myodome atrophied and the dichost suppressed, the supraoccipital pushed forward by the extensive development of the epiotics which encroach forward on the roof as well as back and sides of the cranium, and with short ribs. (Gill.) Superficial characters are the very long dorsal, extending the whole length of the back and with the rays at the nape much produced; pectorals very short; caudal fin short or wanting; anal very low; head small; mouth very short; no air bladder; pyloric caeca numerous. One genus, with 2 or more species. Very large, surface-swimming fishes of the open seas; the great size, undulating motion and projecting mane causing them frequently to be taken for sea serpents. (Regalecida, Gill, Standard Nat. Hist., III, 1885; GiLL, Amer. Nat. 1890, 482.)

roro. REGALECUS, Brünnich.

\section{( $(\dot{A}$ AR-Fishes.)}

Regalecus, Brünnicir, Nya Sammlung, III, 414, 1788 (glesne).

Gymnetrus, BLOCH \& SCHNeIDER, Syst. Ichth., 487, 1801 (remipes).

Xypterus, RAFINESQUE, Indice, 59, 1810 (imperati).

Characters of the genus included above. "It is not certain that there is more than 1 species of Regalecus, although, as the synonymy which follows clearly shows, various names liave been suggested in connection with the comparatively fow individuals which, during the past century and a half, have been captured in the North Atlantic. There appears to be consider- 
able possibility of individual variation in proportions of height to length, and in the number of rays in the dorsal fin, but it is a fact well known to ichthyologists that constancy is not to be expected in forms in which the number of vertebræ and fin rays has been extended far beyond the normal average. It should also besaid that most of the individuals studied have been in very imperfect condition, and also that in many instances the observations have been made by untrained observers, so that it seems doubtful whether there is really more than 1 species to be assigned to the Atlantic fauna. At all events, Günther, Collett, Liitken, and Day agree in the idea that it is impossible to discriminate between the forms already described, and we follow their lead in considering them all, for the present, as a single species. It is not impossible, of course, that, should better material be obtained, it may be desirable to separate the group into more subspecies, but until this shall be done discrimination leads to confusion rather than to definite knowledge. The fishes belonging to the genus Regalecus are very remarkable, not only on account of their peculiar appearance and structure, but because of their enormous size. They have been known to attain the length of 20 feet, and it is more than probable that they grow very much longer, and that many of the creatures popularly identified with the "sea serpent" are only large individuals of this type. Indeed, it seems quite safe to assign to this group all the socalled "sea serpents" which have been described as swimming rapidly near the surface, with a horse-like head raised above the water, surmonuted by a mane-like crest of red or brown. The individual which came ashore at Hungry Bay, in Bermuda, in 1860, and which was about 17 feet long, was described by the people who saw it before its capture as being very much larger, and as having a head of an immense horse with a flaming red mane." (Goode \& Bean.) (rex, king; halec, herring. The species havelong been known as "king of the herrings," as have those of Trachyptcrus.)

2971. REGALECUS GLESNE (Ascanius).

(OAr-Fish; Sea Serpent.)

Head 16 to 20 ; depth 12 to 24 ; eje 4 to 6 in head; snont short, truncated. D. 275 to 400 ; P. 11 to 14 ; V. I. Body very elongate. Cleft of month vertical, tho upper jaw very protractile; jaws minute or absent. Anterior 8 to 15 rays of dorsal forming an elevated crest, sometimes in 2 parts, the posterior rays with membranaceous tips; each ventral ray with a lobate membranaceous tip; skin with numerous bony tubercles; lateral line placed low. Color silvery gray, with a few spots or streaks of darker hue, most numerous anteriorly. Günther (Challenger Report, xxir, 73 to 76) has in the most painstaking manner brought together a list of the specimens taken in the North Atlantic, as far as they are known to science. He mentions 14 known upon the Scandinavian coasts from 1740 to 1852 ; 19 on the British coasts from 1759 to $1884 ; 1$ in the Mediterranean (he states, however, that about $\frac{1}{2}$ a dozen specimens have been observed in the Mediterranean); 1 in the Bermndas; 3 at the Cape of Good Hope; 1 in the Indian Ocean, and 5 off the coast of New Zealand. He calls attention to 
the fact that of those observed on the British and Scandinavian coasts 4 were observed in the month of January, 5 in February, 8 in March, 2 in April, 1 in May, 1 in June, 1 in July, 2 in August, 1 in September, and 1 in October. He also calls attention to the fact that by far the greater proportion of their eapture, in the Northern Hemisphere at least, is in the stormy season. This agrees with what we know of the capture of Trachypterus, which likewise seems to be brought to the surface only by great commotions of the ocean. The popular name of Regalecus is oarfish, in allusion to the blade-like expansion of the extremities of the 2 ventral fins. Regalecus is also called in the books the "king of the herrings." Strangely enough, no representative of this genus has been found on the coast of North America. Guinther is of the opinion that the distribution of this fish in the depths of the sea is the same as that of Trachypterus. The similarity in their geographical distribution is quite remarkable. (Goode \& Bean.) (Eu.) (glesne, from "Glesnæs," a farm at Glesvær, near Bergen, where the type of the species was taken.)

Spada marina, Imperato, Hist. Nat., 679, 687, 1599, Naples.

Regalecus glesne, Ascanius, Icones Rerum Nat., II, pl. 11, about 1788, Glesvær, Norway. Ophidium glesne, Ascanius, Nya Saml. Vid. Selsk. Skrivt., III, 419, 1788.

Regalecus remipes, BRÜNNICH, Nya Saml. Vid. Selsk. Skrivt., III, 1788, 414, taf. B., figs.4, 5;

WaLBaUM, Artedi Piscium, III, 647, tab. 3, fig. 4, 1792.

Cepola gladius, WaLbaUm, Artedi Piscium, III, 617, 1792.

Gymnetrus hawkenii, BLOCH, Ichthyol., xII, 88, 425, 1792.

Gymnetrus grillii, LINDROTH, Vet. Akad. Handl. 1798, 291, pl. 8.

Gymnetrus ascanii, SHAw, Gen. Zool., Iv, 197, 1803; after Ascanius.

Xypterus imperati, RAFINESQUE, Indice, 59, 1810; after Ferrante Imperato.

Gymnetrus longiradiatus, Risso, Eur. Mérid., III, 296, 1826, Nice.

Gymnetrus telium, Cuvier \& Valenciennes, Hist. Nat. Poiss., x, 361, pl. 299, 1834, Nice.

Regalecus banksii, Cuvier \& Valenciennes, Hist. Nat. Poiss., $\mathrm{x}, 365,1834$, Filey Bay, Yorkshire.

Gymnetrus capensis, Cuvim \& VAlenciennes, Hist. Nat. Poiss., x, 376, 1834, Cape of Good Hope.

Regalecus glesne, Ascanius, Icones Rerum Naturalium, 1806, pl. 11; LACÉPÈDE, Hist. Nat. Poiss., Ir, 214, 215, 1800; GOODE \& BeAN, Oceanic Ichthyology, 480, tig. 395, 1896.

Gymnetrus remipes, BLOCH \& SCHNEIDER, Syst. Ichth., 482, tab. 88, 1801; YARRELL, Brit.

Fishes, Ed. 2, 1, 223, and Ed. 3, Ir, 301.

Gymnetrus glesne, Cuvier \& Valenciennes, Hist. Nat. Poiss., $\mathrm{x}, 366$.

Gymnetrus gladius, Cuvier \& Valenciennes, Hist. Nat. Poiss., $\mathrm{x}, 352, \mathrm{pl} .298,1835$.

Regalecus gladius, Günther, Cat., III, 308, 1861.

\section{Family CCXVII. TRACHYPTERIDA.}

\section{(The King of the Herrings.)}

Body moderately elongate, strongly compressed, naked, the skin smooth or prickly. Lateral line present. Head short; the mouth rather small, terminal, with feeble teeth; premaxillaries protractile; opercles unarmed; ópercular apparatus abbreviated (the operculum extended downward, the suboperculum below it, and the interoperculum contracted backward and bounded behind by the operculum and suboperculum); the cranium with a myodome and dichost, the supraoccipital continued behind into a prominence; the epiotics confined to the sides and back of the cranium, and without ribs. Eye large, lateral; branchiostegals 6; gill membranes 
separate, free from the isthmus; gills 4, a slit behind the fourth. Pseudobranchix well-developed, in a pouch formed by a fold of the mucous membrane. Dorsal fin single, extending from the head to the tail, its rays all technically spinous, being neither articulated nor branehed, bnt all very soft, flexible, and fragile; anal fin wanting; pectorals short; ventrals thoracic, the rays elongate, less than I, 5 in number, usually atrophied in the adult; caudal fin either rudimentary or else divided into 2 parts, the upper and larger fan-shaped, directed obliquely upward from the slender tip of the tail. Bones very soft, the muscles little coherent. Pyloric caca very numerous. Vertebræ in large number. Deep-sea fishes, often of large size, found in most warm seas. Their extreme fragility renders them rare in collections, and the species are little known. One genus; species about 12 . The ribbon-fishes are well known in the Eastern Atluntic and the Mediterranean, and have even been found as far west as Madeira [and Cuba]. Some few representatives have been found on the west coast of South America, and 1 or 2 examples have been taken in New Zealand. They are generally admitted to be true deep-sea fishes, which live at very great depths, and are only found when floating dead on the surface or washed ashore by the waves. Almost nothing is known of their habits except through Nilsson's observations in the Far North. This naturalist, as well as Olafsen, appears to have had the opportunity of observing them in life. They say that they approach the shore at flood tide on sandy shelving bottoms, and are often left by the retreating waves. Nilsson's opinion is that its habits resemble those of the flat fishes, and that they move with one side turned obliquely upward, the other toward the ground; and he says that they have been seen on the bottom in 2 or 3 fathoms of water, where the fisherman hook them up with the implements employed to raise dead seals, and that they are slow swimmers. This is not necessarily the case, however, for the removal of pressure and the rough treatment by which they were probably washed upon the shore would be demoralizing, to say the least. Trichiurus, a fish similar in form, is a very strong, swift swimmer, and so is Regalecus. Whether or not the habits of Trachypterus arcticus, on which these observations were made, are a safe guide in regard to the other forms is a matter of some doubt, but it is certain that they live far from the surface, except near the Arctic Circle, and that they only come ashore accidentally. They have never been taken by the deep-sea dredge or trawlnet, and, indeed, perfect specimens are very rare, the bodies being very soft and brittle, the bones and fin rays exceedingly fragile. A considerable number of species have been described, but in most instances each was based upon 1 or 2 specimens. It is probable that future studies may be as fruitful as that of Emery, who, by means of a series of 23 specimens, succeeded iu uniting at least 3 of the Mediterranean species, which for half a century or more had been regarded as distinct. The common species of the Eastern Atlantic, Trachypterus atlanticus, is not rare, 1 or more specimens, according to Giinther, being secured along the coast of northern Europe after almost every severe gale. We desire to quote the recommendation of Dr. Günther, and to strongly urge upon any one who may be so fortu- 
nate as to secure 1 of these fishes, that no attempt should be made to keep it entire, but that it should be cut into short lengths and preserved in the strongest spirits, each piece wrapped separately in muslin. (Goodo \& Bean.)

\section{IOII. TRACHYPTERUS, Gouan.}

\section{(King of the Herrings.)}

Trachypterus, Gouan, Hist. Poiss., 104, 153, 1770 (trachypterus).

Bogma? us, BLOCI \& SCHNEIDER, Syst. Ichth., 518, 1801 (islandicus =arcticus).

Body elongate, compressed, ribbon-shaped, the dorsal fin extending the entire length of the back. Anal absent; each ventral well developed, if present, but sometimes absent. Caudal present and placed for the most part above the longitudinal axis of the body. No air bladder. Pyloric appendages numerous. Ventrals appearing to be absent in some individuals, but Day calls attention to the fact that most of the specimens of $T$. arcticus taken along the coast of Great Britain had no ventrals. In the very young, as has been shown by Emery, the fin rays commence to grow when it is about $6 \mathrm{~mm}$. long, and continue to lengthen until it is about $24 \mathrm{~mm}$. long, after which a partial shortening takes place. Ventrals very elongate in the young, and the caudal rays much longer than in the grown fish. Young individuals (from 2 to 4 inches) are not rarely met with near the surface; they possess the most extraordinary development of fin rays observed in the whole class of fishes, some of them being several times larger than the body, and provided with lappet-like dilatations. There is no doubt that fishes with such delicate appendages are bred and live in depths where the water is absolutely quiet, as a sojourn in the disturbed water of the surface would deprive them at once of organs which must be of some utility for their preservation. (Goode $\&$ Bean.) ( $\tau \rho \alpha \chi \dot{v} 5$, rough; $\pi \tau \varepsilon \rho \dot{v}$, fin.)

a. Color bright metallic silvery, a jet-black blotch at base of dorsal; 3 dark spots on side, 2 smaller ones on belly; anterior profile, snout, and tip of mandible, jet black; caudal and ventral fins carmine red in life.

aa. Color shining leaden gray; no black. REX-SALMONORUM, 2972. TRACHYURUS, 2973.

2972. TRACHYPTERUS REX-SALMONORUM, Jordan \& Gilbert.

(KING OF THE SALMON.)

Head $8 \frac{1}{9}$; cross depth at nape 8 . D. V-170; C. 8 ; V.6; P. 11. Body long and slender, closely compressed and ribbon-shaped, as usual in the genus. Head short, deeper than long, the anterior profile steep and nearly straight to the base of the nuchal crest; dorsal fin beginning on the top of nuchal crest, which is directly over the second third of the diameter of eye; height of crest slightly more than diameter of eye, the latter greater than length of snout, and 3 in head. Mouth oblique; maxillary rugose and very broad, its width $\frac{1}{2}$ its length; length of lower jaw greater than length of snout, $2 \frac{1}{5}$ in head, its angle under the front of the orbit. Opercular bones rugose, entirely covering the gills. Premaxillary covered with minute and feeble teeth, in addition to which in this specimen are 3 canines, 2 on one side and 1 on the other, directed very obliquely 
backward. On the side having 2 canines, 1 is placed directly behind the other; lower jaw with 3 strong canines on one side and 2 strong and 1 weak canine on the other, all directed obliquely backward and inward. Dorsal fins slightly connected at base; the filamentous rays of the first dorsal not quite twice the length of head; ventrals inserted just below axil of pectorals, filamentous, about $\frac{1}{2}$ longer than head; pectorals $\frac{1}{6}$ longer than eye; caudal rays simple to near tip, where is sometimes a single fork, the longest filamentous rays about 3 times length of head; dorsal fin much lower than body, longest rays of second dorsal nearly $\frac{2}{8}$ length of head; a series of spinules along base of dorsal, 1 pair for each ray. Lateral line well developed, with a series of small inconspicuous plates, each of which has a minute central prickle. Lower part of the body thickly beset with small spinous tubercles; rest of the skin naked; rays of all the fins accompanied by a series of small prickles. Coloration everywhere bright metallic silvery, an oblong jet-black blotch a little longer than eye lying close along base of dorsal and beginning $1 \frac{1}{2}$ diameters of eye behind eye; 3 larger spots, dusky but not black, lying behind this along side between lateral line and dorsal fin; 2 smaller dusky spots on belly, the one just behind base of ventrals, the other under the second of the 4 spots of back; these spots, except the first one mentioned, are all diffuse and a little less than twice the diameter of eye in length and about twice as long as deep; anterior profile below crest, including front of snout and tip of mandible, jet-black; caudal and ventral fins carmine red in life; other fins unmarked. Length 17 inches. This species bears some resemblance to Trachypterus altivelis described by Kner from Valparaiso. The latter species has, however, the nuchal erest much lower and farther back, the first dorsal and the ventrals much lower, the second dorsal fin higher, the skin rougher, the 4 black spots different in size and position from those found in our specimen, and the caudal rays divided near the base. It is probable that the 3 specimens of Trachypterus mentioned in the Synopsis of the Fishes of North America, p. 619, and referred with doubt to Trachypterus altivelis, really belong to the present species. Four specimens known; 1 from Santa Cruz, California, taken by Dr. C. L. Anderson; 2 from the Straits of Fuca, taken by Mr. J. G. Swan, and the type, obtained by a fisherman (Mr. Knox) in the open sea outside the bay of San Francisco. According to Mr. Swan the species is known by the Makah Indians west of the Straits of Fuca as "king of the salmon," and its destruction is believed to have a baneful influence on the salmon fishing. "When the king of the salmon is killed the salmon will cease to run." (rex, king; salmonorum, of the salmon.)

?Trachypterus altivelis, JORDAN \& GILBERT, Proc. U. S. Nat. Mus. 1881, 52; JoRDAN \& GILBERT, Synopsis, 618, 1883; specimen from Santa Cruz; not of KNER.

Trachypterus rex-salmonorum, JoRdAN \& GiLBERT, Proc. Cal. Ac. Sci. 1894, 145, pl. 9, open sea outside Bay of San Francisco. (Type, No. 1382, L. S. Jr. Univ. Coll. Mr. Knox.)

2973. TRACHYPTERUS TRACHYURU, Poey.

D. 82 ; P. 15 ; V. 6 . Eye $2 \frac{1}{2}$ in head, high, as long as snout. Mouth almost vertical. Bones of head thin as paper. Lateral line a little concave on the middle of trunk. No scales; pectorals small; ventrals behind 
pectorals, very long, reaching past vent, which is at second third of length, including caudal; dorsal almost as high as body, without plume in frout. Vertebra $36+18$. Shining leaden gray, a silvery band produced by the vertebral column showing through. Cuba. (Poey); not seen by us.

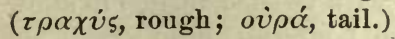

Trachypterus trachyurus, POEY, Memorias, II, 420, 1861, Cuba.

\section{Family CCXVIII. STYLEPHORID瓜.}

Body elongate, compressed, ribbon-shaped; the dorsal extending from head nearly to end of tail ; tail terminating in an exceedingly long, cordlike appendage, about twice as long as head. Anal absent; ventrals absent; caudal erected upward, having its rays connected by a rather firm membrane. Snout produced; mouth small, toothless; maxillary bones small, short, hidden behind premaxillaries; mandible long, extending far behind the eye. Eye large, turned forward; suborbital very large, covering nearly the whole of cheek and extending backward behind eye. Opercles small. Gill openings wide; gills 4. Vent premedian. Branchiostegals 4. (Goode \& Bean.) This family is based on a single specimen obtained in the West Indies in 1790 and preserved in the British Museum. The relations of the fish are uncertain, and it may not belong to the Toniosomi. Its nearest relations are, however, apparently with Trachyterus. (Stylephoridce, Swarnson, Nat. Hist. Class'n Fishes, II, 47, 1839.)

IO12. STYLEPHORUS, Shaw.

Stylephorus, SHAW, Trans. Linn. Soc. Lond., I, 1791, 90 (chordatus).

Characters of the genus included above. ( $\sigma \tau \tilde{v} \lambda \circ)^{2}$, a style or projecting

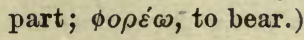

\section{STYLEPIORUS CHORDATUS, Shaw.}

Head 6 ; depth 5. D. 110 ; C. 6 ; P. 13 ; B. 4 . Snout produced, subcylindrical; mouth small and toothless; maxillary bones small, short, and hidden behind the intermaxillaries; mandiblelong, extending far behind eje; eyes large, close together, directed forward toward snout; suborbital very large, covering nearly the whole of cheek, and extending backward behind eye; opercles small; gill openings very wide; gills 4. Vent situated before middle of total length; pectorals pointed, directed upward, about $\frac{1}{2}$ as long as head; dorsal extending from head nearly to end of tail; caudal directed upward, and having its rays connected by a rather firm membrane, the tail terminating in a narrow band-like appendage about twice as long as body. Color uniform silvery. (Günther.) This remarkable form is known only from a single specimen, 11 inches long, with the caudal appendage 22 inches in length, which was taken in the Atlantic, between Cuba and Martinique, about the year 1790, and is now in the British Museum. It is undoubtedly an inhabitant of great depths. (Goode \& Bean.) (chordatus, with a chord; from $\chi o ́ \rho \delta \eta$, string.)

Stylephorus chordatus, SHAw, Trans. Linn. Soc. London, I, 1791,90, pl. 6, between Cuba and Martinique; SHAw, Zool., IV, 87; SHAw, Naturalists' Miscellany, vIII, pl. 274; Blainville, Journ. Phys., LXXxvir, 60, pl. 1, tig. 1; Cuvier. \& Valenciennes, Hist. Nat. Poiss., X, 381; GUNThER, Cat., III, 306, 1861; GOODE \& BEAN, Oceanic Ichthyology, 482, pl. 66, figs. 393 and $394,1896$.

3030 86 


\section{Subórder HETEROSOMATA.}

\section{(The Flatfishes.)}

"Cranium posteriorly normal; anteriorly with twisted vertex, to allow 2 orbits on the same side, or 1 vertical and 1 lateral; basis cranii not quite simple. Dorsal fin long, of jointed rays; superior pharyngeals 4, the third longest, much extended forward, the inferior separate." (Cope.) This suborder includes the 2 families, Pleuronectida and Soleida. Its nearest relationship is probably with the Gadida, although the developed pseudobranchiæ and the thoracic ventral fins, indicate an early differentiation from the anacanthine fishes. In the very young fishes the 2 sides of the body are alike and the eyes are 1 on each side, with normal cranium.

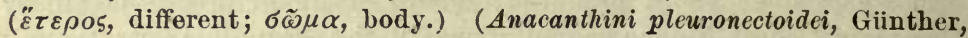
Cat., IV, 399, 504.)

\section{Families of Heterosomata.}

a. Preopercular margin more or less distinct, not hidden by the skin and scales of the head; eyes large, well separated; mouth moderate or large; teeth present.

Pleuronectide, cCxix.

aa. Preopercular margin adnate, hidden by the skin and scales of the head; eyes small, close together; mouth very small, much twisted; teeth rudimentary or wanting.

SOLEIDA, CCXX.

\section{Family CCXIX. PLEURONECTIDA.*}

\section{(The Flounders.)}

Body strongly compressed, oval or elliptieal in outline; head unsynmetrical, the cranium twisted, both eyes being on the same side of the body, which is horizontal in life, the eyed side being uppermost and colored, the blind side lowermost and usually plain. In the very young fish the bones of the head are symmetrical, 1 eye on each side, and the body is vertical in the water. In most species the cranium becomes twisted, bringing the upper eye over with it. Eyes large, well separated. Mouth small or large, the dentition various, the teeth always present; premaxillaries protractile; no supplemental maxillary bone; pseudobranchixe present. Gills 4, a slit behind the fourth; lower pharyngeals separate; no air bladder; preoperele with its margin usually distinct, not wholly adnate or hidden by the skin of the head; vent not far belind head, the viscera confined to the anterior part of the body. Seales various, rarely absent, usually small. Lateral line usually present, extending on the caudal fin, sometimes duplicated or wanting. Dorsal fin long, continuous, of soft rays only, beginning on the head; anal similar, shorter; caudal various, sometimes coalescent with dorsal and anal; pectorals inserted rather high, rarely wanting; ventrals under the pectorals, usually of several soft rays, one of them sometimes wanting. Fishes mostly carnivorous, inhabiting sandy bottoms in all seas, some species ascending rivers. Many of them are important food-fishes. Genera about 55 ; species

* For complete synonymy and descriptions of the American species of this family of fishes. see "A review of the flounders and soles (Pleuronectidae) of A merica and Europe," by David Starr Jordan and David Kop Goss, in Report United States Fish Comm. for 1886, $225-342$, pls. 1 to 9 , first published in 1889 . 
nearly 500. The group "Bibroniide" recently recognized by some of the Italian ichthyologists as a separate family ("Bibronidi"), is composed entirely of larval forms in the early stages of their development. In this condition the eyes are symmetrical and the body translucent. Several generic names have been given to these peculiar forms (Pcloria, Bibronia, Coccolus, Charybdia, Bascanius, Delothyris), but, of course, these genera can have no permanent place in the system. Peloria has been shown by Dr. Emery to be the young of Platophrys. The others seem to belong to the Cynoglossina or to some allied group, but we are not yet certain as to the correct identification of any of them. We recognize among the Pleuronectida 6 subfamilies-Hippoglossina, Psettina, Samarina, Pleuronectina, Oncopterince, and Pelecanichthyinc. These subfamilies are natural groups and are in most cases easily distinguished, although some few aberrant genera exist, which serve as links joining one group to another. Thus Isopsetta of the Pleuronectina is certainly a near ally of Psettichthys, which is as certainly a genuine member of the Hippoglossince. The Hippoglossina and the Pleuroncctince are largely arctic in their distribution, fow of the former group and none of the latter extending into the Tropics. The Oncopterina seem to take the place of the Pleuronectince in antarctic waters, but the species of this group are fow in number. The Psettina and the soles are, on the other hand, essentially warm-water fishes, their representatives in the north being comparatively few. The Samarina are fow in number and belong to the East Indian fauna, and the single species of Pelccanichthyince belongs to the bassalian fauna of the Pacific. As the tropical Hippoglossince and all the Psettince are sinistral species, the eyes and color being on the left side of the body, it follows that the tropical flounders are nearly all left-sided species, while those of arctic and antarctic waters are chiefly dextral species, the eyes and color on the right. The Hippoglossince are the most generalized of the flatfishes. From the northern representatives of this group, the allies of Hippoglossoides, the Pleuronectina, are certainly descended. The Psettince are apparently derived from ancestors of the type of Paralichthys. The soles show closest affinities with the Psettince, from ancestors of which group they have become degraded. Very remarkable is the relation between the number of vertebræ and the geographical distribution of the various species. It has been already noticed by Dr. Gill, Dr. Giinther and others that in some groups of fishes northern representatives have the number of vertebro increased. In no group is this more striking than in the flounders, as the following table, showing the numbers of the vertebra in various species, will clearly show. The numbers inclosed in brackets are copied from Dr. Gïther; the others represent our own count of specimens.

Numbers of vertebra in flounders.

\section{I.-HIPPOGLOSSIN E.}

Hippoglossus hippoglossus . .......................

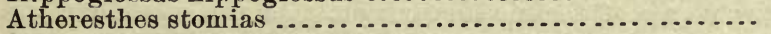
Hippoglossoirles platessoides........................... Lyopsetta exilis ..................................

Eopsetta jordani

$16+34=50$

$12+37=49$

$13+32=45$

$11+34=45$

$11+32=43$ 
Psettichthys melanostictus.

Paralichthys oblongus

Paralichthys dentatus

Paralichthys lethostigmus

Paralichthys albiguttus.

Paralichthys californicus

Xystreurys liolepis

Ancylopsetta quadrocellata.

\section{II.-Pleuronectin.}

Glyptocephalus zachirus

Glyptocephalus eynoglossus

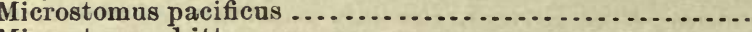

Microstomus kitt.

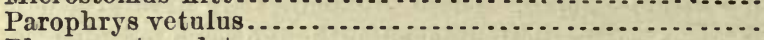

Pleuronectes platessa.

Isopsetta isolepis.

Lepidopsetta bilineata...........................

Limanda limanda.................................

Liopsetta glacialis...

Pleuronichthys decurrens.

Pleuronichthys verticalis.

Flesus glaber.

Flesus flesus .

Pseudopleuronectes americanus.

Hypopsetta guttulata

Platichthys stellatus.

\section{III.-PsetTinde.}

Monolene sessilicanda

Lepidorhombus whiff-iagonis

Citharichthys sordidus

Platophrys lunatus.

Arnoglossus laterna.............................

Arnoglossus grohmanni.

Zeugopterus punctatus

Platophrys ocellatus...

Platophry o collatus...............................

Lophopsetta maculata...............................

Bothus rhombus................................

Syacium papillosum ...............................

Citharichthys arctifrons.

Syacium micrurum

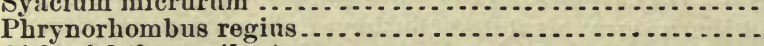

Citharichthys spilopterus.........................

Citharichthys macrops............................

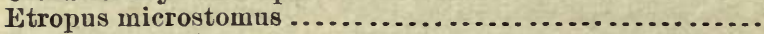

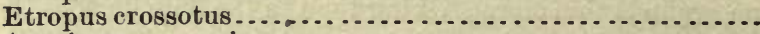

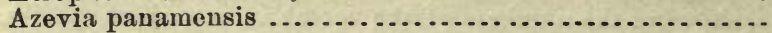

Psetta maxima

The subdivision of the flounders into genera leaves room for considerable variety of opinion. Most of the species are well defined and easily recognized, but they do not fall readily into generic groups nnless we regard almost every well-marked species as the type of a distinct genus. A natural result of an attempt at sharply defining the genera is to reach what seems an extreme degree of generic subdivision. On the other hand, attempts to unite these smaller groups to form larger ones often leave these larger ones at once unnatural and ill-defined.

$11+29=40$
$11+30=41$
$10+30=40$
$10+27=37$
$10+27=37$
$10+25=35$
$12+25=37$
$9+26=35$

$13+52=65$

$12+40=52$

$[13+35=48]$

$11+33=44$

$[14+29=43]$

$10+32=42$

$11+29=40$

$13+27=40$

$14+26=40$

$13+25=38$

$11+26=37$

$[12+24=36]$

$10+26=36$

$11+24=35$

$12+23=35$

$$
\begin{gathered}
{[11+30=41]} \\
11+29=40 \\
9+30=39 \\
10+28=38 \\
10+28=38 \\
{[12+25=37]} \\
10+27=37 \\
11+25=36 \\
12+24=36 \\
11+25=36 \\
10+26=36 \\
10+25=35 \\
10+25=35 \\
10+24=34 \\
10+24=34 \\
10+24=34 \\
10+24=34 \\
\\
12+19=31
\end{gathered}
$$


It will probably appear to some that the process of generic subdivision has been in this paper carried too far. It is possible that this is true, but the arrangement which we have adopted seems to bring out the relations of the different forms better than can be done by a more conservative view of the genera. (Pleuronectide, Günther, Cat., Iv, 1862.)

\section{Subfamilies of Pledronectida.}

A. Ventral fins symmetrical, similar in position and in form of base, the ventral of the colored side not extended along the ridge of the abdomen.

$a$. Mouth nearly symmetrical, the dentition nearly equally developed on both sides, the gape usually but not always wide. (Halibut tribe.) HippogLossinde, 1 .

aa. Mouth unsymmetrical, the jaws on the eyed side with nearly straight outline, the bones on the blind side strongly curved; teeth chiefly on the blind side.

b. Eyes and color on the right side (with occasional exceptions). (Flounder tribe.)

Pieuronectine, in.

AA. Ventral fins unsymmetrical, dissimilar in position and usually also in form, the ventral fin of the eyed side being extended along the ridge of the abdomen. Eyes and color on the left side. (Turbot tribe.)

Psettinea, III.

\section{ANALYsis of GenERA.}

\section{HIPPOGLOSSINA.}

\section{(HaLibut Tribe.)}

Large-mouthed flounders with the ventral fins symmetrical.-Mouth symmetrical, the jaws and the dentition nearly equally developed on both sides; gape usually wide, the maxillary more than $\frac{1}{3}$ length of head. Lower pharyngeals narrow, usually with but 1 or 2 rows of sharp teeth; teeth in jaws usually acute. Eyes large; edge of preopercle free. Pectoral and ventral fins well developed, the ventral fins similar in position and in form of base, the ventral fin of the eyed side not being attached along the ridge of the abdomen. Septum of gill cavity without foramen.

a. Vertebræ and fin rajs much increased in number (the vertebræ about 50; dorsal ray8 about 100 , anal rays about 85 ); body comparatively elongate; caudal fin lunate; lateral line simplo; anal spine mostly obsolete. Dextral species, arctic in distribution. (Genera allied to Hippoglossus.)

b. Large teeth in both jaws arrow-shaped, biserial, some of them depressible; upper eye with vertical range; gill rakers short; scales deciduous, ciliated; lateral line without arch; flesh soft. Vertebræ (in A. stomias) $12+37=49$.

A theresthes, 1013.

bb. Large teeth not arrow-shaped, biserial above, uniserial below; scales very small, cycloid; gill rakers long and slender; eyes strictly lateral.

c. Lateral line without anterior arch; lower pharyngeal teeth uniserial.

REINHARDTIUS, 1014.

ce. Lateral line with an anterior arch; lower pharyngeal teeth biserial; vertebræ (in $H$. hippoglossus) $16+34=50$.

Hippoglossus, 1015.

aa. Vertebræ and fin rays in moderate number (vertebræ less than 46 ; dorsal rays fower than 95; anal rays fewer than 75); caudal fin double truncate or rounded, the median rays longest.

d. Lateral line without distinct anterior arch; vertebræ 40 to 46 ; body normally dextral; * caudal pednncle distinct; scales ciliated; anal spine usually stroug. Species of subarctic distribution. (Genera allied to Hippoglossoides.) 
e. Lateral line simple, withont accessory dorsal branch; teeth sharp, these of lower jaw uniserial; dorsal beginning above eye.

$f$. Teeth in the upper jaw biserial.

g. Scales comparatively large, thin, and deciduons; lateral line 70 ; body slender, the flesh soft; vertebræ (in $L$. exilis) $11+34=45$.

LYOPSETTA, 1016.

- $\quad$ g. Scales small and adherent; lateral line 96; body robust, the flesh firm; vertebræ (in $E$. jordani) $11+32=43$.

EOPSETTA, 1017.

ff. Teeth in the upper jaw uniserial; scales small and fiesh firm; verte-

bræ (in $H$. platessoides) $13+32=45$. HIPPOGLOSSOIDES, 1018 .

ee. Lateral line with an accessory dorsal branch; scales small, firm, ctenoid; dorsal tin beginning before the eye; teeth sharp, unequal, seme of them canine-like; month not large; lower pharyngeal teeth sharp, uniserial; vertebræ (in $P$. melanostictus) $11+29=40 . \quad$ PsetTichthys, 1019.

$d d$. Lateral line with an arch in frent; no accessory branch; vertebræ in smaller number (35 to 41 ); anal spine usually obsolete; body normally sinistral. (Species chiefly of the temperate or subtropical seas, none of them Aretic and none European.) (Genera allied to Paralichthys.)

$h$. Dorsal fin beginning above the pupil; teeth rather small; no canines; body indifferently dextral or sinistral (in some species at least).

$i$. Scales ctenoid.

$j$. Teeth in upper jaw in 2 series; gill rakers broad.

Verasper, 1020.

jj. Teeth all uniserial; gill rakers slender. HippoGLOssina, 1021.

ii. Scales cycloid; teeth uniserial; gill rakers short and thick.

$k$. Teeth small, pointed, equal.

Lioglossina, 1022.

$k k$. 'Teeth unequal, blunt, conical; caudal fin subsessile, the caudal peduncle extremely short; skin of shoulder girdle with patches of cup-shaped scales; vertebræ (in X. liolepis) $12+$ $25=37$.

XYstreurys, 1023.

hh. Dorsal fin beginning in advance of eye; teeth sharp, nniserial or smooth.

l. Scales weakly ciliated; caudal fin with a distinct peduncle; mouth

large; teeth unequal, some of the anterior canine like; gill rakers rather long and slender; no dorsal lobe nor produced ventral rays; vertebræ 35 to $41 . \quad$ Paralichthys, 1024.

ll. Scales very strongly ctenoid on both sides of body; mouth smallish, with small, sharp teeth; anterior rays of dorsal more or less exserted, thus forming a more or less distinct lebe; gill membranes considerably united; gill rakers short and broad; caudal peduncle short; left ventral produced; vertebræ (in $A$. quadrocellata) $9+26=35$.

$m$. Lateral line with its tubes much branched, covering parts of contiguous scales; dorsal lobe low; left ventral much produced.

RAMULARIA, 1025.

$m m$. Lateral line with its tubes simple, not branched.

$n$. Body broad, ovate, the depth more than $\frac{1}{2}$ length; dorsal lobe and left ventral moderately produced.

ANCYLOPSETTA, 1026.

$n n$. Body elliptical, the depth not more than $\frac{1}{2}$ length; dorsal lobe and left ventral greatly produced.

NoTOSEMA, 1027.

III. Scales entirely smooth; caudal peduncle short; mouth small; gill rakers short and thick; dorsal with an anterior lobe; left ventral elongate.

GASTROPSETTA, 1028 


\section{II.-PLEURONECTINA.}

\section{(Flounder Tribe.)}

Mouth small, unsymmetrical, the jaws on the eyed side with nearly straight outline, the bones on the blind side strongly curved; dentition chiefly developed on the blind side; eyes large; edge of preopercle not hidden by the scales; pectoral fins well developed; vertical fins well separated; ventral fins nearly or quite symmetrical, that of the eyed side not prolonged along the ridge of the abdomen; anal spine usually strong (obsolete in Microstomus and Embassichthys). Body dextral (except frequently in Platichthys stellatus). Species arctic or subarctic in distribution.

a. Vertebræ in moderate number, from $10+26=36$ to $11+33=44$; dorsal rays 65 to 80 ; anal rays 45 to 60 .

b. Teeth small, acute, in several series; lateral line nearly straight, with an accessory dorsal branch; lower pharyngeals narrow, with small biserial teeth; scales cycloid.

c. Lips thick, each with several longitudinal folds; dorsal fin beginning on the blind side; vertebræ 38 to 40.

Pleuronichthys, 1029.

cc. Lips simple; dorsal fin beginning on the median line; vertebræ (in H.guttulata) $11+24=35$.

HYPSOPSETTA, 1030.

$b b$. Teeth chiefly uniserial, all more or less blunt, conical or incisor-like.

$d$. Lateral line with an accessory dorsal branch.

e. Lateral line withoùt distinct aroh in front.

$f$. Teeth compressed, incisor-like, close set.

g. Seales closely imbricated, mostly cycloid; upper eye on median line; vertebræ (in $P$. vetulus) $11+33=44$.

Parophrys, 1031.

gg. Scales scarcely imbricated, all very strongly ctenoid; eyes both lateral.

INOPSETTA, 1032.

fi. Teeth conical, separated, not incisor-like; scales closely imbricated, all strongly ctenoid; mouth comparatively large (approaching that of Psettichthys); vertebra (in I. isolepis) $10+$ $32=42$.

IsOPSETTA, 1033.

ee. Lateral line with a distinct arch in front; scales imbricated, roughctenoid; vertebræ (in $L$. bilineata) $11+29=40$.

dd. Lateral line without accessory dorsal branch.

LEPIDOPSETTA, 1034.

$h$. Lateral line with a distinct arch in front; scales imbricated, roughctenoid; vertebræ (in $L$. limanda) about $40 . \quad$ LIMANDA, 1035.

hh. Lateral line without distinct arch in front.

$i$. Scales regularly imbricate, all (on eyed side ctenoid in both sexes; no stellate tubercles on head nor on bases of dorsal and anal fins; teeth, incisor-like, close set; lower pharyngeals very narrow, each with 2 rows of separate, conical teeth; fin rays scaly.

Pae udopleuronectes, 1036.

ii. Scales imperfectly imbricated, or else not all ctenoid.

$j$. Scales chiefly cycloid in both sexes; lower pharyngeals small and narrow, separate, each with about 1 row of small, bluntish teeth; teeth incisor-like, close set, forming a cutting edge; no stellate scales at base of dorsal and anal.

Pleuronectes, 1037.

jj. Seales rough-ctenoid in the male, more or less cycloid in the female (fin rays scaly in the male, naked in the female); lower pharyngeals vory large, more or less united in the adult, their surface somewhat concave, the teeth in 5 or 6 rows, large, blunt, close set; teeth in jaws incisor-like; fin rays of dorsal and anal without tubercles at base.

LIOPSETTA, 1038. 
$j j j$. Scales all in both sexes and on both sides of the body represented by coarse scattered stellate tubercles; similar tubercles between bases of dorsal and anal rays; lateral line without scales; lower pharyngeals broad, each with 3 rows of blunt, coarse teeth; teeth incisor-like. $\quad$ PLATichthys, 1039.

aa. Vertebræ in increased number (varying from $13+35=48$ to $13+52=65$ ) ; dorsal rays 90 to 120 ; anal rays 70 to 100 ; teeth broad, incisor-like; scales small, all cycloid. (Genera allied to Glyptocephalus.)

$\boldsymbol{k}$. Left side of skull normal; anal spine obsolete; vertebræ 48 to 52.

l. Body elongate, the depth $2 \frac{1}{3}$ to 3 in length; vertebræ 48 to 52 .

Mrcrostomus, 1040.

ll. Body stonter, the depth 2 to $2 \frac{1}{3}$ in length; vertebræ more numerous, about 63.

EMBASSICHTHYS, 1041.

$k k$. Left side of skull with large mucous cavities; anal spine strong; vertebræ 58 to 65 .

GLYPTOCEPHALUS, 1042.

\section{III.-PSETTINA.}

\section{(TURBOT TRIBE.)}

Large-mouthed flounders, with the ventral fins unsymmetrical.-Mouth sym. metrical, the dentition nearly equally developed on both sides; gape usually wide (narrow in Platophrys, Etropus, etc.), the maxillary commonly more than $\frac{1}{8}$ length of head; lower pharyngeals narrow, each with one or more rows or a narrow band of small, sharp teet'; teeth in jaws acute; eyes not minute; pectorals and ventrals usually well developed; edge of preopercle free; ventral fins dissimilar in form or in position, that of the left or eyed side inserted on the ridge of the abdomen, its base extended along this ridge, its rays more or less wide apart; caudal fin rounded or subtruncate; no accessory lateral line; anal spine usually weak or obsolete; a pelvic spine sometimes developed; vertebræ in moderate or small number, 31 to 45. Body sinistral. Species chiefly tropical or subtropical in distribution.

a. Pectoral fin of both sides present; septum of gill cavity below gill arches without foramen; a deep emargination near the isthmus; ventral fins free from anal.

b. Vomer with teeth; lateral line with a strong arch in front; teeth subequal, in villiform bands; body broadly ovate; caudal fin subsessile; interorbital area broad; scales small, cycloid; gill rakers long and slender; anterior dorsal rays produced; vertebræ 36. LOPHOPSETTA, 1043.

$b b$. Vomer toothless; ventral tins free from anal; candal fin subsessile.

c. Lateral line with a distinct arch in front; teeth small, uniserial, or imperfectly biserial.

d. Interorbital space more or less broad, deeply concave, at least in the males; form broad ovate; gill rakers short and thick.

e. Scales small, ctenoid, adherent, 75 to 100 or more; anterior rays of dorsal not elevated; pectoral of left side usually filamentous in the male; vertebra (in P. lunatus) $9+30=39$.

Platophrys, 1044.

ee. Scales moderate, 60 to 70 ; anterior rays of dorsal greatly pro. duced; no lateral line on blind side.

Perissias, 1045.

$d d$. Interorbital space a narrow ridge; dorsal not elevated in front.

f. Gill rakers obsolete; interorbital area armed with a spine; scales rough.

ENGYOPHRYs, 1046.

ff. Gill rakers slender; right ventral elongate; scales ctenoid.

TrichopsetTA, 1047. 
cc. Lateral line without arch in front.

g. Teeth in upper jaw biserial, in the lower uniserial, the front teeth of upper jaw enlarged; vertebræ 35 or 36 ; gill rakers short; interorbital space broad in the male.

SYACIUM, 1048.

gg. Tecth in each jaw uniserial; interorbital space very narrow, the ridges coalescing between the eyes.

$h$. Mouth not very small, the maxillary more than $\frac{1}{3}$ length of head.

$i$. Gill rakers very short and thick, tnbercle-like.

j. Scales cycloid, small, and firm. Cxclopsetra, 1049.

jj. Scales small, firm, ctenoid. Azevia, 1050.

ii. Gill rakers slender, of moderate length; scales thin, decidnous, ciliated; vertebræo 34 to 40 . CitharichtiYs, 1051.

$h h$. Mouth very small, the tecth subequal, the maxillary less than

$\frac{1}{3}$ length of head; scales thin; teeth uniserial; vertebro $9+25=34$.

ETropus, 1052.

aa. Pectoral fin of blind side wanting; eyes very close together; caudal fin subsessile; teeth small, uniserial; mouth moderate; lateral line of eyed side arched, that of right side nearly straight; dorsal fin beginning on snout, its anterior rays not exserted, its rays all simple and very numerous; gill rakers few and feeble; scales small; body thin, very elongate; vertebræ (in $M$. sessilicauda) 43; (deepsea flounders). MONOLENE, 1053.

Ior3. ATHERESTHES, Jordan \& Gilbert.

Atheresthes, Jordan \& GILberT, Proc. U.S. Nat. Mus. 1880, 51 (stomias).

Eyes and color on the right side. Body very long and slender, closely compressed, tapering into a long and slender caudal peduncle; head elongate, narrow; mouth extremely large, oblique; the long and narrow maxillary extending beyoud the eye; each jaw with 2 irregular series of sharp, unequal, arrow-shaped teeth, some of them long and wide set, and others short and close set, sharp; the long teeth freely depressible. Gill rakers numerous, long, slender, and stiff, strongly dentate within. Scales rather large, thin and readily deciduous, slightly ciliated, those on the blind side similar, smooth; lateral line without arch. Fins low and fragile; dorsal commencing over the eye, its anterior rays low, the posterior rays somewhat forked; no anal spine; pectorals and ventrals small, both of the latter lateral; caudal lunate. The single species which constitutes this genus is one of the most remarkable of the flounders. Of all the group, it approaches in form and general characters most nearly to the Gadoid fishes, from ancestors of which we may presume the flounders to be descended, although Dr. Gill has suggested the possibility of their descent from Trachypteroid fishes. ( $\dot{\alpha} \theta \dot{\eta} \rho$, the beard or spike of an ear of corn; $\varepsilon \sigma 0 i \omega$, to eat; from the arrow-shaped teeth.)

2975. ATHERESTHES STOMIAS (Jordan \& Gilbert).

\section{(THE ARROW-TOOTHED HALIBUT.)}

Head about $3 \frac{3}{5}$ in length; depth $3 \frac{1}{2}$; eye large, $4 \frac{8}{4}$ in head. D. $103 ; \mathrm{A}$. 86 ; scales 135 ; vertebra $12+37=49$. Head long, the snout protruding, somewhat truncate at tip; month excessively large; the maxillary moro than $\frac{1}{2}$ length of head, and reaching behind eye; premaxillary in front above the level of the lower eye; teeth in apper jaw anteriorly in a single 
series, long, slender, and wide set, much smaller and closer set behind; on sides of jaw the teeth are very small and in 2 distinct series, the inner of which corresponds to the single series in front, the tecth thus gradually increasing in size forward; teeth in inner series of lower jaw very sharp and slender, longer than the upper teeth, wide set, alternating with shorter, depressed teeth; outside of these larger teeth is a series of fixed small teeth; all of the long teeth in both jaws depressible and conspicuously arrow-shaped toward their tips; inner series of small teeth in upper jaw also arrow-shaped, depressible; interorbital space scaly, ridged, not a third width of eye. Gill rakers long and strong, about $4+13$ in number, the longest more than $\frac{1}{2}$ diameter of eye. Upper eye with its range entirely vertical. Scales extremely thin, irregular in size, not evenly imbricated; lateral line very prominent. Dorsal fin beginning just behind the middle of the eye; caudal peduncle nearly as long as the pectoral fin, about $\frac{2}{5}$ length of head. Plain olive brown; the margins of the scales darker; blind side dusted with black points. Length 2 feet. Bering Sea to San Francisco, common northward; not rare in deep water off San Francisco, and is brought in in considerable numbers from the sweep-nets (parranzelle) used in Drakes Bay. At Unalaska it occurs commonly in shallow water. In the north the flesh is firmer and the coloration more pronounced. Dr. Gilbert dredged it in abundance on both sides of the peninsula of Alaska and in Bristol Bay, in 32 to 406 fathoms. Mr. Scofield found it abundant in Chignik Bay, and it was taken by us in 1897 at Unga

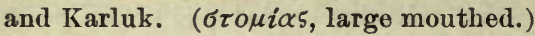

Platysomatichthys stomias, Jordan \& GILBERT, Proc. U. S. Nat. Mus. 1880, 51, 301, San Francisco. (Coll. Jordan \& Gilbert.)

Atheresthes stomias, Jordan \& Gilbert, Proc. U. S. Nat. Mus. 1880, 57, 454 ; Bean, Proc. U. S. Nat. Mus. 1881, 242; Jordan \& Gilbert, Proc. U. S. Nat. Mus. 1881, 66; Jordan \& GrLbert, Synopsis, 820, 1883; BeAN, Proc. U.S. Nat. Mus. 1883, 354; Jokdan, Nat. Hist. Aquat. Anim., 188, pl. 53, 1884; Jordan \& Goss, Review Flounders and Soles, 236, pl. 1, 1889; GilberT, Rept. U. S. Fish Comm. 1893 (1896), 459.

Ior4. REINHARDTIUS, Gill.

Reinhardtius, GrLL, Cat. Fishes East Coast N. A., 50, 1861 (hippoglossoides; no description).

Platysomatichthys, Blekker, Comptes Rendus, Ac. Sci. Amsterdam, xuI, 1862, 426 (pinguis $=$ hippoglossoides).

Reinhardtius, Gill, Proc. Ac. Nat. Sci. Phila.1864, 218 (hippoglossoides).

Eyes and color on right side. Body more or less elongate, compressed; head long and large; mouth large; maxillary reaching beyond eye; jaws with strong, unequal teeth, the upper with 2 series in front, these converging behind; lower jaw with a single series of strong, distant teeth; no teeth on vomer or palatines. Gill rakers few, short, stout, and rough. Fins rather low; caudal fin lunate. Lower pharyngeal teeth in 1 row. Scales small, cycloid; lateral line without anterior curve. One species known, an aretic fish, in some degree intermediate between the true halibut and Atheresthes. (Named for Prof. Johann Reinhardt, of the University of Copenhagen, an able investigator of the fishes of Greenland.) 


\section{REINHARDTIUS HIPPOGLOSSOIDES (Walbaum).}

(Greenland Halibut.)

Head 34 in length; depth nearly 3. D. 100 ; A. 75 ; scales 160 ; orbit 8 in head; suout about $3 \frac{1}{2}$, more than twice as long as orbit; eyes even in front; interorbital space flat, scaly, wider than the orbit; lower jaw prominent; length of maxillary $2 \frac{1}{2}$ in head; teeth conical, pointed; upper jaw with 2 series, convergent posteriorly, those of the outer series gradually smaller posteriorly; a pair of strong canine teeth anteriorly in the inner series, the other teeth of this series being very small; lower jaw with a series of strong, distant teeth. Gill rakers short, thick, and strongly dentate. Fins naked. Longest dorsal rays $\frac{1}{8}$ length of head; no anal spine; dorsal and anal rays all simple, the dorsal beginning over posterior third of the eye. Scales very small, not ciliated. Yellowish brown. Reaching a very large size. Arctic parts of the Atlantic, south to Finland

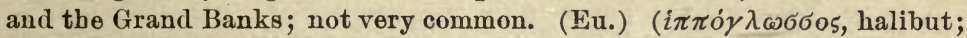
$\varepsilon \tau^{\tau} \delta \circ 5$, resemblance.)

Pleuronectes cynoglossus, FABRicius, Fauna Grœnlandica, 163, 1780, Greenland; not of LinNeus.

Pleuronectes hippoglossoides, WALBAUM, Artedi Piscium, 115, 1792; based on FABricius. Pleuronectes pinguis, FABRICIUs, Zoologiske Bídrag., 43, 1824, Greenland.

Hippoglossus groenlandicus, GÜNTHER, Cat., IV, 404, 1862, Greenland.

Reinhardtius hippoglossoides, GlLL, Cat. Fishes East Coast N. A., 50, 1861; Grul, Proc. Ac. Nat. Sei. Phila. 1864, 218.

Platysomatichthys hippoglossoides, Goode \& BEAN, Bull. Essex Inst., II, 7, 1879; CoLlETT,

Norske Nord-Havs Exped., 142, 1880; Jordan \& Gilbert, Synopsis, 819, 1883; Goode,

Nat. Hist. Aquat. Anim., 197, pl. 56, 1884; JoRdan \& Goss, Review Flounders and Soles, 237, pl. II, 1889; and of late American writers generally.

Hippoglossus pinguis, ReINHARDT, Kgl. Dansk. Vidensk. Selsk., 116, 1838.

Platysomatichthys pinguis, BLEEKER, l.c., 426, 1862.

\section{ror5. HIPPOGLOSSUS, Cuvier.}

\section{(HALIBUt.)}

Hippoglossus, Cuvier, Règne Animal, Ed.1, II, 221, 1817 (hippoglossus).

Eyes and color on the right side. Form oblong, not strongly compressed. Mouth wide, oblique; teeth in the upper jaw in 2 series, those below in 1; anterior teeth in upper jaw, and lateral teeth in lower, strong; no teeth on vomer or palatines; lower pharyngeal teeth in 2 rows. Dorsal fin beginning above the eye, its middle rays elevated, the posterior rays of dorsal and anal bifid; caudal fin lunate; ventral fins both lateral. Scales very small, cycloid; lateral line with a strong curve in front. Gill rakers few, short, compressed, wide set. Vertebræ $16+34$. Largest of the flounders. This genus contains but 1 species, the well-known halibut; abundant on both coasts of the North Atlantic and of the North Pacific. (Hippoglossus, the ancient name of the halibut, from $i \pi \pi \circ 5$, horse; $\gamma \lambda \tilde{\omega} \sigma \sigma \alpha$, tongue.)

\section{HIPPOGLOSSUS HIPPOGLOSSUS (Linnæus).}

\section{(HALIBUT.)}

Head 38; depth about 3. D. 105 ; A. 78 ; scales 150 or more. Body comparatively elongate, not strongly compressed, deep mesially, thence rapidly tapering each way; head broad; eyes large, separated by a very broad 
flattish area; lower eye slightly advanced; mouth large, the maxillary reaching middle of orbit. Nearly uniform dark brown; blind side white. One of our most important food-fishes, reaching a weight sometimes of 400 pounds. Found in all northern seas, southward in deep water to France, Sandy Hook, and occasionally to the Farallones off San Francisco; abundant throughout the North Atlantic as also the North Pacific and Bering Sea, in water of moderate depth; taken with hook and line on all cod banks.

Pleuronectes hippoglossus, LinNdus, Systema Naturæ, Ed.x, 269, 1758, European Ocean. Hippoglossus vulgaris, Fleming, British Animals, 197, 1828; Günther, Cat., IV, 403, 1862;

DAy, Fishes Great Britain, II, 5, pl. 44; Storer, Fish. Mass., 145, 1839; De KAY,

Now York Fauna: Fishes, pl. 49, f. 157, 294, 1842; Storer, Synopsis Fish. N. A., 475, 1847; Lockington, Rep. Com. Fisheries California, 39, 1878-79; Lockington, Proc. U. S. Nat. Mus. 1879, 71; Bean, Proc. U. S. Nat, Mus. 1879, 63; Jordan \& GilberT, Proc. U. S. Nat. Mus. 1880, 454; Goode, Proc. U.S. Nat. Mus. 1880, 471; JoRdAN \& GiLBerT, Proc. U.S.Nat. Mus.1881, 66; Bean, Proc. U.S. Nat. Mus. 1881, 242; Jordan \& Gmbert, Synopsis, 819, 1883; Bean, Cat. Col. Fish. U.S. Nat. Mus. 1883, 20; Dresel, Proc. U.S. Nat. Mns. 1884, 244; Goode, Nat. Hist. Aquatic Anim., 189, pl. 54, 1884; and of American writers generally.

Hippoglossus maximus, GотTSCHE, Archiv fur Natargesch. 1835, 164, no locality.

Hippoglossus gigas, SwAInson, Nat. Hist. Class'n Anim., Ir, 302, 1839, no locality.

Hippoglossus ponticus, BoNaPaRte, Catalogo Metodico, 47, 1846, Black Sea; after Pallas. Hippoglossus americanus, Gru, Proc. Ac. Nat. Sci. Phila. 1864, 220.

Hippoglossus hippoglossus, Jordan, Cat. Fish. N. A., 133, 1885; JoRdan \& Goss, Review Flounders and Soles, 237, pl. 3, 1889.

ror6. LYOPSETTA, Jordan \& Goss.

Lyopsetta, JoRdAN \& GOSS, in JoRdAN, Cat. Fish. N. A., 135, 1885 (exilis).

Teeth sharp, those of the lower jaw uniserial, the upper jaw biserial; lateral line simple (without accessory dorsal branch) and withont distinct anterior arch. Scales comparatively large, thin, ciliated, and deciduous; body dextral; anal spine usually strong; vertebra about 45 ; body slender, the flesh soft; dorsal fin beginning above eye. This genus contains but a single species, a small, soft-bodied flounder, of the waters of the North Pacific. In its technical characters Lyopsetta is very close to Hippoglossoides, but the species has the soft flesh of Atheresthes. ( $\lambda \dot{v} \omega$, to loosen; $\psi \tilde{\eta} \tau \tau \alpha$, flounder.)

2978. LYOPSETTA EXILIS (Jordan \& Gilbert).

Head 4; depth $3 \frac{1}{4}$. D. 78; A. 62; V.6; scales 16-71-18. Body slender, compressed, the flesh soft; caudal peduncle slender; mouth not large, very oblique, the gape curved; lower jaw scarcely projecting, with a knob at symphysis; maxillary rather narrow, reaching middle of pnpil, $2 \frac{2}{8}$ in length of hearl; teeth small, slender, close set, nearly uniform; above in 2 series, below in 1. Eyes large, separated by a sharp, scaly ridge; lower eje advanced. Scales comparatively large, thin and deciduous, ctenoid, but not so rough as in the other species, those on blind side similar, less rough. Lateral line prominent, rising anteriorly, without trace of arch. Fins low, fragile; anal preceded by a spine; caudal fin long, rather pointed; pectorals small, the riglut pectoral little more 
than $\frac{1}{2}$ length of head. Dorsal beginning immediately in front of pupil; aual higher than dorsal. Gill rakers short, slender, toothed, 9 below angle, the longest about $\frac{1}{8}$ diameter of orbit. Pale olivaceous brown, with dark points, forming edgings on each scale; bronze spots sometimes present; fins mostly dusky; dorsal and anal edged anteriorly with yellowish; ventrals largely yellow. Length 12 inches. North Pacific, in rather deep water; San Francisco to Puget Sound. This small flounder is brought in in large quantities by the sweep nets off San Francisco. It is of little value as a food-fish. (exilis, slender.)

Hippoglossoides exilis, Jordan \& GILbert, Proc. U. S. Nat. Mus. 1880, 154, off San Francisco (Type, No. 27121. Coll. Jordan \& Gilbert); JordaN \& Gilbert, Proc. U. S. Nat. Mus. 1880, 454; Jordan \& Gilbeit, Proc. U. S. Nat. Mus. 1881, 67; Jordan \& Gilbert, Synopsis, 827, 1883.

Lyopsetta exilis, Jordan \& Goss, Review Flounders and Soles, 238, 1889.

ror7. EOPSETTA, Jordan \& Goss.

Eopsetta, Jordan \& Goss, in Jordan, Cat. Fish. N. A., 135, 1885 (jordani).

Teeth sharp, those of the lower jaw uniserial, the upper biserial; scales small, eiliated, and adherent; lateral line without accessory dorsal branch and without distinct anterior arch; anal spine usually strong; body normally dextral, robust, the flesh firm; dorsal fin beginning above eye; vertebræ about 43 . This genus contains but a single species, a large flounder which is abundant on the coast of California. It is very close to the genus Hippoglossoides. ( $\dot{\varepsilon} \omega 5$, morning; $\psi \tilde{\eta} \tau \tau \alpha$, flounder.)

\section{EOPSETTA JORDANI (Lockington).}

(CALIFORNIA "SOLE.")

Head $3 \frac{1}{8}$; depth $2 \frac{1}{2}$. D. 94 ; A. 72; scales 96 . Body broadly elliptical. Dorsal and ventral outline equally and regularly curved. Mouth oblique, the jaws about even, the symphyseal knob but little projecting; gape curved; maxillary broad, reaching to behind pupil, $2 \frac{2}{8}$ in head; teeth in 2 series in the upper jaw, the inner series small and distant from the outer, which is considerably enlarged in front; lower jaw with a single series similar to the outer series in the npper jaw, but larger. Gill rakers roughish, strong, about 15 below angle, the longest about $\frac{1}{2}$ as long as eye. Lower pharyngeals rather narrow, each with a single row of sharp teeth. Eyes large; interorbital space a narrow, blunt, scaly ridge. Dorsal beginning over anterior margin of pupil, the rays all simple; caudal fin with the middle rays slightly produced; anal preceded by a spine; pectoral $\frac{1}{2}$ length of head. Scales of colored side small, firm, strongly ciliated, nearly uniform over head and body; lower jaw and snout scaleless; scales on blind side smooth. Olive brown, nearly uniform; membrane of dorsal and anal fins clouded with darker. Length 20 inches. Pacific Coast of the United States from Puget Sound to Point Concepcion. One of the commonest flatfishes of the California coast, being found in abundance in shallow water from Monterey northward. It is a good food-fish, and large numbers are dried each year by the Chinese. (Named for David Starr Jordan.) 
Hippoglossoides jordani, Lockington, Proc. U. S. Nat. Mus. 1879, 73, San Francisco (Coll. W. N. Lockington); Lockington, Rep. Com. Fisheries California 1878-79, 40; LockIngton, Scientific Press Supplement, April, 1879, 120; Jordan \& GiLbert, Proc. U.S. Nat. Mus. 1880, 454; Jordan \& Gilbert, Proc. U.S. Nat. Mus. 1881, 67; JordaN \& GiL. BERT, Synopsis, 826, 1883 ; Jordan, Nat. Hist. Aquat. Anim., 187, 1884.

Eopsetta jordani, JordaN \& Goss, Review Flounders and Soles, 239, 1889.

\section{ror8. HIPPOGLOSSOIDES, Gottsche.}

Hippoglossoides, GoTTSCHE, Archiv fur Naturgesch. 1835, 164 ("limanda"= platessoides). Citharus, ReINhAIRT, Kong. Dansk. Vid. Selsk. 1838, 116 (platessoides); not Citharus BLEEKER, 1862.

Drepanopsetta, Gin, Cat. Fish. Wast Coast N. A., 50, 1861 (platessoides).

Pomatopsetta, GiLL, Proc. Ac. Nat. Sci. Phila. 1864, 217 ("dentata" = platessoides).

Eyes and color on the right side (except sometimes in $H$. elassodon). Body oblong, moderately compressed; month rather large, with 1 row of sharp teeth on each jaw; no teeth on vomer or palatines; gill rakers rather long and slender; scales ctenoid; lateral line nearly straight, simple; dorsal fin low in frout, beginning over or before the eye; ventrals both lateral; caudal double truncate, produced behind. This genus, as here restricted, contains 3 closely related species, 2 of the North Pacific, 1 of the North Atlantic. All are essentially arctic species, inhabiting shal-

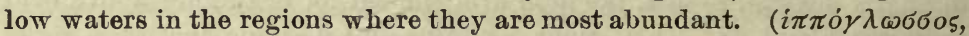
Hippoglossus; $\varepsilon i \tilde{\delta}$ o5, resemblance.)

a. Dorsal rays about 88 ; anal about 70 ; gill rakers $x+10$; interorbital space with an obtuse, prominent, rather broad ridge.

Platessoides, 2980.

aa. Dorsal rays about 82 ; anal about 61 ; gill rakers $x+12$ to 14 ; interorbital space with a narrow, nearly naked ridge.

ELASSODON, 2981.

aaa. Dorsal rays 72 to 76 ; anal 56 to 60 ; gill rakers $x+12$; interorbital space moderate, with 2 rows of scales.

b. Depth $2 \frac{1}{6}$ in length; D. 76; A. 60; pectoral $\frac{1}{2}$ length of head. ROBUsTus, 2982. bb. Depth 22 in length; D. 72; A. 56; pectoral $\frac{2}{3}$ in length of head.

HAMILTONI, 2983.

2980. HiPPOGLOSSOIDES PLATESSOIDES (Fabricius).

(SAND-DAB.)

Head $3 \frac{8}{4}$; depth $2 \frac{1}{2}$. D. 88 (80 to 93 ); A. 70 (64 to 75 ); scales 90 (pores). Body ovate; mouth moderate, oblique; maxillary narrow, reaching to below pupil, $2 \frac{2}{3}$ in length of head ; teeth rather small, conical, larger anteriorly, in 1 row in each jaw, those in the lower largest. Eyes rather large, the upper longer than snout, $4 \frac{1}{8}$ in head; lower jaw included, but with a projecting knob at the chin; snout thick, scaly; interorbital space narrow, with a raised obtuse ridge entirely covered with rough scales in about 6 series; mandible with a series of scales; gill rakers ratber short and robust, not toothed, about 10 below angle, the longest less than $\frac{1}{8}$ length of eye; fins with small, rough scales; a strong preanal spine; pectoral not quite $\frac{1}{2}$ length of head. Reddish brown, nearly plain. The identity of the American and European representatives of this species (platessoides and limandoides) is now conceded by all writers. A littlo difference is recognizable between arctic and subarctic examples, the 
former having a somewhat greater number of fin rays. Thus Greenland specimens, according to Collett, have D. 88 , A. 69 ; specimens from Finmark have D. 92, A. 72; these representing the var. platessoides. Specimens from England (var. limandoides) have D.80, A. 66, while those from intermediate localities present in general fin formulø likewise intermediate, showing that no sharp division is possible. This is a rather common foodfish of the deep waters northward, on both sides of the ocean. North Atlantic, south to Cape Cod, and the coasts of England and Scandinavia. (Eu.) (platessa, the plaice; $\varepsilon \tilde{z} \delta \circ 5$, resemblance.)

Pleuronectes linguatula, MÜLLER, Zool. Dan. Prodromus, 45, 1776; not of LinNaUE.

Pheuronectes platessoides, FABRICIUs, Fauna Grœnlandica, 164, 1780, Greenland.

Pleuronectes limandoides, BLOCH, Ausl. Fische, III, 24 tab. 186, 1787, Europe, and of various copyists.

Pleuronectes limandanus, PARNeLl, Edinburgh Now Phil. Journ. 1835, 210.

Citharus platessoides, ReinhaRDT, Kongl. Dansk. Vid. Selsk., 116, 1838.

Drepanopsetta platessoides, GrLL, Cat. Fish. East Coast N. A., 50, 1861.

Hippoglossoides platessoides, Gili, Proc. Ac. Nat. Sci. Phila. 1864, 217; ColletT, Norske Nord-Havs. Exped., 144, 1880; Goode, Proc. U. S. Nat. Mus. 1880, 471; JordaN \& GILBert, Synopsis, 826, 1883; Stearns, Proc. U. S. Nat. Mus.1883, 125; Goode, Nat. Hist. Aquatic Anim., 197, pl. 55, 1884; Jordan \& Goss, Review Flounders and Soles, 240, pl. 4, 1889; Goove \& BEAN, Ocean Ichthyology, 438, 1896, and of recent American writers generally.

Hippoglossoides limandoides, Günther, Cat., IV, 405, 1862; DAY, Fishes Great Britain and Ireland, $1 \mathrm{I}, 9, \mathrm{pl} .45,1884$.

Hippoglossoides limanda, GoтTsche, Archiv fur Naturgesch. 1835, 168; not Pl. limanda, LINNAUS.

Platessa dentata, Storer, Rept. Fish. Mass., 143, 1839; DE KAY, N. Y. Fauna: Fishes, 298, 1842; STORER, Synopsis, 476, 1846.

Hippoglossoides dentatus, GüNTHER, Cat., IV, 406, 1862; GÚNTHER, Challenger Report, XXII, Fishes, 3, 1887.

Pomatopsetta dentata, Grul, Proc. Ac. Nat. Sci. Phila. 1864, 217.

2951. HIPPOGLOSSOIDES ELASSODON, Jordan \& Gilbert.

Head $3 \frac{1}{2}$; depth $2 \frac{1}{2}$; eye 4 in head. D. 77 to 87 ; A. 59 to 67 ; V. 6 ; scales 45-100-40. Body oblong-elliptical; caudal peduncle about as long as deep; upper profile of head continuqus with the outline of back; depression over eye slight; mouth rather large, the gape curved, considerably wider on the blind side; lower jaw projecting, with a symphyseal knob;. maxillary narrow, reaching beyond middle of pupil, $2 \frac{1}{2}$ in head; teeth small, close set, nearly uniform, in a single row. Gill rakers slender, smooth, 14 to 16 below arch, the longest nearly $\frac{1}{2}$ diameter of orbit. Eyes large, separated by a narrow, knife-like ridge, which is naked, or with a single series of scales. Scales small, firm, rough, those on tail roughest, those on blind side similar, mostly smooth anteriorly. Lateral line rising anteriorly, but without arch; dorsal beginning immediately in front of pupil; anal preceded by a spine; candal long; pectoral of eyed side $\frac{1}{2}$ length of head; ventral reaching past front of anal; pectoral and ventral of eyed side with prickle-like scales. Brownish, nearly uniform, sometimes spotted with darker; fins grayish, irregularly blotched with dusky. Body sometimes sinistral. Length 18 inches. Bering Sea south to Cape Fattery; a rather abundant shore fish in Puget Sound, and it 
seems to be still more common northward, being, in Alaska, a food-fish of some importance. Abundant north and south of the Alentian Islands and in Bristol Bay. Our specimens from Kamchatka agree in all respects; D. 77 to 84 ; A. 60 or 61 . Pectoral not quite $\frac{1}{2}$ liead. Interorbital ridge sharp, with 1 series of scales; gill rakers $x+14$. ( $\varepsilon \lambda \alpha \sigma \sigma o ́ \omega$, to diminish; ósoús, tooth.)

Hippoglossoides elassodon, Jordan \& GiLberT, Proc. U. S. Nat. Mus. 1880, 278, Seattle; Tacoma (Type, No. 27263. Coll. D. S. Jordan); Jordan \& Gllbert, Proc. U. S. Nat. Mus. 1880, 454; Bran, Proc. U. S. Nat. Mus. 1881, 242; Jordan \& GIlbert, Synopsis, 826, 1883; Bean, Proc. U. S. Nat. Mus. 1883, 20; Jordan, Nat. Hist. Aquat. A nim., 188. pl. 52, 1884; Jordan \& Goss, Review Flounders and Soles, 241, pl.5, 1889; JoRdAN \& GilBert, Rept. Fur Seal Invest., 1898.

2982. HIPPOGLOSSOIDES ROBLSTUS, Gill \& Townsend.

Head $3 \frac{3}{5}$; depth $2 \frac{1}{6}$; eye $5 \frac{2}{5}$ in head. D. $76 ;$ A. 60 ; scales 95 (pores). Interorbital space a broad, somewhat elevated ridge with 2 rows of scales. Body rather high, its greatest height nearly equaling $\frac{1}{2}$ the length from snout to base of caudal; profile decurved above the eye; body thick; scales on head separate and rarely touch each other. Gill rakers long, $x+11$. Maxillary $2 \frac{1}{2}$ in head, directed upward anteriorly; teeth of the single row mostly separated from each other by intervals equal to width of teeth, curved inward, and uniform on the sides; toward front 4 or 5 enlarged, preceded by 2 smaller, leaving the middle toothless; in the lower jaw of nearly uniform size and inclining backward. Pectoral $\frac{1}{3}$ head; ventrals reaching first or second anal ray. Scales on body ciliated or weakly ctenoid, those on cheek sinoother; no ctenoid scales on blind side. Caudal shorter than in H. hamiltoni, $1_{5}^{3}$ in head. No exserted nasal

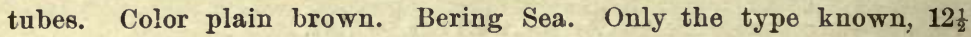
inches long, from which we have taken the above description. (robustus, robust.)

Hippoglossoides robustus, GILL \& TownsEnd, Proc. Biol. Soc. Wash., XI, 1897 (Sept. 17, 1897), 234, Bering Sea, Lat. $56^{\circ} 14^{\prime}$ N., Long. $164^{\circ} 08^{\prime}$ W., Albatross Station 354 , in 49 fathoms. (Type, No.48766, U. S. Nat. Mus. Coll. Albatross.)

2983. HIPPOGLOSSOIDES HAMILTONI, Jordan \& Gilbert, new species.

Head $3 \frac{1}{5}$ in length; depth $2 \frac{2}{5}$; longest diameter of upper eye $3 \frac{1}{2}$ in head; snout (measured from upper eye) 5 in head; maxillary of colored side $2 \frac{1}{3}$, of blind side $2 \frac{1}{6}$, in head; depth of caudal peduncle equaling its length, $3 \frac{1}{8}$ in head. D. 72 ; A.56; P.11; pores in lateral line 91. Upper profile of head continuing the dorsal curve without interruption, there being a slight depression above the eye and an increased convexity on the snout; mandible very heavy, projecting anteriorly, so that its symphyseal profile completes the curve of the snout; a very short prominence at symphysis directed vertically downward; gape strongly curved and the mouth narrowed anteriorly, so that the maxillary and premaxillary are almost wholly concealed along the middle of their length by the overarching prefrontal; teeth acute, in a single series in each jaw, all except the anterior teeth in each jaw short; at the symphysis of lower jaw the teeth are 
longer and directed inward, while in the anterior end of each premaxillary the teeth are still more enlarged, and the series on each side describes a strong curve with its convex side toward the median line; maxillary reaching vertical from slightly behind middle of lower eye; nostril tubes conspicuous, the anterior in elosest proximity to the upper lip, which it entirely overhangs; posterior nostril tube wider and slightly shorter; eyes of nearly equal size, and opposite, separated by a wider ridge than in $H$. elassodon, the ridge bearing in its narrowest portion 2 well-defined rows of strongly spinous scales; a conspicuous series of pores joining lateral line with upper margin of upper eye, and another encircling the lower eye below and behind; a third series along mandible and preopercle; 1 large pore above posterior nostril; gill rakers slender, unarmed, 2 above the angle, 11 or 12 below it, the longest $2{ }^{2}$ in eye; dorsal fin beginning above front of pupil, the longest ray $2 \frac{5}{6}$ in head; anal preceded by a strong spine, its height equaling that of dorsal; pectoral very long and slender, $\frac{2}{8}$ length of head, that of blind side shorter, $\frac{1}{2}$ length of head; ventrals reaching to base of fourth or fifth anal ray; caudal long, evenly rounded behind, the middle rays not longer than those adjacent, their length equaling distance from tip of snout to preopercular margin; scales on colored side strongly ctenoid except in a strip along middle of sides anteriorly; elsewhere each scale provided with 2 to 4 long spines; on blind side they are sinooth except on nape and candal peduncle; cheeks, opercles, and interorbital space covered with larger, rougher scales than those on sides; mandible and snout naked; a single series surrounding each eye anteriorly, and 1 on maxillary or colored side; blind side of head with maxillary naked; cheeks covered with minute smooth thin scales, the opercles with a few scattered spinous scales, the preopercle naked. Color nearly uniform brownish, without distinctive markings on body or fins. One specimen, $17 \mathrm{~cm}$. long, from Albatross Station 3641, off Dalnoi Point, Kamchatka; depth 16 fathoms. Allied to Hippoglossoides elassodon, from which it differs in the fewer fin rays and scales, the wider interorbital space, the longer caudal and pectoral fins and the much smaller symphyseal knob. The nasal tubes are larger, the scales rougher, and the anterior part of lateral line more arehed. Its relations with $H$. robustus are much nearer but the species are apparently distinct. (Named for Gerald Edwin H. Barrett-Hamilton, of Dublin, member of the British Commission of Fur Seal Investigation, 1896 and 1897, who made valuable collections of Kamchatkan fishes.)

Hippoglossoides hamiltoni, JoRDAN \& GILBERT, Rept. Fur Seal Invest., 1898, Dalnoi Point, Kamchatka. (Coll. Albatross.)

ıоr. PSETTICHTHYS, Girard.

Psettichthys, GIRARD, Proc. Ac. Nat. Sci. Phila. 1854, 140 (melanostictus).

Body dextral; teeth uniserial, sharp, unequal, some of them caninelike; mouth moderate, the lower pharyngeal teeth sharp, uniserial; seales small, etenoid, ciliated, and firm; lateral line with an accessory dorsal branch and without distinct anterior arch; anal spine strong; dorsal fin $3030-87$ 
beginning before the eye; vertebra about 40 ; flesh firm. This genus contains but 1 species, found on the coast of California. It is nearly related to Hippoglossoides, but possesses the peculiar accessory dorsal branch to the lateral line, characteristic of so many of the Pacific coast flounders. ( $\psi \tilde{\eta} \tau \tau \alpha$, the turbot; $i \chi \theta \dot{v} 5$, fish.)

2954. PSETtichthis MeLANostictes, Girard.

Head 4 ; depth $2 \frac{1}{3}$. D. 85 ; A. 60 ; scales 112 . Body not very deep, elliptical; mouth rather small, the maxillary extending to below pupil, $2 \frac{3}{7}$ in head; teeth large, in a single series in each jaw, those in lower jaw largest; a few large canines in front of each jaw. Eyes very small, separated by a broad, flat, scaly space, without ridge; lower oye slightly in advance of upper; gill rakers rather stout, weak, hooked at tip, 14 below the angle; scales very small, ctenoid on colored side; lateral line nearly straight, with a long accessory dorsal branch; dorsal commencing in advance of upper eye, the anterior rays elevated, slender and exserted, the longest about $\frac{1}{8}$ length of head; first ray of dorsal nearly free from its membrane; pectoral fin short, $2 \frac{1}{3}$ in head; anal fin preceded by a spine; caudal large, strongly convex; lower pharyngeals very narrow, each with 1 row of sharp, recurved teeth. Grayish brown, finely speckled with darker on body and fins. Pacific coast of North America, from Sitka south to Monterey. This is one of the commoner flounders of the Pacific coast, being everywhere known by the name of "Sole." It lives near the shore, and reaches a length of about 20 inches. In color this species is quite unlike the species of Hippoglossoides, but in most other respects the two groups

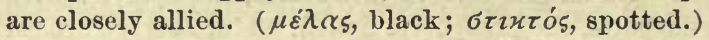

Prettichthys melanostictus, Girard, Proc. Ac. Nat. Sci. Phila. 1854, 140, San Francisco; Astoria, Oregon; Grrard, U. S. Pac. R. R. Surv., x, Fishes, 154, 1858; GünTHer, Cat., IV, 120, 1862; Lockington, Rep. Com. Fisheries Cal. 1878-79, 40; Lockington, Proc. U. S. Nat. Mus. 1879, 76; Jordan \& Gilbert, Proc. U. S. Nat. Mus. 1880, 453; Jordan \& Gilbert, Proc. U. S. Nat. Mus. 1881, 67; Jordan, Nat. Hist. Acquatic Animals, 186, pl. 51, 1884; JoRDAN \& Goss, Review Flounders and Soles, 241, pl. 6, 1889.

Hippoglossoides melanostictus, JORDAN \& GILBERT, Synopsis, 828, 1883.

1020. VERASPER, Jordan \& Gilbert, new genus.

Verasper, JoRDAN \& GILBERT, Report Fur Seal Invest., 1898 MS. (moseri).

This genus is allied to Xystreurys and Hippoglossina, having few short gill rakers like the former and strongly ctenoid scales like the latter. It differs strougly from all its congeners in having the premaxillary teeth in 2 series, teeth uniformly small, without canines. Body dextral; dorsal inserted above the front of pupil; lateral line strongly arched above the root of the pectoral, without recurrent dorsal branch; scales firm, extremely spinous; gill rakers short, thick, and triangular, few in number; noue of the fin rays notably produced or exserted. Japan and Kuril Islands; 2 species known, the following and $V$.variegatus (Schlegel), a common food fish of Japan, the 2 very closely related. (verus, true; asper, rough, the word being suggested by Veratrum.) 
2955. VERASPER MOSERI, Jordan \& Gilbert, new species.

Head $3 \frac{1}{3}$ in length to base of caudal; depth 2. D. 82 ; A. 58; pectoral 12 ; pores in lateral line 84 . Depth of caudal peduncle 4 in greatest depth of body; length of caudal perluncle, measured axially, $1 \frac{2}{8}$ in its depth. Head much depressed, with rather wide, flat interorbital space, resembling in appearance Psettichthys melanostictus, its thickness at interorbital space equaling distance between pupils of upper and lower eyes. Mouth small, very oblique, the gape strongly arched, the broad maxillary reaching a vertical behind middle of pupil, $2 \frac{4}{5}$ in head; mandible narrowing toward tip, with very rudimentary symphyseal knob. Teeth in upper jaw in 2 distinct series throughout, those of the outer series increasing slightly in size toward front of jaw, but none of them canine-like; mandibular teeth in 1 row, except at symphysis, where a few teeth form a short outer series. Nasal openings of eyed side approximated in front of middle of interorbital space, the anterior with a short tube, the posterior with a raised rim. Eyes small, their anterior margins opposite, the diameter of lower eye equaling distance from tip of snout to posterior nostral, $6 \frac{1}{8}$ in head. Interorbital space rather broad and flat, not ridge-like, its total width equaling $\frac{1}{2}$ diameter of orbit. Gill rakers short, broad, triangular, minutely toothed on inner margin, $\frac{1}{8}$ diameter of eye; 7 present on horizontal limb of outer arch. Lateral line with a short high anterior arch, the cord of which is $\frac{1}{5}$ the straight portion; height of arch $\frac{1}{8}$ its length; behind the arch lateral line descending in a gentle curve to middle of sides, the scales very rough, each possessing several long, sharp spines diverging from median portion of posterior margin; anterior and posterior portions of dorsal and anal fins naked, the rays of the middle portion each with a series of strongly ctenoid scales; caudal densely scaled to tip; pectorals and ventrals naked; head covered with strongly spinous scales, excepting snout, maxillary, and mandible; on blind side of head the snout, jaws, preopercle, subopercle, lower half of opercle, and all but a central strip on interopercle, scaleless; on blind side the scales are rough on head, ventral area, and along bases of ventral fins, largely smooth elsewhere. Dorsal beginning above front of pupil, the rays increasing in length to the forty-fifth, which is $2 \frac{2}{7}$ in head; longest anal ray (the seventeenth) $2 \frac{1}{7}$ in head. Caudal broadly rounded, $1 \frac{2}{5}$ in head; pectoral short and broad, $2 \frac{2}{5}$ in head; ventrals of nearly equal length, reaching origin of anal, $3 \frac{1}{5}$ in head; no anal spine. Color in spirits, centers of the scales light gray, the margins dark brown; fins light or dusky, the vertical fins with conspicuous black bars, parallel with the rays, these most evident on under side where the pigment seems principally to occur, and are seen through the fin more faintly on the colored side; lining of cheeks and gill cover of colored side dusky; peritoneum gray. Kuril Islands; 1 male $28 \mathrm{~cm}$. long, from Shana Bay, Iturup Island; also taken at Hakodate. (Named for Jefferson Franklin Moser, U. S. N., Lieutenant-Commander, in charge of the U. S. Fish Commission Steamer Albatross, and a member of the United States Fur Seal Commission for 1896.)

Verasper moseri, JoRdan \& GiLbert, Rept. Fur Seal Invest., 1898 MS., Shana Bay, Iturup

Island, Kuril Group. (Type No. 48797. Coll. Albatross, Capt.J. F. Moser.) 
1021. HIPPOGLOSSINA, Steindachner.

Uippoglossina, STEINDACHnER, Ichth. Beiträge, v, 13, 1876 (macrops).

Teeth rather small, uniserial, no canines; lateral line with a strong arch in front, and with no accessory dorsal branch; anal spine obsolete; body indifferently dextral or sinistral (in some species at least). Scales etenoid; dorsal fin begiming abore pupil; gill rakers rather long and slender. This genus is intermediate between Hippoglossoides and Paralichthys, agreeing with the former in the insertion of the dorsal and in general appearance, and with the latter in the direction of the lateral line. Several species are now known. Some of them are dextral, and perhaps all of them are normally so, or perhaps, as in the case of Xystreurys liolepis, all are indifferently dextral or sinistral. (A diminutive of Hippoglossus, the halibut.)

a. Mouth large, the maxillary extending to opposite posterior margin of eye, 2 in head; gill rakers numerous, $4+13$; dorsal rays about 68 ; anal $53 . \quad$ sTомAтA, 2986.

aa. Mouth moderate, the maxillary extending to opposite middle of pupil, about $2 \frac{1}{2}$ in head.

b. Dorsal rays about 66; anal 52; depth of body $2 \frac{1}{3}$ in length. MACroPs, 2987. bb. Dorsal rays about 62 ; anal 48 ; depth of body $2 \frac{2}{3}$ in length; gill rakers $2+8$ or 9.

BOLLMANI, 2988.

2956. HiPPOGLOSSIXA STONATA, Eigenmann \& Eigenmann.

Head $2 \frac{8}{4}$ to 3 in length; depth $2 \frac{1}{2}$ to $2 \frac{2}{5}$. D. 67 to $70 ;$ A. 52 to 54 ; scales 80. Sinistral. Eye (not orbit) large, 5 in head; lower orbit sliglitly in advance of upper; interorbital a narrow ridge. Form, elongate elliptical, the profile depressed over the eje: Mouth large, maxillary extending to posterior margin of eye, as long as or longer than pectoral, 2 in hearl; lower jaw about $1 \frac{8}{4}$ in head. Teeth small, nniserial; anterior nares of each side with long dermal flaps. Scales of left side all etenoid, those of right side eycloid on anterior half or two-thirds of body; middle third of interorbital naked, anterior and posterior thirds sealed. Gill rakers $4+$ 13 or 14. Dorsal beginning over middle of eye, anterior rays with but 1 or 2 seales, rest scaled to near tip, all but last 8 rays simple; anal similar to dorsal, with a strong procumbent spine; highest dorsal and anal rajs about $3 \frac{1}{8}$ in head; pectoral of colored side about 2 in head, that of blind side shorter; eaudal double truneate, 5 to $5 \frac{1}{2}$ in length. Brown, strongly tinged in life with robin's-egg blue; numerous spots of light blue and light and dark brown; 5 pairs of large, dark-brown ocelli along dorsal and ventral parts of eyed side, the alternate ones longer and more conspieuous; fins colored like body, profusely mottled with light and dark; sinistral pectoral barred; a dark-brown spot above and below on caudal peduncle just in front of caudal, showing conspicuously on blind side. The eggs are probably pelagie; they are transparent, and measure $1.2 \mathrm{~mm}$. in diameter; the single oil globule measures $0.16 \mathrm{~mm}$. Coast of southern California; 2 specimens obtained in decp water off San Diego, November 7, 1889, both females, 1 with ripe eggs. (Eigenmann \& Eigenmann.)

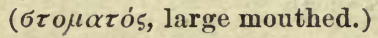

Iyppoglossina stomata, Eigenarann \& Eigenaunn, Proc. Cal. Ac. Sci. 1890, 22, San Diego. (Coll. C. H. Eigenmann.) 
2987. HIPPOGLOSSINA MACROPS, Steindachner.

Head $2 \frac{8}{4}$; depth $2 \frac{1}{3}$. D. $66 ;$ A. 52 ; scales 75 to 80 ; upper orbit $3 \frac{1}{2}$ in head. Body elliptical, deeper than in related species; mouth moderate, the maxillary reaching to middle of eye; teeth small, sharp, uniserial; lower eye slightly in front of upper; eyes separated by a naked narrow ridge; nostrils close together, the anterior ending in a tube; horizontal limb of preopercle somewhat concave, the vertical convex. Dorsal beginning over middle of eye; pectoral of left side $\frac{1}{2}$ hear, much longer than maxillary, which is $2 \frac{2}{3}$ in head; interorbital space a narrow ridge; scales of left side all strongly ctenoid, those on blind side ciliated only on posterior third of body; no anal spine. Color brownish, with olscure darker blotches. Borly sinistral (in the only specimen known). (Steindachner.) Pacific coast of Mexico. One specimen from Mazatlan; not seen by us. ( large; œ้ $\psi$, eye.)

Hippoglossina macrops, Sterndachner, Ichth. Beitr., v, 13, pl.3, 1876, Mazatlan ; JoRdAN \& Goss, Review Flounders and Soles, 242, 1889.

2989. HIPPOGLOSSINA BOLLMANI, Gilbert.

Head $3^{1}\left(3 \frac{8}{4}\right.$ to $\left.3 \frac{4}{5}\right)$ in length; depth $2 \frac{2}{3}$ to $2 \frac{8}{4}\left(3 \frac{1}{8}\right.$ to $\left.3 \frac{1}{2}\right)$; snont 5 in head. D. 60 to 63 ; A. 47 to 49 ; scales along lateral line 70 to 75 . Body regularly elongate, olliptical; dorsal and ventral outlines equally curved; orbital rim entering anterior profile, which is equally curved before and behind eyes; greatest depth of body above pectorals. Mouth rather large, the maxillary reaching about to middle of pupil, $2 \frac{1}{3}$ to $2 \frac{3}{5}$ in liead. Teeth equally developed on both sides, small and equal, uniserial. Premaxillary spine prominent. Interorbital space a narrow, sharp, naked ridge; eyes large, the lower slightly in advance of npper, $3 \frac{2}{3}$ to 4 in head. Gill rakers moderatcly long and slender, the longest 3 in length of ventral of eyed side; $2+8$ or 9 developed, the last 2 much shorter. Scales small, firm, strongly ctenoid, those below pectoral much reduced, about 40 in a cross series; arch of lateral line strongly marked, $2 \frac{2}{8}$ to $2 \frac{1}{6}$ jn straight part. Dorsal beginning above middle of pupil of upper eye, its anterior rays low, its longest rays $2 \frac{4}{7}$ in head; a strong antrorse spine before anal; pectoral of eyed side 2 in head, that of blind side $2 \frac{1}{2}$ to $2 \frac{2}{8}$ in head; ventrals subequal, each 6-rayed, 4 in head, extending more than $\frac{1}{2}$ their length beyond anus; each is lateral, but that of eyed side nearest ridge of abdomen, and a little behind its fellow; last ray of left ventral joined to abdomen alongside of anal spine; caudal acute, its peduncle long. Color grayish brown, a row of 6 round, bluish spots, smaller than pupil, along base of dorsal, 4 similar spots along base of anal, and a few indistinct smaller ones on rest of body and head; body with 6 large black spots somewhat smaller than eye, these regularly 4 below dorsal and 2 above anal, the first of dorsal above arch of lateral line, the second above anterior third of straight part, the third at base of last rass and almost forming a cross bar with the 1 at base of anal rays. Dorsal, anal, and caudal dusky, with small whitish spots; a pale spot at base of last 4 dorsal and anal rays; a small black spot at base of onter caudal rays on peduncle; pectorals and rentrals dusky, but not spotted; right side immaculate. Length 
7 inches. Pacific coast of Colombia. Numerous specimens were dredged at Albatross Station 2805, at a depth of $51 \frac{1}{2}$ fathoms. This species differs from Hippoglossina stomata in the gill rakers, which are shorter and fewer in number, and in the larger scales on sides. Scales in 16 rows between lateral line and back, instead of 21 or 22, as in H. stomata. Gill rakers somewhat shorter, 8 or 9 on anterior limb, 2 on upper limb. In H. macrops the gill rakers are slender, close set, 13 or 14 on anterior limb, 4 on vertical limb. In other respects of color, fin rays, and squamation agreeing perfectly with $H$. stomata. (Named for Charles Harvey Bollman.)

Hippoglossina macrops, Jordan \& Bollman, Proc. U.S. Nat. Mus.1889, 175; not of STEINDACHNER.

Hippoglossina bollmani, Grlbert, Proc. U. S. Nat. Mus. 1890, 122, Albatross Station 2805, southwest of Panama, in $5 \mathrm{I} \frac{1}{2}$ fathoms. ('Type, No. 41143.)

\section{ro22. LIOGLOSSINA, Gilbert.}

Lioglossina, GiLbert, Proc. U. S. Nat. Mus. 1890, 122 (tetrophthalmus).

This genus is allied to Hippoglossina, but its scales are all cycloid, the teeth are small, pointed, uniserial, and uniform, and the gill rakers short and thick. $(\lambda \varepsilon \tau \tilde{\delta} \varsigma$, smooth; $\pi \lambda \tilde{\omega} \sigma \sigma \alpha$, tongue; for Hippoglossina.)

2989. LIOGLOSSINA TETROPITHALMA, Gilbert.

Head large, $3 \frac{1}{4}$ in length in a specimen 1 foot long. D. 76 to $83 ;$ A. 58 to 62 ; lateral line (pores) 97. Body of moderate height, the profile distinctly angulated above upper pupil, the snout projecting; length of caudal peduncle $\frac{1}{2}$ its depth, its outlines diverging backward; depth of body $2 \frac{1}{3}$ in length; snout projecting beyond profile, bluntly rounded, the lower jaw included. Mouth large, the maxillary reaching nearly to vertical from posterior border of lower eye, $2 \frac{1}{5}$ in head; a blunt projecting process anteriorly from head of maxillary. Teeth small, pointed, in a single close-set series in each jaw, none of them enlarged; vomer toothless; lower eye slightly in advance of upper; vertical from front of upper falling midway between front of orbit and front of pupil of lower eye; vertical diameter of upper orbit but little more than $\frac{1}{2}$ its longitudinal diameter, which is contained $3 \frac{1}{2}$ in head; interorbital space a blunt high ridge, entirely scaleless, its width $\frac{2}{5}$ diameter of orbit. Anterior nostril of blind side with a very long flap, that of eyed side shorter; a well-marked cutaneons flap on lower eye above pupil. Gill rakers very large, broad, and strong, well toothed on inner edges, longest equaling diameter of pupil, the number on outer gill arch 10 or 11 . First dorsal ray over anterior margin of pupil of upper eye, the fin not high, its highest ray 3 in head; anal similar; caudal sharply donble truncate, the median rays produced; rentrals rounded, equal, barely reaching front of anal; no spine before anal fin; pectorals moderate, with 9 or 10 developed rays, $\frac{1}{2}$ length of head; ventral 6. Scales rather small, growing distinctly larger posteriorly, everywhere sinooth; head scaled, except smout, interorbital area, mandible, and part of maxillary, the latter with a patch of scales on posterior end of its expanded portion; on blind side an area around nostrils, and the greater part of exposerl portion of preorbital, scaleless; fin rays of vertical fins, 
all with bauds of fine scales, those on caudal especially broad; lateral line with a broad arch in front, the cord of which is $3 \frac{2}{5}$ in straight portion. Color dusky brownish, with 2 conspicuous pairs of round black spots narrowly edged with gray, the anterior pair about $\frac{1}{2}$ size of orbit, the posterior larger than pupil; the anterior pair under beginning of posterior third of dorsal, and about halfway between lateral line and dorsal and anal margins, respectively; the posterior pair nearer outline of body and about under the tenth before the last dorsal ray; vertical fins obseurely blotched with darker; ventral of eyed side with conspicuons black bloteh margined with white, occupying the distal portion of its inner 2 rays; pectoral unmarked; membrane of gill cavity and peritoneum white. Two specimens, each about 12 inches long, from tho Gulf of California, taken in 29 and 76 fathoms, at Albatross Stations 3014 and 3016. (Gilbert.) ( $\tau \varepsilon \tau \rho \alpha-$, four ; $\dot{\emptyset} \theta \alpha \lambda \mu o ́ s$, eye, or eye-like spot.)

Lioglossina tetrophthalmus, GILBERT, Proc. U.S. Nat. Mus. 1890, 122, Gulf of California. (Coll. Dr. Gilbert.)

\section{XYSTREURYS, Jordan \& Gilbert.}

Xystreurys, Jordan \& GiLbert, Proc. U. S. Nat. Mus. 1880, 34 (liolepis).

Body broad, covered with small smooth scales. Teeth rather small, uniserial and bluntly conical, unequal; no canines; caudal fin subsessile, the caudal peduncle extremely short; skin of shoulder girdle with patches of cup-shaped scales; lateral line with a strong anterior arch, no accessory branch; vertebr:e about 37; gill rakers short and thick. This genus is very close to Hippoglossina, differing chiefly in the subsessile caudal fin, the smooth-scales, and the peculiar, short, thick gill rakers. The typical species, like some other Parific coast flounders, is almost indifferently dextral or sinistral. ( $\xi \dot{v} \sigma \tau \rho o v$, raker; $\varepsilon \dot{v} \rho \dot{v} \zeta$, wide, from the broad gill rakers.)

2990. XYSTREURYS LIOLEPIS, Jordan \& Gilbert.

Head $3 \frac{4}{5}$; depth $1 \frac{5}{6}$. D. 80 ; A. 62 ; scales 123 . Vertebræ $12+25=37$. Body elliptical ovato, broad and compressed, its curves regular; the profile continuous with curve of back; month small, very oblique, the lower jaw included; maxillary reaching about to pupil, $2 \frac{2}{8}$ in head ; eyes rather large, $4 \frac{1}{2}$ in head, separated by a very narrow, blunt scaly ridge; teeth small, conical, blunt, in a single row; those in lower jaw subequal, closo set; those in upper jaw more distant, decreasing in size backward; teeth $\frac{12+13}{14+15}$. Gill rakers $2+7$, very short, broad, and strong, minutely serrate on inner margin, about 7 below angle, the longest scarcely $\frac{1}{4}$ as long as the eye. Scales small, oblong, cycloid, the smaller accessory scales extremely numerous; lateral line without dorsal branch, with a broad curve above pectorals; branchial arches and skin of the shoulder girdle with small, cup-shaped, tubercular scales. Dorsal rather high, firm, low in front, beginning just in advance of middle of pupil, highest near the middle of the body; caudal pednncle very short and deep, its depth 4 times its length. Pectoral of eyed side falcate, usually much longer than heal, 
its length varying considerably. Caudal fin somewhat double truncate, with rounded angles, the middle rays being produced. Anterior nostril of blind side with a long flap. Color olive brown, mottled with darker, sometimes with very distinet round black blotches; vertical fins blotehed with dark; peetoral of colored side with oblique bars. Length 15 inches. Southern California, rather common from Point Concepcion southwarl to San Diego. It is a very variable species, the coloration and the length of the pectoral fins having a wide range of variation. The botly is indifferently dextral or sinistral. ( $\lambda \varepsilon i ̄ o 5$, smooth; $\lambda \varepsilon \pi i 5$, scale.)

Xystreurys liolepis, Jordan \& Gilbert, Proc. U. S. Nat. Mus. 1880, 34, Santa Barbara; Jordan \& Gilbert, Proc. U. S. Nat. Mus. 1880, 454; Jordan \& Gilbert, Proc. U. S. Nat. Mus. 1881, 66; Jordan \& Goss, Review of Flounders and Soles, 243, 1889.

Paralichthys liolepis, JoRDAN \& GILBERT, Synopsis, 825, 1883.

I024. PARALICHTHYȘ, Girard.

\section{(Bastard Halibuts.)}

Paralichthys, GrRARD, U.S. Pac. R. R. Surv., X, 146, 1858 (maculosus=californicus).

Pseudorhombus, Bleeker, Comptes Reudus, Acad. Sci. Amsterd., XIII, 1862, 5, Notice sur quelques genres de la famille des Pleuronectida (polyspilos).

Uropsetta, GILL, Proc. Ac. Nat. Sci. Phila. 1862, 330 (californicus=maculosus).

Choenopsetta, Grul, Proc. Ac. Nat. Sei.Phila. 1864, 218 (ocellaris=dentatus).

Eyes and color normally on the left side. Body oblong; mouth large, oblique; each jaw with a single row of usually slender and sharp teeth, which are more or less enlarged anteriorly; no teeth on vomer or palatines. Gill rakers slender. Seales small, weakly ctenoid or ciliated; lateral line simple, with a strong curve anteriorly. Dorsal fine beginning beforo the eye, its anterior rays not produced; both ventrals lateral; caudal fin double trumeate, or double concave, its middle rays produced; no anal spine. Species numerous, found in all warm seas. This genus, as now restricted, contains a considerable number of species, inhabiting both eoasts of America and the eastern and southern coasts of Asia. As indicated by the reduced number of vertebræ, the speeies range further southward than do those of the type of Hippoglossoides. ( $\pi \alpha \rho \alpha \dot{\lambda} \lambda \lambda_{\eta} \lambda$ os, parallel; $i \chi$ 'vs, fish.)

a. Gill rakers in large number, about $9+20$.

b. Gill rakers as long as eve and very slender. D. 72 ; A. 55; depth $2 \frac{2}{3}$ in length.

CALIFORNICUS, 2991.

$b b$. Gill rakers shorter, about $\frac{9}{3}$ length of eye. D. 80; A. 61; depth $2 \frac{1}{4}$ in length.

ASTUARIUS, 2992.

$a a$. Gill rakers in moderate number $(5+11$ to $6+21)$, rather long and slender.

c. Dorsal rays 70 to 75 ; anal rays 54 to 60 .

d. Head small, lateral line $4 \frac{1}{6}$ in length; depth $2 \frac{1}{5}$; interorbital space rather broad and flatish, $\frac{2}{3}$ diameter of eye; eyes small, $5 \frac{2}{3}$ in head; gill rakers rather short, $4+15$, the longest about $\frac{3}{8}$ eye.

BRASILIENSIS, 2993.

dd. Head rather large, $3 \frac{1}{2}$ in length; depth 2 to $2 \frac{1}{4}$; eyes small.

e. Gill rakers 5 to $6+15$ to 18 ; eyes wide apart. ADSPERsus, 2994.

ee. Gill rakers $5+11$; eyes close together. WooLmani, 2995.

cc. Dorsal rajs 85 to 93 ; anal rays 67 to 73 ; gill rakers $5+15$ or 16 , long and slen-

der, the longest $\frac{8}{3}$ length of eye; body ovate, the depth about $2 \frac{1}{6}$ in length ;

head about 3 ?

DENTATUS, 2996. 
aan. Gill rakers few, shortish, wide set, the number $2+8$ to $3+10$.

$f$. Body ovate, more or less compressed and opaque; depth about $2 \frac{1}{3}$ in length; no distinct, definitely placed ocelli; scales cycloid.

$g$. Dorsal rays in large number ( 85 to 93 , as in $P$. dentatus); anal rays 65 to 73 ; pores of the lateral line about 100 ; accessory scales few; gill rakers $2+10$, lanceolate, dentate, wide set, and much shorter than the eye. LETHOSTIGMUS, 2997.

gg. Dorsal rays in moderate number ( 70 to 80 ); anal rays 54 to 61.

$h$. Scales very small, about 120 in lateral line; depth of body about $\frac{1}{2}$ length; head $3 \frac{?}{5}$ in length; gill rakers roughly toothed, $3+9$ in number.

SQUAMILENTUS, 2998.

$h h$. Scales moderate, 90 to 100 pores in the lateral line; interorbital width about equal to length of eye; dorsal rays 75 to 81 ; anal rays 59 to 61 ; gill rakers 2 or $3+9$ or 10 . Coloration, grayish brown with numorous (more or less distinct) whitish blotches, which are rarely obsolete; vertebræ $10+27=37$.

ALBIGUTTUS, 2999.

ff. Body oblong. strongly compressed, semitranslucent; scales weakly ciliated; about 93 pores in lateral line. Coloration, light grayish, thickly mottled with darker; 4 large horizontally oblong, black ocelli, each surronnded by pinkish area; 1 just behind midlle of the boly, below the dorsal, 1 opposite this, above aual, and 2 similar smaller spots below last rays of dorsal and above last of anal; vertebræ $11+30=41$.

OBLONGUS, 3000 .

2991. PARALICHTIYS CAIIFORNICUS (Ayres).

(Bastard Halibut; Monterey Halibut.)

Head $3 \frac{8}{4}$ to $4 \frac{1}{4}$; depth $2 \frac{2}{3}$. D. $70 ;$ A. 55 ; scales 100 . Vertebra $10+25=35$. Body rather long and thickish; caudal peduncle long; head small; eye small, little wider than the broad, flattish interorbital space; maxillary as long as pectoral, $\frac{1}{2}$ length of head, reaching beyond eje; teeth slender, sharp, rather long, the canines moderate. Scales small, finely ciliate, each scale surrounded by narrow accessory scales; scales on blind side similar; fins with ctenoid scales. Dorsal low, beginning over front of upper eye just past pectoral, pointed, reaching curve of lateral line, $2 \frac{1}{4}$ in head, that of blind side shorter and rounded behind; arch of lateral line $3 \frac{1}{2}$ or 4 in straight part. Gill rakers very long and slender, numerous, as long as өye, abont $9+20$; lower pharyrngeals narow, with small slender teeth. Anal spine small, concealed. Grayish brown, uniform, or mottled with blackish and pale, the head sometimes sprinkled with black dots; joung brownish, with bluish spots. Coast of California, Tomales Bay to Cerros Island. This large flounder is one of the common food-fishes of the Pacific coast, where it takes the place occupied on the Atlantic side by Paralichthys dentatus. It reaches a length of 3 feet and a weight of 60 pounds. From its resembiance to the halibut, it usually goes by the name of bastard halibut. It is readily listinguished from the Atlantic members of the same genus by its fewer fin rays and by its more numerous gill rakers. As was first shown by Mr. Lockington, the small fish called Paralichthys maculosus, is simply the young of the larger fish, then called Uropsetta californica. Unlike other species of the genus, Paralichthys californicus is almost as frequently dextral as sinistral. (californicus, Californian.) 
Pleurnectes maculosus, Girard, Proc. Ac. Nat. Sci. Phila. 1854, 155, young, San Diego.

Paralichthys maculosus, GIRARD, U.S. Pac. R. R. Surv., X, Fishes, 147, 1858, not Rhombus maculosus, Cuvier, also a species of Paralichthys; GüNTHER, Cat., IV, 431, 1862; GILL, Proc. Ac. Nat. Sci. Phila. 1864, 197; Lockington, Rep. Com. Fisheries California 1878-79, 41; Lockington, Proc. U. S. Nat. Mus. 1879, 79; Jordan \& Gilbert, Proc. U. S. Nat. Mus. 1880, 454; Jordan \& GLberT, Proc. U. S. Nat. Mus. 1881, 66; Jordan, Nat. His. Aquat. Anim., 182, 1884.

Hippoglossus californicus, A Yres, Proc. Cal. Ac. Nat. Sci. 1859, 29, and 1860, fig. 10, adult, San Francisco.

Pseudorhombus californicus, GüNTHER, Cat., IV, 426, 1862.

Uropsetta californica, Gill, Proc. Ac. Nat. Sci. Phila. 1862, 330; GrL, Proc. Ac. Nat. Sci. Phila. 1864, 198.

Paralichthys californicus, Jordan \& GILBERT, Synopsis, 821, 1883; JoRdAN \& Goss, Review Flounders and Soles, 245, 1889.

2992. PARALICHTHYS ESTUARICS, Gilbert \& Scofield.

Head $3 \frac{2}{3}$; depth $2 \frac{1}{4}$; eye $5 \frac{1}{2}$; interorbital space flat, 12 in head, $\frac{1}{2}$ diameter of eye; maxillary 2 in head, equal to pectoral fin; gill rakers $9+20$, the longest $\frac{2}{8}$ length of eje. D. 72 to 83 ; A. 58 to 64 . (In 7 specimens examined therays are: Dorsal $72,79,81,81,82,83,83$; anal $58,60,60,62,63$, 63,64 .) Vertebræ $10+28$; scales weakly ciliated, with small accessory scales, 105 in the lateral line; length of the arch contained 4 times in straight part of lateral line, 2 in head; height of arch $4 \frac{1}{2}$ in head. Four of the 7 specimens are sinistral. Color pale chocolate brown. Specimens small, 6 to 9 inches in length. Taken at Shoal Point, at mouth of the Colorado River, Mexico, by the United States Fish Commission steamer Albatros8. This species is distinguished from other members of the genus by its numerous fin rays and many gill rakers. It is nearest related to Paralichthys cclifornicus. (astuarius, pertaining to the river mouth.)

Paralichthys aestuarius, GiLberT \& Scofield, Proc. U. S. Nat. Mus. 1897, 499, pl. xxix, Gulf of California, at mouth of Colorado River, Sonora. (Type, No.48128. Coll. C. H. Gilbert.)

2993. PaRAlichthys BRasiliexsis (Ranzani).

Head $4 \frac{1}{5}$; depth $2 \frac{1}{5}$. D. 70 to 75 ; A. 54 to 60 ; scales not very small, about 100 in course of lateral line; interorbital space rather broad and flattish, $\frac{2}{3}$ diameter of eye ; eyes small, $5 \frac{2}{3}$ in head; gill rakers rather short, $4+15$, the longest about $\frac{3}{5}$ eye; pectoral $1 \frac{1}{8}$ in head; curve of lateral line high and short, 4 in straight part, its height $1 \frac{8}{4}$ in its length; mouth moderate, the maxillary $2 \frac{1}{\bar{y}}$ in head; teeth rather few, the anterior canines large. Color dark brown, more or less mottled and spotted with paler. South America; said to range northward to Guatemala. Here describerl from numerous specimens from Rio Janeiro and from Maldonado, in the Musenm of Comparative Zoology. The locality "Guatemala" given by Giinther seems to be somewhat doubtful, and the species may not occur in West Indian waters at all. (brasiliensis, living in Brazil.)

Hippoglossus brasiliensis, RAnzani, Nov. Spec. Piso., 10, tab. 3, 1840, Brazil.

Platessa orbignyana, Valenciennes, D'Orbigny Voy. S. Amer. Mérid. Poiss., pt. 5, pl. 16, fig. $1,1847$.

Rhombus a ramaca, Castelnad, Anim. nouv. ou rares, Poiss., 78, pl. 40, fig. 3 ; not of Cuvier. Preudorhombus vorax, GUnTHER, Cat., IV, 429, 1862, South America.

Pseudorhombus brasilicnsis, GÜnTHER, Fishes Centr. Amor., 473, 1869.

Paralichthys brasiliensis, JoRdan \& Goss, Review Flounders and Soles, 246, 1889. 
2994. PARALICHTHYS ADSPERSUS (Steindachner).

Head $3 \frac{1}{2}$; depth $2 \frac{1}{4}$. D. 75 ; A. 58 ; scales 106 ; eye 6 in head; interorbital $\frac{8}{4}$ vertical diameter of eye; maxillary $2 \frac{1}{8}$; mandible $1 \frac{5}{6}$; pectoral 2 ; caudal $1 \frac{3}{5}$. Body moderately elongate and compressed; mouth large, the maxillary reaching a little past eye; teeth large, sharp, and slightly recurved, larger in front of jaws; snout very slightly produced; interorbital moderately wide, its posterior half with scales; anterior nostril with a flap which reaches to middle of posterior nostril; gill rakers 3 to $6+15$ to 17 , hardly as long as eye. Snout and mandible naked; end of maxillary and rest of head with scales; the rays of all the fius with small scales; the membrane naked; each scale on body with a row of aecessory scales around its posterior edge; scales cycloid, the accessory scales giving the fish a rough feeling; curve of lateral line nearly 5 in the straight part, pectoral reaching slightly past curve of lateral line, its tip pointed; pectoral of blind side shorter, not reaching to end of curve, its tip blunt; origin of dorsal over anterior edge of upper eye, bending slightly toward the blind side; caudal double lunate. Color brownish gray, thickly mottled with many larger and smaller spots, points, and rings; side with 3 or 4 larger spots of irregular form and ocellated with paler.

Specimens taken by Dr. Jordan at Mazatlan are described as follows: "Ilead $3 \frac{1}{2}$; depth about 2 in length of body. D. 73 (70 to 76); A. 57 (53 to $60)$; P. 12; V.6. Scales on lateral line about $106+8$ with 35 dorsally and 36 ventrally. Flesh firm. Body oblong, moderately compressed; mouth large, oblique, the mandible very heavy, slightly projecting; 4 canine teeth on each side of lower jaw in adult specimens, 8 in young, the 2 anterior teeth long; anterior teeth of upper jaw strong, but smaller than those in the lower jaw; the lateral teeth very small and close set. Eye small, shorter than snout, about 7 (6 to 8$)$ in length of head; interorbital area smooth, flattish, $\frac{2}{3}$ width of eye. Scales cycloid, small anteriorly and larger posteriorly; lateral line strongly arched anteriorly, arch about $3 \frac{1}{3}$ in straight part. Gill rakers of medium length, broad, retrorse-serrate on inner side, longest about $\frac{2}{8}$ length of eye, from $4+13$ to $5+14$ in number, counted in 8 specimens; pectoral fin about as long as mandible, slightly more than $\frac{1}{2}$ length of head. Dorsal low, anterior origin opposite anterior margin of eye; caudal barely double concave; caudal peduncle very strong; anal spine obsolete; ventral fins small, inserted symmetrically; fins all scaly. Color: Large specimens are dark brown, with blotches on tins; small specimens are covered with pearly white and very dark brown blotches; the brown blotches almost circular, larger and with less definite outlines near the center of the body, very dark and distinct on eaudal. Seven specimens were taken by the Hopkins Expedition in the estuary at Mazatlan, where they reach a length of $44 \mathrm{~cm}$. Several specimens were also taken at La Paz. These specimens seem to be identical with Paralichthys adspersus. The original types have on an average more gill rakers than we find in our Mazatlan specimens, but this character is subject to variation, and no other distinction appears. In one of Dr. Steindachner's types from Callao (No. 11,417, Mus. Comp. Zool.) we find the gill rakers longer, $6+17$; depth $2 \frac{1}{2}$ in length; D.67; A.51; scales 120 ; 
arch of lateral line barely twice as long as high, nearly 5 in straight part; maxillary $2 \frac{1}{6}$ in head. Mr. Garman has kindly examined for us 6 other specimens, with the following results:

"Paralichthys adspersus from Callao, has gill rakers-

" " ${ }^{7} \mathrm{r}$ as long as eye;

"6" $\frac{5}{15}$ about $\frac{2}{8}$ as long as the eye.

"6 $\frac{7}{18}$ nearly as long as the eye.

" ${ }^{3} 4$ about $\frac{2}{8}$ as long as the eye.

"6 $\frac{5}{15}$ about $\frac{2}{3}$ as long as the eye.

" " $\frac{6}{7}$ near $\frac{8}{4}$ as long as eye.", *

We are now disposed to regard these Mazatlan specimens as identical with Paralichthys adspersus, the range of variation in the number of gill rakers in the latter probably including the former. Pacific coast of tropical America, from Gulf of California to the coast of Peru ; everywhere abundant and very variable. (adspersus, covered with spots.)

Pseudorhombus adspersus, Steindachner, Ichthyol. Notizen, v, 9, pl. 2, 1867, Chinchas Islands.

Paralichthys adspersus, JoRDAN \& GILBERT, Proc. U. S. Nat. Mns. 1882, 370; JORDAN \& Grzbert, Bull. U. S. Fish. Comm. 1882, 108 and 111; Jornan, Cat. Fish N. A., 133, 1885; Jordañ \& Goss, Review Flounders and Soles, 246, 1889; JoRdan \& Williams, Proc. Cal. Ac. Sci. 1895, 503.

2995. PARALICHTHYS WOOLMAYI, Jordan \& Williams.

Head $3 \frac{1}{2}$; depth abont 2 ; gill rakers $5+11$. D. 74 ; A.57; P. $12 ;$ V. 6 ; scales 100. Flesh firm; body oblong; mouth large, mandible heavy, not projecting; about 8 teeth on each side of lower jaw, the anterior ones long and slender; teeth in upper jaw smaller than those in lower jaw,

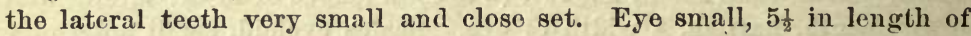
head; interorbital area moderately prominent, narrow, about $\frac{2}{5}$ length of eye. Scales cyeloid, small anteriorly and increasing in size posteriorly, covering head and fins; lateral line greatly arched anteriorly, arch about $3 \frac{1}{2}$ times in length of straight portion. Gill rakers slender, the longest about $\frac{1}{2}$ in length of eye. Pectoral and ventral fins small; pectoral about $\frac{1}{2}$ in length of head; origin of dorsal opposite anterior margin of eye; caudal ending in an obtuse angle, not double concave; caudal peduncle strong; anal spine obsolete. Body and fins blotched with deep brown and pearly white and specked with very dark brown, blotches more definite on median fins and especially on caudal where there are 3 indefinite lines of blotches crossing the fin. Galapagos Islands. One specimen taken by the Albatross in 1890, which was at first identified as Paralichthys adspersus, from which species it differs but little exeept in the number of gill rakers. (Named for Mr. Albert Jefferson Woolman, of Duluth, Minnesota, in recognition of his work on the fishes of Mexico and Florida.)

Paralichthys woolmani, Jordan \& Williams, Proc. U. S. Nat. Mus. 1896, 457, Galapagos Islands. (Type, No.47575. Coll. Albatross.) 


\section{PARALICHTHYS DENTATUS (Linnæus).}

(Summer Flounder.)

Head $3 \frac{1}{2}$ to 4 ; depth $2 \frac{2}{5}$; eye 6 in heal; maxillary 2 ; pectoral $2 \frac{1}{5}$; ven-

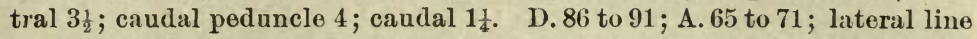
108 (tubes). Curve of lateral line $3 \frac{2}{8}$ to $4 \frac{1}{8}$ in straight portion; body ovate; maxillary about $\frac{1}{2}$ head, reaching past posterior margin of eye; mouth large, oblique, the gape curved; canines large, conical, wide set; gill rakers comparatively long and slender, longest $\frac{2}{8}$ eye, $5+15$ to $6+18$ in number; interorbital area a rather flattish ridge, in the adult about equal to vertical diameter of eye, narrower in the young, forming a bony ridge; scales cyeloid, each with mumerous small accessory scales; vertebræ $11+$ $30=41$. Color in life, light olive brown; adults with very numerous small white spots on body and vertical fins; sometimes a series of larger white spots along bases of dorsal and anal fins; about 14 ocellated dark spots on sides, these sometimes little conspicuous, but always present; a series of 4 or 5 along base of dorsal, and 3 or 4 along base of anal, those of the 2 series opposite, and forming pairs; 2 pairs of smaller less distinct spots midway between these basal series and lateral line anteriorly, with a small one on lateral line in the center between them; a large distinct spot on lateral line behind middle of straight portion; fins without the round dark blotches. Atlantic coast of United States, from Cape Cod to Florida; the common flounder of the coasts of the Northern States, its range apparently not extending much south of Charleston. Of the species found in that region it is the most important from a commercial point of view. It reaches a length of about 3 feet and a weight of about 15 pounds. It has been confounded by nearly all writers with the more southern species now called $P$. lethostigmus, from which it is best distinguished by its much greater number of gill rakers and by its mottled coloration. On aceount of this confusion it is impossible wholly to disentangle its synonymy from that of $P$. lethostigmus. So far as the proper nomenclature of the two is concerned, this confusion makes little difference. There is no doubt that this is the original Pleuronectes dentatus of Linneus, as the original Linnean type is still preserved in London. This has been examined by Dr. Bean and its identity with the present species fully established. It seems also eertain that this is the Platessa ocellaris of De Kay, who properly distinguishes his ocellaris from his oblonga, the latter being $P$. lethostigmus. A little doubt must be attached to the $P$. melanogaster of Mitchill, very scantily described from a doubled (black-bellied) example of this species or of $P$. lethostigmus. As the former species is much more common about New York than the latter it is probable that Mitchill's fish belonged to it. We have also received a doubled example from New York corresponding exactly to Mitchill's description. We may therefore regard the name melanogaster as a synonym of dentatus. The differences in the gill rakers of these species were first noticed by Jordan \& Gilbert in 1883. These authors erroneously referred all these synonyms to the species with the few gill rakers and described the present one as new under the name Paralichthys ophryas. The discovery of the Linnæan type of Pleuronectes dentatus has rendered a reconsideration of this matter 
necessary, and it is evident that to the " $P$. ophryas" belong also the prior names dentatus, melanogaster, and ocellaris. (dentatus, toothed.)

Pleuronectes dentatus, LiNNAUS, Syst. Nat., Ed. xII, 1, 458, 1766, and of numerous copyists; MrrchilL, Trans. Lit. and Phil. Soc. N. Y. 1815, 390.

Pleuronectes melanogaster, MrTchIL, Trans. Lit. and Phil. Soc. N. Y. 1815, 390, New York; doubled example.

Platessa ocellaris, De KAY, N. Y. Fanna: Fishes, 300, pl.47, fig. 152, 1842, New York.

Paralichthys ophryas, JORDAN \& GILBERT, Synopsis, 822, 1883, Charleston.

Platessa dentata, Storer, Rept. Fish. Mass., 143, 1839.

Pseudorhombus dentatus, Goode \& BEAN, Proc. U. S. Nat. Mus. 1879, 123.

Paralichthys dentatus, GOoDE, Nat. Hist. Aquat. Anim., 178, 1884, detailed account; includes P.lethostigma; Jordan, Cat. Fish. N. A., 134, 1885; JordAN \& Goss, Review Flounders and Soles, 246, 1889.

Preudorhombus ocellaris, GÜNTHER, Cat., Iv, 430, 1862; JoRdAN \& GILBERT, Proc. U. S. Nat. Mus. $1878,370$.

Chanopsetta ocellaris, Gill, Proc. Ac. Nat. Sci. Phila. 1864, 218.

Paralichthys ocellaris, Jordan \& GiLBerT, Proc. U. S. Nat. Mus. 1882, 617.

2997. PARALICHTHYS LETHOSTIGMUS, Jordan \& Gilbert.

(SOUTHERN Flounder.)

Head $3 \frac{2}{3}$; depth $2 \frac{1}{8}$. D. 85 to 92 ; A. 65 to 73 ; pores about 100 . Body ovate, more or less compressed and opaque; no distinct, definitely placed ocelli; scales eycloid. Mouth wide, oblique, the mandible very heavy and much projecting; 8 to 10 teeth on each side of the lower jaw, the 2 anterior teeth very long; anterior teeth of upper jaw strong, but smaller than those in the lower jaw; the lateral teeth very small and elose set; eyes small, shorter than the snout, about 6 in head; interorbital space in adult broad, flattish, and scaly, as wide as length of eye. Accessory scales few; gill rakers $2+10$, lanceolate, dentate, wide set, and much shorter than the eye; caudal peduncle rather loug; length of arch of lateral line nearly $\frac{1}{8}$ that of straight part. Color dusky olive, darker than in $P$. dentatus, and with very few darker mottlings or spots. This species is the common large flounder of the South Atlantic and Gulf coasts of the United States, ranging as far north as New York. It very closely resembles Paralichthys dentatus, with which it has been repeatedly confounded. It is, however, sharply distinguished by the character of the gill cakers. It is also always darker in color, and almost uniform, while $P$. dentatus is usually profusely spotted. Its only tenable name is the recent one, Paralichthys lethostigmus. South Atlantic and Gulf coasts of United States, north to New York. ( $\lambda \dot{\eta} \theta \eta$, forgetfulness; $\sigma \tau i \gamma \mu \alpha$, spot, from the absence of spots.)

Platessa oblonga, DE KAY, New York Fauna: Fishes, 299, pl.48, fig. 156, 1842, New York, not Pleuronectes oblongus, Mitchill; Storer, Syn. Fish. N. A., 477, 1846.

Paralichthys lethostigma, Jordan \& GiLbert, Proc. U. S. Nat. Mus. 1884, 237, Jacksonville, Florida; JoRdan \& Goss, Review Flounders and Soles, 247, 1889.

Pseudorhombus oblongus, GÜNTHER, Cat., IV, 426, 1862.

Choenopsetta dentata, Gil,, Proc. Ac. Nat. Sci. Phila. 1864, 218.

Pseudorhombus dentatus, Goode, Proc. U.S. Nat. Mus. 1879, 110; Goode \& Bean, Proc. U. S. Nat. Mus. $1879,123$.

Paralichthys dentatus, Jordan \& Gilbert, Proc. U. S. Nat. Mus. 1882, 302; Jordan \& GiLBerT, Proc. U. S. Nat. Mus. 1882, 617; Bean, Cat. Coll. Fish, Proc. U. S. Nat. Mus. 1883, 45; JORDAN \& GILBERT, Synopsis, 822, 1883. 


\section{PARALIChTHYS SQUAMLENTUs, Jordan \& Gilbert.}

Head 3 ; ; depth 2. D. 78 ; A. 59 ; scales 123 (pores). Body deep, strongly compressed; caudal peduncle very short; profile angulated at front of upper eye. Head wide, the eyes large, wide apart. Mouth very large, oblique, the broad maxillary reaching well beyond pupil, its length more than $\frac{1}{2}$ the head. Lower jaw projecting; mandible with a sharp compressed knob at symphysis; teeth few, unequal, in a single row, about 8 in each jaw canine-like, the 2 in front of lower jaw longest; lateral teeth of upper jaw minute. Interorbital space a narrow scaleless bony ridge, slightly concave anteriorly, scarcely $\frac{1}{2}$ diameter of pupil. Scales very small, smooth, adherent; eurve of lateral line $4 \frac{1}{8}$ in straight part; snout, jaws, and preopercle naked. Gill rakers short, $3+9$ in number, triangular, ronghly toothed, little higher than wide, the longest nearly $\frac{1}{2}$ eye. Dorsal beginning over front of eye, the anterior rays $4 \frac{1}{2}$ in head; pectoral short, shorter than maxillary; anal spine weak; caudal double rounded. Brownish; body and fins spotted with darker; candal mottled with white; peetorals banded, with dark spots. South Atlantic and Gulf coasts of United States. This species is very close to Paralichthys albiguttus, from which it differs chiefly in the small scales. It seems to be rather rare. Besides the original types from Pensacola, another referred to the same species is in the National Museum from Charleston. (squamilentus, scaly.)

Paralichthys squamilentus, JoRDAN \& GiLBerT, Proc. U.S. Nat. Mus.1882, 303, Pensacola (Type, No. 30862); Jordan \& Gilbert, Synopsis, 823, 1883; Bean, Cat. Coll. Fish, U. S. Nat. Mus. 1883, 45; JoRdaN \& Goss, Review Flounders and Soles, 248, 1889.

2999. Paralichthys albigutTUs, Jordan \& Gilbert.

(GUlF Flounder.)

Head $3 \frac{8}{4}$; depth $2 \frac{1}{3}$. D. 72 to 80 ; A. 59 to 61 ; scales 9 to 100 (pores); eye 6 or 7 in head; maxillary $1 \frac{7}{8}$; pectoral $2 \frac{1}{5}$; ventral 3 ; caudal $1 \frac{1}{2}$; curve of lateral line 3 in straight part. Body moderately elongate-elliptical; mouth large, the maxillary reaching past eye; jaws subequal; teeth strong, slender, and curved, about 7 on side of lower jaw, 4 or 5 moderate canines in front of upper jaw, the lateral teeth being minute, close set; interorbital space $\frac{2}{3}$ length of eye, the upper ridge rather prominent behind upper eye, scaled posteriorly; mandibles naked; a small patch of scales on maxillary; gill rakers broad and toothed behind, the longest $2 \frac{1}{2}$ in eye, $3+10$ in number. Fins low; anterior rays of dorsal not elevated nor exserted, the longest rays behind the middle, $2 \frac{8}{4}$ in head; pectoral not reaching to end of curve; caudal double lunate. Scales moderate, cycloid, covered with epidermis which bears small flaps about the borders of many of the scales. Dark olive, mottled with dusky, and marked by numerous more or less distinct pale spots, which are sometimes obsolete; three dark spots, bordered with white, sometimes present, particularly in the young, 1 on lateral line posteriorly and 1 above and below anterior end of straight part of lateral line. Vertebræ $10+27=37$. South Atlantic and Gulf coasts of the United States. This species is common on the South Atlantie and Gulf coasts. It has the few gill rakers of $P$. lethostigmus, the mottled coloration of $P$. dentatus, while from each it is distinguished by its smaller number 
of dorsal and anal rays. In the number of its vertebro it agrees with $P$. lethostigmus. It seems to reach a smaller size than either of these species. Here described from a specimen, 16 inches in length, collected at Cedar Key, Florida. (albus, white; gutta, spot.)

Pseudorhombus dentatus, Jordan \& Gilbert, Proc. U. S. Nat. Mus. 1878, 370; not of LiNNAEUS.

Paralichthys albigutta, Jordan \& GILBERT, Proc. U. S. Nat. Mus. 1882, 302, Pensacola (Type, No. 30818. Coll. Dr. Jordan); Jordan \& Gilbert, Synopsis, 823, 1883; Jordan \& Swain, Proc. U. S. Nat. Mus. 1884, 233; Jordan \& Goss, Review Flounders and Soles, 248, 1889.

\section{PARALIChTHIS OBLONGLS (Mitchill).}

(Four-SPOTted FloUNdER.)

Head 4; depth $2 \frac{1}{4}$. D. 72 ; A. 60 ; scales 93 . Body comparatively elongate, strongly compressed. Eyes large, nearly 4 in head, separated by a prominent, narrow, sharp ridge. Upper jaw with very numerous small, close-set teeth laterally, and 4 or 5 canines in front; the lateral teeth abruptly smaller than the anterior; each side of lower jaw with 7 to 10 teeth. Chin prominent. Maxillary narrow, reaching past middle of pupil, $2 \frac{1}{4}$ in length of head. Gape cnrved; gill rakers short and toothed behind, $2+8$. Scales weakly ctenoid or cycloid. Dorsal low, beginning over front of eye, some of the anterior rays exserted, but not elongate, the longest rays behind middle of fin, not quite $\frac{1}{2}$ hcad; caudal $1 \frac{1}{4}$ in head; pectoral 15; anal spine obsolete. Grayish, thickly mottled with darker and somewhat translucent; 4 large, horizontally oblong, black ocelli, each surrounded by a pinkish area, 1 just behind middle of the body below the dorsal, 1 opposite this above anal, 2 similar smaller spots below last rays of dorsal and above last of anal. Coasts of New England and New York. This species is rather common on the coast of Cape Cod and the neighboring islands, but it has been rarely noticed elsewhere. The limits of its range are not yet definitely known. It is a very strongly marked species. Its translucency of coloration indicates that it lives in deeper water than the other species of the genus. Here described from specimen from Woods Hole.

Another specimen in our collection from Woods Hole, Massachusetts, referred to this species, shows the following characters: Brownish, somewhat mottled, without traces of ocelli (possibly faded); fins similar. Body rather elongate, slenderer than in other species and more compressed; mouth rather large, oblique, the lower jaw not projecting, the naxillary $2 \frac{1}{5}$ in head, reaching to opposite posterior border of pupil ; about 12 teeth on each side of lower jaw, the anterior rather long, about equal to anterior teeth of upper jaw; lateral teeth of upper jav becoming gradually smaller posteriorly, much larger, less numerous, and more widely set than in other species of this genus. Eyes large, longer than snout, 4 to $4 \frac{1}{2}$ in head, separated by a narrow, elevated, bony ridge, narrower than pupil, anteriorly scaleless, and curved behind the upper ejo posteriorly. Scales moderate, cycloid, rather thin; curve of lateral line $4 \frac{8}{4}$ in straight part. Gill rakers $2+8$ in number, rather long and slender, about $4 \frac{1}{2}$ in maxillary. Dorsal beginning above middle of eye, its anterior rays not longer than 
others, the middle rays a little louger than longest of anal, which are about $\frac{1}{2}$ head; caudal as long as head; anal spine obsolete; ventrals small; pectoral $1 \frac{8}{4}$ in head. Head $4 \frac{1}{6}$; deptl $2 \frac{3}{5}$. D. 77 ; A. 63 ; scales 90 . Length about 14 inches. (oblongus, oblong.)

Pleuronectes oblongus, MrтchıL, Trans. Lit. and Phil. Soc., I, 1815, 391, New York. .

Platessa quadrocellata, Storer, Proc. Boston Soc. Nat. Hist. 1847, 242; Storen, Mist. Fish. Mass., 397, pl. 31, fig. 3, Provincetown.

Choenopsetta oblonga, GiLr, Proc. Ac. Nat. Sel. Phila. 1864, 218.

Paralichthys oblongus, Goode, Proc. U.S. Nat. Mus. 1880, 472 ; Jordan \& Gilbert, Synopsis, 824, 1883; Jordan \& Goss, Review Flounders and Soles, 249, pl. 8, 1889; GoodE \& BEAN, Oceanic Ichthyology, 436, 1896.

\section{RAMULARIA, Jordan \& Evermann.}

Ramularia, JoRdan \& Evermann, new genus (dendriticus).

This genus is close to Ancylopsetta, differing mainly in the structure of the lateral line, the tubes of which are borne by series of smaller, concealed cycloid scales, the free edges of which are notched to the opening of the pore; these scales are concealed in the skin, and from the pores proceed backward membranaceous tubes which ramify over the bases of contiguous scales. Dorsal scarcely elevated in front; left ventral much produced. Body broad ovate, sinistral, with very rough scales. Gill rakers few, very broad. (ramulus, a branchlet, from the tubes of the lateral line.)

\section{RAIULARIA DENDRITICA (Gilbert).}

Head $3 \frac{5}{6}$ in length; depth $1 \frac{2}{3}$. D. $84 ;$ A. 63 ; scales $100 ; 36$ scales in a series upward and backward from lateral line. Body very broad, its depth $1 \frac{2}{8}$ in length, the two outlines equally curved; profile not very strongly angulated in front of upper eye. Lower eye slightly in advance of upper; interorbital space a rather broad, convex, scaly ridge, about $\frac{1}{3}$ upper eye, which is contained about 5 times in head and is equal to snout. A blunt spine on suout on head of maxillary. Nostril openings very broad, without tube, the anterior with a narrow flap. Mouth moderate, very oblique, the gape curved, the maxillary reaching slightly beyond vertical from middle of lower eye, 3 in head. Teeth in a single, rather close-set series in each jaw, strong, conical, directed very obliquely inward, becoming. gradually larger toward front of jaw, but not canine-like. Gill rakers very short, barely movable, as broad as long, strongly toothed, 6 on anterior limb. Dorsal beginniug over middle of upper eye, the anterior rays partly free toward tips, but little, if any, elevated above those that follow, the first $2 \frac{2}{3}$ in head; dorsal highest in its posterior third, the longest ray $22_{5}^{2}$ in head; anal similar, the rays of posterior third of each fin slightly forked at tip; caudal peduncle deep and short, its depth about $\frac{1}{2}$ head, its length $\frac{1}{2}$ its depth; candal rounded, almost double truncate; ventrals with narrow bases, the left one slightly in advance of the right; fin greatly produced, reaching far beyond front of anal, a trifle shorter than head; left pectoral $1 \frac{3}{5}$ in head. Scales very strongly ctenoid, the edge spinous, the entire exposed portion rough; width of anterior arch of lateral line $3 \frac{1}{2}$ in straight portion; tubes of lateral line borne by a series of smaller con$3030-88$ 
cealed cycloid scales, the free edges of which are notched to the opening of the pore; these scales entirely covered by the integument, and from the pores there proceed backward membranaceous tubes, ramifying over the bases of contiguous scales; this is true also of lateral line of blind side; eyed side entirely scaled except snout and mandible. Vertical fins covered with thick skin, each ray accompanied by 1 or 2 series of ctenoid scales; left ventral also scaled. Color olive brown, with 3 large black ocellated spots larger than orbit, the posterior one on lateral line in front of caudal peduncle, the 2 anterior under middle of dorsal, halfway between lateral line and dorsal and anal ontlines, respectively; each spot with a light center; distal portion of vertical fins more or less brown on right side. (Gilbert.) Gulf of California. A single specimen, 13 inches long, from Albatross Station 3022, in 11 fathoms. (dendriticus, like a treo, branched; $\delta \dot{\varepsilon} v \delta \rho o \nu$, treo.)

Ancylopsetta dendritica, Gilbert, Proc. U.S. Nat. Mus. 1890, 121, Gulf of California at Albatross Station 3022 , in II fathoms.

ro26. ANCYLOPSETTA, Gill.

Ancylossetta, Gill, Proc. Ac. Nat. Sci. Phila. 1864, 224 (quadrocellata).

Body sinistral, broadly ovate, the depth more than $\frac{1}{2}$ length; mouth moderate; teeth uniserial, unequal, some of the anterior enlarged; caudal fin with a very short peduncle; scales very strongly etenoid on both sides of the body; anterior rays of dorsal notably exserted, the rays of the anterior part of the fin elongate, thus forming a distinct lobe; gill membranes considerably united; gill rakers short and broad, with rough teoth; left ventral produced; vertebræ about 35 . This genus is very close to Paralichthys, differing in the subsessile candal fin, the short gill rakers, the rough scales, and in the prolongation of the anterior rays of

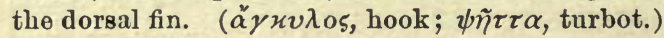

\section{ANCYLOPSETTA QUADROCELLATA, Gill.}

Head $3 \frac{8}{4}$ to $3 \frac{4}{5}$; depth $1 \frac{2}{8}$. D. 70 to $76 ; A .57$ to 59 ; pores in lateral line 83 to 90 ; vertical series of scales 70 ; fourth or fifth dorsal ray longest, nearly $\frac{2}{8}$ length of head. Caudal $1 \frac{1}{5}$ in head; ventral of colored side $1 \frac{2}{3}$. Body oval, compressed, very deep; an abrupt"angle above eye; mouth very small, the maxillary reaching to below middle of orbit, $2 \frac{1}{2}$ in length of head; teeth comparatively small, about 14 on each side of lower jaw; no strongly differentiated canines in either jaw. Eyes moderate, separated by a very narrow, sharp, scaly ridge; gill rakers very short, thick, few in number, $2+6$ or 7 , the longest less than $\frac{1}{2}$ diameter of pupil; scales rather small, very strongly ctenoid, those on blind side also rough; curve of lateral line rather low; tubes of lateral line simple; dorsal beginning in front of pupil, its anterior rays long and filiform, much exserted; candal short and rounded, 1 if in head; ventral fin of colored side rather long, as long as pectoral, $\frac{1}{2}$ length of head; anal spine wanting. Brownish olive, with 4 large, oblong, ocellated spots, the first above the arch of the lateral line; the 3 posterior forming an isosceles triangle, the hindmost 
being on the lateral line; the ocellated spots are frequently furnished with a bright white center, and the sides and vertical fins have often a few seattered white spots; a suall, indistinct, dark spot on middle of each eighth or tenth ray of dorsal and anal. Vertebr:e $9+26=35$. South Atlantic and Gulf coasts of the United States; not rare; a very handsome species. (quadrocellatus, having 4 ocelli.)

Ancylopsetta quadrocellata, GIL, Proc. Ac. Nat. Sci. Phila. 1864, 224; not Platessa quadrocellata, Storer; Jordan \& Goss, Review Flounders and Soles, 250, 1889.

Paralichthys ommatus, Jordan \& Ginbert, Proc. U. S. Nat. Mus. 1882, 616, Charleston; Jordan \& Gilbert, Synopsis, 824, 1883; Jordan \& Swaln, Proc. U. S. Nat. Mus. 1884 ; 234 ; JoRdAN \& Goss, Review Flounders and Soles, 250, 1889.

Pseudorhombus quadrocellatu\&, Jordan \& Gilbert, Proc. U. S. Nat. Mus. 1878, 370.

1027. NOTOSEMA, Goode \& Bean.

Notosema, Goode \& BeAN, Bull. Mus. Comp. Zool., x, No. 5, 192, 1883 (dilecta).

Body sinistral, elliptical in form, the caudal fin pedunculate. Mouth moderate, beneath the central axis of the body. Eyes large, close together, the upper one nearly encroaching upon the profile, the lower slightly in advance of the upper. Teeth in a single series in the jaws, about equally developed on each side, largest in front, absent on vomer and palatines. Pectoral fins somewhat unequal, that upon the blind side $\frac{x^{4}}{\text { as large as the }}$ other; dorsal fin commencing slightly behind anterior margin of npper eye, the first 8 rays separated into a distinct subdivision of the fin, several of them being prolonged; caudal rounded, sinistral; ventral much elongated. Scales small, etenoid on colored side of body; lateral line prominent, strongly arched, alike on both sides, the tubes simple. Gill rakers moderately numerous, rather stout, subtriangular, pectinate posteriorly. Pseudobranchiæ well developed. Vertebræ 35 . This genus is scarcely distinct from Ancylopsetta, the body more elongate, the dorsal and ventral rays more produced. ( $(\tilde{\omega} \tau o 5$, back; $\sigma \tilde{\eta} \mu \alpha$, banner.)

3003. Notosema DILECTUM (Goode \& Bean).

Head $3 \frac{1}{2}$; depth 2. D. 68 ; V. 6. A. 54 to 56 ; scales 48 (pores) on straight part of lateral line; width of interorbital area almost imperceptible; mandible reaching to middle of pupil of lower eye, its length 2 in head; upper jaw $2 \frac{1}{2}$ times length of head. Origin of dorsal over anterior margin of eye, second and third rays the longest, which are 2 in greatest depth of body; anal beginning close to vent, its posterior rays longest; caudal pedunculate, double truncate; pectoral of eyed side subtriangular, its length $5 \frac{1}{2}$ in length of body; ventral of eyed side much produced, its length more than 3 times that of its mate. Color dark brown, speckled with darker, 3 large subcircular ocellated spots nearly as large as eye, with white center, dark iris, narrow, light margin, and a brown encircling ontline, these arranged in an isosceles triangle, the apex on the lateral line, the others before it and distant from the lateral line a distance equal to their own diameter; blind side white; fins blotched with dark brown. (Goode \& Bean.) Gulf Stream. Known from the original 
types obtained in the deep waters (75 fathoms) of the Gulf Stream, off the Carolina coast. (dilectus, delightful.)

Notosema dilecta, Goode \& BeAN, Bull. Mus. Comp. Zool., x, No. 5, 193, 1883, Gulf Stream off the coast of South Carolina; Goode \& BEAN, Oceanic Ichthyology, 437, 1896.

Paralichthys stigmatias, Goode, Nat. Hist. Aquat. Anim., 182, 1881; by inadvertance for dilectus.

Ancylopsetta dilecta, Jordan, Cat. Fish. N. A., 134, 1885; Jordan \& Goss, Review Flounders and Soles, 250, 1889.

1028. GASTROPSETTA, B. A. Bean.

Gastropsetta, Barton A. BeAn, Proc. U.S. Nat. Mus. 1894, 633 (frontalis).

Body oblong-ovate, highly arched in front, covered with small, cycloid, embedded scales; lateral line arched in front, deflected downward on caudal peduncle. Teeth small, in a single series in each jaw. Dorsal fin beginning in advance of eyc, its anterior rays produced, not connected by the irregular and broadly fringed membrane. Gill rakers very short, almost as broad as long, few in number. Ventral of eyed side produced, ending in a long filamentous ray in the young. This genus is closely allied to Ancylopsetta, from which it differs in form of body, and especially in the entirely smooth scales, singularly branched and produced anterior dorsal rays, and very short and broad gill rakers. ( $\gamma \alpha \sigma \tau \dot{\eta} \rho$, belly; $\psi \tilde{\eta} \tau \tau \alpha$, turbot or flounder.)

3004. GASTROPSETTA FRONTALIS, B. A. Bean.

Head $4 \frac{8}{4}$; depth $2 \frac{1}{2}$; middle caudal rays $2 \frac{4}{5}$; eye large, $3 \frac{8}{4}$ in head. D. 60 ; A. 48 ; V. 6 ; P. I, 10 . Mouth of moderate size, maxillary $2 \frac{1}{2}$ in head, the jaws curved; interorbital ridge prominent, very narrow. Dorsal lieginning in front of eye on snout, its anterior rays singularly branched, the third and fourth longest, almost equaling length of head; anal fin beginning at vent, which is situated on blind side, its anterior rays scarcely produced; ventral of colored side much produced; middle caudal rays long. Color in spirits, light brown; 3 black spots on body, 2 along back, and 1 near anal base; fins with dusky blotches; several vertical stripes across eyes. A smaller specimen from Albatross Station 2317 has D. 62; A. 52; V. 6; P. I, 11. Gill rakers short, broad laminx, 2+7. Teeth weak, uniserial. Anterior rays of dorsal greatly produccd, the third $1 \frac{1}{2}$ times as long as head. Ventral of eyed side very long, ending in a thread-like filament. Color as in the preceding. An example from Albatross Station 2373 near Apalachicola, is $224 \mathrm{~mm}$. long; its depth $90 \mathrm{~mm}$. D. 60; A. 49; P. I, 10; V. 6; C. 15. Vent situated in a deep notch, which forms the front margin of abdomen, and not on side, as in other specimens. Color darker than that of the Key West examples, being dark reddish brown; body spotted and fins blotched as in the preceding. Two specimens obtained by the Albatross, January 15, 1885, at Station 2317, Lat. $24^{\circ} 25^{\prime}$ $45^{\prime \prime}$ N., Long. $81^{\circ} 46^{\prime} 45^{\prime \prime}$ W., near Key West, Florida, in 45 fathoms of water, the type 8 inches long, the other one 6 inches. (B. A. Bean.) (frontalis, pertaining to the forehead.)

Gastropsetta frontalis, Barton A. Bean, Proc. U. S. Nat. Mus. 1894, 633, Key West. (Type, No. 37668, U.S. Nat. Mus. Coll. Albatross.) 


\section{PLEURONICHTHYS, Girard.}

Pleuronichthys, GIRARD, Proc. Ac. Nat. Sci. Phila. 1854, 139 (conosus).

Heteroprosopon, BLEEKER, Comptes Rendus Acad. Amsterdam, XIII, 1862, 8 (cornutus).

Parophrys, GüNTHER, Cat. Fishes, IV, 454, 1862; not of Girard.

Eyes and color on the right side. Body deep; head short, with very short, blunt snout; month small, with several series of slender, acute teeth, which are most developed on the blind side, and are often wanting in 1 or both jaws on the colored side; no teeth on vomer or palatines; lips thick, with several lengthwise folds within which is a series of sliort fringes. Lower pharyngeals narrow, each with a double row of very small teeth. Gill rakers wide set, very short and woak. Lateral line nearly straight, with a dorsal branch in our species. Scales small, cycloid, nonimbricate, embedded. Dorsal fin anteriorly twisted from the dorsal ridge toward the blind side; anal fin preceded by a spine; caudal fin convex behind. Intestinal canal elongate. Herbivorous species, feeding chiefly on alga. Pacific Occan. This well-marked genus contains 3 American species, which are very closely related to each other. The Asiatic species, Platessa cornuta, Schlegel, of the coasts of China and Japan, is also a member of this group, having an accessory branch to the lateral line as in the American species. This species bears some resemblance to $\mathrm{Pl}$. verticalis. The species of Pleuronichthys spawn in the spring, and live in comparatively deep water. ( $\pi \lambda \varepsilon \tilde{v} \rho \circ \nu$, side; $i \chi \theta \dot{v} \varsigma$, fish.)

a. Dorsal fin beginning on the level of the lower lip, its first 9 rays on the blind side. DECURRENS, 3005.

aa. Dorsal fin beginning on level of upper lip, its first 5 rays being on the blind side.

b. Interorbital ridge posteriorly with a strong spine directed backward, some tubercles on interorbital ridge.

VERTICALIS, 3006 .

$b b$. Interorbital ridge prominent, but without spines and conspicuous tubercles. CaENOSUS, 3007.

3005. PLEURoNiChTHYS DECURRENS, Jordan \& Gilbert.

Head $3 \frac{1}{2}$; depth $1 \frac{2}{3}$. D. 72 ; A. 40 ; scales 80 ; eye 3 in head; maxillary $4 \frac{1}{2}$; pectoral $1 \frac{2}{3}$; highest dorsal rays $1 \frac{1}{2}$; anal rays $1 \frac{3}{5}$; caudal 1 . Body short and wide; mouth very small, the maxillary reaching nearly to pupil; teeth villiform, in moderate bands on blind side, a narrow band on eyed side of lower jaw; eyes very large, the upper edge of upper eye even with profile; snout extremely short; a blunt tubercle in front of upper eye, another at each end of the narrow interorbital ridge, the posterior largest, but usually not spine-like; 2 or 3 above the latter behind the upper eye; some prominences above the opercle; gill opening short, not extending above upper edge of pectoral. Dorsal beginning very low, on level of end of maxillary, its first 9 rays on the blind side; anal spine well developed, the origin of anal a little behind vertical from base of pectoral; pectoral of eyed side a little larger than its mato, both rounded behind; ventral of blind side shorter than that of eyed side, and placed slightly before it, candal well rounded. Scales cycloid, embedded, a space between them anteriorly; lateral line without arch, slightly curved. Color brownish, usually much mottled with chocolate and grayish, often finely spotted with brownish on body and fins; all fins darker than body; 
dorsal, anal, caudal, and ventrals narrowly edged with white; pectoral uniformly blackish. Pacific coast of United States, south to Monterey. This species is rather scarce along the California coast, being taken chiefly in deep water. It reaches a larger size than either $P$. verticalis or $P$. conosus. Here described from a specimen from San Francisco market, 8 inches in length. (decurrens, running down.)

Pleuronichthys conosus, Lockington, Proc. U. S. Nat. Mus. 1879, 97; not Pleuronichthys conosus, GIRARD.

Pleuronichthys quadrituberculatus, JoRdan \& GmBERT, Proc. U. S. Nat. Mus. 1880, 50, not of Pallas; Jordan, Nat. Hist. Aquat. Anim., 189, 1884.

Pleuronichythys decurrens, Jordan \& Gilbert, Proc. U.S. Nat. Mus. 1880, 453, San Francisco; Monterey Bay (Coll. Jordan \& Gilbert); Jordan \& Gllbrrt, Proc. U. S. Nat. Mus. 1881, 69; Jordan \& Gilbert, Synopsis, 829, 1883; Jordan \& Goss, Review Flounders and Soles, 282, 1889.

3006. PIEURONICHTHYS VERTICALIS, Jordan \& Gilbert.

Head 4 in body; depth 2. D. 65 ; A. 45 ; scales about 80 ; vetebræ $13+$ $25=38$. Form broad ovate, the outlines regular; head small, somewhat constricted behind the upper eye; eyes large, but smaller than in $P$. decurrens. Interorbital ridge narrow; a small tubercle or prominence in front of upper eye; a large one in front of upper edge of lower eye; another larger and sharper at interior edge of the interocular space; another at the posterior edge of interocular spine ridge; this latter developed into a long, sharp, triangular spine, which is nearly as long as the pupil, and is directed backward; a prominent tubercle at posterior lower angle of upper eye; upper edge of opercle somewhat uneven, but no other tubercles present. Mouth small, as in other species; the lips thick, with lengthwise plicse. Teeth in a broad band on the left (blind) side of each jaw; no teeth on the right side in either jaw. Gill rakers very small, weak, and flexible, about 10 in number. Scales essentially as in other species, small, cycloid, embedded, scarcely imbricated; lateral line nearly straight, with an accessory branch which extends to the middle of the dorsal fin. Dorsal fin beginning on blind side at level of premaxillary, there being but about 4 of its rays on left side of median line; vertical fins less elevated than in other species, the longest rays of dorsal about $\frac{1}{2}$ length of head; anal fin preceded by a spine; caudal peduncle short and deep; caudal fin elongate, rounded behind; pectorals short, nearly equal; ventrals moderate, reaching anal spine. Color dark olive brown, with round grayish spots, the body and fins mottled with blackish. This species agrees in habits and general characters with Plcuronichthys decurrens. Coast of California, in rather deep water. The above description from the original type. (verticalis, pertaining to the vertex.)

Pleuronichthys verticalis, JoRdan \& GILBERT, Proc. U. S. Nat. Mus. 1880, 49, San Francisco (Coll. Jordan \& Gilbert); Jordan \& GilberT, Proc. U.S, Nat. Mus. 1881, 169; Jordan \& Gilbert, Synopsis, 829, 1883; Jordan, Nat. Hist. Aquat. Anim., 189, 1884; JokDAN \& Goss, Review Flounders and Soles, 282, 1889.

3007. PLEURonichthys chNosus, Girard.

Head $3 \frac{8}{4}$; depth 2. D. 68 ; A. 49 ; scales 61 ; eye 3 in head; pectoral $1 \frac{1}{2}$; dorsal and anal rays $1 \frac{1}{2}$; candal a little longer than head. Body ovate; snout scarcely produced; mouth small, maxillary reaching past front of 
lower eye; 3 or 4 rows of teeth on blind side of jaws, 1 on eyed side of lower; eyes very large; interorbital a high, narrow ridge, somewhat angulated behind, but with no conspicuous spine or tubercle; snout very short, about $\frac{1}{2}$ eje; gill opening not extending above upper edge of pectoral. Scales cycloid, embedded, some distance apart anteriorly, their edges not in contact; lateral line nearly straight, with a long dorsal branch which reaches past middle of body. Dorsal and anal high; origin of dorsal on blind side on a level with premaxillary, its first 5 rays on blind side; origin of anal under base of pectoral; pectoral of eyed side a little larger than its mate; caudal well rounded. Color dark brown, usually mottled, the colors variable; our specimens from Puget Sound, very dark, the fins colored like body, with light and dark spots; a conspicuous black spot on lateral line on middle of sides. Pacific coast, from Sitka to San Diego. This species is comparatively common in rather deep water and about rocks, being most abundant about Puget Sound. Its apparent abundance as compared with the other species of the genus is doubtless due to its inhabiting shallower waters than they. It is quite variable in form. The above description from a specimen, 6 inches long, from Seattle. (cœnosus, muddy.)

Pleuronichthys conosus, Girard, Proc. Ac. Nat. Sci. Phila. 1854, 139, San Francisco; Girard, U. S. Pac. R. R. Surv., X, Fishes, 151, 1858; Lockington, Rep. Com. Fisheries California, 1878-79, 45; Lockintron, Proc. U. S. Nat. Mus. 1879, 97; Jordan \& GilrerT, Proc. U.S. Nat. Mus. 1880, 50; Jordan \& Gilbert, Proc. U.S. Nat. Mus. 1880, 453; JokDAN \& Gilbert, Proc. U. S. Nat. Mus. 1881, 68; Jordan \& Gilbert, Synopsis, 830, 1883; Jordan, Nat. Hist. Aquat. Anim., 189, 1884; JordAN \& Goss, Review Flounders and Soles, 282, 1889; Jordan, Proc. Cal. Ac. Sci. 1895, 852.

Parophrys coenosa, GüNther, Cat., IV, 456, 1862.

\section{ro3o. HYPSOPSETTA, Gill.}

\section{(Diamond Flounders.)}

Hypsopsetta, Grul, Proc. Ac. Nat. Sci. Phila.1864, 195 (guttulatus).

Eyes and color on the right side; body broad, ovate, rhomboid; mouth very small; teeth slender, equal, acute, in several series; lips thick, not plicate; lateral line nearly straight, with an accessory dorsal branch; scales small, smooth; dorsal fin beginning on the dorsal ridge, not turned to the blind side at its insertion; anal spine present; caudal fin convex; gill rakers little developed. This genus consists of a single species, abundant on the coast of California. It is very close to Pleuronichthys, from which it differs only in a few characters of comparatively minor importance. Its range is in shallower and warmer water than that of the species of Pleuronichthys, and, in accordance with this fact, its flesh is firmer and its number of vertebro fewer than in the latter genus. ( $\ddot{\psi} \psi t$, deep; $\psi \tilde{\eta} \tau \tau \alpha$, flounder.)

3008. HYSOPSETTA GUTTULATA (Girard).

(Diamond Flounder.)

Head 38 ; depth 12. D. 68 ; A. 50; scales 95 . Body very deep, somewhat angulated near middle of back and belly; eyes moderate, separated by a flattish, raised area; head without spines or tubercles; scales of opercular 
region little developed; those of blind side reduced; no teeth on right side of either jaw; accessory lateral line long, $\frac{1}{2}$ length of body; anal spine snall; pectorals about $\frac{1}{2}$ length of head; ventrals rather short; caudal peduncle much deeper than long; caudal large, nearly as long as head. Brown, with numerous pale-bluish blotches in life, these disappearing in spirits; blind side white, with a strong tinge of yellow along profile of head; fins plain, sometimes with black specks. Coast of California and southward, Cape Mendocino to Magdalena Bay. This speeies is one of the most abundant in the shore waters of the California coast. It is a foodfish of fair quality. (guttulatus, with small spots.)

Pleuronichthys guttulatus, Girard, Prąc. Ac. Nat. Sci. Phila. 1856, 137, Tomales Bay, California (Coll. E. Samuels) ; GrRarD, Journ. Boston Soc. Nat. Hist. 1857, pl. 25, figs. 1-4 ; Girard, U.S. Pac. R. R. Surv., x, Fishes, 152, 1858; Lockington, Rep. Com. Fisheries California, 1878-79, 44; Lockington, Proc. U. S. Nat. Mus. 1879, 94.

Parophrys ayresi, GüNTHer, Cat., IV, 1862, 457, San Francisco. (Coll. Dr. W. O. Ayres.)

Pleuronectes guttulatus, GüNTHER, Cat., IV, 445, 1862.

Hypsopsetta guttulala, Gill, Proc. Ac. Nat. Sci. Phila. 1864, 195; Jordan \& Gilbert, Proc. U.S. Nat. Mus. 1880, 453; Jordan \& Gilbert, Proc. U. S. Nat. Mus. 1881, 68; Jordan \& Gilbert, Synopsis, 830, 1883; Jordan, Nat. Hist. Aquat. Anim., 185, 1884; Jordan \& Goss, Review of Flounders and Soles, 283, 1889.

\section{I03I. PAROPHRYS, Girard.}

Parophrys, GrRard, Proc. Ac. Nat. Sci. Phila. 1854, 139 (vetulus).

Body rather elongate, covered with small, cycloid scales; scales of the head roughish. Head rather pointed; mouth small, the teeth uniserial, all more or less blunt, compressed, incisor-like, close set. Lateral line with an accessory dorsal brauch; upper eye on median line of top of hear. A single species, on the Pacific coast of America. The narrow interorbital space and the vertical range of the upper eye give it a peculiar physiognomy, but in most regards it is not very different from some of the species of Pleuronectes. ( $\pi \alpha \rho \alpha \dot{\alpha}$, near; ò $\phi v \dot{s}$, eyebrow, from the narrow interbital.)

3009. PAROPHRTS VETULCS, Girard.

Head $3 \frac{1}{2}$; depth $2 \frac{1}{2}$; eye $4 \frac{1}{2}$ in head. D. 74 to 86 ; A. 54 to 68 ; scales 105 (tubes). Body elongate-elliptical; snout very prominent, much protruding, forming an abrupt angle with the descending profile; depth of head opposite middle of upper eje about equaling distance from middle of orbit to snout; eyes large, separated by a very narrow, high ridge, the upper with vertical range; mouth very small; maxillary not reaching pupil; teeth trenchant, small, and rather narrow, widened at tip, about 45 teeth on left side of lower jaw; few teeth on right side of lower jaw. Accessory lateral line long. Pectoral about $\frac{1}{2}$ length of head; caudal truncate, $1 \frac{1}{2}$ in head; fin rays entirely scaleless; scales on body all cycloid, those on cheeks often slightly ciliated. Uniform light olive brown; the young somew hat spotter with blackish. Pacific coast of North America, Sitka to Santa Barbara. This small flounder lives in waters of moderate depth. It is, next to Platichthys stcllatus, probably the most abundant of the flounders of the California coast. (vetulus, an old man.) 
Parophrys vetulus, Girard, Proc. Ac. Nat. Sci. Phila.1854, 140, California ; Günther, Cat., IV, 455, 1862; Lockington, Rep. Com. Fish. Cal. 1878-79, 45; Lockington, Proc. U. S. Nat. Mus. 1879, 100; Jordan \& Gilbert, Proc. U. S. Nat. Mus. 1880, 453; JordaN \& Gilbert, Proc. U.S. Nat. Mus. 1881, 68; Jordan, Nat. Hist. Aquat. Anim., 185, 1884; JoRdAN \& Goss, Review Flounders and Soles, 284, 1889.

Pleuronectes digrammus, GünTHER, Cat., IV, 445, 1862, Victoria. (Coll. Earl Russell.)

Parophry\& hubbardi, GiLL, Proc. Ac. Nat. Sci. Phila. 1862, 281, San Francisco.

Pleuronectes vetulus, JoRDAN \& GILBERT, Synopsis, 831, 1883.

I032. INOPSETTA, Jordan \& Goss.

Inopsetta, JoRdan \& Goss, in JORDAN, Cat. Fish. N. Ä., 136, 1885 (ischyrus).

This genus resembles Parophrys, differing chiefly in having the scales less imbricated, all strongly ctenoid, and having the eyes both lateral, the snout much less acute than in Parophrys. A single species, closely allied to Platichthys stellatus, but separated from it by the curious character common to many of our Pacific coast flounders, of having an accessory branch to the lateral line. ( $i$ 's, strength; $\psi \tilde{\eta} \tau \tau \alpha$, flounder.)

3010. INOPSETTA ISCHYRA (Jordan \& Gilbert).

Head $3 \frac{1}{4}$; depth 2. D. 70 to 76 ; A. 52 to $57 ;$ V. 6 ; scales 85 . Body oblong, robust; candal peduncle rather long; suout projecting, forming an angle with the profile; mouth oblique, the chin projecting; teeth $\frac{5+25}{10+22}$, narrowly incisor-like, bluntish, in a single, rather close-set series; maxillary reaching past front of orbit, $5_{\frac{2}{3}}^{2}$ in head; eyes large; interorbital space rather broad, scaly, continuous with a ridge above opercle; head mostly covered with scales like those of the body, but smaller and rougher; gill rakers feeble; lower pharyngeals each with 2 rows of coarse, blunt teeth; scales thick and firm, adherent, not closely imbricated, those in front well apart; all the scales strongly etenoid; blind side with similar scales, almost as strongly ctenoid; vertical fins mostly scaly; lateral line conspicuous, its scales less rough than the others; a distinct short accessory lateral line on both sides, extending to about the tenth dorsal ray, less than $\frac{1}{6}$ head; a series of pores around lower eye behind; dorsal beginning over pupil, its anterior rays low, its highest rays nearly $\frac{1}{2}$ length of head; caudal large, double truncate; pectoral of right side about $\frac{1}{2}$ head. Light olive-brown, vaguely clouded with light and dark; fins reddish brown; a few roundish dusky blotches on dorsal and anal; pectoral and caudal tipped with dusky; blind side white, immaculate, or with small, round rusty spots; left side of head sometimes rusty tinged. Puget Sound. This species is known only from 4 specimens taken by Dr. Jordan at Seattle in 1880. It is a large, rough flounder, with firm, white flesh.

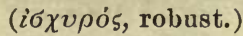

Parophrys ischyrus, JoRdan \& GILBERT, Proc. U. S. Nat. Mus. 1880, 276 and 453, Puget Sound (Coll. Dr. Jordan); Jordan \& GLiberT, Proc. U. S. Nat. Mus. 1881, 67; Jordan, Nat. Hist. Aquat. Anim., 185, 1884.

Pleuronectes ischyrus, JoRdAN \& GILBERT, Synopsis, 832, 1883.

Inopsetta ischyra, JoRDAN, Cat. Fish. N. A., 136, 1885; JoRDAN \& Goss, Review Flounders and Soles, 284, 1889. 
1033. ISOPSETTA, Lockington.

Isopsetta, Lockington MS., in JORDAN \& GILBERT, Synopsis, 832, 1883 (isolepis).

Body much compressed, elliptical in form; mouth rather large; the teeth chiefly uniserial, all more or less blunt, separated, not incisor-like; scales closely imbricated, all strongly ctenoid; lower pharyngeals each with a double row of bluntish teeth. A single species found on the coast of California. Isopsetta approaches in many respects very close to the large-mouthed flounders of the type of Hippoglossoides, and it may fairly be said to be intermediate between Psettichthys and Lepidopsetta. Its affinities on the whole are nearest the latter, but the close relation of the

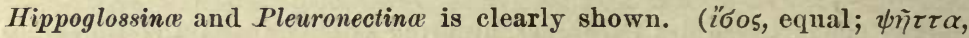
flounder.)

\section{ISOPSETTA ISOLEPIS (Lockington).}

Head 4 ; depth 21 . D. 88 ; A. 65 ; scales 88 ; vertebra $10+32=42$. Body elliptical, much compressed, moderately deep, the curvature very regular; head moderate, strongly compressed, the profile little depressed above the eye; eyes rather large; interorbital space broad, flattish, with several series of scales. Scales on cheeks similar to those on body, rather large, ctenoid, and closely imbricated. Mouth comparatively large, maxillary reaching pupil, $3 \frac{2}{8}$ in head; teeth not large, about $\frac{11+14}{9+24}$, conical, close set, in 1 somewhat irregular series, or partly in 2 series, those on colored side small; lower pharyngeals each with a double row of bluntish teeth. On the blind side the scales are more or less ctenoid, sometimes smooth; those on the cheeks weakly ctenoid; most of the opercle, the preopercle, interopercle, and subopercle on blind side naked; lateral line with a very slight arch in front, the depth of which is less than $\frac{1}{6}$ the length; accessory branch nearly as long as head; fins rather low, mostly covered with ctenoid scales. Color brownish, mottled and blotched with darker. This small flounder is rather common off the coast of California, where it reaches a length of about 15 inches. It much resembles Prettichthys melanostictus, but its small mouth and blunt dentition indicate a real affinity with the small-mouthed flounders, among which it is here placed. Its nearest relative among our species is doubtless Lepidopsetta bilineata. Puget Sound to Point Concepcion, in rather deep water; not rare. (¿ઢo5, equal; $\lambda \varepsilon \pi i 5$, scale.)

Lepidopsetta umbrosa, Lockington, Proc. U.S. Nat. Mus. 1879, 106; not of Girard. Lepidopsetta isolepis, Lockington, Proc. U. S. Nat. Mns. 1880, 325, San Francisco.

Parophrys isolepis, Jordan \& GILBERT, Proc. U. S. Nat. Mus. 1880, 453 and 1881, 67; Jordan \& Gilbert, Synopsis, 832, 1883; Jordan, Nat. Hist. Aquat. Anim., 186, 1884.

Isopsetta isolepis, Jordan, Cat. Fish. N. A., 136, 1885; JoRDAN \& Goss, Review Flounders and Soles, 285, 1889.

\section{LEPIDOPSETTA, Gill.}

Lepidopsetta, GrLl, Proc. Ac. Nat. Sci. Phila. 1864, 195 (umbrosus).

Body robust; mouth small. Teeth stout, conical, little compressed, bluntish, in 1 series, rather irregularly placed. Lateral line with a distinct arch in front and accessory dorsal branch; scales imbricated, 
rough ctenoid, smooth in the very young. A single species, abundant on the Pacific coast of North America. It is close to Inopsetta, from which it is separated by the arch of the lateral line, and still closer to Limanda, from which the accessory branch of the lateral line alone separates it. ( $\lambda \varepsilon \pi i 5$, scale; $\psi \tilde{\eta} \tau \tau \alpha$, flounder.)

3012. LEPIDOPSETTA BILINEATA (Ayres).

Head $3 \frac{3}{5}$; depth $2 \frac{1}{8}$. D. 80 ; A. 60 ; teeth $\frac{27+7}{25+10}$; scales 85 . Vertebra $11+$ $29=40$. Body broadly ovate, thickish; mouth moderate, turned toward the left side; teeth stout, conical, little compressed, bluntish, in 1 series, rather irregularly placed. Lower pharyngeals broad, with 2 rows of blunt teeth. Gill rakers few, very short, thick and weak, withont teeth. Snout projecting; eves large, separated by a prominent ridge, which, like the cheeks and upper portion of opercle, is covered with rough stellate scales; lower eye advanced; opercle, subopercle, and interopercle of left side scaly; preopercle naked. Scales rather small, mostly ctenoid, not closely imbricated, those on the blind side smooth; scales on cheeks and other parts of head very rough; scales of body smoother and less closely imbricated anteriorly, the degree of roughness variable, northern specimens (var. umbrosus) being roughest. Lateral line moderately arched anteriorly, with an accessory dorsal branch, which is less than $\frac{1}{2}$ length of head; height of arch less than $\frac{1}{8}$ its length. Dorsal beginning over eye, its anterior rays low; caudal convex; anal preceded by a spine; a concealed spine behind ventrals; rays of dorsal and anal all simple; dorsal and anal somewhat scaly; caudal $\frac{3}{5}$ length of head; pectoral $\frac{1}{2}$ head. Lower pharyngeals broad, each with 2 rows of blunt teeth. Yellowish brown, with numerous round pale blotches. Pacific coast of North America, Bering Strait to Monterey. This species is one of the commonest of the flounders of the Pacific coast, its abundance apparently increasing toward the northward. In Bering Sea it far outnumbers all other flounders. We have specimens from Bering Island, Medni Island, Unalaska, St. Paul, St. George, and Chignik Bay. It reaches a weight of 5 or 6 pounds and is an inhabitant of shallow waters. Specimens from Puget Sound and northward are rougher than southeru specimens and constitute a slight geographical variety, for which the name Lepidopsetta bilineata umbrosa may be used. This is the same as P.perarcuatus of Cope. (bilineatus, two-lined.)

Platessa bilineata, A Yres, Proc. Ac. Nat. Sci. Cal.1855, 40, San Francisco.

Platichthys umbrosus, GIRARD, Proc. Ac. Nat. Sci. Phila. 1856, 136, Puget Sound.

Pleuronectes perarcuatus, Cope, Proc. Ac. Nat. Sci. Phila. 1873, 30, Unalaska.

Pleuronectes umbrosus, GüNTHER, Cat., IV, 454, 1862.

Pleuronectes bilineatus, Günther, Cat., Iv, 444, 1862; JoRdan \& GLbERT, Synopsis, 833, 1883.

Lepidopsetta bilineata, Gill, Proc. Ac. Nat. Sci. Phila. 1864, 195; Lockinaton, Proc. U. S. Nat. Mus. 1879, 103; Lockington, Rep. Com. Fisheries California, 1878-79, 46; Jordan \& Gmbert, Proc. U.S. Nat. Mus. 1880,453; Jordan \& Gilbert, Proc. U. S. Nat. Mus. 1881, 68; Bean, Proc. U. S. Nat. Mus. 1881, 241; Bean, Cat. Coll. Fish. U. S. Nat. Mus. 1883, 19; Bran, Proc. U. S. Nat. Mus. 1883, 353; Jordan, Nat. Hist. Aquat. Anim., pl. $50,184,1884$; JoRdan \& Goss, Review Flounders and Soles, 286, 1889. 
ro35. LIMANDA, Gottsche.

(MUD DABS.)

Limanda, GoTTsche, Archiv fur Naturgsch. 1835, 100 (limanda).

Myzopsetta, GrLL, Proc. Ac. Nat. Sci. Phila. 1864, 217 (ferruginea).

Teeth chiefly uniserial; lateral line with a distinct arch in front, and without accessory dorsal branch; scales imbricated, rough ctenoid; vertebra about 40. This genus is closely allied to Pseudopleuronectes, from which it differs only in the presence of an arch on the anterior part of the lateral line. (Limanda, an old name of the European Dab, Limanda limanda, from limus, mud.)

a. Head comparatively large, $3 \frac{1}{4}$ to $4 \frac{1}{2}$ in length.

b. Dorsal rays 85; anal rays 62.

c. Scales rather small, 90 to 100 in lateral line; scales of right side ctenoid, closely imbricated, those of blind side mostly smooth; teeth conical, close set, forming a continuous series, about $11+30$ in lower jaw ; snout abruptly projecting, forming in front of upper eye a sharp angle with the descending profile.

FERRUG INEA, 3013 .

ce. Scales larger, wide spart, abont 80 in lateral line; scales of blind side more or less rough.

ASPERA, 3014 .

bb. Dorsal rays 60 to 70 ; anal 47 to 53 ; scales small, 86 to 95 ; snout long, protrud-

ing; scales of blind side smooth.

PROBOSCIDEA, 3015.

$a a$. Head very short, $5 \frac{1}{2}$ in length; snout very short; interorbital space very narrow.

D. 64 ; A. 63 ; scales 88 .

BEANII, 3016.

3013. LIMANDA FERRTGINEA (Storer).

(RUSTY DAB.)

Hear 4 in length; depth $2 \frac{1}{5}$. D. 85 ; A. 62 ; scales 100. Body ovate-elliptical, strongly compressed; teeth small, conical, close set, in a single series on each side in each jaw, about $11+30$ in the lower jaw ; snout projecting, forming a strong angle above npper eye, with the descending profile; gill rakers of moderate length, very weak, not toothed; eyes moderate, $4 \frac{1}{2}$ in head, the lower slightly in advance of upper, separated by a high, very narrow ridge, which is scaled posteriorly, and is continued backward as an inconspicuous but rough ridge to the beginning of the lateral line; scales imbricate, nearly uniform, those on right side rough ctenoid, those on left side nearly or quite smooth; scales on boly rongher than on cheeks; candal peduncle short, higher than long; dorsal inserted over middle of eye, its middle rays highest; pectoral less than $\frac{2}{5}$ length of head; caudal fin rounded; anal spine present; lateral line simple, with a rather low arch in front, the depth of which is barely $f$ the length; a concealed spine behind ventrals; ventral of colored side partly lateral, the other wholly so; anal spine strong. Brownish olive, with numerous, irregular, reddish spots; fins similarly marked; left side with candal fin, candal peduncle and margins of dorsal and anal fins lemon yellow. Atlantic coast of North America, Labrador to New York. This species is rather common northward on our Atlantic coast. It is allied to the European Dab, but has smaller scales and a more prominent snout. Our specimens are from the east coast of Massachusetts. (ferrugineus, rusty red.) 
Platessa ferruginea, D. H.Storer, Rept. Fish. Mass., 141, pl. 2, 1839, Cape Ann; DE ÍAx New York Fauna: Fishes, 297, pl. 48, fig. 155, 1842; STOREr, Syn. Fish. N. A., 476, 1846.

Platessa rostrata, H. R. SToRkR, Bost. Journ. Nat. Hist., vi, 1850, 268, Labrador.

Pleuronectes ferrugineus, GünTHER, Cat., Iv, 447, 1862; JoRDAN \& GILBERT, Synopsis, 834, 1882.

Myzopsetta ferruginea, GiLL. Proc. Ac. Nat. Sci. Phila. 1864, 217.

Limanda ferruginea, Goode, Proc. U.S. Nat. Mus. 1880, 472; Goode, Hist. Aquat. Anim., pl.49,1884; GOODE \& BEAN, Oceanic Ichthyology, 427, 1896; JoRDAN \& Goss, Review Flounders and Soles, 287, 1889.

Limanda rostrata, GiLL, Proc. Ac. Nat. Sci. Phila. 1864, 217.

3014. LIMANDA ASPERA (Pallas).

(Alaska DAB.)

Head $3 \frac{1}{2}$; depth 2 . D. $69 ;$ A.53; scales about 80 . Form of Lepidopsctta bilineata. Teeth small, almost conical, on both sides of the mouth; interorbital space narrow, scaly; opercle and preopercle naked below ; gill rakers very feeble; pharyngeals not very broad, their teeth bluntish, not paved; scales small, wide apart, partly embedded, each one with 1 to 4 spinules, which are almost erect; anterior scales with 3 to 4 of these spinules; posterior mostly with 1; scales of blind side smoother; only middle rays of dorsal and anal scaly; no accessory lateral line; anal spine present; twentieth anal ray and thirty-seventh dorsal ray longest; caudal double truncate. Brown, nearly plain, the blind side with tinges of lemon yellow. Bering Sea, generally common, south to Vancouver Island and to the Okhotsk Sea. We have specimens from Petropaulski and Robben Reef, Bristol Bay, and Herendeen Bay. It is especially abundant in Bristol Bay, and, according to Dr. Gilbert, it is an excellent food-fish. Dr. Bean has also collected it in various localities in Alaska. Its scales are larger and rougher than in $L$. ferruginea which, in many respects, it resembles. A specimen from the island of Saghalien is in the museum at Cambridge. The above description is from examples taken by Dr. Bean. (asper, rough.)

Pleuronectes asper, PALlas, Zoogr. Rosso-Asiat., III, 425, 1811, east coast of Siberia ; GüNTHER, Cat., IV, 454, 1862; STEINDAChNer, Pleuronectiden, etc., aus Decastris Bay, 1870 1875 ; JoRdan \& Gilbert, Synopsis, 835, 1883.

Limanda aspera, Bean, Proc. U.S. Nat. Mus. 1881, 242 ; Bean, Cat. Coll. Fish, U.S. Nat. Mus. 1883, 20 ; Bean, Proc. U. S. Nat. Mus. 1883, 354; Bean, Hist. Aquat. Anim., 184, pl. 48, 1884 ; JoRDAN \& Goss, Review Flounders and Soles, 288, 1889.

3015. LIMANDA PROBOSCIDEA, Gilbert.

Depth $2 \frac{1}{4}$ to $2 \frac{1}{2}$ in length; head large, 3 to $3 \frac{1}{5}$ in length in a specimen 7 inches long. D. 63 to 67 ; A. 47 to 49 ; scales 86 to 95 . Resembling L.ferruginea, but having fewer rays in dorsal and anal, larger scales and longer suout. Profile sharply angulated above front of upper eye, the snont convexly protruding; form varying from very slender to broadly elliptical, the 2 outlines equally curved; caudal peduncle short, widening backward, its least depth twice its length; mouth oblique, maxillary reaching beyond front of lower eye, 4 in head; teeth narrow, little compressed, in a single series on both sides of the jaw, extending farther back on the blind side; eyes on right side; lower eye well in advance of upper, the diameter of 
upper eye $5 \frac{1}{2}$ to 6 in head, $1 \frac{1}{2}$ in snout; vertical from front of upper eye, falling midway between front of orbit and front of pupil of lower eye; interorbital space a very narrow, sharp ridge, naked in females, with a single series of ctenoid scales in males; gill rakers short, about equal to diameter of pupil, 13 or 14 in number, 9 or 10 on lower limb; scales loosely imbricated, ctenoid in males on colored side, smooth in females; blind side of both sexes smooth; head scaled on eyed side in males; the opercle, subopercle, interopercle, and preopercle mostly naked iu females; head on blind side naked; rays of vertical fins with a single series of ctenoid scales; dorsal fin beginning slightly behind front of upper eye, the first 3 rays usually higher and with membranes more deeply incised than in those which follow; highest portions of both dorsal and anal fins behind the middle of the body; these fins about equal, their longest rays equal to the snout and eye; caudal $\frac{2}{8}$ head; pectorals short, $\frac{1}{8}$ in bead; ventrals reaching beyond front of anal, $3 \frac{1}{8}$ in head; the usual small antrorse spine in front of anal fin. Color light grayish or brownish, thickly covered with small whitish spots; entire left side with margins of dorsal, caudal, and anal fins bright lemon yellow (as in ferruginea); vertical fins grayish, with an occasional dark-brown ray. Specimens described $7 \frac{1}{2}$ inches long. Bering Sea; several specimens from Albatross Stations 3239 and 3240 , in Bristol Bay, in $11 \frac{1}{2}$ to $14 \frac{1}{2}$ fathoms; 1 young individual from Herendeen Bay. (Gilbert.) (proboscideus, having a long snout or proboscis.)

Limanda proboscidea, GILBERT, Report U.S. Fish Comm. 1893 (1896), 460, pl. 33, Bristol Bay and Herendeen Bay. (Coll. Albatross.)

\section{LIMANDA BEAYII, Goode.}

Head $5 \frac{1}{2}$; depth $2 \frac{3}{5}$. D. 64 ; A. 63 ; scales 88 . Body elliptical, with angular outlines, strongly compressed; head very short; snout abbreviated; mouth small, subvertical; teeth small, apparently in two rows, chiefly on the blind side of lower jaw; eyes large, as long as mandible; interorbital space very narrow. Dorsal fin beginning about pupil, its rays long, wide apart, exserted; right ventral near the median line; caudal broad, fanshaped. Lateral line with an abrupt curve, the length of which is twice its height and abont equal to length of head, its scales highly specialized; lateral line on colored side less developed; scales small, strongly ctenoid on the right side; larger and cycloid on the blind side. Grayish, mottled with darker; a conspicuous black blotch on the outer rays of candal on each side. (Goode.) Deep water off the coasts of New England; not common. (Named for Dr. Tarleton Hoffman Bean.)

Limanda beanii, Goode, Proc. U. S. Nat. Mus. 1880 (Feb. 16, 1881), 473, southern coast New England, Fish Hawk Stations, 875, 876; GoodE \& BEAN, Oceanic Ichthyology, 428 , pl. 102 , figs. $355 \mathrm{a}$ and $355 \mathrm{~b}, 1896$.

Pleuronectes beani, JoRdAN \& GILBERT, Synopsis, 835, 1883; JoRdan \& Goss, Review Flounders and Soles, 288, 1889.

\section{I036. PSEUDOPLEURONECTES, Bleeker.}

\section{(WiNTER FloUnders.)}

Pseudopleuronectes, BLEEKER, Comptes Rendus Acad. Amst., Pleuron., 7, 1862 (planus).

Body oblong, with firm flesh; the scales firm, regularly imbricated, strongly ctenoid on eyed side in both sexes; fin rays scaly; mouth small; 
teeth uniserial, incisor-like, close set, all more or less blunt; lower pharyngeals very narrow, each with 2 rows of separate, conical teeth. This genus is distinguished from Pleuronectes chiefly by the well-imbricated ctenoid scales, and from Limanda, which it more closely resembles, by the want of arch to the lateral line. Besides the typical species, we refer to this genus a second from the North Pacific. ( $\psi \varepsilon \tilde{v} \delta \circ 5$, false; Pleuronectes.)

a. Dorsal rays 65 ; anal rays 48 ; scales 83 ; vertical fins nearly plain.

AMERICANUS, 3017.

aa. Dorsal rays 58 ; anal rays 38 ; scales 70 ; vertical fins with black bars.

PINNIFASCLATUS, 3018.

3017. PSEUdOPLEURONECTES AMERICANUS (Walbaum).

(Common Flatfish; Winter Flounder.)

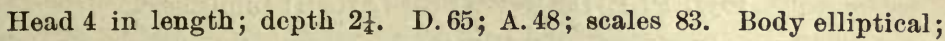
an angle above eye. Head covered above with imbricated, strongly ctenoid scales, similar to those on the body; blind side of head nearly naked; interorbital space rather broad, strongly convex, its width $\frac{1}{2}$ eye, entirely scaled; teeth compressed, incisor-like, widened toward tips, close set, forming a continuous cutting edge; some of teeth often emarginate, sometimes movable; right side of each jaw toothless. Highest dorsal rays less than length of pectorals, and more than $\frac{1}{2}$ length of head; anal spines present. Dark rusty brown, spotted or nearly plain; young olive brown, more or less spotted and blotched with reddish. Atlantic coast of North America, from Labrador to Chesapeake Bay. This small flounder is one of the most abundant of the group on our Atlantic coast. It reaches a length of about 15 inches and a weight of less than 2 pounds. It is a very good food-fish and sells readily in the markets. Along the south coast of Massachusetts this species is more abundant than any other of the flatfishes. The specimens examined by us are from Labrador, Cape Breton, Anticosti, Grand Menan, Boston, Provincetown, Woods Hole, Now Bedford, and Somers Point, New Jersey.

Flounder, Schöpғ, Sohrift. Gesellschaft Naturforscher Freunde, vII, 1788, 148, New York. Pleuronectes americanus, WALBAUM, Artedi Piscium,113,1792, based on the Flounder of Schöpf; Bloch \& SchneIder, Syst. Ichth., 150, 1801; GünTHER, Cat., IV, 443, 1862 ; Jordan \& Gilbert, Synopsis, 837, 1883 ; Stearns, Proc. U. S. Nat. Mus. 1883, 125.

Pleuronectes planus, MrtchrL,, Trans. Lit. \& Philos. Soc. N. Y., I, 1815, 387, New York.

Platessa pusilla, DE KAY, New York Fauna: Fishes, 296, pl.47, fig.153, 1842, New York; S'Torer, Synopsis, 477, 1846.

Platessa plana, Storer, Rept. Fishes Mass., 140, 1839; DE KAY, New York Fauna: Fishes, 295, pl. 49, fig. 158, 1842; Storer, Synopsis, 476, 1846.

Preudopleuronectes planus, BLEEKER, Comptes Rendus Amsterd., XIII, $1862,7$.

Pseudopleuronectes americanus, Gich, Proc.Ac. Nat. Sci. Phila. 1864, 216; Goode, Nat. Hist. Aquat. Anim., 182, pl.44,1884; JokdAN \& Goss, Review Flounders and Soles, 289, 1889.

3018. PSEUDOPLEURONECTES PINNIFASCIATUS (Kner).

Head $3 \frac{1}{4}$ in body; depth $2 \frac{1}{6}$. D. 58 ; A. 38 ; scales 70 ; eye $5 \frac{2}{8}$ in head; snout 5 ; highest anal ray 2 ; pectoral 2 ; caudal $4 \frac{1}{2}$ in body. Body subelliptical, the snout rather pointed and not forming an angle above eye; mouth rather small, maxillary reaching scarcely to the middle of the lower eye; interorbital space rather broad, $\frac{1}{2}$ width of eye; a rather prominent 
rugose ridge above operele, with a smaller similar ridge behind it; both sides of jaws with teeth, those on blind side stronger; origin of dorsal over middle of upper eye. Color brown, with vague dusky spots; 6 or 7 blackish vertical bars on dorsal and anal; similar lengthwise blotches on caudal. Okhotsk Sea, east to Kamchatka. (Steindachner.) Not seen by us. From the excellent figure we conclude that it belongs to I'seudopleuroncetes, although its pharyngeals have not been described. It seems to us nearer to $P$. americanus than to Liopsetta glacialis. (pinna, fin; fasciatus, banded.)

Pleuronectes pinnifasciatus, KNer, in Steindachner, Ueber einige Pleuronectiden, etc., aus Decastris Bay, 2, pl. 1, fig. 1, 1870, Decastris Bay, mouth of Amur River; JokDAN \& Goss, Review Flounders aud Soles, 290, 1889.

\section{PLEURONECTES (Artedi) Linnæus.}

(PlaICE.)

Pleuronectes, ARTEDI, Genera, etc., in part, $16 ; 1738$.

Pleuronectes, Linnaus, Syst. Nat., Ed. x, 268, 1758 (plate88a); included all known Pleuronectidoe.

Platessa, Cuvier, Règne Animal, Ed. 1, II, 220, 1817 (platessa).

Pleuronectes, SwaInson, Nat. Hist. Class'n Anim., II, 302, 1839 (platessa).

Pleuronectes, BLEEker, Comptes Rendus Acad. Amsterd., xil, 1862 (platessa); and of most recent authors.

Body oblong, with firm flesh. Mouth small, teeth uniserial, incisor-like, compressed, forming a contiuuous cutting edge. Lateral line straightish, without arch or accessory dorsal branch. Seales imperfectly imbricated, chiefly cycloid in both sexes; lower pharyngeals small and narrow, separate, each with 1 or 2 rows of small bluntish teeth. No stellate scales along bases of dorsal and anal. Species mostly European; valued as food. ( $\pi \lambda \varepsilon \tilde{v} \rho \circ \nu$, side; $\nu \varepsilon \dot{\varkappa} \tau \zeta 5$, swimmer.)

\section{Pleuronectes QUadritubrculatus, Pallas.}

Head $3 \frac{2}{8}$; depth 2. D. 68 ; A. 50 ; scales 78 . Mouth very small, with small, incisor-like teeth, rounded at tip. Eyes separated by a narrow ridge; about 5 small, prominent, conical, obtuse, bony tubercles in a row above the opercle, continuous with the direction of the lateral line, which is straight, without accessory dorsal branch; tubercle above opercle largest. Scales small, cycloid in all specimens examined. Anal spine present. Grayish, mottled with paler and with round black spots; fins very dark. Bering Sea on both coasts, south to Kadiak; not common. Our specimens from Avatcha Bay, Bristol Bay, Herendeen Bay, Chernofsky Harbor, Grantley Harbor, Chignik Bay, and Robben Island. The above description from a small specimen (No. 28025, U. S. Nat. Mus. ) collected by Mr. W. J. Fisher at Kadiak. The species proves, as suspected by Jordan \& Goss, to be a true Pleuroncctes, having the lower pharyngeals narrow, separate, with 2 rows of bluntish teeth. (quadrituberculatus, having four tubercles.)

Pleuronectes quadrituberculatus, PALLAS, Zoogr. Rosso-A siat., 1II, 423, 1811, sea between Kamchatka and Alaska; Bean, Proc. U.S. Nat.Mns.1881, 241; Jordan \& GilberT, Synopsis, 836, 1883.

Pleuronectus pallasii, SteINDACHNER, Ichth. Beitr., vil, 45, 1879, Kamchatka.

Parophrys quadrituberculatus, GÜNTHER, Cat., IV, 456, 1862.

Platessa quadrituberculata, JoRDAN \& Goss, Review Flounders and Soles, 292, 1889. 
1038. LIOPSETTA, Gill.

\section{(ELL-BACK Floundirs.)}

Liopsetta, Gich, Proc. Ac. Nat. Sei. Phila. 1864, 217 (glaber); females.

Euchalarodus, GILl, Proc. Ac. Nat. Sci. Phila. 1864, 222 (putnami); males.

Teeth chiefly uniserial, incisor-like; seales imperfectly imbricated, rough etenoid in the male, more or less cycloid in the female (fin rays scaly in the male, naked in the female); lower pharyngeals very large, more or less united in the adult, their surface somewhat concave, with teeth in 5 or 6 rows, large, blunt, elose set; lateral line without arch or dorsal branch. This genus comprises several species of small flounders of the Aretic seas. The genus is distinguished by the large, half-united pharyngeals, as also by the peculiar squamation, the scales in the males being very rough, in the females smooth. This difference has given rise to the nominal genus Euchalarodus, based on the males, while Liopsetta was based on the smoother females, which were erroneously supposed to be scaleless. ( $\lambda \varepsilon \check{\circ} \circ$, smooth; $\psi \tilde{\eta} \tau \tau \alpha$, flounder.)

a. Dorsal rays 55 or 56 ; anal 40 to 42 .

b. Pectoral fin short, $\frac{1}{2}$ length of head in males, shorter in females. GLacracis, 3020.

bb. Pectoral fin long, $1 \frac{1}{2}$ in head in males, nearly 2 in females.

aa. Dorsal rays 59 to 62 ; anal 45 or 46 ; pectoral $1 \frac{3}{5}$ in head in males. PUTNAMI, 3021. OBSCURA, 3022.

\section{LIOPSETTA GLACIALIS (Pallas).}

(ARCTiC Flounder.)

Head 4 ; depth $2 \frac{1}{2}$. D.56; A. 42. Form of Liopsetta putnami. A roughened ridge above the cheeks and opercles on the eyed side. Eyes separated by a narrow, smooth, bony ridge. Scales minute, embedded, .nonimbricate, ctenoid in the males, smooth in the females; scales on blind side similar, less developed; scales of lateral line a little larger. Teeth colored, incisor-like, forming an even edge, mostly on blind side. An anal spine; pectorals short. Dark brown, the fins spotted. Arctic shores of Alaska and Siberia, south in Bering Sea to Petropaulski, St. Michaels, and Bristol Bay. Our specimens from Port Clarence, Petropaulski, Bristol Bay, mouth of Nushagak River, and Kotzebue Sound; the description from specimens from the last-named locality taken by Dr. Bean. It is said to be abundant in the Arctic Ocean and as far south as Bristol Bay. "Although small, its great abundance and fine flavor make it important as an article of food." The male is the rough fish described by Pallas as $P$. cicatricosus. The smoother female is Dr. Giinther's Pleuronectes franklinii, the sexual differences being much as in Liopsetta putnami. Liopsetta dvinensis of the northern coasts of Russia may be the same species. (glacialis, icy.)

Pleuronectes glacialis, PaLhas, Itin., III, App., 706, mouth of River Obi; BLOCH \& Schneider, Syst. Ichth., 150, 1801; Pallas, Zoogr. Rosso-Asiat., 111, 424, 1811; Richardson, FaunaBor.-Anner., Fish., 258, 1836; DE KAY, N.Y.Fauna: Fishes, 302, 1842 ; STORER, Synopsis Fish. N. A., 479, 1846; BEAN, Proc. U. S. Nat. Mus. 1881, 241; JoRdAN \& GILBert, Synopsis, 837, 1883; BeAn, Cat. Coll. Fish. U. S. Nat. Mus., 20, 1883; BEAN, Nat. Hist. Aquat. Anim., 184, pl. 47, 1884.

Pleuronectes cicatricosus, Pallas, Zoogr. Rosso-Asiat., III, 424, 1811, male, sea between Kamchatka and Alaska.

$3030-89$ 
? Platassa dvinensis, LILIJEBorg, Veb. Ah. Handl. 1850, 360, tab.20, mouth of River Dwina. Pleuronectes franklinii, Gïnther, Cat. Fish., IV, 442. 1862, Arctic seas of America, female; BEAN, Proc. U. S. Nat. Mus. 1881, 241.

Liopsetta glacialis, JoRDAN \& Goss, Review Flounders and Soles, 295, pl. 17, 1889.

\section{LIOPSETTA PUTNAMI (Gill).}

(EEL-BACK Flounder.)

Head $3 \frac{1}{2}$; depth 2. D. 55 ; A. 40 ; scales 70 (pores). Body oblong, ovate. Eyes rather small, separated by a naked elevated ridge. Jaws sometimes each with 2 distinct rows of teeth, the interrupted onter series of truncate, close set, thickish, incisor-like teeth, which are sometimes movable; the inner row of similar teeth more widely set and rather distant from the outer row (ani often or generally wanting); about 20 teeth in outer row in lower jaw; right side of each jaw toothless; interorbital ridge continuous, with a broad, naked, smoothish, tuberculose ridge, which joins the lateral line. Scales small, distant, nonimbricate, smooth in the female, and more or less ctenoid in the male, those on blind side smaller. Fins moderate, somewhat scaly; anterior rays of dorsal low; peetoral a little more than $\frac{1}{2}$ head; bases of vertical fins not tuberculate; anal spine present; lower pharyngeals separate, broad, with coarse teeth. Grayish brown, mottled with darker brown; fins with blackish spots. Length 10 inches. Atlantic coast of North America, from Cape Cod northward to Labrador and beyond; occasionally found in abundance. This species is rather common along the coast of northern Massachusetts and northward to Labrador. Specimens are frequently found in the markets, mixed with those of Pseudopleuronectes americanus. The numerous specimens in our possession were found in the markets of Indianapolis, having been sent thither from Boston. The remarkable sexual differences in the species have been fully discussed by Dr. Bean (Proc. U. S. Nat. Mus. 1878, 345), the form formerly ealled Euchalarodus putnami being the male, and that called Pleuronectes glaber being the female of the same species. These conclusions of Dr. Bean are fully corroborated by our series of specimens in which both sexes are fully represented.

Although Liopsetta putnami is abundant where found, its ascertained range is somewhat limited. The specimens in the United States National Museum represent localities from Salem, Massachusetts, to Belfast, Maine. In the Museum of Comparative Zoology the localities represented are Providence, Boston, Salem, Grand Manan, and Labrador. (Named for Prof. Frederic Ward Putnam.)

Platessa glabra, Storer, Proc. Boston Soc. Nat. Hist. 1843, 130, female, Massachusetts; Storer, Syn. Fish. N. A., 477, 1816; Storer, Hist. Fish. Mass., 199, pl. 31, fig. 1, 1867; PutNay, Bull. Essex Inst., vr, 1874, 12; not Platessa glabra of RATHKE, 1837, a species of Flesus.

Euchalarodus putnami, GiLl, Proc. Ac. Nat. Sci. Phila. 1864, 216-221, Salem, Massachusetts (Coll. F. W.Putnam), male; GrLx, Report U. S. Fish Comm. 1873, 794; GoodE \& BEAN, Amer. Journ. Sei. and Arts, xiv, 1877.

Liopsetta glabra, GiLL, Proc. Ac. Nat. Sci. Phila. 1864, 217.

Pleuronectes glaber, GrL, Report U. S. Fish Comm. 1873, 794; GoodE \& BEAN, Amer. Journ. Sci. and Arts, xiv, 1877, 476; XviI, 1879, 40; Goode \& BEAN, Proc. U.S. Nat. Mus. 1878, 347; Jordan \& Gilbert, Synopsis, 836, 1883; Goode, Nat. Hist. Aquat. Anim., 183, pl. $45,1884$.

Liopsetta putnami, JoRDAN \& Goss, Review Flounders and Soles, 294, pl. 16, 1889. 
3022. LIOPSETTA OBSCURA (Herzenstein).

To this species we refer 2 males from Shana Bay, Iturup Island. The scales on the colored side are every where strongly ctenoid and imbricated, while in Herzenstein's types (supposed to be females) they were cycloid. In our specimens the head is somewhat smaller, $3 \frac{9}{10}$ in length instead of $3 \frac{1}{16}$ to $3 \frac{5}{9}$; the depth is greater, $2 \frac{1}{5}$ in length instead of $2 \frac{3}{7}$ to $2 \frac{8}{3}$; the interorbital space is covered with very fine scales, not naked; the curve of the lateral line seems more marked, its cord contained 5 instead of 6 times in the straight portion. All of the fins are higher than in the female types, the pectoral of colored side being $1 \frac{3}{5}$ head, the caudal $1 \frac{1}{6}$, the ventral $\frac{1}{2}$ head, and the highest dorsal ray $1 \frac{2}{5}$. Some of these differences may well be sexual. The lower pharyngeals are short and broad, the two closely appressed but united in our specimens, 27 and $29 \mathrm{~cm}$. long. The teeth are large and very blunt, like cobble stones, and are arranged in 1 row along the outer edge; a row of larger teeth along the inner edge, and a short row along the posterior edge of the triangle. The arrangement is very similar is that found in $L$. glacialis, but here a few small teeth, without definite arrangement, are interposed in the middle of the bone, between the third series described. Dorsal 59 and 62 ; anal 45 and 46 ; tubes in the lateral line 79. Color on eyed side uniform dark brown on body and fins, the extreme tips of the fin rays white; on blind side yellowish white, with a few irregular scattered dark spots; dorsal and anal yellowish at base, becoming more or less mottled with dusky on distal half, the fins marked with broad dark bars parallel with the rays, about 7 on the anal fin, 10 or 11 on the dorsal; caudal light on basal half more or less blotched with darker, becoming black posteriorly. With this species we identify also a number of young individuals, 9 to $15 \mathrm{~cm}$. long, from the same locality (Iturup Island). They are probably young females, but the viscera are in such condition as to prevent positive determination. The scales are perfectly smooth, but in other respects they agree perfectly with the adult males, except in their more varied coloration; head and body brownish, profusely spotted in coarser or finer pattern with light gray; also with a few scattered black spots edged with gray; markings on the fins as described for adults. In 7 specimens the dorsal contains $60,62,62,62,64$, 65 , and 66 rays; anal $45,45,45,46,47,47,48$. Sea of Okhotsk. Our specimens from Shana Bay, Iturup Island, one of the Kurils; originally (lescribed from Mantchuria. (obscurus, dark.)

Pleuronectes obscurus, Herzenstein, Mélanges Biologiques, 127, 1890, Mantchuria. liopsetta obscura, JoRDAN \& GILBERT, Rep. Fur Seal Invest., 1898.

1039. PLATICHTHYS, Girard.

(Starry Flounders.)

Platichthys, GIrARd, Proc. Ac. Nat. Sci. Phila.1854, 136 (rugosus=stellatus).

Body very robust, broad, not greatly compressed. Mouth small; teoth chiefly uniserial, incisor-like. Scales all in both sexes and on both sides of body reduced to coarse scattered stellate tubercles, which are not 
imbricated; similar tubercles between bases of dorsal and anal rays; lateral line without scales, with no anterior arch or accessory lateral line; lower pharyngeals broad, each with 3 rows of blunt coarse teeth. A single species, the largest of the small-mouthed flounders, and distinguished from related forms chiefly by the development of coarse stellate tubercles instead of scales. ( $\pi \lambda \propto \alpha \dot{v} \varsigma$, flat; $i \chi \theta \dot{v} 5$, fish.)

302:. PLATICHTHXS STELITUS (Pallas).

\section{(Great Flounder.)}

Head $3 \frac{2}{5}$; depth 2. D. 58; A. 42. Vertebra 34. Body broad and short, the snout forming a slight angle with the profile; lower jaw projecting; interocular space rather broad, with very rongh scales; large rough scales at base of dorsal and anal rays and on sides of head; similar but smaller scales scattered over the body; lateral line smooth; fins without scales; a cluster of bony prominences above opercle. Teeth incisor-like, truneate, rather broad, $\frac{10+15}{12+16}$. Lower pharyngeals broad, with coarse paved teeth. Dark brown or nearly black, with lighter markings; fins redelish brown; dorsal and anal with 4 or 5 vertical black bands; caudal with 3 or 4 black longitudinal bands. Pacific coast of America, from Point Coneepcion to the Arctic Ocean and south to the Amur River. This is one of the largest of the American flounders, reaching a weight of 15 to 20 pounds. Of the small-mouther flounders it is much the largest species known. It is an excellent food-fish, and from its size and abundance it is one of the most important of the group in the region where it is found, constituting lalf the total catch of flounders on our Pacific coast, and it is equally abundant in Bering Sea. It lives in shallow water and sometimes ascends the larger rivers. It is one of the most widely distributed of all the flounders, its range extending from San Luis Obispo, where it was obtained by Jordan \& Gilbert, to the mouth of the Anderson and Colville rivers on the Aretic coast, where it was observed by Dr. Bean, and to Port Clarence, where Mr. Scofield obtained specimens. We have also specimens from Petropaulski, Bering, Medni, and Robben islands and from Bristol Bay. A specimen from the island of Saghalien in Asia is in the museum at Cambridge. (stellatus, starry.)

Pleuronectes stellatus, PALtAs, Zoographia Rosso-Asiatica, III, 416, 1811, Kamchatka, Aleutian and Kuril Islands; GÜNTher, Cat., IV, 443, 1862; Steindachner, Pleur. von Decastris Bay, 1870, 1; Jordan \& Gibert, Proc. U. S. Nat. Mus. 1880, 453; Jordan \& Gilbert, Proc. U.S. Nat. Mus. 1881, 68; Bean, Proc. U. S. Nat. Mus. 1881, 420; Jor. Dan \& Gilbert, Synopsis 835, 1883; Bean, Proc. U. S. Nat. Mus. 1883, 353; Bean. Cat. Coll. Fish. U. S. Nat. Mus. 1883, 20; Jordan, Nat. Hist. Aquat. Anim., 184, pl. 46, 1884.

Platichthys rugosus, Girard, Proc. Ac. Nat. Sci. Phila. 1854, 139, 155, San Francisco; Presidio; Petaluma; Girard, U.S. Pac. R. R. Surv., X, Fishes, 148, 1858.

Platessa stellata, DE KAx, N. Y. Fauna: Fishes, 301, 1842; S'ToleEr, Synopsis, 478, 1846.

Platichthys stellatus, Lockington, Rep. Com. Fish. Cal. 1878-79, 43; Lockington, Proc. U.S. Nat. Mus. 1879, 91; JoRDAN \& Goss, Review Flounders and Soles, 296, 1889. 


\section{I040. MICROSTOMUS, * Gottsche.}

\section{(SMEAR DABS.)}

Microstomu8, GоттsсHe, Archiv fur Naturgesch. 1835, 150 (latidens) ; not Microstoma, RIsso, 1826.

Cynicoglossus, Bonaparte, Fauna Italica, 1837, fasc., XIX (cynoglossus, NiLsson, not of L.). Cynoglossa, Bonaparte, Catalogo Metodico Pesci Europei, 48, 1846 (microcephalus); not Cynoclossus, HaMiLton, 1822.

Brachyprosopon, BleEker, Comptes Rendus Acad. Sci. Amsterd., XIII, Pleuron., 7, 1862 (microcephalus).

Cynicoglossus, JORDAN \& GILBERT, Synopsis, 460, 1883 (microcephalus).

Body elongate, compressed; month very small; teeth broad, incisorlike, on blind side only; scales small, all cycloid; vertebræ numerous ( 48 to 52 ); dorsal rays 90 to 100 ; anal rays 70 to 85 ; anal spine obsolete; left side of skull normal, without mucons cavities; ventral fins with 5 rays each. Arctic seas. This genus is widely separated from Pleuronectes

* We here retain the generic name Microstomus, although in accordance with recent usage of most ornithologists and ichthyologists, it should be suppressed, as identical with Microstoma. The two words are from the same root, and differ only in the termination. But is not this difference enough? The code of nomenclature of the American Ornithologists' Union very properly declares that "a name is only a name, and has no necessary meaning." and therefore no necessarily correct spelling, except the spelling selected by the writer from whom it dates its origin. As a result of this, the original spelling of each generic name is (undoubted misprints aside) the orthograpliy to be adopted, regardless of all questions as to the correct etymology of the word. As a necessary sequence, it scems to us that all generic names, not actually preoccupied by names spelled in the same way, should be tenable. There is no other certain boundary line between names tenable and names untenable. We therefore regard all generic names as available unless used in zoology earlier and in exactly the same orthography. Among American genera of fislies wo may therefore use the following, notwithstanding thoir earlier analogies:

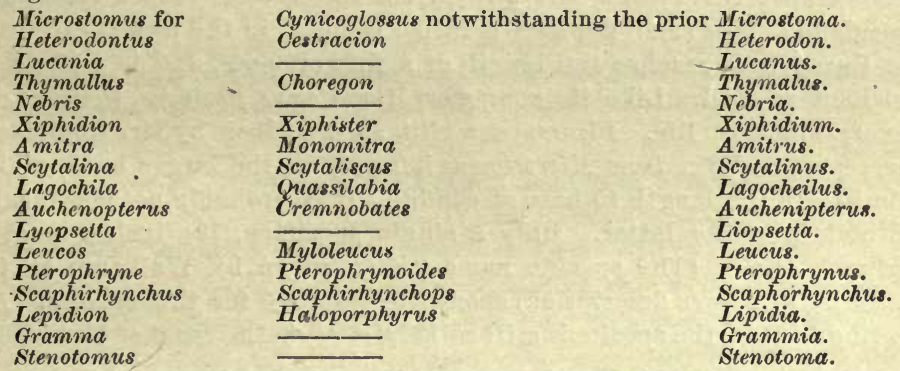

If Microstomus be discarded, the next name in order of date is Cynicoglossus.

The following is Bonaparte's definition of Cynicoglossus as quoted by Gill (Proc. Ac. Nat. Sci. Phila. 1864, 222) :

"Secundo d Cynicoglossus nob. che come il $\mathrm{Pl}$. cynoglossus $\mathrm{L}$. ha la linea laterale retta, la bocca piccola, i denti come quello di sopra [Platessa] ma la mascelle iguale, con labbra turgide, $\theta l^{\prime}$ ano senza spina.

Later, in his Catalogo Metodico dei Pesci Europei, Bonaparte changes this name from Cynicoglossus to Cynoglossa, giving the sole species as Cynoglossa microcephala, and quoting as its synonym "Pleuronectes cynoglossus, N. Nilss.", showing that his identification of the Linnean species coincided with that of Nilsson, who at first nsed the name "Pleuronectes cynoglossus" for the present epecies instead of the species of Glyptocephalus. In Bonaparte's Catalogo, Glyptecephalus, Gottsche, is regarded by Bonaparte as synonymous with Platessa.

It is thus evident, as Dr. Gill has suggested, that Bonaparte meant to refer to the Pleuronectes microcephalus instead of Pl. cynoglossus, he "having followed Nilsson in his erroneons identification" of the latter with the former. In further evidence of this we have the fact that Cynicoglossus microcephalus (kitt) has no anal spine, while such a spine is present in the species of Glyptocephalus. We would be, therefore, justified in the nse of Cynicoglossus instead of the later Brachyprosopon, if Microstomus should be regarded as ineligible on account of the prior name liticrostoma. (Jordan \& Goss.) 
and its allies by its greatly increased number of vertebræ, a character accompanied by a similar increase in the number of fin rays. It is close to Flyptocephalus, but the lack of the cavernous structure of the bones of the head, a strueture peculiar to the species of that genus, sufficiently distinguishes it. (

a. Dorsal rays 85 to 93 ; anal rays 70 to 76 ; head very small, about 5 in length; eje 4 in heal.

KITT, 3024.

aa. Dorsal rays 102; anal ray 85; head $4 \frac{1}{2}$ in length; eye 3 in head. PACIFICUs, 3025.

3024. MICROSTONIS KITT (Walbaum).

(SMEAR DAB.)

Head $5 \frac{1}{4}$ in length; depth $2 \frac{1}{3}$. D. 85 to 93 ; A. 70 to 76 ; scales 130 ; caudal $1 \frac{1}{8}$ in head; pectoral $1 \frac{8}{4}$. Body moderately elongate; mouth small, the maxillary not reaching to front of lower eye; teeth on blind side conical, rather compressed and blunted, 11 to 13 on either jaw ; eyes close together, the lower slightly in advance; gill rakers short, not numerous. Origin of dorsal above middle of upper eye, its rays larger in the posterior half of body; pectorals about equal in size; no spine before anal; caudal rounded; head, except snout, entirely scaled; scales cycloid; lateral line with a small curve; vertebra $13+35=48$. Color dull yellowish, blotched, and with dark spots, especially over the chest and along the base of anal fin; dark blotches and spots on anal, caudal, and ventral fins; dark base to pectoral, which has also some cloudy markings. (Day.) Seas of the north of Europe in rather deep water, south to Cornwall. Recorded by Steindachner (as Pleuroncetes gilli), from the sea between Iceland and Greenland. This small flounder is rather common in the waters of northern Europe. It reaches the length of a foot or more, and is said to be excellent as food. Like its congener, Microstomus pacificus, this species is very slimy in life. Pleuronectes gilli, as described by Dr. Steindachner, seems to differ from Microstomus kitt only in the larger head, which is but $4 \frac{2}{5}$ in the length to base of caudal. It is probably not specifically distinct from the latter. Only a single specimen, $10 \frac{1}{2}$ inches long, is known. (Eu.) (The specific name "kitt," given by Walbaum on the anthority of Jago's description, should be adopted for this species. Ac-

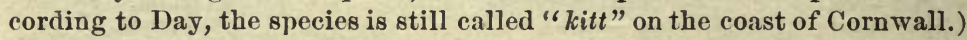

Rhombus loevis cornubiensis, JAGO, in Ray, "Syn. Pisc., 162, tab. 1, fig. 1, 1713."

The Smear Dab, Pennant, British Zoology, III, 230, pl. 41, 1776.

Pleuronectes kitt, WALBAUM, Artedi Piscium, III, 120, 1792, after RAY; the description in part confused with that of Lepidorhombus.

Pleuronectes laevis, SHAw. Gen'l Zool., IV, 299, 1803.

Pleuronectes quenseli, HöLв̈̈LL, Bohusläns Fiske, Iv, 59, 1821, Bohusläns, Sweden.

Pleuronectes quadridens, FABRICIUs, Kongl. Iansk.Vid. Selsk. Af handl., I, 39, 1824, Iceland. Microstomus latidens, GoTTsche, Archiv fur Naturgsch. 1835, 150, Zealand.

Pleuronectes gilli, STEINDACHNeR, Ichth. Notizen, VII, 40, 1868, Polar Sea north of Iceland.

Pleuronectes microcephalui, Dovovan, British Fishes, II, pl. 42, 1802; GUNTHER, Cat., IV, 447; Steindachner, Ichth. Beitr., viI, 47; Day, Fishes Great Britain, 11, 28, pl.102; Colletr, Norges Fiske, 145, and of recent European writers generally.

Pleuronectes microstomus, FABER, Isis, 886, 1828.

Platessa microcephala, Fleming, British Anim., 198, 1828, and of numerous writers.

Cynoglossa microcephala, Bonaparte, Catalogo Metodico Pesci Eur., 48, 1845.

Microstomus kitt, JORDAN \& Goss, Review of Flounders and Soles, 1886, 298. 
3025. MICROSTOMUS PACLFICUS (Lockington).

(SLIPPERY SOLE.)

Head $4 \frac{1}{4}$ in body; depth $2 \frac{5}{6}$. D. 102 ; A. 85 ; seales 140 ; eye $3 \frac{1}{2}$ in head; maxillary 5 ; pectoral $1 \frac{3}{5}$; greatest height of dorsal $2 \frac{1}{3}$; anal $2 \frac{1}{3}$; caudal 12 ; vertebra $12+40=52$. Borly elongate, elliptical; mouth small, the maxillary reaching just past front of lower eye; teeth long and broad, forming a continuous cntting edge, on blind side only, about 10 teeth on lower jaw; eyes very large, nearly twice as long as snout, the upper even with profile above; interorbital a narrow scaly ridge; gill opening adnate to shoulder girdlo above pectoral ; gill rakers short, 8 below angle, 5 or 6 very small searcely developed ones above; scales small, cycloid, not closely imbricated, lateral line nearly straight. Origin of dorsal slightly behind middle of upper eye, caudal truncate or slightly rounded. Color olive brown, blotched on body and fins with darker, all fins blackish toward the ends of the rays. Pacific coast of North America, Monterey to Unalaska, in rather deep water, 15 to 50 fathoms; common. Here described from a specimen, about 14 inches in length, from Albatross Station 2927, off the coast of California. This small flounder abounds in deep water about San Francisco, but comes near the shore farther north. It is exceedingly slimy when first taken. The large individuals are considerer excellent as food; the smaller are thrown away. It rarely reaches the weight of a pound.

Glyptocephalus pacificus, Lockineton, Rep. Cal. Com. Fisheries, 1878-79, 43, off Point

Reyes, California; Lockington, Proc. U. S. Nat. Mus. 1879, 86; Jordan, Nat. Hist.

Aquat. Anim., 188, 1884.

Cynicoglossus pacificus, Jordan \& Gilbert, Proc. U. S. Nat. Mus. 1880, 453; Jordan \&

Gilbert, Proc. U.S. Nat. Mus. 1881, 68; Jordan \& Gilbert, Synopsis, 838, 1883.

Microstomus pacificus, Jordan \& Goss, Review Flounders and Soles, 299, 1889.

ro4r. EMBASSICHTHYS, Jordan \& Evermann.

Embassichthys, JoRdAN \& Evermann, Check-List Fishes, 506, 1896 (bathybius).

This genus is a deep sea representative of Microstomus, from which it differs in the increased number of vertebræ (63 instead of 48 to 52). Its fin rays are correspondingly increased, the body is deeper than in Microstomus, and it has teeth on both sides of the jaws, as in Glyptocephalus. ( $\dot{\varepsilon} v$, in ; $\beta \alpha \dot{\alpha} \sigma o s$, for $\beta \alpha \theta \dot{v}$ s deep; $i \chi \theta \dot{v} \varsigma$, fish; a fish in the depths.)

\section{EMBASSICHTHYS BATHYBIUS (Gilbert).}

Head 4 to $4 \frac{2}{5}$ in length; depth 2 to $2 \frac{1}{3}$. D. 111 to 117 ; A. 96 to 98 ; vertebra $14+49=63$. Body oval, very thiu and deep, the greatest depth at anterior third of body; upper profile very abruptly angulated opposite hinder margin of upper pupil, the anterior half of head conspicuously protruding beyond general outline. Caudal nearly sessile, the peduncle very short. Mouth small, maxillary about $\frac{1}{5}$ length of head in specimens 1 foot long. Teeth broad incisors, slightly notched at tip, nearly equally developerl on blind and colored sides, 21 on blind side of lower jaw, 16 on 
colored side. As in other members of this gromp, the lower jaw is the longer, the upper teeth included. Interorbital space wholly scaled, with a very high, rather sharp -shaped ridge. Eyes very large, the upper entering largely into the upper profile, the lower much in advance; front margin of upper orbit on vertical of front of lower pupil; diameter of upper eye $2 \frac{8}{4}$ to $2 \frac{4}{5}$ in head. Anterior nostrils of both sides in rather long tubes, the posterior margins produced to form short flaps. Preopercular margins adnate, as usual, concealed by scales. No conspicuous mucous excavations on blind side. Gill rakers weak and rather short, 10 or 11 on anterior of arch. Scales very small, cycloid, in about 165 cross rows, the tubes of lateral line much fewer, not regularly arranged; over 50 longitudinal rows above lateral line. Dorsal leginning over posterior edge of pupil; fins low, the highest dorsal rays behind middle of borly, $\frac{2}{5}$ length of head; caudal rounded, $1 \frac{1}{2}$ in head; pectorals 2 in head; ventrals small, each with 5 rays, as in Microstomus pacificus. (Glyptocephalus cynoglossus and zachirus have 6 rays in each ventral.) Color of eyed side warm brown, darker toward margins, becoming black on vertical fins; everywhere on body and fins coarsely blotched with light blue, the marks so arranged on upper and lower thirds of sides as to form 5 broad bars of bluish, alternating with those of the ground color, and corresponding above and below; lips and branchiostegal membraues black; blind side dusky brownish. This well-marked species differs from the species of Microstomus in its much greater depth and bright coloration, and in having teeth well developed on both sides of jaws, as in the species of Glyptocephalus. Two specimens from the Santa Barbara Channel, in deep water. (Gilbert.) ( $\beta \alpha 0 v_{5}$, deep; $\beta i o s$, lífe.)

Cynicoglossus bathybius, Gilbert, Proc. U. S. Nat. Mus. 1890, 123, Santa Barbara Channel, at Albatross Station 2980, Lat. $33^{\circ} 49^{\prime} 45^{\prime \prime}$ N., Long. $119^{\circ} 24^{\prime} 30^{\prime \prime}$ W., in 603 fathoms. (Type in U. S. N.M. Coll, Gilbert.)

1042. GLYPTOCEPHALUS, Gottsche.

(FLUKES.)

Glyptocephalus, GотTSCHE, Archiv fur Naturgsch. 1835, 156 (type saxicola=cynoglossus, L.).

Eyes and color on the right side. Body extreinely elongate, more than twice as long as deep, much compressed. Head very small and short, its blind side with many excavations and mucous cavities in the skull, mandible, and preopercle. Mouth very small; teeth moderate, incisor-like, broad, equal, close set, in a single series; no teeth on vomer or palatines. Gill rakers short, weak. Lower pharyngeals narrow, with 1 or 2 rows of conical teeth. Lateral line nearly straight, simple; scales very small, smooth; dorsal and anal very long, there being more than 90 rays in the dorsal and more than 80 in the anal; caudal fin rounded; anal spine present; ventral rays 6. Vertebra in increased number, 58 to 65 . Northern seas, in deep water. This genus is one of the most strongly marked in the family, being distinguished from most of the genera by the greatly increased number of vertebra, and from all of them by the remarkable cavernous 
structure of the bones of the head. 'Two species known. ( $\gamma \lambda v \pi \tau o$ s, sculptured; $\varkappa \varepsilon \phi \alpha \lambda \eta \dot{\eta}$, head.)

a. Pectoral fins very short, not falcate, that of right side about $\frac{1}{2}$ length of head; vertebræ 58. CYNOGLOSSUS, 3027.

aa. Pectoral fins of colored side falcate, longer than the head; vertebræ 65.

ZACHIRUS, 3028.

3027. GLYP'TOCEPHLUS CYNOGLOSSUS (Linnæus).

(Craig Fluke; Pole Flounder.).

Head 5 to $5 \frac{1}{4}$ in body; depth $2 \frac{1}{2}$ to 3 . D. 101 to 112 ; A. 87 to 100 ; scales 125; V.6; highest dorsal and anal rays 2 in head; pectoral a little more than 2 ; vertebre 58 . Body oblong, fusiform; head small, ovate; the profile slightly decurved; month very small, with the cleft oblique; teeth on blind side close set, with incisoral edges, $\frac{17}{20}$; on the eyed side, distant, obtusely conic, $\frac{6}{7}$; eyes moderate, the lower advanced, close together, 3 in head; scales regularly imbricated, lateral line straight; pectoral short, falcate; origin of clorsal above middle of upper eye; anal spine present; caudal convex or angulated behind; pectoral fins very short, not falcate, that of right side about $\frac{1}{2}$ length of head; upper jaw with about 30 teeth; opercle adnate to the shoulder girdle for a short distance only. Color grayish brown; fins with dark spots; tip of pectoral dusky above. North Atlantic, on both coasts, chiefly in deep water, south to Cape Cod and France. This species is found in rather deep water on sandy bottoms. It reaches a length of 12 to 18 inches. This flounder has been taken in great numbers with the beam trawl in deep water off our New England coast. It is pronouncer by the United States Fish Commission to be not inferior as' a food-fish to the European sole. (Eu.) (cynoglossus, a sole; xv'øv, $\log ; \gamma \lambda \tilde{\varkappa} \sigma \sigma \alpha$, tongu⿶.)

Pleuronectes, etc., Corpore oblongo glabro, Gronow, Museum Ichthyol., 1, Iv, 39, etc., Belgium.

Pleuronectes cynoglossus, LINN必U, Syst. Nat., Ed. X, 269, 1758, after Gronow; GÜNTHER, Cat., IV, 449, 1862; DAY, Fishes Great Britain, 11, 30, pl. 103; LILuJBBorg, Sveriges och Norges Fiske, II, 386, 1891; and of European writers generally.

Platessa pola, Cuvikr, Règne Animal, Ed. II, Vol. 2, 339, 1829, after la Pole of Duhamel.

Pleuronectes 8axicola, FABER, Tidsskr. f. Naturv., 5 B., 244, 1828, Denmark.

Pleuronectes nigromanus, Nusson, Prodr. Ichth. Scand., 55, 1832.

Platessa elongata, YARrell, Hist. Brit. Fish., 619, 1859, young.

Glyptocephalus acadianus, Gil,, Proc. Ac. Nat. Sci. Phila. 1873, 360, Nova Scotia. (Type, No. 12685.)

Glyptocephalus cynoglossus, Gill, Proc. Ac. Nat. Sci. Phila.1873, 360; Goode \& BeAN, Proc. U. S. Nat. Mus. 1878, 21; Goode, Proc. U. S. Nat. Mus.1880, 337; Goode, Proc. U. S. Nat. Mus.1880,475; Collett, Norske Nord-Havs Exped.1880, 150; Goode \& BeaN, Bull. Mus. Comp. Zool., X, No. 5, 195, 1883; JordaN \& GilberT, Synopsis, 838, 1883; Goode, Nat. Hist. Aquat. Anim., 198, 1884; JoRdAN \& Goss, Review Flounders and Soles, 300, pl. 19, 1889.

Solea cynoglossa, RAFINESQUE, Indice di Ittiologia Siciliana, 53, 1810; based on the Sole or Cynoglossum of RONDELET.

Glyptocephalus saxicola, GoTTsche, Archiv fur Naturgsch. 1835, 156.

Platessa saxicola, KRöYER, Danmark's Fiske, 338, 1843.

Pleuronectes elongatus, GüNTHER, Cat., IV, 450, 1862.

Gyptocephalus clongatus, GiLl, Proc. Ac. Nat. Sci.Phila. 1873, 362. 
302S. GLYPTOCEPHALUS ZACHIRUS, Lockington.

(LONG-FINNED SOLE.)

Head $5 \frac{1}{3}$ to $5 \frac{4}{7}$; greatest width of body $3 \frac{1}{3}$ to $3 \frac{1}{2}$; eye $3 \frac{1}{3}$ in head; snont 8 . D. 94 to 106 ; A. 79 to 89 ; P. 11 to 13 ; V. 6 ; vertebre $13+52=65$. Body elongate-ovate, anterior portion of the oval shorter than posterior; snout declivous, almost vertical, its tip level with upper margin of lower eye, its curve uniting withont sensible depression with that of nape; dorsal outline rising wich a regular gentle curve from snout to about twenty-second dorsal ray, thence declining very gradually and regularly with but slight curvature to caudal peduncle; abdominal outline almost straight from knob of mandible to ventral; from thence to end of anal curved in same manner as dorsal outline; peduncle of tail expanded toward caudal, its least width about $\frac{1}{4}$ of greatest depth of body; greatest distance from anal to lateral line less than length of head. Eyes large, elliptical, the lower in advance of the upper abont $\frac{1}{2}$ length of pupil, and scarcely reaching dorsal profile anteriorly. Interocular space very narrow, about $\frac{1}{8}$ of longitudinal diameter of eye, smooth; not raised above the eye in a fresh fish; a slight ridge rising at its posterior part, forming lower posterior margin of upper eye, and dying out on cheek. Nostrils of right side level with upper margin of lower eye; anterior nostril witl a short tube, the posterior with a raised margin, and vertical with the front margin of the lower orbit; posterior nostril of blind side in advance of eje; anterior nostril nearly as on colored side; nostrils small and inconspicuous. Gape of mouth very small on colored side, considerably larger on blind side; on the colored side the cleft.is nearer vertical than horizontal; posterior end of maxillary reaching very little behind anterior margin of orbit of lower eye, and the symphysis of intermaxillaries about level with upper edge of orbit; mandible projecting in the closed mouth, short, not passing a vertical from front margin of pupil, with a prominent knob below the symphysis, and a smaller one at its posterior extremity. Teeth on both sides of jaws throughout the full length of the gape, in a single row, broad, but thick, forming a blunt, continuous edge, about 34 in lower jaw and rather fewer in the upper, in an individual $11_{1 \frac{3}{6}}^{3}$ inches long; in an example $14 \frac{5}{8}$ inches long there were 14 teeth on the colored side and 26 on the blind side of the mandible, the latter the larger; in the intermaxillaries, 13 on the colored side and 23 on the blind side; each lower pharyngeal with a double row of teeth, the inner larger than the outer; the 4 anterior tecth of outer row conspicuously larger than those following; about 12 teeth in each inner row; upper pharyngeals each with a close-set row of 6 or 7 blunt conical teeth. Branchiostegals 7 ; gill rakers few, flexible, very short. Dorsal commencing between front of orbit and pupil, considerably behind nostrils, long and low, forming a continuous arch of slightly greater curvature than dorsal outline, the longest rays in central portion, and ending opposite anal at about $\frac{2}{3}$ of width of caudal peduncle from origin of caudal ; anal with a horizontal spine, the first ray rather listant from the visible portion of the spine, and nearly length of ventral behind pectoral base, similar to the clorsal; almost all the rays of dorsal and anal directly backward; caudal convex on posterior margin, rather narrow, the rays once bifurcate, 
sometimes bifurcate again near the tips; pectoral of colored side exceedingly long and lanceolate, about $\frac{1}{4}$ of total length of fish; first 5 rays simple, the others once bifurcate; fourth ray longest, fifth nearly equal, sixth a little longer than third, thence diminishing rapidly. Usual proportion of the first 4 rays $3-8-10-12$; pectoral of blind side lanceolate, rather more than $\frac{1}{3}$ of length of that of eolored side, and formed of the same number of rays, first 4 simple, the others once forked; fourth and fifth rays longest; ventrals inserted so that their hinder axil is vertical with, or a little posterior to, anterior axil of pectoral, their tips reaching to first anal ray; 4 posterior rays once bifureate. Lateral line almost straight, rising very slightly anteriorly, formed of a double row of tubes, about 138 in number, excluding those upon caudal; a row of similar pores commencing at ridge under upper eye, and continuing around lower eye almost to its front margin; scales small, smooth, uniform over the body, and extending over the head to suout, on which they are smaller; intermaxillaries and mandible scaleless; scales on blind side similar; caudal scaly on both sides; no scales on the other fins. Color uniform brownish or cinereous; fins darker; the color formed by minute dark spots on the scales; membrane between the fin rays closely set with dark points; blind side whitish, the ground tint clouded with numerous black points. Deep waters of the Northern Pacific, from San Francisco northward; found throughout Bering Sea in 35 to 350 fathoms. This species is a thin, dry flounder, reaching a length of something over a foot. It is taken in the sweep nets in deep water about San Francisco. It is readily known by its long pectoral fin. ( $\zeta \alpha-$, an intensive particle; $\chi \varepsilon i \rho$, hand, from the long pectoral.)

Glyptocephalus zachirus, Lockington, Proc. U. S. Nat. Mus. 1879, 88, San Francisco; Lockington, Rep. Com. Fisheries California 1878-79, 42; Jordan \& GIBbert, Proc. U. S. Nat. Mus. 1880, 453; JuRdan \& Gilbert, Proc. U.S. Nat. Mus. 1881, 68; Jordan \& Gilbert, Synopsis, 838, 1883; Jordan, Nat. Hist. Aquat. Anim., 188, 1884; Jordan \& Goss, Review Flounders and Soles, 301, 1889; GlLBerT, Rept. U. S. Fish. Comm. 1893 (1896), 460 .

r043. LOPHOPSETTA, Gill.

\section{(WIndow Panes.)}

Lophopsetta, Gill, Proc. Ac. Nat. Sci. Phila. 1862, 216 (maculatus).

Eyes and eolor on the left side. Body broadly ovate, strongly compressed, pellucid; mouth large, oblique, the maxillary reaching to beyond eye; teeth subequal, in narrow bands, or in single series; a small patch of teeth on the vomer. Scales small, cycloid, imbricate, the skin withont bony tubercles. Lateral line strongly arched in front, without accessory branch. Dorsal fin beginning on the suout, its anterior rays exserted; anal fin not preceded by a spine; ventral of left side free from the anal, inserted nearly on the ridge of the abdomen, its base broad, the rays well separated; pectoral and ventral fins moderate. One species. Very close to the European genus Bothus, Rafinesque (= Scophthalmus, Rafinesque, = Rhombus, Cuvier, = Passer, Valanciennes), from which it differs in the more numerous gill rakers, pellucid body, and produced dorsal rays, all characters of minor importance. The European Turbot (Psetta, Swainson), is 
also closely related, but the typical species, Psetta maxima, is a large robust fish, scaleless and beset with bony tubercles. ( $\lambda$ ó $\sigma_{\circ}$, crest; $\psi \tilde{\eta} \tau \tau \alpha$, turbot.)

\section{LOPHOPSETTA MACULATA (Mitchill).}

(WLindow PANe.)

Head $3 \frac{1}{2}$; depth $1 \frac{3}{5}$. D. 65 ; A, 52 ; scales 85 ; eje 4 in head; pectoral $1 \frac{1}{3}$; highest dorsal rays $1 \frac{7}{8}$; highest anal rays $1 \frac{4}{5}$; interorbital space $\frac{1}{2}$ eye. Body broadly rhomboid, strongly compressed, translucent in-life; mouth large, the maxillary reaching nearly to posterior margin of eye, maxillary of eyed side with a bony tubercle on its anterior end; jaws subequal, the lower with a sharp knob at symphysis; teeth in each jaw in 1 series laterally, in a very narrow band in front; interorbital space rather broad, slightly concave, its posterior third or fourth with scales; gill rakers short and slender, about $8+25$; maxillary, mandibles, snout, and the greater part of interorbital naked; scales on head and body cycloid, loosely imbricated, those on the blind side a little smaller. Anterior rays of dorsal produced, their ends brancherl and free, the first on tip of suout, the rays at the beginning of posterior third of fin the highest; origin of anal directly under angle of preopercle; base of ventrals long, that of the eyed side extending along ridge of body from notch in isthmus to front of anal, base of ventral on blind side shorter; pectoral reaching past curve on eyed side, its mate much smaller; caudal rather long. Color light olive brown, almost translucent, everywhere marbled with paler, and with many small, irregular, sharply defined black spots; dorsal, anal, and caudal with larger, round, blended spots of dark brown; pectoral with brown, interrupted cross lines. This small flounder much resembles the European Brill (Bothus rhombus), but is smaller, thinner, and more translucent in body. Its weight rarely exceerls a pound or two, and its value as a food-fish is but slight; nevertheless, it is a near ally of the European Turbot (Pretta maxima), and in its technical characters it very closely agrees with the latter species. Atlantic coast of United States, from Casco Bay to South Carolina; common. (maculatus, spotted.)

Pleuronectes maculatus, Mrtchill, Rept. in part, Fish. N. Y., 9, 1814, New York; DE KAY, New York Fauna: Fishes, 301, pl. 47, fig. 151, 1842; Storer, Synopsis, 479, 1846; Storer, Hist. Fish. Mass., 204, 1867; Jordan \& Goss, Review of Flounders and Soles, $258,1889$.

Pleuronectes aquosus, MrтchmL, Trans. Lit. and Phil. Soc. N. Y., I, 1815, 389, pl.2, fig. 3, New York.

Lophopsetta maculata, GILL, Proc. Ac. Nat. Sci. Phila.1862, 216; ibid, 1864, 220; Jordan \& GiLbert, Proc. U.S. Nat. Mus. 1878, 371.

Bothus maculatus, JORDAN \& GILBERT, Synopsis, 815, 1883.

Rhombus aquosus, GüNTHeR, Cat., 1V, 411, 1862.

1044. PLATOPHRYS, Swainson.

Solea, Rafinesque, Indice di Ittiologia Siciliana, 52,1810 (rhomboide); not of Quensei, 1806.

Platophrys, Swainson, Nat. Hist. Class'n Fishes, II, 302, 1839 (ocellatus).

Peloria, Cocco, Intorno ad Alcuni Pesci del mar di Messina, Giorn. del Gabin., 1844, 21-30, Lettere di Messina (heckeli, a larval form of $P$. podas); not Pelorus of MONTFORT, 1808. 
? Coccolus, * Bonaparte, in Cocco, Alcuni Pesci Messina, 21, 1844 (annectens; larval formprobably of $P$. podas, with the right eye in transit to the left side).

Bothus, Bonaparte, Catologo Metodico, 49,1846 (podas); not of Rafinesque.

Rhomboidichthys, BLEEKER, Act. Soc. Sci. Indo-Nederl. Manad. and Makassar, 67, 1357-58 (myriaster).

Platophrys, Blekker, Comptes Rendus Acad. Sci. Amsterd., XıII, 1862, Pleuron., 5 (ocellatus).

Eyes and color on the left side. Body ovate, strongly compressed; mouth of the large type, but comparatively small; the maxillary $\frac{1}{3}$ or less of the length of the head; teeth small, subequal, in 1 or 2 series; no teeth on vomer or palatines. Interorbital space broad and concave, broadest in adult males. Gill rakers moderate. Dorsal fin beginning in front of eye, all its rays simple; ventral of colored side ou ridge of abdomen; caudal convex behind; pectoral of left side usually with 1 or more filamentous rays, longest in the male. Scales very small, ctenoid, adherent; lateral line with a strong arch in front. Coloration usually variegated.

This well-marked genus is widely diffused in the warm seas. The sexual differences are greater than usual among flounders, and the different sexes have often been taken for different species. As a rule, in the males, the pectoral fin on the left side is much prolonged, the interorbital area is much widened and very concave, and there are some tubercles about the snout and lower eye. The young fishes, as is usually the case, resemble the adult females. Lately, Dr. Emery has shown that the larval flounder, known as Peloria heckeli, is in all probability the young of Pleuronectes podas. The generic name, Coccolus, based on forms slightly more mature than those called Peloria, probably belongs here also. We have seen no larval forms so young as those which have been described as Peloria heckeli. We have, however, examined small transparent flounders, one with the eyes quite symmetrical, taken in the Gulf Stream, and another with the eyes on the left side, taken at Key West. Both these may be larvie of Platophrys ocellatus. The figures published by Emery seem to make it almost certain that the corresponding European forms belong to $\boldsymbol{P}$. podas, although some doubt as to this is expressed by Facciolà. The species of Platophrys are widely distributed through the warm seas, no tropical waters being wholly without them. All the species of Platophrys are extremely closely related and can be distinguished with difficulty. On the other hand, the variations due to differences of age and sex are greater than in any other of our genera. The following analysis of the species of Platophrys is very unsatisfactory. There are certainly 3 speeies (podas, the European species, maculifer, and lunatus) which are known to be distinct in their adult state. The young forms of maculifer and lunatus are not well known, nor is it known how they differ from ocellatus, spinosus, and other species which presumably reach a smaller size. Only a thorough study of the species, in all stages of development in their native waters, can give us the characters by which the species can be really discruminated. ( $\pi \lambda \alpha \tau \dot{v} 5$, broad; $\dot{\phi} \rho \dot{v} 5$, eyebrow.)

* "Parvus mole et pleuronectiformis, medius inter Pleuronectidas et Bibroniinos hic piscis videtur! Attamen dum illi oculos unilaterales habeant, iste vero bilaterales; in boc novo genere oculi, alter a latere, altere in vertice vix ad appositum latus convenus positi sunt." (Bonaparte: quoted by Facciola, Su di Alcuni Rari Pleuronettidi.) 
a. Anal rays, at least anteriorly, each with a spinule at base (these formea by a slight widening of the tip of the interhæmal spines, each being covered by a little rough scale); front of dorsal with similar projections.

b. Color brown, with pale rounded spots; fins dotted with brown; a faint dark spot at first $\frac{2}{3}$ of lateral line; snout with horny points; mouth small, the maxillary reaching front of eye.

SPINOSUS, 3030

aa. Anal rays without spinules at their base.

c. Anterior profile of head convex before the interorbital area, the rery short snout scarcely forming a reentrant angle at its base; form elliptic-ovate, the outlines more regular than in $P$. lunatus.

d. Dorsal rays 85 to 95 .

e. Scales not very small, about 75 pores in lateral line; no blue mark. ings, at least in the young.

$f$. Mouth small, the maxillary 3 in head; no spines about the snout; eye $3 \frac{1}{3}$ in length; interorbital width 3 in head (in the type); pectoral short; curve of lateral line 6 times in straight part. Color dark brown, with uumerous stellate white spots, the most distinct of them with darker edgings; these generally scattered over the body; but some of them on sides of body gathered together in little rings; these spots blue rather than white in life.

CONSTELLATUS, 3031.

$f f$. Mouth smaller, the maxillary $3_{4}^{3}$ in head. Color light grayish, tinged with reddish, with small round spots of darker gray, and with lighter rings inclosing spaces of ground color.

ocellatus, 3032.

ee. Scales smaller, 90 to 95 pores in lateral line. Color of adult, reddish gray, the body everywhere covered with rings formed of round, sky-blue spots, which are not confluent and not edged with black; besides these, very few detached spots or other blue markings.

MACULIFER, 3033.

$d d$. Dorsal rays 105; aual rays 80 ; pectoral short; interorbital space $2 \frac{3}{4}$ in head; depth $1 \frac{3}{4}$ in length; scales 91 ; body deep. Color (specimen $4 \frac{3}{4}$ inches long) grayish, much spotted and mottled with whitish, no blue in young example.

ELLIPTICUS, 3034.

$c c$. Anterior profile of head strongly concave before interorbital area, the projecting snout leaving a marked reentrant angle above it.

g. Mouth not very small; maxillary 3 in head. Color dark olive, with many rings, curved spots, and small round dots of sky blue edged with darker on body, these largest near middle of sides, where some are as large as eye; 3 obscure dark blotches on straight part of lateral line.

LUNATU8, 3035.

gg. Mouth small; maxillary $3 \frac{4}{6}$ in head. Color highly rariegated with different shades of gray, the pale blotches rounded, very irregular in size and position; no blue spots.

LEOPARDINUS, 3036.

\section{PLATOPHRTS SPINOSUS (Poey).}

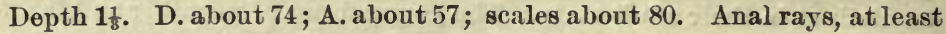
anteriorly, each with a spinule at base, these formed by a slight widening of the tips of the interhæmal spines, each being covered by a little rough scale; front of dorsal with similar projections. Snout with horny points; mouth small, the maxillary reaching front of eye. Eyes very wide apart, $2 \frac{2}{8}$ in head, the interorbital space $1 \frac{1}{5}$ in head; pectoral fin short; curve of lateral line 5 in straight part. Color brown, covered with pale rounded spots; fins dotted with brown; a faint dark spot at first third of lateral line. Described from specimens from Cuba, probably the types, $4 \frac{1}{4}$ inches 
long, which have been partly dried before being placed in alcohol. Cuba. The original description of this species is a very scanty one. In all respects, unless it be the color, it agrees with the European species, Platophrys podas. We have found 2 small specimens sent by Professor Poey to the Musenm of Comparative Zoology, which may be the types of this species. They are $4 \frac{1}{4}$ iuches long, and have been partly dried in the sun. $\Lambda$ result of this has been to increase the prominence of the interhemal spines. Whether these be the original types or not, the species is an extremely doubtful one. The eyes are farther apart in these specimens than in any of Platophrys ocellatus, which we have examined. They agree in this respect with Agassiz's figure of Rhombus ocellatus. (spinosus, spinous.)

- Rhomboįdichthys spinosus, PoEY, Synopsis, 409, 1868, Cuba; PoEY, Enumeratio, 139, 1875. Platophrys spinosus, JORDAN \& Goss, Review Flounders and Soles, 266, 1889.

\section{Platophrys constellatus, Jordan.}

Head 4; depth $1 \frac{1}{2}$; eye $3 \frac{1}{3}$ in head; interorbital width 3 . D. 89 ; A, 65; scales 75. Body elliptic-ovate, the outlines more regular than in P. lunatus; anterior profile of head convex before the interorbital area, the very short snout scarcely forming a reentrant angle at its base; anal rays without spinules at their base; mouth small, the maxillary 3 in head; no spines about the snout; pectoral short; curve of lateral line 6 times in straight part. Color dark brown, with numerous stellate white spots, the most distinct of them with darker edgings; these generally scattered over the body, but some of them on sides of body are gathered together in little rings (perhaps these spots are blue rather than white in life); fins mottled with dark brown, the pectoral finely barred. Specimens examined $3 \frac{1}{2}$ inches long. Galapagos Archipelago. Originally described from 3 specimens, the largest $3 \frac{1}{2}$ inches long, numbered 11146 on the register of the Museum of Comparative Zoology. They are from James Island, in the Galapagos. The species is closely related to $P$. ocellatus and others, but in color, at least, it is different, and its habitat is remote; locally common. (constellatus, with star-like spots.)

Platophrys constellatus, Jordan, in Jordan \& Goss, Review Flounders and Soles, 266, 1889, James Island, Galapagos Archipelago. (Types in M.C.Z.)

3032. PLATOPHRYS OCELLATUS (Agassiz).

Head 4 in length; depth $1 \frac{1}{2}$; eye (lower) $3 \frac{2}{3}$ in head; snout 5. D. 85; A. 64 ; scales 75 (pores); vertebrie 37. Body ovate, deep anteriorly, the profile descending steeply, rendered abruptly concave in front of interorbital space by the conspicuously projecting short snout. Mouth very small and oblique, the maxillary reaching vertical from front of lower eye, $3 \frac{8}{4}$ in head; tip of lower jaw entering the profile. Teeth fine, conical, in 2 series in the upper jaw, 1 in the lower, those of the outer row in upper jaw larger and more widely separated than those of the inner series. Snout very short, equaling interorbital width. Interorbital space narrow, deeply concave, closely scaled. Eyes large, the lower in advance of upper. Gill rakers obsolete, 7 rudiments on horizontal branch of anterior arch. Scales moderate, not extending on the fins, those on colored side 
ctenoid, those on blind side smooth; arch of lateral line short and high, its base contained $4 \frac{1}{2}$ to 5 times in the straight portion. Dorsal fin beginning opposite anterior nostril, the rays nearly uniform in length, the longest about $\frac{1}{2}$ head; pectoral of colored side $4 \frac{8}{4}$ in length; ventral of colored side beginning under middle of lower eye, with 6 rays; the right ventral with 5 rays. Color in life, light grayish with reddish tinge, covered with small round spots of darker gray and with lighter rings inclosing spaces of the ground color; vertical fins similarly colored, with a small black spot near base of each ninth or tenth ray; 2 black spots on median line of body divide the length into nearly equal thirds; some other small black spots seattered over colored side. Western Atlantic, from Long Island to Rio Janeiro, on sandy shores. Here described from Key West specimens, types of $P$.nebularis. This species is very common at Key West in clear, shallow water on sandy bottom. The largest of the numerous specimens taken is 3 inches in length. A specimen similar to these has been taken by Dr. Bean on the south coast of Long Island. This seems to be the same as the Cuban species called Rhomboidichthys ocellatus by Poey, and some of the specimens sent by Poey to the Museum of Comparative Zoology are apparently identical with the types of $P$. nebularis. In the Museum of Comparative Zoology we have compared specimens of the real Platophrys ocellatus (No. 11423, Rio Janeiro, Agassiz) with a representative specimen of $P$. nebularis (No. 26147, from the Tortugas, Florida), and are unable to find any differences. Wo adopt, therefore, the name Platophrys ocellatus for all, and regard it as one of the widely distributed flounders, like Etropus crossotus and Citharichthys spilopterus. (ocellatus, with eye-like spots.)

Rhombus ocellatus, Agassiz, Spix, Pisc. Brasil., 85, pl.46, 1829, Brazil.

Rhombus bahianus, CASTELAN , Anim. nouv. rares Amérique du Sud, 1855, Bahia.

Platophrys nebularis, JoRdan \& GILBERT, Proc. U. S. Nat. Mus. 1884, 31, 143, Key West

(Type, 34972. Coll. Dr. Jordan); Goode \& BEan, Oceanic Ichthyology, 441, 1896.

Platophrys ocellatus, SwaInson, Nat. Hist. Class'n Fishes, II, 302, 1839; Jordan \& Goss,

Review Flounders and Soles, 266, 1889.

Rhomboidichthys ocellatus, GüNTHER, Cat., 1v, 433, 1862; PoEx, Synopsis, 408, 1868.

3033. PLATOPHRYS MACULIFER (Poey).

Head 4 ; depth $1 \frac{5}{6}$. D. 90 to 95 ; A. 70 ; scales 90 to 95 . Body elliptical, ovate. Mouth small, oblique, the maxillary $3 \frac{2}{5}$ in head; teeth in each jaw in 2 irregular series; filamentous rays of pectorals reaching very nearly to last rays of dorsal; arch of lateral line short and high, its length $1 \frac{4}{5}$ times its height and $2 \frac{2}{5}$ in head; snout very short, 4 in head; interorbital area $3 \frac{8}{4}$ in head. Color of adult reddish gray, the body everywhere covered with rings formed of round, sky-blue spots, which are not confluent and are not edged with black; besides these, very fow detached spots or other blue markings; head with similar blue spots, but no rings; area inclosed in the blue rings not different from the ground color; caudal with blue spots, other fins with none; dorsal and anal mottled; a large, diffuse, dusky spot at front of straight part of lateral line; 1 better defined on middle of lateral line; a faint one farther back; pectorals grayish, with dark bars. Cuba. Wo identify specimens taken by Dr. 
Jordan at Havana with this species. In the Museum of Comparative Zoology are other specimens similar to these, sent to Cambridge by Poey. In several respects these specimens agree fairly with Poey's $P$. ellipticus, but that species is said to have 104 dorsal rays. (macula, spot; fero, I bear.)

? Pleuronectes maculiferus, PoEx, Memorias, II, 316, 1860, Cienfuegos. (Coll. Poey.)

? Rhomboidichthys maculiferus, PoEy, Synopsis, 408, 1868; PoEy, Enumeratio, 139, 1875.

Platophrys maculifer, JoRdAN \& Goss, Review Flounders and Soles, 267, 1889.

Platophrys ellipticus, Jordan, Proc. U.S. Nat. Mus. 1886, 51; not of Poey.

\section{PLATOPHRTS ELLipticus (Poey).}

Depth 18:. D. 105 ; A. 80 ; scales 91 . Body elliptical, ovate; anterior profile of head convex before the interorbital area; pectoral short; interorbital space $2 \frac{8}{4}$ in head; body deep. Color (specimen $4 \frac{8}{4}$ inches long) grayish, much spotted and mottled with whitish; no blue (in young example). Cuba. Poey describes his $P$. ellipticus as having 104 dorsal rays. In none of our other species does the number of these rays reach 100 . Among the specimens sent by Poey to the museum at Cambridge is 1 , described above, $4 \frac{8}{4}$ inches long, which has 105 dorsal rays. We have therefore assumed that the species to which this specimen belongs is the real P.ellipticus, and that the one heretofore called P.ellipticus is Poey's $P$.maculifer. Both these assumptions are open to considerable doubt. (ellipticus, elliptical.)

? Pleuronectes ellipticus, PoEy, Memorias, II, 315, 1860, Cuba. (Coll. Poey.)

? Romboidichthys ellipticus, GÜNTHer, Cat., IV, 434, 1862; PoEY, Synopsis, 408, 1868; Poex, Enumeratio, 139, 1875.

Platophrys elliptivus, JoRDAN \& Goss, Review Flounders and Soles, 267, 1889.

3035. PLATOPHRYS LUNATUS (Linnæus).

(Peacock Flounder.)

Head $3 \frac{2}{5}$ in length; depth 2. D. 93 ; A. 70 ; scales 90 ; lower eye 6 in head; maxillary $2 \frac{2}{3}$; interorbital $2 \frac{2}{5}$; highest dorsal rays $2 \frac{2}{3}$; highest anal rays $2 \frac{1}{2}$; caudal $1 \frac{1}{2}$; base of ventral of eyed side $3 \frac{1}{4}$. Vertebra $9+30=39$. Body elliptical, ovate, strongly compressed; anterior profile concave, the snout projecting, leaving a reentrant angle above it; mouth moderate, the maxillary reaching to middle of pupil of lower eye; jaws subequal, the lower with a well-developed knob at symphysis, teeth small, in an irregular double series in each jaw; anterior end of maxillary with a large blunt spine, pointing outward and forward, a smaller one behind it on upper edge of maxillary, pointing upward and backward; interorbital vers wide and deeply concave; orbital rim, below on npper orbit, above on lower, broken up into blunt papillæ; gill rakers short and thick, 9 developed on lower part of arch, none on upper. Anterior part of interorbital, snout, maxillary, and mandible, naked; scales all cycloid; the rays of dorsal and anal with scales, a few on ventral of eyed side; arch of lateral line 5 in straight part. Pectoral of eyed side filamentous, reaching to base of caudal, its mate of opposite side shorter, about $1 \frac{8}{4}$ in head; origin of dorsal over snout; ventral of eyed side with a long base, extending from $3030-90$ 
angle at istbmus, along ridge of body, slightly past front of anal; base of ventral of blind side $\frac{1}{2}$ the length of that of its mate; caudal with the middle rays produced, double convex. Color dark olive, with many rings, curred spots, and small round dots of sky blue edged with darker on body, these largest near middle of sides, where some are as large as the eye; 3 obscure dark blotches on straight part of lateral line; head and vertical fins with sharply defined blue spots, which are mostly round; spots on opercles larger and curved; pectorals with dark bars. West Indies, north to Florida; common. Here described from a specimen from Green Turtle Cay, Florida, 14 inches in length. This handsome and curiously colored species is not rare in the waters of the West Indies. The specimens examined by us are from Cuba, Sombrero, St. Thomas, and other localities in the West Indies. Tho original figure of this species published by Catesby is a very good one and leaves no room for doubt as to the species intended. The figure of Bloch, called Pleuronectes argus, is also fairly accurate, and can refer to no other species. 'This species reaches a leugth of some 18 inches, and is the largest in size of the American species of Platophrys. We have never seen any young examples which certainly belong to it, and till its development is traced some of the species known from small examples only must be doubtful. (lunatus, crescent-shaped, from the spots.)

Solea lunata et punctata (the Sole), CATESBY, Nat. Hist. Carolina, tab. 27, 1725, Bahamas. Pleuronectes lunatus, Linnæus, Syst. Nat., Ed. x, 269, 1758, Bahamas; based on CATESBY; and of the various copyists.

Pleuronectes argus, BLOCH, Ichthyol., tab. 48, 1783, Martinique; after Plumier.

?Pleuronectes surinamensis, BLOCH \& SCHNEIDER, Syst. Ichth., 156, 1801, Surinam; "satis parva et glabra;" fins scaly; mouth small; lateral line arched in front; D. 96; A. 55.

Rhomboidichthys lunatus, GÜnthER, Cat., IV, 433, 1862; PokY, Synopsis, 408, 1868.

Rhomboidichthys lunulatus, POEx, Enumeratio, 138, 1875.

Platophrys lunatus, Jordan, Proc. U. S. Nat. Mus. 1886, 51 ; Jordan \& Goss, Review Flounders and Soles, 267, 1889 .

3036. PLATOPHRYS LEOPARDINUS (Günther).

Head $3 \frac{8}{4}$ in length; depth $1 \frac{8}{4}$; eye (lower) $3 \frac{1}{2}$ in head. D. 86 to 88 ; A. 64 (62 to 66 ); scales about 80 . Mouth very small, the maxillary $3 \frac{4}{5}$ in head; teeth very small, biserial above. Interorbital space concave, rather broad, its width $3 \frac{1}{2}$ in head. Eyes large, the lower considerably before the upper. Lateral line with a short sharp curve anteriorly. Gill rakers very small. Anterior rays of dorsal not elevated; left pectoral not produced, little longer than right, $1 \frac{1}{4}$ in head. Coloration highly variegated with different shades of gray, the pale blotches rounded, very irregular in size and position; no distinct black spots along the lateral line; a large whitish cloud between the eyes; blind side pale, scaled like the eyed side. Gulf of California. This species is known only from the origina] type from unknown locality, and from a single specimen, $2 \frac{2}{8}$ inches long, in the United States National Museum, taken by Mr. H. F. Emeric, at Guaymas, Sinaloa. From this the above description was taken. (leopardinus, leopard-like.)

Rhomboidichthys leopardinus, GUNTHER, Cat. Fish., 1v, 434, 1862, locality unknown.

Platophrys leopardinus, JoRDAN, Proc. U. S. Nat. Mus. 1884, 260, specimen from Guaymas; JoRDAN \& Goss, Review of Flounders and Soles, 268, 1889. 
1045. PERISSIAS, Jordan \& Evermann.

Perissias, Jordan \& Evermann, new genus (tceneopterus).

This genus differs from Platophrys in the larger scales, narrower interorbital, and especially in the greatly produced ribbon-like lobe at the front of the dorsal. From Engyprosopon it differs in the short thick gill rakers and in the produced dorsal rays. The lateral line is wanting on the blind side. Deep sea. ( $\pi \varepsilon \rho \imath \sigma \sigma o ́ \varsigma$, strange.)

\section{PERISSIAS TENIOPTERUS (Gilbert).}

Head $3 \frac{2}{3}$; depth $2 \frac{1}{2}$. D. 86 to 88 ; A. 67 to 70 ; scales 60 to 65 , the arch with 15 pores; 20 seales in a series running upward and backward from lateral line. Body elongate; candal fin subsessile, the last anal and dorsal rays inserted near rudimentary caudal rays; height of caudal peduncle 4 in height of body; upper profile descending very obliquely anteriorly, a slight reentrant angle in front of lower eye; in males the profile slightly angulated in front of upper orbit, below whieh it ascends more steeply; lower eye much in advance of upper; in females eyes close together, the vertical from middle of lower eye passing through front of upper orbit; diameter of upper orbit $3 \frac{1}{2}$ in head; in males the lower eye may be entirely in advance of upper; in females 3 inches long, and in very young males the interorbital space is a narrow, concave, scaleless groove, less than diameter of pupil, running into a deep pit behind lower eye; in males 2 inches long the interorbital space has already widened, and in specimens $3 \frac{1}{2}$ inches long is as wide as longitudinal diameter of orbit; it is traversed by an oblique ridge running upward and backward from front of lower eye, separating the anterior scaleless portion from the deep scalely pit behind; supraorbital ridge of lower eye serrated, forming a strong series of spines, less marked in females; anterior rim of upper orbit similarly but less strongly marked; a strong double spine on maxillary in front of nostrils; a spine near end of maxillary in males; mouth small, maxillary not reaching front of pupil, equaling diameter of orbit; teeth small, in a single close-set series in each jaw, equally developed on both sides, with enlarged canines; gill rakers very short and weak, 8 on horizontal limb; anterior nostrils with very short flaps; dorsal beginning above front of lower eye; in all specimens, females as well as males, the first 2 rays detached from the rest of fin, the second ray produced into a flat, ribbonshaped filament about as long as head; dorsal and anal rays all unbranehed; median caudal rays forked; no anal spine; ventral of colored side on ridge of abdomen, the 2 anterior rays in males connected by membrane at base only, produced into flat filaments as long as head, extending far beyond front of anal; pectoral of left side well developed, but small, slightly more than $\frac{1}{2}$ head; that of blind side little developed, about $\frac{1}{2}$ diameter of orbit; scales of left side strongly ctenoid, absent on interorbital space, snout, maxillary, and mandible; lateral line with strong curve anteriorly, the cord of which is contained 5 times in straight portion. Along lateral line are occasional broad cutaneons flaps, colored blue in life; scales of blind side cycloid, the tubes of lateral line obsolete, the course of lateral 
line indistinctly indicated by pits at bases of scales and occasional porelike markings; median rays of dorsal and anal on left side with series of ctenoid scales, otherwise scaleless; caudal rays with double series on both sides. Color on left side olive brown, with many small irregular spots of light gray, with darker border; 3 or 4 dark blotches along lateral line; along dorsal and ventral outlines about 5 pairs of light spots, broadly ocellated with blackish; males with a bright blue spot on anterior profile at base of each of first 10 or 12 dorsal rays and 1 on end of snout; blind side in males with a broad oblique bar covering about $\frac{1}{4}$ of sides, bluish black in life, dark brown in spirits; from its upper anterior part a number of narrow parallel streaks run forward toward head, much as in Engyophrys sancti-laurentii; filamentous rays of dorsal and ventral white; fins all speckled; a small black spot at base of median eaudal rays. Differing from all known species of Platophrys in the ribbon-shaped prolongations of second dorsal ray and first and second ventral rays of eyed side, and in the obsolete lateral line of blind side. Several specimens from the Gulf of California and the western coast of Lower California, in 40 fathoms. (Gilbert.) ( $\tau \alpha \imath \nu i \alpha$, ribbon; $\pi \tau \varepsilon \rho o \dot{\nu}$, fin.)

Platophrys tceniopterus, GiLBerT, Proc. U. S. Nat. Mus. 1890,118, Gulf of California, north of La Paz, at Albatross Station 2998, Lat. $24^{\circ} 5 x^{\prime}$ N., Long. $110^{\circ} 39^{\prime}$ W., in 40 fathoms. (Type, No. 43095. Coll. Gilbert.)

\section{ENGYOPHRYS, Jordan \& Bollman.}

\section{Engyophrys, Jordan \& Bollman, Proc. U. S. Nat. Mus. 1889, 176, (8ancti-laurentii).}

This genus is allied to Platophrys, Swainson, but differs from it in having the interorbital space very narrow and armed with a spine, and the scales of moderate size and ctenoid, Gill rakers obsolete. No anal spine. Gill membranes entirely separate. It is still nearer the genus Engyprosopon, Giuther, but in that group the interorbital space is broader and the gill rakers are developed and slender. ( $\dot{y} y \dot{v} 5$, near together;

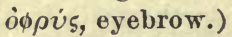

3038. ENGYOPHRYS SANCTI-LAURENTII, Jordan \& Bollman.

Head $2 \frac{2}{5}$ to $2 \frac{4}{7}$ ( 3 to $\left.3 \frac{1}{2}\right)$; depth $1 \frac{2}{8}$ to 2 ( 2 to $\left.2 \frac{1}{3}\right)$. D. 78 to 85 ; A. 68 to 72 ; scales 60 to 68 , along lateral line. Body broadly ovate, much compressed, the greatest depth over pectorals; dorsal and ventral outlines equally curved; profile scarcely concave before eyes. Mouth very small, oblique, the maxillary reaching opposite pupil of lower eye, 4 to $4 \frac{1}{2}$ in head. Teeth present on blind side, well developed, close set and even, none on vomer. Snout short, $4 \frac{1}{2}$ to 5 in head. Interorbital space a very narrow, sharp, scaleless ridge, the ridge forking above pupil, leaving a very narrow concavity anteriorly; lower ridge armed with a strong spine, turned backward, inserted just above pupil of lower eye. Anterior orbital rim of upper eye rather high, entering profile. Eyes large, lower in adrance of upper, 38 to 4 in head. Gill rakers almost obsolete, represented by 5 or 6 small fleshy papilla. Scales moderately small, ctenoid, aud not very firmly attached; small scales on rays of dorsal and 
anal fins; arch of lateral line short and small, but abrupt, 4 to 5 times in straight part. Dorsal beginning on blind side just behind posterior nostril and in front of eye; pectoral of colored side 2 in head, that of blind side $2 \frac{1}{2}$ in head; ventrals of colored side slightly longest, 3 in head; that of colored side with 6 rays, of blind side with 5 or 6 rays. Color of left or eyed side, blackish brown, with scattered white and black spots, the latter most prominent along base of dorsal and anal fin; 3 large, black, nonocellated blotches on straight part of lateral line, the first at beginning, second at middle, and third on peduncle; fins dusky; dorsal and anal with scattered white and black spots; caudal with 5 black spots arranged in a curved series; blind side with 5 or 6 curved parallel dusky bands as wide as eye, the first beginning on interopercle and curving across cheek to along base of dorsal; second beginning at throat and curving along posterior margin of preopercle, and extending on back, parallel with the first from vent; third curving around in front of pectorals, across posterior part of opercle, and extending to base of dorsal fin behind the middle; rest behind pectorals. All of these bands fade out behind middle of boty, so that the posterior portion is immaculate. In young examples these bands are very faint or obsolete. Coast of Colombia, southwest of Panama. Numerous specimens, the largest about $4 \frac{1}{2}$ inches long, were dredged at Albatross Station 2795, at a depth of 33 fathoms, and at Albatross Station 2805 at a depth of $51 \frac{1}{2}$ fathoms. This peculiar species is distinguished from the species of Platophrys and Engyprosopon by its very narrow interorbital ridge, from the species of Arnoglossus by the form of the body, the short gill rakers, etc., and from all related species by the peculiar coloration of the blind side. (Named for St. Lawrence, in allusion to the gridiron-like markings of the blind side.)

Engyophrys sancti-laurentii, Jordan \& Bollman, Proc. U. S. Nat. Mus. 1889, 176, Pacific Oceán, off coast of Colombia, at Albatross Station 2805 , Lat. $7^{\circ} 5^{6^{\prime}} \mathrm{N}$., Long. $79^{\circ}$ $4^{x^{\prime}} 3^{\prime \prime}$ W., and Station 2795 , Lat. $7^{\circ} 57^{\prime}$ N., Long. $7^{\circ} 55^{\prime}$ W. (Type, No. 41155.)

I047. TRICHOPSETTA, Gill.

Trichopsetta, GILL, Proc. U.S. Nat. Mus. 1888, 603 (ventralis).

Body ovate, covered with rather large, ctenoid adherent scales; mouth moderate, the chin prominent; vomer toothless; teeth small, somewhat enlarged and hooked in front, uniserial; maxillaries obliquely truncated behind; interorbital area a narrow ridge, with a median groove in front; none of the dorsal rays produced; ventrals free from the anal; caudal fin subsessile; both pectoral fins present; right ventral much produced, the left on the ridge of the abdomen; lateral line with a strong arch in front. ( $\theta \rho i \xi$, hair; $\psi \tilde{\eta} \tau \tau \alpha$, turbot, from the prolonged ventral.)

\section{TRICHOPSETTA VENTRALIS (Goode \& Bean).}

Head 4 in body; depth $2 \frac{1}{8}$. D. 93 ; A. 73 ; pectoral 11 (eyed side), 7 or 8 (blind side); scales 19-66-23; eye $3 \frac{2}{3}$ in head; maxillary scarcely 2 ; interorbital very narrow, scaleless, its width 8 in eyo; scales strongly ctenoid; dorsal beginning upon suout upon the blind side, in advance of eyes, its 
highest rays equaling length of mandible; origin of anal under base of pectoral, its longest ray equaling or slightly exceeding $\frac{1}{2}$ the distance of its anterior ray from snout; caudal equal to length of head without snout; pectorals inserted considerably below origin of lateral line, close to gill opening, that of the eyed side 6 in length of body; that of the blind side almost as long as head. Color light brownish gray; a dark blotch as long as eye on the anterior rays of the anal, a few obscure on different parts, of lighter hue at the junction of the curved and straight portion of the lateral line. (Goode \& Bean.) Deep waters of the Gulf of Mexico. (ventralis, pertaining to the ventrals.)

Citharichthys ventralis, GOoDE \& BEAN, Proc. U. S. Nat. Mus. 1885, 592, deep waters of Gulf of Mexico. (Coll. Albatross.)

A rnoglossus ? ventralis, JORDAN \& GOSS, Review Flounders and Soles, 262, 1889.

Trichopsetta ventralis, GooDe \& BEAN, Oceanic Ichthyology, 440, pl. 109, fig. 372, 1896.

I048. SYACIUM, Ranzani.

Syacium, Ranzani, Novis Speciebus Piscium, Diss. Sec., 20, 1840 (micrurum).

Hemirhombus, BLEeker, Comptes Rendus Acad. Sci. Amsterd., xili, Pleuron., 4, 1862 (guinënsis).

Aramaca, Jordan \& Goss, in JoRdan, Cat. Fish. N. A., 133, 1885 (patula).

Body elliptic-ovate, much compressed; interorbital space broad in the males and more or less concave, narrowed in the female; mouth moderate, the gape curved; teeth in the upper jaw biserial, in the lower uniserial; the front teeth of the upper jaw enlarged; vomer toothless; scales rather large, ciliate; lateral line without arch in front; pectoral fins on both sides present; septum of gill cavity below gill arches without foramen; a deep emargination near the isthmus; gill rakers short and thick; dorsal low, its anterior rays not elevated; pectorals both present; caudal subsessile; no anal spine; pectorals produced in the males; ventral fins short, that of colored side on ridge of abdomen. This genus contains a considerable number of species, mostly American and African, which form a transition from Platophrys to Citharichthys. They fall readily into 2 groups distinguished by the width of the interorbital space. As this width is dependent on age, and as it is subject to various intergradations, the group Aramaca founded on it can not be admitted as a distinct genus. (бváxıov, diminutive of $\sigma \tilde{v} \alpha \xi$, a kind of pulse, the application unexplained.)

a. Snout and orbits without spines or spinous processes.

b. Scales rather large, 50 to 57 in the lateral line; interorbital space broad. Color nearly plain brown, with darker dots or mottlings, no ring-like spots or ocelli; fins mottled; left pectoral barred; blind side sometimes wholly or partly dusky, especially in northern specimens. PAPILlos UM, 3040.

$b b$. Scales rather small, 58 to 70 in the lateral line.

c. Scales 65 to 70 . Color dark brown, with many rings and spots of light gray and blackish, some of the dark rings with a black central spot; a dif. fuse dusky blotch on lateral line above pectoral, and 1 near base of caudal peduncle; fins with numerous inky spots and dark markings; blind side pale.

cc. Scales 58 to 60 . MICRURUM, 3041. 
d. Interorbital space in male broader than eye. Color light brown, with grayish and light bluish dots, some darker areas, and a few round brown spots ocellated with lighter; interorbital space with a vertical brown bar bordered by lighter; fins mottled and spotted.

LATIFRONS, 3042.

$d d$. Interorbital space not broader than pupil. Color light olive brown, nearly uniform, the vertical fins with elongate dark spots.

OVALE, 3043.

3040. SYACIUM PAPILLOSUM (Linnæus).

Head $3 \frac{2}{3}$ in length; depth $2 \frac{1}{8}$. D. 82 ; A. 63 to 70 ; scales 53 ; eye 5 in head; maxillary $2 \frac{2}{3}$; pectoral of eyed side $1_{6}^{1}$; caudal $1 \frac{2}{5}$. Body elliptic-ovate, the anterior profile regularly decurved, forming an angle above the snout; mouth rather large, arched; maxillary extending to below middle of eye, its posterior end concave; teeth in upper jaw in 2 series, some of the outer forming small canines; lower teeth in 1 row; eye large, 4 in head; lower eye in advance of upper, especially in the adult; interorbital space broad, concave, greater than the long diameter of the eye in the males, about equal to the vertical diameter in the females; accessory scales very numerous; mandible, maxillary, and interorbital with scales; gill rakers short, scarcely as long as pupil, about $2+8$; dorsal rather low, beginning slightly in front of lower eye, the first 3 or 4 rays on blind side, the anterior rays produced beyond the membrane; ventrals with moderate base, that of eyed side on ridge of body, that of blind side slightly in advance of its mate; anal beginning a little in advance of pectoral; pectoral of eyed side pointed behind, the upper rays filamentous (at least in the male); caudal double truncate. Vertebræ $10+26=36$. Color nearly plain brown, with darker dots or mottlings, no ring-like spots or ocelli; fins mottled; left pectoral barred; blind side sometimes wholly or partly dusky, especially in northern specimens. Charleston to Rio Janeiro, in rather deep water. Here described from an adult specimen from Charleston, a foot in length. Of the species found in the deep waters about Pensacola, and called by Dr. Bean Hemirhombus patulus, we have numerous specimens. Lately we have received from Mr. Charles C. Leslie, of Charleston, a specimen which shows its presence also in Carolina waters. It has not yet been recorded from Cuba, but in the Muscum of Comparative Zoology is a specimen (26104) taken by Mr. Samuel Garman, at Kingston, Saint Vincent. But its range extends much farther to the southward, for among the collections made by Professor Agassiz, at Rio Janeiro, there are many specimens $(11375,4666)$, the largest about a foot long. These seem to be completely identical with Florida examples, differing only in having the blind side pale, it being usually partly blackish in northern samples. These Brazilian specimens agree very closely with the figure of Rhombus soleceformis, except that Agassiz has represented that species as having a dusky blotch at the shoulder. No such marking is apparent in any of our specimens. The coloration and the breadth of the interorbital both render it unlikely that Agassiz's soleaformis could have been micrurum. The Aramaca of Maregrave, which is the sole basis of Pleuronectes papillosus. Pleuronectes macrolepidotus, and Rhombus aramaca, can not well be any known species other than the present one. According 
to Marcgrave's rude figure and his description, this species has the form of a sole, the eyes wide apart, the left pectoral produced, the mouth very large, the body oblong, and the coloration stone-like (sand color) on the left side and white on the eyed side. Syacium micrurum is not colored in that way, and its eyes are not noticeably far apart. We therefore adopt. for this species the oldest name, Syacium papillosum. (papillosus, having papillæ.)

A ramaca, MARCGRAve, Hist. Brasil., 181, 1648, Brazil.

Pleuronectes papillosus, LinNæus, Syst. Nat., X, 271, 1758, Brazil; based on MARCGRAYE.

? Pleuronectes macrolepidotus, BLOCH, A usländische Fishe, v1, 25, tab. 190, 1787; apparently based on MARCGRAVE.

Pleuronectes aramaca, DonndorF, Beiträge zur Ausgabe des Linnæischen Natursystems, XIII, 386, 1798; after MARCGRAVE.

Rhombus aramaca, Cuvier, Règne Animal, Ed.2, 1I, 341, 1829; after MARCGRAVE.

Rhombus soleaformis, AGassiz, Spix, Pisc. Brasil., 86, tab. 47, 1829, Atlantic Ocean.

Hippoglossus intermedius, Ranzani, Novis Speciebus, Piscium Dissertatio Secundo, 1840, 14, pl. 4, Brazil.

Hemirhombus soleceformis, GüNTHER, Cat. Fish., IV̀, 423, 1862.

Hemirhombus paetulus, Bean MS., Jordan \& Gilbert, Proc. U. S. Nat. Mus. 1882, 304, Pensacola (Coll. Silas Stearns); Goode \& Bean, Proc. U. S. Nat. Mus. 1882, 414; Bean, Cat. Coll. Fish U. S. Nat. Mus. 1883, 45.

Citharichthy a a amaca, JoRDAN \& GILBERT, Synopsis, 816, 1883.

Citharichthys patulus, JoRdan \& GiLBerT, Synopsis, 964, 1883; JoRDAn, Proc: U. S. Nat. Mus. 1884, 38; Goode \& BEAN, Oceanic Ichthyology, 448, pl. 109, fig. 373, 1896.

Aramaca papillosa, Jordan, Proc. U.S. Nat. Mus. 1886, 602; synonymy confused with $S$. micrurum.

A ramaca soleaeformis, Jordan, Proc. U. S. Nat. Mus. 1886, 602.

Syacium papillosum, JoRDAN \& Goss, Review Flounders and Soles, 268, 1889.

\section{SYACIUM MICRURUM, Ranzani.}

Head $3 \frac{4}{5}$ in length; depth $2 \%$ D. 87 to 92 ; A. 54 to 68 ; scales 65 to 70 (pores); eye 4 in head; maxillary $2 \frac{1}{2}$ to 3 . Form regularly elliptical, the profile ovenly convex to end of snout; eyes large, nearly even in front, the male with the interorbital space deeply concave, its width $\frac{2}{3}$ the vertical depth of the eye (or more in Brazilian specimens); female with interorbital area much narrower, with a more or less perfect median groove, its width about equal to depth of pupil; mouth small, the maxillary reaching to below middle of eye; teeth small, slender, in 2 rows above, in 1 row below, the outer series in upper jaw somewhat enlarged, but hardly canine-like; gill rakers very short and thick, about $1+7$ in number. Scales small, firm, moderately ctenoid; pectoral $1 \frac{1}{8}$ in head in the female, reaching nearly to base of caudal in the male; vertebræ $9+24=33$. Color dark brown, with many rings and spots of light gray and blackish, some of the dark rings with a black central spot; a diffuse dusky bloteh on lateral line above pectoral, and 1 near base of caudal peduncle; fins with numerous inky spots and dark markings; blind side pale. West Indian fauna, Key West to Rio Janeiro; rather common. We have found in the Museum of Comparative Zoology specimens purporting to be the types of Hemirhombus ocellatus, Poey (No. 11144; Poey's number, 88). These are female examples, and they differ from the types of Hemirhombus athalion, obtained in Cuba by Dr. Jordan, only in their greater size. Numerous 
specimens (11373) from Rio Janeiro belong to the same species. Among these are males, which have the interorbital space much broader than in the types of ocellatus and athalion. Besides these specimens we have examined others from Hayti, Cuba, and Key West, and there can be no reasonable doubt of their identity, and that all are identical with Gïnther's Hemirhombus aramaca. This fish is described and fairly well figured by Ranzani under the name of Syacium micrurum. It is the type of his genus Syacium, a generic name which, strangely enough, has received no notice

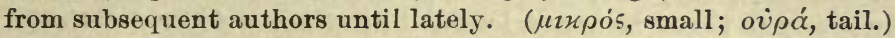

Syacium micrurum, Ranzani, Nov. Spec. Pisc. Diss. Sec., 20, pl. 5, 1840, Brazil; JoRdan \& Goss, Review Flounders and Soles, 269, 1889.

Hippoglossus ocellatus, PoEY, Memorias, II, 314, 1860, Cuba.

Hemirhombus aramaca, GÜNTHER, Cat., IV, 42,1862, Cuba ; Jamaica ; not Rhombus aramaca, Cuvier.

Citharichthys athalion, Jordan, Proc. U. S. Nat. Mus. 1886, 52, Havana. (Type, No. 37748. Coll. D. S. Jordan.)

Hemirhombus ocellatus, PoEY, Synopsis, 407, 1868; POEY, Enumeratio, 138, 1875.

Citharichthys ocellatus, Jordan \& GiLbert, Synopsis, 964, 1883; Jordan, Proc. U. S. Nat. Mus. 1884, 143.

Hemirhombus aethalion, JoRdan, Proc. U. S. Nat. Mus. 1886, 602.

3042. SYACIUM LATIFRONS (Jordan \& Gilbert).

Head 4 ; depth $2 \frac{1}{2}$. D. 92 ; A. 72 ; scales 60 . Body elliptical, the dorsal and ventral outlines equally arched; mouth placed low, below axis of body ; snout with an abrupt constriction in front of upper orbit, the outline then again convex; eyes on left side, distant, the lower in advance of the upper; a vertical line from anterior margin of upper orbit passing through middle of lower; distance of upper eye from dorsal outline equaling $\frac{2}{3}$ its vertical diameter; interorbital space concave, very wide, its width $1 \frac{1}{2}$ times diameter of orbit in a specimen 8 inches long, much narrower in the young; a ridge from upper angle in lower eye runs upward and backward to join a ridge from upper orbit. Nostrils on a level with upper margin of lower eye, the anterior with a flap, distant from the posterior, which is circular; length of snout to front of lower eye $4 \frac{1}{3}$ to 5 in head; mouth very oblique, the gape convex upward and backward; maxillary $\frac{2}{5}$ length of head, reaching to middle of lower pupil, very narrow and covered with small scales; teeth small, the upper jaw with 2 series, the front teeth of the outer series somewhat enlarged; lower jaw with a single series; vomer and palatines toothless; gill rakers short and broad, the longest about $\frac{1}{2}$ vertical diameter of pupil; about 7 on anterior limb of arch; pseurlobranchia present; preopercle with posterior margin nearly vertical, only the lower third free, the upper $\frac{2}{8}$ grown fast to opercle and scaled over; the lower margin running very obliquely downward and forward, the angle thus an obtuse one; dorsal fin commencing on the snout in front of upper eye, the first 4 or 5 rays exserted and turned over to the blind side; the highest rays are behind the middle of the fin and are about $\frac{2}{5}$ length of head; anal fin similar to dorsal, its origin under base of pectorals; caudal short, about $\frac{2}{3}$ length of head, the middle rays the longest, the outer rays slightly prolonged; ventrals un- 
symmetrical, that of colored side on the ridge of the abdomen, the other inserted in front of it; pectoral of colored side long, the rays very slender, the two upper prolonged and filamentous, the upper (in adults) more than $\frac{7}{8}$ total length; pectoral of blind side more than $\frac{2}{5}$ of length of head; scales ciliated, somewhat irregular, of moderate size, with small scales intermixed; snout naked, head and body otherwise scaly; scales on interorbital region very small; a series of small scales on basal half of each dorsal and anal ray; base of caudal thickly scaled, a series of small scales running nearly to tip of each ray, lateral line slightly rising anteriorly, but without distinct curve. Color light brown, with grayish and light bluish dots, somedarker areas and a few round brown spots ocellated with lighter; interorbital space with a vertical brown bar bordered by lighter; fins mottled and spotted. This species is known only from the original types, taken by Professor Gilbert at Panama. The several variations in this species have not been studied. The spẹcies differs from Syacium ovale chiefly in the much broader interorbital space. We should regard this as unquestionably the adult male of $S$. ovale were it not that in making large collections of the latter species at Mazatlan we found not one referable to S.latifrons. (latus, broad; frons, forehead:)

Citharichthy latifrons, JoRdaN \& GILBERT, Bull. U. S. Fish Comm. 1881, 334, Panama.

(Coll. C. H. Gilbert.)

Syacium latifrons, JoRDAN \& Goss, Review Flounders and Soles, 271, 1889.

\section{SYACIUM OVALE (Günther).}

Head $3 \frac{3}{5}$ in length; depth $2 \frac{1}{10}$. D. 86 ; A. 69; scales 58 ; eye $4 \frac{1}{2}$ in head; maxillary $2 \frac{3}{5}$; pectoral $1 \frac{1}{2}$; caudal 1 ? . Body elliptic-ovate, body outline from snout to caudal peduncle uniform, the snout not produced; mouth moderate; maxillary concave behind, reaching to middle of pupil of lower eye; lower jaw slightly included; teeth biserial in upper jaw, the inner series small and sharp, the outer much larger, irregular, uniserial in lower jaw; the lower eye slightly in advance of the upper; interorbital space narrow, as broad as pupil, concave; gill rakers as long as pupil, $2+8$ in number. Seales strongly ctenoid; scales on mandible, maxillary, and a few in front of interorbital, the middle of which is naked; lateral line not curved. Dorsal beginning slightly in front of upper eye on blind side, the anterior rays produced a little beyond membrane; base of ventral of blind side wider than that of eyed side; caudal double lunate. Color light olive brown, nearly uniform, the vertical fins with elongate dark spots; caudal with large, irregular black spots. Pacific coast of tropical America; common at Mazatlan and Panama. Here described from specimens 6 or 7 inches in length, collected at Mazatlan, Mexico, by the Hopkins experlition to Sinaloa. None of these shows the broad interorbital area of Syacium latifrons. (ovalis, oval.)

Hemirhombus ovalis, Günther, Proc. Zool. Soc. Lond.1864, 154, Panama; GünTHER, Fish. Centr. Amer., 4i2, pl. 80, fig. 1, 1860; Jordan \& Gilbert, Bull. U. S. Fish Comm. 1882, 108-111.

Witharichthys ovalis, Jordan, Proc. U. S. Nat. Mus. 1885, 391.

Syacium ovale, JORDAN \& GOss, Review Flounders and Soles, 271, 1889. 


\section{ז049. CYCLOPSETTA, Gill.}

Cyclopsetta, GiLL, Proc. U.S. Nat. Mus., XI, 1888, 601 ( $f$ imbriata).

Mouth very large; jaws squarely truncatcd behind; teeth uniserial, those of the upper jaw moderate, of lower jaw enlarged and largest at sides; dorsal and anal almost symmetrical, dorsal commencing in front of eye on snout, scarcely deflected on blind side; caudal slightly pedunculate and convex; pectorals subequal and with a subtruncate free margin; ventrals nearly equal, the left on the preanal ridge, the right lateral, each with the inner ray connected by membrane to the body; interbranchial membrane imperforate; gill rakers tubercular and surmounted by blunt denticles. This genus differs from Azevia only in the smooth scales. ( $\varkappa \dot{\varkappa} \lambda o_{5}$, circle; $\psi \tilde{\eta} \tau \tau \alpha$, flounder, from the cycloid scales.)

a. Dorsal rays 91 to 95 ; anal 73 to 75 ; scales 90 to 95 . Color nearly plain, the fins blotched.

QUERNA, 3044.

aa. Dorsal rays 80 to 82 ; anal 62 ; dorsal and anal with dark ocelli.

b. Scales small, about 90 ; pectoral fin uncolored; anterior dorsal rays scarcely produced.

CHITTENDENI, 3045.

bb. Scales larger, about 70 ; pectoral fin with black ocellus; anterior rays of dorsal somewhat produced. FIMBRIATA, 3046.

3044. CYCLOPSETTA QUERNA (Jordan \& Bollman).

Head $3 \frac{1}{3}$ to $3 \frac{3}{5}$; depth $2 \frac{1}{8}$. D. 91 to 95 ; A. 73 to 75 ; scales along lateral line 90 to 95 . Borly shaped as in Azevia panamensis. Mouth large, maxillary $1 \frac{4}{5}$ in head. Teeth as in A.panamensis, in single series, rather long and slender, the anterior somewhat more enlarged. Snout 5 in head, its tip hooked over the lower jaw so that the outer canines project. Interorbital space rather narrow, slightly concave, with a few small scales, its width a little less than pupil, $\frac{1}{8}$ diameter of eye. Eyes moderate, $5 \frac{1}{2}$ in head, the upper somewhat in advance. Gill rakers short and broad, as in A. panamensis, each with 3 or 4 strong teeth. Scales small, cycloid on both sides, those below pectorals more reduced than in A.panamensis, about 65 in a cross series; anterior part of lateral line bent slightly upward, this portion about $3 \frac{1}{2}$ in straight part. Dorsal beginning above and between the nostrils, the anterior rays short, but with free tips; longest ray $2 \frac{1}{2}$ in head; pectoral of eye side $1 \frac{4}{5}$ to 2 in head, of blind side $2 \frac{1}{3}$ to $2 \frac{1}{2}$; ventrals subequal, each 6-rayed, $2 \frac{4}{5}$ in head, extending $\frac{1}{8}$ their length beyond vent. Color plain brown, unspotted; fins dusky, thickly punctulate; young with 2 large oval indistinct dark spots on dorsal and anal; 3 on caudal, of which the middle is much larger. Distinguished from $A$. panamensis (Steindachner) by having much smaller cycloid scales on eyed side and by its plain coloration. Coast of Colombia. Numerous specimens, the largest about 8 inches in length, were dredged in 7 fathoms at Albatross Station 2800 and in 16 fathoms at Station 2802. (quernus, oaken, i. e., tanned.)

Azevia querna, JoRdan \& Bollman, Proc. U.S. Nat. Mus. 1889, 174, Pacific Ocean off coast of Colombia, at Albatross Station 2802 , Lat. $8^{\circ} 3^{8^{\prime}}$ N., Long. $79^{\circ} 31^{\prime} 30^{\prime \prime}$ W. (Type, No. 41159.) 
3045. CYCLOPSETTA CHITTENDENI, B. A. Bean.

Head $3 \frac{1}{2}$ in body; depth $2 \frac{1}{5}$. D. 82 ; A. 62 ; scales 90 ; eye 5 in head. Mouth widely cleft, oblique, the jaws curved; cleft of mouth less than 2 in bead. Teeth of each jaw in a single series, those of lower jaw strong and sharp, curved inward and backward, those of upper jaw not so large, and very irregular in size. Ventral fins well developed, that of eyed side being on abdominal ridge, and about $\frac{8}{4}$ as long as pectoral; pectorals $\frac{1}{2}$ as long as head, their length equaling a little more than $\frac{1}{8}$ of body depth, posterior margin oblique; gill rakers very short, tubercular, almost as broad as long, 3 or $4+8$ in number. Color brown; fins lighter, marked with blackish; 3 small faint blotches of black on first half of dorsal fin, and 3 rather distinct blotches on second half, last blotch extending to caudal peduncle; anal fin with 3 black blotches situaterl as and similar to those of dorsal fin; ventral of eyed side blackish, that of blind side pale; caudal fin with 3 black spots at its extremity; pectoral fin of colored side blackish; quite a large blotch of black on body under this fin. 'This species is distinguished from Cyclopsetta fimbriata by its shorter head, smaller and closely adhering scales, larger teeth, the little-produced anterior dorsal rays and by the oblique posterior margin of the pectorals. In $C$. fimbriata the scales are rather large and deciduous, the teeth small, the anterior rays of the dorsal considerabiy produced, and the posterior margin of the pectoral is subtruncate. A single specimen collected by Dr. John F. Chittenden, of the Victoria Institute, Port of Spain, Trinidad Island, and named in his honor. It is $7 \frac{8}{4}$ inches in length. (B. A. Bean.)

Cyclopsetta chittendeni, B. A. Bean, Proe. U.S. Nat. Mus. 1894,635, Trinidad. (Type, No. 44100. Coll. Dr. Chittenden.)

3046. CYCLOPSETTA FIMBRIATA (Goode \& Beau).

Head $3 \frac{1}{2}$ in length; depth nearly 2. D. 80 ; A. 60 or 61 ; pectoral 10 ; ventral 6; scales 25-70-31; maxillary 2 in head; caudal $4 \frac{4}{6}$ in total length; pectoral $5 \frac{1}{2}$. Mouth very large, the npper jaw strongly curved, lower jaw included; teeth uniserial in each jaw, some of the anterior ones in the upper jaw being much larger than those following, while those in the lower jaw are still larger than these, some of the teeth in each jaw depressed; upper eye placed at a distance from profile equal to $\frac{1}{2}$ its own diameter, which is a little less than 5 in head; eyes in the same vertical; interorbital ridge low, 4 in eye; gill rakers very short, tubercular, about 9 on lower part of angle. Scales cycloid; curve of lateral line slight, curve $3 \frac{1}{8}$ in straight part. Dorsal beginning on snout in advance of nostrils, first ray higher than second, highest rays behind middle of fin; origin of anal under base of pectoral, its highest rays behind middle of fin, higher than highest dorsal rays; ventral of eyed side on ridge of abdomen; middle caudal rays produced. Color grayish brown; dorsal and anal fins each with 2 round dark blotches upon their posterior halves, which are slightly larger than eye; a similar dark blotch upon middle of caudal, sometimes with smaller blotches irregularly placed near its outer margin; pectoral with a very narrow dark band near its base, whole of outer half marked with a dark blotch, reticulated and nottled with 
lighter; intervening portion pearly white with dark specks upon the rays; blind side cream colored. Deep waters of the Gulf of Mexico. (Goode \& Bean.) (fimbriatus, fringed; from the produced dorsal rays.)

Hemirhombus fimbriatus, Goode \& Bein, Proc. U.S. Nat. Mus. 1885, 591, Jeep waters of the Gulf of Mexico, between Mississippi Delta and Cedar Keys. (Type, No. 37330. Coll. Albatross.)

Arnoglossus? fimbriatus, JoRDAN \& Goss, Review Flounders and Soles, 262, 1889.

Cyclopsetta fimbriata, Goode \& BEAN, Oceanic Icthyology, 451, fig. 368, 1896.

I050. AZEVIA, Jordan.

Azevia, JoRdan, in Jordan \& Goss, Review Flounders and Soles, 271, 1889 (panamensis).

Body elliptical, compressed, covered with small, firm, ctenoid scales; mouth large; teeth in both jaws uniserial; vomer without teeth; gill rakers very short and thick, tubercle-like; interorbital space very narrow in both sexes, the ridges coalescing between the eyes; lateral line without arch in front; ventrals free from the anal; septum of gill cavity below gill arches, without foramen; a deep emargination near isthmus. None of the fins especially modified or with elongate rays. This genus differs from Citharichthys in its tubercular gill rakers, as also in its small, firm scales, and other characters of minor importance. (Azevia, a Portuguese name for the sole, used at Lisbon, according to Brito-Capello. It probably corresponds to the Cuban name Acedia.)

3047. AZEVIA PANAMENSIS (Steindachner).

Head $3 \frac{2}{8}$ in length; depth $2 \frac{1}{4}$. D. 95 ; A. 73 to 78 ; scales 73 to 78 ; eye 5 in head ; maxillary 2 ; pectoral $1 \frac{3}{6}$; caudal $\frac{1}{2}$. Body rather elongate; anterior profile evenly convex; mouth large, the maxillary reaching to posterior border of eye, the upper jaw somewhat hooked over the lower; about 3 teeth in upper jaw enlarged and hooked, canines in lower jaw long and sharp; eyes about even in head; interorbital space very narrow, less than diameter of pupil, a ridge along its middle; gill rakers divided into many sharp points around its edge, very short, as wide as long, about $4+9$ in number. Scales on posterior part of interorbital, maxillary, and mandible; tip of snout, the greater part of interorbital, and tip of lower jaw naked; scales all strongly ctenoid; lateral line not curved anteriorly. Origin of dorsal at the vertical between tip of snout and front of eyes, searcely on blind side, the anterior rays somewhat produced beyond membrane, the fin rather low; origin of anal below angle of opercle; pectorals short, that of eyed side pointed, its mate of the opposite side broadly rounded behind; candal double lunate. Here described from a specimen collected by the Hopkins Expedition to Sinaloa, at Mazatlan, Mexico, about 11 inches in length. Wo have also examined specimens from Panama, in the museum at Cambridge, a part of the series of Dr. Steindachner's original types. Pacific coast of Central America; common at Mazatlan and Panama. (panamensis, from Panama.)

Citharichthys panamensis, STEINDACHNER, Ichth. Beitr., III, 62, 1875, Panama; JoRDAN \& Gilbert, Bull. U. S. Fish Comm, 1882, 108 and 111; Grlbert, Bull. U.S. Fish Comm. $1882,112$.

Azevia panamensis, JORDAN \& GOSs, Review Flounders and Soles, 272, 1889; JORDAN, Pruc. Cal. Ac. Sci. 1895, 503. 
I051. CITHARICHTHYS,* Bleeker.

\section{(WHIFFs.)}

Citharichthys, BLEeker, Comptes Rendus Acad. Sci. Amsterd., XIII, Pleuronectoidei, 6 1862 (cayennensis = spilopterus).

Orthopsetta, Gill, Proc. Ac. Nat. Sci. Phila.1862, 330 (sordidus).

Metoponops, Grul, Proc. Ac. Nat. Sei. Phila. 1864, 198 (cooperi=sordidus).

Eyes and color on the left side. Body oblong; mouth of the large type, but comparatively small, with 1 series of small, sharp teeth in each jaw; no teeth on vomer or palatines. Gill rakers moderate, slender. Dorsal fin beginning just in front of eye; all the fin rays simple; ventrals of colored side on the ridge of the abdomen; no anal spine; caudal fin convex or double truncate behind; none of the fins produced. Scales thin, deciduous, slightly ctenoid. Lateral line nearly straight, simple. Lower pharyngeals separate, each with a single row of teeth. Vertebræ 30 to 40. This genus includes small flounders of weak organization, especially characteristic of the sandy shores of tropical America. The subgenus Orthopsetta includes species of more northern range and somewhat different form, and especially noteworthy as having an increased number of vertebra. The two groups intergrade so perfectly that no sharp line of division can be drawn between them. (Citharus, an allied genus; $i \chi \theta \dot{v} 5$, fish-a fish which lies on its $\varkappa i \theta \alpha \rho \circ \varsigma$, or ribs; that is, on its side.)

ORTHOPSETTA (o’ $\rho$ ós, straight; $\psi \hat{\eta} \tau r a$, flounder):

$a$. Vertebræ 37 to 40 ; interorbital ridge sharply elevated; the head not closely compressed; eyes large; species of the North Pacific.

b. Interocular space concave, scaly, at least behind.

c. Gill rakers $x+16$ to 18 .

d. Scales 65 to 70 ; dorsal rays 95 ; anal 77 ; depth $2 \frac{1}{3}$. sordidus, 3048 . $d d$. Scales 46 to 50 ; dorsal rays 83 to 87 ; aual 67 to 70 ; depth 23 in length.

FRAGILIS, 3049.

cc. Gill rakers $x+10$ or 11 ; dorsal rays about 84 ; anal 65 ; scales 50 ; depth $2 \frac{1}{4}$ in length.

XANTHOS'TIGMUS, 3050 .

bb. Interocular space a sharp, naked ridge; dorsal rays 85 to 90 ; anal 68 to 72 ; CithaRichthys : scales 55 to 60 ; head $3 \frac{3}{4}$ in length; depth $2 \frac{1}{5}$.

STIGMAUS, 3051.

$a a$. Vertebræ 33 to 36 ; interorbital ridge low and narrow, the head closely compressed. Species of the Atlantic or the Tropics.

e. Eyes large, 3 to $4 \frac{1}{2}$ in head.

$f$. Head large, 3 to $3 \frac{1}{3}$ in length.

g. Interorbital space very narrow, 5 in eye; snout with a spine; pectoral of eyed side elongate, $\frac{1}{3}$ longer than head; maxillary $2 \frac{1}{4}$ in head. D. 91 ; A. 73 ; scales 48.

DINOCEROS, 3052.

$g g$. Interorbital space very broad, 2 in eye; snout without spine; pectoral of eyed side shorter than head; maxillary $2 \frac{1}{2}$ in head. D. 78; A. 62 ; scales 43.

PLATOPHRYS, 3053.

ff. Head smaller, about 4 in length.

$h$. Body comparatively elongate, the depth about $2 \frac{1}{2}$ in length; mouth very small; the maxillary $3 \frac{1}{2}$ in head; dorsal rays 83 ; aual 67 ; scales 40 ; eye 4 in head. ARCTIFRONS, 3054 .

\footnotetext{
* "As the name Citharichthys was introduced a short time before that of Orthopsetta, proposed for the Prettichthys sordidus, and was framed for a species related to that type, that name must be adopted if the 0 . sordida is not regarded as genericaliy distinct." (Gill.)
} 
hh. Body comparatively broad, the depth about $\frac{1}{2}$ the length; mouth larger.

$i$. Snout with a strong, sharp spine on eyed side, above upper lip; eyes large, 3 in head; greatest depth of body over the pectorals ; interorbital space with a wide ridge, about $\frac{1}{2}$ diameter of eye. D. 74 ; A. 60 ; seales $40 . \quad$ UNICOnNIs, 3055.

ii. Snout without distinct spine; eyes moderate, $3 \frac{1}{2}$ to $4 \frac{1}{2}$ in head; greatest depth of body under middle of dorsal; interorbital space a narrow, scaly ridge with a slight median groove; maxillary $2 \frac{2}{3}$ in head; teeth small, those in front slightly enlarged; body not very thin; gill rakers moderate, $6+13$. j. Dorsal rays 68 ; anal 52 ; scales smaller, the lateral line with about 53 pores; sides with whitish blotches.

UHLERI, 3056.

jj. Dorsal rays 80 ; anal 56; scales large, 41 in lateral line; sides and fins with dark blotches. MACROPS, 3057.

ee. Eyes quite small, 5 to 6 in head; snout short, forming an angle with the profile; mouth moderate, oblique, the maxillary $2 \frac{1}{2}$ to $2 \frac{3}{3}$ in head; teeth small, the anterior somewhat enlarged; dorsal rays about 80 ; anal rays 60 ; body and fins speckled.

$k$. Scales not very large, 45 to 48 in lateral line; gill rakers long and slender, longer than pupil.

SPILOPTERUS, 3058.

$k k$. Scales large, 40 to 46 in lateral line; gill rakers short, not longer than pupil.

GILBERTI, 3059.

Subgenus ORTHOPSETTA, Gill.

3048. CITHARICHTHYS SORDIDUS (Girard).

(SOFT FLOUNDER.)

Head $3 \frac{3}{5}$; depth $2 \frac{1}{8}$. D. 95 ; A. 77; scales 65 to 70. Form elliptical; interocular space concave, scaly, a conspicuous sharp ridge above the lower eye; mouth not large, the maxillary abont 3 in length of head; teeth anteriorly subequal, growing much smaller behind. Gill rakers about $7+16$. Lower pharyngeals narrow, each with 1 row of slender teeth. Scales rather large, thin, and membranaceous, readily deciduous, their edges slightly ciliate; accessory scales numerous. Eye large, much longer than snout, $3 \frac{1}{2}$ in head; depth of caudal peduncle less than $\frac{1}{8}$ head; pectorals long, nearly $\frac{2}{3}$ length of head. Vertebræ $11+29=40$. Dull olive brownish of varying shade, the males with dull orange spots and blotches; each scale with a darker edge; dorsal and anal fins in the male blackish, with dull orange blotches, and edged anteriorly with yellowish; female paler, the fins nearly plain. Pacific coast of North America, in water of moderate depth; British Columbia to Lower California. This small flounder is one of the commonest species on the Pacific coast, being found in water of 10 fathoms or more depth in all localities from the Mexican boundary to British Columbia. Although much larger in size than any other species of the genus, it rarely exceeds 2 pounds in weight. In its deciduous scales and soft flesh it much resembles Lyopsetta exilis and Atheresthes stomias, 2 species which are often taken in company with it. Of all the species of Citharichthys, this one has the most extended range to the northward. (sordidus, sordid, from its dull coloration.) 
Psettichthys sordidus, Girard, Proc. Ac. Nat. Sci. Phila., viI, 1854, 142, San Francisco; Tomales Bay; Girard, U. S. Pac. R. I. Surv., x, Fishes, 155, 1858.

Metoponops cooperi, Gri, Proc. Ac. Nat. Sci. Phila. 1864, 198, Santa Barbara; shrivelled specimen. (Type, No. 9407.)

Orthopsetta sordida, GiLl, Proc. Ac. Nat. Sci. Phila. 1862, 330.

Citharichthys sordidus, Lockington, Rep. Com. Fisheries of California, 1878-79, 42; LockINGton, Proc. U. S. Nat. Mus. 1879, 83; JordaN \& GrLbert, Proc. U. S. Nat. Mus. 1880, 453; Jordan \& Gilbert, Proc. U. S. Nat. Mus. 1881, 67; Jordan \& Gilbert, Synopsis, 817, 1883; BeAn, Yroc. U. S. Nat. Mus. 1883, 353; Jordan \& Goss, Review Flounders and Soles, 274, 1889.

3049. CITHARICHTHYS FRAGILIS, Gilbert.

Head $3 \frac{2}{5}$ to $3 \frac{3}{5}$ in length; depth $2 \frac{2}{3}$ to $2 \frac{8}{4}$ (in specimens 5 inches long.) D. 83 to 87 ; A. 67 to 70 ; scales 46 to 50 . Vertebra $10+27$. Body elongate, posteriorly sharply wedge-shaped, tapering to base of caudal; anterior profile very conspicuously angulated above front of upper eye, the snout strongly projecting, its anterior. profile nearly vertical; depth of caudal peduncle $2 \frac{7}{8}$ in head. Anterior nostril with a short tube and flap, the latter nearly obsolete on blind side. Mouth more oblique than in C. 80 rdidus; maxillary reaching vertical from front of pupil, $2 \frac{2}{5}$ to $2 \frac{3}{5}$ in head. Teeth in a single series, close set, those anteriorily somewhat enlarged, but none of them canine-like. Eyes large, the vertical from front margin of upper eye falling through front of lower pupil; longest diameter of upper orbit $2 \frac{2}{3}$ in head; interorbital space narrow, concave, scaled, the lower ridge strongest, its width about $\frac{1}{8}$ diameter of orbit. Symphyseal knob sharp. Gill rakers long, slender, close set (as in C, sordidus), 18 on anterior limb of arch, the longest $\frac{1}{8}$ orbit. Scales large, deciduous, somewhat irregularly arranged, 12 or 13 series above lateral line; scales smooth on blind side, minutely spinous on eyed side; lateral line without anterior arch. Dorsal beginning slightly in advance of eye, the longest ray $\frac{1}{2}$ head; pectorals long and narrow, with 11 rays on colored side. Color dusky olivaceous, with occasional slaty-blue spots. This species is closely related to $C$. sordidus, from which it differs in the fewer vertebrio and fin rays and in the larger scales. Many specimens from the Gulf of California in from 18 to 76 fathoms, at Albatross Stations 3011, 3016 to 3018, and 3033. (Gilbert.) (fragilis, fragile.)

Citharichthy fragilis, GILBert, Proc. U. S. Nat. Mus. 1890, 120, Gulf of California, east coast of Lower California. (Type, No. 44409. Coll. Dr. Gilbert.)

\section{CITHARICHTHYS XANTHOSTIGMUS, Gilbert.}

D. 81 to 86 ; A. 63 to 67 ; scales 50 . Vertebræ $11+26$. Body deep, varying from $2 \frac{1}{3}$ (in young, 3 inches long) to $2 \frac{1}{10}$ ( 7 inches long) in length of body. Profile angulated above front of upper eye, the snout convexly projecting. Depth of caudal pednncle $\frac{1}{8}$ head. Lower eye in advance, the vertical from front of the upper passing through front of lower pupil. Mouth rather small, the outline somewhat curved, the maxillary reaching the vertical from front of lower pupil, 3 to $3 \frac{1}{4}$ in head; mandible with a sharp downward-directed point at symphysis. Teeth in a single close-set series in each jaw, growing slightly larger anteriorly, but without canines. 
Anterior nostril with a short tube, and a narrow flap arising from its inner edge. Interorbital width $3 \frac{8}{4}$ to 5 in orbit, slightly concave, the lower ridge much stronger and higher than the upper, scaled posteriorly. Eye large, the orbit $3 \frac{1}{8}$ to $3 \frac{2}{3}$ in head. Gill rakers rather long and slender, coarsely dentate on inner margin, distant, 10 or 11 on anterior limb of areh. Scales large, in regular series, appearing cycloid, but the edges very minutely spinous; lateral line gently rising on anterior $\frac{1}{3}$, but without curve; fifty vertical series of scales, with as many pores in lateral line; 13 to 15 horizontal series above lateral line. Dorsal beginning immediately behind posterior nostril of blind side, ending so as to leave caudal pedunele free for a distance equaling $\frac{1}{2}$ diameter of eye; ventrals long, reaching beyond origin of anal; pectoral very long and slender, normally with 9 rays, the longest ray on colored side longer than head, about $\frac{1}{8}$ length of body. Color light olive brown, irregularly flecked with slaty, and with numerous bright yellow spots broadly ocellated with brownish black, a series of these usually on lateral line, and 2 others halfway between it and the dorsal and ventral outlines, respectively, those of the latter series forming pairs; fins not conspicuously marked, the pectorals sometimes with faint broad dusky cross bars. Both coasts of Lower California. In external appearance the speeies closely resembles C. sordidus, to which, however, it is not closely related, differing in number of scales, fin rays, and vertebrie, and in the size and number of gill rakers. (Gilbert.) Many specimens, from Albatross Stations 3039, 3043,

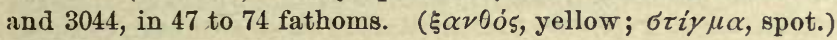

Citharichthys xanthostigma, GILBERT, Proc. U. S. Nat. Mus. 1890, 120, Gulf of California, west coast of Lower California, and Magdalena Bay. (Type, No. 44408. Coll. Dr. Gilbert.)

3051. CITHARICHTIYS STIGMEUS, Jordan \& Gilbert.

Head $3 \frac{8}{4}$ in length without caudal; depth $2 \frac{1}{5}$; dorsal 87 ; anal 68 ; scales 54 (pores). Body moderately deep, the 2 profiles regularly and equally arched; snout short, gibbous, projecting a little beyond the outline; caudal peduncle very short, not high, its length (from end of last vertebra to vertical from last anal ray) about $\frac{2}{5}$ its height, which is $\frac{3}{7}$ length of head; caudal fin appearing sessile. Mouth moderate, very oblique, the maxillary reacbing beyond front of pupil, $2 \frac{8}{4}$ in head; teeth in a single series, subequal in the two jaws, rather long, very slender and numerous, decreasing toward angle of mouth; about 40 teeth in the upper jaw, and 30 in the lower on blind side. Eyes large, close together, separated by a narrow, sharp, scaleless ridge; the upper eye largest, slightly behind the lower, with considerable vertical range; diameter of upper eye $3 \frac{1}{8}$ in head. Snout and lower jaw scaleless; end of maxillary and rest of head scaled. Gill rakers moderate, not strong, about 9 on anterior limb. Dorsal fin beginning on the vertical from front of upper eye, the first 3 rays being somewhat turned to blind side; the fin low, the highest at beginning of its posterior third, the longest ray nearly $\frac{1}{2}$ length of head; anal spine present, very small; caudal rounded, about equalling length of head; pectoral of colored side $1 \frac{2}{5}$ in head, of blind side, $2 \frac{1}{5}$. Scales $3030-91$ 
moderate, those forming the lateral line persistent, the others deciduous, those on colored side with ciliated margins, on blind side smooth; lateral line without anterior curve, the scales crowded and smaller anteriorly. Color in spirits uniform olivaceous, the scales dark edged; lips and some of the membrane bones of head margined with blackish; fins dusky, each seventh (to tenth) ray of vertical fins with a very small but conspicuons black spot on its middle. The above description is from the original type from Santa Barbara. Numerous specimens dredged by the Albatross in 9 to 41 fathoms off the coast of California show the following characters: Gill rakers $x+9$. Specimens $5 \mathrm{~mm}$. long show white spots each with a black half ring on the outer side symmetrically arranged along bases of dorsal and anal; 4 distinct pairs of these, 2 unpaired ones more anteriorly along dorsal base, and a few fainter ones midway between these rows and the lateral line and alternating with them; there are some other scattered light spots. The abdomen is covered by a broad black streak; this, however, is wanting in specimens larger and smaller. Coast of California; rare; in rather deep water. The original type of this species is a young example, taken near Santa Barbara by Capt. Andrea Larco. In the Museum of Comparative Zoology are other specimens collected by Mr. Cary at San Francisco. These have 72 anal rays, while the original type had but 68 . A few other specimens have been since obtained. Some of these are full of spawn at a length of 5 inches. ( $\sigma \tau \imath \gamma \mu \alpha i ั o s, ~ s p e c k l e d$.

Citharichthys stigmaeus, Jordan \& Gilbert, Proc. U. S. Nat. Mus. 1882, 410, 411, Santa Barbara (Coll. A. Larco. Type, 31099 U.S. Nat. Mus.); Jordan \& GILBert, Synopsis, 965, 1883; Jordan \& Goss, Review Flounders and Soles, 274, 1889; GiLBert, Rept. U. S. Fish. Conım. 1893 (1896) 473.

Subgenus CITHARICHTHYS.

3052. CITHARICHTHYS DINOCEROS, Goode \& Bean.

Head $3 \frac{1}{3}$ in length; depth $2 \frac{1}{8}$. D. 91 ; A. 73 ; scales $14-48-16$; eye $3 \frac{1}{2}$ in head; maxillary a little less than 2 ; greatest height of dorsal 2 ; pectoral $2 \frac{1}{2}$ in body; caudal $5 \frac{1}{2}$. Teeth uniserial in both jaws, those in the front much the largest; a strong spine upon the snout overhanging the upper lip, above this a second shorter spine; interorbital very narrow, its width less than 5 in eye, ridge rather prominent, narrow, sharp. Scales thin, deciduous, cycloid, large; lateral line slightly curved over the pectoral. Dorsal beginning on snout, in advance of eye, upon the blind side, its highest rays behind the middle; origin of anal under base of pectoral; third and fourth pectoral rays upon the eyed side elongate, the tin $\frac{2}{8}$ longer than its mate of the opposite side ; caudal subsessile, pointed. Color grayish brown above, white below. Vertebræ 33 to 36 . West Indies, in deep water. The type specimen, $92 \mathrm{~mm}$. long to base of caudal, was taken by the Blake, off Guadeloupe; others were taken off St. Lucie and Barbados, from 310 to 955 fathoms. (Goode \& Bean.) ( $\varepsilon \varepsilon \imath \nu \dot{s}$, terrible; $\varkappa \varepsilon \rho \alpha \varsigma$, horn.)

Citharichthy\& dinocero8, Goode \& BEAN, Bull. Mus. Comp. Zool., xII, No. 5, 157, 1886, off Martinique, St. Lucie, and Barbados; JoRdan \& Goss, Review Flounders and Soles, 275, 1889; Goode \& BEAN, Oceanic Ichthyology, 447, 1896. 
3053. CITHARICHTHYS PLATOPHRYS, Gilbert.

Head 3 ; depth 2. D. 78 ; A. 62 ; scales 43 . Body ovate; caudal fin subsessile, the free portion of caudal peduncle about $\frac{1}{2}$ as long as diameter of pupil, its depth $\frac{1}{3}$ length of head. Month very oblique; maxillary $2 \frac{1}{2}$ in head, reaching vertical from middle of lower eye. Teeth slender, close set, in a single series in each jaw, those in front of upper jaw largest, but not canine-like. Eyes large, the lower much in advance of the upper, their horizontal diameter $3 \frac{8}{4}$ in head. Interorbital space very wide for the genus, concave, divided by an oblique ridge running backward from middle of upper orbit; interorbital width 83 in head, nearly $\frac{1}{2}$ as wide as eye. Distance from tip of snout to front of lower eye $\frac{2}{8}$ diameter of eye, from tip of snout to upper eye $\frac{1}{8}$ head. Gill rakers short and very slender, less than diameter of pupil, 9 present on horizontal limb of outer arch. Scales large, those on blind side very weakly ctenoid. Dorsal beginning behind nostril on blind side of snout, its longest ray $2 \frac{1}{5}$ in head; pectoral of eyed side long and narrow, 4 in length, containing 11 rays, that of blind side but $\frac{1}{2}$ its length; ventrals short; caudal rounded, $1 \frac{2}{5}$ in head. Color in spirits, uniform light brownish (olivaceons in life), without distinctive marks; fins somewhat dusky; ventral of eyed side jet-black, that of blind side blackish on distal portion of inner rays. (Gilbert.) One specimen known, from Albatross Station 2799, southwest of Panama. ( $\pi \lambda \alpha \tau \dot{v} 5$, broad; ò $\rho \dot{v} 5$, eyebrow.)

Citharichthys platophrys, GILBERT, Proc. U.S. Nat. Mus. 1890, 454, Albatross Station 2799, southwest of Panama. (Coll. Albatross.)

3054. CITHARICHTHYS ARCTIFroNs, Goode.

Head 4 in body; depth $2 \frac{2}{8}$. D. 82 ; A. 67 ; pectorals 9 or 10,7 ; scales $8-40-8$; eye 4 in head; maxillary $3 \frac{1}{2}$; caudal 1 . Body comparatively elongate; mouth small; teeth small, the anterior scarcely enlarged; interorbital space narrow, sharp, scaleless; scales cycloid, deciduous; small scales on the rays of the ventral fins; lateral line sharply defined, straight. Dorsal beginning above front of upper eye, its highest ray about 3 times the distance from snout to first ray; origin of anal under base of pectoral; caudal subsessile, triangular; rays of vertical fins all exserted; pectoral inserted low, that of eyed side twice the length of the other. Color dirty light brown. Deep waters of the Gulf Stream. (arctus, contracted; frons, forehead.)

Citharichthy 8 aretifrons, GoodE, Proc. U. S. Nat. Mus. 1880, 341, 472, Gulf Stream off southern coast of New England; GoodE \& BEAN, Bull. Mus. Comp. Zool., Vol. x, No. 5, XIx, 194, 1883; JoRdan \& Gilbert, Synopsis, 818, 1883; Jordan \& Goss, Review Flounders and Soles, 275, 1889; GOoDE \& BEAN, Oceanio Ichthyology, 442, fig. 366, 1896.

3055. CITHARICHTHYS UNICORNIS, Goode.

Head 4 in length; depth a little less than length. D. $74 ;$ A. $60 ; P: 4$ (right), 10 (left); scales 12-40-12; eye 3 in head; maxillary scarcely 2 ; lighest dorsal ray 2. Body deep, its greatest height over the pectorals; 
scales thin, deciduous; eje equal to snout or interorbital space; interorbital with a strong ridge; teeth minute, close set, in a single series, stronger on the blind side; a strong, sharp spine on the snout at the anterior termination of the ridge at lower margin of upper eye; caudal pointed, triangular, subsessile; pectoral of left side twice as long as the eye, not $\frac{1}{2}$ longer than right pectoral. Dorsal beginning at side of preorbital spine, its anterior rays being slightly upon the blind side; anal equal to dorsal in height. Ashy gray, with dark lateral line; eyes black. (Goode.) Deep waters of the Gulf Stream. (unicornis, having one horn.) Citharichthys unicornis, Goode, Proc. U.S. Nat. Mus.1880, 342, Gulf Stream off southeast of New England; Jordan \& GiLbert, Synopsis, 818, 1883; JordaN \& Goss, Review Flounders and Soles, 275, 1889; Goode \& BEAN, Oceanic Ichthyology, 444, fig. 369, $A \& B, 1896$.

3056. CITHARICHTHYS UHLERI, Jordan.

D. 68 ; A. 52 ; scales 53 (pores). Body comparatively broad, regularly oval, without angle; greatest depth of body under middle of dorsal; eyes moderate, $4 \frac{1}{2}$ in head, close together, the orbital ridges coalescent, the lower larger. Teeth small, uniserial; maxillary $2 \frac{1}{5}$ in head; gill rakers short and very slender, $x+12$. Color dark brown, with whitish blotches, the fins mottled. Hayti. A single specimen in the Museum of Comparative Zoology, $4 \frac{1}{2}$ inches in length. The species is close to Citharichthys macrops, but its fin rays and scales are considerably more numerous than in the latter. (Named for Mr. Philip Reese Uhler, the well-known entomologist, its discoverer.)

Citharichthys uhleri, JoRdaN \& Goss, Review Flounders and Soles, 275, 1889, Hayti. (Coll. P. R. Uhler. Type in Mus. Comp. Zool.)

\section{CITHARICTHYS MACROPS, Dresel.}

Head 4 in body; depth scarcely 2. D. 80 ; A. 56; scales 14-41-16; lower eye 4 in head; maxillary $2 \frac{1}{2}$; highest dorsal rays a little over 2 ; pectoral of eyed side $1 \frac{2}{3}$; caudal 4 in bod 5 ; vertebræ $9+25=34$. Body suboval ; upper profile very convex, descending in a sharp curve from nape to front of upper eye, and forming an abrupt angle with the short, blunt snout; mouth moderate, very oblique and curved; maxillary reaching to below middle of eye; teeth minute, uniserial, slightly larger on blind side; interorbital narrow, with a scaleless ridge, which curves upward and backward to upper angle of gill opening; upper eye very close to profile, its anterior margin on the same vertical line with lower; snout shorter than eye; gill rakers about $\frac{1}{2}$ the length of eye, $6+13$ in number. Scales large, not ciliated, no accessory scales; origin of dorsal on blind side near tip of snout, anterior rays exserted, the first ray as long as eye, the fin highest at its middle portion; origin of anal under base of pectoral, its highest part a little higher than dorsal; caudal pointed; pectoral of blind side somewhat shorter than that of eyed side. Color in spirits, light-olive brown; body with some 20 darkbrown spots, the largest as large as eye, 4 of these arranged at equal intervals along the lateral line, the second near the middle the most prominent; dorsal and anal fins with a series of round, brown spots, 1 at the middle of every sixth or seventh ray, besides small irregular spots and mottlings; 
caudal spotted and mottled with dark brown, and with 2 round, brown spots, 1 above the other at the base of the fin. (Dresel.) South Atlantic and Gulf coasts of the United States; rather common; a well-marked species. We have examined several specimens dredged in the harbor of

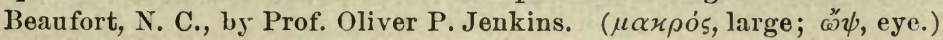

Citharichthys macrops, Dresel, Proc. U. S. Nat. Mus. 1884, 539, Pensacola (Type No. 21500) ; Jordá, Proc. U. S. Nat. Mus. 1886, 29 ; Jordan \& Goss, Review Flounders and Soles, 275, 1889.

3059. CITHARICITHYS SPILOPTERUS, Günther.

Head $3 \frac{1}{2}$ in body; depth $2 \frac{1}{6}$. D. 75 to 80 ; A. 58 to 61 ; seales 45 to 48 ; eye 6 in head; maxillary $2 \frac{1}{2}$; pectoral $2 \frac{1}{8}$; highest dorsal and anal rays 2 ; caudal $1 \frac{1}{8}$. Body moderately elongate, much compressed; snout short, forming an angle with the profile; jaws strongly curved, the upper somewhat hooked over the lower; lower jaw slightly included; maxillary reaching to posterior margin of lower orbit; teeth small, in a single row, the anterior a little enlarged; interorbital area a low, narrow ridge, which is divided only anteriorly; gill rakers short and rather slender, about 3 in eye, $4+12$ in number; scales eycloid. Origin of dorsal above anterior edge of upper eye, very slightly on blind side, its highest rays in its posterior half; origin of anal slightly behind base of pectoral; pectoral of eyed side very slightly shorter than that of eyed side; vertebræ 34 . Color olive brownish, somewhat translucent, with darker dots and blotches; a series of distant obscure blotches along bases of dorsal and anal. Atlantic coast of tropical America north to New Jersey; very common on sandy shores; not found in the Pacific, all west coast references belonging to C. gilberti. Here described from a specimen from Havana, 6 inches in length. This little flounder is almost everywhere abundant on the sandy shores of the warmer parts of the Western Atlantic, in shallow water. Careful comparison of specimens from South Carolina, Cuba, and Brazil shows no tangible difference, and we are compelled to regard all as forming a siugle species. It rarely exceeds 5 or 6 inches in length. It usually comes into the markets mixed with other shore fishes, and it nowhere receives any notice as a food-fish. This species is common in the markets of Havana, and it is evidently the original of Poey's Hemirhombus fuscus, although in Poey's description there seems to be some confusion, because the teeth are said to be biserial above, and 60 scales are counted in the lateral line. A specimen from Poey in the museum at Cambridge is labeled "Hemirhombus fuscus, type. Collector's number, 87." This belongs to C. spilopterus, and it has 48 scales in the lateral line. Bleeker's $C$. guatemalensis agrees in all respects with $C$. spilopterus. We are unable to find any description of $C$. cayennensis, if, indeed, the species has ever been described. Specimens of $C$. spilopterus are in the museum at Cambridge from Cuba, Pará, Sambaia, Pernambuco, Camaru, Rio das Velhas, Rio Janeiro, and San Matheo. ( $\sigma \pi i \lambda(\iota s$, spot; $\pi \tau \varepsilon \rho o ́ \nu$, fin.)

Citharichthys spilopterus, GUNTHER, Cat., Iv, 421, 1862, New Orleans, San Domingo, Jamaica; Jord.AN \& Gilbert, Proc. U. S. Nat. Mus. 1882, 618; Jorddn \& GiLBert, Synopsis, 817, 1883; Jordan, Proc. U. S. Nat. Mus. 1886, 53; JoRdan \& Goss, Review Flounders and Soles, 276, 1889. 
Citharichthys cayennensis, BLEEKER, Comptes Rendus Acad. Sci. Amsterd., xIII, 1862, 6, Cayenne; name only.

Citharichthys guatemalensis, BLEEKER, Neder. Tydschr. Dierk. 1864, 73, Guatemala; GÜNTHER, Fish. Centr. Amer., 472, 1869.

Hemirhombus fuscus, PoEx, Synopsis, 406, 1868, Havana; PoEx, Enumeratio, 138, 1875.

3059. CITHARICHTHYS GILBERTI, Jenking \& Evermann.

Head $3 \frac{1}{2}$ to $3 \frac{2}{5}$; depth of head 4 ; depth of body $1_{10}^{9}$ to $2 \frac{1}{6}$. D. 77 to 82 ; A. 57 to 61 ; acales 18-40 to 46-19. Body comparatively broad, formed as in C. spilopterus, the two profiles about equally arched; snout slightly longer than longest diameter of eye, and without a distinct spine. Eyes on left side, equal in size, small, 5 to $5 \frac{2}{3}$ in head; interorbital space narrow, $1 \frac{2}{8}$ in eye, low, slightly grooved, and scaled on posterior portion only. Maxillary $2 \xi$ in head, reaching barely to posterior border of eye; upper jaw projecting. Teeth small, in a single series; gill rakers $4+13$, short and slender, not longer than pupil, with a rather broad base, narrowing to a slender stalk. Dorsal fin beginning in front of upper eye, the first 3 rays growing from the blind side, the distance of origin from snout 7 in head; fin rays all simple, $23_{10}^{3}$ in head; pectorals nearly equal, the one on colored side being slightly longer, $1_{1}^{9}$ in head; rays on colored side 9 ; on blind side 8 ; ventrals $2 \frac{3}{10}$ in head; caudal rounded, caudal peduncle short, its depth 8 in the body, equaling height of anal; scales large, ciliated, pretty uniform, those toward head and margins of disk becoming smaller; lateral line gradually descending along the course of about 16 scales, from which point it is straight. Color light brown, with about 15 irregular dark blotches of various sizes, the largest being a pair on the latter third of the disk, 1 on each side of lateral line, as great in diameter as length of ventral fin. Specimens from fresh waters (C. sumichrasti) are much darker in color; gray, everywhere closely peppered with dark specks; pectoral and caudal nottled. Pacific coast of tropical America; very abundant in sandy bays from Guaymas to Panama, ascending all the streams. This species very closely resembles $C$. spilopterus, representing the latter on the Pacific coast, and it has been frequently recorded under the name C. spilopterus. C. gilberti differs mainly in the shorter gill rakers and in the slightly larger scales. Fresh-water specimens (as the type of C. sumichrasti from Rio Zanatenco, Chiapas, and numerous examples collected by us in Rio Presidio, near Mazatlan) differ considerably in color, being much darker, but there is no other difference. ("This species is dedicated to Prof. Charles H. Gilbert, whose collection and notes on fishes from Mazatlan, containing undescribed species, this among them, were destroyed by fire in 1883.")

Citharichthys gilberti, Jenkins \& Evermann, Proc. U. S. Nat. Mus. 1888, 157, Guaymas, Mexico (Type, No. 39627. Coll. Jenkins \& Evermann); Jordan, Proc. Cal. Ac. Sci. $1895,503$.

Citharichthys sumichrasti, JORDAN \& Goss, Review Flounders and Soles, 276, 1889, Rio Zanatenco, Chiapas. (Coll. Prof. Francis E. Sunichrast. Type, 25299, M. C. Z.)

Citharichthys spilopterus, Günther, Fish. Centr. Amer., 471, pl. 80, fig. 2, 1869; Jordan \& Gilbert, Proc. U. S. Nat. Mus. 1882, 382; Jordan \& Gilbert, Proc. U. S. Nat. Mus. 1882, 630; Jordan \& Gilbert, Bull. U. S. Fish Comm. 1882, 108-111; not of GÜTHER, 1862 . 
1052. ETROPUS, Jordan \& Gilbert.

Etropu\&, Jordan \& GILberT, Proc. U. S. Nat. Mus. 1881, 364 (crossotus).

Eyes and color on left side. Borly regularly oval, deep, and compressed. Hearl small; mouth very small, the teeth close set, slender; and pointed, somewhat incurved, mostly on the blind side; no teeth on vomer. Eyes small, separated by a narrow, scaleless ridge; margin of preopercle free. Ventrals free from anal, that of colored side inserted on ridge of abdomen, its base rather long. Dorsal fin beginning above eye ; caudal double truncate; anal without spine. Scales thin, deciduous, ctenoid on lett side, cycloid on blind side. Lateral line simple, nearly straight. Size small. This genus is very close to Citharichthys, from which it differs only in the very small size of the mouth, and in the correspondingly weak dentition. The 3 or 4 known species are similar in appearance to the species of Citharichthys, and they inhabit the same waters. Another genus extremely close to Etropus and Citharichthys is Thysanopsetta, a Sonth American genus. The teeth in Thysanopsetta are, however, arranged in a band. The larval forms are translucent and symmetrical, as in Platophrys, Monolene, Arno-

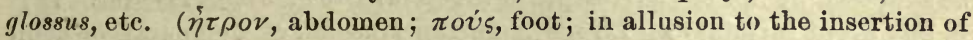
the ventrals, common to all the Psettine, but not found in other smallmouthed species.)

a. Snout not acute; dorsal rays 75 to 85 .

b. Body comparatively elongate, the depth rather less than $\frac{1}{2}$ length.

c. Dorsal rays 81; anal 58; head $4 \frac{1}{4}$ in length; eye $3 \frac{3}{5}$ in head; maxillary 4.

MICROSTOMUS, 3060.

cc. Dorsal rays 77; anal 61; head 4 in length; eye $3 \frac{1}{2}$ in head; maxillary $4 \frac{1}{3}$.

RIMOSUS, 3061.

bb. Body very deep, the depth more than $\frac{1}{2}$ length; eye $3 \frac{3}{4}$ in head; maxillary 4 ; heal $4 \frac{1}{5}$; depth 14 to 2 ; D. 76 to 85 ; A. 56 to 67 ; scales 42 to 48 ; cirri on subopercle of blind side very numerous, white; olive ground, with darker blotches; fins sanded.

CROssotus, 3062.

\section{ETROPUS MICROSTONUS (Gill).}

"D. 81 ; A. 58 ; caudal 4, $6,5,3$; pectoral 10 ; ventral 6 . The height of the body enters about $2 \frac{2}{8}$ times $(0.36-0.37)$ in the extreme length; that of the caudal peduncle about 11 times. The head forms a fifth of the length, is rather abbreviated, scarcely sinuous above the eyes, blunt at the snout, which scarcely exceeds $\frac{1}{7}$ of the head's length and the rostral area is rhombic, and not higher than loug. The eyes are even; the longitudinal diameter contained about $3 \frac{3}{5}$ times $\left(0.05_{2}^{\frac{1}{2}}\right)$ in the head's length. The mouth is rather small, the length of the upper only equaling $\frac{1}{4}$ of the length, and that of the lower $\frac{2}{5}$ of the head's length. The teeth are very small, and close together; larger in front. The dorsal commences above the front of the orbit, and is highest and convergent near the fortieth ray, which equals about $t_{0}$ of the total length; the anal is highest at about the twenty-fifth ray, and is as high or oven higher than the dorsal. The caudal is rounded behind, and forms about $\frac{1}{6}$ of the length. The pectoral fins are unequally developed, that of the dark side being prolonged, and contained only $6 \frac{2}{8}$ times in the total length, while that of the white side only equals $\frac{1}{10}$ of the same; the rays are all simple. 
The ventral fins are also unequally developed, the right being on the abdominal ridge at its origin, rather in advance of the opercular margin and with its longest rays contained about 14 times in the total length; stretched backward, it extends to the second anal ray; the fin on the white side is more advanced, wider, and its rays longer, contained less than 12 times in the length and exteuds backward to nearly the third anal ray. The scales are large, angular behind, covered with smaller ones, especially near the point of junction of contiguous ones, where alone they are developed on the blind side; the scales of the eyed side are mostly minutely ciliated behind, unarmed, however, near the lateral line, the seales of which last are quadrate and mostly covered; the scales of the blind side are less angular behind and unarmed. The lateral line runs through about 42 seales, while of longitudinal rows there are 10 above and 14 below the lateral line. The color is uniform reddish brown. A single specimen, little more than 3 inches long, was first obtained by Professor Baird, at Beesleys Point." (Gill.)

This species has not been certainly recognized by recent writers, unless, as supposed by Jordan \& Goss, it is identical with Etropus rimosus. It is in any event certainly an Etropus. In the Museum of Comparative Zoology are numerous young specimens collected at Somers Point, New Jersey, by Dr. Stimpson. These seem to belong to the genus Etropus. The teeth are equal; the scales are 44 , and the depth of the body is $2 \frac{1}{6}$ in its length. The eye is 4 in head, the dorsal rays 75 to 80 , and the anal rays 56 or 57 . The color is light brown, mottled and spotted with darker. These probably represent the Citharichthys microstomus of Gill, collected in the same neighborhood by the same naturalist. We are unable to distinguish them from Etropus rimosus. ( $(\mu \imath \varkappa \rho o ́ s, ~ s m a l l ; ~ б \tau o ́ \mu \alpha$, mouth.)

Citharichthys microstomus, GILL, Proc. Ac. Nat. Sci. Phila. 1864, 223, Beesleys Point, New

Jersey (Coll. Prof. S. F. Baird); Goode \& BEAN, Oceanic Ichthyology, 446, 1896;

Jordan, Proc. U.S. Nat. Mus. 1890, 332.

Etropus microstomus, JoRDAN \& Goss, Review Flounders and Soles, 278, 1889.

3061. ETROPUs Rintosus, Goode \& Bean.

Head 4 in body; depth 2 to $2 \frac{1}{4}$. D. 77; A. 61 ; seales $12-41-14$; eye $3 \frac{1}{2}$ in head; maxillary $4 \frac{1}{3}$; snout 8 ; caudal 1 . Body somewhat elongate, pearshaped; month very small, its cleft less than $\frac{1}{2}$ the orbit, its angle below anterior margin of lower eye; teeth well developed on blind side on each jaw, also on eyed side of lower jaw in front; eyes placed in the same vertical; upper eye close to dorsal profile, and separated from its mate by a space less than $\frac{1}{8}$ its diameter; interorbital ridge low; nostrils in a line with the interorbital ridge, each in a short tube, the posterior the larger, the anterior midway between tip of snout and front of lower orbit; head entirely scaled; accessory scales numerous. Dorsal commencing on blind side at anterior margin of eye, the highest rays somewhat behind middle of fin, its length 7 times in total length; origin of anal under base of pectoral, its highest rays equal to those of dorsal; pectoral of eyed side longest, equal to head without snout; eaudal fin rounded. Color gray, hoary above, with a few irregularly placed indistinct brownish blotches, none of them larger than eye; white below. West coast of Florida; 
type, $100 \mathrm{~mm}$. long, collected by the Albatross at Station 2408, depth 21 fathoms, between Pensacola and Cedar Keys, Florida. (Goode \& Bean.) On reexamining our specimens of Etropus, we find that those obtained by Jordan \& Evermann from Pensacola differ from the others in the greater elongation of the body and in the somewhat grayer coloration. These correspond fairly to the description and figure of Etropus rimosus. All other specimens from the United States coast collected by Dr. Jordan and his associates are, in our opinion, referable to Etropus crossotus. The original description of Citharichthys microstomus, Gill, fits this species better than any other known. The fish in question is much too elongate for Etropus crossotus (depth $2 \frac{2}{8}$ in total length), and the mouth is too small for any of the known species of Citharichthys (maxillary 4 in head; mandible $2 \frac{1}{2}$ ). We have little doubt of the identity of Etropus rimosus and microstomus, but leave the matter for further investigation. The separation of E. rimosus from $E$. crossotus is not beyond question. (rimosus, frosted.)

Etropus rimosus, GOODE \& BEAN, Proc. U. S. Nat. Mus. 1885, 593, coast of Florida, between Pensacola and Cedar Keys, dredged at the depth of 21 fathoms; GoOnE \& BEAN, Oceanic Ichthyology, 455, pl. 104, figs. 360, 361, 1896. (The latter figure an excellent representation of the symmetrical, translucent larval form, before the right eye has crossed the forehead.)

Etropus crossotus, Jordan \& Evermann, Proc. U. S. Nat. Mus. 1886, 476; not of Jordan \& GiLBERT.

3062. ETROPUS CROSSOTUS, Jordan \& Gilbert.

Head $4 \frac{4}{5}$ in length; depth $1 \frac{8}{4}$ to 2 . D. 76 to 85 ; A. 56 to 67 ; V. 6 ; scales 42 to 48 ; vertebra $9+25=34$. Body oval, strongly compressed, with the dorsal and ventral curves nearly equal; both outlines strongly arched anteriorly, the body much deeper in adult specimens. Head very small; snont short; mouth very small, its cleft not so long as diameter of orbit. Teeth conical, pointed, close set, strongly incurved, in a single series, those in upper jaw on blind side only, those in lower jaw on both sides. Eyes large, the lower in advance of the upper, the two separated by a very narrow scaleless ridge, which extends backward above preopercle; edge of opercle on blind side, with a row of conspicuous white cilia. Upper nostril turned somewhat to blind side; anterior nostril on left side, with a very slender cirrus. Dorsal fin commencing over front of upper eye, its middle rays highest, the anterior not elevated; anal fin not preceded by a spine, its middle rays highest; candal fin very sharply double-truncate, as long as head; pectorals short, that of left side the longer, about $\frac{8}{4}$ length of head; ventral of colored side on ridge of abdomen, the membrane of its last rays nearly reaching base of first ray of anal; ventral of blind side longer than the other, $\frac{1}{2}$ length of head, inserted farther forward than that of colored side. Vent lateral, with a wellcleveloped aual papilla. Scales thin, large, ctenoid on colored side, smooth on blind side, those on the middle part of the body larger; head entirely scaly, except snout and interorbital ridge; rays of vertical fins with scales on the basal half, on colored side; lateral line developed equally on both sides, nearly straight. Color olive brown, with some darker blotches most distinct in the larger specimens; vertical fins finely mottled and streaked with black and gray; pectoral and ventral on left 
side spotted. Tropical America on both coasts, north to Cerros Island and North Carolina, south to Panama and Rio Janeiro; the type a single specimen, about 5 inches long, taken with a seine in the Astillero at Mazatlan. This little fish seems to be abundant in all warm and sandy shores of tropical America. It is the smallest and feeblest of all our flounders, and has therefore been generally overlooked by collectors. In the Museum of Comparative Zoology are specimens of this species from Rio Janeiro, Santos, Victoria, Para, and Sambaia, in Brazil. The largest of these is 6 inches in length. Hear 5 in length; depth $1_{10}^{9}$; scales 44 ; D. 85 ; A. 67 . We have specimens from Charleston, Cedar Keys, New Orleans, Galveston, Beaufort, North Carolina, Mazatlan, Panama, and from several localities along both sides of the coast of Lower California. These vary in form, color, and squamation, but we are unable to point out

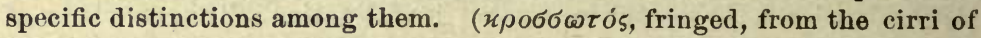
the subopercle.)

Etropus crossotus, Jordan \& GILBert, Proc. U. S. Nat. Mus. 1881, 364, Mazatlan; Jordan \& Gilbert, Proc. U.S. Nat. Mus. 1882, 305; Jordan \& Gilbert, Proc. U. S. Nat. Mus. 1882, 618; JoRdAN \& GILbERT, Bull. U. S. Fish Comm. 1882, 108-111; JordAN \& GILBERT, Sjnopsis, 839, 1883; Bean, Cat. Fish. Intern. Exh. 1883, 44; Jordan \& Swain, Proc. U.S. Nat. Mus. 1884, 234; JoRdaN \& Goss, Review Flounders and Soles, 278, 1889.

Etropus microstomus, JoRdan, Proc. U. S. Nat. Mus. 1886, 29; not Citharichthys microstomus, GILL.

I053. MONOLENE, Goode.

Monolene, Goode, Proc. U.S. Nat. Mus. 1880, 338 (sessilicauda).

Thyris, Goode, Proc. U.S. Nat. Mus. 1880, 344 (pellucidus; larval form); name preoccupied. Delothyris, Goode, Proc. U.S. Nat. Mus. 1883, 110 (pellucidus); substitute for Thyris.

Body thin, elongate; eyes on the left side, very close together, near the profile; mouth moderate, the length of the maxillary less than $\frac{1}{8}$ that of the head; teeth ininute, in a single series, nearly equal on both sides; no teeth on vomer or palatines. Scales rather large, ctenoid on colored side, cycloid on blind side. Lateral line well marked, that of colored side strongly and angularly curved anteriorly, that of blind side nearly straight. Pectoral of blind side wholly absent; dorsal beginning on the snout, its rays all simple. Caudal fin sessile, almost conflicent with dorsal and anal. Ventral fins normal, that of the left side on the ridge of the abdomen; gill rakers few, feeble. Vertebri 43. Deep-sea fishes, closely allied to Trichopsetta and Arnoglossus, but with the right pectoral obsolete. The translucent larva of Monolene is similar to the larva of Platophrys. It was at first described as a distinct genns (Thyris=Delothyris) by Dr. Goode before its true character was recognized. The following are the characters ascribed to the larval genus Delothyris :*

* The following are the characters of the species, Delothyris pellucidus, Goode:

Colorless, translucent; 3 conspicuous, dusky, longitudinal lines on left side, the middle one faintest. Two streaks on right side; eyes black. Body thin, pellucid, divided into 3 longitudinal tracks by depressions at the bases of the rows of interspinous processes. Scales small, thin, caducous. Head very small; eyes small, protruding, their diameter equal to the interorbital space and the length of the snout; mouth small, formed as in the soles, the upper jaw somewhat hook-shaped. Dorsal fin brginning in advance of the eye, of long, flexihle, simple rays, the tips of which are much exserted. Pectorals inserted far below lateral line, that on blind side as long as orbit, the other as long as snout; ventrals reaching past front of anal Head 5; deptll 3 . D. $100 ; \mathrm{A} .80 ; \mathrm{P} .12$ (left), 4 (right). Length 3 inches. (Goode.) Gulf Stream, ofl the coast of Rhode Island. 
Body elongate, soft, and translucent. Head very short; mouth small, toothless. Eyes sinistral, close together, the lower slightly advanced. Pectoral of blind side smallest; ventrals crowded together on median keel of body, their bases prolonged on this keel. Rays simple; dorsal beginning on the snout; caudal subsessile, almost confluent with dorsal and anal. Scales very thin, easily detached, probably cycloid. Lateral

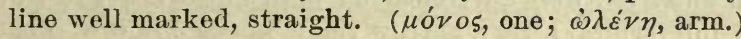

a. Dorsal rays 99 to 103 ; anal rays 79 to 81 ; scales 92 . $a a$. Dorsal rays 124; anal rays 100 ; scales 105 .

SESSILICAUDA, 3063. ATRIMANA, 3064.

3063. MONOLENE SESSILICAUDA, Goode.

Head 5 in body; depth $2 \frac{2}{3}$. D. 99 to 103 ; A. 79 to 84 ; scales $23-92-25$; eye 4 in head; highest dorsal ray 2 ; highest anal rays slightly more than

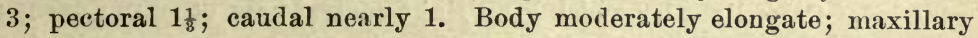
extending slightly past front of lower eye, with uniserial, subequal teeth; lower eye in advance of upper; interorbital space very small, less than $\frac{1}{6}$ the diameter of eye; head everywhere closely scaled; scales ctenoid; lateral line strongly curved over anterior $\frac{2}{3}$ of pectoral, the curve with 2 angles, 72 scales along straight portion; lateral line of blind side nearly straight. Origin of dorsal over anterior edge of lower eye, longest rays in the posterior fourth of the fin; origin of anal under base of pectoral; pectoral present only on eyed side. Color on left side ashy brown, with numerous more or less distinct darker brown spots; on blind side white, pectoral blackish with traces of lighter transverse bands. Specimens from shallow water near Key West (Coll. Prof. C. C. Nutting), according to Mr. Garman, are much more brightly colored. These are "grayish brown, with numerous spots of darker to blackish over head and body, the spots being $\frac{1}{2}$ as large as the eye or smaller, arranged for the greater part in broad transverse bands as wide as the interspaces, of which bands the first and foremost passes from the nape to the opercle, the second lies immediately behind the pectoral, the third just in front, and the fourth just behind the middle of total length, and the fifth, more indistinct, crosses near the ends of the dorsal and anal; the caudal is crossed by 2 rather indefinite narrow streaks; the pectoral is white at its base and bears 3 or 4 narrow curved transverse bands of white, separating 3 or 4 similar bands of black, which with the white are more distinct in the lower half of the fin." Specimens from 150 fathoms or more have markings similar but less distinct. D. 104 ; A. 84 ; V. 6 ; P. 11; scales 22-93-24. Deep waters of the Gulf Stream, Cape Cod to Key West. (sessilis, sessile; cauda, tail.)

Monolene sessilicauda, Goode, Proc. U.S. Nat. Mas. 1880,337, 338, deep sea south of New England; Goode, Proc. U.S. Nat. Mus. 1880,472; JordAN \& GILbERT, Synopsis, 841, 1883; JoRdAN \& Goss, Review Flounders and Soles, 280, 1889; Groode \& BEAN, Oceanic Ichthyology, 452, figs. 357 A \& B, 1896; GARMAN, Bull. Iowa Lab. Nat. Hist. 1896, 91.

Thyris pellucidus, GoodE, Proc. U. S. Nat. Mus. 1880, 344, Gulf Stream off the coast of Rhode Island.

Delothyris pellucidus, Goode, Proc. U.S. Nat. Mus. 1883, 109. 
3064. MONOLENE ATRIMANA, Goode \& Bean.

Head $4 \frac{1}{4}$ in length of body; depth about 3 . D. 124 ; A. 100 ; scales 30

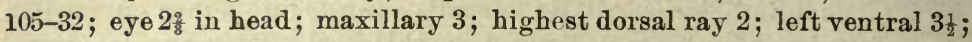
pectoral $4 \frac{1}{4}$ in body; caudal 6 . Body rather elongate; snout slightly produced. Mouth oblique, the maxillary extending to a little belind front of lower eye, teeth uniserial, well developed on both sides; lower eye in advance of upper; interorbital a very narrow ridge, about 9 in eye; nostrils in very short tubes in the same line with the interorbital ridge, the posterior one is slightly less distant from lower eye than the anterior one is from the snout; head everywhere scaly; lateral line strongly arched over anterior third of pectoral. Origin of dorsal on blind side above front of lower eye, longest rays in posterior fourth of fin; highest rays of anal a little higher than dorsal rays; pectoral on eyed side only; candal sessile, rounded. Color light brownish gray, right ventral pale, other fins dusky; pectoral and eyelids black. West Indies. The type was taken by the Blake in 288 fathoms, off Barbados; its length is $114 \mathrm{~mm}$. (Goode \& Bean.) (ater, black; manus, hand.)

Monolene atrimana, Goode \& BEAN, Bull. Mus. Comp. Zool., XII, 155, 1886, deep waters off

Barbados; Jordan \& Goss, Review Flounders and Soles, 280, 1889; GOODE \& BEAN, Oceanic Ichthyology, 455, fig. 358, 1896.

\section{Family CCXX. SOLEIDÆ.}

\section{(The Soles.)}

Body oblong or elongate, usually scaly; mouth very small, much twisted toward the eyed side; the teeth in villiform bands, very small or obsolete; eyes small, close together, with or without a bony ridge between them; edge of preopercle adnate, concealed by the skin and scales; gill openings narrow, the gill membranes adnate to the shoulder girdle above; pectoral fins small or wanting; ventral fins small, 1 or both sometimes wanting. Small fishes living on sandy bottoms, similar to the Pleuronectidce in structure, but much degraded, the fins and teeth having lost many of their distinctive qualities. The vertebræ are usually in increased numbers.*

* The following are the numbers of vertebra in several species of Soleida:

\section{I.-ACHIRINAE.}

Achirus fasciatus..
Achirus inseriptus $8+20=28$ $9+19=28$

II.-SOLEINA.

Synaptura zebra

Solea solea.

Solea kleini

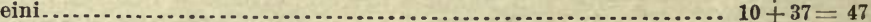

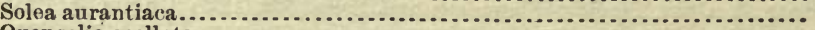

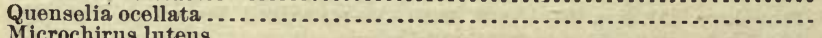

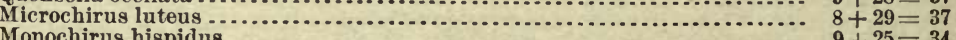

$9+28=37$

III.-CyNOGLOSSTINA.

Symphurus atricandus........................................ $10+42=52$

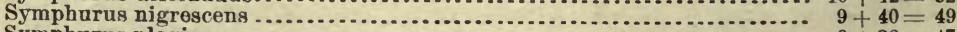

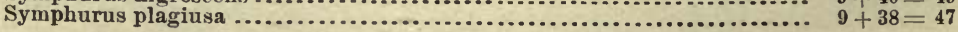


They are numerous in the warm seas, and those of sufficient size are valued as food. Genera about 12 ; species 150 . The North American species belong to 2 subfamilies very different one from the other. The soles are naturally divisible into 3 subfamilies, each quite distinct from the others, and possibly independently descended or degraded from normal Pleuronectida. The Achirina, or American soles, are apparently allied to the Psettina, and as in the latter, the ventral fin of the eyed side extends along the ridge of the abdomen. The Soleina, or European soles, show in the insertion of ventral and in other respects a strong resemblance to the Pleuronectina. The more aberrant Cynoglossina, or tongue fishes, are perhaps degraded Soleinc, but the eyes are sinistral, as in the Psettina. In the Soleince and Achirina the eyes are dextral, as in the Pleuronectina.

ACHIRINA:

I. Soles with the eyes on the right side and separated by a distinct bony ridge; tie ventral with long base confluent with the anal. Body oblong or ovate, with the color on the right side; eyes moderate or small, the upper eye usually more or less in advance of the lower; mouth small, more or less twisted toward the blind side; teeth little developed, in villiform bands; edge of opercle adnate, usually concealed by the scales; gill openings more or less narrowed, the gill membraues adnate to the shoulder girdle above; blind side of bead usually with fringes; pectoral fins small, sometimes wanting; ventral fins developed, one or both of them sometimes obsolete; scales usually etenoid, rarely wanting; lateral line straight, usually single; right ventral with extended base, confluent with the anal fin.

a. Gill openings of moderate extent, confluent below; vertical fins well separated; body ovate in outline, the depth nearly $\frac{1}{2}$ the length; pectoral fins rudimentary or wanting; lateral line straight; scales well developed, ctenoid, those on the head more or less enlarged, those of the blind side of the hear with fringes; vertebra about 28.

AcHirus, 1054.

aa. Gill openings very small, separate, each rednced to a small slit below angle of opercle; right rentral beginning at the chin; pectoral fins minute or wanting; lateral line straight; snout dilated, the dorsal beginuing upon it.

b. Scales present, ctenoid; caudal somewhat confluent with dorsal.

c. Left ventral rudimentary, with 2 rays.

APIONICHTHYS, 1055.

$b b$. Scales none; caudal free from dorsal and anal. GyMnachirus, 1056.

CyNOGLOSSINA:

II. Soles with the eyes on the left side, not separated by a bony ridge. Body elongate, more or less lanceolate in outline, with the color on the left side; eyes small, very close together, with no distinct interorbital ridge between them; mouth small, twisted toward the blind side; teeth little developed, in villiform bands; gill openings narrow, the gill membranes adnate to the shoulder girdle above, joined together and free from the isthmus below; pectoral fins wanting (in the adult); ventral fins small, that of the blind side often wanting; vertical fins more or less confluent; scales ctenoid; lateral lines sometimes wanting, sometimes duplicated.

d. Ventral fin of eyed side only present, free from the anal; no pectoral fins; no lateral line; head without fringes.

SYMPHURUS, 1057.

1054. ACHIRUS, Lacépède.

\section{(AMERICAN SOLES.)}

Achirus, LACÉPÈDE, Hist. Nat. Poiss., IV, 659, 1803 (fasciatus, etc.).

Achirus, Cuvier, Règne Animal, Ed. 2, II, 343, 1829 (restriction to fasciatus, etc.).

Trinecte8, Rafinesque, Atlantic Journal and Friend of Knowledge, 1, 1832 (scabra).

Grammichthys, KAUP, A rchiv fur Naturgsch. 1858, 94 (lineatus; fasciatus); Achirus being restricted to Pardachirus barbatus, etc. 
Monochirus, KAUP, Archiv fur Naturgsch. 1858, 94 (maculipinnis); not of RAFINESQUE. 1814 , a genus of Soleince.

? Aseraggodes, KAUP, Archiv fur Naturgsch. 1858, 103 (guttulata).

Baiostoma, BeAN, Proc. U.S. Nat. Mus. 1882, 413 (brachiale).

Boeostoma, JORDAN \& GILBERT, Synopsis, 965, 1883; amended orthography.

Eyes and color on the right side. Body oblong, bluntly rounded anteriorly. Head small; eyes small, close together, the upper eye in advance of the lower, the two separated by a bony ridge; mouth sinall, somewhat turned toward the colored side; nasal flaps present, the nostril of the blind side fringed; lip of the colored side fringed; teeth very small, on blind side only; gill openings rather narrow, but confluent below, not reduced to a slit; the branchiostegal region scaled. Head elosely scaled everywhere, the scales on the colored side similar to those on the body, those of the nape and chin much enlarged; scales on the blind side anteriorly with their pectinations more or less produced, forming cirri; scales of both sides extremely rongh, extending on the fins. Lateral line straight, simple; edge of preopercle covered by the scales. Dorsal beginning on the snout, low in front and thickly scaled, its rays divided; anal tin similar, without spine; candal fin free, convex; caudal peduncle very short and deep; pectoral fin of left side wanting, that of right side small or obsolete; ventral rays 3 or 4 , the ventral fin of the colored side long, connected with the anal by a membrane. This strongly marked genus contains numerous species, all very closely related, and nearly all American. It has been united by Dr. Giinther with Solea, but for no good reason, as the number of vertebre is very much fower than in the European soles, and the right ventral fin is decurrent along the abdomen and united with the anal in the American soles, while it is short and wholly free in all the European forms. The 2 groups belong in fact to distinct subfamilies. It is also worth noticing that the name Achirus is prior in date to that of Solea. The species with rudimentary pectoral fins have been set apart by Dr. Bean to form the genus Baiostoma, but the very slight development of these organs in some of the species and the evidently very close relationship of them all lead us to regard Baiostoma as a subgenus only. If we follow Kaup in restricting the name Achirus to the Asiatic group called Pardachirus, the present genus would receive the name of Trinectes. It seems to us, however, that both Lacépède and Cuvier regarded the species called by us fasciatus as the type of their genus Achirus. ( $\alpha$ $\chi \varepsilon \imath \rho$, withont hands; without pectoral fins.)

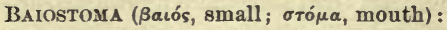

a. Pectoral fins small, present at least on the right side.

$b$. Pectoral fin present on both sides, that of the left side rudimentary, of a single ras; that of the eyed side with about 3 rays.

c. Dorsal rays 60 to 67 ; anal rays about 48 ; scales 80 ; depth $1 \frac{2}{3}$ in length. Color browuish, irregularly spotted with darker, and with about 10 black vertical lines crossing the lateral line. $\triangle C H I R U S, 3065$.

$c c$. Dorsal rays 53 to 57 ; scales 75 to 80 ; depth 13 in length; scales not very rongh, those of colored side with scattered, hair-like appendages, some black, others pale. Color olivaceous; head, body, dorsal, and anal fins covered with a network of dark lines; traces of about 8 dark cross streaks sometimes present. INSCRIPTUS, 3066. 
$b b$. Pectoral of right side only present.

$d$. Dorsal rays 65 or 66 ; anal rays 48 to 51 .

$e$. Pectoral well developed, with about 6 rays; scales of eyed side without hair-like filaments; scales of lateral line 77 to 80 ; chin little prominent.

KLUNZINGERI, 3067.

$d d$. Dorsal rays 50 to 58 ; anal rays 38 to 48 .

$f$. Pectoral fin of 4 to 6 rays, considerably longer than eye; body with 8 to 10 narrow, vertical dark bars, these sometimes obsolete with age.

$g$. Vertical fins all with round, dark spots, these usually especially distinct on the caudal fin; some of the scales of eyed side with black, hair-like appendages; pectoral fin with 5 or 6 rays, about 3 in head, its length equal to that from outer edge of 1 eye to outer edge of another. Head $3 \frac{1}{2}$; depth $1 \frac{1}{2}$. Body with 8 narrow, vertical cross streaks. LINEATUs, 3068 .

gg. Vertical fins dark, without distinct markings. Body broad, ovate, the depth about $1 \frac{1}{2}$ in length; pectoral fin with 4 rays; scales of right side with numerons black, hair-like appendages. D. 56 ; A.42; scales 70 . MAZATLANUS, 3069 .

ff. Pectoral fins of 1 to 3 rays, about as long as eye.

$h$. Body with 6 narrow, dark bands, these sometimes obsolete. Body rather narrowly ovate, its depth $1 \frac{5}{6}$ in length. D. 58 ; A. 44 ; scales 85 .

FONSECENSIS, 3070 .

$h$. Body with about 10 black cross lines; depth $1 \frac{8}{9}$ in length. D. 61 ; A. 44 ; scales 60 ; pectoral of a single ray.

FISCHERI, 3071.

$h h h$. Body with very numerous (20 to 40 ) black cross bands, which are as broad as the interspaces.

$j$. Blind side of snout with few fringes. Depth $1 \frac{1}{3}$ in length. D. 55 ; A. 48; scales 80 . Body covered by many blackish, wavy bands; caudal with black

ACHIRUs: spots.

SCUTUM, 3072.

$a a$. Pectoral fins wholly wanting.

$k$. Dorsal rays 46; anal rays 33; right lower lip with serrated fringes; nostril in a fringed tube; depth $1 \frac{1}{2}$ in length; head 3 . Color brown, head and body with numerous large, rounded or kidney-shaped white spots, edged with dark brown; scales 70 .

FimbRiatus, 3073.

$k k$. Dorsal rays 50 to 55 ; anal rays 37 to 46 ; right lower lip fringed; left nostril with some fringes; depth 14 in length; head 4; none of the scales of eyed side with hair-like appendages. Color dusky olive, more or less mottled with about 8 dark vertical stripes, these varying very much in width and number; caudal spotted.

FASCIATUS, 3074.

$k k k$. Dorsal rays 59 or 60 ; anal rays 41 to 45 ; snout and chin without evident fringe or barbel; right lower lip fringed; head 4 in length; depth $1 \frac{3}{4}$; scales 64 . Body with 12 black cross bands with narrower ones between; caudal spotted.

PANAMENSIS, 3075 .

Subgenus BAIOSTOMA, Bean.

3065. ACHIRUS ACHIRUS (Linnæus).

D. 60 to 67 ; A. 48 ; P. right 3 , left 1 ; scales 80 . Pectorals rudimentary on both sides; right ventral fin composed of 5 rays, which are continuous with the anal. Scales on the nape and on chin twice as large as those on body; snout with a few fringes on blind side; right lower lip fringed. Height of body $1 \frac{2}{3}$ in total length (without caudal); width of interorbital space nearly equal to, or rather more than diameter of eye; upper eye 
slightly in advance of lower; longest dorsal rays are in posterior fifth of the fin, $\frac{2}{8}$ of length of head; caudal rounded, rather louger than head. Brownish, irregularly spotted with darker, and with about 10 black vertical liues crossing the lateral line. Coasts of Surinam. (Giinther.) Not secn by us.

We know this species only from Dr. Giinther's descriptiou. Pleuronectes achirus, Linnseus, is based on a description by Gronow of some Achirus from Surinam. Gronow's fish agrees with the present species in having 60 dorsal rays and 48 anal rays, in being brown, with trausverse black bands, with dark spots on the fins, as well as in coming from Surinam. But Gronow explicitly denies the presence of pectorals, and the present species has rudimentary pectoral fins on both sides. Probably these were overlooked by Gronow, and as no other species found in the same region has so large a number of rays, we feel justified in the use of the name Achirus achirus for this species. ( $\dot{\alpha}-$, without; $\chi \varepsilon i \rho$, hand.)

Pleuronectes oculis dextris, corpore glabro, pinnis pectoralibus nullis, GRoNow, Museum, I, No.42, Surinam.

Pleuronectes achirus, Linn eus, Syst. Nat., Ed. x, 268, 1758, Surinam; based on Growow. Solea gronovii, GÜNHER, Cat.j IV, 472, 1862, Surinam.

Achirus gronovii, JoRdAN, Proc. U. S. Nat. Mus. 1886, 602.

Achirus achirus, JoRDAN \& Goss, Review Flounders and Soles, 311, 1889.

\section{ACHIRUS INSCRIPTUS, Gosse.}

Head $3 \frac{8}{4}$ in body; depth $1 \frac{8}{4}$. D. 53 to 57 ; A. 40 ; scales 75 to 80 ; interorbital width less than eye; upper eye in advance of lower. Pectoral fin present ou each side, that of the left side rudimentary, of a single ray; that of the eyed side with about 3 ; left ventral with 1 or 2 small rays, in some specimens entirely absent; right ventral joined to anal. Scales smaller and less rough than usual in this genus, those of nape scarcely enlarged ou eyed side, those of blind side much fringed; scales of colored side with scattered hair-like appendages, some black, others pale. Color olivaceous; head, body, dorsal, and anal fins covered with a network of lark lines; traces of about 8 dark cross streaks sometimes present; caudal fin yellowish, nearly plain, or with a few dark dots or reticulations, its base dusky. Vertebrie $8+20=28$. West Indies north to Key West. Known to us from numerous specimens taken by Dr. Jordan at Key West, and from specimens from Hayti, in the museum at Cambridge. These specimens belong undoubtedly to the species called reticulatus by Poey, and this is apparently not different from the inscriptus of Gosse, as the agreement with the latter is even closer than with the former description. (inscriptus, written on.)

Achirus inscriptus, Gosse, Nat. Sojourn Jamaica, 52, pl.1, fig. 4, 1851, Jamaica ; JoRDAN, Proc. U. S. Nat. Mus. 1884, 143; JoRdAN \& Goss, Review Flounders and Soles, 311, 1889. Monochir reticulatus, PoEY, Memorias, II, 317, 1861, Cuba; Poey, Synopsis, 409; PoEY, Enumeratio, 139.

Solea reticulata, GüNTHER, Cat., IV, 472, 1862.

Solea inscripta, Günther, Cat., rv, 473, 1862.

Boeostoma reticulatum, BeAN \& Dresel, Proc. U. S. Nat. Mus. 1884, 152. 
3067. ACHIRUS KIUNZINGERI (Steindachner).

Head $3 \frac{2}{3}$ in body; depth $1 \frac{5}{7}$. D. 65 ; A. 51 ; seales $37-80-42$; eyo $3 \frac{2}{5}$ in liead; height of dorsal and anal $1 \frac{1}{2}$; caudal 1 . Body moderately broad; eyes in the same vertical line; interorbital as wide as length of eye; angle of mouth reaching a little past front of lower eye; right under lip fringed; scales near upper profile of head enlarged, all scales strongly ctenoid; scales of eyed side without hair-like filaments. Pectoral of right sido only present, with about 6 rays; caudal round behind. Color brownish, with 9 or 10 narrow blackish cross lines; small rounderl blackish spots on the membranes of each of the vertical fins, much as in A. lineatus. (Steindachner.) Pacific coast of tropical America; Panama to Guayaquil. (Named for Dr. C. B. Klunzinger, Professor of Zoology at Stuttgart, author of Memoirs on the Fishes of the Red Sea.)

Solea klunzingeri, Steindachner, Zur Fische des Cauca und der Flïsse bei Guayaquil, 44, 1879, Guayaquil.

Achirus klunzingeri, JoRdan, Proc. U. S. Nat. Mus. 1885, 391; JoRDan \& Goss, Review Flounders and Soles, 312, 1889.

\section{ACHIRUS LINEATUS (Linnæus).}

Head $3 \frac{1}{2}$; depth about $1 \frac{1}{2}$. D. 49 to 58 ; A. 38 to 44 ; scales 75 to 85 . Pectoral fin of right side only developed, of 4 to 6 rays, considerably longer than eye. Body with 8 to 10 narrow vertical dark bars, these sometimes obsolete with age; vertical fins all with round dark spots, these usually especially distinct on the caudal fin; some of the scales of eyed side with black, hair-like appendages; pectoral fin with 5 or 6 rays, about 3 in head, its length equal to that from outer edge of one eye to outer edge of another. Color brown, the young spotted with whitish, the adult sometimes with darker; body with about 8 narrow vertical cross streaks of blackish. West Indies and Brazil, Florida Keys to Uruguay; common and variable.

We have placed the Florida species, comifer and brachialis, in the synonymy of lineatus. They differ from the latter only in the slightly smaller number of the scales and fin rays. The following table shows our count of a number of specimens from different localities:

\begin{tabular}{|c|c|c|c|c|}
\hline Locality. & Species. & D. & A. & Scales. \\
\hline 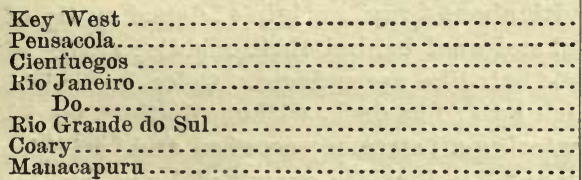 & $\begin{array}{l}\text { comifer } \ldots \ldots \ldots . . . . . \\
\text { brachialis.......... } \\
\text { lineatus .......... } \\
\text { maculipinnis...... } \\
\text { maculipinnis...... } \\
\text { maculipinnis...... } \\
\text { maculipinnis...... } \\
\text { maculipinnis...... }\end{array}$ & $\begin{array}{l}50 \\
51 \\
54 \\
57 \\
54 \\
49 \\
53 \\
55\end{array}$ & $\begin{array}{l}35 \\
37 \\
43 \\
42 \\
44 \\
38 \\
40 \\
42\end{array}$ & $\begin{array}{r}55 \text { to } 67 \\
75 \text { to } 77 \\
85 \\
85 \\
72 \\
70 \\
68 \\
75\end{array}$ \\
\hline
\end{tabular}

It is evident from this table that neither the fin rays nor the scales form characters by which the subspecies can be absolutely distinguished. It is evident also, from the examination of large series of specimens, that the $3030 \longrightarrow 92$ 
coloration is subject to very great variations-as great as in Achirus fasciatus. In some of these the caudal is dark and immaculate, in others pale and usually profuscly spotted. In some the ground color is nearly plain blackish, in others it is pale, usually with narrow dark cross bands, but sometimes closely spotted everywhere. The specimens examined by us are from Pensacola and Egmont Key (brachialis), Key West (comifer), Cienfuegos (Cuba, Poey), Coary, Teffy, Tapajos, Porto Alegre, Pernambuco, Cannarivieras, Manacapuru, Porto do Moz, Rio Grande do Sul, Rio Janeiro, San Matheo, Rosario, Itabapuana, Obidos, Xingu, Gurupa, Jutaby, Curaçao, Para, Bahia, Santarem, Iça, Fonteboa, San Paolo, Rio Trompetas, Sambaia, Manes, Javary, and Tabatinga. The species would appear to be one of the commonest in Brazil. (lineatus, striped.)

$$
\text { a. Var. lineatus. }
$$

Passer lineis transversis notatus, SLOANE, Jamaica, 2, 77, pl. 246, fig. 2, 1725, Jamaica.

Pleuronectes fuscus subrotundus glaber, BRowne, Jamaica, 445, 1756, Jamaica.

Pleuronectes lineatus, LinNeus, Syst. Nat., Ed. x, 268, 1758, Jamaica; based on Browne and SLOANE; not of Ed. XII, which is Achirus fasciatus.

Monochir maculipinnis, AGAssiz, Spix, Pisc. Brasil., 88, pl. 49, 1829, Brazil; Poky, Synopsis, $409,1868$.

Monochir lineatus, QUOY \& GAIMARD, Voy. Uranie, Zool., 238, 1824.

Achirus lineatus, D'Orbigny, Voyage Amér. Mérid., Poiss., pl. 16, fig. 2, 1847; Jordan \& Goss, Review Flounders and Soles, 312, 1889.

Solea maculipinnis, GüNTHER, Cat, IV, 473, 1862; KNER, Novara Fische, III, 289, 1866.

Achirus maculipinnis, JoRDAN, Proc. U.S. Nat. Mus. 1886, 602.

\section{b. Var. brachialis.}

Baiostoma brachialis, BeAN, Proc. U. S. Nat. Mus. 1882, 413, Appalachicola Bay and South Florida. (Types, Nos. 26605 and 30463. Coll. Silas Stearns.)

Baeostoma brachiale, JoRDAN \& GILBERT, Synopsis, 965, 1883.

Achirus brachialis, Jordan, Proc. U. S. Nat. Mus. 1884, 149.

$$
\text { c. Var, comifer. }
$$

Achirus comifer, Jordan \& Gilbert, Proo. U. S. Nat. Mus. 1884, 31, Key West. (Coll. Dr. Jordan. )

3069. ACHIRUS MAZATLANUS (Steindachner).

(Mexican Sole; Lenguado de Rio; Teipalcate.)

Head $3 \frac{1}{3}$ in body; depth $1 \frac{1}{2}$. D. 56 ; A. 42 ; scales 70 ; eye $7 \frac{1}{2}$ in head; dorsal and anal rays $3 \frac{1}{2}$ in depth of body; caudal 3. Body broad, oval; eyes small, the upper in advance of the lower; interorbital about $\frac{1}{2}$ the diameter of eye; nostril in a tube, placed just above middle of mouth; pectoral developed on eyed side only, with about 4 rays; origin of dorsal on tip of snout; greatest height of dorsal and anal behind their middle; scales of right side with numerous black hair-like appendages. Color brownish, with 8 or 9 narrow vertical black bars; fins dark, without distinct markings. West coast of Mexico, entering all streams; common and variable. Many specimens from Mazatlan and Rio Presidio examined by us, as also a specimen from Chiapas. (Name from Mazatlan, ${ }^{*}$ the river of the deer.)

* "With eternal sun above thee,

'T is not strange the tall deer loved thee,

That he gave his name, Mazatl,

To thy river, Mazatlan!" 
Solea mazatlana, Steindachner, Ichth. Notizen, IX, 23, 1869, Mazatlan; Jordan \& GILBERT, Bull. U. S. Fish Comm. 1882, 108.

Solea pilosa, Peters, Berliner Monatsber. 1869, 709, Mazatlan.

Achirus mazatlanus, Jordan, Proc. U. S. Nat. Mas. 1885, 391; Jordan \& Goss, Review Flounders and Soles, 313, 1889; Jordan, Proc. Cal. Ac. Sci. 1895, 505.

\section{ACHIRUS FONSECENSIS (Günther).}

Head $3 \frac{1}{8}$; depth $1 \frac{5}{6}$. D. 58 ; A. $44 ;$ P. 2 ; scales about 85 . No trace of a pectoral on the left side, that on the right not much longer than the eye; right ventral fin composed of 5 rays, which are continuous with the anal. Seales on the nape twice or thrice as large as those on the body. The upper part of the snout slightly overlaps the lower jaw. The left anterior part of the head with numerous tentacles; the right lower lip with very distinet slender fringes; nostril on the right side in a wide and short tube. The width of the interorbital space is less than the diameter of the eye; the upper eye is in advance of the lower. The rays of the vertical fins are branched; the longest dorsal rays are $\frac{2}{8}$ of the length of the head. Caudal rounded, as long as the head. Brownish olive, with 6 pairs of deep brown vertical lines extending on the dorsal and anal fins. Pacific Coast of Tropical America. (Günther.) Described from 1 specimen $4 \frac{1}{4}$ inches long, from Gulf of Fonseca; 2 others since taken by us in Rio Presidio, near Mazatlan. (Name from Fonseca, the type locality.)

Solea fonsecensis, Günther, Cat., IV, 475, 1862, Gulf of Fonseca. (Coll. Sir John Richardson.)

Achirus fonsecensis, JoRdan \& Goss, Review Flounders and Soles, 314, 1889; JoRDAN, Proc. Cal. Ac. Sci. 1895, 505.

3071. ACHIRUS FISCHERI (Steindachner).

(Pege OJa.)

Head $3 \frac{1}{2}$ in body; depth $1 \frac{8}{9}$; caudal $3 \frac{1}{4}$. D. 61 ; A. 44 ; P.right. 1 ; V.5; seales 60 to 62 . Pectoral wanting on left side, rudimentary on right, of a single ray scarcely longer than eye; right ventral connected with the anal. Scales on neck and lower portion of head $1 \frac{1}{2}$ to 2 times as large as those on body; right side of lower lip fringed; upper jaw not projecting forward over lower jaw; left side of head with dermal flaps only around corner of mouth and on lower jaw. Eyes small, the npper a little further forward than the other, and 2 in snout; breadth of forehead equaling diameter of eye. Dorsal rays increasing gradually in length to the forty-eighth, which is about $\frac{5}{8}$ length of head. Scales strongly ctenoid, the teeth considerably largest at the middle; rays of all the fins, except of pectorals, scaled to their tips, the membranes less fully sealed; only the anterior third of the caudal membranes scaled, and between the last dorsal and anal rays the scales extend slightly upon the fins. A few black threadlike appendages on right side of body between scales. Color of right side dark gray; 2 or 3 blackish cross lines on head, about 10 on body, between them numberless spots of similar color; spots on fins, especially those on caudal, a little larger; a few large dark spots on body, irregular 
and poorly defined; blind side reddish yellow. Total length about $10 \mathrm{~cm}$. Rio Mamone, near Panama; known to us only from Steindachner's description and figure. (Steindachner.) Not seen by us. (Named for W. Fischer.)

Solea fischeri, Steindachner, Bejträge Kenntniss Fluss-Fische Sudamer., I, 13, 1879, Rio Mamone, near Panama.

Achiris fischeri, JoRdan, Proc. Ac. Nat. Sci. Phila. 1887, 391.

\section{ACHIRUS SCUTUM (Günther).}

Head $3 \frac{2}{3}$; depth $1 \frac{1}{2}$. D. 55 ; A. 48 ; P. 3 ; scales 80 . No trace of a pectoral on left side; right pectoral quite rudimentary, scarcely longer than the eye; right ventral composed of 5 rays, which are continuous with anal. Scales on nape nearly twice as large as those on the body; snout with scarcely any fringes on the blind side, right lower lip fringed. Width of interorbital space less than horizontal diameter of orbit; upper eye slightly in advance of lower. Longest dorsal rays in posterior third of fin, $\frac{2}{8}$ length of head; caudal rounded, longer than head. Grayish; head, body, and fins with numcrous blackish, irregular, waving, sometimes bifurcate, transverse bands, which are broader than the interspaces; caudal with rounded deep black spots; the left side uniform white. Pacific coast of Central America. (Günther.) Not seen by us. (scutum, a shield.)

Solea scutum, Günther, Cat., Iv, 474, 1862, Gulf of Fonseca, Panama.

Achirus scutum, JoRDAN \& Goss, Review Flounders and Soles, 314, 1889.

\section{Subgenus ACHIRUS.}

3073. ACHIRUS FIMBRIATUS (Günther).

Head 3 ; depth $1 \frac{1}{2}$. D. 46 ; A. 33 ; scales 70 . Pectorals none; right ventral of 5 rays, which are continuous with the anal. Scales on nape 4 times, those on the chin twice, as large as on the body. Upper part of the snout slightly bent downward over the mandible and forming a short hook; right lower lip broadly fringed, each fringe being serrated; nostril in a short, wide, fringed tube. No tentacles on left side of head. Width of interorbital space equaling diameter of circular sinall orbit; upper eye slightly in advance of lower. Longest dorsal rays $\frac{2}{8}$ of length of head; rays of vertical fins branched; caudal rounded, its length being $\frac{1}{4}$ of the total. Brown; head and body with numerous large, rounded, or kidney-shaped white spots, edged with dark brown. Gulf of Fonseca, Central America. (Guinther.) Known from 1 specimen, $3 \frac{1}{6}$ inches long. (fimbriatus, fringed.)

Solea fimbriata, GÜnтHer, Cat., IV, 477, 1862, Gulf of Fonseca. (Coll. Sir John Richardson.) Achirus fimbriatus, JoRDAN \& Goss, Review Flounders and Soles, 315, 1889.

\section{ACHiRUS FASCiatus, Lacépède.}

(AMERICAN SOLE; Hog CHOKER.)

Head 4 in body; depth $1 \frac{4}{5}$. D. 50 to 55 ; A. 37 to 46 ; scales 66 to 75 ; eye 7 in head; height of dorsal and anal nearly 2; caudal $1 \frac{1}{6}$. Borly broad, regularly elliptical; mouth moderate, reaching just past front of lower 
eye; right lower lip fringed; eyes very small, the upper one in advance of the lower; nostril ending in a wide tube, nearer lower eye than tip of suout; interorbital space with scales, more than $\frac{1}{2}$ eye; head and body scaled with strongly ctenoid scales, none of them with hair-like appendages; lateral line nearly straight; gill opening short, about twice as long as maxillary. Origin of dorsal on tip of snout; last few rays of dorsal and anal rapidly decreasing, giving the fins a truncate appearance posteriorly; pectorals wholly wanting; eaudal rounded. Color dusky olive, more or less mottled, and with about 8 dark, vertical stripes, these varying very much in width and in number; vertical fins with the membrane of every second or third pair of rays blackish, besides dark cloudings at base of fin; caudal with numerous longitudinally oblong spots; blind side often with round, dark spots, especially in northern specimens, usually immaculate in southern ones (var. browni). Vertebra $8+20=28$. South Atlantic and Gulf coast, from Cape Ann to Brazos Santiago, ascending sandy streams in shallow water. The species is the best known of the American soles, and it is common along our coast, ascending the rivers for a considerable distance above tide water. It seldom exceeds 5 or 6 inches in length, and is of but little value as food on account of its small size. Here described from a specimen, 4 inches long, from Beaufort, North Carolina. This species has not yet been recorded from the West Indies. The form found along the Gulf coast has been described as a distinct species under the name Solea browni. The differences are not very evident. We have compared a number of specimens from Boston (fasciatus) with others from Pensacola, and find the following differences, none of which is constant: In the Gulf variety (browni) the blind side is always immacnlate, while in almost all Atlantic examples (fasciatus) the blind side is profusely covered with round, dark spots. In 1 specimen, however (11360, Boston), the blind side is immaculate. The darker cross streaks on the eyed side are usually broader and more numerous in southern specimens, and the scales on the blind side of the head rougher. There are no constant differences either in the fin rays or in the scales. We have examined specimens of this species from Boston, Chestertown, Tarrytown, New York, Port Monmonth, Havre de Grace, Potomac River, Neuse River, Beaufort, Charleston, Pensacola, Mobile, and Galveston. In 1 large specimen from Pensacola (11482, M. C. Z.) there is a rudiment of a pectoral fin on the eyed side. It consists of a single ray $\frac{2}{8}$ as long as the eye. (fasciatus, banded.)

Pleuronectes lineatus, LINNad, Syst. Nat., Ed. XII, 458, 1766, on a specimen from Charleston, received from Dr. Garden; not Pleuronectes lineatus of Ed. $x$.

Achirus fasciatus, LACÉṖ̀DE, Hist. Nat., Poiss., IV, 659, 662, 1803, Charleston; excl, syn., description based entirely on the Linnæan account of the fish sent by Garden; JoRDAN \& Goss, Review Flounders and Soles, 315, 1889.

Pleuronectes mollis, Mrtchill, Trans. Lit. and Phil. Soc. N. Y., I, 1815, 388, pl. 2, fig.4, New York.

Pleuronectes apoda, MrTCHIL, Amer. Monthly Mag. and Crit. Rev., Feb., 1818, 244, Straits of Bahama; perhaps A. lineatus.

Trinectes scabra, RAFinesque, Atlantic Journal and Friend of Knowledge, I, 1832, Pennsylvania, in fresh water.

Solea browni, Gưnther, Cat., IV, 477, 1862, New Orleans; Texas. 
A chirus lineatus, CUvier, Règne Animal, Ed. 2, II, 343, 1829; Gru, Cat. Fishes East Coast N. Am., in Rept. U. S. Fish Comm., 1871-72, 794; Jordan \& Grlrert, Proc. U. S. Nat. Mus. 1878, 368; GOODE, l. c., 1879, 110; GOODE \& BEAN, 1. c., 1879, 123; BEAN, 1. c., 1880, 77; JORDAN \& GILBERT, 1. c , 1882, 618; BEAN, 1. c., 1883, 365.

Grammichthys lincatus, KAUP, Archiv fur Naturgesch. 1858, 101.

Achirus mollis, Storer, Synopsis, 228, 1846; Storer, Hist. Fish. Mass., 206, pl. 32, 1867;

DE KAY, New York Fauna: Fishes, 303, pl. 49, fig. 159, 1842.

Achirus achirus mollis, Jordan, Cat. Fish. N. A., 137, 1885.

Solea achirus, GÜNTHEr, Cat., IV, 476, 1862; not Pleuronectes achirus L.

A chirus achirus, Jordan, Proc. U. S. Nat. Mus. 1885, 19; JoRDAN, Cat. Fish. N. A., 137, 1885. A chirus lineatus, var. browni, JordaN \& GILBERT, Proc. U. S. Nat. Mus. 1882, 305.

\section{ACHIRUS PANAMENSIS (Steindachner).}

Head 4 in body; depth $1 \frac{8}{4}$. D. 59 ; A. 45; scales 63 to 65 ; highest dorsal and anal spines 2 in head; caudal 1. Body broad, elliptical; angle of mouth below middle of lower eje; edgé of lower lip, on the eyed side, fringed; eyes small, the upper in advance of the lower; interorbital scaled, scarcely as wide as diameter of eye; scales ctenoid; pectorals wholly wanting; origin of dorsal on end of snout; highest rays of anal and dorsal behind their middle; ventral rays short; middle rays of caudal the longest, fin sharply rounded behind. Color brown; about 12 dark cross bands on head and body; between these faint, paler cross bands, which form spots on dorsal and anal; caudal similarly spotted, the spots forming obscure cross bands. (Steindachner.) Pacific coast of tropical America, Panama.

Solea panamensis, SteindaChNer, Ichthyol. Beiträge, v, 10, taf. Ir, 1876, Panama. Achirus panamensis, JoRDAN \& Goss, Review Flounders and Soles, 316, 1889.

\section{APIONICHTHYS, Kaup.}

Apionichthys, KAUP, Archiv fur Naturgesch. 1858, 104 (dumeriti).

Soleotalpa, GüNTHer, Cat., IV, 489, 1862 (unicolor).

Gill openings very small, separate, each reduced to a slight slit below angle of opercle; right ventral beginning at the chin, confluent with the anal; pectoral fins wanting or very small; lateral line present, straight; eyes small; snout dilated, the dorsal beginning upon it. Scales present, ctenoid; caudal fin somewhat confluent with dorsal. Left ventral rudimentary, with 2 rays. West Indies and Brazil. This genus is closely related to Achiropsis, Steindachner, of the rivers of Brazil, but in the latter genus the ventrals are both well developed. ( $\dot{\alpha}-$, not; $\pi i \omega v$, fat; $i \chi \theta \dot{v} 5$, fish.)

\section{APIONICHTHYS DNICOLOR (Günther).}

D. 76 ; A. 57; V. right 5 , left 2 ; scales 92 . Body very flat and thin, its height being contained $2 \frac{8}{4}$ times in the total length (without caudal), the length of the head $4 \frac{1}{8}$ times. The upper part of the snout is dilated, bent downward like an aquiline nose, the end covering the symphysis of the mandibles; the cleft of the month is curved, the lower eye being immediately above its angle. The eyes are mere points, rather distant from 
each other. The gill opening is reduced to a very small slit, the gill membrane being attached to the sicles of the throat. The dorsal fin commences on the extremity of the snout and terminates at the root of the caudal, its rays are simple, and each is accompanied by a series of very small ctenoid scales; the longest rays are not quite $\frac{1}{2}$ as long as the head, and occupy the middle and the third quarter of the fin. Caudal quite free, as long as the head, somewhat pointed. The right ventral appears as a mere continuation of the anal; the left is reduced to 2 minute rays near the vent. The scales on both sides are ctenoid, those on the neck and on the chin being twice the size of those on the body. Color uniform brownish gray. Coast of Surinam and Brazil. The above description from Günther, taken from the type of Soleotalpa unicolor. A specimen (No. 4677, M. C. Z.), fronı Obydos, Brazil, examined by us, differs in coloration, being pale brown, the body and fins profusely covered with round, dark spots of varying sizes, the largest as wide as from eye to eye. Head $4 \frac{1}{5}$; depth $2 \frac{2}{8}$. D. 78 ; A. 56 ; scales $100 ;$ V. 2. Eyes reduced to points, the upper in advance of lower, near middle of length of head; gill openings small, subequal; right ventral beginning at the chin, continuous with anal; dorsal and anal slightly connected with caudal. Steindachner gives D. 72 ; A. 53 ; scales 95. Color brownish, mottled with darker spots. Probably Gïnther's specimen is faded. (unicolor, one-colored.)

A pionichthys dumerili, KAUP, Archiv fur Naturgesch. 1858, 104, no locality; no description.

Soleotalpa unicolor, GüNTHER, Cat., Iv, 489, 1862, West Indies. (Coll. Scrivener.)

A pionichthys nebulosus, Peters, Berliner Monatsberichte 1869, 709, Surinam.

? A pionichthys bleekeri, Horst, Nederl. Tydschr. Dierk., IV, 30, 1878, locality nnknown; specimen in Mus. Utrecht. (Description not seen by us.)

A pionichthys unicolor, JoRDAN, Proc. U.S. Nat. Mus. 1886, 603.

Apionichthys dumerili, BleEker, Nederl. Tydschr, voor Dierkunde, II, 1865, 305; StetNDACHNER, Ichth. Beitr., viII, 48, 1878.

\section{GYMNACHIRUS, Kaup.}

Gymnachirus, KaUP, Uebersicht der Soleinæ, Archiv fur Naturgesch. 1858, 101 (nudus).

This genus differs from Achirus in the absence of scales; the dorsal and anal are free from the caudal. Brazil. ( $\gamma v \mu \nu$ ós, naked; Achirus.)

3077. GYMNACHIRUS FASCIATUS, Günther.

Head $4 \frac{1}{2}$; depth $1 \frac{1}{2}$. D. 68 ; A. 50 ; pectoral of right side present, very small, of 2 rays, $\frac{1}{8}$ length of eye; jaws hidden in thick skin; lips and left side of head covered with fringes. Gill opening not extending upward as far as pectoral; vertical fins in thick skin. Olive, with 14 brown cross bands as broad as the interspaces, all extending on dorsal and anal, the first across snout, the second and third across eye; caudal with 3 brown bands. (Giinther.) Locality unknown, probably Surinam or Brazil; a related species (G. nudus, Kaup; no pectoral fins. D. 51; A. 42), being described from Bahia. (fasciatus, banded.)

Gymnachirus fasciatus, GüNTHER, Cat., IV, 488, 1862, locality unknown; JorDAN \& Goss.

Review Flounders and Soles, 317, 1889. 


\section{SYMPHURUS, * Rafinesque.}

\section{(TONGUE-FISHES.)}

Symphurus, RAFLNEsQEE, Indice d'Ittiologia Siciliana, 52, 1810 (nigrescens).

Bibronia, Cocco, Alcuni Pesci del mare di Messina, 15, 1844 (ligulata; larval form).

Plagusia, Cuvier, Règne Animal, Ed. 2, II, 344, 1829 (based on Plagusia of Brown); name preoccupied in Crustaceans, Latreille, 1806.

Plagiusa, Bonaparte, Catalogo Metodico, 51, 1846 (lactea); substitute for Plagusia preoccupied.

A phoristia, KAUP, Archiv fur Naturgesch.1858, 106 (ornata).

Glossichthys, GiLL, Cat. Fish. E. Coast N. A., 51, 1861 (plagiusa).

A mmopleurops, GÜNTHER, Cat., IV, 490, 1862 (lacteus=nigrescens).

? Bascanius, SchiöDte, Naturhist. Tydsskr., v, 269, 1867 (tcedifer; larval form).

Acedia, Jordan, in Jordan \& Goss, Review Flounders and Soles, 321, 1889 (nebulosus).

Body elongate, more or less lanceolate in outline, with the eyes and color on the left side; ejes small, very close together, with no distinct interorbital ridge between them; mouth small, twisted toward the blind side; teeth little developed, in villiform bands; edge of preopercle covered by the scales; gill openings narrow, the gill membranes adnate to the shoulder girdle above, joined together and free from the isthmus below; pectoral fins wanting (in the adult); vertical fins more or less confluent; scales ctenoid; lateral line wanting. Ventral fin of eyed side only present, free from the anal; head without fringes. ( $\sigma \dot{v} v$, together; $\phi \dot{v} \omega$, to grow; ovं $\alpha$, tail ; from the united vertical fins.)

SYMPHURUS :

a. Scales not minute, etenoid, 65 to 105 in number; dorsal rays 86 to 100 ; anal rays 70 to 87 .

b. Scales rather large, about 65 ; head $4 \frac{1}{3}$; depth $4 \frac{1}{3}$; color, clouded brown.

PIGER, 3078.

bb. Scales small, moderately ctenoid, 75 to 105 in a longitudinal series.

c. Dorsal and anal pale anteriorly, becoming more or less abruptly black posteriorly.

d. Caudal fin abruptly pale, at least at tip.

e. Body elongate, depth $4 \frac{1}{2}$ in length; head $5 \frac{1}{2}$. D. 96 to $100 ;$ A. 86 or 87 ; scales 88 to 90 . Color, grayish, speckled with brown; dorsal and anal fins black on last tenth, the caudal abruptly pale; tips of fin rays vermilion.

MARGINATUS, 3079 .

ee. Body deeper, the depth $3 \frac{1}{3}$ to $3 \frac{2}{3}$ in length.

$f$. Color, light brown, irregularly barred and marbled with darker; dorsal and anal with 3 to 6 inky blotches posteriorly. D.92 to 95 ; A. 75 to 78 . ATRAMENTATUs, 3080 .

\footnotetext{
* We follow Jordan \& Goss in using the name Symphurus instead of Aphoristia, as the so-called A mmopleurops lacteus is a genuine member of the latter genus, and as it seems to be evident that the latter species is the original of Symphurus nigrescens of Rañn. esque. 'The following is Rafinesque's description: "III. Gen. Symphurus. Ala caudale acuta, o riunita all' ale dorsali, ed anali, occhj alla sinistra. Osserv. Si dovranno ragguagliare in questo genere duo specie del genere A chirus di Lacepede, cioè gli A. bilineatus, - A.ornatus. Sp.no.44. Symphurus nigrescens. Nerastro senza fascie, allungato, una sola linea laterale da ogui lato."

This single lateral line assumed to distinguish Ammopleurops from Aphoristia is not a real lateral line, but a depression along the median line produced by the juuction of the muscles. The species of Symphurus are somewhat numerous and rery closely allied. With the exception of the European Symphurus nigrescens, all of them are A merican. The development of the spcoies is imperfectly known. According to Giglioli, the larva called Bibronia, may belong to this genus, and so possibly may Charybdia. The name Plagusia belongs properly to the present genus rather than to the type of Plagusia bilineata, to which it has been restricted by Kaup and Günther. It is, however, preoccupied in erustaceans, and in any case, both Plagusia and the substitute name Plagiusa are antedated by the name Symphurus.
} 
ff. Color, light olive, with numerous roundish brownish black spots much larger than eyes, dorsal and anal black, with narrow white margin. D. 94 ; A. 77; scales 95.

FASCIOLARIS, 3081.

$d d$. Caudal fin black, as is a large part of dorsal and anal, the black either continuous or in the form of large spots. Color brownish, often mottled, usually with more or less distinct darker cross bands and with longitudinal streaks along the rows of scales, sometimes nearly plain brown.

$g$. Scales quite small, 98 to 105.

$h$. Body decidedly elongate, the depth about $4 \frac{2}{5}$ in length. D. 97 ; A. 82 ; scales 98.

ELONGATUE, 3082

$h h$. Body less elongate, the depth $3 \frac{1}{3}$ in length; head $5 \frac{1}{3}$; longitudinal streaks very distinct. D. 100 ; A. 80 ; scales 105.

ATRICAUDES, 3083.

gg. Seales rather larger, 75 to 90 .

$i$. Body rather elongate, the depth $3 \frac{4}{5}$ to $4 \frac{1}{3}$; dorsal rays 80 to 90 ; anal 80 to 85 ; opercular flap large; body with 3 or 4 dark cross bands.

LEEI, 3084.

ii. Body less elongate, the depth $3 \frac{x}{10}$ to $3 \frac{2}{3}$ in length; the head $5 \frac{1}{3}$ to $5 \frac{3}{4}$. D. 90 to $95 ;$ A. 75 to 80 .

PLAGUSIA, 3085.

cc. Dorsal and anal pale throughont, or more or less mottled or spotted with darker, the caudal similarly colored, not distinctly black. Body not very elongate, the depth 3 to $3 \frac{1}{3}$ in length. (Probably all varieties of S. plagiusa.)

j. Body with dark cross bands more or less distinct; the fins mottled or speckled; upper eye slightly in advance of lower.

$k$. Dorsal rays 86 to 95 ; anal rays 75 to 80 ; head 5 in length; depth $3 \frac{1}{4}$; scales 85 to 93 ; cross bands more distinct than in related species.

PLAGIUSA, 3086.

$k k$. Dorsal rays 78 to 85 ; anal rays 70 to 72 ; head 5 in length; depth $3 \frac{1}{2}$; scales 80 to 90 . Color, light brown, with darker cross bars, which become obsolete with age. Pusillus, 3087.

$j j$. Body uniform grayish, without cross bands ; last part of dorsal and anal with 3 or 4 oblong black blotches, each somewhat larger than the eye; upper eye directly above lower; head $5 \frac{2}{3}$ in length. Scales 85 ; D. 92; A. 75. DIOMEDEANUS, 3088.

$d d d$. Caudal and posterior part of dorsal and anal not black, scarcely darker than anterior part; scales $92 ;$ D. 93; A. 73. WILLIAMSI, 3089.

ACEnIA (Spanish name of Symphurus plagusia at Havana):

$a a$. Scales very small, ctenoid, each with a median dark streak, which simulates a keel, but is not a ridge; snout and jaws naked; fin rays in increased number.

l. Head $5 \frac{2}{3}$; depth $4 \frac{2}{3}$. D. $11.9 ;$ A. 107 ; scales 120 . Grayish, everywhere mottled with brown.

NEBULOSUS, 3090.

\section{Subgenus SYMPHURUS.}

3078. STMPHURUS PIGER (Goode \& Bean).

Head $4 \frac{1}{3}$ in total length; depth $3 \frac{1}{7}$. D. 90 ; A. 69 to 75 ; ventral 4; scales 65-34 (transverse); eve 6 in head; snout $4 \frac{1}{2}$; mouth oblique, curved, its angle below middle of lower eye; teeth feeble, closely placed, a little stronger on colored side; nostril tubular, a little nearer eye than tip of snout; eyes moderate in size, very close together, the upper very slightly in advance, its distance from the dorsal outline equal to its diameter; scales large, ctenoid, deciduous. Dorsal begining over middle of upper eye; longest dorsal and anal rays 3 in rlepth of body; pectorals obsolete. 
Color grayish and brownish, with a submetallic luster upon the scales when examined separately; the denticulations of the scales dark and prominent, giving a clouded general aspect; some of the smaller specimens with large, irregular, brownish blotches above, and a dark subcircular blotch near the root of the tail, its diameter twice eye; colorless below. (Goode \& Bean.) West Indies and Gulf of Mexico, in deep water; a welldefined species. (piger, sluggish.)

Aphoristia pigra, Goode \& BF.AN, Bull. Mus. Comp. Zool., xII, 5, 154, 1886, St. Kitts, in about 250 fathoms (Coll. Blake); Goode \& BEAN, Oceanic Ichthyology, 460, 1896. Symphurus piger, JoRDAN \& Goss, Review Flounders and Soles, 326, 1889.

3079. SMMPHURUS MARGINATUS (Goode \& Bean).

Head $5 \frac{1}{2}$ in total length; depth $4 \frac{1}{2}$. D. 96 to 100 ; A. 86 or 87 ; ventral 4 ; scales 88 to 90 ; eye $4 \frac{1}{2}$ in head; snout $4 \frac{1}{2}$. Body slender, lanceolate; mouth moderate, oblique, curved, its angle below front of pupil of upper eye; dentition feeble; eyes moderate, close together, the upper very slightly in advance; nostril in a long slender tube, midway between lower eye and tip of snout; scales moderate, strongly and sharply denticulate, not keeled; origin of dorsal above posterior margin of upper eye; anal scarcely so high as dorsal; median caudal rays short. Color in life, reddish gray, much speckled with brown; belly bluish gray; bases and membranes covering fin rays dark brown; caudal abruptly pale; tips of dorsal and anal rays and some of the membrane covering caudal rays vermilion. West Indies, in deep water. Described from a specimen, $102 \mathrm{~mm}$. in length, collected by the Blake at Station CLXXXI, in 321 fathoms. (Goode \& Bean.) (marginatus, edged.)

Aphoristia marginata, Groode \& BrAN, Bull. Mus. Comp. Zool., XIT, No. 5, 153, 1886, off St.

Vincent (Coll. Blake); GOODE \& BEAN, Oceanic Ich thyology, 459, fig. 376, 1896.

Symphurus marginatus, JoRdAN \& Goss, Review Flounders and Soles, 323, 1889.

3080. SYMPHURUS ATRAMENTATUS, Jordan \& Bollman.

Head $4 \frac{2}{8}$ to 5 ; depth $3 \frac{1}{8}$ to $3 \frac{2}{3}$. D. 92 to 95 ; A. 75 to 78 ; scales 95 to 100 , 38 in a cross series. Body more elongate than in S. atricaudus. Eyes larger, the upper in advance of lower, vertical diameter of each $3 \frac{1}{2}$ to 4 in head. Cleft of mouth somewhat more curved than in S. atricaudus, otherwise similar. Scales larger than in S. atricaudus; spines on posterior margin not so strong. Ventral fins (measured from angle of gill opening) $2 \frac{2}{8}$ to 3 in head. Color light brown, irregularly barred and marbled with darker; several irregular grayish bars must distinct on posterior parts, a distinct narrow, dark bar behind gill opening; anterior part of dorsal and anal fin pale, posterior dark; anterior part with 4 to 7 dusky oblique areas, posterior part with 3 to 6 roundish inky-black spots; caudal black, narrowly tipped with white; each scale with a narrow dark edge. Length about $4 \frac{1}{2}$ inches. Pacific Ocean off Colombia, in water of moderate depth; common. Related to Symphurus atricaudus (Jordan \& Gilbert), but distinguished by having 3 to 6 lolack oblong blotches on posterior part of dorsal 
and anal; the general coloration darker; the scales and eyes larger. (atramentatus, inked.)

Symphurus atramentatus, JoRdan \& Bollman, Proc. U. S. Nat. Mus. 1889, 177, off coast of Colombia, at Albatross Station 2795 , Lat. $7^{\circ} 57^{\prime}$ N., Long. $78^{\circ} 55^{\prime}$ W., in 33 fathoms. (Type, 41157, U. S. Nat. Mus. Coll. Albatross.)

3081. SYMPHURUS FASCIOLARIS, Gilbert.

Depth 3 2. in length; head $5 \frac{1}{5}$. D. 94 ; A. 77 ; scales 95. Eye small, 7 in head ; cleft of mouth reaching to below middle of lower eye. Color light olive, with numerous roundish brownish-black spots much larger than eye, the largest arranged in 5 vertical dusky cross bars, the spots being connected by a darker ground color; a vertical dusky streak through cye; a widedusky cross bar, bounded by darker lines on cheeks; dorsal and anal posteriorly black, with narrow white margin ; caudal jet-black, with white edge; ventral white. Gulf of California, where several specimens were dredged by the Albatross, in shallow water. (Gilbert.) (fasciolaris, with narrow bands.)

Symphurus fasciolaris, GILBert, Proc. U. S. Nat. Mus. 1891, 566, Gulf of California. (Coll. Dr. Gilbert.)

\section{SYMPHURUS ELONGATUS (Günther).}

Head $5 \frac{1}{6}$ in body; depth $4 \frac{2}{5}$. D. 97 ; A. 82 ; scales 98 to 105 ; eve 10 or 11 in head; gape of mouth $3 \frac{1}{2}$; eaudal $2 \frac{1}{2}$. Body extremely elongate; mouth strongly curved, reaching past lower eye; eyes in contact, the upper in advance; opercle vertical behind, devided into 2 convex flaps by a concave portion, its upper end hardly reaching axis of body; scales not keeled, ctenoid. Pectorals obsolete; dorsal beginning above eye; rays of dorsal and anal short, subequal, the fins confluent with the caudal, which ends in a sharp point; ventral of blind side obsolete, that of ejed side on the body ridge, separated from the anal. Color brownish, often mottled, usually with more or less distinct darker cross bands, and with longitudinal streaks along the rows of scales, sometimes nearly plain brown; caudal fin black, as is a large part of the dorsal and anal, the black either continuous or in the form of large spots. Pacific coast of Central America; not rare. Here described from a specimen, 6 inches long, from Albatross Station 2804, in Panama Bay, in 47 fathoms. (elongatus, elongate.)

A phoristia ornata, var. elongata, GüNTHER, Fishes Centr. Amer., 473, 1869, Panama. Aphoristia elongata, JoRDAN \& GILBERT, Bull. U. S. Fish. Comm. 1882, 111.

Symphurus elongatus, JoRDAN \& Goss, Review Flounders and Soles, 323, 1885.

3083. SYMPHURUS ATRICAUDUS (Jordan \& Gilbert).

\section{(SAN Dikgo SOLE.)}

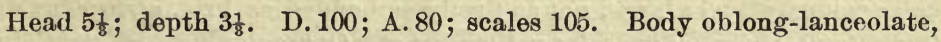
anteriorly somewhat blunt, regularly narrowed behind and ending in a point; the snout rather abruptly truncate; eyes and color on the left side. Eyes very small, nearly even behind, the upper eye the larger and extending farther forward. A single nostril in front of interorbital space, and 
apparently a single smaller one below it. Mouth moderate, extending to opposite eye, somewhat turned toward eyed side; lips large, not fringed, the upper with a small black papilla in advance of lower eye, this apparently normal, but it may be a detached piece of skin, hardened by the alcohol; upper jaw scarcely produced, not forming a hook. Teeth small, on blind side only, the edge of the jaw on eyed side forming a smooth ridge. Gill openings narrow, not extending up to level of mouth. Scales very small, ctenoid, pretty regular over the body, much smaller on the head, the rows of scales rendered very distinct by black dots, the stripes converging toward the snout; scales on the 2 sides of the body similar; no lateral line on either side; abont 105 scales (100 to 110$)$ in a longitudinal series from the head to the tail, 45 to 50 in cross series. Dorsal fin beginning on head, continuous with anal around the tail; ventral fin of colored side only present, nearly on ridge of abdomen, and separated from the anal by an interval $\frac{1}{2}$ longer than cleft of mouth; rays of middle parts of dorsal and anal fins with a fleshy border at base on blind side. Coloration brownish olive, with vertical dark half bars, irregular in size and position, some of them coming down from the back and others up from the belly, these posteriorly nearly meeting, but anteriorly alternating; streaks of dark points along the rows of scales, these forming very distinct longitudinal streaks; posterior part of dorsal and anal broadly edged with black; right side plain white. San Diego to Cape San Lucas, in sandy bays; common in the bay of San Diego, in which locality the numerous specimens before us were taken. A small specimen, $1 \frac{1}{2}$ inches long, with light spots on the colored side and a pale ocellation on the black of the tail, taken by Mr. Lyman Belding near Cape San Lucas, probably belongs to the same species. (ater, black; cauda, tail.)

Aphoristia atricauda, JoRdAN \& GILBERT, Proc. U. S. Nat. Mus. 1880, 23, San Diego; JoRDAN \& Gilbert, Synopsis, 842, 1883; Jordan \& GLbert, Proc. U. S. Nat. Mus. 1882, 380; Jordan, Proc. U. S. Nat. Mus. 1886, 54.

Symphurus atricauda, JoRDAN \& Goss, Review Flounders and Soles, 324, 1889.

3084. SYMPHURUS LEEI, Jordan \& Bollman.

Head 4 to $4 \frac{1}{2}$ ( $4 \frac{1}{8}$ to $4 \frac{2}{8}$ ); depth $3 \frac{4}{5}$ to 4 ( $4 \frac{1}{5}$ to $4 \frac{1}{8}$ ). D. 95 to 100 ; A. 80 to 85 ; scales 80 to 90,35 to 38 in a cross series; ventrals $3 \frac{1}{3}$ to $3 \frac{1}{2}$ in head. Body more elongate than in S. atricaudus or S. atramentatus, approaching that of S. elongatus; outline of under part of head more oblique than in the other Pacific coast species. Eyes larger than in the preceding species, the upper in advance of lower, their vertical diameter 5 to $5 \frac{1}{2}$ in head; cleft of mouth extending slightly farther back than in $S$. atricaudus or atramentatus, but not beyond eye as in S. elongatus; maxillary reaching posterior border of eye, $3 \frac{2}{3}$ to 4 in head; snout $5 \frac{1}{5}$ to $5 \frac{2}{8}$ in head. Scales comparatively large, not so firmly embedded as in S. atricaudus or atramentatus, those on opercles rather large. Opercular flap larger than in other Pacific species. Color light brown, speckled with darker, and with 3 or 4 broad black cross bands, width of median bands $2 \frac{1}{2}$ to 3 in head, the posterior band widest; caudal and the posterior $\frac{2}{6}$ of the dorsal and anal 
black; no black spots on dorsal; scales thickly punctulate, but with no distinct darker edgings. Related to Symphurus atricaudus (Jordan \& Gilbert), but the body with 4 wide black cross bands, and the form more elongate. Bay of Panama. Many specimens of this species were obtained at Albatross Station 2804, at a depth of 47 fathoms. It is evidently very different from $S$. atramentatus, and needs comparison only with $S$. elongatus, from which it seems to be sufficiently distinct. Length of type $4 \frac{1}{2}$ inches. (Named for Prof. Leslie A. Lee and Mr. Thomas Lee, naturalists on board the Albatross when the species was discovered.)

Symphurus leei, JoRdan \& Bollman, Proc. U. S. Nat. Mus. 1889, 178, Lat. $8^{\circ} 16^{\prime} 30^{\prime \prime}$ N. Long. $79^{\circ} 37^{\prime} 45^{\prime \prime}$ W. (Type, No.41134. Coll. Prof. L. A. Lee and Mr. Thomas Lee.)

3085. SYMPHURUS PLAGUSIA* (Bloch \& Schneider).

(ACEDIA.)

Head $5 \frac{1}{3}$ to $5 \frac{2}{3}$; depth $3 \frac{1}{10}$ to $3 \frac{2}{3}$ in length. D. 90 to 95 ; A. 75 to 80 ; scales 75 to 85 . Body rather elongate. Color brownish, often mottled, usually with more or less distinct darker cross bands, and with longitudinal streaks along the rows of scales, sometimes nearly plain brown; caudal black, including a large part of dorsal and anal, the black continuous as in the form of spots. West Indies to Brazil; Cuba to Rio Janeiro; common. The numerous specimens of this species examined by us are from Havana, Pernambuco, Santos, Rio Janeiro, Curuça, and Victoria. (plagusia, an old name, from $\pi \lambda \dot{\alpha} \gamma z o s$, oblique.)

Plagusia, BRowne, Jamaica, 445, No. 1, 1756, Jamaica.

Pleuronectes plagusia, BLOCH \& SCHNEIDER, Syst. Ichth., 162, 1801, Jamaica; after Browne. Achirus ornatus, LACÉP̀̀DE, Hist. Nat. Poiss., IV, 659, 1803, on a specimen "presented by

Holland to France."

Plagusia tessella ta, Quoy \& GaIMARD, Voyage Uranie, Zoologie, 240, 1824, Rio Janeiro.

Plagusia brasiluensis, AGASSI\%, Spix, Pisc. Brasil., 89, tab. 50, 1827, Brazil.

* The syuonymy of this species is somewhat doubtful. The original type of Pleuronectes plagiusa was sent to Linnæus by Dr. Garden, of Charleston. It would therefore appear probable that this specimen represented the species of this genus which is found on the Carolina coast. But this typical specimen is stil. preserved in the rooms of the Linnæan Society in London, where it has been examined by Goode and Bean. From their notes (Proc. U.S. Nat. Mus. 1885, 196) we quote:

"The type of this species may have come from Africa or India. There is considerable doubt as to its origin. (See Garden's Correspondenee with Linne, p. 314.) D. ca 92, A. ca 80 ; scales 77 . The species is more elongate than our specimens of A phoristia plagiusa, so called, the depth being contained in the total length without caudal $4 \frac{1}{3}$ times and the head 6 times.'

As, however, no species of this genus are yet known from Africa or India, it is rather probable that Garden's fish actually came from Charleston. The greater slenderness of the original type is perhaps due to distortion, and the smaller number than usual of the scales does not afford a marked distinction. The name Achirus ornatus is also doubtful in its proper application. The only thing distinctive in the description of Lacépède is that the typical specimen was "given by Holland to France." Many of the species in this Dutch collection seem to have come from Surinam, and this is probably no exception. But Lacépède's description might apply as well to any other species of Symphurus as to this. The name Pleuronectes plagusia, given by Schneider to the species described by Browne, seems to admit of no doubt, as this is the only one of the group yet known from Jamaica. If, therefore, the name Symphurus plagiusa be used for the northern species, or dropped altogether as not identified, the present species will stand as Symphurus plagusia. We have compared numerous specimens from Rio Janeiro (representing the nominal species tessellatus or brasiliensis) with others ( plagusia =ornata) from Havana. There is certainly no permanent difference. The Brazilian specimens are a little more slender on an average, but there are numerous exceptions, and all variations in color are found in both. 
A phoristia ornata, KAuP, Archiv fur Naturgesch. 1858, 106; GünTHER, Cat., IV, 490, 1862 ; Pokx, Synopsis, 409, 1868; PoEY, Enumeratio, 140, 1875; KNER, Novara Fische, III, 292; D. 90 ; A. 75 ; depth $3 \frac{1}{4}$ in length.

A phoristia plagiusa, JoRdAx, Proc. U.S. Nat. Mus. 1886, 53; not S. plagiusa of this paper. Symphurus plagusia, JoRDAN \& Goss, Review Flounders and Soles, 324, 1889.

\section{SYMPHURUS PLAGIUSA* (Linnæus).}

\section{(Tongue Fish.)}

Head 5; depth 3 to $3 \frac{1}{3}$. D. 86 to 95 ; A. 75 to 80 ; scales 85 to 93 . Body not very elongate. Body grayish, with dark cross bands more distinct than in related species; dorsal and anal more or less mottled or spotted with darker; caudal similarly colored, not distinctly black. South Atlantic and Gulf coasts of the United States, from Cape Hatteras to Pensacola and Key West, replacing S. plagusia northward, the species as similar as the two names; very common on the sandy shores of our South Atlantic and Gulf States. Our numerous specimens are from Beaufort, Charleston, Pensacola, and Key West. Those from Key West nearly plain gray, as would be expected in fishes taken from the coral sands. ( $\pi \lambda \dot{\alpha} y \imath o$, oblique.)

Pleuronectes plagiusa, LINNAUs, Syst. Nat., Ed. XII, 455, 1766, on a specimen from Dr. Garden, probably from Charleston, but the locality not quite certain; and of various copyists.

Plagusia fasciata, Holbrook MS., DE KAY, New York Fauna: Fishes, 304, 1842, Charleston.

Glossichthys plagiusa, GILL, Cat. Fish East Coast N. Am., 51, 1861.

Plagusia plagiusa, GILL, Cat. Fish. East Coast N. Am., 794, 1873.

Aphoristia plagiusa, Jordan \& Gilbert, Proc. U. S. Nat. Mus. 1878, 368; JordaN, l. $c$., 1880, 22 ; JoRdAN \& Gilbert, l. c., 1882, 305 and 618; JoRDAN \& Gilbert, Synopsis, 842, 1883 ; JoRdan, Proc. U. S. Nat. Mus. 1884, 144.

A phoristia fasciata, JoRdan, Proc. U. S. Nat. Mus. 1886, 53.

Symphurus plagiusa, JoRDAN \& Goss, Review Flounders and Soles, 325, 1889.

\section{SYMPHURUS PUSILLUS (Goode \& Bean).}

Head 5 in total length; depth $3 \frac{1}{2}$. D. 78 ; A. 70 ; scales 85 to $90-35$ (transverse); eye $5 \frac{1}{2}$ in head; snout $5 \frac{1}{2}$; length of gape of mouth $4 \frac{2}{3}$. Body slender, lanceolate; mouth small, oblique, curved, its angle under anterior margin of pupil of lower eye; dentition feeble; eyes small, close together, in the same vertical line; tubular nostril midway between lower eye and tip of snout; scales small, strongly ctenoid; jaws and snout scaled. Dorsal beginning above middle of eye, its highest rays $2 \frac{2}{8}$ in depth of body; greatest height of anal 3 ; median caudal rays short; ventrals well separated from anal. Color light brown, with 6 or 7 cross bars of slightly

* A specinien of Symphurus, nearly 6 inches long, collected at Beaufort, North Carolina, by Prof. O.P. Jenkins, seems referable to Symphurus pusillus rather than to the typical plagiusa. It is highly mottled in coloration, the body and fins being profusely speckled and blotched with blackish, besides 9 or 10 rather distinct cross bands. D. $85 ; \mathbf{A} .72$; scales about 80 . Depth $3 \frac{1}{4}$ in length. Another large specimen, 7 inches long, from the Florida Keys, is in the museum at Cambridge. This has: D. 82; A. 72; scales 76. Depth 3 in length. Color brown, almost plain, except that the fins are mottled, especially posteriorly; caudal fin not black. If these two specimens are really typical of Symphurus pusillus, it probably can not be separated as a species from S. plagiusa. 
darker hue; fins pale, with dusky blotches; blind side white. (Goode \& Bean.) Gulf Stream, in deep water. Very close to Symphurus plagiusa. ( $p$ usillus, weak.)

Aphoristia pusilla, Goode \& BEAN, Proc. U. S. Nat. Mus. 1885, 590, Gulf Stream, Lat. $40^{\circ}$

N., in deep water; GoodE \& BEAN, Oceanic Ichthyology, 461, fig. 379, 1896.

symphurus pusillus, Jordan, Proc. U. S. Nat. Mus. 1889, 651.

\section{0s8. STMPHURUS DIOMEDEANUS (Goode \& Bean).}

Head $5 \frac{2}{8}$ in body; depth $3 \frac{1}{2}$. D. 96 (including $\frac{1}{2}$ of caudal); A. 79 ; scales 85 ; eye 6 in head; snout 5 ; caudal 10 in total length. Mouth oblique, curved, its angle below front of eye, teeth very feeble; nostril tubular, nearer eye than tip of snout; eyes moderate, equal, very close together, upper eye directly over the lower; scales moderate, somewhat deciduous, ctenoid; jaws and snout with small thin scales. Origin of dorsal above middle of upper eye, highest rays $3 \frac{1}{2}$ times depth of body; ventrals well separated from the anal. Color uniform gray, lighter below, the scales above somewhat metallic in luster; the last fourth of dorsal with 3 oblong black blotches somewhat larger than eye, the anal with 4 , similar in position; in the young there is a slight brownish marginal line upon each scale, and an appearance of indistinct cloudings of brown upon the colored side. Off Trinidad and Dominica and in the Gulf of Mexico. The specimen here described was collected by the Albatross at Station 2414, in the Gulf of Mexico, north of the Tortugas, at a depth of 26 fathoms; its length is $140 \mathrm{~mm}$. Other specimens were dredged by the Albatros8 at Station 2362 , in Lat. $22^{\circ} 08^{\prime} 30^{\prime \prime} \mathrm{N}$., L.ong. $86^{\circ} 53^{\prime} 30^{\prime \prime} \mathrm{W}$., in 25 fathoms, and at Stations 2121 and 2122 , between Lat. $10^{\circ} 37^{\prime} 40^{\prime \prime} \mathrm{N}$., Long. $61^{\circ} 42^{\prime} 40^{\prime \prime} \mathrm{W}$., and Lat. $10^{\circ} 37^{\prime} \mathrm{N}$., Long. $61^{\circ} 44^{\prime} 22^{\prime \prime} \mathrm{W}$., in 31 to 34 fathoms. Specimens were also secured by the Blake at Stations XXIV and XXV, off Dominica. (Goode \& Bean.) Evidently very close to Symphurus plagiusa. (Diomedea, the Albatross; from the name of the steamer by which most of the deep-sea explorations of the United States Fish Commission have been accomplished.)

Aphoristia diomedeana, Goode \& Bean, Proc. U. S. Nat. Mus. 1885, 589, Gulf of Mexico,

Lat. $25^{\circ} 04^{\prime} 33^{\prime \prime}$ N., Long. $82^{\circ} 59^{\prime} 15^{\prime \prime}$ W. ('Type, No. 37347. Coll. Albatross); Goode \& BEAN, Oceanic Ichthyology, 460, fig. $378,1896$.

3089. SYMPHURUS WILLIAMSI, Jordan \& Culver.

Head $4 \frac{4}{5}$; depth $3 \frac{2}{3}$. D. 93 ; A. 73 ; scales 92 . Body more slender than in $S$. plagiusa, which it much resembles, but less slender than S. elongatus; upper eye slightly in advance of lower. Sand color in life; light gray, everywhere finely mottled with light and dark; traces of a few very narrow dark cross bands; fins all mottled; caudal and posterior part of dorsal and anal not black, scarcely darker than anterior part. Known only from Mazatlan, where 2 specimens, the larger about $1 \frac{1}{2}$ inches long, were obtained by Mr. T. M. Williams, in tide pools with sandy bottom in very shallow water near the estuary. (Named for Thomas Marion Williams, a student in biology in Stanford University, discoverer of the species.)

Symphurus williamsi, Jordan, Proc. Cal. Ac. Sci. 1895, 506, pl.55, Mazatlan. (Coll. Hopkins Exped. to Mazatlan.) 
Subgenus ACEDIA, Jordan.

3090. STMPHURUS NEBULOSUS (Goode \& Bean).

Head $5 \frac{2}{8}$ in total length; depth $4 \frac{2}{3}$. D. 119 (to middle of base of caudal); A. 107; V. 5; scales 120 ; eye $7 \frac{1}{2}$ in head; snout 5 . Body slender; angle of mouth below front of lower pupil; teeth feeble, very slender, and rather closely placed, apparently equally developed on both sides; eyes small, close together, separated by a single row of scales, the upper one very slightly in advance; tubular nostril nearer eye than tip of snout; scales small, ctenoid, each with a median dark streak (but not keeled, as erroneously stated in the original description);* jaws and snout naked. Origin of dorsal a little behind eyes, highest rays 3 in depth of body; longest anal rays twice length of snout; median caudal rays longest, twice length of snout; pectorals obsolete; ventrals well separated. Color grayish, everywhere mottled with brown; a dark median line on scales. (Goode \& Bean.) Gulf stream. A well-marked species. The increased number of fin rays indicates a probability that the number of vertebræ will also be found similarly increased. (nebulosus, clouded.)

Aphoristia nebulosa, Goode \& BeaN, Bull. Mus. Comp. Zool., x, No. 5, 192, 1883, Gulf Stream, off the coast of Carolina; GoODE \& BEAN, Oceanic Ichthyology, 458, fig. 375, 1896.

Symphurus nebulosus, JoRDAN \& Goss, Review Flounders and Soles, 326, 1889.

\section{Order CC. PEDICULATI.}

\section{(The Pediculate Fishes.)}

Carpal bones notably elongate, forming a kind of arm (pseudobrachium) which supports the broad pectoral. Gill opening reduced to a large or small foramen situated in or near the axil, more or less posterior to the pectorals. Ventral fins jugular if present; anterior dorsal reduced to a few tentacle-like, mostly isolated spines; soft dorsal and anal short; no scales. First vertebra united to cranium by a suture; epiotics united behind supraoccipital; elongate basal pectoral radii (actinosts) reduced in number; no interclavicles; post-temporal broad, flat, simple; upper pharyngeals 2, similar, spatulate, with anterior stem and transverse blade; basis of cranium simple; no air duct to the swim bladder. Marine fishes, chiefly of the tropics and the oceanic abysses. The group is an offshoot from the Acanthopteri, its ehief modificatious being in the elongation of the actinosts and in the position of the gill opening. Its nearest relatives among the spiny-rayed fishes are, perhaps, the Batrachoidida. (pediculatus, having a footstalk.)

\section{Analysis of Families of Pediculati.}

a. Gill openings in or behind the lower axil of the pectoral; mouth large, terminal.

b. Pseudobranchice present; pseudobrachia with 2 actinosts; head broad, depressed, the enormous mouth with very strong teeth; ventrals present.

LOPHIDA, CCXXI.

* The appearance of " keeled scales," described by Goode \& Bean, is due to a black line on the skin under the center of each row of scales. There seems to be no real keel, and the species is congeneric with the other species of Symphurus. 
bb. Pseudobranchia none; pseudobrachia with 3 actinosts.

c. Ventrals present; arm angulate, the pseudobrachia elongate.

ANTENNARIIDA, CCXXII.

cc. Ventrals wanting, arm not angulate, the pseudobrachia moderate.

Ceratido, CCXXiI,

$a a$. Gill openings in or behind the upper axil of the pectoral; mouth small, usually inferior.

OGCOCEPHALIDA, CCXXIV.

Family CCXXI. LOPHIIDA.

(The ANglers.)

Head wide, depressed, very large. Body contracted, conical, tapering rapidly backward from the shoulders. Mouth exceedingly large, terminal, opening into an enormous stomach; upper jaw protractile; maxillary without supplementary bone; lower jaw projecting; both jaws with very strong, unequal, cardiform teeth, some of the teeth canine-like, most of them depressible; vomer and palatines usually with strong teeth. Gill openings comparatively large, in the lower axil of the pectorals. Pseudobranchiæ present. Gill rakers none. Gills 3. Skin mostly smooth, naked, with many dermal flaps about the head. Spinous dorsal of 3 isolated, tentacle-like spines on the head, and 3 smaller ones behind, which form a continuous fin; second dorsal moderate, similar to the anal; pectoral members scarcely geniculated, each with 2 actinosts and with elongate pseudobrachia; ventrals jugular, I, 5, widely separated, large, much enlarged in the young. Young with the head spinous. Pyloric crea present. Two genera, with 4 or 5 species, living on sea bottoms, at moderate or great depths; remarkable for their great voracity. (Pediculati, part, genus Lophius, Günther, Cat., III, 178-182, 1861.)

a. Vertebræ 27 to 31.

LopHIUs, 1058.

aa. Vertebræ 18 or 19 only. LOPHIOMUs, 1059.

\section{LOPHIUS (Artedi) Linnæus.}

(Fishing-Frogs.)

Lophius (ARTEDI) LiNndeus, Syst. Nat., Ed. x, 1, 236, 1758 (piscatorius).

Characters of the genus included above. Vertebræ numerous, about 30 in number. (Lophius, the ancient name of $L$. piscatorius, from $\lambda o ́ \phi o s, a$ crest.)

\section{LOPHIUS PISCATORIUS, Linnæus.}

(Common Angler; Fishing-FroG; Monkfish; Goosefish; dLl-Mouth; Bellows-Fish.)

D. I-I-I, III-10; A.9. Body depressed, tapering, scarcely longer than head. Humeral spine with 3 points, of which the posterior is the longest. Head surrounded with a fringe of barbels; top of head, in young, with many strong spines. Anterior dorsal spine elongate, fleshy at tip. Brownish, mottled, below white; mouth behind the hyoid bone immaculate; pectorals and candal black at tip; peritoneum black. Length 3 feet. North $3030 \_-93$ 
Atlantic, on both coasts; generally common, ranging southward along the shore to Cape Hatteras; found in deep water as far south as Barbados, in 209 fathoms, and to the Cape of Good Hope; northward to Norway and Nova Scotia. A well-known fish of singular ugliness of appearance, and of enormons voracity. (Eu.) (piscatorius, pertaining to an angler, in allusion to the baited dorsal spines which overhang the cavernous mouth.)

Lophius piscatorius, * LINNÆUS, Syst. Nat., Ed. $\mathrm{x}, 1,236,1758$, seas of Europe ; after ARTEDI, Lophius ore cirrhoso, etc.; Günther, Cat., III, 179, 1861; GILL, Proc. U. S. Nat. Mus. 1878, 219; JoRdAN \& GilberT, Synopsis, 844, 1883.

Lophius americanus, Cuvier \& Valenciennes, Hist. Nat. Poiss., xII, 380, 1837, Philadelphia (Coll. Le Sueur); STorer, Hist. Fish. Mass., pl. 18, fig. 2, 101, 1867.

I059. LOPHIOMUS, Gill.

Lophiomus, GiL, Proc. U.S. Nat. Mus. 1882, 552 (setigerus).

This genus is closely allied to Lophius in external characters, but it is strikingly distinguished by the reduced number of its vertebræ, which are only 18 or 19 , a fact which is associated with its tropical habitat. One species from the Pacitic. (Lophius; $\omega^{\prime} \mu o ́ s$, shoulder, in apparent allusion to the trifid humeral spine.)

3092. LOPHIOMUS SETIGERUS (Vahl).

Dorsal III-III-9; A. 5. Head above orbits and laterally with numerous spines and prickles; humeral bone ending in 3 blunt points; numerous cirri scattered along sides of head and body. Vertebræ 18. Color dusky; floor of mouth black posteriorly, but without white spots; pectorals and ventrals pale on basal half, black distally; caudal and anal black, with some white spots; soft dorsal translucent, with black specks; first dorsal spine with its membranaceous tip white, the latter provided with 2 black eye-like spots. Pacific Ocean; not uncommon in rather deep water off coasts of China and Japan. Known on the American coast from 1 speci-

* According to Professor Horace A. Hoffman this fish is called in A thens $\Pi \epsilon \sigma \kappa a \nu \delta \rho i \tau \zeta \alpha$

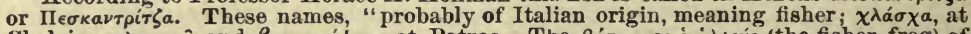

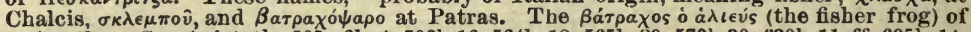
Aristotle. (See Áristotle 505a 6b 4, 506b 16, 564b 18,565b 29, 570b 30, 620b 11 ff, 695b 14,

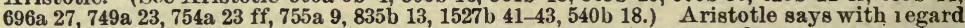
to the $\beta$ árpaxos: 'Inasmuch as the flat front part is not fleshy, nature has compensated for this by adding to the rear and the tail as much fleshy substance as has been subtractec in front.' The Bárpaxos is called the angler. He fishes with the hair-like filaments liung before his eyes. On the end of each filament is a little knob just as if it had been placed there for a bait. He makes a disturbance in sandy or muddy places, hides himself and raises these filaments. When the little fishes strike at them he leads them down with

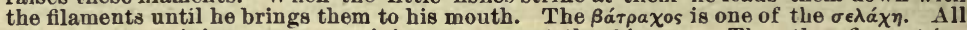

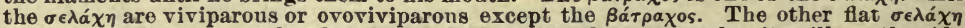
have their gills uncovered and underneath them, bnt the $\beta a ́$ 'paxos has its gills on the side and covered with skinny opercula, not with horny opercula like the fish which are not $\sigma \in \lambda a \chi \omega \delta \delta$. Some fishes have the gall bladder upon the liver, others have it upon the intestine, more or less remote from the liver and attached to it by a duct. Such are $\beta a ́ \tau \rho a \chi 0 s$,

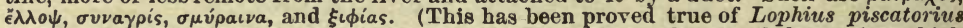

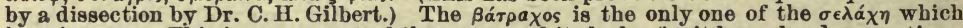
is oviparons. This is on account of the nature of its body, for it has a head many times as large as the rest of its body, and spiny and very rongh. For this same reason it does not afterwards admit its yonng into itself. The size and roughness of the head prevents them both from coming out (i. $\theta$., being born alive) and from going in (being taken into the mouth of the parent). The $\beta a \tau_{p a \chi}{ }^{\circ}$ is most prolific of the $\sigma \in \lambda a ́ \chi \eta$, but they are scarce because the eggs are easily destroyed, for it lays them in a bunch near the shore." (Hoffman \& Jordan, Proc. Ac. Nat. Sci. Phila., 1892, 278.) 
men, $2 \frac{1}{2}$ inches long, dredged at Albatross Station 2805, southwest of Panama. From this specimen, the above description is taken. Comparing this with a larger specimen taken at Tokio by Prof. K. Otaki, we find no differences likely to prove permanent. (seta, bristle; gero, I bear.)

Lophius setigerus, VAHL, ${ }^{*}$ Skrivt. Naturb., IV, 214, tab. 3, figs. 5 and 6, 1797, China Sea; Cuvier \& Valenciennes, Hist. Nat. Poiss., XII, 383, 1837; GUnther, Cat., III, 180, 1861.

Lophius viviparu\&, BLoch \& SCHNeIDER, Syst. Ichth., 142, 1801, tab. 32, China Sea; after Vahl.

Lophiomus setigerus, Gilbert, Proc. U. S. Nat. Mus. 1890, 454.

\section{Family CCXXII. ANTENNARIIDA.}

\section{(The Frog-Fishes.)}

Head and body more or less compressed. Month vertical or very oblique, opening upward; lower jaw projecting; jaws with cardiform teeth; premaxillaries protractile. Gill openings small, pore-like, in or behind the lower axils of the pectorals. No pseudobranchia. Gills $2 \frac{1}{2}$ or 3 ; skin naked, smooth, or prickly. Pectoral members forming an elbow-like angle. Pseudobrachia long, with 3 aetinosts. Ventral fins present, jugular, near together. Spinous dorsal of 1 to 3 separated, tentacle-like spines; soft dorsal long, larger than anal. Pyloric crea none. Genera about 5 ; species 50. Inhabitants of tropical seas, "living on floating seaweed, and enabled, by filling the capacious stomach with air, to sustain themselves on the surface of the water " therefore widely dispersed by currents in the sea. (Pediculati, pt., Günther, Cat., III, 182 to 200,1861 .)

a. Head compressed; a rostral spine or tentacle, followed by 2 larger spines; palatine tecth developed; dorsal spines disconnected.

b. Skin naked and smooth; ventral fins elongate.

$b b$. Skin covered with prickles; ventral fins shcrt.

Pterophryne, 1060.

ANTENNARIUS, 1061.

aa. Head cuboid; a single rostral spine or tentacle, received in a grooro; soft dorsal low.

Chaunax, 1062.

1060. PTEROPHRYNE, Gill.

\section{(Mouse-Fish.)}

Pterophryne, Gill, Proc. Ac. Nat. Sci. Phila. 1863, 90 (bougainvillei).

Pterophrynoides, Gill, Proc. U.S. Nat. Mus., I, 1878, 216 (histrio); name a substitute for Pterophryne, if the latter be regarded as preoccupied by the earlier Pterophrynus.

Body smooth or scarcely granular, short, somewhat compressed, with tumid abdomen; mouth small, oblique; palate with teeth; wrist and pectoral fin slender; ventrals elongated; soft dorsal and anal vertically

*Lophiomus setigerus, is thus described by Dr. Günther:

"Dorsal III-III, 8 or 9 ; A. 6 or 7 . Teeth arranged in 2 alternate series in the upper jaw, in 3 in the lower; 2 or 3 teeth on each side of the vomer; humeral spine terminating in 3 points; the mouth behind the hyoid bone purplish black, with white spots. Vertebræ 19 , the anterior ones very short, the middle and posterior ones nearly equal in length. Coasts of China and Japan." (Günther.) 
expanded. Small fishes of fantastic shape in the West Indies and Gulf Stream. ( $\pi \tau \varepsilon \rho \dot{v}$, wing; $\phi \rho \dot{v} \nu \eta$, toad.)

a. "Bait" on first dorsal spine bifurcate at tip.

HISTRIO, 3093. aa. "Bait" on first dorsal spine bulbous, covered with fleshy filaments. GIBBA, 3094.

3093. PTEROPHRYNE HISTRIO (Linnæus).

\section{(MOUSE-Fish; SARgassum-Fish.)}

Head $2 \frac{1}{4}$; depth $1 \frac{4}{5}$. D. III-14; A. 7; V. 5. Skin of head and body, as well as dorsal fins, with fleshy tags, which are most numerous on the dorsal spines and abdomen. Wrist slender; ventrals large, nearly $\frac{1}{2}$ as long as head. Dorsal and anal with the posterior rays not adnate to candal peduncle; first dorsal spine bifurcate at tip. Yellowish, marbled with brown; 3 dark bands radiating from eye; vertical fins barred with brown; belly and sides with small white spots. Tropical parts of the Atlantic; abundant on our Gulf coast and occasional northward to Cape Hatteras or beyond, especially in floating masses of Sargassum. Once taken in Europe (Vadsö, Norway) in floating seaweed from the Gulf Stream. Recorded from the coast of Senegambia; its history and synonymy confused with that of the following species. A remarkable fish, excessively variable in coloration. (histrio, a harlequin.)

Lophins tumidus, OsBeck, Iter Chinensis, 400, 1757, Open Sea; pre-Linnæan.

Lophius histrio,* Linnæus, Syst. Nat., Ed. x, 237, 1758, after varions authors, especially Balistes guaperva seu chinensis, Linneus, Mus. Ad. Fr., 56.

Pterophryne histrio, GIL, Proc. U. S. Nat. Mus. 1878, 216; GoOdE \& BEAN, Oceanic Ichthy. ology, 486, 1896.

Antennarius histrio, Jordan \& GILBERT, Synopsis, 846, 1883; Collett, Campagnes Hirondelle, 38, 1896.

* Concerning the use of the name histrio for this species, Dr. Gill remarks :

"In 1794 (as appears from the dates on the plates), Shaw published a number of his 'Naturalists' Miscellany,' in which he described 3 fishes under the generic name of' Lophius. These were described as (1) Lophius striatus (the Striated Lophius), pl. 175; (2) Lophius pictus (the Variegated Lophius), pl.176, npper figure, and (3) Lophius marmoratus (the Marbled Lophius), pl. 176, lower figure. The originals of these are evidently the varieties $(a, b$, and $c)$ of Lophius histrio admitted by Bloch \& Schneider. It is quite clear that the first two were based on species of typical Antennarius (not Pterophryne), while the third is incomprehensible, and, if the figure is at all correct, must represent a factitious fish; it most certainly has nothing to do with Pterophryne. The other species, how. ever, notwithstanding the bad? figures, are readily identifiable. The Lophius striatus (as has recently been recognizea by Günther) is the first name of an Antennarius peculiar to the Pacific, and quite distinct from the Caribbean Antennarius scaber $(=A$. histrio Giinther), with which it was at first confounded by Günther. The Lophius pictus was evidently based on the species or variety of Antennarius which was afterwards named Antennarius phymatodes by Bleeker, and it agrees very ciosely, in the distribution of colors, with a specimen figured by that ichthyologist, and would probably be considered by Günther as a variety of his Antennarius commersonii. But whatever may be the value of the forms embraced under the name Antennarius commersonii by Günther--whether species or varieties-the name Antennarius pictus must be revived from Shaw, either especially for the Antennarius phymatodes of Bleeker or for the collection designated as Antennarius commersonii. It has thus been demonstrated (1) that the Linnean name, Lophius histrio, was originally created for the common Pterophryne, and (2) that the names generally employed for the Pterophryne were originally applied to very different forms, and mem. bers of even a different genus. Hence if the laws of priority, as formulated by the British and American Associations for the Advancement of Science, are to guide us, there can be no question that the species of Pterophryne must hereafter be designated as Pterophryne histrio; if, however, it is allowable to go behind even the tenth edition of the Systema Naturæ and to take the oldest binomial name, without other considerations, the designation tumidus must be revived. It seems best, however, to follow general usage." (Gill, Proc. U. S. Nat. Mus., I, 1878, 226.) 
Chironectes pictu\&, Cuvier \& VAlencrennes, Hist. Nat. Poiss., xir, 393, 1837, Surinam.

Chironectes tumidus, Cuvier \& Valencrennes, Hist. Nat. Poiss., XII, 397, 1837, "Cabinet du Roi," Sargasso Sea. (Coll. Péron.)

Chironectes arcticus, Düben \& Konen, Kong. Vet. Akad. Abh. Stockholm 1844, 72, Vadsö, Norway, from a specimen carried northward in Sargassum; the only European rec. ord; fide ColletT.

Antennarius marmoratus, GUNTHER, Cat., III, 185, 1861; in part; not of Cuvier.

Ohironectes lavigatus, DE KAY, N. Y. Fauna: Fishes, 165, pl.27, fig. 83, 1842; not of Cuvikr.

\section{PTEROPHRYNE GIBBA (Mitchill).}

Garman refers to this species certain specimens obtained in Gulf weed about Key West and the Tortugas. These resemble P. histrio, but "differ markedly in certain respects. The bait on the first dorsal spine, for instance, is bulbous and covered with slender fleshy filaments in our individuals, but in $P$. histrio it is bifureate. $P$. gibbus is fairly represented by Cuvier, 1817, in his Chironectes lavigatus. The formula for the individuals in hand is D. III, 12; A. 7; V.5; P. 10; C. 9." (Garman.) West Indies, north to Key West and the Tortugas; not examined by us; probably common, but hitherto confounded with $P$. histrio. (gibbus, gibbous.)

Lophius gibbus, Mrтchrı, Trans. Lit. and Phil. Soc. N. Y. 1815, 1, pl.4, f. 9, off St. Croix, Lat. $22^{\circ}$ N., Long. $64^{\circ}$ W. (Coll. Dr. John D. Jaques.)

Chironectes lavigatus, Cuvier, Mém. du Mus., IrI, 423, pl. 16, fig. 1, 1817, South Carolina (Coll. Bosc); Cuvier \& VAlenciennes, Hist. Nat. Poiss., xII, 399, 1837.

Pterophryne loevigata, GrLl, Proc. Ac. Nat. Sci. Phila. 1863, 90.

? Ohironectes sonntagii,* Baron J. W. voN MüLLER, Reisen in den Vereinigten Staaten, Canada und Mexico, Band I, 180, 1864, in floating seaweed; no exact locality stated.

Pterophrynoides gibbus, Garman, Bull. Iowa Lab. Nat. Hist. 1896, 81.

\section{ro6r. ANTENNARIUS, Lacépède. -}

Antennarius (Commerson) LACḰPk̀de, Hist. Nat. Poiss., I, 421, 1798 (chironectes).

Histrio, Fischer, Zoognosia, 78, 1813 (histrio, etc.). (No type; includes all known Antennariida; description transposed with that of Lophius by error.)

Chironectes, Cuvier, Règne Animal, Ed.2, vol.II, 252, 1829 (chironectes); preoccupied in mammals, nlliger, 1811.

Body oblong, compressed, very deep through the occipital region, tapering behind; breast tumid; mouth rather large, more or less oblique, or even vertical; cardiform teeth on jaws, vomer, and palatines; eye small; skin with small granules or spinules, these usually forked, and numerous fleshy slips. First dorsal spine developed as a small rostral tentacle;

* The following is the substance of the long account of P. sonntagii (Von Müller):

"D. II, 10 to 12 ; P. 10 or 11; C. 6 to 7 ('Strahlenpaare'); B.6. Head and body slightly compressed; dorsal spines like little horns, covered over and over with spinous growths. Mouth wide, with numerous rows of small teeth; throat and belly with many fleshy slips. Pectorals produced on a long peduncle like the flippers of a tortoise; ventrals similar, but formed more like feet; anal fin like a rudder. Color clear yellowish green, with greenish brown stripes; a broad dark stripe across breast to root of pectoral; another on the back; another on the side, running backward in the form of a hammer, paler at last on lower part of back; several stripes and spots, more or less dusky, on the tail and othor extremities; on the soft underside to tho anal intense reddish golden yellow spots; between the dark streaks and the yellow ground color of the body are often white shades and markings; eye tiery orange. Atlantic Ocean or Gult of Mexico; living in floating seaweed."

This species must be a Pterophryne, and it is not evidently different from Pterophryne gioba. 
second and third dorsal spines strong, covered with skin, with numerous fleshy filaments; soft dorsal high and long; anal short and deep; caudal fin rounded, the peduncle free; pectoral fins wide, with a rather wide wrist, at the lower posterior angle of which are the very small gill openings; ventral fins short. Fantastic-looking fishes, often gaily colorer; very numerous in warm seas. (antenna, a feeler or tentacle.)

a. Bulbous tip or "bait" of first dorsal spine simple, undivided at tip.

b. Skin smoothish except abont eyes; first dorsal spine short, second rough. Body brown, with whitish spots; no ocelli.

INOPS, 3095 .

$b b$. Skin with prickles, velvety or shagreen-like.

c. Prickles simple, none of them bifid.

$d$. Color black; tips of pectorals and ventrals and one or two spots on side white (prickles undescribed). PRINCIPIS, 3096.

$d d$. Color dusky ; dorsal with 3 ocelli ; caudal with many spots; first dorsal longer than second; no dermal flaps. TENEBRosus, 3097.

$d d d$. Color reddish or grayish, reticulate with heavy black lines; first dorsal spine short. RETICULARIS, 3098.

cc. Prickles or spinules on body mostly bifid.

$e$. Body without ocelli; first dorsal spine filiform.

$f$. Mouth immaculate within; body with numerous rosy and dnsky tracts, the latter forming bars and concentric streaks below; fins barred. STRIGATUS, 3099.

ff. Mouth largely black within; body blood red, with black spots on sides and below dorsal. SANGUINEUS, 3100 .

ee. Body with 3 large ocelli, 1 on dorsal, 1 on caudal, and 1 on middle of side, besides many black spots and streaks; tip of first dorsal spine fringed; month largely black within. OCELLATUS, 3101 .

$a a$. Bulbons tip or "bait" on first dorsal spine bifid at tip; skin shagreen-like.

g. Color reddish, with brown spots, those abont the eye radiating.

$h$. Dermal flaps numerous on body; spinules on skin short and stiff, rendering the surface shagreen-like. SCABER, 3102.

$h h$. Dermal flaps few; spinules on skin longer and slender, rendering the surface velvety.

TIGRIS, 3103 .

gg. Color uniform black; surface of body rongh, shagreen-like; inside of mouth white; first dorsal spine short, little longer than second. NUTTINGII, 3104.

aaa. Bulbous tip or "bait" of first dorsal spine trifid.

i. First dorsal ray twice as long as second and as long as caudal; sides with numerous black ocelli, besides other streaks and dark spots; skin smoothish.

MULTIOCELLATUS, 3105.

ii. First dorsal spine barely $\frac{1}{2}$ longer than second; shorter than candal; sides with dark streaks and reticulations; a large ocellus under middle of soft dorsal; body rough, with shagreen.

RADIOSUS, 3106 .

\section{ANTENNARIUS INOPS, Poey.}

Depth $2 \frac{8}{4}$ with caudal. Skin lustrous, smooth, except for some points behind and below eye; third of the first 3 dorsal rays largest, its membrane not reaching to vent; second ray also large, but shorter, placed between eyes; first spine developed as a fishing rod, filiform, ending in a small, membranaceous lobe, its base close to that of second, and, therefore, distant from end of snout, its spine short, the tip not reaching middle of second spine; short tentacles, like horns, on anterior part of third spine, over the nostrils, and under the mouth; caudal rounded; pectoral so joined that it can not be turned forward as usual in this group, but rising 
obliquely backward and upward. Eye slightly longer than snout; mouth brown within. Color brown, with white spots on the body and median fins, 6 of the largest of these each with the center yellowish, the largest from ouce to twice diameter of eye; spots on dorsal fins small; eye golden. Porto Rico. (Poey.) Not seen by us. The type $70 \mathrm{~mm}$. long. (inops, helpless. "I call this species 'inops' on account of the miserable fishing rod which has fallen to its lot." Poey.)

Antennarius inops, Pokr, Anal. Soc. Esp. Hist. Nat., X, 1881, 340, Porto Rico. (Coll. Don Juan Gündlach.)

3096. ANTENNARIUS PRINCIPIS (Cuvier \& Valenciennes).

D. III-11; A. 7; P. 10. Anterior dorsal spine twice as long as second, ending in a small, slender lobe; membrane behind third spine extending to root of soft dorsal; last ray of dorsal not reaching caudal. Skin rough, covered with small spines; no cutaneous fringes. Black; tips of pectorals and ventrals white; a small white spot above pectoral. (Günther.) West Indies to Brazil; not seen by us. Günther's specimen, above described, from Para. (principis, of the prince. Named for its discoverer, Prince Maurice of Nassau.)

Chironectes principis, * Cuvier \& VAlenciennes, Hist. Nat. Poiss., XII, 416, 1837, Brazil; on 2 drawings by Prince MAurice, the second representing the present species to which Günther restricts the name principis. The first figure is more like tigris. Antennarius principis, Günther, Cat., III, 193, 1861.

3097. ANTENNARIUS TENEBROSUS (Poey).

D. III-12; A. 7; P.11. Anterior dorsal spine longer than second, terminating in a simple and slender tentacle; soft dorsal fin terminating at some distance from caudal. Skin rough, covered with small spines, without cutaneous fringes. Blackish brown, marbled with darker and lighter; a series of 3 black, blue-edged ocelli on upper posterior part of dorsal fin; many similar ocelli on caudal fin, irregularly disposed. (Poey.) Cuba. Not seen by us. (tenebrosus, dusky.)

Chironectes tenebrosus, Poky, Memorias, I, 219, pl. 17, fig. 1, 1851, Cuba.

Antennarius tenebrosus, GÜnTHER, Cat., III, 197, 1861.

\section{ANTENNARIUS RETICULARIS, Gilbert.}

D. III-12; A. 7. First dorsal spine short, very slender and filiform, not reaching tip of second, terminating in a short, fleshy flap; second spine moderately robust, flexible, not curved backward, wholly free and with-

* Concerning this nominal species and Chironectes mentzelii, both of which were based on drawings by Prince Maurice, Cuvier \& Valenciennes remark:

"We here cite these figures, and we give them specific names only to fix the attention of travelers and to get them to find the species which have served as models for these figures."

The following is the substance of the original description of Chironectes principis:

In the first figure, color very deep brown, speckled with black spots on body and fins; dorsal fin with only 1 series of spots. Filament of first spine twice as long as that of the second, and terminating in a little knob or bait, the second spine free from the first and similar in shape.

Second figure of the same form, the second dorsal longer, the first ray ending in a spiral, and the whole body white, with 2 white round spots on each side, one above the other. 
out membrane; third spine nearly erect, not free, depressible with diffculty; not curved as in A. sanguineus; spines on the body rather coarse and shagreen-like, with expanded, undivided tips. Color in spirits, top of head, including dorsal spines and front of soft dorsal, coral red, the body otherwise light gray, broadly reticulated on sides and below with heavy black lines, which inclose 5 or 6 large pale spots; pectorals, ventrals, and anal with narrow terminal and wide median black bars. Soft dorsal uniformly light. This species closely resembles A. sanguineus, but differs from it in the straight, erect spinules, the color, and the character of the plates on the body. Length $1 \frac{1}{4}$ inches. Gulf of California. (Gilbert.) Only the type known. (reticularis, netted.)

Antennarius reticularis, GiLbert, Proc. U. S. Nat. Mns. 1891, 566, Gulf of California, at Albatross Station 2825. (Coll. Gilbert.)

3099. ANTENNARIUS STRIGATUS, Gill.

D. III-12; A. 7. First dorsal spine elongate, filiform, twice length of second, with very slender, dermal tip; third spine more robust than second, wholly concealed in the skin, its length equal to that of first spine. Lips, maxillary, and a large transverse area behind second dorsal spine naked, each side of this area with a few spinous tubercles; skiu elsewhere covered with fine shagreen-like armature. Color in spirits, olivaceous everywhere on body and on inside of mouth, finely mottled with light olive brown; many irregular blackish areas on head and body, those on lower side of head showing a tendency to form concentric bars; some on sides forming irregular bars downward from back; posterior portion of body not darker than the anterior; terminal parts of all the fins largely blackish, but with distinct black bars; some scattered round blotches on sides, each consisting of a number of smaller black spots on an olive ground; head and body with numerous pinkish and rose-red spots and loars, the latter sinuous, irregular, with wavy margins; a pinkish bar behind maxillary; a broad, saddle-like pinkish blotch across interval between second and third dorsal spines; a third bar from in front of origin of second dorsal downward toward base of pectorals; a fourth across top of caudal peduncle; first dorsal spine narrowly barred with brown. Pacific coast of tropical America, from Cape San Lucas to Panama. Here described from an adult, 10 inches in length, from Panama. This differs considerably from the descriptions of the young (strigatus, tenuifilis) given by Gill and Günther.

Two young individuals, types of $A$. strigatus, are thus characterized by Dr. Gill:

"The anterior dorsal spine is very slender and filiform, without appendages; the second is straight and moderate; the third concealed and developed as a hump, obtuse behind. The spines which cover the body are small and mostly bifid. The back and front of the dorsal fin are reddish; the rest light brown, with black stripes which diverge downward above the pectorals, those in front being parallel with the profile and at right angles with those behind; around the pectoral fins and on the flanks, the streaks are generally blended to form a continuous black 
area; a black dorsal saddle is in front of the dorsal fin, and a black band covers the posterior half of the caudal fin ; the abdomen is broadly reticulated with black, and the brown intervals themselves are frequently striated with the same color; the interior of the mouth is immaculate." (strigatus, striped.)

Antennarius strigatus, GiLL, Proc. Ac. Nat. Sci. Phila. 1863, 92, Cape San Lucas (Coll.

J. Xantus), young; Jordan \& GilberT, Proc. U. S. Nat. Mus., 1882, 650, adult; JordAN, Cat. Fishes, 138, 1885.

Antennarius tenuifilis, GünTHER, Fishes Centr. Amer., 440, 1869, Panama; young.

3100. ANTENYARIUS SANGUINEUS, Gill.

Auterior dorsal spine very slender, $2 \frac{1}{2}$ in length of caudal fin, terminating in a flap extended on each side, laciniated outward; second spine rough, robust, and curved strongly backward at its end; third not free, but apparent as a hump pointed backward, and extending $\frac{2}{8}$ of the distance from its insertion to that of dorsal fin; skin covered with small bifid spines, whose prongs diverge considerably and are acute. Color blood red, except on abdomen, but with several more or less distinct black spots under origin of dorsal fin and on sides; abdomen light or yellowish brown, spotted with black; intervals between caudal and anal rays also marked with black; floor of mouth behind tongue with 2 lateral black bands converging toward the front, while the posterior margin of the tongue itself is also sometimes lined with black. (Gill.) Pacific coast of tropical America, Cape San Lucas to Panama; scarce. (sanguineus, bloody.)

Antennarius sanguineus, Gill, Proc. Ac. Nat. Sci. Phila. 1863,91, Cape San Lucas (Coll. Xantus); Jordan, Cat. Fishes, 138, 1885.

Antennarius leopardinus, GÜnTHer, Proc. Zool. Soc. London, 1864, 151, Panama.

3101. ANTENNARIUS OCELLATUS (Bloch \& Schneider).

Depth $1 \frac{2}{5}$ in length. D. II-I-14; A. 8 ; P. 11; orbit equaling snout, eye much smaller; maxillary $3 \frac{1}{2}$ in body; pectoral rays $5 \frac{1}{5}$; caudal 4 . Body short, oblong, compressed, very deep through occipital region; mouth large, subvertical; teeth small, sharp, cardiform, in wide bands on jaws, vomer, and palatines; maxillary extending downward to below axis of body; a very large knob at symphysis; lower part of head with many large, thick tentacles. First 2 dorsal spines on interorbital space, the first slender, terminating in a fringed lobe, the second shorter and much thicker, behind it a smooth depression; the third spine exceedingly rough and thick, blunt at tip and adnate to body; soft dorsal long and low, its origin in front of middle of body, tips of last rays reaching base of caudal; anal posterior, tips of its rays coterminous with dorsal rays, its height equal to its length; pectorals near middle of body, placed far below axis; ventrals short, the rays thickened, their position under poste. rior edge of eye. Skin covered with minute bifurcate spines, running upon dorsal, anal, and caudal rays; gill opening in front and below pectoral, its length about equal to snout. Color brown, marbled with 
lighter, and with scattered black dots, especially ou belly and outer portions of dorsal and caudal; each side with 3 large black spots ocellated with brownish, 1 on dorsal near its base, a second immediately below it on the sides, and a third in the middle of the caudal fin; mouth behind tongue black, with yellow lines. West Indies, worth to Florida. Common in the West Indies; the most abundant of the American species. Here described from a specimen from off Pensacola, Florida, about 15 inches in length.

Mr. Garman gives the following note on Antennarius ocellatus :

"The species was tolerably figured by Parra, but has not been recognized by some of the subsequent writers. On 5 specimens before me the amount of variations in markings is comparatively small. The 3 large ocelli, on dorsal, caudal, and middle of side, are present on each, as is also the case with the numerous small spots of black on the ventral portions of the body and on the outer portions of dorsal and caudal. The dorsal ocellus lies between the sixth and seventh rays, on the middle of the fin; that on the flank is situated on the vent, and that on the caudal between the fourth and fifth rays, from the top, near the middle of the fin. The black portion of either of these spots is larger than the orbit, which latter is rather small when coutrasted with that of other species. The white circle around the black, again, is surrounded by a narrow one of brown. On the caudal, at each side of the ocellus, there are transverse streaks. The first ray of the dorsal is as long as the second, and is covered by scales. The bulb apparently is simple, and bears numerous lacinix. The second dorsal spine is shorter than the third; both are club shaped. The space behind the second dorsal spine is covered by scales." (ocellatus, with eye-like spots.)

Pescador, PARra, Dif. Piezas, Hist. Nat., 1, tab. 1, 1780, Cuba.

Lophius ĭistrio, var. ocellatus, BLOCH \& SCHNEIDER, Syst. Ichth., 142, 1801; after PARRA.

Antennarius pleurophthalmus, GILl, Proc. Ac. Nat. Sci. Phila. 1863, 92, Key West; JoRdAN \& Gilbert, Synopsis, 846, 1883; Jordan, Cat. Fishes, 138, 1885; Goode \& Bean, Oceanic Ichthyology, 487, 1895.

Antennarius ocellatus, Pokx, Synopsis, 105, 1868; Garman, Bull. Iowa Lab. Nat. Hist. $1896,82$.

3102. ANTENNARIUS SCABER (Cuvier).

D. III-12; A. 7; P.9 or 10 . Anterior dorsal spine as long as second, and provided with 2 long and thick cutaneous flaps at its tip; third dorsal spine not continuous with the soft dorsal; soft dorsal fin terninating at some distance from the caudal, its last ray not extending to root of caudal, if laid backward; dorsal spines, head, back, and sides of the borly with more or less numerous cutaneous fringes, those of dorsal spines sometimes forming a dense cluster; skin very rough, covered with small spines. Ground color yellowish or reddish, with numerous brown spots, those around the eye forming radiating streaks; dorsal and anal fins with 3 series of round brown spots, the middle of which is formed by the largest and most constant spots; sometimes uniform brown. Caribbean Sea. (Günther.) A small specimen from Port Castries, St. Lucia, has the body 
light brown, elouded with darker, fins all with round black spots, those of the base of the dorsal somewhat larger than others; ventrals tipped with black. (scaber, rough.)

Chironectes scaber, Cuvier, Mém. Mus., III, 425, pl.16, fig, 2, 1817, Martinique (Coll.Plée); Cuvier \& Valenciennes, Hist. Nat. Poiss., XII, 412, 1837.

Lophius spectrum, Gronow, Cat. Fish., Ed. Gray, 49, 1854, Antilles; after Lophius acute scabra, Gronow, Zoophyl., 210, 1781.

Antennarius scaber, Jordan, Proc. U.S. Nat. Mus. 1889, 652, specimen from Port Castries, St. Lucia.

Antennarius histrio, GÜNTHER, Cat., IV, 188, 1861; not Lophius histrio, LINNæשS.

\section{ANTENNARIUS TIGRIS, Poey.}

D. III-12; A. 7; P. 11. Anterior dorsal spine longer than second, terminating in 2 long cutaneous flaps; third dorsal spine connected with soft dorsal by a broad membrane, the latter terminating at some distanee from the caudal, and its last ray not extending to root of caudal if laid backward. Skin rough, eovered with small spines, withont cutaneous fringes. Ground color yellow, with numerous brown spots and streaks, the latter radiating from the eye; dorsal fin irregularly spotted, with a series of large round brown spots. (Poey.) Cuba. Not seen by us. According to Mr. Garman, Antennarius rcaber and A. tigris " are closely allied, but if placed side by side the squamation and filaments suffice to distinguish them, great similarity in color notwithstanding. A. scaber has coarser scales, with shorter, rougher spines, the scales are farther apart, and the cutaneous flaps appear on the body much as figured by Cuvier. On $A$. tigris there are fow of the eutaneous appendages, the scales are closer together, the spines are longer and more slender, giving rise to an appearance more like velvet, and the head and body are more compressed." (tigris, tiger.)

Ohironectes tigris, Pokx, Memorias, 1, 217, pl.17, fig. 2, 1851, Cuba.

Antennarius tigris, GaRMAN, Bull. Iowa Lab. Nat. Hist. 1896, 83.

\section{ANTENNARIUS NUTTINGII, Garman.}

D. $3+12$; A. 7 ; V. 5 ; P. 11 ; C. 9 . In form this species is shorter, more massive anteriorly, and less compressed than either $A$. ocellatus or $A$. radiosus. A transerve section across the middle of the body is a nearly equilateral triangle. Caudal region short. Head nearly as wide as high; eheeks swollen; forehead rather broad, converging forward on the edges. Occipital concavity wide and deep, free from seales in a wide space below the ends of the first and second dorsal rays, this bare space being apparently for the reception of the fleshy bait bulb, which latter has 2 elongate lobes. Snout as long as the orbit, broad, truncate; chin vertical; symphyseal knob prominent. Mouth wide, subvertical. Eye small; orbit twice as long, hardly more than $\frac{1}{2}$ the interorbital space. First and second dorsal rays equal in length, not inclusive of the 2 elongate fleshy fringed lobes surmounting the first. The base of the first ray stands forward prominently over the mouth, being free for some distance. The 
greater portion of the second ray is free, while the third is connected with the dorsum, by the skin, from base nearly to tip. This last ray is larger than either of its fellows. Soft dorsal large; middle rays longest, as long as the distance from the maxillary to the hind edge of the operculum, or as long as the rays of the caudal fin; fin not reaching back to the bases of the caudal rays, fringed. Hind margin of caudal convex, fringed. Anal moderate, rays prominent in the margin, fin with a blunt angle on the outer edge, subtending, when laid up against the tail, $\frac{1}{4}$ or more of the length of the caudal rays. The rays on the pectoral fins extend out beyond the margins more noticeably than those of the other fins. Ventrals small, in most instances with 6 points on the onter margin, in one case having but 5. Greatest length of the caudal nearly $\frac{1}{4}$ of the total length. Length of each maxillary $\frac{2}{3}$ of the caudal. Scales short, small, close set, harsh to the touch, having none of the velvety appearance. Uniform black; inside of the mouth black; "bait" white. Great Bahama Banks. Besides the specimens in Nutting's collection there are several others in that of the Mus. Com. Zool. "This species is readily separated from $A$. principis of authors by the short first dorsal spine." ("The specific name is given in honor of Prof. C. C. Nutting, to whom science is so much indebted for the origination and successful accomplishment of the expeditiou.")

Antennarius nuttingii, GARMan, Bull. Iowa Lab. Nat. Hist. 1896, 83, pl. II, Great Bahama Banks. (Coll. C. C. Nutting.)

"Phironectes mentzelii, ${ }^{*}$ CUVIER \& VALENCIENNES, Hist. Nat. Poiss., xir, 417, Brazil; on a drawing by Prince MAURICE.

3105. ANTENNARIUS MULTIOCELLATUS (Cuvier \& Valenciennes).

(Martin Pescador.)

Mouth large, vertical. First dorsal spine slender and straight, nearly equal to length of caudal, terminating in 3 simple tentacles; second dorsal spine curved at the middle and extending to the base of the third; third dorsal spine partly embedded in the skin, reaching halfway to dorsal; wrists and pectorals widened; ventrals short. Skin covered with bifid spines. Fawn color, lighter below; many black spots ocellated with white, both on the body and fins; body with several pink areas, 1 of which forms a triangular saddle in front of the dorsal and another a broad ring around the base of the caudal fin; angles of mouth with a pink spot. West Indies, north to Florida Keys; common. This description (after Gill) from the type of Antennarius annulatus from Garden Key. According to Mr. Garman, "this species is distinguished by the trifid bulb and the long first dorsal ray, near twice as long as the second and quite as long as the candal, by the high nape, by the large third dorsal ray, much larger and more swollen than the second, and by the coloration. The eye is very small. The black centers of the largest of the ocelli are smaller than the eye. Besides the ocellus on the soft dorsal that on the anal and the 3

* The following is the substance of the very brief description of this nominal species: "First dorsal filament not longer than the second, and ending in a small bait or knob. Body black, with large marblings." 
forming a triangle on the caudal, there are others scattered over the caudal and other fins, and over the sides of the body. Below the eye on the cheek and under the chin and the chest the spots are little more than black dots. Over the sides, a specimen in hand, the type of $A$. corallinus, Poey, is freckled with lighter rounded spots. Behind the pectoral, on the side, there is a small ocellus with a black center. On cach side in the same position, a short distance above the pectoral, there is a brown ocellus larger than the orbit, in the center of which there is a white dot. A brown streak passes back from the upper part of the orbit and curves down toward the anal ocellus, another passes back from the middle of the eye and curves down toward the pectoral, and a third below the third dorsal spine runs down and then forward toward the lower end of the maxillary. The forehead is comparatively narrow; behind the second dorsal ray the bare space is hardly large enough to receive the bait."

Poey thus describes Antennarius corallinus, which according to Garman, is the same as $A$. multiocellatus:

"D. II-I, 12; A. 7; V. I, 5; C. 17. Two dorsal spines in front of eye, formed like horns, another higher on the nape; gill opening spiral, at the lower base of the pectoral; general form of the fish almost globular; the mouth vertical; tongue marbled with black and white; caudal rounded; eyes very small; pectoral low, reaching middle of body without caudal; ventrals short; vent near anal; first dorsal spine ending in a single short filament. Color reddish with black spots; 2 of these spots eje-like, with a larger black center and the iris of the color of the body, surrounded with a black circle; 1 spot at the base of the soft dorsal at the second third of its length, a very weak one at base of anal; between first spot and pectoral fin 3 small inconspicuous ocellate spots, of which the pupil is a small point; middle of the body with dusky spots; dorsal, anal, and caudal with black points; tubercles about eye and on the cheek, but not spinous. Type 95 mm. long. Cuba." (Poey.) (multus, many; ocellus, an eye-like spot.)

Chironectes multiocellatus, Cuvier \& VAlenciennes, Hist. Nat. Poiss., XI, 422, 1837, Martinique. (Coll. M. Garnot.)

Antennarius annulatus, Grul, Proc. Ac. Nat. Sci. Phila. 1863, 91, Garden Key, Florida (Coll. Lieut. Wright); Jordan \& GILBERT, Synopsis, 846, 1883.

Antennarius corallinus, Poey, Repertorio, I, 188, 1865, Cuba. (Coll. Poey.)

Antennarius multiocellatus, Günther, Cat, III, 194, 1861; Garman, Bull. Iowa Lab. Nat. Hist. 1896, 82.

3106. ANTENYARIUS RADIOSUS, Garman.

D. $3+13$; A. 8 ; V.5; P.11; C.9. Resembling A.tigris, Poey, in shape, squamation, etc., but differing in coloration and in possession of a much longer dorsal ray. The staff in this ray is very slender, much longer than the second ray, and bears a small, trifid "bait." Second and third dorsal rays shorter than the first, the third well tied down by the skin. Scales uniform, sharp. No cutaneous fringes on large specimens. Grayish or brownish white, darker on nape and dorsal fin, with numerous spots of light color, as large as the orbit, surrounded by more or less complete 
edgings of brown, producing a semblance to reticulation, or to spottings by drops of liquid; 7 streaks of brown radiate from the eye; as in $A$. tigris, they are continued upon the head and down toward the ventrals; a large spot of black, white-edged, a little larger than the orbit, $\frac{1}{2}$ on the fin and $\frac{1}{2}$ on the muscles of the body, occupies the space between the eighth and the tenth rays of the soft dorsal fin; the light areas vary in intensity, and lie close together over nearly the whole of body and fins; belly lighter, with faint indications of lines of brownish, radiating from the head; caudal with oblique transverse clondings of brownish; hindmost $\frac{1}{4}$ light. The color in life was probably reddish or yellowish. Secured off Key West, in about 50 fathoms. A young individual, of less than an inch, taken opposite Havana, is of lighter gray, and has a large ocellus, of light color in the center, between the black one at the base of the dorsal and the upper end of the humerus. There are small cutaneous fringes on the flanks. (Garman.) (radiosus, rayed.)

Antennarius radiosus, GarMaN, Bull. Lab. Nat. Hist. Iowa Univ. 1896, 85, pl. 1, off Key West, in 50 fathoms. (Coll. C. C. Nutting.)

I062. CHAUNAX, Lowe.

Chaunax, Lo.,HE, Trans. Zool. Soc. Lond., III, 1846, 339 (pictus).

Head very large, depressed, cuboid. Mouth large, subvertical; jaws and palate with bands of small teeth. Skin with small, sharp spines. Spinous dorsal reduced to a small tentacle above the snout, retractile into a groove; soft dorsal moderate, low; anal short; ventrals small. Gills $2 \frac{1}{2}$; no pseudobranchiæ. Muciferous channels very conspicuous, the lateral line prominent, undulate; another series of mucous tubes extending from lower jaws to axil ; still another extends backward from snout and maxillary to a point behind eye, when it ceases, uniting with a vertical line which extends from the lateral line to the lower line; these lines thus inclose a quadrate area on the cheek. Gill opening small, well behind pectoral under front of soft dorsal. Deep seas. ( $\chi \alpha \dot{v} v \alpha \xi$, one who gapes.)

a. Dorsal rays 11; anal 5; depth $2 \frac{1}{2}$ in length.

aa. Dorsal rays 13; anal 7; depth $2 \frac{2}{6}$ in length.

PICTUS, 3107. NUTTINGII, 3108.

\section{CHAUNAX PICTUS, Lowe.}

Head $1 \frac{1}{8}$; depth $2 \frac{1}{2}$. D. I, 11; A. 5; P. 11; V.4; C. 7 . Rostral tentacle short, pedicellate; muciferous channels appearing as chain-like rows of pits. Bright orange above; sides rosy; fins vermilion. Deep waters of the Atlantic; recorded from Madeiro, Soudan, Cape Verdes, Barbados, off Rhode Island, and elsewhere in the Gulf Stream, in 130 to 428 fathoms. A similar species (Chaunax fimbriatus), regarded by Giinther as the same, occurs in the Japan Seas, Bay of Bengal and the Fiji Islands. (pictus, painted.)

Chaunax pictu\&, Lowe, Trans. Zoöl. Soc. Lond. 1846, 339, Camera de Lobos, Madeira; Günther, Cat., III, 200, 1861; Goode, Proc. U. S. Nat. Mus. 1880, 470 ; Jordan \& GILbert, Synopsis, 847, 1883; Goode \& BEAN, Oceanic Ichthyology, 487, fig. 398, 1896.

1 Chaunax flmbriatus, HILGeNDorf, Sitzber. Ges. Naturf. Freunde 1879, 80, Sea of Japan.

? Chaunax nuttingii, Garman, Bull. Lab. Nat. Hist. Iowa Univ. 1896, 85, pl. In, fig. 2, near Sand Key Light, Florida, in 120 fathoms. (Coll. C. C. Nutting.) 


\section{CHAUNAX NUTTINGII, Garman.}

B. 6. D. II, 13; A. 7; V.4; P.14; C.9. Form resembles that of Chaunax pictus, but is shorter, broader, and possessed of more fin rays. Anteriorly it is broad and depressed, posteriorly compressed. From head to soft dorsal on the nape it is arched very little. Head broader than high, flattened or slightly concave on the occiput, nearly vertical on the chin. Snout short, broad, truncate. Eye medium, the length of the scaleless area covering it equals the width of that between the canals on the interorbital space, or about $\frac{2}{3}$ of the space itself; the distance from the maxillary is about the ocular width. The niche in which the first dorsal spine is received is subelliptical and about $\frac{8}{4}$ as long as the eye; the tentacle is little more than $\frac{1}{2}$ as long as the niche, is broad near the base, tapers rapidly and bears a 2-lobed "bait" with slender fringes. Mouth wide, oblique, maxillary about 3 times as long as the eye, widened and rounded at the outer end; intermaxillaries alone forming upper border of month. Teeth small, slender, sharp, in villiform bands. Origin of soft dorsal in the middle of the distance from the rostral tentacle to the base of the caudal fin, fourth ray above the gill opening, anterior rays shorter. Vent below the seventh ray of the second dorsal. Pectorals short, broad, rounded. The canals of the lateral system are in the main like those of C. pictus, but have stronger curves; they begin to curve outward immediately behind the niche, not remaining parallel or converging as in Lowe's species. Scales very fine, sharp and close together. In life this fish was probably red or yellowish with transverse cloudings or blotches of brownish, it is now dingy brownish white; one of the blotches lies just behind the eye, another lies below the orbit, and apparently 3 transverse bands cross the back through the soft dorsal; orbit blackish; tentacular niche black. The coloration of the individual described indicates a habitat within reach of the effects of sunlight. Florida Keys; the type dredged nearly 8 miles south of Sand Key Light, Florida, in about 120 fathoms. (Garman.) This species is evidently not very different from Chaunax pictus and may be the same. (Named for C. C. Nutting, professor of zoology in the University of Iowa, director of the Bahama Expedition of 1893.)

Chaunax nuttingii, Garman, Bull. Lab. Nat. Hist. Iowa Univ. 1896. 86, pl. III, f. 2, Sand Key Light, Florida. (Coll. C. C. Nutting.)

\section{Family CCXXIII. CERATIIDE.}

\section{(The Sea Devils.)}

Head and body compressed. Mouth terminal, more or less oblique. Gill openings small, in the lower part of the axils. No pseudobranchir. Spinous dorsal represented by 1 or more tentacles. Pectoral members not geniculated, with short pseudobrachia and 3 actinosts. No ventral fins. Fishes of the open seas, usually inhabiting considerable depths; 13 genera and 15 species known. All are uniform blackish in color.

"The bathybial sea devils," writes Günther, "are degraded forms of Lophius; they descend to the greatest depths of the ocean. Their bones 
are of an extremely light and thin texture, and frequently other parts of their organization, their integuments, muscles, and intestines are equally loose in texture when the specimens are brought to the surface. In their habits they probably do not differ in any degree from their surface representative, Lophius. The number of the dorsal spines is always reduced, and at the end of the series of these species only 1 spine remains, with a simple, very small lamella at the extremity (Melanoctus johnsonii, Melanocetus murrayi). In other forms sometimes a second cephalic spine, sometimes a spine on the back of the trunk, is preserved. The first cephalic spine always retains the original function of a lure for other marine creatures, but to render it more effective a special luminous organ is sometimes developed in connection with the filaments with which its extreuity is provided (Ceratias bispinosus, Oneirodes eschrichtii). So far as it is known at present these complicated tentacles attain to the highest degree of development in Himantolophus and Egaconichthys. In other species very peculiar dermal appendages are developed, either accompanying the spine on the back or replacing it. They may be paired or form a group of 3 , are pear-shaped, covered with common skin, and perforated at the top, a delicate tentacle sometimes issuing from the foramen." (Pediculati, genus Ceratias, Günther, Cat., III, 205, 1861; Ceratiida, Gill, Proc. U. S. Nat. Mus. 1878, 216.)

a. Mouth moderate.

b. Gills in $2 \frac{1}{2}$ pairs.

Ceratinnat:

c. Cleft of unouth nearly vertical; skin prickly.

$d$. Cephalic spine single.

e. Dorsal spine present; lateral caruncles present; no teeth on vomer.

Ceratias, 1063.

ee. Dorsal spine wanting; caruncles present.

f. Caruncles remote from soft dorsal.

Mancalias, 1064.

$f f$. Caruncles close to soft dorsal.

CRYPTOPSARAS, 1065.

ONEIRODINAE:

cc. Cleft of mouth nearly horizontal; skin smooth; 1 cephalic spine and 1 postcephalic spine.

ONEIRODES, 1066.

\section{HIMANTOLOPHINA:}

$b b$. Gills in $\frac{1}{2} 2 \frac{1}{2}$ pairs; body with scattered tubercular scutella; no second dorsal spine.

g. Body and head compressed; mouth oblique; joint of mandible below or behind eye; eye rudimentary.

h. Body oblong, oval; dorsal rays 9; pectoral 12. Himantolophus, 1067. $h$. Body short and deep; dorsal rays 4; pectoral about 17.

aa. Mouth with enormous gape.

Corynolophus, 1068.

Melarocetine:

i. Cleft of mouth nearly vertical; pectoral small, in adrance of dorsal and of gill opening; second dorsal spine wanting; gills in $2 \frac{1}{2}$ l airs.

j. Gular tentacle wanting; no teeth on vomer.

$j j$. Gular tentacle present; 1 tooth on the vomer.

LIOCETUS, 1069.

LINOPHRYNE, 1070.

\section{CaUlophrinine:}

ii. Cleft of mouth nearly horizontal; pectorals below dorsal and behind gill opening; gills in $\frac{1}{2} 2 \frac{1}{2}$ pairs.

$k$. Dorsal and anal greatly produced; skin naked; head and body with many luminous filaments. 
I063. CERATIAS, Kröyer.

Ceratia, KRöYer, Naturhist. Tidsskrift. 2 Række, I, 639, 1844 (holbolli).

Head and body much compressed and elevated, oblong, covered with prickly skin. Mouth wille, its cleft nearly vertical; teeth in jaws conic, movable, of moderate size; no teeth on vomer or palatines. Gills $2 \frac{1}{2}$; gill arches unarmed. Spinous dorsal reduced to 2 spines, 1 on the head, the other on the back, the basal element of the second spine exserted; the cephalic spine much elongate; soft dorsal and anal short; pectorals very short, broad, of about 20 rays. Caudal fin much produced, fan-shaped, with exserted rays. Pyloric cæca 2, small. Skeleton soft, fibrous. Greenland. ( $x \varepsilon \rho \alpha \tau i \alpha 5$, onre that has horns.)

\section{CERATIAS HOLBOLLI, Kröyer.}

D. I-I, 4; A. 4; P. 19; C. 10 . Head $2 \frac{2}{3}$; depth nearly 2 ; head deeper than long; eyes small, not more than $\frac{1}{20}$ the length of the head; free rays of the head a little shorter than to the base of the caudal fin; the forked part of the caudal fin shorter than the length of the fish; the length of the pectoral fin equals almost $\frac{1}{20}$ the entire length of the fish, the membranes from the dorsal and anal fins posteriorly extend almost to the base of the caudal fin. Color entirely black. (Kröyer.) North Atlantic; 4 specimens known; 3 from Greenland, 1 from Nova Scotia. (Named for C. Holböll, a Danish naturalist.)

Oeratias holbolli, KRöYer, Naturh. Tidsskr. 1844, 639, Greenland; GünTHer, Cat., III, 205, 1861; Jordan \& Gilbert, Synopsis, 847, 1883; Goode \& BEAN, Uceanic Ichthyology, 489, pl. 117, fig. 394, 1896.

1064. MANCALIAS, Gill.

Mancalias, GiLl, Proc. U.S. Nat. Mus., I, 1878, 227 (uranoscopus).

Typhlopsaras, GiLh, Forest and Stream, Now York, 1883, Nov. 8, 284 (shufeldti).

General characters of Ceratias, but with the spinous dorsal reduced to a single rostral spine, and 2 fleshy claviform tubercles or caruncles behind it. Pectoral fins narrow, with 10 to 15 slender rays. (mancus, defective, "with a quasi-diminutive termination to correspond with Ceratias.")

a. Dorsal caruncles placed before dorsal fin a distance 6 times in length of trunk from gill opening to base of caudal.

URANOSCOPUS, 3110.

aa. Dorsal caruncles placed nearer dorsal, the distance from dorsal $4 \frac{1}{2}$ times in trunk, as above. SHUFELDTI, 3111 .

\section{MANCALIAS URANOSCOPUS (Mnrray).}

D. I, 3 or 4 ; A. 4 ; C. 8 ; P. 10 . Anterior spine of first dorsal produced in a long filament, ending in a pear-shaped bulb, terminating in a semitransparent whitish spot, this spine originating on posterior part of head, and reaching, when depressed, nearly to the tip of tail; far behind this are 2 short, fleshy tubercles, lying in a depression in front of secoud dorsal. Teeth moderate, depressible. Skin overywhere with minute embedded conical spines. Eye very small, placed high on the middle of the head. 
Color uniform black. (Murray.) To this description Goode \& Bean add from the same specimen: "Anal opposite second dorsal, the 4 median cauclal rays being much larger than the others and bifid; pectorals small, above the gill opening; the upper jaw is formed by the intermaxillaries, and is armed, together with the lower jaw, with a series of tecth of moderate size, which can be depressed as in Lophius. The skin is thickly covered with minute embedded conical spines; the eyes are very small and are placed high upon the middle of the head." Mid-Atlantic, in very deep water; 2 specimens known, the type in 2,400 fathoms, taken between the Canary and Cape Verde islands, the second (26159) in 372 fathoms off the

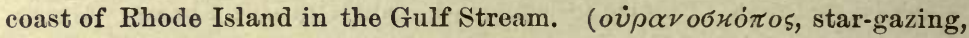
from the upturned eyes.)

Ceratias uranoscopus, Murray, in Wyville Thompson, The Atlantic, II, 67, fig. 20, 1878, mid-Atlantic, between Canary and Cape Verde Islands in 2,400 fathoms; GüNTHER, Challenger Report, xxII, 54, pl. 11, fig. C, 1887.

Mancalias uranoscopus, GrL, Proc. U. S. Nat. Mus. 1878, 228; Goode, Proc. U. S. Nat. Mus. 1880,469; Jordan \& Gilbert, Synopsis, 818, 1883; Goode \& Bean, Oceanic Ich thyology, 490, 1896.

\section{MANCALIAS SHUFELDTI (Gill).}

Maxillary $\frac{1}{8}$ the length from gill opening to caudal base; intermaxillary $3 \frac{1}{2}$ times in this length. Form more slender than that figured by Günther, with 4 rays in the dorsal, and apparently 15 in pectoral. There are no vomerines; intermaxillary and mandible armed with a narrow band of depressible teeth of various lengths. The skin with a fine granular appearance and everywhere covered with minute prickles. The caruncles only 2 in number and situated as in Mancalias uranoscopus, as figured in the Challenger fishes. Length of dorsal spine, without the joint bearing the pear-shaped appendage, equaling distance from gill opening to root of tail; the joint bearing the appendage is $\frac{2}{5}$ of this distance; in Mancalias uranoscopus (No. 26159) the first dorsal, without the joint bearing the appendage, contains the distance from the gill opening to the root of the tail $1 \frac{1}{4}$ times. The joint containing the appendage is $\frac{1}{2}$ as long as the distance from the gill opening to root of tail. Dermal caruncles distant from the dorsal a space equal to $\frac{1}{6}$ of distance from the gill opening to root of tail. In $M$. shufeldti the caruncles are placed at a distance from the dorsal a space contained $4 \frac{1}{2}$ times in the distance from the gill opening to the root of the tail. In the specimens described by Goode \& Bean as Mancalias uranoscopus (No.26159), the length $3 \frac{1}{4}$ inches, the length of the maxillary is $\frac{1}{8}$ of length from gill opening to root of tail, and the intermaxillary $3 \frac{1}{2}$ times in same distance. Teeth in jaws depressible, in narrow bands, and of unequal size; vomer toothless. Two small caruncles not far from front of dorsal fin, and instead of being placed opposite each other, according to the nsual arrangement, one is placed behind the other. Skin covered with minute granules or papillae, each one surmounted by a slender prickle, as in Typhlopsaras. The pectoral of the individual described contains 15 rays. The pectorals of $T$. shufeldti are imperfect. (Goode \& Bean.) Gulf Stream, off the coast of southern New England; 
1 specimen known. (Named for Dr. Robert W. Shufeldt, United States Army, the well-known ornithotomist.)

Typhlopsaras shufeldti, ${ }^{*}$ GILL, Forest and Stream, Nov. 8, 1883, Western Atlantic (Type, No. 33552); JoRdan, Cat. Fishes, 138, 1885.

Ceratius shufeldti, Günther, Challenger Report, xxı1, Deep-Sea Fishes, 54, 1887.

Mancalias shufeldti, Goode \& BEAN, Oceanic Ichthyology, 490, fig. 401, 1896.

1065. CRYPTOPSARAS, Gill.

Cryptopsaras, GiLl, Forest and Stream, Nov. 8, 1883, 284 (couesii).

Body shortened; back longitudinally convex, eyes small but conspicuous; anterior spine with concealed basal joint and elongated terminal joint; a large intermediate globular and a pair of subpedunculated lateral dorsal appendages or caruncles close to the front of the dorsal fin; pectorals well developed, of about 15 rays. Deep seas. ( modern Greek $\psi \alpha \rho \tilde{\alpha} 5$, fisherman, in reference to the concealed rod bearing the dorsal spine or fishing apparatus.)

3112. CRYPTOPSARAS COUESII, Gill.

The basal joint of the rod-like spine is almost entirely concealed and procumbent, and the distal joint alone free, reaching backward to the dorsal tubercle; the bulb is pyriform, and surmounted by a long whitish filament; dorsal and anal each with 4 spines, the eaudal 8 (the 4 iniddle dichotomous) and the pectorals each about 15 rays. (Gill.) A specimen of Cryptopsaras (No.33558, U. S. Nat. Mus.) was obtained, by the Albatross, from Station 2101, in Lat. $38^{\circ} 18^{\prime} 30^{\prime \prime}$ N., Long. $68^{\circ} 24^{\prime}$ W., at a depth of 1,686 fathoms. The type of Cryptopsaras couesii is only $35 \mathrm{~mm}$. long. The caudal is imperfect. The length without caudal is $30 \mathrm{~mm}$. and contains the greatest height $2 \frac{1}{2}$ times. The bulb on the dorsal spine when laid backward can be made to reach to the dermal caruncles on the back. The length of the upper jaw is about $\frac{1}{6}$ of the length without caudal; gill opening nearly midway between front of head and root of tail; mouth placed vertically; intermaxillary teeth occupying about entire length of bone; mandibulary teeth unequal in size; at symphysis of mandible a pair of minute spines closely connected at base and slightly separated at the extremity. Specimen No. 39483 is $58 \mathrm{~mm}$. long; $47 \mathrm{~mm}$. to base of caudal. Greatest height $2 \frac{2}{8}$ in length without caudal. Gill opening a little nearer end of caudal than to front of head; distal portion of dorsal spine about $\frac{1}{2}$ length without caudal; median dermal caruncle very much

* The following is the original acenunt of Typhlopsaras:

"Typhlopsaras.-Ceratiines with an elongated trunk, rectilinear back, obsolete or no eyes, far exserted basal joint of the anterior spine and shortened terminal joint, a small intermediate and a pair of pedunculated dorsal appendages some distance in advance of the dorsal fin, and reduced pectoral fin with about 5 or 6 rays.

"Typhlopsaras shufeldti. - The first joint of the rod-like spine reaches to the axil of the dorsal fin, and the bulb to the base of the caudal fin, when the spine is bent backward; the bulb is pear-shaped and without any appendages; the dorsal has 4 rays, the anal 4, the caudal 8 (the median 4 of which are forked), and there are 4 or 5 pectoral rays. A single specimen was found. I have dedicated the species to my esteemed friend, Dr. R. W. Shufeldt, U.S. A., the well-known ornithotomist.

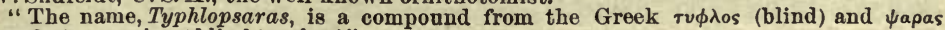
(angler), meaning 'blind angler.'" 
larger than the two lateral ones; skin covered with minute granules of uniform size; pectoral with 16 rays, its length about $\frac{1}{5}$ that of head; length of upper jaw about $\frac{1}{5}$ of total without caudal; pair of spines at symphysis of mandible replaced by a very small knob; teeth in intermaxillary very small, diminishing in number toward the symphysis, apparently uniserial. On each side of head of vomer 2 or 3 depressible teeth; palatines apparently wanting. We have seen something like traces of similar teeth on the vomer of Mancalias uranoscopus, but owing to the condition of the specimen can not be certain about this character. (Goode \& Bean.) Gulf Stream, off the coast of New England. (Named for the eminent ornithologist, Dr. Elliott Coues.)

Cryptopsaras couesii, GuL, Forest and Stream, Nov. 8, 1883, 284, Gulf Stream off New England (Coll. Albatross); JoRDAN, Cat Fishes, 138, 1885; GoOdE \& BEAN, Oceanic Ichthyology, 491, fig. 402, 1896.

Ceratias couesii, GƯNTHFR, Challenger Report, XXII, 55, 1887.

? Ceratias carunculatus, GínTHeR, Challenger Report, XXII, 55, pl.11, fig. $d$, 1887, south of Yezo, Japan, in 345 fathoms; $1 \frac{1}{2}$ inches long. (ColI. Challenger.)

\section{I066. ONEIRODES, Lïtken.}

Oneirodes, Lütkex, Overs. Kong. Dansk. Vidensk. Selsk. Forhandl. 1871, 56 (eschrichtii).

Body compressed, oval, short, covered with smooth skin. Head compressed, very large. Mouth moderate, almost horizontal, the joint of mandible behind eyes. Teeth unequal, depressible; vomer with teeth. Gill arches unarmed; gills in $2 \frac{1}{2}$ pairs. Spinous dorsal represented by a cephalic spine, the basal element of which is procumbent and subcutaneous, the tip bulbous, and a second spine about midway between the rostral spine and the soft dorsal; soft dorsal and anal short; no ventrals; no pyloric

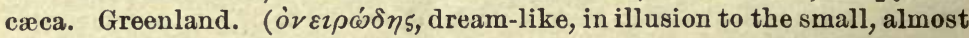
covered, eyes.)

3113. OXEIRODES ESCHRICHTII, Lütkèn.

D. I-I, 6 ; A. 8 ; C. 8 . Terminal half of the bulb of the cephalic spine whitish. Cephalic spine with a bulbous termination, surmounted by slender filaments in several trausverse rows. Caudal fin shorter than trunk without head. Color black. Deep sea, off Greenland. Known from a single specimen 8 inches long. (Gill.) (Named for D. F. Eschricht, a Danish naturalist, a student of the Cetacea.)

Oneirodes eschrichtii, LÜTKEN, Overs. Dansk. Vidensk. Selsk. Forhandl. 1871, 56, 9-18, pl. 2, deep sea off Greenland; GiLl, Proc. U. S. Nat. Mus.1878, 218; Jordan \& GilberT, Synopsis, 818, 1883; GOODE \& BEAN, Oceanic Ichthyology, 492, 1896.

I067. HIMANTOLOPHUS, Reinhardt.

Himantolophus, REINHARDT, Dansk. Vidensk. Selsk. Nat. 1837, 74 (gronlandicus).

Head large, compressed. Skin thick, with scattered, round, prickly scales. Body oval, compressed. Mouth moderate, the cleft oblique, the joint of the mandible below or behind the eyes. Gills in $\frac{1}{2} 2 \frac{1}{2}$ pairs; gill arches armed with dentigerous tubercles. Spinous dorsal represented 
only by a singrle long rostral spine, the basal element of which is procumbent and subcutaneous; the extremity with numerous long filaments. Soft dorsal short, with 9 rays; anal short; pectoral rather broad, with 12

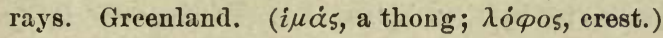

\section{HIMANTOLOPHUS GROEIANDICUS, Reinhardt.}

Depth $2 \frac{1}{2}$ in total length. D. I-9; P. 12. Body oblong oval. Cephalic ray provided with about 11 tentacles. (Gill.) Greenland. "This species has never been fully described, the only existing example being an imperfect one, 23 inches long, obtained off the coast of Greenland, about 1837."

Himantolophus grœnlandicus, Reinhardt, Dansk. Vid. Selsk. Nat. Math. Afh. 1837, 74, Greenland; Gill, Proc. U.S. Nat. Mus.1878, 218; Jordan \& Gilbert, Synopsis, 849, 1883.

1068. CORYNOLOPHUS, Gill.

Corynolophus, GrLL, Proc. U. S. Nat. Mus. 1878, 219 (reinhardti).

This genus is scarcely distinct* from Himantolophus, differing in the short oval form, the short dorsal of about 5 rays, and the broader pectoral

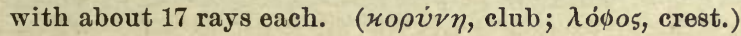

\section{CORYNOLOPHUS REINHARDTI (Lütken).}

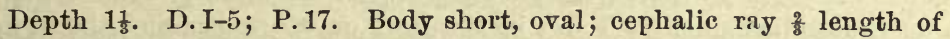
head, with about 8 tentacles, which branch out forming a brush at tip; skin sparsely covered with thorn-like prickles. Greenland. One specimen known, 14 inches long. (Named for Prof. Johann Reinhardt, naturalist at the University of Copenhagen.)

Himantolophus reinhardti, LÜTKEN, Kong. Nansk. Vidensk. Selsk. 1878, 321, Greenland. Corynolophus reinhardti, GiLL, Proc. U. S. Nat. Mus. 1878, 219.

Io69. LIOCETUS, Gïnther.

Liocetus, GÜNTHER, Challenger Report, XX.., 57, 1887 (murrayi).

Mouth enormous, the clefi nearly vertical; pectorals small, in advance of dorsal and of gill opening; second dorsal spine wanting; gills in $2 \frac{1}{2}$ pairs; no gular tentacle. This genus is similar to Melanocetus, differing in having no teeth on the vomer, a greater projection of the mandible,

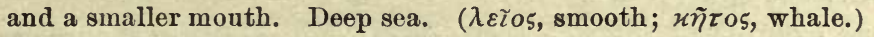

\section{LIOCETUS MURRAYI (Günther).}

D. I-13; 4.4; C.9; P.14. (Giinther.) Extremely similar to Melanocetus johnsonii, but without trace of vomerine teeth, while there is no distinction between the two species as regards dentition of jaws; posterior angle

*Dr. Gill, replying to certain strictures as to the validity of this genus, made by Liitken [who calls it a "wanton" subdivision], states that the "differences alleged to exist between Himantolophus and Corynolophus are very marked. If they do exist as stated there can be no doubt that the two should be kept apart. I know of no reason except the singularity and greatness of the difference specified for doubting the correctness of Reinhardt's observatious." 
of mandible projecting more and forming a salient point; mouth comparatively less wide, and the maxillary considerably shorter, being about $\frac{2}{5}$ of total length, without caudal, while it is rather more than $\frac{1}{2}$ in the Madeiran species. Eye rudimentary. One cephalic spine, shorter than maxillary; last dorsal ray connected by a short and delicato membrane with caudal fin; most of the caudal rays bifid, the longest shorter than maxillary; pectoral fin as much developed as in Melanocetus johnsonii. Entirely black. Total length 44 lines; length of mandible 14 lines; length of maxillary 12 lines; length of caudal fin $10 \frac{1}{2}$ lines. A young individual, 44 lines in length, was taken by H.M. S. Challenger in the mid-Atlantic, at a depth of 1,850 fathoms (Station 106); another of 13 lines at the depth of 2,450 fathoms 'Station 348). (Goode \& Bean.) (Named for Dr. John Murray, second director of the civilian staff on board H. M. S. Challenger.)

Melanocetus bispinosus, GÜNTHER, Study of Fishes, 473, 1880; name only.

Melanocetus (Liocetus) murrayi, GüNTHER, Challenger Report, xxII, 57, pl.11, fig. A, 1887, mid-Atlantic.

Liocetus murrayi, Goode \& BEAN, Oceanic Ichthyology, 495, fig. 407, 1896.

ro7o. LINOPHRYNE, Collett.

Linophryne, CoĽLFT, Proc. Zool. Soc. London 1886, 138 (lucifer).

Head enormous; the body slender, compressed, mouth oblique. Spinous dorsal reduced to a single cephalic tentacle, the basal part of which is erect, not procumbent. Teeth in the jaws on the vomer and the upper pharyngeals. Gill openings exceedingly narrow, situated a little below the root of the pectoral. Soft dorsal and anal very short; ventrals none. Abdominal cavity forming a sac, suspended from the trunk. Skin smooth; a long tentacle on the throat. This genus differs from Melanocetus in the presence of the gular tentacle. ( $\lambda$ ivos, linen, net; $\phi \rho \dot{v} v \eta$, a toad.)

\section{LINOPHRYNE LUCIFER, Collett.}

D. I-3; A. 2; C. 9 ; P. 14 or 15 . A spinous projection or horn above each orbit. Cephalic tentacle black, with a large ovate bulb, the upper half of which is white; gular tentacle much larger, terminating in 2 tongue-like appendages, which are furnished on the upper edge with a row of round, white papilla. (Goode \& Bean.) Mid-Atlantic, northwest of Madeira, Lat. $36^{\circ} \mathrm{N}$., Long. $20^{\circ} \mathrm{W}$. One specimen known. (Lucifer, an evil spirit; lux, light; fero, I bear.)

Linophryne lucifer, Colletr, Proc. Zool. Soc. London 1886, 138, pl.15, mid-Atlantic, between Madeira and the West Indies (Coll. Capt. P. Andresen. Mus. Univ. Christiania); GüNTHER, Challenger Report, $\mathbf{x} I 1,37,1887$; GoOdE \& BEAN, Oceanic Ichthy. ology, 496, fig. 408, 1896.

\section{I071. CAULOPHRYNE, Goode \& Bean.}

Caulophryne, GOoDE \& BEAN, Oceanic Ichthyology, 496, 1896 (jordani).

Head large, compressed; mouth with the cleft nearly horizontal; body short, much compressed. Spinous dorsal reduced to a single cephalic tentacle, which is supported on a short procumbent base. Teeth of unequal size in the intermaxillary and the mandible; vomer, palatines, and upper 
pharyngeals toothed. Gill openings narrow, horizontal slits placed below and in front of root of pectorals. Branchix in $\frac{1}{2} 2 \frac{1}{2}$ pairs. Branchial arches armed with dentigerous tubercles. Skin naked. Numerous luminous filaments on head and body. Soft dorsal and anal many-rayed, the rays greatly produced; caudal long, tapering; ventrals none; pectorals very broad, sessile, postmedian, under dorsal fin, with numerous rays. Pyloric appendage reduced to 1 small rudiment. Air bladder absent. ( $\alpha v \lambda \dot{s}$, stem; $\phi \rho v \dot{v} \eta$, toad, from the many stems or fin rays.)

3119. CAULOPHRYNe JORDANI, Goode \& Bean.

Depth about 2 in length without caudal, the greatest height occurring behind the head. Cephalic appendage with a pale tuft at its tip, the length of the distal portion 3 in length of body. The tuft somewhat mutilated, but showing no evidence of a laminated structure; basal portion of cephalic appendage about twice as long as the very small eye; maxillary very slender, narrow, extending about as far backward as intermaxillary; intermaxillary slightly protractile and with about 10 teeth on each side, several of which are nearly twice as large as the rest, its length $2 \frac{1}{2}$ in body; mandible as long as head without snout, with 8 teeth on each side, the anterior pair and several other pairs along shaft of bone being greatly enlarged; a pair of enlarged teeth on head of vomer; several similar teeth on palatines; upper pharyngeals armed with several strong teeth; eye very small, inconspicuous, its distance from tip of snout equaling nearly $\frac{1}{8}$ its distance from soft dorsal origin. Intestine shorter than length without caudal. Soft dorsal with 16 rays, all of which, except the last 4, are greatly produced; the second, third, and fourth rays longest, nearly twice as long as body. Anal with 14 rays, all of which, except last 3 , are much produced, the fin not quite perfect, yet its anterior rays are longer than body; caudal with 8 rays, the 4 inner ones divided, the rest simple; middle rays of caudal as long as distance from tip of lower jaw to base of pectoral; pectoral comparatively short, with 16 simple articulated rays, the longest about $\frac{1}{2}$ as long as head. About 9 luminous filaments on each side of head, 7 more between nape and dorsal, and about 12 on sides; the filaments nearly twice as long as eye. Head and body black; caudal, cephalic tuft, and most of the rays pale. Gulf Stream. The type of the species (No. 39265) was taken by the steamer Albatross, September 19,1887 , in Lat. $39^{\circ} 27^{\prime}$ N., Long. $71^{\circ} 15^{\prime}$ W., 1,276 fathoms. (Named for David Starr Jordan.)

Oaulophryne jordani, GOODE \& BEAN, Oceanic Ichthyology, 496, pl. 21, fig. 409, 1896, Gulf Stream, off Carolina, in 1,276 fathoms. (Coll. Albatross; the plate named Oaulophryne setosus, by slip in proof reading.)

\section{Family CCXXIV. OGCOCEPHALIDA.}

\section{(The Bat-Fishes.)}

Head very broad and depressed, the snout more or less elevated, the trunk short and slender. Mouth not large, subterminal or inferior, the lower jaw included; teeth villiform or cardiform. Gill openings very 
small, above and behind the axils of the pectoral fins. Body and head covered with bony tubercles or spines. Spinous dorsal reduced to a small rostral tentacle, which is retractile intc a cavity under a prominent process on the forehead; in 1 genus the rostral tentacle is obsolete; soft dorsal and anal fins small and short; ventrals well developed; pectoral fin well developed, its base strongly angled, with long pseudobrachia and 3 actinosts. Branchiostegals 5 ; no pseudobranchiæ. Genera 8; species about 30, chiefly American, some of them in the deep sea. (Pediculati, part; genera Malthe and Halieutoea, Günther, III, 200-205, 1861.)

OGCOCEPHALINA:

$a$. Disk with the frontal region elevated and the snout more or less produced forward, the tail stout; orbits lateral; teeth on vomer and palatines; rostral tentacle present.

b. Gills $2 \frac{1}{2}$; disk longer than broad.

OGCOCEPHALUS, 1072.

$b b$. Gills $2 \frac{1}{2}$; disk broader than long.

ZALIEUTES, 1073.

HALIEUTINE:

aa. Disk with the frontal region depressed, not elevated above the rest; eyes partly superior; snout rounded, obtuse in front; tail slender.

c. Dorsal fin present.

d. Vomer and palatines with teeth.

$d d$. Vomer and palatines toothless.

HALIEUTICHTHYS, 1074.

e. Disk subcircular; gills $2 \frac{1}{2}$.

$f$. Mouth rather large, subvertical; prickles rather strong.

ff. Mouth rather small, terminal; prickles feeble.

HALIEUT AEA, 1075.

Halieutella, 1076.

ee. Disk subtriangular; gills 2; prickles very strong.

DiBRANCHC8, 1077.

1072. OGCOCEPHALUS, Fischer.

(SEA-BATS.)

Ogcocephalus, Fischer, Zoognosia, 78, 1813 (vespertilio).

Oncocephalus, GILL, modified spelling.

Malthe, Cuvier, Règne Animal, Ed. I, II, 311, 1817 (vespertilio).

Malthoea, corrected spelling.

Body stoutish, tapering backward; head very broad and depressed, triangular in form, the forehead elevated and produced. Eyes large, lateral. Mouth rather small, subinferior under the snout; villiform teeth in bands, on jaws, vomer, and palatines. Skin covered with rough, bony tubercles. Dorsal and anal fins very small; rostral tentacle present, retractile into a cavity under a bony prominence on the forehead; ventrals present, I, 5,

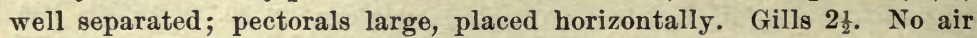
bladder; no pyloric cæca. Tropical America, in shallow water; small fishes of singular form, often regarded by the ignorant as venomous.

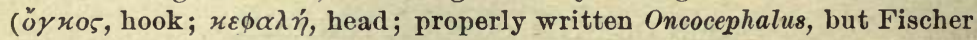
chose the above moustrous spelling.)

a. Snout produced, the rostral process pointed, 6 to 10 in length of body.

VESPERTILIO, 3119.

aa. Snout short, the rostral process 12 to 15 times in length of body. NAsutus, 3120. aaa. Snout short, the rostral tubercle reduced to a button-like tubercle, which is about 25 times in length of boriy. RADIATUS, 3121. 
3119. OGCOCEPHAIUS VESPERTIIIO (Linngus).

(Bat Frsh; Diablo.)

Head, from tip of upper jaw to gill opening, nearly $\frac{1}{2}$ the length; depth 5 in length from upper jaw to base of caudal; width $1 \frac{4}{5}$. D. 4 ; A.4; rostral process from 6 to 10 (9 in our specimens from Havana); P. $4 \frac{1}{2}$; V. 6 ; C. $4 \frac{1}{4}$. Body stoutish, much depressed, rostral process longer than in the other species, variable in length; mouth small, the maxillary reaching nearly to posterior margin of eye; villiform teeth in bands, on jaws, vomer, and palatines; interorbital flattish, its width less between anterior edge of eyes than posterior edge; rostral groove longer than broad; body covered with bony protuberances, variable in size, and not very definite in position, lower parts with a shagreen-like covering; posterior edge of pectorals much behind middle of body; ventrals long, reaching outward to edge of the disk-like, anterior part of body; origin of dorsal over posterior edge of pectoral; anal under the vertical of tips of dorsal rays, anal reaching nearly to base of caudal. Pale grayish brown above, reddish below; back with round black spots, conspicuous in life, but growing fainter and sometimes disappearing in spirits; belly in life a coppery red; pectorals nearly plain dusky. Length 12 inches. West Indies, north to the Florida Keys; common in shallow water. Here described from a specimen from Havana, Cuba, about 10 inches in length. The length of the snout is subject to great variation, but it is never short and button-like, as in $O$. radiatus. (vespertilio, a bat.)

Lophius vespertilio, LINNeUs, Syst. Nat., Ed. X, I, 236, 1758, American Seas ; after Lophius fronti unicorni of ARTEDr.

Malthoea vespertilio, Cuvier \&. VALenciennes, Hist. Nat. Poiss., XIr, 440, 1837; prominence un snout 10 in length; DE KAY, N. Y. Fauna: Fishes, 167, 1842; GüNTHER, Cat., IIr, 200, 1861; Jordan \& Gilbert, Syopsis, 850, 1883; Jordan \& SwaIn, Proc. U. S. Nat. Mus. $1884,234$.

Lophius rostratus, SHAW, Zool., IV, 383, pl. 163, 1803.

Malthoea longirostris, Cuvier \& VAlencrennes, Hist. Nat. Poiss., XII, 452, 1837, Bahia (Coll. Blanchet); snout 6 in length.

3120. OGCOCEPHALUS NASUTUS (Cuvier \& Valenciennes).

Head 2. D. 4; A. 4. Rostral process short, about 12 to 15 times in length of body. Cavity of nostril tentacle higher than broad; width of body 2 in length; vent behind middle of body. Dusky above, with round black spots, edged with whitish. West Indies. (Lütken); not seen by us; perhaps a variation of $O$. vespertilio. (nasutus, long-nosed.)

Malthoea nusuta, Cuvier \& VAlenciennes, Hist. Nat. Poiss., Xrr, 452, 1837, Martinique.

Malthe nasuta, LÜtkeN, Nat. For. Vid. Medd. 1865, 4; JordAN \& Gubert, Synopsis, 850, 1883.

Malthoea notata, Cuvier \& VALENCIENNES, Hist. Nat. Poiss., XII, 453, 1837, Surinam; snout 15 in length; body spotted. 
3121. OGCOCEPHALUS RADIATUS (Mitchill).

(SHORT-NOSED BAT-FISH.)

Head 2. Dorsal 4; A. 4. Rostral cavity somewhat broader than high, or width equal to height; distance between anterior angles of orbits about equal to that between the posterior angles; eye a little wider than interorbital width; snout, exclusive of rostral tubercle, not produced beyond the rostral cavity, but with a cylindrical button-like tubercle, slightly contracted at base, pointing obliquely upward and forward, its length 25 times in body; posterior edge of pectoral slightly nearer base of candal than upper jaw; caudal peduncle very thick and heavy; vent about midway between tip of jaw and base of caudal fin. Color brownish, with dark round spots sometimes edged with white; pectorals with a network of white lines dividing the dark color into dark brown spots; tip of caudal blackish, belly coppery red. Length 8 to 12 inches. Coast of Florida and neighboring waters; very common in shallow bays among weeds, especially about the Florida Keys. Here described from a specimen from Cedar Key, Florida, 7 to 8 inches in length. (radiatus, rayed.)

Lophius radiatus, Mrтchil.L, Amer. Monthly Mag., March, 1818, 326, Straits of the Bahamas.

Malthe cubifrons, RichaRdson, Fauna Bor.-Amer., Ir, 103, 1836, said to be from Labrador

(Coll. J. J. Audubon), but this is certainly an error; Audubon collected also in Carolina and Florida; GưNTHER, Cat., III, 203, 1861; JoRDAN \& GLLBERT, Synopsis, 850, 1883; Jordan, Cat. Fishes, 139, 1885.

? Malthaea truncata, Cuvier \& VAlenciennes, Hist. Nat. Poiss., XII, 454, 1837, America ; snout wholly obsolete; perhaps a species of Zalieutes.

Malthoea angusta, Cuvier \& VALENCIENNES, Hist. Nat. Poiss., XIr, 454, 1837, Dutch Guiana; snout more than 20 in length.

I073. ZALIEUTES, Jordan \& Evermann.

Zalieutes, Jordan \& Evermann, Check-List Fish. N. and M. A., 511, 1896 (elater).

Disk wider than long, about as long as rest of body (including caudal fin); middle line of head elevated, but the forehead not projecting beyond mouth; rostral tentacle present, the cavity about as wide as high; mouth small; minute teeth on vomer and palatines. Gills $2 \frac{1}{2}$. Eastern Pacific. The genus is very close to Malthopsis, Alcock, ${ }^{*}$ but the latter, like Ogcocephalus, has the disk longer than broad, but the gills are reduced to 2 . ( $\zeta \dot{\alpha} \lambda \eta$, surge of the sea; $\dot{\alpha} \lambda \imath \varepsilon v \tau \dot{\eta} 5$, fisher.)

3122. ZALIEUTES ELATER (Jordan \& Gilbert).

Body very broad and depressed, the disk considerably broader than long, its width $1_{5}^{2}$ times in length of body; back and snont considerably raised above rest of body; greatest depth of body scarcely more than width of month. Mouth small, its width $\frac{1}{2}$ greater than diameter of orbit; snout very short, scarcely projecting beyond mouth, its length

*Malthopsis, Alcock, Ann. and Mag. Nat. Hist. 1891, 26; Malthopsis luteus, from the Andaman Sea; Malthopsis mitriger, Gilbert \& CraMer, Proc. U. S. Nat. Mus. 1896, 434, with plate, off Hawaiian Islands. 
about equal to interorbital width, shorter than its own width in front. Eye rather large, much longer than snout, wider than interorbital area. Process representing first dorsal spine present, small. Skin covered with spines, which are comparatively slender and sharp, their stellate bases inconspicuous, those on snout and middle of back and tail largest, much slenderer and sharper than in Ogcocephalus vespertilio; no spines on ocelli of back; belly rough; under side of tail with tubercular plates; tail depressed toward base of fin. Pectorals $\frac{1}{3}$ longer than ventrals, their length $1 \frac{2}{3}$ width of mouth; caudal a little longer than pectoral, $4 \frac{1}{3}$ in body. Color light olive, above everywhere thickly and uniformly covered with small round spots of dark brown, these about as large as the pupil and about as wide as the lighter interspaces; a conspicuous ocellus, larger than eye, on each side of back, this ocellus with a bright yellow spot in the center, surrounded by a black ring, around which is a pale ring, and finally a fainter dark one; under parts plain white; pectorals spotted; caudal yellowish at base, with a terminal blackish band. Length 4 inches. Pacific coast of Mexico, south to Panama, in water of moderate depth; very rare near the shore, but obtained in abundance by the Albatross at Stations 2794 and 2795, near Panama. (Elater, the spring beetle, from the resemblance of the ocelli to the eye-like spots on the back of Elater.)

Malthe elater, Jordan \& GILBERT, Proc. U.S. Nat. Mus.1881, 365, Mazatlan. (Type, No. 28127. Coll. Dr. J. U. Bastow.)

Ogcocephalus elater, Jordan, Proc. Cal. Ac. Sci. 1895, 506.

1074. HALIEUTICHTHYS, Poey.

Halieutichthys, PoEx, Proc. Ac. Nat. Sci. Phila. 1863, 83 (reticulatus).

Disk subcircular, anteriorly cordiform, the head merging into the body, very large and much depressed; cranial portion not elevated; interorbital space low and narrow; eyes partly superior; mouth terminal, horizontal, the jaws subequal, the lower jaw nearly semicircular; teeth fine, on jaws and palate. Gills $2 \frac{1}{2}$; no gill rakers; gill openings anterior to pectoral; rostral tentacle very small, retractile; dorsal and anal few-rayed; pectorals large, the carpus slender; caudal rounded; skin above sparsely armed with stellate tubercles; lower surface smooth. ( $\dot{\alpha} \lambda \imath \varepsilon v \tau \eta \dot{\eta} 5$, fisher; $i \chi \theta \dot{s}$, fish.)

a. Surface of body covered with brownish reticulations; fins not barred with black. ACULEATUS, 3123.

aa. Surface of body blackish, not reticulate; pectorals with a broad black bar mesially, the tip pale; caudal blackish toward the tip. CARIBBEUS, 3124.

\section{HALIEUTICHTHYS ACULEATUS (Mitchill).}

D. I, 4 or 5 ; A. 4 ; V. I, 5 ; P. 16 to 18 ; C. 9 ; gills $2 \frac{1}{2}$. Disk cordiform, about as wide as long, its length more than $\frac{2}{3}$ that of body. Body covered above with stout conical spines with stellular bases, largest upon the trunk, upon which they are arranged in about 2 irregular longitudinal 
rows on each side of the dorsal; upon the disk they are placed above the principal bones of the skeleton, most abundant upon its cranial portion; a single row of stout spines, usually 3-pointed, on the outer margin of disk, a particularly large one at each outer angle; body entirely smooth below; snout very short, obtuse; bridge over the rostral cavity covered in front with a 3-pointed spine, having on each side a simple spine; short; stout, simple spines upon each supraorbital margin, the front of which is immediately above and behind the cavity containing the nostrils; vertex with several similar spines; many spines closely placed upon the humeral area; numerous short tentacles upon margin of disk and on sides of trunk; supraoral cavity elliptical, small (horizontal diameter $\frac{2}{7}$ diameter of orbit), containing a well-developed, club-shaped, very perceptible tentacle; width of opening of anterior nostril, which is in a short tube, $\frac{1}{2}$ that of posterior nostril, which is not tubular; width of mouth much less than distance between pupils and equaling diameter of orbit. Diameter of orbit $8 \frac{1}{2}$ times in distance from snout to base of caudal, 6 times in distance from suout to origin of soft dorsal, $6 \frac{1}{2}$ times in distance to origin of anal, 3 times in distance to base of ventrals, and 6 times in distance to angle between pectorals and trunk, $4 \frac{2}{8}$ times in distance from snout to gill opening, 6 in greatest width of disk, and nearly 2 in that of trunk; width of interorbital area $\frac{2}{5}$ diameter of orbit. First dorsal ray longest, equal to diameter of orbit; anal fin inserted under third ray of dorsal, with 4 rays, the third or longest very slightly longer than the longest dorsal ray; ventral fins inserted nearly under the middle of the disk, with 1 rudimentary and 5 dorsal rays, increasing in length posteriorly, the last and longest contained 5 times in total length; distances between origins of ventrals $6 \frac{1}{2}$ in total length; pectorals with peduncles entirely included in common membrane, with blades far back, horizontal, lying close to trunk, composed of 16 rays, the middle or longest $3 \frac{2}{3}$ in total length ; caudal fin rounded, composed of 9 rays, the external rays, 1 above and 2 below, simple, the others bifid; length of middle ray equal to that of trunk (measured from junction of pectorals to base of caudal rays) and slightly exceeding the longest pectoral ray. Length of intestine contained $1 \frac{2}{3}$ times in total length. Color, body covered above with reticulations of brown, the general hue varying from light yellowish gray to grayish brown, the markings being darker upon darker specimens; pectoral and caudal fins with about 3 dark. bars; the terminal bars in young very black; body beneath milky white (Goode \& Bean.) West Indies, Gulf of Mexico, and Gulf Stream, in water of moderate depth; taken by the Blake and the Albatross at numerous stations in depths ranging from 10 to 95 fathoms. "As in Halieutar, Dibranchus, and allies, a rostral tentacle is present in this genus. Among specimens belonging to the Museum of Comparative Zoology there is evidence of the existence of a couple of distinct forms in the West Indian waters. The true $H$. aculeatus is much the lighter in the ground colors and has brownish reticulations across the back, 2 or 3 narrowish transverse bands of the same color across the pectorals, and 2 or 3 similar bands appear on the caudal, the posterior being darkest. The margins of the fins are light in color. The rostrum is acnte; it ends in a spine which 
turns upward, and, seen from above, it is hardly long enough to cover the tentacular niche. Evidently this type belongs to the shallower waters. The localities noted carry its distribution from the Bahamas to the Yucatan Banks, in depths of 40 fathoms and less." (Garman.) (aculeatus, with needle-like spines.)

Lophius aculeatus, MitchILL, Amer. Mon. Mag., II, 1818, 325, Straits of Bahama.

Halieutichthys reticulatus (Poex MS.) GILL, Proc. Ac. Nat. Sci. Phila. 1863, 91, Cuba (Coll. Prof. Felipe Poey); Jordan \& Gilbert, Synopsis, 851, 1883.

Halieutichthys aculeatus, GOode, Proc. U.S. Nat. Mus. 1879, 109; GOode \& BEAN, Oceanic Ichthyology, 504, pl. 122, fig. 414a and b, 1896; GARMan, Bull. Lab. Nat. Hist. Iowa Univ. 1896, 87, pl. 4, fig. 1.

3124. HALIEUTICHTHYS CARIBBEUS, Garman.

D. I-5; A. 4; V. 5; P. 17; C. 9. Color darker than H. aculeatus; the reticulations are not present; the outer half of the pectoral, except at the margin, is black; and, excepting the narrow posterior margin, the hinder fifth of the caudal fin is black; the upper surface is clouded brownish without traces of the network pattern common to $H$. aculeatus. On the specimens described, the rostrum is acute, and the spine extends forward to cover the cavity receiving the tentacle so that it is not visible when viewed from above. West Indies. As now known, this species ranges from Jamaica to Barbados in depths of 70 to 150 fathoms or more. (Garman.) (caribbceus, from the Caribbean Sea.)

Halieutichthys caribbous, Garman, Bull. Lab. Nat. Hist. Iowa Univ. 1896, 87, pl. 4, fig. 2, Jamaica to Barbados.

1075. HALIEUT EA, Cuvier \& Valeneiennes.

Halieutcea, Cuvier \& VAlenciennes, Hist. Nat. Poiss., XII, 455, 1837 (stellatus).

Head very large, broad, depressed, its outline nearly circular; cleft of the mouth wide, horizontal; jaws with small eardiform teeth; no teeth on vomer or palatines. Skin everywhere covered with small, stellate spines. Forehead with a transverse bony ridge, beneath which is a tentacle, retractile into a cavity, the only rudiment of the spinous dorsal fin; soft dorsal and anal very short, far back. Gills $2 \frac{1}{2}$, the anterior gill arch without laminæ. Branchiostegals 5̆; vertebræ 17. Pacific Ocean. ( $\dot{\alpha} \lambda \imath \varepsilon v \tau \eta ் 5$, one who fishes.)

\section{HALIEUTEA SPONGIOSA, Gilbert.}

D. 6 ; A. 4 ; C. 9 ; V. 4 ; P. 12 or 13 . This species is remarkable for the soft, spongy texture of the body, and the membranaceous or cartilaginous character of its bones. Width of head $1 \frac{1}{5}$ in its length; tail long and slender, the vent midway between base of candal and articulation of mandible; width of base of tail $4 \frac{1}{8}$ in its length; mouth little or not at all overpassed by the snout, its width $2 \frac{8}{4}$ to 3 in that of head, lower jaw usually not included; gape of mouth oblique, almost wholly anterior. Teeth in wide cardiform bands in the jaws, none of them enlarged; palate toothless. Interorbital width slightly greater than length of snout, 5 in width of 
head; eye 18 in interorbital width. Rostral tentacle short, with an expanded 3-lobed tip; front of dorsal midway between base of caudal and occiput; caudal long, rounded, the lower rays more shortened than the upper, the longest nearly $\frac{1}{2}$ width of head; anal rays high, closely bound together, the fin slender, shaped like the intromittent organ of Gambusia, the length of its base equaling $\frac{2}{3}$ diameter of orbit, its longest ray reaching base of caudal; pectorals long, the posterior rays rapidly shortened, the longest $\frac{1}{2}$ width of head; head and body everywhere with broadly conical, tubercular plates, varying in size, marked with strong lines, radiating from the center; the apex sometimes blunt, more often provided with a slender spine, sometimes bifid or trifid; on the tail these spines become longer and are directed backward; plates along edge of disk not compressed nor specially modified. A deep groove-like channel just behind mandible and following curve of latter, becoming continuous with another deeper channel running just below edge of disk to near base of pectorals; a third groove runs backward from nostrils, uniting with the others, these grooves spanned at intervals by pairs of fleshy tentacles with fringed tips, which spring from the edges of the grooves and meet across them; at the bottom of the grooves under each pair of tentacles is a small fleshy tubercle. Fin rays, at least at base, with series of small curved prickles. Color uniform dusky, the tail sometimes lighter; fins blackish, more or less edged with white. One specimen with the body and tail uniformly light. Pacific coast of Mexico in deep water. Numerous specimens, the largest $4 \frac{1}{2}$ inches long, from Albatross Station 2992, in 460 fathoms. (Gilbert.) (spongiosus, spongy.)

Halieutcea spongiosa, GLLBERT, Proc. U. S. Nat. Mus. 1890, 124, west of Revillagigedo Islands, at Albatross Station 2992, Lat. $18^{\circ} 17^{\prime} 30^{\prime \prime}$ N., Long. $114^{\circ} 43^{\prime} 15^{\prime \prime}$ W., in 460 fathoms. (Coll. Gilbert.)

1076. HALIEUTELLA, Goode \& Bean.

Halieutella, Goode \& Bean, Proc. Biol. Soc. Washington, 1882, 88 (lappa).

Body subcircular, depressed, its width equal to its length, covered with flaccid, inflatable skin. Spines feebler and less numerous than in Halieutaca. Head merged in body; forehead with a transverse bony ridge; no perceptible supraoral cavity; no tentacle. Mouth small, terminal; lower jaw slightly curved forward. Teeth in the jaws minute, cardiform, not discernible on palate, though possibly present. Carpus broad, slightly exserted; pectoral fins remote from tail, obliquely placed, with membranes subvertical. Branchial aperture posterior to carpus, upon the disk, and not remote from its margin. Gills $2 \frac{1}{2}$. Dorsal fin 5-rayed, inserted at junction of disk with caudal peduncle; anal fin 4-rayed, originating at root of caudal peduncle. ( $\dot{\alpha} \lambda \imath \varepsilon v \tau \dot{\eta} \rho$, a fisherman.)

3126. HALIEUTELIA LAPPA, Goode \& Bean.

D. 5; A. 4; C. 9 ; P. 15; V.5. Disk subcircular, more than $\frac{2}{8}$ as long as the body. Body covered with a loose, flaccid, inflatable skin, which so obscure its proportion, that it is impossible to determine its exact height, 
but it is not nearly so much depressed as in the related genera. When the body is inflated the height and length of the disk is nearly equal. Spines rather feeble; about 10 between snout and dorsal fin; about 6 strong spines, with conical bases and stellular tips, on outer margin of disk on each side, the anterior of them being opposite the eye; in front of these spines on the discal margin, and between them and the snout, are several small, simple spines, pointing backward; belly armed with spines similar to those on the back, but weaker; a stellate spine upon tip of snout, with 2 weaker, simple spines on each side; nasal openings midway between eyo and tip of snout; mouth small, upon the margin of the disk; upper jaw shorter than diameter of eye. Teeth as described in the generic diagnosis. Dorsal fin inserted at posterior limit of disk, with 5 simple, articulated rays, its longest ray $\frac{1}{5}$ as long as disk; anal fin with 4 simple, articulated rays, inserted directly beneath fourth ray of dorsal, its second and longest ray $\frac{1}{4}$ as long as disk; caudal twice as long as anal, and slightly longer than caudal peduncle, with 9 simple, articulated rays. Carpus inserted at a distance from snout equal to twice length of longest pectoral ray, which is slightly greater than distance of posterior margin of carpus, at its junction with disk, from vent; number of pectoral rays 15; ventral inserted at a point equidistant from the snout and origin of anal, its longest ray (the fourth) equal to $\frac{1}{2}$ distance of anal fin from snout. Color yellowish white. Gulf Stream. A single specimen, $1 \frac{1}{4}$ inches long, known. (lappa, the burdock, from its prickles.)

Ifalieutella lappa, Goode \& Bean, Proc. Biol. Soc. Washington, $11,1882,88$, Gulf Stream, at Fish Hawk Station 1151 , Lat. $39^{\circ} 58^{\prime} 30^{\prime \prime}$ N., Long. $70^{\circ} 37^{\prime}$ W., in 125 fathoms; GOODE \& BEAN, Oceanic Ichthyology, 500, pl. 122, figs. 512a and 512b, 1896.

\section{ro77. DIBRANCHUS, Peters.}

Dibranchus, Peters, Monatsber. Kon. Akad. Wiss. Berlin 1876, 736 (atlanticus).

Head merged in body, very large, much depressed, forming a broadly ovate disk, with margin laterally prolonged; cranial portion not elevated; the interorbital area low, narrow, with orbits partly superior; supraoval cavity large, protected above by a transverse bony ridge. Mouth terminal, horizontal, wide; lower jaw convex; teeth in cardiform bands, none on vomer or palatines. Gills 2; no gill rakers; gill openings small, anterior to pectorals. Rostral tentacle retractile, trilobate at tip. Skin with numerous strong stellate spines above and below, those at margins of disk especially strong, 3-pointed. Atlantic; distinguished from related genera by the reduction of the gills to 2 pairs. ( $\delta i 5$, two; $\beta \rho \alpha \gamma \chi \circ 5$, gill.)

\section{Dibranchus atlanticus, Peters.}

D. 6 or 7 ; A. 4 ; C. 9 ; P. 13 to 15 ; V. I, 5 ; Br. 6 ; gills 2 . Disk orbicular, nearly as wide as long, its length about $\frac{1}{2}$ that of body, its lateral outline prolonged on each side, and terminating in a strong spine armed at the tip with a group of irregularly arranged acicular spinelets. Body covered above with numerous stout conical spines with stellular bases, these 
largest upon the trunk, where they are arranged approximately in about 4 irregular longitudinal rows upon each side of the dorsal fiu; closely set rows of these stout spines mark the outer margin of the disk, and there is also a cluster of 5 to 7 upon each carpal peduncle; outside of these marginal spines, upon each side, is an irregular marginal row of 5 depressed knife-like spines, each tipped with a crown of 3 acicular spinelets; on the anterior margin of the disk the 2 rows coalesce to a greater or less extent and form a bristling array of closely set spines, some pointing dorsally, some laterally, some ventrally; 2 kinds of spines upon the dorsal surface, in addition to the large ones already described, some large, somewhat remote from each other, conical, stellular; others, much more numerous and filling the interspaces, pickle-like, stellular; belly armed with numerous closely-set spines of a similar kind; snout somewhat projecting, armed with 3 many-tipped spines; a spine-armed ridge in front of the eyes, over the top of the snout; in this 4 spines are conspicuous, 1 in front of each eye, and between these a larger pair in front of the supraorbital ridges; from these last mentioned spines extend spine-armed ridges along the upper marg ins of each orbit; under the snout is a cavity (horizontal diameter $\frac{1}{2}$ that of the orbit) containing a barbel, pediceled, with thick, club-shaped, trilobate tip ; on each side of this cavity are the nasal openings, which are as in Halieutichthys. Width of mouth equal to distance between centers of pupils of eyes. Diameter of orbit contained as follows in other dimensions of the body: In total length $9 \frac{1}{2}$; in distance from snout to dorsal 6 ; same to anal 7 ; the base of ventrals 3 ; to angle between pectorals and trunk $5 \frac{1}{2}$; to gill openings 5 ; in greatest width of disk $5 \frac{1}{2}$; of trunk 4 . Width of interorbital area in diameter of orbit $\frac{2}{3}$. Dorsal fin with 6 or 7 rays, the longest (third) $1 \frac{1}{2}$ times diameter of orbit and 6 times in total length; anal fin inserted entirely behind dorsal, with 4 rays, the longest (third) about as long as longest in dorsal fin; ventral fins inserted nearly under middle of disk, a little nearer vent than to mandibular symphysis, with 1 rudimentary and 5 well-developed rays, increasing in length posteriorly, the last and longest $6 \frac{1}{2}$ times in total ; distance between ventral organs $7 \frac{1}{2}$ in total length. Pectorals with peduncles slightly exserted, bases included in common membrane, composed of 13 to 15 rays, the longest third or fourth $4 \frac{2}{8}$ in total. Candal fin rounded, consisting of 9 rays, all bifid except the 2 external ones; length of middle ray abont $\frac{1}{2}$ that of trunk and exceeding that of pectoral, being contained $4 \frac{1}{3}$ times in total length. Stomach egg-shaped, intestine somewhat longer than body; liver very wide and large. Color uniform reddish, gray above, slightly lighter below. Deep waters of the Atlantic; very abundant, in about 300 fathoms. Known from the west coast of Africa, off the Cape Verdes, off Barbados, and north in the Gulf Stream to Newport. (atlanticus, of the Atlantic.)

Dibranchus atlanticus, PETRRS, Monatsber. Kon. Akad. Wiss. Berlin 1876, 736, with plate, West Africa, Lat. $10^{\circ}$ N., Long. $17^{\circ}$ W., in 360 fathoms (Coll. H. M. S. Gazelle); GÜN. THER, Challenger Report, XXII, 59, 1887; VAILlANT, Travailleur, etc., 343, 1888; GoodE \& BEAN, Oceanic Ichthyology, 501, pl. 122, fig. 413, 1896. 


\section{ADDENDA.}

Page 12. After Entosphenus tridentatus add:

\section{1(a). ENTOSPHENUS CAMTSCHATICUS (Tilesius).}

A lamprey taken by Steller in the Bolschaya River, Kamchatka, has not been recorded by subsequent writers. It is reported by Steller as $13 \frac{1}{2}$ inches in length; the head $\frac{1}{3}$ of an inch; mouth long, with 2 teeth above, 6 below; dorsals 2. Color shining brassy, dark above; sides with dusky serpentine lines. A figure published by Tilesius shows the upper teeth as bifid, and 9 teeth below.

Pallas describes specimens from the sea at Petropaulski as 7 inches long, not marbled nor variegated. The species of Steller is probably an Entosphenus. That of Pallas may be the same, or it may be a Lampetra, allied to or identical with $L$. aurea.

Petromyzon marinus camtschaticus, Tilesius, Mém. Acad. St. Petersburg 1809, 240, with plate, Kamchatka.

Petromyzon camtschaticus, TuLsius, $l$. c., 241.

Lampetra variegata (STEller MS.) TILESIUS, l. c., 247, Bolschaya River, Kamchatka.

?Petromyzon marinus camtschaticus, Pallas, Zoogr. Ross. Asiat., III, 1810, 67, Petropaulski.

Page 14. From the synonymy of Lampetra vilderi omit "Petromyzon branchialis, Günther, Cat., virI, 504, 1870," and after the last synonym add: Not $P$. branchialis, Linnæus, which is the larva of some European species, perhaps of $P$. marinus.

Page 25. In the description of Catulus uter the teeth should read $\frac{60}{54}$ instead of $\frac{60}{64}$.

Page 27. In the key, under $d d$, read: Root of tail with a conspicuous notch above.

Page 28. The following key to West Coast species of Galeus and Mustelus will prove helpful.

a. Eye large, spiracle small, the latter not more than $\frac{1}{4}$ major diameter of orbit.

b. Mouth broad, snout broadly rounded, mandibular angle of $90^{\circ}$ or more. Fins less deeply incised; the lower caudal lobe rounded; pectoral and ventral margins nearly straight.

Galeus californicus, 33.

$b b$. Mouth narrow, snout long, acute, mandibular angle $60^{\circ}$ to $65^{\circ}$. Fins deeply incised; lower caudal lobe acute; pectoral and ventral margins concave.

Mustilus lunulatus, 30.

aa. Eye small, spiracle large, the latter $\frac{2}{5}$ to $\frac{1}{2}$ the major diameter of orbit. Snout sharp, mouth narrow, the mandibular angle about 70\%. Terminal lobe of caudal broad, obliquely truncate posteriorly. Nostrils very large, their width nearly equaling width of interspace. Fins less incised. 
Page 37. After Carcharhinus henlei add:

45(a). CARCHARHIYUS CERDALE, Gilbert, new species.

Body moderately compressed, not elevated, the depth at front of dorsal not more than $\frac{1}{4}$ greater than the oblique anterior margin of dorsal fin, less than distance from the nostril to first gill slit. Head depressed, the snout flattened, long and narrow, acute; length of snout beyond mouth $\frac{1}{6}$ to $\frac{1}{10}$ greater than distance between angles of mouth in all but one (the largest) of our specimens, in which it is slightly less than width of mouth; $\frac{3}{5}$ to $\frac{4}{5}$ greater than distance from tip of lower jaw to a line connecting angles of mouth; $\frac{1}{7}$ to $\frac{1}{12}$ greater than width of snout opposite outer angle of nostrils. Interorbital width equaling distance from tip of snout to front of eye in young, to middle or posterior border of eye in older individuals; less than $\frac{1}{2}$ distance to first gill opening. Middle of eye nearer nostril than angle of mouth by $\frac{1}{2}$ to $\frac{4}{5}$ its diameter; distance from eye to nostril $\frac{1}{2}$ or slightly more than $\frac{1}{2}$ distance from nostril to tip of snout; middle of nostrils much nearer front of mouth than tip of snout; nasal flap with a very narrow, short, acute lobe, placed at end of inner third of flap; outer angle of nostrils nearly at margin of snout, the inner angles separated by a distance equaling or slightly exceeding that between inner angle of nostril and back of eye. Lips very little developer, the lower entirely concealed in closed mouth, the upper visible as a very short fold. Teeth in lower jaw narrow, erect, serrulate on both margins, more coarsely so toward base; the serration more conspicuous in our smallest specimens (450 mm.), and is obsolescent on some of the teeth in adults; teeth in upper jaw broadly triangular, in front of jaw narrower and erect, those in sides of jaw growing at once broader and more and more oblique; the lateral teeth with a strong notch on the outer side; both margins strongly serrate, the serrations increasing toward base, one or more of those below notch sometimes enlarger and cusp-like in adults; teeth about $\frac{28}{2}$. Conspicuous areas of large and of small pores on underside of head. Gill openings of moderate width, the longest equaling distance between eye and nostril, the fifth much shortened, about $\frac{8}{4}$ length of first. Eje small, equaling length of nasal opening, 18 to 2 in middle gill slit. Pectoral short and broad, the posterior margin not strongly incurved; tip of fin extending to a vertical intersecting dorsal base at origin of its posterior third or fourth; anterior margin of pectoral 3 times length of inner or posterior margin, the latter less than width of base; first dorsal beginning behind a vertical from axil of pectoral a distance about equaling that which separates eye from nostril; free margin of fin gently concave, the anterior angle extending to a point midway between base and tip of posterior lobe, when the fin is depressed; base of first dorsal $2 \frac{1}{2}$ to $2 \frac{3}{5}$ in interspace between dorsals; base of second dorsal 7 in interspace between dorsals, $2 \frac{1}{5}$ in its distance from anterior margin of pit; origin of second dorsal falling over or behind middle of anal base, the fin but slightly concave, with rounded anterior angle, its posterior angle much produced, the posterior margin exceeding base of fin, which about equals length of anterior margin; anal inserted more ante- 
riorly than second dorsal, its base longer, its margin much more deeply concave, the length of base contained about $1 \frac{4}{5}$ times in its distance from lower caudal lobe; lower caudal pit in advance of the upper; caudal broad throughout, the lower lobe not falcate, slightly less ( $1_{1}^{1}$ to $\left.\frac{1}{4}\right)$ than $\frac{1}{2}$ length of upper lobe, which is about $4 \frac{1}{4}$ in total length. Shagreen coarse. Color varying from light to rlark gray above, the belly and lower part of sides whitish; fins all dusky or grayish, the caudal often with a blackish border; pectoral with or without a black tip, the latter when present not as conspicuous as in C. athalorus, usually not extended into inner face of fin.- A specimen $730 \mathrm{~mm}$. long has the claspers undeveloped, extending slightly beyond margin of ventrals. Another specimen, $850 \mathrm{~mm}$. long, has the claspers fully developed, extending beyond the margin of the ventrals for a distance of $50 \mathrm{~mm}$. Strongly resembling $C$. athalorus, with which it is associated in the Bay of Panama. It is distinguishable at sight by the narrower gill slits, broader and less falcate fins, and by the much less conspicuous black tips to the pectorals. The dentition is very dissimilar in the two, and makes it necessary to arrange them in different subgenera. Abundant at Panama, where numerous specimens were secured. (Gilbert.) ( $\varkappa \varepsilon \rho \delta \dot{\alpha} \lambda \eta$, wary, fox-like.)

Carcharhinus, sp. indescr., Jondan, Proc. U. S. Nat. Mus. 1885, 363.

Carcharhinus cerdale, Gilbert, Fishes of Panama, MS. 1898, Panama. (Type, No. 11884, L. S. Jr. Univ. Mus. Coll, Dr. Gilbert.)

Page 39. Carcharhinus nicaraguensis or its marine original form was found in abundance in the Bay of Panama by Dr. Gilbert.

\section{Page 41. After Carcharhinus oxyrhynchus add:}

54(b). CARCHARHINUS VRLOX, Gilbert, new species.

Preoral portion of snout slightly more than $1 \frac{2}{8}$ times width of mouth, 5 times distance between nostrils, 12 times width of snout opposite outer angles of nostrils, $1 \frac{1}{4}$ times interorbital width, 24 times distance from chin to line joiniug angles of mouth. Nostrils transverse in position, the inner angle nearer mouth than tip of snout by a distance slightly less than length of nostril. Front of eye equidistant from nostril and front of mouth, the middle of eye nearer angle of mouth than nostril; diameter of eye less than nostril, slightly more than $\frac{1}{2}$ longest gill slit. Snout very porous. Folds at angle of mouth slightly longer than usual. Gill slits rather wide, the middle one $1 \frac{8}{4}$ times diameter of orbit. Teeth of lower jaw very narrow, erect, very minutely serrulate, appearing entire except under a leus. Teeth in upper jaw very oblique, wide at base, with a deep notch on outer margin, the terminal cusp rather narrowly triangular. Pectoral broadly falcate, the anterior margin convex, the distal edge concave, both angles rounded; tip of pectoral reaching a short distance beyond base of first dorsal; anterior margiu of pectoral $2 \frac{2}{5}$ times the posterior (inner) margin, about $1 \frac{1}{8}$ times the distal edge; first dorsal inserted about the diameter of orbit behind a vertical from axil of pectoral, nearer pectoral, therefore, than ventral; anterior margin concave basally, convex on distal half, the anterior angle rounded; free margin concave, largely owing to the much pro- 
dnced acnte posterior lobe; vertical height of fin exceerling length of base, the anterior lobe very high, extending beyond tip of posterior when the fin is declined, equaling $\frac{7}{9}$ length of anterior margin of pectoral; posterior margin of dorsal $3 \frac{1}{4}$ in the anterior margin; base of first dorsal contained $2 \frac{1}{2}$ times in interspace between dorsals; base of second dorsal 62 times; margin of second dorsal gently concave; front margin low, the angle broadly rounded, barely reaching posterior end of base when fin is declined; posterior lobe much produced and acute, slightly longer than base of fin, the latter 15 in the distance from its base to front of caudal pit; npper lobe of caudal $3 \frac{2}{3}$ in total length, the lower lobe $2 \frac{1}{2}$ in the upper; terminal lobe of caudal $3 \frac{2}{8}$ in the upper lobe; anal larger than second dorsal, higher, with deeply ineurved margin, its base a little longer, its origin slightly in advance of that of second dorsal, the posterior insertions of the two fins nearly opposite; length of anal base $1 \frac{3}{5}$ in its distance from anterior edge of caudal pit. Color bluish above, whitish or grayish below; free margin of pectoral narrowly white, the anterior edge narrowly bordered with black, most evident when seen from the outer surface, the inner surface being dusky; first dorsal unmarked, the second dorsal with dnsky anterior lobe; upper edge of caudal black, the lower margin faintly dusky; fins otherwise unmarked. A single specimen, a female 4 feet long, was procured from the Panama market. As preserved, it is partially skinned. The following measurements were taken when the specimen was intact, before preservation. Where not agreeing with dimensions given above, the latter will be found more reliable:

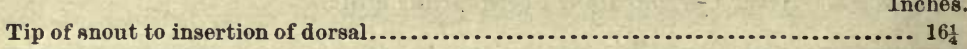

Base of first dorsal. ................................................. $4 \frac{3}{8}$

Distance between dorsals ................................................ 11

Base of second dorsal ................................................... 14

From second dorsal to front of caudal pit................................. $2 \frac{\gamma}{8}$

Front of caudal pit to tip of caudal......................................... $13 \frac{3}{4}$

Tip of snout to axil of pectoral.......................................... 15

Axil of pectoral to front of base of ventrals................................ $11 \frac{1}{8}$

Front of ventrals to front of anal........................................ $6 \frac{1}{2}$

Front of anal to front of caudal pit......................................... $4 \frac{9}{18}$

Girth at front of first dorsal............................................. $17 \frac{3}{4}$

Distinguished from other known sharks of the Pacific coast of America by the excessively long, slender, acute snout, the slender body, and the very long caudal fin. Panama; only the type known. (velox, swift.)

Carcharhinus velox, Gilbert, Fishes of Panama, MS. 1898, Panama. (Type, No. 11893, L. S.Jr. Univ. Mus. Coll. Dr. Gilbert.)

Page 42. Scoliodon longurio has the teeth serrulate at base only. The base of the first dorsal is $2 \frac{8}{4}$ in the interspace between the dorsals.

Page 44. Sphyrna tiburo occur also in the Pacific. We have recently secured specimens at Mazatlan, where $S$. tudes and $S$. zygana are also found.

Page 47. Carcharias litloralis reaches a length of 8 feet 7 inches. (Specimens from Beaufort, North Carolina. Coll. H. H. Brimley.) 
Page 49. Lamna cornubica, the salmon shark, is abundant and destructive to salmon on the coasts of southern Alaska, especially about Kadiak, where it was seen by us.

Page 53. Under Squalida, read ovoviviparous for "oviparous."

Page 54. Squalus sucklii has been but once recorded from Bering Sea. (Bering Island. Coll. Dr. L. Stejneger.) It is very abundant at Kadiak.

Page 60. Pristis perrotteti is not authentically known except from the rivers of Africa. Our west coast species is doubtless distinct and should stand as Pristis zephyreus. Pristis pectinatus occurs northward at least to Beanfort, North Carolina. (Specimen $12 \frac{1}{2}$ feet long. Coll. H. H. Brimley.)

Page 61. After the synonymy of Pristis pectinatus insert:

80(a). PRISTIS ZEPHYREUS, Jordan \& Starks.

(Pez de Espada.)

Snout to nostrils, 3 in length to base of candal; breadth of saw at anterior end between first 2 pairs of teeth $\frac{1}{2}$ breadth of its base behind the last pairs; teeth on saw trenchant behind, arranged in 22 pairs; hinder teeth wide apart, the interspaces 5 times their base; posterior teeth turned slightly backward, a groove on their posterior edge; front teeth not quite $\frac{1}{2}$ as long as the saw is broad at their base; distance between first and second tooth 3 times base of first. (Other specimens examined for us by Dr. G. W. Rogers show 18 to 21 pairs of teeth.) Eye equal to spiracle, contained 3 times in base of saw just behind last pair of teeth; width of mouth a little greater than base of saw; mouth with about 65 series of blunt teeth; slant height of pectoral in front a little more than half distance from tip of snout to month. Dorsals subequal; first dorsal inserted in advance of ventrals, about $\frac{1}{2}$ its base over ventrals; caudal with a lower lobe, which is equal to slant height of pectoral; tail with a keel on side. Color plain olive gray abore, light below. Measurements: Length 50 inches; caudal 7 inches; pectoral 7 inches; dorsal front $5 \frac{1}{8}$ inches; snout without nostril 11 inches. Type: A skin in L. S. Jr. Uuiv. Museum. Common in brackish waters at the mouth of the Rio Presidio, where 1 fine specimen was obtained. The species is also reeorded (as Pristis perrotteti) by Dr. Gilbert from Mazatlan, and by Dr. Guinther from Chiapas. Dr. Günther identifies this species with Pristis perrotteti described by Müller \& Henle, from the Senegal River. In view of the great difference in the fauna of the Gulf of California from that of equatorial Africa this identification may be questioned, especially as there are. several detals in which the description of $P$. perrotteti differs from our specimen.

Pristis zephyreus, Jordan \& Starks, Fishes of Sinaloa, 383, 1895, Mazatlan, Mexico. (Coll. Hopkins Exped. to Sinaloa.) 
Page 62. After Rhinobatus lentiginosus, add:

81(a). RHINOBATUS STELLIO, Jordan \& Rutter.

Disk triangular, its greatest width a little less than $\frac{1}{2}$ the distance from snout to dorsal, and equal to distance from suout to a line connecting points of greatest width. Sides of disk straight, tip of snout rounded, posterior point of pectoral more broadly rounded than snout. Length of snout equal to, or a little less than, $\frac{1}{2}$ greatest width of disk, equal to distance between outer points of anterior gill openings; interorbital width 4 to $4 \frac{2}{8}$ in snont, a little less than length of eye and spiracle, but about equal to length of nostril; interuasal width equal to orbit; spiracle $\frac{1}{8}$ length of eye, a prominent curved papulla and a slight ridge in its posterior side. Anterior nasal valve with a long slender flap extending across the nostril; 3 broad flaps on posterior side. Rostral ridges separate for their entire length, width between them at base equal to width of spiracle. Mouth nearly straight, its width $2 \frac{3}{4}$ in its distance from snout and equal to distance between inner folds on posterior side of spiracle. Eye $4 \frac{1}{2}$ to $5 \frac{1}{4}$ in snout. Width of body at axil of pectorals $1 \frac{1}{8}$ in snout. Dorsal fins about equal in size and shape, the distance between them $2 \frac{1}{2}$ times base of first, the distance between the origins of the two fins equal to snout and about equal to distance from axil of pectoral to origin of first dorsal. Sides of tail with a conspicuous fold. Skin above with a fine uniform shagreen, nearly smooth below except near margins of the disk. A series of very small spines above eye and spiracle, 1 or 2 minute spiñes on shoulder girdle; the largest spines of body situated along median line of back, extending beyond first dorsal; no spine on snout, but in 2 of the 3 specimens there is a pair of minute spineless plates near its tip. Color dusky brown above, about 7 faint dusky bars on the side of the tail behind first dorsal; uniform pale below; large translucent areas on each side of the snout; back with numerous small light spots, much smaller than pupil, arranged symmetrically but not in the same pattern on the 3 type specimens; 2 or 3 pairs between eyes, a few pairs behind eyes near median line, some below eye, where they approach nearest the margin of disk, usually 1 or 2 on median line, sometimes 2 are confluent, about 40 or 45 pairs in all; axil of pectoral in 1 specimen with a dusky blotch on upper side. This species is most nearly related to Rhinobatus glaucostigma of the Pacific coast, differing in having a narrow interorbital, narrower body behind disk, and in the very different color. The description is based on 3 specimens, each about 90 inches. Jamaica. (stellio, the starry one.)

Rhinobatus stellio, Jordan \& RUTTEr, Proc. Ac. Nat. Sci. 1897, 91, Kingston, Jamaica. (Type, No.11851, L. S. Jr. Univ. Mus. Coll. Joseph Seed Roberts.)

Page 66. To the synonymy of Raja add: Cephaleutherus, Rafinesque, Indice, 61, 1810 (maculatus).

The genus Cephaleutherus, Rafinesque, was, as Dr. Gill has shown (in - lit.), probably based on a monstrous example of the genus Raja, in which the pectoral fins were not developed on the snout. It should be transferred to the syuonymy of Raja, leaving Myliobatis as the generic name of the Eagle Rays. 
Page 74. After Raja equatorialis add:

104(a). RAjA ROSISPINIS, Gill \& Townsend.

Snout moderately produced, with a soft, moderately warrow, rostral cartilage and a bluntish tip; interorbital space nearly plane; snout with a number of plates having stellate bases about middle, and many smaller asperities, leaving only the borders of the pectorals and ventrals naked; larger spines with stellate bases are interspersed between the disk and the pectoral rajs; back with sparse, coarse prickles; a row of about 26 thornlike spines, with radiating ridges, extends from the interhumeral area to the dorsal fins; 2 spines on each shoulder, 1 spine above antocular region, another above postocular region, and another behind it about $\frac{1}{2}$ the distance; skeleton soft. Bering Sea; only the type known. (roseus, rosy; spinus, spine.)

Raia rosispinis, Gill \& Townsend, Proc. Biol. Soc. Wash., XI, 1897 (Sept. 17, 1897), 231, Bering Sea. (Type, No.48762, U.S. Nat. Mus. Coll. Albatross.)

Raia obtusa, * Gill \& Townsend, Proc. Biol. Soc. Wash., xI, 1897 (Sept. 17, 1897), 231, Bering Sea. ('Type, No. 48763, U.S. Nat.Mus. Coll. Albatross.)

104(b). RAJA INTERRUPTA, Gill \& Townsend.

Snout moderately produced, with a very soft attenuated rostral cartilage and a blunt tip; interorbital space concave; mouth small; the width equal to $\frac{1}{2}$ preoral area; entire back covered with very small embedded spines, extending nearly uniformly over the disk and snout, leaving only the tip of the latter naked; a row of compressed, acutely curved, smooth spines along middle of back, extending from the interhumeral region to dorsal, but interrupted along the posterior half of disk, where the spines are absent or obsolete; about 4 spines are in the anterior portion and the series recommences on a line with the emargination of the disk; a single spine on each shoulder and occasionally a rudimentary second; no specialized supraorbital spines. Bering Sea; only the type known. (interruptus, interrupted.)

Raia interrupta, Gill \& Townsend, Proc. Biol. Soc. Wash., XI, 1897 (Sept. 17, 1897), 232, Bering Sea. (Type, No.48760, U.S. Nat. Mus. Coll. Albatross.)

Page 75. Raja aleutica and Raja abyssicola were described by Gilbert (not Gilbert \& Thoburn) in Rept. U. S. Fish. Comm. 1893 (Dec. 9, 1896), 396 and 397 , pls. 20 and 21.

\footnotetext{
* The following is the original description of this nominal species:

Snout not at all produced, but very bluntly rounded; interorbital space narrow; mouth small, rectilinear; minute distant prickles on the snout, the anterior portion of disk and interorbital area, as well as in a broal median band exteuding on tail to dorsal and conmencing at the interhumeral area; a row of scarcely enlarged acute spines above the eye; an uninterrupted row of unguiform spines with smooth bases extending from the interhumeral area tc dorsal fin; 2 similar spines arm each shoulder. Bering Sea; only the type known. ((vill and Townsend.) To which we add: Spines in longitudinal series 23 to 25; width of mouth 13 in preoral area; width of disk 1 ; times its length; tail a little longer than disk; interorbital width 3 in snout; snout from eye $3 \frac{2}{3}$ in disk to end of base of ven. trals. Color plain brown, rather pale. One specimen 11 inches long, a very young male in very bad condition. Evidently the young of $R$. rosispinis.
} 
Page 78. After Narcine brasiliensis insert:

112(a). NARCINE ENTEMEDOR, Jordan \& Starks.

(ENTEMEDOR.)

Snout $3 \frac{8}{4}$ in length of disk; preocular part of snout equals preoral; interocular space in snout $1 \frac{1}{2}$; width of mouth $2 \frac{1}{4}$. Eye much smaller than spiracle; spiracles edged with small tubercles. Length of disk equal to its width; disk equal to length of tail, without caudal fin; tail with a loose fold of skin on each side. First and second dorsals equal, rounded behind; ventrals large, ending midway between posterior edge of disk and caudal fin. Color pale olive brown, a little clouded with darker; second dorsal edged with pale; dots on head dusky. Two specimens taken in the estuary at Mazatlan, and a third procured by Mr. James A. Richardson in the harbor of La Paz. Specimens had also been obtained by Dr. Gilbert, at Panama, in 1883, but having been destroyed by fire, the species has remained undescribed until recently. Length of largest specimen 20 inches. (The Spanish name Entemedor seems to be equivalent to Intimidator.)

Narcine entemedor, JoRdan \& Starks, Fishes of Sinaloa, 386, 1895, Mazatlan, Mexico.

(Type, No. 1699, L. S. Jr. Univ. Mus. Coll. Hopkins Exped. to Sinaloa.)

Page 81. After Urolophus nebulosus add:

115 (a). UROLOPHUS UMBRIFER, Jordan \& Starks.

Disk round, not wider than loug, its length greater than tail; snout pointed, not exserted. Snout from eje $4 \frac{1}{2}$ in disk; eyes equal to spiracles; month 2 in distance to tip of snout; caudal spine inserted in front of middle of tail; skin perfectly smooth. Color brown above, with blackish cross shades or bars, radiating from the shoulder; a dark band behind eyes, and 1 from eyes; caudal fin dark. Mazatlan. One adult female specimen, the uterus containing 4 young. Occasionally taken with Urolophus mundus, but inuch less common. This is probably not identical with Garman's Urolophus nebulosus, being perfectly smooth and different in color. (umbra, shade; fero, I bear.)

Urolophus umbrifer, JoRdan \& StaRks, Fishes of Sinaloa, 389, 1895, Mazatlan, Mexico.

(Coll. Hopkins Exped. to Sinaloa.)

Page 82. Urolophus a.sterias, Jordan \& Gilbert, is identical with Urolophus mundus (Gill), as is shown by specimens recently collected by D.. Gilbert at Panama.

120(a). UROLOPHUS ROGERSI, Jordan \& Starks.

Disk broader than long by a distance $2 \frac{1}{2}$ times the interorbital width; anterior margins of disk nearly straight, the tip of snout projecting; snout from eye $3 \frac{8}{4}$ in length of disk; eye little smaller than spiracles; width of mouth $2 \frac{1}{2}$ times in preoral part of snout; caudal spine inserted in front of middle of tail; skin with minute prickles on margin of pectorals and - on middle of back, leaving smooth areas near middle of pectorals and 
over branchial arches; 16 to 20 large spinules along median line of back and tail. Color plain brown; caudal fin darker, edged with white. This species differs from Crolophus asterias in having a wider disk, more acute snout, much smaller prickles, and fewer spinules on back and tail. Mazatlan. Three specimens obtained in the Astillero, the longest 18 inches in entire length. (This species is named for Dr. George Warren Rogers, a scholarly physician, native of Vermont, but long resident in Mazatlan.)

Urolophus rogersi, JoRdan \& Starks, Fishes of Sinaloa, 388, 1895, Mazatlan, Mexico. (Type, No. 1700, L. S. Jr. Univ. Mus. Coll. Hopkins Exped. to Sinaloa.)

Page 88. In the key at top of page for Rhinopterina read Myliobatina.

\section{AETOBATUS LATICEPS (Gill).}

This species is probably not different from $A$. narinari and may be omitted. We find no differences between specimens from Mazatlan and the West Indies. The following description is based upon Mazatlan specimens:

Length of dise $1 \frac{2}{3}$ in width; proximal $\frac{1}{2}$ of anterior margin of pectoral fins straight, distal $\frac{1}{2}$ convex; posterior margin concave, the end of each ray forming a small scallop; lateral angle sharp. Snout forming an angle, from its tip to division of nasal lobes, $1 \frac{1}{3}$ times breadth of head; width of snout $1 \frac{1}{5}$ times distance from its tip to the division of nasal lobes; nasal lobes projecting back over the mouth; width of mouth $1 \frac{1}{2}$ its distance to tip of snout; numerous blunt buccal papilla around upper dental plate and on ridge betwèen nostrils; interorbital $4 \frac{8}{4}$ in disk; eyes smaller than spiracles, which are as long as base of dorsal. Ventrals well rounded, $3 \frac{2}{3}$ in length of disk; tail $3 \frac{1}{2}$ times disk. First candal spine equals base of dorsal, which is $\frac{1}{2}$ second spine. Color bluish black with many round yellowish spots scattered equally over the back and ventral fins; spots about as large as eye on back, smaller on head, sometimes two spots run together forming an elliptical spot, about 16 spots from eye along anterior margin of pectoral to lateral angle; posterior margin of pectoral very narrowly margined with white; ventral side pearly white. From the description of Aetobatus laticeps this species differs in the following respects: Disk not so broad; tail not so long; width of head and snout less; ventrals not truncated behind; pectorals not margined with blackish; spots on ventrals not assuming the form of ocelli. (Jordan.)

Page 87. For the description of Pteroplatea crebripunctata in text substitute the following:

Width of disk twice length to posterior end of anal slit; snout forming a regular curve from a little in front of middle of pectorals, a very small blunt projection at tip; anterior margin of disk convex near snout and lateral angles, pectorals concave medially; posterior margin weakly convex; posterior angle broadly rounded; lateral angle sharply rounded; distance from snout to a line drawn through lateral angles, $2 \frac{1}{2}$ times in distance to tip of tail. Interorbital a little wider than its distance to tip of snont; eyes twice spiracles; month equals snout, $6 \frac{1}{2}$ in disk. Tail rat- 
like, with a scarcely perceptible fold of skin on its dorsal side. Ground color olive brown, everywhere with small dark points, not so close set as in Pteroplatea raia, indistinct grayish spots, $\frac{1}{2}$ as large as iris, scattered over the body among the dark points, these spots more distinet on anterior edge of disk; tail mottled with darker; lower parts light. Markings nowhere so distinct as in P. vava. Very common on sandy shores everywhere about Mazatlan, from which locality it was originally described; also taken by Dr. Gilbert.

\section{Page 87. After Pteroplatea marmorata add:}

130(a). PTERoplatea RAYA, Jordan \& Starks.

\section{(Mantaraia Colorada.)}

Length of disk $1 \frac{2}{8}$ width; snout forming an angle which is almost a right angle; pectorals slightly concave inedially; posterior margin of disk weakly convex; posterior angle not broadly rounded, but curved in somewhat suddenly; lateral angles acute. A line drawn through lateral angles would bisect a line from snout to tip of tail. Interorbital $1 \frac{1}{8}$ in snout; eye $1 \frac{1}{2}$ in spiracles; mouth 7 in disk, $1 \frac{1}{2}$ in snout; tail straight and slender, with a very slight fold on dorsal side. Ground color light olive brown, thickly set with sharp-cut black points; conspicuous gray or white spots, $\frac{1}{2}$ as large as iris, scattered over the body, around which the black spots form rings; brighter yellowish spots and half-spots around anterior edge of disk ; tail mottled above with darker; lower parts chiefly light orange red or rust-colored in life. All the markings are very distinct and clear cut, the reddish of the belly conspicuous. Mazatlan. One specimen 12 inches long. (ravus, reddish.)

Pteroplatea rava, Jordan \& Starks, Fishes of Sinaloa, 390, 1895, Mazatlan, Mexico. (Type, No. 1587, L. S. Jr. Univ. Mus. Coll. Hopkins Exped, to Sinaloa.)

Page 90. After Myliobatis californicus add:

134(a). MYLIOBATIS ASPERRIMUS, Gilbert, new species.

Upper surface of head and body, excepting the snout, an area on outer side of spiracle, the pectoral margin and its posterior angle, and the ventral fins thickly covered with minute, usually stellate prickles, of uniform size, most numerous on median portions of head and back; those on basal $\frac{1}{2}$ or $\frac{2}{8}$ of pectoral least crowded and arranged in definite longitudinal series, corresponding with the muscle bands; tail very rough throughout, covered with similar stellate prickles and also crossed by numerous narrow grooves, or indented lines, mostly convex forward, somewhat irregular iu position and direction, and not corresponding on the two sides. In the type they follow at an average interval of about $10 \mathrm{~mm}$. Lower side of disk mostly smooth, with some prickles on the basal part of pectorals anteriorly, arranged in lengthwise series, and other patches on lower side of head, belly, and base of ventrals. Color dusky brown above, the anterior portion of pectorals with 8 to 10 narrow transverse bars of bluish 
white, most of which break up into series of spots toward outer margin of disk, the posterior ones also breaking up toward middle line; the bars and spots fainter anteriorly, becoming whiter and more intense posteriorly ; tow ard outer angles of disk the bars sometimes separated by intermediate series of light round spots, the bars usually failing to meet across the back; posterior portion of disk including base of tail and upper surface of ventrals covered with round white spots not much larger than pupil, some of those immediately succeeding the bars showing a transverse serial arrangement; top of head with one or more pairs of indistinct light spots; margin of snout and of pectorals blackish; spiracular border black; dorsal with a black blotch posteriorly; underside of head and disk bright white; proximal portion of tail blackish above, lighter below, the entire tail becoming black more posteriorly.

Dimensions of type specimen.

Length of disk to front of anms Millimeters.

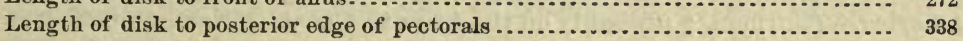

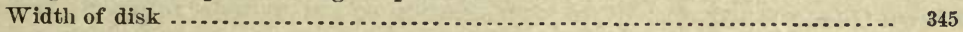

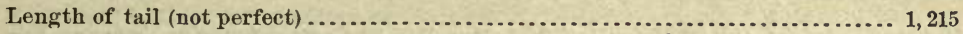

Greater width of head at origin of pectorals............................. 79

Width of cranium between orbits.......................................... 45

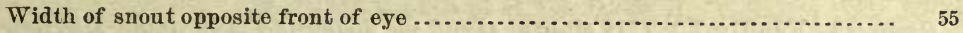

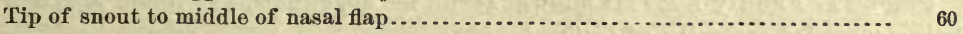

Length of nasal flap........

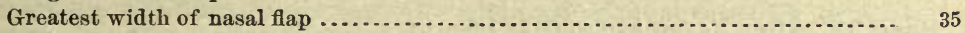

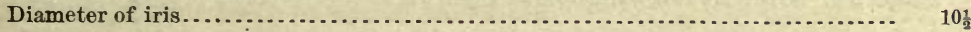

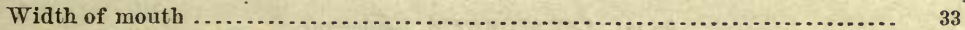

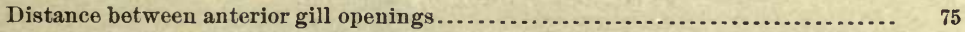

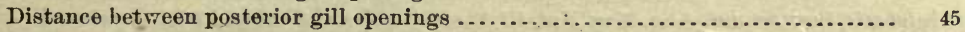

Distance from anterior to posterior gill openings $\ldots \ldots \ldots \ldots \ldots \ldots \ldots \ldots \ldots \ldots \ldots \ldots . . .64$

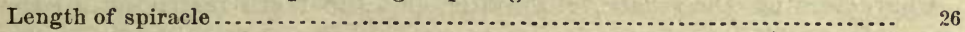

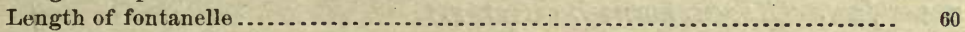

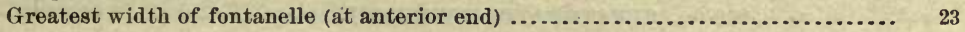

Rostrofrontal fontanel scarcely constricted anteriorly, the bounding ridges diverging abruptly at their anterior ends. Nasal flap with a shallow median notch, covering the mouth except the median portion of lower dental plate; posterior margin coarsely fringed. Teeth in each jaw in 1 broad median row, and 3 lateral rows, those of median row about 5 times as broad as long anteroposteriorly.

One specimen, a male, with undeveloped claspers which do not nearly reach odge of ventrals, from Panama. (Gilbert.) (asperrimus, very rough.)

Myliobatis asperrimus, GILberT, Fishes of Panama, MS. 1898. (Type, No.11895, L. S. Jr. Univ. Mus. Coll. Dr. Gilbert.)

\section{4(b). MYLIOBATIS GOODEI, Garman.}

Disk about $\frac{2}{3}$ as long as broad ; lateral angles acnte, bluntly rounded at the apices; posterior angles of pectorals nearly right; snont very broad, short, with a slight prominence in front; the fin, or flange, beneath the eye at the side of the head is very wide, much wider than in either $M$. freminvillei or M. californicus; eye very small, withont a prominence above in either 
male or female (immature specimens); tail less than 2 and more than $1 \frac{2}{3}$ times length of the disk; dorsal fin smaller than that of freminvillei; teeth in 7 series, much shorter and narrower than those of freminvillei, third row about 2 and middle row about 4 times as wide as long. Body smooth. Entire length 29 inches; snout to eud of ventrals 11.5, vent to end of tail 18.5, and width of disk 17.5 inches. Olivaceous, darker on the center; white below. The Museum of Comparative Zoölogy has a large specimen which agrees well with this description. Compared with $\boldsymbol{M}$. freminvillei, this species has very small eyes, the pectoral below the orbit is wider than the eyeball, and the fin in front of the skull is but little wider than at its sides. In freminvillei the eyeball is twice as wide as the fin beneath it, and the fin in front of the skull is much wider than below the eye. Comparing specimens of about the same size, of the same sex, of freminvillei, californicus, and goodei, the latter is readily distinguished from the former two by the broad flange at the side of the head, the small eyes, the small teeth, and the broader lateral angles of the pectorals. Central America. (Garman); probably on the Atlantic Coast. (Named for George Brown Goode.)

Myliobatis goodei, Garman, Proc. U. S. Nat. Mns. 1885, 39, Central America. (Types, Nos. 9524 male, and 9529 female.)

Page 91. Family XXVIII should stand as Aodontide, the name Mantida being used for a family of Orthoptera.

Page 92. After Aodon hypostomus insert:

59 (a). CERATOBATIS, Boulenger.

Ceratobatis, Boulenger, Ann. Mag. Nat. Hist., ser. 6, vol. xx, August, 1897, 227 (robertsii).

Characters of Dicerobatis, Blainville, but the teeth restricted to the

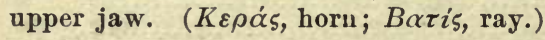

138 (a). CERATOBatis ROBERTSI; Boulengẹ.

Band of teeth occupying only $\frac{1}{2}$ width of mouth, its width 10 times in its length; teeth tessellated, hexagonal, 2 to 3 times as broad as long, rugose with numerous obtuse ridges; mouth inferior, wide. Pupil vertically elliptic. Body smooth; pectoral fins with nearly straight, slightly convex anterior and slightly concave posterior border; cephalic fins measuring a little less than width of mouth; spiracles behind the eves; space between last branchial clefts $\frac{1}{4}$ that between first; dorsal fin between the ventrals; tail slender, withont spine, nearly twice length of body.

Millimeters.

Length of disk, withont cephalic appendages............................... 350

Width of disk ........................................................ 780

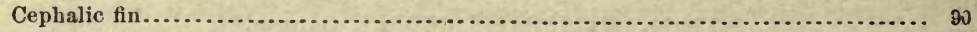

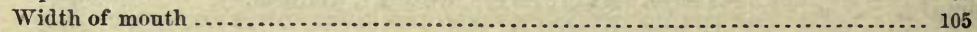

Diameter of eye

Ventral fin.......................................................... 70

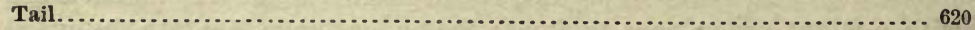

Black above, white beneath. Jamaica. One specimen known. This ray grows to a very great size, but specimens are almost impossible to obtain, 
owing to the superstitious fear of the fishermen. (Named for Rev. Joseph Seed Roberts.)

Ceratobatis robertsii, Buvlenger, Ann. Mag. Nat. Hist., ser. 6, vol. xx, August, 1897, 227,

Jamaica. (Type in British Mus. Coll. J. S. Roberts.)

Page 105. There is no truth in the statement that Acipenser medirostris is poisonous. It is a good food-fish, and on the coast of Washington it is somewhat abundant.

\section{Page 116.}

\section{ADDITIONAL NOTES ON TACHYSURIN $Æ$.}

In the text of this work, pages 116 to 133 , the descriptions of the species of Tachysurina are for the most part too brief to render certain the discrimunation of species. The following additional descriptions of these species will be found useful as supplementary to those given in the text. A slight change in the arrangement of the genera has been found desirable, and 3 new species are added.

\section{SCIADEICHTHYS, Bleeker.}

Dorsal shield much enlarged, formed like an armorial shield; tecth on palate villiform; posterior nasal openings not connected by membrane; band of palatine toeth extended backward.

\section{SCIADEICHTHYS TROSCHELI (Gill).}

Head $3 \frac{1}{4}$ ( $3 \frac{5}{6}$ in total with caudal); width of head $4 \frac{1}{5}\left(4 \frac{5}{6}\right.$ in total); depth $5\left(6 \frac{1}{5}\right)$. D. I, 7; P. I, 12; A. 18. Body comparatively robust, broad anteriorly; head not much depressed, broader than high; eye moderate, 7 to 8 times in length of head; width of interorbital space $1 \frac{2}{8}$; breadth of mouth $1 \frac{2}{8}$; length of snout $3 \frac{1}{4}$. Teeth all villiform; band of vomerine teetb simple, trapezoidal, quadrangular, longer than broad, without division on median line; band of palatine teeth very large, each separated in young specimens from the vomerine band by a narrow toothless line; in old specimens the vomerine and palatine bands are wholly confluent; each palatine band with a narrow backward prolongation on the median line; band of premaxillary teeth broad, abont six times as long as wide; lower jaw included. Maxillary barbel nearly or quite reaching gill opening; outer mental barbels about $\frac{2}{5}$ head, the inner nearly $\frac{4}{5}$. Dorsal shield much larger than in most species, shaped like an armorial shield, its posterior margin concave, its anterior end acute, wedged into a deep emargination of the occipital process, the two becoming coossified with age; length of antedorsal plate on the median line 5 to 6 in head, a little more than its width; occipital process short and broad, much broader than long, its median line with a broad keel, its edges nearly straight. Shields all coarsely granular, the granulations anteriorly forming radiating strixe. Fontanel large, claviform, broadest posteriorly, its posterior end about midway between tip of snout and front of dorsal, its greatest 
breadth about equal to the dianeter of the eye, and $\frac{1}{6}$ its length, a short groove extending backward from its obtuse tip; sides of fontanel bony and grauulated for its whole length, the granules extending forward to opposite nostrils. Dorsal spine strong, $1 \frac{3}{5}$ in head, moderately compressed; pectoral spine $1 \frac{4}{5}$ in head. Axillary pore obsolete. Humeral process coarse, granular, broad, nearly $\frac{1}{2}$ length of pectoral spine; base of adipose fin scarcely $\frac{2}{3}$ length of anal, its posterior margin little free; caudal deeply lunate, small, its upper lobe slightly the longer and narrower, 1 in head; ventrals not quite reaching anal; vent much nearer base of ventrals than anal. Dark brown, with strong bronze luster above, white below; dorsal dusky, especially above; pectorals blackish; anal dark; caudal rather pale; ventrals usually dark toward the tip, their inner side pale; maxillary barbel dusky; mental barbels pale. This species is not rare along the Pacific coast of tropical America, specimens having been observed at Mazatlan, Punta Arenas, and Panama.

Sciades troscheli, Grum, Proc. Ac. Nat. Sci. Phila. 1863, 171, Panama. (Coll. Capt. Dow.) Arius brandtii, jordan \& GILbERT, Bull. U. S. Fish Comm., II, 1882, 39; description from 28230 , U. S. Nat. Mus., 24 inches in length.

The following is the original description of Sciades troscheli, Gill: "Dorsal I, 7 ; anal 16 ; caudal $11,1,6 ; 7,1,11$. The greatest height is contained about $4 \frac{1}{2}$ times in the length to the base of the candal fin, and $5 \frac{1}{2}$ times in the total. 'The caudal peduncle, behind the anal, equals the interval between the snout and the eye, and its least height that between the center of the anterior nostril and the eye. The head in front and on the sides is smooth, and a smooth, oblong, triangular area extends nearly to the vertical from the upper angle of the preoperculum; a triangular area on each side is incurved externally to the narrow anterior extremity, and covered with white pisiform granulations. The dorsal buckler is a pentagon, with a semicircular excavation behind and with its surface rugose. The head enters 3 times in the length before the end of the anal fin and more than 4 times in the total; its width equals the interval between the snout and upper angle of preoperculum, and the interocular area equals $\frac{1}{2}$ the head's length. The eye is elliptical, and its diameter is contained $6 \frac{1}{2}$ times in the head's length. 'The distance of the posterior nostril from it equals a diameter. The maxillary barbels extend to about the middle of the pectoral; the outer mental to its base, and the inner mental are $\frac{2}{8}$ as long as the outer. There are 3 villiform patches on the palate which are almost contiguous, and together describe an arch in front; the median patch is small, rather transverse, and widest towarl the front; the outer are oblong, subtriangular. The band of the upper jaw is nearly uniform and quite wide; the lower, interrupted at the symphysis, is nearly $\frac{1}{2}$ as wide as the upper, and is narrowed toward its ends. The dorsal spine enters $1 \frac{1}{2}$ times in the head's length; has in front, first, minute teeth pointed downward, and then a row of small pisiform tubercles; teeth pointed downward on its hinder border. The first ray is little higher than the spine. The anal commences at a distance from the snout $3 \frac{2}{8}$ times as great as that from the base of the caudal 
fin ; its length enters $6 \frac{2}{3}$ in the length, exclusive of the candal, and when bent back it reaches to the supernumerary caudal rays; the greatest height nearly equals the length. The pectoral fins extend rather beyond the base of the dorsal and exceed $\frac{1}{5}$ of the length, exclusive of the caudal; the spine equals that of the dorsal. The ventrals are inserted midway between the base of the pectoral spines and the axil of the anal, and extend to the origin of the anal. The fins are almost blackish." A single specimen is in the collection of Captain Dow from Panama. The type of Sciades troscheli is now lost. At our request, Dr. Gill has again considered this description, in connection with the species now known from the coast. $\mathrm{He}$ is positive that his type of troscheli had the large dorsal shield characteristic of brandtii. Apparently Dr. Eigenmann is right in regarding troscheli and brandtii as identieal.

\section{SCHADEICHTUYS EMPIISETUS (Müller \& Troschel).}

Head $3 \frac{4}{5}$; depth 6 . D. I, 7; A. 18 . Closely related to Sciadeichthys troscheli. Depth little greater than the width. Profile straight, less steep than in S. troscheli. Depth of the head 18 in its length, its width $1 \frac{1}{4}$. Top of the head sparsely and coarsely granular, the granulation extending forward only to middle of cheek; fontanel bordered anteriorly by smooth ridges; occipital process coarsely and closely granular, without a prominent keel, its margins convex, its tips emarginate, not coossified with the clorsal plate; dorsal plate shield-shaped, not keeled, its surface irregularly pitted, its margin more finely graven, its length about $3 \frac{1}{2}$ in the head. In the specimen examined the dorsal plate seems to have been at some time slightly broken in front, a small, narrow, sharp process of the occipital process fitting into the split. Eye small, 3 in the snout, 11 in tho hearl, 5 in the interocular. Maxillary barbels flattened, reaching to below middle or end of dorsal fin, postmentals not quite to base of pectorals. Upper jaw slightly projecting; all the teeth minute, villiform, the vomerine pateh emarginate in front and behind, joined to the subtriangular palatine patches; pterygoid patches long-elliptical. Gill membrane with a narrower free margin than in troscheli. Distance of dorsal fin from tip of snout 28 in the length, the dorsal spine $1 \frac{2}{7}$ in the head, granular in front, recurved teeth on its inner margin. Distance between the dorsal aud adipose fins $3 f$ in the length; adipose fin about as long as the dorsal fin. Caudal deeply forked, the upper lobe longer, $3 \frac{2}{8}$ in the length; anal little longer than high; ventrals reaching nearly to the anal, about 2 in the head; pectoral spine $1 \frac{1}{4}$ in the head, its outer margin granular, the inner rather finely toothed. The skin on the dorsal surface of the head and humeral region finely reticulate with mucous canals. Yellowish brown, lighter below, the fins yellowish, finely punctulate. One specimen $0.51 \mathrm{~m}$. Surinam. (Eigenmann \& Eigenmann, Nematognathi, 53.) 
167. SCIADEICHTHYS TEMMIXCKIAYUS (Cuvier \& Valenciennes), text, p. 122.

169. SUIADEICHTHYS FLAVESCENS (Cuvier \& Valenciennes), text, p. 123.

169. SCIADICHTHYS MESOPS (Cuvier \& Valenciennes).

170. SCIADEICHTHYS PROOPS (Cuvier \& Valenciennes).

Head 4 to $4 \frac{1}{8}$; depth 7. D. I, 7; A. 18 ; eye $1 \frac{1}{4}$ to $1 \frac{1}{2}$ in snout, $5 \frac{1}{2}$ to 8 in head, $1 \frac{8}{4}$ to $2 \frac{2}{8}$ in the interorbital, $2 \frac{1}{4}$ to $3 \frac{8}{4}$ in the interocular. Slencler and elongate, broader than deep. Head depressed, its width $1 \frac{1}{3}$ in its length, its depth '2, width at mouth 2 ; anterior portion of the heac flat above; top of the head, humeral process, and dorsal plate coarsely granular, the granules arrauged in series along the fontanel. Oceipital process mucronate, broader than long; dorsal plate large, butterfly-shaped. Opercle striate; fontanel $1 \frac{1}{2}$ times as long. as the eye, its center in front of the middle of the eje, continued as a shallow groove. Jaws subequal; teeth all villiform, the intermaxillary band very wide and shallow; teeth on the roof of the mouth in 6 contiguous patches. Gill membranes meeting in an angle, forming a broad fold across the isthmus; gill rakers $5+10$. Pectoral pores large; vertical series of pores. Distance of dorsal spine from the snont $2 \frac{t}{3}$ in the length; the dorsal spine granular in front, striate on the sides, weakly serrate behind, its length $1 \frac{1}{4}$ to $1 \frac{1}{2}$ in head; space between dorsal and adipose fins $2 \frac{4}{5}$ to 3 in length, the adipose fin little shorter than the dorsal, the posterior margin free. Caudal deeply forked, its upper lobe longer, 4 to $4 \frac{1}{2}$ in the length; anal emarginate, as high as long, 2 to $2 \frac{1}{3}$ in head; ventrals 2 in head; pectoral spine roughened or granular in front, serrated behind, $1 \frac{1}{5}$ to $1 \frac{1}{8}$ in head. Plumbeous above, with blue luster, white below; maxillary barbels dark, the mental barbels white; fins all more or less dotted with brown. Five specimens 0.25 to $0.46 \mathrm{~m}$. long. Peruambuco. (Hartt \& Fletcher.) Northern coast of South America to Pernambuco. (Eigenmann \& Eigenmann, Nematognathi, 57.)

171. SCIADEICHTYS PASSAXY (Cuvier \& Valenciennes), text, p. 124.

172. SCIADEICHTHYS ALBICANS (Cuvier \& Valenciennes), text, p. 124.

71. SELENASPIS, Bleeker.

Dorsal shield much enlarged, truncate before, in the adult; palatine teeth villiform, the patch extended backward in the adult; posterior nasal openings connected by membrane.

173. SFLENASPIS HERZBERGII (Bleeker).

Head $3 \frac{3}{5}$ to $3 \frac{8}{4}$; depth 5 to 6 . D. I, 7 ; A. 18 ; eye $1 \frac{8}{4}$ to $2 \frac{1}{2}$ in suout, $5 \frac{1}{2}$ to 8 in head, $2 \frac{1}{8}$ to 4 in interocular. Elongate, the width as great or greater than the depth. Width of the head $1 \frac{1}{4}$ to $1 \frac{1}{3}$ in its length, at the angle of the mouth about 2 ; depth $1 \frac{2}{8}$ to $1 \frac{8}{4}$ in its length. Humeral process, dorsal plate, top of head to between the eyes, granular. Occipital 
process wider than long, scarcely keeled. Fontanel not continued behind the eyes, and withou backward projecting groove; posterior nostrils connected by a nembrane. Barbels flattish, those of the maxillary reaching to near the ventrals, to middle of pectorals in older individuals; postmental to or beyond base of pectoral, mental to gill opening. Teeth villiform; vomerine and palatine patches of about equal size and shape in the young; a separate patch behind the palatines is developed later. Gill membranes meeting in an angle, forming a fold across the isthmus; gill rakers $6+10$. Distance of dorsal spine from snout $2 \frac{1}{2}$ to $2 \frac{8}{4}$ in the length; dorsal and pectoral spines subterete, the outer margins roughened, the sides striate; the dorsal spine slightly serrate behind; a little shorter than the pectoral spine, $1 \frac{2}{5}$ to $1 \frac{3}{5}$ in the head; pectoral spine strongly serrate behind; space between dorsal and adipose fins $3 \frac{2}{5}$ to 4 in the length; adipose fin as long as the dorsal; upper caudal lobe longer, about 4 in the length; anal as high as long, 2 in head; ventrals $1 \frac{3}{5}$ to 2 in head; pectoral pore minute; sides with vertical series of pores. Color plumbeous above, silvery on sides; fins dusky. The specimens examined measure from 0.14 to 0.38 meters. Para; Curuca; Bahia. (Eigenmanu \& Eigenmann, Nematognathi, 59.)

\section{SELENASPIS DOWII (Gill).}

Head $3 \frac{1}{2}$; depth 6. D. I, 7; A. 19 ; eye small, elliptical, 3 in snout, 12 in head, 6 in interocular. A narrow flap of skin across the snout connecting the posterior nasal openings. Width below the dorsal spine a little greater than the depth, less than the width at the humeral process, which equals the greatest width of the head measurerl-at the opercles. Head depressed, its depth at base of occipital process $1 \frac{1}{3}$ in the greatest width, becoming gradually more depressed forward; width at angle of mouth $1 \frac{2}{8}$ in length of head, its greatest width about $1 \frac{1}{8}$ in its length; snout short, 4 in head. Top of head coarsely granular, the granules forming striæ in front, vermiculations posteriorly or, in places, more or less regular strix. Occipital process truncate, its width at tip greater than its length, the dorsal plate large, saldle-shaped, its bony tubercles forming strix which are parallel with the strongly convex margin of the "saddle"; opercular bones granular striate, the humeral process with bony tubercles. Foutanel nearly obsolete, the granular bony surface being separated in front by thick skin, which covers an elongate area about 7 times longer than wide. Maxillary barbels reaching beyond humeral process; postmental barbels beyond gill opening, the mentals shorter. Upper jaw produced, equal to the short diameter of the eye. Tecth oi the intermaxillaries in a villiform band which is narrowed in front, not produced backward to the angle of the mouth; vomer with a rather broad band confluent with the much wider subquadrate palatine patches which are produced backward in an angle; ovate patches on the pterygolds separate from the palatine teeth; teeth of the lower jaw in a comparatively shallow band, tapering very gradually to the angle of the mouth; the teeth of the jaws minute villiform, those of the palate and $3030-96$ 
vomer bluntly conical. Gill membranes broadly united, meeting in an angle, joined to the isthmus, but with a free margin; gill rakers $9+15$. Distance of dorsal from end of snout $2 \frac{8}{4}$ in the length. Dorsal spine granular on sides and in front, about $\frac{1}{2}$ the length of the head in height; listance of the adipose fin from the dorsal $3 \frac{1}{4}$ in the length, the height of the adipose fin about $2 \frac{1}{2}$ in its length, which is contained $2 \frac{3}{5}$ in the length of the head. Candal deeply forked, $5 \frac{1}{2}$ in the length; anterior $\frac{2}{8}$ of the anal strongly convex, the posterior $\frac{1}{8}$ slightly emarginate, the highest ray about $2 \frac{1}{2}$ in head. Ventrals reaching to anal, about 2 in head, their distance behind the dorsal equal to the length of dorsal and $\frac{1}{2}$ the dorsal plate; pectoral spine granulose on sides, the outer margin with a series of larger granules which become recurved notches toward the tip, the inner edge with recurved hooks, its height $1 \frac{2}{8}$ in the length of the head; a small pectoral pore; no evident series of vertical pores. Bluish gray above, becoming white below; the fins brownish with dots. Description from the type of Arius alatus, .68 m. long, from Panama; collected by Dr. Steindachner. (Eigenmann \& Eigenmann, Nematognathi, 61.)

Selenaspis dowii is thus characterized by Jordan \& Gilbert:* Head 4 ( $4 \frac{3}{5}$ with caudal); depth $6 \frac{1}{2}\left(7 \frac{1}{2}\right)$; width of head $5 \frac{1}{5}$. D. I, $8 ;$ A. 4, 12 . Length (29529, U. S. Nat. Mus.) 10 inches. Body elongate, narrow, and slender, the caudal peduncle $1 \%$ in head. Head low and narrow, tapering anteriorly, the snout subtruncate. Eye small, 7 in head, placed rather high; interorbital space little arched, with ridges and depressions, $2 \frac{4}{5}$ in head; snout $3 \frac{4}{5}$ in head; breadth of mouth $2 \frac{1}{5}$ in head. Mouth moderate, with thinnish lips; teeth villiform, bluntish; vomerine teeth forming 2 smallish, rounded patches, separated by a moderate interspace; each patch confluent with the neighboring palatine patch, which is rounded and rather large; the suture marked by a constriction; palatine bands without backward prolongation; premaxillary band of teeth broad. Barbels very long; maxillary barbel extending well beyond tip of pectoral fin; outer mental barbel reaching well past front of pectoral; inner $2 \frac{4}{5}$ in head. Dorsal shield comparatively large, not distinctly crescent-sbaped, its divisions produced backward, their length about twice the length of the shield on the median line; anterior margin with 2 emarginations, the point fitting into an emargination of the occipital process; dorsal shield without keel. Occipital process very broad and short, its edges nearly straight, its breadth at base considerably greater than its length; its median line with a rather low keel. Fontanel broad and very short, ending obtusely at a point not far behind eye, the distance from this point to tip of snout $1 \frac{2}{8}$ in its distance from base of dorsal; each side of fontanel with a conspicuous smooth ridge, the 2 ridges converging anteriorly; shields of head rather finely granulated, few of the granulations forming lines, none of them extending farther forward than posterior margin of eye. Opercle striate. Gill membranes meeting below in a sharp angle, forming a rather broad fold across isthmus. Dorsal spine very short, its length a trifle less than pectoral spine, $2 \frac{1}{4}$ in head. Axillary pore obsolete. Humeral process granulated, rather narrowly triangular, a

*Bull. U. S. Fish Comm., II, 1882, 50. 
little less than $\frac{1}{2}$ length of pectoral spine, which extends barely $q$ the distance to the ventral fins; adipose fin long and low, very nearly or quite coterminous with the anal; candal narrow, rather short, the upper lobe the longer, 13 in head; anal rather low and shor $i$; ventrals short, the vent not far behind them. Color dusky above, pale below, the fins all more or less dusky; maxillary barbels dusky, others pale. A single young male was obtained at Panama.

7I(a). ASPISTOR, Jordan \& Evermann, new genus.

Aspistor, JoRdan \& EVERMANN, new genus (luniscutis).

This genus differs from Selenaspis in the presence of granular teeth on the palate and in the absence of a membranaceous flap connecting the posterior

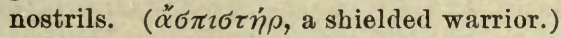

175. ASPISTOR LUNISCU'IS (Cuvier \& Valenciennes).

Head $3 \frac{3}{5}$; depth $5 \frac{1}{2}$ to 6 . D. I, 7; A. 16 to 19 ; eye 2 to 3 in snout, 6 to 9 in head, 3 to $4 \frac{1}{2}$ in the interocular. Body comparatively stout, the greatest width equaling the greatest depth. Head large, flattish above; profile descending; width of head $1 \frac{1}{6}$ in its length, width at the mouth 2 to $2 \frac{2}{5}$, its depth at the base of the occipital process scarcely less than its greatest width; top of head coarsely granular in young, the granules becoming finer and more regularly arranged in the adult; opercles smooth; humeral process with radiating lines of granules. Occipital process variable in shape, broader than long, the posterior margin convex; dorsal plate variable in outline, rounded anteriorly, saddle-shaped, either broader than long or longer than broad; middle of the fontanel above the posterior margin of the eye; the fontanel divided into 3 by 2 bony ridges, the middle portion being more than $\frac{1}{2}$ of its whole length. Sides of head with reticulating mucous canals. No skinny flap connecting the posterior nostrils. Maxillary barbels extending little beyond the base of the pectoral, or shorter; mental barbels short. Upper jaw little produced; teeth in the jaws rather large, conical; teeth of vomer and palatines finely granular, the vomerine patches separated from each other and from the palatine patches in the young, united and covering almost the entire roof of the mouth in the adult; the inner margins of the palatine patches approximated, sometimes a small elliptical patch of teeth between. Gill membranes forming a broad marginal flap across the isthmus. Gill rakers 3 to $4+7$ to 9 . Axillary pore minute or wanting; vertical series of pores present. Distance of dorsal from tip of snout $2 \frac{1}{2}$ in the length; the spine $1 \frac{1}{2}$ to $1 \frac{3}{5}$ in the head, granular in front, scarcely serrate behind; distance of adipose fin from the dorsal 38 to 4 in the length, the adipose fin twice as long as high, adnate, as long as the dorsal fin; caudal forked, the upper lobe longer, $4 \frac{1}{2}$ to $4 \frac{1}{8}$ in the length; anal fin about as long as high, $2 \frac{1}{7}$ to $2 \frac{1}{4}$ in head; ventrals 18 to 2 in head; pectoral spine stout, $1 \frac{1}{4}$ to $1 \frac{1}{4}$ in head, granular in front (serrate in the very young), striate on sides, serrate along inner margin. Color purplish brown above, sprinkled with brown dots below; fins about the color of the back. Nunerous specimens 
examined 0.11 to $0.44 \mathrm{~m}$. long. Porto Alegre; Bahia; Nazareth, near Bahia ; Rio Janeiro; Pará; Porto Seguro; São Matheos; Canuavierias. (Eigenmanu \& Eigenmann, Newatognathi, 63.)

176. SELENASPIS PARKERI (Traill), text, p. 125.

72. NETUMA, Bleeker.

Dorsal shield small, lunate; teeth on palate villiform, the patch on each side with a backward-extending process or angle.

Subgenus NOTARIUS, Gill.

Occipital process constricted at base.

177. NETUMA GRANDiCaSSIS (Cụvier \& Valencienneg).

Head $3 \frac{2}{5}$ to $3 \frac{8}{4}$; depth $5 \frac{2}{3}$ to 6 . D. I, 7 ; A. 18 ; eye 3 to $3 \frac{1}{2}$ in snout, $8 \frac{1}{2}$ to 10 in head, 4 to $4 \frac{1}{2}$ in interocular. Body cylindrical in front, tapering to a slender caudal peduncle. Head greatly depressed, profile almost straight, descending, the width of the head $1 \frac{1}{8}$ to $1 \frac{2}{5}$ in its length, its depth $1 \frac{4}{5}$ to 2 in its length. Occipital process with a deep constriction where it joins the occiput, shaped like a clover leaflet, much as Felichthys panamensis, sometimes broader than long, sometimes much longer than broad, sometimes keeled. Center of the fontanel over the middle of eye, the fontanel not continued backward as a groove; occipital process, top of head, and humeral process granular; interorbital region with 4 ridges, the inner ones bounding the fontanel, the outer ones running obliquely backward from near the posterior nasal opening. Maxillary barbels reaching to the base of the pectoral, mentals to gill opening, postmentals a little longer. Upper jaw projecting a diameter of the eye or more, the lip very wide, especially in front, making the nose pointed; teeth of both jaws rather large, those on the palate somewhat smaller; the depth of the intermaxillary band 7 to 9 in its width; the mandibulary band very shallow; vomerine teeth none in 3 of the examples, a small patch on one side in another specimen, and a small patch on each side in another; palatine patches triangular, produced backward. Gill membranes meeting in an angle, forming a fold across the isthmus; gill rakers $6+10$. Distance of dorsal spine from snout $2 \frac{1}{3}$ to $2 \frac{1}{2}$ in the length, the spine broken in the specimen studied. Distance of adipose fin from the dorsal $3 \frac{3}{5}$ to 4 in the length; adipose fin at least as long as the dorsal fin, adnate. Caudal fin forked, the upper lobe longer, about 5 in the length, the tips broken; anal fin apparently longer than high, but the rays are somewhat worn off; ventrals small; pectoral pore large, slit-like. Color light brown above, soniewhat smutty below from the occurrence of minute scattered dots. We have examined 4 specimens from $0.23 \mathrm{~m}$. to $0.33 \mathrm{~m}$. long, collected by Agassiz \& Bourget, Thayer Expedition, at Maranhao, and a fifth, $0.21 \mathrm{~m}$. long, collected by Professor Agassiz at Bahia. (Eigenmann \& Eigenmann, Nematognathi, 65.) 
178. NETUMA STRICTICASSIS (Cuvier \& Valenciennes), text, p.126.

Subgenus NETUMA.

Occipital process not constricted.

179. NETCMA DUBIA (Bleeker), text, p. 126.

190. NETUMA KESSLERI (Steindachner).

Head $3 \frac{1}{8}$ (4 in total with caudal); depth 6 (7 in total); width of head 4 . D. I, 7; A. IV, 13. Length (29252, U. S. Nat. Mus.) 14 inches. Body rather long and low ; the head long, broad and much depressed, much broader than deep. Eye very small, about 10 in head, placed well above the mouth. Interorbital space 2 in head; snout $3 \frac{1}{3}$; breadth of mouth 2 . Mouth large, with thickish lips, the upper jaw considerably projecting. Teeth all villiform, rather pointed. Vomerine patches rather large, roundish, usually fully confluent into a trapezoidal band, without division on the median line, and separated by a very narrow groove from the palatine bands. Palatine bands very large, broadly triangular, with a backward prolongation from the inner margin. (Teeth on vomer and palatines all forming one continuous band in old specimens, according to Steindachner.) Bands of teeth in jaws broad, the jaws strong. Barbels rather short and very slender, the maxillary barbels reaching little past base of pectoral; outer mental barbels about reaching gill opening; inner about as long as snout. Antedorsal shield short, crescent-shaped, rough, but without median keel. Occipital process long, narrowly triangular, its edges straight, its length $\frac{1}{4}$ to $\frac{1}{2}$ more than its width at base, its median line sharply keeled. Fontanel broad and shallow, its posterior end obtuse or almost truncate, its tip not prolonged in a groove, its edge bounded by a bony ridge, which is not granulated in front of middle of eye; end of fontanel about midway between tip of snont and front of dorsal, its greatest width about equal to length of eye. Shields of head all very coarsely granular, the ronghnesses extending forward about to tho eye. Gill membranes forming a broad free fold across isthmus. Dorsal spine moderate, a little more than $\frac{1}{2}$ head, about equal to pectoral spine; humeral process triangular, granular, not quite ${ }_{5}^{2}$ length of pectoral spine; axillary pore obsolete; adipose fin long and low, its posterior margin little free; caudal short and broad, the upper lobe the longer, $1 \frac{2}{3}$ in head; anal and ventrals rather small, the vent close behind the latter. Color dark brown, with bronze reflections; belly white; fins all dusky in 1 specimen, in the other mostly pale; maxillary barbels dusky, others pale. Two large specimens obtained at Panama by Gilbert. (Jordan \& Gilbert, Bull. U. S. Fish Comm., II, 1882, 40.)

181. NETUMA INSCULPTA (Jordan \& Gilbert).

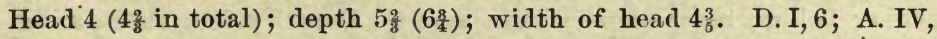
14. Length (29415) 13 inches. Body moderately elongate, little compressed, the caudal peduncle slender and short. Head shortish, low and 
broad, anteriorly depressed. Eye rather large, $6 \frac{1}{2}$ in head, placed rather high. Interorbital space flat and nearly smooth, 2 in head; snout 3 ; breadth of mouth $11_{1}^{9} \sigma$; snout very bluntly rounded, almost truncate in front. Mouth large; teeth all villiform; vomerine bands of teeth large (fully confluent with each other in the type, partly separated in smaller examples), and with the large, club-shaped band on the palatines, from which they are separated by a slight furrow and constriction; palatine band of teeth with a backward prolongation; premaxillary band of teeth large; maxillary barbel long, somewhat compressed, extending to middle of pectoral spine; outer mental barbel reaching base of pectoral spine, inner 2 in head. Dorsal shield short, crescent-shaped, without median keel, its tips produced, its length on the median line about $\frac{2}{5}$ the length of 1 of its halves. Occipital process about as broad at base as long, with a moderate median keel, its lateral margins somewhat concave; fontanel becoming gradually contracted at a point a little nearer base of dorsal than tip of snout, thence forming a narrow groove, which extends to within a diameter of the pupil of the base of the occipital process; this groove sometimes nearly obsolete; greatest width of fontanel about $\frac{3}{5}$ diameter of eye. Granulated striæ extending along the sides of the fontanel to a point opposite or in front of middle of eye. Shield of head finely and evenly granulated, the roughnesses more uniform than usual, and many of them arranged in lines, especially anteriorly; opercle not striate, the skin marked with fine vermiculations; gill membranes forming a broad fold across the isthmus. Dorsal and pectoral spines long, about equal, $1 \frac{1}{8}$ in head. No axiliary pores; humeral process very large, triangular, finely granular, about $\frac{7}{2}$ as long as pectoral spine; adipose fin large, without free tip; upper lobe of caudal the longer, $1 \frac{1}{5}$ in head; anal and ventrals moderate, the vent close behind the latter. Color rather pale; belly pale; fins and barbels all pale, or but slightly tinged with dusky. A single adult male was obtained by Dr. Gilbert at Panama. Two smaller ones are in the Musenm collection, also from Panama. (Jordan \& Gilbert, Bull. U. S. Fish Comm., Ir, 1882, 41.)

\section{NETCMA PLANICEPS (Steindachner).}

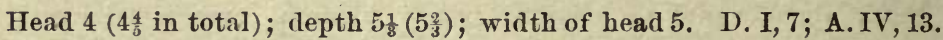
Length (29417) 11 inches. Body comparatively elongate; the head small, rather narrow, depressed anteriorly; the snout rather narrow and moderately rounded. Eyo moderate, placed well above mouth, its length $5 \frac{1}{2}$ in head. Interorbital space flat and smooth, $2 \frac{1}{4}$ in head; snout $3 \frac{1}{5}$; breadth of mouth 2. Mouth rather large, with thickish lips; teeth villiform; vomerine bands moderate, conflnent with each other and with the mnch larger ovate palatine bands, a slight coustriction or furrow making the divisions; palatine bands each with a backward prolongation; premaxillary band moderate; barbels very short; maxillary barbel scarcely or not reaching to base of pectoral; outer mental barbel scarcely past gill opening below; inner shorter than snout. Dorsal shield short, anteriorly truncate, not keeled, the length on the median line about $\frac{1}{2}$ of 1 of its halves. Occipital process subtriangular, rather narrow, truncate 
behind, its margins straight, becoming concave forward, its width at base about equal to its length; fontanel an almost obsolete groove, its posterior end not reaching base of occipital process by about the diameter of the eye, the groove extending forward to a point about midway between tip of snout and base of dorsal spine; anterior to this point is an equilateral triangle, flat, covered with smooth slin, the base of the triangie formed by the smooth, flattish interorbital area. Shields of head rather coarsely granular-striate, the granulations beginning anteriorly about opposite posterior margin of eye; opercle scarcely striate; gll membranes forming a moderate fold across the isthmus. Dorsal spine high, about equal to pectoral spine, and but little shorter than head; no axillary pore; humeral process triangular, granulated, a little more than $\frac{1}{3}$ length of pectoral spine; adipose fin rather long; upper lobe of caudal the longer, a little shorter than head; ventrals and anal moderate. Color brownish, not very lark; belly pale, thickly speckled with brown; fins more or less dusky; maxillary barbels black; mental barbels pale. 'T'wo specimens were obtained by Dr. Gilbert at Panama. They disagree in several details from Steindachner's description, and it is barely possible that they belong to a different species. The head in Steindachner's types is $3 \frac{8}{4}$ to $3 \frac{4}{5}$ in length, and the occipital process is narrower and less widened anteriorly. (Jordan \& Gilbert, Bull. U. S. Fish Comm., II, 1882, 42.)

\section{NETUMA PLATYPOGON (Günther).}

Head $3 \frac{3}{5}\left(4 \frac{3}{5}\right)$; width of head $4 \frac{3}{5} ;$ depth $5 \frac{1}{5}\left(6 \frac{3}{5}\right)$. D. I, 7; A. IV, 14. Length (28286) $15 \frac{1}{2}$ inches. Body rather elougate, the head not very broad nor much depressed, a little broader than deep. Eye rather large, 5 to 6 in head. Interorbital space slightly more than $\frac{1}{2}$ head, a trifle less than width of mouth; length of snout $3 \frac{1}{5}$ in head. Teeth all pointed; bands of vomerine teeth small, roundish, their boundaries traceable by a slight depression in the young, in the adult fully confluent with each other and with the palatine bands; palatine bands broad, ovate, several times as large as the patches on vomer, continued backward over the pierygoid region; premaxillary band rather broad, 5 to 6 times as broad as long; maxillary barbel reaching past base of pectoral in the young, not to gill opening in the adult, its base a little broader and nore compressed than usual; outer mental barbels 2 in head; inner $2 \frac{1}{2}$. Dorsal shield very short, lunate, subtruncate in front, its breadth more than 3 times its length on the median line; occipital process long, triangular, with straight margins, its length abont $1 \frac{3}{5}$ times its width in front, its broad median line rather sharply keeled. In the young it is proportionally shorter, little longer than broad. At the beginning of this keel is the end of the long, narrow, groove-like fontanel, which extends forward to a point just behind the eye, where it merges into the flattish and smooth anterior part of the head. Shields of the head all finely granular, the granules rarely forming distinct lines. Dorsal spine long, $1 \frac{1}{3}$ to $1 \frac{1}{2}$ in head, the soft rays projecting beyond the spine; pectoral spine about as long as dorsal, sharply serrate behind, the anterior 
serra not very sharp; axillary pore small or absent; humeral process nearly smooth, rather narrow and short, $\frac{1}{2}$ length of pectoral spine; adipose fin short and rather high, its base barely $\frac{2}{5}$ length of base of anal; caudal deeply forked, its upper lobe the longer and slightly falcate, about as long as head; ventrals very short, reaching anal in females, shorter in the males; vent nearer base of ventrals than anal. Color in life very pale olive brown, with bronze and blue reflections, white below; fins all pale, the tip of anal and edges of caudal somewhat dusky; female with fins rather darker, the upper edge of the pectorals and ventrals largely black; in the males these fins are pale, or somewhat brown above; maxillary barbels blackish; lower pale. Generally abundant along the Pacific coast of tropical America. Specimens were observed by Dr. Gilbert at Mazatlan, Libertad, Punta Arenas, and Panama. It reaches a length of about 18 inches, and is seldom eaten. It resembles Galeichthys gilberti, but is readily distinguished by the small, pale ventrals, as also by the generic character of the dentition. The males of this species, according to Dr. Steindachner, carry the eggs in their mouths until after hatching. (Jordan \& Gilbert, Bull. U. S. Fish Comm., II, 1882, 44.)

\section{NETCMA OSCULA (Jordan \& Gilbert).}

Head $3 \frac{7}{8}\left(4 \frac{8}{4}\right.$ in total); depth $6 \frac{1}{4}\left(7 \frac{2}{8}\right)$; width of head $4 \frac{8}{4}$. D. I, 7; A. IV, 14. Body moderately elongate, the hearl short, rather narrow, tapering forward, considerably broader than deep. Eye small, $7 \frac{1}{2}$ in head, placed well above the mouth. Interorbital space $1_{10}^{9}$ in head; snout 3 ; breadth of mouth $2 \frac{2}{5}$. Mouth very small for the genus, with thick lips. Teeth on vomer and palatines villiform, but rather coarse and bluntish. Vomerine patches small, rather longer than broad, separated on the median line, and each also separated by a narrow groove from the large and roundish palatine bands, which have a distinct backward prolongation. Premaxillary band of teeth very broad, barely 3 times as long as wide. Barbels short, the maxillary. barbels reaching slightiy bejond base of pectorals, the outer mental barbels scarcely past gill opening below; inner mental barbels about as long as snout. Dorsal shield short, crescentshaped, granulated, but without median keel, its length about $\frac{1}{4}$ its breadth. Occipital process narrow, its edges almost parallel until abruptly widened at base; the narrow part considerably longer than broad, with curved edges; a well-developed median keel. Fontanel broad and shallow, abruptly contracted at a point midway between tip of snout and end of occipital process, thence continued backward as a narrow groove to a point less than an eye's diameter in front of the base of the occipital process. Greatest width of fontanel about $\frac{3}{5}$ eye. Shielis of top of head all coarsely and rather sparsely granular, and anteriorly striate. Interorbital space nearly plane, with a few low, smooth ridges. Opercles scarcely rugose. Gill membranes forming a narrow fold across isthmus posteriorly. Dorsal spine very high, $1 \frac{1}{b}$ in head, a little longer than pectoral spine; humeral process granular, not quite $\frac{2}{\delta}$ length of pectoral spine; no axillary pore; adipose fin adnate posteriorly; caudal long, 
its upper lobe the longer, somewhat falcate, $1_{Y^{1} 0}^{1}$ in head; anal rather high. Color brown, with bluish reflections; lower parts dusky, with dark punctulations; fins all blackish; maxillary and outer mental barbels dusky. A single male example 11 inches long was obtained at Panama by Dr. Gilbert. (Jorian \& Gilbert, Bull. U. S. Fish Comm., II, 1882, 46.)

185. NETUMA ELATTURA (Jordan \& Gilbert).

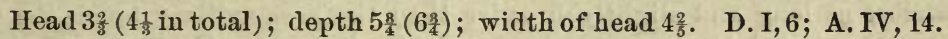
Length (29408, U. S. Nat Mus.) $12 \frac{1}{2}$ inckes. Body low, not very elongate, the head rather short and very broad, much broader than deep, the snout depressed and very broadly rounded, almost truncate. Eye moderate, placed rather high, its diameter 7 in head. Interorbital space $2 \frac{1}{6}$ in head; snout $3 \frac{1}{3}$; breadth of mouth $1 \frac{7}{8}$. Mouth large, with thickish lips, the upper jaw considerably projecting. Teeth on vomer and palatines villiform, but bluntly conical, less acute than in most of the species. Vomerine patches oblong, small, separated by a narrow interspace from each other and from the palatine bands, which are roundish and comparatively small, with a backward prolongation. Teeth in jaws in broad bands. Barbels rather short, the maxiliary barbels reaching a little past base of pectorals, the outer mental barbels a little past gill opening, the inner a little more than $\frac{1}{8}$ head. Dorsal shicld not very short, erescent-shaped, with a distinct median keel, its length on the median line about $\frac{1}{8}$ its breadth. Occipital process short, broadly triangular, with concave sides which spread ont abruptly near the base, forming a sort of shoulder, its length scarcely equal to its width at base. Median keel well developed. Fontanel broad and shallow, abruptly narrowed posteriorly at a point a little nearer base of dorsal than tip of snout, but extenting as a groove to a point distant less than a diameter of the eye from the base of the occipital process, this groove indistinct in the smaller specimen. Greatest width of fontanel scarcely more than $\frac{1}{2}$ the eye. Shields of head granular-striate, the roughness less coarse than in A. kessleri. Interorbital space with 2 prominent ridges and numerous strix, none of them granular, the granulations chiefly confined to the region behind widest part of fontanel. Opercle striate. Gill membranes forming a moderate fold across isthmus. Dorsal spine low, shorter than pectoral spine, which is $1 \frac{3}{5}$ in head, the anterior edges of both bluntly serrate; humeral process broadly triangular, granulated, not $\frac{2}{5}$ length of pectoral spine, much smaller than in $A$. insculptus; no axillary pore; adipose fin long and low, without free posterior margin; lower fins of moderate length; vent much nearer ventrals than anal. Caudal short, the upper lobe longest, $1 \frac{3}{5}$ in head (a little more than $\frac{1}{2}$ head in the smaller specimens). Color dusky above, the lower parts soiled with dark points; fins all more or less dusky with dark points; maxillary barbels dusky, others pale. One male individual (29408) was obtained at Panama by Dr. Gilbert; another (30995) at Pauama by Mr. Rowell. (Jordan \& Gilbert, Bull. U. S. Fish Comm., II, 1882, 45.) 
185 (a). NETUMA INSULA RUM, Flora Hartley Greene.

Head $3 \frac{2}{8}$ in length; width of head $4 \frac{3}{5}$ in length; interorbital space in length 7 ; interorbital space in head scarcely 2 ; snout in head 3 ; breadth of mouth in head 2 ; eje in head $6 \frac{2}{3}$. D. I, 7; A. 17. Head much broader than deep; snout depressed and broadly rounded; eye above the level of. the mouth. Upper jaw projecting. Teeth on vomer and palatines villiform and bluntly conical, the 2 vomerine patches forming together a band almost as loug and slightly broader than the premaxillary band, the 2 sides separated by a narrow interspace; palatine teeth well separated from the vomerine teeth and in 2 large triangular patches which extend backward over the pterygoid region; each triangle has a sharp notch in its anterior side; its antero-posterior length is twice its lateral width; teeth of lower jaw in a narrower band than the upper jaw. Maxillary barbel extending to end of first third of the length of the pectoral spine; outer mental barbel to base of pectoral; inner mental barbel past gill opening, $2 \frac{1}{8}$ in head. Dorsal shield crescent-shaped, without median keel, length on median line $2 \frac{2}{3}$ in distance between the horns of the crescent; 2 notches on its anterior side to meet the corresponding points from the occipital process. Occipital process broadly triangular, with the outer sides concave and 2 small projections at its posterior end. Median keel evident, rather short. Occipital process much broader at base than long; its length $3 \frac{1}{2}$ in head; posterior breadth 2 in length of process. Fontanel broad and shallow, narrowed gradually posleriorly to a point halfway between snout and base of dorsal spine. A narrow line runs back from it the distance of a long diameter of the eye. Greatest width of the fontanel equals the short diameter of the eye. Shields of the head granularstriate, the strix evident and extending to the middle of the interorbital space, and on the side to meet the humeral process at the top of the gill opening. Opercles nearly smooth. Gill membranes forming a fold across the isthmus. Dorsal and pectoral spines crenulate in front and sharply decurved serrate behind. Dorsal shorter than pectoral, which is $1 \frac{1}{8}$ in head. No axillary pore evident. Adipose fin long and low with posterior margin attached. Vent much nearer ventrals than anal. Color in alcohol, dark blue above, light blue on side, and white below; maxillary barbel dusky; fins all dusky. The type of this species (No. 47577, U. S. Nat. Mus.) was collected by the Albatross in the Galapagos Archipelago, being part of the collection studied by Jordan \& Bollman in 1889. It was recorded by them (Proc. U. S. Nat. Mus. 1889, 179) as "Tachysurus elatturus (var १)." Its relations to Netuma elattura are close, but its fins are better developed and there are several differences in details of structure.

Netuma insularum, Flora Hartley Greene in Gmbert, Proc. U. S. Nat. Mus. 1896 (Feb. 5, 1897), 439, Galapagos Archipelago.

69. GALEICHTHYS, Cuvier \& Valenciennes.

Dorsal shield small, lunate; teeth on palate villiform, the patches on each side not exterding backward over the pterygoid region. 


\section{Subgenus GALEICHTHYS.}

Shields of head mostly covered by soft skin, hiding the granulations.

163. GALEICHTHYS LENTIGINOSUS (Eigenmann \& Eigenmann).

Head 4 to $4 \frac{1}{5}$; depth 5 to 6 . D. I, 6 ; A. 22 . Eye $2 \frac{1}{2}$ in snout, $8 \frac{1}{2}$ in head, $4 \frac{1}{2}$ in interocular, $2 \frac{1}{4}$ in interorbital. Body nearly terete anteriorly, becoming compressed backward; the width, above the pectorals, a little greater than the depth. Head flat, depressed, its depth at base of occipital process $1 \frac{1}{6}$ in its greatest width, which is about $1 \frac{1}{4}$ in its length. Occipital process somewhat roughened, about twice as long as its greatest width, its margin straight and oblique; the middle of the fontanel above the posterior part of the eye. Head everywhere covered with skin; sides of the head and opercle with vermiculating canals. Snout somewhat pointed; upper jaw very little projecting; lips thick; teeth all villiform; the intermaxillary band strongly curved; vomerine teeth in 2 oval patches joined to the larger patches of the palatines; mandibulary band of teeth separated in front, the outer margins, if continued forward, forming an angle at the symphysis. Maxillary barbels reaching beyond base of pectorals; mental barbels reaching about $\frac{3}{5}$ toward the gill opening; the postmentals to the gill opening in 1 specimen, a littie before in the other. Gill membranes forming a broad, free margin across the isthmus. Gill rakers $3+4$. Pectoral pore minute; humeral process pointed behind. Distance of dorsal from snout $2 \frac{4}{5}$ in the length, the dorsal spine covered with a membrane, its outer margin granular, its height $1 \frac{3}{5}$ in the head, the first soft ray $1 \frac{3}{5}$ the length of the fin; distance of adipose fin from the dorsal $3 \frac{3}{5}$ to 4 in the length, the fin adnate, longer than the dorsal; caudal lunate, the upper lobe longer, somewhat falcate, $4 \frac{1}{2}$ to 5 in the length; anal fin twice as long as high, the highest ray 2 to $2 \frac{1}{4}$ in the head; ventrals short and broad, 15 in the head; pectoral spine covered with a membrane, $1 \frac{1}{2}$ to $1 \frac{2}{5}$ in head. Light brown, becoming nearly white below, the sides freckled; fins reddish. Panama. (Eigenmann \& Eigenmann, Nematognathi, 50.)

\section{GALEICHTHYS PERUVIANUS, Lütken.}

Head $3 \frac{1}{2}$; depth $4 \frac{1}{8}$ to $5 \frac{1}{2}$. D I, 7 ; A. 14 to 16 . Eye 2 in snout, 7 in head, 4 in the interocular, 2 in the interorbital. Subterete, tapering to a long, slender caudal peduncle; the greatest width about equal to the greatest depth. Head not much depressed; interorbital area flattish, the greatest depth of the head 18 in its length, its greatest width 18 to 13 ; the width at angle of mouth 2 in its length; the surface of the cranial bones longitudinally furrowed, covered with muscle and skin. Occipital process more than 3 times as long as wide; anterior fontanel elongate, its center over the middle of the eye, continued as a deep groove to the base of occipital process; a small opening a pupil's distance behind the anterior fontanel, and a larger one in the occipital bone at the end of the groove. Snout, upper part of the neck, and the opercle sometimes with conspicuous reticulating mucous canals. Snout blunt, decurved. Maxillary barbels extending beyond base of pectoral, mentals about to gill 
openings, the postmentals about 1 diameter of the eye farther. Jaws sulbequal, the upper longer; teeth all fine, villiform; intermaxillary band of teeth very wide, its depth about 8 in its width; 2 small patches on the vomer; palatine patches very wide and shallow, tapering to a point. Gill membranes meeting at an acute angle, forming a fold across the isthmus; gill rakers $3+10$. Hnmeral process very thin, covered with skin, more than $\frac{1}{2}$ as long as the pectoral spine, broadly expanded and rouuded behind; pectoral pore present. Distance of dorsal spine from snout $2 \frac{2}{5}$ to 28 in the length; the dorsal spine broken off in all the specimens; distance of adipose from the dorsal $3 \frac{3}{5}$ to $3 \frac{2}{8}$ in the length; adipose fin as long as the dorsal tin, adnate; caudal fin broadly lunate, the upper lobe longer, falcate, $3 \frac{8}{4}$ in the length; anal fin higher than long, the highest ray 2 to $2 \frac{3}{5}$ in head; ventrals reaching to the anal, $1 \frac{1}{2}$ to 2 in head; pectoral spines broken in all the specimens. Back, top of head, and a band from humeral process to the lower caudal lobe, blue black; a broad conspicnous, bluishsilvery band along the lateral line; lower parts white; fins blackish; ventrals and anal sometimes with light areas. Eleven specimens, 0.25 to 0.35 m. long. Callao, Peru; Haslar Expedition. (Eigenmann \& Eigenmann, Nematognathi, 5.)

\section{Subgenus HEXANEMATICHTHYS, Bleeker.}

Shields not entirely covered by soft skin, the granulations evident, especially in the male.

\section{GALEICHTHYS SEEMANNI (Günther).}

D.I, 7; A.19; P.I, 10. The height of the body is contained $4 \frac{1}{2}$ times in the total length (without caudal); the length of the head $2 \frac{1}{8}$; head much broader than high, its greatest width being equal to its length without snout. Eyes of moderate size, much nearer to the end of the snout than to the operculum; the length of the snout is $\frac{3}{5}$ of the width of the interorbital space. The median longitudinal fonticulus on the upper side of the head extends to the base of the occipital process. Teeth on the vomer separated in the middle by a short interspace, forming a pair of small subquadrangular patches which are confluent with those of the palatines. The latter are much longer than broad, elliptical. The band of intermaxillary teeth is $5 \frac{1}{2}$ times as broad as long. The maxillary barbels extend nearly to the end of the head, and are about twice as long as the outer ones of the mandible. Crown of the head, and nape finely granular; occipital process broader than long, with a prominent ridge along its middle. The basal bone of the dorsal spine is small, with a few fine granules. Dorsal spine of moderate strength, more than $\frac{1}{2}$ as long as the head, serrated along both edges; the first soft ray is as high as the body. Adipose fin rather shorter than dorsal. The upper caudal lobe is the longer, 2 of total length. Porus axillaris present. Ventral fin shorter than pectoral. Sides of the body silvery; basal half of the inner side of the paired fins black. Central America. A fine specimen 12 inches long, from the Haslar collection, collected by Dr. Seemann. (Günther.)

Arius seemanni, GUNTHEk, Cat., $\nabla, 147,1864$, Central America. 
Jordan (Proc. Ac. Nat. Sci. Phila. 1883, 282) adds the following note on the type of this species: "Fontanel extending backward in a deep and narrow groove which reaches the occipital process. Middle of top of head smooth, much as in A. platypogon."

The following account is given by Eigenmann \& Eigenmann (Nematognathi, 78):

Head $3 \frac{8}{4}$; depth 5. D. I, 7; A. 18. Body about as deep as wide, tapering to a slender peduncle. Head flat, depressed in front, top of the head coarsely granular; opercles smooth or with faint striations; humeral process slightly granular, covered with skin; the greatest depth of the head $1 \frac{3}{5}$ in its length, greatest width $1 \frac{1}{3}$ to $1 \frac{2}{5}$; the width at angles of the mouth 21. Occipital process wider than long; fontanel open to above the posterior margin of the eye, with a deep backward-extending groove. Interorbital area smooth, without ridges. Eye 2 in snout, 7 in head, $3 \frac{3}{5}$ to 4 in the interocular, $2 \frac{1}{8}$ in the interorbital. Maxillary barbels reaching slightly beyond base of pectorals, mental barbels $\frac{2}{8}$ toward the gill opening, the postmentals $\frac{1}{2}$ a diameter of the eye behind the gill opening or farther. Upper jaw longer; teeth all villiform; vomerine teeth in 2 small ovate patches, which are separated from each other but joined to the much larger palatine patches. Gill membranes forming a moderate fold across the isthmus. Gill rakers $5+12$. Pectoral pore large; vertical series of pores present. Distance of dorsal fin from tip of snout $2 \frac{1}{8}$ to $2 \frac{3}{5}$ in the length, the spine rather stout, $1 \frac{2}{8}$ in head, its outer edge granular toothed, its inner edge with short, recurved teeth; distance of the adipose fin from the dorsal $3 \frac{1}{2}$ to $3 \frac{1}{6}$ in the length; adipose fin slightly longer than high, shorter than the dorsal fin. Caudal 4 in the length; anal emarginate, little longer than high; ventrals 18 to 2 in the length of the head; pectoral spine $1 \frac{1}{3}$ in head, its anterior margin granular toothed, its inner edge with long, straight teeth. Plumbeous, silvery below; fins dusky, inner surface of ventrals and pectorals dark. One female $0.28 \mathrm{~m}$., Panama. One unale $0.21 \mathrm{~m}$. , Panama.

187 (a). GAIEICHTHYS GILBERTI, Jordan \& Williams.

Head $3 \frac{4}{7}$ to 4 ; width of head $5 \frac{1}{5}$; depth 5. D. I, 7; A. IV, 14. Body comparatively elongate, the head depressed but not very broad, somewhat broader than high; eye rather large, 5 to 6 in length of head; width of interorbital space $2 \frac{1}{4}$ in head; breadth of mouth $1 \frac{8}{4}$; length of snout $3 \frac{1}{8}$. Teeth all villiform; bands of vomerine teeth separated by a rather wide interval, each small, roundish, confluent with the neighboring palatine band, the junction marked by a slight constriction; palatine band ovate, broad behind, varying considerably in size and somewhat in form, the width ranging from $\frac{1}{8}$ diameter of eye to $\frac{2}{8}$, being generally largest in adults; band of palatine teeth without backward prolongation; band of maxillary teeth rather broad and short, its length about 5 times its breadth. Maxillary barbel flattened at base, reaching a little past base of pectoral in young, scarcely to gill opening in adult; outer mental barbels 2 in head, inner 3 . Gill rakers $4+12$. Dorsal shield very short, narrowly erescent-shaped, its length on median line not more than $\frac{1}{2}$ that of one 
of its sides. Occipital process subtriangular, not quite as long as broad at base, with a strong median keel, its sides slightly curved. A short distance in front of the beginning of the keel is the end of the very narrow groove-like fontanel, which is somewhat widened anteriorly, finally merging into the broad, flat, smooth interorbital area, the boundaries of which are not well defined; shields of head unusually smooth, all finely and very sparsely granular, the granules not forming distinct lines. Some specimens (probably females) about as smooth as in the subgenus Galeichthys. Gill membranes forming a rather broad fold across isthmus. Dorsal spine long, usually, but not always, shorter than the pectoral spine, about $1 \frac{8}{4}$ in head; axillary pore absent; humeral process rather broadly triangular, not much produced backward, less than $\frac{1}{2}$ length of pectoral spine, its surface not granular, covered with skin; adipose fin $\frac{1}{2}$ length of anal, its posterior margin little free; upper lobe of caudal the longer and somewhat falcate, about as long as head; ventrals long, about reaching anal in females, rather shorter in males; vent much nearer base of ventrals than anal. Color olive green, with bluish luster, white below; upper fins dusky olivaceous; caudal yellowish dusky at tip; anal yellowish with a median dusky shade; ventrals yellowish, the basal half of upper side abruptly black; pectorals similarly colored, the black area rather smaller; maxillary barbel blackish; other barbels pale. Length 12 to 18 inches. Coast of Sinaloa; very common; by far the most abundant species at Mazatlan; not recorded from localities farther south.

A rius assimilis, JoRDAN \& GILBERT, Bull. U.S. Fish Comm., II, 1882, 47; not of GÜNTHER. Galeichthys gilberti, JoRdan \& Williams, Rept. Fishes Sinaloa, in Proc. Cal. Ac. Sci. 1895,

395, pl. 26, Mazatlan. (Type, No. 29213. Coll. Chas. H. Gilbert.)

185. GALEICHTHYS JORDANI (Eigenmann \& Eigenmann).

Head $3 \frac{2}{5}$ to $3 \frac{3}{5}$; depth $5 \frac{1}{2}$ to $5 \frac{5}{6}$. D. I, 7; A. 18; өye large, $1 \frac{8}{4}$ i`1 snout, $5 \frac{1}{2}$ in head, 2 in the interorbital, $2 \frac{8}{4}$ to 3 in the interocular. The specimens agree very closely with the description of assimilis by Jordan \& Gilbert (gilberti of the present paper). They differ in the width of the mouth and in having a pectoral pore. Rather robust, the width little less than the depth; caudal peduncle compressed. Head heavy, little broader than high, its height $1 \frac{1}{2}$ in its length, its width $1 \frac{2}{5}$ to $1 \frac{1}{3}$, width at the angle of the mouth 2 to $2 \frac{1}{4}$; interorbital area flat and smooth; posterior portion of the head fincly and sparsely granular; opercle and humeral process smooth; occipital process about as long as broad, unusually sharply keeled; fontanel extending to above the posterior part of the orbit, continuing as a deep groove to the base of the occipital process; maxillary barbels extending to the pectoral pore, postmentals at least to the gill opening, mental about $\frac{3}{5}$ as long as the postmental barbels; snout blunt, decurved; upper jaw a little produced; teeth all villiform, those on the vomer forming 2 small, separate, ovate patches, which are contiguous to the twice or thrice as large palatine patches; gill membranes forming a fold across the isthmus; gillrakers $6+9$; pectoral pore large; vertical series of pores present; distance of dorsal spine from tip of snout $2 \frac{2}{5}$ to $2 \frac{4}{5}$ in the length; the spine of the dorsal and pectoral fins granular on the 
basal half of their outer margin; almost the entire inner margins serrate, the spines of equal length, $1 \frac{1}{2}$ in head; distance of adipose fin from the dorsal $3 \frac{2}{5}$ in the length; the adipose more than $\frac{1}{2}$ as long as the dorsal fin, its posterior margin free; caudal deeply forked, the upper lobe longer, somewhat falcate, $3 \frac{8}{4}$ to 4 in length; anal fiu about as long as high, deeply emarginate, its highest ray $2 \frac{2}{5}$ in head; rentral fins not reaching to the anal, 2 in head. Dorsal surface dark blue, with metallic luster, becoming silvery below; lower caudal lobe dusky; basal half of the inner surface of the paired fins black. (Eigenmann \& Eigenmann, Nematognathi, 79.) Panama; known only from specimens in the Museum of Comparative Zoology. The specimens from Mazatlan referred to jordani, seemanni, and assimilis by authors belong to Galeichthys gilberti.

\section{8(a). GALEICHTHYS AZUREUS, Jordan \& Williams.}

Fead $3 \frac{1}{4}$; width of head $4 \frac{5}{9}$; depth 9 . D. I, 7; P. I, 10; A. IV, 14 . Gill rakers $6+13$. Body robust, its width anteriorly greater than its depth; caudal peduncle short, stout; distance from end of anal fin to base of median caudal rays about $\frac{1}{2}$ length of head. Head flat, very broad, its depth at posterior angle of jaw about $\frac{1}{2}$ its width; interorbital region flat, smooth anteriorly and granulated posteriorly; fontanel almost obsolete, wide anteriorly and ending in a short groove posteriorly at a point $\frac{1}{2}$ distance from tip of snout to posterior end of occipital process; top of head, occipital process, and antedorsal shield finely granular, granulations mostly arranged in radiating strix and extending forward to a line with the pupils; nostrils very large and close together, posterior one with a broad valve; occipital process pentagonal, its length $4 \frac{1}{2}$ in head, about as long as wide, with a very low ridge; dorsal shield crescent-shaped, with points extending back on each side of fiu, its median length about $\frac{1}{2}$ the length of the side; eye small, about 9 in head; interorbital width almost 2 in head; snout almost 4 in head; breadth of month $2_{1}^{3}$ in head; maxillary barbel slender, thick at base, $1 \frac{4}{5}$ in head; outer mental barbel reaching to posterior angle of jaw, about $2 \frac{3}{5}$ in head; inner mental barbel about 4 in head; teeth all villiform; premaxillary band narrow, about $\frac{1}{8}$ as wide as long: vomerine and palatine bands of teeth fully confluent on each side, forming together a crescent-shaped patch, narrowly divided on the median line of the vomer; form of vomerine bands similar to that of the palatine bands but smaller; palatine band of teeth without backward prolongations; opercle with radiating ridges; humeral process granular, triangular, lower posterior corner prominent; axillary pore very small; gill membranes forming a broad fold across isthmus; dorsal fin short, base not including spine equal to base of adipose dorsal; dorsal spine robust, but little shorter than pectoral spine, about 2 in head, its anterior serræ small and tubercle-like, its posterior edge, as well as that of pectoral, retrorsely serrate; soft rays of dorsal extending but little beyond spine, the longest about $\frac{3}{5}$ length of head; adipose dorsal about $\frac{1}{2}$ as high as long; caudal lobes unequal, the upper lobe about $\frac{1}{8}$ longer than lower lobe; anal short, of medium height; distance from vent to base of ventrals $\frac{1}{2}$ distance from 
origin of anal; pectoral spine very strong, its anterior margin with serræ toward the tip, becoming small tubercles toward base; soft rays but little longer than spine, which reaches slightly beyond $\frac{1}{2}$ distance from origin to base of ventrals. Color dark blue, with silvery reflections on sides; belly pale; mental barbels dusky; maxillary barbels light below and black above; paired fins darkest on inner side; other fins almost uniformly dusky. One specimen, $19 \frac{1}{4}$ inches long, taken by the Hopkins Expedition at Mazatlan; probably not distinct from G. guatemalensis.

Galeichthys azureus, Jordan \& Williams, Rept. Fishes Sinaloa, in Proc. Cal. Ac. Sci. 1895, 398, pl. 27, Mazatlan. (Type, No. 1575, L. S. Jr. Univ. Mus. Coll. Hopkins Exped. to Sinaloa.)

\section{GALEICHTIYS CERULESCENS (Günther).}

D. I, 7; A. 17; P. I, 10.' The height of the body is contained about 5 times in the total length (without caudal), the length of the head $3 \frac{1}{2}$ or $3 \frac{2}{8}$ times; head much broader than high, its greatest width being $\frac{8}{4}$ of its length. Eyes rather small, their diameter being $\frac{1}{2}$ of the extent of the snout, $\frac{2}{7}$ of their distance from the gill opening, and $\frac{1}{3}$ of the width of the interorbital space. The teeth on the palate form a slightly curved bard, composed of 2 vomerine patches which are much broader than long, and of a pair of palatine patches which are subcontinuous with, scarcely broader and longer than, those of the vomer. The barbels of the maxillaries extend to the middle, the outer ones of the mandible to the base of the pectoral. Crown of the head granular; occipital process broader than long, subtriangular, subtruncated behind, and slightly raised along the median line; the basal bone of the dorsal spine is subtriangular, small. Dorsal spine of moderate strength, more than $\frac{1}{2}$ as leng as the head, granulated in front and slightly serrated behind; the first soft ray is as high as the body; adipose fin shorter than the dorsal; caudal deeply forked, with the upper lobe the longer, its length being nearly equal to that of the head; pectoral spine serrated along its inner edge and on the extremity of its outer edge; it is as long as the head vithout snout. Ventral fin shorter than pectoral. Sides steel-blue iridescent, blackish toward the back, and silvery below; vertical fins black; inner side of the paired fins blackish. Guatemala. a-b. Fine specimens, 12 inches long. Huamuchal. From the collection of Messrs. Godman and Salvin. (Giinther, Cat., v, 149.)

The following note on the types of this species is given by Jordan (Proc. Ac. Nat. Sci. Phila. 1883, 282): "Head more depressed than in A. assimilis. Fontanel very short, ending abruptly behind and not produced in a groove behind the smooth area of the top of the head, the boundary of the smooth area being rather abruptly convex. Occipital process broader than long, its edges nearly straight. Bands of palatine teeth small, not produced backward on the inner margin. Paired fins black at base above." No recent collector has found this species. 
189(a). GALEICHTIYS XENAUCHEN, Gilbert, new species.

Head $3 \frac{7}{8}$ in length; depth at front of dorsal $5 \frac{1}{2}$; anal 23. Width of head at opercle $1 \%$ in its length; width at front of eyes 2 in head; width of mouth at inner angles $2 \frac{2}{5}$ in head; interorbital width $2 \frac{1}{10}$; eye very small, $9 \mathrm{in} \mathrm{head,} 3 \frac{1}{5}$ in its distance from tip of snout, $4 \frac{5}{6}$ in postocnlar part of head, $4 \frac{1}{8}$ in interorbital width. Teeth all villiform; mandibular bands well separated on middle line, very broad mesially, rapidly tapering to a point laterally, the band produced beyond angle of mouth, its greatest width 24 times in its length; premaxillary band very convexly curved, following the outline of the snout, its width $5 \frac{2}{5}$ in its length; vomerine patches roundish, separated by an evident medial groove, marked off from the palatine patches by a narrower groove and a constriction; the palatine patches are equal in width to the vomerine patches, and less than twice as long, of nearly equal width throughout. Maxillary barbels very slender, reaching slightly beyond the base of the pectoral spine; the mental barbels do not reach edge of gill membrane, the outer pair equaling length of snont and $\frac{1}{2}$ of eye. Nostrils very large, the anterior broadly oval, with widely reflexed rim; the posterior widely elliptical, not concealed by the valve; distance from anterior nostril to tip of snout equaling that from posterior nostril to front of eye. Fontanel wide, with nearly parallel edges on frontal region, abruptly narrowing at front of occiput, where it is continuous with a narrow and shallow groove; the latter fails to reach base of occipital process by a distance equaling $\frac{1}{2}$ diameter of eye. The raised margins of the fontanel continuous with a pair of sharp ridges bounding the groove, these accompanied by a pair of lower ridges on their outer sides and parallel with them; posteriorly these ridges roughened with granules and merging into the granulated area on posterior part of occiput; occipital process granulated, the granules arranged in more or less definite lines radiating backward and downward on each side from median point of base; lateral portions of occiput with an area of radiating stria separated from the central ridges by a smooth groove-like depression; a narrow granulated area extending forward on each side of fontanel to above back of orbits; occipital process very long and narrow, its width opposite its middle being but $\frac{2}{9}$ of its length, abruptly expanding near base, the basal width being $\frac{1}{2}$ its length plus that of dorsal plate on median line; opercles and humeral plate weakly striate. Gill membranes with a wide, free fold posteriorly; gill rakers weak and short, $1+4$ movable ones; no evident axial pore. Dorsal spine slender, with a series of sharp granulations on anterior edge, minutely roughened, not serrate, behind, broken in the type, but its length was about $\frac{2}{8}$ that of head; pectoral spines rather slender, rough granular on outer margins, with short, fine serra within, both mutilated in the type, but their length was about equal to that of dorsal spine; pectoral extending nearly $\frac{2}{8}$ distance to ventrals, the ventrals nearly to origin of anal; distance from anus to base of ventrals $\frac{2}{5}$ its distance from front of anal; anal fin very long, its base $1 \frac{1}{4}$ in head, its longest ray $\frac{1}{8}$ head; distance between dorsals $3 \frac{4}{5}$ in length; adipose fin long, highest about opposite the middle, a short, almost verti$3030-97$ 
cal, free posterior margin, its vertical height $3_{6}^{5}$ in its length; the latter over twice its distance from rudimentary caudal rays, greater than base of first dorsal, equal to $\frac{1}{2}$ length of head; caudal with broad lobes, the lower rounded; the upper mutilated in the type, but evidently acute and longer than the lower. Color purplish above, more bluish anteriorly, the lower parts silvery, coarsely punctate with brown; fins all blackish except the lower surface of the paired fins. In appearance most closely allied to species of Netuma, having the low, depressed head with the lateral ontlines converging forward to the narrow pointed snout, and a long, largely adherent adipose dorsal. The palatine patches are, however, narrow and without backwardly projecting lobes. The species is distinguished from all those known from the Pacific coast of America by the long and extraordinarily narrow occipital process. Type, a female $380 \mathrm{~mm}$. long, from

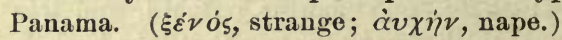

Galeichthys xenauchen, GiLbert, Fishes of Panama, MS. 1898, Panama.

190. GALEICHTHYS GUATEMALENSIS (Günther).

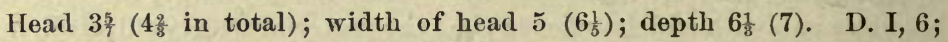

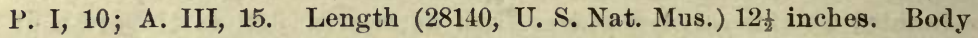
slender, its width anteriorly greater than depth; candal peduncle compressed, short; distance from end of anal to base of median caudal rays about $\frac{1}{2}$ length of head. Head depressed, not very broad, its depth at posterior margin of branchiostegal membranes less than $\frac{3}{5}$ its width; interorbital region flat, smooth, the smooth area forming a broad equilateral triangle, its base at the interorbital space, the apex at a point $\frac{4}{y}$ the distance from snout to dorsal, the triangle forming the termination of the almost obsolete fontanel; top of head, occipital process, and antedorsal shield finely granular, some of the anterior granulations only arranged in lines, none of them in radiating striæ. Occipital process broadly trapezoidal, its width slightly greater than the length of its side, with a slight or obsolete median carina; its posterior margin truncated; its sides slightly convex posteriorly, concave toward the frout. Dorsal shield small, narrow, crescent-shaped, its median length about $\frac{1}{2}$ the length of its side. Eye small, 6 in head; interorbital width $2{ }_{\gamma}^{2}$ in head; snout 4 in heal; breadth of mouth 2. Maxillary barbel very slender, reaching base of pectoral spine; outer mental barbel to well beyond margin of branchiostegal nembranes, its length about $\frac{1}{2}$ head; inuer mental barbel 3 in head. Teeth all villiform; width of premaxillary band about $\frac{1}{6}$ its length; vomerine and palatine bands of teeth fully confluent on each side, forming together a crescent-shaped patch, narrowly divided on the median line of the vomer; form of vomerine band similar to that of the palatine band; palatine band of teeth without backward prolongation; opercle with radiating ridges; humeral process granular, narrow, produced backward, not quite $\frac{1}{2}$ length of pectoral spines; no axillary pore. Gill membranes forming a narrow fold across isthmus. Dorsal short, its base about equal to that of the adipose dorsal; dorsal spine robust, but little shorter than the pectoral spine, about $\frac{3}{5}$ length of head, its auterior serrse small and tubercle-like; its posterior edge, as well as that of the pectoral, retrorsely scrrate; soft rays of dorsal extending much beyond the spine, 
the longest about $\frac{8}{4}$ length of head; adipose dorsal about $\frac{1}{2}$ as high as long, its posterior margin largely free; caudal very widely forked, the upper lobe falcate, nearly $\frac{1}{3}$ longer than the lower, as long as head; aual short and low; distance from vent to base of ventrals slightly more than $\frac{1}{2}$ its distance from origin of anal; pectoral spine very strong, much stronger than dorsal spine, its anterior margin with serra toward the tip, becoming small tubercles toward base; inner edge with strong retrorse serra, the soft rays longer than spines, reaching $\frac{8}{4}$ distance to base of ventrals. Color very dark bluish or greenish above; sides with bronze luster; belly silvery; mental barbels white, with black edge; maxillary barbels blackish; fins all blackish, the caudal nearly uniform; paired fins darkest on inner sicle; sides with vertical series of mucous pores, conspicuous in life. This species is not uncommon at Mazatlan, where several specimens were obtained by Dr. Gilbert. Four specimens from Colima are also in the National Musenm. It has not been observed at Panama. The original description of this species is brief and not entirely correct. That it was intended to refer to the species here described we have ascertained by the examination of Dr. Giinther's origiual types in the British Museum. (Jordan \& Gilbert, Bull. U.S. Fish Comm., I, 1882, 48.)

191. GALEICHTHYS ASSIMILIS (Günther).

D. I, 7; A.19; P.I, 10. The height of the body is contained $4 \frac{2}{8}$ times in the total length (without canclal), the length of head $3 \frac{3}{5}$; head much broader than high, its greatest width being $\frac{8}{4}$ of its length. Eyes rather small, situated nearer to the end of snout than to that of operculum; the length of snont is $\frac{3}{5}$ of the width of interorbital space. The median longitudinal fonticulus on the upper side of the head does not extend to the base of occipital process. Teeth on vomer but slightly separated in the middle, forming a pair of oblong transverse patches which are confluent with those on the palatine bones; the latter areshort, club-shaped. The band of intermaxillary tecth is 5 times as broad as long. All the tecth villiform. The maxillary barbels extend nearly to the end of head; the length of the outer ones of the mandible is $\frac{1}{2}$ or $\frac{2}{8}$ that of the head. Crown of the head granular, the granulations being arranged in radiating streaks. Occipital process broader than long, triangular, with its hinder end concave. The basal bone of the dorsal spine of moderate size, cresceut-shaped. Dorsal spine of moderate strength, more than $\frac{1}{2}$ as long as head, granulated in front and slightly serrated behind; the first soft ray longer than spine and as high as body; adipose fin shor ter than dorsal; caudal deeply forked, with the upper lobe the longer, its length being contained $5 \frac{1}{2}$ times in the total; pectoral spine serrated along its inner edge and on the extremity of the outer edge; ventral fin shorter than pectoral. Sicles of the body silvery; vertical fins grayish; basal half of the inner side of the paired fins black. Guatemala. A fine specimen, 13 inches long. Lake of Yzabal. From the collection of Messrs. Godman and Salvin. (Günther, Cat., v, 146.)

Jordan (Proc. Ac. Nat. Sci. Phila. 1883, 281) has the following note on the type of this species: "Area between the eyes smooth, extending backward in the form of a rather narrow triangle, which is moderately 
obtuse behind. Fontanel narrow and short, ending far in front of occipital process, not extending backward as a groove behind the smooth area of the top of the head; posterior end of fontanel midway between tip of snout and middle of dorsal shield. Occipital process broad, its edges not straight. Band of palatine teeth large, but not produced backward on the inner margin. * * * There is no evidence of the occurrence of the true A. assimilis in Pacific waters."

192. GALEICHTHYS SURINAMEXSIS (Bleeker), text, p. 129.

193. GALEICHTHYS DASYCEPHALUS (Günther).

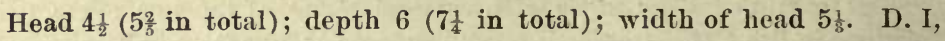
7; A. IV, 17. Length (29400) 11 inches. Body elongate, compressed behind, the head small, narrow, and moderately depressed anteriorly, the snout not very blunt. Eye rather large, placed somewhat above level of angle of mouth, its length 5 in head; width of interorbital space $2 \frac{1}{6}$ in head; breadth of mouth $2 \frac{1}{2}$; length of snout $3 \frac{1}{4}$. Teeth villiform, those of vomer and palatines rather coarse, bluntly conic; bands of vomerine teeth separated by a rather broad area, each confluent with the neighboring palatine band, the two forming a small oblong patch much sinaller than the eye, the division between the palatine and vomer scarcely appreciable. Palatine bands without backward prolongation. Bands of teeth in jaws short and broad. Maxillary barbel reaching about to middle of pectoral spine; outer mental barbel to base of pectoral; inner slightly more than $\frac{1}{2}$ head. Dorsal shield short, crescent-shaped, a little more than 3 times as broad as long on the median line. Occipital process subtriangular, its sides straight, slightly longer than broad, its median line rather sharply keeled. Close in front of its base begins the deep fontanel, which is narrow and groove-like posteriorly, becoming rather abruptly broader above the opercle, then gradually narrowed anteriorly. Ridges bounding fontanel prominent anteriorly to a point just behind vertical from nostrils, coarsely granular for their whole length, the graunles mostly arranged in 1 series. Between these ridges and the eye on each side is another ridge extending obliquely backward and inward from above front of eye, likewise very coarsely granular, the grauules mostly in 2 series. Shields of head all rongh granular, the granules forming irregular lines. Gill membranes forming a narrow fold across isthmus. Dorsal spine moderate, abont equal to pectoral spine, $1 \frac{1}{4}$ in head; axillary pore present, small; humeral process broad, scarcely granular, about $\frac{2}{5}$ pectoral spine; adipose fin rather long and low; caudal long, the upper lobe the longer, somewhat longer than head; anal long and high, its outline emarginate, its longest rays a little more than $\frac{1}{2}$ head; ventrals long, the vent nearer their base than that of anal. Color dusky, the entire ventral surface soiled with dark points; fins all largely blackish; barbels black. Two specimens were obtained at Panama by Dr. Gilbert. This species may be known at once by the 4 granulated ridges, which extend the length of the interorbital space. In the female, later taken, the granulations on the head are largely covered by soft skin. 


\section{GALEICHTHYS IONGICEPHALUS (Eigenmann \& Eigennann).}

Head $3 \frac{3}{5}$; depth $6 \frac{1}{2}$. D. I, 7 ; A. 20. Elongate, slender, greatest ${ }^{\circ}$ width little greater than the depth. Head long and depressed, its greatest width $1 \frac{1}{2}$ in its length, its greatest depth little more than $\frac{1}{2}$ its length. Top of head with faint granules almost entirely concealed by the skin; interorbital area flat and with 4 ridges which are obscurely granular, the inner two borclering the fontanel, the outer ones curved in front extending obliquely backward from near the posterior nasal opening; occipital process as long as broad, its margins concave; fontanel produced as a deep groove to the base of the occipital process; opercle faintly striate; humeral process entirely covered with thick skin, not granular. Eye lateral, well above the angle of the mouth, its diameter $1 \frac{1}{2}$ in snout, 6 in head, 3 in interocular; snout depressed and rounded in front. Maxillary barbels extending scarcely beyond base of pectoral, mentals not to gill opening. Upper jaw little projecting; width of the mouth $2 \frac{1}{6}$ in the head; intermaxillary teeth long and slender, the depth of the band $4 \frac{1}{2}$ in its width; vomerine and palatine teeth obtusely conical, the vomerine patches separate, contiguous to, but not confluent with, the palatine patches. Gill membranes not forming an angle where they meet, with a rather broad, free margin. Gill rakers short and thick, $4+5$. Pectoral pore small; vertical series of pores present; distance of dorsal fin from tip of snout $2 \frac{3}{5}$ in the length, the spine 18 in the head, its outer margin granular-toothed near its base, its inner margin with short teeth; distance of adipose fin from the dorsal $3 \frac{1}{6}$ in the length; adipose fin much longer than high, as long as the dorsal fin; caudal forked, the upper lobe $\frac{1}{8}$ longer than the lower, very nearly as long as head, $3 \frac{4}{5}$ in the length; anal fin emargiuate, scarcely longer than high, its height $2 \frac{1}{8}$ in the head; ventrals reaching almost to the anal, about 2 in head; pectoral spine a little longer than the dorsal spine 13 in the head; its outer edge roughened, inner edge with rather sharp teeth. Brown above, the sides silvery, entire ventral surface sprinkled with brown dots; a black median line on the back; fins dusky; barbels blackish. One specimen, a male, .29 m.long (No. 4972, M. C. Z.). Panama. Steindachner. (Eigenmann \& Eigenmann, Nematognathi, 82.)

\section{GALEICITHYS RUGISPINIS (Cuvier \& Valenciennes)}

Head $3 \frac{1}{2}$ to 4 ; depth $5 \frac{1}{2}$ to 6 . D. I, 7 ; A. 19 to 21 . Slender, compressed on the tail. Head broad and depressed, tapering forward; witth of the head $1 \frac{1}{2}$ to $1 \frac{2}{5}$ in its length, at the angle of the mouth $2 \frac{2}{5}$ to $2 \frac{1}{2}$; depth of head $1 \frac{3}{5}$ to 2 ; profile rather steep. 'Top of head, humeral process, front and sides of spines, and dorsal plate granular, the granulation not extending forward to above middle of cheeks. Occipital process triangular, about as long as broad, the median ridge not very prominent. Middle of fontanel behind the eye, the posterior portion separated by a bridge, not continued backward as a groove; interorbital region with 4 ridges. Eye small, 3 in snout, 10 in head, $3 \frac{1}{2}$ in the interocular. Barbels villiform. Maxillary barbel reaching to or beyond base of pectoral; postmental to gill opening, mental barbels much shorter. Mouth inferior, lower jaw 
included, lips thick; teeth villiform, the anterior ones in the jaws longer; depth of the intermaxillary band 4 in its width; palatine patches 1 diameter of eye apart, the width of the patches less than 1 diameter of eye. Gill membranes meeting in an angle, forming a fold across the isthmus. Gill rakers $6+11$. Pectoral pore none; vertical series of pores present. Distance of dorsal spine from the snout $2 \frac{1}{3}$ to $2 \frac{1}{2}$ in the length, the spine broken in the specimens examined. Space betwcen dorsal and adipose fins 4 to $4 \frac{2}{8}$ in the length. Adipose fin adnate, as long as the anal fin; ventrals $2 \frac{1}{2}$ in the head; pectoral spine serrated belind (broken). Two specimens $0.22 \mathrm{~m}$. and $0.26 \mathrm{~m}$. long. Para. Agassiz and Bourget. (Eigenmann \& Eigenmann, Nematognathi, 83.)

196. Galeichthys Phrygiatus (Cuvier $\star$ Valenciennes), text, p. 130.

\section{TACHYSURUS, Lacépède.}

Teeth on palate granular; dorsal shield small; palatine bands of teeth without backward projecting angle.

\section{TACHYSURUs NUCHALIS (Günther).}

D. I, 7 ; A. 21; P. I, 10. The height of the body $\frac{1}{6}$ of the total length (without caudal), the lengtl of head $\frac{1}{4}$. Head as broad as high, its greatest width being $\frac{2}{3}$ its length; its upper surface granulated; occipital process triangular, as long as broad, with the lateral margins slightly concave; it is elevated into an obtuse ridge running along the middle; the longitudinal groove in the middle of the forehead is rather wide, narrow behind, and does not extend to the base of occipital process. Teeth on palate are coarsely granular, and form 2 subtriangular patches of moderate extent, which, sometimes, are subcontinuous with their anterior angles. The maxillary barbels extend nearly to end of pectoral. Dorsal spine of moderate strength, slightly serrated along both edges, $\frac{5}{6}$ length of head; adipose fin small, shorter than dorsal; pectoral spine as long as, but stronger than, that of dorsal; pectoral fin shorter than head. British Guiana. a-c. Six inches long. Purchased of Mr. Scrivener. d-f. Young. Presented by Sir R. Schomburgk. (Gïnther, Cat., V, 171.)

198. TACHYSURUS FISSUS (Cuvier \& Valenciennes).

D. I, 7 ; A. 20 or 21 . Length of head $\frac{1}{8}$ of the total (withont caudal). The distance between the end of snout and that of occipital process $\frac{1}{8}$ of the total length (with caudal); basal bone of dorsal spine small. The teeth on the palate form 2 separate subovate patches. The maxillary barbel extends to, or nearly to, the middle of pectoral fin. Adipose fin small. Cayenue. a-b. Presented by Prof. R. Owen. These specimens having had the cavity of the mouth and of the gills extended in an extraordinary manner, I was induced to examine the cause of it, when, to my great surprise, I found them filled with abont 20 eggs, rather larger than an ordinary pea, perfectly uninjured, and with the embryos in a forward state of 
development. The specimens are males, from 6 to 7 inches long, and in each the stomach was almost empty. Although the eggs might have been put into the mouth of the fish by their captor, this does not appear probable. On the other hand, it is a well-known fact that the American Siluroids take care of their progeny in various ways; and I have no doult that in this species and in its allies the males carry the eggs in their mouth, depositing them in places of safety, and removing them when they fear the approach of danger or disturbance. (Günther, Cat., v, 172.)

\section{TACHYSURUS SPIXII (Agassiz).}

Head $3 \frac{3}{5}$ to 4 ; depth 5 to $5 \frac{1}{2}$. D. I, 7 ; A. 21 . Body eompressed, espeeially toward the caudal fin, the depth greater than the width. Head narrowed forward, its greatest width $1 \frac{1}{8}$ in its length, its greatest depth $1 \frac{1}{2}$; width at the mouth $2 \frac{1}{5}$ in the length of the head. Top of the head granular in the young, the granules becoming more or less united in the adult, forming fine retieulating ridges, especially on the occipital process, longer than broad, with a blunt median ridge, the margins coneave. Fontanel narrow, without interruptions, continued as a deep tapering groove to near the base of the oceipital process; interorbital area with 4 ridges; opcrcles and humeral process roughened, covered with skin; sides of the liead, and snout with reticulating mueous eanals. Eye $1 \frac{1}{2}$ to 2 in the snout, 5 to $6 \frac{1}{2}$ in the head, $2 \frac{8}{4}$ to 3 in the interocular. Maxillary barbels varying in extent, from about the middle of the pectoral to the base of the ventrals; postmental barbels extending to the base of pectoral or to near its tip; mentals to edge of gill membrane or to beyond base of pectoral. Upper jaw projecting; lips more or less papillose; teeth on the intermaxillary and the outer ones of the mandible, villiform; the inner series of the mandible and the palate with granular teeth; the palatine patches of teeth small, subovate, sometimes contiguous in front. Gill membranes united, joined to the isthmus, not forming a free margin across it; gill rakers $6+11$ to 13 . Pectoral pore moderate; distance of dorsal spine from snout $2 \frac{1}{8}$ to $2 \frac{4}{7}$ in the length; the spine $1 \frac{1}{5}$ to $1 \frac{1}{2}$ in head, serrated on its inner margin, granular or almost sinooth on its outer margin. Distanee of adipose from the dorsal fin $3 \frac{1}{5}$ to $3 \frac{3}{5}$ in the length, the adipose fin shorter than the dorsal fin, free posteriorly; eaudal forked, the upper lobe slightly the longer, 4 to 5 in the length; anal fin scarcely longer than high, its highest ray about 2 in head; ventral fin $1 \frac{2}{3}$ to 2 in head; pectoral spine strong, about as long as the dorsal spine, serrated on its inner margin, granular or scarcely ronghened on the outer margin. Color brownish above, sides and ventral surfaee silvery, sometimes with brown dots. We have examined over 70 specimens measuring from 0.07 to $0.24 \mathrm{~m}$. from Maranhao, Bahia, Rio Janeiro, Para, Santos in São Paulo, Abrolhos, Brazil. The specimens from Para are mueh dariker in color, the lips more papillose, the barbels longer than those of other specimens. The Santos speeimens are ashy above, white below the lateral line, with rather large brown dots on sides, becoming fewer below. (Eigenmann \& Eigenmann, Nematognathi, 89.) 
200. TACHYSURUS MEIANOPUS (Günther).

D. I, 7; A. 21; P. I, 10. The height of the body is contained 5 times in the total length (without caudal), the length of the head $4 \frac{1}{8}$ times; head somewhat broader than high, its greatest width being 8 of its length; the occiput and nape are finely granulated; occipital process subtriangular, as long as broad, with the lateral margins somewhat concave, and with the median ridge a little elevated. The longitudinal groove in the middle of the crown of the head is indistinct, narrow, linear behind, scarcely extending to the base of the occipital process. The teeth on the palatines are obtusely conical, and form 2 rather small subovate patches, apart from each other, and situated on the front part of the palate. The maxillary barbels do not quite extend to the middle of the pectoral fin. Dorsal spine of moderate strength, scarcely serrated anteriorly, equal in length to the distance of the gill opening from the anterior margin of the orbit, or even somewhat shorter; adipose fin sinall, the length of its base being less than that of the dorsal; pectoral spine nearly as long and strong as that of the dorsal fin, very strongly serrated anteriorly. Porous axillaries nearly as wide as a nasal opening. The upper (inner) surface of the ventral fins deep black, the lower (oiter) white; the inner surface of the pectorals blackish. Rio Motagua (east slope). a-b. From 8 to 9 inches long. From Mr. Salvin's collection. (Giinther, Cat., V, 172.) The specimens from the Pacific Coast mentioned in the text (page 132) belong to the following species.

200(a). 'TACIYSURUS LIROPUS, Susan B. Bristol.

Head $3 \frac{3}{7}$ to $3 \frac{8}{4}$; depth $4 \frac{3}{5}$ to $5_{1}^{1}$. D. I, 6 ; A. II, 19; P. I, 9 or 10 . Body elongate, its width anteriorally a little less than depth, the posterior portion much compressed; back elevated at front of dorsal; anterior profile from front of dorsal to tip of snout oblique; head flat, very broad, its width $1 \frac{1}{2}$ in its length; snout broad, rounded, $1 \frac{1}{10}$ to $1 \frac{1}{6}$ in interorbital width; eye rather large, laterally placed, its width about $1_{5}^{3}$ in its length, $4 \frac{1}{6}$ to $4_{10}^{9}$ in head; mouth small, upper jaw considerably projecting, its breadth 23 to 3 in head; jaws thin; wide bands of ninute pointed teeth present on both jaws; vomerine bands widely separated, and indistinguishable from the palatine band, which is small, oblong-ovate, and scarcely prolonged backward; interval separating vomerine bands about $2 \frac{1}{2}$ or 3 in eye; the teeth on these bands larger than those on jaws, and very bluntly conical. Interorbital space broad, $2 \frac{1}{2}$ to 3 in head. Barbels long and slender, the maxillary barbel extending to, nearly to, or, in some cases, past base of pectoral, $1_{14}^{\frac{1}{1}}$ to $1 \frac{2}{5}$ in head; outer mental barbel $1 \frac{1}{2}$ to $1 \frac{8}{4}$ in head; inner mental barbel $2 \frac{1}{8}$ to $2 \frac{5}{6}$ in head. Antedorsal shield very short, narrowly crescent-shaped, its length on the median line about 2 or 3 in its width; occipital process subtriangular, a little longer than broad at base, its edge slightly concave, its median keel strong. The long, narrow groove of the fontanel beginning abruptly a short distance in front of occipital keel, the distance from its end to base of dorsal 13 to 2 in the distance to tip of snout. Shields of head rather smooth, finely granular, the granules forming distinct lines anteriorly. The flat 
area between eyes triangular, with a median groove extending from fontanel forward to tip of snout, its posterior end a little behind eye, the granulations on each side of it extending forward as far as posterior border of pupil; opercles with no radiating striæ. Gill membranes forming a very narrow fold across the isthmus. Gill rakers $5+12$. Nostrils 2 on either side, large, placed close together and near tip of snout, the posterior with a large flap; axillary pore well developed; humeral process smooth, very short, 4 to $5 \frac{1}{2}$ in pectoral spine. Base of dorsal $2 \frac{3}{5}$ to $21^{9}$ in head; dorsal spine long and very strong, $1 \frac{1}{7}$ to $1 \frac{1}{3}$ in head, its upper anterior serre small and tubercle-like, its upper posterior and its lower edges retrosely serrate; the soft rays extending considerably beyoud the spine, $1 \frac{1}{6}$ to $1 \frac{1}{4}$ in head; adipose fin small, its base $3 \frac{1}{2}$ to $4 \frac{1}{2}$ in head, its height $1 \frac{3}{5}$ to 2 in its base; caudal widely forked, the upper lobe, measured from base of caudal to its tip, the longer, about $1 \frac{1}{4}$ in head; base of anal $1 \frac{3}{5}$ to $1 \frac{6}{7}$ in head, its longest ray $2 \frac{1}{8}$ to $2 \frac{1}{3}$ in head; ventrals reaching $\frac{5}{6}$ to $\frac{7}{8}$ the distance to origin of anal; vent about midway between origin of ventrals and origin of anal; pectoral spine $1 \frac{1}{2}$ in head, serrate, the serræ on inner edge larger and sharper than those on outer, the upper anterior serræ tubercle-like, the rays a little longer than spine. Bluish silvery, light yellowish below; top of head and back brown; fins dusky olive, lighter at base, all margined with darker; ventrals pale; adipose fin covered with minute black dots; maxillary barbels dark brown, with bluish silvery luster; other barbels lighter; eye yellowish. Here described from 6 specimens from San Juan Lagoon, mouth of Rio Ahome, Sonora, Mexico (No. 47584, U. S. Nat. Museum). Length $7 \frac{1}{4}$ to 9 inches.

Tachysurus liropus, Brișol, in Gilbert, Proc. U. S. Nat. Mus. 1896 (Feb. 5, 1897), 438, San Juan Lagoon, near mouth of Rio Ahome, Sonora, Mexico.

200(b). TACHYSURUS EMMELANE, Gilbert, new species.

Head $3 \frac{2}{5}$ in length ( $4 \frac{1}{10}$ in total); depth 5 (6 in total). A. $27(3+24)$. Eye 7 in head, $2 \frac{1}{2}$ in its distance from tip of snout, 4 in postorbital part of head, $3 \frac{2}{3}$ in interorbital width, $2 \frac{1}{5}$ in frontal width opposite middle of eyes. Mouth of moderate width, gently convex, the distance between its angles (measured internally) $2 \frac{4}{5}$ in head. Teeth in premaxillary and front of mandible finely villiform; posterior mandibular teeth stronger than those in front, bluntly conic, not, however, granular or flat and pavementlike, as are the posterior mandibular teeth in T. furthii, T. melanopus, and T. liropus. Mandibular bands with a wide interspace mesially, each widest near symphysis, rapidly tapering laterally, and extending beyond angle of mouth. The width of the bands is less than in related species, $\frac{1}{4}$ eye at their widest point. The length of 1 of the mandibular bands is slightly greater $\left(1_{10}^{\frac{1}{0}}\right)$ than length of eye. Premaxillary band very short, its length but $\frac{1}{6}$ greater than that of 1 of the mandibular bands, extending on each side less than $\frac{1}{2}$ distance from median line to angle of mouth; width of band $\frac{1}{5}$ its length. Palatine teeth granular, in small oblanceolate patches, which taper to a point laterally, and are widely separated on medial line, the patches agreeing in size and shape with those in T. liropus. Head depressed, tapering and at the same tume narrowing 
anteriorly, as in other species of Tachysurus; profile rising in a uniform, gently convex curve to occiput, where it becomes concave, owing to the more rapidly ascending outline of the occipital process. Eye low, but little above angle of mouth, the interorbital space decidedly convex. Barbels slender, the maxillary barbels reaching edge of gill membrane in front of pectoral spine, the outer mental barbels extending beyond gill. membrane, $1 \frac{t}{5}$ in head, the inner not to edge of membrane. Gill membrane widely attached to isthmus, without free edge. Occipital region with very fine granulations, those on middle of occiput forming parallel series along the fontanel groove, those on median portion of occipital process in series which diverge backward from the median line. The sculptured area extends forward to a vertical which traverses the cheek at a distance of its own diameter behind the eye; anterior edge of granulated area equidistant between tip of snout and front of dorsal plate; fontanel produced backward as a deep, narrow groove, which fails to reach base of occipital process by a distance equaling the length of the process on the median line; the groove widening but little anteriorly; an area behind and on each side of the groove with parallel series of granulations, and marked off from the rest of the head by a shallow trench; base of occipital process similarly indicated by a transverse indented line; occipital process not keeled, very wide at base, becoming abruptly very narrow behind, its posterior $\frac{1}{8}$ having parallel margins and being as wide as long, the lateral margins therefore deeply concave; width of process at base equaling its length on median line, plus that of dorsal plate, its hinder edge deeply incised to receive the anterior rounded wedge process of the dorsal plate, the latter finely granulated anteriorly, the lateral wings concealed under the smooth skin; a narrow groove as long as eye occupies the anterior end of the fontanel; no similar groove found in $T$. furthii, a short roundish one present in the trpe of $T$. liropus, and a continuous one the entire length of fontanel in the specimen which weidentify with T.melanopus; opercle without radiating ridges; a short, slit-like axillary pore present; humeral process short, the exposed portion not broadly triangular, the surface smooth, or indistinctly rough. Gill rakers $6+13$, of moderate length and thickness, the longest below the angle, $\frac{2}{3}$ diameter of eye. Dorsal spine with a series of obtuse granulations in front and very weak retrorse serra behiud, its length to tip of calcified portion $1 \frac{1}{5}$ in head; longest soft ray $1 \frac{2}{5}$ in head; adipose dorsal not adnate, its anterior insertion about over middle of anal; distance between dorsals equal to length of head; base of adipose dorsal much greater than its height, less than base of first dorsal; pectoral spine strong, ridged and granulated in front, the hinder edge with very strong serrx; length of spine $1 \frac{8}{4}$ in head, the fin projecting beyond tip of spine and reaching $\frac{2}{3}$ distance from axil to base of ventrals; ventrals reaching to or nearly to origin of anal; vent midway between base of ventrals and front of anal; base of anal equaling length of pectoral spine; margin of anal gently concave, the longest ray $2 \frac{7}{8}$ in head; candal with pointed lobes, the lower longest in the type, $1 \frac{2}{5}$ in head Color dark steel blue or

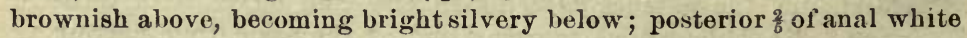


the anterior portion black with a narrow white edge; pectorals and ventrals with anterior (outer) face white or slightly dusky; pectorals with inner face of upper rays black; a black blotch covers all of inner face of ventrals, except terminal half of inner rays; barbels blackish. Closely related to $T$. melanopus and $T$. multiradiatus, differing from the former in the longer anal fin, from the latter in the black markings on lower fins. The description of the type of $T$. multiradiatus (Bagrus? arioides) Kner \& Steindachner, Abhandl der K. bayer Akad. der Wissen, X, I, 1864, indicates a species with much rougher seulpturing of the head, a longer fontanel groove, narrower occipital process, and more anteriorly inserted adipose dorsal. The type is a single specimen, $280 \mathrm{~mm}$. long, from Panama. (Gilbert.) ( $" \varepsilon v$, in $\mu \varepsilon \lambda \alpha v \eta$, ink.)

Tachysurus emmelane, GILBERT, Fishes Panama, MS. 1898, Panama.

\section{TACHYSURUS FURTHII (Steindachner).}

Head $3 \frac{1}{4}$ to $3 \frac{8}{4}$; depth 5 to $5 \frac{1}{2}$. D. I, 7; A. 20 . Body compressed posteriorly; profile slightly convex. Head broad, tapering forward, its greatest width $1 \frac{2}{5}$ to $1 \frac{1}{2}$ in its length; width, at the angle of the mouth, $2 \frac{3}{5}$ to $2 \frac{4}{5}$ in the head. Top of head densely covered with fine granules. Occipital process abont as long as broad, with a median ridge, emarginate on its sides and at tip; interorbital region with 4 smooth ridges, the inner bordering the fontanel, the other extending obliquely backward from near the posterior nasal opening; sides of head and snout with vermiculating mucous pores. Middle of the fontanel over the pupil. Eye strictly lateral, not entirely above the angle of the mouth, its center in front of the posterior end of the mandible, 2 in snout, 6 to 7 in head, $3 \frac{1}{2}$ to 4 in the distance between the eyes. Maxillary barbels thin, reaching to the middle of the pectoral or shorter, postmentals beyond base of pectorals, or sometimes not beyond edge of gill membrane; mentals to edge of gill membrane or shorter. Jaws about equal, the upper rather thin; teeth on the intermaxillaries villiform; the mandible with villiform teeth except the inner 2 or 3 series, which are granular; like the palatine patches irregular, suboval, sometimes the anterior end, sometimes the posterior, and sometimes both ends pointed. Gill membranes united, joined to the isthmus withont a free margin. Gill rakers long and slender, $4+11$. Axillary pore small; vertical series of pores present. Distance of dorsal from snout $2 \frac{2}{5}$ to $2 \frac{3}{5}$ in the length; the dorsal spine $1 \frac{2}{5}$ to $1 \frac{3}{5}$ in the head, on sides and front granular, with small, sharp teeth on its inner margin; the first soft ray little, if any, higher than the spine. Distance of adipose fin from the dorsal 3 to $3 \frac{1}{3}$ in the length, the fin longer than high, shorter than the dorsal fin. Caudal fin forked, the lobes rounded, $4 \frac{1}{2}$ in the length. Anal little longer than high, the highest ray 2 in the length of the head. Ventrals short, $1 \frac{2}{3}$ to $2 \frac{2}{5}$ in head. Pectoral spine long and slender, $1 \frac{4}{7}$ to $1 \frac{2}{5}$ in the head, outer margin granular, inner margin with short teeth. Ashy above, white below. We have examined 15 specimens, the largest measuring $0.29 \mathrm{~m}$. The sexes do not differ externally. Panama. (Eigenmann \& Eigenmann, Nematognathi, 90.) 
202. TACHYSURUS VARIOLOSUS (Cuvier \& Valenciennes), text, p. 132 ,

203. TACHYSURUS MULTiRADIATUS (Günther), text, p. 132.

75. CATHOROPS, Jordan \& Gilbert, text, p. 133.

204. CATHOROPS HYPOPHTHAIMUS (Steindachner), text, p. 133.

205. CATHOROPS GULOSUS (Eigenmann \& Eigenmann), text, p. 133.

Page 134. After Ictalurus furcatus add:

206(a). ICTAIURUS ANGUILLA, Evermann \& Kendall.

(Eel Cat; Willow Cat.)

Head 4; depth $4 \frac{1}{2}$; eye 7 in head; snout $2 \frac{4}{5}$; interorbital $1 \frac{4}{5}$; maxillary (without barbel) 3 ; free portion of maxillary barbel longer than head; dorsal spine 2 in head; pectoral spine 2 ; width of mouth 2 . D. I, 6 ; A. 24 ; vertebrie 42. Head large, broad, and heavy; the mouth unusually broad; cheeks and postocular portion of top of head very prominent; interorbital space flat, a broad, deep groove extending backward to origin of dorsal fin; body stout, compressed posteriorly; back scarcely elevated. Eye small; maxillary barbel long, reaching considerably past gill opening; other barbels short. Origin of dorsal fin equidistant between snout and origin of adipose fin, its distance from snout 23 in length of body; base of dorsal fin $3 \frac{1}{2}$ in head; longest dorsal ray $1 \frac{8}{4}$ in head; dorsal spine strong, entire both before and behind; pectoral spine strong, entire in front, a series of strong, retrorse serra behind; humeral process $2 \frac{1}{5}$ in pectoral spine; ventrals barely reaching origin of anal, their length 2 in head; anal fin long and low, the longest rays about $2 \frac{1}{5}$. in head; base of fin greater than head, $3 \frac{1}{5}$ in body; caudal moderately forked, the middle rays about $2 \frac{1}{5}$ in outer rays, which are about $1 \frac{2}{5}$ in head. Color uniform pale yellowish or olivaceous; no spots anywhere.

An examination of the 6 cotypes shows that there is not much variation, all the important characters remaining quite constant. The maxillary barbel varies somewhat in length, in some individuals scarcely reaching gill opening, and the number of anal rays varies from 24 to 26 .

A comparison of the skull of this species with that of $I$. furcatus and of I. punctatus of the same size shows a number of very marked differences. Nearly all the bones in $I$. anguilla are heavier than in the other species; the supraoccipital is broadly triangular, and its upper surface finely grooved, while in each of the other species it is much longer and narrower and the upper surface nearly smooth.

From the blue cat (Ictalurus furcatus) this species differs chiefly in the fewer rays in the anal fin, the wider mouth, the shorter, heavier head, the much longer maxillary barbel, and in the cranial characters already given. From the spotted cat (I. punctatus) it may be distinguished by its wider mouth, more blunt snout, heavier head, the color, and the cranial characters already mentioned. 
The eel cat rarely attains a greater weight than 5 pounds, and usually does not exceed 3 pounds. Its flesh is firm and of excellent flavor. The spawning season appears to be during the spring, as several of the individuals examined were in mature spawning condition.* Lower Mississippi Valley; thus far known only from the Atchafalaya River, Louisiana and the Ohio River at Louisville. (anguilla, the generic name of the eel.)

Ictalurus anguilla, Evermann \& Kendall, Bull. U. S. Fish Comm. 1897 (Feb. 9, 1898), 125, pl. 6, fig. 1, Atchafalaya River, Louisiana. (Type, No.48788. Coll. Evermann \& Chamberlain.)

Recent studies of the catfishes of the Lower Mississippi Valley by Dr. Evermann have shown that the most abundant and most important species of catfish in that region is Ictaburus furcatus (Le Suenr), and not Ameiurus lacustris (Walbaum), as has hitherto been supposed. The large specimen described by Dr. Bean as Amiurus ponderosus is an Ictalurus (as shown by the skeleton now in the United States National Museum) and apparently $I$. furcatus. The common names "Great Fork-tailed Cat," "Mississippi Cat," and "Blue"Cat" all belong to I. furcatus.

Page 138. The species called Ameiurus dugesii belongs to the genus Villarius, Rutter.

Page 142. After Ameiurus nigrilabris add:

77 (a). VILLARIUS, Rutter.

Villarius, RutTer, Proc. Cal. Ac. Sci., ser. 2, vol. vi, 1896, 256 (pricei).

Allied to Ameiurus, differing in the presence of scattered cilia on the sides. Backward process from occipital short, broad, emarginate, connected by ligament with the first interspinal buckler; in adults the distance between this process and the buckler is equal to the length of the former; in young examples the process overlaps the keel on the underside of the buckler. Head narrow, width of intermaxillary band of teeth $\frac{1}{8}$ of head; caudal deeply forked, the upper lobe the longer; barbels long, those of the maxillary extending past the gill opening. Sides with scattered hair-like cirri ; these are very noticeable under a lens, but not readily distinguished by the naked eye. This genus differs from all others of the family in having hair-like cirri on the sides. It differs from Ictalurus in having the occipital process and the interspinal buckler widely separated and oonnected by ligament; from Ameiurus in having a narrow head and a deeply forked caudal. Two species known, the following and Villarius dugesii (Bean). (villus, a hair.)

* This species is well known to the fishermen of the Atchafalaya River, by whom it is usually called the "eel cat," though the name "willow cat" is sometimes applied to it. It was explained by the fishermen that the name "eel cat" was given on account of the long feelers (i. e., barbels) and the name "willow cat" because it is most frequently found about the roots of willow trees. The eel cat is not an abundant species in the Atchafalaya River. During six days (April 19-24) spent at Morgan City several liundred catfish were examined at the three fish houses, and the total number of eel cats seen was fewer than twenty-five. The fishermen report that this proportion is about as great as at any time of the year. Of the four commercial species of catfishes handled on this river the most abundant one is the blue cat (Ictalurus furcatus), and the next is the yellow cat or goujon (Leptops olivaris); the eel cat comes next and the spotted cat (Ictalurus punctatus) last. The blue cat and the yellow cat probably constitute 98 per cent of the entire catch. 


\section{0(a). VillariUS PRICEI, Rutter.}

B. 8 ; D. I, 6 ; A. 22 or 23 ; C. 17 ; P. I, 9 ; V. 8 . Head $3 \frac{1}{3}$ to $3 \frac{8}{4}$ in body ; eye 5 to 7 in head; snout $2 \frac{2}{3}$; maxillary $5 \frac{1}{2}$ to 6 . Maxillary barbel very long, reaching beyond the pectoral spine, in the adult about to its tip when depressed, 3 to 4 times as long as the barbel at nostril. Origin of dorsal midway between snout and middle of base of adipose fin; pectorals inserted halfway between suout and ventrals; longest dorsal ray 6 to 7 times in length of body; spine of dorsal longer than its base, equal to base of adipose fin; longest pectoral ray about half of head, pectoral spine $2 \frac{1}{2}$ to 3 in head, with about 12 distinct hooked serra behind, these fower and somewhat smaller in the young; base of anal 3 times in its distance from snout, its longest ray equal to length of ventral; caudal deeply forked. Lateral line faint. This species differs from $V$. dugesii (Bean) in having very prominent serrations on the pectoral spines, the types of dugesii having the pectoral spines without serra. We have examined a specimen of dugesii, 4 inches long, from Salamanca, Mexico, which is in the type basin ; it has the cirri minute and light in color, a row of papilla along the lateral line, and the pectoral spines with 4 or 5 degenerate serra. (Named for William Wightman Price, who collected the type specimen.)

Villarius pricei, RutTER, Proc. Cal. Ac. Sci., ser. 2, vol. v1, 1896, 257, San Bernardino

Creek, a tributary of the Yaqui River, southern Arizona. (Type, No.4826, L. S. Jr. Univ. Mus.)

Page 143. Leptops olivaris is known as the Goujon in Louisiana, where it is an important food-fish.

Page 146. In Schilbeodes gyrinus the anal rays are 14 to 16 ; not 13.

Page 152. Under Rhamdia salvini read "Osbert Salvin" for "Oscar Salvin."

Page 170. Pantosteus arizona, Gilbert, is described and figured in Proc. U. S. Nat. Mus. 1898, 488, pl. 36 .

Page 174. Catostomus discobolus is distinct from the true C. latipinnis. The two species are confused in the description of $C$. latipinnis given by us. They may each be described as follows:

\section{CATOSTONUS LATIPINNIS, Baird \& Girard.}

Head 4; depth about $5 \frac{1}{2}$; eye high up and small, 5 to 7 in head, 3 to $3 \frac{1}{2}$ il snout, $2 \frac{1}{8}$ to $2 \frac{3}{4}$ in interorbital space; interorbital width $2 \frac{3}{5}$ in head. D. 14 or 15 ; A. 7 ; scales 19 or $20-89$ to $102-16$ to 18,46 to 50 transverse rows in front of dorsal fin. Head depressed and flat above, its greatest depth $1 \frac{4}{5}$ in its length, the depth below lower edge of orbit 3 in its length. Least depth of caudal peduncle $4 \frac{1}{2}$ in head, or $3 \frac{1}{2}$ in its own length. Fins very large, the dorsal with its npper margin concave; ventrals and pectorals rounded; dorsal as long as its longest ray, $1_{10}^{\frac{1}{10}}$ in head, its last ray a little less than $\frac{1}{2}$ the length of the first ray; origin of dorsal fin nearer tip of snout than base of caudal; ventrals not reaching quite to vent, 1 \% in head. Muzzle not projecting; about 6 rows of short, thick papillæ on upper lip, the smallest above; lower lip large, incised to its base, with 
about 12 rows of short, thick papilla, posteriorly quite small; distance from front of upper lip to back of lower $1 \frac{1}{2}$ in snout; jaws with a slight cartilaginous sheath; width of preorbital a little less than $\frac{1}{2}$ its length. Reaches a length of about 2 feet. Lower Coloralo River basin. This description by Gilbert \& Scofield, based upon specimens from the Gila River at 'Tempe, Arizona.

279(a). CATOSTOMUS DISCOBOLUS, Cope.

Head $3 \frac{4}{5}$ to $4 \frac{1}{2}$; depth about $5 \frac{1}{4}$; eye small, high up, $5 \frac{1}{2}$ to 6 in head, $2 \frac{3}{5}$ in snout, $2 \frac{2}{5}$ in interorbital width, which is $8 \frac{1}{2}$ in head; width of preorbital less than $\frac{1}{2}$ its length; least depth of caudal peduncle $2 \frac{1}{2}$ in its length, or 2 in head; greatest depth of head $1 \frac{3}{5}$ in its length; depth from lower edge of orbit $3 \frac{1}{4}$ in head. D. 12 or 13 ; A. 7 ; scales 19 to 21-101 to 109-17 to 21 , 52 to 63 in front of dorsal. Muzzle projecting slightly beyond upper lip. Upper margin of dorsal very slightly concave, the length of its base $1 \frac{1}{5}$ in its longest ray, or $1 \frac{1}{2}$ in head; last dorsal ray $\frac{1}{2}$ length of first; origin of dorsal midway between tip of snout and base of caudal; ventral rounded, $1 \frac{2}{5}$ in head, not quite reaching vent. Mouth as in C. latipinnis except that the posterior tubercles on lower lip are long and not nearly so closely set, there being 9 or 10 rows; jaws with a slight cartilaginous pellicle. Upper portion of the Colorado River basin. Attains the length of a foot or more. The above description by Gilbert \& Scofield from specimens from Green River at Green River Station, Wyoming.

Catostomus discobolus, Cope, Hayden's Geol. Surv. Wyo., 435, 1870, Green River, Wyoming; Gilbert \& SCOField, Proc. U.S. Nat. Mus. 1898, 490.

\section{Page 175. After Catostomus griseus add:}

\section{0(a). CATOSTONUS RETROPINNIS, Jordan.}

A doubtful species which is, however, not yet shown to be invalid. Head $4 \frac{1}{3}$; depth $5 \frac{1}{3}$; eye $6 \frac{8}{4}$ in head; snout 2 ; interorbital $2 \frac{1}{2}$. D. 11 ; A. 7 ; scales 17-108-14. Body slender, head slender, snout very long, caudal peduncle long, its least depth less than snout, $2 \frac{1}{3}$ in head; dorsal profile very little elevated; mouth large, wholly inferior; overhung by the piglike projecting snout; lips thin but very broad, lower lip incised nearly to base, with about 6 rows of moderate papillæ; lobes of lower lip very long, about $\frac{1}{2}$ of snout; gill rakers short and weak. Origin of dorsal a little nearer base of caudal than tip of snout; base of dorsal equal to snout; longest dorsal ray a little greater than base of fin; anal fin long and pointed, the fourth ray longest, $1 \frac{1}{10}$ in head; caudal lunate, the middle ray $1 \frac{1}{2}$ in outer rays; pectoral somewhat falcate, the longest $1 \frac{1}{4}$ in head; ventrals rather short, not reaching vent by more than an eye's diameter. Length 14 inches.

Catostomus retropinnis, JoRdan, Bull. U. S. Nat. Mus., XII, 178, 1878, Milk River, Montana. (Type, No. 21197. Coll. Dr. Elliott Coues.) 
Page 176. After Catostomus catostomus add:

282(a). CATOSTOMUS Rimculus, Gilbert \& Snyder.

Head $4 \frac{1}{6}$ in body; depth 5 ; depth of caudal peduncle $2 \frac{8}{4}$ in head; eye $7 \frac{1}{2}$; dorsal rays 11 ; scales $18-91-13$, before dorsal 42 . D. 11 ; A. 7 ; pectoral 17. Head as deep as wide. Both lips full, the lobe of lower lip broadly rownded behind, the cleft not nearly reaching base of lip, the portion between mandible and apex of cleft with 4 series of tubereles; tubercles coarse and blunt, becoming reduced in size toward margins of lips, but less so than in related species; upper lip with 5 rows of tubercles. Eyes very small, the front of the eye nearly midway of head; interorbital space convex, 24 in head. Scales comparatively smooth, gradually growing smaller posteriorly. Dorsal fin inserted midway between end of snout and base of caudal, first ray preceded by 2 short, simple ones; last ray divided to base; length of base of fin equal to the height, which is contained $6 \frac{1}{2}$ times in the body; height of anal twice the length of the base, 5 in body; length of pectorals $4 \frac{2}{8}$ in body; ventrals $6 \frac{1}{2}$ in body; caudal $4 \frac{1}{4}$. Color above dusky, the central parts of scales lighter; under parts white; dorsal and caudal fius dusky, others white. This species belongs to the C. catostomus type, with very small scales, and is most nearly related to C. tahoensis. From the latter it differs in the smaller eye, less deeply cleft lower lip, blunter labial tubercles, larger scales, and the much smaller fontanel, which is reduced in adults to a very narrow linear slit, or more commonly entirely obsolete. Lower portion of the Klamath River basin, northern California. (Diminutive of rimus, crevice, from the small fontanel.)

Catostomus rimiculus, GILBERT \& SNYDER, Bull. U. S. Fish Comm. 1897 (Jan. 6, 1898), 3, Trinity River, Humboldt County, California. (Type, No. 5654, L. S. Jr. Univ, Mus. Coll. Capt. W. E. Dougherty.)

Page 177. Catostomus rex is identical with Deltistes luxatus and should be added to the synonymy of that species, p. 183.

The type of Catostomus labiatus did not come from Klamath Lake, but from the Sacramento River, at Stockton, California. It is identical with C. occidentalis. The species from Klamath Lake has been recently described as

\section{CATOSTOMUS SNYDERI, Gilbert.}

Head $4 \frac{1}{8}$ in length; snout $23_{10}^{3}$ in head, equaling interorbital width; eye 54. D. 11 ; A. 7 ; scales 13 or $14-69$ to $77-10$ or 11 . Mouth very small, the width between angles but $\frac{1}{2}$ length of snout in our largest specimen; greatest width of lobe of lower lip $\frac{2}{3}$ diameter of eye; lower lip deeply incised, with 1 or 2 papilla between symphysis and base of cleft; upper lip narrow, with 5 or 6 papilla in a cross series, the uppermost becoming very small; basal portion of the lower lip with coarse tubercles, those toward posterior margin becoming very fine and arranged in evident series separated by grooves. Mucous canals on head forming conspicuous raised ridges with prominent pores, the system much more conspicuously developed than in any related species. Origin of dorsal fin constantly 
nearer snout than base of caudal; the dorsal fin short, its base not exceeding the height of tlie longest ray, usually less. In our specimens the pectorals reach scarcely $\frac{2}{8}$ distance to ventrals and the ventrals scarcely $\frac{2}{8}$ distance to vent; the anal may extend beyond base of rudimentary caudal rays. Scales strongly ridged, their margins crenate; the anterior scales are sinaller, but do not appear greatly crowderl; the average number of tubes in the lateral line is about 73, the number varying from 69 to 77. Dusky, the lower part of sides with coarse black specks, the under parts white; fins all dusky. (Gilbert.)

A larger specimen has been described as follows: Head $4 \frac{1}{6}$; depth 4 ; eye $6 \frac{1}{2}$ in head; snout $2 \frac{1}{2}$; maxillary $3 \frac{1}{5}$; mandible $2 \frac{1}{5}$; interorbital $2 \frac{1}{3}$; width of mouth $3 \frac{1}{2}$ in head, more than $\frac{1}{2}$ length of snont; greatest width of lower lip $\frac{8}{4}$ diameter of eye. D. II, 11; A. 7; scales 13-70-11. Body rather slender; head long, moutl moderate, horizontal; lips thick papillose, the upper with about 4 or 5 rows of papilla, lower with about 7 ; lower lip divided nearly to base, leaving only 1 row of papilla crossing the symphysis; premaxillary not much projecting and not forming a prominent hump; maxillary rather short, not reaching vertical at front of anterior nostril; eye equally distant between snout and posterior edge of opercle; mucous canals on head forming raised rilges, the pores conspicuous. Fins moderate; origin of dorsal a little nearer snout than base of caudal, sixth spine over insertion of ventrals; pectoral $1 \frac{1}{4}$ in head, reaching slightly more than $\frac{2}{3}$ distance to ventrals; ventrals not quite reaching vent, the seventh ray longest, $1 \frac{3}{5}$ in head; anal long, pointed, reaching to base of caudal, $1 \frac{1}{6}$ in head. Scales crowded anteriorly, about 32 transverse rows in front of dorsal, strongly ridged, the margins crenate. (Evermann \& Meek.) Length 1 to 2 feet. Klamath Lakes, Oregon; specimens examined from Upper Klamath Lake, Lost River, and Williamson River. (Named for Mr. John O. Snyler, instructor in Zoology in Stanford University.)

Oatostomus snyderi, Gilbert, Bull. U. S. Fish Comm. 1897 (Jan. 6, 1898) 3, Upper Klamath Lake, Oregon (Type, No. 48222. Coll. Gilbert, Cramer \& Otaki); Evermann \& MeEk, Bull. U. S. Fish Comm. 1887, 69.

Page 178. After Catostomus occidentalis add:

296(a). CASTOSTOMUS TSILTCOOSENSIS, Evermann \& Meek.

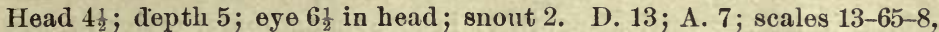
34 before the dorsal. Pectoral $1 \frac{1}{b}$ in head; longest dorsal ray $1 \frac{2}{3}$; base of dorsal $1 \frac{2}{5}$; longest anal ray $1 \frac{1}{4}$; ventral 13. Body rather slender, subterete; head small, snout long and pointed; mouth inferior, overhung by the projecting snout; lips rather thin, 1 row of large papilla on upper lip, and about 2 irregular rows of sinaller ones behind or inside of it; lower lip incised nearly to base, 1 or 2 rows of small papilla across the isthmus; lobes of lower lip moderately long and thin, the bases with papilla merging into plications toward the tips. Eye quite small, the anterior edge of orbit at middle of head. Top of head flat or very slightly convex between the eyes. Fins small; pectorals short and rounded; ventrals short, rounded, $3030-98$ 
the middle rays but little longer than the others; anal small, somewhat pointed; margin of dorsal somewhat concave; caudal lunate, not deeply forked. Muciferous canals on head not strongly developed. Scales moderately large; lateral line nearly straight, not running upward toward nape. This species differs from $C$. occidentalis, to which it is related, in the smaller head, longer, more pointed snout, smaller eye, larger scales, and its much smaller fins. In $C$. occidentalis the pectoral fins are falcate, while in this species they are more rounded; the ventrals also are less pointed. Length a foot or less. Coastal streams of middle western Oregon; known from Tsiltcoos Lake and the Siuslaw River. (tsiltcoosensis, from the type locality.)

Catostomus tsiltcoosensis, Evermann \& MeEk, Bull. U. S. Fish Comm. 1897 (Jan. 6, 1898), 68, fig. 1, Tsiltcoos Lake, Lane County, Oregon. (Type, No. 48479. Coll. Dr. Seth E. Meek.)

Page 180. The species called Catostomus fecundus in the text belongs in the genus Chasmistes, to which it should be transferred as Chasmistes fecundus (Cope \& Yarrow).

Page 182. The species of Chasmistes are not confined to the Great Basin. One species (C. brevirostris) occurs in the Klamath Lakes basin.

Page 183. The species called Chasmistes luxatus in the text belongs to a genus distinct from Chasmistes, which may be characterized as follows:

\section{3(a). DELTISTES, Seale.}

Deltistes, Seale, Proc. Cal. Ac. Sci., ser. 2, vol. vi, 1896, 269 (luxatus).

This genius is close to Chasmistes, agreeing with it in every respect except in the peculiar structure of the gill rakers. In Chasmistes they are as in Catostomus, while in Deltistes they are broad, shaped like the Greek letter $\Delta$ (delta), and their edges are unarmed and entire. Lower pharyngeals weak, with numerous small teeth. Deltistes lixatus (Cope) is the single known species. ( $\delta \dot{\varepsilon} \lambda \tau \alpha$, the Greek letter corresponding to D.)

After Chasmistes cujus add:

297(a). CHASMISTES STOMIAS, Gilbert.

Head $4 \frac{1}{8}$; depth $4 \frac{1}{4}$; eye 7 ; snout $2 \frac{3}{5}$; maxillary (measured from free end to tip of snout) $3 \frac{1}{8}$; mandible $2 \frac{1}{2}$. D. II, 11; A. I, 7; scales $13-85-10$; interorbital width $2 \frac{1}{4}$; vertical depth of head at manclibular articulation $2 \frac{1}{6}$. Head small, body heavy forward, the back strongly and regularly arched from suout to origin of dorsal fin, thence cleclined in a nearly straight line to base of caudal; ventral surface nearly straight. Premaxillary spines strongly protruding, forming a prominently projecting snout; mouth rather small, inclined upward at an angle of about $40^{\circ}$, maxillary scarcely reaching vertical from front of anterior nostril; width of mouth $1 \frac{3}{5}$ in snout or $4 \frac{2}{5}$ in head; upper lip thin, without papilla; lower lip thin, interrupted at symphysis, forming uarrow lateral lobes, the width of which is about 23 times in their length; faint indications of a few papillæ; mucous canals forming ridges, the pores conspicuous; gill rakers long, 
narrowly triangular at the tip when viewed from behind, densely tufted on the anterior edge; fontanel narrow, its length 22 in the suout, its width about $\frac{1}{7}$ its length. Fins all large; the origin of the dorsal a little nearer tip of snout than base of caudal, the six th ray over base of ventral, its base $1_{5}^{3}$ in head, the free edge nearly straight, the last ray $1_{5}^{3}$ in the first, which is $1 \frac{1}{2}$ in head; pectorals scarcely falcate, reaching a little more than $\frac{2}{8}$ distance to base of ventrals, their length $1 \frac{1}{4}$ in head; ventrals long, reaching vent, the rays gradually increasing in length from the outer to the seventh and eighth, which are longest, the ninth and tenth being but slightly shorter, the length of the longest ray $1 \frac{3}{5}$ in head or about $\frac{1}{5}$ longer than the first; anal long and pointed, the fourth ray longest, reaching base of caulal, $1 \frac{1}{6}$ in head; each ray of anal fin with 8 to 12 strong tubercles; caudal lobes about equal, their length $1 \frac{7}{8}$ times the middle ray. Length a foot or more. Upper Klamath Lake, Oregon, where it is abundant and of some importance as a food-fish. The Klamath

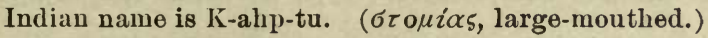

Chasmistes stomias, GilberT, Bull. U.S. Fish Comm. 1897 (Jan. 6, 1898), 5, with plate, Upper Klamath Lake, Oregon (Type, No. 48223. Coll. Gilbert, Cramer \& Otaki); EverMANN \& MEeK, Bull. U.S. Fish Comm. 1897, 70.

297(b). CIIASMISTES COPEI, Evermann \& Meek.

Head $3 \frac{2}{3}$; depth 4 ; eye $6 \frac{1}{5}$; snont $2 \frac{1}{2}$; maxillary (measured from free end to tip of snout) 3 ; mandible $22_{5}^{2}$. D. II, 10 ; A. I, 7 ; scales $13-80-12$; interorbital width $2 \frac{1}{4}$; vertical depth of head at mandibular articulation $2 \frac{1}{5}$. Head large, cheek very deep, the depth equal to distance from tip of suout to nostril; body stout, back scarcely elevated, caudal peduncle rather short and stout; ventral surface somewhat convex. Premaxillary spines less protruding than in $C$. stomias, not forming a prominent hump ; mouth large, inclined upward at an angle of $45^{\circ}$, maxillary not nearly reaching vertical at front of anterior nostril; width of mouth $1 \frac{4}{5}$ in snout, or 4 in head; upper lip thin, without papillæ; lower lip thin, entirely without papillæ, interrupted at symphysis, forming rather broad lateral lobes; pores on head very conspicuous; gill rakers larger than in $C$. stomias, broadly triangular at tip when viewed from behind, densely tufted on anterior elge, each appendage more or less bifid and clubshaped, closely resembling those of $C$. liorus; fontanel narrow, its length $2 \frac{1}{3}$ in snout, width $\frac{1}{5}$ its length. Fins all small; origin of dorsal a little nearer snout than base of caudal, its sixth ray over base of ventrals, free edge straight, base $2 \frac{1}{8}$ in head, last ray a little less than 2 in first, which is 2 in head; pectorals somewhat falcate, reaching slightly more than $\frac{1}{2}$ distance to ventrals, their length $1 \frac{3}{5}$ in head; ventrals very short, reaching only $\frac{2}{8}$ distance to vent, free end nearly straight; outer ray longest, 22 in head; inner shortest, $3 \frac{1}{5}$ in head ; anal fin short, bluntly pointed, not reaching base of caudal, third and fourth rays longest, $1 \frac{7}{8}$ in head; no tubercles on aual rays; caudal lobes equal, length about $1 \frac{7}{8}$ times the middle ray. Scales small and crowded anteriorly, about 14 rows downward and backward from fiont of dorsal to lateral line, 11 vertically upward from base of ventral to lateral line, about 38 oblique series before 
dorsal; lateral line nearly straight, with about 80 scales. Entire upper parts of head and body, and sides nearly to level of base of pectorals, dark olivaceous; under parts abruptly whitish or yellowish in alcohol; a dark spot in upper part of axil; dorsal and caudal dark; pectorals dark on inner surface; ventrals and anal plain. From Chasmistes stomias this species is readily distinguished by its larger head, larger, more oblique month, less prominent snout, and very small fins. The differences in the fins are very great, particularly in the ventrals. It differs from C. brevirostris, as characterized by Dr. Gilbert, in its much larger, more oblique mouth, the absence of papillæe on the lips, and shorter fins. Length 2 feet. Upper Klamath Lake, Oregon. Klamath Indian name "Tswam." (Named for the late Prof. Edward Drinker Cope, who wrote the first paper on the fishes of Upper Klamath Lake.)

Ohasmistes copei, Evermann \& MeEk, Bull. U. S. Fish Comm. 1897 (Jan. 6, 1898), 70, fig. 3 , Pelican Bay, Upper Klamath Lake, Oregon. (Type, No. 48224. Coll. Meek \& Alexander.)

Page 205. Campostoma pricei can not be distinguished by us from C. ornatum. See Rutter, Proc. Cal. Ac. Sci., ser. 2, vol. vi, 1896, 259.

Page 211. After Algansea tincella add:

337 (a). ALGaysea TARASCORUM, Steindachner.

Head $3 \frac{2}{5}$; depth $4 \frac{2}{5}$; eje less than 5 ; snout about 4 ; interorbital $3 . \quad$ D. III, 7 ; A. III, 6 ; P. 17 ; V. 9 ; scales 84 or 85,18 or 19 . Body stouter than in $A$. lacustris, head shorter, lateral line more decurved and nearer ventral line at middle of body, and scales more numerous. Mouth very oblique, lower jaw not projecting, maxillary not quite reaching vertical at anterior edge of eye. Teeth 4-4, hooked, and with narrow grinding surface. Origin of dorsal in advance of ventrals, equally distant between base of candal and middle of eye; height of dorsal twice its base. Ventrals not reaching anal fin by an eye's diameter; caudal deeply notched. A dark gray longitudinal band with metallic luster extending from opercle to caudal fin, lying chiefly above lateral line; color otherwise plain. Length $5 \frac{1}{2}$ inches. Lake Pátzcuaro, Mexico. (Steindachner.)

Algansea tarascorum, Steindachner, Einige Fischarten Mex., II, pl. 3, figs. 2-2c, 1895, Lake Pátzcuaro, Mexico. (Coll. Princess 'Theresa von Bayern.)

Page 218. To the synonymy of Pimephales notatus add:

Spinicephalus fibulatus, Le SUedr, in VAILLANT, Bull. Soc. Philom., viII, 1896, 29, pl. 26.

Page 225. After Ptychocheilus oregonensis add:

358. PTYCHOCHEILUS GRANDIS (Ayres).

(Sacramento Pike.)

This species differs from $P$. oregonensis principally in the larger size of the scales above the lateral line, the smaller number of rays in the dorsal fin, and the lighter and slenderer pharyngeal bones. Head $3 \frac{1}{3}$ to $3 \frac{4}{7}$ in length; depth 5 to $5 \frac{1}{10}$; eye $3 \frac{3}{5}$ to 4 in head; scales 13 to 16 above lateral 
line, 70 to 80 transverse rows along lateral line (16 to 18 above lateral line, 69 to 72 transverse rows in $P$. oregonensis). D. 8 ; A. 8 . In other respects similar to $P$. oregonensis. Ptychocheilus harfordi is apparently not distinct from $P$. grandis, being based on a specimen with very small scales. $P$. grandis is confined to waters of California, $P$. oregonensis to Washington, Idaho, and Oregon.

Gila grandis, Ayres, Proc. Cal. Ac. Nat. Sci.1854, 18, San Francisco.

Ptychocheilus major, AgAssiz, Am. Jour. Sci. Arts 1855, 229, San Francisco.

Ptychochcilus harfordi, JoRdaN \& GILBERT, Proc. U.S. Nat. Mus. 1881, 72, Sacramento River ('Type, No. 27246. Coll. Jordan \& Gilbert); JordaN \& GILBERT, Synopsis, 2261883.

Page 239. After Lenciscus balteatus add:

376(a). LEUCISCUS SIUSLAWI, Evermann \& Meek.

Head $4 \frac{1}{3}$; depth $4 \frac{1}{5}$; eye 4 ; snout $3 \frac{1}{2}$; maxillary $3 \frac{2}{5}$. D. II, 9 ; A. II, 12 or 13 ; scales $11-58-8$; teeth $2,4-5,2$, somewhat hooked. Body rather slender, slightly elevated and somewhat compressed; head small and pointed, cheek not deep; snout pointed, somewhat longer than eye; mouth moderate, somewhat oblique, maxillary just reaching vertical at front of orbit; jaws subequal, the lower sometimes slightly projecting; eye large, not as great as snout. Origin of dorsal fin behind base of ventrals and much nearer base of caudal than tip of snout, the longest ray $1 \frac{1}{2}$ in head, greater than base of fin; origin of anal fin under last dorsal ray but 2 , its height equal to that of dorsal, its base equal to its longest ray; free edges of dorsal and anal nearly straight; pectoral $1 \frac{1}{4}$ to $1 \frac{1}{2}$ in head, not reaching insertion of ventrals; ventrals short, $1 \frac{1}{5}$ in pectoral, reaching anus; caudal deeply forked; lateral line complete, decurved. Color in spirits, brownish or olivaceous above, middle of side with a broad dark band involving the lateral line anteriorly and posteriorly, but lying chiefly above it mesially; middle of side from gill opening to beneath dorsal fin with a broad rosy band, following closely beneath the lateral line; lower part of siles and under parts silvery, dusted over with fine dark specks; a light yellowish band extending backward from npper posterior border of eye nearly halfway to origin of dorsal fin; cheek with a silvery or golden crescent; top of head dark; opercles dusky silvery; snout dusky; fins plain, dorsal and candal somewhat dusky. This species is close to $L$. balteatus, but has smaller anal and dorsal fins, a more slender body, smaller and more slencler head, and longer, more pointed snout. The extent of variation in proportional measurements and in the number of anal fin rays appears to be much less than in L. balteatus. It also resembles $L$. cooperi, but has a much shorter lower jaw and a more pointed snout. Known only from the Siuslaw River and Tsiltcoos Lake, western Oregon, where it is common. (siuslawi, of the Sinslaw River.)

Leuciscus siuslawi, Evermann \& MeEk, Bull. U. S. Fish Comm. 1897 (Jan. 6, 1898), 72, fig. 4, Siuslaw River, Mapleton, Oregon. (Type, No. 48480. Coll. Dr. Meek.)

Page 240. After Leuciscus elongatus add: 
378(a). LEUCISCUS NACHTRIEBI, Cox.

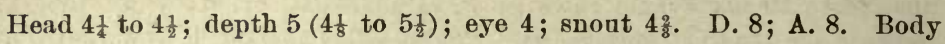
rather heavy, not greatly compressed; back slightly elevated, its curve a little greater than that of the belly; caudal perluncle rather stout, its depth $\frac{1}{2}$ the length of the head. Head rather short, not any more compressed than the body, upper surface slightly flattened; snout quite blunt in mature individuals, its length $1 \frac{1}{6}$ times width of eye; mouth not very large, but little oblique, luwer jaw included; maxillary scarcely reaching to front of orbit; pharyngeal teeth 2, 4-5, 2. Dorsal fin inserted nearer base of candal than tip of snout, also slightly back of ventrals; caudal fin forked; anal slightly smaller than dorsal; ventrals small, not reaching vent by $\frac{1}{3}$ their length; pectorals inserted rather high, not reaching the ventrals by $\frac{8}{4}$ their length; scales small, 12-72-9, lateral line complete on mature individuals, decurved, the pores extending on head in several lines, 1 passing back of eye, another down to nostril. General color dusky, darkest on back; sides above lateral line dnll silvery, below lateral line light silvery ; a faint dark dorsal band in some specimens, in others absent; no black lateral band, bnt some specimens have a very faint dusky shade along lateral line; no light stripe above lateral line; upper portion of opercles with a dusky shade, lower part bright silvery; upper part of head dark-colored; all the above colors typical in the young as well as adults. Length 4 inches. L. nachtriebi differs from $L$. neogaus in having a well-developed lateral line, a smaller eye, fewer scales, less oblique mouth, a shorter maxillary, and in being a larger fish and differently colored. It differs from $L$. elongatus in having a smaller mouth, the lower jaw never projecting, head less pointed, a shorter maxillary, finer scales, and the absence of the black lateral band. Lakes of northern Minnesota; at present known from Mille Lacs, Man Trap, Mud and Elbow lakes. (Named for Prof. Henry F. Nachtrieb, State zoologist of Minnesota.)

Leuciscus nachtriebi, Cox, Rept. U. S. Fish Comm. 1894 (Dec. 14, 1896), 615, Mille Lacs Lake, Aikin County, Minnesota. (Type, No. 47688. Coll. Minn. Nat. Hist. Surv.)

Page 241. To the synonymy of Leuciscus neogous add:

Cyprinus burtonianus, LE SUEUR in VAILLANT, Bull. Soc. Philom., viri, 1896, 28, with plate, Burton Mine, Missouri.

Page 244. Leucos and Myloleucus can not be maintained as subgenera, the characters of the teeth not being constant.

The following notes on Rutilus olivaceus as seen at Emerald Bay, Lake Tahoe, may prove useful.

\section{RUTILUS OLIVACEUS (Cope).}

(Tahoz Chub.)

This species is very different from Rutilus symmetricus, looking like Leuciscus lineatus. Very common; reaches 2 to 3 pounds weight; devours eggs of trout. No doubt the records of Leuciscus lineatus (atrarius) from Lake Tahoe belong to this species. Head 4 ; depth $4 \frac{1}{5}$ to $4 \frac{1}{3}$. D. 8 ; A. 8 ; scales 11-56-6; teeth always 5-5, with broad grinding surface. Body oblong, 
moderately compressed, the back somewhat elevated anteriorly in old examples. Head conieal, rounded above; eye moderate, $1 \frac{1}{2}$ in snout ( 6 inches long), 5 in head; about as long as maxillary. Mouth terminal, very oblique, the lower jaw included; the snout not prominent; the short maxillary not reaching eye. Dorsal high and pointed; anal short, rather high; pectoral long, reaching $\frac{2}{3}$ distance to ventrals, which reach vent; ventrals below front of dorsal, which is behind middle of body. Scales with edges largely exposed; lateral line runuing low, complete. Dusky olive above and on sides to level of ventrals, with brassy luster everywhere; muddle of belly only white, a pale yellowish area between pectorals and ventrals; head brassy, dusky above, elosely dotted above and on sides; body everywhere closely dotted with black, except on middle line below ; fins all dusky, with dark points. This species is well separated from all the $R$. symmetricus tribe.

Page 247. Luxilinus occidentalis is the young of Lavinia exilicauda, Baird \& Girard (p. 209), and must be placed in the synonymy of that species. Luxilinus is a pure synonym of Lavinia.

Page 249. Under Opsopcoodus bollmani, for "Buckland Creek" read "Buckhead Creek."

Page 254. For Azteca, line 22, substitute Aztecula, Jordan \& Evermann, new subgenus. The former name is preoccupied by Azteca, Forel, 1878, a genus of ants. The same substitution to be made in the key on page 255 and on page 258 .

Page 260. Before Notropis cayuga insert:

404(a). NOTROPIS WELAKA, Evermann \& Kendall.

Head $4 \frac{1}{5}$; depth 5 ; eye 3 in head; snout $3 \frac{1}{4}$. D. 8 ; A. 8 or 9 ; seales 6-35-3; teeth 4-4, hooked. Body rather slender, moderately compressed; head short, snout bluntly pointed; mouth moderate, somewhat oblique, lower jaw slightly included, maxillary scarcely reaching front of eye; premaxillaries protractile. Eye large; posterior edge of pupil at middle of longitudinal length of head; interorbital width greater than eye; caudal pedunele long and slender. Dorsal fin inserted well behind base of ventrals, a little nearer base of caudal than tip of snout, its longest rays shorter than head, but slightly longer than longest anal rays; anterior dorsal and anal rays longest; pectoral $1 \frac{1}{5}$ in head; ventrals reaching origin of anal; caudal deeply notched, the lobes long and pointed. Scales large, lateral line incomplete, developed only on 6 to 10 scales. Back olivaceons; side with a broad black band extending from snout through eye, and ending in a rather distinct black spot on base of caudal, the black spot in some specimens (probably mature males) surrounded by orange; the black line bordered above by a narrow orange or reddish line, less distinct, or even whitish, in females ancl immature individuals; under parts plain; fins all plain; dorsal and candal somewhat dusky; dusky specks on body along base of anal and under side of caudal peduncle; lower jaw tipped with dusky. This species resembles Notropis anogenus, but differs in having the mouth somewhat larger and less oblique, 
the lower jaw more included, the body more slender, the lateral line less leveloped, the dorsal fin more posterior, and the anal rays more numerous. It was found in considerable abundance in the St. Johns River, near Welaka, Florida. (welaka, from the type locality.)

Notropis velaka, Evermann \& KendalL, Bull. U. S. Fish Comm. 1897 (Feb. 9, 1898), 126, pl. 6, fig. 2, St. Johns River, near Welaka, Florida. (Type, No.48786. Coll. Dr. W. C Kendall.)

Page 262. After Notropis blennius add:

408(a). Notropis BUChANANI, Meek.

Head 4; depth 4. D. 8; A. 8; scales 6-31-2; teeth 4-4. Body rather robust, back considerably elevated, snout blunt, mouth small and nearly horizontal. Snout short, about $\frac{2}{8}$ diameter of eye. Preorbital bone slightly longer than broad. Eye moderate, 3 in head. Lateral line complete, or nearly so; about 12 scales in a series before dorsal fin. Dorsal fin slightly nearer tip of snout than base of caudal; pectorals reaching ventrals; ventrals reaching anal. Color light olivaceous, a faint silvery lateral band; no dark lateral band or black caudal spot. This species belongs to the N. blennius type. It is a smaller species, lighter in color, and has ferrer scales in the lateral line. Potean River, Arkansas. (Named for Dr. John L. Buchanan, president of the Arkansas Industrial University.)

Notropis buchanani, MEek, Bull. U. S. Fish Comm. 1895 (A pril 13, 1896), 342, small creek near Poteau, Indian Territory. (Tỷpe, No. 47532. Coll. Dr. Meek.)

Page 267. Under Notropis nux; nuece, not neche, is nut in Spanish.

Page 274, line 11, for luxoides, read luxiloides.

Page 287. After Notropis lutipinnis insert:

466(a). NOTROPIS CHAMBERLAINI, Evermann, new species.

Head $4 \frac{1}{3}$; depth $4 \frac{1}{5}$; eye 4 ; snont 4 . D. 7 ; A. 9 ; scales $7-39-3$, about 15 before the dorsal. Genoral form much like that of Hybognathus; body only moderately compressed, dorsal and ventral outlines slightly arched; head rather small, pointed; mouth small, a little oblique, the maxillary scarcely reaching anterior border of orbit, lower jaw slightly included; snout equal to eye; eye in axis of body. Fins all rather small; origin of dorsal slightly behind vertical at insertion of ventrals; free edge of dorsal fin somewhat concave, the anterior rays about equal to length of head; pectoral short, slightly falcate, the longest rays about $1 \frac{2}{5}$ in head; rentrals shorter than pectoral, barely reaching vent; anal similar to dorsal, the rays shorter; caudal widely forked, the middle rays $2 \frac{1}{2}$ in the outer, the lobes as long as head, the lower lobe slightly longer than the upper. Scales moderately imbricated, the exposed portions not deeper than long; lateral line complete, somewhat decurved. Teeth $2,4-4,2$ or 1 , rather weak, hooked, and with small grinding surface. Intestine short; peritoneum silvery. General color light straw; middle of side with a broad, well-defined silvery band from upper end of gill opening to iniddle of 
base of caudal fin, the anterior half lying wholly above the lateral line, the posterior portion lying partly below it; this silvery band bounder above by a narrow dark border; cheeks and opercles silvery; a darkish band along median line of back; fins all plain straw color or pale lemon. Fourteen examples of this species, 2 to 3 inches in length, were obtained from the Atchafalaya River at Melville, Louisiana, by Mr. Fred M. Chamberlain, for whom the species is named.

Notropis chamberlaini, Evermann MS., Atchafalaya River, Melville, Louisiana. (Type, No. 48901.)

Page 291. Notropis scopifer, Eigenmann \& Eigenmann, is identical with Notropis hudsonius selene (Jordan), (p. 269), and should be omitted.

Page 294. After Notropis dilectus insert:

487 (a). NOTROPIS LOUISIANE, Evermann, new species.

Head $4 \frac{2}{5}$; depth $5 \frac{1}{4}$; eye 3 ; snout 3 . D. 7 ; A. 11 ; scales $7-37-3,19$ or 20 before the dorsal. Teeth 1, 4-4, 2, little hooked. Body long and slender, back not arched; head short, but pointed; month rather large, oblique, maxillary scarcely reaching orbit, lower jaw somewhat included; eye large, equal to or greater than snout. Fins rather small; origin of dorsal far behind insertion of ventrals, its longest rays $1 \frac{2}{5}$ in head; pectorals short, their length equal to height of anal; ventrals very short, 2 in head; candal deeply forked. Scales firm, moderately imbricated; lateral line complete, gently decurved. Color pale; side with a faint plumbeous band; back and upper part of sides with numerous dark specks chiefly on the margins of the scales, thus forming cross-hatchings; a narrow dark vertebral band on caudal peduncle; peritonenm silvery, with numerous minute round black specks. Length $2 \frac{1}{2}$ inches. This species resembles Notropis dilectus, but has a much smaller mouth, blunter suout, and in being less silvery along the side. Known only from the Atchafalaya River, Louisiana.

Notropis louisiance, Evermann MS., Atchafalaya River, Melville, Louisiana. (Type, No. 48902. Coll. Fred M. Chamberlain.)

Page 348. Anguilla chrysypa is abundant in the Gulf of St. Lawrence, according to Dr. Wm. Wakeham.

Page 355. The original type of Congermurana is C. habenata, Kaup, a species with blunt or granular teeth. The American species all belong to a distinct genus, Congrellus, Ogilby (type balearica), distinguished by the villiform teeth. These genera are charactered by Mr. Ogilby in a paper as yet unpublished.

Pages 356 and 357. In Congermurana flava the upper jaw projects far beyond the lower. By a slip in the original description the reverse is said to be the case.

Page 359. Murenesox coniceps is called Culevra Blanca at Mazatlan, and reaches a length of 7 feet.

Page 368. Avocettina gilli, Bean, should probably stand as a species distinct from Avocttina infans. The description in the footnote on page 
368 is sufficiently full. See Jordan, Proc. Cal. Ac. Sci., ser. 2, vol. vi, 1896, 206, pl. 21.

Page 369. No. 604, Labichthys elongatus, is a true Avocettina, having the vent far behind the head. It should stand as-

602(a). AVOCETTINA ELONGATA (Gill \& Ryder).

Page 376. After Myrichthys tigrinus, Girard, add:

61ว̆(a). MYRICHTHYS XYSTURCS, Jordan \& Gilbert.

Teeth all more or less blunt and granular; a band of 3 or 4 series on each side of lower jaw; a band of 2 rows on each side of upper jaw; vomer with a long series divided into 2 for about $\frac{1}{2}$ its length. Anterior nasal tubes conspicuous. turned downward. Eye $2 \frac{1}{2}$ in snout; front of eye above middle of gape, the length of which is a little more than $\frac{1}{8}$ of head; the angle of mouth well behind eye. Interorbital width about $\frac{2}{8}$ length of the rather long and slender snout, which projects much beyond lower jaw, the tip of the latter about reaching middle of snout. Length of head contained $4 \frac{1}{4}$ times in that of trunk; head and trunk together shorter than tail, and contained $2 \frac{1}{8}$ to $2 \frac{1}{2}$ times in total length. Pectoral very small, its length about equal to depth of gill opening. Dorsal beginning close behind nape, much in front of gill opening; fins low; tail pointed, the tip sharp. Color light olive; sides each with 3 series of large round brown spots, those of the 2 upper series of equal size, those of lower scarcely $\frac{1}{2}$ as large, faint, and often obsolete anteriorly; the spots irregular in their arrangement, those of the upper series usually twice as numerous as those of the next; those of the upper series along base of dorsal fin extending partly on the base of the fin; lower series of spots along base of anal, some of them extending on the fin or even entirely upon it; on the belly are sometimes small dark spots, scarcely arranged in series; dorsal fin with a terminal series of dark spots, which are partly confluent, the fin narrowly margined with white; anal reddish, with a lighter margin;-pectoral with a blackish blotch; head covered with round black spots, which become smaller and more numerous toward the snout; lower jaw with dark spots; iris light yellow. Pacific coast of Mexico; common among the rocks about Mazat-

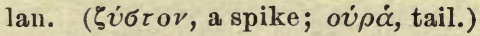

A species distinct from $M$. tigrinus, which is known only from the original type figured by Jordan \& Davis, and described in the text of Part I of this work, page 376. This specimen, said to be from "Adair Bay, Oregon," may not be American, as there is no such bay in Oregon, and no second specimen of the true Myrichthys tigrinus has been found anywhere.

Ophichthys xysturus, JoRdan \& GILBERT, Proc. U. S. Nat. Mus. 1881, 346, Mazatlan, Mezico. (Type No. 28142. Coll. Dr. Gilbert.)

615(b). MYRICHTHYS PANTOSTIGMIUS, Jordan \& McGregor.

Ilead $3 \frac{4}{5}$ in trunk; liead and trunk $1 \frac{1}{3}$ in tail; cleft of mouth 3 in head; eye $2 \frac{2}{8}$ in snout, which is 5 in head; pectorals 2 in snout; anterior nasal tube equal to the eye. Color olivaceous, with distinct rows of roundish 
blackish spots, some oblong, smaller on head and covering the whole belly; 39 spots in the dorsal row, these spots usually alternating each with its fellow on the other side of dorsal, sometimes opposite; spots of second row usually opposite; spots of third row smaller and more numerous, extending from the cheeks to opposite the vent, thence running along base of anal, not running on fin, most of the spots of this row little more than $\frac{1}{2}$ length of snout; 2 rows of smaller spots along belly from gill opening to front of anal; spots on nape rather large, on head larger and more numerous than in $M$. xysturus; pale color of head reduced to reticulations; chin and throat spotted as much as head; no pale centers to any of the spots; dorsal without spots or with only a few, which come up from back; from beginning to ond the dorsal has a broad black margin about $\frac{1}{8}$ height of fin; anal mostly pale, but toward tip having some black markings; pectoral with upper half jet-black, a white margin posteriorly, a small black spot in lower corner. This species is distinguishable from all others by the great number of spots of small size and without pale centers; the black edge of dorsal; the black spot on the rather large pectoral, and especially by having the belly spotted as much as the other parts. Clarion Island. One specimen, about a foot long, known. ( $\pi \dot{\alpha} 5$, whole, entire, all; $\sigma \tau i \gamma \mu \alpha$, spot.)

Myrichthys pantostigmius, JoRdAN \& MCGREGOR, Rept. U.S. Fish Comm. 1898, pl. 4, Clarion Island. (Type, No. 5710, L. S. Jr. Univ. Mus. Coll. R. C. MeGregor.)

Page 377. After Pisoodonophis cruentifer add:

618(a). PISOODONOPHIS DASPILOTUS, Gilbert, new species.

Brownish above, gray below, the head and body usually thickly covered with black spots sinaller than the eye; these are smaller and more numerous on the head, fewer and fainter on the lighter interior surface, and become indistinct or entirely disappear on the terminal portion of tail. In 1 specimen the head and trunk are spotted and the entire tail unicolor. In another no spots are present, the upper parts being a uniform dark brown, the under parts lighter brown, a few dark freckles only being present on sides of head. In all specimens the snout and lower jaw are blackish. The anus is near the middle of the total length, sometimes nearer the tip of snout, sometimes nearer tip of tail. The cheeks are not greatly swollen. The gape extends behind the eye, its lengtl, measured from tip of lower jaw to angle of mouth, being contained $4 \frac{3}{5}$ to $4 \frac{8}{4}$ in head. The snout projects beyond the lower jaw for a distance about equaling diameter of orbit. Eye 2 to $2 \frac{1}{8}$ in snout, $1 \frac{2}{8}$ to $2 \frac{1}{7}$ in interorbital width. Tubes of anterior nostrils about $\frac{1}{2}$ diameter of eye, directed downward near tip of snout. Posterior nostrils under front of eye, concealed in the upper lip as usual. Teeth all bluntly conic, in rather wide bands on jaws and vomer; they are usually not disposed in regular series within the bands, but each band has about the width of 4 series, and these are sometimes distinguishable. The mandibular teeth become larger on approaching the symphysis, those at point of mandible and those on head of vomer being much the largest teeth present. The patch on shaft of vomer tapers 
backward to a point considerably behind angle of mouth. Origin of dorsal entirely behind tip of pectorals, its distance from snout $\frac{1}{8}$ to $\frac{1}{8}$ greater than length of the head. The tip of the tail is compressed, acute, horny, used for defense. Pectoral very short, from a wide base which slightly exceeds length of gill slit. The fin rapidly narrows down ward, the longest portion contained 12 to 14 times in length of head. The width of gill slit is about $\frac{1}{8}$ head.

The following table gives measurements of 4 specimens in millimeters:

\begin{tabular}{|c|c|c|c|c|c|c|c|c|c|c|c|c|c|c|}
\hline 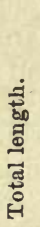 & 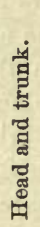 & సีं & ت્ّુ & \&્ & $\stackrel{\dot{S}}{\text { 穴 }}$ & 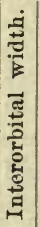 & 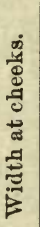 & 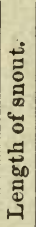 & 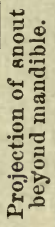 & 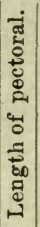 & 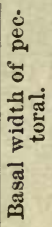 & 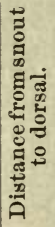 & 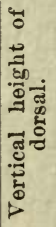 & 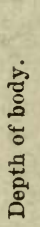 \\
\hline 362 & 177 & 185 & 38 & 8 & 3 & 5 & $9 \frac{1}{2}$ & $6 \frac{1}{4}$ & 23 & $3 \frac{1}{2}$ & 5 & 48 & 3 & 12 \\
\hline 401 & 203 & 198 & 48 & $10 \frac{1}{2}$ & 3 & 7 & $11^{\circ}$ & $7 \frac{1}{2}$ & $3 \frac{11}{2}$ & $4^{2}$ & 6 & 53 & 4 & $14 \frac{1}{2}$ \\
\hline 492 & 248 & 244 & 52 & $11^{2}$ & $3]_{2}$ & $7 \frac{1}{2}$ & $16 \frac{1}{2}$ & $8 \frac{1}{4}$ & $3 \frac{1}{2}$ & $3 \frac{3}{4}$ & 61 & 68 & $5 \frac{1}{2}$ & 18 \\
\hline 494 & 255 & 239 & 56 & 12 & $4 \frac{1}{4}$ & $7^{2}$ & $16^{2}$ & $8 \frac{1}{2}$ & $4 \frac{1}{2}$ & 4 & 6 & $68 \frac{1}{2}$ & $5 \frac{1}{2}$ & 16 \\
\hline
\end{tabular}

Four specimens were secured, 3 obtained in brackish water at the mouth of a small stream which empties into Panama Bay, the fourth in a freshwater pond at Miraflores. There is some reason to suppose that they burrow in the mud.

Pisoodonophis daspilotus, GILBERT, Fishes of Panama, MS. 1898, Panama.

Page 382. Murana ophis, Linnaus, is without much doubt the original Ophichthus havannensis. The species would therefore stand as-

626. OPHICHTHUS OPIIS (Linnæus).

Page 396. Sidera castanea, Jordan \& Gilbert, should be removed from the synonomy of Lycodontis funebris. It is apparently a valid species and should be inserted as -

650(a). LYCODONTIS CASTANEUS (Jordan \& Gilbert).

(Morena Prieta.)

Tail about as long as rest of body, or slightly longer. Head $2 \frac{1}{2}$ in length of trunk; cleft of mouth wide, $2 \frac{1}{3}$ to $2 \frac{1}{2}$ in head. Teeth everywhere uniserial or nearly so, those on sides of mandible small, compressed, close set, subtriangular, directed backward, about 18 in number on each side; mandible with about 4 large canines anteriorly; upper jaw with the teeth partly in 2 series, some of the teeth being movable, the other mostly stronger, caninelike, especially anteriorly; front of vomer with 2 very long, slender canines, behind them a single series of small teeth; teeth all entire. Eye large, slightly nearer tip of snout than angle of mouth, its diameter 2 to $2 \frac{1}{2}$ in snout; gill opening $\frac{1}{8}$ wider than orbit; tube of anterior nostril short, less than $\frac{1}{2}$ diameter of orbit; posterior nostril with- 
out tube; occiput not especially elevated, the anterior profile scarcely concave (perfectly straight in young 2 feet long). Dorsal fin commencing much in advance of gill opening, becoming unusually high posteriorly, where its vertical height is more than $\frac{1}{2}$ greatest depth of borly; the length of the longest ray more than greatest depth of body. Color light brownish chestnut, slightly paler on abdomen; no spots or bands anywhere; fins without dark margins; no dark spot on gill opening or at angle of mouth ; no black about eye; head without conspicuons pores. The specimen here described is 44 inches in length; others about 2 feet in length agree very closely. This enormous eel is very common among the rocks about Mazatlan, where it reaches a length of 6 feet. It is close to the West Indian species, L. funebris, but the colors are not the same, funebris being a greenish black, while castaneus is a purplish chestnut, without shades of olive or green. (castaneus, chestuut.)

Sidera castanea, Jordan \& GILbert, Proc. U. S. Nat. Mus. 1882, 647, Mazatlan. (Type, Nos. 28246, 29535 and 29591. Coll. C. H. Gilbert.)

After Lycodontis mordax add:

649(a). LYCODONTIS PICTUS (Ahl).

Head 4 in trunk; tail about as long as body; eye $2 \frac{1}{2}$ in snout, situated midway between snout and angle of mouth; cleft of mouth $2 \frac{2}{3}$ in head; snout 5 ? in head; anterior nasal tube 5 in snout; gill opening 11 in head. Teeth in each jaw in a single series; palatine series either parallel with these or divergent; no distinct canines; teeth comparatively small; anterior vomerine 1 or 2 in number, bluntish and conical; posterior vomerine teeth rather blunt. Anterior nasal tubes moderate. Dorsal low anteriorly and beginning in front of gill opening. Color brownish gray or purplish, everywhere covered with small purplish black spots, which are not confluent; in the adult the spots are arranged in roundish or ringlike blotches on the sides; fins colored like bods, without dark edges; young pale with black ring-shaped markings; variation in color and form of markings numerous. East Indies; everywhere common. East to offshore islands of Mexico. Two specimens, about 3 feet in length, taken at Clarion Island by Mr. R. C. MeGregor. (pictus, painted.)

Murcena picta, AHL, lo Muræna et ophichtho, vi, 6, tab. 2, f. 2; GUnther, Cat. Fish, viII, 116.

Gymnothorax pictus, BLEeKer, All. Ichth., Muræna, 87, tab. 26, 28, 29, 45.

Murcenophis pantherina, LACÉPÈDE, Hist. Nat. Poiss., v, 628, 1803.

Muraena variegata, QUOY \& GaImaRD, Voy. Uranie, Zool., 246, pl. 52, f. 1.

Murcena lita, RICHARDSON, Voy. Erebus and Terror, 84, Moluccas.

Murcena siderea, RICHARDSON, Voy. Erebus and Terror, 85, pl. 48, f. 1-5, Australia.

Murcena pfeifferi, Blefker, Nat. Tyds. Ned. Ind., v, 173, Celebes.

Sidera pfeifferi, KAUP, A podes, 70.

Page 401. After Murana argus insert:

660(a). MURENA CLEPSYDRA, Gilbert, new species.

Closely related to $M$. insularum and $M$. argus, from the tropical Pacific, differing from both in color. Nostrils tubular, of almost equal length. 
Mouth closing completely, the teeth entirely concealed by the lips. Gape straight, horizontal, extending to well behind the eyes, $2 \frac{1}{8}$ to $2 \frac{9}{4}$ in head. Toeth in jaws large, compressed, and wide at base, tapering uniformly to an acute point, directed backward, close set, everywhere uniserial; those in sides of mandible noticeably smaller than those of upper jaw, the teeth in both jaws increasing in size anteriorly; as many as 18 or 20 teeth may be present in the half of either jaw, but many of them are usually wanting, leaving gaps in the series; a single row of small teeth on shaft of vomer, beginning opposite front of eye; head of vomer with 2 long canines, larger than any of the other teeth, one or both of these usually wanting in larger specimens, having apparently fallen out. Head 2 ( $1 \frac{11}{12}$ to $2 \frac{1}{12}$ ) in trunk; head and trunk $1 \frac{1}{3}$ to $1 \frac{1}{7}$ in tail; depth at anus approximately $\frac{1}{2}$ length of head; eye small, its diameter contained 12 to 16 times in head; snout 5 to $5 \frac{1}{3}$. Dorsal beginning on the head, its dietance from snout $1 \frac{1}{3}$ to $1 \frac{1}{2}$ in head. Color dark brown, lighter on belly, dull whitish on under side of head; liead, body, and fins closely coverer with white spots, those on posterior parts larger, with some smaller ones intermingled, the larger spots with a more or less evident central constriction which makes them hourglass-shaped; toward the head the spots become very small and crowded, not more than $\frac{1}{2}$ as large as pupil; fins indistinctly light margined; a large elliptical jet-black blotch surrounds the gill slit, distinctly margined by a series of confluent white spots; the longitudinal diameter of the blotch is contained 5 to $5 \frac{1}{2}$ times in the length of the head; angle of mouth with a small black blotch, often obscure, preceded by a pale spot on mandible; the throat is marked with a number of parallel lengtliwise folds, the bottom of each fold with a dark line.

The following table gives measurements in millimeters of 5 specimens:

\begin{tabular}{|r|r|r|r|r|r|r|r|r|}
\hline $\begin{array}{c}\text { Total } \\
\text { length. }\end{array}$ & $\begin{array}{c}\text { Head and } \\
\text { trunk. }\end{array}$ & Tail. & Heal. & Gape. & Snout. & Eye. & $\begin{array}{c}\text { Distance } \\
\text { Depth at } \\
\text { anus. } \\
\text { from } \\
\text { origin to } \\
\text { of } \\
\text { dorsal. }\end{array}$ \\
\hline & & & & & & & \\
675 & 311 & 364 & 106 & 45 & 201 & 7 & 59 & 72 \\
630 & 289 & 341 & 96 & 38 & $18 \frac{1}{2}$ & 6 & $52 \frac{1}{2}$ & 70 \\
612 & 287 & 325 & 98 & 39 & 19 & $6 \frac{1}{4}$ & 47 & 64 \\
473 & 203 & 270 & 66 & 28 & 13 & 54 & 40 & 50 \\
397 & 177 & 220 & 58 & 21 & 11 & $4 \frac{1}{2}$ & 27 & 39 \\
\hline
\end{tabular}

This species is abundant at Panama, where it is frequently brought to market. About 25 specimens were seen during our visit, all essentially alike in coloration. The t5pe is 397 millimeters long (see table of measurements), and has the spots on body less numerous than in larger specimens. (clepsydra, $\varkappa \lambda \varepsilon \psi v \dot{v} \rho \alpha$, an hourglass, from its markings.)

Murcena clepsydra, GlLBert, Fishes of Panama, MS. 1898, Panama.

Page 410. It is probable that several species are confounded under the name Elops saurus. According to Ogilby the Australian species has only 63 vertebræ. 
Page 411. 199. Genus ALBULA, Bloch \& Schnoider.

The proper binomial authority for this generic name, as well as for the names Synodus, Umbra, and Anableps, is Scopoli, as Dr. Gill informs us. 'These pre-Linnæan names, with others, were first used in binomial nomenclature as names of genera by Scopoli, Introd. His. Nat. 1777, pp. 449 (Synodus) and 450 (Albula, Umbra, Anableps). The genera should then stand as follows:

Page 411. 199. ALBULA (Gronow) Scopoli.

Page 533. 248. SYNODUS (Gronow) Scopoli.

Page 623. 298. UMBRA (Krämer) Scopoli.

Page 684. 312. ANABLEPS (Artedi) Scopoli.

Page 414. To the description of Chanos chanos the following may be added:

The skeletal peculiarities of Chanos are numerous and remarkable, many archaic characters persisting. The following account of the skeleton has been prepared by Mr. Starks:

\section{SKELETON OF CHANOS CHANOS.}

a. Cranium:

The frontals are very large, covering nearly the whole top of the head, and extending over the dorsoanterior part of the parietals, supraoccipital and the parotic process. On the side of the skull there is an area bounded by the supraocipital, the opisthotic and the sphenotic, which is not ossified, but is composed of cartilage. Between the frontals, at about their middle, there is a place in which the bone is fibrous and largely cartilaginous; it is easily broken through. The basal cavity under the brain cavity is large. On the npper part of the operculum is a large scale-like bone. The suborbitals are well developed and plate-like, extending back nearly to the posterior edge of the preopercle.

b. Vertebral column:

There are 42 vertebræ in the spinal column. The first vertebra is coossified to the skull, and apparently bears no ribs; the second vertebra supports a pair of very small, slender ribs, which articulate directly with the sides of the vertebra; the third vertebra supports the first pair of large ribs; they are articulated with the transverse processes. The first 14 or 15 neural spines and pairs of transverse processes are articulated with the vertebrie by sutures; they are easily separated from the vertebra by boiling or maceration. The vertebra gradually increase in size and reach their largest size about $\frac{2}{8}$ of the distance from the anterior to the posterior end of the spinal column, where they are 3 or 4 times the size of the anterior ones. This character is more marked in the adult than in the young. 
c. Shoulder girdle:

The shoulder girdle is exceelingly well braced, the post-temporal is widely forked, and strongly articnlated to the epiotic processes of the skull. The supraclavicle is long and slender, its posterior face is hollower out and attached some distance from the upper end of the clavicle, which projects upward. This projecting upper end of the clavicle is braced to the skull by two long bones. The first bone is very slender, at its anterior end it is connected to the exoccipital; near its middle it is connected with the posterior end of the post-temporal, at which point it turns at a sharp angle and runs to the clavicle. The second bone is much larger; it is articulated to the basioccipital. Its posterior edge is nearly straight for its whole length, but its anterior erge is produced and much swollen near its middle, and joins the post-temporal over the first bone, then runs to the upper end of the clavicle. The inner part of the elavicle and the coracoid are thin and pierced by many holes, so that the bone in places is little more than network. The hypercoracoid has a very large foramen; at its posterior erge is a projection which supports a thin bone, probably a dermal bone. The mesocoracoid is well developed. There are 4 actinosts; the first is long, but they rapidly decrease in size to the fourth, which is short and triangular. The first ray of the pectoral is large at the basal end, and hullowed out; it works directly on the hypercoracoid.

\section{d. Branehial apparatus:}

The branchial apparatus is peculiar in the adult, in having gill rakers somewhat resembling the filaments of a feather, on both sides of each areh and on the basibranchial. They meet in a middle line between the arches and unite, forming a continuons lattice-work screen, through which nothing but the very smallest bodies can jass. The pharyngeals have no teeth, but have gill rakers similar to those on the arches; they are inclosed in sac-like projections on each side. This description is taken from the skeleton of a large specimen 4 feet long. The gill rakers are not united in young individuals.

e. Other parts:

The septre between the myotomes are ossified about $\frac{1}{2}$ an inch nnder the skin, forming long, slender rays of bone. There is an npper series running from the middle of the sides up on the back, and a lower series from the sides down on the belly, and form a sort of a basket around the the body. Those below have a single branch near the middle of each, the ones above have 2 branches each; these branehes are lost toward the posterior end. These bones are not present in the young. The large candal fin is attached very firmly to the hypural, the long rays of each lobe join the hypural at about the same oblique angle, the base of each ray is deeply divided and articulated immorably with the hypural. The middle short rays are all nearly horizontal and are much less firmly fastened. The first interspinal ray of the anal is hollow and cone-shaped, the posterior end of the air bladder runs into it as in the genera Eucinostonus and Calames. The scales are very thick and closely imbricated; the skin anteriorly is $\frac{1}{1}$ inch thick. (Jordan, Fishes of Sinaloa, 404-409.) 
Page 417. After Dorosoma petenense add:

202(a). SIGNALOSA, Evermann of Kendall.

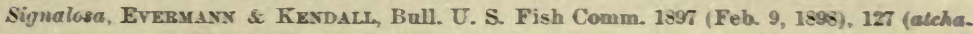
falayce).

Body short, deep, and compressed, the form somewhat elliptical; rentral outline more strongly curved than the dorsal; head rather large, snout sharp and pointed, not tumid ; month small, oblique, the lower jaw scarcely included; maxillary of 3 pieces, broad and enrved, but without notch in the outer margin as in Dorosoma; caudal perlunele short and deep. Branchiostegals 5; pseudobranchia large; gill rakers short and very numerons, about 340 in number. No teeth; adipose eyelid present; stomach gizzarilike; scutes about $17+10$. Last ray of dorsal very long and filamentons. This genus is allied to Dorosoma, from which it is plainly distinguished by the absence of the notch in the maxillary, the more pointed snout, the less-included lower jaw, the shorter anal fin, larger seales, and the fewer scutes. It differs from Alosa in the very numerous gill rakers, the character of the dorsal fin, and in other respects. (signмm, a flagstaff or pole; Alosa, the shad; a reference to the long dorsal ray.)

679(a). SIGNALOSA ATCHAFALAYE, Evermann \& Kendall.

Head $3 \frac{3}{5}$; depth $3 \frac{1}{2}$; eye $3 \frac{1}{3}$ in head; snont $5 \frac{1}{2}$; maxillary $3 \frac{1}{5}$. D. I, 12 ; A. I, 24; seales 42-15; scutes $17+10$. Body oblong-elliptical, compressed, the back in front of dorsal narrow; ventral edge sharp, serrate; head small, mouth terminal, oblique, lower jaw slightly included; snont rather pointed, not blunt, as in Dorosoma cepedianum; maxillary in 3 pieces, long and curved, reaching vertical at front of pnpil, the onter edge not notehed; no teeth. Candal pelnncleshort, compressed, and deep. Origin of dorsal fin over base of ventrals, much nearer tip of snout than base of candal, the last ray filamentons, about $\frac{1}{4}$ longer than head and nearly reaching base of caudal; the first dorsal ray abont 2 in the last one; pectoral $1+$ in head, reaching base of ventrals; ventrals short, reaching only halfway to vent, their length $1 \frac{t}{3}$ in pectorals; anal rays short, base of tin $1 \frac{1}{6}$ in head; sentes moderate; caudal widely forked, the lower lobe the longer; scales large, thin, deciduous, somewhat crowded anteriorly; accessory scales at bases of pectorals and ventrals; base of eandal with small scales. Color blnish black or dark olivaceous on back and sides to level of the jet-black humeral spot; rest of sides and nuder parts bright silvery; dorsal and caudal dusky; other fins plain. The cotypes from Grand Plams Bayou are 2 females with ripe roe. They are $4 \frac{1}{2}$ and $5 \frac{1}{2}$ inches long, respectively, and differ from the types only in the deeper body and the much darker coloration of the upper parts. $3030 \_-99$ 
The amount of variation in this speeies, shown by the material at hand, is exhibited in the following table:

\begin{tabular}{|c|c|c|c|c|c|c|c|c|c|c|}
\hline No. & Head. & Depth. & Eye. & Snout. & Max. & Dorsal. & Anal. & Scutes. & Scales. & Locality. \\
\hline $\begin{array}{l}1 \\
2 \\
3 \\
4 \\
5 \\
6 \\
7 \\
8 \\
9\end{array}$ & $\begin{array}{l}4 \frac{1}{6} \\
4 \\
4 \\
3 \\
3 \frac{3}{6} \\
3 \frac{3}{5} \\
3 \frac{3}{8} \\
3 \frac{1}{2} \\
3 \frac{1}{2} \\
3 \frac{1}{4}\end{array}$ & $\begin{array}{l}3 \\
2 \frac{5}{6} \\
3 \\
31 \frac{1}{7} \\
3 \\
3 \\
3 \\
3 \\
2 \frac{5}{6}\end{array}$ & $\begin{array}{l}3 \frac{3}{4} \\
3 \frac{1}{4} \\
3 \frac{4}{5} \\
3 \frac{1}{2} \\
4 \\
3 \frac{3}{4} \\
3 \frac{1}{4} \\
3 \frac{1}{2} \\
3 \frac{1}{2}\end{array}$ & $\begin{array}{l}5 \frac{1}{4} \\
5 \frac{1}{3} \\
5 \frac{1}{3} \\
5 \frac{1}{2} \\
5 \\
5 \frac{1}{2} \\
5 \\
5 \\
5 \frac{1}{4}\end{array}$ & $\begin{array}{l}3 \frac{4}{5} \\
3 \frac{1}{5} \\
3 \frac{3}{4} \\
3_{5}^{1} \\
3 \frac{2}{5} \\
3 \\
3 \frac{1}{5} \\
3 \\
3\end{array}$ & $\begin{array}{l}\mathbf{I}, 12 \\
\mathbf{I}, 12 \\
\mathbf{I}, 12 \\
\mathbf{I}, 12 \\
\mathbf{I}, 12 \\
\mathbf{I}, 12 \\
I, 12 \\
I, 12 \\
I, 12\end{array}$ & $\begin{array}{l}\text { I, } 24 \\
\text { I, 24 } \\
\text { I, 24 } \\
\text { I, } 24 \\
\text { I, } 24 \\
\text { I, } 24 \\
\text { I, } 24 \\
\text { I, } 24 \\
\text { I, } 24\end{array}$ & $\begin{array}{l}16+11 \\
16+11 \\
16+10 \\
17+10 \\
16+11 \\
16+10 \\
17+9 \\
17+9 \\
17+9\end{array}$ & $\begin{array}{l}40-15 \\
42-15 \\
42-14 \\
42-15 \\
43-15 \\
41-15 \\
41-15 \\
41-15 \\
40-15\end{array}$ & $\left\{\begin{array}{l}\text { Grand Pla ins } \\
\text { Bayou, Miss. } \\
\text { Melville, La. } \\
\text { Grand Pla ins } \\
\text { Bayou, Miss. } \\
\text { Black Ba y o a, } \\
\text { Miss. }\end{array}\right.$ \\
\hline
\end{tabular}

This species appears to be rather common in the larger lowland streams and bayous of Lonisiana and Mississippi. It probably does not reach a large size, adult exanples being less than 6 inches long. It is not user as food, but is of considerable value as bait in the eatfish fishery of the Atchafalaya River and its connecting lakes and bayous. Length 4 to 6 inches. (atchafalaya, from the type locality.)

Signalosa atchafalaya, Evermann \& Kendall, Bull. U. S. Fish Comm. 1897 (Feb. 9, 1898), 127, pl. 7, fig. 4, Atchafalaya River, Melville, Louisiana. (Type, No. 48790. Coll. Fred M. Chamberlain.)

Page 425. The statement that Pomolobus mediocris does not ascend rivers to spawn is not correct. This species is known to ascend the St. Johns River, Florida, at least as far as Lake Monroe, during the winter. They usually run somewhat earlier than the shad.

Page 427. After Alosa, Cuvier, add:

a. Gill rakers numerous, 93 to 120 ; upper jaw with sharp, deep notch at tip; lower jaw not projecting.

SAPIDISSIMA, 693.

aa. Gill rakers fewer than 76 ; notch in upper jaw smaller; lower jaw more strongly projecting. ALABAM $\cong, 693(a)$.

Page 428. After synonymy of Alosa sapidissima add:

693(a). ALOSA ALABAME, Jordan \& Evermann.

(Alabama Shad; Gulf Shad.)

Head $4 \frac{3}{5}$; depth 3 ; snout $4 \frac{1}{2}$; eye $4 \frac{1}{8}$; maxillary $2 \frac{1}{8}$. D. 15 ; A. 20; scales $55,-16$ in a crosswise series; scutes $21+15$; vertebra 54 ; gill rakers 56 to 68. Body deep; back gently and evenly arched from tip of snout to origin of dorsal fin, thence descending in a regular curve to base of caudal fin; ventral outline nearly straight from tip of mandible to ventrals, and also from there to base of candal. Head small, suout pointed; upper lip with a small notch, into which fits the tip of the slightly projecting lower jaw; maxillary narrow; cheek much deeper than long; teeth on tongue and maxillary scarcely perceptible. Origin of dorsal nearer snont than base of caudal, the fin low, the longest ray shorter than the base, or about equal to snout and eye; base of anal somewhat greater 
than that of dorsal, or equal to length of pectoral. Gill rakers 68, the longest about equal to length of snout. Peritoneum pale. Color as in Alosa sapidissima; the caudal, dorsal, and pectoral tins rather darker tipped. The male differs from the female only in being somewhat more slender. This species differs from Alosa sapidissima chiefly in the fewer gill rakers, its sharper, more pointed suout, smaller notch in upper jaw, more projecting mandible, and more slender maxillary. It seems to reach maturity at a much smaller size than the common shad. Streams tributary to the Gulf of Mexico; known from Tuscaloosa, Alabama, and Pensacola, Florida.

Alosa alabama, Jordan \& Evermann, in Evermann, Rept. U. S. Fish Comm. 1895 (Dec. 28, 1896), 203, Black Warrior River, Tuscaloosa, Alabama (Type, Nos. 47689 and 47690. Coll. J. H. Fitts); Evermann \& Kendall, Bull. U. S. Fish Comm. 1807, 127, pl. 7 , figs. 5 and 6.

According to Ogilby, Kowala is a genus distinct from Sardinella.

Page 436. Ilisha panamensis is not separable from $I$. furthi. The latter name has priority.

Page 437. Opisthopterus lutipinnis is very abundant on the outer sand beaches about Mazatlan.

Page 445. Species 728, Stolephorus poeyi, is a species of Lycengraulis, and should stand as-

743(a). LYCENGRAULIS POEYI (Kner \& Steindachner).

Numerous specimens lately taken by Dr. Gilbert at Panama. A large species used as food. The teeth are unequal in Iycengraulis, but none of them can be properly described as canine-like.

Page 447. After Stolephorus lucidus add:

732(a). STOLEPIORUS RASTRALIS, Gilbert \& Pierson, new species.

Head 3.16 (3.1 to 3.3); depth 3.8 (3.5 to 4.2 ); eye 3.4 in head (3.33 to 4 ). D. 14 (12 to 15 ); A. 26 to 32 . Body much compressed and deep; belly sharply keeled in front of ventrals; dorsal outline much less eurved than ventral, the lower profile rising very rapidly from a point opposite middle of pectorals to tip of snout, in shape of head thus closely resembling the species of Cetengranlis. Maxillary reaching almost but not quite to gill opening; suout high, compressed, its length $\frac{1}{2}$ to $\frac{8}{4}$ diameter of eye. Gill rakers averaging in larger exampłes $51+64$, in smaller specimens $44+50$; the largest about as long as eye. Insertion of dorsal fin variable, but never posterior to a point midway between base of caudal and middle of eye; pectoral fins reaching to or uearly to insertion of ventrals, the latter not to vent. Color olivaceons, the lower part of side with violet reflections; sides of head silvery; a conspicuous silvery lateral band varying in width from about $1 \frac{1}{8}$ times length of orbit in the largest examples to less than $\frac{1}{2}$ orbit in the smaller specimens; the band is widest before dorsal, tapering to $\frac{1}{2}$ or less than $\frac{1}{2}$ its greatest width on caudal peduncle, where it frequently disappears in the young. In larger specimens the ventral edge of this band is frequently ill-defined anteriorly; top of head with 
widely spaced black specks; a dark vertebral streak, more or less of it often consisting of 2 narrow lines; tips of caudal lobes often blackish; fins otherwise unmarked. This species differs from closely allied species in the following characters: From Stolephorus lucidus, in the much longer head, more compressed body, well-defined lateral stripe, and smaller eye; from $S$. compressus, in the longer head and wider lateral band; from S.panamensis and $S$. mundeolus, in the much more numerous gill rakers, and the more anterior position of the dorsal relative to the anal, the origin of the anal being under the middle of the dorsal, while in S. panamensis the origins of the two fins lie in the same vertical. Length 2 to 3 inches. Panama. Many specimens. (Gilbert \& Pierson.) (rastrum, a rake, from the long gill rakers.)

Stolephorus rastralis, GLLBert \& Pierson, Fishes of Panama, MS. 1898, Panama.

732(b). STOLEPHORUS MUNDEOLUS, Gilbert \& Pierson, new species.

Head 4.15 (4 to 4.25); depth 3.77 (3.40 to 4.25); eye 3.44 in head (3.12 to 3.70 ). D. 13 or 14 ; A. 33 ( 33 to 35 ); scales 36 (35 to 39$)$. Dorsal and ventral contours about equally and gradually rounded from the middle region of body to the tip of snout and base of caudal fin. Snout short, high, compressed, blunt at tip, its length 1.8 in eye. Eye very large. Maxillary broad, tapering to a sharp point, which reaches margin of gill opening. Gill rakers 17 to $22+21$ to 24 ; the longest 1.5 to 2 in eye. Anterior insertion of dorsal fin varying from a point midway between base of caudal and middle of eye, to a point midway between the caudal and tip of snout. In 10 examples its insertion is before that of the anal. Anal fin long, averaging 33 rays, its origin beneath the anterior third of the dorsal; length of base shorter than in S. panamensis, being 3.04 in length, while in the latter its length is contained 2.5 in length. Pectoral long, reaching well beyond the insertion of the ventrals, equaling length of head behind front of pupil; a large axillary scale; ventrals scarcely reaching vent. Uniform light olive, with silvery reflections; a faint, narrow, silvery-gray lateral stripe, sometimes scarcely distinguishable; sides of head plain silvery; upper margin of orbital rim black; dorsal region blackish; a faint, narrow dark line on each side of the light middorsal streak; candal slightly dusky; fins otherwise unmarked. This species is closely allied to Stolephorus panamensis and S. compressus, but may be distinguished from the former by its longer head, larger eye, greater depth, fewer scales along the ${ }^{\circ}$ lateral line, and its much shorter anal base; also by the much fainter lateral silvery stripe. The eye is contained 14 to 16 times in length, excluding the caudal, while in $S$. panamensis the length contains the eye 16 to 20 times. From $S$. compressus it differs in the relative length of the head and maxillary. In S. mundeolus the maxillary is contained in the head 1.27 times (1.19 to 1.37 ); in compressus 1.48 times (1.30 to 1.81 ). In mundeolus the head is contained 4.15 times in the length; in compressus 4.44 times. Length 4 to $6 \frac{1}{2}$ inches. Panama; many specimens. (Gilbert.) (mundeolus, somewhat shining, from mundus, neat or clean.)

Stolephorus mundeolus, GiLbert \& Pitrson, Fishes of Panama, MS. 1898, Panama. 
732(c). STOLEPHORUS NASO, Gilbert \& Pierson, new species.

Head 3.3 to 3.5 ; depth 4.7 to 5.8 ; eje $4 \frac{1}{2}$ to 5 in head. D. 14 or 15 ; A. 22 to 24 ; lateral line about 35 ( $q)$. Dorsal and ventral outlines weakly arched; body slender, its greatest depth 1.5 in head, compressed; belly carinated in front of ventrals, and sometimes behind them in larger specimens. Head long and slender, its greatest width 1.5 to $1.7 \mathrm{in}$ its length, the lower profile much more oblique than the upper. Snout long, compressed, bluntly rounded, its length exceeding the small eye. Cheek with a very acute posterior angle. Opercle narrow, oblique. Maxillary rather bluntly pointed, failing to reach gill opening by about $\frac{1}{2}$ diameter of pupil. Teeth on the maxillary quite prominent and directed forward. Gill rakers short, $17+20$ in number, the longest 1.5 in eye. Scales large, thin, deciduous, only a few scattering ones remaining in our specimens. Dorsal fin inserted midway between front or middle of orbit and base of median eaudal rays. Origin of anal under or sliglitly behind middle of dorsal; length of anal base about equal to the distance from front of orbit to base of ventral fin; pectorals not reaching ventrals, their length about $\frac{1}{2}$ length of head. Length of ventrals equaling or slightly exceeding distance from tip of snout to middle of pupil. Color light olive, with the usual bright reflections; a large dark patch of brown dots on occiput; a double series of dots along median line posterior to dorsal, this absent in some specimens; large specimens with a bright, well-defined silvery streak, slightly narrowing anteriorly and on caudal peduncle, its greatest width about equaling diameter of eye; in the young, this band is fainter and narrower; a conspicuous series of black dots at base of anal. Characterized by the slender form, well-defined silvery streak, sharply carinated breast, the small eye, and the very long, compressed, deep, and rather bluntly rounded snout. Most closely resembling S. starksi, from which it differs in the smaller eje, longer snout, and slightly longer anal. Length 2 to $2 \frac{1}{4}$ inches. Panama; eommon. (Gilbert \& Pierson.) (naso, long-nosed.)

Stolephorus naso, Gilbert \& Pierson, Fishes of Panama, MS. 1898, Panama.

732(d). STOLEPHORUS STARKSI, Gilbert \& Pierson, new species.

Head 3.3 to 3.6 ; depth 4.8 to 5.5 in length, $1 \frac{1}{3}$ in head; eye 3 to 3.5 in head. D. 15 or 16 ; A. 17 to 22 ; seales about 41 . Body long and slender, slightly deeper and more compressed than in S. ischanus, which much resembles this species. Dorsal outline very little arched; ventral outline nearly straight from gill opening to insertion of anal fin, the lower profile of head oblique, nearly straight. Belly compressed, keeled for anterior $\frac{2}{3}$ of distance anterior to base of ventrals. Head long and pointed, its width $1 \frac{1}{2}$ times in its length; maxillary abruptly widened at the mandibular joint, tapering posteriorly to a blunt point, which reaches almost to the gill opening, its length equal to length of base of anal; snont long, sharp, and projeeting, abruptly compressed in its terminal portion as seen from above, its length $\frac{2}{8}$ diameter of orbit, or slightly more. Branchiostegal membranes united at base for a very short distance. In 4 exam. 
ples examined as to this point, the gill rakers are as follows: $20+25$, $23+24,21+23,19+30$, the longest contained $1 \frac{1}{2}$ to $1 \frac{2}{3}$ in eye. Scales large, thin, and deciduous, a few only remaining on the specimens at hand. Origin of the dorsal fin equally distant from the base of the eaudal fin and tip of snout or front of eye. Anal inserted nuder beginning of posterior third of base of dorsal; pectorals not reaching ventrals, the latter $\frac{3}{5}$ distance to front of anal. Color light olive, with broad, well-defined lateral silvery streak of nearly uniform width, usually narrowing anteriorly and on middle of caudal peduncle, its width in our largest specimen $\frac{5}{6}$ diameter of eye; the silvery streak has a slight golden tinge; a narrow dark vertebral line, which widens on the nape; occiput blackish. Vertebræ 40, counted in 1 example only. This species differs from Stolephorus cultratus in its slenderer body, shorter snout, wider opercle and smaller teeth; the belly is also not sharply carinate, the dorsal is more anteriorly placed, the ventrals are farther back, and the silvery streak is wider anteriorly. It differs from $S$. delicatissimus in its longer, slenderer head and body, smaller eye, longer, sharper snout, and much wider, better-defined silvery streak. Length $1 \frac{1}{2}$ to $2 \frac{1}{4}$ inches. Panama; common. (Gilbert \& Pierson.) (Named for Edwin Chapin Starks.)

Stolephorus starksi, Gilbert \& Pikrson, Fishes of Panama, MS. 1898, Panama.

Page 448. After Stolephorus spinifer add:

737(a). STOLEPIORUS SCOFIELID, Jordan \& Culver.

Head $3 \frac{8}{4}$ to 390 in length to base of candal; depth $4 \frac{1}{4}$ to 5 ; eje $3 \frac{8}{4}$ to 4 in head. D. 12 ; A. 25 or 26 ; scales 41 or 42 . Body somewhat compressed and elevated, the belly not carinated nor serrated. Teeth in both jaws, and on palatines, a few on vomer; maxillary covered with teeth its entire length and reaching beyond base of mandible, but not to opercular margin. Gill rakers $10+12$, the longest a little more than $\frac{1}{2}$ the eye. Origin of dorsal midway between base of median candal rays and center of eye; anal not quite as long as head, its origin below the middle of dorsal; lower caudal lobe longer than upper; longest ray equaling length of the head; shortest caudal ray $2 \frac{1}{2}$ in longest. Pectorals not reaching ventrals, $1 \frac{8}{4}$ in head. Both anal and dorsal fins preceded by a rudimentary spine, not $\frac{1}{2}$ length of first true ray. Color translucent, with a distinet broad silvery stripe as wide as the eye, growing more diffuse at lower anterior edge, narrowing on caudal peduncle, and becoming fan-shaped on the base of caudal; tip of snout black; a distinct median band of black specks extending from tip of snout to base of caudal; no distinct black markings on fins. Close to Stolephorus delicatissimus, but with larger head, wider lateral band, and greater number of dorsal and anal rays. Length 3 inches. Found in the Astillero at Mazatlan; not very abundant. (Named for Mr. Norman Bishop Scofield, a member of the Hopkins expedition to Sinaloa.)

Stolephorus seofieldi, Jordan \& Culver, Fishes of Sinaloa, 110, 1895, Mazatlan, Mexico.

(Type, No. 2941, L. S. Jr. Univ. Mus. Coll. Hopkins Exped. .o Sinaloa.) 
737 (b). STOLEPHORUS ASTILBE, Jordan \& Rutter.

Head $4 \frac{1}{8}$ in length; depth $4 \frac{1}{2}$ to 5 . D. 12 ; A. 19 to 22 ; eye $3 \frac{1}{2}$ in head; pectoral $1 \frac{4}{5}$; base of anal $1 \frac{1}{6}$. Body rather elongate, not greatly compressed; edge of belly moderately sharp; head sharp; snout projecting beyond lower jaw, shorter than diameter of eye; tip of lower jaw reaching a little past anterior edge of orbit; maxillary reaching gill opening, its end tapering to a sharp point; eye longer than snout, nearly 2 in postorbital part of head; gill rakers $\frac{2}{3}$ eye; a slight keel on top of head. Origin of dorsal midway between base of caudal and eye; scales caducous. Translucent, head silvery; sides without lateral band; a dark spot on top of head; back with black points. This species is similar to Stolephorus brownii, but more slender, head shorter, and lateral silvery stripe wanting. Length 3 inches. Jamaica. Numerous specimens obtained. ( $\alpha$, not; $\sigma \tau i \lambda \beta \eta$, shining.)

Stolephorus astilbe, Jordan \& Rutter, Proc. Ac. Nat. Sei. Phila. 1897, 95, Jamaica. (Type, No. 4854, L. S. Jr. Univ. Mus. Coll. Joseph Seed Roberts.)

737 (c). STOLEPHORUS ROBERTSI, Jordan \& Rutter.

Head 3 in length; depth 4. D. 14; A. 23; scales about 35 ; eye 4 in head; pectoral $2 \frac{1}{2}$; base of anal $1 \frac{2}{3}$; caudal $1 \frac{1}{2}$. Body deep, strongly compressed, abdomen compressed to an edge, head large, compressed, the snout rather sharp, projecting beyond lower jaw, a little shorter than eye; cheek triangular; opercle large; distance from lower angle of cheek to edge of opercle equal to distance from same point to posterior edge of eye; maxillary short, not reaching root of mandible, its end rounded; lower jaw not reaching beyond anterior edge of orbit; gill rakers longer than eye, as long as orbit. Origin of dorsal midway between base of caudal and front of eye; scales caducous. Color translucent; head silvery, punctulate above; a silvery lateral band nearly as broad as eye; caudal with dark points, other fins colorless. This species seems to be related to Stolephorus opercularis, but the lateral band is distinct and the opercle is shorter. Jamaica; only the type, 2 inches long, known. (Named for Rev. Joseph Seed Roberts, of Kingston, Jamaica, who collected the type specimen.)

Stolephorus robertsi, Jogdan \& RUtter, Proc. Ac. Nat. Sei. Phila. 1897, 95, Jamaica. (Type, No. 4853, L. S. Jr. Univ. Mus.)

Page 449. Anchovia can not be maintained as a distinct genus. The name must be placed as a synonym of Stolephorus.

Page 450. Add:

741(a). CetergraUi.S Fyaymer, Gilbert \& Pierson, new species.

Head 3 to 3.3 ; depth 4 to 4.9 ; eye 4 in head. D. 14 or 15 ; A. 20 to 23 ; B. 7 (9); vertebra 41. Body compressed, fusiform, not so deep as in $C$. mysticetus or $C$. edentulus. The dorsal and ventral outlines being about equally and regularly curved in the larger specimens; in the smaller specimens the ventral contour is more nearly straight. Belly trenchant, but 
not carinate nor serrate; caudal peduncle moderate, its depth being contained 1.5 times in its length. Head similar to C. mysticetus; the snout longer, contained 5.5 to 7 times in head, $1 \frac{1}{2}$ times in eye (the snout contained 8 to 9 times in head in C. mysticetus). Both jaws bear minute teeth, those on the maxillary largest. Branchiostegal membranes united for only $\frac{2}{3}$ to $\frac{8}{4}$ of the distance between tip of mandible and mandibular articulation, wholly free from the isthmus. Tip of mandible directly beneath the anterior border of orbit. Gill rakers long, $\frac{9}{10}$ diameter of eye, 20 to 30 on the upper limb, 25 to 30 on the lower limb; in 5 examples as follows: $25+30,27+25,30+26,(23+29$ to $20+25), 25+30$. The origin of the dorsal is midway between base of median caudal rays and a point varying between front and middle of the eye. Insertion of anal below the posterior fourth or third of the dorsal, its length equaling the distance from the posterior border of the eye to insertion of pectoral. The pectoral is short, $2 \frac{1}{4}$ to $2 \frac{1}{3}$ in lead, failing to reach the insertion of the ventrals by $\frac{1}{2}$ or nearly $\frac{1}{2}$ its length. Caudal deeply forked, its median rays $2 \frac{1}{2}$ to 3 times in head. Color uniformly silvery with a distinct, well-defined lateral silvery band extending from upper angle of gill opening to base of caudal, its greatest width equaling the diameter of orbit, becoming narrower on eaudal peduncle. This species differs from C. mysticetus in the much narrower union of the gill membranes, the less numerous gill rakers, and in the longer snout. Length $1 \frac{1}{2}$ to $2 \frac{1}{2}$ inches. Panama Bay. Not rare. (Gilbert \& Pierson.) ('cy $\gamma \dot{v} s$, near; $\delta \mu \dot{\eta} \nu$, membrane.)

Page 451. Lycengraulis has the teeth large and somewhat unequal, but none of them is properly described as "canine-like."

Page 459. Add :

229(a). ERICARA, Gill \& Townsend.

Ericara, GILl and Townsend, Proc. Biol. Soc. Wash., XI, 1897 (Sept. 17, 1897), 232 (salmonea).

Alepocephalids with small, perfectly smooth, imbricated cycloid scales, wide cranium, projecting snout, deeply eleft mouth, uniserial and acrodont teeth on vomer and anterior portion of palatines, and dorsal and anal of normal extent and opposite each other. Bering Sea. ( $\dot{c} \rho i$, an intensive particle; $\varkappa \alpha \rho \dot{\alpha}$, head.)

753(a). ERICARA SALMONEA, Gill \& Townsend.

D. 17; A. 24. Maxillary extending to vertical of posterior border of orbit; head large; length $8 \frac{1}{2}$; depth 5 ; width $4 \frac{1}{2}$. Bering Sea; only the type kuown, a large example in good condition.

Ericara 8almonea, Gill \& Townsend, Proc. Biol. Soc. Wash., XI, 1897 (Sept. 17, 1897), 232, Bering Sea, southwest of Pribilof Islands, at Albatross Station 3603, in 1,771 fathoms. (Type, No. 48769, U. S. Nat. Mus. Coll. Albatross.)

Page 465. Dr. G. A. Boulenger has kindly sent us the following note regarding the types of Coregonus richardsonii which are in the British Museum :

I have examined the types (dry) of Coregonus richardsonii. There are about 20 gill rakers on the lower part of the anterior arch, the longest $\frac{1}{2}$ the diameter of the eye. The maxillary extends to below anterior border of eye, and its length is 4 times in length of 
head as stated by Gïnther, therefore a little shorter than in $C$. clupeiformis. Tongne with 4 series of teeth, as in $C$. labradoricus. It seems to agree best with $C$. nelsoni (description), but has fewer scales in lateral line. In short, I can not identify $O$. richardsonii with any of the forms known to me.

Page 471. After Argyrosomus lauretta add:

768(a). ARGYROSOMUS ALASCANUS, Scofield, new species.

Head $4 \frac{1}{4}$; depth about 4 . D. 12 ; A. 12 ; scales $10-85-9$. Eye a little shorter than snout, 5 in head, $1 \frac{1}{3}$ in interorbital space. Head wedgeshaped, the upper and lower profiles straight and meeting with a sharp angle at the suout. Viewed from above the snout is blunt, almost square, with the narrow, pale rounded tip of the lower jaw slightly projecting. Mouth oblique; the distanee from tip of snout to tip of maxillary is equal to the distance from tip of snout to center of pupil; the maxillary from its anterior articulation is contained $3 \frac{1}{2}$ in the head, its wilth 3 in its length, its upper anterior edge closing under the preorbital; maudible $2 \frac{1}{8}$ in head, its articulation with the quadrate bone beneath the posterior edge of the eye; width of supplemental bone a little more than $\frac{1}{2}$ width of maxillary. Preorbital broad, its greatest width equaling $\frac{8}{8}$ its length or diameter of pupil; width of supraorbital equals $\frac{2}{7}$ its length. Gill rakers 12 to $14+21$ to 23 , long and slender, the longest $\frac{2}{3}$ diameter of the eye. The tongue, vomer, and palatines without teeth. Distance from tip of snout to nape equaling $\frac{1}{2}$ the distance from nape to the front of the dorsal or $\frac{2}{3}$ length of head. Adipose fin large; ventral scale $\frac{1}{2}$ length of fin; longest dorsal ray $1 \frac{1}{2}$ in head; longest anal ray 2 in head; the pectorals reach more than $\frac{1}{2}$ to the ventrals; the ventrals reach $\frac{2}{3}$ to vent; the caudal is forked for a little more than $\frac{1}{2}$ its length. Color dusky above, silvery beneath; the dorsal, adipose fin, tips of caudal rays and upper side of anterior pectoral rays dusky; the rest pale. This species appears nearest related to Argyrosomus artedi, from which it differs chiefly in the number of gill rakers. * Length about a foot. Northern Alaska near Bering Straits; 3 specimens known, 1 from salt water at Point Hope, the others from fresh water at Grantley Harbor.

Argyrosomus alascanus, Scofiesd, in JoRdAN, Rept. U. S. Fur Seal Investigations, 1898, Point Hope and Grantley Harbor, Alaska. (Coll. Scofield \& Scale.)

Page 482. Beginning with line 10 from the bottom, the statement that the small form of the redfish has been traced from the mouth of the Columbia to Wallowa Lake is not true. The remark was meant to apply to the large form. The question as to whether the small form descends to the sea is still unsettled.

* The fin tormula, etc., of these 3 specimens are as follows:

\begin{tabular}{r|r|r|r|r|r|r}
\hline \multicolumn{1}{c|}{ Locality. } & Length. & \multicolumn{2}{|c|}{ Gill rakers. } & Dorsal. & Anal. & Scales. \\
\hline Grantley Harbor........... & $8 \frac{1}{2}$ in. & $14+23$ & $14+22$ & 12 & 14 & 88 \\
Do .................. & 9 in. & $14+22$ & $12+22$ & 12 & 12 & 87 \\
Point Hope, Alaska........ & 11 in. & $13+21$ & $12+21$ & 12 & 12 & 85 \\
\hline
\end{tabular}




\section{Page 492:}

779. SALMO MYKISS, Walbaum.

(Mykiss; Somka; Kamchatka Salmon Trout.)

By an unfortunate error the writers have heretofore used the name Salmo mykiss for the Cutthroat Trout of the Northwest. It was known that the Cutthroat is the only true or black-spotted tront in Alaska, and it was assumed that its range extended along the coast to all streams in Bering Sea. But our recent explorations have shown that it probably does not occur in Bering Sea, nor is there any undoubted record to the north of Wrangell. If it reaches Kadiak or Sitka or Prince William Sound, it is only rarely, and the streams of the Aleutian Islands and the east coast of Bering Sea contain no species of Salmo. The name Salmo mykiss must, therefore, be restricted to the Kamchatkan species, while the species of the American rivers heretofore called Salmo mykiss must stand as Salmo clarkii. We have, therefore, studied with great interest a specimen of the genuine Salmo mykiss, the first on record since the times of Pallas, Krasheninnikof, and Steller. The specimen, an adult male, $960 \mathrm{~mm}$. long, was taken by Dr. Leonhard Stejneger, September 15, 1897, in the Kalakhtyrka River, near Petropaulski, Kamchatka. It was called "Souka" or "Somka" by the natives. It is said to occur rarely and to be found in but few rivers, the Kalakhtyrka among them. It is considered to be superior as food to other Salmonida, except the King Salmon (O. trchaw$y$ tscha). Head 4 in length; depth $4 \frac{1}{4}$. D. 11 . A. 10 (developed rays); scales 125-24. Mouth large, the maxillary $1 \frac{4}{5}$ in head, being somewhat prodnced at tip; vomerine teeth few, evidently deciduous, only 3 being present. Eye $8 \frac{1}{2}$ in head; snout $2 \%$. Pectoral 2 in head, longest anal ray $2 \frac{2}{7}$. Anal fin high and somewhat falcate; ventrals inserted under anterior third of dorsal, reaching about halfway to vent; adipose fin over posterior end of anal; caudal lnnate. Color dark grayish above, sides silvery; a few small, faint, round black spots on back and on top of head, these sparse and obscure; a few faint spots on base of dorsal, and some on adipose dorsal; spots on caudal small, but distinct, especially in middle of fin; no trace of red at throat, in example preserved in formalin, and doubtless none in life. The specimen is now a half skin, in good condition.

The following measurements were taken from the fresh specimen by Dr. Stejneger :

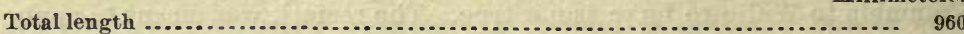

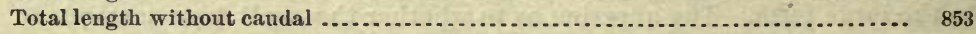

Head................................................................ 215

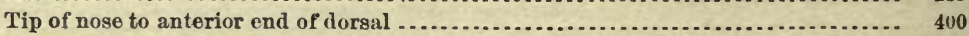

Length of baso of dorsal ................................................... 100

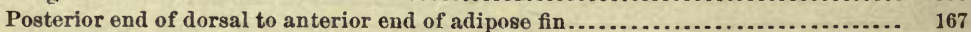

Length of base of adipose fin ................................................. $\quad 17$

Posterior end of adipose to candal .......................................... $\quad$-81

Posterior end of anal to candal .............................................. 81

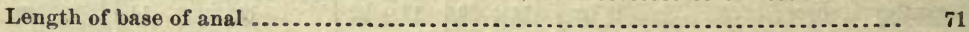

Anterior end of anal to posterior end of ventral................................ 165

Height of body in front of dorsal ........................................... 195

Height of body at posterior end of adipose and anal fins $\ldots \ldots \ldots \ldots \ldots \ldots \ldots \ldots \ldots \ldots . .105$ 
Millimeters.

Height of body at beginning of caudal

Ventrals under anterior third of dorsal; adipose fin over posterior end of anal; ventrals reach about $\frac{1}{2}$ distance to vent; 24 scales in transverse series from origin of dorsal to lateral line; 125 scales in lateral line. Color silvery gray on back, black spots obsolete.

This species is evidently a close ally of the Atlantic salmon, belonging to the restricted subgenus Salmo. From Salmo salar it differs in the slightly larger mouth and rather different coloration and in very little else.

Mykiss, Pennant, Arctic Zool., Intro., 126,1792, Kamchatka; after KRAsheninnikoF, etc. Salmo mykiss, WALBAUM, Artedi Piscinm, 59, 1792, Kamchatka; based on Mykiss of

PenNaNT.

Salmo penshinensis, Pallas, Zool. Rosso-Asiat., III, 1811, Gulf of Penshin.

Salmo purpuratus, PALLAs, Zool. Rosso-Asiat., III, 374, 1811, Bering Sea.

The correct names of the American Cutthroat Trout and its numerous known varieties are the following:

780. SALMO CLARKII (Richardson).

780(a). SALMO CLARKII LEWISI (Girard).

780(b). SAIMO CLARKII GIBBSII (Suckley).

780 (c). SAIMO CLARKII IIENSHAWI (Gill \& Jordan).

780(d). SALMO CLARKII VIRGINALIS" (Girard).

780 (e). SAIMO CLARKII SPILURUS (Cope).

780(f). SALMO CLARKII PLEURITICUS (Cope).

780(g). SALMO CLARKII BOUVIERI (Bendire).

780(h). SALMO CLARKII STOMIAS (Cope).

780 (i). SAIMO CLARKII MACDONALDI, Jordan \& Evermann.

Page 500. Before Salmo irideus insert the following:

781(b). SAIMO GAIRDNERI BEARDSLEEI, Jordan \& Seale.

(Blueback Trout of Lake Crescent.)

Head $3 \frac{4}{5}$ in length to base of candal; depth about 4 ; eye $4 \frac{5}{6}$ in head, $1 \frac{2}{5}$ in snout; scales 24-130-20, 130 cross series, those in front of dorsal numerous, about 70 if connted along median line, 60 if the rows along upper side aro counted; dorsal with 10 branched rays; anal with 11 branched rays; branchiostegals 11 ; gill rakers $8+13$, rather long and slender, the longest nearly $\frac{5}{16}$ in length, 7 to 9 in maxillary. Head pointed; mouth rather large; maxillary extending to hinder margin of eye, $1 \frac{4}{5}$ in head, with about 20 teeth; snout 33 in head; preorbital very narrow, the maxillary almost touching the orbit; posterior suborbitals shorter than eye, about 6 in head; opercle not very broad, equal to eye, its free part $4 \frac{5}{6}$ in head; interorbital width $3 \frac{3}{5}$ in head, equal to snout; several large teeth along margin of tongue; no hyoid teeth; teeth on vomer in zigzag series. Origin of dorsal in middle of the length, margin slightly concave, the first ray $1 \frac{5}{6}$ times the last, the last ray being pointed, slightly grcater than base, $2 \frac{1}{10}$ in head. Origin of anal midway between origin of dorsal and base of caudal, margin straight, the tip of the last ray slightly exserted; anterior rays $3 \frac{1}{4}$ times posterior, and equal to base of fin, $2 \frac{1}{3}$ in head. Adi- 
pose fin high and slender, situated above or anterior to end of anal. Pectorals $1 \frac{1}{2}$ in head; ventrals under middle of dorsal, $2 \frac{1}{3}$ in head. Caudal broad, nearly truncate, the middle portions abruptly lunate when spread open, with pointed angles, each lobe being somewhat convex on its edge; longest rays $1 \frac{1}{3}$ in head. Least depth of caudal peduncle $2 \frac{8}{4}$ in head. Pyloric cæca 50 to 60, short and thick, the longest about 3 in head. Color in spirits very dark blue above, sides abruptly brighter, with many scales abruptly silvery; below white, lower jaw white, its margin dusky; cheeks below suborbitals very dark; sides, top of head, dorsal, and caudal fins spotted, the spots all very small; pectorals and ventrals nearly colorless, without spots, and slightly dusky; adipose fin with 2 spots; tips of lower fins faintly tinged with yellowish. Two specimens, each 16 inches long, Nos. 1861 and 1862, L. S. Jr. Univ. Mus. They were taken on March 12 and 16, 1896, in Lake Crescent, by Mrs. George E. Mitchell, of Fairholme, and sent to us by Mr. M. J. Carrigan, of Port Angeles.

A third specimen shows the following characters: Head $3 \frac{5}{6}$; depth $3 \frac{2}{3}$. D. 12 ; A. 12 branched rays; branchiostegals 11 or 12 ; scales $23-123-26,64$ before dorsal; snout $2 \frac{5}{6}$; eye $7 \frac{2}{3}$; maxillary $1 \frac{2}{8}$ in head, its depth 8 in its length. Body robust, little compressed; head large; maxillary moderate, extending beyond eye; operclo moderate, its width $5 \frac{2}{3}$ in head. Last ray of dorsal pointed. Candal subtruncate, lunate mesially, each lobe somewhat convex, pointed at tip. Caudal peduncle short and thick. Series of vomerine teeth long, in double row. Color above dark green, with black spots, which are small and sparse on body, extending to below lateral line; many small spots on head, dorsal, and caudal; spots not more numerous behind than before; sides and belly bright silvery; no red on lower jaw; a faint pink shade along lateral line; pectorals colorless except the upper ray; ventrals and anal colorless; flesh.pale; gill rakers removed. This specimen, male, was taken in Lake Crescent. Length $26 \frac{1}{2}$ inches; weight in life 14 pounds. This specimen differs from a large gairdneri most in the large scales. In addition the head is much larger, and the body deeper.

A fourth, still larger, specimen (No. 1865, L. S. Jr. Univ.), an old spent male, 27 inches long, has been still later received. It shows the following characters: D. 11; A. 12 . Head $3 \frac{3}{5}$ in length; gill rakers $8+12$, of medium size, rather broad but sharp pointed; opercle $3 \frac{1}{2}$ in head; eye 7 in head; brauchiostegals 11; maxillary long, reaching beyond eye, $1 \frac{2}{2}$ in head, its width $9 \frac{1}{2}$ in length. A double row of sharp teeth extending to within a short distance of end, where they are replaced by a single row of slightly larger teeth; teeth on tongue rather large; no teeth on hyoid; teeth on vomer in zigzag series. Scales 137-26. This specimen, a spent male, has the flabby muscles and slimy, half-concealed scales of the spent male salmon. The dark dots are very numerous and small and show very distinctly on back and sides, as also on head and fins; there is a dull red lateral band on head and body - this is alout an inch broad, its outlines diffuse; a black blotch on cheek; maxillary dusky with a red blotch toward its tip; lower jaw and branchiostegals dusky; pectoral, ventral, and anal dark; back dark green, belly dusky. 
The following account of the life coloration of Salmo beardsleei is given by Mr. George E. Mitchell:

The Blueback Tront caught in Lake Crescent are on the back a deep dark-blue ultramarine color of a peculiar transparency, dotted with small round black spots from the size of a pin's head to a little larger. The 2 fins on the top of the back are a dark snoky color, also dotted as on back end, and are transparent. The tail is the color and transparency with dots also - same as the top fins. The side fins and the bottom fins are dead white and sometimes faintly tinged with a pinkish hue at the edges; the belly is white. Looking at the fish sideways the sides of the fish show the scales to be iridescent, the red tlash predominating. The head has very much the polish of mother-of-pearl around the lower jaws and jowls, red and pale-blue colors predominating; under the eyes a few black spots; on top of head the blue much darker than on top of back - so dark, in fact. that the black spots on it look blacker than the rest. The nearer the shore these fish are canght the lighter the blue on back, the fish often having an impression of the surroundings distinctly marked on them.

The following notes are added by Admiral Beardslee:

\section{HABITS.}

The Blueback is a deep-water dweller; those taken by me in late October were caught at depths varying from 30 to 50 feet, on large spoons. They fought hard until brought near the surface, then gave up, and when landed were found puffed up with air. Specimens taken in spring and put in pools in mountain streams with other trout died very soon, while the others lived. The trout caught by Mr. Mitchell, in March, was taken near bottom, by a large spoon, and it is not on record that at so early a date one has previously been eaught.

FLESH.

Light lemon color before cooking; devoid of the oily salmon flavor, and very excellent; whitening by cooking.

ova.

October 28. The eggs in the large fish were in individual size, and in size of cluster much smaller than those of a salmon of the same size.

The following extracts from a letter from Mr. Carrigan, dated Port Angeles, April 30, are of much interest:

* * * Answering your direct inquiries: The Beardslees and Crescents are readily distinguishable, and can always be told apart. There are no red spots at the points indicated on the Crescent trout - no markings to suggest the Cutthroat trout.

(Named for Admiral L. A. Beardslee, U. S. N., in recognition of his active and intelligent interest in American game fishes.)

Salmo gairdneri beardsleei, Jordan \& Seale, Proc. Cal. Ac. Sci., ser. 2, vol. vi, 1896, 209, pl. 23, Crescent Lake, Clallam County, Washington. (Coll. Mrs. George E, Mitchell. Type, No. 1864, L. S. Jr. Univ. Mus.)

780(c). SALMo GAIRDNERI CRESCENTIS, Jordan \& Beardsleo.

(Speckled Trout or Lake Crescent.)

Hoad $3 \frac{4}{5}$ in length to base of caudal; depth 5 ; exposed portion of eye 6 in head, $1 \frac{2}{8}$ in snout; scales $32-151-34,151$ cross series, 83 in front of dorsal; dorsal with 10 branched rays, anal with 11; branchiostegals 10 ; gill rakers $6+11$, counting rudiments, these very short and thick, the longest but $\frac{3}{16}$ inch in length, $18 \frac{1}{2}$ in maxillary; mouth large, maxillary extending much beyond eye, $1 \frac{2}{8}$ in head, with about 20 teeth; tongue with 
the usual teeth; teeth on vomer in zigzag series; hyoid region of tongue without teeth. Snout $3 \frac{1}{2}$ in head; preorbital very narrow, not so wide as maxillary adjacent to it; the posterior suborbitals longer than eye, $5 \frac{1}{3}$ in head; opercle and subopercle very narrow, scarcely as wide as eye, the free part of opercle $6 \frac{1}{8}$ in head; interorbital width $4 \frac{1}{4}$ in head. Origin of dorsal in middle of length of body, its margin straight, anterior $2 \frac{1}{2}$ times posterior, and slightly longer than base, $2 \frac{1}{8}$ in head; last ray of dorsal pointer. Origin of anal midway between origin of dorsal and base of caudal, margin irregular, anterior rays 3 times length of posterior and equal to base of fin, $22_{\overline{5}}$ in head. Adipose fin high and slender, situated immediately behind anal; pectoral $1 \frac{4}{5}$ in head; ventrals under middle of dorsal, 23 in head; caudal broad, slightly emarginate, nearly truncate when spread, its corners not ronnded, its longest rays $1 \frac{1}{2}$ in head; least depth of caudal peduncle $3 \frac{3}{5}$ in head. Pyloric creca about 51 , the longest about $1 \frac{5}{6}$ in head, and very slender. Color in alcohol, very dark steel blue above, becoming paler below, nearly white anteriorly on belly, where only the margins of the scales are punctate; no silvery anywhere; lower jaw dusky, a large black blotch on cheek between suborbital and premaxillary; sides, back, top of head, dorsal and caudal fins with fow small dark spots; pectorals dusky, slightly spotted at base; anal slightly dusky, withont spots; ventrals dusky with a few spots in middle; adipose fin with a few spots; lower fins all tipped with pale, probably yellowish red in life; spots all very small and faint, not confined to posierior part of body. The specimen before us, No. 1863, L. S. Jr. Univ., is a male, $18 \frac{1}{4}$ inches long. It was taken at Fairholme on Lake Crescent, Clallam County, Washington, March 12, 1896, by Mrs. G. E. Mitchell, of Fairholme. (Named for Crescent Lake, Washington, the type locality.)

Salmo gairdneri crescentis, Jobdan \& Beardsiee, Proc. Cal. Ac. Sci., ser. 2, vol. vi, 1896, 207, pl. 22, Crescent Lake, Clallam County, Washington. (Coll. Mrs. George E. Mitchell. Type, No. 1863, L. S. Jr. Univ. Mus.)

Page 504. Under Cristivomer for "Eastern North America" read "Northern North America." The genus occurs also in the lakes of Alaska and British Columbia.

Page 508. Before Salvelinus alpinus insert:

\section{4(a). SALVELINUS KUNDSCHA, Pallas.}

This seems to be a species very distinct from S. malma. A specimen in the United States National Museum (No. 33814) from Petropaulski has been described by Bean \& Bean as follows:

Similar in form to $S$. malma, but the body stouter and less elongate. Head $4 \frac{1}{2}$ to $4 \frac{2}{8}$ ( $4 \frac{1}{7}$ in the Tareinsky Bay specimen); depth $4 \frac{1}{2}$ to $4 \frac{2}{3}$; eye $5 \frac{1}{8}$ in head, 2 in interorbital, or $1 \frac{1}{2}$ in snout; maxillary reaching to or beyond vertical through posterior edge of orbit; upper jaw nearly $\frac{1}{2}$ length of head; lower jaw slightly shorter than upper. Hyoid teeth feebly developed. Scales small, 36-195, 122 pores. Fins all short; origin of dorsal about midway between tip of snout and base of upper caudal lobe, the base of the fin nearly as long as the longest ray, or $\frac{1}{2}$ as long as hearl, its 
upper margin very slightly concave, the last ray 2 in the longest; adipose fin over end of anal, its width about $\frac{1}{2}$ its length, which is about equal to eye; pectoral 7 to $7 \frac{1}{2}$ in body length; ventral under middle of dorsal, not nearly reaching vent, its length 2 in head; caudal emarginate, its middle rays $\frac{1}{2}$ the outer; anal scarcely concave when expanded. Pyloric crea 22 ; branchiostegals 12 ; gill rakers $6+10$, the longest less than $\frac{1}{2}$ eye. Color bluish gray above, whitish below; the sides with numerous large white spots, some of which are $\frac{2}{3}$ as large as eye. (Bean \& Bean.)

This species is said to be common from Kamchatka northward, but only 6 specimens are actually extant, 4 obtained at Petropaulski by Dr. Leonhard Stejueger and 1 by Col. N. Grebnitski, and now in the United States National Museum, and 1 obtained from Tareinsky Bay by Mr. Gerald E. H. Barrett-Hawilton and now in the museum of Stanford University.

Salmo kundscha, PALLAS, Zoogr. Rosso-Asiat., II, 250, 1811, Kamchatka. Salmo leucomoenis, PAllaS, Zoogr. Rosso-Asiat., III, 250, 1811, Kamchatka.

Salmo curilus, PALLAS, Zoogr. Rosso-Asiat., III, 251, 1811, Kuril Islands.

The true Salvelinus malma is very common at Unalaska, Kadiak, Komandorski Islands, and Petropaulski. Specimens from these various places are all alike. Head $4 \frac{1}{4}$ to $4 \frac{1}{5}$; depth $4 \frac{1}{4}$ to $4 \frac{3}{5}$. Spots grayish, tinged with red, much smaller than eye. Caudal well forked; lower fins short; pectoral reaching halfway to vent. Hyoid teeth present. The head seems much shorter than in examples from the United States. The dwarf form from the little brook (Pyramid Creek) at the head of Captains Harbor agrees fully in form with large examples taken in the sea about Unalaska. The small ones are brighter in color and mature at 4 to 6 inches. The form occurring throughout the northwestern United States, and described on page 508 as Salvelinus malma, should apparently be regarded as a species distinct from S. malma, and would stand as-

\section{4(a). SALVELINUS PARKEI (Suckley).}

\section{Page 515. Add this footnote to Salvelinus oquassa marstoni:}

A specimen of Salmo marstoni sent me some days ago indicates a more distinct spocies than was at first supposed. This is the most sleuder of our charrs, apparently the swift. est. The male is gorgeous; brilliant red extends upon the back and onto the dorsal and caudal fins as well as upon the other fins. Though quite distinct, the species is nearer to S. oquasra than any other. (Garman, in lit., March 24, 1895.)

Page 524. After Osmerus dentex add:

794(a). OSMEIUS ALBATROSSIS, Jordan \& Gilbert, new species.

(KADIAK SMeLT.)

Head $4 \frac{4}{5}$; depth $5 \frac{1}{2}$. D. 2,$10 ;$ A. 1,20 ; scales 75 ; maxillary $2 \frac{1}{10}$; eye $5 \frac{1}{4}$; snout $3 \frac{4}{5}$; mandible 2 ; pectorals $1 \frac{1}{2}$; ventrals $1 \frac{1}{2}$; dorsal $1 \frac{2}{5}$; caudal 12. Body elongate, moderately compressed; back elevated at nape so that anterior profile is somewhat depressed between and behind eyes; interorbital space $3 \frac{2}{8}$ in head. Mouth large, lower jaw heavy, strongly projecting; opercle with concentric striæ; pectorals moderate; ventrals long; dorsal high; anal fin low, very long, its longest ray 22 in head; caudal moderate, well forked; ventrals inserted before dorsal. 
Scales small, deciduous, those on back still smaller; lateral line distinct. Gill rakers long and slender, about 12 below angle of arch, longest about as long as eye. Tongue with moderate teeth, the anterior 2 to 4 small hooked canines; upper jaw with small sharp teoth similar to those in lower jaw, none of them canine-like; small teeth on palatines and pterygoids; vomer with 2 very small canines scarcely fang-like. Color bluish above with bright reflections; scales margined with dark points; sides silvery with golden and coppery luster; inside of gill openings dusky; fins white, somewhat dotted. About Kadiak Island, Alaska. Two specimens caught in the upward haul of a dredge in Shelikof Straits, north of Karluk, Kadiak Island, Alaska, at Albatross Station No. 3675. The depth of the dredge haul was 109 fathoms, but these fishes were no doubt taken from near the surface. One specimen is 8 , the other about 7 inches in length. The species is allied to Osmerus dentex, the Rainbow Smelt, but differs in the extremely long anal and in the very weak vomerine and lingual canines. The flesh is firm, as in $O$. dentex. (Named for the U. S. Fish Commission steamer Albatross.)

Osmerus albatrossis, JoRdan \& GILBERT, Rept. Fur. Seal Invest., MS. 1898, Shelikof Straits, north of Karluk, Alaska.

Mesopus should replace Hypomesus. It is originally characterized on page 14 (not 168) Proc. Ac. Nat. Sci. Phila. 1862, Hypomesus on page 15. The ventrals are inserted below front of dorsal in Mesopus as in allied genera, and there are 8 branchiostegals as in allied groups. The feeble teeth distinguish Mesopus from Osmerus. The statement that the stomach is cacal in Argentinida is true of a few genera only, and the character has no high systematic value. In Mesopus pretiosus and Osmerus dentex, the stomach is siphonal, as in Salmonida. In Thaleichthys pacificus, however, the stomach forms a blind sac. The small number of pyloric cæca and the peculiar structure of the ovaries remain to define Argentinida as a family distinct from Salmonida.

Page 525. 'To the synonymy of Hypomesus olidus add:

Osmerus oligodon, KNER.

The specics ranges south to Amur River.

Page 530. After Bathylagus pacificus add:

SO4(a). BATHYLAGLS BOREALIS, Gilbert.

Head $4 \frac{1}{12}$ to base of caudal; depth $5 \frac{2}{5}$; eye $2 \frac{1}{2}$ in head; snout $2 \frac{3}{4}$ in eje. D. 8 ; A. 19; ventral 8 ; pectoral 8 . Scales in about 40 rows, judging from the scars; head scaleless. Interorbital width grooved, the groove widening posteriorly, opening onto the flat occipital region, which is not swollen. Width of cartilaginous portion of interorbital space $\frac{1}{3}$ orbit; including the thin membranaceous plates which overarch the orbits, the interorbital width is $\frac{8}{4}$ orbit. The anterior profile of snout declines gently, bringing the mesial portion of premaxillaries on a level with lower margin of pupil. Distance from tip of snout to end of maxillary slightly exceeding length of snout, $2 \frac{1}{5}$ in orbit. Opercle with 2 strong ridges diverging downward and backward from behind the eye. Front of dorsal midway 
between front of snout and adipose fin; base of dorsal contained $3 \frac{1}{3}$ times in length of head. Ventrals inserted nnder posterior portion of dorsal. Free portion of adipose fin very long and narrow, rising above the base of the second and third anal rays before the last, its tip reaching rudimentary caudal rays when depressed; anal fin rather long, the base $1_{i}^{2}$ in head, the vent immediately before it. Kength of tail much exceeding head, $3 \frac{2}{5}$ in total length without caudal. Uniform blackish brown on sides, the head and ventral region blue black. Differing from B. pacificus in its much greater depth, longer tail, longer anal fin, and flat occiput. Length $132 \mathrm{~mm}$. Bering Sea, in deep water north of Unalaska; 2 specimens known. (borealis, northern.)

Bathylagus borealis, GruberT, Rept. U. S. Fish Comm. 1893 (Dec. 9, 1896), 402, Bering Sea at Albatross Station 3327, north of Unalaska, in 322 fathoms.

804(b). BATIIYLAUS MILLERI, Jordan \& Gilbert, new species.

Distinguished by the posterior insertion of the dorsal fin and the greatly swollen occipital region provided with a median keel. The type is in very poor condition, the skin being largely denuded from heal and body. No traces remain of the scales, the pectoral and ventral fins are lost and the others greatly mutilated. Enough remains, however, to demonstrate that it is distinct from all known species and to furnish characters by which the species may be recognized. The interorbital space is converted into a very deep channel by 2 vertical thin lamella which arise on either side, and mark off the narrow interorbital space from the contiguous supraocular areas. From the base of these vertical lamella arise externally the thin supraocular plates, which extend outward and upward and roof over the orbit. A deep narrow channel is included between the lamella and the plates. The floor of the interorbital groove is raised mesially into a sharp ridge, which is continuous anteriorly with the ethmoidal ridge and posteriorly with a ridge running along middle of occiput. On anterior half of occiput this ridge is a high strong keel; posteriorly, it becomes lower and rounded. The occipital region is swollen and prominent, much higher than the interorbital space. It is bounded laterly by 2 strong rounded rilges which originate at the npper posterior margin of the orbit and converge rapidly backward. The occipital cartilage is heavy and strong, not yielding readily to pressnre. The width of interorbital space is $\frac{1}{5}$ orbit; the distance between outer margins of orbital plates above middle of eyes is $\frac{3}{5}$ dianeter of eye. The opercle is marked with delicate striæ diverging downward and backward, but is without strong ridges. The front of dorsal is midway between adipose fin and gill opening, slightly nearer base of caudal than tip of snout. The fin contains 8 rays. Anal badly mutilated, containing at least 24 rays. The mutilated condition of the type will not permit further description. Length $155 \mathrm{~mm}$. Cortez Banks off San Diego, California, in deep water; known only from the type taken by the Albatross at Station 3627, in 776 fathoms. (Named for Walter Miller, professor of classical philology in Leland Stanford Jr. University, in recognition of his intelligent interest in zoological nomenclature.) 
Page 531. In kej under $h$, for "incomplete" read " complete."

Page 537. We can not separate Synodus jenkinsi from Synodus scituliceps, and the former name should probably be abandoned.

Page 555. Macrostoma angustidens and related species need further study. The synonymy and application of the names angustidens, elongatus, and resplendens are uncertain. Macrostoma brachychir is probably a good species.

In $M$. caudispinosum the dorsal has 20 , not 36 , rays.

Page 580. The generic name Bonapartia, Goode \& Bean, is preoccupied in ornithology. For its use in fishes the name Zaphotias is proposed, taking the same species (pedaliota) as type. The genus and its species would then stand as follows:

274. ZAPHOTIAS, Goode \& Bean, new generic name.

(Zaphotias, having organs which emit light; $\zeta \alpha$, intensive particle; $\phi \tilde{\omega} 5$, light.)

872. ZaPhotias PEDaliotus (Goode \& Bean).

Page 582. Cyclothone microdon occurs also in Bering Sea in very deep water.

Page 586. Astronesthes is from $\alpha$ $\sigma \tau \rho \circ \nu$, star; $\varepsilon \sigma 0 \eta \dot{\eta} 5$, vestment.

Page 594. Plagyodus (Steller) should probably supersede Alepisaurus, in which case the family becomes Plagyodontida.

Page 603. Sternoptyx diaphana is common off both the Japanese and Hawaiian islands.

Page 608. For Aldrorandia, Goode $\&$ Bean, substitute the carlier name Halosauropsis, Collett.

Hallosauropsis, Collett, Camp. Sci. Hirondelle, June, 1896, 143 (macrochir).

Page 618. Add:

916(a). MACDONALDIA ALTA, Gill \& Townsend.

D. 32 ; A. 31 to end of dorsal, 52 spines, 125 rays. Body comparatively high, greatest height equal to $3 \frac{2}{3}$ the distance between vent and tip of suout; pectoral fin with its root twice as far from upper eleft of branchial aperture as from the lateral line, and much nearer to the posterior end of operculum than to lateral line. Bering Sea; only the type known. (altus, deep.)

Macdonaldia alta, Gill \& Townsend, Proc. Biol. Soc. Wash., XI, 1897 (Sept. 17, 1897), 232 ,

Bering Sea, Lat. N. $54^{\circ} 54^{\prime}$, Long. W. $168^{\circ} 59^{\prime}$, Albatross Station 3604 , Aug. 13, 1895' in 1,401 fathoms. (Type, No. 48774, U. S. Nat. Mus. Coll. Albatross.)

916(b). MACDONALDIA LONGA, Gill \& Townsend.

D. 33; A. 26 to opposite end of dorsal, 55 spines, 111 rays. Body comparatively slender, with the greatest height about $\frac{1}{5}$ distance between vent and tip of snout; pectoral fin with its root 3 times as far from upper cleft of branchial aperture as from lateral line, and very much nearer 
lateral line than end of operculum. Bering Sea; only the type known. (longus, long.)

Miacdonaldia longa, GiLl \& Townsend, Proc. Biol. Soc. Wash., xI, 1897 (Sept. 17, 1897), 232,

Bering Sea, Albatross Station 3607,1895 , in 900 fathoms. ('Type, No. 48775, U. S. Nat.

Mus. Coll. Albatross.)

Page 627. Lucius vermiculatus occurs also in 'Texas, specimens having been obtained in both the Trinity and Neches rivers near Palestine, by Evermann \& Scovell.

Page 632. Aplocheilus $=$ Apocheilichthys $=$ Haplocheilus $=$ Panchax, is a genus distinct from Fundulus, and should be erased from the synonymy of the latter. The genus is defined by the flat, much produeed snout, and the long anal tin.

To the synonymy of Fundulus add:

Plancterus, Garman, Monogr. Cyprinodonts, in Mem. M. C. Z., xix, No. 1, 96, 1895 (kansoe= zebrinus.)

Page 635. In the key, under $a a$, the phrase "inhabiting mountain springs and brooks" applies only to Nos. 943 and 944 . It should be transferred and made a part of 8 .

Page 637. Fundulus punctatus and $F$. vinctus are wrongly placed by Garman in the synonymy of $F$. parvipinnis.

Page 638. Fundulus pallidus is placed by Garman in the synonymy of F. grandis, to which it bears but little resemblance.

Page 639. To the synonymy of Fundulus majalis add:

Hydrargyra formosa, STORER, Proc. Bost. Soc. Nat. Hist. 1837, 76.

Page 641. To the synonymy of Fundulus heteroclitus macrolepidotus add:

Hydrargyra ornata, Le Sueur, Journ. Ac. Nat. Sci. Phila., I, 1817, 131, Delaware River, near Philadelphia. (Coll. G. Ord.)

Garman regards Fundulus grandis as a good species. We have recently compared specimens from Cape Cod with others from Tampa, and reach the same conclusion.

Page 642. Before Fundulus occllaris insert:

932(c). FUNDULUS HETEROCLITUS BADIUS, Garman.

(This is the form found about Grand Manan, named but not characterized by Garman.)

Garman refers Fundulus ocellaris to the synonymy of Fundulus grandis, which is very doubtful.

Page 643. Garman refors Fundulus fonticola also to the synonymy of F. grandis, which is not correct. He also wrongly regards Fundulus bermuda as a variety of hcteroclitus.

Page 644. Fundulus robustus is referred, probably by error, by Garman to the synonymy of $F$. labialis, which is certainly incorrectly made a variety of $F$. parvipinnis.

Page 645. Garman refers Fundulus zebra, zebrinus, and extensus to the synonymy of Fundulus adinia, all of which is certainly wrong. Such ref- 
erences defy all our knowledge of the geographic distribution of these fishes. For example, $F$. extcnsus is a brackish-water fish of Cape San Lucas; $F$. zebra, which is the basis of $F$. zebrinus, is a fish of the mountain streams of New Mexico, Colorado, and northeastward, while F.adinia is found near the mouth of the Ris Grande. There is no doubt that the original Fundulus zebra is the species called zebrinus by us and kanso by Garman. It came from some point ketween "Fort Union and Fort Defiance." In other words, it came from the head waters of the Canalian River or the Rio Grande. No species of this type has been recorded from the upper Rio Grande, but the species called zebrinus and kanse is in all the upper waters of the Arkansas basin, to which the Canadian River belongs, and doubtless in the streams above Fort Union.

Page 646. To the synonymy of Fundulus zebrinus add:

Fundulue kanso,; Garman, Monogr. Cyprinodouts, 103, pl. 2, fig. 10, 1895, Kansas.

This species (F. zebrinus) is rightly made the type of a new subgenus, or possibly genus, Plancterus, by Garman. It has long, convoluted intestines and very small pharyngeals. Fundulus seminolis (subgenus Fontinus) has short intestines and coarse pharyngeals.

Page 648. Fundulus stellifer is wrongly referred by Garman to the synonymy of $F$. catenatus.

Page 649. Fundulus lineatus is referred by Garman to the synonymy of F. sciadicus, which reference seems to be correct.

Fundulus albolineatus, which Garman also refers to $F$. sciadicus, seems to be a perfectly good species. It is certainly not $F$. sciadicus.

Garman refers Fundulus confluentus to the synonymy of $F$. grandis, which is probably not correct.

Page 650. Garman's reference of Fundulus funduloides to the synonymy of $F$. grandis may be correct.

The species called Fundulus dovii in the text is an Aplocheilus and should stand as:

968(a). APLOCHEILUS DOVII (Günther).

Garman recognizes Zygonectes as a distinct genus, but its boundaries are not easily defined.

The description of Fundulus confluentus should be modified to include the following, taken from the type: Head $3 \frac{3}{5}$; depth $4 \frac{1}{2}$. D. 11 ; scales 44 or fewer. A black spot on middle of membrane of last 3 dorsal rays. This species resembles $F$. diaphanus rather than $F$. majalis. Fundulus ocellaris seems to be identical with $F$. confuentus.

Page 651. Garman refers Fundulus macdonaldi to the synonymy of $F$. sciadicus, which is probably correct, but the reference of F. floripinnis to the same synonymy is certainly wrong.

Page 652. Garman refers $F$. pulvereus to the synonymy of $F$.grandis, which is without warrant.

Page 655. To the synonymy of Fundulus chrysotus add:

Gambusia arlingtonia, GOODE \& BEAN, Proc. U. S. Nat. Mus. 1879, 118, Arlington River, Florida. (Type, No. 21308. Coll: Dr. Goode.) 
Zygonectes henshalli, JoRdan, Proc. U. S. Nat. Mus. 1879, 237, San Sebastian River, Florida. ('Type, No.23449. Coll. Dr. James A. Henshall.)

To the synonymy of Fundulus cingulatus add :

Zygonectes rubrifrons, JoRdan, Proc. U. S. Nat. Mus. 1879, 237, San Sebastian River, Florida. (Type, No. 23450. Coll. Dr. James A. Henshall.)

Zygonectes auroguttatus, HAY, Proe. U. S. Nat. Mus. 1885, 556, Westville, Florida. (Type, No. 37362. Con. Mann \& Davison.)

An examination of a large amount of material recently collected in Florida by Drs. Evermann and Kendall shows that the synonjmy of these species should stand as indicated above.

Examination of the type of Gambusia arlingtonia shows it to be the young of the form hitherto known as Z. henshalli, which, from an examination of the type and other specimens, proves to be the female of Fundulus chrysotus. The dorsal in Gambusia arlingtonia is not inserted so far back as the sixth anal ray, but is rather over the third or fourth. Both $G$. arlingtonia and $Z$. henshalli, agree with descriptions of $F$. chrysotus except in coloration. Both are females, as shown by form of anal fin. All specimens examined of the henshalli form are females, as shown in part by dissection and by the form of the anal fin. All specimens examined of the form agreeing with descriptions of $F$. chrysotus prove to be males, as shown partly by dissection and by the form of the anal fin. Front series of teeth much enlarged in all; anal fin usually with 11 rays.

The type of Z. rubrifrons differs from that of $Z$. henshalli in having a heavier head, really longer snout, mandible more oblique, giving the muzzle a truncated appearance, and the slope of the back to the snont beginning farther forward.

The type of Z. rubrifrons agrees with the description of $F$. cingulatus, except in the number of anal rays, there being 10 instead of 8 , as given in the description, which is a redescription of the type of F. cingulatus. Cuvier \& Valenciennes, however, give 10 anal rays in the original description. Specimens in the United States National Museum labeled Zygonectes cingulatus, from Pensacola, Florida, agree with the type of Z.rubrifrons, with the exception of 1 specimen, which has 11 anal rays.

National Museum specimens collected by Dr. Shufeldt at New Orleaus, labelled Zygonectes chrysotus, contain both the Z. henshalli and Z. chrysotus forms, i. e., those with pearly spots and no cross bars (females) and those with dark cross bars (males) - that is, male and female of Fundulus chry8otus. Comparison of specimens collected at Tampa and Welaka, Florida, reveal 2 color forms. Most of those from Tampa have the heavier head, truncated muzzle, and outlines of $F$. cingulatus. The 2 color forms are those with dark cross bars, all males as shown by dissection and form of anal fin, and those with no cross bars and no pearly spots, which are all females. The majority of individuals have 10 anal rays each.

Most of the Welaka specimens have more slender and pointed head, preorbital less deep, really shorter snout, and the curve of the borly toward the snout beginning farther back than in the preceding, and the majority have each 11 anal rays. The 2 color forms represent the 2 sexes-females with pearly spots and no cross bars, and males with dark cross bars and many with small brown spots. 
While a few of the chysotus form are found in the Tampa collection, and a few of the cingulatus form with the Welaka lot, they can be easily distinguished. A very few of the cingulatus form have 11 anal rays and a very few of chrysotus 10, but they can be otherwise distinguished. Whereas the females of $F$. cingulatus have no trace of pearly spots the females of $F$. chrysotus almost invariably have them. As a rule, the cross bars in the male, $F$. cingulatus, are narrower and more numerous than in the male of $F$. chrysotus, though young individuals of the latter do not differ in this respect. In Fundulus cingulatus there are often faint spots on the scales of the back forming longitudinal lines which seem to be absent in $F$. chrysotus. The teeth in the front row of $F$. chrysotus are larger than in F. cingulatus.

Page 658. Garman refers Fundulus guttatus to $F$. nottii, which is very doubtful, but he is right in so referring $F$. hieroglyphicus. He also refers $F$. dispar to $F$. nottii, which is probably wrong.

Page 658. Fundulus guttatus (Agassiz) can not be separated from Fundulus nottii (Agassiz).

Page 659. Fundulus melapleurus is, as Garman observes, a Gambusia, and should stand as Gambusia melapleura.

Adinia guatemalensis and A. pachycephala are recklessly referred by Garman to the synonymy of Fundulus parvipinnis. They might just as well have been placed at random under any other species of a totally different fauna.

Page 660. Before Adinia insert:

300(a). APLOCHEILUS, MeClelland.

Snout flat, both jaws much depressed. Bones of mandible firmly united; upper jaw protractile; each jaw with a narrow band of villiform teeth. Body oblong, depressed anteriorly, compressed posteriorly. Dorsal fin short, commencing behind the origin of the anal, which is more or less elongate. Intestinal tract but slightly convoluted; air bladder present. (Giinther.)

Aplocheilus, McCleldand, Ind. Cypr. As. Res., XIX, 301, 1839 (chrysostigmus=panchax). Panchax, Cuvier \& VAlenciennes, Hist. Nat. Poiss., XVIII, 380, 1846 (panchax).

Haplochilus, GǘNTHER, Cat., vI, 310, 1866, corrected spelling.

\section{8(a). APLOCILILUS DOVII (Günther).}

For description and synonymy see p. 650.

Page 662. According to Garman the air bladder is present in Rivulus.

He refers $R$. marmoratus to the synonymy of $R$. cylindraceus, which is probably correct.

Add the following species:

973(a). RIVULUS ISTIMENSIS, Garman.

Head $3 \frac{1}{8}$ in body; eye 3 in head; snont 6 . D. $9 ;$ A. $11 ;$ V. $6 ;$ P. 15 ; scales 32-8. Elongate, compressed posteriorly, depressed forward; head broad, much lepressed, flattened on the crown; snout medium, blunt; 
interorbital width greater than eye. Origin of dorsal fin over middle of base of anal, $\frac{2}{8}$ distance from suout to base of caudal; origin of aual fin midway between head and caudal, the last ray nearly as far back as that of dorsal ; caudal elongate, pointed, as long as head. Light olivaceous, with a dark blotch at base of dorsal and another on back above or in front of first anal ray; apparently a light, transverse streak at base of caudal. Rio San Jose, Costa Rica.

Rivulus isthmensis, Garman, The Cyprinodonts, Mem. Mus. Comp. Zool., xix, No. 1, July, 1895, 140, Rio San Jose, Costa Rica. (Trpe in M. C. Z.)

Page 663. Lucania ommata is wrongly referred to the synonymy of Heterandria formosa by Garman.

Page 664. The species called Lucania goodei in the text has 2 rows of teeth and is a true Fundulus, or rather Zygonectes, as Garman has shown. It may stand as Fundulus goodei.

Page 665. Lucania venusta is wrongly referred by Garman to L. parva, to which, however, it is closely related.

Page 668. Garman wrongly refers Characodon bilineatus and C.variatus to the synonymy of $C$. lateralis.

Page 669. Add:

883(a). CHARACODON EISENI, Rutter.

Head $3 \frac{1}{2}$; depth $3 \frac{1}{4}$; eye 3 . D. 11 to 13 ; A. 13; scales 30 to $32-12$. Snout shorter than eye, lower jaw projecting. About 9 teeth in upper jaw and about 14 in lower; teeth strongly bicuspid, the villiform teeth not developed. Mouth almost vertical when closed, mandible about $\frac{1}{2}$ length of eye; interorbital space flat, the anterior part equal to orbit, wider posteriorly. Insertion of dorsal in middle of total length; anal inserted under fourth ray of dorsal; pectoral reaching past insertion of ventral; tips of depressed dorsal and anal in vertical through middle of candal peduncle; candal broad, truncate, length of middle rays equal to length of top of candal peduncle. Head about $\frac{1}{4}$ of total; greatest depth of body above ventrals; depth of caudal peduncle $\frac{1}{2}$ its length. Color in alcohol, male with a broad indefinite lateral band; female with dark blotches on sides which in 1 of 3 specimens form distinct cross bands. This species is most closely related to Characodon variatus, Bean. It differs from that species in having fewer rays and scales, much fewer teeth, larger eye, much more posterior position of dorsal, and in color. Length $1 \frac{1}{4}$ inches. Rio Grande de Santiago, Tepic, Mexico.

Characodon eiseni, RuTter, Proc. Cal. Ac. Sci. 1896, 266, Rio Grande de Santiago, Tepic, Mexico. (Type, No. 4999, L. S.Jr. Univ. Mus. Coll. Dr. Gustav Eisen.)

Page 670. Add the following:

The specimens from Parras, Mexico, referred by Garman to C. lateralis, appear to be new. They may be described as follows:

984(a). CHARACODON GARMANI, Jordan \& Evermann, new species.

B. 4 ; D. 12 ; A. 12 ; V. 6 ; P. 17 ; scales $32-11$ or 12 ; vertebra $15+18$. Body compressed, moderately stout, caudal pedicel deep, back gently 
arched. Head about $\frac{1}{3}$ of length to base of caudal; very little arched transversely. Snout short, not as long as the eye; chin steep. Mouth medium; upper jaw protractile. Teeth in outer series bicuspid. Eye large, nearly equal to interorbital space, $\frac{1}{8}$ Ionger than snout, $\frac{2}{7}$ of head. The specimen examined had 4 branchiostegal rays on each side; whether this is normal must be decided from others. Fins small ; dorsal origin about $\frac{5}{7}$ of the distance from snout to caudal; anal opposed to dorsal; posterior margin of caudal subtruncate. Olive to reddish brown, with seattered small spots of darker on the back, a darker band with or without spots of dark along the flank, more distinct posteriorly. Fins with fine dots of dark color. Parras, Coahuila, Mexico. (Named for Prof. Samuel Garman of the Museum of Comparative Zoology, in recognition of his valuable studies of the Cyprinodonts.)

Caracodon lateralis, Garman, The Cyprinodonts, Mem. Mus. Comp. Zool., xix, No. 1, pl.1, fig. 9, 1895, Parras, Coahuila, Mexico; not of GÜnTHER.

954(b). CHARACODON LUITPOLDII, Steindachner.

Head $4 \frac{1}{3}$ to $4 \frac{2}{5}$; depth 3 to $3 \frac{5}{18}$; eye 4 to $4 \frac{2}{3}$ in head; snout 3 to $3 \frac{2}{3}$; interorbital $1 \frac{8}{4}$ to 2 . D. 14 ; A. 15 or $16 ;$ P. 15 or $16 ;$ V. 6 ; scales $40-17$. Body moderately slender; caudal peduncle strongly compressed; head short; upper profile slightly arched, somewhat depressed at occiput; ventral outline more convex; bases of anal and dorsal quite oblique. Dorsal rounded, longest ray 1\% in head; anal somewhat smaller. Outer teeth slender, movable, broadened toward front of jaw which is notched; behind these a band of minute teeth, scarcely distinguishable. Two rows of scales below eye; preorbital, jaws, and narrow border of preopercle scaleless. Pectoral shorter than head, not reaching ventrals, which are nearer snout than base of caudal; origin of dorsal nearer base of caudal than gill opening; anal slightly behind dorsal. Color in alcohol, upper half of body light brown or brownish gray, lighter gray or silvery gray below, fading to yellowish white toward ventral line; a silvery gray band along middle of side, not well defined, its width that of 1 or 2 seales. Lake Pátzcuaro, Mexico. (Steindachner.)

Oharacodon luitpoldii, Steindachner, Einige Fischarten Mexico, 12, pl.2, figs. 3-3b, 1895, Lake Pátzcuaro, Mexico. (Coll. Princess Theresa von Bayern.)

Page 675. Garman refers Cyprinodon elegans to the synonymy of $C$. eximius and $C$. felicianus to that of $C$. viverendi, both of which seem to be correct.

Page 680. Gambusia infans is probably identical with G. gracilis, as indicated by Garman.

Page 681. Garman calls our Gambusia affinis G. patruelis and makes $G$. holbrooki, the northern form, a distinct species, neither of which views seems to be justifiable.

Page 682. Gambusia nobilis and G. nicaraguensis are referred by Garman to the synonymy of $G$. gracilis, which is questionable; but his reference to G. puncticulata of $G$. picturata is probably correct. 
Page 682. After Gambusia affinis add:

1000 (a). GAMBUSLA TRIDENTIGER, Garman.

Head $4 \frac{1}{2}$; depth at anal $4 \frac{1}{2}$; snout short, not as long as eje, narrow, rounded forward, and blunt. D. 7 or 8 ; A. $10 ;$ V. 6 ; P. 12 ; scales 28 to 30-8; vertebra. $14+17$. Mouth medium, directed obliquely upward; lower jaw longer than the upper, which is short, narrow, and protractile. Teeth in the outer series larger, strongly hooked, pointed, broadened somewhat toward the apex; inner series very small, in bands, tricuspid as in Pocilia; pharyngeal with a shoulder. Eye large, longer than snout, 3 in head. Fins small, excepting the caudal; dorsal smaller than anal and farther back, its origin about midway from occiput to end of caudal, nearly above the hindmost anal ray, 17 or 18 scales from the head; anal origin midway between snout and end of caudal; farther forward on the male, between the ventrals, and the fin is modified to form an intromittent organ about $\frac{1}{3}$ length of entire fish; caudal deep, as long as head, rounded on hiuder margin. Scales large, median series on flank as wide as eye. Intestine short. Light olivaceous, yellowish or brownish, with 7 or 8 vertical bars of brownish, separated by light or silvery spaces of equal width, on the sides of the caudal portion, edges of scales darker, the centers or median series more or less silvery; belly and lower surface of head silvery or golden; peritoneum black, showing through abdnominal wall; occiput dark; top of snout light; a dark line between anal and caudal; dorsal with a faint spot or group of puncticulations behind the middle near the base; other fins plain to dark tipped. (Garman.) Isthmus of Panania, in fresh water (tridentiger, bearing trifid teeth).

Gambusia tridentiger, GarMan, Cyprinodonts, Mem. Mus. Comp. Zool., xix, No. 1, 89, pl. 4, fig. 10, 1895, Isthmus of Panama.

Pages 688 and 689. Heterandria versicolor and H. occidentalis are correctly referred by Garman to the genus Pocilia. It is not improbable that $H$. versicolor is the same as Pocilia vivipara, Bloch \& Schneider.

Lebistes is doubtless identical with Pocilia, as is also Acropocilia. Acropocilia tridens is probably identical with Pocilia dominicensis, as stated by Garman.

Page 691. Garman wrongly refers Pocilia butleri to the synonymy of P. sphenops.

Most of the Mexican and Central American species are imperfectly known and imperfectly described. Of these Garman refers the following to the synonymy of $P$. sphenops, whether correctly or not only a study of adequate material can determine: Pocilia mexicana, $P$. thermalis, $P$. petenensis, $P$. dovii, $P$. conchiana, $P$. plumbeus, $P$. fasciatus, and $P$. spilurus.

Pocilia pavonina is referred, perhaps correctly, to the synonymy of $P$. vittata.

Page 696. Garman thinks that Pocilia vandepolli is identical with $P$. reticulata, Peters, which may be described as follows:

1032. Pecilia Reticulata, Peters.

D. 7 or 8 ; A. 8 or 9 ; V. 5 ; scales 26 to $28-8$. Depth of body $\frac{2}{7}$ and length of head nearly $\frac{1}{4}$ of the length to the base of the caudal. Males rather more 
slender. Eye longer than snout, not quite $\frac{1}{8}$ of head, $\frac{3}{5}$ of interorbital space. Forehead flat. Dorsal origin somewhat nearer to end of snout than to end of caudal, opposite first ray of anal on females. Anal of male advanced, between the ventrals, which are elongate; anal process as long as the head, without hooks. Caudal large, rather longer than head, obtusely rounded; free portion of tail somewhat elongate, base of anal being $\frac{1}{3}$ of its distance from the caudal; ventrals reaching anal; pectorals as long as the head, not reaching ventrals. Female yellowish olive, scales with a narrow blackish edge, belly silvery, trunk above the belly blackish. Male with 2 brown streaks along the trunk, sometimes conflu. ent into a band, a brown streak along the middle of the side of the tail, a round black spot behind the shoulder, another at the commencement of the caudal streak, and a third at the root of the caudal; 1 or 2 of thcse spots may be absent. Trinidad; Venezuela (reticulatus, netted).

The male from Venezuela differs in color from those from Trividad. It has large silvery patches between the brown streaks, and a large ovate black spot in the middle of the side of the tail. (Guinther.)

Note.-The following is the original description: "Grüngelblich mit einem schwarzen Netzwerk, dessen Maschen den Rändern der Schuppen parallel liegen, am Bauche silbrig. Schnppen in 7 Längs : und in 27 Querreihen; obwohl einige derselben durchbohrt erscheinen, ist doch keine deutliche Seitenlinie zu sehen. Ganze Länge 39, Höhe 9, Länge des Kopfes 7 Millimeter. D. 8; A. 10. Caracas; in dem Guayre-Flusse von Gollner gesammelt."

Poecilia reticulata, Peters, Monatsb. Berl. Ak. 1859, 412, Caracas; Garman, Cyprinodonts, 63, 1895.

Girardinus guppii, Günther, Cat., vi, 353, 1866, Trinidad; Venezuela; EIGLnmann, Proc. U. S. Nat. Mus. 1891, 65.

Girardinus vandepolli, VAN LINDTh DE JEUDE, Notes from Leyden Museim, IX, 137, 1887, Curaçao, one of the Leeward Islands.

Pocilia vandepolli arubensis, VAN LINDTH DE JEUDE, Notes from Leyden Museum, IX, 137,1887 , Aruba, one of the Leeward Islands.

Pocilia branneri, Eigenmann, Ann. N. Y. Ac. Sci.1894, 629.

Page 697. Garman refers Pocilia elongata, one of the best marked species of large size, and marine in its habitat, to the synonymy of $P$. gillii. This is certainly wrong, as is also the reference to $P$. gillii of $P$. chisoyensis and $P$. boucardi.

$P$. melanogaster is probably correctly referred to $P$. dominicensis.

Page 698. Add:

1037 (a). P(ECILIA CUNEATA, Garman.

B. 5 ; D. 8 to 10 ; A. 10 or 9 ; V. 6 ; P. 15 or 16 ; scales 28 or $29-9$. Short and deep; caudal pedicel deep. Head depressed, broad, flat on the crown, equaling depth between dorsal and anal, or $\frac{1}{4}$ of the length to the base of the caudal; snout as long as the eye, broad, truncate; chin short, steep; mouth wide, directed upward; jaws weak, loosely joined, lower short, upper shorter, protractile; outer series of teeth slender, oar-shaped, hooked, movable; inner in bands, small, pointed; eye large, as long as snout, $\frac{1}{2}$ of interorbital space, $\frac{2}{7}$ of head. Dorsal larger than anal, origin midway from head to base of caudal, over third ray of anal, 13 scales behiud the occiput. Anal small, acute angled, third ray longest; on the 
male the base of the anal is forward of that of the dorsal, the fin is modified to form a sharp-pointed organ in which the rays are less changed than in most species; its length is less than that of the head. Ventrals small, not reaching the anal. Pectorals reaching back over 7 scales. Caudal deep, as long as the head, hind margin rounded. Scales large. Intestine long. Brownish, olive tinted, bases of scales dark, back darker, and top of head darkest; more or less of the hind margin, or $\frac{1}{2}$ of the scale, is whitish to silvery on the scales of the flank; lighter to silvery under head and abdomen; dorsal with 1 to several transverse series of small spots of black; fin sometimes black tipped; a brownish streak extending back and upward on the opercle behind the eye; candal with small spots of black on the basal half, or with a couple of clonded transverse bands; other fins uniform or puncticulate; very small ones are lighter with a faint silvery band along the middle of the flank, but without vertical bars; a large one has numerous small white spots, somewhat like Fundulus heteroclitus. Females $2 \frac{1}{2}$ and males $11_{10}^{9}$ inches. Turbo, Gulf of Darien. Pocilia cuncata, Garman, Cyprinodonts, 62, pl. 5, fig. 3, 1895, Turbo, Gulf of Darien.

Page 704. After Typhlichihys, Girard, add:

a. No scleral cartilages; no pigment in or about the eye; retinal elements readily separable into ganglionic, inner reticular, and nuclear layers, the nuclear and outer reticular layers rarely distiguishable; diameter of eye about .150 $\mathrm{mm}$.

SUBTERRANEUS, 1047.

$a a$. Scleral cartilages large, forming a hood over front of eye; a mass of pigment in front of eye; pigment layer of retina with more or less pigment; eye a mere vestige, about $.040 \mathrm{~mm}$. in diameter.

ROSA, 1047(a).

Page 706. After Typhlichthys subterraneus add:

1047 (a). TYPHICHTHYS ROSE, Eigenmann.

Extremely close to $T$. subterraneus, from which it seems to differ only in the less development of the eye. Scleral cartilages large, forming a hood over the front of the eye; a mass of pigment in front of eye; pigment layer of retina with more or less pigment; eye a mere vestige, $\frac{1}{8}$ the size of that of $T$. subterraneus, about $.040 \mathrm{~mm}$. in diameter. The types of this species are 2 small, thoronghly dissected specimens, in the Museum of Indiana University, collected from a cave in Jasper County, Missonri, by Miss Ruth Hoppin. (Named for Mrs. Rosa Smith Eigenmann.)

Typhluchthys rosce, Eraenmann, Science, N. S., vol. vir, No. 164, 227, February 18, 1898, cave near Sarcoxie, Jasper County, Missouri.

Page 723. Hemiramphus balao is a valid species as defined.

\section{Page 729 :}

Exocctus volitans, Linnæus, as Lönnberg has shown, is identical with $E$. evolans L. As the genus Exocotus, Syst. Nat., Ed, x, 316, is based solely on Exococtus volitans, the name Exocotus must go with this species, taking the place of Halocypselus. The ordinary flying fishes must therefore be called Cypsilurus. The species with long anal fin may, however, be held as generically distinct from the type of Cypsilurus, and for them (exsiliens, rondeletii, etc.) the name Exonautes has been proposed by Jordan \& Evermann, Check List, 322. (Type, exsiliens.) ( $\varepsilon^{\prime} \xi o$, out of; $v \alpha v \tau \eta \dot{v}$, swimmer.) 
Our species of Exonautes are the following:

1080. EXONAUTES EXSILIEXS (Miiller).

1081. EXONAUTLS RONDELETII (Cuvier \& Valenciennes).

1082. EXONAUTES VINCIGUERRE (Jordan \& Meek).

1083. EXOXAUTES SPECULIGER (Cuvier \& Valenciennes).

1084. EXONAUTES RUFIPINNIS (Cuvier \& Valenciennes).

To these should be added the following :

1084(a). EXONAUTES AFFINIS (Günther).

Head 4 ; depth 6 ; eye $3 \frac{1}{2}$; snout $3 \frac{1}{2}$. D. 11 to 13 ; A. 11 to 13 ; scales $6-50$ to 52,35 before dorsal. Interorbital space flat, slightly greater than eye. Pectoral fin extending scarcely beyoud dorsal and anal; base of ventral midway between eye and base of caudal, its rays reaching beyond middle of base of anal; dorsal opposite anal, its anterior rays $2 \frac{1}{2}$ in head. Pectoral with an oblique white blotch across its lower half, and with a narrow whitish margin; ventrals grayish. Cuba? Atlantic; West Africa. (Guinther.) Probably distinct from E. speculiger.

Fxocotus affinis, GunTHER, Cat., vI, 288, 1866, Cuba ?

The species of Cypsilurus are the following:

1085. CYPSILURUS HETERURUS (Rafinesque).

1086. CYPSILURUS LUTKENI (Jordan \& Evermann).

1087. CYPSILURUS FURCATUS (Mitchill).

1088. CYPSILURUS NigRICANS (Bennett).

1089. CY PSILURUS XENOPTERUS (Gilbert).

1090. CYPSILURUS LINEATUS (Cuvier \& Valenciennes).

Under this species (p. 739) for Corea (in 3 places) read Gorea.

1091. CYPSILURUS CYANOPTERUS (Cuvier \& Valenciennes).

This is a good species. The specimens recorded from James Island belong to C. bahiensis.

1092. CYPSILURUS BAHIENSIS (Ranzani).

1093. CYPSILURUS CALIFORICUS (Cooper).

1094. CYPSILURUS CALLOPTERUS (Günther).

1095. CYPSILURUS GIBBIFROXS (Cuvier \& Valenciennes).

Page 732. In the key, for " $j j$ " read " $h h$," for " $j i j$ " read " $h h h$," for " $k k$ " read " $i i$," for " $i i$ " read " $g g$," and for " $h h$ " read " $f f . "$

Page 746. According to the studies of Mr. Rutter and Dr. (xilbert all the forms of Gasterosteus should probably be reduced to a single species (Gasterosteus aculeatus), having 3 or 4 geographic varieties, each running into a number of forms which differ in the degree of armature of the body.

Page 749. After Gasterosteus bispinosus cuvieri, insert:

1100 (a). GASTEROSTEUS GLADIUNCULUS, Kendall.

Head $3 \frac{1}{3}$; depth $3 \frac{4}{5}$; D. II-I, 10; A. I, 8. Head rather long; eye about 3 times in bead; opercle not striate; body deep, conpressed, with 5 lateral 
dermal plates anteriorly counting from pectoral fin, none posteriorly; caudal peduncle short, naked, not keeled; innominate bone lanceolate, its width about 3 times in length; ventral spines rather long, about $1 \frac{3}{0}$ times in head, serrated above and below, a strong cusp at base on both upper and lower edge. Color in life, grass green, mottled and finely punctated with black on top of head and back; sides of head and body golden, with lark blotches; breast silvery, ventrals scarlet. In alcohol the back becomes smoky black, the mottling and black dots more distinct, the golden hue of the sides fades, becoming more or less silvery, the dark blotches more pronounced. Coast of Maine and Woods Hole, Massachusetts. (gladiunculus, little sword; sticklebacks being called by the boys about Portland, Maine, "Little swordfish.")

Gasterosteus gladiunculus, Kendall, Proc. U. S. Nat. Mus. 1895, 623, off Seguin Island,

Maine. (Type, No.47589. Coll. Grampus.)

Page 754. Aulostomus maculatus is pinkish-red in life.

Page 757. Fistularia tabacaria has been recorded by Storer from Holmes Hole, Massachusetts, and H. M. Smith records it from Buzzards Bay, near Quisset, and from about Woods Hole.

Page 762. In the key to species of Siphostoma read:

eee. Dorsal covering 4 or 5 caudal (not body) rings.

o. Rings 16 to $18+29$ to 33 .

$q$. Kings $16+30$ to 33 ; dorsal 30 to 34 , on $3+5$ rings.

Page 767. It is doubtful if Siphostoma pelagicum occurs in America. $S$. rousseaui has probably been sometimes mistaken for it.

Page 768. After Siphostoma jonesi add:

1124(a). SIPHOSTOMA ROBERTSI, Jordan \& Rutter.

Head $7 \frac{1}{2}$ in length; depth $2 \frac{4}{5}$ in head; eye $5 \frac{2}{8}$ in head. Dorsal 20, on $0+4$ rings; segments $17+32$. Snout $2 \frac{1}{5}$ in head, with a slight keel; a slight keel on top of head, another above opercle, and 1 on anterior side of opercle, but not reaching posterior edge; shields without spines; lateral keel ending on last body segment; ventral keel on next to last; upper body keel extending nearly to end of dorsal fin, upper caudal beginning below it on first caudal segment; all ridges of body very prominent, the tail with 4 plain ridges; caudal pouch 3 in total length. Color mottled brown, paler below, the membrane connecting the segments pale bluish, forming cross stripes which are especially marked on the egg pouch; prominent pale cross bars on lower side of head; dorsal colorless, except that the base is finely dusted with brown; caudal thickly dusted with brown, except near base. This species is most closely related to Siphostoma jonesi, differing $1 \mathrm{n}$ having a shorter dorsal with more rays, and in the lateral keel ending distinct from lower caudal keel. Jamaica; 1 specimen, $4 \frac{1}{2}$ inches long, known. (Named for Rev. Joseph Seed Roberts, who collected the type.)

Siphostoma robertsi, JoRdan \& Rutter, Proc. Ac. Nat. Sci. Phila. 1897, 97, Kingston, Jamaica. ('Type, No. 4988, L. S. Jr. Univ. Mus.) 
1124(b). SIPHOSTOMA STARKSII, Jorlan \& Culver.

Head $10 \frac{1}{2}$; depth 21 . Dorsal 38 , on $0+10$ or 11 rings. Rings 13 or $14+37$ or 38. Head and body in tail 2. Snout $2 \frac{3}{5}$ in head. Dorsal $\frac{1}{2}$ longer than head. Body rather stont. Head scarcely carinate above. Snout with a slight smooth carina. Two lateral keels, confluent into 1 behind. Belly slightly keeled; no keel on opercle. Color dark olive, much mottled with darker but without distinct markings; yellow below. Male and female common in the fresh waters of Rio Presidio at Mazatlan, among alga ; not seen in salt or brackish water. The pouch of the male teeming with eggs in January. Length 4 to 6 inches. Mazatlan, Mexico. Common in the Rio Presidio in sluggish water, on the bottom, about a mile below the village of Presidio. The species is probably found in brackish and fresh waters rather than in the sea.

Siphostoma starksii, Jordan \& Culver, Fishes Sinaloa, in Proc. Cal. Ac. Sci. 1895, 416, pl.30, Rio Presidio, Mazatlan. (Type, No. 2686, L. S. Jr. Univ. Mus. Coll. Hopkins Exped. to Mazatlan.)

1124(c). SIPHOSTOMA SINALOE, Jordan \& Starks, new species.

Allied to Siphostoma arctum Jenkins \& Evermann.

Head $8 \frac{1}{2}$ in length to base of caudal; depth $3 \frac{1}{2}$ in head. Dorsal 26, on $1 \frac{1}{2}+$ 5 rings, $14+35$. Snout $1 \frac{1}{4}$ in head, a strong median ridge above running to between middle of eyes, a ridge ou each side from angle of mouth to below eye, occipital and nuchal plates keeled, a slight keel on anterior part of opercle; dorsal keels ceasing in front of the last 4 or 5 rays of dorsal, the lateral ridge running up and continuing as dorsal ridges; belly with a keel on each side. Preanal part of belly $1 \frac{8}{4}$ in postanal part; pectoral shorter than eye, caudal 3 in head. Color olive brown above, abruptly lighter below lateral ridges anteriorly, the edges of the plates dark, forming reticulations on lower parts of body; between every 4 rings is a narrow white cross bar; from each eye is a warrow light bar running upward and backward to occiput; caudal dark. The 2 type specimens, 1 of which was sent to the British Museum, collected by the Hopkins Expedition at Mazatlan. They were erroneously referred to siphostoma arctum in our paper on the Fishes of Sinaloa. Type, No. 2945, L. S. Jr. Univ. Museum.

Page 772. Corythroichthy8, Kaup, should apparently be recognized as a genus distinct from Siphostoma. The species belonging in it are the following:

1134. CORYTHROICHTHYS ALBIROSTRIS, Heckel.

1135. CORYTHROICHTHYS CAYANNENSIS (Sauvage).

1135(a). CORYTHROICHTIYS CAYORUM, Evermann \& Kendall.

Head $8 \frac{3}{5}$; depth $12 \frac{3}{5}$; snout $3 \frac{1}{5}$ in head; eye $4 \frac{1}{8}$. D. 21 rays, on $1 \frac{1}{2}+3 \frac{1}{2}$ rings; A. 3, on first caudal ring; C. $10 ;$ P. 10 . Rings $17+26=43$. Body short and stout; head short, snout very short; tail but little longer thau head and trunk. Cranial ridges strong; a high, sharp keel on snout, the occipital keel very high, its edge convex, notched near the middle, not 
continuous with keel on snont; a strong supraocular ridge, beginning opposite posterior end of nasal keol and contiuuing backward with 1 hiatus upon upper edge of opercle; just below this on the opercle another longer but scarcely stronger ridge; another short ridge on anterior part of opercle at level of lower part of eye; opercles very convex, as if swollen outward; keels on body and tail all strong; the 2 lateral keels on body terminating on third caudal ring; the 2 lateral keels on tail beginning on the last body ring, thus overlapping the body keels; median keel on side well developed, terninating on sixteenth body ring; ventral keels strong; abdominal keel very strong. Egg sac on first 18 caudal rings. Color yellowish brown, with darker punctulations; tip of snout white; cheek, throat, and under parts of snout white, crossed by about 7 or 8 irregular brownish bars extending downward and backward; opercles brown; fins pale. This species is related to $C$. albirostris of Heckel, differing from it chiefly in the shorter snout, smaller dorsal, and fewer rings. Key West, Florida. (cayorum, of the Keys; from Cayo Hueso, Bone Key, the original Spanish name of the island of Key West.)

Corythoichthys cayorum, Evermann \& Kendal, Bull. U.S. Fish Comm. 1897 (Feb. 9, 1898), 128, pl. 7, fig. 7, near Crawfish Bar, Key West, Florida. (Type, a male $3 \frac{1}{2}$ inches long, No. 48784. Coll. Drs. Evermann \& Kendall.)

Page 774. Syngnathus aquoreus is doubtfully American. Until a comparison of specimens can be made our species may stand as-

\section{SYNGNATHUS HECKELI (Kanp).}

Page 792. Lethostole, Jordan \& Evermann, is identical with Chirostoma, and the definition assigned is that of Chirostoma.

To the synonymy of Chirostoma estor add:

Atherinichthys albus, Steindachner, Anzeiger der Kais. Akad. Wiss. Wien, 1894, 148, Lake Pátzcuaro, Mexico. (Coll. Princess Therese von Bayern.)

Page 793. In Chirostoma humboldtianum the scales are serrulate. After this species insert the following:

\section{5 (a). CHIROSTOMA GRANDOCULE (Steindachner).}

Head 4; depth $5 \frac{3}{5}$; eye $3 \frac{2}{5}$ in head; interorbital width $4 \frac{1}{8}$; pectoral fin $1 \frac{1}{2}$; ventral $2 \frac{1}{4}$; caudal $1 \frac{1}{6}$; anal base $1 \frac{1}{4}$, its greatest height $1 \frac{2}{3}$. D. V-I, 10; A. I, 20 ; P. 15 or 16 ; scales 60 to $62-15$ or 16 . Upper profile of head merging gradually into that of back, rising slightly toward beginning of second dorsal. Lower jaw slightly projecting; posterior end of upper jaw reaching eye. Teeth on maxillary sharp, brush-like, in 3 or 4 rows, the inner teeth of the maxillary and the outer teeth of lower jaw somewhat enlarged and close set. Cheek narrower than in C. humboldtianum and C. estor, and with 4 rows of scales. Origin of first dorsal midway between anterior border of eye and base of caudal, the second dorsal $\frac{1}{2}$ diameter of eye nearer base of caudal than hinder border of eye; greatest height of second dorsal scarcely greater than base of fin. Longest anal ray about $1 \frac{1}{5}$ in base of fin ; dorsal and anal concave on free border; origin of anal nearly an eye's diameter in front of that of second dorsal; caudal deeply incised, the mid- 
dle rays about 2 in the longest; caudal peduncle more than $4 \frac{3}{5}$ in body, its least depth somewhat more than 2 in greatest depth of body. Scales slightly ctenoid. Side with a broad, sharply defined silvery-gray band. Body much more slender, snout shorter, and eye larger than in C. humboldtianum or $C$. estor. Length 5 inches. Lake Pátzcuaro, Mexico.

Atherinichthys grandoculis, SteIndachner, Anzeiger der Kais. Akad.d. Wissensch. Wien. 1894, 149, Lake Pátzcuaro, Mexico. (Coll. Princess Therese von Bayern.)

\section{4(a). ESLOPSARUM, Jordan \& Evermann.}

Eslopsarum, JoRdan \& Evermann, Check-List Fishes, 330, 1896 (jordani).

This genus is close to Chirostoma, from which it differs in the large entire scales. To it belong the 2 following species:

1156. ESLOPSARUM BARTONI (Jordan \& Evermann).

1157. ESLOPSARUM JORDANI (Woolman).

To the symonymy of this species should be added

Atherinichthys brevis, SteindaChNer, Anzeiger der Kais. Akad. d. Wissensch. Wien. 1894, 149, Lake Cuitzeo, Mexico. (Coll. Prinzessin Therese von Bayern.)

Page 793. In Eslopsarum jordani the anal is I, 16, not I, 6.

Page 795. Kirtlandia laciniata has been found to intergrade with $K$. vagrans and should stand as-

1158a. KIRTLANDIA VAGRANS LACINiATA (Swain).

Page 796. Under $d$ in the key read:

d. Snout about equal to eye, which is 3 to $3 \frac{1}{2}$ in head.

Page 800. An examination of numerous specimens of Menidia from various places between Florida and Halifax shows that $M$. notata and $M$. menidia intergrade perfectly. The first will therefore stand as-

1167a. MENIDIA MENIDIA NOTATA (Mitchill).

Page 801. Menidia guatemalensis and Menidia pachylepis belong in the genus Thyrina, Jordan \& Culver.

Page 819. Agonostomus nasutus has the anal usually II, 10, sometimes II, 9.

Page 821. Add the following:

In the Transactious of the Jamaica Society of Arts for 1855, Mr. Richard Hill gives a paper on "Fishes of the Jamaica Shores and Rivers" which has been overlooked by subsequent writers. The list is chiefly a nominal one, but it contains a number of vernacular names not elsewhere given. The only new species are given under the head of Labrax (page 142) and Mugil (page 143), and these are named rather than described. They are the following:

There is another Labrax, common enough in the Kingston market when the rains send strong freshets from the river into the harbor. The fishermen call it the river chub, and confound it with the mucronatus. It is a different species; it is marked with 
batis like the Perca fluviatilis of Europe, and the Perca granulata of America. We will eail it the Labrax pluvialis, rainy weather clubb.

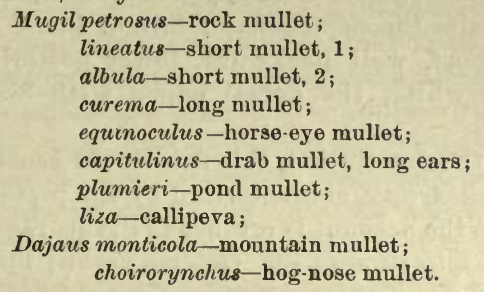

The Dajaus monticola inhabits only the mountain streams; the choirorynchus or hog. nose mullet is a fish of double the size of the monticola, and found in the same waters. The mugil liza is the largest of the mullets, from 20 inches to 3 feet long; the callipeva is the name by which it is exclusively known. This is, no doubt, its Indian name. The equinoculus and capitulinus, known in the market as long mullets, are readily distinguishable from each other by the size of the head, and especially by the size of the eye: the horse-eye mullet has the large eye, the capitulinus unusually small. The plumieri, Plumier's mullet of Cuvier \& Valenciennes, is a long mullet; and the lineatus and albula what the market people distinguish as short mullets. The callipeva is a river mullet seldom extending further than the embouchure of streams, or into the ponds and marshes. The curema is a large mullet found on the sea banks; it is the most highly colored of all the mullets, the back is a golden green and it has scales on the second dorsal fin.

Dajaus choirorynchus is identical with Agonostomus nasutus, but the scanty description hardly justifies the substitution of this name for the later one. The other new species we fail to identify. Labrax pluvialis we do not recognize.

Page 823. The great Barracuda should stand as-

1199. SPHYRENA BARRACUDA (Walbaum),

To its synonymy add :

Esox barracuda, Walbaum, Artedi Piscium, III, 94, 1792; after Catesby.

Page 827. The ventrals in the Polynemida are truly thoracic, the long pubic bone being attached to the shoulder girdle. This family is probably nearest allied to the Scianida.

Page 833. After Ammodytes personatus add:

372(a). RHYNCHIAS, Gill, new genus.

Rhynchias, GILL, MS., new genus (septipinnis).

This generic name is provisionally given to a species known only from a description of Pallas, and supposed to differ from Ammodytes in tho presence of ventral fins. It may prove to belong to some different family. ( $\rho \ddot{v} \gamma \chi 05$, snout.)

\section{4(a). RHYNCHIAS SEPTIPINNIS (Pallas).}

This spscies has not been recognized by any recent collector, and it is not certain to what family it belongs. The following is the substance of Pallas's description:

D. 43 ; A. 24 ; V. 8 ; P. 16 ; C. 24 . Form of Ammodytes tobianus. Head $3030-101$ 
compressed; snout long, slender, depressed. Maxillary with fine teeth; rictus long. Branchiostegals 4. Body compressed, slender, with transverse streaks. Scales inconspicuous; 1 lateral line. Pectoral large, unarmed. Dorsal short, well backward, lower posteriorly; caudal sub. bifurcate. Color white, the dorsal edged with darker. Kamchatka. (Pallas.)

If we can trust the description, this fish would seem to represent a distinct genus of Immodytida, characterized by the presence of ventral fins, but it may be that the account is erroneous in this regard and that Pallas had in mind Ammodytes personatus. (septem, seven; pinna, fin.)

Ammodytes septipinnis, Pallas, Rosso-Asiat., III, 1811, Kamchatka.

Page 833. Ammodytes alascanus is not separable from A. personatus.

Page 839. Caulolepis longidens occurs also in the Pacific, specimens having been collected by the Albatross at Cortez Banks, off San Diego, California, in 1896.

Page 847. Aảd:

1230(a). MYRIPRISTIS CLARIONENSIS, Gilbert.

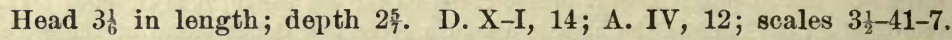
Least depth of caudal peduncle $\frac{1}{2}$ length of snout and eye. Greatest (oblique) diameter of eye $2 \frac{1}{2}$ in head. Least interorbital width equaling length of snout, $4 \frac{1}{2}$ in head. Mouth less oblique than in related species, the line of upper jaw with a more pronounced double curve. Lower jaw the longer, with well-developed symphyseal knob. Teeth finely villiform, very slightly enlarged toward middle of both jaws; wide patches of similar teeth on head of vomer and on palatine bones. Length of maxillary (measured from front of upper jaw) very slightly (about $\frac{1}{20}$ ) less thau length of snout and eye. Color before immersion in spirits, reddish, the upper parts dusky, especially on top of head and on the margins of the scales; evident horizontal dusky streaks between the rows of scales; opercular membrane blackish ; fins all light, without dark markings. Differing from all known American species of Myripristis in having $3 \frac{1}{2}$ series of scales between the lateral line and the base of the spinous dorsal, instead of $2 \frac{1}{2}$. Length $6 \frac{1}{4}$ inches. Revillagigedo Islands; only the type known. Myripristis clarionensis, Gilbert, Proc. U. S. Nat. Mus. 1896, 441, pl. 69, Clarion Island, Revillagigedo Archipelago. (Type, No. 47746. Coll. Dr. Gilbert.)

Page 852. Insert the following description by Jordan \& Rutter of Holocentrus marianus, based upon a specimen 6 inches long from Jamaica:

Head $2 \frac{3}{5}$; depth 3 in length; eye $2 \frac{1}{2}$ in head. D. XI, 13; A. IV, 9; scales 4-45-7. Dorsal outline much more curved than ventral; month low, but little oblique, the lower jaw projectiug and entering upper profile; maxillary to below middle of eye; eje large, lower margin of orbit cut by a line connecting tip of snout and upper base of pectoral; angle of opercle high, higher than top of pupil, with 3 sharp teeth, small teeth along the margin next the subopercle; subopercle long and narrow, dentate near upper end; preopercle very finely serrate, with a strong spine at augle; a single row of scales on opercle along margin of preopercle; suborbital 
bones very narrow, finely serrate; premaxillary groove on top of head as long as eye; length of pectoral equals hearl behind middle of eye; spinous dorsal depressible into a groove, highest (anterior) rays of soft dorsal equal to ventrals, longer than soft rays of anal; third anal spine very long aud lieavy, as long as pectorals; caudal forked almost to base, the lobes equal, as loug as pectorals. Each row of seales with a red band, yellow lines between the rows; fins all yellowish. This is a strongly marked species, very different from Holocentrus ascensionis, perhaps the type of a distinct genus, characterized by the large mouth and projecting chin.

Page 856. Dr. Bean reports the Red Mullet or Goat Fish (Mullus auratus) as being plentiful at Sandy Hook in September and October.

Page 857. The nominal genus Mulloides can not bo separated from Upeneus.

Page 866. In Scomber colias read: Head about 3 ; depth $4 \frac{3}{5}$; first dorsal longer than high.

Page 873. 'To the synonymy of Scomberomorus add:

Polipturus, RAFInesque, Anal. de la Nature 1815, 84; substitute for Scomberomorus.

Page 874. In line 12 of description of Scomberomorus maculatus, for "side" read "part."

Page 878. Bipinnula, Jordan \& Evermann, is a synonym of Escolar, Jordan and Evermann, in Goode and Bean, Oceanic Ichthyology, 519, 1896. The error resulted from Goode \& Bean taking our original MS. name Escolar, for which we afterwards substituted Bipinnula.

This genus and its species will therefore stand as follows:

396. ESCOLAR, Jordan \& Evermann.

Escolar, Jordan \& Evermann, in Goode \& Bean, Oceanic Ichthyology, 519, Aug. 23, 1896 (violaceus).

Bipinnula, Jordan \& EvermanN, Fishes North and Middle Amer., 878, Oct. 3, 1896 (violaceus).

\section{HSCOLAR VIOLACEUS (Bean).}

Page 886. Instead of Lepidopus caudatus, which is not yet known to occur in American waters, insert:

1276. LEPIDOPUS XANTUSI, Goode \& Bean.

Head $4 \frac{2}{3}$ in body; depth 3 in head; eye $5 \frac{1}{3}$; interorbital space $8 \frac{1}{3}$; snout 3 ; maxillary $3 \frac{1}{8}$. D. 82 ; A. II, 45. Jaws with long, sharp teeth in front, followed by single rows of weaker ones, arranged in groups of twos and threes. Height of dorsal, near middle of body, 3 in head. Anal preceded by 2 scutes, the first minute, the second wide, strongly keeled, its length s the diameter of eye. Pectorals of 12 rays, length 2 in head. Each ventral consists of a flat keeled spine followed by a minute ray. This species is known from 2 small mutilated specimens, both found on the beach near San Jose del Cabo, Cape San Lucas. The type was taken by John Xantus, about 1860, and recorded by Jordan \& Gilbert as Lepidopus caudatus. The second, of about the same size ( $5 \frac{1}{2}$ inches), was taken by 
Richard C. McGregor, in 1897. From the latter the above account was taken. The species differs from Lepidopus caudatus in the much shorter dorsal and longer anal. D. 103; A. 24. (Named for John Xantus de Vesey.)

Lepidopus caudatus, Jordan \& Gilbert, Proc. U. S. Nat. Mus. 1882, 358; not of Euphrasen. Lepidopus xantusi, GoodE \& BEAN, Ocean. Ichth., 519, 1896; same type; no description.

Page 889. Trichiurus lepturus is recorded by Storer from Buzzards Bay (1840) and Wellfleet, Massachusetts (1845), and H. M. Smith records it from Woods Hole (1897).

Page 892. The synonymy at top of page under Tetrapturus imperator belongs to the footnote on same page.

Page 899. Add:

1286(a). OLIGOPLITES MUNDUS, Jordan \& Starks, new species.

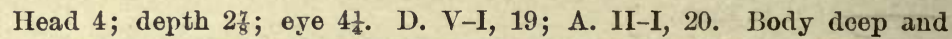
compressed. Length of head about $\frac{1}{6}$ greater than its depth at nape; eye equal to snout and to interorbital; maxillary extending considerably beyond vertical from hinder margin of eye, its length $1 \frac{2}{5}$ in head; second suborbital not over $\frac{1}{2}$ as wide as lowest, and much shorter, thus forming a prominent notch in posterior margin of suborbital bones; a slight emargination in opercle in front of pectoral. Teeth small, sharp, in a band in each jaw, narrow in upper. Origin of soft dorsal midway between snout and base of eaudal, the anal opposite; the anterior rays of both somewhat produced; second soft ray of each equal to head behind pupil, and equal to pectoral; ventrals equal to $\frac{8}{4}$ of pectorals, their inner margins fastened to body; caudal deeply forked, the middle rays $3 \frac{1}{3}$ in longest, which are longer than head. Lateral line nearly straight, but forming a broad angle above pectoral. Color silvery on sides, becoming darker above; fins colorless. This species differs from Oligoplites altus in the much larger mouth and in having the suborbital bones notched posteriorly. Oligoplites saliens of the West Indies seems to be more elongate in body and with the suborbitals even behind as in $O$. altus. Pacific coast of tropical America.

This description is based on a specimen 11 inches long from San Juan Lagoon, Mexico, at the mouth of Ahome River, collected by the Albatross. Three other specimens from Algodones Lagoon, Mexico (Albatross Coll.), agree in every respect, except that 1 of them has but 4 free spines in front of dorsal.

Numerous other specimens have been since bronght by Dr. Gilbert from Panama.

Oligophites mundus, Jordan \& Starks, in Jordan \& Evermann, Check-List Fishes, 344. 1896, Mazatlan, Mexico; name only.

Page 909. The Californian species Trachurus symmetricus is probably a species distinct from $T$. picturatus, described from Madeira. The two forms have never been properly compared.

Page 912. The identity of Hemicaranx amblyrhynchus with Caranx falcatus, Holbrook, needs proof. The latter species, if distinct, may be described as follows: 
1305(a). HEMICARANX FALCATUS (Holbrook).

Head 6 in total length; depth about 3. D. VII-I, 28; A. II-I, 25; C. 19 ; V.5; P. 16; lateral line with 50 plates. Body oval, compressed; the head short, the facial outline descending in a gentle curve to snont, which is rounded though narrow. Eye large, in the middle third of the head, the posterior margin rather nearer suout than posterior margin of opercle; nostrils close together, nearly midway between eye and snout, and on a line within the orbit, the posterior larger, subround, the anterior ovoidal. Mouth small; each jaw with a single row of slender, conical teeth; a small patch of minute teeth on the vomer, and a small, narrow group of similar teeth on the palatines; tongue small, narrow, a few minute teeth near its base; pharyngeal bones armed with numerous card-like teeth, longer than those of the jaws. Soft dorsal long and low, the first 3 or 4 rays moderately elevated, the fin scaled at base; pectoral falcate, very long, extending to anterior third of soft dorsal; ventral small, very short, reaching beyond vent; anal shaped like the soft dorsal; caudal very long and widely forked, the upper lobe more than $\frac{1}{3}$ longer than the lower. Lateral line at first almost semicircular; at origin of soft dorsal descending to median plane, then straight; plates beginning with the soft dorsal increasing in size to the thirty-fifth, whence they decrease rapidly; scales minute, those of lateral line elongated quadrilateral, with 1 angle prolonged and rounded. Color, upper part of head and body above lateral line pale brown with slight bluish tint; lower jaw, opercle, and side yellowish; belly silvery, with a slight golden tint; anterior dorsal transparent; posterior transparent but with a yellowish tint; caudal yellowish. Known certainly only from Charleston, South Carolina.

Caranx falcatus, HоLввоок, Ichth. South Carolina, 92, pl. 13, fig. 2, Charleston, South Carolina.

Page 914. Add:

1306(a). HEMICARANX ZELOTES, Gilbert, new species.

Head 4 to $4 \frac{1}{5}$; depth 22 to $2 \frac{3}{5}$. D. VII-I, 26 to 29 ; A. II-I, 23 to 25 ; P. 20 to 22 ; scutes about 52 . Body regularly elliptical, its greatest depth about in middle of its length, exclusive of caudal peduncle. Head small; anterior profile more decurved, and hence the snout is blunter than in $H$. atrimanus; depth of head just behind eye about $\frac{5}{6}$ its length. Jaws subequal, tip of lower slightly projecting; maxillary narrow, not quite reaching anterior

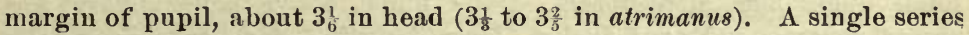
of small, elose-set, subequal teeth in eaeh jaw; no teeth on vomer, palatines, or tongue. Orbit considerably greater than snout, $3 \frac{1}{3}$ to $3 \frac{4}{7}$ in head. Interorbital width (taken at anterior margin of orbit) slightly less than orbit. Occiput with an evident carina. Distance from snout to first dorsal spine greater than length of pectoral. Spinous dorsal very low, the highest spine considerably less than orbit (greater than orbit in atrimanus); a well-developed antrorse spine before the dorsal; soft dorsal and anal similar, not falcate, the rays decreasing in size from the first; highest ray of soft dorsal 2 to $2 \frac{1}{2}$ in head ; highest ray of anal about $2 \frac{1}{8}$ in head; dorsal and anal depressible into a high sheath of scales, the last 3 or 4 rays 
uncovered; caudal fin wide, well forked, the upper lobe the longer, the longest ray not quite $\frac{1}{4}$ total length of body; pectoral fin long, $3 \frac{1}{8}$ to $3 \frac{1}{2}$ in

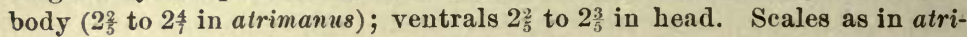
manus; lateral line with a very strong curve anteriorly, the height of the curve $2 \frac{2}{8}$ to $3 \frac{1}{8}$ in its length; its length $2 \frac{1}{8}$ to $2 \frac{1}{4}$ in the straight portion; entire length of straight portion with scutes, which are very small in front and behind; scutes considerably wider and lower than in atrimanus, the widest about $\frac{1}{2}$ liameter of orbit (about $\frac{1}{3}$ diameter of orbit in atrimanus). Coloration much as in $H$. atrimanus, but darker, and the fins without yellow; blackish olive above, dusky silvery below; top of head and snout black; spinous dorsal and the broad margins of soft dorsal and anal black; candal dark, margined with black; pectorals very dark, black inside, the extreme lower rays light; a large jet-black blotch at base, on each side of pectorals, extending for about $\frac{1}{5}$ the whole length of the fin; axil black. Closely related to Hemicaranx atrimanus. Like it, it has a large jet-black area at axil and base of pectoral, and differs from it in the following characters: In having a sborter pectoral, shorter ventrals, profile of snout more rounded, a lower spinous dorsal, a shorter maxillary, a higher, shorter curve.in lateral line, wider scutes, which are less sharply carinated, and darker fins. Panama. ( $\zeta \varepsilon \lambda \circ \tau \eta \dot{\zeta}$, an imitator.)

Page 921. Caranx crysos and Caranx pisquetus are probably distinct speeies, the former ranging from New York to Florida, the latter from the West Indies to Brazil.

In Caranx pisquetus the pectoral fins are very long, as in the Pacific species Caranx caballus, from which we can not separate it. The species need further study.

Page 934. After Vomer setipinnis add:

1329(a). VOMER SPIXII (Swainson).

Head $2 \frac{7}{8}$; depth $1 \frac{3}{5} ;$ D. VI-I, 22; A. I, 18; eye $3 \frac{2}{8}$ in head; maxillary $2 \frac{1}{3}$;

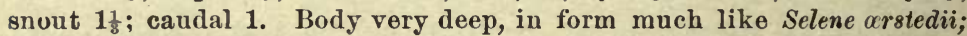
profile very steep, almost vertical; snout slightly protruding. Mouth oblique, maxillary reaching to the vertical from front of eye; gill rakers 7 to 27 , the longest a little more than $\frac{1}{2}$ eye. Lateral line strongly arched in front, the arch $1 \frac{1}{4}$ the straight part; plates of lateral line little differentiated; pectoral falcate, as long or slightly longer than head; ventrals small, under base of pectorals. Color bluish above, sides silvery, fins except ventrals and anal dusky. Here described from specimens from Jamaica about 10 inches in length. These specimens are evidently different from the Northern Vomer setipinnis (=Vomer browni), the body in specimens of the same length being much deeper. It corresponds to the figur. given by Agassiz of Vomer browni, this figure being the basis of Vomer. spixii of Swainson. Probably all West Indian records of Vomer setipinnis belong to Tomer spixii. (Named for Jean Baptiste Spix, of Munich, naturalist and explorer.)

Platysomus spixii, SwanNson, Class. Fishes, III, 250 and 406, 1839, Brazil; after AgAssiz \& SPIX.

Vomer gabonensis, Guichenot, Ann. Soc. Maine et Loire, 1865, 42, Gaboon. 
- Page 938. To the synonymy of Chloroscombrus chrysurus add:

Seriola cosmopolita, Cuvier, Règne Animal, Ed. 2, vol. II, 1829, Gorea; after Scomber chloris, BLOCH.

Add the following species:

1334(a). CHLOROSCOMBRUS ECTENURUS, Jordan \& Osgood.

Head $3 \frac{7}{8}$; depth $2 \frac{3}{5}$. D. VIII-I, 27; A. II-I, 26. Snout slightly shorter than eye, which is $3 \frac{1}{2}$ in head. Chord of curved part of lateral line $1 \frac{3}{5}$ in straight part. Depth of caudal peduncle 2 in its length, measuring from the base of the last dorsal ray to the base of the first caudal ray. Pectorals long and falcate, 3 in length; ventrals short, $2 \frac{1}{5}$ in head, extending beyond the vent, which is situated in a groove in which these fins fit. Depth of head equal to or slightly less than its length; maxillary reaching anterior edge of eye, 23 in head. Lateral line unarmed; curve of ventral outline very slightly more pronounced than that of the dorsal; dorsal and anal fin sheaths well developed. Tips of upper spines and rays dusky; a black blotch at base of upper rays of caudal, and a black axillary and opercular spot. The species is closely related to Chloroscombrus chrysurvs, the common species of the South Atlantic and Gulf States, which it evidently represents in the West Indies. The species chrysurus is deeper in every way, having a deeper body, a deeper head, and a deeper caudal peduncle. In chrysurus also the eye is larger, the mouth more nearly vertical, and the arch of the lateral line higher. When specimens of equal size from Florida and Havana are compared the characters are very evident. In 2 specimens, each $7 \frac{1}{2}$ inches in length, from Havana and Florida, respectively, the depth of the body of the one is contained $1 \frac{1}{4}$ times in that of the other, the depth of the head $1 \frac{1}{5}$, the depth of the caudal peduncle $1 \frac{1}{5}$, and the length of the eye $1 \frac{1}{\bar{b}}$. The names chrysurus (South Carolina), latus (Carolina), and caribaus (Texas) evidently all belong to the species of the United States coast. The type of chloris came from Acara, in Guinea, and cosmopolita of Cuvier was originally as a mere substitute for chloris. Until the African species can be examined, it is better not to use the name for either of the American forms. Probably Chloroscombrus chloris, when studied, will be found distinct from either. If not, that name would take the place of ectenurus. West Indies; known from Jamaica and Cuba.

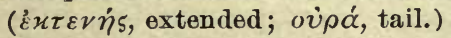

Chloroscombrus ectenurus, JoRdAN \& OsGOoD, Proc. Ac. Nat. Sci. Phila. 1897, 101, Jamaica. (Coll. J.S. Roberts.)

'The validity of Chloroscombrus ectenurus is still doubtful.

Page 942. After Trachinotus falcatus add:

1337 (a). TRACHINOTUS RIIOMBOIDES (Bloch).

Head $3 \frac{1}{6}$; depth $1 \frac{3}{5}$ in length; eye $3 \frac{1}{5}$ in head. D. VI-I, 20; A. II-I 18. Back much elevated, but not angulated at origin of soft dorsal; end of snout not vertical, curved; head slightly concave at occiput. Maxillary to below anterior margin of pupil; eye on level of lower edge of premax1llary and axil of pectoral. Origin of soft dorsal behind tip of pectoral, 
its lobe much elongated, extending to middle of caudal ; lobe of anal reaching to below base of caudal; caudal lobes equal, $2 \frac{1}{3}$ in body; pectoral rounded, $1 \frac{1}{2}$ in head; ventrals $2 \frac{8}{4}$ in head. Scales minute, large posteriorly near lateral line. Pale olive above, becoming silvery on belly; lobes of vertical fins dusky. This West Indian species is apparently different from the northern Trachinotus falcatus with which it has been confounded. Trachinotus falcatus seems to be confined to the coasts of the United States. In specimens of the same size the vertical fins are much higher in the West Indian species. ( $\rho \dot{\alpha} \mu \beta o_{5}$, rhomb; $\varepsilon \tilde{\delta} \delta \omega s$, resemblance.)

Chatorion rhomboides, BLOCH, Ichth., 1787, pl. 209, Martinique.

Page 945. After Trachinotus paloma insert:

\section{8(a). ZALOCYS, Jordan.\& MeGregor.}

Zalocys, Jordan \& MCG Regor, Rept. U. S. Fish Comm. 1898 (stilbe).

This genus is closely allied to Hypodis, Rafinesque (=Lichia, Cuvier), differing in the absence of a procurrent spine before the dorsal, and in the cultrate thoracic region. From Trachinotus it is distinguished by the same characters and also by the lower forehead and nonfalcate dorsal and anal fins. Hypodis is scarcely different from Trachinotus, the only tangible characters being the larger teeth, the low dorsal, and the less elevated forehead. Porthmeus, Cuvier (= Lichia amia and L.vadigo) is a well-defined genus, distinguished by the large mouth and projecting lower jaw. ( $\zeta \alpha \lambda \lambda \eta$, surge of the sea; $\dot{\alpha} x \dot{v} 5$, swift.)

1344(a). ZALOCYS STILBE, Jordan \& McGregor.

Head $4 \frac{1}{5}$; depth $2 \frac{1}{2}$. D. VI-I, 26; A. II-I, 23. Body elliptical, deeper than in Hypodis glaucus; belly sharply compressed; ventral outline similar to that of dorsal; anterior profile of the head elevated and sharp, the eye being rather below than above its middle; eye 5 in head, with conspicu.ous adipose eyelid before and behind; posterior nostril much larger than anterior; vertically oblong maxillary broad, without supplemental bone, extending to pupil, $2 \frac{5}{6}$ in head. Mouth moderate, oblique; each jaw with bands of villiform teeth; similar teeth on vomer, palatines, and tongue. Preopercle very broad; cheek moderate; suborbital narrow; preorbital very narrow, 4 in eye. No pseudobranchix. Gill rakers very long and slender, numerous. No procumbent spine before dorsal; spines low and separate, progressively higher; soft dorsal and anal each with a sheath of scales; first rays of dorsal very slightly elevated, $2 \frac{1}{8}$ in head; anal without distinct anterior lobe, longest ray 28 in head; caudal peduncle long and slender; depth $3 \frac{8}{4}$ in head; length below $2 \frac{1}{8}$ in head; caudal fin widely forked; lobes long and slender, upper a little the longer, more than $\frac{1}{2}$ longer than the head and $2 \frac{2}{5}$ in body; pectoral moderate, $1 \frac{1}{5}$ in head; ventrals very small, $6 \frac{1}{2}$ in head; snout $3 \frac{8}{4}$ in head; premaxillary protractile. Color dark steel blue or blackish above; lower parts soiled white; axil and base of pectoral within jet-black; dorsal and anal each with a narrow whitish edging; candal black, each lobe with a narrow whitish edging within. Body covered with small smooth scales, much as in Trachinotus; 
lateral line undulate, very slightly arched anteriorly. Clarion Island; 1 specimen, 16 inches in length, known. ( $\sigma \tau i \lambda \beta \eta$, shining.)

Zalocys stilbe, Jordan \& MCGregor, Rept. U. S. Fish Comm. 1898, pl. 5, Clarion Island,

Revillagigedo Archipelago. (Type, No. 11996, L. S. Jr. U.M. Coll. R. C. McGregor.)

Page 965. Rhombus, Palometa, and Poronotus should probably stand as distinct genera. The species placed in Rhombus in the text would then stand as follows:

1363. RHOMBUS PARU (Linnæus).

1364. RIOMBUS XANTHURUS (Quoy \& Gaimard).

1365. PALOMETA PALOMETA (Jordan \& Bollman).

1366. Paloneta medi (Peters).

1367. Paloneta Similima (Ajres).

1368. PORONOTUS TRIACANTHUS (Peck).

The identity of the South Atlantic Coast Rhombus alepidotus with the West Indian Rhombus paru is very doubtful.

Page 973. The genus Acrotus, Bean, represents a family distinct from Icosteida.

Family CXXXVI(a). ACROTIDAs.

Two additional specimens of Acrotus willoughbyi have lately come to light-the one from Port Townsend, the other from Monterey.

After Acrotus willoughbyi insert:

\section{Family CXXXVI(b). ZAPRORIDA.}

Body robust, moderately compressed, the back not elevated, the belly not carinate. Body covered with small adherent cycloid scales, which cover the membranes of all the fins except the distal third, as also the gill membranes, lower jaw, cheeks, opercles, and nuchal region. No lateral line; no spinules. Head short, the nape not elevated, the forehead broad and abruptly convex in profile; eye moderate, placed high; preopercle, parietal region, and region about eye with very large open mucous pores. No spines on head; edges of membrane bones of head covered with thick scaly skin. Mouth moderate, terminal, oblique, its cleft mainly anterior; upper jaw protractile, but not movable; maxillary rather narrow, simple; lower jaw very heavy, its thick lip projecting beyoud upper jaw. Teeth alike in both jaws, rather strong, blunt, even, close set, forming a uniform cutting edge; no teeth on vomer, palatines, or tongue, the tongue very thick. Lower pharyngeals narrow, with bluntish teeth, those on the edge larger; upper pharyngeals rather large, with small, blunt, velvety teeth; no distinct tooth-like processes in the œesophagus; pseudobranchiæ present; gill rakers very slender and flexible, rather short; gills 4, a large slit behind the fourth; gill membranes separate, free from the isthmus; opercle adnate to shoulder girdle above its angle; coracoids not largely developed. Pectoral fin long, rounded, attached a little nearer 
ventral than dorsal outline; ventrals wholly wanting. Dorsal fin beginning above gill opening, composed entirely of simple inarticulate rays or spines, these moderately flexible, attached to the membrane to their tips, and all except the first and last of about equal length. Caudal peduncle short and stout, not contracted, the large caudal subtruncate or rounded at tip, and without procurrent rays; vent nearly median. Anal much shorter than dorsal, somewhat higher, and composed of soft rays, subequal in length. Skeleton rather limp and flexible, but much less so than in Icosteus.

445(a). ZAPRORA, Jordan.

Zaprord, JoRdan, Proc. Cal. Ac. Sci. 1896, 202 (silenus).

Characters of the genus included above.

This genus bears some resemblance to Icichthys, but differs in the stout caudal peduncle, absence of ventrals and lateral line, and in the form and structure of the head. Among the genera known to us it seems to come nearest to Icichthys, and it might be placed among the Icosteida were it not for the presence of pharyngeal teeth. ( $\zeta \dot{\alpha}$, an intensive particle; $\pi \rho \dot{s}_{\rho} \alpha$, prow.)

1372(a). ZAPRORA SILENUS, Jordan.

Head $5 \frac{2}{5}$ in length to base of caudal; depth $4 \frac{1}{8}$. D. LVI; A. 27 ; P. 20 to 22 ; C. 22 ; scales about $200-85$. Greatest thickness of body about $\frac{2}{5}$ its depth; length of caudal peduncle $1 \frac{2}{5}$ in its least depth, which is $11^{2}$ in head. Eye $5 \frac{1}{3}$ in head; snout $5 \frac{1}{3}$; interorbital space 3 ; maxillary $2 \frac{3}{4}$, ending under front of pupil; mandible $2 \frac{1}{2}$, its depth $4 \frac{2}{3}$; teeth about $\frac{45}{30}$ on each side; lips, snout, and bones about eye naked; rest of head covered with small scales. Lower jaw with a thick lip, slightly fringed on its edge, and with a mesial frenum; the rounded tip entering the profile when the mouth is closed. Three large pores on each ramus of mandible; behind these 3 others in a line on horizontal limb of preopercle; 3 on vertical limb; 2 close together in frout of eye; 1 near the nostrils, so similar to them that there seem to be 3 nasal openings; 7 on suborbitals; 4 in 2 rows behind eye; 1 above eye, and before upper edge of preopercle; a horizontal row of 5 along temporal region, the last and largest of all in opercular flap above gill opening; 1 at vertex; 1 between vertex and eye, and 2 on each side of nape. Gill rakers $8+20$, the longest $\frac{1}{2}$ eye. No trace of lateral line. Scales small, resembling those of a salmon, covering the membrawes of all the fins on the basal two-thirds. Pectoral as long as head, its base $2 \frac{1}{8}$ in head; longest dorsal spine $1 \frac{5}{6}$; caudal $1 \frac{1}{1} \sigma$; longest anal ray $1 \frac{2}{5}$. Color in spirits uniform dusky, without markings on the body, the belly pale, and the side of the head irregularly blotched with lemon yellow, apparently bright in life, and brightest about the pores of the head. Coast of British Columbia; only the type, 29 inches

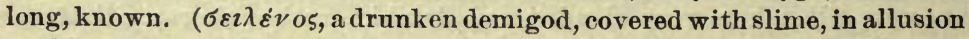
to the open mucous pores.)

Zaprora silenus, Jordan, Proc. Cal. Ac. Sci. 1896, 203, pl. 20, Nanaimo, Vancouver

Island. (Type in Provincial Museum at Victoria. Coll. H T. Stainton.) 
Page 982. Prof. Harrison Garman records Elassoma zonatum from Waccamaw River, Whitesville, North Carolina, and Little Pedee River, South Carolina. Vertebræ 29 ; scales 34 to 36 ; D. IV, 9 ; A. III, 5.

Page 1019. Under $k k$ read: "gill membranes narrowly or broadly connected."

Page 1047. Before Ulocentra insert:

1436(a). COTTOGASTER CHENEYI, Evermann \& Kendall.

Head 4 ; depth 6 ; eye 4 in head; snout 4 ; maxillary $3 \frac{1}{2}$; interorbital width $5 \frac{1}{2}$. D. XI-12; A. II, 8; scales 7-56-6. Body rather stout, heavy forward, compressed behind; head heavy; mouth moderate, slightly oblique, lower jaw included, maxillary reaching front of pupil; premaxillaries protractile. Cheeks, opercles, breast, and nape entirely naked; scales of body large and strongly ctenoid; lateral line complete, straight; median line of belly naked anteriorly, with ordinary scales posteriorly. Fins large; dorsals separated by a space equal to $\frac{1}{2}$ diameter of eye; origin of spinous dorsal a little nearer origin of soft dorsal than tip of snout, its base about equal to length of head; longest dorsal spine $2 \frac{1}{2}$ in head, the outline of the fin gently and regularly rounded; soft dorsal higher than spinous portion, the second to tenth rays about equal in length, scarcely 2 in head, the first, eleventh, and twelfth rays but slightly shorter than the others; anal moderate, its origin under base of third dorsal ray, the spines slender, the second a little longer than the first, whose length is $3 \frac{8}{4}$ in head; longest anal rays about $2 \frac{1}{5}$ in head; caudal lunate, the lobes more produced and pointed than usual among darters; pectorals long and pointed, the middle rays longest, about $1 \frac{1}{6}$ in head, reaching tips of ventrals; ventrals well separated, not nearly reaching vent, the longest rays $1 \frac{1}{4}$ in head. Color in alcohol, back dark brownish, covered with irregular spots and blotches of darker; side with about 8 or 9 large dark spots lying on the lateral line; belly pale; top of head dark; snout black; lower jaw and throat dark; a broad black line downward from eye to throat; cheek and opereles rusty; spinous dorsal crossed by a median dark line; ventrals blue black; other fins pale, but dnsted with rusty specks. An examination of the 14 cotypes shows some variation in the species. In 2 examples there is a well-developed frenum, rendering the premaxillaries nonprotractile, and in a third specimen the frenum is partially developed; in some individuals the origin of the spinous dorsal is exactly midway between the tip of snout and origin of soft dorsal. The females and immature males are less highly colored than the adult male described above. Length $1 \frac{8}{4}$ to $2 \frac{1}{4}$ inches. This species is most closely related to Cottogaster shumardi, from which it may be readily distinguished by the shorter snout, the naked cheeks and opercles, the smaller soft dorsal, the smaller anal, and the different coloration. Fifteen examples of this interesting darter were obtained July 18, 1894, by Messrs. Evermann \& Bean in the Racket River near Norfolk, St. Lawrence County, Now York. It did not seem to be very common, as only 15 examples resulted from numerons hauls of the collecting seine. (Named for Mr. A. Nelson Cheney, State fish-culturist of New York, in recognition 
of his valuable contributions to our knowledge of the food and game fishes of that State.)

Cottogaster cheneyi, Evermann \& Kendal, Eull. U. S. Fish Comm. 1897 (Feb. 9, 1898), 129, pl. 8, fig. 8, Racket River near Noriolk, New York. (Type, No. 48781. Coll. Evermann \& Bean.)

Page 1049. After Ulocentra gilberti add :

1439(a). ULOCENTRA MEADIE, Jordan \& Evermann, new species.

Head $3 \frac{4}{5}$; depth $4 \frac{8}{4}$; eye $3 \frac{1}{2}$ in head; snout $3 \frac{8}{4}$; interorbital 5. D. XII-12; A. II, 7; scales 7-48-6. Body rather heavy, somewhat fusiform; head large; snout blunt, decurved, profile rising abruptly to interorbital, thence nearly horizontal to origin of dorsal, from which it descends gently in a straight line to caudal peduncle; opereular spine small but sharp; mouth low, horizontal, rather large, the maxillary reaching vertical at front of orbit; premaxillaries protractile; branchiostegal membranes not connected, free from the isthmus; ventral fins close together, the space separating their bases about $\frac{1}{2}$ diameter of orbit; fins all moderate; distance from tip of snont to origin of spinons dorsal 3 in body; spinous and soft dorsals close together, the space separating them about 2 in orbit; longest soft dorsal rays $1 \frac{4}{5}$ in head, about equaling those of anal; the two anal spines of about equal leugth, the first the stouter; pectorals long, longer than head, their tips passing those of ventrals but not reaching vent; ventrals short, $1 \frac{1}{6}$ in head; caudal slightly lunate when expanded. Scales rather large, strongly ctenoid; cheeks and breast naked; opercle scaled above, naked below; nape scaled; lateral line complete, straight; ventral line of body covered with ordinary adherent scales. Color in alcohol, yellowish or olivaceous above and on sides, the back with 6 dark saddle-like blotches, the first just anterior to origin of spinous dorsal, the second under the fifth and sixth spines, the third under the last two spines, the fourth under the sixth and seventh soft rays, the fifth just posterior to the last dorsal ray, and the sixth, which is quite small, upon the caudal peduncle at the base of the caudal fin ; sides blotehed with dark, 6 to 8 larger dark blotches along side just below lateral line, sometimes more or less continuous with the dark dorsal blotches; a dark blotch at base of middle caurlal rays; belly pale; top of head dark; a dark spot at lower posterior angle of eye and a smaller one back of it on upper edge of opercle; a dark band downward from eye; opercle dark; upper lip dark, interrupted by a light line at the symphysis; spinous dorsal pale, with a broad dark band through its lower third; soft dorsal erossed by 3 or 4 irregular lines of dark specks; candal with about 4 broad dark cross bars; other fins pale. Length 2 inches. This species somewhat resembles $U$. gilberti, but differs from it in the larger head, stouter body, larger scales, naked cheeks, larger mouth, and in other respects. Known only from Indian Creek, basin of Powell River, east Tennessee, where 3 examples were collected October 17, 1893. (Named for Mrs. Meadie Hawkins Everinann.)

Ulocentra meadice, Jordan \& Everman, new species, Indian Creek, Cumberland Gap, Tennessee. (Type, No. 48903. Toll. Dr. R. R. Gurley.) 
Page 1051. To the synonymy of Ulocentra simotera add:

Etheostoma duryi, Henshall, Journ. Cin'ti Soc. Nat. Mist., A pril, 1889, 32, small tributary of Tennessee River at Whiteside, Tennessee. (Type in Mus. Cin'ti Soc. Nat. Hist. Coll. Charles Dury.)

Page 1089. To the synonymy of Etheostoma caruleum add :

Etheostoma formosa, Henshald, Journ. Cin'ti Soc. Nat. Hist., April, 1889, 32, small tribu. tary of Tennessee River at Whiteside, Tennessee. (Typo in Mus. Cin'ti Soc. Nat. Hist. Coll. Charles Dury.)

Page 1109. Add:

1501(a). APOGON ATRICAUDUS, Jordan \& MeGregor.

Head $2 \frac{1}{2}$; depth 3. D. VI-I, 9; A. II, 8; scales largely ctenoid; eye $3 \frac{1}{2}$ in head; second dorsal spine stoutest, about 2 in head; gill rakers 17, moderate. Body similar in shape to A. vetrosellus. Jaws reaching to posterior border of eye, $1 \frac{5}{6}$ in head. Pectoral reaching to opposite front of anal, 12 in head. Color rosy, darkened with dusky points; more or less olivaceous above; head and throat verging on orange; first dorsal black; second dorsal rosy; caudal dusky, more or less flushed with rosy, other fins paler; no black spot on head or on base of candal, there being no definite markings anywhere except the dusky red of the tail. West coast of Mexico. Numerous specimens collected at San Benedicto, Socorro, and Clarion islands. Usual length 3 to 4 inches. (ater, black; cauda, tail.)

A pogon atricaudus, JordaN \& MCGregor, Rept. U.S. Fish Comm. 1898, Socorro, Clarion and San Benedicto islands. (Coll. R. C. McGregor.)

Page 1125. Centropomus affinis can not be separated from C.ensiferus.

Page 1148. To the synonymy of Epinephelus add:

Phrynotitan, GilL, Stand. Nat. Hist., III, 255, 1885 (Batrachus gigas).

Page 1150. In the key under $d d$, read : Lower jaw strongly projecting.

Page 1156. Add:

1551(a). KPINEPHELUS NIPIOBLES, Gilbert \& Starks.

Head $2 \frac{2}{5}$ in body; depth $2 \frac{1}{2}$. D. XI, 14 ; A. III, 9; scales 16-116-40; eye 5 in head; maxillary 2 ; third dorsal spine $2 \frac{2}{3}$; middle dorsal rays $2 \frac{1}{8}$; highest anal rays 2 ; third anal spine $3 \frac{1}{10}$; pectoral $1 \frac{5}{6}$; ventrals $1 \frac{8}{4}$; caudal 18. Form rather robust, moderately compressed ; dorsal outline uniformly curved from tip of snout to candal peduncle; mouth large, the maxillary reaching to below posterior orbital rim; lower jaw strongly projecting; teeth conical and sharp, in 1 or 2 bands at sides of jaws, 3 or 4 in front; upper jaw with a rather strong canine on each side of front; snout longer than $ә y \theta$; nostrils close together, the posterior one the larger, a little in front of the vertical from front of eye, the anterior in a short, wide tube with a flap behind; vertical and horizontal limbs of preopercle meeting at right angles, its edge with blunt serræ, those at angle enlarged; opercle with 3 flat spines before the flap; gill rakers moderate, nearly. $\frac{1}{2}$ eye, $8+16$ in number. 'T'op of head, orbitals, maxillary, and mandible, naked; fine scales on checks aud opercles; scales on body ctenoid; 
fins without scales. Dorsal beginning a little in front of the vertical from pectoral base, the third spine a little the highest, but the ones behind it not much shortened; soft dorsal higher than spinous, its outline rounded; pectoral rounded behind, reaching to below the base of eighth dorsal spine; third aual spine the longest, not nearly so long as the soft rays, the anal fin similar in shape to the soft dorsal; ventrals reaching past vent, scarcely to front of anal, their ends rounded, as are all the fins; caudal broadly rounded. Color in spirits brownish red, sides with clearcut, distinct, white spots about as large as pupil, about 6 at base of dorsal, 6 or 7 along lateral line, following its arch, a horizontal series of 4 extending back from opercular flap, about 3 from base of pectoral following curve of ventral outline, 2 at base of anal, 1 behind lower edge of caudal peduncle and 1 above anus; a well-marked streak above maxillary following its outline; lips colored like rest of head; dorsal dusky, with vaguo white spots; ventrals and anal nearly black, with a reddish tinge; anal with a narrow white border below; pectoral and caulal uniform yellowish. Magdalena Bay, Lower California; only the type, 6 inches long. known. ( $\nu \imath \circ \beta \not ́ \zeta$, snowed over, from the white spots.)

Epinephelus niphobles, Gilbert \& StaRks, Proc. U.S. Nat. Mus. 1896, 442, Magdelena

Bay, Lower California. (Type, No. 47582. Coll. Albatross.)

Page 1164. Species 1558 should probably be called Alphestcs chloropterus (Cuvier \& Valenciennes). The name afer, given to a specimen from Guinea, may belong to some other species.

Page 1168. Add:

1560(a). DERMATOLEPIS ZANCLUS, Evermann \& Kendall.

Head $2 \frac{8}{4}$; depth $2{ }_{16}^{9}$; eye 8 in head; snout $3 \frac{1}{5}$; maxillary 3 ; mandible 2. D. XI, 19 ; A. III, 10; scales difficult to count, but about $30-130-35$, those above lateral line counted obliquely backward and downward from origin of dorsal, those below from origin of anal upward and forward to lateral line. Branchiostegals 8 ; gill rakers $8+12$, short and stout, the longest $1 \frac{3}{5}$ in orbit. Body stout, compressed, oblong-elliptical, the dorsal and ventral outlines about equally curved; head moderate, the profile rising from tip of snout to origin of dorsal fin, thence descending in a regular, gentle curve to caudal peduncle; a depression above nostrils and a slight one on nape; interorbital very narrow, equal to orbit; mouth moderate, somewhat oblique; premaxillaries protractile; maxillary broad at tip, reaching vertical at posterior edge of the pupil; supplemental bone well developed; lower anterior edge of maxillary covered by the broad dermal flap of the premaxillary; eye small, high up; nostrils close together and close to eye, the anterior small and round, the posterior oblong-oval, much larger than the other. Small cardiform teeth on each jaw, those in front movable, scarcely canine-like; similar teeth on vomer and a long, uarrow band on each palatine. Preopercle coarsely serrate, the serræ short and blunt, more or less obscured by the skin; opercle with a broad dermal border, somewhat produced at lower angle. Fins all large; origin of dorsal slightly in advance of base of pectoral, its distance from tip of snout equal 
to length of head; third dorsal spine longest, its length about 24 in head or $2 \frac{1}{2}$ times length of first ray ; interspinal membranes of the spinous dorsal deeply incised, the anterior portion of each somewhat produced beyond its spine; soft dorsal high, the middle rays longest, $1 \frac{8}{4}$ in head, the anterior portion of the fin gently convex, the posterior slightly concave; pectoral short, broad, and rounded, barely reaching origin of anal, the length $1 \frac{1}{2}$ in head; ventral pointed, the second and third rays longest, $1 \frac{1}{5}$ in pectoral, the fin somewhat falcate; anal fin strongly falcate, the fourth and fifth rays longest, longer than pectoral, $1 \frac{1}{4}$ in head, $2 \frac{1}{2}$ times length of last anal ray; second anal spine short, $5 \frac{1}{2}$ in head; candal shallowly lunate, the lobes $1 \frac{1}{2}$ in head. Scales small, smooth, and thin, closely but irregularly imbricated; nape, opercles, and cheeks scaled, snout and lower jaw naked; bases of all the fins except the ventrals densely scaled; lateral line beginning at upper angle of opercle, gently arched above pectoral fin, following approximately the curvature of the back and on median line of caudal peduncle. General color of body in life brown, with large, irregular blotches of dirty white on back and upper part of sides, these blotches with small rusty spots; lower part of sides, belly, and caudal peduncle with irregular whitish spots; belly brassy brown; snout and nape with numerous small, round dark spots; cheek with large blotches of whitish overlaid with black and brassy spots; lips whitish, with dark spots; spinous dorsal blotched with white, olivaceous and black; soft dorsal brown, with numerous white spots and a fow black ones, the posterior rays tipped with white and orange; anal olivaceous, with irregular white spots, greenish at edge, the produced rays black toward distal ends; pectoral dark olivaceous, with greenish white splotches, the edge yellowish; ventral ravs greenish white, the membranes black; inside of mouth white; eye brown. Related to $D$. inermis (Cuvier \& Valenciennes), but differing notably from that species in the shorter, stouter gill rakers, the emarginate caudal, the shorter anal spines, and the strongly falcate anal fin. Length

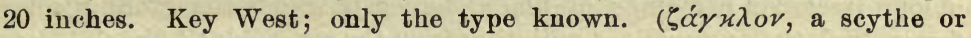
sickle, from the falcate anal fin.)

Dermatolepis zanclus, Evermann \& Kendall, Bull. U. S. Fish Comm. 1897 (Feb. 9, 1898), 129, pl. 8, fig. 9, Key West, Florida. (Type, No. 48843 . Coll. Drs. Evermann \& Kendall.)

\section{Page 1186. Add:}

1576(a). MYCTFROPERCA HOPKINSI, Jordan \& Rutter.

Head $2 \frac{2}{3}$; depth $4 \frac{1}{2}$. D. XI, 15; A. III, 11 ; scales about 125 ; eye 6 in head, $1 \frac{1}{2}$ in snout. Body long, not much compressed; angle of preopercle sharply serrate; gill rakers $6+9$, counting rudiments; nostrils close together, the posterior larger, with a horizontal septum across base; profile concave above nostrils; maxillary nearly to posterior margin of eye, $2 \frac{1}{6}$ in head; lower jaw projecting; 2 anterior canines of upper jaw very strong; third and fourth dorsal spines longest; posterior portion of anal truncate; caudal concave. Pectorals 2 , ventrals $2 \frac{1}{5}$, and caudal $1 \frac{1}{2}$ in head. Color of alcoholic specimen nearly uniform brownish, sirle of jaws paler; soft dorsal, anal, ventrals, and caudal with a narrow pale edging, 
these fins otherwise brownish olive, with a subterminal band of black; pectorals pale, darker in middle. Allied to Mycteroperca calliura, differing in having fower gill rakers, more slender body, smaller scales, and a less lunate caudal. Jamaica; only 1 specimen, 6 inches long, known. (Named for Timothy Hopkins.)

Iycteroperca hopkinsi, Jordan \& Rutter, Proc. Ac. Nat. Sci. Phila. 1897, 105, Jamaica. (Type, No. 5073, L. S. Jr. Univ. Mus. Coll. J. S. Roberts.)

Page 1187. Insert:

1576(a). MYCTEROPERCA BOULEXGERI, Jordan \& Starks.

Head $2 \frac{4}{5}$ in length; depth 25 . D. XI, 14 or 15 ; A. III, 9 or 10 ; scales about 90,20 above and 42 below; snout $3 \frac{1}{2}$ in head; maxillary $2 \frac{1}{5}$; eye $5 \frac{1}{2}$; pectoral $1 \frac{8}{4}$; ventral $1 \frac{5}{6}$; longest anal ray $1 \frac{2}{3}$; caudal $1 \frac{3}{5}$; longest dorsal spine $2 \frac{1}{2}$; gill rakers short, about $6+17$, the longest about $\frac{3}{5}$ eye; longest dorsal ray 2 in head. Body short and deep, compressed; head moderate, compressed, its profile not steep, nearly straight, a depression before eye. The supraoccipital and temporal crests are high, the supraoccipital crest extending to the posterior margin of orbit; the temporal crests are parallel to each other, and extending to pupil; interorbital space concave. Upper canines moderate, the lower quite small. Nostrils small, well separated, the anterior slightly larger. Lower jaw very strongly projecting; maxillary reaching opposite posterior edge of pupil. Preopcrele slightly notched, the angle slightly salient, with enlarged teeth. Dorsal not deeply notched, the fourth spine not much elevated; second dorsal high, not long, its angle not rounded; caudal scarcely lunate, the upper lobe long, the lower truncate; anal very high, strongly elevated, its posterior border incised, the anterior rounded; pectoral and ventral moderate. Scales smoothish, not very small. Color olive gray, covered everywhere with oblong irregular markings of black, between which the ground color forms rivulations; gray lines radiating from the eye; a black bloteh below maxillary; pectoral olive yellow; other fins blackish, clouded with pale; first dorsal with faint small black spots. Mazatlan, Mexico. (Named for George Albert Boulenger, ichthyologist of the British Museuin, in recognition of his epoch marking work on the Percoid fishes.)

Mycteroperca boulengeri, JoRdan \& STARKs, Fishes Sinaloa, 445, pl. 38, 1895, Mazatlan, Sinaloa, Mexico. (Type, No. 1621, L. S. Jr. Univ. Mus. Coll. Hopkins Exped. to Sinaloa )

Page 1235. The original type of Lobotes is surinamensis, not erate.

Lobotes erate is a species distinct from $L$. surinamensis, inhabiting the coasts of India and China. Lobotes farkhari and $L$. incurvus are probably identical with $L$. erate, and all 3 should be erased from the synonymy of L. surinamensis.

Page 1236. After Lobotes surinamensis add:

The Lobotes of the Pacific coast of Central America is distinguished from the other known species, $L$. surinamensis and $L$. erate, by the small 
size of the preopercular serrations, those at the angle not elongated and spine-like, even in the young. The following description is furnished by Dr. Gilbert:

1623(a). LOBOTES PACIFICUS, Gilbert, new species.

(BERRUGATE.)

Head $2 \frac{8}{4}$ in length; depth $2 \frac{1}{5}$ to $2 \frac{1}{10}$ (to base of candal rays); depth of caudal peduncle $2 \frac{1}{2}$ in head. D. XII, 15; A. III, 11; pectoral 15 . Scales 11-46 ( +6 on base of caudal) -18 ; vertebræ $12+12$; Br. 6 . Body more elongated than $L$. surinamensis, agreeing in this respect with $L$. erate, the depth less than $\frac{1}{2}$ the length. Upper profile deeply concave at occiput, thence strongly convex to front of dorsal; head shorter and narrower than in $L$. surinamensis, the interorbital width but slightly longer than snout, $3 \frac{9}{10}$ to 4 in head ( $3 \frac{1}{3}$ to $3 \frac{2}{5}$ in head in $L$. surinamensis). Eye small, $6 \frac{2}{3}$ to $7 \frac{1}{3}$ in head, 2 or $2 \frac{1}{10}$ in interorbital width. Mandible strongly protruding, but without symphyseal knob; maxillary narrow, not concealed in closed mouth, its tip reaching vertical from middle of pupil, $2 \frac{6}{7}$ to $2 \frac{9}{10}$ in head. Upper jaw with a moderate villiform band of teeth, in front of which is a single series of conical, close-set canines; lower jaw with a single series, similar to outer series of upper jaw, and behind them a very narrow band of villiform teeth, which grow slightly larger toward symphysis; palate toothless. Posterior margin of preopercle vertical, the angle protruding but little in the young. In 5 young examples, 7 to 11 inches long, the preopercular teeth are fine, acnte, short, and inconspicuous, abont as in species of Pomadasis. They increase but little in size toward the angle, where they are never spine-like; on lower limb they are perceptible only in the immediate vicinity of the angle, the remainder of the horizontal limb being entire. In the adult the vertical limb is finely and evenly toothed, the angle and lower limb slightly roughened or entire; opercle with 2 short spinons points, behind the lower of which a narrow tongue-shaped process of the subopercle extends to near the edge of opereular membrane; humeral process very weakly toothed, contrasting with the strong serrate condition in L. surinamensis. Gill rakers short, $2 \frac{1}{2}$ in eye in young, comparatively shorter in adults, 6 on vertical limb, all but one of which are broad, firmly fixed tubercles, 14 on horizontal limb, the anterior 2 or 3 tubercular. Spinous dorsal low, with gently rounded outline; notch between dorsals shallow, the eleventh spine $\frac{2}{3}$ the length of the longest, which is contained 2 to $2 \frac{1}{8}$ times in head in the young, 3 times in adults; when declined the spines are partially received within a scaly grove; soft dorsal, anal, and caudal with dorsal portions densely scaled and with series of scales running up on membrane to beyond middle of fin; soft dorsal and anal of equal height, forming bluntly rounded lobes, the longest rays of which are about $\frac{1}{2}$ head in adults, $1 \frac{1}{2}$ to $1 \frac{2}{8}$ in young; third anal spine about $\frac{1}{2}$ length of longest ray; pectorals shorter than ventrals, 2 to $2 \frac{1}{8}$ in head; ventrals $1_{\frac{1}{2}}$ in head in young, shorter in adults. Scales less strongly ctenoid than in $L$. surinamensis; tubes of lateral line mostly simple, occasionally with 1 to 3 branches. Color grayish or brownish, with plumbeous or silvery reflections. The youngest examples show faintly the dark streaks so con- 
spicuous in young of $L$. surinamensis, viz, a pair running backward from interorbital space; a pair from upper posterior border of eye converging toward front of dorsal, and a broader band from eye downward and backward across cheek; soft dorsal, anal, and caudal uniform blackish, or the caudal with an ill-defined lighter edge; pectorals translucent; ventrals blackish. Abundant at Panama, where it is known as Berrugate.

Lobotes auctorum, STEINDACHNER, Ichth. Beitr., IV, 6, 1875; not of GüNTHER.

Lobotes surinamensis, JoRDAN \& GilberT, Bull. U. S. Fish Comm., II, 1882, 110; GilberT,

1. c., 112 ; Jordan. Proc. U. S. Nat. Mus. 1885, 378; not L. surinamensis of BLoch.

Lobotes pacificus, Gilbert, Fishes of Panama, 1898 MS., Panama. ' (Type, No. 5883, L. S. Jr. Univ. Mus. Coll. Gilbert.)

Page 1238. After Priacanthus cruentatus add the following:

1625(a). Priacantiús Caroilixus, Lesson.

This species is very close to Priacanthus cruentatus, distinguished by the larger spine on preopercle, which reaches the edges of the opercle and is $2 \frac{1}{2}$ in eye; that of $P$. cruentatus not reaching opercle and measuring 4 in eye, its edge less rough. Body a little deeper than that of $P$. cruentatus; depth of the latter 3 in the length. In $P$. carolinus the depth is $2 \frac{3}{5}$ in the length; caudal truncate. In color and gencral appearance the 2 species are similar. The distinctness of this species from $P$. cruentatus is very doubtful. Abundant at Clarion Island, where it was taken by Mr. R. C. McGregor. (carolinus, from Caroline Islands.)

Priacanthus carolinus, Lesson, Voyage Coquille, Poiss., 204, 1826, Caroline Islands.

Priacanthus schlegeli, HilaENDORF, Sitzgber. Ges. Naturf. 1879, 79, Japan.

Page 1262. In the first line of the description of Neomanis vivanus read:

Head $2 \frac{2}{8}$ to $2 \frac{8}{4}$; depth $2 \frac{1}{2}$ to 3 . D. X, 14; A. III, 8 or 9 ; eye $4 \frac{8}{4}$ in head; scales (7) 8-72-17, 50 pores.

Page 1264. After Neomanis vivanus add:

1639(a). NEOMENIS HASTINGSI, Bean.

(Bermuda Silk Snapper.)

Head 3 ; depth 3 ; least depth of caudal peduncle 9 in length of type to caudal base. D. X, 14; A. III, 8 ; V. I, 5 ; P. 16 ; scales 8 or $9-65-17$. Maxillary reaching scarcely past front of eye, 3 in head. Vomerine teeth in an arrow-shaped patch, with a backward extension which is fully $\frac{1}{8}$ as long as the eye; canines in upper jaw very feeble; 2 or 3 posterior teeth of mandible are weak canines; 7 rows of scales on cheeks, 9 rows on gill cover. Least interorbital width equal to eye, which is $1 \frac{1}{8} \mathrm{in}$ snout and 4 in head. Gill rakers $7+9$, the one in the angle conspicuously longest, about 2 in eye. First dorsal spine 7 in head; fifth and longest spine about 3 in head; last dorsal spine equal to eye in length; longest ray of soft dorsal equal to maxillary, or 3 in head; first anal spine 8, the second and third about 4 in head, the second slightly longer than third; anal base nearly $2 \frac{1}{2}$ in head; third and longest anal ray about equal to anal base; pectoral extending to vent; ventral not reaching vent by a space $\frac{1}{2}$ as long as the eye. Colors in life, ground color vermilion, the upper parts over- 
laid with coppery brown, lower parts vermilion; 4 or 5 narrow golden stripes below lateral line; caudal dark brown with a narrow black margin; anal dusky, the spines and the membranes of last 2 rays pale; a narrow black blotch at pectoral base; ventral pale, somewhat mingled with dusky; membranes of spinous and soft dorsal uniformly dark; snout copper color; eye lemon yellow; pupil blue black; many scales, especially on front of body, with a minute brown dot at base; brownish spots on scales forming many oblique streaks above lateral line. Some living examples show a faint dark lateral blotch much like that of $N$. synagris, and similarly placed. In spirits the body is pink with the upper parts brownish; the dusky color remains on the anal and the black blotch at base of pectoral; black margin of caudal becoming merged with the general dark color of the fin. (Bean.) Most closely related to $N$. vivanus. Length of type $11 \frac{1}{2}$ inches. Bermuda, where numerous specimens were obtained in 1897. (Named for General Russell Hastings of Soncy, Bermuda.)

Neomaenis hastingsi, BeAN, Bull. Amer. Mus. Nat. Hist., X, Article III, 45, 1898, Bermuda.

Page 1290. Under $g$ read: Anal fin short, its rays III, 7 to III, 13.

Page 1413. In first line of description of Cynoscion phoxocephalus for "A. III, 10" read "A. II, 10."

Page 1416. In last line of description of Sagenichthys ancylodon for "companion" read "comparison."

Page 1605. Instead of Chlorichthys read:

640. THALASSOMA, Swainson.

Thalassoma, Swainson, Nat. Hist. Class. Fishes, II, 224, 1839 (purpureus). Julis, GÜNTHER, Cat., IV, 179, 1862; not of Cưvier \& VAlenciennes.

The species of Thalassoma (pavo, unimaculatus, bifasciatus) examined have 3 anal spines, as is the case with the American species referrerl to Chlorichthys. The first spine, small and hidden in the skin, is easily overlooked. There is therefore no distinction between Thalassoma and Chlorichthys, and all the American species must be referred to the former genus.

The species will stand as follows:

2014. TIIALASSOMA LUCASANUM (Gill).

2015. THALASSOMA SOCORROENSE, Gilbert.

2016. THALASSOMA NITIDUM (Günther).

2017. TIIALASSOMA NITIDISSIMUM (Goode).

2018. THALASSOMA STEINDACHNERI (Jordan).

2019. TIALASSOMA BIFASCIATUM (Bloch).

2020. TIALASSOMA GRAMMATICUM, Gilbert.

2021. THALASSOMA VIRENS, Gilbert.

Page 1670. In Pomacanthus (P. paru, species examined by Mr. E. C. Starks) and Chatodon the air bladder is wholly contained in the body cavity, while in Holacanthus and Angelichthys (A. ciliaris species examined) it is posteriorly separated from the body cavity. The 2 latter genera con- 
stitute the subfamily Holacanthine, distinct alike from Chatodontince and Pomacanthina.

Page 1717. Ceratacanthus, including Osbeckia, should stand as a valid genus distinguished from Alutera by the convex or lanceolate caudal. The species will then stand as follows:
2135. CERATACANTHUS SCHEPFII (Walbaum).
2136. Ceratacanthus punetatus (Agassiz).
2137. CERATACANTHUS SCRIPTUS (Osbeck).
2138. ALUTERA MONOCEROS (Osbeck).

Page 1741, line 17, read: Swainson takes " $\mathcal{\alpha} \alpha \nu \theta \alpha$ " to mean spine, not " $\alpha \varkappa \alpha \nu \theta \alpha$ " which is the correct word for spine. There is no classical warrant for Cantherines and Canthigaster, unless derived from $\varkappa \alpha \dot{\nu} 0 \circ 5$, the ass.

Page 1776. In sixth line from bottom read "increased" for "self."

Page 1786. Note on Sebastodes rufus:

This species is ovate in form, like $S$. oralis, from which it differs in color and form of mouth and head. Its depth is $2 \frac{2}{3}$ in length, not $3 \frac{8}{4}$, as stated (through misprint) by Dr. Eigenmann. A fine specimen before us was taken by Dr. Gilbert off San Diego.

Page 1790. The type number of Sebastodes hopkinsi is 2282, not 2286.

Page 1795. The subgenus Zalopyr does not include Sebastodes atrorubens nor S. atrovirens. These 2 species belong in the subgenus Rosicola.

Page 1799. In first line under Sebastodes crameri for "P. $199_{10}^{9}$ " read "P. 19."

Page 1805. After line 4 add: (intro, within; niger, black.)

Page 1815. The type of Sebastodes zacentrus came from Albatross Station 2946, not 2996.

Page 1829. After line 2 insert Subgenus Sebastosomus.

Page 1831. Specimens of Sebastodes taczanowskii were obtained in 1896 by the Albatross at the Kuril Islands, and this species should therefore go in the regular text.

Page 1832. After line 15 insert Subgenus Sebastomus.

Page 1833. Before Sebastodes matsubark (Hilgendorf) insert Subgenus Zalopyr.

Page 1833. In fifth line from bottom insert Subgenus Ptcropodus after "nebulosus."

Page 1836. In key at bottom of page, to $a$ add: mouth plumbeous within. To $a a$ add: mouth black within.

Page 1837, line 2, for "Cardonniera" read "Cardouniera." For "Scorfanudi Funal" read "Scorfana di Funal."

Page 1840. Above "a. Breast scaly," insert Parascorpæna ( $\pi \alpha \rho \alpha$, near; to Scorpana). Before 2236. Scorpana agassizii, Goode \& Bean, insert Subgenus Parascorpana, Bleeker.

Page 1850. In last line of synonymy of Scorpana mystes for 1501 read 1601. 


\section{Page 1854. After Scorpona inermis add:}

\section{7(a). SCORPENA NEMATOPHTIALMUS (Günther).}

Head 3 in total length; depth $3 \frac{1}{2}$; eye 4 in head; snout rather less than 4. D. XII, 10; A. III, 5; scales 40 or 41 . Dorsal outline much arched at greatest depth of body. Eye placed high, entering upper outline of head. Intermaxillaries styli form, armed, like the dentaries, with a rather narrow band of villiform teeth; band of vomerine teeth angularly bent, produced forward at the angle; maxillaries styliform at superior extremity, moderately dilated at the lower. Head scaled to posterior angle of orbit above and to the preorbital and angle of mouth laterally. Spines on head very prominent and acute in the young, more obtuse in older examples; 2 turbinal spines; on each side of the occiput a series of 5 spines between orbit and nape; 2 between eye and scapula; preorbital armed with 2 strong, recurved spines at the inferior margin; 3 spines on interorbital ridge; preopercular margin rounded, with 4 spines, the uppermost and strongest opposite end of interorbital ridge; opercle with 2 flat spines; a pair of spines at throat. The only skinny appendage is a long, slender, tapering filament above posterior angle of orbit. Origin of dorsal immediately behind vertical from suprascapula, its distance from occiput equaling length of first spine, which is about $\frac{1}{2}$ length of second; third and fourth spines longest, $2 \frac{3}{5}$ in head; the following spines gradually decreasing to the eleventh, which equals the first; twelfth spine much longer, apparently belonging to the soft portion, which is supported by it; margin of soft portion rounded, very little higher than the spinous, posteriorly fixed to the back of the tail by a membrane; caudal subtruncated; origin of anal somewhat behind that of soft dorsal, its second spine strong, rather longer than the third dorsal, and with a longitudinal groove; pectoral reaching anal; ventral reaching vent. Scales of moderate size, rather irregularly arranged. Color probably uniform red. Supposed to be from the West Indies. (Guinther.) Only the type known. ( $\nu \tilde{\eta} \mu \alpha$, thread.

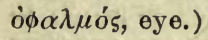

Sebastes nematophthalmus, GUNTHER, Cat., III, 99, 1860, West Indies; the exact locality unknown. (Coll. Sir R. Schomburgk.)

Page 1862. Anoplopoma fimbria is occasionally taken off Santa Catalina in deep water. A specimen was seen by us at Redondo Beach.

Page 1866, line 7 from bottom, read "always," not "usually."

Page 1867. In the key, $b$ should read as follows:

$b$. Fourth line of pores forking in advance of base of ventrals, the lower branch running to base of ventral fin, the upper to middle of ventral. OCTOGRAMMUS, 2259.

In the footnote for "Keinosuke Otaki" read "Keinoske Otaki."

Page 1879, line 27, for "jointed" read "joined." Line 37, after "hypercoracoid" add "and hypocoracoid."

Page 1880. In the key read:

$m$. Lateral line armed with a series of bony plates; preopercular antler-like processes usually numerous. 
Page 1881. The key should be modified to read:

q. Interorbital space deeply concave or grooved. Head with cirri (in lateralis), or without (in asperulus).

ARTEDIUS, 712.

A better distinction between Artedius and Axyrias is found in the presence of patches of ctenoid scales on the head in the latter.

Page 1884. In line 19, for Hexagrammide read Zaniolepidina.

Page 1898. The type number of Icelinus strabo is 5045, not 5451.

Page 1902. Artedius asperulus is better separated from A. lateralis by the coalescence of the bands of scales behind the dorsal and their continuance upon the caudal peduncle. In the description of the genus Artedius the bands of scales are said not to meet behind the dorsal. This applies to $A$. lateralis only.

Page 1902. To the description of Artedius add: No patches of ctenoid scales on the head.

Page 1903. To the description of Artedius asperulus add: Head without cirri.

Page 1906. The type of Artediellus atlanticus is No. 418 L. S. Jr. Univ. Mus.

Page 1940. In the key, under $a$, add: Preopercnlar spine with 3 hooks above. Under $a a$, add: Preopercular spine with 6 or 7 hooks above.

Page 1958. Cottus aleuticus extends southward in the Coast Range to Monterey.

Page 1964. In key under $h$ for "anal" read "axil."

Page 2000. After Porocottus tentaculatus add:

2371(a). POROCOTTTUS BRADFORDI, Rutter, new species.

Head 3 ; depth $3 \frac{8}{4}$ to $4 \frac{1}{4}$; eye 4 . D. IX, $15^{*}$ or $16 ;$ A. 11 to $13 ;$ P. 13 or 14 ; B. 6. Head broad, somewhat depressed; bones of head cavernous; lower jaw included, maxillary to below middle or hinder edge of pupil, $2 \frac{1}{3}$ in head; teeth in jaws and in a narrow crescent on vomer; eye equal to snout; nasal spines blunt, covered by the skin; no ocular, opercular, nor suprascapular spines; preopercular spines 3 , upper slender, curved in ward, lower straight, pointing downward, middle 1 short and blunt, a mere tubercle; a very slight tubercle represents the fourth spine belonging to the genus; no slit behind last gill; 3 pairs of cirri on top of head, 1 above eje, multifid, another at occiput, single or bifid, the other between them, trifid to multifid; a minute barbel on tip of maxillary; whole top and side of head, lower jaw, and edge of preopercle thickly covered with pores; a double series of pores, 34 to 36 each, along lateral line with many accessory pores, these arranged in groups of 1 to 5 between the pairs of the

\begin{tabular}{|c|c|c|c|c|c|c|c|}
\hline * & & & D. & & & A. & \\
\hline 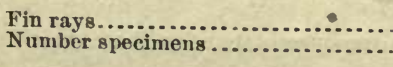 & $\operatorname{IX}_{11} 15$ & $\operatorname{IX}_{12}$ & $\mathrm{IX}_{1}, 17$ & $\underset{1}{\text { VIII, } 17}$ & $\begin{array}{c}11 \\
1\end{array}$ & $\begin{array}{l}12 \\
22\end{array}$ & $\begin{array}{c}13 \\
2\end{array}$ \\
\hline
\end{tabular}


lateral line; nostrils with short tubes; dorsals united at base, the spines with short filaments, middle spines 3 in head, middle rays of soft dorsal $2 \frac{1}{2}$ in head; caudal and ventrals $1 \frac{2}{5}$ in head, ventrals usually reaching vent or anal, but sometimes falling short of each; pectoral $1 \frac{1}{4}$ in head, reaching to or beyond anal. Color dusky, below colorless, a pale bar across occiput (often absent), another between dorsals, 2 across body under soft dorsal and another behind soft dorsal; sometimes the pale color predominates and the dusky portion is left as 4 bars; sometimes plain dusky without cross bars; spinous dorsal dusky with 3 or 4 colorless spaces on the web; other fins barred with series of dusky blotches, ventrals sometimes colorless; 5 to 8 oval white spots behind pectoral, sometimes obscure; males with inner ray or rays of ventral tuberculate or serrate. This species differs from Porocottus sellaris in the presence of cirri on top of head; it has more numerous fin rays and more cirri on head than Porocottus quadrifilis. This species is the most common fish in the rock pools at Karluk, where many specimens were taken. These are in the U. S. National Museum, in the collection of the U. S. Fish Commission, and in that of Leland Stanford Junior University. (Named for Mr. William B. Bradford, secretary of the Alaska Packers' Association, from whom the collector received many favors.)

Page 2015. Before Oxycottus insert the following:

745(a). SIGMISTES, Rutter, new genus.

Sigmistes, RUTTER, MS., new genus (caulias).

This genus differs from Oxycottus, to which it is most closely related, in the decp compressed body, strongly arched lateral line, long dorsal fin, and large mouth. Body deep and compressed; skin smooth; lateral line complete, strongly arched anteriorly; gill membranes united, free from isthmus ; no slit behind last gill ; preopercular spine simple, short, strongly curved upward, anal papilla large; vent immediately behind ventral fins, about $\frac{3}{5}$ of distance from gill membrane to anal ; ventral rays I, 3. (бi $y \mu \alpha$, the letter $S$, from the form of the lateral line.)

2382(a). SIGMISTES CAULIAS, Rutter, new species.

Head $3 \frac{2}{5}$; depth $3 \frac{1}{2}$. D. IX, 20 (IX, 21 in 1 specimen); A. 15 (14 in each of 2 specimens); P. 13. Back elevated, body compressed; eyes lateral, $4 \frac{1}{3}$ in head; snout $3 \frac{1}{2}$; cleft of mouth lateral; maxillary 2 in head, reaching to below pupil (only a little past front of eye in 1 specimen). Tecth coarse, cardiform, the inner row of upper jaw enlarged, almost caninelike; a similar pair in inner series of mandible, near symphysis; a sinall patch on vomer, and 1 on front of palatines; preopercular spine small, sharp, appressed, strongly curved upward, the preopercular margin without spines or tubercules below it; nostrils in short tubes, 1 pair directly behind nasal spines, 1 pair lateral, directly in front of eyes; nasal spines strong, sharp; a pair of tufted cirri above eyes, a pair simple or branched at occiput, and a pair of simple ones halfway between these; a filament on nasal spine, a series of 3 or 4 short ones on margin of preopercle and 1 
at opercular angle; a series of pores around under side of jaw and along edge of preopercle, 2 concentric series under eye and across cheek, and others scattered on head behind eyes; skin smooth, lateral line strongly arched. Dorsal fins connected at base, third spine longest, $2 \frac{8}{4}$ in head, margin of fin even from third to sixth spines, origin of spinous dorsal over upper edge of gill opening; soft dorsal higher, longest rays 2 in head, base of soft dorsal $\frac{2}{5}$ length; tips of anal rays all free, longest $2 \frac{1}{3}$ in hear ; origin of anal under third ray of soft dorsal; longest pectoral ray a little longer than hearl; caudal truncate, $1 \frac{1}{2}$ in head; ventral about reaching anal, about same length as anal papilla; tail slender, least depth slightly less than eye, length from anal $1 \frac{4}{5}$ in head, its length from dorsal about equal to its depth. Color in life, pale pinkish; spinous dorsal dusky, nearly black along margin; soft dorsal plain or with dusky cross bars; anal with about 7 dusky cross bars, extending downward and forward almost at right angles to the rays; 3 or 4 pale blotchos surrounded by a black ring along base of dorsal, 1 between dorsals, 1 at end of soft dorsal, and others at base of soft dorsal (some or all sometimes absent); a curved dark line from snout through eye to preopercular spine. Six speci-

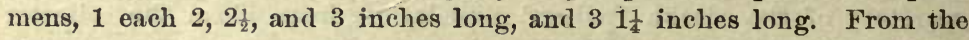
rock pools at Karluk, on the Island of Kadiak. Coll. Cloudsley Rutter. The type is in Leland Stanford Junior University Museum. Cotypes are in the U.S. Fish Commission and U.S. National Museum. ( $x \alpha \dot{v} \lambda o s$, stem, from the many dorsal rays.)

Page 2015. In third line under Oxycottus acuticeps instead of "region" read "reaching."

Oxycottus is much nearer Blennicottus than Oligocottus, and perhaps is best placed as a subgenus of Blennicottus. There is no slit behind the last gill in any of the species. In the subgenus Oxycottus should be placed:

2353. BLENNICOTTUS ACUTICEPS (Gilbert).

2384. BLENNICOTTUS EMBRYUM (Jordan \& Gilbert).

Page 2042. In line 9 for Phalangistes substitute Brachyopsis.

Page 2051. In first line of footnote, for "Dr. Gilbert" read "Scofield \& Seale."

Page 2071. In line 14 of the description of Averruncus sterletus read "upward," not "downward."

Page 2108. The synonymy on this page and the last synonym on page 2107 all belong with the footnote.

Page 2113. The type number of Ncoliparis greeni is 3019, not 3010.

Page 2128. Before Bathyphasma insert the following:

785(a). CRYSTALLICHTHYS, Jordan \& Gilbert, new genus.

Crystallichthys, JoRdAN \& GILBERT, new genus (mirabilis).

Closely allied to Liparis, but with nostril single. A single dorsal fin; a well-devoloped sucking disk; wide bands of teeth, many of which are trilobate near tip; an inferior mouth, much overhung by the prodncer 
conical snout; a single nostril, corresponding to the anterior nostril of other Liparids, the posterior opening being wholly wanting. The typical species, C. mirabilis, differs from all known species of Liparis except $L$. cyclostigma in its large size, compressed form, and translucent gelatinous

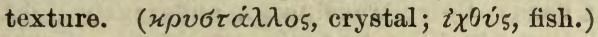

2458(a). CRYSTALIICHTIYS MIRABIJIS, Jordan \& Gilbert, new species.

Head 4 in length; depth $2 \frac{1}{2}$; snont $2 \frac{1}{\gamma}$ in head; eye $3 \frac{1}{2}$ in snout; width of mouth $\frac{1}{2}$ length of head; length of gill slit $\frac{1}{2}$ snout, equaling distance from front of eye to front of nostril tube; P. 33. Head and body compressed, especially along upper profile, which descends in a gentle, nearly even curve to tip of snout; lower profile less curved, nearly straight and horizontal on auterior third of body; snout conical, tapering to a sharp tip, its lower profile nearly horizontal, protruding beyond the mouth for a distance (measured axially) equaling $\frac{2}{5}$ its length; mandibular symphysis vertically below nostril tube; npper jaw strongly arched anteriorly, the mandible much shorter, nearly transverse in position. When the mouth is closed, there is exposed the entire width of the thick upper lip and the anterior portion of the band of fringes which precedes the premaxillary teeth. Teeth slender, shorter than in Liparis cyclostigma, arranged in about 25 oblique series in the $\frac{1}{2}$ of each jaw; the posterior longer teeth more or less distinctly 3-lobed in both jaws, the anterior teeth shorter, simple. A deep cleft on lower side of snout running from its tip to front of premaxillaries, deepening backward, opening into the deep groove above premaxillaries; from base of cleft arises a high free fold, the sharp edge of which nearly reaches the margins of the eleft; a series of 3 large pores along each side of this cleft, with 3 more equally spaced on each side and parallel with front of mouth; belonging to this series but distant from them and much smaller, is another on middle of cheok below eye, and 1 halfway between eye and middle of gill slit; a pore behind eye, and a series of 4 on each side of nape complete the pores of the head; no pore in the position of the posterior nasal opening; a second series of 6 on each side of mandible and preopercle; no other pores on head. Nostril single, in a distinct wide tube, as long as the diameter of pupil; distance from eye to angle of mouth $3 \frac{1}{5}$ in head; vertical from angle of mouth, passing through front of orbit. Gill cleft narrow, reaching base of first pectoral ray, its length $4 \frac{3}{5}$ in head. Lateral line rising in an abrupt curve from upper end of gill opening, decurved again behind pectorals, to reach middle of sides, on the posterior half of which it becomes obsolete; anteriorly the lateral line is aceompanied above by a second series of pores which is not curved, but runs straight forward from just above the summit of the curve. Dorsal and anal fins enveloped anteriorly in thick gelatinous tissue, so that their points of origin and number of fin rays can not be determined, the fins high, the longest anal ray equaling length of snout and eye; 32 dorsal and 33 anal rays can be distinguished in the posterior transparent portions of the fins, the total number of rays being greater; last anal ray joining outer caudal ray at middle of length of the latter; dorsal joined narrowly to 
base of caudal at end of basal seventh of outer caudal ray; longest caudal ray $2 \frac{1}{2}$ in head; lower 7 pectoral rays thickened, forming a lobe, the distal third of each ray free from the membrane; longest pectoral ray $1 \frac{1}{4}$ in head; disk of moterate size, anteriorly placed, its posterior margin under the gill slit, its length $\frac{1}{3}$ that of head. Color translucent, apparently light grayish or purplish in life, the dorsal region, including dorsal fin, marked with many large round spots, probably reddish in life, each spot surrounded with a faint darker ring. A large species, noft and gelatinous in texture, the color translucent grayish or purplish, marked on back with many large light circles which were probably reddish in life. Type, a specimen $330 \mathrm{~mm}$. long, from Albatross Station 3643, off Provostmaya, Kamchatka, at a depth of 100 fathoms. Bering Sea; 1 specimen from Kamchatka, a smaller one dredged off St. Paul Island, Pribilof group. (mirabilis, wonderful.)

Crystallichthys mirabilis, Jordan \& GiLBert, Rept. Fur Seal Invest., MS., 1898, Provostmaya, Kamchatka. (Coll. Albatross.)

Page 2129. Allurus is preoccupied by Allurus, Forster, 1862, a genus of Hymenoptera; also by Allurus, Eisen, 1874, a genus of worms. We substitute for our use of it the name Allinectes.

Allinectes, Jordan \& Evermann, new subgenus (ectenes).

Page 2131, line 7, for "Alldurus" read "Allurus." In lines 4 and 7, for " $\dot{\alpha} \lambda \lambda \dot{\delta} \varsigma$ " read " $\alpha$ $\lambda \lambda$ os."

Page 2137. After Careproctus ectenes add:

787(a). PROGNURUS, Jordan \& Evermann, new genus.

Prognurus, JoRdan \& EvermanN, new genus (cypselurus).

This genus is distinguished from Careproctus by the very elongate caudal which is forked at the tip. ( $\pi \rho \dot{\gamma} \gamma v \eta$, a swallow or martin; ovं $\dot{\alpha}$, tail.)

2469(a). PROGNURUS CYPSELURUS, Jordan \& Gilbert, new species.

Head $4 \frac{2}{5}$ in length; depth $41_{0}^{9}$; cleft of mouth $1 \frac{8}{4}$ in head, $\frac{5}{7}$ distance from symphysis of lower jaw to angle of mouth; total interorbital width $2 \frac{1}{5}$ in head; eye large, equaling length of snout, $3 \frac{8}{4}$ in head; gill opening entirely above base of pectoral, not reaching base of upper ray, its length 3 in head; opercular lobe broadly rounded. Snout blunt, broadly rounded, the mouth horizontal along its lower margin, scarcely overlapped by it; upper lip wide. Teeth acnte, without cusps, in about 27 oblique rows in 1 side of each jaw; maxillary reaching the vertical from posterior edge of the pupil; nostril opening in a wide, low tube. Front margin of ventral disk very slightly behind angle of month, its diameter $\frac{3}{5}$ that of eye, about $\frac{1}{7}$ length of head. Pectorals broadly rounded, regularly shortened below, not deeply notched, the lower 7 rays thickened and exserted; the longest free ray about $\frac{1}{2}$ length of head; upper portion of fin with $26 \mathrm{rajs}$, the tips only protruding, the longest equaling length of head; dorsal beginning shortly behind vertical from gill slit, its distance from tip of snout $3 \frac{7}{8}$ in length; dorsal with about 58 rays; caudal very long and narrow, only its basal third connate with last 
rays of dorsal and anal. Unlike all other Liparids, the caudal is forked at tip, the terminal notch involving about $\frac{1}{7}$ of fin. Translucent dusky, darker around snout, gill openings, and on the fins, the vertical fins largely jet-black; mouth and gill cavity dusky, not black. This species is most nearly related to Careproctus melanurus, from which it differs in darker coloration and shorter gill slit. From all known species of Carcproctus it differs in the very elongate caudal fin which is forked at the tip. Bering Sea and North Pacific. The type, a single specimen, $21 \mathrm{~cm}$. long, dredged at Albatross Station 3644, off Bogoslof Island, at a depth of 664 fathoms. A second specimen was obtained by the Albatross in 1889, at Station 3074, off the coast of Washington, in 877 fathoms, but it was too seriously mutilated to admit of description. ( $\varkappa v \psi \varepsilon \lambda \delta^{\prime} \varsigma$, a swift; ov́ $\rho \dot{\alpha}$, tail.)

Page 2175. The genus Chelidonichthys should becompared with Trigla rather than with Prionotus.

Chelidonichthys pictipinnis is probably not American, and should be omitted or, at most, admitted only in a footnote.

The genus Chelidonichthys differs from Trigla in the absence of lateral plates.

Page 2183. To the synonymy of Cephalacanthus add:

Cephalacandia, RAFinesque, Anal. de la Nature 1815, 85; substitute for Cephalacanthus.

Page 2196, line 5, for "Pañeca" read "Puñeca."

Page 2207. Sicya being preoccupied in Lcpidoptera we substitute for our use of it the name Sicyosus.

Sicyosus, JoRdAN \& EverMaNn, new subgenus (gymnogaster).

Page 2207. Add the following species:

2531(a). Sicydidn PUnCtatum, Perugia.

D. VI-I, 11 ; A. I, 10 ; scales 56 . Head $5 \frac{1}{4}$ in total length without caudal, its width equaling its height or $\frac{8}{4}$ that of body under first dorsal. Scales of body larger than those of head or nape; maxillary reaching posterior border of eye. Eye 4 in head, or $1 \frac{1}{4}$ in interorbital space. Snout 4 ; pectoral equaling head in length; spines of first dorsal somewhat elongated, the longest (third) twice height of body; second dorsal as high as body and like the anal. Teeth of upper jaw fine, very slender, and ending behind in an obtuse angle; lower jaw with conic robust teeth and minute horizontal ones. Color grayish, the ventral gall color (giallognolo); under part of head with numerous small black spots; scales strongly ciliated and each with a brown spot in the center; dorsals brown; anal transparent, with a narrow black line; ventral disk yellowish. Length $8 \mathrm{~cm}$. This species is not $S$. plumieri of Cuvier \& Valenciennes, nor is it $S$. antillarum, Ogilvie-Grant, because of the difference in the number of scales, the different proportions and a different coloration. The type was collected by Captain Guiseppe Capurro at St. Pierre, Martinique. (Perugia.)

Sicydium punctatum, Perugia, Annali del Museo Civico di Storia Naturali di Genova, ser. 2, vol. XVI, 1896, 18, Martinique. (Coll. Capt. Guiseppe Capurro.)

Page 2226. Gobius zebra has 26 scales. Many fine specimens of this species, 3 to 4 inches long, from Clarion Island, are in the museum of Stanford University. 
Page 2227. The type locality of Gobius bosci is Martinique.

Page 2230, second line, read "EMḱraude" for "EMrrandE."

Page 2241. Insert the following synonymy after No. 2572:

Gobius lucretioe, Eigenmanx \& Eigenmann, Proc. Cal. Ac. Sci., ser. 2, vol. I, Jan. 25, 1888, 57, Pearl Island, Gulf of Panama.

Page 2263. To the synonymy of Gobioides add:

Plecopodus, RAFINESQUE, Anal. de la Nature 1815, 87; substitute for Gobioides.

Page 2269. Omit the last reference but one.

Page 2314. To the synonymy of Batrachoides add:

Batrictius, RAFINESQUe, Anal. de la Nature 1815, 82 ; substitute for Batrachoides.

Page 2350. After Enneanectes carminalis insert:

868(a). DIALOMMUS, Gilbert.

Dialommus, GILBert, Proc. U.S. Nat. Mus. 1890, 452 ( fuscus).

Teeth conic, strong, in a narrow band in the front of both jaws, this narrowing to a single series laterally; outer teeth enlarged in both jaws. Teeth on vomer in a single series; palatines smooth. A single slender tentacle above orbits, and 1 on each side of nape. Body with moderate cycloid scales; lateral line high in front, declining behind pectoral fins, not strongly developed, evident on a few scales near head, the remainder of its course traceable by occasional pores on bases of scales or by their notched margins. Dorsal beginning on the nape, its anterior $\frac{5}{7}$ composed of slender flexible spines, the remainder of soft rays, unbranched; anal without spines; caudal distinct, rounded; ventrals well developed, I, 3. Eyes as in Anableps, the cornea divided by an oblique pigmented band into an anterior lower and a posterior upper half. One species known. ( $\Sigma \imath \dot{x} \gamma \dot{v} \omega$, to loose one from another, to part asunder; ó $\mu \mu \alpha$, eye.)

2687(a). DIALOMMUS FUSCUS, Gilbert.

Head 5 in length; depth 6 to 7. D. XXV, 13 or 14; A. I, 28; lateral line, 52. Elongate, slender, scarcely tapering. Head short, transversely evenly rounded, with very short, blunt, decurved snont; width of head greater than its depth, and more than $\frac{2}{3}$ its length. Mouth horizontal at lower outline of snout, the maxillary nearly reaching vertical from posterior margin of orbit, $2 \frac{2}{8}$ in head. Teeth strong, conical, the outer series enlarged in both jaws, a narrow band of villiform teeth behind the outer series; vomer with a single series; palatines toothless. Eyes large, round, closely approximated, their diameter greater than length of snout, twice the width of interorbital space, $3 \frac{1}{8}$ in head. Gill membranes very widely joined, free from isthmus. No hook on inner edge of shoulder girdle. Dorsal fin beginning on the nape, over front of opercle, its spines slender and flexible, much lower than soft rays; height of anterior and middle spines about equal, $\frac{1}{8}$ length of hear; the posterior spines shortened, about $\frac{1}{2}$ that length; height of soft rays $\frac{1}{2}$ head; first anal ray short and spinous, the succeeding rays articulated, but not branched (like those of dorsal). Interradial membranes of anal fin very deeply incised; caudal 
fin wholly free, rounded, its length nearly equaling that of heads pectorals slightly shorter than head, posteriorly pointed, the longest rays below the middle of fin; ventrals comparatively broad, inserted but little in front of pectorals, their bases separated by a space equal to $\frac{1}{8}$ diameter of orbit. Color in spirits, brownish above and on sides, becoming blackish on hearl; nnder side of head, belly, and a line along each side of anal fin light; back with traces of about 10 black cross bars, which invade bass of dorsal fin and extend onto middle of sides; in 1 specimen the scales of the interspaces are marked each with a light spot (probably blue in life); fins all dusky, the caudal variegated with lighter in fine pattern; ventrals light at base. Two specimens from the Galapagos Islands-1 from Duncan Island, $72 \mathrm{~nm}$. long, the other from Albemarle Island, $75 \mathrm{~mm}$. long.

Dialommus fuscus, Gilbert, Proc. U. S. Nat. Mus, 1890, 452, Galapagos Islands. (Coll. Albatross.)

Page 2352. Gibbonsia evides intergrades with Gibbonsia elegans and must apparently be regarded as a subspecies of the latter.

Page 2356. Under Malacoctenus ocellatus for "A. II, 8" read "A. II, 18."

Page 2413. Genus 904 should read Vlvicola, Gilbert, not "Gilbert \& Starks."

Page 2421. Anoplarchus alectrolophus is the type of a now genus:

908(a). ALECTRIAS, Jordan \& Evermann.

Alectrias, Jordan \& EVERManN, new genus (alectrolophus).

This genus is distinguished from Anoplarchus by having the gill membranes free from the isthmus, as in Cebedichthys. ( $\dot{\alpha} \lambda \dot{\varepsilon} \varkappa \tau \omega \rho$, a cock; from the crest.)

Page 2422, under Anoplarchus alectrolophus: The 2 specimens obtained in Monterey Bay by Arthur W. Greeley were erroneonsly referred to this species. They are the young of Cebedichthys.

Page 2470. To synonymy of Lycenchelys add:

Lycodophis, VallLant, Exp. Sei. Trav. et Talisman, 311, 1888 (albus).

Page 2472. Furcella is preoccupied by Furcella, Lamarck, 1801, a genus of Mollusca. We substitute for our use of it the name Furcimanus.

Furcimanus, JoRDAN \& EVERMANN, new genus (diapterus).

Page 2473. In lines 33, 36, and 37 read "in 282 to 376 fathoms" instead of the depths given.

Page 2475. In lines 26 and 28, for "coast of Alaska" read "coast of California."

Page 2480. The locality for Melanostigma pammelas is coast of California, not Alaska.

Page 2567. In first line of footnote read "fin," not "spine."

Page 2601, line 20, for "Trachyterus" read "Trachypterus."

Page 494. The large "Silver Trout" of Lake Tahoe, a specimen of which is described on page 494, should probably be separated subspecific- 
ally from its parent form, Salmo clarkii henshawi. It may be described as follows:

780(d). SALMO CLARKII TAHOENSIS, Jordan \& Evermann, new subspecies.

(Silver Trout of Lake Tahoe.)

Head $4 \frac{1}{15}$; depth $3 \frac{4}{5}$; eye $7 \frac{2}{8}$ in head. D. 9 ; A. 12; Br. 10; scales $33-205-40 ; 140$ pores. Pectoral $1 \frac{2}{8}$ in head; maxillary $1 \frac{2}{8}$. Body very robust, compressed, unusually deep for a trout, the outline elliptical. Head large, rather more compressed than in typical Salmo clarkii henshavi; eye small, silvery. Vomerine teeth in 2 long series, those of the 2 series alternating in position; hyoid teeth distinct, in a rather long series; gill rakers short, thickish, $5+13$. Mouth large, the maxillary extending well beyond the eye. Preopercle moderate, its lower posterior edge not evenly rounded, but with a slightly projecting, rounded lobe and a slight concavity above and below, this character not strongly marked; opercle evenly, but not strongly, rounded. Scales small, reduced above and below, those in or near lateral line largest. Fins moderate, the anal rather high, with 1 more ray than usual; caudal slightly lunate, almost truncate when spread open. Color dark green above, belly silvery; sides with a broad coppery shade covering cheeks and opercles; sides of lower jaw yellowish; fins olivaceous, a little reddish below; orange dashes between rami of lower jaw moderately conspicuous; back, from tip of snont to tail, closely covered with large, unequal black spots; spots on top of head and nape round; posteriorly the spots run together, forming variously shaped markings, usually vertically oblong; these may be regarded as formed of 3 or 4 spots placed in a series, or with 1 or 2 at the side of the other; the longest of the oblong markings not quite as long as eye; along side of head and body the spots are very sparse, those on head round, those behind vertically oblong; belly profusely covered with small black spots which are nearly round; still smaller round spots numerous on lower jaw; all the spots on caudal peduncle vertically oblong or curved; dorsal and caudal densely covered with oblong spots, smaller than those on the body; aual with rather numerous round spots; pectorals and ventrals with a few small spots, the first ray in each case with a series of faint small spots; adipose fin spotted. The above description from a specimen 2 feet 4 inches long and weighing $7 \frac{1}{2}$ pounds. This form attains a weight of 10 to 30 pounds and spawns only in the depths of the lake. Salmo clarkii henshawi reaches a much smaller size, is much darker in color, and spawns in the streams. Thus far known only from the deep waters of Lake Tahoe. (tahoensis, from Lake Tahoe.)

Salmo clarkii tahoensis, Jordan \& Everman, new subspecies, Lake Tahoe. (Coll. A. J. Bayley.)

Page 518. It is wholly uncertain where Valenciennes got the specimen which he called Thymallus ontariensis. It is probably the ordinary Grayling (Thymallus thymallus) of Europe, erroneously attributed to Milbert's New York collection. In any case, its identity with the Michigan (xrayling is more than doubtful, as the rivers in which the latter occurs were then unexplored. 'The American Graylings would therefore stand as follows: 
787. TIIYMLIUS SIGNIFER (Richardson).

(A rctic Grayling; Poisson Bleeu.)

789. THYMALLUS TRICOLOR, Cope.

(Michigan Graylixg.)

788(a). TIYMALLUS TRICOLOR MONTANUS (Milner).

(Montana Grayling.)

To the synonymy of the Montana Grayling add the following wholly unnecessary synonym:

Thymallus lewisi, HensHaLL, Forest and Stream, July 23, 1898, 70, headwaters Jefferson

River, Red Rock Lake, Montana; after notes of Lewis \& Clark.

Dr. J. C. Merrill, U. S. A., informs us that this Grayling is found also in Sun River at Fort Shaw, Montana.

Page 852. The species called Holocentrus marianus, Cuvier \& Valenciennes, is the type of a distinct genus:

382 (a). FLAMMEO, Jordan \& Evermann, new genus.

Flammeo, Jordan \& Everman,, new genus (marianus).

This genus is distinguished by the very large mouth and projecting chin. The lower jaw is considerably more than $\frac{1}{2}$ the length of the head, and the chin projects beyond the upper jaw. In the spccies properly referable to Holocentrus, the lower jaw is slightly included and its length is less than $\frac{1}{8}$ the head. The single known species of this genus is

1238. FLAMmeo mariands (Cuvier \& Valenciennes).

Page 858. In line 13 the interorbital space in Upeneus is said to be "concave;" this should, of course, read "convex."

Page 2013. Oligocottus maculosus, Girard, was evidently based on a specimen from the Farallones of the species called by us Oligocottus borealis, Jordan \& Snyder. The name maculosus must therefore be transferred to the latter species. The species called by us Oligocottus maculosus must therefore be renamed and may stand as

2381. OLIGOCOTTUS SNYDERI, Greeley, new species.

Oliyocottus snyderi, GreELEY, MS. 1898.

Page 2126, lines 13 and 14. The specimens from St. Paul Island and Petropaulski, referred by us to Liparis cyclostigma, Gilbert, belong to Crystallichthys mirabilis, Jordan \& Gilbert, described on page 2865.

Page 2626. Before Paralichthys astuarius, Gilbert \& Scofield, insert:

2991(a). Paralichthys magdiene, Abbott, new species.

Head $3 \frac{5}{6}$; depth $2 \frac{1}{5}$. D. 80 ; A. 64 ; scales 120 . Body oval-elliptical, the dorsal outline evenly bowed, the greatest depth in the middle of the body. 
Ventral outline straighter anteriorly. Mouth large; mandible somewhat projecting, about $1 \frac{1}{4}$ in head; maxillary large, extending considerably beyond orbit; snout (measuring from upper orbit) about 4 in head, $\frac{2}{8}$ length of eye; interorbital about $9 \frac{1}{2}$ in head; eye 6 in head. Teeth moderately strong, the anterior ones in the lower jaw somewhat larger than the others; gill rakers $7+17$, slender, weakly serrate, the longest a trifle less than eye. Scales cycloid, on cheeks, opercles and maxillary; snont, interorbital, and mandible naked; accessory scales present, especially prominent among the small crowded scales in the region below the pectoral; arch of lateral line $3 \frac{1}{2}$ in straight part; pores about $38+82$. Ventral $3 \frac{1}{2}$ in head; pectoral 2; dorsal beginning above anterior rim of orbit; middls rays of anal and dorsal longest, $2 \frac{1}{2}$ in head, equaling width of caudal peduncle; caudal double lunate, the middle rays the longest; pectoral of blind side rounded, $2 \frac{1}{2}$ in head. Color dark reddish brown, closely peppered with darker dots; a series of indistinct white spots, 4 or 5 in number, following margins of the body, as in $P$. californicus; traces of darker mottling along sides of body. Length 17 inches.

This species, represented by a specimen from Magdelona Bay, Lower California, is closely related to $P$. californicus, resembling it in the large number and close arrangement of the gill rakers, but differing from it in having cycloid scales, a greater number of fin rays, somewhat narrower interorbital, and greater depth in proportion to the length.

Paralichthys magdalena, Аввотт MS., new species, Magdalena Bay, Lower California. (Type, No. 10196, L. S. Jr. Univ. Mus. Coll. Charles H. Gilbert.)

Page 2627. Instead of Paralichthys adspersus (Steindachner), read :

2994. PARAICHTHYS SINALOE, Jordan \& Abbott, new species.

The specimens described in the text (from Mazatlan and La Paz), under the name Paralichthys adspersus, belong to a distinct species, thus far known only from the west coast of Mexico and Central America and which may be called Paralichthys sinaloce, one of the many specimens taken by the Hopkins Expedition at Mazatlan and La Paz being taken as type, and the following as cotypes: Nos. 11726, 11727, 11728, 11729, 11730, 11731, L. S. Jr. Univ. Mus., all from Mazatlan. Paralichthys adspersus is known only from the coast of Peru, the specimens before us being from Callao. (Coll. Admiral L. A. Beardslee.)

Paralichthys sinaloce is distinguished from $P$. adspersus by its cycloid scales and broader interorbital space. The gill rakers in $P$. adspersus are close-set, rather long and slender, about $\frac{8}{4}$ to $\frac{4}{5}$ of eye, and with rather slender spinules on the inner margin. In $P$. sinalow they are set farther apart on the limb of the gill arch, are shorter and thicker-about 2 in eye-and have the inner edge armed with coarser teeth. All specimens of $P$. sinaloce have each 14 or 13 gill rakers on the lower limb of the arch, while in 4 examples of $P$. adspersus, from Callao, there are 16 or 17 gill rakers on the lower limb (19 in 1 specimen), and 7 or 6 above ( 5 in 1 specimen), showing that while there may be variation in the number yet it is confined within limits which do not intergrade and the average number 
in the 2 species is quite different. In the single known specimen of $P$. woolmani the number of gill rakers given is $5+11$, which makes it probable that the present species is not the same. The more striking difference between $P$. adspersus and $P$. sinalow lies in the scales, which in the latter are cycloid, while in the true $P$. adspersus they are strongly toothed as stated by Steindachner. The specimens from Callao referred by us in the text to adspersus belong to that species, but they are not original types of adspersus, belonging to the later collections of Agassiz and Steindachner.

Paralichthys sinaloce, Jordan \& Aввотт MS., new species, Mazatlan, Sinaloa, Mexico.

(Type, No. 2930, L. S. Jr. Univ. Mus. Coll. Hopkins Exped. to Mazatlan.)

Page 686. After Platypœcilus maculatus add:

1009(a). Platipycilus QUitzeonisis, B. A. Bean.

Head $3 \frac{1}{2}$; depth $2 \frac{4}{5}$; eye $3 \frac{1}{4}$ in head; snout 4 ; interorbital width $2 \frac{2}{3}$. D. 13; A. 13; scales 30, 10 . Body compressed, back elevated, head small and lepressed, flat on top; suout short. Mouth small, cleft oblique, the lower jaw heavy, projecting; teeth conic, those in upper jaw in an irregular series, those below very small, apparently irregularly arranged and closeset. Origin of dorsal fin in advance of that of anal, midway between tip of upper jaw and end of caudal rays, the first ray of anal being under sixth dorsal ray. Color in alcohol light brown, with traces of darker on back; interorbital space and edge of scales dark brown; 3 dark bars on posterior part of body, the first extending from median line to origin of anal, the secoud from median line to end of anal base, the third midway between end of anal and origin of caudal; 2 dark spots on end of caudal peduncle; fins all pale. Lake Quitzeo, Michoacan, Mexico. Only the type known.

Platypcecilus quitzeoensis, B. A. Bean, Proc. U. S. Nat. Mus. 1898, 540, with text figure,

Lake Quitzeo, Michoacan, Mexico. (Type, No.48209. Coll. E. W. Nelson.) $3030-103$ 



\section{ARTIFICIAL KEY TO THE FAMILIES OF THE TRUE FISHES OR TELEOSTEI.}

The following key is intended simply to facilitate the identification of species of the true fishes. No attempt is made to indicate the natural characters or relations of the families, and only those species of any group which are included in the present work are taken into consideration. Most of the ordinary fishes can be readily placed by its means, but it should not be trusted in the study of ichthyological rarities, or of fishes from the deep seas.

\section{I.-VENTRAL FINS PRESENT, ABDOMINAL.}

A. Back with an adipose fin behind the single rayed dorsal fin.

B. Adipose fin composed of a single spine with a thin membrane; body mailed.................XXXV, LORICARIID 2 , 155.

BB. Adipose fin without spine.

C. Head with 4 to 8 long barbels about the mouth and nostrils; body scaleless; a single spine in each pectoral and in

CC. Head without barbels as described above. dorsal fin .....................XXXIV, SILURIDE, 115.

D. Sides of body without photophores or luminous glands; no barbel at throat.

E. Body scaleless; teeth very strong, some of them fang-like.

$\mathrm{F}$. Dorsal fin very long and high, occupying nearly whole length of back ..................... XXXI, ALEPISAURID $\$$, 593 .

FF. Dorsal fin short, median or posterior.

EE. Body scaly.

LXXXII, Odontostomatide, 597.

G. Pseudobranchiæ present.

H. Dorsal, anal, and ventrals each with a small but distinct spine; scales ctenoid.................... IV, Percopside, 783.

HH. Dorsal, anal and ventral without distinct spine.

I. Head naked.

J. Branchiostegals 6 to 20.

K. Dorsal fin long and high, of about 24 rays.

KK. Dorsal fin moderate, of fewer than 20 rays.

LXV, Thymallide, E17.

L. Stomach with many pyloric coeca.

LL. Stomach with few pyloric cæca; size small.

LXIV, SALMONID $2,460$.

JJ. Branchiostegals 3 or 4 ; mouth very small.

LXVI, ARgentinid A, 519.

II. Head scaly on sides.

LXVII, Microstomatida, 527.

M. Maxillary very narrow, rudimentary, or obsolete; hypocoracoids not divergent. ..............XVIII, SYNoDONTID $2,532$.

MM. Maxillary well developed, dilated behind; pectorals normal; hypocoracoids mostly divergent. LXIX, AULOPODIDE, 541.

GG. Pseudobranchiæ absent.

N. Pectorals normally formed, teeth incisor-like or else rudimentary; pseudobranchiæ absent...... XXXIX, CharacinID $2,331$. 
NN. Pectorals not normally formed.

O. Pectorals undivided, subhumeral; psendobranchiæ absent.

LXX, BENTHOSAURIDA, 543.

OO. Pectoral rays elongate, arranged in two groups.

LXXI, BATHYPTEROIDID $2,544$.

DD. Sides of body with photophores more or less developed.

P. Barbel at throat present, very long; body naked.

PP. Barbels none.

LXXXVIII, Astronesthid a, 586.

Q. Vertebral spines projecting through skin of back before dorsal fin; body short and deep, greatly compressed.

LXXXIV, STERNOPTYCHIDE, 603.

QQ. Vertebral spines not exserted in front of dorsal.

R. Pseudobranchia present.

S. Premaxillaries forming entire margin of upper jaw; body scaly ; opercles complete.

T. Form elongate, the snout pointed, barracuda-like; photophores very small................ LXXXIII, PARALEPIDID A, 599.

TT. Form oblong, the snout not much produced; photophores conspicuous.....................XXV, MYctopHIde, 550.

SS. Premaxillaries not forming the whole margin of upper jaw, the maxillary entering into it; body naked; opercular apparatus incomplete............ LXXVI, MAUROLOCIDE, 576.

RR. Pseudobranchiæ absent; mouth large, with canine teeth; scales deciduous or wanting... LXXVII, ChauliodonTIDA, 578.

AA. Back without adipose fin.

B. Back with a single dorsal fin made up of rays and not preceded by a series of free spines or followed by finlets.

C. Tail evidently strongly heterocercal.

D. Body naked; snout with a spatulate blade; mouth wide, withont barbels ....................XXX, PoLYONONTID 101.

$D D$. Body with 5 series of body shields; month, inferior, toothless,

$D D D$. Body scaly. preceded by 4 barbels ........XXXI, ACIPENSERIDE, 102.

$E$. Scales cycloid; a broad bony gular plate; dorsal fin many rayed.

$E E$. Scales ganoid; no gular plate; dorsal fin short.

XXXIII, AMIIDE, 112.

CC. Tail not evidently hetorocercal.

$F$. Tail tapering to a point, withont candal fin; anal fin very long, of about 200 rays; body scaly.

LXXXVI, HaLOSAURIDA, 606.

$F F$. Tail not tapering to a point; caudal fin developed.

$G$. Body naked.

$H$. Throat with a long barbel; no caudal filament; month large.

I. Barbel free at tip ....................XXXIX, STOMIID £, 587.

II. Barbel connecting throat with symphysis of lower jaw.

LXXX, Malacosteid a 592.

$H H$. Throat without barbel.

$J$. Caudal fin with a long filament; body elongate; mouth very

JJ. Caudal fin without filament.

$$
\text { small ......................... CI, FistulariId }
$$

$K$. Pectorals present.

$L$. Gill membranes joined to the isthmus; opercles complete.

XXXVII, CYPRINIDA, 199.

$L L$. Gill membranes free from isthmus; opercles incomplete.

LXXIII, RONDKLETID

$K K$. Pectorals wanting; body snake-like; dorsal long and low.

GG. Body scaly.

LXXXV, IDIACANTHID A, 604. 
M. Head with a large divided luminous plate in place of eyes.

LXXII, IPNOPID $\$$, 546 .

$M M$. Head with eyes concealed beneath the skin; vent at the throat.

MMM. Head with normally developed eyes. XCIII, AMBLYOPSIDE, 702.

$N$. Body with a coat of mail; maxillary with barbels.

$N N$. Body with ordinary scales.

XXXV, LORICARIID 155.

$O$. Anal fin with many spines; mouth toothless, sucker-like.

OO. Anal fin without distinct spines.

LXXXVIII, LIPOGENYID

$P$. Pectoral fins inserted high, near axis of body; lower pharyngeals united; lateral line along sides of belly.

Q. Jaws each with long sharp teeth mixed with smaller ones.

$Q Q$. Jaws with small equal teeth, conic or tricuspid.

XCIV, ESOCIDE, 708.

$R$. Lower jaw more or less produced; teeth tricuspid.

XCV, HeMIRAMPHID 718.

$R R$. Lower jaw a little produced; teeth conic; pectorals elongate, forming an organ of flight...... XCVII, ExOCGTID $1,726$.

$P P$. Pectoral fins inserted below axis of body; lower pharyngeals separate.

$S$. Gill membranes broadly joined to the isthmus; head naked; no teeth in jaws.

$T$. Lower pharyngeal teeth very numerous, in 1 row like the teeth of a comb. (Suckers.)........XXXVI, CATostomin \&, 161.

TT. Lower pharyngeal teeth few, fewer than 8, in 1 to 3 rows. (Carp; Chubs; Minnows.)............ XXXVII, CYPRINID As, 199.

SS. Gill membranes free from the isthmus.

$U$. Throat with a long barbel; sides with phosphorescent spots.

$U U$. Throat without barbels.

LXXIX, STOMIATIDA, 587.

$V$. Phosphorescent spots present; teeth unequal.

$V V$. Phosphorescent spots none.

LXXVII, Chauliodontide, 578.

$W$. Heal scaly, more or less.

$X$. Maxillaries connate with premaxillaries; jaws long.

XX. Maxillaries distinct.

LXVII, SYNODONTIDE, 532.

$Y$. Upper jaw not protractile, its lateral margins formed by the maxillaries; lateral line more or less developed.

Z. Teeth cardiform; jaws depressed, prolonged.XCI, LUCIID $2,624$.

$Z Z$. Teeth villiform; jaws short; no lateral line.

a. Pectoral very broad, of about 35 rays.. LXXXIX, DALIIIDE, 620.

aa. Pectoral narrow, of about 13 rays.......... XC, UMBRID $A, 622$.

$Y Y$. Upper jaw protractile, its margin formed by premaxillaries

$W W$. Head naked. alone; no lateral line............. XCII, PoCILIID E, 630.

a. Anterior vertebræ coalesced and modified; no pseudobranchiæ; jaws with strong canines...XXXVIII, ERYTHRINID A, 330.

aa. Anterior vertebræ normal, not modified.

b. Dorsal fin inserted more or less before anal (rarely slightly behind it); shore fishes or river fishes, usually silvery in coloration and with skeleton firm; air bladder well developed.

c. Gular plate present, between branches of lower jaw; mouth large; teeth present, all pointed; axillary scales and sheaths large..................... LVI, ÉLOPIDA, 408.

cc. Gular plate none.

d. Lateral line well developed.

e. Teeth present, no accessory branchial organ. 
$f$. Mouth small, horizontal; posterior part of tongue and roof of mouth covered with coarse-paved teeth.

LVII, Albuline, 410.

ff. Mouth large, the teeth all pointed, some of them canine, none paved or molar ................. LVIII, HiodonTID $2,412$.

$e e$. Teeth none; an accessory branchial organ behind gill cavity.

.dd. Lateral line wanting; no gular plate.

LIX, Chanide, 414.

$g$. Mouth small, inferior, toothless, the maxillary simple or nearly so; stomach gizzard-like........X, Dorosomatid s, 415.

gg. Mouth moderate, terminal, the maxillary of about 3 pieces; stomach not gizzard-like............ LXI, ClUPEID A, 417 .

ggg. Mouth subinferior, very large, below a tapering, pig-like snout; maxillary very long........... LXII, ENGRAULIDID

$b b$. Dorsal fin posterior, opposite anal; deep-sea fishes, of loose organization; mostly blackish in color; mouth small, with small pointed teeth; air bladder wanting.

$B B$. Dorsal fin single, preceded by free spines.

LXIII, Alepocephalid e, 451.

$h$. Body scaleless, naked or with bony plates.

$i$. Ventral fins I, 1 , the spine strong; snout moderate.

XCVIII, Gasterosteide, 742.

ii. Ventral fins, I, 5 , the spine slender; snout prolonged.

XCIX, AULORHYNCHID, 752.

hh. Body scaly; snout tubular ............. C, Aulostomid E, 754.

$B B B$. Dorsal fin composed of free spines; ventrals with 1 or 2 spines each; body elongate..... LXXXVII, NoTACANTHID $2,613$.

$B B B B$. Dorsal fins 2, the anterior of spines only, the posterior ehiefly of soft rays.

j. Pectoral fin with 5 to 8 lowermost rays detached and filamentous ......................... CIX, Polynemide, 827.

jj. Pectoral fin entire.

$k$. Snout tubular, bearing the short jaws at the end; body compressed .................. CII, MACRORHAMPHOSIDA, 758.

$k k$. Snout not tubular.

1. Teeth strong, unequal; lateral line present.

ll. Teeth small or wanting; lateral line obsolete.

CVIII, SPHYRANIDA, 822.

$m$. Dorsal spines 4, stout; anal spines 3...... CVII, MUGLLID E, 808. $m m$. Dorsal spines 4 to 8 , slender; anal spine single.

CVI, ATHERINIDe, 788.

$B B B B B$. Dorsal fin soft-rayed, followed by a series of detached finlets.

XCVI, SCOMBRESOCIDA, 724.

\section{II.-VENTRAL FINS. PRESENT, THORACIC OR SUBJUGULAR, THE NUMCBER OF RAYS DEFINITELY I, 5.}

A. Gill openings in front of the pectoral fins.

B. Body more or less scaly or armed with bony plates.

C. Ventral fins completely united; gill membranes joined to the isthmus; no lateral line..... CI.XXXVIII, GOBIDE, 2188.

CC. Ventral fins separate.

D. Suborbital with a bony stay, which extends across the cheek to or toward the preopercle; cheeks sometimes entirely mailed.

E. Pectoral fin with 3 lower rays detached and free; head bony.

CLXXXIV, T'RIGLID 2147.

EE. Pectoral fin with 2 lower rays detached and free; body mailed.

EEE. Pectoral fin entire.

CLXXXV, Perist:DiIDE, 2177.

F. Slit behind fourth gill small or wanting. 
G. Dorsal spines 4; lips fringed; eyes superior.

GG. Dorsal spines 8 to 17 .

CXCVII, URANOSCOPIDA, 2305.

H. Anal spines 3 ; body scaly......... CLXXVI, ScokPANID A, 1758.

HH. Anal spines obsolete; body partly or wholly naked.

FF. Slit behind fourth gill large; body scaled.

CLXXIX, CотTID a, 1879.

1. Nostril single on each side, a small pore above it; dorsal fin continuous........... CLXXVIII, HeXaGramMID 1863.

II. Nostrils 2 on each side; dorsal fins 2, separate, except in the genus Erilepis ......... CLXXVII, ANOPLOPOMATIDE, 1861.

DD. Suborbital stay wanting; cheeks not mailed.

J. Spinous dorsal transformed into a sucking disk on top of head, composed of 8 to 30 transverse plates.

CLXXXIX, ECHeNeIDID A, 2265.

JJ. Spinous dorsal (if present) not transformed into a sucking disk.

K. Dorsal spines all or nearly all disconneeted from each other.

L. Body elongate, spindle-shaped.. CXXVII, RACHYCENTRID

LL. Body oblong or ovate, compressed.

M. Caudal peduncle very slender, the fin widely forked; preopercle MM. Caudal peduncle stoutish, the fin little forked.

N. Gill membranes free from the isthmus; preopercle serrulate.

CXXXIV, Centrolophida, 962.

NN. Gill membranes broadly united to the isthmus; preopercle entire.

CLXIV, EPHIPPID As, 1666.

KK. Doŕsal spines (if present) all, or most of them, connected by membrane.

O. Pectoral fin with 4 to 9 lowermost rays detached and filiform.

OO. Pectoral fin entire.

CIX, POLYNEMIDE, 827.

P. Dorsal and anal each with 1 or more detached finlets.

Q. Anal preceded by 2 free spines.......... CXXV, Carangide, 895.

QQ. Anal not preceded by 2 free spines.

R. Caudal peduncle keeled............... CXVIII, SCOMBRID E, 863.

RR. Caudal peduncle not keeled................XXIX, GFMPYLID E, 877.

PP. Dorsal and anal withont finlets.

S. Lateral line armed posteriorly with a series of keeled plates; 2 free anal spines; gill membranes free from isthmus.

CXXV, CaRangide, 895.

SS. Lateral line armed posteriorly with a sharp, movable, lancetlike spine, or with a few bony tubercles; scales small, rough; gill membranes adherent to isthmus.

CLXVII, Teuthidide, 1688.

SSS. Lateral line unarmed.

T. Throat with 2 long barbels (placed just behind chin); dorsal

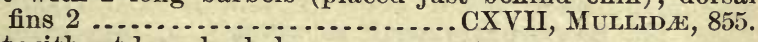

TT. Throat without long barbels.

U. Head with a short bony horn before each eye; gill membranes united to isthmus; scales very small, rough.

CLXVI, ZANCLID A, 1687.

UU. Head without bony prominence or horns.

$V$. Anal fin preceded by 2 free spines (these obsolete in the very old, joined by membrane in the very young).

W. Preopercle entire; teeth moderate if present.

CXXV, CarangIDas, 895.

WW. Preopercle serrate; teeth unequal, some of them very strong.

VV. Anal fin not preceded by free spines.

CXXVI, Pomatomide, 945.

$X$. Nostril single on each side; lateral line interrupted; lower pharyngeals united. 
Y. Anal spines 2.................. CLIX, Pomacentrid 1543.

YY. Anal spines 3 to 11. Fresh-water fishes.CLVIII, CICHLIDE, 1512.

XX. Nostril double on each side.

$Z$. Lateral line extending to tip of middle rays of caudal.

a. Anal spines 3 , the second strong.

b. Dorsal fins 2, separate; body elongate.

CXLV, Centropomida, 1116.

$b b$. Dorsal fin continuons..................... H A.MULID 1289.

aa. Anal spines 1 or 2 , the second large or small.

CLV, SCIANIDA, 1392.

ZZ. Lateral line not extending beyond base of caudal fin.

c. Gills $3 \frac{1}{2}$, the slit behind the last very small or wanting.

d. Mouth not vertical, the lips not fringed; dorsal tin continuous, the spines 8 to 18 ; scales cycloid; lower pharyngeals united.

e. Teeth in each side of each jaw united, forming a sort of beak.

CLXI, SCARID 1620.

$e e$. Teeth distinct or nearly so, the anterior usually more or less

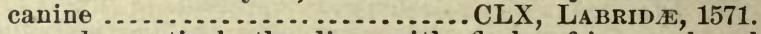

dd. Mouth nearly vertical, the lips with fleshy fringes; dorsal divided, the spinous part short, of about 4 spines; lower pharyugeals separate .... CXCVII, URANOSCOPID $\$, 2305$.

cc. Gills 4, a long slit behind the fourth.

$f$. Teeth setiform, like the teeth of a brush; body elevated, longer than deep, the soft fins completely scaled; gill membranes attached to the isthmus.

g. Dorsal fin continuous............ CLXV, Chætodontid 1669.

gg. Dorsal fin divided ................. CLXIV, EPHIPPID $1,1666$.

ff. Teeth not setiform.

$h$. Body deeper than long, covered with rough scales; dorsal spines 8 ; anal spines 3 ; soft fins very long.

hh. Body longer than deep.

CLXIII, CAPROID 1663.

i. Gill membranes broadly joined to isthmus; body long and low; no lateral line ............. CLXXXXII, GoBIID 2188.

ii. Gill membranes free from isthmus or very nearly so.

$j$. Premaxillaries excessively protractile, their basal process very long, in a groore at top of cranium.

$k$. Teeth small; scales large, silvery; spines strong.

CLIII, GerRID 1366.

$k k$. Teeth none; spines slender .............CLII, MÆNID 1364.

jj. Premaxillaries moderately protractile or not protractile.

l. Lower pharyngeals united; scales large; anal fin with 3 spines and more than 15 soft rays; preopercle entire. (Viviparous fishes of the Californian fauna:)

ll. Lower pharyngeals separate.

CLVII, Embiotocide, 1493.

$m$. Body elongate, not compressed, covered with hard grooved scales; jaws box-like.. CXXXVIII, TeTragonURID $A, 975$.

$m m$. Body not as above.

n. Lateral line incomplete or interrupted, running close to dorsal fin; dorsal spines very slender, continuous with the soft rajs; body low, covered with small scales; anal fin very long.

o. Anal rays fewer than 30 ; maxillary produced behind.

CXCI, OPISTHOGNATHIDE, 2279.

oo. Anal rays more than 30 ; maxillary not produced behind.

nn. Lateral line, if present, not as above.

CXCII, BATHYMASTERID 2287.

p. Scales circular, cycloid, nonimbricate, each with 1 or 2 erect spines; dorsal spines obsolete.

CXII, Stephanolerycide, 835. 
$p p$. Scales not as above.

$q$. Anal fin much longer than dorsal; body much compressed, the belly prominent.

$r$. Dorsal spines none; scales cycloid. . CXI, BathyCLUPEID 2,834 .

$r r$. Dorsal spines few, graduated; anal spines 3.

CXXXIX, Pempheridide, 977.

$q q$. Anal fin not much, if any, longer than dorsal.

8. Psendobranchire wanting or covered by skin.

$t$. Dorsal fin of soft rays, only beginning as a crest on the head; caudal widely forked. Pelagic tishes.

CXXIX, CORYPHANID A, 951.

$t t$. Dorsal fin with spines anteriorly; not beginning on the head. Fresh-water fishes.

$u$. Anal spines 3 to 10 .

$v$. Dorsal spines 6 to 12 ; lateral line well developed.

CXLI, Centrarchide, 984.

$v v$. Dorsal spines about 4 ; no lateral line; length less than 2 inches.

CXL, Elassomatid a, 981.

uu. Anal spines 1 or 2 ; body oblong or elongate; length less than 8

88. Pseudobranchia developed. inches...................... CXLIII, PERCID $A$, 1015.

$w$. Spinous dorsal of 2 or 3 short spines only; anal without spines; scales small, smooth......... CXLVI, SERranIDE, 1126.

$w w$. Spinous dorsal, if present, not as above.

$x$. Opercle ending in a long sealy flap; snont depressed, spatulate; mouth very large, the lower jaw projecting.

CXCIV, CHЕNICHTHYid 2293.

$x x$. Opercle not ending in a long scaly flap; snout not greatly depressed.

$y$. Pectoral fin broad, its lower rays thickened and not branched.

CLVI, Cirrhitid se, 1490.

$y y$. Pectoral rather narrow at base, its lower rays branched, like the others.

$z$. Dorsal fin continuous, the spines few, slender; maxillary usually with an enlarged tooth behind; nape sometimes with an adipose appendage; anal fin long, even.

CXC, Malacanthide, 2274.

$z z$. Dursal fin continuous or divided, not as above.

a. Perch-like fishes, the caudal peduncle not very slender, the scales well developed, etenoid or cycloid; the dorsal with distinct spines; the anal with at least 1 spine, its soft rays usually few.

b. Maxillary not sheathed by the preorbital, or only partially covered by the edge of the latter; ventral with its accessory scale very small or wanting; pectoral withont accessory scale; sheath at base of spinous dorsal little developed; vomer usually with teeth; opercle usually ending in a spine.

c. Precaudal vertebra with transverse processes from the third or fourth to the last; ribs all but the last 1 to 4 sessile, inserted on the centra behind the transverse processes; anal spines 3 ; species silvery in color, the dorsal deeply notched, with 10 spines; vertebræ $10+15=25$.

CXLII, KuHLIID A, 1013.

cc. Precaudal vertebrie normal, anteriorly withont transverse processes; all or most of the ribs inserted on the transverse processes when these are developed.

d. Anal spines 2 or 1 ; pseudobranchixe small; preopercle with a hook-like spine below; vertebræ increased in number $(30$ to 46). Fresh-water fishes....... CXLIII, PerCID A, 1015.

dd. Anal spines 2, rarely 3 ; vertebræ 24 or 25 ; dorsal fin divided. Marine fishes ........... CXLIV, CheIlodiPTERID A, 1105. 
ddd. Anal spines 3, never 2 nor 1 ; dorsal fin continuous or divided; vertebræ 24 to 35 .

$e$. Vomer, and usually palatines also, with teeth.

$f$. Anal fin shorter than dorsal; head not everywhere covered with rough scales; postocular part of head not shortened.

CXLVI, Serranid a, 1126.

$f f$. Anal fin scarcely shorter than dorsal and similar to it; head and body everywhere covered with rough scales; body deep, compressed, the posterior part of head shortened.

CXLViII, Priacanthin a, 1236.

$e e$. Vomer without teeth; dorsal fin continuous; body deep, com-

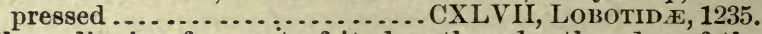

bb. Maxillary slipping for most of its length under the edge of the preorbital, which forms a more or less distinct sheath; ventrals with an accessory scale; opercle without spines; maxillary without supplemental bone; anal spines 3 , rarely 2.

g. Fishes carnivorous; intestines of moderate length; teeth in jaws not all incisor-like; vertebræ usually 24 or 25.

$h$. Vomer with teeth, these sometimes very small; maxillary long.

CXLIX, LuTIANID 1241. CXLIX, LuTIANID E, 1241.
tongue toothless.

$i$. Teeth on sides of jaws not molar; maxillaries formed essentially as in the Serranida; preopercle mostly serrate.

CL, HAMULID 1289.

ii. Teeth on sides of jaws molar; maxillaries peculiar in form and in articulation; anterior teeth conical or else more or less incisor-like; preopercle entire...CLI, SPARID.E, 1343.

gg. Fishes herbivorous; intestinal canal elongate; anterior teeth in jaws incisor-like; no molars or canines; premaxillaries moderately protractile..........CLIV, KYPHOSID E, 1380.

aa. Mackerel-like fishes, with the caudal peduncle usually very slender, the fin widely forked, the scales various, usually not ctenoid; the dorsal spines various, anal fin long.

$j$. Scales tirm, linear, parchment-like; body compressed; bones of head rough; dorsal spines few; month small.

jj. Scales not linear, mostly cycloid.

CXXXVII, GRAmmicolepidide, 973.

$k$. Dorsal spines numerous, most of them produced in long filaments; pectorals very long.. CXXIV, NwMATISTIID $2,894$.

$k k$. Dorsal spines mostly low, not more than 2 of them filameutous.

$l$. Dorsal fin very long, all the rays soft; skeleton soft.

ll. Dorsal fin with 3 or more spines.

CXXXVI, ICOSTEIDE. 968.

$m$. Dorsal fin divided, the spines 6 to 12 in number.

$n$. Scales weak, cycloid; jaws without canines.

CXXVIII, NOMEIDE, 948.

nn. Scales ciliate; jaws with canines... CXXVI, Pomatomid $2,945$.

$n n n$. Scales firm, each with a median ridge; no canines.

$m m$. Dorsal spines 3 or 4 , the fin not divided.

CXXX́III, STEINEGERIIDA, 960.

o. Scales minute, body oblong, the shoulder girdle moderate.

CXXXIV, CeNTrolophid 962.

oo. Scales rather large, firm; body broad, ovate, the shoulder girdle very strong................... CXXXII, BRAMID

BB. Body scaleless, smooth or armed with tubercles, prickles, or scattered bony plates.

C. Breast with a sucking disk.

D. Gill membrane free from the isthnus; no spinous dorsal; a large sucking disk between the ventral fins.

CXCIX, GobIesocid N, 2326. 
DD. Gill membranes joined to the isthmus; a sucking disk formed of the ventral fins.

E. Skin perfectly smooth; spinous dorsal not distinct.

CLXXXIII, LIPARIDIDE, 2105.

EE. Skin with tubercles or spines, or else with a distinct spinous dorsal.....................XXXII, CyCLOPTERIDE, 2094.

CC. Breast withont sucking disk.

F. Gill membranes broadly attached to the isthmus.

G. Ventrals completely united....... CLXXX VIII, GoBmde, 2188.

GG. Ventrals widely separated; body depressed; preopercle with a strong spine .......... CLXXXVII, CALLIONYMID E, 2184.

FF. Gill membranes nearly or quite free from the isthmus.

H. Anal preceded by 2 free spines (these lost with age; connected by membranes in the very young).. CXXV, CARANGID $A, 895$.

HH. Anal withont free spines.

I. Dorsal and anal fins followed by finlets. CXVIII, SCOMBRID E, 863.

II. Dorsal and anal without finlets.

J. Suborbital with a bony stay; no free anal spines.

JJ. Suborbital without bony stay.

CLXXIX, СотTID 1879.

K. Mouth very large, nearly horizontal, the teeth sharp; no pseudobranehice............. CXL'III, CHIASMODONTIDA, 2291.

KK. Mouth large, nearly vertical; body compressed; preopercle armed with spines .......... CXCV, TrICHODONTID $\approx$, 2295.

AA. Gill openings small, behind, above, or below the pectoral fins, which are more or less pediculate.

L. Gill openings in or behind upper axil of pectorals; mouth small. CCXXIV, OGCOCEPHAI.ID A, 2735.

LL. Gill openings in or behind lower axil of pectoral; mouth large.

M. Head compressed; no psendobranchix.

MM. Head depressed; pseudobranchise present.

CCXXII, ANTENNARIIDE, 2715. CCXXI, LOPHIIDA, 2713.

\section{III.-VENTRAL FINS PRESENT, THORACIC OR JUGULAR, THE NUMBER OF RAYS NOT DEFINITELY I, 5.}

A. Eyes nnsymmetrical, both on the same side of head.

B. Eyes large, well separated; edge of preopercle usually evident. CCXIX, Pleuronectide, 2602.

BB. Eyes small, very close together; edge of preopercle hidden by skin; mouth very small........... CCXX, SOLEID A, 2692.

AA. Eyes symmetrical, one on each side of the head.

C. Ventral rays with or withont spine, the number of soft rays more than 5 .

D. Caudal fin wanting; scales spinous . CCXV, MACrourId \&, 2561.

DD. Caudal fin well developed.

E. Tail isocercal, the vertebræ progressively smaller to base of candal; ventrals jugular; no spines in any of the fins.

F. Jaws and vomer with strong canines; second dorsal and anal deeply notehed; no barbel.. CCXIII, MerluCCIID \&, 2529.

FF. Jaws and vomer. without distinct cauines; chin usually with a barbel ...................... CCXIV, GADID 2531.

EE. Tail not isocercal, the last vertebra not redueed in size.

G. Ventral rays about 15 ; dorsal fin single, elevated.

GG. Ventral rays I, 3 or I, 5 ; dorsal very high.

CXXX, LAMPRIDIDA, 953.

CXXXi, Pteraclidida, 955.

GGG. Ventral rays I, 6 to I, 10; dorsal with spines. 
H. Vent anterior; dorsal spines 3 or 4 ; scales ctenoid.

HH. Vent normal.

CV, APHREDOderide, 785.

I. Chin with two long barbels, behind symphysis; dorsal continuous, with 5 spines ............. CXVI, PoLYMIXIID se, 854.

II. Chin without barbels.

J. Dorsal fin divided, the anterior part of a single slender spine; ventrals elongate....... CCXII, BREGMACEROTID $x, 2525$.

JJ. Dorsal fin divided, the anterior part of many spines.

K. Body covered with firm serrated scales; anal spines 4 ; dorsal spines not elevated............ CXV, HOLOCENTrID $\&, 845$.

KK. Body naked or covered with small scales, besides bony plates or warts ............................ CLXII, ZKIDE, 1659.

KKK. Body uniformly covered with eycloid scales; dorsal spines mostly very high and filamentous.

CXXIV, NeMATISTID E, 894.

JJJ. Dorsal fin continuous, its spines 2 to 8.

L. Suborbitals narrow, not covering the cheeks.

LL. Suborbitals very broad, covering the cheeks.

CXIV, BERYCID E, 837.

CXIII, 'TRaChichthyID A, 836.

CC. Ventral fins with or without spine, the number of soft rays fewer than 5 .

M. Gill opening before the pectoral fin.

N. Anal tin present; caudal fin not directed upward.

O. Upper jaw not prolonged into a sword.

P. Dorsal fin with some spines or simple rays.

Q. Dorsal fin without soft rays, composed of spines only.

CC, BLENNIID E, 2344.

QQ. Dorsal fin with soft rays anteriorly, with spines posteriorly; gill membranes joined to isthmus.. CCVI, ZOARCID N, 2455.

QQQ. Dorsal fin of spines anteriorly, with soft rays posteriorly.

R. Dorsal spines all separate and unconnected; body scaleless, naked, or with bony plates; ventral with a sharp spine. XCVIII, Gasterosteid a, 742.

RR. Dorsal spines connected by membrane.

S. Suborbital with a bony stay, extending across the cheek, to or toward the preopercle, the cheek sometimes entirely covered with a coat of mail.

T. Pectoral fin divided into 2 parts, 1 of them very long; head bony................ CLXXVI, Cephalacanthid $2,2182$.

TT. Pectoral fin not divided.

U. Body entirely covered with an armor of bony plates; head bony. CLXXXI, AGONIDE, 2031.

UU. Body naked, or more or less rough or scaly, not entirely covered by bony plates.

V. Gill opening very small, not extending below upper edge of pectoral; skin everywhere prickly; head very large, bony above................. CLXXX, RHAMPHOCOTTIDE, 2029.

VV. Gill opening large, extending downward nearly or quite to lowest pectoral ray............. CLXXIX, CoTTID 1879.

SS. Suborbital without bony stay.

W. Dorsal spines 2 to 4 only; head very broad, depressed; gills 3 ; gill membranes broadly united to the isthmus.

$x$. Ventrals each a strong spine; teeth incisor-like; scales shagreenlike.................. CLXVIII, TriacanthId Ee, 1697.

$x x$. Ventrals not reduced each to a single spine.

WW. Dorsal spines numerous; gills 4 .

CXCVIII, Batrachoididze, 2313.

$X$. Gill membranes separate, free from the isthmus.

Y. Body greatly elongate; lower jaw with a slit at base to permit free motion; lips not fringed. 
Z. Soft dorsal and anal with a distinct lobe anteriorly, distinct from spinous part............. CXIX, GEMPYLIDE, 877.

ZZ. Soft dorsal and anal without anterior lobe, continuous with spinous part.................. CXX, LEPIDOPODIDE, 884.

YY. Body moderately elongate; opercles and lips fringed; eyes supe-

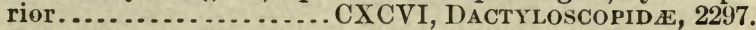

XX. Gill membranes broadly united, attached to the isthmus or not.

$x$. Gill opening moderate or large...........CC, BLENNIID \&, 2344.

$x x$. Gill opening's very small, reduced to oblique slits before the pectoral fins ...................... CIII, CERDaLIDE, 2448.

PP. Dorsal fins of soft rays only.

a. Breast with a large sucking dish between ventral fins.

aa. Breast without sucking disk.

CXCIX, Gobiesocide, 2326.

b. Body covered with a coat of mail; dorsal very short.

$b b$. Body not mailed; dorsal many-rayed.

CLXXXI, Agonide, 2031.

c. Lateral line and base of dorsal beset with prickles; skeleton very soft; body compressed ... CXXXVI, ICOSTEID \&, 968.

cc. Lateral line unarmed.

d. Tail isocercal, the vertebral column pointed behind, the last vertebræ very small; hypercoracoid not perforate; no pseudobranchix.

e. Caudal tin present........................ CXIV, GADID жs, 2531.

ee. Caudal fin wanting....................

dd. Tail not isocercal, truncate at base of caudal; hypercoracoid perforate.

$f$. Gill membraues joined to the isthmus; pseudobranchiæ present.

g. Ventral fins nnder shoulder girdle..... CCVI, ZoARCID $2,2455$.

gg. Ventral fins inserted below the eyes.

CCVII, DEREPODICHTHYIDA, 2480.

$f f$. Gill membranes free from the isthmus.

$h$. Ventral fins inserted below or before the eyes; pseudobranchix generally well developed .......CCVIII, OPHIDIID \&, 2481.

$h$. Ventral fins inserted below shoulder girdle; no pseudobranchix.

CCXI, BROTULIDE, 2498.

OO. Upper jaw prolonged into a bony sword; dorsal fin long and high ; size large ............. CXXII, IsTIOPHORID E, 890.

NN. Anal fin wanting; caudal fin distorted or directed upward; body ribbon-like.

$i$. Ventral fins each of a few slender rays.

CCXVII, TRACHYPTERIDAe, 2597.

ii. Ventral fins each reduced to a long slender filament.

MM. Gill openings behind the pectoral fins.

CCXVI, REgalecid 2595.

$j$. Gill openings above and behind pectorals; mouth small, low.

CCXXIV, OGCOCEPHALIDA, 2735.

jj. Gill openings below and behind pectorals; mouth large, nearly vertical .................CXXII, ANTENNARIID 2715.

\section{IV.-VEKTRAL FINS WHOLIY WANTING.}

A. Premaxillary and maxillary wanting or grown fast to the palatines; body greatly elongate, eel-shaped; gill openings restricted to the sicles; scales minute or wanting; scapular arch not attached to the skull. Eels.

B. Gill openings not very far behind cranium; gape not inordinately distensible; gill arches 4 pairs.

C. Gill openings well developed, leading to large interbranchial slits; tongue present; opercles and branchial bones well developed; scapular arch present. 
D. Skin eovered with rudimentary embedded scales, usually linear in form, arranged in small groups, and placed obliquely at right angles to those of the neighboring groups; peetorals and vertical fins well developed, the latter confluent about the tail; lateral line present; posterior nostril in front of eyes; tongue with its margins free.

E. Gill openings well separated; brauchiostegals long, bent upward behind.

F. Gill openings lateral and rertieal; snout conie, the jaws not very heavy; gape longitudinal; lips thick; lower jaw projecting; teeth in cardiform bands on jaws and vomer; eggs minute.................XIIII, ANGUILLID $E, 346$.

FF. Gill openings horizontal, inferior.

G. Snout very blunt, with very strong jaws; gape transverse; lips obsolete; teeth blunt, in 1 series, on jaws only.

XLIV, SIMENCHELYID $2,348$.

GG. Snout eonical and slender, the jaws of moderate strength; gape lateral; lips obsolete; tongue but little developed; teeth acute, in bands on jaws and vomer.

XLV, ILYOPIIDID $\mathrm{E}, 349$.

EE. Gill openings inferior, very elose together, apparently confluent; branchiostegal rays abbreviated behind; head eonieal; tongue small; posterior nostrils in front of eye.

XLVI, SYNAPHOBRANCHIDE, 350.

DD. Seales wholly wanting; eggs (so far as known) of moderate size, much as in ordinary fishes.

H. Tip of tail with a more or less distinct fin, the dorsal and anal fins confluent around it; the tail sometimes ending in a long filament. Coloration almost always plain, brownish, blackish, or silvery, the fins often black-margined.

I. Posterior nostril without tube, situated entirely above the upper lip.

J. Tongue broad, largely free anteriorly and on sides; vomerine teeth morlerate.

K. Pectoral fins well dereloped; body not excessively elongate; lower jaw not projecting; anterior nostril remote from eye .................... XLVII, LEPTOCEPHALID

JJ. Tongue narrow, adnate to the floor of the mouth or only the tip slightly free; vomerine teeth well developed, sometimes enlarged.

L. Jaws not attennate and reeurved at tip; gill openings well separated; anterior nostril remote from eye.

M. Pectoral fins well developed; skin thick; skeleton firm; snout moderate; tail not ending in a filiform tip.

XLVIII, Muranesocide, 358.

MM. Pectoral fins wholly wanting; snout and jaws much produced, the upper longer; jaws straight; skin thin and skeleton weak; tail ending in a filiform tip; gill openings small, subinferior; teeth sharp, subequal, reeurved, a long series on the vomer. Deep-sea eels, soft in body, black in color ................. XIIX, NetTAastomatide, 364 .

LL. Jaws long and slender, tapering to a point, recurved at tip; nostrils large, both pairs close in front of eye; gill open. ings convergent forward, separate or confluent; pectorals and vertieal fins well developed; membranes of fins thin, not enveloping the rays; skeleton well developed. Deepsea eels ....................... L, Nemichthyid A, 366.

II. Posterior nostril close to the edge of the upper lip; tongue more or less fully adnate to the floor of the mouth; teeth subequal............................. MY MID E, 370.

HH. Tip of tail without rays, projecting beyond the dorsal and anal fius (not filiform); posterior nostril on the edge of the 
upper lip; anterior nostril near tip of snout, usually in a small tube; tongue usually adnate to the floor of the mouth. Coloration frequently variegated.

LII, OPHICHTHYIDE, 372.

CC. Gill openings small, roundish, leading to restricted interbranchial slits; tongue wanting; pectoral fins (typically) wanting; opercles feebly developed; fonrth gill arch modified, strengthened, and supporting pharyngeal jaws.

N. Scapular arch obsolete or represented by cartilage; heart not far back; pectorals wanting; (skin thick; coloration often variegated ) ...................III, MURENIDE, 388 .

BB. Gill openings far behind cranium; gape of mouth inordinately distensible; gill arches 5 or 6 pairs; tail excessively long, tapering to a point.

O. Distance from gill opening to vent much greater than that from tip of snout to gill opening.

LIV, SACCOPHARYNGID $2,405$.

OO. Distance from gill opeuing to vent much less than from tip of snout to gill opening......... LV, EURYPHARYNGIDE, 406.

AA. Premaxillary and maxillary present, often immovably united to rest of cranium.

P. Gill openings united in a single slit below throat; no pectoral fins; body eel-shaped......... XLI, SYMBRANCHID 2 , 342.

PP. Gill openings not united in a longitudinal slit.

Q. Dorsal fin wanting; anal fin very long; vent near the head; candal obsolete; body band-like......XL, GYMNOTID E, 340.

QQ. Dorsal fin present.

R. Body eel-shaped, contracted at the neck; the vertical fins confluent around the tail; premaxillary and maxillary immovably united to the sknll...XLII, DERICHTHYIDE, 343.

RR. Body eel-shaped, ending in a long filament, longer than rest of body.

X. No anal or caudal fin.......... CCXVIII, STYLEPHORIDA, 2601.

XX. No caudal fin; anal present........ CCIV, PTILICHTHYIDE, 2451.

RRR. Body not truly eel-shaped.

S. Gill openings far behind pectoral fins; mouth oblique, very large; spinous dorsal represented by fleshy tentacles.

SS. Gill openings before pectoral fins.

CCXXIII, Ceratidne, 2727.

'1. Gill membranes broadly united to the isthmus, restricting the gill openings to the sides.

U. Snout tubular, bearing the short, toothless mouth at the end;

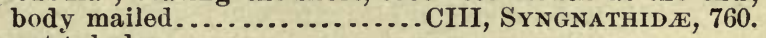

UU. Snout not tubular.

V. Breast without sucking disk.

W. Dorsal fin single, of spines or undivided rays only.

$\mathrm{X}$. Jaws and vomer with coarse molar teeth.

XX. Jaws and vomer without molars. CCII, Anarhicitadide, 2445.

Y. Mouth nearly vertical; dorsal spines slender, rather high.

CCI, CRYPTACANTHODIDE, 2442.

YY. Month not nearly vertical; dorsal spines moderate or low, some or all of them usually pungent..... CC, BIENNIIDE, 2344.

WW. Dorsal fins 2, the anterior of spines; the posterior of soft rays; body short and deep.

Z. Spinous dorsal of 2 or 3 spines; scales rather large, rough or bony ....................... CLIX, BALISTIDA, 1698.

ZZ. Spinous dorsal of 1 or 2 spines; scales minute, rough, forming a velvety covering.........CLXX, MONACANTHIDE, 1712 .

WWW. Dorsal fin continuous, of soft rays only.

a. Body oblong or elongate, the back not elevated; dorsal and anal joined to caudal. 
b. Pectoral rather narrow, the lower rays similar to the others.

CCVI, ZOARCID E, 2455.

$b b$. Pectorals very broad, the lower rays procurrent and produced at tip ................. CLXXXIII, LIPARIDID.E, 2105.

aa. Body short, not elongate; dorsal and anal free from caudal.

c. Teeth in each jaw confluen into 1.

d. Body compressed, rough ................ CLXXV, Molid E, 1752.

dd. Body not compressed, spinous .... CLXXIV, DIODONTIDE, 1742.

cc. Teeth in each jaw confluent into 2 .

$x$. Back broadly rounded.......... CLXXII, TETRAODONTID.E, 1726.

$x x$. Back with a sharp median ridge.

cce. Teeth separate; body enveloped in a bony box.

VV. Breast with a sucking disk.

CLXXI, Ostracinde, 1721.

e. Skin perfectly smooth; dorsal continuous or slightly notched.

ee. Skin more or less tuberevilar; dorsal usually divided.

CLXXXIII, LIPARIDID 210 .

T'T. Gill membranes free from the isthmus.

CLXXXII, CyCLOPTERID 2094.

$f$. Vent at the throat.

$g$. Vertical fins confluent; borly elongate, almost eel-shrped.

gg. Vertical fins separate; body oblong, scaly.

ff. Vent posterior, not at the throat.

XCIII, АмвLYOPSIDN, 702.

$h$. Candal fin wanting; body naked, greatly elongate.

hh. Caudal fin present.

CXXI, TRICHURID e, 888.

$i$. Upper jaw prolonged into a sword; size very large.

ii. Upper jaw not prolonged into a sword.

CXXIII, XIPHIDA, 893.

$j$. Belly with a series of bony scutes along its edge; body much coinpressed...................... LXI, CLUPEID s, 417.

ji. Belly not armed with scutes.

$k$. Mouth inordinately large, formed like the mouth of a whale, with sharp teeth; no scales... LXXIV, Cetomimide, 548.

$k k$. Mouth not inordinately large, not peculiar in form.

l. Body ovate, much compressed.

$m$ Scales small, cjcloid, silvery...... CXXXV, STromateid.e, 964.

$\mathbf{m m}$. Scales wanting; caudal peduncle very slender.

l. Body oblong or elongate, much longer than deep.

CXXXVI, ICOSTEID_E, 968.

n. Gill membranes broadly united; teeth present.

o. Dorsel fin of spines only.............. CC, BLEnnin . F, 2344.

oo. Dorsal fin of soft rays only; body eel-shaped.

CCV, SCyTalinid E, 2453.

ooo. Dorsal fin single, the posterior half of soft rays, the anterior of spines; body elongate, covered with small scales.

CC, BLenNiID I, 2344.

oooo. Dorsal fins 2, the anterior of slender spines, posterior soft, looly naked ..................... CLXXIX, CoTTID A, 1879.

nn. Gill membranes separate.

p. Jaws toothless, the lower jaw projecting; body scaly, with eross folds of skin..................... AX, AMMODYTID 8,831 .

pp. Jaws with teeth.

q. Body naked, withont folds of skin; no pseudobranchia.

CCIX, LYCODAPODID E, 2491.

$q q$. Body with small scales; pseudobranchia present; head with very large mucous pores; lower jaw very strong.

CXXXVIb, ZAPRORID 2849. 


\section{GLOSSARY OF TECHNICAL TERMS.*}

Abdomen. Belly.

Abdominal. Pertaining to the belly; said of the ventral fins of fishes when inserted considerably behind the pectorals, the pelvic bones to which the ventral fins are attached having no connection with the shoulder girdle.

Abortive. Remaining or becoming imperfect.

Actinosts. A series of bones at the base of the pectoral rays.

Acuminate. Tapering gradually to a point.

Acute. Sharp-pointed.

Adipose fin. A pecnliar, fleshy, fin-like projection behind the dorsal fin, on the backs of salmons, catfishes, etc.

Adult. A mature animal.

Airbladder. A sac filled with air, lying beneath the backbone of fishes, corresponding to the lungs of higher vertebrates.

Alisphenoid. A small bowe on the anterior lateral wall of the brain case. Amphicclian. Double concave; said of vertebræ.

Anadromous. Running up; said of marine fishes which run up rivers to spawn.

Anal. Pertaining to the anus or vent.

Anal fin. The fin on the median line behind the vent, in fishes.

Anchylosed. Grown firmly together.

Angular. A small bone on the posterior end of the mandible.

Antrorse. Turned forward.

Anus. The exterual opening of the intestine; the vent.

Arterial bulb. The muscular swelling, at the base of the great artery, in fishes.

Articular. The bone of the mandible supporting the dentary.

Articulate. Jointed.

Atlas. The first vertebra.

Atrophy. Nondevelopment.

Attenuate. Long and slender, as if drawn ont.

Auditory capsule. The ventrolateral swelling of the skull.

Barbel. An elongated fleshy projection, usually about the head, in fishes.

Basal. Pertaining to the base; at or near the base.

Basibranchials. A lower median series of bones of the branchial arches.

Basioccipital. A median posterior ventral bone of the skull to which the atlas is attached.

Basis cranii. Formed by shelves of bone developed from the inner sides of the prootics which meet and form a roof to the myodome and a floor to the brain cavity.

Bicolor. Two-colored.

Bicuspid. Having 2 points.

Brachial ossicles. Synonymous with actinosts, q. v.

Branchice. Gills; respiratory organs of fishes.

Branchial. Pertaining to the gills.

Branchihyals. Small bones at base of gill arches.

Branchiostegals. The bony rays supporting the branchiostegal membranes, under the head of a fish, below the opercular bones, and behind the lower jaw.

* In the preparation of this Glossary the authors are indelted to Mr. Edwin Chapin Starks for valuable assistance. 
Bristle. A stiff hair, or hair-like feather.

Buccal. Pertaining to the mouth.

Caducous. Falling off early.

Cacal: Of the form of a blind sac.

Cacum. An appendage of the form of a blind sac, connected with the alimentary canal at the posterior end of the stomach, or pylorus.

Canines. The teeth behind the incisors-the "eye-teeth;" in fishes, any conical teeth in the front part of the jaws, longer than the others.

Cardiform (teeth). Teeth coarse and sharp, like wool cards.

Carinate. Keoled; having a ridge along the middle line.

Carotid. The great artery running to the head.

Carpus. The wrist.

Catadromous. Running down; said of fresh-water species which run down to the sea to spawn.

Caudal. Pertaining to the tail.

Caudal fin. The fin on the tail of fishes and whales.

Caudal peduncle. The region between the anal and cauclal fins in fishes.

Cavernous. Containing cavities, either empty or filled with a mucous secretion.

Centrum. The body of a vertebra.

Cephalic fins. Fins on the head of certain rays; a detached portion of the pectoral.

Ceratobranchials. Bones of the branchial arches just below their angle.

Ceratohyal. One of the hyoid bones.

Chiasma. Crossing of the fibers of the optic nerve.

Chin. The space between the rami of the lower jaw.

Ciliated. Fringed with eyelash-like projections.

Cirri. Fringes.

Claspers. Organs attached to the ventral fins in the male of sharks, skates, etc.

Clavicle. The collar bone, or lower anterior part of shoulder girdle, not entering into socket of arm.

Compressed. Flattened laterally.

Condyle. Articulating surface of a bone.

Coracoid. The principal bone of the shoulder girdle in fishes; otherwise a bone or cartilage on the ventral side, helping to form the arm socket. Synonymous with hypercoracoid, q. v.

Cranial. Pertaining to the cranium or skull.

Ctenoid. Rough-edged; said of scales when the posteriur margin is minutely spinous or pectinated.

Cycloid. Smooth-edged; said of scales not ctenoid, but concentrically striate.

Deciduons. Temporary; falling off.

Decurved. Curved downward.

Dentary. The principal or anterior boue of the lower jaw or mandible, usually bearing the teeth.

Dentate. With tooth-like notches.

Denticle. A little tooth.

Depressed. Flattened vertically.

Depth. Vertical diameter (usually of the body of fishes).

Dermal. Pertaining to the skin.

Diaphanous. Translucent.

Distal. Remote from point of attachment.

Dursal. Pertaining to the back.

Dorsal fin. The fin on the back of fishes.

Emarginate. Slightly forked or notched at the tip.

Endoskeleton. The skeleton proper; the inner bony framework of the body. Enteron. The alimentary canal.

Epibranchials. The bones directly above the angle of the branchial arches.

Epihyal. One of the hyoid bones.

Epipleurals. Rays of bone attached to the ribs and anterior vertebrie usually touching the skin in the vicinity of the lateral line. 
Erectile. Susceptible of being raised or erected.

Ethmoid. A median anterior bone of the skull.

Exoccipitals. Two bones of the skull, 1 on each side of the foramen magnum.

Exoskeleton. Hard parts (scales, scutes) on the surface of the body.

Exserted. Projecting beyond the general level.

Extralimital. Beyond the limits (of this book).

Facial. Pertaining to the face.

Falcate. Scy the-shaped; long, narrow, and curved.

Falciform. Curved, like a scythe.

Fauna. The animals inhabiting any region, taken collectively.

Femoral. Pertaining to the femur, or proximal bone of the hinder leg.

Filament. Any slender or thread-like structure.

Filiform. Thread form.

Fontanel. An unossified space on top of head covered with membrane.

Foramen. A hole or opening.

Foramen magnum. The aperture in the posterior part of the skull for the passage of the spinal cord.

Forehead. Frontal curve of head.

Forficate. Deeply forked; scissors-like.

Fosse (nasal). Groves in which the nostrils open.

Frontal bone. Anterior bone of top of head, usually paired.

Fulera. Rudimentary spine-like projections extending ou the anterior rays of the fins of ganoid fishes.

Furcate. Forked.

Fusiform. Spindle-shaped; tapering toward both ends, but rather more abruptly forward.

Ganglion. A nerve center.

Ganoid. Scales or plates of bone covered by enamel.

Gape. Opening of the mouth.

Gill arches. The bony arches to which the gills are attached.

Gill openings. Openings leading to or from the branchise.

Gill rakers. A series of bony appendages, variously formed, along the inner edge of the ante rior gill arch.

Gills. Organs for breathing the $a^{\mathrm{i}} \mathrm{r}$ contained in water.

Glabrous. Smooth.

Glossohyal. The tongue bone.

Graduated (spines). Progressively longer backward, the third being as much longer than the second as second is longer than first.

Granulate. Rough with small prominences.

Gular. Pertaining to the gula, or upper foreneck.

Hamal arch. An arch under a hromal spine for the passage of a blood vessel.

Hamal canal. The series of hrmal arches as a whole.

Hamal spine. The lowermost spine of a caudal vertebra, in fishes.

Hamopophyses. Appendages on the lower side of abdominal vertebra, in fishes.

Height. Vertical diameter.

Heterocercal. Said of the tail of a fish when unequal; the backbone evidently running into the upper lobe.

Homocercal. Said of the tail of a fish when not evidently unequal; the backbone apparently stopping at the middle of the base of the caudal fin.

Humerus. Bone of the upper arm.

Hyoid. Pertaining to the tongue.

Hyoid apparatus. Formed by a series of bones extending along the inner side of the mandible and supporting the tongue.

Hyomandibular. A bone by which the posterior end of the suspensorium is articulated with the skull; the supporting element of the suspensorium, the mandible, the hyoid apparatus, and the opercular apparatus.

Hypercoracoid. The upper of the 2 bones attached to the clavicle, indirectly bearing the pectoral fin. 
Hypleural. The modified last vertebra supporting the caudal fin.

Hypobranchials. Bones of the branchial arches below the ceratobranchials. Hypocoracoid. The lower of the 2 bones attached to the clavicle bebind.

Hypohyals. Small bones, usually 4, by which the respective sides of the hyoid apparatus are joined.

Imbricate. Overlapping, like shingles on a roof.

Imperforate. Not pierced through.

Inarticulate. Not jointed.

Incisors. 'The front or cutting teeth.

Inferior pharyngeals. Synonymous with pharyngeals, q. v.

Infraoral. Below the mouth.

Interhomal spines. Elements supporting the anal fin.

Interhamals. Bones to which anal rays are attacbed, in fishes.

Interhyal. Upper hyoid bone attached to hyomandibular.

Intermusculars. Synonym of epipleurals, $q$. v.

Interneural spines. Elements supporting the dorsal fins.

Interspinous bones. The interneurals and the interhremals.

Intermaxillaries. The premaxillaries; the bones forming the middle of the front part of the upper jaw, in fishes.

Interneurals. Bones to which dorsal rays are attached, in fishes.

Interopercle. Membrane bone between the preopercle and the branchiostegals.

Interorbital. Space between the eyes.

Interspinals. Bones to which fin rays are attached (in fishes); inserted between neural spines above and hæmal spines below.

Isocercal (tail). Last vertebrio progressively smaller and ending in median line of caudal tin, as in the codfish.

Jugular. Pertaining to tho lower throat; said of the ventral fins, when placed in advance of the attachment of the pectorals.

Keeled. Having a ridge along the middle line.

Lacustrine. Living in lakes.

Lamella. Plate-like processes like those inside the bill of a duck.

Larva. An immature form, which must undergo change of appearance before becoming adult.

Lateral. To or toward the side.

Lateral line. A series of muciferous tubes forming a raised line along the sides of a fish.

Lateral processes. Synonym of parapophyses, q. v.

Laterally. Sidewise.

Lunate. Form of the new moon; having a broad and rather shallow fork.

Mandible. Under jaw.

Maxilla, or maxillary. Upper jaw.

Maxillaries. Outermost or hindmost bones of the upper jaw, in fishes; they are joined to the premaxillaries in front, and usually extend farther back than the latter.

Mesethmoid. Synonym of ethmoid, q. v.

Mesopterygoid. A bone of the suspensorium.

Metapterygoid. A bone of the suspensorium, or chain supporting the lower

Molars. The grinding teeth; posterior teeth in the jaw.

Muciferous. Producing or containing mucus.

Myocomma. A muscular band.

Myodome. Cavity under the brain cavity for the reception of the rectus muscles of the eye.

Nape. Upper part of neck, next to the oceiput.

Nares. Nostrils, anterior and posterior.

Nasal. Pertaining to the nostrils.

Nasal plate. Plate in which the nostrils are inserted.

Neural arch. An opening through the base of the neural spine for the passage of the spinal cord. 
Neural canal. The neural arches as a whole.

Neural processes. Two plates rising vertically, 1 on each side of the centrum of the vertebra, which unite toward their ends and form a spine.

Neural spine. The uppermost spine of a vertebra.

Nictitating membrane. The third or inner eyelid of birds, sharks, etc.

Notochord. A cellular chord which in the embryo precedes the vertebral column.

Nuchal. Pertaining to the nape or nucha.

Obsolete. Faintly marked; scarcely evident.

Obtuse. Blint.

Occipital. Pertaining to the occiput.

Occipital condyle. That part of the occipital bone modified to articulate with the atlas.

Occiput. Back of the head.

Ocellate. With eye-like spots, generally roundish and with a lighter border.

Oid (suffix). Like; as Percoid, perch-like.

Opercle, or operculum. Gill cover; the posterior membrane bone of the side of the head, in fishes.

Opercular bones. Membrane bones of the side of the head, in fishes.

Opcrcular flap. Prolongation of the upper posterior angle of the opercle, in sunfishes.

Opisthocolian. Concave behind only; said of vertebræ which connect by ball-and-socket joints.

Opisthotic. A bone of the skull to which the lower limb of the posttemporal usually articulates.

Orbicular. Nearly circular.

Orbit. Eye socket.

Osseous. Bony.

Ossicula auditus. Bones of the ear, in fishes.

Osteology. Study of bones.

Oviparous. Producing eggs which are developed after exclusion from the body, as in all birds and most fishes.

Ovoviviparous. Producing eggs which are hatched before exclusion, as in the dogfish and garter snake.

Ovum. Egg.

Palate. The roof of the mouth.

Palatines. Membrane bones of the roof of the month, 1 on each side extending outward and backward from the vomer.

Palustrine. Living in swamps.

Papilla. A small fleshy projection.

Papillose. Covered with papillæ.

Parapophyses. The lateral projections on some of the abdominal vertebræ to support ribs.

Parasphenoid. Bone of roof of mouth behind the vomer. Synonym of prefrontal.

Parietal. Bone of the side of head above.

Parotic process. A posterior lateral process of the skull formed by the pterotic and opisthotic.

Pectinate. Having teeth like a comb.

Pectoral. Pertaining to the breast.

Pectoral fins. The anterior or uppermost of the paired fins, in fishes, corresponding to the anterior limbs of the higher vertebrates.

Pelagic. Living on or in the high seas.

Pelvic giralc. The bones supporting the ventral fins or pelvics.

Pelvis. The bones to which the hinder limbs (ventral fins in fishes) are attached.

Perforate. Pierced throngh.

Peritoneum. The membrane lining the abdominal cavity. 
Pharyngeal bones. Bones behind the gills and at the beginning of the œsophagus of fishes, of various forms, almost always provided with teeth; usually 1 pair below and 2 pairs above. They represent a fifth gill arch.

Pharyngobranchials. Upper elements of the branchial arches, usually bearing teeth.

Pharyngognathous. Having the lower pharyngeal bones united.

Physoclistous. Having the air bladder closed.

Physostomous. Having the air bladder connected by a tube with the alimentary canal.

Pigment. Coloring matter.

Pineal body. A small ganglion in the brain; a rudiment of an optic lobe, which in certain lizards (and in extinct forms) is connected with a third or median eye.

Pituitary body. A small ganglion in the brain.

Plicate. Folded; showing transverse folds or wrinkles.

Plumbeous. Lead colored; dull bluish gray.

Polygamous. Mating with more than 1 female.

Postclavicle. A ray composed of 1 or 2 bones attached to the inner upper surface of the clavicle and extending downward.

Postorbital. Behind the eye.

Post-temporal. The bone, in fishes, by which the shoulder girdle is suspended to the cranium.

Pracoracoid. A portion of coracoid more or less separated from the rest.

Pracoracoid arch. An arch in front of the coracoid in most soft-rayed fishes.

Prefrontals. Bones forming lateral projections at the anterior end of the skull.

Premaxillaries. The bones, 1 on either side, forming the front of the upper jaw in fishes. They are usually larger than the maxillaries and commonly bear most of the upper teeth.

Premolars. The small grinders; the teeth between the canines and the true molars.

Preocular. Before the eye.

Preopercle. The membrane bone lying in front of the opercle and more or less nearly parallel with it.

Pieorbital. The large membrane bone before the eye, in fishes.

Procolian. Concave in front only.

Procurrent (fin). With the lower rays inserted progressively farther forward.

Projectile. Capable of being thrust forward.

Prootic. A bone forming an anterolateral ossification of the brain case.

Protractile. Capable of being drawn forward.

Proximal. Nearest.

Preudobranchice. Small gills developed on the inner sicle of the opercle, near its junction with the preopercle.

Pterotic. A bone at the posterior lateral process of the skull.

Pterygoids. Bones of roof of mouth in fishes, behind the palatines.

Pubic bones. Same as pelvic bones, q. v.

Pubis. Anterior lower part of pelvis.

Pulmonary. Pertaining to the lungs.

Punctate. Dotted with points.

Pyloric caca. Glandular appendages in the form of blind sacs opening into the alimentary canal of most fishes at the pylorus, or passage from the stomach to the intestine.

Quadrate. A bone of the suspensorium on which the mandible is hinged.

Quincunx. Set of 5 arranged alternately, thus

Radius. Outer bone of forearm. 
Ray. One of the cartilaginous rods which support the membrane of the fin of a fish.

Recurved. Curved upward.

Reticulate. Marked with a network of lines.

Retrorse. Turned backward.

Rudimentary. Undeveloped.

Rugose. Rough with wrinkles.

Sacral. Pertaining to the sacrum, or vertebræ of the pelvic region.

Scapula. Shoulder blade; in fishes, the bone of the shoulder girdle below the post-temporal.

Scapular arch. Shoulder girdle.

Scute. Any external bony or horny plate.

second dorsal. The posterior or soft part of the dorsal fin, when the two parts are separated.

Septum. A thin partition.

Serrate. Notched, like a saw.

Sessile. Without a stem or peduncle.

Setaccous. Bristly.

Setiform. Bristle-like.

Shaft. Stiff axis of a quill.

Shoulder givdle. The bony girdle posterior to the head, to which the anterior limbs are attached (post-temporal, scapula, and coracoid or clavicle).

Soft dorsal. The posterior part of the dorsal fin in fishes, when composed of soft rays.

Soft rays. Fin rays which are articulate and usually branched.

Spatulate. Shaped like a spatula.

Sphenoid. Basal bone of skull.

Sphenotic. A lateral bone of the skull.

Spine. Any sharp projecting point; in fishes those fin rays which are $\mathrm{un}$ branched, inarticulate, and usually, but not always, more or less stiffenerl.

Spinous. Stiff or composed of spines.

Spinous dorsal. The anterior part of the dorsal fin when composed of spinous rays.

Spiracles. Openings in the head and neck of some fishes and batrachians.

Stellate. Star-like; with radiating ridges.

Striate. Striped or streaked.

$S u b$ (in composition). Less thun; somewhat; not quite; under, etc.

Subcaudal. Under the tail.

Subopercle. The bone immediately below the opercle (the suture connecting the two often hirlden by scales).

Suborbital. Below the eye.

Suborbital stay. A bone extending from one of the suborbital bones in certain fishes, across the cheek, to or toward the preopercle.

Subulate. Awl-shaperl.

Superciliary. Pertaining to the region of the eyebrow.

Superior pharyngeals. Synonym of pharyngobranchials, q. v.

Supplemental maxillary. A' small bone lying along upper edge of the maxillary in some fishes.

Supraclavicle. A bone interposed between the clavicle and the posttemporal.

Supraoccipital. The bone at posterior part of skull in fishes, usually with a raised crest above.

Supraoral. Above the mouth.

Supraorbital. Above the eye.

Suprascapular. The post-temporal or bone by which the shoulder girdle in fishes is joined to the skull.

Suspensorium. 'The chain of bones from the hyomandibular to the palatine.

Suspensory bones. Bones by which the lower jaw, in fishes, is fastened to the skull. 
Suture. The line of union of 2 bones, as in the skull.

Symphysis. Point of junction of the 2 parts of lower jaw ; tip of chin.

Symplectic. The bone in fishes that keys together the hyomandibular and quadrate posteriorly.

Synonym. A different word having the same or a similar meaning.

Synonymy. A collection of different names for the same group, species, or thing; "A burden and a disgrace to science." (Coues.)

Tail. In fishes (usually), the part of the body posterior to the anal fin. (Often used more or less vaguely.)

Temporal. Pertaining to the region of the temples.

Terete. Cylindrical and tapering.

Terminal. At the ond.

Tessellated. Marked with little checks or squares, like mosaic work.

Thoracic. Pertaining to the chest; ventral fins are thoracic when attached immediately below the pectorals, as in the perch, the pelvic bones being fastened to the shoulder girdle.

Transverse. Crosswise.

Trenchant. Compressed to a sharp edge.

Truncate. Abrupt, as if cut squarely off.

Tubercle. A small excrescence, like a pimple.

Type (of a genus). The species upon which was based the genus to which it belongs.

Type (of a species). The particular specimen. upon which the original specific description was based.

Type locality. The particular place or locality at which the type specimen was collected.

Typical. Of a structure the most usual in a given group.

Ultimate. Last or farthest.

Unicolor. Of a single color.

Vent. The external opening of the alimentary canal.

Ventral. Pertaining to the abdomen.

Ventral fins. The paired fins behind or below the pectoral fins in fishes, corresponding to the posterior limbs in the higher vertebrates.

Ventral plates. In serpents or fishes, the row of plates along the belly between throat and vent.

Ventricle. One of the thick-walled chambers of the heart.

Versatile. Capable of being turned either way.

Vertebra. One of the bones of the spinal column.

Vertical. Up and down.

Vertical fine. 'The fins on the median line of the body; the dorsal, anal, and caudal fins.

Villiform. Said of the teeth of fishes when slender and crowded into velvety bands.

Viscous. Slimy.

Viviparous. Bringing forth living young.

Vomer. In fishes, the frost part of the roof of the mouth; a bone lying immediately behind the premaxillaries.

Zygapophyses. Points of bone affording to the vertebra more or less definite articulation with each other. 


\section{N D E X.}

abacurus, Eleotris..................

Page.

2200

1184

764

524

95

900

1496

1497

1497

1497

1193

1136

1136

1635

1635

2240

2241

2195

2236

2240

2241

249

Abramidopsis.

Abramis

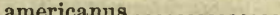

balteatus .................

crysolencas ...............

bosci..........

gardoneus ................

lateralis .................

leptosomus ...............

occidentalis...............

versicolor.

Abudefduf

analogio

declivifrons

rudis ..................

saxatilis ................

taurus ..................

abyssicola, Raja ..................

acadian, Cottus

acadianus, Glyptocephalus..........

Hemitripterus ...........

Acantharchus.

pomotis..............

Acanthias........................

americanus .............

blainvillei ..............

sucklii..................

vulgaris . acanthias, Squalus.................

Page.

Acanthidium.................... 55

pusillum ............ $\quad 55$

Acantbinion .................. 939

rhomboides .......... 942

acanthistius, Bodianus............ 1147

Acanthochætodon................ 1682

Acanthoclinus .................. $\quad 2374$

chaperi........... 2375

Acanthocottus ................. 1970, 1971

labradoricus ........ 2001

laticeps ............ 1989

mucosus ........... 1975

ocellatus........... 1976

patris ............. 2009

profundorum........ 1991

sellaris............. 1998

variabilis .......... 1975

virginianus........ 1976

Acanthocybiinæ ................ 865

Acanthocybium .................. 876

petus............ $\quad 877$

solandri .......... $\quad 876$

250 Acanthoderma............... 879, 1713

239 temminkii ......... 880

250 acanthoderma, Thyrsites ........... 880

251 Acantholabrus exoletus........... 1576

251 Acantholebius.................. 1866

$239 \quad$ nobulosus........... 1872

250 Acantholepis.................... 525

247 Acanthonotus.................. 614

250 nasus.............. 615

1560 acanthophorus, Serranus .......... 1196

1563 Acanthopteri .................. 779, 1241

1562 Acanthorhinus................... 53

1563 Acanthosuma ................... 1753

$1561 \quad$ carinatum ........... 1754

1563 Acanthostracion ........... 1721, 1722, 1724

76,2751 polygonius ....... 1725

2023 Acanthurus.................... 1689

2657 aliala................ 1694

2023 bahianus............ 1693

$989 \quad$ brevis............... 1691

989 broussonetii.......... 1691

$53 \quad$ cæruleus............. 1691

$54 \quad$ chirurgus .............. 1692

57 glaucoparcius........ 1694

$54 \quad$ hepatus.............. 1692

$54 \quad$ hirundo .............. 1691

4

(1)

(1)

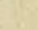




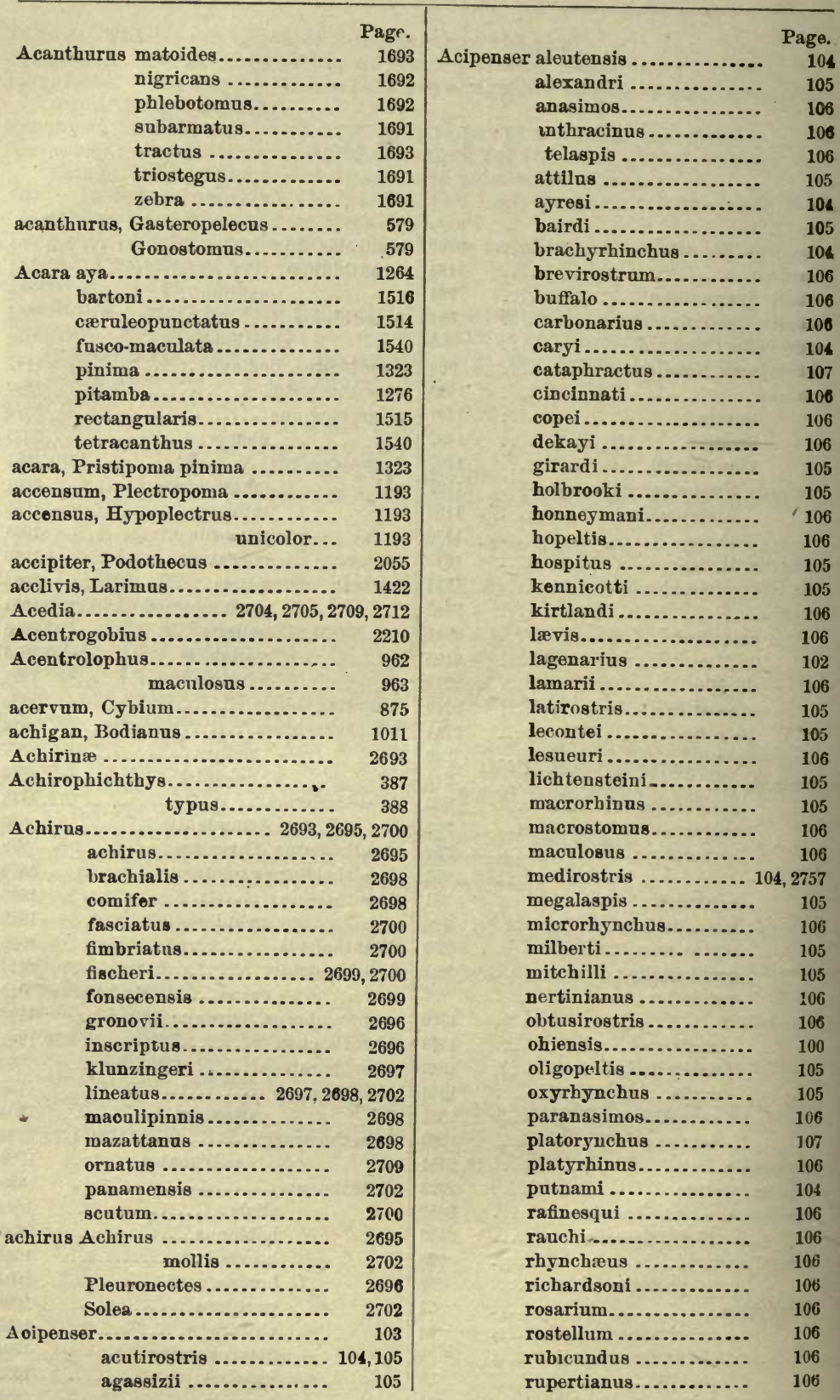




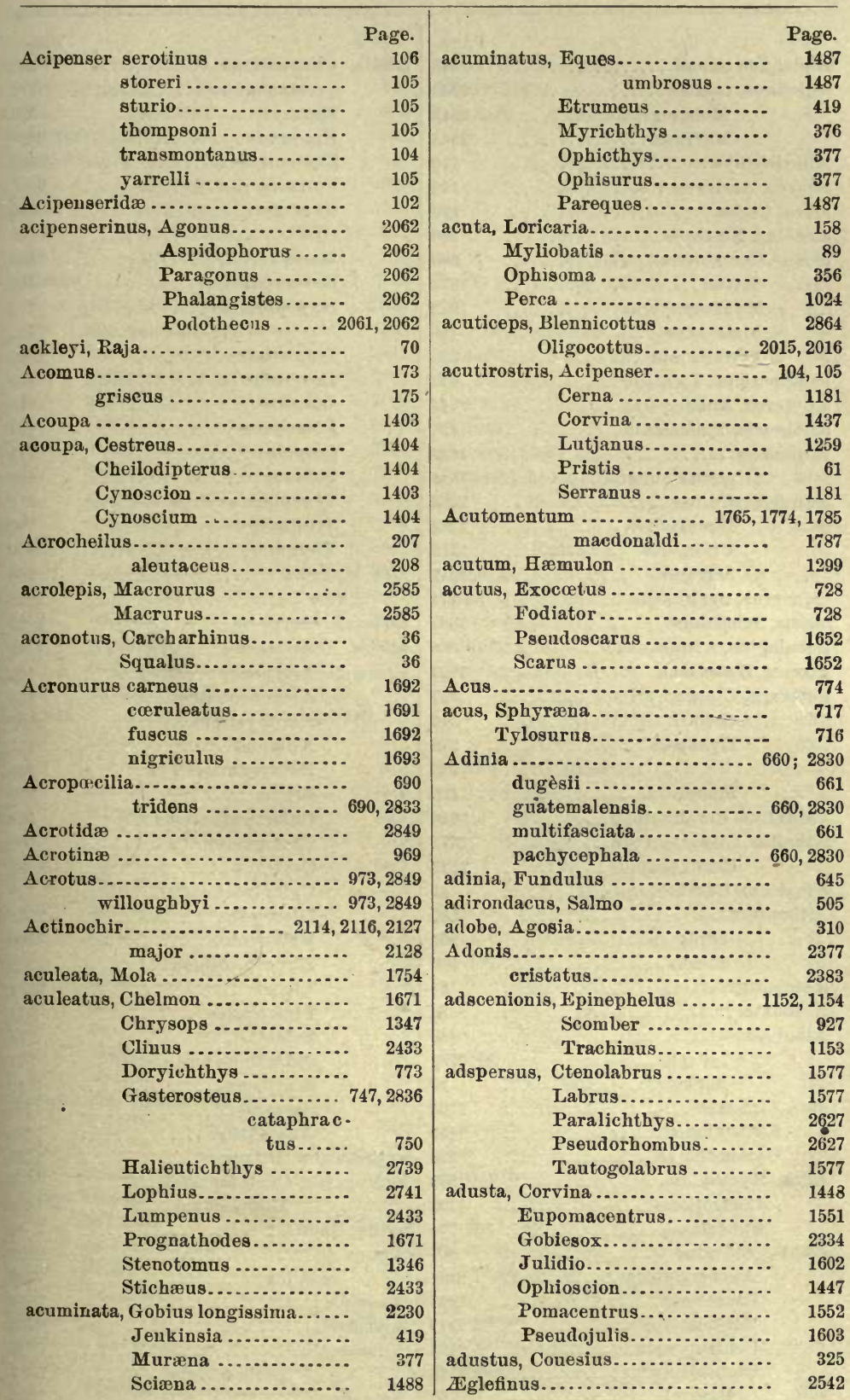


Eglefinus linnæi

Page.

2543

rglefinus, Gadus

Melanogrammus...... 2542. 2543

Morrhua

2542.2543
2543

Elurichthys ....................

alurus, Amiurus.................

ænea, Cichla .....................

æneolus, Notropis.................

æneus, Centrarchus ................

Cottus ......................

Myoxocephalus.............

Pimelodus .................

Tetragonopterus...........

ænigmaticus, Icosteus .............

æpyterus, Ammocœtes .............

æquatoris, Talismania .............

Equidens ..........................

cærulopunctatus ........

aquidens, Culius.

Eleotris :................

Prionodes ................

Serranus ...............

æqnoreus, Syngnathus............

areus, Sebastodes.

asculapius, Alepisaurus ....

æsopus, Boleosoma................

gestivalis, Clupea..................

Gobio....................

Hybopsis ...............

marconis ......

Pomolobus...............

æstuarius, Paralichthys............

æthalion, Citharichthys...........

Hemirhombus ...........

gethalorus, Carcharhinus ...........

Ethoprora .......................

effulgens...............

lucida.............

Aetobatinæ .....................

A tobatis ........................

Aetobatus .......................

laticeps.............. 88, 2753

narinari ..............

afer, Alphestes....................

- Epinephelus.................

Gymnothorax...............

affine, Myctophum ................

Plectropoma................

Siphostoma ...............

affinis, Atherinops................

Auchenopterus ............

Carapus...................

Caulolatilus .............

Centropomus .............

Cheilodipterus............

Climæra..................
116

140

990

266

990

1973

1972

143

333

972

11

456

1513

1514

2202

2202

1210

1211

774

1807

595

1057

427

316

316

316

426

2626

2673

2673

40

565

566

565

88

88

88

$\begin{array}{r}88 \\ \hline\end{array}$

1164

1165

395

570

1193

769,770

807

2371

2497

2277

1124

1113

95 affinis, Clinostomus ..............

Page.

Cremnobates.............. 2372

Esox ................... 628

Exocœtus ............... 735, 2836

Exonautes ............... 2836

Fierasfer................. $\quad 2495$

Gambusia................ 680

Gila ..................... 228

Heros.................. 1529

Heterandria.............. 681

Hypoplectrus ............. 1193

unicolor..... 1193

Isopisthus . . . . . . . . . . . . 1399

Leuciscus ................ $\quad 240$

Lucania................. 665

Pimelodus ................ 134

Scopelus ................. 571

Stomias ................. 588

Synaphobranchus........ $\quad 351$

Syngnathus.............. $\quad 769$

Thynnus................ 869

afra, Muræna .................. $\quad 396$

Perca ...................... 1833

africana, Scorprena............... 1833

afrum, Plectropoma.............. 1166

agassizii, Acipenser .............. 105

Alepocephalus.......... 453

Amphysticus........... 1502

Aulopus................ 541

Bathysaurus........... $\quad 540$

Brama............... 959

Chlorophthalmus ........ 541

Chologaster............. 704

Cratinus............... 1188

Cylindrosteus .......... $\quad 111$

Dicromita ............. 2506

Holconotus ............. 1506

Hvperprosopon......... 1502

Liparis ............... 2121

Pimephales............ 217

Salmo................. 507

Salvelinus fontinalis..... $\quad 507$

Scorpæna.............. 1840

Serranus............... 1189

Xenichthys............. 1287

aggregatum, Ditrema............ 1499

aggregatus, Cymatogaster......... 1498

Micrometrus......... 1499

agilis, Gadus................... 2534

Agnus........................ 2306

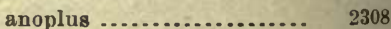

A gronidie ...................... 2031

$\Delta$ goninæ ...................... 2033

A gonomalus ................... 2036

proboscidalis ........ 2037

Agonopsis ..................... 2068 
Agonopsis chiloensis

A gonostoma globiceps ............

nasutum ..............

A gonostominæ.

Page.

2069

821

820

809

818

A gonostomns ....................

microps ............

monticola...........

nasutus ...... $819,2840,2841$

percoides.

820

819

819

2064

2062

acipenserinus ............

annæ

2043

barkani.................. 2044

cataphractus ........... 2065, 2067

chiloensis............... 2069

curilicus ............... 2036

decagonus................

dodecaedron.............

gilberti..................

japonicus.................

lævigatus ................

niger ....................

quadricornis ............

rostratus ..................

spinosissimus ............

stegophthalmus...........

volsug.

A gosia.................... 308, 309, 313

adobe ................ $\quad 310$

chrysogaster ............. 313

couesii .................. $\quad 310$

falcata ................ 313

shuswap......... 313

metallica................ $\quad 314$

nevadensis .............. 310

novemradiata ........... 312

nubila.................. 311, 312

carringtonii....... 311

oscula.................. 309

shuswap ............... 313

umatilla................ 313

velifera ................ $\quad 212$

yarrowi............... $\quad 309$

agua-bonita, Salmo irideus........ 503

mykiss....... 504

Aguaji.

1174,1177

aguaji, Trisotropis............... 1175

Aguja Blanca.................... 892

de Casta................ 715, 892

de Paladar .............. 892

Prieta................... 891

Voladora................. 891

Agujon ..................... 714, 715, 716

Agulha, Peixe.................... 711

Ahlia

egmontis aigula, Lachnolaimus.............

Ailurichthys......................

bagre

eudouxii............ 118

filamentosus ........ $\quad 118$

gronovii ............ $\quad 117$

longispinis.......... 119

marinus............ 118

nuchalis ........... 117

panamensis ......... $\quad 117$

pinnimaculatus ...... $\quad 117$

ailurus, Pimelodus............... $\quad 140$

Aimaras ...................... $\quad 330$

aix, Pallasina .................. $\quad 2050$

Aka nevo ....................... 1833

Aka soi ......................... 1830

Alabama Sharl .................. 2810

alabamæ, Alosa ................. $\quad 2810$

Etheostoma ........... 1095

whipplei ... 1095

Notropis .............. 298

Alalonga, Albacora ............. $\quad 871$

alalonga, Orcynus ................ 871

Ala-lunga.................... 871

alalunga, Germo................. 871

alascanus, Ammodytes .......... $\quad 832$

Argyrosomus ......... 2817

Sebastolobus........... 1761

Xenochirus ............ 2081

Alaska Blacktishes ............. 620,621

Codfish.................. 2541

Dab.................... $\quad 2645$

Dog salmon ............. 478

Greenfish ................ 1869

Stickleback .............. $\quad 749$

Alaskan Pollacks ................ 2535

alatunga, Scomber .............. $\quad 871$

alatus, Arius ................... 125

Lampanyctus............ $\quad 559$

Mugil .................. $\quad 733$

Prionotus ............... 2159

Alausa..................... 427

californica .............. 423

striata................. 431

Alausella ..................... $\quad 424$

alba, Rogenia................... 422

Albacora ....................... $\quad 869$

alalonga.............. 871

thynnus.............. 870

albacora, Thynnus.............. 871

Albacore, Great................ $\quad 870$

Long-finned ........... 871

Albacores....................... 870

albacores, Scomber ............... $\quad 870$

Albatrossia ................... $\quad 2573$

pectoralis........... 2573 
Page.

albatrossis, Osmerus ............. 2823

albeolus, Notropis megalops.... 259, 283, 284

albescens, Echeneis ............... 2272

Remora................ $\quad 2272$

albicans, Bagrus................. 124

Sciadeichthys........... 124, 2760

Tachisurus ............. 124

albicauda, Echeneis ............... $\quad 2269$

albidactylus, Exocœetus ........... $\quad 739$

albidum, Hæmulon............... 1299

Moxostoma............. 192

albidns, Amiurus................ 138

Gadus .................. 2531

Ictalurus................ 138

Labrax.................. 1132

Osmerus ................. $\quad \mathbf{5 3 8}$

Pimelodus ............... 132, 138

Ptychostomus ............ 192

Tetrapturus .............. 892

albigutta, Cathetostoma........... 2313

Kathetostoma.......... 2312

albiguttus, Paralichthys .......... 2631

albirostre, Siphostoma ........... $\quad 772$

albirostris, Corythroichthys ...... 772, 2838

Prionotus............. 2163

Syngnathus .......... $\quad 772$

albolineatus, Fundulus............ $\quad 649$

albomaculatus, Paralabrax........ 1197

Serranus .......... 1197

Albramis oligaspis.............. 294

Albula ....................... 411, 2807

conorynchus ............... 411

erythrocheilos.............. $\quad 412$

fosteri.................... 412

goreensis................ 412

neoguinaica ............. $\quad 412$

parræ ................... 411

rostrata................. 412

seminuda............... $\quad 412$

vulpes.................... 411

albula, Mugil................... 812, 2841

Albulidæ...................... $\quad 410$

albulus, Bryttus................. $\quad 1007$

Lepomis................ 1007

album, Hæmulon. ............. 1295, 1296

Moxostoma.............. 191

Alburnellus................... 254

altipinnis............ 287

amabilis............... 291

amœnus............. $\quad 296$

arge

jaculus.............. 293

jemezanus............ 294

matutinus............ 301

megalops............. 291

micropteryx.......... 297
Alburnellus percobromus .......... Page.

rubrifrons............ 295

simus ............... $\quad 267$

umbratilis............ 299

Alburnops .................. 254, 256, 261

blennius............... 262

heterodon .............. 261

illecebrosus ............ $\quad 269$

longirostris............ $\quad 267$

nubilus............... $\quad 215$

plumbeolus ............ $\quad 283$

saludanus ............. $\quad 270$

shumardi............. $\quad 268$

taurbcephalus .......... $\quad 253$

Alburnus amabilis ................ 291

americanus............. 1475

dilectus................ 294

formosus .............. $\quad 280$

lepidulus ............... 294

lineolatus............... 263

megalops ............... 291

nitidus ................ 293

oligaspis............... 294

rubellus................ 293

rubrifrons .............. 295

socius ................ 292

umbratilis.............. 299

zonatus................. 285

alburnus, Centropomus ........... 1475

Menticirrhus........... $\quad 1475$

Perca.................. 1475

Umbrina .............. 1475

albus, Atherinichthys............. 2839

Centropomus............... 1135

Cestreus .................. 1411

Coregonus.................. $\quad 466$

Crnoscion.................. 1411

Gymnotus................ $\quad 340$

Lepisosteus ............... $\quad 110$

Otolithus.................. 1411

Ptychostomus.............. 191

Alcidea .......................... 1886

thoburni ................ 1887

Aldrovandia .................. 608, 2826

goodei .............. 610

gracilis ............... 610

macrochir ........... 609

pallida $\ldots . . . . . . . . . . .6 \quad 611$

rostrata ............. 609

Alecrin ....................... 32

Alectis ......................... 931

ciliaris .................. 931

crinitus................... 932

Alectrias....................... 2869

alectrolophus, Anoplarchus.. 2421, 2422, 2869

Blennius ............ 2422

Centronotus ......... 2422 


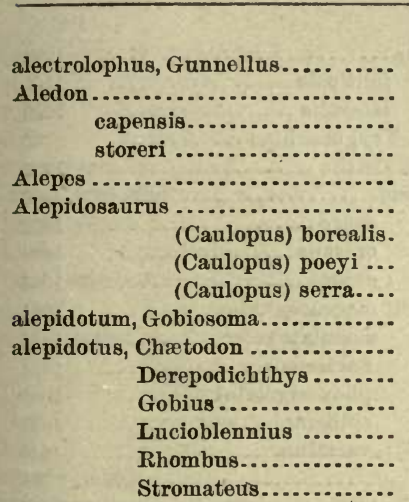

Alepisauridæ

Stromateurs.

Alepisaurus

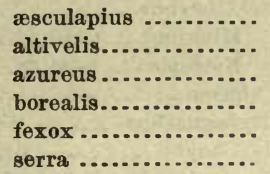

Alepocephalidæ

Alepocephalus

agassizii ...........

bairdii .............

macropterus ........

productus...........

tenebrosus ..........

Aleposomus.......................

copei ...................

aleutensis, Acipenser ..............

Lyconectes ..............

Alevitera .........................

aleutianus, Sebastodes..............

aleutica, Raja................... 75

aleuticus, Cottus ...................

Alewife ...........................

Alewives..........................

alexandri, Acipenser ...............

alexandrini, Orthragoriscus .........

Alexurus

armiger.................

Alfione............................

Alfoncino ..........................

Alfonsin a Casta Cumprida ........

Larga ............

Alfonsines ........................

Algansea.........................

antica..................

bicolor ...................

dugesi ..................

formosa .................

obesa
Page.

2422

1753

1754

1754

915

594

597

596

597

2259

966

2480

2259

2404

966

966

593

594,2826

595

596

595

596

595

597

451

452

453

454

458

452

453

459

459

104

2444

2860

1795

5; 2751

1957

426

424

105

1754

2202

2803

1507

i107

844

844

844

211

245

245

211

246

246 |
Algansea sallæi .................. $\begin{array}{r}\text { Page. } \\ 212\end{array}$

tarascorum ............. 2796

tincella ...............211,2796

algeriensis, Gssterosteus ......... $\quad 748$

Algoma ........................ 212

amara................... 215

fluvistilis............... $\quad 215$

alia, Labrus tantogs............... 1579

aliala, Acanthurus................ 1694

Touthis.................... 1693

aliciæ, Leuciscus.................. $\quad 236$

Squalius.................. 236

aliciolus, Trachurus .............. 904

Alilonghi......................... 871

alipes, Salmo ...................... 509

Salvelinus alpinus......... $\quad 509$

alleghaniensis, Salmo............ 507

alleterata, Gymnosarda........... $\quad 869$

alleteratus, Scomber............. $\quad 869$

allidus, Merlucius................ 2531

Alligator Gar .................... $\quad 111$

Allinectes...................... 2866

alliteratus, Euthynnus........... 869

Orcynus............. 869

All-Mouth ...................... 2713

Allochir................. 2129, 2131, 2135

Allosomus ....................... 467, 473

Allurus .............. 2129, 2131, 2136, 2866

almeida, Belone ................. $\quad 715$

Tylosurus............... $\quad 715$

Almejero, Mojarra................ 1294

Alopecias vulpes................. 45,46

alopecias, Squalus................ $\quad 46$

Alopias ........................ 45

macrourus............... 46

vulpes.................. 45

Alopiidæ....................... 45

Alosa .......................... 427, 2810

alabamæ.................. 2810

apicalis.................. $\quad 429$

bishopi ................. $\quad 430$

cyanonoton............... 427

lineata.................. $\quad 426$

menhaden .................. 432

præstabilis ................ 428

sapidissima .......... 427, 428, 2810

teres..................... 420

alosoides, Amphiodon............ $\quad 413$

Hiodon ................ 413

Alphestes...................... 1164

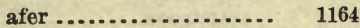

chloropterus ........... 2854

multiguttatus......... $\quad 1165$

alpinus, Salmo ................... 509,514

Salmo, nivalis ........... 509

Salvelinus.............. 508 
alpinus, Salvelinus alipes .......... arcturus........ aureolus........ stagnalis

Alpismaris....................... risso

alta, Cliola .

Macdonaldia. alter, Atinga minor orbicularis.... alternans, Scarus. ................. alternata, Perca mitchilli ......... alticolus, Catostomus ............. Alticus.......................... altifrons, Heros .................. altipinna, Belone................. altipinuis, Alburnellus.............

Micropogon ............

Minnilus...............

Notropis ..............

altivelis, Alepisaurus .............

Auchenopterus ..........

Cremnobates .............

Sebastolobus ............

altus, Bubalichthys ..............

Chorinemus...............

Hudsonius .................

Hybopsis .................

Oligoplites.................

Priacanthus ..............

Pseudopriacanthus .........

alusis, Muræna ..................

aluta, Bairdiella ...................

Sciæna ....................

alutaceus, Acrocheilus.............

Alutarius amphacanthus ......... macracanthus.......... obliteratus .............

$1717,1718,1720$

Alutera

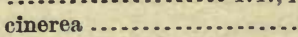

cuspicauda ...............

guntheriana..............

monoceros............. 1720, 2860

picturata ................ 1719

punctata ............... 1718, 1719

schøpfi................ 1718

scripta.................. 1719

Aluteres ......................... 1717

berardi................ 1720

pareva.................. 1719

Aluterus anginosus ............... 1720

cultifrons .............. 1718

holbrooki .............. 1718

venosus ................ 1719

alutus, Apogon ..................

A pogonichthys ............

Sebastodes
Alvarius

Page.

1099

fonticola.............. 1105

lateralis ............... 1099

alveata, Trygonorhina ........... $\quad 65$

alvordii, Cottus ................. 1952

Alvordius................. 1028, 1029, 1030

aspro ................. 1033

crassus............... 1034

ovides ................. 1037

macrocephalus ......... 1031

maculatus ........... 1032, 1034

nevisensis............. 1034

phoxocephalus......... 1031

spillmani............. 1039

variatus.............. $\quad 1034$

Alysia ........................ 568

loricata................ $\quad 569$

amabalis, Alburnellus............ 291

Alburnus .............. 291

Minuilus............... 291

Notropis ................ 291

anara, Algoma................. $\quad 215$

Hybognathus............ $\quad 215$

Amarilla, Chopa................. 1386

Guativere........... 1144, 1145

Salmonete ............. 859

A marillas, Mojarra de las Aletas... $\quad 1376$

Amarillo, Cibi.................. $\quad 919$

Pargo................. 1260

Ronco................ 1303

amarus, Hadsonius ............... 270

Hybognathus............. 215

Notropis hudsonius....... $\quad 270$

amazonica, Sciæna .............. 1419

amazonicns, Johnius .............. 1419

ambassis, Sargus............... 1346

Amber-fish, Great................ 903

Amber-fishes.................... 901

Amber Jack ..................... 903

ambiguus, Lutjanus.............. 1272

Merluccius ............ 2530

Mesoprion............ 1272

Neomænis ............ 1271

Amblodon .................... 1483

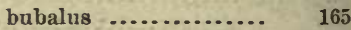

concinnus ............. 1484

grunniens............. 1484

lineatus ............. 1484

neglectus............. 1484

niger................ 169

saturnus ............. 1456

Ambloplites ................... $\quad 989$

interruptus........... 991

pomotis ............. 989

rupestris............ 990

cavifrons.... 990 


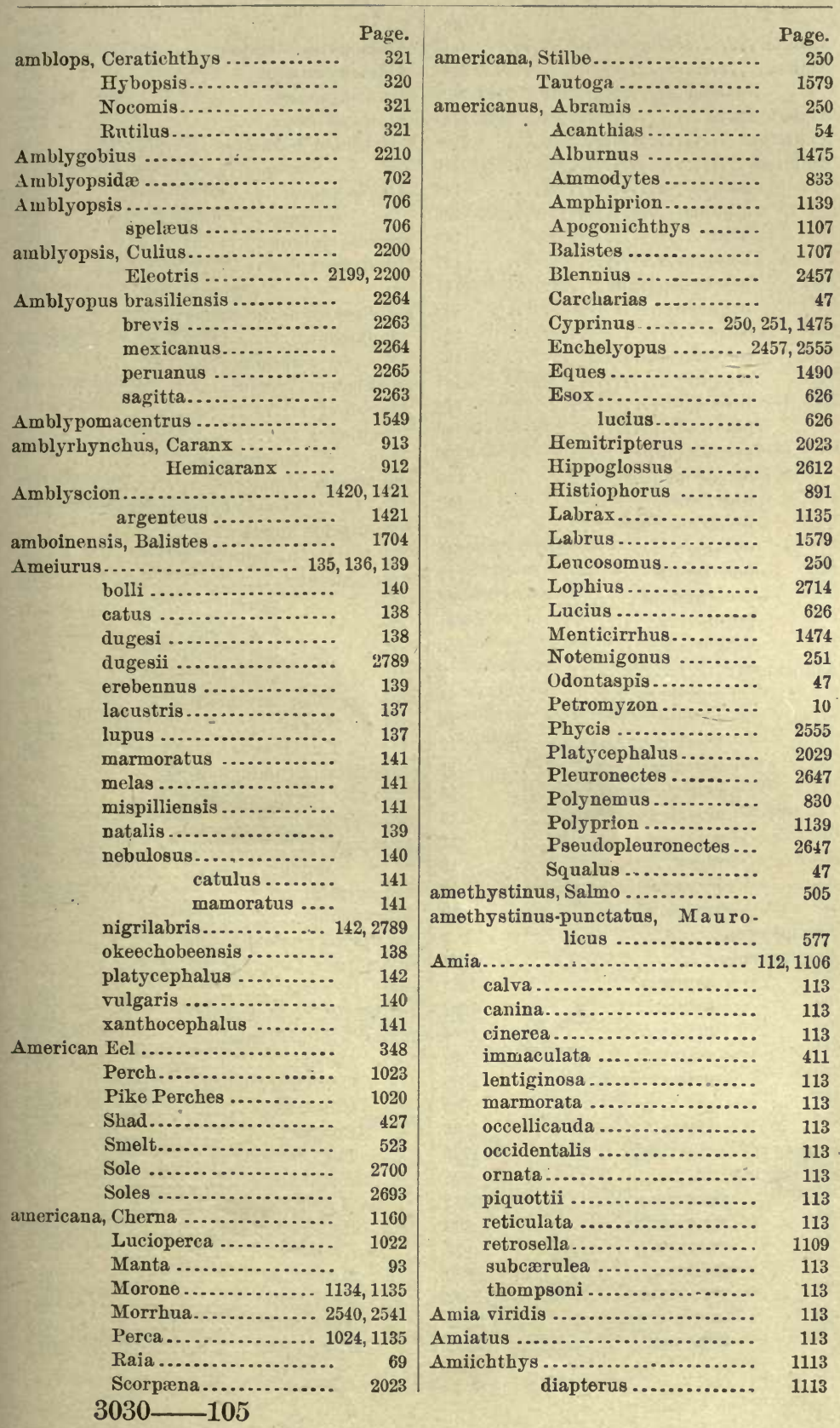




\begin{tabular}{|c|c|c|}
\hline …......... & $\begin{array}{r}\text { Page. } \\
112\end{array}$ & A mmody tes vittatus .......... \\
\hline ........... & 2138 & 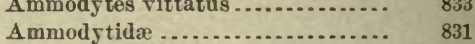 \\
\hline liparina.. & 8,2139 & Ammodytoidei ............... \\
\hline itrichthys ....... & 9,2141 & Ammopleurops............. \\
\hline mitrinæ .......... & 2106 & amœnus, Alburnellus... \\
\hline 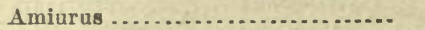 & 135 & Notropis........ \\
\hline ælur & 140 & Amore guaco......... \\
\hline .... & 138 & pixuma \\
\hline .... & 140 & amorea, Gobi \\
\hline ..... & 137 & Amorphocephalus.......... \\
\hline canthas..... & 141 & granulatus \\
\hline is $\ldots \ldots \ldots \ldots \ldots$ & 142 & amphacanthns, alutarins.... \\
\hline 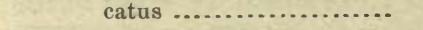 & 141 & Amphiodon .................. \\
\hline catus................. & 135 & ides......... \\
\hline (n.............. & 141 & amphiodon, $\mathrm{Hy}$ \\
\hline is $\ldots . . . \ldots \ldots$ & 134 & Amphioxi ................... \\
\hline (n) & 138 & Amphioxus .................. \\
\hline lis ................ & 135 & tus ...... \\
\hline alis ............... & 140 & amphioxys, Mon \\
\hline 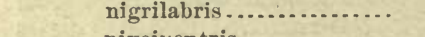 & 14 & $\mathrm{Ps}_{\mathrm{s}}$ \\
\hline (n) & 138 & Amphiprion amer \\
\hline$\ldots \ldots \ldots \ldots$ & & elo....... \\
\hline s $\ldots . . . . . . . .$. & & Amphistichus................ \\
\hline ins $\ldots . . . . . . . .$. & & zi....... \\
\hline (n) & 141 & argenteus..... \\
\hline (n) & 140 & heermanni... \\
\hline -............ & 9 & ...... \\
\hline$\cdots$ & 11 & lus... \\
\hline & & (............... \\
\hline olor .............. & 10 & Tetra \\
\hline lis .................. & 11 & ampullaceus, Ophiognathus.. \\
\hline branchialis ............. & 14 & Saccopharynx... \\
\hline cibarins ................ & 13 & Anablepinæ................... \\
\hline concolor ................. & 11 & Anableps ...................... \\
\hline (n) & & dovii............ \\
\hline tridentatus............. & 12 & 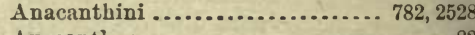 \\
\hline unicolor $\ldots \ldots \ldots \ldots$ & 10 & Anacanthus........................ 82 \\
\hline $\operatorname{tu}(\ldots \ldots \ldots \ldots \ldots \ldots$ & & Anacyrtus guatemalensis..... \\
\hline mocrypta................... & $106 \mathrm{i}$ & anagallinus, Lepomis............... \\
\hline asprella.......... & 1061 & Ditrema ................ \\
\hline ..... & 1064 & ligutta, Pomacentrus ...... \\
\hline & 1064 & atalis ............. \\
\hline ida.......... & 1062 & ............ \\
\hline pellucida clara ........ & 1063 & dermichthys ..... \\
\hline vivax... & 1063 & Clinocottus ............. \\
\hline (n.............. & 1065 & .............. \\
\hline yptus, Tetrodon.......... & 1735 & Eupoinacentrus.............. \\
\hline ytes ........................ & 832 & Holconotus ................ \\
\hline alascanus ............ 832 & 2,2842 & Нуреrprosopon ............... \\
\hline americanus............ & 833 & Hypocritichthys.......... 1500,1501 \\
\hline ureus ............ & 13 & Lutjjanus................. \\
\hline ius $\ldots \ldots \ldots \ldots \ldots \ldots$ & 832 & Mesoprion ................... \\
\hline personatus...... 833,2841 & 1,2812 & is . . . . . . . . . . . . . . \\
\hline & 2842 & Notacauthus............... \\
\hline tobianus ....... & 2811 & Oligocottus .............. \\
\hline
\end{tabular}


analis, Ophisoma

Orthragoriscus ....................

Pomacentrus..

Scyris ....................

Umbrina.................

analogus, Abulefduf .

Epinephelus ............

Euschistodus ............

Kyphosus..............

Pimelepterus

analostana, Cliola .................

Cyprinella .............

analostanus, Leuciscus............

Notropis.............

Anarhichadidæ

Anarhichas

latifrons

lupus

Anarmostus

.......

karrak ..............

leopardus............

maculatus............

minor ................

orientalis..............

pantherinus ..........

strigosus ............

vomerinus...........

Inarrhichthyinæ .................

Anarrhichthys ...................

felis...............

ocellatus...........

anasimos, Acipenser ............... anceps, Cottus (Acanthocottns) .... Plesioperca ...............

Anchisomus

augusticeps..........

caudicinctus ..........

geometricus...........

reticularis

Anchoa pelada ...................

Anchovia ..................... 4

macrolepidota ..........

Sardinella ...............

anchovia, Clupea ..................

Anchovies ..

Silvery................

Anchovy, California..............

Striped ................

A nchybopsis .....................

Ancistrus .......................

chagresi ................

Anclyopsetta

dendritica .............

Anclyopsetta dilecta.
Page.

356

1754

1555

932

1468

1563

1152

1563

1385

1386

279

279

279

279

2445

2445

2446

2447

1291

2446

2446

2446

2446

2446

2447

2446

2447

2447

2445

2447

2448

2448

106

1973

1039

1729

1731

1742

1736

$\lcm{735}$

436

49,2815

449

429

429

439,448

439

448

443

243

160

160

2634

2633

2636
Anclyopsetta quadrocellata....... 2635

Ancylodion ..................... 1416

ancylodon ............. 1416

jaculidens ............ 1416

parvipinnis ........... 1399

ancylodon, I.ouchurus ........... 1416

Sagenichthys......... 1416

andreæ, Rhinoscopelus............ 569

Scopelus ............... 569

Stenobrachius........... 569

andrei, Grobius .................. . 2218

Pomadasis .............. 1332

Pristipoma............. 1332

Angerl ....................... 414

Angel, Black ..................... 1679

Angel fish.............. 58, 1668, 1684, 1685

Angel Sharks ................... 58

Angelichthys .................. 1684, 2859

ciliaris ........... 1684, 1685

iodocus ............ 1686

isabelita........... 1685

angelus, Squatina ............... . $\quad 59$

anginosus, Aluterus.............. 1720

Angler, Common ................. 2713

Anglers ........................ 2713

anglorum, Lumpus.............. 2097

anguiformis, Ophichthys (Sphage-

branchus) .................... 374

anguiformis, Sphagebranchus...... $\quad 374$

Anguilla ..................... 347

aterrima............... 318

blephura............... $\quad 348$

chrysypa.............. 348, 2801

cubana.................. 348

laticauda .............. $\quad 348$

lutea................... 348

novæterræ.............. 348

novæorleanensis......... 348

oceanica ................ $\quad 355$

punctatissima ........... $\quad 348$

rostrata................ 348

tenuirostris............. $\quad 348$

texana................ 348

tyrannus................ 348

wabashensis ............ $\quad 348$

xanthomelas............. $\quad 348$

anguilla, Anguilla rostrata........ $\quad 348$

Ictalurus............... 2788

anguillaris, Blennius .......... 24:36, 2457

Gunnellus............ 2436

Lunipenus ........... 2436

Stichrus............. 2436

Zoarces ............... 2457

Angnillidøec.................... $\quad 346$

anguilliformis, Pholidichthys ..... 2405 
anguina, Muræna

anguineus, Chlamydoselachus.......

Nerophis..............

angulifer, Heros..................

anguliterum, Cichlasoma...........

angusta, Malthæa ................

angusticeps, Belone ...............

Coregonus ............

Sphæroides...........

Tetrodon .............

Tylosurus ............

angustidens, Macrostoma ........ 555, 2826

angustifirons, Dernatolepis ........

Serranus............

angustus, Platycephalus ...........

A ñil............................

Anisarchus .....................

medius............

Anisochretodon ...................

Page.

390

16

774

1517

1517

2738

712

466

1731

1731

712

1159

1159

2029

1193

2435

2436

1672

Anisotramus .............. 1314, 1315, 1318

bicolor ............ 1319

bilineatus ............

1319

cresius................

davidsonii.............

dovii .................

interruptus .........

pacifici ................

scap ularis............

1316

1321

1317

1319

1316

1320

serrula ...............

1323

spleniatus........... 1321

sur'namensis....... 1318, 1319

interrup-

tus....

tæniatus ............ 1322

trilineatus .......... 1320

virginicus......... 1322, 1323

anisurum, Moxostoma ............ 190, 196

anisurus, Catostomus............. $\quad 190$

anna-carolina, Magilomorus ....... $\quad 410$

annæ, Agonus (Brachy psis)....... 2043

Cottus..................... 1960

annularis, Centropristes .......... 1214

Nauclerus ............ 900

Pomoxis ............... 987

Serranns.............. 1214

annulata, Melanura.............. 624

annulatum, Exoglossum ...........

annulatus, Antennarius.

Spheroides .............

Sphæroides politus..... testadineus

Tetrodon..............

327

2725

1735

1736

1736

1736

anogenus, Notropis ............. 259, 260

anolis, Saurus ................. 535

anomala, Dekaya............... $\quad 2277$

anomalum, Campostoma............ anomalus, Caulolatilus ............. Page.

Rutilus ................ 206

Anoplagonus............... 2088, 2089, 2093

inermis............. 2094

Anoplarchus................... 2421

alectrolophus - 2421, 2422, 2869

atropurpureus ......2422, 2423

cristagalli........... 2423

purpurescens ........ 2423

Anoplogaster .................... 839

cornutus.......... 840

Anoplogastrinæe............... 838

Anoplopoma .................. 1861

fimbria.............2861, 1862

merlangus ........... 1862

Anoplopomatid.æ................ 1861

Anoplopomatinæ................ 1861

anoplos, Astroscopus............. 2308

Uranoscopus ............ 2308

anoplus, Agnus ................. $\quad 2308$

Astroscopus ............ 2308

Anopsus ..................... 7

A nosmius...................... 1741

Antaceus ....................... 103

antecessor, Gasterosteus .......... 900

Antennariidæ.................. $\quad 2715$

Antennarius .................... $\quad 2717$

annulatus............ 2725

corallinus............ 2725

histrio........... 2716,2723

inops ............... 2718

leopardinus.......... $\quad 2721$

marmoratus ......... 2717

multiocellatus ........ 2724

nuttingii.............. 2723

ocellatus............. 2721

pleurophtalmus...... 2722

principis.............. 2719

radiosus............. 2725

reticularis........... 2719

sanguineus .......... 2721

scaber .............. $\quad 2722$

strigatus.............. $\quad 2720$

tenebrosus........... $\quad 2719$

tenuifilis............. 2721

tigris .............. 2723

antennatus, Chilomycterus........ 1750

Diodon ............... 1750

Anthias....................... 1226

aquilonaris .............. 1283

asperilinguis ............ 1227

caballerote .............. 1257

chema................. 1157

formosus ............... 1304

furcifer................. 1222

jocu................... 1258 
Page

Anthias multifasciatus........... 1226

oculatus................. $\quad 1283$

peruanus.................

(Hermianthias) peruanus..

quartus rondeleti..........

rabirubia.................

saponaceus ...............

striatus..................

trifurcus .................

vivanus ..................

Anthiinæ

anthracinus, Acipenser ............

antica, Algansea..................

anticus, Leucus..................

Antigonia........................

capros ..................

mulleri.................

Antigoniinæ

antillanus, Conodon...............

antillarum, Caranx.

Chilomycterus

Sicydium

Talismania

Antimora ........................

microlepis

viola....................

antiquorun, Hippocampus.........

antiquus, Hippocampus............

antistius, Chænobryttus...........

antoniensis, Pimelodus .............

Antonino

antrostomus, Idiacanthus...........

Aodon ...........................

hypostomns............... 92, 2756

Aodontidæ......................

Apeltes

quadracus

apeltes, Gasterosteus ...............

Apeltinæ

aper, Labrus.

Aphanopinæ

Aphanopus

minor

Aphododerus cookianus............

Aphoristia ........................

atricauda .............

diomedeana ............

elongata................

fasciata ...............

marginata..............

nebulosa ................

ornata .............. 2707, 2710

pigra.................. 2706

plagiusa .............. 2710

pusilla................ 2711

Aphredoderidæ
1223

1223

1266

1276

1232

1157

1202

1224

1131

106

245

245

1664

1665

1665

1663

1324

921

1748

2206

455

2544

2545

2544

776

776

992

140

909

605

91

2756

752

752

752

743

1586

885

885

885

787

2704

2708

2711

2707

2710

2706

2712

710

2710
2711

785
Aphredoderus................... $\quad 786$

gibbosus.......... 787

sayanus ........... $\quad 786$

Aphyoninæ.................... 2499

Aphyonus ....................... $\quad 2525$

mollis................ 2525

apia, Pirati...................... 1174

apiarius, Petrometopon ........... 1142

Saranus ............... 1142

apiatus, Lepomis................. 998

apicalis, Alosa .................. $\quad 429$

Clupea.................. 429

Echeneis................ 2268

Sardinella.............. 429

Apionichthys .................. 2702

bleekeri ............ 2703

dumerili............ 2703

nebulosus.......... 2703

unicolor............ 2702

Aplesion........................ 1010

pottsii................. 1083

Aplites ....................... 1010

A plocheilus......... 632; 2827; $2828 ; 2830$

dovii ............. 2828, 2830

Aplodinotinæ ................... 1397

Aplodinotus...................... 1483

grunniens ........... 1484

Aplurus...................... 879

simplex............... 880

Apocheilichthys ............... 633, 2827

Apocope ...................... 308, 309

carringtonii............ 312

couesii................. $\quad 310$

henshavii ............... $\quad 312$

nubila ................. 311

oscula................. 309

ventricosa .............. 309

vulnerata............... 312

apoda, Perca .................... 1259

Pleuronectes............... 2701

Apodes........................ $\quad 344$

A podichthys .................... 2411

flavidus ............. 2411

fucorum............. 2413

inornatns ............ 2412

sanguineus.......... 2412

univittatus........... 2412

violaceus............ 2127

virescens............ 2412

Apodontis....................... 873

apodus, Neomænis................ 1258

A pogon ....................... 1106

alutns .................. 1110

atricaudus............... 2853

binotatus................ 1109

dovii .................. 1108

imberbis................ 1107 
A pogon maculatus ................

pigmentarius..............

retrosella.................

rex-mullorum.............

ruber .....................

Apogonichthys...................

alutus ............

americanus ........

puncticulatus......

stellatus ...........

A pomotis ..........................

cliætodon...............

cyanellus................

isehyrus ...............

murinus ................

obesus..................

phenax................

punctatus ...............

symmetricus ...........

apos, Gunnellus...................

appendiculatus, Centropomus.....

Exocotus.........

appendix, Lepomis................

Petromyzon .............

approximans, Polydactylus ........

Polynemus ...........

Pomadasys ..........

Trichidion ...........

Aprion

ariommus.................

macrophthalmus ........ 1280, 128

aprion, Gerres.................... 1373

Aprionodon.................... 42

isodon............

Aprodon .........................

cortezianus...............

A psicephalus ....................

A psilus ...........................

dentatus.................

Apterichthys ....................

selachops ............

Apterurus .......................

apua, Bodianus ..................

Epinephelus.................

Mrcteroperca venenosa.... 1173, 1174

Serranns.................. 1158

apus, Centronotus .................

Platytroctes ................

aqua-rlulcis, Gymnothorax.........

Muræena............

Rabula...............

Aquarina .......................

aquilonaris, Anthias .............

Etelis.................

aquosus, Pleuronectes..............

Rhombus..............

1109

1109

1108

1107

1107

1110

1110

1107

1111

1110

995

995

996

997

996
993

993

997

998

2430

1119

736

1005

10

829

1333

829

2, 1279

1278

2460

2461

1729

1278

1278

373

374

1174

1159

1158
2430

458

391

391

390

1204

1283

1283

2660

2660
Page.

arc

insanum, Etheostoma zonale.... 1075

arcansanus, Notropis telescopus.... $\quad 292$

archidium, Bairdiella............. 1432

Elattarchus ........... 1431

arabatsch, Salmo

Page.

483

Mabicus, Chanos................. 415

aracanga, Pseudosearus ........... 1648

Scarus .............. 1642, 1647

Sparisoma............ 1642

aræa, Atherina................. $\quad 790$

aræopus, Catostomus............. 172

Aramaca

papillora.............. 2672

soleœ formis............ $\quad 2672$

aramaca, Citharichthys .......... $\quad 2672$

Hemirhombus........... 2673

Pleuronectes........... 2672

Rbombus ............ 2626, 2672

arangoi, Chærojulis ............... 1597

A rará, Bonaci................... 1174

arara, Hæwulon.................: 1306

Ronco ................... 1304

Serranus ................ 1159, 1175

aratus, Lutjanus ................. $\quad 1274$

Mesoprion ............... 1274

Neomænis................ 1273

Arbaciosa ..................... $\quad 2340$

eos.................. 2343

humeralis ............. 2341

rhessodon ............ 2340

rupestris .............. 2311

zebra 2341

Odontoscium .......... 1422

Archistes ....................... 1900

plumarius ............ 1900, 1901

Arehocentrus.............. 1514, 1515, 1525

Archoperca ................... 1169, 1171

Archoplites ................... $\quad \$ 90$

interruptus.......... 991

Archosargus . ............. 1358, 1359, 1361

aries............... 1361

pourtalesii........... 1360 probatocephalus.... 1361, 1362 tridens ............. 1360 unimaculatus....... 1359, 1360

Archosion parvipinnis ............ $13 ! 99$ remifer............... 1399

Arctic Flounder................ $\quad 2649$

Grayling ................ 517

Sculpin................. 1973

arctica, Liparis................. 2121

arcticum, Benthosema ............ $57 t$

arcticus Chironectes............... $\quad 2717$

Salmo .................. 521

arcticus Scopelus................ $\quad 574$ 
aretifrous, Calamus ..............

Citharichthys ...........

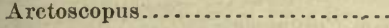
japonicus .............

Arctozenus...................... borealis................ coruscans..............

aretum, Siphostoma .............. arcturus, Salmo .................

Salvelinus alpinus.......

arcuata, Harengula..............

arcuatum, Ditrema ...............

Hæmulon .............

Hy perprospon ..........

arcuatus, Bathygadus.............

Chrtodon ...............

Hyperprosopon ..........

Pomacanthus .......... 1679, 1681

ardens, Catostomus

Hypsilepis ................

Leuciscus ................

Minnilus.................

Notropis umbratilis ........ ardeola, Belone

Tylosurus ...............

ariesiaca, Gila ....................

ardesiacus, Lepomis...............

Squalins ...............

arenata, Umbrina ................

arenatus, Arius ..................

Priacanthus .......... 1237, 1238

Rhinichthys ........... 308

Rypticus.............. 1232

arenicola, Fierasfer .............. 2496

Gillellus .............. 2299

ąrenosus, Gadus.................. 2541

argalus, Belone ....................

arge, Alburnellus..................

Kuhlia.....................

Notropis

argentata, Ciliata ................

Couchia................

Motella.

argentatus, Astyanax .............

Gaidropsarus ..........

Merluccius ............

Plargyrus .............

Tetragonopterus.......

urgentea, Bathyclupea..............

Chimæra................

Muræna................

Selene.

Sphyræna...............

Steindachneria .......... argenteum, Ditrema
Page.

1355

2683

2297

2297

601

601

771

510

510

431

1502

1305

1502

2564

1680

1502

179

301

301

301

301

713

713

237

1006

237

1474

132

96

2541
713

294

1014

294

2559

2559

2559

336

2559

2530

283

336

835

95

348

936

826

2568

1504 a!genteum, Hyperprosopon Page.

1502

puncta

tum .. $\quad 1502$

argenteus, Amblyscion........... 1421

Amphistichus........ 1503, 1504

Centronotus........... 899

Diplodus............. 1363

Eucinostomus.......... 1371

Gerres................ 1371

Hyperprosopon....... 1501, 1502

Ichthyomyzon.......... 11

Larimus............... 1421

Leuciscus ............. 221

Micropogon ............ 1463

Pagrus ................. 1357

Petromyzon ............ 11

Pimelodus.............. 125

Sarchirus ............. $\quad 110$

Sargus ............... 1363

Sparns .............. 1357

Synodus............... 411

Trachinotus:........... 944

Trachynotus........... 944

Trichiurus ............ $\quad 889$

Argentina.................... $\quad 525$

carolina .............. 410

glissodonta ........... 411

machnata ............. 410

menidia............... 443

pennanti.............. 577

pretiosa .............. 525

sialis ................. $\quad 526$

silus................. $\quad 526$

striata............... 526

syrtensium........... $\quad 526$

Argentines..................... 525

Argentinidæ.................. $\quad 519$

argentinus, Pimelodus ............ $\quad 135$

argentipinnis, Rhombus .......... 966

argentissimus, Gasterosteus ....... $\quad 747$

Plagopterus....... $\quad 329$

argentiventris, Lutianus .......... 1261

Lutjanus .......... 1261

Mesoprion.......... 1261

Neomænis......... 1260

argenti-vittatus, Thynnus ........ 871

argentosa, Dionda............... $\quad 215$

Argo ........................ 957

argus, Muræena................. 401

Plenronectes.............. 2666

Squalus .................. 26

Argyrea...................... -796

Argyreiosus.................... 935

gabonensis........... 935

pacificus ............. 936 
Argyreiosus setipinnis

Page.

unimaculatus

vomer.................

argyreiosus, Leucosomns ...........

Pogonichthys ..........

Symmetrurus .........

Argyreus .......................

dulcis ..................

nasutus ................

notabilis ...............

nubilus .................

osculus ................

rubripinnis,$\ldots \ldots . . . . . .$.

argyrens, Fario ....................

Lepidopus ..............

Salmo..................

Argyriosis capillaris ..............

spixii..................

triacanthus.............

Argyriosus brevoorti ..............

filamentosus ...........

mauricei ...............

mitchilli ..............

setifer .................

argyritis, Hybognuthus ...........

Argyrlepes.

A rgyrocottus ....................

zanderi ..............

argyroleuca, Bairdiella ............

Corvina ...............

argyroleucus, Bodianus ............

argyromelas, Seriola ..............

Argyropelecus ...................

durvillii...........

hemigrnmus .......

olfersi ..............

arg.yrophanus, Engraulis..........

Stolephorus.........

argyropomus, Gasterosteus ........

Argyrops caprinus ................

argyrops, Sparus .................

argyrosoma, Damalichthys .........

Embiotoca .............

Argyrosomus ....................

alascanus............

artedi................

sisco $\ldots . . . . .$.

hoyi ............. 469, 472

laurettre.........471, 2817

lucidus ............ 470

nigripinnis........ 472

osmeriformis ....... 468

prognathus......... 471

pusillns ............ 470

tullibee............. 473

bisselli..... 473 argsrosomus, Damalichthys....... 1509

Argyrotænia.................... 832

vittata......... .833

argyrurus, Coryphæna ........... . 953

argyrus, Pimelodns .............. $\quad 135$

aries, Archosargus ............... 1361

Sargus.................. 1362

arioides, Bagrus ................. 133

ariomnus, Aprion ............... 1278

Minnilus .............. 290

Notropiş.............. $\quad 290$

Photogenis ............ 290

Ariopsis......................... 119

A riosoma ..................... $\quad 353$

Arius .......................... 119

alatus................... 125

arenatus................... 132

assimilis ................. 129, 2774

brandtii .................. 122, 2758

cærulescens................ 129

dasycephalus ............. $\quad 130$

dowi.................... 125

dubius................. 127

elatturus ................ 128

emphysetus................ 122

equestris ................. $\quad 128$

felis ..................... 128

fissus .................... 131

flavescens................. 123

furthii.................. $\quad 132$

grandicassis ............... 126

guatemalensis ............ 129

herzbergii ................. 125

hypophthalmus............ 133

insculptus................ $\quad 127$

kessleri................... 127

laticeps.................. 132

luniscutis ................ 125

melanopus............... 132

mesops .................. 123

milberti ................. 128

multiradiatus.............. 133

nuchalis.................. 131

oscula .................... 127

parkeri................... 126

passany .................. 124

phrygiatus ............... 131

planiceps................. $\quad 127$

platypogon ............... 127

puncticulatus .............. 131

quadriscutis............... $\quad 126$

rugispinis ................ $\quad 130$

seemani .................. 128

seemanni................. 2772

stricticassist................ $\quad 126$

surinamensis .............. 130 
A rius temminckii

ralencienn

variolosus

arizonæ, Pantosteus...............

Arlina

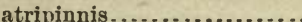

effulgens..................

arlingtonia, Gambusia ....... 652, 2828, 2829

arlingtonius, Funduluse.......... $\quad 652$

armata, Bairdiella ................

Corvina..................

armatus, Aspidophorus ...........

Centridermichthys ........

Centropomus .............

Serranus ................

armiger, Alexurus ................

Arnillo

arnillo, Mesoprion

Tropidinins

A rnillos.

arnillus, Lutjanus

A rnoglossus fimbriatus...........

ventralis .............

Aroide

.......................

A rothron.......................

erethizon ................

Arrow-toothed Halibut...........

artedi, Argyrosomus...............

Polyneming sisco.........

1436

1437

2067

2012

1123

1165

2203

1278

1279

1279

1278

1279

2677

2670

119

1738

1739

2609

468

469

828

Artediellus .................... 1905 atlanticus........... 1906, 2862 pacificus ............. 1906 uncinatus........... 1905, 1906

Artedius.................... 1902, 2862

asperulus............ 1903, 2862

fenestralis .............. 1900

lateralis................ 1902

pugetensis.............. 1890

quadriseriatus ............ 1897

artesiæ, Etheostoma

1897
1094

Pnecilichthys............. 1094

arubensis, Pœcilia vanderpolli.... 696, 2834

arundinaceus, Syngnathus........ 765

ascanii, Salmo................... 509

Silus................... 526

Ascelichthyinæ................. 1883

Ascelichthys.................... 2024

rhodorus ........... 2025

ascendens, Siphostoma.............

Syngnathus ............

ascensionis, Caranx

Epinephelus ............

Holocentrus..........

rufus .....

Perca

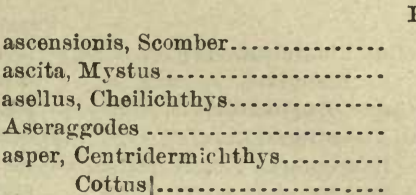

Diodon................. 1744, 1752

Exerpes.................. 2367

Hexagrammos ........... 1872

Macrurus .................. $\quad 2572$

Pleuronectes ............... 2645

aspera, Limanda ................. $\quad 2645$

Uranidea................ 1944

asperilinguis, Anthias ............ 1227

Odontanthias ...... 1227

asperrimus, Balistes .............. 1706

Myliobatis ........... 2754

aspersus, Epinephelus ........... $\quad 1154$

Serranus.............. 1153

asperulus, Artedius ............. 1903

Asphidorus quadricornis.......... 2041

Aspicottus .................... 1937, 1938

bison ................ 1938

aspidolepis, Chætostomus......... $\quad 159$

Hemlancistrus ....... 159

Aspidophoroides............... 2088

bartoni .......... 2092

grœnlandicus..... 2092

guntheri......... 2090

inermis.......... 2093

monopterygius - 2091, 2092

olriki............ $\quad 2089$

tranquebar ....... 2092

Aspidophoroidinæ ............. 2033

Aspidophorus .................... 2064

acipenserinus ....... 2062

armatus............ 2067

cataphractus........ 2067

chiloensis .......... 2069

decagonus........... 2054

dodecaedrus........ 2046

europæus .......... 2067

lisiza.............. 2036

malarmoides ........ 2054

niger.............. 2069

proboscidalis........ 2038

rostratus ........... 2048

spinosissimus...... 2054

superciliosus....... 2036

aspidurus, Urolophus............ 81

Aspistor....................... 2763

luniscutis ............... $\quad 2763$

Aspisurus...................... 1689

asprella, Ammocrypta ........... 1061

Crystallaria............. 1061

asprellns, Etheostoma............ 1061 
Page.

asprellus, Pleurolepis ..............

Radulinus ...............

asprigenis, Pœcilichthys...........

aspro, Alvordius ..................

Hadropterus ...............

Percina....................

Asproperea .....................

zebra ................ 1027

assimilis, Arius ................. 129, 2774

Galeichthys............ 2779

Hexanematichthys....... 129

Astatichthys.................... cœruleus............. zonalis

asterias, Blennius

Mustelus................

Urolophus ................

Asternopteryx gunelliformis

Asternotremia ................... mesotrema..........

Asterospondyli ..................

Asthenuras

atripinnis............

astilbe, Stolephorus ................

astori, Ichthyomyzon...............

Lampetra ..................

Petromyzon ................

Astracion tricornis................

Astrolytes

notospilotus ............

Astronesthes.....................

barbatus............

gemmifer ............

niger................

richardsoni

Astronesthidæ

Astroscopus .........................

anoplos..............

anoplus ..............

guttatus.............

y-græcum ............

zephyreus ............

Astyanax ......................

argentatus..............

Asymmetron.....................

lucayanum ............

atæniatus, Chætodon ...............

Sarothrodus.............

atchafalayæ, Signalosa ..............

atelaspis, Acipenser................

aterrima, Anguilla ................

Muræna ................

Thyrsoidea ..............

Atheresthes ....................

stomias
1061

1920

1033

1032

1833

1024

1089

1075

2383

29

82,2752

2420

2420

786

787

19

2526

2527

2815

12

12

12

1725

1898

1899

586

586

586

586

587

586

2306

2308

$230 \mathrm{~S}$

2310

2307

2309

333

336

4

1676

1676

2809

106

348
Atherina.

aræa

bosei

brownii

carolina .................

harringtonensis ..........

humboldtiana ............

insularum ...............

laticeps..................

martinica.................

menidia

microps

mordax...................

notata ...................

stipes ...................

storeri....................

veliana .................

viridescens ...............

vomerina ................

A therinella ........................

crystallina

eriarcha ..............

evermanni .............

panamensis ............

Atherinichthys ....................

albus ..............

brevis ..............

californiensis......

gracilis ...........

grandoculis........

guatemalensis.....

humboldti ..........

menidia ...........

notata .............

pachylepis.........

Atherinidæ ......................

Atherinoides.....................

atherinoides, Chriodorus..........

Clupea.............

Engraulis...........

Notropis ............

Pterengraulis .......

A therinops .......................

affinis .................

insularum.............

regis ..................

Atherinopsis.

californiensis........

tenuis.

Athlennes........................

hians..................

Atimostoma.........................

Atinga...........................

A tinga alter minor orbicularis.....

Chilomycterus ..............

Diodon....................

atinga, Guamaiacu ..............
Page.

789

790

801

443

791

791

793

807

790

795

801

791

523

800

790

807

790

800

793

805

805

803

804

805

792

2839

2840

807

797

2840

801

793

800

800

801

788

792

719

451

451

254,293

450

807

807

807

808

806

806

802

717

718

950

1750

1749

1750

1746

1749 
Atka-fish atkinsi, Gasterostens bispinosus... atlantica, Elacate.................

Emblemaria.............

atlanticum, Oreosoma ............. atlanticus, Artediellus .............

Benthodesmus..........

Bregmaceros...........

Callorhynchus :.........

Dibranchus............

Epinephelus ...........

Megalops ..............

Neoliparis ..............

Prometheus.............

Promethichthys ........

Rnpiscartes ............

Salarias ................

Sparus .................

Tarpon ................

Tetragonurus..........

Thynnus ..............

atomarium, Sparisoma ........... atomarius, Scarus ................ Atopoclinus

ringens. ..............

Atractoperca.....................

Atractosion .................... nobilis................

Atractosteus. lucius ................ tropicus.............

atramentatus, Sympliurus .......... atraria, Perca ......................

Siboma ..................

atrarius, Centropristis .............

Pimelodus ...............

Serranus.................

Squalius ................

Xenomystax .............

atricauda, A phoristia ............. Hydrargira............

atricaudus, Apogon Symphurus ........... atrilatus, Zy gonectes............... atrilobatus, Chromis .............. atrimana, Monolene ............... atrimanus, Caranx ................ Hemicaranx........... atripes, Ditrema ................. Lythrurus................ Minnilus ................. Notropis umbratilis ....... Phanerodon ............... atripinnis, Arlina Asthenurus
Page.

1864

748

948

2402

1663

1906

887

2527

95

2743

1154

409

2107

883

883

2397

2397

1153

409

976

871

1631

1631

2376

2376

1194

1198

402,1413

1413

109,111

111

111

2706

1200

233

1200

140

1200

233

361

2708

624

2853

2707

682

1546

2692

914

913

1507

300

300

300

1507

1051

2527. atripinnis, Bregmaceros .......... 2527

Goodea............... 685

atrocandalis, Notropis cayuga ..... $\quad 260$

atrocyameus, Pomacentrus ......... 1552

atromaculata, Esox .............. 629

Etheostoma ......... 1057

atromaculatus, Cyprinus .......... 222

Semotilus .......... 222

thoreani-

anus... 223

atronasus, Cyprinus ............. $\quad 307$

Rhinichthys .......... $\quad 307$

croceus :-.. $\quad 308$

lunatus... 308

meleagris. $\quad 308$

atropurpureum, Ophidium ........ 2423

atropurpureus, Anoplarchus.... 2422, 2423

Atropus...................... $\quad 929$

atrorubens, Sebastodes............ 1796

atrovirens, Sebastichthys .......... 1798

Sebastodes ........... 1797

attenuata, $\nabla$ incigurria ............ $\quad 577$

attenuatus, Maurolicus ........... $\quad 577$

Merlucius ............ 2546.

Osmerus.............. 523

attilus, Acipenser.............. 105

atwoodi, Carcharias .............. $\quad 50$

aubrieti, Lutjanus ............... 1271

A uchenionchus ................. $\quad 2360$

Auchenopterus................ 2369, 2371

affinis ............. 2371

altivelis ........... 2370

asper.............. 2368

fasciatus ,......... 2373

integripinnis ....... 2372

marmoratus....... 2371

monophthalmus.... $\quad 2372$

nigripinnis ........ 2369

nox.............. 2373

auctorum, Lobotes . . ............ 1236, 2858

Auctospina ............... 1765, 1776, 1817

audens, Menidia .................. $\quad 798$

augusticeps, Anchisomus ......... 1731

Aulastome maregrarii ............ $\quad 757$

Auliscops..................... $\quad 753$

spinescens............ 754

auliscus, Siphostoma............ $\quad 767$

Aulopidæ ...................... 541

Anlopus agassizii............... 541

Aulorhynchidæ................ $\quad 752$

Aulorhynchus ................. $\quad 753$

flavidus........... 754

Aulostoma ..................... $\quad 754$

cineream ............. 755

coloratum............. 755

A ulostomidx.................. 754 


\begin{tabular}{|c|c|}
\hline & Page. \\
\hline ulostomus... & aurolineatum, Hæmulon . \\
\hline 755 & 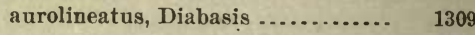 \\
\hline maculatus.......... 754,2837 & auropunctatus, Callyodon ........... \\
\hline aurantiacum, Etheostoma.......... 1041 & Cryptotomus....... \\
\hline urantiacus, Balistes............... & aurora, Abeona ...................... \\
\hline Ceratacanthus ........ & Caproponus ................... \\
\hline er......... & Catostomus ................. \\
\hline ms.......... & Fario $\ldots \ldots \ldots \ldots \ldots$ \\
\hline Hypohomus ........... & Salmo $\ldots \ldots \ldots \ldots \ldots \ldots$ \\
\hline urata, Cliola..................... & Sebastichthys.............. \\
\hline ................... & Sebastodes ..................... \\
\hline Moniana ................. & ristis.......... \\
\hline Saleima ................. $\quad 1386$ & Lutjanus.............. \\
\hline auratum, Pristipoma............ 1324, 1343 & Mesoprion............. \\
\hline auratus, Carassius............... 201 & Rhomboplites ....... 1277, 1278 \\
\hline Centropomus .............. & aurovittatus, Mesoprion ........... 1270 \\
\hline rinus ................ & Ocyrus............... \\
\hline us $\ldots \ldots \ldots \ldots \ldots \ldots$ & australe, Etheostoma.............. \\
\hline Holocentrus ............. & Zoplendum \\
\hline Mallus .................. & australis, Echoneis............. 2269, 2271 \\
\hline barbatus.......... & Esox $\ldots \ldots \ldots \ldots \ldots$ \\
\hline Notemigonus ............. & us ................... \\
\hline (n.................... & is .................. \\
\hline s.................. & ia $\ldots \ldots \ldots \ldots \ldots$ \\
\hline us ......... & a................ \\
\hline .......... & a............ \\
\hline$\ldots \ldots \ldots \ldots . . .6$ & a............. \\
\hline aureolum, Moxostoma............ 192 & Auxis........... \\
\hline aureolus, Catostomus ............. 192, 196 & rochei \\
\hline Gerres ................ 1375 & 868 \\
\hline is alpinus ....... & (n..................... \\
\hline (n................ & aoides .................. \\
\hline $8 \ldots \ldots \ldots \ldots \ldots$ & vulgaris........................ \\
\hline ena $\ldots . . . . . .$. & A verruncus................. 2069, 2864 \\
\hline œtes............... & emmelane............ 2069 \\
\hline (n..................... & s ............... \\
\hline n............... & ostoma.......... \\
\hline 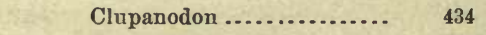 & $r \ldots \ldots \ldots \ldots$ \\
\hline is ................ & avocetta, Nemichthys .............. \\
\hline ................ & Arocettina ........................ \\
\hline ns................ & elongata............... \\
\hline n............... & ............ 2801 \\
\hline n........... & infans.............. 367,2801 \\
\hline ............. & ............... 414 \\
\hline auriculatus, Sebastodes .......... 1817, 1818 & ,,$\ldots . .$. \\
\hline dallii....... 1818 & 2235 \\
\hline anriga, Dules & moxicanus ............... \\
\hline .................... & (n................. \\
\hline , n & taiasica.................. \\
\hline auritus, Labrus ................... 1001 & axillare, Pristipoma ............... \\
\hline Lepomis ............... 1001, 1009 & axillaris, Boreocottus .............. \\
\hline solis............. 1001 & Brachydenterus .......... \\
\hline aurofrenatum, Sparisoma .......... & Cottus .................. \\
\hline urofrenatus, Scarus .............. 1634 & Gerres................. 1378 \\
\hline ruttatus, Zygonectes ......... 654, 2829 & Myoxocephalus........ 1980, 1981 \\
\hline aurolineatum, Bathystoma ........ $\quad 1310$ & Pomadasis.............. 1328 \\
\hline
\end{tabular}




\begin{tabular}{|c|c|c|}
\hline & & Page. \\
\hline axinophrys, Xystes ... & & Bagrus macronemus. \\
\hline Axyrias.................. & 3,2862 & mesops..... \\
\hline & & 124 \\
\hline aya, Acara ....................... & 1264 & 125 \\
\hline Bodianus .................... & & \\
\hline Chætodon ..................... & 1675 & \\
\hline a............... & 1265 & valenciennes \\
\hline ................. & 1264 & Bahama Lar \\
\hline n.................. & 1264 & dis.......... \\
\hline Aylopon............................ & 1226 & n............. \\
\hline (............ & 1228 & bahianus, Acar \\
\hline yresi, Aci & 104 & (n................ \\
\hline (n................. & 1205 & .............. \\
\hline ............... & 264 & ............... \\
\hline Petromyzon................. & 13 & n.............. \\
\hline \multicolumn{2}{|c|}{ Ayresia ..................... 1545,1548} & ys............. \\
\hline & 1548 & (n................ \\
\hline 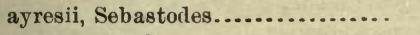 & & baileyi, Cypri \\
\hline & & ......... \\
\hline \multirow{5}{*}{\multicolumn{2}{|c|}{ 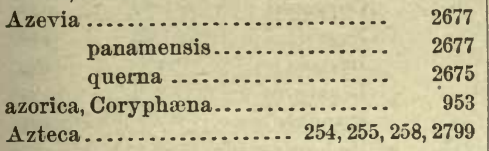 }} & $\ldots \ldots \ldots$ \\
\hline & & Baiostoma.................... 2694, 2695 \\
\hline & & s $\ldots \ldots \ldots \ldots \ldots .2698$ \\
\hline & & bairdi, Aciper \\
\hline & & us ................. \\
\hline & 2799 & tulatus......... 1950 \\
\hline (n.................. & 258 & ma.......... 765,770 \\
\hline ................. & 1553 & ps ............. \\
\hline .................... & 1549 & Syngnathus.......... 770 \\
\hline a .............. 1383 & 3,1384 & Bairdiella...................... 1432, 1433 \\
\hline As................ & 595 & aluta $\ldots \ldots \ldots \ldots \ldots \ldots$ \\
\hline & & (n) \\
\hline ................... & 1544 & ca ............... \\
\hline hirundo.............. & & …. \\
\hline \multirow{4}{*}{$\begin{array}{r}\text { azurissimus, Microspathodon....... } \\
\text { dorsa. } \\
\text { lis .. }\end{array}$} & 1570 & ca $\ldots \ldots \ldots$ \\
\hline & & (n................ \\
\hline & 1570 & (n).............. \\
\hline & & \\
\hline 118 & & ata $\ldots . . . . . . . . . .$. \\
\hline$\cdots$ & 2230 & s ............... \\
\hline 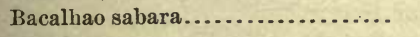 & 2230 & ephalus............ \\
\hline & 987 & n $\ldots . . . \ldots \ldots . .$. \\
\hline ............ & 222 & 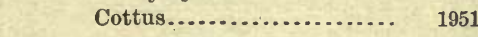 \\
\hline oclitus ..... & & (....... \\
\hline & 22 & .............. 25 \\
\hline$\ldots \ldots \ldots \ldots \ldots$ & 308 & thodon.......... 1566, 1567 \\
\hline bagre, Ail & 11 & Mitchillina.............. $\quad 454$ \\
\hline ................ & 11 & n $\ldots \ldots \ldots \ldots \ldots$ \\
\hline .................. & 11 & rus $\ldots . . . . . . . .$. \\
\hline Bagre Col & 122 & ..................... \\
\hline & 2319 & \\
\hline & 149 & 1352 \\
\hline $\sin 2$ & 124 & bajonado, Calamus ............... 1352, 1353 \\
\hline & 13 & Pagellus ................ 1352 \\
\hline ............... & 125 & Sparus ................. \\
\hline emphysetus............... & 122 & balantiophthalmus, Scomber ........ \\
\hline flavescens ................. & 123 & balao, Hemiramphus ............. \\
\hline
\end{tabular}


Page.

Balaos ..................... 718, 722, 723

balearica, Conger-muræna......... 356

Congermuræna......... $\quad 356$

Muræna ............... $\quad 356$

balearicum, Ophisoma .............

balias, Chirns ....................

Baliste, Le Bridé..................

Balistes.................. 1699, 1700, 1703

amboinensis............. 1704

americauus.............. 1707

asperrimus .............. 1706

aurantiacus .............. 1718

barbatus ............... 1720

bellus :.................. 1703

brocens ................ 1716

buniva ................ 1701, 1711

capistratus............... 1704

caprinus ................ 1702

capriscus................ 1701

carolinensis ............... 1701

cicatricosus .............. 1709

ciliaris ................. 1702

ciliatus.................. 1715

curassavicus............. 1709

equestris................. 1702

forcipatus.............. 1702

frenatus................. 1705

fuliginosus.............. 1702

guttatus ............... 1702

heckeli................. 1709

hippe ................. 1705

hispidus ................

kleinei $\ldots \ldots \ldots \ldots \ldots \ldots . . . .$.

læris....................

liberiensis ................

lineo-punctatus ...........

linguatula ...............

longus $\ldots . . . . . . . . . . .$.

macrops.................

macropterus .............

maculatus.

1707,1708

melanopterus............ 1707

mento .................. 1710

mitis .................. 1705

monoceros............. 1719, 1720

moribundus ............. 1702

naufragium ............ 1700, 1701

niger................... 1711

nigra................. 1711

nitidus ................ 1709

notatus................ 1709

oblongiusculus ........... 1720

oculatus............... 1707

ornatus................ 1719

picens ....................

polylepis .................

powelli.
Page.

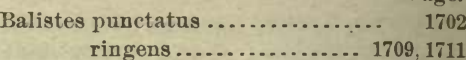

rufus . ................ 1707

schmittii ................ 1705

schœpfii................ 1718

8colopax............... $\quad 759$

scriptus ................ 1719

serraticornis............. 1720

sobaco .................. 1706

spilotopterygius.......... 1702

sufflamen ................ 1706

treniopterus ............. 1702

unicornus ............... 1720

urantiacus .............. 1718

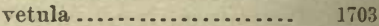

Balistidr....................... 1698

Ballerus......................... $\quad 249$

balteatum, Chichlasoma ........... $\quad 1521$

balteatus, A bramis ................ 239

Cyprinus (A bramis)..... 239

Eques ................. 1490

Heros................ 1522

Lenciscus.............. 238

Pomacanthus.......... 1680

Richardsonius .......... $\quad 239$

Thynnus .............. 871

Upeneus.............. 860

banana, Butyrinus .............. 411

Gobius................. 2236

Banana-fish .................. 411

bancrofti, Torpedo............... $\quad 78$

Banded Pickerel ................ 626

Sunfishes ................ 994

Bang ......................... 423

banksi, Citula .................... 927

Barathrodemus................. 2517

2517

2524

2524

765

2500

158

2049

2557

2556

587

2474

586

1720

2500

2541

2118

1482

856

2050

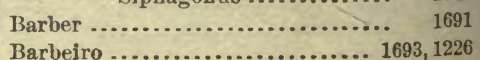




\begin{tabular}{|c|c|c|}
\hline Barbero & $\begin{array}{l}\text { Page. } \\
1691\end{array}$ & Bass, Oswego . \\
\hline Negro ..... & 1692 & Rock ................. \\
\hline 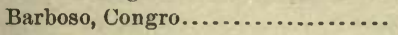 & 155 & Rock Sea................. 1201 \\
\hline Barbu .......................... & 829 & Round..................... \\
\hline Barbuda, Lija .................... & 1720 & Sea......................... \\
\hline Barbudo......................... & 150,829 & Stone ..................... \\
\hline Barbudos........................ & 828,854 & Strawberry................. \\
\hline Barbulifer....................... & 2260 & Striped.................. 1131, 1132 \\
\hline ceuthocus................ & 2260 & White.................... 1132 \\
\hline ............... & 2261 & White Lake................... \\
\hline oliparis............ & 2145 & "White Sea" of California ... \\
\hline , Minomus.................. & 171 & Yellow ..................... \\
\hline .............. & 987 & Bassogigas ....... \\
\hline s (Brachyopsis) ..... & 2044 & (n............ \\
\hline$\ldots \ldots \ldots \ldots$ & 71 & stelliferoides ............ \\
\hline us .......... & 151 & 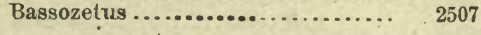 \\
\hline n............ & 151 & catena................... \\
\hline (n).......... & 82 & compressus............ \\
\hline a........................ & 28 & normalis............... \\
\hline California ............... & & a.................. \\
\hline ............. & 826 & s................... \\
\hline n.............. & 823 & t.................... \\
\hline (n................ & 825 & Weakfish ................. \\
\hline 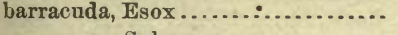 & 823 & batabana, Corvula.................. \\
\hline Sphyræna ............... & 2841. & batabanus, Johnius ................. \\
\hline Barracudas............................. & 822 & Larimus................ 1431 \\
\hline (n............. & 1102 & Batfish $\ldots \ldots \ldots \ldots \ldots \ldots \ldots \ldots, 89,2183,2737$ \\
\hline$\because \ldots \ldots \ldots \ldots$ & 1102 & Short-nosed................. 2738 \\
\hline $8 \ldots \ldots . . . . .$. & 1102 & 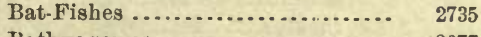 \\
\hline ................... & 2264 & Bathyagonus....................... \\
\hline 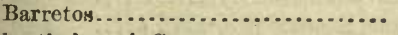 & 2263 & nigripinnis ........... \\
\hline ax................. & 919 & bathybius, Cynico \\
\hline (................... & 1516 & hys........ \\
\hline roides ........... & 2092 & hus......... \\
\hline$\ldots \ldots \ldots \ldots \ldots$ & 793 & Synaphobranchus....... \\
\hline (n.................. & 1515 & Bathyclupea...$\ldots \ldots \ldots \ldots \ldots \ldots$ \\
\hline Cylindrosteus $\quad \ldots . . . \ldots . .$. & 111 & argentea $\ldots \ldots \ldots \ldots \ldots$ \\
\hline Eslopsarum........... & 2840 & yelupeidæ $\ldots \ldots \ldots \ldots \ldots \ldots \ldots$ \\
\hline $\begin{array}{r}\text { Bascanichthys ... } \\
\text { bas }\end{array}$ & 378 & ggadinæ....................... \\
\hline (n............ & & Bathygadus........................ \\
\hline (n. & & ( ............ \\
\hline bascanium, Base & & ..... \\
\hline Coect & & ...... \\
\hline 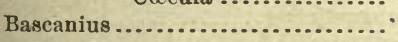 & & 2566 \\
\hline 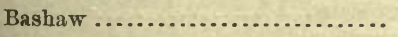 & 143 & Batbylaco.... \\
\hline basilaris, Heros .................. & 1532 & $\begin{array}{r}\text { Batbyiaco ....... } \\
\text { nigric }\end{array}$ \\
\hline gharks .................. & 50 & 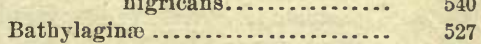 \\
\hline Bass, Bayou ....................... & 1012 & 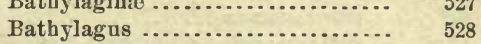 \\
\hline Black ...................... & 1010 & benedicti ............... \\
\hline Sea.... & 1198 & borealis ............ 2824, 2825 \\
\hline & 987 & euryops ............. $\quad 529$ \\
\hline & 1453 & 2825 \\
\hline nmon Rock & 990 & pacificus............. 530, 2824 \\
\hline Grass........................ & 987 & Bathy master ........................ \\
\hline Green . & 1012 & hypoplectus ........... \\
\hline
\end{tabular}




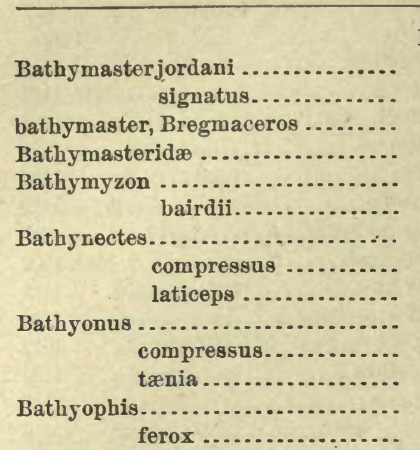

Bathyphasma ................. 2128, 286 ovigerum........... 2128

bathyphila, Cyclothone........... 582

bathyphilum, Neostoma........... 583

Bathypteroidæ ....................

Bathypterois.

longipes.............. quadrifilis............

Bathysaurus ...................... agassizii............. ferox.

Bathysebastes

Bathystoma

aurolineatum rimator ............... striatum ..............

Bathytroctes.

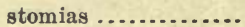

Batis ...........................

Batoidei...........................

Batrachoides

pacifici............. surinamensis......... tau ................... vernullas............. variegatus ...........

Batrachoididæ ...................

Batrachops........................

Batrachus.

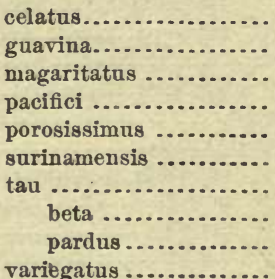

Batrictius......................... battaræ, Orthragoriscus............ Bay Shark
Page.

2289

2288

2527

2287

9

2507

2508

2523

2507

2509

2510

605

605

58
583
544

544

546

545

539

540

539

1860

1308

1310

1308

1310

454

454

66

59

2314,2868

2314

2314

2314

2316

2316

2313

1740

2314,2315

2316

2195

2323

2315

2321

2314

2316

2316

2317

2316

2868

1754

37
Baya ..........................

bayanus, Pomadasis...............

Bayou Bass

bdellium, Petromyzon..............

Bdellostoma dombey ...............

polytrema.............

stouti .................

beadlei, Synechoglanis .............

beani, Caranx

Heros

Ophidion................... 2487

Pleuronectes............... 2646

Pœcilichthys .............. $\quad 1057$

Triglops .................. 1924

beanii, Ammocrypta ............. 1064

Limanda................. $\quad 2646$

Melamphaes............... 843

Plectromus............... $\quad 842$

Prionotus ................ $\quad 2170$

Serrivomer ............... $\quad 367$

beardsleei, Salmo gairdneri ....... $\quad 2819$

Bear Lake Bullhead .............. 1954

Beau Gregory .................. 1555

Beauty, Rock ................... 1684

beck withi, Cyprinella............. $\quad 273$

Becuna......................... 823

becuna, Sphyræna .............. 823

beldingii, Cottus................. 1958

belengeri, Caranx............... 923

belisanus, Belonesox .............. $\quad 684$

belizianus, Eleotris (Culins) ....... 2201

bella, Hypoclydonia ............... $\quad 1115$

Bellator......................... 2173

egretta.................. 2174

militaris.................. 2173

bellicus, Nocomis ................. 3213

Bellows-fish................... 759, 2713

bellus, Balistes................. 1703

Minnilus................. $\quad 297$

Notropis................. 297

Belly, Yellow ................... 1001

Belone almeida.................... $\quad 715$

altipinna................ $\quad 717$

angusticeps............... 712

ardeola ................... 713

argalus.................. 713

caribbæa ................. 717

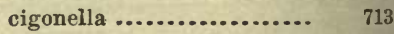

crassa .................... 716

depressa................ 711,713

diplotænia................ 712

exilis ...................... $\quad 714$

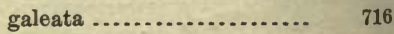

gerania................... $\quad 716$

guianensis................. $\quad 715$

hians ................... 718 


\begin{tabular}{|c|c|c|c|}
\hline & Page. & & Page. \\
\hline Belone jonesi.. & 717 & beryllina, Menidia... & 797 \\
\hline & 717 & & 797 \\
\hline & 718 & beryllinum, Chirostoma ............ & 798 \\
\hline (n)............ & 716 & beryllinus, Cryptotomus ........... & 1624 \\
\hline c............ & 712 & 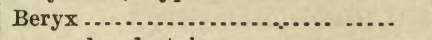 & 844 \\
\hline ............. & 711 & decadactylus ............... & 814 \\
\hline .......... & 716 & splendens.................. & 844 \\
\hline .......... & 716 & 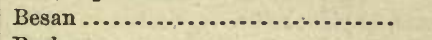 & 1687 \\
\hline n......... & 714 & Beshow ..... & 1862 \\
\hline ......... & 713 & & 1356 \\
\hline ......... & 711 & beta, Batrachus & \\
\hline & 715 & tes................. & 1492 \\
\hline ............ 71 & 14,715 & terosteus ........... & 748 \\
\hline belone Esox.......... & 714 & Biajaiba.......................... & 1270 \\
\hline (n........... & 892 & de lo Alto............. & 1140 \\
\hline ............. & 892 & Bibronia ................................ & 2704 \\
\hline 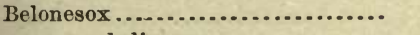 & 884 & biçaudalis, Lactophrys .............. & 1723 \\
\hline (n)........... & 684 & n & 1723 \\
\hline (n..................... & 773 & (n).................. & 245 \\
\hline .............. & 369 & s...................... & 10 \\
\hline iii ............. & 369 & as................... & 1319 \\
\hline .................. & 1965 & is ................. & 2524 \\
\hline n............ & & ................ & 738 \\
\hline n............ & & notus............ & 726 \\
\hline (n.............. & 57 & us..................232 & 32,245 \\
\hline n............... & 57 & (n)....................... & 245 \\
\hline Benthocomete & 2514 & a................... & 1320 \\
\hline & 251 & s....................... & 1232 \\
\hline Benthodesmus . & 88 & (a $\ldots \ldots \ldots \ldots \ldots$ & 548 \\
\hline & 88 & (.................. & 244 \\
\hline & 888 & (n.............. & 1231 \\
\hline ........... & 543 & s.................. & 1232 \\
\hline ........ & & (n.................. & 232 \\
\hline grall & 543 & (n)..................... & 232 \\
\hline Benthosema.... & 573 & dermichthys......... & 1913 \\
\hline & 574 & .................... & 1913 \\
\hline & & (..................... & 1911 \\
\hline .............. & & (n.................... & 480 \\
\hline & & asoma.............. & 1521 \\
\hline & & aа......... 1610, &, 285 \\
\hline & 2581 & ichthys ........... & 160 \\
\hline & & $\cdots .$. & 1521 \\
\hline & & & 1610 \\
\hline Bermuda Ca & 88 & . & 1609 \\
\hline & 1387 & soma............ & 1610 \\
\hline & 643 & ................. & 259 \\
\hline bermudensis, $\mathrm{F}$ & 2497 & psis.............. & 259 \\
\hline & 2497 & Notropis.................. & 258 \\
\hline 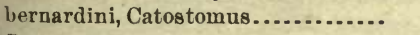 & 178 & ifurca, Chrtodon cauda............ & 1562 \\
\hline & 2857 & ................ & 1238 \\
\hline & 971 & .............. 410 & 0,426 \\
\hline & 837 & & 911 \\
\hline & 838 & Big-headed Gurnard ............. & 2171 \\
\hline Berycoid Fishes..................... & 823 & Big Skate & 68 \\
\hline Berycoidei .................... 781, 83 & 333,834 & of California ............ & 72 \\
\hline $\begin{array}{l}\text { Berycoids } . . . \ldots \ldots \ldots \ldots \\
\qquad 3030-106\end{array}$ & 837 & biguttata, Cochlognathus ........... & 252 \\
\hline
\end{tabular}




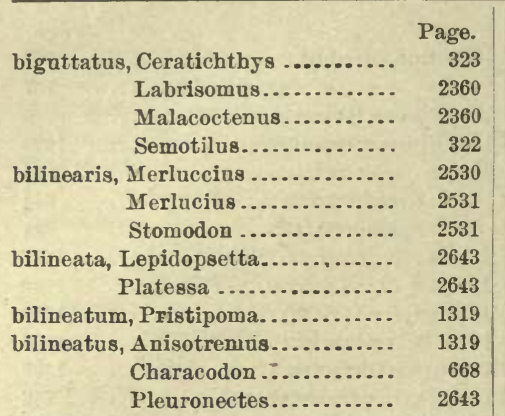

Billfish.................. 109, 714, 725, 892

billingsiana, Cliola ............... 272

Cyprinella............. $\quad 272$

biloba, Corvina ................... 1460

Pachypops................ 1460

bilobus, Blepsias .................. 2018

Histiocottus.............. 2018

Peropus ................. 2018

bimaculata, Percina.............. 1027

Pileoma.............. 1027

bimaculatus, Chætodon ........... 1674

Clinus ............... 2358

Malacoctenus ........ $\quad 2358$

Pœcilioides.......... 678

Psendoxiphophorus .. $\quad 678$

Sayris ............... 725

Xiphophorus ......... 678

binoculata, Raja ............... $\quad 72$

Uraptera $: . . . . . . . . . . .6 \quad 73$

binotatus, Apogon .............. 1109

Bipinnula ..................... 878, 2813

violacea ............... 878

bipinnulata, Seriola .............. 907

bipinnulatus Elagatis............. 906

birostratus, Prionotus ........... 2152, 2156

birostris, Raia ...................

Manta ................ 92

bishopi, Alosa ................. 430

Sardinella.............. 430

bison, Aspicottus ............... 1938

Carpiodes ................. $\quad 166$

Enophrys ................ 1938

Lepisosteus ............... $\quad 110$

bispinosus, Gasterosteus.......... $\quad 748$

atkinsi... 748

cuvieri... $\quad 749$

Melanocetus.......... 2734

Melichthys........... 1711

Myliobatis........... $\quad 89$

bisselli, Argyrosomus tullibee...... 473

Coregonus tullibee ........ 473

bistrispinns, Bodianus ............ 1234

Rypticus ............ 1233

bisus, Scomber................. $\quad 867$

bivittata, Elacate ................ 948

Haliperca .............. 1205

bivittatus, Centropristis .......... 1205

Cbærojulis............ $\quad 1597$

Halichres ............ 1597

Hybopsis ............. 233

Iridio................. $\quad 1595$

Labrus ............... 1596

Minnilus .............. 233

Platyglossus........... $\quad 1597$

Serranus............... 1205

bixanthopterus, Caranx............ 926

Black and yellow Rockfish......... 1825

Angel ................... $\quad 1679$

Black-banded Rockfish........... 1827

Sunfish............. 995

Bass................... 1010

Large-mouthed......... 1012

Small-mouthed ......... 1011

Black-belly.................... 426

Bullhead .................. 141

Croaker .................... $\quad 1456$

Drums..................... 1454

Blackfin....................... $\quad 472$

Snapper............... 1261

Black-fish.......... 207, 963, 1199, 1200, 1578

blackfish, Labrus................. 1578

Blackfishes, Alaska............ 620, 261

Grouper............ 1161, 1174

Grunt.............. 1297

Guativere............ 1146

Harry .............. $\quad 1199$

Black-head Minnow.............. 217

Blackhorse....................... 168

Black Jewfish................... 1161

Moray ..................... 396

nosed Dace ................. 305, 307

Oldwife.................. 1711

Perch..................... $\quad 1504$

Pilot..................... 1555

Rock fish.................. $\quad 1784$

Rudder Fishes ............. 996

Ruffe.................... 963

Rutfs...................... 962

Sculpin.................. 1985

Sea Bass................. 1198

Black-sided Darter.............. 1028, 1032

Black-spotted Trout.............. 487

Swallowers................ 2291

Will ...................... 1199

blackfordi, Lutjanus ............... 1265

Yarrella................ 584

blainvillei, Acanthias .............. 51

Blakea.......................... 2351

elegans.................. 2353 


\begin{tabular}{|c|c|c|}
\hline $\begin{array}{rr} & \text { Page. } \\
\text {.......... } & 892\end{array}$ & Blennius filicornis.... & $\begin{aligned} & \text { Page. } \\
& 2381\end{aligned}$ \\
\hline Chopa................. 1388 & fimbriatus ........ & 2457 \\
\hline Lisa...................... & fucorum...$\ldots \ldots \ldots \ldots$ & 2379 \\
\hline Mojarra.................. & geminatus ............... & 2385 \\
\hline Pesca ..................... & gentilis .................. & 2388 \\
\hline Sardina .................... & gracilis .................. & 2438 \\
\hline (n)................ & gunnellus................. & 2419 \\
\hline a .............. & $z \ldots \ldots \ldots \ldots \ldots$ & 2390 \\
\hline inus.............. & ninier ................. & 2362 \\
\hline Blanco, Burro ...................... & labrosus ..................... & 2457 \\
\hline Matajuelo ................. 2275, 2276 & lampetræformis ............ & 438 \\
\hline Pescado de Chapala........ 792 & lumpenus.................. & 2438 \\
\hline Ronco ..................... & ts........ & 2381 \\
\hline Blancos, Pescados............... $\quad 792$ & mus.......... & 2385 \\
\hline Blanquillo ................... 2276, 2278 & multiflis........... & 2385 \\
\hline Blanquillos ..................... 2274, 2276 & murænoides........ & 2419 \\
\hline ionichthys ............ 2703 & lis ........... & 2383 \\
\hline (n)................. & s $\ldots \ldots \ldots \ldots \ldots$ & 2379 \\
\hline Pellona ............... & is $\ldots \ldots \ldots \ldots . . . . . .$. & 2380 \\
\hline Blenitrachus .................... 2391 & $\ldots \ldots \ldots \ldots \ldots \ldots$ & 2469 \\
\hline Blennicottus ..................... 2016, 2864 & cephalus .......... & 2409 \\
\hline acuticeps .............. 2864 & punctatus.............. 2390 & 0,2440 \\
\hline embryum .......... 2016, 2864 & (n) & 2553 \\
\hline globiceps ............. $\quad 2017$ & 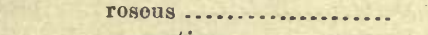 & 2420 \\
\hline bryosus...... & Ius ................ & 2439 \\
\hline Blennies ........................ 2344, 2377 & si & 2379 \\
\hline Snake.................. $\quad 2435$ & (n......... & 2388 \\
\hline Blenniidæ........................ & tænia ........ & 2418 \\
\hline Blenniinæ $\ldots \ldots \ldots \ldots \ldots \ldots \ldots \ldots$ & (.......... & 2561 \\
\hline Blennioclinus . . . . . . . . . . . & atus ................... & 2381 \\
\hline ishes................... & (n.................. & 2382 \\
\hline oidea $\ldots \ldots \ldots \ldots \ldots \ldots \ldots \ldots, \ldots$ & es ?) polaris ........ & 2469 \\
\hline (1) & blenvius, Alburnops................. & 262 \\
\hline n & Etheostoma............. 1072 & 2,1073 \\
\hline oma.......... 1033 & (n..................... & 262 \\
\hline …....... 2386, 2390 & Notropis............ & 261 \\
\hline , Hyostoma ........... 1053 & Blennophis... & 2400 \\
\hline Blenniophidium ..................... & $\ldots \ldots \ldots, \ldots, \ldots$ & 2401 \\
\hline petropauli.......... 2430 & Blenny, Snake ..................... & 2438 \\
\hline $\begin{array}{c}\text { Blennius ................... 2377, 2378, } 2553 \\
\text { alectrolophus ............ } 2422\end{array}$ & 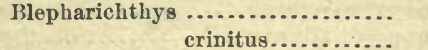 & $\begin{array}{l}931 \\
932\end{array}$ \\
\hline americanus .............. $\quad 2457$ & Blepharis ........................ & 932 \\
\hline laris .............2436, 2457 & crinitus................... & 932 \\
\hline 2383 & major................... & 932 \\
\hline s.................. & sutor ..................... & 932 \\
\hline is ..................... & ris, Carangoides ............. & 932 \\
\hline .................... & ra, Anguilla................... & 348 \\
\hline (n.................. & ( & 2018 \\
\hline 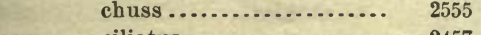 & & 2018 \\
\hline ................ & cirrhosus ................ & 2018 \\
\hline us .......... & oculofasciatus ............. & 2021 \\
\hline 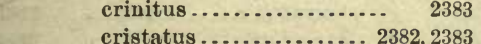 & trilobus ........................ & 2019 \\
\hline yaster ........... 2417 & (n) & $\begin{array}{l}1936 \\
1883\end{array}$ \\
\hline 2419 & & 517 \\
\hline 2380 & & 2501 \\
\hline
\end{tabular}




\begin{tabular}{|c|c|c|c|}
\hline & Page. & & Page. \\
\hline Blindfish, of tbe Mammoth Cave... & 706 & Bodianus bistrispinus.............. & 1234 \\
\hline Small $\ldots \ldots \ldots \ldots \ldots$ & 704 & blochii $\ldots \ldots \ldots \ldots \ldots$ & 1583 \\
\hline Blind Fishes ..................... & 702 & bodianus ................ & 1583 \\
\hline Gobies...$\ldots \ldots \ldots \ldots$ & 2261 & costatus................. & 1462 \\
\hline Goby of Point Loma .......... & 2262 & cruentatus.............. & 1142 \\
\hline 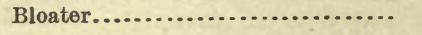 & 471 & diplotænia.............. & 1582 \\
\hline Blob..................................... & 1950 & dubius ................... & 1146 \\
\hline blochii, Bodianus .................. & 1583 & .............. & 1433 \\
\hline Caranx & 919 & flavescens............... & 1024 \\
\hline Galeichthys ............... & 118 & fulvus................... & 1144 \\
\hline Orthrogoriscus ............ & 1754 & punctatus......... & 1146 \\
\hline dus .................. & 155 & \multicolumn{2}{|c|}{ ruber........... 1145, 1146} \\
\hline Piramutana............... & 155 & guativere ................ & 1145 \\
\hline 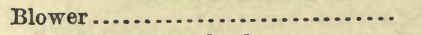 & 1733 & jaguar.................. & 849 \\
\hline Blow-fish, Spring-back............. & 1734 & ginatus............... & 1174 \\
\hline Blue-back ........................... & 426 & pallidus ................. & 1433 \\
\hline Mullet $\ldots \ldots \ldots \ldots \ldots$ & 813 & nensis.............. & 1141 \\
\hline n $\ldots . . . \ldots \ldots \ldots . .$. & 481 & is............... & 1582 \\
\hline (...................... & 514 & thus............. & 849 \\
\hline of Lake Crescent.. & 2819 & n............... & 1584 \\
\hline Blue Bream ........................... & 1005 & n............ & 1146 \\
\hline Cat............................... & 134 & $8 \ldots \ldots \ldots \ldots$ & 1147 \\
\hline Cod $\ldots \ldots \ldots \ldots \ldots \ldots$ & 1875 & ruber ................... & 1265 \\
\hline Darter ........................ & 1088 & \multicolumn{2}{|c|}{ rufus ................ 1135,1583} \\
\hline Herring ....................... & 425 & rupestris ............... & 990 \\
\hline Mullet ......................... & 191 & stellifer.................. & 1443 \\
\hline Parrot-fish ................. 1636 & 36,1652 & (............ & 1259 \\
\hline Perch ...................... 1505 & 5,1577 & iops................... & 1144 \\
\hline Pike ........................ & 1021 & triurus .................. & 1236 \\
\hline 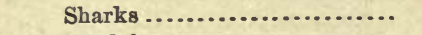 & 33 & t..................... & 1257 \\
\hline ish $\ldots \ldots \ldots \ldots \ldots \ldots \ldots$ & 1005 & \multirow{2}{*}{ 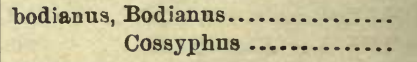 } & 1583 \\
\hline Surgeon.......................... & 1691 & & 1588 \\
\hline Tang............................. & 1691 & Bodieron ............................ & 1867 \\
\hline Blue-breasted Darter............... & 1076 & \multirow{2}{*}{$\begin{array}{r}\text { Bøostoma brachiale } . . . . . . . . . . . . \\
\text { reticulatum............ }\end{array}$} & 2698 \\
\hline (1) & 472 & & 2696 \\
\hline Bluefish, California.................. & 1410 & 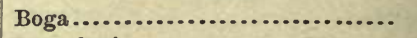 & 1365 \\
\hline (n) & 45,946 & \multirow{2}{*}{ 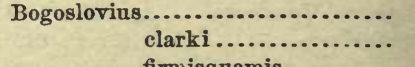 } & 2574 \\
\hline ................ & 1005 & & 2575 \\
\hline ker $\ldots \ldots \ldots \ldots \ldots$ & 171 & firmisquamis........ & 2575 \\
\hline fish $\ldots \ldots \ldots \ldots \ldots$ & 996 & Bola............................... & 1455 \\
\hline Blunt-nosed Minnow................ & 218 & \multirow{2}{*}{$\begin{array}{r}\text { Boleichthys } \ldots \ldots \ldots \ldots \ldots \ldots \ldots \\
\text { eos } \ldots \ldots \ldots \ldots \ldots \ldots \ldots\end{array}$} & 1101 \\
\hline . & 934 & & 1102 \\
\hline$\ldots \ldots \ldots \ldots \ldots$ & 1663 & \multirow{2}{*}{ 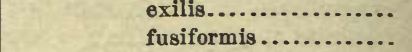 } & 1103 \\
\hline Boar Grunt $\ldots \ldots \ldots \ldots \ldots \ldots \ldots$ & 1303 & & 1101 \\
\hline 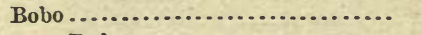 & 821 & warreni.................... & 1103 \\
\hline Boca Dulce......................... & 29 & whipplii............... & 1096 \\
\hline Negra ...................... & 1837 & boleoides, Cottus.................... & 1968 \\
\hline Bocaccio ................................ & 1780 & $\begin{array}{l}\text { Radulinus } \ldots \ldots \ldots \ldots \ldots \ldots \\
\text { Uranidea } . . . . \ldots \ldots \ldots \ldots\end{array}$ & 1919 \\
\hline Bocon .............................. 44 & 42,450 & Uranidea.................. & 1968 \\
\hline bocona, Sardina .................... & 449 & \multirow{2}{*}{$\begin{array}{r}\text { Boleosoma } \\
\text { æesopus } \ldots \ldots \ldots \ldots \ldots \ldots \\
\end{array}$} & 1054 \\
\hline .................. 1143 & 3,1581 & & 1057 \\
\hline anthistius .............. & 1147 & & 110 \\
\hline & 1011 & & 1060 \\
\hline & 117 & chlorosoma ............. & 1060 \\
\hline argyroleucus............. & & copelandi ................ & 1046 \\
\hline aya....................... & 1265 & fusiformis .............. & 1102 \\
\hline
\end{tabular}




\begin{tabular}{|c|c|c|}
\hline \multirow{2}{*}{ 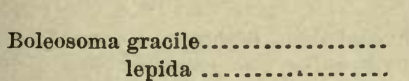 } & Page. & Page. \\
\hline & 1102 & Bonito California......... \\
\hline lepida $\ldots . . . . . . . . .$. & 1089 & Oceanic $\ldots \ldots \ldots \ldots \ldots . . . . . . .$. \\
\hline lepidnm ................ & 1089 & Bonitos .................... \\
\hline longimanus ............. & 1054 & Bonnet-head ............. \\
\hline maculatum .......... 1057 & 7,1077 & Bony-fish ...................... 410,433 \\
\hline mutatum.............. & 1057 & Bony Fishes .................... \\
\hline nigrum ............... & 1056 & Ganoids .................. \\
\hline ffulgens........ . & 1058 & 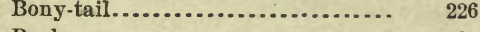 \\
\hline aculaticeps.... & 1058 & Boohoo............... \\
\hline m......... & 1059 & boops, Caranx ...................... \\
\hline di ......... & 1057 & Centaurus................. \\
\hline vexillare....... & 1058 & Myctophum................ \\
\hline olmstedi brevipinnis.... & 1057 & Notropis ............ \\
\hline $\mathbf{x} \ldots \ldots \ldots \ldots \ldots$ & 1052 & Ostracion ........... \\
\hline stemone........... & 1055 & Scopelns ................ \\
\hline pottsii .................. & 1083 & Trachurus .................. \\
\hline um $\ldots \ldots \ldots$ & 1091 & Borborys................... \\
\hline rdi $\ldots . . . . . . . .$. & 1047 & borea, Lucioperca .................. \\
\hline stigmæum ............. & 1048 & boreale, Etheostoma................. \\
\hline (n) & 1059 & borealis, Alepidosaurus (Caulopus). \\
\hline$m \ldots \ldots \ldots 1046$ & 6,1057 & Alepisaurus.............. \\
\hline atum........... & 1070 & Amiurus .................... \\
\hline & 1096 & es.......... \\
\hline boleosoma Gobius.................. & 1102 & Arctozenus ............. \\
\hline meiurus $\ldots \ldots \ldots \ldots \ldots \ldots$ & 140 & Bathylagus ........... 2824, 2825 \\
\hline lossina ........... & 2621 & Chimæra............ .95 \\
\hline Opsopœeodus $\ldots \ldots \ldots \ldots$ & 249 & Fierasfer................ \\
\hline (n................. & 1646 & Icelinus .................. \\
\hline Bollmannia . . . . . . . . & 2237 & Læmargus .. . ............ \\
\hline chlamydes.............. & 2238 & Maurolicus................ \\
\hline macropoma........... & 2239 & Notorhynchus ............ \\
\hline ocellata.................. & 2238 & Oligocottus ............... \\
\hline aatura ............. & 2239 & Paralepis................... \\
\hline bombifrons, Lepomis................ & 1003 & yzon................ \\
\hline Pomotis................ & 1003 & Pimelodus ................. \\
\hline Bonací Arará ..................... & 1174 & Pœeilichthys............. \\
\hline Cardenal ................ 1173 & 3,1174 & Scopelus .................. \\
\hline de Piedra................... & 1172 & Sphyræna................ \\
\hline Gato............... & 1187 & Squalus................... \\
\hline bonaci, Epinephelus ............... & -1175 & Sudis................... \\
\hline Mycteroperca .................. & 1174 & Boregat ............ \\
\hline xanthosticta. & 1176 & Boreocottus...... \\
\hline Serranus............. & 1175 & axillaris .......... \\
\hline Trisotropis................... & 1175 & Boreogadus .............................. \\
\hline Bonapartia...................... 580 & 0,2826 & polaris...... \\
\hline pedaliota........... 580 & 0,2826 & saida $\ldots \ldots \ldots \ldots \ldots$ \\
\hline bonapartii, Scopelus ............... & 557 & 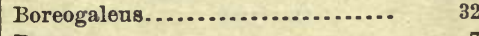 \\
\hline bonariense, Hæmulon .............. & 1297 & Borer .................................. \\
\hline bonariensis, Halatractus ........... & 905 & Borers.............................. \\
\hline Seriola............ & 905 & boreum, Stizostedion canadense.... \\
\hline bonasus, Bubalichthys............ & 164 & 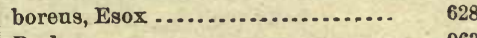 \\
\hline Raja......................... & 90 & Borlase............................... \\
\hline Rhinoptera ............... & 90 & bosci, Abramis crysoleucas.......... \\
\hline Bone-fish....... & 411 & Atherina ............................... \\
\hline 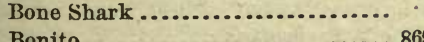 & 51 & Gobiosoma.................... \\
\hline Bonito $\ldots \ldots \ldots \ldots \ldots \ldots \ldots \ldots \ldots \ldots$ & 69,948 & Gobius.................... 22 \\
\hline
\end{tabular}


bosci, Halatractus ...............

Leuciscus..................

Pimelepterus ...............

Zonichthys ................

boscianus, Chasmodes.............

boscii, Seriola ......................

bosqui, Cyphosus .................

bosquianus, Blenuius ..............

Chasmodes............

bosquii, Pimelepterus .............

bostonensis, Catostomus ...........

bostoniensis, Muræua ..............

Botete...........................

Bothragonus ..................... swavii............ 2086, 2088

Bothrocara..................... mollis ................ pusilla ................

Bothrolæmus.....................

Bothus.

maculatus................

Boucanelle.......................

boucardi, Leuciscus .................

Leucus..................

Poecilia...................

Pristipoma ...............

Rutilus .................

boulengeri, Mycteroperca ....... 1171

Bont de Tabac.

bouvieri, Salmo clarkii .............

mykiss ............

purpuratus .........

bovinum, Plectropoma.............

bovinus, Cyprinodon................

Hypoplectrus............

unicolor....

Bowfin

Bowfing

bowmani, Plargyrus ...............

Box, Tobacco.....................

Boxaodon

brachiale, Boeostoma..............

Sparisoma..............

brachialis, Achirus ...............

Ammocotes ..............

Baiostoma ..............

Petromyzon .............

Scarus................

brachiatus, Diodon................

Brachioptilon

hamiltoui

brachiurug, Gymnotus -........ brachiusculus, Grammicolepis .... brachyacanthus, A minrus........... brachycentrus, Gasterosteus....... Nauclerus .........
Page. brachycephalum, Siphostoma.....

brachycephalus, Exocoetus.........

Syngnathus......

Uranichthys

brachychir, Macrostoma ........... Myctophum

brachychirus, Trachurops .........

Brachyconger .....................

savanna . 2..........

Brachydeuterus.

axillaris.$--2 .-0$.

corvinæformis

lenciscus ...........

nitidus.........

Brachygenys.....................

chrysargyreus....... 1307

tæniata............. 1308

frenatus............. 1499

Brachymullus................... $\quad 858$

Brachyopsis................... 2046, 2864

annæ .............. 2043

barkani............. 2044

decayonis............ 2054

dodecaedrus .......... 2046

rostratus.......... 2046, 2048

segaliensis........... 2048

verrucosus........... 2044

xyosternus .......... 2043

Brachyospinæ.................. 2032

brachypoda, Gasterosteus pungitius $\quad 746$

Pygosteus pungitius.. $\quad 746$

Brachypomacentrus.............. $\quad 1549$

Brachyprosopon ................. 2653

brachyptera, Echeneis ............ $\quad 2272$

Remora............. 2272

Rhamdia ............ 151

brachypterus, Holocentrus........ 852

Lutjanus............ 1268

Neomænis.......... 1268

Pimelodus ........... $\quad 152$

Remoropsis ......... 2272

Thynnus........... 870

Zygonectes......... 682

brachyrhinchus, Acipenser....... 104

Brachyrhinus .................. 1221

creolus ............ 1222

furcifer............ 1222

Brachysomophis ................ 387 crocodilinus ..... 388 horridus ......... $\quad 388$

brachysomus, Calamus............. 1353

Epinephelus ........ 1154

Sparus ............ 1353

brachyurus, Oxydontichthys...... $\quad 385$

bradfordi, Porocottus ............. 2862 
Brama

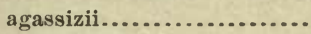

brevoortii .................

chilensis .................

dussumieri

orcini.

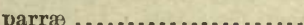

raii

raji........................

saussurii.

brama, Cynædus..................

Bramble Sharks.

Bramidæo .

Bramocharax

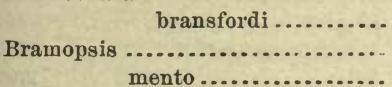

Branch Herring...................

branchialis, Ammocotes .........

Petromyzon ............

Branchiostegus ..................

Branchiostoma ...................

californieuse........

californiensis.......

caribæum ..........

lanceolatum ........

lubricum ...........

Branchiostomatidæ

Branchiostomidæ

Branderius.

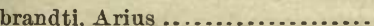

Cottus .........................

Myoxocephalus...........

Tachisurus ...............

brandtii, A rius...................

branicki, Pomadasis...............

Pristipoma ..............

branneri, Pœeilia ..................

bransfordi, Bramocharax..........

Loricaria ...............

Rhamdia ...............

brasilianus, Gerres.................

brasiliense, Pristipoma............

brasiliensibus, Capeuna ............

Guabi coara..........

brasiliensis, Amblyopus...........

Centropristis ...........

Chirostoma............

Chlorichthys..........

Clupea ................

Conger...............

Esox ..................

Hemiramphus.........

Hippoglossus..........

Labrus ................

Menidia
Page.

958

959

959

960

960

960

1586

958, 959

960

958

1360

57

956

338

339

1501

1502

426

14

14

2578

3,4

4
Page
brasiliensis, Mugil ............ $810,814,816$

Muræna seu conger.... 403

Narcine ............ 78, 2752

Paralichthys .......... 2626

Plagusia............. 2709

Pseudorhombus ....... 2626

Scorpæna............ 1842

Serranus............ 1221

Thynnus ............. 869

Torpedo............. 78

Vomer............... 934

braytoni, Notropis ................ $\quad 264$

Bream ................ 250, 1009, 1358, 1360

Bream, Blue................... 1005

Copper-nosed.............. 1005

Redbreast ................ 1001

Bregmaceros .................... 2526

atlanticus.......... $\quad 2527$

atripinnis .......... $\quad 2527$

bathymaster ........ 2527

macclellandii........ 2526

Bregmacerotidæ.................. $\quad 2525$

Bresson .......................... 125

brevibarbe, Lepophidium .......... $\quad 2485$

Ophidium ............. 2485

brevicauda, Pomoxys.............. 987

Salmo............... 493

brevicaudata, Brevoortia tyrannus. $\quad 434$

Breviceps ...................... 116

breviceps, Evorthodus............. 2208

Gasterosteus........... $\quad \mathbf{7 4 6}$

Larimus ............... 1423

Moxostoma............ 196

Pomotis .............. 1003

Ptychostomus .......... 196

brevidens, Gonostoma............ $\quad 579$

brevimanus, Gerres .............. $\quad 1377$

Tetragonopterus..... 335

brevipes, Lycodes................. $\quad 2467$

brevipinna, Scymnus............. $\quad 57$

Somniosus............ 57

brevipinne, Ditrema.............. 1499

Pristipoma........... 1341

brevipinnis, Blennins ............. 2391

Boleosoma olmstedi ... 1057

Hypsoblennius........ 2390

Isaciella ............. 1341

Orthopristis.......... 1341

Thynnichthys........ 869

Thynnus............ 869

brevirostris, Chasmistes........... 183, 199

Cololabis............. $\quad 726$

Gerres ............... 1376

Hippocampus ......... $\quad 776$

Histiophorus......... 892

Hypoprion ........... 41 
brevirostris, Macrognathus......... Saurus ................

Scombresox ...........

Syngnathus...........

brevirostrum, Acipenser ...........

Hæmulon............

brevis, Acanthurus...............

Amblyopus ................

Atherinichthys .............

Centropomus ...............

Cephalus ..................

Cetengraulis................

Engraulis.................

Tyntlastes................

brevispinis, Sebastichthys .........

Sebastodes ..............

brevoorti, A rgyriusus ...............

Euleptorhamphas .......

Brevoortia ........................ tyrannus .............. anrea......... brevicaudata. patronus .....

brevoortii, Braina .................

bricei, Chætodon ..................

bristolæ, Emmnion ................

Broad Shad .......................

Whitefish ...................

Broad-head, Grubber ................

broccus, Balistes ..................

Monacanthus..............

Brochet de Mer .....................

brodamus, Cottus...................

Brook Lampreys ...................

Silverside.................

Stickleback ................

Sucker ....................

Trout ....................

Trout of western Oregon....

Brosme.

brosme ....................

brosme, Brosme ..................

Brosmius .................

Enchelyopus..............

Gadus ....................

brosmiana, Lota ..................

Brosminæ ........................

Brosmius..........................

brosme ..................

flavescens ................

flavesny .................

marginatus...............

vulgaris .................

Brosmophycinæ..................

Brosmophycis ....................

marginatus.
Page.

723

533

726

765

106

1300

1691

2263

2840

1125

1754

450

450

2262

1788

1787

936

724

433

433

434

431

434

959

1678

2375

1372

464

447

1716

1716

1118

2066

12

805

744

178

506

501

2561

2561

2561

2561

2561

2561

2551

2532

2561

2561

2561

2561

2502

2561

2498

2502

3502

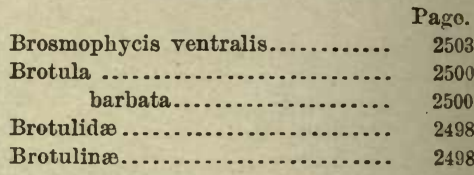

Brotuloid Fishes................ 2498

broussoneti, Gobioides............. 2264

broussonetii, Acanthurus ......... 1691

Umbrina ............ 1466

broussonnetii, Gobiodes .......... 2263

Brown Cat .................... 142

Hind.................... 1142

Rockfish ................ 1817

browni, Atherina............... 443

Engraulis ................ 443

Hemirhamphus ........... $\quad 723$

Solea.................... 2701

Stolephorus .............. 443

Vomer .................. 934

Brown-winged Sea-robin .......... 2167

brucus, Squalus ................ $\quad 58$

brunnea, Majnea................ 2476

brunneus, A miurus .............. $\quad 142$

Catulus ............... 24

Gobius .............. 2218

Iyophis .............. $\quad 350$

Serranus .............. 1175

Trisotropis ............ 1175

Brycon....................... $\quad 337$

dentex................ 337

striatulus ................ $\quad 337$

bryoporus, Spratelloides........... 422

Bryostemma .................... 2408

nugator............ 2410

polyactocephalum .. 2408, 2409

bryosus, Blennicottus glubiceps .... 2017

Bryssetæres.................... 2328

pinniger............. 2328

Bryssophilus.................. 2329, 2330

Bryttus ....................... 995

albulus ................. 1007

fasciatus ................ 993

gloriosus ............... 994

humilis................. 1004

mineopas ................ 996

oculatus.................. 1004

punctatus ................ 998

reticulatus ............... 998

signifer................. 996

unicolor ................. 1001

Bubalichthys ................. 163

altus............... 165

bonasus ............ 164

bubalinus........... 165

bubalus ........... 516

niger............... 164 
Bubalichths urus.

.

Bubbler .........................

buccanella, Lutjanus..............

Mesoprion .............

Neomænis .............

buccata, Ericymba ...............

bucciferus, Labrisomus..............

bucco, Moxostoma ................

Ptycbostomus .............

bucculentus, Chonophorus.........

buchauani, Notropis ...............

Buffalo Cod ......................

Common ..................

fishes ....................

Mongrel ..................

Razor-backed ..............

Red mouth .................

Small-mouthed .............

Sucker-mouthed ...........

buffalo, Acipenser.................

buto, Lophius.....................

Scorpæna ...................

Bugara........................

Bugfish . ........................

Bull Red-fish.....................

Bull Trout .......................

bullaris, Cyprinus ................

Semotilus ...............

bulleri, Prionodes..................

Serranus..................

Bullhead

Bullhead, Bear Lake ...............

Black ..................

Common ................

Prickly .................

Rocky Mountaín........

Bullhead Shark ..................

Sharks ..................

Bullon

Page.

$16 \pm$

273

273

165

273

273

1972

1971

165

165

165

164

164

1484

1262

1262

1261

302

2363

190

191

2236

2800

1875

163

163

164

161

163

164

164

106

2316

1849

1508

433

1453

507

221

222

1213

1214

1950

1954

141

140

1944

1949

20

19

1650

938

Bumper..........................

buniva, Balistes.

1701,1711

Burbots.

2550

Burgall ...........................

burgall, Ctenolabrus.
1577

1577
Page.

Burr-fish, Common ............... 1748

Burr-fishes..................... 1747

Burrito ...................... 1333, 1327

Burritos ...................... 1325

Burro ......................... 1332

Blanco.................... 1328

Burros .......................... 1329

burtonianus, Cyprinus........... 2798

busculus, Prionodes............... 1211

Butirinus maderaspatensis ....... $\quad 415$

butleri, Pœcilia................... 691

butlerianus, Poecilichthys......... 1102

Butter-fish ............ 967, 1144, 2416, 2419

Butter-fishes..................... 965

Butterfly..................... 1677

Butterfly-fishes ................ 1669, 1672

Butterfly Ray ................... 86

Butyrinus...................... 411

banana............... 411

Bythites ........................ 2504

Bythitinæ...................... 2498

caballa, Cybium................. 876

Scomberomorus.......... 876

Caballerote................... 1255, 1257

caballerote, Anthias............. 1257

Lutjanus ............ 1257

Mesoprion ............. 1257

caballus, Caranx.................. $\quad 921$

Cabezon.................... 1423, 1889, 2321

Smooth................. 2012

Cabezones....................... 1889

Cabezote......................... $\quad 790$

Cabezuda, Lisa .................. $\quad 811$

caboverdianus, Ginglymostoma .... $\quad 26$

Cabra Mora ...................... 1152

Cabrilla ................... 1158, 1197, 1832

Calamaria ............... 1184

de Raizero............... 1171

Piritita................. 1181

Cabrilla, Spotted................. 1196

Cabrillas Verdes .................. 1194

Cabrillo de Astillero ............... 1176

Cachucho ....................... 1282

Caçonetta....................... $\quad 40$

Cæcilia......................... 373

cælolepis, Centroscymnus......... $\quad 55$

cænicola, Pœcilia .................. $\quad 641$

cænosus, Pimelodus .............. $\quad 140$

cærulea, Cliola................... $\quad 277$

Clupea................. 421

Codoma................ 277

Coryphæna............. 1653

Maletta................ 423 


\begin{tabular}{|c|c|c|c|}
\hline cærulea, Noracula.................. & $\begin{array}{r}\text { Page. } \\
1653\end{array}$ & California Barracuda .... & $\begin{array}{r}\text { Page. } \\
826\end{array}$ \\
\hline Tautoga ................... & 1577 & Big Skate .... & 72 \\
\hline cæruleatus, Acronurus ............ & 1691 & "Bluefish" ........ & 1410 \\
\hline cæruleo-aureus, Harpe............. & 1583 & Bonito .............. & 872 \\
\hline cæruleopunctatus, Acara ........... & 1514 & Conger Eel......... & 395 \\
\hline cærulescens, Arius................. & 129 & Dogfish ..... & $5 \pm$ \\
\hline Galeichthys ........... & 2776 & Hagfish......... & 6 \\
\hline Hexanematichthys ... & 129 & Herring............. & 422 \\
\hline Pimelodus............ & 135 & Jewfish ............. & 1137 \\
\hline eæruleus, Acanthurus .............. & 1691 & Lancelet ............. & 4 \\
\hline Carcharhinus............ & 37 & Pompano............. & 967 \\
\hline Carcharias................. & 37 & Redfish .................. & 1585 \\
\hline Cheonda................. & 232 & Sardine ................. & 423 \\
\hline Clupanodon .............. & 423 & Smelt ............... & 806 \\
\hline Ctenolabrus ............... & 1577 & Sole ................. & 2613 \\
\hline Cyclopterus .............. & 2097 & Stickleback ......... & 751 \\
\hline Notropis ................ & 277 & Stingray......... & 89 \\
\hline Photogenis ............... & 277 & Tomeod ............ & 2539 \\
\hline Pseudoscarus ............ & 1654 & Torpedo............. & 77 \\
\hline Scarus............... 1652 & 2,1654 & Whiting...$\ldots \ldots \ldots$. & 1476 \\
\hline Squalius................. & 232 & californica, Alausa............. & 423 \\
\hline us .................. & 33 & Morrhua ................... & 2539 \\
\hline Teuthis ................ & 1691 & Squatina................ & 59 \\
\hline cærulopunctatus, Equidens ........ & 1514 & Tetronarce.......... & 77 \\
\hline Cæsar.................................. & 1308 & Torpedo............ & 78 \\
\hline Cæsiomorus...................... & 939 & Uropsetta.......... & 2626 \\
\hline Cæsiosoma californiense ............ & 1391 & californicus, Cypsilurus ....... & 2836 \\
\hline cæsius, Anisotremus............... & 1316 & Exocotus ........ & 30,740 \\
\hline Pomadasys ................... & 1317 & Gadus ............. & 2539 \\
\hline Cagon de lo Alto ........................ & 1277 & Galeus............. & 30 \\
\hline Cailleu .................................... & 429 & Halichæres ........ & 1601 \\
\hline Cailleu-tassart $\ldots \ldots \ldots \ldots \ldots \ldots \ldots$ & 432 & Hippoglossus..... & 2626 \\
\hline Caiman & 2216 & Mustelus ......... & 30 \\
\hline Cajín.................................. & 1258 & Myliobatis...... & 89 \\
\hline Calafate,$\ldots \ldots \ldots \ldots \ldots$ & 1711 & Oxyjulis ........... & 1601 \\
\hline Calamaria, Cabrilla ................ & 1184 & Paralichthys ....... 262? & 5,2626 \\
\hline Calamus ......................... 1347 & 7,1349 & Pseudojulis............ & 1601 \\
\hline arctifrons................... & 1355 & Pseudorhombus ....... & 2626 \\
\hline bajonado............... 1352 & 2,1353 & Stereolepis............. & 1138 \\
\hline brachysomus .............. & 1353 & californiense, Branchiostoma ....... & 4 \\
\hline calamus ................. & 1349 & Cæsiosoma & 1391 \\
\hline leucosteus ................. & 1353 & Myctophnm .......... & 572 \\
\hline macrops ................ 1350 & 0,1354 & Siphostoma........... & 764 \\
\hline medius................... & 1350 & californiensis, Atherinichthys ..... & 807 \\
\hline megacephalus.......... 1350 & 0,1351 & Atherinopsis........ & 806 \\
\hline penna.................. 135t & $t, 1355$ & Branchiostoma...... & 4 \\
\hline la................... & 1351 & Chilomycterus ....... & 1751 \\
\hline plumatula ............... & 1352 & Cyprinodon .......... & 674 \\
\hline proridens .................. & 1350 & Diapterus............ & 1370 \\
\hline taurinus $\ldots . . . . . . . . .$. & 1354 & Doryichthys ......... & 774 \\
\hline calamus, Calamus................... & 1349 & Doryrhamphus...... & 773 \\
\hline Chrysophrys............ & 1350 & Eucinostomus....... & 1369 \\
\hline Pagellas ................ & 1350 & Gerres .............. & 1370 \\
\hline calcarata, Scorpæna................ & 1854 & Medialuna .......... & 1391 \\
\hline Calico Bass ....................... & 987 & Ophisurus ......... & 384 \\
\hline California Anchovy ................ & 448 & Otolithus ............ & 1413 \\
\hline
\end{tabular}


californiensis, Polynemus......... Scorpis................ Syngnathus........ Trphlogobius ....... Xenichthys ......... Xenistius ........... callarias, Gadus.................. callaris, Salmo ................... Callaus.......................... Callechelys.

murgena. peninsulæ $\ldots . . . . . . .$.

Calliclinas ....................... Calliodon dentiens............... 1623 gibbosus.............. 1296 lineatus................ 1651 retractus .............. 1623

calliodon, Liparis ................ Calliony midx ................... Callionymus.

bairdi ................

calliurus ..............

himantophorus ........ panciradiatus......... pelagicus ..............

callipteryx, Campostoma........... callisema, Cliola.

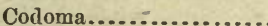

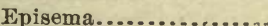

Notropis................

callisoma, Herpetoichthys..........

callistia, Cliola...................

Codoma...................

callistius, Notropis.................

Photogenis ..............

calliura, Cliola ..................

Cyprinella ................

Etheostoma..............

Myteroperca..............

Calliurus..................... 995, 101

diaphanus..............

floridensis...............

formosus .................

longulus .................

melanops..................

microps .................

murinus.................

punctulatus

calliurus, Callionymus .............

Ioglossus ................

Trisotropis ..............

Callogobius

callolepis, Harengula ...............

callopterus, Cypsilurus

Exocotus
Page.

829

1391

764

2262

1286

1286

2541

508

1455

378

378

379

2360

1650

96
623
2120

2184

2185

2185

2187

2186

2188

2184

206

273

273

273

272

384

276

276

276

276

275

275

1011

1186

996

992

996

996

992

996

996

2, 1011

2193

1186

2210

430

2836

740
Calloptilum .

mirum................

Callorhynchus atlanticus ......... 95

centrina.......... 95

Callyodon................ 1621, 1642, 1651

auropunctatus ......... 1624

flavescens .............. $\quad 1640$

psittacus.............. 1638

ustus.................. 1624

callyodon, Cyclopterus ........... 2110

Liparis............... 2111

Neoliparis ............ 2110

calopteryx, Serranus............. 1213

Calotomus ...................... 1626

xenodon ............... 1626

calva, Amia .................... 113

Calycilepidotus .................. 1936

lateralis .......... $\quad 1899$

spinosus......... 1937

Camarina ...................... 1381

nigricans.............. 1382

camelopardalis, Mycteroperca tigris 1187

Serranus .......... 1187

campbelli, Moxostoma ........... 186

Salmo............... 508

Campbellite.................... 987

campechianus, Lutjanus.......... 1265

Mesoprion.......... 1265

camperi, Scombresox............. $\quad 725$

Campostoma .................... 204

anomalum ........... 205

callipteryx .......... 206

dubium............. 206

formosulum ......... 206

gobionium.......... 206

hippops ............ 206

mormyrus........... 206

nasutum ........... 206

ornatum............ 205

pricei..............205, 2796

prolixum ............ 206

Campostominæ................ $\quad 202$

Campylodon .................... 614

fabricii .............. 615

camtschatica, Lampetra ........... 13

camtschaticus, Entosphenus ....... 2745

Pteromyzon....... $\quad 2745$

marinus 2745

camura, Cliola .................... $\quad 280$

Vaillantia ................ 1060

camurum, Boleosoma ............ 1060

Etheostoma ............ $\quad 1076$

camurus, Nanostoma............. 1076

Notropis............... $\quad 279$

camurus, Poecilichthys ........... 1076

Caña-bota...................... 19 


\begin{tabular}{|c|c|c|c|}
\hline & $\begin{array}{r}\text { Page. } \\
\quad 948\end{array}$ & capeuna, Hæmulon . & $\begin{aligned} \text { Page. } \\
1311\end{aligned}$ \\
\hline canadense, Stizostedion ..... & 1022 & Hæmylum .............. & 1311 \\
\hline boreum.... & 1022 & Serranus $\ldots . . . . . . . . . .$. & 1311 \\
\hline & 1022 & capillaris, Argyriosis .............. & 936 \\
\hline canadensis, Lncioperca ............ & 1022 & Zens...................... & 936 \\
\hline Salmo..................... & 507 & capillatus, Clinus.......... & 2362 \\
\hline canadus, Gasterosteus ... & 948 & Labrisomus ............. & 362 \\
\hline Rachycentron ............. & 948 & capistratus, Balistes ............... & 704 \\
\hline canaliculatus, I & 1917 & Chætodon .......... & 1677 \\
\hline (n................... & 2362 & thus ........... & 1704 \\
\hline candidissimus, Leptocephalus....... & 354 & Sarothrodus ............ & 1678 \\
\hline Candil ....................... & 816 & Tetrodon....... & 1742 \\
\hline (n.......... & 521 & Capitaine......., & 1579 \\
\hline (n............. & 48 & $\begin{array}{l}\text { capite, Eleotris plagioplateo......... } \\
\text { Labrus obtuso .............. }\end{array}$ & 2201 \\
\hline 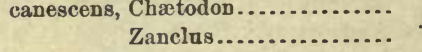 & $\begin{array}{l}1688 \\
1688\end{array}$ & (n) & \\
\hline 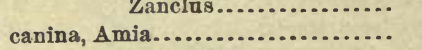 & $\begin{array}{r}1688 \\
113\end{array}$ & s $, \ldots \ldots, \ldots \ldots \ldots$ & \\
\hline (n). & $\begin{array}{l}113 \\
570\end{array}$ & $1, \ldots \ldots \ldots \ldots$ & \\
\hline (n) & $\begin{array}{l}570 \\
921\end{array}$ & caprinus, Argyrops ................. & 1345 \\
\hline laimus............. & 1580 & Balistes ...................... & 1702 \\
\hline ............... & 1352 & nus ............. & 168 \\
\hline$\ldots \ldots \ldots \ldots$ & 38 & ter............... & 1345 \\
\hline ........... & 29 & Stenotomus............... & 1345 \\
\hline ................. & 479 & Capriscus ...................... 1699, & , 1700 \\
\hline n..................... & 29 & capriscus, Balistes .................. & 1701 \\
\hline canna, Hæmulon ................ 1297 & 7,1299 & murium dentibus minutis & 1720 \\
\hline (n................. & 756 & caprodes, Etheostoma .............. & 1027 \\
\hline istipoma ............ & 1340 & Percina....$\ldots \ldots \ldots$ & 1026 \\
\hline cantharinus, Orthopristis......... 1339 & 39,1340 & manitou........... & 1028 \\
\hline Cantharus nigromaculatus.......... & 987 & zebra........ & 1027 \\
\hline Cantherines......................... & 1713 & Sciæna.................. & 1027 \\
\hline .............. & 1713 & 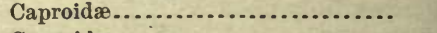 & 1663 \\
\hline pullus................. & 1713 & dea $\ldots \ldots \ldots \ldots \ldots \ldots \ldots$ & 1663 \\
\hline (................... & 1705 & Caprophonns....................... & 1664 \\
\hline maculatns ........ 170 & 06,1707 & aurora $\ldots . . . \ldots \ldots \ldots . .$. & 1665 \\
\hline sobaco............... & 1705 & capros, Antigonia .................. & 1665 \\
\hline n $\ldots \ldots \ldots \ldots$ & 1706 & caramura, Murenophis .............. & 395 \\
\hline eii ........... & 1707 & Carangichthys ................ 916,917 & \\
\hline Canthigaster.... & 1741 & Carangidø...$\ldots \ldots \ldots \ldots$ & 895 \\
\hline candicinctus....... & 1742 & 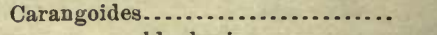 & 928 \\
\hline (n........... & 1732 & blepharis .............. & 932 \\
\hline issimus ........ & 1741 & cibi.................... & 920 \\
\hline ............ & 1741 & dorsalis................. & 930 \\
\hline Canthigasteridæ...$\ldots \ldots \ldots \ldots \ldots$ & 1740 & thys $\ldots . . . . . . .$. & 932 \\
\hline Canthirhyncus........... & 2088 & linus................. & 919 \\
\hline gins... & 2092 & immus.......... & 928 \\
\hline .......... & 1713 & carangoides, Seriolophus ........... & 895 \\
\hline leña, Mojarra..... & 1369 & Carangops... & 912 \\
\hline (.......... & 520 & heteropygus.......... & 913 \\
\hline (n) & 1754 & lns............ & 914 \\
\hline odon ........... & 50 & carangua, Caranx ... & 920 \\
\hline Elops...................... & 410 & Carangus .......................... 915 & 5,916 \\
\hline Scorpæna................ & 1833 & chrysos $\ldots . . . \ldots . . . . .$. & 921 \\
\hline Sebastes................... & 1833 & esculentus............... & 921 \\
\hline Sebastodes ............... & 1833 & fallax...... $.6 \ldots \ldots$ & 923 \\
\hline Capenna brasiliensibus ............. & 1311 & bippos .................... & 921 \\
\hline
\end{tabular}


Carangus lugubris

Page.

925

carangus, Scomber

920

Caranx................ 915, 916, 919, 927

amblyrhynchus ........... 913

analis................... $\quad 927$

antillarum ...............

ascensionis................

atrimanus................

aureus ...................

bartholomæi ..............

beani....................

belengeri..................

bixanthopterus.............

blochii ....................

boops .....................

caballns................. 921, 2846

caninus .................. 921

carangua................ 920

chilensis ................ 927

chrysus .................. 921

cibi....................... 920

crinitus................. 932

crumenophthalmus......... 911

crysos.................. 921, 2846

cuvierri .................. 910

daubentonii ............... 920

defensor.................. 921

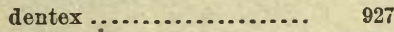

dorsalis.................. 930

dumerili ................ 904

ekala..................... 921

erythrurus................ 920

falcatus............. 913, 2844, 2845

fallax .................. 923

fasciatus ..................

fosteri.....................

frontalis ..................

furthii ....................

georgianus ................

girardi

guara .....................

heteropygus...............

hippos ..................

iridinus ....................

latus .....................

lepturus..................

lessoni ....................

leucurus ..................

lugubris ..................

luna.......................

macarellus .................

macrophthalmus ...........

marginatus................

medusicola .................

melampygus ...............

muroadsi.
Page.

929

930

928

923

923

picturatus ................ 910

pisquetus ................921, 2846

platessa................. 927

plumieri ................. 912

poloosoo ................. 928

punctatus................ 908

richardi................. 923

ruber ................... 919

sanctæ-belenæ........... 908

scombrinus ............... 908

secundus................ 914

sem .................. 923

semispinosus............. 911

setipinnis dorsalis......... 934 gambonensis .... 934

solea ................... 927

speciosus ................ 928

stellatus ................. 926

suareus ................. 908

sutor................... 932

symmetricus............. $\quad 910$

trachurus ............... 910

cuvieri......... 910

vinctus ................. 918

xanthopygus............. 921

Caranxomorus .................. 952

plumierianus ....... 911

carapinus, Coryphænoides......... 2579

Carapo ......................... $\quad 340$

carapo, Gymnotus............... . 341

Carapus....................... $\quad 340$

affinis.................. 2497

fasciatus ................ 341

inæquilabiatus........... $\quad 341$

Carassius ...................... 201

auratns............... 201

Carauna...................... 1145

carbonaria, Pileoma............. 1027

carbonarium, Hæmulon.......... 1300

carbonarius, Acipenser........... 106

Gadus.............. 2534

Pollachius........... 2535

Salmo............... $\quad 509$

Carbonero....................... 919

Carbonero, Ronco.............. 1300

carbunculus, Etelis .............. 1283

Carcharhinæ................... 28

Carcharhinus ............... 33, 35, 37, 2747

acrunotus........... 36

æthalorus .......... 40

cæruleus .......... $\quad 37$ 


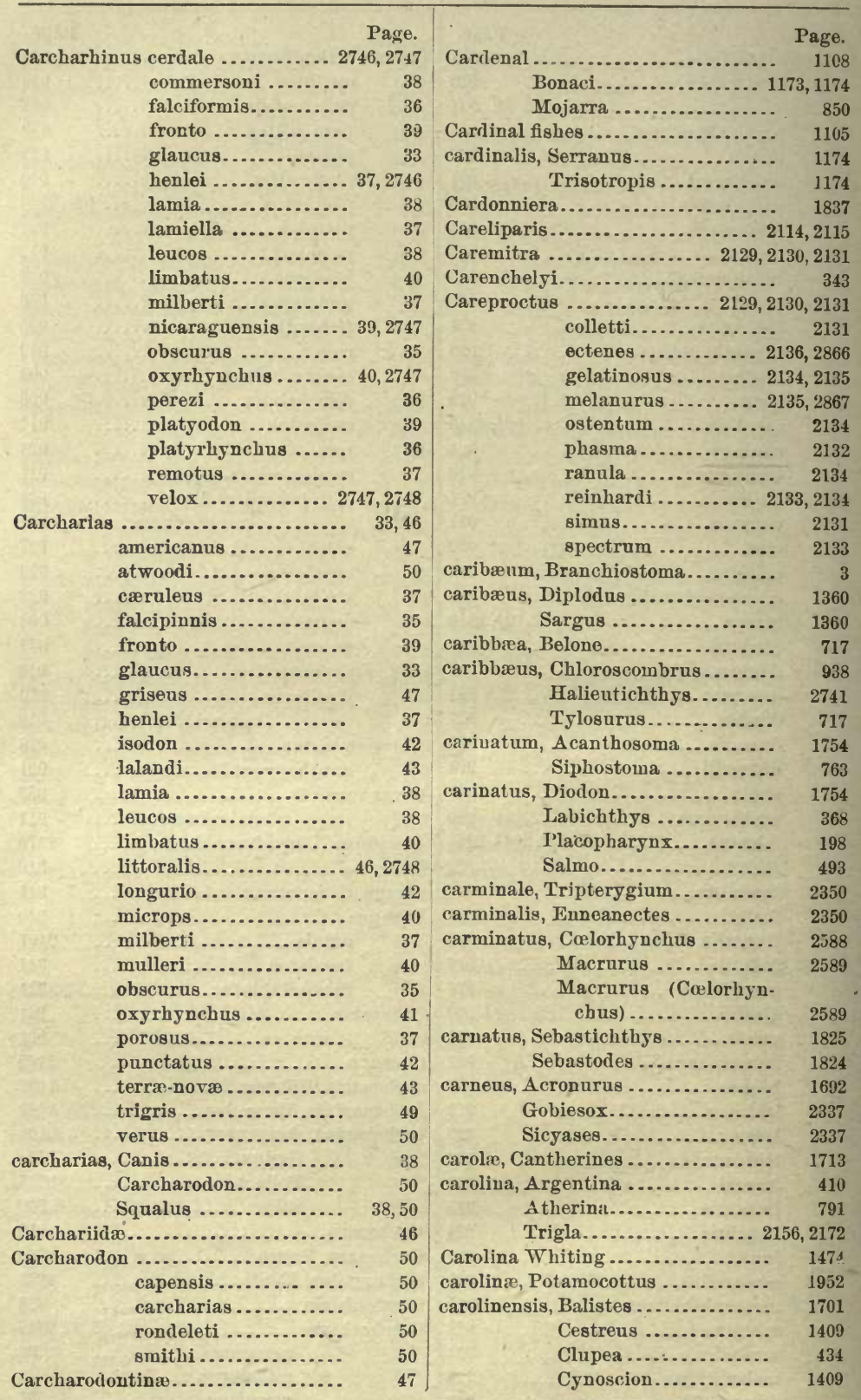


čarolinensis Gobius

Hyperistiug

(tius.............

Mystus ..............

Otolithus .............

Seriola zonata.........

carolinus, Blennius.................

Gasterosteus ............

Labrus .................

Pholis ..................

Priacanthus............

Prionotus

. 2156,2157

Pteraclis.

Trachinotus

Trachynotus

Carp, Lake

Sucker

Suckers .....................

carpio, Carpiodes...................

Catostomus................ 166, 190

Cyprinodon................

Cyprinus ..................

Moxostoma.................

Carpiodes.

bison .....................
carpio .................
cutisanserinus ..........

cyprinus

.. 167,168

damalis ............... $\quad 167$

difformis ............... $\quad 166$

grayi ...................

nummifer ...............

selene ...................

taurus ...................

thompsoni...............

tumidus ................

urus....................

vacca....................

velifer.

vitulus

Carp-like Fishes

Carps .

Crucian .

carribæus, Cœlorhynchus ..........

carribbæus, Macrurus ..............

Carrilla Pinta

carringtonii, Agosia nubila.........

Apocope ..............

Cartilaginous Ganoids .............

carunculatus, Ceratias .............

caryi, Acipenser ...................

Ditrema....................

Embiotoca ................. 1509

Hypsurus ................ 1508, 1509

Casabe

Casabes
Page.

2218

117

1409

902

2378

944

$15 \% 8$

2379

2858

956

944

944

167

166

165

166

675

201.

190

165

166

166

167

167

167

166

167

165

167

167

164

168

167

165

160

161, 199

201

2589

2590

1152

311

312

100

2732

104

1509

509
509

938

937 cassidyi, Embiotoca ............... 1505

cassini, Muræna ................. $\quad 356$

Casta Cumprida, Alfonsin a....... 844

Casta Larga, Alfonsiu ............ $\quad 844$

Castagnole....................... $\quad 959$

castanea, Sidera.................. $\quad 396$

castaneola, Sparus ............... $\quad 960$

castaneum, Macrostoma.......... 556.

castaneus, Ichthyomyzon .......... 11

Lycodontis............ 2804

Notoscopelus........... $\quad 556$

Petromyzon............ 11

castelnæana, Pellona............. $\quad 436$

castelnavi, Cylindrosteus.......... 111

castor, Pontinus.................. 1856

Scorpæna................. 1856

Cat Shark...................... 31

Sharks.................... 22

Cat, Blne...................... 134

Brown..................... 142

Channel ................... 134

Channel of the Potomac ....... 138

Chuckle-headed .............. 134

Duck-bill ................... 101

Eel ........................ 2788

Flannel-mouth.............. 137

Florida .................... 137

Great Fork-tailed............. 137

Mississippi................. 137

Mud ..................... 142, 143

Russian .................... 143

Sacramento................. 140

Schuylkill ................... 140

Spoon-bill.................. 101

Stone..................... 144

White ..................... 134, 138

Willow .................... 2788

Yellow.................... 139, 143

Catablemella .................... $\quad 554$

Catætyx ....................... 2504

rubrirostris.............. 2505

Catalina........................ 1322

Catalineta................... 1322, 1684

Catalinetas.................... 1682

Catalufa ...................... 1237, 1238

de lo Alto............... 978

catalufa, Priacanthus ............. 1238

Catalufas......................... 1236

Deep-water............. 977

Cataphracti ..................... $\quad 781$

Cataphractus schoneveldii ........ 2067

cataphractus, Acipenser.......... $\quad 107$

Agonus........... 2065, 2067

Aspidophorns ...... 2067

Cottus...........2053, 2066 


\begin{tabular}{|c|c|c|}
\hline Page. & & Page. \\
\hline cataphractus, Gasterosteus.......... & Catostomus & commersonii ............ \\
\hline aculeatus & & communis.............. \\
\hline Scaphirhynchus..... & & congestus.. \\
\hline aractæ, Ceratichthys............ & & cypho ...... \\
\hline Gobio ...................... & & .... $172,175,2791$ \\
\hline Rhinichthys............ & & duquesni.. \\
\hline dulcis ..... & & duquesnii \\
\hline aractus, Lencosomus............. & & elongatus. \\
\hline na, Bassozetus.................. & & erythrurus. \\
\hline enata, Echidna.................. & & fasciatus .............. \\
\hline Muræna................... & & fasciolaris............. \\
\hline Pœcilia .................. & & fecundus............ 180, 279 \\
\hline Xenisma ................. & & flexuosus............. \\
\hline catenatus, Fundulus ............... & & forsterianus............ \\
\hline Gynmothorax........... & & generosus .............. \\
\hline tenula, Murænophis ............. & & gibbosus ............... \\
\hline tesbæi, Scarus .................... & & gila $\ldots . . . \ldots \ldots \ldots \ldots . .$. \\
\hline Sparisoma...$\ldots \ldots \ldots \ldots$ & & gracilis ................ \\
\hline catesbei, Pomotis ................... & & griseus.............. 175, 279] \\
\hline esby, Scarus .................... & & guzmaniensis ......... \\
\hline esbyi, Sparisoma................. & & hudsonius.............. \\
\hline tfish of the Lakes.................. & & insignis ................ \\
\hline atfish, Bermuda................. 882 & & labiatus ............. 177, 279 \\
\hline Sea................... 118, 119, 128 & & lactarius .............. 175 \\
\hline Small ..................... 140,141 & & latipinnis ............ 174, 279 \\
\hline Catfishes ............................. 114, 115 & & lesueurii............. \\
\hline Gaff-topsail ............. $\quad 116$ & & longirostris ............ \\
\hline rinæ, Pristipoma .............. & & longirostrum.......... \\
\hline thetoplateo, Ostracion oblongus.. & & macrocheilus........... \\
\hline Cathetostoma albigutta ............ 2313 & & macrolepidotus......... \\
\hline Cathorops....................... 133, 2788 & & maculosus ............ \\
\hline gulosus................. 133, 2788 & & megastomus ........... \\
\hline hypophthalmus ......... 133, 2788 & & melanops.............. \\
\hline atochænum $\ldots \ldots \ldots \ldots \ldots \ldots \ldots \ldots .$. & & melanotus......... 206, 218, 32 \\
\hline tonotus......................... & & nanomyzon........... 17 \\
\hline fasciatus ............... & & nebulifer.............. \\
\hline flabellatus............... & & nebuliferus............ \\
\hline kennicotti............... & & nigricans.............. \\
\hline lineatus................. & & etowanus.... 18 \\
\hline Catostomidæ ....................... & & occidentalis........... 178, 279: \\
\hline Catostominæ ..................... 162 & & oneida................. \\
\hline Catostomns ..................... 173,174 & & pallidus ....... \\
\hline alticolus .............. $\quad 179$ & & planiceps .............. \\
\hline anisurus ............... & & plebeius................ \\
\hline aræopus............... & & pocatello ............... \\
\hline ardens $\ldots \ldots \ldots \ldots \ldots \ldots . . \quad 179$ & & reticulatus ............ 17 \\
\hline aureolus $\ldots \ldots \ldots \ldots \ldots \ldots$ 193, 196 & & retropinnis ........... 175, 279 \\
\hline aurora............... $\quad 176$ & & rex $\ldots \ldots \ldots \ldots \ldots \ldots . .177,2792$ \\
\hline bernardini ............. & & rhothøecus............ 181 \\
\hline bostonensis ............ & & rimiculus.............. \\
\hline bubalus ................ & & snyderi................ \\
\hline caprinus .............. & & sucklii................. \\
\hline carpio................ 166, 190 & & tahoensis............... \\
\hline catostomus.......... 176, 2792 & & teres.................. \\
\hline chloropteron ............ & & texanus ............... \\
\hline clarki ................. & & tsiltcoosensis.......... \\
\hline
\end{tabular}




\begin{tabular}{|c|c|}
\hline Page. & Page. \\
\hline Catostomus tuberculatus. & candispinosus, Scopelus... \\
\hline 179 & Caularchus................ \\
\hline velifer.......... & maandricus.............. \\
\hline ....... & caulias, Sigmistes.................. \\
\hline catostomus, Catostomus............. & 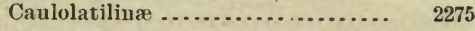 \\
\hline Cyprinus .............. & Caulolatílus....................... \\
\hline Phenacobius............ & affinis $\ldots . . . \ldots \ldots \ldots . . .$. \\
\hline 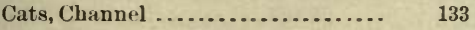 & anomalus.............. \\
\hline Mud.......... & chrysops ............... \\
\hline Stone...................... & eyanops ............... \\
\hline Catulus ............................. & n.......... \\
\hline brunneus.................. & ..... 2276,2277 \\
\hline n.............. & Caulolepis........................ 838 \\
\hline retifer.................. 25 & longidens .............. 839,2842 \\
\hline uter .................... 25,2745 & Caulophryne .................... 2734 \\
\hline xaniurus $\ldots \ldots \ldots \ldots \ldots \ldots . .24$ & jordani........... \\
\hline s nebulosus ....... & Caulophryninæ ..................... \\
\hline hodus ................. & Caulopus....................... 594,596 \\
\hline Gobius ................... & hes ............... \\
\hline Pimelodus.................. & s (Leuciseus) ..... \\
\hline eatus, Aneiurus ................... & us ................ \\
\hline Amiurus $\ldots \ldots \ldots \ldots \ldots$ & Mylocheilus .............. 219, 220 \\
\hline Epinephelus.................. & Sebastes .................. \\
\hline Pimelodus ................... & Sebastodes................ \\
\hline Serranus .................... & Cavalla.............................. \\
\hline 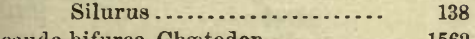 & cavalla, Cybium.................... \\
\hline a n........... & rus $\ldots . . . . . . . . .$. \\
\hline ima acuminata & 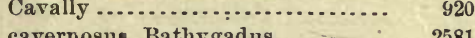 \\
\hline (n................ & cavernosus, Bathyga \\
\hline a $\ldots \ldots \ldots \ldots . .$. & sphalus ...... \\
\hline eaudacuta, M & cavifrons, Ambloplites rupestris .. \\
\hline s $\ldots \ldots \ldots \ldots$ & ............. \\
\hline candafurcatus, An & Hemitripterus ........... \\
\hline Pimelodus.......... & n.............. \\
\hline caudalis, Halichæres............... & 'Tirandichthys ........... \\
\hline Iridio...$\ldots \ldots \ldots \ldots \ldots$ & ( \\
\hline Julis ................... $\quad 1599$ & caxis, Lutjanus .................... \\
\hline Platyglossus ............. 1599, 1600 & Mesoprion...$\ldots \ldots \ldots \ldots \ldots$ \\
\hline Pomacentrus............. $\cdot 1556$ & Sparus ..................... \\
\hline caudanotatus, Mesoprion ........... & cayanus, Pristigaster ............... \\
\hline caudata, Lamna ..................... & cayennense, Siphostoma ............ \\
\hline caudatus, Lepidopus ............. 887, 2844 & cayennensis, Citharichthys ........ \\
\hline s $\ldots \ldots \ldots \ldots \ldots$ & Corythroichthys ..... \\
\hline candicinctus, Prilonotus (Anchiso- & s $\ldots \ldots \ldots \ldots . .1404$ \\
\hline 1742 & Is........... 1404, 1411 \\
\hline ......... & athus.......... 773 \\
\hline candicula, Conges & Trachinotus........... \\
\hline Leptocephalus ........... & Cayennia ........ \\
\hline caudilimbatus, Conger.. & guichenoti............... \\
\hline Echelus ............. & cayennsis, Vomer.................. \\
\hline Leptocephalus ...... & cayorum, Corythroichthys ........ \\
\hline randimacula, Diplodus.............. & Ogilbia...$\ldots \ldots \ldots \ldots \ldots$ \\
\hline Hæmulon...... 1299, 1302, 1309 & cayuga, Encalia inconstans......... \\
\hline Sargus.............. & Notropis ................... \\
\hline caudispinosum, Macrostoma ...... 556, 2826 & atrocaudalis ...... \\
\hline caudispinosus, Notoscopelus........ & Cazon de Playa \\
\hline
\end{tabular}




\begin{tabular}{|c|c|c|c|}
\hline & Page. & \multirow{7}{*}{\multicolumn{2}{|c|}{$\begin{array}{crr} & & \text { Page. } \\
\text { Centronotus } & \text { gurelliformis.......... } & 2421 \\
\text { gunnellus ............. } & 2419 \\
\text { islandicus.............. } & 2438 \\
& \text { latus............... } & 2420 \\
\text { nebulosus........... } & 2414 \\
\text { (Opisthoc entru s) } & \end{array}$}} \\
\hline Cebedichthyinæ................... & 2349 & & \\
\hline Cebedichthys ................... 2426 & 6,2869 & & \\
\hline cristagalli ............ & 2427 & & \\
\hline violaceus............ & 2427 & & \\
\hline Céfalo................................ & 811 & & \\
\hline celatus, Batrachus................. & 2316 & & \\
\hline Cenisophius............................ & 243 & quinquemaculatus. & 2430 \\
\hline Centaurus $\ldots \ldots \ldots \ldots \ldots \ldots \ldots \ldots$ & 1753 & pictus ................ & 2416 \\
\hline boops.................. & 1755 & roseus......... & 2420 \\
\hline Centrarchidæ $\ldots \ldots \ldots \ldots \ldots \ldots \ldots \ldots$ & 984 & spinosus........ & 918 \\
\hline Centrarchina ..................... & 985 & taczanowskii.......... & 2416 \\
\hline Centrarchus ............................ & 988 & Centrophorus cœlolepis ............. & 55 \\
\hline æneus $\ldots \ldots \ldots \ldots \ldots$ & 990 & Cottus semiscabra ... & 1945 \\
\hline fasciatus ............. & 1012 & 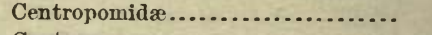 & 1116 \\
\hline hexacanthus.......... & 987 & Centropomus............................. & 1117 \\
\hline interruptus........... & 991 & affinis $\ldots \ldots \ldots \ldots \ldots$ 1124 & 4,2853 \\
\hline macropterus........... & 988 & alburnus...$\ldots \ldots \ldots$. & 1475 \\
\hline maculosus............ & 991 & albus .................. & 1135 \\
\hline pentacanthus.......... & 990 & appendiculatus........ & 1119 \\
\hline pomotis............... & 989 & armatus .............. & 1123 \\
\hline tetracanthns.......... & 1540 & auratus............... & 1107 \\
\hline viridis................ & 992 & is $\ldots \ldots \ldots \ldots \ldots$. & 1125 \\
\hline centrarchus, Cichlasoma............ & 1526 & cnvieri ................. & 1121 \\
\hline Heros............ & 1526 & ensiferus........... 1125 & 5,2853 \\
\hline Centridermichtlyys analis ........... & 2013 & grandoculatus........ & 1120 \\
\hline asper............ & 1944 & luteus ................. & 1024 \\
\hline bicornis......... & 1913 & medius ............... & 1120 \\
\hline globiceps....... & 2017 & mexicanus ............ & 1121 \\
\hline gulosus ......... & 1945 & nigrescens ........... & 1119 \\
\hline - maculosus ..... & 2014 & parallelus ............. & 1122 \\
\hline uncinatus...... & 1906 & pectinatus ............ & 1122 \\
\hline centrina, Callorhynchus............ & 95 & pedimacula ........... & 1119 \\
\hline 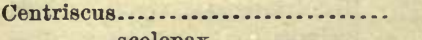 & 759 & robalito $\ldots \ldots \ldots \ldots \ldots$ & 1123 \\
\hline scolopax................. & 759 & rubens ................ & 1107 \\
\hline Centroblennius . . . . . . . . . . . . & 2435 & scaber................ & 1124 \\
\hline nubilus............. & 2438 & undecimalis........... & 1118 \\
\hline centrognathus, Zanclus ............ & 1638 & undecimradiatus...... & 1119 \\
\hline Centrolabrus ...................... & 1575 & unionensis ............ & 1122 \\
\hline exoletus .............. & 1576 & viridis ............... & 1118 \\
\hline phidæ .................... & 962 & Centropristes ... & 1198 \\
\hline phinæ ..................... & ¿62 & laris .............. & 1214 \\
\hline Centrolophus............................. & 962 & atrarius .............. & 1200 \\
\hline liparis................ & 963 & aurorubens ........... & 1278 \\
\hline morio $. . . \ldots \ldots \ldots . . .$. & 963 & ayresi $\ldots . . . \ldots \ldots \ldots$ & 1205 \\
\hline niger ................. & 963 & bivittatus ............ & 1205 \\
\hline pompilas.............. & 963 & brasiliensis........... & 1221 \\
\hline Centronotus ....................... 900, &, 2414 & dispilurus ............ & 1220 \\
\hline alectrolophus.......... & 2422 & fascicularis ........... & 1208 \\
\hline apus................. & 2430 & fusculus ............. & 1211 \\
\hline argenteus......... & 899 & lnciopercanus ....... & 1218 \\
\hline conductor ............. & 900 & macrophthalmus .... & 1281 \\
\hline istagalli ............. & 2423 & macropoma........... & 1206 \\
\hline lichogaster.......... & 2417 & merus ............... & 1162 \\
\hline wskii............ & 2431 & nigricans ............ & 1200 \\
\hline fasciatus $\ldots \ldots \ldots \ldots$ & 2418 & oculatus............. & 1283 \\
\hline gardenii .............. & 948 & ocyurus ........... & 1200 \\
\hline
\end{tabular}




\begin{tabular}{|c|c|c|}
\hline \multirow{2}{*}{ Centropristes philadelphicus ....... } & Page. & Page. \\
\hline & 1201 & cephalus, Semotilus ... \\
\hline phœbe............... & 1212 & Cepolophis ........................... \\
\hline præstigiator.......... & 1214 & Cepphus ........................... \\
\hline psittacinus ........... & 1213 & cerapalus, Opsanus .............. \\
\hline radialis .............. & 1205 & cerasinus, Gobiesox....... \\
\hline radians.............. & 1208 & Hypsilepis cornutus.... \\
\hline rufus................. & 1199 & Notropis ................ \\
\hline striatus ............ & 1199 & Ceratacanthus ............. 1717, 1718,2860 \\
\hline subligarius.......... & 1219 & aurantiacus ........ 1718 \\
\hline tabacarius............ & 1215 & punctatus .......... \\
\hline tridens .............. & 1202 & schœpfii $\therefore$ \\
\hline trifurca.............. & 1202 & scriptus. \\
\hline trifurcus ............. & 1202 & Ceratias................. \\
\hline Centropyge ...................... & 1682 & carunculatus... \\
\hline Centroscyllium .................. & 56 & couesii ......... \\
\hline fabricii ............. & 56 & holbolli........ \\
\hline Centroseymnus .................. & 54 & uranoscopus ... \\
\hline cœlolepis .......... & 55 & Ceratichthys..................... 252, 314 \\
\hline centrura, Dasibatis ................ & 83 & amblops.......... \\
\hline Dasyatis.................... & 83 & biguttatus ............ \\
\hline Raja & 83 & cataractæ .............. \\
\hline Centrurophis........................ & 381 & cumingii................ \\
\hline ntridermichthys armatus........ & 2012 & cyclotis............... \\
\hline ediana, Megalops ................ & 416 & dissimilis ............. \\
\hline pedianum, Dorosoma............. & 416 & gelidus ................ \\
\hline exile....... & 416 & hyalinus.............. \\
\hline cepedianus, Chatoessus ............. & 416 & hypsinotus ........... \\
\hline Priacanthus........... & 1238 & labrosus \\
\hline Cephalacandia .................... & 2867 & leptocephalus.......... \\
\hline Cephalacanthidæ .................. & 2182 & lucens............. \\
\hline Cephalacanthus................. 218 & 83,2867 & micropogon ........... \\
\hline volitans........... & 2183 & monacus .............. \\
\hline Cephaleutherus $\ldots . \ldots \ldots \ldots \ldots \ldots . .68$ & 89,2750 & nubilus ............... \\
\hline Cephalocassis ..................... & 119 & physignathus.......... \\
\hline Cephalogobius ....................... & 2210 & plumbeus.............. \\
\hline ephaloides, Cottus ................ & 2008 & prosthemius .......... \\
\hline Cephalopholis..................... & 1143 & rubrifrons ............ \\
\hline Cephaloptera...................... & 92 & sallæi ................. \\
\hline johni................. & 93 & squamilentus.......... \\
\hline manta............... & 93 & sterletus.............. \\
\hline vampyrus........... & 93 & stigmaticus ........... \\
\hline Cephalopterus ................... & 92 & symmetricus.......... \\
\hline giorna $\ldots . . . . . . .$. & 93 & ventricosus ........... \\
\hline hypostomus......... & 92 & vigilax.............. \\
\hline Cephaloseyllium .................. & 23,25 & zanemus ............. \\
\hline Cephalus.......................... 22 & 28,1753 & Ceratiidæ ......................... \\
\hline brevis.................... & 1754 & Ceratiinæ ........................ \\
\hline cocherani ................ & 1756 & Ceratius shufeldti.................. \\
\hline elongatus ................. & 1756 & Ceratobatis.$\ldots \ldots \ldots \ldots \ldots \ldots \ldots \ldots$ \\
\hline orthogoriscus ............ & 1754 & robertsii $\ldots . . . \ldots \ldots . . .$. \\
\hline pallasianus .............. & 1754 & Ceratocottus .................... 1939 \\
\hline varius..................... & 1756 & diceraus............. 1940, 1941 \\
\hline cephalus, Catulus.................. & 25 & lucasi ................ 1940 \\
\hline Gobiesox $\ldots . . . \ldots \ldots$ & 2332 & Ceratoptera ....................... \\
\hline Mugil .................. & 811 & vampyrus .............. \\
\hline Paraliparis .............. & 2141 & Ceratoscopelus .................... \\
\hline
\end{tabular}




\begin{tabular}{|c|c|c|c|}
\hline & Page. & & Page. \\
\hline Ceratoscopelus madeirensis ......... & 557 & Cetominus storeri................... & 550 \\
\hline cercostigma, Cyprinella ............. & 275 & Cetorhinidæ......................... & 50 \\
\hline Minuilus................. & 275 & 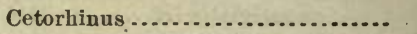 & 51 \\
\hline Notropis .............. & 274 & 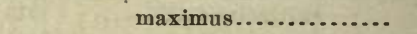 & 51 \\
\hline Cerdale $\ldots \ldots \ldots \ldots \ldots$ & 2448 & sharianus ............. & 51 \\
\hline ionthas .......................... & 2449 & ceuthœecum, Gobisoma ............ & 2261 \\
\hline өrdale, Cårcharhinus ............ 2746 & 16,2747 & ceuthrecus, Barbulifer.............. & 2260 \\
\hline Scytalina $\ldots . . . . . . . .$. & 2454 & Chænichthyidæ ................... & 2293 \\
\hline Cerdalidæe........................... & 2448 & 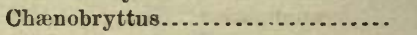 & 991 \\
\hline (n................ & 1148 & antistius............. & 9.92 \\
\hline 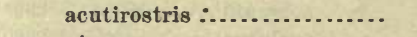 & 1181 & gulosus .............. & 992 \\
\hline (n.................... & 1154 & Chænomugil ...................... & 816 \\
\hline ................... & 1181 & proboscidens... & 816 \\
\hline ............. & 1181 & Chænopsinæ ............ & 2347 \\
\hline ..... & 1162 & Chænopsis .................... & 2403 \\
\hline (................. & 1139 & ocellatus ........... & 2403 \\
\hline & 1139 & Chærojulis $\ldots \ldots \ldots \ldots \ldots \ldots \ldots$ & 1587 \\
\hline (................... & 875 & arangoi $\ldots . . . . . . . . .$. & 1597 \\
\hline hidium........... 2484 & 34,2485 & bivattatus............... & 1597 \\
\hline stoma................ & 197 & cinctus. ................. & 1593 \\
\hline tomus ............. & 197 & as $\ldots \ldots \ldots \ldots \ldots$ & 1598 \\
\hline 18................. & 197 & ma.......... & 1591 \\
\hline ervus, Synauceia .................. & 1941 & grandisquamis .......... & 1597 \\
\hline Cestracion.................................. & 43 & humeralis ............... & 1597 \\
\hline francisci $\quad$ f................ & 21 & internasalis ............ & 1594 \\
\hline orinus .............. & 21 & maculipinna.... & 1595 \\
\hline (n)................. & 21 & radiatus ......... & 1591 \\
\hline Cestraciont Sharks.................. & 19 & ruptus.................. & 1593 \\
\hline Testreus acoupa......................... & 1404 & Chætodipterus ...................... & 1667 \\
\hline (................... & 1411 & faber $\ldots . . . . . . .$. & 1668 \\
\hline $8 \ldots \ldots \ldots \ldots . . . . .6$ & & a $\ldots \ldots \ldots \ldots$ & 1668 \\
\hline n.................. & 1415 & Chætodon ......... 1672, 1673, 1677, 1679 & 79,2859 \\
\hline jidotus.......... & 1415 & alepìilotus $\ldots . . . \ldots \ldots \ldots$ & 966 \\
\hline s............... & 1409 & arcuatus ................. & 1680 \\
\hline (n)................... & 1413 & niatus ............... & 1676 \\
\hline (n................. & 1407 & areus ............. & 1680 \\
\hline tus.................. & 1405 & (............. & 1675 \\
\hline terus........... & 1405 & bimaculatus............. & 1674 \\
\hline nis ................ & 1410 & bricei $\ldots . . . . . . . . . . . . . .$. & 1678 \\
\hline phoxocephalus............ & 1414 & canescens ........ & 1688 \\
\hline (n................. & 1407 & capistratus.............. & 1677 \\
\hline alassinns......... & 1408 & rea.......... & 1562 \\
\hline ulatus.................. & 1409 & chirurgus ............... & 1692 \\
\hline innis ............. & 1404 & liaris ................. & 1685 \\
\hline (1.................... & 1412 & $8 \ldots \ldots \ldots \ldots \ldots$ & 1688 \\
\hline xanthulum............... & 1411 & $h_{1}$ & 1691 \\
\hline ................ & $4:$ & ceus............... & 1388 \\
\hline (n................... & 51 & (n)............. & 1668 \\
\hline Cetengraulis ... & 450 & glaucus ............ & 941 \\
\hline & 450 & … & $167 \tilde{0}$ \\
\hline ulus ........... & 450 & humeralis ............... & 1674 \\
\hline engymen .............. & 2815 & lanceolatus............... & 1490 \\
\hline icetus ............. & 450 & littoricola ................. & 1680 \\
\hline Cetomimidr........................ & 549 & Iutescens................ & 1680 \\
\hline Cetomimus........................ & 549 & ' macrolepidotus........... & 1677 \\
\hline & 549 & maculocinctus........... & 1674 \\
\hline
\end{tabular}




\begin{tabular}{|c|c|}
\hline & Page. \\
\hline Chætodon & marginatus ............ \\
\hline & mauritii .............. 1562 \\
\hline & nigrirostris .......... 1673, 1674 \\
\hline & ocellatus .............. 1674 \\
\hline & oviformis ................. \\
\hline & parræ ................. \\
\hline & paru ..................... \\
\hline & plumteri .............. 1668 \\
\hline & rhomboides ........... 942, 2848 \\
\hline & sargoides............... 1562 \\
\hline & saxatilis................ \\
\hline & sedentarius ............. \\
\hline & squamulosus ............. \\
\hline & striatus ................ \\
\hline & tricolor ................ \\
\hline & triostegus............... \\
\hline & unicolor................ \\
\hline & zebra.................. \\
\hline chætodon, & Apomotis ............... \\
\hline & Cottus ................ \\
\hline & Mesogonistius .......... \\
\hline & Pomotis.................. \\
\hline
\end{tabular}

Chætodontidæ 1669,1670

Chrtodontinæ

Chrtodontops

Chætostomus

aspidiolepis .........
fischeri ..............
gaucharote ...........

chagresensis, Chalcinopsis ........

chagresi, Ancistrus ...............

Pimelodella...............

Pimelodus.

chalceum, Pristopoma..............

chalceus, Orthopristis .............

Chalcinopsis .....................

chagresensis..........

dentex...............

striatulus............

chalcogramma, Theragra..........

chalcogrammus, Gadus.............

Pollachius

chalinius, Epinephelus

Chalinura.

fllifera

serrula .................

simula

Chalinurus.

Chalisoma.

velata..............

challengeri, Macdonaldia...........

Notacanthus..........

chalybæus, Hybopsis..............

Minnilus.............

Notropis ...............

chalybeius, Chlorophthalmus chalybeius, Hyphalonedrus........

Page.

chamæleonticeps, Lopholatilus.....

chamberlaini, Notropis.............

Chani.

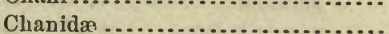

\section{2}

2278

2800

414

414

1453

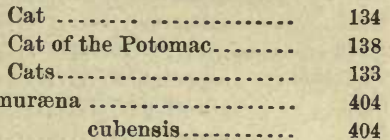

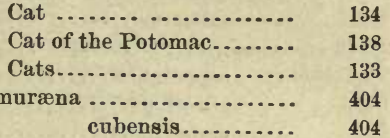

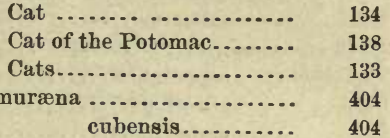

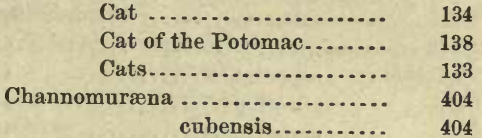

vittata.......... 404

Chanos........................ 414

arabicus................ 415

chanos ................. 414, 2807

chloropterus ............. 415

cyprinella.............. $\quad 415$

indicus................. 415

mento ................... 415

nuchalis ............... $\quad 415$

orientalis ............... $\quad 415$

salmoneus .............. $\quad 415$

chanos, Chanos.................. 414

Mugil.................. $\quad 415$

chantenay, Raia................ 71

chaperi, Acanthoclinus........... $\quad 2375$

Paraclinus................ 2374

Chapin....................... 1722, 1723

Chapinus ............... 1721, 1722, 1723

Chappaul ...................... 224

Characinidr.................. $\quad 331$

Characininæ.................. $\quad 332$

Characius ..................... $\quad 331$

Characodon ..................... 667

bilineatus ..........668, 2831

eiseni............... 2831

ferrugineus........... 669

furcidens ............. 669

garmani............. 2832

lateralis ........... 668, 2831

luitpoldii............ 2832

variatus .............669, 2831

Charr, Enropean ................. 508

Greenland............... 508,510

Long-finned............. $\quad 509$

Oregoll.................. 507

Charrs ...................... 506

charybdis, Lepomis .............. 992

Chasmistes ....................... 182

brevirostris .......... 183, 199

copei ............... 2795

cujus ............... 183, 2794

fecundus ............ 2794

liorns............... 183

luxatus.............. 183, 2794

stomias............. 2794 
Index.

\begin{tabular}{|c|c|c|c|}
\hline & Page. & & Page. \\
\hline Chasmodes ....... & 2391 & cherna, Anthias & 1157 \\
\hline boscianus .............. & 2394 & Cherna Criolla.............. & 1157 \\
\hline bosquianus............. & 2394 & de Vivero ............ & 1160 \\
\hline jenkinsi .............. 2391 & 1,2392 & Cherno de lo Alto ............. & 1151 \\
\hline novemlineatus.......... & 2393 & chesteri, Phycis.............. & 2556 \\
\hline quadrifasciatus ........ & 2392 & Urophyeis ........... & 2556 \\
\hline saburræ ................ & 2392 & Chevalier, Ombre ............ & 508 \\
\hline Chatoessus ............................... & 415 & chevola, Gallichthys........ & 932 \\
\hline . cepedianus............... & 416 & Chi........................... & 209 \\
\hline ellipticus................ & 416 & Chiasmodon ..................... & 2291 \\
\hline eumorphus.............. & 433 & niger ........... & 91,2292 \\
\hline anus $\ldots \ldots \ldots \ldots$ & 416 & Chiasmodontidæ ............. & 2291 \\
\hline asis ............... & 417 & Chiasmodus................. & 2291 \\
\hline signifer ................ & 433 & Chicarro ................... & 911 \\
\hline Chauffe-soleil ....................... & 1548 & chickasavensis, Luxilus..... & 275 \\
\hline Chauffe-soleils ..................... & 1545 & Chicolar...................... & 879 \\
\hline Chauliodontidæ .................... & 578 & Chigh ...................... & 209 \\
\hline Chauliodontinæ.................... & 578 & chihuahua, Notropis......... & 265 \\
\hline Chauliodus........................... & 584 & Chilara......................... & 2488 \\
\hline macouni................. & 585 & taylori................. & 2489 \\
\hline richardsoni.............. & 587 & chilensis, Brama .............. & 960 \\
\hline schneideri.............. & 585 & Caranx $\ldots \ldots \ldots$ & 927 \\
\hline setinotus............... & 585 & Exocœtus ................. & 730 \\
\hline sloanei .................. & 585 & Pelamys ................. & 873 \\
\hline Chaunax $\ldots . . . \ldots \ldots \ldots \ldots \ldots$ & 2726 & Sarda $\ldots \ldots \ldots \ldots$ & 872 \\
\hline fimbriatus.................. & 2726 & chiliticus, Hybopsis......... & 287 \\
\hline nuttingii .............. 2726 &, 2727 & Notropis ................... & 287 \\
\hline pictus............. & 2726 & Chilodipterus ................ & 1112 \\
\hline Cheilichthys ............. 1729; 1730; & 1734 & chiloensis, Agonopsis............. & 2069 \\
\hline asellus................ & 1740 & Agonus................. & 2069 \\
\hline psittacus ............. & 1740 & Aspidorphorus .......... & 2069 \\
\hline pachygaster ........... & 1738 & Chilomycterus............... 1747, 1748 & 8,1750 \\
\hline Cheilodipteridæ ................... & 1105 & antennatus ........... & 1750 \\
\hline Cheilodipterinæ..................... & 1105 & antillarum ..... & 1749 \\
\hline Cheilodipterus ...................... 946, &, 1112 & atinga...... & 1750 \\
\hline aconpa $\ldots . . . . .$. & 1404 & californiensis.... & 1751 \\
\hline affinis ................. & 1113 & fuliginosus .......... & 1749 \\
\hline chrysopterus ........ & 1324 & geometricus......... & 1749 \\
\hline heptacanthus....... & 947 & puncticulatus ........ & 1750 \\
\hline Cheilonemus ....................... & 220 & retiçulatus........... & 1751 \\
\hline pulchellns............ & 222 & spinosus ............ & 1749 \\
\hline Cheilotrema....................... 1455, & 1456 & Chilorhinus....................... & 372 \\
\hline Cheiragonus ........................ & 2038 & suensonii ......... & 372 \\
\hline gradiens............... & 2041 & Chimæra .............................. & 94 \\
\hline Chelidonichthys .................. 2175, & 2867 & abbreviata.................. & 95 \\
\hline pictipinnis ..... 2175, & 2867 & is....................... & 95 \\
\hline elmo pelta.............................. & 1671 & rgentea ................... & 95 \\
\hline aculeatus .................. & 1671 & borealis.................... & 95 \\
\hline zii, Notacanthus............ & 614 & cristata...$\ldots \ldots \ldots \ldots \ldots$ & 95 \\
\hline eneyi, Cottogaster ............... & 2851 & mediterranea ............. & \$5 \\
\hline eonda $\ldots \ldots \ldots \ldots \ldots \ldots \ldots \ldots \ldots \ldots, 228,230$ & 0,236 & monstrosa ................... & 94 \\
\hline & 232 & plumbea .................. & 95 \\
\hline & 236 & 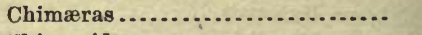 & 93 \\
\hline modesta................. & 234 & Chimæridæ ....................... & 93 \\
\hline & 1157 & Chimærinæ ......................... & 94 \\
\hline & 1160 & & 93 \\
\hline
\end{tabular}


Page.

Chimæroids

Chino, Escolar

Mojarra

Chinook Salmon.

chiostictus, Entomacrodus

$$
\text { Salarias }
$$

chiquita, Abuma

$$
\text { Gobius }
$$

Chirivita

Chirivitas .

Chiro

Chirocentrodon

tæniatus

Chirolophinæ

Chirolophis polyactocephalus ......

Chirolophus japonicus .............

Chironectes

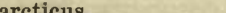

lævigatus ............

mentzelii ...............

multiocellatus .........

pictus .................

principis ..............

scaber .................

sonntagii ...............

tenebrosus ............

tigris .................

tumidus ...............

Chiropsis

constellatus .............

guttatns................

nebulosus ..............

1114,1284

1377

479

2398

2398

2241

2241

1679

1679

410

435

435

2347

2409

2409

2717

2717

2717

2724

2725

2717

2719

2723

2717

2719

2723

2717

1866

1868

1869

1872

Chirostoma ................ 792, 2839, 2840

bartoni ................

brasiliensis ............

beryllinum ............

estor ............... 792, 2839

grandocule ........... 2839

humboldtianum....... 793, 2839

jordani .............. 793

peninsulæ ............ 797

sicculum..............

vagrans............

chirurgus, Acanthurus............

Chætodon.

c

(1)

c

Chirus

balias ................... constellatus.

decagrammus.............

guttatus .................

hexagrammus.............

maculoseriatus ............

monopterygins.............

nebulosus.................

1866

1873

1869

1869

1868

1872

1868

1866

1872

octogrammus ..............

1870

ordinatus
Page.

1873

1872

2424

2424

Chisel-mouths ................... 207, 208

chisozensis, Pœcilia .............. 693

Chitonotus....................... 1889

Chitonotus megacephalus ......... 1891 pugetensis ........... 1890, 1891

chittendeni, Cyclopsetta .......... $\quad-2676$

Chivo .......................... $\quad 860$

chlamydes, Bollmannia........... 2238

Chlamydoselachidæ............... 16

Chlamydoselachus ................ 16

anguineus ...... 16

chlevastes, Gymnothorax .......... $\quad 399$

Lycodontis ............. 398

Sidora............... $\quad 399$

Chlopsis ......................... 364

equatorialis ............. 364

chlora, Cliola ..................... 263

Chlorichthys................... 1605; 2859

bifasciatus ......... 1609, 1610

brasiliensis........... 1591

grammaticus ......... 1610

luçasanus ........... $\quad 1607$

nitidissinus......... 1608

nitidus............. 1608

socorroensis ......... 1607

steindachneri........ 1609

virens.............. 1610

chloris, Psendoscaris.............. 1648

Pseudoscarus ............. 1654

Searus ................ 1637, 1640

Scomber .................. 938

chloristia, Cliola.................. $\quad 278$

Codoma ............... 278

chloristius. Notropis niveus........ 278

chlorocephalus, $\mathrm{Hybopsis} \mathrm{..........} \quad 286$

Minnilus .......... 286

Notropis .......... 286

chloropteron, Catostomus.......... $\quad 179$

chloropterum, Plectropoma......... 1165

chloropterus, Chanos............. $\quad 415$

Prospinas........... 1165

Chlorophthalmus ................ 541

agassizii........ 541

chalybeius....... 54

Chloroscombrus. $\quad 897$

caribbæus........ 938

chloris ........... 2847

chrysurus....... 938, 2847

ectenurus......... 2847

orqueta .......... 937

stirurus.......... 938 


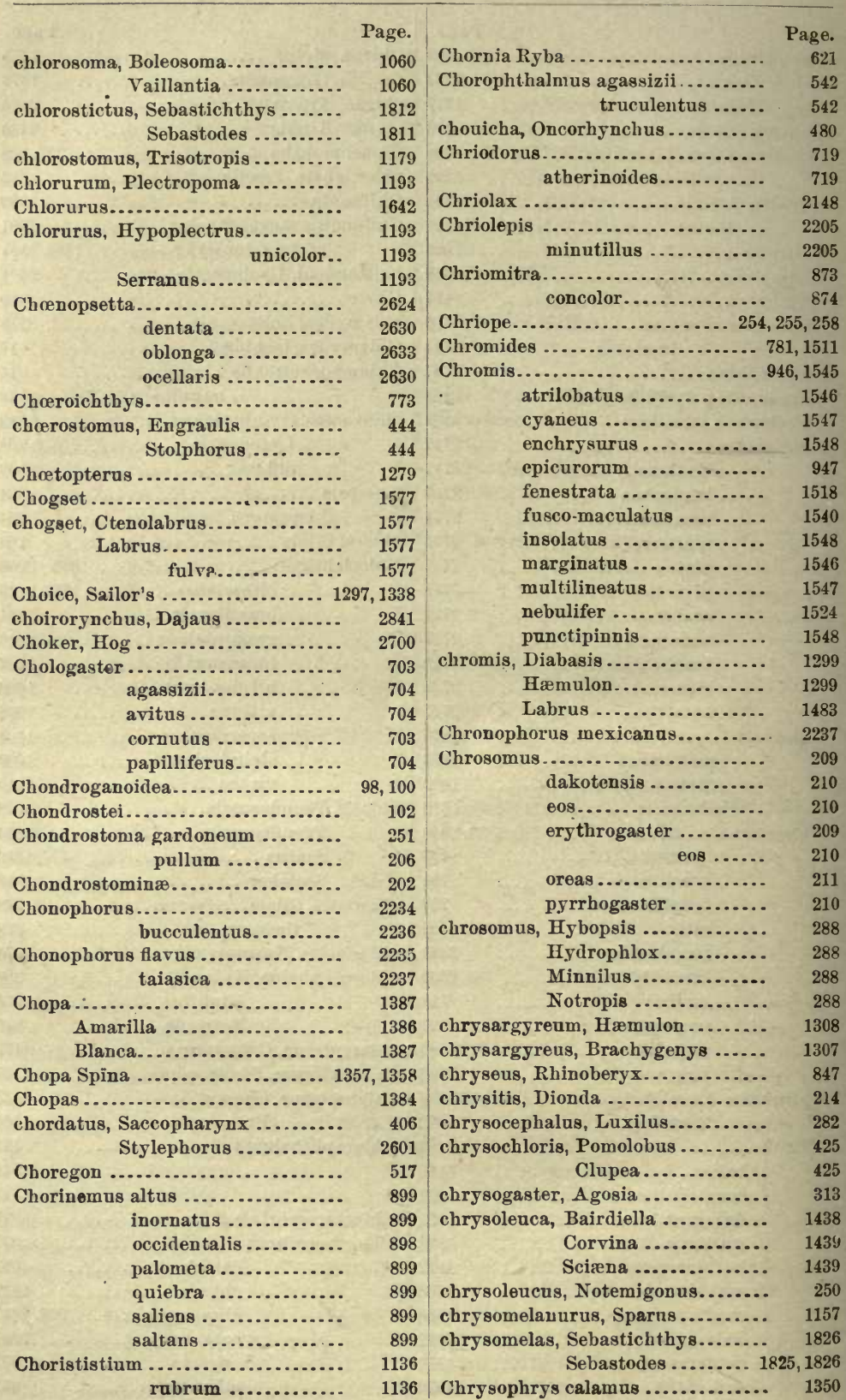


Chrysophrys cyanoptera taurina.

Chrysops aculeatus ................ chrysops, Caulolatilus.

Latilus .................

Ophichthys.............

Ophisurus ..............

Perca ...................

Roceus ..................

Sparus.................

Stenotomus ..............

chrysopsis, Hyodon...............

chrysoptera, Perca................

chrysopteron, Hæmulon...........

chysopterum, Hæmulon

Sparisoma 1636,1637

chrysopterus, Cheilodipterus......

Diabasis.............

Leuciseus ...........

Orthopristis .........

Scarus...............

chrysos, Carangus ................

Chrysotosus ......................

chrysotus, Fundulus...............

Haplochilus ............

Zygoneetes .............

chrysura, Bairdiella................

Sciana..................

chrysurus, Chloroscombrus........

Coryphæna............

Dipteron ..............

Glyphidodon ...........

Lutjanus..............

Mesoprion .............

Micropteryx ............

Microspathodon .........

Ocyurus ...............

Scomber ................

Sparus.................

chrysus, Caranx...................

chrysypa, Anguilla................

Chub

Bermuda

Columbia....................

Flat-headed .................

Great......................

Indian.....................

Nigger ....................

River.......................

Sacramento.................

Silver ....................221, 320

Steelbacked ................

Tahoe

Chub Mackerel. ....................

Chub of the Rio Grande............

Suckers....................
Page.

1354

1354

1347

2277

2278

385

385

1132

1132

1346

1346

413

1339

1309

1309

1324

1309

221

1338

1637

921

954

655

656

656

1433

1434

938

952

1433

1567

1276

1276

938

1567

1275

938

1276

921

348

1387

1387

219

326

232

322

327

322

231

205

2798

866

233

184
Chub of Utah Lake Page.

Chuckle-headed Cat ...................

Chuss.......................... 2555

chuss, Phycis ................... $\quad 2555$

Urophycis ............... 2555

Chylomycterus schœpfi .......... $\quad 1748$

cibaria, Lampetra ................ 13

cibarius, Ammocotes ............. 13

Cibi Amarillo .................... $\quad 919$

Mancho ..................... 919

cibi, Carangoides................. $\quad 920$

Caranx..................... 920

cicatricosus, Balistes............. 1709

Pleuronectes......... 2649

Xanthichthys......... 1709

Cichla ænea..................... $\quad 990$

fasciata............... 1012

floridana................. 1012

minima................ 1012

ohioensis ............... 1012

storeria .................. 987

Cichlasoma.................... 1514, 1515

anguliferum.......... 1517

balteatum ............. 1521

bartoni ............... $\quad 1515$

bifasciatum ........... 1521

centrarchus.......... 1526

deppii ................ 1524

fenestratum ........... 1518

goodmanni ........... $\quad 1516$

helleri ............... 1521

intermedium .......... $\quad 1517$

lentiginosum .......... 1524

longimanus........... 1520

macracanthum ......... 1518

margaritiferum ....... 1519

melanopogon .......... 1523

melanurum........... 1523

montezuma........... 1518

multispinosum ........ 1525

nebuliferum........... 1524

nigrofasciatum ........ $\quad \mathbf{1 5 2 5}$

parma................ 1519

rectangulare........... $\quad 1515$

rostratum ............ 1522

sieboldii.............. 1516

spilurum ............. 1520

Cichlidw ........................ 1512

Cichlids......................... 1512

Ciego, Pez...................... 2501

Cigar-fish ..................... 907

cigonella, Belone................ $\quad 713$

ciliaris, Alectis ................ 931

A ugelichthys ........... 1684, 1685

Balistes.................. 1702

Chætodon ............... 1685 


\begin{tabular}{|c|c|c|c|}
\hline & $\mathbf{P}$ & & Page. \\
\hline ciliaris, Holacanthus ......... & 1685 & Cirrimens.... & 1469 \\
\hline Pomacanthus........... 16 & 35,1686 & cirris, Cottus plurimis.... & 2066 \\
\hline Zeus..................... & 932 & Cirrostomes ....................... & 2 \\
\hline Ciliata argentata....... & 2559 & Cisco................ & 468 \\
\hline ciliatus, Balistes ..... & 1715 & Moon-eye .... & 469 \\
\hline Blennius.................... & 2457 & Cisco of Lake Michigan... & 469 \\
\hline Epinephelus.............. & 1784 & Tippecanoe. & 469 \\
\hline Monacanthus ............. 17 & 14,1715 & Ciscoes................... & 467 \\
\hline Petromyzon ................ & 12 & cismontanus, Coregonus williamsoni & 463 \\
\hline Sebastodes ................. & 1783 & Citharædus ................ & 1672 \\
\hline eimbria, Motella .................... & 2560 & Citharichthys .............. & 8,2682 \\
\hline helyopus .............. & 2561 & æthalion.............. & 2673 \\
\hline us ................ & 2560 & aramaca.......... & 2672 \\
\hline 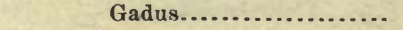 & 2560 & ns............. & 2683 \\
\hline (n................ & 2561 & ensis ......... & 2686 \\
\hline us ............... & 2561 & $08 \ldots \ldots \ldots \ldots$ & 2682 \\
\hline er.............. & 106 & fragilis .............. & 2680 \\
\hline is $\ldots . . . \ldots \ldots . . . .$. & 1593 & ….... & 2686 \\
\hline Julis...................... & 1593 & guatemalensis ....... & 2686 \\
\hline cinerea, Alutera.................. & 1720 & n........... & 2674 \\
\hline Amia ........................ & 113 & ........ & 2684 \\
\hline Etheostoma................ & 1078 & microstomus......... & 2688 \\
\hline cinereum, A ulostoma.............. & 755 & 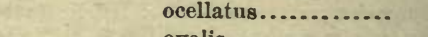 & 2673 \\
\hline Etheostoma........... & 1078 & a......... & 2674 \\
\hline ............... & 1372 & s........... & 2677 \\
\hline ans $\ldots \ldots \ldots \ldots$ & 755 & hrys ........... & 2683 \\
\hline Gerres $\ldots \ldots \ldots$ & 1370 & (................ & 2672 \\
\hline urus ............... & 2585 & .............. & 2679 \\
\hline Microspathodon .......... & $15 \% 0$ & spilopterus ......... 2685 & 5,2686 \\
\hline dorsalis.. & 1570 & stigmæus............. & 2681 \\
\hline (n................ & 1373 & sumichrasti ......... & 2686 \\
\hline is ..................... & 1078 & nhleri ............... & 2684 \\
\hline Turdus peltatus ........... & 1373 & unicornis ............ & 2683 \\
\hline cingulatus, Fundnlus .............. & 656 & ventralis ............ & 2670 \\
\hline Pomacanthus ........... & 1680 & xanthostigmus ...... & 2680 \\
\hline Zygonectes............... & 55,656 & Citharus.$\ldots \ldots \ldots \ldots \ldots \ldots$ & 2614 \\
\hline circumnotatus, Scarus ............. & 1641 & platessoides.............. & 2615 \\
\hline cirratum, Ginglymostoma ........... & 26 & citrineilus, Heros ................. & 1534 \\
\hline cirratus, Milvus ................... & 2183 & Citula $\ldots \ldots \ldots \ldots \ldots \ldots$ & $9 \div 9$ \\
\hline 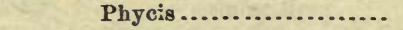 & 2554 & ............ & 927 \\
\hline 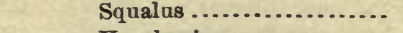 & 26 & lis..................... & 930 \\
\hline cis.................. & 2553 & lus.................... & 356 \\
\hline 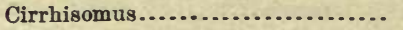 & 1729 & gnathus................ & 215 \\
\hline ................. & 1491 & Clam Cracker ....................... & 83 \\
\hline (n.......... & 1492 & Clamagore. & 1652 \\
\hline rivula & 1491 & clara, Ammocrypta pellucida ....... & 1063 \\
\hline Cirrhitichthys $\ldots \ldots \ldots \ldots \ldots \ldots \ldots$ & 1491 & Menidia.......$\ldots \ldots \ldots$ & 801 \\
\hline rivulatus ............ & 1492 & clarias, Pimelodus ...... & 155 \\
\hline Cirrhitidæ......................... & 1490 & Silurus..................... & 155 \\
\hline Cirrhitoid Fishes ................... & 1490 & Claricola ..................... 1066, 1069, & 9,1093 \\
\hline Cirrhitoide....$\ldots \ldots \ldots \ldots \ldots \ldots \ldots$ & 781 & clarionensis, Holacanthus .......... & 1683 \\
\hline Cirrhitoidei ........................ & 1490 & Myripristis............ & 2842 \\
\hline Cirrhitoids ......................... & 1490 & clarionis, Xesurus .................. & 1695 \\
\hline hosum, Lepisoma............... & 2362 & clarki, Bogoslovius ................ & 2575 \\
\hline cirrhosus, Blepslas.................. & 2018 & Catostomus................. & 173 \\
\hline Trachinus................ & 2019 & Fario $\ldots . . . . . . . . . . . . . .$. & 501 \\
\hline
\end{tabular}


clarki, Pantostens

Page.

clarkii, Salmo.

bouvireri $\ldots \ldots \ldots \ldots$

henshawi ..........

lewisi ...............

macdonaldi..........

pleuriticus ..........

spilurus.............

stomias .............

tahoensis...........

virginalis...........

clarum, Etheostoma pellucidum ...

clathrata, Atratoperca ............

clathratus, Labrax.

Paralabrax

1197,1198

Serranus.............. 1198

claudalus, Hyodon

413

claviformis, Moxostoma

claviger, Cottus.

Enophrys.

lepsydra, Murma

clepsydra, Muræna ................

Clepticinæ.

Clepticus

genizara .......................

parræ...................

clevelandi, Phoxinus...............

Clevelandia

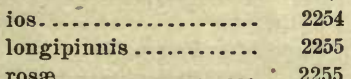

rosm................. 2255

Cling-fishes

2326,2329

Clininæ

2344

Clinocottus

2012

analis $\ldots \ldots \ldots \ldots \ldots \ldots . .2612$

Clinostomus ................... $228,230,239$
affinis............... 239

elongatus............. 240

funduloides.......... 239

hydrophlox.......... 238

nirgarita............ 241

montanus............. 238

pandora.............. 234

phlegethontis........ 243

proriger .............. 240

tænia............... 238

Clinus aculeatus

2433

2358

2362

2362

2359

2353

2358

2365

2362

2438
Clinus macrocephalus.

Page.

2364

maculatus ................. 2433

medius ................... 2435

mohri................... 2438

nebulosus ............... 2438

nigripinnis ............. $\quad 2370$

nuchipinnis.............. 2262

ocellatus.................. $\quad 2357$

ocellifer................... 2353

pectinifer ................. 2362

philipii................... 2359

præcisns.................. 2441

punctatus ................ $\quad 2440$

unimaculatus.............. 2441

zonifer................... 2359

Cliola ........................ 252

alta...................... 322

analostana.................. 279

a urata.................... 272

billingsiana ............... 272

bubalina................... 273

cærulea................... $\quad 277$

callisema .................. $\quad 273$

callistia .................. 276

calliura.................... 275

camura ................... 280

chlora .................... 263

chloristia................ $\quad 278$

cobitis.................... 305

deliciosa.................. 272

euryopa .................. $\quad 270$

eurystoma................. $\quad 277$

forbesi .................. $\quad 272$

formosa.................. 271

fretensis.................. 261

galactura................. $\quad 279$

gibbosa.................. $\quad 272$

gunnisoni ................. 273

hæmatura ................ 218

hudsonia ................. $\quad 269$

hypseloptera............... $\quad 280$

iris ..................... 272

jugalis................... $\quad 272$

leonina .................... 271

lepida ..................... $\quad 273$

lineolata................... 263

longirostris................ 267

ludibrinda................. $\quad 273$

lutrensis ................. $\quad 272$

microstoma................ 264

missuriensis ................ 262

montiregis.................. 272

nigrotæniata ............... 264

nivea .................. 278

notata................... 274

nubila.................. 215 
Cliola ornata

Page.

procne

pyrrhomelas................

rubripinna..................

sallæi.....................

saludana .................

sima.....................

smithii ....................

spectruncula ...............

stigmatura .................

storeriana ..................

straminea ..................

suavis.....................

taurocephala ...............

trichroistia .................

tuditana ...................

nmbrosa....................

urostigma ................

velox .....................

venusta...................

vigilax $. . . \ldots \ldots \ldots . . . . . .$.

vittata.....................

vivax.....................

whipplei..................

xæunra......................

Clodalus

clodalus, Hiodon ..................

Clapanodon......................

aureus.................

cæruleus ..............

pseudohispanicus .....

Clupea ..........................

æstivalis ..................

anchovia ..................

apicalis ...................

atherinoides ..............

aurea ....................

brasiliensis.................

cærulea ...................

carolinensis ...............

chrysochloris ..............

elongata ..................

esca.......................

fasciata ...................

halec ....................

harengus..................

heterura ...................

hudsonia..................

humeralis ..................

indigena ...................

lamprotænia ..............

latulus .....................

leachi ....................

libertatis ...................

lineolata ..................

macrocephala
Clupea macropthalma. .

Page.

mattowacea.............. $\quad 426$

mediocri................. $\quad 426$

megalops................. $\quad 426$

membras ................. 421

menhaden............... 434

minima................. 422

mirabilis ................ 422

neglecta................ 434

pallasii.................. $\quad 422$

parvula .................. $\quad 426$

pseudoharengus........... $\quad 426$

pseudohispanica.......... 424

pusilla ................... 426

sadina.................. $\quad 420$

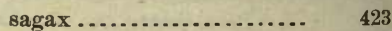

stolifera............... 432

thrissa.................. 432

thrissina............... 431

tyrannus................ 434

vernalis.................. 426

villosa .................. 521

virescens................. 426

vittata................. 421

Clupeidæ....................... 417

clupeiformis, Coregonus .......... 465, 469

Salmo.............$\quad 466$

Clupeinær...................... $\quad 418$

Clupeoidea.................... 407

clupeoides, Engraulis ............ 447

Stolephorus........... 447

clupeola, Harengula ............ 429, 430

Sardinella............. $\quad 429$

Clupeonia..................... $\quad 428$

Clypeocottus...................... 1937

robustus............ 1938

Coal-fish ....................... 1862, 2534

coara, Guabi brasiliensibus....... 1305

Coast Range Trout.............. $\quad 500$

Coballito del Mar ................ 776, 777

Cobbler ....................... 640, 641, 931

Cobessicontic Smelt............... 524

Cobia ........................... 948

Cobitis heteroclita.............. 641

killifish ................. 641

majalis................. 639

cobitis, Cliola .................... 305

Leuciscus............... 305

Tiaroga................. 305

coccineus, Lycodes ............... 2469

Scarus................ 1635

coccogenis, Hypsilepis........... 285

Leuciscus............. 285

Minnilus.............. 285

Notropis.............. 284

coccoi, Rhinoscopelus............ 568 
caccoi, Scopelus.

Page.

Stenobrachius..............

cocherani, Cephalus...............

Cochinito

Cochino.

Cochlognathus .

biguttata......

ornata .............

ornatus ............

Cocinera .........................

Cocinero Dorado ..................

Cock and hen Paddle...............

Cockeye Pilot. ..................... 1555, 1561

Cocuyo....................... 1709

Cod, Blue ...................... - 1875

Buffalo................... 1875

Cultus .................... 1875

Green................... 2534

Wachna ................. 2537

Codfish, Alaska................. 2541

Common ................ 2541

Greenland ............. 2542

Codfishes . . . . . . . . . . . . . . . 2531, 2540

Codling ..................... 2552, 2555

Codoma.................... 254, 256, 270

cærulea ................ 277

callisema............... $\quad 273$

callistia ................ $\quad 276$

chloristia................ 278

eurystoma.............. $\quad 285$

ornata................ 271

pyrrhomelas............ 281

stigmatura ............. 275

trichroistia............. $\quad 276$

vittata ................ 258

xænura................. $\quad 280$

Codorniz...................... 1467

Cods, Cultus ..................... 1875

Cœeilophis..................... $\quad 381$

Coecula bascanium.............. $\quad 380$

scuticaris .............. 379

teres .................. 379

coecus, Gastrobranchus ...........

colestinus, Bagrus................

Pseudoscarus ........ 1655, 1656

Scarus .............. $1656^{\circ}$

Coelho ......................... 882

cololepis, Centrophorus .......... । 55

Colorhynchus .................. 2587

carminatus ...... 2588, ¿2589

carribæus ......... 2589

occa .............. 2587

scaphopsis ...... 2590, 2591

ccenosa, Parophrys............... 2639

cœnosus, Pleuronichthys ....... 2638, 2639

cceruleum; Etheostoma .......... 1088 coruleum, Etheostoma spectabile .. $\quad 1089$ cœruleus, Astatichthys.......... 1089

Pœcilichthys........... 1089

cognata, Uranidea .............. 1955

cognatus, Cottus................ 1954

Coho Salmon................... $\quad 480$

colias, Scomber ................. 866

colii, Salmo .................... 509

colinus, Gadus .................. $\quad 2535$

Coliscus....................... $\quad 217$

parietalis ............... $\quad 217$

collapsum, Moxostoma........... $\quad 190$

collapsus, Ptychostomus.......... 190

colletti, Careproctus .............. $\quad 2131$

Collettia ..................... 567

nocturna.............. 567

rafinesquei.............. 567

colliei, Hydrolagus................ 95

Colocephali .................... 346, 388

Cololabis..................... $\quad .726$

brevirostris ............ 726

Colomesinæ.................... 1727

Colomesus ...................... 1740

psittacus ............. 1740

colonus, Serranus ............... 1222

Colorada, Mautararia ............ 2754

colorada, Lija .................. 1713

Vieja................ 1639

Colorado, Bagre .................. 122

Pargo ........... 1264, 1267, 1356

Perro................. 1583

Pescacio ................. 1453

colorado, Lutianus .............. 1268

Lutjanus ............... 1268

Neomænis............. 1267

Colorado River Trout............ 496

coloratum, Aulostoma............. $\quad 755$

coluber, Gempylus ............... $\quad 884$

Columbia ....................... $\quad 784$

Chub................. 219

River Sucker.......... 178

Trout............ 492

Salmon............... 479

Columbia transmontana........... 784

columbianus, Pantosteus ......... $\quad 172$

Vomer .............. 934

comatus, Cypselurus ............. $\quad 736$

Exocotus .............. 736

comes, Roccus................. 1407

commersoni, Carcharhinus ........ $\quad 38$

commersonii, Catostomus.......... 178

Cyprinus............ $\quad 179$

Fistularia.......... $\quad 758$

Common Alligator Fish.......... 2061

American Sea-Horse ..... $\quad \mathbf{7 7 7}$

Angler.............. 2713 


\begin{tabular}{|c|c|c|c|}
\hline & $\mathbf{I}$ & & Pag \\
\hline Common Atlantic Salmon. & 486 & concatenatus, Ostracion ... & 1723 \\
\hline Buffalo Fish..... & 163 & Conchognathus ........... & 349 \\
\hline Bullhead ..... & 140 & grimaldii & 349 \\
\hline Burr-fish ..... & 1748 & concinnus, Amblodon ..... & 1484 \\
\hline Cobbler...... & 641 & Gasterosteus... & 745 \\
\hline Codfish ...... & 2541 & concolor, Ammocotes ..... & 11 \\
\hline Dolphin ........... & 952 & Chriomitra .......... & 874 \\
\hline Eastern Pickerel ...... & 627 & Euschistodus ....... & 1559 \\
\hline Stickleback. & 748 & Ichthyomyzon ....... & 11 \\
\hline Flatfish .......... & 2647 & Lycodes................ & 2463 \\
\hline Gar Pike ................. & 109 & Nexilarius ............. & 1559 \\
\hline Grunt ................... & 1304 & Petromyzon ............ & 11 \\
\hline Gurnard.............. & 2156 & Scomberomorus ............ & 873 \\
\hline Half-beak ................. & 721 & Thyrsoidea................ & 396 \\
\hline Herring .................. & 421 & Condenado, Ronco.................. & 1306 \\
\hline Killifish ................. & 640 & conductor, Centronotus ............. & 900 \\
\hline Mackerel .............. & 865 & Conejo .......................... & 596,882 \\
\hline Mullet................. & 811 & Coney $\ldots \ldots \ldots \ldots \ldots \ldots \ldots$ & 1141 \\
\hline Pámpano.............. & 944 & confertus, Hyborhynchus ........... & 217,218 \\
\hline Pike.................... & 628 & Pimephales promelas.... & 217 \\
\hline Pipefish .................. & 770 & confinis, Pimelodus................ & 141 \\
\hline Rat-tail ................... & 2583 & Salmo & 505 \\
\hline Red Horse................. & 192 & confluentus, Fundulus ............. & 650 \\
\hline Rock Bass.............. & 990 & Salmo................ & 480 \\
\hline sh........... & 60 & conformis, Lavinia .................. & 231 \\
\hline (................ & 1346 & Lenciscus............... & 231 \\
\hline Shad ...................... & 427 & Squalius ................. & 231 \\
\hline Skate..................... & 68 & Tigoma............. & 231 \\
\hline of California.......... & 73 & congener, Paru brasiliense.......... & 966 \\
\hline Spotted Moray ........ & 395 & Conger....$\ldots \ldots \ldots \ldots \ldots$ & 353 \\
\hline Sting Ray ............... & 83 & analis $\ldots \ldots \ldots \ldots \ldots$ & 356 \\
\hline Sturgeon ................... & 105 & brasiliensis.................. & 360 \\
\hline (................ & 178 & caudicaula........... & 355 \\
\hline Suntish .................... & 1009 & eaudilimbatus.............. & 355 \\
\hline Surf-fish................... & 1504 & esculentus ............. & 355 \\
\hline Surgeon .................. & 1691 & impressus.................. & 356 \\
\hline Swordfish ............. & 894 & 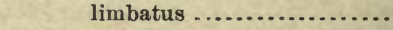 & 360 \\
\hline fish.......... & 1723 & rops..................... & 355 \\
\hline Weakfish.............. & 1407 & microstomus ................ & 356 \\
\hline Whitefish ................ & 465 & $\operatorname{mordax}(\ldots \ldots \ldots \ldots \ldots$ & 387 \\
\hline communis, Catostomus........... & 179 & niger................... & 355 \\
\hline Leucosomus.......... & 326 & occidentalis .............. & 355 \\
\hline Liparis ................. & 2118 & opisthophthalmus.......... & 356 \\
\hline Platygobio .............. & 326 & orbignyanus .................. & 355 \\
\hline Pogonichthys ......... & 326 & rubescens .................... & 355 \\
\hline complanata, Cyprinella........... & 272 & verreauxi............... & 355 \\
\hline Moniana .............. & 272 & verus $\ldots . . . . . . . . . . .$. & 355 \\
\hline mpressa, Lota . . . . . . . . . . . . & 2551 & vulgaris.................. & 355 \\
\hline ompressus, Bassozetus ............. & 2508 & Conger Eel of California ............ & 395 \\
\hline Bathynectes............. & 2509 & Eels..................... & 352,354 \\
\hline Bathyonus ........... & 2509 & conger, Leptocephalus ......... & 354 \\
\hline Engraulis ........... & 447 & Muræna .................... & 354 \\
\hline Gadus................ & 2551 & Congermuræena.................. & 355 \\
\hline Nauclerus ............. & 900 & balearica......... & 356 \\
\hline Rutilus................. & 282,296 & flava............ & 357,2801 \\
\hline Stolephorus .......... & 447 & macrura ....... & 356 \\
\hline
\end{tabular}


Congermuræna mellissii ........... nitens............. prorigera

congestum, Moxostoma ............ congestus, Catostomas ,............. Congresox ....................... Congro Barboso ................... Congros Barbosos ................

Congrus......................... curvidens............... leucophrus.............. coniceps, Murænesox ............. conico, Ostracion oblongus......... conlferum, Oreosoma ............... Conocara....................... macdonaldi............. macroptera.............. conocephala, Gila ................. conocephalus, Mylopharodon ...... Conodon

antillanus

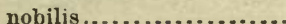
pacifici .................. plumieri ................ serrifer ..................

Conorhychus.................... conorynchus, Albula ............. conspersa, Muræua...............

Tigoma................. conspersus, Gymnothorax......... Lycodontis ............ Serranus.............. Squalius ............... Constantino de las Aletas Prietas.. constellatus, Chiropsis ............. Platophrys ........... Sebastichthys ........ Sebastodes............ consuetus, Salmo ................. continuum, Hamulon ............. contractus, Rhinogobius .......... contrainii, Tylosurus.............. conus, Moxostoma.................

Ptychostomus ............... convexa Turdus cauda ............. convexifrons, Pomotis.............. Cony, Horny ......................

Cook, Rock .................... 1 cookianus, Aphododerus ........... cooperi, Cheonda ................

Leuciscus.................

Metoponopus .............

Raia .....................

Salmo ....................

Squalius ...................

copei, Acipenser
Page.

356

357

357

192

192

359

155

154

353,381

360

355

359

1745

1663

456

457

457,458

219

219

1324

1324

1324

1316

1324

1324

411

411

397

234

397

397

1156

234

1119

1868

2663

1807

1806

479

1297

2236

717

196

196

1145.

1003

1715

575,1576

787

236

$23 \dot{6}$

2680

73

483

236

106 copei, Aleposomus .............. $\quad 459$

Chasmistes ................ 2795

Cottus .................... 1968

Paraliparis ............... 2143

Squalius.................. $\quad 236$

Copelandellus ................... 1100

quiescens .......... 1100

copelandi, Boleosoma.............. 1046

Cottogaster............ 1045

Rheocrypta............ 1046

Copelandia...................... 992

eriarcha.............. 994

copii, Leuciscus ................... 293

Copper-nosed Bream .............. $\quad 1005$

Corallicola ...................... $\quad 2369$

corallina, Narcine brasiliensis...... $\quad 78$

corallinum, Cryptotrema .......... $\quad 2366$

corallinus, Antennarius ........... $\quad 2725$

Corbineta ..................... $\quad 1435$

Cordylus ....................... $\quad 865$

Coregoni ...................... 461

Coregoninæ.................... 461

coregonoides, Paralepis............ 602

Coregonus.................. 461, 462, 465

albus ................. 466

angusticeps............ 466

clupeiformis .......... 465, 469

couesii............... 463

coulterii ............... 462

harengus ............. 469

hoyi ................468, 470

keunicotti ............ $\quad 464$

labradoricus........... 466

latior................ $\quad 466$

lucidus .............. 471

merckii.............. $\quad 470$

nelsonii ............... 466

neohantoniensis ....... $\quad 466$

nigripinnis ........... 472

novæ-angliæ........... 465

osmeriformis ........... 468

otsego ............... $\quad 466$

prognathus............ 472

quadrilateralis.......... 465

richardsonii ..........465, 2816

ruber ................ 538

sapidissimus .......... 466

signifer.............. 518

thymalloides.......... 518

tullibee ............... 473

bisselli ........ 473

williamsoni........... 463

cismontanus $\quad 463$

coregonus, Moxostoma........... 191

Ptychostomus......... 191

coretta, Thynnus ............... $\quad 870$ 


\begin{tabular}{|c|c|c|c|}
\hline riaceus, Eleutheractis............ & $\begin{array}{r}\text { Page. } \\
1233\end{array}$ & Corvina armata . & $\begin{array}{r}\text { Page. } \\
1437\end{array}$ \\
\hline Rypticus................... & 1233 & biloba & 1460 \\
\hline corinus, Hexanchus ................ & 18 & chrysoleuca ......... & 1439 \\
\hline cormura, Thyrsoidea.............. & 394 & deliciosa............. & 1456 \\
\hline Cornet-fishes............................. & 755 & dentex....................... & 1426 \\
\hline Corveta ................................ & 757 & ns................... & 1435 \\
\hline cornifer, Achirus ......................... & 2698 & ræa & 1460 \\
\hline cornubioa, Lamna.................. 49 & 19,2749 & bi $\ldots \ldots \ldots+\ldots, \ldots$ & 1441 \\
\hline ualus ................ & 49 & ps $\ldots \ldots \ldots \ldots \ldots \ldots$ & 1428 \\
\hline padogaster......... & 2108 & microps ........ & 1445 \\
\hline Pimelepterus ......... & 964 & ntha ............ & 1419 \\
\hline Rhombus lævis...... & 2654 & n................... & 1484 \\
\hline cornutus, Anoplogaster ............. & 840 & ta...................... & 1454 \\
\hline Chætodon................. & 1688 & scion ................. & 1448 \\
\hline ter................. & 703 & a $\ldots \ldots \ldots \ldots \ldots \ldots \ldots$ & 1484 \\
\hline bys................... & 1749 & 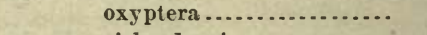 & 1222 \\
\hline s.................. & 282 & soni...$\ldots \ldots \ldots \ldots$ & 1484 \\
\hline ans................ & 1685 & is ....................... & 1436 \\
\hline Hypsilepis ................ & 283 & (n...................... & 1457 \\
\hline cerasinus..... & 283 & (n) & 1458 \\
\hline$\cdots .$. & 283 & ra $\ldots . . . \ldots \ldots \ldots \ldots$ & 1445 \\
\hline gibbus......... & 283 & alis................ & 1429 \\
\hline Lenciscus................ & 283 & sa $\ldots \ldots \ldots \ldots \ldots$ & 1443 \\
\hline Minnilus................. & 283 & icularis .............. & 1453 \\
\hline Notropis ................. & 281 & s Amarillas.... & 1410 \\
\hline cyaneus ......... & 283 & corvinæforme, Brachydeuterus .... & 1326 \\
\hline frontalis......... & 283 & Hæmulon... & 1327 \\
\hline Silurus.................... & 759 & Pomadasis........... & 1327 \\
\hline Zanclus ................ 1687 & 37,1688 & Corvinus (Johnius) jacobi........... & 1457 \\
\hline coro, Pristipoma .................... & 1324 & Corvula ................................ & 1427 \\
\hline Sciæna............................ & 1324 & batabana......................... & 1430 \\
\hline coroides, Umbrina.................. & 1466 & pps................ 1427 & 7,1428 \\
\hline Coronado................................ & 903 & sanctre-lucir ................ & 1429 \\
\hline (...................... & 905 & 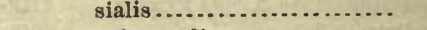 & 1428 \\
\hline coronatus, Cyclopterus ............... & 2097 & subæqualis ................ & 1429 \\
\hline Enneacentrus guttatus .. & 1142 & Corynolophus ........................... & 2733 \\
\hline Halatractus ............. & 905 & reinhardti $\ldots . . .$. & 2733 \\
\hline Petrometopon cruentatus & 1142 & Coryphæna...................... & 952 \\
\hline Serranus ............... & 1142 & us..... & 953 \\
\hline Zonichthys............... & 905 & (1) & 953 \\
\hline .................... & & zorica ................. & 953 \\
\hline corporalis, Cyprinus ............... 22 & 221,222 & .......... & 1653 \\
\hline Leucosomus........... & 222 & hrysurus............... & 952 \\
\hline Semotilus.............. 22 & 21,222 & 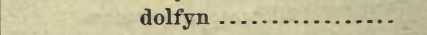 & 953 \\
\hline Corpore oblongo glabro ............. & 2657 & do ................... & 953 \\
\hline Corsair................................... & 1808 & equisetis ................ & 953 \\
\hline cortezianus, Aprodon ............... & 2461 & fasciolatus ............. & 952 \\
\hline coruscans, Arctozenns ............. & 601 & hippurus............... & 952 \\
\hline Paralepis .................. & 602 & immaculata ........... & 953 \\
\hline Sudis ................... & 602 & erialis .............. & 952 \\
\hline coruscus, Holocentrus .............. & 851 & $i i \ldots \ldots \ldots \ldots . . . .$. & 953 \\
\hline Corvalos .............................. & 1477 & $\ldots \ldots \ldots \ldots \ldots$ & 1619 \\
\hline Corvina............... 1408, 1425, 1455 & 55,1461 & gravii ............... & 953 \\
\hline & 1437 & & 1619 \\
\hline & 144 & perciformis ......... & 964 \\
\hline & 1434 & plumieri ........ & 2276 \\
\hline
\end{tabular}




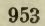

virgata. . .

vlamingii :................

Coryphænidæ...................

Coryphænoides ...................

carapinus..........

norvegiens ........

rupestris ..........

Coryphœena lineolata.

nigrescens .............

psittacus.

Coryphopterus

glaucofrænum......

953

953

953

953

953

951

2578

2579

2579

2578

1619

1200

1619

2210

2220

Corythroichthys ........ 761, 763, 772, 2838 albirostris...... 772, 2838 cayannensis...... 2838 cayoruin ........ 2838

cosmopolita, Micropteryx .......... 938

Seriola............ 938, 2847

Cossyphus ...................... 1581

bodianus............. 1583

darwinii ............. 1586

diplotænia........... 1582

eclancheri............ 1583

pectoralis .............. 1582

puellaris ............. 1584

pulchellus............ 1584

rufus ................. 1583

verres............... 1583

costatesi, Smaragdus............. 2225

costatus, Bodianus............... 1462

Micropogon ............. 1462

costellatus, Chirus ............... 1869

Cottilı.......................... 1879

Cottinæ....................... 1882

Cottogaster .................... 1044

aurantiacus .......... 1041

cheneyi.............. 2851

copelandi............ 1045

putnami............. 1046

shumardi........... 1046, 2851

uranidea ............ 1044, 1045

Cottopsis:..................... 1942

asper.................. 1944

gulosus ............... 1945

parvus ................ 1945

semiscaber ............. 1950

Cottunculus................... 1992

microps ............. 1992

thomsonii ............ 1993

torvus.............. 1994

Cottus .............. 1493, 1941, 1953, 1970

acadian .................. 2023

æneus.................... 1973

$3030-108$ $\begin{array}{ll}\text { Cottus aleuticus................. 1957, } 2862 & \text { Page. }\end{array}$

alvordii .................. 1952

anceps ................... 1973

anna..................... 1960

asper...................... 1944

axillaris.................. 1981

bairdi ..................... 1950

beldingii ................. 1958

bicornis .................. 1913

boleoides .................. 1968

brandti.................... 1984

brodamus .................. 2066

bubalis................... 1972

cataphractus ............. 2053, 2066

cephaloides ............... 2008

chrtodon .................. 2316

cirris plurimis............. 2066

claviger................... 1939

cognatus ................. 1954, 1955

copei.................... 1968

criniger ................... 2013

decastrensis............... 1983

diceraus.................. 1941

elegans................... 1939

evermanni ............... 1945

fabricii .................. 2009

formosus .................. 1969

franklini .................. 1967

glaber.................. 2316

glacialis.................. 1976

gobio............... 1941, 1968, 2009

gobioides.................. 1968

gracilis................... 1968

grœenlandicus ............. 1975

gulosus ................... 1944

hemilepidotus.............. 1936

hexacornis ................. 2003

hirundo ................. 2011

hispidus ................ 2023

humilis ................... 1979

ictalops ................. 1950

undicus.................. 2092

jaok...................... 1978

japonicus ............... 2036

klamathensis .............. 1955

labradoricus............... 2004

leiopomus ................. 1962

maculatus................ 1972

marginatus................ 1966

marmoratus............... 1983

meridionalis................ 1951

mertensii.................. 1986

minutus.................. 1958

mitchilli ................. 1973

monopterygius ............. 2092

niger.................. 1983, 1986 


\begin{tabular}{|c|c|c|c|}
\hline & Page. & & Page. \\
\hline Cottus nigricans & 1973 & Couchii, Serranus ....... & 1139 \\
\hline nivosus .... & 1985 & Couchu.............. & 160 \\
\hline octodecimspinosus & 1976 & couesii, Agosia ........ & 310 \\
\hline onychus........... & 1953 & Apocope......... & 310 \\
\hline pachypus. & 1973 & Ceratias .......... & 2732 \\
\hline perplexus... & 1955 & Coregonus...... & 463 \\
\hline philonips.... & 1959 & Cryptopsaras.... & 2731 \\
\hline pistilliger ......... & 2008 & Prosopium .......... & 463 \\
\hline platycephalus...... & 3,1988 & Couesius ................. & 323 \\
\hline polaris ..................... & 1999 & adustus .................... & 325 \\
\hline s................ 1941 & 1,1953 & nilis .................. & 324 \\
\hline hocephalus......... & 1977 & i..................... & 324 \\
\hline 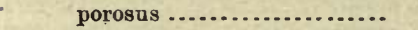 & 1975 & gnathus .............. & 326 \\
\hline 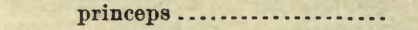 & 1962 & as ..................... & 323 \\
\hline tus............... 1948 & 8,1951 & us ............... & 324 \\
\hline quadricornis ........ & 2001 & squamilentus............. & 323 \\
\hline quadrifilis.............. 1998 & 8,2000 & Couia .............................. & 183 \\
\hline (n................... & 1946 & coulterii, Coregonus ................ & 462 \\
\hline ............ & 1952 & courbina, Pogonathus............. & 1483 \\
\hline soni ........ & 1951 & Pogonias................. & 1483 \\
\hline ............. & 1973 & cromis .......... & 1483 \\
\hline oides.......... & 1973 & (................... & 976 \\
\hline 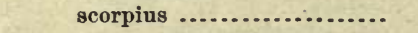 & 1974 & us................ & 1152 \\
\hline reanlandicne & 1975 & courvina, Johnius.................... & 1419 \\
\hline scaber .................... & 1949 & Sciæna & 1419 \\
\hline bra centropleura ..... & 1945 & n.................. & 1724 \\
\hline (n................... & 1947 & Cow-nose Ray................ & 90 \\
\hline 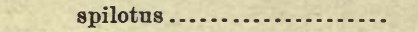 & 1961 & Cow-pilot ........................ & 1561 \\
\hline (n................ & 1941 & Cow Shark......................... & 19 \\
\hline tæniopterus .............. 1979 & 9,1988 & Sharks ......................... & 17 \\
\hline atus ................ & 2000 & Crab Eater......................... & 948 \\
\hline ii .................... & 1994 & Crabra ................................... & 1837 \\
\hline us ........... & 1936 & Cracker, Clam..................... & 83 \\
\hline is ............. & 2009 & cragini Amiurus . . . . . . . . . . . . . & 141 \\
\hline ygius ........ & 2023 & Etheostoma ................. & 1091 \\
\hline uncinatus........... & 1906 & Craig Fluke........................... & 2656 \\
\hline ................ 2008 & 8,2009 & $1 e s \ldots \ldots \ldots \ldots \ldots$ & 802 \\
\hline us ................... & 1980 & Sebastodes.................. & 1799 \\
\hline$\ldots \ldots \ldots \ldots \ldots \ldots \ldots$ & 2022 & Crampfish............................. & 77 \\
\hline us $\ldots \ldots \ldots \ldots \ldots$ & 1976 & 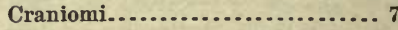 & 781,2146 \\
\hline . & 1968 & Crapet $\ldots \ldots \ldots \ldots \ldots \ldots \ldots$ & 987 \\
\hline (n)..................... & 1952 & (n.................. & 986,987 \\
\hline is nigripinnis.................. & 2332 & crassa, Belone....................... & 716 \\
\hline n............... & 2331 & Tigoma..................... & 231 \\
\hline i.............. & 2332 & erassicauda, Lavinia ................ & 231 \\
\hline i $\ldots \ldots \ldots \ldots \ldots \ldots$ & 2104 & Leuciscas.............. & 231 \\
\hline $\cos u s \ldots . . .$. & 2104 & Siboma................ & 231 \\
\hline 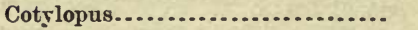 & 2207 & crassiceps, Melamphaes............. & 843 \\
\hline nogaster............. & 2207 & Plectromus ............... & 843 \\
\hline salvini ................... & 2208 & Scopelus................. & 843 \\
\hline couchi, Dionda . ..................... & 216 & crassilabre, Moxostoma............ & 194,196 \\
\hline & 272 & crassilabris, Embry & 2458 \\
\hline ata ... & 2559 & Geophagus............ & 1543 \\
\hline 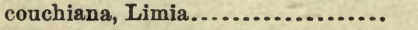 & 695 & Lycodopsis............. & 2458 \\
\hline Pøcilia........ & 695 & & 2869 \\
\hline couchii, Poecilia..... & 695 & Ptychostomus.......... & 194 \\
\hline
\end{tabular}


crassilabris, Satanoperca..........

crassus, Alvordius...............

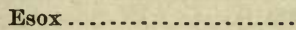

Lepidosteus..............

Squalius .................

Tylosurus................

craticula, Zygonectes

Cratinus .

agassizi . . . . . . . . . . . . .

Cravo ...........................

Crawl-a-bottom ..................

Crayracion .......................

crebripunctata, Pteroplatea........

Creek Chub.......................

Creekfish

Cremnobates

affinis...............

altivelis..............

fasciatus............

integripinnis ........

marmoratus..........

monophthalmus .....

nox..................

cremnobates, Labrosomus..........

Starksia ......... 2365, 2366

Crenilabrus ......................

microstoma............

crenulare, Myctophım.............

crenularis, Tarletonbeania.........

crenulatus, Rhombus .............

Creole...........................

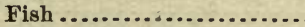

creolus, Brachyrhinus .............

Paranthias ...............

Serranus .................

crescentale, Gobiosoma ...........

crescentalis, Gobiosoma ...........

Pomacanthus.........

crescentis, Salmo gairdneri ........

Crested Gobies....................

crestonis, Teuthis.................

Crevallé, Horse ..................

Crevallés $915,920,921$

crinigerum, Siphostoma...........

crinitus, Alectis ..................

Blennius ................

Blepharichthys...........

Blepharis................

Caranx..................

Gallichthys .............

Zous.....................

Criolla, Cherna.....................

Criollo, Pargo......................

cristagalli, Anoplarchus

Cebedichthys

Centronotus
Page.

1542

1034

627

110

231

716

657

1188

1188

954

81,1038

1746

87

222

185

2369

2372

2371

2373

2373

2371

2372

2374

2366

1581

1576

575

575

966

1586

1221

1222

1222

1222

2259

2260

1682

2821

2209

1692

920

771

932

2383

932

932

932

932

932

1157

1265

2423

2427

2423

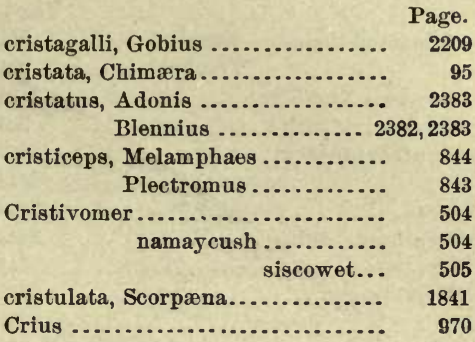

bertheloti.................. 971

Croaker........................ 1460, 1484

Black.................. 1456

White ................. 1397

Yellow-tailed ............ 1467

croaker, Sciæna................. 1462

Croakers . ...................... 1392, 1461

croceus, Leuciscus .............. $\quad 308$

Rhinichthys atronasus.... $\quad 308$

crocodilinus, Branchysomophis.... $\quad 388$

Ophichthys ......... 388

Ophisurus .......... $\quad 388$

crocodilus, Gasteropelecus........ $\quad 558$

Lampanyctus ......... $\quad 558$

Scopelus ............. 558

crocota, Plectropoma ............. 1192

crocotus, Hypoplectrus ............. 1192

unicolor ... 1192

crocro, Pomadasis................ 1333

Pristipoma ............... 1333

croicensis, Erychthys............. 1651

Scarus ................ 1650

Cromileptes ..................... 1148

cromis, Labrus.................... 1483

Pogonias................. 1482

courbina ........ 1483

crossotus, Etropus .............. $\quad 2689$

crotalina, Lycolia ................. $\quad 2869$

crotalinus, Embryx .............. 2458

Lucodopsis ........... $\quad 2459$

Crotalopsis...................... $\quad 386$

$\operatorname{mordax} \ldots \ldots \ldots . . . . . .387$

punctifer ............. $\quad 387$

crotaphus, Chærojulis ............ 1598

Julis............... 1591, 1598

Platyglossus........... 1598

Crucian Carps .................... 201

cruentatus, Bodianus ............ 1142

Labrus .............. 1238

Petrometopon ......... 1141

coronatus 1142

Priacanthrs........ 1238, 2858

Sparus .............. 1142

cruentifer, Pisoodonophis......... $\quad 377$

crumenophthalmus, Caranx....... 911 


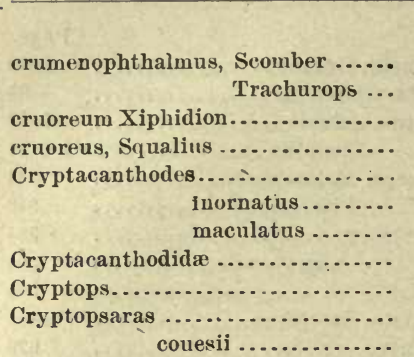

Cryptopterus.

$$
\text { puncticeps ........... }
$$

cryptosus, Stromateus............ Cryptotomus.

$$
\begin{aligned}
& \text { auropunctatus ....... } \\
& \text { beryllinus............ } \\
& \text { dentiens .............. } \\
& \text { retractus ............. } \\
& \text { rosens................ } \\
& \text { ustus ............... }
\end{aligned}
$$

Cryptotrema ..................... corallinum ............

crysoleucas, Abramis ..............

$$
\text { bosci ......... }
$$

Cyprinus..............

crysos, Caranx...................

Scomber..................

Crystallaria.......................

$$
\text { asprella ................ }
$$

Crystallichthys ................... mirabilis ...........

crystallina, Atherinella........... Thyrina ...............

Crystallogobiinæ..................

Ctenodax.........................

- Ctenodon.......................... maculatus...............

Page.

Ctenogobius

fasciatus.............

Ctenolabrus adspersus............. burgall,.............. cæruleus............. chogset .............. uninotatus ............

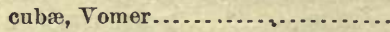
Cuban Blindfish ................... cubana, Anguilla ...............

Muræna................

cubanus, Engraulis ..............

Epinephelus ............

Stolephorus.............

cubensis, Channomuræna.........

Hynnis.................

Limia.

Pocilia.

\section{Cubera.}

cubera, Lutjanus

Cubiceps.

indicus. multiradiatus ............ pauciradiatis ............

cubifrons, Malthe.................

Cub-shark ......................

Cuckold......................... cuculus, Trigla ................ $\quad 2177$ cucuri, Prionodon............... 40 Cucuyo ..................... 1701, 1709

Cugupugnacu................. 1158, 1163 cujus, Chasmistes............... 183

Culius ....................... 2199

æquidens ................. 2202

amblyopsis............... 2200

belizianus................. 2201

perniger ................. 2201

cultrata, Novacula.............. 1619

cultratus, Stolephorus ........... 443

Xyrichthys............ 1619

cultriferum, Pristipoma.......... 1333

cultrifrons, Alutera............. 1718

Cultus Cod........................ 1875

culveri, Trachinotus............. 942

cumberlandicum, Etheostoma fla-

bellare ........................ 1098

cumingii, Ceratichthys ........... $\quad 318$

Hybopsis.............. $\quad 318$

cuneata, Pocilia................ 2834

Cunner ...................... 1576, 1577

cupreoides, Pimelodas ........... $\quad 140$

cupreus, Pimelodus ................ 140

Silurus................ 140

Trachinotus............. 944

Trachynotus............. 944

curassavicus, Balistes............ 1709

curema, Mugil ................. 813, 2841

curilicus, A gonus................ 2036

curilus, Salmo ................ 508, $28 \mathrm{E} 3$

Curimata .................... $\quad 332$ magdalenæ ............ $\quad 332$

Curimatella................... $\quad 332$

Curimatina .................... 331

Curimatus ................... $\quad 332$ magdalenæ............ 332

curtus, Stolephorus............. 445

Vomer ................. 9934

curvidens, Congrus............. $\quad 360$

curvilineata, Murenophis......... $\quad 395$

curvus, Tetrodon ............... 1728

Cusk Eels..................... 2481, 2487

Cusks.......................... 2561

cuspicauda, Alutera ............. 1718

cutisanserinus, Carpiodes......... 167 


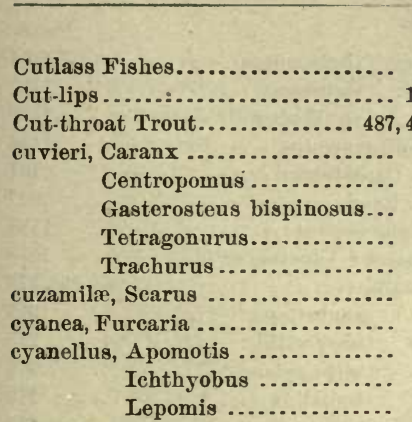

cyaneus, Chromis .

Heliastes .................

Hypsilepis cornutus......

Notropis cornutus........

Cyanichthys

cyanocephalus, Iridio

Labrus .............

Lythrurns .........

Minnilus ...........

Notropis umbratilis

cyanoguttatus, Herichthys.........

Heros .............

eyanolene, Sparisoma..............

cyanonoton, Alosa..................

Cyanoperea .......................

cyanophrys, Naucrates.............

Psenes ...............

eyanops, Caulolatilus ...............

cyanoptera, Chrysophrys ..........

cyanopterus, Cypsilurus ...........

Exocœtus.............

Lutjanus .............

Mesoprion ............

Neomænis ............

cyanostigma, Chærojulis...........

Julis ................

Platyglossus ..........

Cybium .........................

acervum .................

caballa ...................

cavalla ...................

immaculatum.............

maculatum ................

petus

regale ....................

sara .....................

solandri ..................

verany...................

Cycleptinæ

Cycleptus .........................

elongatus

nigrescens

Page.

888

199,327

492,493

910

1121

749

976

910

1648

1547

996

164

996

1547

1547

283

283

1747

1594

1594

300

300

300

1538

1537

1633

427

1022

900

950

2278

1354

2836

739

1255

1255

1254

1591

1591

1591

873

875

876

876

876

874

877

875

877

877

877

162

168

168

169

Cyclichthys
Cyclichthys cornutus.

ycloganoidea................... $\quad 111$

Cyclogaster...................... 2114

pulchellus............ $\quad 2127$

cyclogaster, Liparis ............... 2118

Cyclogobius...................... 2249

cyclolepis, Microgobius ........... $\quad 2247$

Moseleya.............. 2570

Nematonurus........... 2571

Zalypnus............. $\quad 2246$

Cyclonarce...................... $\quad 78$

cyclopomatus, Serranus............ 1175

Cyclopsetta ..................... 2675

chitteüdeni........... 2676

fimbriata............. 2676

querna ................ 2675

Cyclopteichthys ................. 2103

glaber.......... 2104

stelleri........... 2104

ventricosus....... 2104

Cyclopteridæ ..................... 2094

Cyclopterinæ .................... 2095

Cyclopteroides................... 2102

gyrinops .......... 2102

2096

2097

2110

2097

2135

lineatus ............. 2118
liparis ............ 2118,2123

major......... 2118

minor......... 2121

liparoides............ 2108

lumpus ........... 2096, 2097

minutus............. 2097

montacuti............ 2108

musenlus ............ $\quad 2118$

nudus............... 2336

orbis................ 2100

pavoninus............ 2097

pyramidatus ......... 2097

spinosus ........... 2099, 2100

stelleri ............... $210 t$

ventricosus .......... 2104

cyclopus, Liparis................ 2112, 2118

Cyclospondyli.................. 52,53

Cyclospondylous Sharks ........... $\quad 52$

cyclostigma, Liparis ............. $\quad 2125$

Cyclothone .................... 581, 582

bathyphila............ $\quad 582$

elongata .............. $\quad 583$

Insea ................ 582

microdon ............ 582, 2826

eyclotis, Ceratichthys............. 323

cylindraceus, Rivulus............ 662 


\begin{tabular}{r}
\hline Cylindrosteus.................... 1 \\
agassizii............ \\
bartoni ............. \\
castelnaui .......... \\
productus .......... \\
rafinesquei .......... \\
zadocki............
\end{tabular}

Cymatogaster.

aggregatus ..........
ellipticus ............
larkinsii .............
minimus ............
pulchellus ...........
rosaceus ............

eymatogramma, Pileoma ........... cymatotænia, Etheostoma (Hadropterus) ............... Hypohomus.........

Cynædus brama .................. Cynichthys . Cynicoglossus. bathybius ............
pacificus............ Cynocephalus pacificus............

cynodon, Lutjanus ................ $\begin{array}{rr}\text { Mesoprion............. } & 1255,1260 \\ \text { Cynoglossa..................... } & 2653 \\ \text { microcephala .......... } & 2655 \\ \text { cynoglossa, Solea................ } & 2657 \\ \text { Cynoglossinm .................. } & 2693 \\ \text { cynoglossus, Glyptocephalus....... } & 2656 \\ \text { Pleuronectes.......... } & 2611\end{array}$ Cynoperca..................... 1020, 1021 Cynoponticus ................... $\quad 359$ $\begin{aligned} \text { ferox } \ldots \ldots \ldots \ldots \ldots \ldots & 360 \\ \text { Cynoscion..................... } & 3401,1403\end{aligned}$ acoupa................ 1403 albus ................. 1411 carolinensis............. 1409 jamaicensis............ 1406 leiarchus............... 1414 macdonaldi ............. 1411 maculatum ............. 1409 microlepidotus ......... 1415 nebulosus............... 1409 nobilis................. 1413 nothus................ 1406 obliquatus............. 1405 othonopterus ........... 1404 parvipinnis............ 1410 phoxocephalus......... 1413, 2859 regale................. 1407 regalis.................. 1407 reticulatus ............ 1408 squamipinnis.......... 1404, 1405 stolzmanni . 1412

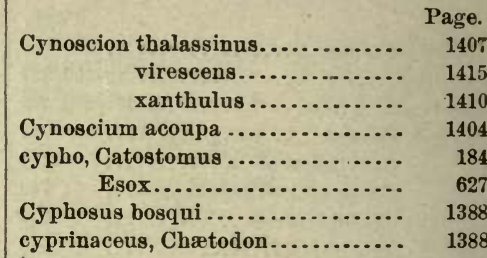

Cyprinella................. 254, 256, 273 analostana............ $\quad 279$ beckwithi ............... 273 billingsiana............. $\quad 272$ bubalina............... $\quad 273$

calliura................. $\quad 275$

cercostigma ............ 275

complanata............ $\quad 272$

forbesi................ 272

gunnisoni .............. 273

lepida .................. 273

ludibunda.............. 273

lugubris................ 274

luxoides................ 274

macrostoma ............ 274

notata ................ 274

rubripinna............. 281

suavis ............... 272

texana.................. 274

umbrosa............... 273

venusta................ 274

whipplii............... 279

cyprinella, Chanos............... $\quad 415$

Ictiobus............... 163

Sclerognathus.......... 164

Cyprinidæ .................... 199, 200

Cyprininæ ..................... 201

Cyprinodon .................... 670

baileyi.............. 675

bovinus ............. 673

californiensis.......... 674

carpio ................ 675

elegans .............675, 2832

eximius............ 073,2832

felicianns..........676, 2832

gibbosus............. 672

latifasciatus ........... $\quad 676$

macularius ........... 674

baileyi..... $\quad 675$

martæ............... $\quad 675$

mydrus.............. $\quad 676$

nevadensis ............ 674

parvus ............... $\quad 666$

riverendi ........... 673,2832

variegatus............ $\quad 671$

Cyprinorlontinæ.................. 631

cyprinoides, Gobius............... 2209

Lophogobius ......... 2209 
Cyprinus....................

americanus.........250, 251, 147

atromaculatus...........

atronasus ...............

auratus .................

balteatus.................

bullaris .................

burtonianus.............

carpio ....................

catostomus..............

caurinus ...............

commersonii ............

cornutus................

corporalis. 221,222

crysoleucas ...............

gracilis ................

hemiplus ..............

maxillingna..............

megalops ...............

melanurus

oblongus................

oregonensis.............

pala....................

smithii.................

sucetta ................

sueurii ..................

teres....................

tolo .....................

vittatus.

.

250

326

250

327

282

282

186

225

415

413

186

195

179

415

307

cyprinus, Carpiodes............ 167, 168

Cypselurus.......... 730, 731, 735, 2835, 2836

bahiensis............. 2836

californicus ........... 2836

callopterus ............ 2836

comatus.............. $\quad 736$

cyanopterus........... 2836

furcatus............. 737, 2836

gibbifrons............ 2836

heterurus ............ 2836

lineatus.............. 2836

nigricans............. 2836

xenopterus........... 2836

cypselurus, Prognurus ............

Cyttinæ........................

Cyttus hololepis...................

2866

1660

1662

Dab, Alaska......................

2645

Rusty ...................... 2644

Smear...................... 2654

Dabbler, Mud ................... $\quad 640$

Dabs, Mud ...................... 2644

Smear ..................... 2653

Dace.

Black-nosed ................... 305, 307

Long-nosed $\ldots . . . . \ldots \ldots \ldots . .$.

Dace, Red-bellied................
D

Dacentrus.

Page.

1495

1496

Dactylagnus .................. 2304

mundus ............ 2304

dactyloptera, Scorpæna.......... 1837

Dactylopterus................... 2183

communis........... 2184

pirapeda........... 2183

volitans........... 2183

dactylopterus, Helicolenus ......... 1837

Sebastes .......... 1837, 1838

Siebastoplus........ 1837

Drctyloscopidæ................ 2297

Dactyloscopus ................. 2300,2301

lunaticus.......... 2302

pectoralis ......... 2301

poeyi............. 2302

tridigitatus........ 2301

zelotes............. 2303

dactylosus, Paraliparis ............ 2144

Daddy Sculpin ................. 1974

Dretor......................... 2325

dowi ................. 2325

Dajaus....................... 818,819

choirorynchus............ 2841

microps ................. 820

monticola................. 2841

dakotensis, Chrosomus............ $\quad 210$

Dalatiidæ..................... 56,620

dalli, Gobius ..................... 2230

Dallia......................... 621

delicatissima.............. 621

pectoralis ................. 621

dallii, Pteropodus ................. 1819

Sebastodes auriculatus ...... $\quad 1818$

Damalichthys................. 1509

argyrosoma ........ 1510

argyrosomus ....... 1509

vacca.............. 1510

damalis, Carpiodes .............. $\quad 167$

d'A mplora, Maire ................ $\quad 555$

Dark-green Parrot-fish............ 1638

Darter, Black-sided ............ 1028, 1032

Blue.................... 1088

Blue-breasted ............. 1076

Fan-tailed............... 1079

Green-sided ............... 1053

Johnny ................. 1056

Least ................... 1104

Maniton ................ 1027

Rainbow ................ 1088

Tessellated............... 1057

Sand .................. 1061, 1062

darwini, Cossyphus .............. 1586

Pimelometopon .......... 1586

Sebastes ............... 1832 
darwini, Sebastodes ...............

Trochocopus

Dasibatis

centrura.

dipterura ................

hastata .................

longa ...................

sabina..............

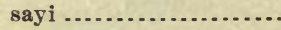

tuberculata ..............

daspilotus, Pisoodonophis.

Dasyatidæ

Dasyatinæ

Dasyatis.

centrura

dipterura ................

gymnura ................

hastata ..................

longa ...................

sabina...............

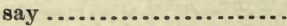

Dasybatus .

dipterurus..............

dasycephalus, Arius................

Galeichthys .........

Hexanematichthys..

Dasyscopelus .

spinosus............

Dasycottus........................

setiger ...............

daubentonii, Caranx ..............

davidsonii, Anisotremus ...........

Monacanthus ..........

Pomadasys............

Pristipoma...........

davisoni, Etheostoma ..............

Ulocentra...............

Decactylus.

$173,174,177$

decadactylus, Beryx ..............

decagonus, Agonus...............

Aspiclophorus ..........

Brachyopsis ............

Leptagouus .............

decagrammus, Chirus ...............

Hexagrammos ......

Hexagrammus ......

Labrax .............

Decapterus .....................

hypodus ..............

macarellus ............

punctatus..............

sanctæ-helenæ .........

scombrinus ............

Decaptus .........................

decastrensis, Cottus.

decimalis, Serranus
Page.

1832

1586

82

83

85

84

85

85

86

84

2803

79

79

82,83

83

85

84

83

85

84

86

66,82

85

130

2780

130

574

575

1991

1991

920

1321

1715

1321

1321

1049

1049

844

2053

2054

2054

2052

1869

1867

1875

1868

907

908

909

907

908

908

906

1983

1175 declivifrons, Abudefduf............. $\quad$ Page.

Euschistodus......... 1562

Glyphidodon.......... 1562

declivis, Seriola................. 905

Zonichthys.............. 905

Decodon ........................ 1584

puellaris................ 1584

decoratus, Entomacrodus ......... 2399

Promicropterus........ 1234

Rhypticus ............. 1234

decurrens, Pleuronichthys ..... . 2637, 2638

de Casta, Aguja.................. 892

Mojarra............... 1372

de Chapala, Pescado Blanco........ $\quad 792$

dé dos Colores, Pescado Azul ...... 1557

Vaqueta ............ 1684

de España, Sardina............... 423

de Gallo, Pez...................... $\quad 895$

de la Alto, Isabelito................ 1674

de la Piedras, Mojarra............. 1681

de las Piedras, Pez............... $\quad 1700$

de Ley, Mojarra................... 1370

de lo Alto, Cagon ................. 1277

Pargo................. 1262

Sesi................... 1261

de Mar, A boma .................. 2195

Esmeralda................ 2204

Esmeraldas ............... 2203

de Marais, Poisson ................ 113

de Paladar, A guja................. $\quad 892$

de Perdriz, Liza Ojo................ 814

de Playa, Cazon.................. $\quad 36$

de Pluma, Pez.................. 1347

de Raizero, Pargo ................ 1273

de Rio, Aboma .................... 2236

Bagres ................... 149

Lengnado ................. 2698

de Vivero, Cherna................ $\quad 1160$

Deep-water Catalufas ............. $\quad 977$

2177

1344

defensor, Caranx ................. 921

de Gato Pai ...................... 1837

Dekaya ........................ 2276

anomala................. 2277

dekayi, Acipenser................. 106

Gasterosteus .............. $\quad 746$

Isuropsis................ 48

Isurus .................. 48

Phycis ................. $\quad 2555$

Pimelodus................. $\quad 140$

Scomber................. 867

Syngnathus .............. 771

delalandi, Labrisomus.............. $\quad 2359$

Malacoctenus........... 2358

delalandii, Clinus ............... 2359 
de Ley, Sardina

delicatissina, Dallia

Umbra

delicatissimus, Engraulis ..........

Stolephorus ........

deliciosa, Cliola...................

Corvina ..................

Moniana .................

Sciæna ....................

Delolepis.........................

virgatus $\ldots . . . . . . . . .$.

Delothyris

pellucidus...........

delphinus, Minomus ..............

Pantosteus .............

del Rey, Pescadillos

Pescado

$\mathrm{Pez}$

Deltentostens.

Deltistes

luxatus

de Mer, Brochet.

Demoiselle

dendritica Anclyopsetta

Ramularia ...

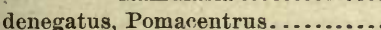

dennyi, Liparis

dentata, Chœenopsetta.

Platessa

Pomatopsetta.............

Stygicola ................

dentatus A psilus

Grammatostomias

Hippoglossoides ........

Lucifuga .................

Lutjanus .................

Mesoprion...............

Paralichthys ......... 2629, 2630

Pleuronectes ........... 2630

Pseudorhombus ....... 2630, 2632

Stygicola.............. 2500

Tropidinius ............ 1279

Upeneus................ 859

Dentex ....................... 1288

filamentosus............ 1289

dentex, Brycon ..................

Caranx ..................

Chalcinopsis

Corvina

Engraulis...............

Larimus .................

Menidia ..................

Odontoscion ..............

Osmerus ..................

Sconuber

Denticinæ
Page.

430
621

621

414

444

272

1456

262

1455

2442

2690

2691

171

171
807

806

799

2210

2794
2792

1118

2634

2633

1567

2124

2630

2615

2500

1278

590

2615

1255

279

30

00

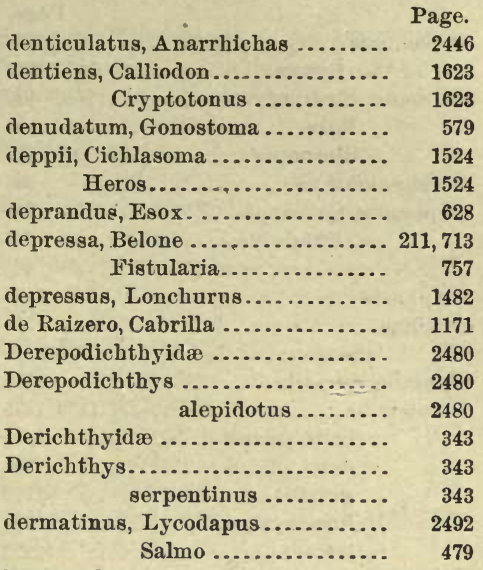

Dermatolepis................ 1166, 1168 angustifrons ........ 1169

inermis .......... 1167, 2855 punctatus........... 1168 zanclus ............ 2854

dermatolepis, Epinephelus ........ 1169

Dernatostethus ............... 761, 763 punctipinnis...... 763

desmarestia, Raia............... $\quad 71$

detersor, Julis................... 1610

detrusus, Gillichthys ............ 2251

Devilfish ...................... 92

Devil, Sea ................. 91, 92, 2727

Diabasis...................... 1291

aurolineatus............. 1309

chromis ................ 1299

chrysopterus........... 1309

elegans................. 1304

flavolineatus ............. 1306

fremebundus ............ 1297

maculicauda............. 1314

obliquatus .............. 1304

parra.................. 1299

plumieri................ 1306

scudderi................ 1300

steindachneri ............ 1302

trivittatus .............. 1311

Diablo........................ 2737

Diabolichthys ................. 92

elliotti ............ 93

diabolus, Raja marinus .......... 93

Diacope ...................... 1247

viridis................. 1246

diadema, Pseudoscarus ........... 1646

Scarus ................ 1646

Diagramma cavifrons ............ 1343

melanospilum ........ 1321 


\begin{tabular}{|c|c|c|c|}
\hline ............ & $\begin{array}{r}\text { Page. } \\
2868\end{array}$ & dimidiatus, Leucus.................. & $\begin{array}{r}\text { Page. } \\
244\end{array}$ \\
\hline fuscus.................... & 2868 & Platyglossus ............ & 1594 \\
\hline ana, Hydrargyra .............. & 645 & Serranus ........ & 1179 \\
\hline Raia....................... & 71 & Syngnathus ............ & 765 \\
\hline Sternoptyx............6 603 & 3,2826 & Trisotropis............. & 1179 \\
\hline aphanichthys.................... & 353 & 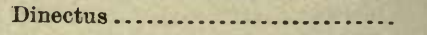 & 103 \\
\hline phanus, Calliurus................ & 996 & truncatus.................. & 106 \\
\hline Fundulus ................ & 645 & Dinematichthys marginatus ........ & 2502 \\
\hline menona...... & 645 & ventralis........... & 2503 \\
\hline$=7$ & 2495 & Dinemus ............................... & 854 \\
\hline aphus..................... & 564 & venustus................. & 854 \\
\hline theta.................... 56 & 564,565 & dinemus, Minnilus ................ & 293 \\
\hline ra, Furcella.................. & 2472 & dinoceros, Citharichthys ........... & 2682 \\
\hline apterus..................... 1373 & 73,1375 & Diodon........................ 1744 & 14,1747 \\
\hline californiensis & 1370 & antennatus.................. & 1750 \\
\hline dowi ..................... & 1368 & asper.................. 1744 & 44,1752 \\
\hline gracilis ................... & 1370 & atinga................... 1746 & 6,1750 \\
\hline homonymus.............. & 1371 & brachiatus ..................... & 1746 \\
\hline lefroyi ................... & 1372 & carinatus.......................... & 1754 \\
\hline apterus, Amiichthys ............. & 1113 & echinus .................... & 1746 \\
\hline Lycodes..................... & 2473 & fuliginosus................. & 1749 \\
\hline unchus .............................. & 2743 & geometricus............. 1748 & 8,1749 \\
\hline atlanticns .............. & 2743 & holocanthus... ............. & 1746 \\
\hline ceraus, Ceratocottus ........... 1940 & 10,1941 & hystrix................. 1744 & 14,1746 \\
\hline Cottus $\ldots . . . . . . . .$. & 1941 & liturosis................... & 1746 \\
\hline Enophrys ................. & 1941 & maculatus................... & 1746 \\
\hline robatis .......................... & 2756 & maculifer................... & 1747 \\
\hline robatus....................... & 92 & maculostriatus .............. & 1748 \\
\hline ick, Nigger ............................ & 327 & melanopis .................. & 1746 \\
\hline Slippery....$\ldots \ldots \ldots \ldots \ldots$ & 1595 & meulini .......................... & 1748 \\
\hline icrolene .................................. & 2522 & multimaculatus ............. & 1746 \\
\hline intronigra ................ & 2522 & nigrolineatus............... & 1749 \\
\hline omita................. & 2506 & novemmaculatus ........... & 1740 \\
\hline agassizii ................. & 2506 & pilosus ................... 1744 & 14,1752 \\
\hline 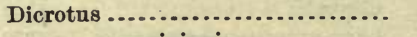 & 882 & punctatus .................. & . 1746 \\
\hline parvipinnis............... & 883 & quadrimaculatus........... & 1746 \\
\hline ctyosomatinæ................... & 2349 & reticulatus .................. & 1751 \\
\hline go, Scomber..................... & 867 & rivulatus.................. & 1748 \\
\hline ncæus, Eupomacentrus......... & 1552 & schœpfi $\ldots . . . . . . . . . . . . .$. & 1748 \\
\hline formis, Carpiodes................ & 166 & sexmaculatus .............. & 1746 \\
\hline itatus, Lycodes .................. & 2466 & spinosissimus ............... & 1746 \\
\hline itis, Trigla vicensis............... & 2183 & spinosus .................. & 1749 \\
\hline immus, Pleuronectes........... & 2641 & verrucosus .................. & 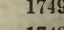 \\
\hline ecta, Anclyopsetta ............... & 2636 & ontidæ $\ldots \ldots \ldots \ldots \ldots \ldots$ & $174:$ \\
\hline Notosema................. & 2636 & edeana, A phoristia ............. & 2711 \\
\hline lectum, Notosema................. & 2635 & diomedeanus, Hoplunnis............ & 361 \\
\hline lectus, Alburnus.................. & 294 & Symphurus........... & 2711 \\
\hline Notropis ................. & 294 & Dionda....................... 212, 21 & 13,214 \\
\hline lacocentrus.................... & 1613 & argentosa................... & 215 \\
\hline e, Cane & 48 & chrysitis........... & 21 \\
\hline ata, Mycteroperca ............ & 1179 & couchi ...................... & 216 \\
\hline nidiatus, Epinephelus ........... & 1179 & ерiscopa................... & 215 \\
\hline Gasterosteus........... & 749 & grisea,$\ldots \ldots \ldots \ldots \ldots \ldots$ & 216 \\
\hline Halichæres ............ & 1594 & melanops .................. & 216 \\
\hline Icthycallus..... & 1594 & & 21 \\
\hline & 1594 & & 216 \\
\hline
\end{tabular}


Dionda punctifer

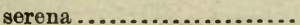

spadicea....................

texensis ...................

Dioplites

nuecensis treculii........

variabilis

diplænia, Hypsilepis .............

diplæmius, Minnilus.

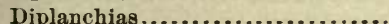
nasus............

Diplectrum .............. 1203, 1204, 1207 euryplectrum........ 1206

fasciculare........... 1208 formosum............. macropoma ............ radiale............... radialis ................ radians............ sciurus ...............

diplemius, Semotilus.............. Diplesion

blennioides

fasciatus................

Diplesinm blennioides ............ Diplodus

argenteus ................

caribæus................

caudimacula ..............

flarolineatus ............

holbrookii...............

probatocephalus .........

rhomboides ..............

sargus .................

Diplolepis...................... squamosissimus........

diploproa, Sebastichthys ..........

Sebastodes..............

Diplospondyli.

diplotænia, Belone

Bodianus ................

Cossyphus .............

Harpe................

diplotænia, Tylosurus ...........

Dipterodon.

hexacanthus

ruber

Dipteron chrysurus.

dipterura, Dasibatis...............

Dasyatis ................

dipterurus, Dasybatıs .............

Dipterygonotus ..................

Dipturus.......................

dipus, Microdesmus ...............

Discoboli..........................

Discoboli liparldina ...............
Page.

215

214

216

215

1010

1012

1012

300

300

1753

1754

1207

1205

1204

1205

1208

1204

222

1052

1053

1081

1053

1362

1363

1360

1363

1360

1362

1361

1358

1363

1418

1419

1802

1801

16

712

1582

1582

1582

712

1106

1107

1107

1433

85

85

85

1365

66

2450

1758

2105
Page.

discobolus, Catostomus . . . . . . 172, 175, 2791

Discocephali .................. 781, 2265

Discopyge ................... $\quad 78$

ommata.............. 78

dispar, Fundulus................ $\quad 658$

Zygonectes ............... 659

dispilurus, Centropristis .......... 1220

Dules................. 1219

dispilus, Halichæres ............. 1598

Iridio .................. 1597

Platyglossus ............ 1598

dissimilis, Ceratichthys........... $\quad 319$

Couesius .............. 324

Hybopsis ............. $\quad 318$

Lencosomus........... $\quad 324$

Luxilus .............. $\quad 319$

distickus, Salmo ................ $\quad 509$

distinctum, Sparisoma ........ . 1635, 1636

distinctus, Scarus .............. 1636

Ditrema...................... 1510

aggregatum............ 1499

anale.................. 1501

arcuatum .............. 1502

argenteum .............. 1504

atripes.................. 1507

brevipinne.............. 1499

caryi.................. 1509

furcatum............... 1506

jacksoni ............... 1505

læve................. 1511

laterale................ 1506

megalops............... 1502

orthonotus.............. 1507

rhodoterum ............. 1503

temminckii ............ 1510, 1511

toxotes................. 1508

vacca ................. 1510

Divør, Sand ................... $\quad 535$

Dobula....................... 228

Doctor-fish.................... 1689, 1691

dodecaedron, Agonus............. 2046

Occa ................ 2044

dodecaedrus, $\Delta$ spidophorus....... 2046

Brachyopsis......... 2046

Dodecagrammos ............... 1866

Dogfish ...................... 113, 623

California ............... 53,54

Dog Salmon .................... 478

of Alaska........... $\quad 478$

Shark .................... 28, 29

Snapper.................. 1257

dolfyn,Coryphrena .............. 953

dolichocephalus, Gobius........... 2237

dolichogaster, Blennius ........... 2417

Centronotus........ $\quad 2417$

Gunnellus.......... 2417 


\begin{tabular}{|c|}
\hline 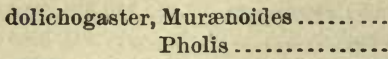 \\
\hline Doliodon ................................ \\
\hline Dollardee ............. \\
\hline Dollar-fish ................ \\
\hline Dollfish ............................... \\
\hline Dolly Varden Trout............ \\
\hline dolomieu, Micropterus........... \\
\hline Dolphin, Common................ \\
\hline 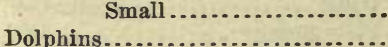 \\
\hline dombey, Bdellostoma.............. \\
\hline Gastrobranchus ......... \\
\hline Le Gastrobranche..... \\
\hline \\
\hline
\end{tabular}

Dómine

Polistotrema..............

dominicensis, Pocilia..............

Vomer.

domninus, Protoporus..............

Doncella ........................ 1590

Doncellas

1590,1595

Dorada, Mojarra ..................

Dorado................................

Cocinero ..................

dorado, Coryphæua ...............

Doratonotus

megalepis............

thalassinus

Dories, John

Dormeur.........................

Dormitator......................

gundlacbi .............

latifrons ..............

lineatus ................

maculatus........... 2196, 219

microphthalmus ....... 2198

dormitator, Philypnus............. 2195

Platycephalus......... 2195

dormitatrix, Electris ..............

dormitor, Gobiomorus ..............

Phily pnus...............

Dorosoma ......................

cepedianum..........

exile........

insociabilis ..............

mexicanum ..............

notata .................

petenense..............

Dorosomidæ.........................

dorsale, Hæmulon .................

dorsalis azurissimus, Microspatho. don

Carangoides

Caranx .................. getipinnis.

cinereus, Microspathodon
Page.

2417

2416

939

1005

967

1674

507

1011

952

953

951,952

6

6

1587

928

952

921

953

1611

1611

1612

1659

1235

2195

2198

2197

2198

2195

2198

2194

415 dorsalis Citula

Page.

Galeus.

30

Halatractus ............. $\quad 902$

Hybopsis................ 262

Hypsypops............. $\quad 1570$

Macrurus................ 2585

Microspathodon ......... 1568, 1570

Mustelus ................. $\quad 30$

Pomatoprion ............ $\quad 1570$

Semotilus ............... $\quad 222$

Seriola.................. 902

Umbrina ................ 1469

Vomer.................. 934

dorsatus, Petromyzon marinus ..... $\quad 10$

dorso, Perca monapterygia ......... 1833

dorsomacula, Girella.............. 1382

dorsopunicans, Pomacentrus ....... 1557

Dorsuarius..................... 1384

Dory ........................... 1021

Doryichthys ................... 773

aculeatus............ 773

californiensis......... $\quad 774$

lineatus............ 773

Doryrhamphus.................. $\quad 773$ californiensis ...... 773

lineatus........... 773

Dough-belly ................... 205

Dourade ........................ 952

Dovetail Fish .................... 1563

dovii, Anableps .................. $\quad 685$

A nisotremus .............. 1318

A plocheilus ............... 2828, 2830

Apogon .................. 1108

Fundulus ................. $\quad 650$

Gymnothorax ............. $\quad 397$

Haplochilus ............... $\quad 650$

Heros ...................... 1535

Lycodontis................ $\quad 397$

Muræna................... $\quad 397$

Opisthopterus.............. 437

Pœcilia.................... 695

Pomadasis................. 1318

Pristigaster ................ 437

Pristipoma ................ 1318

Sidera ..................... $\quad 397$

dowi, Arius ..................... 125

Dæctor.................... 2325

Diapterus.................. 1368

Eucinostomus............... 136?

Exocœtus.................. $\quad 735$

Gerres .................... 1368

Leptarius .................. 125

Selenaspis ................ 125, 2761

Tachisurus ................. 125

Thalassophryne............ 2326

Doydixodon..................... 1382 


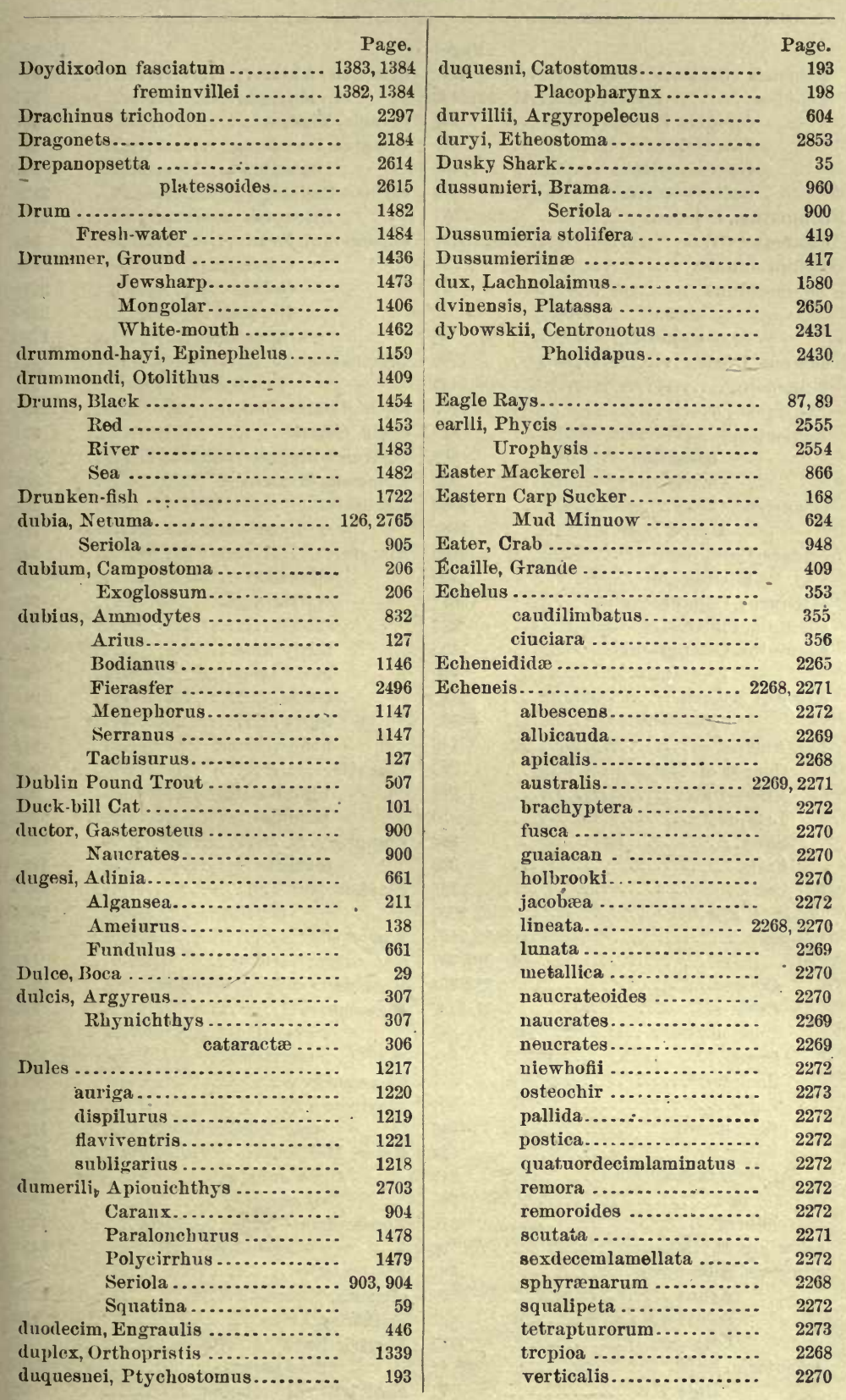




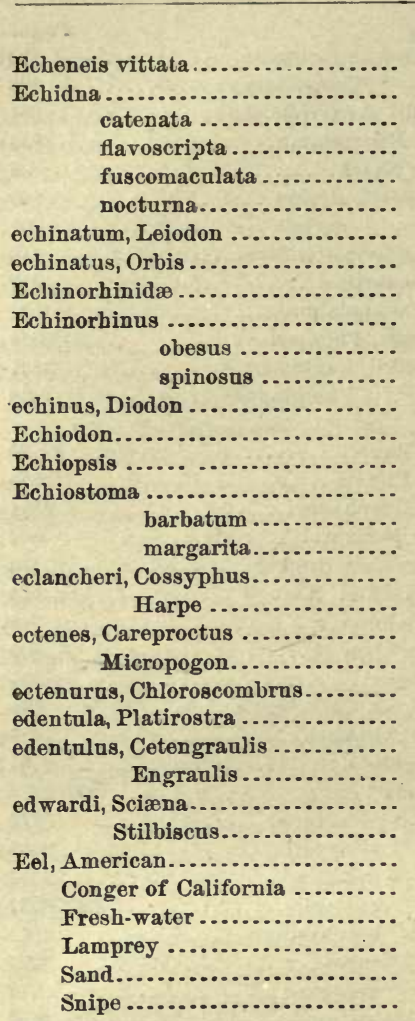

Eel Cat..........................

Eel-back Flounder .

2649,2650

Eel-pout

$2453,2455,2456,2457$

Eels....................... 344, 346, 347

Conger..................... 352, 354

Cusk ................... 2481, 2487

Long-necked ................

Ooze.........................

Snake......................

Snipe ......................

Snub-nosed .................

Spiny ........................

Symbranchoid ...............

True........................

Worm

eeltenkee, Myliobatis ...............

effulgens, Ethoprora ..............

Arlina .................

Boleosoma nigrum .......

Larimus ................

eglanteria, Raia.

Raja

Page.

2269

403

402

57
1745

57

58

58
1746

1583

1583

2136

1463

2847

102

450

450

1490
402

403

403

57

2495

386

589

589

589

363

348

395

348

10

833

369

\section{E}

Elapsopsis ...........................

elassochir, Noturus ...............

elassodon, Hippoglossoides ........

Elassoma ..........................

evergladei.............. 982

Page.

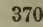

371

237

237

237

2174

2175

304

2339

2218

2339

1789

341

341

2831

921

2108

389

389

389

948

948

948

948

948

948

948

948

948

906

906

907

1930

1930

2006

2008

381

147

2615

982

zonatum............. 982, 2851

Elassomidæ.................... 981

Elastoma...................... 1281

macrophthalmus ........ 1281

elater, Malthe................... $\quad 2739$

Ogcocephalus .............. $\quad 2739$

Zalieutes.................. 2738

Elattarchus .................... 1431

archidium........... 1431

Elattonistius.................. $\quad 412$

elattura, Netuma .............. 128, 2769

elatturus, Arius................. 128

Electric Rays ..................... $\quad 76$

Star-gazers.............. 2306

electricus, Rhinobatus ........... 63 


\begin{tabular}{|c|c|c|c|}
\hline & Page. & & Page. \\
\hline ctris dormitatrix ...... & 2195 & ellipsoidea, Lebias.... . & 672 \\
\hline gans, Blakea ...................... & 2353 & ellipticus, Chatoessus ............... & 416 \\
\hline Cottus ............................... & 1939 & Cymatogaster ............ & 1503 \\
\hline Cyprinodon ............... & 675 & Platophrys .............. & 2665 \\
\hline Diabasis ................... & 1304 & Pleuronectes ............. & 2665 \\
\hline Etheostoma .............. & 1074 & Rhomboidichthys ........ & 2665 \\
\hline Gasterosteus .............. & 748 & Ellwife............................. & 426 \\
\hline Gibbonsia.............. 235 & 3,2869 & elongata, Aphoristia ............... & 2707 \\
\hline Gila...................... & 226 & Clupea ................... & 421 \\
\hline Hæmulon ................ & 1304 & Cyclothone .............. & 583 \\
\hline Kурhosus................ & 1387 & Platessa ................. & 2657 \\
\hline Labeo..................... & 186 & Pocilia .................. & 697 \\
\hline Leuciscus................ & 227 & Umbrina ................ & 1476 \\
\hline Mesoprion ................. & 1278 & elongatum, Gonostoma ............. & 583 \\
\hline Myxodes.................. & 2353 & elongatus, A vocettina............. & 2802 \\
\hline Nanostoma............... & 1075 & Benthodesmus .......... & 888 \\
\hline goriscus............ & 1754 & Catostomus .............. & 169 \\
\hline Pimelepterus............. & 1387 & Cephalus ................. & 1756 \\
\hline Rhomboplites ............ & 1278 & Clinostomus .............. & 240 \\
\hline Sebastes ................ & 1830 & Cycleptus................ & 168 \\
\hline Sebastodes................. & 1830 & Labichthys .............. & 369 \\
\hline Eleginus ............................. & 2537 & Leuciscus............... & 240 \\
\hline navaga....$\ldots \ldots \ldots \ldots$ & 2537 & Luxilus................. & 240 \\
\hline Eleotridinæ ....................... & 2188 & Megalops ................ & 409 \\
\hline is $\ldots \ldots \ldots \ldots+\ldots, \ldots, \ldots$ & 2199 & Menticirrhus ............ & 1476 \\
\hline abacurus ................. & 2200 & Ophiodon ................. & 1875 \\
\hline æquidens.................... & 2202 & Osmerus ................. & 525 \\
\hline amblyopsis .............. 2199 & 9,2200 & Plenronectes.............. & 2657 \\
\hline belizianus................., & 2201 & Pomadasis ............... & 1328 \\
\hline capite plagioplateo ......... & 2201 & Pomotis.................. & 1001 \\
\hline grandisquama............ & 2198 & Sclerognathus ........... & 169 \\
\hline guavina ....................... & 2199 & Scopelus ................ & 555 \\
\hline gyrinus ................... & 2201 & Sebastes................. & 1816 \\
\hline lateralis ................... & 2195 & Sebastodes............... & 1815 \\
\hline latifrons.................. & 2198 & Squalius .................. & 240 \\
\hline longiceps................. & 2195 & Symphurus ............. & 2707 \\
\hline mauritii .................. & 950 & Zoarces............ & 2457 \\
\hline mugiloides ................ & 2198 & Elopidæ .......................... & 408 \\
\hline locyanens............... & 2198 & 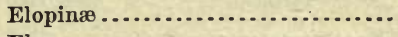 & 408 \\
\hline rniger................... & 2201 & Elops................................ & 409 \\
\hline ctus ..................... & 2201 & capensis ....................... & 410 \\
\hline pisonis .................. 2200 & 0,2201 & inermis.................. & 410 \\
\hline minuda................... & 2204 & purpurascens................. & 410 \\
\hline a.......................... & 2198 & saurus .......................... & 10,2806 \\
\hline smaragdus ................ & 2204 & elucens, Siphostoma ............... & 768 \\
\hline somnolentus................ & 2198 & Syngnathus ............... & 768 \\
\hline Elephant Fish ........................ & 95 & El Verde ........................... & 817 \\
\hline Fishes.................... & 94 & emarginatum, Scarus.............. & 1641 \\
\hline Shark $\ldots . . . \ldots \ldots \ldots$ & 51 & Sparisoma........... & 1641 \\
\hline elephas, Squalus ................. & 51 & emarginatus, Lobotes............... & 1257 \\
\hline Eleutheractis ..................... & 1229 & Serranus ............. & 1181 \\
\hline coriaceus ............ & 1233 & 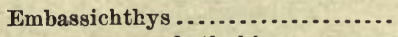 & 2655 \\
\hline eleutherus, Noturus............... 14 & 48,149 & bathybius .......... & 2655 \\
\hline Schilbeodes ............ & 148 & Embiotoca................................ & 1504 \\
\hline $\begin{array}{l}\text { Elliops } \\
\text { elliotti, Diabolichthrs }\end{array}$ & $\begin{array}{r}133 \\
03\end{array}$ & argyrosoma............ & 1510 \\
\hline & 93 & caryi..................... & 1509 \\
\hline
\end{tabular}




\begin{tabular}{|c|c|c|}
\hline Page. & & Page. \\
\hline Embiotoca cassidyi.............. 1505 & Enchelyeore... & 389 \\
\hline jacksoni ............... 1504, 1505 & euryrhina............. & 390 \\
\hline lateralis............... 1506 & nigricans ............ & 389 \\
\hline lineata ................. & Enchelyopus.......... 889, 2456, 2540 & 10,2560 \\
\hline ornata.............. & americanus......... 2457 & 57,2555 \\
\hline perspicabilis............. & barbatus .............. & 2500 \\
\hline webbi................... & brosme.............. & 2561 \\
\hline Embiotocidæ....$\ldots \ldots$ & cimbricus ........... & 2561 \\
\hline Embiotocinæ .................... & cimbrius ........... & 2560 \\
\hline Emblemaria ...................... & regalis ............... & 2553 \\
\hline atlantica ............. & Enchrasicholus......... & 448 \\
\hline nivipes........... & is............... & 1548 \\
\hline oculocirris ........ & Endormi Emerande ................. & 2230 \\
\hline Emblemariinæ ............... & Enedrias ......................... & 2414 \\
\hline emblematicus, Gobius.............. & . $\quad$ nebulosus ................ & 2414 \\
\hline Lepidogobius....... & 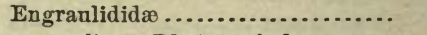 & 439 \\
\hline Scarus ............... & engraulinus, Photogenis leucops... & 296 \\
\hline Zalypnus ............ & Engraulis ....................... & 448 \\
\hline embryum,Blennicot. & us ............. & 445 \\
\hline tus... 2016, 2864 & ............... & 451 \\
\hline Oligocot. & brevis .................... & 450 \\
\hline tus ..... & brownii.................. & 443 \\
\hline Embryx............................. & chœrostomus ............. & 444 \\
\hline crassilabris ................ & clupeoides .............. & 447 \\
\hline 2458 & 3............... & 447 \\
\hline res.................... & ............... & 442 \\
\hline sh $\ldots \ldots \ldots \ldots \ldots, \ldots, \ldots$ & aus............ & 444 \\
\hline nde, Endormi ................. & ................... & 451 \\
\hline ys megalops................ & n................... & 446 \\
\hline Opsopœodus............... & (n................. & 450 \\
\hline .................. & grossidens............... & 451 \\
\hline n............. & ................. & 451 \\
\hline mmelane, A verruncus............ & lemniscatus ............ & 443 \\
\hline Tachysurus ............. & lonisiana ................ & 446 \\
\hline Emmelas .................. 1765, 1773, 1777 & epidotus .......... & 449 \\
\hline Lepophidium ............ 2483 & li.................. & 446 \\
\hline Emmelichthyinæ................ & (................. & 448 \\
\hline Emmelichthys ..................... 1365 & mysticetus ............... & 450 \\
\hline vittatus........... 1365, 1366 & n............... & 449 \\
\hline Emmnion ...................... $\quad 2375$ & sis ............. & 448 \\
\hline bristol & us .............. & 442 \\
\hline inæ............................ & piquitinga.............. & 443 \\
\hline ............... & (................ & 445 \\
\hline ................ & productus .............. & 447 \\
\hline rador.......................... & spinifer.................. & 448 \\
\hline Empetrichthys................... & surinamensis ........... & 447 \\
\hline merriami.......... 667 & tricolor...$\ldots \ldots \ldots \ldots \ldots$ & 443 \\
\hline Emphycus ...................... 2552, 2554 & engymen, Cetengraulis.............. & 2815 \\
\hline emphysetus, Arins .................. & Engyophrys...................... & 2668 \\
\hline Bagrus............. 122 & sancti-laurentii ....... & 2668 \\
\hline Sciadeichthys ....... 122, 2759 & philus .......... & 972 \\
\hline urus......... $\quad 122$ & (n................ & 1141 \\
\hline Enantioliparis.. & Enjambres ......... & 1140 \\
\hline 2223 & Enneacanthus...................... & 992 \\
\hline Encheliopus..................... 2457 & eriarchus ....... & 994 \\
\hline Enchelycephali .. & gloriosus.... & 993 \\
\hline
\end{tabular}


Enneacanthus margarotis

Page.

obesus ...............

pinniger ............

simulans

Enneacentrus.

fulvug

ontalibi ......

guttatus........... coronatus..

panamensis.........

punctatus .........

tæniops ............

enneagrammus, Ernogrammus.....

Stichrus.........

Enneanectes ....................

carminalis.........2350, 2868

Enneistus................... 1143, 1147

Ennichthys

Enophrys .

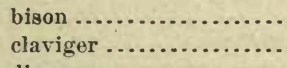

diceraus ................

Enseigne, Porte ..................

ensenadæ, Rhinoptera ............

ensifera, Bairdiella................

Sciæna....................

ensiferus, Centropomus...........

ensiformis, Trichiurus............

ensis, Gaidropsarus..............

Motella....................

Onos

Sphyrena .................

Entemedor ......................

entemedor, Narcine..............

Entomacrodus....................

chiostictus ..........

decoratus...........

margaritaceus .......

nigricans............

entomelas, Sebastichthys.........

Sebastodes ..............

Entosphenus.................... camtschaticus........ epibexodon ........... tridentatus...........

Entoxychirus

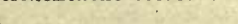

Fnxaréo

Enypnias ...................... 2231, 2233

Eopsetta. jordani.

2613

2613

2343

1102

210

Gobiesox ....................

2262 eos, Precilichthys ................... Page.

Pronotogrammus............ 1225

Sebastodes ................. 1810

Eosebastes ............... 1765, 1775, 1798

Eperlanus.................... $\quad 522$

Ephippida................... 1666

Ephippinæ................... 1667

ephippium, Plectropoma .......... 1192

Ephippus faber ................. 1668

1668

1669

2529

2530

epicurorum, Chromis ..............
Epigonichthys ..................

Epigonus ...................... 1111

occidentalis ............ 1112

epihexodon, Entosphenas......... $\quad 12$

Lampetra........... 12

Epinephelinæ ................... 1128

Epinephelus ............ 1148, 1152, 2853

adscensionis........ 1152, 1154

afer................ 1165

analogus............ 1152

apua................ 1159

ascensionis........... 1154

aspersus............ 1154

atlanticus ........... 1154

bonaci.............. 1175

brachysomus........ 1154

calliurus............ 1186

catus ............... 1159

chalinius ........... 1181

ciliatus ............. 1784

cubanus............. 1158

dermatolepis ......... 1169

dimidiatus .......... 1179

drummond-hayi ...... $\quad 1159$

falcatus.............. 1185

flavolimbatus........ $\quad 1155$

galeus ............. 1164

gigas .............. 1154

guaza .............. 1154

guttatus........... 1142, 1159

inermis............ 1168

interstitialis........ $\quad \mathbf{1 1 7 9}$

jordani ............. 1177

labriformis ........... $\quad 1155$

lunulatus........... $\quad 1159$

maculosus........... 1158

merus .............. 1162

microlepis........... 1178

morio............... 1160

multignttatus....... 1166

mystacinus.......... 1151

nigritus .......... 1162 


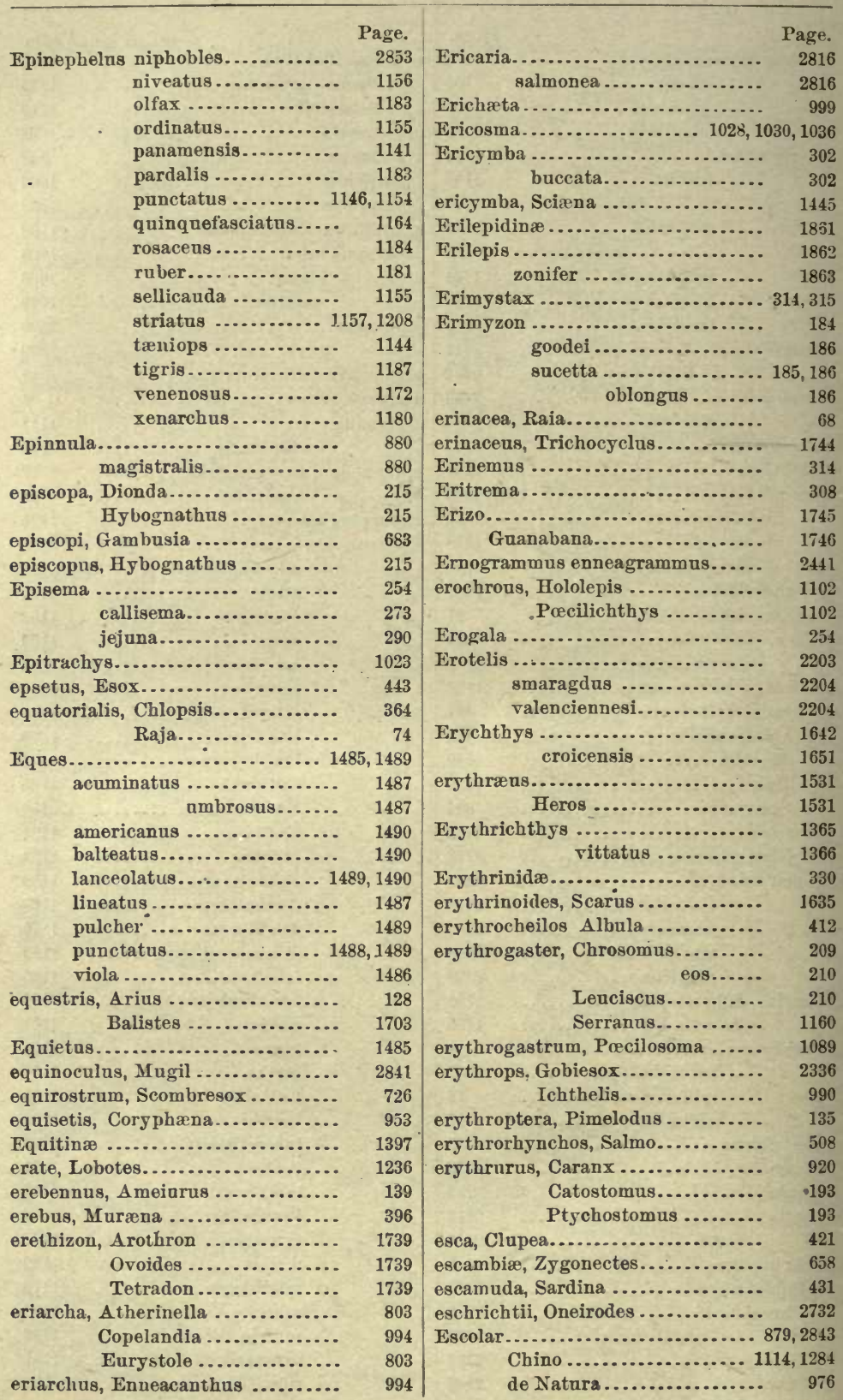




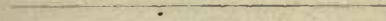

Escolor violaceus.

\section{Page.}

4843

Escolares.

Escolars.

Escribano.

esculentus, Carangus .

Conger

Merlucing .

........................

bartoni...............

jordani ...............

Esloscopus.

ycodes

2300,2303

esmarkii, Lycodes ............... 2463

Esmeralda

de Mar

2227,2230

Negra

2203,2204

2204

Esocidæ 708

esopus, Labeo

Esox

affinis.

americanng

atromaculat

australis

barracuda ...................

belone ......................

boreus ......................

brasilieusis .

crassus .....................

cypho......................

deprandus ..................

epsetus.................

estor.......................

fasciatus...................

flavulus....................

immaculatus ................

imperialis...................

lineatus.....................

longirostris ................

lucioides.....................

lucius......................

lugubrosus .................

marinus ....................

masquiuongy ..................

immaculatus....

niger ....................

nobilior ....................

ohiensis ....................

ornatus .....................

osseus .....................

ovinus ......................

phaleratus ..................

pisciculus ..................

pisculentus ..................

porosus.....................

raveneli .....................

reticulatus.................

salmoneus

$538,627,629$
Page.

scomberius ................ 626

spet....................... 826

sphyræna:................ 826

stomias ................... 585

synodus ................. $\quad 536$

timucu................... 711

tridecemlineatus............. 628

tristœchus................. 111

umbrosus.................. 627

vermiculatus ............... 627

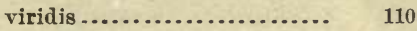

vittatus................... 628

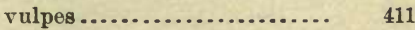

zonatus................... 639

Espada....................... 894

Pez de .................. 2749

Espadon ....................... 891

Espagnol, Quatilibi.............. 1140

Espino, Puerco ................... $\quad 1745$

estor, Chirostoma ............... $\quad 792$

Esox..................... 628

Gila .................... 240

Lethostole................ 792

Leuciscus................. 240

Squalius .................. 240.

Estrella..................... 1054

Etelinæ ........................ 1243

Etelis ......................... 1281

aquilonaris............... 1283

carbonculus ............... 1283

oculatus .................. 1282

Etheostoma.......... 1028, 1066, 1069, 1097

alabamæ ............ 1095

artesiæ.............. 1094

asprellus ............. 1061

atromaculata ......... 1057

aurantiacum .......... 1041

australe ............. 1081

blennioides......... 1033, 1053

blennius............ 1072, 1073

boreale ............. 1082

cæruleum .......... 1089, 2853

spectabile .. 1089

calliura............. 1011

camurum ............. 1076

caprodes.............. 1027

cinerea ............. 1078

cinereum ............ 1078

cragini .............. 1091

eymatotænia ......... $\quad 1042$

davisoni .............. 1049

duryi ................ $\quad 2853$

elegans.............. 1074

evides ................ 1037

exile................ 1103 


\begin{tabular}{|c|c|c|c|c|}
\hline & & & & Page. \\
\hline Etheostoma & flabellare ................. & 1097 & Etheostoma schumardi.. & 1047 \\
\hline & $\begin{array}{c}\text { cumberland- } \\
\text { icum } \ldots . . .\end{array}$ & & scierunı... & 1038 \\
\hline & $\begin{array}{r}\text { icum ....... } \\
\text { lineolatum... }\end{array}$ & 1098 & scovellii ..... & 1082 \\
\hline & $\begin{array}{l}\text { lineolatum... } \\
\text { flabellaris ............ }\end{array}$ & 1098 & squamatus .. & 1040 \\
\hline & flabellaris .............. & 1097 & squamiceps ............. & 1096 \\
\hline & flabellata .............. & 1097 & stigmæum ............. & 1048 \\
\hline & fonticola................. & 1105 & swannanoa ............. & 1070 \\
\hline & fontinalis............... & 1097 & tessellatum ............. & 1078 \\
\hline & formosa $\ldots . . . . . . . . .$. & 2853 & thalassinum ............ & 1071 \\
\hline & fusiforme.............. & 1103 & tippecanoe.............. & 1090 \\
\hline & guntheri ................ & 1034 & tuscumbia .............. & 1100 \\
\hline & histrio ................... & 1051 & uranidea ................ & 1045 \\
\hline & inscriptum ............ & 1072 & variatum......$\ldots \ldots \ldots$ & 1069 \\
\hline & ioæ $\ldots . . . \ldots \ldots \ldots \ldots$ & 1084 & verecundum ............ & 1050 \\
\hline & iowæ $\ldots \ldots \ldots \ldots \ldots \ldots$ & 1083 & vexillare............ & 1058 \\
\hline & jessiæ ...................... & 1084 & virgatum ............... & 1093 \\
\hline & jordani ............. 107 & 79,1080 & vulneratum............ & 1077 \\
\hline & juliæ ................... & 1093 & whipplei alabamæ ..... & 1095 \\
\hline & laterale................. & 1099 & whipplii ............... & 1095 \\
\hline & lepidogenys ............ & 1087 & wrighti............... & 1047 \\
\hline & lepidum ................ & 1089 & zonale ................. & 1075 \\
\hline & linsleyi ................. & 1097 & areansanum .... & 1075 \\
\hline & longiuana............. & 1054 & etheostoma, Aboma ................. & 2240 \\
\hline & luteovinctum........... & 1086 & 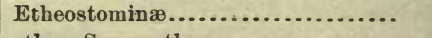 & 1018 \\
\hline & lynceum................ & 1075 & ethon, Svngnathus ................. & 767 \\
\hline & macrocephalum......... & 1031 & Etmopterus ........................ & 55 \\
\hline & maculatum ............ & 1077 & pusillus........... & 55 \\
\hline & microperca ............. & 1104 & etowanus, Catostomus nigricans ... & 181 \\
\hline & micropterns ........... & 1083 & Etropus ............................. & 2687 \\
\hline & nevisense.............. & 1034 & crossotus .................. & 2689 \\
\hline & nianguæ............... & 1043 & microstomus ........... 2687, & 7,2690 \\
\hline & spilotum...... & 1044 & rimosus & 2688 \\
\hline & nigrofasciatun ........ & 1039 & Etrumeus ............................ & 419 \\
\hline & nigrum................ & 1057 & acuminatus................. & 419 \\
\hline & notatum ............... & 1070 & sadina........$\ldots \ldots \ldots$ & 420 \\
\hline & obeyense ............... & 1092 & teres......................... & 420 \\
\hline & olmstedi................ & 1057 & Eucalia $\ldots . . \ldots \ldots \ldots \ldots \ldots$ & 743 \\
\hline & ouachitæ ............... & 1035 & inconstans................... & 744 \\
\hline & pagei .................. & 1092 & cayuga .......... & 744 \\
\hline & parvipinne......... & 1096 & pygmæa ......... & 744 \\
\hline & pellucidum clarum .... & 1063 & Eucentrarchus.................... & 988 \\
\hline & peltatum ................ & 1034 & Euchalarodus ...................... & 2649 \\
\hline & phoxocephalum......... & 1031 & putnami.......... & 2650 \\
\hline & podostemone ........... & 1055 & Eucinostomus .................... & 1367 \\
\hline & pottsii................ & 1082 & argenteus............. & 1371 \\
\hline & proeliare................ & 1104 & californiensis ........ & 1369 \\
\hline & prœliaris ................ & 1104 & dowi................... & 1367 \\
\hline & punctulatum ........... & 1090 & gula.............. & 1370 \\
\hline & quappella.............. & 1084 & gulula .............. & 1371 \\
\hline & quiescens.............. & 1101 & harengulus ........... & 1368 \\
\hline & rex $\ldots \ldots \ldots \ldots \ldots \ldots$ & 1026 & lefroyi............... & 1372 \\
\hline & roanoka ............... & 1036 & productus........... & 1372 \\
\hline & rufilineatum............ & 1079 & pseudogula ........... & 1368 \\
\hline & olineatum ........... & 1079 & Euctenogobius............. 2210, 2215, & 5,2226 \\
\hline & & 1073 & badius ............... & 2227 \\
\hline & sagitta................... & 1080 & latus................ & 2237 \\
\hline
\end{tabular}


Euctenogobius lyricus

$$
\text { sagittula .......... }
$$

Eueyclogobius ................... newberryi ..........

eudonxii, Ailurichthys.

Felichthys ...............

Galeichthys

Eugaleus

.................

Eulachon.......................

Eulamia.

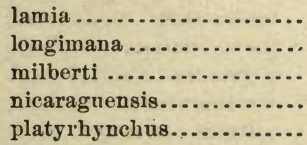

oulepis, Microgobius

Euleptorhamphus................

brevoorti ........

longirostris......

velox............

Eumesogrammus.................

præcisus ........ subbifurcatus ....

Eumicrotremus .................

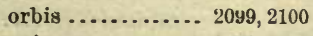

spinosus ........ 2098, 2099

eumorphus, Chatoessus ...........

Eupomacentrus .............1549, 1550, 1551

adustus .......... 1551

analis............. 1554

diencæus ......... 1552

flavilatus ......... 1557

flaviventer........ 1557

ruscus............ 1552

leucorus ....e.

leucostictus ........

otophorus .........

partitus ............

planifrons ..........

rectifrænum.......

Eupomotis ......................

aureus .................

euryorus..............

heros .................

holbrooki .

humilis

1551

1555

1555

1558

1559

1553

1006, 1007

1010

1008

1009

1007

1008

1004

macrochirus

pallidus.

1005

1006

2067

2419

Blennius . . . . . . . . . . . .

Trachurus

911

826

European Barracuda

Charr

\section{F}

European Hake .....

Lancelets................ 3

Porgies ................ 1356

Sculpin ............... 1974

Stickleback............ $\quad 747$

Eurymyctera .................. $\quad 392$

euryopa, Cliola................... $\quad 270$

Hudsonins ............ 270

ouryops, Bathylagus.............. $\quad 529$

Icelus ............... 1915, 1916

Myxostoma............ 193

Tylosurus............. 711

euryorus, Eupomotis............. 1008

Lepomis.............. 1009

Eurypharyugidæ ............... 406

euryplectrum, Diplectrum ........ 1206

euryrhina, Enchel zcore.......... $\quad 390$

Enrystole..................... 802

eriarcha............. 803

eurystole, Stolephorus ........... $\quad 445$

eurystoma, Cliola ................ 277

Codoma.............. 285

Eurystomus..................... 173

eurystomus, Notropis............ 277

Photogenis .......... 277

Euscarus................. 1627, 1629, 1639

Euschistodus ................. 1560, 1562

analogus............ 1563

concolor ............ 1559

declivifrons ........ $\quad 1562$

Eusebastes...................... 1760

Eusphyra ..................... 43

Eustomatodus ................. 907

Euthyunus.................... 868

alliteratus ........... 869

pelamys.............. 869

Eutychelithus .................. 1483

evansi, Hybognathus .............. 213

Evapristis................ 1334, 1336, 1340

Evarra....................... 304 eigenmanni .............. 304

Eventognathi .................... 161

Evepigymnus.................... 907

overgladei, Elassoma.............. 982

evermanni, Atherinella . ......... 804

Cottus ............... 1945

Scarus ................ 1651

Sjnodus .............. 535

Thyrina............. 804

Evermarnia...................... 2256

longipinnis........... 2256

zosterura ............ 2256

Evertzens, Jacob ................ 1143

evides, Alvordius ................ 1037

Clinus .................. 2353

Etheostoma ............. 1037 


\begin{tabular}{|c|c|c|}
\hline $\begin{array}{r}\text { Page. } \\
\text { evides, Gibbonsia ................. 2352, } 2869\end{array}$ & Exocœtus fasciatus . & $\begin{array}{r}\text { Page. } \\
733\end{array}$ \\
\hline Hadropterus .............. 1036 & furcatus & 737 \\
\hline Plectobranchus ... & georgianus. & 730 \\
\hline evionthas, Ophichthus ... & gibbifrons... & 741 \\
\hline Quassiremus.. & gryllus..... & 729 \\
\hline olans, Exocœtus ....... & heterurus... & 735 \\
\hline Halocypselus.... & hillianus ................ & 729 \\
\hline Prionotus .......... 2167, 2168, 2169 & lamellifer ................. & 733 \\
\hline Trigla .................... 2169 & lineatus.................. & 739 \\
\hline Evoplites .......................... & lutkeni................... & 736 \\
\hline viridis $\ldots \ldots \ldots \ldots \ldots \ldots \ldots$. & maculipinnis ............. & 737 \\
\hline rorthodus ................. & melanurus ............... & 735,736 \\
\hline breviceps... & mesogaster.............. & 729 \\
\hline catulus.. & monocirrus............... & 730 \\
\hline oxymetopon ............ & nigricans................ & 737 \\
\hline tæniatus. & noveboracensis.......... & 735,736 \\
\hline casperata, Platyrhina... & nuttalli $\ldots \ldots \ldots \ldots \ldots$ & 737 \\
\hline Syrrhina $\ldots . . . . . . . .$. & obtusirostris .............. & 730 \\
\hline rasperatus, Rhinobatus ............ & gianus .............. & 729 \\
\hline Zapteryx ... & parræ $\ldots \ldots \ldots \ldots \ldots \ldots \ldots$ & 740 \\
\hline Exerpes............................ & procne $\ldots \ldots \ldots \ldots . . . . . .$. & 737 \\
\hline asper.$\ldots \ldots \ldots \ldots \ldots \ldots \ldots$ & riremis.............. & 735 \\
\hline exiguus, Bodianus .................. & i $\ldots \ldots \ldots \ldots \ldots \ldots$ & 735 \\
\hline Stolephorus.............. & us $\ldots \ldots \ldots \ldots \ldots$ & 736 \\
\hline xile, Dorosoma cepedianum........ & rondeletii............. & 733,734 \\
\hline Etheostoma.................. & rubescens . ................ & 734 \\
\hline cilicanda, Lavinia ........ & rufipinnis ............... & 735 \\
\hline Leuciscus ............. 209 & scylla .................. & 735 \\
\hline csiliens, Exocœtus............... 732, 734 & speculiger................ & 734 \\
\hline ilis, Bekone ....................... & spilonotopterus .......... & 740 \\
\hline Boleichthys .................. & spilopus................... & 738 \\
\hline Hippoglossoides.............. & splendens ................ & 731) \\
\hline Lyopsetta ..................... & latus............. & 740 \\
\hline Notnrus..................... & vinciguerræ............. & 734 \\
\hline Poecilichthys ................. & olador.................... & 733 \\
\hline es $\ldots \ldots \ldots \ldots \ldots \ldots$ & volitans ........... 734, & 736,2835 \\
\hline Tylosurus .................... & zenopterus .............. & 738 \\
\hline imius, Cyprinodon ............. & Exoglossinæ .................. & 204 \\
\hline Exocotidæ....................... $\quad 726$ & Exoglossum... & 327 \\
\hline xocœtus................. $730,731,732,734$ & annulatum...$\ldots \ldots \ldots$ & 327 \\
\hline acutus ................. 728 & dubium................. & 206 \\
\hline affinis $\ldots \ldots \ldots \ldots \ldots \ldots \ldots \ldots \ldots$ & lesueurianum .......... & 327 \\
\hline albidactylus ............. & maxillingua........... & 327 \\
\hline appendiculatus.......... & mirabile................. & 303 \\
\hline bahiensis ............... & nigrescens ............. & 327 \\
\hline (................... & spinicephalum ......... & 206 \\
\hline brachycephalus ......... 733 & vittatum ............. & 327 \\
\hline californicus ............. 730,740 & exoletus, Acantholabrus ............ & 1576 \\
\hline terus............. $\quad \mathbf{7 4 0}$ & Centrolabrus .............. & 1576 \\
\hline s .................... & Labrus .................... & 1576 \\
\hline tus........................ & 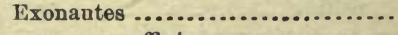 & 2835 \\
\hline cyanopterus............ & affinis............. & 2836 \\
\hline 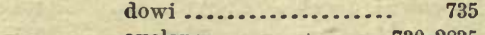 & exsiliens ................ & 2836 \\
\hline evolans .................. 730,2835 & rondelettii ............ & 2836 \\
\hline & rufipinnis. & 2836 \\
\hline
\end{tabular}




\section{-}

Exonautes speculiger ............. vinciguerræ ...........

expansum, Ostracion ..............

exsiliens, Exonautes ...............

extensus, Fundulus...............

Lycodapus

faber, Chætodipterus .............

Chrtodon ..................

Ephippus ..................

Faber marinus ..................

fabricii, Campylodon ...............

Centroseyllium . .........

Cottus .....................

Gadus ...................

Gunnellus .................

Liparis .............. 2121, 2128

Lumpenus.............. 2437

Macrorus............... 2582

Spinax................ 56

falcata, Agosia ................. 313

$$
\text { shuswap......... } 313
$$

Mycteroperca............ 1184

phenax..... 1185

Seriola ................. 905

falcatus, Caranx.............. 913, 2845

Epinephelus ............ 1185

Hemicaranx ............ 2845

Labrus................. 942

Lachnolaimus........... 1580

Serranus............... 1185

Sparus ................. 1583

Trachinotus............. 941

Trisotropis............. 1185

falciformis, Carcharbinus......... $\quad 36$

Carcharias ............ 35

Platypodon............ $\quad 36$

falcipinnis, Elacate.............. 948

fallax, Carangus................. 923

Caranx .................. 923

Pomotis.................. 1003

Trachurus ............... 910

Fallfish, Red ....................

Fall-tishes......................

286

220,221

425

1837

Fanegal........................

fanfarus, Naucrates ...............

Fanguito.......................

Fan-tailed Darter .................

Mullet.................

Fario..........................

argyreus ...................

aurora ....................

clarkii ....................

gairdneri..................

Fario newberryi.

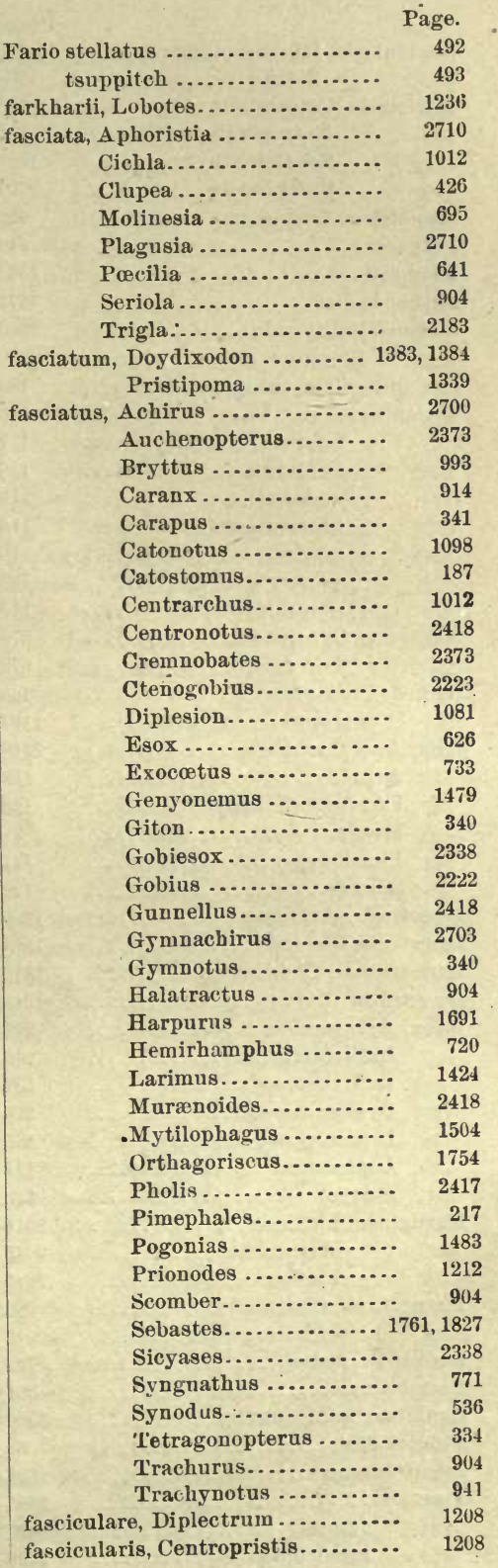

Page.

493

710

1012

695

710

641

183

1339

373

993

914

1098

187

2418

2373

1081

626

733

1479

2338

$22: 22$

2418

340

904

691

1424

2418

504

2417

217

1483

212 1827 338 


$\begin{aligned} \text { fascicularis, } & \text { Hippocampus ......... } \\ & \text { Serranus............. } \\ \text { fasciolaris, } & \text { Catostomus ........... } \\ & \text { Notropis umbratilis.... } \\ & \text { Sebastichthys......... } \\ & \text { Symphurus ........... }\end{aligned}$

fasciolatus, Coryphæna............

Fatback

Fat-head

Father-lasher

favosus, Bathygadus .................

Blennius .................

fecundus, Catostomus..............

Felichthys ......................

bagre .................

bahiensis ..............

endouxii...............

filamentosus............

marinus ...............

panamensis ............

pinnimaculatus.........

felicianus, Cyprinodon ..............

Trifarcius..............

felinus, Pimelodus

Serranus

felis, Anarrhichthys ..............

Arius .....................

Hexanematichthys ...........

Mustelis ...................

Pimelodus..................

Silurus.....................

fenestralis, Artedius..............

fenestrata, Chromis ................

fenestratum, Cichlasoma...........

fenestratus, Heros ................

ferox, Alepisaurus................

Bathyophis................

Bathysaurus ...............

Cynoponticus ...............

Idiacanthus ................

Lepisosteus ................

Stomias

ferruginea, Limanda ..............

Myzopsetta ...........

Platessa ...............

ferrugineus, Characodon...........

Pleuronectes ..........

feuille, Polyodon.................

Fiatolas.........................

fibulatus, Spinicephalus...........

Fiddler Fish .....................

fieldii Stomias....................

Fierasfer.......................

affinis................... arenicola ................ bermudensis
Page.

778

1208

186

301

1827

2707

952

433,946

217,1585

1971

2565

2380

180

116

117

118

118

118

118

117

117

676

676

140

1187

2448

128

128

1518

1518

595

605

539
Fierasfer borealis ............... $\quad 2443$

dubius.................. 2496

fierasfer, Lycodapus .............. $\quad 2493$

Fierasferidx ................... 2494

filamentosus, Ailurichthys........ 118

Argyriosus ......... 936

Dentex............ 1289

Felichthys......... 118

Hemirhamphus ...... $\quad 723$

Icelinus............ 1893

Monacanthis ........ 1716

Scomber........... 932

Taraudichthys ....... 1892

Filefish ........... 1712, 1715, 1717, 1718

Orange................ 1718

filicornis, Blennius .............. 2381

filifera, Chalinura.............. 2577

fimbria, Anoplopoma............. 1862

Gadus ................. 1862

fimbriata, Cyclopsetta ............ 2676

Raia................. 93

Solea................ 2700

Squatina ............ $\quad 59$

fimbriatus, Achirus............. $\quad 2700$

Arnoglossus .......... 2677

Blennius.............. $\quad 2457$

Chaunax ............. $\quad 2726$

Hemirhombus......... 2677

Icelinus............. 1894

Serranus............ 1154

Zoarces .............. 2457

Fimbriotorpedo ................ $\quad 77$

Fine-scaled Suckèr............... 173, 178

firmisquamis, Bogoslovius ........ 2575

Macrurus .......... 2576

fischeri, Achiris................. 2700

Achirus............... 2699

Chætostomus............ 160

Solea................. 2700

Tetragonopterus ......... $\quad 334$

Fish, Angel................... $\quad 58$

Bat ..................... 2737

Butter................... 2419

Cobbler................... 931

Common Alligator .......... 2061

Common Buffalo ........... 163

Creek .................... 185

Creole.................... 1221

Devil ..................... $\quad 92$

Dismal Swamp............. $\quad 703$

Doll..................... 1674

Dovetail .................. 1563

Elephant................. 95

Emerald ................. 2229

File................... 1715, 1718

Fiddler.................. 63 
Fish, Fool................... 1715, 1718

Glance ................... $\$ 54$

Globe ................... 1734

Good .................... 487

Guitar ...................

Hand-saw ................. $\quad 596$

Harvest .................... 965

Indian .................... 1680

Leather ................ 1714, 1715

Lion..................... 1850

Lizard ................... $\quad 538$

Log .................... 964

Mutton.................... 1376

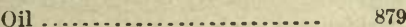

Portuguese Man-of-War..... 949

Prick

Priest..................... 1784

Rabbit................... 882

Rainwater................. $\quad 665$

Red-mouth Buffalo ........... $\quad 163$

Red Parrot................. 1635

Ribbon.................. 1489, 1490

San Pedro.................. 954

Scabbard................... 887,889

Seour ................... 879

Sergeant ................. 948

Singing .................. 2321

Soldier ................... $1(188$

Tongue ................... 2710

Tyrant................... $\quad 886$

Ugly ..................... 137

Unicorn................... $\quad 1719$

Yellow.................... 1144

Fishes

Angel

Black Rudder .............

Blennioid .................

Blind.....................

Bony.

Brotuloid ...............

Buffalo ...................

Cardinal .................

Carp-like.................

Cirrhitoid .................

Cutlass...................

Elephant

File

Four-eyed ................

Ganoid...

Guitar

Isospondylous.............

Jugular

Lancet

Lantern

Lizard $593,594.595$

530,550

533
Fishes, Mackerel-like

Page.

Mail-cheeked.

860

Milk

1756

Parrott.................. 1620

Pediculate ............... 2712

Perch-like............... 979

Pike-like................. 62 ?

Plectognathous ........... 1696

Porcmpine............... 1742, 1744

Rag .................... 968

Rudder.................. 1380

Scorpion ................ $\quad 1839$

Sergeant ............... 917

Spiny-rayed .............. $\quad \mathbf{7 7 9}$

Synentognathous.......... 707

Trachinoid .............. 2273

True ................... 97

Trunk ................. 1720

Fishing-Frogs.................. 2713

fissuratus, Neoliparis ............ 2113

fissus, Arius ................... 131

Tachisurus ............. 131

Tachysurus............. 131, 2782

Fistularia ....................

commersonii ............ $\quad \mathbf{7 5 8}$

depressa ............... $\quad 757$

immaculata ............ $\quad 758$

neoboracensis .......... 757

petimba............... $\quad 758$

serrata............... $\quad 758$

tabacaria......... 757, 758, 2837

Fistulariidæ ................... $\quad \mathbf{7 5 5}$

fistularis, Flagellaria.............. $\quad 757$

fistulatum, Siphostoma............. 765

fistulatus, Syngnathus........... $\quad 765$

flabellare, Etheostoma............ 1097

cumberlandi.

cum....... 1098

lineolatum ... 1098

flabellaris, Etheostoma........... 1097

flabellata, Ethenstoma............. 1097

flabbellatus, Catonotus............ 1098

Flag, Spanish ................. 1817

Flagellaria ..................... $\quad 756$

fistularis............. $\quad 757$

flagellum, Raia................. $\quad 88$

Saccopharynx .......... 406

Flags, Spanish ................. 1139

Flamenco ....................... 1269

Flammeo..................... 2871

marianus .............. 2871

flammens, Leuciscus .............. $\quad 242$

Phoxinus.............. $\quad 242$

Flannel-mouth Cat............... 137

Sucker............ 174

Flasher ....................... 1235 
Page.

Flatfish .

Common

Flat - seaded Chub.

flava, Cougermurena

Haveseens, A riug.

Bagrus

Bodianus ..............

Brosmius .............

Callyodon ..............

Mesoprion..............

Morone................

Perca...................

fluviatilis ........

Prionodes ..............

Scarus.................

Sciadeichthys ........ 123, 2760

Sparisoma........... 1639, 1640

Táchisurus........... 123

flavesny, Brosmius................

flavicauda, Hy porthodus...........

flavidus, A podichthys .............

A ulorhynchus............

Sebastichthys .............

Sebastodes...............

flavignttatum, Hæmulon..........

$$
\text { Lythrulon.......... }
$$

flaviguttatus, Hæmulon...........

flavilatus, Eupomacentrus ........

Pomacentrus...........

flavipinnis, Hybognathus.........

Ilisha................

Pellona................

Pristigaster ...........

flavirostre, Siphostoma ...........

flavirostris, Syngnathus..........

flavissimus, Forcipiger............

flaviventer, Eupomacentrus........

flaviventris, Dules ...............

Serranus .............

flavolimbatus, Epinephelus ........

flavolineatum, Hremulon..........

flavolineatus, Diabasis............

Diplodus ............

Pimelepterus ........

Sargus..............

flavomarginatus, Psendoscarns ....

Scarus ............

flavoscripta, Echidna.............

flavoscriptus, Gymnothorax .......

flavovittatus, Mulloides ...........

Upeneus..............

flavulus, Esox...................

flavus, Awaous .................

Chonophorus ..............

Gobius...................

Noturus
2561

1156

2411

754

1782

1781

1312

1312

1312

1557

1558

215

435

436

436

768

768

1671

1557

1221

1221

1155

1306

1306

1360

1386

1360

1652

1652

403

395

860

860

639

2235

2235

2235

144 flavus, Turdus

Page.

1583

1824

1107

1011

179

988

1793

2111

1597

137

677

766

1012

2554

2554

992

.642

651

651

651

2649

2650

2632

2652

2631

2665

2657

2679

2630

2651

2629

2646

Fluke, Craig ................... 2656, 2657

fluviatilis, Algoma ............... $\quad 215$

Hudsonius ............ 269

Hybognathus .......... 215

Perca tlavescens ....... 1024

Sargosomus ........... 1496

Fly-fish ...................... 1809

Flying-fish, Great ............... $\quad 740$

Sharp-nosed .......... 728

Flying-fishes................... 726, 730

Flying Gurnard . .............. 2182, 2183

Robin .................. 2183

Fodiator .................... 727

acutus................. 728

fodiator, Tylosurus............... $\quad 715$

foetens, Salmo .................. $\quad 538$

Saurus ................. $\quad 538$

Synodus................ 538

folium, Polyodon .................. 102

fonsecensis, Achirus .............. 2699

Solea ................ 2699

fonticola, Alvarius ................ $\quad 1105$

Etheostoma............ 1105

Fundulus .............. 643

Microperca............ $110 t$ 


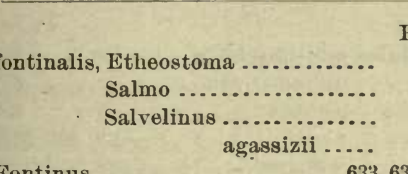

Page.

1097

507

506

507

Fontinus $633,634,645$

Foolfish

1715,1718

forbesi, Cliola

Cyprinella ...................
Orthopristis ..............

forcipatus, Balistes

Forcipiger.

flavissimus .............

Guaperva lata............

formosa, Algansea ................

Cliola ...................

Etheostoma ...............

Heterandria .............

Hydrargyra.............

Leucos...................

Mollienisia...............

Moniana .................

Perca ...................

Uranidea.

formosulum, Campostoma..........

formosum, Diplectrum

Hæmulon

formosus, Alburnus.

Anthias .................

Calliurus ................

Cottus ..................

Girardinus ..............

Holacantlius .............

Leuciscus ...............

Leucus ..................

Notropis...............

Spheroides

Tetrodon

forskali, Glossodus.

forsteri, Sphyræna ...............

forsterianus, Catostomus...........

fosteri, Albula ...................

Caranx ....................

Scombresox ................

Four-Bearded Rocklings ............

Four-eyed Fishes...................

Four-spotted Flounder .............

Fox Shark.

fragilis, Citharichthys .............

Francesa, Lisa ...................

francisci, Crestacion ..............

Gyropleurodus ...........

franklini, Cottus ..................

Pleuronectes .............

Uranidea

Fraser River Salmon
27

272

1336

1702

1671

1671

1930

1702

246

271

2853

687

2827

246

699

271

1208

1969

206

1207

1305

280

1304

996

1969

688

1685

246

246

271

1736

1737

411

824

176

412

923

726

2560

684

2632

45

2680

410

21

20

1967

2650

1967

481 fraterculus,

fremebundus, Diabasis............ 1297

freminvilloi, Doydixodon......... 1382, 1384

Myliobatis........... 89

frenatus, Balistes ............... 1705

Brachyistius ........... 1499

Micrometrus ............ 1499

Odontopyxis ............ 2675

Sarritor ............... 2073

Zaniolepis............. 1877

French Grunt.................... 1306

Mullet................ 813

Frère Jacques. .................. 846

Fresh-water Drum . . ............... 1484

Eel ................. 348

fretensis, Cliola ................. 261

Hybopsis................ 261

Notropis .............. 261

Friars. ....................... $\quad 789$

friedrichsthali, Heros ............. $\quad 1528$

Frigate Mackerels ................. 867

frigida, Moniana ................. 271

frigidus, Notropis............... 271

Lycodes................ 2465

Frilled Sharks .................. 16

Frog Fishes..................... 2715

frondosum, Sparisoma .......... 1641, 1642

frondosus, Scarus .............. 1636, 1642

frontalis, Caranx................ $\quad 925$

Gastropsetta ........... 2636

Leuciscus ............... 283

Notropis cornutus....... 283

fronto, Carcharhinus............. $\quad 39$

Carcharias ................ 39

Frostfish...................... 2540

Frost Fishes ................... $\quad 886$

Fry, Hog-mouth ............... 444

fuconsis, Liparis................. $\quad 2119$

Theragra.............. 2586

fucorum, Apodichthys........... 2413

Blennius............... 2379

Xererpes............... 2413

fulgens, Corvina ................. 1435

Myriopristis ............ 846

Priacanthus............. 1238

fulgida, Meda .................. $\quad 329$

fuliginosus, Balistes ............. 1702

Chilomycterus ....... 1749

Diodor............... 1749

Holconotus ........... 1505

Symbranchus ........ 342

fulva, Labrus chogset............ 1577

fulvomaculatum,-Pristipoma...... 1339

fulvomaculatus, Labrus........... 1339

fulvum, Ginglymostoma ......... 26 


\begin{tabular}{|c|c|}
\hline Page. & Page. \\
\hline fulvus, Bodianus .................. & Fundulns multifasciatus........... \\
\hline 1146 & nigrofasciatu......... \\
\hline ruber......... 1145,1146 & notatus ................. \\
\hline Enneacentrus ............. $\quad 1145$ & nottii............... 656,2830 \\
\hline outalibi ..... & ocellaris ........... $642,2827,2828$ \\
\hline Labrus....................... & pachycephalus .......... $\quad 661$ \\
\hline Physiculus.................. & pallidus ................. 638,2827 \\
\hline s f................ & parvipinnis....... $640,2827,2830$ \\
\hline corfanudi................. & pisculentus............. 641 \\
\hline uncinita .......................... & pulvereus ............. 652,2828 \\
\hline næ $\ldots \ldots \ldots \ldots \ldots \ldots \ldots \ldots . .$. & punctatus ............ 637,2827 \\
\hline ostomus .... & rathbuni............... 649 \\
\hline Fundulus............. & rhizophore ............. 644 \\
\hline Leuciscus ........... & robustus ............. 644,2827 \\
\hline Squalius .............. & rubrifrons .............. 653 \\
\hline Zygonectes ............ & scartes .................. \\
\hline Gundulus ............... $632,633,637,2827$ & sciadicus .............. 654,2828 \\
\hline adinia ................. 645,2827 & lis .............. $64 \pi, 2828$ \\
\hline s........... 649, 2828 & 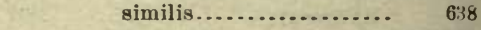 \\
\hline (n.............. & stellifer.............. 648,2828 \\
\hline ............ $\quad 659$ & swampina ............... 645 \\
\hline bermudæ............. 643,2827 & tenellus ............... $\quad 659$ \\
\hline atus ............ 648,2828 & vinetus.............. 637,2827 \\
\hline otus ............. 655,2828 & viridescens ............ $\quad 641$ \\
\hline atus............656, 2829 & xenicus................ 662 \\
\hline contluentus............650, 2828 & zebra............ $641,647,2827$ \\
\hline diaphnus ............. 645,2828 & as ......... $646,2827,2828$ \\
\hline nienona....... 645 & $8 \ldots \ldots \ldots \ldots \ldots \ldots .6 \quad 657$ \\
\hline dispar............... 658,2830 & 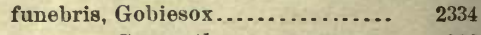 \\
\hline 650,2828 & horax.......... \\
\hline ii $\ldots . . . \ldots \ldots \ldots \ldots . .661$ & Lycodontis.............. \\
\hline onsus $\ldots \ldots \ldots \ldots \ldots 6,646,2827$ & s................ \\
\hline is .......... $642,651,2$ & les .............. \\
\hline la..............643, 2927 & (n.................... \\
\hline des ........... 650,2828 & furca, Perca...................... \\
\hline$\ldots \ldots \ldots \ldots \ldots .6 \quad 62 t$ & Furearia ........................ 1545, 1546 \\
\hline goodei................ 2831 & cyanea................. 1547 \\
\hline grandis.............. 2827, 2828 & puncta.................... \\
\hline malensis.......... $\quad 660$ & furcatum, Ditrema............... \\
\hline tus............. 658,2830 & furcatus, Amiurus ............... 134 \\
\hline alli .............. $\quad 653$ & Cypselurus............. 737,2836 \\
\hline heteroclitus ............. & Exocotus............... 737 \\
\hline badins........ & Ietalurus $\ldots ., \ldots \ldots \ldots \ldots$ \\
\hline grandis....... & lon $\ldots \ldots \ldots \ldots$ \\
\hline macrolepido- & $18 \ldots \ldots \ldots \ldots \ldots, 134$ \\
\hline tus.......6641, 2827 & Furcella ...................... 2472,2869 \\
\hline hieroglyphicas ........ 658,2830 & diaptera................ $\quad 2472$ \\
\hline ...... 651 & odon ............. \\
\hline 2828 & r, Anthias.................... \\
\hline is . . . . . . . . . 644, 2727 & Brachyrbinus ............ \\
\hline us $\ldots \ldots \ldots \ldots 643,649,2828$ & Paranthias ................ \\
\hline ciæ $\ldots \ldots \ldots \ldots \ldots \ldots \ldots .654$ & Pimelodus ............... \\
\hline macdonaldi ............650, 2828 & Serranus.................. \\
\hline majali3 ............ $636,2827,2828$ & furciger, Icelus .................. \\
\hline melapleurus........... 659,2830 & Furcimanus...................... \\
\hline mudfish .............. 641 & furcræa, Corvina................. \\
\hline
\end{tabular}


furcræa, Perca

furcrieus, Pachy

Pachyurus

furiosus, Noturus...

Schilbeodes...............

furnieri, Micropogon

Umbrina.....................

furthi, Arius ...................

Caranx ....................

Corvina (Homoprion).......

Hemicaranx...............

Ilisha ....................

Pellona...................

Pristipoma ...............

Scirna ...................

Sphæroides................

Spheroides ...............

Stellifer

Tachisurus

Tachysurus

furvus, Serranus

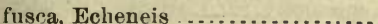

Hydrargyra ..............

Labrus tautoga.............

Sciæna .....................

fuscatus, Silurus.................

fuscoauratus, Tetragonopterus ....

fusco-maculata, Acara............ Echidna..........

fusco-maculatus, Chromis..........

fuscula, Haliperca ................

fusculus, Centropristes ...........

fuscum, Siphostorna ..............

fuscus, Acronurus................

Bythites ..................

Dialommus................

Eupomacentrus ...........

Fundulus ................

Gadus tomcodus ...........

Hemirhombus. .............

Pomacentrus...............

Psenes ...................

Serranus .................

Synguathus...............

Trachinotus ...............

fusiforme, Etheostoma............

fusiformis, Boleichthys ...........

Boleosoma..............

Hololepis................

Phalangistes ............

Pocilichthys.

fyllæ, Raja

-

Gabilan

gabonensis, Árgyreiosus
Page.

1460

1459

1460

149

149

1462

1463

132

914

1441

914

436

436

1319

1441

1737

1737

1441

132

132,2787

1200

2270

624

1579

1483

140

334

1540

403

1540

1211

1211

770

1692

2504

2868

1552

624

2540

2686

1552

951

1181

770

- 942

1103

1101

1102

1102

2048

1102

69 $\begin{aligned} \text { gabonensis, Caranx setipinnis ..... } & \begin{array}{r}\text { Page. } \\ 935\end{array} \\ \text { Vomer............... } & 934,2846\end{aligned}$

Gadella ...................... 2545

Gadidæ ...................... 2531

Gadinæ ........................ 2531

Gadus........................ 2540

æglefinus ................ 2543

agilis.................... 2534

albidus................... 2531

arenosus................. 2541

auratus.................. 2542

barbatus ................. 2541

brosme................... 2561

californicus ............... $\quad 2539$

callarias................. 2541

carbonarius ............... 2534

chalcogrammus .......... $\quad 2536$

cimbrius ................. 2560

colinus.................. $\quad 2535$

compressus ............... 2551

fabricii.................. $\quad 2534$

fimbria................. 1862

glacialis................... 2534

gracilis ................. $\quad 2538$

heteroglossus ............ 2541

lacustris ................ 137, 2551

longipes.................. 2555

lubb...................... 2561

macrocephalus ............ 2541

maculosus ................ 2551

manus .................. 2541

maraldi .................. $\quad 2546$

merlucciua............... $\quad 2530$

merlus ................... $\quad 2530$

molva ................... 2552

morrhua ................. 2541

ogac ................... 2542

ogat................... 2542

periscopus............... 2536

polymorphus.............. $\quad 2540$

productus................ 2531

proximus ................ $\quad 2539$

pruinosus................. $\quad 2540$

punctatus................. $\quad 2553$

pygmæus ................ 2542

raptor.................. 2552

ruber..................... 2530

rupestris................. 2541

saida..................... 2534

tau..................... 2316

tenuis.................... 2555

tomeod ................... 2540

tomcodus ................. 2540

fuscus .......... 2540

luteus........... $\quad 2540$

mixtus.......... 2540 
Gadus torsk

vertagus

virens.

Gaff-topsail .

Catfishes ...............

Pánupano ...............

Gag

Gaidropsarina ...................

Gaidropsarus

argentatus $\ldots . . . . .$.

ensis ................

septentrionalis ......

gaimardianus, Mugil ...............

geirdneri, Fario . . . . . . . . . . . . . .

Salmo ...................

beardsleei .........

crescentis ........

kamloops .........

shasta...........

stonei ............

galactura, Cliola...................

galacturus, $\mathrm{Hy}_{\mathrm{y}} \mathrm{silepis} \mathrm{.............}$

Notropis ...............

Galafate.........................

galapagorum, Umbrina............

galeata, Belone...................

galeatus, Gymnocanthus..........

Tylosurus................

Galei............................

Galeichthys............ 119, 122, 2770, 2771

assimilis .............

azureus................

bahiensis.............

blochii................

cærulescens ...........

chevola...............

crinitus................

dasycephalus ..........

eydonxii...............

gilberti ................

gronovii ..............

guatemalensis .........

jordani ...............

lentiginosus.......... 1

longicephalus .........

peruvianus.......... 1

phrygiatus ............

rugispinis ............

seemanni.............

surinamensis ..........

xenauchen............

galeichthys, Carangoides...........

Galeidæ

Galeinæ

Galeocerdo

maculatus
Page.

2561

2541

2534

118

116

940

1177

2532

2557

2559

2558

2559

814

499

497

2819

2821

499

502

503

279

279

279

1711

1468

716

2010

716

21

2779

2775 .

119

118

2776

932

932

2780

118

2773

117

2778

2774

22, 2771

2781

22,2771

2782

2781

2772

2780

2777

932
Galeocerdo tigrinus ...............

galeoides, Otophidium ............ 2491

Galeorhininæ .................. $\quad 27$

Galeorhinus................... $\quad 31$

zyopterus ............ 32

Galeus .................... 29, 31, 2745

californicus ............. $\quad 30$

dorsalis ................ 32

maculatus............... $\quad 30$

galens, Epinephelus............... 1164

Serranus ................. 1164

Gallichthys ..................... 931

gallinula, Monacanthns.......... 1716

Galliwasp ...................... $\quad 538$

Gallus ....................... 931

virescens................ 932

gallus, Zeus..................... 936

galtipo, Squalius ................... $\quad 237$

Gambusia....................... 678

affinis...........660, 6832,2833 arlingtonia ........ 652, 2828, 2829 episcopi............... 683 gracilis ...........6 682, 683, 2832 holbrooki............681, 2832

humilis............... 682

infans ............... 680, 2832

melapleura ............ 2830

modesta ............... 693

nicarauguensis ........ 682, 2832

nobilis.............. 682, 2832

patruelis.............. 682, 2832

picturata .............683, 2832

plumbea ............... 695

punctata............... 679

puncticulata........... 680, 2832

senilis ................. 682

speciosa.............. 681

tridentiger ............. 2833

Gambusiinæ .................... 632

Gambusinus ................ 633, 635,648

gamphodon, Oxyrhina............ $\quad 49$

Ganoid Fishes ................... 100

Ganoidei ....................... 100

Ganoids, Bony ................... 107

Cartilaginous........... 100

Gar, Alligator ................... 111

Great ...................... 111

Long-nosed .................. 109

Short-nosed................. 110

Gar Pikes ........................ 108

garabata, Mojarra ............... 1353

gardeniana, Hiatula............. 1578

gardenii, Centronotus ............. 948

Sternoptyx ............. 966

Stromateus............. 966

gardoneum, Chondrostoma........ 251 
gardoneus, Abramis.

Leuciscus .............

Gardonus ...........................

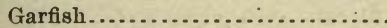

Garibaldi

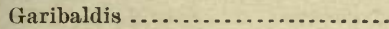

Garlopa

garmani, Characodon ..............

Gobius...................

Lepomis

Notropis.................

251

251

251

243

714

1564

1564

1186

2832

2225

1002

281

Garmannia

$$
\begin{aligned}
& \text { hemigymna ............ } \\
& \text { paradoxa............. }
\end{aligned}
$$

seminuda

garnoti, Halichæres

Iridio

Julis

Platyglossus

..............

231,2232

2233

2232

2233

1593

1593

1593

1593

Garrupa

$$
\text { nigrita.. }
$$

1161,1797

Gascon

1161

Gaspereau

910

Gaspergou

426

Gasteracanthus

1484

Gasteropelecus.

acanthurus.........

crocodilus..........

humboldti..........

maculatus .........

Trachinus ..........

Gasterostea .....................

blanchardi .............

Gasterosteidæ

Gasterosteinæ

Gasterosteus.

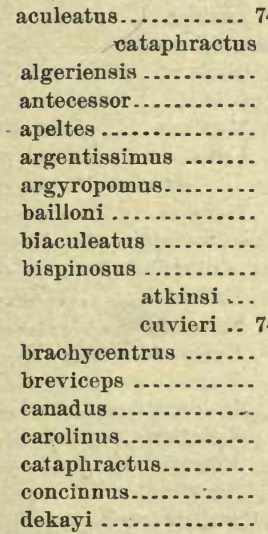

750

748

900

752

747

748

747

748

748

748

749,2836

748

746

948

944

749

745

746
Gasterosteus, dimidiatus...........

ductor ...............

elegans ...............

gladiunculus.........

globiceps ........... $\quad 744$

gymnurus ........... $\quad \mathbf{7 4 8}$

inconstans........... $\quad \mathbf{7 4 4}$

insculptus.......... $\quad 750$

intermedius......... $\quad \mathbf{7 5 0}$

islandicus............ $\quad 748$

lævis ............... $\quad \mathbf{7 4 5}$

leiurus.............. $\quad 747$

loricatus ........... $\quad 747$.

lotharingus.......... $\quad \mathbf{7 4 6}$

mainensis........... 745

micropus............ $\quad 744$

millipunctatus....... $\quad \mathbf{7 5 2}$

nebulosua ............ $\quad \mathbf{7 4 6}$

néustrianus.......... $\quad 747$

obolarius ........... $\quad 750$

occidentalis.......... $\mathbf{7 4 5}$

plebeius ............. $\quad 751$

ponticus ............ $\quad \mathbf{7 4 7}$

pugetti ............. $\quad 751$

pungitius ............ $\quad \mathbf{7 4 5}$

brachypoda. $\quad 746$

pygmæus ........... $\quad \mathbf{7 4 4}$

quadracus ............ $\quad \mathbf{7 5 2}$

saltatrix ............ $\quad 947$

semiarmatus......... $\quad \mathbf{7 4 7}$

semiloricatus ....... $\quad \mathbf{7 4 7}$

serratus............. 750

spinulosus.......... $\quad 748$

tetracanthus......... $\quad 748$

trachurus........... $\quad \mathbf{7 4 7}$

wheatlandi.......... $\quad \mathbf{7 4 9}$

williamsoni......... $\quad 750$

microcephalus..... $\quad \mathbf{7 5 0}$

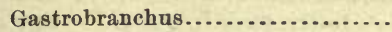

cæcns ..............

dombey............

Gastrophysus ................... $\quad 1727$

Gastropsetta .................. 2636

frontalis ............ $\quad 2636$

Gastrostomus ................... 406

bairdii .............. $\quad 406$

Gata ............................... 26

Gato ........................... 28

Bonaci .................... $\quad 1187$

gaucharote, Chætostomus .......... 159

Hemiancistrus......... $\quad \mathbf{- 1 5 9}$

Hypostomus........... $\quad 159$

gavailis, Lepisosteus ............. $\quad 110$

gayi, Epicopus ................. $\quad 2530$

gelatinosum, Melanostigma ........ 2479 


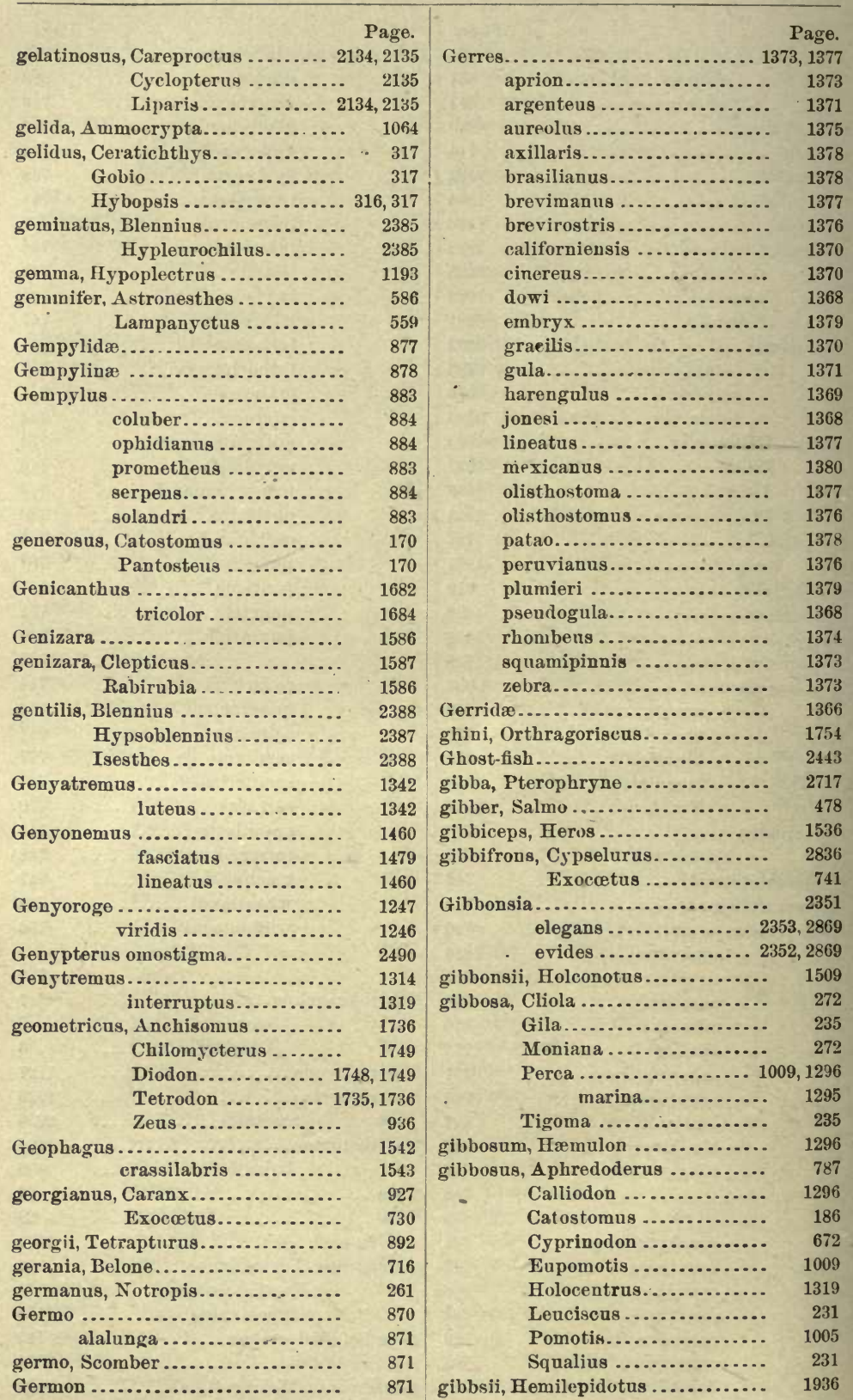


gibbsii, Salmo

clarkii...............

mykiss ..............

gibbus, Hypsilepis cornutus .......

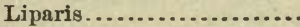

Lophius...................

gigas, Cerna.....................

Ephippus...................

Epinephelus................

Hippoglossus..............

Mugil ....................

Perca.....................

Sciæna ....................

Seriola....................

Serranus ..................

Stereolepis ................

Zonichthys .................

Gila affinis....................... ardesiaca .................... conocephala ................. elegans ..................... emoryi....................... estor........................ gibbosa...................... gracilus .................... grahami ..................... grandis..................... gula ........................ microlepidota................. montana..................... nacrea..................... nigra ...................... phlegethontis................. pulchella ................... robusta..................... seminuda.................... vandoisula ...................

Gila Trout ......................

gila, Catostomus.................

gilberti, Agonus ..................

Citharichthys............

Galeichthys..............

Hypsoblennius ...........

Ilypnus.................

Isesthes.................

Lepidogobius ............

Menidia..................

Notropis ................

Noturus.................

Podothecus ...............

Salmo irideus .............

Schilbeodes ...............

Sebastodes .................

Ulocentra ................

Gilbertina

$3030-110$
Page.
Gilbertina sigolutes...............

Gillellus .......................

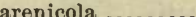

ornatus................ 2299

semicinctus............ 2298

gilli,-Labichthys . . . . . . . . . . . . . $\quad 368$

Leuciscus ................. 239

Pleuronectes ............... 2654

Sebastodes................... 1811

Synchirus ................. 2024

Gillia ......................... 2249

gillianus, Julis.................. 1610

Gillichthys.................... 2249

detrusus.............. 2251

guaymasiæ........... 2252 mirabilis ............. 2250 y-cauda ............. 2252

gillii, Bassogigas.............. . $\quad 2515$

Cetomimus ............... $\quad \mathbf{5 4 9}$

Clinus ................... $\quad 2358$

Lepomis .................. 992

Lipogenys................ 619

Malacoctenus ............. $\quad 2358$

Neobythites................ 2513

Pœeilia.................. 692

Stephanoberyx ........... $\quad 836$

Xiphophorus ............. $\quad 692$

Xystroplites............... 1007

Ginglymostoma.................. 26 caboverdianus..... 26 cirratum.......... 26 fulvum ........... 26

Ginglymostomidæ.............. $\quad 25$

giorna, Cephalopterus............ 93

girardi, Acipenser.............. 106

Caranx ................. 922

Girardinicbthys................ 666 innominatus....... 666

Girardinus..................... 686

formosus............ 688

guppii............... 2834

metallicus............. 687

occidentalis ........... $\quad 689$

plenrospilus........... $\quad 688$

sonoriensis........... 689

uninotatus ........... 687

vandepolli............ 2834

versicolor ............ $\quad 689$

Girella ........................ 1381

dorsomacula.............. 1382

nigricans ................. 1382

Girellinæ.................... 1381

Giton ....................... $\quad 340$

fasciatus ................ $\quad 340$

Gizzard Shads ................. $\quad 415$

glaber, Cottus................. 2316 
glaber, Cyclopterichthys .

Ostracion oblongus

Pleuronectes..............

glabra, Liopsetta .................

Platessa...................

glabro, Corpore oblongo ...........

Ostracion subrotundus ven-

tre ......................

glaciale, Myctophum..............

glacialis, Cottus ..................

Gadus...................

Liopsetta ............ 2649, 2650

Pleuronectes............ 2649

Scopelus ............... 574

Squalus ............... $\quad 57$

gladiunculus, Gasterosteas........

gladius, Trichiurus ...............

Tylosurus...............

Xiphias ..................

Glance Fish.....................

Glasseye.......................

glauca, Prionaco.

glancofrænum, Coryphopterus.....

Gobius.............

glaucoides, Trachynotus...........

glancopareius, Acauthurus ........

glaucos, Sebastodes................

glaucostictus, Rhinobatus .........

glaucostigma, Rhinobatus .........

glaucus, Carcharhinus .............

Carcharias...............

Chætodon................

Isuropsis ...............

Squalus.................

Trachinotus .............

Trachynotus .............

Glaustegus ....................

Globefish

........................

globiceps, A gonostoma ...........

Blennicottus ............ bryosus ...

Centridermichthys......

Gasterosteus............

Oligocottus .............

globosa, Lyosphæra...............

gloriosus, Bryttus ................

Enneacanthus...........

Glossamia........................

pandionis...............

Glossichthys....................

$$
\text { plagiusa } . . . . . . . . .
$$

Glossodon.......................

harengoides...........

heterurus..............

glossodonta, Argentina ...........

Glossodus
Page.

2104

1735

2650

2650

2650

2657

1749

574

1976

2534

57
2836

887

716

894

954

1021

33

2220

2219

941

1694

1777

63

62

33

33

941

48

33

940

941

61

1734

821

2017

2017

2017

744

2017

1752

994

993

1111

1111

2704

2710

412

413

413

411

411
Glossodus forskali ............... Page.

Glossoplites...................... 991

gloveri, Salmo.................... $\quad 487$

Glut Herring . ................. 426

glutinosa, Myxine................ $\quad 7$

Glyphidodon .................... 1560

chrysarus ........... $\quad 1567$

declivifrons .......... 1562

rudis ............... 1563

saxatilis............ 1562

taurus.............. 1563

troschelli........... 1562

Glyphisodon ................... 1560, 1561

moucharra........... 1562

Glyptocephalus ......................

acadianus.......... $26: 7$

cynoglossus ....... 2656

pacificus.......... 2655

saxicola .......... 2657

zachirus .......... 2658

Gnathanodon ................. 927

Gnathobolus .................... $\quad 437$

mucronatus ......... 438

Gnathocentrum ................... 1687

Gnathodon speciosus............. $\quad 928$

gnathodus, Pseudoscarus ......... 1650

Scarus .............. 1650

Gnatholepis.................... 2210

Gnathophis ................... $\quad 355$

Gnathypops................... 2283

macrops ............. 2284

maxillosa ............ 2284

maxillosus ............ 2284

mystacina............ 2286

mystacinus .......... 2286

rhomalea............ 2285

scops................ 2283

snyderi.............. 2285

Goattish, Red.................. $\quad 858$

Yellow ................ 859

Goatfishes ..................... 857

Gobies ................... 2184, 2188, 2210

Blind................... 2261

Crested................... 2209

Half-naked ................ 2231

Naked................... 2257

Gobiesocida .................... 2326

Gobiesocinæ .................... 2327

Gobiesox................ 2329, 2330, 2331 adustus ................ 2334

carneus ................. 2337

cephalus ............... 2332

cerasinus............... 2336

eigeumanni ............ $\quad 2339$

eoss................... 2343 


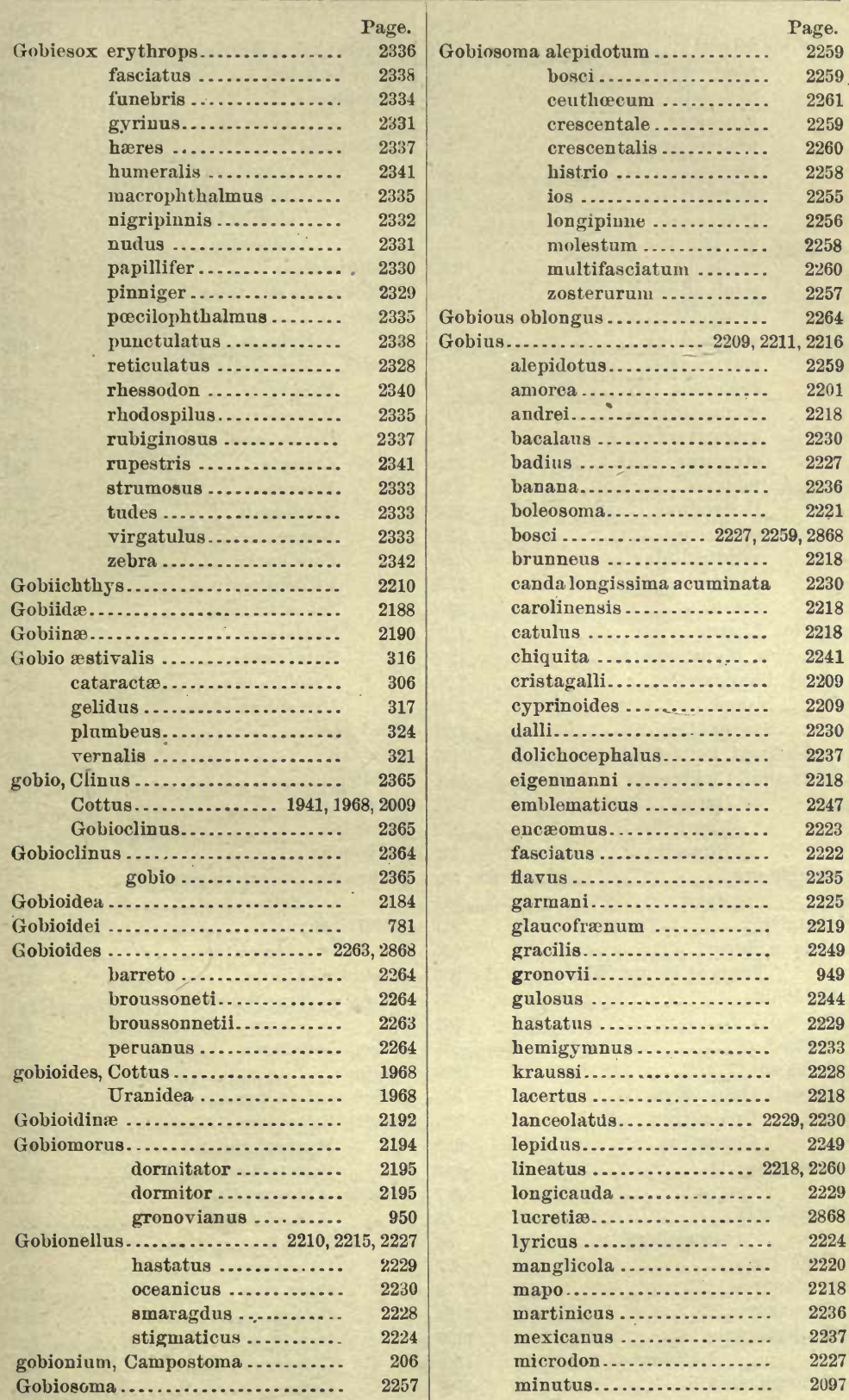


Gobius nelsoni ..................

newberryi...............

nicholsii

oceanicus

paradoxus..............

pisonis ..................

plumieri..................

poeyi.....................

quadriporus...............

sagittula .................

seminudus ................

shufeldti ..................

smaragdus ...............

smyrnensis................

soporator.................

stigmaticus ...............

stigmaturus...............

strigatus .................

taiasica ...................

thalassinus................

townsendi..................

viridipallidus ..............

wurdemanni ..............

zebra.....................

gobius, Liparis . . . . . . . . . . . . . . .

goboirles, Hypsicometes. . . . . . . . . . .

Goby, Long-jawed................

Naked......................

Sharp-tailed ................

goddeffiroyi, Percichthys ...........

godmanni, Cichlasoma............

Heros..................

Pimelodus ...............

Rhamdia ...............

Groggle-eye....................

Jack .................

Goggler ........................

Golden Shiner................... Goldfish

Trout of Mount Whitney ..

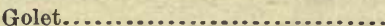

Goltra.

Goma soi.......................

gomesii, Ophichthus ..............

Ophichthys..............

Ophisurus ...............

Gonenion ........................ serra....................

Goniobatis ..................... macroptera.............

Goniodus ......................

Gonionarce .....................

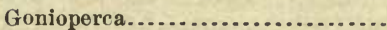

Gonioplectrus.................... hispanus ..........

Gonocephalus .

\begin{tabular}{r|}
\hline Page. \\
\hline 2235 \\
2248 \\
2218 \\
2230 \\
2232 \\
2201 \\
2206 \\
2226 \\
2221 \\
2228 \\
2234 \\
2221 \\
2227 \\
2118 \\
2216 \\
2224 \\
2220 \\
2228 \\
2236 \\
2245 \\
2250 \\
2259 \\
2225 \\
2226 \\
2108 \\
2294 \\
2250 \\
2259 \\
2229 \\
1197 \\
1516 \\
1516 \\
152 \\
152 \\
\hline 992 \\
\hline
\end{tabular}

990,992

911

911.

250

503

201

507

.508

1833
Gonocephalus macrocephalus ...... Page.

Gonochætodon ................... 1672

Gonopterus .................... 1687

mœrens.............. 1688

Gonostoma................... $\quad 578$

brevidens............ $\quad 579$

denudatum........... $\quad 579$

elongatum ........... 583

microdon............ 582

Gonostominæ .................. $\quad 578$

Goriostomus acanthurus.......... $\quad 579$

Goodea........................ 685

atripinnis ............... $\quad 685$

goodei, Aldrovandia .............. $\quad 610$

Erimyzon ................. 186

Halosaurus............... 610

Hymenocephalus.......... 2572

Lucania ................. $\quad 664$

Macrurus ................ 2572

Myliobatis ............... 2755

Nematonurus ............ 2571

Paralonchurus............. 1480

Ptilichthys............... 2452

Sebastichthys............ 1780

Sebastodes .............. 1779

Spinivomer............... $\quad 367$

Trachinotus............. $\quad 943$

Urolophus............... 81

Groodeinæ .................... 632

Goodfish ..................... 487

Goodies ........................ 1458

Goody....................... $\quad \mathbf{1 4 5 8}$

Goosefish ..................... 2713

Gorbuscha ................... $\quad 478$

gorbuscha, Oncorhynchus......... $\quad 478$

Salmo .............. $\quad 478$

Gordiichthys.................. $\quad 363$

irretitus ........... 363

goreensis, Albula ............... 412

Trachynotus........... 943

Vomer............... 934

gouani, Lepidopus ............... $\quad 887$

Goujon......................... $\quad 2790$

Gourd-seed Sucker............... 168

gracile, Boleosoma.............. 1102

Myctophum ............. 572

Peristedion.............. 2179

gracilis, Aldrovandia ............ $\quad 610$

Atherinichthys ......... $\quad 797$

Blennius ................ 2438

Catustomus............. 179

Chætodon ............... 1675

Cottus.................. 1968

Cyprinus ................. $\quad 326$

Diapterus ............... 1370

Gadus .................... 2538 
Page

gracilis, Gambusia ............... 682, 683

Gerres ................. 1370

Gila................... 227

Gobius .................. 2249

Hippocampus ............ $\quad 777$

Hybopsis.................

Lepidogobius.

Lepisosteus ...............

Leptocephalus ...........

Leuciscus ............... 283, 326

Lycodes ................... 2465

Menidia .................. $\quad 797$

beryllina ........ 797

Moniana..................

Perca

Photonertes...............

Pimelodus .................

Platygobio.

Pleurogadus

Poeilichthys..............

Ptychocheilus .............

Scomber ..................

Scopelus..................

Septogunnellus.

Tigoma..................

Tilesia.

Tmbrima

Uranidea

Xiphophorus

221

2249

110

354

465

272

1024

591

135

326

2538

1103

225

867

572

2436

236

2538

1474

1968

683

135

graciosus, Pimelodus ............... gradiens, Hypsagonus (Cheira-

gonus) ......................

graellsi, Gphidion .................

grahami, Gila.

Leuciscus...............

Oligocephalus............

grallator benthosaurus.............

Gramma

loreto ...................

2041

2488

227

228

1089

543

1228

1229

Grammateus.

$1347,1348,1353$

humilis .............

medius ...............

1355

1356

grammaticum, Thalassoma. ...... 1610, 2859

grammaticus, Chlorichthys ........ 1610

Grammatopleurus................. 1866

lagocophalus.... 1875

Grammatostomias................. dentatus ........

Grammichthys................... lineatus .............

Grammicolepididæ

$$
590
$$

590

2693

2702

973

974

Grammiconotus ...................

$$
\text { bicolor. }
$$

Gramminæ
Grammistes acuminatus ........... $\quad \begin{array}{r}\text { Page. } \\ 1487\end{array}$

hepatus ............ 1343

mauritii............. 1323

trivittatus ........... 1311

unimaculatus ......... 1360

Grand Oranchee................. 1057

Grande Écaille.................. $\quad 409$

grandicassis, Arius................ 126

Netuma .......... 126, 2764

Tachisurus.......... 126

stricticas-

sis ..... $\quad 126$

grandicornis, Scorpæna ........... 1850

grandipinnis, Photogenis........... $\quad 280$

grandis, Fundulus ................ $\quad 2827$

heteroclitus .... 641

Gila .................. 225, 2797

Leuciscus............... 225

Ptychocheilus........... 225, 2796

grandisquama, Eleotris .......... 2198

grandisquamis, Chærojulis........ • 1597

Platyglossus ....... $\quad 1597$

Upeneus ........... 860

grandoculatus, Centropomus....... 1120

grandocule, Chirostoma.......... $\quad 2839$

grandoculis, Atherinichthys...... 2840

granulata, Perca .................. 1024

Raia................... 72

granulatus, Amorphocephalus ..... 1619

granulosa, Pristis................ 61

Graodus........................ 254

nigrotæniatus........... 264

Grass Bass..................... 987

Porgy .................... 1355

Rockfish .................. 1819

Gray Grunt...................... 1296

Pike ..................... 1022

Snapper.................. 1255

grayi, Carpiodes.................. 167

Lepidosteus .............. 111

Salmo................... 509

Grayling, Arctic .............. 517, 2871

European .............. 2870

Mir.higan .............518, 2871

Montana.............. 519, 2871

Graylings.................... $\quad 517$

Great Albacore ................. $\quad 870$

Amber-fish ............... 903

Barracuda................. 823

Bear Lake Herring ......... $\quad 470$

Blue Shark ................ 33

Chub .................... 232

Flounder ................ 2652

Flying-fish .............. 740

Fork-tailed Cat............ 137

Gar...................... 111 
Great Lake Tront .................

Northern Pike .............

Pámpano .....................

Pike........................

Pipefish ...................

Seulpin..................

Sculpins..................

Sea Lamprey

Tunnies ..................

White Shark ..............

grebnitskii, Pholidapus ...........

Green Bass........................

Cod .......................

Parrot-fish ............... 1638, 1657

Pike .................... 627

Sturgeon .................. 104

Sunfish................... 996

Green-back Trout................ $\quad 497$

Green-fish..............................

Alaska ....................

greenei, Uranidea ..................

greeni, Couesius .................

Neoliparis .................

Greenland Charr.

Codfish .................

Halibut.

Greenling

1382

1869

1965

324

2112

508, 510

2542

2611

1871

Greenlings ...................... 1863, 1866

Green-sided Darter............... 1053

Gregory, Beau ....................

Grenadiers.......................

grex, Scomber....................

grimaldii, Conchognathus ..........

Grindle

grisea, Dionda

Lucioperca..................

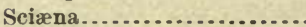

Unibranchapertura.........

griseolineatum, Siphostoma........

griseolineatus, Syngnathus ........

griseum, Stizostedion canadense...

griseus, Acomus.................

Carcharias ................

Catostomus.................

Hexanchus ...............

Labrus ....................

Lntjanus ..................

Mesoprion.................

Neomanis................

Notidanus.................

Saurus ..................

Squalus ...................

groellsi, Ophidium ................. groenlandica, Nansenia............ gruenlandicus, Aspidophoroides.... Cottus
1555

2561

867

349

113

216

1022

1484

342

764

764

1022

175

47

175

19

1257

1257

1257

1255

19

537

19

2487

528

2092

1975 grienlandicus, Cottus seorpius .....

Page.

Gunnellus .......... 2418

Himantolophus ..... 2733

Hippoglossus ....... 2611

Microstomus....... 528

Myoxocephalus..... 1974

Salmo.............. 521

Gronias ................... 135, 136, 142

nigrilabris............... 142

gronovianus, Gobiomorus........ $\quad 950$

gronovii, Achirus ................ 2696

Ailurichthys............ 117

Galeichthys ........... $\quad 117$

Gobius............... 949

Nomeus ............... 949

Ostracion ............... 1725

Solea................... 2696

Zoarces ................. 2457

grossidens, Engraulis............ 451

Lycengraulis ......... 451

Ground Drummer............... 1436

Spearing............... 533

Gronper, Black ................ 1161, 1174

Mangrove.............. 1171

Nassa11............... 1157

Red ................... 1160

Yellow................ 1183

Yellow-finned .......... 1155, 1172

Groupers..................... 1148

Grubber Broed-head ............. $\quad 447$

Grubby ........................ 1973

grunniens, Amblodon............ 1484

Aplodinotus .......... 1484

Haploidonotus ......... $148 t$

Labrus............... 1483

Mugil ............... 1483

Grunt, Black.................. 1297

Boar.................. 1303

Common................. 1304

French ................. 1306

Gray ................. 1296

Margaret................ 1295

Open-mouthed............ 1306

Red-mouthed:.............. 1308

Striped .................. 1296

White.................... 1310

Yellow .................. 1303

Grunters...................... 1289

Grunts....................... 1291

Striped................. 1313

gryllus, Exocotus ............... $\quad 729$

Grystes ......................... 1010

lineatus ................. 1868

megastoma.............. 1012

nobilis................... 1012

nuecensis................ 1012 
Page.

Guacamaia guacamaia, Hemistoma............ 1659

Pseudoscarus ........ 1656, 1659

Scarus ............ 1656, 1658

Guacamaias.................... 1655

guachancho, Sphyræna......... 824

Guachinango, Pargo ...............

guaco, Amore ...................

Guaguanche .....................

\section{Pelon}

guaiacan, Echeneis

Guajacon

Guajacones

Guajica .

Guamaiacu atinga

Guamajacu guara

guanabana, Erizo

Guapena

Guaperva ......................

lataforeipata............

guara, Caranx...................

Guarnajacu ...............

Scomber

Guarapucu

1264

2236

824

824

2270

679

678

692

1749

1745

1746

1489

1703

1702

926

1745

927

876

Guardfish

715

Guasa.............................

guasa, Promicrops ...............

Serranus..................

Guaseta ........................

guatemalensis, Arius...............

Adinia .............

Anacyrtus.........

Atherinielithys.....

Citharichthys ......

Fundulus..........

Galeichthys ........

Hexanematichthys .

Menidia ............

Pimelodus..........

Rhamdia.

Roboides

154,1162

1164

1164

1164

129

660

338

801

2686

660

2778

129

801

152

152

338

Guativere..................... 1144, 1145

Amarilla ............ 1144, 1145

Black ............... 1146

Red .................. 1145

guativere, Bodianus.............. $\quad 1145$

Serranus............. 1145

Guatucupa juba................. 1323

Guavina ................. 2194, 2198, 2201

guavina................ 2198

Hoyera ............... 2236

Mapo ................... 2196

Tétard ................. 2200

guavina, Batrachus .............. 2195

Eleotris................ 2199 guavina, Guavina ................ Page.

Guavinas ....................... 2194

guaymasiæ, Gillichthys.......... 2252

guaza, Epinephelus .............. 115

Labrus.................. 1154

Gudlax...................... 954

Guebucu ........................ 891

guebucu, Skeponopodus.......... 891

guentheri, Percina ................ $\quad 1034$

Guerubaco ...................... 2198

Gueule, Petite................... 1370

guianensis, Belone............. $\quad 715$

guichenoti, Cayennia............. $\quad 2265$

guineensis, Ostracion ............ 1725

Guiritinga ..................... $\quad 119$

Guitarfish..................... 63

Guitarfishes.................... 61

Guitarro...................... 62

gula, Eucinostomus.............. 1370

Gerres ................... 1371

Gila..................... 234

Squalius .................. 234

Gulf Flounder ................. 2631

Menhaden................. 434

Shad ...................... 2810

gulo, Holocentrus................ 1139

gulonellus, Lencosomus........... $\quad 326$

Pogonichthys (P1aty gobio) .............. 236

gulosa, Uranidea................ 1945

gulosus, Cathorops............. 133, 2788

Centridermichthys....... 1945

Chænobryttus ........... 992

Cottopsis ............... 1945

Cottus ................. 1944

Gobius................ 2244

Lepidogobius ............ 2244

Pomotis................. 992

Tachisurus.............. 133

Gulpers....................... 404

gulula, Eucinostomus........... 1371

gummigutta, Hypoplectrus....... 1192

unicolor 1192

Plectropoma ........ 1192

gundlachi, Dormitator ........... 2198

gunelliformis, Asternopteryx...... 2420

Centronotus ........ 2421

Murænoides ........ 2421

Gunellus ingens ................ $\quad 2419$

macrocephalus......... $\quad 2419$

Gunnell...................... 2419

Gunnellops ................... 2420

roseus............... 2420

Gunnellus alectrolophus......... $\quad 2422$

anguillaris............ 2436

apos................. 2430 
Gunnellus dolichogaster ........... fabricii ................

fasciatus ............... grænlandicus........... islandicus ............. murænoides ............. nebulosum.............. ornatus................ punctatus .............. ruberrimus............. vulgaris ...............

gunnellus, Blennius................ Centronotus............

Murænoides............

Page.

2417

2438

2418

2418

2439

2418

2414

2420

2440

2417

2419

2419

2419

2419

2419

2414

Gunnels........................

gunneri, Scomber ................

gunnerianus, Squalus.............

gunnisoni, Cliola..................

Cyprinella..............

guntheri, Aspidophoroides.........

Etheostoma ..............

Hadropterus .............

Halosaurus .............

Hoplopagrus.............

Lampanyctus............

Mugil..................

Sirembo .................

Sphyræna...............

Xiphophorus ............

guntheriana, Alutera ..............

guppii, Girardinus ................

Gurnard, Big-headed ..............

Common ................

Flying................ 2183

Northern Striped...... 2167, 2168

Red................... 2177

Gurnards ............... 2147, 2148, 2152

Deep-water.............

Flying.

2177

Mailed....................

Small-scaled .............

Gurnardus

2182

2176

2175

2148

1162

1174

guttata, Mycteroperca venenosa...

Perca

1142,1164

Seorpæna

1847

guttatus, Astroscopus.

2310

Balistes

Chiropsis ................

Chirus

1702

1869

1868

Enneacentrus ........... 1142

coronatus .

Epinephelus

Fundalus

1142,1159

Hippocampus

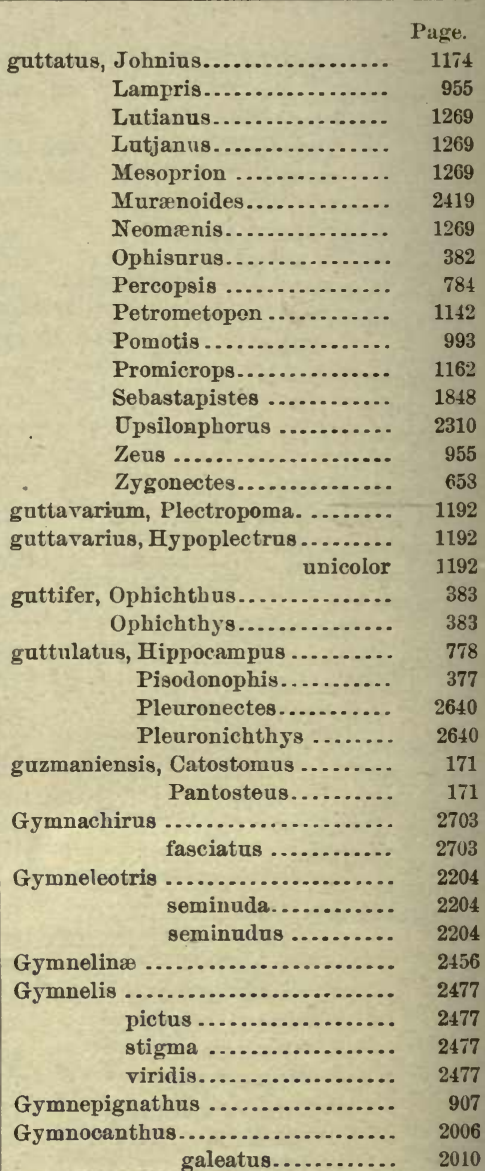

galeatus........... 2010
pistilliger... 2006, 2008, 2009

tricuspis ........... 2008

Grmnocephalus................. 962

ruber............. 1146

Gymnodontes ................. 781, 1726

Gymnogaster .................. $\quad 889$

gymnogaster, Cotylopus ........... 2207

Sicydium........... 2208

Sicyopterus ......... 2208

Gymnomuræna ................ 402, 403

nectura.......... 404

vittata .......... 404

Gymnonoti.....................

Gymnopsis..................... $40^{\circ}$

Gymnosarda ................... 868

alleterata............ 869 
Page.

Gymnosarda pelamis ............ 868

gymnostethus, Prionotus ......... 2153

Gymnothorax............... 392,400,401

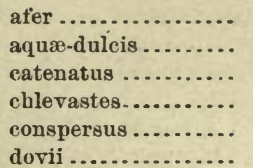

elaboratus ..........

flavoscriptus.......

funebris.............

longicauda ..........

marmoreus..........

miliaris .............

mordax..........

moringua ...........

nigrocastaneus......

obseuratus..........

ocellatus

nigromarginatus. saxicola ...

panamensis .........

picturatus ...........

pictus...............

polygonius ..........

rostratus............

sanctæ-helenæ ......

scriptus...........

umbrosus ...........

verrilli ..............

versipunctatus......

vicinus..............

virescens.............

Gymnotidx

.......................

Gymnotorpedo ....................

Gymnotus albus ...................

bachinrus .............

carapo ..................

fasciatus...............

putaol ..................

gymnura, Dasyatis................

Trygon .................

gyrans, Querimana................

Gyrinichthys .................... minytremus .........

gyrinops, Cyclopteroides...........

gyrinus, Eleotris.................

Gobiesox .................

Noturus

Schilbeodes

Silurus ...................

Gyropleurodus.

Gyropleurodus francisci

quoyi
Haddo.

Page.

Haddock, Jerusalem ............... 954

Haddocks .................... $\quad 2542$

Hadropterus .............. 1028, 1030, 1038 aspro.............. 1032

aurantiacus ........... 1041

cjmatotænia......... 1042

ovides.............. 1036

guntheri ............ 1033

macrocephalus....... 1031

maculatus.......... 1031, 1034

nianguæ ............ 1043

nigrofasciatus........ 1038

ouachitr............ 1035

peltatus.............. 1034

phoxocephalus....... $\quad 1030$

roanoka............. 1036

scierus ............. 1037

serrula....... 1038

shumardi ........... 1047

squamatus ............ 1040

tessellatus ........... 1070

variatus.............. 1070

hæmatura, Cliola................ $\quad 218$

hæmaturus, Hybopsis ........... $\quad 218$

Leuciseus............. 218

Hæmulidæ .................... 1289

Hæmulon........................ 1291

acutum ................ 1299

albidum............... 1299

album................ 1295, 1296

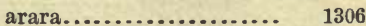

arcuatum .............. 1305

aurolineatum ........... 1310

bonariense............. 1297

brevirostrum ........... $\quad 1300$

cana................... 1299

canna................ 1297

capeuna ............... 1311

carbonarium........... 1300

caudimacula...... 1299, 1302, 1309

chromis................ 1299

chrysargyreum .......... 1308

chrysopteron ........... 1309

chrysopterum .......... 1309

continuum............ 1297

corvinæforme........... 1327

dorsale................ 1303

elegans ................ 1304

flaviguttatum .......... 1312

flaviguttatus ........... 1312

flavolineatum.......... 1306

formosum.............. 1305

fremebundum.......... $\quad 1297$

gibbosum .............. 1296

heterodon.............. 1306

hians ................ 1304 


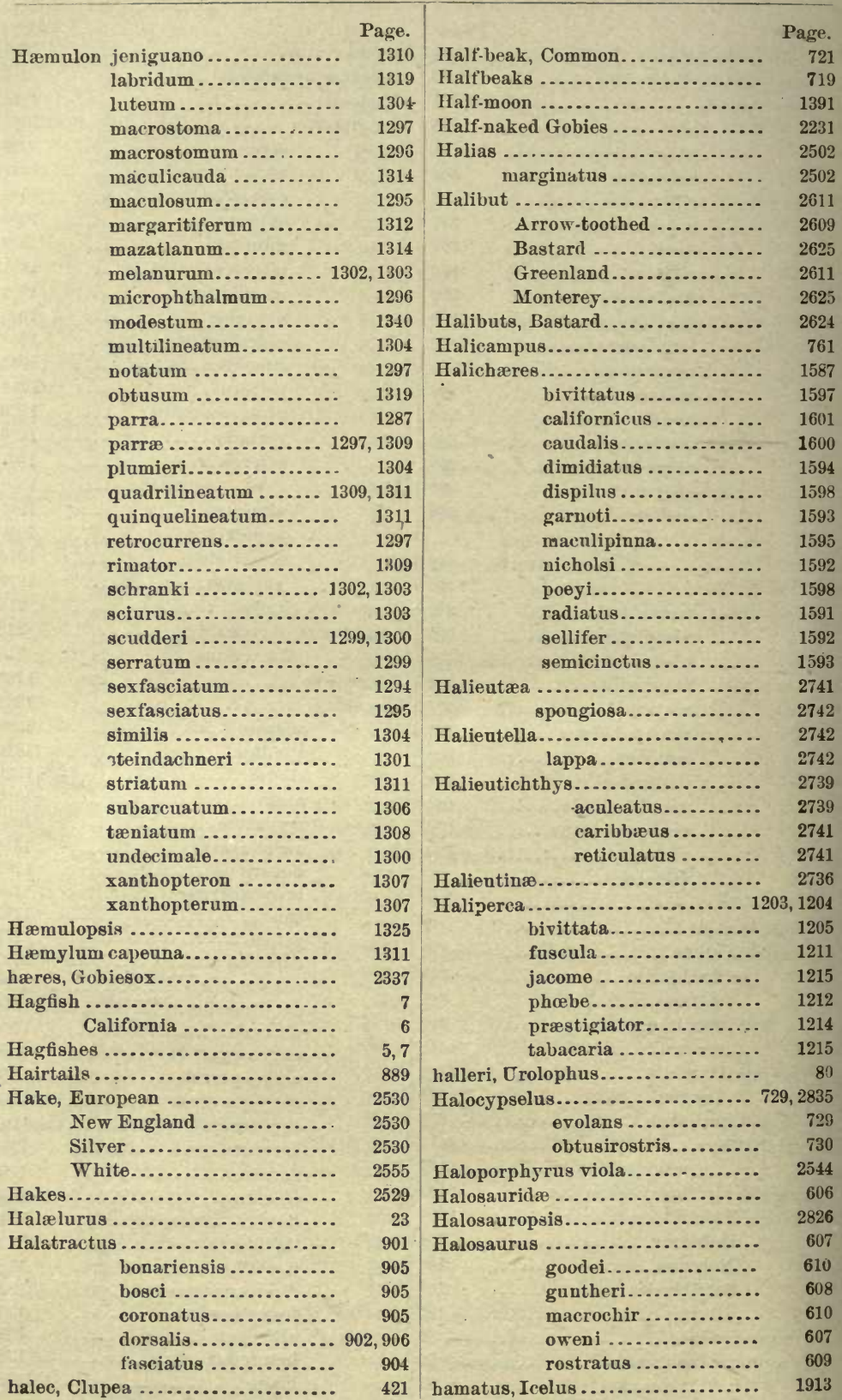


Page.

hamiltoni, Brachioptilon

Hippoglossoides ........ 2616

Hamlet........................ 395, 1157

hamlini, Podothecus............... 2056

Hammer.head .................... 181

Shark ..............

hammondi, Percopsis..............

Pimelodus..............

Semotilus ..............

Hand-saw Fish

Hannahill .

Haplocheilus

Haplochilus aureus .

$633,2827,2831$

45

784

135

222

596

1199

659

chrysotus .............

dovii ..................

floripinnis............

luciæ.................

melanopleurus........

melanops..............

pulchellus.............

seiadicus .............

Haplodoci . . . . . . . . . . . . . . . . . 782, 2313

haplognathus, Lepomis ........... 1004

Haploidonotus .................. 1483

grunniens......... 1484

Haplomi ..................... $\quad 622$

Harder......................... 949

Hardhead ..................... 497

Hardheads ..................... 719

Hardmouth ................... 208

Hardtail ....................... . 921

Hare-lip Sucker................... 199

harengoides, Glossodon ........... 413

H.rengula .................... 428, 430

arcuata............. 431

callolepis ............. 430

clupeola ..............4 429,430

humeralis............. 431

jaguana ............. 430

macropthalma......... $\quad 430$

maculosa ............. 430

pensacolæ............ 431

sardina............. 430

harengulus, Eucinostomus........ 1368

Gerres .............. 1369

harengus, Clupea ............... 421, 422

Coregonns ........... 469

Lavinia .............. 209

Myxus............... 818

Querimana............ 817

Salmo................ 469

harfordi, Ptychocheilus .......... 22j, 2797

Harpe........................ 1581

cæruleo-aureus ........... 1583

diplotænia.............. 1582

eclancheri............... 1583

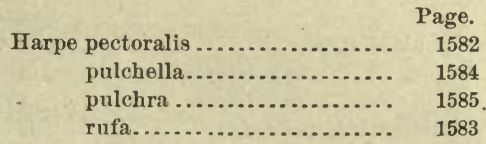

Harpinæ ..................... 1572, 1574

Harpurus ..................... 1689

fasciatus .............. 1691

harringtonensis, Atheriua ........ 791

harringtoni, Axvrias .............. 1904

Harriotta ...................... 96

raleighana ............. 96

Harriottinæ..................... 94

Harry, Black .................... 1199

Harvest Fish ................. 965,967

hasselti, Paraserranus ............ 1205

hastata, Dasibatis............... $\quad 84$

Dasyatis ............... 83

Trygon................ 84

hastatus, Gobionellus............ 2229

Gobius................ 2229

hastingsi, Neomænis............. 2858

Haustor.................... 135, 136, 137

havannensis, Muræna........... $\quad 382$

Ophichthus ......... 382

Uranichthys........ 382

haydeni, Ptychostomus ............ 187

hayi, Hybognathus .............. $\quad 214$

Hay-ko...................... 478

Head-fish ....................... 1753

Head-fishes .................... 1752, 1753

hearnei, Salmo .................. $\quad 510$

heberi, Scomber.................. 923

Hechudo...................... 447

heckeli, Balistes.................. 1709

Nerophis ............... 774

Syngnathus ............ 2839

Hectoria . ..................... 1138

heermanni, Amphistichus.......... 1504

Heliases................. 1545, 1546, 1548 insolatus ............... 1548

multilineatus............ 1547

Heliastes ..................... 1545

cyaneus............... $\quad 1547$

Helicolenus..................... 1836

dactylopterus .......... 1837

maderensis........... 1837

Helioperca..................... 999, 1004

helleri, Cichlasoma.............. 1521

Heros ................. 1521

Xiphophorus............ 701, 702

Helmichthys .................. 353

Helmictis .................... $\quad 353$

helolepis, Trachyrincus.......... 2568

Helops ........................ 103

helvomaculatus, Sebastodes....... 1808

Hemdurgan ..................... 1760 


\begin{tabular}{|c|c|c|}
\hline Hemiancistrus .. & $\begin{array}{r}\text { Page. } \\
159\end{array}$ & $\begin{array}{r}\text { Page. } \\
\text { Hemirhamphus unifasciatus....... } 720,721\end{array}$ \\
\hline aspidolepis........... & 159 & Hemirhombus.................. $\quad 2670$ \\
\hline gaucharote.......... & 159 & æthalion ............. \\
\hline Hemianthias, peruanus............... & 1222 & aramaca.............. \\
\hline vivanus............... & 1223 & fimbriatus........... \\
\hline Hemiarius ........................ & 119 & fuscus.............. \\
\hline [emibranchii ...................... & 741 & ocellatus ............ \\
\hline Comibranchs ..................... & 711 & (n............... \\
\hline [emibrycon ........... & 333 & is ............... \\
\hline Iemicaranx............................ & 912 & solec for \\
\hline amblyrhynchus....... 912 & 2,2844 & Hemirrhamphus ................. \\
\hline …....... 9 & 3. 2846 & Hemistoma........................... \\
\hline falcatus ............... & 2845 & guacamaia ............ 1659 \\
\hline furthii $. \ldots . . . . . . . . .$. & 914 & Hemitremia.................. 228, 230, 242 \\
\hline (n................. & 914 & bifrenata $\ldots \ldots \ldots \ldots \ldots$ \\
\hline n............ & 914 & don .............. \\
\hline (n................ & 2845 & maculata .............. \\
\hline Hemichætodon ........................ & 1672 & vittata ............... \\
\hline Hemigobius............................. & 2210 & Hemitripterinæ................... \\
\hline Hemigrammus .......................... & 333 & Hemitripterus .................... \\
\hline emigymna, Garmannia............. & 2233 & us ........... \\
\hline ropelecus........ & 604 & americanus........ \\
\hline Gobius .............. & 2233 & cavifrons.......... 2023 \\
\hline Hemilepidotinæ................... & 1880 & marmoratus ..... 1889,2022 \\
\hline Hemilepidotus ..................... & 1934 & $\ldots 2,83$ \\
\hline gibbsii $\ldots . . . . . . .$. & 1936 & tus .......... 2408 \\
\hline pidotus ....... & 1935 & henlei, Carcharhinus.............. 37, 2746 \\
\hline 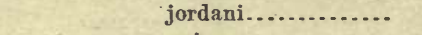 & 1934 & rias ............... $\quad 37$ \\
\hline ......... & 1937 & Rhinotriacis............... \\
\hline (n) & 1936 & (n................... \\
\hline hemilepidotus, Cottus.............. & 1936 & henshalli, Fundulus .............. 653 \\
\hline Hemilepidotus ..... & 1935 & Zygonectes.............653,2829 \\
\hline Hemiodon......................., 15 & 56,157 & henshavii, Apocope ............. 312 \\
\hline .............. & 156 & Rhinichthys ............ \\
\hline Hemioplites simulans ............. & 994 & henshawi, Salmo clarkii............ \\
\hline itus...................... & 992 & mykiss ....... \\
\hline Hemiplus . & 249 & us ..................... \\
\hline s $\ldots \ldots \ldots \ldots \ldots$ & 250 & us............... \\
\hline prinus............... & 250 & hentzi, Hypsoblennius............. \\
\hline aphidx $\ldots \ldots \ldots \ldots \ldots \ldots$ & 718 & Isesthes................... \\
\hline Hemiramphus......................... & 722 & Hepatus .................... \\
\hline balao............... 723 & 3,2835 & hepatus, Acanthurus ... \\
\hline brasiliensis ......... & 722 & Grammistes................. \\
\hline browni .............. & 723 & Teuthis .................. \\
\hline Jemirhamphus fasciatus .......... & 720 & heptacanthus, Cheilodipterns....... \\
\hline filamentosus....... & 723 & heptagonus, Hippocampus......... 775, 777 \\
\hline longirostris........ & 724 & Heptatremidæ ................... 5 \\
\hline gerochirus....... & 723 & Heptranchias maculatus........... \\
\hline ynchus.... & 724 & li, Tetrodon .................. \\
\hline rginatus ......... & 723 & Herichthys .......................... \\
\hline i................ & 720 & tatus......... \\
\hline (n........... & 723 & tyx $\ldots \ldots \ldots \ldots$ \\
\hline n.......... & 720 & (n.................. \\
\hline & 720 & inier, Blennius................ \\
\hline & 721 & herminiger, Labrisomus ........... \\
\hline & 722 & Hermosilla........................ 1383, 1384 \\
\hline
\end{tabular}


Page.

Hermosilla azurea.

Heros.

affinis

altifrons

angulifer

aureus.....................

balteatus ..................

basilaris...................

beani

bifasciatus .................

centrarchus ................

citrinellus

cyanoguttatus..............

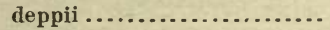

dovii .....................

erythræus .................

ery threus..................

fenestratus ................

friedrichsthali..............

gibbiceps.

godmanni ..................

helleri

intermedius ...............

irregularis.

labiatus .

lentiginosus.

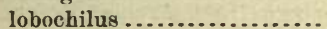

longimanus................

macracanthus .............

maculipinnis ..............

managuénsis ..............

margaritifer...............

melanopogon ...............

melanurus..................

microphthalmus.............

montezuma.................

motaguensis................

multispinosus ..............

nicarauguensis ............

nigrofasciatus .............

oblongus ..................

parma .....................

pavonaceus................

rostratus ..................

salvini ....................

sieboldii ...................

spilurus...................

tetracanthus...............

triagramma ...............

trimaculatus ..............

troscheli...................

urophthalmus ..............

heros, Eupomotis...................

heros, Lepomis ...................

Pomotis ...................

Herpetoichthys
383,1384

1526

1529

1538

1517

1533

1522

1532

1538

1521

1526

1534

1537

1524

1535

1531

1531

1518

1528

1536

1516

1521

1517

1541

1530

1524

1531

1521

1519

1529

1533

1520

1523

1524

1536

1518

1534

1526

1532

1525

1535

1519

1538

1523

1528

1517

1520

1539

1529

1529

1537

1537

1007

1008

1007

381 \begin{tabular}{rr} 
& \multicolumn{2}{c}{ Page. } \\
Herpetoichthys, callisoma........... & 384 \\
ocellatus ........... & 384 \\
sulcatus .......... & 382
\end{tabular}

Herring, Big-eyed............... 410,426

Blue.................. 425

Branch................ 426

California .............. $\quad 422$

Common............... 421

Fall ................. 425

Glut................. $\quad 426$

Great Bear Lake........ $\quad 470$

Lake................. $\quad 468$

Michigan.............. 468

Mountain .............. 463

Rainbow ............... $\quad 524$

Round................ 420

Summer............... $\quad 426$

Tailor ................. 425

Thread ................ 432

Toothed................ $\quad 413$

Wall-eyed.............. 426

Herrings....................... 417, 421

he̊rschelii, Histiophorus .......... $\quad 892$

Tetrapturus.......... 892

herschelinus, Liparis............. 2123

herzbergii, Arius ................ $\quad 125$

Selenaspis ........... 124, 2760

Silurus.............. 125

Tachyswrus........... 125

Hesperanthias ................. 1281

oculatus .......... 1283

Heterandria .................. $\quad 686$

affinis.............. 681

formosa...........687, 2831

holbrooki........... 681

metallica ........... 687

nobilis.............. 682

occidentalis......... 689,2833

ommata............ 664

patruelis ............ 681

pleurospilus......... $\quad 688$

uninotata.......... 687

versicolor...........688, 2833

heteroclita, Cobitis ................ 641

heteroclitus, Fundulus.......... 640, 2827

badius ...... 2827

graudis..... 641

macrolepido-

tus ....... 641

heterodon, Alburnops............ 261

Hæmulon............ 1306

Hemitremia ........... 261

Hybopsis............. 261

heterodon, Leuciscus ............ $\quad 261$

Notropis............. 261

Heterodontidæ.................. 19 


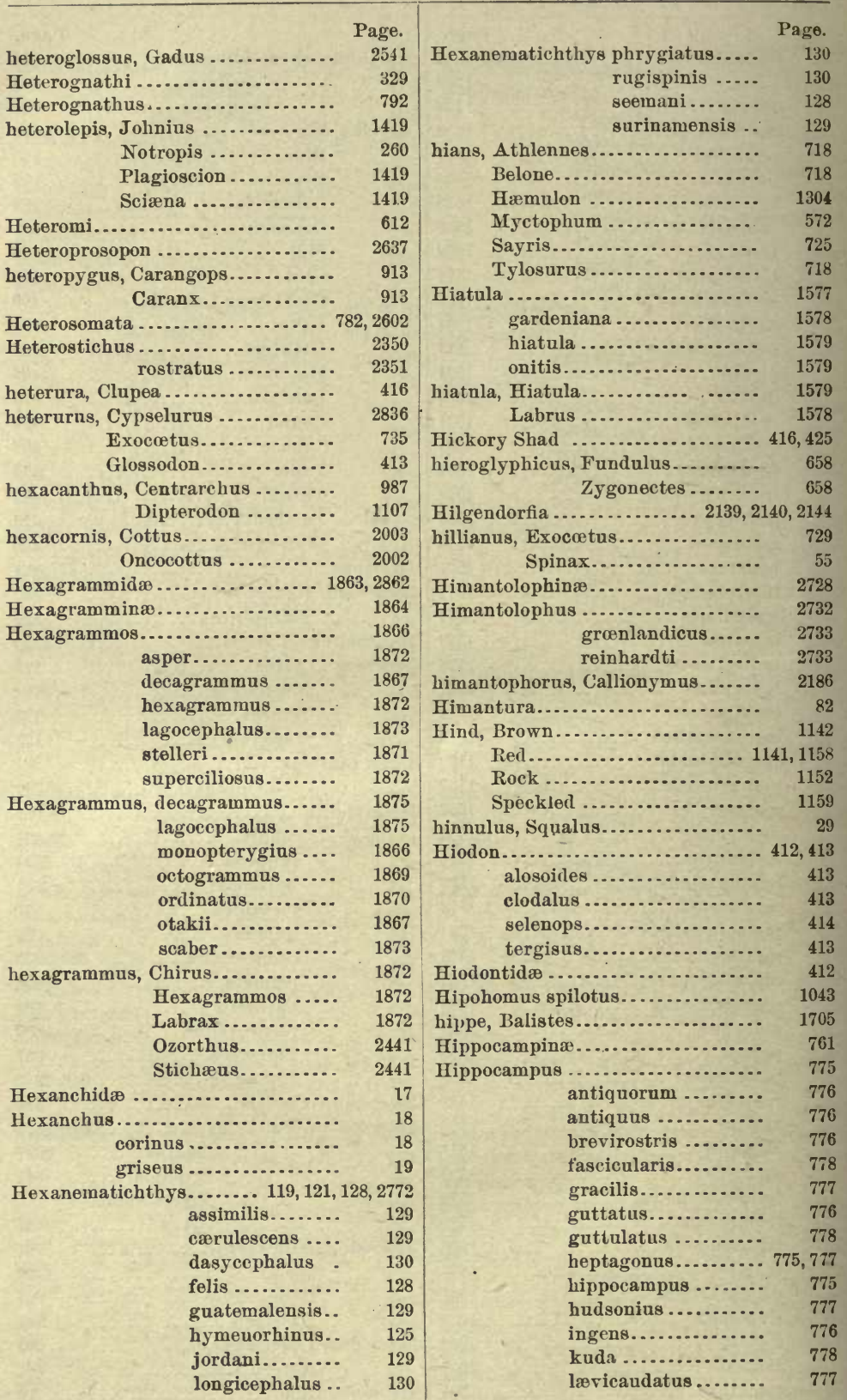


Hippocampus longirostris.

marginalis . ............

punetulatus ........

stylifer

zosteræ.............

hippocampus, Hippocampus ...... . Syngnathus ........

Hippocephalus

japonicus

superciliosus......

Hippoglossina

bollmani ...........

macrops ............

stomata.

Hippoglossinæ

Hippoglossoides

dentatus

elassodon

exilis..............

hamiltori ........

jordani...........

limanda...........

limandoides.......

melanostictus.....

platessoides.......

robustus ..........

hippoglossoides, Platysomatichthy

Pleuronectes......

Reinhardtius .....

Hippoglossus .................. americanus.......... brasiliensis.......... californicus ......... gigas ............... grœenlandicns ....... hippoglossus ........ intermedius ......... maximus.

ocellatus ............ pinguis............. ponticus............ vulgaris .............

hippoglossus, Hippoglossus ........ Pleuronectes ........

hippops, Campostoma .............

hippos, Carangus................

Caranx.

Scomber.

hippuroides, Lepimphis

hippurus, Coryphæna

hirudo, Ichthyomẏzon

hirundinaceus, Squalus

Hirundo.

Acanthurus

Azurina ..................

Cottus.
Page. hirundo, Leiocottus............... $\quad 2011$

Hispaña, Serrana................. 1488

hispanis, Serrana................ 1489

Hispaniscus .............. 1765, 1776, 1813

hispanum, Plectroporna ........... 1140

hispanus, Gonioplectrus.......... $\quad 1140$

hispidus, Balistes ............... 1716

Cottus................ 2023

Monacanthus........... 1715

Tetrodon ............... 1733

Histiobranchus ................ $\quad 351$

bathybius ......... 352

infernalis......... $\quad 352$

Histiocottus................... 2018

bilobus ............. 2018

Histiophorus.................. $\quad 890$

americanus.......... 891

belone.............. 892

brevirostris ......... 892

herschelii.......... 892

pulchellus........... 891

Histrio...................... 2717

histrio, Anteunarius ........... 2716, 2723

Etheostoma (Ulocentra).... 1051

Gobiosoma.............. $\quad 2258$

Lophins................ 2716, 2722

Petrophryn $\theta . . . . . . . . . . \quad 2716$

Scorpæna .............. 1843, 1846

Ulocentra ............... 1050, 1051

Hitch ........................ 209

livileus, Stolephorus ............. $\quad 443$

Hog Choker.................... 2700

Molly ..................... 181, 1026

Sucker.................... 181

Hogfish ................. 1026, 1338, 1579

Spanish................ 1583

Hog-mouth Fry ................ $\quad 444$

Holacanthinæ ................... 2860

Holacanthus . .............. 1682, 1729, 2859 ciliaris ............. 1685

- clarionensis........ . 1683 cornutus............ 1685

formosus............ $\quad 1685$

iodocus.............. 1687

leionothos ........... 1735

melanothus ........... 1728

passer............... 1682

strigatus............ 1683

tricolor.............. 1684

holacanthus, Diodon............. 1746

Ostracion oblongus.... 1746

Holanthias martinicensis ......... 1228

holbolli. Ceratias ................ 2729

holbrooki, Acipenser .............. 105

Aluterus .............. 1718

Echeneis ............. 2270 
holbrooki, Enpomotis............. 1008

Gambusia ..............

Heterandria .............

Ophidion ................

Ophidium ...............

Pomotis ..................

holbrookii, Diplodus ..............

Lepomis ................

Sargus.................

Inolconoti

Holconotus

agassizii...............

analis .................

fuliginosus .............

gibbonsii ...............

megalops ..............

rhodoterus .............

trowbridgii.

Holia.

hollardi, Hollardia ...............

Hollardia .........................

hollardi..................

holocanthus, Diodon................

Holocenthrus ...................

Holocentridæe .....................

Holocentrum . . . . . . . . . . . . . . . .

longipinne...........

perlatum ..............

productum............

prospinosum..........

retrospinis............

riparium .............

rostratum............

sicciferum ...........

vexillarium ...........

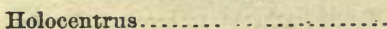

ascensionis.........848, 2843

$$
\text { rufus..... }
$$

auratus...............

brachypterus..........

cornseus ..............

gibbosus ..............

gulo..................

marianus............ 8

meron ................

osculus...............

pentacanthus ..........

punctatus.............

rostratus ...............

sancti-pauli ...........

sanguineus............

siccifer..............

sogo..................

striatus ...............

suborbitalis ...........

surinamensis.
Page.

681

681

2487

2488

1008

1362

1008

1363

81,1493

502,1505

1506

1501

1505

1509

1502

1502

1497

478

1698

1697

1698

1746

847

847

849

853

852

853

853

852

852

850

852

847

1145

852

851

1319

1139

852,2842

1154

853

849

1153

849

853

1761

849

849

849

850

1236

\section{Holocentrus t}

tigrinus

Page.

1214

1192

vexillarius .......... 852

Holocephali ...................... 93

holocyaneos, Scarus.............. 1654

Hololepis barratti ............... 1102

$\begin{array}{ll}\text { erochrous .............. } & 1102 \\ \text { fusiformis ............. } & 1102\end{array}$

hololepis, Cyttus............... 1662

Zenion................. 1661

holomelas, Paraliparis............ $\quad 2140$

Holoporphyrus................. 2543

Holorhinus...................... 89

vespertilio............ 90

Holostei....................... 98, 107

holotrachys, Macrourus.......... 2582

Homalogrystes.................. 1148

Homalopomus................. $\quad 2529$

trowbridgii......... 2531

Homesthes...................... 2394

Homesthes caulopus ............. 2394

homianus, Squalus............... 51

homonymus, "Diapterus ........... 1371

Homoprion.................... 1439

acutirostris .......... 1437

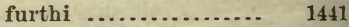

lanceolatus............ 1444

subtruncatus ......... 1434

xanthurus........... 1434, 1459

honneymani, Acipenser.......... 106

hoodi, Salmo .................. 505

hoodii, Salmo .................. 507, 510

Hoopid Salmon................ 480

hopkinsi, Hyninis .............. 933

Mycteroperca......... 2855

Plagiogrammus......... 2428

Sebastodes............. 1789

Hopladelus..................... 142

olivaris............... 143

Hoplarchus ................... 1526

hopliticus, Paricelinus........... 1886

hoplomystax, Sparisoma.......... 1632

Hoplopagrinæ.................. 1242

Hoplopagrus ..................... 1244

guntheri ............. 1244

Hoplostethus ................. 837

japonicus.......... 837

mediterraneus....... 837

Hoplunnis .................... $\quad 361$

diomedianus........... 361

schmidtii ............. 361

Horned Dace..................... 222

Pout.................... 135, 140

Horny Cony ................... 1715

Hornyhead................... $\quad 322$

Hornyheads..................... 314 
horrens, Prionotus

horridus, Brachysomophis.........

Horse Crevallé.

Mackerel

Horse-eye Jack

Horsefish

Irorseluead

hospes, Mugil

hospitus, Acipenser...............

houghi, Pimelodus .

Hound, Smooth ..............

Houndfish

Hoyera, Guavina

hoyi, Argyrosomus

Coregonus

Pimelodus

Uranidea.

....................

.................

hubbardi, Parophrys . .............

hudsonia, Cliola .................

Clupea.................

hudsonicus, Salmo.

Hudsonius

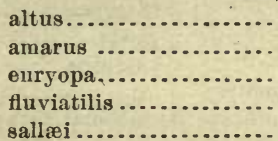

lıudsonius, Catostomus.............

Hippocampus ..........

Hybopsis .............

Leuciscus ..............

Notropis...............

amarus .......

saludanus.....

selene.........

humboldti, Atherinichthys........

Eigenmannia..........

Gasteropelecus ........

Leuciscus .............

Myctophum ............

Scopelus

.. 572,577

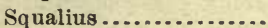

Sternopygus...........

Tigoma

humboldtiana, Atherina............

humboltiannm, Chirostoma

793

humeralis, Arbaciosa

793,2839

Chærojulis.............

Chætodon...............

Clupea.

1597

1674

431

Gobiesox

2341

Harengula .............

Julis..................

431

1596

Leiostomus ..............

1459

Oligocephalus.......... 1097

Paralabrax

1196,1197
1597

431

Scarns............... 1641

Serranus.............. 1197

humeri-maculatus, Sarcus......... 1360

humile, Pristipoma................ 1331

humilis, Bryttus ................. 1004

Cottus................. 1979

Eupomotis .............. 1004

Gambusia............... 682

Grammateus ............. 1355

Lepomis ................ $100 t$

Pagellus ................. 1355

Pomadasis ............... 1331

Tetragonopterus ........ 335

Humpback Salmon.............. 478

Sucker.............. 184

Whitefish ............ 466

huntia, Molva.................. $\quad 2551$

Huro........................ 1010

nigricans................. 1012

huronensis, Lepisosteus.......... $\quad 110$

Huso....................... 103

hyalinus, Ceratichthys ........... $\quad 321$

hyalope, Squalius .............. 222

Hybognathus .................. 212, 213

amara........... .215

arnarus ............ 215

argyritis ........... 214

civilis ............. 215

episcopa........... 214

episcopus........... 215

evansi............. 213

flavipinnis ......... 215

Huvialltis .......... 215

hayi ............... 214

melanops ............ 216

nigrotæniata ....... 214

nubila............. $\quad 215$

nuchalis ............ 213

osmerinus ........... 213

perspicuus .......... 218

placitus ............ 213

plumbea............ 216

procne............. 264

punctifer........... 215

regius ............. 213

serena............. 214

stramineus ......... 262

volucellus .......... 263

Hybopsis . . ................. 314, 315,319

æstivalis ............. $\quad 316$

marconis...... 316

altus .................. 321

amblops ............... 320

bifrenatus ............. 259 
Hybopsis bivittatus

chalybæus..............

chiliticus ...............

chlorocephalus .........

chrosomus ..............

cumingii................

dissintilis ...............

dorsalis.................

fretensis...............

gelidus

gracilis................

hæmaturus ............

heterodon ..............

hudsonius ..............

hyostomus..............

hypsinotus ..............

kentuckiensis ...........

labrosus .................

lacertosus ..............

longiceps...............

meeki ..................

missuriensis............

monacus...............

montanus..............

niveus.................

phaenna...............

procne ...................

rubricroceus............

rubrifrons ...............

scylla ..................

spectrunculus ...........

storerianus

stramineus ..............

tetranemus .............

timpanogensis...........

tuditanus...............

volucellus ...............

watauga ................

winchelli ...............

xænocephalus ...........

Hyborhynchus ...................

confertus ..........

nigellus ............

notatus............

puniceus ...........

siderius ............

superciliosus.......

tenellus .............

Hydrargira . . . . . . . . . . . . . . . . .

atricauda ..............

Hydrargyra diaphana.............

formosa...........

fusca..............

limi..............

luciæ.................

majalis.
Page.

233

288

287

286

388

318

318

262

261

316, 317

321

218

261

269

316

320

322

319

284

264

317

262

318

317

278

270

264

286

320

263

265

270,321

262

315

233

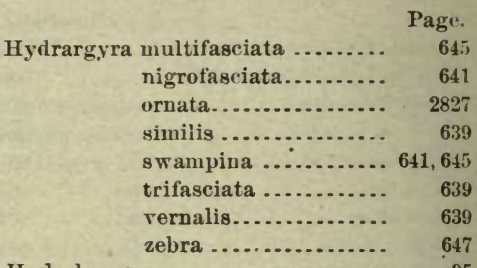

Hydrolagus ................... 95

colliei ............... 95

Hydrophlox................ 254, 257, 284

chrosomus ........... 288

lutipinnis ............ $\quad 287$

rubricroceus ......... 286

hydrophlox, Clinostomus ......... 238

Lenciscus............ * 238

Squalius ............ 238

hygomii, Myctophum ............ 573

Scopelus................ 573

Hylomyzon .................... 173

nigricans............. 181

Hymenocephalus ............... 2580

cavernosus...... 2580

goodei ......... 2572

longifilis ......... 2567

Hymenoptera .................... 2866

hymenorhinus, Hexanematichthys . 125

Hynnis . . . . . . . . . . . . . . . . . . . 932

cubensis ................ 932

hopkinsi ................. 933

Hyodon amphiodon .............. $\quad 413$

chrysopsis............... 413

claudalus................ 413

vernalis ................ 413

Hynganoidea................... 98

Hyostoma . . . . . . . . . . . . . . . . 1052

blemnioperca ........... 1053

newmani.............. 1053

simoterum ............. 1051

hyostomas, Hybopsis ............ $\quad 316$

Nocomis............. $\quad 316$

hypacanthus, Psednoblennius ..... $\quad 2466$

Hypargyrus ..................... 252

tuditanus ............ 253

Hypeneus...................... 858

Hyperistius..................... 980

carolinensis .......... 988

Hyperoartii .....................

Hyperotreti .....................

Hyperprosopon .................. 1501

agassizi $\ldots \ldots \ldots \ldots . \quad 1502$

analis ............ 1501

arcuatum........ 1502

arcuatus.......... 1502

argenteum......... 1502

puncta-
tunı.. $\quad 1502$ 
Page.

Hyperprosopon argenteus ....... 1501, 1502

Hypilepis cornutus cerasinus...... 283

Hypentelium ............... 173, 174, 181

macropterum ........ 181

Hyperchoristus .................. $\quad 589$

tanneri ........... 589

chalybeius........ $\quad 542$

Hypleurochilus ................. 2385 geminatus ........ 2385 multifilis ......... 2385

punctatus......... $\quad 2390$

Hypocaranx................... 927

Hypoclydonia................... 1115

Hypocritichthys

analis ......... 1500, 1501

Hypodis...................... 915, 2848

glaucus ................ 2848

hypodus, Decapterus.............. 908

Hypogymnogobius .............. $\quad 2210$

Hypohomus................... 1039, 1040

aurantiacus .......... $\quad 1040$

cymatotænia.......... 1041

nianguæ ............. 1042

squamatus........... 1040

Hypomesus ................... 524

olidus ...............525, 2824

pretiosus ............. 525

hypophthalmus, Arius ........... 133

Cathorops ........ 133, 2798

hypoplecta, Rathbunella ........... 2290

Hypoplectrus .................... 1187

accensus............ 1193

affinis.............. 1193

bovinus ............ 1193

chlorurus........... 1193

crocotus ............ $\quad 1192$

gemma ............ $\quad 1193$

gummigutta ........ 1192

guttavarius ........ 1192

indigo ............. 1193

lamprurus......... $\quad 1190$

maculiferus......... 1192

puella ............. 1192

unicolor .......... 1190, 1192

aberrans.... 1193

accensus ... 1193

affinis ...... 1193

bovinus .... 1193

chlorirus... 1192

crocotus.... 1192

gummigutta 1192

guttavarius $\quad 1192$

indigo...... 1193

nigricans... 1193 $\begin{array}{lr}\text { Hypoplectrus unicolor primivarius } & \text { Page. } \\ & 1192\end{array}$

puella...... $\quad 1192$

vitulinus ... 1192

hypoplectus, Bathymaster ........ 2290

Hypoplites..................... 1247

Hypoprion .................... 41

brevirostris............ 41

longirostris............. 41

signatus............... 41

Hy poprionodon .................. 41

Hyporhamphus ................. $\quad 719$

roberti ........... 721

rosæ............. 721

tricuspidatus...... $\quad 720$

unifasciatus...... $\quad 720$

Hyporthodus .................... 1148

flavicauda .......... 1156

Hyposerranus................... 1148

Hypostominæ.................... 156

Hypostomus gaucharote .......... $\quad 159$

hypostomus, Aodon ............... 92

Cephalopterus........ $\quad 92$

Hypsagonus .................... 2038

gradiens .............. 2041

quadricornis ........ 2038, 2041

swanii ............... 2088

hypseloptera, Cliola ............... 280

hypselopterus, Leuciscus .......... $\quad 280$

Notropis............ $\quad 280$

hypselurus, Pimelodus ............. 152

Rhamdia ............ 152

Hypsicometes.................. 2293

goboides............ 2294

Hypsifario ................. 474, 477, 481

kennerlyi............. 483

Hypsilepis ardens................ $\quad 301$

coccogenis ............ $\quad 285$

cornutus .............. 283

cyaneus...... 283

gibbus ....... 283

diplæmia............. $\quad 300$

galacturus ............ $\quad 279$

iris.................. 272

kentuckiensis......... $\quad 279$

Hypsinotus .................... 1664

rubescens ............. 1665

hypsinotus, Ceratichthys ......... 320

Hybopsis............. 320

Hypsoblennius................. $\quad 2386$

brevipinnis ........ 2390

gentilis........... 2387

gilberti ........... $\quad 2386$

hentz ............. 2390

hentzi ............. 2390

ionthas............. 2388

striatus ......... 2388, 2392 


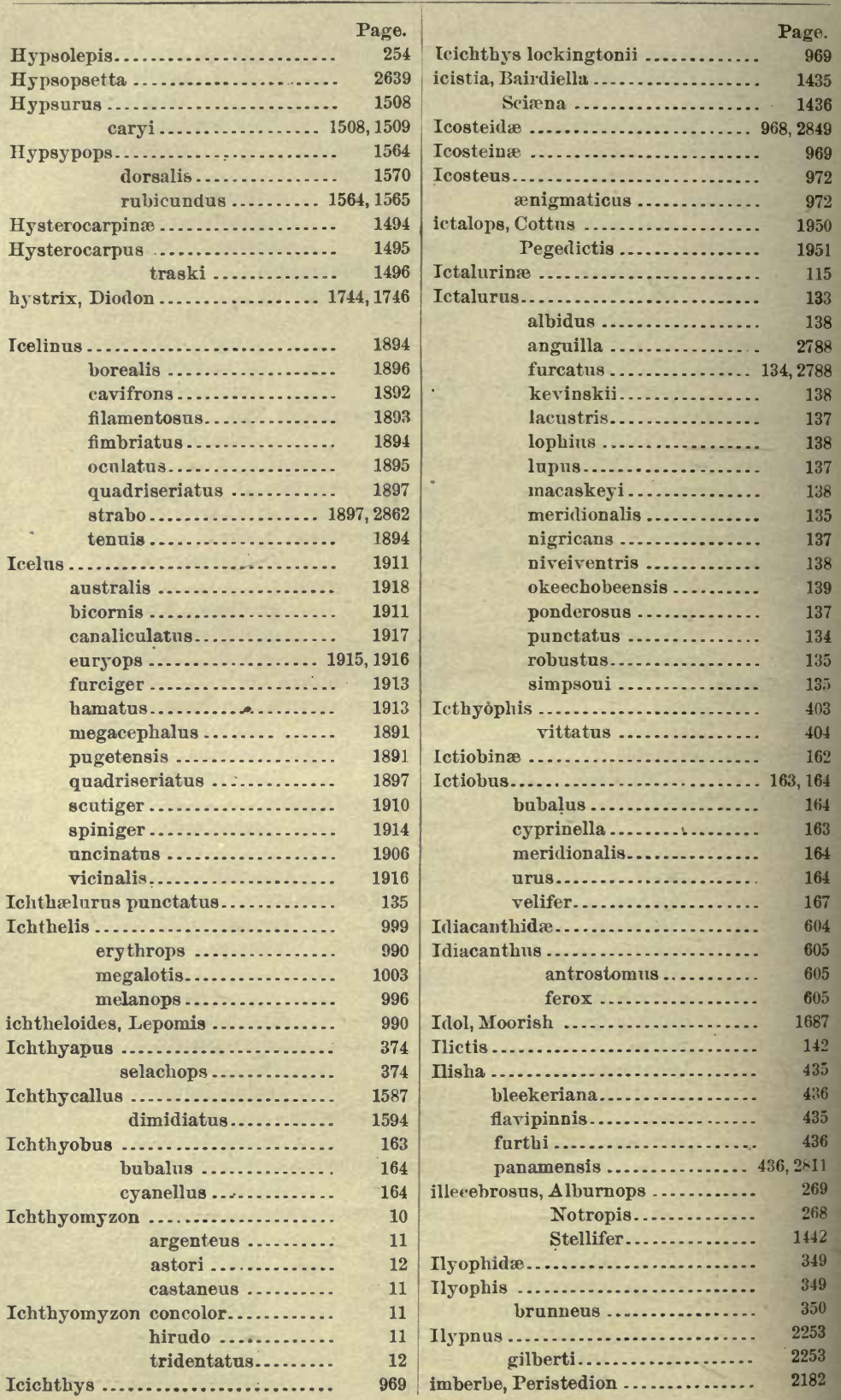


imberbi, Ophidium

imberbis, A pogon

Mullus.

Sciæna.

$\nabla$ ulsiculus

imiceps, Ophioscion ...............

Sciæna.................

immaculata, A mia.

Coryphæna ..........

Fistularia............

Perca ................

Unibranchapertura ...

immaculatum, Cybinm ............

immaculatus, Esox ............... masquinongy ...

Lucius masquinongy.

Salmo ................

Symbranchus .......

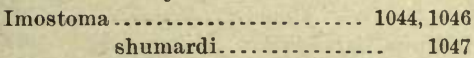

imperator, Tetrapterus............

Xiphias...............

Imperial, Serran

imperialis, Coryphæna

Sebastes

1837,1838

Trachurus

Zeus

impetiginosus, Serranus.

impressus, Conger

inrequilabiatus, Carapus ..........

inaequilobus, Lencosomus ..........

Pogonichthys ........

incilis, Mugil

Pogonichthys ........

incisor, Pimelepterus..............

Pomotis.

Inconnu

892
892

1837

952

717

927

955

1153

356

341

224

224

813

1386

1005

inconstans, Eucalia ..............

cayuga ........

pygmæa.......

Gasterosteus..........

incrassatus, Leucosomus...........

incurvus, Lobotes................

inclefatigabile, Otophidium ..........

Indian Chub

$$
\text { Fish. }
$$

indicus, Chanos

Cottus.

Cubiceps.

Naucrates.

Tetrapterus

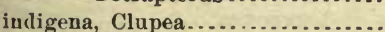

iudigo, Hypoplectrus ..... . . . . . . .

unicolor .....

Plectropoma...............
473,474

744

744

744

744

222

1236

2490

322

1680

415

2092

951

900

892

428

1193

1193

1193

1365
Inermia vittata

Page.

1366

2094

2093

1167

410

1168

1168

1275

1275

1723

1274

73

1853

1829

1829

1168

367

680

368

352

396

352

1616

1616

2419

776

1619

1620

530

382

666

2718

2641

2641

2551

73

73

2412

899

2443

1341

899

1342

1604

2696

1072

1072

2696

1072

1003

insculpata, Netuma............ 127, 2765

insculptus, Arius ............... 127

insculptus, Gasterosteus......... $\quad 750$

Luciocharax .......... 339

insigne, Pimelodus............... 147

insignis, Catostomus............ $\quad 180$ 
insignis, Noturus ................

Schilbeodes .............

insociabilis, Dorosoma ............

insolatus, Chromis ................

Heliases ................

insulæ-sanctæ-crucis, Scarus.......

insularum, Atherina..............

Atherinops.............

Muræna...............

Netuma ...............

integripinnis, Auchenopterus.......

Cremnobates.........

intermedia, Tigoma...............

intermedium, Cichlasoma ..........

intermedius, Gasterosteus .........

Heros ...............

Hippoglossus ........

Leuciscus ............

Paralepis ............

Pomoxys .............

Saurus ...............

Squalius .............

Sudis ...............

Synodus ............ 535, 536

internasalis, Chærojulis.............

Julis.................

Platyglossus.........

interrupta, Morone ...............

Perca mitchilli.........

Raja ..................

interruptus, Ambloplites ...........

Anisotremus..........

surinam. ensis...

Archoplites ...........

Centrarchus ...........

Genytremus ..........

Luxilus ...............

interstitialis, Epinephelus..........

Mycteroperca .......

Serranus.............

Trisotropis ...........

intertinctus, Mystriophis .........

Ophichthys...........

Ophisura ............

introniger, Sebastichthys ..........

Sebastodes .............

intronigra, Dicrolene ..............

inurus, Zygonectes ................

Ioa.

vigil.

vitrea....................

ioæ, Etheostoma ...................

iodocus, Angelichthys .............

Holacanthus ....
Page.

147

147

416

1548

1548

1651

807

807

400

2770

2372

2373

235

1517

750

1517

2672

235

600

987

535

235

600

1594

1594

1594

1134

1133

2751

891

1319

1319

991

991

1319

282

1179

1178

1179

1179

386

387

387

1805

1805

2522

682

1064

1065

1064

1084

1686

1687
Ioglossus ..................... $\quad \begin{array}{r}\text { Page. } \\ 2192\end{array}$

callinrus.............. 2193

ionthas, Cerdale................. 2449

Hypsoblennius........... 2388

Isesthes ............... 2389

ios, Clevelandia................. 2254

Gobiosoma .................. 2255

Iotichthys ................... 228, 231, 243

iowre, Etheostoma ................ 1083

Ipnopidæ.................... 546

Ipnops ....................... 546

murrayi................. 547

irideus, Labrus ................. 988

Salmo .................. $\quad 500$

agua-bonita........ 503

gilberti........... 502

masoni ........... 501

shasta $\ldots \ldots \ldots \ldots . . . . .6502$

stonei............. 503

iridinus, Carangoides ............ 919.

Caranx ................ 919

Iridio ........................... 1587

bivattatus ................. 1595

caudalis ................... 1599

cyanocephalus.............. 1594

dispilus ................. 1597

garnoti ................... 1593

kirschii................... 1598

maculipinna .............. 1594

nicholsi .................. 1591

pictus .................... 1599

poeyi ...................... 1599

radiatus :.................. 1590

sellifer ................... 1592

semicinetus............... 1592

iris, Cliola .................... 272

Hypsilepsis................ 272

Leuciscus................... 222

Irish Lord ....................... 1934

Pompano.................. 1376

irradians, Serranus .............. 1208

irregularis, Heros................ 1541

Theraps .............. 1540

irretitus, Gordiichthys.......... 363

Magil................. 819

irroratus, Monacanthus.......... 1713

Isabelita . . . . . . . . . . . . . . . . . . 1684

isabelita, Angelichthys ........... 1685

Isabelito de la Alto............... 1674

Isaciella ........................ 1340

brevipimis............. 1341

ischanus, Notemigouus .......... 251

Stolephorus........... $\quad 442$

ischinagi, Megaperca............. 1138

ischyra, Inopsetta............... 2641 
ischyrus, Apomotis .

Page.

Lepiopomus

Lepomis

Pleuronectes.............

Isesthes..........................

gentilis ..................

gilberti...................

hentzi...................

ionthas...................

punctatus................

serutator.................

striatus ..................

islandicus, Centronotus............

Gasterosteus...........

Gunnellus..............

Stichæus ...............

isodon, Aprionodon

Carcharias.................

Mesoprion

isodus, Squalus

Isogomphodon

limbatus............

maculipinnis .......

isolepis, Isopsetta................

Lepilopsetta..............

Parophrys ...............

Sternotremia...............

Isopisthus

affinis ..................

parvipinnis ............

remifêr.

Isopsetta........................

isolepis.................

Isospondyli ......................

Isospondylous Fishes .............

isthimensis, Rivulus ...............

Istiophoridx .....................

Istiophorus .

nigricans..........

Isuropsis........................

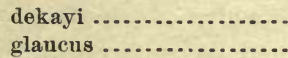

Isurus

dekayi .....................

oxyrhinchus ...............

spallanzani

Itaiara

itaiara, Promicrops ...............

Serranus .................

Jabon .............................

Jaboncillo.

627, 020,1780

Jack

Amber

\section{7}

997

997

2641

2641

2386

2388

2387

2390

2389

2390

2389

2388

2438

748

2439

2439

42

42

1267

51

$33,35,40$

40

40

2642

2642

2642

787

1399

1399

1399

1399

2642

2642

407

407

2830

890

890

891.

47,48

48

48

47,48

48

48,49

49

1142,1162

1164

1164

1232

1232

1780
Tack Goggle-eye

Horse-eye .................. 923

Yellow .................... 919

Jack Salmon .................... 1021

Jacket, Leather .................. $\quad 1701$

Jackets, Leather ................ $\quad 898$

jacksoni, Ditrema ................ 1505

Embiotoca............. 1504, 1505

Jacob Evertzens ................. 1143

jacobæa, Echeneis ................. 2272

Remora................. 2272

jacobi, Corvinus (Johnius) ........ 1457

Sciæna.................. $\quad 1457$

jacobus, Myripristis............. $\quad 846$

Jacome....................... 1215

jacome, Haliperca ............... 1215

Serranus................ 1215

jaculidens, Ancylodon............. 1416

jaculus, Alburnellus ............... 293

Jaguacaguare................... 1562

jaguana, Harengula .............. $\quad 430$

jaguar, Bodianus ................. 849

Jallao .......................... 1295

jamaicensis, Cynoscion............ 1406

Otolithus............. 1406

Raja ................ 81

Urolophus ........... 81

janeiro, Engraulis................ 451

Janissary ...................... 1586

januaria, Umbrina................ 1474

jaok, Cottus .................... 1978

Myoxocephalus ............ 1977

japonensis, Salmo ............... 479

japonica, Squatina .............. $\quad 59$

japonicus, Agonus .............. 2036

Arctoscopus ........... $\quad 2297$

Chirolophus............ 2409

Cottus ................ 2036

Hippocephalus .......... $\quad 2036$

Hoplostethus .......... $\quad 837$

Pereis................. 2034

Phalangistes ............ 2036

Physiculus............. $\quad 2549$

Trichodon............... 2297

Jaqueta......................... 1561

Jaquette, Petitie ................ $\quad 1559$

jarrovii, Lepidomeda.............. $\quad 328$

Minomus................ $\quad \mathbf{1 7 0}$

Pantosteus............... 171

javanicus, Psenes ................ 951

Jaw-fishes....................... 2279

jejuna, Episema................. 290

jejunus, Minnilus............... 290

Notropis ................ $\quad 290$

jemezanus, Alburnellus........... 294 


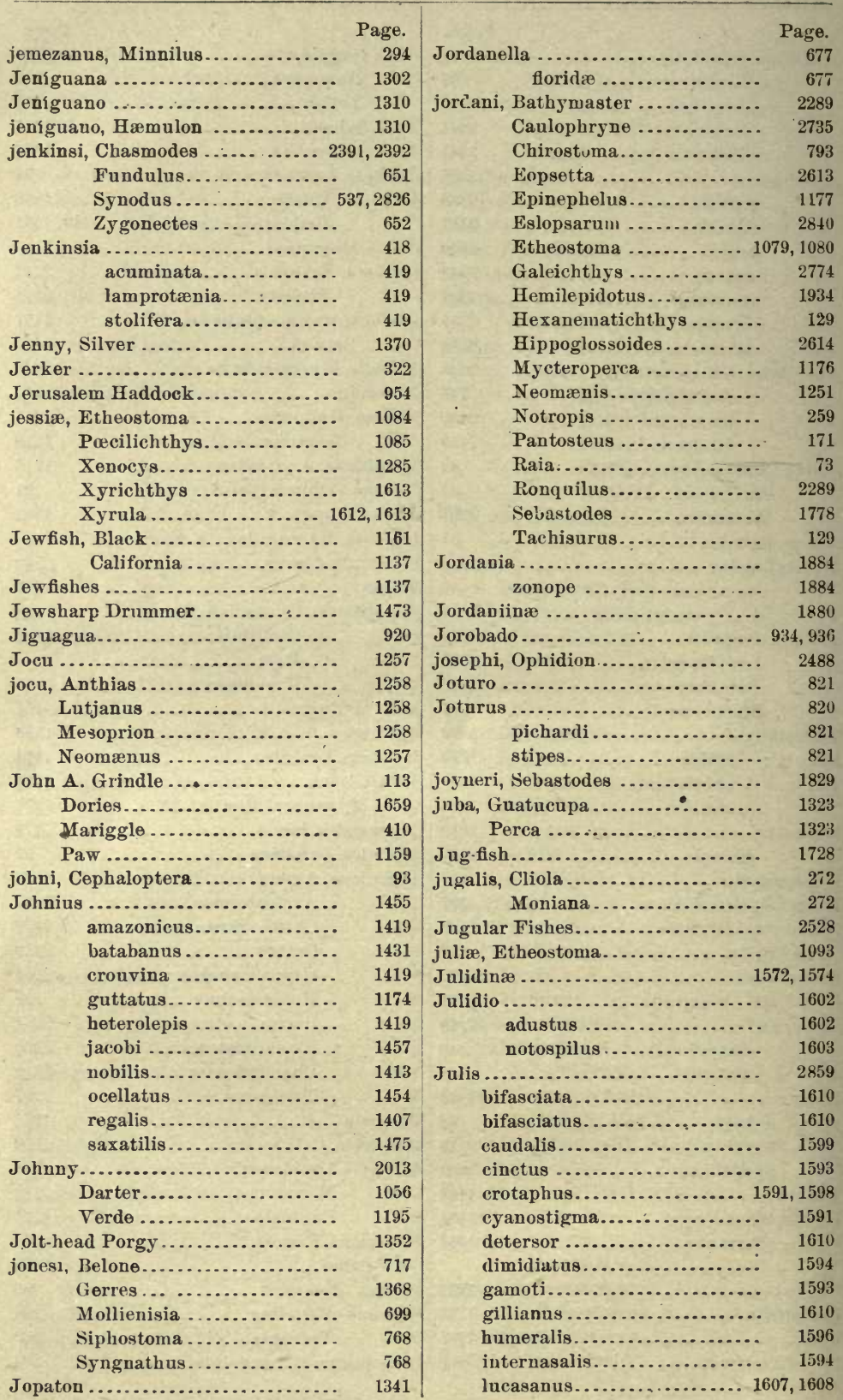


Julis maculipinna melanochir. modestus nitida nitidissima opalina patatus pictus.

principis.................... psittaculus

semicinctus.

Jumping Mullet.

Jump-rocks

June Sucker of Utah Lake.........

Jurel.

Jurvucapeba.

$899,921,923$

Kalog

Kamchatka Salmon Trout.........

kamloops, Salmo gairdneri.........

Kamloops Trout..................

kanawha, Notropis................

kansæ, Fundulus ................

karrak, Anarrhichas..............

Kathetostoma.....................

albigutta............ averruncus..........

Kathetostomatinæ ............... kaupi, Physiculus ............... kaupii, Synaphobranchus.......... Kelpfish

Spotted.................

kendalli, Sphagebranchus..........

Verma..................

kennedyi, Trachinotus............

kennerlyi, Hypsifario .............

Moxostoma.............

Oncorhynchus nerka....

Salmo..................

kennicotti, Acipenser.

Catonotus..............

Coregonus..............

Kenoza...........................

kentuckiensis, Hybopsis.......... Hypsilepis......... Leuciscus........... Luxilus.

279,32

Kern River Trout.................

Keshimugo......................

kessleri, Arius

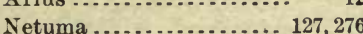

Tachisurus...............

keta, Oncorhynchus...............

keta vel kayko, Salmo..............

kevinskii, Ictalurus .................

Kieye of Lake Michigan .
Page.

1595

1609

1601

1608

1608

1591

1591

1600

1591

1597

1593

197

197

183

1142

1976

2818

499

499

264

2828

2446

2311

2312

2311

2306

2548

351

1, 2352

2353

375

375

942

483

186

483

483

105

1098

464

625,626

322

279

279

502

1833

127

127

478

479

138

469
Killeir, Salmon

Page.

Killifish....................... 639,641

Common................ 640

killifish, Cobitis................. 641

Killifishes..................... 630,632

killinensis, Salmo ................ $\quad 509$

King of the Mackerels ............ $\quad 1755$

Mullets............. 1106

Salmon.................. 479

Kingfish ............ 875, 1460, 1469, 1475

kirschii, Iridio.................. 1598

kirtlandi, Acipenser .............. 106

Kirtlandia ...................... 794

laciniata............ 795, 2840

martinica ............ 795

vagrans ............. 794, 2840

laciniata...... $\quad 2840$

Kisutch....................... 480

kisutch, Oncorhynchus........... $\quad 480$

Salmo ................. 481

kitt, Microstomus................ 2654

Pleuronectes................ 2654

klamathensis, Cottus.............. 1955

kleinii, Balistes .................. 1720

klunzingeri, Achirus.............. 2697

Solea............... 2697

kneri, Pristopoma............... 1338

Kodiak Smelt .................... 2823

kœlreuteri, Scomber .............. $\quad 900$

Kogumeso ....................... 1833

Kowala ...................... 428, 2811

Krasnaya Ryba ................. 481

kraussi, Gobius .................. $\quad 2228$

Krohnius ..................... 2587

kroyeri, Scopelus................. $\quad 556$

kuda, Hippocampus.............. $\quad 778$

Kublia........................ 1013

arge..................... 1014

xenura................... 1015

Kuhliidæ ...................... 1013

kumlieni, Uranidea ................ 1967

kundscha, Salmo................ 2823

Salvelinus ............ 2822

Kuro Soi ...................... 1834

Kyach ....................... $\quad 426$

Kyphosidæ ..................... 1380

Kурhosinæ ..................... 1381

Kýphosus...................... 1384

analogus.............. 1385

elegans ............... 1387

incisor............... 1386

lutescens ............. 1388

ocynrus............... 1390

sectatrix............. 1387

Labeo elegans.................. 186 
Labeo esopus ....................

longatus ...................

Page.

186

186

labialis, Fundulus ................

labiatus, Catostomus..............

Heros ....................

Labichthys .

carinatus..............

elongatus ........... 369, 2802

gilli ...................

Labidesthes ....................... sicculus ..............

Labracopsis .......................

labradoricus, Acanthocottus ....... Coregouns............

Cottus ...............

Oncocottus ...........

Labrax.

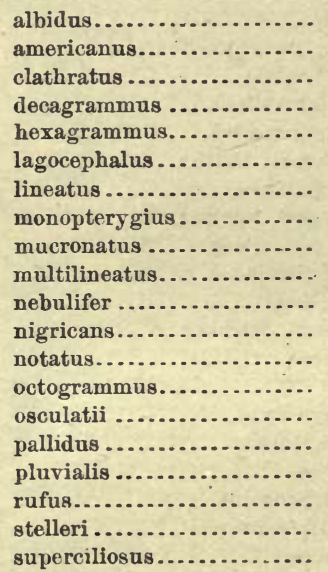

Labriđææ.

superciliosus..............

labridum, Hæmulon...............

labriformis, Epinephelus...........

Serranus .............

Labrinæ

.................... 1572

Labrisomus

biguttatus ............

bucciferus ............

capillatus .............

delalandi.............

herminiger...........

microlepidotus........

nuchipinnis...........

xanti..................

Labroid Fishes...................

Labroperca.

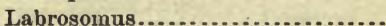

cremnobates........... macrocephalus

177

1530

368

368

368

805

805

1135

2001

466

2004

2004

866,2840

1132

1135

1198

1868

1872

1875

1113

1866

1135

1132

1195

1135

1132

1870

1132

1135

$-2841$

1135

1872

1873

1571

1319

1155

1155

1572-1573

2360

2360

2363

2362

2350

2361

2363

2362

2362

1571

1148

2360

2366

2364
Labrosomus microlepidotus ........ pectinifer

xanti

Page.

2364

2362

2363

2457

319

319

2457

1577

1579

1586

1001

1609

1596

1578

1591

1609

1578

1577

1577

1483

1483

1238

1594

1576

942

1339

1145

1257

1483

1154

1578

988

988

1580

1578

1610

1005

1576

1305

1596

1585

1633

1591

1677

1583

1012

1583

$\begin{array}{lr}\text { sparoides................... } & 987 \\ \text { squeteague............... } & 1407,1409\end{array}$

striatus ................ 1200

subfuscus............... 1578

tautoga ................. 1579

alia.............. 1579

fusca ............ 1579

rubens ........... 1579

tessellatus ............... 1578 
Labrus torquatus

versicolor ...................

Lac de Marbre Trout

lacera, Lagochila.

lacerta, Lampanyetus.

Myctophum

Synodus

lacertinus, Synodus

Lacerto

lacertosus, $\mathrm{Hybopsis}$

Minnilus..........-

Totropis

lacertus, Gobius.

Scomber

Lachnolæmus

$$
\text { maximus ............ }
$$

Lachnolaimus.

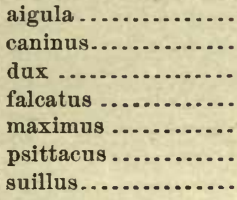

lachrymalis, Ptychostomus.........

laciniata Kirtlandia .......... 795, 2840

vagrans.......

Menidia vagrans ...........

lacrimosum, Sparisoma.............

lacrimosus, Scarus................

lactarias, Catostomus ...............

Lactophrys

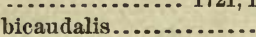

oviceps..................

tricornis ...............

trigonus............. 1723, 1724

triqueter............. 1722

lacustris, Ameiurus ............... 137

Gadus................. 137, 2551

Hemiplus .............. 250

Ictalurus............... 137

Pomolobus pseudoharengus

Lady-fish..................... 411, 1583

Spanish................ 1583

Lad 5 -tishes .................. 410, 1581

Læmargus

borealis.

Læmonema.

barbatala

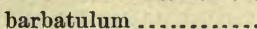

melanurum.............

lætabilis, Moniana

lætus, Centronotus

lævicaudatus, Hippocampus

515

199

199

60

537

536

281

284

284

218

867
579

1580

1580
1580

1580

579
580

1580

2840

795

\section{9}

46

1579

1580

194

1632

632

2

1

Tahoe Trout ............. 493, 2870

lalandi, Carcharias ............... 43

Seriola ................. 902, 903

lamarii, Acipenser .............. 106

lamellifer, Exocœtus ............. 733

Lamia........................ 38, 49,50

lamia, Carcharhinus.............. $\quad 38$

Carcharias................ 38

Eulamia.................. 38

lamiella, Carcharhinus ............ $\quad 37$

Lamiopsis.................... 33

Lamna ...................... 49

caudata................. $\quad 37$

cornubica ................ 49, 2749

punctata................. 48

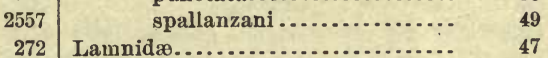

2420 Lamninæ...................... 47

777 lamotteni, Petromyzon ........... 10 
Lampadena

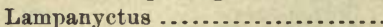

alatus ...............

crocodilus ...........

gemmifer...........

guntheri............

lacerta..............

resplendens .........

townsendi

Lamperina

Lampetra

astori.

camtochatica

cibaria..................

epikexodon ...............

plumbea................

spadicea.................

tridentata .............

variegata...............

wilderi

13,2745

lampetræformis, Blennius..........

Lumpenus .........

Lamprey Eel....................

Lamprey, Great Sea..............

Silvery ..................

Small Black..........

Lampreys .......................

Brook ...................

River.................

Lamprida.

Lampris.

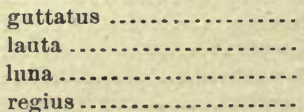

lamprotæuia, Clupea..............

Jenkinsia . . . ..........

Spatelloides .........

lamprurus, Hypoplectrus .........

Serranus ..............

Lampugus ......................

neapolitanus ..........

punctulatus ............

siculus ................

lanatus, Merlucius...............

Lancelet, Balıma...............

California...............

West Indian ...........

Lancelets .........................

European ..............

lanceolata, Perca.................

Sciæna.................

lanceolatum, Branchiostoma .......

lanceolatus, Amphioxus .
Page.

560

561

557

559

558

559

559

560

555

558

6

12

12

13

13

13

12

13

13

12

2745

2438

2438

10

10

11

13

$4,8,9$ lanceolatus, Chretodon............ Page.

Eques............. 1489, 1490

Gobius............. 2229, 2230

Homoprion........... 1444

Limax .............. 3

Lonchiurus .......... 1482

Lonchurus.......... 1482

Stellifer............. 1443

Lancet-fish....................... 1691

Lancet Fishes............... 593, 594, 595

Landlocked Salmon ................ 487

Lane Snapper ................... $\quad 1270$

Langbarn ...................... 2433

Lant .......................... 833

Lantern Fishes ................. 530,550

Lapon........................ 1849

lappa, Halieutella................ $\quad 2742$

La Quesche ..................... 413

Large-mouthed Black Bass......... 1012

Large-scaled Sucker ................ 192

Larimus ..................... 1420, 1421

acclivis ................ 1422

argenteus............... 1421

batabanus .............. 1431

breviceps................ 1423

dentex................. 1426

effulgens................. 1421

fasciatus............... 1424

pacificus................ 1424

stahli................. 1423

larkinsii, Cymatogaster.......... 1503

lata, Guaperva forcipata .......... 1702

Latebrus......................... 1114

oculatns ................ 1115

latepictus, Serranus ............. $\quad 1175$

laterale, Ditrema .................. 1506

Etheostoma............. 1099

lateralis, Abramis................ $\quad 239$

Alvarius ............... 1099

Artedius ............... 1902

Calyeilepidotus........... 1900

Caracodon ............... 2832

Characodon............. 668

Eleotris ............... 2195

Embiotoca.............. 1506

Leucisens balteatus ..... 239

Mylocheilus............ $\quad 220$

Notropis .............. 263

Phanerodon ............. 1506

Philspnus.............. 2195

Pimelodus.............. 135

Precilichthys........... 1099

Richardsonius........... 239

Scarus................. 1637

Scorpronichthys .......... 1902

Truniotoca........... 2505, 1506 
lateralis, Zygonectes...............

laticauda, Anguilla.

Rhamdia ...................

laticaudus, Pimelodus ..............

laticeps, Acanthocottus............

Aetobatus .... ......... 88, 2753

Arius...................

Atherina ................

Bathynectes.............

Megalocottus .............

Mixonus.................

laticlavius, Prionurus.............

Xesurus .................

latidens, Microstomus .............

latifasciatus, Cy prinodon ..........

latifrons, Anarhichas ..............

Citharichthys............

Dormitator ..............

Eleotris ................

Syacium .................

Xenochirus ..............

Latilina ........................

Latilus chrysops ...................

princeps ..................

latimaculatus, Ophisurus ..........

latimana, Belone..................

latior, Coregonus ..................

latipinna, Mollienisia .............

latipinnis, Catostomus.......... 174, 2790

Zaniolepis............ 1876

latirostris, Acipenser ............ 105

Lepidosteus ............ 111

latulus, Clupea....................

422

922

\begin{tabular}{rr} 
Euctenogobius.............. & 2237 \\
\hline
\end{tabular}

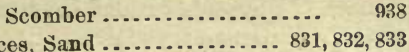

Launces, Sand ................
laurettæ, Argyrosomus............

\begin{tabular}{l} 
laurettæ, Argyrosomus............. \\
Laurida ........................... 471 \\
\hline
\end{tabular}

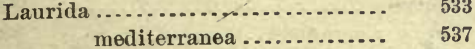

laurito, Sparisoma............... 1637

lauta, Lampris . . . . . . . . . . . . . . . $\quad 955$

lavaretus, Salmo ..................

Lavinia ..........................

conformis.................

crassicauda.............. 231

exilicauda .............. 208, 2799

harengus ................ 209

Lawyer ....................... 113, 1255

Lawyer, Lake ................... $\quad 2550$

leachi, Clupea.................... $\quad 422$

leachianus, Thynnus.............. 869

Least Darter ..................... 1104

Leather Fisl ..................... 1714, 1715

Leather Jacket.................... 1701

Jackets.

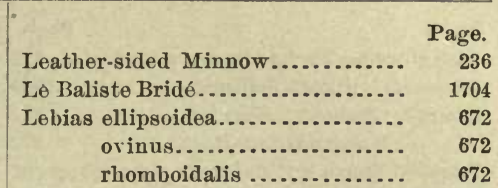

Lebistes....................... 689, 2833

pøeciliodes................ 689

Lebius ........................... 1866

Lebrancho ...................... $\quad 810$

lebranchus, Mugil................ 811

lecontei, Acipenser................ 105

Le Diodon......................... 1746

Orbe................. 1749

Tacheté............... 1746

leei, Symphurus.................. 2708

lefroyi, Diapterus................ 1372

Eucinostomus............ 1372

Ulæma.................. 1371

Lefruyia ...................... 2495

bermudensis ............ $\quad 2497$

Le Gastrobranche Dombey......... 6

loiarchus, Cestreus............... $\quad 1415$

Cynoscion ............... 1414

Otolithus.............. 1415

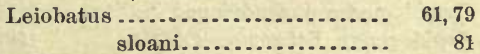

Leiocottus ..................... 2010

hirundo............... 2011

Leiodon ....................... $\quad 56$

echinatum.............. 57

Leioglossus ..................... $\quad 916$

leionothos, Holacanthus........... 1735

leiopomus, Cottus ............... 1962

Leiostomus ....................... 1558

humeralis............ 1459

lineatus ............. 1460

obliquus .............. 1459

xanthurus ............ 1458

Leiurus ...................... $\quad 746$

leiurus, Gasterosteus ............. $\quad 747$

Lo Kai Salmon .................... 478

Lembus .......................... 2194

lemmoni, Squalius................ 235

lemniscatus, Engraulis........... 443

Osmerus ............. 533

Pimelodus ............ $\quad 147$

Lemnisoma ..................... 883

thyrsitoides .......... 884

Lenguado de Rio................... 2698

lenibus, Ostracion triangulatus.... 1724

lentiginosa, Amia................ 113

Muræna............. 402

lentiginosum, Cichlasoma......... 1524

Jentiginosus, Galeichthys........ 122, 2771

Heros .............. 1524

Rhinobatus.........62, 2750 
Ientiginosus, Tachysurns ..........

leonensis, Oligocephalus ..........

leonina, Cliola....................

Moniana.................

Leopard Shark ..................

leopardinus, Antennarius ..........

Platophrys ...........

Rhomboidichthys.....

leopardus, Anarrhichas ...........

Lepadogaster cornubiensis......... nudus ............... reticulatus .......... testar...............

Lepibema ......................

lineatum.............. mitchilli ...............

lepida, Boleosoma ................ Cliola....................

Cyprinella................

Lepidamia

Lopidion

verecundum............

Lepidochætodon .................

Lepidocybium..................

Lepidogaster mæandricus..........

lepidogenys, Etheostoma.........

Lepidogobius

emblematicus

gilberti .............

gracilis ..............

gulosus .............

lepidus ..............

newberryi ...........

thalassinus..........

Lepidolepus.................... norvegicus ..........

Lepidomeda......................

jarrovii ...............

vittata ................

Lepidomegas

Lepidopidæ

Lepidopinæ

Lepidopsetta.

bilineata $2.0-20$.

isolepis

umbrosa..............

Le̊pidopus .....................

argyreus...............

caudatus............ 887, 2844

gouani ............... 887

peronii .............. 887

xantusi ............. 2843, 2844

Lepidosoma................... 2568

Lepidosteus..................... 109

berlandieri........... 111

crassus ............. 110
Lepidosteus grayi

111

latirostris............ 111

leptorhynchus ....... $\quad 110$

manjuari............ 111

oculatus ............. 111

otarius .............. 110

viridis .............. 111

lepidulus, Alburnus............. 294

lepidum, Boleosoma ............. 1089

Etheostoma ............ 1089

lepidus, Gobius ................ $\quad 2249$

Lepidogobius............ $\quad 2249$

Pœeilichthys............. 1089

Lepimphis ..................... 952

hippuroides .......... 952

Lepiopomus.................... 999

ischyrus ........... 997

Lepisoma .................... 2360

cirrhosum ............. 2362

Lepisosteidæ................... 108

Lepisosteus ..................... 109

albus................ 110

bison ............... 110

ferox.............. 111

garailis ............. 110

gracilis ............. 110

huronensis.......... 110

lineatus.............. 110

longirostris .......... $\quad 110$

osseus ............... 109

oxyuras............. 110

platostomus.......... $\quad 110$

platyrhincus......... 111

platystomus ......... $\quad 110$

semiradiatus .......... 110

spatula.............. 111

tristøechus ........... 111

tropicus.............. 111

Lepodus ...................... 958

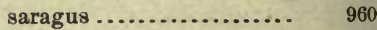

Lepominæ .................... 985

Lepomis ..................... 999, 1010

albulns ................ 1007

annagallinus............ 1004

apiatus ................. 998

sppendix ................ 1005

ardesiacus.............. 1006

auritus .............. 1001, 1009

solis ............ 1001

bombifrons ............. 1003

charybdis............... 992

cyanellus................ 996

euryorus................ 1009

flexuolaris.............. 1011

garmani ............... 1002

gillii................ 992 
Lepomis haplognathus

Page.

holbrookii ......................

humilis ................

ichtheloides...............

ischyrus ................

lirus

longispinis ..............

macrochirus ..............

marginatus ..............

megalotis ...............

miniatus.................

inystacalis ..............

notata .................

notatus ...................

ophthalmicus ............

pallida ..................

pallidus..................

peltastes.................

phenax .................

punctatus.................

purpurescens.............

salmonea ................

symmetricus.............

trifasciata ...............

Lepomotis nephelus..............

Lepophidium....................

brevibarbe..........

cervinum.

2484,2485

emmelas ............

marmoratum.........

microlepis

pardale

profundorum ........

stigmatistium .......

leptacanthus, Noturus ............

Schilbeodes..........

Leptagonus ..................... decagonus ............

spinosissimus .........

Leptarius ......................

dowi.....................

Leptaspis . . .....................

Leptecheneis ......................

naucrateoides .........

naucrates ............

Leptoblennius................... nubilus............. serpentinus .........

Leptocardii ......................

Leptocephalichthys...............

Leptocephalidæ ..................

Leptocephalus

candidissimus .......

caudicula...........

caudilimbatus ......
1004

1008

1008

1004

990

997

1007

1006

1005

1003

1002

1002

1001

1011

1008

1001

1012

1005

1003

997

998

1006

1011

999

1011

1005

2482

2485

248

2482

2486

2486

2484

2483

146

146

2052

2052

2054

119

125

916

2268

2270

2269

2435

2438

2439

2

353

352
Leptocephalus conger............ gracilis............. morrissi ............ spallanzanii ........

leptocephalus, Ceratichthys........ Merlangus..........

Leptoclinus maculatus.

Leptoconger . prolongus ............

Leptocottus . ..................... armatus ...............

Leptodes.........................

Leptogunnellus ...................

Leptophidium.

marmoratum

microlepis............

prorates.

Leptops...................... 142

olivaris ................ 143, 2790

Leptorhinophis ................. 381

leptorhynchum, Siphostoma........ $\quad 764$

Leptorhynchus................. $\quad 369$

leuchtenbergii ..... $\quad 369$

leptorhynchus, Lepidosteus........ 110

Odontopyxis....... 2076

Sarritor........... 2075

Syngnathus ......... 765

leptosomus, $\Delta$ bramis............. $\quad 250$

Luxilus .............. 250

Notemigonus .......... $\quad 250$

Lepturus........................ $\quad 889$

lepturus.............. 889

lepturus, Caranx................ $\quad 923$

Lepturus............... $\quad 889$

Macrourus .............. 2584

Trichiurus ............. 889

Le Sphéroide Tuberculé.......... 1733

Tetrodon Plumier ............. 1733

Les Alutères...................... 1717

Batrachopes ................ $\quad 1740$

Brosmes ..................... 2561

Curimates .................. 332

Dichotomyctères............. 1738

Dilobomyctères............... 1738

Elacates.................... 948

Lottes ...................... $\quad 2550$

Mustèles...................... 2557

Ovoides....................... 1738

Pristipomes................. 1329

Promecocepales............... 1727

Sphéroides.................. 1729

Stellifères..................... 1439

Stenometopes............... 1729

lessoni, Caranx................... 923

Tetrapturus.............. 892 
lessonii, Coryphrena.

Page.

lesueuri, Acipenser

Moxostom

lesueurianum, Exoglossum

lesueurii, Catostonus .............

Letharcus........................ velifer

lethopristis, Orthopristis.

lethostigmus, Paralichthys.........

Lethostole

estor.

792,2839

Lethotremn

(1)

muticus ..............

vinolentus............

leuchtenbergii, Belonopsis ......... Leptorhynchus ....

leuciodus, Minnilus ...............

Notropis ...............

Photogenis.............

Leuciscinæ

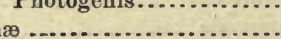

Leuciscus.

affinis .................

228,252

analostanus ............

ardens ..................

argenteus ................

balteatus................

lateralis .......

bicolor

bosci

boucardi

bubalinus ...............

chrysopterus............

cobitis .................

coccogenis ..............

conformis ...............

cooperi ..................

copii

cornutus ................

crassicauda .............

croceus.................

egregius ................

elegans................

elongatus ............. 240, 2797

emorii................ 227

erythrogaster ..........

estor ....................

exilicauda...............

flammeus...............

formosus .................

frontalis ...............

funduloides ..............

gardoneus.

gibbosus

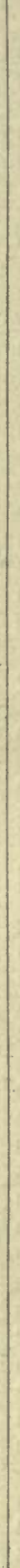

Page.

Leuciscus gracilis. ............... 283, 326

grahami.............. 228

grandis .............. 225

hæmaturus............. 218

heterodon .............. 261

hudsonius.............. 269

humboldti.............. 236

hydrophlox............ 238

hypselopterus........... $\quad 280$

intermedius............ 235

iris.................. 222

kentuckiensis.......... 279

lineatus.............. 232

lntrensis .............. 272

macrolepidotus......... 224

margarita.............. 241

milnerianus............ 242

montanus ............. $\quad 238$

nachtriebi............. 2798

nasutus .............. 306

neogrus.............. 240, 2798

niger................. 235

nigrescens.............. 233

nitidus ................ 221

obesus................. 246, 282

orcutti ................ 241

oregonensis............ 225

phlegethontis :......... 243

photogenis ............. 296

procue................. 264

productus ............... 240

prolixus................ 206

proriger................ $\quad 240$

pulchelloides........... 222

pulchellus.............. 221

purpureus ............ 234

pygmæus .............. 624

robustus ............... 228

rotengulus............. 221

rubellus............... 293

rubrifrons.............. 295

siuslawi............... 2797

spilopterus............ $\quad 279$

spirlingulus............ $\quad 282$

storeri................ 222

storerianus............. 270

telescopus.............. 292

tincella................. 211

tuditanns ............... 253

vandoisulus........... 239

vittatus ............... 282

volucellus............. 263

zeylonicus ............. 415

zunnensis ............. 227

leuciscus, Brachydeuterus ........ 1327

Pomadasis.............. 1328 
leuciscus, Pomarlasys..............

Pristipoma

leucomænis, Salnı..

leucophæus, Congrus............... lencopsarum, Myctophum (Stenobrachius) ..........

Nannobrachium..... leucops, Photogenis............. engraulinus...

leucopus, Photogenis..............

Rhamphoberyx .........

leucorhynchus, Rhinobatus ........

leucorus, Eupomacentrus .........

Leucos .................. 243, 244, 2798

bicolor.................. 245

formosa ................ $\quad 246$

obesus................... 246

leucos, Carcharhinns............. $\quad 38$

Carcharias ............... 38

Leucosomus ................ 220, 221, 250

americanus .......... 250

argyreiosus ...........

cataractus ............

caurinus..........

communis ............

corporalis.............

dissimilis ............

gulonellus ............

inæquilobus ...........

incrassatus ...........

occidentalis...........

pallidus..............

pulchollus ............

rhothens.............

symmetricus.........

leucosteus, Calamus..............

leucostictus, Eupomacentrus ......

Pomacentrus .........

leucurus, Caranx

Hemicaran $x . . . . . . . .$.
Nauclerus ...............

Leucus anticus ..................

boucardi .................

dimidiatus ................

formosus ...............

olivaceus..................

tincella ..................

Leuresthes.....................

crameri ..............

tenuis.

Leuroglossus

stilbius.............

Leurynnis.......................

paucidens ..............

levis, Sebastichthys ..............

Sebastodes................. $3030-112$ lewis, Squatina ................. $\quad \begin{array}{r}59 \\ \text { Page. }\end{array}$

lewisi, Salar ................... 493

Salmo clarkii............. 2819

mykiss ............ 493

Zygæna ................. 45

liberiensis, Balistes.............. 1702

libertate, Opisthonema........... 433

libertatis, Clupea ................ 433

Meletta ................ 433

Opisthonema........... 433

Lichia quiebra .................. $\quad 899$

lichtensteini, Acipenser.......... $\quad 105$

ligulata, Seriola.................. 905

Lija................... 1714, 1715, 1718

Barbuda................... 1720

Colorada..................... 1713

Trompa .................... 1719

Lile...................... 428, 429, 431

lima, Loricaria ................... 158

Limamuræna................. $\quad 400$

melanotis .......... 402

Limanda ...................... 2644

aspera.................. 2645

beanii .................. 2646

ferruginoa.............. 2644

proboscidea............. 2645

rostrata ................. 2645

limanda, Hippoglossoides.......... 2615

limandoides, Hippoglossoides...... 2615

Plouronectes......... 2615

Limax lanceolatus...............

limbatus, Carcharhinus.......... $\quad 40$

Carcharias ............ $\quad 40$

Conger................ $\quad 360$

Fundulns .............. 643

Isogomphodon ......... 40

Oxydontichthys........ 385

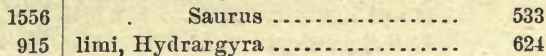

915 limi, Hydrargyra ................

$914 \quad$ pygmæa $\ldots . . . \ldots \ldots . . .6 .624$

245 Limia ......................... 690

$247 \quad$ couchiana ................ 695

$244 \quad$ cubensis................... 692

246 matamorensis ............. 700

244 pavonia .................. 692

211 Pociloides ................. 700

$801 \quad$ venusta $\ldots \ldots \ldots \ldots \ldots \ldots . . .6 .665$

802 Limnurgus..................... 666

$802 \quad$ variegatus............ 666

527 limosa, Myxine ................. 8

527 limosus, Pilodictis .............. 142

$2460 \quad$ Pylodictis............... 143

$2460 \quad$ Silnrus.................. 143

1816 linea, Mesoprion ................. 1260

1816 Siphostoma............... 768 


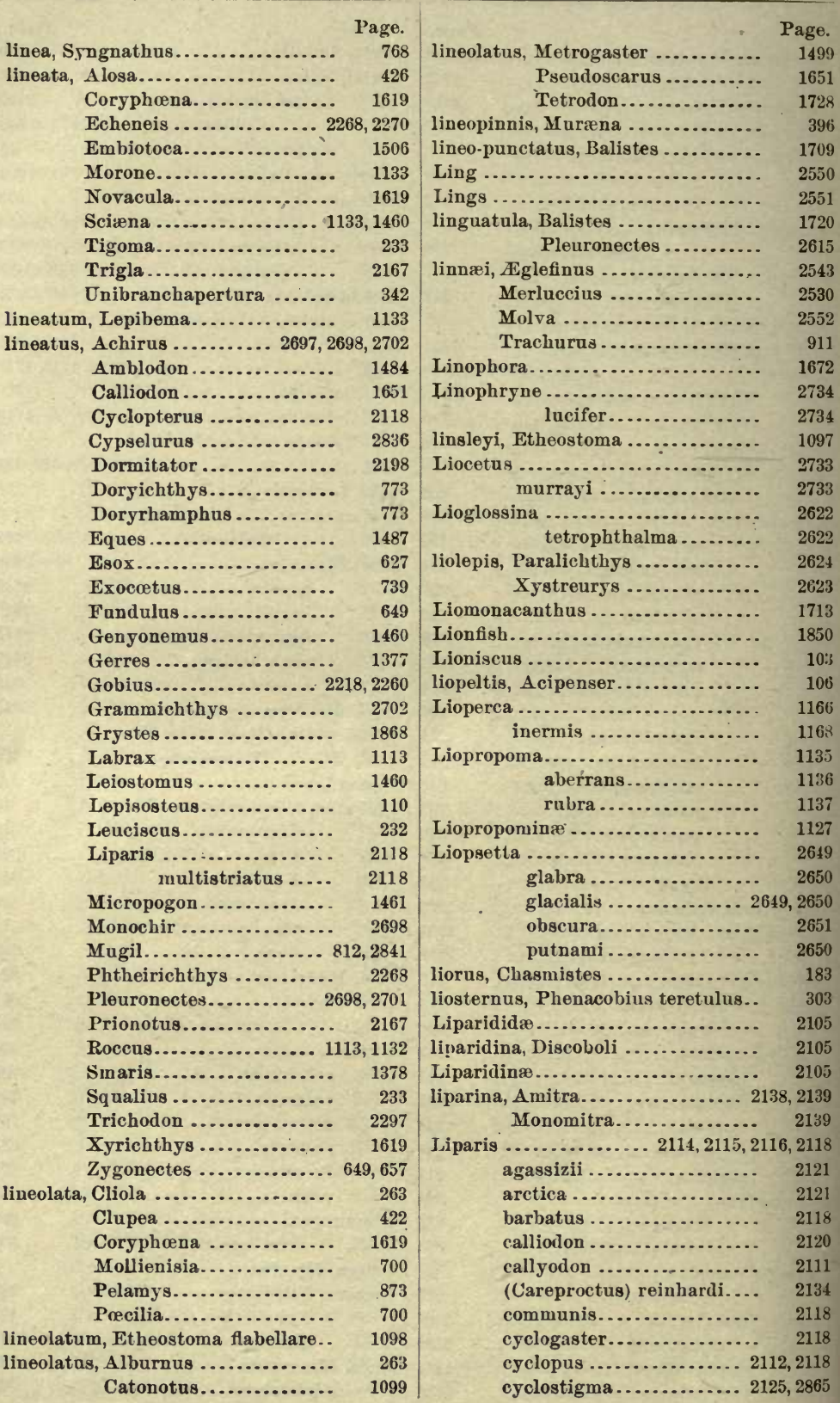




\begin{tabular}{|c|c|c|}
\hline iparis dennyi .. & $\begin{array}{r}\text { Page. } \\
2124\end{array}$ & Little Tunny.. \\
\hline ekstromi & 2108 & Little-head Porgy................... 1350 \\
\hline fabricii................. 2121 & 1,2128 & Little-month Porgy ............... \\
\hline fucensis.................. & 2119 & littoralis, Carcharias .............. 46, 2748 \\
\hline gelatinosus ............. 2134 & 4,2135 & Eugomphodus............ $\quad 47$ \\
\hline (n..................... & 2123 & Menticirrhus............ \\
\hline n................. & 2108 & …........... \\
\hline us $\ldots \ldots \ldots \ldots \ldots$ & 2123 & (n).......... \\
\hline lineatus .................... & 2118 & littoricola, Chætodon \\
\hline iatus. & 2118 & (n............. \\
\hline 2116 & 6,2118 & liturosus, Dic \\
\hline 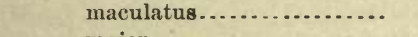 & 2108 & lividus, Petromyzon.. \\
\hline ............... & 2127 & Silurus $\ldots \ldots \ldots \ldots \ldots \ldots$ \\
\hline 2107 & 7,2108 & Liza.................................. \\
\hline (n............ & 2111 & liza, Mugil ...................... 81 \\
\hline n............. & 2118 & Liza Ojo de Perdriz ... \\
\hline (n)............. & 2118 & (n) \\
\hline ........... & 2126 & 53 \\
\hline a & 2134 & $\begin{array}{r}\text { lobatus, Canthogaster .............. } \\
\text { Spheroides ............... } 17331,1732\end{array}$ \\
\hline $\begin{array}{l}\text { reticiuata ...................... } \\
\text { stellatus .................... }\end{array}$ & 2118 & lobochilus, Heros................... 1531 \\
\hline tunicata................ 2121 & 1,2128 & Lobotes ........................... \\
\hline n................... & 2120 & auctorum............... 1236, 2858 \\
\hline ................. & 2118 & emarginatus............... $\quad 1257$ \\
\hline paris, Centr & 963 & 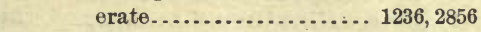 \\
\hline Cyclopterus............... & 2123 & farkharii ..............1236, 2856 \\
\hline major....... & & incurvus ............... 1236, 2856 \\
\hline $\operatorname{minor} . . . . . . . .$. & & .............. 2857, 2858 \\
\hline Liparis................. 2116 & 6,2118 & somnolentus ................. \\
\hline rus............. & 2108 & surinamensis ........ $1235,2856,2858$ \\
\hline (n................. & 2104 & Lobotidær......................... \\
\hline$\ldots \ldots \ldots \ldots \ldots$ & 2104 & lockingtonii, Icichthys .............. \\
\hline (n................ & 2095 & 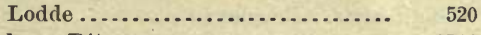 \\
\hline$\ldots \ldots \ldots \ldots \ldots \ldots \ldots$ & 619 & love, Ditrema ...................... \\
\hline enyidw.......................... & 619 & Log Fish ........................... 964 \\
\hline ipogenys gillii..................... & 619 & Perches ................... 1024, 1026 \\
\hline 2377 & 7,2378 & Lonchiurus ..................... 1481 \\
\hline s n................. & 2784 & atus ................. \\
\hline & 964 & Lonchopisthus ..................... \\
\hline (n) & & athus ....... \\
\hline (n) & & $\begin{array}{l}\text { Im, Opisthognathus......... } \\
\text { us ancylodon .............. }\end{array}$ \\
\hline $\begin{array}{r}\text { Notropis } \\
\text { Lisa Blanca... }\end{array}$ & & 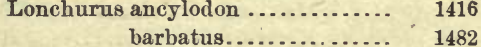 \\
\hline $\begin{array}{l}\text { Lisa Blanca ... } \\
\text { Cabezuda }\end{array}$ & 813 & $\begin{array}{l}\text { barbatus................. } \\
\text { depressus................ }\end{array}$ \\
\hline (n) & 410 & $\begin{array}{l}\text { depressus................. } \\
\text { lanceolatus ............. }\end{array}$ \\
\hline (n) & 2036 & loncharus, Opisthognathus......... \\
\hline (n................... & 814 & ................ \\
\hline $\operatorname{tracion} \ldots \ldots \ldots \ldots \ldots \ldots$ & 1725 & Long.jawed Goby .................... \\
\hline lita, Muræna.................... & 2805 & Long-jaws......................... 710,711 \\
\hline tœehus................ & 111 & Long Mingo......................... \\
\hline (.................... & 627 & longa, Dasibatis................... \\
\hline (n................ & 996 & ratis .................... \\
\hline 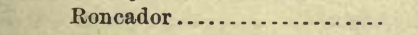 & 1460 & naldia ................. \\
\hline n.............. & 68 & Iongatus, Labeo ................... \\
\hline & 807 & .................... \\
\hline & 868 & Long-eared Sunfish . \\
\hline
\end{tabular}


Long-finned Albacore.............. Charr................

Sole...

longicauda, Gobius................

Gymnothorax .........

Muræna ...............

Rabula ...............

longicephalus, Galeichthys ........ Hexanematichthys .

Tachisurus .........

longiceps, Eleotris ................

Hybopsis .................

Siboma.

longicollis, Myrophis

longidens, Caulolepis.

longifilis, Bathygadus

Hymenocephalus ........

longimana, Etheostoma ...........

Eulamia...............

longimanus, Boleosoma ............

Cichlasoma............

Heros ................

Squalus ...............

Xystroplites ...........

longipes, Bathypterois ............

Gadus....................

longipinne, Gobiosoma ............

Holocentruın ..........

longipinnis, Clevelandia ..........

Evermannia...........

Rhombus..............

Stromateus ...........

longirostris, Alburnops ...........

Catostomus ...........

Cliola .................

Esox...................

Euleptorhamphus ....

Hemirhamphus.......

Hippocampus .........

Hy poprion ............

Lepisosteus...........

Malthæa..............

Notropis .............

Saurus...............

Tylosurus ............

longirostrum, Catostomus .........

longispathum, Peristedion ..........

longispinis, Ailurichthys ..........

Lepomis ..............

Pontinus ..............

Long necked Eels ................

Long-nosed Dace..................

Gar.

Sucker................

Long-spined Sculpin

Long-tail Shark.
Page. $\begin{array}{rr}\text { longalus, Calliurus................. } & \begin{array}{r}\text { Page. } \\ 996\end{array} \\ \text { Pomotis................. } & 996 \\ \text { longurio, Carcharias ............... } & 49\end{array}$

Scoliodon .............. 42,2748

longus, Balistes................ 1707

Ophisurus................ $\quad 377$

Pisodonophis............. $\quad 377$

Look-Down ..................... 996

lophar, Perca .................. 947

Lopharis ........................ 946

mediterraneus ........... 947

Lophiidæ ....................... 2713

Lophiomus ....

setigerus............. $\quad 2714$

Lophius......................... 2713

aculeatus............... 2741

americanus............. 2714

bufo ................... 2316

gibbus................. 2717

histrio .............. 2716, 2722

ocellatus................ 2722

piscatorius .............. 2713

radiatus ................ 2738

rostratus ................ 2737

setigerus ................ 2715

spectrum .............. 2723

tumidus ................ 2716

viviparus ................ 2715

lophius, Amiurus ................ 138

Ictalurus................ 138

Lophobranchii .................. $\quad 759$

Lophobranchs .................. 759

Lophogobius................... 2209

cyprinoides.......... 2209

Lopholatilus .................... 2278 chamaleonticeps..... 2278

Lophopsetta .................... 2659 maculata ........... 2660

Lord, Irish. ....................... 1934

lordii, Salmo .................... 508

loreto, Gramma ................. 1229

Loricaria................... 156, 157, 159

acuta.................. 158

barbata ................ 158

bransfordi.............. 158

lima................... 158

panamensis $. . . \ldots \ldots \ldots . .157$

rostrata............... $15 i$

strigilata............... 158

uracantha.............. 158

variegata............$\quad 159$

Loricariichthys ................ 156

Loricariidæ ..................... 155

Loricariinz..................... $\quad 156$

loricata, Alysia ................. $\quad 569$

Loricati....................... 1756 
Page.

loricatus, Gasterosteus

Macrognathus.

Phalangistes

Loro $\ldots \ldots . \ldots \ldots \ldots \ldots . . \ldots 1652,1653,1655,1657$

Loros ............................ 1642

Lota ......................... 2550

brosmiana .................. 2551

compressa ...................

inornata ...................

maculusa ...................

Lotella ...........................

maxillaris ..................

lotharingus, Gasterosteus..........

Lotinæ..........................

loubina, Perca ...................

lonisiana, Engraulis

louisianæ, Notropis.

Siphostoma .............

Synguathus ............

lowei, Polymixia.................

lowii, Omosudis ...................

loxias, Prionotus .................

lubb, Gadus.....................

lubricum, Branchiostoma .........

Lucania.

affinis ...................

goodei................. 664, 2831

ommata ................663, 6631

parra..................665, 2831

venusta ..............665, 2831

lucasana, Splyræna ............. $\quad 826$

lucasanum, Thalassoma ......... 1607, 2859

lueasanus, Chlorichthys.......... 1607

Julis ................ 1607, 1608

lucasi, Ceratocottus................ 1940

lucayanum, Asymmetron ..........

Luccius vorax....................

lucens, Ceratichthys ..............

Dacentrus ..................

luciæ, Fundulus.................

Haplochilus ...............

Hydrargyra ................

Zygonectes ..................

lucida, Atthoprora.................

lucidus, Argyrosomus..............

Coregonus .................

Luxilus...................

Notemigonus ..............

Salmo (Coregonus) .........

Stolephorus...............

Lucifer

lucifer, Linophryne ...............

Lucifnga

dentatus.

subterraneus
1940

628

321

1496

654

655

$6 \overline{5} 5$

655

565

470

471
Page.

Lucifuginæ .................... 2498

Lneiidæ....................... 624

Lucioblennius..................... 2404

alepidotus.......... $\quad 2404$

lucioceps, Saurus................. $\quad 539$

Syuodus............... $\quad 539$

Luciocharax ................... $\quad 339$ insculptus ........... $\quad 339$

lucioides, Esox ................. $\quad 628$

Lucioperca americana............ 1022

borea............... 1022

canadensis ............. 1022

grisea ............... 1022

pepinus ............... 1022

vitrea................ 1022

luciopercana, Mentiperea ......... 1216

luciopercanus, Centropristis........ 1216

Prionodes .......... 1216

Serranus ........... 1216

Luciopercinæ ..................... 1018

Luciotrutta .................... 473

mackenzii .......... 474

Lucius ..................... 625, 626, 628

americanus............... $\quad 626$

lucius .................... $\quad 628$

masquinongy............. 629

immaculatus . 630

ohiensis ...... 629

reticulatus ............... 627

vermiculatus........... 627,2827

lucius, Atractosteus.............. $\quad 111$

Esox.................... 628

americanus ........... $\quad 626$

Lucius.................. $\quad 628$

Ptychocheilus .............. 225

Lucky Proach................... 1971

lucretiæ, Aboma.................. 2241

Gobius................ $\quad 2868$

ludibunda, Cliola................. 273

Cyprinella............. $\quad 373$

ludibundus, Notropis .............. 273

Lugger, Stone ................. 181

lugubris, Caranx ................ 924

Cyprinella .............. 274

Malacoctenus ........... 2357

Melamphaes ........... $\quad 842$

Myxodes................ $\quad 2357$

Plectromus ............ $\quad 842$

lugubrosus, Esox ................ 628

luitpoldii, Characodon ............. $\quad 2832$

lumbricus, Muræna............... $\quad 342$

Myrophis ............. $\quad 371$

Lumpeninæ.................... $\quad 2349$

Lumpenus .................... 2435, 2436

aculeatus ............. 2433

anguillaris............. 2436 


\begin{tabular}{|c|c|c|c|}
\hline Lumpenus fabricii .... & $\begin{array}{r}\text { Page. } \\
2437\end{array}$ & luteus, Genyatremus ........ & $\begin{array}{r}\text { Page. } \\
1342\end{array}$ \\
\hline $\begin{array}{l}\text { Lampetræformis. } \\
\text {. }\end{array}$ & 2438 & Lutianus ............. & 1343 \\
\hline mackayı ........ & 2436 & Noturus ...... & 144 \\
\hline maculatus & 2433 & Rhinichthys........ & 307 \\
\hline medius ... & 2435 & Lutianidæ ............... & 1241 \\
\hline nubilus... & 2438 & Lutianinæ ................. & 1242 \\
\hline ocule & 2433 & Lutianus....................... & 1247 \\
\hline lumpenus, Blennius................. & 3438 & argentiventris $\ldots . .$. & 1261 \\
\hline Clinus..................... & 2438 & colorado.............. & 1268 \\
\hline Stichæus ............... & 2438 & us ............ & 1269 \\
\hline Lumpfish .............................. & 2096 & luteus............. & 1343 \\
\hline Lump Sucker................... 2094, & 4,2096 & novemfasciatus .... & 1253 \\
\hline Lumpus ............................. & 2096 & stearnsi ............. & 1256 \\
\hline anglorum & 2097 & lutipinnis, Hydrophlox......... & 287 \\
\hline s..................... & 2099 & Minnilus........... & $28 \pi$ \\
\hline s n...................... & 2097 & Notropis............. & 286 \\
\hline lumpus, Cyclopterus............ 2096, & 6,2097 & Opisthopterus ....... & 437 \\
\hline Luna, piscis ........................... & 1754 & Pristigaster ......... & 437 \\
\hline 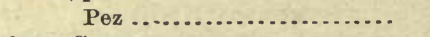 & 1753 & lutjanoides, Lutjanus ............ & 1261 \\
\hline 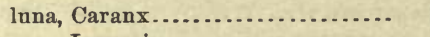 & 927 & Neomænis.......... & 1261 \\
\hline pris...................... & 954 & as.............. & 1261 \\
\hline Pomotis ..................... & 1006 & Lutjanus acutirostris ........... & 1259 \\
\hline Zeus $\ldots \ldots \ldots \ldots \ldots \ldots$ & 955 & ambiguus ............ & 1272 \\
\hline lunaris, Orthragoriscus ............ & 1754 & n............. & 1267 \\
\hline lunata, Echeneis.................... & 2269 & (n......... & 1274 \\
\hline lunaticus, Dactyloscopus ........... & 2302 & tiventris ....... & 1261 \\
\hline lunatus, Platophrys ................ & 2665 & s $\ldots \ldots \ldots \ldots$ & 1279 \\
\hline Pleuronectes........... & 2666 & anbrieti .............. & 1271 \\
\hline Rhinichthys .............. & 308 & aurorubens........... & 1278 \\
\hline $\begin{array}{r}\text { atronasus.... } \\
\text { Rhomboidichthys......... }\end{array}$ & 308 & aya.................. & 1265 \\
\hline 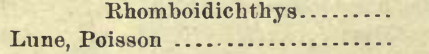 & 2666 & blackfordi......... & 1265 \\
\hline 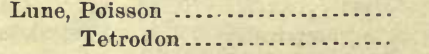 & 954 & brachypterus ....... & 1268 \\
\hline $\begin{array}{r}\text { Tetrodon } \ldots \ldots \ldots \ldots \\
\text { luniscutis, Arius } \ldots \ldots \ldots \ldots \ldots \ldots\end{array}$ & 1754 & buccanella .......... & 1262 \\
\hline or & 125 & te $\ldots \ldots \ldots$ & 1257 \\
\hline 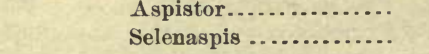 & 2763 & chianus..... & 1265 \\
\hline rus .................... & $\begin{array}{l}125 \\
125\end{array}$ & ............... & 1260 \\
\hline phelus .............. & $\begin{array}{r}120 \\
1159\end{array}$ & is ......... & 1404 \\
\hline nus..................... & 1158 & (n) & $\begin{array}{l}1276 \\
1268\end{array}$ \\
\hline Mustelus................ & 28 & $\begin{array}{l}\text { colorado................. } \\
\text { cyanopterus.......... }\end{array}$ & 1255 \\
\hline Rhomboidichthys....... & 2666 & cynodon.................... & 1255 \\
\hline Serranus............... & 1159 & cubera............. & 1255 \\
\hline lupus, Ameiurus ................... & 137 & dentatus ............ & 1255 \\
\hline Anarhichas ........................ & 2447 & griseus............. & 1257 \\
\hline Ietalurus ................... & 137 & guttatus ........... & 1269 \\
\hline Pimelolus .................... & 137 & inermis................ & 1275 \\
\hline lusca, Cyclothone ................... & 582 & 1................... & 1258 \\
\hline sitanıcus, Vandellius......... & 887 & latus .......... & 1158 \\
\hline ea, Anguilla................ & 348 & goides........... & 1261 \\
\hline teovinctum, Etheostoma & 1086 & & 1273 \\
\hline lutescens, Chæ & 1680 & us ....... & 1276 \\
\hline $18, \ldots \ldots \ldots \ldots . .$. & 1388 & asciatus. & 1253 \\
\hline erus .............. & 1389 & & 1273 \\
\hline (s) & 1304 & pacificus ........... & 1253 \\
\hline pomus ................. & 1024 & profundus . . .......... & $\begin{array}{l}1253 \\
1264\end{array}$ \\
\hline
\end{tabular}




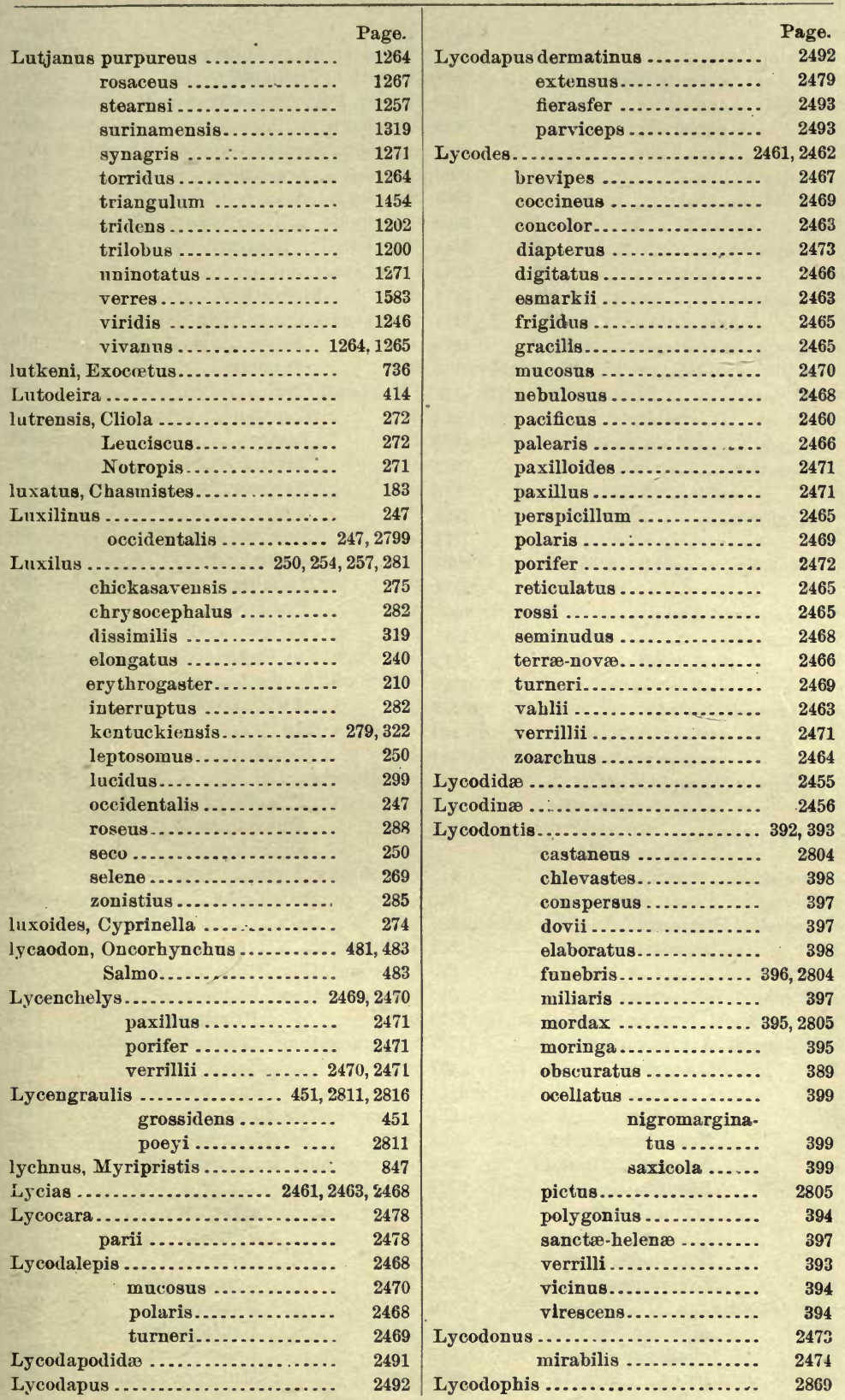




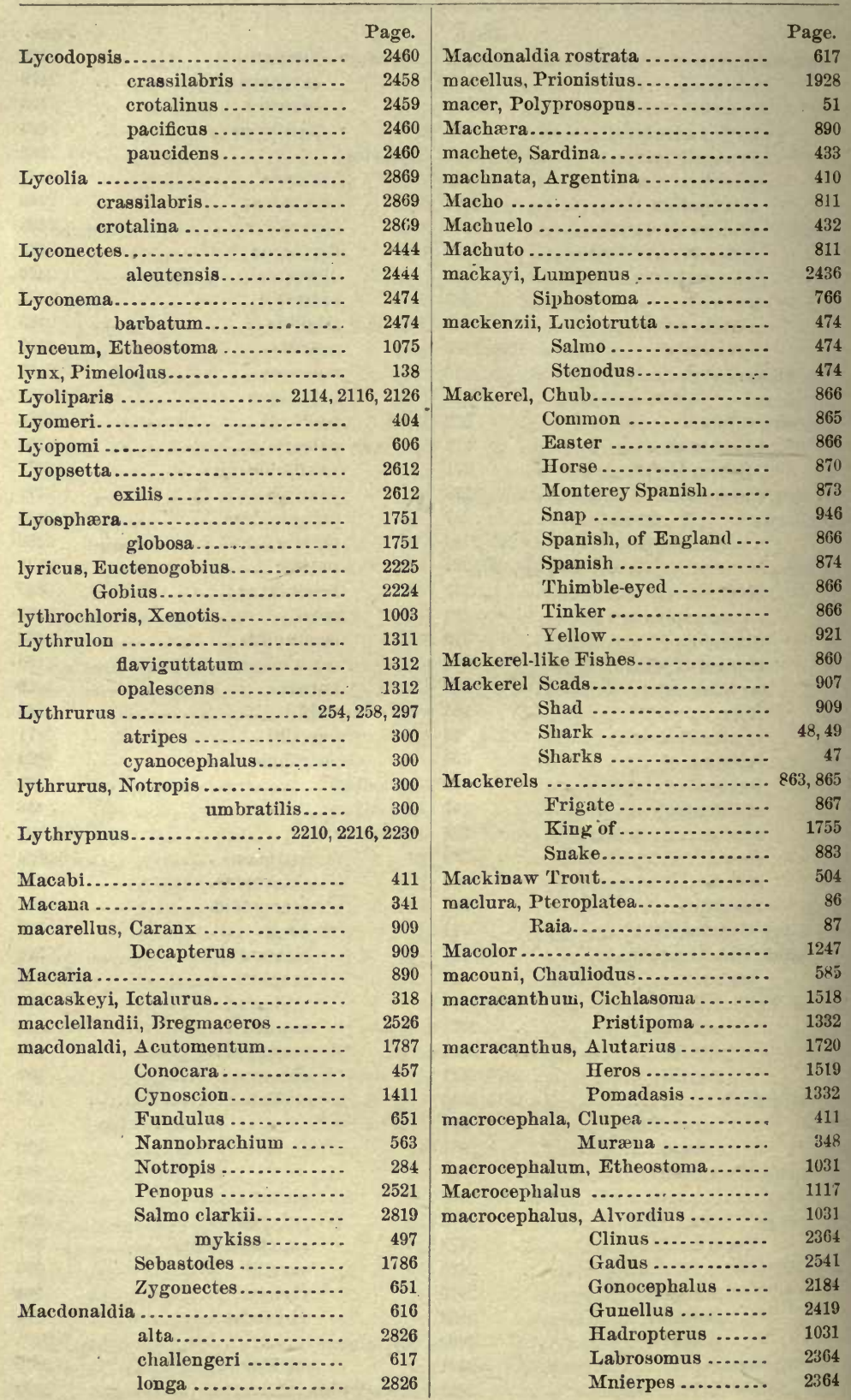


macrocephalus, Percina............ Semotilus..........

macrocerus, Monacanthus.......... macrocheilus, Catostomus.......... macrochir, Aldrovandia...........

Halosaurus ............

Sebastolobus ...........

macrochirus, Eupomotis ...........

Hemirhamphus ......

Lepomis .............

Macrodon ........................

malabaricus ............

microlepis ...............

Macrodonophis

$\operatorname{mordax} . . . . . . . .$.

macrodus, Squalus............... macrogenis, Cerna ................ macrognathum, Opisthognathus ... Macrognathus................... brevirostris........ loricatus ............

macrognathus, Opisthognathus .... macrolepidota, Anchovia.......... Poecilia............ macrolepidotum, Moxostoma...... macrolepidotus, Catostomus.......

Ch:etodon ......... Engraulis ........ Fundulus heteroclitus.........

Lenciscus ........

Notropis .........

Pleuronectes .....

Pogonichtliys ....

Stolephorus ......

macrolepis, Pontinus .............. macronema, Pimelodus ........... macronemus, Bagrus..............

Nemipterus .........

Polynemus...........

Synagris .............

macrophthalma, Clnpea............

Harengula....... macrophthalmus, Aprion ........ 1280, 1281

Caranx ..........

Centropristis ....

Elastoma........

Gobiesox .........

Priacanthus ....

Sardinella ........

Scomber .........

macropoma, Bollmannia...........

Centropristis..........

Diplectrum ..........

Macrops.......................... oculatus.
Page.

1031

222

1713

178

609

610

1763

1005

723

1005

330

330

330

386

387

47

1181

2281

759

723

110

2282

449

641

193

194

1677

449

\section{1}

224

299

2672

223

449

1855

155

117

1289

828

1289

430

430

911

1281

1281

2335

1238

430

867

2239

1206

1205

1281

1283
Page.

macrops, Balistes ................ 1706

Bathygadus ............ 2560

Calamus.............. 1350, 1534

Citharichthys........... 2684

Conger ................. 355

Curvina................ 1428

Corvula ............. 1427, 1428

Gnathypops............ 2284

Hippoglossina.......... 2621

Opisthognathus ......... 2284

Opisthopterus........... 437

Pristigaster ............ $\quad 437$

Scixna ................. 1428

macroptera, Conocara ............. 457, 458

Goniobatis ........... 88

macropterum, Hypentelium........ 181

macropterus, Alepocephalus ....... $\quad 458$

Balistes ............. 1707

Centrarchus ......... 988

Labrus............. 988

Thynnus............ 871

macropus, Malacoctenus .......... 2357

Myxodes............... 2357

Macrorhamphosida .............. $\quad 758$

Macrorhamphosus............... $\quad 759$

scolopax......$\quad 759$

macrorhinus, Acipenser........... 105

macrorhynchus, Hemirhamphus ... 724

macrospila, Piramutana........... $\quad 155$

Macrostoma.................... 554

angustidens..........555, 2826

brachychir ........... 2826

castaneum ........... 556

caudispinosum ....... 559, 2826

margaritiferum ....... $\quad 555$

quercinum ........... 554

macrostoma, Cyprinella ........... 274

Hremulon ............ 1297

Salmo ............... 481

macrostomum, Hæmulon.......... 1296

macrostomus, Acipenser.......... 106

Notropis ........... 274

Macrouridæ..................... 2561

Macrourinæ.................... 2562

Macrourus..................... 2581

acrolepis ............. 2585

bairdii................ 2583

berglax............... 2581

cinereus.............. 2586

fabricii.............. 2582

holotrachys ........... 2582

lepturus.............. 2584

rupestris ............. 2582

stelgidolepis........... 2585

stromii ............... 2579

nacrourus, Alopias.............. 46 
Macrozoarces

Page.

2456

macrura, Congermuræna..........

Macruroplns .....................

macrurum, Ophisoma .............

Macrurus

acrolepis $\ldots . . . . . . . . .$.

asper ....................

carminatus ..............

carribbæus ...............

dorsalis .................

firmisquamis ............

goodei.................

(Nematonurus) magnus..

ocea ...................

pectoralis ................

rupestris ...............

scaphopsis..............

simulus ................

suborbitalis .............

macrurus, Oxydontichthys ........

macularius, Cyprinodon ...........

$$
\text { baileyi.... }
$$

maculata, Apogon ................

Belone................

Hemitremia............

Lophopsetta ............

Morone .................

Muræna nigra...........

Nerophis..............

Perca ..................

Sciæna.................

maculaticeps, Boleosoma nigrum .. maculatofasciatus, Paralabrax.....

Serranus.......

maculatum, Boleosoma ......... 1057, 1077

Cybium ...............

Cynoscion..............

Etheostoma ...........

maculatus, Alvordius

vordius ........... 1032, 1034

Anarrhichas ........... 2446

A pogon ............... 1109

Aulostomus........... 754

Balistes ............. 1707, 1708

Bothus............... 2660

Canthidermis........ 1706, 1707

Clinus................. 2433

Cottus................ 1972

Cryptacanthodes....... 2443

Ctenodon.............. 2433

Diodon............... 1746

Dormitator........... 2196, 219

Galeocerdo............ 32

Galeus ............... $\quad 32$

Gasteropelecus......... 338

Hadropterus ......... 1031, 1034

Heptranchias

18

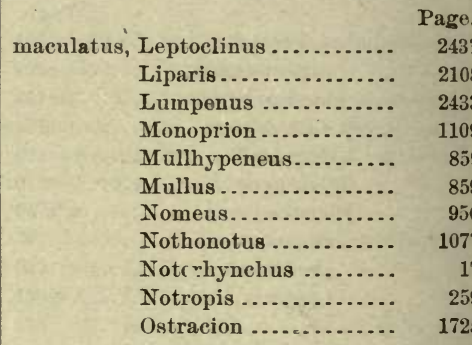

Pimelodus ............. 135, 155

Platyprecilus........... $\quad 686$

Pleuronectes.......... 2660

Procerus.............. 102

Psenes ................. 951

Rhypticus ............ 1234

Scomber ............. 867,874

Scomberomorus. ...... 874,875

Serranus............. 1153

Spherides............. 1733

Spheroides............ 1733

Stichreus ............. 2433

Upenens .............. 858

ınaculicauda, Diabasis ........... 1314

Hæmulon ........... 1314

Orthostœchus ....... 1313

maculifer, Diodon ................ 1747

Platophrys............. 2664

Pleuronectes........... 2665

maculiferus, Hypoplectrus........ 1192

Rhomboidichthys..... 2665

maculipinna, Chærojulis .......... 1595

Halichæres ......... 1595

Iridio .............. 1594

Julis ............... 1595

Platyg lossus ......... 1595

2698

$\begin{array}{lr}\text { Exocnetus ............ } & 737 \\ \text { Heros .............. } & 1529\end{array}$

$\begin{array}{lr}\text { Exocnetus ........... } & 737 \\ \text { Heros .............. } & 1529\end{array}$

Isogomphodon ...... 40

Monochir .......... 2698

Muræna............ 394

Solea.............. 2698

Thyrsoidea......... 394

maculocinctus, Chætodon .......... 1674

Sarothrodus........ 1674

maculosa, Harengula.............. 430

Lota................. 2550

Molva................ 2551

Muræena.............. 382

Thalassophryne........ 2324

maculoseriatus, Chirus ........... 1868

maculostriatus, Diodon ............ 1748

maculosum, Hæmulon............ 1295

maculosus; Acentrolophus......... 963 
maculosus, Acipenser.

Catostomus

rarchus............

Centridermichthys....

Epinephelus ...........

Gadus...................

Nomeus ...............

Oligocottus.............

Paralichthys ...........

Pimephales.

promelas ...

Pleuronectes...........

Serpens marinus ........

Serranus ..............

madeirensis, Ceratoscopelus .......

Scopelus .............

Marlemoiselle

......................

maderaspatensis, Butirinus.......

maderensis, Helicolenus..........

Madregal

Mad Tom

mreandricns, Caularchus ..........

Lepidogaster.........

Mænidæ

Mæninæ

magdalenæ, Curimata...............

Otolithus.............

Paralichthys.........

Sciæna..............

magistralis, Epinnula...........

magnioculis, Ophichthus ...........

Ophichthys..........

Scytalophis...........

magnus, Macrurus (Nematonurus).

Mahogany Snapper ..............

mahogoni, Lutjanus ..............

Mesopriou............

Neomænis ..............

Mail-cheeked Fishes ..............

Mailed Gurnards...................

mainensis, Gasterosteus ...........

Maire d'Amplora.................. .

majalis, Cobitis....................

Fundulus .............. 639, 2827

Hydrargyra............. 639

Majarra, Raiada ................. 1561

major, Actinochir ............... 2128

Blepharis ................. 932

Cyclopterus liparis ........ $\quad 2128$

Liparis.................... 2127

Ptychocheilus ............ 225, 2797

Major, Sergeant ................... 1561

Makaira ....................... 890

nigricans

makaira, Xiphias

181

991

2014

158

950

2013

2626

217

2626

1159

557

557
1433

415

1837

905

144

2328

2328

1364

332

2872

1420

880
385

385

385

2574

1272

1273
1273

1272

1756

745

555

639
106
Page.

(1)

$M$

Malthe

makua, Ranzania .................

malabarica, Elacate...............

nılabaricus, Macrodon ............

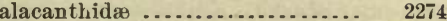

Malacanthinæ................... 2275

Malacanthus .................... $\quad 2275$

plumieri ............. 2275

trachinus ........... 2276

Malachorhinus................. $\quad 66$

Malacocephalus ................. $\quad 2569$

occidentalis....... 2570

Malacocottus..................... 1994

zonurus ............ 1994

Malacoctenus ..................... 3356

biguttatus .......... 2360

bimaculatus ........ 2358

delalandi ........... 2358

gillii............... 2358

lugubris............ $\quad 2357$

macropus.......... 2357

ocellatus ......... 2356, 2869

varius ............. 2357

versicolor.......... $\quad 2359$

Malacosteidæ ................. 592

Malacosteus..................... 592

niger.............. 593

Malapterinæ .................... $\quad 1572$

malarmoides, Aspidophorus ...... 2054

Maletta carulea................. 423

maliger, Sebastichthys........... 1823

Sebastodes............. 1822

malleus, Squalus................ 45

Zygæna................ 45

Mallotus ...................... $\quad 520$

villosus............... $\quad 520$

Malma ....................... 507,508

malma, Salmo ................. 508

Salvelinus ............. 507, 2823

Malthra ....................... 2736

arigusta................ 2738

longirostris............. 2737

nasuta................. 2737

notata ................. 2737

truncata ................ $\quad 2738$

vespertilio.............. 2737

2736

2738

2739

Mammoth Cave Blindfish ......... $\quad 706$

Mammy ........................ 205

managuensis, Heros ............. 1533

Pimelodus.......... 153

Rhamdia ........... 153

manatia, Raia .................. 93

891 manatinus, Barathrodemus......... 2517

891 Mancalias ...................... 2729 


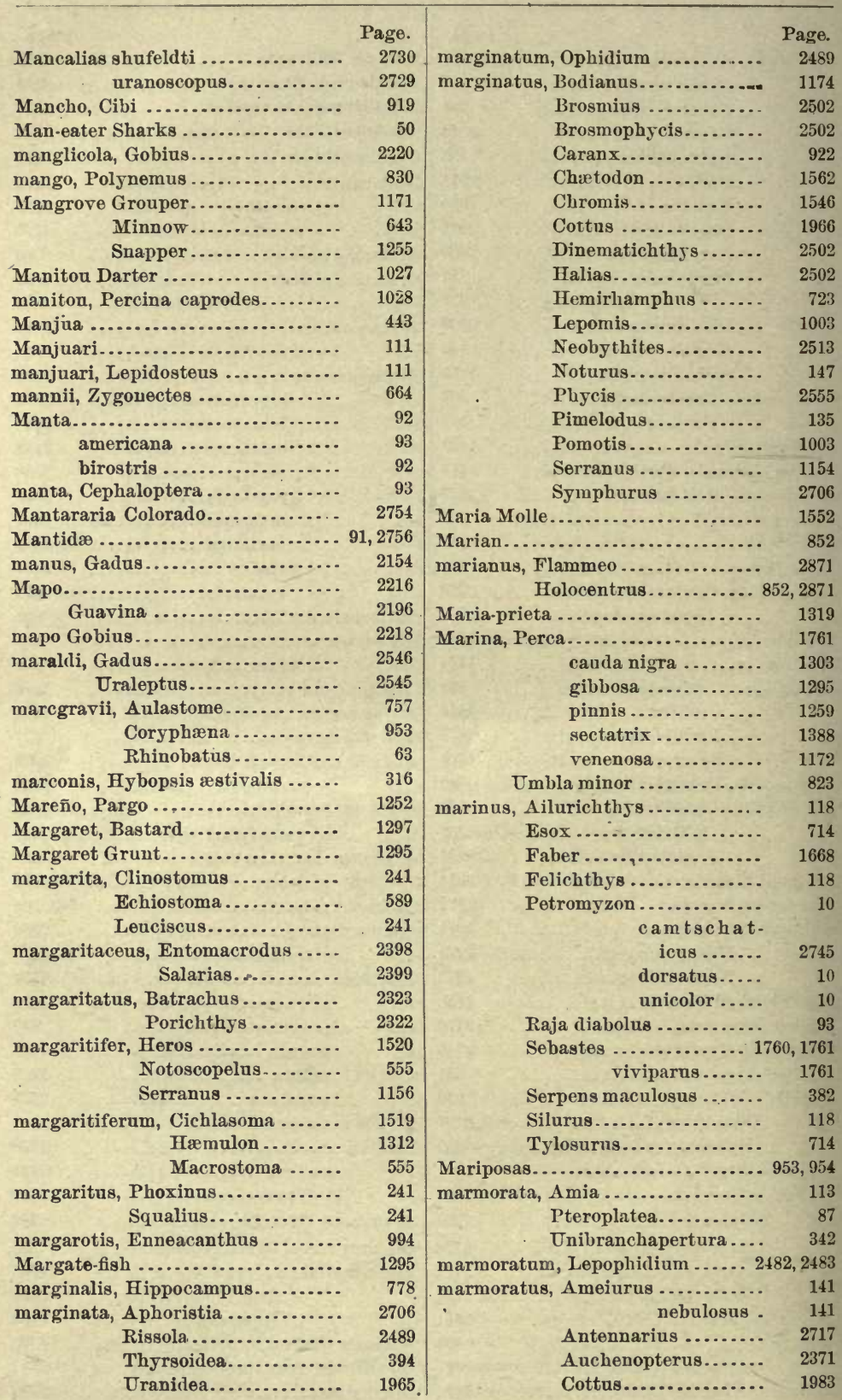


marmoratus, Cremnobates ......... $\quad \begin{array}{r}\text { Page. } \\ 2371\end{array}$

Hemitripterus...... 1889, 2022

Pimelodus........... 141

Rhinichthys......... 306

Rivulus...........663, 2830

Scorpænichthys...... 1889

Spheroides .......... 1734

Symbranchus........ $\quad 342$

Tirus.............. 537

marmorea, Rabula ............... $\quad 391$

marmoreum, Siphostoma.......... $\quad 768$

marmoreus, Blennius ..............

Gymmothorax .........

Murænophis...........

Syngnathus ...........

Marsipobranchii

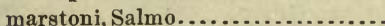

Salvelinus oquassa.......

martæ, Cyprinodon ...............

martii, Pristigaster...............

Martin Pescador ..................

martinica, Atherina............. 795

Kirtlandia............ 795

Menidia............... 795

Spicara .............. 1364, 1365

martinicensis, Aylopon ........... 1228

Holanthias......... 1228

Menticirrhus....... 1473

Nerophis........... $\quad 774$

Novacula.......... 1617

Novaculichthys .....

Ocyanthias..........

Odontanthias ........

Umbrina .............

Vomer ................

Xyrichthys .........

martinicus, Gobius................

Smaris................

Upeneus..............

1616

1228

1228

1474

934

1617

2236

1365

859

504

Masamacush

$625,626,629$

maschalespilos, Scarus........... $\quad 1642$

Sparisoma........ 1641

Maskinongy ..................... masoni, Salmo.

masquinongy, Esox.

Lucius ...............
immaculatus

massachusettensis, Monacanthus... massiliensis, Scorprena.

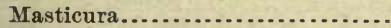
Matejuelo

Blanco 2975,2276

Real

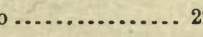

... matejuelo, . mphiprion

Page.

mathematicus, Tetrodon $\ldots . . . . .1728$

Mathemeg ..................... 137

matoides, Acanthurus............. 1693

matsubaræ, Sebastodes............ 1833

Mattowacca................... $\quad 425$

mattowacca, Clupea............. $\quad 426$

matutinus, Alburnellus .......... $\quad 301$

Minnilus .............. 301

Notropis............. $\quad 301$

umbratilis .... $\quad 301$

matzubaræ, Sebastodes............ 1796

mauricei, Argyriosus............... $\quad 936$

mauritii, Chætodon............... 1562

Eleotris ............... 950

Grammistes ............ 1323

maurolici, Scopelus.............. $\quad 577$

Maurolicidæ................... $\quad 576$

Maurolicus .................... 576

amethystino-punctatus $\quad 577$

attenuatus............ $\quad 577$

borealis.............. 577

mulleri............. 577

pennanti............. $\quad 577$

tripunctulatus ........ $\quad 578$

maxillaris, Lotella................ $\quad 2546$

Murænoides........... 2418

Maxillingua................... $\quad 327$

maxillingua Cyprinus............ $\quad 327$

Exoglossum.......... 327

maxillosa, Gnathypops........... $\quad 2284$

maxillosus, Gnathspops .......... 2284

Opisthognathus...... 2284

Rhinichthys.......... 307

maxima, Selache ................ 51

maximus, Cetorhinus ............. 51

Hippoglossus .......... 2612

Labrus............... $\quad 1580$

Lachnolæmus.......... $\quad 1580$

Lachnolaimus.......... 1579

Selachas .............. 51

Squalus ............... 51

maycus, Salmo omisco ........... $\quad 487$

Mayfish...................... 639

Maynea brunnea............... 2476

pusilla ................. 2476

May Sucker..................... 199

mazatlana, Seriola............... 904

Solea ................ 2699

mazatlanum, Hæmulon ........... 1314

mazatlanus, Achirus............. 2698

McCloud River Rainbow Trout... 502

meadiæ, Ulocentra.............. $\quad 2852$

meanyi, Ruscarius............... 1908

Meda ......................... $\quad 328$

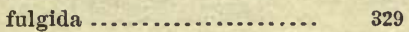




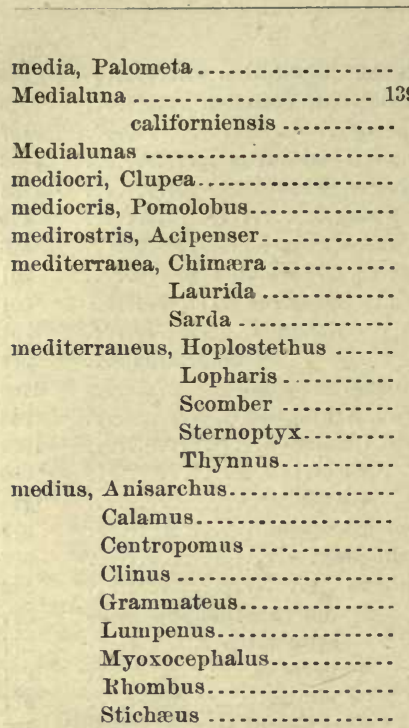

Medregal

medusicola, Caranx ............... medusophagus, Schedopholus...... meeki, Hybopsis .................. megacephalus, Calamus.......... 13 Chitonotus .......... Icelus ..............

Megaderus....................... megalaspis, Acipenser............. megalepis, Doratonotus ............ Megalobrycon.................... Megalocottus....................... laticeps.............. platycephalns .......

megalodon, Pristis ................. Megalopina ...................... Megalops atlanticus ............... cepediana................ elongatus................ notata ................... oglina .................. thrissoides .............. megalops, Alburnellus ............

Alburnus ............... Clupea.................. Cyprinus ............... Ditrema................ Ennichthys............. Holconotus

Micropogon... Minnilus................ Notropis albeolus .......
Page.

2849

1390,1391

1391

1390

426

425

104

95

537

872

837

947

872

604

870

2436

1355

1120

2436

1356

2435

1983

967

2436

904

924

970

317

550,1351

1891

1891

402

105

1612

337

1987

1988

1987

61

408

409

416

409

432

432

409

291

291

426

282

1502

1502

1502

1463

291

284 megalops, Opsopœodus

Page.

Pimelodus .............. 135

Trycherodon........... $\quad 249$

megalotis, Ichthelis.............. 1003

Lepmis .............. $\quad 1002$

Megaperca ..................... 1137

ischinagi............. $\quad 1138$

Megaphalus..................... 2320

megastoma, Grystes .............. 1012

Opisthognathus ....... 2282

megastomus, Catostomus .......... 181

Melamphaes beanii............... 843

crassiceps............ 843

cristiceps ........... 844

lugubris ............ $\quad 842$

Melamphainæ.................. 838

melampterus, Salmo .............. 483

melampygus, Caranx............. 925

Melanichthys .................. 1381, 1711

melanocephalus, Plargyrus ........ $\quad 217$

Melanocetinæ .................... 2728

Mclanocetus bispinosus............ 2734

(Liocetus) murrayi... 2734

melanochir, Julis ................ 1609

melanochira, Belone.............. 716

melanogaster, Pleuronectes........ 2630

Pocilia ............ $\quad 696$

Melauogrammus ................ $\quad 2542$

aglefinus........ 2542, 2543

melanopis, Diodon ............... 1746

melanopleurus, Haplochilus ...... $\quad 660$

melanopogon, Cichlasoma ......... 1523

Heros ............. 1523

melanopoma, Polynenus........... 831

melanops, Calliurus............... 992

Catostomus ............ $\quad 187$

Dionda................. $\quad 216$

Haplochilus ............ $\quad 682$

Hybognathus .......... 216

Ichthelis ............... 996

Minytrema............. 187

Sebastes ............... 1783

Sebastodes............ 1782, 1783

Zygonectes.............. 682

melanopterum, Pristipoma........ 1319

melanopterus, Balistes............ 1707

melanopus, Arius............... 132

Tachysurus.......... 132, 2784

melanorhina, Plectropoma......... 1192

melanospilum, Diagramma........ 1321

melanostictus, Hippoglossoides.... 2618

Psettichthys....... 2618

Melanostigma.................... 2478

gelatinosum ........ 2479

pammelas ......... 2479, 2869

Melanostigmatinæ ............... $\quad 2456$ 
melanostomus, Sebastodes

Page.

1803

melanothus, Holacanthus

melanotis, Limanura.

Murgena ..................

Psendojulis ............

Searus ............... 1638

uelanotus, Catostomus........ 206, 218, 32 은

Melaumra .................... 623

annulata.............. 624

melanurum, Cichlasoma.......... 1523

Hrmulon .......... 1302, 1303

Lremonema.......... 2557

Perca ............... 1303

melanurus, Careproctirs.......... 2135

Cyprinus............. 282

Exocotus............ 735, 736

Heros ................ 1524

Lutjanus.............. 1276

Rutilus ............... 193

melaplenra, Puecilia.............. $\quad \mathbf{6 6 0}$

melapleurus, Fundulus............ 659

melas, Ameiurus ................ 141

Silurus.................. 141

meleagris, Muræua .............. 399

Priodonophis .......... 399

Rhinichthys .......... 308

atronasus.. $\quad 308$

Meletta ....................... 424

libertatis .............. 433

suoerii .................. 425

vellosa..................

Melichthys

bispinosus ............

piceus.................

ringens ..............

Melletes

papilio ...................

mellissli, Congromurana..........

Membras.

membras, Clupea

Menephorus

dubius .................

punctiferus .......... 1147

menhaden, Alosa ................

Clnpea ...................

Gulf.

434

434

434

433

Menhadens

$443,796,2840$

Menidia.

audens

798

beryllina .................

brasiliensis

clara

dentex

gilberti

gracilis

beryllina

M

menidia, Argentina.................

Page.

Meuidia gnatemalensis ......... 801, 2840

ulartinica ............... 795

menidia................ 800

notata......... 2840

notata............... 800, 2840

pachylepis .............. 801, 2840

peuinsulæ.............. 797

sardina................ 799

vagrans................ 795

laciniata........ 79 Ј

Atherina.............. 801

Atherinichthys ......... $\quad 800$

Menidia ............... $\quad 800$

notata.......... 2840

Menomine Whitefish............ 465

menona, Fundulus diaphanus ...... $\quad 645$

mentalis, Platypocilus............ 686

Menticirrhus.................. 1469, 1470

alburnus............ 1475

americanus .......... 1474

elongatus ........... 1476

littoralis............. 1477

martinicensis........ $\quad 1473$

nasus............. 1472, 1473

nebulosus ........... 1475

panamensis........... 1473

saxatilis ............ 1475

simus.............. 1472

undulatus ........... 1476

Mentiperca ............... 1208, 1209, 1214

luciopercana ......... 1216

mento, Balistes .................. 1710

Bramopsis................ 1502

Chanos ................. 415

Paraliparis .............. 2142

Xanthichthys ............ 1710

meztzelii, Chironectes ............ $\quad 7224$

Serranus ............... 1154

merckii, Coregonus .............. $\quad 470$

meridionalis, Amiurus............ 135

Cottus ............... 1951

Ictalurus............ 135

Ictiobus............ 164

Sclerognathus....... 164

Merlangus ...................... 2529

leptocephalus ......... $\quad 2535$

polaris ............... $253 t$

productus ............ 2531

purpurens............ 2535

801 merlangus, A noplopoma .......... 1862

801 Merlucciidæ ................... 2529

801 Merlnccius...................... 2529

798 ambiguis ............. 2530

$797 \quad$ argentatus ............ 2530

797 bilinearis ......... 2530, 2531 


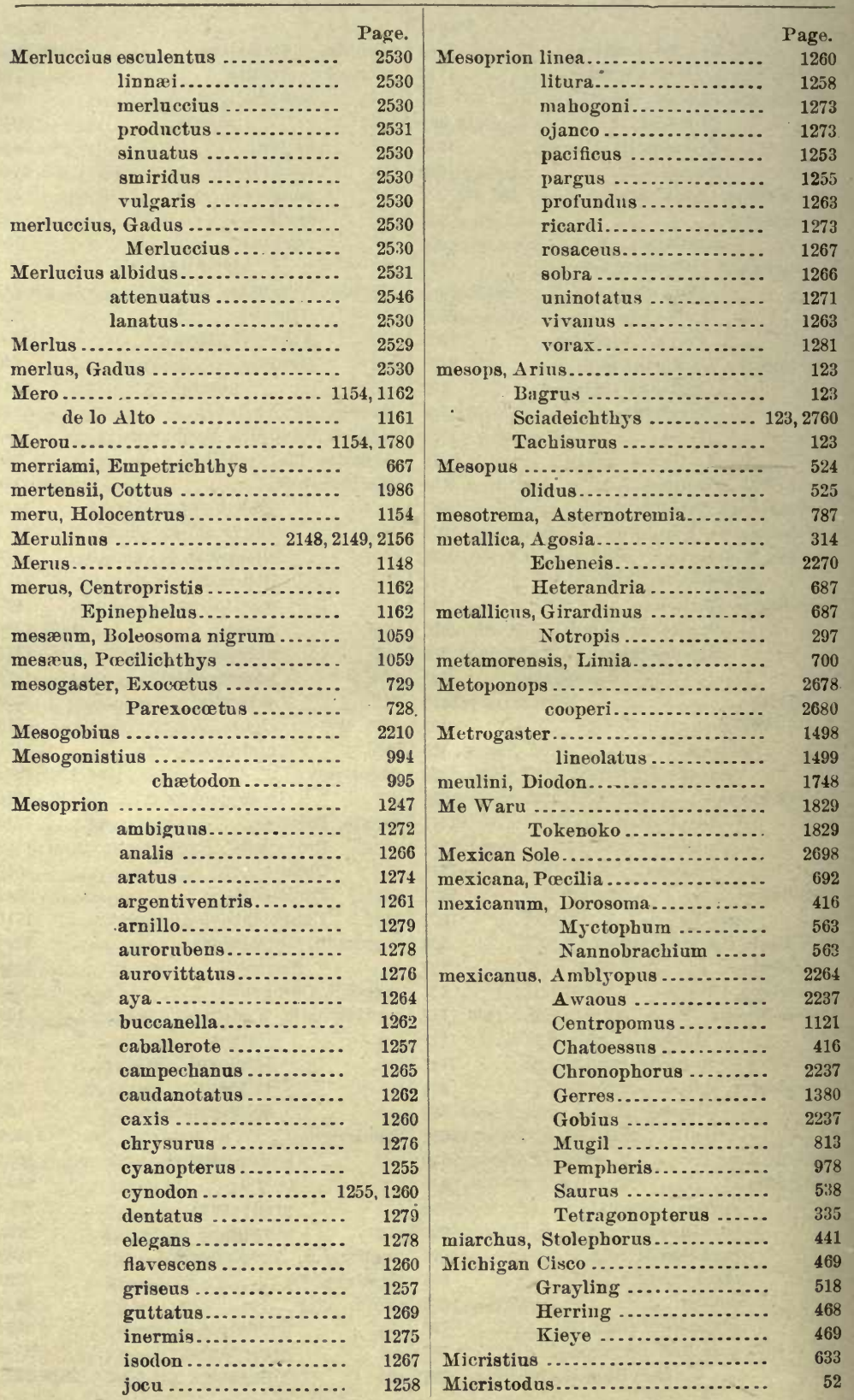


Micristodus punctatus

microcephala, Cynoglossa ..........

Platessa ..............

microcephalus, Gasterosteus wil-

liamsoni ..........

Pleuronectes .......

Somniosus ..........

Squalus .............

Microdesmus.....................

dipus ...............

retropinnis ..........

microdon, Cyclothone ............ 582, 2826

Gobius ................ 2227

Gonostoma............ 582

Osmerus................ 521

Pseudotriakis ........... 27

Microdonophis ...................

Microgadus .......................

proximus.............

tomcod .................

micrognathus, Lonchopisthus ......

Opisthognathus.....

Microgobius

syclolepis.............

eulepis...............

gulosus ...............

signatus ..............

thalassinus ...........

microlepidota, Gila .................

Microlepidotus...................

inornatus ..........

microlepidotus, Cestreus...........

Cynoscion ..........

Labrisomus ........

Labrosomus ........

Orthodon ...........

Otolithus..........

Microlepis ........................

microlepis, Antimora .............

Epinephelús ..........

Lepophidinm ...........

Macrodon ...............

Mycteroperca ..........

Trisotropis ..............

microlophus, Poinotis ..............

Micromesus

Micrometrus

aggregatus ...........

frenatus . . .............

micronema, Peristethus............

micronemus, Peristedion...........

Microperca.........................

fonticola ..............

proliaris ...............

punctulata .............

3030

113
Page.

52

2655

2654

751

2654

57

57

2450

2450

450

27
582
27
381

2538

2539

2540

2287

2287

2242

2247

2244

2243

2246

2245

207

1341

1341

1415

1415

2363

2364

207

1415

228

2545

1178

2486

330

1177

1178

1008

90, 91

1496,1498

1499

1499

1500

2182

2182

1103

1104

1103

1104 microperca, Etheostoma........... 110

Microphis....................... 773

microphthalmum, Hæmulon ....... 1296

microphthalmus, Dormitator ...... 2198

Heros........... 1536

Tetragonopterus. $\quad 334$

Micropogon..................... 1461

altipinnis ............ 1464

argenteus ............. 1463

costatus ............. 1462

ectenes............... 1463

furnieri............. 1462

lineatus............. 1461

megalops............ 1463

opercularis........... 1461

undulatus............ 1461

micropogon, Ceratichthys......... 323

microps, Agonostomus........... $\quad 820$

Atherina .............. 791

Belone.................. $\quad 712$

Calliurus ................ 996

Carcharias.............. $\quad 40$

Caulolatilus ............. 2277

Corvina ................ 1445

Cottunculus .............. 1992

Dajaus ................. 820

Nebris................. 1417

Otolithus............... 1415

Pagellus................ $\quad 1355$

Rhypticus............... 1232

Stellifer ................ 1445

Tylosurus............... $\quad 712$

microptera, Rhamdia............ $\quad 153$

Micropterinæ ................... 986

Micropterus ................... 1010

dolomieu............. 1011

salmoides ............ 1012

micropterus, Etheostoma.......... 1083

Pimelodus........... 153

Micropteryx ................... 901, 937

chrysurus .......... 938

cosmopolita......... 938

micropteryx, Alburnellus......... $\quad 297$

Minnilus........... 297

Notropis............ 296

Platysomus.......... 934

micropus, Gasterosteus ........... $\quad 744$

microrhynchus, Acipenser........ 106

microrrhinos, Pseudoscarus....... $\quad 1655$

Microspathodon ................. 1565

azurissimus...... 1570

bairdii ......... 1566, 1567

chrysurus........ 1567

cinereus ......... $\quad 1570$

dorsalis ......... 1568, 1570

azurissimus $\quad 1570$ 
Microspathodon dorsalis cinereus.. niveatus..........

Microspathodontinæ .............. microstigmius, Myrophis .......... mierostoma, Cliola ................

Crenilabrus ............

Scartella ..............

Tetragonopterus ......

Uranidea..............

Microstomidæ

Microstominæ....................

Microstomus

grønlandicus........
kitt.....................
latidens .............
pacificus.............

microstomus, Blennius .............

Citharichthys .......

Conger ..............

Etropus .......... 2687, 2690

Minnilus ............ 262

Pleuronectes........ 2654

micrurum, Syacium ...............

Midshipman .................. 2317, 2321

Mikiss .......................... $\quad 2819$

milberti, Acipenser.............. 105

Arius ................. $\quad 128$

Carcharhinus ........... $\quad 37$

Carcharias ............... $\quad 37$

Eulamia................. 37

milbertianus, Syngnathus ......... 771

miles, Porogadus.................. $\quad 2520$

Prionotus ................. $\quad 2160$

milesi, Pimephales............... $\quad 217$

miliaris, Bellator ................ 2173

Gymnothorax ............ 398

Lycodontis .............. $\quad 397$

Muræna................. 398

Thrysoidea.............. 398

Milk Fishes..................... $\quad 414$

milktschiteh, Salmo............... 481

milleri, Bathylagus.............. 2825

Miller's Thumb............... 1941, 1950

millipunctatus, Gasterosteus ...... $\quad 752$

milneri, Nocomis ................. 324

Pagellus................. 1355

Sparus ................. 1355

milnerianus, Leuciscus ........... 242

Phoxinus............ 242

Milvus cirratus .................. $\quad 2183$

mineopas, Bryttus ............... 996

Mingo, Long.................... 1718

miniatum, Peristedion ............. 2178

miniatus, Lepomis ................ 1002

Sebastichthys .......... 1795

Sebastodes ............. 1794
Miniellus ..................... Page.

minima, Abeona ................ 1497

Cichla.................... 1012

Clupea ................. $\quad 422$

Perca .................. $105 i$

minimus, Cymatogaster........... 1497

miniofrenatus, Searus............. 1634

Mink, Sea..................... 1475

Minnilus, altipinnis .............. 287

amabalis ............... $\quad 291$

ardens ................. 301

ariommus.............. $\quad 290$

atripes ................. $\quad 300$

bellus.................. $\quad 297$

bivittatus............... 233

blennius ................ 262

cercostigma ............. 275

chalybæus .............. 288

chlorocephalus........... $\quad 286$

chrosomus .............. $\quad 288$

coccogenis ................ 285

cornutus ................ 283

cyanocephalus .......... 300

dinemus................. 293

diplæmins ............. $\quad 300$

jejunus................. 290

jemezanus............... 294

lacertosus............... $\quad 284$

leuciodus................. 291

lirus .................. 298

lutipinnis.............. $\quad 287$

matutinus............... $\quad 301$

megalops............... 291

micropteryx ........... 297

microstomus ............ 262

nigripinnis.............. 299

notatus .................. 218

oligaspis ............... 294

percobromus ............ 295

plumbeolus ............. $\quad 283$

purctulatus............. 302

roseus.................. $\quad 288$

rubellus................. 293

rubricroceus ............. $\quad 286$

rubrifrons............... $\quad 295$

rubripinnis ............ 298

scabriceps.............. 268, 290

scepticus................ $\quad 296$

selene .................. 269

shumardi ............... 268, 269

stilbius.................. 293

telescopus............... 292

timpanogensis ........... $\quad 233$

umbratilis .............. $\quad 299$

xænocepha lus........... $\quad 289$

xænurns............... $\quad 280$ 
Minnilus, zonistius .

Minnow, Black-head.

Blunt-nosed

Eastern Mud.

Leather-sided ............

Mangrove..............

Sheepshead..............

Silver-sided

Silvery

Spot tailed ..............

Spotted-tail...............

Star-headed ..............

Straw-colored ............

Top .................. 659,680

Minnows, Mud.................

Pursy . . . ............. 670,671

Minomus.

bardus ...

delphinus...............

jarrovii .................

platyrhynchus..........

minor, Anarhichas ................

Anarrhichas..............

Aphanopus..

Atinga alter orbicularis....

Csclopterus liparis.........

Stellifer

Umbla marina.............. minutillus, Chriolepis.............. minutus, Cottus

Cyclopter as

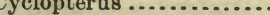

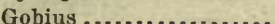

Minytrema.

anstrinum $-2.00-0.00$

melanops

minytremus, Gyrinichthys ........

Mionurus .......................

mirabile, Exoglossum.............

mirabilis, Clupea

Crystallichthys.........

Gillichthys..............

Lycodonus .............

Phenacobius.............

mirum, Calloptilum..............

mispilliensis, Ameiurus ............

Mississippi Cat ...................

mississippiensis, Morone ..........

Pristis

Missouri Sucker missuriensis, Cliola

Hybopsis

mitchilli, Argyriosus.

Acipenser...............

Cottus ..................

Engraulis...............

Lepibema
Page.

285

217

218

624

236

643

671

238

213

269

275

655

261

623

173

171

171

170

170

2446

2446

885

1749

2121

1442

823

2205

1958

2097

2097

186

192

187

2137

1106

303

422

2865

2250

2474

303

2527

141

137

1134

61

168

262

262

$9: 36$

105

1973

446

1133 mitchilli, Perca

Page.

1133

alternata ......... 1133

interrupta........ 1133

Stolephorus ............ 446

Mitchillina.................... $\quad 453$

bairdii .............. 454

mitis, Balistes................... 1705

mitzukurii, Sebastodes ............ 1831

miurus, Mystriophis ............. 387

Noturus ............... 148

Ophichthys............... 387

Schilbeodes............... 148

Scytalichthys ........... $\quad 387$

Mixonus ...................... 2523

laticeps................. 2523

mixtus Gadus tomcodus .......... $\quad 2540$

Mnierpes...................... 2364

macrocephalus.......... 2364

Mobula ...................... 91

modesta, Cheonda................ 234

Gambusia.............. 693

Pimelodella .............. $\quad 154$

morlestum, Hæmulon............. 1340

modestus, Julis ................ 1601

Oxyjulis .............. 1601

Pimelodus .............. 154

Pomadasys............. 1321

Pseudojulis ............ 1601

Squalius .............. 234

Xyrichthys ............ 1619

Møbia ....................... 2510

promelas................. 2511

mœerens, Gonopterus ............. 1688

Moharra ...................... 1373, 1374

mohri, Clinus ................... 2438

Mojarra....................... 1379

Almejero ............... 1294

Blanca................. 1372

Cantileña .............. 1369

Cardenal ............... $\quad 850$

China.................. i 377

de Casta ............... 1372

de la Piedras.............. 1681

de las Aletas Amarillas... 1376

de Ley ................. 1370

Dorada................. 928

Garabata............... 1353

Prieta................. $\quad 1299$

Verde.................. 1538

Mojarras.................... 1366, 1373

Mojarritas ................... 1367

Mojarron...................... 1319

Mola........................ 1753

aculeata .................. 1754

mola ...................... 1753

nasus .................... 1754 
Mola planci

Page.

retzii

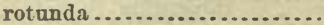

mola, Mola

Orthagoriscus..............

Tetrodon

Molacanthus

Molarii.

molestum, Gobiosoma .............

Molidæ...........................

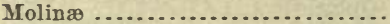

molle, Maria

Mollienisia........................

fasciata .................

formosa................

jonesi..................

latipinna...............

lineolata ................

petenensis ..............

mollis, Achirus mollis.............

Aphyonus ................

Bothrocara.................

Pleuronectes ...............

Molly, Hog....................... Molva

huntia ...................

linnæi....................

maculosa.................

molva ......................

vulgaris..................

molva, Gadus ....................

Molva ......................

monacantha, Corrina..............

Monacanthidre.................

Monacanthus

amphioxys...........

auriga ..............

broccus ..............

ciliatus .......... 1714, 1715

davidsoni............

filamentosus.........

gallinula............

hispidus.............

irroratus ............

macrocerus ...........

massachusettensis...

monoceros ............

occidentalis...........

oppositus .............

pardalis ............

parraianus ..........

piraaca ..............

proboscideus .........

pullus ...............

punctatus........ 1713,

scriptus
1756

1754

1754

1753

1754

1754

1753

402

2258

1752

1752

1552

698

695

699

699

700

700

700

$2 \% 02$

2525

2476

2701

81,1026

2551

2551

2552

2551

2551

2552

2552

2551

1419

1712

1714

1717

1716

1716

1715

1716

1716

1715

1713

1713

1716

1720

1715

1716

1713

1713

1715

1719

1713

1719

1719
Monacanthus setifer

Page.

1716

signifer ............ 1716

spilonotus......... 1716

stratus ............. 1713

ruppelii............ 1713

varius............. 1716

monacanthus, Plectropoma........ $\quad 1165$

monacus, Ceratichthys............ $\quad 318$

Hybopsis .............. 318

monæ, Stephanoberyx............ 836

monapterygia, Pesca dorso........ 1833

Monda...................... 899

monensis, Squalus............... 49

moriestichus, Salmo.............. $\quad 509$

Mongolar Drummer............... 1406

Mongrel Buffalo.................. 164

Whitefish .............. 473

Moniana .................. 254, 256, 271

aurata................. 272

complanata............. 272

couchi................. 272

deliciosa................ 262

formosa ................ 271

frigida.................. 271

gibbosa................ 272

gracilis................ 272

jugalis ................ 272

lætabilis................ 272

leonina ................ 272

nitida................ 265

proserpina............... 272

pulchella............... 272

rutila ................. 272

tristis ................ 272

Monkfish ....................... 58,2713

monoceros, Alutera ............ 1720, 2860

Balistes ............. 1719, 1720

Monacanthus ......... 1720

Monochir lineatus................ 2698

maculipinnis............ 2698

reticulatus............. 2696

Monochirus .................... 2694

monocirrus, Exocœtus ........... $\quad 730$

Monodactylinæ................ $\quad 1667$

Monolene...................... 2690

atrimana .............. 2692

sessilicauda ............. 2691

Monomitra.................... 2138

liparina............. 2139

monophthalmus, Auchenopterus... 2372

Crennobates...... 2372

Monoprion ...................... 1106

maculatus ............. 1109

pigmentarins.......... 1109

Monopterhinus.................. 18

monopterygius, Aspidophoroides 2091, 2092 
monopterygius, Canthirbynchus..

Chirus ..............

Hexagrammus ....

Labrax............ Pleurogrammus...

Monosira stahli

(1....................

monstrosa, Chimæra.............

montacuti, Cylopterus .............

montagui, Liparis .............. 2107, 2108

Montana Grayling ............... 519, 2871

montana, Gila ................. 238

montanus, Clinostomus........... 238

Hybopsis............. 317

Leuciscus ... ......... 238

Squalius............. $\quad 238$

Thymallus ontariensis . $\quad 519$

signifer..... 519

tricolor.....

Monterey Hulibut.................

Spanish Mackerel ........

montezuma, Cichlasoma............

Heros ................

monticola, Agonostomus..........

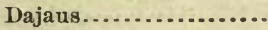

Mugil

montiregis, Cliola

Moon-eye

Moon-eyes .........................

Moonfish..

Moonfishes........................

Moorish Idol......................

Mora, Cabra ........................

Moray, Black ....................

Common Spotted...........

Spotted ...................

Morays ..........................

mordax, Atherina................

Conger..................

Crotalopsis ...............

Engraulis .................

Gymnothorax............

Lycodontis...............

Macrodonophis ...........

Muræna .................

Osmerus ..................

abbotti ...........

spectrum ........

Sidera...................

Morena Pinta ......................

Pintita ...................

Prieta ...................

Verde .....................

moribundus, Balistes ..............

Morinæ
2871

2625

837

1518

1518

819

2841

819

272

413

469

412

934,954

935

1687

1152

396

395

399

388,400

523

387

387

448

396

395.

387

396

523

524

523

396

402

397

2804

396

1702

2532

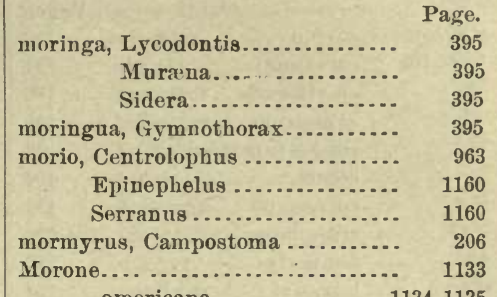

americana.............. 1134, 1135

Havescens................. 1024

interrupta............... 1134

lineata................. 1133

maculata................. 1010

mississippiensis........... 1134

multilineata.............. 1132

pallida................... 1135

rufa..................... 1135

Moroninæ...................... 1127

Moronopsis.................... 1013

Morrhua ....................... 2540

æglefinus............... 2543

americana............ 2540, 2541

californica.............. 2539

punctatus ............... 2543

morrbua, Gadus ................. 2541

morrissi, Leptocephalus ........... $\quad 354$

Moseleya...................... 2570

cyclolepis .............. 2570

moseri, Verasper.................. $\quad 2619$

Mossbunker .................... 433

motaguensis, Heros............... 1534

Pimelodus ........... 151

Rhamdia............ 151

Motella ....................... 2558

argentata................. 2559

caudacuta ................ 2560

cimbria.................. 2560

ensis ................... 2559

reinhardti ............... 2559

septentrionalis ........... 2560

Mother of Eels................... $\quad 2457$

motta, Elacate .................. 948

moucharra, Glyphisodon.......... 1562

Mountain Herring ................ 463

Suckers ................ 169, 170

Mouse-Fish .................. 2715, 2716

Moxostoma ...................... 185, 187

albidum ............. 192

album .............. 191

anisurum............ 190, 196

aureolum ............. 192

austrinum........... 192

breviceps............. 196

bucco................. 190

campbelli............. 186 
Moxostoma carpio

claviformis

collapsum ............

congestum ............

conus.................

coregonus .............

crassilabre............. 194, 196

kennerly1............ 186

lesueuri .............. 194

macrolepidotum ...... 193

oblongum............. 186

oneida .............. 193

papillosum ............ 189

pidiense.............. 191

pœecilurum ........... 196

robustum............. 193

rupiscartes ............ 196

tenue................ 186

thalassinum .......... 191

trisignatum ........... 179

valenciennesi......... 190

velatum .............. $\quad 190$

victoriæ .............. 187

mucosum, Xiphidion ............. 2425

Xiphister............. 2425

mucosus, Acanthocottus ........... 1975

Liparis................ 2111

Lycodalepis............

Lycodes.................

Neoliparis ..............

mucronata, Odontognathus.........

Perca ..................

mucronatum, Ophidium............

mucronatus, Gnathobolus..........

Labrax...............

Neoconger ............

Odontognathus.......

Pristigaster ..........

Mud Cat ..........................

Dabbler.....................

Dabs........................

Minnows ...................

Parrot .....................

Sunfish .....................

Mudfish

$113,640,1649$

mudfish, Fundulus.

Mudfishes .

Muffle-jaw

2470

2461

2111

438

1135

2419

438

1135

362

438

438

142,143

640

2644

622

1639

989

641
6

623

1950

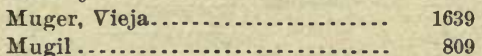

alatus .................... 733

albula ................... 812, 2841

berlandieri ................ 812

brasiliensis............ $810,814,816$

eapitulinus.............. 2841

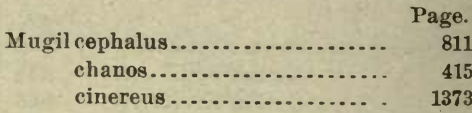

curema .................. 813, 2841

equinoculus .............. 2841

gaimardianus.............. 814

gigas................... 1483

grunniens ................. 1483

guntheri ................. 812

hospes.................. 814

incilis ................. 813

irretitus ................. 819

lebranchus ............... 811

lineatus ................ 812,2841

liza..................... 811, 2841

mexicanus............... 813

monticola................ 819

nigro-strigatas............ $\quad 817$

obliquas.................. $\quad 1459$

petrosus................. 814, 2841

plumieri................. 812, 2841

proboscidens .............. 816

rammelsbergii ............. 812

salmoneus ............... $\quad 415$

setosus .................. 815

tang .................... 812

thoburni ................ 813

trichodon.................. 816

Mugilidæ..................... 808

Mugilinæ...................... 809

mugiloides, Eleotris ............. 2198

Mugilomorus ................... 409

anna.carolina ....... $\quad 410$

muikiss, Salmo.................. 492

Muksun of the Russians.......... 464

muksun, Salmo.................. 464

mulleri, Antigonia............... 1665

Benthosema............. 574

Carcharias .............. 40

Maurolieus............. 577

Pempheris............... 978

Salmo .................. 574

Scopelus................ 570, 574

Mullet ...................... 192

Blue.................... 191

Blue-back ............... 813

Common .................. 811

Fan-tail................ 816

French .................. 813

Jumping................. 197

Red-eye ................ 814

Snip-nose............... 964

Striped ................ 811

Whirligig ............... 818

White ................... 189, 813

Mullet of Utah Lake.............. 179 
Mullets

Page.

Mulleypeneus maculatus

Mullidæ

Mulloides. ....................... 857, 2843 flavovittatus ........... 860 rathbuni............... 857

Mullus ........................ 856

auratus................. 856,2843

barbatus auratus.......... $\quad 856$

imberbis................. $\quad 1107$

maculatus............... 859

multifasciata, Adinia............ 661

Hydrargyra ........ $\quad 645$

Sciæna.............. 1459

1226

645

multifasciatus, Anthias ...........

Fundulus ..........

Pronotogrammus ..

multifilis, Blennius ...............

$$
\text { Hypleurochilus.......... }
$$

multiguttatus, Alphestes ..........

Epinephelus .......

Plectropoma........

multilineata, Morone..............

Pcecilia...............

multilineatum, Hæmulon ..........

multimaculatus, Chromis ..........

Diodon............

Heliases ..........

Labrax ...........

multiosellata, Muræna ............. multiocellatus, Antenuarius ......

Chirouectes........

multiradiatus, Arius..............

Cubiceps ............

Tachysurus ....... 132, 2788

multispinosum, Cichlasoma....... 1525

multispinosus, Heros ............ 1526

multistriatus, Liparis lineatus..... 2118

Mummichog .................... $\quad 640$

mundeolus, Stolephorus .......... 2812

mundiceps, Novacula .............. 1618

Xyrichthys ........... 1618

mundicorpus, Iniistius .......... 1620

Noracula.......... $\quad 1620$

mundns, Dactylagnus............. 2304

Oligoplites .............. 2844

Urolophus............... 81

Urotrygon............... 81

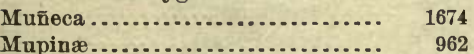

Muræna ...................... 347,400

acuminata ............. $\quad 377$

afra................... $\quad 396$

alusis ................. 403

anguina
Muræna aquæ-dulcis .............. Page.

argentea ................. 348

argus .................4 401, 2805

aterrima ................ 396

balearica............... $\quad 356$

bostoniensis............. $\quad 348$

cassini................. $\quad 356$

catenata............... 403

clepsydra............... 2805

conger.................. $\quad 354$

coniceps................ $\quad 359$

conspersa............. 397

cubana................. $\quad 348$

dovii................... 397

elaborata................ $\quad 389$

erebus .................. 396

havennensis ............. 382

infernalis ............... $\quad 396$

insularum .............. $\quad 400$

lentiginosa .............. 402

lineopinuis .............. 396

lita ................... 2805

longicauda............... 392

lumbricus................ $\quad 342$

macrocephala ............ $\quad 348$

maculata nigra........... $\quad 395$

maculipinnis............. $\quad 394$

maculosa............... 382

melanatis ............... 402

melanotis ................. 401, 402

meleagris ................ 399

miliaris .................. $\quad 398$

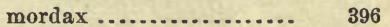

moringa................. $\quad 395$

multiocellata............. $\quad 398$

nigra.................. $\quad 355$

nigricans................. $\quad 390$

ocellata .................. 399

ophis.................... 382, 2804

panamensis .............. 391

pfeifferi................ 2805

picta................... 2805

pinnata ................. 351

pinta.................... 402

pintiti................... 397

punctata ................. 395

retifera ................. 401

rostrata ................ 348

sanctæ-helenæ........... $\quad 397$

sanguinea............... $\quad 390$

savanna................. 360

serpentina .............. $\quad 348$

sen conger brasiliensis .... 403

sidera................... 2805

sordida ................ 403

variegata............. 2805 


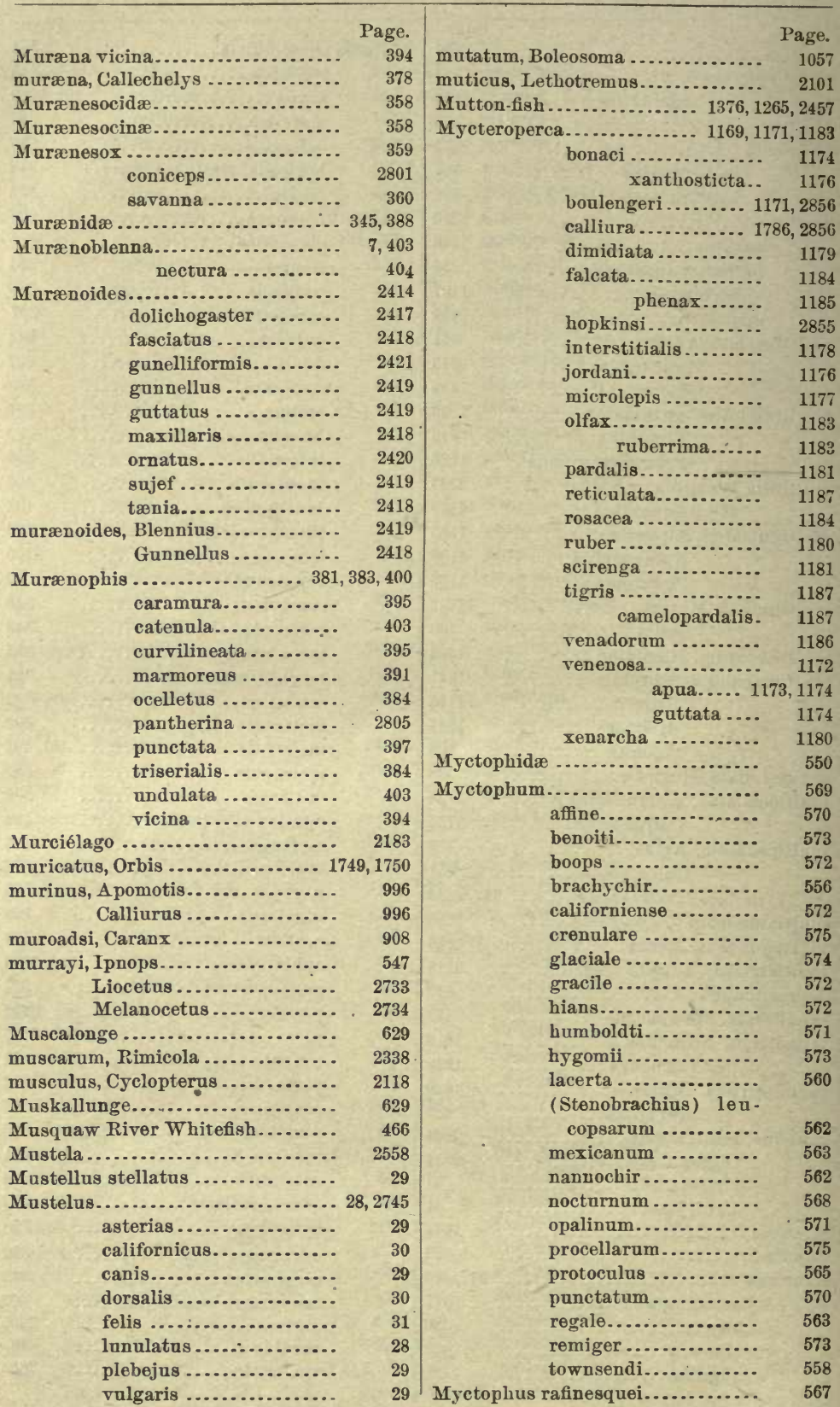


Page.

mydrus, Cyprinodon .............. $\quad 676$

Mykiss ........................ 492, 2818

mykiss, Salmo ............ 487, 492, 2818

agua-bonita........ 504

bouvieri........... 496

gibbsi1............. 493

henshawi .......... 493

lewisi............. $\quad 493$

macdonaldi ......... 497

pleuriticus.......... 496

spilurus ............ 495

stomias ............

virginalis

Myliobatidæ

(n)...........

Myliobatina

497

493

87

2753

Myliobatis

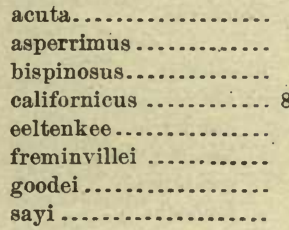

89,2750

89

2754

89

89,2754

88

89

2755

86

219

Mylocheilus.

caurinus ............ 219, 220

fraterculus............

lateralis..............

220

220

Myloleucus ................. 243, 244, 2798

parovanus............ 246

pulverulentus ......... $\quad 246$

thalassinus ............ 245

Mylopharodon

conocephalus .......

robustus............

Mylopharodontinæ................

Mylorhina.

myops, Salmo

Saurus

Synodus

'Trachinocephalo

Myoxocephalus

\section{8}

219

æneus ............

axillaris ......... 1980, 1981

brandti ............ 1984

bubalis ........... 1971

grnenlandicus......

jaok ..............

mednius

niger .............

nivosus.

octodecimspinosus.

polyacanthoce pha -

lus .............

scorpioides ........

scorpius
Myoxocephalus stelleri

verrucosus ........

Myrichthys

acuminatus...........

oculatus ................

pantostigmius ..........

tigrinus ............ 376, 2802

xysturus ............ 2802

Myridæ....................... $\quad 370$

Myriolepis ..................... 1862

zonifer............... 1863

Myriosteon..................... 60

Myripristis .................... 846

clarionensis .......... 2842

fulgens .............. $\quad 846$

jacobus .............. 846

lychnus............. 847

occidentalis........... 847

pœcilopus ........... 847

trachypoma.......... 846

Myrophls ...................... $\quad 371$

egmontis ............... 371

longicollis............. $\quad 371$

lumbricus ............. $\quad 371$

microstigmius.......... $\quad 371$

punctatus.............. $\quad 371$

vafer................ $\quad 372$

mystacalis, Lepomis .............. 1001

mystacina, Gnathypops ........... . 2286

mystacinus, Epinephelus ......... 1151

Gnathypops......... . 2286

Schistorus ........... 1151

Serranus ............ 1151

Mystaconurus .................. 2580

mystes, Scorpæna............... 1849

mysticetus, Cetengraulis......... $\quad 450$

Engraulis ............ $\quad 450$

mystinus, Sebastichthys.......... 1785

Sebastodes........... 1784, 1785

Mystriophis.................... 386

intertinctus ........... $\quad 386$

minrus $\ldots \ldots \ldots \ldots \ldots . . . . . . .387$

Mystus ....................... 116

ascita.................. 155

carolinensis ............. 117

Mytilophagus .................. 1503

fasciatus.......... 1504

Myxine ...................... 7

glutinosa.............. 7

limosa.................. 8

Myxinidæ...................... 7

Myxodagnus.................... $\quad 2305$

opercularis .......... 2305

Myxodes elegans................ 2353

lugubris .............. 2357

macropus ............ 2357 
Myxodes varius

versicolor

Myzostoma austrina ...............

euryops...............

pœecilura..............

Myxns harengus.

Myzopsetta

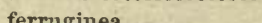

Naccaysh .

nachtriebi, Lenciscus

nacrea, Gila......................

Naked Gobies.....................

Goby .....................

nalnal, Sparactodon...............

Namaycush .....................

Salmon ................

namaycush, Cristivomer ...........

siscowet..

Salveliuus............ siscowet....

Nanuobrachium.

leucopsarum .......
macdonaldi........
mexicannm........
nannochir .........
regale .............

nannochir, Myctophum ............

Nannobrachium ........

nanomyzon, Catostomus ...........

Nanostoma............... 1066, 1067, 1070

camurus ..............

elegans................

inscriptum ............

vinctipes..............

zonale .................

Nansenia........................

grœenlandica ............

nanus, Engraulis................

Nareacion ......................

Narciue.

brasiliensis................

entemedor ................

nigra ...................

umbrosa ..................

Narcobatidæ

Narcobatus

uaresi, Salno

Salvelinus oquassa.......

narinari, Aetobatus ...............

Raia .....................

Stoasadon

naso, Stolephorus

Nassau Grouper.
Pago.

2357

2359

192

193

196

818

2644

20345

413

2798

228

2257

2259

947

504

505

504

505

505

505

561

562

563

563

562

563

562

562

177

1076

1075

1072

1075

1075

528

528

449

77

78

78,2752

78

2752

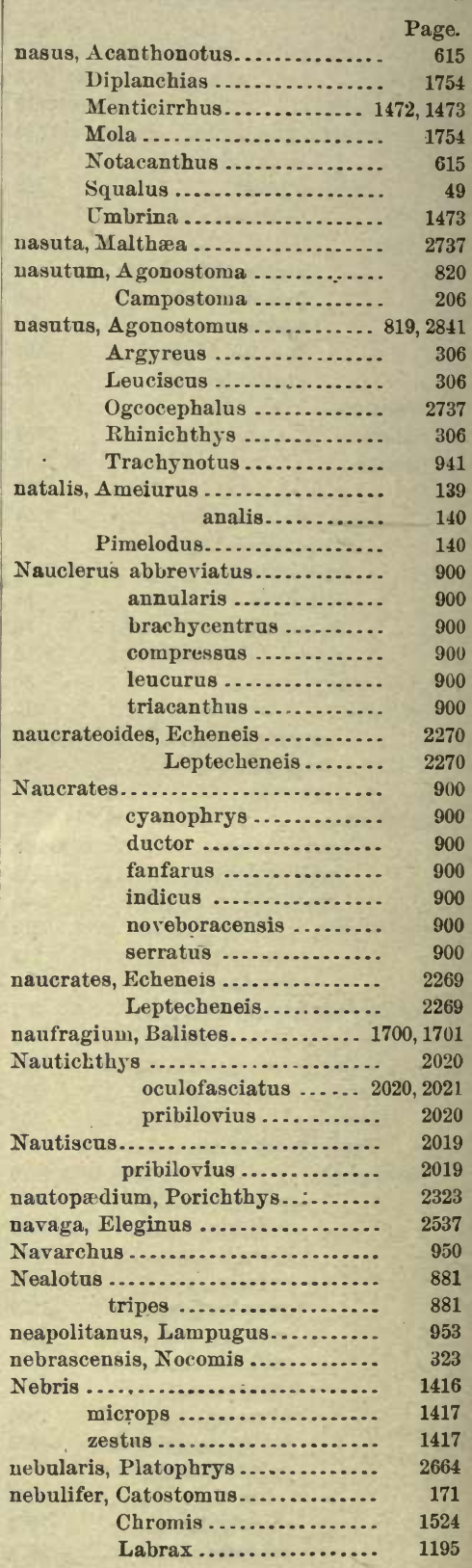

615

1473

49

1473

820

206

306

306

306

941

139

900

900

900

900

900

70

270

900

900

900

900

900

900

269

269

2020

021

2019

2019

2323

2537

950

881

53

323

1416

1417

1417

2664

171

195 
Page.

nebulifer, Paralabrax Serranus

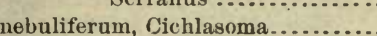

nebuliferus, Catostomus ...........

nebulosa, A phoristia...............

Cerna .................

Percina ................

Pileoma ................

Umbrina .................

nebulosum, Gunnellus............

nebulosus, Acantholebius..........

Ameiurus ..............

catulus...... marmoratus.

Apionichthys ..........

Centronotus............

Cestrens...............

Chiropsis.............

Chirus ................

Clinus................

Cynoscion ..............

Enedrias ...............

Gasterosteus ...........

Lycodes ...............

Menticirrhus...........

Otolithus ...............

Pimelodus.............

Sebastodes .............

Silurus ................

Symphurus.............

Urolophus .

Nector ...........................

nectura, Gymnomuræna ...........

Muræuoblenna............

necturus, Uropterygius ............

Needlefish .......................

Needlefishes......................

Neetroplus

nematopus ............

nicaraguensis ...........

nefastus, Pomotis

neglecta, Clupea...................

Corvina (Amblodon) .......

neglectus, Amblodon...............

Negra, Boca......................

Esmeralda................

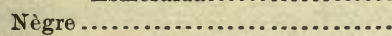

Petite

Negro, Barbero....................

Pargo.....................

Negro-fish........................

negromaculatus, Rhypticus........

nelsoni, A waous

Gobius .

nelsonii, Coregonus ................

Nematistiidæ
195,1196

1196

1524

171

$2 \pi 12$

1181

1027

1027

1475

2414

1872

140

141

141

2703

2414

1409

1872

1872

2438

1409

2414

746

2468

1475

1409

140

1826

143

2712

80,2752

1436

404

404

404

714

708

1541

1541

1542

1003

434

1484

1484

1837

2204

1160

1142

1692

1252

1146

1233

2235

2235

466

894

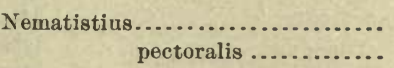

Page.

895

Nematognathi..................

895

114

Nematonurus .................. 2571

cyclolepis .......... 2571

goodei .............. 2571

Macrurus magnus ... 2574

suborbit-

alis ... 2572, 2573

Nematonus.................... 2518

pectoralis ............. 2518

nematophthalmus, Scorpæna...... 2861

Sebastes........ 2861

nematopus, Neetroplus............ 1541

Physiculus ........... 2548

Nematostoma .................. $\quad 774$

Nemichthyidæ ................. $\quad 366$

Nemichthys.................... $\quad 369$

avocetta............ $\quad 369$

infans.............. 368

8colopacea .......... $\quad 369$

scolopaceus .......... $\quad 369$

Nemipterus ...................... 1288

macronemus ......... 1289

Nemobrama .................... $\quad 854$

Nemocampsis. ................... 1010

neoboracensis, Fistularia.......... $\quad 757$

Neobythites.................... 2512

gillii............... 2513

maginatus ........... 2513

ocellatus............ 2513

robustus............. 2515

stelliferoilles......... 2516

Neoclinus ...................... 2354

blanchardi............. 2354

satiricus............... 2355

Neoconger .................... $\quad 362$

mucronatus .......... 362

perlongus ............. $\quad 363$

vermiformis ........... 362

Neoditrema ................... 1511

ransonnetii........... 1511

neogæus, Leuciscus ............... $\quad 240$

Phoxinus............. 241

neoguinaica, Albula............. $\quad 412$

neohantoniensis, Coregonus....... $\quad 466$

Neoliparis...................... 2106

atlanticus............. 2107

callyodon .............. 2110

fissuratus............ 2113

floræ................ 2111

greeni............... 2112

mucosus .............. 2111

rutteri.............. 2108

Neomænis ................ 1247, 1248, 1251

ambiguus............ 1271 
Neomænis analis

Page.

apodus.................

aratus ..................

argentiventris .........

aya ...................

brachypterus ..........

buccanella .............

colorado.................

cyanopterus.............

griseus.................

guttatus ...............

hastingsi ..............

jocu..................

jordani.................

lutjanoides..............

mahogoni ..............

novemfasciatus .........

synagris ..............

vivanus.............. 1262, 2858

Neomuræna .

$$
\text { nigromarginata ....... }
$$

Neosebastes .....................

Noostoma ....................... bathyphilum ...........

Neozoarces...................... pulcher

nephelus, Lepomotis

Tetrodoni. turgidus .......

nerka, Oncorhynchus ............. kennerlyi...

Salmo......................

Nerophis .

anguineus..............

heckeli ..................

maculata ................

martinicensis.............

nertinianus, Acipenser............

Nestis...........................

Nettastoma procerum ............

Nettastomidre...................

Netuma ............ 119, 120, 126, 2764, 2765 dubia.................. 126, 2765 elattura................. 128, 2769 grandicassis ............. 126, 2764 insculpta . . . . . . . . . . . . . 127, 2765 insularum .............. 2770 kessleri.................. 127, 2765 oscula.................. 127, 2768 planiceps ............... 127, 2766 platypogon ............. 127, 2767 proops ................... 124 quadriscutis .............. 126 stricticassis ............ 126, 2765 neucrates, Echeneis ............... 2269 neustrianus, Gasterosteus......... 747
Page.

nevadensis, Agrosia ............. $\quad 310$ Cyprinodon ........... 674 Rhinichthys (Apocope) 311

1034

1034

2248

499

2248

2248

2530

987

1053

468

1559

1559

concolor................

nianguæ, Etheostoma ( $\mathrm{H}$ adropterus) ................ 1043

Etheostoma spilotum .... 1044

Hypohomus ............ 1042

nicaraguensis, Carcharhinus ...... 39, 2747

Eulamia........... $\quad 39$

Gambusia ........... $\quad 682$

Heros ............. 1532

Neetroplus ......... $\quad 1542$

Pimelodus........... 152

Rhamdia........... 152

nicholsi, Halichæres ............... 1592

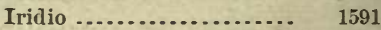

Platyglossus............ 1592

nicholsii, Gobins ................ 2218

nieuhofii, Echeneis ............... $\quad 2272$

nigellus, Hyborhynchus.......... $\quad 217$

niger, Agonus.................. 2069

Amblodon ................ 169

Ammocoties ................ $\quad 14$

Aspidorphorus ............ $\quad 2069$

Astronesthes ............... $\quad 586$

Balistes .................. 1711

Bubalichtbys.............. 164

Centrolophus.............. 963

Chiasmodon ............... 2291

Chiasmodus ............... 2292

Conger .................... 355

Cottus.................. 1983, 1986

Esox .................... 626

Leuciscus ................. 235

Malacosteus ................ 593

Myoxocephalus ........... 1985

Perca...................... 963

Scomber................... 948

Sparus.................... 960

Squalius................... $\quad 235$

T'autoga ................... 1577

Thyrsites.................. 879

Zeus.................... 936

Nigger Chub................. $\quad 327$ 


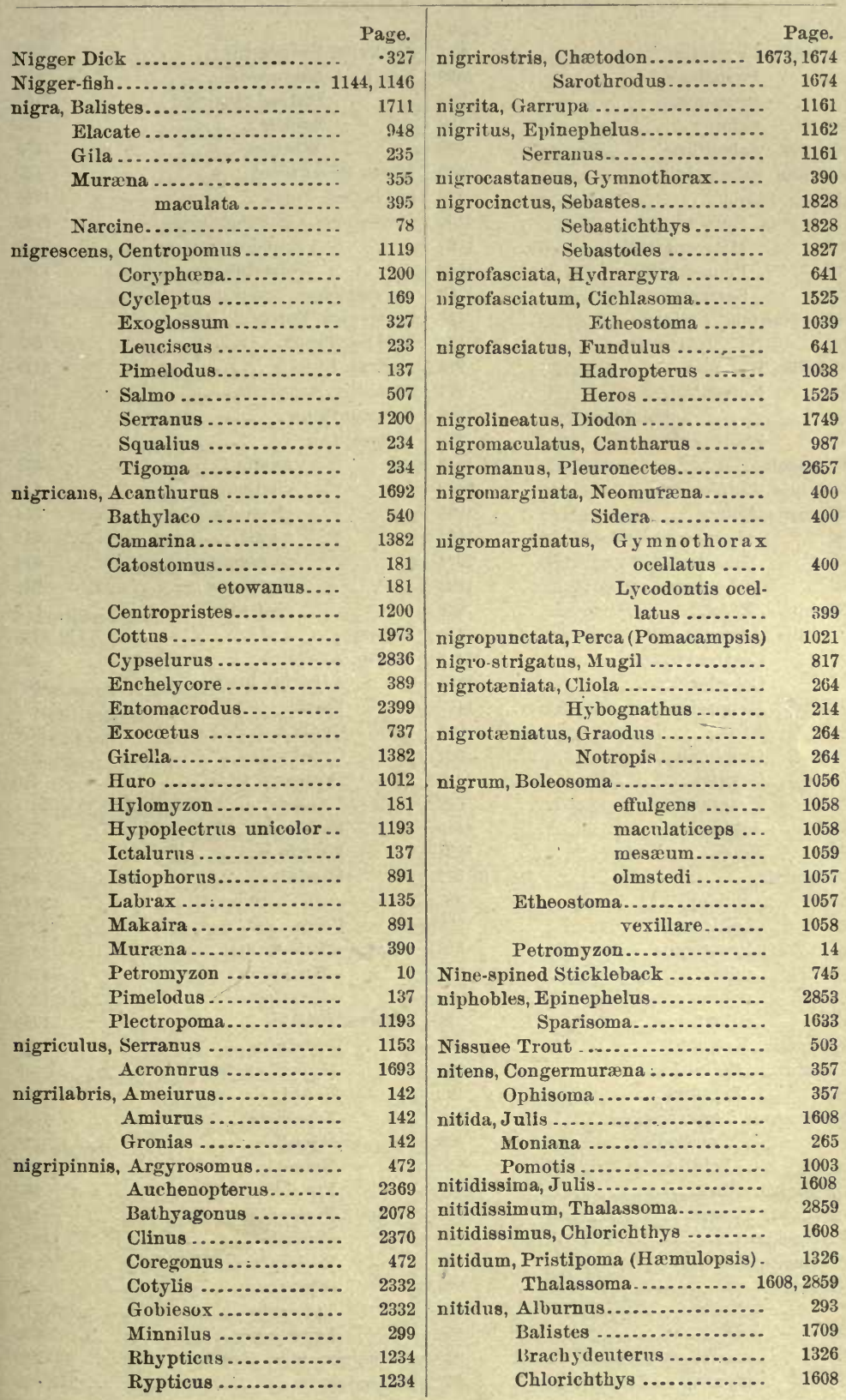


nitidus, Leuciscns

Pomadasis.

Promoxis.

Salmo

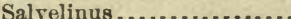

nivalis, Salmo alpinus............. uvea, Cliola ..................... niveatus, Epinephelus

Microspathodon..........

Pomacentrus .............

Serranus ................

niveiventris, Amiurus .............

Ictalurus............

niveus, Hybopsis ...............

Notropis ................ chloristius........

Photogenis...............

Nivicola........................ 1066, 1082

nivipes, Emblemaria ..............

nivosus, Cottus ..................

Myoxocephalus...........

Sebastes .................

Sebastodes ................

nobilior, Esox...................

nobilis, Atractoscion.

Cestreus ....................

Conodon ...................

Cynoscion .................

Esox......................

Gambusia.................

Grystes ...................

Heterandria ..............

Johinus..................

Perca .....................

Nocomis

amblops ................

bellicus..................

hyostomus...............

milneri ..................

nebrascensis..............

rubrifrons ................

nocomis, Notropis................

nocturna, Collettia.................

Echidna ................

nocturnus, Noturnns ............

Poecilophis ............

Schilbeodes ............

Noire, Oreille ...................

no Mai, Yanagi..................

Nomeidæ........................

Nomeinæ.........................

Nomeus.

gronovii ..................

maculatus ................

maculosus ................

oxyurus .
Page.

221

1326

987

509

509

509

278

1156

1567

1568

1156

138

138

278

277.

278

278

2402

1985

1984

1834

1833

629

1413

1413

1324

1413

629

682

1012

682

.1413

1324

, 315, 322

\section{1}

323

316

324

323

320

268

567

402

146

403

146

1261

1830

948

949

949

949

950

950

950 normalis, Bassozetus.

Page.

Northern Barracuda .............. $\quad 825$

Striped Gurnard ........ $\quad 2167$

Sucker................ 176

Whiting ............... 1475

North-River Shad ............... $\quad 427$

norvegica, Perca ................... 1761

norvegicus, Coryphrenoides ....... $\quad 2579$

Lepidoleprus ........ 2579

Sebastes .............. 1761

norwegianus, Squalus............ $\quad 57$

norwegica, Perca................. 1761

No-shee Trout................... $\quad 503$

nostras, Liparis ................. . 2118

notabilis, A rgyreus ............... $\quad 309$

Notacanthinæ.................. 613

Notacanthus .................... 614

analis .............. 615

challengeri ............ 618

chemnitzii........... 614

nasus............... 615

phasganorus.......... 616

rissoanus ............ 618

rostratus ............ 617

Notarius ...................... 119, 2764

notata, Atherina................ 800

Atherinichthys........... 800

Belone.................. 711

Cliola................... 274

Cyprinella................ 274

Dorosoma ................ $\quad 416$

Lepomis .................. 1011

Malthæa................ 2737

Megalops ................ 432

Menidia ................. 800

menidia .......... 2840

Perca.................... 1024

notatum, Etheostoma ............. 1070

Hæmulon............... 1297

Pristipoma .............. 1321

notatus, Balistes ................. 1709

Fundulus............... 653

Hyborhynchus ........... 218

Labrax................. 1132

Lepomis ................ 1008

Minnilus ............... 218

Notropis................ 274

Pimelodus................ 135

Pimephales............... 218

Pomotis ................ 1008

Poriclitliys .............. 2321

Semotilus................ 6.59

Tylosurus .............. 710,711

Zygonectes.............. 659

notemigonoides, Notropis......... 292

Notemigonus................... 249, 250 
Notemigonus americanus ..........

Page.

auratus ..............

chrysoleucus .........

gardoneus ............

ischanus ............

leptosomus ...........

lucidus ...............

occidentalis ..........

nothochir, Ophichthys ............

Quassiremus...........

Nothonotus ................1066, 1067, 1076

cinereus ............. 1078

inscriptus ........... $\quad 1072$

jordani .............. 1080

maculatus ............ 1077

rufilineatus........... 1079

sanguitluns........... 1077

tessellatus............ 1078

thalassinum .......... 1072

vulneratus............. 1077

nothus, Cestreus .................. 1407

Cynoscion ................ 1406

Otolithus .............. 1407

Notidanoid Sharks.............. 16

Notidanus....................... 18

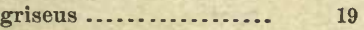

Notistium ........................

Notocanthidro ....................

Notoglanis

890

613

149

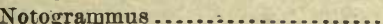

rothrocki............

Notorhynchus....................

borealis...........

maculatus ............

Notoscopelus......................

castaneus.............

caudispinosus ........

margaritifer ...........

quercinus .............

Notosema ........................

dilecta.................

dilectum................

notospilotus, Astrolytes............

Julidio .................

Pseudojulis........... 1603

Notropis ................ 254, 257-258, 290

æneolus ............... $\quad 266$

alabamæ................ 298

albeolus .............. 259, 283

altipinnis............... 287

amabalis................. 291

amøus................. 296

analostanus ............. 279

anogenus ............... 259, 260

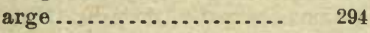

ariommus...........$\quad 290$
Page.

Notropis atherinoides ............ 254, 293

aztecus................ 258

bellus ................. 297

bifrenatus.............. 258

blennius.............. 261, 2800

boops................... 268

braytoni................. 264

bubalinus .............. 273

buchanani.............. 2800

cæruleus ............... 277

callisema ............... 272

callistius ............... $\quad 276$

camurus............... 279

cayuga ................ 260, 2799

atrocaudalis...... 260

cerasinus.............. 283

cercostigma ............. 274

chalybæus.............. 288

chamberlaini ............ 2800

chihuahua.............. 265

chiliticus............... 287

chlorocephalus .......... $\quad 286$

chrosomus.............. 288

coccogenis............. 284

cornutus ............... 281

cyaneus ........ 283

frontalis....... 283

dilectus................ 294, 2801

eurystomus.............. 277

formosus ............... 271

fretensis................ 261

frigidus ................ $\quad 271$

fumeus ............... 294

galacturus............. 279

garmani ............... 281

germanus .............. 261

gilberti.................. 266

heterodon ............... 261

heteorlepis .............. 260

hudsonius............... 269

amarus....... 270

saludanus..... $\quad 270$

selene ....... 269, 2801

hypselopterus ........... $\quad 280$

illecebrosus ............. 268

jejunus ................. 290

jordani ................ 259

kanawha ............... 264

lacertosus ............... 284

lateralis ................ 263

leuciodus ................ 291

lirus .................... 297

longirostris .............. 267

louisianæ.............. 2801

ludibundus .............. 273

lutipinnis.............286, 2800 
Notropis lutrensis.................

lythrurus.................

macronaldi ...............

macrolepidotus ............

macrostomus .............

maculatus ................

matutinus ...............

megalops albeolus ........

metallicus ................

micropteryx ..............

nigrotreniatus ............

niveus ...................

chloristius .........

nocomis..................

notatus..................

notemigonoides...........

nux.....................

orca................

ornatus..................

ozareanus ................

phenacobius ..............

photogenis............... 295, 296

piptolepis................ $\quad 266$

procne .................. 264

proserpina.............. $\quad 272$

pyrrhomelas ............. $\quad 280$

reticulatus.............. 262

roseipinnis .............. 298

roseus .................. 287

rubricroceus..............

rubrifrons.................

sabinæ...................

scabriceps ................

scepticus .................

scopifer ..................

scylla....................

shumardi................

simus....................

socius ...................

spectrunculus............

stigmaturus .............

stilbius..................

swaini ...................

telescopus...............

arcansanus....

texanus .................

topeka....................

trichroistius.............. umbratilis.

ardens .........

atripes ........

cyanocephalus

fasciolaris.....

lythrurus .....

matutinus.....

punctulatus...
Page.

271

284

299

274

259

301

284
297

296

264
277

278

268

274

292

267

289

265

63

6

72

Page.

299

274

venustus $\ldots \ldots \ldots \ldots \ldots \ldots .274,275$

volucellus .............. 263

welaka............ .2799

whipplii............... $\quad 278$

xænocephalus ........... $\quad 289$

xænurus............... $\quad 280$

zonatus............... 285

zonistius .............. 277, 285

nottii, Fundulus ................ $\quad 656$

Zygonectes................ 657

Noturus..................... 143

elassochir.............. 147

eleutherus.............. 148, 149

exilis .................. 147

flavus................. 144

funebris ................ 147

furiosus ............... 149

gilberti ................. 148

gyrinus................. 146

insignis............... 147

leptacanthus............ $\quad 146$

luteus.................. $\quad 144$

marginatus.............. 147

miurus................. 148

nocturnns ............. $\quad 146$

occidentalis.............. 144

platycephalus............. $\quad 144$

sialis................... 146

Novacula ....................... 1617

cæralea............... 1653

cultrata................ 1619

lineata................ 1619

martinicensis $\varepsilon . . . . . . . . \quad 1617$

mundiceps............. 1618

mundicorpus ........... 1620

novacula, Coryphœna .............. 1619

Xyrichthys............. 1619

Novaculichthys ................. 1613

infirmus.......... 1616

martinicensis...... 1616

rosipes ............ 1614

ventralis .......... 1615

novæ-angliæ, Coregonus.......... 465

novæorleanensis, Anguilla........ 348

novæterræ, Anguilla ............ $\quad 348$

noveboracensis, Exocœtus ......... 735. 736

Naucrates........ $\quad 900$

Vomer............ 934

novemfasciatus, Lutianus......... 1253

Neomænis ........ 1252

novemlineatus, Chasmodes ....... 2393

Pholis ............. 2393

novemmaculatus, Diodon ......... 1746

novemradiata, Agosia............ $\quad 312$ 
nox, Anchenopterus

Page.

Cremnobates.

2373

2374

nubila, A gosia

carringtonii ........

A pocope....................

Cliola........................

Hybognathus .............

nubilus, Alburnops ..............

Argyreus ...............

Centroblennius ..........

Ceratichthys..............

Leptoblennius ............

Lumpenus ...............

Stichrus.................

uuchalis, Ailurichthys............

Arius ..................

Chanos ...................

Hybognathus ...........

Psendoscarus .............

Searus..................

'Tachisurus ..............

Tachysurus.

212,311

311

311

215

215

215

311

2438

312

2438

2438

2438

117

131

415

213

1654

1654

131

nuchifilis, Blennius

131,2782

2383

2362

2362

2331

nuda, Cotylis

Labrisomus ..........

nudus, Cyclopterus.

Gobiesor - -..-.

Lepadogaster ................

nuecensis, Dioplites treculii........

Grystes ................

nugator, Bryostemma ..............

Numbfish ........................

nummifer, Carpiodes ..............

Salmo..................

Nurse ...........................

Nurse Shark

nuttalli, Exocœtus ... ..............

nuttingii, Antemnaríus............

nux, Notropis

Nyctophus..................... 569

obesa, Algansea ...................

Tigoma.....................

obesus, Amiurus ..................

Apomotis ...................

Echinorhinus ..............

Enneacanthus.............

Leuciscus . . ............... 246, 282

Leucos.....................

Pomotis...................

Squalius .................

obeyense, Etheostoma ..............

oblarius, Gasterosteus ..............

obliqua, Sciæna ..................

obliteratus, Alutarius
246

233

141

993

85

993

246

993

233

1092

750

1459

1720 obliquatus, Cestreus

Page.

1405

1405

Diabasis .............. 1304

Otolithus.............. 1405

obliquus, Mugil ................. 1459

oblonga, Chnopsetta............ 2633

Platessa................. 2630

oblongior, Pimelepterus........... 1388

oblongiusculus, Balistes........... 1720

oblongo, Corpore glabro ............ $\quad 2657$

oblongum, Moxostoma .............. 186

oblongus, Cyprinus ............... 186

Erimyzon sucetta....... $\quad 186$

Gobius ................. 2264

Heros................... 1535

Orthagoriscus .......... 1756

Ostracion catheloplateo.. $\quad 1728$ conico........ 1745

glaber........ 1735

holacanthus... 1746

Paralichthys ........... 2632

Pleuronectes ............ 2633

Pseudorhombus........ $\quad 2630$

Sebastes............... 1830

Sebastodes.............. 1830

Sparus ............... 2276

obscura, Liopsetta ............... 2651

obscuratus, Gymnothorax......... $\quad 389$

Lycodontis ........... 389

Pomacentrus........ 1552, 1555

obscurus, Carcharhinus........... 35

Carcharias.............. $\quad 35$

Centrarchns........... 1012

Pleuronectes ............ 2651

Pomotis ............... 1006

Squalus ................ $\quad 35$

obtusa, Labrus capite............. 1609

Ophisoma................. $\quad 355$

Raia ..................... 2751

obtusirostris, Acipenser .......... 106

Exocœtus............ $\quad 730$

Halocypsèlus....... $\quad 730$

obtusum, Hæmulon ................ 1319

obtusus, Pseudoscarus ............. 1654

Rhinichthys............ 308

Scarus .................. 1654

Squalus................. $\quad 39$

obvelatus, Prionodon............. $\quad 35$

Occa .......................... 2043

dodecaedron ................. 2044

verru cosa .................. 2043

occa, Cœlorhynchus............... 2587

Macrurus .................. 2588

Pristis .................... 61

occidentalis, Abramis............ 247

Amia............. $\quad 113$ 
occidentalis, Catostomus...........

Chorinemis...........

Conger ...............

Epigonus.............

Gasterostens .........

Girardinus ............

Heterandria ...........

Leucosomus...........

Luxilinus.............

Lnxilus ..............

Malacocephalus ......

Monacanthus.........

Myripristis

Notemigonus........

Noturus .............

Oligoplites............

Scombroides..........

Tetronarce ...........

Torpedo

occipitalis, Scorpæna.

Ocean Pipetish

Tang.

Turbot

Oceanic Bonito .................... oceanica, Anguilla

oceanicus, Blennius

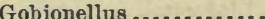

Gobius

ocella, Rhinichthys ................

ocellaris, Chøonopsetta .............

Fundulus..............

Platessa .................

Pseudorhombus ..........

ocellata, Bollmannia ...............

Corvina ..................

Muræna .................

Perca ....................

Raia ....................

Raja ...................

Sciæna..................

Sidera ...................

ocellatum, Ophidium ............... ocellatus, Acanthocottus...........

Anarrhichthys...........

Antennarius .............

Chænopsis ...............

Chretodon ................

Citharichthys............

Clinus....................

Gymnothorax ............

nigromarginatus.. saxicola ...

Hemirhombus............

Herpetoichthys ...........

Hippoglcssus
Page.

178

898

355

1112

745

689

689

247

247

247

2570

1715

847

247

144

898

899

77

77

1854

774

1693

1706

868

355

2379

2230

2230

307

2630

42,2827

2630

2630

2238

1454

399

1454

69

68

1454

399

2430

1976

2448

2721

2403

1674

2673

2357

399

400

399

2673

384

2673 ocellatus, Johnius

Page.

Lophius.

1454

2722

Lycodontis

nigromargina-

tus ......... 399

saxicola ...... $\quad 399$

Malacoctenus .......... 2356, 2869

Murænophis ............. 384

Neobythites............. 2513

Ophichthus ............. $\quad 383$

Ophichthys ............. $\quad 384$

Opisthocentrus ......... 2429

Platophrys.............. $\quad 2663$

Priodonophis............ $\quad 399$

Rhomboidichthys........ 2664

Rhombus............... 266t

Sciænops............... 1453

Zenopsis ................. 1660

Zens.................... 1661

ocellicauda, Amia .................. 113

ocellifer, Clinus ................... 2353

octodecimspinosus, Cottus ......... 1976

Myoxocephalns 1975

octofilis, Polynemus.............. 830

Trichidion .............. 830

Octogrammus .................. 1866

pallasi.............. 1870

octogrammus, Chirus ............. 1870

Hexagrammos ...... 1869

Labrax............ $\quad 1870$

octonemus, Polydactylus ........... $\quad 830$

Polyneinus ............ $\quad 830$

Trichidion ............ 830

oculata, Sebastes................ 1832

Squatina ................ $\quad 59$

oculatus, Anthias ............... 1283

Balistes ................ 1707

Bryttus ................ 1004

Centropristis............ 1283

Etelis ................. 1282

Hesperanthias .......... 1283

Icelinus................ 1895

Latebrus ............... $\quad 1115$

Lepidosteus .............. 111

Lumpenus .............. 2433

Macrops................. 1283

Myrichthys ............. $\quad 376$

Pisoodonophis........... $\quad 376$

Orthragoriscus .......... $\quad 1754$

Scombrops .............. 1114

Sebastodes .............. 1832

Serranus ................ 1283

oculocirris, Emblemaria............ 2403

oculofasciatus, Blepsias............ 2021

Nautichthys .....2020, 2021

oculo-radiato, Turdus ............. 1591 
oculo, Turdus radiato

Oeyanthias martinicensis.

Ocyurus

anrovittatus

chrysurus.

lutjanoides.

rijgersmœi .

ocyurus, Centropristes

Kyphosus ...............

Pimelepterus .............

Sectator .................

Serranus ................

Odontanthias asperilinguis ........ martinicensis........

Odontapsis .

americanus.

Odontognathus...................

mucronata .........

mucronatus ........

panamensis

Odontogobius

Odontopyxis

frenatug

leptorhynchus ........

trispinosus ........... trispinous

Odontoscion ........................

dentex................

xanthops ...............

Odontoscium archidium............

Odontostomidæ....................

œrstedii, selene ....................

Tetragonopterus..........

ogac, Gadus

ogat, Gadus.

Ogcocephalidx.

Ogcocephalus

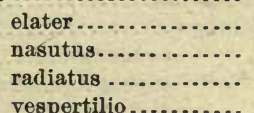

Ogilbia......................... cayorum .................. ventralis ..................

oglina, Megalops.................. oglinum, Opisthonema............. Ognichodes...................... ohiensis, Acipenser.

Esox..................... Lucius masqninongy......

Ohio Sturgeon................... ohioensis, Cichla.

Oil Fish.

Shark

Oja, Pege.
Page.

1703

1227

1228

1275

1276

1275

1261

1276

1200

1390

1390

$\mathbf{3} 389$

1201

1227

1228

46

47

437

438

438

438

2210

2085

2075

2076

2085

2086

1425

1425

1427

1432

597

935

334

2542

2542

2735,2739

2736

2739

2737

2738

2737

2502

2503

2503

432

432

2263

106

630

629

106

1012

879

32

2699
Ojanco

Page.

vjanco, Lutjanus.................

139

139

Old Wench.................... 1703

Wif $\Theta . . . . . . . . . . .940,1458,1649,1703$

Black................. 1711

olfax, Epineplelus ............... 1183

Mycteroperca............... 1183

ruberrima.... 1183

Serranus................ 1183

olfersi, Argyropelecns............ 604

Pleurothyris.............. 604

Sternoptyx .............. 604

olidus, Hypomesus.............. 525

Mesopus................ 525

Salmo (Osmerus).......... $\quad 525$

oligaspis, Abramis.............. 294

Alburnus .............. 294

Minnilus.............. 294

Oligocephalus............ 1066, 1068, 1083

grahami........... 1089

humeralis ......... 1097

leonensis ........... 1089

pulchellus.......... 1089

Oligocottus................... 2013, 2864

acuticeps ............. 2016

analis ................ 2013

borealis ............. 2014

embryum ............ 2017

globiceps ............ 2017

maculosus ........... 2013

snvdori .............. 2871

oligodon, Osmerus............... 2824

Polynemus ............. 830

Oligolepis ....................... 2210

oligopeltis, Acipenser........... 105

Oligoplites ..................... 898

altus ............... 899,2844

inornatus............ 899

mundus .............. 2844

occidentalis........... 898

saliens............... 899, 2844

palometa...... 899

saurus............... 898

Oligopodns.................... $\quad 955$

olisthostoma, Gerres ............. $\quad 1377$

olisthostomus, Gerres ............. 1376

olivacea, Pocilia ................. $\quad 659$

olivaceus, Leucus ................. 244

Rutilus................ 244

olivaris, Hopladelus............... 143

Leptops................. 143

Pelodichthys............. 143

Pilodictis ............... 143 
olivaris, Silurus.

olmstedi, Boleosoma brevipinnis

$$
\text { nigrum ....... }
$$

Etheostoma ..............

olriki, Aspidophoroides ............

Ombre Chevalier

ommata, Discopyge ...............

Heterandria

Lucania

Opisthognathus...........

ommatum, Opisthognathus......... onımatus, Paralichthys ............ omnisco, Salmo maycus ............ omocyaneus, Eleotris............... omostigma, Genypterus............ Otophidium ............

omosudis ......................... lowii ....................

Oncocephalus .....................

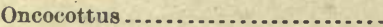

hexacornis ............

labradoricus............

quadricornis ...........

Oncorhynchus

$474,477,478$

chouicha ...........

gorbuscha ...........

keta ................

kisutch............

lagocephalus .......

lycaodon ........... 481, 483

nerka.............. kennerlyi ....

orientalis ............

paucidens ..........

proteus.............

quinnat ............

sanguinolentus....

scouleri.

tschawytscha.......

tsuppitich.

oneida, Catostomus

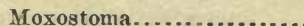

Ptychostomus..............

Oneirodes.

eschrichtii...............

Oneirodina .......................

ongus, Serranus...................

onitis, Hiatula ....................

Labrus ....................

Tautoga................. 1578, 1579

Onos ............................

cinubrius $=\ldots \ldots . . . . . . . . .$.

ensis .........................

reinliardti ...................

rufus .....................

septentrionalis
Page.

143

1057

1057

1057

2089

508

78

664.

663

2283

2282

2635

487

2198

2490

2490

598

598

2736

2000

2002

2004

2001

480

478

478

480

479

481

483

480

483

478

480

481

478

479

481

193

193

193

2732

2732

2728

1154

1579

1578

2558

2561

2559

2559

2559

2560 ontariensis, Thymallus.

Page.

518

montanus .. $\quad 519$

signifer.... $\quad 519$

Onus......................... 2529, 2558

riali ....................... 2530

onychus, Cottus ................. 1953

Oolachan....................... $\quad 521$

Oonidus........................ 1738

Ooze Eels . ..................... $\quad 349$

Opah.......................... 954

opah, Zeus....................... $\quad 955$

opalescens, Lythrulon ............ 131'

opalina, Julis .................... 1591

opalinum, Myctophum ............ $\quad 571$

opalinus, Platyglossus ............ 1591

Open-mouthed Grunt ............... 1306

opercularis, Micropogon.......... 1461

Myxodagnus .......... 2305

Polydactylus .......... 831

Polynemus ............ 831

Sciæna ................ 1461

Stolephorus........... $\quad 445$

Trichidion........... 831

Ophichthus..................... $\quad 381$

evionthas ............ 381

gomesii .............. 384

guttifer.............. $\quad 383$

havannensis.......... 382, 2804

magnioculis .......... $\quad 385$

ocellatus .............. 383

ophis................ 2804

parilis................ $\quad 386$

puncticeps............ 382

retropinnis............ 383

rugifer ............... $\quad 384$

triserialis ............ $\quad 384$

zophochir ............ $\quad 385$

Ophichthyidx................. $\quad 372$

Ophichthys .................... 381, 382

acuminatus........... 377

(Sphagebranchus) anguiformis........... 374

chrysops.............. 385

crocodilinus ........... $\quad 388$

gomesii.............. 385

guttifer............... 383

intertinctus .......... $\quad 387$

magnioculis .......... $\quad 385$

miurus .............. $\quad 387$

nothochir............ $\quad 380$

ocellatus.............. 384

pardalis .............. $\quad 376$

parilis ............... $\quad 386$

panciporis............ 386

pisavarius ............ $\quad 377$

puncticeps ........... 382 
Ophichthys punctifer

retropinnis

schneideri ............

triserialis..............

xysturus .............

zophochir.

ophidianus, Gempylus

Ophididio

Ophidioidea

Ophidioidei

Ophidion.

beani

grallsi..................

holbrooki ...............

josephi.

Ophidium

atropurpureum ........

brevibarbe..............

grøellsi .................

holbrooki ..............

imberbi.................

josephi

marginatum .............

mucronatum............

ocellatuni...............

parii....................

pellucidum .............

profundorum ............

taylori.

unernak.

viride.

ophidoides, Liparis

Ophioblenniinæ

Ophioblennius

steindachneri.......

webbii.............

Ophiodon ........................

elongatus..............

pantherinus .............

Ophiodontina

Ophiognathus

.....................

ampullaceus.

Ophioscion

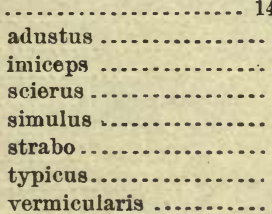

ophioscion, Corvina :..............

Sciæna................

ophis, Muræna

Ophichthus

Ophisoma .

acuta
Page.

2453

782

2487

2487

2488

2487

2488

2487

2423

2485

2487

2488

2443

2489

2489

2419

2430

2478

354

2484

2489

2477

2477

2118

2347

2400

2401

2401

1875

1875

1876

1864

405

406

1446,1447

1447

1451

1452

1449

1448

1448

1452

1148

1448

382

2804

353,355

356
Ophisoma analis

Page.

balearicum ............ 356

macrurum ............. 357

nitens ................. 357

obtusa................. 355

Ophisomus ..

$\begin{array}{lr}\text { prorigerum ............. } & 357 \\ 8414\end{array}$

Ophisternon................... $\quad 342$

Ophisura intertinctus ............. 387

sugillatus.............. $\quad 387$

Ophisuraphis .................. 374

Ophisurus...................... 375, 381

acuminatus ........... 377

californiensis.......... $\quad 384$

chrysops .............. 385

crocodilinus............ 388

gomesii ............... 385

guttatus .............. 382

latimaculatns .......... $\quad 376$

longus ................ $\quad 377$

parilis................ 386

remiger ............... $38 t$

xysturus ............... $\quad 376$

ophryas, Paralichthys ............. 2630

Prionotus ............... 2164

ophthalmicus, Lepomis ........... 1001

Opisthistius.................... 1384

Opisthocentrinæ ................ 2349

Opisthocentrus.................. $\quad 2428$

ocellatus .......... 2428

quinquemaculatus . $\quad 2430$

tenuis ............ 2430

Opisthognathidæ............... 2279

Opisthognathus................ 2280

lonchurum ....... 2281

lonchurus ......... 2281

macrognathum .... 2281

macrognathus ..... 2282

macrops.......... 2284

maxillosus ........ 2284

megastoma....... 2282

micrognathus ..... $\quad 2287$

ommata......... 2283

ominatum ........ 2282

punctatum ........ 2281

punctatus......... 2281

rhomaleus........ 2285

scaphiurus....... 2282

Opisthonema................... 432

libertate............ 433

libertatis ............ 433

oglinum ............ 43. 43

Opisthopterus.................. 436

dovii ............. 437

lutipinnis ........4 437, 2811

macrops.......... 437 
opisthophthalmus, Conger .........

Opladelus .........................

Oplopoma .......................

pantherina ..............

oppositus, Monocanthus ..........

Opsanus..........................

cerapalus ...............

pardus...................

tau......................

Opsopoea ..................... 247,

Opsopreodus .....................

emiliæ ...............

megalops .............

osculus ................

Opthalmolophns ..................

Oquassa Trout .....................

oquassa, Salmo

Salvelinus

marstoni.......

naresi ..........

Oranchee, Grand .................

Orange Filefish...................

Rockfish ..................

Orbe, Le Diodon ...................

orbieularis, Atinga alter minor.....

Rhombus ..............

Orbidus . ..........................

orbignianus, Exoccetus.............

orbignyana, Pellona................

Platessa...............

orbignyanus, Conger...............

Orbis echinatus .

lævis variegatus............

mnricatus ...................

reticulatus .................

orbis, Cyclopterus..................

Eumicrotremus ........... 2099, 2100

orbitarins, Pagellus................ 1350

Sparus ............... 1350

orca, Notropis.................. $\quad 289$

Orcella. .................... 254, 257, 289

orcini, Brama.................... 960

orcutti, Leuciscns................. 241

Phoxinus ................ 242

Orcynus......................... 869,870

alalonga................ 871

alliteratus ................ 869

pelamys..................

schlegelii.................

subulatus ................

thunnia ..................

thynnus.................

ordinatus, Chirus .................

Epinephelus ............

Hexagrammus

356

142

876

1716

2315

2316

2315

7,248

248

248

248

514

515

515

1057

1718

1793

1749

966

1729

729

436
2626

355

1745

\begin{tabular}{l}
1749 \\
\hline
\end{tabular}

750

00

Ord

Orqueta ........................ 937

orqueta, Chloroscombrus ......... 937

orsini, Ozodura .................. 1754

orthagoriscus, Cephalus .......... 1754

Orthagoriscus.................... 1754

Orthichthys..................... 759

Orthodon....................... 206

microlepidotus.......... 207

orthogrammus, Carangoides........ 928

Caranx............ 929

869 Orthonops e08................... 2262

870 orthonotus, Ditréma .............. 1507

871 Orthopristis............... 1334, 1335, 1336

869 brevipinnis .......... 1341

870 eantharinus........ 1339, 1340

$1870 \quad$ chalceus ............ 1337

1155 chrysopterus ........ 1338

1870 duplex............. 1339 


\begin{tabular}{|c|c|c|c|}
\hline & & & \\
\hline Orthopristis forbesi .... & 1336 & Osmerus mordax abbotti ........... & \\
\hline inornatus ............. & 1342 & & 523 \\
\hline lethopristis ............ & 1340 & 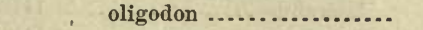 & 2824 \\
\hline ............... & 1339 & pretiosus ................. & 525 \\
\hline reddingi........... & 1386 & thaleichthys ............. & 522 \\
\hline Orthopsetta ..................... 2678, & 3, 2679 & viridescens........... & 523 \\
\hline sordida............ & 2680 & Osphyolax ........................ & 775 \\
\hline rthostœchus ...................... & 1313 & pellucidus .............. & 775 \\
\hline maculicauda......... & 1313 & osseus, Esox...................... & 110 \\
\hline Orthragoriscus ..................... & 1753 & Lepisosteus.... & 109 \\
\hline drini......... & 1754 & Ostariophysi ............ & 114 \\
\hline ....... & 1754 & ostentum, Careproctu & 2134 \\
\hline ............. & 1754 & osteochir, Echeneis . & 2273 \\
\hline n............ & 1754 & chirus........... & 2273 \\
\hline - & 1754 & ............... & 84 \\
\hline & 1554 & 1ys ........................ & 846 \\
\hline (n)............ & 1754 & Ostorhinchus ....................... & 1106 \\
\hline ispidus............ & 1754 & fleurieu........... & 107 \\
\hline (n)............. & 1754 & dae............................. & 721 \\
\hline (............. & 1754 & 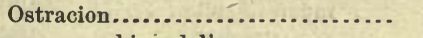 & 1721 \\
\hline as ............ & 1756 & bicaudalis................. & 1723 \\
\hline s............. & 175 & boops ................... & 1755 \\
\hline (n.......... & 175 & gus .. & 1728 \\
\hline (n)............. & 175 & (n).......... & 1723 \\
\hline (n.............. & 1754 & n.......... & 745 \\
\hline tii ........... & 1754 & am $\ldots \ldots \ldots \ldots \ldots$ & 1724 \\
\hline …......... & 1754 & i $\ldots \ldots \ldots \ldots . . . . . .$. & 1725 \\
\hline s ............. & 175 & sis $\ldots . . . . . . . . . .$. & 1725 \\
\hline s ............ & 1756 & (n)............... & 725 \\
\hline n........... & 17 & maculatus .............. & 1725 \\
\hline sbeck, Trachinus ................ & 1153 & oblongus holacanthus.... & 1746 \\
\hline Osbeckia............. 1717, 1718, 1719, & 2860 & glaber.......... & 1735 \\
\hline oscitans Sciæna................... 1 & 1441 & polydon inermis triqueter & 1723 \\
\hline ellifer................... & 1440 & is . .............. & 1725 \\
\hline oscula, Ag & & 18 $\ldots \ldots \ldots \ldots . .$. & 1725 \\
\hline e $\ldots \ldots \ldots \ldots \ldots \ldots \ldots$ & & as ventre glabro & 1749 \\
\hline (.................... & 127 & - $\ldots \ldots \ldots \ldots$ & 1740 \\
\hline a & 1484 & .............. & 1723 \\
\hline Netuma................ 127, &, 2768 & tus ... & 1724 \\
\hline n.................... 1 & 1484 & yalei & 1724 \\
\hline urus .................. & 127 & Ostracium quadricorne.... & 1725 \\
\hline ............. & 1132 & trigonum........ & 1724 \\
\hline osculus, & 309 & trigonus ............. & 1724 \\
\hline Holocentrus.............. & 853 & Ostracodermi..................... 781 & 31,1720 \\
\hline Opsopœeodus................ & 248 & Oswego Bass........................ & 1012 \\
\hline meriformis, Coregonus ............ & 468 & otakii, Hexagrammus .............. & 1867 \\
\hline osmerinus, Hybognathus........... & 213 & otarius, Lepidosteus ................ & 110 \\
\hline Osmerus ........................... 522, & 2,523 & Othonops.......................... & 2261 \\
\hline & 2823 & s, Perkinsia.................. & 420 \\
\hline ............... & 539 & othonopterus, Ces & 1405 \\
\hline & 523 & & \\
\hline ................ 524, 2 &, 2823 & Otolithinæ ........................... & 1393 \\
\hline elongatus................ & 525 & Otolithus albus .................... & 1411 \\
\hline lemniscatus .............. & 533 & californiensis ............ & 1413 \\
\hline microdon................. & 521 & carolinensis ................ & 1409 \\
\hline & & & \\
\hline
\end{tabular}


Otolithus drummondi .

Page.

jamaicensis

leiarchus.

magdalenæ

microlepidotus.

microps

nebulosus................

nothus

obliquatus

regalis

reticulatus.

rhomboidalis

squamipinnis

stolzmanni.

thalassinus.

toeroe.

virescens.

Otophidium

galeoides ..............

indefatigabile .........

omostigma..............

otophorus, Eupomacentrus.........

Pomacentrus ...........

Otrynter ........................

caprinus .................

otrynter, Caranx..................

otsego, Coregonus.................

ouachitæ, Hadropterus.............

ouananiche, Salmo salar............

Ouatilibi

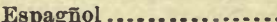

outalibi, wnneacentrus fulvus......

Serranus .................

ovale, Syacium...................

ovalis, Citharichthys..............

Hemirhombus .............

Sebastichthys..............

Sebastodes..................

ovatus, Trachynotus ...............

ovicephalus, Sparus...............

oriceps, Lactophrys................

oviformis, Chætodon ...............

ovigerum, Bathyphasma...........

ovinus, Esox

Lebias

ovis, Sargus.

Ovoides

erethizon

setosus

Ovum

oweni, $\mathrm{H}$ alogaurus

Oxybeles

oxybrachium, Sparisoma

oxybrachius, Scarus...................

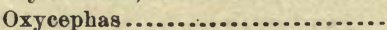

Ox scottus

$2015,2863,2864$
1409

1406

1415

1410

1415

1415

1409

1407

1405

1407

1409

1404

1404

1412

1408

1404

1415.

2490

2491

2490

2490

1555

1555

1344

1345

930

466

1035

487

1145

1140

1146

1146

2674

2674

2674

1789

1788

942

1361

1724

1668

2128

672

672

1361

1738

1739

1739

1738

607

2495

1634

1635

2568
Oxycottus acuticeps .

Page.

... 2015, 2864

Oxygeneum ..................... 207 pulverulentum ........ 207

oxygenius, Polyprion ............. 1139

Oxyjulis ....................... 1601

- californicus.............. 1601

modestus ................ 1601

Oxylabrax ...................... 1117

Oxylebiinæ...................... 1864

Oxylebius....................... 1878

pictus................ 1878

Oxyloricaria..................... 156

Oxymacrurus ................... 2587

Oxymetopontinæ................. 2188

Oxyodontichthys ................ $\quad 381$

brachyurus..... $\quad 385$

limbatus........ 385

macrurus ....... $\quad 385$

oxyptera, Corvina................ 1222

Oxyrhina ..................... 47

gamphodon ............ 49

spallanzani ............ 49

oxyrhynchus, Acipenser .......... 105

Carcharhinus........ 40

Carcharias ......... 41

Isurus............. 48,49

Tetrodon ........... 1741

Oxyurichthys ................... 2210

Oxyurus ...................... 353

oxyurus, Lepisosteus ............. $\quad 110$

Nomeus ............... 950

Oyster-fish :..................... 1578, 2315

ozarcanus, Notropis............... 265

Ozodura......................... 1753

orsini .................. 1754

ozodnra, Orthragoriscus .......... 1755

()zorthus hexagrammus.......... 2441

pachycephala, Adinia ............. 660

pachycephalus, Fundulus .......... 661

Lagocephalus...... 1729

Tetrodon ......... 1729

pachygaster, Spheroides........... 1738

Tetrodon ............. 1738

Pachylabrus ...................... 1507

variegatus........... 1508

pachylepis, Atherinichthys ....... 801

Menidia.............. 801

Pachynathus................... 1703

capistratus ......... $\quad \mathbf{1 7 0 4}$

triangularis......... 1705

Pachypops ....................... 1459

biloba ................ 1460

furcræus ............. 1459

pachypus, Cottus................. 1973

Pachyurus furcræus ............. 1460 
Pachyurus squamosissimus . pacifica, Relone.................... pacifici, Anisotremus

Batrachoides

Batrachus ................

Conodon..................

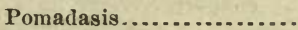

pacificus, Argy reiosus..............

Artediellus...............

Bathylagus .............

Cynicoglossus............

Glyptocephalus ..........

Larimus..................

Lobotes 2857,2858

Lutjanus 1253

Lycodes.

Mesoprion .................

Microstomus .............

(Mallotus) Salmo.........

Thaleichthys............

Thynnus..................

Tylosurus.

Pardde, Cock and Hen

Paddle-fish

Padde-fishe

pretulus, Hemirhom...............

patiulus, Hamirhombus..............

pagei, Etheostoma

Pagellus bajonado.

caninus ...................

humilis .................

microps.................

milneri.

orbitarius.................

penna...................

Pagrus. ..........................

argenteus .................

pagrus ...................

vulgaris....................

pagrus, Pagrus ....................

Sparus ....................

Pai de Gato

Pajarito.

pala, Cyprinus

palearis, Lycorles

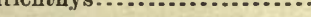

perciformis..........

Palinurus ....................... perciformis .............

pallasi, Octogrammus ..............

$$
\text { Pallasia ................... }
$$

Pallasia.......................... pallasi ...................

pallasianus, Cephalus .............. pallasii, Clupea
1253
2460

Page.

1419

716

1316

2314

2315

1316

1316

936

1906

530

2655

2655

1424

2460

1253

2655

521

521

871

716

2096

101

100

2672

1092

1352

1350

1352

1355

1355

1355

1350

1355

1356

1357

1356

1357

1356

1357

1837

721

415

2466

963

964

963

964

1870

1754

1753

1754

1754

422 pallasii, Pleuronectes .

Page.

Pallasina....................... 2C48

aix................... 2050

barbata............... 2049

pallida, Aldrovandia ............. 611

Echeneis................. 2272

Iepomis ................. 1012

Morone .................. 1135

palliclus, Bodianus ................ 1433

Catostonus.............. 179

Eupomotis.............. 1006

Fundulus..............638, 2827

Labrax ................ 1135

Labrus ................. 1005

Lepomis ................ 1005

Lencosomus .............. 222

Pimelodus................ 135

Platygobio ............... $\quad 326$

Pomotis ................ 1007

Salmo .................. 505

palmipes, Prionotus............... $\quad 2157$

Trigla ................. 2156

paloma, Trachinotus............. $\quad 945$

Palometa.. 940, 941, 942, 943, 965, 966, 967, 2849

media ................. 2849

palometa............... 2849

simillima............... $\quad 2849$

palometa, Chorinemus............ $\quad 899$

Oligoplites saliens...... 899

Palometa ............... 2849

Rhombus............... 966

Stomateus ............... 967

Palu Brasiliense congener.......... 966

palustris, Pœcilichthys............ 1102

Pammelas ........................ 963

perciformis ............. 964

pammelas, Melanostigma ..... 2479, 2869

Pampanito ....................... 941

Pámpano....................... 930,933

Common ................. 944

Gaff-topsail ............. $\quad \mathbf{9 4 0}$

Great ................... 943

Round ................. 941

Pámpanos ....................... 895, 939

pampanus, Trachynotus............ 944

panamense, Pristipoma............ 1331

panamensis, Achirus ............. 2702

Ailurichthys......... $\quad 117$

Atherinella ........... 805

Azevia.............. $\quad 2677$

Bodianus............. 1141

Caranx............. 928

Citharichthys........ $\quad 2677$

Engraulis ............ 448

Enneacentrus ......... 114i

Epinephelus .......... 1141 
panamensis, Felichthys ...........

Gymnothorax .........

Ilisha ...............

Loricaria..............

Menticirrhus..........

Muræna .............

Odontognathus........

Parapsettus...........

Pellona................

Petrometopon.........

Piabucina.............

Pomadasis..............

Pristigaster (Odontog. nathns)

Rabnla...

(n..............

Sidera................

Solea .................

Stolephorus ...........

Tetragonopterus ......

Umbrina ..............

Panchax .................. 633, 2827, 2830

pauciradiatus, Cubiceps............

pandionis, Glossamia ..............

pandora, Clinostomus .............

Squalius.................

Pañeca..........................

pannosa, Scorpæna...............

pantherina, Murenophis ...........

Oplopoma .............

pantherinus, Anarrhichas ..........

Cestracion .............

Ophiodon ..............

Pseudariodes ..........

Pantosteus.......................

aræopus...............

arizonæ $\ldots . . . . . . . . .$.

clarki ..................

columbianns ............

delphinus ..............

generosus ...............

guzmaniensis ..........

jarrovii ................

jordani ................

platyrhynchus .........

plebeius................

virescens.............. 171,

pantostigmius, Myrichthys..........

Papagallo .........................

Papagallos

papalis, Dionda

papilio, Melletes...................

papillifer, Gobiesox ................

papilliferus, Chologaster ...........

papillosa, A ramaca.................

papillosum, Moxostoma ...........
Page.

117

391

436

157

1473

391

438

1669

436

1141

332

1331

438

391

1141

391

2702

448

334

1473

957

1111

234

234

2196

1845

2805

1876

2446

21

1876

155

169

172

170,2790

172

172

171

170

171

171

171

170

171

171,172

2802

895

894

214

1932

2330

704

2672

189 papillosum, Syacinm

Page.

papillosus, Barbulifer .............. 2261

2671

Pleuronectes........... 2672

Ptychostomus......... 189

Paraclinus ...................... 2374

chaperi............... 2374

Paraconodon............... 1314, 1315, 1316

Paradiodon...................... 1744 quadrimaculatus....... $\quad 1746$

paradoxa, Garmannia ............. $\quad 2232$

paradoxus, Gobius ............... 2232

Psychrolutes.......... $\quad 2026$

Paradules......................... 1013

Paragonus ....................... 2054

acipenserinus ......... 2062

sturioides.............. 2063

Parahemiodon.............. 156, 157, 158

Paralabrax...................... 1194

albomaculatus ........ 1197

clathratus.......... 1197, 1198

humeralis ........... 1196, 1197

maculatofasciatus...... $\quad 1196$

nebulifer............ 1195, 1196

Paralepididæ.................... 599

Paralepinæ..................... $\quad 599$

Paralepis......................... 602

borealis................ 601

coregonoides............. 602

coruscans.............. 602

intermedius............ 600

Paralichthys ..................... 2624

adspersus ......... 2627, 2872

æestuarius ......... 2626, 2872

albiguttus.......... 2631

brasiliensis........... 2626

californicns......... 2625, 2626

dentatus............ 2629, 2630

lethostigma .......... 2630

lethostigmus ......... 2630

liolepis.............. 2624

maculosus........... 2626

magdalenæ.......... 2872

oblongus ............ 2632

ommatus ............ 2635

ophryas .............. 2630

sinaloæ............. 2872

squamilentus......... 2631

stigmatias........... 2636

woolmani............ 2628

Paraliparis................... 2139, 2140

cephalus .............. 2141

copei................. 2143

dactylosus ............ 2144

holomelas ............. 2140

liparinus ............. $\quad 2139$

mento ................ 2142 
P'age.

Paraliparis rosaceus............. 2142 ulochir............... 2144

parallelus, Centropomus.......... 1122

Paralonchurus ................. 1477, 1478

dumerili........... 1478

goodei............ 1480

petersi ........... 1481

rathbuni......... 1479

Paramacrurus................. 2587

Paramia....................... 1112

paranasimos, Acipenser ........... 106

Paranthias......................

creolus .................

1221

1222

furcifer

1221

Parapomacentrus

1549,1550

I'arap settus...................... 1669

panamensis........... 1669

Paraques........................ 1485

Parascorpæna................. 1839, 2860

Paraserranus hasselti............. 1205

parasiticus, Simenchelys .......... $\quad 349$

paraspistes, Caranx ............... 923

Paratractus ................ 916,917,921

pisquetus............ 921

Parché ....................... 1674, 1677

pardale, Leptophidium ............ 2486

pardalis, Epinephelus ............. 1183

Monacanthus............ 1713

Mycteroperca............ 1181

Ophichthys ............. $\quad 376$

pardus, Batrachus tau............ 2317

Opsanus................. 2316

Parepinephelus ........... 1169, 1170,1180

Pareques..................... 1485, 1486 acuminatus............. 1487

pareva, Aluteres .................. 1719

Parexocøtus ..................... $\quad 728$

mesogaster.......... 728

Pargo ....................... 1244, 1265

A marillo................. 1260

Colorado............ 1264, 1267, 1356

Criollo.................... 1265

de lo Alto................. 1262

de Raizero................. 1273

Guachinango ............. 1264

Mareño .................... 1252

Negro................... 1252

Prieto ................... 1252

pargus, Mesoprion............... 1255

Paricelinus...................... 1885

hopliticus ............ 1886

thoburni ............. 1888

parietalis, Coliscus................

parii, Lycocara...................

Ophidium ..................

Uronectes parilis, Ophichthus................ $\quad \begin{array}{r}\text { Page. } \\ 386\end{array}$

Ophichthys.............. $\quad 386$

Ophisurus ............... $\quad 386$

parkei, Salmo................. 508

Salveliuus ............... 2823

parkeri, A rius.................... 126

Selenaspis .............. 125, 2764

Silurus ................ $\quad 126$

Trachisurus ............. 126

Parma rubicundå................ 1565

parma, Cichlasoma ............... 1519

Heros.................... 1519

parmifera, Raia ................. $\quad 75$

Raja................. $\quad 74$

parnatus, Setarches .............. 1860

Parophrys..................... 2637, 2640

ayresi................ 2640

cøenosa................ 2639

hubbardi ............. 2641

ischyrus .............. 2641

isolepis ............... 2642

quadrituberculatus..... 2648

vetulus .............. 2640

parovanus, Cyprinodon .......... $\quad 666$

Myloleucus ............ $\quad 246$

Upeneus .............. 859

parra, Diabasis................... 1299

Hæmulon. ................ 1297

parræ, Albula................. 411

Brama.................. 1586

Chætodon ................ 1685

Clepticus ................. $\quad 1586$

Exocœtus................ $\quad 740$

Hæmulon.............. 1297, 1309

Parraserranus................... 1203

parrianus, Monacanthus........... 1713

Parrot-fish, Blue............... 1636, 1652

Dark-green ........... 1638

Green............... 1657

Parrot Fishes................. 1620, 1642

Parrot, Mud ................... 1639

Rose-back............... 1635

parryi, Rhamdella................ 153

Rhamdia................ 153

partitus, Eupomacentrus ......... 1558

Pomacentrus ........... 1558

Para ............................ 1680

paru, Chætodon ................ 1680, 1681

Pomacanthus ............... 1680

Rhombus................. 965, 2849

Stromateus................. 966

Parupeneus .................... $\quad 858$

parva, Lucania................. $\quad 665$

parviceps, Lycodapns............. 2493

parvipinne, Etheostoma........... 1096

parvipinnis, Archosion........... 1399 


\begin{tabular}{|c|c|c|c|}
\hline rvipinnis, Cestreus ....... & $\begin{array}{r}\text { Page. } \\
1410\end{array}$ & pectoralis, Dallia. & $\begin{array}{r}\text { Page. } \\
621\end{array}$ \\
\hline Cynoscion..... & 1410 & Harpe $\ldots . . . .$. & 1582 \\
\hline Dicrotus..... & 883 & Macrurns (Malacocepha- & \\
\hline Fundulus ........... 640 & 0,2827 & lus) & 2574 \\
\hline Isopisthus .............. & 1399 & Nematisti & 895 \\
\hline Promethichthys ...... & 883 & Nematonus & 2518 \\
\hline arvula, Clupea ............ & 426 & Pedalion ................ & 1753 \\
\hline ...... & 1945 & pedaliota, Bon & 580 \\
\hline Arius....................... & 124 & pedaliotus, $Z$ & 2826 \\
\hline Bagrus ..................... & 124 & Pediculate F & 2712 \\
\hline Sciadeichthys ............ 124 & 4,2760 & 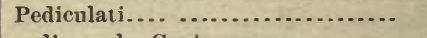 & 2712 \\
\hline s................. & 124 & Aimacula, C & 1119 \\
\hline asser, Hola & 1682 & Pega ............... & 2269 \\
\hline .......... & 1683 & Pegador........ & 2269 \\
\hline naca .... & 82 & Pege Oja ..... & 2699 \\
\hline Pastor.................. & 949 & Pegedictis ........... & 12, 1944 \\
\hline atao....................... & 1378 & ictalops... & 1951 \\
\hline Gerres............ & 1378 & Peixe Agulha ...... & 711 \\
\hline Julis ........................... & 1591 & Peixe-fonda ......... & 1312 \\
\hline tus ............... & 2009 & Rөу............ & 806 \\
\hline aus..... & 434 & , & 436 \\
\hline ......... & 682 & stoma....... & 767 \\
\hline ia .... & 681 & pelagicus, $\mathrm{C}$ & 2184 \\
\hline avicidens, Le & 2460 & n............ & 952 \\
\hline is $\ldots . . . \ldots \ldots . .$. & 2460 & us........ & 770 \\
\hline nchus ........... & 483 & elamides, & 869 \\
\hline$\cdots \cdot$ & 483 & pelamis, Gy & 868 \\
\hline thys .............. & 386 & . & 869 \\
\hline onymus .......... & 2188 & elamitus, $\mathrm{S}$ & 872 \\
\hline odon .............. & 1399 & Pelamys....... & 871 \\
\hline tes $\ldots \ldots \ldots \ldots . . .$. & 178 & ................ & 873 \\
\hline Sebastodes ............ & & .............. & 873 \\
\hline . & & & 873 \\
\hline avonia, Limi & 622 & & 872 \\
\hline Pœс & 692 & pelamys, Euth & 869 \\
\hline nus, Cyclopterns ... & 2097 & $\ldots \ldots \ldots \ldots$ & 869 \\
\hline$\cdots$ & 1159 & r $\ldots \ldots \ldots \ldots \ldots$ & 872 \\
\hline (n................. & 2471 & is ...................... & 869 \\
\hline lys................ & 2471 & lus .............. & 51 \\
\hline ................... & 247 & 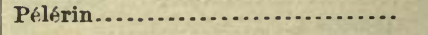 & 51 \\
\hline ................ & 2665 & ellona................................ & 435 \\
\hline Sucker......................... & 19 & ana .............. & 436 \\
\hline sh $\ldots \ldots \ldots \ldots \ldots \ldots \ldots \ldots$ & 2495 . & na............... & 436 \\
\hline shes ........................ & 2494 & s $\ldots \ldots \ldots \ldots$ & 436 \\
\hline che ...................... & 338 & (n.................. & 436 \\
\hline être.............................. & 1784 & na................... & 436 \\
\hline yngnathus ............ & 771 & panamensis ................. & 436 \\
\hline , & 770 & pellucida, Ammocrypta ............ & 1062 \\
\hline pomus........... & & clara ...... & 1063 \\
\hline$\ldots \ldots \ldots \ldots \ldots 60,61$ & & vivax. & 1063 \\
\hline (n................. & 2362 & perca .............. & 784 \\
\hline & 2362 & Thyris ................. & 2691 \\
\hline ectoralis, Albatrossia ............... & 2573 & pellucidum, Etheostoma clarum.... & 1063 \\
\hline Bodianus .................. & 1582 & Ophidium.........- & 354 \\
\hline 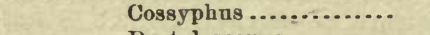 & 1582 & pellucidus, Delothyris. & 2691 \\
\hline & 2301 & Osphyolax .... & 775 \\
\hline
\end{tabular}


pellucidus, Pleurolepis.............

Psenes ...................

Pelodichthys

$$
\text { olivaris.............. }
$$

Pelon, Guaguanche ...............

Peloria.

pelta, Chelmo

peltastes, Lepomis .................

peltata, Percina ...................

peltatum, Etheostoma..............

peltatus, Hadropterus.............

Turdus cinereus..........

pemecus, Bagrus................

Pempheridø .....................

Pempheris .

mexicanus

mulleri.

poeyi .................. schomburgki...........

peninsulæ, Bascanichthys ........

Callechelys.............

Chirostoma............

Menidia

peuna, Calamus

Pagellus

1354,1355

1355

pennanti,.Argentina ............. $\quad 577$

Maurolicus ............ $\quad 577$

Squalus............... $\quad 49$

pennatula, Calamus.............. 1351

Penopus

macdonaldi .

2520

2521

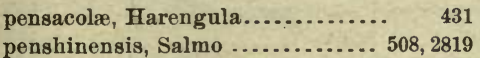

pentacanthus, Bodianus........... 849

Centrarchus........ $\quad 990$

Holocentrus ........ 849

Labrus ............. $\quad 1576$

Xenochirus.......... 2081

Pentanemas.................... 828

quinquarius ......... 828

1022

965

2643

1023

1136

1024

1833

alburnus................... 1475

americana .............. 1024, 1135

apoda..................... 1259

ascensionis .............. $\quad 849$

atraria.................. 1200

chrysops ................. 1132

chrysoptera ............... 1339

dorso monapterygia ........ 1833

flavescens ............... 1023
Page.

2841

1024

1208

1200

furcræa.................... 1460
gibbosa................. 1009, 1296

gigas................... 1154

gracilis.................. 1024

granulata................. 1024, 2841

guttata ................. 1142, 1164

immaculata................ 1135

juba ................... 1323

lanceolata ................ 1482

lophar................... 947

loubina.................. 1119

maculata ................. 1153

marina .................... 1761

cauda nigra......... 1303

gibbosa............. 1295

pinnis .............. 1259

puncticulata........ 1146

sectatrix ........... 1388

venenosa ........... 1172

melanurum ................. 1303

minima ................... 1057

mitchilli.................. 1133

alternata.......... 1133

interrupta ........ 1133

mucronata............... 1135

niger................... 963

(Pomacampsis) nigropunctata 1021

nobilis................... 1324

norwegica................. 1761

notata ................... 1024

ocellata................... 1454

philadelphica.............. 1202

punctata ............ 1145, 1146, 1433

pusilla.................... 1107

robusta................... 1154

rock-fish.................. 1133

rufa ..................... 849

salmonea ................. 1021

saltatrix................947, 1388

saxatilis.................. 1133

sectatrix.................. 1388

septentrionalis ............ 1133

serratogranulata ........... 1024

stellio ..................... 1153

striata................... 1311

tota maculis ............... 1153

trifurca ................. 1202

undulata .................. 1462

unicolor ................... 1192

unimaculata ............... 1360

varia .................... 1200

variabilis ............... 1784, 1796 


\begin{tabular}{|c|}
\hline 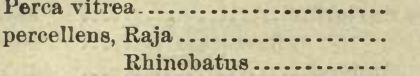 \\
\hline Percesoces ....................... 78 \\
\hline Perch, American .................... \\
\hline Black.$\ldots \ldots \ldots \ldots \ldots \ldots$ \\
\hline Blue $\ldots \ldots \ldots \ldots \ldots \ldots . . . .$. \\
\hline Pike ......................... \\
\hline Pirate............$\ldots \ldots \ldots$ \\
\hline Raccoon .................... \\
\hline 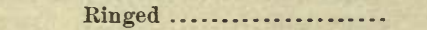 \\
\hline River .................... \\
\hline Sacramento................ \\
\hline Trout................... 7 \\
\hline Viviparous ............... \\
\hline White ..... 1133, 1134, 1484, 1501, \\
\hline Yellow ..................... \\
\hline Perch-like fishes .................... \\
\hline Perches ............................. \\
\hline Perches, American Pike ............ \\
\hline $\log (\ldots \ldots \ldots \ldots$ \\
\hline Percidø............................ \\
\hline 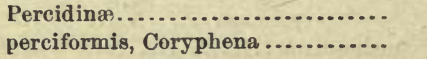 \\
\hline Lirus......... \\
\hline Palinurichthys ....... \\
\hline Palinurus............. \\
\hline Pammelas ............. \\
\hline
\end{tabular}

Percina

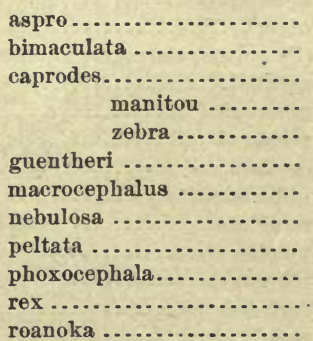

Percinæ..........................

Percis............................

japonicus ..................

percobromus, Alburnellus.......... Minnilus............

Percoidea

Percoidei. 979,1241 percoides, A gonostomns Percoids, Spariform .................. Percopsidæ

Percopsis ........................... guttatıs............... hammoudi ...............

perezi, Carcharlinus ............... Platypodon.
Page.

1021

63

63

781,787

1023

1504

05,1577

1021

785,786

1023

1023

1023

991

782,784

1498

1509

979

1015

1020

1024

1015

2032

964

964

964

964

964

1024,1026

1033

1027

1026

1028

1027

1034

1031

1027

1034

1031

1025

1036

1018

2033

2034

295

295

781

819

1241

783

783

784

784

36

36 perfasciatus, En

Stolephorus

Perichthys godeffroyi

periscopus, Gadus

perisii, Salmo.

Perissias .

treniopt

Peristediida

Peristedion.

gracile ................

imberbe ................

longispathum ..........

micronemus............

miniatum ..............

platycephalum .........

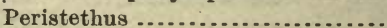

micronema ...........

peristethus, Podothecus............

Perkinsia ........................

othonops ...............

perlatum, Holocentrum............

perlongus, Neoconger ..............

Permit............................

perniger, Culius..................

Eleotris

peroni, Caranx

peronii, Lepidopus

Peropus.

bilobus..................

perplexus, Cottus ................

Perrico............................

perrico, Pseudoscarus .............

Scarus

Perro Colorado

Perro

perrotteti, Pristis

personatus, Ammodytes............

perspicabilis, Embiotoca............

perspicillum, Lycodes ..............

perspicuus, Hybognathus ..........

perthecatus, Stolephorus..........

peruanus, Amblyopus.............

Anthias ................

Gobioiles ................

Hemianthias ............

Promotogrammus .......

peruvanus, Galeichthys ........ 122

peruvianus, Galeichthys ......... 122, 2771

Gerres.............. 1376

Tachyeurus ........... 122

Pesca Blanca..................... $\quad 321$

Vermiglia................. 1811

Pescadillo del Rerl................ 1416

Pescadillos del Rey.............. 807

Pescadito ..................... 233

Pescado Azul .................... 1553

Azul de dos Colores ....... 1557 
Pescado Blanco de Chapala ....... Colorado................. del Rey

Pescador.

Martin

Pescados Azules

Blancos .................

Pesce Re

Tondo.

petenense, Dorosoma

petenensis, Chatoessus

Mollienisia............

Pimelodus .............

Pœecilia ................

Rhamdia ..............

Tetragonopterus .......

Petenia ......................... splendida ................

petersi, Paralonchurus ............. petimba, Fistularia .............. Petimbuaba.

Petite Gueule....................

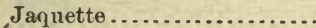
Nègre.

Scie.

Petos

Petrometopon apiarius ............. cruentatus ........... coronatus.

guttatus ............ panamensis .........

Petromyzon ...................... americanus ............ appendix

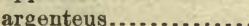
astori. ayresi bairdii. bdellinm . . .

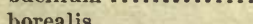
branchialis.

14,2745

camtschaticus........

castaneus

ciliatus

concolor.

lamotteni.

lividus. marinus

chamts cliat $i$ cus ......... dorsatus....... unicolor .......

nigricans............. nigrum. plumbeus
Page.

1453

806

2722

2724

1549

792

806

48

417

417

700

153

694

153

335

1513

1513

1481.

758

757

1370

1559

1142

1323

876

1140

1142

1141

1142

1142

1141

9

10

10

11

12

13

9

11

13

2745

11

12

11

10

12

10

2745

10

10

10

14

13

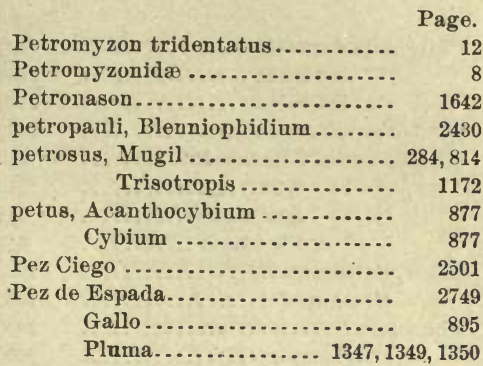

del Rey ................... 799, 808

Luna...................... 1753

Puerco .................... 1700, 1704

Sierra..................... 60

pfeifferi, Muræena................ $\quad 2805$

Sidera ................. 2805

phaenna, Hybopsis................ $\quad 270$

Phænodon .................... 586

ringens .............. 586

phaton, Pristigaster............ $\quad 438$

phalæna, Umbrina ............... 1475

Phalangistes ................. 2064, 2864

acipenserinus ....... 2062

fusiformis ........... $\quad 2048$

japonicus............ 2036

livigatus ........... 2048

loricatus .......... 2046

phaleratus, Esox ............... $\quad 628$

Phanerodon .................... 1506

atripes .............. 1507

furcatus ............. 1506

lateralis ............. $\quad 1506$

Pharyngognathi................ 781, 1571

phasganorus, Notacanthus........ $\quad 616$

phasma, Careproctus............. 2132

Phenacobius .................. $\quad 302$

catostomus .......... 304

mirabilis............ 303

scopifer............ 303

scopiferus .......... 303

teretulus............ 303

liosternus...

phenacobius, Notropis ............ $\quad 263$

phenax, A pomotis............... 997

Lepomis ................ 997

Mycteroperca falcata ...... $\quad 1185$

philadelphica, Perca ............. 1202

philadelphicus, Centropistes ...... 1201

Serranus......... 1202

philipii, Clinns................. $\quad 2359$

philonips, Cottus ................ 1960

Philosophe ...................... 1693

Philypnus .................... 2194 


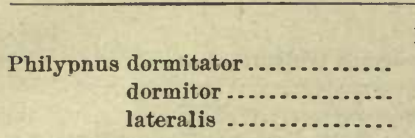

phlebotomus, Acanthurus ...........

phlegethontis, Clinostomus .........

Gila................

Leuciseus...........

Phoxinus ............

phlox, Boleosoma..................

Ulocentra ..................

Phobetor .........................

tricuspis.................

Phøbe ...........................

phœbe, Centropristis..............

Prionodes ..................

Serranus .................

Pholidapus.

$$
\begin{aligned}
& \text { dybowskii ................ } \\
& \text { grebnitskii ............. }
\end{aligned}
$$

Pholidichthyinæ ..................

Pholidichthys .

anguilliformis ........

Pholidinæ ..........................

Pholis................ 2377, 2414, 2415, 2417

carolinus .................. 2379

dolicogaster ............... 2416

fasciatus ................... 2417

gunnellus ................. 2419

novemlineatas............. 2393

ornatus .................... 2419

pictus .................. 2415, 2416

quadrifasciatus........... 2392, 2394

ruberrimus ................. 2417

subbifurcata............... 2440

taczanowskii ............... 2416

Photogenis....................... 254

ariommus............ 290

cæruleus ............. $\quad 277$

callistius ............. $\quad 276$

engraulinus............ 296

eurystomus ............ 277

grandipinnis.......... 280

leuciodus .............. 291

leucops ............... 296

leucopus ............. 277

niveus ................

pyrrhomelas ...........

gcabriceps ..............

spilopterus .............

stigmaturus ...........

telescopus ..............

photogenis, Leuciscus..............

Notropis............. 295, 926

Squalius ..............

Photonectes......................

gracilis

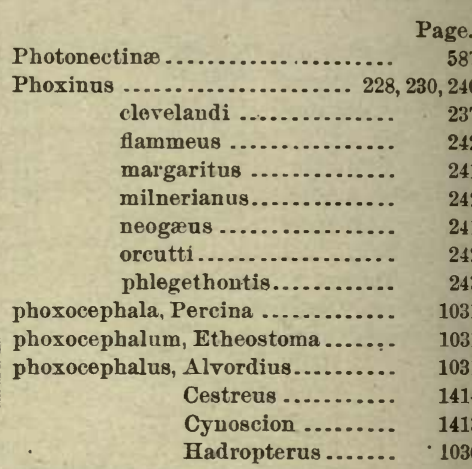

phrygiatus, Arius ................. 131

Hexanematichthys .... 130

Tachisurus rugispinis . 131

Phrynotitan.................... 2853

Phtheirichthys ................. 2268

lineatus.......... 2268

Phycinæ...................... 2532

Phycis ......................... 2552

americanus............... 2555

chesteri ................... 2556

chuss..................... 2555

cirratus ................. 2554

dekayi.................. 2555

earlli ................... 2555

floridanus ................ 2554

marginatus............... 2555

punctatus ................ 2553

regalis.................... 2553

regius .................. 2553

rostratus................ 2555

tenuis.................. 2555

Physiculus..................... 2547

fulvus................ 2547

japonicus ............. 2549

kaupi ................. 2547

nematopus ............ 2548

rastrelliger............ $\quad 2549$

physignathus, Ceratichthys....... $\quad 326$

Couesius........... $\quad 326$

Platygobio .......... $\quad 324$

$\begin{array}{lr}\text { Physogaster...................... } & 1727 \\ \text { Piabucina ....................... } & 332\end{array}$

$\begin{array}{rr}\text { Piabucina ...................... } & 332 \\ \text { panamensis............. } & 332\end{array}$

Picarels .......................... 1364

picarti, Hemirhamphus ........... $\quad 720$

Picconou........................ 194

piceus, Balistes................. 1711

Melichthys............... 1711

pichardi, Joturus................. $\quad 821$

Pickerel ......................... 628

Banded.................. 626 
Pickerel Common Eastern..........

Page. Little

Pickering

Picorellus ........................ picta, Muræna..................... pictipinuis, Cheliclonichthys ....... Trigla ................

picturata, Alutera ................

Gambusia ...............

Seriola ...................

picturatum, Siphostoma...........

pieturatus, Caranx...............

Gymnothorax .........

Syngnathus...........

Trachurus .............

pictus, Centronotus

Chaunax ..................

Chironectes................

Chirus....................

Eleotris...................

Gymnelis.................

Gymnothorax ..............

Iridis . . . . . . . . . . . . . . . .

Julis .....................

Lycodontis ................

Oxylebius ...................

Pholis ................... 2415, 2416

Platyglossus............. 1600

Torpedo ................. 78

Urocentrus................ 2416

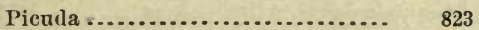

picuda, Sphyræna................ 823

Picudilla........................ 824

picudilla, Sphyræna..............

pidiense, Moxostoma..............

pidiensis, Ptychostomus ..........

piger, Symphurus................

Pigfish

Pigfishes ..............................

pigmentarius, A pogon ............

Monoprion ...........

Pigmy Sunfishes ..................

pigra, Aphoristia .................

Pigus ...........................

Pike, Blue .......................

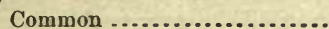

Gar..................

Gray .......................

Great .....................

Northern ...............

Green .....................

Sand ...................... 1022

Wall-eyed.................. 1021

Yellow .................... 1021

Pike-liko Fishes................. 622
Pike Perch...................... Page

Pikea ............................ 1135

Pikes ........................... 624

Gar..................... 108

pilatus, Prionotus............... 2156

Pileoma ........................ 1024

bimaculata............. 1027

carbonari ............... 1027

cymatogramma .......... 1053

nebulosa ................ 1027

semifasciatum .......... 1027

zebra.................. 1028

pilicornis, Blennius.............. $\quad 2380$

Pilodictis limosus................. 142

olivaris ................ 143

pilosa, Solea..................... 2699

pilosus, Diodon ................. 1744, 1752

Tricliodiodon........... 1743, 1744

Pilot, Black .................... 1555

Cockeje................. 1555, 1561

Pilot-fish....................... 465

Pilot-fishes...................... 900

Pilot, Shark's ..................... 902

Pimelepterus..................... 1384

analogus............ 1386

bosci............... 1388

bosquii.............. 1388

cornubiensis........ 964

elegans .............. $\quad 1387$

flavolineatus........ $\quad 1386$

incisor ............. 1386

lutescens............. 1389

oblongior ............ 1388

ocyurus............ 1390

Pimelodella ..................... 153

chagresi ............. $\quad 154$

modesta ............... 154

Pimelodinæ ..................... $\quad 116$

Pimelodus........................ 116, 154

æneus................ 143

affinis ................. 134

ailurus................ $\quad 140$

albidus................ 132,138

antoniensis ............ $\quad 140$

argenteus............... 125

argentinus............ 135

argsrus............... 135

atrarius............... $\quad 140$

baronis-mulleri ......... 151

blochii................ 155

borealis............... 137

brachypterus .......... $\quad 152$

cænosus .............. 140

cærulescens............ 135

catulus ............... 141

catus ................ $\quad 140$ 


\begin{tabular}{|c|c|c|c|}
\hline & & Page. & Page. \\
\hline imelodus & saudafurcatus .......... & 135 & Pimelometopon pulcher........... \\
\hline & chagresi ............... & 154 & Pimelonotus............................ \\
\hline & clarias ................. & 155 & Pimephales...$\ldots \ldots \ldots \ldots \ldots$. \\
\hline & confinis ............... & 141 & agassizii.............. \\
\hline & cupreoides ............. & 140 & fasciatus ............ \\
\hline & cupreus................ & 140 & maculosns ............ \\
\hline & dekayi ................... & 140 & milesi ................ \\
\hline & erythroptera........... & 135 & notatus............ 218, 2796 \\
\hline & felinus............... & 140 & promelas ........... $\quad 217$ \\
\hline & felis............. & 141 & confertus.... \\
\hline & furcatus $\ldots \ldots \ldots \ldots$. & 134 & maculosus... \\
\hline & furcifer ............... & 135 & Pincers.............................. \\
\hline & godmani ............... & 152 & Pinfish...$\ldots \ldots \ldots \ldots \ldots \ldots$ \\
\hline & gracilis ................ & 135 & pingeli, Triglops................ 1923, 1925 \\
\hline & graciosus ............. & 135 & pinguis, Hippoglossus ............ 2611 \\
\hline & guatemalensis ......... & 152 & Platysomatichthys....... \\
\hline & hammondi ............ & 135 & Pleuronectes .............. \\
\hline & houghi................. & 135 & pini, Trigla ....................... \\
\hline & hoyi .................. & 141 & pinima, Acara................... \\
\hline & hypselurus............. & 152 & Pristipoma acara .......... \\
\hline & insigne ............... & 147 & Pink-fish............... \\
\hline & lateralis ................. & 135 & pinnata, Murana ................. \\
\hline & laticaudus ............. & 152 & pinnatus, Synaphobranchus ....... \\
\hline & lemniscatus........... & 147 & pinnifasciatus, Pseudopleuronectes \\
\hline & lupus .................. & 137 & pinniger, Bryssetæres............. \\
\hline & lynx .................... & 138 & Enneacanthus........... \\
\hline & macronema ............. & 155 & Gobiesox................. \\
\hline & maculatus ............ & 135,155 & Sebastichthys.......... \\
\hline & managuensis............ & 153 & Sebastodes ............ 1793,1794 \\
\hline & marginatus ............ & 135 & Sebastosomus.......... 179 \\
\hline & marmoratus ............ & 141 & pinnimaculatus, Ailnrichthys...... \\
\hline & megalops .............. & 135 & Felichthys....... \\
\hline & micropterus ........... & 153 & pinnis, Perca marina .............. \\
\hline & modestus ............... & 154 & Turdus branchialibus ...... \\
\hline & aguensis ............ & 151 & pinnirarius, Hypoplectrus unicolor \\
\hline & natalis................ & 140 & pinnulata, Seriola ................ \\
\hline & nebulosus.............. & 140 & pinnulatus, Elegatis .............. \\
\hline & nicaraguensis.......... & 152 & Pinta, Carilla ........................ \\
\hline & nigrescens ............. & 137 & Morena............. \\
\hline & nigricans ................ & 137 & Pintado.............. \\
\hline & 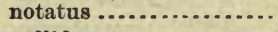 & 135 & Pintano ................................ \\
\hline & pallidus................ & 135 & 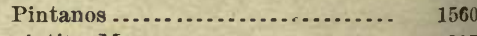 \\
\hline & petenensis ............. & 153 & pintita, Morena .................. \\
\hline & platycephalus.......... & 142 & pintiti, Muræna................. \\
\hline & polycaulus............. & 153 & Pipe............................... \\
\hline & pullus ...................... & 141 & Pipefish, Common ................. \\
\hline & punctulatus............. & 143 & Great $\ldots . . . . . . . . . .$. \\
\hline & rigidas................. & 155 & Ocean $\ldots . . . \ldots \ldots \ldots . . . .$. \\
\hline & salvini .................. & 152 & Pipefishes......................... \\
\hline & spixii ............. & 132 & Piper............................. \\
\hline & vulgaris ............... & 140 & piptolepis, Notropis.............. \\
\hline & valpeculus............. & 141 & Piquier........................... \\
\hline & valpes............. & 135 & 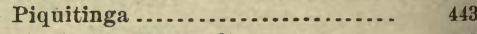 \\
\hline & wagneri................ & 151 & piquitinga, Engranlis ............. \\
\hline & topon.................... & 1585 & piquottii, Amia .................. \\
\hline & darwinii........... & 1586 & piraaca, Monacanthus............ \\
\hline
\end{tabular}


Pirabelóe

Page.

Piracoaba

Piramutana blochii ................

$$
\text { macrospila ............ }
$$

pirapeda, Dactylopterus............

Pira-pixauga or Gat-visch.........

Pirate Perches

Pirati apia

piritita, Cabrilla ..................

pisavarius, Oplichthys ............

piscatorins, Lophius ...............

piscatrix, Psendorhamdia..........

Pisces.

pisces, Unicornu bahamensis .......

pisciculas, Esox..................

piscis, Luna.

Piscis viridis bahamensis .........

pisculentus, Esox.................

Fundulus .............

pisonis, Eleotris................ 2201, 2200

Gobius.................. 2201

Pisoodonophis .................... 375, 377

cruentifer ........ 377, 2803

daspilotus ......... 2803

guttulatus.......... 377

longus ............. $\quad 377$

oculatus ............ $\quad 376$

xysturus........... $\quad 376$

pisquetus, Caranx ............... 921

Paratractus............ 921

pistilliger, Cottus ................ 2008

Elaphocottus .......... 2008

Gymnocanthus .. 2006, 2008, 2009

Pitamba, Acara...................

1276

pituitosus, Rhypticus..............

pixanga, Serranus ................

pixuma, Amore ...................

placitus, Hybognathus............

Placopharynx .....................

carinatus............

duquesnii ...........

Plagiogrammus

hopkinsi...........

plagioplateo, Eleotris capite .......

Plagioscion.

heterolepis

squamosissimus........

surinamensis..........

Plagiusa ..........................

plagiusa; Aphoristia ..............

Glossichthys .............

Plagusia .................

Pleuronectes ..............

Symphurus ..............

Plagopterinæ

1234

1153

2201

213

197

198

198

2427

2428

2201

1418

1419

1418

1419

2704

2710

2710

2710

2710

2710

204

329
Plagopterus argentissimuse.

Plag. 329

brasiliensis ............. 2709

fasciata................. 2710

plagiusa ................ $\quad 2710$

tessellata............... 2709

plagusia, Pleuronectes............ 2709

Symphurus ............. 2709

Plagyodontidæ.................... 2826

Plagyodus .................. 594, 596, 2826

Plaice.......................... 2648

Plain-tail......................... 879

plana, Platessa .................. $\quad 2647$

planci, Mola...................... 1756

Tympanomium............ 1754

Plancterus ..................... 2827, 2828

planiceps, Arius................. 127

Catostomus............. 181

Netuma .............. 127, 2766

Rhinobatus............. 64

planifrons, Eupomacentrus........ 1559

Pomacentrus ........... 1559

Planirostra..................... 101

spatula............... 102

planus, Pleuronectes .............. $\quad 2647$

Pseudopleuronectes........ 2647

Plargyrus ....................... 250, 254

argentatus ............. 283

bowmani ............... 283

melanocephalus......... 217

typicus................ 283

plargyrus, Rutilus............... $\quad 282$

Plate-fish....................... 1722

Platessa........................ 2648

bilineata ................ 2643

dentata ............... 2615, 2630

dvinensis................ $\quad 2650$

olongata................. $\quad 2657$

ferruginea ............... 2645

glabra.................. $\quad 2650$

microcephala............ 2654

oblonga ................. 2630

ocellaris................ 2630

orbignyana .............. 2626

plana.................... 2647

pola ..................... 2657

pusilla ................... 2647

quadrituberculata........ 2648

quadrocellata ............ 2633

rostrata ................. 2645

stellata.................. 2652

platessa, Caranx ................. $\quad 927$

platessoides, Citharus............. 2615

Drepanopsetta...... 2615

Hippoglossoides...... 2614

Pleuronectes........ 2615 


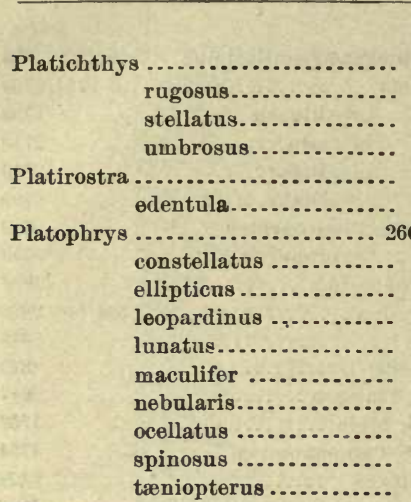

platophrys, Citharichthys.......... Platopterus

platorynchus, Acipenser...........

Scaphirhynchus.....

platostomus, Lepisosteus .......... platycephalum, Peristedion........

Platycephalus.....................

americanus...........

angustus............

dormitator ...........

platycephalus, Ameiurus...........

Cottus ............ 1983, 198

Megalocottus....... 1987

Noturus ............ $\quad 144$

Pimelodus......... 142

Platygaster

bivittatus

435

1597

caudalis ........... 1599, 1600

crotaphus ............

cyanostigma .........

dimidiatus ...........

dispilus ..............

florealis

1598

1591

1594

1598

1597

1593

garnoti

1597

grandisquamis

humeralis ............

internasalis ..........

maculipinna.........

nicholsi ..............

opalinus..............

pictus...............

poeyi ................

principis .............

radiatus........... 1591, 1597

ruptus ..............

semicinctus ...........

Platygobio .......................

communis .............

gracilis

palliủus

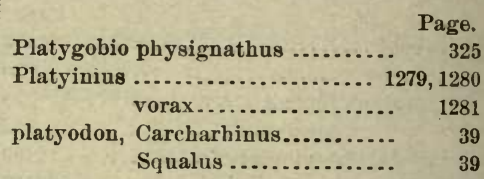

Platypodon.................... $33,34,35$

falciformis ............ $\quad 36$

perezi ................. $\quad 36$

Platypocilus..................... $\quad 685$

maculatus........... 686

mentalis............ $\quad 686$

quitzeoensis......... 2873

platypogon, Arius................ 127

Netuma............. 127, 2767

Tachisurus ............ 127

Platyrhina exasperata............ 65

triseriata............. $\quad 66$

platyrhincis, Lepisosteus......... $\quad 111$

Platyrhinoidis ................. 65

triseriatus......... 65,66

platyrhinus, Acipenser............ 106

platyrhynchus, Carcharhinus ...... $\quad 36$

Eulamia ........... $\quad 36$

Minomus .......... 170

Pantosteus........ $\quad 170$

Scaphirhynchus ... $\quad 107$

platyrrhynchus, Scaphirhynchops . $\quad 107$

Platysomatichthys............... 2610

hippoglossoicies 2611

pinguis........ 2611

stomias....... 2610

Platysomus ..................... 933

micropteryx .......... 934

spixii.............. 934, 2846

Platysqualus................... 43,44

platystomus, Lepisosteus ......... $\quad 110$

Platytroctes..................... $\quad 458$

apus.............. 458

plebeius, Catostomus............. $\quad 171$

Gasterosteus ............ $\quad 751$

Pantosteus.............. 171

plebejus, Mustelus............... $\quad 29$

Plecopodus..................... 2263, 2868

Plectobranchinæ................ 2349

Plectobranchus ................... 24:31

evidles $\ldots . . . . . . . \quad 2432$

Plectognathi ...................... 1696

Plectognathous Fishes............ 1696

Plectospondyli................... $\quad 160$

plectrodon, Porichthys............ 2321

Plectromus ..................... 840

beanii ............... 842

crassiceps ............ $84: 3$

eristiceps............ 843

lugubris ............. 842

suborbitalis .......... 841 
Plectropoma accensum

Page.

aftine

afrum ..............

bovinum............

chloropterum .........

chlorurum ............

crocota ..............

ephippium...........

gummigutta ..........

guttavarium.........

hispan um...........

indigo ...............

melanorhina ..........

mouacanthus .........

multiguttatus ........

nigricans ............

puella ................

vitulinum

Plectrypops

retrospinis ............

pleianus, Pseudoscarus ............

Scarus ...................

pleii, Hemirhamphus ..............

Plesioperca

anceps.

Pleuracromy lon ...................

pleuriticus, Salmo clarkii ..........

mykiss .........

I'leurogadus

gracilis

..................

gracilis ..............

Pleurogrammus

monopterygius.. 1864, 1866

Pleurolepis

asprellus .............

pellucidus ..............

Pleuronectes ........................

achirus ..............

americanus ............

apoda.................

aquosus ..............

aramaca...........

argus................

asper ................

beanii................

bilineatus .............

cicatricosus ..........

cynoglossus....... 2611, 2657

dentatus.............. 2630

digrammus .......... 2641

ellipticus .............

elongatus.............

ferrugineus ..........

franklinii

gilli

glaber

glacialls
1193

1166

1193

1165

1193

1192

1192

1192

1192

1140

1193

1192

1165

1166

1193

1192

1192

853

853

1656

1656

723

1028

1039

29

2819

496

2537

2538

1864

1061

1061

1063

2648

2696

$264 i$

2701

2660

2672

2666

2645

2646

2643

2649

2665

2657

2645

2650

2654

2650

2649
Pleuronectes guttulatus............ 2640

hippoglossoides ...... 2611

hippoglossus ........ 2612

ischyrus............ 2641

kitt ............... 2654

lævis ............... 2654

limandoides ......... 2615

lineatus............ 2698, 2701

linguatula.......... 2615

lunatus ............. 2666

macrolepidotus ....... 2672

maculatus ........... $\quad 2660$

maculifer............ 2665

maculosus ........... 2626

- melanogaster ......... 2630

microcephalus ....... 2654

microstomus......... 2654

mollis................ 2701

nigromanus ......... 2657

oblongus............. 2633

obscurus............. 2651

pallasii .............. 2648

papillosus .......... $\quad 2672$

perarcuatus .......... 2643

pinguis............. 2611

plagiusa............ $\quad 2710$

plagusia............ 2709

planus ............. 2647

platessoides......... $\quad 2615$

quadridens ........... $\quad 2654$

quadrituberculatus... $\quad 2648$

quenseli ............. 2654

saxicola ............ $\quad 2657$

stellatus ............. 2652

surinamensis ........ 2666

umbrosus............ 2643

vetulus .............. 2641

Pleuronectidæ.................... 2602

Pleuronectinæ ................... 2607

Pleuronichthys ................ 2637

cœnosus........ 2638, 2639

decurrens........ 2637, 2683

guttulatus......... 2640

quadrituberculatus $\quad 2638$

verticallis ......... 2638

pleurophthalmus, Antennarius .... 2722

pleurospilns, Girardinus.......... $\quad 688$

Heterandria......... 688

pleurostictus, Triglops........... 1923

Pleurothyris .................. 603

olfersi .............. 604

plumarius, Archistes ........... 1900, 1901

plumatula, Calamus.............. 1352

plumbea, Chimæra.............. $\quad 95$

Dionda ............... 216

Gambusia ............. 695 
plumbea, Hybognathus...........

Page.

Lampetra................

plumbeolus, Alburuops ............

Minnilus.............

plumbeum, Zophendum.............

plumbeus, Ceratichthys............

Couesius................

Gobio..................

Petromyzon.

plumier, Le Tetrodon

plumieri, Caranx ...................

Chaetodon ...............

Conodon .................

Coryphœna ..............

Diabasis ................

Gerres ...................

Gobius ..................

Hæmulon ...............

Labrus..................

Malacanthus............

Mugil

Sciæna ..................

Scomber..................

Scomberomorus ..........

Scorpæna ................

Sicydium................

Tetrodon .................

Trachurops ..............

Trichidion ...............

plumierianus, Caranxomorus.......

plumierii, Polydactylus............

Polynemus ..............

plurimis, Cottus cirris .............

plutonia, Raja...................

pluvialis, Labrax..................

Poacher, Sea .....................

Poachers, Sea ...................

pocatello, Catostomus ...............

podostemone, Boleosoma ...........

Etheostoma...........

Podothecus ..........................

accipiter ...............

acipenserinus........ 2061, 2062

gilberti ............... 2058

hamlini .............. 2056

peristethus ............ 2062

sturioides............. 2063

thompsoni ............ 2060

veternus........... 2063, 2064

vulsus ............... 2068

I'œcilia ........................ 690, 2833

boucardi ...............695, 2834

branneri................ 2834

butleri................6 691, 2833

cænicola................. 641

catenata................. 648

Page.

Pocilia chisoyensis .............. 693, 2834

couchiana.............. 695, 2833

conchii ................... 695

cubensis ................. $\quad 692$

cuneata................. 2834

dominicensis ........696, 2833,2834

dovii................. 695, 2833

elongata .............. 697, 2834

fasciata.................. 641

fasciatus ................ 2833

gillii .................692, 2834

lineolata................ 700

macrolepidota ............ 641

melanogaster ............ 696, 2834

melapleura................ $\quad 660$

mexicana ............... 692, 2833

multilineata .............. 700

olivacea................. $\quad 659$

pavonia................ 692, 2833

petenensis .............. 694, 2833

plumbeus................ $\quad 2833$

presidionis............... $\quad 697$

reticulata................ 2833

schneideri ................ 691

sphenops ...............694, 2833

spilurus ............... 697, 2833

surinamensis ............. 691

thermalis ................693, 2833

(Acropocilia) tridens...... 690

vandepolli............. 696, 2833

arubensis ..... 696, 2834

vittata.................692, 2833

vivipara ...............6 691, 2833

Poecilichthys.............. 1066, 1067, 1069

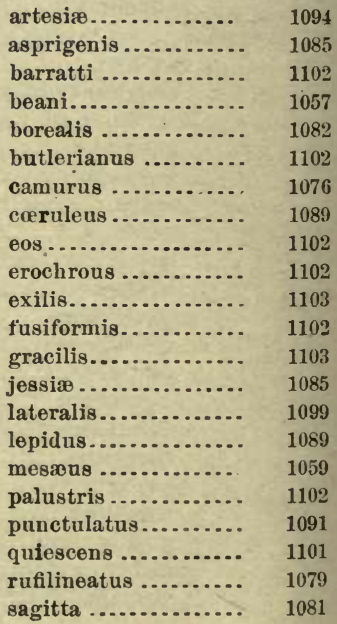


Poecilichthys sanguifluus .......... saxatilis ............. spectabilis ........... swaini .............. versicolor ............ -virgatus vitreus. vulneratus .......... warreni .............

zonalis ...............

Poeciliida

Preciliinx

Pocilioides

bimaculatus ...........

Poecilocephalus

poeciloides, Lebistes.

Limia ................

Precilophis...................... nocturnus............. pocilophthalmus, Gobiesox........ poecilopus, Myripristis............ Rhamphoberyx........

Poecilosoma...................... erythrogastrum...... transversnm ...........

pœecilura, Myxostoma ............. Poecilurichthys ................... puecilurum, Moxostoma........... poetulus, Citharichthys ............ poeyi, Alepidosaurus (Caulopus) :..

Dactyloscopus .............

Engraulis ..................

Gobius ....................

Halichæres................

Hemirhamphus ............

Iridio

Lycengraulis ..............

Orthopristis................

Pempheris ................

Platyglossus ..............

Siphostoma ...............

Stolephorus ................ Synodus

Pogge

Pogonathus ....................... courbina..............

Pogonias

courbina................

cromis ....................

courbina...........

fasciatus ...............

Pogonichthys

argyreiosus .........

communis ...........

(Platygobio) gulonel. lus
Page.

1077

1048

1089 .

1086

1089

1093

1065

1077

1103

1075

630

632

678

678

381

689

700

402

403

2335

847

847

$1066^{\circ}$

1089

1089

196

333

196

2672

596

2302

445

2226

1598

720

1599

2811

1339

979

1599

766

445

536

2065

1482

1483

1482

1483

1482

1483

1483

223
Page.

macrolepidotus ..... 223

symmetricus ........ $\quad 246$

Pogy ......................... 433

Po-he-wa ........................ 238

Point Loma, Blind Goby of........ $\quad 2262$

Poison Toad-tishes .............. 2323, 2325

Poisson Bleu ..................... 517

de Marais................ 113

Luni .................... 954

pola, Platessa ................... 2657

polaris, Blennius................ 2469

Boreogadus .............. 2534

Cottus .................... 1999

Lycodalepis .............. 2468

Lycodes .................. 2469

Merlangus ............... 2534

Pollachius............... 2534

Porocottus................. 1998

Pole Flounder................... 2657

Polistotrema .................... 6

dombey ............. 6

stouti ............... 6

politus, Seriphus................ 1397

Sphæroides .............. 1736

annulatus.... $\quad 1736$

Tetrodon ................ 1736

Pollachius ..................... 2534

carbonarius............ 2535

chalcogrammus ....... 2536, 2537

polaris................ 2534

virens ............... 2534

Pollack........................ 2534

Puget Sound ............. 2536

Wall-eyed ................ 2536

Pollacks ........................ 2534

Alaskan ............... 2535

pollicaris, Cottus............... 1941, 1953

Uranidea............... 1954

pollux, Pontinus .................. $\quad 1857$

poloosoo, Caranx ................. $\quad 928$

polyacanthocephalus, Cottus....... 1977

Myoxocepha-

lus ....... $\quad 1976$

Polyacanthonotinæ............... 613

polyactocephalum, Bryostemma.. 2408, 2409

polyactocephalus, Blennius ....... 2409

Chirolophis ..... 2409

polycaulus, Pimelodus ............. 153

Rhamdia............ 153

Polycirrhus ..................... 1477

dumerili ............. 1479

rathbuni ............ 1479

Polyclemus .................... 1477, 1478

Polydactylus .................... 828

approximans........ $\quad 829$ 


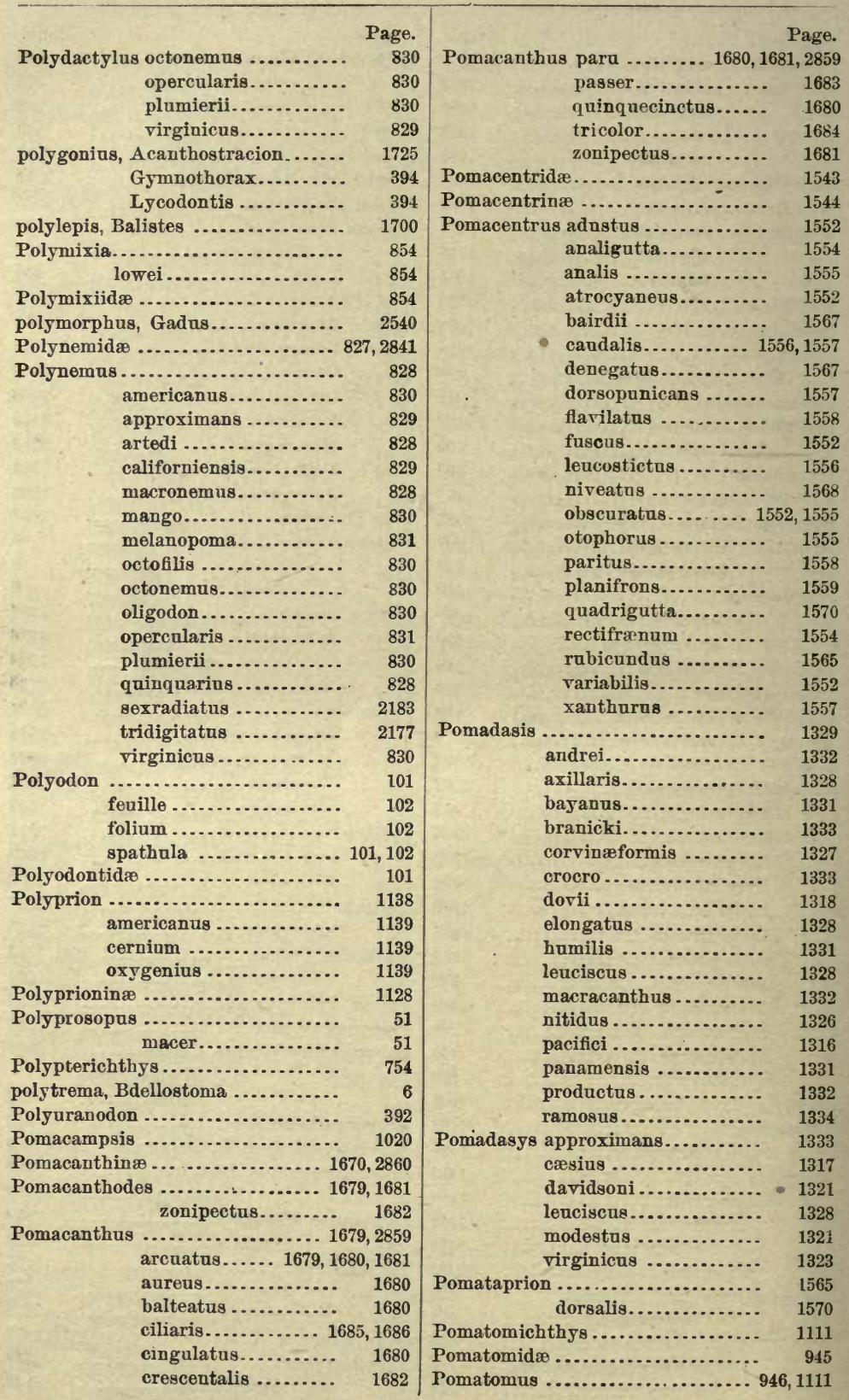




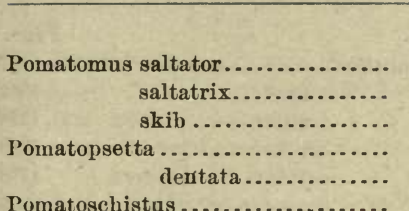

Ponfrets.

Pomolobus.

æstivalis .............

chrysochloris..........

mediocris.

425,2810

pseudoharengus........

$1 \mathrm{acus}$ -

tris..

vernalis

Pomotis.

breviceps .................

catesbei ..................

chætodon .................

convexifrons ...............

elongatus ...............

fallax .....................

gibbosus .................

gulosus .................

guttatus .................

heros.

holbrooki

incisor

inscriptus....................

longulus .................

luna......................

marginatus ..............

microlophns..............

nefastus..................

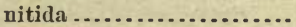

notatus .................

obesus ...................

obscurus ...................

pallidus....................

popeii ....................

ravenelii ...................

rubicauda.................

sanguinolentus ...........

solis.....................

speciosus ............... 1006, 1008

rulgaris................ 1010

pomotis, Acantharchus ...........

Ambloplites ..............

Centrarchus ..............

Pomoxis

annularis ............ sparoides

Pomoxys

brevicauda ..............

intermedius
999,1006

1003

1003

1010

995

1003

1001

1003

1005

992

993

1007

1008

1005

1003

996

1006

1003

1008

1003

1003

1008

993

1006

1007

1003

1010

1001

1003

1001

989

989

989

986

987

987

986

987

987
Pomoxys protacanthus

sparoides.

Pompano, California...............

Common................

Irish

Pomphilus

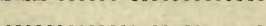

Pompilus .......................

pompilus, Centrolophus.

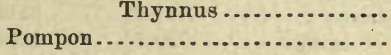

Ponco Prieto .........................

Pond Smelt.

ponderosus, A miurus

Ictalurus .............

pondiceriana, Elacate..............

ponticus, Gasterosteus.............

Hippoglossus ............

Pontinus........................

castor................

longispinis ..............

macrolepis ...............

pollux.

rathbuni ..................

sierra .........................

popeii, Pomotis ...................

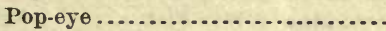

Porbeagles .......................

porca, Scorpæna...................

Porcupine-fish .................. 1742, 1714

Porgee........................ 1509

Porgies ......................... 1343

Deep-water.............. 1344

European ................ 1356

Porgy ......................... 1346

Grass ................... 1355

Jolt-head.................. 1352

Little-head ................. 1350

Little-mouth ............... 1354

Red ..................... 1356

Saucer-eуe ................ 1349

Shad .................... 1355

Sheepshead ............... 1354

Southern ................ 1349

White-bone ............... 1353

Porichthys .................... 2317

margaritatus.......... 2322

nautopædium ......... $\quad 2323$

notatus.............. 2321

plectrodon ............ 2321

porosissimus ......... 2319, 2321

porifer, Lycenchelys .............. 2471

Lycodes................. 2472

Porkfish ........................ 1322

Porobronchus.................. 2495

Poroclinus ..................... 2433

rothrocki............ 2434 
Porocottas

bradfordi.............. 2862

polaris ................ 1998

quadratus............. 1998

quadrifilis....... 1999, 2000, 2863

sellaris............... 1996, 2863

tentaculatus ........ 2000, 2862

Poroderma .......................... 23

Porogadus ........................ 2519

miles................. 2520

promelas .............. 2512

Porogobius..................... 2210

Poromitra....................... 840

capito................ 840

Poronotus.................. 965, 967, 2849

simillimus ............. 967

triacanthus ............ 2849

porosissimus, Batrachus .......... 2321

Porichthys ........ 2319, 2321

porosus, Carcharias ............... 37

Cottus ................... 1975

Esox

Porte Enseigne ....................

Porthmens..........................

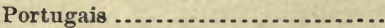

Portugnese Man-of-War Fish......

Post Croaker.

postica, Echeneis ..................

Potamocottus

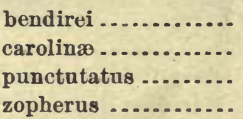

Potomae Shad......................

pottsii, Aplesion ....................

Boleosoma..................

Etheostoma .................

pourtalesii, Archosargus..........

Sargus.................

Pout, Horned

627

1687

2848

1679

949

1458

2272

1942

1965

1952

1949

1952

427

1083

1083

1082

1360

1360

powelli, Balistes ..................

precisus, Clinus ....................

Eumesogrammus ........

præstabilis, Alosa

prestigiator, Centropristis ..........

Serranus ...............

presidionis, Poecilia.

135,140

1702

2441

2411

428

1214

1214

697

525

525

525

879

880

837

1784

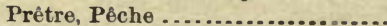

Priacanthichthys ..................

Priacanthidm

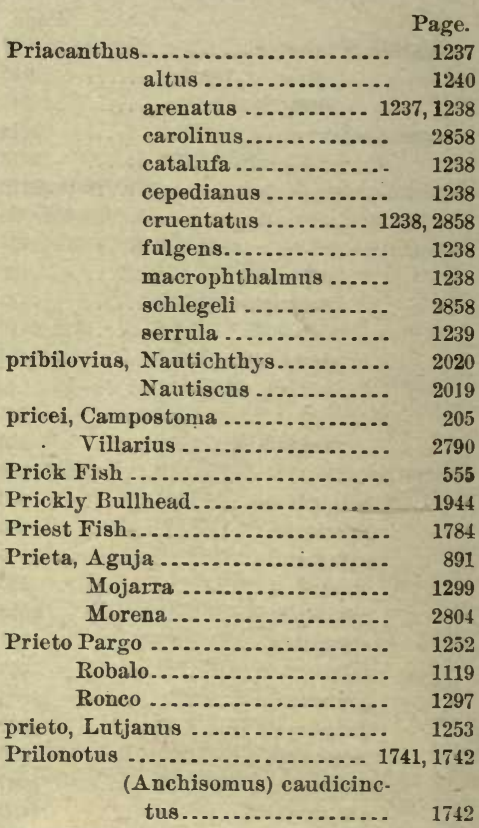

Prinuospina ................ 1765, 1774, 1783

princeps, Caulolatilus........... 2276, 2277

Cottus .................. 1962

Latilus.................. 2277

principis, Antennarius ............ $\quad 2719$

Chironectes ............. 2719

Julis .................. 1591

Platyglossus ............ 1591

Prinodon......................... 670

Priodonophis................. 392, 393, 399 meleagris ........... 399

ocellatus ............ $\quad 399$

Prionace ........................ 33

glauca................. 33

Prionistius....................... 1927

macellus ............... 1928

Prionodes .................. 1208, 1209, 1210

æquidens .............. 1210

bulleri .................. 1213

fasciatus .............. 1212

flavescens .............. $\quad 1215$

fusculus ............... 1211

laciopercanus .......... 1216

phobe ................. 1211

stilbostigma ............ 1216

tabacarius ............. 1215

tigrinus ............... 1214

1236 Prionodon cucuri ................. 40 


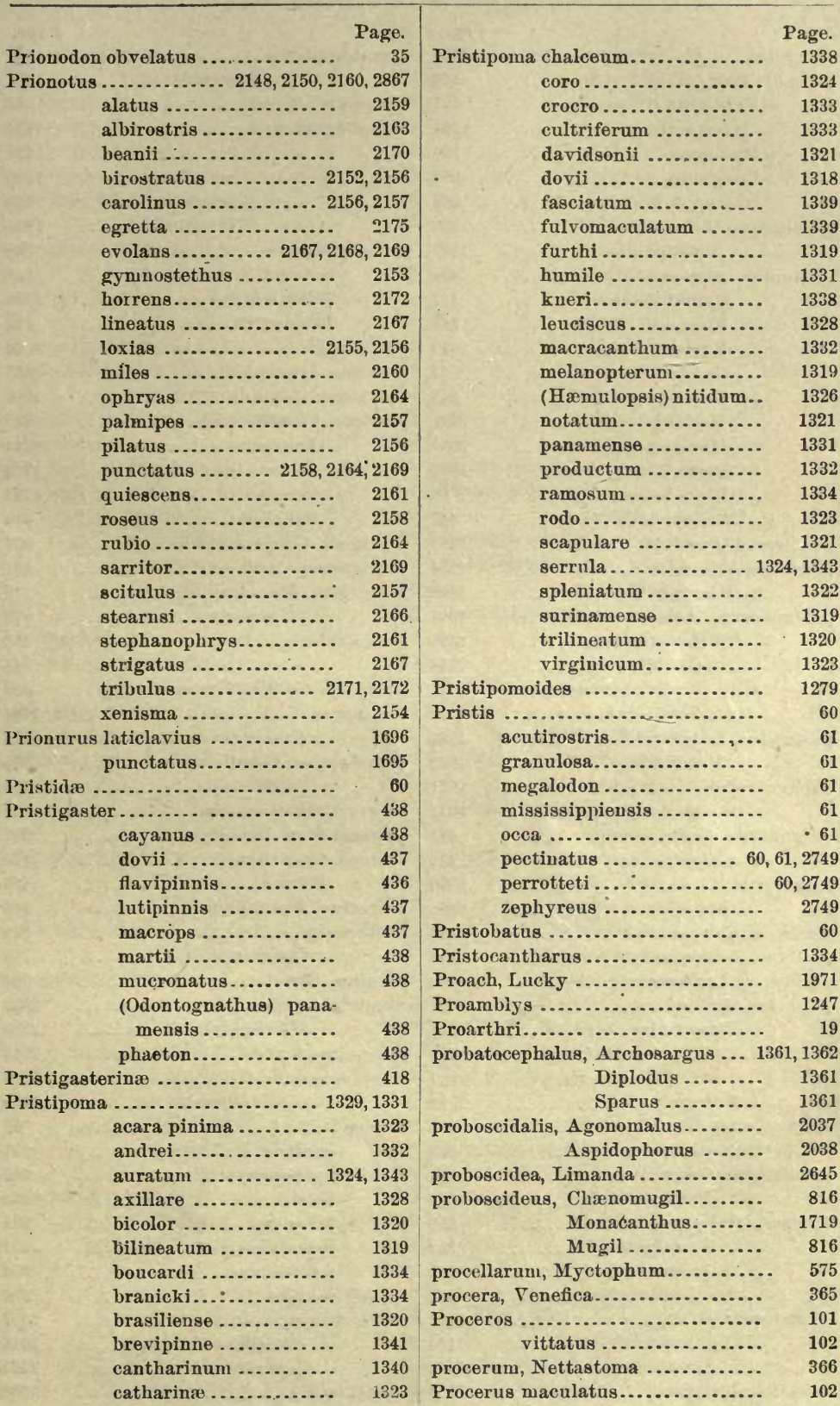


Prochilus

procne, Cliola .....................

Exocœtus (Cypselurus)....

Hybognathus .............

Hybopsis .................

Leuciscns................

Notropis .................

productum, Holocentrum ..........

Pristipoma ...........

productus, Alepocephalus..........

Cylindrosteus ..........

Engraulis .............

Eucinostomus ..........

Gadus ...................

Leuciscus ..............

Merlangus..............

Merluccius.............

Pomadasis..............

Rhinobatus............

Stolephorus ...........

prœliare, Etheostoma ..............

prœliaris, Etheostoma.

Microperca ..............

profundorum, Acanthocottus.......

Lepophidium ........

Ophidium...........

Scylliorhinas ........

Zesticelus ...........

profundus, Lutjanus ...............

Mesoprion..............

Prognathodes ....................

aculeatus............

prognathus, Argyrosomus .........

Coregonus ............

Prognurus

cypselurus ..............

prolixum, Campostoma............

prolixus, Leuciscus . ................

prolongus, Leptoconger............

promelas, Møbia..................

Pimephales.............

confertus....

maculosus...

Porogadus..............

Prometheus.......................

Prometheus atlanticus .

prometheus, Gempylus..............

Promethichthys ......

Promethichthys.................. atlanticus .......... parvipinnis........ prometheus........

Promicrops

guasa...............

guttatus...............

itaiara
Page.

2195

264

737

264

264

264

264

852

1332

452

111

447

1372

2531

240

2531

2531

1332

. 63

447

1104

1104

1103

1991

2484

2484

22

1990

1264

1263

1671

1671

471

472

2866

2866

206

206

363

2511

217

217

217

2512

882

883

883

882

882

883

883

882

1162

1164

1162

1164
Page.
Promicropterus ............. 1229, 1231, 1233

decoratus......... 1234

Promoxis nitidus ................. 987

Pronotogrammus ................ 1224

eos............ 1224

multifasciatus .. $\quad 1226$

peruanus....... 1223

vivanus ........ 1224

proops, Bagrus.................. 124

Netuma ................. 124

Sciadeichthys............ 123, 2760

Tachismrus.............. 124

Propterygia.................... $\quad 66$

prorates, Leptophidium........... 2485

proridens, Calamus ............... 1350

proriger, Clinostomus............. $\quad 240$

Leuciscus .............. 240

Sebastichthys......... 1788, 1793

Sebastodes ............ 1787, 1792

Squalius .............. $\quad 240$

prorigera, Congermuræna......... $\quad 357$

prorigerum, Ophisoma ............ $\quad 357$

proserpina, Moniana............. $\quad 272$

Notropis.............. 272

Prosopium .................... 461, 462

couesii ............... 463

prospinosum, Holocentrum ....... $\quad 853$

Prospinus....................... 1164

chloropterus........... 1165

prosthemius, Ceratichthys........ $\quad 324$

Couesius............ 324

prosthistius, Amiurus ............ $\quad 139$

protacanthus, Pomoxys........... 987

proteas, Oncorhynchus ........... $\quad 478$

Salmo ................... 478

protoclus, Myctophum........... $\quad 565$

Protoporus....................... 228

domninus ............. $\quad 233$

proxima, Seriola ................. 904

proximus, Gadus................ $\quad 2539$

Microgadus ............ 2539

pruinosus, Gadus ............... 2540

Psednoblennius ................... 2406

hypacanthus ...... 2406

Psenes ........................... 950

auratus .................. 951

cyanophrys .............. 950

fuscus.................. 951

jaranicus ................. 951

maculatus............... 951

pellucidus................. 950

regulus ................... 951

Psettichthys .................... $\quad 2617$

melanostictus ........ 2618

sordidus............ $\quad 2680$

Psettinæ ......................... 2608 


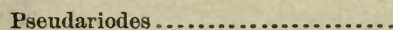

pantherinus ..........

Pseudarius.......................

Pseudobastes

Pseudocanthicus..................

pseudocrocodilus, Scopelus........

pseudogula, Eucinostomus .........

Gerres ..............

pseudoharengus, Clupea...........

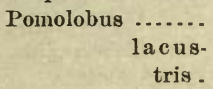

Pseudohemiorlon ..................

pseudohispanica, Clupea............

Sardinia ..........

pseudohispanicus, Clupanodon .....

Pseudojulis

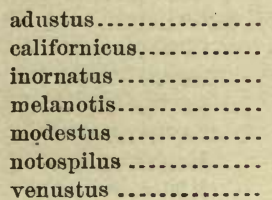

Pseudoloricaria

Pseudomonacanthus

amphioxss...

Pseudomuræna ..................

Pseudophoxinus

Pseudopleuronectes.

americanus...

pinnifasciatus.

planus ........

Psoudopriacanthus

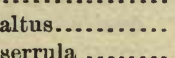

serrula.......

Pseudorhamdia .................. 153, 154

piscatrix ......... 155

Pseudorhombus................. 2624

adspersus ........ 2627

brasiliensis........ 2626

californicus ....... 2626

dentatus ....... 2030, 2632

oblongus .......... 2630

ocellaris ........... 2630

quadrocellatus .... 2635

vorax............ 20.26

Psendoscarus acutus.............

1652

$16 \pm 8$

aracanga ............

cæruleus

1654

chloris.

1648,165

cœlestinus.

1655,1656

diadema

1646

flavomarginatus .....

1652

gnathodus

guacamaia.... 1656, 1657, 1659
Pseudoscarus lineolatus ...........

microrrhinos ........

nuchalis .............

obtusus .............

perrico ..............

pleianus.............

punctulatus .........

psittacus ............

quadrispinosus......

rostratus ............

sanctre-crucis........

superbus ........... 1650

tæniopterus ....... 1646, 1647

trispinosus ......... 1648

turchesius.......... 1659

vetula............. 1650

Pseudosciæna surinamensis........ $\quad 1420$

Pseudoscopelus ................... $\quad 2292$

seriptus .......... 2292

Pseudotriakidæ.................. $\quad 26$

Pseudotriakis.................... $\quad 27$

microdon $\ldots . . . . . . .27$

Pseudoxiphophorns.............. $\quad 678$

bimaculatus... $\quad 678$

reticulatus.... $\quad 678$

Pseudupeneus ................... $\quad 858$

Psilonotus ....................... $\quad 1741$

punctatissimus........ 1741

psittacinus, Centropristis......... 1213

Serranus............ 1213

psittaculus, Julis ................. 1597

Labrus ............... 1596

psittacus, Callyodon .............. 1638

Cheilichthys........... 1740

Colomesus ............. 1740

Coryphœna............ 1619

Lachnolaimus.......... $\quad 1580$

Pseudoscarus .......... 1647

Scarus ................. 1647

Tetrodon.............. 1740

Xyrichthys ........... 1618, 1619

Psychrolutes.................... $\quad 2025$

paradoxus........... 2026

zebra............... 2027

Psychrolutinæ................. 1883

Psychromaster................... 1199

tuscumbia......... 1160

Pteraclidæ...................... 955

Pteraclis ....................... $\$ 55$

carolinus............... 956

trichopterus............ 956

Pterengraulis.................. 450

atherinoides........ 450

Pterocephala................... 92

Pterognathus .................. 2354, 2355 
Pteronotus.

Pterophryne.

histrio.

(n)............

Pterophrynoides ..................

Pteroplatea

crebripunctata........ 87, 2753

maclura ...............

marmorata............88 87, 2754

rava................ 2754

Pteropodus ............ 1765, 1776, 1819, 2860

dallii .................

1819

Ptilichthyidæ

2451

Ptilichthys.

goodei

2452

2452

Ptychocheilus

gracilis..............

grandis............ 225, 2796

harfordi ........... 225. 2797

lucius ..............

major ............. 225, 2797

oregonensis ....... 224, 2796

$\operatorname{rapax} . . . . . . . . . . .225$

vorax..........$\quad 227$

Ptycholepis ..................... 414

Ptychostomus..................... $\quad 187$

albidus ............ 192

albus .............. 191

breviceps ........... 196

buceo ...............

191

cervinus .............

collapsus ...........

197

conus ................

coregonus...........

crassilabris ..........

duquesnei ..........

ervthrurus..........

haydeni............

lachrymalis .........

oneida

papillosus...........

pidiensis...........

robustus ...........

thalassinus ........

velatus

Ptyonotus........................

thompsonii.

Pudding-wife

Pudiano

Verde

1590,1591

Vermelho

puella, Hypoplectrus..............

unicolor......

Plectropoma................

puellaris, Decodon ................ $\quad \begin{array}{r}\text { Page. } \\ 1584\end{array}$

Puerco Espino...................... 1745

Pez................... 1700, 1704

Puffer .......................... 1733

Smooth.................. 1728

Southeru .................. 1732

Puffers ........................... 1726

Sharp-nosed ............... 1740

pugetensis, Artedius.............. 1890

Chitonotus ......... 1890, 1891

Icelus................ 1891

Puget Sound Pollack.............. $\quad 2536$

pugetti, Gasterosteus .............. 751

pulchella, Gila .................... 234

Harpe................. 1584

Moniana .............. 272

pulchelloides, Leuciscus............ $\quad 222$

pulchellns, Bodiamus ............... 1584

Cheilonemus .......... 222

Cossyphus............ $\quad 1581$

Cyclogaster ........... 2127

Cymatogaster .......... 1503

Haplochilus ........... 659

Histiophorus .......... 891

Leuciscus ............. 221

Leucosomus.......... 222

Liparis ............... 2126

Oligocephalus ......... 1089

Squalius............... 234

Zygonectes............ 659

pulcher, Eques . :................. 1489

Labrus .................. 1585

Neozoarches............. 2426

Pimelometopon........... 1585

Semicossyphus........... 1585

Squalius ............... 234

Trochocopus ............ 1585

pulchra, Harpe................. 1585

Tigoma ................ 234

pullum, Chondrostoma ........... 206

pullus, Amiurus ................ 141

Cantherines .............. 1713

Monacanthus............. 1713

Pimelodus................ 141

pulvereus, Fundulus ............. $\quad 652$

Zygonectes............. 652

pulverulentum, Oxygeneum....... 207

pulverulentus, Myloleucus......... $\quad 246$

Pumpkin Seed.................... 1009

Punarn........................ 2397

puncta, Furcaria ................. 1547

punctata, Alutera .............. 1718, 1719

Bairdiella ............. $\quad 1434$

Gambusia .............. $\quad 679$

Lamna ................ 48

Muræna............... 395 
Page.

punctata, Murænophis

397

Perca ............ 1145, 1146, 1433

Sciæna

$1145,1146,1433$

Trigla

2170

punctatissima, Anguilla ...........

punetatissimus, Canthigaster......

Tetrodon...........

punctatum, Hyperprosopon argen-

teum...............

Myctophum...........

Opisthognathus ........

Sicydium.............

1741

1741

1502

570

2281

2867

punctatus, A pomotis

997

Balistes

1702

Blennius ............ 2390, 2440

Bodianus............ 1146

fulvus....... 1146

Bryttus ...............

Caranx ................

Carcharias.............

Ceratacanthus...........

Clinus ..................

Decapterus .............

Dermatolepis ...........

Diodon .................

998

908

41

2860

2440

907

1168

1746

Enneacentrus .......... 1146

Epinephelus.......... 1154,1146

Eques ................ 1488, 1489

Fundulus ........... 637, 2827

Gadus................. 2553

Gunnellus............. $\quad 2440$

Holocentrus............ 1153

Hypleurochilus ....... $\quad 2390$

Ichthælurus .......... $\quad 135$

Ictalurus.............. 134

Isesthes............... $\quad 2390$

Lepomis ............. $\quad 998$

Micristodus ........... 52

Monacanthus ........ 1713, 1719

Morrhua .............. 2543

Myrophis ............. 371

Opisthognathus ........ 2281

Prionotus ...... 2158, 2164, 2169

Prionurus............ $\quad 1695$

Silurus................ 135

Squalus .............. 26, 43

Stichæus............. $\quad 2439$

Tetrodon.............. 1735

Trachinus............. 1153

Upeneus ............. 859

Xesurus............. 1694, 1695

puncticeps, Cryptopterus.......... 382

Ophichthus............ 382

Ophichthys............ 382

puncticulata, Gambusia...........

Perca marina

puncticulatus, Apogonichthys .....

Page.

1111

Arius............. 131

Chilomycterus...... 1750

punctifer, Crotalopsis............. $\quad 387$

Dionda................ 215

Ophichthys ............ $\quad 387$

Hybognathus (Dionda).. 215

punctiferus, Bodianus............. $\quad 1147$

Menephorus.......... $\quad 1147$

punetipinne, Siphostoma.......... $\quad .763$

punctipinnis, Ayresia............. 1548

Chromis ........... 1518

Dermatostethus ..... 763

punctulata, Coryphrna............ 953

Microperca.......... $\quad 1104$

Uranidea ............. 1949

punctulatum, Boleosoma .......... 1091

Etheostoma......... 1090

punctulatus, Calliurus ........... 992, 1011

Cottus .............. 1948

bairdi ......... 1950

Gobiesox ........... 2338

Hippocampus........ $\quad \mathbf{7 7 7}$

Lampugus........... $\quad 953$

Minnilus .......... $\quad 302$

Notropis umbratilis .. $\quad 301$

Pimelodus........... $\quad 143$

Pocilichthys ........ 1091

Potamocottus........ 1949

Pseudoscarus ......... 1046

Scarus .............. 1645

Sicyases ............ 2338

Squalus............. $\quad 26$

Puñecas........................ 2195

pungitius, Gasterosteus........... $\quad 745$

$\begin{array}{rr}\text { brachyporla } & \mathbf{7 4 6} \\ \text { Pygosteus .............. } & \mathbf{7 4 5} \\ \text { brachypoda.. } & \mathbf{7 4 6}\end{array}$

pun.ceus, Hyborhynchus .......... 218

Puraque ........................ 63

purpurascens, Elops ............. $\quad 410$

purpuratus, Salmo ........... 492, 499, 2819

bouvieri ........ 496

purpurea, Tigoma............... 234

purpurescens, Anoplarchus....... 2423

Lepomis ........... 1006

Salpa variegata..... $\quad 1271$

purpureus, Leuciscus ............ $\quad 234$

Lutjanus............. 1264

Merlangus ............ 2535

Sebastichthys.......... 1826

Squalius .............. 234

Pursy Minnows................ 670,671

pusilla, Aphoristia............... 2711

Bothrocara .............. 2476

Clupea.................. $\quad 426$ 
pusilla, Maynea....................

Perca ......................

Platessa ....................

pusillum, Acanthidium

pusillus, Argyrosomus............

Etmopterus ...............

Spinax

Symphurus..............

putaol, Gymnotus

putuami, Acipenser ... . . . . . . . . . . .

Cottogaster ..............

Euchalarodus .............

Liopsetta ..............

pygmæa, Eucalia inconstans.......

Umbra

limi

pygmæus, Gadus

Gasterosteus .............

Leuciscus ...............

Pygosteus......................

pungitius ..............

brachypoda..

Pylodictis limosus ................

pyramidatus Cyclopterns..........

pyrrhogaster, Chrosomns ..........

pyrrhomelas, Cliola ................

Codoma

Notropis ............

Photogenis..........

Pythonichthys...

sanguineus .......

quadracus, Apeltes ...............

Gasterosteus..........

quadrangularis, Selene..............

quadratus, Porocottus .............

Zeus

quadricorne, Ostracium............

quadricornis, Agonus ..............

Aspidophorus........

Cottus ...............

Hypsagonus . . . . . . 20 2038, 20\$1

Ostracion ............ 1725

quadridens, Pleuronectes .......... 2654

quadrifasciatus, Chasmodes........ 2392

Pholis.......... 2392, 2394

quadrifilis, Bathypterois .......... $\quad 545$

Cottus ............. 1998, 2000

Porocottus ........... 1999, 2000

quadrigutta, Pomacentrus ......... $\quad 1570$

quadrilateralis, Coregonus........ 465

quadrilineatum, Hæmulon ....... 1309, 1311

quadriloba, Raia ................. 90

Rhinoptera............

quadrimaculatus, Diodon ..........

Paradiodon....... quadriporus, Gobius

Page.

quadripunctatus, Scomber........ $\quad 869$

quadriremi 4 , Exocotus ........... $\quad 735$

quadriscutis, Arins ............... 126

Netuma ............ $\quad 126$

quadriseriatus, Artedins........... 1897

Icelinus .......... 1897

Icelus ............ $\quad 1897$

quadrispinosus, Pseudoscarus..... 1648

Scarus ........... 1648

quadrituberculata, Platessa........ . 2648

quadrituberculatus, Parophrys .... 2648 Pleuronectes.. 2648

Pleuronich thys....... 2638

quadrocellata, Anclyopsetta ....... 2635

Platessa ........... 2633

quadrocellatus, Pseudorhombus.... 2635

quappella, Etheostoma............. 1804

quartus, Anthias rondeleti........ 1266

Quasky ....................... 514

Quassilabia .................... 198

lacera............... 199

Quassiremus .................... $\quad 380$

evionthas ........... $\quad 380$

nothochir ........... $\quad 380$

quatuordecimlaminatus, Echeneis.. $\quad 2272$

Queenfish ....................... 1397

quenseli, Pleuronectes ............. $\quad 2654$

quercinum, Macrostoma............ $\quad 554$

quercinus, Notoscopelus .......... $\quad 555$

Qneriman ..................... $\quad 810$

Querimana ..................... 817

gyrans ............... 818

harengus............. 817

querna, Azevia.................. $\quad 2675$

Cyclopsetta.............. 2675

Quia-quia ...................... 907

Quiebra ....................... 898

qniebra, Chorinemus .............. 899

Lichia.................... 899

quiescens, Copelandellus .......... 1100

Etheostoma............ 1101

Poecilichthys .......... 1101

Prionotus.............. 2161

Uranidea .............. 1968

Quietula ...................... 2251

y-canda.............. 2251, 2252

Quillback..................... 167

Quill-fishes..................... 2451

Quinnat Salınon ................ 474, 479

quinnat, Oncorbynchus .......... 480

Salmo ................. 480

quinquarius, Pentanemus ......... 828

Polynemus .......... 828

$\begin{array}{rrr}1746 & \text { Polynemus ........... } & 828 \\ 1746 & \text { quinqneaculeata, Raja............. }\end{array}$ 
quinquecinctus, Pomacanthus...... quinquefasciatus, Epinephelus.....

Serranus ........

quinquelineatum, Hæmulon........ quiquemaculatus, Centronotus..... Opisthocentrus..

Quisutsch

quoyi, Cestracion................... .

Gyropleurodus

Page.

1680

1164

1164

1311

2430

2430

480

21

21

Rabbit-fish .

882,1748

Rabbit-mouth Sucker ............ 198, 199

Rabdophorus ................. 1672

Rabida..................... 144, 145, 146

Rabirubia.................... 1274, 1275

de lo Alto ............ 1221

ganizara .............. 1586

inermis............$\quad 1274$

rabirubia, Anthias............... 1276

Rabirubias ..................... • 1275

Rabula...................... $\quad 390$

aquæ-dulcis............. $\quad 390$

lougicauda.............. $\quad 391$

marmorea............... 391

panamensis ............... $\quad 391$

Raccoon Perch .................. 1023

Rachycentrida................. 946

Rachycentron .................. 948

canadus........... 948

ractiale, Diplectrum ............. 1204

radialis, Centropristis........... 1205

Diplectrum ............. 1205

Serranus ............... 1205

radians, Centropristis........... 1208

Diplectrum ............. 1208

Labrus................. 1633

Scarus ................ 1632, 1633

Serranus ............... 1208

Sparisoma............... 1632

radiata, Raia....................

Raja ..................

radiato, Turdus oculo .............

radiatus, Chærojulis

Halichæres..............

Iridio ..................

Labrus ..................

Lophius.................

radiatus, Ogcocephalus ...........

Platyglossus .......... 1591, 1597

Sparus ............... 1596

radiosus, Antennarius .......... $\quad 2725$

Radulinus........................ 1919

asprellus .............. 1920

boleoides.............. 1919

rafinesquei, Acipenser ........... 106

Collettia............ 567

Cylindrosteus ........ 111

$3030-116$ rafinesquei, Myctophus ............ $\quad 567$

Scaphirhynchus ...... $\quad 107$

Scopelus............ $\quad 567$

Rafinesquiellus............ 1066, 1068, 1082

Rag Fishes..................... 968

Raia ......................... 66

americana ................ 69

birostris ................. 93

chantenay ................ 71

cooperi .................. 73

desmarestia................. 71

diaphana ................ $\quad 71$

eglauteria................ 68,71

erinacea ................. 68

fimbriata ............... $\quad 93$

flagellum ................. $\quad 88$

inornata................ $\quad 73$

inermis ............ 73

jordani .................. $\quad 73$

maclura .................. 87

manatia .................. 93

narinari ................ 88

obtusa.................... 2751

ocellata................... 69

parmifera.................. $\quad 75$

quadriloba................. 90

radiata.................... 69

rhina ................... 72

trachura ................. $\quad 76$

tuberculata ............... 84

Raiada, Majarra................. 1561

Raiado, Roncador ............. 1301, 1313

Sargo................... 1361

Raie tuberculée................ 84

raii, Brama.................... 958, 959

Sparus ................... 960

Rainbow Darter................. 1088

Herring................. 524

Trout ................. 500

Rainwater Fish ................. $\quad 665$

Raizero ................ 1247, 1251, 1273

Raja .......................66, 6650

abyssicola................. 76, 2751

ackleyi..................... 70

aleutica ................... 75, 2751

binoculata ................ $\quad 72$

bonasus................... 90

centrura .................. 83

diabolus marinus............ $\quad 93$

eglanteria.................. 71

equatorialis................. 74, 2751

erinacea................... 69

fyllæ..................... 68

granulata .................. 72

inornata ................... 73

interrupta ................ 2751 
Raja jamaicensis

lævis..................

ocellata ......................

ornata........................

partmifera ....................

percellens...................

plutonia.....................

quinqueaculeata .............

radiata.....................

rhina.

rosispinis

say.

senta.

sloani .......................

stellulata ...................

trachura .....................

raji, Brama......................

Rajidæ

raleighana, Harriotta..............

rammelsbergii, Mngil ...............

ramosum, Pristipoma ..............

ramosus, Pomadasis ...............

Ramularia ....................... dendritica.

ransonnetii, Neoditrema. ........... ranula, Careproctus ................

Liparis....................

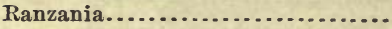

makna .................

truncata.............. 17

Ranzaninæ

rapax, Ptychocheilus ..............

raphidoma, Belone.................

Tylosurus .............

raptor, Gadus....................

Raro .............................

rarus, Rhinoscopelus.

Scopelus

Rascacio

rascacio, Scorpæna

Rasciera........................

Rasher .........................

rashleighanus, Squalus ............

rastralis, Stolephorus .............

rastrelliger, Physiculus ............

Sebastichthys.........

Sebastodes .......... 1819

Rastrinus ........................

scutiger ..................

Ratfish ..........................

Rathbunella ....................

hypoplecta...........

rathbuni, Fundulus ................

Mulloides ................

Paralonchurus ............

Polycirrhus
Page.

81

71

68

71

74

63

69,70

88

69

72

2751

86

71

81

75

75

960

66

96

812

1334

1334

2633

2633

1511

2134

2134

1755

1755

755,1756

1752

225

716

715

2552

404

569

569

1848

1849

1794

1794

51

2811

2549

1820

819,1821

1909

1909

95

2289

2290

649

857

1479

1479
Page.

Upeneus ...............

Raton ......................... $\quad 829$

Rat-tail, Common ................ 2583

rauchi, Acipenser ................ 106

raucus, Sargus.................. 1364

rava, Pteroplatea............... 2754

Raven, Sea .................... 976, 2023

raveneli, Esox.................. $\quad 626$

ravenelii, Pomotis ................ $\quad 1010$

Ravens, Sea...................... 2022

Ray, Butterfly................... $\quad 86$

California Sting............ $\quad 89$

Common Sting .............. 83

Cow-nose .................. 90

Sonthern Sting............. 86

Spotted Sting .............. 88

Rays......................... 59

Eagle................... 87,89

Electric .................. $\quad 76$

Round Sting.............. $\quad 79$

Sting .................... 79,82

Thick-tailed................ $\quad 60$

Whip-tailed ................ $\quad 79$

Razor-back Buffalo............... 164

Sucker .............. 184

Razor-fish................... 1617, 1618

Real, Matajuelo................. $\quad 410$

rectangulare, Cichlasoma.......... $\quad 1515$

rectangularis, Acara ............. 1515

rectifrænum, Eupomacentrus ...... 1553

Pomacentrus........ 1554

recurvirostris, Sayris............. 725

Red-bellied Dace................ $\quad 209$

Redbreast Bream................. 1001

reddingi, Orthopristis .............. 1336

Red Drums ..................... 1453

Red-eye...................... 990

Little .................. 996

Mullet ................. 814

Red Fallfish..................... $\quad 286$

Red-fin........................ 281, 298

Redfish ................... 481, 1453, 1760

Bull .................. 1453

California .............. 1585

Little.................. 482

Red Goatfish................... $\quad 858$

Grouper.................. $\quad 1160$

Guativere ................... 1145

Gurnard................... $\quad 2177$

Hind .................... 1141, 1158

Redhorse....................... 187

Common .............. 192

Tехая ................. 192

redi, Orthragoriscus.............. 1754

Red-mouth Buffalo Fish........... 163 
Red-mouth (Yrunt

Red Parrot Fish

Porgy .........................

Rockfish

Rock Trout

Roncador.

Sculpin.

Snapper

Sturgeon

Sucker.

Red-sided Shiner..................

Red-spotted Sunfish

'Trout

Red-tail Snapper

Red-winged Sea-robin

reflexo, Labrus rostro

regale, Cybium.

Cynoscion

Myctophum ................

Nannobrachium ............

regalis, Cestreus .................

thalassinus ........

Cynoscion .................

Enchelyopus..............

Johnius..................

Otolithus

Phycis...................

Scomber ..................

Scomberomorus...........

regis, Atherinops ................

regius, Blennius ..................

Hybognathus .............

Lampris ...................

Phycis....................

Urophycis ................

Zeus........................

rogulus, Psenes ....................

Sebastes ..................

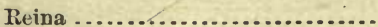

reinhardi, Careproctus . ......... 2133, 213

reinhardti, Corynolophus ......... $\quad 2733$

Himantolophus........ 2733

Motella............... 2559

Onos ..................

Reinhardtius....................

hippoglossoides .....

remifer, Archosion

Isopisthus................

remiger, Myctophum ..............

Ophisurus...............

Remilegia .

australis...........................

Remora

albescens ..................

brachyptera ...............

jacobæa
Page.

1308

1635

1356

1805

1872

1456

1935

1264

106

176

240

1004

507

1270

2156

1677

875

1407

563

563

1407

1408

1407

2553

1407

1407

2553

875

875

808

2553

213

955

2553

2553

955

951

1761

1815

34

2559

2610

2611

1399

1399

573

384

2270

2270

2271

2272

2272

2272

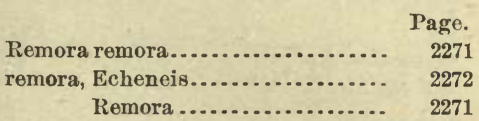

Remoras .................... 2265, 2271

Remorina ................... 2271, 2272

remoroides, Echeneis............. 2272

Remoropsis ................... 2271, 2272

brachypterus......... $\quad 3272$

remotus, Carcharhinus ........... $\quad 37$

Serranus............... 1160

Reniceps tiburo ................. 44

repandus, Serranus............... 1187

Requiem ..................... $\quad 38$

Sharks ............... 27

Requin....................... $\quad 38$

resplendens, Lampanyctus ......... $\quad 555$

reticularis, Anchisomus.......... $\quad 1735$

Antennarius .......... 2719

reticnlata, Amia ................ $\quad 113$

Liparis............... 2108

Mycteroperca .......... $\quad 1187$

Precilia................ 2833

Solea.................. 2696

Spatularia ............ 102

Thalassophryne........ 2325

reticulatum, Boeostoma........... $\quad 2696$

reticulatus, Bryttus.............. 998

Catostomus........... 179

Cestreus.............. 1409

Chilomycterus........ 1751

Cynoscion ............ 1408

Diodon .............. 1751

Eqox................ 628

Gobiesox............ 2328

Halientichthys ........ 2741

Lepadogaster......... 2328

Lucius................ 627

Lycodes ............. 2465

Monochir............. 2696

Notropis.............. 262

Orbis ................. 1750

Otolithus ............ 1409

Pseudoxiphophorus.... 678

Trisotropis ........... $\quad 1187$

retifer, Catulus.................. $\quad 25$

Scylliorhinus............. $\quad 25$

retifera, Muræna................ 401

retiferum, Scyllium .............. $\quad 25$

retractus, Calliodon .............. 1623

Cryptotomus........... 1623

retrocurrens, Hæmulon ........... 1297

retropinnis, Catostomus.......... 175, 2791

Microdesmus......... 2450

Ophichthus .......... $\quad 383$

Ophichthys ........... 383

retrosella, Amia................ 1109 
retrosella, Apogon ...............

retrospinis, Holocentrum ..........

Plectrypops ...........

retzii, Mola......................

Orthragoriscus ............

rex, Catostomus...................

Etheostoma .................

Percina

rex-mullorum, Apogon

Rey, Peixe .

Rhacochilus..

$$
\text { toxotes .............. } 1507
$$

Rhamdella .................. 149, 150, 151

$$
\text { parryi }
$$

Rhamdia

baronis-mulleri.......... 151 brachyptera ............. 151 bransfordi............... 151 godmani............... 152 guatemalensis........... 152 hypselurus ............. 152 laticanda ............... 152 managuensis ............ 153 microptera ............. 153 motaguensis .............. $15 i$ nicaraguensis ........... 152 parryi................... 153 petenensis.............. 153 polycaulus ............. 153 salvini .............. 152, 2790 wagneri ............... 150,151

Rhamphoberyx ................ 846

$$
\begin{aligned}
& \text { leucopus ............ } \\
& \text { pœecilopus .......... }
\end{aligned}
$$

Rhamphocottidæ .................

Rhamphocottus .................. richardsoni........

Rhegnopteri 781,827

Rhencus 1329,1331

Rheocrypta. copelandi.

1044 1046

rhessodon, Arbaciosa ............. Gobiesox ................ 2340 2340

Rhina

$$
\text { squatina................... }
$$

rhina, Raia......................

$$
\text { Raja. }
$$

Rhineloricaria $156,157,158$

Rhinesomus. 1721,1722

rhinichthyoides, Tigoma. Rhinichthys

arenatus. atronasus.............

croceus..... lunatus..... meleagris...
Rhinichthys badins.

Page.

cataractæ.............

307

henshavii........... $\quad 312$

lunatus............. 308

luteus ............. 307

marmoratus ......... 306

maxillosus........... $\quad 307$

meleagris............ 308

nasutus ............ 306

(Apocope) nevadensis. 311

obtusus............. $\quad 308$

ocel!a.............. $\quad 307$

simus.............. $\quad 307$

transmontanus ....... $\quad 307$

(A pocope) velifer.... $\quad 312$

Rhinobatidæ ................... 61

Rhinobatus ...................... 61

electricus............. 63

exasperatus .......... 65

glaucostictus......... 63

glaucostigma......... 62

lentiginosus .......... 62, 2750

leucorhynchus........ $\quad 62$

marcgravii ............ 63

percellens ............ 63

planiceps .............. 64

productus ............ 63

spinosus............. 63

stellio ............... 2750

triseriątus............ $\quad 66$

undulatus ........... 63

Rhinoberyx .................... 818

chrysens ........... 847

Rhinodontinæ.................. $\quad 52$

Rhinogobius contractus........... 2236

Rhinoliparis ................... 2145

barbulifer ........... 2145

Rhinonemus .................. $\quad 2560$

caudacuta.......... $\quad 2560$

cimbrius............ 2561

Rhinoptera.................... 90

bonasus .............. 90

ensenadx .............. 91

quadriloba ............ 90

steindachneri.......... 91

vespertilio ............ 90

Rhinopterinæ ................. 88, 2753

Rhinoscion..................... 1455

saturnus ............ 1457

Rhinoscopelus ................ 568

andrea $\ldots \ldots \ldots \ldots . . . . .569$

coccoi ............ 568

rarus $\ldots \ldots \ldots \ldots \ldots . . \ldots 50$

Rhinoscymnus ................ $\quad 56$ 


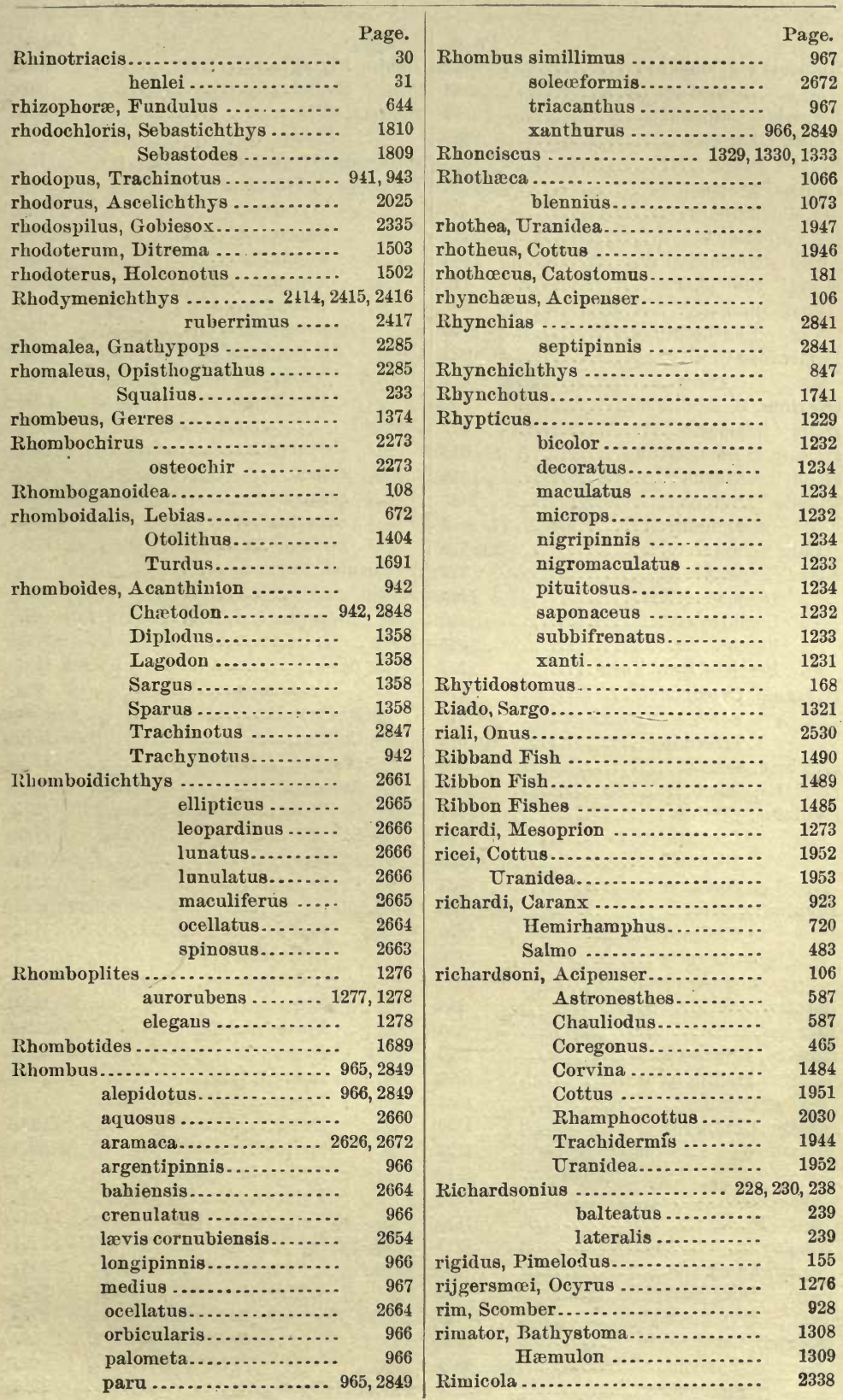


Index.

Rimicola eigenmanni

.

Page.

2339

2338

2792

2688

1023

2376

1709

1711

586

449

601

1709

Xanthichthys..............

Rio Grande Chub

$$
\text { Trout. }
$$

riparium, Holocentrum

(n)............

risso, Alpismaris ................

rissoanus, Notacanthus ...........

rissoi, Trachnrus ..................

Rissola.

marginata.................

rivalis, Salmo ....................

River Chub.

Drums .

Lampregs

Perch .....................

Perch of New York ......... riverendi, Cyprinodon

\section{variegatus..}

rivoliana, Seriola

rivularis, Salmo....................

rivulatas, Cirrhites.................

Cirrhitichthys ...........

Diodon . .................

Serranus ................

Rivulus.

cylindraceus ............. 662, 2830

isthmensis .............. 2830

marmoratus............. 663, 2830

Roach ....................... $\quad 250$

Roaches......................... 243

roanoka, Etheostoma............. 1036

Hadropterus............. 1036

Percina................. 1036

robalito, Centropomus ..............

Robalito de las Aletas Amarillas...

Prietas......

Robalo

Prieto ......................

Robalos ..........................

roberti, Exocotus.

Hemirhamphus ............

Hyporhamphus...........

robertsii, Ceratobatis

Siphostoma .............

Stolephorus

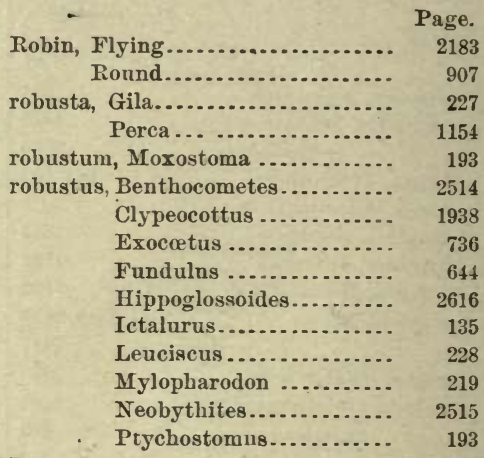

Roccus . ..................... 1131, 1132

chrysops ................ 1132

comes ................... 1407

lineatus .................. 1113, 1132

saxatilis ................. 1133

striatus ................. 1133

rocheanus, Thynnus ............. 868

rochei, Auxis .................... $\quad 868$

Scomber................. 867

Rock ........................... 1132

Bass ..................... 989, 1197

Common ............... 990

Beauty................... 1684

Cook .................... 1575, 1576

Hind .................... 1152

Salmon.................... 905

Sea Bass .................. 1201

Shellfish ................... 1722

Sturgeon .................. 106

Trout ............... 1866, 1867, 1872

Rockfish ............. 639, 1026, 1132, 1172

Black.................. 1784

Black and jellow ........ 1825

Black-bandled............ 1827

Brown................ 1817

Flesh-colored............ 1824

Grass ................. 1819

Orange................ 1793

Perca................... 1133

Pied .................... 1805

Spotted................. 1806

Yellow-backed ............ 1822

Yellow-spotted ........... 1826

1119 Tellow-tail .............. 11781

735 Rocklings, Four-Bearded ......... 2560

$721 \quad$ Three-Bearded ......... 2557

721 Rocky Mountain Bullhead ......... 1949

2756 Trout........... 487

2837 Whitefish....... 463

2815 rodo, Pristipoma.................. 1323 
Page.

Rœboides ....................... 338

guatemalensis .......... 338

Rogenia........................ 421

alba ..................... 422

rogersi, Urolophus ............. 2752, 2753

Roller, Stone ..................... 181, 204

Rollers, Sand ..................... 783, 784

Romero........................ 900

Roneadina ...................... 1461

Roneador ...................... 1457

Little................... 1460

Raiado............... 1301, 1313

Red................... $\quad 1456$

Yellow-finned .......... 1467

Roncador stearnsi............... 1457

roncador, Umbrina............... $\quad 1467$

ronchus, Bairdiella ................ $\quad 1436$

Corvina................. 1436

Sciæna.................. 1436

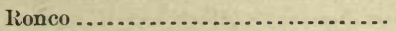

A marillo ...................

Arará .....................

Blanco ....................

Carbonero..................

Condenado ...................

Prieto .......................

Ronco....................

Roncos..........................

Rondanin

rondeleti, Anthias quartus .........

Carcharodon .............

Scombresox..............

Xiphias.................

Rondeletia

bicolor ..................

rondeletii, Exocœetus .

Exonautes .............

Orthragoriscus..........

Sargus .................

Rondeletiidis .......................

Ronquil .........................

Ronquils ..........................

Ronquilus.........................

jordani ................

rosacea, Mycteroperea..............

rosaceus, Cymatogaster ............

Epinephelus .............

Lutjanus ................

Mesoprion...............

Micrometrus ............

Paraliparis ..............

Sebastes.................

Sebastodes ...............

Trisotropis...............

Zalembius................

rosæ, Clevelandia
1436

1303

1304

1297

1300

1306

1297

1304

1291

959

1266

50

726

894

548

548

733,734

2836

1754

1364

547

2289

2287

2289

2289

1184

1500

1184

1267

1267

1500

2142

1794

1808

1184

1500 .

$2255^{\circ}$ ros:e, Hemirhamphus

Page.

722

Hyporhamphus ............ $\quad 721$

Typhlichthys ............... $\quad 2835$

rosarium, Acipenser ............. 106

Rose-back Parrot ................ 1635

Rose-fish ...................... 1760

Rose-fishes .................... $\quad 1760$

roseipinnis, Notropis............. 298

roseus, Blennius .................. $\quad 2420$

Centronotus.............. $\quad 2420$

Cryptotomus............... $\quad 1626$

Gunnellops................ $\quad 2420$

Luxilus ................. 288

Minnilus ................. $\quad 288$

Notropis ................ $\quad 287$

Prionotus ................ $\quad 2159$

Rosicola ................. 1765, 1775, 1793

rosipes, Novaculichthys........... 1614

Xyrichthys............... $\quad 1615$

rosispinis, Raja ................. 2751

rossi, Lycodes.................... $\quad 2465$

Salvelinus ................ $\quad 510$

rossii, Salmo ................... $\quad 510$

rostellum, Acipenser............. 106

rostrata, Albula.................. $\quad 412$

Aldrovandia............. 609

Anguilla............... $\quad \mathbf{3 4 8}$

angutlia ......... 348

Limanda................ $\quad 2645$

Loricaria............... $\quad 157$

Macdonaldia ............. $\quad 617$

Muræna ................ $\quad \mathbf{3 4 8}$

Platessa ................ 2645

rostratum, Cichlasoma ............ 1522

Holocentrum .......... 852

rostratus, Agonus................ 2048

Aspidophorus .......... 2048

Brachyopsis . . . . . . . . . 2046, 2048

Canthigaster ........... 1741

Gymnothorax........... 395

Halosaurus ............. 609

Heros.................. 1523

Heterostichus .......... 2351

Holocentrus ............ 849

Lophius .............. 2797

Notacanthus........... $\quad 617$

Phycis................ 2555

Pseudoscarus........... 1659

Scarus................. 1658

Sphagebranchus........ 373

Squalus............... 49

Tetrodon.............. 1742

Zeus................... 936

rostro, Labrus reflexo ............. 1677

rotengulus, Leneiscus.............. 221

rotheus, Leucosomus.............. 222 
rothrocki, Notogrammus...........

Poroclinus .............

rotunda, Mola .....................

Round Bass ......................

Herring..............

Pámpano...................

Robin ....................

Sting Rays...............

Sunfish ...................

Whitefish .................

Round-tail.....................

rousseau, Siphostoma ............

Syngnathus............

Roussettes......................

Rovetto .........................

Rovetus temminkii ..............

rubella, Sciæna ...................

rubellus, Alburnus................

Leuciscus ................

Minnilus ................

rubens, Centropomus .............

Labrus tautoga..........

Trigla tota................

ruber, A pogon.

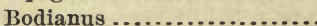

fulvas .............

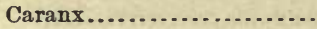

Coregonus.................

Dipterorlon.................

- Epinephelus ................

Gadus......................

Gymnocephalus............

Mycteroperca ..............

Rutilus ...................

Scomber..................

Sebastes...................

Sebastodes ................

Serranus ..................

ruberrima, Mycteroperca olfax..... ruberrimus, Gunnellus.

Pholis...................

Rhodymenichthys.....

Sebastodes ........ 1805, 1806

rubescens, Conier.................

Exocœtus..............

Hypsinotus .............

Steinegeria .............

rubicauda, Pomotus................

rubicunda, Parma.................

rubicundus, Acipenser.............

Glyphisodon .........

Hypsypops......... 1564, 1565

Pomacentrus......... 1565

rubiginosus, Gobiesox ...........

Sicyases .............

rubio, Prionotus
Page.

2440

2434

1754

988

420

941

907

79

988

465

227

767

767

22

879

880

1418

293

293

293

1107

1579

2177

1107

1265

1146

919

538

1107

1181

2530

1146

1180

300

919

1818

1806

1181

1183

2417

2417

2417

355

734

1665

961

1001

1565

106

1565

2337

2337

2164
Rubio Volador ................... $\quad 2164$

rubra, Liopropoma ................ 1137

Sciæna.................. 849

rubricrocens, Hybopsis ........... 286

Hydrophlox......... 286

Minnilus........... 286

Notropis ............ 286

rubrifrons, Alburnellus ........... $\quad 295$

Alburnus.............. 295

Ceratichthys .......... 320

Fundulus ........... 653

Hybopsis............. 320

Leuciscus ............ 295

Minnilus ............. 295

Nocomis.............. 320

Notropis ............. 295

Zygonectes............654, 2829

rubripinna, Cliola ................. 281

Cyprinella............ 281

rubripinne, Sparisoma ............ 1640

rubripinnis, Argyreus ............. $\quad 282$

Minnilus............ 298

Scarus .............. 1640

rubrirostris, Catætyx............ $\quad 2505$

rubrivinctus, Sebastichthys ....... 1817

Sebastodes........... 1817

rubropunctatus, Salarias ........... 2396 Scartichthys ...... $\quad 2396$

rubrum, Chorististium ............ 1136

Rudder-fish ................... 902, 1387

Radler-fishes ............... 962, 964, 1380

radis, Abudefduf ................ 1563

Glyphidodon ............... 1563

rufa, Harpe .................... 1583

Morone................... 1135

Perca..................... 849

Ruffs, Black................... 962, 963

ruflineatum, Etheostoma ......... 1079

rufilineatus, Nothonotus ......... 1079

Poecilichthys......... 1079

rufipinnis, Exocœtus .............. $\quad 735$

Exonautes ............. 2836

rufolineatum, Etheostoma......... 1079

rufus, Balistes .................. 1707

Bodianus................. 1135, 1583

Centropristes ............. 1199

Cossyphus ................. 1583

Holocentrus ascensionis .... $\quad 849$

Labrax.................. 1135

Labrus................... 1583

Onos ...................... 2559

Sebastodes................ 1780

rugifer, Ophichthus.............. $\quad 384$

rugispinis, Arius................. $\quad 130$

Galeichthys ........... 2781

Hexanematichtbys ..... 130 


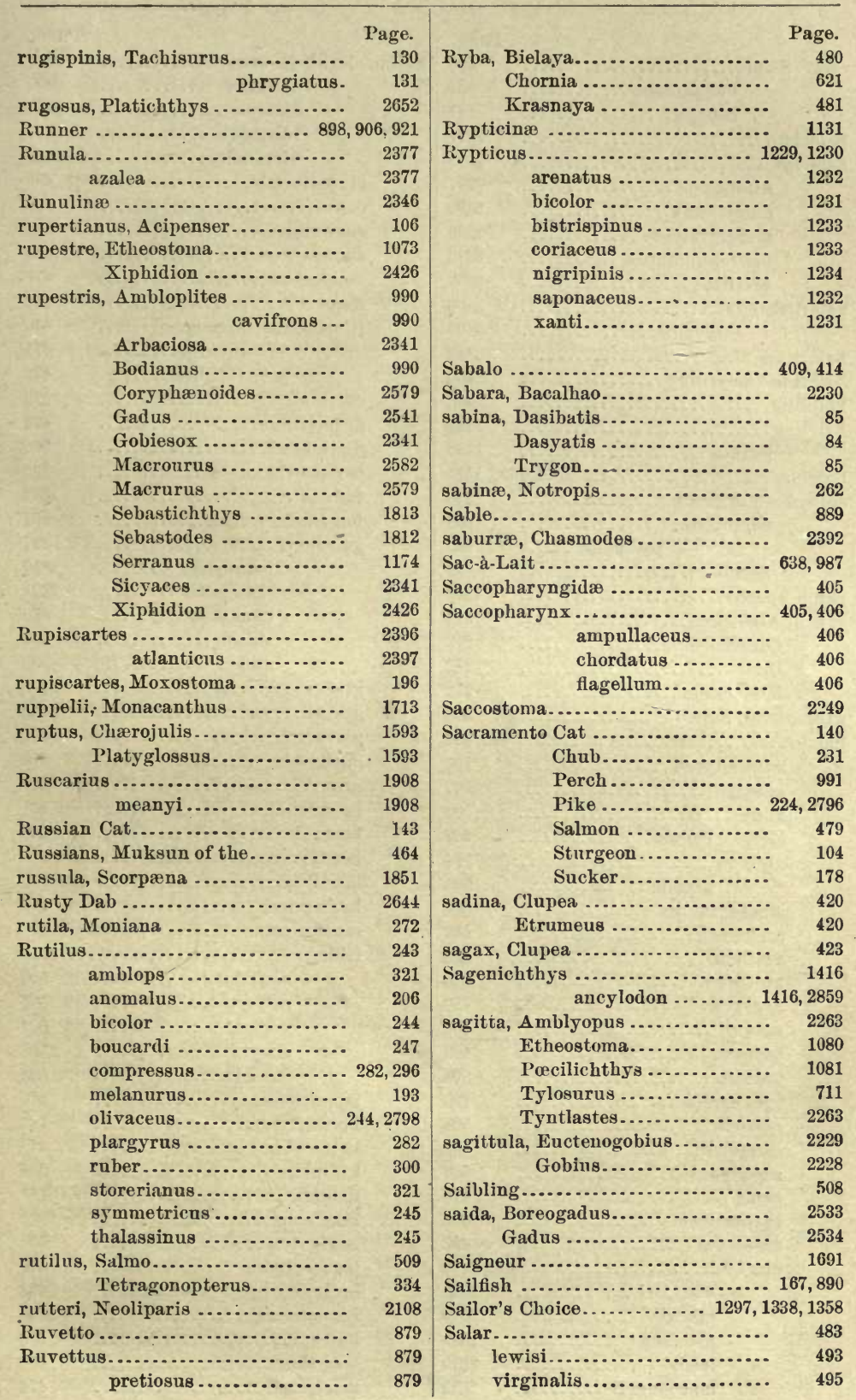


salar, Salmo

ouananiche

sebago $\ldots . . . . . . . . . .$.

Salariæ

Salarias

atlanticus

margaritaceus .............

rubropunctatus ............

textilis

Salariichthys.....................

textilis..............

Salariinæ ........................

Salarius vomerinus ...............

Sälbling.........................

Saleima .........................

aurata .....................

Page.

486

487

487

2377

2397

2397

2398

2399

2396

2400

2400

2400

2346

2400

508

1384

1386

Salema $1358,1359,1385$

saliens, Chorinemns

899

899

Oligoplites

palometa.......

Scomber ..................

salin, Sparus....................

sallxi, Algansea.

Ceratichthys...............

Cliola ........................

Hudsonius .................

salmarinus, Salmo

Salmo

adirondacus .................

agassizii....................

alipes......................

alleghaniensis

alpinus .............

nivalis ...............

amothystinus...............

arabatsch ...................

arcticus ....................

arcturus....................

argyrens ..................

ascanil ......................

aurora ......................

bairdii......................

brevicauda .................

callaris .....................

campbelli....................

canadensis .................

canis .......................

carbonarius .................

carinatus ....................

clarkii.

bouvieri.............

gibbsii ...............

henshawi.............

lewisi ................

macdonaldi.
Page.

2819

2819

2819

2870

2819

466

509

505

480

479

483

469

471

tullibee $\ldots \ldots \ldots . .473$

curilus .....................508, 2223
cermatinus ............... 479

$\begin{array}{ll}\text { Cermatinus } \ldots \ldots \ldots \ldots \ldots \ldots . . . & 479 \\ \text { distichus ................... } & 509\end{array}$

erythrorhynchos ............ 508

foetens .................... 538

fontinalis................... 507

gairdneri ................. $\quad 497$

beardsleei ......... 2819

crescentis ......... 2821

kamloops ......... $\quad 499$

shasta............ 502

stonei ............ 503

gibber..................... $\quad \mathbf{4 7 8}$

gibbsii.................... 493

gloveri .................... 487

gorbuscha................. 478

grayi .................... $\quad 509$

groenlandicus............... $\quad 521$

hearnei................... 510

hoodi...................... 505

hoodii .................... 507,510

hudsonicus ............... 507

immaculatus .............. 507

irideus ................. 500, 2819

agua-bonita......... $\quad 503$

gilberti............. 502

masoni ............. 501

shasta ............. 502

stonei............... 503

japnnensis................ 479

kennerlyi.................. 483

keta vel kayko ............. $\quad 479$

killinensis................. 509

kisutch................... 481

kundscha................. 2823

lævigatus ................ 508

lagocephalus .............. $\quad 479$

lavaretus muchsun .......... 464

leucomænis................. 2823

lordii................... 508

lycaodon .................. $\quad 483$

mackenzii................ 474 
Salmo macrostoma

Page.

(Mallotus) pacificus ......... malma.................... niarstoni.................

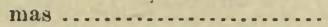
masoni .................... melampterus ............... milktschitch.............. monestichus ............... muikisi................... muksun .................. mulleri .................... mykiss... $487,492,2818$ gua-bonita .... 487, 492, 2818 bourieri. clarkii .............. gibbsii ............. henshawi. ........... lewisi ............... macdonaldi ......... pleuriticus ........... spilurus............ stomias ............ virginalis ........... myops..................... naresi .................... nerka ..................... nigrescens................. nitidus ..................... nummifer ................. omisco maycus .............. oquassa ................... orientalis................. (Osmerus) olidus ............ pallidus................... parkei.................... paucidens .................. yenshinensis. 508,2819 perisii.................... 509 proteus................... $\quad 478$ purpuratus............. 492, 499, 2819 bouvieri ........ 496 quinnat .................. 480 richardi .................. 483 rivalis................... 509,510 rivularis ................ : 500 rossii.................... 510 rutilus .................. 509 salar ................... 486 ouananiche.......... 487 sebago.............. 487 salmarinus ................. salvelinus................. sanguinolentus............. saurus. 509 509 481 537 scouleri

Sal

$521 \quad$ siskawitz............... 505

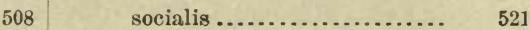

516 spectabilis................. 508

$487 \quad$ stagnalis $\ldots \ldots \ldots \ldots \ldots \ldots \ldots . .5 \%$

$501 \quad$ stellatus................. 493

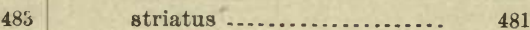

481 symmetricus ............. 505

509 tapdisma................ 483

492 (Thymallus) signifer....... 518

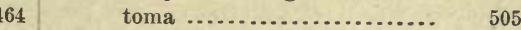

44 trachinus................ 533

truncatus.................. 499

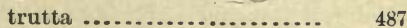

tschawytscha............. 480

tschawytschiformis ........ 478

tsuppitch................. 481, 495

tudes .................... 508

umbla................... 509

ursinus.................. $\quad 505$

utah ..................... 495

ventricosus................ 509

warreni.................. 483

willughbii ................ $\quad 509$

salmoides, Labrus ................ 1012

Micropterus ............ 1012

Salmon ....................... 483

Atlantic ................. 486

Blue-back................ 481

Chinook................. $\quad 479$

Coho ................... 480

Columbia ................ $\quad 479$

Common Atlantic ......... $\quad 486$

Dog ................... 478

Family ................. 460

Fraser River............. 481

Hoopid................. $\quad 480$

Humpiack ................ $\quad 478$

Jack .................... 1021

Killer ................. $\quad 749$

King ................... $\quad 479$

Landlocked .............. $\quad 487$

Le kai.................. 478

Namaycush .............. $\quad 505$

Quinnat................ 474, 479

Rock................... 905

Sacramento ............. $\quad 479$

Saw-qui................. 481

Silver .................. 480

Trout ................. 497, 2818

Tyee................... 479

White, of the Colorado ..... 225

salmonea, Ericaria............... $\quad 2816$

Lepomis ............... 1011

Perca .................. 1021

Salmonete................... $\quad 858$ 


\begin{tabular}{|c|c|}
\hline $\begin{array}{r}\text { Page. } \\
859\end{array}$ & sanctæ-helene, Caranx \\
\hline $\begin{array}{l}\text { almonete Amarill } \\
\text { almoneus, Chanos }\end{array}$ & $\begin{array}{r}\text { sanctæ-helente, Caranx.............. } \\
\text { Decapterus ......... }\end{array}$ \\
\hline $538,627,629$ & $\begin{array}{l}\text { Decapterus .......... } \\
\text { Gymnothorax...... }\end{array}$ \\
\hline Mugil .................. $\quad 415$ & Lycodontis ........ \\
\hline brocottus........... & Muræna........... \\
\hline falmonidæ ............................. & sanctæ-luciæ, Corvula... \\
\hline n.................. & (n.......... \\
\hline .......... & sanctæ-petri, Vomer ..... \\
\hline n.......... & (n......... \\
\hline da................. & hrys....... \\
\hline ........ 780,782 & sancti-pauli, Holoce \\
\hline ta...... 1271 & Sand Dab......... \\
\hline 899 & Darters............ \\
\hline 947 & Diver.............. \\
\hline .......... & Eel ............. \\
\hline (n)..................... & Launces .......... \\
\hline steus ............. 947 & Pike............... \\
\hline Perca $\ldots \ldots \ldots \ldots \ldots \ldots \ldots . . .647,1388$ & Rollers ...................... 783,784 \\
\hline nus .............. 946 & Shark ......................... \\
\hline (n).............. & Star-gazers ..................... \\
\hline ops................ & er ....................... \\
\hline hudsonius.,... & iting...................... 1474 \\
\hline (n.................... & Sand-fish......................... 1207, 2295 \\
\hline ( & Sanducha .......................... 411 \\
\hline alpinus ............... 508, 2822 & sanguifluus, Nothonotus ........... \\
\hline alipes .......... $\quad 509$ & Foecilichthys........... \\
\hline as ......... & sanguinea, Murneva............... \\
\hline aureolus......... & sangnineus, Anten \\
\hline stagnalis ........ & 8 .............. \\
\hline bairdii ................... & s............. \\
\hline fontinalis ................ & ys ......... \\
\hline agassizii...... & sanguinolentus, Onc \\
\hline kundscha ............... 2822 & tis ............ \\
\hline malma................. 507, 2823 & Salmo $\quad . . . . . . . .$. \\
\hline namajeush $\ldots \ldots \ldots \ldots \ldots . \quad 505$ & Sa-pen-que ......................... $\quad 487$ \\
\hline siscowet ..... & a................ 427,428 \\
\hline (n) & sapidissimus, Coregonus........... 466 \\
\hline nitidus................. $\quad 509$ & Sapo ................. 2314, 2315, 2316, 2321 \\
\hline oquassa ................ 514,515 & Bagre........................ \\
\hline $\begin{array}{l}\text { marstoni ....... 51 } \\
\text { naresi .......... }\end{array}$ & saponaceus, An \\
\hline $\begin{array}{r}\text { naresi ........... } \\
\text { parkei .................... }\end{array}$ & Rhypticus............. \\
\hline 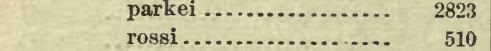 & Rypticus ............... \\
\hline bilis .............. & sara, Cybium........................... \\
\hline ilis................ & s, Lepodns.................... \\
\hline (n) & is apiarius.................... \\
\hline (........... & Sarchirus...$\ldots \ldots \ldots \ldots \ldots \ldots \ldots \ldots$ \\
\hline 2208 & argentens.................. \\
\hline 1528 & n.............. \\
\hline (n............... & Sarcidium........................... \\
\hline (n).............. & n.............. \\
\hline (n).................. & (n........... \\
\hline Sicyopterus ............... & 59,60 \\
\hline in Diego Sole ...................... & 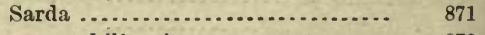 \\
\hline (n) & chiliensis.................... \\
\hline udoscarus ........ & mediterranea ................. \\
\hline 1651 & sarda \\
\hline
\end{tabular}


sarla, Pelamys................... Scomber.

Sardina Blanca..................

Bocona ...................

de España...............

de Ley ...................

Escamuda .................

Machete..................

psendohispanica...........

sarlina, Harengula ...............

Menidia..................

Sardinella.

Sardina

Sardine, Califorina ................

Sardinella................. 428,429, 2811

anchovia ................

apicalis .................

bishopi .................

clupeola.................

humoralis ................

macrophthalmus ........

sardina..................

stolifera................

thrissina ................

Sardines, Scaled..................

True ...................

Sarlinia..........................

Sargassum Fish..................

Sargo

Raiado

sargoides, Chrtodon .............. 1562

Sargosomus ..................... 1495

fluviatilis............ 1496

Sargus ....................... 1362

ambassis ................ 1346

argenteus ............... 1363

aries ......................

caribæus ..................

caudimactla .............

flavolineatus ..............

holbrookii. ................

humeri-maculatus .........

ovis ......................

pourtalesii ................

raucus ...................

rhomboides

rondeletii ...............

tridens....................

unimaculatus.

variegatus ...............

vitula .....................

sargus, Diplodus

Sparus

1362

1360

1363

1360

1363

1360

1361

1360

1364

1358

1364

1364

1360

1364

1364

1363

1364

1672

1674

amplexicollis..........

atæniatus

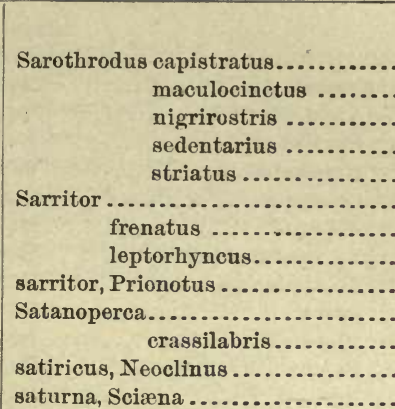

satnrnus, A mblodon

Rhinoscion...............

Saucer-eje Porgy ................

Saurels...................... 909, 910

Saurenchelys .................. $\quad 364$

Sauries ...................... 724, 725

Saurus ..................... 533

anolis................... 535

brevirostris.............. 533

foetens.................. 538

griseus ................. 537

intermedius ............. 535

limbatus................. 533

longirostris ............... $\quad 538$

lucioceps ................ $\quad 539$

mexicanus............... 538

myops.................. 533

spixianus................ $\quad 538$

synodus ................ 536

truncatus................ 533

varius .................. 536

saurus, Elops ................... $\quad 410$

Esox.................. 725

Oligoplites.............. $\quad 898$

Salmo.................. 537

Scomber ............... $\quad 898$

Scombresox............. $\quad 725$

Synodus ............... $\quad 537$

Trachurus . .............. 911

Saury ........................ $\quad 725$

saussurii, Brama ................ 958

Taractes .............. 957

Sauteur...................... 898, 899

Savalle....................... 409

Savanilla...................... 409

savanna, Brachyconger........... $\quad 360$

Muræna............... $\quad 360$

Muranesox............. $\quad 360$

Savola.......................... $\quad 889$

Saw-belly ...................... 426

Sawfish, Common............... 60 
Saw-kwey

Saw-qui Salmon saxatilis, Abudefduf

Chretodon ................

Glyphidodon ..............

Gymnothorax ocellatus .. Johnius .................. Lycodontis ocellatus ..... Menticirrhus.............

Perca

Platessa..................

Poecilichthys..............

Roccus ..................

saxicola, Pleuronectes..............

Sebastichtbys...........

Sebastodes

say, Dasyatis.

Raja.

ragang, Aphredoderus

Scolopsis

sayi, Dasibatis

Myliobatis....................

Trygon ..................... Sayris.

bimaculatus................

hians.....................

recurvirostris ..............

serratus.

Scabbard k'ish

scaber, Antennarius ...............

Centropomus ..............

Chironectes ...............

Hexagrammus.............

scabra, Trinectes..................

scabriceps, Minnilus.

Notropis ...............
Photogenis .............

scabripinnis, Tetragonopterus .....

Scad.

Big-eyed ....................

Mackerel.......................

Scaled Sardines ....................

Scaly-fins

Scamp.

1665

Scaphirhynchops platyrrhynchus.. $\quad 107$

Scaphirhynchus................. 107

cataphractus ..... $\quad 107$

platorynchus...... 107

platyrhyrchus.... 107

rafinesquei ........ 107

scaphiurus, Opisthognathus .......

scaphopsis, Coelorhynchus .........

Macrurus (C’œlorbyuchns) .............. 2591

Scaphyrhynchops............... $\quad 107$

scapulare, Pristipoma............. 1321 scapularis, A nisotremus .......... 1320

Tylosurns............ 711

Scarid* ...................... 1572, 1620

Scarina ......................... 1621

Scartella ....................... 2384

microstoma............. 2384

Scartes .......................... 2395

scartes, Fundulus................ 654

Scartichthys .................... 2395

rubropunctatus ...... 2396

Scarus .............. 1627, 1642, 1643, 1645

abildgaardi .............. 1635

acutus.................... 1652

alternans ................. 1651

amplus .................. 1635

aracanga........... 1642, 1647, 1648

atomarius................ 1631

aureoruber............... 1635

aurofrenatus.............. 1634

bollmani .................. $\quad 1646$

brachialis................ 1641

carnleus................. 1652, 1654

catesbœi................. 1638

catesby .................. 1638

chloris................. 1637, 1646

chrysopterus ............. 1637

circumnotatus ............. 1641

coccineus.................. 1635

cœlestinus................ 1656

croicensis................. 1650

cuzamilge .................. 1648

diadema ................... 1646

distinetus $=. . \ldots \ldots \ldots \ldots \ldots . .1636$

emarginatum .............. 1641

emblematicus.............. 1654

erythrinoides ............... 1635

evermanni ................. 1651

flavescens.................. 1640

flavomarginatus ........... 1652

frondosus............... 1636, 1642

gnathodus ................ 1650

guacamaia .............. 1656, 1658

holocyaneos.............. 1654

hoplomystax.............. 1633

humeralis................ 1641

insulæ-sanetæ-crucis ....... 1651

lacrimosus............... 1632

lateralis ................ 1637

loro ..................... 1654

maschalespilos............ 1642

melanotis................. 1638

miniofrenatus ............. 1634

nuchalis .................. 1654

obtusus.................... 1654

oxybrachius ............... 1635

perrico ................. 1659 


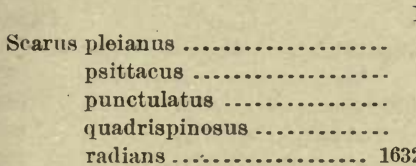

rostratus ..................

rubripinnis ..

sancta-crucis..............

simplex

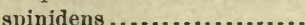

squalidus ..................

strigatus..................

superbus ...................

treniopterus ................

triolabatus .................

trispinosus .................

truncatus ..................

turchesius .................

vetula

virens ....................

virginalis ..................

viridis

scepticus, Minnilus .............

Notropis..................

Triglops ................

Scherdophilina ...................

Schedophilopsis ...................

spinosus ..........

Schedophilus ..................... enigmaticus.......... medusophagus

Schilbeodes eleutherus............ $\quad 148$ exilis ................. 147

funebris .............. $\quad 147$

furiosus .............. $\quad 149$

gilberti.............. 148

gyrinus............. 146, 2790

insignis............... 147

leptacanthus .......... $\quad 146$

miurus ............... 148

nocturnus ............. 146

Schistorus ................... 1148, 1151 mystacinus ............ 1151

schlegeli, Orcynus............... $\quad 870$

Priacanthis............. $\quad 2858$

Sebastodes.............. 1834

schmidtii, Hoplunnis............... 361

schmittii, Balistes................. 1705

schneideri, Chauliodus.............

Ophichthys .............

Pocilia

schœpfii, Alutera

Balistes .................

Ceratacanthus...........

Chylomycterus.
1056

1647

645

633

640

1651

656

637

1639

650

646

654

1641

658

1649

1647

638

296

1925

972

972

970

972

70

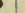

48

7

7

8

0.

46

6

51

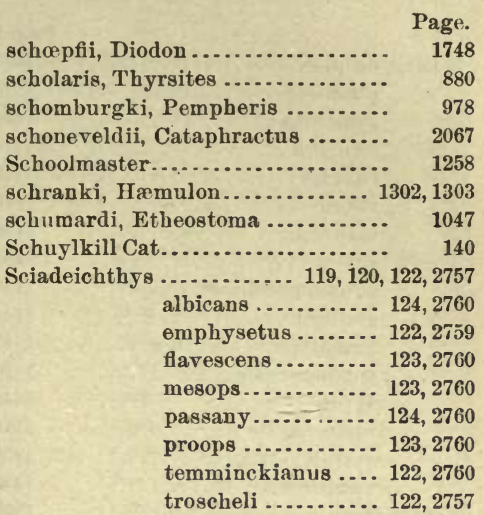

Sciades troscheli ............... 122, 2758

sciadicus, Fundulus............... 654

Haplochilus ............ 654

Zygonectes ............. 654

Sciæna..................... 1454, 1465

acuminata .............. 1488

aluta................... $\quad 1438$

amazonica ............... 1419

caprodes ................... 1027

chrysoleuca.............. 1439

chrysura................. 1434

coro.................... 1324

croker ................... 1462

(Corvina) adusta.......... 1448

crouvina ................. 1419

deliciosa .................. 1455

edwardi .................. 1490

ericymba................ 1445

ensifera.................. 1435

furthi ................... 1441

fusca................... 148:3

gigas................... 1483

grisea ................... 1484

heterolepis................ 1419

icistia.................. 1436

imberbis .................. 1454

imiceps .................. 1451

jacobi .................... 1457

lanceolata................ 1444

lineata................ 1133, 1460

macrops................... 1428

maculata................ $\quad 2198$

magdalenæ.............. 1420

multifasciata............. 1459

obliqua.................. $\quad 1459$

ocellata................... 1454

opercularis................ 1461

ophioscion ............... 1448

oscitans .................. 1441 
Sciæna oscula .

plumieri.

Page.

punctata

ronchus

1324

rubella ....................

1434

1436

1418

rubra......................

849

saturna .................. 1456

sciera ..................... 1452

squamosissimus........... 1418

stellifer ................... $\quad 1444$

(Stelliferus) stellifer ....... 1443

surinamensis.............. 1420

typica ................... 1448

undecimalis ............... 1119

vermicularis ............ 1452, 1453

xanthurus ............... 1459

Sciænidæ

1392

Sciænops.........................

ocellatus

1453

sciera, Sciæna....................

1452

scierum, Etheostoma...............

1038

scierus, Hadropterus.

1037

1038

Ophioscion............... 1452

Scirenga ........................ 1180

scirenga, Mycteroperca ........... 1181

scituliceps, Synodus ............ 537, 2826

gcitulus, Prionotus ............... 2157

sciurus, Diplectrnm............... 1204

Hæmulon................ 1303

Serranus ................ 1204

Sparus ................. 1304

Sclæninæ ...................... 1394

Sclerodermi .................... 781, 1697

Sclerognathus.................... 163

cyprinella........... 164

elongatus ........... 169

meridionalis ........ 164

urus.............$\quad 165$

scofieldi, Stolephorus ............. 2814

Scolecosoma...................... 10

Scoliodon...................... 42

longurio ............... 42, 2748

terræ-novæ ............. 43

scolopacea, Nemichthys........... 369

scolopaceus, Nemichthys.......... 369

scolopax, Balistes ................. $\quad 759$

Centriscus .............. 759

Macrorhamphosus ...... $\quad 759$

Scolopsis sayanus.................

Scomber

adscensionls

alatunga ...................

albacores .................

alleteratus................

asconsionis

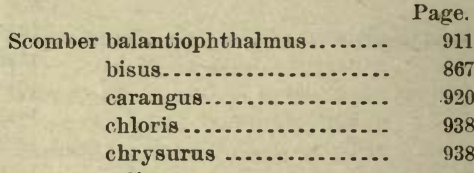

colias ................. 866, 2843

crumenophthalmus ....... 911

crysos .................. 921

dekayi................. 867

dentex................ 927

diego .................. $\quad 867$

fasciatus............... 904

filamentosus............. 932

germo.................. 871

gracilis ................ 867

grex .................. 867

guara ................. 927

gunneri................ 955

heberi................... 923

hippos ................. 908,920

kolreuteri.............. 900

lacertus................. 867

latus.................... 938

macroptlalmus .......... 867

maculatus ............ 867,874

mediterraneus ........... 872

niger.................. 948

pelagicus ............... 952

pelamides............... 869

pelamis ................. 869

pelamitus............... 872

pelamys ................ 872

plumieri ................ 911

pneamatophorus.......... 867

quadripunctatus......... $\quad 869$

regalis................. 875

rim .................. 928

rochei.................. 867

ruber ................... 919

saliens ................ 899

sarda ................ 872

saurus ................. 898

scombrus ............... 865

sloanei................. $\quad 870$

speciosus ................ 928

thazard ................ 867

thynnus ................ 870

trachurus............... 910

undulatus................ 867

vernalis ................. 866

zonatus ................. 902

scomberius, Esox ................ 626

Scomberodon.................... 873

Scomberoides, saltator ........... 899

Coryphæna........ 953

Sco uberomorus .............. 873,4843 
Page.

Scomberomorus caballa .

concolor maculatus

plumieri.

regalis

sierra.

Scombresocida

Scombresox

brevirostris........
camperi ...............

equirostrum ...........

fosteri .................

rondeleti ..............

saurus ................

scutellatum...........

storeri ................

Sicombridæ

........................

Scombrina .......................

scombrinus, Caranx ...............

Decapterus............

Scombrocottus ..................

salmoneus..........

Scombroidei

Scombroides occidentalis..........

Scombroidina

Scombropina

Scombrops

oculatus ....................

scombrus, Scomber

Scopelus

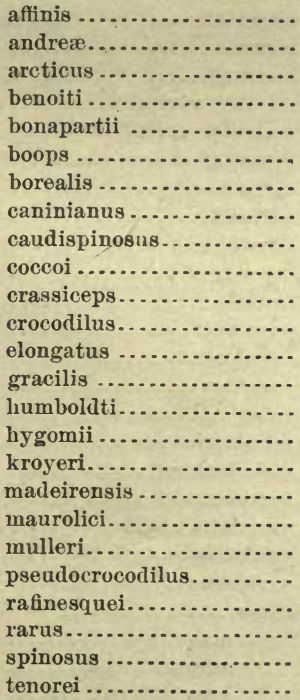

scopifer, Notropis

$$
3030-117
$$

875,876

873

, 4843

875

875

874

724

725

726

725

726

726

726

725

726

726

863

864

908

908

1861

1862

781,860

899

896

1106

1114

1114

865

569

571

569

574

573

557

572

577

570

556

569

843

558

555

572,574

572,577

573

556

557

577

570,574

556

567

569

575

577

291 scopifer, Phenacobius.

Page.

scopiferum, Sarcidium

scopiferus, Phenacobius...........

scops, Gnathypops ...............

Scorfanudi Funal.................

Scorpæna ........................

agassizii.............. 1840, 2860

americana............. 2023

brasiliensis ............. 1842

bufo .................. 1849

calcarata .............. $\quad 1854$

capensis.............. 1833

castor ................. 1856

cristulata............. 1841

dactyloptera........... $\quad 1837$

grandicornis............ $\quad 1850$

guttata ................ 1847

histrio ............... 1843, 1846

inermis .............. 1853, 2861

massiliensis............ 1139

mystes................. 1849

nematophthalmus ...... 2861

occipitalis ............. $\quad 1854$

pannosa ............... 1845

plumieri ............... 1848

porca ................. 1839

rascacio ............... 1849

russula ................ 1851

sierra................ 1860

sonora .............. 1852

stearnsi............... 1843

Scorpænichthyinæ ............... 1880

Scorpænichthys................. 1889

lateralis.......... 1902

marmoratus...... 1889

Scorpænidæ.................... 1758

Scorpæninæ.................... 1759

Scorpene..................... 1847

scorpio, Cottus.................. 1973

scorpioides, Cottus................ 1973

Myoxocephalus........ 1973

Scorpion ....................... 1847

Fishes................ 1839

Scorpis californiensis ............. 1391

Scorpius virginianus............. 1976

scorpius, Cottus.................. 1974

Cottus groenlandicus..... 1975

scouleri, Oncorhynchus........... 478

Salmo .................. 478, 481

Scour Fish .................... $\quad 879$

scovelli, Etheostoma ............. 1082

Siphostoma.............. $\quad 769$

scripta, Alutera.................. 1719

scriptus, Balistes................. 1719

Ceratacanthus........... 2860 
scriptus, Gymnothorax.............

Monacanthus .............

Pseudoscopelus............

scrutator, Belone..................

Isesthes ................

scudderi, Diabasis

Hæmulon.............. 1299, 1300

Sculpin

Aretic.

Black.

Daddy

European.

Great.

Long-spined

Red..........................

Yellow

Sculpins

Spineless ...............

Stone

Scup, Common

Scuppang

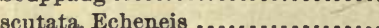

scutellatum, Scombresox...........

Scutica

scuticaris, Bascanichthys ..........

Cocula.................

Sphagebranchus ........

scutiger, Icelus

Rastrinus..................

seutum, Achirus

Solea

scylla, Exocotus

Hybopsis .................

Notropis ...................

Scylliorhinidæ

Scylliorhininæ

Scylliorhinus

profundorum :

retifer................

Scyllium

retiferum.................

ventriosum ...............

Scymnoid Sharks ..................

Scymnus brevipinna ..............

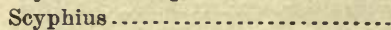

Seyris.

Scyris analis .....................

Scytalichthys .....................

miurus..........

Seytalina......................... cerdale ...................

Scytalinidx

Scytaliseus. magnioculis
Page.

398

1719

2292

714

2389

1300

1847

1973

1985

1974

1974

1976

1976

1935

1934

1879

1970

2025

1937

1346

1346

2271

726

403,404

378

379

379

1910

1809

2700

2700

735

263

263

22

22

22

22

25

22

25

25

56

57

774

931

932

387

387

2454

2454

2453

2454

381,384

385

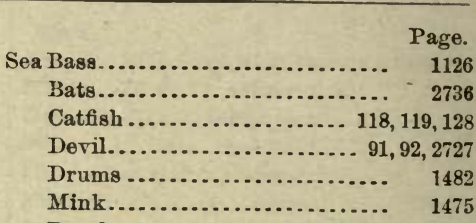

Poacher............... 2031, 2065, 2091

Raven................. 976, 2622, 2023

Serpent.................... 384

Snail................ 2105, 2114, 2116

Snipe...................... 714

Trout ...................... 1407

Spotted................ 1409

Sea-horse...................... $\quad 775$

Common American...... $\quad 777$

Sea Robin, Brown-winged ......... $\quad 2167$

Red-winged............ 2156

sebago, Salmo salar............... 487

Sebastapistes .................... 1839

guttatus ............ 1848

Sebastes ....................... 1760

auriculatus .............. 1818

capensis ................ 1833

caurinus................ 1821

dactylopterus........... 1837, 1838

darwini................ 1832

elegans ................. 1830

elongatus............... 1816

fasciatus.............. 1761, 1827

helvomaculatus.......... 1808

imperialis.............. 1837, 1838

inermis ................ 1829

marinus................ 1760, 1761

viviparus....... 1761

melanops ................ 1783

nematophthalmus........ 2861

nigrocinctus ............. 1828

nivosus................. 1834

norwegicus ............. 1761

oblongus................ 1830

oculata ................ 1832

paucispinis .............. 1781

regulus ................ 1761

rosaceus ............... 1794

ruber .................. 1818

septentrionalis........... 1761

steindachneri........... $\quad 1830$

taczanowskii ........... 1832

variabilis ............... 1784

ventricosus............. 1829

viviparus ............... 1761

Sebastichthys............ 1765, 1777, 1827

atrovirens.......... 1798

aurora.............. 1803

brevispinis......... 1788

carnatus ........... 1825 


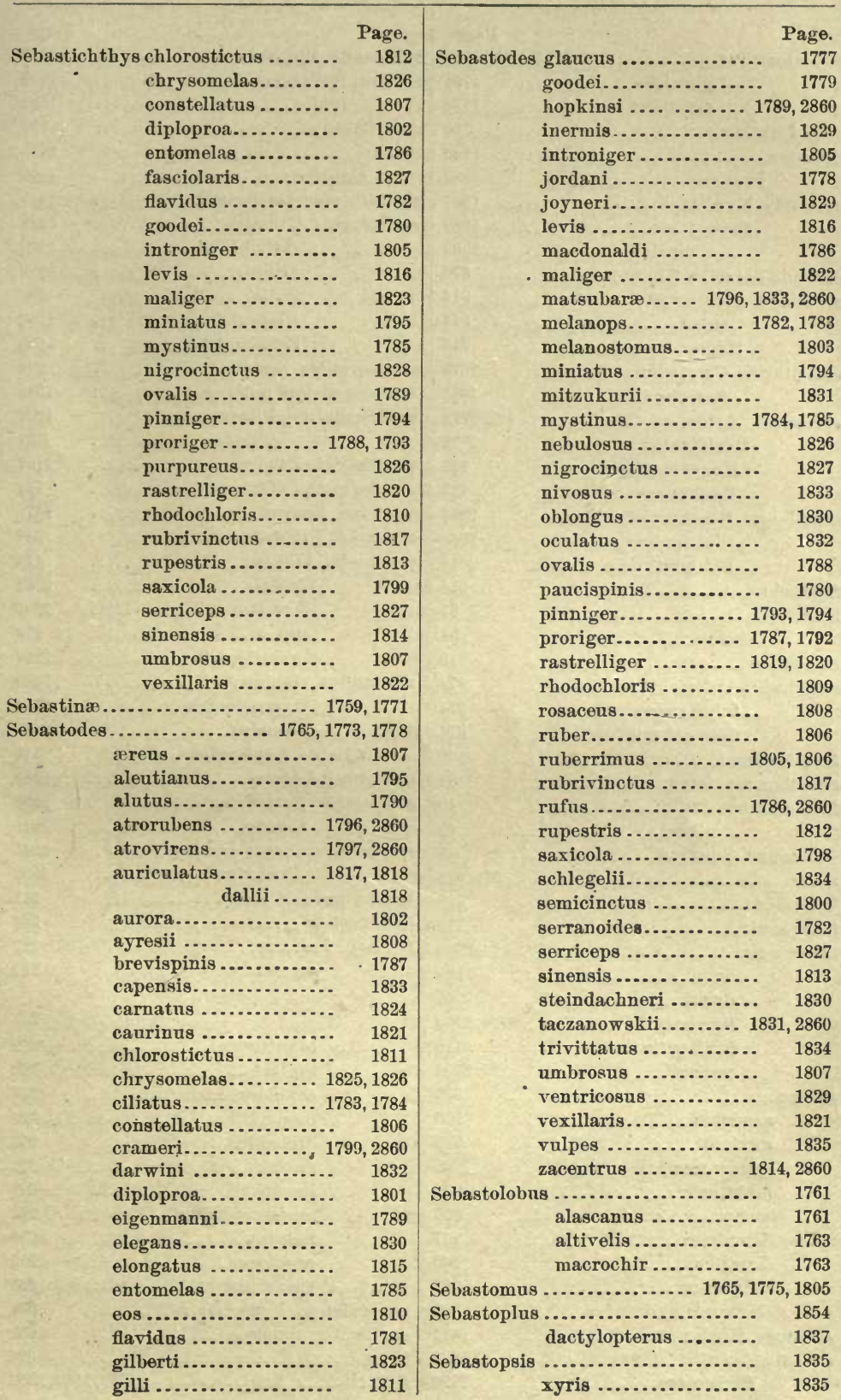




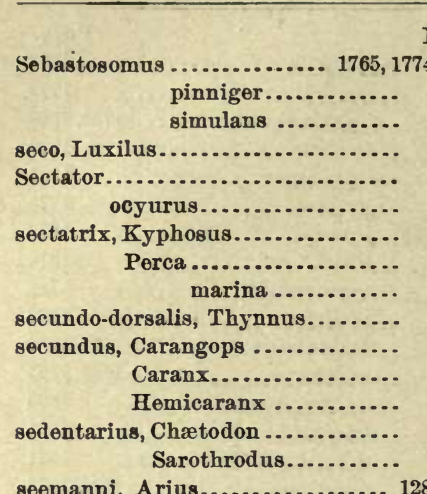

seomanni, Arius

Galeichthys ............

Hexanematichthys .....

Tachisurus .............

segaliensis, Brachyopsis............

Siphagonus ............

Syngnathus............

Segundo .........................

Selache .........................

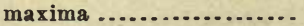

Selachii ..

selachops, Apterichthys ..........

Ichthyapus ............

Sphagebranchus ........

Selachostomi.

Selachus maximus

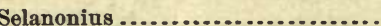

walkeri ................

selanonus, Squalus ...............

Selar.

916,918

Selaroides.

Selenaspis

Selenaspis

dowi.

...

119

, 124, 2760

dow

125

276

herzbergii ............ 124, 2760

luniscutis.............. 125

parkeri ............... 125, 2764

Selene...........................

argentea .................

œrstedii....................

quadrangularis ...........

setipinnis.................

vomer .....................

selene, Carpiodes.................

Luxilus..................

Minnilus ..................

Notropis hudsonius........

selonops, Hiodon

sellaris, Acanthocottus

Porocottus. sellicauda, Epinephelus .

Page.

1592

1592

sem, Caranx..................... 923

Sema.......................... 1498

signifer ................. 1499

semiarmatus, Gasterosteus ....... $\quad 747$

semicinctus, Gillellus ............. $\quad 2298$

Halichæres .......... 1593

Iridio............... 1592

Julis................ 1593

Platyglossus......... 1593

Sebastodes.......... 1800

semicoronata, Seriola.............. 904

Semicossyphus pulcher ............ 1585

semifasciatum, Pileoma ............ 1027

Triakis........... 31

semifasciatus, Serranus .......... 1197

semiloricatus, Gasterosteus ....... $\quad 747$

semiluna, Sparus ................ 1276

seminolis, Fundulus.............. 647

seminuda, Albula................ $\quad 412$

Eleotris ................ 2204

Garmannia............ 2233

Gila.................. 228

Gymneleotris .......... 2204

seminudus, Gobius ............... 2234

Gymnoleotris ......... 2204

Lycodes.............. 2468

semiradiatus, Lepisosteus : ........ $\quad 110$

semiruber, Labrus................. $\quad 1583$

semiscaber, Cottopsis............... 1950

Cottus :............... 1949

semiscabra, Cottus centropleura.... 1945

Uranidea ............. 1950

semispinosus, Caranx ............ $\quad 911$

Semitapicis ..................... $\quad 332$

Semotilus . .................. 220, 221, 222

atromaculatus ........... 222

thoreauia-

nus .... 223

biguttatus............. 32 ?

bullaris................ 222

cephalus............... $\quad 222$

corporalis ............. 221, 222

diplemius.............. 222

dorsalis................ 222

hammondi .............. 222

macrocephalus.......... 222

notatus................ 659

speciosus............. $\quad 222$

thoreauianus ........... 223

senegalensis, Vomer................ 934

senilis, Gambusia ............... $\quad 682$

Sennet ....................... 826

Señorita. . . . . . . . . . . . 1592, 1601, 2352 
senta, Raja

septentrionalis, Gaidropsarus.....

Motella............

Onos...............

Perca..............

Sebastes ............

septipinnis, Ammodytes .

Rhynchias.

Septogunnellus gracilis -...-. (eptogunnellus gracilis ...........

Hybognathus .............

Sergeant Fish.

Major ...................

Seriola .........................

argyromelas ...............

bipinnulata................

bonariensis................

boscii.....................

coronata..................

cosmopolita ............. 938, 2847

declivis................. 905

dorsalis .................. 902

dubia.................... 905

dumerili . . ................. 903,904

dussumieri ................ 900

falcata.................. 905

fasciata ................ 904

gigas ..................... 903

lalandi .................. 902,903

ligulata.................. 905

mazatlana............... 904

picturata ................. 910

pinnulata................. 907

proxima................... 904

rivoliana ................. 904

semicomata............... 904

stearnsii.................. 903

succincta................. 900

zonata.................... 902

carolinensis........ 902

Seriolichthys..................... 906

Seriolinæ......................... 896

Seriolophus ..................... 895

carangoides .......... 895

Seriphus ....................... 1397

politus ................. 1397

serotinus, Acipenser .............. 106

serpens, Gempvlus ................ 884

Serpens marinus maculosus....... $\quad 382$

Serpent, Sea...................... 384

serpentina, Muræna.............. $\quad 348$

serpentinus, Blennius............. 2439

Derichthys .......... 343

Leptoblennius ........ 2439

$\begin{array}{lr}\text { Serra.............................. } & 597 \\ \text { serra Alepidosaurus (Canlopus) ... } & 597\end{array}$
Page.

serra, Alepisaurus ............... $\quad 597$

Gonenion .................. 947

Serran Imperial.................. 1837

Serrana ....................... 1489, 1490

Hispana................ 1488

hispanis ................ $\quad 1489$

Serranidæ...................... 1126

Serraninæ....................... 1129

Serrano ......................... 1207

serranoides, Sebastodes ............ 1782

Serranos ....................... 1208

Serranus acanthophorus .......... 1196

acutirostris.............. 1181

requidens............... 1211

agassizii................ 1189

albomaculatus........... $\quad 1197$

angustifrons ............ 1159

annularis................ 1214

apua................... 1158

arara .................1159, 1175

armatus ................ 1165

aspersus................ 1153

atrarins ................. 1200

auratus................. $\quad 1145$

auriga.................. 1221

bivittatus ............... 1205

bonaci.................. 1175

brasiliensis.............. 1221

brunneus............... 1175

bulleri.................. 1214

calopteryx.............. 1213

capeuna ................. 1311

carauna ................. 1146

cardinalis ............... 1174

camelopardalis .......... 1187

eatus ................... 1159

cblorurus................ 1193

clathratus................ 1198

colonus................. 1222

conspersus .............. 1156

coronatus .............. 1142

couchii ................. 1139

courtadei ............... 1152

creolus ................. 1222

cyclopomatus............. 1175

decimalis ................ 1175

dimidiatus............... 1179

dubius ................ 1146

emarginatus............. 1181

erythrogaster............ 1160

falcatus ................. $\quad 1185$

fascicularis.............. 1208

felinus ................ $\quad 1187$

fimbriatus............... 1154

flaviventris.............. 1221

furcifer................ 1222 
Serranus furvus.................

fusculus .................

fuscus .................

galeus ...................

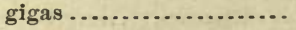

guasa...................

guativere...............

humeralis ...............

impetiginosus ...........

inermis..................

interstitialis.............

irradians ................

itaiara.................

jacome ..................

labriformis ..............

lamprurus................

latepictus ................

luciopercanus ............

lunulatus................

maculatofasciatus ........

maculatus ................

maculosus ...............

margaritifer .............

marginatus ...............

mentzeli...................

morio.....................

mystacinus..............

nebulifer .................

nigrescens...............

nigriculas ...............

nigritus ................

niveatus................

oculatus .................

ocyurus ................

olfax ...................

ongus ..................

ouatalibi ................

panamensis...............

philadelphicus............

phobe..................

pixanga ..................

præstigiator..............

psittacinus..............

quinquefasciatus .........

radialis ..................

radians ...................

remotus ...................

repandus .................

rivulatus .................

ruber....................

rupestris

sciurus ..................

semifasciatus.............

stadthouderi .............

stilbostigma ..............

striatus..................
Page.

1200

1211

1181

1164

1154

1164

1145

1197

1153

1168

1179

1208

1164

1215

1155

1190

1175

1216

1159

1196

1153

1159

1156

1154

1154

1160

1151

1196

1200

1153

1161

1156

1283

1201

1183

1154

1146

1141

1202

1212

1153

1214

1213

1164

1205

1208

1160

1187

1187

1181

1174

1204

1197

1159

1217

1157

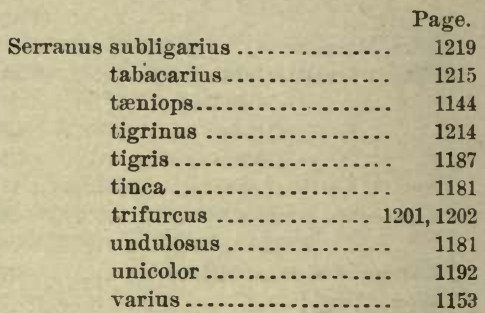

Serraria................. 1028, 1030, 1037

serrata, Fistularia ............... $\quad 758$

serraticornis, Balistes.............. 1720

serratogranulata, Perca............ 1024

serratum, Hiemulon............... 1299

serratus, Gasterosteus............ $\quad 750$

Naucrates.............. 900

Sayris................. 726

serriceps, Sebastichthys........... 1827

Sebastodes ............. 1827

serrifer, Conodon.................. 1324

Serrivomer..................... $\quad 367$

beanii............... $\quad 367$

serrula, Anisotremus.............. 1323

Chalinura ............... $\quad 2576$

Hadropterus scierus...... $\quad 1038$

Priacanthus ............. 1239

Pristipoma ............. 1324, 1343

Pseudopriacanthus....... $\quad 1239$

Seserinus xanthurus ............. 966

Sesi de lo Alto .................... 1261

sessilicauda, Monglene............ 2691

Setarches ........................ 1860

parmatus.............. 1860

setifer, Argyriosus ................ 996

Monacanthus............. 1716

Stephanolepis ............. 1716

setiger, Dasycottus................ 1991

setigerus, Lophiomus ............ $\quad 2714$

Lophius ................ 2715

setinotus, Chanliodus ............. $\quad 585$

setipinnis, Argyreiosus ........... $\quad 934$

Caranx dorsalis........ 934

gabonensis ..... 935

Selene................ 934

Vomer ................ 934

Zeus ................ 934

setosus, Mugil................... $\quad 815$

Ovoides.................. 1739

Tetraodon ............... 1740

seu conger, Muræna brasiliensis ... 403

sexcornutus, Ostracion........... 1725

sexdecemlamellata, Fcheneis...... $\quad 2272$

sexfasciatum, Hæmalon........... 1294

sexfasciatus, Hæmulon............ 1295

sexmaculatus, Diodon............ 1746 
sexradiatus, Polynemus............

Shad

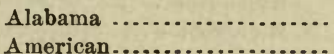

Broad.......................

Common....................

Gulf.

Hickory

Mackerel.

Potomac

Shad Porgy

Shad-waiter

Shads, Gizzard

Shark, Bay ...

Bone

Bullhead

Cat.

Cow...........................

Dusky

Elephant

White.

Hammer-headed

Leopard ........................

Long-tail .................

Mackerel ..................

North River

Nurse....................

Oil .

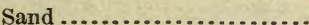

Sharp-nosed................

Shovel-head...............

Shovel-nosed................

Sleeper.....................

Soup-fin...................

Swell ......................

Tiger .......................

Shark Pilot ......................

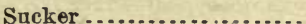

Shark8

Angel ......................

Basking..................

Blue .....................

Bramble...................

Bullhead ...................

Cat.........................

Cestraciont ................

Cow ........................

Cyclospondylous..........

Dog ....................

Frilled

Hammer-headed............

Mackerel

Man-eater ...................

Notidanoid...............

Nurse
Page.

2183

427

2810

427

1372

427

2810

416,425

909

427

1355

465

415

37
Sharks, Requiem ................

Sand $\ldots \ldots \ldots \ldots \ldots \ldots \ldots \ldots . . \ldots \ldots$

Scymnoid ................ 56

Thresher................ 45

True................... 21

Typical .................. 19

Whale.................. 52

Sharp-nosed Flying-fish.......... $\quad 728$

Puffers............... 1740

Shark.............. 43

Sharp tailed Goby............... $\quad 2229$

shasta, Cottus ................... 1947

Salmo gairdneri.......... 502 irideus............ 502

shavianus, Cetorhinus ............ 51

Sheepshead .................... 1358, 1361

Minnow ............. 671

Porgy $. . . \ldots \ldots \ldots \ldots . \quad 1354$

Sheepshead, Lake .................. 1484

Shellfish ....................... 1723

Shellfish, Rock.................. 1722

Shi Shida1..................... 1665

Shidai, Shi .................... 1665

Shima Soi ....................... 1834

Shiner ......................... 269, 281

Blunt-nosed .............. 934

Golden .................. 250

Red-sided ................ $\quad 240$

Spotted ................. $\quad 318$

Shiners ....................... $\quad 254$

Short-nosed Bat-Fish ........... 2738

Gar................ $\quad 110$

Sturgeon ............ 106, 107

shnfeldti, Ceratius ............... 2731

Gobius ................ 2221

Mancalias ............. $\quad 2730$

Typhlopsaras........... 2731

shumardi, Alburnops ............. $\quad 268$

Bolcosoma............. 1047

Cottogaster ............. 1046

Hadropterus ........... 1047

Imostoma ............. 1047

Minnilus............. 268, 269

Notropis ............. 268

shuswap, Agosia............... $\quad 313$

falcata $\ldots \ldots \ldots . \quad 313$

sialis, Argentina................ $\quad 526$

sialis, Corvula .................. 1428

Noturus.................. $\quad 146$

sibbaldi, Syngnathus ............. 774

Siboma...................... 228, 231

atraria .................. 233

erassicauda.............. 231

longiceps................ $\quad 253$

gicana, Cerna ................... 1162

siccifer, Holocentrus............ 849 
...........

sicculum, Chirostoma ...............

sicculus, Labidesthes...............

siculus, Lampugus.

Sicya.......................... 2207, 2867

Sicyases .................. 2329, 2330, 2336

carneus................. 2337

fasciatus................ 2338

punctulatus ............. 2338

rubiginosus.............. 2337

rupestris ................ 2341

Sicydiinæ...................... 2190

Sicydium....................... 2205

antillarum ........... 2206, 2867

gymnogaster........... 2208

plumieri .............. 2206, 2867

punctatum.............. 2867

salvini................ 2208

siragus ................. 2206

vincente............... 2207

Sicyogaster ..................... 2229

Sicyopterus gymnogaster ......... 2208

salvini ............... 2208

Sicyosus ....................... 2867

Sidera ........................... $\quad 392$

castanea ................... 396, 2804

chlevastes ................ $\quad 399$

dovii..................... 397

funebris................... $\quad 396$

moordax .................. 396

moringa.................. $\quad 395$

nigromarginata.......... $\quad 400$

ocellata ................... $\quad 399$

panamensis ................ $\quad 391$

pfeifferi................... 2805

verrilli ...................... 394

vicina.................... $\quad 394$

siderea, Muræna ................. 2805

siderium, Zophendum............. 314

siderius, Hyborhynchus ..........

sieboldii, Cichlasoma...............

Heros ............................

Sierra

1516

1517

Sierra, Pez

84,875

60

1859

874

Scomberomorus .............

Scorpæna..................

Sierrita

1860

713

713

2863

Sigmistes

2863

Sigmops...................... 581, 582 stigmaticus............ 583

Sigmurus ................ 1446, 1447, 1452

Sígualosa........................ 2809 atchafalayæ 2809
Page.

2288

Hypoprion............. 41

Microgobius ............. 2246

signifer, Bryttus .................. 996

Chatoessus............... 433

Coregonus ............... 518

Monacanthus ............ 1716

Salmo (Thymallus)....... $\quad 518$

Sema................... 1499

Stypodon ............... 220

Thymallus............... 517, 2871

lewisi ........ 2871

montanus ..... 519

ontariensis.... 519

tricolor....... $\quad 519$

sigolutes, Gilbertina .............. 2028

silenus, Zaprora.................. $\quad 2850$

Silk Snapper................... 1262, 2858

Siluridæ ....................... 115

Silurus bagre................... 117

catus..................... 138

clarias .................. $\quad 155$

cornutus ................. $\quad 759$

cuprens .................. $\quad 140$

felis..................... 128

furcatus.................. 140

gyrinus .................. 146

herzbergii................ 125

limosus.................. 143

lividus.................. $\quad 140$

marinus .................. 118

melas..................... 141

nebulosus ................. 143

olivaris.................. 143

parkeri.................... 126

pnnctatus................ 135

viscosus................ 143

xanthocephalus ........... 141

Silus ........................... $\quad 525$

ascanii .................... 526

silus, Argentina.................. $\quad 526$

Silver Chub ..................... 221, 320

Hake.................... $\quad 2530$

Jenny .................... 1370

Salmon ................... 480

'Trout .................... 493

Whiting ................. 1477

Silver-fin ......................... 278

Silver-fish. .................. 409, 795,889

Silverside ....................... 800

Brook ................ 805

Silver-gided Minnow............. 238

Silversides ....................... 788,796

Silvery Anchovies ................. 439

Lamprey .................. 11

Minnow ................. 213 
sima, Cliola

Eleotris

Simenchelyidæ

Simenchelys parasiticus

simulis, Amphistichus

Fumlulug

Han

Harumlon .................

Hydrargyra..............

simillima, Palometa ..............

simillimus, Poronotus .............

Rhombus.............

Stromateus..........

simotera, Ulocentra

simoterum, Hyostoma............

simplex, A plurus.

Pseudoscarus ..................

Scarus ..................

Tetragonurus ............

simpsoni, Ictalurus ...............

simula, Chalinura ................

simulans, Enneacanthus...........

Hemioplites.............

Sebastosomus ............

simulus, Macrurus

Ophioscion .............................

simus, Alburnellus.

Careproctus ...............

Menticirrhus ..............

Notropis . .................

Rhinichthys ...............

sinaloze, Paralichthys............

Siphostoma ..............

Umbrina ....................

sinesis, Sebastichthys .............

Sebastodes ................

Singing Fish .....................

sinuatus, Merluccius ..............

Siphagonus.....................

barbatus...............

segaliensis............

Siphateles .......................

vittatus...............

Siphostoma ................ 761, 763, 2837 affine ............... 769,770

albirostre ..............

arctum ............ 771, 2838

ascendens............. $\quad 768$

auliscus ............. 767

bairdianum........... 765, 770

barbaræ ............. 765

brachycephalum ....... 769

californiense...........

carinatum .............

cayennense . ..........

crinigerum ...........

267

2198

348

349

1504

638

1304

639

2849

967
967

967

1051

1051

880

1656

1656
880

135

2578

994

994

1783

2578

1449
627

2131

1472

267

2872

2838

1468

1814

1813

2530

2046

2050

2048

243

244

764

763

772

771
Page.

S

S

Skipper......................... 725

Skowitz....................... 480

Sleeper.................. 2194, 2200, 2216

Slimer-

Slippery Dick

Siphostoma elucens .............. $\quad 768$

fistulatum ............ 765

flavirostre ........... 768

floridæ.............. $\quad \mathbf{7 6 6}$

fuscum ............. $\quad 770$

griseolineatum ....... 764

jonesi................ 768, 2837

linea ............... 768

louisianæ............ $\quad \mathbf{7 7 0}$

mackayi ............. $\quad 766$

marmoreum ......... 768

pelagicum .......... 767, 2837

picturatum ........... $\quad 768$

punctipinne........... 763

robertsi.............. 2837

rousseau...........767.2837

scovelli............... 769

sinaloæ ............. 2838

starksi ............ 771, 2838

zatropis ............. 772

siragus, Sicydium ............... 2206

2206

Sisco of Lake Tippecanoe.......... $\quad 469$

siscowet, Cristivomer namaycush .. $\quad 505$

Salmo ................. 505

Salvelinus namaycnsh ... $\quad 505$

siskawitz, Salmo ............... 505

Skate, Barndoor

Big...................... 68,72

Common ................ 68

Little .................. 68

Skates .......................... 15,66

Skeponopodus................... 891

guebucu......... 891

typus ........... 892

947

1862

1861

Skimback ...................... 167

Skipjack................ 425, 805, 872, 946

2655

sloanei, Chauliodus................ $\quad 585$

Scomber ................ 870

sloani, Leiobatus ................. 81

Raja ................. 81 


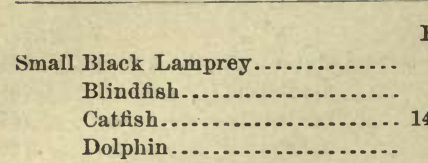

Small-mouthed Plack Bass......... Buffalo .............

Sinall-scaled Gurnards ............ Smaragdus . costalesi ............... stigmaticus ........... valenciennei ...........

smaragdus, Eleotris ................ Gobionellns ............. Gobius .................

Smaris ...................................

lineatus ...................

martinicus ................

Smear Dab

Page.

13

704

140,141

953

1011

164

2175

2210

2225

2224

2228

2204

2228

2227

1364

1378

1365

Smecticns.

bicolor ..................

Snelt, American ..................

California ..................

Cobessicontic ..............

Kodiak

Little

Pond ..............................

Wilton ........................

Smelt of the New York Lakes......

Smelts

Surf ...............................

smiridus, Merluccius .............

smithi, Carcharodon ..............

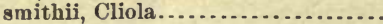

Cyprinns (Abramis?)......

Smooth Cabezon ...................

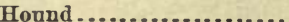

Puffer

smyrnensis, Gobins

Snake Blennies

$2105,2114,2116$

Eels.

Mackerel

Snap Mackerel . . . . . . . . . . . . . . . .

Snapper.........................

Black-fin .................

Dog .......................

Gray ....................

Lane

Mahogany ...............

Mangrove.................

Red ......................

Red-tail ..................

Silk................. 1262, 2858

Snappers...................... 1241, 1247

Snipe Eel ....................... 366, 369

Snipe, Sea.

714

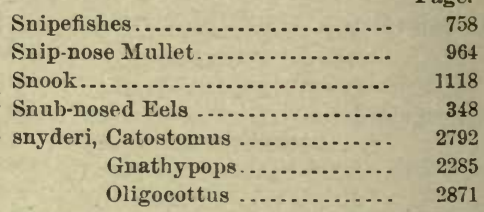

Soapfish................... 538, 1229, 1232

Sobaco . . . . . . . . . . . . . . . . . . . 1705, 1706

sobaco, Balistes.................. 1706

Canthidermis............. 1705

Sobacos ......................... 1705

sobra, Mesoprion் ................ 1266

socialis, Salmo .................. $\quad 521$

socip̣s, Alburnus ................ 292

Notropis ................. 292

socorroense, Thalassoma........ 1608, 2859

socorroensis, Chlorichthys........ 1607

Soft Flounders................... $\quad 2679$

sogo, Holocentras.................. 849

Soi, Aka ....................... 1830

Groma ....................... 1833

Kuro........................ 1834

Shima...................... 1834

solandri, Acanthocybium ......... $\quad 876$

Cybium ............... 877

Gempylus.............. 883

solaris, Orthragoriscus........... 1754

Soldado ......................... 848

Soldier Fish..................... 1088

Sole, American ................. 2700

California................... 2613

Long-finned.................. 2658

Mexican ..................... 2698

San Diego ................... 2707

Slippery ..................... 2655

Solea........................... 2660

achirus.................... 2702

browni................... 2701

cynoglossa................ 2657

fimbriata................. 2700

fischeri.................... 2700

fousecensis................. 2699

gronovii.................... 2696

inscripta.................. 2696

klunzingeri ................. 2697

maculipinnis............... 2698

mazatlana.................. 2699

panamensis ................ 2702

pilosa ....................... 2699

reticulata ................... 2696

scutum................... 2700

solea, Caranx...................... $\quad 927$

Soleidær ........................ 2692

Solenostomus .................. 754, 756

soleœformis, Aramaca .......... $\quad 2672$ 


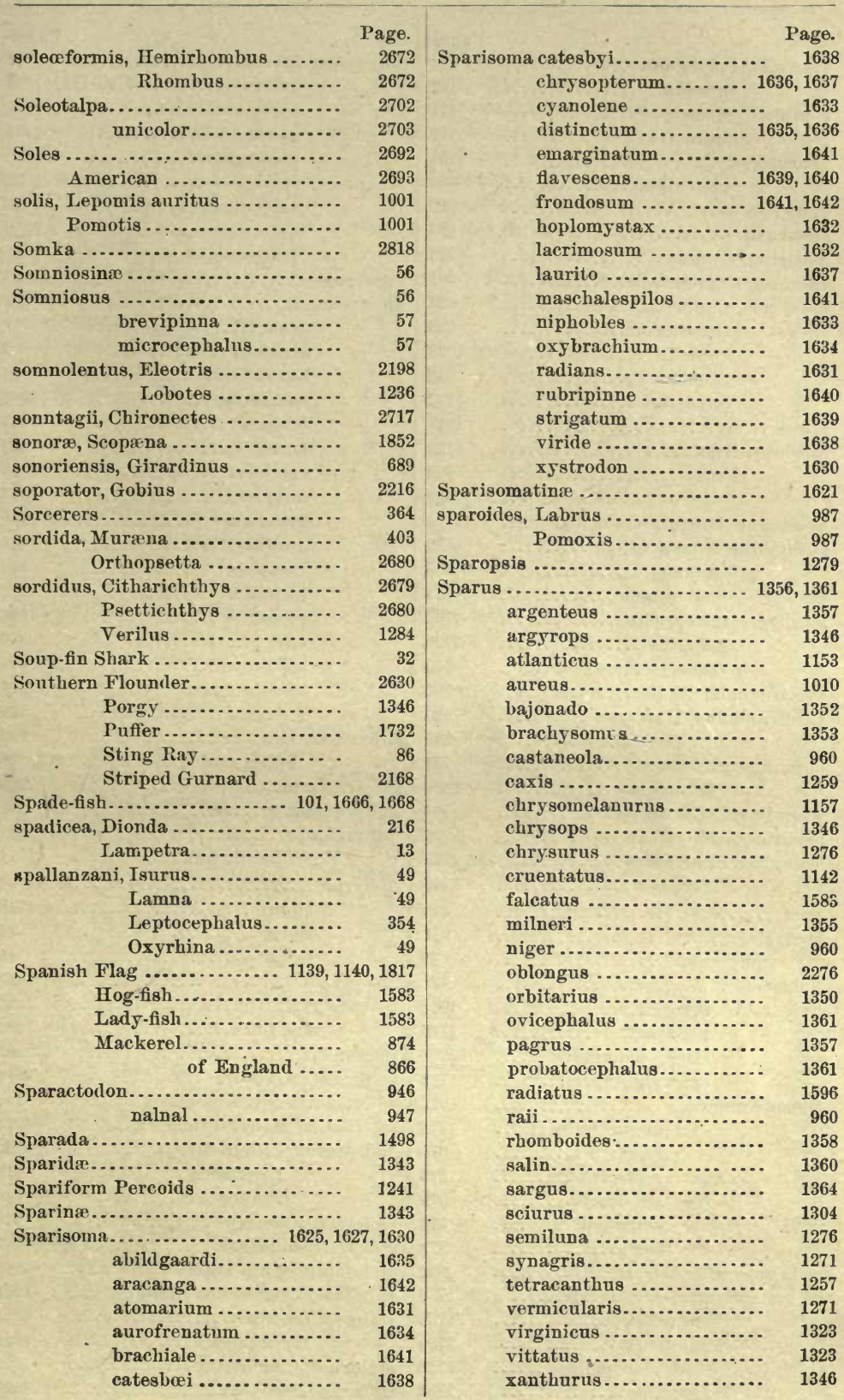


spathula, Polyodon Squalus.

spatula, I.episosteus Planirostra ...............

Spatularia.

$$
\text { reticulata .............. }
$$

Spawn-eater

Spearfish

Spearing,"Ground

$167,891,892$

speciosa, Gambusia

speciosus, Caranx

Gnathodon

Pomotis ............. 1006, 1008

Scomber .............. 928

Semotilus .............. 222

Speck ...........................

Speckled Hind .

1047

1159

Tront ................. 508

of Lake Crescent .. spectabile, Etheostoma cœruleam.. spectabilis, Pocilichthys ..........

Salmo ..................

Salvelinus .

spectrum, Careproctus.

Lophius ..............

Osmerus mordax ........

spectruncula, Cliola ...............

spectrunculus, $\mathrm{H}_{y}$ bopsis .........

$$
\text { Notropis .......... }
$$

speculiger, Exocotus .............

Exonautes .............

speculigera, Lampadena ...........

spelæus, Amblyopsis ..............

spengleri, Spheroides

Tetrodon.

1732,1733

2821

1089

1089

508

508

2133

2723

523

265

265

265

734

2836

561

706

1733

Spet.............................

spet, Esox........................

Sphyræna

Sphærina

Sphæroides furthi.

politus................

trichocephalus.........

tuberculatus...........

Sphagebranchus ..................

anguiformis ......

kendalli ...........

rostratus .........

scuticaris.........

selachops.........

teres..............

sphenops, Poecilia..................

Spheroides

angusticeps............

annulatus...............

politus ......

formosus ...............
826

826

826

822

1737

1736

1738

1733

373

374

375

373
Spheroides furthi

Page.

lobatus

1737

maculatus ............ 1733

marmoratus........... 1734

pachygaster........... 1738

spengleri............. 1732, 1733

testudineus ............ 1734

annulatus.. $\quad 1736$

trichocephalus ........ $\quad 1737$

Sphorodies ..................... 1729

Sphyræna...................... 822

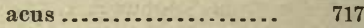

argentea.............. 826

a ureoviridis ............ $\quad 1119$

barracuda .............. 2841

becuna ................. 823

borealis................ 825

ensis ................ 824

forsteri............... 824

guachancho ........... 824

guntheri................ 824

lucasana............... $\quad 826$

picuda............... 823

piendilla............... 824

spet .................. 826

sphyræna............. 823, 826

viridescens ............. 826

vulgaris .............. 826

sphyræna, Esox................. 826

Sphyræna ............ 823,826

sphyrænarum, Echeneis .......... 2268

Sphyrænidæ .................... 822

Sphyrænops...................... 1114

bairdianns ........... 1114

Sphyrna ..................... 43,44,45

tiburo .................44, 2748

tudes .................. 44

zygæna................ 45

Sphy rnidra ..................... 43

Spicara ........................ 1364

martinica............. 1364, 1365

Spikefish....................... 891

spillmani, Alvordius .............. 1039

spilonotopterus, Exocœtus........ $\quad 740$

spilonotus, Monacanthus.......... 1716

spilopterus, Citharichthys ...... 2685, 2686

Leuciscus ............ $\quad 279$

Photogenis ........... 279

spilopus, Exoccetus .............. $\quad 738$

spilota, Uranidea. .............. 1953, 1962

spilotopterygius, Balistes .......... 1702

spilotum, Etheostoma niangure .... 1044

spilotus, Cottris ................... 1961

Hypohomus ............. 1043

spilurum, Cichlasoma ............ $\quad 1520$

spilurus, Heros ................ 1520 
Page.

spilurus, Pocilia

Salmo clarkii mykiss

Spina, Chopa.

Spinax

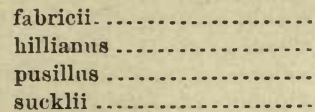

Spineless Sculpins

spinescens, Auliscops............. spinicephalum, Exoglossum........ Spinicephalus fibulatus ........... spinidens, Scarus ................ spinifer, Engraulis ...............

Stolephorus..............

spiniger, Icelus . . . . . . . . . . . . . . . .

Spinivomer .....................

goodei ................

spinosissimus, Agonus...........

Aspidophorus ......

Diodon ..............

Leptagonus .......

spinosus, Calycilepidotus .........

Centronotus..............

Chilomycterus ..........

Cyclopterus............2099, 210

Dasyscopelus ...........

Diodon..................

Ehinorhinus ...........

Eumicrotremus ....... 2098, 2099

Hemilepidotus .......... 1937

Lumpus................ 2099

Orthagoriscus.......... 1754

Platophrys............. 2662

Rhinobatus ............ 63

Rhomboidichthys....... 2663

Schedophilopsis......... 972

Scopolus .............. $\quad 575$

Squalus ............... $\quad 58$

Trachinotus............ 942

spinulosus, Gasterostens .......... $\quad 748$

Spiny.back Blowfish .............. 1734

Spiny Eels ........................ 612

Spiny-rayed Fishes ............... $\quad 779$

Spirinchus .................... 524

spirlingulus, Leuciscus ........... $\quad 282$

spixianus, Saurus ............... $\quad 538$

Synodus.............. 538

spixii, Argyriosus................ 936

Pimelodus................ 132

Platysomus .............. 934, 2846

Tachisurus:.............. 132

Tachysurus .............. 131, 2783

Vomer ................... 2846

splendens, Beryx............... 844 splendens, Exocotus ..............

splendida, Petenia................ 1513

spleniatum, Pristipoma ........... 1322

spleniatus, Anisotremus ......... 1321

Split-mouth Sucker .............. $\quad 199$

Split-tail ....................... 223

spongiosa, Halieutæa ............ 2742

Spoon-bill Cat.................... 101

Spot........................... 1458

Spot-tailed Minnow ............... $\quad 269$

Spotted Cabrilla.................. 1196

Jewfish.................. 1162

Kelptish ................ . 2353

Moray .................. $\quad 399$

Rockfish................ 180t

Sea Trout............... 1409

Shiner.................. $\quad 318$

Sting Ray .............. 88

Suckers ................ 186, 187

Trunk-fish............... 1723

Weakfish ................ 1409

Spotted-tail Minnow .............. $\quad 275$

Sprat........................ 432,450

Spratella ...................... 424

Spratelloides bryoporus .......... $\quad 422$

lamprotænia ........ 419

Springfish.................... 1950

Squalidæ..................... 53, 2749

squalidus, Scarus ................ $\quad 1640$

squalipeta, Echeneis............. 2272

Squalius........................ $\quad 228$

alieia................... 236

ardesiacus............... $\quad 237$

atrarius ................. 233

bicolor ................. 232

cæruleus................ 232

canis .................. 29

conformis................ 231

conspersus .............. 234

cooperi .................. 236

copei ................... $\quad 236$

crassus ................. 231

cruoreus................ 233

egregius................ 237

elongatus ................ $\quad 240$

estor................... 240

funduloides .............. $\quad 240$

galtiæ.................. 237

gibbosus................ 231

gula ................... 234

humboldti ............... 237

hyalope................. 222

hyirophlox............. 238

intermedius .............. 235

lemmoni................. $\quad 235$

lineatus............... 233 
Squalius margaritus

modestus .................

montanus.................

niger ....................

nigrescens................

obesus...................

pandora...................

photogenis...............

proriger ..................

pulchellus . . ...............

pulcher..................

purpureus ................

rhomaleus ................

squamatus...............

tænia ....................

vandoisulus

Squalus

acronotus..................

alopecias...................

americanus ................

argus .....................

borealis..................

brucus ....................

cæruleus .................

carcharias .................

(Carcharias) terræ-novæ...

cetaceus ...................

cirratus ...................

cornubicus ................

elephas ....................

glacialis ...................

glancus....................

griseus.....................

gunnerianus...............

hinnulus ..................

hirundinaceus............

homianus.................

isodus ......................

littoralis...................

longimanus...............

macrodus..................

malleus ...................

maximus .................

microcephalus.............

monensis ..................

nasus....................

norwegianus

obscurus

pelegrinus.

pennanti.

platyodon

punctatus

punctulatus ...............

rashleighanus
Page.

Squalus

squamatus, Etheostoma (Hadropterus) ...............

Hypohomus ..........

Sqvalius............. 233

squamiceps, Etheostoma ........... 1096

squamilentus, Ceratichthys ........ 323

Couesius ............. 323

Paralichthys ....... 2631

Squamipinnes................... 781, 1665

squamipinnis, Cestreus ........... 1404

Cynoscion ........ 1404, 1405

Gerres ............ $\quad 1373$

Otolithus ........... 1404

squamosissimus, Diplolepis ....... 1419

Pachyurus........ 1419

Plagioscion....... 1418

Sciæna.......... 1418

squamosus, Trachurus........... 921

squamulosus, Chætodon............ 1685

Square-mouth ................... 208

Square-tails ................... 975, 976

Squatina ....................... 58

angelns.................. 59

californica............... $\quad 59$

dumerili ................ $\quad 59$

fimbriata ............... 59

japonica ................ 59

lævis ................... 59

lewis.................. 59

oculata .................. $\quad 59$

squatina................. $\quad 58$

vulgaris .............. $\quad 58$

squatina, Rhiva ................. $\quad 59$

Squalus ............... $\quad 59$

Squatina ............... 58

Squatinidæ..................... 58

Squato ......................... 58

Squaw-fish ...................... 224

Squeteague ................... 1407

squeteague, Labrus............. 1407, 1409

Squirrel-fish ........... 845, 847, 1203, 1207

Squirrel Hake................... 2555

stadthouderi, Serranus............ $\quad \mathbf{1 1 5 9}$

stagnalis, Salmo................. $\quad 510$

Salvelinus ............. 509 
stagnalis, Salvelinus alpinus ....... stahli, Larimus

Monosira .................... stannii, Cotylis.

Star-gazers.

................

Sand ..................

Star-headed Minnow ..............

starksi, Siphostoma................

Stolephorus .............

Starksia.........................

cremnobates ........... 2365, 2366

starksii, Siphostoma ............. 2838

Starry Flounders.................

Stathmonotina...................

Stathmonotus

hemphillii ...........

stearnsi, Blennius.................

Corvina.................

Lutianus ................

Lutjanus ................

Prionotus................

Roneador ..................

Scorpæna................

stearnsii, Seriola ..................

Steel-backed Chub ................

Steelhead.

stegophthalmus, Agonus...........

steindachneri, Chlorichthys .........

Diabasis ............

Hæmulon ...........

Ophioblennius ......

Rhinoptera.........

Seluastes.............

Sebastodes ..........

Thalassoma ....... 160

Steiudachnerella ..................

Steindachneria ...................

argentea.........

Steinegeria.......................

rubescens.............

Steinegeriidæ

stejnegeri, Stelgistrum

stelgidolepis, Macrourus ...........

Stelgis ...........................

vulsus...................

Stelgistrum .

stejnegeri ..............

stelifera, Corvina..................

Sciæna (Stelliferus).......

Xenisma ..................

stellata, Platessa..................

stellatus, A pogonichthys..........

Caranx.....................

Fario ........................

Liparis.
Page.

510

1423

1423

2332

2305

2306

2297

656

771

2814

2365

2651

2347

2408

2408

2379

1458

1256

1257

2166

1457

1843

903

205

497

2036

1609

1302

1301

2401

91

1830

1830

09, 2859

2567

2567

2568

960

961

960

1921

2585

2067

2067

1921

1921

1445

1443

648

2652

1110

926

492

2118 stellatus, Mustellus

Page.

Platichthys............. 2652

Pleuronectes............ 2652

stellaus, Salmo .................. 493

stelleri, Cottus.................... 1941

Cotylis ................. 2104

Cyclopterichthys ......... 2104

Cyclopterus .............. 2104

Hexagrammos............ 1871

Labrax ................. 1872

Liparops................. 2104

Myoxocephalus........... 1981

Trichodon ............... 2297

Stellerina ...................... 2041

xyosterna .............. 2042

Stellicarens ................. 1439, 1440, 1445

Stellifer ........................ 1439, 1443

ericymba ............... 1444

furthi................... 1441

illecebrosus.............. 1442

lanceolatus.............. 1443

microps................... 1445

minor................... 1442

oscitans ................ 1440

stellifer.................. 1443

zestocarus ............... 1445

stellifer, Bodianus ............... 1443

Fundulus ............... 648

Sciæna................. 1444

Stellifer................. 1443

stelliferoides, Bassogigas.......... 2516

Neobythites ......... 2516

stellio, Perca ...................... $\quad 1153$

Rhinobatus.............. $\quad 2750$

stellulata, Raja................. $\quad 75$

Stenobrachius.................. 561

andreæ............ $\quad 569$

coccoi............. $\quad 569$

Stenodus...................... 473

mackenzii .............. 474

Stenogobius ..................... 2210

Stenotomus ..................... 1345

aculeatus .............. 1346

caprinus............. 1345

chrysops.............. 1346

Stephanoberycidæ.............. $\quad 835$

Stephanoberyx................. 836

gillii ............ 836

monæ ............ 836

Stephanolepis.................... 1714

setifer............. 1716

stephanophrys, Prionotus .......... $\quad 2161$

Stereolepis .................... 1137

californicus .......... 1138

gigas ................ 1137

Sterletus ...................... 103 
sterletus, Averruncus

Pa

Page.
2071
316
1926
1927
603
603

diaphana...........603, 2826

gardenii

hermanii

mediterraneus

olfersi.

Sternopygus humboldti

Sternotremia.

isolepis.............

stevensi, Thaleichthys ............

Stichæinæ........................

Stichæus

aculeatus .................

anguillaris ..............

enneagrammus ..........

hexagrammus ...........

islandicus ...............

lumpenns ...............

maculatus ..............

medius .................

nubilus.................

punctatus ...............

unimaculatus ............

Stickleback, Alaska..............

Brook .....................

California ............

Common Eastern......

European ............

Nine-spined ...........

Two-spined ...........

Sticklebacks

stigma, Gymnelis..................

stigmæa, Ulocentra ...............

stigmæum, Boleosoma.............

Etheostoma ............

stigmæus, Citharichthys ..........

stigmatias, Paralichthy's ...........

stigmaticus, Ceratichthys ..........

Gobionellus ..........

Gobins ...............

Sigmops..............

Smaragdus ...........

stigmatisticum, Lepophidium . . . . 2483, 2484

Stigmatogobius .................

stigmatura, Bolımannıa...........

Cliola...................

Codoma................

stigmaturus, Gobius ..............

Notropis.............

Photogenis

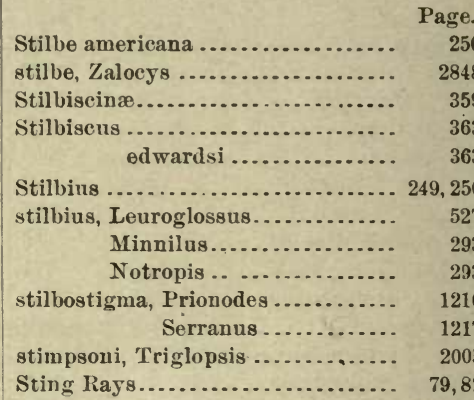

Stingaree ...................... $\quad 83$

stipes, Atherina................ $\quad 790$

Joturus................. 821

Stipvisch ...................... 1702

stirurus, Chloroscombrus .......... 938

Stit-tse..................... $\quad 499$

Stizostedion.................. 1020, 1021

canadense ........... 1022

boreum.... 1022

griseum .... 1022

vitreum ............. 1021

Stizostethium ................... 1020

Stoasodon ..................... 88

narinari ............. 88

Stolephorus .................. 439

argyrophanus........ 444

astilbe .............. 2815

brownii ............. 443

chœrostomus......... 444

clupeoiries............ $\quad 447$

compressus .......... 447

cubanus............. $\quad 442$

cultratus........... 443

curtus .............. $\quad 445$

delicatissimus....... 444

engymen ............. 2815

eurystole............. 445

exiguus ............. 442

hiulcus.............. 443

ischanus ............ 442

lucidus ............ 446, 2811

macrolepidotus....... $\quad 449$

miarchus............ 441

mitchilli ............ $\quad 446$

mundeolus ........... 2812

naso................ 2813

opercularis........... $\quad 445$

panamensis .......... 448

perfasciatus..........441,445

perthecatus .......... $\quad 442$

poeyi............. 445, 2811

productus ............ 447

rastralis............. 2811

Stilbe 


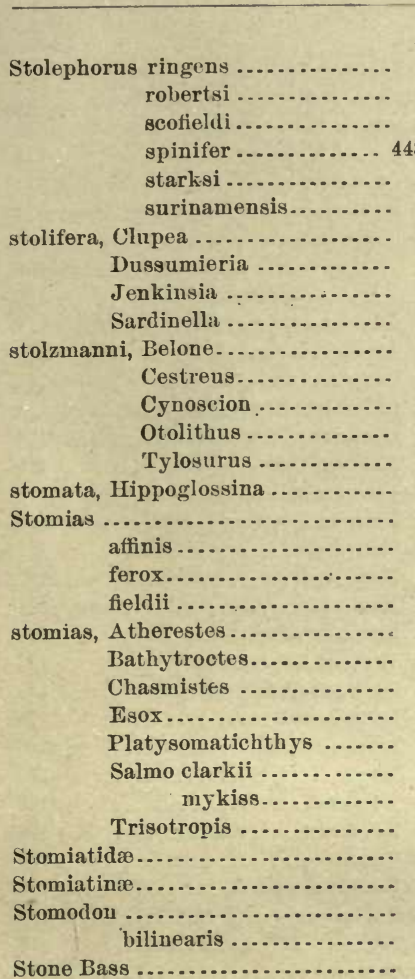

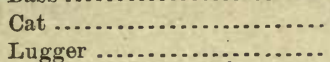

Roller.....................

Sculpins ...................

Sturgeon.................. stonei, Salmo gairdneri............. irideus .............. storeri, Acipenser .................

Aledon .....................

Atherina ..................

Cetomimus .................

Leuciscus .................

Scombresox ............... storeria, Cichla . . . . . . . . . . . ....... storeriana, Cliola .................. storerianus, Hybopsis............. Leuciscus ............. Rutilus ............... stouti, Bdellostoma...............

Polistotrema ............... strabo, Icelinus . . . . . . . . . . . . . . . Ophioscion................. straminea, Cliola. $3030-118$
Page.

449

2815

2814

448,2814

2813

447

432

419

419

431

713

1412

1412

1412

713

2620

588

588

588

586

2609

454

2794

585

2610

2819

497

1178

587

587

2529

2531

1139

143,144

181,205

181, 204

1937

106

503

503

105

1754

807

550

222

726

987

270

270,321

270

321

6 stramineus, Hylognathus ..........

Hybopsis .............

stratus, Monacanthus ..............

Strawberry Bass .................

Straw-colored Minnow ............

striata, A lausa ..................

Argentina.................

Perca .....................

striatulus, Brycon.................

Chalcinopsis ............

striatum, Bathystoma ..............

Hremulon ...............

striatus, Anthias.................

Blennius .................

Bodianus ..................

Centropristes..............

Chætodon .................

Epinephelus............ 1157, 1208

Holocentrus .............. $\quad 849$

Hypsoblennius . . . . . . . . . 2388, 2392.

Isesthes................ 2388

Labrus ................. 1200

Roccus ................. 1133

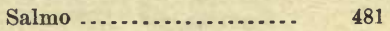

Sarothrodus............. $\quad 1677$

Serranus............... 1157

stricticassis, Arius.............. $\quad 126$

Netuma ........... 126, 2765

Tachisurus grandicassis............... 126

strigata, Trigla.................. 2167

strigatum, Sparisoma ............ 1639

strigatus, Antennarius ............ 2720

Gobius ............... 2228

Holacanthus........... 1683

Prionotus ............. 2167

Scarus............... 1639

strigilata, Loricaria .............. $\quad 158$

strigosus, Anarrhichas........... 2447

Striped Anchovy.............. $\quad 443$

Bass ................. 1131, 1132

Grunt .................. 1296, 1313

Gurnard ............... 2167

Mullet ................. 811

Surf-fish ................ 1505

strœmii, Zeus .................. $\quad 955$

Stromateidæ .................... 964

Stromateus alepidotus ........... $\quad 966$

cryptosus............. 968

gardenii ............. 966

longipinnis ........... 966

palometa ............. 967

paru .................. 966

simillimus ............ 967

triacanthus ........... 968

stromii, Macrourus ............. $\quad 2579$ 
atrumosus, Gobiesox

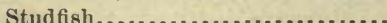

Sturgeon, Common ................

Green .................

Lake ..................

Ohio..................

Oregon ..................

Red ...................

Rock ..................

Sacramento.............

Short-mosed ............

Stone..................

White ............... 104, 107

Sturgeons......................

Shovelnose............

Sturio ...........................

vulgaris..................

sturio, Acipenser .................

sturioides, Paragonus...............

Podothecus..............

Sturisoma.

Stygicola.......................

dentata.................

dentatus................

Stylephoridæ

Stylephorus. ..................

chordatus .............

stylifer, Hippocampus .............

Stypodon........................

signifer .................

suareus, Caranx...................

suavis, Cliola .....................

Cyprinella ................

subæqualis, Corvilla ...............

Corvina ...............

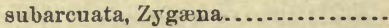
subarcuatum, Hremulon............ subarmatus, Acanthurus .......... Subatka.

subbifrenatus, Rhypticus.......... subbifurcata, Pholis.

Ulvaria ....................

subbifurcatus, Eumesogrammus ... subcærulea, Amia................ subfuscus, Labrus ................. subligarius, Centropristis..........

Dules.................

Serranus .............

suborbitalis, Holocentrus ..........

Macrurus (Nomatonurus) .............

Nematonurus.........

Plectromus............ subrotundus, Ostracion ventre glabro..............

subterraneus, Lucifuga ............
Page.

2333

648

105

104

106

106

104

106

106

104

106

106

102

107

103

105

105

2063

2063

156,157

2500

2500

2500

2601

2601

2601.

778

220

220

908

272

272

1429

1429

45

1306

1691

595

1233

2440

2440

2440

113

1578

1219

1218

1219

850

2573

2572

811

1749

2501 subterraneus, Typhlichthys........

subtruncata, Belone..............

subtruncatus, Homoprion........ .

Tylosurus..........

subulatus, Orcynus ...............

succincta, Seriola.

sucetta, Cyprinus

Erimyzon.

oblongus........

Sucker, Blue-headed.................

Brook ....................

Carp .....................

Columbia River ...........

Common ...................

Eastern Carp..............

Fine-scaled.................

Flaunel-mouthed...........

Gourd-seed.................

Hare-lip..................

Hog ....................

Hump-backed ..............

June, of Utah Lake ........

Large-scaled ..............

Long-nosed ................

Lump ...................

May....................

Missouri..................

Northern..................

Pea-lip ...................

Rabbit-mouth 198,199

Razor-back ........... 198, 199

Red ..................... 176

Sacramento .............. 178

Sand ................... 1476

Split-mouth.............. 199

Tahoe................... 177

Webug.................. 180

White................... 178, 192

Winter................... 187

Suckerel ........................ 168

Sucker-mouthed Buffalo........... 164

Suckers......................... 161

Carp .................. 165

Chub................... 185

Fine-scaled.............. 173

Lump .................. 2094

Mountain ............... 169, 170

Suckers Spotted ................. 186, 187

White-nosed ............. 190

Suck-fish...................... 2328

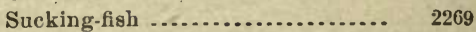

sucklii, Acanthias............... 54

Catostomus ............... 179

Spinax ................. 54

Squalns ................. 54, 2749

Sudis....................... 599 
Sudis borealis

intermediug

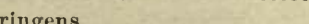

suensonii, Chilorhinus ............

sueuri, Coryphrena................

Cyprinus (Catostomus).....

snfflamen, Balistes................

Canthidermis ..........

sugillatus, Ophisura .............

Suillus

suillus, Lachnolaimus.............

sujef, Murænoides ..................

sulcatus, Herpetoichthys ..........

Trachonurus .............

sumiclirasti, Citharichthys ........

Summer Flounder.

Herring ........

Sunapee Trout...................

Sunfish

Black.banded .............

Blue ......................

Blue-spotted ..............

Common ...................

Green ....................

Long-eared ...............

Mud.

Red-spotted ...............

Round ....................

Sunfishes.

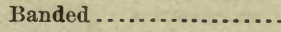

Pigmy .

Sunny

.........................

suœrii, Meletta

superbus, Fseudoscarus ..........

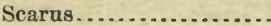

superciliosus, Aspidophorus .......

Hexagrammos.......

Hippocephalus ......

Hyborhynchus......

Labrax

Surf Smelts

Whiting

Surf-fish.

Common

Striped

Wall-eyed ............. 1493, 1501

surgeon, Blue.

White ...........................

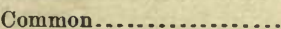

Surgeon-fishes ....................

surinamense, Pristipoma..........

surinamensis, Anisotremus ...... 1318, 1319

$\begin{array}{rr} & \begin{array}{r}\text { inter } \\ \text { ruptus }\end{array} \\ \text { Arius ................ } & 1319\end{array}$

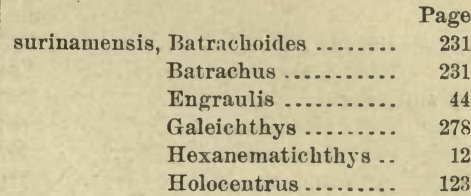

Lobotes............ 1235, 2858

Lutjanus ............ 1319

Plagioscion......... 1419

Pleuronecies ........ $\quad 2666$

Pocilia............. 691

Pseudosciæna....... 1420

Sciæna ............. 1420

Stolephorus ........ 447

Tachisurus......... 130

Surmullets ................... 855, 856

susanæ, Boleosoma............... 1059

sutor, Blepharis................. $\quad 932$

Caranx ................... 932

swaini, Notropis ................ $\quad 290$

Pœcilichthys............. 1086

Swainia ...................... 1039, 1040

Swallowers, Black .............. 2291

swampina, Hyllargira ........... $\quad 641$

Hydrargyra........... $\quad 645$

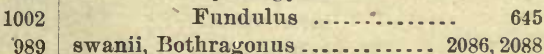

1004 Hypsagonus .............. 2088

988 swannanoa, Etheostoma ......... 1070

Swellfish ..................... 1729, 1748

Swell Shark.................... 25

Toad................ 1732, 1733, 1748

Swingle Tail................... 45

Swordfish, Common ............... $\quad 894$

Swordfishes ..................... 893

Syacium....................... 2670

latifrons............... 2673

micrurum ............... 2672

ovale .................... 2674

papillosum ............... 2671

Symbranchia .................... $\quad 341$

Symbranchidæ.................. $\quad 342$

Symbranchoid Eels............... $\quad 342$

Symbranchus .................. $\quad 342$

immaculatus........ $\quad 342$

marmoratus ......... 342

vittatus $\ldots \ldots \ldots \ldots . . . . . .342$

symmetricus, Apomotis ........... $\quad 998$

Caranx............. 910

Ceratichthys........ 246

Lepomis ........... 999

Leucosomus ......... 246

Pogonichthys........ 246

Rutilus ............. 245

Salmo.............. 505

Trachurus .......... 910 


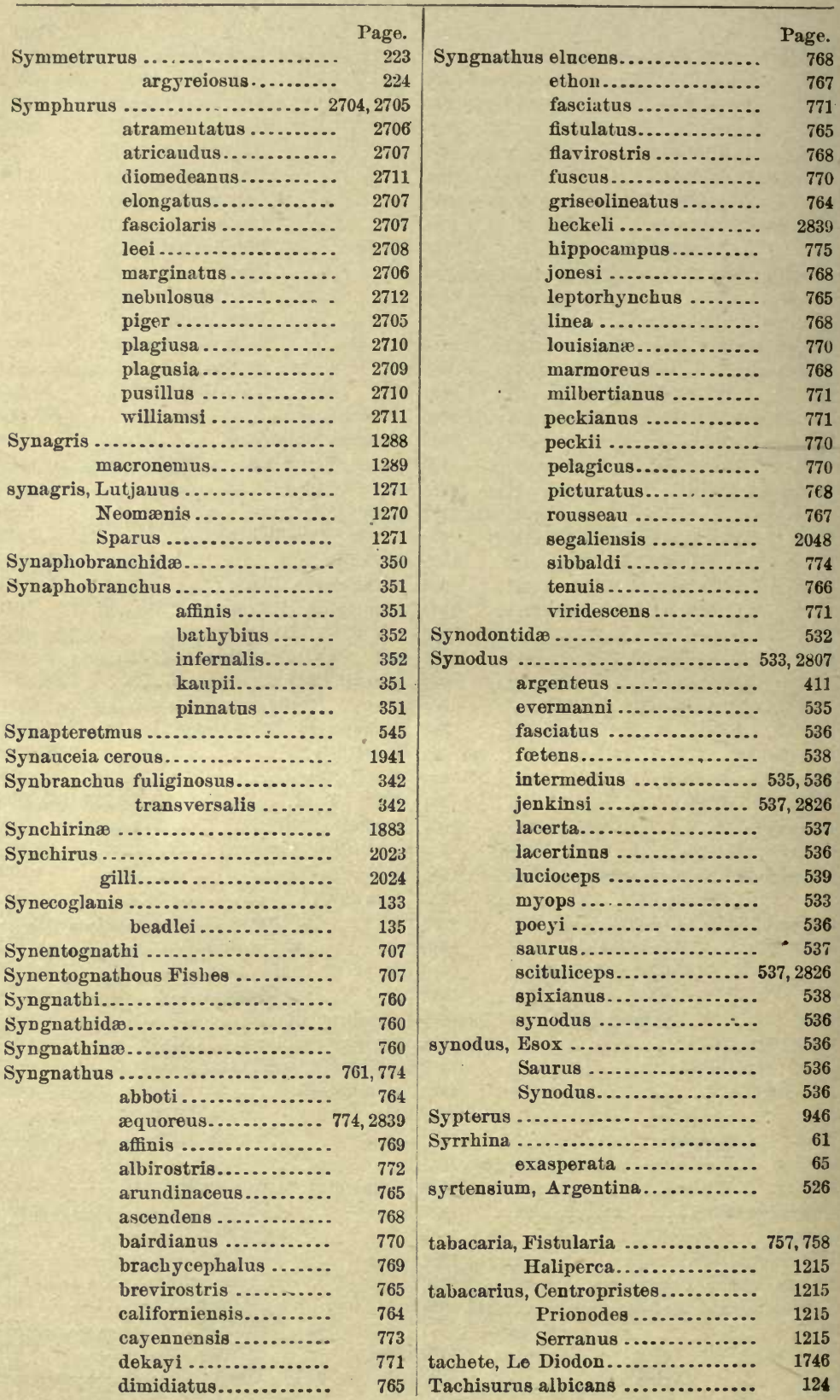




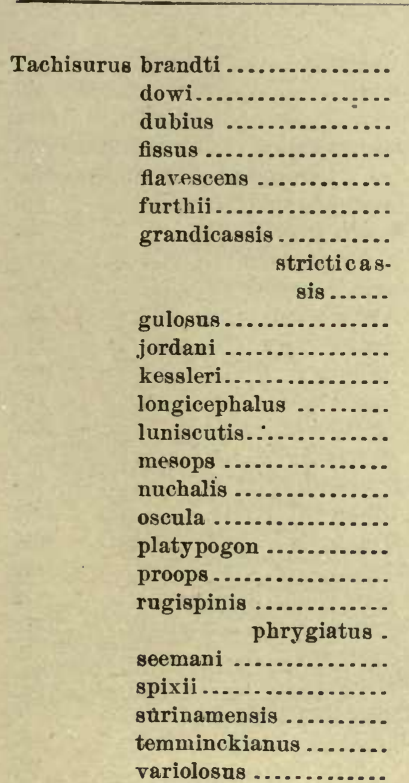

Tachysurinæe

Tachysurus.

\begin{tabular}{|c|c|}
\hline ane.......... & \\
\hline 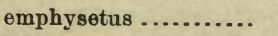 & 122 \\
\hline \multirow{2}{*}{\multicolumn{2}{|c|}{$\begin{array}{l}\text { fissus } \ldots \ldots \ldots \ldots \ldots \ldots \ldots \\
\text { furthii................. } 131,2782,2787\end{array}$}} \\
\hline & \\
\hline herzbergii .............. & 125 \\
\hline 48........ & 122 \\
\hline opus .................. & 2784 \\
\hline opus........... 1 & 2784 \\
\hline iatus ....... 13 & 2788 \\
\hline halis............... & 2782 \\
\hline $8 \ldots \ldots \ldots \ldots$ & 131 \\
\hline ................... & 124 \\
\hline ianus............ & 122 \\
\hline ........ & \\
\hline
\end{tabular}

taczanowskii, Centronotus.........

Pholis..............

Sebastodes

trenia, Bassozetus

Blennius ...................

Clinostomus ................

Murænoides.................

Squalius

treniatum, Hæmulon

tæniatus, Anisotremus.

Chirocentrodon ..........

Evoxymetopon

Page.

126

131

123

132

115,2757

782

785
122

125

127

131

123

132

126

133

129

127

130

125

123

127

127

124

130

131

129

132

130

Titin Ta} $5 \mathrm{~T}$

T

tæniotus, Tetragonopterus......... Page.

Tæniophis ........................ 392

westphali............. 396

tæniops Bodianus................. 1144

Enneacentrus............ 1144

Epinephelus ............. 1144

Serranus ................. 1144

tæniopterus, Balistes............... 1702

Cottus ............. 1979, 1988

Perissias............. $\quad 2667$

Platophrss........... $\quad 2668$

Pseudoscarus ......... 1646

Scarus ............... 1646

Tæniosomi ....................... $\quad 782$

Tæniotoca....................... 1505

lateralis .............. 1505, 1506

Tahoe Chub ..................... 2798

Lake Trout..............493, 2870

Sucker ................... $\quad 177$

tahoensis, Catostomus............ 177

taiasica, Awaous .................. 2236

Chonophorus............. 2237

Gobius.................. 2236

Tail, Hard...................... 921

Tailor Herring ................... 425

Tails, Square ................... 975, 976

Talismania..................... 455

æquatoris .............. $\quad 456$

antillarum ............ 455

Tally-wag....................... 1199

Tambor .................. 1732, 1734, 1805

Tang......................... 1691

Blue...................... 1691

Ocean ..................... 1693

tang, Mugil .................... 812

Tangbrosme .................... 2438

tanneri, Hyperchoristus............ $\quad 589$

tapdisma, Salmo.................. 483

tapeinosoma, A uxis ............... 868

Taractes ....................... $\quad 957$

saussurii................ $\quad 957$

Tarandichthys .................. 1891

$\begin{array}{lll}2416 & \text { cavifrons............ } & 1891 \\ 2416 & \text { filamentosus........ } & 1892\end{array}$

1831 tarascorum, Algansea ............. 2796

2510 Tarentola ....................... 537

2510 Tarletonbeania................... 575

$2418 \quad$ crenularis.......... 575

238 tenua ............ 575

2418 Tarpon........................ 409

$238 \quad$ atlanticus ................. 409

1308 Tarpons......................... 408

1322 Tarpum...................... 409

435 Tates, Tom .................... 1308

886 tau, Batrachus................... 2316 
Page.

2314

Tau, Batrachoides................

Batrachus beta.............. pardus .............

Gadus ........................

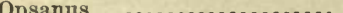

Tauridea.

$1942,1943,1952$

taurina, Chrysophrys ..............

taurinus, Calamus.................

taurocephala, Cliola ...............

taurocephalus, Alburnops..........

taurus, A budefduf ................

Carpiodes ..................

Glyphidodon ...............

Tautoga.

americana................ .

cærulea

2316

2317

2316

2315

1354

1354

253

253

1563

165

1563

1577

1579

1577

niger.

1577

onitis tessellata

1578,1579

1579

1579

1579

fusca..............

rubens ............

1579

Tautogolabrus ................... adspersus

1576

1577

Tautogs

taylori, Chilara

$$
\text { Ophidium }
$$

1577,1578

Tchaviche

Tectospondyli.

Teipalcate

Teleostei.

(1)...............

.......................

Teleostomi

telescopus, Leuciscus ..............

Minnilns ..............

Notropis ............... arcansanus ...

Photogenis............

Telestes........................

Telipomis .......................

temmiuckianus, Bagrus ............

Sciadeichthys .... 122.2760

Tachisurus........ 123

temminckii, Arius................. 123

Ditrema ........... 1510, 1511

temminkii, Acanthoderma.......... $\quad 880$

Rovetus .............. 880

Temnistia .......................

ventricosa.............

Temnodon .......................

saltator ...............

tenebrosus, Alepocephalus........

Antennarius..........

Chironectes............

tenellus, Fundulus ................

Hyborhynchus........... tenorei, Scopelus

Page.

tentabunda, Trigla............... 2183

tentaculatus, Cottus ............. 2000

Porocottus .......... 2000

tenua, Tarletonbeania ............. $\quad 575$

tenue, Moxostoma................ $\quad 186$

tenuifilis, Antennarius ............ 2721

tenuirostris, Anguilla............. $\quad 348$

tenuis, Atherinopsis .............. $\quad 802$

Gadus ................... 2555

Icelinus ................... 1894

Leuresthes ................ 802

Opisthocentrus ............. 2430

Phycis .................. 2555

Syngnathus ............... $\quad 766$

Uranidea.................. 1966

Urophycis................ 2555

teres, Alosa.................... 420

Catostomus............... $\quad 179$

Coecula .................... $\quad 379$

Cyprinus .................. 179

Etrumeus................. 420

Sphagebranchus............ $\quad 379$

Teretulus ...................... 187

cervinus .............. 197

teretulus, Phenacobius........... 303

liosternus.. 303

tergisus, Hiodon ................ 413

terræ-novæ, Carcharias ........... 43

Lycodes.............. 2466

Scoliodon............. 43

Squalus (Carcharias).. $\quad 43$

tessellata, Plagusia............... $\quad 2709$

Tautoga.............. 1579

Tessellated Darter ............... 1057

tessellatum, Boleosoma.......... 1046, 1057

Etheostoma ........... 1078

tessellatus, Hadropterus .......... 1070

Labrus ............... 1578

Nothonotus ........... 1078

Testar.......................... 2332

testar, Lepadogaster .............. 2332

testudineus, Sphæroides annulatus. $\quad 1736$

Spheroides ........... 1734

Tetraodon............ 1735

Tetrodon............. 1735

Tétard .......................... 2332

tetard, Guavina................. 2200

Tête-de-roche .................... 1323

Tetrabranchus .................. $\quad 342$

tetracanthus, Acara............. $\quad 1540$

Centrarchus.......... 1540

Gasterosteus ......... 748

Heros .............. 1539

Sparus ............. 1257 


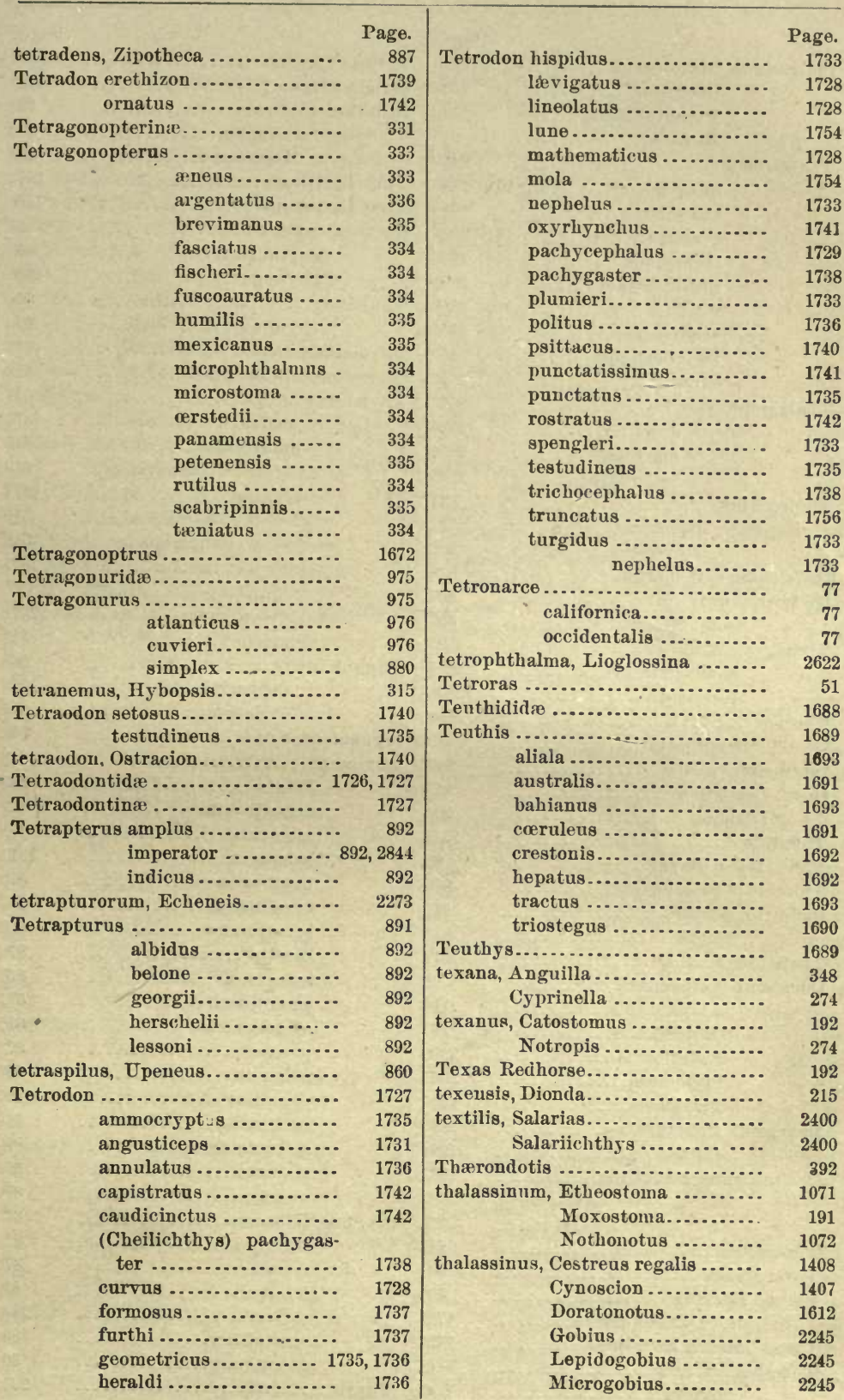




\begin{tabular}{|c|c|c|}
\hline & Page. & Page \\
\hline \multirow{2}{*}{$\begin{array}{l}\text { thalassinus, Myloleucus ............. } \\
\text { Otolithrs............ }\end{array}$} & 245 & Thrissa \\
\hline & 1408 & thrissa Clupea .......... \\
\hline Ptychostomus......... & 192 & thrissina, Clupea................. \\
\hline Rutilus............... & 245 & nella ............... \\
\hline Thalassoma ....................... & 2859 & thrissoides, Megalops .............. \\
\hline \multicolumn{2}{|c|}{ bifasciatum.......... 1610, 2859} & Thumb, Miller's................... 1941, 1950 \\
\hline bifasciatus.............. & 1610 & Thunder-pumper.................... $\quad 1484$ \\
\hline \multirow{2}{*}{\multicolumn{2}{|c|}{ 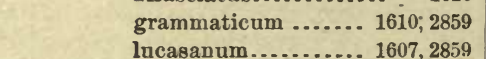 }} & thunnia, Orcynus . \\
\hline & & hthys ............. \\
\hline \multicolumn{2}{|c|}{ nitidissimum ......... 2859} & (...................... \\
\hline \multirow{2}{*}{\multicolumn{2}{|c|}{$\begin{array}{l}\text { nitidum } \ldots \ldots \ldots \ldots \ldots \\
\text { socorroense........... 1608, } 16859 \\
2859\end{array}$}} & Thunnus........................... \\
\hline & & thynnus...................... \\
\hline \multicolumn{2}{|c|}{ steindachneri........ 1609, 2859} & Thymallidæ...................... \\
\hline \multirow{2}{*}{\multicolumn{2}{|c|}{$\begin{array}{r}\text { virens ................ } \\
\text { Thalassophryne.................... } 28511,2323\end{array}$}} & oides, Coregonus ............ \\
\hline & & Thymallus ........................ \\
\hline dowi $\ldots . . . . . .$. & 2326 & lewisi $\ldots . . . . . . . . . . .$. \\
\hline sa........... & 2324 & ontariensis ............... \\
\hline reticulata....... & 2325 & montanus... 519 \\
\hline \multicolumn{2}{|l|}{ Thaleichthys...................... } & signifer .............. 517, 2871 \\
\hline pacificus.......... & 521 & montanus...... $\quad 519$ \\
\hline \multirow{2}{*}{$\begin{array}{l}\text { stevensi ............. } \\
\text { thaleichthys, Osmerus ............. }\end{array}$} & 521 & ontariensis .... $\quad 519$ \\
\hline & 522 & tricolor ....... 519,2871 \\
\hline \multirow{2}{*}{ 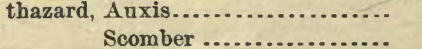 } & 867 & \\
\hline & 867 & nus... \\
\hline \multirow{2}{*}{$\begin{array}{r}\text { Theragra } \\
\text { chalcogramma } \ldots \ldots \ldots \ldots \\
\text { fucensis } \ldots \ldots \ldots \ldots \ldots \ldots\end{array}$} & 2535 & tricolor................... \\
\hline & 2535 & Thynnichthys... \\
\hline \multirow{2}{*}{ 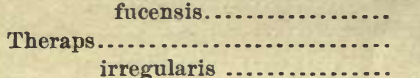 } & 2536 & vipinnis........... \\
\hline & 1540 & thunnia........... \\
\hline $\begin{array}{l}\text { irregularis } . . . . . \ldots \ldots . . . \\
\text { thermalis, Poecilia.................. }\end{array}$ & 1540 & thynnoides, A uxis................... 868 \\
\hline thermalis, Pocilia................. & 693 & Thynnus .......................... 868,869 \\
\hline 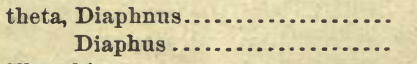 & 565 & .............. $\quad 869$ \\
\hline Diaphus .................. & 564 & argenti-vittatus ........... \\
\hline $\begin{array}{l}\text { Theuthis } \\
\text { Thick-tailed Rays } \ldots \ldots \ldots \ldots \ldots \ldots \ldots \\
\end{array}$ & 1689 & atlanticus ................ \\
\hline Thick.tailed Rays.................. & 60 & balteatus ................. \\
\hline Thimble-eyed Mackerel............. & 866 & rus................ \\
\hline thoburni, Alcidea .................. & 1887 & s $\ldots \ldots \ldots+\ldots$ \\
\hline .... & 813 & jinnis ............. \\
\hline$\cdots \ldots$ & 1672 & 870 \\
\hline thomponi, Aci & 105 & Is................... \\
\hline (................. & 113 & us................ \\
\hline ........ & 167 & eus.............. \\
\hline cus $\ldots \ldots \ldots \ldots$ & 2060 & a.......... \\
\hline (n)........... & 2005 & (........... \\
\hline (n) & 2005 & ilus ................... \\
\hline thomsonii, Cottunculus ............. & 1993 & rocheanus ................. \\
\hline (n................. & 1994 & orsalis............ \\
\hline thoreauianus, Semotilus............. & 223 & thunnia .................. \\
\hline atromacn- & & (.................... \\
\hline & 223 & a n................... \\
\hline .................. & 827 & (n.................... \\
\hline ............. & 931 & - $\ldots \ldots \ldots \ldots \ldots$ \\
\hline (n................ & 432 & 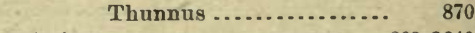 \\
\hline led Trunk-fishes.......... & 1721 & ............... 803,2840 \\
\hline Chree-bearded Rocklings ........... & 2557 & crystallina............... 804 \\
\hline (n............... & 45 & evermanni ................. \\
\hline & 45 & Thyris \\
\hline
\end{tabular}


Thyris pellucida

Thyrsites acanthoderma .......... niger .................. pretiosus .............. scholaris.

Thyrsitinæ.

thyrsitoides, Lemnisoma...........

Thyrsitops violaceus..............

Thyrsoidea aterrima.

concolor

cormura ...............

maculipinnis ...........

marginata ............ 1niliaris.

Tiaroga ....................... cobitis.

tiburo, Reniceps

Sphyrna.

Squalus

Zygæna

Tiburon.

Ticky-ticky

Tiger Shark

Tigoma

$228,230,231$

bicolor...................

conformis.................

conspersa.................

crassa .

egregia ..................

gibbosa ..................

gracilis .

humboldti ................

intermedia................

lineata...................

nigrescens...............

obesa ....................

pulchra..................

purpurea .................

rhinichthyoides ............

squamata................

tigrinus, Galeocerdo ..............

Holocentrus ..............

Myrichthys ..............

Prionodes ................

Serranus .................

tigris, Anteńnarius .

Carcharias

Chironectes ..........

Epinephelus ...............

Mycteroperca ...............

camelopardalis

Serranus ..................

Trisotropis.................

Tigrone

Tilefish

Tilesia
Page.

2691

880

879

880

880

877

884

879

396

396
Tilesia gracilis

Page.

tilesii, Hemilepidotus ............ 1936

timpanogensis, $\mathrm{Hybopsis} \mathrm{.........} 233$

Timucu .................... 711, 715

timucu, Belone ................... $\quad 715$

Esox................... 711

tinca, Serranus ................... 1181

tincella, Algansea ............. 211, 2796

Leuciscus............... 211

Lencus.................. 211

Tinker Mackerel ................... . 866

Tiñosa .......................... 924

tippecanoe, Etheostoma........... 1090

Tippecanoe Sisco ................ $\quad 469$

Tirantes ....................... . 885

Tiru ....................... 537

Tirus ......................... 533

marmoratus .............. 537

Toad, Swell .................... 1732, 1733

Toadfish ............. 1733, 1748, 2313, 2315

Toad-fishes, Poison .............. 2323

Tobacco Box ................... $\quad 68$

Toeroe......................... 1403

toeroe, Otolithus ................. 1404

Togue......................... 504

Tokenoko me waru............... 1829

Tom, $\mathrm{Mad}$...................... 144, 147

toma, Salmo .................. 505

Tomeod, California.............. 2539

tomcod, Gadus .................. $\quad 2540$

Microgadus .............. 2540

Tomcods ..................... 2538, 2540

tomcodus, Gadus ................. $\quad 2540$

fuscus.......... 2540

luteus.......... 2540

mixtus .......... 2540

Tomicodon .................... 2329

Tomtate....................... 1308

Tondo, Pesce.................... 48

Tongue Fish.................. 2704, 2710

Toothed Herring................ $\quad 413$

Top Minnow .................. 659,680

topeka, Notropis ................ $\quad 266$

Topes ........................ $\quad 31$

Toro ........................ 920, 1724

torpedinus, Trygonobatus......... 81

Urolophus ........... 81

Torpedo..................... $\quad 77$

bancrofti............... 78

brasiliensis............... $\quad 78$

californica .............. $\quad 78$

occideutalis ............. $\quad 77$

pictus.................. 78

torpedo, California ............... $\quad 77$

torquatus, Labrus................ 1609 
Page.

Torrentaria ............... 1066, 1068, 1080

torridus, Lutjanus................. 1264

torsk, Blennius.................... 2561

Gadus .................... 2561

torvus, Cottunculus ............... 1994

tota, Perca maculis ............... 1153

Toter......................... 181

toto, Cyprinus.................. $\quad 415$

Totuava....................... 1411

townsendi, Gobius............... $\quad 2250$

Lampanyctus......... $\quad 558$

Myctophum........... $\quad 558$

toxotes, Ditrema ................ 1508

Rhacochilus............. 1507

Trachelocirrus................. 950

Trachichthyidæ................ $\quad 836$

Trachichthys pretiosus .......... 837

Trachidermis richardsoni ......... 1944.

Trachinocephalus ................ 533

myops.......... 533

Trachinoid Fishes .............. 2273

Trachinoidea................... 2273

Trachinoidei ................... 781

Trachinotina .................. 897

Trachinotus..................... 939

argentens .............

carolinus..............

cayennensis...........

culveri...............

cupreus ..............

falcatus...........941, 2847

fuscus............ .

glaucus ..............

goodei ...............

kennedyi.............

paloma............. 945, 2848

rhodopus ............ 9:1, 943

rhomboides ............

spinosus ..............

Trachinus adsencionis ............

cirrhosus ...............

gasteropelecus ..........

osbeck .................

punctatus...............

trichodon ...............

trachinus, Malacauthus ...........

Salmo ..................

Trachisurus parkeri .

Trachonurus.

trachura, Raia

sulcatus..............

Raja ...................

Trachurops

brachychirus .......... crumenophthalmus.... plumieri.

\section{Trachurus}

aliciolus

boops .................

cuvieri................ 910

europæus .............. 911

fallax ............... 910

fasciatus.............. 904

imperialis............ 927

linnæi ............... 911

picturatus ........... 909, 2844

rissoi ................. 910

saurus .............. 911

squamosus ............ 921

symmetricus........... 910, 2844

trachurus ............. 910

trachurus, Caranx............... $\quad 910$

Cottus ................ 1936

Gasterosteus........... $\quad 747$

Hemilepidotus......... 1936

Scomber .............. 910

Trachurus ............ 910

Trachynotus argentens............ 941

carolinus ............ 944

cupreus............. 944

fasciatus ........... 941

glaucoides ........... 941

glaucus.............. 941

goreensis ............ 943

nasutus............. 941

ovatus.............. 942

pampanas ........... 944

rhomboides .......... 942

trachypoma, Myripristis .......... 846

Trachypterus .................. 2870

trachyurus ......... 2601

Trachyrhamphus .............. 761, 2568

Trachyriuchinæ................ 2562

Trachyrincus ................... 2568

Helolepis ........... 2568

trachyurus, Trachypterus......... 2601

tractus, Acanthurus ............. 1693

Teuthis................. 1693

Trahiras ..................... $\quad 330$

tranquebar, Aspidophoroides ...... 2092

transmontana, Columbia........... $\quad 784$

trausmontanus, Acipenser ......... 104

Rhinichtliys....... 307 .

transversalis, Synbranchus ....... $\quad 342$

trausversum, Pœeilosoma .......... 1089

traski, Hysterocarpus............. 1496

treculii, Dioplites nuecensis....... $\quad 1012$

Treefish ........................ 1827

T'rematopsis ................... 1753

willugbei ........... 1754

Triacanthidre ................. 1697

Triacanthodinæ............... 1697 
Page.

triacanthus, Argyriosus............

Nanclerus.............

Poronotus.............

Rhombus..............

Stromateus............

Xenochirus

Triaeis henlei

triagramma, Heros.

Triakis.

semifasciatum

triangularis, Ostracion tuberculus .

Pachynathus.........

triangulum, Lutjanus..............

Tribe, Flounder...................

Halibut ...................

Turbot.....................

tribulus, Prionotus ............. 2171, 2172

Trigla .................. 2172

Trichidion

approximans............

octofilis .................

octonemus ...............

opercularis ..............

plumieri...............

Trichinridæ......................

Trichiurus

argenteus ..............

caudatus ...............

ensiformis ..............

gladins ................ 887

lepturus............. 889, 2844

trichocephalus, Sphæroides ........ 1738

Tetrodon ......... 1738

Trichocyclus.................. 1743, 1744

erinaceus ............ 1744

Trichoderma ..................... 1714

Trichodiodon................... 1743, 1744

pilosus ............ 1743, 1744

Trichodon..................... 2295

japonicus ...............

lineatus ................

stelleri..................

trichodon................

trichodon, Drachinus..............

Mugil ..................

Trachinus..............

Trichodon...............

Trichodontidæ ....................

Trichonotus

Trichopsetta

ventralis -0.00

trichopterus, Pteraclis .............

trichroistia, Cliola..................

Codoma ...............

trichroistius, Notropis ............

tricocephalus, Spheroides tricolor, Chretodon

Page,

Engraulis ............... 443

Genicanthus ............. 1684

Holacanthus .............. 1684

Pomacanthus ............ 1684

Thymallus ............... $\quad 519$

signifer....... $\quad 519$

Tricopterus................. 915, 917, 920

tricornis, Lactophrys ............ 1724

Ostracion ............... $\quad 1725$

tricuspidatus, Hrporhamphus ..... $\quad 720$

tricuspis, Cottus ................. 2009

Gymnocanthus .......... 2008

Phobetor............... 2009

tridecemlineatus, Esox............ 628

tridens, Acropocilia ............. $\quad 690$

A rchosargus............. $\quad 1360$

Centropristis ............. 1202

Lutjanus................. 1202

Pœcilia (Acropocilia)...... $\quad 690$

Sargus .................... 1361

tridentata, Lampetra............. 12

tridentatus, Ammocœtes........... 12

Entosphenus .......... 12

Ichthyomyzon......... 12

Petromyzon ........... 12

tridentiger, Gambusia.............. 2833

tridigitatus, Dactyloscopus........ 2301

Polynemus........... $\quad 2177$

Trifarcius...................... $\quad 670$

felicianus............... $\quad 676$

riverendi ............... 673

rifasciata, Hydrargyra ........... $\quad 639$

Lepomis.............. 1011

trifurca, Centropristes ............. 1202

Perca .................. 1202

trifurcus, Anthias .............. 1202

Centropristis........... 1202

Serranus............. 1201, 1202

trigammus, Chirus ............... 1872

Trigger Fishes ................. 1698, 1699

Trigla ....................... 2176, 2867

carolina ................. 2156, 2172

cuculus ................... 2177

digitis vicensis palmatis.... 2183

evolans ................... $\quad 2169$

fasciata ................... 2183

lineata ................... $\quad 2167$

palmipes.................. $\quad 2156$

pictipinnis ................. 2176

pini ...................... 2177

punctata................. $\quad 2170$

strigata .................. 2167

tentabunda ................ 2183

tota rubens ................ 2177

tribulus.................. $\quad 2172$ 


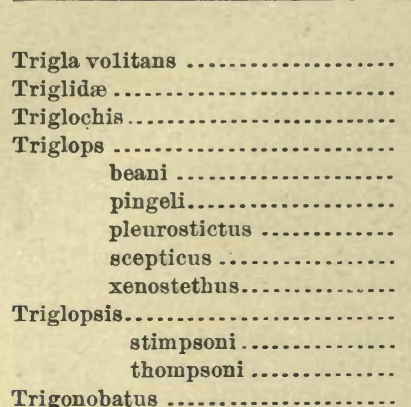

trigonum, Ostracium ...............

trigonus, Lactophrys ............ 172

Ostracium...............

trilineatum, Pristipoma............

trilineatus, Anisotremus ........... .

trilobatus, Scarus .................

Triloburus …............ 1198, 1199, 1201

trilobus, Blepsias .................. 2019

Lutjanus ................ 1200

trimaculatus, Heros...............

Trinectes ........................

scabra..................

triostegus, Acanthurus.............

Chætodon...............

Teuthis .................

tripes, Nealotus...................

Triple-tail........................

Tripteronotus....................

Tripterygium carminale ...........

tripterygius, Cottus...............

tripunctulatus, Maurolicus ........

Valenciennellus ...

triqueter, Lactophrys..............

Ostracion................

triserialis, Murenopsis.............

Ophichthus..............

Ophichthys..............

triseriata, Platyrhina ..............

triseriatus, Platyrhinoidis .........

Rhinobatus ............

trisignatum, Moxostoma ............

Trisotropis.......................

aguaji .................

bonaci................

brunneus ..............

callinrus ...............

camelopardalis .........

cardinalis ..............

chlorostomus...........

dimidiatus .............

falcatus ...............

interstitialis ...........

microlepis.
Page.

2183

2147

46

1923

1924

1923

1923

1925

1927

2005

2005

2005

82

1724

, 1724

1724

1320

1320

1654

2693

2701

1691

1691

1690

881

1235

461

2350

2023

578

578

1722

1723

384

384

384

66

65,66

66

179

169,1172

1175

1175

1175

1186

1187

11 i.

1179

1179

1185

1179

1178
2019
1200
1529 reticulatus............ 1187

rosaceus .............. 1184

stomias .............. 1178

tigris................ 1187

trispinosa, Corvina ............... 1443

trispinosus, Odontopyxis ........ 2085

Pseudoscarus.......... 1648

Scarus................ 1648

trispinous, Odontopyxis.......... 2086

tristis, Moniana................... 272

tristœchns, Esox.................. 111

Lepisosteus............ 111

Litholepis ............ 111

triurus, Bodianus ................ 1236

trivittatus, Diabasis ............. 1311

Grammistes........... 1311

Sebastodes........... $\quad 1834$

Trochocopus darwinii............ $\quad 1586$

pulcher............. 1585

Trompa ......................... 1653

Lija .................... 171

Trompetero ................... 754, 757

tropica, Echeneis................. 2268

tropicus, Atractosteus ............ 111

Lepisostens ............. 111

Tropidichthys ................... 1741

Tropidinius ..................... 1278

arnillo.............. $\quad 1279$

dentatus.............. $\quad 1279$

Tropidodus .................... 20

troscheli, Heros .................. 1537

Sciadeichtliys .......... 122, 2757

Sciades ............... 122, 2758

troschelli, Glyphidodon ........... 1562

Trout ............................ 483

Black-spotted .............. $\quad 487$

Blue-back ............... 514, 2819

Brook ................... 506

Bull .................... 507

Coast Range.............. $\quad 500$

Colorado River ............. $\quad 496$

Columbia River ............ 492

Cut-throat............. 487, 492, 493

Dolly Varden.............. 507

Dublin Pound ............. $\quad 507$

Gila .................... 226

Golden of Mount Whitney... $\quad 503$

Great Lake................ 504

Green-back................ 497

Kamchatka Salmon ......... . 2818

Kamloops ................. 499

Kern River............... 502

Lac de Marbre ............ $\quad 515$

Lake Tahoe .............. 493, 2870

Mackinaw ............... 504 


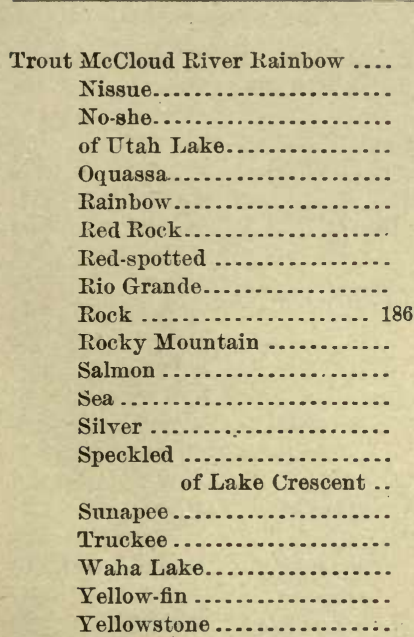

Trout Perch

trowbridgii, Abeona ...............

$$
\begin{aligned}
& \text { Holconotus ............ } \\
& \text { Homalopomus ........ }
\end{aligned}
$$

Trucha........................

Truckee Trout

truculentus, Chorophthalmus ....

True Eels

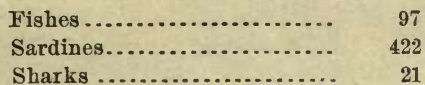

Trumpet-fish............... 7 $54,756,759$

truncata, Belone ................ 714, 715

Malthra............... 2738

Ranzania............. 1755, 1756

truncatus, Blennius ............... 2381

Dinectus ............... 106

Orthagoriscus.......... 1756

Salmo ................. 499

Saurus ................ 533

Scarus ................ 1641

Tetrodon .............. 1756

Trunk-fish ........... 1720, 1721, 1722, 1723

Spotted .............. 1723

Three-angled .......... 1721

Trutta ................... 483,486,487

trutta, Salmo ....................

Truttæ

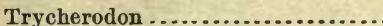
megalops ..............

Trygon

gymnura .................

hastata.

osteosticta.................

sabina
487

483

247

249

82

84

84

84

85
Trygon sayi

tuberculata.............. 84

Trygonobatus torpedinus ......... 81

Trygonorhina alveata ............ 65

Tschawytscha.................. $\quad 479$

tschawytscha, Oncorbynchus ...... $\quad 479$

Salmo............. 480

tschawytschiformis, Salmo ........ $\quad 478$

tsiltcoosensis, Catostomus.......... 2793

tsuppitch, Fario................ $\quad 493$

Oncorhynchus ......... 481

Salmo ................. 481, 495

tuberculata, Dasibatis............. 84

Raia................ 84

Trygon.............. 84

tubereulatus, Catostomus .......... 186

Sphæroides .......... 1733

tuberculé, Le Sphéroide........... 1733

tuberculée, Raie.................. 84

tudes, Gobiesox .................. $\quad 2333$

Salmo ................... 508

Sphyrna.................. 44

Zygæna.................. 44

tuditana, Cliola................... 253

tuditanis, Hybopsis .............. 253

tuditanus, Hypargurus .......... 253

Leuciscus............. 253

Tullibee....................... $\quad 473$

tullibee, Argyrosotwus ............ 473

bisselli ..... 473

Coregonus ............. 473

bisselli........ 473

Salmo (Coregonus) ....... $\quad \mathbf{4 7 3}$

tumidus, Carpiodes ............... 167

Chironectes............. 2717

Lophius............... 2716

Tuna......................... $\quad 870$

tunicata, Liparis ............... 2121, 2128

tunicatus, Liparis ................ $\quad 2120$

'Tunnies......................... 869

Little .................. 868

Tunny ....................... 870

Little................... 869

Turbot ......................... 1701

Ocean ................... 1706

Tribe.................... 2608

turchesius, Pseudoscarus ......... $\quad 1659$

Scarus ............... 1658

Turdus cauda convexa............ $\quad 1145$

cinereus peltatus .......... 1373

flavus ................... 1583

oculo radiato ............ 1591, 1703

pinnis branchialibus ...... 1257

rhomboidalis ............. 1691

turgidus, Tetrodon................ 1733

nephelus...... 1733 
turneri, Lycodalepis ..............

Lycodes .................

tuscumbia, Etheostoma...........

Psychromaster........

Two-spined Stickelback............

Tyee Salmon ......................

Tylosurus......................

acus ....................

almeida .................

angusticeps.............

ardeola..................

caribbrus ..............

contrainii..............

crassus .................

diplotænia .............

euryops.................

exilis ..................

fodiator...............

galeatus ................

gladius .................

hians ..................

longirostris .............

marinus................

microps................

notatus ...............

pacificus ...............

raphidoma .............

sagitta................

scapularis .............

sierrita ................

stolzmanni.............

subtruncatus ...........

timucu..................

Tympanomium .

Tympanomilum

Tyntlastes ........................

brevis .................

sagitta....................

Typhlichthys

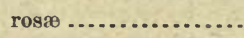

gubterraneus -

Typhlogobius .................. 2261

californiensis ....... 2262

2729

2731

1448

19

1448

283

388

892

348

433

434

aurea.........

brevicaudata.

patronus .....

1753
2469

469

100

100

748

479

708

16

715

712

17

16

712

711

714

715

716

718

714

714

712

713

713

711

711

1754

262

62

$1 \mathrm{um}$

Amellns.

ulochir, Paraliparis ............... 2144

ulvæ, Xiphidion.................. 2424

Ulvaria ......................... 2440

subbifurcata.............. 2440

Ulvicola........................ 2413, 2869

sanctre.rosæ............. 2413

umatilla, Agosia................... 313

Umbla .......................... 506

minor marina ............. 823

umbla, Salmo.................... 509

Umbra ......................... 623, 2807

delicatissima ............. 621

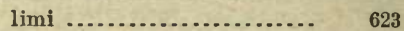

pygma.............. 624

pygmxa .................. 624

Alburnus ............. 299

Minnilus............... 299

Notropis .............. 298

ardens........ 301

atripes ...... 300

cyanocephalus $\quad 300$

fasciolaris .... $\quad 301$

1ythrurus..... 300

matutinus .... 301

punctulatus .. $\quad 301$

umbratilis.... 299

Umbridx........................ 622

umbrifer, Notropis................ 274

Urolophus .............. 2752

Umbrina ....................... 1465

alburnus ............... 1475

analis .................. 1468

arenata................. 1474 


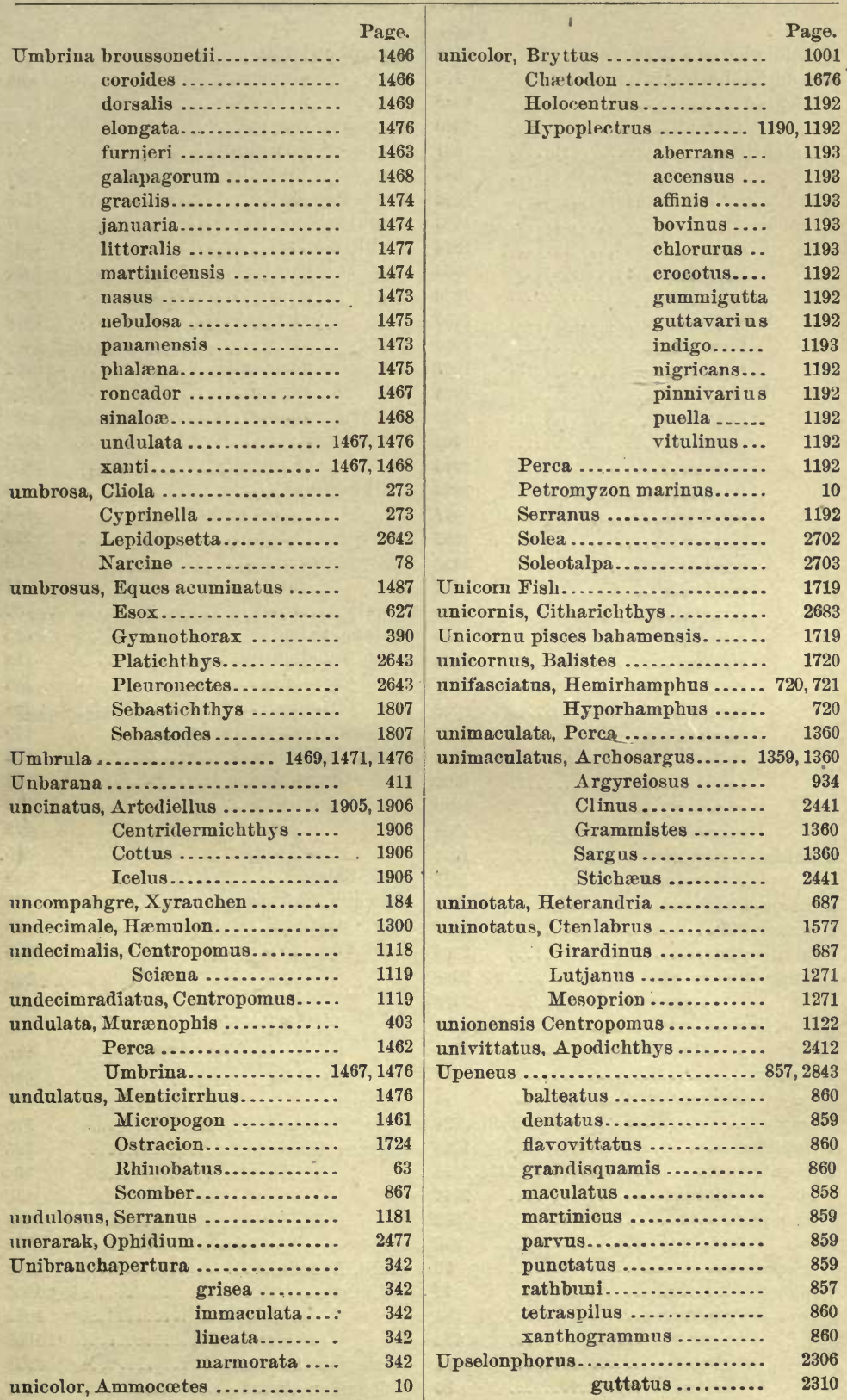




\begin{tabular}{l}
\hline \\
Upselonphorus y-græcum $\ldots . . . .$. \\
uracantha, Loricaria ............... \\
Uraleptus ....................... \\
maraldi...............
\end{tabular}

Uranichthys ...................... brachycephalus........ havannensis..........

Uranillea.........................

aspera.................. bendirei................. boleoides .................. cognata .................. formosa . . . . . . . . . . . . . franklini ................ gobioides............... gracilis................. greenei................. gulosa................... hoyi.

kumlieni

marginata.

marginata................

microstoma..............

pollicaris .................

punctulata..............

quiescens ...............

rhothea ...............

ricei......................

richardsoni .............

semiscabra

spilota.

tenuis......................

vheeleri.................

viscosa..................

uranidea, Cottogaster

Etheostoma ..............

uranops, Phenacobius.............

Uranoscopid:o....................

Uranoscopinæ.

Uranoscopns anoplos

y-græcum ...........

uranoscopus, Ceratias..............

Mancalias............

Uraptera

binoculnta ..............

Uraspis ..................... 916,918, 926

Uriphrton

Urocentrus

2414,2415

pictus ............... 2416

Urocunger .................... $\quad 358$

vicinus............. $\quad 358$

Urolophinæ .....................

Urolophus

aspidurus.............

asterias............... 82, 2752

goodei ..................

halleri

1966
1143

Page.

2308

158

2545

2545

382

382

1963

1944

1964

1968

1955

1967

1968

1968

1965

1945

1969

1967

1965

1958

1954

1949

1968

1947

1953

1952

1950

1950

1968

1044

1045

304

2305

2308

2308

2730

2729

Va$$
\text { ra }
$$

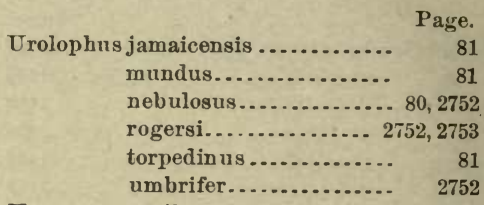

Uronectes parii .................. 2478

urophthalmus, Heros............. 1537

Urophycis....................... 2552

chesteri ................ 2556

chuss ................ 2555

cirratus ............... 2553

èarlli.................. 2554

floridanus............. 2554

regius................ 2553

tennis................ 2555

Uropsetta ....................... 2624

californica............. 2626

Uropterygius ................... 403

necturus........... 404

urostigma, Cliola ................ $\quad 275$

Urotrygon ..................... 80

mundns $\ldots . . . \ldots \ldots \ldots . . . .81$

Uroxis ........................ 82

ursinus, Salmo ................... 505

urus, Bubalichthys .............. 164

Carpiodes .................. 164

Ictiobus.... ............... 164

Sclerognathus.............. 165

ustus, Callyodon ................... 1624

Cryptotomus .............. 1624

Utah Lake Chub .................. 232

Mullet ................ 179

Trout ................ 495

utah, Salmo .................... $\quad 495$

utawana, Catostomus .............. $\quad 179$

nter, Catulus..................... 25

Uwo Aka .................... 1833

Vaca.......................... 1190

Vacas ........................... 1189

vacca, Capriodes .................. $\quad 168$

Damali.hthys.............. 1510

Ditrema.................. 1510

Vacnocua ........................ 1427

vafer, Myrophis................. $\quad 372$

vagrans, Chirostoma............. $\quad 795$

Kirtlandia.............. 794

794
laciniata.......

Menidia ................. 795 laciniata........ 795

79 vahlii, Lycodes..................... 2463

79 Vaillantia..................... 1054, 1060

81. camura ................ 1060

chlorosoma ............ 1060

valenciennei, Smaragdus........... 2228

80 Valenciennellus ................. 577 


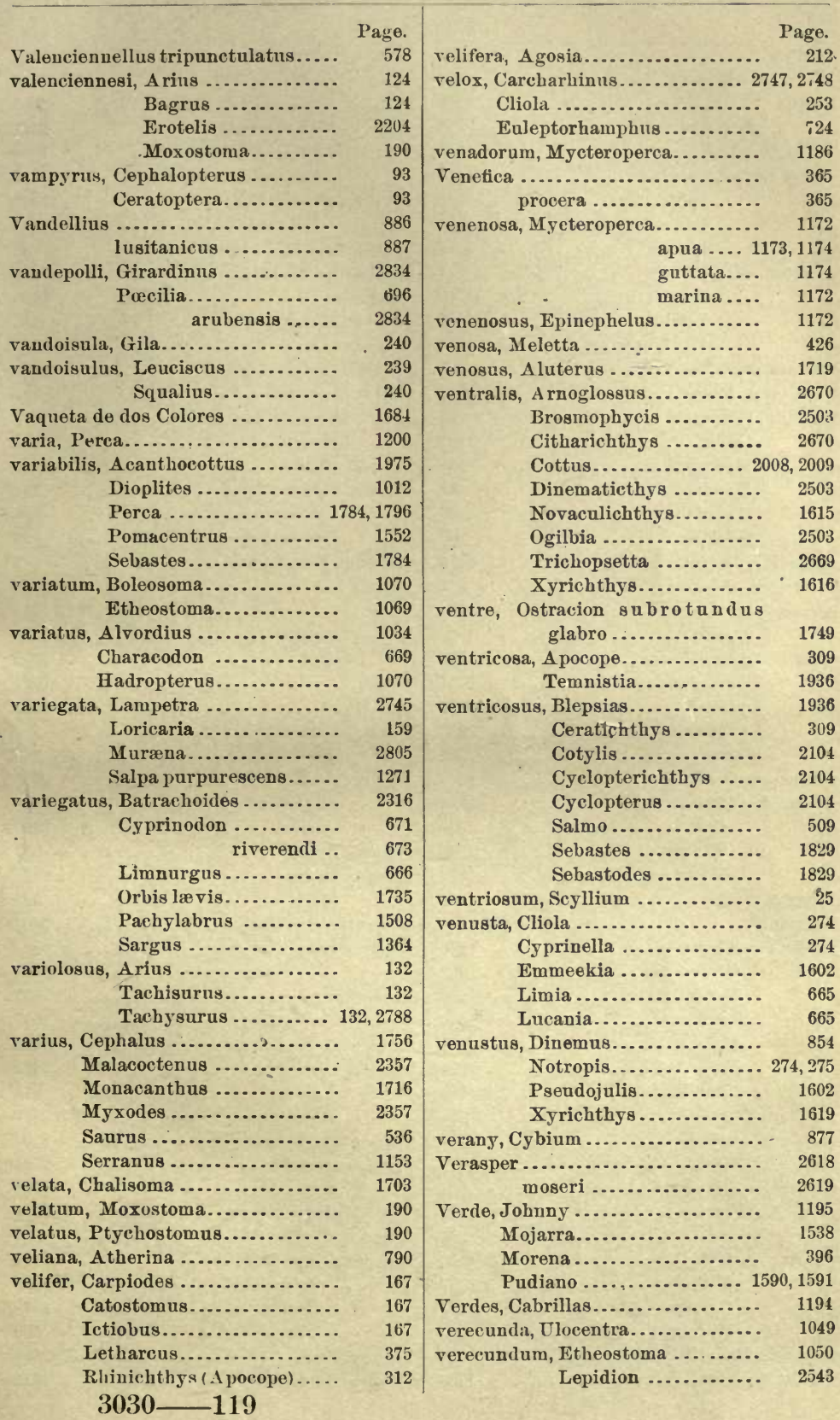




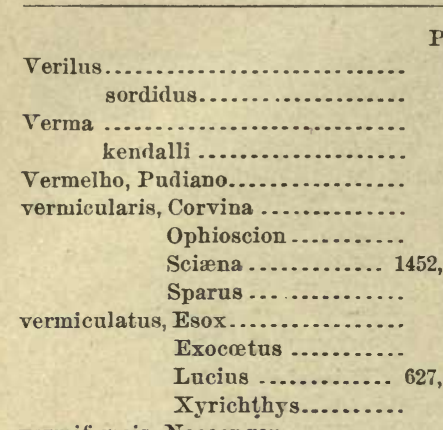

vermiformis, Neoconger...........

Vermiglia, Pesca..................

vernalis, Clupea ...................

Gobio....................

Hydrargyra .............

Hyodon.................

Pomolobus................

Scomber ...................

vernullas, Batrachoides ............

verreauxi, Conger..

rerres, Cossyphus ................

Lutjanus..................

verrilli, Gymnothorax.............

Lycenchelys........... 2470, 2471

Lycodes ................. 2471

Lycodontis ............... 393

Sidera ...................

verrucosa, Occa ...................

verrucosus, Brachyopsis ............

Cottus ................

Diodon ................

Myoxocephalus........

Verrugata.........................

Verrugato

1462,1463

versicolor, Abramis ................

Girardinus..............

Heterandria............

Labrus................

Malacoctec us ............

Myxodes ................

Pocilich thys...........

versipunctatus, Gymnothorax......

vertagus, Gadus ..................

verticalis, Echeneis ................

verticallis, Pleuronichthys..........

verus, Carcharias .................

Conger....

vespertilio, Holorhinus ..............

Malthæa ...............

Ogcocephalụs ...........

Rhinoptera.............

veternus, Podothecus.............. 2063, 2064 retula, Balistes.
Page.

1283

1284

374

375

1583

1453

1452

1271

627

740

1619

362

1811

426

321

639

413

426

866

2316

355

1583

1583

394

393
394

2043

2044

1980

1749

1979

1476

250

689

688

1346

2359

2359

1089

394

2541

2270

2638

50

355

90

2737

2737

90

64

1703 retula, Pseudoscarns............. $\quad 1650$

Scarus................. 1647, 1649

vetulus, Parophrys............... 2640

Pleuronectes .............. 2641

vexillare, Boleosoma nigrum ....... 1058

Etheostoma nigrum..... 1058

vexillaris, Sebastichthys ........... 1822

Sebastodes ............ 1821

vexillarium, Holocentrum ......... $\quad 852$

vexillarius, Holocentrus .......... $\quad 852$

Texillifer ...................... 2495

vheeleri, Uranidea................. 1950

Viajaca ......................... 1539

vicensis, Trigla digitis ........... 2183

vicina, Murzena .................. 394

Murænophis .............. 394

Sidera ................... $\quad 394$

vicinalis, Icelus .................. 1916

vicinus, Gymnothorax............ $\quad 394$

Lycodontis .............. 394

Uroconger............... $\quad 358$

victorix, Moxostoma ............. $\quad 187$

Vicuda ....................... 824

Vieja..................... 1635, 1636, 1649

Colorada .................. 1639

Muger................... 1639

Viejas....................... 1627

rigil, Ioa ........................ 1065

vigilax, Ceratichthys............. 253

Clivla ................... 253

Villarius ....................... $\quad 2789$

dugesii................. $\quad 2789$

pricei................. 2790

villosa, Clupea ................. $\quad 521$

villosus Cottus.................. 2022

Mallotus ................ $\quad 520$

vincente, Sicydium............... 2207

vinciguerræ, Exocœtus ........... $\quad 734$

Exonautes .......... 2836

Vinciguerria ................. $\quad 577$

attenuata $\ldots \ldots \ldots \ldots \ldots . . .577$

vinctipes, Nanostoma............ 1075

vinctus, Blennius.................. 2382

Caranx ................. 918

Fundulus .............6.637,2827

vinolentus, Lethotremus .......... 2101

viola, Antimora .................. 2544

Eques.................... 1486

Haloporphyrus ............ $\quad 2544$

violacea, Bipinnula............. $\quad 878$

violaceus, A podichthys ........... 2427

Cebedichthys.......... 2427

Escolar............... $\quad 4843$

Thyrsitops ............ $\quad 879$

Viper-fishes ................. 578, 584

virens, Chlorichthys ............ 1610 


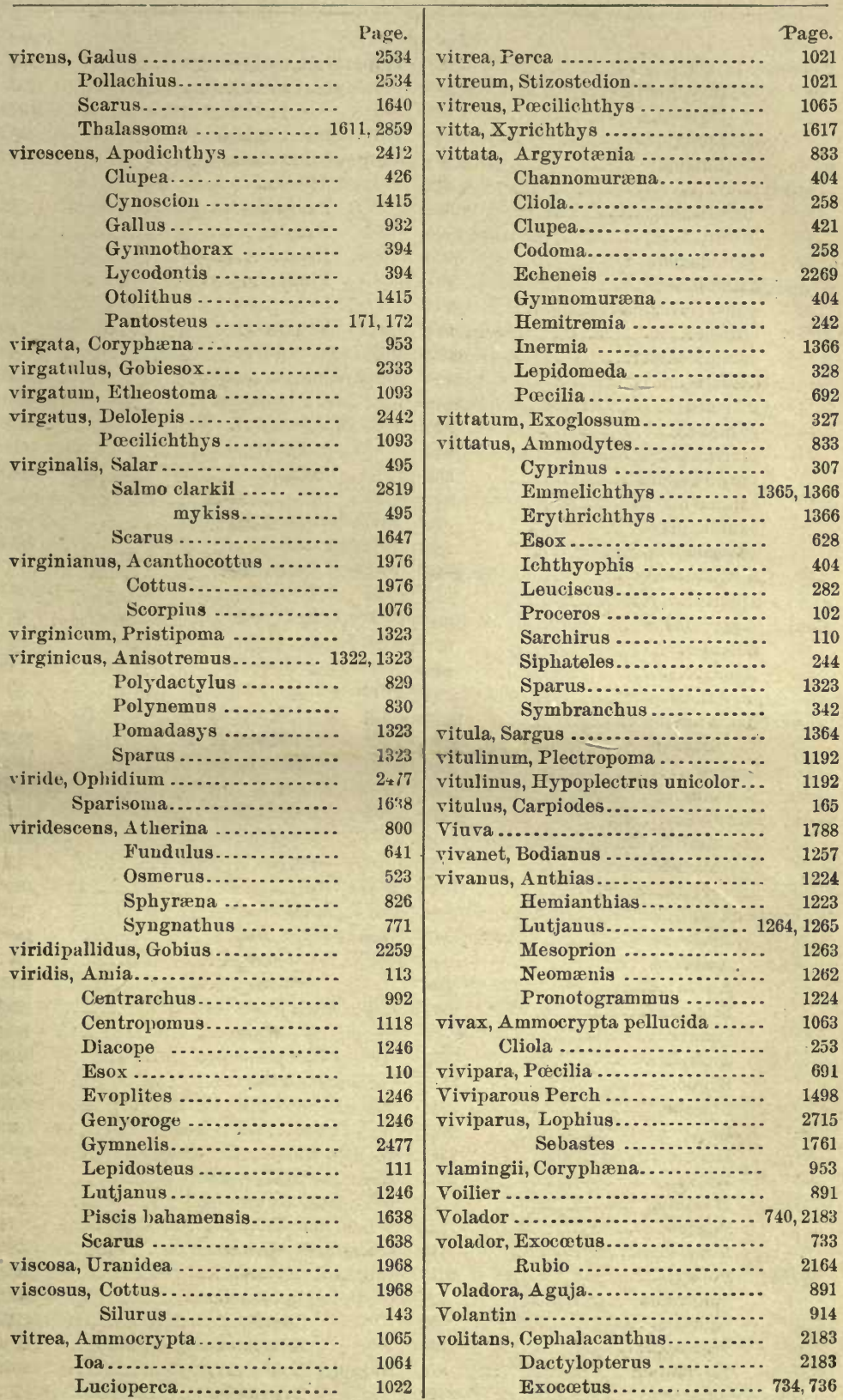


volitans, Trigla ........... 2183

volucellus, Hybognathus .......... 263

Hybopsis ...............

Lenciscus.............

Notropis ...............

Vomer ............................

brasiliensis ................

browni .................. 934, 2846

cayennensis .............. 934

columbianus.............. 934

cubæ................... 934

curtus ....................

dominicensis...............

dorsalis ...................

gabonensis .............. 934, 2846

goreensis ..................

martinicensis ..............

noveboracensis ............

sanctio martha ............

sanctæ-petri ...............

senegalensis ...............

setipinnis.

spixii

934,2846

vomer, Argyreiosus

Selene......................

Zeus.

vomerina, Atherina

vomerinus, Anarrhichas.

Salarius

vorax, Lucius

\section{Mesoprion}

Mesoprion..................

Platyinius.................

Pseudorhombus.............

Ptychocheilus..............

Voraz

vulgaris, Acanthias

Ameiurus

A miurus

Auxis..................

Brosmius................

Conger ..................

Gunnellus.

Hippoglossus ............

Liparis .................

Lumpus ................

Merluccius ...............

Molva ....................

Mustelus

Pagrus .

Pimelodus.

Pomotis.

Sphyræna..............

Squatina ...............

Sturio ..................

Thynnus ...............

vulnerata, A pocope.

59

105

870

312 $\mathrm{v}$

vulneratum, Etheostoma.......... 1077

vulneratus, Nothonotus.......... 1077

Poecilichthys .......... 1077

vulpeculus, Pimelodus ............ 141

Vulpes bahamensis ............. $\quad 411$

vulpes, Albula ................. 411

Alopecias ................ 46

Alopias ................. $\quad 45$

Esox .................... 411

Pimeloilus................ 135

Sebastodes ............... 1835

Squalıs................ 46

vulpinus, Squalus............... $\quad 46$

Vulsiculus ...................... 2181

imberbis .............. 2181

vulsus, Agonus ................. 2068

Podothecus ............... 2068

Stelgis ................ 2067

wabashensis, A nguilla ............ $\quad 348$

Wachna Cod ..................... $\quad 2537$

wagneri, Pimelorlus .............. $\quad 151$

Rhamdia............... 150, 151

Waha Lake Trout................ 496

Wahoo....................... 876

walkeri, Selanonius .............. $\quad 49$

Wall-eyed Herring .............. $\quad 426$

Pike ................. 1021

Pollack ............... 2536

628 Surf-fishes ............ 1501

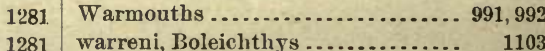

$2626 \quad$ Poeilichthys ............ 1103

$227 \quad$ Salmo.................. 483

1280 Waru, Me..................... 1829

54 watanga, Hybopsis .............. 319

140 Weakfish, Bastard ............. 1406

140 Common .............. 1407

$868 \quad$ Spotted ............... 1409

2561 webbi, Embiotoca ................ 1505

355 webbii, Blennophis ............... 2401

2419 Ophioblennius ............ 2401

2612 Webug Sucker ................... 180

2118 welaka, Notropis................ 2799

2097 Welshman ...................... 848

2530 Wench, Old.................... 1703

2552 West Indian Lancelet............ 3

29 westphali, Tæniophis............ 396

1357 Whale Sharks................... 52

140 wheatlandi, Gasterosteus ......... 749

1010 Whiffs ......................... 2678

826 whipplei, Boleosoma ............. 1096

Cliola ................... 279

Etheostoma alabamæ.... 1095

whipplii, Boleichthys ............. 1096

Cyprinella ............. 279 
whipplii, Etheostoma

Notropis

Whip-tailed Rays

Whirligig Mullet

White Bass

Cat.

Croaker

Grunt

Hake

Lake Bass

Mullet

Perch . . 1133, 1134, 148t,1501, 1509

Salmon of the Colorado

Sea Bass of California

Sturgeon

Sucker.

Surf-fish

White-bill

White-bone Porgy

Porgy . ................

Whitefish

\section{Broad ..................}

Common.................

Humpback ..............

Menominee.............

Mongrel ................

Musquaw River .........

Rocky Mountain ........

Round...................

Sault

White-mouthed Drummer

White-nosed Suckers.

Whiting

Calitornia.

Carolina.

Northern

Sand.

Silver.

Surf.

Whiting of Lake Winnipiseogee...

Widow-fish........................

Wife, Old

wilderi, Lampetra

Will, Black. williamsi, Symphurus.

williamsoni, Coregonus .

cismontanus

Gasterosteus..........

Gasterosteus micro-

cephalus ......................

willoughbyi, Acrotus .............

Willow Cat

willughbeii, Canthidermis .........

Salmo.................

Trematopsis

wilsoni, Cottus
Page.

1095

278

79

818

1132

134,138

1397

1310

2555

1132

189,813

1509
225

1413

104, 107

178,192

1506

431

1353

1021

1,2276

464

465

466

465

473

466

463

465

466

1462

190

2530

1477

1474

1475

1474

1477

1477

466

1788

940,1703

13,2745

1199

2711

463

463

750

751

973

2788

1707

509

1754

1952
Wilton Smelt. ................... Page.

winchelli, Hybopsis............... 321

Wind-fish ...................... 221

Window Panes................. 2659, 2660

Winninish ...................... 487

Winnipiscogee, Whiting ......... $\quad 466$

Winter Flounders............... 2646

Sucker.................. 187

Wolf Eel....................... 2448

Wolf-fish.................. 595, 2445, 2447

woolmani, Paralichthys ........... 2628

Wurm Eels...................... $\quad 370$

Wrasse-fishes .................. 1571

Wreckfish ................... 1138, 1139

wrighti, Etheostoma ............. 1047

Wry-mouth ................... 2442, 2443

wurdemanni, Gobius ............ 2225

xænocephalus, Hybopsis ......... 289

Minnilus.......... $\quad 289$

Notropis.......... $\quad 289$

xænura, Cliola ................... $\quad 280$

Codoma ................. $\quad 280$

xænurus, Minnilus............... $\quad 280$

Notropis.............. 280

xaniurus, Catulus............... 24

Xanthichthys.................. 1708

cicatricosus ........ 1709

mento............. 1760

ringens............. 1709

xanthocephalus, Ameiurns ....... 141

Silurus .......... 141

xanthogrammus, Upeneus ........ $\quad 860$

xanthomelas, Anguilla........... $\quad 348$

xanthops, Odontoscion ........... 1427

xanthopteron, Hæmulon .......... 1307

xanthopterum, Hæmulon .......... 1307

xanthopus, Catostomus ........... 181

xanthopygus, Caraux ............. 921

xanthosticta, Mycteroperca bonaci. $\quad 1176$

xanthostigmus, Citharichthys...... 2680

xanthulum, Cestreus............. 1411

xanthulus, Cynoscion ............ 1410

xanthurus, Homoprion.......... 1434, 1459

Leiostomus............ 1458

Pomacentrus........... 1557

Rhombus............. 966, 2849

Seiæna.............. 1459

Seserinus ............ 966

Sparus .............. 1346

xanti, Labrisonus ............. 2362, 2363

Rhypticus................ 1231

Rypticus ................. 1231

Umbrina ................ 1467, 1468

Xenichthys .............. 1288

xantusi, Lepidopus ............ 2844, 4843 


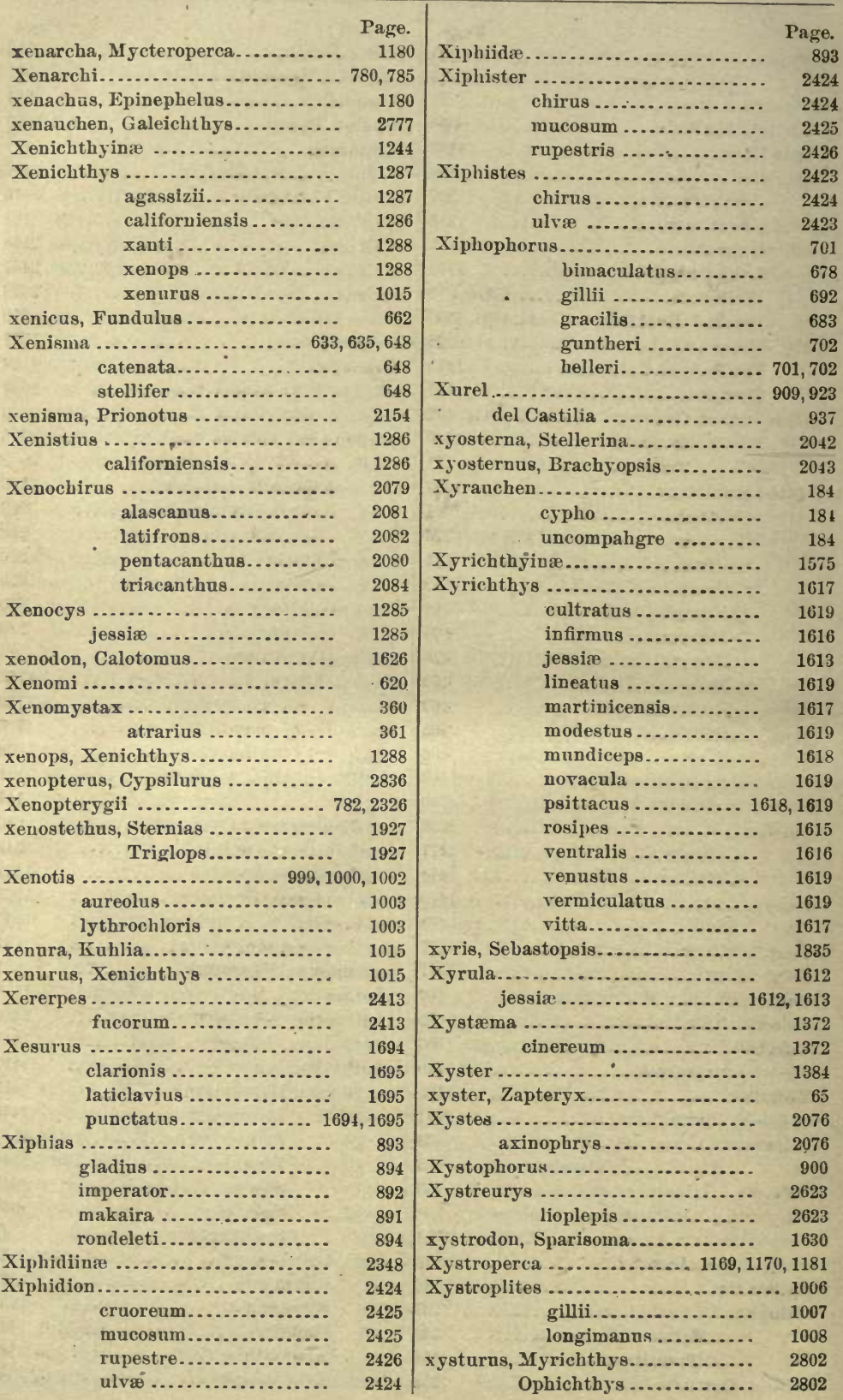


xysturus, Ophisurus

Page.

Pisodonophis

yalei, Ostracion

Yanagi Nomai

Yarrella

blackfordi

yarrelli; Acipenser

yarrowi, Agosia.

y-ca ' $d$ da, Gillichthys

Yellow-backer Rocktish ........... 1822

Yellow Bass

1134

Belly

1001

Cat

139,143

Yellow-finued Grouper

1155,1172

Roncador

1467

Trout

Yellow Fish.

1144

Goatfish

Grouper

859

Grunt

1183

1303

Jack

919

Mackerel

Perch

921

Pike

1023

Sculpin

1021

1934

1826

Yellow-spotted Rockfish..........

493

Yellow-tail............. 902,906, 1275, 1433

Croaker............. 1467

Rockfish ............. 1781

y-græecum, Astroscopus .......... 2307

Upsilonphorus......... 2308

Uranoscopus ........... 2308

Yuriria $314,315,321$

zacentrus, Sebastichthys

1815

zachirus, Glyptocephalus

2658

Zaclemus ................ 1477, 1478, 1480

zadocki, Cylindrosteus .............

Zalembius

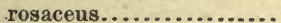

Zalieutes

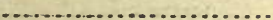

111

1499

1500

2738

2738

Zalocys

elater ..................

2848

stilbe ................. 2848

Zalopyr ...................... 1795, 2880

Zalypuus...................... 2246

cyclolepis.............. $\quad 2246$

emblematicus.......... 2247

Zanclurus ....................... 890

Zanclus ........................ 1687

canescens............... 1688

centrognathus........... 1688

cornutus

1687,1688
2854

1995

319

2862

1876

1877

$\begin{array}{lr}\text { frenatus................ } & 1877 \\ \text { Latipinnis ............ } & 1876\end{array}$

Zapaters ....................... 898

Zaphotias ..................... 2826 pedaliotus............. $\quad 2826$

Zaprora ........................ 2850 silenus ................ 2850

Zaproridæ................... 2849

Zapteryx....................... 64

exasperatus............ 64

xyster................ 65

zatropis, Siphostoma............. $\quad 772$

zebra, Acanthurus ............... 1691

A rbaciosa ................ 2341

Asproperca .............. 1027

Chætodon ................. 1691

Fundulus...............641, 647

Gerres.................... 1373

Gobiesox ................. 2342

Gobius ................... 2226

Hydrargyra ............... $\quad 647$

Percina caprodes .......... 1027

Pileoma................... 1028

Psychrolutes.............. 2027

zebrinus, Fundulus .............. $\quad 646$

Zeidæ......................... 1659

Zeinæ......................... 1660

zelotes, Dactyloscopus ............ 2303

Hermicaranx ............ 2845

Zenion ....................... 1661

hololepis................. 1661

Zenopsis ........................ 1660

ocellatus................ 1660

zenopterus, Exocœtus............. $\quad 738$

Zeoidea ....................... 1559

zephyreus, Astroscopns........... 2309

Zegticelus .

1990

1990

Zestidium.................... 1439, 1442

Zestis ......................... 1439, 1440

zestocarus, Stellifer............. $\quad 1445$

zestus, Nebris................. $\quad 1417$

Zeus capillaris ................ 936

ciliaris .................. 932

crinitus ................... 932

gallus .................... 936

geometricus ................ 936

guttatus................... 955

imperialis ................ 955

luna................... 955 
Zeus niger $. . . \ldots \ldots \ldots . . . . . . . .$.

ocellatus.....................

opah.......................

quadratus ...................

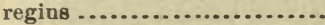

rostratus ....................

setipinnis ..................

stromii

vomer

zeylonicus, Leuciscus .............

Ziphotheca......................

tetradens...............

Zoarces .........................

anguillaris...............

elongatus ................

fimbriatus ................

gronovii .................

labrosus ..................

polaris...................

Zoarchidæ.......................

Zoarchus........................

zoarchus, Lycodes.................

Zoarcidæ........................

Zoarcinæ.........................

zonale, Etheostoma............... arcansanum ....

Nanostoma .................

zonalis, Astatichthys .............

Pœcilichthys .............

zonata, Seriola carolinensis........

zonatum, Elassoma...............

zonatus, Alburnus ...............

Chætodipterus .............

Ephippus ................

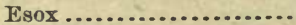

Fundulus ................

Notropis .................

Scomber ................

Zygonectes...............

Zonichthys

bosci ..................

coronatas ..............

declivis ................

gigas..................

zonifer, Clinus ..................

Erilepis ...................

zonifer, Myriolepis .................

Zygonectes................

zonipectus, Pomacanthodes ........

Pomacanthus ...........

zonistius, Lnxilus................

Minnilus ...............

Notropis.............. 277, 285

Zonogobius .................... 2210

zonope, Jordania ................. 1884

Zonoscion

$1477,1478,1479$

1661

955

1668

955

936

934

955

936

415

887

887

2456

2457

2457

2457

2457

2457

2469

2455

2456

2464

2455

2455

1075

1075

1075

1075

1075

902

982

285

1668

1669

639

657

285

902

659

901,904

905

905

905

903

2359

1863

1863

657

1682

1681

285

285
210

ygonectes zonifer ............... 65 ?

Zygonectus ..................... 633,635

zyopterus, Galeorhinus .......... $\quad 32$

Zyphothyca................... 883 atrilatus ............. 682

auroguttatus.........654, 2829

brachypterus......... $\quad 682$

chrysotus ............. 656

cingulatus ..........655, 656

craticula ............. 657

dispar................ 659

floripinnis............ 651

funduloides ........... $\quad 650$

guttatus .............. 658

henshalli............653, 2829

hieroglyphicus........ 658

inurus .............. 682

jenkinsi............... 652

lateralis.............. $\quad 659$

lineatus.............. 649

lineolatus ............ 657

luciw................ $\quad 655$

macdonaldi............ 651

mannii ............... 664

melanops............. 682

notatus ............. 659

nottii .............. 657

pulchellus ............ $\quad 659$

pulvereus ............. $\quad 652$

rubrifrons ........... 654, 2829

sciadicus .............. 654

zonatus ............. 659

57

32 escambir ............. 658 

- 
This book is due on the last date stamped below, or on the date to which renewed.

Renewed books are subject to immediate recall.

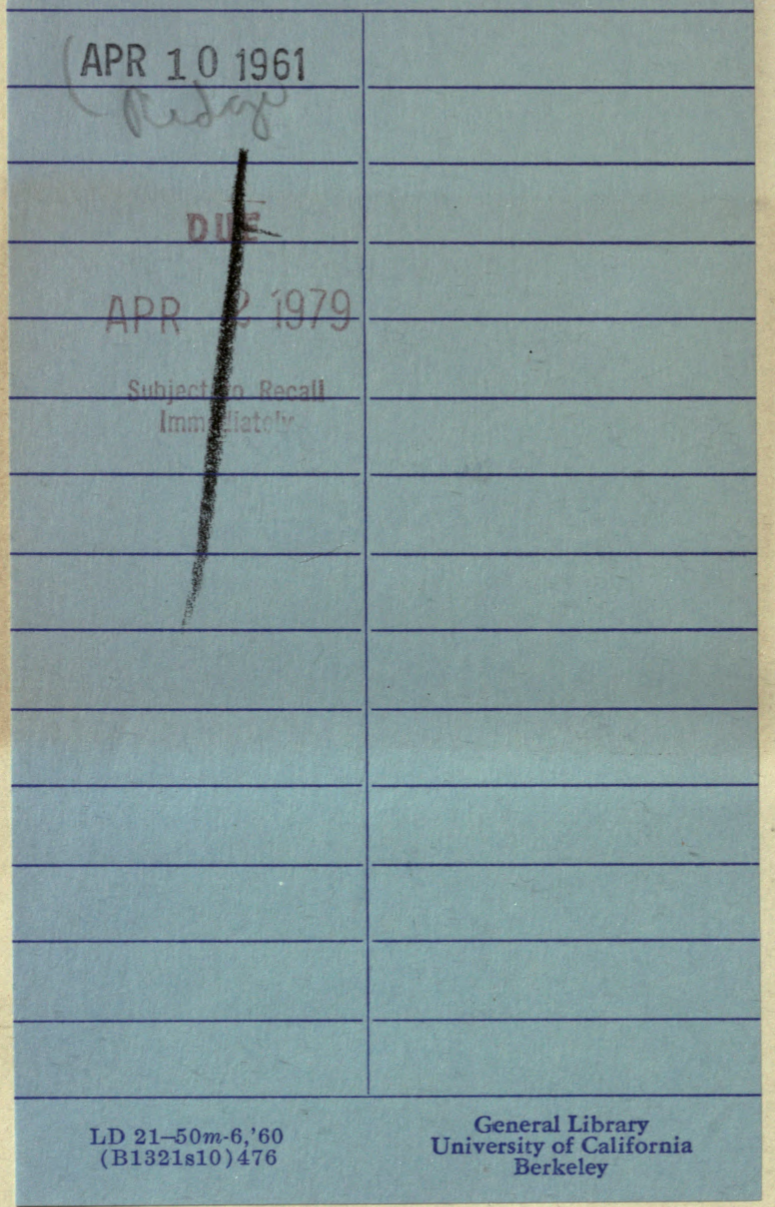




\section{9}

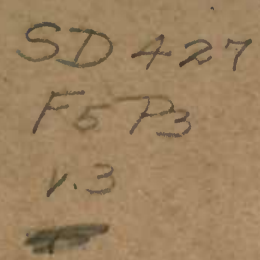

UNIVERSITY OF CALIFORNIA LIBRARY

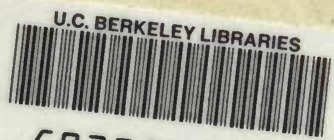

$\operatorname{co3} 3562424$ 
